\title{
INTERNATIONAL GONFERENGE ON EURASIAN ECONOMIES 2016
}




\title{
INTERNATIONAL CONFERENCE ON EURASIAN ECONOMIES 2016
}

\author{
Editors: \\ Selahattin Sarı \\ Alp H. Gencer \\ İlyas Sözen
}

\author{
Copyright (C) 2016 \\ Eurasian Economists Association
}

\begin{abstract}
ALL RIGHTS RESERVED.
This book contains material protected under International and Federal Copyright Laws and Treaties. Any unauthorized reprint or use of this material is prohibited. No part of this book may be reproduced or transmitted in any form or by any means, electronic or mechanical, including photocopying, recording, or by any information storage and retrieval system without express written permission from the publisher.
\end{abstract}

Beykent University Publications No:115

ISBN: 978-975-6319-26-O

Typesetting: Alp H. Gencer 


\section{INTERNATIONAL GONFERENGE ON EURASIAN ECONOMIES 2016}

Kaposvár - Hungary

29-31 August 2016 


\section{FOREWORD}

We are proud to have completed the seventh International Conference on Eurasian Economies, held in Kaposvár, Hungary with the cooperation of Beykent University, Kaposvár State University, Manas University, Eurasian Economists Association and Turkish-Hungarian Businessman Association on August 29-31, 2016. As in previous years, our conference attracted many economists interested in the region. More than 350 applicants from 15 countries submitted abstracts for consideration. As it is not possible to allocate time slots for this many presentations within a two-day span of the sessions, only a total of 180 submissions were accepted for presentation.

The unfortunate events that took place in Turkey on July 15th, 2016 adversely impacted many conferences, which had to be cancelled or rescheduled. However, the organization committee decided to stick with the original plan. Initially, Turkey imposed restrictions on foreign travel for academicians and government employees; however, later relaxed these restrictions and made traveling subject to permissions obtained from authorities. Therefore, only 121 accepted papers could be presented at the conference. On the other hand, with the attendance of academicians not presenting papers, the number of participants was170. Despite all of the difficulties, this demonstrates that our conference is held in very high regard.

The participation of many deans, professors and associate professors, people from the financial sector and executive boards substantiates the place of our conference within the scientific community. We would like to extend our deepest appreciation to all participants and sponsors who have trusted and supported the conference's organizing committee.

As in previous years, presented papers are collected into this proceedings book. A considerable amount of time and effort is put into evaluating and formatting the papers for the book. Each paper is evaluated by at least two judges before being accepted. I would like to thank our judges, scientific and organization committee members who contributed their valuable time and support to evaluating every paper. Additionally, we would like to extend our gratitude to Dr. Alp Gencer, who helped to design our web platform with great patience despite all of the difficulties and prepared the book of proceedings for publication.

We would like to extend our greatest appreciation for the continuous support of International Conference on Eurasian Economies by Beykent University's Board of Trustees' Chairman and members, The University President Prof. Dr. Mehmet Emin Karahan, the Secretary General Murat Süslü and Public Relations Department, as well as the administrative staff.

Our appreciation is also extended to our partners. We would like to thank the President of Kaposvár University Prof. Dr. Ferenec Szavai and the staff members of the Foreign Relations Department of the University. Thanks to Prof. Dr. Jusuf Primbaev of Manas University and his team for evaluating Russian submissions and disseminating announcements about the conference in Central Asia. Specials thanks goes to the President of the Turkish-Hungarian Businessmen Association and The Honorary Consulate of Turkey Dr. Osman Şahbaz for resolving some of the problems we encountered along the way. Also, we would like to acknowledge the Eurasian Economists Association for funding the first ever presented "Best Paper Award". The Hiç family deserves a special thanks for presenting the "Doctoral Studies Support Award" in memory of Prof. Dr. Mükerrem Hiç.

Financial support is one of the most important elements in organizing scientific conferences. For this, our gratitude goes out to the Republic of Turkey Prime Ministry - Turkish Cooperation and Coordination Agency's (TIKA's) President and the corresponding head of department Dr. Mehmet Y1lmaz along with his staff for their continued support since the beginning of The International Eurasian Conference.

Finally, our greatest appreciation goes to all of the academicians, researchers and participants whose contributions have made this conference a success. We hope and believe that the International Eurasian Conference 2016 has made important contributions to the Eurasian region and scientific community at large.

We hope to see you in our next conference to be held in Istanbul in 2017.

\section{Prof. Dr. Selahattin Sarı}

Conference Chair 


\section{ÖNSÖZ}

Uluslararası Avrasya Ekonomileri Konferansı'nın yedincisi bu sene; Beykent Üniversitesi, Kaposvár Devlet Üniversitesi, Manas Üniversitesi, Avrasya Ekonomistler Derneği ve Türk-Macar İşadamları Derneği' nin ortak organizasyonuyla Macaristan'ın Kaposvár şehrinde 29-31 Ağustos 2016 tarihlerinde gerçekleştirilmiş bulunuyoruz. Her y1l olduğu gibi bu sene de konferans çok yoğun bir ilgi görmüştür. Konferansa özet gönderim aşamasında 15 ülkeden 350nin üzerinde başvuru olmuştur. Bu tarz bilimsel organizasyonlarda 2 gün içerisinde bu kadar çok bildirinin sunulup tartış1labilmesi maalesef mümkün değildir. Dolayısıyla kabul verilen bildiri sayısı 180 civarında olabilmiştir.

Türkiye'de 15 Temmuz 2016 tarihinde ortaya çıkan talihsiz gelişmeler maalesef düzenlenen konferansları olumsuz etkilemiş, bir çok konferans iptal edilmiştir. Ancak organizasyon komitesi olarak, konferansın yapılması kararımızı değiştirmedik. Türkiye'de öğretim üyelerinin ve kamu personelinin başlangıçta yurt dışına çıkışlarının yasaklanması, daha sonra izne bağlanması katılımcıları etkilemiş ve konferansta sunulan bildiri sayıs1 121'e inmiştir. Diğer taraftan konferansta bildirisi olmayan çok sayıda öğretim üyesi dileyici olarak iştirak etmiş ve konferans yaklaşık 170 katılımcının iştiraki ile gerçekleşmiştir. Bütün olumsuzluklara rağmen katılımın yüksekliği konferansa olan ilginin büyüklüğünü göstermektedir.

Konferansa çok sayıda dekanın katılması, profesör ve doçentlerin ağırlıklı olması finans sektörü ve üst kurullardan katılımlar konferansın bilim dünyasındaki yerini ifade etmektedir. Konferans düzenleme komitesine olan güven ve desteklerini konferansa iştirakleriyle şereflendiren tüm katılımcılara öncelikle teşekkürlerimizi arz ediyoruz.

Her sene olduğu gibi bu sene de konferansta sunulan bildiriler kitap haline getirilmiştir. Gerek bildirilerin değerlendirilmesi aşamasında, gerekse kitap haline getirilmesi aşamasında ciddi emek sarf edilmektedir. Her bildiri en az iki hakem tarafından değerlendirilmektedir. Bu değerlendirmelere zaman ayıran ve destek veren hakemlerimize, bilim kurulu üyelerimize, konferans hazırlıklarının başlamasından itibaren çok yoğun mesai harcayan organizasyon komitesindeki arkadaşlarımıza, web sayfası dizaynında her türlü müdahaleye rağmen sabırla işlemleri yerine getiren Dr. Alp Gencer'e teşekkürlerimizi sunarız.

Uluslararası Avrasya Ekonomileri Konferansı'nın gerçekleştirilmesinde her konferans hazırlığında olduğu gibi desteklerini esirgemeyen Beykent Üniversitesi Mütevelli Heyet Başkan ve üyelerine, Üniversite Rektörü Prof. Dr. Mehmet Emin Karahan, Genel Sekreter Murat Süslü ve başta Halkla İlişkiler olmak üzere tüm idari birimlerin personeline sonsuz teşekkürler.

Konferansı birlikte düzenlediğimiz Kaposvár Üniversitesi Rektörü Prof. Dr. Ferenec Szavai ve üniversitenin özellikle Dış İlişkiler Departmanı ve ilgili personeline, Manas Üniversitesi olarak Rusça bildirilerin değerlendirilmesi ve Orta Asya'da gerekli duyuruların yapılmasında destek veren Prof. Dr. Jusup Primbaev ve ekibine, özellikle zaman zaman ortaya çıkan problemlerin çözümündeki katkılarıyla destek sağlayan Türk Macar İşadamları Derneği Başkanı ve Fahri Konsolos Dr. Osman Şahbaz'a, ilk defa "En İyi Bildiri" ödülünü tahsis ederek konferansa destek veren Avrasya Ekonomistler Derneği yetkililerine, yine konferansa "Prof. Dr. Mükerrem Hiç Doktora Teşvik Ödülü"nü tahsis ederek destek veren sayın Hiç ailesine teşekkürlerimizi sunarız.

Konferansların gerçekleştirilmesinde en önemli unsur finansman kaynağıdır. Uluslararası Avrasya Ekonomileri Konferansı'nın en başından itibaren her zaman yanımızda olan ve destek veren T.C. Başbakanlık Türk İşbirliği ve Koordinasyon Ajansının başta başkanı olmak üzere ilgili daire başkanı Dr. Mehmet Yılmaz'a, ilgili Uzman ve personeline teşekkürler.

En büyük teşekkürümüz elbette ki konferansın oluşmasını sağlayan akademisyen, araştırmacı ve katılımcılaradır. Uluslararası Avrasya Ekonomileri Konferans1 2016'nın başta Avrasya Ülkeleri olmak üzere bilim dünyasına katkı sağlayacağı inanç ve dileğiyle, 2017 konferansında İstanbul'da buluşmak üzere...

\section{Prof. Dr. Selahattin Sarı}

Organizasyon Kurulu Başkanı 


\section{ADVISORY BOARD}

- Prof. Dr. Ferenec Szavai (Rector, Kaposvar University, Hungary)

- Prof. Dr. Mehmet Emin Karahan (Rector, Beykent University, Turkey)

- Dr. Anett Paradi-Dolgos (Dean, Faculty of Economics, Kaposvar University, Hungary)

- Prof. Dr. Selahattin Sar1 (Dean, Faculty of Economic and Administrative Sciences, Beykent University, Turkey)

\section{ORGANIZING COMMITTEE}

- Assoc. Prof. Dr. Osman Şahbaz (Kaposvar University, Hungary)

- Assoc. Prof. Dr. İlyas Sözen (Beykent University, Turkey)

- Assoc. Prof. Dr. Ayşen Hiç Gencer (Istanbul Aydın University, Turkey)

- Dr. Gabor Papai (Kaposvar University, Hungary)

- Asst. Prof. Dr. Aynura Turdalieva (Kyrgyzstan-Turkey Manas University, Kyrgyzstan)

- Asst. Prof. Dr. Naime İrem Koşan (Beykent University, Turkey)

- Asst. Prof. Dr. Sitk1 Sönmezer (Beykent University, Turkey)

- Ph.D. Candidate Mustafa Batuhan Tufaner (Beykent University, Turkey)

- Mrs. Aylin Gencer (Justus Liebig University, Germany)

\section{WEB \& PRINT DESIGN}

- Dr. Alp Gencer 


\section{SCIENTIFIC BOARD}

- Prof. Dr. Ahmet Ay (Selçuk University, Turkey)

- Prof. Dr. Harun Bal (Çukurova University, Turkey)

- Prof. Dr. Mehmet Balcilar (Eastern Mediterranean University, Cyprus)

- Prof. Dr. Viktor Barhatov (Chelyabinsk State University, Russia)

- Prof. Dr. Tansu Barker (Brock University, Canada)

- Prof. Dr. Ersan Bocutoğlu (Karadeniz Technical University, Turkey)

- Prof. Dr. Cihan Çobanoğlu (University of South Florida, United States of America)

- Prof. Dr. Mustafa Kemal Değer (Karadeniz Technical University, Turkey)

- Prof. Dr. Ljubomir Drakulevski (Ss. Cyril and Methodius University, Macedonia)

- Prof. Dr. Dzhumabek Dzhailov (Ministry of Agriculture, Kyrgyzstan)

- Prof. Dr. Hüseyin Avni Egeli (Dokuz Eylül University, Turkey)

- Prof. Dr. Ömer Selçuk Emsen (Atatürk University, Turkey)

- Prof. Dr. Cevat Gerni (Doğuş University, Turkey)

- Prof. Dr. Nuray Gökçek Karaca (Anadolu University, Turkey)

- Prof. Dr. Ahmet İncekara (İstanbul University, Turkey)

- Prof. Dr. Danijela Jacimovic (University of Montenegro, Montenegro)

- Prof. Dr. Gani Kaliev (Academy of Agricultural Sciences, Kazakhstan)

- Prof. Dr. S. Ridvan Karluk (Anadolu University, Turkey)

- Prof. Dr. Nuriddin Kayumov (Tajikistan Academy of Sciences, Tajikistan)

- Prof. Dr. Recep Kök (Dokuz Eylül University, Turkey)

- Assoc. Prof. Dr. Igor Kokh (Kazan Federal University, Russia)

- Prof. Dr. Turar Koychuev (National Academy of Sciences, Kyrgyzstan)

- Prof. Dr. Fevzi Okumuş (University of Central Florida, United States of America)

- Prof. Dr. Zekai Özdemir (Istanbul University, Turkey)

- Prof. Dr. Jusup Pirimbaev (Kyrgyzstan-Turkey Manas University, Kyrgyzstan)

- Prof. Dr. Tatiana Pyshkina (Academy of Economic Studies of Moldova (ASEM), Moldova)

- Prof. Dr. Alisher Rasulev (Institute of Economics, Uzbekistan)

- Prof. Dr. Orazaly Sabden (Institute of Economics, Kazakhstan)

- Prof. Dr. Mehmet Sarışık (Sakarya University, Turkey)

- Prof. Dr. Euphrasia Susy Suhendra (Gunadarma University, Indonesia)

- Dr. Katalin Szendro (Kaposvar University, Hungary)

- Prof. Dr. Muammer Tekeoğlu (Çukurova University, Turkey)

- Prof. Dr. Mustafa Topaloğlu (Beykent University, Turkey)

- Prof. Dr. Khodjamakhmad Umarov (Institute of Economics, Tajikistan)

- Prof. Dr. Bahadir Umurzakov (G.V. Plekhanov Russian University of Economics in Tashkent, Uzbekistan)

- Dr. Jozsef Varga (Kaposvar University, Hungary) 


\section{Contents}

\section{OPENING SESSION}

\#1815: Global Economy and Turkey: 2016 and Beyond 1

- Mr. Durmuş Yılmaz (Central Bank of Turkey, Turkey)*

SESSION 1A: Regional Studies

Session Chair: Prof. Dr. Gonca Bayraktar Durgun

\#1668: A Crossroad For Turkey: European Union Or Eurasian Economic Union

- Ph.D. Candidate Nergiz Başeğmez (Beykent University, Turkey)

- Asst. Prof. Dr. Kerem Toker (Beykent University, Turkey) *

\#1647: Circular Migration Between Georgia and Turkey: Is Triple Win a Solution for Illegal Employment? ...14

- Prof. Dr. Adem Kalça (Karadeniz Technical University, Turkey)

- Yilmaz Onur Ari (Bayburt University, Turkey)*

\#1502: Is There a Relation Between the Level of Development and Government Systems? An Overview on Latin America, Euroasia and the East Asia

- Ph.D. Candidate Yaşar Pınar Özmen (Gazi University, Turkey)

- Prof. Dr. Gonca Bayraktar Durgun (Gazi University, Turkey) *

\#1486: State in Terms of Structure and Function: A Comparative Analysis

- Prof. Dr. Şenol Durgun (Ankara Sosyal Bilimler University, Turkey) *

\section{SESSION 2A: Growth}

Session Chair: Assoc. Prof. Dr. Kutluk Kă̆an Sümer

\#1776: The Effect of Research and Development Expenditures on Economic Growth: New Evidences 36

- Asst. Prof. Dr. Mustafa Ildırar (Çukurova University, Turkey)

- Assoc. Prof. Dr. Mehmet Özmen (Çukurova University, Turkey)

- Asst. Prof. Dr. Erhan İşcan (Çukurova University, Turkey) *

\#1475: The Effects of R\&D and High Technology Exports on Economic Growth: A Comparative Cointegration Analysis for Turkey and South Korea

- Asst. Prof. Dr. Ayfer Ustabaş (Beykent University, Turkey) *

- Assoc. Prof. Dr. Özgür Ömer Ersin (Beykent University, Turkey)

\#1677: The Relationship between Military Expenditures and Economic Growth: Panel Data Analysis for G-20

Countries

- Assoc. Prof. Dr. Kutluk Kağan Sümer (İstanbul University, Turkey) *

\#1541: Bilgi Ekonomisi Yolunda Türkiye: Bilgi, İletişim Teknolojileri ve Politikalar

- Ph.D. Candidate Burcu Sakız (Istanbul Aydın University, Turkey) *

- Semih Sakız (Garanti Technology, Turkey)

\#1494: International Trade and Macro-Economic Policy in Eurasian Economies

- Asst. Prof. Dr. Naime İrem Koşan (Beykent University, Turkey) *

- Prof. Dr. Sudi Apak (Esenyurt University, Turkey)

- Prof. Dr. Selahattin Sarı (Beykent University, Turkey)

\section{SESSION 3A: Tourism}

\section{Session Chair: Prof. Dr. Mehmet Sarıısık}

\#1459: The World Bank's Role in Tourism Development: The Case of Uzbekistan

- Prof. Dr. Mithat Zeki Dinçer (İstanbul University, Turkey)

- Prof. Dr. Fatma Füsun İstanbullu Dinçer (İstanbul University, Turkey) *

- Ph.D. Candidate Zaid Alrawadieh (Istanbul University, Turkey) 
\#1809: The Situation of the Hungarian Wheat from the Grain Trading Point of View in 2016

- Ph.D. Candidate András Bence Szerb (Kaposvár University, Hungary) *

- Dr. Ferenc Csima (Kaposvár University, Hungary)

\#1654: Analyzing the Important Factors for Cloud Service Provider Selection among the IT firms in Turkey ..87

- Asst. Prof. Dr. Ediz Şaykol (Beykent University, Turkey)

- Ayşe Seçil Başer (Beykent University, Turkey) *

- Assoc. Prof. Dr. Kazim Sari (Beykent University, Turkey)

SESSION 4A: Finance

Session Chair: Prof. Dr. Sudi Apak

\#1675: Do Financial Markets Exhibit Chaotic Behavior? Evidence from BIST

- Assoc. Prof. Dr. Kutluk Kağan Sümer (İstanbul University, Turkey) *

\#1731: The Financial Risk Evaluation in Turkish Banking System

- Asst. Prof. Dr. Semin Paksoy (Çukurova University, Turkey)*

- Ph.D. Candidate Mehmet Fatih Traş (Çukurova University, Turkey)

\#1742: The Relationship between Firms’ Environmental Performance and Financial Performance: The Case of

Turkey

- Asst. Prof. Dr. Füsun Küçükbay (Celal Bayar University, Turkey) *

- Ph.D. Candidate Tuğba Arpazlı Fazlılar (Celal Bayar University, Turkey)

SESSION 5A: Banking

Session Chair: Dr. Jozsef Varga

\#1803: The Analysis of the Turkish Islamic Banking System Between 2005 and 2014 116

- Lívia Tálos (Kaposvár University, Hungary)*

- Dr. Gyöngyi Bánkuti (Kaposvár University, Hungary)

- Dr. Jozsef Varga (Kaposvar University, Hungary)

\#1804: The Comparative Analysis of the Islamic and Conventional Bank System in Turkey

- Vivien Pavelka (Kaposvár University, Hungary)*

- Dr. Gyöngyi Bánkuti (Kaposvár University, Hungary)

- Dr. Jozsef Varga (Kaposvar University, Hungary)

\#1788: The Comparative Analysis of the Alternative Crisis Management Models of the Islamic- and Christian-

Based Bank System

- Dr. Balazs Cseh (Kaposvar University, Hungary)

- Dr. Jozsef Varga (Kaposvar University, Hungary)*

\#1508: Improvement of the Corporate Loan Process in the Turkish Banking Sector: A Model

- Prof. Dr. Semra Birgün (Beykent University, Turkey)

- Prof. Dr. Sudi Apak (Esenyurt University, Turkey)*

SESSION 1B: Girişimcilik

Session Chair: Assoc. Prof. Dr. Volkan Öngel

\#1516: İş Hayatında Nicel Başarı Tanımlamasına Bir Karşı Duruş: Erdem Etiği Yaklaşımı 140

- Prof. Dr. Sabahat Bayrak Kök (Pamukkale University, Turkey)*

- Asst. Prof. Dr. İbrahim Aksel (Pamukkale University, Turkey)

\#1519: Postmodern Kültür Bağlamında Kuşaklararası Girişimcilik Olgusu ve Davranış Tutarsızlığı Üzerine Bir Araştırma 150

- Prof. Dr. Feyzullah Eroğlu (Pamukkale University, Turkey) *

- Ph.D. Candidate Mehtap Sarıkaya (Pamukkale University, Turkey)

- Asst. Prof. Dr. Şeyma Gün Eroğlu (Muğla Sitkı Koçman University, Turkey) 
\#1514: Girişimcilikte Sosyal Değer İnşası: Sosyal Girişimcilik

- Prof. Dr. Sabahat Bayrak Kök (Pamukkale University, Turkey) *

- Esvet Mert (Pamukkale University, Turkey)

\#1523: Kırsal Girişimcilik: Tarihten Günümüze Yatağan Örneği

- Prof. Dr. Ayşe İrmiş (Pamukkale University, Turkey) *

- Ph.D. Candidate Hatice Çoban (Pamukkale University, Turkey)

- Dr. Serkan Başol (Pamukkale University, Turkey)

\#1525: Öğrenen Örgütün İç Girişimcilik Davranışına Etkisi Üzerine Bir Araştırma

- Ph.D. Candidate Mehtap Sarıkaya (Pamukkale University, Turkey)

- Prof. Dr. Sabahat Bayrak Kök (Pamukkale University, Turkey)*

- Ph.D. Candidate Sümeyra Babacan (Muğla Sitkı Koçman University, Turkey)

SESSION 2B: Bölgesel Çalışmalar

Session Chair: Prof. Dr. Şenol Durgun

\#1763: Avrupa Enerji Birliği (AEB) ve Türkiye’nin Bölgesel Enerji Hub'1 Olabilirliği: Fırsat ve Zorluklar ...190

- Dr. Nuran Belet (Gazi University, Turkey)*

\#1652: Ukrayna Krizi Çerçevesinde Avrupa Birliği'nin Doğu Avrupa'daki İstikrara Etkisi

- Asst. Prof. Dr. Ömer Uğur (Gümüşhane University, Turkey) *

\#1755: Orta Asya Entegrasyon Süreçlerine "Büyük Güçlerin" Etkisi 206

- Ediliia Abdykadyrova (Kyrgyz-Turkish Manas University, Kyrgyzstan) *

\#1658: Çin’in Kültürel Diplomasisinin “Çin Tehdidi” Algısının Kırılmasındaki Önemi

- Dr. Cemre Pekcan (Çanakkale Onsekiz Mart University, Turkey) *

\#1466: Orta Asya'da Oluşturulan Ekonomik ve Siyasi Entegrasyonlar Kapsamında Türkiye Özbekistan İlişkileri

- Prof. Dr. S. Ridvan Karluk (Anadolu University, Turkey)

- Assoc. Prof. Dr. Ayşen Hiç Gencer (Istanbul Aydın University, Turkey) *

\#1679: Gelişen Ülkelerde Çevresel Bozulma, Gelir Ve Enerji Tüketimi İlişkisi

- Assoc. Prof. Dr. Cengiz Aytun (Çukurova University, Turkey) *

- Assoc. Prof. Dr. Cemil Serhat Akın (Mustafa Kemal University, Turkey)

- Assoc. Prof. Dr. Neşe Algan (Çukurova University, Turkey)

\section{SESSION 3B: Hukuk}

Session Chair: Prof. Dr. Ethem Atay

\#1754: Türk Sosyal Güvenlik Hukuku'nda Sigortalı Lehine Yorum İlkesi

- Asst. Prof. Dr. Nurgül Emine Barın (Afyon Kocatepe University, Turkey) *

\#1744: Türkiye'de Mülteci Sorunu ve Mültecilerin Çalışma ve Sosyal Güvenlik Hakları

- Prof. Dr. İbrahim Aydınlı (Ankara Sosyal Bilimler University, Turkey) *

\#1571: Türkiye'de İpoteğe Dayalı Menkul Kıymetlerle İlgili Son Gelişmeler 248

- Prof. Dr. Mustafa Topaloğlu (Beykent University, Turkey)*

\#1564: Vergilemede Adalet Açısından Türkiye'nin Dolaysız ve Dolaylı Vergileme Politikası 256

- Prof. Dr. Sabahat Binnur Çelik (Beykent University, Turkey) *

\#1544: Tazminat Uyuşmazlıklarının İdari Yargı Öncesi Sulh Yoluyla Çözümü

- Assoc. Prof. Dr. Gürsel Özkan (Danıştay, Turkey) *

\#1535: Türk Ticaret Kanunu’nda Haksız Rekabet Suçu

- Prof. Dr. Çetin Arslan (Hacettepe University, Turkey)

- Ph.D. Candidate Didar Özdemir (Hacettepe University, Turkey)

- Prof. Dr. Ethem Atay (Gazi Üniversitesi, Turkey)* 
SESSION 4B: Mikroekonomi

Session Chair: Assoc. Prof. Dr. Neşe Algan

\#1587: Yatırım Projelerinin Değerlendirilmesi: Türk Çimento Sektöründen Bir Örnek

- Miyase Karabulut (Türk Hava Yolları, Turkey)

- Asst. Prof. Dr. Sitkı Sönmezer (Beykent University, Turkey) *

- Asst. Prof. Dr. Vedat Zeki Yenen (Beykent University, Turkey)

- Mrs. Zeynep Emir (Beykent University, Turkey)

\#1660: Yeşil Pazarlamada Sürdürülebilirlik ve Dünya'dan Bir Örnek: Tchibo

- Asst. Prof. Dr. İsmail Erkan Çelik (Beykent University, Turkey)

- Ph.D. Candidate Öznur Akman (Beykent University, Turkey)

- Ph.D. Candidate Ayben Ceyhan (Beykent University, Turkey)*

- Asst. Prof. Dr. Vedat Akman (Beykent University, Turkey)

\#1559: Bir Fizikçinin Gözüyle Ekonomi Bilimine Termodinamik Bir Bakış

- Asst. Prof. Dr. Nergin Günay (Beykent University, Turkey)*

\#1684: Potansiyel Yönetici Adaylarının Kurumsal Sosyal Sorumluluğa İlişskin Görüş ve Algılamalarının Belirlenmesi Üzerine Bir Araştırma

- Ph.D. Candidate Erhan Boğan (Sakarya University, Turkey)

- Ph.D. Candidate Saadet Zafer Kavacik (Akdeniz University, Turkey)

- Prof. Dr. Mehmet Sarışık (Sakarya University, Turkey) *

\#1753: Şehir Markalamasında Duygusal Yaklaşım: Deneyimsel Pazarlama

- Asst. Prof. Dr. Alparslan Özmen (Afyon Kocatepe University, Turkey) *

SESSION 5B: Uluslararası Ticaret

Session Chair: Assoc. Prof. Dr. Ayşen Hiç Gencer

\#1793: Türkiye ve Avrasya Ülkeleri Arasındaki Dış Ticaret İlişkisi: Ampirik Bir Çalışma 305

- Ph.D. Candidate Tacinur Akça (İstanbul University, Turkey) *

\#1787: İhracata Dayalı Büyüme: Teknolojik Bakış

- Prof. Dr. Harun Bal (Çukurova University, Turkey)

- Asst. Prof. Dr. Hakkı Çiftçi (Çukurova University, Turkey)

- Asst. Prof. Dr. Erhan İşcan (Çukurova University, Turkey) *

- Ph.D. Candidate Duygu Serin (Çukurova University, Turkey)

\#1643: Türkiye'nin Merkezi ve Doğu Avrupa Ülkelerine İhracat Artışında Yaygın ve Yoğun Ticaretin Rolü 317

- Ph.D. Candidate Gizem Akbulut (Gümüşhane University, Turkey) *

\#1521: Türkiye ve Orta Asya Türk Ülkeleri Arasinda Endüstri İçi Ticaretin Düzeyi Ve Sektörel Rekabet Gücünün Belirlenmesi

- Assoc. Prof. Dr. Sabri Azgün (Atatürk University, Turkey)*

- Asst. Prof. Dr. Ziya Çağlar Yurttançıkmaz (Atatürk University, Turkey)

- Prof. Dr. Mine Gerni (Marmara University, Turkey)

- Prof. Dr. Selahattin Sar1 (Beykent University, Turkey)

\#1533: Selçuklu Deniz Ticaretinin Anadolu Ekonomisinin Dünya Ekonomisine Entegrasyonundaki Rolü .....330

- Assoc. Prof. Dr. Ayşe Dudu Kuşçu (Konya Necmettin Erbakan University, Turkey) *

\section{SESSION 1C: Kalkınma I}

Session Chair: Prof. Dr. Süreyya Hiç

\#1757: 1990-2015 Yılları Arasında Bin Yı1 Kalkınma Hedefleri ve Yoksulluk: Türkiye Örneği

- Mr. Hüseyin Çelik (Çukurova University, Turkey) *

- Ph.D. Candidate Ahmet Duran Çelik (Mustafa Kemal University, Turkey)

- Prof. Dr. Mahir Fisunoğlu (Çukurova University, Turkey) 
\#1625: Sosyal Sermaye, Duygu ve Motivasyon Temelinde Çalışanların Bilgi Paylaşma Niyetinin Belirleyicileri

- Assoc. Prof. Dr. Canan Nur Karabey (Atatürk University, Turkey)*

- Ph.D. Candidate Isil Karabey (Hacettepe University, Turkey)

\#1750: Enformasyon Yoksulluğu: Yeni İletişim Teknolojilerinin Yaygınlaştırılması Yoluyla Yoksulluğun

Azaltılmas1

- Asst. Prof. Dr. Barış Yıldız (Gümüşhane University, Turkey) *

\#1499: Türkiye'de Neoliberal Ekonomi Politikaları Sürecinde Gelir Bölüşümü ve İktisadi Büyüme İlişkisinin

Analizi ....

- Prof. Dr. Ahmet İncekara (İstanbul University, Turkey) * . .358

- Ph.D. Candidate Betül Mutlugün (İstanbul University, Turkey)

\#1711: Türkiye'de Çocuk Yoksulluğu .368

- Assoc. Prof. Dr. Özlem Durgun (Istanbul University, Turkey) *

SESSION 2C: Kalkınma II

Session Chair: Prof. Dr. Murat Nişancı

\#1490: Almanya'daki Türk Göçmen Kadınların İşçileşme Süreci ve Gelecek Beklentileri 375

- Prof. Dr. Nuray Gökçek Karaca (Anadolu University, Turkey) *

- Asst. Prof. Dr. Erol Karaca (Anadolu University, Turkey)

\#1489: Almanya'daki Türk Göçmen Kadınların Çalışma Yaşamına Katılım Konusundaki Tutumlarını

Belirlemeye Yönelik Ölçek Çalışması

- Asst. Prof. Dr. Erol Karaca (Anadolu University, Turkey)*

- Prof. Dr. Nuray Gökçek Karaca (Anadolu University, Turkey)

\#1715: Ekonomik Büyüme ve Göç İlişkisi: Gelişmekte Olan Ülkelere Dayalı Bir Analiz

- Asst. Prof. Dr. Haktan Sevinç (Iğdır University, Turkey)*

- Asst. Prof. Dr. Eda Bozkurt (Atatürk University, Turkey)

- Asst. Prof. Dr. Serkan Künü (Iğdır University, Turkey)

- Ph.D. Candidate Demet Eroğlu Sevinç (Iğdır University, Turkey)

\#1688: Orta Gelir Tuzağının Belirleyenleri: Türkiye Örneği

- Prof. Dr. Harun Bal (Çukurova University, Turkey)

- Assoc. Prof. Dr. Neşe Algan (Çukurova University, Turkey)

- Ph.D. Candidate Müge Manga (Çukurova University, Turkey)

- Ph.D. Candidate Esra Ballı (Çukurova University, Turkey) *

\#1550: Emek Verimliliğinin Belirleyen Demografik Unsurlar: Seçilmiş Ülkeler Üzerine Analizler (1960-2010)

- Prof. Dr. Murat Nişancı (Erzincan University, Turkey)

- Ph.D. Candidate Aslı Cansin Doker (Erzincan University, Turkey) *

- Ph.D. Candidate Adem Türkmen (Erzincan University, Turkey)

- Prof. Dr. Ömer Selçuk Emsen (Atatürk University, Turkey)

\#1513: Türkiye'de İç Göçün Belirleyicileri 421

- Assoc. Prof. Dr. Rüştü Yayar (Gaziosmanpaşa University, Turkey) *

- Meltem Uçgunoğlu (Gaziosmanpaşa University, Turkey)

- Ph.D. Candidate Yusuf Demir (Cumhuriyet University, Turkey)

SESSION 3C: Kalkınma III

Session Chair: Prof. Dr. Ömer Selçuk Emsen

\#1603: Düzgün İş Endeksi Çerçevesinde OECD Ülkeleri İçinde Türkiye’nin ve Diğer Ülkelerin Düzgün İş Yapılarının Karşılaştırmalı Analizi .431

- Assoc. Prof. Dr. Elif Haykır Hobikoğlu (İstanbul University, Turkey) *

- Prof. Dr. Ahmet İncekara (İstanbul University, Turkey) 
\#1634: G-20 Ülkelerinde İşsizlik ve Askeri Harcamalar Arasındaki İlişkiler

- Asst. Prof. Dr. Ahmet Fatih Aydemir (Atatürk University, Turkey)*

- Asst. Prof. Dr. Dilek Özdemir (Atatürk University, Turkey)

- Prof. Dr. Ömer Selçuk Emsen (Atatürk University, Turkey)

\#1770: Kırsal Alanlarda Sürdürülebilir Kalkınma İçin Göçün Önlenmesinde Yaygın Formal Eğitim Önerisi: Bir

Pilot Araştırma 445

- Assoc. Prof. Dr. Lutfiye Özdemir (İnönü University, Turkey)

- Ph.D. Candidate Orhan Polat (İnönü University, Turkey)*

\#1777: Çalışma Hayatında Yaşanan Dönüşüm ve Çalışan Yoksulluğu 455

- Asst. Prof. Dr. Gülşen Sarı Gerşil (Celal Bayar University, Turkey) *

SESSION 4C: Sağlık Ekonomisi

Session Chair: Prof. Dr. Sudi Apak

\#1592: Hemşirelerin Örgütsel Bağlılık Düzeyinin ve İş Doyumunun Beklenen Personel Devir Hızı Üzerine Etkisi 465

- Asst. Prof. Dr. Irfan Özcan (Akdeniz University, Turkey)

- Asst. Prof. Dr. Gökhan Aba (Bandırma Onyedi Eylül University, Turkey) *

- Prof. Dr. Metin Ateş (İstanbul Aydın University, Turkey)

\#1749: Türkiye'de Sağlık Sektörü ve Sağlık Harcamalarının Büyüme Üzerindeki Etkisinin 2000-2014 Yılları için Analizi

- Asst. Prof. Dr. Müjgan Hacığlu Deniz (İstanbul University, Turkey) *

- Assoc. Prof. Dr. Kutluk Kağan Sümer (İstanbul University, Turkey)

\#1710: İş Sağlığı Ve Güvenliği Uygulamalarının Sağlık Çalışanları Tarafından Değerlendirilmesi: Bir Özel

Hastane Örneği

- Selin Dayan (Beykent University, Turkey)

- Assoc. Prof. Dr. Volkan Öngel (Beykent University, Turkey) *

\#1477: Sağlık Kurumlarında Yönetim ve Estetik Tıp Merkezlerindeki Stratejik Hedefler

- Ph.D. Candidate Gülay Tamer (İstanbul Gelişim University, Turkey) *

SESSION 5C: Çevre ve Tarım Ekonomisi

Session Chair: Assoc. Prof. Dr. Kutluk Kă̆an Sümer

\#1775: Türkiye’de Çevre Amaçlı Tarım Arazilerini Koruma Programı Uygulamaları

- Dr. Mehmet Hasdemir (Ministry of Food, Agriculture and Livestock, Turkey) *

- Mine Hasdemir (Agricultural Economy and Policy Development Institute, Turkey)

\#1774: Geri Dönüşümün Ekonomi Üzerine Etkileri, İnşaat Sektöründe Atık Lastik Kullanımı Örneği

- Ph.D. Candidate Hümeyra Tosun (Aksaray University, Turkey) *

- Asst. Prof. Dr. Fatih Kürşat Firat (Aksaray University, Turkey)

\#1772: Türkiye'de Uygulanan Tarımsal Belgelendirme Programları ve Bu Programların Çevresel

Sürdürülebilirliğe Olan Etkileri

- Dr. Mehmet Hasdemir (Ministry of Food, Agriculture and Livestock, Turkey)*

- Dr. Füsun Zehra Özkan (, Turkey)

\#1762: Kooperatif Ortaklarının Kooperatif Yönetimine Katılma Durumları ve Eğilimleri: Tarım Kredi Kooperatifleri Balıkesir Bölge Birliği Örneği

- Dr. Bengü Everest (Çanakkale Onsekiz Mart University, Turkey) *

- Prof. Dr. Murat Yercan (Ege University, Turkey)

\#1627: Çevre Dostu Ürünlere Ödeme İsteğini Etkileyen Faktörlerin Belirlenmesi: Türkiye’den Deneysel Bulgular

- Assoc. Prof. Dr. Rüştü Yayar (Gaziosmanpaşa University, Turkey)* 
SESSION 1D: Finans I

\section{Session Chair: Prof. Dr. Turgut Özkan}

\#1568: Kırgızistan'da Mikro Finans Uygulamasının Yoksulluk Üzerindeki Etkisi

- Ph.D. Candidate Kadyrbek Sultakeev (Kyrgyzstan-Turkey Manas University, Kyrgyzstan) *

- Assoc. Prof. Dr. Metin Bayrak (Kyrgyzstan-Turkey Manas University, Turkey)

\#1680: Borç Krizinde Kemer Sıkma Politikaları Ne Kadar Başarılı?

- Prof. Dr. Naci Tolga Saruç (İstanbul University, Turkey)

- Candan Yılmaz (Gümüşhane University, Turkey) *

\#1566: Bazı Geçiş Ekonomisi Ülkelerinde Uygulanan Mikrofinans Sistemi Etkinliğinın Faiz Oranlarına Tesiri

- Assoc. Prof. Dr. Metin Bayrak (Kyrgyzstan-Turkey Manas University, Turkey)

- Ph.D. Candidate Kadyrbek Sultakeev (Kyrgyzstan-Turkey Manas University, Kyrgyzstan)

- Ph.D. Candidate Dastan Aseinov (Kyrgyzstan-Turkey Manas University, Kyrgyzstan) *

\#1808: Uluslararası Sermaye Hareketlerinin Finansal Krizlere ve Bankalara Etkileri

- Asst. Prof. Dr. İsmail Erkan Çelik (Beykent University, Turkey)

- Assoc. Prof. Dr. Kamil Uslu (Kavram MYO, Turkey)*

- Midzhit Hodzhaniyazov (Marmara University, Turkey)

\#1462: Finansal Varlık Olarak Altının Arz-Talep Dengesinin Kısa ve Uzun Dönem Kantitatif Analizi ve Altın Fiyat Fonksiyonunun Ampirik Olarak Test Edilmesi

- Prof. Dr. Sudi Apak (Esenyurt University, Turkey)*

- Asst. Prof. Dr. Ali Osman Serdar Citak (Medipol University, Turkey)

\#1728: Türkiye'de Altın Fiyatlarına Etki Eden Temel Faktörlerin Analizi

- Prof. Dr. Turgut Özkan (Beykent University, Turkey)*

- Çiğdem Kolay (Beykent University, Turkey)

SESSION 2D: Finans II

\section{Session Chair: Prof. Dr. Ahmet Yörük}

\#1561: 2008 Finansal Krizinin Türk İmalat Firmalarının Finansal Performanslarına Etkileri

- Prof. Dr. Reşat Karcıoğlu (Atatürk University, Turkey)*

- Asst. Prof. Dr. Ensar Ağırman (Atatürk University, Turkey)

- Ph.D. Candidate Durmuş Yıldırım (Atatürk University, Turkey)

\#1683: Bireysel Emeklilik, Tasarruf Oranı ve Cari Açık Arasındaki İlişkiler: OECD Ülkeleri Üzerine Bir Uygulama

- Prof. Dr. Selim Başar (Atatürk University, Turkey)

- Ph.D. Candidate Murat Eren (Atatürk University, Turkey)*

- Ph.D. Candidate Gürkan Bozma (Iğdır University, Turkey)

\#1736: Döviz Kuru, Altın Fiyatları ve Borsa Getirileri Yönünün Yüksek Dereceden Markov Zincirleri Modelleri ile Tahmini .598

- Prof. Dr. Süleyman Bilgin Kılıç (Çukurova University, Turkey)

- Salih Çam (Çukurova University, Turkey)*

\#1727: Sermaye Kaçışı ve Geçiş Ekonomileri

- Prof. Dr. Harun Bal (Çukurova University, Turkey)

- Assoc. Prof. Dr. Neşe Algan (Çukurova University, Turkey)

- Mrs. Gamze Leman Ulaştırıcı (Çukurova University, Turkey) *

\#1700: Finansal Piyasalara İlişkin Bir Değerlendirme: Avrupa Birliğine Üye Ülke Macaristan ve Aday Ülke

Türkiye

- Asst. Prof. Dr. Fatma Gündoğdu Odabaşıŏlu (Atatürk University, Turkey) *

\#1706: Terörizmin Finansal Piyasalara Etkisi: Türkiye Örneği

- Assoc. Prof. Dr. Neşe Algan (Çukurova University, Turkey)

- Prof. Dr. Mehmet Balc1lar (Eastern Mediterranean University, Cyprus)

- Prof. Dr. Harun Bal (Çukurova University, Turkey)

- Ph.D. Candidate Müge Manga (Çukurova University, Turkey)* 
SESSION 3D: Finans III

Session Chair: Prof. Dr. Feyzullah Eroğlu

\#1768: Rusya Borsası'nın Petrol Fiyatlarına Bağımlılığı

- Asst. Prof. Dr. Dilek Özdemir (Atatürk University, Turkey)*

- Asst. Prof. Dr. Özge Buzdağlı (Atatürk University, Turkey)

- Ph.D. Candidate Murat Akdağ (Atatürk University, Turkey)

- Prof. Dr. Ömer Selçuk Emsen (Atatürk University, Turkey)

\#1553: Türkiye'de Seçimler ve Reel Döviz Kuru Oynaklığı (1992-2014)

- Prof. Dr. Cevat Gerni (Doğuş University, Turkey)

- Asst. Prof. Dr. Özge Buzdağlı (Atatürk University, Turkey) *

- Asst. Prof. Dr. Dilek Özdemir (Atatürk University, Turkey)

- Prof. Dr. Ömer Selçuk Emsen (Atatürk University, Turkey)

\#1503: Döviz Kurunun Çıktı Üzerindeki Etkisi: Geçiş Ülkeleri Örneği

- Prof. Dr. Ebru Çağlayan Akay (Marmara University, Turkey)

- Asst. Prof. Dr. Raziiakhan Abdieva (Kyrgyzstan-Turkey Manas University, Kyrgyzstan)

- Asst. Prof. Dr. Zamira Oskonbaeva (Kyrgyzstan-Turkey Manas University, Kyrgyzstan) *

\#1666: Faiz Koridoru Uygulamasının Merkez Bankası Politikalarına Etkisi

- Ph.D. Candidate Mustafa Batuhan Tufaner (Beykent University, Turkey) *

- Assoc. Prof. Dr. Kamil Uslu (Kavram MYO, Turkey)

- Assoc. Prof. Dr. İlyas Sözen (Beykent University, Turkey)

\#1637: Kredi Balonlarının Ekonomik İstikrarsızlık Üzerine Etkisi: 1998 -2016 Dönemi Türkiye Örneği 667

- Asst. Prof. Dr. Özge Korkmaz (Bayburt University, Turkey) *

\section{SESSION 4D: Finans IV}

Session Chair: Prof. Dr. Muammer Tekeoğlu

\#1607: Kırgizistan'da Vergi Bilinci 677

- Asst. Prof. Dr. Raziiakhan Abdieva (Kyrgyzstan-Turkey Manas University, Kyrgyzstan)

- Tolkun Cumakunova (Kyrgyzstan-Turkey Manas University, Kyrgyzstan) *

\#1662: Bir Mali Politika Aracı Olarak Çevre Vergileri: Baltık Ülkeleri Örneği

- Dr. Hilal Görkem (Çanakkale Onsekiz Mart University, Turkey) *

\#1782: İşletmelerde Kriz Yönetimi Çalışmaları ve İşletmelerin Kriz Öncesi, Kriz Anı ve Kriz Sonrası Yaptıkları Uygulamalara Yönelik Alan Araştırması

- Ph.D. Candidate Özgül Uyan (İstanbul Gelişim University, Turkey) *

\#1631: Yönetimde Yaratıcı Yenilik Bileşenlerinin Aydınlatılması

- Prof. Dr. Erdoğan Taşkın (Beykent University, Turkey) *

\#1771: İnşaat Endüstrisinde İnovasyon ve Ekonomi Üzerindeki Etkisi

- Asst. Prof. Dr. Fatih Kürşat Firat (Aksaray University, Turkey)*

- Ph.D. Candidate Hümeyra Tosun (Aksaray University, Turkey)

\section{SESSION 5D: Turizm}

\section{Session Chair: Prof. Dr. Mithat Zeki Dinçer}

\#1801: Türkiye'nin Kalkınma Planlarında Turizm Politikası

- Asst. Prof. Dr. Yaşar Akça (Bartın University, Turkey) *

\#1712: Zincir ve Grup Otel İşletmelerinin Kurumsal Sosyal Sorumluluk Faaliyetlerini Duyurmada Web Sitelerinin Etkinliği Üzerine Bir Araştırma: Türkiye Örneği

- Ph.D. Candidate Erhan Boğan (Sakarya University, Turkey) *

- Asst. Prof. Dr. Şevki Ulama (Sakarya University, Turkey)

- Prof. Dr. Mehmet Sarışık (Sakarya University, Turkey)

\#1653: Otel Oda Fiyatlarının Hedonik Model İle Analizi: Erzurum Örneği

- Asst. Prof. Dr. Cem Işık (Atatürk University, Turkey)

- Asst. Prof. Dr. Nilgün Bilici (Atatürk University, Turkey) * 
\#1674: Turizm Lisans Öğrencilerinin Girişimcilik Eğilimleri Üzerine Bir Araştırma: Sakarya Üniversitesi Örneği

- Asst. Prof. Dr. Şevki Ulama (Sakarya University, Turkey)

- Prof. Dr. Mehmet Sarışık (Sakarya University, Turkey)*

SESSION 1E: Büyüme I

Session Chair: Prof. Dr. Harun Bal

\#1639: Petrol Gelirlerine Bağımlılığın Yüksek Olduğu Geçiş Ekonomilerinde Petrol Fiyatları-İhracat-İstihdam ve Ekonomik Büyüme İlişkileri 752

- Prof. Dr. Murat Nişancı (Erzincan University, Turkey)

- Asst. Prof. Dr. Ziya Çağlar Yurttançıkmaz (Atatürk University, Turkey)

- Ph.D. Candidate Aslı Cansın Doker (Erzincan University, Turkey)

- Prof. Dr. Ömer Selçuk Emsen (Atatürk University, Turkey) *

\#1528: Orta Asya Ülkelerinde CO2 Emisyonu, İktisadi ve Finansal Gelişme ve Fosil Yakıt Enerji Tüketimi İlişkisi

- Asst. Prof. Dr. Mahmut Erdoğan (Kyrgyzstan-Turkey Manas University, Kyrgyzstan)

- Asst. Prof. Dr. Junus Ganiev (Kyrgyzstan-Turkey Manas University, Kyrgyzstan) *

\#1624: Girdi-Çıktı Analizi Yaklaşımıyla Kırgızistan Ekonomisinde Ekonomik Büyümenin Kaynaklarının

Belirlenmesi

- Assoc. Prof. Dr. Tuncer Özdil (Celal Bayar University, Turkey)

- Asst. Prof. Dr. Aynura Turdalieva (Kyrgyzstan-Turkey Manas University, Kyrgyzstan) *

\#1473: Devlet Harcamaları ve Gelirleri Arasındaki İlișkinin Test Edilmesi: Kırgızistan Örneği

- Prof. Dr. Hakan Çetintaş (Kyrgyzstan-Turkey Manas University, Kyrgyzstan) *

- Dr. Damira Baigonushova (Kyrgyzstan-Turkey Manas University, Kyrgyzstan)

\#1534: Orta Asya Türk Cumhuriyetlerinin Ekonomik Performanslarının Analitik Hiyerarşi Süreci ve VIKOR

Metodu ile Karşılaştırılması

- Dr. Engin Karakıș (Cumhuriyet University, Turkey)

- Prof. Dr. Ziya Gökalp Göktolga (Cumhuriyet University, Turkey) *

\#1693: Enerji Fiyatlarının Dünya Gıda Fiyatları Üzerine Etkisi: Bir Sınır Testi Yaklaşımı

- Assoc. Prof. Dr. Neşe Algan (Çukurova University, Turkey)

- Asst. Prof. Dr. Erhan İşcan (Çukurova University, Turkey)

- Ph.D. Candidate Duygu Serin (Çukurova University, Turkey) *

SESSION 2E: Büyüme II

Session Chair: Prof. Dr. Ahmet Incekara

\#1732: Küresel Ekonomiye Entegrasyon Süreçlerinde Türkiye İçin Küreselleşme Derecesinin Büyümeye Etkisinin Ölçülmesi, 1961-2013

- Asst. Prof. Dr. Hakan Acaroğlu (Eskişehir Osmangazi University, Turkey)*

- Assoc. Prof. Dr. Zeki Kartal (Eskisehir Osmangazi University, Turkey)

\#1726: Doğrudan Yabancı Yatırımların Ekonomik Büyüme Üzerindeki Etkisi: Türkiye Örneği

- Ph.D. Candidate Yılmaz Köprücü (Eskişehir Osmangazi University, Turkey) *

\#1689: Ekonomik Büyüme ve Finansal Gelişme İlişkisi: Türkiye Örneği

- Ph.D. Candidate Müge Manga (Çukurova University, Turkey)

- Ph.D. Candidate Mehmet Akif Destek (Gaziantep University, Turkey)

- Prof. Dr. Muammer Tekeoğlu (Çukurova University, Turkey) *

- Prof. Dr. Erkut Düzakın (Çukurova University, Turkey)

\#1645: Kalkınmakta Olan Ülkelerin Dış Borç, Büyüme Sorunları ve Türkiye Örneği

- Assoc. Prof. Dr. Oğuz Bal (Kocaeli University, Turkey)*

\#1599: Kalkınmada Ar\&Ge ve İnovasyonun Önemi; Türkiye Örneği

- Asst. Prof. Dr. Emine Firat (Aksaray University, Turkey) *

- Prof. Dr. Zeynep Karaçor (Selçuk University, Turkey)

- Prof. Dr. Serdar Altınok (Gazi University, Turkey) 
SESSION 3E: Teknoloji ve Rekabet

Session Chair: Prof. Dr. Erdoğan Taşkın

\#1756: Yükselen Piyasalarda Ar-Ge ve İnovasyonun Kalkınma Üzerindeki Etkisi

- Esra Soyu (Aksaray University, Turkey)*

- Prof. Dr. Serdar Altınok (Gazi University, Turkey)

- Asst. Prof. Dr. Emine Firat (Aksaray University, Turkey)

\#1606: Kalkınmada Ar\&Ge ve İnovasyonun Önemi; Güney Kore Örneği

- Prof. Dr. Bedriye Tunçsiper (Balıkesir University, Turkey)

- Asst. Prof. Dr. Emine Firat (Aksaray University, Turkey) *

\#1501: Rekabet Kavramına Yeni Bir Alternatif Yaklaşım: Sistemik Rekabet

- Asst. Prof. Dr. Nurgün Topallı (Bozok University, Turkey) *

- Assoc. Prof. Dr. Birol Mercan (Necmettin Erbakan University, Turkey)

\#1765: Ekonomik Büyümede Girişimcilik Eğitiminin Önemi

- Prof. Dr. Harun Bal (Çukurova University, Turkey)

- Asst. Prof. Dr. Erhan İşcan (Çukurova University, Turkey)

- Birgül Katar (Çukurova University, Turkey) *

\#1743: Avrasya'nın Rekabet Gücü Türkiye

- Asst. Prof. Dr. Hakkı Çiftçi (Çukurova University, Turkey)

- Aliye Erşahinoğlu (Çukurova University, Turkey) *

\#1644: Kurumsal Sürdürülebilirlik Yaklaşımı - Bir Örnek

- Ph.D. Candidate Binnur Gürül (İstanbul Gelişim University, Turkey) *

SESSION 4E: Экономический рост

Session Chair: Assoc. Prof. Dr. Damira Japarova

\#1799: Структура Экономики Раннесредневековых Кыргызов

- Assoc. Prof. Dr. Muratbek Kozhobekov (Kyrgyzstan-Turkey Manas University, Kyrgyzstan) *

\#1708: Экономический Рост И Перспективы Развития Аграрной Экономики Кыргызстана В Условиях

Экономической Интеграции

- Prof. Dr. Jusup Pirimbaev (Kyrgyzstan-Turkey Manas University, Kyrgyzstan) *

- Prof. Dr. Dzhumabek Dzhailov (Ministry of Agriculture, Kyrgyzstan)

- Umet Momunov (Osh Technological University, Kyrgyzstan)

\#1659: Необходимость Диверсификации Промышленности Азербайджана

- Assoc. Prof. Dr. Lala Hamidova (Azerbaijan State Economic University, Azerbaijan) *

\#1505: Влияние финансово-кредитной политики на социально-экономическое положение Кыргызской Республики

- Prof. Dr. Merim Koichueva (Kyrgyz-Russian Slavic University, Kyrgyzstan) *

SESSION 5E: Экономической развитие

Session Chair: Prof. Dr. Jusup Pirimbaev

\#1620: Качество Медицинских Услуг В Кыргызстане 904

- Assoc. Prof. Dr. Damira Japarova (Kyrgyzstan-Turkey Manas University, Kyrgyzstan)*

- Dr. Damira Baigonushova (Kyrgyzstan-Turkey Manas University, Kyrgyzstan)

\#1551: Перспективы Туристического Бизнеса В Кыргызстане

- Prof. Dr. Anara Kamalova (Kyrgyz National University, Kyrgyzstan) *

\#1474: Обязательное медицинское страхование в Кыргызстане: проблемы и пути совершенствования

- Assoc. Prof. Dr. Damira Japarova (Kyrgyzstan-Turkey Manas University, Kyrgyzstan) *

\footnotetext{
* Presenting author
} 


\title{
Keynote Speech \\ Global Economy and Turkey: 2016 and Beyond
}

\author{
Durmuş Y1lmaz (Central Bank of Turkey, Turkey)
}

\begin{abstract}
Irrespective of whether advanced economies (AEs) or emerging market economies (EMEs), the number one problem of the global economy is not being able to generate a satisfactory growth. Income levels is in some countries are barely above the per-crisis level. Despite ample liquidity due to quantitative monetary policies, consumption and investment demands are weak. Because high level of indebtedness deter economic agents from using credit. Credit markets still do not function well either. Quantitative easing policies have been successful in containing further deterioration. Despite ample liquidity inflation has not risen, but it did delivered the expected growth. Because banking system in AEs is weak and monetary transmission mechanisms are not functioning well. As for EMEs, commodity prices and World trade appears to be weak; economic growth are slowing down, capex is visibly falling in heavy industrial sectors due to already existing excess capacity. The academia as well as the business community are worried about the appropriateness of the present policies in case another recession comes, central banks will have little ammunition to deal with it. The option being talked of now is what is dubbed as "helicopter Money". Turkey being an open economy, has been and will be effected by the developments in the global economy through trade, capital flows and expectation channels. By international standards, Turkey have a reasonable growth rate of 3 to $4 \%$, implying a new growth era where high growth cycle ended due to changing global financial conditions and its structural problems. Future growth performance will depend on the level of investments and savings to finance it. As her own saving is low, foreign capital flows is crucial. High inflation and interest rate are the two negatives, but it has a strong fiscal position, debt / GDP is $32.3 \%$, the budget is almost balanced, producing primary surplus which proved it is resilience in the face of recent failed coup and the negative attitudes displayed by the rating.
\end{abstract}

Following the stagflation era of the early ' 70 s due to the first oil shock, the global economy went through a very benign period ending with a crisis in august 2007. This era spanning for almost 20 years is called Great Moderation where the global economy, especially the Advanced Economies (AEs), generated, in relative terms, reasonably high and sustained growth, low inflation as well as high employment.

This benign environment had a profound impact on the economic policy designs and the regulatory approaches. That is free markets were functioning well, the lesser the interventions into the workings of the markets, the better it would have been. Because, at the time it was thought that less regulation and supervision would have led to higher efficacy and financial innovation, which in turn would reduce the cost of doing business and further enhance the economic growth. This thinking was in fact formulated into a set of neo-classical rules which are today known as "Washington Consensus".

However, this episode ended unhappily in august 2007 with a crisis first in the financial sector, where asset prices plunged, and then permeating itself on to the real economy, causing dislocations in every part of the economies resulting in rising unemployment and falling output.

Since the crisis manifested itself first in the financial sector of the AEs with toxic assets, and the Emerging Market Economies (EMEs), being free of these assets, served at the early stages of the crisis, as the growth engine of the global economy. That is, while the AEs went into recession quarter after quarter, the EMEs played a vital role for the World Economy by generating a reasonably high growth by eliminating the demand deficiency to a certain extent and contained further contraction.

Today, irrespective of whether the AE or the EMEs, the most urgent and the number one problem of the global economy is not being able to generate a satisfactory sustainable growth. In some countries income levels are barely above the pre-crisis level. Despite ample liquidity due to the very large accommodative monetary policies, consumption and investment demands are weak. This is so, despite the fact that, in many AEs, the cost of capital is zero or close to. Even in some major economies interest rates are negative and literally money is free. In the meantime, what is ironic is the rise of global debt level. Indeed, as the combined global GDP went up to 78 trillion US dollars in 2014 from 28 trillion US dollars in 1994, the combined global debt, however, increased to 225 trillion US dollars in 2014 from 40 trillion US dollars in 1994.

Also economic policies coordination wise has changed. At the onset of the crisis, all countries especially the EAs, more or less being on the same or similar business cycles, made the global economic policy coordination easy. In this respect the G20 and the Financial Stability Board (FSB) served as policy coordinating platforms for both in terms of intellectual analysis and policy designs.

The response of the authorities, on the G20 and the FSB meetings, to the crisis was to take and implement strict austerity measures. Because the diagnoses made were that the crisis was the result of the debt burden mainly of private sector; households and corporates, which through various bailing out programs turned into public debt. As 
a corollary, while fiscal policies were geared towards fiscal consolidation, the burden of tackling the problem fell on the monetary policy. The central banks of the major AEs adopted accommodative monetary policies known as Quantitive Easing (QE). Today the combined size of the balance sheet of four central banks has increased by five folds to around 18 trillion US dollars. The strict fiscal policy approach was then aided and justified by the academic literature that when the public debt of a country reaches to 90 percent of its GDP, the crisis becomes inevitable. Nowadays, this is disputed and challenged and the policy coordination by the G20 and the FSB is more difficult, since each country's needs are different. That is each country is on different phase of the business cycle.

Have these QEs policies worked? To a certain extent yes. It was effective in containing further deterioration and deepening the crisis, and in buying the time for politicians and other decision makers to address the structural issues. However, it cannot be said that politicians, especially in the European Union (EU) and the Euro Zone (EZ), used the time effectively and efficiently. It is true that cheap or rather free money has not generated inflation, neither did it deliver expected growth, but unemployment levels have come down in some countries. Except Russia, India, Brazil, South Africa and Turkey, in the rest of the World, inflation is very low, even negative in some countries. The average world inflation forecasted for 2016 is 4.3 percent and for the EMEs is 4.5 percent. Why then has the accommodative monetary policy, which is Keynesian in essence and aims at stimulating total aggregate demand, not worked? I believe the answer lies in the fact that, as an initial condition, the level of indebtedness of households and corporates was and is very high. Indeed household debt to the GDP is over 60 percent in the EU, 79.5 percent in the USA and 120.9 percent in Japan. When we look at the household debt to the disposable income levels, we see that it is 95.6 percent in the EU, 104.7 percent in the USA and 129.5 percent in Japan. Furthermore, those whose propensity to spend is high, do not have enough income; and those who have income but indebted save it in order to pay off their already high level of debt. Because in a recessionary environment, falling prices makes the debt burden even higher. This has led to the loss of confidence and spending cuts or postponements. For these reasons money is not demanded and hence the velocity of money tends to fall close to zero. This indicates that there are serious problems on both demand and supply sides of the credit markets.

Having, passed the mid-year and close to entering the last quarter of the year, what is the prospectus future of the global economy? When the International Monetary Fund (IMF) released it's the World Economic Outlook and the Global Financial Stability Reports on the occasion of the IMF-WB spring meeting in last April warned the world community that already weak growth will continue in 2016 at an increasingly disappointing pace. In fact the title of the Report was "too slow for too long". In the said reports the IMF forecasted the world economy to grow 3.2 percent 2016 and 3.5 percent in 2017. Since then, these numbers have been revised downwards. For the downward revisions, the IMF has cited two risks: one is financial which capital flight from the EMEs to AEs is. This so far has not been materialized on a grand scale. The other risk was a non-economic one such as loss of confidence, further depreciation of the EMEs currencies, geopolitics risks, and the developments in China and its impact on the rest of the world.

As for country specific developments, the USA economy, which was the first to go into crisis, has also been the first to begin to recover earlier than any other country. But it has not recovered fully yet. Despite the ample liquidity provided by the FED, households, under the low inflation and the low interest rate environment, are not too eager to spend. The level of indebtedness was/is already too high. The economy, as if, was/is going through a liquidity trap. The growth forecasted by the IMF is 3.4 percent in 2016 and 2.5 percent in 2017 . However, it seems that the economy has settled down to a growth rate of around 2 percent. The latest figure is 1.8 percent. Labor market is in better shape and inflation is around 0.8 percent, well below 2 percent target rate.

The FED in order to convince the markets that QEs policies are working, in May 2013 verbally communicated to markets, without any action then, that it will end the expansionary monetary policy sometimes in future. In fact, the FED stopped buying securities in October 2014, and hiked the policy late, the FED Fund Rate, by 25 basis points to 50 basis points in December 2015. Since then, market participants have been guessing how many times more the FED will hike.

Early in the year, the FED watchers said there would be 4 hikes bringing the policy rate to 2.5 percent by end 2016. However, 4 hikes were reduced to 2 and now expectations are that in the remaining part of 2016 the FED will hike only once, probably in December. When and what number of hikes are made, it will have great impact on the global capital flows. Why has the FED postponed the rate hikes? Probably economy is weaker then it first appears to be. It is also aware of its action that will negatively affect the rest of the world. Another reason might be that the USA Banks and other financial institutions have large exposures to high yield corporate bond market. In order to finance the investments in shale oil sector, companies borrowed heavily but with the fall in oil prices, the companies have become unable to generate enough income to service bond payments and other borrowings. Higher interest rates would make these debt services even more difficult. In terms of capitalization and capital adequacy ratio, although there are still number of other issues to be tackled with, the USA banks are in a better shape than the continental banks.

In 2015 the Euro Zone (EZ) grew 1.6 percent and this has just brought the GDP to pre 2008 level. The IMF's April forecasts were 1.5 percent for 2016 and 1.6 percent for 2017. In order to sustain the fragile growth momentum, the European Central Bank (ECB) took further measures to support this incipient growth, where the 
policy rate is zero. The union wide unemployment rate is 10.1 percent, public sector debt to the GDP is 90.8 percent which is rather high compared to post European standards, inflation is low around 0.2 percent. The EZ growth rate in the Q1 2016 is 1.6, the EU28 growth rate is 1.8 percent.

The ECB with its twin mandates of price and financial stability, in order to influence the economy through monetary policy, need a strong and efficient banking system, which is precondition to have a well-functioning monetary transmission mechanism. This even becomes more important under circumstances of negative interest rate environment. A strong banking system in its own right provides many indispensable externalities to the whole economy. For this reason one might say that "banking is a public good". The European Banks under the regulation and supervision of the Banking Union are in need of further capitalization and re-structuring. The non-performing loans are rising, and existing excess capacity means that there are more banks than needed and therefore there is a need for further consolidation. Greek debt problems still pose a threat to the system and Brexit has made a dent into the institutional structure and to the decision making process. The question asked is: is this a market failure or institutional failure?

Japan has been in recession for more than 20 years now. The prices are falling and inflation is low, in fact it is negative 0.4 percent which increases the burden of debt. The levels of public and household debt are very high. Some say that the high levels of these debts are not for concern. Because all of the debt is denominated in national currency, Yen, and owed to the residents. However if and when interest rates begin to rise re-financing this level of debt would become costly. Japanese unemployment is low. As the EZ banks, Japanese banks' financial conditions are weak and the monetary transmission mechanism is not working well either. Of late, the Bank of Japan (BOJ) has increased amount of bond purchases and brought the policy rate to negative area. Notwithstanding all these, the economy is weak and not growing. End of Q2 2016 y.o.y growth is a mere 0.1 percent. This indicates that Japan is really in liquidity trap for a considerable time.

The Brexit was cited by the IMF as one of the risks that might negatively impact the world growth. The UK has to negotiate the exit with the EU within 2 years. The UK decision to leave the EU will have wide range of disruptions and damages to the world trade and investment relationships due to the changing nature of international cross border productions pattern and trade. Since leave decision, the Bank of England (BOE) has cut the interest rate to lessen the negative impact on its own growth.

Russia, Brazil, South Africa, once the stars of the EMEs are experiencing hardships. Their economies are contracting, unemployment is rising and incomes are falling, due to the falling commodity prices. Russia's inflation is 7.2 percent, and y.o.y growth at end Q2 2016 is minus 0.6 percent. Among the EMEs India is the best performer with the highest growth rate of 7 percent in the world.

China seems to be at the threshold of a paradigm change in terms of its growth model. As the global economy is slowing, demand for Chinese goods are not increasing as before, China is mulling to switch from export led growth to domestic demand led growth. China grew 6.9 percent in 2015 and according to the IMF forecast it will grow 6.5 and 6.2 percent in 2016-2017 respectively. These are high growth rates by international standards but not by China's own historical performance standards. 6 to 7 percent growth rate is said to be not enough for China's social cohesion. Its public central government debt / GDP is low but private and local government sectors within the last couple of years have accumulated huge debt, at least 2.5 times of the GDP. The debt is owed to banks as well as what is called shadow banking outside regulatory and supervisory realm. According to the said IMF Report "the health of the corporate sector is declining due to slower growth and lower profitability. This is reflected in the share of the debt by the firms that do not earn enough to cover their interest payments". "Corporate bank loans potentially at risk amount to almost 1.3 trillion US dollars, approximately 7 percent of the GDP". In an unpredictable and volatile environment, where commodity prices and world trade appear to be weak, China has already slowed down capital expenditure in heavy industrial sectors of mining, ship building, steel and aluminum. In these sectors there has emerged and excess capacity. On the financial front the Chinese currency has been accepted to the SDR basket and China is trying to internationalize its currency with the ultimate aim of making it convertible. China is also encouraging the use of its currency in regional as well as in international trade.

Coming back to the policy choices and their implementations, academic worlds as well as business community are worried about the appropriateness of the present policies. Because the expansionary monetary policies might have come to its limits. Here the worry is that if another recession comes, central banks will have little or no ammunition to deal with it. Academic world and the policy designers are now discussing what is metaphorically called "the helicopter money". The former FED chairman Bernanke has written on this extensively. In case QEs policies fail completely, Bernanke proposes what he calls "Money Financed Fiscal Programs" where central banks are directly financing earmarked government spending.

The performance of the economy of any country depends on its own internal dynamics as well as how far it has been integrated into the global economy. Turkey, being an open economy, has been and will be affected by the developments in the global economy through trade, capital flows and expectation channels.

In terms of the league of biggest GNPs, Turkey is the 18th largest economy with a 720 billion USA dollars GDP at end 2015. Of lately, its ranking has oscillated between 17th and 19th places. 
Turkey's growth model rest on the realization of high current account deficit (CAD). High growth rate means high CAD. Because high growth entails high rate of investment, which under ideal conditions, should be financed by domestic savings. Since Turkey's domestic savings are low, the deficiency in saving is matched with the import of other countries saving through capital flows. In terms of economic activity, Turkey's growth model prioritize construction industry over manufacturing. In terms of expenditure it is the domestic consumption rather than external demand is decisive. Hence at the end, the total expenditure exceeds the total income which results in CAD. Turkey had current account surplus on its Balance of Payments (BOP) only in those years in which the economy grew negative.

The Turkish economy, at end Q1 2016, grew 4.8 percent y.o.y, mainly driven by domestic consumption, private sector investment being zero or negative for at least 13 quarters. In the medium term program, 2016 growth target is 4.5 percent and the latest forecasts by the WB, the IMF and the OECD are in a range of $3.5-3.9$ percent. Latest available data for leading indicators such as industrial production, capacity utilization and similar other survey numbers suggest that 2016 growth will be around 4 percent. However, no one should attempt to little this performance. It is a reasonable growth by international comparisons. However, it is not really very satisfactory when compared to its own recent performances as well as to its own potential growth rate, which is estimated to be around 5.5 percent.

With this level of growth, Turkey cannot accomplish a catching up process and close the per capita income gap vis-a-vis the developed economies. When one examines the dynamics of the Turkish economic growth sees that growth pattern has been very erratic. Average growth rate of the past 50 years is around 4.8 percent. Due to instability, both political and economic, the volatility of growth has been rather high. Highest and lowest rates of growth realized were 9.5 percent in 1976 and minus 7.8 percent in 2001. Per capita growth trend has lacked behind that of European Economies. The standard deviation of the growth has also been high. It was 5.1 in ' $90 \mathrm{~s}$ and 5.3 in 2000. The per capita income being 1,500 US dollars in 1980 increased to 3,000 in 1990 and to 10,000 US dollars in 2008. Since then, it remained around that amount; even fell below that in 2015 . After 9.2 percent and 8.5 percent growth rates in 2010 and 2011, Turkish economy seems to be settled to a 3 - 4 percent growth band. 2012-2015 average growth rate is 3.2 percent. This implies that Turkey has entered a new growth era where high growth cycle ended due to changing global financial conditions and its structural problems. Should we say that it is already in middle income trap? It may not be so. But it is at the threshold. Turkey should waste no time to address its structural problems.

Under this low growth environment, if yearly labor forces happen to be growing around 3 percent, employment growth will be below economic growth. Therefore, in the coming period the level of per capita will be determined by the rate of population growth and the rate of economic growth. For example if the economy grows 4 percent yearly and the population growth happens to be 1.3 percent, in 20 years from now Turkey's per capita income, based on 2015 GDP of 725 billion US dollars, will be 20,000 US dollars. If population growth remains at 1,3 percent and the economy grows at 3percent yearly rather than 4 percent, then in 20 years per capita will be around 15,000 US dollars, which is far below the per capita income target of 25,000 US dollars in 2023 target.

By the way, according to the data released by the TURKSTAT the unemployment rate was 9.4 percent in May 2016 compared to 9.3 percent in April 2016 and 9.3 percent in May 2015. Seasonally adjusted rated jumped from 9.8 percent to 10.2 percent being the highest since October 2015 . What has happened that the unemployment rate increased? Is this a temporary phenomenon or, it is the beginning of a new trend due to the concerns mentioned above.

What should be done? After 2001 crisis up until 2007, the bulk of the growth came from productivity growths due to the structural reforms accomplished. Since then, productivity gains are falling. This is so whether it is measured in terms of output per worker or output per hour worked. It is low and stagnant.

High inflation and high interest rates are two of negatives of the Turkish economy. In its last inflation Report the Central Bank of the Republic of Turkey (CBRT) has revised its assumptions on oil and import prices upward. At the same time it made downward revisions to its food prices assumptions. Based on these assumptions, it forecasted the year end inflation as 7.5 percent and 6 percent in 2017, 5 percent in 2018, which is the target. Markets do not share this optimism. The latest expectations survey shows that market participants see the inflation at the end of the year as 8.21 percent up from 7.81 percent, 12 and 24 months expectations stands at 7.61 and 7.16 percent respectively. Market's position is understandable because, core inflation which is more sensitive to the interest rate changes is rather high and not responding much to policy changes.

In last august the CBRT communicated to the market that it would simplify its interest rate policy, meaning that when the process ended, it will give all the liquidity at the one week repo rate. Since then it has cut upper band of the corridor several times. Now its upper corridor lending rate is 8.75 percent. The corridor has been narrowed. The headline inflation being at 8.76 percent at the end of July, does not give further maneuver for the CBRT, I believe. The composite funding cost has come down from 9 percent level to just above 8 percent which is just about equal to inflation. 
As was mentioned above, Turkey's growth model entail current account deficit. Because, Turkish manufacturing industry is dependent on imported raw materials and semi-finished goods. There is a high degree of tradeoff between growth and imports. According to a study, the rate of dependency of manufacturing industry on imports was 41 percent in 2008, 38, 40, 43 percent in 2009, 2010, 2011 respectively. These are average figures. The dependency ratio in iron and steel sector was 69 percent and in chemicals 56 percent etc. Due mainly to the collapsed commodity prices and the slower economic activity during the last 12 month, the current account position had improved considerably. However, June 2016 Balance of Payment (BOP) figures show that this improvement has been halted The declining tourism revenues which make up 3 percent of GDP and 13 percent of total hard currency earnings, and rising imports seem to be the likely the cause behind this reversal. On a 12 month rolling basis the deficit widened from 27.7 billion US dollars to 29.4 billion US dollars. In terms of percentages the current account deficit to the GDP now stands at 3.5 percent down from 7.9 percent at end 2013. Re-establishing good relations with Russia is a right step in the right direction. But Turkey will feel its full impact next year.

As for capital flows into the country, which is vital for a saving deficit country, after the initial negative reaction in the wake of the failed coup attempt, flows continue as before. In the latest BOP, one can see that real sector, as of end June, was able to refinance its maturing debt to the extent of 179 percent. Similarly long term external debt roll-over ratio of banks was 123 percent. The FDI flows continue at a reasonable pace.

In the immediate aftermath of the failed coup, the Turkish currency depreciated to the tune of 6 percent. However when markets opened following Monday, currency recovered fast and it is now at pre-crisis level. It was a sell opportunity for domestic residents with foreign exchange deposits at the banks. Their foreign exchange sales as well as the communication with market by the CBRT and government were instrumental in restoring the confidence quickly.

Turkey is one of the few countries having exceptionally strong public finance positions. Budget deficit is forecasted as just below 1 percent and still producing primary surplus. In fact with the July numbers, one sees that the budget balance was in surplus by 1.3 billion TL in the first seven month of the year. In the same period the primary surplus was realized as 31.9 billion TL. Despite this overwhelming fact, in the markets there were concerns for the Turkish economy's investment grade rating. Yes there had been a failed coup, but it caused no damage to basic fundamentals of the economy. It is also true that there is high foreign exchange denominated debt maturing in a year' time. This is not a new thing, market already knew it. What mattered was and is the confidence of the investors in the economy. Out of 3 Rating Agencies, the 2 have acknowledged Turkey's investable rating grade and capital flows continue as before. Had one of the Agencies downgraded Turkey, by regulation, institutional investors would have to leave the country creating pressure on the currency.

Since 2001 crisis the Turkish economy has moved a long way through implementing the first generation of the reforms and the structural changes. Now there is a need for a second generation of reforms and structural changes. In this respect for development, volume of physical and human capital accumulation, including factories machines, tools and educational qualifications are all important. But more than that are the need for advanced knowledge, innovation, culture, social norms and well-functioning institutions.

For this end to maintain the resilience of the economy, the authorities must be ready to eradicate corruption, informal economy, political intransigence, weak legal system and the feeling of the wide spread insecurity. For the level playing for all, impartial and transparent enforcement of the rule of law, protection of the property rights, incentivizing for higher value added innovation and giving general assurance that peoples' rights not get violated must be the utmost priority of the authorities. 


\title{
A Crossroad For Turkey: European Union Or Eurasian Economic Union
}

\author{
Ph.D. Candidate Nergiz Başeğmez (Beykent University, Turkey) \\ Asst. Prof. Dr. Kerem Toker (Beykent University, Turkey)
}

\begin{abstract}
With a long and complicated history with Turkey's EU relations began in 1963 with Ankara Agreement. Turkey has been engaged the full membership since 2005 but nevertheless it could not have achieved results during the negotiations. Behind the slow pace of Turkey's membership, many political and cultural barriers can be shown. The events showed that reveals Turkey cannot be an EU member as soon as possible. This case may cause the Turkey have different pursuits in the political world arena. Turkey moved away from the EU, it can be motivated to participate in different political and economic union at the same time. Because, the world is constantly changing in terms of economic and political conditions and Turkey is hard to question the position in these new conditions. Founded in 2015 Eurasian Union has similar cultural and historical heritage alongside the geographical closely EAEU with Turkey. This common history may create opportunities for both sides. In this study, economic, social and political relations between Turkey and the EAEU countries are briefly discussed. Datas about this issue were gathered by Eurostat, europa.eu, wto.org and eurasiancommission.org etc. official data sources. The findings were compared with similar indicators between Turkey and the EU. So the EAEU is evaluated likely to be an alternative political and economic union to Turkey. Such a vision changes in Turkey will revise its economic and political stability of the region. This paper may contribute to further studies by providing a solid base.
\end{abstract}

\section{Introduction}

Following the Second World War, Turkey choosed to take part in the Western Block and it applied to membership of European Economic Community after it was accepted the membership of North Atlantic Treaty Organization (NATO). This step would affect all subsequent decisions of Turkey (Uysal, 2001). In this way, Ankara Agreement between the European Economic Community and Turkey signed as the partnership agreement in 1963. This agreement predicted to three stages as "preparation," "transition" and "final" until it reaches full membership. Upon entry into force of the Ankara Agreement in 1964 began the preparatory phase ended with the Additional Protocol, signed in 1970 and began the transition phase. This phase ended with the signing of the Agreement on the European Customs Union in 1995. Thus, the hoped-for result of Turkey-European Union full membership in the relations "final" phase began (Demirkıran at all., 2010). With a long history in Turkey - EU relations represents the undulate but also important process for two sides. Despite all the tensions, both of sides never give up the other to date (Uysal, 2001).

It has also increased Turkey's expectations for full membership with the inclusion EU Customs Union (CU). However, some leading conservative European heads of government of Turkey's increasingly after the 1980 Europeans being stated that away. In particular, religious, geographical, because of problems related to human rights and Greece, which also difficult to be a full member of the Community indicated. A similar emphasis, particularly after 1980, also extensively discussed and processed in written and visual media in Europe. This negative development in Turkey has been the contribution of people who are refugees in Europe (Aslan, 2000). One of the big reasons of the European Union to refrain from pronouncing the date of full membership for Turkey to defer the risk of suddenly entering an irreversible process (Arsava, 2002). At this point, it would be appropriate to examine the contribution of the European Customs Union on the relationships between the Turkey - European Union.

Although Eurasian Economic Union is a young foundation, it provides a future with important expansions for Turkey due to geographical closeness to Turkey, common logistical networks, energy corridors and potential trade. Commercial partnerships with Eurasian Economic Union. Turkey will contribute an active power into EAEU with its existent economic and population potential. Cyclical negative relations between Russia and Turkey are assumed to get better in long term and both will need each other for the future of global world.

\section{European Customs Union and Turkey}

Today, the EU is the most advanced regional bloc which is stage of economic integration in the worlds. It has been implemented six expansionary phase until today and it has 28 member of EU. The EU reached the international economic forces, take part in these blocks has become attractive to other countries (Akçay, 2008). One of these countries is Turkey. Turkey as a member of the customs union in 1996 is the first step to be a part of this economic bloc. At the same time, Turkey has undergone a "Final Phase" pursuant to Ankara Agreement in partnership relations with the EU. Together with the Customs Union with Turkey is an important development affecting the entire economy, customs duties on trade in industrial products between the EU and Turkey, 
quantitative restrictions and measures having equivalent effect removed, Turkey has started to implement the Common Customs Tariff to third countries (Doğan and Kaya, 2011). It is very difficult to reach a definitive judgment by examining the Customs Union at the benefit-risk axis. But a number of studies examining the judgment and will lead to some statistics (AABBM, 2010). In the period after the Customs Union, Turkey's share in foreign trade in the EU While there wasn't a significant change, change in the composition of Turkey's exports it was observed. In particular, it has gained importance value-added and provider of high employment as white goods, automotive industry and competitiveness in the sectors has experienced positive developments (Doğan and Kaya, 2011).

\begin{tabular}{ccccc}
\hline Country Groups (1996) & Exports & Imports & $\begin{array}{c}\text { Balance of Foreign } \\
\text { Trade }\end{array}$ & $\begin{array}{c}\text { Proportion of Imports } \\
\text { Covered by Exports } \\
\text { (\%) }\end{array}$ \\
\hline Total & 23.224 .465 & 43.626 .642 & -20.402 .177 & 53,2 \\
\hline European Union (EU-28) & 12.590 .475 & 24.349 .181 & -11.758 .706 & 51,7 \\
\hline $\begin{array}{c}\text { Share of EU-15 in Total } \\
(\%)\end{array}$ & 54,2 & 55,8 & 57,6 & - \\
\hline
\end{tabular}

Table 1. Foreign Trades of Turkey at the Beginning of European Customs Union Source: Turkish Statistical Institute (TUIK), (2016)

Beginning in 1996, Turkey's foreign trade deficit began to grow rapidly with the EU. The average annual foreign trade deficit reached $\$ 10$ billion. The Turkish market is rapidly it became a EU 6th largest market in the world. The crisis of Turkey's manufacturing industry also largely depends on it. In return to Turkey's EU exports do not increase. Already textile industry is constitute $65 \%$ of Turkey's exports to the EU. Because the EU textile, are sourced from countries of the former Eastern European countries and established a special relationship countries such as China and India (Doğan, 2004). Turkey, while exports to consumer goods such as textile, clothing and food products to EU, mainly from the EU chemical, intermediate and investment goods such as machines and vehicles, iron and steel products are imported. This means that about half of the import and export amount of Turkey is dependent on the EU economy (Aktaş ve Güven, 2003).

\begin{tabular}{ccccc}
\hline Country Groups (2015) & Exports & Imports & $\begin{array}{c}\text { Balance of } \\
\text { Foreign Trade }\end{array}$ & $\begin{array}{c}\text { Proportion of } \\
\text { Imports Covered by } \\
\text { Exports (\%) }\end{array}$ \\
\hline Total & 143.861 .522 & 207.206 .813 & -63.345 .291 & 69,4 \\
\hline $\begin{array}{c}\text { European Union (EU- } \\
\mathbf{2 8})\end{array}$ & 64.003 .582 & 78.668 .777 & -14.665 .195 & -3 \\
\hline $\begin{array}{c}\text { Share of EU-28 in Total } \\
(\%)\end{array}$ & 44,4 & 37,9 & 23,1 & - \\
\hline
\end{tabular}

Table 2. Foreign Trades of Turkey with European Union (Thousand \$) Source: Turkish Statistical Institute (TUIK), (2016)

As shown in Table 2, almost half of Turkey's total foreign trade volume is carried out by the EU. The main reason of commercial concentration between the EU and Turkey; it is the cultural and geographical closeness. Customs Union has contributed to the establishment of economic closeness between the parties (Özsan, 2015).

However it did not come from the EU capital for investment, even decreased. EU companies of Turkey to the EU would open all doors to goods sent to Turkey instead build factories in Turkey. In fact, they get produced goods to cheaper third countries and after deal to Turkey. Therefore, investment from Europe declined since 1996. Foreign capital is generally invested in that country to overcome the wall when there tariff barriers. This capital has gone to China because of customs barriers (Özsan, 2015). Therefore, it is difficult to say that Turkey expects to find from customs union agreement.

\section{Demographic Structure of EU and Turkey}

Population and development relationship is an issue that always focus on countries. Because the population is an important element in providing labor required for development on the one hand; the other hand, excessive population growth is slowing down the development besides an issue that may cause a reduction in per capita income and various problems (Şahin, 2008). Labor force is an indicator of human element in the economic activity. 


\begin{tabular}{|c|c|c|c|c|}
\hline \multicolumn{3}{|c|}{ European Union (EU-28) } & \multicolumn{2}{|c|}{ Turkey } \\
\hline \multicolumn{3}{|c|}{508.450 .856} & \multicolumn{2}{|c|}{77.695 .904} \\
\hline \multicolumn{3}{|c|}{ Years } & \multicolumn{2}{|c|}{ Years } \\
\hline $0-14$ & $15-64$ & $65+$ & $0-14$ & $65+$ \\
\hline$\% 15,6$ & $\% 65,9$ & $\% 18,5$ & $\% 24,6$ & $\% 7,7$ \\
\hline
\end{tabular}

Table 3. The Population Structures of EU and Turkey Source: Eurostat, (2016)

In addition to these problems, the most serious problem for the European Union is the decrease of young population and the decrease of old age population. As population aging in European Union causes various problems, the decline of working capacity and fertility becomes at the head of the problems. While looking the estimations for the years between 2020 and 2025 it is said that old age population rate will pass over young population rate in European Union. Accordingly, the need for labor force will increase within the decrease of fertility (Şen, 2014). In contrast with young population structure of Turkey, it is seen that the population of European Union is old and aging process maintains. European Union may benefit from the young population of Turkey in the policies about the protection of producing power. However, despite of the high young population rate in Turkey, the lacks in education and quality of this population make the adaptation to the employment process in European Union difficult.

When the population of European Union countries have decreased, Turkey has attracted all the attentions due to the increase of Turkish population and the highest migration tendency as 6,2 percent among the candidates for European Union. In view of young and employed population; within the membership of Turkey into European Union migration to Turkey may cause positive impact for European Union due to the free circulation of labor force as a data. On the other side, because the number of qualified employee will begin to decrease, the high rate for the migration tendency of many individuals in Turkey is a positive development for European Union. Within the context of Turkey's membership to European Union, it is estimated that more than 2,7 million people will migrate in the common result for the works in order to evaluate possible migration movements (Şen, 2014).

\section{Eurasian Economic Union}

Regional economic integration is a noticeable trend in the global economy, whose future, probably, will largely depend on the effectiveness of global dialogue of integrational entities and on their internal stability. Eurasian Economic Union (EAEU) which laid the foundations with a treaty among the leaders of Belarus, Kazakhstan and Russia on 29 May 2014 with Armenian involvement on 9 October 2014 was officially founded on 1 January 2015. Kirghizstan took a decision for the membership on 11 April 2011 and officially became the member on 8 May 2015 in Russia’s capital city Moscow (Sülün, 2015). In this way Eurasian Economic Union has consisted of five countries as Belarus, Kazakhstan, Russia, Armenia and Kirghizstan. The Union has 182,1 million people as a population and 2,411,2 billion dollar as Gross Domestic Product (GDP). At the same time Eurasian Economic Union has executed industry production valuing 1,3 trillion dollar (eurasiancommission.org, 2015). On the other side, the Union has signed "Free Trade Agreement" with some countries. The first draft agreement was confirmed by Russian government on 25 May 2015 for the foundation of free trade area between Eurasian Economic Union and Vietnam. Eurasian Economic Union has aimed to enhance its economic hinterland by signing free trade agreement with Egypt in the next months. Besides, it is expected that Central Asian countries such as Uzbekistan, Tajikistan and Turkmenistan and some countries such as Azerbaijan and Ukraine will play a part in Eurasian Economic Union in the forthcoming days (İncekara ve İncekara B., 2015).

It is difficult to forecast that Eurasian Economic Union which began with Customs Union Agreement will transform into either political integration or not. In addition to this, Eurasian Economic Union has aimed integration in plenty of field from the food sector to energy. For example, Nazarbayev suggested to constitute a Common Technical Area in the region. A common electric network has also been at issue. Moreover, each side has been in search of solving food problems in the region (İşyar, 2012). To provide economic union as a common goal has become clear with notably targets and all the movements in concrete economic field by straitening the frame rather looking after political interests as an ultimate goal in the foundation of the Union. The main basis of integration is economy (Bahtiyar, 2015). In line with these developments, Turkey has continued to enlarge and deepen its existent historical links with Eurasian Economic Union countries down from long years.

\subsection{The Economic Relations between Turkey and Armenia}

While evaluating the economic relations between Turkey and Eurasian Economic Union, the matter has become more complicated. It is possible to say that Eurasian Economic Union Project has had an important position for Turkish foreign policy. However, Turkey which recognized first the independence of Armenia among the other countries after the disintegration of the Soviet Union closed border gate with Armenia in 1993 as its Azerbaijan policy and took a decision laying an economic embargo to Armenia. But the trade between Turkey and Armenia 
has gone on proceed by the way of largely Georgia and Iran. Today the use of Turkish construction materials in the buildings of Armenia and Turkish products in workplaces and general stores are seen by naked by without indepth research. Despite inclose borders, trading volume between two sides was 4,5 million dollar in 1993, scaled up 30 million dollar in 1997, 120 million dollar in 2007 and has been 200 million dollar since 2008 (Ozinian, 2013). This situation indicates the need of steps for the normalization of commercial relation policies between Turkey and Armenia.

Accordingly; within the frame of a will about the normalization of relations and overcome the problems between Armenia and Turkey, the process beginning in 2007 with the mediatorship of Switzerland entered to a new process with "The Protocol of Setting Diplomatic Relations" and "The Protocol for Developing Bilateral Relations" (Bahtiyar, 2015). Despite of all well-disposed attempts between these two Armenia and Turkey, recognition process of the protocols were ceased by both countries.

\subsection{The Economic Relations between Turkey and Russia}

Russia has been the biggest and the most important neighbor and the most serious competitor of Turkey in immediate environment at least for 250 years. Today the two biggest economic and military power from GermanyItaly to China-Iincekarandia border in wide Central Eurasia Area is undoubtedly Russia and Turkey. This condition has led to witnessing many conflicts, competitions and wars in Turkish-Russian relations in all the periods of history (Zengin, 2015). Both Russian Federation and the old Union of Soviet Socialist Republics (U.S.S.R.) are one of the important trading partners of Turkey. Since the beginning of 1990's Russia has had a fluctuated structure in commercial relations. Balance of trade between these countries is against Turkey (Duman ve Samadov, 2003). In the recent period, there has been economic and commercial matters consisting of energy and defense industry at the center of relations between the two countries (Çelikpala, 2015).

While Turkey has mostly exported to European Union countries, it has also mostly imported from Russia which is one of the countries of Eurasian Economic Union. Namely, the maximum export share in Turkish foreign trade has respectively belonged to Germany, England, Italy and France among the European Union countries. Turkey has mostly had export with Germany and this export has been almost 13,96 billion dollar since 2011. While the datas are examining in terms of import, it is seen that Turkey's import has respectively been with Russian Federation, Germany, China and U.S.A. (Zengin, 2015). In 2013 Aleksandr Lukasevic- the spokesman Russian Foreign Ministry stated that Russia composed 9,3 percent in share of total foreign trade in Turkish Republic and trading volume between two countries in 2012 increased than the previous year and reached 34,3 billion dollar (Demir, 2014).

Turkey and Russian Federation have a mutually complementary structure in terms of economic and commercial relations. Turkey's services export such as consumer products and the construction business, entertainment of Russian tourists, purchase of semi-manufactured products, petrol, natural gas and coal seem to verify this diagnosis (Zengin, 2015). Russia has reached the condition of a broad market in fresh fruit, vegetable, chocolate, biscuit, macaroni, tobacco, liquor, non-alcoholic drink, vegetable oil, tea, textile, ready wear, personel auto, electronic item, white goods and many other products which are known as fragile goods in West market and are produced by Turkey. The visible rise in making these products in Turkey has partially actualized with demand increase in Russian market.

\subsection{The Economic Relations between Turkey and Kazakhstan}

In the evaluation of economic relations between Turkey and Kazakhstan, primarily building trade should be regarded. Building trade of Kazakhstan has a high rate as 6,6 percent in GDP. This is one of the foremost sectors for the country and Turkey has an important place in terms of investments to the country with the steps for building trade (Başç1, 2015). Thus, after the independence of Kazakhstan, Turkish private sector has strongly fronted to get in contact with the region. Also, the concentration in the field of construction business has been seen. These companies has a comparative superiority in many respects in comparison to other international companies competing for similar works. The reasons of this situation are that the business is large-scaled and quality according to Central Asian criteria, the prices are comparatively low and the companies are open to various payment kinds (Dikkaya ve Bora, 2006).

While analyzing commercial relations between Turkey and Kazakhstan, it can be thought that there is a considerable level of these relations. Turkey has had commercial relations with approximately 220 countries. While analyzing exports with these countries, it is observed that Kazakhstan has an array between 29 and 37 during the years between 2005 and 2015. In import this array is between 21 and 37. From 2005 to 2012 a continuous increase in trading volume except crisis years is observed. After 2012, there has been a decrease. Equilibrium datas indicates the remarkable point that the import of Turkey to Kazakhstan is higher than export to the same country (Başç1, 2015). Commercial relations between two countries show that Turkey has a potential for being strategic partner of Kazakhstan by developing cooperation in Eurasia with the impacts of their common history, common ethnicity and common cultural features. At the same time, Turkey is candidate for being important market with its ever-growing industry, increasing consumption expenditures and growing export potentials (Dikkaya ve Bora, 
2006). Especially the importance of economic intimacy with Kazakhstan has increased whereas Turkey's foreigndependent energy policies.

\subsection{The Economic Relations between Turkey and Belarus}

Belarus is 68th in world economy with its 76,1 billion dollar GDP according to datas of World Bank 2014 Report (worldbank, 2016). Turkey was the first country recognizing the independence of Belarus and diplomatic relations began on March 25, 1992. The relations between two countries has proceeded at a positive course (mfa.gov.tr, 2016). Turkey has adopted constructive policy because providing common ground and interests with international society will develop the dialogue and cooperation with the European-Atlantic institutions and provide both regional peace and stability and national interest of Belarus (Bahtiyar, 2015). In total investments to Belarus, Turkey has been one of the first five countries with 1,1 billion dollars. Turkish entrepreneurs has put important projects into practice and total value has reached 900 million dollars. Bilateral trading volume which is at humble level as being 379 million dollars by year 2014 on November is aimed to keep up 1 billion dollars in the upcoming years. Besides, Turkey has had presidentship of Working Group from 2010 about participation of Belarus in World Trade Organization. In 2014, the number of tourists from Belarus to Turkey increased 10 percent and surpassed 220 thousand. The visa-free travel regime coming into force on June 2014 indicates the positive contribution to Turkey's human relations. The positive commercial and human relations between these two countries for years give hope to bigger economic developments.

\subsection{The Economic Relations between Turkey and Kirghizstan}

Despite of being a small country, Kirghizstan has had a great effort in order to be integrated into world trade. The country has amended and made some comprehensive regulations as a reform in order to develop economically. Foreign trade regulation has considerably been liberalized. In this context, extraverted economy policy has been adopted. The country has made some institutional arrangements to be integrated into world economy without any dependency to Russia (İnançlı at all., 2015).

The relations between Turkey and Kirghizstan has followed a positive course in strategic partnership level with mutual strong will. Turkey has supported the institutionalization of Kirghizstan with its all state-owned companies and non-governmental organizations. Multidimensional relations in the field of policy, economy, trade, military, culture, education, health and transportation has maintained within the scope of a broad legal basis containing more than 200 hundred agreements and protocols. Turkey has exported jewelry and its sections, textile products, woven carpets, personal cleaning products, cacao- free sugary products, electric waterheaters, electrothermic devices, space heaters, blow dryers and iron. Besides that Turkey imported from Kirghizstan legume, cotton, copper scraps, canned vegetables, aluminum scraps, gold, fresh and dried fruits, unfinished bullet and aluminum. About 300 Turkish capital companies carrying on various sectors have contributed Kirgiz economy with 304 million dollars capital and have employed more than five thousand Kirgiz citizens. On the other side, 163 company with Kirgiz capital has been active by year 2015 on December. Up to now, Turkish contracting companies has undertaken 65 projects valuing 689 million dollars (mfa.gov.tr, 2016). Commercial relations between two countries has widened from year to year.

The main documents of strategic partnership between two countries are "Agreement of Perpetual Friendship and Cooperation" signed in 1997 by both the presidents of Turkey and Kirgizstan, the assertion as "Turkey and Kirgizstan: to 21 st century together" published in 1997 and "Common Statement about the Foundation of HighLevel Strategic Partnership Cooperation" signed in 2011. There has been no problem in political relations between Turkey and Kirghizstan and in multilateral plan Kirgiz administration has supported and played a part in formations as in Turkish Council (Bahtiyar, 2015). In relevant term, the average export to Kirghizstan has composed of 7,84 percent investment goods, 29,53 percent raw materials, 62,11 percent consumer goods and 0,52 percent other product groups. The average import from Kirghizstan has composed of 0,86 investment goods, 42,67 percent raw materials, 56,46 percent consumer goods and 0,02 percent other product groups (İnançlı at all., 2015).

\section{The Relations between Turkey and Eurasian Economic Union}

Turkey has always a role in the Eurasian Economic Union region with the impact of historic links. After the Second World War, Turkey pursued a west- sided foreign policy containing United States of America and European Union. However, the country has had an observable understanding that other regions of the world have been seen (İncekara ve İncekara B., 2015). There are geopolitical, economic, political and even sociologic features of Turkey in a possible membership to Eurasian Economic Union. Geopolitically, within the membership of Turkey new geopolitical and trade routes will open. The membership of Turkey means that Eurasian Economic Union can go down to the Middle East and Mediterranean. Russia can find the opportunity to reach Eastern Europe by way of Belarus and Turkistan and the Far Asia by way of Kazakhstan. For Turkey, the membership of Union is an opportunity to reach the South. This means that the membership will obtain the opening of new trade routes. One of the most important routes is the Black Sea region putting to sea as a unique direction for the Union. Thus, Black Sea region can be duty- free entrance door for coming products (Hazir, 2015). 


\begin{tabular}{ccccc}
\hline Country Groups (2015) & Exports & Imports & $\begin{array}{c}\text { Balance of } \\
\text { Foreign Trade }\end{array}$ & $\begin{array}{c}\text { Proportion of } \\
\text { Imports Covered by } \\
\text { Exports (\%) }\end{array}$ \\
\hline $\begin{array}{c}\text { Total of Turkey } \\
\begin{array}{c}\text { Eurasian Economic Union } \\
(\text { EAEU -5) }\end{array}\end{array}$ & 143.861 .522 & 207.206 .813 & -63.345 .291 & 69,4 \\
\hline $\begin{array}{c}\text { Share of EAEU-5 in Total } \\
(\%)\end{array}$ & 6,7 & 21.780 .315 & -12.101 .381 & 44,4 \\
\hline
\end{tabular}

Table 4. Foreign Trades of Turkey with Eurasian Economic Union (Thousand \$) Source: Turkish Statistical Institute (TUIK), (2016)

Commercially, Eurasian Economic Union countries are the first in petrol and natural gas production all around the world. These countries have 183 million population and 2,7 trillion dollars economic volume. Turkey may be an important country in the supply the needs of millions of people. Turkey is also an important country in contributing market economy of Eurasian Economic Union. Turkey can reach Turkistan through Caucasus and in this way the productions of Kazakhstan can easily reach to Turkey (Hazır, 2015). In addition to this, the common market is seen as decennary goal without legislation barriers in the production of energy, petrol and petroleum product over Eurasian region (İncekara ve İncekara B., 2015). Under these circumstances, Turkey which has been foreign- dependent in energy may be advantageous for the Union.

\section{Demographic Structure of EAEU and Turkey}

Eurasian Economic Union has composed a common labour market in order to provide a dynamic structure for the population movement. Now, ordinary citizens of each member state can easily get a job in other member state without getting work permit and foreign workers quota. The obligation for the registration to Police Department for workers and their families in the relevant region has been cancelled. Down to 30 days they can stay as unregistered. In addition to this, since 2015 on January 1 university diplomas of the member states are automatically recognized in other member states (Bahtiyar, 2015).

\begin{tabular}{cccccc}
\hline \multicolumn{2}{c}{ Euroasia Economic Union (EAEU-5) } & \multicolumn{3}{c}{ Turkey } \\
\hline \multicolumn{3}{c}{183.319 .693} & & Years & \\
\hline $0-14$ & Years & & 095.904 & \\
\hline$\% 21,9$ & $15-64$ & $65+$ & $0-14$ & $15-64$ & $65+$ \\
\hline
\end{tabular}

Table 5. The Population Structures of EAEU and Turkey Source: http://www.un.org/ (2016)

As seen at above table 5, population structures of both Turkey and Eurasian Economic Union shows a similar characteristic. This situation may provide an opportunity to improve positive policies in terms of market opportunities and mutual mobility of the work force. While 0-14 group of age in Eurasian Economic Union has 21,9 percent share in total population, this rate in Turkey is 24,6 percent. The rate of old age population $(+65)$ is 9,8 percent in EAEU and 7,7 in Turkey. The potential membership of Turkey into EAEU will create a positive impact in terms of youthening of the Union population.

\section{Conclusion}

Meanwhile, the success of the negotiation process for candidates to circumvent the country is instantly opening the way to full membership. Because Turkish people was formed such a belief. Even the very difficult negotiation process completes, Turkey won't immediately open the way for full membership. So in the end the success of the negotiations does not guarantee membership. If the negotiations end with success in Turkey can be vetoed by a member country. For example; England, despite the period to complete the negotiations, France had been vetoed twice by President Charles de Gaulle in 1963 and 1967. England, the French referendum in 1972 could enter the EU (Özer, 2009). In addition to this, young and purchasing power of the population of Turkey is an important market for EU countries. Indeed, it is quite difficult to sell to many industrial products produced to different less developed countries. Therefore, the population of Turkey is an important market potential for EU countries. In addition, Turkey's population provides cheap labor to EU despite aging population of the EU countries (Şahin, 2008).

Full membership of Turkey into European Union is more preferable than Customs Union. Because, with the full membership the advantages and disadvantages of the Customs Union will realize in any case. However, the full membership will bring Turkey many aids and credits of the European Union, provide stability in social security, money and budget policies, reform democracy and complete integrations with western countries. On the other 
hand, the full membership will guarantee the free circulation of labor force (Yalçınkaya at all., 2009). Thus, obvious discourses and concrete calendars are necessary to reveal the full membership of Turkey for European Union.

Having said that, Turkey is still NATO member. For this reason, it is not possible for Turkey to move off western block in the short term. European Union countries has 50 percent share in trading volume. There is also Customs Union Agreement with Europe. This agreement can be seen as obstacle for the entrance to EAEU of Turkey; but it must be noted that this agreement is on behalf of Europe and may damage Turkish economy. Because Turkey is directly affected by agreements of European Union with third parties. At the same time, full membership of Turkey into European Union appears impossible for now. Turkey doesn't have in mind to wait at the European Union gate. Consequently the country wants to evaluate many alternatives. In this context, Eurasian Economic Union is significant for the future vision of Turkey (Hazır, 2015). Another significant point is the necessity for the termination of European Customs Union Agreement with Turkey which wants to enter Eurasian Economic Union. As current Ankara Treaty and Additional Protocol doesn't change, Turkey cannot exist in two different customs union in compliance with World Trade Organization and General Agreement on Tariffs and Trade (Karluk,2015).

On the other hand, Turkey' EAEU membership is not only disengagement of U.C. but also cause tension between U.S.A. and Turkey. In terms of balance of foreign policy for Turkey, EAEU membership means a radical disengagement of West. Psychological reason of this disengagement is that Turkey has been faithfully kept to westernization vision but Turkey could not see the same sensitiveness. In Turkey, economical rota alteration can assist to the Far East bazaar which is becoming richer with EAEU. For instance, EAEU membership can be a step to Shangai Cooperation Organization. All the same this economical potential and strategic alternative are evaluated, it can be say that Turkey has a potential to create a lot of occasion for future economical world. But it is very important that a long term national decree, which can be evaluate these occasions, for different economical and political strategies.

\section{References}

- Akçay, 2008. “Avrupa Birliği’nin Ekonomik Kriterleri ve Türkiye”, Maliye Dergisi, Vol:155, p. 11-38.

- $\quad$ Aktaş and Güven, 2003. "Gümrük Birliği Sonrasında Türkiye'nin İthalat Fonksiyonu Katsayılarındaki Değişimin İncelenmesi”, Dumlupınar Üniversitesi Sosyal Bilimler Dergisi, Vol:9, p. 67-80.

- Antalya AB Bilgi Merkezi Raporu, 2010. “Gümrük Birliği’nin Türk Ekonomisine Etkileri”, p. 1-11.

- Arsava, 2002. Kopenhag Zirvesi Işı̆̆ında Türkiye - AB İlişkileri, Rekabet Kurumu Perşembe Konferansları, Aralık, p. 1-6.

- Aslan, 2000. “Türkiye-Avrupa Birliği: Sancılı Gelişen İlişki”, Ankara Üniversitesi SBF Dergisi, Vol:55(3), p.1-20.

- Bahtiyar, 2015. “Türkiye Ve Ab’nin Avrasya Ekonomik Birliğiyle Tarımsal Ürün Ticareti Üzerine Analiz”, Gıda Tarım Ve Hayvancılık Bakanlığg Avrupa Birliği ve Dış İlişkiler Genel Müdürlüğü AB Uzmanlık Tezi, Ankara.

- C Çelikpala, 2015. "Rekabet ve İşbirliği İkileminde Yönünü Arayan Türk-Rus İlişkileri”, Bilig, Vol:72, p. 117144.

- Demir, 2014. "Tarihsel Perspektif Işı̆̆ında Türkiye Cumhuriyeti ve Rusya Federasyonu Arasındaki İlişkiler”, Yönetim ve Ekonomi, Vol:21(2), p. 179-197.

- Demirkıran, Çiçek, Eltetik, and Sarıkçıŏglu, 2010. Türkiye-Avrupa Birliği İlişkilerinde "Son Dönem”, Niğde Üniversitesi İIBF Dergisi, Vol:3(1), p. 57-75.

- Dikkaya and Bora, 2006. “Çăgdaş Kazakistan’ın Ekonomi Politiği Ve Türkiye'nin Yeri Türkiye'nin Yeri”, $O A K A$, Vol:1(2), p. 110-127.

- Doğan, 2004. “On Yıllık Dönemde Gümrük Birliği’nin Etkileri Ve Sonuçları Üzerine Bir Değerlendirme”, Mevzuat Dergisi, Vol:79, p. 1-12.

- Doğan and Kaya, 2011. “Gümrük Birliği Sonrasında (1996-2009) Türkiye’nin Avrupa Birliği İle D1ş Ticaretinin Ülke Ve Fasıl Bazlı Yoğunlaşma Analizi”, Ekonometri ve İstatistik, Vol:14, p.1-18.

- Duman and Samadov, 2003. "Türkiye ile Rusya Federasyonu Arasındaki İktisadi ve Ticari İlişkilerin Yapısı Üzerine Bir İnceleme”, Kocaeli Üniversitesi Sosyal Bilimler Enstitüsü Dergisi, Vol:(6), p. 25-47.

- Eurasian Economic Integration: Facts And Figures, 2015. http://www.eurasiancommission.org/en/Documents/broshura26_ENGL_2014.pdf

- Eurostat, Population Data, 2016. http://ec.europa.eu/eurostat/web/population-demography-migrationprojections/population-data

- Hazır, 2015. Türkiye’nin Avrasya Ekonomik Birliği’ne Üyeliği Mümkün mü?, Akademik Perspektif. 
- IInançlı, Konak and Ashimova, 2015. "Türkiye-Kırgızistan Ekonomik İlişkilerinin Dış Ticaret Üzerine Yapısal Ve Sektörel Olarak Yansımaları”, Kastamonu Üniversitesi İktisadi ve İdari Bilimler Fakültesi Dergisi, Vol:8, p. 111-124.

- IIncekara and İncekara, 2015. “Avrasya Ekonomik Birliği Ve Politik Ekonomik Etkileri”, Nişantaşı Üniversitesi Sosyal Bilimler Dergisi, Vol: 3(1), p. 111-129.

- İşyar, 2012. “Avrasya’daki Güncel Gelişmelerin Analizi”, Diplomatik Gündem, Vol:2(17), p. 2-11.

- Karluk, 2015. “Avrasya Gümrük Birliği ve Türkiye’nin Üyeliği”, Uluslararası Avrasya Ekonomileri Konferans1, SESSION 7B: Bölgesel Ekonomiler III, p. 337-344.

- Ozinian, 2013. “Türkiye-Ermenistan Ticaretine Genel Bakış ve Olası İşbirliklerinin Geliştirilmesi”, TurkishArmenian Bussiness Development Council.

- Ö̈zer, 2009. “Avrupa Birliğine Tam Üyeliğin Esiğinde Türkiye”, Yönetim Ve Ekonomi, Vol:16(1), p. 89-105.

- Ö̈zsan, 2015., “Avrupa Birliği’ndeki Ekonomik Yavaşlamanın Türkiye’nin Sektörel İhracatı Üzerindeki Etkisi”, Kalkınma Bakanlığı Ekonomi Çalışma Tebliğleri Serisi, Vol: 2015/2, p. 1.

- Sülün, 2015. “Avrasya Ekonomik Birliği”, İzmir Ticaret Odas1, http://izto.org.tr/demo_betanix/uploads/cms/yonetim.ieu.edu.tr/6025_1438764630.pdf

- SSahin, 2008. “Avrupa Birliğinde Demografik Dönüşümler Ve Türk Nüfusun Geleceği”, TSA Dergisi, Vol:2, p. 187-205.

- SŞen, 2014. “Adaylık Sürecinde AB ve Türkiye'nin Nüfus Yapısı Açısından Karşılaştırılması”, HAK-İŞ Uluslararası Emek ve Toplum Dergisi, Vol:3(7), p.120-145.

- Turkish Statistical Institute, 2016. http://www.tuik.gov.tr/PreTablo.do?alt_id=1046

- Türkiye Cumhuriyeti Dışişleri Bakanlığı, 2016. http://www.mfa.gov.tr/default.tr.mfa

- United Nations, Population Statistics of Eurasia Region, 2016. http://unstats.un.org/unsd/databases.htm

- Uysal, 2001. “Türkiye - Avrupa Birliği İlişkilerinin Tarihsel Süreci ve Son Gelişmeler”, Akdeniz I.I. B.F. Dergisi, Vol:1, p. 140-153.

- Yalçınkaya, Çılbant and Özçalık, 2009. “Avrupa Birliği Sürecinde Türk İmalat Sanayi Dış Ticaretinin Rekabet Gücü: 1989-2009 Dönemi VAR Analizi”, Yönetim ve Ekonomi, Vol:16(1), p. 115-137.

- World Bank, 2016. http://databank.worldbank.org/data/download/GDP.pdf

- Zengin, 2015. “Türkiye Ve Rusya Federasyonu Ticari İlişkileri”, Avrasya İncelemeleri Dergisi (AVID), Vol:I4(1), p. 61-103. 


\title{
Circular Migration Between Georgia and Turkey: Is Triple Win a Solution for Illegal Employment?
}

\author{
Prof. Dr. Adem Kalça (Karadeniz Technical University, Turkey) \\ Y1lmaz Onur Ari (Bayburt University, Turkey)
}

\begin{abstract}
Migrants who come from Georgia is one of the main issues in Turkey's migration policy. Just like other Eastern Bloc Countries, after socialism collapsed in Georgia, its economy had many problems and impoverished many Georgia citizens. Therefore, Georgian people migrate to Turkey in a circular way in order to work or trade with the strategy for survival. Unfortunately, circular movements from Georgia to Turkey are not subject to a program and it causes many problems like illegal employment, bad living conditions and lack of migrants' skill and knowledge development.

The concept of circular migration and the effects of triple win solution are discussed theoretically in this study. Also a swot analysis of demographic and labor market of autonomous border region of Georgia is made and both negatives and positives of Georgian circular migration to Eastern Black Sea Region are analyzed.

According to the results, it's emphasized that a circular migration program between Georgia and Turkey is necessary to practice the triple win scenario. Triple win scenario supports many economic benefits for all three elements of circular migration, namely home and host countries and the migrants themselves, provided that there is a regulated circular migration. Several measures can be taken to prevent unregistered employment and poor working conditions of migrants, the most importantly the spontaneous circular movement between Georgia and Turkey can be transformed to programmed circular movement.
\end{abstract}

\section{Introduction}

Circular migration is a temporary and repetitive movement between home and host countries, which migrants mostly do for working, especially in agriculture, tourism and construction sectors.

Triple win scenario supports many economic benefits for all three elements of circular migration, namely home and host countries and the migrants themselves, provided that there is a regulated circular migration. Unfortunately, circular migration from Georgia to Turkey is not regulated and programmed so it creates many problems such as unregistered employment, bad living standards and lack of knowledge and new skills of migrants.

Thanks to circular migration programmes, circular migrants fill labor shortages in host countries, remittances sent home by migrants contribute to the economic development of home countries. Migrants gain new knowledges and skills. Also they can use them when they go back to their countries. Circular migration reduces the brain drain and encourage transfer of skills.

In some cases, circular migration may create some problems and bring negatives to migrants. Potential problems in the host country include lack of employment protection and opportunities for integration, and exposure to antimigrant attitudes and behaviors.

In this study it's emphasized that a circular migration program between Georgia and Turkey is necessary to practice the triple win scenario. Also its economic effects with advantages and disadvantages and the future of this movement were discussed.

\section{Definition and Terminology of Circular Migration}

International migrations include many processes such as the decision of migration and return. Circular migration is the result of the range of decisions and arises from social networks between two places (Haug, 2012). In Figure1 , there are some preferences about migrants' decisions. While some of the migrants never migrate, some of them can choose to live in destination country permanently. Some of them are return migrants, they stay and work in destination country and return to their homeland permanently. Circular migration is a temporary form of return migration. 


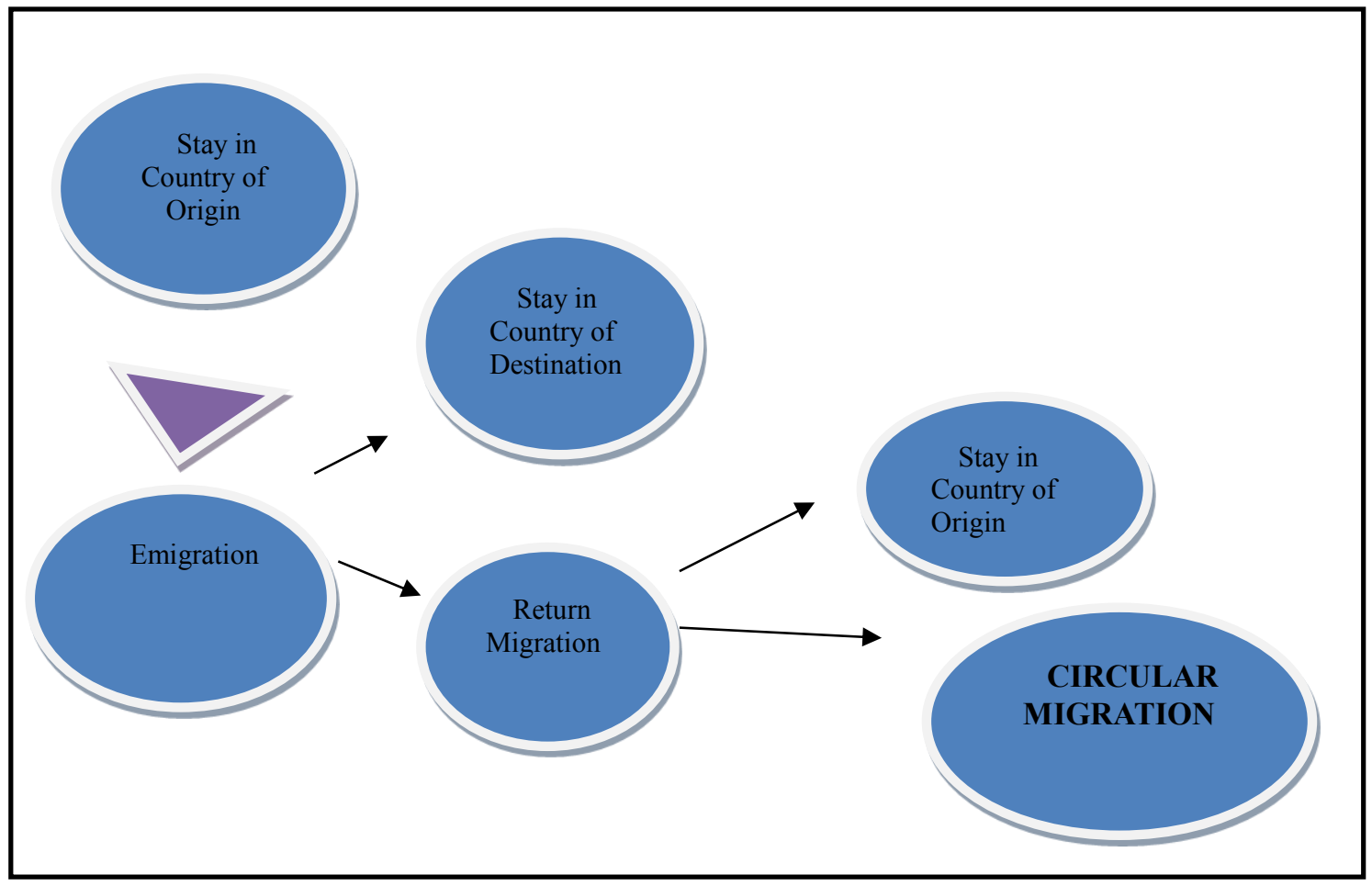

Figure-1: Decision to Migrate and to Return-Circular Migration Source: Haug, 2012: 8

Circular migration is characterized as a back-and-forth movement which raises the development of country of origin and country of destination as well as migrant workers (Government Offices of Sweden, 2010). Constant et al. (2012) defined circular migration as "systematic and regular migrant movements between source and destination countries in order to work". Both skilled and unskilled workers migrate circularly. In literature circular migration has many synonyms: repeat, rotating, cyclical, circuit, shuttling.

Circular migration is related to the temporary movements of migrants, so sometimes it is also used "temporary migration". Although returning to home is emphasized in European Migration Network definitions, contrary to temporary migration, circularity is defined as "legal migration which is repeated between two or more countries by the same worker". Another difference is about the length of stay. Seasonal migration from 3 months to 9 months is considered as "circular migration" (Kazmierkiewicz, 2013).

\section{Spontaneous Circular Migration}

Spontaneous circular migration is also called "embedded circular migration" migration type occurs in borders where there are frequent interactions and frequent circular movements. Grassroots patterns of mobility- often unmanaged- may characterize them. It happens more to countries with close ties such as Lebanon and Syria, and Nepal and India (Wickramasekara, 2011).

Cultural ties between country of origin and country of destination enables circular migration to shape. Mutual interactions between both countries and people, bilateral trade of goods and transactions by citizens who live in borderline make these movements circular. Besides, these mutual relationships sometimes changed the national politics of governments. Changes in visa requirement between Turkey and Syria is a good example. Similarly, this situation can be seen between Bulgarian and Turkish citizens in Edirne, which is a border town in Turkey (Ozkul, 2011).

Some obstacles may impede people to migrate across the border, in that case circular migration is in a spontaneous way. For example, political and military tension between two countries. Obstacles may result with tight migration politics and forced border controls, so this situation blocks circular migration and doesn't leave no alternative except permanent migration (Cassarino, 2008). As a result, spontaneous circular migration can be limited with law or encourage, although it is considered as a natural migration movement. Some general factors which make the circular migration easy are low communication and transportation costs, to eliminate the entry barriers for destination country, to give residence permit in destination country for a long time, liberal conditions for allowing naturalization and dual citizenship, simplified processes for entry permits for repeat migrants, portability of pensions and tax relief that encourages circularity, for example. Best facilitating factor for spontaneous circular migration is to give migrants a legal status, which allows for increased mobility with no risk (Herveus, 2014). 
Circular migration is promoted as a "triple win scenario" which provides benefits to origin country, destination country and migrants, and it is considered as a development-friendly mechanism of labor migration. After the importance of remittances in world economics was understood particularly, this type of temporary migration became popular. The worldwide value of remittances has increased incrementally since $90 \mathrm{~s}$ and has exceeded over 105 billion dollars annually. Today this increase continues. USA estimated that the total value of global remittances was approximately 232 billion dollars in 2006, and it will increase if unofficial flows are added. In addition to this, "The Communication on Migration and Development Report" published by the European Commission in 2005, proposes that circular migration could play a crucial role in fostering the transfer of skills to the developing world. Finally, in 2005 the European Commission addressed circular migration in a second document named "Policy Plan on Legal Migration" outlining how circular migration would make it even easier for employers to hire temporary labor migrants and identifying possible measures that could enable circular migration programs (Bassina, 2012).

\begin{tabular}{|l|l|l|l|l|}
\hline Migrant & $\begin{array}{l}\text { - Increased earnings and remittances } \\
\text { - Improved skills } \\
\text { - Improved earning possibilities upon return through } \\
\text { investment }\end{array}$ \\
\hline Country of & $\begin{array}{l}\text { - Fulfillment of labor shortages } \\
\text { - Minimised training costs if same migrants are hired } \\
\text { seasonally. } \\
\text { - Increased domination over workers. }\end{array}$ \\
\hline Country of & $\begin{array}{l}\text { - Access to destination country's labor markets. } \\
\text { - Inflow of remittances } \\
\text { - Replacing brain drain with brain circulation } \\
\text { - Benefits from investments of migrant workers }\end{array}$ \\
\hline Origin
\end{tabular}

Figure-2: Triple-Win: Positive Effects of Circular Migration on Country of Destination, Country of Origin and Migrants Source: Sana, 2012: 38

In Figure-2, we can say that all the three elements of triple win scenario, namely country of origin, country of destination and migrants gain many advantages thanks to circular migration. Circular migration provides the connection between migration and development in country of origin by supporting return investment and human capital. It is considered as a supplementary policy to remittances and diaspora investments. From this perspective, main policy goal is to maximize the potential benefit of returning to country of origin and to create a synergy between remittances and return investments. If we combine all these approaches, circular migration is considered as an ideal solution to decrease illegal migration. Providing the migrants legally to the labor market lowers the number of migrants who work illegally in country of destination.

\section{Circular Migration: The Case of Georgia and Turkey}

"Migrants who come from Georgia" is one of the main issues in Turkey's migration policy. Just like other Eastern Bloc Countries, after socialism collapsed in Georgia, its economy had many problems and impoverished many Georgia citizens. Therefore, Georgian people migrate to Turkey in order to work or trade with the strategy for survival (Ulukan and Ulukan, 2012).

When visa regime is analyzed between Turkey and Georgia in terms of migration policy, a liberal policy seems prioritized. Sarp Border Gate was firstly opened in 1989 and 1-month tourist visa was acknowledged for Georgian citizens. With the agreement between two countries in 1996, visa was started to get at border gate. In 2006 visa regime became more liberal. According to that bilateral agreement, citizens of both Georgia and Turkey had the right to enter and exit reciprocally within 90 days without any visa (Ulukan and Ulukan, 2012). Table-1 shows the number of Georgian people who entered Turkey between 2000 and 2014. It's seen that there is an increase in number of Georgian people in Turkey after 2006 agreement. 


\begin{tabular}{|c|c|c|c|c|c|c|}
\hline Years & By Plane & $\begin{array}{c}\text { By } \\
\text { Highway }\end{array}$ & By Train & By Ship & Total & $\begin{array}{c}\text { Share in the total } \\
\text { amount of foreign } \\
\text { visitors (\%) }\end{array}$ \\
\hline 2000 & 10.034 & 166.973 & 314 & 2.330 & 179.651 & 1.72 \\
\hline 2001 & 8.906 & 152.616 & 421 & 2.115 & 164.058 & 1.41 \\
\hline 2002 & 10.207 & 149.393 & 77 & 1.698 & 161.375 & 1.22 \\
\hline 2003 & 8.082 & 157.852 & 57 & 1.920 & 167.911 & 1.20 \\
\hline 2004 & 11.294 & 221.161 & 36 & 2.446 & 234.937 & 1.34 \\
\hline 2005 & 16.698 & 348.461 & 66 & 2.113 & 367.338 & 1.74 \\
\hline 2006 & 27.709 & 517.910 & 48 & 3.661 & 549.328 & 2.77 \\
\hline 2007 & 41.131 & 584.260 & 69 & 5.519 & 630.979 & 2.70 \\
\hline 2008 & 52.849 & 771.295 & 64 & 5.976 & 830.184 & 3.15 \\
\hline 2009 & 44.126 & 945.014 & 52 & 6.189 & 995.381 & 3.68 \\
\hline 2010 & 42.041 & 1.063 .906 & 59 & 6.187 & 1.112 .193 & 0.21 \\
\hline 2011 & 55.203 & 1.090 .721 & 21 & 6.716 & 1.152 .661 & 3.66 \\
\hline 2012 & 51.992 & 1.346 .712 & 3 & 6.175 & 1.404 .882 & 4.42 \\
\hline 2013 & 68.169 & 1.694 .105 & 12 & 7.161 & 1.769 .447 & 5.07 \\
\hline 2014 & 85.010 & 1.661 .591 & 1 & 8.687 & 1.755 .289 & 4.76 \\
\hline
\end{tabular}

Table-1: Number of Georgian Citizens Who Entered to Turkey Source: (Kültür ve Turizm Bakanlığl, 2015)

Distribution of Georgian citizens with respect to border gates and provinces is shown at Table-2:

\begin{tabular}{|c|c|c|c|c|c|c|c|c|c|c|c|}
\hline & $\begin{array}{c}\text { Artvin } \\
(\text { Sarp})\end{array}$ & $\begin{array}{c}\text { Hopa } \\
(\mathrm{S})\end{array}$ & $\begin{array}{c}\text { Rize } \\
(\mathrm{S})\end{array}$ & $\begin{array}{c}\text { Trabzon } \\
(\mathrm{S})\end{array}$ & $\begin{array}{c}\text { Trabzon } \\
(\mathrm{P})\end{array}$ & $\begin{array}{c}\text { Ordu } \\
(\mathrm{S})\end{array}$ & $\begin{array}{c}\text { Ünye } \\
(\mathrm{S})\end{array}$ & $\begin{array}{c}\text { Samsun } \\
(\mathrm{S})\end{array}$ & $\begin{array}{c}\text { Samsun } \\
(\mathrm{P})\end{array}$ & $\begin{array}{c}\text { Giresun } \\
(\mathrm{S})\end{array}$ & $\begin{array}{c}\text { Ardahan } \\
(\text { Türközü})\end{array}$ \\
\hline 2001 & 115.251 & - & - & \multicolumn{2}{|c|}{1019} & 1 & - & 379 & - & & 11.198 \\
\hline 2002 & 110.546 & - & 34 & 171 & 472 & 1 & - & 214 & - & & 9.910 \\
\hline 2003 & 118.148 & 2 & 522 & 215 & 228 & 2 & - & 234 & 1 & & 8.076 \\
\hline 2004 & 176.371 & - & 444 & 96 & 381 & 8 & - & 287 & 5 & & 9587 \\
\hline 2005 & 303.456 & 19 & 166 & 178 & 244 & 4 & - & 304 & 1 & & 6.607 \\
\hline 2006 & 468.330 & 1 & 25 & 781 & 134 & 162 & - & 430 & 11 & & 5.735 \\
\hline 2007 & 533.977 & 123 & - & 841 & 365 & 203 & 102 & 670 & 9 & & 4.359 \\
\hline 2008 & 722.095 & 5 & 2 & 734 & 373 & 66 & 82 & 1.190 & 17 & & 5.010 \\
\hline 2009 & 898.344 & 5 & 7 & 686 & 393 & 26 & 16 & 1.812 & 1 & & 6.019 \\
\hline 2010 & 1.016 .169 & 84 & 1 & 557 & 442 & 80 & 24 & 2.226 & 10 & & 6.934 \\
\hline 2011 & 1.037 .124 & 15 & - & 222 & 193 & 4 & 20 & 2.897 & 10 & & 6.662 \\
\hline 2012 & 1.287 .212 & 16 & 3 & 132 & 162 & 2 & 27 & 2.731 & 20 & & 7.693 \\
\hline 2013 & 1.632 .575 & 19 & 2 & 161 & 96 & - & 29 & 2.906 & 21 & & 10.632 \\
\hline 2014 & 1.606 .376 & 66 & 5 & 230 & 238 & 3 & - & 4.304 & 17 & & 11.530 \\
\hline
\end{tabular}

Table-2: Distribution of Georgian Citizens with Respect to Border Gates and Provinces S: By Sea, P: By Plane Source: (Kültür ve Turizm Bakanlı̆̆, 2015 )

The economy of Eastern Black Sea region is based on agriculture. Hazelnut and tea are major agricultural products in this region. Georgian migrants have been working as a hazelnut and tea pickers as circular migrant workers recent years. For the last decade, thanks to the effect of non-visa entry agreement between Georgian and Turkish governments, the circularity has increased. Georgian migrants have been known "hard-working, clean and cheap", according to the owners of hazelnut and tea field. They generally cross the border legally but work illegally in agricultural areas, because they don't have a work permit. Georgian workers usually engage in low paying, dirty, dangerous and difficult jobs. Hence, Georgian migrants are preferred by landowners and landowners gain advantage by employing low paid and hard working migrants (Ulukan and Ulukan, 2010).

There is not a specific circular migration program or an agreement between Turkey and Georgia. It is completely a spontaneous movement and it may create some problems like poor working conditions, informal employment and tax losses for Turkey etc.

From Georgia's perspective circular migration programs will be necessary and beneficial for the following reasons. The sending countries (i) are relieved from any unemployment frictions and labor market imbalances, (ii) benefit tremendously from the remittances that emigrants send back, (iii) gain from new skills and knowledge that return migrants acquired abroad and bring with them upon return, (iv) through bilateral or multilateral agreements in migration, the sending countries may also strike additional agreements in trade and development and benefit even further from cooperation (Constant et al., 2012).

From Turkey's point of view circular migration programs will be also beneficial. Circular migration program can buy time for receiving country governments and employers to train native employers to meet labor shortages and can have a rejuvenating effect on aging societies. Because free movement back and forth keeps migrants' 
options open in both home and host countries, it reduces the risk of long term settlement in the host country and illegal overstaying of visas (Zimmermann, 2014).

Finally, circular migrants who return home will use new skills and knowledge they gain abroad. They may also start new businesses in their communities of origin. For sending countries, circular migration reduces the negative effects of brain drain and encourages brain circulation.

\begin{tabular}{|c|c|}
\hline Strengths & Weaknesses \\
\hline $\begin{array}{l}\text { - High rates of population growth due to } \\
\text { natural increase; } \\
\text { - } \quad \text { High population ratio of people of able- } \\
\text { bodied age and younger; } \\
\text { - } \quad \text { High countryside population ratio; } \\
\text { - } \quad \text { Cheap labour force; } \\
\text { - } \quad \text { Hard-working population; } \\
\text { - } \quad \text { Favourable location of populated areas }\end{array}$ & $\begin{array}{l}\text { - Population migration from the region } \\
\text { and the country; } \\
\text { - High unemployment rate; } \\
\text { - } \text { High poverty rate; } \\
\text { poor quality of population social } \\
\text { - Poor quality of demographic processes } \\
\text { management; } \\
\text { - Structural and qualitative imbalances } \\
\text { between the demand on and supply of } \\
\text { labour force; } \\
\text { - Insufficient orientation of higher } \\
\text { education and vocational training } \\
\text { systems on the demands of labour } \\
\text { market; } \\
\text { Poorly developed employment } \\
\text { structure }\end{array}$ \\
\hline $\begin{array}{l}\text { Opportumities } \\
\text { - } \\
\text { Creation of strong labour market } \\
\text { - Imprastructure; } \\
\text { meeting the demands of labour market; } \\
\text { - } \\
\text { Training and re-training of experienced } \\
\text { personnel by state, international, and non- } \\
\text { governmental organizations, educational } \\
\text { system and private sector; } \\
\text { - Overcoming unemployment by increasing } \\
\text { private investments; } \\
\text { Overcoming unemployment by } \\
\text { government infrastructural projects; } \\
\text { - Improvement of social protection system; }\end{array}$ & $\begin{array}{l}\text { Threats } \\
-\quad \text { Macroeconomic instability and } \\
\text { unfavourable investment climate; } \\
\text { - Wide scales of external and internal } \\
\text { migration; } \\
\text { - Worsening of social problems; } \\
\text { - Speculation on social problems by } \\
\text { - Poposition; } \\
\text { Political instability }\end{array}$ \\
\hline
\end{tabular}

Table-3: SWOT Analysis of Demographic and Labor Market of Ajara, Georgia Source: Regional Development Strategy of the Autonomous Republic of Ajara, 2011

In Table-3, there is a swot analysis of the labor market of Ajara. Ajara is an autonomous border region of Georgia and most of the Georgian migrants come from this region to Turkey to work. It is clear that both strengths and weaknesses of Adjara labor market are opportunities for Turkish employers and labor market.

\section{Conclusion}

In this study circular migration within the scope of triple win scenario was analyzed between Turkey and Georgia. Triple win scenario supports many economic benefits for all three elements of circular migration, namely home and host countries and the migrants themselves, provided that there is a regulated circular migration. Unfortunately, circular migration from Georgia to Turkey is not regulated and programmed so it creates many problems such as unregistered employment, poor living standards and lack of knowledge and new skills of migrants.

Several measures can be taken to prevent unregistered employment and poor working conditions of migrants, the most importantly the spontaneous circular movement between Georgia and Turkey can be transformed to programmed circular movement. Thus, Turkey, Georgia and the circular migrants can gain more advantage from the effects of triple win. Turkey can minimize the loss of tax due to informal employment, Georgia can gain more remittances thanks to an equal and fair wage between domestic and migrant workers. Finally, Georgian migrant workers can gain new skills and use it when they turn back to Georgia and work in the same job.

\section{References}

- Bassina, R., 2012. "The Future of Circular and Return Migration: Integrative Migration Frameworks and Decided Return as the Only Way Forward". Major Research Paper. 
- Cassarino, J.P., 2008. "Patterns of Circular Migration in the Euro-Mediterranean Area: Implications for Policy Making”. CARIM Analytic and Synthetic Notes, 2008/29.

- Constant, A. et al., 2012. "The Economics of Circular Migration”. IZA Discussion Paper, No. 6940.

- Government Offices of Sweden, 2010. "Sweden's Committee for Circular Migration and Development”. Fact Sheet, pp.1-4.

- Haug, S., 2012. "Migration and Return Migration: The Case of Italian Migrants in Germany”. Workshop of Labor Migration and Transnationalism in Europe, Regenburg: Südost-Institut.

- Herveus, K., 2014. "The Concept of Circular Migration-Towards a Common EU Framework for Migration". Paper for the 7th Nordic Working Life Conference.

- Kazmierkiewicz, P., 2013. “Opportunities for Developing Circular Migration Schemes Between Georgia and the EU'. Georgian Young Lawyers'Association \& Caucasus Institute for Peace Democracy and Development, pp.1-19.

- Kültür ve Turizm Bakanlığ1, 2015,http://yigm.kulturturizm.gov.tr/ (Access Date: 27.12.2015)

- Newland, K., 2009. Circular Migration and Human Development. UNDP.

- Ozkul, D., 2011. Circular Migration Schemes: Renewed Interests in the Destination Countries. Best Participant Essays Series, 2011/61.

- Regional Development Strategy of the Autonomous Republic of Ajara, 2011, http://www.ajara.gov.ge/acg/files/Adjara-Development-Strategy.pdf (Access Date: 27.12.2015)

- Sana, M. W., 2012. "Circular Migration Between Guatemala and Canada: Perspectives of Guatemalan Migrant Workers". Master Thesis, University of Helsinki Faculty of Social Sciences.

- Skeldon, R., 2012. “Managing Migration for Development: Is Circular Migration the Answer?".The Whitehead Journal of Diplomacy and International Relations, pp. 21-34. 


\title{
Is There a Relation Between the Level of Development and Government Systems? An Overview on Latin America, Euroasia and the East Asia
}

\author{
Ph. D. Candidate Yaşar Pınar Özmen (Gazi University, Turkey) \\ Prof. Dr. Gonca Bayraktar Durgun (Gazi University, Turkey)
}

\begin{abstract}
The purpose of this paper is to study if a meaningful relation can be argued between government systems and the level of development by using main socioeconomic indicators. The systems of government in the Latin American, Eurasian and the East Asian countries are classified as presidentialism, president- parliamentary, premier - presidential and parliamentarism. For the aim of the paper, the countries are selected according to the two criteria, population and income. On the basis of 1995-2013 annual data, the time series are obtained from the international organizations and research institutes. The panel data analysis covers socioeconomic indicators (population, gross domestic product per capita, unemployment rate) and some composite indicators (human development index and democracy scores).
\end{abstract}

\section{Introduction}

The debate on government systems flared up in the aftermath of the dissolution of Yugoslavia and of the Soviet Union. In the early 1990 s, the argument that there was a qualitative difference in terms of democratic persistence and consolidation between the parliamentary system and the presidential system was the focal point of the debate. During the same period, the institutional structures of democratic governments replacing the military dictatorships in Latin America and Asia were a particular area of research for political science. The comparison effort of the new period to that of military coups or of the earlier interruption of democratic order has been widespread in academic studies. In that period where the pessimistic view for the presidential system was prevalent, the thesis as "the supremacy of parliamentarism to presidentialism" suggested by Linz (1990) was widespreadly supported. This viewpoint was very influential for later debates. In this context, the fragility of democracies and the threat of turning back to authoritarianism in the countries with presidential systems excluding United States of America were particularly often explained in the frame of "the perils of presidentialism". Low level of economic development was emphasized as a factor increasing fragility. However, the situation changed rapidly after 1994 with the end of hyper-inflation in the countries in question and revealed more optimistic comments about governability related to presidentialism. Meanwhile, considerable amounts of data were revealed which could not verify empirically the thesis of perils of presidentialism prevailing in the previous period.

In this study, the relation of government systems with development and democracy is investigated concerning Latin American, Eurasian and the East Asian countries. The study reveals that there is no strong evidence about superiority of any government system according to development and democracy indicators. While no significant relationship between socio-economic development and government systems is established, however it can be argued that the link between government system and democracy is significant. The variation of decision making process in each category prevents making comparisons with general definitive classifications. In other respects, authoritarian and imperial history of country, management of natural resources and correspondingly sociocultural environment are variables which are mostly difficult to measure.

\section{Political Systems, Development and Government Systems}

The comparison of political systems has been a research theme that can be traced back to Aristotle's classical work. The oldest and most widely discussed subject is related to the classification of systems in political research. However, the relationship between economic development and political systems is also a very common issue. Especially researches related to structural changes in political systems resulting in the formation of new states in the world have been at the center of comparative politics. While the number of democratic countries has increased since the early 1990s, accordingly, the comparisons of political systems, government systems and other related institutional systems have been widespread. More specifically, the comparison studies between the authoritarian/totalitarian political systems and democratic systems in terms of socioeconomic indicators have concentrated.

In these researches dealing with the relation between democracy and development, the focal point has been about which one of them has preceded the other. Accordingly, three different views can be generalized from those researches: (a) democracy provides favorable conditions for economic development, (b) demand for democracy only emerges after a certain degree of development is reached, (c) there is not a direct relation between the two. Thus, on the one hand, it is argued that democracy, compared to the more authoritarian systems, contributes more to economic development and due to this reason it is a prerequisite. On the other hand, studies are available rooted 
in the argument that democracy is not a prerequisite for economic growth. Even the latter argues that autocratic systems affect economic development in a more positive way. There are studies that draw attention to the fact that development does not directly cause democratization (or authoritarianization) of a country. Considering the studies pointed out that there is not a clear relationship between qualifications of government systems and economic development, it is clearly revealed that relations among presumptions, assumptions and data should be handled cautiously for the purposes of the researcher.

As one of the works on this subject, Lipset (1959), Cutright (1963) found a positive linear relationship between democracy and development. Lipset (1959: 56), one of the modernization theorists argue that democracy can only be sustained in countries with high economic development. Neubauer (1967), Jackman (1973) identified a curvilinear relationship; democratic performance increased and then leveled off at a certain level of economic development. Huntington (1968), Linz (1978), Bollen (1979), Przeworski \& Limongi (1997), Gasiorowski (1995), Haggart \& Kaufman (1995), Przeworski et al (1996), Gasiorowski \& Power (1998) are other researchers claim that higher levels of economic development and positive economic performance enable democracies to endure (Bernhard et al, 2001). Huntington (1968) and Olson (1982) suggested that rapid economic growth could also destabilize democracy for the reason that accelerated growth could produce social upheaval by disrupting traditional social relations (Bernhard et al, 2001).

Kurzman, Werum and Burkhart summarize the findings of the 47 quantitative studies applied between 1963 and 1997 as for the relationship between growth and democracy. According to this, 19 studies identified a positive relationship, 6 studies found negative relationship and 10 studies could not find a significant relationship between growth and democracy. Depending on the models used and sample coverage, 7 studies have a positive and insignificant relationship, and 2 studies have negative and insignificant relationships. Both positive and negative mixed results were achieved in two studies, and an inverted U-shaped relationship was achieved in a research (as cited in Doğan, 2005). Przeworski et al (2000), analyze a large cross-section time-series dataset, encompassing a time span from 1950 to 1990 with 135 countries and they conclude that development does not cause to the emergence of democracy, it merely helps democracy endure once it is established.

Przeworski showed in his work (2004) that the relation between economic development and political system is more complex. Among the 135 countries considered, forty-four countries remained under dictatorships during which they were independent between 1950 and 1999, while thirty-four countries had been democratic during this entire period. Twenty-nine countries experienced one regime transition: two from democracy to dictatorship, twenty-seven from dictatorship to democracy. Sixteen countries experienced at least two transitions, e.g. Argentina, had eight. He argues that democracies are unlikely to be established in poor countries, and less likely if a dictatorship exists in a country with a high level of per capita income. He points out that the income levels at which democracies emerge vary widely and there is not any development level for a dictatorship to die.

Relating the relationship between political modernization and development, as mentioned above, since the 1990 s, the studies focused on the relationship between government systems and the continuity or fragility of democracy. In this focal point they have also reached different conclusions. The concept of government system represents the entire rules and institutions related to distribution and arrangement of the state's legislative, executive and judicial powers. Government system classification is specifically based on the relationship between the legislative and executive power in democratic systems, with the assumption that judiciary should be independent. Since legislative and executive powers are as well apart from each other according to the principle of the separation of power; presidential, semi-presidential and parliamentary system has emerged as a classic government classification systems. The presidential system of the United States, the semi-presidential system of France and the parliamentary system of the United Kingdom are mostly used for the basis of typology for comparative political systems.

However, different practices have been observed that were not in accordance with the classical typologies since the late 1980s with emergence of new democratic systems. It marked a new era of new democratic governments, whereby many countries had to make difficult constitutional choices about which form of government to adopt. They preferred the new hybrid systems combining the various features of different systems (Yücel, 2003; Elgie, 2005; Shugart, 2005; Elgie \& Schleiter, 2009). The semi-presidential system is decomposed as different three subclasses between pure presidential and pure parliamentary system in both ends. This distinction actually was first made by Shugart and Carey (1992).

However, this distinction for semi-presidential system has not always been appreciated in the literature and criticized on various terms (Shugart, 2005). It is under debate due to differences between structure of formal institutional relations and implementation. Elgie (1999), provides a minimalist description for semipresidentialism; where a constitution includes a popularly elected fixed-term president and a prime minister and cabinet who are collectively responsible to the legislature. Accordingly, three types of semi-presidential system are described: Semi-presidential system which is very close to presidential system, semi-presidential system with ceremonial (symbolic) president, and semi-presidential system that balanced the power of the prime minister and president. As of 2013, Russia, Azerbaijan, Belarus, Kazakhstan, Ukraine and Peru have systems very close to presidential systems. Bulgaria, Portugal and Slovenia can be given as examples of symbolic presidential system. 
France, Poland and Croatia are examples for the third group of semi-presidential system. According to Elgie and Schleiter, there seem to be two reasons for constitution drafters to choose semi-presidentialism: a desire for constitutional rules that require power-sharing, and the desire for flexibility through presidential action. They emphasize that the direction towards investing the presidency with extensive powers appear to have a price in terms of democratic survival (Elgie \& Schleiter 2009).

For the purposes of this study the typology dividing government systems into five classes according to maximalist approach is used. This grounds the criteria on the election of president and effectiveness provided by the legal and political power (Shugart \& Carey, 1992). These categories are listed below in descending order according to the president's influence on executive power:

- Pure presidential system: There is a directly elected (or popularly elected) president for fixed-term. President is also the head of executive branch and has too wide power. Cabinet members are not collectively responsible to the legislature. The secretaries serve as ministers subject to the president. The president has the power to appoint and dismiss cabinet members. The United States are typical example of this system.

- President-parliamentarism: The president is popularly elected. The president has the power to dissolve parliament and to dismiss government. Both the prime minister and cabinet are collectively responsible to both the legislature and the president ("dual accountability", Shugart \&Carey, 1992). The parliament may dissolve the government and this is the key difference from pure presidential system. The term "Super-presidential" for this system was first used by Fisher in an article he wrote in 1997 for Russia (Gönenç, 2007). While German Weimar Republic provides a classic example, the current Russian Federation's system is a typical case.

- Premier presidential (semi presidential): The popularly elected president has important powers including dissolving the parliament, but cannot make a restriction on government. The president cannot dismiss the cabinet. The prime minister and cabinet are collectively responsible solely to the legislature.

- Parliamentary with president: A popularly elected president is accompanied by parliamentary system. The fact that popularly elected president provides a political program for voters constitutes the basis of the difference from the parliamentary system.

- Pure parliamentary system: There is a parliament which is determined by voters' choice and the dynamics of the electoral system where the prime minister and cabinet are collectively responsible to the legislature. The government is determined by the parliament and may be dismissed. The president is the head of state and mostly ceremonial without a political program. The United Kingdom parliamentary system is the most authentic example.

In the study, the classification of government systems is based on the typology of Shugart and Carey (1992) as mentioned above, but "the parliamentary with president" category was added to semi-presidential systems according to Elgie's (2015) remarks on it.

Another classification was also developed by Siaroff (2003) on the grounds of incompetence of classical classifications. In this classification, eight categories are defined according to dispositional combinations. The key initial distinction involves whether the head of state is also the sole head of government. And the answer of the questions designates the categories: Is the head of state popularly elected or not? Is the head of government (who may also be the head of state) accountable to the legislature and thus removable by a vote of non-confidence? Siaroff (2003) wants to show that the categories of presidential, parliamentary and semi-presidential systems can certainly all be defined conceptually, but definitions are of varying utility in telling us about the powers of presidents.

Government systems are compared according to variables of stability and development level of countries. Linz $(1978,1990)$ bases his argument about the superiority of parliamentary systems over presidential systems with respect to democratic stability. The argument of instability of the presidential systems have a lot of supporters following Linz, e.g. Stepan \& Skach (1993), Jones (1995: 34), Mainwaring \& Scully (1995). In their study about democracy and development, Prezeworski et al. (2000) point out that parliamentary democracies are much more likely to survive than presidential ones. Many researchers assert that parliamentary systems have more centralized decision-making process, incentives for negotiations and coalition formations these inferences have become a common view in the literature.

On the other hand, while comparative studies regarding the government systems continue, the criticisms relating to these kinds of comparisons have also been made. In a similar manner to Siaroff (2003), Cheibub and Limongi (2002) reconsider general descriptions of government forms and state that conceptual categories cannot reflect the diversity in the practices. Accordingly, the main difference between presidential and parliamentary systems lies in the way the decision-making process is organized. But the generalized conceptual definitions cannot provide enough information about the sustainability of the system. "Parliamentary systems do not operate under a "majoritarian imperative"; deadlock is not as frequent as supposed under presidentialism and is not absent from parliamentarism; coalition governments are not foreign to presidential systems and emerge for the same reasons as they do in parliamentary systems; decision making is not always centralized under parliamentarism and is not always decentralized under presidentialism" (Cheibub \& Limongi, 2002). Bernhard et al. (2001) likewise suggest that in and of themselves institutions do not determine democratic survival. The impact of institutions on durability 
varies according to economic performance depending upon the way they concentrate or disperse decision-making power. In their model, parliamentarism and presidentialism have an effect on survival in combination with different party systems due to the extent that they concentrate or disperse decision-making power. Consequently, previous findings, inferences and generalizations based on the conceptual definitions need to be considered very carefully.

\section{The Scope of the Research and Methodology}

In the study, 53 countries are selected from Latin America, Eurasia and Pacific regions according to the population and income criteria. Former Soviet Union, Yugoslavia and independent countries of former Eastern Bloc, Latin America and Asia are in the scope. Majority of these countries was ruled by totalitarian and authoritarian regimes in recent history and started to democratization in 1970s. Jamaica and Papua New Guinea achieved independence from dominating countries in the same period. Costa Rica has also been included in the study as Latin America's oldest democracy.

53 countries in the scope of the research are shown below in Table 1 (The countries have been covered with more than two million population and GDP per capita between 1,500 and 20,000 US dollars. Only exceptions, Estonia and Montenegro (population less than two million), Kyrgyz Republic (GDP per capita less than 1,500 US dollars), Slovenia and South Korea (GDP per capita more than 20,000 US dollars) are taken into the scope for the sake of regional completeness in comparison)

\begin{tabular}{|c|c|c|}
\hline Presidential & Semi-presidential & Parliamentary \\
\hline $\begin{array}{l}\text { Latin America \& Caribbean } \\
\text { Argentina } \\
\text { Bolivia } \\
\text { Brazil } \\
\text { Chile } \\
\text { Colombia } \\
\text { Costa Rica } \\
\text { Dominican Republic } \\
\text { Ecuador } \\
\text { El Salvador } \\
\text { Guatemala } \\
\text { Honduras } \\
\text { Mexico } \\
\text { Nicaragua } \\
\text { Panama } \\
\text { Paraguay } \\
\text { Uruguay } \\
\text { Venezuela, RB } \\
\text { East Asia \& Pacific } \\
\text { Indonesia } \\
\text { Philippines } \\
\text { South Korea } \\
\text { Europe \& Central Asia } \\
\text { Uzbekistan } \\
\text { Turkmenistan }\end{array}$ & $\begin{array}{l}\text { East Asia \& Pacific } \\
\text { Mongolia } \\
\text { Europe \& Central Asia } \\
\text { Azerbaijan }(*) \\
\text { Armenia } \\
\text { Belarus (*) } \\
\text { Bulgaria } \\
\text { Croatia } \\
\text { Czech Republic } \\
\text { Georgia } \\
\text { Kazakhstan }(*) \\
\text { Kyrgyz Republic } \\
\text { Lithuania } \\
\text { Macedonia, FYR } \\
\text { Montenegro } \\
\text { Poland } \\
\text { Romania } \\
\text { Russian Federation }(*) \\
\text { Serbia } \\
\text { Slovak Republic } \\
\text { Slovenia } \\
\text { Ukraine }(*)\end{array}$ & $\begin{array}{l}\text { East Asia \& Pacific } \\
\text { Malaysia } \\
\text { Papua New Guinea } \\
\text { Thailand } \\
\text { Europe \& Central Asia } \\
\text { Albania } \\
\text { Estonia } \\
\text { Hungary } \\
\text { Latvia } \\
\text { Moldova } \\
\text { Turkey }\end{array}$ \\
\hline
\end{tabular}

Table 1. Countries by Government Systems

The countries with $(*)$ correspond president-parliamentary systems in the classification of Shugart and Carey (1992). Elgie (2015) classified them as semi presidential systems.

Countries are grouped according to classic government system categories in Table 1. Azerbaijan, Belarus, Kazakhstan, Peru, the Russian Federation and Ukraine are categorized as president-parliamentary in keeping with classification of Shugart and Carey (1992). Government system changes in countries are also taken into account in the period of 1995-2013. The implementation periods of systems by countries are as follows: "Presidentparliamentary" for 1995-2004, "Semi presidential" for 2005-2013 in Armenia; "President-parliamentary" for 
1995-1999, "Parliamentary" for 2000-2013 in Croatia; "Semi presidential" for 1995-2000, "Parliamentary" for 2001-2013 in Moldova; "President-parliamentary" for 1996-2006 and for 2011-2013, "Parliamentary" for 20072011 in Ukraine (Elgie, 2015).

Two statistical analysis techniques were performed for comparison. Firstly, principal component analysis was used with the average of 1995-2013 annual data. Panel data analysis for 53 countries in the period 1995-2013 has also been performed in order to examine the relationship between government systems and socioeconomic indicators. Information about the data used in the analysis is in Table 2 below.

\begin{tabular}{|c|c|c|c|}
\hline Variable & Definition & Scale & Data Source \\
\hline Government system & $\begin{array}{l}\text { (1) presidential, (2) president-parliamentary, (3) semi- } \\
\text { presidential, (4) parliamentary }\end{array}$ & Categorical & $\begin{array}{l}\text { Elgie (2015), } \\
\text { Shugart \& } \\
\text { Carey }(1992)\end{array}$ \\
\hline Population $(\log )$ & Annual population data & Ratio & World Bank \\
\hline GDP (constant) $(\log )$ & Data are in constant 2005 U.S. dollars & Ratio & World Bank \\
\hline GDP per capita $(\log )$ & Current GDP per capita in US Dollars. & Ratio & World Bank \\
\hline $\begin{array}{l}\text { Life expectancy at } \\
\text { birth }(\log )\end{array}$ & $\begin{array}{l}\text { It is the average number of years an infant is supposed to live } \\
\text { having been exposed to age specific mortality rates at certain } \\
\text { periods all through his/her life (TÜIK, 2015). }\end{array}$ & Ratio & World Bank \\
\hline Unemployment $(\log )$ & Annual unemployment rate. & Ratio & World Bank \\
\hline GDP growth $(\log )$ & Annual growth rate for GDP. & Ratio & World Bank \\
\hline $\begin{array}{l}\text { Internet users (per } \\
100 \text { people) }\end{array}$ & $\begin{array}{l}\text { Internet users are individuals who have used the Internet } \\
\text { (from any location) in the last } 12 \text { months. Internet can be } \\
\text { used via a computer, mobile phone, personal digital assistant, } \\
\text { games machine, digital TV etc. }\end{array}$ & Ratio & World Bank \\
\hline $\begin{array}{l}\text { Corruption Perception } \\
\text { Index (CPI) }\end{array}$ & $\begin{array}{l}\text { CPI Score relates to perceptions of the degree of corruption } \\
\text { as seen by business people, risk analysts and the general } \\
\text { public, and ranges between } 10 \text { (highly clean) and } 0 \text { (highly } \\
\text { corrupt). }\end{array}$ & Ratio & $\begin{array}{l}\text { Transparency } \\
\text { International }\end{array}$ \\
\hline $\begin{array}{l}\text { Human Development } \\
\text { Index (HDI) }\end{array}$ & $\begin{array}{l}\text { HDI is a composite indicator of life expectancy, education, } \\
\text { and income per capita indicators, which are used to rank } \\
\text { countries (between } 0-1 \text { ) }\end{array}$ & Ratio & $\begin{array}{l}\text { United Nations } \\
\text { Development } \\
\text { Program }\end{array}$ \\
\hline Environment & Environmental Wellbeing Scores & Ratio & $\begin{array}{l}\text { Sustainable } \\
\text { Society } \\
\text { Foundation } \\
\end{array}$ \\
\hline Political rights & \multirow{2}{*}{$\begin{array}{l}\text { The political rights questions are grouped into three } \\
\text { subcategories: Electoral Process, Political Pluralism and } \\
\text { Participation, and Functioning of Government (scores } \\
\text { between 0-40). The civil liberties questions are grouped into } \\
\text { four subcategories: Freedom of Expression and Belief, } \\
\text { Associational and Organizational Rights, Rule of Law, and } \\
\text { Personal Autonomy and Individual Rights (scores between 0- } \\
\text { 60). A country or territory is assigned two ratings ( } 7 \text { to 1) one } \\
\text { for political rights and one for civil liberties. }\end{array}$} & Categorical & $\begin{array}{l}\text { Freedom } \\
\text { House } \\
\text { Organization } \\
\end{array}$ \\
\hline Civil liberties & & Categorical & $\begin{array}{l}\text { Freedom } \\
\text { House } \\
\text { Organization }\end{array}$ \\
\hline $\begin{array}{l}\text { Vanhanen's } \\
\text { democracy index }\end{array}$ & $\begin{array}{l}\text { Developed by Tatu Vanhanen in early 1970s } \\
\text { Competition and Participation. Both are calculated using } \\
\text { election data, and the democracy index is estimated by } \\
\text { combining the two. Competition: the percentage share of the } \\
\text { smaller parties and independents of votes cast in } \\
\text { parliamentary elections, or of the seats in parliament } \\
\text { Participation: the percentage of population that voted in } \\
\text { elections }\end{array}$ & Ratio & $\begin{array}{l}\text { Finnish Social } \\
\text { Science Data } \\
\text { Archive (FSD) }\end{array}$ \\
\hline Polity score & $\begin{array}{l}\text { (polity } 2 \text { variable) The "Polity Score" captures this regime } \\
\text { authority spectrum on a } 21 \text {-pont scale ranging from }-10 \\
\text { (hereditary monarchy) to }+10 \text { (consolidated democracy). The } \\
\text { Polity scores can also be converted into regime categories in } \\
\text { a suggested three-part categorization of "autocracies" }(-10 \text { to } \\
-6) \text {, "anocracies" }(-5 \text { to }+5) \text {, and "democracies" }(+6 \text { to }+10) \text {. }\end{array}$ & Interval & $\begin{array}{l}\text { Center for } \\
\text { Systemic } \\
\text { Peace }\end{array}$ \\
\hline EIU democracy & $\begin{array}{l}\text { The index is based on } 60 \text { indicators grouped in five different } \\
\text { categories measuring pluralism, civil liberties, and political } \\
\text { culture. In addition to a numeric score ((between } 0-10) \text { and a } \\
\text { ranking, the index categorizes countries as one of four regime } \\
\text { types full democracies, flawed democracies, hybrid regimes } \\
\text { and authoritarian regimes. }\end{array}$ & Ratio & $\begin{array}{l}\text { The Economist } \\
\text { Intelligent Unit }\end{array}$ \\
\hline
\end{tabular}

Table 2. Data Features and Resources 


\subsection{Comparison of Government Systems Using Principal Component Analysis}

Principal component analysis is one of the earliest multivariate analysis techniques which was firstly used by Pearson in 1901 and developed by Hotelling in 1933. It reduces the dimensionality of multivariate data while preserving as much of the relevant information as possible. It transforms the dataset of a large number of interrelated variables to uncorrelated dataset with less variables.

Data set for principal component analysis consists of various indicators of countries i.e. population, GDP, GDP per capita, life expectancy at birth, internet users, corruption perception, human development, environmental wellbeing, political rights, civil liberties, Vanhanen's democracy index, polity and EIU democracy scores. Analysis was performed by using SPSS version 23 (IBM Corp., 2015). First of all Kaiser-Meyer-Olkin (KMO) and Barttlett's test of sphericity were applied measures of sampling adequacy for principal component analysis. KMO is expected to be greater than 0.5 for sampling adequacy (Cerny \& Kaiser, 1977). Bartlett's test of sphericity is for the overall significance of all correlations within a correlation matrix (Bartlett, 1950). The test results in Table 3 show that the data set is appropriate for principal component analysis $(\mathrm{KMO}>0.50$ and $\mathrm{P}<0.01)$.

\begin{tabular}{|l|l|l|}
\hline \multicolumn{2}{|l|}{ Kaiser-Meyer-Olkin Measure of Sampling } & 0.789 \\
Adequacy & Approx. Chi-Square & 701.233 \\
\hline $\begin{array}{l}\text { Bartlett's Test of } \\
\text { Sphericity }\end{array}$ & df (degree of freedom) & 78 \\
\hline & $\begin{array}{l}\text { Significance } \\
\text { probability }\end{array}$ & 0.000 \\
\hline
\end{tabular}

Table 3. KMO Measure and Bartlett's Test of Sphericity

Number of variables in data set was reduced to three components providing meaningful information. These three dimensions were named "democracy," "development" and "structural size" in accordance with the content variables. Countries were compared with respect to these new components. Component matrix is shown in Table 4.

Rotated Component Matrix ${ }^{\mathrm{a}}$

\begin{tabular}{|l|l|l|l|}
\hline \multicolumn{2}{|l|}{} & \multicolumn{2}{|l|}{ Component } \\
\cline { 2 - 4 } & 1 (Democracy) & 2 (Development) & 3 (Structural Size) \\
\hline Population & 0.011 & -0.128 & $\mathbf{0 . 9 3 8}$ \\
GDP (constant \$) & 0.038 & 0.269 & $\mathbf{0 . 9 0 6}$ \\
GDP per capita (current \$) & 0.237 & $\mathbf{0 . 8 9 4}$ & 0.150 \\
Life expectancy at birth & 0.525 & $\mathbf{0 . 6 2 9}$ & -0.065 \\
Internet users & 0.218 & $\mathbf{0 . 8 7 6}$ & -0.037 \\
Corruption perception & 0.636 & $\mathbf{0 . 6 0 3}$ & -0.099 \\
Human development & 0.226 & $\mathbf{0 . 9 2 6}$ & 0.041 \\
Environmental well-being & 0.424 & $\mathbf{- 0 . 6 5 0}$ & -0.179 \\
Political rights & $\mathbf{- 0 . 9 2 7}$ & -0.184 & 0.059 \\
Civil liberties & $\mathbf{- 0 . 9 0 6}$ & -0.300 & 0.115 \\
Vanhanen democracy & $\mathbf{0 . 6 4 3}$ & 0.145 & 0.206 \\
PolityIV score (polity2) & $\mathbf{0 . 9 4 4}$ & -0.044 & 0.028 \\
EIU democracy & $\mathbf{0 . 9 2 8}$ & 0.196 & 0.055 \\
\hline
\end{tabular}

Extraction Method: Principal Component Analysis.

Rotation Method: Varimax with Kaiser Normalization.

a. Rotation converged in 5 iterations.

Component Transformation Matrix

\begin{tabular}{|l|l|l|l|}
\hline Component & 1 (Democracy) & 2 (Development) & 3 (Structural Size) \\
\hline 1 (Democracy) & 0.796 & 0.605 & 0.031 \\
\hline 2 (Development) & -0.587 & 0.758 & 0.286 \\
\hline 3 (Structural Size) & 0.150 & -0.245 & 0.958 \\
\hline
\end{tabular}

Extraction Method: Principal Component Analysis.

Rotation Method: Varimax with Kaiser Normalization.

\section{Table 4. Principal Components and Transformation Matrix}

Principal components analysis provided composite scores of countries for these new factors to use in comparisons. The countries were sorted by scores for each component. In terms of development component, most 
developed countries in the first places are South Korea is presidential; Slovenia is semi-presidential and Estonia is a parliamentary democracy. Nicaragua, the Philippines, Guatemala, Indonesia, Honduras, Bolivia, El Salvador and Paraguay as the countries with lower socioeconomic development scores, are governed by presidential systems. But the lowest score belongs to Papua New Guinea, which is a parliamentary system. In terms of democracy component, the results show that low scores are observed in presidential and president-parliamentary systems. Turkmenistan, Uzbekistan with presidential systems and Belarus, Kazakhstan, Azerbaijan and Russia ruled by president-parliamentary system have lower scores. On the other hand, there are four presidential systems (Costa Rica, Uruguay, Chile and Panama), five semi-presidential systems (Slovenia, the Czech Republic, Lithuania, Slovakia and Poland) and one parliamentary system (Hungary) among the 10 highest scores of democracy component. It should be remembered that the number of countries with parliamentary systems is less in the scope of study. Even so, there are good examples in terms of democracy and development.

Results show that countries vary according to government systems in terms of better development and democracy indicators. But the reservation can be made for the president-parliamentary systems in terms of democracy scores, four out of six countries have the lower values. And it is also striking that these countries have very high economic development level relatively depending on national resources.

\subsection{Comparison of Government Systems Using Panel Data Analysis}

Panel data is a dataset in which the behavior of entities (individuals, countries, provinces, companies etc.) is observed across time. Panel data analysis is used to make inferences about relationships among the variables considering changes over time. Even though panel data analysis is based on earlier theoretical work, practical work began in the 1990s depending on advances in computer and software technology. The literature on panel data analysis has developed rapidly and it is increasingly being used as its advantages over cross-sectional analysis.

In this study, panel data covers annual data of 53 countries for the period 1995-2013. Panel data analysis was performed using STATA software version 14 (StataCorp., 2015). First of all, stationarity was tested, which is an important assumption in time series. Stationary series wander up and down around of horizontal line indicating the mean of the series, without any consistent trend (upward or downward) over the entire time span. The use of non-stationary series can produce invalid estimates yielding deceptive relationships actually without meaning. Panel unit root tests (Im, Pesaran \& Shin, 2003) were performed to check the stationary properties of the variables. According to results, population, GDP per capita and unemployment rate are non-stationary series while growth rate, life expectancy and democracy scores are stationary. First differences of the non-stationary series are stationary and they were used in the panel data. Generalized linear latent and mixed models (gllamm) which is a STATA command independently developed by Rabe-Hesketh, Skrondal \& Pickles $(2002,2005)$ were used in the analysis. The model allows using unordered categorical independent variables. The degree of the relationships between government systems and development or and democracy in the long run can be analyzed.

In the first model, population, GDP per capita, unemployment rate, growth rate, life expectancy at birth and Polity score for democracy were the independent variable. The choice of variables was made on the basis of data availability for balanced panel, considering pairwise correlations and results of principal component analysis. The estimation by using GLAMM shows that there is no significant relationship between government systems and economic development indicators i.e. GDP per capita, unemployment rate and growth rate. Population, life expectancy and Polity scores are significant variables in the model. The results of estimation were given in Table 5 .

The second model is the simplified one and covers GDP per capita, life expectancy at birth and Polity score. The results were obtained in the same direction (Table 6). When Vanhanen competition index, instead of Polity scores, was used in the model, the relationship between Vanhanen competition index and development are not significant. Polity score represents a wider definition of democracy that is directly or indirectly is affected by the other socioeconomic indicators. Vanhanen index stands for a narrower idea of democracy. Insignificant relationship means political participation and competition differ in each government systems.

\begin{tabular}{|ll|l|l|l|}
\hline \multicolumn{5}{|l|}{ Government system (dependent variable) } \\
\hline Independent variables & & Coefficients & $\begin{array}{l}\text { Significance } \\
\text { probability }\end{array}$ & \\
\hline Population & $(\mathrm{ln}, 1$. diff.) & -62.1231 & 0.000 & significant at the 1\% level \\
\hline GDP per capita & $(\mathrm{ln}, 1$. diff $)$ & 0.3036 & 0.405 & - \\
\hline Unemployment rate & $(\mathrm{ln}, 1$. diff $)$ & -0.2200 & 0.383 & - \\
\hline Growth rate & $(\mathrm{ln})$ & 0.0882 & 0.862 & - \\
\hline Life expectancy at birth & $(\mathrm{ln})$ & -2.8671 & 0.000 & significant at the 1\% level \\
\hline Democracy score & Polity score & 0.0302 & 0.019 & significant at the 5\% level \\
\hline Constant & 14.5845 & 0.000 & significant at the 1\% level \\
\hline $\begin{array}{l}\text { log likelihood = -1139.2938 } \\
\text { Variance (at level 1) } 0.9610409(0.0478178)\end{array}$ & & \\
\hline
\end{tabular}

Table 5. Panel Data Model (GLAMM 1) 


\begin{tabular}{|ll|l|l|l|}
\hline \multicolumn{5}{|c|}{ Government system (dependent variable) } \\
\hline Independent variables & Coefficients & $\begin{array}{l}\text { Significance } \\
\text { probability }\end{array}$ & \\
\hline Population & $(\ln , 1$. diff.) & -59.7538 & 0.000 & significant at the 1\% level \\
\hline GDP per capita & $(\ln , 1$. diff.) & 0.0689 & 0.776 & - \\
\hline Life expectancy at birth & $(\ln )$ & -3.5883 & 0.000 & significant at the 1\% level \\
\hline Democracy score & Polity score & 0.0300 & 0.038 & significant at the 5\% level \\
\hline Constant & 17.7051 & 0.000 & significant at the 1\% level \\
\hline $\begin{array}{l}\text { log likelihood = -1331.1841 } \\
\text { Variance (at level 1) 1.0053(0.04667) }\end{array}$ & \\
\hline
\end{tabular}

Table 6. Panel Data Model (GLAMM 2)

In order to compare results, the analysis was repeated with a binary logistic panel model for each government systems (binary - xtlogit). Three models were established with the variables in the simplified model above. In binary models categorical variable is equal to 1 if a country's system is presidential and to 0 otherwise. Models were created for semi-presidential and parliamentary systems likewise. The results from Hausman test is in favor of random effects model. The test results and significance probabilities are shown in Table 7.

\begin{tabular}{|c|c|c|c|}
\hline & \multicolumn{3}{|c|}{ Dependent variables (binomial) } \\
\hline & Presidential (1) & Semi-presidential (1) & Parliamentary (1) \\
\hline Independent variables & \multicolumn{3}{|c|}{ Significance probability $(\mathrm{p})$} \\
\hline Population & 0.021 & 0.002 & 0.201 \\
\hline GDP per capita & 0.987 & 0.127 & 0.121 \\
\hline Life expectancy at birth & 0.051 & 0.099 & 0.949 \\
\hline Democracy score & 0.323 & 0.001 & 0.000 \\
\hline Constant & 0.041 & 0.092 & 0.000 \\
\hline $\begin{array}{l}\text { Hausman Test } \quad \text { chi2(4) } \\
\text { p }\end{array}$ & - & $\begin{array}{l}5.06 \\
0.2812 \\
\end{array}$ & $\begin{array}{l}4,13 \\
0.3891\end{array}$ \\
\hline \multirow[t]{4}{*}{ Model } & Random effects & Random effects & Random effects \\
\hline & Waldchi2 $2(4)=8.38$ & Wald chi2 $(4)=19.26$ & Wald chi2 $(4)=53.76$ \\
\hline & Prob $>$ chi $2=0.0785$ & Prob $>$ chi $2=0.0007$ & Prob $>$ chi $2=0.0000$ \\
\hline & $\begin{array}{l}\text { Model is significant at } \\
\text { the } 10 \% \text { level }\end{array}$ & $\begin{array}{l}\text { Model is significant at } \\
\text { the } 1 \% \text { level }\end{array}$ & $\begin{array}{l}\text { Model is significant at } \\
\text { the } 1 \% \text { level }\end{array}$ \\
\hline
\end{tabular}

Table 7. Panel Data Model (binary - xtlogit)

According to the logistic model, presidential systems vary for different level of socioeconomic indicators, only population has impact on the presidential systems since they are common in more populated countries. The effect of democracy scores is significant in semi-presidential systems and parliamentary systems. Here it is understood that democracy impact on government systems comes from the president-parliamentary systems positioned in semi-presidential group. The results also show that GDP per capita and life expectancy at birth, which are among the elements of human development index, have no significant relationship with government systems at the 5\% level. Accordingly, government systems cannot be explained by the level of economic development.

Finally, the relationship between development and democracy were analyzed by using the panel data method. Three models were defined for different dependent variables. Government systems are used as categorical independent variable in each model. Fixed effects model was preferred in analysis according to Hausman test. The results shown in Table 8 are in accordance with the previous results in terms of government systems. GDP per capita is not explained by government systems. Government systems have a significant impact on life expectancy at birth and democracy scores.

In the context of the relationship between democracy and development, the results are not straightforward to establish such causality. The two development indicators (i.e. GDP per capita and life expectancy) and government systems have significant impact on the polity scores. Similarly the polity scores have a positive impact on both development indicators.

When Vanhanen competition index was used instead of Polity scores, the relationship between democracy and development is not significant, similar to the previous model. The two development indicators (i.e. GDP per capita and life expectancy) and government systems have no impact on the competition in the country. Actually the model is statistically insignificant (Table 9). 


\begin{tabular}{|l|l|l|l|}
\hline \multirow{2}{*}{ Independent variables } & Dependent variables \\
\cline { 2 - 4 } & GDP per capita & Life expectancy at birth & Democracy (Polity) \\
\hline GDP per capita & & $0.0172(0.001)$ & $0.8493(0.037)$ \\
\hline Life expectancy at birth & $0.7374(0.001)$ & & $13.5572(0.000)$ \\
\hline Democracy (Polity) & $0.0058(0.037)$ & $0.0022(0.000)$ & \\
\hline Government system & $0.0145(0.605)$ & $0.0132(0.002)$ & $1.9114(0.000)$ \\
\hline Constant & $-3.1417(0.001)$ & $4.2250(0.000)$ & $-56.1085(0.000)$ \\
\hline Hausman Test chi2 $(\mathrm{p})$ & $26.00(0.000)$ & $9.30(0.026)$ & $17.07(0.007)$ \\
\hline Model & Fixed effects & Fixed effects & Fixed effects \\
\hline & $\mathrm{F}(3,878)=7.00$ & $\mathrm{~F}(3,878)=20.48$ & $\mathrm{~F}(3,878)=26.27$ \\
\hline & Prob $>\mathrm{F}=0.0001$ & Prob $>\mathrm{F}=0.0000$ & Prob $>\mathrm{F}=0.000$ \\
\hline & $\begin{array}{l}\text { Model is significant at } \\
\text { the 1\% level }\end{array}$ & $\begin{array}{l}\text { Model is significant at } \\
\text { the 1\% level }\end{array}$ & $\begin{array}{l}\text { Model is significant at } \\
\text { the 1\% level }\end{array}$ \\
\hline
\end{tabular}

Table 8. Panel Data Model for Development and Democracy (Polity scores)

\begin{tabular}{|l|l|l|l|}
\hline \multirow{2}{*}{ Independent variables } & Dependent variables & \multicolumn{2}{|l|}{} \\
\cline { 2 - 4 } & GDP per capita & $\begin{array}{l}\text { Life expectancy at } \\
\text { birth }\end{array}$ & Democracy(Vanhanen) \\
\hline GDP per capita & & $0.0197(0.000)$ & $1.3033(0.499)$ \\
\hline Life expectancy at birth & $0.8251(0.000)$ & & $-13.4661(0.281)$ \\
\hline Democracy (Vanhanen) & $0.0004(0.499)$ & $-0.0000(0.281)$ & \\
\hline Government system & $0.0253(0.358)$ & $0.0179(0.000)$ & $0.9094(0.563)$ \\
\hline Constant & $-3.5241(0.000)$ & $4.2322(0.000)$ & $103.823(0.050)$ \\
\hline Hausman Test chi2 $(\mathrm{p})$ & $19.97(0.000)$ & $60.68(0.000)$ & $8.23(0.0415)$ \\
\hline Model & Fixed effects & Fixed effects & Fixed effects \\
\hline & $\mathrm{F}(3,878)=5.68$ & $\mathrm{~F}(3,878)=11.74$ & $\mathrm{~F}(3,878)=0.56$ \\
\hline & Prob $>\mathrm{F}=0.0007$ & Prob $>\mathrm{F}=0.0000$ & Prob $>\mathrm{F}=0.6436$ \\
\hline & $\begin{array}{l}\text { Model is significant at } \\
\text { the 1\% level }\end{array}$ & $\begin{array}{l}\text { Model is significant at } \\
\text { the 1\% level }\end{array}$ & Model is insignificant \\
\hline
\end{tabular}

Table 9. Panel Data Model for Development and Democracy (Vanhanen)

\section{Conclusions}

In this study, the relationship between socioeconomic development level and government systems of countries was examined. The different techniques show that evaluations related to the presence of such relationship seem to be meaningless. As stated by Bernhard et al. (2001), Cheibub \& Limongi, (2002) and Siaroff (2003), diversity in the practices makes the conceptual categories useless in terms of government systems. The variation within decision making processes in each category prevents making comparisons with general definitive classifications. In other respects, authoritarian or imperial histories of countries, managements of natural resources and correspondingly socio-cultural environments are variables which are mostly difficult to measure and include in the model.

On the other hand, democracy scores and government systems have an impact on each other in panel analysis. It is also a conceptional issue from several perspectives. Democracy with a narrower definition, which is represented by competition of more than one political party, does not have an impact on neither development nor government systems. The significant relationship between democracy in a wider concept and government systems is due to relatively small number of president-parliamentary systems and parliamentary systems in the scope have homogeneous scores in terms of democracy. Presidential systems vary according to democracy level.

As a frequently discussed topic, the relationship between development and democracy is a derivative subject in the study. Development indicators and wider conception of democracy are closely related, because this conceptional approach counts that level of democracy is also one of components of development.

\section{References}

- Bartlett, M. (1950). “Tests of Significance in Factor Analysis”. British Journal of Statistical Psychology, 3 (2), 77-85.

- Bernhard, M., Nordstrom, T. \& Reenock, C. (2001). "Economic performance, institutional intermediation, and democratic survival". Journal of Politics , 63 (3), 775-803.

- Center For Systemic Peace (2015). The Polity Project, Polity Score. http://www.systemicpeace.org/inscrdata.html (1.11. 2015) 
- Cerny, C. \& Kaiser, H. (1977). "A study of a measure of sampling adequacy for factor-analytic correlation matrices”. Multivariate Behavioral Research, 12 (1), 43-47.

- Cheibub, J. A. \& Limongi, F. (2002). "Democratic Institutions And Regime Survival: Parliamentary and Presidential Democracies Reconsidered”. Annual Review Political Science , 5, 151-79.

- Cutright, P. (1963). "National political development: Measurement and analysis". American Sociological Review, 28, 253-264.

- Doğan, A. (2005). "Demokrasi ve ekonomik gelişme”. Erciyes Üniversitesi İktisadi ve İdari Bilimler Fakültesi Dergisi (25), 1-19.

- $\quad$ Elgie, R. \& Schleiter, P. (2009). 'Variation in the durability of semi-presidential democracies'. In Conference of 21st World Congress of International Political Science Association. (8.3.2015) http://paperroom.ipsa.org/papers/paper_2514.pdf.

- Elgie, R. (1999). The Politics of Semi-Presidentialism. R. Elgie (Ed.) Semi-Presidentialism in Europe (s. 1-21). Oxford: Oxford University Press.

- Elgie, R. (2005). “From Linz to Tsebelis: three waves of presidential/parliamentary studies?”. Democratization , 12 (1), 106-122.

- Elgie, R. (2015). Semi presidentialism: http://www.semipresidentialism.com (10.12.2015)

- $\quad$ Finnish Social Science Data Archive (2015). Vanhanen Demokrasi Endeksi. Finnish Social Science Data Archive (FSD): http://www.fsd.uta.fi/en/ (10.3.2015)

- $\quad$ Freedom House Organization (2015). Freedom In The World 2015. https://freedomhouse.org/report/freedom-world-2015/methodology (10.10.2015)

- Gönenç, L. (2007). "Hükümet Sistemi Tartışmalarında Başkanlı Parlamenter Hükümet Sistemi Seçeneği”. Güncel Hukuk, 44, 39-43 (10.3.2015) . http://www.yasayananayasa.ankara.edu.tr/belgeler/makaleler/baskanli_parlamenter_sistem.pdf

- IBMCorp. (2015). IBM SPSS Statistics for Windows, Version 23.0. Armonk, NY: IBM Corp.

- Im, K., Pesaran, H. \& Shin, Y. (2003). “Testing for Unit Roots in Heterogenous Panels”. Journal of Econometrics , 115 (1), 53-74.

- Jackman, R. W. (1973). "On the Relation of Economic Development to Democratic Performance". American Journal of Political Science , 17 (3), 611-21.

- Jones, M. P. (1995). Electoral laws and the survival of presidential democracies. Notre Dame: University of Notre Dame Press.

- Lijphart, A. (1991). "Constitutional choices for new democracies". Journal of Democracy, 2(1), 72-84.

- Linz, J. J. (1978). The Breakdown of Democratic Regimes. J. Linz \& A. Stepan (Ed.) içinde, The Breakdown of Democratic Regimes: Crisis, Breakdown, and Reequilibration (s. 3-124). Baltimore: The John Hopkins University Press.

- Linz, J. J. (1990). “The Perils of Presidentialism”. Journal of Democracy, 1(1). s. 51-69.

- Linz, J. J. (1990). “The Virtues of Parliamentarism”. Journal of Democracy, 1(4). 84-91.

- $\quad$ Lipset, S. S. (1959). "Some social requisites of democracy: Economic development and political legitimacy”. The American Political Science Review , 53 (1), 69-105.

- Mainwaring, S. \& Scully, T. (1995). Building Democratic Institutions: Party Systems in Latin America. Stanford: Stanford University Press.

- Neubauer, D. (1967). "Some Conditions of Democracy”. American Political Science Review , 61 (4), $1002-$ 9.

- Przeworski, A. \& Limongi, F. (1997). “Modernization, Theories and Facts". World Politics, 49(2): $155-83$.

- Przeworski, A. (2004). Democracy and Economic Development. E. D. Mansfield \& R. Sisson (Ed.), Political Science and the Public Interest. Columbus: Ohio State University Press.

- Przeworski, A., Alvarez, M. E., Cheibub, J. A. \& Limongi, F. (2000). Democracy and Development: Political Institutions and Well-Being in the World, 1950-1990. Cambridge University Press.

- Przeworski, A., Alvarez, M., Cheibub J. A. \& Limongi F. (1996). "What Makes Democracy Endure?" Journal of Democracy, 7(1): 39-55.

- $\quad$ Rabe-Hesketh, S., Skrondal, A. \& Pickles, A. (2005). "Maximum likelihood estimation of limited and discrete dependent variable models with nested random effects". Journal of Econometrics , 128 (2), 301323. 
- $\quad$ Rabe-Hesketh, S., Skrondal, A. \& Pickles, S. (2002). "Reliable estimation of general linear mixed models using adaptive quadrature”. The Stata Journal , 1, 1-21.

- Sayarı, S. \& Dikici Bilgin, H. (2013). Karşılaştırmalı Siyaset. İstanbul Bilgi Üniversitesi Yayınları.

- Shugart, M. (2005). "Semi-presidential systems: Dual executive and mixed authority patterns". French Politics , 3 (3), 323-351.

- $\quad$ Shugart, M. S. \& Carey, J. M. (1992). Presidents and assemblies: Constitutional design and electoral dynamics. Cambridge University Press.

- $\quad$ Siaroff, A. (2003). "Comparative presidencies: The inadequacy of the presidential, semi-presidential and parliamentary distinction”. European Journal of Political Research, 42 (3), 287-312.

- StataCorp. (2015). Stata Statistical Software: Release 14. College Station, TX: StataCorp LP.

- $\quad$ Stepan, A. \& Skach, C. (1993). "Constitutional frameworks and democratic consolidation: Parliamentarianism versus presidentialism”. World Politics, 46 (01), 1-22.

- Sustainable Society Foundation (2015). Environmental Wellbeing Index Scores. http://www.ssfindex.com/ssi/ (1.11. 2015)

- The Economist Intelligence Unit (EIU) (2015). Democracy Index 2014. http://www.eiu.com/ (1.11. 2015).

- Transparency International (2015). Corruption Perception Index (Yolsuzluk Alg1sı Endeksi). https://www.transparency.org/research/cpi/cpi_early (1.11.2015)

- TurkStat (Turkish Statistical Institution) (2015). Metadata of Life Tables (Hayat Tabloları Metaverisi). http://www.turkstat.gov.tr/PreTablo.do?alt_id=1100 (1.5.2016)

- $\quad$ United Nations Development Programme (UNDP) (2015). Human Development Index. (1.11.2015) http://hdr.undp.org/en/content/exporting-data-and-understanding-api

- Yücel, B. (2003). "Yarı-Başkanlık Sisteminin Hükümet Modeli Üzerine Karşılaştırmalı Bir Çalışma: Fransa Modeli ve Komünizm Sonrası Polonya.” AÜHFD, 52 (4), 335-364. 


\title{
State in Terms of Structure and Function: A Comparative Analysis
}

\author{
Prof. Dr. Şenol Durgun (Ankara Sosyal Bilimler University, Turkey)
}

\begin{abstract}
This study deals with the concept of the state in terms of structure and function and aims to comparatively analyze the perception of the state in the Turkish thought. In the literature on the state today, there is a tendency to reject a universal state theory. It is argued that there can be a conception of the state for each country in their own context. The type of organization and conditions of each state can cause the formation of different structures and functions, and hence to insist on a universal approach would not be appropriate. However, to understand the conception of state in terms of structure and function in our political culture, the dominant Western thought on the state constitutes an important criterion.
\end{abstract}

\section{Introduction}

A literal comparative analysis of state as a broad concept in terms of structure and function would be too bold a claim to make; hence, what we aim to do here is to conceive of the structures and functions of the state brought about by Western and Turkish thoughts, each with its own tradition and cultural climate. To go beyond this would be an exaggerated claim and such an attitude would not be justifiable on subjective and objective grounds.

To begin with, we have no such knowledge of any literature that would enable us to define state objectively and explain it in terms of structure and function. Despite some studies with such titles as "universal history" and "world history," it is obvious that they are all loaded with subjective judgement: they intrinsically reflect the mindsets of their authors, elaborating a thought extensively and ignoring or despising the others. This perspective, based on the notion that non-western world has societies with "no history", deeply seated in western world approaches the concept of state with a Westernist attitude. Clearly, this is a myopic view that disregards the rest of the world. Secondly, there is little research into the history of the non-western world. As a result, the current writer has no claim that the paper comprehensively analyzes the concept of state from all points of views. Rather, the attempt is restricted to conceiving of the state emergent as in two different worldviews, for the formation of an understanding of state is caused by such factors as living conditions, geographical location, beliefs and values held, civilization and culture, the relationships with other societies, and the problems faced. Therefore, we disagree with the conception of universal theory of state and highlight that every country has their own conception of state within their political circumstances.

\section{A General Outlook on the Concept of State in Western Thought}

We need to understand the basic dynamics of the western societies and western thought to understand what state and politics come to mean on a world scale because western thought is dominant globally.

The historical conditions of the capitalist state, the nature of class struggle or the structure of production all play a central role in defining and analyzing the structures and functions of the contemporary states. However, western thought has followed a changing course in different periods of history in terms of the conception of state, its structure, and function. In the beginning, the liberal form of the bourgeois government was largely shaped by the distribution of ownership, and the exercise power was represented by a small of group of citizens, while, in later periods, the political power started to represent a wide range of groups, and wealth and income was controlled by free market (Eroğul, 2002:125). Emerging to control the desires and interests of the people, the liberal theory of state based on individual rights and the notion of "common good" had undergone a set of substantial changes in the direction of the fact that the best service for the country and the world was possible through civil society and free market economy. Those changes were caused mostly by the political struggles capitalism lived through in Britain and France (Carnoy, 2014: 18). In fact, having witnessed the rise of the interest groups and the decline of liberal democracy in the political realm, the scholars of the $19^{\text {th }}$ and $20^{\text {th }}$ century brought up the need for a new social and political order which was to be based on operational autonomous socio-economic organizations cooperating with the state in the sectoral and national decision-making bodies for class harmony and social unity in the civil society. That new system was corporate statism. Unlike the liberal conception of state, the new perspective held that the common good was represented by the state. Further, the common good as the ultimate aim of the state was the source of legitimacy and moral authority of the state. Consequently, in addition to symbolizing the public values and norms, the state stood for morality and ideology for the public. In other words, corporate statism was regarded to be a way to resolve the conflicts of interests without resorting to violence in a political system in which only one higher good was thought to exist, aiming in such a manner to get rid of the limits the liberal understanding of state placed on the economic role of the state. However, in contrast to the liberal one, the corporatist state strengthened the position of the independent bureaucratic power in the political structure 
rather than weakening it, for corporate statism gave a central role to the state to play in capitalist development. Thus, democratic form of government could straightforwardly be delayed for the sake of economic growth and national order. The state, in such a climate, was not regarded as an organization intervening in the efficiency of free market economy but an integral part of the body that rationalized free market economy. Clearly, the efforts to solve the problem caused by the conflicts of interests in the society paved the way for a state with new functions in a different form of organization, resulting in a new type of state.

In addition to corporate statism, social welfare state emerged in a way to protect democratic values, to eliminate the problems brought about by liberal state. The driving force of the capitalist state was based on private enterprise. The private sector was like the center for social change until 1930s. However, social welfare state gained significance during the period from 1930s to 1970s, with the result that the role played by the state in economy was increased to balance it through the public sector. Social welfare state, popular in the West until 1970s, was replaced by neoliberal state, indicating a return to the liberal values adopted in the circumstances of the time. With neoliberalism, the structure and functions of the state were reshaped according to the new conditions.

Another development was the Marxist understanding of state. This understanding was different for the previous ones in that the state was defined as a tool for hegemony building of one group over another as an expression of class relationships. Thus, the state in the Marxist view was considered to be both the product and shape-giver of this hegemonic relationships (Oppenheimer, 1984:61). Influenced by Marx, Lenin defined the state as an agency of class dominance. To him, the state was a special organization of force, an organization of violence for the suppression of some class, weakening the class conflict, legitimizing and continuing this suppression. Hence, it was thought to be necessary to eliminate the state which was regarded as the armed force of the bourgeoisie. In Marx's, Engels', and Lenin's terms, the state was structure required to suppress the oppressed classes and to regenerate class relationships. If, they claimed, there was no such a situation, that is, in case of the existence of classless societies, then the state would be redundant and would fade away. Though these theories based on class were initially shaped by Marx, Engels, and Lenin, they came a long way, afterwards. In fact, the Marxist view of the state pursued an orthodox approach until 1950s, when it started to change its direction as discussed among the western Marxists. Being the turning point for Marxist ideology, the 1950s witnessed the end of Stalinism and the beginning of the Cold War. As the Leninist theory of state was indisputably dominant in the Marxist thought after the success of the Russian Revolution, it was dictated until the early 1960s, and the other theoretical and practical efforts were deliberately ostracized.

To sum up, state was examined in two perspectives in the western thought, excluding the classical Marxist view, which opposed the presence of the state. The first view holds that state is "autonomous and irrational" and thus the solution is to minimize the state in all areas of social life. The second view puts forward that the irrationality of the state is not caused by its autonomous nature but by its sensitivity to "irrational" masses and thus the solution is to increase the role of the state and take the state away from the control of the masses. Consequently, these two views provide us with a good amount of information about the state in the western sense: on the one hand, there is state that represents the general will independent of the economic power relationships or completely autonomous from civil society; on the other, state that operates independently neither of the general will nor of the capitalists.

\section{A General Outlook on the Concept of State in Turkish Thought}

The living conditions, geographical location, historical circumstances and the sociocultural values have formed a different conception of state in Turks from the one in the west. The historical political legacy in the Turkish society, living under the rule of state based on western values for over two hundred years, has always experienced problems with the state of westernist nature. Therefore, with no reference to this legacy would it be unreasonable to try to understand and provide solutions to the problems involved with the structure of the state based on western values (Sezer, 1979:2).

The Turks have formed an authentic state culture and conception of state due to a number of factors. First, the Turks have had to move from one place to another due mostly to the socio-political circumstances from the early periods of history. Second, they have lived in organized tribes, with no classes based on land ownership or clergy. Third, they have always lived under the rule of a state, with their own conception of history. Historically, then, the central position of the state in Turkish culture has had a hold over the cultural and social realms. In this respect, the conception of the state by the Turks is authentic.

The Turkish conception of state is of sacred origin and the view that a similar, unshakable, indefectible, perfect order as in the universe should be established on earth has always been the emblem in the course of history. Just as the heavens surround the earth like a marquee, so Hakan's marquee should rein over the world as a whole as "the World Government." In other words, it was believed that the heavens is for God's rule, and the world should be under the rule of only one government controlled by Hakan. Hence, the world government vision articulated in the Legend of Oghuz Khagan and the Orkhon Inscriptions laid the foundation for the Turkish conception of state. To this view, the state is a grant offered by God to Khagan, representing the unification of the social order with universal order. 
Present in the pre-Islamic period, this view has continued to exist in the Islamic period (with no ownership in a classless society). As a matter of fact, a social structure consisting of classes based on land ownership did not emerge in the Ottoman times, the closest era to the Republican period, and because there was no aristocracy originating from land ownership, the distinction between the state and the public as in Western Europe was out of question here. Consequently, the public did not regard the state as enemy as in societies consisting of classes but saw it as father. In this period, the state was not the state of a certain class but a structure made up of divine dynasty members and civil servants of the public (Sezer, 1981:149). Due to the superior position of the state over the society, maintaining social order and promoting justice were among the functional priorities of the state. At this point comes out a fundamentally different attitude towards accumulation of wealth from the western approach: Accumulation of wealth was regarded to be one of the sources of injustice and thus must be inhibited. In the preIslamic period, there were common practices to prevent any unjust structure to emerge, such as Hakan's order to sack the possessions, confiscation of property by the state and using it for pious foundations, restraining ways for the individuals to get rich, and violation of human rights being among the biggest sins in Islam.

It is clear that status-oriented values rather than market-oriented ones dominated the Turkish tradition of state. The relationships between the economic realm and the political power were far more different than those in Western Europe. Rather than the economic power paving the way for political power as in Western Europe, it was political power (higher positions in bureaucracy) that took one to the biggest material wealth. Still, accumulation of wealth was not allowed to take the form of permanent fortune in the hands of the few. For this reason, on the whole, the power of the state elites was never seriously challenged by the public. Neither the bourgeoisie of commerce nor landowners had ever reached such a position as to control or restrict the power of the state. As a result, the ultimate social division did not rest on economic foundations but on political criteria. As a matter of course, the central role carved out for the state was to take the responsibility of social and world orders, which was expressed as Order of the World (Nizam-i Alem) in classical Ottoman period and New Order (Nizam-i Cedid) in the period of modernization. The act of establishing a worldly state was conceived of through the concepts that come to mean establishing a state on the whole world similar to that of God all over the universe. Actually, the state was thought to be eternal (ebed müddet), meaning that the state is a never-ending sacred organization, which is an indication of the continuation of the historical legacy of the conception.

These developments occurring at the beginning of the modernization period in a process of adaptation with the historical legacy entered a new era and followed a different path afterwards, resulting in a state primarily based on European / Western values. In other words, the Western conception of state, based on a market-oriented organization, was of a far more different character than that in the western experience. In the early period of Turkish modernization, the Ottoman intellectuals were seeking to save a state which was about to collapse through a new legal system, unlike their counterparts in the west who were concerned about such problems as inequality caused by the domination of the church and social class structure. In fact, the Ottoman intellectuals were not convinced that the solution to their problem was a social contract as in Europe. Rather, they intended to benefit from the ideas of the thinkers of the Enlightenment, wanting to understand and use those ideas as explanatory models. However, the method adopted in the shaping of the new civilization was traditional in nature and thus no change was allowed without the permission of the state and it was believed that for a change to be legitimate it should be introduced only by the state. Explicitly, it was thought that change must start from the state and spread to the society from it. As a matter of fact, the last century of the Ottoman State, having realized the need for change in the early 1800 s and the Republican Period, which cannot be thought independently of the Ottoman State, witnessed this type of changes. Consequently, even in the modernization period, the state was defined as the only authorized political agent to design and modernize the society.

\section{A Comparative Analysis}

As the Turkish state tradition was not based on social classes as in the West, the state in the course of Turkish history did not act upon the interests of a social class and thus politics was thought to be not a matter of the public but a matter of bureaucrats. As a result, the state affairs were considered as relationships not concerned with the public, and the political events, as they occurred, were watched by the public from a certain distance. To put it another way, the fact that the state did not represent the economic structure of the society brought about the existence of the state hierarchically over the public. The presence of a society having no classes and private property, the lack of an organized religion with hierarchy hindered the emergence of the social grassroots with internal conflicts experienced in societies that have classes, private property and an organized religion. Thus, in the course of the Turkish history, the public had to adopt a solution produced out of the limits of its structure and power. As the essence of the state was far from the conflicts of interests among the people, the public was not able to influence the state using their conflicts. Each person in the society was considered to be equal to one another, for the value system neither required the people to exploit each other nor allowed one to claim superiority over others. As a result, each of the principles that helped maintain the social order was valid for the whole society and thus the state was responsible for creating the conditions ripe for living accordingly. In this way, the state, with its 
structure different from that of the West, occupied a central position in the Turkish political history as the social and individual existence required.

In the Western history of political thought, the walks of life and organizations in the society which were the result of the historical legacy were thought to be autonomous, whilst in the Turkish history of political thought, a spirit of community and identification among the social institutions were so common that an identification was always required between "the state" and "the people," or "the state" and "the public." In other words, the integrative processes with the state were designed not by a process of negotiation between and among the autonomous social fields but by a holistic approach. Due to its superior and sacred characteristics, the state was privileged; accordingly, the political behavior differed from the one in the west, which is still the same. Although the modernization process started quite a long time ago, and Western values and the pursuit of democratic ideals have long been extensively discussed in both the political and social spheres, the idea that the state has a superior position continues to exist in our political culture. As a matter of fact, the Constitution of 1961 states "the constitution was prepared by the Turkish Nation, who fomented the Revolution of May 27, 1960 using its right to withstand the government which lost its legitimacy by acting against the constitution and the law." The Turkish Nation "declares that it accepts this constitution, prepared by the Founding Assembly of the Republic of Turkey." In fact, however, it was National Unity Council directed by the 38 military staff of the Coup of 27 May 1960 that prepared the constitution of 1961. The procedure followed was far from the principles of free elections, general vote and representation of parties. Originally, the coup had the "Chamber of Representatives" prepare the constitution. Far from having such characteristics as being elected, representative, and deputy, National Unity Council played a big part in shaping the resulting script of the constitution. In other words, the preamble of the Constitution of 1961 created a "fiction" identifying the will and act of the military coup with those of the public, paving the way for legitimizing military interventions and constitutions prepared by coups in the Turkish political life.

Normally, the movement leading to the coup in 1960 did have the economic, social, and political elements of "revolutions" and conditions for the "right to resist." Likewise, the 1982 Constitution states "the constitution was brought about by the military action of 12 September 1980 inspired by the call by the Turkish public for intervention to the inseparable part of the Turkish Nation, the Turkish Military Forces. It was prepared by the Advisory Council, the legitimate representative body of the Turkish Nation, shaped by National Security Council, and instituted and endorsed directly by the Turkish Nation." A constitution of five people was presented as the constitution of the public. As the members of Advisory Council were all appointed by the military, it is a baseless argument to claim that they were the "legitimate representatives of the Turkish Nation." As stated in the constitution, the final form of it was given by National Security Council, which has nothing to do with representation. Therefore, it is a groundless statement to say that "the constitution was instituted and endorsed directly by the Turkish Nation" (Parla, 2002:32-33).

In the preamble of the current constitution of 1982, “...to the unity of the eternal Turkish Nation and land and the presence of the Holy Turkish State" was replaced in 1995 with "the eternal presence of the Turkish land and nation and the indivisible unity of the Supreme Turkish State," which means that "sacred" is excluded; "eternal" is maintained, and "supreme" is added. Despite this, the same mentality has been maintained as reflected in "the Supreme Turkish State" in the place of "the Holy Turkish State" (Parla,2002:151). Such phrases as "the moral values and the history of the Turks," "the material and moral happiness of the Republic of Turkey...," and "for each Turkish citizen to develop morally and economically" have cosmic connotations directly in opposition with the Kemalist conception of laicism. These phrases go far beyond the phrases like "sharing the same fate, honor, and concern," "the spirit of national unity," (1961 Constitution) "sharing national pride, joy, and sorrow," and "filled with feelings of mutual love and brotherhood" (1982 Constitution) (Parla,2002:36). Exalting the state as such has always been supported by the education system and the bureaucratic elites (e.g., the military) to maintain the gained dominance within the system. Although a political reconstruction in the western sense was adopted with the political power taken from the heavens and granted to the public, the political practice has shown that such an ideal has never been internalized, even though the Republican State formally follows a western structure, which indicates that the traditional understanding of the state is still powerful in the governmental structure even in the modern times. In fact, the bureaucrats have always felt suspicious about other groups or organizations, or political parties exalting the state, and they still regard themselves as the guard of the state and public interests. Anyway, the structuring of the emerging political parties in the period of modernization was not like the ones in the West but was formed by our own political culture. Even when a political party of western character was needed, it was required that the new party must comply with the criterion: the supremacy of the state. To put it more clearly, the political parties of western character were allowed; however, what is expected of the political parties has been to represent the public interests, considering the central position of the state, without resorting to the interests of certain groups. The Turkish political life has witnessed this kind of a procedure the political parties have followed. When a political party tried the opposite, it could not continue to exist. In other words, though the structure of the state in the period of modernization has been influenced by the West, the political elite's responsible attitude have helped the conception of state peculiar to their own state tradition survive up until now. The centuries-old 
submissive attitude of the public towards the state has made it difficult for democracy to flourish in the society. Further, this has been hindered by the conscious efforts of the state officials, alongside with the distinction between the state and the public.

In brief, the traditional conception of state as holy and supreme has been regarded significant in the Republican period in terms of national unity and the power of the state with the public. Thus, representing the centuries-old governmental experience, this conception of state should not be destroyed for the sake of "becoming modern." On the other hand, the political or bureaucratic authorities should not act highhandedly, exploiting the holiness or supremacy of the state. In this respect, if the supremacy of law is reflected in practical situations, then the historical advantages of the political culture could be put to good use. Otherwise, the political system may become corrupt due to such irresponsible behavior for the sake of "holiness" or "supremacy."

\section{Conclusion}

The organization of the state in Turkish history cannot be truly understood with reference to the material needs or economic interests of the crowds or individuals in the society, as in the West, where the state has no supreme or holy position. However, the Turkish conception of state stipulates that the state encompasses all the public, is over them, and is not an area for showdown about social conflicts. Therefore, what we need is to greatly benefit from the Turkish state tradition, instead of losing it in the way for western politics.

There have been ongoing discussions about state, despite a good amount of literature about the state, and the discussions take many different shapes and contents in different historical and cultural environments. Though there are a wide variety of topics covered in these discussions, two questions still remain significant: "Does the state refer to a holy place or an area for showdown?" and "Is the state for order or the public?"

\section{References}

- Carnoy, Martin: Devlet ve Siyaset Teorisi, Çev. Simten Coşar-Aykut Örküp-Mete Pamir-Mehmet Yetiş, Dipnot Yayınları, Ankara 2014

- $\quad$ Eroğul, Cem: Devlet Nedir?, 3. Baskı, İmge Kitabevi, Ankara 2002

- Oppenheimer, Franz: Devlet, Çev. Alaeddin Şenel-Yavuz Sabuncu, Kaynak Yayınları, İstanbul 1984

- Parla, Taha: Türkiye'de Anayasalar, 3. Baskı, İletişim Yayınları, İstanbul 2002

- Sezer, Baykan: Asya Tarihinde Su Boyu Ovaları ve Bozkır Uygarlıkları, İstanbul Üniversitesi Edebiyat Fakültesi Yayınları, İstanbul 1979

- Sezer, Baykan: Toplum Farklılaşmaları ve Din Olayı, İstanbul Üniversitesi Edebiyat Fakültesi Yayınları, İstanbul 1981 


\title{
The Effect of Research and Development Expenditures on Economic Growth: New Evidences
}

\author{
Asst. Prof. Dr. Mustafa Ildırar (Çukurova University, Turkey) \\ Assoc. Prof. Dr. Mehmet Özmen (Çukurova University, Turkey) \\ Asst. Prof. Dr. Erhan İşcan (Çukurova University, Turkey)
}

\begin{abstract}
Research and Development (R\&D) is one of the most important variables that affect the country's economic growth and development through increasing the technology capabilities, enlargement of resource base and promoting in the capability of resource utilization. Countries that innovate by conducting R\&D activities always have high economic growth and many researchers emphasized this prominent role of the R\&D on economic growth in numerous studies. This study contributes in two ways to this stream of research. Providing new estimates of the effect of R\&D expenditures on economic growth is the first contribution to literature. On the other hand, there are different types of R\&D expenditures and each of them has different magnitude on the economic growth. Therefore, this study provides evidences about the magnitudes of R\&D expenditures. The effect of different types of $R \& D$ expenditures on economic growth for the selected OECD countries is examined in this study by utilizing from GMM framework using the data belonging the period of 2003-2014. Income and different R\&D expenditure data used to analyze that obtained from OECD Stat. As a conclusion, it is found that all of the R\&D expenditures have positive and significant effect on economic growth in selected OECD countries but magnitudes are various. Therefore, policy makers should design the R\&D stimulation policies depending on the characteristics of the countries. Accordingly, countries must allocate more resources to different types R\&D expenditure for achieving sustainable rate of growth.
\end{abstract}

\section{Introduction}

Being an information society in the first quarter of 21 st century in the world maintains its priority. Technological development not only affects the country's economic system but also changes political and social structure of the country. That's why all the countries deal their science and technology politics as a system and get in a big race in order to get the globalized technology. Today's advanced and modern societies are known as "Information Society". Information society expresses a public organization for that all kinds of knowledge are produced, obtained, spread and used easily. It shouldn't be ignored that the truth of being an information society is not easy. In this regard, it is necessary to develop technology. As one of the gaining ways of technology, different factors have to get together in order to develop technology in the country.

Central countries have a high effect on the nearby countries on the field of information and technological level in today's world economies. It is seems that these countries effects are increasing both on political and economic side. Also development in the globalization period formed with the technological development and reflected as the new economic politics.

The most important role in creating the new development process is the technological development. Technological superiority that determines the economic balances creates a rivalry environment among all world countries. Industrial enterprises that symbolize the countries wealthiness, economic power, welfare level are continuing competition of efficiency for directing the future from today. Today, technology is the key of economic rivalry. That is why the countries which do not want to fall behind in competition have to follow an affective technology policy.

Developed and developing countries emphasize improving technology to overcome crisis or to increase the competitiveness. 21st century's essential characteristic for all areas is the continuous change. Between all the varieties of changes so far the most important one is technological change. There are several sources of technological inventions and innovation. Today, the most important source is the work of R\&D units operating in various industries. $R \& D$ refers for activities of corporate or governmental innovation. R\&D is a component of innovation and also an aimless invention effort. Innovation builds on R\&D and commercializing complete the phase. Basic characteristics of $\mathrm{R} \% \mathrm{D}$ are taking long periods with high costs and uncertain results with chance of failure. However, that risk of failure could be reduced to minimum level by organizing R\&D activities very effectively and planned.

\section{Theoretical Framework}

Emphasizing the importance of economic growth is a quite difficult. The fact that income increased more than ten folds in USA and some European countries in the 20th Century is beyond doubt the result of technological progress. Understanding the fact of economic growth has particularly progressed from the 1980s. From the beginning of mid-1980s, the case of economic growth has become one of the most highlighted research subjects 
in the science of economy. In this framework, it is clear that literature has significantly expanded to determine the sources of economic growth or factors affecting this growth. Majority of the studies on growth theory can be divided into three groups (Evenson, 1997, Jones, 2007, Bozkurt, 2015):

First group is the Post-Keynesians growth models that emphasize the incentive role of saving and investment on growth.

Second group is the Neo-Classical growth models that signify the technologic progresses as the locomotive of economic growth.

Third group is the New Growth Theory, also known as the Endogenous Growth Theory, which emphasizes the important effects of the factors behind the technological development such as R\&D, human capital accumulation, and externalities on long term growth, instead of assuming that the growth occurs as a result of the technological developments which are kept out of the model and emerge spontaneously.

The traditional theory of economy claims that the technology moves freely between the countries to a great extent and technological change has a key role in explaining the growth. However, it is known that there are big and continuous differences among the growth rates of countries. The New Growth Theory developed by a group of economists leaded by Romer (1986) and Lucas (1988) by looking at the deficiencies of the traditional economy has not only created a new interest on determinant qualifications of economic growth and technological progress, but also revived the discussions on the optimum role of the State in R\&D activities.

It is observed within the new endogenous theories that the primary drive power to ensure the sustainability of the growth is based on the R\&D sector and models putting importance to support the inputs relevant to R\&D have an important place. Despite the fact that literature includes many studies on the subject, three approaches can be considered to be distinct and other studies are the derivatives which are based on these three. These three models are Paul Romer's model (1990), Grossman and Helpman's model (1991), and Aghion and Howitt's (1992) model. The common characteristics of these three studies should be; R\&D activities, Human capital employed in the R\&D sector, and the growth models based on the R\&D specific new products.

The fact that the economy has not only the level effect but also the continuous growth effect in the long term depends on the number of researchers (science people, engineer, technical personnel) transferred to the sector by the economy. The more economy has such inputs and ensures the development of new products and technologies by means of conveying these resources to the R\&D sector successfully, the more the rate of the economic growth will be higher (Romer 1990, Grossman and Helpman 1991, Aghion and Howitt 1992, Ateş 1998).

In today's literature of economy, it is observed that technology strengthens its place in all production functions as an endogenous but not an external factor for economics. The cost reducing nature of the technology in given capital and labor force conditions through time utility comes first among the most discussed and interested subjects. The studies carried out in this regard also stresses the features of R\&D and the technological change caused by it as following:

i. Technological change is mainly shaped by the R\&D activities of the companies under their own body,

ii. The idea that the small and incremental technological change is the most important determinant of the productivity increases both in company level and macro level started to be accepted by many,

iii. The studies on industrialized countries indicate that these small and incremental technological changes have been performed in the different departments inside the company rather than the regular R\&D departments,

iv. This small and incremental technological change does not only reduce the unit costs, but also has an influence on capacity increase, quality and input increase, and many other variables thereof.

Considering these characteristics of the technological change, the thought that the technology is monopolized by some countries and all innovations can be realized by them should be avoided by developing countries in particular. As clear, the determinant role of technology on economic development and growth process seems to increase more and more nowadays. And even, the role of science and technology in trade and international competition has become so significant that the international economic development classifications are now modified as the countries producing technology and others with no production of technology.

\section{The Importance of R\&D Expenditures and R\&D Expenditures in Some Selected OECD Countries}

R\&D activities on a large scale have reached its scientific content and professional specialization size. Technological innovation in advanced laboratories and pilot founding's to full time employees are emerging as a result of the activities of highly qualified specialists. On the other hand about three activities of R\&D can be mentioned. First is the basic research. They are the studies which are original studies in order to obtain new scientific knowledge and understanding. The applicability of knowledge in basic research and practical value of the research isn't concern of the researches. Second is the applied research that is using information obtained as a result of basic research aimed to find exact or approximate solution to a problem. Third is the development that is 
using scientific knowledge in order to put new substantially improved materials, tools, products and manufacturing processes to the system or the service. In other words the results of basic and applied research activities are related to products or production processes.

Today, R\&D activities have reached a large scale, scientific content and vocational expertise level. Technological innovations have been arisen by high qualified full-time paid experts' works in the developed laboratories and pilot plants. It can be said that R\&D is an indispensable element of today's industrial companies in terms of efficiency and profitability. Thus, today, in both the USA and EU countries, and also in Japan, no matter how big the company is, each of them place big importance on R\&D works so as to create a new product, new production processes or to develop products.

Changes in the age of information have led countries to place more importance on R\&D. Firms, corporations and universities are coming up with new products and solutions by benefiting from staff of $\mathrm{R} \% \mathrm{D}$ and accumulation of knowledge obtained from previous studies. R\&D expenditures are one of the variables commonly used to define the ability of a corporation or a country to use technology. R\&D expenditures are of capital importance in every stage of technological activities such as coming up with a new product, developing production method and using, modifying and altering existing or imported technology effectively. Countries have started to compete with one another about $R \& D$ expenditures. The main reason why countries place such great importance on $R \& D$ expenditures is because the added value and price made by these expenditures are very high. This is shown in Table 1.

\begin{tabular}{|l|l|}
\hline Concrete & 1 cent \\
\hline Cement & 5 cent \\
\hline Iron and Steel & 50 cent \\
\hline Aluminum & 1.5 dollar \\
\hline Automobile & $10-100$ dollar \\
\hline Commercial plane & $100-1.000$ dollar \\
\hline Gunship & $2.000-3.000$ dollar \\
\hline Mobile phone & 4.000 dollar \\
\hline Fighter & 10.000 dollar \\
\hline Satellite & 100.000 dollar \\
\hline Micro and Nano chips & 4.000 .000 dollar \\
\hline
\end{tabular}

Table 1. The Price of 1 Kilo of Product Source: http://www.bursa-smmmo.org.tr/yazarlar/makaleler/132AGE.pdf

Technological composition of the products manufactured is crucial as it allows one to evaluate the competitive powers, production structures of the countries and how much importance they place on R\&D. Concordantly, it is clearly shown in Table 1 how important it is to manufacture products that have high added-value. We can consider the knowledge-based economy is important for producing goods and services that has high added value. One of the most important criteria of producing a product that have high added-value is not to forget to increase $R \& D$ expenditures within gross national product.

R\&D expenditures are accepted as one of the most important indication of countries' creative efforts. In this context, in the years of 2000 and 2013, the proportion of R\&D expenditures as the percentage of gross national product and the amount of average national income per person in some OECD countries are shown in Table 2. Among some chosen countries (29 countries), member of OECD, South Korea is the first by spending approximately $42 \%$ of its GNP on the R\&D works, followed by Israel and Japan, respectively. While average in OECD countries was $2.14 \%$ in 2000 , this rate rose to $2.37 \%$ in 2013 . As there were 22 countries below the average in 2000, that number fell to 17 in 2013. Across the entire OECD area, a majority of countries increased R\&D expenditures in this period. There has also been a significant increase in GDP per capita. 


\begin{tabular}{|c|c|c|c|c|}
\hline \multirow[t]{2}{*}{ Country } & \multicolumn{2}{|c|}{$\begin{array}{l}\text { Gross Domestic Expenditures on R\&D } \\
\text { (as \% of GDP) }\end{array}$} & \multicolumn{2}{|c|}{$\begin{array}{c}\text { Gross Domestic Product (GDP) } \\
\text { US dollars/capita }\end{array}$} \\
\hline & 2000 & 2013 & 2000 & 2013 \\
\hline Austria & 1.89 & 2.96 & 29574 & 45133 \\
\hline Belgium & 1.92 & 2.43 & 28300 & 41595 \\
\hline Canada & 1.87 & 1.69 & 29156 & 43038 \\
\hline Czech Rep. & 1.12 & 1.91 & 16259 & 28963 \\
\hline Denmark & n.a & 3.06 & 29575 & 43797 \\
\hline Estonia & 0.60 & 1.71 & 9680 & 26160 \\
\hline France & 2.08 & 2.24 & 25996 & 37617 \\
\hline Germany & 2.39 & 2.83 & 26645 & 43282 \\
\hline Greece & n.a & 0.81 & 19344 & 25523 \\
\hline Hungary & 0.79 & 1.40 & 12089 & 23507 \\
\hline Ireland & 1.09 & 1.54 & 29627 & 46858 \\
\hline Israel & 3.93 & 4.09 & 24832 & 32713 \\
\hline Italy & 1.01 & 1.31 & 26658 & 34781 \\
\hline Japan & 3.00 & 3.47 & 25941 & 36225 \\
\hline Korea & 2.18 & 4.15 & 18092 & 33089 \\
\hline Luxembourg & 1.57 & 1.30 & 56518 & 93234 \\
\hline Mexico & 0.33 & 0.50 & 9974 & 16891 \\
\hline Netherlands & 1.81 & 1.96 & 31543 & 46749 \\
\hline Norway & n.a & 1.65 & 36799 & 65635 \\
\hline Poland & 0.64 & 0.87 & 10611 & 23616 \\
\hline Portugal & 0.72 & 1.33 & 17852 & 27651 \\
\hline Slovak Rep. & 0.64 & 0.83 & 11137 & 26586 \\
\hline Slovenia & 1.36 & 2.60 & 17878 & 28675 \\
\hline Spain & 0.88 & 1.26 & 21718 & 32549 \\
\hline Sweden & n.a & 3.31 & 29385 & 44586 \\
\hline Turkey & 0.48 & 0.94 & 9177 & 18599 \\
\hline U.K & 1.72 & 1.66 & 27451 & 38743 \\
\hline USA & 2.62 & 2.74 & 36416 & 52592 \\
\hline OECD Total & 2.14 & 2.37 & 25090 & 37815 \\
\hline
\end{tabular}

Table 2. Gross Domestic Expenditures on R\&D (as \% of GDP) and Gross National Product (per capita) in Some Selected OECD Countries Source: OECD

\section{Literature Review}

There are too many scientific studies that investigate whether any factor has a possible influence on economic growth. With the adoption of the fact that technological change is one of the most important factors which will affect economic growth through new growth theories, numerous theoretical and empirical studies analyzing also the effects of R\&D, which is an indispensable component of technological change, on economic growth have taken place in the literature. In this context, while in general the relationship between R\&D expenditures and economic growth is handled in the majority of conducted studies, it is seen that in some studies the relationship between patent and growth and the one between high-tech exports and economic growth have been covered. Except for those, it is also seen that the studies investigating the causal relationship between R\&D and exports have been conducted (Sungur et al, 2016). In empirical studies made on R\&D, the results obtained may be arguable and findings may differ depending upon the distinctions of analysis procedure, analysis period, economic structure in examination and indicators.

Lichtenberg (1993) examined the relationship between the private and public sector R\&D expenditures and economic growth for the period 1964-1989 by incorporating 74 countries into the analysis. In the study, it is concluded that while private sector $R \& D$ expenditures affect growth in a positive way, public sector $R \& D$ expenditures do not create any positive effect on economic growth and even sometimes they have a negative impact on it.

Goel and Ram (1994), in their study covering 52 countries for the period 1960-1980, found that there is a significant relationship between R\&D expenditures and economic growth in the long term; however, the direction of causality between the variables could not be determined.

Park (1995) concluded that local private sector R\&D investments are a significant determinant of the increase in both local and foreign factor productivity with the data of 10 OECD countries in the period of 1970-1987.

Freire - Seren (1999) detected a $1 \%$ increase in total R\&D expenditures increases real gross domestic product (GDP) at a rate of $0.08 \%$; in the case of taking the parameters that define the innovation technology into account 
they concluded that the elasticity of R\&D expenditures is close to one with the data of 21 OECD countries during the period 1965-1990.

Slywester (2001) found that there is no any relationship between R\&D expenditures and growth for the countries in question; when G-7 countries are taken into consideration, the results revealed that there is a positive relationship between especially industrial R\&D expenditures and growth with data of 20 OECD countries.

Ülkü (2004) analyzed the relationship between R\&D, innovation and economic growth by means of various panel data procedures for 30 countries (20 OECD, 10 non-OECD) for the period 1981-1997 and concluded that for both OECD and non-OECD countries under investigation, there is a positive relationship between innovation created by R\&D sector and GDP per capita; however, innovation does not lead to a continuous increase of economic growth.

Yanyun and Mingqian (2004) used Partial Least Square (PLS) regression model by using the data pertaining to some Asian countries and found that R\&D expenditures have a positive impact on economic growth. In a similar manner, Falk (2007) analyzed the long term relationship between R\&D investments and economic growth for the period 1970-2004 and put emphases on that as the share of R\&D investments in GDP becomes larger, GDP per capita also increases.

Wang (2007) expressed that the countries which employ R\&D expenditures effectively will achieve a better economic growth performance with the data of 30 countries. In their study covering USA data, Goel, Pay and Ram (2008) investigated if a relationship exists between federal and non-federal R\&D expenditures and economic growth for the period 1953-2000 and concluded that the relationship between economic growth and federal R\&D expenditures is much stronger than the other. Kue and Yang (2008) made a research upon the effects of the knowledge capital and technological diffusion on regional economic growth for China and emphasized that R\&D capital and technology imports contribute significantly to economic growth.

Samimi and Alerasoul (2009) used panel data method in their research for the period 2000-2006 and 30 developing countries and the findings have shown that because of low R\&D expenditures in these countries, economic growth and R\&D expenditures do not exhibit a mutual causal relationship.

On the other hand, Sandrouil and Zina (2009) conducted a study which covers 23 countries for the period 1992 2004 by applying dynamic panel data method and found that there is a positive and significant relationship between R\&D expenditures and economic growth.

Saraç (2009) revealed that R\&D expenditures affect economic growth in a positive direction for the period 19832004 and 10 OECD countries.

Korkmaz (2010) evaluated the relationship between R\&D expenditures and economic growth for Turkey through Johansen cointegration method for the period 1990-2008. They found that there is a long term relationship between R\&D and economic growth.

Bravo-Ortega and Marin (2011) examined the data of 65 countries for the period 1965-2005. According to the study conducted by panel data procedure, $10 \%$ increase in R\&D expenditure per capita will increase total factor productivity by approximately $1.6 \%$ in the long term.

Eid (2012) found that R\&D expenditures made through higher education effects growth by increasing productivity with the data of 17 high-income OECD countries between period 1981-2006.

Gülmez and Yardımcıoglu (2012) analyzed the relationship between R\&D expenditures and economic growth by using panel causality and cointegration methods for the period 1990-2010 and 21 OECD countries. According to the findings obtained in the study, it has been observed that there is a bidirectional causal relationship between $\mathrm{R} \& \mathrm{D}$ expenditures and economic growth in the long term and $1 \%$ increase in R\&D expenditures will increase economic growth at a rate of $0.77 \%$.

Wang et al. (2013) found that R\&D expenditures for high-tech sectors effects GDP per capita levels with the data of 23 OECD countries for the period 1991-2006. These expenditures have a positive influence on GDP per capita.

Amaghouss and Ibourk (2013) examined the relationship between entrepreneurship, innovation and economic growth through panel data method for OECD countries with the data of 2001-2009 periods. They used the entrepreneurial activities and innovation to measure entrepreneurship and found that entrepreneurial activities and innovation have significant and positive effects on economic growth.

Inekwe (2014) made a classification of 66 countries into different income groups for 2000-2009 periods. Inekwe expressed that impact of R\&D expenditures on economic growth exhibits differences over the short and long term and in countries with upper-middle income level; the impact is much larger and significant when compared to countries with low-income levels. 


\section{Methods and Data}

This research investigates the impact of $R \& D$ expenditures on economic growth. For this purpose, we used dynamic panel data based on the two-step generalized method of moments (GMM) the model. Annual data of 29 selected OECD countries from 2003 until 2014 is used in this study and obtained from OECD statistics. According to theoretical framework, the empirical model is as follows:

$$
\begin{aligned}
& \mathrm{GDP}_{\mathrm{i}, \mathrm{t}}=\alpha_{0}+\beta_{1} \mathrm{GDP}_{\mathrm{i}, \mathrm{t}-1}+\beta_{2} \mathrm{BX}_{\mathrm{i}, \mathrm{t}}+\beta_{2} \mathrm{GX}_{\mathrm{i}, \mathrm{t}}+\varepsilon_{\mathrm{i}, \mathrm{t}} \\
& \text { where }
\end{aligned}
$$

GDP $_{\mathbf{i}, \mathbf{t}} \quad$ : Gross domestic product for country $\mathrm{i}$ in period $\mathrm{t}$

$\mathbf{G D P}_{\mathbf{i}, \mathbf{t}-\mathbf{1}}$ : The lag of dependent variable

$\mathbf{B X}_{\mathbf{i}, \mathbf{t}} \quad$ : Business enterprise expenditure on $R \& D$ for country $i$ in period $t$

$\mathbf{G X}_{\mathbf{i}, \mathbf{t}} \quad$ : Government Intramural Expenditure on R\&D for country $\mathrm{i}$ in period $\mathrm{t}$

$\varepsilon_{\mathrm{i}, \mathrm{t}} \quad:$ Errors terms

All the variables in the model are in logarithmic form. Then, we use two-step the generalized method of moment estimator (GMM) for estimating effect of R\&D expenditures on economic growth. It is based on dynamic panel models and this type of GMM estimator eliminates the problems of serial correlation, heteroscedasticity, and endogeneity of some variables. Specifying the instrumental variables in this approach is especially important. The GMM estimator is consistent only if the lagged values of the explanatory variables are valid instruments. Sargan test is used to examine the overall validity of the instruments. Also we must the specification test to investigate the second-order serial correlation of the residuals in first differences. Besides to confirm convenient model specification, the first-order serial correlation should be confirmed whereas the second-order serial correlation should be rejected (Khordehfrosh and Tehranchian, 2015).

\section{Empirical Results}

As stated in equation (1), we examine the effects of R\&D expenditures on economic growth of selected OECD countries. In this model, business enterprise expenditure and government intramural expenditure are used as independent variables for analysis and Gross Domestic Product as an explanatory variable in the model. The results of the model's estimation using the generalized method of moments are presented in Table 3.

\begin{tabular}{|l|l|}
\hline Variables & Coeff \\
\hline $\mathrm{GDP}_{\mathrm{i}, \mathrm{t}-1}$ & .688765 \\
& $(0.000)^{*}$ \\
\hline $\mathrm{BX}_{\mathrm{i}, \mathrm{t}}$ & .097779 \\
& $(0.000)^{*}$ \\
\hline $\mathrm{GX}_{\mathrm{i}, \mathrm{t}}$ & .0178965 \\
& $(0.000)^{*}$ \\
\hline Wald Test & $\chi^{2}(3)=52611.44$ \\
& {$[0.0000]^{*}$} \\
\hline Sargan Test & $\chi^{2}(54)=28.94915$ \\
& {$[0.9979]$} \\
\hline Specification Tests & -3.055 \\
\hline AR(1) & {$[0.0022]$} \\
\hline AR(2) & -1.604 \\
& {$[0.1087]$} \\
\hline
\end{tabular}

Table 3. The Results of Estimation * represent statistical significance at the $1 \%$.

According to the estimation results, business enterprise expenditure has a positive and statistically significant effect on economic growth. This result implies that if business enterprise expenditure increases one percent, GDP increases about $0.1 \%$. Government intramural expenditure is the second variable that we interpreted. Likewise, Government intramural expenditure has a significant and positive effect on economic growth in our model. This result also implies that if government intramural expenditure increases one percent, GDP increases about $0.02 \%$. All of the results are similar with the literature. The estimated variables are statistically significant and the signs are as expected. We run the entire diagnostic tests for the estimation and found no any problem about the estimation. There is only one issue about the estimation results: magnitude of the coefficients. The coefficients are quite slight but these are not only the determinants of the GDP so this magnitude is also expected. As a result, these estimation results indicate that $R \& D$ expenditures have a significant impact on economic growth in selected OECD countries. 


\section{Conclusion}

Nowadays, R\&D and innovation play an important role for economic development. According to the international statistics, if a country's R\&D intensity is high, in that situation, the national competitiveness of this country would be much higher than in other countries. On the other hand, many scholars have investigated the relationship between $R \& D$ and economic growth. According to the endogenous growth model, the long term economic development could be achieved through gaining productivity. The increase in productivity, it is provided with technological development. Most studies agree that Technological competitiveness of providing high efficiency and innovation lead to acceleration of economic growth rate. Additionally, it is observed that the differences between welfare of the countries are determined according to the knowledge and innovation capacity. To sum up, science and technology affects the countries' economic transformation and sustainable growth. It is concluded that technological development arises from R\&D activities. In this context, countries to achieve sustainable economic growth transfer large amounts of resources to R\&D activities and innovation. Because, technological development, if and only occur with the R\&D activities.

\section{Acknowledgements}

This study was supported by Research Fund of the Cukurova University.

\section{References}

- Aghion, Howitt, 1992. “A model of Growth in through Creative Destruction”, Econometrica, 60 (2) , p.323

- Amaghouss, Ibourk 2013. "Entrepreneurial Activities, Innovation and Economic Growth: The Role of Cyclical Factors Evidence from OECD Countries for the Period 2001-2009”, International Business Research, 6(1), p. 153

- $\quad$ Ateş, 1998. Yeni İçsel Büyüme Teorileri ve Türkiye Ekonomisinin Büyüme Dinamiklerinin Analizi, Doktora Tezi, Çukurova Üniversitesi, Sosyal Bilimler Enstitüsü, Adana,1998

- Bozkurt, 2015. "R\&D Expenditures and Economic Growth Relationship in Turkey", International Journal of Economics and Financial Issues, 5(1), p.188

- Bravo-Ortega, Marin, 2011. “R\&D and Productivity: A Two Way Avenue?”, World Development Vol. 39, No. 7, pp. 1090

- $\quad$ Eid, 2012. "Higher Education R\&D and Productivity Growth: An Emprical Study on High-Income OECD Countries", Education Economics, 20(1), p.53

- Evenson, 1997. "Economic Growth, International Technological Spillovers and Public Policy:Theory and Emprical Evidence from Asia", Yale University Economic Growth Center Discussion Paper No:777

- Falk, 2007. "R\&D spending in the high-tech sector and economic growth", Research in Economics, 61(3), p. 140

- $\quad$ Freire-Seren, 1999. “Aggregate R\&D Expenditure and Endogenous Economic Growth”, WP,436.99

- Goel, Ram, 1994. "Research and Development Expenditures and Economic Growth:A Cross Country Study", Economic Development and Cultural Change, 42(2),p.403

- Goel, Payne, Ram, 2008. "R\&D expenditures and US economic growth: A disaagrgated approach", Journal of Policy Modelling, 30(2),p.237

- Grossman, Helpman, 1991. Innovation and Growth in the Global Economy, The MIT Press, London.

- Gülmez, Yardımcıoğlu, 2012. "OECD Ülkelerinde Ar-Ge Harcamaları ve Ekonomik Büyüme İlişkisi: Panel Eşbütünleşmeve Panel Nedensellik Analizi (1990-2010)”, MaliyeDergisi, 163, p.335

- Inekwe, 2014. "The Countribution of R\&D Expenditures to Economic Growth in Developing Countries", Social Indicators Research, (124), p.1

- Jones, 2007. İktisadi Büyümeye Giriş (2nd ed.). Çev: Sanlı Ateş \& İsmail Tuncer, İstanbul: Literatür Yayıncilik.

- Khordehfrosh, Tehranchian, 2015. "The Impact of Monetary Policies on the Exchange Rate: A GMM Approach", Iranian Economic Review, 19(2), 177-191.

- Korkmaz, 2010. “Türkiye'de AR-GE Yatırımları ve Ekonomik Büyüme Arasındaki İlişkinin Var Modeli İle Analizi”, Journal of Yasar University, 20(5),p.320

- Kuo, Yang, 2008. "Knowledge Capital and Spillover on Regional-Economic Growth: Evidence From China”, China Economic Review, 19(4),p.594.

- Lichtenberg, 1993. "R\&D Investment and International Productivity Differences", NBER Working Papers, Vol.W4161 
- Lucas, 1988. “On the mechanics of Economic Development”, Journal of Monetary Economics. (22), p.3

- Park, 1995. “International Spillovers of R\&D Investment and OECD Economic Growth”, Economic Inquiry 33(4), p. 571

- Romer, 1986. "Increasing returns and long-run growth", Journal of Political Economy, (94), p.71

- Romer ,1990, “Endogenous Technological Change”, Journal of Political Economy, 98 (5), p.71

- Samimi, Alerasoul, 2009. "R\&D and Economic Growth: New Evidence from Some Developing Countries", Australian Journal of Basic and Applied Sciences, 3(4),p.3464

- Sandrouil, Zina, 2009. "A Dynamic Panel Data Analysis for R\&D Cooperation and Economic Growth", International Journal of Foresight and Innovation Policy, 5(4), p.218

- Saraç,2009.“Araştırma-Geliştirme Harcamalarının Ekonomik BüyümeÜzerindekiEtkisi: Panel Veri Analizi”, Econ Anadolu, 2009Anadolu International Conference in Economics, 17-19 Haziran, Eskişehir.

- Slywester, 2001. "R\&D and Economic Growth, Knowledge”, Technology and Policy, 13(4), p.71

- Sungur, Aydın, Eren, 2016. “Türkiye'de Ar-Ge, İnovasyon, İhracat ve Ekonomik Büyüme Arasındaki İlişki:AsimetrikNedensellikAnalizi”,Süleyman Demirel Üniversitesi İktisadi ve İdari Bilimler Fakültesi Dergisi C.21, S.1, p.173

- Ülkü, 2004. "R\&D, Innovation and Economic Growth: An Emprical Analysis", IMF Working Paper, $\mathrm{W} / \mathrm{P} / 04 / 185$

- Wang, 2007. "R\&D efficiency and economic performance: A cross country analysis using the stochastic frontier approach", Journal of Policy Modelling, 30(2), p.237

- Wang, Tiffany, Liu, 2013. "Heterogeneous Effect of High-Tech Industrial R\&D Spending on Economic Growth", Journal of Business Research, 66(10),p.1990

- Yanyun, Mingqian, 2004. "R\& D and Economic Growth: Panel Data Analysis in ASEAN+3 Countries" A Joint Conference of AKES, RCIE and KDI: Korea and the World Economy, III, July 3-4, Sungkyunkwan. 


\title{
The Effects of R\&D and High Technology Exports on Economic Growth: A Comparative Cointegration Analysis for Turkey and South Korea
}

\author{
Asst. Prof. Dr. Ayfer Ustabaş (Beykent University, Turkey) \\ Assoc. Prof. Dr. Özgür Ömer Ersin (Beykent University, Turkey)
}

\begin{abstract}
The importance of technology and research and development (R\&D) on economic development through international trade has been discussed in many studies. However, the empirical studies focusing on the role of high technology exports has been limited. The study aims at filling this gap by evaluating the relationship between high technology exports and GDP per capita levels with structural unit root tests and cointegration methodologies for Turkey and South Korea for the 1989-2014 period. The following hypothesis is evaluated: by increasing high technology manufactured goods' exports, countries could increase their GDP per capita which also requires increased R\&D that translates itself as high technology manufactured exports. The empirical methodology is as follows: both GDP per capita and high-tech exports variables are tested with traditional ADF, PP unit root and KPSS stationarity tests. The series are further evaluated with Zivot-Andrews single break and Lee-Strazicich two break unit root tests. The structural break tests are necessary; it is well-known that structural breaks lead to biased results in the traditional unit root and additionally in the cointegration tests. Lastly, both variables are tested for cointegration with Engle-Granger and Johansen tests by incorporating the break dates as exogenous dummy variables. The estimated models are further checked for parameter instability with CUSUM type tests. The results obtained for Turkey and South Korea are slightly different: $i$. both variables are cointegrated for both countries; ii. For South Korea, the positive impact of high-tech exports on GDP cannot be rejected in the long and short run; $i i$. This conclusion cannot be obtained for Turkey, iii. the parameter estimates for Turkey hint a limited positive effect of high tech exports in the short-run only. The results suggest that, in the future, Turkey should increase the investments in human capital and R\&D directed to high tech exports to which could accelerate the economic growth.
\end{abstract}

\section{Introduction}

One point that cannot be overlooked regarding the importance of technological achievements on economic development is that, technological innovations and research and development play a crucial role not only in industrial and economic development, but additionally, the effects of creating heterogeneous products through technology in international trade cannot be disregarded. The technologically improved products are well known to create comparative advantage in exports. This type of an advantage could result from the increasing returns and endogenous technological progress which in turn affect the standards of living (Frankel \& Romer, 1999). By shifting the percentage of manufactured exports from low technology to high technology products could result in comparatively value-added products which are subject to a type of monopolistic competition instead of products being traded in perfectly competitive products. Recent experiences of many Asian Economies in 1990's and additionally the experience of South Korea has been discussed to provide an example of such an economic growth strategy (Westphal, 1990). Within this perspective, the study aims at evaluating and comparing the long-run and short-run effects of high technology exports on economic development in Turkey and South Korea. It should also be kept in mind that, though the increase in export revenues from the high-technology products are expected to create significant contribution to economic growth, both of these countries have comparatively different characteristics and policies followed in 1960's and in the post 1980's, the liberalization period. Therefore, the study is restricted to evaluate the roles of high technology exports in economic development in terms of GDP per capita levels only and the role of R\&D levels in the determination of high technology exports will also be evaluated. Nevertheless, both countries implemented important industrial policies in 1960's, their performances in terms of per capita GDP and high technology products and their share in manufactured exports had been considerably different.

As stated by Helleiner, industrialization has played an important role in the national modernization policies of all developing countries. With the increasing role of industry in the economies of these developing countries, trade in manufacturing has also become an important channel for strengthening their position in the world economy (Helleiner, 2002, xi). Salvatore notes that, from 1950s to 1970s, most developing nations generally opted for a policy of import substitution to industrialize by protecting their infant industries rather than continuing to specialize in the production of primary commodities, as defined by traditional trade theory. However, the import substitution policy led to very inefficient domestic industries and very high prices for domestic consumers; then, starting in the 1980s, many developing nations began to liberalize trade and adopt an outward orientation. These, in turn, resulted in a much higher degree of openness, as measured by the sum of exports plus imports as a ratio of GDP, a sharp increase in the ratio of manufactures in total exports (Salvatore, 2013, 347-348). However, it is also 
discussed in recent studies that, an export-led-growth strategy could be achieved with international trade if the traded goods are coupled with R\&D being directed to technological progress that results in high-technology exports which are highly value added and could benefit the countries in terms of GDP per capita levels (Van den Berg, 2015).

Turkey and South Korea represent two different cases of export-oriented growth. The export-led industrialization policy of Turkey is realized by the shift of industrial capacity toward international markets via a significant contraction of real wages, excessive export subsidies, and real devaluations. Adjustment in South Korea, in contrast to Turkey, based on a nationalized financial sector, dual interest rates, rationing in the credit markets as a means of subsidizing exports, controls over foreign direct investments shaped the business environment until the mid or late 1980s. As a result, South Korea, which started with a much lower per capita GDP from 1960's, reached a comparable level already as of 1978, and since then has reached much higher levels (Onaran and Stockhammer, 2005, 73-74).

This study examines the relationship between research and development (R\&D) expenditures and high technology exports and growth in Turkey and South Korea during the period 1989-2014. The empirical research in this field is scarce, most probably resulting from the availability of data: as will be shown, the R\&D data is limited to 1996-2013 period, while the high technology exports data is comparatively large while still being limited to the 1989-2014 period. Therefore, due to availability of data, the analysis in the study aims at evaluating the relationship between the high technology manufactured exports and economic development for the 1989-2014 period. The sections of the study are as follows. The economic literature is given in Section 2. The comparative analysis of South Korea and Turkey is given in Section 3. The econometrics literature review is given in Section 4. The econometric evaluation and results are given in Section 5. Conclusion is given in Section 6.

\section{Theoretical Framework}

The classical economists of the eighteenth and nineteenth centuries argued that technological change and capital accumulation were the engines of growth. In 1930s, Joseph Schumpeter, founder of modern growth theory, emphasized the importance of innovation as stimuli to economic growth (Trott, 2012, 7).

The Schumpeterian model of technological progress supports the hypothesis that international trade stimulates technological progress and, therefore, economic growth because it makes innovations available to more people in more countries, and increases the world's effective resources that can be allocated to innovative activities. Furthermore, Levine and Renelt (1992), Edwards (1998), Frankel and Romer (1999), Wacziarg (2001), and Easterly and Levine (2001) found evidence showing that international trade's effect on economic growth operates through technological progress (Van den Berg, 2015, 174).

Robert Solow, who was a student of Schumpeter, advanced his professor's theories in such a way that, in the absence of technological progress, factor accumulation is subject to diminishing returns and an economy sooner or later settles at a steady state where economic growth ceases (Van den Berg, 2015, 111).

In 1967, Gruber, Mehta, and Vernon found a strong correlation between expenditures on research and development and export performance. The authors took expenditures on research and development as a proxy for the temporary comparative advantage that firms and nations acquire in new products and new production processes (Salvatore, 2013, 173).

The new theory of endogenous economic growth starting with Romer (1986) and Lucas (1988) postulated that international trade will speed up the rate of economic growth and development in the long run especially by allowing developing nations to absorb the technology developed in advanced nations and increasing the benefits that flow from research and development (Salvatore, 2013, 336).

South Korea is considered to be one of the good examples of countries providing its economic growth through international trade. Combined with a rapid slowing down in population growth, this growth resulted in important increases in per capita income through rising wages and rapid job creation. As a result, since the early $1960 \mathrm{~s}$, this country had averaged between $6 \%$ and $8 \%$ growth per year (Jaffe, 2010, 51). Chau underlined that the outstanding economic growth of Korea has resulted from the promotion of merchandise exports. Korea established its exportoriented light industry by using cheap labor and thus low wages. But when the labor became more expensive compared to other developing countries, their industrial composition shifted to heavy and chemical industries in 1970s. When these industries started to become competitive in world market after mid-1980s, they began to upgrade their technology to produce and develop sophisticated high-tech products (Chau, 2001, 140). Many researchers underline the importance of state intervention to promote economic development in South Korea. Westphal argued that Korea's government has selectively intervened to affect the allocation of resources among industrial activities and has also used policies such as taxes and subsidies, credit rationing, licensing, and the creation of public enterprises (Westphal, 1990, 41). According to Amsden, industrial expansion of this country could be explained as a good co-integration of market principles and of the institutions financially supporting them. Another reason why South Korea appear to have industrialized rapidly is that this country has invested 
relatively heavily in formal education of the workforce and the apprenticeship of firms to foreign technical assistants (Amsden, 1989).

\section{A Comparative Analysis of Population, R\&D, Sectoral Development, High-Tech Exports and Economic Performance in South Korea and Turkey}

In 1962, the population sizes of Turkey (28.909.985) and South Korea (26.513.030) were close to each other. In South Korea, with a rapid slowing down in population growth from 1970s on, the population size reached to 50.423.955 in 2014 whereas Turkey's population size has made a big jump to reach to 75.932.348.

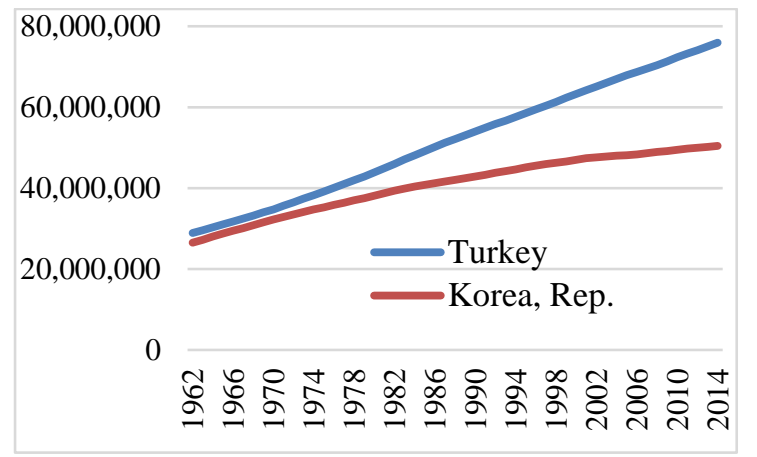

Figure 1. Evolution of Population in South Korea and Turkey (1962-2014) Source: World Bank, World Development Indicators

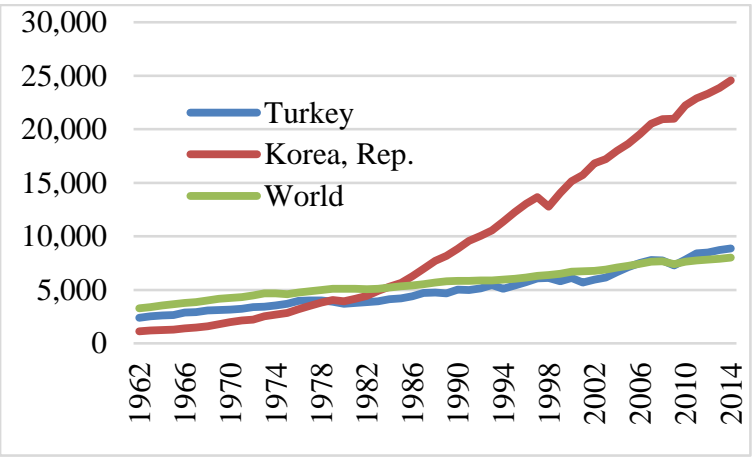

Figure 2. Per Capita GDP in South Korea, Turkey and The World (1962-2014) Source: World Bank, World Development Indicators

As the Figure 2 suggests, in 1962, per capita GDP in Turkey (US\$2.387) is 2,1times that of S. Korea's at US\$1.123 (world average is US\$3.275). However, beginning with 1980s, South Korea has made a big attack; as of 2014 Turkey’s GDP per capita is US\$8.865 whereas S. Korea’s GDP is 2,7 times that of Turkey’s at US\$24.566 (world average is US\$8.011).

Both Turkey and South Korea started as resource-poor, agrarian economy. As the Figures 3 and 4 indicate, agricultural and services sectors were dominant in these countries during 1960s. The share of industry in the whole economy was close to each other in Turkey (19.9\%) and South Korea (21.3\%) in 1965. A rapid industrialization process took place in South Korea as of 1970s as a result of which the share of industrial sector in GDP reached as high as $39 \%$ in 1990 s. In Turkey, the share of industry went to 27.1 percent in 2014 while this share made relatively a big jump to reach to 38.2 percent in South Korea. For Turkey the highest rate recorded for the share of industrial sector is 35\% achieved in 1999. Agriculture's share shrank to $8.0 \%$ and $2.3 \%$ in Turkey and in South Korea respectively. As noted by Chau, South Korea's economic development in this period was fueled by an intensive increase in factor input and rapid expansion of exports after which, within three decades, the economy was transformed from a backward poor agrarian economy into an industrial economy (Chau, 2001, 125).

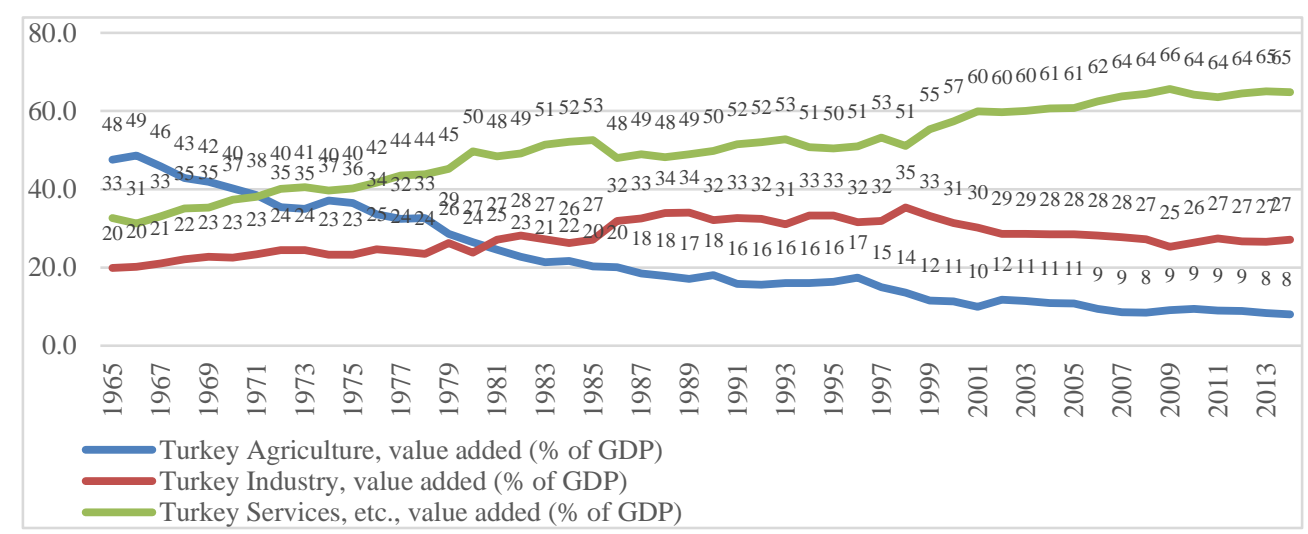

Figure 3. Evolution of Production in Turkey (1965-2014) Source: World Bank, World Development Indicators

Industrial development in South Korea and Turkey started out with developing labor intensive light manufacturing industries. But, in South Korea, as early as mid-1973, the aim of state policy was to develop heavy and chemical industries producing for exports (Arslanhan and Kutsal, 2010a). For this purpose, six industries (industrial machinery, shipbuilding, electronics, steel, petrochemical and non-ferrous metal) were targeted for promotion. By 1990, products from these industries accounted for 40\% of total exports (Chau, 2001, 123). 


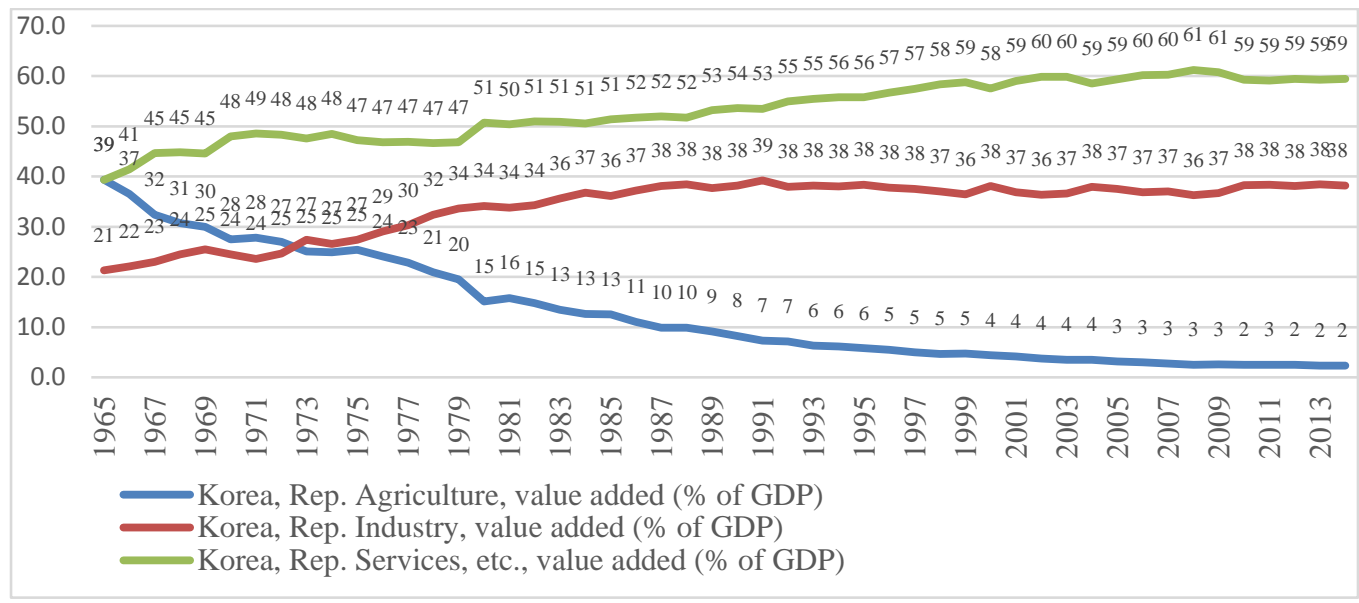

Figure 4. Evolution of Sectoral Production in South Korea (1965-2014) Source: World Bank, World Development Indicators

From 1990s to early 2000, the share of electrical and electronics goods increased from 15 to $25 \%$ in South Korea. Over the same period the gap between the share of the said sectors and low-tech labor intensive food, beverages and textiles sector, which dropped below 5\%, widened significantly and the dominance of the sectors requiring high technology gained importance. This process proves the dominance of innovation, Information and Communication Technologies (ICT) and R\&D activities in industrial development in the context of the 'Innovation Process' in South Korea (Arslanhan and Kutsal, 2010, 4).

Examination of Turkey and South Korea's share of high technology exports in manufactured exports for the period 1989 and 2014 indicates that South Korea enabled rapid switch to high technology whereas Turkey went through a direction towards medium and low technology sectors (Figure 5).

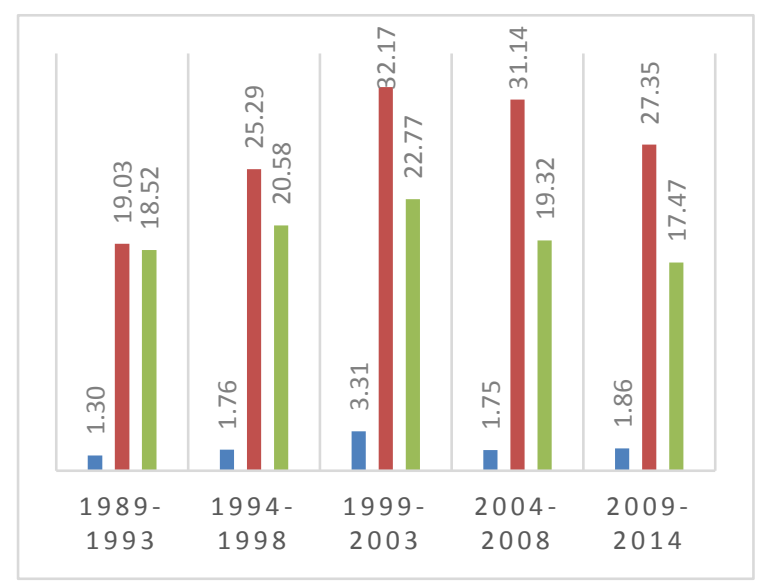

Figure 5. The \% of High-Technology Exports in Manufactured Exports, 5 Year Averages, 1989-2014

Notes. Turkey (blue), South Korea (red), World (green).

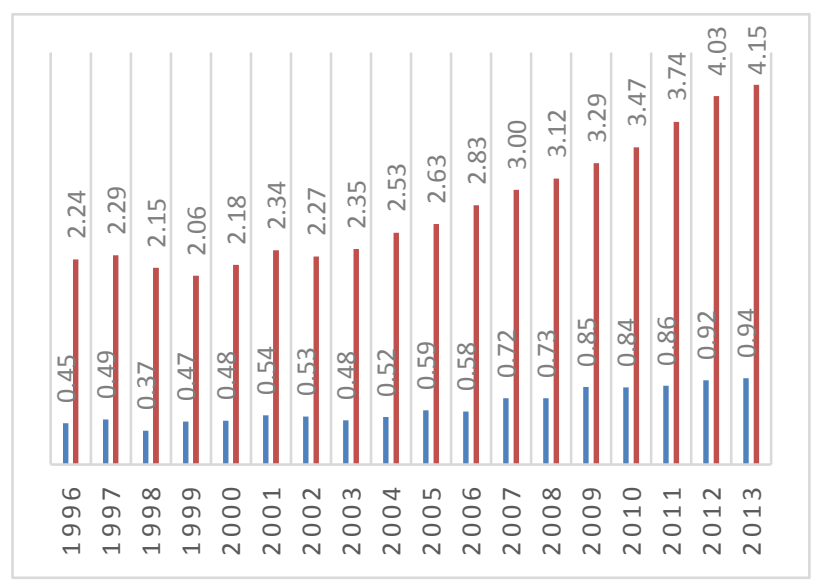

Figure 6. Research and Development Expenditures, \% of GDP, 1996-2014

Source: World Bank, World Development Indicators

As the Figure 6 clearly indicates, R\&D expenditures constitutes relatively an important part in South Korea's GDP when compared to Turkey. R\&D increased its share of GDP from 2,24 \% to 4,15\% in 1996-2013 in South Korea whereas this share moved from $0,45 \%$ to $0,94 \%$ in Turkey. The biggest contribution to rapid economic growth in South Korea was made through the development of the R\&D system. As a response to incentives and increasing competition in the international market, the number of corporate R\&D laboratories and patent registrations rapidly increased (Chau, 2001, 146). In 1960s, the Korean government created a Bureau of Technologies which was upgraded into the full-fledged Ministry of Science and Technology in 1967. Furthermore, Economic Planning Board created in 1962 played a central role in Korea's economic planning, national budgeting, foreign capital management and statistics (Chau, 2001, 214-218). With the help of the Heavy and Chemical Industry (HCI) policies, the HCI product group has performed well, in the sense that its market share in Korea's total exports increased consistently and sharply. Some of the projects promoted by the HCI policies have turned a few Korean companies into big multinational corporations (Chau, 2001, 23). For instance, Korean transnational producer, Hyundai, which had been dependent for its early development on close technological and marketing relationships with US and Japanese firms, was the world's fourth largest producer in terms of market share in automobile manufacturing (OICA, 2015). 


\section{Empirical Literature Review}

Our research showed that though the relationship between economic development and exports has been investigated empirically in an important amount of studies, the empirical studies focusing on R\&D and economic development is comparatively limited. Further, as of our search conducted on these three variables showed that, the role of high technology manufactured export products on economic growth has not been investigated. Therefore, our study will provide a pioneering analysis on the role of high-tech export products on economic development. As a result, the literature review below will focus on the literature focusing on exports and economic growth and R\&D and economic growth relations.

The empirical literature on exports and economic development began to be more widely discussed among researchers in recent years. Economists performed a variety of statistical tests to prove or disprove the existence of a relationship between research and development, human capital, innovations, exports and economic growth. If an overlook is provided, the results of these studies largely support the hypothesis that, countries investing in research and development provide their residents with higher incomes and higher rates of economic growth. Xu proved that in a sample of 32 economies, the export-led model is supported by 17 economies and is strongly supported by 9 economies (Xu, 1996, 172-184). Bayoumi, Coe, and Helpman (1999) estimated that if all developed countries increase their R\&D expenditures by an amount equal to one-half of one percent of their GDPs, all industrial countries would raise their output after 80 years by nearly $20 \%$ and developing countries by almost $15 \%$. Evenson and Singh (1997) tested for technology spillovers in 11 Asian economies and confirmed that domestic institutions and education are significant determinants of technology inflows. Technology spillovers have been small in the South Asian economies of Bangladesh, India, Nepal, Pakistan, and Sri Lanka compared to the fastgrowing East Asian economies. The second group of countries, invested more in education, improved their institutions so that they were more favorable to investment and innovation, and opened their economies more widely to trade (Van den Berg, 2015, 240-241).

K1lıç, Bayar and Özekicioğlu examined the relationship between research and development expenditures and high technology exports in G-8 countries during the period 1996-2011 by using panel data analysis. They found that research and development expenditures and real effective exchange rate had positive impact on high technology exports. Moreover, they emphasized that there was bidirectional causality between research and development expenditures and high technology exports and between research and development expenditures and real effective exchange rate and unidirectional causality from high technology exports to real effective exchange rate (Kılıç et. al., 2014).

Göçer analyzed the effects of research and development expenditures on high technology exports, informationcommunication technology exports, total exports and economic growth for 11 developing Asian countries by using data of 1996-2012 period with panel data analysis. As a result of the analysis, it has been determined that an increase by $1 \%$ in $R \& D$ expenditures raised the high technology export by $6.5 \%$, the information-communication technology exports by $0.6 \%$ and the economic growth by $0.43 \%$ (Göçer, 2013, 215).

Our study focuses on the role of high-tech product exports on economic growth. One reason of this approach is that we focus on providing a comparative analysis of South Korea and Turkey, therefore, we fail to adopt a panel regression approach as done by the above mentioned literature. Further, the study will aim on evaluation of long run and short run effects of high-tech exports on economic growth. Therefore, the study will focus on cointegration methodology of Engle-Granger (1987) and structural break unit root tests to determine the break dates, of high tech exports and economic development. It should be noted that, the R\&D data is very limited and reported largely for the post 1996 period in institutions such as the World Bank. Similarly, the data for high tech exports could be obtained for a comparatively larger period starting from 1989. Within our approach, we make a generalization that high-tech exports could be considered as a proxy or as an indirect product of R\&D itself. It should be noted that the R\&D is an important result of the long run development strategies of the economies of today. These strategies include investment in education, science, technology, health and research among many other factors of human development. This type of strategy would mimic the endogenous growth models. However, the technological export-led growth strategy should be considered as being under the influence of development strategies such as the unbalanced and balanced growth models in addition to important critics directed towards the relationship between the exports and the imports goods, the type of products traded and importance of power through trade which result from the supply effect and influence effect of trade (readers are referred to Hirshman, 1969; Singer, 1958). Further, underdeveloped countries could be under the influence of a poverty-cycle that results in very limited investment on human capital (Nurkse, 1966). However, the aim of the study is restricted in terms of focus on the investigation of possibly cointegrated long-run relations between high-tech exports and economic performances to provide a comparative analysis for Turkey and South Korea. Therefore, a throughout analysis of the role of $\mathrm{R} \& \mathrm{D}$, education, human capital, and many important external factors as discussed in orthodox and heterodox development approaches were left for the future studies.

It should be noted that, our literature search resulted in no studies focusing on the effects of high technology manufactured product exports on economic growth within a time series context, we believe that this was largely 
due to the availability of data. To overcome this difficulty, few studies followed panel regression approaches to increase the sample size through pooling of the dataset for homogeneous characteristics as noted above.

\section{Data and Empirical Results}

The paper aims at investigating the relationships between high-technology manufactured exports, economic development and R\&D expenditures with cointegration techniques. Within this purpose, the Engle and Granger (1987) two-stage cointegration methodology will be analyzed. The cointegration approach is solely based on the common integration of the variables at the same level $d$ and requiring variables following integrated of order $\mathrm{d}$, I(d) processes. Therefore, the cointegration approach could be affected by possible structural breaks caused by factors including economic crises which in turn might hinder the reliability of traditional unit root tests. As a result, the econometric methodology also aims at investigating stationarity of data with Zivot-Andrews (1992) and LeeStrazicich (2003) structural break unit root tests in addition to the traditional unit root tests.

\subsection{Data}

In this study, the GDP per capita, high-tech exports and R\&D expenditures are taken from the World Development Indicators (WDI) 2015 database of the World Bank. The dataset for GDP per capita and the percentage of high-tech exports in total manufactured exports corresponds to 1989-2014 period, while the R\&D expenditures in GDP corresponds to 1996-2013 period. Due to the sample size limitations of the R\&D data, the analysis is conducted with the GDP per capita and high-tech exports data. Further, since high-tech exports are also considered as a proxy for R\&D focusing on differentiation of the export product, this type of limitation could be considered as resulting from the availability of R\&D data for a large span. In the analysis, the GDP per capita is denoted as $y_{t}$, which is given in constant 2005 US dollars. The \% of high tech exports in total manufacturing exports is given in US dollars and is denoted as $h t_{t}$. All variables are subject to natural logarithms with the following transformation: $l h t_{t}=\ln \left(h t_{t}\right), l y_{t}=\ln \left(y_{t}\right)$. Additionally, the first differenced variables in natural logarithms are calculated as $\Delta l h t_{t}=l h t_{t}-l h t_{t-l}$ and $\Delta l y_{t}=l y_{t}-l y_{t-l}$ which represent the yearly growth rates of the respected variables. The distributional characteristics of the analyzed variables are given in Table 1 below.

\begin{tabular}{|l|l|l|l|l|l|}
\hline Variable: & Mean & Min. & Max. & Std.dev. & JB \\
\hline$l h t_{t, T R}$ & 0.61 & $-2.77 \mathrm{E}-05$ & 1.57 & 0.36 & $6.87[0.03]$ \\
\hline$l h t_{t, S K}$ & 3.28 & 2.88 & 3.56 & 0.20 & $2.49[0.29]$ \\
\hline$\Delta l h t_{t, T R}$ & 0.004 & -0.77 & 0.64 & 0.27 & $4.04[0.13]$ \\
\hline$\Delta l h t_{t, S K}$ & 0.02 & -0.16 & 0.17 & 0.08 & $0.64[0.72]$ \\
\hline$l y_{t, T R}$ & 8.77 & 8.45 & 9.09 & 0.20 & $1.77[0.41]$ \\
\hline$l y_{t, S K}$ & 9.65 & 9.00 & 10.11 & 0.33 & $1.74[0.42]$ \\
\hline$\Delta l y_{t, T R}$ & 0.02 & -0.07 & 0.08 & 0.05 & $3.36[0.19]$ \\
\hline$\Delta l y_{t, S K}$ & 0.04 & -0.07 & 0.09 & 0.03 & $22.01[0.00]$ \\
\hline
\end{tabular}

Table 1. Descriptive Statistics for the Analyzed Variables of South Korea and Turkey

The results in Table 1 show that the high technology exports in total exports has been comparatively larger in terms of their means South Korea if $l h t_{t, S K}$ and $l h t_{t, T R}$ variables are evaluated. If their growth rates are compared, the average of $\Delta l h t_{t, S K}$, the growth rate of high tech exports has been yearly around $2 \%$ in South Korea, while the average of $\Delta l h t_{t, T R}$ represent an average growth rate of high tech exports has been $0.4 \%$. If the economic growth rates are to be compared $\left(\Delta y_{t, S K}\right.$ and $\left.\Delta l y_{t, T R}\right)$ the GDP per capita growth rates in South Korea has been $4 \%$; twice as large of that in Turkey. The results for the Jarque-Berra test statistics (JB) show that, normality of the series cannot be rejected at $5 \%$ significance level except for $l h t_{t, T R}$ and $\Delta y_{t, S K}$. However, the analysis of normality of the residuals should be checked especially for the residuals of the estimated regression models. Further, the dataset is subject to structural breaks as to be discussed in the next section.

\subsection{Econometric Methodology}

The econometric methodology followed in the study consists of several steps. At the first step, the stationary of high tech exports and GDP per capita levels is evaluated with traditional ADF and PP unit root tests. The KPSS stationarity test is known as having better properties for various types of data including time series following nonlinear processes of being subject to structural breaks. Further, it is well known that the results obtained with traditional unit root test might be altered if the evaluated time series contain structural breaks. Therefore, to test for an Engle \& Granger (1987) type cointegration relation between the analyzed variables, the research should focus an initial analysis of structural breaks and unit roots testing in addition to the general approaches based on posterior, i.e. after estimation, instability tests of parameters with CUSUM, CUSUMSQ type tests.

\subsubsection{Stationarity, Structural Breaks and Cointegration}

As noted by Esteve et.al., (2013), linear cointegration tests might produce instability due to structural breaks and long run regressions may suffer instability. To overcome this difficulty, Arai \& Kurozumi (2007) proposed residualbased tests in which the null hypothesis of cointegration with a structural break could be tested against the alternative of no cointegration. However, the high-tech exports data is rather limited in terms of sample size. Therefore, splitting the regression space into sub-samples might produce further misleading results. 
The study aims at benefiting from Engle and Granger (1987) approach which to investigate the effects of high technology exports on economic performance. The cointegration approach requires the evaluation of stationarity of the analyzed time series. However, as noted above, structural breaks in time series could lead to a tendency towards the acceptance of the null hypothesis of unit root in ADF type unit root tests. Additionally, structural breaks not only effect the results of cointegration tests, the estimated models could also be subject to biased parameter estimates. Further, in addition to testing for structural breaks and unit roots before the estimation of the cointegration models, testing of parameter instability after the estimation of these models is a necessity.

As a result of the above mentioned limitations, the study aims at benefiting from structural break tests developed by Zivot \& Andrews (1992) and Lee \& Strazicich (2003). Zivot \& Andrews (1992) and Perron (1997) tests are among the pioneering approaches however, these tests allow single structural break testing. Lee \& Strazicich (2013) developed tests based on LM tests that allow testing of unit root hypothesis under two endogenous breaks. A common approach under variables that constitute structural breaks is to apply diagnostics tests including the CUSUM and CUSUMSQ. These tests are residual based tests and are applied after the estimation of the regressions for possible structural breaks. In the study, these type of post-estimation tests are also conducted for both the longrun and short-run regressions in cointegrating relationships. A similar approach is followed by Farhani et.al., (2014); Shahbaz, et.al., (2015) and Shahbaz, et.al., (2016) studies which utilized ARDL type cointegration analysis (Pesaran et.al., 2001). The traditional Engle \& Granger (1987) cointegration technique requires common order of integration, i.e. both variables should be I(1) processes. Therefore, we propose the following methodology. The steps are specified in terms of the specification, estimation and evaluation ala Box-Jenkins (1986):

I. Specification. i. Evaluate the order of integration with ADF, PP and KPSS tests. KPSS test is known to produce more reliable results if the series is subject to structural breaks and nonlinearity. $i i$. For a cautionary measure, test the null hypothesis of unit root with ZA and LS tests to check for possible breaks. The breaks could result from factors such as the economic crises. Check if the ZA and LS tests also confirm that the series are I(1) after controlling for the structural breaks. iii. Create dummy variables corresponding to the estimated break/outlier dates, conduct the Engle-Granger test by including the crises dummy variables as exogenous variables and check for cointegration; this step could also be checked with Johansen cointegration test.

II. Estimation. Since the sample size is not large, the incorporation of possible structural breaks caused by factors such as the economic crises could be incorporated to the models with dummy variables. We avoid splitting the regression space into two or more sub-samples. The reason is the small size of the dataset. $i$. Estimate the model with OLS by following the Engle and Granger (1987) methodology; use crises dummy variables as exogenous variables; $i$. The ZA and LS tests give information about the type of breaks: the breaks could be "impulse, i.e. in the intercept", "trend, i.e. break in slope" or "both". These correspond to three different modelling types, Model A, B and C (see LS, 2003). iii. Use the information obtained by the ZA and LS tests as initial information for the dates of breaks in the variables entering the regressions. The parameters of the dummy variables should be tested for significance after being estimated.

III. Evaluation. Diagnostic tests. $i$. general group of tests include: Ljung-Box Q test for autocorrelation, ARCHLM heteroscedasticity test and RESET misspecification test; $i$. test the parameter instability: CUSUM and CUSUMSQ. Check if the parameter stability is achieved and the models are capable of coping with parameter instability after the inclusion of the crises' dummy variables. If parameter stability cannot be rejected, the estimation results could be considered for economic policy analysis. Note that cointegration is at the center of the analysis and the cointegration tests require a minimum sample size of 25 to obtain reliable results (See the User's Guide, Eviews 9).

In the literature, due to sample size limits, many analyses are conducted even with lower number of observations, however, the small sample size properties of the structural break unit root tests are derived for larger sample sizes. For example, the application section of ZA (1992) include samples with $\mathrm{T}=61$ and $\mathrm{T}=11$ and the critical values of LS (2003) were derived for $\mathrm{T}=125$. However, many studies in the literature had to be conducted for sample sizes due to availability of data (Farhani et al., 2014).

\subsection{Empirical Results}

At the first stage, the variables are tested with ADF and PP unit root and KPSS stationarity tests. The results are given in Table 2. Accordingly, the test results suggest that both GDP per capita and high-tech exports variables in natural logarithms for both countries are unit root processes and stationarity of the series cannot be accepted at conventional significance levels. Accordingly, the variables are first differenced and the first differenced series are tested for unit roots and stationarity. The overall results of the ADF, PP and KPSS tests suggest that all analyzed series are integrated of order 1 ; and they become stationary after being first differenced.

At the second stage, the variables are tested with Zivot-Andrews (1992, ZA) unit root test that allows one and the Lee \& Strazicich $(2003$, LS) test that allows two endogenous structural breaks in unit roots testing. Due to availability of sample size, to minimize the loss of degrees of freedom, the lag length in these tests are selected with Schwarz information criteria (SIC). The results of structural break unit root tests are given in Table 3. 


\begin{tabular}{|c|c|c|c|c|c|c|c|}
\hline \multicolumn{4}{|c|}{ South Korea: } & \multicolumn{4}{|c|}{ Turkey: } \\
\hline Variable: & ADF & $\mathbf{P P}$ & KPSS & Variable: & ADF & PP & KPSS \\
\hline lyk & $\begin{array}{c}-2.11 \\
{[0](t+i n t)}\end{array}$ & $\begin{array}{c}-1.93 \\
{[5](t+i n t)}\end{array}$ & $\begin{array}{c}1.40 \\
(t+i n t)\end{array}$ & lytr & $\begin{array}{c}-2.53 \\
{[0](t+i n t)}\end{array}$ & $\begin{array}{c}-2.71 \\
{[1](t+i n t)}\end{array}$ & $\begin{array}{c}1.17 \\
(t+i n t)\end{array}$ \\
\hline$\Delta l y k$ & $\begin{array}{c}-3.93 * * \\
{[3](t+i n t)}\end{array}$ & $\begin{array}{l}-11.21 * * * \\
{[5](t+i n t)}\end{array}$ & $\begin{array}{c}0.07 * * * \\
(t+i n t)\end{array}$ & $\Delta l y t r$ & $\begin{array}{c}-4.77 * * * \\
{[0](t+i n t)}\end{array}$ & $\begin{array}{c}-5.51 * * * \\
{[1](\text { int })}\end{array}$ & $\begin{array}{c}0.03 * * * \\
(t+i n t)\end{array}$ \\
\hline lhtk & $\begin{array}{c}-2.19 \\
{[0](\text { int })}\end{array}$ & $\begin{array}{c}-2.26 \\
{[4](t+i n t)}\end{array}$ & $\begin{array}{c}2.41 \\
(t+i n t)\end{array}$ & lhttr & $\begin{array}{c}-2.07 \\
{[0](\text { int })}\end{array}$ & $\begin{array}{c}-2.04 \\
{[2](\text { int })}\end{array}$ & $\begin{array}{l}0.88 \\
(\text { int })\end{array}$ \\
\hline$\Delta$ lhtk & $\begin{array}{c}-4.96^{* * *} \\
{[1](t+i n t)}\end{array}$ & $\begin{array}{c}-5.92 * * * \\
{[1](t+i n t)}\end{array}$ & $\begin{array}{c}0.04 * * * \\
(t+i n t)\end{array}$ & $\Delta$ lhttr & $\begin{array}{c}-4.06 * * * \\
{[0](\mathrm{int})}\end{array}$ & $\begin{array}{c}-4.51 * * * \\
{[1](\text { int })}\end{array}$ & $\begin{array}{c}0.07 * * * \\
\text { (int) }\end{array}$ \\
\hline
\end{tabular}

Table 2. Traditional Unit Root Tests Results

Notes. *, **, *** denote significance at $\alpha=0.10,0.05$ and 0.01. The selected lag length is given in brackets. The assumptions of the unit root tests are reported in parentheses: $t$ and int represent trend and intercept, respectively. The intercept (int) only Mckinnon (1996) critical values are $-3.72,-2.98$ and -2.63 at 1\%, 5\% and 10\% significance levels. The intercept and trend Mckinnon (1996) critical values are -4.37, -3.60 and -3.24 at $1 \%, 5 \%$ and $10 \%$ significance levels. For the KPSS test, the default of Bartlett kernel is used for spectral estimation and the bandwidth is selected with Newey-West option. The critical values for the KPSS test are 0.74, 0.46 and 0.35 with allowing int and these values under the $t+$ int assumption are 0.22, 0.15 and 0.12 at $\alpha=0.01,0.05$ and 0.10 , respectively.

The ZA and LS tests allow testing the structural break unit root under the null hypothesis. The critical values are reported from ZA (1992) and LS (2003). While both tests allow testing structural unit roots in analyzed series, in both tests, the break date is not predetermined by the researcher; therefore, both tests give preliminary information regarding the structural break dates. Further, the LS test allows two structural breaks while the ZA test allows single structural unit root testing. As noted in Section 4, structural breaks could result in biased parameter estimates in the traditional ADF and PP test results and could lead over acceptance of the null hypothesis of unit root in these tests (Esteve et.al, 2013). However, both the ZA and LS tests confirmed that all analyzed series in levels are I(1), integrated of order 1, processes and after taking first differences, (i.e. series denoted with $\Delta$ ) they become stationary. Therefore, the ZA and LS tests confirmed that both high-tech exports and GDP per capita series are integrated of a common order, I(1). According to the ZA test results, the structural break dates are in years 20082009 (the Global Crisis) and 1998 (post effects of 1997 Asian Crisis) for South Korea and 2000-2001 Economic Crisis for Turkey.

\begin{tabular}{|c|c|c|c|c|c|c|}
\hline & \multicolumn{2}{|c|}{ Zivot-Andrews Test } & \multicolumn{4}{|c|}{ Lee-Strazicich Test Results } \\
\hline & ZA-Stat: & Break date: & Model type: & LS-Stat: & Break Date 1 & Break Date 2 \\
\hline lyk & $\begin{array}{c}-2.90 \\
{[0]}\end{array}$ & 2009 & $\mathrm{~A}$ & $\begin{array}{c}-2.30 \\
{[1]}\end{array}$ & $\begin{array}{c}1998 \\
(2.62 * *)\end{array}$ & $\begin{array}{c}2008 \\
(-0.92)\end{array}$ \\
\hline$\Delta l y k$ & $\begin{array}{c}-5.14 * * * \\
{[3]}\end{array}$ & 1998 & $\mathrm{C}$ & $\begin{array}{c}-13.32 * * * \\
{[1]}\end{array}$ & $\begin{array}{c}1998 \\
\left(-15.11^{* * *}, 11.54 * * *\right)\end{array}$ & $\begin{array}{c}2002 \\
\left(6.96^{* * *},-13.53^{* * *}\right)\end{array}$ \\
\hline lhtk & $\begin{array}{c}-3.45 \\
{[0]}\end{array}$ & 1999 & $\mathrm{C}$ & $\begin{array}{c}-5.23 \\
{[1]}\end{array}$ & $\begin{array}{c}1998 \\
\left(-2.35^{* * *}, 2.94 * * *\right)\end{array}$ & $\begin{array}{c}2007 \\
(0.66,-5.02 * * *)\end{array}$ \\
\hline$\Delta$ lhtk & $\begin{array}{c}-6.51 * * * \\
{[1]}\end{array}$ & 2001 & $\mathrm{C}$ & $\begin{array}{c}-9.39 * * * \\
{[3]}\end{array}$ & $\begin{array}{c}1998 \\
(-6.13 * * *, 5.09 * * *)\end{array}$ & $\begin{array}{c}2008 \\
(-3.58 * * *, 3.33 * * *)\end{array}$ \\
\hline lytr & $\begin{array}{c}-3.34 \\
{[0]}\end{array}$ & 2002 & $\mathrm{C}$ & $\begin{array}{c}-5.29 \\
{[2]}\end{array}$ & $\begin{array}{c}2001 \\
(3.77 * * *,-4.37 * * *)\end{array}$ & $\begin{array}{c}2007 * * * \\
(-0.09,3.12 * * *)\end{array}$ \\
\hline$\Delta l y t r$ & $\begin{array}{c}-6.29 * * * \\
{[0]}\end{array}$ & 2003 & $\mathrm{C}$ & $\begin{array}{c}-7.41 * * * \\
{[5]}\end{array}$ & $\begin{array}{c}2001 \\
(5.23 * * *,-7.58 * * *)\end{array}$ & $\begin{array}{c}2008 \\
(-7.02 * * *, 7.10 * * *)\end{array}$ \\
\hline lhttr & $\begin{array}{c}-3.58 \\
{[0]}\end{array}$ & 2000 & $\mathrm{C}$ & $\begin{array}{c}-4.95 \\
{[0]}\end{array}$ & $\begin{array}{c}1997 \\
(-2.59 * * *, 4.93 * * *)\end{array}$ & $\begin{array}{c}2001 \\
(-4.57 * * *, 4.37 * * *)\end{array}$ \\
\hline slhttr & $\begin{array}{c}-6.36^{* * * *} \\
{[0]}\end{array}$ & 2001 & $\mathrm{C}$ & $\begin{array}{c}-6.95 * * * \\
{[0]}\end{array}$ & $\begin{array}{c}1999 \\
(0.47,-2.07 * *)\end{array}$ & $\begin{array}{c}2003 \\
(-0.41,3.76 * * *)\end{array}$ \\
\hline
\end{tabular}

Table 3. Structural Break Unit Root Test Results

Notes. $*, * *, * * *$ denote significance at $\alpha=0.10,0.05$ and 0.01. The selected lag length is given in brackets. ZA (1992) critical values are5.34, -4.93 and -4.58 at $1 \%, 5 \%$ and $10 \%$ significance levels. In LS (2003) test, Model A allows structural change in the intercept while, Model $B$ and $C$ allow in trend and in both the intercept and the trend. The LS test critical values for Model A are -4.545 -3.842 -3.504 for $\alpha=0.01$, 0.05 and 0.10. The critical values also depend on $\lambda$, the position of break $t$ in the sample, $t / T$. Here, the values for $\lambda=0.4$ are reported to save space: $-6.45,-5.67,-5.31$ for $\alpha=0.01,0.05$ and 0.10 . In the LS tests, the 11 and $t 2$ statistics represent the t statistics of the level and slope break parameters which are given in parentheses under each break date.

With allowing two structural breaks, the LS test gives more reliable results and the results: following the LS test results, for South Korea, the first break date is estimated as the year 1998 while the second break corresponds to 2007-2008 Global Crisis for 3 out of 4 tested variables. For Turkey, the LS tests suggest that the first break date coincides with 2001 Crisis and the post effects of 1997 Asian Crisis in 1998 while the second break corresponds to either 2001 Crisis or 1998 depending on the first estimated break. Overall, the LS test suggest inclusion of 20072008 Global Crisis and 2001 Economic Crisis as exogenous dummy variables in both the cointegration tests and into the regression models for Turkey.

The Engle-Granger and Johansen Cointegration test results are given in Table 4. The Engle-Granger test is conducted twice for each country, once by taking $l y$ and once by taking $l h t$ as dependent variables. Further, both cointegration tests are conducted with allowing crises' dummies defined as exogenous variables in the testing process, D2001, D2008 and D1998 for Turkey and D1998 and D2008 for South Korea. Additionally, the test is conducted with linear trend assumption. The test results suggest that, for South Korea, cointegration cannot be rejected at $5 \%$ significance level and cointegration is accepted between the two variables if the GDP per capita (ly) 
is taken as the dependent variable. The results show that while being both $l h t$ and $l y$ are integrated of order (1), their linear combination is a stationary I(0) process integrated of order 0. According to the Engle-Granger test results for Turkey, at 5\% significance level, if $l y$ is taken as the dependent variable, the null hypothesis of no cointegration cannot be accepted and the results are in favor of cointegration between the ly and lht variables. As a result, for both countries, the two series are accepted to be cointegrated at 5\% significance level.

\begin{tabular}{|c|c|c|c|}
\hline \multicolumn{5}{|c|}{ Engle-Granger Cointegration Tests } \\
\hline South Korea: & tau-statistic: & Dependent variable: & tau-statistic: \\
\hline Dependent variable: & $-4.23 * * *$ & Iy & $-3.93 * *$ \\
\hline Iht & $-3.36^{*}$ & Iht & -2.98 \\
\hline \multicolumn{4}{|c|}{ Johansen Cointegration Test Results: Turkey } \\
\hline Hypothesized no. of cointegrating vectors & Eigenvalue & Trace Stat & Max.-Eigen Statistic \\
\hline none & 0.64 & $29.90 * * *$ & $24.42 * * *$ \\
\hline at most 1 Johansen Cointegration Test Results: South Korea & 5.48 \\
\hline Hypothesized no. of cointegrating vectors & Eigenvalue & Trace Stat & Max.-Eigen Statistic \\
\hline none & 0.66 & $31.59 * * *$ & $25.09 * * *$ \\
\hline
\end{tabular}

Table 4. Cointegration Test Results

Notes. *,**,*** denote significance at $\alpha=0.10,0.05$ and 0.01. In both countries' Engle-Granger tests, intercept and linear trend is assumed in addition to dummy variables included for crises'years as exogenous variables. For Turkey, the cointegration equation deterministics are: constant, linear trend, D2001, D2008 and D1998 which correspond to the years 2001, 1998 and 2008. For S. Korea, deterministics are D1998 and D2008 in addition to the intercept and the deterministic trend. For the Johansen tests, for both countries, deterministic trend in the cointegration equation is assumed in addition to the above-mentioned dummy variables. In the Engle-Granger test, the critical values are: 4.39, -3.61 and -3.24 for $1 \%, 5 \%$ and $10 \%$ significance levels.

The Johansen cointegration tests are given in the second part of the Table. In the Johansen cointegration test, similar to the Engle-Granger test, deterministic trend is assumed in the cointegration relation. Additionally, the dummy variables included as exogenous variables are D2001, D2008 and D1998 for Turkey; and, D2008 and D1998 for South Korea. Both trace and maximum eigen statistics are statistically larger than the critical values and the results suggest acceptance of 1 cointegrating vector for the variables. Both Engle-Granger and Johansen tests suggest that $l y$ and $l h t$ are cointegrated at conventional significance levels and a long-run relation between high-tech exports and GDP per capita levels cannot be rejected for Turkey and South Korea.

At the last stage, after the confirmation of cointegration between high-technology exports and GDP per capita, the long-run and short-run regressions are estimated. The results are given in Table 5.

\begin{tabular}{|c|c|c|c|c|c|c|c|}
\hline \multicolumn{4}{|c|}{ Long-Run Regressions: } & \multicolumn{4}{|c|}{ Short-Run Regressions: } \\
\hline \multicolumn{2}{|c|}{$\begin{array}{l}\text { South Korea } \\
\text { Dependent variable: lyk }\end{array}$} & \multicolumn{2}{|c|}{$\begin{array}{c}\text { Turkey } \\
\text { Dependent variable: } \text { lytr }\end{array}$} & \multicolumn{2}{|c|}{$\begin{array}{c}\text { South Korea } \\
\text { Dependent variable: } \Delta l y k\end{array}$} & \multicolumn{2}{|c|}{$\begin{array}{c}\text { Turkey } \\
\text { Dependent variable: } \Delta \text { lytr }\end{array}$} \\
\hline$l h t_{t}$ & $\begin{array}{l}0.25^{* * *} \\
(6.96)\end{array}$ & $l h t_{t}$ & $\begin{array}{l}-0.051 * * \\
(-2.49)\end{array}$ & $\Delta l h t_{t}$ & $\begin{array}{l}0.20^{* * * *} \\
(2.89)\end{array}$ & $\Delta l h t_{t}$ & $\begin{array}{l}-0.002 \\
(-0.07)\end{array}$ \\
\hline Trend $_{t}$ & $\begin{array}{l}0.04 * * * \\
(42.07)\end{array}$ & Trend $_{t}$ & $\begin{array}{l}0.03 * * * \\
(21.95)\end{array}$ & $\Delta l h t_{t-1}$ & $\begin{array}{l}-0.02 \\
(-0.27)\end{array}$ & $\Delta l h t_{t-1}$ & $\begin{array}{l}0.09 * * * \\
(3.06)\end{array}$ \\
\hline D1998t & $\begin{array}{l}-0.07 * * \\
(-2.36)\end{array}$ & $D 2001_{t}$ & $\begin{array}{l}-0.079 * * \\
(-2.20)\end{array}$ & $\Delta l h t_{t-2}$ & $\begin{array}{l}0.17 * * \\
(2.63)\end{array}$ & $\Delta l h t_{t-2}$ & $\begin{array}{l}-0.08 * * * \\
(-3.44)\end{array}$ \\
\hline \multirow[t]{4}{*}{$c$} & $\begin{array}{l}8.35 * * * \\
(75.50)\end{array}$ & $\overline{D 2008_{t}}$ & $\begin{array}{l}-0.06^{*} \\
(-2.01)\end{array}$ & $\Delta l y_{t-1}$ & $\begin{array}{l}0.04 \\
(0.20)\end{array}$ & $\Delta l y_{t-1}$ & $\begin{array}{l}0.25 * * \\
(2.07)\end{array}$ \\
\hline & & $D 1998_{t}$ & $\begin{array}{l}0.07^{*} \\
(1.92)\end{array}$ & $e c m_{t-1}$ & $\begin{array}{l}-0.6139 * * \\
(-2.55)\end{array}$ & $\Delta l y_{t-2}$ & $\begin{array}{l}-0.08 \\
(-0.34)\end{array}$ \\
\hline & & $c$ & $\begin{array}{l}8.46 * * * \\
(440.82)\end{array}$ & $c$ & $\begin{array}{l}0.04 * * * \\
(3.92)\end{array}$ & $e c m_{t-1}$ & $\begin{array}{l}-0.9945 * * \\
(-3.43)\end{array}$ \\
\hline & & & & & & $c$ & $\begin{array}{l}0.02 * \\
(1.90)\end{array}$ \\
\hline \multicolumn{2}{|c|}{$\begin{array}{l}\mathrm{R}^{2}: 0.9915, \text { Adj. } \\
\text { F: }: 0.9908, \\
\text { BG (2): } 0.75(0.49), \\
\text { BPG(4): } 0.34(0.85)\end{array}$} & \multicolumn{2}{|c|}{$\begin{array}{l}\mathrm{R}^{2}: 0.9587, \mathrm{Ad} . \mathrm{R}^{2}: 0.9465, \\
\mathrm{~F}: 78.90[0.000], \mathrm{DW}: 1.66, \\
\text { BG (2): } 0.47(0.63), \\
\text { BPG(5): } 0.49(0.78)\end{array}$} & \multicolumn{2}{|c|}{$\begin{array}{l}\mathrm{R}^{2}: 0.5583, \text { Adj. } \mathrm{R}^{2}: 0.4285 \text {, } \\
\text { F: } 4.30 \text { [0.01], DW: } 1.93, \\
\text { BG (2): } 0.49(0.61) \\
\text { BPG(5): } 2.34(0.09)\end{array}$} & \multicolumn{2}{|c|}{$\begin{array}{l}\mathrm{R}^{2}: 0.6201, \text { Adj. } \mathrm{R}^{2}: 0.4777, \\
\mathrm{~F}: 4.35 \text { [0.008], DW: } 2.18, \\
\text { BG (2): } 0.89(0.43) \\
\text { BPG(6): } 1.72(0.18)\end{array}$} \\
\hline
\end{tabular}

Table 5. Estimated Long-Run and Short-Run Regressions for South Korea and Turkey

Notes. *,**, *** denote significance at $\alpha=0.10,0.05$ and 0.01 significance levels. For the parameter estimates, the $t$-values are given in parentheses. In the diagnostics tests given at the bottom of the Table, BPG is the Breusch-Pagan-Godfrey test of heteroscedasticity; BG is the Breusch-Godfrey LM test of autocorrelation. In both tests, the F test statistic is reported and the degrees of freedom is given in parentheses.

The long run models are estimated with dummy variables corresponding to 1998 (donated as D1998), the post effects of 1997 Asian Crisis in South Korea. Further, following the ZA and LS tests, a dummy variable is also added for the year 2008 (denoted as D2008) which corresponds to the Global Economic Crisis, however, the parameter of D2008 could not be accepted as statistically significant at 5\% significance level. The long-run regression is estimated with D1998 dummy variable and the trend variable following the previous analyses. According to the results, the positive impact of high tech exports on GDP per capita cannot be rejected at $1 \%$ 
significance level and a $1 \%$ point increase in $l h t$ results in a $0.25 \%$-point increase in GDP per capita levels in South Korea. Further, as noted in the unit root tests, a trend variable entered significantly to the model. The parameter of the 1998 Crisis is statistically significant and points at the negative effect of the crisis on the GDP per capita of South Korea.

The short-run regression results for South Korea are reported at the second part of the Table 5. The parameter of the error correction term $(\mathrm{ecm})$ is negative and between 0 and 1 in absolute terms. The ecm parameter is statistically significant and is estimated as -0.61 suggesting that $61 \%$ of the deviations from the long-run equilibrium is corrected in 1 period (i.e. 1 year) in the short run for South Korea and the duration of the error correction takes $1 / 0.61=1.64$ period. Further, though the SIC information criterion suggested inclusion of the $1^{\text {st }}$ lag only, following Akaike AIC criterion, the second lag of $\Delta l h t_{t i s}$ is also added to the short-run model to overcome the autocorrelation in residuals. The parameter of $\Delta l h t_{t}$ and $\Delta l h t_{t-2}$ are estimated as 0.20 and 0.17 , both positive and statistically significant. The parameter estimates of high-tech exports' growth rates also suggest positive impacts of high-tech exports on economic growth.

The results of the cointegration analysis for Turkey are reported $2^{\text {nd }}$ and $4^{\text {th }}$ columns of Table 5 . The long run model for Turkey is estimated with dummy variables corresponding to 1998, post effects of the 1997 Asian Crisis, the 2001 Crisis and the 2008 Global Recession. According to the results, parameters of D2008 and D1998 are statistically significant at $10 \%$, the parameter of D2001 is statistically significant at 5\% significance level. One striking result in the long-run regression is that, the parameter of high tech exports unexpectedly negative (-0.05) and is statistically significant at 5\% significance level. As a result, the positive effects of high tech exports on GDP per capita levels cannot be accepted for Turkey. If the short-run regression results is evaluated, the parameters of $\Delta l h t_{t-1}$ and $\Delta l h t_{t-2}$ are statistically significant and the relevant parameter estimates are calculated as 0.09 and -0.08 ; suggesting that, in accumulated terms, the effect of high tech exports growth rates almost cancels out suggesting a very limited positive effect of high-tech export growth on economic growth rates.

The parameter of the ecm term is calculated as -0.9945 suggesting that $99.45 \%$, i.e. almost all, of the deviations from the long-run equilibrium are corrected within 1 year. According to the diagnostic tests, the Breusch-Godfrey autocorrelation and Breusch-Pagan-Godrey heteroscedasticity tests suggest rejection of autocorrelation and heteroscedasticity in the residuals. Additionally, CUSUM and CUSUMSQ tests suggest that parameter stability cannot be rejected for the models estimated (See Figure 7).

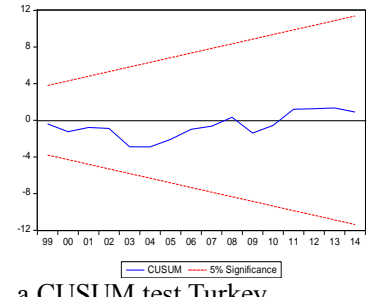

a.CUSUM test, Turkey

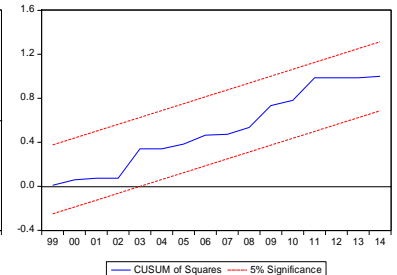

b.CUSUM-SQ test, Turkey

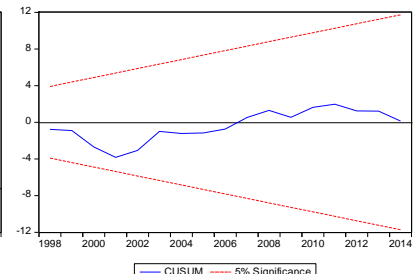

c.CUSUM test,South Korea

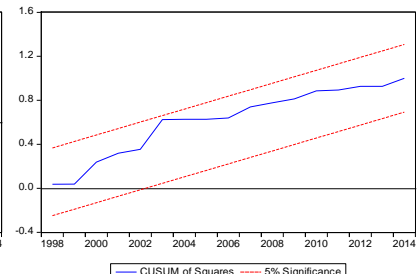

d.CUSUM-SQ test,South Korea

Figure 7. CUSUM and CUSUM-SQ Tests for Parameter Instability

The overall results suggest that, while the increases in high technology manufactured export goods contributed positively on the GDP per capita levels of South Korea, this conclusion cannot be derived for Turkey. According to the results, such positive effects exist only in the short-run with a very limited amount. Furthermore, given the fact that the percentage of exports in GDP in Turkey compared to South Korea, the percentage of high technology exports in manufactured goods exports is even a lower percentage, as noted in Figure 5. As a result, even though a very little positive impact of high technology exports' growth rates on economic growth rates could be observed in the short-run regression of Turkey, this positive effect cannot be accepted to result in increases in the GDP per capita growth rates considering the percentage of high-technology exports in total exports in Turkey. This conclusion could be easily drawn by comparing the magnitude of the parameter estimates obtained for South Korea to those of Turkey. However, this conclusion shouldn't be considered discouraging since Turkey could benefit in the future by investing in R\&D that is also directed towards the development of high technology and comparatively advantageous products within a dynamic comparative advantage approach.

\section{Conclusions}

In 1950's both Turkey and South Korea were two agrarian countries having capital shortage and enterprises. Market institutions for commerce, trade and finance were insufficient. The government had to take the lead to mobilize internal resources, to administer foreign aids, and to direct the allocation of resources to develop industrialization. Korea's powerful government agencies insulated from political or legislative interference were in charge of industry planning and development. Korean government's successful use of selective intervention is designed to promote and develop the domestic industries in the strategic, high-technology sectors. In general, the policy of both countries succeeded in sustaining a considerable rate of export-led growth. But, South Korea's 
growth was spectacular in comparison to Turkish case. Their growth rate, which was quite similar in 1960's has considerably diverged beginning with 1980 's. Korea was particularly successful about industrial upgrading of its export commodities that is, in changing its leading exports from low tech, labor intensive light industrial goods, to heavy industrial goods, then high-tech products because it has developed a comparative advantage in R\&D activity and new product introductions. Additionally, the high-technology exports were also considered as a variable that was also under the influence of R\&D in the country. The large and positive impact of R\&D on high technology exports had been investigated and been shown in the empirical research as discussed in the literature review section.

In the empirical section, the high technology exports and GDP per capita variables were evaluated for stationarity, structural breaks and cointegration for South Korea and Turkey. At the first stage, the variables are tested for structural unit roots with ZA and LS tests in addition to traditional ADF, PP and KPSS unit root and stationarity tests. The test results suggested that in addition to obtaining the conclusion that both the GDP per capita and high technology exports variables as following I(1) processes, an initial information was also attained in terms of determining the structural break dates. The estimated structural breaks coincided with the post effects of 1997 Asian Crisis and the 2008 Global Recession for South Korea. For Turkey, 2001 Economic Crisis were also determined to be added to the cointegration tests as exogenous deterministic factors in addition to 1997 and 2008 Economic Crises.

At the second stage, the cointegration between the variables were analyzed with Engle-Granger and Johansen cointegration tests with the incorporation of the estimated structural breaks as dummy variables entering the testing procedure as exogenous deterministic factors. According to the test results, for both Turkey and South Korea, the long-run relationship between high-technology exports and GDP per capita levels could not be rejected. At the third stage, the long run and short run regression models with error correction mechanisms were estimated. For South Korea, the parameter estimates suggested that in both of the long-run and short-run models, high technology exports had strong positive impacts on GDP per capita and economic growth rates. However, the results obtained for Turkey suggested a different result: such a positive effect of high-technology exports could not be drawn for the analyzed period. Additionally, though a very limited positive effect of high-technology exports' growth could be observed only for the short-run regression of Turkey, this effect is very limited and point at a strong difference from the results obtained for South Korea.

Given the fact that the slightly low percentage of high-technology manufactured exports in total exports of Turkey, the conclusion that Turkey benefited from high-technology exports could not be derived from the empirical results. However, the results obtained at this point should encourage the future trade and development policies of Turkey. Nevertheless, Turkey could benefit in the future by investing in human capital and R\&D which are also directed towards the development of high technology and comparatively advantageous products to alter the comparative advantages in favor of the country.

\section{References}

- Amsden, 1989. Asia's next Giant, South Korea and Late Industrialization, Oxford University Press, New York.

- Arai \& Kurozumi, 2007. "Testing for the Null Hypothesis of Cointegration with a Structural Break", Econometric Reviews, 26(6), p. 705-739.

- Arslanhan and Kutsal, 2010. "To what South Korea Owes Success in Innovations? Implications for Turkey" TEPAV Policy Note.

- Chau, Leung-Chuen, Kai-Sun, Kwong, Lui, Francis T. 2001. Industrial Development in Singapore, Taiwan, \& South Korea, WSPC.

- Engle \& Granger, C.W.J. 1987. "Co-Integration and Error Correction: Representation, Estimation, and Testing”, Econometrica, 55(2), p. 251-276.

- Esteve, Navarro-Ibáñez \& Prats, 2013. "The Spanish term structure of interest rates revisited: Cointegration with multiple structural breaks, 1974-2010”, International Review of Economics \& Finance 25, 24-34.

- Farhani, Shahbaz, Arouri, M., \& Teulon, 2014. "The role of natural gas consumption and trade in Tunisia's output”. Energy Policy, 66, 677-684.

- $\quad$ Frankel \& Romer, 1999. “Does Trade Cause Growth?” American Economic Review, 89 (3), p. 1-69.

- Göçer, 2013. "Effects of R\&D Expenditures on High Technology Exports, Balance of Foreign Trade and Economic Growth”, Maliye Dergisi, 165, p. 215-240.

- Helleiner, et. al., 2002. Manufacturing for Export in the Developing World: Problems and Possibilities. Routledge, London.

- Hirschman, 1969. National Power and the Structure of International Trade, University of California Press, Berkeley. 
- Jaffe and Kim, 2010. New Korea: An Inside Look at South Korea's Economic Rise. AMACOM Books, NY, USA.

- Johansen, 1991. "Estimation and Hypothesis Testing of Cointegration Vectors in Gaussian Vector Autoregressive Models," Econometrica, 59, p. 1551-1580.

- Kilıç, et. al., 2014. "Effect of Research and Development Expenditures on High Technology Exports: A Panel Data Analysis for G-8 Countries” Erciyes Üniversitesi İ̈BF Fakültesi Dergisi,44,p.115-131.

- Lee, \& Strazicich, 2013. "Minimum LM unit root test with one structural break", Economics Bulletin, 33(4), p. 2483-2492.

- Nurkse, 1966. Problems of Capital-Formation in Underdeveloped Countries. Oxford University Press.

- OICA, 2014 Production Statistics. http://www.oica.net/wp-content/uploads//Ranking-2014-Q4-Rev.-22July.pdf

- Onaran and Stockhammer, 2005. "Two Different Export-Oriented Growth Strategies: Accumulation and Distribution in Turkey and South Korea”, Emerging Markets Finance and Trade, 41(1), p. 65-89.

- Perron, 1997. "Further evidence on breaking trend functions in macroeconomic variables", Journal of Econometrics, 80(2), p. 355-385.

- Pesaran, Shin \& Smith, 2001. "Bounds testing approaches to the analysis of level relationships". Journal of Applied Econometrics, 16(3), p. 289-326.

- Salvatore, Dominick, 2013. International Economics, Eleventh Edition, Wiley.

- Shahbaz, Dube, Ozturk \& Jalil, 2015. "Testing the environmental kuznets curve hypothesis in Portugal", International Journal of Energy Economics and Policy, 5(2), p. 475-481.

- Shahbaz, Solarin \& Ozturk, 2016. "Environmental Kuznets Curve hypothesis and the role of globalization in selected African countries," Ecological Indicators, 67, 623-636.

- Singer, 1958. "The Concept of Balanced Growth and Economic Development; Theory and Facts," University of Texas Conference on Economic Development.

- Trott, 2012. Innovation Management and New Product Development, Prentice Hall.

- Van den Berg and Lewer, 2015. International Trade and Economic Growth. Armonk, GB: Routledge.

- Westphal, 1990. Journal of Economic Perspectives- Volume 4, Number 3.

- World Bank, World Development Indicators, WDI Database, 2015. http://databank.worldbank.org/data/reports.aspx?source=world-development-indicators\#.

- Xu, 1996. "On the Causality between Export Growth and GDP Growth: An Empirical Reinvestigation", Review of International Economics, 4 (2).

- Zivot \& Andrews, 1992. "Further Evidence on the Great Crash, the Oil-Price Shock, and the Unit-Root Hypothesis", Journal of Business \& Economic Statistics, 10(3), p. 251-270. 


\title{
The Relationship between Military Expenditures and Economic Growth: Panel Data Analysis for G-20 Countries
}

\author{
Assoc. Prof. Dr. Kutluk Kağan Sümer (Istanbul University, Turkey)
}

\begin{abstract}
As though it is a frequently researched topic that the relationship between military expenditures and economic growth, it is ignored that the level of military expenditures of countries based on their rival and allied countries or international organizations which they are members. Accordingly, in study, the relationship between military expenditures and economic growth is examined with the panel data analysis for 19 G-20countries. In this study two groups of Panel data models are applied. First panel group is military exporter. Second is military importer. The results of study support that feedback hypothesis exists for the U.S., growth hypothesis is valid for G-20 Countries and Turkey.

First hypothesis has been called as "growth hypothesis" based on the hypothesis of "guns or butter" depending on the study made by Benoit $(1973,1978)$ and finding of this study which is regarded as a pioneer for studies examining the relation between military expenses and economic growth. According to this hypothesis, there is a one-way positive causal relation from military expenses to economic growth. Second hypothesis is a hypothesis based on the argument of "guns or butter" and defending the view that there is a one-way causal relation from military expenses to economic growth but it is a negative one and called as "growth detriment hypothesis". Third hypothesis is a hypothesis based on the view that a two-way causal relation is effective in between military expenses and economic growth and called as "feedback hypothesis". According to this hypothesis, while military expenses have an effect on economic growth; economically more (less) developed countries allocate more (less) resource for military expenses (Kollias vd., 2004:557). And the last hypothesis is a hypothesis called as "neutrality hypothesis" and defending the view that there is no causal relation between military expenses and economic growth. According to this hypothesis, both military expenses does not affect economic activities, and economic growth is not effective on determination the level of military expenses.
\end{abstract}

\section{a. Economic Growth}

The concept of economic growth is nothing more than an increase of total production in agriculture, industry and services sectors of a country. It collects the basic factors which determine the national production in three groups as of modern development and growth theories, available production factors and growth rates, education and research activities and technologic changes. These basic factors and context of these factors are summarized in a table below (Table-1).

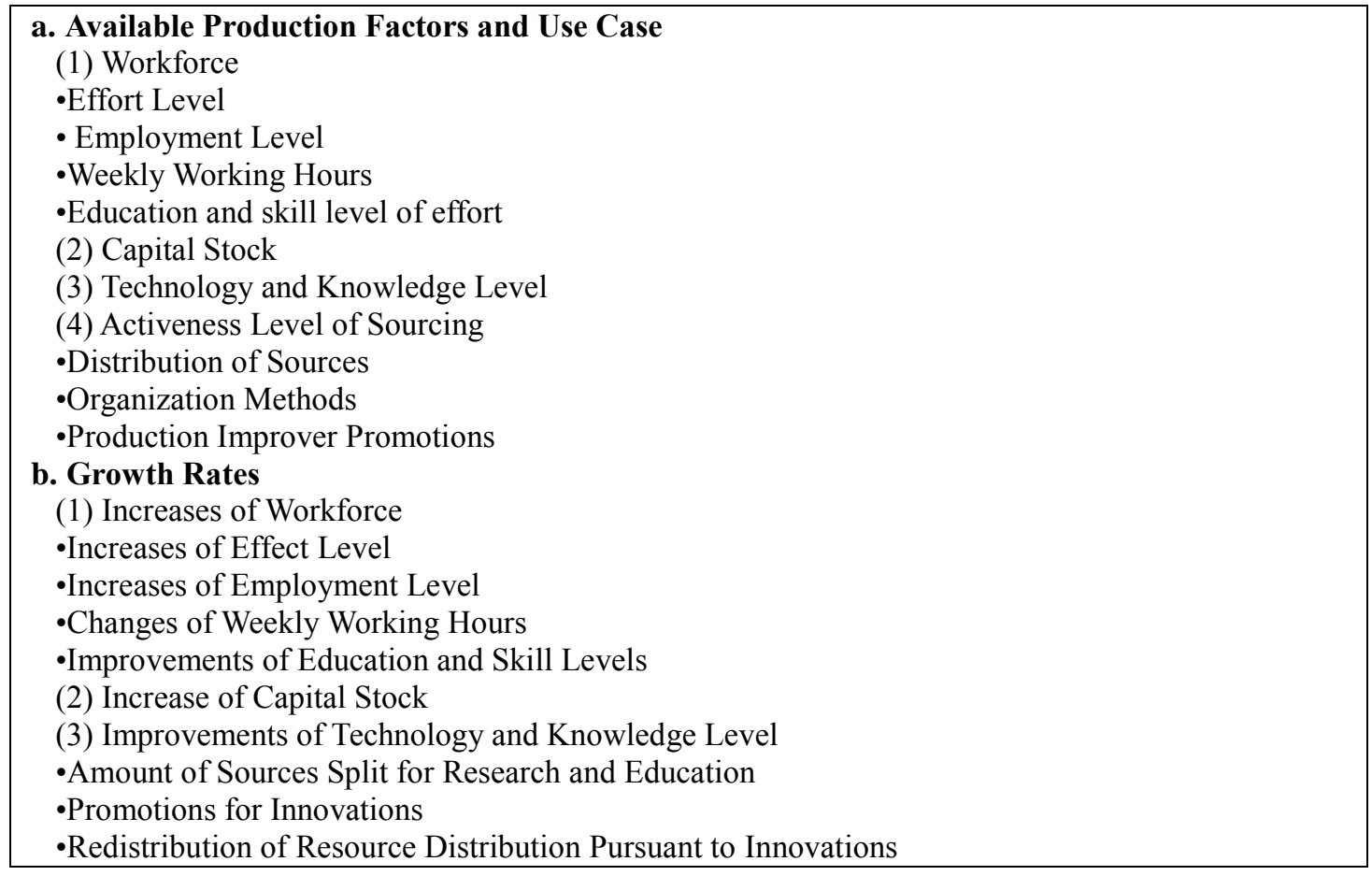

Table-1: Basic Factors Which Determine the National Production

\section{b. Defense Expenses}


Determination of military production, in a more concrete expression, determination of defense budget is based on two complementary different approaches. One of these approaches is foreign policy approach. In these approach, firstly worldview (in a more technical phrase, national values) then foreign policy of nation is determined. Later, the strategy which is necessary for effectuation of this foreign policy and appropriate military power for this strategy are planned. The expense to be required for this military power determines the defense budget. Second approach is called as domestic policy approach. In this approach, national development objectives and allocatable resource for these objectives are determined. When maximum limit of defense budget occurs in this resource distribution, developable military power alternatives in this limit is determined and then the most appropriate one of these alternatives for national defense objectives is selected. As we stated above, indeed it needs to address these two approaches as two complementary approaches. Following figure (Figure-1) shows that domestic and foreign policy approaches establish the whole national values together. In this figure, foreign approach is showed in left part under the title of foreign policy objectives; domestic policy approaches are showed in right part under the title of domestic policy objectives. It is impossible that a nation determines defense budget without considering developments of world policy and how these developments affect itself. Likewise, it cannot be rational to determine foreign policy objectives without considering national economic power.

\section{International and National Condition \\ Organizations and Decision Units}

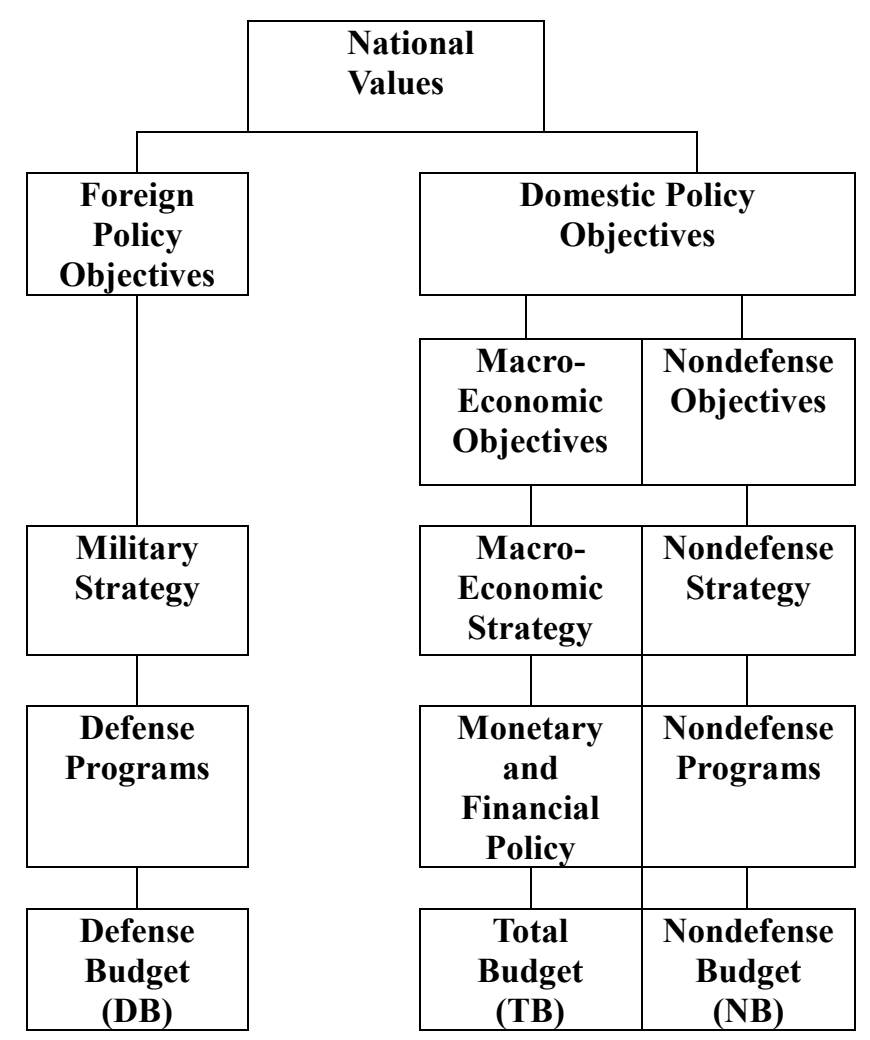

Figure-1: Evaluation Together of Domestic and Foreign Policy Approaches Source: War Economy; War Colleges Publications; Istanbul; 1985

\section{c. Defense Expenses and Economic Growth Relations}

Well, how can be defined the relation between defense expenses and economic growth? In shortly, it is possible to define this relation as increase on government expenses causes an increase on total demand in market; upliftment of industry by the mentioned demand increase and enlargement of economy with increasing industry production. However, expense of the mentioned growth (production growth) leads to increase of inflation. Even if demand shock creates short-term production growths at first, it does not change production level in long-term. It causes an increase on interest rates and inflation levels. Of course, this definition is an effective concept for government and defense expenses in state of a sudden shock wave.

In fact, general balance of economy will absorb the mentioned shock effect so as not to encounter an economic shock in long-term expenses.

If the American economy is examined, a lot of medium and large sized enterprises draw attention which make research for defense industry and produce defense industry systems. These enterprises play an important role in American economy in terms of whether new technologies they produced, or inputs they took from other sectors 
and outputs they gave the other sectors. If inputs they took from other sectors and outputs they gave the other sectors are examined, for example, defense industry takes a big support from scientific research sector and it financially supports this sector. Likewise, it supports sectors such as communication and transportation with its newly produced technologies. Today, communication technologies such as cell phone we used and aviation technologies are in state of output for defense industry. These output technologies positively affect the good and service production by making easier or faster transportation and communication. It is possible to evaluate this as a production shock.

Production-oriented shock (demand) in market both increases national income and decreases prices general level. This type of demand shocks generally appears thanks to new technologies. Industry revolution is one of the best examples for this type of demand shocks. It will decrease total demand in terms of economic policy, and promotions will be more effective than monetary and financial policies in terms of whether decrease price level or increase production.

On the other hand, according to two well-known economists of traditional economy, David RICARDO and Adam SIMITH; military expenses are nonproductive, confined to its own sector, only consuming and unnecessary expenses. They do not have effect on growth. According to 1973 economic growth report of the United Nations, defense expenses are shown as an important obstacle to growth for economies of developing countries.

On the other side, by giving arm markets of USA and Soviets in a bipolar world as examples, Paul Kennedy (1987) mentioned that the party which increases its military expenses, it will lose an important market by losing its share in world arms trade. According to Kennedy, arms trade is an economic activity which has an effect on production after all.

Meanwhile, it is necessary the people to defense themselves against their enemies to survive and defense expenses made for this.

Panel Data Analysis

Different types of data are used in economic studies. These types of data can only be analyzed with the models that are appropriate for their structure. Different analysis can be performed with time series data and horizontal vertical section data. The method of estimation of economic relations by using the section series that have time dimension is referred as panel data analysis. In this analysis, data set, which both have time dimension and section dimension, is formed by combining time series and section series. Today in many studies, data sets are formed by combining time and horizontal section data. Panel data model can be expressed as the equation below.

$$
\begin{aligned}
& Y_{\text {it }}=\beta_{1 i t}+\beta_{2 i t} X_{2 i t}+\ldots \ldots .+\beta_{\text {kit }} X_{\text {kit }}+e_{\text {it }} \\
& i=1, \ldots \ldots ., N \quad t=1, \ldots . ., T
\end{aligned}
$$

Here $\mathrm{N}$ defines units as $\mathrm{t}$ defines time. When $\mathrm{Y}$ variable became a dependent variable which has different values from one unit to another unit and from a time period to a consecutive time period, it can be expressed with two sub index which are $\mathrm{i}$ for section dimension and $\mathrm{t}$ for time period. This general model allows fixed parameters and regression parameters to separate each individual in each time period.

Panel data has various advantages when compared to horizontal section only or time series only. The advantages of using panel data are as follows: In panel data models, the number of observations will be more when compared to section and time series. In this case, the parameter estimations will be more reliable and the estimated models will depend on less restrictive assumption. Whereas, there is a risk of deviant results in studies with time series or section series only, the difference of the units cannot be controlled in detail. Moreover, panel data models allow establishment and control of behavior models more complex than section or time series. However, the omitted variables lead to deviation in estimating the results in studies. In case the omitted variable or the variables are stable with units or time, panel data usage provides the control of deviation. Another advantage of panel data usage is that, while only differences in between the units can be analyzed in making estimations using horizontal section data, by using panel data both differences in units and the difference in units by time can be analyzed (Baltagi, 1995; 3-5, Hsiao, 1986; 2-3).

In the model expressed in Equation (1), the coefficients take different values for different units in different time periods. In this case, the estimated number of parameters exceed the number of observations used i.e. model cannot be determined. Because of this disadvantage, in studies made with panel data different models can be obtained by making different assumptions about the characteristics of error terms and volatility of coefficients. Models obtained by different assumptions are "Fixed Effects" and "Random Effects" models. In each model, it is assumed that in all time periods and for all individuals, $\mathrm{e}_{i t}$ errors are distributed independently and as $\mathrm{N}\left(0, \sigma e^{2}\right)$ (Griffits, 1993; 571-573).

\section{a) Fixed Effect Models}

In studies utilized by panel data, a way to include the change caused by the difference in between the units or the change caused in between the units in time into the model is to assume that the current change will lead to a change in some or all of the coefficients of the regression model. Models which are assumed that the coefficients change by units or by units and time, are referred as "Fixed effect model" 
The general formulation of the model assumes that the difference in between the units can be captured in the differences in the fixed term (Pazarlıoğlu, 2001). For this purpose, panel data model can be assumed with the help of the dummy variable. When model number 1 is considered;

$$
\beta 1 \text { it }=\beta 1 ; \beta 2 \text { it }=\beta 2 ; \beta 3 \text { it }=\beta 3 \quad \text { (2) }
$$

is assumed. Here only the fixed parameters do change and the fixed term differentiate not by time but in section basis. So, even though the time dimension is reserved by the constant, it demonstrates difference in behaviors among individuals. Model number 1 becomes;

$$
\mathrm{Y}_{\mathrm{it}}=\beta_{1 \mathrm{i}}+\beta_{2 \mathrm{i}} \mathrm{X}_{2 \mathrm{it}}+\ldots \ldots . .+\beta_{\mathrm{ki}} \mathrm{X}_{\mathrm{kit}}+\mathrm{e}_{\mathrm{it}}
$$

If this model is rewritten by expanding the $\beta_{1 \text { it }}$ expression;

$$
\begin{aligned}
& Y_{i t}=\beta_{11} D_{1 i}+\beta_{12} D_{2 i}+\ldots \ldots . .+\beta_{1 N} D_{N i}+\beta_{2 i} X_{2 i t}+\beta_{k i} X_{k i t}+e_{i t} \\
& \sum^{N} \beta_{1 j} D_{j i}+\sum^{K} \beta_{k} X_{k t}+e_{i t}
\end{aligned}
$$

Here there are $\mathrm{N}$ number of units and $\mathrm{K}-1$ number of explanatory variables. Besides;

$$
D_{1 i}=\left\{\begin{array}{lc}
1, & i-1 \\
0, & \text { Other Cases }
\end{array} \quad, D_{1 N}= \begin{cases}1, & i-N \\
0, & \text { Other Cases }\end{cases}\right.
$$

In this model, as there is no fixed coefficient, the difference in between the $\mathrm{N}$ number of units is analyzed by using N number of dummy variables.

\section{b) Random Effect Models}

Studies utilizing panel data models, the change caused by units or the differences occurred according to units and time can be analyzed by using "Fixed Effect Methods" as well as "Random Effect Methods". In random effect model, the changes occurred in units or according to units and time are included in the model as a component of the error term. The main reason is to prevent the loss of degree of freedom encountered in fixed effect models.(Baltagi, 1995; 13). Because the important thing in random effects model is not having special coefficients for units or units and time but to have special error components for units or units and time. Moreover, in random effects model the section in the observed sample not only consider the effect of the differences occurred in units and time but also the effects other than the sample (Greene, 2003). We can explain the random effects model as follows. In model number (3), $\beta_{1 \mathrm{i}}$ can be taken as random variable;

$$
\beta_{1 i}=\bar{\beta}_{1}+\mu_{\mathrm{i}}
$$

and modeled like this. $\bar{\beta}_{1}$ i is universe mean constant and an unknown parameter. $\mu_{\mathrm{i}}$ are unobserved random errors that consider individual differences in individual behaviors. $\mu_{\mathrm{i}}$ are independent from each other from $\mathrm{e}_{\mathrm{it}}$. If the equation number (5) is placed in model number (3);

$$
\begin{aligned}
& \mathrm{Y}_{\mathrm{it}}=\left(\bar{\beta}_{1}+\mu_{\mathrm{i}}\right)+\beta_{2} \mathrm{X}_{2 \mathrm{it}}+\ldots . .+\beta_{\mathrm{k}} \mathrm{X}_{\mathrm{kit}}+\mathrm{e}_{\mathrm{it}} \\
& =\bar{\beta}_{1}+\sum_{k=2}^{K} \beta_{k} X_{k i t}+\left(e_{i t}+\mu_{i}\right)
\end{aligned}
$$

is obtained. The expression in $(6 b)$ is the general format of error component model. "Error component" expression is based on $\mathrm{e}_{\mathrm{it}}+\mu_{\mathrm{i}}$. This term is composed of two components: while $\mathrm{e}_{\mathrm{it}}$ indicates all errors, $\mu_{\mathrm{i}}$ indicates the individual "specific" error, individual differences and the change in between the individuals according to constant time.

\section{c) Hausman Test}

The coefficients that represent the unit or unit and time differences which is the validity of the hypothesis of error term components of random effects model being irrelevant from the independent variables in the model, can be analyzed by the test statistics suggested by Hausman (Greene, 2003). In this case, the difference between the fixed effect model parameter estimators and the random effects model parameter estimators should be analyzed whether for being statistically significant or not. In order to make a preference in between the two models Hausman test statistics is used. Hausman test statistics indicate the "Random effects estimator is right" and in zero hypothesis the chi-squared distribution of $\mathrm{k}$ degrees of freedom. In case of actualization, it can be decided that error terms components of random effects model are not relevant with independent variables. In this case fixed effects model shall be preferred.

\section{Used Data Set}

In this study, SIPRI Military Expenditure Database (C) SIPRI 2014 and IMF data have been used. Defense expenses belong to G-20 countries have been supplied from SIPRI and GSMH data from IMF database. It is studied with 22-year observation in between the years of 1992-2013. Used data logarithmic states of whether defense expenses or GSMH data. Thus, direct flexibilities between could be obtained.

\section{Empirical Results:}


After modelling studies had been made and Hausman test, it is decided upon Random effects model; after tests related to specification and deviations from assumptions were made on established random effects models, robust estimation models were established. During this modelling process, three different panel data econometrics model as of a model including all of the G-20 countries, a model including arms-exporting countries and a model including arms-importing countries were established. Finally, a classical economics model specific to Turkey were established. Main purpose here became the parameter tests according to country groups. Last-established classical economics model specific to Turkey, was accepted after tests had been made related to specifications and deviations from assumptions.

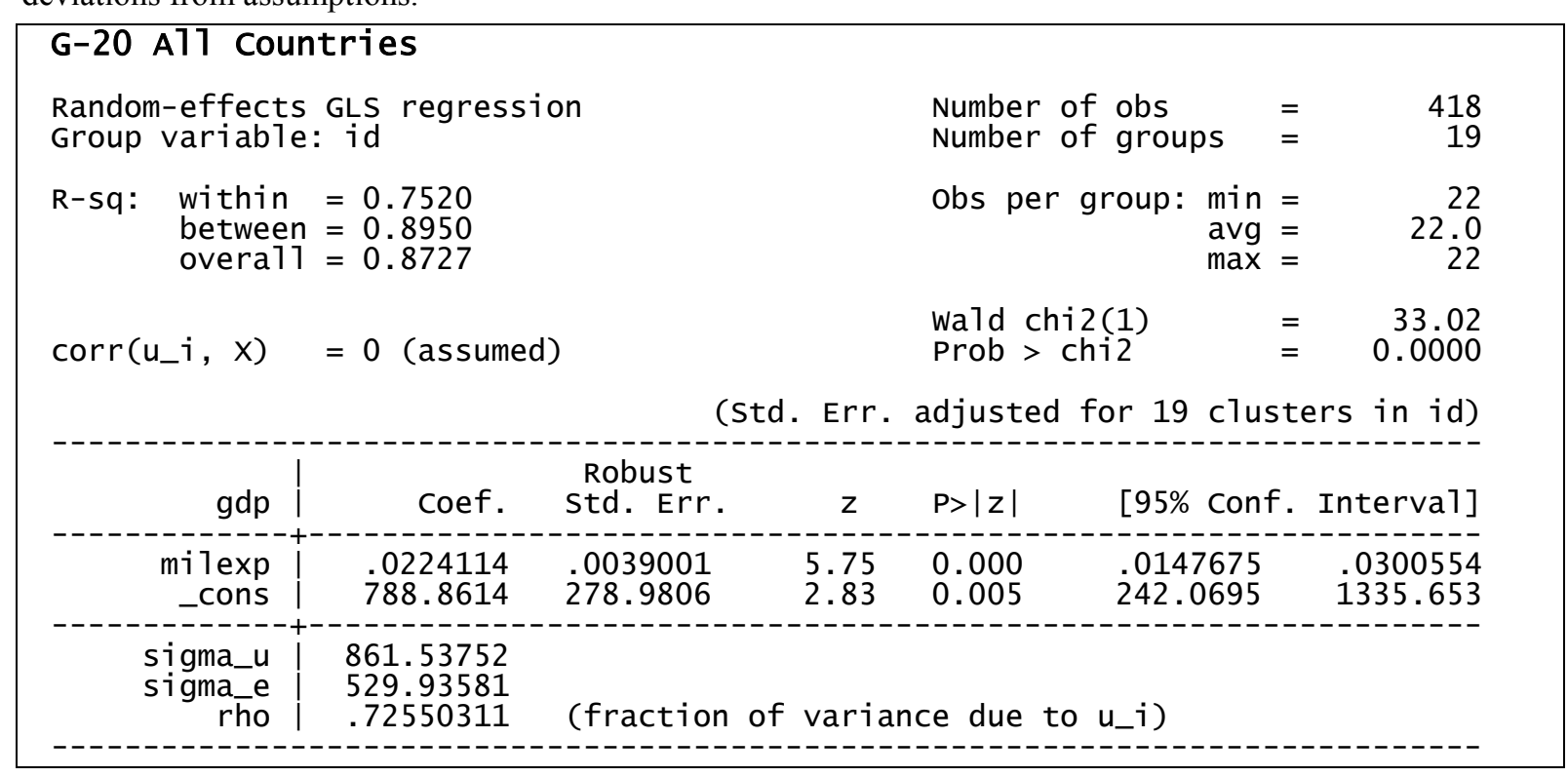

Table-2: G-20 All Countries Panel Econometrical Model Output

It is seen that defense expenses have a positive effect on general of G-20, when the model is examined. It has power to create $1 \%$ increase on military expenses and $0,022 \%$ increase on GSMH.

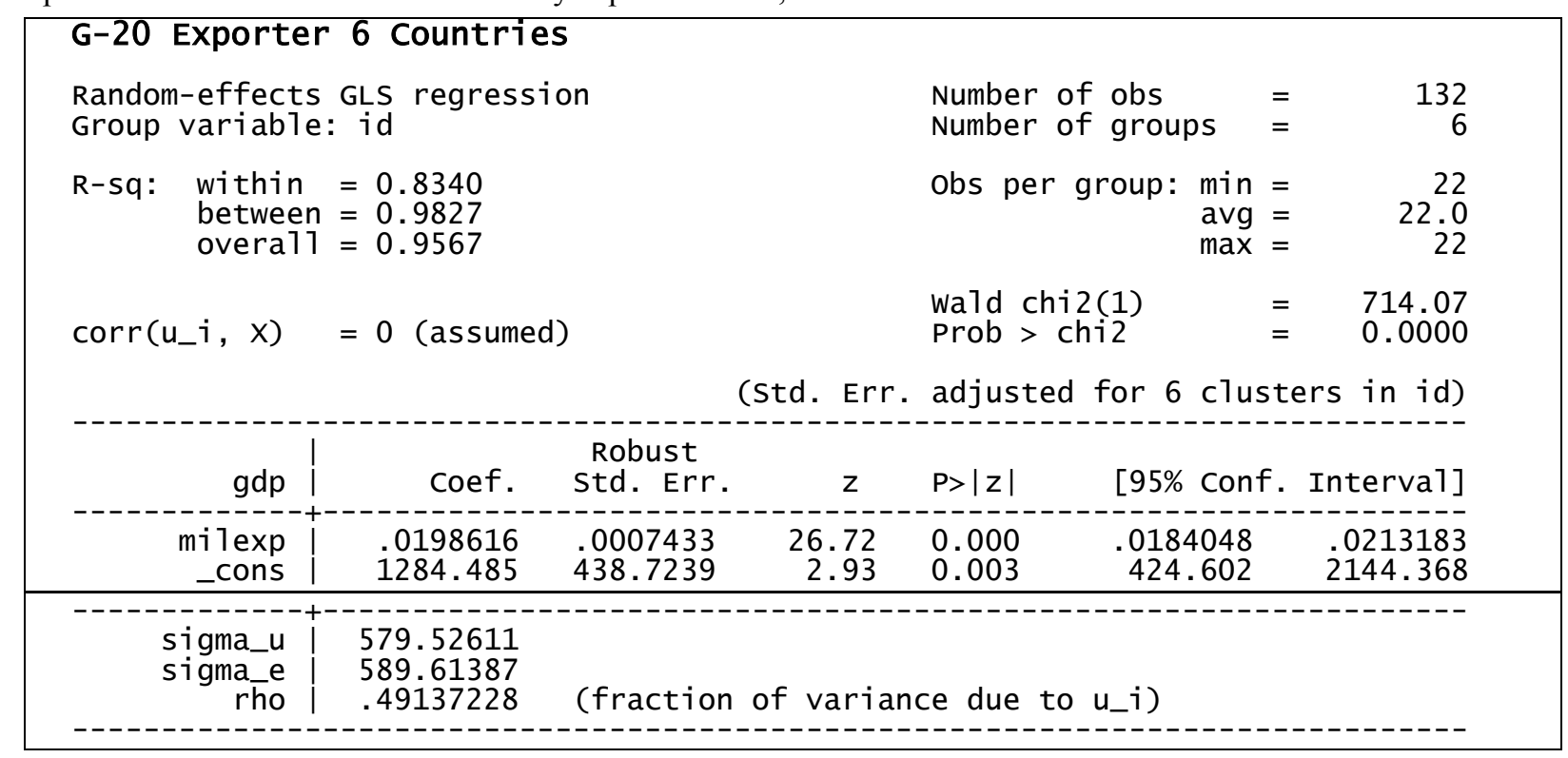

Table-3: G-20 Exporter 6 Countries Panel Econometrical Model Output

It is seen that defense expenses have a positive effect on six arms-exporting countries, when the model is examined. It has power to create $1 \%$ increase on military expenses and $0,020 \%$ increase on GSMH. 


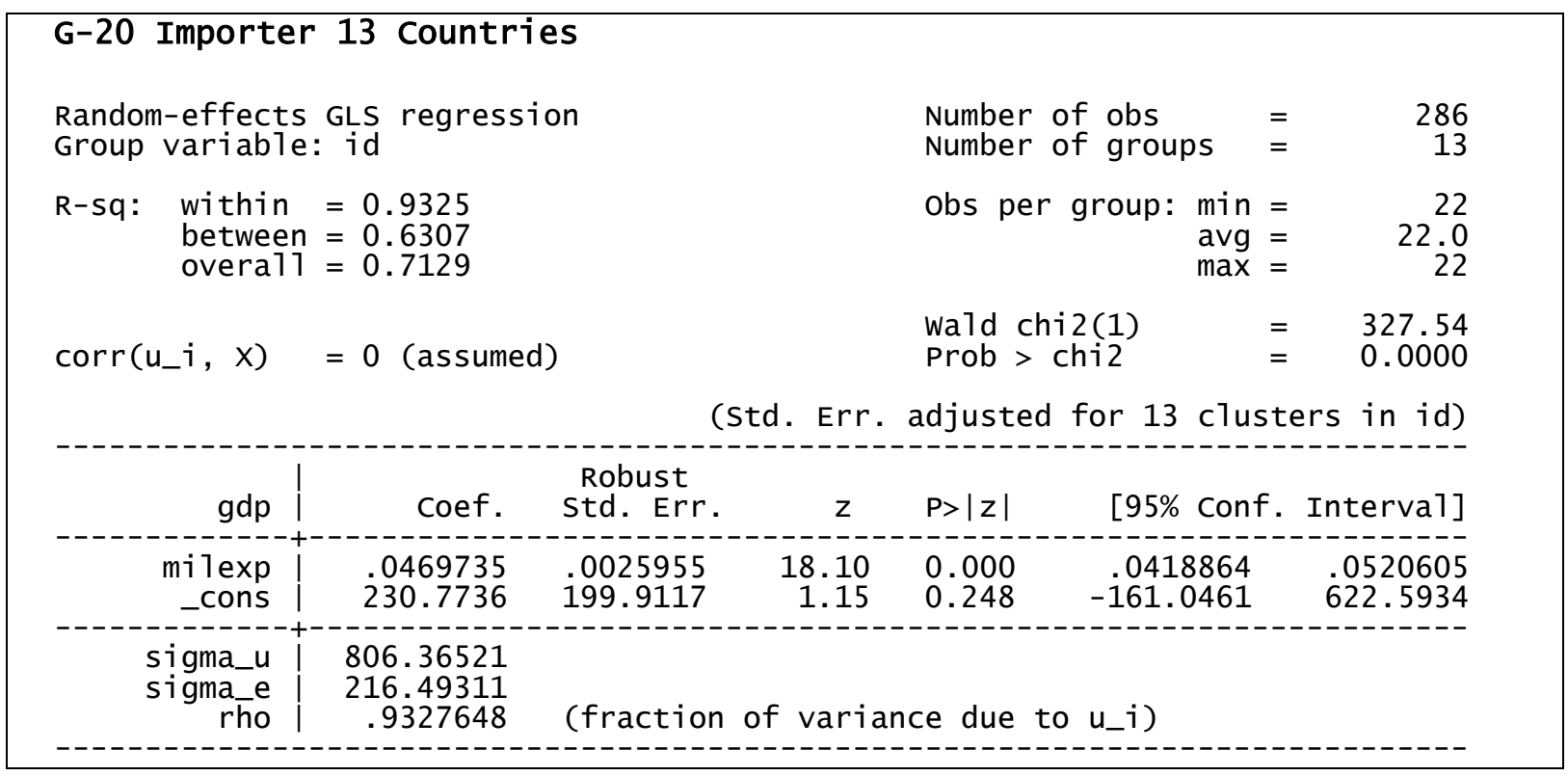

Table-4: G-20 Importer 13 Countries Panel Econometrical Model Output

7It is seen that defense expenses have a positive effect on thirteen arms-exporting countries, when the model is examined. It has power to create $1 \%$ increase on military expenses and $0,046 \%$ increase on GSMH. It is interesting that it has a bigger elasticity on these arms-importing countries.

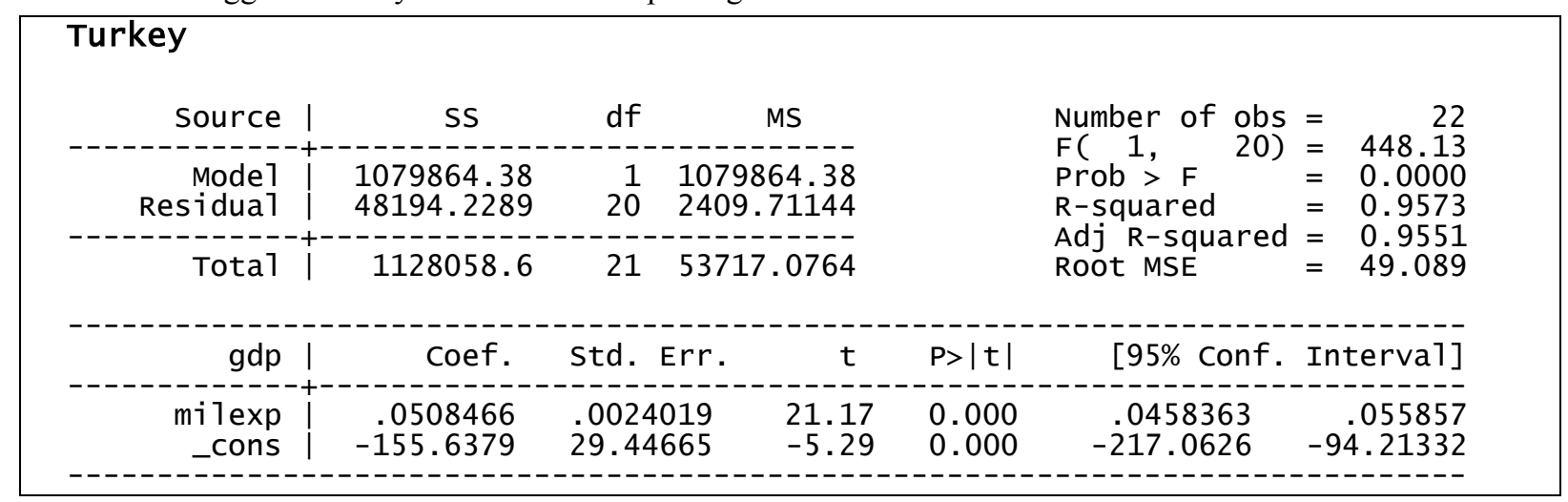

Table-5: Turkey Econometrical Model Output

It is seen that defense expenses have a positive effect on Turkey, when the model is examined. It has power to create $1 \%$ increase on military expenses and $0,050 \%$ increase on GSMH. It can be said that elasticity of defense expenses of national income in Turkey is very high among G-20.

\section{Conclusion:}

It is seen that defense expenses have a positive effect on general of G-20, when the first model is examined. It has power to create $1 \%$ increase on military expenses and $0,022 \%$ increase on GSMH.

It is seen that defense expenses have a positive effect on six arms-exporting countries, when the second model is examined. It has power to create $1 \%$ increase on military expenses and $0,020 \%$ increase on GSMH.

It is seen that defense expenses have a positive effect on thirteen arms-exporting countries, when the third model is examined. It has power to create $1 \%$ increase on military expenses and $0,046 \%$ increase on GSMH. It is interesting that it has a bigger elasticity on these arms-importing countries.

It is seen that defense expenses have a positive effect on Turkey, when the model belong to Turkey is examined. It has power to create $1 \%$ increase on military expenses and $0,050 \%$ increase on GSMH. It can be said that elasticity of defense expenses of national income in Turkey is very high among G-20.

\section{Discussion:}

It is reached the end of that defense expenses of these already developed countries have a positive effect on growth when G-20 countries were examined in terms of defense expenses. This positive effect results from 
technology generation effect of defense expenses in already industrialized countries. It is necessary to discuss that elasticity of defense expenses of national income in thirteen arms-exporting countries and Turkey are very high among G-20. It is obviously seen that income generation effect of improving defense industry in Turkey and increasing defense expenses can be obviously seen at the end of these models.

\section{References}

- Baltagi B.H., (1995), Econometric Analysis Of Panel Data, John Wiley \& Sons Ltd, England

- Benoit, E. (1973) Defense and economic growth in developing countries. Boston: D.C. Heath \& Company.

- Greene, W.H. (2003), Econometric Analysis, Prentice Hall, New Jersey

- Griffits, W. E. R \& Carte H. (1993). Learning And Practicing Econometrics, John Wiley, New York,

- Günlük-Şenesen G. , "The Role Of Defence On External Indebtedness: An Assessment Of Turkey", Defence And Peace Economics, Vol.15, No.2, Pp.145-156, 2004

- Günlük-Şenesen G. , "Türkiye’de Savunma Harcamaları Ve Ekonomik Etkileri, 1980-2001, Kitap", Tesev, İstanbul, 2002

- Harp Ekonomisi; Harp Akademisi Komutanlığı Yayınları; İstanbul; 1985

- Hsiao C. (1986) Analysis Of Panel Data, Cambridge University Press

- $\quad$ IMF Database (C) IMF 2014

- Kennedy, Paul M.; Rise and Fall of the Great Powers: Economic Change and Military Conflict from 1500 to 2000

- Kollias, C., \& Paleologou, S.M, (2013). Guns, Highways and Economic Growth in the United States. Econ. Model. 30: 449-455..

- $\quad$ Kollias, C., Naxakis, C., \& Zaranga, L., (2004). Defence Spending and Growth İn Cyprus: A Causal Analysis. Defence And Peace Economics 15: 299-207

- Pazarlıoğlu, .M. V. (2001) 1980-1990 Döneminde Türkiye’de İç Göç Üzerine Ekonometrik Model Çalışması, V.Ulusal Ekonometri Ve İstatistik Sempozyumu, 19-22 Eylül 2001, Adana

- Pazarlığlu, Gürler; Telekomünikasyon Yatırımları Ve Ekonomik Büyüme: Panel Veri Yaklaşımı; 8. Türkiye Ekonometri Ve İstatistik Kongresi 24-25 Mayıs 2007 - İnönü Üniversitesi Malatya

- $\quad$ SIPRI Military Expenditure Database C SIPRI 2014

- $\quad$ Sümer K.K., "Savunma Harcamalarının Ekonomik Büyüme Üzerine Etkisinin İncelenmesi", Harp Akademileri Komutanlığı Güvenlik Stratejileri Dergisi, Ss.80-91, 2005

- Tatoğlu, Ferda (2012) Yerdelen Panel Veri Ekonometrisi; Beta Basım A.Ş.; Istanbul; 2012

- Yildirim, J., Sezgin, S. \& Ocal, N., (2005), Military Expenditure and Economic Growth İn Middle Eastern Countries: A Dynamic Panel Data Analysis. Defence And Peace Economics 16(4): 283-295

\section{Annex}

\begin{tabular}{|c|c|}
\hline & $\begin{array}{cc}\text { (b) } & \text { (B) } \\
\text { fe } & \text { re }\end{array}$ \\
\hline milexp | & $.0221463 \quad .0224114$ \\
\hline $\begin{array}{r}\mathrm{B}= \\
\text { Test: } \mathrm{Ho}:\end{array}$ & $\begin{array}{l}\mathrm{b}=\text { consistent under Ho and Ha; obtained from xtreg } \\
\text { inconsistent under Ha, efficient under Ho; obtained from xtreg } \\
\text { difference in coefficients not systematic } \\
\qquad \begin{aligned} \text { chi2 }(1)= & (b-B)^{\prime}\left[\left(V_{-} b-V_{-} B\right) \wedge(-1)\right](b-B) \\
= & 2.11\end{aligned} \\
\begin{aligned} \text { Prob }>\text { chi2 }= & 0.1464\end{aligned}\end{array}$ \\
\hline
\end{tabular}

Annex 1: Hausman Test Result 


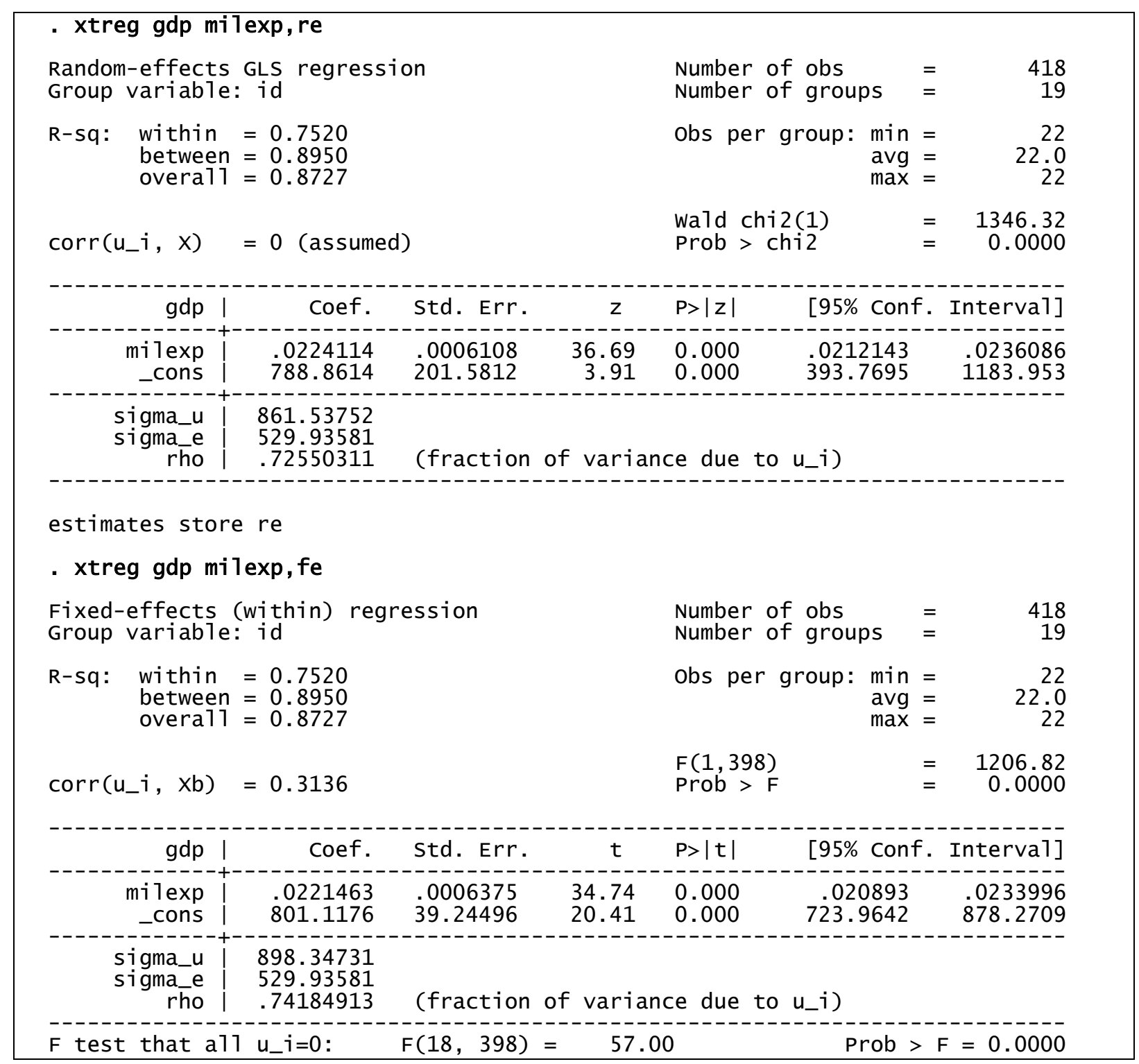

Annex 2: Pooled Model and Fixed Effects Model Results 


\title{
Bilgi Ekonomisi Yolunda Türkiye: Bilgi, İletişim Teknolojileri ve Politikalar
}

\section{Turkey on the Path of Establishing Knowledge Economy: Icts and Policies}

\author{
Ph.D. Candidate Burcu Sakız (Istanbul Aydın University, Turkey) \\ Semih Sakız (Garanti Technology, Turkey)
}

\begin{abstract}
Economical development and knowledge are highly related to each other. In today's world, knowledge-based economy is redefining enterprises, empowering individuals and re-shaping the links between education and work. It is clear that advent of the knowledge economy shapes and changes the ways in which enterprises organize their activities in the market place. The application of knowledge is one of the main sources of growth in the global economy and it becomes the strategic factor for the success. This paper presents the concept of the knowledge economy and its framework. World Bank developed a methodology called "Knowledge Assessment Methodology" to measure the progress of countries towards having a knowledge based economy and provide a basic assessment of their readiness for the knowledge economy. It has 4 pillars including 83 structural and qualitative variables and 12 knowledge indicators. Countries can get reports of their relative performance and do benchmarks to see their similarities, differences, strengths, weaknesses. This paper introduces the analysis of knowledge economy from Turkey's perspective especially for the role of Economic and institutional regime and Information and Communication Technologies (ICTs) pillars in the development of Turkey.
\end{abstract}

\section{Introduction}

History has transitions as agricultural economy, industrial economy, post-industrial and mass production economy and finally knowledge based economy. One of the crucial elements of economic growth becomes knowledge in addition to physical capital and labor force in time. It is true that achieving sustainable development is possible with knowledge creation, knowledge flows, and the capitalization of knowledge. Knowledge becomes most important factor for capital assets that are needed to create wealth. Knowledge replaced and become most valuable assets when it compares to land, physical labor, machines and factories. Thomas Thomas A. (1997) asserts that wealth is production of knowledge in today's world. According to him, "knowledge and intellectual capital which is organized knowledge that can be used to produce wealth is becoming corporate America's most valuable asset and can be its sharpest competitive weapon. The challenge is to find what you have-and use it". He demonstrated how knowledge has become the most important factor in economic life instead of natural resources, machinery, or financial capital. In the knowledge society that we are in service/knowledge technologies have come into prominence. Computers triggered a new wave during The Second World War and knowledge age has started with the improvement of first programmable computer which is called ENIAC in 1945. Use of computers and communication technologies especially in academic and business world and in personal life has increased year by year. Therefore, major changes have been observed in social and economic structure especially in developed countries. Knowledge Society has witnessed to alteration and transformation of populations. Knowledge brings speed and effectiveness for production and it plays the key role for the world's economy. In the 21st century, the knowledge-based economy has become the major trend for international societies (George, et al., 2008).

Knowledge-based economy' driving forces are common use of the Internet, technological development such as the evolution of the Information and Communication Technologies and Globalization. Knowledge-based economy requires research, innovation, specialization and learning to achieve a success and create wealth. The change towards a knowledge-based economy is happening on a global scale, a transformation is taking place in all industrialized economies and many developing economies are also aspiring to reach this target. Daniele (2010) states that: "Governments must devise new and appropriate policies. At the same time organizational changes need to be introduced, processes have to be improved and strengthened to cope with increasing competition, while this increasing competition, in turn, call for improved co-ordination between institutions. Various institutional changes must be introduced and these institutional changes that need to be made will involve the public and also private sectors. Additionally, since the difficulties for the institutions to build and establish itself over time, it is necessary a certain degree of flexibility in the institutional regime and, hence, the ability to respond to uncertainties".

\section{Literature Review}

In this section primarily a literature study about the knowledge-based economy was carried out to give information about some studies in Turkey for knowledge economy. The first study we reviewed is Umut's (2001) study about constructing a new framework that utilizes assessment of possible strategies can be applied during the 
transition to a knowledge based economy. A mixed integer programming model developed by him to determine the required levels of human resources and information and communications technology investments for given levels of R\&D investment of the country. Results indicated Turkish government should increase R\&D to considerable levels in order to trigger the transition to a knowledge-based economy.

S. Metin (2003) analysed "Knowledge economy and Turkey" in his master thesis. He studied knowledge economy concept and stated that information communication technologies dramatically effected economic system, production and relations and resulted to birth of a new economic revolution. Information technologies have become the major actor of the economic sector's structural change. Since then, instead of the terminology of developed nondeveloped or developing - underdeveloping countries, it has been started to use the societies of the agriculture, industry and information society.

Kerim (2007) studied organizations extent to be knowledge-based in UK and Turkey to do a comparative analysis. Results indicated organizations of Turkey has capability to compete with top knowledge economies in terms of awareness on strategic importance of knowledge. Unfortunately, in terms of innovation organizations in Turkey are behind organizations in UK.

Burcu (2008) studied Turkey's shift of labor towards knowledge intensive industries, knowledge occupations and ICT utilization. Results showed that although there is an increase in knowledge and services employment in Turkey, manufacturing employment also continues to increase and middle knowledge intensity sectors shows the largest employment growth. Also despite the increase in utilization of main ICTs, Turkey is still behind usage level in developed countries.

Çiğdem (2008)'s paper' which is named as “An analysis of the present situation in Turkey as a result of changing to a knowledge economy" purpose is to explain the main changes in the new economical structure, called knowledge economy, to analyze the situation in Turkey and in the world in relation to these changes according to statistically data, and to determine priority goals.

Selahattin (2008) studied the meaning of knowledge economy and the economic effects of it in Turkey. He used World Bank's KAM (Knowledge Assessment Methodology). He analyzed 83 parameters with Basic Score-card, Custom Score-card and Knowledge Economy Index for Turkey. The results indicate that Turkey had a moderate performance.

Tuncay (2008) studied the place and importance of knowledge economy in the economic growth process. an augmented Cobb-Douglas production function, which is an approach based on neo-classical theory is used in investigating the effect of knowledge on the economic growth of Turkey and thus the direction and size of the relation between investments in knowledge communication technology and economic growth in Turkey during years between 1980 to 2006 . The results showed that the investments in communication technology knowledge have a positive effect on economic growth for Turkey.

Hatice Ş. (2009) studied the importance of human capital and knowledge economy for economic development on Turkey. Changing development process of the economic development conditions were reviewed by relationship between human capital and the knowledge economy. After explaining the concept of human capital and knowledge economy, the ways that how human capital and knowledge economy contribute for the economic development given and the structure of the human capital and the proximity to the knowledge economy for Turkey tried to be determined with social and economic datas provided.

Senem (2011) studied discussions on clarifying of relationship with knowledge economy and growth and productivity paradox by linking the presence of threshold effects. "being over of a specific level of some factors that countries have, leads to differences in the relationship with knowledge economy and growth" is the hypothesis. The panel data set is analyzed consisting of 39 countries with different level of development with fixed effects method for years 1995, 2000, 2007, 2008, 2009. In growth model which is per capita income is dependent variable; Knowledge Economy Index (KEI), R\&D, capital, employment ratio are explanatory variables examined for the threshold effects for KEI and R\&D variables as well as the numerical and statistical chancing of KEI coefficient is examined for indexes containing human capital, technological knowledge and innovation capacity, information and communication technologies (ICT).

Memişoglu (2012) studied major factors of knowledge-based economies between years 2000-2010 based on World Bank Knowledge Assessment Framework, on economic performance indicators such as Gross Domestic Product (GDP), GDP per capita and economic growth rate in Brazil, Russia, India, China, South Africa and Turkey (BRICST). Secondary education and ICT infrastructure are found to be important infrastructure factors affect GDP per capita positively for BRICST countries. Country's ability to innovate, benefit from ICT and enhance economic performance can be affected by accumulation of educated people in Research and Development. Also personnel number of R\&D which is an indicator for innovation potential has positive influence on the GDP. The major things affect economic performance found as ICT infrastructure expansion together with educated R\&D personnel in the BRICST countries.

Ümit (2014) assessed the potential impact of the worldwide emerging information and communication technologies in tourism sector in Turkey. In the result of the study, it is understood that there is a parallelism 
between tourism movements and technological growth in Turkey. But, besides technological development, the attitudes of the country are important factors. These factors can be achieved with analysis of internal and external environment in economic, social, cultural, political, technological, implementation issues.

Vuslat (2014) studied reviews institutional transition in particular universities around the world by means of knowledge-based economy. The aim of her study is to comprehend the institutional transition by means of knowledge-based economy in general and transition of universities is investigated deeply among institutions as an important part for innovation and knowledge in 4 Turkish Universities as Istanbul Technical University, Boğaziçi University, Sabancı University, and Istanbul Bilgi University. Also some universities from the world are examined about their management, productivity, and academic change.

Hayal (2014) studied how technological improvements that altered economic and social parameters of 21 th century are getting reflected in the literature and how these economic and social dynamics are interacted with the notion of e-government. She first discussed the terms "economy of knowledge" and "e-government," and then investigated the advancement of e-government system at both domestic (Turkey) and global level with the help of statistical data. In essence, e-government means to provide public services in an electronic medium. Evolvement of e-government has been affecting public life positively in many respects.

\section{Knowledge-based Economy}

The economic structures called as agricultural society, industrial society and knowledge society define the three important conversions of the economic structure until 21 st century. Rapid developments on information technologies and knowledge led to redefine the concept of "knowledge" and resulted in the introduction of a new concept "knowledge economy". Knowledge is increasingly considered to be a commodity. By this recognition a new focus raised about role of technology, learning in economic performance and information. The current conditions of the information society have been created the knowledge economy. The knowledge economy can be defined as "In the use of knowledge to generate tangible and intangible values. Technology helps to transform a part of human knowledge to machines and tools. This knowledge could be used by decision support systems and generate economic values in various fields". Besides, emerging technologies and changes in the production structure have changed the demand structure significantly (Sadık, 2000). As Charles Leadbeater (2000) states, more of the value of manufactured products will come from the software and intelligence that they embody, and more of what we consume will be in the form of services in the new economy. The knowledge across all sectors, content of products and processes is ascending. Everything is getting smarter from computers and photocopiers to cars and corn." (p. 43).

It is emerged as a result of intensive knowledge in economic activities, globalization of economic activities and improvements in information and communication Technologies (ICTs). OECD (Organisation for Economic Cooperation and Development) defines knowledge economy as: "Economy in which knowledge is being used in distribution and production." (OECD, 1996). According to OECD Knowledge-Based Economy Report (1996), the new driver of productivity and economic growth was defined as knowledge. The new global economy is very distinctive in terms of its strategies of flexible production organized around principles of knowledge based economy that knowledge is accepted as the main drive of the economic growth.

Susan (2005) sets the essence of the knowledge economy as:

- the balance between knowledge and resources (labor and capital) has shifted toward knowledge;

- $\quad$ securing long term economic growth will be much more dependent on knowledge

- $\quad$ education will play a critical role in economic growth;

- in order to play this critical role, education systems will need to respond in new ways to the demands of knowledge economy.

Knowledge economy features have been determined by Don Don (1998) as follows:

- Knowledge is the basic production factor,

- Knowledge economy is a digital economy,

- Virtualization plays an important role in the knowledge economy.

- Developments in information and communication technologies affect all economic units.

- The economic structure becomes very dynamic, complex and difficult to predict.

We can say that use of intensive knowledge in economic activities, improvements in Information and Communication Technologies, and globalization of economic activities emerged the knowledge economy. Technology has an effect on the nature of production organization. The narration of globalization through knowledge-based economy and information communication technologies have taken place to take attention to the vital role of education in providing human capital that is equipped with the capacity and capability to produce knowledge both as an economic advantage and as a way to cultural development. 
Economic incentives and institutional regime, policies and information and communications technologies (ICTs) are pillars of the knowledge-based economy. Access to networking is essential in acquiring and disseminating knowledge and the Internet is one of the key drivers of ICT, resulting in new approaches to doing things. We are witness to arising of new important definitions and drivers for economic performance. Such as information society with increasing communication and computer networks, learning economy with the need of workers to acquire a range of skills and to steady adapt these skills, and national innovation systems with the raising importance of knowledge and technology diffusion requires better understanding of knowledge networks are defined in knowledge-based economy (OECD, 1996). There has been a knowledge explosion because of new inventions especially in the last five decades by growth in technological researches and in the usage of the technical tools and equipments.

Knowledge-based economy also leads collaboration opportunities for information and communication technologies to conceive high qualified products with low costs (European Commission, 2001). Economic model in which knowledge comes into prominence, drives existing business processes and way of doing works to be more qualified (Oytun, 2013). As a matter of fact, any kind of production is knowledge-based. Economy's main elements which are production, consumption, distribution and their relationships also new market structure have been restructured based on knowledge. Consumers began taking goods and services faster, without being limited by time and location. Researchers can analyze consumer behaviors better and more accurate with more datum in digital environments. Barriers to market entry and exit reduce and information becomes a function of competition (Oğuz, 2005). Since barriers have been removed, producing innovative gods and services have become a must. The economic effects of physical distances, geographical differences and the cost of access to information have been decreased result of using ICTs. Moreover, new startups costs are declining and the advantage to compete in new markets is increasing. Despite financial capital has accepted as a formerly scarce resource, in today's world qualified human resources become scarce resources (Kamil, 2007).

Since knowledge has no fixed capacity, shows more rapid change in that sense and tends to be obsolete in a short period of time, it is difficult to calculate knowledge's market value. Additionally, knowledge is difficult component to quantify. The first attempt for the assessment of knowledge and development of a framework to interpretation of data related to science, information, technology, communication and innovation has been made by OECD. The OECD (1996c) report notes that OECD countries continue to evidence a shift from industrial to post-industrial knowledge-based economies. Here productivity and growth are largely determined by the rate of technical progress and the accumulation of knowledge. Of key importance are networks or systems which can efficiently distribute knowledge and information. Learning on the part of individuals and firms is crucial for realizing the productivity potential of new technologies and longer-term economic growth\| (p. 18).

Many other institutions like World Bank, Eurostat Eurostat, UNESCO, International Telecommunication Union and United Nations have introduced a range of indicators in order to analyze country's potential for knowledge and knowledge based economy. They have been built several indexes. Well-known institutions which develop these indexes are The World Bank, Harvard University International Development Center, McConnell International, The Economist Intelligent Unit, UNCTAD, The United Nations Development Program, World Economic Forum and The Mosaic Group (Leila, et.al, 2007).

\section{Pillars of Knowledge Economy}

Main pillars of knowledge economy are Economic incentives and institutional regime, Information and communication Technologies, innovation and Education according to the World Bank (World Bank, 2010). They developed KAM (Knowledge Assessment Methodology) which is a method aims to show opportunities countries and provide identifying problems may them face towards transition to knowledge economy in 1999. In order to facilitate countries in the phase of transition to the knowledge-based economy, the Knowledge Assessment Methodology (KAM) was developed. KAM is designed to supply basic assessment of countries' readiness for the knowledge economy, and identifies sectors or specific areas where policymakers may need to focus more attention or future investments. The KAM is currently being widely used both internally and externally to the World Bank. Additionally, it frequently facilitates engagements and policy discussions with government officials from client countries.

KAM is an online interactive tool that produces the Knowledge Economy Index (KEI)-an aggregate index representing a country's or region's overall preparedness to compete in the Knowledge Economy (KE). That methodology has 69 structural \& qualitative variables on 4 pillars and normalized from 0 (worst) to 10 (best) for 100 countries. The unique strength of the KAM lies in its cross-sectoral approach that allows a holistic view of the wide spectrum of factors relevant to the knowledge economy.

These factors defined by World Bank are briefly summed up as follows:

- Information and Communication Technologies: Here, some of the important indicators are the number of phone subscriptions, the number of computers and use of the internet. 
- Appropriate business environment that the knowledge economy can be developed in: Here, some of the important indicators are scheduled and unscheduled barriers, quality and applicability of the regulations, local loans given to the private sector, the number of days to start a business, the intensity of local competition, and political stability

- $\quad$ R\&D and Innovation: National Innovation System which contains innovation policies aiming development and commercialization of local and global innovations, R\&D system, institutions and support mechanisms. Here, some of the important indicators are the number of patents, royalty payments and scientific publications.

- Education: Knowledge economy information specialists as the most important element of knowledge economy, an innovative and dynamic educational system that contains public and private education institutions in training technology literate workforce and qualified human resources. Here, some of the important indicators are the adult literacy rate, participation in secondary education and participation in higher education.

Four pillars of knowledge economy are briefly summed up in the following table.

\begin{tabular}{|l|l|}
\hline Indicators & Pillars \\
\hline $\begin{array}{l}\text { Regulatory quality } \\
\text { Rule of law } \\
\text { Tariff and non-tariff barriers }\end{array}$ & Economic and Institutional Regime \\
\hline $\begin{array}{l}\text { Internet users per 1.000 people } \\
\text { Telephones per 1,000 people } \\
\text { Computers per 1,000 people }\end{array}$ & $\begin{array}{l}\text { Information and Communication Technologies } \\
\text { (ICTs) }\end{array}$ \\
\hline $\begin{array}{l}\text { Rate of: } \\
\text { Gross tertiary enrollment } \\
\text { Adult literacy } \\
\text { Gross secondary enrollment }\end{array}$ & Education and Skills \\
\hline $\begin{array}{l}\text { Patents granted to nationals by the U.S. Patent } \\
\text { and trademark office per million people } \\
\text { Royalty payments and receipts, US\$ per person } \\
\text { Technical journal articles per million people }\end{array}$ & \\
\hline
\end{tabular}

\section{Table 1. Pillars of Knowledge Economy. Source: WorldBank}

Knowledge economy concept is measured by using the basic score card, the knowledge economy index and specific score card models of knowledge assessment methodology. KEI stands for knowledge Economy Index which is used to produce economic performance and to possibility of making comparisons through knowledge based indicators. Basic score card determines the performance by using four basic factors of knowledge economy. Knowledge Economy Index indicates a country's or a region's overall level of development in terms of knowledge economy. Specific score cards are used when making more flexible comparisons are needed.

Another performance analysis related to use of information and communication technologies in a country which was developed by World Economic Forum is "Networked Readiness Index" (NRI). Index aims to measure preparedness level of countries for using information and communication technologies. It is one of the studies which measures to what extent these countries internalize these technologies (World Economic Forum, 2014). Measurement method has been evolved since it was configured; studies have been carried out to make it more inclusive. This index has 4 factors such as Environmental Conditions, Preparedness, Use and Impact and its subcomponents are as follows:

- Environmental Conditions: Appropriateness of the policy environment and regulatory environment; Terms of business and innovation.

- Preparedness: Infrastructure and digital content; Accessibility and compliance with purchasing power; Skills and abilities.

- Use: Individual usage, Use of businesses; Use of public administration.

- Impact: Impact on economy; Impact on society.

Since 2001, when the index was first published, Turkey is among countries which have taken in scope of analysis. NRI table and Turkey data given in below table. 


\begin{tabular}{|l|l|l|l|l|l|l|l|}
\hline Years $\rightarrow$ & $\begin{array}{l}2006- \\
2007\end{array}$ & $\begin{array}{l}2007- \\
2008\end{array}$ & $\begin{array}{l}2008- \\
2009\end{array}$ & $\begin{array}{l}2009- \\
2010\end{array}$ & $\begin{array}{l}2011- \\
2012\end{array}$ & $\begin{array}{l}2012- \\
2013\end{array}$ & $\begin{array}{l}2013- \\
2014\end{array}$ \\
\hline Number of Countries & 122 & 127 & 134 & 133 & 142 & 144 & 148 \\
\hline Turkey's place on the rank & 52 & 55 & 61 & 69 & 52 & 45 & 51 \\
\hline Percentage & 0,43 & 0,43 & 0,46 & 0,52 & 0,37 & 0,31 & 0,34 \\
\hline NRI & 3,86 & 3,96 & 3,91 & 3,68 & 4,07 & 4,22 & 4,30 \\
\hline
\end{tabular}

Table 2. Turkey's Place on the Rank through Years. Source: WEF, 2014

\section{On The Path of Establishing Knowledge Economy and Turkey}

Turkey would be count as to be a young industrial country by the courtesy of policies such as protectionism and incentives. Turkey owes partial change to the law of diminishing returns. Law of diminishing returns, gives developing countries a chance to learn producing goods with high added value. However, law of increasing returns is valid in knowledge society. Thus, specialization in the production of goods with high added value and making production more efficient through knowledge are required (Sadık, 2000).

Turkey's government aware that role of information and communication technologies will be more important in the future. According to the Turkey Prime Ministry Investment Support and Promotion Agency, development and search for solutions that appropriate for age's requirements which growth brought along and today's economic and social life's access to the most current and fast solutions as soon as possible underlie the information and communication technologies. In this respect, Turkey has increased the interest ICT since past decades. The most obvious ones in this study are new incentives for investors and Research and Development Laws. Forecasts are as follows:

- Expenditures for information and communication technologies are expected to grow faster than average of the world. When potential and large domestic market is taken into account, sector is expected to grow with a 7\% compound rate of growth during 2012-2017.

- As the young population and the online market grow, the number of mobile phone subscribers is expected to reach 75 million by 2017 .

- Computers with internet access are available in more than half of the households in Turkey; this rate is expected to rise by $65.6 \%$ in next five years.

- Expenditures for hardware, software, information and communication services and telecommunication services are expected to rise to $\$ 25$ billion by 2016 .

- $\quad$ Rate of Internet users in Turkey is about $42 \%$; this rate is expected to rise over $47 \%$ in 2017.

According to the "Information and Communication Technologies toward 2023 Goals" report of International Investors Association, it is expected that impact of 1 unit of growth in information and communication sector will be 1.8 units of growth in whole economy. In 2011, ICT sector size at the global level has reached \$4.1 trillion. And the size of the sector in Turkey is estimated to be $\$ 30,3$ billion. Turkey's country's share in global information and communication sector remaining at $0.75 \%$ indicates the sector's growth potential. When the sub-sectors of the market in Turkey are analyzed, it is seen that the growth potential of ICT industry whose share is $0.4 \%$ in global market, is much higher. In case of reaching targeted 8\% share of ICTs in \$2 billion GDP, merely to be provided contribution through total factor productivity growth is estimated to be over $\$ 71$ billion (YASED International Investors Association, 2014).

In accordance with Turkey's vision for year 2023, ICT sector is expected on higher goals. These goals include as follows:

- Become one of ten biggest countries in e-transformation.

- Have $80 \%$ of population gained ability of computer using.

- Increase the number of broadband subscribers to 30 million.

- Provide 14 million households Internet connection at $1000 \mathrm{Mbps}$.

- Increase the share of sector in GDP from $2.9 \%$ to $8 \%$.

- Increase the number of companies which operates in Technology Development Zones to 5500; increasing the number of employers to 65000; increasing the export to $\$ 10$ million.

- Make size of Information and communication technologies sector reach $\$ 160$ billion with a market growth by about $15 \%$ every year.

- Increase the share of Research and development expenditures in GDP from $0.85 \%$ to $3 \%$ (Turkey Prime Ministry Investment Support and Promotion Agency, 2014). 


\subsection{Turkey and World Knowledge Economy Comparisons}

The underlying reasons behind differences in countries' long-term growth performances are grouped under four main headings such as investment (fixed capital, and information and communication technology sector), nonformal education, innovation and structural change. According to our study, relationship between the Knowledge Economy Index (KEI) and GDP founded as positive. According to our regression test depicted below, the correlation between KEI and economical performance is about $85 \%$.

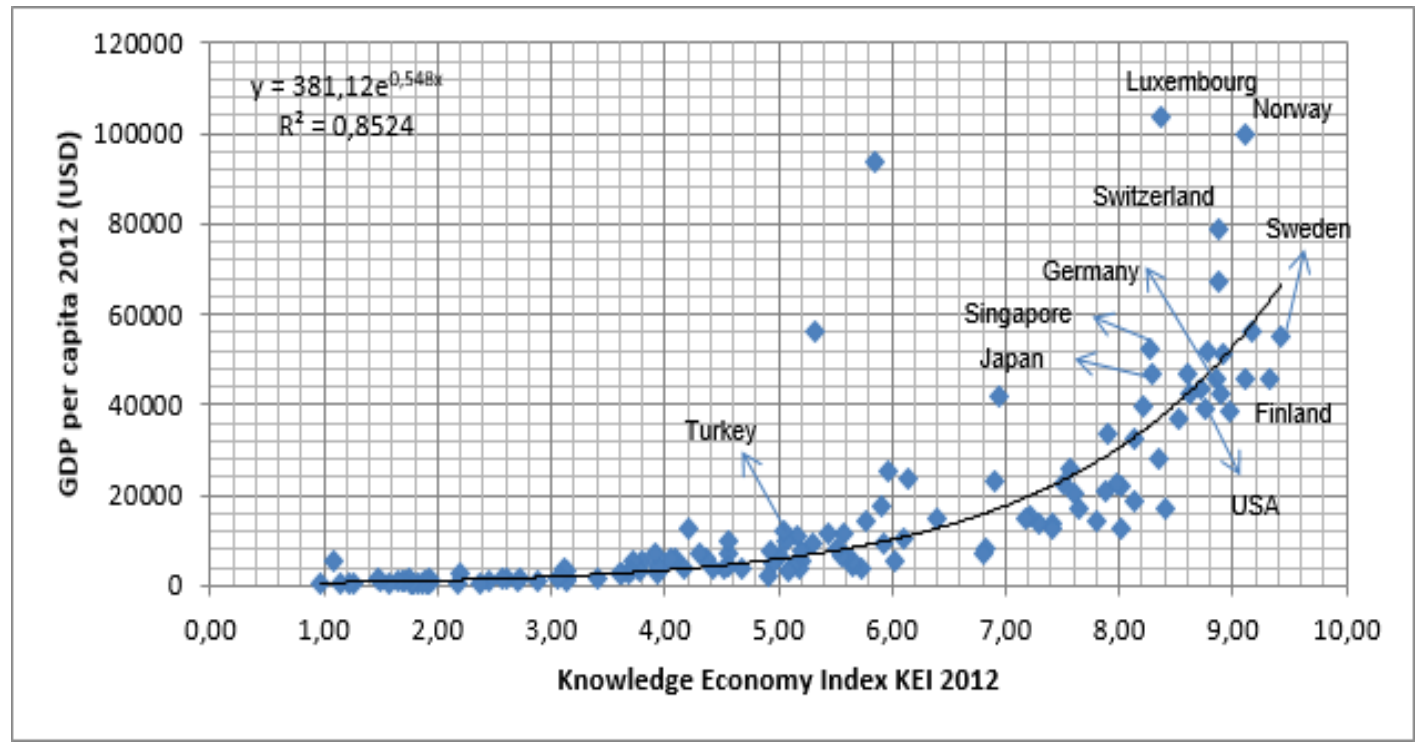

Figure 1: GDP per Capita \& KEI Relation. Source: World Bank, 2014.

Knowledge Economy Index of Turkey pillars graphic and KEI table are given below.

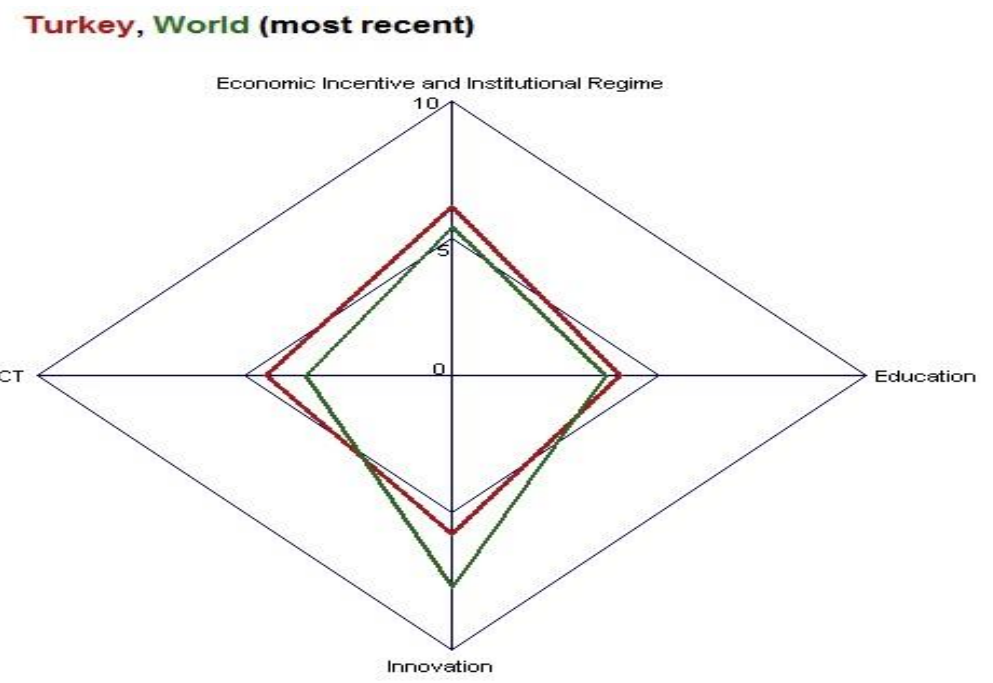

Figure 2. Turkey and World KEI Source: World Bank.

According to "Informatics for Breakthrough, Turkey for Economics Information and Communication Technology Sector-Breakthrough Strategy 2023" report, while Turkey's competitiveness in the information and communication sector (ICS) is poor, some other developing countries' competitiveness is high. While South Korea, Singapore and Brazil don't show any alteration, in China and India there has been a significant increase in competitiveness in the last three years. ICS's productivity in Turkey is four times of total private sector productivity. Despite this importance, it is seen that contribution that ICSs should make in increasing productivity in Turkey hasn't occurred. A conclusion shouldn't be drawn like there is no effect of ICS in increase in productivity. The underlying reason of this is ICS' small share in whole economy and this small is decreased rather than increase in the examined period. Taking into account all variables of Turkey's KI and KEI ranks, results are: fixed capital investment and information and communication sector investments are not enough; Research \& Development expenditures fall behind the fast developing countries, but increase in production efficiency by innovating could be achieved; develop the educational level of human capital not achieved, tendency to high-tech products in the 
structure of production remained limited. In below table knowledge related indexes are given for World and Turkey.

\begin{tabular}{|l|c|c|}
\hline Index & World & Turkey \\
\hline Knowledge Economy Index & 5,12 & 5,16 \\
\hline Knowledge Index & 5,01 & 4,81 \\
\hline Economic Incentives and Institutional Regime & 5,45 & 6,19 \\
\hline ICT & 3,58 & 4,5 \\
\hline Innovation & 7,72 & 5,83 \\
\hline Education & 3,72 & 4,11 \\
\hline
\end{tabular}

Table 3. Turkey and World Knowledge Related Indexes Source: World Bank, 2014.

\subsection{ICTs and EIR Pillars}

Knowledge has always been important for development. The application of knowledge is one of the key sources of growth in the global economy. Unfortunately, a lot of developing countries fail to tap the vast stock of global knowledge and apply it to their needs. Countries must articulate their goals and develop policies and investments to achieve them. In the 21 st century, we are in the midst of "knowledge revolution" that increased importance of education, innovations and also updated skills for sustainable economic performance and improvement.

The knowledge economy is transforming the demands of the labor market in economies throughout the world. In industrial countries, where knowledge based industries are expanding rapidly, labor market demands are changing accordingly (World Bank, 2003: 1).

ICT includes a dynamic information infrastructure-ranging from radio to the internet-is required to facilitate the effective communication, dissemination and processing of information. A dynamic information infrastructure is needed to facilitate the effective communication, dissemination, and processing of information. Information infrastructure that facilitates the communication, dissemination, and processing of information and technology. The increased flow of information and knowledge worldwide reduces transactions costs, leading to greater communication, productivity and output.

We can define Economic Incentive \& Institutional Regime (EIR) pillar as a regulatory and economic environment that enables the free flow of knowledge, supports investment in Information and Communications Technology (ICT), and encourages entrepreneurship is central to the knowledge economy. The country's economic and institutional regime must provide incentives for the efficient use of existing and new knowledge and the flourishing of entrepreneurship. Economic and institutional regime is conducive to the creation, diffusion, and utilization of knowledge that provides incentives that encourage the use and allocation of existing and new knowledge efficiently will help to foster policy change. The economic environment must have good policies and be favorable to market transactions, i.e. being open to free trade and foreign direct investment. Governments should protect property rights to encourage entrepreneurship and knowledge investments.

Today's global competitive environment, becoming successful and increasing the productivity will be possible not only by structure-process and technological changes but also by using knowledge and utilizing of ICTs (Information and Communication Technologies) especially teaching and developing of high quality human sources and by preparing them for the new concepts. ICTs lower the costs of various aspects of knowledge activities. How intense countries use their knowledge and ICTs and contributions do these technologies becomes very important. In this context, Turkey has been reconstructing certain processes and policies to keep pace with alterations and to be competitive benefiting from advantages of the process (Eda, 2011).

When it comes to Turkey, by implementing good economic policies, adopting a high-growth development programme, and increasing social capital and improving the labour force through enhanced education, Turkey has been on the path of transforming itself into a knowledge economy. Contrary to expectations, information and communication technology was growing at a fast rate. Improvements to the information infrastructure still persist. Like globalization, knowledge is both a new problem and panacea for our times. If we don't have enough of it, we are destined to become 3rd world countries.

\section{Conclusion}

Knowledge economy discourse borrows heavily from work developed by a group of 1960s intellectuals, futurologists and information economists, like Peter Drucker (1969), Fritz Machlup (1962) and Daniel Bell (1973) that industrial societies were in transition to becoming variously knowledge economies, post-capitalist and postindustrial societies. It is an economy in which knowledge is created, acquired, transmitted and used more efficiently and effectively by governments, enterprises, organizations, individuals and communities and it promotes economic and social development. In 1999 the World Bank Institute launched a project entitled "Knowledge for Development" (K4D). Its aims were to raise awareness among national policymakers about the 
powerful growth effects of knowledge and to encourage economists to combine global and local knowledge in order to accentuate comparative advantages (World Bank, 2008). According to the Knowledge Economy Index factors, Turkey should increase investments in information and communication Technologies, also increase R\&D expenditures, increase level of productivity in production by innovations, upgrade the level of education to have required necessary qualified human resources and should be directed to high-tech products in the production structure. Turkey should give special attention to innovation, education, cultural and intellectual production which is necessary for developing knowledge society and to be able to gain competitive advantage

\section{References}

- S Sadık, 2000. "Bilgi Çağı ekonomisine Teorik Bir Yaklaşım", Dokuz Eylül Üniversitesi İ.İ.B.F Dergisi, 15, s 87-101.

- $\quad$ Leila, vd, 2007. "Adoption A Proper Tool for E-Readiness Assessment In Developıng Countrıes; Case Studies: Iran, Turkey And Malaysia", Journal of Knowledge Economy \& Knowledge Management Volume II Spring, s.54.

- Vuslat, 2014. "The transition of institutions by means of knowledge based Economy: case of Turkish universities”, ITU, Department of Urban and Regional Planning Regional Planning Programme, M.Sc. Thesis, Istanbul

- Eda, 2011. "Enformasyon Toplumu ve Bilgi Çağında Türkiye'nin Gelişim Süreci", Marmara Üniversitesi, Sosyal Bilimler Enstitüsü, İktisat Politikası Bilim Dalı, Master Thesis, İstanbul.

- Paul \& Dominique, 2002. "Economic Fundamentals of the Knowledge Society”, Stanford University SIEPR Discussion Paper No.01-14.

- Burcu, 2008. "Knowledge sector dimension of Turkish economy”, Marmara University Social Sciences Institute, Economics, Master's thesis, İstanbul.

- Umut, 2001. Assessment of possible effective strategies in the transition process to a knowledge-based economy: The case of Turkey, Middle East Technical University Industrial Engineering Department, Master's Thesis, Ankara.

- $\quad$ George \& Yi-Hsing \& Zheng-Yi, 2008. "Competition policy for technological innovation in an era of knowledge-based economy.” Knowledge-Based Systems, Vol. 21, pp. 826-832.

- Oğuz, 2005. "Bilgi Ekonomisi'nin Olası Mikro Ekonomik Etkilerinin Teorik Analizi”, http://oguzkara.com/Bilgi\%20Ekonomisi'nin\%20Olasi\%20Mikro\%20Ekonomik\%20Etkilerinin\%20Teorik $\% 20$ Analizi.pdf.

- Çiğgem, 2008. "An analysis of the present situation in Turkey as a result of changing to a knowledge economy”, Dicle Üniversitesi / Sosyal Bilimler Enstitüsü / Ekonomi Bölümü / Maliye ve Ekonomi Anabilim Dalı / Ekonomi-Maliye Bilim Dalı, Yüksek Lisans Tezi, Dicle

- Selahattin, 2008. "Knowledge economy and an application to Turkey in the process of the transition to the knowledge society”, Atatürk Üniversitesi / Sosyal Bilimler Enstitüsü / İktisat Anabilim Dalı, Ekonomi, Doktora Tezi, Erzurum

- S. Metin, 2003. "Knowledge economy and Turkey ", Gaziantep Üniversitesi Sosyal Bilimler Enstitüsü / İktisat Anabilim Dalı, Ekonomi, Yüksek Lisans Tezi, Gaziantep

- Charles. 2000. The weightless society: Living in the new economy bubble. NewYork: Texere.

- Oytun, 2013. "Türkiye İçin 2010-2012 Dönemi Karşılaştırmalı Bilgi Ekonomisi Analizi", Eskişehir Osmangazi Üniversitesi İktisadi ve İdari Bilimler Fakültesi Dergisi, 2013, 8(2), s. 115-139.

- Özge, 2012. "Knowledge-based economy and economic growth: Empirical analysis of BRICST Countries", Boğaziçi University Social Sciences International Trade Depaortment, Economics, Master's Thesis, İstanbul

- OECD, 1996. OECD, The Knowledge Based Economy, No. General Distribution OECD/GD(96)102, Paris.

- Senem, 2011. "Analyzing of threshold effect in relationship with knowledge economy and growth", Hacettepe Üniversitesi, Sosyal Bilimler Enstitüsü / İktisat Anabilim Dalı, Ekonomi, Yüksek Lisans Tezi

- Kerim, 2007. "The case of organizations in Turkey from the perspective of knowledge economy", Afyon Kocatepe Üniversitesi, International Trade Department, Business Administration, Phd Thesis, Afyon

- Hayal, 2014. "The concept of knowledge economy and e-government applications in Turkey", Kirıkkale Üniversitesi, Sosyal Bilimler Enstitüsü / İktisat Anabilim Dalı, Economi, Yüksek Lisans Tezi

- Hatice Ş., 2009. "The importance of human capital and knowledge economy for economic develeopment: An analysis on Turkey", İstanbul Üniversitesi, Sosyal Bilimler Enstitüsü, İktisat Anabilim Dalı, Ekonomi, Yüksek Lisans Tezi 
- Susan, 2005. Re-imagining and rescripting the future of education: global knowledge economy discourses and the challenge to education systems, Comparative Education, 41 (2), 151-170.

- Tuncay, 2008. "Knowledge economy and economic growth: An econometric analysis on Turkey (19802006)”, Atatürk Üniversitesi / Sosyal Bilimler Enstitüsü / İktisat Anabilim Dalı, Ekonomi, Erzurum

- Daniele, 2010. "Knowledge-based economies and the institutional environment". Munich Personal RePEc Archive, Paper No. 37138.

- Thomas A., 1997. Intellectual Capital: The new wealth of organization, Crown Business; 1st edition, San Francisco, CA

- $\quad$ Ümit, 2014. "Technological development in the knowledge economy effects on the tourism sector in Turkey”, İstanbul Üniversitesi, Sosyal Bilimler Enstitüsü, İktisat Anabilim Dalı, Ekonomi, Yüksek Lisans Tezi

- Don, 1998. Dijital Ekonomi, Hora Matbaası, İstanbul.

- Kamil, 2007. “Teorik Çerçevesi ve Uygulama Örnekleriyle Dünyada ve Türkiye'deYazılım Endüstrisi”, Devlet Planlama Teşkilatı Müsteşarlığı, Planlama Uzmanlığı Tezi (yayımlanmamış eser), Ankara.

- T.C Başbakanlık Türkiye Yatırım Destek ve Tanıtım Ajansı, 2014, http://www.invest.gov.tr/trtr/sectors/Pages/ICT.aspx .

- World Bank, 2003. Lifelong Learning for a Global Knowledge Economy, Washington, DC

- World Bank, 2004. "Turkey Knowledge Economy Assessment Study", http://wwwwds.worldbank.org/external/default/WDSContentServer/WDSP/IB/2007/04/06/000310607_2007040611350 1/Rendered/PDF/393650TR0Knowledge0economy01PUBLIC1.pdf .

- World Bank, 2010. Knowledge Assessment Methodology, http://www.worldbank.org/kam .

- World Bank, 2015. http://data.worldbank.org/indicator/SE.SEC.NENR/countries

- YASED International Investors Association,2014, http://www.yased.org.tr/webportal/Turkish/Yayinlar/Pages/YASED2023HedefleriYolundaBIT.aspx 


\title{
International Trade and Macro-Economic Policy in Eurasian Economies
}

\author{
Asst. Prof. Dr. Naime İrem Koşan (Beykent University, Turkey) \\ Prof. Dr. Sudi Apak (Esenyurt University, Turkey) \\ Prof. Dr. Selahattin Sarı (Beykent University, Turkey)
}

\begin{abstract}
International trade is defined the exchange of goods, services, and capital among various countries and regions. Also the potential of imports and exports account for an important part of growth. On the other hand, total value of international trade in goods and services shows the countries' integration into the world economy. In this paper we focused on to analyze the effects on imports and make inferences for Eurasian Countries.

In this paper we aim to examine the relationship between imports and macro-economic indicators in 6 Eurasian economies. To analyze the relationship, we used panel data regression analysis. Data obtained from World Bank. The panel data covers 1996-2012 periods and 6 countries which named Kazakhstan, Russian Federation, Uzbekistan, Kyrgyz Republic, Azerbaijan and Turkmenistan. We predicted pooled, fixed effects and random effects panel data models using the Stata and analyzed them. The dependent variable is defined the imports in our model. It has been found that gross domestic savings, foreign direct investments and, and exports are statistically significant for this countries.

The results found in this paper show that gross domestic savings has negative effects on imports. On the other hand, for this 6 countries foreign direct investments (inflow) and exports have positive effects on imports as we expected. It shows us the economic positions of Eurasian countries still depend on Russian Federation. Also, these findings have important policy implications for Eurasian Countries. Our interpretation of these findings is that, integration to world economy has generally positive effects on foreign direct investments for this countries.
\end{abstract}

\section{Introduction}

The analysis of foreign trade and macroeconomic policy has been a popular area of interest for a very long time.

The aim of the study is to propose policy making suggestions to the countries by examining macroeconomic variables that affect the imports. In this paper in order to examine the relationship between imports and macroeconomic indicators, panel data analysis has been used. The data covers 1996-2012 periods and 6 Eurasian economies. Data obtained from World Bank.

\section{Literature Review}

When we examine the studies related to the Eurasian economies, we observe that the studies are mostly related with gas trade, political processes in the region and assessment of such policies.

Hartwell (2013) had analyzed the customs union agreement signed between Belarus, Kazakhstan in 2012 and observed the opportunities for the region in his study. He examined and assessed the trade liberties of the countries in the Commonwealth of Independent States of Eurasian integration and as in conclusion, he stated that the trade between such states will be strengthened and this can be done with supportive policies and this is a great opportunity for these countries.

Mustafa (2013) has examined the Eurasianism concept in his study and analyzed the role of Kazakhstan within this concept. He further states that there are opportunities and challenges for the Eurasian union and political developments, organizational structures, and democratic processes are effective in such countries and nationalist movements in Russia, in particular, may be challenging.

Libman and Vinokurov (2012) analyzed the regional integration and economic convergence of the Soviet Union countries between 1999 and 2008 after the Soviet period. The countries such as Azerbaijan, Armenia, Kazakhstan, Kyrgyzstan, Tajikistan, Belarus, Georgia, Moldova, and Russia have had cluster analysis for trade integration, labor migration, and macroeconomic convergence variable. As a result of the study, they observed that integration highly depends on the geographical convergence and economic relations convergence depends on the domestic economy politics and economic growths of the country. However, it has been concluded that economic integration and relations of countries with each other are not affected by each other.

Kid (2007), has made a comparative analysis by examining the social variables such as macroeconomic and education for Central Asia. In its conclusion, it has been stated that there are opportunities in Asia and Maglev speed train network is significant for connection (via transportation) between the Central Asia and Eurasia countries to restructure the region. 
Norling and Swanstrom (2007) states that it is required to restructure the infrastructure decrease the inefficiency arising out of the customs and improve the cooperation in the region to assess the potential in the Eurasia continent. However, they state that the energy is an integral factor and brings together the region. They also stated that donor countries and international organizations can remove the trade barriers on energy and as a result the national income of Afghanistan and Central Asia could increase.

\section{Data Source}

Data set comprises 1996-2012 period of 6 Eurasian economies. Data of Azerbaijan, Russian Federation, Uzbekistan, Kazakhstan, Kyrgyz Republic and Turkmenistan are obtained from Worldbank. Imports is selected as dependent variable and Gross Domestic Savings, Foreign Direct Investments of countries and exports are selected as independent variables in the study. The import used as a dependent variable shows the share of all commodities and services that imported by the country within the GDP.

The export variable shows the share of all commodities and services exported by the country within the GDP.

Gross Domestic Savings is obtained by subtracting the final consumption expenditures from the Gross Domestic Product. Domestic savings is one of the most important variables when economy is analyzed in its entirety. According to the tendency to saving in a country, the rate of external savings to be made, the field where the investment will be made and the way of position to be taken in that country will be determined. In our study, the numbers of gross domestic savings are taken as the percentage in the gross domestic product.

Foreign direct Investments is the variable involving the equity and investments with long and short-term capital inflow in the balance of payment reported from the activities of the foreign investors. This variable is included in the model by proportioning to GDP such as other variables.

\section{Empirical Results}

Pooled regression model, fixed effects panel regression model and random effects panel regression model are used in the model prediction. The results for every three models are presented in the following table

\begin{tabular}{|l|c|c|c|}
\hline & Pooled OLS & Fixed Effects & Random Effects \\
\hline $\mathrm{c}$ & $\mathbf{2 8 . 7 9 1} * * *$ & $\mathbf{3 6 . 1 7 8} * * *$ & $\mathbf{3 2 . 2 2 1} * * *$ \\
& $(12.94)$ & $(12.92)$ & $(12.12)$ \\
\hline \multirow{2}{*}{ Exports } & $\mathbf{1 . 0 8 6} * * *$ & $\mathbf{0 . 8 5 4} * * *$ & $\mathbf{0 . 9 8 3 * * *}$ \\
& $(19.23)$ & $(10.72)$ & $(14.60)$ \\
\hline Gross Domestic & $\mathbf{- 0 . 9 3 8 * * *}$ & $\mathbf{- 0 . 9 1 7 * * *}$ & $\mathbf{- 0 . 9 4 0 * * *}$ \\
Savings & $(-21.61)$ & $(-16.50)$ & $(-18.97)$ \\
\hline Foreign Direct & $\mathbf{0 . 6 2 5} * * *$ & $\mathbf{0 . 8 8 3} * * *$ & $\mathbf{0 . 7 7 8 * * *}$ \\
Investments & $(6.82)$ & $(8.92)$ & $(8.08)$ \\
\hline F stat & $204.57 * * *$ & $115.58 * * *$ & $444.83 * * *$ \\
\hline
\end{tabular}

Table 1: Effect Of Exports, Gross Domestic Savings and Foreign Direct Investments on Imports Note: Terms on brackets denote $t$-stat based on robust standard errors. *, **, *** indicate significances at the \%10, \%5 and \%1 levels. The coefficients in bold are the ones that are statistically significant.

With respect to the pooled panel regression model, index of exports, gross domestic savings and foreign direct investments is observed to be statistically significant according to the 5\% significance level. According to these results, while one unit of increase in the index of exports increases the imports 1.086 unit, one unit of increase in foreign direct investments leads to a 0.625 unit increase in the imports. One unit of increase in the percentage of gross domestic savings in gross domestic product, however, leads to a -0.938 unit of decrease in imports. Signs of the coefficients are suitable to our financial expectations. When fixed effects panel regression model is predicted, however, coefficients of every three variables are observed to be suitable to our financial expectations as in pooled model and to be significant in 5\% significance level. One unit of increase in the index of exports increases imports about 0.854 unit while one unit of increase in the percentage of domestic savings in gross domestic product decreases the imports 0.917 unit. One unit of increase of the foreign direct investments, on the other hand, increases the imports 0.883 unit.

Finally, random effects panel regression model is predicted. In this model all the coefficients are economically significant. While one unit of increase in the foreign direct investments the imports 0.778 unit, one unit of increase in the exports increases the imports 0.983 unit. One unit of increase in the percentage of gross domestic savings in gross domestic product, however, leads to a 0.940 unit of decrease in imports.

After the coefficients for the three models are interpreted, model comparison is performed. $\mathrm{F}$ test can be applied for the comparison of pooled model and one way fixed effects model. The hypothesis where all the unit effects are equal to zero is tested in F test. To carry out this test, fixed effects model is predicted and F statistics calculated here is compared with the table value. F statistics value obtained here is tested by being compared with $\mathrm{F}$ 
distribution table with $6-1=5$ and $(\mathrm{N}(\mathrm{T}-1)-\mathrm{K})=93$ degree of freedom. According to the obtained $\mathrm{F}(5,93)=10.26$ and Prob $>F=0.0000$ result, the hypothesis that the unit effects are equal to 0 is rejected and thus, it is understood that unit effects are present. Pooled model is not suitable. Hausman test is conducted for the comparison of fixed effects and random effects models. Hausman test results are given in the table. As known, Hausman test shows which of the fixed effects model and random effects model predictors are consistent. Actually in this test the significance of the difference between the fixed effects model parameter predictors and random effects model parameter predictors is examined. The biggest difference between the fixed effects and random effects models is that while unit effects are allowed to be correlated with independent variables in the fixed effects model, this correlation is not at stake and is random in the random effects model. If there is no correlation between the unit effects and explanatory variables, the use of random effects model predictors will be suitable. The main hypothesis of Hausman test is as the following: "No correlation is available between explanatory variables and unit effects" and the alternative hypothesis thereof, however, is as the following: "Explanatory variables and unit effects are correlated".

Test results are given in the Table 2. Zero hypothesis will be rejected according to the Hausman test results. In conclusion, it was determined that fixed effects model predictor is valid for this model.

\begin{tabular}{|c|c|c|c|c|}
\hline & Fixed Effects & $\begin{array}{c}\text { Random } \\
\text { Effects }\end{array}$ & Difference & $\begin{array}{c}\text { Standard } \\
\text { Error }\end{array}$ \\
\hline Exports & 0.85 & 0.98 & -0.13 & 0.042 \\
\hline $\begin{array}{c}\text { Gross Domestic } \\
\text { Savings }\end{array}$ & -0.92 & -.04 & 0.02 & 0.025 \\
\hline $\begin{array}{c}\text { Foreign Direct } \\
\text { Investments }\end{array}$ & 0.88 & 0.77 & 0.11 & 0.023 \\
\hline chi2(3)= & \multicolumn{4}{|c|}{1872.85} \\
\hline Prob $>$ chi2 & \multicolumn{4}{|c|}{0.0000} \\
\hline
\end{tabular}

Table 2: Hausman Test's results

\section{Concluding Remarks}

Macroeconomic variables affecting the imports of Eurasian countries were analyzed in our study. When pool panel regression model, fixed effects and random effects models are predicted, it has been determined exports, foreign direct investments and gross domestic savings variables are statistically significant for every three model. Every three variables are positively correlated with the imports. In conclusion, while export and foreign direct investments variables have a positive effect on the import-dependent variable, the gross domestic savings variable have a negative effect in the 6 Eurasian countries for the 1996-2012 period. We can interpret that import, export and foreign direct investments influencing each other in the same way is the positive result of openness of country economies. We can interpret that negative effect of gross domestic savings on import can have a positive effect on the import for perking up the economies in the region but countries have to develop restrictive politics in the long run for saving aspects

\section{References}

- Hartwell, 2013. "A Eurasian (or a Soviet) Union? Consequences of further economic integration in the Commonwealth of Independent States ", Business Horizons, 56, pp:411-420.

- Kidd, 2007. "The Great Game evolves for Central Asia and opportunities beckon", Management Decision, 45, pp:1224-1251.

- Libman and Vinokurov, 2012. "Regional Integration and Economic Convergence in the Post-Soviet Space: Experience of the Decade of Growth, Journal of Common Market Studies, 50, pp: 112-128.

- Norling and Swanström .2007. "The Virtues and Potential Gains of Continental Trade in Eurasia ", Asian Survey, 47, pp: 351-373.

- Mostafa, 2013. "The concept of 'Eurasia': Kazakhstan’s Eurasian policy and its implications", Journal of Eurasian Studies, 4, pp: 411-420.

- World Bank 2015, Foreign Direct Investments Statistics

- http://data.worldbank.org/indicator/BX.KLT.DINV.WD.GD.ZS

- World Bank 2015, Gross Domestic Savings Statistics

- http://data.worldbank.org/indicator/NY.GDS.TOTL.ZS

- World Bank 2015, Imports Statistics

- $\quad$ http://data.worldbank.org/indicator/NE.IMP.GNFS.ZS

- World Bank 2015, Exports Statistics

- $\quad$ http://data.worldbank.org/indicator/NE.EXP.GNFS.ZS 


\title{
The World Bank's Role in Tourism Development: The Case of Uzbekistan
}

\author{
Prof. Dr. Mithat Zeki Dinçer (İstanbul University, Turkey) \\ Prof. Dr. Fatma Füsun İstanbullu Dinçer (İstanbul University, Turkey) \\ Ph.D. Candidate Zaid Alrawadieh (İstanbul University, Turkey)
}

\begin{abstract}
After the collapse of the former Soviet Union, Uzbekistan started to build its own national economy with serious attempt to integrate with the international economy. Right after the independence, Uzbekistan joined the international organizations such the World Bank and the United Nations World Tourism Organization. Development projects were initiated and radical changes were noted through developing the infrastructure and building new airports and railways. Tourism was considered a priority and a tool for development in Uzbekistan. With these thoughts in mind, this paper attempts to examine the World Bank's role in the tourism development in Uzbekistan. For the purpose of this study, the bank's documents related to 39 projects that were implanted or are being currently implemented in the country were reviewed and content analyzed. The study suggested that, since the independence of Uzbekistan in 1991 and its enrollment to the World Bank in 1992 there has been no tourismfocus projects supported by the bank. Yet, a number of projects that addressed areas such as urban development and human resources development are expected to affect indirectly the growth and development of tourism industry in the country. The paper recommends tourism planners in Uzbekistan to reevaluate their connections with the international organizations to maximize their role in lunching projects that would contribute to the tourism development in the country.
\end{abstract}

\section{Introduction}

During the former Soviet Union, Uzbekistan was a major tourist destination connected with the Moscow-based organizations. After the independence in 1991, the country started to build its own independent tourist product. The political instability, the economic problems and the major changes following the collapse of the Soviet Union were among the major difficulties in the face of the tourism development (Airey and Shackley, 1997). Yet, 3 years after the independence, Uzbekistan became a member-state in the United Nations World Tourism Organization (UNWTO) and tourism was considered one of the ten priorities included in the government's investment program (Centre for Cooperation with European Economies in Transition, 1996). The national company "Uzbektourism" was founded in 1992 to be the first state body acting not only as tourism promotion agency but also operating the country's main hotels.

There is a common consensus that tourism is a passport to development (de Kadt, 1979) specially for small economies (Ayres, 2000). The international organizations acknowledge the pivotal role of tourism activity in countries' economic growth and development. In Uzbekistan, the richness of cultural heritage and historical sites was recognized and many restoration projects were funded by overseas sources such as Arab league and UNESCO (Airey and Shackley,1997). One of the global organizations that acknowledged, in an early stage, the role of tourism as a development tool was the World Bank.

With these thoughts in mind, this paper aims at examining the World Bank's role in tourism development in Uzbekistan. For the purpose of this study, all the development projects supported by the World Bank were reviewed and content analyzed to gain insights on the World Bank's role in enhancing tourism development in the central Asian Ex-Soviet state. Since the independence of Uzbekistan from the former Soviet Union, the World Bank supported and funded 39 projects in the country. of these 39 projects, 21 projects are currently being implemented (active) whereas the rest are accomplished (closed). Documents related to these projects and made available on the World Bank's official website were analyzed. Results are discussed throughout the following sections.

\section{Tourism Development in Uzbekistan}

The Stalin's 1924 borders made today's Uzbekistan the home of the most important central Asian historical monuments (Kurzman, 1999), including the UNESCO World Heritage Listed cities of Khiva, Bukhara, Shakhrisyabz and Samarkand. These sites constitute the core of tourism product in the country (Baum and Thompson, 2007). The richness of the historical, archeological and ecological attractions along the Ancient Silk Road is a source of wealth that can offer real opportunities for development and economic growth in Uzbekistan (Kantarci, 2007a).

According to the figures of the World Travel and Tourism Council (WTTC), the direct contribution of Uzbekistan tourism sector to Gross Domestic Product (GDP) is $0.9 \%$ (World Travel and Tourism Council, 2015). Tourism industry in Uzbekistan created a total of 387.500 jobs, that is, 2.6 of the total employment. By 2025, the number of jobs is expected to reach about 570.000 jobs. The figures indicate that tourism exports account for 1.6 of the 
total exports in 2014. The percentage of tourism exports of the total exports is forecast to be stable over the period 2015-2025 (World Travel and Tourism Council, 2015). Although the contribution of tourism in Uzbekistan national economy seems to be modest in the current time, yet, if the existing opportunities and potential are to be properly used and tourism investment is enhanced, the sector will be an important income-generating sector in the future (Kantarci, 2007a).

It seems to be difficult to obtain reliable data related to the numbers of international arrivals to Uzbekistan prior to its independence from the former Soviet Union. However, the number of tourists to Uzbekistan was estimated to have reached about 288.000 in 1980 and doubled in 1995 (Agzamov \& Tashmuratov 1995, as cited in Airey and Shackley, 1997).

As depicted in figure 1, the number of international arrivals was about one million in 1997 whereas over the following 8 years the number declined registering only 242.000 tourists in 2005 . The number increased gradually between 2006-2009 but declined again 2010 presumably as a consequence of the international economic crisis. In 2013 (the most recent available data), the number of tourists visiting Uzbekistan is only one step away from 2 million.

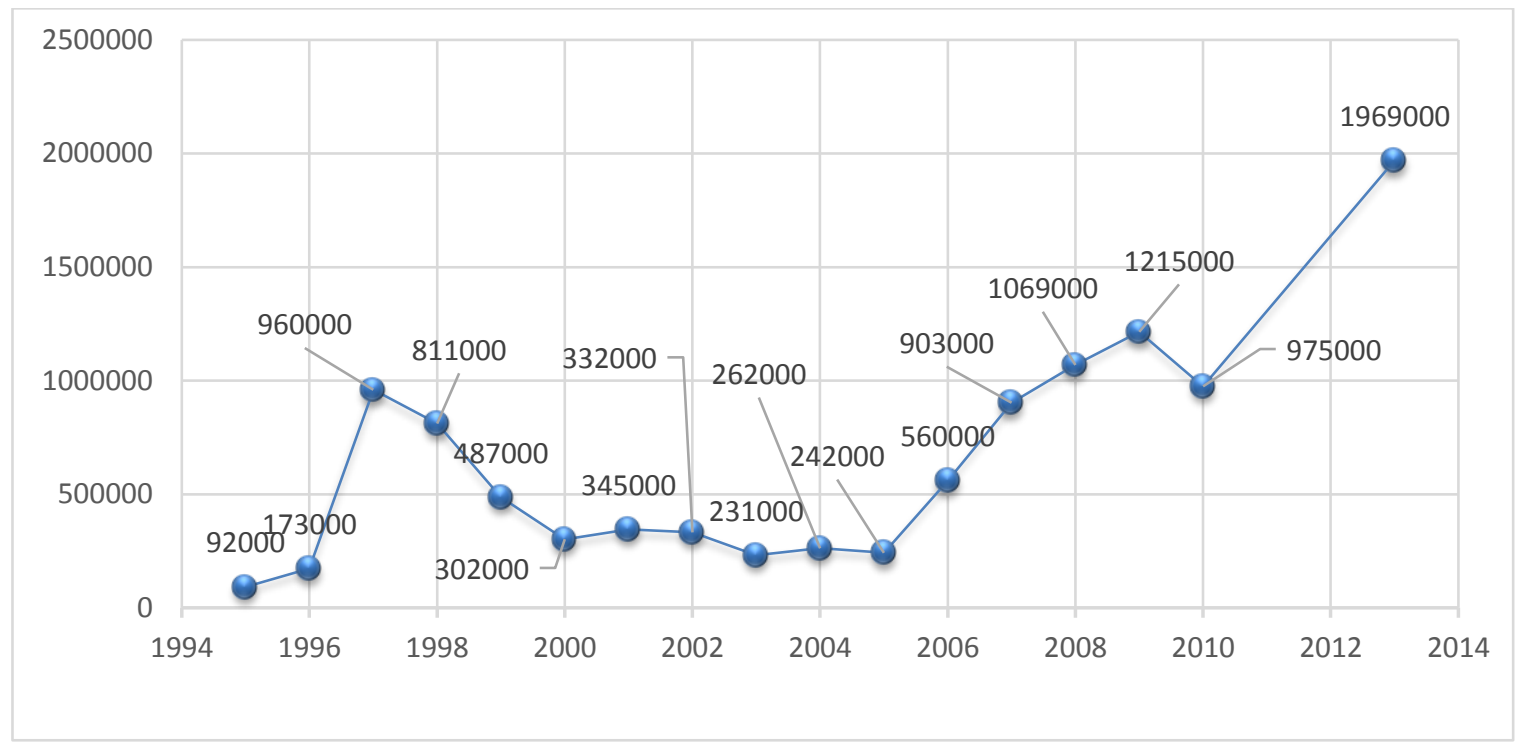

Figure 1. The Number of International Arrivals as to Uzbekistan (1995-2013) Source: World Bank (2016a)

* Number of arrivals for the years 2011 and 2012 is unavailable.

Considering the population of Uzbekistan (over 30 million) and the potential tourist attractions in the country, the current indicators of the tourism sector rise the urgent need to exercise more efforts to promote the Uzbek tourist destinations and adopt adequate strategies to maximize the tourism exports. Like the other Central Asian countries, Uzbekistan's share of the international tourism market is considered to be very marginal, according to Kantraci (2007b), Uzbekistan, as a tourism destination, suffers from the lack of a strong image that would motivate world travelers to visit. In addition, bureaucracy is considered one of the potential obstacles in the face of tourism development in the country (Kapiki and Tarikulov, 2014, Sancar, Kıngır, and Soyalın, 2015). Although the country has a number of significant attractions and adequate services, transformation of tourism seems to be infantile (Airey and Shackley, 1997).

One of the issues that may discourage international travelers to choose Uzbekistan as a tourism destination may be related to the uneasy accessibility to the country. Entry barriers may need to be reduced through modifying the visa issuing procedures. According to the Uzbek tourism official promotional website, only citizens of Kyrgyzstan, Armenia, Azerbaijan, Belarus, Georgia, Kazakhstan, Moldova, Russia and Ukraine are allowed to enter the country without the need of issuing visa (Welcome Uzbekistan, 2016).

\section{The World Bank and Tourism Development}

The World Bank showed commitment to the tourism sector in the developing countries through providing funds and/or technical assistance and advisory. This commitment saw its golden age during the 1970s, particularly with the establishment of the Tourism Projects Department (TPD) in 1969. The department was established to support tourism sector in the client countries. However, 9 years later, the world bank decided to close the Tourism Projects Department. The reasons were mainly attributed to the high cost of the manpower and difficulties in coordination resulted of the complexity of the projects. In addition, the ultimate users of the investments were said not to be poor people (Hawkins and Mann, 2007). At the time the department was closed, 18 tourism projects were supported in 14 different countries. 
In their study, Hawkins and Mann (2007) reviewed over 300 projects to examine to the role that the World Bank played since the mid-60s in tourism development. The study suggested that the Bank's lending policy experienced a shift from macro to micro development. The study pointed out that since 1980s, the World Bank dropped its engagement in tourism activity, this disengagement is an institutional millstone to overcome (Hawkins and Mann, 2007).

Uzbekistan is among the Lower-middle-income economies (The World Bank 2016b). According the Bank's classifications of countries, Uzbekistan is among the Blend countries. These countries are considered financially creditworthy and therefore are eligible for International Development Association (IDA) loans and also for the International Bank for Reconstruction and Development (IBRD) loans (The World Bank, 2016d).

The Word's Bank commitments offered to Uzbekistan through the lending program reached 550 million US\$ in 2015 (The World Bank 2016c).

According to the World Bank, "the Bank's support has been focused on improving people's livelihoods, supporting the modernization of the country's social sectors and infrastructure, and sharing its knowledge and experience with the government and people of Uzbekistan." (The World Bank 2016c)

Since Uzbekistan joined the World Bank in 1992, 48 project have been launched. Of these projects, 21 projects are still active, and 18 projects are closed (completed). The rest are dropped (7) and expected to be implemented ( 2 projects). By reviewing the active and closed projects, that is, the projects that are being currently implemented and those which have been completed, it is interesting to find out the none of the projects have tourism as a main theme (see table no.1).

The active and closed projects seem to target mainly the development of infrastructure (e.g. Roads development), the resources management (e.g. Water supply, electricity), the industrial enterprises (e.g. Cotton industry) and the essential services (e.g. Heath system, education).

\begin{tabular}{|c|c|c|}
\hline Project title & Status & Year \\
\hline Modernizing Higher Education Project & Active & 2016 \\
\hline Integrated Single Window Office for Social Assistance and Employment & Active & 2015 \\
\hline Regional Roads Development Project & Active & 2015 \\
\hline Additional Financing for Bukhara and Samarkand Sewerage Project & Active & 2015 \\
\hline Pap-Angren Railway & Active & 2015 \\
\hline Improving Pre-primary and General Secondary Education Project & Active & 2014 \\
\hline South Karakalpakstan Water Resources Management Improvement & Active & 2014 \\
\hline Horticulture Development Project & Active & 2014 \\
\hline Additional Financing Energy Efficiency - Industrial Enterprises & Active & 2013 \\
\hline Additional Financing to Health System Improvement Project & Active & 2013 \\
\hline Sustainable Agriculture and Climate Change Mitigation Project & Active & 2013 \\
\hline Alat and Karakul Water Supply Project & Active & 2012 \\
\hline Additional Financing for the Second Rural Enterprise Support Project & Active & 2012 \\
\hline Advanced Electricity Metering Project & Active & 2012 \\
\hline Health System Improvement Project & Active & 2011 \\
\hline Talimarjan Transmission Project & Active & 2011 \\
\hline Syrdarya Water Supply Project & Active & 2011 \\
\hline Energy Efficiency Facility for Industrial Enterprises & Active & 2010 \\
\hline Ferghana Valley Water Resources Management Phase-I Project & Active & 2009 \\
\hline Uzbekistan Bukhara and Samarkand Sewerage Project & Active & 2009 \\
\hline Second Basic Education & Closed & 2009 \\
\hline Rural Enterprise Support Project Phase II & Active & 2008 \\
\hline Uzbekistan - Avian Influenza Control \& Human Pandemic Preparedness & Closed & 2007 \\
\hline Basic Education, Phase I & Closed & 2006 \\
\hline Global Alliance for Improved Nutrition - Nat'l Flour Fortification Program & Closed & 2004 \\
\hline Health 2 Project & Closed & 2004 \\
\hline Drainage, Irrigation \& Wetlands Improvement Project - Phase 1 & Closed & 2003 \\
\hline Bukhara \& Samarkand Water Supply Project & Closed & 2002 \\
\hline Rural Enterprise Support Project & Closed & 2001 \\
\hline Urban Transport Project & Closed & 2000 \\
\hline Financial Institution Building Project & Closed & 1999 \\
\hline Health Project & Closed & 1998 \\
\hline Enterprise Institution Building Project & Closed & 1998 \\
\hline Tashkent Solid Waste Management Project & Closed & 1998 \\
\hline Water Supply, Sanitation and Health Project & Closed & 1997 \\
\hline Pilot Water Supply Project & Closed & 1996 \\
\hline Cotton Sub-Sector Improvement Project & Closed & 1995 \\
\hline Rehabilitation Project & Closed & 1995 \\
\hline Institution Building Technical Assistance Project & Closed & 1993 \\
\hline
\end{tabular}

Table 1. World Bank's Development Projects in Uzbekistan Source: The World Bank (2016c). 
Till the moment, there has not been any project with the target to develop the tourism sector in Uzbekistan. Yet, taking into consideration the interdisciplinary nature of tourism, the outcomes of some projects that are not related to tourism may have indirect impact on the tourism development in the country. For instant, the adequate infrastructure is one of the main elements of any tourism destination. the "Regional Roads Development Project" approved by the World Bank in 2015 aims to improve the efficiency for transport infrastructure. According to a survey conducted as a part of the project, local communities recognize the positive role of the project in the "development of the tourism industry with forward linkages to other well-established sectors, particularly textiles and handicrafts" (The World Bank, 2015a: 64). An earlier project entitled the "Urban Transport Project" was approved in 2000 and aimed to provide "efficient and sustainable urban passenger transport services in Samarkand, Namangan, Bukhara, Nukus and Almalyk" (The World Bank, 2000: 23) A similar project approved 2015 addressed to transportation market in Uzbekistan and aimed to "enhance the efficiency of transport services into and out of the Uzbek part of the Ferghana Valley" (The World Bank, 2015b:4).

Researcher noted that human resources in Uzbekistan should be developed to ensure the quality of tourism services (Airey and Shackley, 1997, Baum and Thompson, 2007 Kapiki and Tarikulov, 2014). In addition, there is an urgent need in Uzbekistan for qualified personnel armed with knowledge to manage the tourism businesses (UNDP, 2007). The most recent project approved by the World Bank in April 2016 has the improvement of the quality of higher education as its main objective. According to the Project Appraisal Document, "since the mid2000s, Uzbekistan's economy is shifting out of agriculture into services. Nearly 80 percent of newly created jobs are in the service sector, which will create demand for a highly skilled workforce" (The World Bank, 2016e: 56). The service sector, and more specifically, the tourism sector depends mainly on human performance, in this regard, well trained and highly educated workers and employees have undoubtedly a pivotal role in the competitiveness of the tourism sector in the country. It can be presumed therefore, that "Modernizing Higher Education Project" may also have its indirect positive impacts on the tourism industry in the country.

The World Bank role is not restricted to financial support, technical assistance and advisory is also considered an important part of the bank's activity to help governments identifying opportunities and transforming them to tool of development. For instant, jointly with the International Finance Corporation (IFC), the world bank prepared an assessment report and presented it to the government in 2013. The report, entitled "Transforming Tourism Opportunities in Uzbekistan," was intended to assist the government in its efforts to lunch a long-term development strategy (World Bank, 2015c).

\section{Discussion and Conclusion}

This paper attempted to provide insights on the extent to which international organizations such as the World Bank contribute to the tourism development in an important emergent tourist destination in Central Asia. Researchers noted the scarcity of research on the role of external, that is, non-national organizations in the development of tourism industry (Hawkins and Mann, 2007). Therefore, this paper is intended to contribute to the body of knowledge in this direction.

The richness of Uzbekistan historical, natural and cultural sites and the relatively adequate infrastructure may pose tourism sector in the head of the most important income-generating sectors in the country. To achieve that, foreign capital is needed. Yet, tourism industry in Uzbekistan is apparently not among the priorities of the World Bank's development projects. Loans offered by the International Development Association (IDA) and the International Bank for Reconstruction and Development (IBRD) are mainly related to the infrastructure, resources management, industrial enterprises and essential services. It can be argued that the missing of a comprehensive tourism policy in Uzbekistan is one of the potential reasons why the sector in absent on the World Bank's agenda.

Central Asia States (CAS) are among the emerging destinations that, if the opportunities well-used, may attract larger numbers of international arrivals in the future. The recent integration of the CAS with international economy after the collapse of the former Soviet Union and the relatively new connections with international organizations might be among the reasons why tourism is still in its infantile stage in these countries.

It is hoped that the findings of this paper would encourage tourism planners in Uzbekistan reevaluate their connections with the international organizations to maximize their role in implementing projects that would contribute to the tourism development in the country.

The present paper is based mainly on secondary data through reviewing the World Bank's published reports related to the approved development projects in Uzbekistan. Obtaining primary data from tourism experts and tourism planners from both the public and the private sector would provide deeper insights on the topic. In addition, future studies may approach this topic through examining the role of other external (non-national) organizations in tourism development in the country such as the European Union and the Arab league.

\section{References}

- Agzamov, S, \& Tashmuratov T., 1995. Perspectives of Development of International Tourism in Uzbekistan Tashkent State Economics University, Tashkent. 
- Airey, D., \& Shackley, M., 1997. “Tourism development in Uzbekistan”. Tourism Management, 18(4), 199208.

- Ayres, R., 2000. "Tourism as a Passport to Development in Small States: Reflections on Cyprus". International Journal of Social Economics, 27(2),114-133.

- $\quad$ Baum, T. \& Thompson, K., 2007. "Skills aLabour Markets in Transition: A Tourism Skills Inventory of Kyrgyzstan, Mongolia and Uzbekistan”. Asia Pacific Journal of Human Resources, 45(2), 235-255.

- de Kadt, E., 1979. Tourism: Passport to Development, Oxford University Press, Oxford.

- Hawkins, D. E., \& Mann, S., 2007. “The World Bank's Role in Tourism Development”. Annals of Tourism Research, 34(2), 348-363.

- Kantarci, K., 2007a. "Perceptions of Foreign Investors on the Tourism Market in central Asia Including Kyrgyzstan, Kazakhstan, Uzbekistan, Turkmenistan”. Tourism Management, 28(3), 820-829.

- Kantarci. K., 2007b. "The Image of Central Asia Countries: Kyrgyzstan, Kazakhstan, Uzbekistan, and Turkmenistan". Tourism Analysis 12, 307-318.

- $\quad$ Kapiki, S. T. \& Tarikulov, M., 2014. "Development Prospects of Uzbekistan's Tourism and Hospitality Industry by Utilizing the EU Experience". in Proceedings of the International Conference on Tourism Milestones - Preparing for tomorrow, Sharjah, United Arab Emirates

- Kurzman, C., 1999. “Uzbekistan: The Invention of Nationalism in an Invented Nation”. Critique: Critical Middle Eastern Studies, 8(15), 77-98.

- Sancar, M. F., Kıngır, S. and Soyalın, M., 2015. "Orta Asya Türk Devletleri ile Türkiye Arasındaki Turizm Potansiyeli ve Ekonomi Açısından İncelenmesi”. In Proceedings of International Conference On Eurasian Economies (291-297), 9-11 September, Kazan-Russia.

- The Centre for Co-operation with the Economies in Transition, 1996. Investment Guide to Uzbekistan. OECD, Paris.

- $\quad$ The World Bank, 2000. Urban Transport Project. http://wwwwds.worldbank.org/external/default/WDSContentServer/WDSP/IB/2000/05/16/000094946 0004280530202 $\underline{0 / \text { Rendered/PDF/multi_page.pdf }}$

- $\quad$ The World Bank, 2015a. Regional Roads Development Project. http://wwwwds.worldbank.org/external/default/WDSContentServer/WDSP/IB/2015/06/08/090224b082f02167/1_0/Ren dered/PDF/Uzbekistan000R0Development0Project0.pdf

- The World Bank, 2015b. Pap-Angren Railway. http://wwwwds.worldbank.org/external/default/WDSContentServer/WDSP/IB/2015/01/28/000470435 2015012808484 8/Rendered/PDF/880150PAD0P146010Box385411B00OUO090.pdf

- $\quad$ The World Bank, 2015d. World Bank Group - Uzbekistan Partnership: Country Program Snapshot. https://www.worldbank.org/content/dam/Worldbank/document/Uzbekistan-Snapshot.pdf

- $\quad$ The World Bank, 2016a. World Development Indicators. http://data.worldbank.org/country/uzbekistan\#cp_wdi

- The World Bank, 2016b. Country and Lending Groups. http://data.worldbank.org/about/country-andlending-groups

- The World Bank (2016c). Projects \& Programs. http://www.worldbank.org/en/country/uzbekistan/projects

- The World Bank, 2016d. How does the World Bank classify countries? https://datahelpdesk.worldbank.org/knowledgebase/articles/378834-how-does-the-world-bank-classifycountries

- The World Bank, 2016e. Modernizing Higher Education Project. http://wwwwds.worldbank.org/external/default/WDSContentServer/WDSP/IB/2016/04/11/090224b084282e47/1_0/Ren dered/PDF/Uzbekistan000M0r0Education0Project0.pdf

- UNDP (2007). Uzbekistan`s Tourism Sector - an Unrealized Potential. 2(9) Policy brief. UNDP Uzbekistan.

- Welcome Uzbekistan, 2016. Visa. http://welcomeuzbekistan.uz/en/useful/visa.html

- World Travel and Tourism Council, 2015. Travel \& Tourism Economic Impact 2015 Uzbekistan. https://www.wttc.org//media/files/reports/economic\%20impact\%20research/countries\%202015/uzbekistan2015.pdf 


\title{
The Situation of the Hungarian Wheat from the Grain Trading Point of View in 2016
}

\author{
Ph.D. Candidate András Bence Szerb (Kaposvár University, Hungary) \\ Dr. Ferenc Csima (Kaposvár University, Hungary)
}

\begin{abstract}
Hungary is traditionally an agricultural country and the agricultural sector is still a dominant one in the economy but its importance is weakening nowadays. The agriculture is export oriented, which helps to improve the performance of the national foreign trade balance of the country.

On a global scale wheat is one of the most important grain products both globally and in Hungary as well. During the past years wheat has had the second biggest volume after corn on the local market. In this paper the authors examine the situation of the wheat according to data bases of different institutions both on the Hungarian and the international markets.

On the global agricultural market, the grain sector plays a decisive role since it produces the necessary basic food for humanity. During the last decades the sector has needed to face higher demands for grain products on the agricultural markets which trend may probably continue in the near future as well. The volume increase of the products has affected the agribusiness markets also. Such a small and export oriented country like Hungary should follow the global and EU trends on the agricultural market to keep its competitiveness.
\end{abstract}

\section{Introduction}

For long centuries Hungary was traditionally a country where the dominance of agriculture within the national economy was significant. Agriculture was important because of employment, food supply but at the same time it played an important role in the daily life of the families (Nagy, 2006). The Hungarian agriculture has gone through important and fast changes during the last decades of the previous century. First the Soviet system collapsed which caused a big shock for the agriculture, which the transition period of the 90s followed and in 2004 Hungary joined the EU where the country had to integrate into a new system again. The changes affected not just the agriculture itself but the trading directions of the products as well in the whole Central-East European Region (Fertö, 2006). $13.7 \%$ of the GDP was produced by the agriculture in 1989 and $17 \%$ of the employed people worked in the sector. By the millennium the agricultural sector lost its weight in the national economy (Kiss, 2002). 4.1\% of the GDP was produced in 2001 by the agriculture in Hungary while in 2004 this number decreased even more until 3.7\% and only $4.6 \%$ was the share of the sector from the employment.

Even though the previously mentioned negative changes characterized the sector during the past decades the Hungarian agriculture is still a dominant part of the economy. Out of the total territory of the country $79 \%$ is cultivation land and 5.3 million hectare is used by the sector. The export import ratio of agriculture has been positive during the past years. From the study's point of view it is more important that during the last three years the volume of wheat has been over 5 million tons/year in Hungary. The sown area of wheat is quite stable in the country and it is the second most important crop after corn. The agriculture of Hungary is important not just on the national level but also in the EU. $2 \%$ of the total output of the EU has been produced by the country, but the performance has been even more dominant in case of crops $(2.3 \%)$ and in the grain sector where Hungary's production has reached almost the 5\% in 2014 (KSH, 2015).

\section{Wheat on the Global Market}

The world wheat production shows increasing tendency according to the data of Table 1 and with its volume wheat is among the most popular crops of the world besides the leader corn and rice. In the last crop year more than 14 million tons of wheat was harvested than 2 years before in 2013/14. The biggest change which is visible in the table is the volume increase of the EU. In the last two years the volume has increased by 15 million tons. Besides the volume increase of the EU Russia and Ukraine which are geographically close and have influence on the EU market could have increase their volume as well in the past years. There is a slight volume decrease visible in case of the USA while more dramatic decrease can be examined in Canada and India. In Asia, China could increase its productions in the past years. 


\begin{tabular}{|c|c|c|c|}
\hline Country & $13 / 14$ & $14 / 15$ & $15 / 16$ \\
\hline EU & 143 & 156 & 158 \\
\hline Russia & 52 & 59 & 61 \\
\hline USA & 58 & 55 & 56 \\
\hline Ukraine & 22 & 25 & 27 \\
\hline Canada & 38 & 29 & 28 \\
\hline Australia & 25 & 23 & 24 \\
\hline Kazahstan & 14 & 13 & 14 \\
\hline Argentina & 9 & 14 & 11 \\
\hline China & 122 & 126 & 130 \\
\hline India & 94 & 96 & 87 \\
\hline World total & 717 & 728 & 731 \\
\hline
\end{tabular}

Table 1. Wheat Production of the World (million tons) Source: MGTKSZ (2016a)

On the world market according to FAPRI (2011) projections the net trade of wheat grows $2.5 \%$ on an annual base and it may reach $135 \mathrm{mmt}$ in 2025/26. There might be changes in terms of the market share of exporters and importers as well according to the projections. The net wheat import of the African countries may increase with $13.5 \mathrm{mmt}$ while Asians with $1.2 \mathrm{mmt}$ over the next fifteen years. The market share of the USA on the world export market of wheat declines while the position of China and India might be stronger in 2025/26.

According to the projections of OECD (2014) the prices of the major cereals, including wheat remain under downward pressure in the near future. As the forecasts shows the price of wheat has mostly followed the price trends of the other cereals during the past years. The projection of OECD (2014) says that the prices of corn, rice and wheat may slightly decrease until 2023 compared to the beginning of the decade. The oilseed products have different future in term of prices according to the projection as there is a slightly increasing price visible in the trends. The price differences may be constant, which means that wheat will probably stay in the third position just in front of corn as it is visible in Table 2.

\begin{tabular}{|l|r|r|r|r|r|}
\hline & \multicolumn{7}{|c|}{ EU-27/EU-28 (Croatia from 01.07.2013.) } \\
\hline & \multicolumn{7}{|c|}{$\mathbf{2 0 1 6}$} & \multicolumn{7}{|c|}{$\mathbf{2 0 1 5}$} & $\mathbf{2 0 1 4}$ & $\mathbf{2 0 1 3}$ & $\mathbf{2 0 1 2}$ \\
\hline Wheat & 24164 & 24238 & 24155 & 23223 & 22801 \\
\hline Land & 60 & 62 & 61 & 59 & 56 \\
\hline Yield & 145225 & 150328 & 148504 & 136453 & 127008 \\
\hline Crop & 57129 & 56634 & 57313 & 57225 & 55992 \\
\hline Grains Total & 54 & 55 & 57 & 53 & 50 \\
\hline Land & 306282 & 308864 & 325046 & 301097 & 281751 \\
\hline Yield & \multicolumn{7}{|c|}{}
\end{tabular}

Table 2. EU Volume Production between 2012-2016 (land $1.000 \mathrm{ha} /$ yield $100 \mathrm{~kg} / \mathrm{ha} / \mathrm{crop} 1.000$ t) Source: COCERAL, 2016.

Getting closer towards the Hungarian market the paper must show some data about the wheat market of the European Union. As the data of Table 2 shows the arable land use of wheat has increased during the past years just as it is visible in case of grains in total. In case of yield in both cases in the shown period the numbers reflect that the changes are not significant and it rather happened because of the weather conditions of the given year of the continent than the changes in the sector. The situation of crop is in parallel to land and yield so the same tendency is visible in the table.

According to MGTKSZ (2016b) the wheat balance of the EU in 2016/17 crop year might be more balanced than in the past years. After a relatively high open stock (17million tons), a lower volume of harvested crop and also import is expected. The processing industry is significant and stable and in the meantime the export import balance of the EU has been positive in the past years as it has exported more than imported. The question of the near future is the issues of the position and the situation of the Ukrainian and the Russian markets because they produce a huge volume of wheat and traditionally at a lower price than the production of the EU states. The stronger integration of the Ukraine within the EU might have effect on mostly the Central-Eastern European agricultural market.

\section{Hungarian Wheat's Position on the Domestic and Foreign Markets}

Hungary is a small country with a relatively big cultivation area. There is more than 7.3 million hectares of land available in Hungary and out of this the use of agriculture is around 5.3 million hectares which means it is more than the $80 \%$ of its arable land. The grain production is one of the most dominant within the agricultural sector. In $2015,38 \%$ of the total harvested area of grains was wheat which followed long years of tradition as wheat was the second most dominant crop after corn and before barley (KSH, 2016). In case of average volume 2015 was a good 
crop year in Hungary for wheat as it was higher than 5 tons/hectare. The total volume of wheat has been over 5 million tons during the past three years in Hungary which represents stability at wheat production on the market as Figure 2 shows.

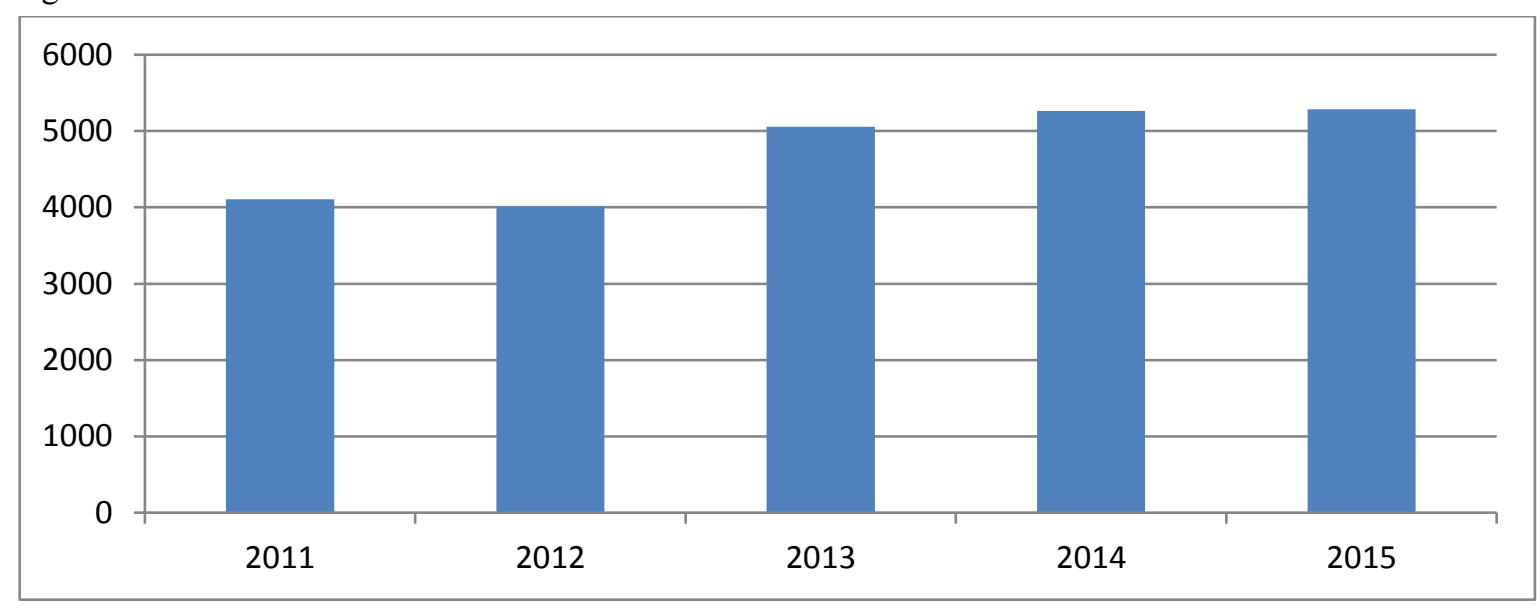

Figure 1. Harvested Volume of Wheat in Tons in Hungary Source: The Author's Own Construction Based on KSH (2016)

The volume of wheat produced in the country is significant domestically compared to other crops, but on the EU level the average production of Hungary was between $3 \%$ and $4 \%$ of the total production as Table 3 shows. The market leaders (Germany, Great Britain, Poland, France) are taking a huge share of the EU market but regionally the situation is better. In the Central-East European Region Hungary is between the biggest producers with Romania and Bulgaria.

\begin{tabular}{|c|c|c|c|c|c|}
\hline & 2005 & 2006 & 2007 & 2008 & 2009 \\
\hline Hungary & 5088 & 4376 & 3987 & 5631 & 4419 \\
\hline EU 28 & 136030 & 127540 & 121076 & 151200 & 139480 \\
\hline & 2010 & 2011 & 2012 & 2013 & 2014 \\
\hline Hungary & 3745 & 4107 & 4011 & 5058 & 5262 \\
\hline EU 28 & 137574 & 138744 & 136488 & 144280 & 157230 \\
\hline
\end{tabular}

Table 3. Volume of Wheat between 2005-2014 in Hungary Source: KSH (2016)

The data of Figure 2 shows that the export volume of wheat in the past three years has increased compared with the 1.5 million tons of annual export during the first years of the decade. In the meantime the authors must highlight that there is a slightly decreasing tendency visible in Figure 2 between 2013 and 2015.

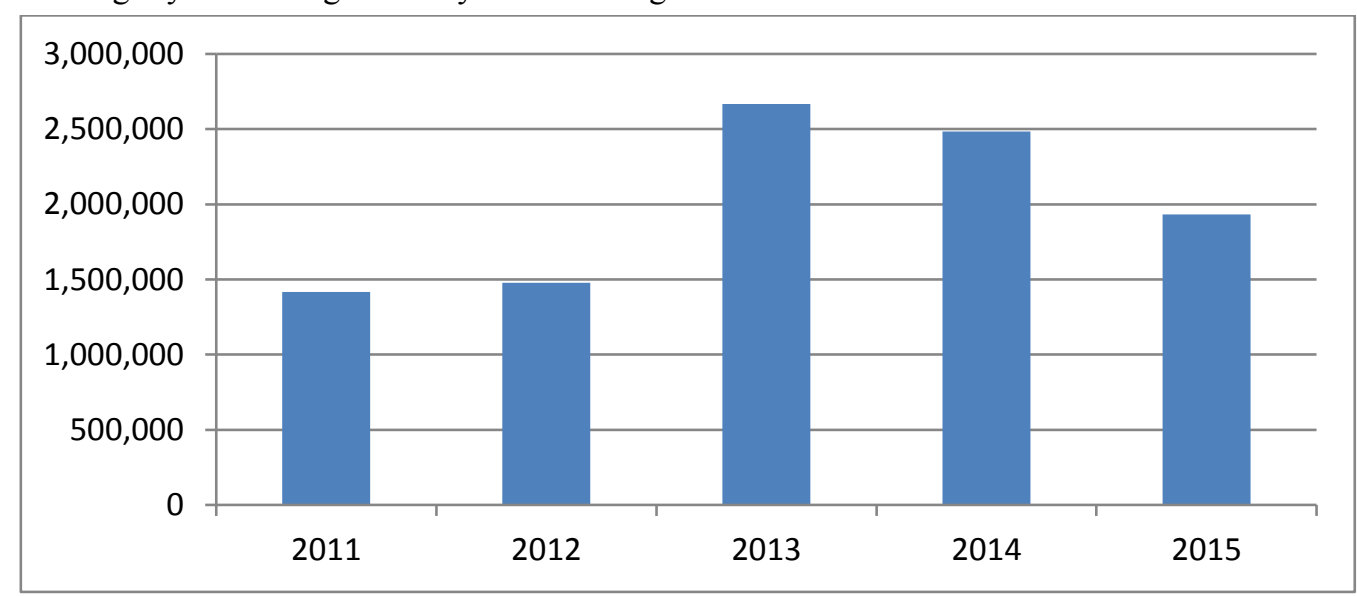

Figure 2. Hungarian Wheat Export in Tons between 2011-2015 Source: The Author's Own Construction Based on MGTKSZ, $2016 \mathrm{~b}$

The Hungarian wheat export is quite concentrated as Figure 3 shows. After the country joined the EU in 2004 the main export direction of the product went towards different EU member states and this tendency is similar also today. Almost $90 \%$ of the total exported volume went to the EU in 2015 . Traditionally Italy is the most dominant export direction of Hungarian wheat because of its huge processing sector and in 2015 more than $35 \%$ of the total wheat export of the country was exported there. Other dominant countries where the Hungarian export has gone are traditionally our neighbors like Romania, Austria and also Slovenia which has a big processing sector compared to the size of the country. In case of the 3rd country only $10 \%$ of the export volume was exported there but an 
important fact that $91 \%$ of this volume went to Bosnia and Hercegovina. The country at the West Balkan has become a significant export market during the past years.

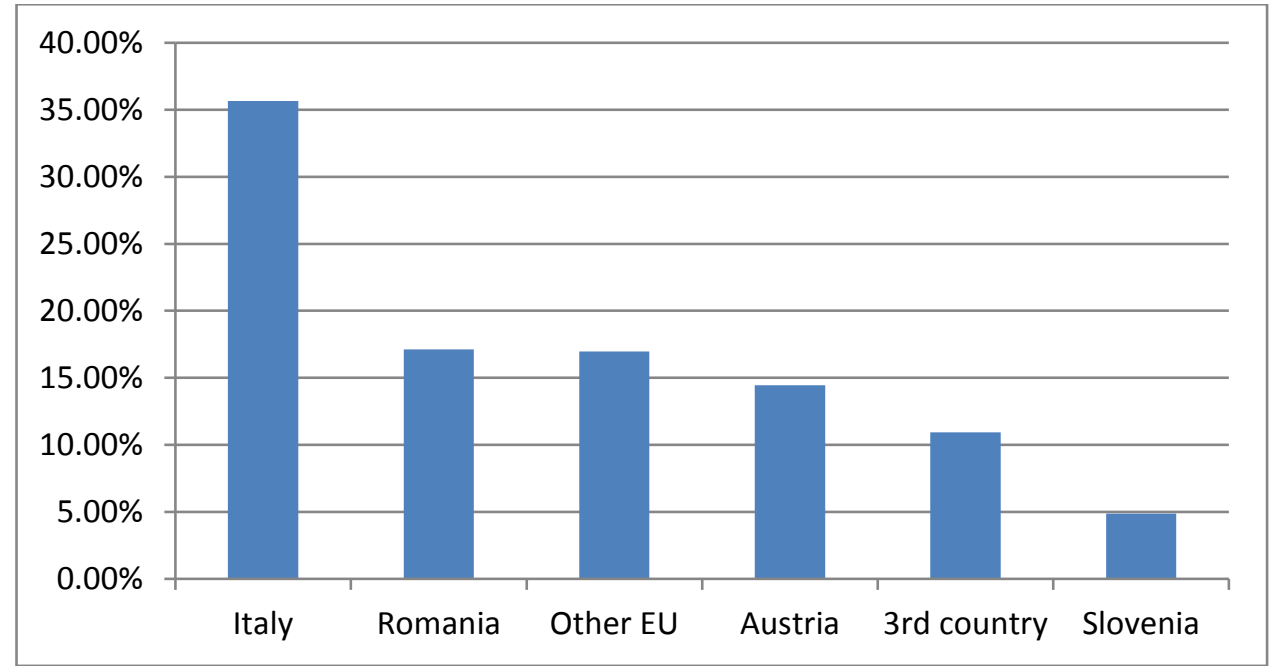

Figure 3. Hungarian Wheat Export by Countries in 2015 (KN:10019099) Source: The Author's Own Construction Based on MGTKSZ, $2016 c$.

In case of freight types as it is visible in Figure 4 there have been changes in the past years. Although truck is still the most dominant freight type but both river transport and train transport could increase their volume. In case of train export there was a slight increase from 2010 which basically followed the export volume increase of the product itself. The biggest change is visible if we look at the export data of the volume done on the Danube. The exported wheat done on the river was quadrupled in the examined period of Figure 4. The authors expect some changes in case of the main export direction because of the increased export volume of wheat along the Danube during the last years. Probably the export volume shifts towards countries along the Danube in the next years. Besides all the previously mentioned facts in case of the Danube export the exporter should take into consideration the risks originated from the nature (low water level, flooding).

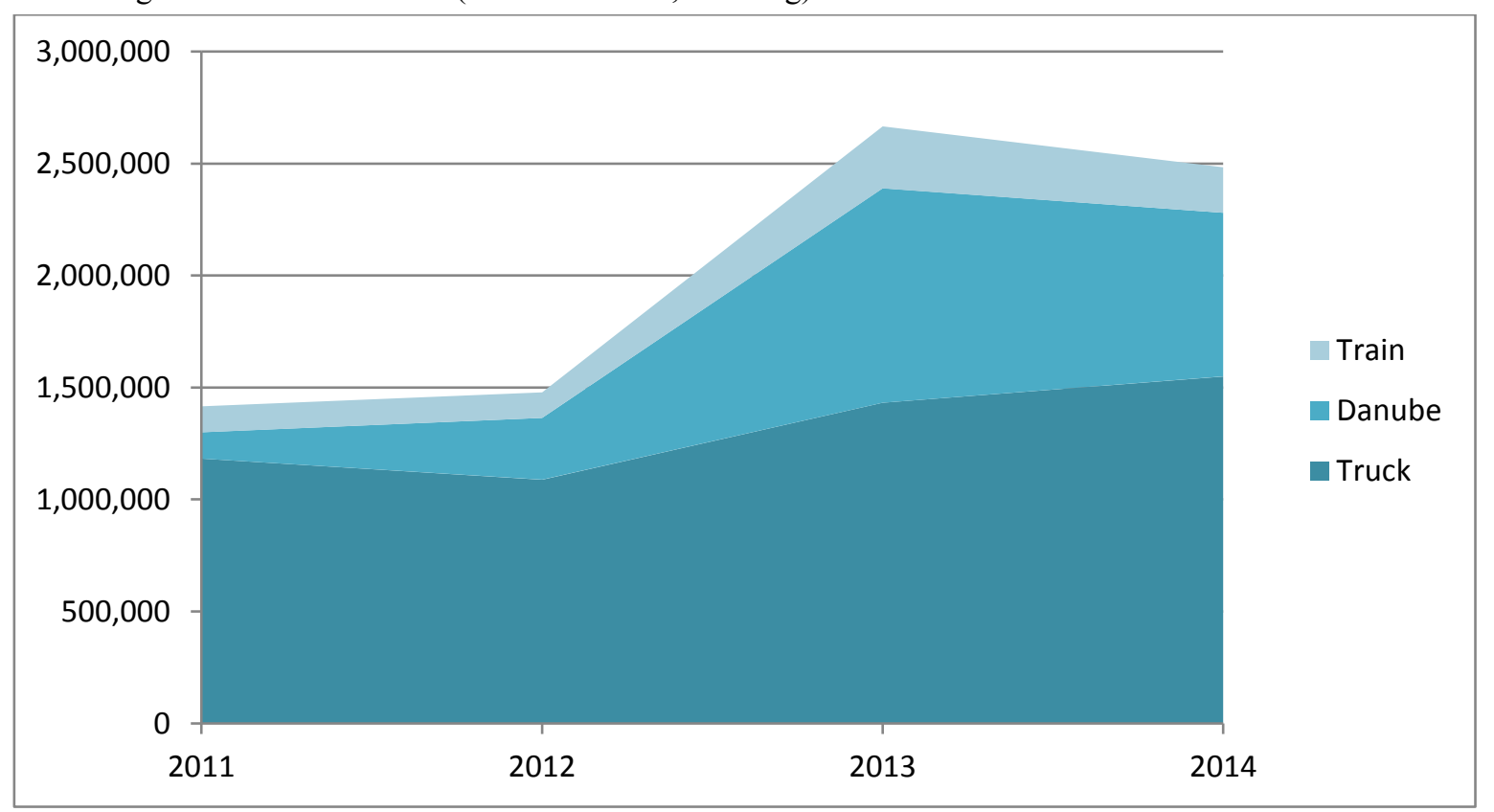

Figure 4. Wheat Export by Freight Types between 2011-2014 in Hungary. Source: The Authors' Own Construction Based on MGTKSZ, $2016 c$.

\section{Conclusions}

Hungary is a country where agriculture has long centuries of history. Today as the country is part of the global agricultural market it must follow the global trends of the sector. The position of the wheat on the world market of different crops is relatively stable. During the past decades wheat has been one of the world's most dominant cereal besides corn and rice and according to different forecasts this tendency may go on. In Hungary this tendency is 
similar. Wheat is the second most important product after corn on the domestic market and its position is stable with its sowing area and its increasing volume year by year. Besides the domestic market the wheat export of Hungary is also significant mainly on the agribusiness market of the Central-East European region as the main importers of the product are the countries situated close to the Hungarian border.

There are questions in the near future with regard to Hungarian wheat such as the domestic sowing structure and the issues of neighboring countries as there are some changes visible. Oil seeds are taking bigger areas year by year while there is a slight decrease in case of corn sowing area in Hungary. A bigger issue is the question and the position of the Ukraine as it has huge available arable land and data shows increasing volume of wheat in the past years. The future integration of the Ukraine to the EU might cause significant changes mainly in the Central European market including Hungary. Another open question is the Russian embargo. Russia has a huge agricultural market and production and the country is situated close to Hungary so all dramatic changes in its agribusiness sector probably has an effect on the domestic wheat production of Hungary as well.

\section{References}

- FAPRI, 2011. Overview of the FAPRI-ISU 2011 World Agricultural Outlook, http://www.fapri.iastate.edu/outlook/2011/text/commodity_overview.pdf

- Fertő, 2006. Az agrárkereskedelem átalakulása Magyarországon és a Kelet- Közép Európai országokban. MTA Közgazdaságtudományi Intézet, Budapest

- Kiss, 2002. A magyar mezőgazdaság világgazdasági mozgástere. Akadémiai Kiadó Rt., Budapest

- Nagy G. (2006): Country Pasture/Forage Resource Profiles - Hungary. FAO, Rome

- $\quad$ COCERAL, 2016. EU-28 GRAIN CROP FORECAST March 2016., http://www.coceral.com/data/1457967495Corrigendum\%20\%20Coceral\%20GRAIN\%20estimates_2016_March_11032016.pdf

- MGTKSZ, 2016a. Kereskedelmi hírlevél 0316, http://www.gabonaszovetseg.hu/hirek.php?c=4028

- MGTKSZ, 2016b. Kereskedelmi hírlevél 0516, http://www.gabonaszovetseg.hu/hirek.php?c=4042

- $\quad$ MGTKSZ, 2016c. Export-import, downloaded (2016.03.30.) http://www.gabonaszovetseg.hu/informaciobazis.php? $\mathrm{m}=$ exportimport

- $\quad \mathrm{KSH}, 2015$. A mezőgazdaság szerepe a nemzetgazdaságban, 2014, http://www.ksh.hu/docs/hun/xftp/idoszaki/mezo/mezoszerepe14.pdf

- KSH, 2016. Táblák (STADAT) - Idősoros éves adatok - Mezőgazdaság, https://www.ksh.hu/stadat_eves_4_1

- OECD/Food and Agriculture Organization of the United Nations, 2014. OECD-FAO Agricultural Outlook 2014, https://www.embrapa.br/documents/10180/9523522/OECD-FAO+Agricultural+Outlook+20142023/3d92f64c-5d31-48e5-bce5-779ae6d88018 


\title{
Analyzing the Important Factors for Cloud Service Provider Selection among the IT firms in Turkey
}

\author{
Asst. Prof. Dr. Ediz Şaykol (Beykent University, Turkey) \\ Ayşe Seçil Başer (Beykent University, Turkey) \\ Assoc. Prof. Dr. Kazim Sari (Beykent University, Turkey)
}

\begin{abstract}
Cloud computing, as being one of the trendy topics, provides mechanisms for the companies to meet all the information technology and management requirements at a desired performance level with reduced upfront investments. From the economical perspective, it creates a positive impact by helping them focus on their own business. With this positive impact, it causes a huge increase on the number of user firms, and many service providers try to provide solutions based on the user firms' needs. There are studies on identifying the factors that are used in selecting cloud service solutions in the literature. Having examined the pivotal points among the Information Technology (IT) sector in Turkey, we conducted a survey among the managers of various firms to gather information about their cloud service provider and the factors that provision their choice. Since that decision is very strategic, and once decided it is very hard to alter, it is worth analyzing the set of factors that are used in the survey further in order to identify the most important ones and help new companies for their selection. We provide statistical evaluations based on the results of the survey in this study.
\end{abstract}

\section{Introduction}

It is quite impossible to remain indifferent to technological innovations. These innovations on Information Technology (IT) world not only affect itself but also affect the other sectors, like a domino tile effect as well. With the progress of the information technologies, the IT sector becomes an important part and an indispensable identity of our lives. In today's world not being able to reach information; communication problems between themselves or not being up to news has been perished. In order to be able to have a more effective working strategy, companies/business enterprises have started to look for new horizons and technologies. The old servers which have not been favoured and left behind the technology race has long been replaced with virtual technologies. At the same time the demand and attention to virtual technologies have enabled business enterprises which are in a constant competition with other enterprises to keep the upper hand. This means whoever uses the technological advancements more actively and effectively, starts the competition a few steps ahead.

Even though the term "Cloud Computing" has been more popular than ever, the real functionality of cloud computing is not thoroughly known (Armbrust et al., 2009). This issue is caused by business enterprises who are using the cloud computing systems passing over the main key questions. The key questions should be "what am I using cloud computing for, what do I need". After identifying the answers to these key questions, cloud computing providers can custom fit the system to the end users' needs. With the perfect custom fit for the needs of the supply and demand; business enterprises can easily get the services for their needs, pay per usage, change the content of the services when they need and so forth decrease the costs with flexible cloud services. Thus it is obvious that cloud computing has a lot to offer to business enterprises. The statistical study of the survey for this paper aims to enlighten which of these elements are more demanded by the business enterprises. Via these results, business enterprises which decide to use cloud computing but do not know where to start can have an opinion by analyzing the other enterprises who are in the same sector or same scale using cloud computing. The main goal of this paper to shine a mirror on the usage of cloud computing and service providers among the IT firms in Turkey.

In this paper, some preliminary information is given in Section 2 for those who are unfamiliar to cloud computing terms at all. Section 3 gives brief examples of previous academic works and Section 4 is showing the main purpose of the paper which is the survey that obtained to SME's (Small-Medium Enterprises). Section 5 states statistical analysis based on the survey and finally, Section 6 concludes the paper.

\section{Preliminaries on Cloud Computing}

Cloud computing concept can differ in definitions but the main purpose is without any obstacles on locations reaching the data from anywhere and collaboration with multiple teams. Cloud computing is not a product that end users have but a service that meet the needs of the end user. The platform enables the sharing of information via internet from computers or other devices from anywhere. The most basic but the most extensive definition of cloud computing is controlling the needs of computers like hard disks, software and hardware from a remote location. Also it enables to reach the photographs, documents, media files from other computers. The decision of which of these data will be accessible is done by the service model which has been purchased.

The level of benefit from cloud computing can be categorized under three different service models (Saykol, 2014). The most fundamental cloud computing service IaaS provides virtual servers, operations, storage and 
bandwidths for developers and other cloud computing services. This service model which shows the cluster architectures most effective examples gives and undertaking to high accessibility ratios and back-ups. It is the platform of the system administrator.

Just like Iaas and SaaS which are providing developers as a part of service preparation process; PaaS provides operating systems, database, programming platform and runtime services. It provides the all of the sophisticated medium for the programme to run written by the developer. SaaS is the end user platform. The software is served to end user on this platform. This platform doesn't need extra processes, book value or configuration. It is ready to use and accessible from everywhere. It also provides continuity and data security. Figure 1 shows these three cloud computing service models.

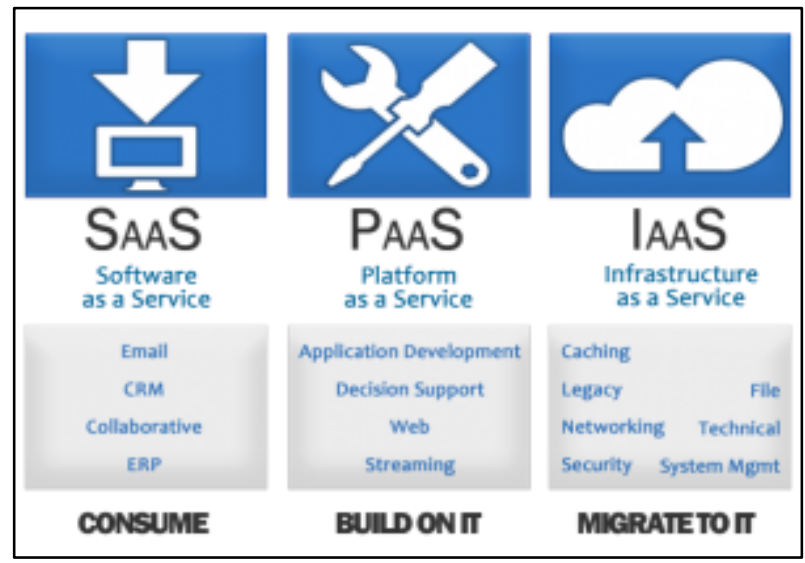

Figure 1. Cloud Computing Service Models Source: (Consultia, 2015).

\section{Literature Survey on Cloud Computing Criteria}

The cloud computing technologies offers the end users and enterprises important gains at the recent years. These technologies anticipate the manageable use of services which are bounded in a multilayered structure offers less book values and more efficient services.

For the last five years the academic researches on cloud computing has reached a number of 10.000 worldwide. The local and global studies subjects are provided below.

(Höfer and Karagiannis, 2011), has searched the building blocks of cloud computing and compared them with other traditional technologies. The study focused on the innovations that are brought by the cloud computing technologies from past to date.

(Kossman and Kraska, 2010) has done researches on book values of cloud computing systems and their costs to enterprises. They have touched upon the correlation between the services provided and usage ratios, also the costs of having these services.

(Pelletier, 2009) chose to identify how to pick the road to import services avoiding heavy costs for end-users or enterprises. Cloud computing has many meanings for end users or enterprises. To explain it simply cloud computing means to reach the applications over the internet in the easiest and fastest way for users. This model which is independent from the user's location provides reaching the datas or applications.

(Svantesson and Clarke, 2010) has researched on the risks that can be faced on using cloud computing especially the data security.

(Barret and Kipper, 2010) has studied the correlation between the virtual technologies and cloud computing and emphasized the role of virtual technologies in cloud computing.

(Issarny et al., 2011) has studied the service based approach and the effects of this approach on the internet in the future.

(Knorr and Gruman, 2008) has researched the cloud based services and the services between the cloud layers.

(De Roure, 2010) has done a research on e-science and web technologies' importance on present-day. In this study the infrastructure that are used to provide the web services to the users have been evaluated.

(Getov and Srinivasan, 2011) has emphasized the services that are provided by the cloud computing service providers.

(Ortiz, 2011) focused on the standardization issue of the cloud Technologies. The study emphasized on the disability of different virtualization technologies' compatibility and coordination between each other. Among this, the comparative analysis between traditional security solutions and cloud computing security has been made. 
Of course it is widely acknowledged that one of the main problems with cloud computing solutions is security. The confidentiality and continuity of the services provided are a big deal for end-users and enterprises. At this point (Garber, 2011) has studied the defined security gaps and risks of the cloud computing technologies and made some conclusions for these issues.

Korkmaz (2010) has focused on the data security, just like (Garber, 2011), legal regulations and service continuity of the cloud computing technologies from Turkey's perspectives.

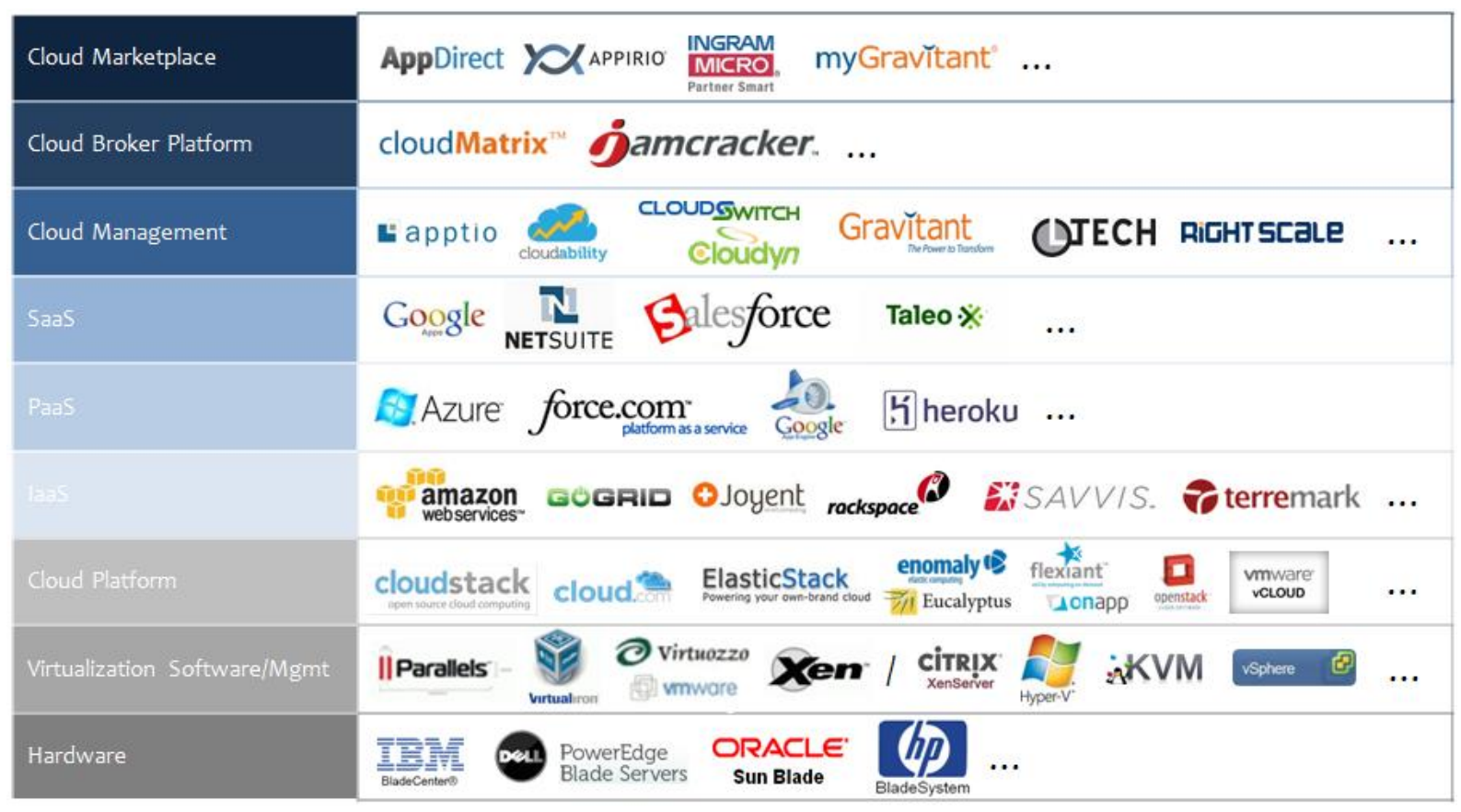

Figure 2. A Set of Cloud Service Providers Based On Service Models Source: (Jackson, 2014).

\section{The Survey to Analyze Cloud Service Providers}

The aim of this survey is to make a statistical analysis for the enterprises whom will benefit from the cloud computing systems especially Small and Medium Enterprises' (S.M.E). We also aim to find the most important factors for the selection of cloud service provider and shine a light on which service is chosen by which priority, by the enterprises that are in Turkey's informatique sectors. Figure 2 gives a set of cloud service providers globally around the world based on the service model they provide.

The survey has been made by the help of 57 volunteers on 21 informatique criteria. The participants have been asked to fill the questionnaire made up by 21 informatique criteria by the order of importance. The most important criteria would be number one whereas the least important criteria was 10 . The participants have also been asked to name the cloud service providers that they have been working with.

The participants are aged between 20-40, either the company owner or the employee of the company whom has a keen understanding on cloud computing. Some of the participants has long been with working with cloud computing systems whereas the others are quite new on these systems.

This paper has been prepared as a continuation of (Saykol and Avc1, 2015), which argues that benefiting from cloud computing services has a win-win effect on both customers and service providers, following a medium established in (Saykol, 2014).

Keeping in mind that cloud computing is in every section of our lives nowadays, taking this matter on an enterprise base; we can see that not only large organizations but in fact S.M.E.'s can also benefit from these services. So this survey has included S.M.E.'s. Due to the requests of the participants the names of the participants have been concealed.

\section{Statistical Analyses of the Survey}

The participants have been asked to complete the survey from most important to least important in an ascending manner. Accordingly, a numeric value is given to each criteria. Namely, the most important criteria was numbered as 10 and least important criteria is numbered as 1 . After that each criteria's mean values and standard deviation values has been calculated as shown in Figure 3 and Figure 4. 
After analyzing the mean values of the criteria for 57 participants, it is observed that expenditure is the most important criterion. This outcome has been expected since the main feature of cloud computing is lowering the costs for the enterprises.

Even though the most contentious and open to enhancement feature of the cloud computing is security; our survey has showed us that our participants have another priority. Since that in our literature review and researches the main drawback issue was security and in our survey the participants prioritized it; we have contacted with the participants.

The answers given by the participants were satisfying:

- The prior systems that they were using for data storage, system administration, performance enhancing were compromising the data security if there were no back-up units; whereas the data stored on the cloud servers has automatically serves a back-up and also these back-ups were accessible from anywhere.

- The enterprises who are working with professional cloud computing service providers has a 24/7 hotline with the provider thus help and proper guidance was in reach.

- In case of a problem caused in their prior systems data centers the enterprises had to ask from another company for maintenance and restoration whereas with cloud computing service providers they only have one interlocutor

In the light of these information given by the participants, customers feel safer in the hands of professional cloud computing service providers and that is why they are choosing to work with these providers.

The following criteria is performance and data accessibility. The participants also stated that they were satisfied with the service providers and the quality of performance. Also being able to access the data 24/7 without any locational limitations was another important criteria for the customers.

The first breaking point that is determined amongst the participants was virtualization. Even though participants have stated that the virtualization of the software and hardware resources was important; the participants dissented from each other about the criteria. The statistical analysis shown Figure 5 indicate that virtualization criteria are number one on standard deviation value.

Another element that draws our attention was pay as you go and services criteria were rated lower than we expected. Thus we can say that customers were choosing a package deal with a fixed price rather than pay per usage deals.

Even though one of the most important feature of cloud computing systems is "services" provided; to deduct that these services are extensively used by our participants would be wrong; due to the demographic distribution of the scales of the enterprises favors in S.M.E's. These S.M.E's are mainly SaaS users which provides limited authorization of control. In this case these enterprises probably know very little about the extent of the services.

The least important features rated by the participants were API and AJAX compatibility. We have identified that the main cause of this score for these features arises from the lack of knowledge of the participants for what these words stand for even though they are using these features. Also the participants who stated that they know about API and AJAX compatibility services stated that these features are a must have on cloud computing systems so forth there's no need to prioritize these features.

Figures 3 and 4 give the mean value analysis and standard deviation results, respectively for the survey carried out during this study.

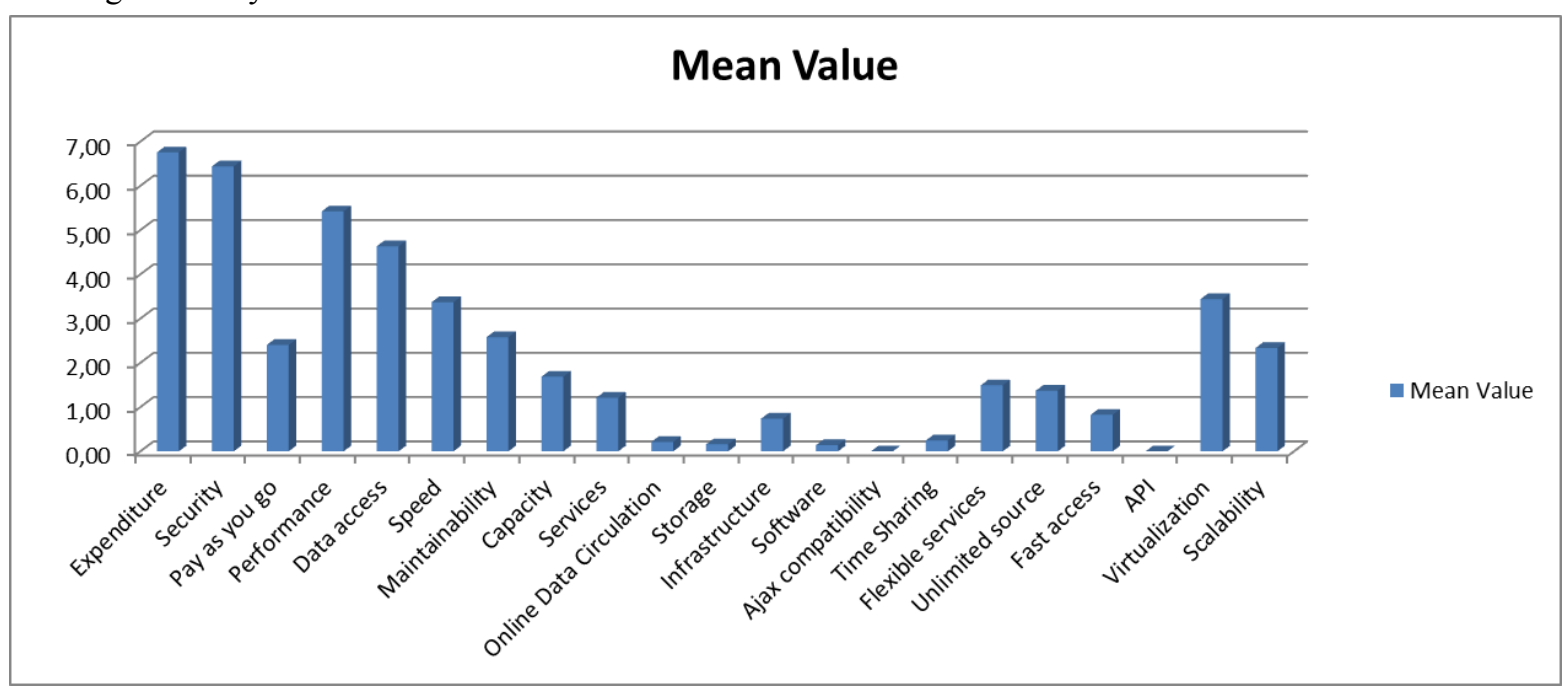

Figure 3. The Mean Value Analysis of the Criteria Used in The Survey. 


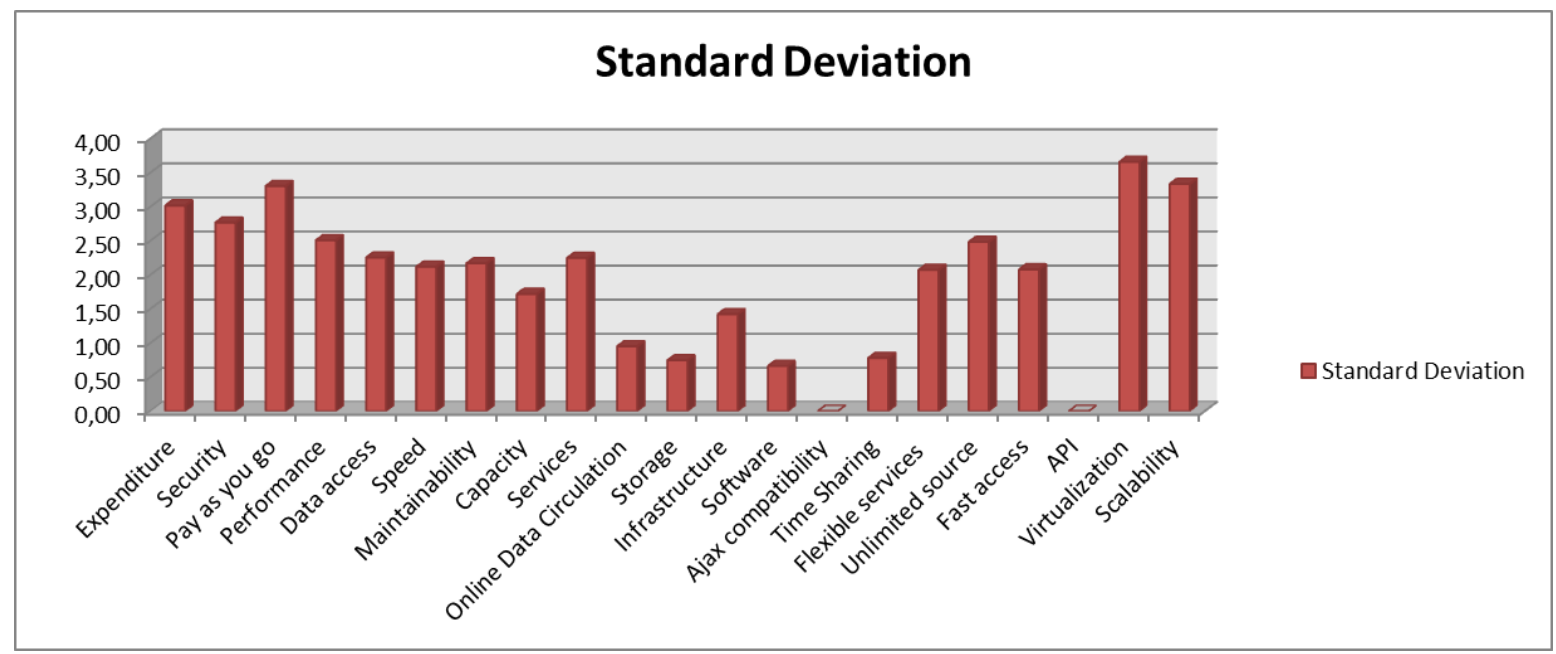

Figure 4. The Standard Deviation of the Criteria Used in The Survey.

Additionally, coefficient of variation for each criterion is also calculated in Figure 5 to find out the confidence interval. This is performed to understand if there is a consensus about the scores of each criterion. This calculation gives the percentage difference of standard deviation to mean value.

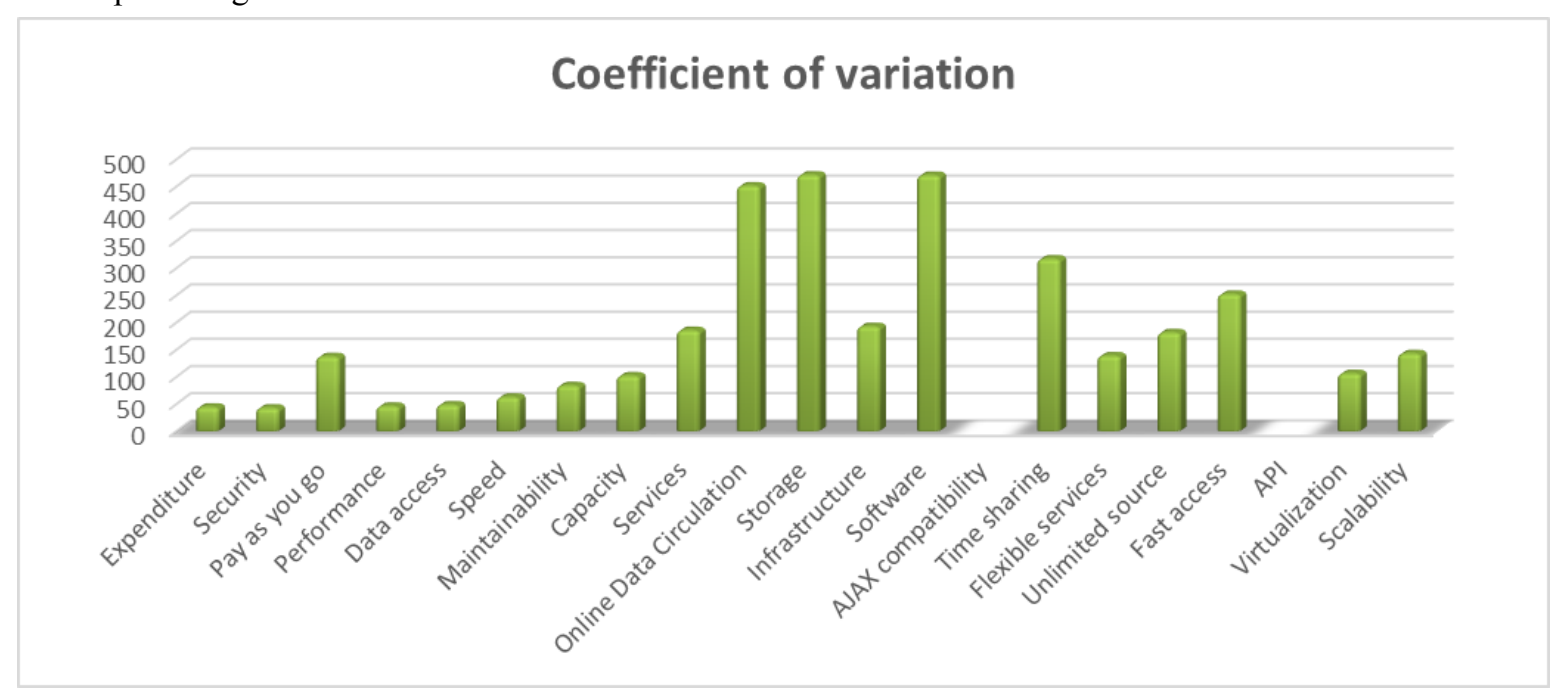

Figure 5. The Coefficient of Variation of the Criteria Used in The Survey.

It can be said from Figure 5 that expenditure, security, performance, data access are the criteria that all most all participants are in consensus while there are some different opinions for the remaining criteria.

\section{Conclusion}

Cloud computing expresses offering the technologies that originate from the past as a service. These services are offered via multiple layers that cloud computing services can be used in. With the invention and increasing usage of the internet, the usage of the cloud computing services by individuals or enterprises has increased as well. By accessing these services for affordable prices and lowering the IT costs; enterprises has profited in acceptable amounts and became more efficient. For the past five years the increasing usage of cloud computing has been more preferred by the S.M.E.'s. The enterprises who choose dynamic service providers data centers over bulky data centers can save from maintenance, personnel and licensing costs.

The usage of cloud computing systems which are providing flexible, scalable and modifiable for the needs of usage for the enterprises is also important for the national energy savings. The aim is to increase the efficiency of the enterprises by removing the unnecessary data center costs and paying per usage. Via accessing and sharing the data from everywhere; a more efficient labour and business benefits can be achieved. For these features cloud computing is seen as the technology of the future.

In this study, an empirical work is performed to reveal the most important factors for the selection of cloud service provider. By this way, it is made clear the managers' decision approach to the cloud service providers. Thus, this study will form a base for the further studies to construct a decision model for this purpose. 


\section{References}

- $\quad$ Armbrust, Michael, Fox, Armando, Griffith, Rean, Joseph, Anthony D., Katz, Randy H., Konwinski, Andrew, Lee, Gunho, Patterson, David A., Rabkin, Ariel, Stoica, Ion and Zaharia, Matei, 2009, "Above the Clouds: A Berkeley View of Cloud Computing", UCB/EECS-2009-28, http://www.eecs.berkeley.edu/Pubs/TechRpts/2009/EECS-2009-28.html.

- Barrett, Diane, Kipper, Gregory, 2010, Virtualization and Forensics: A Digital Forensic Investigator's Guide to Virtual Environments, Elsevier Inc, MA, USA.

- Consultia, 2015, "Cloud computing service models", http://www.consultia.co/choosing-your-right-cloud/.

- De Roure, David, 2010, "e-Science and the Web", IEEE Computer, Volume 43, Issue 5, 90-93, May.

- Garber, Lee, 2011, "News Briefs", IEEE Computer, Volume 44, Issue 7, 17-19, July.

- Getov, Vladimir, Srinivasan, Savitha, 2011, "From invisible grids to smart cloud computing", Proceedings of Euro-Par 2010 Parallel Processing Workshops, Lecture notes in Computer Science Volume 6586, Springer, 263-270.

- Höfer, C.N., Karagiannis, G., 2011, “Cloud Computing Services: Taxonomy and Comparison”, Journal of Internet Services and Applications, Volume 2, Issue 2, 81-94.

- Issarny, Valérie, Georgantas, Nikolaos, Hachem, Sara, Zarras, Apostolos, Vassiliadist, Panos, Autili, Marco, Gerosa, Marco Aurelio, Ben Hamida, Amira, 2011, "Service-oriented middleware for the future internet: state of the art and research directions", Journal of Internet Services and Applications, Volume 2, Issue 1, 23-45, Springer-Verlag.

- Jackson, Kevin, 2014, Forbes, http://blogsimages.forbes.com/kevinjackson/files/2014/06/cloudtechspectrum_vendors_v211.png.

- Knorr, Eric, Gruman, Galen, 2008, "What cloud computing really means", InfoWorld Magazine (online), http://www.infoworld.com/article/2683784/cloud-computing/what-cloud-computing-really-means.html.

- Korkmaz, Yakup, 2010, "Bulut Bilişim Risk Değerlendirmesi”, http://www.bilgiguvenligi.gov.tr/guvenlikteknolojileri/bulut-bilisim-risk-degerlendirmesi-i.html.

- Kossmann, D., Kraska, T., 2011, "Data Management in the Cloud: Promises, State-of-the-art, and Open Questions", Datenbank-Spektrum, Volume 10, Issue 3, 121-129.

- Ortiz, Sixto, 2011, “The Problem with Cloud-Computing Standardization”, IEEE Computer, Volume 44, Issue 7, 13-16, July.

- Pelletier, Stephen, 2009, "What You Need to Know about Cloud Computing”, Associations Now Magazine, (online), December, http://www.asaecenter.org/Resources/ANowDetail.cfm?ItemNumber=46319.

- Saykol, Ediz, 2014, "On the Economical Impacts of Cloud Computing in Information Technology Industry", Proceedings of 5th International Conference on Eurasian Economies (EECON'14), 83-89, Skopje, Macedonia.

- Saykol, Ediz, Avcı, Ayşe Seçil, 2015, "Pivotal Points in Utilizing Cloud Services in Turkey”, Proceedings of 6th International Conference on Eurasian Economies (EECON'15), 170-175, Kazan, Russia.

- Svantesson, D., Clarke, R., 2010, "Privacy and consumer risks in cloud computing”, Computer Law \& Security Review, Volume 26, Issue 4, 391-397. 


\title{
Do Financial Markets Exhibit Chaotic Behavior? Evidence from BIST
}

\author{
Assoc. Prof. Dr. Kutluk Kağan Sümer (Istanbul University, Turkey)
}

\begin{abstract}
Knowing of the chaos theory by the economists has caused the understanding of the difficulties of the balance in economy. The applications of the chaos theory related to economy have aimed to overcome these difficulties. Chaotic deterministic models with sensitive dependence on initial conditions provide a powerful tool in understanding the apparently random movements in financial data. The dynamic systems are analyzed by using linear and/or nonlinear methods in the previous studies. Although the linear methods used for stable linear systems, generally fails at the nonlinear analysis, however, they give intuition about the problem. Due to a nonlinear variable in the difference equations describing the dynamic systems, unpredictable dynamics may occur. The chaos theory or nonlinear analysis methods are used to examine such dynamics systems. The chaos that expresses an irregular condition can be characterized by "sensitive dependence on initial conditions".

We employ four tests, viz. the BDS test on raw data, the BDS test on pre-filtered data, Correlation Dimension test and the Brock's Residual test. The financial markets considered are the stock market, the foreign exchange market. The results from these tests provide very weak evidence for the presence of chaos in Turkish financial markets. BIST, Exchange Rate and Gold Prices. In this study, the methods for the chaotic analysis of the time series, obtained based on the discrete or continuous measurements of a variable are investigated. The chaotic analysis methods have been applied on the time series of various systems.

Chaos, is the way a deterministic system can behave in a disordered manner. For example sometimes chaotic situations can be seen in the flow of a liquid passing from a smooth pipe. Once the flow rate of the fluid passes a certain value, eddies are formed and the Newton laws lose their validity. Namely now the flow is chaotic.

Although J. Henri Poincare is accepted as the father of chaos concept and theory, the most important contribution for the theory was made by Edward Lorenz who became a meteorology professor in M.I.T. in 1960. Lorenz entered data to his computer in order to prepare a simple weather forecast report and as a result showed the temperature values he found in graphics. Lorenz, restarted the function by increasing the randomly selected temperature values in small amounts that even a very sensitive thermometer cannot detect and found out that totally different functions were formed even though he expected functions would not create any difference in graphics. It was observed that the decrease and increase in graphics in long term caused a pattern like a butterfly.
\end{abstract}
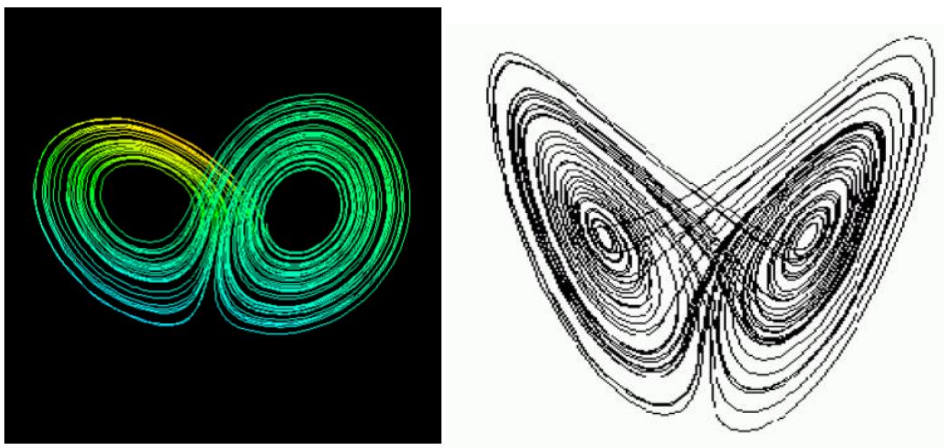

Figure 1: Lorenz Attractions

The comment Lorenz made from this result is as follows: As a result of its chaotic behavior a correct and reliable long-term weather forecast cannot pass a certain time, for this reason, in a system that shows non-periodical behavioristic characteristics is not possible.

Lorenz, tried to explain "chaos theory" by putting forth two main features of chaotic systems that look like disordered but have an internal order. After this study of Lorenz, two main characteristic features of chaotic systems that chaos theory tries to explain, looking like disorder from outside but having an internal order are clearly set forth.

The technical features of chaotic processes are as follows;

\section{Dependency on Beginning Situation}

If the beginning situation and equation of a deterministic system is known, the subsequent behavior of the system can be determined. In chaotic systems, in order to determine the development of the system throughout the time, it is necessary to know the beginning values with an infinite precision. Since chaotic systems are not linear, the error shall increase exponentially in time. 
In theory, essentially everything occurs according to time, for example; pollen production, population increase, economical changes, world ice mass etc... can be chaotic. Chaotic studies can be seen in fields like physics, chemistry, mathematics, communication, biology, physiology, sociology, economics, history, ecology, astronomy, hydraulics, atmospheric, international relations, solar systems, engineering.

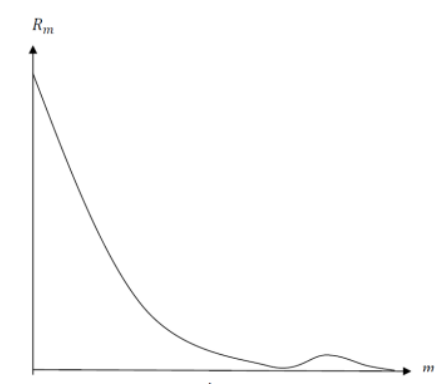

Figure 2: Chaotic Corelogram

The series in a chaotic structure shows a sensitive dependency on beginning conditions. For this reason, the relation between past and feature values is very weak. As can be seen in the Figure, according to this fact, as the delay increases the series that have autocorrelation values converging to zero are the series that have very weak relation between past and future. Consequently, it can be said that this kind of series have a chaotic structure.

\section{The Situation of Being Random.}

In a more clear statement: In fact many events in the world have a chaotic structure (everything is not linear like the way it is thought to us); like the formation of a snowball, the increase of a cigarette smoke, the development of the stems of a tree, the flight of bevy of birds, the movements of waves in the sea. So these behavior patterns conform with the laws of new science. It is claimed that in the process that cannot be set into the concept of causality of classical science and that can be named as dynamic systems, chaos would destroy determinism and brought a new horizon to the science that stuck.

Dynamic Systems and Chaos Theory, is a theory that points out the fact that minor fluctuations made in complex systems which are not linear can lead to big changes in the future. It is a theory that says prediction of events that might happen in the near future is easy, however prediction of the events that might happen in long-term can be hard. The most common example that can be given for chaos theory is butterfly affect.

The basic propositions of chaos theory can be listed as follows;

a. Order creates disorder.

b. There is an order in disorder.

c. Order comes from disorder.

d. In the new system reconciliation and dependency show themselves very shortly after the change.

e. The new order reached, develops into a new direction through a process that was organized by itself.

3. Fractal Geometry

Mandelbrot defines the "fractal" concept as geometrical shapes that the parts and the total Show similar structural characteristics. [Tosun, 2006]. From this point of view, fractal geometry, with its simplest form, can be defined as the geometry of Chaos. The shapes that have fractured dimensions, self-similar structures that give the same shape in every scale, the infinite embranchments and the resemblance of these embranchments with the main structure form the base fractal geometry. It is tried to explain the fractal structure and real nature structures with rules. These self-recurring structures cannot be understood with Oklid geometry. However, fractal geometry can solve the mystery of these shapes. Trying to simplify these structures and explain complex systems with this simplicity that is reached establish the reason for the research of fractal structures [Tosun, 2006].

The basic and simple rule of forming Fractal Shapes, is continuously repeating a rule that is accepted. Namely, if a rule is taken as fixed and continuously applied a fractal shape can be obtained. The fractal structure of WaclawSierpinski that can be seen in Figure 2 can be given as an example for this. Sierpinski forms a new triangle from the median points in an equilateral triangle. By renewing this for every triangle formed here, the triangle shapes in Figure 2 are created [Peters, 1996]. 


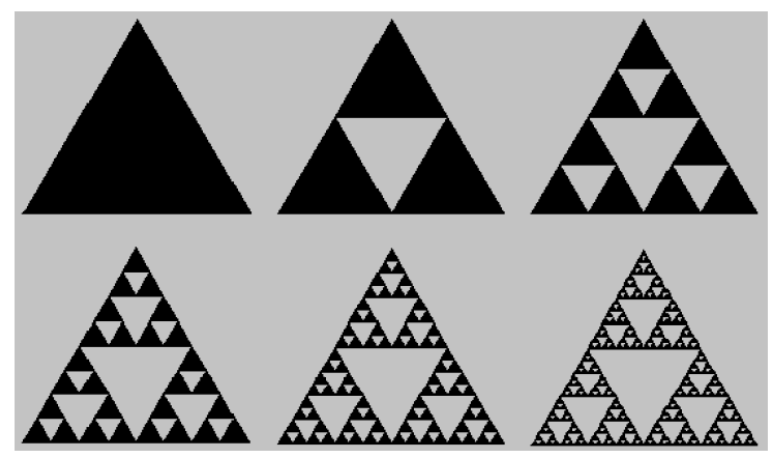

Figure 3: Sierpinskn's Fraktal Sample

Fractal time series for several grounds arises if the display time series in self-similar structures. Fractal time series time series are distributed substantially random and deterministic all the features they do not show in certain periods. Therefore, similar to the structure forms the main structure is made by chance in time series.

A series of linear fractal dimension is also quite close to 1 . Therefore, with high sharpness, the rise and fall of this size is more structure and 2 are both approaching a fractional number. This situation can be explained why the application of chaos theory to Tonis Vaga the financial markets. According to the market in the risks and rewards Vaga has a non-volatile linear structure [Vaga, 1991].Therefore fractal dimension and structure of the system is important to make a good analysis. Because this way, high returns at low risk according to market certain conditions it is possible to achieve. Similarly, investors such as Warren Buffett and George Soros, have declared in a similar way to achieve higher profits than the average over the long term [Tosun, 2006].

Attractions briefly are the pictures of the dynamic system. Accordingly, a dynamic movement is analyzed fractal geometry, work is greatly facilitated. For example, while expressing that point strange attractors stood unchanged by time the system is attractive complex mostly shaped in interesting building. Results have chaotic nature of the system; unpredictable function is a structure constituting the time series. This is equivalent to the function that vary randomly increase and decrease. Differently from each other in phase space for each different chaotic fluctuation in the system it consists of different trailers in other words. A major attraction of the chaos arising in the framework of the historical development work can be summarized as follows [Kasap ve Kurt, 2011].

- Lorenz Attraction

- Rössler Attraction

- Henon Attraction

Here in the conceptual point of view trailers contain two important points. These are attractive to himself and his form. According to the behavior of a system that is understood by fully engaged. Therefore, it is called a tow truck, but it can be described by fractal geometry attracted to strange attractors. The concept of strange attractors of chaos indispensable work have different phase space portrait for each different chaotic time series.
a) Periodic (sinüs) Signal
b) Chaotic (Lorenz) Signal
c) White Noise (Random) Signal
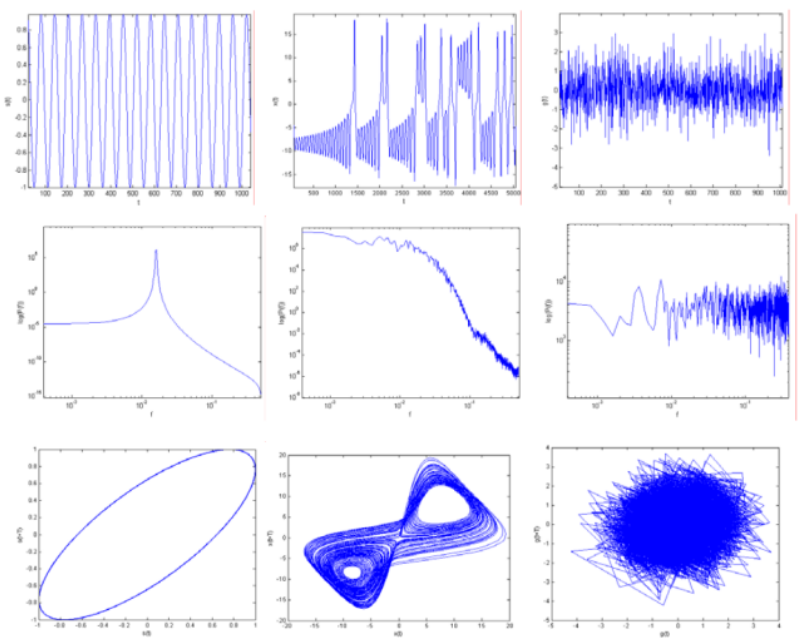

Figure 4: Periodic (Sinusoidal) (A), Chaotic (Lorenz) (B) And Noise (Random) (C) Power Spectra And Phase Of The Signal Takes In Space. Each Column from Top to Bottom, In the Form of Time Series Signal Shows Pulls the Signal Power Spectral Density and Two-Dimensional Phase Space

Analysis for Detecting the Presence of Chaos

Chaotic systems can often be expressed mathematically in two ways: 
i. For continuous systems with discrete differential or difference equations systems,

ii. with experimental data in cases where the equations are unknown.

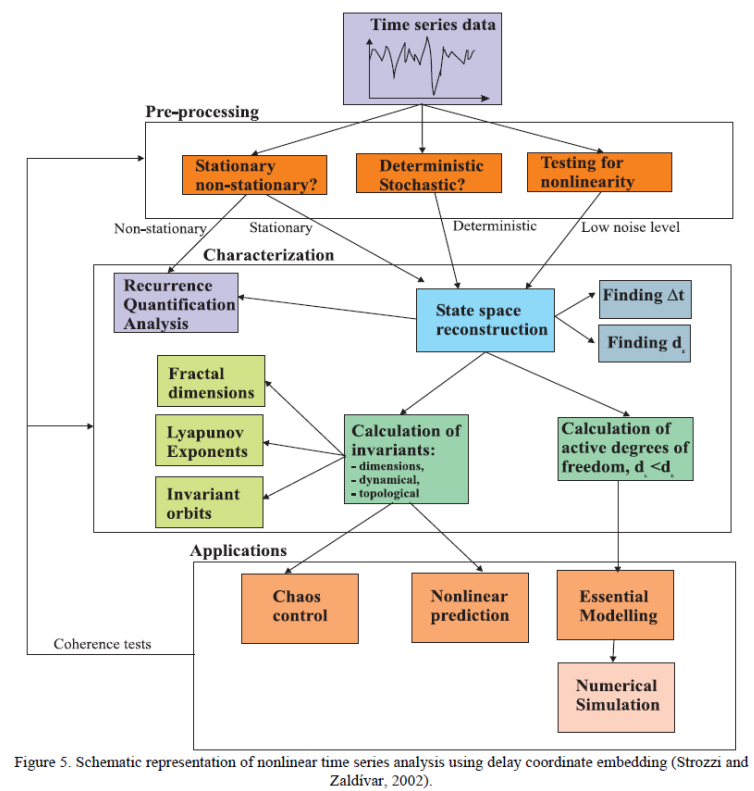

Figure 5: Schematic Representation of Nonlinear Time Series Analysis Using Coordinate Embedding (Strozzi and Zaldivar, 2002)

\section{Mutual information method}

Fraser and Swinney (1986) and Abarbanel (1996)'s proposed mutual information procedure (mutual information) is a method for measuring the information contained on each of the two time series. Here is a time line and used his delayed state. If these two series are independent of each other, mutual information value is zero.

\section{2- Embedded size}

When you start analyzing a time series can be represented in many dimensions of this series it is known as geometric and how to select the delay time. Embedded Takens Theorem (embedding theory) allows a time delay of raw data and the data of the series; she is able to determine the topological structure of a dynamic system. Embedded theorem guarantees us $\mathrm{m}$ in size in the corresponding system of the second vector [Kantz and Schreiber, 2004]. So M in size two points are very close together, $\mathrm{m}$ becomes visible in a space with larger values.

False Nearest Neighbourhood method (FNN) is an often provided by Kennel et al. (1992) a method for commonly used.

\section{Lyapunov Exponents}

The reason why chaotic systems shows non-periodic dynamics, in almost the same initial conditions of each of the phase space have different curves are exponential rate of increase. This condition is called sensitive to initial conditions. Lyapunov Exponent $\lambda$, gives a measure of sensitivity to initial conditions and phase separation is defined as the average of the local extent of the adjacent curve in space. If $\lambda$ negative different initial conditions tend to give the same output value and therefore development is not chaotic. If $\lambda$ is positive data to different output values for different initial values so it means it is a chaotic movement.

\section{Fractal Dimensions}

Fractal geometry is a term introduced by Mandelbrot in the scientific literature. Mandelbrot examined the structural integrity of natural object. At one point, a line, respectively mathematical objects such as a square or a cube zero, one, two or three-dimensional objects are known. Geometric structure of the total size gives us information about the number of objects.

\section{Detecting of Nonlinearity}

Time series of physiological, biological, created with the information obtained from real life such as mechanical systems. These periodic signals, semi-periodic, chaotic or random or be revealed to the computations described above is not entirely consist of noise, but this is a difficult process. A chaotic system is a system of low-dimensional linear and non-linearity is a necessary condition for the detection of chaos. Therefore, various methods have been developed to detect the data of the nonlinearity.

Brock, Dechert and Scheinkman (1987), an independent distribution VmT(I) similar to the true statistical measure of the departure (s) have derived normalization factor. This normalization factor is the integral of complex correlation factors of different sizes. Here utilizing BDS statistics obtained are shown as follows: 


$$
W_{m}^{T}(l)=\sqrt{T} \frac{\left[C_{m}^{T}(l)-\left[C_{m}^{T}(l)\right]^{m}\right]}{V_{m}^{T}(l)}
$$

Here, when is $\mathrm{T} \rightarrow \infty, l>0$ ve $m>1$ Under the hypotheses space for distribution $\mathrm{N}(0,1)$ converges to the distribution [Amilo and Byström, 1998]. The rejection of the null hypothesis testing procedure done here, due to the fact that with a lack of any information on The reasons for not accepting the test has trouble. In contrast, the BDS of the test's lack of distribution test with independent identical distributed errors are estimated from the general part of the parametric model that affected the implementation of the longer Brock Potter and also is shown by Lima is another factor that makes the test advantageous [Brock and Potter, 1993].

\section{Correlation integral}

Definitions of different sizes to show the complexity of dynamic systems are available. It is most commonly used in practice correlation dimension (correlation dimensions). Two reasons are indicated generally in the choice of the correlation dimension. First, similar size, attractive compared to other dimensions such as mutual information size is the scale of research in fine detail. The second reason, correlation is easier than the integration of other dimensions and can be calculated quickly [Öztürk, 2008].

\section{Application}

As can be observed, BIST-100 Return in econometric time-series break and high frequencies generated by the explosion is considered as an example of inconsistent behavior on a linear model is normally distributed.

The reason for this non-linear models, both stochastic, as well as the ability to explain this kind of behavior, which may be deterministic. On the other hand, a chaotic process, proper identification of deterministic and also completely random behavior that is impossible. Hence chaotic systems are also explained by the non-linear model. Deterministic randomness of the system and can be produced in the model, it is very important for the chaotic patterns different from the general situation in the economy.

In the study, the chaotic structure of the mutual information method for the detection, correlation integral, BDS test, Teraesvirt Neural Network Test, White Neural Network Test, and finally, Lyapunov Exponent which may be conclusive evidence of the existence of chaotic structure will be used.

To determine the structure of chaotic, would reveal the true nature of the system to be small when the frequency of the data set Kayseri / hours of data taken from the transformer in Turkey was preferred. According to this study, Kayseri / withdrawn from the transformer in Turkey hourly data collected from 1357 hours of observation values were used.

In practice, a lot of chaos for Data Analysis 5.1 (Visual Recurrence Analysis) program has benefited from the package and R Studio belonging fnonline and tserieschaos package.

\section{LEVEL MARKETS HYPOTHESIS}

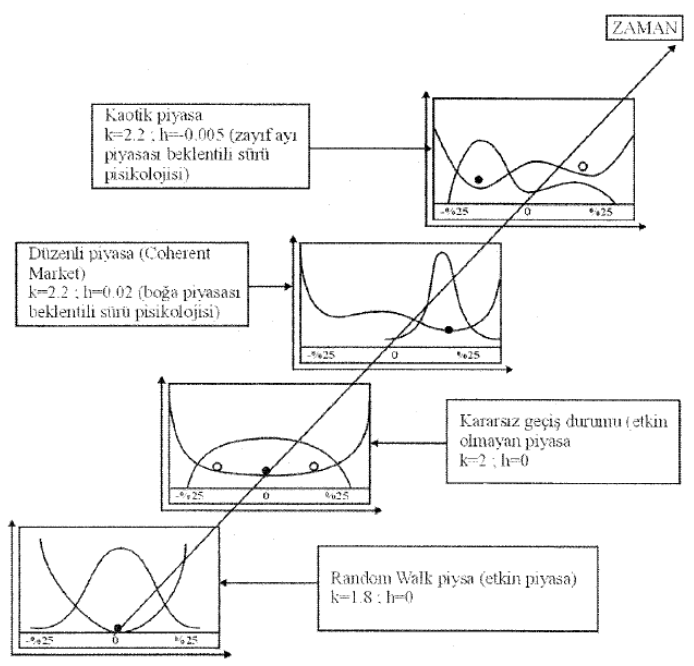

Figure 6: The Graph on The Horizontal Axis S All Returns, Vertical Axis Shows The Probability of Return. Source: Erdinç, Yaşar; Borsada Analiz, Siyasal Kitabevi, Ankara, 1998, S.65. 


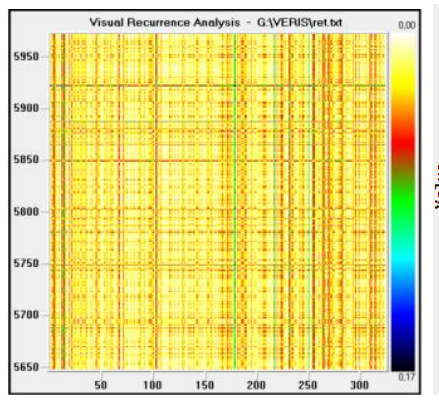

Figure 7: Visual Recurrence Analysis

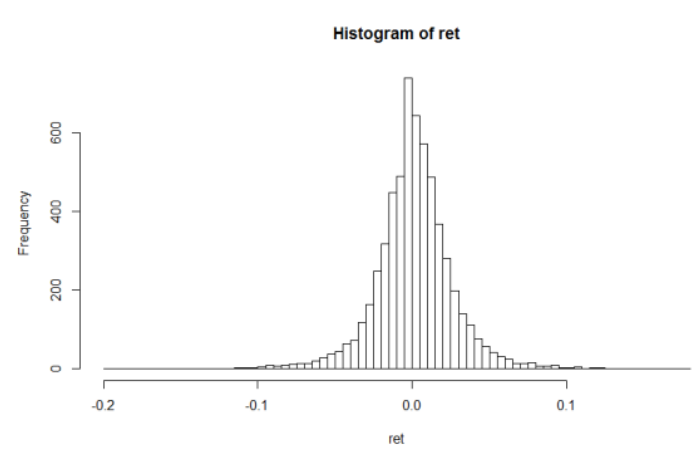

Figure 9: Histogram of Return

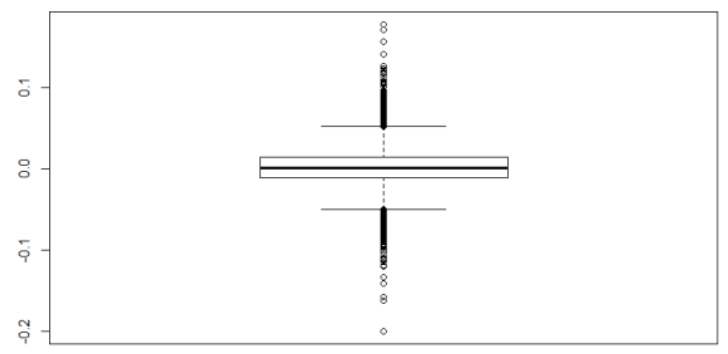

Figure 11: Distribution of Return

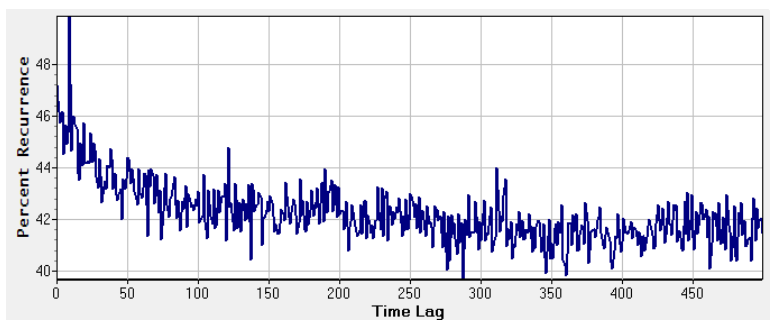

Figure 13: Percent Recurrence

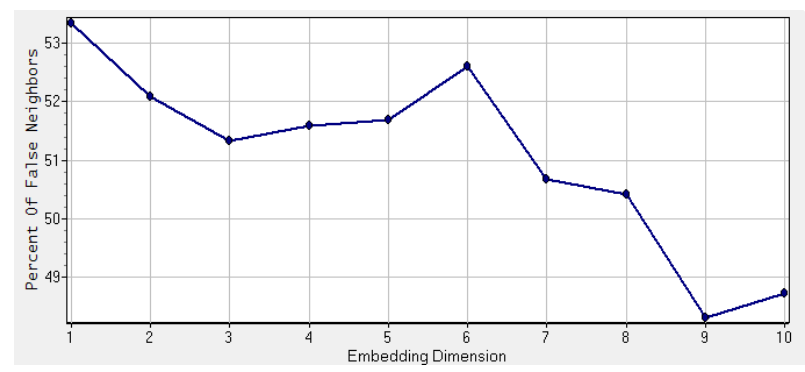

Figure 15: False Neighbours
Figure 8: Analysis of Return

Correlogram for RET

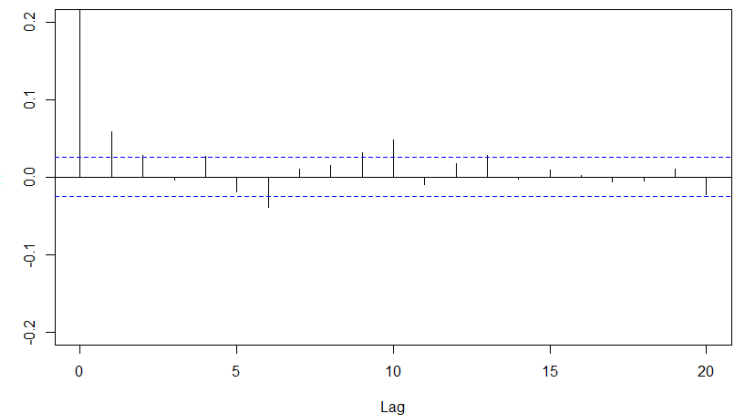

Figure 10: Correlogramı of Return

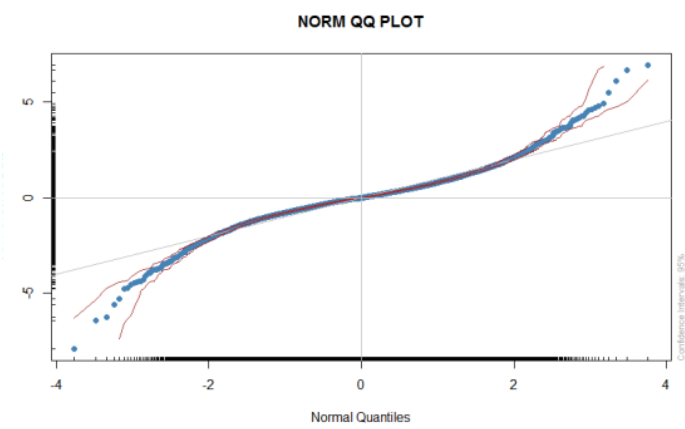

Figure 12: $Q Q$ Plot of Return

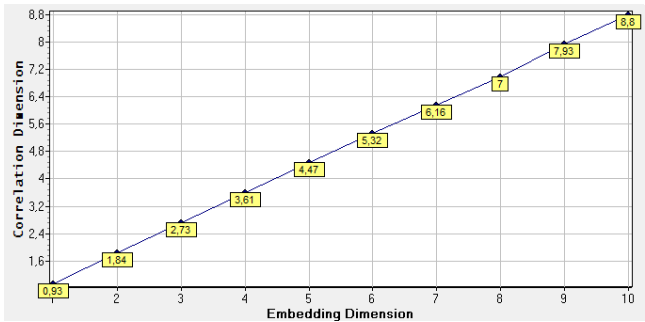

Figure 14: Embebed Dimension

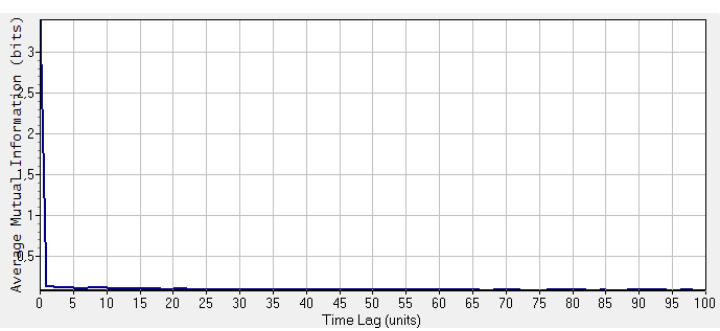

Figure 16: Mutal Information 


\begin{tabular}{|l|l|l|}
\hline BDS Test & $\begin{array}{l}\text { STATISTIC: } \\
\text { eps[1] } \mathrm{m}=2: 16.1014\end{array}$ & $\begin{array}{l}\text { P VALUE: } \\
\text { eps[1] } \mathrm{m}=2:<2.2 \mathrm{e}-16\end{array}$ \\
Test Results: & eps[1] $\mathrm{m}=3: 23.3923$ & eps[1] $\mathrm{m}=3:<2.2 \mathrm{e}-16$ \\
PARAMETER: & eps[2] $\mathrm{m}=2: 18.4324$ & eps[2] $\mathrm{m}=2:<2.2 \mathrm{e}-16$ \\
Max Embedding Dimension: 3 & eps[2] $\mathrm{m}=3: 25.4771$ & eps[2] $\mathrm{m}=3:<2.2 \mathrm{e}-16$ \\
eps[1]: 0.013 & eps[3] $\mathrm{m}=2: 19.5218$ & eps[3] $\mathrm{m}=2:<2.2 \mathrm{e}-16$ \\
eps[2]: 0.025 & eps[3] $\mathrm{m}=3: 25.4946$ & eps[3] $\mathrm{m}=3:<2.2 \mathrm{e}-16$ \\
eps[3]: 0.038 & eps[4] $\mathrm{m}=2: 20.097$ & eps[4] $\mathrm{m}=2:<2.2 \mathrm{e}-16$ \\
eps[4]: 0.051 & eps[4] $\mathrm{m}=3: 24.7045$ & eps[4] $\mathrm{m}=3:<2.2 \mathrm{e}-16$ \\
& & \\
\hline
\end{tabular}

Table 1: BDS Test

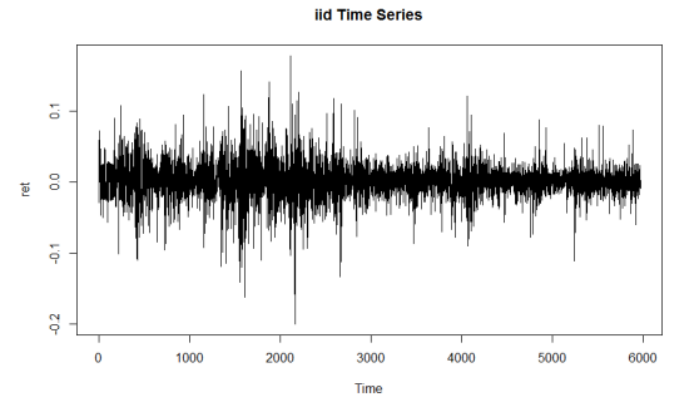

Figure 17: iid Time Series

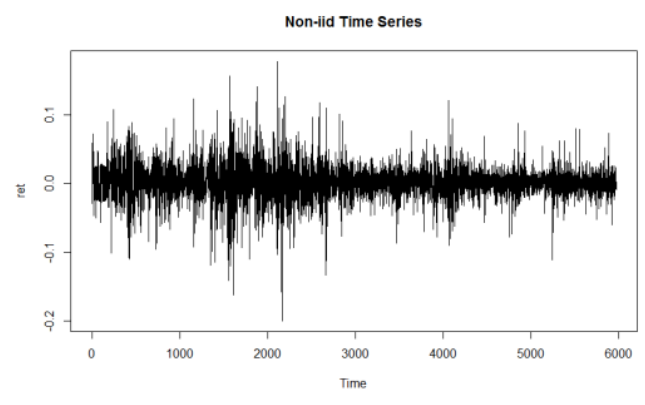

Figure 18: non iid Time Series

\begin{tabular}{|l|l|}
\hline Teraesvirta Neural Network Test & White Neural Network Test \\
Test Results: & Test Results: \\
PARAMETER: & PARAMETER: \\
lag: 1 & lag: 1 \\
m|df: 2 & q: 10 \\
t-lag-m|df: 5969 & range: 4 \\
STATISTIC: & qstar|df: 2 \\
Chi-squared: 28.3039 & t-lag-qstar|df: 5969 \\
F: 14.1784 & STATISTIC: \\
P VALUE: & Chi-squared: 28.2216 \\
Chi-squared: $7.143 \mathrm{e}-07$ & F: 14.1371 \\
F: $7.194 \mathrm{e}-07$ & P VALUE: \\
& Chi-squared: $7.443 \mathrm{e}-07$ \\
& F: $7.496 \mathrm{e}-07$ \\
\hline
\end{tabular}

Table 2: Neural Network Tests

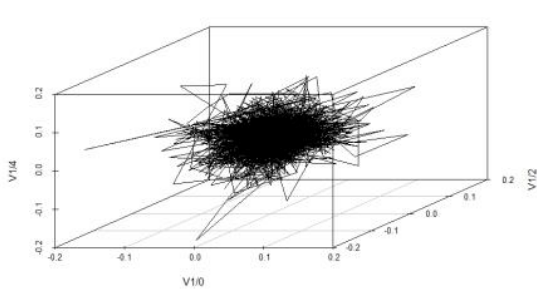

Figure 19: 3D Phase Space

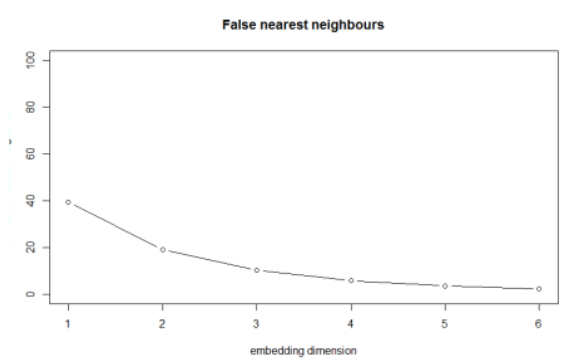

Figure 20: False Nearest Neighbours 


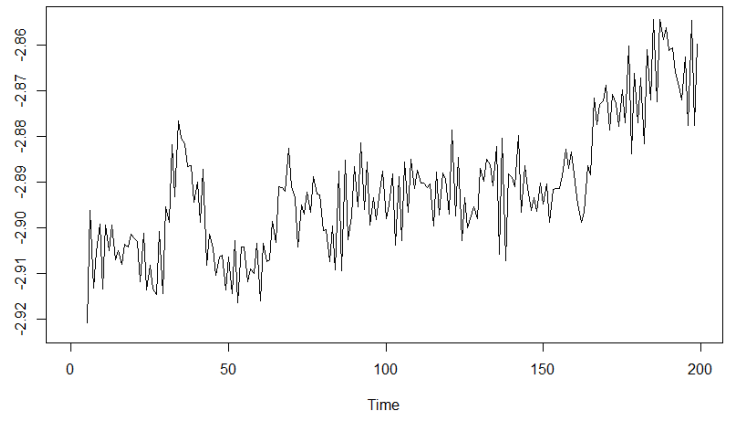

Figure 21: Space-Time Plot

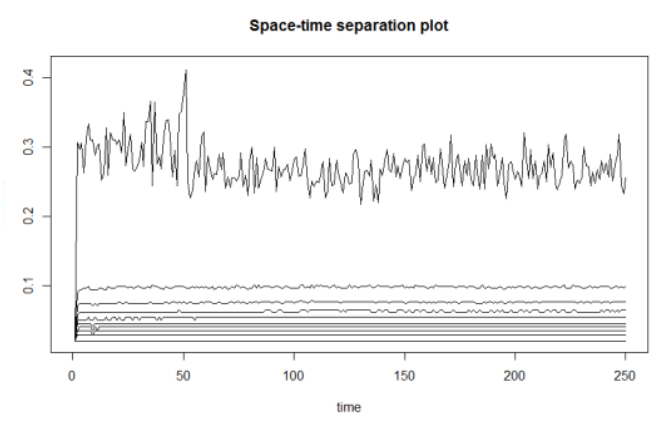

Figure 22: Space-Time Separation Plot

\section{Result}

All the tests and outcomes lends support to the chaos. So Istanbul is not possible to give the bridge crossing linear modeling. Relations can only be investigated by nonlinear equations.

Linear chaotic prediction will be as follows. Model is not possible to make predictions about spikes.

Forecasting the BIST-100 is still one of the big challenges facing financial engineers and econometricians. For the past two decades, many models have been developed to identify the data generating process of the financial econometrics and to produce more accurate forecasts.

Advances in the computing technology have enabled econometricians to develop and to work with nonlinear and complex models with intensive computations more easily. These models seem to be more suitable for estimation and, in particular, forecasting very complex series such as the BIST-100.

In this paper, we examined the statistical features of the BIST-100 return series, using the daily data. The traditional view is that the demand variations can be explained by a trend, history, stochastic factors, or a combination of them.

However, if the data generating process of the return is chaotic, the traditional modeling for estimation and forecasting would be misleading. To shed more lights on the underlying data generating process of the return, we carried out various tests for deterministic chaos. The tests included correlation dimension, BDS, ANN, WNN and Lypunov Exponent. Give the restrictions of the tests, and the fact that each test is developed based on certain characteristics of the chaotic process, the results obtained from them individually cannot be conclusive. Therefore, applying all available tests and comparing the results would allow us to get more robust results.

For this reason, alternative estimation methods as kernel regression and we were to use the Nearest Neighbour Estimate results will be as follows.

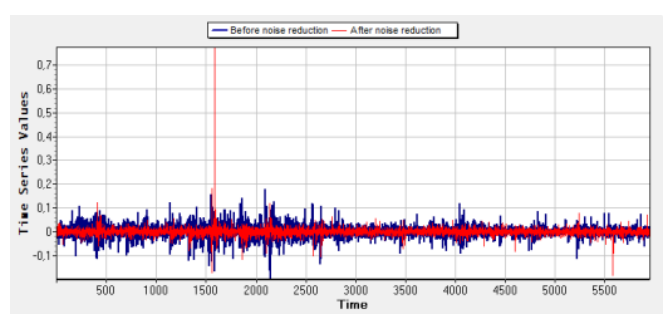

Figure 23: Error Reduction Plot

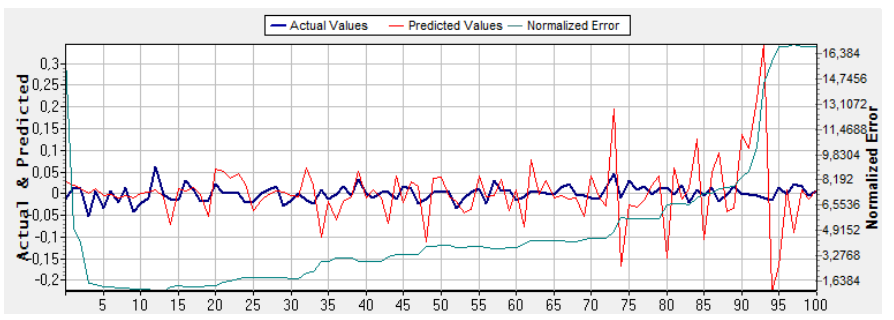

Figure 24: Chaotic Estimation Plot

\section{References}

- $\quad$ Akay, M., Nonlinear Biomedical Signal Processing, Dynamic Analysis and Modelling, Volume II, IEEE Pres, 2000.

- $\quad$ Aktaş, H., \& Kozoğlu, M. ,"Haftanın Günleri Etkisinin İstanbul Menkul Kıymetler Borsası'nda GARCH Modeli ile Test Edilmesi”, Finans Politik \& Ekonomik Yorumlar , 37-45 (2007).

- $\quad$ and Strange Attractors", Physica D, Cilt 8, 435- 444, 1983.

- Awrejcewicz, J., Dzyubak, L. ve Grebogi, C., “A Direct Numerical Method for Quantifying Regular and Chaotic Orbits", Chaos, Solitons and Fractals, Cilt 19, No 3, 503-507, 2004.

- $\quad$ Barnett, W. A. ,"Martingales, Nonlinearity and Chaos",Department of Economics, Campus Box(1998).

- Brock, W., \& Potter, S. ,"Nonlinear Time Series and Macroeconometrics",Handbook of Statistics, 195-229 (1993). 
- Brock, W., Dechert, W., \& Scheinkmann, J. ,"A Test for Independence based on the Correlation Dimension",Wisconsin Madison - Social Systems(1987).

- $\quad$ Brock, W., Lakonishok, J., \& LeBaron, B. ,"Simple Technical Trading Rules and the Stochastic Properties of Stock Returns", The Journal of Finance, 1731-1764 (1992).

- Brock, William A. Is the business cycle characterized by deterministic chaos? Journal of monetary economics 22 (1988) 71-90

- Cao, L., "Practical Method for Determinig the Minimum Embedding Dimension of a Scalar Time Series", Physica D, Cilt 110, No 1, 43-50, 1997.

- Derya Yılmaz, Nihal Fatma Güler; Kaotik Zaman Serisinin Analizi Üzerine Bir Araştırma; Gazi Üniv. Müh. Mim. Fak. Dergisi ; Cilt 21, No 4, 759-779, 2006

- $\quad$ Erdinç, Yaşar; Borsada Analiz, Siyasal Kitabevi, Ankara, 1998, s.65.

- Fernanda Strozzi, Eugénio Gutiérrez Tenrreiro, Carlo Noè, Tommaso Rossi, Massimiliano

- Frrat, U., "Kaotik Zaman Serilerinin Yapay Sinir Ağlarıyla Kestirimi: Deprem Verisi Durumu", Yüksek Lisans Tezi, Yıldız Teknik ÜniversitesiFen Bilimleri Enstitüsü Elektronik ve Haberlesme Anabilim Dalı, İstanbul (2006).

- Grassberger, P., \& Procaccia, I. ,"Characerization of Strange Attractors",Physical Review Letters, 346-349 (1983).

- Hentschel, H.G.E. ve Procaccia, I., "The Infinite Number of Generalized Dimensions of Fractals

- $\quad$ Kalra, S. ,"Global Volatility and Forex Returns in East Asia",IMF Working Paper, 08/208 (2008).

- Kantz, H., \& Schreiber, T. ,"Nonlinear Time Series Analysis",United Kingdom: Cambridge University Press (2004).

- $\quad$ Kasap, P., \& Kurt, D. ,"Karmaşanın Bilimi Kaos",Nobel Yayınevi , Ankara (2011).

- Kennel, M., Brown, R., \& Abarbanel, H. ,"Determining Embedding Dimension for Phase-Space Reconstruction Using a Geometrical Construction",Physics Review, 340-353 (1992).

- Kennel, M.B., Brown R. ve Abarbanel H.D.I., "Determining Embedding Dimension for Phase- Space Reconstruction Using a GeometricalConstruction”, Phys. Rev. A, Cilt 45, 3403-3411, 1992.

- Mandelbrot, B.B., Fractals: Form, chance, and dimension, W.H. Freeman, San Francisco, 1997.

- $\quad$ Öztürk, A. ,"Doppler İşaretlerinin Kaotik Ölçütlerle Sınıflandırılması",Doktora Tezi,Selçuk Üniversitesi Fen Bilimleri Enstitüsü Elektrik-Elektronik Mühendisliği Anabilim Dalı, Konya (2008).

- Özün, Alper; "Kaos Teorisi, Hisse Senedi Getirilerindeki Doğrusal Olmayan Davranışlar, Zayıf İşlem ve GelişenPiyasalarda Piyasa Etkinliği: İMKB Örneği" Y1l.:3, Sayı:9, Ocak/Şubat/Mart 1999.

- Perron, P. (1989), The great crash, the oil price shocks and unit root hypothesis Econometrica 57 1361-1401

- Pindyck, Robert. (1999), The Long-Run Evolution of Energy Prices the Energy Journal, Vol.20, and No.2

- Saeed Moshiri, Testing for deterministic chaos in futures crude oil price;Does neural network lead to better forecast?, May 2004, University of Allameh Tabatabaie

- Selçuk Kendirli, Portföy Yönetiminde Kaos Teoremi; Journal of İstanbul Kültür University 2006/2 pp. 171 180

- Serati, José-Manuel Zaldívar Comenges; Applicatıon Of Non-Linear Time Series Analysis Techniques To The Nordic Spot Electricity Market Data; Liuc Papers N. 200, Serie Tecnologia 11, Marzo 2007

- $\quad$ Sprott, J.C., Chaos and Time-Series Analysis, Oxford University Pres, 2003.

- Strozzi, F., Zaldívar, J. M., \& Zbilut, J. P. 2002. Application of nonlinear time series analysis techniques to high frequency currency exchange data, Physica A 312, 520-538.

- Şahika Gökmen, Zaman Serilerinde Kaos Ve Forex Üzerine Uygulama, Yüksek Lisans Tezi, Gazi Üniversitesi Fen Bilimleri Enstitüsü, 2012

- Tosun, T. ,"Türev Araçlar, Kaos Teorisi ve Fraktal Yapıların Vadeli İșlem Zaman Serilerinde Uygulanması",Yüksek Lisans Tezi,T.C. Marmara Üniversitesi Bankacılık ve Sigortacılık Enstitüsü Sermaye Piyasası ve Borsa , İstanbul (2006).

- Vaga, Tonis; Profiting From Chaos, McGraw Hill, New York, 1994, s.21.

- Yalamova, R., Qi, L., Wang, L., Chen, Y., Mathews, S., \& Gong, G. ,"Detecting Chaos in Financial Time Series", Tech. Print (2006).

- Yu, D., Lu, W. ve Harrison, R.G., "Detecting Dynamical Nonstationarity in Time Series Data”, Chaos, Cilt 9, No 4, 1999. 


\title{
The Financial Risk Evaluation in Turkish Banking System
}

\author{
Asst. Prof. Dr. Semin Paksoy (Çukurova University, Turkey) \\ Ph.D. Candidate Mehmet Fatih Traş (Çukurova University, Turkey)
}

\begin{abstract}
Banking activities exhibit highly dynamic and evolving feature in recent years. Healthy financial position of the banks therefore gains importance in assuring well being of all economic agents in a country. Because of banks' key role in financial markets and real economy, banking failures or inefficient performances may have profound effects on the whole economy. For this reason, it is important to monitor the bank ratios as a strength indicator. Therefore, this paper aims to investigate financial position of the banks in Turkey. To this end, we select particular 29 ratios of the present day banks which are matching the ratios of previously failed banks between the periods 1997-2003. Therefore, we construct a data set by which the banks can be categorized into two groups, namely failed and non-failed banks. Data covering the period 1996-2014 extracted from Banking Regulation and Supervision Agency.

In the first place, we perform ANOVA test to evaluate the most relevant ratios for bank failure. The ANOVA test results reveal that 13 of 29 ratios are not significant. The remaining ratios are used to implement factor analysis in order to categorize ratios and calculate factor scores. Lastly, we estimate a Probit regression model to determine conditional probability of failure for a given bank. Our results show that financial position of the banks exhibits substantial variations in Turkey. Furthermore, given the data set and methods employed, most of the banks have a robust financial position and are unlikely to fail.
\end{abstract}

\section{Introduction}

Nowadays, financial markets are closely linked to each other in the world and therefore the economic crisis occurring in a country can be detected by any other country and can trigger other financial markets in very fast and quick way. Some authors, such as Honohan and Klingebiel (2003) have studied to explain the causes of the crisis and how it spread. Their analysis has concluded that some factors of the global crises are familiar with the past crisis while the others are not. A major common feature of the banking crisis is the higher fiscal costs arising from boosting programs, using public funds. Some other authors have introduced that governments' outlays for support programs have been about $12.8 \%$ of national GDP to cover the losses. In developing countries, these expenses have reached to $14.3 \%$ of GDP. The extreme percentage in their detailed investigation of crisis history is highlighted as 40-55\% of GDP in early 1980s crises in Argentina and Chile (Caprio and Klingebiel, 2002).

Banks, having the important place in the financial market is directly affected from the crisis of today's integrated market. The greatest bank failures occurred in Turkey during the period 1997-2003. During this period, 22 of Turkish banks failed because of the great effects of the outsourcing crisis such as 1997 Asian financial crisis, 1998 Russian financial crisis and 2001 financial crisis. Although the later crisis, such as 2008 global financial crisis have also affected the Turkish economy, there has not been announced any bankruptcy. Many critics argue that Turkey has the ability to withstand the economic crises due to implementing necessary legal and institutional reforms following the liberalization of the Turkish economy in the early 1980's. As a matter of fact, Turkey has been transforming into a market economy since the $1970 \mathrm{~s}$. However, a certain degree of government intervention still existed within the economy. This intervention came in the form of the government's influence over the Central Bank's decisions and its ownership of banks (Chen et.al. 2014) since private depts have come public depts after the crisis (Reinhart and Rogoff, 2010).

Of course, government intervention in terms of support programs have been put regulations into practice to prevent effects of crisis or to restore and enforce banks' performances. These programs include various types of resolution policies; mergers of banks, sales to local/ foreign investments or recapitalization. The cost of support programs have led to displeasure among the taxpayers and economists since there is no optimal resolution mechanism of banking crisis (Contessi and El-Ghazaly, 2011). Therefore it is the most important to analyze and monitor the performance of banks regularly. Monitoring the performance and especially taking necessary steps toward the success have provided the ability in forestalling future crises.

In the literature, several recent studies have investigated various parameters of banking crisis. Papi et.al (2015) has discussed triggers of banking crises considering three indexes of the countries. They are the index of country risk which is for political, financial and economic riskiness, the index of access to sound money which measures the growth rates of money supply and inflation, and the freedom to own foreign currency bank accounts domestically and abroad, and the polity score which ranks governing institutions from autocratic to democratic. Their results show that the access to sound money is an element which mitigates the vulnerability of the banking system to systemic crises.

Reinhart and Rogoff (2011) have investigated what constitutes of a financial crisis and which methods can be used to determine the date of beginning and the end the possible crises, depending on the historical huge data. 
Further, the probability of banking crisis does not differ significantly according to the institutional and policy setup and to the institutionalized democratic regime. On the other side, Claessens et.al (2005) introduced that crisis management policies can affect the magnitude and cost of the crisis. Similarly, Honohan and Klingebiel (2003) introduced that financially strong banks will probably have lower intervention and thereby efficient crisis management have led to lower fiscal cost in the presence of crises.

This paper has two purposes. In the first place, we investigate the financial conditions of the banks operating in Turkey since the period 2001-2003 where a large number of bankrupts were witnessed. Secondly, we aim to scrutinize whether banks were affected by 2008 financial crisis.

The reminder of this study is organized as follows. In the second chapter we summary the methodology and data used. In the third chapter we present our empirical findings, and in the fourth chapter, we conclude.

\section{Methodology}

\subsection{The Sample and Variable Selection}

The sample set of the study covers financial ratios of Turkish deposit banks for the periods 1996-2014 with the exception of 2001 since Turkey was of economic and financial crises in 2001 in which ratios are not published.

There are 49 deposit banks in this study. Twenty-seven of them are current banks three of which are state-owned deposit banks, eleven of which are privately owned banks and thirteen of which are foreign banks entering the Turkish banking sector. In the periods 1996-2003, 22 of 49 deposit banks that were takeover by the Savings Deposit Insurance Fund of Turkey are classified as failed banks, while remaining banks, operating in banking sector after the 2003 are classified as non failed banks. When the whole data is considered for the specified periods 19962014 , failure or non failure state of each bank is described to categorize them into two classes. The failure state is organized as 1 to represent the failure of the banks in one category and as 0 as to represent the other category which is non failure. Failed banks, listed in Table 2 are described according to the declaration of bankruptcy year; one year earlier, two year earlier and three year earlier from the bankruptcy year The failure states for other years of failed banks' and other banks' are organized as 0 to be considered non failed. The system used in the categorization of banks is based on the study of Canbaş et. al.(2005).

\begin{tabular}{|c|c|c|c|}
\hline No & Failed Banks & $\begin{array}{l}\text { Date of Transferred } \\
\text { Funds }\end{array}$ & $\begin{array}{l}\text { Selected Years for Failure } \\
\text { State }\end{array}$ \\
\hline 1 & Türk Ticaret Bankası A.Ş. & November 1997 & 1996,1997 \\
\hline 2 & Bank Ekspres A.Ş & December 1998 & 1997, 1998 \\
\hline 3 & Interbank & January 1999 & $1996,1997,1998,1999$ \\
\hline 4 & Sümerbank A.Ş & December 1999 & $1996,1997,1998,1999$ \\
\hline 5 & $\begin{array}{l}\text { Tütüncüler Failed Banks Bankası } \\
\text { Yaşarbank A.Ş. }\end{array}$ & December 1999 & $1996,1997,1998,1999$ \\
\hline 6 & Yurt Ticaret ve Kredi Bankası A.Ş. & December 1999 & $1996,1997,1998,1999$ \\
\hline 7 & Egebank A.Ş. & December 1999 & $1996,1997,1998,1999$ \\
\hline 8 & Eskişehir Bankası T.A.Ş. & December 1999 & $1996,1997,1998,1999$ \\
\hline 9 & Bank Kapital Türk A.Ş & October 2000 & $1997,1998,1999,2000$ \\
\hline 10 & Etibank A.Ş. & October 2000 & $1997,1998,1999,2000$ \\
\hline 11 & Demirbank T.A.Ş. & December 2000 & $1997,1998,1999,2000$ \\
\hline 12 & Ulusal Bank & February 2001 & $1998,1999,2000^{*}$ \\
\hline 13 & İktisat Bankası T.A.Ş. & March 2001 & $1998,1999,2000^{*}$ \\
\hline 14 & Bayındırbank A.Ş & July 2001 & $1998,1999,2000^{*}$ \\
\hline 15 & Ege Giyim Sanayicileri Bankası A.Ş. & July 2001 & $1998,1999,2000^{*}$ \\
\hline 16 & Kentbank A.Ş. & July 2001 & $1998,1999,2000^{*}$ \\
\hline 17 & Sitebank A.Ş & July 2001 & $1998,1999,2000^{*}$ \\
\hline 18 & Milli Aydın Bankası T.A.Ş. & July 2001 & $1998,1999,2000^{*}$ \\
\hline 19 & Emlakbank & July 2001 & $1998,1999,2000^{*}$ \\
\hline 20 & Toprakbank A.Ş & November 2001 & $1998,1999,2000^{*}$ \\
\hline 21 & Pamukbank T.A.Ş & June 2002 & $1999,2000,2002 *$ \\
\hline 22 & Türkiye İmar Bankası T.A.Ş. & July 2003 & $1999,2000,2002 *$ \\
\hline
\end{tabular}

Selected years are with the exclusion of 2001 since there is missing values for common ratios. Source: Lopcu and K1lıç, 2012 
The number of published financial ratios for the banks operating in the Turkish banking sector, during the period 1996-2000 is only 49 (K1lıç,2006) while there are presently 66 ratios. Among them, only 29 ratios of Turkish deposit banks are common for comparison. Selected ratios for this study are listed in Table 2 . All the branch and activity ratios in current TL are converted to new Turkish Lira (TRY). Furthermore, all monetary variables are expressed in real terms using 2003 based producer price index (PPI).

\begin{tabular}{|c|c|c|c|}
\hline Code & Ratio Categories and Names & Code & Ratio Categories and Names \\
\hline & Assets Quality, \% & $\mathrm{R} 15$ & Total Loans \\
\hline R1 & \multirow{3}{*}{$\begin{array}{l}\text { Total Loans/Total Assets } \\
\text { Non Performing Loans/Total Loans } \\
\text { Permanent Assets/Total Assets }\end{array}$} & $\mathrm{R} 16$ & Total Deposits \\
\hline $\mathrm{R} 2$ & & & Share in Group, \% \\
\hline \multirow[t]{2}{*}{$\mathrm{R} 3$} & & R17 & Total Assets \\
\hline & Liquidity, \% & $\mathrm{R} 18$ & Total Loans \\
\hline R4 & \multirow{3}{*}{$\begin{array}{l}\text { Liquid Assets/Total Assets } \\
\text { Liq.Assets/(Deposits+Non-deposit Funds) } \\
\text { Foreign Ex.Liq.Assets/ForeignEx.Liabilities }\end{array}$} & R19 & Total Deposits \\
\hline R5 & & & Branch Ratios, Million TRY* \\
\hline \multirow[t]{2}{*}{ R6 } & & R20 & Total Assets / No. of Branches \\
\hline & Profitability, $\%$ & $\mathrm{R} 21$ & Total Deposits / No. of Branches \\
\hline R7 & Net Income(Loss)/Average T.Assets & $\mathrm{R} 22$ & TL Deposits / No. of Branches \\
\hline R8 & Net Income(Loss)/Shareholder's Equity & $\mathrm{R} 23$ & Fx Deposits / No. of Branches \\
\hline \multirow[t]{2}{*}{ R9 } & Income Before Tax / Average Total Assets & $\mathrm{R} 24$ & No. of Personnel / No. of Branches \\
\hline & Income-Expenditure Structure, \% & $\mathrm{R} 25$ & Total Loans / No. of Branches \\
\hline R10 & Interest Income/ Total Income & $\mathrm{R} 26$ & $\begin{array}{l}\text { Net Income / No. of Branches Activity } \\
\text { Ratios }\end{array}$ \\
\hline R11 & Interest Income/Interest Expenses & $\mathrm{R} 27$ & $\begin{array}{l}\text { (Salary and Emp'ee Bene. }+ \text { Res. for } \\
\text { Retire.)/No.of Pers.(Billion TL**) }\end{array}$ \\
\hline $\mathrm{R} 12$ & Non-Interest Income/Non-Interest Expenses & $\mathrm{R} 28$ & $\begin{array}{l}\text { Reserve for Seniority } \text { Pay/No.of } \\
\text { Personnel (Billion TL) }\end{array}$ \\
\hline \multirow[t]{2}{*}{$\mathrm{R} 13$} & Total Income/Total Expenditure & R29 & $\begin{array}{l}\text { (Salaries and Emp'ee Benefits }+ \\
\text { Reserve for Retirement)/T.Assets }\end{array}$ \\
\hline & Share in Sector, \% & & \\
\hline R14 & Total Assets & & \\
\hline
\end{tabular}

Table 2. Ratios

\subsection{Probit Model}

A probit model is a type of regression where the dependent variable can only take two values such as bank failure or non failure, and thereby, the probit model is a type of binary classification model. The purpose of the model for binary response variable is to estimate the probability that an observation with particular characteristics will fall into a specific one of the categories. This is reasonable to assume that there is a threshold level. The estimated probabilities greater than 0,5 are treated as classifying an observation into a predicted category.

The main assumption of the binary Probit regression model is that the response function $Y_{i}$ must be in the form of linear regression functions as following equations (1) and (2),

$$
\begin{array}{cl}
Y_{i}=\alpha+\beta X_{i}+\varepsilon_{i} & \\
\text { If } \alpha+\beta X_{i}+\varepsilon_{i}>0, & Y_{i}=1 \text { means bank failure occurs } \\
\text { Otherwise, } & Y_{i}=0 \text { means non failure }
\end{array}
$$

and $Y_{i}$ follows the Bernoulli probability distribution. The use of the least-squares estimator in linear regression in equation (1) is justified by the Gauss-Markov theorem, which does not assume that the distribution is normal. According to the Gauss-Markov theorem, the errors, in a linear regression model have expectation zero and are uncorrelated and have equal variances. The errors $\varepsilon_{i}$ do not need to be normal, nor do they need to be independent and identically distributed. $\varepsilon_{i}$ is also take two values, like $Y_{i}$ (Gujarati, 2003). However, from the perspective of generalized linear models, it is useful to suppose that the distribution function is the normal distribution with constant variance and the link function is the identity, which is the canonical link if the variance is known. Probit model, which employs a probit link function, is most often estimated using the standard maximum likelihood procedure.

The estimating model that emerges from normal cumulative distribution function (CDF) can known as probit model and can be used for the link since the CDF's range is $[0,1]$. $\Phi$ is inverse of the normal CDF $F_{x}: R \rightarrow[0,1]$ of a random variable $\mathrm{x}$ and named as quantile function. CDF $F_{x}$ gives the $\mathrm{p}$ value as a function independent value 
$\mathrm{x}$. The quantile function $\Phi$ in equations (3) and (4) does the opposite, and returns a threshold (minimum) value of $\mathrm{p}$ from among the all values whose CDF exceeds probability $\mathrm{p}$.

$$
\begin{aligned}
& \Phi=\mathrm{F}^{-1} \\
& \Phi(\mathrm{p})=\inf \{x \in R: p \leq F(x)\}
\end{aligned}
$$

In the equation (4), the inf (infimum) function can be replaced by the minimum function. The function $\Phi$ is a popular choice and yields the probit model. For the binary response data $Y_{i}$, the distribution function is generally chosen to be the Bernoulli distribution and the probability, $p$, of $Y_{i}$ taking on the value one. So, for the normal standard variable $\mathrm{z}, \Phi(\mathrm{z})$ is standardized normal CDF and $\Phi(\mathrm{z})=\mathrm{P}(\mathrm{Z} \leq \mathrm{z})$. Then utility index I and threshold of the utility index $I^{*}$ is computed in equation (5). The probability of $I_{i}^{*}$ is less than or equal to $I_{i}$ can be computed from the inverse of the standardized normal CDF $\Phi$ using following equations (6) and (7) (Gujarati, 2003).

$$
\begin{aligned}
& \mathrm{I}_{\mathrm{i}}=\alpha+\beta \mathrm{X}_{\mathrm{i}}+\varepsilon_{i} \text { and } \mathrm{I}_{\mathrm{i}}^{*}=0,5 \\
& P_{i}=\mathrm{P}\left(\mathrm{Y}_{\mathrm{i}}=1 \mid \mathrm{X}\right)=\mathrm{P}\left(\mathrm{I}_{\mathrm{i}}^{*} \leq \mathrm{I}_{\mathrm{i}}\right)=\mathrm{P}\left(\mathrm{Z}_{\mathrm{i}} \leq \alpha+\beta \mathrm{X}_{\mathrm{i}}+\varepsilon_{i}\right)=\Phi\left(\alpha+\beta \mathrm{X}_{\mathrm{i}}+\varepsilon_{i}\right) \\
& P_{i}=\mathrm{P}\left(\mathrm{Y}_{\mathrm{i}}=0 \mid \mathrm{X}\right)=\mathrm{P}\left(\mathrm{I}_{\mathrm{i}}^{*}>\mathrm{I}_{\mathrm{i}}\right)=\mathrm{P}\left(\mathrm{Z}_{\mathrm{i}}>\alpha+\beta \mathrm{X}_{\mathrm{i}}+\varepsilon_{i}\right)=\Phi\left(\alpha+\beta \mathrm{X}_{\mathrm{i}}+\varepsilon_{i}\right)
\end{aligned}
$$

In equation (6), $Y_{i}=1$ represents the bank failure since $I_{i}$ exceeds the threshold $I_{i}^{*}$. Similarly, in equation (7), $Y_{i}=0$ represents the non failure of the bank which occurs when a bank is unable to meet the obligation which is exceeding the threshold level.

\section{Empirical Results}

To evaluate the financial risk in Turkish banking system, we start have started with identifying the most decisive bank ratios for which significant differences across failed and non-failed banks exist. For this reason, we employ ANOVA test. In ANOVA test we use significance level as $1 \%$ to conclude on statistically significant differences. Because there are missing variables on 55 observations in the data set, we perform the analysis using different approaches to overcome this problem. In the first place we ignore the missing data and obtain results accordingly. In the second approach, we replace the missing data with the mean of the corresponding variable. Not least, we carry out the same methodology by replacing the missing data with nearby points. Because in ANOVA and Factor Analysis there are no major differences in the results for the three missing data replacing methods, we mainly present the result of ANOVA and Factor Analysis in the case where missing values are present in the data set. ANOVA test results are given in Table 3.

\begin{tabular}{rrrc}
\hline Ratio & Mean Square & F & Sig. \\
\hline R1 & 2808,09 & 7,25 & $0,01^{*}$ \\
R2 & 147290,95 & 1,28 & 0,26 \\
R3 & 1693,46 & 25,39 & $0,00^{*}$ \\
R4 & 1463,87 & 3,95 & 0,05 \\
R5 & 62981,97 & 3,49 & 0,06 \\
R6 & 10725,03 & 6,59 & $0,01^{*}$ \\
R7 & 19350,19 & 66,99 & $0,00^{*}$ \\
R8 & 94102,62 & 1,42 & 0,23 \\
R9 & 20136,39 & 66,54 & $0,00^{*}$ \\
R10 & 20650,82 & 2,15 & 0,14 \\
R11 & 444405303,99 & 0,19 & 0,66 \\
R12 & 348341,37 & 39,18 & $0,00^{*}$ \\
R13 & 8915,01 & 6,57 & $0,01^{*}$ \\
R14 & 242,93 & 14,02 & $0,00^{*}$ \\
R15 & 209,60 & 13,72 & $0,00^{*}$ \\
R16 & 228,27 & 11,14 & $0,00^{*}$ \\
R17 & 524,34 & 7,71 & $0,01^{*}$ \\
R18 & 1703,75 & 15,47 & $0,00^{*}$ \\
R19 & 357,55 & 4,89 & 0,03 \\
R20 & 135513,88 & 3,50 & 0,06 \\
R21 & 10286,14 & 1,06 & 0,30 \\
R22 & 1624,48 & 1,05 & 0,30 \\
R23 & 3735,13 & 0,85 & 0,36 \\
R24 & 2736,46 & 0,80 & 0,37 \\
R25 & 19522,77 & 5,76 & 0,02 \\
R26 & 2958,03 & 25,96 & $0,00^{*}$ \\
R27 & 62367,84 & 50,45 & $0,00^{*}$ \\
R28 & 18,61 & 17,53 & $0,00^{*}$ \\
R29 & 43,96 & 14,73 & $0,00^{*}$ \\
\hline
\end{tabular}

* Statistically significant ratios 
Our results show that 13 of 29 bank ratios indicate statistically significant differences at $1 \%$ level. These ratios are R1, R3, R6, R7, R9, R12-R18 and R26-R29. The ratios which do not show a significant difference are omitted from the data set.

As the second tool of our empirical strategy, we use factor analysis to group the ratios exhibiting similar characteristics and therefore to reduce the number of variables used in the analysis. In factor analysis the correlation assumption must be controlled. For this purpose we use Kaiser-Meyer-Olkin (KMO) and Bartlett's test. The null hypothesis of Bartlett's test states that variables used in the analysis are orthogonal, that is, the variables are not correlated sufficiently to be used in factor analysis. On the other hand, for an efficient factor analysis results, KMO index is required to be close to 1. (REFERENCE for KMO LIMITS) Our KMO and Bartlett's test results are given in Table 4. KMO index for the data sets where missing values are replaced with mean and nearby points are 0,649 and 0,647, respectively. For both cases in Bartlett's Test we cannot reject the null hypothesis with $99 \%$ confidence level.

\begin{tabular}{l|l|l}
\hline Kaiser-Meyer-Olkin Measure of Sampling Adequacy. & & 0,648 \\
Bartlett's Test of Sphericity & Approx. Chi-Square & 9123,449 \\
& df & 120 \\
& Sig. & 0,00 \\
\hline
\end{tabular}

Table 4. KMO Index and Bartlett's Test Results

According to Table 4, KMO index is sufficiently close to 1 . On the other hand, Bartlett's test results show that we can reject the null of orthogonality among variables at $1 \%$ significance level. These results confirm that our data set is suitable to perform factor analysis. In the factor analysis, we use Varimax for rotation method and use regression to compute the corresponding factor scores. Furthermore, we use the eigenvalue of 1 as the limit to determine the number of factors. Table 5 presents the result of factor analysis. Results show that bank ratios can be classified within four factors. Besides, these four factors can explain $66,34 \%$ variance of total variance. According to the result the factor which explains the total variance most is factor 1 with $25,62 \%$. This factor is followed by factor 2 , which can explain $19,29 \% .44,91 \%$ of the total variance can be explained by these two factors.

\begin{tabular}{llll}
\hline \multicolumn{4}{l}{ Initial Eigenvalues } \\
\hline Component & Total & \% of Variance & Cumulative \% \\
\hline 1 & 4,10 & 25,62 & 25,62 \\
2 & 3,09 & 19,29 & 44,91 \\
3 & 1,80 & 11,27 & 56,19 \\
4 & 1,62 & 10,15 & 66,34 \\
5 & 0,98 & 6,13 & 72,47 \\
6 & 0,87 & 5,42 & 77,89 \\
7 & 0,83 & 5,17 & 83,06 \\
8 & 0,69 & 4,34 & 87,40 \\
9 & 0,59 & 3,69 & 91,09 \\
10 & 0,55 & 3,43 & 94,52 \\
11 & 0,42 & 2,61 & 97,13 \\
12 & 0,34 & 2,13 & 99,26 \\
13 & 0,08 & 0,50 & 99,76 \\
14 & 0,03 & 0,19 & 99,95 \\
15 & 0,01 & 0,03 & 99,98 \\
16 & 0,00 & 0,02 & 100,00 \\
\hline
\end{tabular}

Table 5. Factor Analysis Results

In order to determine the factors which the ratios belong to we use rotated component matrix given in Table 6 . In Table 6, the ratio with the highest score in a raw belongs to the corresponding factor labeled in the column. Accordingly, R14, R16, R15, R17 and R18 are classified within the factor 1. Similarly, R9, R7 and R26 are classified as factor 2, while R27, R12, R28 and R13 are concentrated in factor 3. Lastly, factor 4 is composed of R1, R6, R29 and R3. 


\begin{tabular}{lcccc}
\hline \multicolumn{4}{c}{ Components } \\
\hline R14 & $\mathbf{1}$ & $\mathbf{2}$ & $\mathbf{3}$ & $\mathbf{4}$ \\
R16 & 0,91 & 0,00 & 0,25 & $-0,16$ \\
R15 & 0,87 & $-0,02$ & 0,25 & $-0,14$ \\
R17 & 0,87 & $-0,01$ & 0,19 & $-0,25$ \\
R18 & 0,75 & 0,04 & $-0,25$ & 0,16 \\
R9 & 0,05 & 0,95 & $-0,30$ & 0,11 \\
R7 & 0,05 & 0,94 & 0,05 & $-0,10$ \\
R26 & $-0,08$ & 0,75 & 0,17 & $-0,12$ \\
R27 & $-0,14$ & 0,11 & 0,74 & 0,10 \\
R12 & 0,08 & 0,08 & 0,70 & 0,00 \\
R28 & 0,13 & $-0,02$ & 0,59 & 0,02 \\
R13 & 0,04 & 0,15 & 0,46 & 0,12 \\
R1 & 0,05 & 0,04 & 0,00 & $-0,35$ \\
R6 & 0,01 & 0,22 & 0,39 & 0,84 \\
R29 & $-0,31$ & $-0,31$ & $-0,09$ & 0,48 \\
R3 & 0,02 & $-0,34$ & $-0,37$ & 0,40 \\
\hline
\end{tabular}

Table 6. Rotated Component Matrix

In order to investigate the financial risk in Turkish bank system, as the last tool of ou empirical strategy, we utilize from Probit regression. In this regard, we estimate the following model;

$Y_{i}=\alpha+\beta_{1} X_{1}+\beta_{2} X_{2}+\beta_{3} X_{3}+\beta_{4} X_{4}$

where $Y_{i}$ is a dummy and boolean variable which equals 1 if the corresponding bank is failed. Besides, $X_{i}, i=$ 1,2,3,4 indicates factor scores calculated previously. The results of Probit regression can be found in Table 7. Table 7 indicates that factor 2 and factor 3 have statistically significant and negative impact on failure probability of the banks in Turkey. This finding does not change in the cases where missing values are replaced by mean and nearby points. Furthermore, factor 3 has relatively higher negative effect on the probability of failure in Turkey with the value of $-0,911$, relative to that of factor 2 . This finding is verified by the other two Probit model estimations where the effect of factor 3 are estimated as $-0,999$ and $-0,996$, respectively. On the other hand, given the methodology employed, in all of three regressions, we find no significant association for factor 1 and factor 4 on the probability of failure. Besides, the last significant parameter in all three models is intercept term.

\begin{tabular}{cccc|ccc|ccc}
\hline Variable & $\begin{array}{c}\text { With Missing Values } \\
\text { Estimate }\end{array}$ & $\begin{array}{c}\text { Std. } \\
\text { Error }\end{array}$ & Sig. & With Mean & Estimate & $\begin{array}{c}\text { Std. } \\
\text { Error }\end{array}$ & Sig. & With Nearby Points \\
Estimate & $\begin{array}{c}\text { Std. } \\
\text { Error }\end{array}$ & Sig. \\
\hline X1 & $-0,169$ & 0,114 & 0,140 & $-0,185$ & 0,108 & 0,085 & $-0,209$ & 0,110 & 0,058 \\
X2 & $-0,422$ & 0,074 & 0,000 & $-0,414$ & 0,071 & 0,000 & $-0,411$ & 0,071 & 0,000 \\
X3 & $-0,911$ & 0,135 & 0,000 & $-0,999$ & 0,127 & 0,000 & $-0,996$ & 0,126 & 0,000 \\
X4 & $-0,047$ & 0,115 & 0,680 & $-0,116$ & 0,100 & 0,245 & $-0,117$ & 0,100 & 0,241 \\
Const. & $-1,717$ & 0,122 & 0,000 & $-1,609$ & 0,110 & 0,000 & $-1,615$ & 0,110 & 0,000 \\
\hline
\end{tabular}

Table 7. Probit Regression Results

To evaluate whether the estimated Probit model fits the observed data, we use Chi-square test. In this test, null hypothesis asserts that the Probit model fitted is authentic. Under this null hypothesis, Chi-square test results confirm that null hypothesis cannot be rejected with the significance value of 1 .

Regarding the performance of the models estimated, we compare the forecasted probability of failure with previously failed banks. Failure probabilities for the respective models are presented in Table 8 for previously failed banks and in Table 9 for current banks. In Table 8, we attain a particular importance to the probability forecasted for one year earlier (t-1) from bankruptcy. Results in Table 8 show that we can obtain higher failure probabilities for some banks, while we observe relatively lower probabilities for other banks. The models estimated are especially successful in forecasting the bank failure probability of some banks such as Interbank, (97\%), Türkiye Tütüncüler Bankası-Yaşarbank A.Ş. (73\%), İktisat Bankası T.A.Ş. (85,5\%). The lower probabilities forecasted for previously failed banks are for Bayındırbank A.Ş. (8\%) and Türkiye İmar Bankası (15\%). 


\begin{tabular}{|c|c|c|c|c|c|}
\hline Bank & Year (t-1) & $\begin{array}{l}\text { Missing } \\
\text { Prob. }\end{array}$ & $\begin{array}{l}\text { Mean } \\
\text { Prob. }\end{array}$ & $\begin{array}{c}\text { Nearby Points } \\
\text { Prob. }\end{array}$ & $\begin{array}{c}\text { Average } \\
\text { Prob. }\end{array}$ \\
\hline Türk Ticaret Bankası A.Ş. & 1996 & NA & 0,084 & 0,298 & 0,191 \\
\hline Bank Ekspres A.Ş. $\quad * * *$ & 1997 & NA & 0,250 & 0,301 & 0,276 \\
\hline Interbank & 1998 & 0,958 & 0,992 & 0,963 & 0,971 \\
\hline Sümerbank A.Ş. & 1998 & 0,465 & 0,586 & 0,532 & 0,527 \\
\hline Türkiye Tütüncüler Bankası -Yaşarbank A.Ş. & 1998 & 0,613 & 0,908 & 0,688 & 0,736 \\
\hline Yurt Ticaret ve Kredi Bankası A.Ş. & 1998 & 0,358 & 0,477 & 0,467 & 0,434 \\
\hline Egebank A.Ş. & 1998 & 0,183 & 0,383 & 0,217 & 0,261 \\
\hline Eskişehir Bankası T.A.Ş. & 1998 & 0,454 & 0,761 & 0,500 & 0,572 \\
\hline Bank Kapital Türk A.Ş. & 1999 & 0,125 & 0,161 & 0,166 & 0,151 \\
\hline Etibank A.Ş. & 1999 & 0,270 & 0,343 & 0,343 & 0,319 \\
\hline Demirbank T.A.Ş. & 1999 & 0,119 & 0,168 & 0,148 & 0,145 \\
\hline Ulusal Bank T.A.Ş. & 2000 & 0,669 & 0,596 & 0,764 & 0,676 \\
\hline İktisat Bankası T.A.Ş. & 2000 & 0,834 & 0,876 & 0,854 & 0,855 \\
\hline Bayındırbank A.Ş. & 2000 & 0,075 & 0,082 & 0,084 & 0,080 \\
\hline Ege Giyim Sanayicileri Bankası A.Ş. & 2000 & 0,412 & 0,387 & 0,491 & 0,430 \\
\hline Kentbank A.Ş. & 2000 & 0,154 & 0,178 & 0,202 & 0,178 \\
\hline Sitebank A.Ş. & 2000 & 0,358 & 0,365 & 0,416 & 0,379 \\
\hline Milli Aydın Bankası T.A.Ş. & 2000 & 0,332 & 0,316 & 0,374 & 0,341 \\
\hline Türkiye Emlak Bankası A.Ş. & 2000 & 0,335 & 0,475 & 0,371 & 0,394 \\
\hline Toprakbank A.Ş. & 2000 & 0,253 & 0,341 & 0,290 & 0,295 \\
\hline Pamukbank T.A.Ş. $\quad * * *$ & 2001 & 0,161 & 0,225 & 0,216 & 0,201 \\
\hline Türkiye İmar Bankası T.A.Ş. & 2002 & 0,105 & 0,219 & 0,151 & 0,158 \\
\hline
\end{tabular}

Table 8. Probabilities for Previously Failed Banks

Considering the failure probability of the current Turkish banks, we observe from Table 9 that the maximum failure probability is $10,8 \%$ for B9. When we compare with the Table 8 , we may conclude that these probabilities do not support a possible bankruptcy for current Turkish banks. Besides, our findings imply that all of publiclyowned banks are sound against bankruptcy, with probabilities quite close to zero. Furthermore, we find that 4 of 13 foreign-owned banks are placed as the least risky banks. In addition to that, the major privately owned banks show a robust stance against bankruptcy

\begin{tabular}{lllcl}
\hline Bank Codes & Missing & Mean & Nearby Point & Average \\
\hline B21 & 0,001 & 0,000 & 0,001 & 0,001 \\
B26 & 0,002 & 0,000 & 0,001 & 0,001 \\
B16 & 0,002 & 0,001 & 0,002 & 0,001 \\
B1 & 0,004 & 0,001 & 0,004 & 0,003 \\
B13 & 0,006 & 0,002 & 0,006 & 0,004 \\
B12 & 0,006 & 0,002 & 0,006 & 0,005 \\
B2 & 0,007 & 0,003 & 0,008 & 0,006 \\
B17 & 0,008 & 0,003 & 0,009 & 0,007 \\
B5 & 0,008 & 0,006 & 0,009 & 0,008 \\
B19 & 0,011 & 0,003 & 0,014 & 0,009 \\
B3 & 0,012 & 0,010 & 0,014 & 0,012 \\
B14 & 0,015 & 0,015 & 0,019 & 0,016 \\
B4 & 0,029 & 0,013 & 0,028 & 0,023 \\
B11 & 0,024 & 0,022 & 0,033 & 0,026 \\
B23 & 0,028 & 0,028 & 0,037 & 0,031 \\
B27 & 0,033 & 0,043 & 0,047 & 0,041 \\
B22 & 0,032 & 0,048 & 0,045 & 0,042 \\
B20 & 0,041 & 0,052 & 0,056 & 0,050 \\
B6 & 0,038 & 0,082 & 0,054 & 0,058 \\
B18 & 0,052 & 0,073 & 0,078 & 0,068 \\
B15 & 0,052 & 0,098 & 0,080 & 0,076 \\
B25 & 0,060 & 0,079 & 0,093 & 0,077 \\
B8 & 0,057 & 0,101 & 0,082 & 0,080 \\
B7 & 0,059 & 0,099 & 0,092 & 0,084 \\
B24 & 0,070 & 0,116 & 0,108 & 0,098 \\
B10 & 0,075 & 0,114 & 0,110 & 0,100 \\
B9 & 0,081 & 0,120 & 0,124 & 0,108 \\
\hline
\end{tabular}

Table 9. Probabilities for Current Banks 


\section{Conclusion}

In this study we investigate the failure probability for current deposit Turkish banks using data extracted from Banking Regulation and Supervision Agency for the period 1996-2014. To this end, we utilize from an analysis composed of three stages, namely, ANOVA test, Factor Analysis and Probit Regression Analysis. Having faced with 55 missing data in the original data set, we perform our analysis depending on different missing value replacement approaches, namely replacing with mean and nearby points.

Our principal findings show that the models estimated can be considered successful in terms of forecasting previously failed banks. These results do not change in the cases where missing data problem is eliminated with different approaches. Regarding the failure probabilities of the current banks, we find that there is no any risk of bankruptcy since the failure probabilities are far from the ones predicted for previously failed banks. Therefore, our main conclusion regarding the financial risk in Turkish banking system is that all of the current deposit banks are found to be robust and sound against failure risks. These findings may be interpreted as a result of the economic recovery program launched in 2001 which aimed to regulate baking system in Turkey.

\section{Acknowledgements}

I would like to thank Cukurova Univercity Scientific Research Projects (Project Id: 6550) that helped us to present this study in International Conference on Eurasian Economies, Kaposvar-Hungary.

\section{References}

- Canbaş S., and Erol, C. 1985. “Türkiye’de Ticaret Bankaları Sorunlarının Saptanması: Erken Uyarı Sistemine Giriş", Türkiye Ekonomisi ve Türk Ekonomi Ilmi, No: 1, Marmara University, Turkey Economy Research Center.

- Canbaş, S., Çabuk, A. and Kiliç, S.B. 2005. "Prediction of commercial bank failure via multivariate statistical analysis of financial structures: The Turkish case”, European Journal of Operational Research, 166 (2), 52846

- Caprio, G. and Klingebiel, D. .2002. "Episodes of Systematic and Borderline Banking Crises", World Bank Discussion Papers, No.428, 31-49.

- Claessens, S., D. Klingebiel, and L. Laeven. 2005., "Crisis Resolution, Policies, and Institutions: Empirical Evidence," in Patrick Honohan and Luc Laeven, Systemic Financial Crises: Containment and Resolution (Cambridge University Press).

- Chen, M., Chew M. L., Goyal, S., Matar, M. and Yavuz, Z. 2014. "The Turkish Economy, Post-2001 Crisis: Why Timing, Faith, and Expectations Matter”, UChicago Undergraduate Business Journal, Spring,1-34.

- Contessi, S., and El-Ghazaly, H. S. 2011. Banking crises around the world: different governments, different responses. The Regional Economist, (Apr), 10-16.

- De Claro, L. L., 2013. "Determining The Effectiveness of The Camels Approach Towards Timely Prediction of Bank Failures", Journal of Global Business And Economics, January, VolumE 6, Number 1, 12-17.

- Ecer, F. 2013. "Comparing the bank failure prediction performance of neural networks and support vector machines: The Turkish case, Ekonomska istraživanja - Economic Research 26(3):81-98.

- Erdoğmuş, B. 2010. "Bankalarda Mali Başarısızlıkların Önceden Tespitinde Erken Uyarı Sistemi ve Bir Uygulama”, Ankara Üniversitesi Fen Bilimleri Enstitüsü, YL Tezi.

- Fethi, M. D. and Pasiouras, F. 2010. "Assessing bank efficiency and performance with operational research and artificial intelligence techniques: A survey”, European Journal of Operational Research, 204 (2), 189198.

- Fungacova, Z. and Weill, L. 2013. "Does competition influence bank failures? Evidence from Russia", Economics of Transition, Volume 21(2) 2013, 301-322. DOI: 10.1111/ecot.12013

- Honohan, P. and Klingebie, D. 2003. "The fiscal cost implications of an accommodating approach to banking crises", Journal of Banking \& Finance, Vol.27, Issue.8, 1539-1560.

- Kyle, A. S. 2012. “A commentary on "Déjà Vu All Over Again: The Causes of U.S. Commercial Bank Failures This Time Around”, J Finance Serv Res . 42: 31-34.

- Liu, Z.J. 2014. "Cross-country study on the determinants of bank financial distress”, RAEI São Paulo, V. 55 , n. 5 , 593-603. DOI: http://dx.doi.0rg/1O.1590/S0034-75902015051O

- Lopcu, and K., Kiliç, S.B. 2012. "Effects of Structural Changes in the Turkish Banking Sector Since 2001 Crisis and a Risk Analysis for the Sector", Topics in Middle Eastern and North African Economies, Vol. 14,September, 354-376.

- Papi, L., Presbitero, A. F. and Zazzaro, A. "IMF Lending and Banking Crises", https://www.imf.org/external/pubs/ft/wp/2015/wp1519.pdf 20.5.2016

- Reinhart, Carmen M. and Rogoff, Kenneth S.(2011), ""From Financial Crash to Debt Crisis," American Economic Review, American Economic Association, vol. 101(5), 1676-1706. 


\title{
The Relationship between Firms' Environmental Performance and Financial Performance: The Case of Turkey
}

\author{
Asst. Prof. Dr. Füsun Küçükbay (Celal Bayar University, Turkey) \\ Ph.D. Candidate Tuğba Arpazlı Fazlılar (Celal Bayar University, Turkey)
}

\begin{abstract}
In recent years, the number of firms that give importance to environmental problems such as consumption of natural resources, decline in water resources and global warming are increasing. However, the classical view of literature argues that firms' environmental protection operations decrease the financial performance of them. For that reason, in this study, it is aimed to analyze the relationship between financial performance and environmental performance of the firms. The sample of the study consists of firms listed on Borsa Istanbul 100 index and has a climate change score declared in CDP Turkey Climate Change Report 2015. Climate change score is used for measuring environmental performance. Accounting (Return on Asset) and marketing measures (Market Value/Book Value) are used for measuring financial performance. The relationship between the environmental performance and financial performance of the firms compared with the help of correlation analysis. Findings reveal that there is a positive relation between financial performance and environmental performance. The correlation between market performance and environmental performance is weaker than the correlation between accounting performance and environmental performance. Moreover, multidimensional scaling technique is utilized to cluster the firms in terms of their financial and environmental performance. A map is formed with the help of multidimensional scaling that shows the relative positioning of the sampled firms due to their environmental performance and financial performance.
\end{abstract}

\section{Introduction}

"Sustainability concept" has been discussed in the literature for years. This concept generally described as meeting the demands of people with concerning the responsibilities towards society and the environment and concerning future generations (Bekmezci, 2014). On the other hand, the concept of environmental pollution and environmental issues are also discussed over years in academic studies, but it is responsed in real life quite lately and inadequately.

The firms' product varieties are all shaped by customer demand. As a result of this; today the ecological footprint are $\% 50$ more than the world's biological capacity, this causes the environmental problems and give harm to sustainability. Each year 2,5 ppm (parts per million to atmosphere) carbondioxit are added (twice more than that of 30 years ago) which pollutes the water resources and air rapidly. These developments cause everyone to think about the environmental issues. Consequently, both legal authorities and the firms' authorities start to discuss the role of firms in environmental issues.

In the production process of the firms, harmful wastes occur that threatens the environment seriously. So that, the firms should give importance to environmental issues and should transform their structures from the "brown economy", that have low sensitivity and profit-centric, to the model of 'green economy', that give importance to environmental sustainability (Pointing, 2012; Sukhdev, 2013). According to Shukdev (2013), four fundamental changes has to be made by firms in order to achieve the green economy model and these four reforms ensure both profitability and environmental sustainability:

- First one is reorganizing the taxes and subsidizes. The "bads" such as using fossil fuel have to be taxed more whereas the "goods" such as wages and profit have to be taxed less.

- Second, the rules and limits have to be defined to govern the financial leverage, especially if the borrower is considered "too big to fail".

- $\quad$ Third, advertising norms and standards have to be developed that are more responsible and accountable. For example disclosing the life span of the product or the disclosing the countries of the product.

- $\quad$ The last one is measuring, auditing and reporting the all important externalities in the annual financial statements of the firms. In this way the firms are more transparent and accountable.

Based on this views, many studies in the literature investigate the relationship between environmental performance and financial performance of the firms. According to the literature review, findings in these studies demonstrate that positive correlation is predominant between link of them. For example, Moneva and Ortas (2009) analyzed the environmental and financial performance of a sample of 230 European firms with a partial least squares model (PLS). According to this study the results support the idea that enterprises which obtained higher rates of environmental performance show better financial performance levels in the future. Sahay and Sing (2005) examine the relationship between the environmental performance and the financial performance for different sectors like a pulp and paper, automobile and caustic-chlorine with net sales, PBDIT, net worth and total assets datas. The analysis shows that all the financial parameters have negative correlation for a pulp and paper sector. 
Contrarily, in the automobile sector and the caustic-choline sector, there is a positive correlation among of them. Sahay and Sing (2005) argue that different correlation results for different sectors are because each sector has different level of technology. Jimenez et al. (2013) investigate that why and when the positive correlation occurs between environmental protection and financial performance. However, in this study differences between environmental protections, environmental management practices, environmental proactivity and environmental performance for the firms are emphasized. In the study, regression analysis is used and the sample of the study consists of 186 Welsh firms. According to the results, financial performance has a positive and significant correlation with environmental proactivity and environmental performance, while it has no significant relation with environmental management. Qi et al. (2014) investigate the relationship between environmental and financial performance of Chinese firms. They gather data on all Chinese industrial sectors such as mining, manufacturing and electricity. These industries are the primary source of environmental pollution in China. Qi et al. (2014) use a dynamic panel model in their study. Findings of the paper show that the firm-level conclusion on the environmental performance and financial performance link is consistent with the industry-level analysis. In addition to this, their research supports the hypothesis that resource slack plays a moderating role on environmental performance and financial performance. They argue that these findings suggest that investing in environmental improvements improve firms' financial performance. Muhammad et al. (2015) examine the relationship between environmental performance and financial performance of publicly held firms in Australia for the pre-crisis period (2001-2007) and the post-crisis period (2008-2010). The study consist of 76 firms from Australian stock market. To analyze this effect, two hypotheses are posited: the first one is that there is a positive relationship between environmental performance and financial performance in the time of economic growth and the second one is that there is no relationship between environmental performance and financial performance in the time of financial crisis. The results reveal that the positive relationship is statistically significant only in the time of economic growth.

In this study, the relationship between the environmental performance and the financial performance is investigated. The rest of paper is organized as follows. The second section discusses the aim of the study, defines the variables of the study. In the third part, the methodology is introduced and applied to find the relationship between the environmental performance and financial performance of Turkish firms. The fourth part is devoted to conclude the study.

\section{The Study}

\subsection{The Aim of the Study}

Recently, environmental factors are attracting the attention of both researchers and firms. People are more concerned about the environmental factors because of increasing pollution, decline in water resources and other reasons. Because of dirty water sources and air pollution, many people are dying day by day around the world. According to the global health observatory data $\% 23$ of all estimated global deaths are related with the unhealthy environmental factors such as air pollution and dirty water (WHO, 2016).

Some firms start to give importance to environmental issues and these firms' try to reduce gas emissions and to mitigate the climate change risk. The firms that take ISO 14000 certificate and/or issue environmental reports are increasing recent years. Decreasing gas emissions, clean technology, protecting environment are becoming more important in global business environment. Moreover being sensitive to environmental issues becomes a hallmark for global business environment.

Firms usually are double minded about investing in environmental issues because of the relationship between financial performances and investing in environmental issues. Some firms think that environmental efforts give competitive advantage by cost savings (using less energy, recycling of wastes etc.) and by attaining customer satisfaction, employee loyalty and by gaining positive image reputation and by complying with regulations (Lynes\&Drdge, 2006; Porter Van der Linde, 1995). On the other hand, if the firm invest in poor environmental efforts, the financial performance will be affected negatively because of inefficiency and useless investments (Reinhardt, Porter Van der Linde, 1995).

Due to the increased public concern both in Turkey and in the rest of the world, environmental issues are very important in attaining firm reputation. However, as it is mentioned above, there is a discord in the reality about the relationship between the environmental performance and the financial performance of the firms. For this reason, in this study it is aimed to analyze the relationship of financial performance and environmental performance of the firms operating in Turkey.

\subsection{Variables}

In the study, three variables are used. 2 of them are used for measuring financial performance, one of them is used for measuring environmental performance.

- Variables Used for Measuring Financial Performance

Mangolis etc. (2003) examine the empirical studies that investigate the relationship between firms' social and financial performance between 1972 and 2002 period. In general, accounting performance and market performance measures are used to analyze the financial performance of the firms. Accounting performance measures include 
return on asset, return on investment, profit margins and etc. While market performance includes market value to book value, stock performance and etc.

In the study, Return on Asset and Market Value/Book Value (MV/BV) ratios are used as a variables concerning financial performance. Return on Asset (ROA) is used for measuring the firm's accounting performance and Market Value/Book Value ratio is used to measure the market value. High MV/BV and high ROA values mean high financial performance.

In the study, it is analyzed that the effect of environmental performance on financial performance and it is compared which one is mostly affected by environmental performance; market performance or accounting performance. The financial ratio values are determined by using Finnet 2000 program.

- Variable Used for Measuring Environmental Performance

The environmental performance score of the firms are based on the data obtained by CDP Turkey Climate Change report. Each year firms from around the world are scored based on their environmental performance and disclosure in CDP environmental Climate Change report since 2010. CDP reports are formed by gathering information through questionnaires that are conducted on the firms.

Each year the number of the firms participated in CDP Turkey climate change program increases. In 2010 only 10 firms participated the CDP Turkey climate change program, while, in 2015, 38 firms participated the CDP Turkey climate program.

In the study, the financial scores are also needed so only publicly held firms are chosen as a sample. So only 30 firms are chosen as sample which have both financial scores and environmental performance for 2015 year. 8 of them are omitted from the study as they have no financial scores.

The firms that have a high performance score from CDP Climate Change report means that the firm is measuring and managing its carbon footprint. In other words, the firms that have high CDP climate performance scores give importance to carbon reduction, try to reduce emissions in their operations and save energy by changing machines or equipment or replace their energy resources from fuel resources to renewable energy resources. So high performance score in CDP Climate Change report means high environmental performance.

\section{Methodology}

\section{- Data}

This research investigates the correlation between Turkish firms' financial and environmental performance. For this reason a sample of firms was selected from CDP Climate Change Report. Total 38 firms participated the CDP Climate Change Report but the financial data is available for 30 of these firms. So the sample consists of 30 firms that have both financial and environmental scores.

\section{- Procedure and Results}

In the study, correlation analysis is used to analyze the relationship between the financial performance and environmental performance of the firms. Correlation analysis is performed by using Stata 14 program. Table 1 shows the sampled firms and their environmental performance scores, MV/BV ratio values and ROA scores for 2015 year. At the end of the table the correlation coefficient of environmental performance with financial parameters.

The analysis shows that the environmental performance have positive correlation with accounting measures (ROA) and market measures (BV/MV ratio). On the other words, ROA and MV/BV scores increase with higher environmental performance which is consistent with the expectations. Margolis and Walsh (2003) examine the empirical studies that investigates the association between firms' environmental efforts and financial performance for 30 years. According to their findings almost half of the studies ( 54 of 109 studies) find positive relation between firms' environmental efforts and financial performance, only 7 studies point to a negative relationship between environmental efforts and financial performance. The remaining studies reported non-significant relationships or mixed set of findings.

The relationship between MV/BV and environmental performance is weaker than the relationship with ROA and environmental performance as the correlation is at 0.1444 for $\mathrm{MV} / \mathrm{BV}$ and environmental performance whereas the correlation is at 0.2834 for ROA. As a result, environmental efforts affect highly accounting performance. The relationship between accounting performance and environmental performance is stronger than the relationship between marketing performance and environmental performance, it is probably because of increase in fuel efficiency, replacement of inefficient machines and equipments. These efforts both contribute to accounting performance and environmental performance.

The positive correlation between the environmental performance and market performance is weaker than the relationship between accounting performance and environmental performance that may be because investor has not given too much concern about environmental issues while purchasing stocks of firms in Turkey yet. 


\begin{tabular}{|c|c|c|c|c|}
\hline & Firm Name & $\begin{array}{l}\text { Environmental Performance Score } \\
\text { (EP Score) }\end{array}$ & MV/BV Ratio & ROA Score \\
\hline 1 & Afyon Çimento & 60 & 3.74 & 6.40 \\
\hline 2 & Akbank & 79 & 1.24 & 1.42 \\
\hline 3 & Akçansa & 92 & 2.31 & 17.00 \\
\hline 4 & Ak Enerji & 88 & 0.57 & -8.19 \\
\hline 5 & Alarko Holding & 17 & 0.42 & -5.62 \\
\hline 6 & Arçelik & 96 & 2.77 & 6.87 \\
\hline 7 & Aselsan & 95 & 3.55 & 3.76 \\
\hline 8 & Brisa & 98 & 3.93 & 10.38 \\
\hline 9 & Çelebi Hava Servis & 70 & 5.55 & 13.27 \\
\hline 10 & Çimsa Çimento & 93 & 1.84 & 14.06 \\
\hline 11 & Coca Cola & 94 & 2.84 & 1.45 \\
\hline 12 & Doğan Şirketler Grubu & 31 & 0.58 & -2.25 \\
\hline 13 & İhlas Holding & 30 & 0.41 & -3.06 \\
\hline 14 & Kardemir Karabük & 72 & 0.83 & -0.49 \\
\hline 15 & Migros A.Ş. & 82 & 6.78 & -6.53 \\
\hline 16 & Netaş Telek & 61 & 1.60 & 3.04 \\
\hline 17 & Zorlu Enerji & 92 & 0.22 & -5.06 \\
\hline 18 & Pegasus Hava & 93 & 1.15 & 2.97 \\
\hline 19 & Sabanc1 Holding & 94 & 0.98 & 0.90 \\
\hline 20 & Şekerbank & 89 & 0.73 & 0.45 \\
\hline 21 & Garanti & 98 & 1.14 & 1.45 \\
\hline 22 & T. Sınai Kalkınma Bankası & 99 & 1.17 & 2.33 \\
\hline 23 & T. Şise Ve Cam & 91 & 0.96 & 5.16 \\
\hline 24 & Tav Hav. & 89 & 2.33 & 7.04 \\
\hline 25 & Tofaş & 93 & 4.41 & 9.78 \\
\hline 26 & Turkcell & 97 & 1.78 & 9.94 \\
\hline 27 & Türk Halk Bankası & 93 & 0.70 & 1.35 \\
\hline 28 & Türk Vakıflar Bankası & 91 & 0.74 & 1.13 \\
\hline 29 & Vestel Beyaz Eşya & 62 & 3.14 & 13.27 \\
\hline \multirow[t]{2}{*}{30} & Vestel Elektronik & 95 & 1.54 & 0.72 \\
\hline & $\begin{array}{l}\text { Correlation Coefficient of Environmental } \\
\text { Performance with Financial Parameters }\end{array}$ & 1 & 0.1444 & 0.2834 \\
\hline
\end{tabular}

Table 1: The Relationship of Enviromental and Financial Performance of Turkish Firms

In order to map the relative positioning of the sampled firms in terms of their environmental performance and financial performance, multi dimensional scaling technique is utilized. ROA scores are preferred for measuring their financial performance because ROA and environmental performance have higher correlation compared to $\mathrm{MV} / \mathrm{BV}$ and environmental performance.

Multi dimensional scaling technique enables to show the dissimilarity or similarity of variables. In this study the firms are mapped to their similiratity and dissimilarity to their financial performance and environmental performance. With multidimensional scaling technique a map is produced which clusters the firms in terms of their distances among the environmental and financial performance of firms.

In multi dimensional scaling method similarity and dissimilarity of objects are formed with the help of Euclidean distances. Stata 14 program is used for multi dimensional scaling analysis. Figure 1 illustrates the map that shows the relative distance of the firms in terms of their financial performance and environmental performance.

The map consists of 4 parts. Part I consists of the firms that have both high financial performance and high environmental performance. In part I, 8 firms exist; these firms are Akçansa, Arçelik, Brisa, Çimsa Çimento, T.Şise ve Cam, Tav. Hav., Tofaş and Turkcell. In this section the firms are among the ones that have the highest financial score and the environmental score. This result is consistent with the result of correlation analysis performed. The firms clustered in part I are more concerned with environmental issues and have good financial performance.

Part II consists of the firms that have high environmental performance but low financial performance. The firms in part II are; Ak Enerji, Aselsan, Coca Cola, Zorlu Enerji, Pegasus Hava, Sabancı Holding, Sekerbank, Garanti T. Sınai Kalkınma Bankası, T. Şişe ve Cam, Tav. Hav., Tofaş, Turkcell, Türk Halk Bankası, Türk Vakıflar Bankası, Vestel Beyaz Eşya and Vestel Elektronik. This result is inconsistent with the correlation results. This cause weak the correlation coefficient. Several factors may cause to low financial performance of the firms. The low financial performance may be the result of deficiency of capital, bad management or inefficient internal operations. 
Part III consists of the firms that have both low financial performance and low environmental performance. Firms in part III are; Akbank, Alarko Holding, Doğan Şirketler Grubu, İhlas Holding, Kardemir Karabük and Migros A.Ş. In this section the firms perform poor in both financially and environmentally. This result is consistent with the result of the correlation analysis.

Part IV consists of the firms that have high financial score and low environmental performance. In this part the firms have the lowest environmental score among the sampled firms. Firms in part IV are; Afyon Çimento, Çelebi Hava Servs, Netaş Telek., and Vestel Beyaz Eşya.

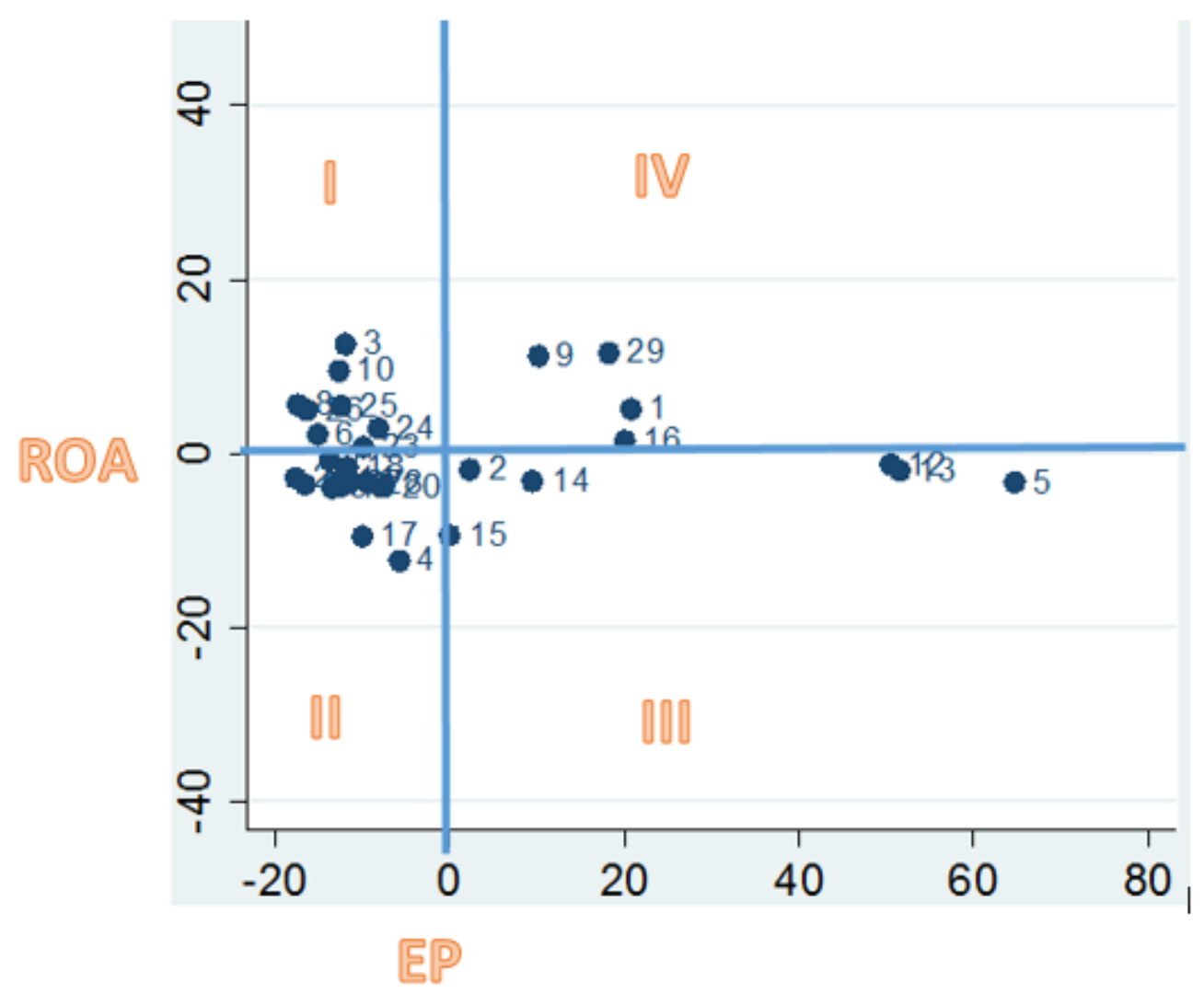

Figure 1. The Map: Environmental Performances (EP) and Return on Asset (ROA)

\section{Conclusion}

More and more environmental issues become important as a result of increase in air pollution, decrease in water resources and increase in other environmental problems. As a result businesses are forced to make arrangements about environmental issues legally or the firms are making arrangements about environmental issues with their own will. In both cases, the firms are anxious about the effect of investing in environmental issues on financial performance. Investing in environmental issues may affect the financial performance positively if the firm gain cost savings through environmental investments such as using less energy, replacement of old technology or increasing efficiencies. On the other hand, if the firm invest in poor environmental investments, this will affect the financial performance negatively.

In this study, it is aimed to analyze the relationship between environmental performance and financial performance of the firms operating in Turkey. The environmental performances of the firms are evaluated with the climate change scores. CDP Turkey Climate Change report calculates the firms' climate change score in the framework of the adaption to climate change, transparency and decrease in emissions. The financial performances of the firms are evaluated with return on asset and market value/book value measures. Market value/book value ratio is selected to analyze the market performance of the firms so that it can be possible to determine how much investors care about the environmental performance of the firms while purchasing the stocks. Return on asset ratio is selected to analyze the accounting performance of the firms.

The sample of the study consists of the firms that have both financial scores and have environmental scores. 30 firms are selected as a sample. The relationship between the environmental performance and financial performance of the firms are compared with the help of correlation analysis. Results of the correlation analysis reveal that there is a positive relation between environmental performance and financial performance. The relationship between 
market performance and environmental performance is weaker than the relationship with accounting and environmental performance. As a result it can be stated that environmental efforts affect the accounting performance more than the market performance. This may be the result of environmental efforts are increasing the productivity of the operations which affect the accounting performance of the firms positively. And also investors may not pay attention about environmental issues while purchasing stocks of firms in Turkey yet.

In the last part of the study the firms are clustered due to their environmental and financial performances with the help of multidimensional scaling technique. A map is developed that clusters the firms according to their similarity and dissimilarity to their financial performance and environmental performance.

A map consists of 4 parts. The firms clustered in Part I perform good in financial performance and environmental performance, the firms clustered in part II perform low in financial performance but good in environmental performance, the firms clustered in part III perform low in both financial performance and environmental performance, the firms clustered in part IV perform high in financial performance but low in environmental performance.

In future research it is needed to expand the observation period (maybe 5-10 years) and the sample. But the real problem is accessing to data in Turkey. The financial performance of the firms is only accessible if they are publicly held and the environmental data of the firms is very hard to access. If all the firms declare their environmental investments and financial scores, the sample and the observation period may be enriched.

\section{References}

- Bekmezci, M., 2014. "Strategies for Corporate Sustainability", Journal of Management, Marketing and Logistics - (JMML), 1(3), p. 218-240.

- Jiménez, J.B, Brust, D.V., Úbeda, J.P., Dijkshoorn, J., 2013. "Environmental protection and financial performance: an empirical analysis in Wales", International Journal of Operations \& Production Management, 33(8), p. 981 - 1018.http://dx.doi.org/10.1108/IJOPM-11-2010-0374.

- $\quad$ Lynes, J. K., \& Dredge, D., 2006. “Going green: motivations for environmental commitment in the airline industry: A case study of Scandinavian airlines”. Journal of Sustainable Tourism, 14, p.116-138. http://dx.doi.org/10.1080/09669580608669048

- Moneva, J., Ortas, E., 2010. "Corporate environmental and financial performance: a multivariateapproach", Industrial Management \& Data Systems, 110 (2), p.193-210. http://www.emeraldinsight.com/doi/ab S/10.1108/02635571011020304

- Margolis, J., Walsh, J., 2003. "Misery loves firms: Rethinking social initiatives by business", Administrative Science Quarterly, 48 (2), p. 268-305

- Muhammad, N., Scrimgeour, F., Reddy, K., Abidin, S., 2015. "The relationship between environmental performance and financial performance in periods of growth and contraction: evidence from Australian publicly listed firms", Journal of Cleaner Production, 102, p.324-332, http://dx.doi.org/10.1016/j.jclepro.2015.04.039

- $\quad$ Pointing, C., 2007, A New Green History of the World, The Environment and the Collapse of Great Civilizations, Penguen Books, United States of America

- $\quad$ Porter, C. Van der Linde, 1995. "Toward a new conception of the environment competitiveness relationship", Journal of Economic Perspectives, 9 (4) , p. 97-118

- Qi, G.Y., Zeng, S.X., Jonathan J. Shi, J.J., Meng, X.H., Lin, H., Yang, Q.X., 2014. "Revisiting the relationship between environmental and financial performance in Chinese industry". Journal of Environmental Management. 145, p.349-356. http://dx.doi.org/10.1016/j.jenvman.2014.07.010

- Reinhardt F.(1998), “Environmental product differentiation: Implications for corporate strategy”, California Management Review, 40 (4) , p. 43-73

- Sahay, A., Singh, N.P., 2005. "Indian corporate environmental and financial performance: empirical relationship between them", Journal of Advances in Management Research, 2 (1), p. 79 - 88. http://dx.doi.org/10.1108/97279810580000373

- Sukhdev, P., 2012. Corporation 2020: Transformin Business for Tomorrow's World, Island Press, Washington D.C

- World Health Organization(WHO), 2016. http://www.who.int/gho/en/ 


\title{
The Analysis of the Turkish Islamic Banking System between 2005 and 2014
}

\author{
Lívia Tálos (Kaposvár University, Hungary) \\ Dr. Gyöngyi Bánkuti (Kaposvár University, Hungary) \\ Dr. Jozsef Varga (Kaposvar University, Hungary)
}

\begin{abstract}
Islamic banking is a banking system that is based on the principles of sharia or Islamic law. The principles of Islamic finance forbid interest - this is commonly known as riba - charity (zakat), forbid high risk (gharar), forbid some transactions like gambling, and are based on PLS (Profit-Loss Share). The most important concept is that both charging and receiving interest are strictly forbidden; money may not generate profits. Islamic banks have largely survived the global economic crisis intact and they offer a safer operation than conventional banks. CAMEL analysis is a supervisory rating system to classify a bank's overall condition according to Capital (C), Assets (A), Management (M), Earnings (E) and Liquidity (L). In the analysis a variety of indicators were calculated based on data from the annual reports. The results of the four banks were averaged separately, then classified $(1=\operatorname{good}, 2$ = adequate, 3 = satisfactory, $4=$ acceptable, $5=$ unacceptable) according to the desired criteria, the changes over the years and the relative values of the four banks.
\end{abstract}

\section{Introduction}

Since the outbreak of the 2008 economic crisis the issue of the stability of the banking system has become increasingly important. The attention has turned from traditional financing strategies to alternative financing forms, and the banks operating on Islamic religious principles have been given a greater role, since they were hit less harder by the crisis than conventional banks (Varga, 2011).

Financial stability is a condition in which the financial system, including key financial markets and financial institutions, is resistant to economic shocks and able to fulfil seamlessly its key functions: intermediating financial resources, management of risk and payment transactions. '(www.mnb.hu, 2015).

In most countries the 2008 economic crisis appeared as a banking crisis, which was reflected by bank failures, recapitalization and nationalization. According to the IMF, bank crisis means phenomena which manifest themselves in the number of increased bankruptcies, in the increase in the proportion of non-performing loans and in the reduction of the banking system's capital, and these processes are associated with the drastic fall in stock and real estate prices, with the rise in real interest rates and with the slowdown of capital inflows (Flecser, et al, 2010). Financial institutions have widely used the deliberate and massive leverage. The main downside of this is that the whole financial system might be threatened if the losses occurring in the case of assets increase counterparty risk and undermine trust. When this actually occurred, the illiquid assets write-offs enforced in developed countries have increased solvency risk and as a counterbalancing attempt a rapid leverage dismantling took place (Nagy, 2010).

The operation of the Islamic banks is based on religious principles; therefore, it can be difficult to understand for the Western world. The primary and fundamental source of Islam is the Islamic holy book, the Quran. The Quran summarizes the early foundations of the faith, the history of mankind, the relationship between God and man, and the conditions of bringing people together (Prieger-Mátyás, 2014). According to Islam, the money is just a simple instrument and it has no value by itself, it is merely used to measure the value of things. On the basis of this it is prohibited to produce money from money by funds rate (Balázs, 2011). "And whatever you give for interest to increase within the wealth of people will not increase with Allah. But what you give in zakah, desiring the countenance of Allah - those are the multipliers." (Quran 30:39).

The operation of the Islamic financial transactions and banking products is rooted in the Islamic religion within that in the Islamic law or saria; that is one must comply with the Sharia requirements in carrying out such operations (Pálfi, 2010).Five principles should be applied; i.e. Sharia extends five main rules for economic activities. The first and perhaps most well-known principle is the prohibition of charging interest or riba (usury). Charging interest was illegal according to Islamic law and was rejected; i.e. it was not allowed to ask for interest on money loans (Balazs, 2011). The second principle is that Zakąt should appear in financing transaction, i.e. the charity of our giving. The next principle is that financial transactions opposing the Islamic values are prohibited. Such transactions are alcohol, gambling or the financing of warfare trade. Unreasonable risk-taking during a financial transaction is also prohibited. In addition to the prohibition of charging interest, or riba, the gharar; i.e. too risky transactions and majszir, i.e. gambling are all prohibited activities for Islamic financial life. The fifth principle is PLS, that is the profit and loss sharing. A transaction may only be undertaken if the risks are shared among the participants (Pálfi, 2010). 
Only those transactions can be undertaken which are compatible with the principles of Islam and where participants have a share from the achieved profit and bear the losses in proportion of their contribution (Balázs, 2011). An Islamic bank can be successful through adherence to the five principles. The phrase 'halal' is used if the transactions comply with the law. In the event of conflict with the principle the phrase haram is used (Pálfi, 2010).

The study aims to examine the behaviour of the Turkish Islamic banks operating according to religious principles, in the period between 2005 and 2014. We search to answer the question what makes Islamic banks different from conventional banks and we present the performance of Turkish Islamic banks with the help of financial indicators, mainly the changes occurring in their operations due to the crisis. In the analysis the CAMEL method was used, which examines the banks according to 5 factors: Capital adequacy, Asset quality, Management, Earnings and Liquidity.

\section{The Turkish Banking System and the Period of the Crisis}

The 2008 crisis initially seemed to have no significant effect on the Turkish economy. Following the conclusion of their IMF program they were proud to report that they would not need the IMF's help in the future. The banking system was healthy, which meant that the capital adequacy ratio was adequate, and there have been only few bad credits. Then the momentum was broken, which was attributed to domestic political reasons and to a halt in the EU accession. Turkey's banking system can be divided into three distinct parts. The first one is Depository Banks, the second is Development and Investory Banks and finally the Islamic banks or interest-free banks. The Turkish banking system consists of 49 banks; four of them operate according to Islamic banking principles (TKBB Annual Report, 2013).

Albaraka Turk Participation Bank Inc. was founded in 1985. The bank is $66 \%$ owned by foreign investors, $54 \%$ by the Albaraka Banking Group, and $7.84 \%$ by the Islamic Development Bank, the rest being owned by other investors. Asya Participation Bank Inc. is the youngest, as it was founded on 24th of October in 1996. Kuveyt Turk Participation Bank Inc., founded in 1989, deals with interest-free financing and is also owned by the Islamic Development Bank (9\%).and the Kuwait Finance House (62\%). Turkiye Finance Participation Bank Inc. was formed on 3rd of October in 1991 (TKBB Annual Report, 2013). Here we would like to mention that the fifth Islamic bank the Turkish Ziraat Participation Bank was founded on 14th of October in 2015 (www.ziraatkatilim.com.tr).

The most significant part of the financial market is the banking sector, followed by the insurance industry and then the public funds. The crisis has slowed down the pace of opening new bank branches and troubles have occurred in the area of lending and credit card business. The number of non-performing credit card debts reached 2.5 million. Despite all these, the Turkish banking sector was able to maintain growth and profitability. The Turkish banks were disciplined and operated under strict rules during the crisis. Learning from the previous recession (2000-2001).they pursued a credit policy with which they could remain profitable. However, it should be noted that the provision for non-performing loans is a serious impediment to growth (TKBB Annual Report, 2013).

Overall, the global economic crisis in late 2008 and in the first quarter of 2009 appeared significantly in the Turkish economy's performance, but as far as the banking sector is concerned, the banking sector's profitability has improved rapidly as a result of the reduction of the base rate by the Central Bank. The Turkish real economy was influenced significantly by the international fluctuations, but if we compare it with the money market, it turns out that Turkey has not conducted such an intensive exchange policy as other countries, and none of the banks or financial institutions went bankrupt or had other major difficulties (TKBB Annual Report, 2009).

After the outbreak of the crisis the interest-free banks got into the centre of attention which operates according to Islamic principles. These banks did not have such "toxic" assets as traditional banks, their loans were not converted into securities, and did not undertake high-risk commercial transactions, nor did they speculate. As soon as the attention was focused on interest-free banking, or, as the world calls it, Islamic banks, several conventional banks have started to open such departments (TKBB Annual Report, 2009). These sections are called 'Islamic windows'. Following the 2008 crisis the demand for Islamic financial products increased, and conventional banks took advantage of this trend and started to open Islamic departments. These windows operate completely according to Islamic principles (Gálosi, 2010).

\section{Material and Method}

In the primary research the analysis was done on the basis of data from the Turkish Islamic banks' reports between 2005 and 2014. The Turkish Islamic banks prepare their annual report according to International Financial Reporting Standards (IFRS) so that they become internationally comparable. The data for the analysis come from the unconsolidated financial statements. During the examination, the CAMEL method was used which gives us comprehensive view about Capital adequacy, Asset quality, the Management, Profitability, and about Liquidity. The CAMEL method is a subjective grading method, but in this case we use it with the objective of presenting the evolution of the performance of the banks. 
The selection of the best indicators of banking activities can be difficult. The CAMEL analysis is considered to be the most appropriate method. The CAMEL method was introduced in 1979 by the US banking supervisors. The mosaic word consists of the following five components:

C - Capital Adequacy

A - Asset

M - Management

E - Earnings

L - Liquidity.

On the basis of this method the analysis of the banks is done in two steps. In the first step the individual factors are graded on a scale of 5 points:

$1=\operatorname{good}$

$2=$ sufficient

$3=$ satisfactory

$4=$ acceptable

$5=$ inadequate.

The next step is the overall classification of financial institutions also on a 5-point scale as an average of the previous ratings:

$1=$ financially strong

2 = basically good, few problems

$3=$ major problems exist

$4=$ deteriorated financial situation

$5=$ high probability of bankruptcy (Baka, et. al, 2012)

\section{The CAMEL Analysis}

In the analysis a variety of indicators were calculated based on data from the annual reports. For the test we used data from the Islamic banks' annual reports in English and in Turkish language between 2005 and 2014, which are available for downloading from their websites on the Internet. On the basis of five criteria 2 indicators per criterion were calculated and evaluated. The results of the four banks were averaged separately, then classified $(1=$ good, 2 = adequate, 3 = satisfactory, $4=$ acceptable, $5=$ unacceptable) according to the desired criteria, the changes over the years and the relative values of the four banks.

\subsection{Capital Adequacy}

The main task of the Capital adequacy ratio (CAR) is maintaining the bank's long-term solvency. The indicator expressing solvency is used worldwide; the value of this index should be at least $8 \%$ in accordance with the Basel standards. Changes in Capital adequacy ratios are shown in the figure below; the data come from the banks' annual reports.

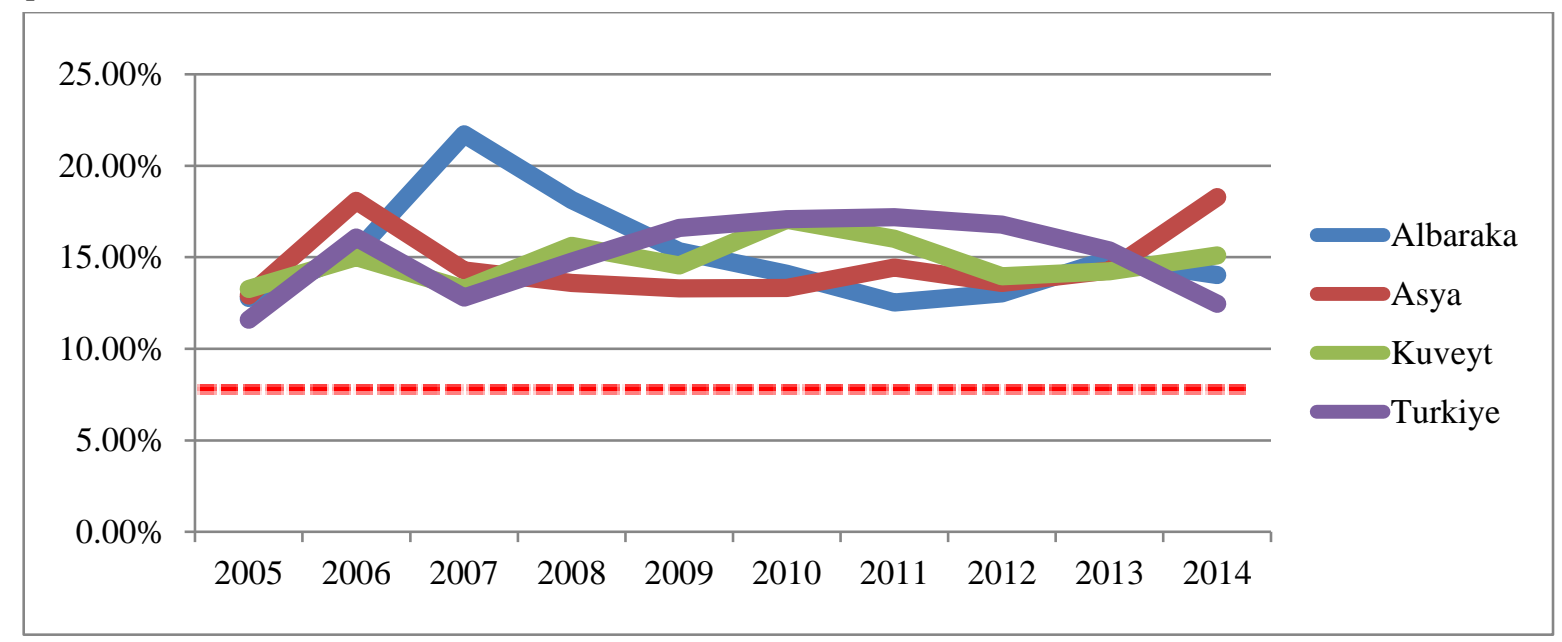

Figure 1. Trends in the Capital Adequacy Ratios

We can see that in the examined years all banks met the $8 \%$ criteria (----) moreover, they reached even higher than that.

In 2007, Albaraka Bank's capital adequacy ratio was above $20 \%$, and then decreased until 2011. During the period of the crisis, the Turkish Islamic banks' indicators fell slightly due to the increase in troubled assets, but after that they could keep their solvency.

The banks are classified as 1 . 
The Leverage ratio values are shown in the following figure. The results of the indicator were obtained by comparing own capital to the relative values of the balance sheet total.

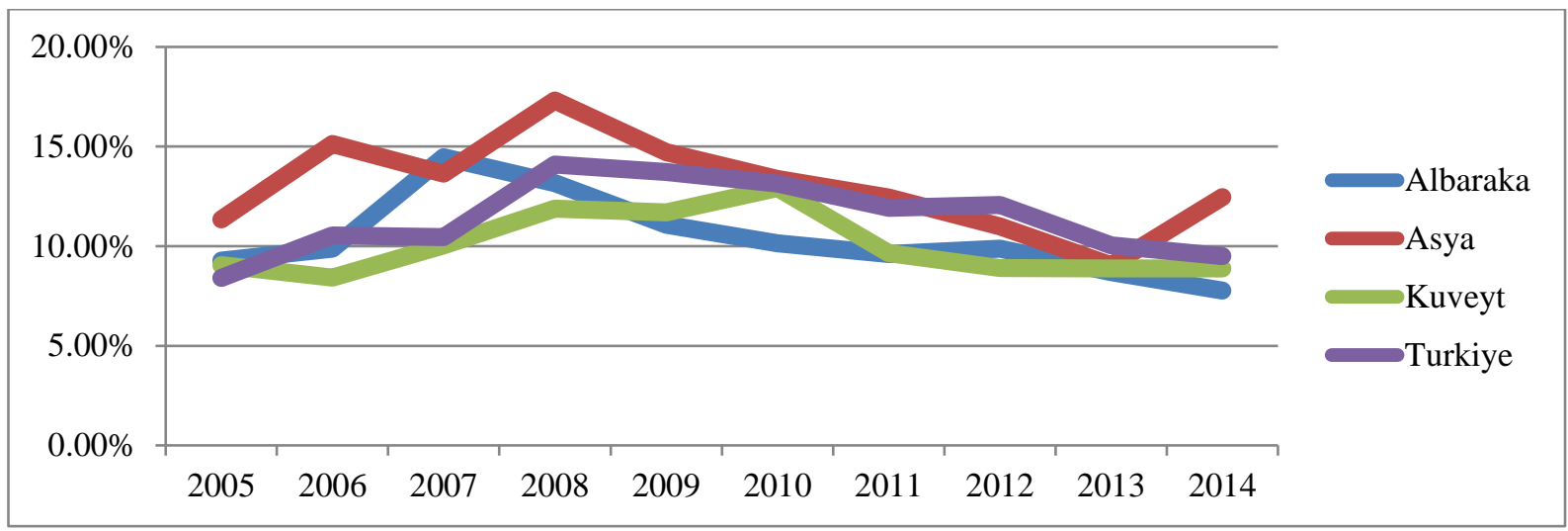

Figure 2. Changes in the Leverage Ratios

The indicator also provides information about the bank's prudence, namely the distribution of equity and debt. The indicator can be interpreted that in 2007 Albaraka Bank's equity accounted for $14.47 \%$ of foreign funds, then the index fell. In the case of Asya it was $13.63 \%$, in the case of Kuveyt it was $10.04 \%$, and $10.46 \%$ in the case of Turkiye. The reductions of the indicators suggest that the equity ratio increased. Banks mostly manage foreign resources so a high leverage is typical.

If the ratio of foreign funds were too high, it would mean that the Turkish Islamic banks pursue risky activities. In this case, following the crisis the change was a decline, i.e. we can talk about careful business, which, however, in turn could lead to a deterioration of profitability. Four of the banks are classified as 3 .

The Turkish Islamic banking sector's capital adequacy is stable, its Capital adequacy indicators were in line with the accepted value and its solvency was not threatened.

\subsection{Assets}

Lending activities are especially important for banks, so it is essential to analyse the quality of the assets in terms of the bank's successful operation and efficiency. We mainly analyse classified loans, especially Non-performing loans (NPL) compared to total loans; i.e. what the proportion of the credit loss is in the total loans. In the crisis a significant jump in the non-performing loans was typical.

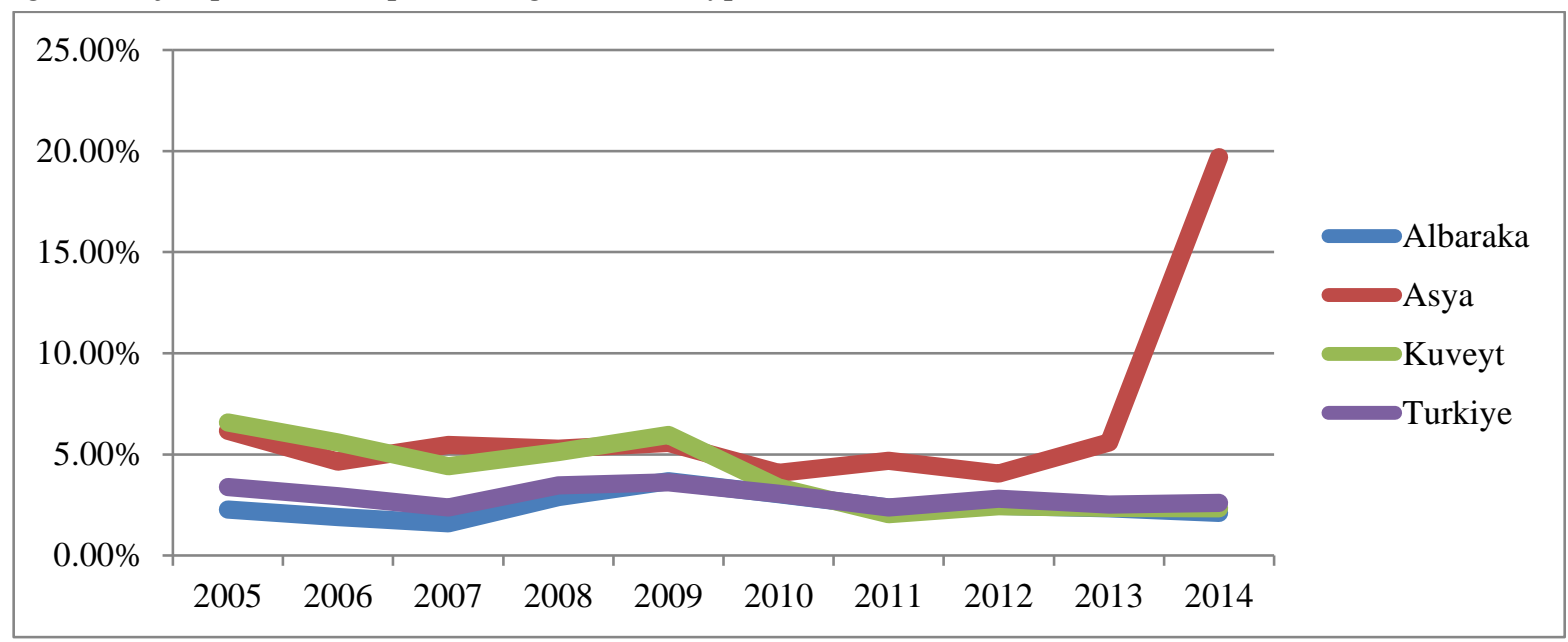

Figure 3. NPL Ratios to Total Loan Portfolios

The figure provides information about the level of Non-performing loans in the total loan portfolio. However, the value of Non-performing loans below $5 \%$ is acceptable.

We can see that between 2008-2009, during the crisis there was a slight increase in the proportion of Nonperforming loans for all four banks and the values of Kuveyt and Asya jumped above the accepted value. However, still nearly $95 \%$ of the loans have no problems. From 2010 to 2012, there may have been adverse events in the operation of Bank Asya, as the proportion of Non-performing loans increased significantly. In 2014, the proportion of the non performing loans to total loan portfolio was $19.70 \%$, which could be attributed to the negative conditions in the consumer loans and credit card business sector. 
To sum up, in the case of banks' operation we can talk about prudential operation, because the credits account only for a very small proportion of the total loan losses, and the other banks' indicators move together from 2011 except Asya. Bank Asya is classified as 4 due to the increase and the average values above 5\%.

The proportion of loans to total assets is shown in the following figure.

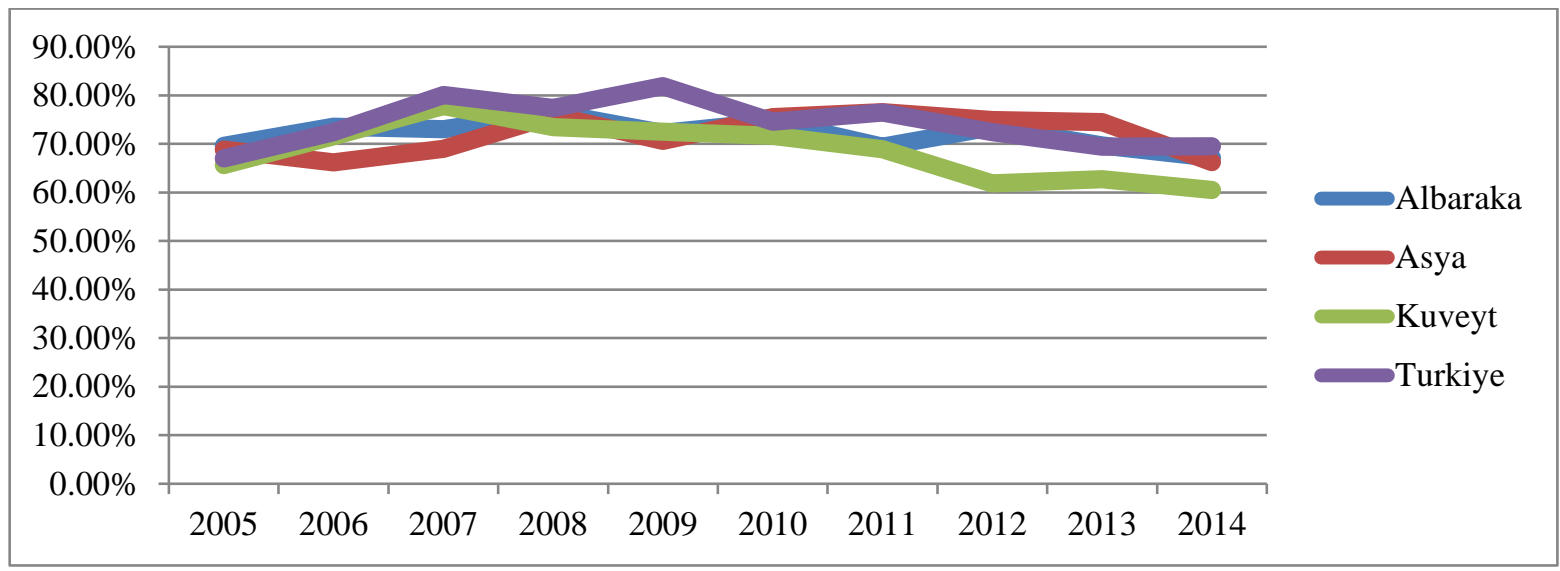

Figure 4. Changes of the Loan Portfolios

It can be seen that the banks' activity is dominated by lending with more than $70 \%$. On the positive side, all of the banks' loan portfolio was higher year after year; i.e. their lending activity has not slowed down. However, we can approach this also from the perspective that a high loan portfolio can be risky, so considering safety i.e. because of the risk of return a high loan portfolio can be negative. However, in the case of banks, lending means a greater profitability than investments for example. The banks are classified as 1 .

\subsection{Management}

The bank's management is extremely important because the strength and the effectiveness of banks may depend on the type of the leadership and its ability to recognize risks and restore operations growth path. This factor is mainly examined with cost efficiency indicators.

The revenues of the Turkish Islamic banks were obtained from Income Statements of Annual reports. Total revenue consists of the revenue from Fees and commissions, Income from trading and other revenues. Naturally, interest and similar income are not found in Islamic banks' revenues. The most significant items are Revenues. This item was unfavourable in 2010, compared to 2009 it decreased by $4.02 \%$ for the whole banking system. Revenues consist of Profit from loans, Profits from the thovable assets,"from the Sale and from Leasing of financial income.

The total cost of the Turkish Islamic banks consists of Expenditures and Other spending items, in which a steady increase was registered during the reference years.

The Cost / Revenue ratio is shown in the following figure.

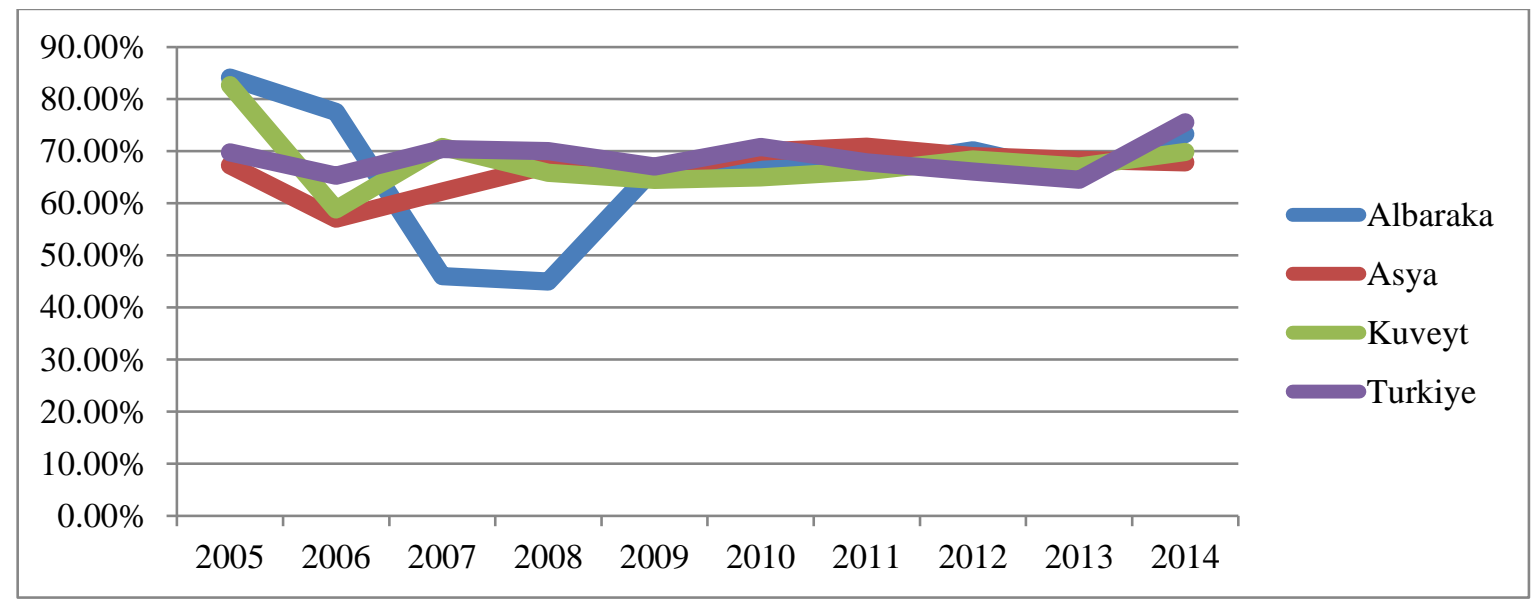

Figure 5. Ratio of Cost/Revenue

The higher the index is the less efficiently a bank operates, i.e. costs erode larger and larger parts of the revenue. The improvement in the cost-effectiveness can be discovered in some places, but it is not significant. Costs consume more than $60 \%$ of the revenue. Comparing the four banks, Turkiye proved to be the least cost-effective, 
and we can see that the ratio of the fourth bank move together from 2009. The banks are classified as 4 due to the high costs.

The following efficiency indicator is Revenue proportionate earnings.

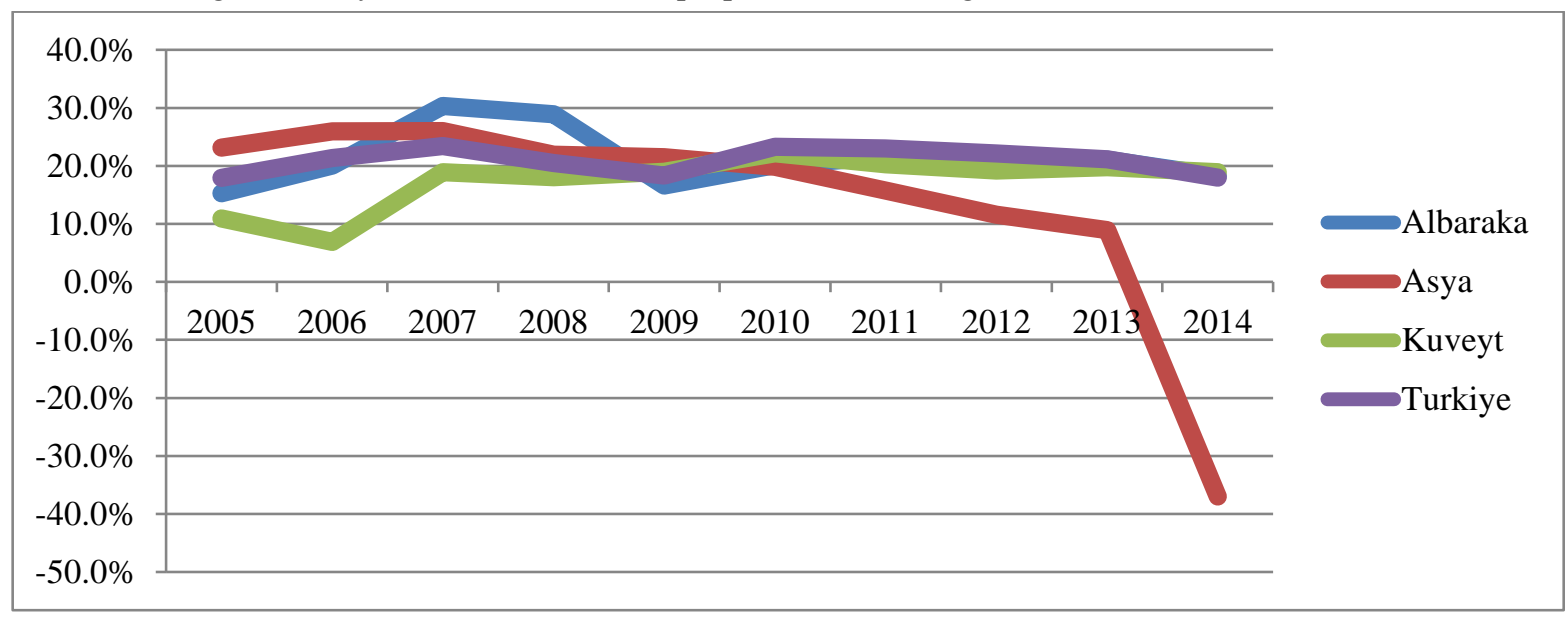

Figure 6. Trends in Revenue Proportionate Earnings

The pre-tax profit/total revenue ratio reflects the operational efficiency, namely how much of the proceeds is made up by the profits. It is clear that the index value fell between 2008 and 2009, but since 2009 the Turkish banks have been improving except Asya. In the case of Bank Asya the negative tendency can be attributed to the loss in 2014. Albaraka, Kuveyt and Turkiye banks are classified as 2, Asya is classified as 3.

The efficiency of the banks showed a slight declining performance due to adverse changes in the costs, which have risen at the expense of profits. Overall, the examination of the Turkish Islamic banking performance indicators showed no dramatic changes except in Asya, which has been in the red since 2013.

\subsection{Earnings}

By using the profitability indicators we can gain information about the effectiveness of management, i.e. how effectively the available funds and the assets acquired from them are used to generate profits. The Turkish banks managed effectively, as net profits grew. But if we analyse the banks one by one there was a decline in 2009 in the case of Albaraka and in the case of Asya from 2010.

As we mentioned, we cannot find interest and similar income in the Islamic banks' profit, but nonetheless they are managed effectively. Return on equity (ROE) and Return on assets (ROA) are commonly used indicators of profitability.

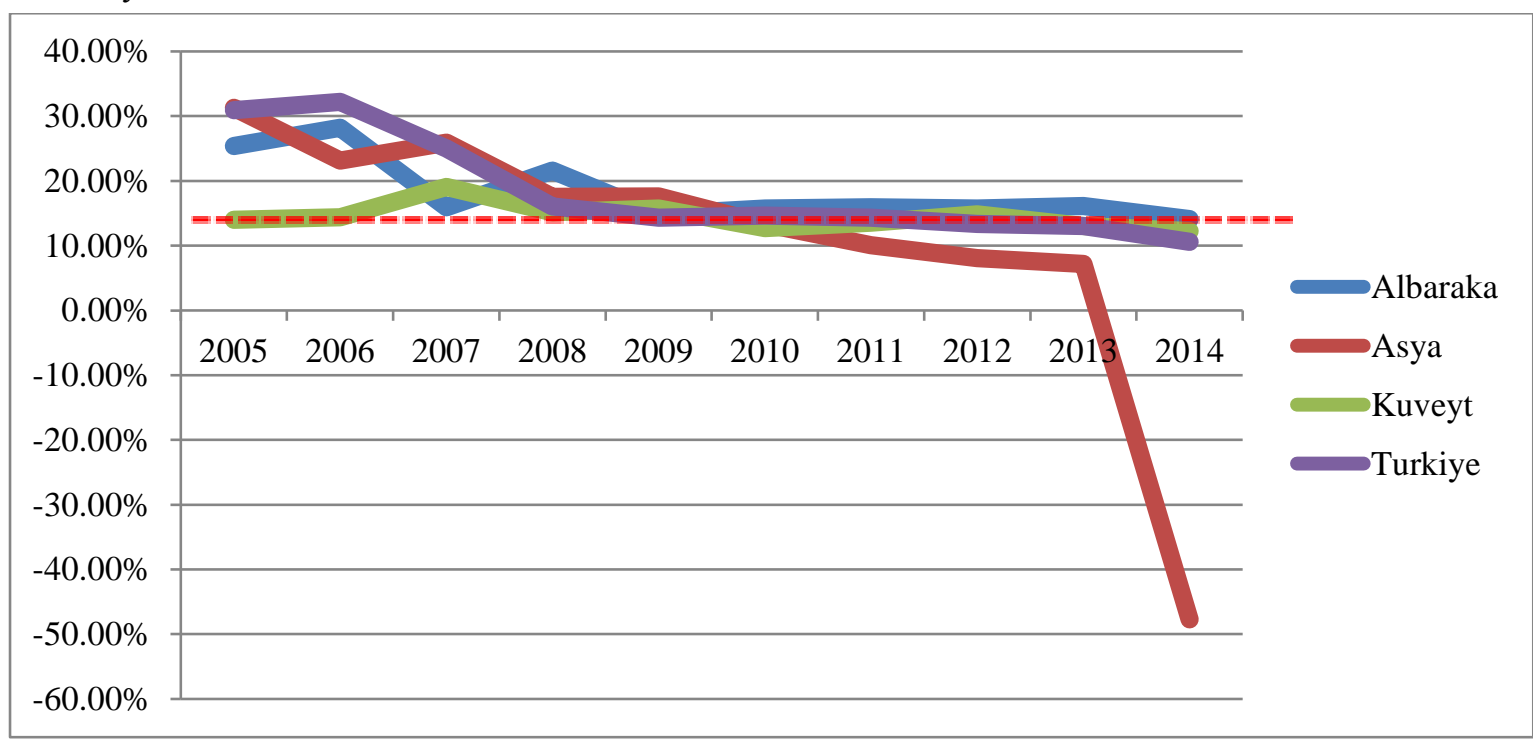

Figure 7. Changes of the ROE Indicators

ROE reflects how the equity produces profit. In case of banks a healthy ROE is around 10-12\% (----). In the case of Bank Asya the indicator is sometimes negative. The profitability decreased significantly and steadily from 2009, which can be explained with the decrease of the net result, and since 2013 it has had negative profit after tax. This resulted in negative ROE and ROA indicators. A negative result can be explained by the fact that due to 
the high rate of non-performing loans provision had to be made, which worsened the outcome. If the ROE is too low, it can also pose risks, since in this case there is a danger that the growth will be marred by another source involved in the operation.

Asya is classified as 3 due to the negative tendency; the other banks are classified as 1 .

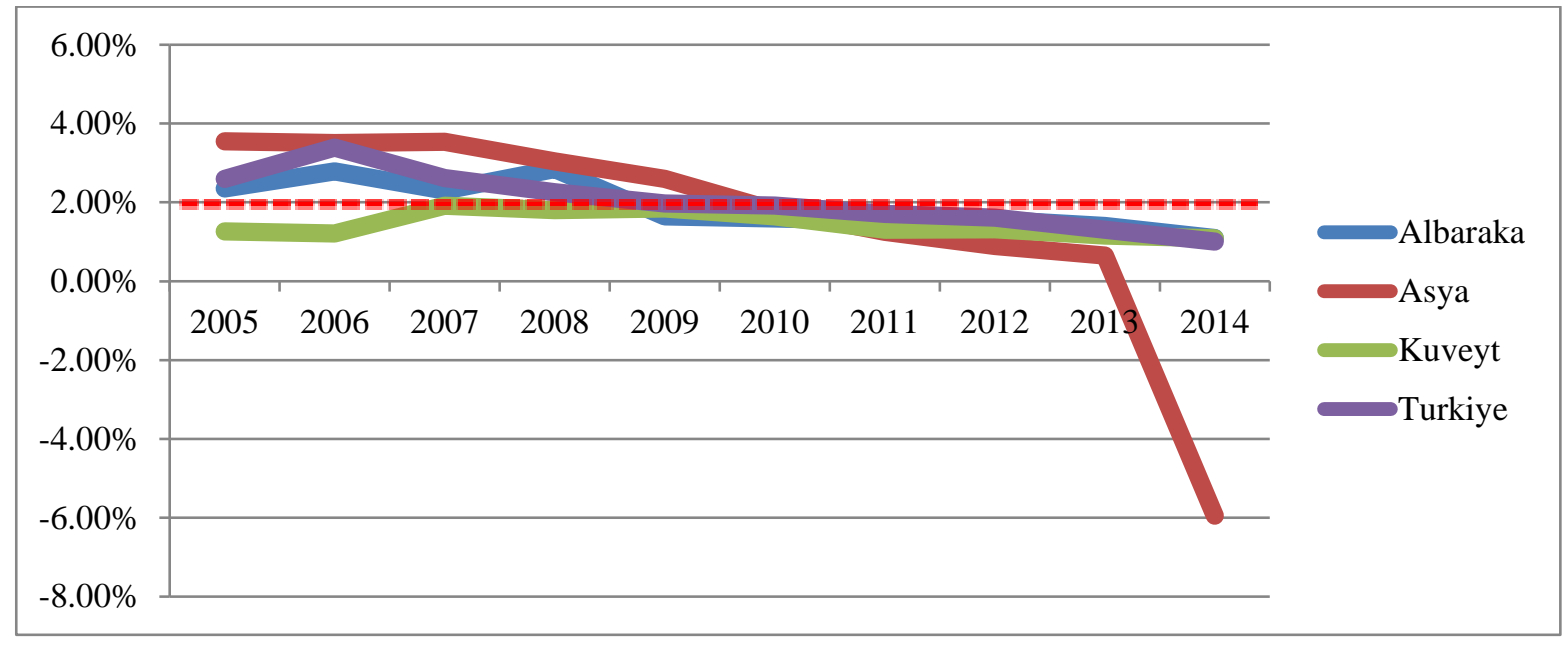

Figure 8. Changes of the ROA Indicators

The ROA gives us data about banks' assets. It shows how good and effective the banks' placements are. The value of the index between 1 and 2 (----) is estimated to be good. The decline of the indexes reflects the deterioration in the banks' recovery. From 2009 a downward trend can be observed. The downward trend in ROA is typical, but it is still within the limits.

In the case of Bank Asya we can see a gradual decline, and in 2014 Bank Asya closed with negative results. Earlier we saw that the Turkish banks' leverage ratio was in decline, which is likely to have a negative effect on the profitability and pushed it down. Asya is classified as 3, the other banks are classified as 1 .

\subsection{Liquidity}

The liquidity indicator informs you how fast the banks' financial instruments can be converted to cash without losses. The higher the index value is the more liquid a bank can be considered. Of course, liquid assets mean lower returns than illiquid assets, so it is important to choose the right assets. The liquid assets of Islamic banks include I. Cash and deposit accounts in the Central Bank, III. Interbank deposits, as well as the V. Financial assets for sale. Item I. Cash and deposit accounts at the Central Bank are clearly the bulk of the Turkish banks' liquid assets.

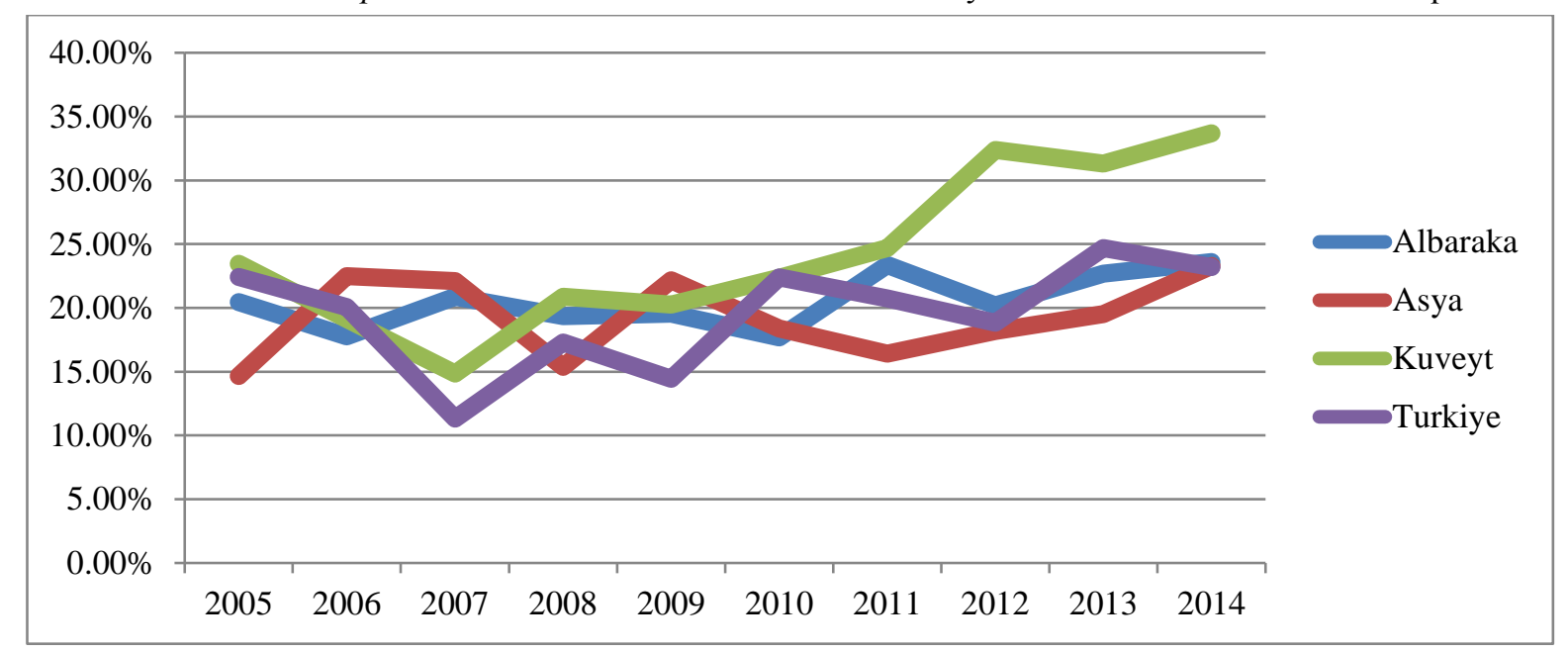

Figure 9. Changes of the Liquidity Ratios

We get a fluctuating picture of the changes of the liquidity of individual banks. The increase and decrease in liquidity may be explained by the changes of banks' liquid assets. In the case of Islamic banks the increase in liquidity can be explained by the rise in Cash and Central Bank accounts. Overall, we can say that the Turkish banks have sufficient liquidity. The banks are classified as 1 .

The Banks' business policy is indicated by the Loan/Deposit ratio. The value of the index above $100 \%$, that is, when the ratio of the loans exceeds the ratio of the deposits, it means aggressive business policy. 


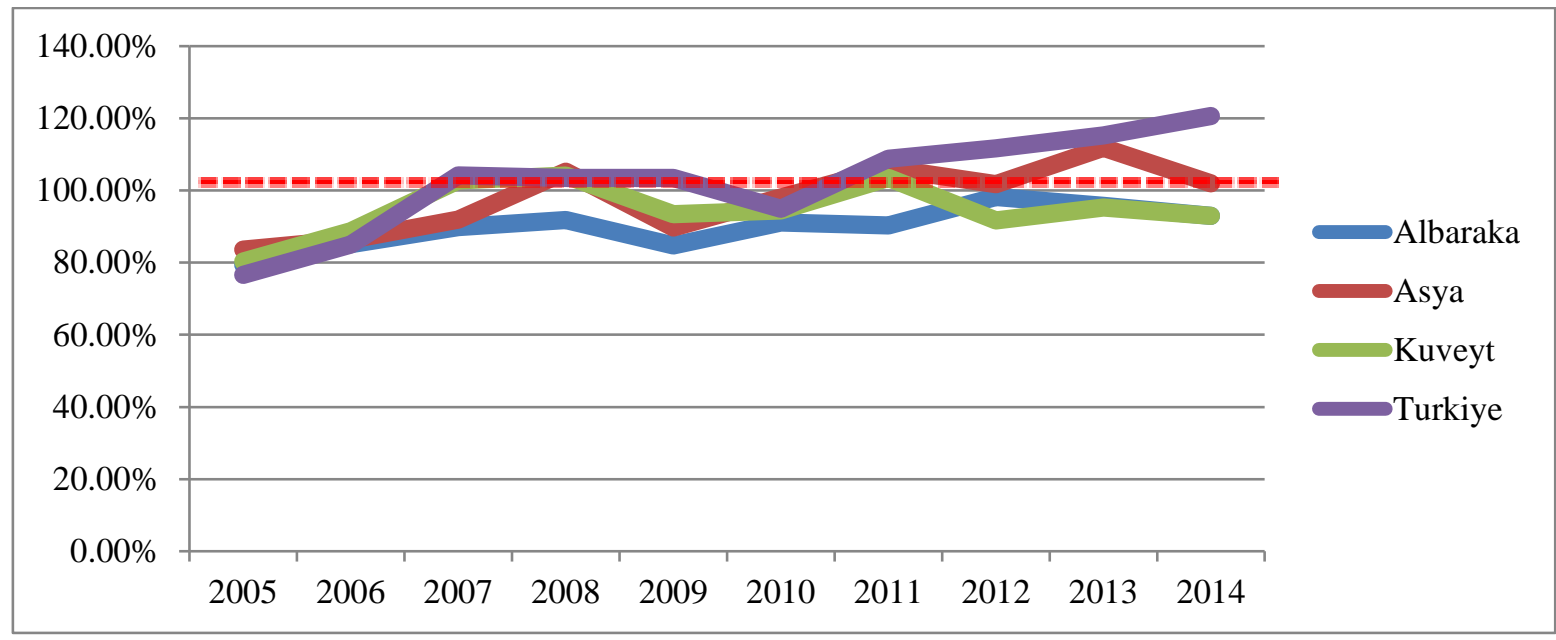

Figure 10. The Loan/Deposit Ratios

In the years between 2011-2013 and in 2008 the index was 100\% (----) that is above the healthy limit, which meant that the Islamic banks were on aggressive business policies, that is the size of the loans exceeded the value of deposits, which has been a liquidity risk.

It may also be an important consideration what the composition of deposits is like, because, if they have a lot of low-value, short-term deposits, instead of the large deposits, the sudden withdraw of the deposits can also cause disturbances in the operation of the banks. Turkiye is classified as 2 due to the value above $100 \%$.

It is clear that the liquidity ratio increased but only slightly whereas the Loan/Deposit ratio was variable, but also slightly.

\subsection{Results of the CAMEL Analysis}

Therefore, for the qualification of the Turkish Islamic banking system we classified various factors, and then the results were averaged. The end result, according to the results of the banking system is 1.83 that is rounded to 2 that is good, which means that basically it is a good banking system, there are just few problems.

\begin{tabular}{|l|c|c|c|c|c|c|}
\hline Banks & C & A & M & E & L & Average \\
\hline Albaraka & 2.00 & 1.00 & 3.00 & 1.00 & 1.00 & 1.60 \\
\hline Asya & 2.00 & 2.50 & 3.50 & 3.00 & 1.00 & 2.40 \\
\hline Kuveyt & 2.00 & 1.00 & 3.00 & 1.00 & 1.00 & 1.60 \\
\hline Turkiye & 2.00 & 1.00 & 3.00 & 1.00 & 1.50 & 1.70 \\
\hline Average & 2.00 & 1.38 & 3.13 & 1.50 & 1.13 & 1.83 \\
\hline
\end{tabular}

Table 1. Results of the Turkish Islamic Banks CAMEL Analysis Source: Based on the Calculation

\section{Summary}

After the 2008 economic crisis, special attention was given to alternative financing techniques, and so to Islamic banks. They are characterized as interest-free banking.

Using the annual reports of the banks in the period between 2005 and 2014 we evaluated the individual banks and the banking system as a whole by indicators, based on of Capital adequacy, Asset quality, the Management efficiency, Profitability, and Liquidity. With the CAMEL analysis, the primary goal was to get a picture of the operation of the Turkish Islamic banks, the developments of their performances in the examined years.

Due to the operational features of the Islamic banks they do not assume high risks, so their operation is not exposed to large losses, at the same time; however, no huge profit is available for them, either. They emphasize partnership, i.e. it is important to consider each transaction from the perspectives of all three participants: the saver, the investor and the bank, too, because whether the transaction brings profit or loss, they are divided among the three participants. This operating principle is important, as it may be relevant for anyone who comes in contact with a bank to monitor their savings because thereby they "can force" banks for safer investments and increase competition between them.

In addition, it is important that thanks to the operating principles we can speak about safer business, because for banks operating on the basis of Islamic religious principles it is forbidden to carry out a number of financing activities violating their religion and these activities can be found in conventional banking, which led to the crisis. These include speculative transactions, or entering transactions with the aforementioned high-risk investments, 
and certain financial market techniques such as securitization are absent. As a result, the "bad" assets did not infect them during the crisis.

On the basis of the calculated indicators we can say that the business of the banks is not endangered. Bank Asya can be considered the weakest among the four banks according to its results. Furthermore, the Turkish Islamic banks performance moved together in most cases. The biggest negative trend appeared in the downward tendency of profitability. The crisis and the changed economic environment were reflected in their performances but did not cause any drastic changes. The strict monetary control of the banks as well as the efforts for safe operation probably contributed to all this. It must be added that there was no bankruptcy in the case of the traditional Turkish banking system, either.

\section{References}

- Balázs J., 2011. Az iszlám bankrendszer: Tanulságok a neoliberális pénzügypolitika figyelmébe, Valóság, Vol. 54. Num. 1.pp. 1-11

- Baka I.-Dancsó J.-Ligeti S.-Szarvas F.-Vágyi F.-Varga J., 2012. Bankismeretek, Budapest, 2012, Tanszék Pénzügyi és Szolgáltató Kft., University book, pp.44-62

- Felcser D.-Körmendi Gy., 2010. Bankválságok nemzetközi tapasztalatai: kezelési eszközök és makrogazdasági következmények

- $\quad$ https://www.mnb.hu/letoltes/felcser-kormendi-mnbszemle-0623.pdf

- Financial statements of Bank Albaraka: http://en.albarakaturk.com.tr/investor_relations/detail.aspx?SectionID=Dr8Cw16dHGqYzoMeqx\%2fjjQ\%3 $\mathrm{d} \% 3 \mathrm{~d} \&$ ContentID=4oEu6KjEmU33gGZTiL4GkQ\%3d\%3d

- http://www.albarakaturk.com.tr/faaliyet-raporlari.aspx

- Financial statements of Bank Asya: http://www.bankasya.com.tr/en/investor-relations-annual-reports.aspx

- $\quad$ Financial statements of Bank Kuveyt: http://www.kuveytturk.com.tr/financial_information.aspxhttp://www.kuveytturk.com.tr/finansal_bilgiler_ha kkimizda.aspx.

- Financial statements of Bank Turkiye: http://www.turkiyefinans.com.tr/en-us/investor-relations/financialdata-and-reports/Pages/annual-reports.aspxhttp://www.turkiyefinans.com.tr/tr-tr/yatirimci-iliskileri/finansalraporlar/Sayfalar/bagimsiz-denetim-raporlari.aspx

- Gálosi M. B., 2010. Iszlám ablak - ablak az iszlámra, Budapesti Corvinus Egyetem, thesis

- MNB: http://www.mnb.hu/penzugyi-stabilitas

- Nagy Gy., 2010. Globális pénzügyi válság - A jelenlegi tényleg más? http://kgk.sze.hu/images/dokumentumok/kautzkiadvany2010/nagy\%20gyula.pdf

- Preiger A. -Mátyás, 2014. Az iszlám jog. Publicationes Universitatis Miskolcinensis Sectio Juridica et Politica, Tomus XXXII., pp. 103-112.: http://www.matarka.hu/koz/ISSN_08666032/tomus_32_2014/ISSN_0866-6032_tomus_32_2014_103-112.pdf

- Reports of Participation Banks Association of Turkey (2009-2013): http://www.tkbb.org.tr/research-andpublications-tkbb-publications-annual-sector-reports

- $\quad$ http://quran.com/30/39

- Varga J., 2011. Az iszlám bankrendszer szerepe a pénzügyi stabilitás helyreállításában, A virtuális intézet Közép-Európa kutatására közleményei 4: (1 (No.7)) pp. 121-132. 


\title{
The Comparative Analysis of the Islamic and Conventional Bank System in Turkey
}

\author{
Vivien Pavelka (Kaposvár University, Hungary) \\ Dr. Gyöngyi Bánkuti (Kaposvár University, Hungary) \\ Dr. Jozsef Varga (Kaposvar University, Hungary)
}

\begin{abstract}
The aim of our study is the comparative analysis of the Islamic and conventional bank systems in Turkey focusing on the years of the last financial crisis. The financial crisis of 2008 shocked the world and impeached the confidence in the conventional bank systems. It drew the attention to the alternative financial forms like Islamic banking. The best known specialty of the Islamic bank system is the prohibition of interests and speculative transactions. The question is: are Islamic banks more crisis-resistant than the conventional banks? Are they really more stable? We would like to get answers for these questions through analyzing the four Islamic banks and four conventional banks with the same size in Turkey. We set up three hypothesizes:

1. The profitability of the Islamic banks was higher during the crisis than the profitability of the conventional banks.

2. The liquidity of the Islamic banks was higher during the crisis than the liquidity of the conventional banks.

3. The leverage ratio of the Islamic banks was higher during the crisis than the leverage ratio of the conventional banks.
\end{abstract}

The time horizon of the research is from 2007 to 2013 and we get the data from the annual reports of the banks.

\section{The Islamic Banking System in General}

French and English investments helped the Islamic banking system to be born during the colonization. The first banks were parts of the colonial banking system and the first banks were the Ottoman Bank and the Bank of Persia. The Ottoman Bank was founded in Turkey by French and English investors, while the Bank of Persia was founded in Iran by English investors. That time the Muslims wanted to found a bank on their own, but they faced some difficulties, mainly the technique of interest, that is against the Sharia law. The solution was the Islamic banks let the European financial experts take part in the bank system. That was the way how Islamic banks has born (YousefiKóbori, 2013).

The Islamic bank system is based on the five principles of Saria. These principles are obligatory for all of the Islamic financial institutions:

1. The prohibition of interests.

2. Paying zakat. Zakat means solidarity tax. As banks have high incomes, that's why they have to pay solidarity tax (Varga, 2013). Prophet Muhammad introduced this taxi in order to maintain the community and decrease the wealth inequalities. Who has significant property has to pay this tax. The amount of the tax is $2,5 \%$ of the property (Yousefi-Kóbor, 2013). The zakat should be paid in every 355 days, which means one lunar year (Falus, 2014).

3. Transactions against the principles of Islam is forbidden. That's why Islamic banks can't finance alcohol, weapons or gambling (Pálfi, 2010).

4. Islamic banks have to avoid transactions with high risks such as speculative transactions (Pálfi, 2010). Every transaction has to be evaluated individually in order to avoid high risk taking. We can't find standardized transactions in the Islamic banking system. There is a special relationship between the bank and the customer, we call it profit and loss share (Balázs et al, 2014).

5. The last principle is profit and loss sharing. The bank and the customer determine in the contract the amount of profit and loss that they will bear (Pálfi, 2010).

\section{The Turkish Bank System}

The Turkish banking system can be divided into three parts: commercial banks, investment banks and Islamic banks (Tálos, 2015). The Islamic banks had the 7\% of the assets of the Turkish banking sector in 2012 (ey.com, 2014). The Turkish Islamic banks had stable growth path since 2000 , when they had only the $2 \%$ of the Turkish bank sector. The whole Islamic banking capital reached the 60 trillion dollar worldwide which is a significant result. The Islamic banks had 966 branches in Turkey in 2014 which is higher by 40\% than in 2011 (herdem.av.tr, 2014).

Recent surveys show that Islamic financial sector will have a bright future, because:

- increasing number of Muslim customers,

- the Turkish state supports the sector, 
- increasing number of small and medium-sized enterprises who are interested in Islamic finance,

- a fifth Islamic bank, Ziraat Bankasi was opened in 2015 and they are planning to open another one (Turkey Islamic Finance Report, 2014).

\section{The Comparative Analysis of the Islamic and Conventional Bank System in Turkey}

We would like to prove that the Islamic banks are more crisis-resistant than the conventional banks in Turkey. We use ratios suitable for examining this, such as profitability ratios (Return on assets -ROA, Return on equityROE), liquidity ratio (IAR) and leverage ratio. On the first diagram we signed the Islamic banks with green - as green is the colour of Islam. We constructed the average of the bank sectors by weighting the total amounts of the balance sheets. This way we got a more detailed picture. The calculation based on the annual reports of the banks. The time horizon is 2007-2014.

\subsection{The Analysis of Profitability}

The profitability shows how effectively the bank operates. ROE calculates how many dollars of profit a company generates with each dollar of shareholders' equity. The healthy percentage of ROE is $10-12 \%$.

\section{The ROE of the two banking systems}

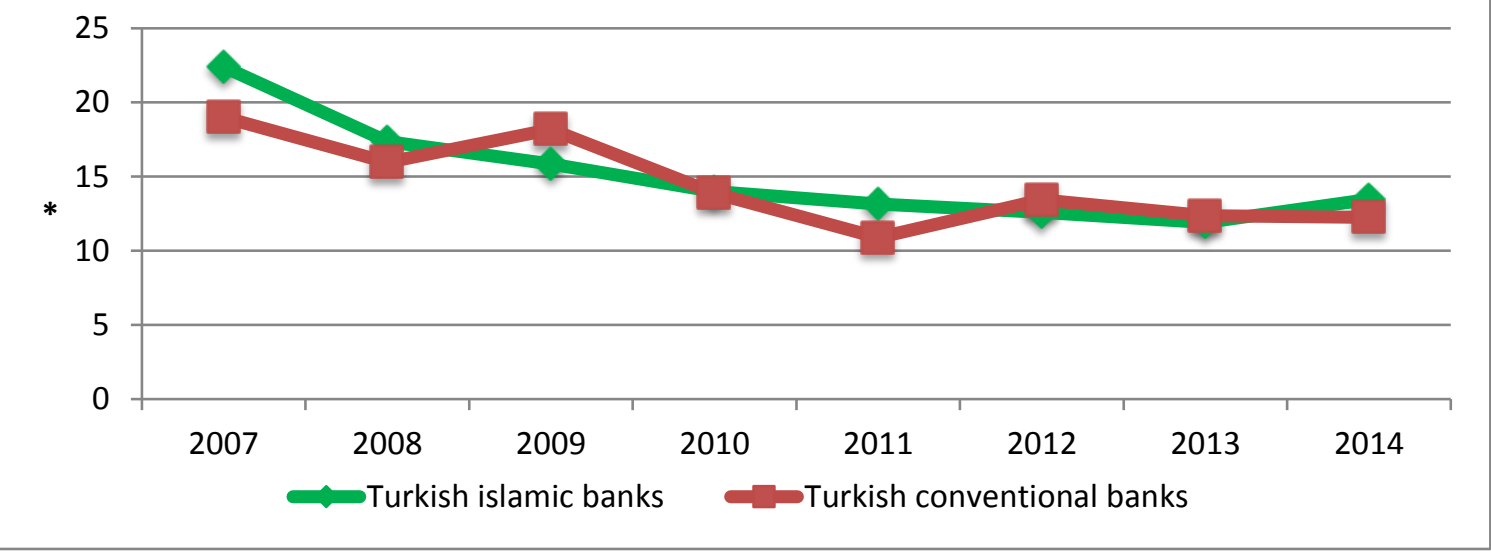

Figure 1: Average ROE of the Two Banking Systems Source: Own Calculation Based on the Annual Reports of the Banks

We can see that ROE of the conventional banks started to decrease in the financial crisis, while there is no similar decrease in the Islamic banking sector. There is a decrease by $12 \%$ during 5 years in the conventional banking sector. We can see a decrease of $9 \%$ during 6 years in the Islamic banking system. But on the other hand, both sector reached the healthy limit of $10 \%$.

The ROA ratio measures how efficiently a company can manage its assets to produce profits during a period. The healthy limit of ROA is between 1 and 2 (Tálos, 2015).

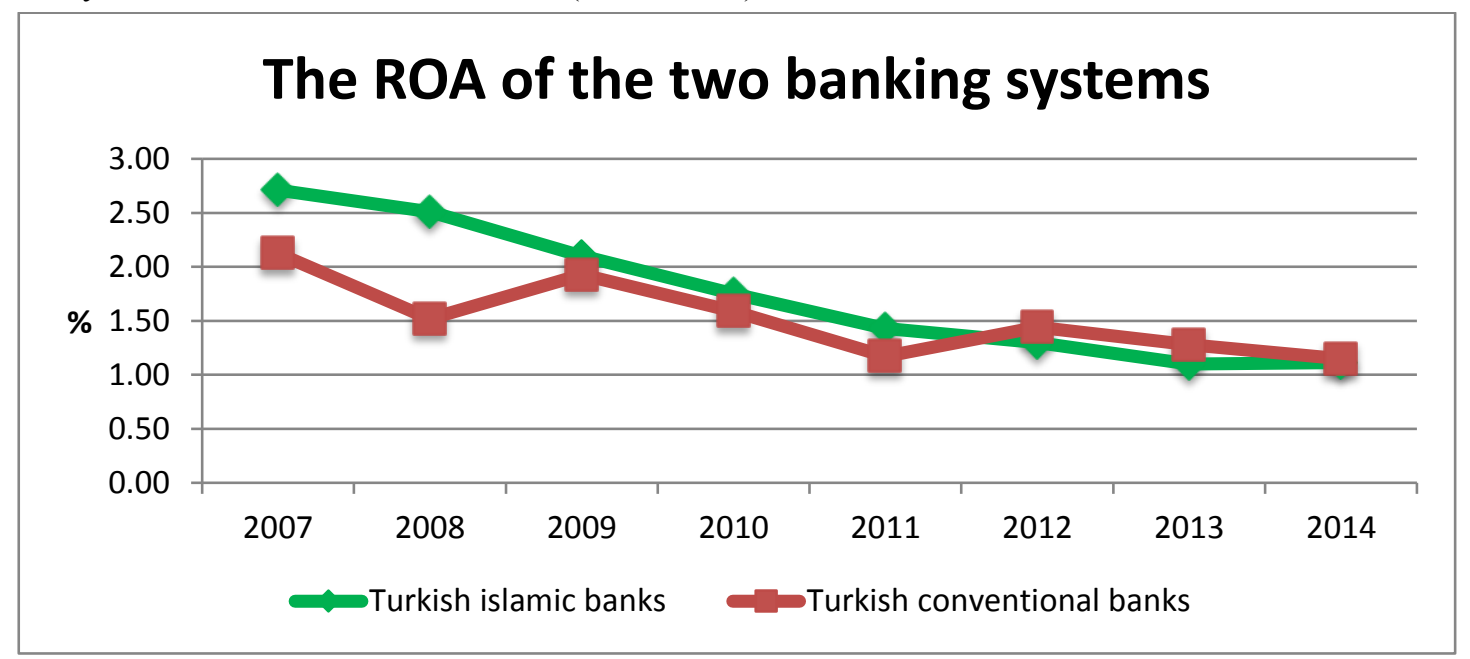

Figure 2: ROA of the Two Banking Systems Source: Own Calculation Based on the Annual Reports of the Banks 
The conventional banks reached lower ROA ratios than the Islamic ones until 2012. The fluctuation of the conventional banks let us think that there is a bigger instability in the conventional banks. The diagram shows a continuous decrease in the Islamic banks but we see more stable picture. Both sector reached the healthy limit.

Finally we have to approve our first hypothesis: the profitability of Islamic banks were better than the profitability of conventional banks during the crisis.

\subsection{The Analysis of Liquidity}

Liquidity means how quickly a bank can convert its assets into cash at face value to meet the cash demands of the depositors and borrowers. It is important to examine the liquidity because the banks had to face with liquidity problems during the crisis. We use the IAR ratio, which indicates what percentages of the assets of the bank are tied up in loans (Mosab, 2014).

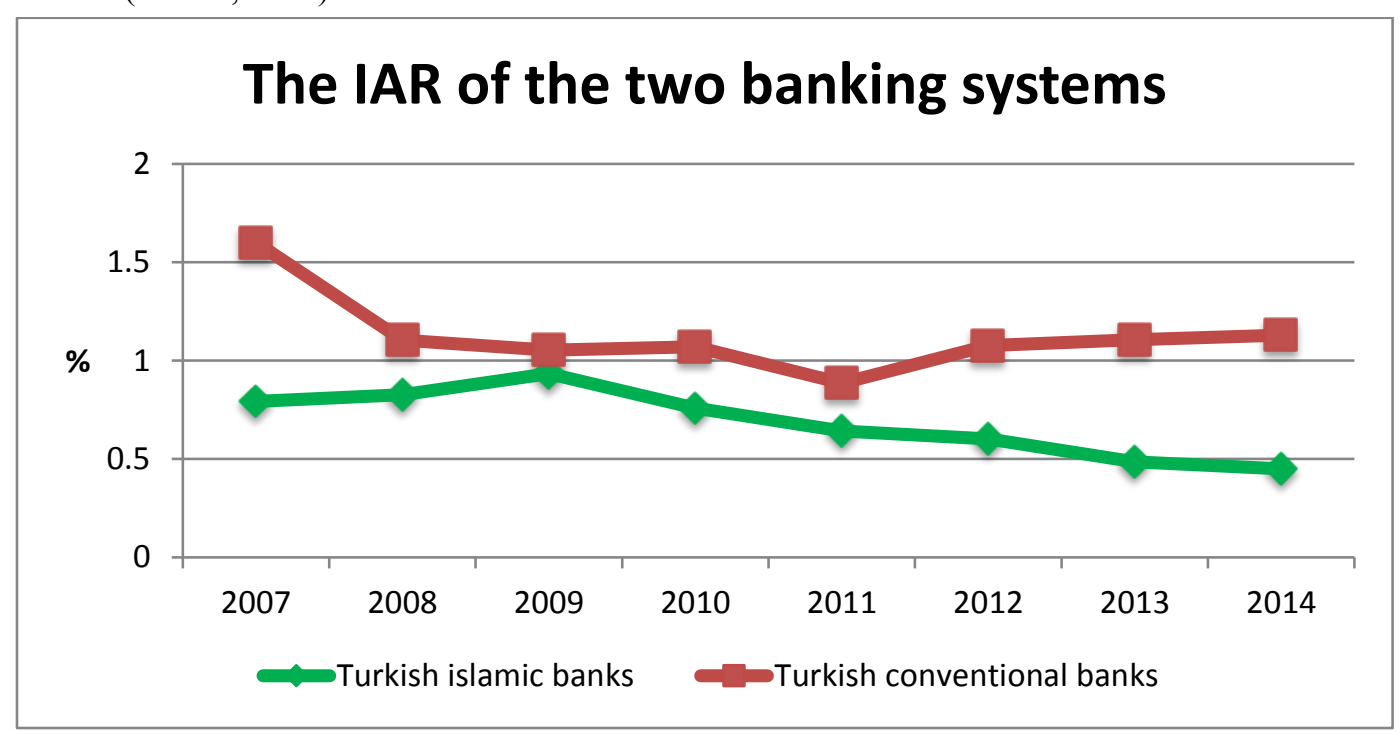

Figure 3: The IAR of the Two Banking Systems Source: Own Calculation Based on the Annual Reports of the Banks

The lower the IAR is the more liquid the bank is. The diagram shows that Islamic banks were in better situation even if they almost reached the level of the conventional banks in 2009. From 2007 to 2009 the IAR ratio of the Islamic banks increased by $0,17 \%$, the reason for it could be the difficulties of the crisis while the ratio of the conventional banks decreased by $0,48 \%$. We can find a reason for it: the investments of the conventional banks decreased while the investments of the Islamic banks increased.

In summary, we can state our second hypothesis has been approved: the liquidity of the Islamic banks were higher than conventional ones during the crisis.

\subsection{The Analysis of Leverage}

A leverage ratio is meant to evaluate a company's debt levels, it shows the proportion of own liabilities and nonown liabilities. If the leverage ratio is too high, then the bank operates with high risk. Low leverage ratio is not good either as it can cause decrease in the profitability (Baka et al, 2012).

\section{The Leverage ratio of the two banking systems}

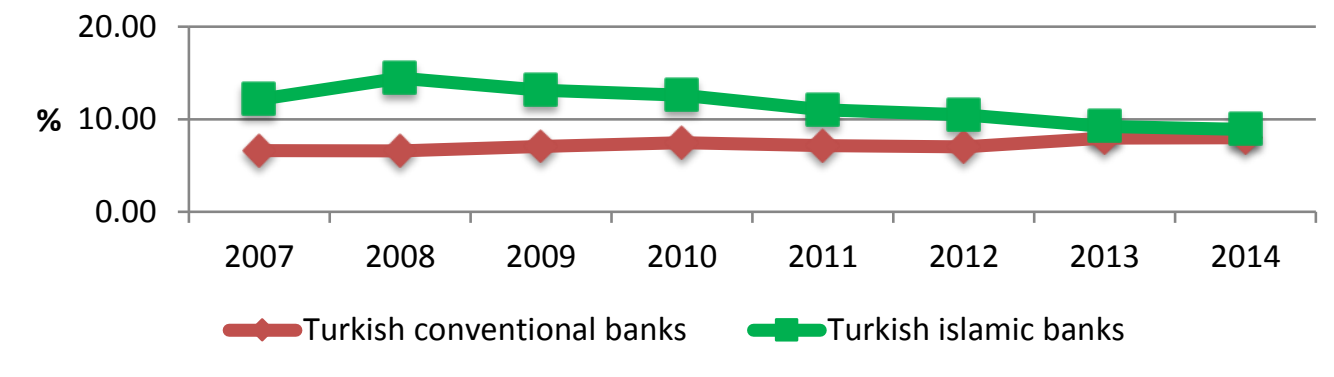

Figure 4: The Leverage Ratio of the Two Banking Systems Source: Own Calculation Based on the Annual Reports of the Banks 
The diagram shows that the Islamic banks have a much higher leverage than the conventional banks in every year. The highest percentage was in 2008 , with the value of $14,44 \%$. It means the equity is $14,44 \%$ of the non-own liabilities. We can see a continuous decrease from 2008, till there is an increase from 2008 in the conventional banks. The high leverage during the crisis let us think, the crisis had not forced Islamic banks decrease their risk taking. So our third hypothesis is proved.

\section{Summary}

Till the crisis in 2008 the conventional banks suffered from crisis of confidence, so the customers started to turn to alternative financial techniques like Islamic banking.

The best-known specialty of Islamic banks is the prohibition of interests. The Islamic banks can only finance real economical transactions, are based on profit and loss sharing, speculative ones are prohibited.

The aim of our study is proving that Islamic banks are more crisis-resistant than the conventional banks. We compared four Islamic banks with four conventional banks in Turkey. We focused on profitability, liquidity and leverage of the banks. We had three hypotheses, all of them were proved by our examination.

Turkey has been less affected by the financial crisis than other developed countries, so there was less decreases in the ratios of Turkish bank system. Furthermore the Turkish Islamic sector reached better results than the Turkish conventional sector.

If Islamic banking sector could cope with the prejudices, there would be bright future for the sector. Some further research field could be to examine a country shocked by the crises more, to get more detailed picture about the crisis-resistance of Islamic and conventional banks.

\section{References}

- Baka I.-Dancsó J.-Ligeti S.-Szarvas F.-Vágyi F.-Varga J.2012: Banking, Budapest

- Balázs J. 2008: „Economy-Venture-Competitiveness in the Islamic communities” Budapest-Sopron-Kairó, p. 5-9.

- Falus O. 2014: „A moral tax-The zakat”, Taylor Gazdálkodás- és szervezéstudományi folyóirat, p. 64-69

- Mosab I. T-Raj S. D. 2014: „The Impact of Global Financial Crisis on the Stability of Islamic Banks: An Empirical Evidence", Journal of Islamic Banking and Finance, p. 377-380

- Pálfi G. 2010: „Islamic finance in the finance markets”, Fordulat, 11

- Tálos L. 2015: „, The analysis of the influence on Turkish Islamic banks of the economic crisis by CAMEL method"p. 10-59

- Varga J. 2013: „The analysis of the balance sheet of the Islamic bank”, ASS Acta Scientiarum Sociolanum, 41

- Yousefi V. - Kóbori J. 2013: „The history of money and bank system of the Islamic world”, Valóság, 56,p. $30-46$

- http://www.ey.com/Publication/vwLUAssets/World_Islamic_Banking_Competitiveness_Report_201314/\$FI LE/World\%20Islamic\%20Banking\%20Competitiveness\%20Report\%202013-14.pdf

- Ceki Bildem: Islamic bankink in Turkey: A safe heaven for investors?, 2014 http://herdem.av.tr/islamicbanking-turkey-safe-haven-investors/

- $\quad$ Turkey Islamic Finance Report 2014

- http://www.irti.org/English/Research/Documents/Report-5.pdf 


\title{
The Comparative Analysis of the Alternative Crisis Management Models of the Islamic- and Christian-Based Bank System
}

\author{
Dr. Balazs Cseh (Kaposvar University, Hungary) \\ Dr. Jozsef Varga (Kaposvar University, Hungary)
}

\begin{abstract}
There is an increasing demand for investments based on religious basics since these ethical investments mean much more stable financial chances. The economic and financial risk of a fragmented reserve banking system has become obvious by the failure of the neoliberal market economy. Therefore, world economy has to reform the entire credit and bank system that could only be achieved by alternative methods. The Islamic bank is a particularly young alternative opportunity that is based on more equitable and moral principles. However, bringing back the Christian-based banking system that looks back on old traditions and that became extinct could also be an alternative. One of the major principles of the Christian-based banking system is that it is not allowed to borrow and invest in worthless bonds without provision. For the Islamic bank, for instance, speculative affairs that are of high risk and monetary derivates are forbidden, there is voluntary risk management. Risk management and risksharing practices based on alternative religious principles will also be analyzed. Due to its procyclic-anticyclic characteristics, the traditional bank system deepens the crisis while the religious bank systems are against the crisis by alleviating the burdens of the debtor. The authors describe and analyze crisis management solutions with a sort of comparative method.
\end{abstract}

\section{Introduction}

Recent events, the rapid economic changes, the needs from the banking system and the endeavour of approaching to the banking system of the European Union required the new regulation of the activities of credit institutions. Financial services, financial institutions and their scope of activities are determined by national law in Christian tradition. In Islam, as opposed to this, fiqh al-Muamaat means everything that gives a framework for or leads Islamic economic and market conducts in civil environment. It takes care of, on the one hand, economic transactions and on the other hand, of such factors that could influence economic conduct since it also deals with economic relations existing on the Islamic financial market, especially with ba'i, ijarah, istisna'a, salam, murabaha, mudaraba economic bank transactions. Fiqh as rules and definitions of understanding occurs in result-oriented relationship of humans and financial law. During this, the relations of human behaviour and economic operators can be recognized. The relevance of the topic is given by the crisis affecting the traditional banking system and the need for a solution responsing as an alternative to the challenges of sustainable economic growth.

\section{Christian and Islamic Bank Models and Structures}

\subsection{The Prudential Operation of Christian Banking System}

The classification of financial institutions is done by national law of Christian countries on the basis of the activities mentioned previously. Generally, a financial institution can be a credit institution or a financial undertaking. The financia institution besides financial services can only provide additonal financial services, insurance brokerage, commodity brokerage, gold trade transactions and stock bookkeeping. A financial undertaking can provide one or more financial services but it cannot provide additional financial services. In the interbank market, however, financial brokerage can only be provided by financial undertakings as exclusive service.

The global financial crisis beginning in 2008 affected the bank system of the world. The total assets of banks decreased significantly in more east-central European countries so in Hungary, too (Bozsik, 2015). The crisis certainly affected Islamic banks as well, nonetheless Islamic financial activity increased all over the world. Islamic banks due to the strict Saria regulation are more stable and more conventional in the world. The big growth rate of Islamic financing can be thanked to these stability-oriented religious-legal regulations. In 2014 the market of Islamic financial products can be estimated to 2000 billion USD. The division of Islamic financing met the expectations, its $78 \%$ were Islamic bank investments, the more and more popular Sukuk securities showed $16 \%$ share, Takaful 1\%, the Islamic funds 4\% and the Islamic microfinancing also 1\% (Tabash and Dhankar, 2014).

The key of prudential bank operation is the capital adequacy of credit institutions. Capital requirement is of three risk capital requirements: credit risk, operational risk and market risk.

Credit risk is the risk of insufficient (re)paying of loan and interest. Operational risk is the risk of banking processes, the wrong or insufficient operation of humans or systems or the risk of loss deriving from external events that refers to the following major factors:

- internal or external fraud 
- violation of occupational safety regulations

- unintentional loss in customer relations

- damages in physical assets

- business disruption, system failure

- implementation and process management errors

Market risk is the risk of re-pricing of certain items. It can be divided into interest rate, currency and price risks. It is treated together with credit risk.

\subsection{Forbidden Affairs According to Islam during the Prudential Operation of Bank System}

According to Al-Jassas's definition riba is the credit amount to be paid given to a determined period and increased by a determined value, so the interest of the loan and the exchange of such assets that have no appropriate balance value. Consequently, it seems that there are two dimensions of the ban of riba. On the one hand, riba duyun that derives from debt and, on the other hand, riba buyu that is based on the exchange of unequal items so on barter affairs. The so-called ribawi items such as gold, silver, wheat, date and salts representing money belong to here that could be the subject of transactions.

The next ban is gharar that excludes the risk of Islamic transactions that prevents the unfair damage of participants. For instance, if one of the participants has a damage on the side of quantity or quality during the transaction, the contract is null or can be nullified (Biermeier, 2007). The ban is deduced from an-Nisaa': 29 poem and prophet Muhammad's words. They distinguish little and big gahrar, the little is yasir and the big one is the fanish. The ban of risk appears in connection with fundamental risk, risk management methods, religious risk (ar Ra'd: 11) as well as Takaful.

The third one is the ban of speculation, the maisir, which is, as opposed to gharar (that is accepted in little amount), completely unacceptable according to the al-Maidah:90 poem (Steffens, 2014).

It ought to be noted that an Islamic transaction is only valid if it does not come up against any bans and besides this, existing (mawjud), allowed (halal), valid (sahih) and there is value in it (mutaqwwim). For this reason, the subject of transaction cannot be, for instance, dematerialized securities so it cannot be paid with transfer. Besides this, businesses of particular products (haram) such as alcohol, tobacco, pornographic content, etc. are also forbidden (Ashrati, 2008).

\subsection{The Regulatory Frame-models of Christian Bank System}

Currently, a constant change can be recognized whose basis is given by the regulatory frames called Basel. Basel II. Regulation is better in risk management than Basel 1. because it did not recognize only credit risk. Another big step is that Basel II. makes the use of inner rating systems possible, thus credit institutions can work with their own models instead of dictated, external keys. In Hungary currently Basel II. Regulation is valid but the introduction of Basel III is in progress. The Baselic capital requirement system was elaborated by BIS, Bank for International Settlements. BIS was founded in the framework of the Young-plan accepted in 1930 in the second Haguae International Conference in 1930. Its original task was the organization of war reparations paid by Germany during which Germany intended to repay its debt by the output of Young-loan. BIS started its operation in Basel in 1931. Its governing body is the Council which meets annually with the participation of central banks. In the periods between the meetings of the Council, professional work is led by the Board of Directors that chooses its president among its members.

The role of BIS changed due to the economic crisis of 1929-1933. Currently, its most important task is the coordination of central banks, the ensurance of the flow of information and the elaboration of directives and regulations affecting international bank operation. As for the cooperation of central banks, it had a significant role in the coordination of international foreign exchange policy measures. The most important institutional difference between the BIS, IMF and World Bank is that members of BIS are not governments but central banks. As a result, the strong politicization that can be recognized in the other two organization occurs in BIS indirectly. A credit institution, to sustain solvency and to be able to fulfill requirements, has to have a proper size of solvency capital. An important rule is that the sum of the solvency capital cannot be lower than the sum of registered capital prescribed for the credit institution.

\subsection{The Functional and Supervisory Models of the Islam-type bank system}

The Sharia Council monitors all relevant parties in financial transactions on both an individual and a corporate level to ensure that they are conducted with diligence and honour in accordance with Usul al-Fiqh and Fiqh alMuamalat, and that there is no financial abuse or ethical issues. All harmful behaviour, misconduct, fraud and deceit are forbidden and severely punished by Islam. Ethical and legal requirements and regulations are considered equally important when conducting business. Sharia law is definitive in Islamic financing and a standard in financial transactions and procedures, supervision and monitoring. All parties in the financial sector follow its regulations (fiqh) consistently and diligently when they are shaping their financial strategies. It is a progressive approach which considers adequate income, benefits and profit as the most crucial factors. Therefore Sharia law 
in the Islamic financial sector can be considered as a possible solution for progress as demonstrated by their known current financial stability. On the other hand, the pace of development in economic and financial systems based on religious and moral principles is obviously slower, and it can vary in different countries as local ethics can be different. It is also important to mention that the branch of Islamic financial services is still new, thus rigid, regulation-based economic systems can jeopardize its healthy, potential growth or limit its independence. Yet a Sharia-based financial system can provide a healthy and viable environment as it is humanistic and strongly embedded into society (Sharia monitoring includes macro and micro level analyses and it is not restricted to the monitoring of developmental procedures, but covers all banking and financial practices. As it was previously mentioned, Sharia Councils not only make decisions in controversial cases, but provide guidelines for proper conduct which is even more important as avoiding conflict and focus on the future are parts of the specific perspective of Islam.). For example the Katar model is an Islamic banks operate under independent regulations. Although there is no central governing institution, Awqaf has an important influence on them. Fiqh al-Muamalat, the Islamic commercial practice functions in accordance with the regulations of fatwas and Sharia law, therefore it is a common practice of Islamic financial institutions to establish and oversee Sharia Councils. They are also important for monitoring and they make ex-ante and ex-post Sharia decisions.

Islamic financial structure is based on the principle of distributive justice which is a characteristic of a purely Islamic model. Inequalities in income and profit distribution are prevented by the Islamic financial system with correctional measures as welfare is a primary consideration. As economic growth is an objective, basic needs are addressed as a priority and it is also trying to motivate activity in the economy. Islamic economical ethics does not take ethical risks with supply and demand and also investment and consumption but focuses on the development of human resources (Hassan and Lewis, 2014).

The Islamic financial structure is based on Islamic business ethics, Islamic values and their universal applications which could provide a perspective for the traditional Western financial system, as alternative economic theories also attempt to shift their focus towards an ethical, humanistic economic system (Mat and Ismail, 2014). Ethics is one of the aspects of the evaluation of liberal or conservative socioeconomic behaviours, therefore the conclusions based on the evaluations affect those behaviours (Hársfai, 2009).

\subsection{Credit Risk Management in Traditional Banking Systems Based on the Hungarian Example}

The credit risk of Hungarian credit institutions can be measured with two methods: the standard method and the internal ratings-based method. In the standard method, the credit institution determines the risk of exposure and creates different exposure classes for transactions. The more important exposure classes currently in force differentiate between the exposure of central government and central bank, regional government and local government, credit institution and investment firm, and between businesses and the population.

The weighting of the balance sheet of assets is carried out with a classification of $0-150 \%$ weight $(0,20,35,50$, $100,150 \%$ weight). Here are some examples for the different weighting classes: e.g.: $0 \%$ weight: claims against EU central governments and central banks; 35\% weight: residential properties with mortgage; $50 \%$ weight: not residential properties with mortgage; $100 \%$ weight: exposure covered by a property. $150 \%$ weight is the worst classification.

With items outside of the balance sheet, generally a $100 \%$ weight is used, with the following exceptions:

- $0 \%$ weight: undrawn promissory notes and credit limits (when the original expiration date is a maximum of one year away), stand-by (it can be revoked unconditionally at any given time) credit

- $20 \%$ weight: letter of credit

- $50 \%$ weight: Issued or confirmed letter of credit, assumed warranty for issuing securities, irrevocable stand-by letter of credit.

Another method of credit risk management is the internal ratings-based method (IRB). The basis of this regulation is risk assessment by determining the probability value of non-payment. The probability of default (PD) is the probability of non-payment within one year. The loss given default (LGD) is calculated by dividing the loss deriving from non-payment of a client with the exposure of default (EAD).

This method therefore substitutes the risk weights and rankings of external classification with experiential factors derived from the operation of the credit institution. The internal ratings-based method is viable for larger banks with adequate capacity.

The items above constitute the I. pillar of Basel II. The II. pillar is the supervisory review system. After the credit institution determines its own internal capital requirements, a supervisory evaluation is conducted. The credit institution calculates credit requirements based on the classifications to determine whether the institution complies with regulations, this is how the classification of receivables into risk exposure is executed. The investigations must determine whether the credit institution would be able to handle a sudden capital adequacy crisis (e.g.: a sudden outflow of high amount deposits or a massive non-payment of credit debts).

The III. pillar of Basel II. regulates public disclosure. Public disclosure obligations must be fulfilled at least once a year within 15 days of the approval of the annual report about changes in the financial status of the credit 
institution. Relevant information on management and accounting must be disclosed within 30 days of obtaining knowledge of the information. Irrelevant, protected and confidential information is exempt from public disclosure.

\section{A Comparison of Corporate Leadership Practices of Islamic and Traditional Banks}

It is useful to have a brief discussion on the questions of accountable corporate leadership in the context of Islamic and traditional banks. We believe that this provides a basis for comparison between the two banking systems which demonstrates the advantages of the credit policy based on the doctrines of Islam.

According to András Kecskés, accountable corporate leadership is comprised of all relationships between management, ownership, employees and other individuals of an institution, which are governed by legal, ethical, rational, and effective conduct of a profit-oriented approach that also has social utility; and the rules of which are shaped by laws and the self-regulatory processes of the market and business (Kecskés, 2011). If we project this definition to the Islamic banks, then it is clear that their conduct meets the requirements of social utility and ethical behaviour, however an interesting distinction is that a major part of the regulations are not provided by state laws or self-regulations of specific banks, but the doctrines of Islam.

The question of whose interests should be prioritized by the leadership of an institution is also important to discuss in the context of this topic (Kecskés, 2008). We can separate two circles: members (or shareholders in the case of joint-stock companies) and stakeholders (Kecskés, 2010). They are the individuals that are affected by the operation of the institution (Budai, et. al. 2011). This is an extremely wide circle as it also includes business partners (Kecskés 2010). It is evident from the credit policies of Islamic banks that they put a much bigger emphasis on ethical conduct.

\section{Summary}

The introduction of Basel III. changes several areas of prudent operating practices of the traditional banking system. The system of the countercyclical capital buffer was created to address financial crises, and new liquidity requirements are introduced because of the growing importance of banking liquidity. However the approach of the system does not change: the intense profit-seeking behaviour, the necessity of constant growth in terms of financial results and the greed of bank management suggest that this system will not be able to provide security in the future either. Although in some cases Basel III. regulates the income of bank management, but this does not influence the operational logic of the system significantly.

The Islamic banking system still has a clear advantage in terms of prudent operating practices. I analyzed some of the aspects of the cooperation of the Islamic and the traditional banking system and I reached the conclusion that based on the procyclical-countercyclical nature of the banking system, the traditional banking system deepens the crisis by putting additional pressure on the debtor with more severe changes in classification while the Islamic banking system alleviates some of the pressure of the debtor to improve on the crisis. The countercyclical economic and financial policy is one of the key issues of the traditional banking system and the introduction of Basel III. serves as a strong example for that.

The second important operational area of the Islamic banking system, where experiences are transferable, is the sharing of risk in the relationship between saving parties and borrowers. The Islamic banking system is a good example of how the depositor can take responsibility - at least partly - for the investment, so mutual interests can be established between saving parties, the bank, and borrowers.

Based on economic indicators and bank balance sheets we reached the conclusion that there is growing demand on the European money market for the financial institutions of the Islamic banking system which should be addressed by legislature by restructuring the different legal systems and by the revision and interpretation of specific regulations.

The cooperation and reconcilement of the conventional and Islamic economic systems is a timely and urgent matter on both the Western and global levels, which can be seen from the compromises in laws in several countries, the increased number of banks, and the various financial institutions discussed in this study The cooperation and harmonization of the banking systems on a global level is an alternative, its development and financing is an opportunity for the future, and it requires further research.

\section{References}

- Ashrati, 2008, Islamic Banking. Wetvorstellungen - Finanzprudukte - Potenziale. 1. Auflage. Frankfurt am Main. Frankfurt School Verlag. p. 13.

- Biermeier, 2007. Islamische Investition und Finanzierung. Chancen schariakonformer Bankdienstleistleistungen für konventionelle Finanzinstitutionen, GRIN Verlag, Bochum, p. 11.

- Bozsik, 2015. A közép-kelet-európai országok bankrendszerének mérlegalkalmazkodási folyamata a gazdasági válság kirobbanása után, in Fejlődő jogrendszer és gazdasági környezet a változó társadalomban. International Research Institute 2015 pp. 133-143. 
- Budai - Hanák - Hardi - Kazár - Kecskés, 2011. Felelős vállalatirányítási és etikai szótár/ Glossary of corporate governance and business integrity terms The American Chamber of Commerce in Hungary, Budapest, p. 44.

- Hársfai, 2009. Bevezetés a politikai és társadalmi etikába. Szent István Társulat, Budapest, pp. 22-34.

- Hassan,- Lewis, 2014. Handbook on Islam and Economic life. Cheltenham - Northampton, Edward Elgar Publishing, p. 46.

- Kecskés, 2008. Részvényárak mindenek felett? Érdekszférák a vállalatirányítás jogában, in Emlékkönyv Román László születésének 80. évfordulójára, Pécs, pp. 215-234.

- Kecskés, 2010. The Legal Theory of Stakeholder Protection, in JURA, 2010/1., Pécs, pp. 67-76.

- Kecskés, 2011. Felelős társaságirányítás (corporate governance). HVG-ORAC, Pécs, p. 387

- Mat - Ismail, A Review of Fiqh al-Mua'malat Subjects, in Economics and Related Programs at International Islamic University Malaysia and University of Brunei Darussalam, http://www.kantakji.com/media/6426/op57.pdf

- $\quad$ Steffens, 2014. Islamic Finance, GRIN Verlag, Bochum, p. 7.

- Tabash - Dhankar, 2014. The Impact of Global Financial Crisis on the Stability of Islamic Banks: An Empirical Evidence, in Journal of Islamic Banking and Finance March 2014, Vol. 2, No. 1, pp. 367-388. 


\title{
Improvement of the Corporate Loan Process in the Turkish Banking Sector: A Model
}

\author{
Prof. Dr. Semra Birgün (Beykent University, Turkey) \\ Prof. Dr. Sudi Apak (Esenyurt University, Turkey)
}

\begin{abstract}
The aim of the present study is to develop a model for the integration of lean thinking into the corporate loan process with a special focus on the utilization of the value stream mapping technique. In line with this aim the study proposes a three-legged model specifically for the corporate loan processes of banks in Turkey as a developing country pursuing to integrate into the global financial world. The three dimensions included in the model are operational dimension, staff dimension and customer experience dimension. The study argues that by applying the proposed model based on the lean six sigma approach, banks can achieve and sustain a high level of improvement that would increase speed, value creation, cost-efficiency, profitability and customer satisfaction and reduce waste, processing time and effort, duplication and prolonging of transactions, redundancies, risks and errors in the whole corporate loan process.
\end{abstract}

\section{Introduction}

Globalization and increased competition require new organizational structures. In order to keep up with rapidly changing trends and the challenges in the financial world, financial organizations are required to follow new finance trends and functions. They have to constantly analyze, redefine and restructure their managerial, operational, organizational processes and procedures to achieve and sustain continuous improvement. In order to fulfill these requirements and survive in the competitive business environment, financial organizations have to perform complicated and multi-dimensional actions oriented toward improvement besides their regular actions toward survival and profitability.

Under such circumstances, the concept of lean management has emerged as an approach that provides organizations the opportunity to lean all these complex, multi-layered and interrelated processes. In basic terms, "lean thinking is striving to achieve perfect efficiency within a business model - with a strong focus on meeting the customers' needs through continuous improvement. Lean thinking mean cutting out unnecessary or 'waste' activities to decrease lead times through the development of the most efficient and cost effective, customer focused processes" (Akdeniz 2014).

Lean management focuses on continuous improvement, reducing waste and increasing value creation at all levels of an organization. It appears as a corporate mind-set that promotes simplification and clarification of work procedures, reducing variation, and increasing customer-value orientedness.

Although lean management applications originated in the manufacturing industry, its full application in the financial services sector is relatively limited. The present paper argues that banks in Turkey should invest on the application of lean management to the corporate loan process management. Drawing on this idea, the paper proposes a three-legged model for "leaning" the operational, staff and customer related processes for the banking sector in Turkey as a developing country pursuing to integrate into the global financial world.

The remaining of the paper is structured as follows: Section 2 presents a brief overview of the challenges in the corporate loan process. Section 3 discusses the basic principles and practices of lean management and six sigma. Section 4 is devoted to the integration of lean six sigma into the corporate loan process. Last section presents the conclusions and suggestions.

\section{Corporate Loan Process}

Corporate loan is a key economic factor that determines the relationships between firms and banks in the banking sector. If corporate loan process is operated effectively, the bank enjoys a superior status in the eyes of its clients and the bank's profitability and market share increase.

One of the critical phases of the corporate loan process is corporate loan decision making (Zimmer in Bergeron et al., 1997) and the loan application process. Mačerinskiene and Ivaškevičiūte argue that 6 main qualitative indicators are evaluated to assess a legal person's creditability: "the history of cooperation with the customer; evaluation of the ownership structure; competitive status of the customer; evaluation of customer's activities; evaluation of management and quality of the accounting" (Mačerinskiene and Ivaškevičiūte, 2008).

Despite the fact that banks attribute great importance to the corporate loan process, the process is open to defects, deficiencies, human errors and delays which would adversely impact profitability, customer satisfaction, value creation, and cost and time efficiency. 
In terms of banks, low quality of the bank staff; improper procedures; delays in decision-making and approval processes that arise when boards of directors do not meet in a timely manner; and the problems arising due to poor coordination among a related branch, management and general management negatively affect the loan process. Such problems create troubles in the process that lead to waste of resources such as the duplication and prolonging of the transactions and cause discontent and dissatisfaction due to late reply.

The present study proposes a three-legged approach for the integration of lean thinking into the corporate loan process with a special focus on the utilization of the value stream mapping technique. The study aims at improving the process with the purpose of reducing waste of resources and increasing client satisfaction. Consequently, advantages to be obtained by the improvement of the process are presented.

\section{Lean Management}

The concept of lean is commonly used in the manufacturing industry for decades. In basic terms, lean is a holistic and sustainable approach of management processes of an organization, a business strategy based on creating value for the customers, while eliminating waste and deficiencies in the process (Văduva, 2011). Another commonly used approach in organizations to eliminate variability and reduce waste in processes is six sigma which is heavily based on the utilization of statistical tools (Banuelas Coronado and Anthony, 2002).

Lean management is a management philosophy that aims at a continuous improvement of a company's value creation capability by engaging all employees. In order to follow this philosophy, the core idea of lean management is to reduce any kind of waste (Womack and Jones in Leyer and Moorman, 2014).

With a full understanding of the various forms of waste and value-added time and effort concepts as well as the requirements of true efficiency, Henry Ford was the first person to integrate an entire production process completely. The result was a huge amount of profit effect and one hundred fold in less than a decade. Ford's approach was revisited by Toyota to establish the Toyota Production System, the origin of lean (Văduva, 2011). Since then lean management concepts have been further developed and enhanced (Ohno in Leyer and Moorman, 2014).

Main characteristics that define lean management are identified as follows:

- $\quad$ the main focus will always be providing customer value

- implementing lean management means adopting a philosophy of continuous and incremental improvement at all levels of the company

- after having studied customer demand, the company will provide exactly what's needed at the right time

- $\quad$ creating a continuous flow in a value-added effective manner

- $\quad$ using techniques for reducing variation and eliminating waste

- $\quad$ respecting people

- $\quad$ adopting a long term approach (Văduva, 2011).

In a nutshell "lean thinking seeks to eliminate waste, specify value, line up value-creating actions in the best sequence, conduct those activities without interruption whenever someone requests them, and perform them more and more effectively" (Womack and Jones in Trent, 2008). Lean management, on the other hand, "must be viewed as an integral system of four, interdependent elements: leadership, culture, team, and practices and tools (Fliedner, 2012).

Banks are among the financial institutions that benefit from and apply lean principles to improve their business processes, standardize procedures and create customer value. By the application of lean practices and techniques, banks can save time, carry out customized activities, eliminate wasted time and effort and thus reduce the total business costs, provide fast and high quality services and increase customer satisfaction, reduce routine, integrate the staff into the improvement, design and application processes and increase their enthusiasm (Văduva, 2011).

The so called 5S are an example of lean practices that should be applied in banks:

1) sort - sorting office materials, maintenance materials or other tools is fundamental for delivery and quality of quality and timely banking services. For instance, sorting emails, files and archive is a Lean activity for any bank employee;

2) straighten - the tools of banking services should be arranged in standard locations for consistent and easy access. These include data bases, references, operating procedures, reports.

3) scrub - means to maintain service tools in a neat and clean condition.

4) systemize - at all levels, as part of staff regulation routine, employees should go through the work environment and maintain;

5) standardize - it is essential for a bank to exercise discipline in maintain the work place and institute processes in a standard manner (Văduva, 2011).

In order to restructure and improve their systems with the further aim of achieving effective and efficient operational and customer processes, banks and financial service providers use the approach combining lean and 
six sigma, frequently referred to as Lean Six Sigma (LSS), "a method that has proven to be of great value for structurally improving customer value streams" (Kuiper et al., 2016).

Six Sigma is defined in the business context as "... a business improvement strategy used to improve business profitability, to drive out waste, to reduce costs of poor quality and to improve the effectiveness and efficiency of all operations so as to meet or even exceed customers' needs and expectations (Antony and Banuelas Coronado, 2001).

Different industries utilize these approaches at several dimensions of their manufactural, financial and operational processes to obtain operational and strategic advantages against their competitors. They consider lean management and the application of six sigma as a process of improvement through simplification.

\section{Integration of Lean Six Sigma into the Corporate Loan Process}

Corporate loan process management is one of the fields in which lean philosophy can be followed as a corporate mind-set for the continual process improvement. Adopting this philosophy throughout a company is supposed to be positively correlated with higher efficiency (Dahlgaard and Dahlgaard-Park in Leyer and Moorman, 2014). Corporate leaders often focus on the "tools and techniques" of their company. But what empower the businesses are the management systems and the human spirit that give their purpose (Văduva, 2011).

Though it has been deployed and developed mostly in the manufacturing industrial business for decades, it has not been utilized enough in the financial services industry. As integrative and multidimensional approaches, lean and six sigma are closely related to measuring and assuring quality as well as improving customer value streams. Precisely at this point, implementation of value stream mapping emerges as a critical tool for the true adoption of lean six sigma as managerial philosophy.

As a lean management method, value stream mapping enables organizations to thoroughly analyze and deeply understand their current practices and state. It also makes it possible to identify problems, consider their solutions and design prospective practices and state for the whole processes of the organization.

Keeping basic lean principles in mind, banks can map the value stream to eliminate waste, perceive transactions as products, target to increase value and decrease waste by regularly using KAIZEN to promote effectiveness of the activities (Văduva 2011).

Lean finance organizations have three components: an operational organization that excels at transaction activities, a series of knowledge or expertise centers that focus on problem solving, and the business partners who are working within line organizations (Randall, 1999).

While Gunn suggests these as the three components of the financial organizations in general, the present study offers a three-legged approach specifically for the corporate loan processes of banks in Turkey. The three dimensions involved in the approach proposed in the present study are operational dimension, staff dimension and customer dimension. As a holistic approach, it considers these three dimensions not in isolation but as the ones which are interrelated and interconnected. The present approach embraces the organizational structure of a financial organization as a whole and suggests to consistently and systematically deploy lean six sigma principles and techniques at all three levels with the ultimate aim of improving their customer value streams.

It is suggested that "improvement of a customer value stream usually involves different improvement projects that focus on different aspects of the value stream. Lean six sigma practitioners can deal with complete value streams by dividing it into subprocesses and sequentially optimizing them" (Kuiper et al., 2016).

In what follows, the present study discusses the three dimensions with a focus on the integration of lean six sigma principles into each dimension of the corporate loan process in banks.

\subsection{Improvement of Operations}

In order to outperform in the highly competitive business and finance world, banks are required to shift to simpler systems focusing on the overall business and activities. They have to develop more flexible systems to better and quickly respond to specific customer needs and demands under the changing local, regional and global conditions. In order to enhance their operational performance, banks need to be lean at each operational level.

In Turkey corporate loan process generally follows the following steps:

1. The branch of the bank receives the loan request from the customer.

2. The branch evaluates the request for pre-approval and delivers the request to the general management.

3. General management evaluates the request and delivers it to the board of directors for the final approval.

4. Board of directors makes a decision and delivers it to general management which sends it back to the branch.

5. The final decision is communicated to the customer by the branch.

However, the process is negatively affected and even blocked due to procedural and operational problems. Timeconsuming transactions and delays in decision-making and approval processes and improper procedures have an adverse impact on the whole process. Furthermore, problems arising due to poor coordination among a related branch, management and general management decreases operational effectiveness and efficiency as well as 
customer value and satisfaction. All these bring along waste of resources, duplication and prolonging of the transactions and increase in costs, resulting in low quality service.

Within the framework of lean six sigma approach, in order to eliminate the mentioned problems and improve the operations involved in the corporate loan process, banks should perform value stream mapping as the first and essential step. Proper application of value stream mapping enables banks to identify the defects and inefficiencies in the corporate loan process.

The value stream consists of all those activities that are necessary to produce and offer a product or service according to the identified customer needs (Bowen and Youngdahl in Leyer and Moorman, 2014, p. 1369). Creating flows within the value streams minimizes delays and wasted time when processing customer orders in a value stream (Koskela in Leyer and Moorman, 2014). Through value stream mapping, banks can improve their organizational processes by becoming fully aware of every single step of their work flows.

Specifically, for the corporate loan processes, one major aspect to be dealt with concerns the proper division, description and fulfillment of tasks. Banks can identify whether the detailed and specific task definitions are in place, and, if yes, whether the branch and the general management fully perform their predefined roles without increasing workload, wasting work force, causing duplication in the flow. One strategy can be providing the branch with the opportunity to take certain initiatives and act independently where necessary. This, without doubt, necessitates proper and continuous training of the related branch staff, which is discussed in the following subsection.

In line with the data obtained from the map, banks can see the exact points to apply their lean approach to improve the processes that are critical for performance, profit and value.

Another major operational aspect concerns the automation of business process by means of the utilization of information technologies (IT) such as modeling, monitoring and data integration tools and process management software. Through the need-specific use of IT, banks can increase their operational efficiency and increase their leanness by monitoring the collection, communication, documentation and reporting of accurate data concerning for instance customer balance sheets, financial background information of customers evaluated by the bank for making decision in the corporate loan process. Specifically, banks can increase the satisfaction of their internal and external customers by using software that produces accurate reports for specific customer needs.

Through the adoption of lean as an operational strategy, banks can eliminate the complexities in the process, increase revenues and lower costs, reduce wastes and increase customer satisfaction.

\subsection{Improvement of Staff}

Human dimension of an organization is of central importance for fully and practically implementing lean six sigma approach in financial organizations. In the context of corporate loan process in banks, preparing detailed task definitions, workloads, working methods and supporting the effective flow of working procedures by means of the utilization of information technologies do not yield the desired results unless they are applied by the staff members who have internalized lean thinking.

Thus, it is essential for organizations to adopt lean thinking as the core of their corporate philosophy. They should create and maintain a corporate culture that allows the internalization and application of lean practices at all levels by all staff members. The first step to achieve these interrelated objectives is to raise awareness of the staff members about the advantages of lean and value-oriented thinking. As underlined by Leyer and Moormann, "[L]ean thinking has to be embedded in the mind of its employees. Ways have to be found so that employees really perform their daily work in a lean way. This is much more important than using specific tools and techniques when applying lean management (Leyer and Moormann, 2014). Moreover, in addition to performing routine procedures, staff members should be able to make their own contribution to the process improvement on the basis of their individual experience and creativity (Văduva, 2011).

Effective and sustainable implementation of lean six sigma approach depends on staff members' continuous focus on value-creating processes, their professional skills of using relevant tools in an independent and creative manner as a natural part of their individual working system. For the achievement of all these requirements with the aim of improving corporate loan process through lean six sigma approach, organizations should provide continuous and multi-dimensional training opportunities for their staff.

In order to act independently and responsibly in line with the corporate guidelines with clear instructions on the standardized processes, related staff members should be trained to be the competent leaders for their professional activities. They should be aware of their role in creating value in the whole organizational system, which should be reflected on their attitudes. Continuous professional training should become a permanent component of the corporate culture and the staff members should be open to continuous personal training in order to serve for the creation of value in the regular flow of the stream.

Continuous training should also target the improvement of the technological and communicative skills of the staff members in order to enable them to keep up with the fast changing business environment. In contemporary world, "'new' finance role requires the ability to communicate complex financial data to individuals in such 
departments as marketing, information technology, and operations during joint efforts to develop creative solutions to business issues. As the function continues to evolve, companies are broadening the job requirements for financial positions to include an emphasis on interpersonal, project management, and leadership skills" (Randall, 1999).

Corporate loan process is definitely a field open to take the utmost advantage of all these practices, thinking ways and innovations. With the help of training their staff, organizations can reorganize their corporate loan processes as an efficiency- and customer-oriented process to produce more value and less waste of time and resources. In this way, banks can have the opportunity to focus on the total value chain and increase the level of service quality and profitability.

To concretize, a properly trained staff member at the branch of a bank can fully and effectively carry out the required transactions and procedures predefined in the related task divisions and thus can obtain an accurate and complete financial data of the customer and deliver it to the general management in a way to eliminate any duplication of the relevant transactions. By acting as the leader of the sub-process, that staff member can complete a considerable amount of the loan processes including the collection and control of the required financial data without directing the customer to different organization units and causing delays, uncertainties and repetitions. In this way, the general management will have more time to guide their subordinates instead of wasting time for performing operational tasks. This would definitely increase the speed of procedures and hence customer value and satisfaction. Moreover, managerial and sales staff would be much more focused on sales-oriented activities with the aim of boosting the number of the customers with less risk, a high credit worthiness and high potential of profitability.

\subsection{Improvement of Customer Experience}

In pursuit of value-creation and value-perfection, the third area of improvement should be customer experience. A two-dimensional strategy might be deployed for producing value in this area: restructuring and standardizing the principles, rules and processes concerning the communication of the bank staff with the existing and prospective customers, and, at the same time, allocating room for flexibility and creativity to be used by the staff depending on customer needs, demands and expectations.

A significant example for the gain obtained through lean activities is that of a Latin American bank which brought lean to its sales operations and thus increased customer appointments by $50 \%$ and total sales volume by $20 \%$, while reducing its non-sales staff by more than $20 \%$ (Ilebrand et al., 2011).

Within the frame of the improvement of customer-related processes, one major step to be taken is to prepare a kind of map that would provide transparency of procedures, transactions and the progress of the flow both for the staff and customer so that customer can follow the overall activities starting from the loan request to the final approval while the staff conduct and monitor the application process without any waste and risk of incorrect and repetitive operation. Furthermore, each unit can easily identify the role/function of itself and other units, which would also lead them to offer need-based, innovative ideas for the further improvement of the corporate loan process.

In the context of customer-related processes, another major step concerns the standardization and automation of certain procedures which are common for most of the corporate loan process such as collection of data on the credit history, cash flow history, financial statements, balance sheets, income statements.

In order to eliminate the risk of obtaining incomplete or inadequate data from the customer and of delays in the transactions and flow of the loan application, evaluation and approval processes, the communication with the customer should be carried out by a single member of the staff who strictly follows the pre-defined procedures and, where necessary, becomes the decision-maker to understand and respond to specific customer needs and demands and customizes other further required processes accordingly. This flexibility would contribute to the increase in customer value, shorten the time spent on operations and eliminate the waste of work force.

\section{Conclusion}

Banks, in line with their ultimate aim to achieve perfection in their operational, organizational and technological processes undergo a constant transformation process. They intend to eliminate complexities and achieve leanness at all levels of the organization. To achieve these aims, they should redesign their corporate guidelines, instructions, documentation, checklists, IT applications, corporate structure, job profiles and task definitions, and customerrelated documents etc. in a lean manner. They should apply lean six sigma principles, practices, techniques and tools to identify, analyze and eliminate defects, inefficiencies. To fulfill this objective, they should utilize value stream mapping technique as the first step.

True integration of lean six sigma into the corporate loan process requires the improvement of not a separate and single aspect of an organization but a holistic, long-term and substantial change. Thus, the present study proposes a three-legged integration model which focuses on operations, staff and customer for the banks in Turkey. 
Unlike traditional complicated practices in the corporate loan processes of banks, the proposed model suggests implementation of value stream mapping technique in the procedural and operational dimensions of the corporate loan process.

In order to eliminate waste, risks and uncertainties, to reduce cycle time and to enhance customer value, banks should ensure the clarity, applicability and functionality of task divisions and definitions and constantly monitor if the branch and the general management perform their predefined roles fully and without causing unnecessary increase in the workload, waste and duplication. Operational improvement should be supported by the needspecific use of IT to increase the operational efficiency and leanness. Banks can also increase customer satisfaction by using IT applications to produce accurate reports for specific customer needs.

Sustainable improvement of corporate loan process can be achieved through the adoption and internalization of lean principles and thinking by all staff members. Staff members should be aware of their role in creating value in the flow of the stream. At this point, training staff members in order to improve their technological, communicative and leadership skills is of critical importance. As the essential component of organizations, staff members should have a full knowledge of the whole corporate loan process and be able to completely understand customer needs to better respond to these needs.

As the third dimension, customer-related processes can be improved through the preparation of a map for the transparency of procedures, transactions and the progress of the flow both for the staff and customer. In this way, customers can follow the overall activities starting from the loan request to the final approval. On the other hand, the staff can conduct and monitor the application process without causing waste, incorrect operation and duplication.

For the further improvement of customer-related processes, another step to be taken is the standardization and automation of common procedures in the corporate loan process such as collection of data on the credit history, cash flow history, financial statements, balance sheets, and income statements.

For obtaining complete or adequate data from the customer and preventing delays in the transactions and flow of the loan application, evaluation and approval processes, the communication with the customer should be carried out by a single member of the staff who both follows standard procedures and makes decisions for customizing processes and shorten processing time on behalf of the customer. In the long run, the banks could have a higher opportunity to find and work with high profile customers, improve their existing customer profile and increase customer value and profitability.

To recapitulate, by applying the proposed model based on the lean six sigma approach, banks can achieve and sustain a high level of improvement that would increase speed, value creation, cost-efficiency, profitability and customer satisfaction and reduce waste, processing time and effort, duplication and prolonging of transactions, redundancies, risks and errors in the whole corporate loan process.

\section{References}

- $\quad$ Akdeniz, 2014. Lean Principles Explained. First Publishing, p. 1.

- Antony and Banuelas Coronado. 2001. “A Strategy for Survival”, Manufacturing Engineer, 80(3), pp. 11921.

- Banuelas Coronado and Anthony, 2002. "Critical Success Factors for the Successful Implementation of Six Sigma Projects in Organizations”, The TQM Magazine, 14(2), p. 92.

- Bergeron et al. 1997. "Application of MCDA to Corporate Loan Requests Evaluation”, Multicriteria Analysis, p. 453.

- Fliedner. 2012. Leading and Managing the Lean Management Process, New York: Business Expert Press, p. 2.

- Ilebrand et al. 2011. "Boosting Sales in Branch and Agency Networks through Lean", Lean Management: New Frontiers for Financial Institutions, Mckinsey\&Company, p.113.

- Kuiper et al. 2016. "Quality Quandaries: Improving a Customer Value Stream at a Financial Service Provider”, Quality Engineering, 28(1), pp. 155, 156, DOI:10.1080/08982112.2015.1089445.

- Leyer and Moormann. 2014. "How Lean Are Financial Service Companies Really? Empirical Evidence from a Large Scale Study in Germany", International Journal of Operations \& Production Management 34(11), pp. 1366, 1368, 1369, 1380.

- Mačerinskiene and Ivaškevičiūte. 2008. "The Evaluation Model of a Commercial Bank Loan Portfolio", Journal of Business Economics and Management, 9(4), pp. 274.

- Randall. 1999. “Challenges in Finance”, Strategic Finance, 80(9), ProQuest Business Collection, p. 32.

- Trent. 2008. End-to-End Lean Management: A Guide to Complete Supply Chain Improvement. J. Ross Publishing, p. 4.

- Văduva. 2011. "Lean Management in Banking”, in Annals of the University of Craiova Economic Sciences Year XXXXI No. 39, pp. 118, 119, 120, 121, 122, 123. 


\title{
İş Hayatında Nicel Başarı Tanımlamasına Bir Karşı Duruş: Erdem Ahlâkı Yaklaşımı
}

\section{Stance against Quantitative Success Descriptive in Professional Life: Virtue Ethics Approach}

\author{
Prof. Dr. Sabahat Bayrak Kök (Pamukkale University, Turkey) \\ Asst. Prof. Dr. İbrahim Aksel (Pamukkale University, Turkey)
}

\begin{abstract}
We argue that capitalist model in society and its success criteria as benefit and profit maximizations have been under heavy attacks these days. The argument in the center of the discussion in this paper is about there being serious distress in moral and socio-cultural indicators, though relatively rise in economical growth indicators. Thus, we argue that global economy suffers deepest moral crisis in line with the proportional shares that governments, international companies, big or small enterprises and their owners bear upon. Among the signs of this moral collapse, we point for unhealthy products to general health, unfair competitive actions, illusive commercials, price-quality inequalities, labor exploitations, bribery scandals and also environmental ruins around. In this point the sole solution for increase in societal trust of social and economical actors is, in our side, clear to take moral principles and standards as a reference. We argue that benefit, or profit maximization based approaches focusing on material gaining in professional life do not provide effective motivations. Rather approaches that putting internal character development forward and aiming good internal mood based on virtue should be placed in professional life. We see virtue based moral approach as a novel formula for regaining humanity where there are increasing rates of uncertainty and distrust. This study aims to show that commercial and economical activities could not be designed as exempted from moral codes and motives, rather it insists on that some notions as character, and virtue should be in heart in place of responsibility, duty, or benefit.
\end{abstract}

\section{Giriş}

Son kırk elli yıl içinde, dünyamızda yaşanan yoğun değişim, bilimsel alanda akıl almaz teknolojik yenilik ve gelişmeleri yaşatırken, küreselleşme ile birlikte kazanımların kayıplara dönüştüğü bir döneme girildiğinin sinyallerini vermiştir. Bu dönem doğanın, bilimin ve tekniğin el ele verişine tanıklık edip değerini yükseltirken, tüm toplumların geleceğini tehdit edecek şekilde bir 'değer göçü'nün ortaya çıkmasına ve ahlâkî kirliliğin yayılışına neden olmuştur. Kirliliğin bütün alanlarda görünür olması ve tüm katmanlara yayılımı, daha iyi bir gelecek kazanmak adına tasarlanan neo-liberal söylem ve uygulamaları merkezî tartışma konusu yapmıştır. Dünyanın bağrına bastığı neo-liberal gündemin peşisıra gelen açlık, yoksulluk, sömürü ve savaş bileşimi, dünya coğrafyasında vahşi kapitalizmin yeniden boy gösterdiği ve bu dönemin sadece vahşi kapitalizmin post-modern bir versiyonu olduğu eleştirilerini beraberinde getirmiştir. Bu eleştiriler ile kimin neyi ifade ettiğini veya neye işaret ettiğini tatmin edici bir şekilde ortaya koymak, şüphesiz bu çalışmanın amacını ve sınırlarını aşmaktadır. Bu yönüyle çalışmanın amacı, teorik bir yaklaşımla, öncelikle bilimden sanata, ekonomiden ekolojiye ve bireyden devlete kadar uzanan bu kirlilikte 'Modern paradigma ve kapitalizmin etkisi nedir?' sorusuna cevap vermek, sonrasında ise sorgulamanın odak noktasına girişimcilik faaliyetini alarak, girişimci sahada görülen çok yönlü kirliliği sonuçsalcı ve deontolojik ahlâkî yaklaşımlar çerçevesinde değerlendirmeyi ve bir çözüm modeli niteliğinde 'erdem ahlâkl' yaklaşımını vermeyi amaçlamaktadır.

\section{Modern Paradigma, Kapitalizmin Birey İnşası ve Sonuç: İnsan Kendini Eksiltir!}

20. yüzyıla hâkim olan pozitif paradigma, maddi değer anlayışı ile insanın teknik ve ekonomik olanı üretirken, doğayı ve aklı merkeze almasını sağlamış, fakat bunun karşısında sosyal ve ahlâkî değer inşası meselesini 'spekülatif' bir alan olarak tanımlayarak insanın ahlâkî davranışı ortaya koyması için gerekli olan bütünlük duygusunu parçalamıştır. Bu durum, insanın yüzünü, kendisini işleyen ve geliştiren ahlâkî niteliğinden ve metâfizik sahasından soyutlayarak salt anlamda teknik olanın sahasına çevirmesine neden olmuş, insanın insan olarak âdeta varlığını tescil eden özünden ayrılmasına, 'ahlâkî' niteliğinden kopmasına yani insanın kendisini moral anlamda sürekli üretmesi şeklindeki öz-niteliğinden soyutlamasına neden olmuştur. Böylece, insanın var oluş gayesi hakkında yeterli değerlendirmeyi yapmasına engel olarak 'insan değerine' zarar vermiştir. Başka bir deyişle, insanın iyi ve doğru olanı ortaya koyma çabasında ve kendini bilme etkinliğini gerçekleştirmesinde, başlangıçta ifa etmesi gereken farkındalığı; tek yanlı olarak maddeye, nesneye, teknik ve bilimsel ilerlemeye, kazanç sağlama güdüsüne dönük bir işlevselliğe dönüştürürken, onu metâfizik değerlerden (yüce ve güzel gibi.) alıkoymak yoluyla ahlâkî değer üretmesine ve bir ahlâkî duruş sergilemesine engel olmuştur. İnsanı kalıcı ve sürekli bir değer merkezinden çıkararak pratik ve gündelik hayatın baş döndürücü değişimine bırakmak, en hafifinden kalıcı ve sürekli olanın zihnimizi inşa eden kalıplarının silikleşmesi tehlikesini yaratırken (Akyol, 
2002), en ağırından insanın kendini ahlâkî niteliğinden ve metâfizik tarafından çekip çıkararak onun özüne yabancılaşmasına ve tüm dünya karşısında özgünlüğünü kaybetmesine neden olmuştur. İnsanın varlığının, özgürlüğünün ve özgünlüğünün anlamını kaybettiği nokta 'hiçlik ve 'anlamsızlıktır'. MaxHorkheimer'in Akıl Tutulması adlı eserinde belirtmiş olduğu gibi bu nokta sadece 'düşüncenin insansızlaştırılması'nı değil, 'insanın insansızlaştırılması' olgusunu da karşımıza çıkarmaktadır (Akyol, 2002).

İnsanın önemli başarıları arasında yer verilen bilimsel, teknik ve ekonomik ilerlemelerin biçim ve içeriğine yönelik yansıma, insanın ahlâkî tarafında bir zayıflamaya işaret etmiştir. İnsanın pozitif ilmî zihniyete, maddi olana sıkı sıkıya bağlılığı, insana maddi hayat standartlarının yüksekliği bakımından cömert sunuşlar sağlarken, insanın kendini öz anlamda tanıma ve tamamlama konusunda gösterdiği en az çabanın harcandığı bir süreci ifade etmiştir. Maddi unsurların ve ekonomik kazancın artan sayıda insan tarafından talep edilir olması, envaî çeşit sorun ile bizi karşı karşıya bırakırken, hırçın kapitalist işleyişe dayalı ' $y$ lkıcı rekabet' şartlarında sorunu kökten çözümleme konusunda alternatif çözüm arayışları yaratmaktadır. Özellikle 1990'lardan sonra ekonomik hayata ve ticari faaliyetlere ahlâkî değer eklemlemesi, bu çözüm arayışlarından biridir. İnsanın ahlâkî değer üreten yanıyla ekonomik sahadaki duruşunun ahlâkî gerilim ve çıkmazlar için rehberlik rolü oynayacağına inanılmaktadır. Diğer taraftan değer odaklı yaklaşım ile sorumlu, güvenilir, ahlâkî olarak kabul edilebilir davranış ekonomik işleyişte yoğunluk kazandıkça, kâr kapitalizminin bir fetiş haline gelen değer inşasıyla gerçekleştirdiği 'eşitsiz mübadele' mantığının önüne geçileceği gibi, finans kapitalinin yarattığı iktidar seçkinleri ile piyasada ötekileştirilerek dışlananlar arasındaki 'asimetrinin' de girişimcilerin ahlâkî değer içeren yeni rolleriyle değişebileceğine inanılmaktadır.

\section{Girişimcilikte Ahlâkî Değer İnşası}

Girişimciler, diğer insanlar ile olan ilişkilerini daha 'üretici'-mal ve hizmet üretimi- rolleriyle arz ve talep dengelerinin arkasına ve 'dolaşıcl' -paranın dolaşımı- rolleriyle faiz ve rant formunun arkasına saklayarak 'değer' kavramını hayatımıza yerleştirecek olursa, rahatlıkla toplumsal ilişkilerimize dair bir indirgemecilikten söz edebiliriz. Bu indirgemeci yaklaşımla; değerin sadece bir mübadele aracı olduğu realitesi ve maddi kazanç perspektifi yorumlaması yani 'değerin varlı̆̆ını varsayarak' ilişkilerimizde tüm değerleri bir eşdeğerlilik ilişkisi içinde değerlendirme cehaletinde kalabiliriz. Oysa 'değer' sadece para formunda hayatımızda yer alamayacağ gibi, bir mübadele ilişkisi içerisinde de vuku bulamaz. Toplumsal ilişkiler maddi bir varlığa, insanlar ve toplumlar da fiziksel bir varlığa indirgenemez. Bu noktada Erdemli (2002), "hangi yüce ülkü uğruna, hangi yüksek erek yolunda olursa olsun, insanı tek yanlı yaşamaya sokmak bir Ortaçăg 'dır. Ortaçağ bir yaşama olayıdır sadece dinle olmaz. Insan yaşamının çok yanlı gelişimini teke indirgemek, insanı yitirmektir. Oysa insan yaşamın çok yönlülüğ̈̈ içindedir ve gelişimi çok yönlü olacaktır; mutluluğu gibi. İnsanı ve yaşamayı bütünlüğü içinde kavramak gerekir", sözleriyle değer bağlamını bütünlüğe taşımamız gerekliliğine işaret etmektedir.

Çalışmanın amacı doğrultusunda 'değer' kavramına çok yanlı bağlamından bakarak fizik-ruh, madde-mana; ekonomik-sosyal temelde birbirini besleyen bir bütünselliğe taşımak istediğimizi belirtmek gerekir. Bu anlayışla, çalışmadaki yaklaşımın temeli, girişimci karakter üzerinden ahlâkî değer anlayışıyla, insanın anlamının ve değerinin kendi doğasına içkin olduğu; değer ve değerlerin boşlukta gerçekleşmediği; değer sorunun 'insan için iyi olan nedir?' sorusundan bağımsız olarak ele alınamayacağından hareketle girişimcilik ve erdem ahlâkı ilişkisini, iş ahlâkı ve iş ahlâkı yaklaşımları çerçevesinden değerlendirmektir.

\section{1 İş Ahlâkı Yoksunluğu: Girişimci Sahada Çok Yönlü Kirlilik}

Piyasa ekonomisi tarihi, aslında bir girişimcilik tarihidir. Şüphesiz, piyasaların taşıyıcı gücü girişimcilerdir. Piyasalarda zamana ve mekâna göre rekabet gücü bileşimlerinde önemli değişiklikler oldukça girişimci de bu yönelime bağlı olarak gücünü artırmaktadır. 1980’lerden sonra finansal küreselleşme ve reel ekonomiden, sanal ekonomiye geçiş, girişimci hareketin piyasalar üzerinde ciddi bir biçimde ağırlığını hissettirmesine neden olmuştur. Küresel menkul kıymetler ve ekonominin para piyasasına dönüşmüş hali, piyasadaki para akış1 aracılığıyla girişimcilerin olağanüstü güç kazanmasına imkân verirken, yüksek kâr marjlarıyla çalışma arzusunu tatmin eden ya da daha fazla kâr kazanmalarını sağlayan alan ve mekânlara gidişini yoğunlaştırmıştır. Bu durum ise, uluslararası ekonomik ilişkiler bağlamında yeni bağımlılık ve yeni yükümlülük fikirlerinin pratiğe dönüşmesine neden olmuştur. Uzun bir perspektiften bakıldığında kökünü Avrupa kapitalizminden ve sömürü kültüründen alan bu işleyiş, küresel ekonomiyi ve parasal akışı yönlendiren yeni sahipleriyle birlikte 'spekülatif kazançları' rekor bir düzeye ulaştırmıştır. Dengelerin 'yeniden kurulması' adıyla başlangıç yapan bu küresel kazanç ve büyüme politikaları, sonrasında düzensizleştirme ve kriz sarmallarıyla iç içe eklemlenerek bölgesel yoksulluklar ve kitlesel genel bir yoksullaşma yaratmıştır.

Yeni küresel ekonomik aktör ve rekabet gücü olarak girişimciler; kapitalist dünya ekonomisinde iş bağlantılarına temel aldıkları 'yıkıcı rekabet' stratejisi aracılığgyla servetlerini multi-trilyon dolarlık marjlara ulaştırırken, 'kâr' kavramını, satış fiyatının ve üretim faktörlerinin bir fonksiyonu olarak değil, 'sömürü', 'rüşvet', 'suistimal' vb. kapsamına giren ahlâkî olmayan uygulamaların toplum üzerindeki etkisi olarak göstermişlerdir. 1970'lerin sermaye/girişimci sınıfının kapitalist uygulamalarla yerini sağlamlaştırarak inşa ettikleri iktidarları, bir taraftan gelir ve servetin 'kişiselleşmesi' (dünyanın en büyük 100 ekonomisinin 51'inin şirketlerden, 49'unun ülkelerden 
oluştuğu belirtiliyor) (Anderson ve Cavanagh, 2000) endişe yaratırken, bundan daha kötü haber ise bu gelirlerinin büyük bölümünün ahlâkî olmayan yollardan kazanılmış olma ihtimalidir. Bu durum, işin eskiden yapıldığg gibi yapıldığı varsayımına dayanamayacağımızın ve girişimci aktivitede dramatik değişimler olduğunun (McNulty ve Hoffman; 2014) açık delilleridir. Söz konusu dramatik değişimlerden birincisi, dünya siyasi sisteminin 193 Birleşmiş Milletler üyesi ulus devletten oluşmadığının; Küresel Sistemin asıl irili ufaklı şirketler ve onların oluşturduğu 'piyasa/kâr/para ağı'ndan oluşan bir sistem olduğunun görülmesidir. Böylece geride birakmakta olduğumuz neo-liberal dönemin aslî unsurlarının ulus devletlerden daha önemli/etkili/güçlü şirketlerden oluştuğu artık gizlenemeyecek kadar büyük bir gerçektir (Caydi, 2011). Bu şirketlerin iş yapma şekillerinin geçmişten giderek daha fazla farklılaşması ve farklılaşırken 'kapitalizmin erdemi' olarak sunulan 'rekabeti' denetime çevirmek yoluyla sadece piyasalar üzerinde değil, siyasetçiler aracılığıyla ulus devletler üzerinde de 'muazzam kontrol gücüne' ulaştıkları ifade edilerek (Vitali vd., 2011) şirketlerin yarattığı etkilerin mikro ve makro perspektiften analizinin dikkatlice yapılması gerekliliğine işaret edilmektedir.

Kapitalist sosyo-ekonomik uygulamaların ve yeni siyasi ve felsefik formların etkisi altında günümüz girişimci sınıfı, yasal boşlukları avantaj olarak değerlendirerek, dünya kamuoyuna hatırı sayılır ölçüde negatif bir miras bırakmıştır. Bu negatif mirasın önemli bir kısmı uluslararası arenada itibar sahibi olarak görülen kurum ve kuruluşlara aittir. 1970 ve sonrasında küresel çapta birbiri ardına ortaya çıkan Arthur Andersen, Enron, Tyco, WorldCom, Adelphia vb. gibi American şirketleri, Ahold, Parmalat, Toyata, Sumitomo vb. gibi uluslararası boyutlu şirketlerin hileli finansal raporlama yapmaları (Giacalone ve Promislo, 2013) ayrıca Ford, General Motors, Nestle, Johnson\&Johnson, Union Carbide gibi firmaların ciddi sonuçlar doğuran (McDonald, 2009) uygulamaları tartışmaların odağında yer almıştır. Zamanla, girişimsel faaliyetlerdeki yolsuzluğun boyutları, dünya genelinde ciddi bir yayılım göstermeye başlamıştır. Güney Amerika, Avrupa, Amerika ve Rus girişimcileri bu negatif mirasın ve kötü gidişatın en önemli kaynaklarıdır. Özellikle Rusya ve Sahra-altı Afrika'da bu durumun giderek bir norm haline geldiği belirtilmekte hatta The Economist Dergisi (1999), 'Rusya'da girişimciliğin suçluluk ile eş anlama geldiğini' belirtmektedir (Fahadunsi ve Rosa, 2002). Her geçen gün dünya ekonomisinde büyüyen ve bazı yazarlar tarafindan 'dysfunction entrepereneurship' (Zahra vd., 2013) yani fonksiyonel olmayan girişimcilik olarak tanımlanan ve ahlâkî değer içermeyen bu girişimcilik, Sardar (1996) tarafından bir tür 'sosyal kanser' olarak tanımlanmıştır. Bu ifade, söz konusu kirliliğin sadece şirketler ve sahipleri adına bir itibarsızlaştırma olarak görülemeyeceğini, bu tecrübenin türevleri aracılığıyla taklit edilebileceğinin, yeni üreme ve çoğalma kapasitesinin göz önünde bulundurulmasıyla birlikte yükselen bir 'criminal entrepreneurship' tanımlamasıyla suça dayalı bir girişimcilik (Sanchez, 2009) oluşturulabileceği ve bunun 'suç ekonomisi' boyutuna sıçrama yaparak insanlığın geleceğini tehdit edebileceğine dikkat çekmek gerekmektedir.

Toplumsal değişim genellikle algılanamaz olduğu için, çok değerli dersler göz ardı edilir. Bu 'yakın körlük' girişimcilik alanında da ortaya çıkmış ve tüm dünyada ahlâkî iş tanımlamasına dönüş yaptırarak, ahlâkı dışarıda bırakan bir çalışma anlayışıyla ekonomik hayatın devam edemeyeceğini göstermiştir. Bu noktadan yaklaşıldığında girişimciliğin ne pahasına olursa olsun para kazanmak olmadığı ve girişimciliğin ekonomik olduğu kadar ahlâkî bir yönünün de olması gerekliliği anlaşılmaktadır. Elbette piyasa koşulları, artan rekabet baskısı ve mevcut firma dinamiklerinin yanına ahlâkî yaklaşımı almak kolay değildir. Ancak önemli olan ekonomik hayatın ahlâkı dışarıda bırakan bir faaliyet alanı olmayacağını net bir biçimde anlamaktır.

\subsection{Girişimcilik ve İş Ahlâkı Yaklaşımlarının Ekonomik Hayata Yansımaları}

Küreselleşme süreciyle yoğun olarak yaşanan ahlâkî olmayan davranış ve kurumların sayısındaki artış, girişimlerin varlıklarını devam ettirebilmelerini, kısa dönemli yaklaşımlar çerçevesinde yüksek kâr marjlı yaklaşımlardan, uzun dönemli stratejik yönelimler çerçevesinde yüksek 'sosyal sorumluluk' ve 'iş ahlâkl' içeren karar ve uygulamaların varlığına bağlamıştır. Bu nedenle günümüz girişimcileri, girişimcilik faaliyetlerinde ahlâkî kararlarının sayısını artırmak suretiyle stratejik bir avantaj yakalarken, ahlâkî kirlilik içeren faaliyet ve uygulamaların rekabet şansını azalttığının bilincindedir.

Son yıllara kadar girişimcilik yazınında ahlâkın göz ardı edildiği veya en azından bu yazında kendine sınırlı bir konu olarak yer edindiği araştırmacılar tarafından kabul edilmiştir (Carr, 2003; Kearins vd., 2004). Böylece, son yıllarda girişimcilik ahlâkına karşı giderek artan bir ilginin varlığı, günlük işlerde girişimcilerin karşılaştıkları bir dizi ahlâkî ve iktisadî sorunun çözümünde yardımcı olabilecek yaklaşımların geliştirilmesine işaret olarak değerlendirilmektedir (Hannafey, 2003). Girişimcilik, ticari faaliyet olarak, neo-klasik iktisatçılardan beri kabul görmüş, girişimcilerin salt ekonomik çıkarlarını maksimize etme sorumlulukları olduğuna dair hâkim dünya görüşünün etkisinde faaliyetlerin yürütüldüğü bir süreç olarak değerlendirilmiştir. Girişimciler kendi ekonomik amaçlarını gerçekleştirirken, nadir olarak ekonomik hayatta kendine yer bulan ahlâkî değer motiflerinin ekonomik hayatı bütünüyle negatif etkilediğine inanmıştır (Friedman, 1970; Sternberg, 1994). Cornwall ve Naughton'un (2003) iddiasına göre, bu ekonomik paradigmanın talihsiz sonucu, başarılı girişimciliğin tamamen maddi açıdan değerlendirilmiş olmasıdır. Neo-klasik yaklaşım, girişimcilik başarısının göstergesinin finansal olduğu fikrini kabul etmesinin yanında, maddi olmayan diğer unsurlara da uygulama ayağında yer verildiği iddiasıyla bu tür unsurların girişimciliğin içine gömülü olduğunu ifade etmiştir. Bu inanç, bir taraftan girişimcilikte uzun yıllar 'karakter/erdem' üzerinden araştırmalar yapılmasını engellemiş, diğer taraftan da finansal açıdan büyümekte olan 
girişimcilerin bu yöndeki eylem ve davranışlarına odaklanan çalışmalara ‘daha üstün’ etiketiyle bakılmasına neden olmuştur.

Girişimcilikle ilgili yapılmış bazı çalışmalar yukarıdaki araştırmalara kanıt olarak gösterilebilir (Cornwall ve Naughton 2003). Örneğin, büyüme konusundaki çalışmaların çoğunlukla ya gelir yada pazar payı odaklı olması (Brush ve Vanderwerf, 1992; Stocia ve Shindehutte, 1999) girişimcilik adına başarının; gelir artışına (Chandler, 1996), şirketin varlığını korumasına (Chrisman vd., 1998) ve toplam istihdam artışına bağlanması (Levine, 1997) gibi. Dahası, Longenecker ve arkadaşları (1986) tarafından yapılan diğer çalışmalarda ise, girişimcilerin bireysel düzeyde, 'başkalarından ziyade kendi kişisel ekonomik kazançlarını maksimize eden eylemleri' onayladıkları ve bu kazancın başkalarının aleyhine kazanılması durumunda bile aksi harekette bulunmadıkları belirtilmektedir. Ancak, tüm olumsuz örneklere rağmen, bütün girişimcilerin sadece para kazanmak için ticari çaba gösterdikleri ya da daha yüksek seviyeli amaçlar ile ilgilenmedikleri iddiası doğru olmayacağı gibi, bugün en başta kendi başarılarını ekonomik sonuçlar açısından olduğu kadar, ahlâkî değer süzgecinden yargılama eğiliminde bulunan girişimcilerin sayısının da azımsanamayacağı görülmektedir.

Günümüzde bu yönelimin bir sonucu olarak girişimcilik faaliyetinde bulunanların karşı karşıya kaldığı önemli sorunların aşılmasında 'ahlâkî olarak kabul edilebilir iş' tanımlaması yapılmak istenmekte ve iş hayatında değerler sisteminin daha yüksek bir seviyesini geliştirmek ve uygulamak için akademik camianın normatif bir çerçeve sağlamaya gayret gösterdiği gözlenmektedir. Bu değerlendirme paralelinde, normatif yaklaşımlar arasından özel olarak bir yaklaşımın diğer yaklaşımların önüne geçtiği ve daha fazla bir rağbet gördüğü anlaşılmaktadır (Wang, 2013). Bu yaklaşım, girişimcilik alanında merkeze alınması arzu edilen ve bu yönüyle çalışmanın karşıllaştırmalı olarak vurgu yapmak istediği 'erdem odaklı ahlâkî yaklaşım'dır. Bu noktada, ilk olarak normatif yaklaşımların genel özelliklerine kısaca yer verilecek, sonrasında ise erdem ahlâkının neden 'fayda' temelli, 'sonuç' ve 'kural' odaklı ahlâkî yaklaşımların önüne bir model olarak alındığı şirket örnekleri üzerinden açıklanmaya çalışılacaktır.

\subsection{Girişimcilik, Ahlâkî Yaklaşımlar ve Normatif Ahlâk Yaklaşımları}

Ahlâk alan yazınına tarihsel olarak bakıldığında ahlâk anlayışının Batılı tarzda genel olarak iki görüş tarafından yönlendirilip belirlendiği söylenebilir. Bunlardan ilki, normatif ahlâk diğeri ise, normatif olmayan ahlâktır. Normatif Ahlâk Yaklaşımları, düşünce tarihinde Sokrates ile birlikte Sofistler tarafından farklı toplumların gelenek ve değer sistemleriyle ilgili gözlemlerine dayalı olarak geliştirilmiştir. Bu yaklaşımlar açısından ahlâk, kural koyucu olmuştur ve olmalıdır. Başka bir ifadeyle, ahlâk için tasnif ve açıklama önemli olmakla birlikte, yeterli değildir. Zira ahlâk dediğimizde anlaşılan daha ziyade insanlar için, neyin doğru ve neyin yanlış, neyin iyi ve neyin kötü olduğuyla birlikte, belirli durumlarda ne yapıp ne yapmamaları ve hayatlarını nasıl sürdürmeleri gerektiğiyle ilgili bilgi vermek ve normlar koyup düzenleyici ilkeler geliştirmektir (Cevizci, 2008). Böylece, normatif ahlâk yaklaşımları, en genel kategorizasyon içinde, ortaya koyduğu normlar çerçevesinde ahlâkî davranışı tanımlamaya çalışır. Normatif Olmayan Ahlâk, K. Baier, R. M. Hare, K. Nielsen vb. yazarların çizgisinde, William K. Frankena'nın görüşlerini merkez alan bir yaklaşımdır. Temel olarak, normatif ahlâk yaklaşımlarına bir tepki olarak ortaya çıkan ve 'çözümlemeci ahlâk' olarak bilinen bu yaklaşımlar için ahlâkî önermeler bilgisel değildir, bu nedenle doğrulanıp yanlışlanamaz, onlar sadece 'duygu anlatımları' ve 'emirler' olarak çözümlenip değerlendirilebilir (Tepe, 1992). Bu nedenle bu yaklaşımlar, normatif yargı gerektiren ya da ihtiva eden bir düşünce biçimi olmayıp, ahlâk sistemlerinin mantığının ve dilinin sistemli incelenmesini içermektedir. Normatif ahlâk üçe ayrılmaktadır: 1-Teleolojik ahlâk/Sonuçsalcılık, 2- Deontolojik ahlâk/Kant'ın ödev ahlâk1, 3- Erdem ahlâkı.

\section{Teleolojik/Sonuçsalcı Ahlâk ve Girişimcilik}

Teleolojik ahlâk, bir gayeye yönlendirmeyi esas almakta ve bu nedenle ahlâkî iyiliği davranışın sonucuna yerleştirmektedir. Bu yaklaşıma göre, insan davranışı tek başına ne doğru/iyi ne de yanlış/kötüdür. Önemli olan konu, belli bir durumda davranışların sonucu olarak meydana gelen şeydir; dolayısıyla davranışları iyi ya da kötü, doğru ya da yanlış yapan şey, 'sonuç'lardır. Teleolojik perspektiften hareketle, hiçbir durum sonuçlarından bağımsız olarak 'doğru' ya da 'yanlış' şeklinde ahlâkî olarak değerlendirilemez. Bu açıdan, teleolojik yaklaşıma göre, 'ĕger sonuçlar iyi ise ya da arzu edilir ise o zaman davranışlar doğru; sonuçlar kötü ya da arzu edilmez iseler o zaman davranışlar yanlıştır'. Bu ifade de yer aldığı gibi, sonuç odaklı bir değerlendirmeyi benimseyen felsefeciler nedeniyle bu yaklaşıma genel olarak 'sonuçsalcılık' adı verilmiştir (Shaw, 1991).

\subsection{Egoizm}

Shaw (1991)' a göre egoizm, herhangi bir bireyin, başkalarına karşı ne yükümlülüğe mecbur olduğunu, ne de bir fedakârlığa katlanmak zorunda olmadığını öne sürerek davranışların ancak bireyin kendisi için en yüksek iyiye izin vermesi durumunda gösterilmesi gerektiği düşüncesini kabul etmiştir. Bu çerçevede egoistler, bir davranışın doğruluğunu ölçerken, kendileri için en iyi ve uzun vadeli kazançları esas alırlar. Eğer bir davranış uzun vadede birey için kötüye oranla 'en yüksek iyi'yi ortaya çıkarıyorsa ya da muhtemelen çıkaracaksa, bireyler o davranış1 ortaya koymalıdır (Bayrak Kök, 2013, newoku.com). Egoizm, bireyler için doğru ve kabul edilebilir davranışları bireyin 'kişisel çıkarı' üzerinden tanımlarken, her bireyin kendi kişisel çıkarlarını maksimize edecek şekilde karar alıp davranacaklarını kabul eder. Egoizm, bu yaklaşımı kişilerin bütün tercihleri için genelleştirirler. Böylece, 
egoizm 'kişisel çıkar, zenginlik, güç, şöhret gibi olgularla kendi çıkarlarını maksimize edişini ahlâkî bir tercih olarak görmektedir. Egoizm yaklaşımı, ahlâkî egoizm ve hazcılık olarak iki bölümde incelenilmektedir.

Ahlâkî egoizm: Bu bakış açısına göre kabul edilebilir tek geçerli davranış standardı, kendini geliştirme olarak görülür. Böylece bu görüş, bir bireyin belirli bir durumda kendisi için uygun olan şartları belirlediğini, kendisi için yararlı ve yararsız olan şeyleri hesapladığını böylece kendi gelişimine en yüksek katkıda bulunacak davranışı gerçekleştirdiğini kabul etmektedir. Ahlâkî egoistler, bireylerin kendi uzun vadeli çıkarlarını takip göz önünde tutarken başkalarının çıkarlarının ne olduğuyla ilgilenmezler (Shaw, 1991). Ahlâkî egoizmin bazı özelliklerine ahlâkın Galileo'su olarak bilinen Thomas Hobbes (1588-1679) katkı yaptığı kabul edilir. Hobbes'un meşhur, 'homo hominislupus'u (insan insanın kurdudur), insan doğasını bencillikle ve saldırganlıkla karakterize etmiştir. İnsan doğal durumunda bencildir ve varlığını koruma içgüdüsüyle hareket etmektedir. Dolayısıyla her insanın insanla savaşı söz konusudur (Hobbes, 1992).

Hazcılık/Hedonizm: Hedone, eski Yunancada haz ve zevk anlamına gelmektedir. Hedonizm ise, hazcılık demektir. Hedonizmin temelinde, 'hayatın en önemli değeri haz ve zevk almaktır ve ideal yaşama ancak bu şekilde ulaşılır’ fikri vardır. Ahlâkî eylemin amacını hazda bulan yaklaşım Aristippos (İ.Ö. 435-355)'da netleşir. Bu yaklaşıma göre iyi demek haz demektir; haz veren her şey iyi, acı veren her şey ise kötüdür. Aristippos'a göre her davranışın nedeni, mutlu olma isteğidir ve hayatın amacı hazdır. Haz insanı insan eden duygudur (Moore, 2004). 'Doğru eylem'in ne olduğu haz temelinden tanımlanır. Bu açıdan, bir eylem, ancak haz getiren ve haz amaçlayan bir eylem ise 'doğru eylem' olur (Özlem, 2004).

\subsection{Faydacilık}

Mill'e göre, faydacı yaklaşım, ahlâk doktrinlerini şekillendirmede büyük bir rol oynamıştır. 'Fayda' ya da 'en büyük mutluluk' ilkesini ahlâkın temeli olarak gören yaklaşım, davranışları bize vermekte oldukları mutluluk oranında iyi, mutluluğun zıddı olan şeyleri getirdikleri oranda da kötü sayar. Mutluluktan haz ya da acının yokluğu, mutsuzluk kelimesiyle de acı ya da mutluluğun yokluğu anlaşılmaktadır (Kılıç, 1993). Faydacı ahlâk yaklaşımı, büyük ölçüde yeniçağ İngiliz felsefesinden çıkmış kabul edilmekte ve 20. yüzyılda Anglo-Sakson dünyasında ortaya çıkan pragmatism gibi öğretilerin devamı olarak düşünülmektedir (Özlem, 2004).

Faydacılığın temel konularını ele alan ve bu teoriyi geliştiren filozoflar Jeremy Bentham (1748-1832) ve John Stuart Mill (1806-1873)'dir. Bentham'ın iyiyi hazza, iyiliği de haz veren şeye eşitleyen faydacılığı hazcı faydacılık; Mill'in iyinin mutlulukla eşdeğer olduğunu öne süren faydacı görüşü mutlulukçu yararcılık olarak bilinir (Cevizci, 2008). Faydacı ahlâk, bir eylemin doğruluğunu tamamen sonuçların değerine bağlamakta ve sonuçlardan hangisinin ağır bastığına karar vermek için iyi ve kötü sonuçların hesaplanması yoluyla fayda-maliyet analizine göre ahlâkî seçimlerin yapılmasını gerekliliğini öne sürmektedir. Faydacı yaklaşımda bir pratiklik ve gerçeklik bulunmakla beraber, faydacı yaklaşım ahlâkî olmayan bir takım karar ve uygulamalara neden olmasıyla sert bir şekilde eleştirilmekte ve ekonomide faydacı ve denotolojik bakışların sınırlı kalışına dikkat çekilmektedir (Staveren, 2007).

Valesquez (1998) bu durum için yaşanmış şu örneği verir: 1960'larda Ford, piyasadaki rekabetten dolayı kısa sürede yeni bir araba üretir. Ancak fazla zaman geçmeden arabanın bir takım tehditler içerdiği anlaşılır. Arabada gaz deposu, dingilin arkasına yerleştirildiği için arkadan çarpma durumunda deponun delinip gazın arka koltuklara doğru yayılma ihtimâli yüksek görülür. Yapılan testler bu ihtimâli kuvvetle destekler. Gerçek bir kaza olması durumunda küçük bir kıvılcım trajik sonuçlara yol açabilir. Bu durumda şirket bir karara varmak durumunda kalır; ya bu hata düzeltilecek ya da görmezden gelinerek üretime devam edilecektir. Kâr-zarar analizi yapılır. Hatanın düzeltilmesi şirkete 137 milyon dolara mal olmaktadır. Ancak bu seçenek 180 kişinin ölümünü, 180 yanık vakasını ve 2100 arabanın yanmasını önleyecektir. Diğer taraftan şirket başka bir seçeneği daha değerlendirir. İlgili dönemde insana, yanıklara ve arabalara biçilen değerdir. Bu seçeneğe göre, insan hayatına biçilen değer resmi olarak 200.000 dolar sigorta şirketlerinin ciddi yanıklara biçtiği değer 67.000 dolar; araba için ise 700 dolar şeklindedir. Ortaya çıkan hesaplara göre, üretimin düzeltilmesi maliyeti 137 dolar iken; üretime devam seçeneğinin toplam maliyeti 49 milyon dolardır. Tabi bu maliyetler satılacak arabalara eklenerek karşılanacağı için tüketiciler arabaları daha pahalıya alacaklardır. Faydacılık yaklaşımına göre doğru karar, daha fazla insana daha fazla kazanç ve en az zarar verecek karardır. Bu durumda düzeltmeye gitmek yerine üretime devam etmek daha doğrudur. Ancak bu sonuç kazanç-maliyet hesaplamasının parasal yüzüdür ve sadece şirket açısından ele alınmış eksik bir hesaplamadır. Yakınlarını kaybedenlerin çektiği acılar, ölenlerin yarım kalan hayatlarında doğurduğu eksiklikler, ölmeyip de yananların çektiği ızdıraplar hiçbir sigorta şirketinin veya resmî kabullerin hesaplarına almadı̆̆ bedellerdir. Bu olayda Ford, üretime devam kararını alır ve satışa devam eder. 60 ölüm ve bunun iki misli de yanık vakası sonucunda araba nihayet piyasadan çekilir (Bayrak Kök, 2013, slideshare.net).

Faydacılık yaklaşımı, sahip olduğu bir takım kolaylıklar yanında bazı eksik ve zayıf yönleri nedeniyle de bir takım eleştirilere maruz kalmıştır (Arslan, 2001). Bu eleştirilerden birincisi, faydacılığın gerçekten işleyen bir teori olup olmadığının sorgulanmasıdır. Bu bakış açısına göre, bazı önemli durumlarda davranışın sonuçlarını tahmin edemeyebiliriz yani davranışın fayda ve değeri hesaplanamayabilir. Bu nedenle bireyden davranışta bulunmadan önce muhtemel sonuçlarını ölçmesini beklemek gerçekçi olmayabilir. Söz konusu teoriye yapılan diğer bir eleştiri, iyi sonuçlar verse bile bazı davranış veya eylemlerin özünde yanlış olabileceğidir (hırsızlık, rüşvet, vergi kaçırma 
vb.). Diğer bir eleştiri ise, faydacılığın adil olmadığıyla ilgilidir. Çünkü faydacılık toplam fayda ile ilgilenmekte ancak bu faydanın nasıl dağıtılacağıyla ilgilenmemektedir. Dolayısıyla potansiyel sorumluluk ve maliyet eşit olmayan bir şekilde yani adaletsizce dağıtılabilir (Bayrak Kök, 2013). Örneğin, aşırı kâr marjları karşısında çalışan ücretlerindeki düşüklük gibi.

\section{Deontolojik Teori ve Girişimcilik}

Deontoloji terimi yapılması gereken, görevler, kurallar ve emirler anlamındaki 'deontos' sözcügüünden türetilmiştir. Deontolojik ahlâk, insanların ne yapması, nasıl davranması gerektiğini belirten ve neyin yanlış neyin doğru olduğuna kişileri yönlendiren evrensel normlarla ilgilidir (Staveren, 2007). Bu yaklaşıma göre; sonuçlarına bakılmaksızın bazı ahlâkî ilkeler bağlayıcıdır. Bu nedenle bir eylemin sonuçları iyi olsa bile, bazı eylemler yanlış olarak değerlendirilebilir. Örneğin, bir deontolojist, yalan söylemenin, hırsızlık yapmanın, daima yanlış olduğunu düşünür. Bu davranışlar sonucunda ortaya çıkacak fayda, ne olursa olsun fark etmez. Çünkü böyle bir davranış sonuçta bir birey olarak kişinin haklarını ihlâl etmektedir. Fakat faydacılara göre, eğer bir kişinin ölümü en yüksek faydayı sağlıyorsa, o davranış kabul edilebilir bir davranış olarak görülebilir. Böylece deontolojik kuramcılar, doğruluğun belirleyiciliğinde doğru olan şeyleri yapmaya yoğunlaşırken (örneğin, dürüstlük gibi ahlâkî ilkelere bağlı olarak) faydacılar toplum refahını en üst düzeye/maksimum faydaya çıkaracak şeyleri yapmaya yoğunlaşırlar (Ferrell ve Fraderich, 1994; Trevino ve Nelson, 1995).

Genel hatlarıyla, deontolojik yaklaşım, bizâtihi davranışın kendisini esas alır. En azından bazı davranışlar sonucuna bakılmaksızın ahlâken bir yükümlülüktür. Ödev, ilke, irade, yükümlülük, yasa ve kurallar deontolojik yaklaşımın anahtar kavramlarıdır. Deontolojik ahlâk teorileri, Kant ahlâkı, haklar teorisi ve adalet teorisi olarak değerlendirilmektedir. Bu başlık altında bildiri açısından sadece Kant'ın ahlâk anlayışına yer verilecektir.

\subsection{Kant'ın Ödev Ahlâkı}

Ödev Ahlâkı'nın batı felsefesindeki en büyük temsilcisi Kant'tır (1724-1804). Aydınlanma filozofu olan Kant'ın ahlâk anlayışı öylesine yenilikler getirmiştir ki, Kant için, 'ahlâkın Newton'u' yakıştırması bile yapılmıştır (Nişanc1, 2010). Kant'ın ödev ahlâkı, bir ahlâkî değer teorisinden ziyade, bir ahlâkî yükümlülük teorisidir. Çünkü ahlâkî değer teorilerinde, iyi ve kötü kavramları temel değerler olup, doğru ve yanlış kavramları onlardan türetilirken ödev ya da yükümlülüklerden pek söz edilmez. Oysa Kant'ın ahlâkında ödev kavramı en temel kavramdır ve ahlâken doğru ya da yanlış ondan çıkarılır. Kant'a göre eylem sadece ödev ya da yükümlülük duygusuyla yapıldığı zaman, onun gerçek bir ahlâkî değeri olabilir. Böylece Kant, ahlâkı, ödev, yükümlülük ya da doğruluk benzeri kavramlarla ahlâkî eylemlerin sonuçlarına bakarak tanımlamaz. Kant'ın ödev ahlâkı, tam tersine, ödev ya da ahlâkî yükümlülüğün sonuçla değil, fakat eylemlerin kendi özellikleri ya da nitelikleriyle ilgili olduğunu öne sürer (Cevizci, 2008).

Böylece Kant'ın ahlâk anlayışı, 'imperativ'/kategorik karaktere sahiptir. Dolayısıyla bu yaklaşıma göre, ahlâklılık, ahlâka boyun eğmekten ibarettir ve şartlı bir emir olmaktan ziyade, kesin bir emirdir. Örneğin, ahlâkî kanun, 'sen yalan söylemeyeceksin' der; 'senin sözüne itimad edilmesini arzu edersen yalan söylemekten sakın' demez. Kanun yalnız emreder ve bizim bildiğimiz şey budur. Dolayısıyla, 'iyi niyet'e dayalı olarak kanuna boyun eğmekten başka hiçbir 'iyi' yoktur. Bu nedenle Kant için 'iyi niyet' tek ve gerçek ahlâk değeridir ve bu nedenle onun en yüce ve göz ardı edilmesi mümkün olmayan bir şey olması gerekir. İnsan ve akıl sahibi her mahlûk için, bu durumun kendisi bir amaçtır ve salt anlamda bir değere sahiptir. Böylece Kant, akıl yürütüp hüküm verme sonucunda şu ilkeye ulaşılacağını belirtir: 'Insanlara o şekilde hareket et ki, hem kendin için, hem de diğerleri için, daima bir amaç olsun ve sen bu amaç uğruna davranmış olasın; ama hiçbir zaman insanı bir araç gibi kullanmış olmayasin'(Bertrand, 2001).

Yukarıdaki cümle her ne kadar kapalı bir ifade olarak değerlendirilse de Kant, bu yaklaşımıyla, bir taraftan ahlâkî kuralların kişilerin bireysel ilgi ve isteklerinden daha yüce ifadeler şeklinde evrensel kurallar olduğuna dikkat çekmiş, diğer taraftan da emirlerin 'imperativ' karaktere sahip olması dolayısıyla, insanların onları kendilerini mutlu eden bir sonuç için değil, doğru olduğu için yapılması istenen bir durum olduğunu belirtmiştir. Kant ahlâkı perspektifinden belli bir kurala uymak, yasal bir çekince değil, amaç edinilmiş ahlâkî bir görevdir. Bu nedenle, bireyle için temel ilk eve kurallar dizisi, bir ahlâk pusulası işlevi görmektedir. Temel ahlâkî ilkeler binlerce yıldır insanlar tarafından bilinmektedir. Bu ahlâk kurallarını öğrenmek ve onlara uygun yaşamak, bütün insanların görevidir (Aydın, 2001).

Kant yaklaşımıyla kategorik emir, ekonomik hayatta eylemlerin ahlâkî olup olmadığına bakan bir test gibi çalıştırılabilir. Bir eylem ancak eylemin temelindeki kategorik testi geçerse gerçekleştirilebilir. Eğer testi geçemezse eylem ahlâkî olarak yasaklanmıştır. Kant'ın yaklaşımına bu noktada şöyle bir örnek verilebilir (Bowie, 2002). Önceden yapılmış anlaşmaların tekrar müzakere edilmesiyle ortaya çıkan bu durum Jose Lopez yönetimindeki ünlü General Motors hilesi olarak bilinen düşündürücü bir örnektir. Jose Lopez, tedarikçisi ile firmasının daha önce yapmış olan anlaşmaları fiyatlama açısından yeniden müzakere ederek, tedarikçisinden fiyatı aşağı çekmesini sağlayacak şekilde bir pazarlık yaparak önemli bir avantaj yakalamış ve böylece şirketin kârına kâr katmıştır. Ancak böylesi bir uygulamada yöneltilen soru, acaba bu tür bir taktik Kant'ın kategorik emir testinden geçer miydi? şeklindedir. Bu soruya verilebilecek cevap, 'hayır'dır. Eğer ekonomik hayatta girişimciler 
arasında anlaşmaları bozmaya izin veren bir kural evrenselleşseydi, ekonomi pratiğinde kontrat ya da sözleşme diye bir şeye yer olamazd1. Ancak, Amerika ve Avrupa'da WorldCom, Enron, Parmelat ve Ahold gibi şirketlerin neden olduğu skandalların (Staveren, 2007) varlığı nedeniyle bir kısım araştırmacılar, uygun rekabet şartlarının sağlanmasına dayalı politikalara yönelik ahlâkın sağlayacağı katkıyı tartışırken, bir kısım yazarlar ise deontolojik yaklaşımın somut ve karmaşık hayat olaylarına uygulanması durumundaki performansının yapılan eleştiri ve taşıdığı sınırlılıkları nedeniyle cüzî kalabileceği fikrini ortaya atmaktadır. İlgili değerlendirmeler nedeniyle araştırmacılar bakış açılarını ekonomide farklı bir yaklaşım olarak görülen erdem ahlâkına çevirmişlerdir (Blackburn ve Mcghee, 1997). Bunlar arasından özellikle Anscombe (1997), 'bütün yaşam olayları hak ve görevlerden oluşan kurallar setiyle düzenlenemeyecek kadar karmaşık yapıdadır, bu nedenle, bütün ahlâkî problemler kurallar aracılığıyla çözümlenemez' demektedir.

\section{Erdem Ahlâkı ve Girişimcilik}

Erdem kavramı, ahlâkî yaklaşımların en temel kavramıdır. Erdem, Antik Yunan'da ahlâkî bir kullanıma kavuşmadan önce 'bir varlı̆̆ın yerine getirmesi gereken işlevi en iyi biçimde yerine getirmesi' olarak anlaşılmıştır (MacIntyre, 2001b). Eski Türkçe Sözlükte erdem terimi, 'artam' şeklinde ifade edilmiştir. 'Artam'ın 'artmak' fiilinden geldiği hatırlandığında 'artam' veya 'erdem'in insanda fazladan bulunması gereken bir kapasite olarak anlaşılıp, her tür üstünlük ve fazilet için kullanıldığı görülmektedir (Bayrak Kök, 2013). 'Er' ile ‘erdem' arasındaki etimolojik ilgi, 'er' adına sahip olmak isteyen herkes için 'erdem' sahibi olmayı önemli ve gerekli görür. Bu nedenle Kutadgu Bilig'in çok yerinde 'erdem'siz insanlar hayvana benzetilir (Y1lmaz, 2014). Erdem, iyi huyluluk, iyi kalplilik, iyi niyetlilik, iyi sözlülük, iyi davranışlılık kısaca, iyi ahlâklılıktır. Bu nedenle, erdemlilik çoğu kere ahlâklı ve karakter sahibi biri olmakla eş anlamlı kullanılır.

Erdem ahlâkı denildiğinde ilk akla gelen filozof Aristo'dur. Aristo için insan ile ilgili sorulması gereken soru 'insanı özgür bir varlık kılan eylem tarzı veya işlev hangisidir?' şeklindedir. Buna verilen cevap erdemdir. Aristo için erdem ise 'insanın işlevlerini en iyi şekilde yerine getirme hali'dir (Özlem, 2004). Kavrama yüklenilen anlamlardan anlaşılacağı gibi, erdem fikrine dayalı bir ahlâk anlayışı, evveliyatında hem Batı hem de Doğu bağlamında itibar gören bir ahlâkî sistem iken, zaman içerisinde insanlığın yitik bir değeri olarak görülmüştür. Erdem kavramının uzun süren dışlanmışlığından sonra, yerine ikame edilmek istenilen Kantçı ve faydacı ahlâk ile birey hayatında 'rasyonel' ilkelerin varlığı esas alınmak istenmişse de, her iki yaklaşım ile arzu edilen sonuçlara ulaşılamadığı değişik alanlarda çalışan araştırmacılar tarafından belirtilmiştir (Anscombe, 1997; Blackburn ve Mcghee, 1997).

20. yüzyılın sonunda felsefeciler insanlık adına, 'statusquo' odaklı ve 'onaylayıcı' bir ahlâkı benimsemek durumunda olmadığını, gerek Batı ve gerekse Doğu felsefe geleneğinde köklerine dönerek 'nasıl yaşamall' sorusuna, insan davranışının ancak erdem tarafıyla cevap verebilmesinin farklılık yaratacağı ileri sürülmeye başlandı. Böylece erdem kavramı, Batı bağlamında eski değerinden belki daha fazla bir ilgiyle yeniden karşılık bularak yeni bir sahiplenme konusu oldu. Erdem kavramını, Batı bağlamında ahlâk alanında ortaya çıkan gerilimlere ve kafa karışıklıklarına son vermek üzere dayanak yapan felsefeci Alasdair MacIntyre bu konuda şöyle demektedir: Erdem kavramının etik soruşturma dışına itilmesi, Aydınlanma ile yaşıttır. Aydınlanma ile birlikte geçmiş dörtyüzyıl içinde 'nasıl yaşamalı' sorusu erdemlere gönderme yapılmaksızın, sözde ussal sistemler ile cevaplanmaya çalışılmıştır. Bu sistemlerden en yaygın ilgi gören ikisi, Kantçı ahlâk ve faydacı ahlâk, bu anlamda, çağdaş kafa karışıklığından en çok sorumlu olanlardır. Aydınlanma ile başlayan 'geleneğe kuşkuyla yaklaşan' ahlâk sistemleri, insanları ahlâkî parçası oldukları toplumsal-kültürel anlatılara başvurmaksızın ahlâkî bir yalıtılmışlık içinde anlamaya ve çözmeye yöneltmişlerdir. Ancak bu yaklaşımların hiçbiri söz konusu sorunu ne anlamaya ne de çözmeye yardımcı olmuştur (MacIntyre; 2001a; 2001b).

MacIntyre, erdem karşısında faydacı ahlâk formülasyonuyla ulaşılmak istenilen rasyonel ilkeyi benimseyen modern bireyi, Mill'in 'sonuçları bakımından, en fazla sayıda kişiye fayda getirecek şekilde davran' sözünü altın kural olarak yorumlanmasıyla hiçbir bireye ahlâkî bir yatkınlık kazandırılamayacağı görüşüyle güçlü bir şekilde eleştirmiştir. Yazara göre; modern toplumda sanki varmış gibi görünene 'ben-arzular', 'ötekiler-beklentiler' şeklinde yaratılan gerilim, Aydınlanma projesinin ahlâk alanındaki başarısızlığının sonucundaki bir yanılsamadır. $\mathrm{Bu}$ sözde gerilim gelenekte olmayan icat edilmiş bir gerilimdir. Giderek bireyselleşmiş ve bireycileşmiş hayatlarımızda seçimlerimiz ve ahlâkî yönelişlerimiz kendi başımıza çözmemiz gereken birer sorun olup çıkmıştır. Oysa parçası olduğumuz tarihsel-kültürel anlatılar, varlığımızı türlü biçimlerde rahatlatacak, yapıp-etmelerimizi akıcı bir doğallıkla yönlendirecek erdemleri barındırmaktadır (MacIntyre; 2001a; 2001b).

Erdem ahlâkını ele alan ilk filozof Aristo'dur. Aristo için erdem 'Insanı özgür bir varlık kılan eylem tarzı veya işlev hangisidir?' sorusuna cevaptır. Aristo açısından erdem, 'insanın işlevlerini en iyi şekilde yerine getirme hali'dir (Özlem, 2004). Böylece Aristo, erdemi, herhangi bir şeyi yerine getirirken en iyi şekilde yapmak, mutluluğu ise, bir şeyi en iyi şekilde yerine getirmenin verdiği duygu olarak tanımlar (Ess, 2012). Aristo'ya göre, gerçek mutluluğa ancak insanın kendi benliğini keşfetmesi, kendini tanıması ve potansiyelinin ortaya çıkması ile ulaşılabilir. Bunun dışında kalan mutluluklar, gerçek mutluluklar değil, ona göre anlık 'zevk' ve 'haz'lardır. Anlık memnuniyet ve haz duygusu hali, kişinin kendisini kısa süreli olarak iyi hissetmesini sağlar, ancak kişinin 
gelişimine katkıda bulunmaz. Bu nedenle haz ve mutluluğu birbirine karıştırmamak gerekir. Haz, bedenin sadece anlık memnuniyeti iken, mutluluk kişisel gelişimin peşinden gitmektir. Dolayısıyla mutluluk, iyi yaşamak ve iyi durumda olmaktan ötedir (Aristo, 2014).

Tüm erdeme dayalı ahlâk sistemleri 'iyi bir yaşam nedir?' ve 'iyi bir yaşama sahip olmak için nasıl bir yol izleyebilirim?' gibi eyleyen merkezli sorulara odaklanırlar. Bu sorularla onlar, herhangi bir zamanda ortaya çıkan belli konulara nasıl yöneleceği sorusu üzerine değil, uzun süreçte birinin hayatını nasıl yaşayacağı üzerine odaklıdırlar. Bu şekliyle bireyleri 'ben ne yapmalıyım' sorusu yerine, 'ben ne olmalıyım' sorusuna yönlendiren erdem ahlâkı, davranıştan ziyade karakter ve kişisel eğilim üzerine odaklıdır. Başka bir ifadeyle, erdem ahlâkı; eylem merkezli değil, eyleyen merkezli; yapmaktan ziyade olmak ile ilgili, doğruluk, ödev, yükümlülük gibi deontik kavramlardan ziyade iyilik, üstünlük, mükemmellik, yiğitlik, cömertlik, sadakat gibi erdemler ile ilgilidir (Hursthouse, 2001). Bu ahlâk anlayışında önemli olan iyi kişinin ahlâkî karakterinin geliştirilmesidir. Bu nedenledir ki, etik kelimesi, Yunanca Ethos'dan adet, alışkanlık anlamlarından gelmektedir. Bu anlam çerçevesinde tekrar edildikçe, insanın iyi huyu, karakteri haline gelir. İyi çizim yapa yapa ressam, adil işler yapa yapa adil olunabilir. Yoksa karakter erdemlerinden hiçbirisi bizde Tanrı vergisi olarak bulunmaz. Aristo, bu nedenle, 'erdem bizim sahip olduğumuz en büyük zenginliktir' demektedir (Aristo, 2014).

Aristo'ya göre, nasıl bir kırlangıç ile bahar gelmez ise, bir erdemli davranış da bütün erdemleri taşımaz. Burada erdemli olmak için, alışkanlık, yani, ahlâk kanununa uygun işler yapmak için kazanılmış bir yetenek gereklidir. Alışkanlık özellikle bir çabayı biriktirme ve içsel insanı icad eden bir irade demektir. Bu nedenle Aristo ve Stoacılar, alışkanlığın erdemde çok büyük bir rolü olduğuna inanmış (Bertrand, 2001) ve erdem ahlâkını, erdemleri ya da kişinin ahlâkî karakteri olarak tanımlamışlardır. Bu yaklaşıma göre, ahlâklılığın temelinde iyi karakter özelliklerinin ve erdemlerinin geliştirilmesi bulunmaktadır. Örneğin, ihtiyacı olan birine yardım gerektiği apaçık bir gerçektir. Bu yardımı gerçekleştirirken sonuçsalcı ya da faydacı biri ‘iyiyi maksimize etmek için’ bir deontolojist 'ahlâkî olan bir kural doğrultusunda davranılacă̆l için' bir erdem etikçisi ise 'hayırsever biri olarak, bir kişinin yardıma ihtiyacı olduğu için' harekete geçer (Hursthouse, 2001). Erdem ahlâkının diğer bir farkı, kişileri toplumsal bağlılık ve kollektif amaç duygusuna odaklamasıdır. Bu yönüyle girişimcinin ahlâkî bir aktör olarak bu anlayış1 kurumuna uygulamasında kolaylık sağlar (Blackburn ve McGhee, 1997). Ayrıca, bu ahlâkî yaklaşımlar, ahlâkî örnekler ve rol modelleri üzerine dayandığından, iyi bir modellemenin örneklenmesi dolayısıyla ahlâkî bir yaşama öncülük edeceğinin altını çizmektedir. Bu konu özellikle ahlâkî bir girişimciliğin eğitim ve modelleme yoluyla sadece bireysel hayat için değil, toplumsal hayat için de önemli olduğuna konuyu götürmektedir (Blackburn ve McGhee, 1997).

Erdem ahlâkı, başarılı girişimciliği değerlendirmede yeni bir bakış açısı sağlamaktadır. Bu güç, onun kurallara dayanmasından ziyade, 'karakter' üzerinde durma şeklinden kaynaklanmaktadır. Böylece diğer normatif yaklaşımlardan daha etkili olarak görülmektedir. Bu etkinlik ve motivasyon modern paradigma sorununa da çözüm olarak görülebilir. Günümüz toplumlarında görülen ve girişimcilik faaliyetlerine de atfedilen, sürekli değişim ve belirsizlik ortamlarının yarattığı gerilimlerden sıyrılmak 'iyi davranış' gerektirmektedir. Modern toplumlarda 'iyi davranış' dışarıdan dayatılan bir beklenti olduğu için ortak norm ve değerlerden çok, zamana göre değişen akışkan normlardan dayanak bulmaktadır. Oysa aşırı kâr etmek veya ahlâklı görünmek yerine, ahlâkî karakter üzerinden yaşayarak belirsizlik ve karmaşıklık problemlerine çözüm üretmek gerekmektedir.

Bu konuda piyasadan verilebilecek şirket örneği, 1901 yılında kurulmuş Monsanto'dur. Monsanto şirketi bugün 8,6 milyar dolar satışıyla dünyanın en büyük tohum şirketidir. Şirket biyoteknoloji ya da organizmaların genetik manipülasyonu konusunda uzmanlaşmıştır. Şirketin elde ettiği 8,6 milyar dolar cironun tamamı genetiği değiştirilmiş tohumlardan meydana gelmektedir. Şirket için çalışan bilim adamları yüksek ürün verimliliği olan ve zararlı böceklere karşı dirençli ürünler geliştirmek için bitki tohumlarının içine yeni genler adapte etmektedir. Bugün dünyada genetiği değiştirilmiş tohumların yüzde 90'1 Monsanto tarafindan satılmakta ya da Monsanto'nun ürettiği genleri kullanan firmalar tarafından satılmaktadır. Şirket faaliyetlerine karşı çıkanlar ise firmanın dünyanın ürün arzını ele geçirdiğini ve biyo çeşitliliği tahrip ettiğini söyleyerek ve biyoteknolojinin muhtemel olumsuz sağlık sorunları ve çevresel etkileriyle ilgilenmektedirler. Ancak bu eleştiriler, dünyanın en büyük firmalarından olan Monsanto üzerinde hiçbir etki yapmamaktadır. Monsanto şirketi bunun dışında Endonezya'da Çevre Bakanlığında üst düzey bir yetkiliye 2002'de verdiği 50.000 dolar rüşvet ile gündeme gelmiş ve şirket böylece çiftçi ve protestocuların karşı çıkmalarına rağmen genetiği değiştirilmiş pamuk tohumunu ülkeye sokabilmiştir. $\mathrm{Bu}$ olay daha sonra ortaya çıkmış ve Amerika Adalet ve Güvenlik Komisyonuna (SEC)'a 500.000 dolar ceza ödemiştir (Ferrell vd., 2011). Fakat şirketin bunun karşısında, 1964'te kurduğu Monsanto Fonu aracılığıyla 2006'da Afrika tahıl araştırmaları merkezine 15 milyon dolar hibe etmesi, Brezilyadaki çocuklar için 'sağlıklı çocuklar sağlıklı gelecek’ programını yürütmesi ayrıca gençlik programlarını da destekleyerek 21. yüzyılın ilk on yılında öğrenimini akademik olarak tarımla ilgili alanlarda sürdürmek isteyen öğrencilere 1,5 milyon dolar bağışlamasına şiddetle karşı çıkılmaktadır. Bu durum piyasa baskısı gibi dışsal etkiler ile ortaya konulan ahlâkî performansın yerine, içsel gerçekleştirilecek ve erdemler olarak ortaya konulacak performansa ne denli ihtiyaç duyulduğunu göstermektedir. 


\section{Sonuç}

Küresel ekonomi ve büyüme baskısı, üretim ve pazar odaklı yaklaşımlar yöneliminde girişimcilik başarısının sadece ekonomik motifler çerçevesinde ve finansal göstergelerle değerlendirilmesine neden olmuştur. Ancak küresel ölçekte yaşanılan ahlâkî kayıplar, girişimci faaliyet ve başarısının sadece ekonomik motif ve finansal göstergelerle değil, ahlâkî motif ve değerler açısından da bir değerlendirmeden geçmesi gerekliliğini ortaya koymaktadır. Bu çalışma, ekonomik faaliyette iş başlatıcı-iş bitirici bir rol üstlenen girişimcilik faaliyetini bu açıdan değerlendirmeye çalışmıştır.

Çalışmada girişimcilerin, ahlâkî bir zeminde hareket sağlamaları iddiasıyla kendilerine sunulmuş farklı yaklaşımlardan sonuçsalcılık, deontolojik yaklaşım ve erdem ahlâkı yaklaşımlarını faaliyetlerinde esas almalarının sadece iş alanında değil, bir bütün olarak yaşamda yaratacağı etki üzerinde durularak, yeniden bir diriliş dönemi yaşayan erdem ahlâkına odaklanılmıştır. Yapılan teorik değerlendirme çerçevesinde girişimcilerin ekonomik büyüme ve gelişme adına kendilerine yön verici yaklaşım olarak ele aldıkları sonuçsalcı ve deontolojik yaklaşımların toplumların gelişimi ve iyiliği adına beklenilen etkiyi arzu edilen düzeyde sağlayamayacağının altı çizilerek, daha büyük bir etki potansiyeline sahip olan bir yaklaşım olarak 'erdem ahlâkı'na yer verilmiştir. Bu bakış doğrultusunda denilebilir ki, tüm toplumlar ve insanlık adına gerçek mutluluk ve başarı iyi yaşam', 'haz', ya da belirli durumlarda geçerli ‘ödev' ve 'yükümlülük' odaklı değil, doğru ve iyiyi 'yapmayı tercih etme', 'yapmaya karar verme’ biçiminde ifade edilebilecek karakter/erdem ile ilgilidir.

\section{Kaynakça}

- $\quad$ Akarsu, 2002. "Değişen Dünyada Bilim ve Değerler", Bilgi ve Değer Sempozyumu Bildiriler Kitabı, Vadi Yayınlar1, s. 15.

- $\quad$ Akyol, 2002. "Bilgiyi Satmak", Bilgi ve Değer Sempozyumu Bildiriler Kitabı, Vadi Yayınları, s. 166.

- Anderson and Cavanagh, 2000. Top 200: The Rise of Corporate Global Power, Institute for Policy Studies, http://www.rrojasdatabank.info/top200.pdf, Erişim Tarihi: 23.05.2016.

- Aristoteles, 2014. Nikomakhos'a Etik, Çev. S. Babür, Bilgesu Yayıncılık, Ankara.

- Arslan, 2001. İş ve Meslek Ahlâkı, Nobel Yayıncılık, Ankara.

- $\quad$ Aydın, 2001. Yönetsel Mesleki ve Örgütsel Etik, Pegem Yayınları, Ankara.

- Bayrak Kök, 2001. İş Ahlâkı ve Sosyal Sorumluluk, Beta Yayınları, İstanbul.

- $\quad$ Bayrak Kök, 2013. “İş Ahlâkı ve Etik Yaklaşımlar”, Işsletmelerde Sosyal Sorumluluk ve Etik, (e-kitap) (8/16002). http://www.nevoku.com/isletmelerde-sosyal-sorumluluk-ve-etik--e-kitap--isletmelerde-sosyalsorumluluk-ve-etik/viewdeck/c148a3d8-160e-45ad-a57a-90a1a34ec2bf http://de.slideshare.net/haticei/isl201-u-iletmelerde-sorumluluk, Erişim Tarihi: 06.06. 2016.

- Beauchamp, 1991. Philosophical Ethics: An Introduction to Moral Philosophy, McGraw-Hill, Inc., NY.

- Bertrand, 2001. Ahlâk Felsefesi, Çev. Salih Tekin, Akçağ Yayınları, Ankara.

- Blackburn and McGhee, 1997. Enterprise and Innovation, Print Sprint, Auckland, NZ

- Bowie, 2002. "Business Ethics and Normative Theories", in A Companion to Business Ethics, (Ed. ) Robert, Frederick Blackwell Publishing, London.

- $\quad$ Brush, Candida and Vanderwerf. 1992. "A Comparison of Methods and Sources for Obtaining Estimates of New Venture Performance". Journal of Business Venturing, 7, p. 157-170.

- Buchholz and Rosenthal, 1998. Business Ethics: The Pragmatic Path Beyond Principles to Process, Prentice Hall Inc.

- $\quad$ Carr, 2003. "Revisiting the Protestant Ethic and the Spirit of Capitalizm: Understanding the Relationship Between Ethics and Enterprise", Journal of Business Ethics, 47, p. 7-16.

- $\quad$ Caydi, 2011. "Dünya Ekonomisini/Siyasetini Yönlendiren A ̆g ve Sistemin Merkez Firmaları", Entelektüel Forum, http//entelektüel.s4.bizhat.com/entellktuel-post-5742.html. Erişim Tarihi: 22.05.2016.

- Cevizci, 2008. Etiğe Giriş, Paradigma Yayıncılık, İstanbul.

- Chandler, 1996. "Business Similarity as a Moderator of the Relationship Between Pre-Ownership Experience and Venture Performance", Entrepreneurship Theory\&Practice, 23, p. 5-29.

- Chrisman, Bauerschmidt and Hofer, 1998. "Determination of New Venture Performance: An Extended Model", Entrepreneurship Theory\&Practice, 23, p. 5-29.

- Cornwall and Naughton, 2003. "Who is the Good Entrepreneur? An Exploration within the Catholic Social Tradition", Journal of Business Ethics, 44, p. 61-75.

- Delius, 2007. “Etik”, Diemer ve diğ. (Ed.) Çev. Doğan, Günümüzde Felsefe Disiplinleri, İnkılâp Kitabevi, İstanbul. 
- $\quad$ Erdemli, 2002. "Yaşama Sorunu Bakımından Bilgi-Değer Bağlamı", Bilgi ve Değer Sempozyumu Bildiriler Kitabı, Vadi Yayınları, s. 233.

- $\quad$ Ess, 2012. Introducing Digital Medya Ethics, Polity Press, Cambridge.

- $\quad$ Fahadunsi ve Rosa, 2002. "Entrepreneurship and Illegality: Insight from the Nigerian Cross-Border Trade". Journal of Business Venturing, 17, p. 399.

- $\quad$ Ferrell and Fraedrich, 1994. Business Ethics, Houghton Miffin Company, Boston.

- $\quad$ Friedman, 1970. "The Social Responsibility of Business is to Increase Its Profits", The New York Times Magazine, 13, p. 173.

- Giacalone and Promislo, 2013. Handbook of Unethical Work Behavior: Implications for Individual Well-Being, Routledge, NewYork.

- Güçlü, Uzun, Uzun ve Yolsal, 2002. Felsefe Sözlüğü, Bilim ve Sanat Yayınları, Ankara.

- Hannafey, 2003, "Entrepreneurship and Ethics: A Literature Review", Journal of Business Ethics, 46, p. 99.

- Hobbes, 1992, Leviathan, Çev. Semih Lim, Yapı Kredi Yayınları, İstanbul.

- Hursthouse, 2001. On Virtue Ethics, Oxford Universty Press, Oxford.

- Hursthouse, 2013. "Normative Virtue Ethics", in Ethical Theory: An Anthology, (Ed. R. Shafer-Landau), Second Edition, John WileyandSons, Inc., UK.

- Kagan, 1992. “The Structure of Normative Ethics”, Philosophical Perspectives Ethics, 6, p. 223-242.

- Kılıç, 1993. Ahlâkı Temellendirme Problemi, Felsefe Kongresi Bildiriler Kitabı.

- Kuçuradi, 2004, "Felsefe ve Etik", Yunus Aran Birlikteliği Konferans Notlarl, http://www.aysuerden.org/yunusaran/pdf/etik_ionna.pdf, Erişim Tarihi: 04.05.2016.

- Levine, 1997. Financial Development and Economic Growth: Views and Agenda, Journal of Economic Literature, 35, p. 688.

- Lloyd, 2006. "What About Ethical Egoism", World Peace Herald Contributor, http://www.tparents.org//library//unification/Talks/Eby/Eby-060607.htm, Erişim Tarihi: 24.05.2016.

- MacIntyre, 2001a. Etiğin Kısa Tarihi: Homerik Çağdan Yirminci Yüzyıla, Çev. H. Hünler ve S. Z. Hünler, Paradigma Yayınları, İstanbul.

- $\quad$ MacIntyre, 2001b. Erdem Peşinde, Çev. M. Özcan, Ayrıntı Yayınları, İstanbul.

- McDonald, 2009. Firm's Image Restoration Stratejies: Cases Ethical Apologia in Corporate Crisis, Honor Thesis, Columbus State Universty.

- McNulty and Hoffman, 2014. "Is Business Bluffing Ethical? The History of Business Ethics", http//corporatecomplianceinsight.com/a-look-back-in-history-learning-the-lesson-of-business-ethics, Erişim Tarihi: 20.05.2016.

- Moore, 2004. “Hedonism”, Substantive Revision, 17, http://plato.stanford.edu/entries/hedonism/, Erişim Tarihi: 23.05.2016..

- $\quad$ Özlem, 2004. Etik: Ahlâk Felsefesi, İnkılâp Kitabevi, İstanbul.

- Sanchez, 2016. Criminal Capital: Violence, Corruptionand Class in Industrial India, Routledge.

- $\quad$ Shaw, 1991. Business Ethics, Wadsworth Publishing Company, California.

- Staveren, 2007. "Beyond Utilitarian is Mand Deontology: Ethics in Economics, Review of Political Economy, 19, p. 23.

- $\quad$ Tepe, 1992. Etik ve Metaetik, Türkiye Felsefe Kurumu, Ankara.

- $\quad$ Trevino and Nelson, 2010. Managing Business Ethics: Straight Talk about How to do It Right, John Wiley and Sons, Inc. New York.

- Wang, 2013. "From Virtue Ethics to Virtuous Corporation-putting Virtues into Business Practice", Journal of Media and Communication, 5, p. 133.

- Velasquez, 1998. Business Ethics: Concepts and Cases, 4th Ed., Prentice-Hall, New Jersey.

- Vitali, Glattfelder and Battiston, 2011. 'The Network of Global Corporate Kontrol', http//arxiv.org./pdf/1107.5728. Erişim Tarihi: 22.05.2016.

- Yılmaz, 2014. "Türk Devlet Felsefesinde "Kut", "Erdem” ve "Töre” Kavramları ile Bunların Aralarındaki İlişki, Kutadgubilig Felsefe-Bilim Araştırmaları Dergisi, Ekim, 26, s. 333.

- Zahra, Pati and Zhao, 2013. How Does Counter Productive Enterepreneurship Undermine Social Wealth Creation?, in Entrepreneurial Business and Society, (Ed.) Welter and et all., Edward Pub., USA. 


\title{
Postmodern Kültür Bağlamında Kuşaklararası Girişimcilik Olgusu ve Davranış Tutarsızlığı Üzerine Bir Araştırma
}

\section{A Study on Intergenerational Entrepreneurial Tendencies and Behavioral Inconsistency in the Context of Postmodern Culture}

\author{
Prof. Dr. Feyzullah Eroğlu (Pamukkale University, Turkey) \\ Ph.D. Candidate Mehtap Sarıkaya (Pamukkale University, Turkey) \\ Dr. Şeyma Gün Eroğlu (Pamukkale University, Turkey)
}

\begin{abstract}
The life-style differences among societies are highly related to the quality level of created culture. Developed Western civilizations has created a high-level culture depending on rational thinking and qualified knowledge. This high-level culture is the back-bone of Western civilizations; and entrepreneurial activities are one of the most effective social behavior style of this culture. The recent and paced cultural changes in societies which have not succeeded in development and modernization created an unqualified postmodern culture in these societies. The dominant behavior styles of postmodern culture are behavioral discrepancies and a common hypocrisy. Postmodern culture actually inhibits entrepreneurship behavior. In this context, Y-Generation, which is known as the after September 12 disturbance generation in Turkey, has great unconformity about entrepreneurship. YGeneration, while pretending to support entrepreneurship in expression and image, fail in action.
\end{abstract}

\section{Genel Kültür Sistemi ve Postmodern Kültür}

Kültür, insanların insanlar tarafından yaratılmış ve tesis edilmiş olan maddi ve manevi öğelerden meydana gelen, önceki kuşaklardan bir tür yaşam biçimi olarak devralınarak, belirli değişimlere maruz kaldıktan sonra da, daha sonraki kuşaklara aktarılan bir sosyal mirastır ( Bilgiseven, 1992). Böylece kültür, her toplumun ortaklaşa ortaya koymuş oldukları her nitelikteki bilgi ve düşüncenin, birer eşya, ilke, kural, yasa, değer ve simgeler biçiminde tasarlanarak toplumsal yaşama katılmış olan çeşitli öğelerden meydana gelmektedir. Her toplumun, bilgi ve düşünce yaratma kapasitesine ve birikimine göre, yaratılmış olan her türlü eşya ve aygıtlar her derecede ilke ve kurallar (sözgelimi, bilimsel teori ve yaklaşımlar ile çeşitli yasalar v.b.g.), her nitelikte değer ve değer yargıları dahil edilebilir (Vernon, 1965).

Her toplumun genel kültür sisteminin içindeki kültür oluşumlarını, özgünlük ve yetkinlik bakımından üç kategoriye ayırmak mümkündür. Bunlar, yukarıdan aşağıya doğru bir kültür piramidi şeklinde sıralandığı vakit, en üstte yüksek kültür, ortada halk kültürü, alt kademede ise popüler kültür öğeleri yer almaktadır (Batmaz, 1981). Yüksek kültür kapsamında yer alan öğeler arasında, bilimsel zihniyet ve yöntemlerle elde edilmiş bilimsel bilgiler, felsefe bilgisi, sanat bilgisi, entelektüel düşünce ve etik değerler gibi nitelikli ve yaratıcı yönleri olan kültür öğeleri sayılabilir. Sözgelimi, bilimsel ve entelektüel düşünceye dayalı bilgilerin kullanımıyla yöneticilerin sorun çözme kapasitelerini artırıcı, yönetilenlerin ise üretkenlik ve verimliliklerini yükseltmeye yönelik girişimcilik faaliyetleri gibi yaklaşımlar ortaya konabilir. Halk kültürü içerisinde ise genel kültürün önceki nesiller tarafından yaratılıp sonraki nesillere sosyal miras yoluyla devrettiği, yaşanılan hayatta da halihazırda işlevi olan, özellikle orta sınıf halk tarafindan paylaşılan geleneksel kültür öğeleri sayılabilir. Bu öğelerden bazıları, halk müziği ve oyunları, geleneksel yemekler ve kıyafetler, bayram-nişan-dügün-doğum-ölüm gibi sosyal olaylardaki geleneksel tutum ve davranışlardır. Popüler kültür kapsamına ise nitelikli bilgilere dayanmamasından dolayı modern olma niteliği bulunmayan, ama geleneksel olma değeri de olmayan, özgünlük ve yetkinlik açısından son derece zayıf kültür öğeleri girmektedir. Mesela, boş "vakit geçirmeye" yarayan magazinsel bilgi ve eğlence öğeleri popüler kültür kapsamındadır (Eroğlu ve Eroğlu, 2014).

Her çağdaş toplumun genel kültür sisteminde, bu üç kültür çeşidi, genel olarak birlikte yer alırlar. Ancak, her kültür sistemindeki bu üç kültür çeşidi birleşiminin oranları birbirinden farklı olmaktadır. Buna göre, bu üç kültür çeşidinden, yüksek kültürün en etkili, halk yani geleneksel kültürün onu takip ettiği ve bir şekilde var olan popüler veya postmodern kültürün en az oranda bulunduğu genel kültür sistemi, en uygun ve ideal kültür birleşimi sayılır. Modernitenin doğduğu ve giderek gelişmiş olduğu gelişmiş Batı toplumlarında, nitelikli bilgilerin yoğun kullanımıyla birlikte, toplumsal süreçlerin gelişimine katkıda bulunabilecek bir yüksek kültür birikimi söz konusudur. Buna karşılık, modernist çabaların bir türlü başarıya ulaşamadığı ve önceki geleneksel kültür biçimlerinin de büyük ölçüde çözülmeye uğradığı az gelişmiş toplumların genel kültür sistemlerinde, en yüksek oranda popüler kültürün, belirli ölçülerde halk kültürünün, en az oranda da yüksek kültürü temsil eden kültürel öğeler mevcuttur. Gelişmiş Batı toplumlarının dişında kalan ve modernleşme konusunda başarısız olan çoğu toplumların genel kültür sistemleri kapsamındaki kültür birleşiminde, "modernleşme" ile "gelenekselliğin" çarpışmasının sonucunda ortaya çıkan "melez” veya "popüler kültürün”, bireysel ve toplumsal davranışların özünü teşkil eden "tutarlılık" konusunda büyük bir çözülmeye ve parçalanmaya yol açtığı görülmektedir. Popüler 
kültürler, rasyonel düşünceye ve yüksek düzeyli bilimsel verilere dayalı modernlik kültürü ile Batı dışı toplumlardaki gelenekçi kültürler arasında sıkışıp kalan ve nitelikli bilgiler bağlamında herhangi bir kökeni olmayan yaşam biçimleri olarak postmodern kültür adıyla da tanınmaktadır.

Modernleşmeyi başarmış ve tamamlamış toplumlar, rasyonel düşünme ve isabetli akıl yürütme kapasitelerini kullanmak suretiyle, başta bilimsel bilgi olmak üzere, felsefe, hukuk, sanat bilgileri gibi “nitelikli bilgiler" üretirler ve bu bilgi malzemeleri ile doğaya ve hayata katma değeri yüksek kültür öğeleri katarlar. Özgünlük ve yetkinlik düzeyi yüksek olan "nitelikli bilgiler" aracılığıyla gerçekleştirilecek kültür öğeleri arasında, "girişimcilik" etkinliklerini de saymak gerekir. Yüksek bir kültürün eseri olan girişimcilik olgusu, yeni bir mal ve hizmet üretmek maksadıyla başta liyakat ve ehliyete sahip insan kaynağı olmak üzere, diğer bütün üretim faktörlerinin, uygun şartlarda ve uygun bir bileşimde bir araya getirme, oluşturma, sevk ve idare edilmesi becerisini gösterme sürecidir. Girişimcilik niteliği bulunan bir kişinin, geleceği isabetli bir şekilde öngörmeye dair güçlü bir bilgi ve sezgi sahibi olması yanında, aynı zamanda yüksek düzeyde cesaret ve risk alma duygusu ile donanmış olması zorunludur.

Modernleşme çabalarında başarısız olmuş, ancak geleneksel kültür sisteminin çözülmesiyle birlikte, "iki arada bir derede kalmış” olan milli kültür sistemlerinin çoğunluğunda yaşandığ1 gibi Türkiye'de de büyük ölçüde köy ve kır kökenli "yeni kentli” kitle toplulukları arasında, melez veya postmodern kültür hızla yayılmıştır. Hızlı ve kapsamlı kültür değişmelerinin varlığı karşısında, geleneksel davranış kalıplarının yetersiz kalması, buna karşılık yeni hayat tarzına gereken uyumu davranışsal olarak göstermeye yarayacak olan modernleşme süreçlerinin ve tavırlarının geliştirilememesi, bir yığın insanın olaylar karşısındaki reaksiyonlarını kalabalıkların güdümüne bırakmalarına yol açmaktadır. Postmodern kültür insanları, konumları ve durumları ne olursa olsun, sıradan, akli denetimden yoksun, kararsız, kişisel sorumluluk ve inisiyatiften uzak, şimdiki zamanı yaşamayı geleceğin önemli beklentilerinden daha önemli görmektedirler. Kendi akıl ve değer yargılarının yönetiminde özgür ve özgün hareket tarzlarıyla yaşamak yerine, ilkesizlik ve kuralsılık içerisinde savrularak çeşitli tutarsızlıklar ve ikiyüzlülük sarmalı içinde kendilerini yığınların akışına ve güçlü egemenlerin yönlendirmelerine bırakmaktadırlar (Eroğlu, 2013; Türkdoğan, 1988). Postmodern kültür, modernleşme sürecinin temel paradigması olan "rasyonel" bireye de uymayan, geleneksel kültürlerin "kanaatkâr" insan tipine de uymayan bir "postmodern insan tipi" ortaya çıkarmıştır. Bu postmodern insan tipinin iş ve çalışma yaşamına dair egemen algılama ve tutumları, kaynağı ne olursa olsun sürekli "tüketmek", "şimdi yaşamaya bakıp, bedelini sonra ödemek" ile " kısa bir süreliğine herkes zirveye çıkabilir" ve "hayatta her şeyin çalışma olmadığı" şeklindeki düşünce yanılsamalarından meydana gelmektedir. Yine, "postmodern insan tipi” kişiler, post-endüstriyel dönüşümler sonrasında alevlenen çeşitli yolsuzluklar özellikle finans alanındaki bir takım spekülatörlerce çalışmaksızın kolay gelir ve servet edinme yollarının çoğalması sonucunda, herhangi bir kayda değer çalışma göstermeden, sanki çok sıkı ve iyi çalışma şartlarını yerine getirmiş gibi, çok büyük kazançlar elde edilebileceği duygusuna kapılmaktadırlar ( Bozkurt, 2014). Başka bir bakış açısıyla "postmodern kişilik", "hem o, hem de o" ve "her şey mubahtır" şeklinde bir davranış örüntüsüdür (Bayhan, 2002).

\section{Kuşaklar Arasındaki Farklııklar ve Girişimcilik Davranışları}

Son yıllarda, yönetim ve organizasyon süreçlerine dair çalışmalarda çok sık rastlanan konulardan biri de, "kuşak olgusunun” iş ve işletme hayatı ilgili alanlardaki davranışsal yansımalarını izlemek ve açıklamaktır. Türkçe’nin iki büyük sözlüklerinden biri olan Misalli Büyük Türkçe Sözlük’te, Arapça kökenli “nesil” olarak yer alan "kuşak", ilk olarak “aynı yıllarda yaşamış olan, yaklaşık aynı yaşta bulunan kişilerin bütünü”; ikinci olarak da "bir kimsenin zürriyeti, evlat ve torunları, soy, sülâle, döl” şeklinde tanımlanmaktadır (Ayverdi, 2006,2332-2333). Türk Dil Kurumu'nun Türkçe Sözlüğünde ise doğrudan "kuşak” olarak yer alan kavram, sosyolojik olarak "yaklaşık olarak yirmi beş, otuz yıllık yaş kümelerini oluşturan bireyler öbeği, göbek, nesil, batın”; felsefî olarak "yaklaşık olarak aynı yıllarda doğmuş, aynı çağın şartlarını, dolayısıyla birbirine benzer sıkıntıları, kaderleri paylaşmış, benzer ödevlerle yükümlü olmuş kişilerin topluluğu,...” şeklinde açıklanmaktadır.

Kuşaklar arası ilk gruplamanın, Alman sosyolog Karl Manheim 'in 1950’lerde yapmış olduğu çalışmaya dayandığı anlaşılmaktadır ( Arsenault, 2004). Kuşaklar olgusu, İngiliz-Amerikan kültür ve bilgi sisteminde kabul gören şekliyle ise ilk olarak William Strauss ve Neil Howe (1991) "Generations: The History of America's Future, 1584 to 2069” adlı kitabında yönetim ve organizasyon alanındaki çalışmalara dahil edilmeye başlanmıştır. Bu çalışmaya göre, kuşaklar dünyaya geldikleri yıllara göre sınıflandırılmış ve her kuşağa karakteristik özellikler atfedilmiştir. Strauss ve Howe' a göre, her kuşağa mensup bireylerin, kişiliklerinin nasıl şekillendiğiyle ilgili hikayeleri ve kendilerine özgü biyografileri vardır (Tsui, 2001). İngiliz-Amerikan kültür sistemindeki kuşaklara dair veriler, bulgular ve olgulardan elde edilen çıkarımlar doğrultusunda, yönetim ve organizasyon literatürüne geçmiş olan ve birbirini takip eden beş kuşak söz konusudur (Atak, 2016, 14-40; Ayhün, 2013): Sessiz Kuşak (1925- 1945), Bebek Patlaması Kuşağı (1946- 1964), X Kuşağı (1965-1979), Y Kuşağı (1980-1999), Z Kuşağ1 (2000 yılı ve sonrası doğanlar).

Bu çalışmada, kuşaklar arası "girişimcilik” olgusunu ve davranışlarını araştırmayı hedeflenmiş olmasıı nedeniyle içinde bulunduğumuz zaman aralığında şu anda iş ve çalışma hayatında fiilen yer alan kuşaklar üzerinden konunun açıklanması düşünülmüştür. Belirli kişi ya da kişilerin inisiyatifi ile başlayıp, birden fazla insanın ve diğer üretim 
faktörlerinin bir araya getirilmesi ile yeni bir mal ve hizmet üretmek üzere "örgütlenme" eylemine girişmeye ve eldeki diğer imkânları faaliyete geçirme işlemlerinin tümüne birden "girişimcilik" denilmektedir. Her çağın ve dönemin kendi imkan ve şartları içerisinde ortaya konulan "girişimcilik" faaliyetleri, o çağ ve dönemin "girişken”, "yaratıcı", "bağımsız", "güçlü ikna yeteneği”, “yüksek başarı arzusu” ve "belirsizlikler karşısında dayanıklı” olma biçimindeki "girişimcilik niteliklerine" sahip insanlar tarafından gerçekleştirilmektedir (Kök, 2007). Her çağ ve dönemde girişimcilik niteliklerine sahip olan insan tipinin, rasyonel ve modern düşünceye sahip toplumlarda nispeten bireysel nitelikler şeklinde ortaya çıkmasına karşılık, bu nitelikteki bireylere yeterince sahip olamayan toplumlarda ise "girişimcilik" olgusu, içinde yaşanılan kültürel iklimle daha fazla ilişkili bir etkinlik olarak dikkat çekmektedir. Her dönemin ve kuşağın, temel algı ve davranış kalıpları arasında, "girişimcilik niteliklerinin" hangi derecelerde yer alıyor olması, o kuşağın "girişimcilik" vasfina sahip insan tipi yetiştirmesinin ana göstergelerinden biridir. Buna göre, mevcut literatüre girmiş bulunan kuşaklardan, Bebek Patlaması Kuşağı (1946- 1964), X Kuşağ (1965-1979) ile Y Kuşağı (1980-1999) kapsamındaki bilgi ve bulgular incelenmeye çalışılacaktır. Bu bağlamda, ilgili kuşaklara dair İngiliz-Amerikan kültür sistemindeki bilgi ve bulgulara göre, Bebek Patlaması Kuşağının iş ve çalışma hayatı bakımından en dikkat çeken yönü, çalışmayı ve bir şeyler üretmeyi, aile ve diğer iş dışı yaşam alanlarından deha değerli bulmalarıdır. Yani, bunlar "çalışmak için yaşayan kuşaklar” olarak dikkat çekmektedirler. $\mathrm{X}$ Kuşağının, iş ve çalışma hayatına dair algı ve tutumları ise "iş-yaşam dengesi”" bağlamında "yaşamak için çalışmak" şeklinde özetlenebilir. Y Kuşağı ile ilgili yapılan çeşitli araştırma bulgularına göre, en belirgin özellikleri, "teknoloji yatkınlığı ve düşkünlügü̈", "teknik becerilerine rağmen soyut düşüncelerde zayıf olmaları", "özgürlüklerine düşkün olmaktan dolayı girişimci olma isteklerinin yüksekliği gibi özelliklere sahip olmalarıdır. Ayrıca, bu kuşak ile ilgili ortaya çıkan başka dikkat çekici bir kişilik özelliği olarak, aşırı özgüvenden kaynaklandığı zannedilen "narsisistik" özellikler taşımalarıdır ( Özer vd, 2013). Kuşaklar arasındaki iş ve çalışma hayatına dair ilişkileri araştıran çeşitli araştırmalara bakılacak olursa, küreselleşme ve özellikle bilişim teknolojilerindeki gelişmenin ve kullanımının yaygınlığından dolayı kültürden bağımsız bir "küresel kuşak" varsayımından söz edildiği görülmektedir. Ancak, ilgili literatür incelendiği vakit, iş ve çalışma hayatındaki mevcut kuşaklar olgusunun, "Batı kaynaklı" bir etkiyle kuşak özelliklerinin bütün kültür sistemlerinde aynı olduğu varsayımıyla ele alınmış olduğu eleştirisi yapılabilir (Özer vd, 2013).

İngiliz-Amerikan kültür sistemindeki kuşakların yetişmesinde, rasyonelliği ve bireyselliği ön plana çıkaran modernist tavırlardan dolayı çoğunlukla bireysel tercihler ve tavırlar baskındır. Buna karşılık, modernleşme çabalarına rağmen, toplumu meydana getiren kişilerin yeterince rasyonel ve bireysel tercihlere dayalı bir davranış biçimine geçememiş olduğu, kişilerin hayatlarında hâlâ sıkı sıkıya bağlı oldukları "küçük toplulukların" etkili olmayı sürdürdüğü toplumlarda ise kişilerin davranışlarının şekillenmesinde, içinde yer aldıkları kuşağın alt kültür alanlarının payı daha fazladır. Strauss ve Howe'ın isabetle belirtmiş olduğu gibi, İngiliz-Amerikan kültür sistemindeki kuşakların yetişmesinde, “ her kuşağa mensup bireylerin, kişiliklerinin nasıl şekillendiğiyle ilgili hikayeleri ve kendilerine özgü biyografileri”, onların nasıl bir kişilik geliştirecekleri konusunda çok belirleyici olmaktadır. Oysa, yeterince rasyonelleşme ve bireyselleşme aşamasına gelememiş (yani modernleşememiş) gelenekçi toplumlar ile özellikle "postmodern kültür" taşıyıcısı topluluklara mensup kişilerin her türlü davranışlarının arka planında, büyük ölçüde "kendilerinin bireysel biyografilerden" çok, aidiyet duydukları "postmodern kültürün” egemen davranış kalıpları daha baskın bir rol oynar.

Türkiye'de bu çalışmaya esas alınan üç kuşaktan ilk ikisiyle ilgili dönemlere dair "kültür-davranış" ilişkilerini yoklayan yaygın bilimsel çalışmalar bulunmamaktadır. Ancak, üçüncü dönemi temsil eden Y Kuşağı (1980-1999) ile ilgili çeşitli kapsamda çalışmalar mevcuttur. Söz gelimi, “Gençlik Ve Postmodern Kimlik Örüntüleri Üniversite Gençliğinin Sosyolojik Profili (İnönü Üniversitesi Uygulaması) "adlı çalışmada, hem geleneksel hem de modern kültürü bir arada yaşama karmaşası içinde bulunan ve bu yüzden de postmodern bir kültüre göre çoğul kimlik örüntüsü taşıyan bir gençlik realitesi oluştuğu ortaya konmaktadır. Bu çalışmada sunulan veriler, İnönü Üniversitesinde 2001 yılından 2013 yılına kadar 12 yıldır yapılan "Üniversite Gençliğinin Sosyolojik Profili" araştırmasına dayanmaktadır. Çalışma kapsamında, on iki yıllık süre içerisinde 48315 öğrenciye birikimsel olarak anket uygulanmıştır. Elbette, bu araştırma bulguları, bütün üniversite gençlerine genelleştirilemez. Fakat Türkiye'nin bütün bölgelerinden gelen gençlerin her biri, içinde yaşanılan dönemin kültürünü temsil ettiği de bir gerçektir. Ayrıca, bu araştırma sonuçları diğer yapılan kamuoyu araştırmaları ile benzerlikler taşımaktadır (Bayhan, 2013).

Türkiye gibi modernleşmesi yarım kalmış toplumsal bir dokuda, geleneksel davranış bütünlüğünün de çözülmüş olması sonucunda, rasyonelliğin ve bireyselliğin yeterince tamamlanamamış olması, yaygın bir postmodern kültür tortusu ortaya çıkarmıştır. Bu bağlamda, Türkiye gibi ülkelerdeki kuşaklar arası egemen davranış özelliklerinin araştırılmasıyla ilgili çalışmalarda, mevcut kuşakların iş ve çalışma hayatına dair olan algı ve tutumlarının oluşumunda, "küresel kuşak" davranış kalıplarından çok, ilgili kuşakların içinde yaşadıkları egemen "kuşak kültürleri” daha etkili rol oynamış olacağı varsayımıyla hareket etmek gerekir. Bu çerçevede, bu çalışmada esas alınacak olan üç kuşaktan birincisi, Bebek Patlaması Kuşağı (1946- 1964) kapsamındaki dönemde, siyaseten çok partili döneme geçiş ve köyden kente göçün başlaması gibi geleneksel toplum yapısından çıkma yönünde kültür değişmeleri yaşanmıştır. Bu dönemin, girişimcilik konusunda dikkat çeken en önemli yönü, devlet kadrolarının büyük kentler civarındaki kamu girişimciliği olgusuna ilave olarak, Anadolu'nun farklı bölgelerindeki kentlerinde 
de özel girişimcilik alanında bir takım gelişmelerin gösterilmiş olmasıdır.. X Kuşağı (1965-1979) kapsamındaki dönemde, 1960 Anayasa'sının getirdiği düşünce ve ifade özgürlüğü ortamına bağlı olarak düşünce akımlarında ve ideolojik hareketlerde belirli bir kıpırdamanın olması, toplum kalkınması bağlamında çok farklı sektörlerde ve Anadolu'nun birçok bölgesinde bir "sanayileşme" olgusu yaşanması, toplumda gelir düzeyinin artışına bağlı olarak daha iyi şartlarda yaşama istek ve arzusunun yaygınlaşması, 1974 Kıbrıs Zaferinin toplumda belirgin bir başarı duygusu yaratması gibi olayların yarattığı etki sonucunda, toplumun değişik kesimlerinde "girişimcilik" davranışlarında bir artış gözlenmiştir. Aslına bakılırsa, bu iki kuşak dönemindeki genel kültür dokusu, "modernleşmenin” ve“ gelenekselliğin” birbiriyle çelişmelerine karşılık, toplumsal yapıda büyük bir çözülme ve melezleşmenin henüz ortaya çıkmadığı zamanlardır. Y Kuşağı (1980-1999), 12 Eylül 1980 İhtilali sonrasının toplumsal travmasının içinde dünyaya gözünü açmış bulunan bir kuşaktır. Bu kuşak, 1980'li yılların emperyalist bir proje olan etnik bölücü ve ayrılıkçı terör örgütünün, aslında önlenebilir olmasına rağmen "yönetici yetersizliği" ve Türkiye'nin Nato üyeliği yüzünden önlenememesi sonucunda, toplum psikolojisi üzerinde yerleşmiş yenilmişlik duygusuyla büyümüş bir kuşaktır. Ayrıca, Y Kuşağı (1980-1999), bu iki önemli travmatik durumla birlikte, uzun yıllardır içten içe sürmekte olan "modernleşmenin" ve“ gelenekselliğin" birbiriyle çatışmasından kaynaklanan postmodern kültürün, başta çocuklar ve gençler olmak üzere, hemen bütün toplum kesimlerinde yaygın bir yaşam biçimi olduğu bir dönemi temsil etmektedir. Bütün bunların üzerine, son derece sanal, geçici, köksüz, tutarsız, kararsız, ufuksuz, çaresiz ve keyif tutkunu insan davranışlarıyla tanınan postmodern kültürün yaygınlaşması, Y Kuşağı'nın girişimcilik tavırları ve niteliklere yönelme potansiyellerine büyük bir ket vurmuştur. Bu kuşağın, postmodern kültürün etkisiyle sıkı çalışmadan zengin olma, şöhret olma, üst düzey yönetici olma eklindeki istek ve arzuları oldukça yüksek bir eğilime sahiptir. Ancak, Y Kuşağı'nın, yine postmodern kültürün etkisiyle kendilerinden beklenen "girişimcilik" gibi son derece önemli ve statüsü yüksek konumlara dair olumlu görüntü ve söylem oluşturmalarına karşılık, bu doğrultuda fiili bir takım etkinlik geliştirme davranışları ise oldukça sınırlı kalmaktadır. Bu durum, postmodern kültürün en açık göstergelerinden biri olarak, "davranışlarda tutarsızlık" ve "kararsızlık" davranış özellikleriyle örtüşen bir davranış örüntüsüdür.

\section{Araştırma}

\subsection{Araştırmanın Amacı ve Yöntemi}

Bu çalışma, modernleşme çabalarında başarılı olamayan, ancak geleneksel yapılarını da muhafaza edemeyen geçiş toplumlarındaki, kendilerine özgü davranışsal tutarsızlıklar çerçevesinde "postmodern kültür" ile son yıllarda yönetim ve organizasyon alanında önemli bir araştırma konusu olan "kuşaklar arasındaki ilişkileri”, önce kavramsal sonra da pratik anlamda açıklamayı hedeflemiştir. Çalışmanın araştırma kısmında iki farklı veri toplama yöntemi kullanılmıştır. Birinci aşamada verilerin toplanması için birincil veri toplama yöntemi olarak anket uygulanmıştır. Y Kuşağının “girişimcilik eğilimleri”ni ölçmek amacıyla Pamukkale Üniversitesi ve Muğla Sitkı Koçman Üniversitesi İktisadi ve İdari Bilimler Fakültesi İşletme Bölümündeki son sınıf öğrencilerine anket uygulanmıştır. Toplamda 850 anket dağıtılmış, 209 anket geri dönmüş ancak çeşitli nedenlerden dolayı 201 tanesi değerlendirmeye uygun bulunmuştur. Geri dönüş oranı \%24,6 olarak gerçekleşmiştir. Araştırmada kullanılan veri toplama ölçeği olarak girişimcilik eğilimi ölçmek için İşcan ve Kaygın (2011)'ın “Üniversite Öğrencilerinin Girişimcilik Eğilimlerini Belirlemeye Yönelik Bir Araştırma" isimli çalışmalarında, çeşitli araştırmalardan derleyerek oluşturdukları ve geçerlilik ile güvenilirliğini yaptıkları 28 ifadeli ölçek kullanılmıştır. Ölçek kendine güven, yenilik, başarma ihtiyacı, kontrol odağı, risk almak ve belirsizliğe karşı tolerans olmak üzere toplam 6 boyuttan oluşmaktadır. Boyutların kısa açıklaması aşağıdaki gibidir (İşcan ve Kaygın, 2011).

Kendine Güven: Kendine güven, bireylerin amaçlarını gerçekleştirmeleri konusunda başarılı olarak gerçekleştirmeyle ilgili yetenekli olduklarıyla ilgili inançlarıdır (Dam vd, 2003).

Yenilik: Yenilik, yeni ürünler, hizmetler, ya da çalışma uygulamaları yaratmada firsatları tanımlamak ve firsatları uygulamak olarak ifade edilir (Koh, 1996).

Başarma İhtiyacı: McCleland'ın başarma ihtiyacı teorisinde, girişimcilik davranışını etkileyen bir faktör olarak ileri sürülen başarma ihtiyacı, yüksek düzeyde performans gösterme ya da rekabet ortamında ön plana çıkma isteği olarak tanımlanmaktadır (Lee, 2001).

Kontrol Odağı: Bireylerin, olayların sonuçlarını kendi kontrol ya da anlayışlarının ötesinde ya da kendi kontrol ya da anlayışlarının içerisinde olduğuyla ilgili algılamalarıdır. İç kontrol ve dış kontrol odağı olarak ikiye ayrılır. Girişimcilik ile doğru orantılı olan iç kontrol odaklı olmadır. İç kontrol odağına sahip bireyler, kendi hayatlarındaki olaylarda kendilerinin güç sahibi olduğuna inanırlar (Lee, 2001).

Risk Alma Eğilimi: Girişimcinin en karakteristik özelliği olarak tanımlanan risk alma eğilimi, kişinin riskli bir durumla yüzleştiğinde riski göze alma yönündeki davranış gösterme eğilimi olarak tanımlanabilir.

Belirsizliğe Karşı Tolerans: Belirsiz bir durum ile karşılaşıldığında, bireyin elinde yeterince veri olmadığı halde, bu duruma olumlu tepki verebilme yeteneğidir (Teoh ve Foo, 1997).

Kullanılan ölçeğin iç tutarlılığını ölçmek amacıyla yapılan güvenilirlik analizi sonuçları Tablo 1'de verilmiştir. Sonuçlar incelendiğinde tüm boyutların alfa değerlerinin 0,7'nin üzerinde olması nedeniyle, ölçeğin güvenilir ve analiz için uygun olduğu görülmektedir. 


\begin{tabular}{|l|c|c|}
\hline Boyutlar & İfade Sayısı & Cronbach's Alfa \\
\hline Kendine Güven & 4 &, 804 \\
\hline Yenilik & 6 &, 769 \\
\hline Başarma İhtiyacı & 5 &, 705 \\
\hline Kontrol Odağ1 & 6 &, 753 \\
\hline Risk Almak & 5 &, 738 \\
\hline Belirsizliğe Karşı Tolerans & 2 &, 788 \\
\hline
\end{tabular}

Tablo 1: Güvenilirlik Analizi Sonuçlart

Verilerin değerlendirilmesi aşamasında tanımlayıcı istatistik yöntemleri olarak sayı, yüzde, ortalama ve standart sapma kullanılmıştır. Öğrenciler arasında anlamlı farklılıklar olup olmadığını test etmek amacıyla bağımsız örneklem $\mathrm{t}$ testleri ve tek yönlü varyans analizi uygulanmıştır.

Araştırmanın ikinci aşamasında ikincil veri analizi yöntemi kullanılmıştır. Bu kapsamda 2000 ila 2016 yılları arasında girişimde bulunan ve Denizli Ticaret Odası ile Muğla Ticaret Odasına kayıt yaptıran girişimcileri sayısal açıdan Kuşaklar teorisi çerçevesinde gösterdikleri dağılım analiz edilmeye çalışılmıştır. Bu kapsamda hem Denizli Ticaret Odası'ndan hem de Muğla Ticaret Odası'ndan veri isteğinde bulunulmuştur. Denizli Ticaret Odası'ndan istenilen verilere ulaşıldığı halde Muğla Ticaret Odası'ndan istenilen veriler elde edilememiştir. Bu nedenle mevcut girişimcilik dağılımları sadece Denizli Ticaret Odası'nın verilerine göre yapılmıştır.

\subsection{Anket Sonuçlarının Değerlendirilmesi}

İş ve çalışma hayatında fiilen yer alan kuşaklar üzerinden yürütülen bu araştırmada, üç kuşak arasında sadece Y Kuşağının, anket yöntemiyle "girişimcilik eğilimleri” ölçülmeye çalışılmıştır. İş ve çalışma hayatında fiilen yer alan kuşaklardan ilk iki grubun, iş ve çalışma hayatına girmeden önceki dönemlerde yani gençlik çağlarında daha önceden "girişimcilik eğilimleri” ile ilgili anlamlı bir çalışma bulunmamaktadır. Buna karşılık, Y Kuşağının bir kesimi fiilen iş ve çalışma hayatında bulunurken, daha sonraki kesimi ise daha iş ve çalışma hayatına geçiş çağında bulunmaktadırlar. Bu nedenle, Y Kuşağının, henüz işin başında olan genç kesimi üzerinde "girişimcilik eğilimleri" ile anket uygulaması gereği ortaya çıkmıştır.

Araştırmanın örneğini oluşturan Pamukkale Üniversitesi ile Muğla S1tkı Koçman Üniversitesi son sınıf öğrencileri üzerinde yapılan ve öğrencilerin "girişimcilik eğilimlerini”” ölçmeye yarayan anket bulgularına göre, Y Kuşağının üniversiteli gençlerinde söylem olarak belirli bir "girişimcilik eğiliminin” olduğu görülmektedir. Ankette yer alan "girişimcilik eğilimleri” ile ilgili boyutlarda ortalamanın üzerinde bir "girişimcilik eğilimi”" gözlenmektedir. Tablo 2' de görüldüğü gibi, aritmetik ortalama ve standart sapmalar incelendiğinde, öğrencilerin kendine güvendikleri $(X=3,79)$, yenilik eğilimine sahip oldukları, $(X=3,69)$, başarma ihtiyaçlarının olduğu $(X$ $=3,70)$, kontrol odağına sahip oldukları $(X=3,85)$ ve risk alma eğilimlerinin olduğunu $(X=3,66)$ ancak ölçeğin son boyutu olan belirsizliğe karşı toleranslarının pek olmadığı $(X=2,11)$ görülmektedir.

Bu araştırmada, Tablo 2' de görüldüğü gibi, toplam altı "girişimcilik boyutundan” beş tanesi birbirine yakın olacak şekilde bir "girişimcilik tutumunun" varlığına, en azından söylem düzeyinde işaret edilirken, sonuncusu olan "Belirsizliğe Karşı Tolerans" boyutunda, diğer boyutlardan dikkat çekecek ölçüde bir düşük eğilim ortaya çıkmıştır. Gerçekte, araştırmaya katılan Y Kuşağı gençliğinin, ilk beş boyut açısından birbiriyle tutarlı değerler ortaya koyarken, altıncı boyutta benzer eğilimi ve tutarlılığı gösterememiş olması, çalışmanın teorik çerçevesinde iddia edildiği gibi, postmodern kültür taşıyıcılığından kaynaklanan bir “davranış tutarsızlığıdır”. Çünkü girişimcilik tutumu, girişimcilik faaliyetleriyle ilgili "duygu”, "düşünce” ve "davranış" öğelerinin, birbiriyle son derece tutarlılık gösteren "bütüncüll" tavırdır. Ayrıca, ilk beş boyut, girişimcilik tutumunun, duygu ve düşünce öğeleriyle yakından ilintili olurken, altıncısı olan "Belirsizliğe Karşı Tolerans” boyutu doğrudan "davranış" öğesiyle ilişkilidir. Bu bağlamda, araştırmaya katılan Y Kuşağı gençliğinin girişimcilik faaliyetleriyle ilgili tutumlarında, "duygu” ve "düşünce" öğeleri bakımından belirli bir tutarlılık olmakla birlikte, "davranış" öğesi konusunda bir çelişki ve tutarsızlığa sahip oldukları anlaşılmaktadır.

\begin{tabular}{|l|c|c|c|}
\hline Boyut & Sayı (N) & Ortalama & $\begin{array}{c}\text { Standart Sapma } \\
\text { (S.S.) }\end{array}$ \\
\hline Kendine Güven & 201 & 3,79 & 0,717 \\
\hline Yenilik & 201 & 3,69 & 0,642 \\
\hline Başarma İhtiyacı & 201 & 3,70 & 1,021 \\
\hline Kontrol Odă̆ı & 201 & 3,85 & 0,653 \\
\hline Risk Almak & 201 & 3,56 & 0,729 \\
\hline Belirsizliğe Karşı Tolerans & 201 & 2,11 & 1,006 \\
\hline
\end{tabular}

Tablo 2: Boyutların Ortalama ve Standart Sapma Sonuçları

Tablo 3'de, araştırmaya katılan iki ayrı üniversite öğrencilerinin girişimcilik eğilimi boyutlarının, üniversitelere göre farklılık gösterip göstermediği incelenmiştir. Üniversiteler açısından, ölçeğin boyutlarının farklılaşıp 
farklılaşmadığını test etmek amacıyla yapılan varyans analizine göre, hiçbir boyutun Pamukkale Üniversitesi ya da Muğla Sıtkı Koçman Üniversitesi’nde öğrenci olmak ile farklılaşmadığı görülmüştür. Bu durum, her iki üniversite öğrencilerinin, araştırmanın temasını oluşturan girişimcilik tutumları konusunda benzer kültürel tutarsızlığı ve çelişkiyi yaşadıklarını göstermektedir. Ayrıca, bu davranışsal tutarsızlık, her iki üniversite öğrencilerinin, teorik çerçevede ve örneklemin seçiminde öngörüldüğü gibi, postmodern kültür çelişkilerinin bir sonucu olmalidir.

\begin{tabular}{|l|c|c|c|c|c|c|}
\hline \multirow{2}{*}{ Boyut } & \multicolumn{2}{|c|}{ Pamukkale (n=110) } & \multicolumn{2}{c|}{ Muğla (n=91) } & t & P \\
\cline { 2 - 7 } & $\overline{\mathbf{x}}$ & Std. Sap. & $\overline{\mathbf{x}}$ & Std. Sap. & & \\
\hline Kendine Güven & 3,71 & 0,701 & 3,88 & 0,729 &, 327 &, 744 \\
\hline Yenilik & 3,68 & 0,631 & 3,65 & 0,658 &, 713 &, 477 \\
\hline Başarma İhtiyacı & 3,75 & 1,191 & 3,64 & 0,771 & $-1,090$ &, 277 \\
\hline Kontrol Odağı & 3,81 & 0,686 & 3,91 & 0,611 & $-1,078$ &, 282 \\
\hline Risk Almak & 3,51 & 0,699 & 3,62 & 0,674 &,- 230 &, 819 \\
\hline Belirsizliğe Karşı Tolerans & 2,10 & 0,986 & 2,14 & 1,035 & $-1,707$ &, 089 \\
\hline
\end{tabular}

Tablo 3: Girişimcilik Eğilimi Boyutlarının Üniversitelere Göre Farklılık Olup Olmadığının İncelenmesi

Tablo 4'de, araştırmaya katılan iki ayrı üniversite öğrencilerinin girişimcilik eğilimi boyutlarının, toplumsal cinsiyet bakımından üniversitelere göre farklılık gösterip göstermediği incelenmiştir. Tablo 3 incelendiğinde, ölçeğin boyutlarıyla sadece risk almak özelliğinin \%95 güven aralığında $(p<0,05)$ kız öğrenciler ile erkek öğrenciler arasında anlamlı farklılık bulunduğu göze çarpmaktadır. Ortalamalar incelendiğinde, erkek öğrencilerin kız öğrencilere göre daha fazla risk alma eğilimi gösterdikleri söylenebilir. Ayrıca, ülkedeki erkek egemenliğinin yer yer hüküm sürüyor olması nedeniyle erkek öğrencilerin "risk alma" eğilimlerinin "duygu" ve "düşünce" öğeleri bakımından yani "söylem” bağlamında, kız öğrencilere göre yüksek olması çok yadırganacak bir durum değildir. Burada, esas olan "risk alma” eğilimlerinin “davranışsal boyutunun” ölçülmesidir. Büyük bir ihtimalle, erkek öğrenciler, erkek egemen toplumsal yapının toplumsal cinsiyet rol davranışları itibarıyla bu yönde bir "duygu" ve "düşünceyi" ifade etmiş olabilirler. Ancak, postmodern kültür tutarsızlığı çerçevesinde, büyük bir ihtimalle erkek öğrencilerin "risk alma" eğilimlerinin "davranışsal boyutunda" aynı tutarlılık ortaya konamayacaktır. Yine de, Türk toplumsal yapısının, özellikle Orta Doğu ve eski Anadolu kültürlerinin olumsuz etkileriyle sosyo-kültürel tarihsel gerçekliğine aykırı olarak, çok yaygın ve kuvvetli bir "erkek egemen toplum" olma özelliğine rağmen, üniversiteli kız öğrencilerin "girişimcilik davranışları” bakımından hiç olmazsa erkek öğrencilerin sahip oldukları değerlere sahip olmaları, ülkenin geleceği açısından oldukça umut verici bir eğilimdir.

\begin{tabular}{|l|c|c|c|c|c|}
\hline \multirow{2}{*}{ Boyut } & \multicolumn{2}{|c|}{ Kız(n=113) } & \multicolumn{2}{c|}{ Erkek(n=88) } & P \\
\cline { 2 - 5 } & $\overline{\mathbf{x}}$ & Std. Sap. & $\overline{\mathbf{x}}$ & Std. Sap. & \\
\hline Kendine Güven & 3,74 & 0,699 & 3,85 & 0,739 &, 280 \\
\hline Yenilik & 3,60 & 0,599 & 3,75 & 0,686 &, 096 \\
\hline Başarma İhtiyacı & 3,63 & 0,709 & 3,78 & 1,318 &, 282 \\
\hline Kontrol Odağı & 3,86 & 0,646 & 3,84 & 0,664 &, 814 \\
\hline Risk Almak & 3,39 & 0,634 & 3,78 & 0,788 &, $000^{*}$ \\
\hline Belirsizliğe Karşı Tolerans & 2,07 & 1,010 & 2,18 & 1,003 &, 439 \\
\hline
\end{tabular}

$* \mathbf{p}<\mathbf{0 , 0 5}$

\section{Tablo 4: Cinsiyete Göre Varyans Analizi Sonuçları}

Tablo 5'de, araştırmaya katılan iki ayrı üniversite öğrencilerinin girişimcilik eğilimi boyutları, "Gelecekte kendi işinizi kurma ihtimaliniz var mı?” sorusu bağlamında test edilmeye çalışılmıştır. Girişimcilik eğilimi ölçeğinin tüm boyutları, öğrencilerin "kendi işinizi kurma ihtimaliniz var mı” sorusuna verdiği cevaplara göre, \%95 güven aralığında $(\mathrm{p}<0,05)$ anlamlı farklılık göstermektedir. Buna göre mezun olduktan sonra kendi işini kurma ihtimali yüksek olanların kendine güven duyguları, yeniliğe olan eğilimleri, başarma ihtiyaçları, kontrol odağı, risk alma eğilimi ve belirsizliğe karşı toleransları iş kurma ihtimali düşük ya da hiç olmayanlara göre daha yüksektir. Bu durum, bu çalışmanın temel teorik iddiasını ve varsayımını oluşturan "Y Kuşağının, girişimcilik faaliyetlerine dair tutumlarında söylem düzeyinde bir "niyet" veya "imaj” olmasına karşılık, gerçek "girişimcilik davranışı" konusunda kayda değer bir tavır gerçekleştiremedikleri şeklindeki görüşü desteklemektedir. Çünkü araştırmaya katılan her iki üniversite öğrencilerinin "girişimcilik tutumlarına" dair boyutların çoğunda olumlu cevap vermiş olmalarına rağmen, bu cevapların davranışsal uzantısı ve gereği niteliğinde olan "gelecekte kendi işlerini kurma" yani tam bir "girişimcilik” fiili gerçekleştirme konusunda kararsızlık göstermektedirler. 


\begin{tabular}{|c|c|c|c|c|c|}
\hline Boyut & $\begin{array}{l}\text { Kendi İşini } \\
\text { Kurma İhtimali }\end{array}$ & $\mathbf{N}$ & Ortalama $(\overline{\mathbf{x}})$ & Standart Sapma & Sig (p) \\
\hline \multirow{5}{*}{ Kendine Güven } & Çok yüksek & 29 & 4,45 & ,556 & \multirow{5}{*}{, 000} \\
\hline & Yüksek & 73 & 3,85 & ,737 & \\
\hline & Düşük & 72 & 3,47 &, 574 & \\
\hline & Çok Düşük & 15 & 3,83 & ,459 & \\
\hline & Yok & 12 & 3,67 &, 874 & \\
\hline \multirow{5}{*}{ Yenilik } & Çok yüksek & 29 & 4,02 & ,754 & \multirow{5}{*}{,002 } \\
\hline & Yüksek & 73 & 3,71 & ,685 & \\
\hline & Düşük & 72 & 3,48 &, 517 & \\
\hline & Çok Düşük & 15 & 3,64 & ,479 & \\
\hline & Yok & 12 & 3,82 &, 561 & \\
\hline \multirow{5}{*}{ Başarma İhtiyacı } & Çok yüksek & 29 & 4,39 & 1,979 & \multirow{5}{*}{, 000} \\
\hline & Yüksek & 73 & 3,80 &, 737 & \\
\hline & Düşük & 72 & 3,41 & ,648 & \\
\hline & Çok Düşük & 15 & 3,40 &, 427 & \\
\hline & Yok & 12 & 3,58 &, 700 & \\
\hline \multirow{5}{*}{ Kontrol Odağı } & Çok yüksek & 29 & 4,09 & ,616 & \multirow{5}{*}{, 020} \\
\hline & Yüksek & 73 & 3,87 &, 718 & \\
\hline & Düşük & 72 & 3,67 & 611 & \\
\hline & Çok Düşük & 15 & 3,91 &, 483 & \\
\hline & Yok & 12 & 4,13 &, 503 & \\
\hline \multirow{5}{*}{ Risk Almak } & Çok yüksek & 29 & 4,16 & ,647 & \multirow{5}{*}{, 000} \\
\hline & Yüksek & 73 & 3,65 & ,702 & \\
\hline & Düşük & 72 & 3,29 & ,698 & \\
\hline & Çok Düşük & 15 & 3,44 & ,591 & \\
\hline & Yok & 12 & 3,43 &, 544 & \\
\hline \multirow{5}{*}{$\begin{array}{l}\text { Belirsizliğe Karşı } \\
\text { Tolerans }\end{array}$} & Çok yüksek & 29 & 2,64 & 1,287 & \multirow{5}{*}{, 003} \\
\hline & Yüksek & 73 & 2,21 & ,949 & \\
\hline & Düşük & 72 & 1,79 &, 807 & \\
\hline & Çok Düşük & 15 & 2,20 & 1,146 & \\
\hline & Yok & 12 & 2,13 & ,979 & \\
\hline
\end{tabular}

Tablo 5: “Gelecekte Kendi İşinizi Kurma İhtimaliniz Var Mı?” Sorusunun Boyutlara Göre Farklılık Gösterip Göstermediğinin Incelenmesi

Tablo 5 incelendiğinde girişimcilik eğilimi boyutlarından kendine güven, yenilik ve risk almak boyutlarının öğrencilerin mezun olduktan sonraki mesleki ideallerine göre istatistikî olarak anlamlı bir şekilde farklılık göstermektedir. Başka bir deyişle, mezun olur olmaz kendi işini kurmayı düşünen öğrencilerin, kendine güven, yenilik davranışı ve risk alma eğilimleri daha yüksektir şeklinde yorumlanabilir.

Tablo 6 incelendiğinde girişimcilik eğilimi boyutlarından kendine güven, yenilik, başarma ihtiyacı ve risk alma eğilimi, öğrencilerin ailelerinde girişimci olup olmama durumlarına göre anlamlı şekilde farklılık göstermektedir. Ailelerinde girişimci olanların kendine güven duyguları, yenilik davranışı, başarma ihtiyacı ve risk alma eğilimleri, ailelerinde girişimci olmayanlara göre daha yüksektir.

\begin{tabular}{|l|l|l|l|l|c|}
\hline \multirow{2}{*}{ Boyut } & \multicolumn{2}{|c|}{$\operatorname{Var}(\mathrm{n}=59)$} & \multicolumn{2}{l|}{ Yok(n=142) } & P \\
\cline { 2 - 6 } & $\overline{\mathbf{x}}$ & Std. Sap. & $\overline{\mathbf{x}}$ & Std. Sap. & \\
\hline Kendine Güven & 4,02 & 0,699 & 3,68 & 0,739 &, $\mathbf{0 0 2}$ \\
\hline Yenilik & 3,87 & 0,599 & 3,58 & 0,686 &, $\mathbf{0 0 4}$ \\
\hline Başarma İhtiyacı & 4,11 & 0,709 & 3,52 & 1,318 &, $\mathbf{0 0 0}$ \\
\hline Kontrol Odă̆ı & 3,94 & 0,646 & 3,81 & 0,664 &, 207 \\
\hline Risk Almak & 3,82 & 0,634 & 3,45 & 0,788 &, $\mathbf{0 0 1}$ \\
\hline Belirsizliğe Karşı Tolerans & 2,09 & 1,010 & 2,13 & 1,003 &, 813 \\
\hline
\end{tabular}

Tablo 6: “Ailenizde Girişimci Var Mı?” Sorusunun Boyutlara Göre Farklılık Gösterip Göstermediğinin Incelenmesi

$\mathrm{Bu}$ bulgular, "girişimcilik" faaliyetleriyle ilgili tutumlarda, girişimcilik tutumunun "duygu" ve "düşünce" öğelerinin (yani girişimcilik niyetinin), önemli bir davranışsal alt yapı oluşturmakla birlikte, bu tutumun 
gerçekleşmesinde asıl belirleyici öğenin, bizzat "davranış" boyutu olduğunu göstermektedir. Böylece, ailesinde girişimcilik deneyimi olan gençlerin, ailesinde girişimcilik deneyimi olmayan gençlere göre, girişimcilik eğilimi boyutlarının daha yüksek olduğu ortaya çıkmış bulunuyor.

\subsection{Denizli Ticaret Odasına Kayıtlı Girişimcilerin Kuşaklararası Karşılaştırılması}

Bu araştırmanın konu edildiği 2000 ila 2016 yılları arasındaki sürede, Bebek Patlaması Kuşağından Denizli Ticaret Odasına kayıtlı girişimcilerin toplam sayısı 1090; X Kuşağının girişimci toplam sayısı 2629; Y Kuşağının girişimci toplam sayısı girişimci toplam sayıs1 1286 'dır. İş ve çalışma hayatında şu anda yer almakta olan girişimcilerin toplam sayılarının kuşaklar arasındaki dağılımına bakıldığı zaman, X Kuşağının 2629 girişimci toplam sayısı ile en iyi durumda olduğu görülmektedir (Verilerin özetlendiği grafikler Ek-1'de gösterilmiştir). Bu kuşağı, 1286 toplam sayısı ile Y Kuşă̆ı, 1090 toplam sayısı ile Bebek Patlaması Kuşağı izlemektedir. Araştırma süresinin başladığı 2000 yılında, Bebek Patlaması Kuşağı için yaklaşık 30’lu ve 50’li yaşlar söz konusu olduğu için ilerleyen yıllarda, girişimcilik faaliyetleri bakımından bu kuşaktaki insanların yaşları da oldukça ilerlemiş olmaktadır. Buna karşılık, 12 Eylül 1980 sonrasının "millî ekonomiyi”, küreselleştirme süreci doğrultusunda yürütülen serbest piyasa ekonomisi görüntüsü adı altında yapılan özelleştirme politikaları kapsamında, ülke ekonomisinde çok sayıda girişimcilik faaliyetleri beklentisi yaratılmıştır. Bu bağlamda, Y Kuşağının iş ve çalışma hayatına katılma dönemi olarak 2000'li yıllardan sonra başta KOSGEB olmak üzere, Tübitak, Ticaret Odaları ve birçok kuruluş, "genç girişimciliği" ve "kadın girişimciliği" şeklindeki projeler adı altında çok önemli kurslar ve teşvikler vermişlerdir. Araştırmaya esas teşkil eden dönem içerisinde, normal şartlarda Y Kuşağının, en fazla girişimci birey yetiştirmesi beklenirken, X Kuşağının 2629 girişimci toplam sayısı ile ilk sırayı alması çok ilgi çekici bir durumu ortaya koymaktadır. Buna göre, X Kuşağının henüz girişimcilik alt yapısı pek gelişmemiş olmasına rağmen, girişimcilik alt yapısı bakımından daha elverişli olan Y Kuşağından daha iyi bir girişimcilik sergilemesinin, birçok nedeni arasında en önemli etkenin bu kuşağın (X Kuşağının) henüz postmodern kültür ile aşırı bir davranışsal bir tutarsızlığa maruz kalmamış olmaları gösterilebilir. Y Kuşağının, önceki kuşakların dönemlerine göre girişimcilik alt yapısı bakımından daha elverişli olmasına rağmen, özellikle bir önceki kuşak olan X Kuşağından daha az girişimci çıkarmış olması, birçok neden arasında taşımakta oldukları postmodern kültürün bu kuşak davranışlarında yaratmış olduğu aşırı tutarsızlıklar ve çelişkiler yüzünden olmalıdır. 1980'den sonraki yıllar, araştırma konusu bakımından iki yönüyle dikkat çekici özelliğe sahiptir. 1980'li yıllar, bir yönüyle Y Kuşağının doğmaya başladığı, öteki yönüyle postmodern kültürün özellikle çocuk ve gençlerin toplumsal davranışları üzerinde, çok yaygın ve yoğun bir şekilde etkili olmaya başladığı yıllardır. 2005 ila 2016 yılları arasındaki zaman dilimi, Y Kuşağının bir önceki X Kuşağına göre, hem daha genç olmaları hem de dönemin teşvik şartlarının uygunluğundan dolayı iş ve çalışma hayatına girişimci olarak katılmalarının daha uygun olduğu yaşlardır. Bu tarihler arasında, Y Kuşağının, toplam girişimcilik sayısı $(312+918) 1230 \mathrm{iken}$, aynı tarihler arasındaki X Kuşağının toplam girişimcilik sayısı (810+1350) 2160 adettir. Bu durumda, yönetim ve organizasyon alanındaki kuşaklar arası karşılaştırmalarla ilgili yabancı literatürde, Y Kuşağının daha girişimci olduğuna dair değerlendirmelerin, Denizli'deki 2000 ila 2016 yılları arasında Ticaret Odasına kayıtlı olan girişimciler üzerinde fazla bir karşıllığı yoktur. Ancak, Y Kuşağı üzerinde Denizli ve Muğla'da yapılan "girişimcilik eğilimi”, anketinde araştırmaya katılan Y Kuşağı gençliğinin, söylem ve imaj itibarıyla girişimcilik faaliyetlerine dair "duygu" ve "düşünceleri" paylaşıyor olmakla birlikte, bizzat girişimcilik faaliyetlerinin "davranış" boyutları hakkında fazla bir tutarllık gösteremedikleri anlaşılmaktadır.

\section{Sonuç}

Kültürel ve toplumsal değişme dalgalanmaları kapsamında, her kuşağın yetişmesinde göreceli olarak farklı yetkinlik ve niteliklerde egemen kültür öğeleri söz konusudur. Bu bağlamda, araştırmaya konu olan üç kuşak üzerindeki egemen kültür öğeleri göz önüne alındığı vakit, Türkiye Cumhuriyet'i tarihinin en çarpıcı kültür değişme dalgalanması, 1980'li yıllardan sonra yaygınlaşarak, başta çocuk ve gençler olmak üzere bütün toplumsal kesimlere ve dokulara nüfuz eden postmodern kültür egemenliğidir. Postmodern kültür, toplumsal çözülme ve kültürel bütünlüğün bozulmasına bağlı olarak davranışsal tutarsızlık ve çelişkiler şeklinde kendini göstermektedir. $\mathrm{Bu}$ yüzden, postmodern kültür taşıyıcısı olan Y Kuşağında, çoğunlukla davranışlarda kararsızlık, geçicilik ve köksüzlük gibi tutarsızlıklar çok fazla temsil edilmektedir. Y Kuşağı, birçok olumlu sonuçları ve durumları, yüksek düzeyde ister ve arzu ederken, bu sonuç ve durumların kazanılması konusunda aktif olarak çaba gösterme konusunda yetersiz kalmaktadır. Postmodern kültürün egemen davranış kalıpları ile bir yüksek kültür niteliği sayılan "girişimcilik nitelikleri" arasında, ciddi bir aykırılık ve çelişki bulunmaktadır. Bu bağlamda, mevcut iş ve çalışma hayatına halihazırda fiilen katılan üç kuşak olarak, Bebek Patlaması Kuşağı (1946- 1964), X Kuşağı (19651979) ve Y Kuşağı (1980-1999) arasındaki girişimcilik faaliyetlerinin karşılaş̧ırılması sonucunda, girişimcilik konusunda en aktif olan kuşağın X Kuşağı (1965-1979) olduğu ortaya çıkmıştır. Üniversite öğrencileri üzerinde yapılan anket çalışmasına göre, Y Kuşağının girişimcilik faaliyetleri konusunda söylem olarak istekli ve arzulu oldukları görülmektedir. Ancak, Denizli'de faaliyet gösteren girişimci topluluğu içerisinde yer alan Y Kuşağı temsilcilerinin sayısı, kendinden önceki X Kuşağı temsilcilerinden daha düşük kalmaktadır. Buradan çıkarılacak en önemli sonuç, Y Kuşağının beklenilenin aksine girişimcilik faaliyetleri konusunda davranışsal olarak yeterince pek harekete geçemedikleri bulgusudur. . 


\section{Kaynakça}

- Arsenault, Paul M, 2004. "Validating Generational Differences", Leadership and Organization Development Journal, 25/2 p.127.

- Atak, N.Ü. 2016. X-Y-Z- Kuşakları ve Kuşaklar Arası Farklılık Yönetimi, Nobel Yayın No:1421, Ankara.

- Ayhün, S. E. 2013. "Kuşaklar Arasındaki Farkl11ıklar ve Örgütsel Yansımaları”, Ekonomi ve Yönetim Araştırmaları Dergisi, Cilt:2, Sayı:1, p.97-102.

- Ayverdi, İ. 2006. Misalli Büyük Türkçe Sözlük, 2. Baskı, Kubbealtı Neşriyat, İstanbul.

- Bayhan, V. 2013. "Gençlik Ve Postmodern Kimlik Örüntüleri Üniversite Gençliğinin Sosyolojik Profili (İnönü Üniversitesi Uygulaması)", Gençlik Araştırmaları Dergisi, Cilt 1, Sayı 1, p.134.

- Bayhan, V. 2002. Gençlik Kimliği, Üniversite Gençliğinin Sosyolojik Profili (İnönü Üniversitesi Uygulaması), İnönü Üniversitesi Yayınları, Malatya.

- Bilgiseven, A. K. 1992. Sosyolojik Açıdan İslâmiyet ve İslâmî Kavramlar, Filiz Kitabevi, İstanbul

- Batmaz, V. 1981. "Popüler Kültür Üzerine Değişik Kuramsal Yaklaşımlar”, AİTíA Gazetecilik ve Halkla İlişkiler Yüksek Okulu İletişim Dergisi, 1981/1,p.163-192

- Bozkurt, V. 2014. Endüstriyel ve Post-endüstriyel Dönüşüm, Bilgi, Ekonomi, Kültür, 3. Baskı, Ekin Basım Yayın Dağıtım, Bursa.

- Dam Van, K., Schipper, M., ve Runhaar, P. 2010. "Developing A Competency-Based Framework For Teachers' Entrepreneurial Behaviour", Teaching and Teacher Education, 26(4), p.967.

- Eroğlu, F. ve Eroğlu, Ş.G. 2014. "Kitle Kültürü Ortamında Stratejik Tutarsızlık ve Örgütsel İkiyüzlülük: Kredi ve Yurtlar Kurumuna Bağlı Yurtlarda Bir Araştırma", International Conference on Eurasian Economies, Üsküp, Makedonya, p. 804-811.

- Eroğlu, F. 2015. Davranış Bilimleri, BETA, 14. Bası, İstanbul.

- Işcan, Ö. F. ve Kaygın Erdoğan (2011), "Üniversite Öğrencilerinin Girişimcilik Eğilimlerini Belirlemeye Yönelik Bir Araştırma”, Atatürk Üniversitesi Sosyal Bilimler Enstitüsü Dergisi, 15/2, p. 446-447.

- Koh, H. C. 1996. "Testing Hypotheses of Entrepreneurial Characteristics, A Study of Hong Kong MBA Sutudents", Journal of Managerial Psychology, 11/3, p.16.

- Kök, S. B. 2007. Küçük ve Orta Ölçekli İşletmeler ve Kadın Girişimciliği, Denizli Ticaret Odası Ekonomik Araştırma Serisi Yayın No:1, Ankara.

- Lee, D. Y. 2001. "The Effects of Entrepreneurial Personality, Background and Network Activities on Venture Growth", Journal of Management Studies, 38/ 4,58 p.586.

- Özer, P. S. ve Eriş, E. D.; Özmen, Ö. N.T. 2013. “Kuşakların Farklılaşan İş Değerlerine İlişkin Emik Bir Araştırma", Dumlupınar Üniversitesi Sosyal Bilimler Dergisi, Sayı 38, p.126, p.138.

- Teoh, H. Y. ve See L. F.. 1997. "Moderating Effects Of Tolerance For Ambiguity And Risktaking Propensity On The Role Conflict-Perceived Performance Relationship: Evidence From Singaporean Entrepreneurs." Journal of business Venturing, 12.1, p.72.

- Tsui, Bonnie 2001. Generation Next, http://adage.com/article/new/generation/55731.

- Türkdoğan, O. 1988. Sosyal Hareketlerin Sosyolojisi, Kültür ve Turizm Bakanlığı Yayınları:858, Ankara.

- Vernon, G. M. 1965. Human Interaction, an Introduction to Sociology, The Ronald Press Company, New York. 


\section{EKLER:}

\section{Denizli Ticaret Odası'ndan Alınan Verilerin Grafikleri}

\section{Y KUŞA ĞI}
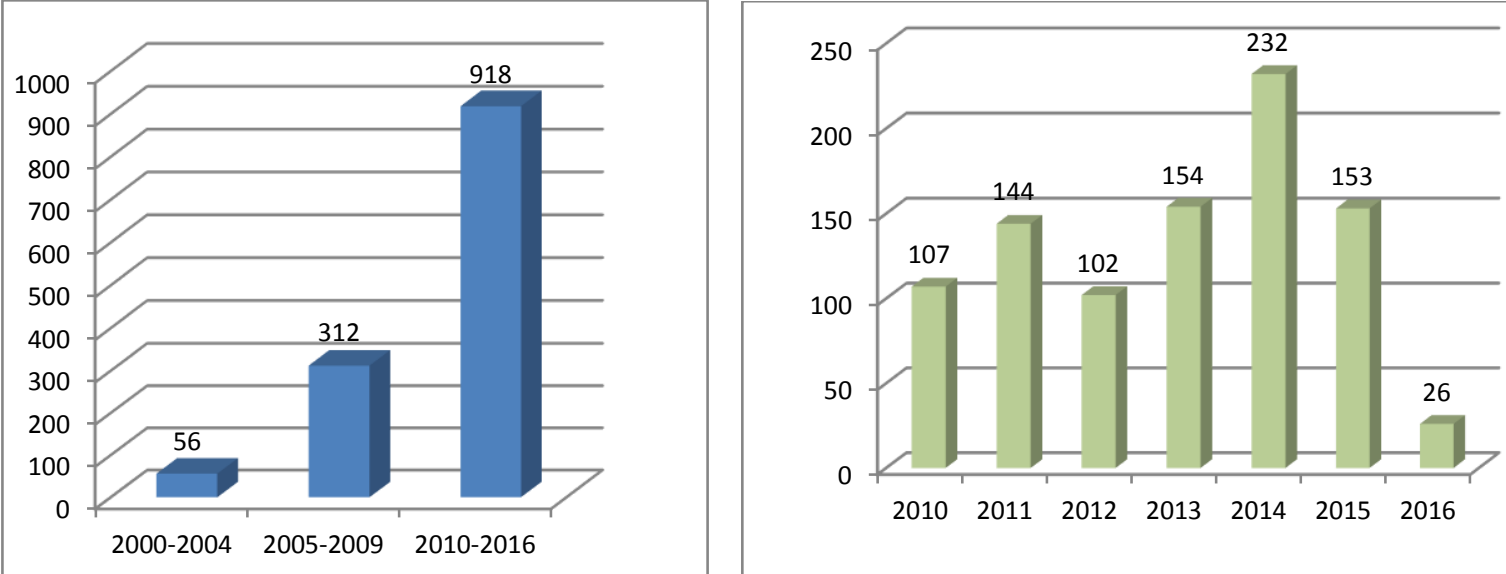

\section{KUŞAĞI}

Toplam:2629
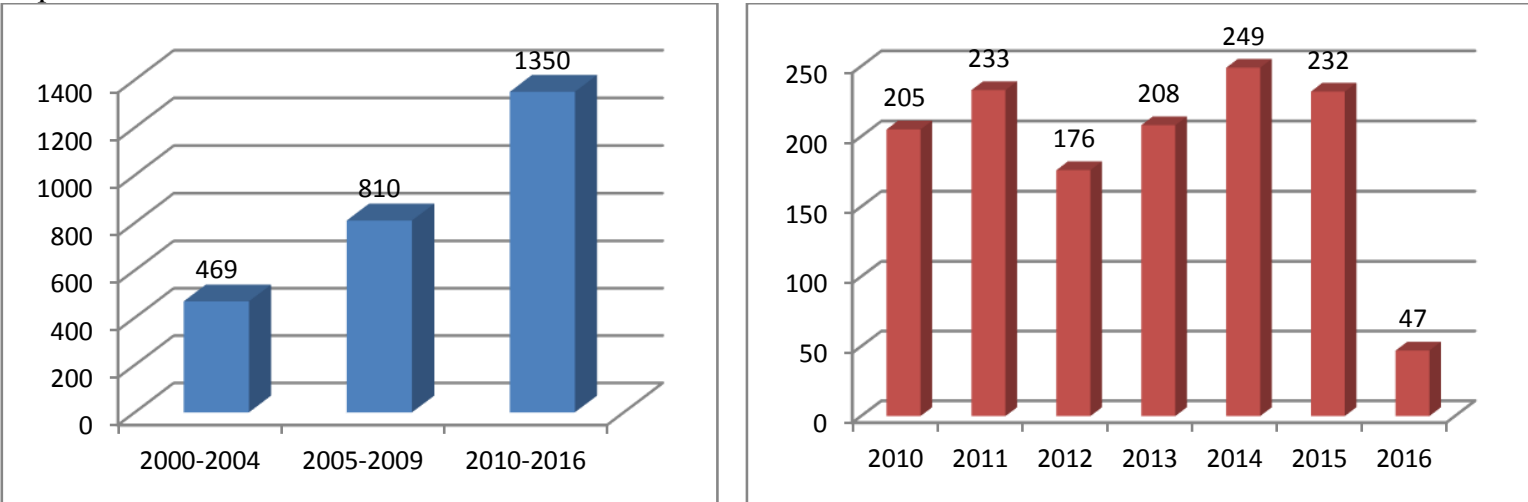

\section{BEBEK PATLAMASI KUSAĞI}

Toplam:1090
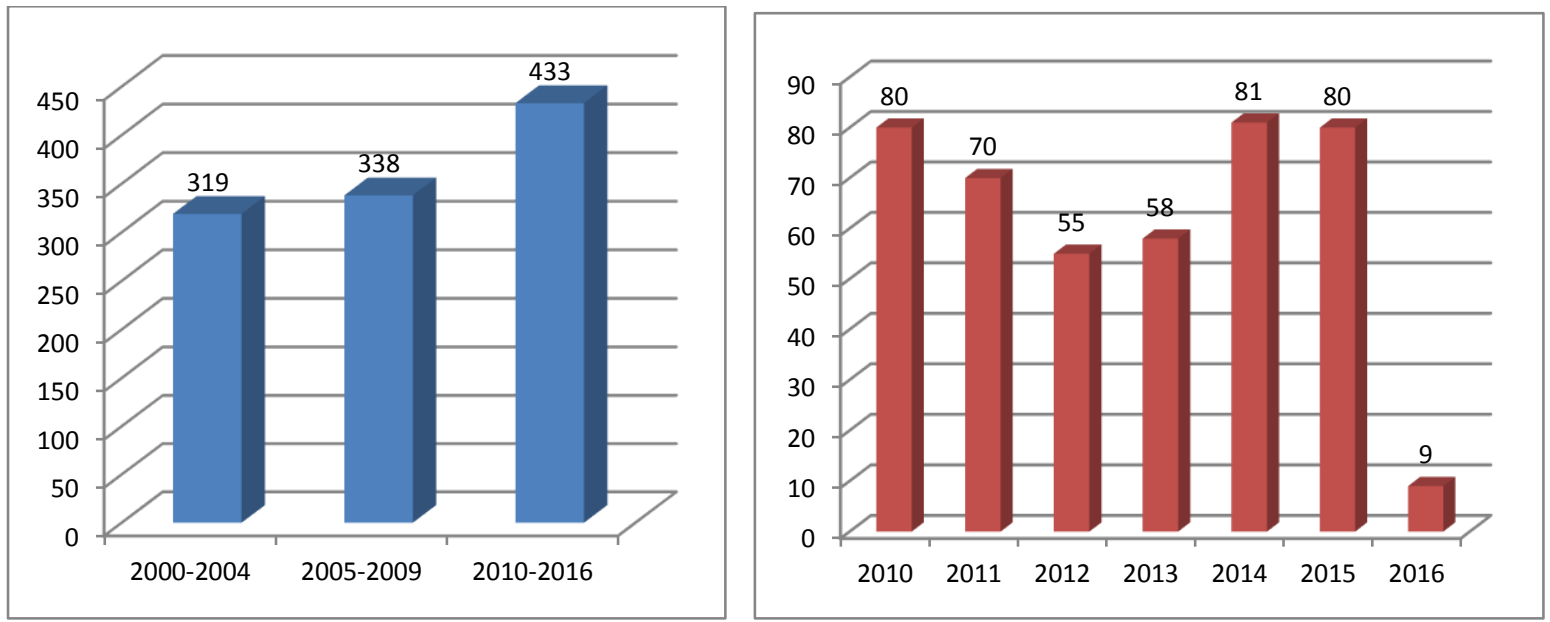


\title{
Girişimcilikte Sosyal Değer İnşası: Sosyal Girişimcilik Construction of Social Value in Entrepreneurship: Social Entrepreneurship
}

\author{
Prof. Dr. Sabahat Bayrak Kök (Pamukkale University, Turkey) \\ Esvet Mert (Pamukkale University, Turkey)
}

\begin{abstract}
We believe that income divide among countries due to globalization, growing poorness and increasing unemployment aroused a necessity for social values to create on economical base. In this context arising economical and social issues bring some new responsibilities upon international institutions, governments, NGO's, and firms. Social entrepreneurship concept is among these responsibilities. This concept is particularly important for firms that are placed in intersection of private and third sector and other institutions adopting market-based methods. Social entrepreneurism that focusing on social missions affect all the decisions how to capture and evaluate opportunities in all the dimensions of life. Social entrepreneurs who are motivated by social bearings rather than solely making profits are present in social and cultural aspects of life in addition to presence in the market. In this study social entrepreneurism producing more economic and social value than its traditional counterpart is about to be examined in Turkish context with two awarded cases. First is SineMASAL (Cine-Tale) social entrepreneurship that aims to embrace all the rural kids with artistic fields including the cinema. This entrepreneurship particularly aims to provide country kids who have limited access to social and economical life with some opportunities that would help them to have a better future, at least to support them having a positive attitude towards potentialities. Another one is the e-Hastam (My e-Patient) entrepreneurship that matches physicians and patients on virtual platform where everybody could benefit from actual health information and activities.
\end{abstract}

\section{Giriş}

21. yüzyıl hem girişimciliğin hem de sosyal girişimciliğin birlikte önem kazandığ bir zamanı temsil etmektedir. Özellikle geride bıraktığımız 30-35 yıllık zaman dilimi içerisinde küresel ölçekli ekonomik, sosyal ve politik koşullar ticari girişimciliğin sorgulanmasına neden olmakta ve yeni bir yönelime kapılarını aralamaktadır. Bu yönelim doğrultusunda, girişimcilerin toplumsal duyarlılığını artırarak piyasada sivil bir hassasiyet göstermesi ve kurumsal sosyal sorumluluk uygulamalarıyla gönüllülük merkezli yaklaşımları piyasa dinamizmi içerisinde harmanlaması beklenmektedir. Özellikle küresel ölçekte tüm dünya toplumlarının karşı karşıya kaldığı sosyal, ekonomik ve ekolojik sorunlar karşısında hem devletin sosyal politika müdahalelerinin yetersizliği hem de piyasa mekanizmasındaki faaliyetlerin ekonomik boyutlarının giderek genişlemesinin yarattığı tatminsizlik 'sosyal ekonomi' yapılanmasını, 'girişim temelli sosyal yatırım' modelini ve 'sosyal girişim' (Trivedi, 2010) şeklindeki örgütlenmeleri gerektirmiştir.

$\mathrm{Bu}$ yönüyle, dünyada sosyal girişimlere yönelen emek, para ve ilgi gün geçtikçe artmakta model ulusal ve uluslararası platformlarda rağbet görerek girişimcilikte yeni bir dönem ve yeni bir yönelime kapıları aralamaktadır. Başka bir ifadeyle, günümüz sosyo-ekonomik ve siyasi koşulları içinde yaşanılan topluma ve çevreye duyarlılık gösterme vb. konuları ön plana çıkarmakta, girişimeci aktivitede sosyal bir hassasiyet geliştirerek 'sosyal değer üretimini’ piyasa mekanizması içerisine harmanlamaktadır. Böylece sosyal girişimcilik kavramı girişimcilik bünyesine alınmakta ve kavram girişimcilikte ekonomik ve sosyal değeri bünyesinde birleştirerek bu iki kavramı harmanlayan yeni bir konsept olarak karşımıza çıkmaktadır (Austin, vd, 2006).

Girişimciliğin ortaçağdan beri devam eden gelişimine sosyal girişimcilik, toplumların mücadelesi en zorlu sosyal sorunlarının bir kısmına alternatif çözüm bulmanın yeni bir sahası olarak dünyada giderek büyüyen bir sosyo-ekonomik dönüşümü temsil etmektedir. Sosyo-ekonomik ve çevresel sorunların yoğun olarak yaşandığı günümüz toplumlarında sosyal girişimcilik klasik girişimciliğe uygun olmayan bir dizi olası 'niş' firsat arasında en çok umut vaad eden yöntem ya da alternatiflerden biri olarak hem teorik hem pratik daha da yoğun bir ilgi görmektedir. Bu nedenle, son yıllarda aldığı ivmeye bağlı olarak küresel ekonomide küçük bir pay oluşturmasına rağmen, etkilerinin giderek büyüdüğü belirtilmektedir (Ratiu, vd, 2014).

\section{Girişimciliğin Kavramsal Çerçevesi}

Tarihte bilinen en eski uğraş alanlarından birisi olarak kabul edilen girişimcilik, kavram olarak daha yeni bir olguyu anlatıyor gibi görünüyor olsa da, aslında faaliyet alanı olarak oldukça eskilere dayanmaktadır (William, vd, 2001). Girişimcilik kavramı sahada görülmeye başlandığı ilk günlerden bugüne değin, iş dünyasında yaşanılan ekonomik, sosyal ve siyasi dinamikler çerçevesinde bir dönüşüm süreci yaşamakta ve bu sürece bağlı olarak yeniden değerlendirilmektedir. Bu süreçte farklı anlamlar ile karşımıza çıkan girişimcilik, kavramsal çerçevede 
daha çok insiyatif kullanma, sosyo-ekonomik mekanizmaları düzenleme ve başarısızlık riskini kabullenme durumlarını içine alan bir davranış şekli olarak ifade edilmektedir (Shapero, 1975).

\subsection{Girişimci ve Girişimcilik Tanımı}

Girișimcilik kavramı, sosyal bilimlerin tüm dallarında, kalkınma ve gelişmede lokomotif güç olarak karşımıza çıkmakta ve kavramın özellikle ekonomi, antropoloji, sosyoloji ve yönetim literatürü açısından merkezi bir değer taşıdığı görülmektedir. Girişimcilik konusunda çok geniş bir yelpazenin varlığı, bir taraftan pek çok yazar tarafından farklı yönleri vurgulanan girişimcilik tanımlarının yapılmasına neden olurken (Bayrak Kök, 2007) diğer taraftan da genel kabul gören bir tanım vermenin zorluğunu ortaya çıkarmıştır. Bu tespitten hareketle, girişimcilik tanımını kavramın gelişim süreci üzerinden vermek daha iyi bir yaklaşım olarak görülebilir.

Sadece bugüne özgü bir olgu olmayan girişimciliğin, ortaçağdan günümüze kadar geçen yaklaşık üç yüzyıl içerisinde farklı şekillerde ele alındığı ve tarihsel süreç içerisinde pek çok teorisyen tarafindan farklı bakış açılarıyla araştırıldığı görülmektedir. Gartner (1988) yaptığı bir çalışmada otuz iki farklı girişim ve girişimcilik tanımı yapıldığını göstermeye çalışmıştır. Kavramın ilk kullanım zamanlarındaki anlamı irdelenmek istenildiğinde ortaçağda kavramın girişimci ve girişimcilik tanımı üzerinden, büyük üretim projelerini yöneten kişi ve onun yaptığı işi tanımlamak üzere kullanıldığı görülecektir. Bu dönemde girişimcilik, risk üstlenilmeden, hükümet tarafından verilen kaynakların kullanıldığı bir süreci temsil etmiş ve girişimci, böylesi büyük projede kaynakları kullanan ve projeyi yöneten kişiyi ifade etmek üzere kullanılmıştır (Carton, vd, 1998).

Girişimci, Fransızca 'entreprendre' ve Almanca 'unternehmen' sözcüklerinden 'üstlenmek' anlamında İngilizce'ye kazandırılmış bir kavramdır. Girişimci kavramı, 1700'lü yılların başında Cantillon tarafından, bir malı belli bir fiyattan satın alan ve aynı malı belirsiz bir fiyattan satarak risk üstlenen kişi olarak tanımlanmıştır. Cantillon tarafından yapılan tanımı ilerleyen yıllarda Jean Bapthise Say genişletmiştir (Carton, vd, 1998). 19. yüzyılın başında Jean Bapthise Say, 'A Treatise on Political Economy and the Production, Distribution and Consumption of Wealth' adlı eserinde, girişimciyi, üretim faktörlerini birleştirip koordine eden ve dolayısıyla hem üretimde hem de dağıtımda merkezi bir rol üstlenmiş kişi olarak tanımlamıştır. Böylece Say'a göre girişimci, örgüt içerisinde hem koordinatör hem de lider ve yönetici rollerini üstlenmektedir. Bu bağlamda, girişimcilik yönetsel rollere dayalı bir süreç olma özelliğiyle karşımıza çıkmaktadır (Arıkan, 2002). Girişimciyi ekonomide üretimin ana ajanı olarak görüp girişimci rolün farklı bir tanımını yapan Say, girişimcinin sermayedardan ayrıldı̆̆ını belirterek girişimcinin ilk belirgin özelliğinin iyi kararlar verebilmesi olduğuna dikkat çekmiştir (Iversen, vd, 2008). Dolayısıyla girişimci kavramı olarak Cantillon ile ekonomi literatürüne girmişse de, yaygın kullanımının Say tarafından yapıldığını söyleyebiliriz.

Tespitlere göre, girişimci teoriye en fazla bilinen ve en önemli görülen katkı, muhtemelen Joseph Schumpeter tarafından yapılmıştır. Bu dönemde tanımlama çabasının girişimcilik üzerine değil, girişimci üzerine odaklandığ 1 görülmektedir. Schumpeter 'The Theory of Economic Development' (1911) adlı kitabında girişimciyi ekonomide yeniliğin yeni kombinasyonlarını sunan kişi olarak tanıtmış ve girişimcinin ana karakteristiğinin yenilik ve liderlik olduğunun altını çizerek bir girişimcinin, sadece yenilikçi değil aynı zamanda liderlik özelliği taşıması gerektiğine dikkat çekmiştir (Aidis, 2003). Schumpeter'in, yeni bir mal ve yeni bir özellik, yeni bir üretim metodu, yeni bir pazar, yeni arz kaynakları ve yeni bir organizasyon şekli bulan kişi olarak tanımladığı girişimcinin bunları icat eden kişi olması değil, bu kombinasyonları üretime nasıl uygulayacağını bilen kişi olarak tanımlanması üzerinde en fazla durulan konulardan biri olmuştur (Iversen, vd, 2008). Sonraki yıllarda Frank Knight (1916) ise, 'Risk, Uncertainty and Profit' adlı doktora tez çalışmasında risk ve belirsizlik arasında bir farklılaştırma yapmış ve girişimcinin elde ettiği kârın belirsizlik şartları altında yapılan faaliyetlerin bir sonucu olduğunu belirtmiştir (Landström, vd, 2012). Daha sonrasında ise Maurice Dobb, girişimciliği aktif ve yaratıcı bir süreç olarak tanımlarken, girişimciyi de kapitalist sistemin arkasındaki sürükleyici güç ya da kapitalist pazar sisteminde merkezi rol oynayan kişi olarak ifade etmiştir (Aidis, 2003).

1970 ve 1980 'lerden sonra ise, küreselleşme olgusunun yaygınlaşması, ekonomik, siyasi, kültürel ve teknolojik alanlarda büyük değişim ve dönüşümlerin yaşanması ile birlikte kavram girişimciden girişimciliğe doğru kaymış ve girişimcilik, hayatta kalmak için kendi girişimsel temellerini harekete geçirmenin veya keşfetmenin yollarını arayarak, bir örgütte girişimsel faaliyette bulunma kabiliyeti, başarıyı ve kazanmayı belirleyen temel faktör olarak görülen iç girişimcilik bağlamına taşınmıştır. 2000'li yıllarda Audretsch (2002), girişimciliğin genel kabul görmüş bir tanımının hâlâ yapılamamasının nedeninin kavramın, belirsizlik ve risk içerme, yenilik yapma, fırsatları araştırma, yönetim becerisi ve bireylerin girişimsel yönleri şeklinde ortaya konulabilecek çok boyutu içermesinden (Iversen, vd, 2008) kaynaklandığını belirtmektedir. Girişimci ve girişimcilik üzerine kavramsal kargaşa bir oranda netleşmiş olsa da konuyu bütünüyle aydınlatacak temel bir argüman eksikliğinin, kavramın zaman içerisinde değişen yolculuğundan kaynaklı olduğunu söyleyebiliriz.

\section{Sosyal Girişimcilik Kavramı}

Girişimciliği geniş anlamda 'kaynakları daha büyük bir değer yaratan yeni bileşimler oluşturacak şekilde bir araya getirme' olarak tanımladığımızda, bu kavramın sadece piyasa mekanizması içinde değerlendirilmesi gerekliliği ortadan kalkmış olacaktır. Böyle bir yaklaşım dahîlinde girişimcilik, gönüllük ilkesi çerçevesinde 
hareket eden üçüncü sektör (Trivedi, 2010) ya da sivil toplum kuruluşları (Hopkins, 2007) ve aynı zamanda kamu sektörü için de uygulanabilirliği olan bir kavram haline gelmektedir (Öktem, vd, 2003).

Halihazırda dünya genelinde her coğrafyada görülen bozuk şehirleşme, artan açlık, yoksulluk, işsizlik ve barınma sorunları, eğitim ve sağlık haklarında yaşanılan sürekli kayıplar, engellilerin desteklenmesi ihtiyacı ve yaşanılan ekolojik kirlilik, sadece hayır kurumları, vakıflar, dernekler ve gönüllü sektöre bırakılamayacak boyutlara varmakta ve ciddi bir sosyo-ekonomik erozyon yaşanmaktadır. Bu durumda girişimci aktivitenin 'değer' üretimini sosyal bir çerçeve ile kuşatan bir piyasa mekanizmasını işletmesi gerekmektedir. Sosyal girişimcilik olgusu, girişimci stratejiyi sosyal amaçlarla birleştirme modeli olarak dikkat çekmektedir. Kâr amacı taşıyan ve taşımayan kurumlar arasındaki sınırları bulanıklaştıran (Haugh, 2005) bu model, bir taraftan karşımıza ekonomik ve sosyal değer kavramlarını harmanlayan bir konsept olarak çıkmakta diğer taraftan da hem ulusal hem de uluslararası platformda rağbet görerek sosyal girişimlere yönelen emek, para ve ilginin gün geçtikçe artmasını sağlamaktadır. Bu doğrultuda ilerleyen süreci İngiltere başbakanlarından Tony Blair 'sosyal bir patlama hareketi' olarak ifade ederken şöyle devam etmektedir:

Bu yüzyılın ilk yarısında, bizler gerekli hizmetleri sunma ve güvenlik açısından uygun zemin oluşturmada devletin yardımı olmaksızın toplumların bu amaçlarına ulaşamayacă̆ını öğrendik. Yüzyılın ikinci yarısında ise hükümetlerin amaçlarına gönüllü çalışan kuruluşlar, işletmeler ve geniş anlamda halkın çaba ve bağlllı̆̆ı olmadan ulaşamayacaklarını öğrendik... Her yıl binlerce sosyal girişimci zor şartlarda olağanüstü şeyler başarmaktadır... Sosyal girişimlere ve gönüllü sektöre katılan milyonlarca kişi olduğu gibi, milyonlarcası da nasıl yapılacağını öğrendikçe bu sürece katılmak isteyeceklerdir... Bundan dolayl, bir mücadele öneriyorum: Gelin bu bin yll, insanların yaşamlarına dokunan 'sosyal hareket' teki bir patlama ile damgalayalım... (Tony Blair'in Ocak 1999 Konuşmasi) (Thompson, vd, 2000).

Sosyal girişimcilik, yeni kullanılmaya başlayan bir kavram olabilir ancak olgu olarak yeni değildir. Her zaman sosyal girişimciler olmuştur ancak sosyal girişimcilik tabiri ile nitelendirilmemişlerdir (Dees, 1998). Sosyal girişimcilik, tarih boyunca karşımıza çıkan girişimcilik aktivitesine sosyal değer yaratma boyutuyla eklemlenen yeni bir yaklaşım olarak değerlendirilmektedir. Kaynak bulma yarışı ve serbest piyasa ideolojisi karşısında devletin geri çekildiği ya da ulaşamadığı toplum/topluluklarda başta sosyal dışlanmışlık yaşayan düşük gelirli topluluklar ve dezavantajlı gruplar olmak üzere toplumsal yaşamda dezavantajlı görülen kesimlerin sorunları aşma ve hayata tutunma perspektifi olmaktadır. Sosyal girişimciliğin özellikle azalan kamu finansmanı karşısında karmaşık sosyal problemlerle başa çıkmada yenilik esaslı bir yaklaşım olarak değerlendirilmesinin (Jonhson, 2000) temel nedeni bu durum olsa gerekir.

Ayrıca küreselleşme, söz konusu gelişmelerle birlikte modern ekonomilerde devletlerin bir gelişim ajanı olma yeteneğini çok ciddi oranda azaltarak devletin yeni rolleri olması gerektiği fikrini teşvik etmektedir. Böylece devlet toplumda yeni rolleri gereği 'katılımcı demokrasi' veya 'kendini destekleme' programları aracılığıly yön vermek istemesi kâr amacı gütmeyen örgütler ya da hükümet dışı örgütler olarak ifade edilen bu örgütlerin etki alanının genişlemesine neden oldu. Böylece devletin ve özel sektörün toplumsal alandaki boşluklarını doldurmada etkili olan ve 'üçüncü yol' ya da 'orta yol' olarak ifade edilen (Mort, vd, 2003; Trivedi ve Stokols, 2011) bir girişimcilik alanı gelişmeye başladı. Bu bağlamda Austin, Stevenson ve Wei-Skillern (2006) sosyal girişimciliği 'kâr amacı gütmeyen, özel ya da kamu sektörlerine karşın ya da bunların içinde ortaya çıkan, sosyal değer yaratan, yenilikçi girişimler' şeklinde tanımlanarak, bu yenilikçi potansiyeli nedeniyle hem küresel hem de yerel düzeyde değişim adına yeni bir paradigma öneren dönüştürücü bir fenomen olarak görülmektedir (Hopkins, 2007).

Kavramın tanınma ve kabul alanın her geçen gün genişlediği son otuz yıllık süreçte sosyal girişimcilik kavramının hâlâ gelişimini devam ettirdiğini (Bacq ve Janssen, 2011) hatta bu kısa süreli gelişimi onun emekleme dönemi olarak tanımlamak gerektiğini belirten çeşitli araştırmacı ve yazarlar kavram konusundaki uzlaşmazlığın onun kısa süreli gelişiminden değil, yasal ve sektörel konumundan kaynaklandığını belirtmektedirler. Türkiye de dâhil olmak üzere kavramın kâr amacı gütmeyen girişim 'non-profit organization' (toplumsal, sosyal örgüt ve dernekler) olarak tanımlanmasının yanlış anlamalara neden olduğu, oysa 'non-profit organization' kavramıyla sosyal girişimcilikte belirtilmek istenilen hususun, kâr amacı güttüğü ancak bu kârın ortaklar arasında dağıtılmadığı şeklinde anlaşılması gerekliliği belirtilmektedir (Ersen, vd, 2010). Dolayısıyla, sosyal girişimciliğin ticari kâr amacı güden ve gütmeyen sosyal misyon ve yatırım hedefli bileşimiyle ya da ekonomik ve sosyal değer örgüsüyle birleşik melez bir model olduğu (Bacq ve Janssen, 2011) üçüncü sektörün girişimcilik uygulamalarıyla ticari faaliyetler içine girme özelliğini ya da kâr amacı güden işletmelerin bulunduğu sektörün de bir parçası olduğunu ifade etmektedirler (Thompson, 2002; Austin, vd, 2006).

\subsection{Sosyal Girișimcilik Tanımı}

Sosyal girişimcilik hem akademik çevrede (Alvord, vd, 2004; Dees, 2001; Haugh, 2005; Martin ve Osberg, 2007; Thompson, vd, 2000) hem de sivil toplum örgütleri formunda (Ashoka.org, Schwab Foundation, Skolls Foundation) dikkat çeken bir kavram olarak hızlı bir gelişme gösterdi (Popoviciu ve Popoviciu, 2011). Bu nedenle Trivedi (2010) sosyal girişimcilik kavramının sivil toplum örgütlenme şekli kadar hayır kurumlarının da kendini 'sosyal girişimci' olarak tanımlamalarının kavramı sadece çekici kılmakla kalmadığını onun aynı zamanda belirsizlik ile çevrelenmesine neden olduğunu belirtmektedir. 
'Sosyal girişim' ve 'sosyal girişimcilik' kavramları birbirlerinin yerine sık sık kullanılmakla birlikte bu iki kavramın birbirinden farklı olduğunu belirtmek gerekmektedir. Girişimci ve girişimci olmayan faaliyetler arasındaki farklar özel sektör içerisinde (Beaver, 2003; Carland, vd, 1984) ve kamu sektörü içerisinde (Linden, 1990; Osborne ve Gaebler, 1992; Ramamurti, 1986) gözlemlenmekte iken aynı farklılık gelecekte üçüncü sektör organizasyonları için de yapılabilir (Luke ve Chu, 2013). Bu konudaki yanlış anlamaları önlemek adına 'girişim' ifadesi ticari iş aktivitesi ile ilgili kullanırken (Chell, 2007; Dart, 2004), 'girişimcilik' firsatları tanımlama, yenilik ve risk (Kirzner, 1979; Shane, 2003; Venkataraman ve Sarasvathy, 2001) ve pazara yeni bir şey sunma (Davidsson, 2006) ile ilişkilendirilmektedir. Bu yönüyle sosyal girişim ifadesi, sosyal bir iş veya yatırım şeklini belirtmek için kullanılırken, sosyal girişimciliğin sosyal bir amacın pazarda değişim sağlayacak şekilde yenilikçi firsatlar sunmakla ilgili olduğu söylenebilir (Luke ve Chu, 2013). Trivedi (2010) Sosyal girişimcilik tanımlarında iki farklı yaklaşım dikkat çekmektedir. Bunlardan ilki, kâr amacı gütmeyen kuruluşların yürüttüğü sosyal girişimcilik faaliyetleri, diğeri ise hem sosyal fayda odaklı olan hem de ticari gelir elde etmek isteyen faaliyetlerdir (Muscat ve Whitty, 2009).

\section{Ekonomik Değer Yaratımının Kısırlığına Bir Eleștiri ve Sosyal Değer Yaratımı}

Girişimcilikte kazanç elde etme motivasyonunu sadece kâr maksimizasyonu ile açıklamak kısır ve yetersiz bir değerlendirme olarak görülmektedir. Girişimciliğin ekonomi üzerine oturtulmuş tarifí ve kâr maksimizasyonu gibi dar bir eksene sıkıştırılmış tahlili, üretim-tüketim-kazanç ilişkilerinde insanı öteleyen ancak kazancı önceleyen değer algısıyla tek taraflı bir kazanım ve kazanç anlayışı ortaya çıkarmıştır. Piyasa mekanizmasının işleyiş̧ini sadece kâr maksimizasyonuna dayalı bir verimlilik-rekabetçilik-sürdürebilirlik formülasyonu üzerinden temellendiren bu ekonomik değer yaklaşımı karşımıza mikro ve makro ölçekte ciddi sorunlar kümesi çıkarmıştır. İnsanı öteleyip kazancı önceleyen bu sığ anlayış, bireyi zenginleştirirken toplumu her geçen gün yoksullaştırmış böylece insanlığı niceliksel bir birikim ve zenginlik sevdasına düşürerek adeta bir 'meta fetişizmi' ortaya çıkarmıştır (Harvey, 2015).

Kapitalist birikim sürecinin hemen her noktasında tekil taraflı bir tercih ve ekonomik bir kazanım esastır. 'Her şeyin bir değeri vardır', ya da 'her şeyin bir değeri olmalıdır' ifadesini nihai hedef olarak alan bu yaklaşımda, her bir işlem ya da işleyişin etkisi ve önemi; ancak ve ancak sonuçta sağladığı ya da sağlayacağı maddi değer ile ilgilidir. Her şeyin kazanç hanesinden niceliksel olarak tarif edildiği ve niceliksel sembollerle maddi boyutta değerlendirildiği kapitalist anlayış içerisinde her türlü olay ve olgu başlangıç ve süreç etkinliğini kaybetmektedir. Dolayısıyla bu yaklaşım perspektifinden ekonomik faaliyetlere toplumsal bağlamından bakmanın hiçbir gereği yoktur. Çünkü bir yerlerde nicel kazanımlar oldukça toplum da her şeyin bir değeri olduğunu somut olarak görecek bu durumu böylece kabul edecektir. Kapitalizmin ekonomik değer esaslı bu niceliksel yaklaşımı, toplumsal ilerleme ve sürdürebilirlik açısından bir kırılmaya neden olmuş ve toplumların ve büyük kitlelerin yoksullaşmasının getirdiği güncel konumuyla insanın, toplumların tek boyutluluğa mahkûm edilişinin toplumsal bağlamdaki geçerliliğinin sorgulanmasını gerektirmiştir.

Çağımızın yeni vebası olan yoksulluk ve işsizlik olgusu, bütün kıtalarda ve gelişmişlik düzeylerinde yaygınlaşırken en güçlü katkıyı devletin neo-liberal konumlanışı sağlamıştır. Devletin 1980 sonrası uygulanan neo-liberal politikaları piyasa mekanizması içerisinde reel olarak konumlandırması ve işleyiş sürecinde girişimci tarafına açık destek vermesi başka bir deyişle, devletin küresel rekabet şartlarında piyasa işleyişini sınırlandırıcı değil, adaletsiz paylaşımı meşrulaştırıcı şekilde hareket etmesi ve yetkisini sermaye üstünlüğünden yana kullanması değerin tek başına ücret, rant, faiz ve kâr üzerinden konumlanamayacağını bizlere gösterdi. Devletler bugün en fazla toplum katmanları arasında hiçbir zaman yok edilemeyen ücret, rant, faiz ve kâr şeklindeki ekonomik değer paylaşımının ekonomi politiği adına en huzursuzluk verici boyutlara varmasının yani 'katlı' bir adaletsizlik yaratmasının mimarı olarak saygınlık ve itibar yitirmektedir. Devletler itibarsızlaştırmayı giderek kaynak sağlayıcı rollerinden sıyrılarak gelir sağlayıcı seçeneklere kaymak suretiyle yaşamışlardır. Devlet nosyonu, tarihteki yerini bu yüzyılda bir taraftan ulus devletlerin kurumsal güç ve siyasi işleyişte iç ilişkilerini düzenleme de dahi zaafa uğratılmış kabiliyet sorunlarıyla diğer taraftan da ekonomik temelli kapitalist zihniyetin toplumsal bütünleşme için yetersizliğini göstererek 'sosyal değer'in toplumsal yaşama idamesini gerektirmiştir.

\section{Dünyanın Restorasyonu: Diğergamlı Kapitalizm ve Sosyal Değer İnşası}

Dünyada kapitalizmin yaşattığı ekonomik hükümranlık ve devletin zengin sınıfların gelir birikimine ve servet yoğunlaşmasına hukukî ve kurumsal olarak destek veren işleyişi, dünya piyasalarını ekonomik değer zincirinin kuşatımı altında bırakmıştır. Başka bir deyişle devletin piyasa işleyiş mekanizmasında paranın temsil ettiği maddi değerin yükselişini öncelemeye yönelik tavrı ve girişimci sınıfın yanında yer aldığı yeni rolü, toplumlardaki zamansal ve mekânsal farklılıkları bir kenara iterek söz konusu bütün toplumları ekonomik, siyasi, çevresel kirlilik ve kriz potansiyeli temelinde homojenleştirmiştir. Geldiğimiz noktada ticari sermayenin küresel hareketliliği ile karşımıza çıkan açlık, yoksulluk, işsizlik vb. toplumsal kirlilik ve kriz tablosu dünyada gelişim ve kalkınma sürecinin esenliği tartışmalarını farklı bir boyuta taşıyarak sosyal boyutlu değer restorasyonu kaçınılmaz kılmıştır. Özellikle 1980’lerden bu yana zenginliğin ve servet birikiminin eşitsiz coğrafi gelişim yanında çok yönlü 
yoksunluk ve yoksulluk ile birleşmesi 1990 ortasından bu yana dünyadaki yeni gündemin 'diğergaml1/şefkatli kapitalizm' (Trivedi ve Misra, 2015; DeVos, 1994) tartışmalarına kaymasına neden olarak gösterilmiştir.

Yukarıda belirtildiği gibi, devletlerin kapitalist kazanım sürecine siyasi olarak verdiği destek ile yaşanan yoksullaşma, ekonomik değer esaslı kazanım yaklaşımının giderek sürdürülemez bir dengesizliğe dönüşümüne dikkat çekmiş taraflar arasında bölüşüm, değişim ve tüketim ilişkilerinin ekonomik dışavurumuna 'sosyal'in idamesi ile birlikte faklı temellerde bir bütünleşmeye gidişi sağlayacağı belirtilmektedir. Sosyal değerin ekonomik değere eklemlenmesinin bizim karşımıza çıkardığı yeni durum, bölüşümün taraflar arasında yarattığı bütün tezatları giderici ya da 'sömürünün imkânsızlığını' garantileyecek bir denklem olmasa da meselenin uzun yıllar ekonomik değer temelli ve kapitalist zihniyet beslenmeli gidişinin yanlış ve eksik taraflarını işaret etmesi bakımından oldukça önemlidir. Burada önemli olan nokta, insanın en yüksek mutluluğunun ve toplumsal huzurun ekonomik ve sosyal değer dengesini kurmasında yattığını ya da maddi ve manevi değer bütünleşmesinde olduğunu görmesini sağlamaktır.

Kapitalist zihniyetin kariyerine neo-liberal politikalar açısından, üst sınıfın/zenginlerin durduğu yerden bakarak ifade edilen muazzam başarı hikâyesinin 1970'lere hâkim olan anlayışa oranla 1980 ve 1990'larda oldukça farklı yapılara dönüşümünün yarattığı tablo bu kariyerin küresel ölçekte her gün yeni tartışma alanlarını yaratırken alternatif düşünce ve uygulama önerilerini de gündeme taşımaktadır. Refah, emeklilik, sağlık hakları, mülkiyet (toprağa yönelik) hakların kaybı, çevrenin (eko-sistem) yağmacı faaliyetler sonrasında uğradığı erozyon ve yaşadığı çok yönlü aşınma alternatif hareketlerin sesini yükseltmektedir. Sosyal girişimcilik, envaî çeşit sorun ile karş1 karşıya kaldığımız küreselleşme sürecinde sorunları kökten çözümleme düşüncesinde yetersiz kalsa da dünyada alt sınıfların/yoksulların yanında yer almanın yarattığı insanî konum ve sosyo-ekonomik fayda nedeniyle yeni değer birleştirme modeli ve adaletsizlik ve eşitsizlikleri sönümleme modeli olabilecek görünümdedir. $\mathrm{Bu}$ modelin değer yayılımı aşağıdaki şekil aracılığıyla verilmek istenmektedir:

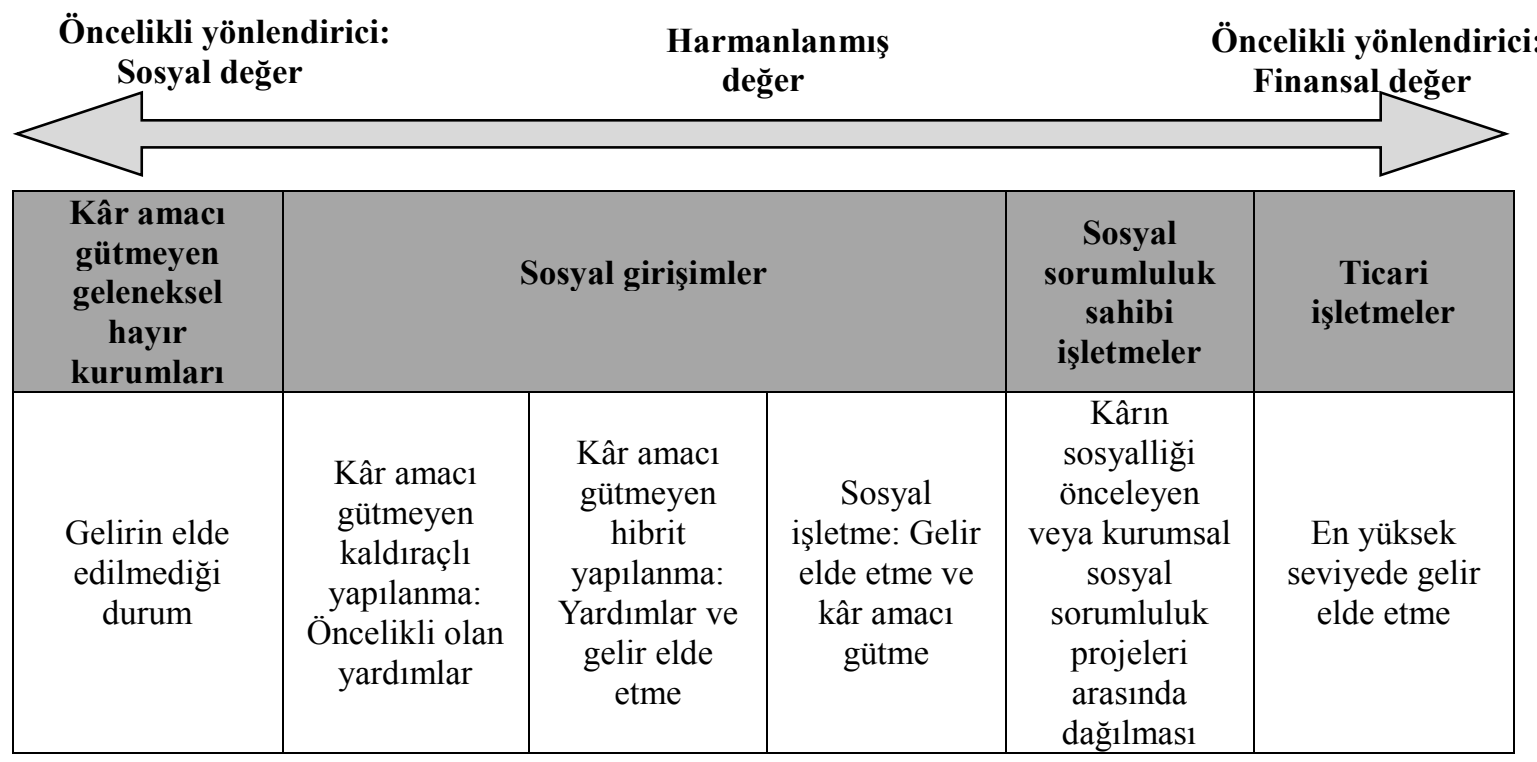

Şekil 1. Sosyal Girişimcilikte Değer Anlayıı̧ı Kaynak: Schöning, 2013

\section{Sinemasal Sosyal Girişimi}

Sosyal girişimler, kişilerin temel gereksinimlerini karşılamaları (Jain, 2009), toplumların yapılarını etkinleştirmeleri ve gelecek kuşakların alternatiflerini arttırabilmek amacıyla; gerekli olan ürün ve hizmetlerin etkin ve verimli bir şekilde ortaya çıkmalarını sağlamaya çalışırlar (White, 2014). Yetersiz koşullar sebebiyle sosyal etkinlikte bulunamayan, kırsal kesimlerde yaşayan çocukların yararlanması için geliştirilen Sinemasal projesi de bu amaca hizmet etmektedir. Tüketmek yerine üretmek düşüncesiyle yola çıkan Enes Kaya'nın çıkış noktası üretimi de bu topraklara özgü bir şekilde gerçekleştirmeye çalışmaktır. Kırsal kesimde yaşayan Enes Kaya ilk kez sinemaya gittiğinde duyduğu heyecandan dolayı çocuklar için bir şeyler yapmaya karar vermiştir. Projenin başlangıcını oluşturan bu düşünceler sosyal imkânı olmayan çocuklara bu koşulları sağlamayı hedeflemektedir. $\mathrm{Bu}$ amaçla kırsal alanlarda kültürel ve sanatsal etkinlikler gerçekleştirme isteğiyle 2007 y1lında bu serüveni gerçekleştirmek adına yola çıkılmıştır.

Projenin kurucusu olan Enes Kaya 1987 yılında Bolu'da dünyaya gelmiştir. Çeşitli sebeplerden dolayı Düzce, Denizli, Söke ve Erzurum'da ikamet etmiştir. 1999 yılı Düzce depreminin ardından Denizli'ye gelen Enes Kaya'nın ilk defa sinema salonuna giderek film izlemesi ve hayata bakış açısının değişmesi projenin ortaya çıkmasına sebep olmuştur. 12 yaşında yaşadığı psikolojik sorunları sadece bir öğrenci bileti ile atlatmaya başladığını fark eden Enes Kaya, üniversite öğrenimi süresince projesi üzerinde düşünmeye devam etmiş̧tir. Kendi yaşadığı bu farkındalık 
sürecini diğer insanların da yaşamasını isteyerek; bu amaçla kendini daha fazla geliştirmek adına Türkiye'de gerçekleşmekte olan festivallere katılmaya başlamıştır. Bu festivaller sayesinde organizasyon anlamında ufkunu genişletme imkânı elde etmiştir. Bu sürecin devamında yaz aylarında film sektörü ile ilgili edinmiş olduğu bir iş tecrübesi de ona farklı değerler kazandırmıştır. Enes Kaya tüm bu düşüncelerle proje fikri hakkında cevaplanmamış sorularına cevaplar bulmaya çalışmıştır: 'Hangi alanlarda neler yapılabilir?', 'Nasıl yapılabilir?', 'Birileri köylerde bir şeyler yapıyor mu?', 'Festivaller düzenleniyor mu?'

Enes Kaya proje kapsamında tüm günün dolu dolu geçtiği organizasyonlar gerçekleştirmek istemektedir. Bu organizasyonlarda sosyal etkinin en üst seviyede olması en fazla arzuladığı durumdur. Bunu gerçekleştirebilmek için de psikolog, eğitimci, film yapımcısı gibi farklı yeteneklere sahip kişileri de organizasyona dâhil etmeye karar vermiştir. Bu etkinliklerin gerçekleşebilmesi için finansal desteğin sağlanması gerekmektedir. Bu amaçla, finans desteği hakkında çeşitli insanlarla görüşmeler gerçekleştirilmektedir. Devamında da 2013 yılında Güneydoğu Anadolu'da bir festival gerçekleştirilmesine karar verilmiştir. Bakanlıktaki eğitim ve gençlik programı kapsamından alınan finansal destek sayesinde yola çıkan Enes Kaya ve arkadaşları hazırlıklara başlamıştır. Tanıtım kapsamında internet sitesi kurularak organizasyonda gerçekleşecek olan kapsamlı etkinlik programı düzenlenmiştir: İngiltere'den kukla oynatıcı, İtalya'dan ressam, Almanya'dan sihirbaz, Hollanda'dan yüz boyama ustası ve İspanya'dan dansçı programa dâhil edilmek istenilmiştir. Onlar için organizasyonun gerçekleştirileceği yer de en az etkinlikler kadar önemli bir konu olmuştur. İlk etkinliğin yerinin tespiti için 6 şehir ve 69 farklı köyde inceleme gerçekleştirilerek, köy seçiminde öncelikle yerli halk, sivil toplum örgütü ve üniversiteden olmak üzere üç kişi araştırma yapmıştır. Bu üç kişilik ekip süreçleri izledikten sonra Enes Kaya ve ekibin kalan kısmı festivalin yapılacağı köye gelerek köy seçiminde aşağıdaki şartları sağlayıp sağlamadığını analiz etmiştir:

- Köyde daha önce benzeri bir festivalin yapılmamış olmalıdır.

- Seçilen köy diğer köylere göre daha kötü şartlarda olmalıdır.

- Köyün popülasyonu en az 300 kişi olmalıdır.

- Köyün toplu taşıma imkânlarına elverişli olması gerekmektedir.

Ekip, bu şartları sağlayan köylerde artık festivalleri düzenlemeye başlamaktadır. Festivalin ilk gününde şehir merkezinde 'şehrin gözdesi' etkinliği kapsamında, küçük bir gösteri düzenlenmektedir. Bunun iki amacı bulunmaktadır: İzleyicilerin tümünün gösteriyi görmesini sağlamak ve herkesin dikkatini çekerek festivale davet edebilmektir. İlk gün gerçekleştirilen etkinlikte, Türkiye'nin dört bir yanını çevreleyen doğal güzelliklerin ve kültürel özelliklerin tanıtımına katkıda bulunan festival illerinin öncelikli konumunda olan özel bölgelerinde yaşayan halka nostaljik açık hava sineması keyfi yaşatılmaktadır. Takip eden günde ise ekip şehre dolaşmaya gitmektedir. Bu kapsamda gidilen illerin tarihi ve kültürel yerlerine düzenlenen gezilerin yanı sıra yöresel müzikler eşliğinde yemekler yenilmektedir. Böylece ulusal ve uluslararası kapsamda buluşmalar da gerçekleşmiş olmaktadır. Üçüncü gün ise festivalin gerçekleştiği en önemli gün olmaktadır. Ekibin köye gelişiyle beraber yüz boyama, resim atölyeleri, kısa film gösterimleri, karaoke yarışması, belgesel kuşağı, söyleşiler, jonglör, pandomim, sihirbaz, kukla ve flamenko dans gösterileri devamında da film gösterimi yapılmaktadır. Tüm bu etkinlikler için, 33'ü Türkiye'den 12'si yurtdışından olmak üzere 45 kişi görevlendirilmektedir. 4 gruba ayrılan ekibin her bir grubunun ayrı fonksiyonları bulunmaktadır:

Birinci grup, yurtdışından gelen ziyaretçilerin oluşturduğu faaliyet grubudur. Çocukları eğlendirecek kukla gösterimleri, yüz boyama, oyunlar oynama, pandomim oynamak ve dans etme etkinliklerinde bulunmaktadırlar.

İkinci grup, diğer köylerden gelen çocukların ulaşımını sağlayan gruptur.

Üçüncü grup, sinema etkinliği ile ilgilenen gruptur. Ekran, ışıklar, film makinası, patlamış mısır ve içecekleri organize etmekle görevlendirilmektedirler.

Dördüncü grup, ise tüm festivali organize etme görevi bulunmaktadır.

Festivali dört grup ile başarılı bir şekilde tamamlayan ekip, büyük bir mutluluk ve heyecan ile program bitiminde, çocuklarla vedalaşarak köyden ayrılmaktadır. Gerçekleştirilen etkinlikte farklı kültür, din ve ulustan insanlar bir arada bulunmaktadır. Farklı özelliklere sahip ekip ile sorunsuz bir şekilde etkinlik tamamlanmış olmakta ve bu noktada şu gerçek gözler önüne serilmektedir; nereden gelirsen gel, hangi kültüre ait olursan ol, hangi dili konuşursan konuş aynı sosyal sorun için çözüm bulunabilmektedir. Hatta farklılıklar beraberinde fayda sağlayarak mevcut bakış açllarını arttırarak zenginlik katmaktadır.

Böylece Enes Kaya, 2007 yılından beri hayalini kurduğu projenin ilkini 2013 yılında Güneydoğu Anadolu bölgesinde gerçekleştirmiş olmaktadır. Projenin devamında finansal kaynaklarda sorunlar yaşanmaya başlanmıştır. Beraberinde borçlanmalarda da artışlar olmuş ve Enes Kaya bu durumla baş edebilmek için türlü destekler için yoğun çaba harcamıştır. Bunlar arasında Bilgi Üniversitesi'nin düzenlediği sosyal girişimcilik yarışması, Avrupa Bakanlığı, Kültür Bakanlığı, valilik ile yurtiçinde ve yurtdışında gerçekleştirilen çeşitli ödüllü proje yarışmalarının katılımı yer almaktadır.

Güneydoğu Anadolu Bölgesinden sonra festivalin ikinci ayağı Karadeniz bölgesinde gerçekleştirilmiştir, ancak yüksek oranda borçlanmalara neden olmuştur. Zamanla çeşitli destekler aracılığıyla kapatılan borçlar sonrasında festivalin 3. ayağı için Doğu Anadolu Bölgesi seçilmiştir. 
'Sinema Artık Köylerde' sloganıyla yola çıkarak; bir filmin yaşattığı duygularla; insanların bakış açılarını ve olaylarla başa çıkışlarını etkilediğini düşünerek, sinemanın büyüsüne inanılmıştır. Kırsalda yaşayan, sosyal açıdan imkânları kısıtlı olan çocukların ve gençlerin; hayata daha olumlu bakabilmelerini, iyi bir gelecek hayal etmelerini ve bunun için ulaşabilecekleri imkânların farkına varmalarını sağlamak için çalışılmaktadır. Sinemasal projesi matematik temelli, psikolojik ve sosyo-kültürel anlamlarda çok yönlü bir çalışmadır. Dünyanın farklı yerlerinden gelen gönüllü insanların kültürel etkileşimleriyle beraber kişiler aldıkları görevlerle yaratıcılıklarını geliştirmektedirler. Tüm bu süreçlerde de kırsalda yaşayan çocukların ve gençlerin geleceklerine, sanatın bütün renklerini kullanarak katkıda bulunulmaktadır. Proje kapsamında kazanılan ödüller ve medyada yer almanın ardından Sinemasal projesinin fark edilirliği ve bilinirliği de artış göstermiştir.

\subsection{Sinemasal'ın Hedefleri ve Sosyal Değer Yaratımına Katkısı}

Sinemasal projesinin hedeflerinin gerçekleştirilebilmesi için sürekliliğinin sağlanabilmesi önceliklidir. Bunu sağlayabilmek için gerekli prensiplerin başında 'gönüllüllük' esası yer almaktadır. Geniş bir tabana yayılmış gönüllülük ağının çalışılan konulara hâkimiyetinin doğru belirlenmesi ve bunun toplumun diğer kesimlerine de iyi anlatılmış olması sahiplenilmeyi sağlayarak gönüllülük ilişkisini güçlendirecektir. Geniş ve nitelikli gönüllü katılımcı projenin hedeflerine ulaşmasında etkin rol oynayacaktır (Güder, 2006). Diğer önemli prensip de 'değer yaratma'dır. Projenin de öncelikli sloganı olan tüketmek yerine üretmek düşüncesi değer yaratarak sürekliliği hedeflemektedir. Prensiplerden biri de 'işbirliğinin sağlanabilmesi'dir. Projenin gerçekleşebilmesi ekibin tüm üyelerinin ortaklaşa işbirliğini gerektirmektedir. Projeyi finanse eden kurumlardan, proje etkinliklerinin tüm aşamalarını gerçekleştiren ekibe kadar ortak bir çaba önem arz etmektedir. Son olarak da projenin 'farkındalık yaratması' sağlanmalıdır. Farkındalık gerek toplum genelinde gerekse projeye dâhil olan katılımcılarda gerekse de projenin hedef kitlesinde gerçekleşebilmelidir. Projenin amacına ulaşmasında farkındalığı artırmak algıyı değiştirerek bilinç oluşturmayı sağlayabilmelidir. Bu dört prensip tam anlamıyla gerçekleştirildiğinde proje sürdürülebilirliğini sağlamaktadır.

Bireyin içinde bulunduğu toplumun sosyal değerlerini anlayabilmesiyle başlayan ve bu değerlere uyan davranışlar sergileyebilmesi onun sosyalleşmesini ortaya koymaktadır. Bu sürecin başlangıcı sayılan çocukluk döneminde ise bireylerin içinde bulunduğu kültür değerlerini özümseyerek hayata geçirebilmesi önemli olmaktadır (Sosyal Gelişim, 2007). Bu düşüncelerle Enes Kaya Sinemasal'ın hedefleri arasına hem kültür ve sanat alanında ilerlemeyi hem de eğitim sistemi ile ilgili değişiklikleri katmaktadır. Bu bağlamda; Sinemasal'ın kültür ve sanat alanıyla ilgili hedefinde, 2018 yılında Kapadokya'da planlanan organizasyonda organik tarım ve alternatif turizme dikkat çekilmek istenmektedir. Daha sonra film akademisi kurulması amaçlanmaktadır. 2021 yılına kadar bahsi geçen hedeflerin gerçekleştirilmesi istenen durumdur. Diğer taraftan eğitim sistemi ile ilgili hedefler de 2030 yll itibariyle eğitim sistemi ile ilgili değişikliklerin gerçekleşmesine katkı sağlayabilmektir. Bu hedef dâhilinde çocukların fikir üretebilmelerine imkân tanıyan ortamların oluşturulmasını teşvik etmek istenmektedir. Çünkü mevcut sistemde çocuklar ezberci eğitimin ortaya çıkardığı olumsuzluklarla karşı karşıya kalmaktadır. Çocukların hayal dünyasının gelişimini sağlayarak özgür düşüncenin gerçekleşmesi amaçlanmaktadır. Diğer bir ifadeyle Enes Kaya ön yargılardan uzak daha iyi ve yapıcı bir yaşam hedeflemektedir. Bunların tamamının gerçekleşebilmesi kolay olmayacaktır. Her şeye rağmen Enes Kaya ve ekibi amaçları doğrultusunda büyük bir zevkle çalışmalarını sürdürmektedir.

\section{E-Hastam Sosyal Girişimi}

Toplum içerisinde bir arada yaşayan bireylerin farkındalıklarını arttırarak sanat ve kültür unsurları ile iç içe yaşamalarının sağlanması kadar bir başka sosyal değer de, sağlık konusunda oluşturulması gereken değerdir. Bu sebep ile bu bildiride iki farklı konuya dikkat çekilmek istenmektedir. Çalışmanın bu kısmında da sağlık konusu ile ilgili oluşturulması gereken sosyal değer incelenecektir. Bu bağlamda bireylerin tümünün eşit, dengeli ve en yüksek düzeyde koruyucu ve tedavi edici sosyal yardım ve sosyal hizmetleri almaları gerekmektedir. Ancak bu faaliyetler örgütlenme sorunu, yönetim sorunu, insan kaynakları sorunu, finansman sorunu, enformasyon sorunu, hizmet sunumu sorunu ve sağlık sorunları sebebiyle tam olarak yerine getirilememektedir. Özellikle yaşanan bu sorunların doğrultusunda, doktorların yaşanan yoğunluk sebebi ile hastalarla yeterince ilgilenememeleri gelmektedir. Kronik hastalıklara bağlı hasta ölümleri bu noktada dikkati çekmektedir. T.C. Sağlık Bakanlığı'nın 'Kronik Hastalıklar ve Risk Faktörleri' adlı çalışmasında dünya üzerindeki ölümlerin yüzde 63'ünün kronik hastalıklar sonucunda oluştuğu ifade edilmiştir. Türkiye'de ise bu oran daha da artarak yüzde $80^{\prime}$ lere ulaşmaktadır (Ünal ve Ergör, 2013).

E-hastam projesinin de çıkış noktasını oluşturan bu düşünceler eczacı Cihan Çetin ve Doktor Zelal Akbayın tarafından sosyal girişimcilik projesi olarak ele alınmıştır. Eczacı Cihan Çetin ve Doktor Zelal Akbayın projenin kurucularındandır. Uzmanlık alanı aile hekimliği olan Zelal Akbayın günde 80 olmak üzere toplamda 4000 hasta ile ilgilenmiştir. Bu hastalardan bazıları kliniği düzenli olarak ziyaret etmiş, kimileri ise nadiren sağlık hizmetlerini talep etmiş̧lerdir. Akbayın bu süreçte hastaları inceleme ve değerlendirme imkânı bulmuştur. Özellikle kronik vakaların ölüme sebebiyet vermedeki artış oranlarının fazlalığı Akbayın'ın dikkatini çekmiştir. E-hastam ile birlikte kronik hastalıklar sebebi ölümlerin azaltılması amaçlanmaktadır. Bunu gerçekleştirebilmek için ilk adım olarak 
etkisiz ve verimsiz doktor ve hasta ilişkinin giderilmesi istenmektedir. Türkiye'de yaklaşık olarak 75 milyon insan vardır. Her bir hastanın bağlı bulunduğu bir aile hekimi vardır. Sağlık Bakanlığı'ndan alınan son bilgilere göre Türkiye'de 22.000 aile hekimi bulunmaktadır (Kamupersoneli, 2016). Aile hekimi başına yaklaşık olarak 3400 hasta düşmektedir. 3400 hasta ile ilgilenmek oldukça karmaşık ve yorucu bir iştir. Bu bağlamda kaynaklar da yetersiz kalmaktadır. Bu aşamada uzun hasta beklemeleri gerilimlere sebep olmaktadır. Özellikle yüksek risk taşıyan bebekler, çocuklar, yaşlılar ve yeni doğum yapmış anneler için önem derecesi artmaktadır. Bu durumda etkili iletişim kanallarının eksiliği nedeniyle rutin kontroller ve danışma hizmetleri aksamaktadır. Tüm bu eksikliklerin fark edilmesi ise beraber E-hastam projesi işler duruma geçirilmiştir. Bu proje ile Türkiye'de özelikle kronik hastalıklara sahip hastaların doktorlarla daha etkin bir iletişim kurmaları istenmektedir. Bununla beraber kan basıncı, kalp hızı, kan şekeri gibi önemli konularla ilgili insanları bilgilendirmek amaçlanmaktadır. Projenin vizyonu hastanın sağlığı ile her türlü bilgiyi öğrenmesini sağlayarak, gerektiğinde doktoru ile iletişime geçmesini sağlayarak kronik hastalık ölümlerinin önlenmesi hedeflenmektedir.

Hasta ve doktor iletişiminin sağlanmasını önceleyen proje, kurulan internet sitesi üzerinden yürütülmektedir. Online erişim sağlanan platformda randevu da talep edilebilmektedir. Aile hekimliği uzmanları ile gerçekleştirilebilen işlemler üç gruba ayrılarak incelenebilmektedir:

1.e-randevu: Hastalar ve doktorlar aralarında anlaşarak planlama yapabilmekte ve randevularını yönetebilmektedirler.

2.e-izleme: Hastaların kronik durumları takip edilebilmektedirler (Örneğin: Kan şekeri, tansiyon takibi gibi).

3.e-posta: Hastalar klinikler dışında bakım alabilmekte ve doktorlar hastalara herhangi bir zamanda kolayca ulaşabilmektedirler (Örneğin: Epidemik salgınlar boyunca gibi).

E-hastam uygulamasının kullanılabilmesi için web sitesinin tasarımı da önem arz etmektedir. Bu sebeple site oldukça anlaşılır ve nettir. Düğmeler ve yazı tipleri karışıklığı engellemek için ortalama büyüklüklerde tutulmuştur. Olabildiğince çok hastanın bu sistemi kullanabilmesi için ücretsiz üyelik olması öncelikli unsurlardandır. Yıllık üyelikleri bulunan doktorların sayısı arttırabilmek için hastanelere de hizmet verilmeye başlanmıştır. Bazı hastaneler E-hastam uygulamasına dâhil olmuşlardır.

Projenin finans kaynakları da diğer önemli unsuru oluşturmaktadır. Bunun için projenin başında dış kaynak bulmak oldukça zor olmuştur. Ancak kişisel fonlar ve gönüllü katılımcılar sayesinde proje finanse edilmiştir. Ehastam uygulamasının pilot çalışma kısmının tamamlanmasının ardından aile hekimliği uzmanları yıllık üyeliklerini satarak para kazanmaya başlamışlardır. Fonların oluşabilmesi için yıllık üyeliklerin yüzde 60 seviyesinde tutulması istenmekteydi. Fonların yüzde 30'luk kısmı e-reklamlardan sağlanmaktadır. Fonların son kalan yüzde 10'luk kısmı da hükümet ve hayırseverler aracılığg ile karşılanmaktadır.

\subsection{E-Hastam'ın Hedefleri ve Sosyal Değer Yaratımına Katkısı}

E-hastam sosyal girişimi teknolojinin gelişme gösterdiği günümüz şartlarında daha sağlıklı ve mutlu bir yaşam için oluşturulmuş bir platformdur. Ana temanın 'insan ve hayat' olduğu proje tüm insanlığı önemseyerek; herkesin hayatına değer katmayı amaçlamaktadır (E-hastam, 2016).

Kişilerin hayatına değer katma hasta ve doktorlar arasındaki iletişim etkili bir şekilde gerçekleşmesi ön koşuluna göre önem kazanmaktadır. Günümüz yoğun ve stresli yaşam koşullarında doktor ve hasta iletişiminin sağlanması birçok hastalığın ilerlemeden önlenmesini sağlamaktadır. Aynı zamanda maddi imkânı el vermeyen kişilere de firsatlar tanıyan proje, her bireyin eşit sağlık koşullarından yararlanmasını amaçlamaktadır. İnsan sağlığının en önemli değer olduğunu vurgulayan proje insan sağlığını dikkate alarak kattığı sosyal değeri arttırmayı hedeflemektedir. Projenin verdiği hizmetten dolayı aldığı ödülleri de doğru yolda olduğunu göstermektedir.

\section{Sonuç}

Sosyal girişimcilik kavramı değer yaratma olgusu ve sosyal sorunları çözme çıkış noktaları ile dikkatleri çekerken, yenilik ve değişim konularını da önemseyerek farklı kaynaklardan yararlanarak fırsatları kollama süreçlerini ifade etmektedir. Bu ifadeleri maddeler şeklinde açıklamak da mümkün olmaktadır:

- Sosyal değer yaratılması ve bunun belirli misyonların sürdürülmesinde kullanılabilmesidir.

- Oluşturulan misyonun yeni firsatlar doğrultusunda değişim ve gelişiminin sağlanmasıdır.

- Belirlenen yenilik ve değişimlerin uyum sağlayarak öğrenme süreçlerine girebilmeleridir.

- Sahip olunan kaynakları yönlendirici güç olarak kullanılabilmeleridir.

- Oluşturulan sosyal değer doğrultusunda yaratılan sonuçlar adına yüksek sorumluluk duygusunun sergilenebilmesidir.

Sinemasal ve E-hastam, yukarıda anlatılmak istenen tanımlamalar doğrultusunda içinde bulunduğu topluma birçok olumlu katkılar yapmış ve sosyal sorunlara çözüm bulmuş, yaratıcı birer sosyal girişim projeleri olarak karşımıza çıkarak; toplumun bölgesel ve yerel sosyal değer odaklı; kültürel, sanatsal ve sağlık alanlarındaki sorunlarına 1 şı tutmaktadır. 
Kırsal bölgede yaşayan sosyal bakımdan uygun şartları olmayan çocukların hayata olumlu bakabilmelerini, çevreleriyle olumlu ilişkiler kurabilmelerini, özgüvenlerini geliştirebilmeleri ve en önemlisi hayata daha güçlü tutunabilmelerini; kültür ve sanat öğelerini kullanarak sağlamaya çalışan Sinemasal sosyal girişimi matematiksel, psikolojik ve sosyo-kültürel anlamlarda çok yönlü bir çalışmadır. Aynı şekilde toplumun bir diğer önemli sosyal sorunu olan sağlık sektöründeki aksaklığa dikkat çeken E-hastam sosyal girişimi de kronik hastalıklara bağlı gerçekleşen hasta ölümlerinin önüne geçebilmek adına çalışmalarını sürdürmektedir. Tüm bu açıklamalar doğrultusunda; toplumsal gelişmenin ve kalkınmanın temelini oluşturan sosyal girişimcilik; sağlıklı ve daha güçlü toplumlar oluşturabilmek için sosyal değer ve fark yaratarak ülkemizdeki birçok sorunun çözümü için oldukça önemli bir kavram olarak değerlendirilebilmektedir.

\section{Kaynakça}

- $\quad$ Aidis, 2003. "Entrepreneurship and Economic Transition", Tinbergen Institute Discussion Paper, Amsterdam, p. 3-5

- $\quad$ Arıkan, 2002. Girişimcilik: Temel Kavramlar ve Bazı Güncel Konular, Siyasal Kitapevi, Ankara.

- $\quad$ Austin, Stevenson and Wei-Skillern, 2006. "Social and Commercial Entrepreneurship: Same, Different, or Both?”, Entrepreneurship: Theory and Practice, 30, p. 1-2.

- $\quad$ Bayrak Kök, 2007. Küçük ve Orta Ölçekli İşletmeler ve Kadın Girişimciliği, Gazi Kitabevi, Ankara.

- Carton, Charles and Meeks, 1998. "The Entrepreneur and Entrepreneurship: Operational Definitions of Their Role in Society", Terry School of Business, p. 1-5.

- Dees, 1998. "The Meaning of Social Entrepreneurship”, Stanford University: Draft Report for the Kauffman Center for Entrepreneurial Leadership, p. 1.

- Devos, 1996. Şefkatli Kapitalizm, Sistem Yayıncılık, İstanbul.

- $\quad$ E-hastam, 2016. http://www.e-hastam.com/, Erişim Tarihi: 18.05.2016.

- $\quad$ Ersen, Kaya ve Meydanoğlu, 2010. Sosyal Girişimler ve Türkiye: İhtiyaç Analizi Raporu, TÜSEV Yayınları, 50, İstanbul.

- Güder, 2006. STK’lar için Gönüllülük ve Gönüllü Yönetim Rehberi. Ankara: Sivil Toplum Geliştirme Merkezi.

- Harvey, 2015. Sermayenin Sınırları, Çev. Utku Balaban, Yazılama Yayınevi, İstanbul.

- Haugh, 2005. "A Research Agenda for Social Entrepreneurship", Social Enterprise Journal, 1, p. 2-3.

- Hopkins, 2007. Social Entrepreneurship: 'Real Word' Activations of the Liberal Arts Education, http//middlab.middlebury.edu.

- Iversen, Jorgensen and Malchow-Moller, 2008. "Defining and Measuring Entrepreneurship, Foundation and Trends in Entrepreneurship", Foundations and Trends in Entrepreneurship, 4, p. 3-5.

- $\quad$ Landström, Harirchi and Aström 2012. "Entrepreneurship: Exploring the Knowledge Base", Research Policy, 41, p. 1155.

- $\quad$ Luke and Chu, 2013. "Social Enterprise Versus Social Entrepreneurship: An Examination of The 'Why' and 'How' in Pursuing Social Change", International Small Business Journal, 31, p. 766.

- Jain, 2009. "Discovering Social Entrepreneurship", Asia-Pacific Business Review, 5, p. 23.

- Kamu personeli, 2016. http://www.kamupersoneli.net/saglik-personelleri/saglik-bakanligi-aile-hekimisayisini-30-bine-cikaracak-h2249.html, Erişim Tarihi: 20.05.2016.

- Mort, Weerawerdena and Carnegie, 2003. "Social Entrepreneurship: Towards Conceptualisation", International Journal of Nonprofit and Voluntary Sector Marketing, 8, p. 77.

- $\quad$ Muscat and Whitty, 2009. "Social Entrepreneurship: Values-Based Leadership to Transform Business Education and Society", The Business Renaissance Quarterly: Enhancing The Life At Work, 4, p. 34.

- Öktem, Leblebici, Aslan, Kılıç ve Aydın, 2003. "Girişimci Örgütsel Kültür ve Çalışanların İç Girişimcilik Düzeyi”, Hacettepe Üniversitesi İktisadi ve İdari Bilimler Fakültesi Dergisi, 1, s. 171-172.

- $\quad$ Popoviciu and Popoviciu, 2011. "Social Enterepreneurship Social Entreprise and the Principles of a Community of Practice", Review Research and Social Intervention, 33, p. 44-45.

- $\quad$ Ratiu, Cherry and Nielson, 2014. Humulity in Social Entrepreneurship: A Virtues Circle, Emerging Research Directions in Social Entrepreneurship, Springer, New York.

- $\quad$ Shapero, 1975. "The Displaced, Uncomfortable Entrepreneur", Psychology Today, 9, p. 31.

- Social Entrepreneurship Network, 2016, Social Enterprise Business Models and Financing, http://www.senstation.org/projects/mirjam-schoening/, Erişim Tarihi: 14.04.2016. 
- Sosyal Gelişim, 2007. Çocuk Gelişimi ve Eğitimi, Milli Eğitim Bakanlı̆̆ı, Ankara.

- Thompson, Geoff, Alvy and Lees, 2000. "Social Entrepreneurship: A New Look at the People and the Potential", Management Decision, 38, p. 328.

- $\quad$ Trivedi, 2010. "Towards a Social Ecological Framework for Social Entrepreneurship", The Journal of Entrepreneurship, 19, p. 63, 68.

- $\quad$ Trivedi and Stokols, 2011. "Social Entreprises and Corporate Enterprises: Fundamental Differences and Defining Features", The Journal of Entrepreneurship, 20, p. 2.

- $\quad$ Trivedi and Misra, 2015. "Relevance of Systems Thinking and Scientific Holism to Social Entrepreneurship", The Journal of Entrepreneurship, 24, p. 39.

- $\quad$ Ünal ve Ergör, 2013. Türkiye Kronik Hastalıklar ve Risk Faktörleri Sıklığı Çalışması, Anıl Matbaa Ltd. Şti, Ankara.

- White, 2014. Creating Public Value: An Examination of Technological Social Enterprise, Pate and Wankel içinde, Advances in Business Ethics Research, Springer, Massachusetts.

- William, Corbett and Gaster, 2001. "Who It Is and What It Does: Finding the "Heffa-Preneur" ", Academy of Entrepreneurship Journal, 7, p. 19. 


\title{
Kırsal Girişimcilik: Tarihten Günümüze Yatağan Örneği Rural Entrepreneurship: Yatagan Example from History to Present
}

\author{
Prof. Dr. Ayşe İrmiş (Pamukkale University, Turkey) \\ Ph.D. Candidate Hatice Çoban (Pamukkale University, Turkey) \\ Dr. Serkan Başol (Pamukkale University, Turkey)
}

\begin{abstract}
Wortman (1989) defines the rural entrepreneurship as the creation of a new organization that introduces a new product, serves or creates a new market, or utilizes a new technology in a rural environment. In other saying, rural entrepreneurship is a value creating activity for both entrepreneur and rural area. Rural entrepreneur is defined as someone who lives in rural and carries out entrepreneurial activities in there. Purpose of this study is to investigate rural entrepreneurship in rural development context. Accordingly, a field research was done in order to reveal rural entrepreneurship findings in Yatagan where Turkish swords and knives produce and market. After examination of documents including historical development and present situaiton of Yatagan's production and entrepreneurship tradition, interviews were conducted with related individuals who attempted on aforementioned area. According to the findings obtained from field research, the business which was founded by the local community failed to ensure its continuity. It means production and marketing activities turned back to the family business level. The production of Yatagan is effectuated in small workshops at the present day. Sales are performed personally or customers directly come to manufacturers and place an order by using the internet or by wholesalers. As a result of the field study, some suggestions have been presented to convert rural entrepreneurship to rural development.
\end{abstract}

\section{Giriş}

Girişimcilik sosyoloji, psikoloji, ekonomi, yönetim, finansman, siyaset bilimi gibi pek çok disiplinde ilgi görmüş ve her bir disiplinin kendi bakış açısıyla tanımlanmıştır. Bundan dolayı yazında, girişimciliğin çok sayıda tanımı mevcuttur. Aynı zamanda girişimcilik, firma düzeyinde, sanayi düzeyinde, bölgesel düzeyde, ulusal düzeyde hatta uluslararası düzeyde dikkate alınarak incelenmiş, bu açıdan da farklı bakış açılarıyla değerlendirilmiştir (Karadeniz, 2008). Ancak hemen hemen bütün tanımların ortak özelliği girişimcilikle bir oluşumun, bir ürünün, bir hizmetin veya bir sürecin risk alarak ortaya çıkarılmasıdır.

Girişimcilik çok genel olarak, bir fikir oluşturma, bu fikri ürün veya hizmete dönüştürme ve daha sonra oluşan ürün veya hizmeti pazara sunma faaliyetlerini kapsayan bir süreci ifade etmektedir. Günümüz rekabet şartları içerisinde girişimcinin girişimcilik süreci müddetince, kaynak temelli yaklaşım yerine firsat temelli yaklaşımla hareket etmesi, yenilikçi olması, bu bağlamda çevrede başkalarının yakalayamadığı firsatları yakalaması, risk alması, birey, topluluk ve toplum için değer yaratması beklenmektedir. Girişimci ise başarma ve rekabet etme güdüsü olan, sorumluluk alan ve yaptığı işi sahiplenen, bağımsız karar verebilen ve hareket edebilen, yeni bilgilere, yeni insanlara ve yeni uygulamalara açık olan, belirsizliği ve karmaşıklı̆ı tolere edebilen, yaratıcı ve esnek düşünen, sorun çözen, karar veren, firsatları görüp değerlendirebilen, alternatifler oluşturabilen, işi, örgütü ve riski yönetme kapasitesi olan, zorluklara karşı dayanıklı, vizyon oluşturan ve etki yaratabilen kişidir (Johnson, 2001). Girişimciler, yeni fikirler oluşturarak, bunları uygulamaya koyarak ve değer yaratarak farklı coğrafyalar arasında ve şimdiki zamandan gelecek zamana bir katalizör görevini görürler.

Slevin ve Covin'e göre girişimcinin, girişimsel vasıflara sahip olması ve girişimcilik davranışı göstermesi tek başına yeterli değildir. Aynı zamanda girişimsel davranışı destekleyen uygun bir kültürün ve uygun bir örgütsel yapının olması da gereklidir (Zhao, 2005). Girişimcilerin içinde bulundukları veya hitap ettikleri yerel, bölgesel, ulusal ve uluslararası çevrenin tarihsel geçmişi, kültürel özellikleri ve sunduğu firsat ve tehditler girişimsel faaliyetlerin varlığını, yoğunluğunu ve gelişimini etkilemektedir. Bu açıdan kırsal girişimcilik de bulunduğu coğrafyadan, sosyal yaşamından, tarihsel geçmişinden, geçim kaynaklarından ve meşguliyetlerinden etkilenir.

Girişimciliğin kırsalda gerçekleşip gerçekleşmeyeceği hususunda, kırsal girişimcilik ile kentsel alanlarda gerçekleşen girişimcilik arasında bir fark olup olmadığına dair fikir birliği oldukça azdır. Wortman kırsal girişimcilikle ilgili yaptığı literatür taramasında, kırsal girişimcilik tanımlarının kentsel alanlardaki girişimcilik tanımlarından ve genel girişimcilik tanımlarından alıntı yapılarak oluşturulduğunu görmüştür. Bu tanımlar risk alma, başarılı bir girişimde bulunma, inovasyon, 'yönetim yeteneği ve örgütleme becerisi' gibi unsurlar üzerinde duran tanımlardır. Keza Babb ve Babb'ın 1992'de Kuzey Florida'da yaptıkları çalı̧̧mada ise kırsaldaki girişimcilerin kişisel özelliklerinin, kırsal olmayan bölgelerdeki ya da kentlerdeki girişimciler ve yöneticilerin diğer çalışmalarda anlatılan özelliklerinden çok büyük farklılıklarının olmadığı sonucuna ulaşılmıştır. Sadece çok az çalışmada kırsal girişimciliğin kentsel girişimcilikten ya da kırsal girişimcilerin kentsel girişimcilerden farklılaşıı̆ı üzerinde durulmuştur (William ve Fortunate, 2014). Açıktır ki, kırsal alanlar girişimsel faaliyetler 
açısından bir takım zorluklara sahiptir. Kırsal kesimde yaşayan insanların elde ettikleri fırsatların ve sahip oldukları noksanlıkların veya yetersizliklerin türü çoğu zaman kentlerde yaşayan insanların sahip oldukları firsatlardan, noksanlıklardan veya yetersizliklerden farklıdır. Gelir, eğitim, yaşam şekli ve kontrol süreçleri vb. açılardan kırsal alanla kentsel alan birbirinden farklılaşmaktadır. Bu sebeple kırsal alandaki insanların önemli bir kısmı daha iyi imkânlara kavuşabilmek için kentlere göç ederken, ulusal ve uluslararası kurumlar da kırsal alanlarda mevcut girişimcilik potansiyelini artırmaya ya da bu alanlarda yeni girişimciliği özendirmeye çalışmakta ve bunun için teşvikler vermektedir. Başka bir ifadeyle, girişimcilik vasıfları ve girişimcilik süreci açısından kırsal alanla kentsel alan birbirine benzer özellikler gösterse de sahip olunan kaynaklar, bu kaynaklara ulaşma şekilleri, üretim gelenekleri, hayata bakış açıları, karşılaşılan sorunlar, sahip olunan firsatlar, işbirliği kültürleri vb. pek çok açıdan farklılaşmaktadırlar. Kırsal girişimcilik süreci ile kentsel girişimcilik süreci arasında dikkat çeken en önemli iki farklılık Lichtenstein ve Lyons (1996) ile Dabson (2001)'ın çalışmalarında dile getirilmiştir. Lichtenstein ve Lyons'a göre kırsal toplumların işe başlayıp devam ettirmelerini sağlayacak olan finans seçenekleri kentsel alanlardakilerine göre kısıtlıdır ve gerçekte, öz kaynakları hiç yoktur ya da işi başlatıp devam ettirmek için yeterli değildir. Ayrıca sınırlı talepten dolayı kırsal girişimler, kendilerine kırsal bölgelerin dışında pazar ve hizmet verecekleri iş alanları bulma mecburiyetinde kalmaktadırlar. Dabson'a göre ise kırsal toplumlar iş networklerinden (iş ağlarından) çok uzakta bulunmaktadırlar. Sınırlı nüfus büyüklüğü sınırlı talep miktarına ve yoğunluğuna sebep olmakta, böylece kırsal işletmelerin ölçek ekonomisine ulaşmasını zorlaştırmaktadır. Kentsel alanlardaki daha büyük olan nüfus yoğunluğu muhtemelen kırsal alanlardakinden daha fazla verimlilik ve kazanç sağlamakta, üstelik sonrasında daha yüksek yaşam maliyetini finanse etmektedir (William ve Fortunate, 2014).

\section{Kırsal Girişimciliğin Tanımı ve Önemi}

Girişimcilik kavramı çok uzun süredir üzerinde araştırma yapılan ve tanımlanan bir konu olmasına rağmen kırsal girişimcilik kavramının literatüre girişi daha ziyade 1980'lerden itibaren gerçekleşmiştir. Günümüze kadar yapılan çalışmalarda, kırsal girişimcilik, girişim süreci, ekonomideki rolü ve girişimcilerinin özellikleri gibi çok sayıda başlık altında incelenmiştir (Pato ve Teixeira, 2013). Ancak ülkemizde kırsal girişimciliğin literatüre girişi daha ziyade kırsal kalkınma başlığı altında sadece bir kavram olarak kalmıştır. Kırsal girişimciliği tanımlayan çalışmalar ve bu konuda yapılan araştırmalar henüz dikkat çekecek düzeyde değildir.

Girişimciliğin farklı disiplinler tarafından tanımlanmış olması, kırsal girişimcilik kavramı için de tek bir tanımın geliştirilmesini zorlaştırmaktadır. Kırsal girişimcilik kavramının ortaya çıkmasındaki kaynak tamamen girişimin yapıldığı alanla ilgilidir. Kırsal alanlarda yaşayan ailelerin veya kişilerin yaşadıkları yeri terk etmek istememeleri ya da terk edememeleri sebebiyle bulundukları bölgede çeşitli gelir kaynakları aramaya başlamaları onları bulundukları alanda girişimde bulunmaya sevk etmektedir. Kırsal alanlarda yapılan girişimler öncelikle o coğrafyada bulunan insanlar için istihdam sağlamakta, geliri artırmakta, üretim ve hizmet faaliyetleriyle bölge halkının hayat kalitesini yükseltmekte, böylece kırsal toplumların gelişimini ve istikrarını sağlayarak, kırsal kalkınmada motor güç olmaktadır. Kırsal girişimcilik kırsal kalkınmayı destekleyen en önemli faaliyetlerden biri olmasına rağmen, kırsal kalkınmadan farklı bir içeriğe ve tanıma sahiptir. Genel girişimcilik tanımları kapsamında, (yeni) bir ürünün üretilmesi, (yeni) bir pazarın oluşturulması, (yeni) bir teknolojik fayda sunan (yeni) örgütün kurulması gibi girişimcilik faaliyetlerinin, kırsal alanda ve kırsal alanın özelliklerine mahsus gerçekleşmesi kırsal girişimcilik olgusunu ortaya çıkarmaktadır (Wortman, 1989a). Kırsal girişimci kavramı da girişimcilik tanımının kırsal alandaki özelliklerine göre şekillenmektedir. Hoy (1983)'a göre kırsal girişimci, bağımsız karar veren ve faaliyete geçen, risk alan, hedef odaklı, kendine güvenen, iyimser, çalışkan ve inovatif özelliklere sahip, kırsal çevredeki girişimcilik faaliyetleriyle yeni istihdam alanları yaratan kişidir (Stathopoulous vd., 2004).

'Kırsal girişimcilik' ile 'kırsal alanda gerçekleşen girişimcilik' kavramları literatürde birbirinden farklı anlamlarda kullanılmıştır. Korsgaard ve arkadaşlarına (2015) göre girişimcilerin çeşitli teşvikler ve avantajlar için kırsal alanda faaliyet göstermeleri kırsal girişimcilik kapsamında sayılmaz. Maliyetleri düşürmek, devlet teşviklerinden yararlanmak gibi amaçlarla girişimcilerin kırsal alanlara yönelmesi "kırsal alanda gerçekleşen girişimcilik" kapsamındadır. Hâlbuki kırsal girişimcilik yalnızca daha kârlı olması gözetildiği için kırsal alanda gerçekleşen girişimcilik faaliyetleri değildir. Kırsal girişimcilikte parasal teşviklerden ve kârdan ziyade ilgili bölgenin girişimci için taşıdığı önem, kişisel, sosyal ve kültürel özellikler ön plandadır. Bu özelliklerinden dolayı kırsal girişimcilik faaliyetleri bulundukları "yer" ile ilişkilidir ve yerinden koparılarak başka bir alana taşınamaz. Kırsal girişimcilik, temelde topluma ve güçlü aile bağlarına dayalıdır ve kırsal toplum üzerinde nispeten daha büyük etkiye sahiptir (Elena vd., 2015). Bu bağlamda hem kırsal alanda gerçekleşen girişimcilik hem de kırsal girişimcilik, kırsal alandaki yoksulluğun ve yoksunluğun azaltılması ve ekonomik dönüşümün sağlanmasında o bölge insanlarının ve kaynaklarının oluşturduğu itici bir güçtür. Ayrıca her iki girişimcilik türünde de ulusal veya küresel pazarlara kıyasla daha pahalı olsa dahi yerel kaynakların kullanımına odaklanılır. Yerel kaynakların üretim için tahsis edilmesi hem ekonomik hem de sosyal olarak değer yaratmakta ve bölgesel dengeyi sağlamaktadır (Korsgaard vd., 2015). Ancak, kırsal alanda gerçekleşen girişimcilikte, devletin ve çeşitli kurumların özellikle finansal desteğinden dolayı başka yerlerdeki girişimcilerin kırsal alanlara gelip burada girişim faaliyetinde bulunması söz konusu olmaktadır. Böyle bir durum hâlihazırda kırsal alanda yaşayan insanların girişimci olmasından ziyade, teşviklerden dolayı başka coğrafyalardan gelen sermayedar ya da girişimcilerin kurdukları 
işyerlerinde işçi olarak çalışmaları sonucunu doğurur. Ayrıca kırsal alanda gerçekleşen girişimcilikte girişimcilik gücünün bir ya da bir kaç özel sermaye sahibinin elinde toplanması mümkündür. Her ne kadar kırsal alanda gerçekleşen girişimcilik de o alanda gelir düzeyini, eğitim düzeyini artırarak ve sermayenin tabana yayılmasını sağlayarak daha iyi bir yaşam tarzına sebep olursa da kırsal girişimcilik, doğrudan o alanda yaşayan çok sayıda insanın girişimci olmasına ve devamlılığını sağlamasına imkân verecektir. Kırsal girişimcilikte esas olan teşviklerden yararlansa da yararlanmasa da halkın girişimciliğidir. Kırsal alanda gerçekleşen girişimcilikte daha yüksek miktardaki sermaye çok daha az girişimcinin elinde toplanır ve kırsal alandaki halk gelirini sadece bir kaç büyük ya da orta düzeydeki firmada çalışan işçi ücretleri düzeyinde yükseltir. Kırsal girişimcilikte ise sermaye o kırsal alanda yaşayan, daha çok sayıda girişimcinin elindedir ve halkın geri kalanı KOBİ niteliğindeki çok sayıda işletmede istihdam edilme fırsatı bulabilmektedir. Kırsal girişimcilik beş kişiden daha az olan mikro işletmecilikten elli kişiden daha çok çalışanı olan büyük işletmeye kadar geniş bir yelpazeyi içine alır. Girişimcilik arzusu olan gençler, kadınlar, esnaflar, yeni göç etmiş kişiler kırsal girişimcilik potansiyelini oluştururlar (Markley, 2006).

Son yıllarda Avrupa Birliği'nin kırsal alanla ilgili politikalarında önemli değişiklikler gözlenmiştir. Bu değişikler tarım politikalarında yapılan reformlarla, Avrupa Birliği fonlarının yapısının değişimiyle, kırsal kalkınma politikalarının güçlendirilmesiyle, uluslararası ticaretin serbestleşmesiyle, teknolojik değişimlerle ve yerelleşmeyle ilişkilidir. Bu gelişmeler çerçevesinde Avrupa Birliği'nin ekonomik etkinliği sağlamak için kırsal bölgelerin entegrasyonuyla bütüncül bir gelişme sağlamak istediği söylenebilir (Stathopoulous vd., 2004).Avrupa Birliği KOBİ kapsamındaki işletmelere önemli ölçüde fon sağlayarak, kırsal kesim girişimciliğinin gelişmesine de dolaylı katkı vermektedir. Benzer şekilde ABD'de de girişimciliği ve küçük işletmeleri desteklemek için pek çok strateji ve program geliştirilmiştir. Kırsal alanlarda ise bu stratejiler ve programlar kırsal girişimcilik üzerine odaklanmıştır. Özellikle yönetim ve ekonomi alanındaki destekleri içeren bu çabalar; kırsal toplum araştırmaları ve teknoloji aktarımlarını, kısmen ya da tamamen devlete ait olan organizasyonların bu alanlarda kurulmasını, küçük işletme geliştirme merkezlerinin açılmasını, küçük ölçekli sanayi hizmet merkezlerinin ve kırsal bölgedeki girişimciliği destekleyen finansal kurumların oluşturulmasını, kırsal girişimcilere eğitim programları sunulmasını kapsamaktadır (Wortman, 1989b).

\subsection{Kırsal Girișimciliğin Faaliyet Alanları}

Kırsal girişimcilik denildiğinde ilk akla gelen faaliyet kolu daha ziyade kırsal alanlarda gerçekleşen tarım faaliyetleridir. Ancak kırsal alanın tarihsel geçmişi ve kültürel sermayesi, girişim konularını daha geniş bir yelpaze içerisinde sınıflandırmaktadır. Kırsal alandaki girişimciliğin varlığı ve gelişmesindeki en önemli faktörlerden biri yerel bilgi birikimiyle zenginleşen kültürel sermayedir. Kültürel sermayenin varlı̆̆ kırsal girişimciliğin hızlanmasında etkin rol oynamaktadır (Çekiç ve Ökten, 2009). Kültürel sermaye bir nesilden diğerine aktarılan genel kültürel birikim, bilgi ve becerinin toplamıdır. Kültürel sermaye ile birey içerisinde bulunduğu sosyal yapının gelir, meslek, yaşam tarzı ve tüketim alışkanlıklarını kazanır ve bunu diğer nesillere aktarabilir (Abdioğlu ve Yavuz, 2013). Yerel bilginin birikimiyle tarihsel süreç içerisinde oluşan kültürel sermaye, nesiller arasında üretimin ve üretim becerisinin yaygınlaşmasını sağlayarak kırsal ve hatta kentsel alanlarda hayatın devamlılığını ve kırsal girişimciliğin yaygınlaşmasını sağlar (İrmiş ve Eroğlu, 2015). Bu bağlamda kültür, yerel kalkınma stratejileri içinde önemli bir bileşen olarak ortaya çıkar (Denis-Jacob, 2012). Özellikle kırsal girişimcilikte önemli rol oynayan KOBİ niteliğindeki işletmeler, içerisinde bulundukları coğrafyanın kültürel sermayesinin kendine kazandırdığı yerel bilgiyi ürünlerine, üretimine, pazarlamasına ve süreçlerine yansıtır. İngiliz Bira ve Pub Derneği ile Rycroft tarafından istatistiklere dayanarak 2013 yılında yapılan açıklamaya göre, İngiltere'deki mikro bira fabrikalarının sayısı, 2002-2013 yılları arasında \%184'lük bir artışla ikiye katlanmıştır. Bu durum, Mark ve arkadaşlarına göre yiyecek ve içecek tercihlerinin kültürel sermaye ve tecrübelerle ilgili tercih olmasından kaynaklanmaktadır. Başka bir ifadeyle, daha yerel ve otantik nitelikleri olan üretim talebi, pazarlama yaklaşımına yansımıştır (Ellis ve Bosworth, 2015). Yerel bilginin birikimiyle oluşan kültürel sermaye ve kültürel tercihler kırsal girişimciliğin üretim ve pazarlama konularını ya da kırsal alanlarda yapılan girişimlerin sektörlerini belirleyen en önemli faktördür.

Kırsal girişimcilik denildiğinde en çok akla gelen ziraatle ilgili konular kırsal girişimciliğin kapsamı içerisinde yer alırken aynı zamanda turistler için yiyecek sağlama, nalbantlık, marangozluk, iplik eğirme vb. birçok zirai olmayan faaliyet de kırsal girişimcilik kapsamında yer alabilmektedir. Zira kırsal girişimciliğin faaliyet konusu o alanın fiziki kaynakları, yerel bilgisi ve kültürel sermayesi ile şekillenmektedir. Bu kaynakların girişimci kombinasyonlarına, turizm hizmetleri, spor ve dinlenme tesisleri, toptancılık ve perakendecilik, mühendislik ve el sanatları gibi endüstriyel uygulamalar; et, süt, ahşap gibi katma değer yaratan ürünler vb. pek çok örnek verilebilir (Saxena, 2012). Bu bağlamda kırsal girişimcilik aşağıda ifade edilen birçok sektörün konusu dahilinde oluşmaktadır (Kushalakshi ve Raghurama, 2014):

1. Tarıma Dayalı İşletmeler: Turşu, şeker üretimi, yağlı tohumlardan yağ elde edilmesi, süt ve süt ürünleri, meyve suyu, baharat üretimi vb.

2. Orman Ürünleri Endüstrisi: Ahşap ürünler, bal yapımı, bambu ürünler vb.

3. Maden Sanayi: Taş kırma, çimento, duvar kaplama malzemesi üretimi vb.

4. Tekstil Endüstrisi: Dokuma, boyama, iplik üretimi ve ağartma gibi faaliyetler 
5. El Sanatları: Yöreye ait ahşap, gümüş, sedef, demir işleme, kakma, çelik işleme gibi el sanatları, geleneksel dekoratif ürünler, oyuncaklar vb.

6. Mühendislik ve Diğer Hizmetler: Tarımsal alet, edavat, traktör ve pompa setleri, onarım işleri vb.

\subsection{Kırsal Girișimciliğin Kalkınmadaki Rolü ve Önemi}

Kırsal girişimciliğin en önemli ve en bilinen katkıları üç alanda gerçekleşmektedir. Bunlar girişimin bulunduğu alandaki kalkınmanın sağlanmasıyla kırsal kalkınmaya, kentlere gereğinden fazla nüfusun göç etmesini engelleyerek, sanayine ara mamül ve fason üretim sağlayarak ve halkın ihtiyacına destek vererek kentsel kalkınmaya ve bir bütün olarak da milli gelirin, üretim hacminin, ihracat oranının, eğitim ve uzmanlaşmanın, istihdamın ve kişi başına gelirin artmasıyla toplumsal ve ulusal kalkınmaya katkı sağlamaktadır. Saxena (2012) kırsal girişimciliğin önemini yedi başlık altında toplamıştır:

1. İstihdam imkânı sağlaması: Kırsal girişimcilik, kırsal alanda endüstri birimlerinin gelişmesini sağlar, istihdam imkânları oluşturur ve gelir yaratmada yüksek bir potansiyele sahiptir.

2. Kırsal nüfusun kente göçünde kontrol sağlaması: Kırsal girişimcilik, kırsal alandaki ve kentteki insanlar arasında bulunan gelir eşitsizliğiyle ilgili boşluğu doldurur. Enerji, yol, köprü gibi altyapı imkânlarını, eğitim firsatlarını sağlar ve geliştirir. Böylece kırsal alandan kentlere göç edilmesinin önüne geçer.

3. Dengeli bölgesel büyüme: Kırsal girişimcilik, sanayi kuruluşlarının kentlerde yoğunlaşmasının önüne geçer ve dengeli bir bölgesel kalkınmaya önayak olur. Aynı zamanda kırsal nüfusun girişim faaliyetlerinde yerel kaynakların optimum kullanımı prensibi (Patel ve Chavda, 2013) küresel rekabette de dengeli bölgesel büyümeye katk1 verir.

4. Sanatsal etkinliklerin desteklenmesi: Kırsal alandaki kültürel zenginlikler, sanatsal faaliyetler ve el sanatları korunarak geliştirilebilir.

5. Toplumsal sıkıntıların önüne geçme: Kırsal girişimciliğin artması, yoksulluk, gecekondulaşma ve kirlilik gibi bir takım sosyal problemleri azaltabilir.

6. Kırsal alandaki gençliğin harekete geçirilmesi: Kırsal girişimcilik, kırsaldaki gençleri harekete geçirebilir ve onların girişimciliği benimsemelerinde ve girişimciliği kariyer olarak tercih etmelerinde farklı alternatifler sunar.

7. Yaşam standardının iyileştirilmesi: Kırsal girişimcilik kırsal nüfusun okuryazarlığını artırır. Kırsal nüfusun artan eğitimi ve serbest meslek uğraşı onları zenginleştirerek ve başarılı kılarak yaşam standartlarını yükseltir.

Kırsal girişimciliğin önemi aynı zamanda kırsal alandaki gençlerin ve kadınların girişimciliğe özendirilmesinde de ortaya çıkmaktadır. Zira girişimciliğin gelişmesi ve girişimci bir topluluğun varlığı, kırsal alandaki diğer insanların da girişimciliğe uyum sağlayacağı bir kültürel değişimin ortaya çıkmasına zemin oluşturur. Rădulescu ve arkadaşlarının (2014) yaptıkları araştırma sonuçlarına göre, girişimcilikteki motivasyonel faktör ilk girişimsel adımdır. Yeni bir işletmenin kurulmasındaki en önemli argümanlardan biri de iyi bir yaşam standardının sağlanmasıyla ilgili beklentidir. Böyle bir beklentinin varlığ 1 , oluşan girişim kültürü içerisinde, girişimde bulunma arzu ve isteğini genç nüfusta ve kadınlarda körükleyecektir.

Özellikle kırsal nüfus içerisinde bulunan kadınların istihdamı, kayıtlı işçi olarak çalışmalarının getirdiği avantajlar ve kadın girişimciliğin oluşumu kırsal girişimcilikle gerçekleşmekte, bu da kırsal kalkınmaya ivme kazandırmaktadır. Literatürdeki pek çok çalışma kırsal girişimcilik konusu içerisinde, kırsal girişimciliğin kırsaldaki kadınların girişimciliğine ve istihdamına verdiği katkıyı, ayrı bir başlık altında ya da daha geniş bir kapsam dahilinde ele almaktadır. Çünkü kırsal kesimdeki kadınların, ekonomide önemli rol oynamalarına rağmen, bilgi eksiklikleri ve bilgiye ulaşma konusundaki zayıflıkları sebebiyle çoğu zaman yaptıkları işle ilgili verimlilikleri ve mevcut potansiyellerini kullanma imkânının azaldığı düşünülür. Lashgarara ve arkadaşlarının (2011) yaptıkları çalışmada da görülmüştür ki, kırsal kesimde yeni bir işe başlayan kadınlar işle ilgili bilgi ve destekleyici sistemler konusunda oldukça zayıftır. Aynı zamanda, yeni girişimde bulunan kadınlar yatırım ve tasarruf gibi donanımlara, yönetim ve eğitim tecrübelerine de sahip değillerdir.

Kırsaldaki kadın girişimcilerin karşılaştıkları problemlerin temeli eğitim düzeylerinin düşüklüğü, girişimde bulundukları işle ilgili altyapılarının yeterli olmaması ve zamanlarını kullanırken iş ve aile dengesini sağlamak zorunda kalmalarıdır. Kırsal alandaki yaşam tarzının daha ziyade ataerkil olması kırsaldaki kadın girişimcilerin karşılaştıkları problemlerden diğeridir. Ataerkil toplumlarda erkekler kadınların girişim faaliyetlerinin finanse edilmesini genellikle büyük bir risk olarak algılayabilmektedirler. Ayrıca, kırsaldaki kadınların okur-yazarlık düzeylerinin ve eğitim seviyelerinin düşüklüğü yeni teknolojilerin kullanımında cahil ya da beceriksiz olmaları sonucunu doğurmaktadır. Kadınların düşük risk alma istekleri, özellikle satış ve pazarlama konusunda altyapı eksikliği ve genellikle kendi tasarrufları ya da aile, akraba ve arkadaşlarından edindikleri borçlarla finans kaynaklarını sağlamaları kırsaldaki kadın girişimcilerin karşı karşıya kaldıkları problemlerin diğer kaynaklarını oluşturur (Mehta ve Mehta, 2011).

Kırsal girişimciliğin bir başka önemi ise örgütlenme ve stratejik iş birliklerinin kurulması açısından görülmektedir. Kırsal alanda tedarik araçlarına ulaşma, finansal kaynak yetersizliği, pazara ulaşma ve aracı kurumlara bağlı kalma gibi problemlerden dolayı kırsal girişimciler, kendi aralarında kooperatif, dernek vb. usullerle örgütlenerek, stratejik işbirliği yapmaya ve güç kazanmaya çalışmaktadırlar. Böyle bir sürecin ve oluşumun varlığı bir taraftan girişimciler arasında sinerji yaratıp, ekonomik gelişme ve kırsal kalkınmaya katkı sağlarken diğer taraftan da, daha büyük sermaye sahiplerine, siyasi güce ve bürokrasiye karşı dirençli durma 
konusunda güç vermekte ve örgütlenme geleneğinin yaygınlaşmasını sağlamaktadır. Kırsal girişimcilik neticesinde örgütlenme olgusunun gelişmesi, sivil toplum olgusu ve sermayenin tabana yayılması demokrasinin de gelişmesi ve tabandan tavana doğru başka bir ifadeyle çevreden merkeze doğru daha kuvvetli ve gerçek anlamıyla vuku bulmasını sağlayacaktır.

\subsection{Kırsal Girişimcilikle İlgili Problemler}

Kırsal girişimcilikle ilgili problemler, kentlerdeki girişimcilikte yaşanan problemlerle bazı yönlerden benzerlik göstermektedir. Ancak, kırsal alanların coğrafya itibariyle diğer alanlardan izole olması ve nispeten daha kapalı bir sistem özelliği gösteren kültür anlayışının varlığı kırsal girişimlerin yaşadığı sorunları kentlerdeki girişimcilerin sorunlarından farklılaştırır. Ayrıca, kırsaldaki girişimlerin boyutunun ağırlıklı olarak küçük, az miktarda da orta düzeyde olması, KOBİ'lerin yaşadıkları bütün problemleri kırsal girişimcilerin de yaşamalarına sebep olmaktadır. Bu bağlamlarıyla, kırsal girişimlerin yaşadıkları sorunların kaynağı çoğu zaman, yerel talebin sınırlı kalması, diğer pazar alanlarına ulaşmadaki güçlük, şebeke oluşturma firsatlarının az olması, modern bilgi teknolojilerini kullanmayla ilgili bilgi ve becerilerinin eksikliği ve sınırlı sermaye olarak görülmektedir (Fuller-Love vd., 2006). Yapılan araştırmalarda kırsal girişimcilikle ilgili yaşanan sorunlar aşağıdaki gibi sınıflandırılmaktadır (Saxena, 2012):

1. Finansal problemler: Kırsal girişimcilerin çoğu, yeterli teminat gösteremedikleri için kredi ve fon bulma konusunda güçlük yaşamaktadırlar. Ayrıca, faiz oranlarının yüksekliğinden dolayı bankalardan borç almanın güç olması, kırsaldaki tüketicilerin satın alma gücünün düşüklüğü, satış hacminin yetersizliği, işe başlamak için finansman eksikliği, mal ve hizmetlerin fiyatlandırılmasından kaynaklanan 'azalan kâr oranları' vb. sebepler de finansal sorunlara yol açmaktadır. Finansal kaynakların ve dış desteklerin eksikliği kırsal girişimciler için risk alma kapasitesini düşürmekte, böylece sürdürülebilir rekabet güçlerini azaltmaktadır.

2. Pazarlama problemleri: Kırsal girişimler, pazarda doğrudan nihai tüketiciye ürünlerini satabilirler ya da aracı kurumla ürünlerini pazara yönlendirirler. Aynı zamanda, büyük ölçekli firmaların ve kentlerdeki girişimcilerin tamamlayıcısı olarak da faaliyet gösterebilirler. Ancak, kırsal alanlarda, yüksek girdi maliyetinden dolayı yüksek ürün maliyetine maruz kalınır. Ürün maliyetinin yüksekliği ve ürünlerinde standardizasyonu yakalamadaki eksiklikleri kırsal girişimlerin, kentlerdeki KOBİ'lerle ve büyük ölçekli firmalarla rekabetini güçleştirir. KOBİ özellikleri ve finansal kaynakların sınırlı olması dolayısıyla çoğu kırsal girişim ürünü herhangi bir markaya sahip değildir, markası olanlar ise markalarına ve satış promosyonlarına harcama yapmayı göze alamayabilirler. Kırsal girişimcilerin, büyük miktardaki kârı ceplerine indiren aracılara bağımlı olmaları, depolama tesislerinin ve nakliye araçlarının yoksunluğu, diğer pazarlama problemlerini oluşturur.

3. Yönetim problemleri: Bilişim teknolojileriyle ilgili bilgi eksiklikleri, teknik bilgi eksiklikleri, yasal işlemlerle ilgili bilgi eksiklikleri ve lisans alma gibi hususlarda birtakım yasal formalitelere uyum sağlama zorlukları, hammadde temini, depolanmasıyla ilgili problemlerin ortaya çıkardığı düşük hammadde kalitesi kırsal girişimcilerin yönetim problemleri olarak ifade edilmektedir. Kırsal girişimciliğin gelişmesindeki en önemli yönetim problemlerinden bir diğeri de standart araç ve ekipman eksikliği ve düşük hammadde kalitesinden dolayı ürünlerin kalitesinin de düşük olmasıdır.

4. İnsan kaynağıyla ilgili problemler: Kırsal alanda çalışan işçilerin ucuz iş gücü olmalarına rağmen, düşük eğitim ve beceri düzeyi personel devir oranlarının yüksek olması, hem çalışanların hem de girişimcilerin yenilikçi düşüncelerinin nispeten daha kısıtlı olması insan kaynağıyla ilgili problemlerine temel teşkil eder. İnsan kaynağıyla ilgili bir başka problem ise girişimcilik firsatlarıyla ilgili bilinç ve bilgi eksikliğinden kaynaklanmaktadır. Aile, toplum ve diğer destek grupları, kişilerin bir kariyer olarak girişimciliği tercih etmelerinde çok cesaret verici değildir. Bu bağlamda kırsal alanlarda girişimcilik kültürü zayıf kalabilmektedir.

\section{Bir Kırsal Girişimcilik Örneği Olarak Yatağan Beldesi}

Kırsal girişimcilik çalışmasının araştırma alanını kırsal bir alan olan Denizli Yatağan beldesindeki üretim ve girişimcilik süreci ve faaliyetleri oluşturmaktadır. Araştırmanın amacı; Yatağan beldesindeki üretim ve girişimcilik faaliyetlerinin tarihsel geçmişini, üretim ve girişimcilik kültürünün oluşumunu ve Yatağan'daki günümüz üretim ve girişimcilik anlayışına yansıyışını, halihazırdaki üretim konusunun ne veya neler olduğunu ve mevcut girişimcilik sürecini keşfetmektir. Araştırmanın ikinci amacı, Yatağan'daki kırsal girişimciliğin kırsal kalkınmaya, örgütlenme faaliyetlerine ve kırsaldaki kadınların istihdamına ve girişimciliğine etkisini araştırmaktır. Araştırmanın üçüncü amacı ise kırsal girişimciliğin gelişmesi ve karşılaştığ problemlere çözüm getirilebilmesi için önerilerde bulunmaktır. Bu doğrultuda hazırlanan araştırma soruları şunlardır:

1. Yatağan'daki üretimin ve girişimciliğin tarihsel ve kültürel geçmişi nasıldır?

2. Yatağan'da girişimcilik faaliyetleri nasıl gerçekleşmektedir?

3. Kadınlar işgücü istihdamında ve girişimcilik sürecinde hangi ölçüde ve nasıl yer almaktadırlar?

4. Yatağan'da üretilen ürünlerin hammaddesi ve ara mamulü nasıl tedarik edilmektedir?

5. Yatağan'da üretilen ürünlerin pazarı nasıl oluşmaktadır?

6. Yatağan'da bu üretimle ilgili halkın oluşturduğu birlikler, örgütler var mıdır? 
Araştırmada bahsi geçen sorulara cevap aramak ve incelemek üzere ilk aşamada Yatağan'daki üretimin ve girişimciliğin tarihsel ve kültürel geçmişini ve bugünkü durumunu incelemek üzere kaynak taraması yapılmıştır. Daha sonra araştırmacılar tarafından bizzat Yatağan'a gidilerek yarı biçimsel mülakatlar yapılmış ve mülakattan elde edilen bilgiler yorumlanmıştır. Yapılan mülakatlara 4'ü kadın 19'u erkek olmak üzere 23 kişi katılmıştır. Yatağan'da kadınların eşlerine üretimde yardımcı olmaları sebebiyle, 4 mülakata kadın ve kocası beraber katılmış ve beraber cevap vermişlerdir. Mülakata katılan kişiler şunlardır:

Hüseyin Can (78 yaşında, hala çalışan en eski usta, yatağan, kılıç, bıçak ve diğer kesici aletleri üretiyor); Ali Vehbi Kocakaya (Kesici el aletleri pazarlıyor, aynı zamanda kemik tarak ustası); Ziya Karaca (YABELTAŞ'ın müdürlüğünü yapmış ve usta); Şener Yatağanbaba (Şimdiki kooperatifin başkanı, bıçak ve kemik tarak yapımı ustası); Süleyman Şahin (Usta, el yapımı bıçaklar ve kılıçlar yapıyor); Osman Can (Usta, el yapımı bıçaklar ve kılıçlar yapıyor, film endüstrisine ve koleksiyonerler yaptığı ürünlerle tanınıyor); Abdurrahi Aydın (Usta, el yapımı ürünlerini İstanbul'da işportada satıyor); Hidayet Akın (Usta, Eski kütüphane memuru); Gürkan Çalhan (Usta); Mehmet Ali Aslankaya (Usta)-Aysel Aslankaya (eşine üretimde yardım ediyor); Ali İhsan Güner (usta)Fatmahanım Güner (eşine üretimde yardım ediyor); Erkan Can (Usta)-Tülay Can (eşine üretimde yardım ediyor); Mehmet Yurttürk (Usta)-Ayşen Yurttürk (eşine üretimde yardım ediyor); Mehmet Baykara (Kazma ağzı üreten atölyenin ortağı ve yöneticisi, kardeşiyle beraber çalışıyor); Vehbi Aydın (Lazer markalama yapıyor); Hüseyin Kocakaya (Bıçak ustası, Aşık-Ozan, Yatağan'a mahsus eski ev eşyaları ve üretim aletlerini, kendisinin müze olarak tanımladığ1 yerde sergiliyor); Alim Ayduran (Usta, Yatağan Esnaf ve Sanatkarlar Odası Başkanı); Hüseyin Ayduran (Koyun kırpma makası ve bıçak atölyesinin ortağı, babası ve iki kardeşiyle beraber çalışıyor); Tuncer Tunçbilek (1994-2004 ve 2009-2014 yıllarında görev yapan Yatağan eski belediye başkanı)

\subsection{Geçmişten Günümüze Yatağan Beldesinin Üretim Ve Girişimcilik Kültürüyle İlgili Elde Edilen Bilgiler}

Yatağan, Denizli şehir merkezine 34 kilometre, bağlı olduğu Serinhisar ilçesine 10 kilometre uzaklıkta bulunan bir beldedir (www.haritatr.com, 2016). Kesici aletler üretimiyle bilinen Yatağan beldesinin Türk yönetimine geçiş tarihi 1200'lü yıllara uzanmaktadır. Daha önceden ilçe olan fakat Denizli ilinin büyükşehir olmasıyla belde olan Yatağan, ismini de üretim konusundan almıştır. Yatağan ismiyle ilgili bilinen iki rivayet vardır. Bir rivayete göre, Yeniçerilerin bellerine bağladıkları meşinden yapılan silahlığın içine, kılıçların ya da bıçakların yanlamasına yatık olarak koyulması sebebiyle bu savaş aletlerine yatağan adı verilmiştir. Bir başka rivayete göre ise, Selçuklu komutanı olan Osman Bey’in Yatağan Baba namıyla ün salmış olmasından kaynaklıdır. Belde ismini Osman Bey'in namı dolayısıyla kazanmıştır. Tüm dünyada Türk kılıcı olarak bilinen Yatağan, döneminin diğer kılıçlarına göre çok daha keskin, sağlam ve sanatsal olarak göz alıcı bilinir. Kabzasının baş kısmı iki kulak şeklinde olup Y harfine benzemektedir. Daha çok yeniçeriler ve zeybekler tarafından kullanılan yatağanlar, kılıçtan daha küçük ve hafif olduğu için belde taşınması daha kolaydır (pamukkale.gov.tr, 2016).

Hüseyin Can'la yapılan mülakattan ve taranan belgelerden elde edilen bilgiye göre Yatağan, Selçuklu Sultanı Alaaddin Keykubat'ın uç beylerinden olan Osman Bey ve komutanı Abdi Bey tarafindan kurulmuştur. Yatağan'ın Türk yönetimine geçmesinde önemli rolü olan Osman Bey daha sonra buraya yerleşerek, Orta Asya'dan getirdikleri demircilik sanatını icra etmiş ve yöre halkına öğretmiştir. Pala ve kılıç yapımında uzmanlaşan Yatağanlılar, Osmanlı ordusuna ve yeniçerilerine de üretim yapmış ve bu konudaki başarılarından ve uzmanlıklarından ötürü Osmanlı Padişahları Yatağan’ı sancak ve beraat ile ödüllendirmişlerdir. Yatağan'da aynı zamanda barut üretimi de yapılmıştır. Osmanlı ordusunun pala, kılıç, barut gibi savaş silahlarının üretim yeri olan Yatağan, İstanbul'un fethinde kullanılan barutların üretim merkezi olması dolayısıyla bir kez daha önem kazanmıştır. Silahın icat olmasıyla beraber Yatağan'ın silah üretimi konusundaki uzmanlığı da zaman içerisinde önemsizleşmeye başlamıştır. Bunun yerine özellikle Cumhuriyet döneminde kılıç ve pala yapma işi; mutfak, ziraat ve el aletleri gibi diğer kesici aletleri yapmaya kaymıştır (Ekol, 2000). Ayrıca, milli mücadele yıllarında baruta duyulan ihtiyaç sebebiyle Yatağan Derin-çay mevkiinin içi bir barut imalathanesi olarak kullanılmış, her aileye burada bir yer verilmiştir. Barut üretiminin de neredeyse bıçak kadar eski bir tarihi olduğu düşünülmektedir (Baykara, 2013). Hatta milli mücadeleden daha sonraki zamanlarda barut üretimine gizlice devam edilmiş fakat birkaç kişinin üretimde ölmesi dolayısıyla günümüze taşınmamıştır. Bunların haricinde Yatağan'da tarakçılık, iplikçilik, kilim dokumacılığı, leblebicilik, kalaycılık gibi üretimler de yapılmıştır. Yapılan mülakatlarda, Ali Vehbi Kocakaya ve Hüseyin Kocakaya' dan elde edinilen bilgiye göre Yatağan'da eski barutlu köstebek tüfeğinin Hüseyin Kocakaya'nın babası tarafından yapıldığı öğrenilmiştir. Ayrıca mülakatlarda kemik tarak yapımının da günümüzde devam ettirildiği ifade edilmiştir.

Yatağan ekonomisinin önemli bir kısmı günümüzde hâlâ ev tipi sanayi faaliyetiyle kesici aletlerin üretim ve pazarlamasına dayanmaktadır. Üretim atölyeleri çoğunlukla evlerin yanında ve genellikle de evlere bitişiktir. Bu konuda dikkat çeken bir diğer husus Yatağan ve çevresinde demir yatağının bulunmamasıdır. Keza tarihi dönemlerde de işletilmiş bir demir yatağı yoktur. Yatağan'ın mevcut üretim sisteminin haricindeki bir diğer geçim kaynağı tarım ve hayvancılıktır (Koca ve Bayram). Belde sınırları içerisindeki ovalık tarım arazilerinin \%25'lik bir kısmı sulanabilir olup, halihazırda meyve, sebze ve tütün yetiştirilmekte, bağcılık yapılmakta, özellikle son yıllarda kültür mantarı üretilmektedir. Hane halkının az bir kısmı da büyükbaş ve küçükbaş hayvancılıkla uğraşmaktadır (Denizli Ticaret Odası, 2012). 
Yapılan mülakatlar ve gözlemler neticesinde görülmüştür ki, Yatağan beldesi üretim geleneğini devam ettirmektedir. Daha ziyade aile işletmeleri içerisinde gerçekleşen üretimin önemli bir kısmı, bıçak, çakı ve özellikle kurban bıçağı şeklindedir. Ancak keser, nacak ve balta ağZı yapan, koyun makası kırpma üretimi yapan ve bunları yurt dışına ihraç eden 4-5 büyük atölyeye de rastlanmış, bunların iki tanesinde de mülakat yapılmıştır. Yatağan ve kılıç üretimi ise süs eşyası sınıfında devam etmektedir. Bununla beraber, çıraklığını çok küçük yaşlarda amcası Hüseyin Can'ın ve babasının yanında yaptığını söyleyen Osman Can'la yapılan mülakatta, yatağan ve kılıcın film sektörü için ve koleksiyoncular için de imal edildiği ve yüksek fiyatla satıldığı öğrenilmiştir. Süleyman Şahin ise işi ilk önce bıçak yapan babasından öğrenmiş fakat daha sonra Ziya Karaca ve dönemin belediye başkanı Tuncer Tunçbilek'in teşvikleriyle kılıç ve yatağan yapım işini de üretimine eklemiştir. Kendisi el işi olarak ürettiği ürünlerini daha ziyade Kültür Bakanlığı El Sanatları Fuarında satışa çıkardığını ve tek bir ürününü dahi 1500 TL'den 15-20 milyar TL'ye kadar satış yaptığını ifade etmiştir. Hidayet Akın, tamamen kendi denemeleriyle bıçak ve kılıç yapımını öğrenmiştir. İnternet üzerinden aktif şekilde satış yapan Hidayet Akın, bu işi devam etmesi için gençleri sürekli desteklediğini ve hatta onlardan topluca bıçak alıp, daha sonraki zamanlarda sattığını ifade etmiştir. Yapılan gözlemde Hidayet Akın'ın deposunda çok fazla miktarda ürün bulunduğu görülmüştür. Keza, ata mesleğinin icra edildiği Yatağan'da adeta “internet devriminin” yaşadığı iddia edilmektedir. Siparişlerini internetten alan ve siparişlere yetişemediklerini belirten Yatağanlı ustalar el emeği-göz nuru döktükleri ürünlerini lazer teknolojisiyle süslemekte ve çoğunlukla internetten satışa çıkarmaktadırlar (Milliyet, 2016). Bugün Yatağan, uluslararası pazarlara açılmak için de emek vermektedir. Büyük Şehir Belediyesi'nin ve Serinhisar Belediyesi'nin verdiği destekle Yatağan bıçaklarını uluslararası alanda tanıtmak amacıyla Fransa'nın Thiers kentinde düzenlenen Dünya Bıçakçılık Başkentleri etkinliklerine Denizli Büyükşehir Belediyesi Turizm ve Tanıtım Şube Müdürü Samet Başer ile Yatağanlı 3 bıçak üreticisi katılmıştır. Organizasyona ev sahibi Fransa ile ABD, Rusya, Japonya, İspanya, İtalya, Avusturya, Çek Cumhuriyeti ve Bulgaristan'ın yanı sıra Türkiye'den sadece Denizli davet edilmiştir. Etkinlikte, Yatağan bıçaklarının tarihi anlatılmış ve Yatağan ürünlerinin tanıtımı yapılmıştır (www.denizli.bel.tr, 2016).

\subsection{Yatağan Beldesinde Girişimcilik Süreci}

Bir kırsal bölge olan Yatağan, geçiminin önemli bir kısmını kesici aletlerin üretimi ve pazarlamasından kazanıyor olması sebebiyle çalışmanın konusunu bu üretim alanındaki girişimcilik faaliyetleri oluşturmuştur. Yatağan üreticilerinin önemli bir kısmı atölyelerini öz sermayeleriyle kurmuş olup, bu konuda kredi almamaya dikkat etmişlerdir. Aldıkları kredileri de işletmeleri için değil daha ziyade kooperatif aracılığıyla almışlar ve evlerini yapmak için kullanmışlardır. Mülakat yapılan ustalardan sadece Hidayet Akın işiyle ilgili kredi aldığını ve hâlâ ödeme yaptığını belirtmiştir. Mülakat yapılan hemen hemen bütün ustalar (girişimciler) işi babalarından gördüklerini, ayrıca başkalarının yanında da çıraklık yaparak öğrendiklerini, daha sonra da askerden geldikten sonra kendi iş yerlerini kurduklarını beyan etmişlerdir. Evlerinin yanında kurdukları küçük atölyeler için büyük sermaye gerekmemiştir. İşletmelerin çoğunluğu aile işletmesidir. Yapılan işlere genellikle eşleri de katkı vermekte, okuldan geldiklerinde ya da yaz tatillerinde çocukları da üretimde yer almaktadırlar. Üreticilerin bir kısmı sadece bıçak, çakı gibi ürünleri üretirken, bir kısmı, tarım işlerinde kullanılabilecek keser, nacak, balta gibi aletleri de üretmektedirler. Benzer şekilde bıçak üreten atölyelerin bir kısmında yukarıda da ifade edildiği gibi Yatağan ve Kılıç üretimi de gerçekleşmektedir. Eski Türk usulü dövme kılıç yapan tek kişi Hüseyin Can’dır. Hüseyin Can bütün ürünlerini kendi el emeğiyle yaptığını, el ustalığı gerektiren hiç bir işi başkasına hatta oğullarına dahi yaptırmadığını söylemiştir. El işi kılıç yapan diğer ustalar ise Osman Can ve Süleyman Şahin'dir. Ürünlerini kendilerinin tasarladıklarını, kimi ürünlerin müşterilerden tasarlanarak geldiğini ve kataloglardan ya da gittikleri festival ve fuarlardan tasarım öğrendiklerini ifade etmişlerdir. Ancak ürünlerine, başka yerlerden tasarım görseler bile, kendi yaratıcılıklarını da katmaktadırlar. Keza Abdurrahim Aydın, yaptığı üretimle ilgili "bu bir sanat, bu bir aşktır" demektedir. İstanbul'da sattığı ürünlerini farklılaştırmak için ürünü satın alan kişinin ya da ürünün hediye edileceği kişinin adını ve satın alınan tarihi ürüne işlemektedir. A. Aydın, "kafama bir şey takılırsa gece kalkar yapardım ama bu işi bize asıl müşteri öğretir, siparişi ve dizaynı o belirler” diye ekleme yapmıştır. Keza mülakata katılan pek çok usta da bu işi severek yaptıklarını belirtmişler, özellikle Hidayet Akın ve Gürkan Çalhan bu işi yaparken büyük bir heyecan duyduklarını, gece yataktan kalkıp ürünün başına geçtiklerini vurgulamışlardır. Bunun haricinde Gürkan Çalhan 46 çeşit ürün yaptığını ve ürünlerini Azerbaycan’a, Pakistan'a, Hava Kuvvetlerine, Deniz Kuvvetlerine, ASELSAN'a, Genel Kurmay'a Atatürk Kültür Merkezi'ne ve İstanbul Emniyet Müdürlüğü'ne yapmaktadır. Yaratıcılık ve pazar konusunda farklılaşan bir diğer isim ise Hüseyin Kocakaya'dır. Kocakaya daha önceden kendi yaptığı traktörünü Yatağan'da rahatlıkla kullandığını, araba da yaptığını fakat fren aksamını beceremediğini anlatmıştır. Kendi geliştirdiği ayrı bir yöntemle bıçakların üzerine yazı yazan Kocakaya el yapımı bıçak üretmekte bunu da kıymetini artırmak için çok sayıda değil haftada sadece iki üç tane yaparak sattığını ifade etmiştir. Aynı zamanda Kocakaya Yatağan'da 100-150 yıllık, üretimde kullanılan eşyaları ve diğer alet edavatı toplayıp, bunlardan küçük bir müze oluşturmuştur. TRT, NTV gibi ulusal kanallar ve yerel kanallar Kocakaya'nın tanıtımını yaptığı bu müzede çekimler yapmıştır.

Mülakat yapılan iki daha büyük atölye bugün yönetiminde ve sahipliğinde bulunan kişilerin babaları tarafından kurulmuştur. Daha ziyade nacak, balta, keser yapımıyla bilinen fakat bıçak üretimi de yapan atölyenin sahiplerinden Mehmet Baykara, bıçakçılığın dede mesleği olduğunu, daha sonra babasının Almanya'da bıçakçılık 
konusunda dövme işinde çalıştığını, yurda dönünce de Almanya'da gördüğü makineleri İstanbul'da yaptırıp, Yatağan'da fabrika kurduğunu ve ilk kerpeten yaparak işe başladıklarını ifade etmiştir. Kısa süre önce Almanya'ya ziyaret gayesiyle giden Baykara, Alman bir ortakla yapacağı stratejik iş birliğinin ilk sözlü girişimlerini yapmıştır. Almanya'daki firmaya fason olarak medikal ürünler üretmeyi planlamaktadırlar. Halihazırda üretilen mamullerin satışlarının bir kısmı kendi markasıyla, bir kısmı da fason olarak yapılmaktadır. Ürünlerinin dağıtım işini toptancılar yapmaktadır. Kendisi ağabeyi ile ortaktır. Atölyede daha önceden 11 kişi çalışırken, makineleşmeden dolayı artık 8 kişinin çalıştığı ifade edilmiştir. Diğer büyük atölyenin sahiplerinden biri olan Hüseyin Ayduran, kardeşi ve babasıyla beraber işi yürütmektedir. İşletme 1979 yılında babaları tarafından kurulmuştur. Bıçak ve koyun kırpma makası üreten işletmede 30 kişi çalışmaktadır. Ayduran en büyük rakiplerinin fiyat avantajlarından dolayı Çin olduğunu, fakat kendilerinin Çin'den daha kaliteli üretim yaptıklarını, bu işin bir miktar da Avusturalya'da yapıldı̆̆ını anlatmıştır. Ürünlerini Türk Cumhuriyetleri, Ortadoğu, Dubai ve Kuveyt'e ihraç ettiklerini, günlük 2000 tane mal ürettiklerini ve işletmelerini artık daha fazla büyütmeyeceklerini söylemiştir. Buna sebep olarak da pazarın belirli olduğu ve pazarın da daha fazla büyümediği gösterilmiştir. Yapılan gözlemlerde işletmenin Sürmene biçaklarına da fason üretim yaptığı görülmüştür.

Tedarik malzemelerinin önemli bir kısmı başka illerden ve ülkelerden gelmektedir. Bıçaklar daha ziyade Ereğli çeliğinden yapılmaktadır. Kılıçlar için kullanılan çelik ise İstanbul'daki toptancılardan alınmakta, İstanbul'a da Avrupa'dan (Fransa ve Almanya) gelmektedir. Ancak Osman Can, domeskus bıçağının çeliğinin Pakistan'dan İstanbul'a geldiğini belirtmiştir. Ayrıca Hüseyin Can ve Osman Can, kılıç çeliğinin arabaların makas yayı olduğunu, bunu da hurdacılardan temin ettiklerini belirtmişlerdir. Bıçak, yatağan ve kılıçların sapları ise daha ziyade Kahramanmaraş ve Gaziantep'ten toptancılar tarafından getirilmektedir. Yatağan'da ayrıca son beş aydır lazerle markalama işine ve yazı yazma işine de başlanmıştır. KOSGEB'den aldığ 1 girişimcilik dersleriyle Vehbi Aydın, KOSGEB'e hazırladığı proje neticesinde babasıyla İstanbul'dan getirttiği lazer makinesinde kılıç ve bıçakların üstüne yazı yazmakta, logo ve marka işlemektedir.

Ürünlerin pazarlamasında en yaygın kullanılan araç internettir. Hemen hemen bütün ustaların ürünlerini pazarladıkları bir web sitesi mevcuttur. Hatta Erkan Can siparişlerini artık whatsapp aracılığıyla pazarladığını ifade etmiştir. Bir diğer satış yöntemi ise özellikle mutfak ve tarım aletlerinde toptancılar vasıtasıyla gerçekleşmektedir. Pazarlama işini yapan kişilerden biri de Ali Vehbi Kocakaya'dır. Kocakaya, kendisinden başka iki işletmenin daha bu pazarlama işini yaptığını fakat onların malları toplayıp, toptancı olarak Türkiye'nin diğer şehirlerine gidip sattıklarını, kendisinin ise tabletine depoladığı ürünleri götürüp müşterilere gösterdiğini, daha sonra siparişleri yerlerine ulaştırdığını ifade etmiştir. Bu açıdan Yatağan üreticisinin modern pazarlama yöntemlerinden yararlandıkları ve aracılara bağlılıklarını da nispeten dengeledikleri söylenebilir. Ancak, iki büyük atölyenin haricinde üreticilerin hemen hemen hepsi internet kullanıyor olmalarına rağmen ve ürünlerini yurt dışında daha pahalıya satacaklarını söylemelerine rağmen ihracat yapamamaktadırlar. Bilal Can'ın ifadesiyle internetten uluslararası sitelere girmeyi becerememektedirler, bunun en büyük sebebi yabancı dil bilmemeleridir. Hatta kendisine 5-6 kez sipariş gelmesine rağmen ürünlerini yollamayı beceremediğini söylemiştir.

\subsection{Yatağan'da Kadın Girişimciliği ve Kadın İstihdamı}

Yatağan'da kadınların kesici alet üretiminde yer almaları çok önceki tarihlerden itibaren söz konusudur. Pek çok atölyede ustalarının anne-baba ve kardeşleriyle üretim yaparken çocukken çekildikleri fotoğraflara rastlanmıştır. Tuncer Tunçbilek’ten edinilen bilgiye göre bundan takriben 20-25 yıl önce Halk Eğitim Merkezi'nin açtı̆̆ kursta Yatağanlı kadınlar halı dokumayı öğrenmişler ve kurulan atölyede ücretli olarak bir firma adına halı dokumuşlardır. Ancak, kadınlar için evde bıçak üretimine katkıda bulunmak daha elverişli geldiği için halı atölyesinden çıkıp, evlerinde eşlerine üretimde katkı vermeye devam etmişlerdir. Kadınların önemli bir kısmının sigortasız çalıştığı sadece bir tanesinin Bağkurlu olduğu görülmüştür. Mülakata katılan dört kadın da bekarken bu işi yapmadıklarını evlendikten sonra işi eşlerinden öğrendiklerini, ücret almadıklarını fakat işin zaten aile işi olduğunu, keselerinin bir olduğunu, para konusunda hiçbir zaman problem yaşamadıklarını vurgulamışlardır. Kadınların üretime katkısı, genellikle sapların 1sıtılması, sapların çakılması, bıçakların yüzlerinin silinmesi şeklinde olmaktadır. Bu anlamda Yatağan'da kadın girişimciliği olmadığı gibi gerçek anlamda bir ücretli ve sosyal güvenceli kadın istihdamı da mevcut değildir.

\subsection{Yatağan Ustalarının Üretim ve Pazarlama Faaliyetleriyle İlgili Örgütlenme Tecrübeleri}

Yatağan'daki örgütlenme tecrübesinde ilk kurulan dernek Berlin-Denizli Yatağanlılar Yardımlaşma Derneği'dir. Ziya Karaca'nın verdiği bilgiye göre Almanya'da çalışan işçilerin bir araya gelip Almanya'da kurdukları dernektir. Derneğin Yatağan'daki temsilcisi Ziya Karaca'dır. Karaca, bu dernek aracılığıyla toplanan paralar vasıtasıyla 100 aileye bakıldığını ve 7-8 üniversite öğrencisi de dahil öğrencilerin okutulduğunu anlatmıştır. Ancak Almanya'dan geri dönüşler sonucunda dernek eski faaliyetlerine devam edememiş ve kapanmıştır. Derneğin faal olduğu dönemde, Belediye Başkanı Tuncer Tunçbilek Almanya'ya gitmiş, Solinger fabrikasını gezmiş ve oradan edindiği bilgilerle Denizli’ye gelerek ortaklı bir sanayi sitesinin kurulması için çaba sarf etmiş ve 100 dönümlük yer alınmıştır. Üyelerden bir miktar para toplandıktan sonra Süleyman Demirel'in o alanı devlet yatırımına dahil etmesiyle paranın asıl büyük kısmı devletten sağlanmıştır. Ancak istimlak sürecinin çok uzun yıllar devam etmesi ve iktidarın değişmesiyle yatırım öylece kalmıştır. Alim Ayduran, eğer orası faaliyete geçerse hem müşteri açısından hem de üretici açısından çok iyi bir gelişmenin olacağını ifade etmektedir. 
Daha sonra Almanya'daki dernek üyelerinden ve KOSGEB'den alınan desteklerle Ortak Kullanım Atölyesi oluşturulmuştur. Bu atölye için Tunçbilek Almanya'ya gidip taşlama makinesi alarak Yatağan’a getirmiştir. Ayrıca ısıl işlem makinesi alınmış fakat birtakım üretim problemleri ve hammaddede standardının sağlanamaması sebebiyle bu girişim de neticelenememiştir. Tunçbilek bu girişimlerinde istediği başarıyı yakalayamamasına rağmen, Yatağan'da belediye bünyesinde bilgisayar ve internet kursunun açılmasını ve ustaların bilgisayar ve internet öğrenmelerini sağlamıştır. Bugünkü inter pazarlamacılığının alt yapısı o dönem atılmıştır.

Yatağan'daki bir diğer örgütlenme ise Yatağan Bıçakçılık ve El Aletleri Anonim Şirketi'dir (YABELTAŞ). Bu şirketin kurulması T. Tunçbilek ve Z. Karaca öncülüğünde halk sermayesiyle gerçekleşmiştir. Yöneticiliğini Z. Karaca yapmıştır. Yatağan bıçaklarının tek bir marka altında pazarlanması gayesiyle oluşturulan ve Yatağanlıların yaptıkları bıçakları bu marka altında daha iyi fiyata satmayı amaçlayan firma, ulusal medyada ses getirecek kadar önemli işlere imza atmış fakat halkın sözleşmeye uymayarak bireysel satışlarını müşteriye daha ucuza yapması sebebiyle uzun süre devam edememiştir. Halihazırda Yatağan'da devam eden bir kooperatif vardır. Kooperatif başkanı Şener Yatağanbaba kooperatifin daha ziyade toptancılık yaparak üyelerine yardımcı olmaya çalıştığını ifade etmiştir.

Mülakat yapılan kişilere örgütlenmenin neden bir türlü yapılamadığı sorulduğunda, örgütlenmeye hâlâ ihtiyaç olduğu fakat insanların birbirlerini kıskanmaları ve birbirlerine güvenmemeleri sebebiyle örgütlenemedikleri ifade edilmiştir. Hatta "burada kardeş kardeşle bile geçinemez" denilmiştir. Yatağanlı girişimciler örgütlenme becerilerini uzun süre sürdüremedikleri gibi devlet kurumlarından da yararlanmayı becermekte güçlük çekmekte, KOSGEB, İş-Kur, Kırsal Kalkınma vb. yerlerden kredi ve hibe alamamaktadırlar.

\section{Sonuç}

Görülmektedir ki, Yatağan’ın girişimcilik ve üretim geleneği yüzyıllar öncesine dayanmaktadır. Kırsal bir alan olan Yatağan, sadece kendi ihtiyacını karşılayacak kadar tarım yapmasına rağmen el sanatları ve geleneksel ürünlerin üretimi ve pazarlamasında günümüz rekabet şartlarına ayak uydurmaya çalışmaktadır. Çok küçük atölyelerde hane halkıyla çalışmaları sebebiyle henüz işgören ve yönetim konusunda problem yaşamamaktadırlar. Ancak bir takım finans kurumlarının ve kamu kurumlarının kendilerine sundukları firsatlardan nasıl yararlanacaklarına dair bilgi ve iletişim düzeyine sahip değillerdir. Bu sebeple danışmanlık firmalarının proje yönteminden yararlanma yoluna gidilmelidir. Ancak gerek danışmanlık firmalarına gerekse bu firmalardan yararlanan kırsal girişimcilere devlet kurumları tarafından denetimlerin yeterli ve etkili yapılması gereklidir (İrmiş ve Eroğlu, 2015). Bu durum kırsal kalkınmanın motorgücü olan kırsal girişimciliğin yönetim ve organizasyona dayalı kurumsallaşma süreciyle gerçekleştirilmelidir (Şekil 1). Bu kurumsallaşma modeliyle kırsal alanda bir değer zinciri yaratılabilecek ve çok daha fazla katma değer, etkinlik ve verimlilik sağlanabilecektir. Böylelikle, uzun dönemdeki kırsal kalkınma yüksek değerli bir toplumsal kalkınmaya dönüştürülebilecektir.

Yatağan'daki kadınların tercih ettikleri çalışma alanı eşlerinin yanında üretime katkı şeklinde olsa bile, kadınlara iş eğitimlerinin verilmesi, kayıtlı çalışanlar haline getirilmeleri, böylece sosyal güvencelerinin de olması sağlanmalıdır. Hatta kadınlar için verilecek girişimcilik eğitimiyle Yatağan'daki mevcut kaynakların kullanımına ve yeni kaynak ve firsatların keşfedilmesine yönelik yeni bir girişim ve istihdam alanı açlabilir.

Aynı zamanda Yatağan'daki örgütlenme geleneğinin tekrar harekete geçirilip, daha bilinçli ve güven esaslı ilerlemesi sağlanmalıdır. İşbirliğiyle oluşturulacak strateji çok daha etkili üretim ve pazarlama imkânı verecektir. Şimdilik çok kısıtlı sayıda üretici dünya pazarlarına açılmışken, böyle bir işbirliğinin sağlanması Yatağan ürünlerinin dünya markası olması ve daha fazla kazanç elde etmesinin önünü açacaktır. Ancak önceden açılan bilgisayar kursu gibi yabancı dil kursunun da açılması ve ustaların dil öğrenmesine katkı verilmesi gereklidir. Yahut bu konuda birkaç kişi görevlendirilmeli ve internet aracılığıyla yurt dışıyla gerekli irtibatlar kurulmalıdır. $\mathrm{Bu}$ da örgütlenme ve işbirliği neticesinde gerçekleştirilebilecektir. 
Proje müddetince ve sonrasında denetim

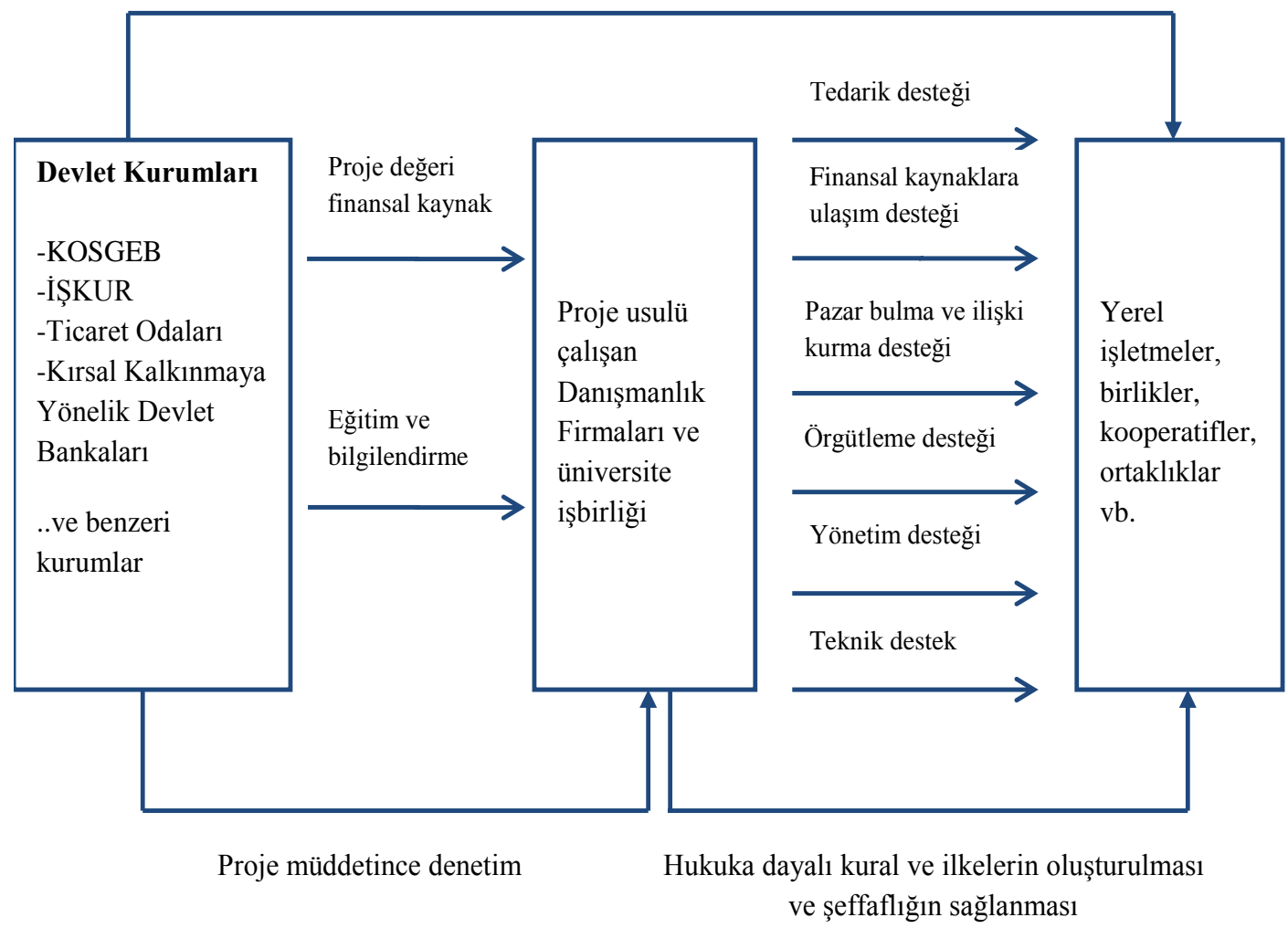

Şekil 1. Kırsal Girişimciliğe Yönelik Yönetim ve Organizasyona Dayalı Kurumsallaşma Modeli

\section{Kaynakça}

- Abdioğlu H., Yavuz S., 2013. "İşletmelerde Sosyal Sermayenin Ölçümlenmesi ve Raporlanmasına Yönelik Bir Araştırma”, Afyon Kocatepe Üniversitesi IIBBF Dergisi, 15/1, s. 28.

- Baykara T, 2013. Yatağan: Her Şeyi ile Tarihi Yaşatma Denemesi, Atatürk Kültür Dil ve Tarih Yüksek Kurumu Yayınları, Ankara.

- Çekiç İ. T., Ökten A. N., 2009. "Sosyal Sermaye Perspektifinden Kırsal Kalkınma Sorunsalına Yeniden Bakış", Megaron, 4/3, s. 205, 207, 210.

- Denis-Jacob J., 2012. “Cultural Industries in Small-sized Canadian Cities: Dreamor Reality?”, Urban Studies, 49/1, p. 97.

- Denizli Büyükşehir Belediyesi, http://www.denizli.bel.tr/Default.aspx?k=haber-detay\&id=16132, Erişim tarihi: 27.05.2016.

- Denizli İl Kültür ve Turizm Müdürlüğü, İlçeler, http://pamukkale.gov.tr/tr/Ilceler/Serinhisar, Erişim tarihi: 29.05.2016.

- Denizli Ticaret Odası İki Aylık Haber, Finans, Araştırma ve İnceleme Dergisi, 2008. Denizli Ticaret Odas1, 73, Temmuz, s. 40.

- $\quad$ Ekol, 2000. Yatağan 21. Yüzyıla Hazırlanıyor, Haziran, 5, s. 8.

- Elena H., Sorina M., Rus D., 2015. “A Predictive Model of Innovation in Rural Entrepreneurship”, Procedia Technology, 19, p. 471, 472.

- Ellis V., Bosworth G., 2015. "Supporting Rural Entrepreneurship in the UK Microbrewery Sector”, British Food Journal, 117/11, p. 2724.

- $\quad$ Fuller-Love N., Midmore P., Thomas D., 2006. "Entrepreneurship and Rural Economic Development: A Scenario Analysis Approach”, International Journal of Entrepreneurial Behaviour, 12, p. 291. 
- İrmiş A., Eroğlu Ş. G., 2015. "Bir Kırsal Kalkınma Modeli Olarak Geleneksel Üretimi Yeniden Canlandırma Örneği: Yeşilyuva Ayakkabı Üretimi”, In Proceedings of International Conference On Eurasian Economies 2015, s. 690.

- Johnson D., 2001. "What is Innovation and Entrepreneurship? Lessons for Larger Organisations", Industrial and Commercial Training, 33/4, p.138.

- Karadeniz E., 2008. Entrepreneurial Economy in Turkey, Yalın Yayıncılık, İstanbul.

- Koca H., Bayram Ç., "Yatağan Kasabasında (Denizli-Serinhisar) Ev Tipi İmalat Sanayinin Coğrafi Özellikleri”, Doğu Coğrafya Dergisi, 14, s. 183.

- $\quad$ Korsgaard S., Müller S., Tanvig H.W., 2015. "Rural Entrepreneurship or Entrepreneurship in theRuralBetween Place and Space", International Journal of Entrepreneurial Behavior\&Research, 21/1 p. $7,8$.

- Kushalakshi, R. A., 2014. "Rural Entrepreneurship: A Catalyst for Rural Development", International Journal of Science and Research, 3/8, pp. 51-52.

- Lashgarara F., Roshani N., Najafabadi M. O., 2011. "Influencing Factors on Entrepreneurial Skills of Rural Women in Illa City, Iran”, African Journal of Business Management, 5/14, p. 5536.

- Markley D. M., 2006. “A Framework for Developing Rural Entrepreneurship”, Economic Development America, Winter 2006, p. 4, 5.

- Mehta A., Mehta M. C., 2011. "Rural Woman Entrepreneurship in India: Opportunities and Challenges", International Conference on Humanities, Geography and Economics, Pattaya Dec., p. 313-314.

- Milliyet, http://www.milliyet.com.tr/kaderi-internetle-degisti-/ekonomi/detay/2253248/default.htm, Erişim tarihi: 28.05.2016.

- Patel B., Chavda K., 2013. "Rural Entrepreneurship in India: Challenge and Problems", International Journal of Advance Research in Computer Science and Management Studies, 1/2, p. 29.

- $\quad$ Pato M. L., Teixeira A. C., 2013. "Twenty Years of Rural Entrepreneurship: A Bibliometric Survey”, FEP Working Papers, Porto, p. 13.

- Rădulescu E., Marian L., Moica S., 2014. "Inovations and Opportunities for Entrepreneurial Rural Developments", Procedia Economics and Finance, 15, p. 1495, 1499.

- Saxena S., 2012. "Problems Faced by Rural Entrepreneurs and Remedies to Solve", IOSR Journal of Business and Management, 3/1, p. 23, 26, 28-29.

- $\quad$ Stathopoulou S., Psaltopoulos D., Skuras D., 2004. "Rural Entrepreneurship in Europe, A Research Framework and Agenda", International Journal of Entrepreneurial Behavior\&Research, 10/6, p. 412, 404.

- Townsend L., Wallace C., Smart A., Norman T., 2016. "Building Virtual Bridges: How Rural MicroEnterprises Develop Social Capital in Online and Face to Face Setting", Journal of the European Society for Rural Sociology, 56/1, p. 32.

- Türkiye Haritas1, http://www.haritatr.com/yatagan-haritasi-e457, Erişim tarihi: 28.05.2016.

- William M., Fortunate P., 2014. "Supporting Rural Entrepreneurship: A Review of Conceptual Developments from Research to Practice”, Community Development, 45/4, p. 391, 392.

- Wortman M. S., 1989. “A Unified Approach for Developing Rural Entrepreneurship in the U.S.”, New Strategies for a New Decade Conference Proceedings Fourth Annual National Conference: United States Association for Small Business and Entrepreneurship, Cleveland, Ohio, p.75-77.

- Wortman M. S., 1989. "Rural Entrepreneurship Research : An Integration Into The Entrepreneurship Field", New Strategies for a New Decade Conference Proceedings Fourth Annual National Conference: United States Association For Small Business and Entrepreneurship, Cleveland, Ohio, p.63, 64.

- Yatağan 21. Yüzyıla Hazırlanıyor, Ekol, Haziran 2000, 5, s. 8.

- Zhao F., 2005. "Exploring the Snergy between Entrepreneurship and Innovation", International Journal of Entrepreneurial Behaviour and Research, 11/1, p. 26. 


\title{
Öğrenen Örgütün İç Girişimcilik Davranışına Etkisi Üzerine Bir Araştırma
}

\section{The Effect of Being a Learning Organization on Intrapreneurship}

\author{
Ph.D. Candidate Mehtap Sarkaya (Pamukkale University, Turkey) \\ Prof. Dr. Sabahat Bayrak Kök (Pamukkale University, Turkey) \\ Ph.D. Candidate Sümeyra Babacan (Mugla Sitkı Koçman University, Turkey)
}

\begin{abstract}
Learning organizations and internal entrepreneurship are among the most important concepts for the organizations who are struggling to survive in the long term through achieving sustainable competency advantage. In this study these two concepts, which allow organizations to be dynamic to adapt change and development, are handled with their dimensions and analyzed for the sample. In addition, the effect of learning organizations concept, which is defined as the ability of an organization to learn from experiences and apply this knowledge to changing environment conditions systematically, on internal entrepreneurship, which means entrepreneurial activity inside the organization. According to the descriptive analysis results; the employees in the sample perceive their organizations as learning organizations in high level; and internal entrepreneurial activities are found to be high. Regression analysis is utilized to test the research model, and the results imply that if an organization is perceived as a learning organization, the internal entrepreneurship activities in the organization display an increase.
\end{abstract}

\section{Giriş}

Bugün gerek iş dünyasının, gerekse sosyal yaşamın sürekli değiştiği ve giderek değişme hızının da arttı̆ğ bir dünyada yaşıyoruz. Piyasa ekonomisine işlerlik kazandırılması, araştırma ve geliştirme çabalarının bağımsızlaşması, bilgi akış sistemlerindeki gelişmelerin talepte hızlı gelişme yaratması, stratejik işbirliği sağlanması, iletişimin küreselleşmesi, yatırım anlayışının değişmesi, esneklik ihtiyacı doğrultusunda yeni bir yapının oluşturulması bu değişimde etkisi olan gelişmelerden birkaçıdır. Üretimin en önemli faktörlerinden biri olan girişimci, küreselleşen dünyanın getirdiği bu yeni koşullar altında, sürdürülebilir rekabet üstünlüğü elde edebilmek ve uzun dönemde varlıkların koruyabilmek amacıyla kendilerini diğer örgütlerden farklılaştıracak düzenleme ve faaliyetlere yönelmektedir. Bu nedenle küreselleşme süreciyle birlikte günümüzün modern, dinamik iş dünyasında örgütlerin bir taraftan büyük ölçüde işbirlikçi stratejilere (Ohmae, 1989; Perlmutter ve Heenan, 1986), diğer taraftan öğrenme stratejilerine (Garvin, 1993; Marquardt, 1996) yöneldiği belirtilmektedir.

Örgütlerin sürdürülebilir rekabet üstünlüğü elde edebilmek ve uzun dönemde varlıklarını devam ettirebilmek amacıyla kendilerini diğer örgütlerden farklılaştırmaya çalıştı̆̆ faaliyetlerinden birisi 'iç girişimcilik' kavramıdır. Kısaca, 'mevcut ya da var olan örgüt içerisinde girişimcilik faaliyetleri' olarak tanımlanan iç girişimcilik, örgütlere yenilik ruhunu ve dinamizmi yeniden kazandıracak davranış ve faaliyetlerle, sadece şirketleri ataletten kurtararak onlara canlılık vermemekte, aynı zamanda yeteneklerini keşfedip ilerleme sağlayarak rekabette onları güçlü kılmaktadır. İç girişimcilik yenilik içeren, kişilerin firsatlara odaklanarak risk alabilmelerini gerektiren bir süreç olması nedeniyle her örgütsel yapı ve kültür ortamında ortaya çıkması ve gelişmesi beklenen bir oluşum değildir. $\mathrm{Bu}$ nedenle, dinamik örgütler, yeni fikir ve yaklaşımların denenmesine, yeni alternatif ve firsatların ortaya çıkmasına imkân veren, ayrıca 'niçin' ve 'nasıl'ı derinlemesine kavramaya yardım eden bir öğrenme ortamı gerektirmektedir. Bu tespit doğrultusunda bildiri, son yıllarda literatürde birbiriyle ilişkili olarak fazla çalışılmamış bir konuyu etkileşim bağlamı üzerinden değerlendirerek ‘öğrenen örgütün iç girişimcilik üzerine etkisi' başlığıyla araştırmayı amaçlamaktadır.

\section{Kuramsal Çerçeve}

\section{1 Öğrenen Örgüt Kavramı}

Yıllar boyunca birçok araştırmacı ‘öğrenen örgüt’ kavramının anlaşılmasının zorluğundan yakınmış, açıı ve net bir tanımlamaya ihtiyaç olduğunu söylemiş (Garvin, 1993; Pedler vd., 1991) ve bunda kavramın birbirine yakın anlamlarıyla farklı şekillerde tanımlanmasının etkisi olduğunu ifade etmişlerdir. Öğrenen kavramına ilk defa Chris Argyris ve Donald Schön'ün (1978) çalışmalarında rastlanmış, Peter Senge (1990) tarafından da 'The Fifth Discipline' isimli eseriyle şekillendirilmiştir. Öğrenen organizasyon kavramı, çevreye uyum sağlama kabiliyetini arttırarak kendi geleceğini yaratma kapasitesini durmadan genişleten örgüt olarak tanımlanmaktadır (Öneren, 2008:164). Senge, Sistem Teorisini öğrenme sürecine uyarladığı "Beşinci Disiplin" adlı eserinde öğrenen organizasyonu kişilerin gerçekten istedikleri sonuçları yaratma kapasitelerini durmadan genişlettikleri, örgüt içinde yeni ve coşkun düşünme tarzı ile beslendikleri, kolektif özlemlere gem vurulmayan, adapte olmayı öğrenmenin yer aldığı örgütler olarak tanımlamaktadır (Senge,1990). 
Aslında, öğrenen organizasyon kavramından bahsedebilmek için, anlık bir değişimin yanı sıra kapsamlı bir dönüşüm sürecinin oluşumunu beklemek gerekmektedir. Çünkü öğrenen bir organizasyona doğru gerçekleşen dönüşüm, mevcut kültür üzerinde iletişim, örgütsel roller, bilgi paylaşımı gibi alanlardaki önemli değişikliklerin gerçekleşmesi demektir. Tüm organizasyonlarda farklı seviyelerde de olsa gerçekleşen öğrenme, örgüt kültürü kalıpları dahilinde gerçekleştiği için kültür, öğrenme sürecinin destekçisi veya engeli olarak görülebilmektedir (Akgün vd., 2009).

\section{2 Öğrenen Örgütler ve Temel Özellikleri}

Günümüzde örgütleri girişimcilik eğilim ve davranışlarına sahip olanlar ve olmayanlar diye sınıflandırmak yanlış bir düşüncenin sonucudur (Morris ve Kuratko, 2002). Çünkü girişimcilik eğilimi, modern ve geleneksel tüm sektörlerdeki örgütlerde, küçük ve büyük ölçekli tüm kurumlarda ve özel ve kamu gibi farklı mülkiyet yapıları içinde var olan geçerli bir olgu olarak karşımıza çıkmaktadır. Bu açıdan tüm örgütlerde girişimsel faaliyetlerin yürütülmesi, onların bazı girişimcilik özelliklerine sahip olduğunun bir göstergesidir. Bu anlamda yeni bir girişimsel model olarak tanımlanan iç girişimciliğin hangi özelliklere sahip olduğu önemlidir.

Senge (1990)'ye göre, öğrenen örgütlerin temel karakteristik özelliği, geleceğini yaratma kapasitesini durmadan genişleten bir organizasyon olmasıdır. Bunun dışında bireylerin öğrenmesini hızlandıran ve kendisini sürekli olarak dönüştüren örgütler olarak bazı özelliklere sahip oldukları belirtilmektedir. Öğrenen organizasyonların yazında yaygın olarak kabul edilen temel özellikleri şunlardır (Rowden, 2001; Watkins ve Marsick, 2003; Watkins ve O’Neil, 2013): 1- Sürekli öğrenme firsatları sağlarlar. 2- Amaçlarına ulaşmak için öğrenmeyi kullanırlar. 3Bireysel performans ile örgütsel performansı ilişkilendirirler. 4- Çalışanların açık bir şekilde düşüncelerini ifade etmeleri ve risk almaları konusunda kendilerini güvende hissetmelerini sağlayarak örgüt içinde diyalog ve dayanışma ortamını geliştirirler. 5- Yenilenme ve enerji kaynağı olan yaratıcı gerilimi kabul ederler. 6- Sürekli olarak çevrenin farkında olup, çevreyle etkileşim içerisinde bulunurlar.

Akgün vd. (2009); örgütlerin dönemsel olarak, esasında bilen, anlayan, düşünen ve nihayetinde öğrenen örgütler şeklinde nitelendirilebileceğinden bahsetmiş ve öğrenen örgütlerin temel özelliklerini organizasyonlardaki uygulamaları olarak yorumlamışlardır. Buna göre yazarlar öğrenen organizasyonların; sistem seviyesinde düşünme kapasitesi, kesintisiz öğrenme, çalışanların kararlara büyük oranda katılımı, hızlı iletişim ve öğrenmeye yönelik kültür ve yapının varlığı ayrıca bilgi yaratma ve paylaşma gibi nitelikleri olduğundan bahsetmektedirler. Söz konusu uygulamalar örgütten örgüte farklılık gösterebileceği gibi, bu sayılan özelliklerin örgütlerdeki yansıma alanlarının da farklılık içerebileceği belirtilmektedir (Akgün, 2009). Kraleva (2011) yaptığı çalışmada, öğrenen örgütlerin sürekli değişimi desteklemelerini ve bu değişimin kişinin kendi tecrübeleri ile birlikte diğerlerinin de tecrübelerini içermesi gerektiğini belirtmiştir. Bununla birlikte öğrenen örgütlerin örgütsel öğrenme yoluyla elde edilen bilginin en iyi şekilde kullanılabilmesi ve örgütün performansını olumlu etkilemesi amacıyla örgütün hangi şekilde en iyi öğrenebileceği sürecine odaklanan kurumlar olduğu söylenebilir.

\section{3 Öğrenen Örgüt Boyutları}

Günümüz dünyasında, gerek teknolojideki gerekse kültürel ve politik bağlamlardaki değişimlerin hızı inkâr edilemez. Sistemin bir parçası olan örgütlerin de bu tür değişmelerden etkileneceği göz önüne alındığında; örgütlerin gelişmek veya en azından mevcut konumlarını korumak için öğrenme kapasitelerini arttırmaları zorunludur (Basım vd., 2009). Ancak bir örgütün öğrenme kapasitesinin artması, o örgütün gelişme potansiyelini arttırır. Bir örgütün öğrenen örgüt olması için, artan öğrenme kapasitesinin ve edinilen yeni bilgilerin davranışları etkilemesi gerekir (Garvin, 1993).

Öğrenen örgüt, öğrenmeyi teşvik eden, çalışanlarını geliştirmeyi ön plana alan, çevre koşullarına adapte olabilen, açık haberleşme ve yapıcı diyalogu öne çıkaran ve tüm bunların sonucunda devamlı surette değişen, gelişen ve kendini yenileyen organizasyon şekli olarak kabul edilmiştir (Senge, 1990). Günümüzde öğrenen örgüt kavramıyla birlikte ciddi bir zihniyet ve uygulama değişikliğinden söz edilmektedir. Özellikle hızla değişen ve gelişen iş ve yönetim dünyasında, geçmişte olduğu haliyle bir kişinin tepeden her şeyi düşünmesi ve diğerlerinin de onu izlemesi düşüncesi terk edilmekte, örgütlerin hantal yapılarına öğrenme aracılığıyla yeniden dinamizm kazandırmak gerekmektedir. Bu şekilde birey esaslı öğrenme önem ve değerini yitirmekte; öğrenme bireyin sorumluluğu olduğu kadar grup, takım ve örgütlerin de sorumluluğu olarak görülmektedir. Marquardt (1996), bu durumu şöyle ifade etmektedir: Bugün birçok yönetici, geçmişte kullanılan bilgi, strateji, teknoloji ve liderlik biçimlerinin; günümüzün modern, dinamik iş dünyasında geçerliliklerini kaybettiğinin farkına varmıştır. Bu yöneticiler, iş dünyasındaki varlıklarını sürdürebilmek için, işletmelerin öğrenme yeteneklerini arttırarak değişen ve sürekli yenilenen çevreye uyum sağlamak zorunda olduklarının bilinciyle hareket etmektedir. Günümüzün yönetsel sorunları eski yapı, anlayış ve bakış açılarıyla çözülemeyecek kadar karmaşık bir durumdadır. Bu nedenle, gelecekte en hızlı öğrenen örgütler, üstünlüğü ellerinde tutacak ve 'dinozor' örgütleri yarış dışına iteceklerdir. Bu değerlendirme çerçevesinde öğrenen örgütleri diğer organizasyonlardan ayıran, bu örgütlerde 'iç girişimciliğin varlığını ortaya koyan temel boyutlar nelerdir?' sorusu önemlidir.

Öğrenen örgüt kavramının yazında şekillenmesinde büyük rolü olan Senge, öğrenen örgütü oluşturan boyutları beş disiplin olarak ifade etmiştir. Bu disiplinler aşağıdaki gibi açıklanabilir (Senge, 1990): 
1-Sistem Düşüncesi: Bu disiplin, tüm olayları parçalar halinde değil de bir bütün olarak açık bir şekilde görme olanağı sağlayarak bunları etkili bir şekilde nasıl değiştirilebileceğini görmeye yardımcı olur. Sistem düşüncesi, birbiriyle ilişkisi olan faaliyetlerin görünmeyen bağlantılarını görme ve yaptıkları etkileri anlaşılır hale getirme becerisinin geliştirilmesi gerekliliğine açıklık getirir. Ayrıca bu disiplin, diğer öğrenen örgüt disiplinlerini bir araya getirme özelliğine sahiptir (Basım vd., 2009).

2-Kişisel Hakimiyet (Ustalık): Kişisel ustalık, birey bazında görme, olayları değerlendirebilme ufkuna sürekli olarak açıklık kazandırma, enerjileri birleştirme, bu konuda sabır gösterebilme ve olayları tüm gerçekliğiyle tarafsız olarak görebilme disiplinidir.

3-Zihni Modeller: Bu disiplin, organize olmuş, uzun vadeli, gelişime açık duygu, inanç ve davranış eğilimlerinin genel adıdır. Örgütte çalışan bireylerin zihni modelleri, onların dünyaya nasıl anlam yükledikleri ve gelecekte hani anlamı vereceklerini tanımlamak açısından önemlidir.

4-Paylaşılan Vizyonun Oluşturulması: Bu disiplin örgütün tüm çalışanları tarafından ortak anlam yükledikleri bir vizyonun oluşturulmasıyla ilgilidir. Ortak vizyon, örgüt bireyleri tarafından benimsenmiş, öğrenme için gerekli odaklanma ve enerjiyi sağlayan ve örgüt için hayati bir öneme sahip olan idealidir.

5-Takım Halinde Öğrenme: Bu disiplin, örgütteki temel öğrenme biriminin takımlar olduğu ve ancak takımlar öğrendikçe öğrenen organizasyonun oluşumunun gerçekleşebileceğiyle ilgilidir.

Yazında çoğunlukla kullanılan bir diğer öğrenen örgüt boyutları Watkins ve Marsick (1993) tarafindan aşağıdaki şekilde açıklanmaktadır:

1-Sürekli Öğrenme: Öğrenme yapılan tüm işlerde önceliklidir. Bireyler çalışırken öğrenirler ve sürekli öğrenmeyle firsatlar yakalanır ve büyüme gerçekleşir.

2-Diyalog ve Araştırma: Örgüt içerisinde kültür bireylerin soru sormasını, geri bildirimini, deney yapmayı destekler hale gelir. Bireyler diğer çalışanlarla iletişim kurma ve araştırma yapma konusunda kendilerini güvende hissederler.

3-Takım Halinde Öğrenme: Çalışanların takımlar halinde öğrenmesi teşvik edilerek, öğrenme örgütün bütününde gerçekleşmesi sağlanır.

4-Paylaşımcı Sistemler: Öğrenmenin gerçekleşmesi için teknolojik sistemlerin oluşturulup, işe entegre edilmesi, erişimin ve ayrıca korunmasını sağlamaktadır.

5-Güçlendirilmiş Çalışanlar: Çalışanların öğrenme isteklerini güdülemek için sorumluluklarının arttırılması ve karar verme mekanizmalarına dahil edilmesi gerekir.

6-Sistemler Arası Bağlantı: Çalışanların yaptıkları işin bütün örgüt üzerindeki etkisini görmelerine yardımcı olunur. Ayrıca bireyler çevrelerini gözleyerek, öğrendiklerini paylaşıp örgütün bilgisi haline getirirler.

7-Destekleyici Liderlik: Örgüt içerisindeki liderler, öğrenme modeli olurlar, öğrenmeyi destekler, geliştirir ve örgütsel stratejilerin belirlenmesinde öğrenmeyi kullanırlar.

\section{4 İç Girişimcilik Kavramı ve Kapsamı}

Küreselleşme, tüm örgütlerin iş yapma şekillerinde derin ve büyük değişmeler yapmasına neden olmaktadır. Bu durum bir taraftan örgütlerin amaçlarını yeniden gözden geçirmesini diğer taraftan ise bu değişim dinamizmi içerisinde ortaya çıkan çevresel olumsuzluk ve tehlikelere cevap verebilecek şekilde stratejik bir pozisyon almalarını gerektirmektedir. 1980'lerden bu yana farklı bakış açılarıyla pek çok araştırmacı ve yazar, örgütlerin bu stratejik konumlanmalarında en önemli hususun, onların reaktif yaklaşımla sadece çevreden etkilenerek tepki veren değil, aksine proaktif bir yaklaşım içerisinde çevreyi etkileyebilecek şekilde hareket edebileceklerinin de mümkün olduğuna dikkat çekmektedir (Thomas, 1999; 2000). Böylece literatürde önemli bir yönelim, örgütlerin girişimsel faaliyetler aracılığıyla rekabet ortamında hayatta kalmalarının mümkün olabileceği fikri şeklindedir. Bu bağlamda karmaşıklık ve belirsizlik ile çevrili bir çevrede, varlığını korumak ve sürdürmek örgütlerin 'sürekli yenilik' anlayışını temel yetenekleri haline getirmeleri ile yakından ilişkilidir. $\mathrm{Bu}$ açıdan son dönem yazar ve akademisyenlerinin üzerinde yoğunlaştığı kavram 'iç girişimcilik’tir. Bu dönemde iç girişimciliğin, sadece 3M, Bell, Atlantic, Acordia, BM, Texas Instrument ve Polaroid gibi büyük şirketlerin değil, bürokratik yapıların da yeni gerçeği olduğunu belirtilmektedir. Hatta bu dönem 'iç girişimcilik' ya da 'kurum içi girişimcilik' aşılama dönemi olarak görülmekte ve Anaconda-Ericsson, Apple Computer, AT\&T, Corona Data System, Data General, DuPont, Sony, Toyata vb. şirketlerin ‘başarı için gizli silah'ları olarak ifade edilmektedir (Jobs, 1980).

İç girişimcilik, örgütsel ve genel ekonomik gelişmede çok önemli bir dinamik olarak değerlendirilmektedir. Gerek akademisyenler gerekse uygulamacıların bu kavrama büyük bir ilgi göstermelerinin temelinde iç girişimciliğin işletmelerde yıllardır kârlılığı artırması, ekonomik büyümeyi canlandırması, en iyi işletme uygulamalarına fırsat vermesi, çalışan verimliliği ve sürekli sergilediği yenilikçi potansiyel yatmaktadır. Kennedy ve College, 2010). İç girişimcilik, yaygın tanımıyla yeni fikir ya da davranışların yaratılması, uygulanması ve geliştirilmesi olarak ifade edilmektedir (Morris ve Kuratko, 2002).

\section{5 İç Girişimei Kavramı ve İç Girişimci Özellikleri}

Drucker (1998), iç girişimcileri 'kuruluş içerisinde girişimsel' (intrapreneurial) karakteristikler gösteren kişiler olarak tanımlarken, Miner (1997) kâr amaçlı örgütlerde içeriği yeniden belirlenmiş bir stratejinin parçası olarak yeni fonksiyonlar geliştiren veya yeni firsatları zorlayan yaratıcı yöneticiler şeklinde, Mescan (1999) ise örgüt içerisinde yenilik geliştiren kişiler olarak tanımlamaktadır. Genel çevre ve piyasa koşullarının, bürokratik 
yapılardan daha hızlı değişmesi, örgütlerin dinamik çevreye uyum sağlamalarını gerektirmektedir. Bu anlamda örgütlerin çevreye uyum sağlaması girişimcilik kültürü ile eş anlamlı olarak kullanılmaktadır (Daft, 1993). Girişimci bir kültürü, uyumu, esnekliği, fırsatları ve yeniliği yakalamak için sürekli kendini yeniler ve dönüştürür. Örgütsel dönüşüm ve yenilenme var olan örgütün bütününü etkileyen faaliyetleri kapsar. Çünkü dönüşüm ve yenilenme örgütün bir bütün olarak yetenek ve becerisini gözden geçirmesini, yeniden örgütlenmesini ve yenilik için sistem çapında değişimler sunmasını içerir. Bu dönüşüm ve yenilenme, yeni firsatların gelişmesi ile sonuçlandığı taktirde iç girişimcilik olarak tanımlanır (Thornberry, 2001).

Örgüt içi girişimcilik sürecinin merkezinde, iç girişimci bulunmaktadır. İç girişimci, girişimcilik sürecinde, girişimcilik dünyası ile örgüt dünyasını bir araya getirir. İç girişimci, vizyonu olan ve var olan bir örgüt içerisinde girişimsel ruh, yenilik ve yeniliğe uygun bir atmosfer yaratma sorumluluğunu üstlenen birisidir. Onun rüyası, bir fikri kârlı bir gerçeğe dönüştürmektir. Bunun için de örgüt içerisinde yapılması gereken her şeyi yapar. Örneğin, IBM, PC'nin geliştirilmesi görevini Philiph Estridge'ye vermiştir. Estridge bir iç girişimci olarak grubu ile birlikte PC geliştirme işinde şirketteki birçok geleneği yıkmış, PC gelişimini hızlandırmak için IBM içerisindeki bölümlere bağlı kalmaktan ziyade dış tedarikçiler kullanmış, IBM satış organizasyonunu kullanmak yerine, PC'yi doğrudan perakendeciler yolu ile pazarlamıştır. İç girişimcilerin var olan bir örgüt içerisinde faaliyet göstermeleri, onların girişimci ve geleneksel yönetici arasında bir profile sahip olmalarını gerektirir. Bu nedenle iç girişimcinin bazı özellikleri yönetici ile bazı özellikleri ise girişimci ile örtüşür. Çünkü iç girişimci, bir yandan sorunları var olan örgütsel sistem içerisinde çözme gibi geleneksel yönetici özellikleri gösterirken, bir yandan da makul olan riskleri üstlenme gibi faaliyetler göstererek girişimci gibi hareket eder (Naktiyok, 2004).

\section{6 İç Girişimcilik Boyutları}

Literatürde bu konunun iki yaklaşım etrafında şekillendiği görülmektedir. Bu yaklaşımlardan ilki, Miller ve Frisen, 1983; Covin ve Slevin, 1991; Lumpkin ve Dess, 1996; 2001; Morris ve Kuratko, 2002, ; Hornsby vd., 2002; Antoncic ve Hisrich, 2000; 2003) çalışmalarını temel dayanak olarak alan ve boyut olarak yenilikçi strateji oluşturma, girişimsel duruş, firma düzeyinde yenilikçilik, risk alma, proaktif olma, özerklik ve rekabetçi agresifliğini esas alan Girişimcilik Odaklı Yönelim Yaklaşımı (Entrepreneurial Orientation Approach)dır. İkinci yaklaşım ise (Guth ve Ginsberg, 1990; Zahra, 1991; 1993; Stanford vd., 1994; Zahra ve Covin, 1995; Antoncic ve Hisrich 2003) çalışmalarını temel dayanak olarak alan ve boyut olarak yeni bir ürün veya teknik sunma, kaynakların yeni ya da farklı kombinasyonlarını geliştirerek pazarın yapısını değiştirme anlamındaki yenilikçilik ve iş girişimi ile stratejik yenilenmeyi boyut olarak benimseyen Kurum İ̧̧i Girişimcilik/İ̧̧ Girişimcilik Yaklaşımı (Intraentrepreneurship Approach)'dir (Antoncic ve Hisrich, 2003).

Antoncic ve Hisrich (2001), iç girişimcilik kavramının temel olarak dört boyutu olduğunu belirtmektedirler:

1-Yeni İş Girişimi Boyutu: Örgütün mevcut ürünleri ve pazarları ile ilgili yeni alanlara girmesi ve sonuç almaya odaklanmasıdır.

2-Yenilikçilik Boyutu: Yeni ürün, yeni süreç, hizmet ve teknolojilerin yaratılmasına yönelmek demektir.

3-Örgütsel Yenilenme Boyutu: Stratejilerin yeniden oluşturulması, örgütsel değişim ve yeniden yapılanma ile ilgilenmeyi ifade etmektedir.

4-Proaktivite Boyutu: Üst yönetimin örgütün rekabet avantajını artırmak üzere cesur bir yaklaşımla inisiyatif kullanabilmesine yöneliktir.

Günümüzde bu boyutların her geçen gün daha fazla önem kazanması nedeniyle şirketler giderek iç girişimciliğe yatırım yapmaktadırlar. Örneğin, General Electric, Dupont, Texas Intruments, FBM ve AT\&T gibi büyük şirketler, örgüt yapılarında iç girişimciliğe imkân veren düzenlemelere gitmektedirler. Özellikle Xerox'un yenilik ve büyüme için kuruluşta girişimci ruhun saklı tutulması ve aşama aşama örgüte benimsetilmesi düşüncesi Amerikan yönetim düşüncesinde bir devrim olarak algılanmaktadır (Gürol, 2000). Dolayısıyla bugünün modern girişimcileri, rekabet edebilmek için ekonomiye destek veren, yeni ürünler, yeni işler, yeni teknolojiler, yeni iş alanları oluşumuna ön ayak olan kişiler olarak ekonomik büyümede önemli bir yapı taşı olurken, iç girişimcilik aracılığıyla da girişimci ruhlu insanların iklimini yaratmayla yenilik olgusunu canlı tutmanın en değerli unsuru olmuşlardır.

\section{Araştırma}

\subsection{Araştırmanın Amacı ve Kapsamı}

Örgüt içindeki girişimcilik faaliyetleri olarak tanımlanan iç girişimcilik davranışı, örgütsel değişme ve gelişme için hayati öneme sahiptir. Örgüt içerisinde gerçekleşen girişimcilik davranışının gelişebilmesi için uygun bir örgüt ortamının oluşturulması gereklidir. Yazında öğrenen örgütlerin çalışanlarda yenilik ve yaratıcılığı desteklediği, bununda bireylerde yeni fikir üretimini ya da örgüt için faydalı bir inovasyonu sağlayarak, örgüt içindeki girişimcileri teşvik ettiği ifade edilmektedir (Haase vd., 2015). Tüm süreçlerde öğrenmeye odaklanan, çalışanları bu yönde geliştiren ve destekleyen, bireylerin öğrenmelerinde süreklilik kazandırmaya çalışan öğrenen örgütlerin, örgütte gerçekleşen girişimcilik davranışları için uygun bir ortam sağlamada öncü olduğu söylenebilir.

$\mathrm{Bu}$ değerlendirmenin çerçevesinde araştırmanın amacı öğrenen örgütlerin iç girişimcilik davranışındaki etki düzeyini belirlemektir. Bu bağlamda araştırmada test edilecek model ve hipotez aşağıdaki şekilde oluşturulmuştur. 


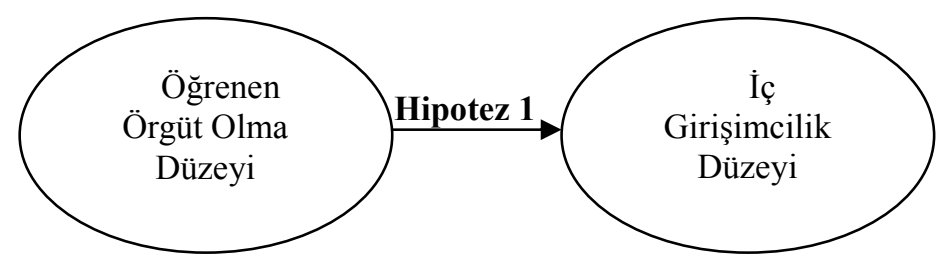

Şekil 1:Araştırma Modeli

Hipotez 1: Öğrenen örgüt olma düzeyi arttıkça iç girişimcilik düzeyi de artmaktadır.

\subsection{Yöntem}

Çalışmanın evreni Denizli'de ihracat yapan ve Denizli İhracatçılar Birliği (DENİB)'e üye olan firmaların beyaz yaka çalışanlarıdır. Bu nedenle DENIB veri tabanında yer alan firmalara, Denib aracılığıyla online anket formları gönderilmiştir. Denib tarafından alınan bilgiye göre araştırmayı kabul eden firmaların beyaz yaka çalışanlarının yaklaşık olarak 1050 olduğu ifade edilmiştir. Toplamda 213 anket geri dönmüş, bunlardan çeşitli nedenlerle güvenilir bulunmayan 9 anket elenerek 204 anket analizler için değerlendirme kapsamına alınmıştır. Uygulamalı araştırmalarda ana kütleden seçilen örnekler üzerinden geri dönüş oranının genellikle \%20 ile \%40 arasında değiştiği dikkate alındığında (Öğüt, 2003), \%20,1 düzeyindeki bir geri dönüş oranı kabul edilebilir bir oran olarak değerlendirilmiştir.

Araştırmada anket yöntemiyle veri toplanmıştır. Araştırmada öğrenen örgüt algısını ölçmek için Watkins ve Marsick (1997) tarafından geliştirilen, Basım vd. (2007) tarafından Türkçeye uyarlanmış, geçerlilik ve güvenilirliği yapılmış 43 ifade ve yedi boyuttan oluşan ölçek kullanılmıştır. Araştırmanın diğer kavramı olan iç girişimcilik davranışını ölçmek için ise Naktiyok ve Kök (2006)' ün yaptığı çalışmada çeşitli ölçeklerden derleyerek oluşturdukları ve geçerlilik ile güvenilirliğini test ettikleri 18 ifade ve dört boyuttan oluşan ölçek kullanılmıştır.

\subsection{Bulgular}

Ölçeğin iç tutarlılığını ölçmek amacıyla yapılan güvenilirlik analizi sonuçları Tablo 1'de verilmiştir. 43 ifadeli öğrenen örgüt ölçeğin güvenilirlik düzeyi \%85,6 $(\alpha=, 856)$ 'dır. Ölçekte yer alan, sürekli öğrenme boyutu için güvenilirlik düzeyi $\% 88,3(\alpha=, 883)$, diyalog ve araştırma $\% 78,1 \quad(\alpha=, 781)$, takım halinde öğrenme $\% 85,3$ $(\alpha=, 853)$, paylaşımcı sistemler $\% 81,2(\alpha=, 812)$, güçlendirilmiş çalışanlar $\% 80,2(\alpha=, 802)$, sistemler arası bağlantı $\% 81,8(\alpha=, 818)$, destekleyici liderlik boyutu \%87,5 $(\alpha=, 875)$ 'dir. 18 ifadeli iç girişimcilik ölçeğinin güvenilirlik düzeyi ise $\% 82,2(\alpha=, 822)$ ' dir. Boyutların güvenirlik düzeyleri ise, yenilik için $\% 80,9(\alpha=, 809)$, yeni girişim yönelimi için $\% 87(\alpha=, 870)$, örgütsel yenilenme $\% 80,1(\alpha=801)$, proaktiflik boyutunun ise $\% 80,3(\alpha=, 803)^{\prime}$ dür.

\begin{tabular}{lcc} 
Boyutlar & İfade Sayısı & Croncach's Alpha $(\boldsymbol{\alpha})$ \\
\hline 1.Öğrenen Örgüt Algısı & $\mathbf{4 3}$ & $\mathbf{8 5 6}$ \\
1a.Sürekli Öğrenme & 7 &, 883 \\
1b.Diyalog ve Araştırma & 6 &, 781 \\
1c.Takım Halinde Öğrenme & 6 &, 853 \\
1d.Paylaşımcı Sistemler & 6 &, 812 \\
1e.Güçlendirilmiş Çalışanlar & 6 &, 802 \\
1f.Sistemler arası Bağlantı & 6 &, 818 \\
1g.Destekleyici Liderlik & 6 &, 875 \\
2.İç Girişimcilik & $\mathbf{1 8}$ & $\mathbf{8 2 2}$ \\
2a.Yenilik & 5 &, 809 \\
2b.Yeni Girişim Yönelimi & 5 &, 870 \\
2c.Örgütsel Yenilenme & 4 &, 801 \\
2d.Proaktiflik & 4 &, 803 \\
\hline
\end{tabular}

Tablo 1: Güvenilirlik Analizi Sonuçlarl

Araştırmaya katılan 204 çalışanın demografik bilgilerine ilişkin bilgiler Tablo 2'de gösterilmiştir. Katılımcıların cinsiyet dağılımına bakıldığında \%52,5'inin erkek, \% 47,5'nin kadın olduğu görülmektedir. Katılımcıların yaş dağılımı incelendiğinde, \%1,5'inin 16-20 yaş aralığında, \%39,7'sinin 21-30 yaş aralığında, \%34,8'inin 31-40 yaş aralığında, \%17,2'sinin 41-50 yaş aralığında, \%5,9' unun 51-60 yaş aralığında ve sadece 1 kişinin 61 yaş ve üzerinde olduğu görülmektedir. Katılımcıların yoğun olarak 21-40 yaşları arasında olduğu dikkat çekmektedir. Katılımcıların \%56,4'ü evli, \%43,6'sı bekârdır. Katılımcıların çalışma süreleri dağılımına göre \%18,6'sının 1 yıl ve daha az, \%40,7'sinin 2-5 y1l arası, \%15,2'sinin 6-10 yıl arası, \%8,3'ünün 11-15 y1l arası, \%17,2'inin ise 16 yıldan daha fazla zamandır mevcut firmalarında çalıştıkları belirlenmiştir. Katılımcıların genel olarak ortalama çalışma süreleri 1 ve 5 yıl arasında olduğu görülmektedir. Eğitim durumları incelendiğinde katılımcıların \%13,2'si lise, \%8,3'ü önlisans, \%65,2'si lisans, \%12,3'si lisansüstü mezunudur. Katılımcıların sadece 2'si ilköğretim mezunudur. Örneklemin beyaz yakalardan oluşması nedeniyle bu sonuçlar şaşırtıcı değildir. 


\begin{tabular}{|l|l|l|l|}
\cline { 3 - 4 } Cinsiyet Dağılımı & Sayı & Yüzde \\
\hline Yaş Dağılımı & Erkek & 107 & 52.5 \\
& Kadın & 97 & 47.5 \\
& $16-20$ & 3 & 1.5 \\
& $21-30$ & 81 & 39.7 \\
& $31-40$ & 71 & 34.8 \\
& $41-50$ & 36 & 17.2 \\
& $51-60$ & 12 & 5.9 \\
& 61 ve üzeri & 1 & .5 \\
\hline Medeni Durum & Evli & 115 & 56.4 \\
& Bekâr & 89 & 43.6 \\
\hline Çalışma Süreleri Dağılımı & 1 yıl ve daha az & 38 & 18.6 \\
& $2-5$ & 83 & 40.7 \\
& $6-10$ & 31 & 15.2 \\
& $11-15$ & 17 & 8.3 \\
& 16 yıl ve üzeri & 35 & 17.2 \\
\hline Eğitim Durumu & İlköğretim & 2 & 1 \\
& Lise & 27 & 13.2 \\
& Önlisans & 17 & 8.3 \\
& Lisans & 133 & 65.2 \\
& Lisansüstü & 25 & 12.3 \\
\hline
\end{tabular}

Tablo 2: Katılımclların Demografik Bilgileri

\begin{tabular}{|l|c|c|c|}
\hline & $\mathbf{( \overline { x } )}$ & S.S. & Düzey $^{*}$ \\
\hline 1. Öğrenen Örgüt & $\mathbf{3 . 4 5}$ & $\mathbf{. 7 4 2}$ & Yüksek \\
\hline 1a. Sürekli Öğrenme & 3.45 & .819 & Yüksek \\
\hline 1b. Diyalog ve Araştırma & 3.54 & .767 & Yüksek \\
\hline 1c. Takım Halinde Öğrenme & 3.42 & .776 & Yüksek \\
\hline 1d. Paylaşımcı Sistemler & 3.42 & .962 & Yüksek \\
\hline 1e. Güçlendirilmiş Çalışanlar & 3.43 & .812 & Yüksek \\
\hline 1f. Sistemler arası Bağlantı & 3.33 & .944 & Orta \\
\hline 1g. Destekleyici Liderlik & 3.56 & .897 & Yüksek \\
\hline 2. İç Girişimcilik & $\mathbf{3 . 6 9}$ & $\mathbf{. 8 2 2}$ & Yüksek \\
\hline 2a. Yenilik & 3.84 & .853 & Yüksek \\
\hline 2b. Yeni Girişim Yönelimi & 3.68 & .852 & Yüksek \\
\hline 2c. Örgütsel Yenilenme & 3.68 & .876 & Yüksek \\
\hline 2d. Proaktiflik & 3.56 & .815 & Yüksek \\
\hline
\end{tabular}

* $\overline{\mathrm{x}}=1-2.59$; Düşük, $\overline{\mathrm{x}}=2,60-3.39$; Orta, $\overline{\mathrm{x}}=3.40-5$; Yüksek

Tablo 3:Verilere İlişkin Ortalama ve Standart Sapma Değerleri

Araştırmaya katılan çalışanların çalıştıkları firmaya karşı algıladıkları öğrenen örgüt düzeyi ve iç girişimcilik düzeyini ölçmek üzere hazırlanan ifadelere verdikleri cevapların ortalama ve standart sapmalarını gösteren tanımlayıcı analiz sonuçları Tablo 3'de verilmiştir. Tabloda görüldüğü gibi öğrenen örgüt düzeyi ortalaması 3,45 ve iç girişimcilik düzeyi ortalaması 3,69'dur. Değişkenlerin boyutları incelendiğinde destekleyici liderlik boyutunun ortalaması 3,56 ile yenilik boyutunun ortalaması 3,84 değeriyle diğer boyutlara göre daha yüksek düzeyde olduğu görülmektedir.

Değişkenler ve değişkenleri oluşturan boyutların birbirleriyle olan ilişkilerini gösteren korelasyon analizi sonuçları Tablo 4'de gösterilmiştir. Öğrenen örgüt boyutlarıyla iç girişimcilik değişkenin boyutları arasındaki tüm ilişkilerin istatistiksel olarak anlamlı olduğu görülmektedir. Bağımlı değişken olarak analize katılan iç girişimcilik boyutları ile bağımsız değişken olarak analize katılan öğrenen örgüt olma düzeyi boyutları arasında güçlü bir korelasyon gözlenmektedir. İki ayrı değişkenin boyutları arasındaki en yüksek düzeyde ilişki, $621(\mathrm{p}<0,01)$ ile öğrenen örgüt değişkenin sürekli öğrenme boyutu ile iç girişimcilik değişkenin yenilik boyutu arasındadır. Bu ilişki orta derecede, doğrusal ve pozitif yönlüdür. Bir örgüt öğrenme faaliyetine süreklilik kazandırdığında bununda beraberinde daha çok yenilik getirdiği, yine yenilik faaliyetleri arttıkça öğrenmenin sürekli hale geleceği gibi bir sonuç çıkarılabilir. En düşük düzeydeki ilişki ise, $388(\mathrm{p}<0,01)$ ile öğrenen örgüt değişkenin paylaşımcı sitemler boyutu ile iç girişimcilik değişkenin yenilik arasında olduğu görülmektedir. Bu ilişkinin derecesi zayıf olup ayrıca doğrusal ve pozitif yönlüdür. Örgütteki yenilik faaliyetleri için öğrenen örgüt boyutlarından paylaşımcı sistemlerin yenilik faaliyetleriyle ilişkisi diğerlerine göre düşüktür. 


\begin{tabular}{|c|c|c|c|c|c|c|c|c|c|c|c|c|c|}
\hline & 1 & $1 \mathrm{a}$ & $1 b$ & 1c & 1d & $1 e$ & 1f & $1 \mathrm{~g}$ & 2. & $2 a$. & $2 b$. & 2c. & 2d. \\
\hline 1. Öğrenen Örgüt & 1 & & & & & & & & & & & & \\
\hline 1a. Sürekli Öğrenme &, $851 * *$ & 1 & & & & & & & & & & & \\
\hline $\begin{array}{l}\text { 1b.Diyalog ve } \\
\text { Araştırma }\end{array}$ &, $829 * *$ &, $844 * *$ & 1 & & & & & & & & & & \\
\hline $\begin{array}{l}\text { 1c.Takım Halinde } \\
\text { Öğrenme }\end{array}$ &, $907 * *$ &, $736^{* *}$ &, $782 * *$ & 1 & & & & & & & & & \\
\hline $\begin{array}{l}\text { 1d.Paylaşımc1 } \\
\text { Sistemler }\end{array}$ &, $818 * *$ &, $618 * *$ &, $571 * *$ &, $663 * *$ & 1 & & & & & & & & \\
\hline $\begin{array}{l}\text { 1e.Güçlendirilmiş } \\
\text { Çalışanlar }\end{array}$ &, $899 * *$ &, $716^{* *}$ &, $657 * *$ &, $771^{* *}$ &, $731 * *$ & 1 & & & & & & & \\
\hline $\begin{array}{c}\text { 1f.Sistemler aras1 } \\
\text { Bağlant1 }\end{array}$ &, $901 * *$ &, $657 * *$ &, $618 * *$ &, $794 * *$ &, $706^{* *}$ &, $829 * *$ & 1 & & & & & & \\
\hline $\begin{array}{l}\text { 1g.Destekleyici } \\
\text { Liderlik }\end{array}$ &, $879 * *$ &, $618 * *$ &, $639 * *$ &, $801 * *$ &, $633 * *$ &, $759 * *$ &, $840 * *$ & 1 & & & & & \\
\hline 2. İç Girişisimcilik &, $709 * *$ &, $652 * *$ &, $829 * *$ &, $625^{* *}$ &, $518 * *$ &, $630 * *$ &, $616 * *$ &, $662 * *$ & 1 & & & & \\
\hline 2a.Yenilik &, $600 * *$ &, $621 * *$ &, $581 * *$ &, $537 * *$ &, $388 * *$ &, $545^{* *}$ &, $450 * *$ &, $562 * *$ &, $869 * *$ & 1 & & & \\
\hline $\begin{array}{l}\text { 2b.Yeni Girişim } \\
\text { Yönelimi }\end{array}$ &, $678 * *$ &, $584 * *$ &, $610 * *$ &, $612 * *$ &, $511 * *$ &, $583 * *$ &, $613 * *$ &, $620 * *$ &, $888 * *$ &, $759 * *$ & 1 & & \\
\hline $\begin{array}{l}\text { 2c.Örgütsel } \\
\text { Yenilenme }\end{array}$ &, $584 * *$ &, $499 * *$ &, $466 * *$ &, $504 * *$ &, $443 * *$ &, $537 * *$ &, $544 * *$ &, $558 * *$ &, $878^{* *}$ &, $627 * *$ &, $680^{* *}$ & 1 & \\
\hline 2d.Proaktiflik &, $641 * *$ &, $618 * *$ &, $563 * *$ &, $556 * *$ &, $481 * *$ &, $549 * *$ &, $553 * *$ &, $589 * *$ &, $868 * *$ &, $719 * *$ &, $714 * *$ &, $663^{* *}$ & 1 \\
\hline
\end{tabular}

\section{Tablo 4: Değişkenler Arası Korelasyon Değerleri}

Araştırmanın hipotezini test etmek amacıyla doğrusal regresyon analizi uygulanmıştır. Analiz sonuçları Tablo 5 'de verilmiştir. Analiz sonuçlarına göre öğrenen örgüt olma düzeyinin iç girişimcilik düzeyini anlamlı $(p<0,05)$ ve pozitif yönde $(\beta=, 678)$ etkilediği görülmektedir. Başka bir ifadeyle çalışanların firmaları hakkında öğrenen örgüt algılama düzeyinin bir birim artması, örgüt içerisinde iç girişimcilik davranışlarını 0, 678 birim arttıracaktır. Açıklanan varyans değeri incelendiğinde öğrenen örgüt algısının, iç girişimcilik davranışını $\%$ 40,1'ini açıkladığı anlaşılmaktadır. Sonuç olarak araştırmanın hipotezi kabul edilerek araştırma modeli desteklenmiştir.

\begin{tabular}{cccccc}
$\begin{array}{c}\text { Bağımlı } \\
\text { Değişken }\end{array}$ & Bağımsız Değişken & $\begin{array}{c}\text { Beta } \\
(\mathbf{B})\end{array}$ & $\mathbf{t}$ & $\mathbf{p}$ & $\mathbf{R}^{\mathbf{2}}$ \\
\hline $\begin{array}{c}\text { Iç Girişimcilik } \\
\text { Düzeyi }\end{array}$ & Öğrenen Örgüt &, 678 & 14,300 &, 000 &, 401
\end{tabular}

Tablo 5: Regresyon Analizi Sonuçları

\section{Sonuç}

Günümüz rekabet dünyası çalışma, başarma ve yaratma duygularıyla harekete geçen girişimcilerin tek başına harekete geçişinin yeterli olmadığına, bir örgütün hareketliliğinin sağlanması gerekliliğine dikkat çekerek 'iç girişimcilik' ya da 'kurum içi girişimcilik' olarak ifade edilen düzenlemelere yer vermiştir. Çünkü küreselleşme olgusu, girişimcilik ve girişim kavramlarını toplumsal kültürün dışına taşıyarak girişimcileri dünya pazar ve rekabet kültürüyle karşı karşıya getirmiştir. Günümüzün rekabetçi pazarlarında gereklilik haline gelen girişimcilik, yenilikçilik ve risk faaliyetleri çerçevesinde yeniden şekillenmektedir. Örgütlerin üst yönetiminden güçlü ve sürekli destek görmesi gereken girişimcilik, örgütün yenilenmesi, yeni iş alanları yaratılması ve üstün bir performans için önem taşımaktadır. Bu bakımdan, günümüzde işletmeler artık, rekabette yenilikçi, yaratıcı ve uygulayıcı alabilmek için, örgüt içindeki girişimcilik ruhunu yakalamanın gerekliliğinin bilincine varmışlardır.

Araștırmalar, başarılı bir örgütte sadece girișimci davranıșların ortaya çıkarılmasının yeterli olmayacağı, bu davranışlarla birlikte uygun kültürel ve örgütsel yapının da bulunması gerektiğine işaret etmektedirler. Bu yapı da ancak öğrenmeyi her düzeyde gerçekleştiren bir örgüt ile gerçekleştirilir. Örgütsel olarak öğrenme, örgütlerin kendi sorunlarını çözmelerine, yeni fikirleri yaratmaları için kapasitelerinin artırmalarına imkân sağlar. Öğrenmenin her düzeyde gerçekleşmesinin önemini vurgulayan öğrenen örgütler ise çalışanların gelişimini sürekli teşvik eden ve besleyen, öğrenmeyi, işletmenin kapasitesini ve başarısını artırmaya yönelik bir yatırım olarak gören, dolayısıyla öğrenmeye ve gelişmeye imkân sağlayan bir ortam yaratan örgütlerdir. 
Bildiri, öğrenen örgütün iç girişimcilik davranışı üzerine etki derecesini ölçmek üzere Denizli'de ihracat yapan firmalar üzerine bir araştırma yapmış ve araştırmadan elde edilen bulgulara göre şu sonuçlara ulaşıllmıştır: Araştırma örneklemini oluşturan beyaz yakalıların öğrenen örgüt algısı $\bar{x}=3,45$ ve iç girişimcilik düzeyi $\bar{x}=3,69$ olarak tespit edilmiştir. Bu durum beyaz yakalıların hem öğrenen örgüt düzeyinin hem de iç girişimcilik düzeyinin yüksek olduğunu göstermektedir. Söz konusu yüksek düzey, ortalama değere yakındır. Bu sonuç araştırma örneklemini oluşturan beyaz yakalılarda her iki boyut açısından da geliştirilmesi gereken hususlar olduğuna dikkat çekmektedir. Araştırmada boyutları oluşturan alt unsurlar arasında ciddi bir farklılık olmaması öğrenen örgüt için aritmetik ortalama değerlerinin $\bar{x}=3,33-3,45$; iç girişimcilik için aritmetik ortalama değerlerinin $\bar{x}=3,56-3,84$ olması dikkate alarak genel olarak firmaların her iki boyutta kurum kültürleri geliştirmeleri önerilebilir. Bu değerler firmaların fason üretim yapmalarıyla da ilişkilendirilebilir. Firmaların küresel pazarlarda rekabet etmek zorunluluğu oldukça bu değerlerin daha yüksek olması beklenmektedir.

\section{Kaynakça}

- $\quad$ Akgün vd., 2009. Bilgi Yönetimi ve Öğrenen Örgütler, Eflatun Yayınevi, Ankara.

- Antoncic and Hisrich, 2003. "Clarifying the Intrapreneurship Concept", Journal of Small Business and Enterprise Development, 10/1, p. 8.

- Antoncic and Hisrich, 2001. "Intrapreneurship: Construct Refinement and Cross-Cultural Validation." Journal Of Business Venturing, 16/5, p. 498.

- Atheya and Arora, 2015. "Augmenting Intrapreneurship in Learning Organizations", Advances in Economies and Business Management (AEBM), 2/12, p. 1167.

- Basım. vd. 2009. “Öğrenen Örgüt Algisinin Örgüt Içi Girişimciliğe Etkisi: Kamuda Bir Araştirma.”Ankara Üniversitesi SBF Dergisi, 64/03, p. 32, p. 34-35.

- Child, 2005. Organization Contemporary Principles and Practice, Blackwell Publishing, Oxford.

- Covin and Slevin, 1991. A Conceptual Model of Entrepreneurship as Firm Behavior, Entrepreneurship Theory and Practice, p.5.

- Daft, 1993. Management, the Dreyden Press, New York.

- Garvin, 1993. "Building a Learning Organization", Harvard Business Review, p.81.

- Gürol, 2000. Türkiye’de Kadın Girişimci ve Küçük İşletmesi: Fırsatlar, Sorunlar, Beklentiler ve Öneriler, Atılım Üniversitesi Yayınları:2, Ankara.

- Guth and Ginsberg, 1990. “Guest Editors' Introduction: Corporate Entrepreneurship”, Strategic Management Journal, 11, p.6.

- Haase et all., 2015. "Organisational Learning and Intrapreneurship: Evidence of Interrelated Concepts." Leadership \& Organization Development Journal, 36/8 , p. 910. p.920.

- Hornsby, Kuratko and Zahra, 2002. "Middle Managers' Perception of the Internal Environment for Corporate Entrepreneurship: Assessing a Measurement Scale", Journal of Business Venturing, 17, p.254255.

- Kenney and College, 2010. "Globalpreneurship: The Need for a Line of Demarcation within Corporate Entrepreneurship Research, Journal of Business Studies, Quarterly, 1/1, p. 3.

- Lumpkin and Dess, 1996. "Clarifying the Entrepreneurial Orientation Construct and Linking it to Performance", Academy of Management Review, 21/1, p.136.

- Marquardt, 1996. Building the Learning Organization. McGraw-Hill. Inc., New York.

- Miller and Friesen 1983. "Strategy-Making and Environment”, Strategic Management Journal, 4, p. 223.

- Molina and Callahan, 2009.“ Fostering Organizational Performance: The Role of Learning and Intrapreneurship” Journal of European Industrial Training, 33/5, p. 335., p. 394-395.

- Morris and Kuratko, 2002. Corporate Entrepreneurship: Entrepreneurial Development within Organizations. South-Western Pub, USA.

- Naktiyok ve Bayrak Kök, 2006. “Çevresel Faktörlerin İç Girişimcilik Üzerine Etkileri”, Afyon Kocatepe Üniversitesi, İI.B.F. Dergisi, VIII/2, p. 84-85.

- Ohmeo, 1989. “The Global Logic of Strategic Alliances, Harvard Business Review, March-April, p. 143.

- Öğüt, 2003. "Küçük ve Orta Ölçekli Sanayi İşletmelerinde Kriz Yönetimi Yaklaşımları: Tekstil Sektörü Örneği”, Selçuk Üniversitesi Sosyal Bilimler Enstitüsü Dergisi, 9, p. 293.

- Öneren, 2012. İşletmelerde Öğrenen Örgütler Yaklaşımı, Uluslararası Yönetim İktisat ve İşletme Dergisi, 4/7, p. 164.

- Pedler et all. 1991. The Learning Company, McGraw-Hill. Inc., New York. 
- $\quad$ Perlmutter and Heenan, 1986. "Cooperate to Compete Globally, Harvard Business Review, March- April, p. 136.

- $\quad$ Rowden, 2001. "The Learning Organization and Strategic Change". SAM Advanced Management Journal, 66/3, p. 12.

- Senge, 1990. The Fifth Discipline-The Art and Practice of the Learning Organization, Currency and Doubleday, Newyork.

- Thomas, 2000. "Developing and Supporting Information Entrepreneurs", Industrial and Commercial Training, 32/6, p. 197.

- Thomas, 1999. "Individuals and Entreprise: Developing Entrepreneurs for the New Millenium", Industrial and Commercial Training, 31/7, p. 258.

- Thornberry, 2001. “Corporate Entrepreneurship, Antidote or Oxymoron?” European Management Journal, 19/5, p. 526.

- Tokgöz, 2015. Çalışanların Öğrenen Örgüt Algılarının İş Tatmini, Örgütsel Bağlılık ve Örgüt İçi Girişimcilikleri Üzerindeki Etkisi: Bilişim Sektörü Üzerine Bir Araştırma, Yayınlanmamış Doktora Tezi, Okan Üniversitesi Sosyal Bilimler Enstitüsü. İstanbul.

- Watkins and O’Neil, 2013. "The Dimension of the Learning Organization Questionneare (the DLOQ): A Nontechnical Manual", Advances in Developing Human Resources, 15/2, p. 135.

- Watkins and Marsick, 1993. Sculptring the Learning Organization, Jossey Bass, San Francisco.

- Zahra, 1991."Predictors and Financial Outcomes of Corporate Entrepreneurship: An Exploratory Study", Journal of Business Venturing, 6/4, p. 261.

- Zahra, 1993. "Environment, Corporate Entrepreneurship and Financial Performance: A Taxonomic Approach", Journal of Business Venturing, 8, p. 322.

- Zahra and Covin, 1995. "Contextual Influences on the Corporate Entrepreneurship-Performance Relationship: A Longitudinal Analysis”, Journal of Business Venturing, 10, p. 44.

- Zahra et all., 2004. "Entrepreneurship in Family vs. non Family Firms: A Resource Based Analysis of the Effect of Organizational Culture." Entrepreneurship Theory and Practice, 28/4, p. 365. 


\title{
Avrupa Enerji Birliği (AEB) ve Türkiye'nin Bölgesel Enerji Hub’ı Olabilirliği: Firsat ve Zorluklar
}

\section{European Energy Association (EEA) and Turkey's Regional "Energy Hub" Possibility: Opportunities and Challenges}

\author{
Dr. Nuran Belet (Gazi University, Turkey)
}

\begin{abstract}
European Union Commission declared its vision on European Energy Association EEA including comprehensive changes on energy strategy about energy cooperation and climate changes, as well as conversion and its multi-dimensional cooperation objectives with its report European Commission, Energy Union Package, COM 2015-80. Current cost of energy to the European Union damages its competitiveness in the international market due to its high dependence on energy supply. EU will play an active role in the international energy market with EEA on both energy dependence and on energy supply security. Only four countries are listed on the EEA vision document among alternative producers, cooperation with transit countries and strategic partners: Algeria, Azerbaijan, Turkmenistan and Turkey. Due to its geo-strategic location Turkey is the most affordable and reliable energy transit route between Central Asia and Europe. In this study Turkey's place as a strategic transit country and its partnership in TAP/TANAP projects as well as its possibility to become a regional energy hub and an oil corridor in the East-West route will be discussed in detail as it is stated in EEA vision document. In this context, possibilities, challenges and related macro-economic policies will be evaluated.
\end{abstract}

\section{Giriş}

Avrupa Birliği (AB) enerji konusunda başta enerji arz güvenliği olmak üzere, enerji kaynaklarının ve tedarikçilerin çeşitlendirilmesi ve rekabetin sağlanması için son yirmi yıldır stratejik politika seçenekleriyle vizyonuna yönelik yol haritası belirlemektedir. Bu anlamda Birlik, enerji maliyetlerini düşürüp verimlilik artışını sağlayarak küresel ticarette rekabet gücünü artırmak ve iklim değişikliği ile daha etkin şekilde mücadele etmek amacıyla 25 Şubat 2015 'te "Avrupa Enerji Birliği (AEB)" olarak adlandırılan paketi açıkladı. Üye devletler tarafından atılması gereken önemli adımları ve önlemleri içeren bu paket, AB'nin enerjide önümüzdeki 50 yıla yönelik vizyon belgesi niteliğindedir.

Türkiye son 20-30 yıldır içinde bulunduğu coğrafyanın avantajlarını da kullanabileceği "enerji merkezli" hedefleri üzerine yoğunlaşmaktadır. Bu anlamda stratejik önem taşıyan projelerin başında Türkiye'nin de içinde olduğu TANAP ve Avrupa için TAP projeleri sayılabilir (Belet,2013). AB'nin enerji alanında yeni bir kavram geliştirme süreci Türkiye'nin enerjide merkez ülke olma stratejileriyle de örtüşmektedir. Türkiye açısından Birliğin enerji perspektifi önemli firsatlar ve işbirliklerinin geliştirilmesine yol açabilecektir. Bu çalışmada, AEB vizyon belgesinde anlatıldığı şekliyle "Türkiye'nin stratejik transit ülke" konumu ve bölgede ortak olduğu TANAP/TAP projeleri ile Doğu - Batı rotasında bölgesel "bir "enerji hubı" gaz koridoru" olabilirliği detaylı olarak ele alınacaktır. Bu kapsamda olasılıklar, firsatlar, zorluklar ve buna yönelik uygulanması gereken tedbirler ve makroekonomik politikalar da değerlendirilecektir.

\section{Avrupa Birliği Enerji Görünümü ve Avrupa Enerji Birliği (AEB)}

\subsection{Avrupa Birliği Enerji Görünümü}

Avrupa Birliği'nde enerji başlı̆̆ 1 kuruluşundan bugüne stratejik öneme sahip olmuştur. Birliğin enerji Politikasının gelişimine bakıldığında, ilk olarak 1958 yılında Avrupa Atom Enerjisi Topluluğu'nu kuran Antlaşmalar imzalanmıştır. O zamandan beri, Enerji Politikası öncelikleri, hedefleri, ihtiyaçları ve çözmesi gereken önemli sorunları arsında yer almıştır. 1973'teki ilk petrol krizi başta gelişmiş ülkelerin çoğunluğunda ve AB üyesi gibi enerji ithalatı yoğun ülkeleri de olumsuz etkilemiştir. Bu süreç ülkeleri enerji arzını dış şoklardan koruyacak bir strateji ihtiyacını da ortaya koymuş, 1980 sonrası başta enerji başlığı olmak üzere, çevrenin korunmasının gerekliliği ve çevreyi koruyacak enerji sistemlerine yönelik öncelikler de gündeme gelmiştir. AB 1995 yılında, enerji piyasalarının serbestleşmesi ve enerji iç pazarının ilke ve hedeflerinin ortaya konulduğu "Avrupa Birliği için Bir Enerji Politikası" başlıklı Beyaz Kitabı deklare etmiş̧tir. AB zaman içinde 2000'li yıllarda beri hedefleri ve öncelikleri doğrultusunda enerji politikalarına yönelik direktifler yayınlayarak çeşitli düzenlemelere gitmiştir. AB Enerji Politikası, doğalgaz ve elektrik piyasalarının tedricen serbestleşmesi yönünde önemli ilerlemeler kaydetmiştir (EU,2016a). Malların serbest dolasımı, hizmet sağlama serbestisi, yerleşme hakkı ve rekabetin korunması ilkeleri enerji sektörlerinde de uygulanmaktadır (Doğalgaz iç piyasasına ilişkin, piyasanın kademeli olarak serbestleştirilmesi de olmak üzere ortak kuralları belirleyen 2003/55/EC sayılı Direktif ve Elektrik iç piyasasına ilişkin ortak kuralları belirleyen 2003/54/EC sayılı Direktif). Bu kapsamda yapılan düzenlemeler, birliğin enerji stratejisinin önümüzdeki yıllarda nasıl şekilleneceğini belirleyerek, AB'nin özellikle Balkanlar'daki 
komşularıyla enerji ortaklığı geliştirmesine temel oluşturacaktır. AB’nin Enerji Politikaları önemi açısından, rekabet gücü, enerji arzının güvenliği ve çevrenin korunması temel başlıklarını içermiştir. Bu yaklaşımla, toplam enerji tüketiminde kömürün payını korumayı, doğal gazın payını artırmayı, nükleer enerji santralleri için azami güvenlik şartları tesis etmeyi ve yenilenebilir enerji kaynaklarının payını artırmayı hedeflemektedir. AB, Avrupa için Akıllı Enerji (2003-2006)" Programı (EU, 2000) Kasım 2000'de Komisyon'un "Enerji Arzın Güvenliği” adlı Yeşil Kitap tarafindan taslağını da oluşturmuştur. Böylece, elektrik sektöründe AB iç ticareti ve transit enerji ağlarının kurulmasına yönelik program ve projeler başlatılmıştır. Bu kapsamda elektrik ve doğalgaz enerji ağlarının kurularak elektrik alanında üye ülkeler arasındaki bağlantıların geliştirilmesi, üye ülkelerle üçüncü ülkelerin bağlantılarının güçlendirilmesi; doğalgaz sektöründe ise, yeni tüketici noktalarına /bölgelere ulaştırılması, izole durumdaki doğalgaz ağlarının güncellendirilmesi, alım ve depolama kapasitesinin geliştirilerek, doğalgaz boru hatlarının arzının artırılarak ulaştırma kapasitesinin yükseltilmesi hedeflenmiştir (EU, 2000). AB'ye 2000'lerin başında katılmış olan Baltık ve Doğu Avrupa ülkeleri özellikle doğalgaz ithalatı, tedarik yolları ve arz güvenliği için daha kritik bir önem arz etmektedir. Avrupa enerji arzı güvenliğinde çeşitli, dönemlerde ciddi sorunlar yaşadığı enerji tedarikçisine (Rusya) olan bağımlılık, özellikle doğal gaz ve elektrik için geçerlidir. Tablo 1 'de AB üyesi üç Baltık ülkesinin (Estonya, Letonya, Litvanya) elektrik ihtiyaçlarının tamamını Rusya'dan ithal ederek karşıladıkları görülmektedir. Ayrıca, doğalgaz da dahil olmak üzere, bütün enerji ihtiyacının dörtte birinden fazlasını Rusya'dan temin etmektedir (SETA, 2016:19-20). Petrolde de durum AB üyesi ülkelerde de benzerdir. Avrupa'nın enerji tedarikine yönelik projeksiyonlar, AB üyesi ülkelerin 2030 yılına yönelik enerji talebinin \%27 artış göstermesi beklenmektedir (SETA, 2015).

\begin{tabular}{|c|c|c|c|c|c|}
\hline \multicolumn{4}{|l|}{ AB Üyesi Ülkeleri } & \multirow{2}{*}{\multicolumn{2}{|c|}{ AB Üyesi Olmayan Ülkeler }} \\
\hline ESTONYA & $(\% 100)$ & SLOVENYA & $(\% 52)$ & & \\
\hline FINLANDIYYA & $(\% 100)$ & AVUSTURYA & $(\% 49)$ & & \\
\hline LITVANYA & $(\% 100)$ & POLONYA & $(\% 48)$ & MAKEDONYA & $(\% 100)$ \\
\hline LETONYA & $(\% 100)$ & HIRVATİSTAN & $(\% 37)$ & BELARUS & $(\% 98)$ \\
\hline SLOVAKYA & $(\% 98)$ & ALMANYA & $(\% 36)$ & KARADAĞ & $(\% 87)$ \\
\hline BULGARİSTAN & $(\% 92)$ & İTALYA & $(\% 27)$ & SIRBİSTAN & $(\% 87)$ \\
\hline MACARİSTAN & $(\% 60)$ & ROMANYA & $(\% 27)$ & UKRAYNA & $(\% 66)$ \\
\hline ÇEK CUMHURIYYETİ & $(\% 78)$ & FRANSA & $(\% 14)$ & TÜRKİYE & $(\% 64)$ \\
\hline YUNANISTAN & $(\% 76)$ & BELÇİKA & $(\% 5)$ & İSVİÇRE & $(\% 12)$ \\
\hline
\end{tabular}

Tablo 1. Avrupa Ülkelerinin Doğal Gaz Tüketiminin Rusya'ya Olan Bă̆ımlılık Oranları, (\%) Kaynak: Pala ve Özden, (2016: 38).

\subsection{Avrupa Enerji Birliği (AEB)}

1970'li yıllarda yaşanan petrol krizleri enerjinin küresel bir güç olduğunu ve ithal eden ülkeler için özellikle de AB'nin gündeminde tek ekonomik birlik hedefinin yansıra ortak tek enerji politikası hedefini birliğin vizyonuna dahil etmiştir. Buna yönelik ilk düzenleme 2009 Lizbon Antlaşması metninde yer alan enerji başlığıdır. AB genelinde diğer konu başlıklarında olduğu gibi düzenleyici yapıların olmasına karşın, son yıllarda Rusya $A B$ ilişkilerinde enerji arz güvenliği konusunda yaşanan sıkıntılar Birliği üyeler için Enerji Birliği'nin oluşturulması stratejisini kuvvetlendirmiştir. Avrupa Komisyonu Enerji Birliği eylem planını 25 Şubat 2015 tarihinde yayımladığı European Commission, Energy Union Package: A Framework Strategy for a Resilient Energy Union with a Forward-Looking Climate Change Policy, COM 2015-80, 25.02.2015) deklarasyonla kamuoyuna duyurmuştur. Bu deklarasyon ile $\mathrm{AB}$, enerji ve iklim değişikliğine yönelik enerji stratejilerinde kapsamlı değişim, dönüşüm ve çok boyutlu işbirliği hedeflerini içeren politikalarından Avrupa Enerji Birliği (AEB) konusundaki hedeflerini deklare etmiştir.

AB ülkeleri, tükettikleri toplam enerjinin \%53'ünü ithal etmektedirler. AB genelinde petrole bağımlılık yaklaşık $\% 90$, doğal gaza bağımlılık \%66, katı yakıtlara bağımlılık \%42 ve nükleer enerjiye bağımlılık \%40 seviyelerindedir. Bu kapsamda Avrupa'nın doğalgaz ithalatı olarak Rusya ya bağımlılı̆̆ $1 \% 60$ 'lara ulaşmaktadır. enerji arz güvenliğinin sağlanması, enerji kaynaklarının ve tedarik yollarının çeşitlendirilmesi öncelikli hedefler arasında belirtilmiştir. Birlik, AEB ile gerek enerji bağımlılığını azaltmak gerekse enerji arz güvenliği konusunda ticaret, teknoloji ve dış politika araçları ile AEA’nin uluslararası enerji piyasasında aktif rol oynamayı hedeflemektedir (EU, 2015). AB'nin mevcut enerji maliyetleri bakımından elektrik toptan satış fiyatları ABD fiyatlarının \%30 üstünde seyrederken, gaz fiyatları ABD fiyatlarının 2 katı civarındadır. Bu durum AB'nin enerji tedarikindeki yüksek bağımlılığı nedeniyle uluslararası piyasalardaki rekabet gücüne zarar vermektedir (Pala ve Özden, 2015: 27). Birliğin yüksek enerji maliyetleri de dikkate alınarak AEB'nin temel hedeflerinin; AB'nin enerji tedarikinde dışa bağımlılığının azaltılması, enerji arzında yeni ülkelerin ve rotaların çeşitliliğinin arttırılması, yüksek enerji maliyetlerinin düşürülmesi ve entegre $\mathrm{AB}$ enerji piyasalarının ve şebekelerinin kurulumu olduğu vurgulanmıştır.

AEB deklasyonunda enerji konusunun stratejik önemine yönelik Avrupa ve birlik için önemli tespitlerde bulunmuştur: (1) AB'nin enerji ihtiyacının \%53'nü ithal ettiği ve bunun da maliyetinin 400 milyar liralık bir tutarla dünyanın en büyün enerji ithalatçısı olduğu, (2) AB üyesi 6 ülke (Finlandiya, Bulgaristan, Slovakya, Estonya, 
Letonya, Litvanya) gaz ihtiyacının tamamını tek bir (Rusya) ülkeden karşılamakta olup, (Ülke bazlı veriler için bkz. Tablo 1) (3) her \%1 lik enerji tüketiminde sağlanan tasarrufun doğalgaz ithalatında \%2,6'lık düşüş sağladığı, (4) Avrupa'da meskenlerin \% 75'nin enerji verimliliğine uygun olmadığı, (5) kullanılan motorlu taşıtların \%94'nün petrol ürünlerine bağımlı olduğu ve bu ürünlerin de \% 90'nın ithal edildiği, (6) AB her yıl doğrudan veya dolaylı olarak enerji alanında 120 milyon Euro'luk sübvansiyon sağlamakta olup, 2020 yılına kadar enerji sektörüne 1 trilyon Euro'luk yatırım yapılması ihtiyacı, (7) Birlik içinde enerji fiyatlarının yüksekliği ve özellikle enerji yoğun sektörleri rekabetsizleştirdiği (EU, 2015:2-3).

Birliğin 25 Şubat belgesinde AEA'nın çok kapsamlı hedef ve düzenlemelerine yer verilmiştir. Bu konular üç ana başlıkta özetlenebilir (Pala Özden, 2015:29-30): (1) Avrupa Birliği’nin (AB), Amerika Birleşik Devletleri (ABD), Japonya ve Çin gibi dünyanın önde gelen ekonomileriyle rekabet gücünü arttırabilmesi için yüksek enerji maliyetlerini düşürmesi. (2) Enerji Tedarikinde Dışa Bağımlılığın Azaltılması ve Kaynak Ülkelerin Çeşitlendirilmesi: AB enerji tedarikinde Rusya'ya bağımlılığı petrolde \%29, doğal gazda ise \%32'dir (bkz. Tablo 1). Ukrayna, Rus gazının Avrupa'ya ulaştırılmasında başlıca transit ülke olup, Rusya ile Ukrayna arasındaki siyasi krizler Avrupa ülkelerine yapılan gaz tedarikini doğrudan etkileyebilmektedir. 2006 ve 2009 yılında üç haftaya varan kesintiler ve gaz akışının durdurulduğu görülmüştür. Bu nedenle AB vizyon belgesinde enerji kaynaklarının çeşitlendirilmesine ve Rus etkisinin azaltılmasına özel bir önem atfedilmiştir (Pala, Özden, 2015: 29). (3) Entegre AB Enerji Piyasalarının ve Şebekelerinin Kurulumu: AB, enterkonnekte (enerji nakil hatlarının bağlantı yerleri) gaz ve elektrik şebekelerinin tesisinden, ortak fonların kullanımına; ortak LNG terminali ve gaz depolama tesislerinin inşa edilmesinden, birlik seviyesinde araştırma ve teknoloji yatırımlarına kadar pek çok iddialı proje ve dönüşümü hedeflemektedir.

Tek bir Avrupa enerji piyasasının oluşturulmasın için enterkonnektelerin bulunduğu bölgelerde, piyasayı dengeleyici düzenlemelerin yapılabildiği, kapasite artırım mekanizmalarının ortaya çıkarıldığı ve piyasa bütünleşmesinin sağlanabildiği ölçüde üye ülkeler arasında bölgesel işbirliğinin güçlendirilmesi hedeflenmektedir. Ayrıca, üye ülkelerin kendi iç enerji piyasalarını düzenleme çalışmalarını tamamlamaları ve vergilendirme sistemlerini gözden geçirmeleri gerekmektedir (Hasan, 2014: 5-6). Avrupa Enerji Birliğinin yol haritasında beş başlık, karşılıklı birbirini güçlendirici unsurlar olarak enerji arzının daha da güvenliği, sürdürülebilirliği ve rekabet edebilirliği bakımından önemle vurgulanmıştı. Bunlar: (1) Enerji Güvenliği, Güven ve Dayanışma, (2) tam entegre olmuş Avrupa enerji piyasası, (3) enerji verimliliği, (4) düşük karbon emisyonlu ekonomi ve (5) araştırma, yenilik ve rekabetçilik (EU, 2015:4).

Avrupa Komisyonu, enerji arzının güvenliği için petrol, doğal gaz depolama, uranyum/nükleer yakıt tedarikine yönelik mevcut alt yapı tesislerin korunması, geliştirilmesi ve takviye edilmesine yönelik tavsiyelerde bulunarak; kamuya ve özel sektöre ait enerji ile ilgili varlıklar arasında denge sağlanmasına yönelik ortak politikalar izlenmesini tavsiye etmektedir. Üye ülkelerin koordinasyon mekanizmaları geliştirmeli, zorunlu hallerde enerji tedarikinin zarar görmemesi için risk değerlendirmelerine göre AB ülkelerinin ihtiyacı olan enerjinin sağlanması için ortak eylem planları hedeflemektedir. Özellikle bu planlamaların doğu Avrupa ülkeleri için ivedilikle yapılması gerekmektedir (Hasan, 2014). AB'nin AEB vizyonunda ülkelerin enerji talebinin makul bir seviyede tutulması için üye ülkeler, 2020'de hedeflenen enerji verimlilik değerlerine ulaşabilmek için binalarda ve sanayi tesislerinde ısınma ve üretim için kullanılan enerjinin israfını önlemek için gerekli teknik önlemlerin alınması öngörülmektedir. Bu kapsamda, 2020 verimli enerji kullanım hedeflerine ulaşılabilmesi için öncelikler belirlenerek "Stratejik Enerji Teknolojileri Planı için Bütünleştirilmiş Yol Haritası” sunulmuştur (EU, 2016b). Birlik içinde enerji üretiminin artırılması için de bazı stratejilere dikkat çekmek. Bunlar arasında, yenilenebilir enerji kaynaklarının yaygınlaştırılması hidrokarbon enerji (petrol, gaz, kömür) kaynaklarının verimli bir şekilde işletilmesi ve temiz kömür üretiminin teşvik edilerek hidrokarbon enerjiye bağımlılığın azaltılmasına yönelik öncelikler bulunmaktadır (Hasan, 2014).

\subsection{Enerji Hub Kavramı}

Hub kavramı, belirli bir aktivitenin tanımlandığı yer olarak adlandırılmaktadır. Bu anlamda enerji hub' konu olan enerji faktörünün yoğun olarak fiziki veya sanal işlem gördüğü yer olarak tanımlanabilir. Dünyadaki örneklerine bakıldığı zaman enerji üssü ve enerji borsasını tanımsal olarak şekilde (Tablo 2) sınıflandırmamız mümkündür. Her iki tanımlamada da dünya örneklerine baktığımızda öne çıkan unsur; başarılı bir borsanın oluşabilmesi için fiziksel ve ticari altyapıyı birlikte destekleyen mevzuat, ticari ve bunu destekleyen piyasa yapısının gerekliliğidir. Hub olan bölge veya ülkelerde birkaç faaliyetin yer aldığı da görülmektedir. Bunlar; gaz veya petrolün toplama ve işleme, iletim, depolama, pazarlama ve ticaret, dağıtım perakende ve katma değer servisleri. Gerek enerji üssü gerek borsası olsun, üslerin ticari amacı; etkin, şeffaf ve rekabetçi piyasayı desteklemek için fiyat oluşumuna referans sağlamaktır. Uluslararası piyasalarda Henry Hub - Lousiana, ABD; Zeebrugge -Belçika ve borsa için de NBP - Birleşik Krallık; TTF - Hollanda örnek verilebilir.

Uluslararası doğalgaz piyasalarının gelişiminde en önemli adımın piyasanın liberalleşmesi olduğu görülmekte. ABD 1985yılında, İngiltere ise 1995 yılında erken başlayan ve en liberal piyasa yapısına ve hub'a sahiptirler. Bununla beraber Hollanda ve Fransa benzer tarihlerde liberalleşme sürecine başlatmış olmalarına rağmen Hollanda çok daha liberal piyasa konumundadır (Petform,2013:36). 


\begin{tabular}{|c|c|}
\hline ENERJİ ÜSSÜ & ENERJI BORSASI \\
\hline $\begin{array}{l}\text { Enerji Üssü standartlaştırılmış ticaret faaliyetlerini } \\
\text { destekleyen kuramsal teslim alanı veya noktasıdır. } \\
\text { Enerji Üssü birden fazla teslimat noktasının tümünü } \\
\text { temsil eder ve dengeleme gibi Piyasa faaliyetlerinde } \\
\text { olduğu üzere ticaret ve yatırım için de likiditeyi } \\
\text { destekler } \\
\text { Enerji Üssü gerçek fiziksel iletim şebekesini temsil } \\
\text { eder; ancak sözleşme görüşmelerindeki spesifik } \\
\text { teslimat noktalarını içermesine gerek yoktur. } \\
\text { Böylece piyasa çapında ortak fiyatlandırma sağlanmış } \\
\text { olur. Enerji üssünde, hem yakın zaman teslimatı için } \\
\text { yapılan gaz ticaretinin olduğu spot piyasa hem de } \\
\text { teslimatın bir kaç yıl uzatılabildiği vadeli işlemler } \\
\text { piyasası ulusal ortak teslimat noktası üzerinden } \\
\text { gerçekleştirilebilir } \\
\text { Enerji üssünde, hem yakın zaman teslimatı için } \\
\text { yapılan gaz ticaretinin olduğu spot piyasa hem de } \\
\text { teslimatın bir kaç yıl uzatılabildiği vadeli işlemler } \\
\text { piyasası ulusal ortak teslimat noktası üzerinden } \\
\text { gerçekleştirilebilir İkili anlaşmalar, tezgah üstü ticaret ve } \\
\text { enerji borsası işlemleri enerji üssü gaz fiyatının } \\
\text { oluşturulmasını sağlar } \\
\text { Enerji üssünün piyasaya olan desteği; şeffaflık, } \\
\text { esneklik sağlama, dengeleme, vadeli ticaret ve risk } \\
\text { yönetimi açısından önemlidir. Şeffaf olmayan fiyatlar } \\
\text { ve standartlaşmamış ikili sözleşmeler yerine birçok } \\
\text { oyuncunun katılımıyla oluşan rekabet bazlı, şeffaf ve } \\
\text { referans olarak değerlendirilebilir fiyatlar bu } \\
\text { koşulların oluşmasında en önemli noktadır }\end{array}$ & $\begin{array}{l}\text { Enerji Borsası, piyasa katılımcılarının etkin bir } \\
\text { şekilde buluşması ve ticaret yapması için } \\
\text { standartlaştırılmış sözleşmelerin bulunduğu organize } \\
\text { edilmiş bir ticaret yeridir } \\
\text { Enerji Borsası sözleşmeleri forwards, futures, } \\
\text { swaps ve options gibi vadeli ürünleri de kapsar. } \\
\text { Bunların her biri önceden belirlenmiş bir zaman ve } \\
\text { yerde bir emtianın teslimini ifade etmektedir } \\
\text { Enerji Borsası sözleşmeleri teslim yeri genellikle } \\
\text { fiziki piyasaya bağlıdır ve bu nedenle gaz enerjisi üssü } \\
\text { ortak referans olarak seçilir } \\
\text { Ticaretler bir alıcı ve bir satıcı arasında, genellikle } \\
\text { anonim olarak sonuçlandırılır. Bunun yanında, takas } \\
\text { bankası sayesinde tüm alıcılar ve satıcılar için karşı } \\
\text { taraf riski ortadan kaldırılmış olur } \\
\text { Enerji Borsaları sanayi ve fiziksel ticaret çevreleri } \\
\text { ile birlikte yatırımcı çevrelerini de cezbetmektedir. } \\
\text { Böylece, enerji üssünde teslim ve fiyatın ortak referansı } \\
\text { üzerinde sonuçlandırılan ticaretlere bağlı olarak, piyasa } \\
\text { likiditesi bu geniş katılımla artmaktadır } \\
\text { Enerji Borsaları, çoğu kez piyasa ve kredi risk } \\
\text { yönetim işlemlerini, forward future işlemleri ile } \\
\text { desteklemektedirler. }\end{array}$ \\
\hline
\end{tabular}

Tablo 2. Karşılaştırmalı Enerji Üssü ve Enerji Borsası Tanımları Kaynak: Petforum, (2013:13).

\section{Türkiye’nin Enerji Görünümü ve Türkiye'nin Hub Olabilirliği: Fırsatlar Zorluklar}

\subsection{Türkiye’nin Enerji Görünümü}

Türkiye'nin enerji görünümünde tükettiği enerjinin yaklaşık dörtte üçünü dışarıdan ithal eden, enerjide dışa bağımlılığın en yüksek olduğu birkaç ülke arasında yer almaktadır. Aşağıdaki tabloda özellikle doğalgaz ithalatında 5. Sıra da yer almaktadır. Özellikle doğalgaza olan talep giderek aratan oranda olmakla birlikte, elektrik üretiminin \% 48.7' doğalgaz ile karşılanmaktadır (TMMOB, 2015:2,6).

\begin{tabular}{|l|c|c|c|c|c|c|}
\hline ENERJİ VERİLERİ & 1990 & 2013 & DEĞİŞİM & KAYNAK & İTHALAT & SIRALAMA \\
\hline $\begin{array}{l}\text { Toplam Enerji Talebi } \\
\text { (milyon tep) }\end{array}$ & 52.9 & 120.29 & $\uparrow \% 127,39 \uparrow$ & Doğalgaz & 45 Milyar m3 & 5 \\
\hline $\begin{array}{l}\text { Toplam Yerli Üretim } \\
\text { (milyon tep) }\end{array}$ & 25.6 & 31.94 & $\uparrow \% 24,78 \uparrow$ & Petrol & 35 Milyon Ton & 13 \\
\hline $\begin{array}{l}\text { Toplam Enerji İthalatı } \\
\text { (milyon tep) }\end{array}$ & 30.9 & 96.29 & $\uparrow \% 211,62 \uparrow$ & Kömür & 30 Milyon Ton & 8 \\
\hline $\begin{array}{l}\text { Yerli Üretimin Talebi } \\
\text { Karş1lama Oranı }\end{array}$ & 48 & $28.5(\%)$ & $\downarrow-\% 40,63 \downarrow$ & Petro kok & 4 Milyon Ton & 4 \\
\hline
\end{tabular}

Tablo 3. Türkiye'nin Genel Enerji Dengesi,(1990-2013),ve Türkiye’nin Enerji İthalatı Stralaması Kaynak: TMMOB, (2015:2,3).

Türkiye içinde bulunduğu coğrafya açısından ise enerji arzında gerek komşu tedarikçi ülkeler gerekse AB ülkeleri açısından enerji arz güvenliğinde oynadığı kritik rol nedeniyle ilgi odağında olmuştur. Ortadoğu, Asya ve özallikle de Hazar bölgesi Türkiyeye komşu çoğrafya olup, petrol ve doğalgaz rezervleri açısından en zengin bölgedir. Ayrıca Türkiye'nin son dönem TANAP gibi içinde olduğu yeni ve alternatif taşıma güzergâhlarının AB ve Türkiye'yi bölgede önemli projelerde işbirliği fırsatlarını da ortaya çıkarmıştır. Türkiye halihazırda 1989 yılında hazırlıkları başlayan Bakü-Ceyhan projesine 1999 yılında Tiflis'in dahil olması ile Bakü-Tiflis-Ceyhan (BTC) petrol boru hattı ve Bakü-Tiflis-Erzurum (BTE) doğalgaz boru hattı ile Hazar Bölgesi'ndeki enerji kaynaklarının aktarımında önemli iş ortağı olmuştur. 
Türkiye 2015 yılında temeli atılan Güney Gaz Koridoru (GGK) kapsamındaki Trans Anadolu Doğalgaz Boru Hattı (TANAP) projesiyle birlikte Hazar Bölgesi'ndeki rezervlerin dünya pazarlarına aktarmayı planlamaktadır. AB üyesi ülkeler ve devamında TAP diğer doğal gaz boru hatlarını da kapsayan projelerle Hazar Bölgesi enerji kaynaklarını küresel enerji piyasalarına açılması planlanmaktadır(Belet, 2014). AEB ile hedefleri arasında belirttiği enerji ithalatında ülke ve rota çeşitliliğini sağlamak isteyen $A B$, Türkiye'nin de içinde yer aldığı, bölge ülkelerinden Azerbaycan doğalgazının Türkiye üzerinden Avrupa ülkelerine transferini sağlayacak olan Güney Gaz Koridoru (GGK) kapsamında TANAP'ın, Türkiye'nin enerjide merkez olmasına önemli katkılar sunması da beklenmektedir (Pala, 2016:10).

Ayrıca yıllık doğalgaz ithalatının yarıdan fazlasının yapıldığı Rusya ile uçak krizi sonrası Türkiye'nin Irak Kürt Bölgesel Yönetimi (IKBY) Türkmenistan ve Katar gibi alternatif pazarlara yönelmesi Türkiye'nin enerji arz güvenliğini güçlendirecektir. Ortaya çıkan bu tablo ile Türkiye, enerji arz ve talep eden ülkelerin "enerji arz güvenliğini” sağlamaya yönelik kritik bir konumda bulunmaktadır Türkiye’ye ciddi firsatlar sunmaktadır (SETA, 2016).

\subsection{Türkiye'nin Hub Olabilirliği: Fursatlar ve Zorluklar}

Türkiye, jeopolitik konumu itibarıyla dünya enerji rezervlerinin $\% 70$ nin bulunduğu bir coğrafyada yer almaktadır. Bu konum içinde $\mathrm{AB}$ ile büyük enerji tedarikçisi Rusya arasındaki iki büyük koridorun işleyişin de de yer almakta veya alabilecek potansiyeli taşımaktadır. Bunlardan birincisi, ABD ve AB merkezli Doğu- Batı Koridoru ve diğeri de Rusya'nın kendi tasarımlarıyla tartışılmaya başlanan Kuzey -Güney koridorunun kesişim noktasında yer almaktadır. Bu tanımlama içinde Doğu-Batı Koridoru 2015yılında birçok ülkenin ilgi odağı haline gelmiştir. Enerji kaynakları transferinin uluslararası diplomaside önemli bir yer edindiği günümüzde, Türkiye enerji piyasasında önemli bir oyuncu olmaya aday konumundadır (Tagliapietra, 2014).

Enerji arz güvenliğinin sağlanmasında stratejik bir avantaja sahip olan Türkiye'nin bu firsatları değerlendirmede kritik proje ve anlaşmalarda yer alması gerekmektedir. Türkiye'nin enerji merkezi olmasında komşu ülkelerin Azerbaycan, Türkmenistan, İran ve Irak'ın jeopolitik gelişimleri ve enerji projelerindeki işbirlikleri de önemli olmaktadır. Türkiye'nin 2014 gaz ithalatının kaynak bazında yüzde dağılımına baktığımızda: Rusya 54.76 ile ilk sırada yer almaktadır. Bunu İran 18.13, Azerbaycan 12.33, Cezayir (LNG) 8.48, Nijerya (LNG) 2.87 ve diğer LNG olarak spot piyasadan 3.43 izlemektedir (SETA, 2016:14).

AB'in AEB deklarasyonunda Birlik için önemli olan alternatif üreticiler ve transit ülkelerle işbirliği imkanları geliştireceği belirtilerek, bu çerçevede sadece 4 ülkenin ismi stratejik ortak çerçevesinde sıralanmıştır: Cezayir, Azerbaycan, Türkmenistan ve transit ülke olarak Türkiye. Bunlara ek olarak iki Bölge, Afrika ve Orta Doğu, vizyon belgesinde yer almıştır (Pala ve Özden, 2015:31). Ayrıca, vizyon belgesinde belirttiği politika önermelerinde enerji güvenliği dayanışma ve güven başlığında belirtiği enerji güzergâhlarından Güney Gaz Koridoru üzerinden Orta Asya ülkelerinden gaz ithalatının yapılması ve LNG için "hub" in Orta Avrupa ve Akdeniz bölgesinde kurulması (EU, 2015:5). Türkiye'nin bulunduğu jeopolitik konum itibarıyla enerji merkezi olma bağlamında elini güçlendirecek hamleler olarak değerlendirilebilir.

AB Komisyonun vizyon belgesinde Türkiye'nin stratejik transit ülke olarak ilk kez bu kadar açık bir biçimde belirtilmesi, ülkemizin doğu - batı boyunca bir gaz ve petrol koridoru olması amacına güçlü bir şekilde katkı sunacaktır. Aynı zamanda bu koridor, Azerbaycan, Türkmenistan ve diğer Orta Asya ülkeleri ile Avrupa arasında en ekonomik ve güvenilir transit enerji güzergahı da olmaktadır. Enerji merkezi olabilirlik perspektifinde doğalgaz iletim şebekesinin giriş noktalarındaki kapasitelerin arttırılması ve şebekenin taşıma kapasitesinin yükseltilmesi önem arz etmektedir. Bu anlamda iletim şebekesi üzerindeki kapasite Türkiye'nin $211 \mathrm{mcm}$ olan günlük teorik giriş kapasitesi, planlanan ve devam eden yatırımlarla birlikte 2019 yılında 250-280 mcm seviyesine yükselecek. Türkiye'nin ancak $600 \mathrm{mcm} /$ gün giriş kapasitesine sahip olması durumunda bir doğalgaz ticaret merkezi olması firsatı kuvvetlenmiş olacaktır (Ertürk, 2016).

Bu güzergâhın transit hub veya köprü mü olacağı ya da ticaret hub’1 yani doğal gaz ticaretinin merkezi olup olamayacağı bütün tartışmanın ana sorunsalı olarak karşımızda durmaktadır. Türkiye'nin enerji merkezi olması tanımı doğalgaz üssü (hub) ve borsasını oluşturmak amacıyla tanımlanmaktadır. Bu kapsamda, bütün doğalgaz değer zincirinin arama ve üretim aşamasından başlayarak arz noktasına kadar, iletim ve depolama fonksiyonları ile pazarlama, ticaret, dağıtım ve perakende konularını içine alan fiziki bir merkez tanımı yanında borsa tanımı içinde enerji borsası tanımlanmaktadır. Enerji Borsası, piyasa katılımcılarının etkin bir şekilde buluşması ve ticaret yapması için standartlaştırılmış sözleşmelerin bulunduğu organize edilmiş bir ticaret yeridir. Her iki tanımın da başlangıcında Türkiye'nin büyük bir pazar ve farklı doğal gaz kaynaklarına en yakın ülke olması, ticaret merkezi olmak için uygun bir konumda ve transit ülke olma kolaylığı gibi firsatlarının yanında önemli zorluk ve riskleri de beraberinde getirmektedir. Öncelikli olarak doğalgaz piyasasının liberalleşerek rekabete açılması görülmelidir. Tablo 3 de Türkiye'nin uzun dönemli kontrat yapısı görülmektedir. Bu kapsamda giriş kapasitesinin arttırılması ve buna yönelik yeni rota ve girişlerin yapılması zorunlu hale gelmektedir. 


\begin{tabular}{|c|c|c|c|c|c|}
\hline $\begin{array}{l}\text { Ithalatçı } \\
\text { Ulke }\end{array}$ & $\begin{array}{l}\text { Hacim } \\
\text { (bcm/yıl) }\end{array}$ & Tip & Periyot (yıl) & $\begin{array}{l}\text { Başlangıc } \\
\text { Yılı }\end{array}$ & Bitiş Yılı \\
\hline Rusya (WS) & 4 & PNG & 23 & 1998 & 2022 \\
\hline Rusya (WS) & 1 & PNG & 23 & 2013 & 2036 \\
\hline Rusya (WS) & 5 & PNG & 30 & 2013 & 2043 \\
\hline Rusya (WS) & 4 & PNG & 23 & 1998 & 2022 \\
\hline Rusya (BS) & 16 & PNG & 25 & 2003 & 2028 \\
\hline Cezayir & 4 & LNG & 20 & 1994 & 2014 \\
\hline Nijerya & 1.2 & LNG & 22 & 1999 & 2021 \\
\hline Iran & 10 & PNG & 25 & 2001 & 2026 \\
\hline Azerbaycan & 6.6 & PNG & 15 & 2007 & 2022 \\
\hline Türkmenistan & 16 & PNG & $30 \mathrm{n} / \mathrm{a}$ & - & - \\
\hline
\end{tabular}

Tablo 4. Doğalgaz İletim Şebekeleri ve Kapasiteleri Kaynak: Petform, (2013:18)

Doğalgazın arz güvenliğinin sağlanmasındaki tekçiden sonraki ana unsur, iletim şebekelerinin giriş noktalarındaki kapasite ve şebekenin taşıma kapasitesidir. Türkiye'nin mevcut iletim şebekesi üzerindeki kapasite yatırımları, bugüne kadar beklenen ve gereken ölçeğin oldukça altında kalmıştır. Türkiye'nin 211 mcm olan günlük teorik giriş kapasitesi, BOTAŞ'ın planlanan ve devam eden yatırımlarla birlikte 2019 yılında 250-280mcm seviyesine yükseltilmesi hedeflenmektedir Türkiye'nin enerji hub'ı olabilirliği fırsatında pik talebinin azami giriş kapasitesine oranının en az İtalya gibi 2.5 olması gerekmektedir. Bu oranın sağlanabilmesi için de doğalgaz giriş kapasitemizin $600 \mathrm{mcm} /$ gün olması gerekmektedir. Bu sağlandığı takdirde bir doğalgaz ticaret merkezi olabilmek için düzenlemelere başlanılması anlamlı olacaktır.

\begin{tabular}{|l|c|c|c|c|}
\hline Şirket & Lokasyon & Tesis Tipi & Depolama Kapasitesi & $\begin{array}{c}\text { Depolama kapasitesi } \\
\text { (mcm gaz) }\end{array}$ \\
\hline BOTAŞ $^{*}$ & $\begin{array}{c}\text { Marmara } \\
\text { Ereğlisi }\end{array}$ & LNG & $255,000 \mathrm{~m} 3$ LNG (85.000m3 x 3) & 149 \\
\hline EGEGAZ* & Aliağa & LNG & $280,000 \mathrm{~m} 3$ LNG (140.000m3 x 2) & 161 \\
\hline TPAO & Silivri & Yeralt1 & 2,661 milyon m3 gas & 2,661 \\
\hline BOTAŞ & $\begin{array}{c}\text { Sultanhanı } \\
\text { (Tuz gölü) }\end{array}$ & $\begin{array}{c}\text { Yeralt1 (devam } \\
\text { etmekte) }\end{array}$ & 1,500 milyon m3 gas & 1,500 \\
\hline
\end{tabular}

*Bu kapasiteler yeniden gaza dönüştürme gibi ilgili süreçlerin şebekeye net gaz teslimatını kapsamaktadır. Mevcut Toplam: 2.98 bcm Planlanan Toplam: $4.47 \mathrm{bcm}$

Tablo 5. Türkiye Mevcut Doğal Gaz Depolama Tesis ve Kapasitesi Kaynak: Petforum, (2013:24)

Doğalgazın arz güvenliğinin sağlanmasındaki tekçiden sonraki ana unsur, iletim şebekelerinin giriş noktalarındaki kapasite ve şebekenin taşıma kapasitesidir. Türkiye'nin mevcut iletim şebekesi üzerindeki kapasite yatırımları, bugüne kadar beklenen ve gereken ölçeğin oldukça altında kalmıştır. Aşağıdaki tablo da AB'nin bu yıl hazırladığı Doğalgaz Arz Güvenliği Düzenleme teklifinde yer alan N-1 formülü ile Hub bölgelerinin skorları yer almaktadır (Ertürk, 2016:16). N-1 formülü ve hesaplanışı aşağıda görülmektedir (Ertürk, 2016:18).

\begin{tabular}{|l|c|c|c|c|}
\hline & EFET 2015 Hub Skoru & $\begin{array}{l}\text { Pik Talep } \\
(\mathrm{mcm})\end{array}$ & $\begin{array}{l}\text { Max. Kapasite } \\
(\mathrm{mcm})\end{array}$ & $\begin{array}{l}\text { Max. Kapasite } \\
\text { /PikTalep }\end{array}$ \\
\hline Avusturya & 14 & 34 & 308 & 9.06 \\
\hline Belçika & 18 & 65 & 424 & 6.52 \\
\hline Hollanda & 19.5 & 160 & 990 & 6.19 \\
\hline Almanya & 19 & 329 & 1579 & 4.80 \\
\hline Fransa & 16.5 & 174 & 554 & 3.18 \\
\hline İtalya & 15 & 273 & 683 & 2.50 \\
\hline Türkiye & 5 & 240 & 200 & 0.83 \\
\hline Türkiye 2015 & & 240 & 600 & 2.50 \\
\hline Türkiye 2020 & & 280 & 700 & 2.50 \\
\hline
\end{tabular}

Tablo 6. EFET 2015 Hub Skorlarına Göre En Yüksek Puan Alan 6 Hub Karşılaştırması Kaynak: (Ertürk, 2016:19) 


\section{CALCULATION METHOD OF THE N-1 FORMULA}

$$
\mathrm{N}-1[\%]=\frac{\mathrm{EP}_{\mathrm{m}}+\mathrm{P}_{\mathrm{m}}+\mathrm{S}_{\mathrm{m}}+\mathrm{LNG}_{\mathrm{m}}-\mathrm{I}_{\mathrm{m}}}{\mathrm{D}_{\max }} \times 100, \mathrm{~N}-1 \geq 100 \%
$$

$\left(\mathrm{EP}_{\mathrm{m}}\right) \quad$ : Üretim dışında giriş noktalarının toplam giriş kapasitesi ( $\left.\mathrm{mcm} / \mathrm{gün}\right)$

$\left(\mathrm{P}_{\mathrm{m}}\right) \quad$ : En yüksek teknik üretim kapasitesi ( $\left.\mathrm{mcm} / \mathrm{gün}\right)$

$\left(\mathrm{S}_{\mathrm{m}}\right) \quad$ : Depodan en yüksek teknik yeniden üretim kapasitesi ( $\mathrm{mcm} /$ gün)

$\left(\mathrm{LNG}_{\mathrm{m}}\right): \mathrm{LNG}$ tesislerinden en yüksek teknik yeniden gazlaştırma kapasitesi ( $\mathrm{mcm} /$ gün)

$\left(\mathrm{I}_{\mathrm{m}}\right) \quad$ : Belirlenen bölgeye gaz temini sağlayan en büyük ve tek giriş kapasitesi ( $\mathrm{mcm} /$ gün)

$\left(D_{\max }\right) \quad$ : Belirlenen bölgenin istatistiksel olarak 20 senede bir olabilecek olağanüstü yüksek gaz talep zamanlarında oluşan toplam günlük talebi ( $\mathrm{mcm} /$ gün)

(Deff) : Temin kısıntısı durumunda pazardan sağlanabilecek miktar.

“Türkiye'nin pik talebinin azami kapasiteye oranının bugün en az İtalya gibi 2.5 olmasını hedeflersek, azami giriş kapasitesinin mevcut kapasitesinin en az üç kat artarak $600 \mathrm{mcm}$ olması lazım. Türkiye, ancak $600 \mathrm{mcm} /$ gün giriş kapasitesine sahip olursa, bir doğalgaz ticaret merkezi olma yolunda çalışmaya başlayabilir ve diğer ülkelerle rekabet etmeye başlayabilir. Aksi halde sadece kendi temin güvenliğini sağlayan ama başka merkezlerin fiyatlarıla gazı alan bir ülke olacak" (Ertürk, 2016: 17).

Buna göre yapılan hesaplamalarda, Avrupa'ya doğu-batı koridorunda Türkiye için en kritik Bölge olan Marmara Bölgesinin N-1 skor yapılan hesaplamayla yaklaşık 0.51 çıkmaktadır. Marmara Bölgesi’nin mevcut giriş kapasitesinin arz güvenliği ve merkez olma konusunda ciddi önlemlere ihtiyaç duyduğu görülmektedir. Özellikle boru hatlarının genişletilmesi yüksek hacimli hatların kurulması ve buna yönelik bölge ülkeleri ile işbirliğine gidilmesi gerekmektedir.

Türkiye'nin mevcut coğrafyası içinde Rusya, Azerbaycan, İran ve Türkmen gazını da içine alacak yeni rotalar ile bu kapasiteleri yakalaması ve Güney Avrupa Bölgesi Hub olabilirlik fırsatını kuvvetlendirici bölgesel projeler ve işbirliğinde bulunması gerekmektedir. Bu anlamda BOTAŞ'ın 2019 yılına planladığı 250-280 mcm seviyesine TANAP'tan gelecek girişlerin eklenmesi ile ulaşılması beklenmektedir. Türkiye'nin böyle bir giriş kapasitesine enterkonnekte hatlarla güçlendireceği şebekelerle ulaşması ve ilk başta da bu miktarlı gazın alım kontratlarının bağlanması gerekmektedir.(Ertürk, 2016). Bu perspektifte özellikle Avrupa'nın yeni düzenlemelerle imkân sağladığı kısa ve esnek kontratlama piyasa için önemli kolaylıklar getirecektir. Türkiye'nin mevcut kontrat yapılarında mevcut kapasite giriş kısıtları nedeniyle müzakere gücü sağlayacak bir esnekliği bulunmamakta Avrupa'ya göre daha pahalı gaz almaktadır. Türkiye'nin ticaret merkezi hedefi için günlük $700 \mathrm{mcm} / \mathrm{gün}$ kapasitelik bir planlama ile mümkün gözükmektedir. Mevcut güzergahlar ve akış dikkate alındığında bunun gerçekleşmesinin önümüzdeki on yıllara yayılan bir hedef olduğunu da göstermektedir. Türkiye Doğalgaz piyasası 2001 yılında 4646 sayılı kanun ile liberalleşme sürecine başlamıştır. Hızlı ve başarılı bir gelişme süreci gösteren doğalgaz piyasasında yeni hedefler göre yeni güncellemelere ihtiyaç duyulmaktadır ( Petform, 2013).

Türkiye piyasasının mevcut durumun ve yurt dışı piyasa örneklerine baktığımızda Türkiye'nin hub olmasının önündeki fiziki ve teknik zorlukları, bunun yanında sahip olunan firsatları 3 ana başlıkta sıralayabiliriz:

1. Fiziki Altyapı: (1) Mevcut boru hatlarının ve kapasitenin geliştirilmesi iyileştirilmesi yeni güzergâhlar ve projelerin oluşturulması, (2) Şebeke kapasitelerinin ve operasyonlarının artırılarak en erken devreye sokulması, (3) Fiziki akışları güçlendirecek interkonnekteliklerin kurulması, (4) Depolama imkânlarının artııılması. Bunun yanında ana tedarikçilerle var olan hatlarımız ve işlerliğinin bulunması yeni rotalar ve projeler için önemli bir firsat olmaktadir.

2. Düzenleyici Unsurlar:(1) Yasal düzenlemelerle doğalgaz mevzuatının geliştirilmesi, piyasanın serbestleşmesinin sağlanması, (2) BOTAŞ'ın ticaret alanındaki baskın payının azaltılması, (3) Dağıtım ve perakende şirketlerinin ayrıştırılması.

3. Piyasa ve Ticaretin İşlerliği: (1) Şeffaf, maliyet bazlı fiyat uygulamasına geçilmesi, (2) standartlaşmış kontratların kullanılması, uzun vadeli kontratların sınırlayıcı unsurlarının olumsuzluklarının azaltılmasına yönelik şartların belirlenmesi, (3) fiyatlamalarda tüketicinin ve rekabetin korunmasının gözetilmesi, (4) spot, vadeli ve dengelemelerinin piyasa mekanizmaları arasında uyumun korunması, işlemlere yönelik finansal hizmetler ve kredi mekanizmaların desteklenmesi.

Bu tanımlamaların kapsamının doğalgaz piyasasının liberalleşmesi yönlü düzenlemeler olduğu görülmekle birlikte dünyadaki belli başlı hub olan merkezlerin ortalama 10-15 y1llık bir süreç geçirdikleri de görülmektedir (Petform, 2013). Bu anlamda Türkiye'nin önünde en erken 10 yılı bulunmaktadır.

Türkiye'nin orta vadeli yapılanmada olası olan Hub stratejisinin uzun vadeli bir süreç olduğu dikkate alınmalıdır. Firsatlar penceresinden bakacak olursak: Türkiye'de gaz rezervinin olmamasına karşın önemli gaz rezervlerinin 
bulunduğu Rusya, İran, Türkmenistan Azerbaycan ve Irak bölgelerinin varlığı Avrupa’ya gaz taşınmasında yeni bir ipek yolu olabilecektir (Taglapietra, 2014:5). Türkiye'nin batı bölgesinden Avrupa'ya gaz sevkiyatında kuracağ 1 yeni rotalarla ilgili olarak Romanya, Bulgaristan, Macaristan ve Avusturya ile 2009 yılında imzaladığı işbirliği anlaşmalarının bu hedefi güçlendiren altyapıları sağlayabilecektir. Özellikle TANAP projesinin Avrupa destekler projesi TAP bu bakımdan önemli bir işbirliği olmaktadır. Ancak bu rotayı gaz miktarıyla destekler yeni partnerlerin bulunması gerektiği de unutulmamamladır. İsrail veya Kıbrıs gazı da daha sonrası için değerlendirilebilir. Türkiye'nin içinde bulunduğu enerji havzası için coğrafi avantajlara rağmen politik ve coğrafi risklerin varlığı unutulmamalıdır. Örneğin, geçmişte körfez savaşı günümüzde ise yakın dönemde yaşadığımı Suriye sorunu içinde bulunduğumuz göz ardı edilmemesi gereken konular olmalıdır.

\section{Sonuç}

Avrupa Birliği’nin enerji ihtiyacının karşılanmasında en önemli tedarikçisi olduğu Rusya'ya olan bağımlılığını azaltma yönündeki tartışmalar uzun zamandır süregelmekle birlikte bugüne kadar somut adımlar atılamamıştır. Dolayısıyla, Avrupa Birliği’nin enerjide Rusya’ya bağımlılığını azaltması, teknik konuların yanı sıra makro ekonomik ilişkilerin de derinlemesine incelenmesini ve bu yönde politikalar oluşturulmasını gerektirmektedir. Avrupa Birliği Avrupa Enerji Ajansının oluşturulması yönlü 2015 deklerasyonunda buna yönelik somut öneriler ve politikalar yer almaktadır. Avrupa Birliği içerisinde son dönemde yenilenebilir enerjiye yönelik fonlamaların gündeme gelmesi özellikle doğal gaz ve petrol konusunda Rusya'ya bağımlılığın azaltılması, enerji arz güvenliğinin sağlanması ve rekabet edebilirliğin korunması amacını taşımaktadır. Buna göre Birliğin bu perspektifte oluşturacağı tek enerji birliği, Avrupa Enerji Ajansı, alternatif enerji merkezleri ve projelerini destekleme imkanı yaratacaktır. Ancak, her şeye rağmen Avrupa ekonomilerinin güçlü bir şekilde varlığını sürdürebilmesine ve üretimin devamlılığı için alternatif enerji kaynakları henüz yetersizdir.

Rusya'ya bağımlılığı azaltma stratejileri belirlenirken, diğer taraftan enerjinin taşınması konusunda yeni proje başlıkları olan TANAP ve yeni enerji merkezi olma vizyonu ile Türkiye alternatifi ortaya çıkmaktadır. Avrupa'ya taşınacak karasal enerjinin (Rusya'nın bypass edilmesi durumunda) Türkiye'den geçmesi daha az maliyetli olması yanında fizibil bir yatırım olarak da görülmektedir.

Avrupa'ya olan enerji arzının çeşitlendirilmesi tartışmalarında, Türkiye gibi AB dışındaki bir ülkenin enerjideki pozisyonu ve stratejileri Türkiye'nin doğu batı enerji koridorunda enerji merkezi doğalgaz hub'ı olma stratejisi ile birleştiğinde kapsamlı bir enerji stratejisi haline dönüşmektedir. Avrupa Birliği, orta vadede, enerji tedarik ağını çeşitlendirmek için yeni enerji tedarik sözleşmesi ve enerji arz güvenliğinde piyasalarını daha da şeffaflaştırması gerekmektedir. Bu bağlamda Norveç, Güney Gaz Koridoru, Akdeniz aktarım merkezi gibi projelerle güçlenecek Avrupa Enerji Birliği Türkiye'nin enerji alanında, jeopolitik konumunun avantajlarını daha da kullanmasına olumlu etki ve imkan yaratmış olacaktır.

Türkiye'nin Avrupa Enerji Ajansının düzenlemeleri içinde yer alabilmesi ve mevcut doğalgaz piyasasında liberalleşmeye yönelik iyileştirici adımlarını hızlandırması gerekmektedir. Türkiye'nin hedeflediği enerji hub olma yönündeki vizyonunu kuvvetlendirmek için taşıdığı dezavantajlarını da göz önünde bulundurarak kapsamı ve aşamaları belli bir yol haritası hazırlaması gerekmektedir. Yol haritasının nihai hedefi enerji arz güvenliğinin sağlandığı rekabetçi ve liberal bir gaz piyasası oluşturmaktır.

Türkiye'nin AB arz güvenliği standartları ile uyumluluğunu sağlayacak fiziksel altyapı çalışmalarına başlanması ve mevcut piyasa ve kurumlarının, buna yönelik mevzuatın uyumlaştırılarak BOTAŞ'ın işlevsel olarak ayrıştırılması ivedilikli olarak ele alınması gereken başlıklardır. Buna ek olarak doğalgaz giriş kapasitelerinin arttırılmasına yönelik teknik alt yapı yatırımlarının ve depolama kapasitelerinin arttırılması öncelikli yatırımlar olarak şekillenmelidir. Uluslararası belli başlı Hub lara baktığımızda bölgesel üs olma sürecinin 10-15 yılı aldığı görülmektedir. Bu nedenle Türkiye'nin jeopolitik konumundan dolayı haklı olarak koyduğu enerji merkezi hub vizyonuna, bir an önce stratejik politika ve vizyonel politikalarla başlayarak desteklemesi gerekmektedir. Türkiye'nin doğru zamanda ve doğru stratejilerle uygulayacağı politikalar içinde bulunduğu coğrafyanın jeopolitik risklerini ve zorluklarını firsata çevirme imkanı da yaratabilecektir. Avrupa enerji arz güvenliği ve Türkiye'nin hub olabilirliği konusunda gelecek vadeden önemli projelere örnek olarak TANAP ve Avrupa uzantısı TAP verilebilir.

\section{Kaynakça}

- Bahgat, Gawdat,2011. Energy Security: An Interdisciplinary Approach, West Sussex, John Wiley\&Sons.

- $\quad$ BP, 2015.Statistical Review of World Energy, London, June

- Belet N.,2013, “Avrupa Birliği ve Enerji Arzı Güvenliği Açısından Trans Anadolu Doğalgaz Boru Hattı” International Conference on Eurasian Economies Bildiri kitab1,Beykent Üniversitesi ,sayfa:999-1008,

- El-Katiri L., Fattouh B.,2015, A Brief Political Economy of Energy Subsidies in The Middle East and North Africa, The Oxford Institue for Energy Studies, OIES PAPER No: 11, Oxford Univ. Press.

- $\quad$ EIA, 2007. System for the Analysis of Global Energy Markets. www.eia.doe.gov/oiaf/aeo,2016

- EU, 2000, http://europa.eu.int/comm/energy/intelligent/index en.html. Erișim Tarihi 2016. 
- EU,2015,http://eur-lex.europa.eu/resource.html?uri=cellar:1bd46c90-bdd4-11e4bbe101aa75ed71a1.0001.03/DOC_1\&format=PDF, page: 2-3). Erişim Tarihi 2016

- EU,2016 ,http://epp.eurostat.ec.europa.eu/portal/page/portal/eurostat/home/, Erişim Tarihi 2016

- EU,2016a,. European Commission, Policy Guidelines for Trans European Networks-Energy. http://europa.eu.int/comm/energy/ten-e/en/policy.html Erişim Tarihi 2016

- EU, 2016b, https:/ec.europa.eu/energy/en/topics/energy-strategy/2020-energy-strategy. Erişim Tarihi 2016

- Hasan,B.,2016, “AB den Enerjide Yeni Aç1lım:Enerji Güvenliği 2020 Strateji Belgesi” http://www.eppen.org/index.php?sayfa=Yorumlar\&link=\&makale=123. Erişim Tarihi 2016

- Heather P., 2012, Continental European Gas Hubs: Are They fit for purpose?, , Oxford Institute for Energy Studies, NG 63.

- Honore,A. 2011, Economic Recession and Natural Gas Demand in Europe: What happened in 2008 2010,University of Oxford, The Oxford Institute for Energy Studies,

- IEA, 2011. Are We Entering AGoldAge of Gas?, World Energy Outlook, Special Report, Paris, OECD/IEA Pub.

- Sachs N. And Boersma T., 2015,The Energy Island: Israel Deals with its Natural Gas Discoveries, Policy Paper,n.35 February, Forein Policy at Brookings.

- SETA, 2016, Türkiye'nin Enerjide Merkez Olma Arayışı, E.Tanas Karagöl, Seyithan A. Ateş, Salihe Kaya, Mehmet Kızıltaş, Ankara

- $\quad$ SETA, 2015,Statü Sorunu İkileminde Hazarda Enerji Denklemi, E.Tanas Karagöl, Salihe Kaya, Mehmet Kızıltaş, Ankara

- $\quad$ Stern J.and Rogers H., 2011, The Transition to Hub-Based Gas Pricing in Continental Europe, University of Oxford, March

- $\quad$ Kate W.vd. 2013, Developing a Natural Gas Trading Hub in Asia, International Energy Agency.

- M.M. Foss, 2011. The Outlook For US. Gas Prices 2020, Henry Hup at 3\$ or 10\$. The Oxford Institute For Energy Studies.

- Tagliapietra, S.,2014, Turkey As A Regional Naturel Hub: Myth or Reality?, FEEM , Italy.

- The Economist, 1998.“A Caspian Gamble”, A Survey of Central Asia, Feb. 7.

- TMMOB, 2015. http://www.mmo.org.tr/resimler/dosya ekler/a5a69d7ec06d9cd ek.pdf?dergi=1522 sayfa, 2,3 Erişim Tarihi 2016.

- Pala, Cenk, 2003.“21. Yüzyıl Dünya Enerji Dengesinde Petrol ve Doğal Gazın Yeri ve Önemi: Hazar Boru Hatlarının Kesişme Noktasında Türkiye”, Avrasya Dosyası, Cilt 9, Sayı 1, Bahar, Ankara: 5-37.

- Pala C.,Özden Ö, 2015, “Avrupa Enerji Birliği”, İktisat ve Toplum, Sayı 54, sayfa; 28-38.

- Pala, C. 2016, “Türk Akımı: Üzerine Uçak Düşen Boru Hattı” İktisat ve Toplum, Sayı 63, sayfa; 4-20.

- PETFORM,2016,http://docs.petform.org.tr/docs/report_10_turkish_natural_gas_market_report_son_181220 13.pdf, Erişim Tarihi 2016.

- Uluatam, Ela,2010. “Avrupa Doğalgaz Piyasasında Yeni Dengeler”, Ekonomik Forum, TOBB, Ağustos, s.62-67.Erişisim Tarihi 2015.

- Winrow,G.M., 2009, Problems and Prospects For The "Fourth Corridor": The Positions and Role of Turkey in Gas Transit to Europe, Oxford Institute for Energy Studies, NG 30.

- $\quad$ http://www.petform.org.tr/

- $\quad$ http://www.tanap.com/ 


\title{
Ukrayna Krizi Çerçevesinde Avrupa Birliği'nin Doğu Avrupa'daki İstikrara Etkisi
}

\section{The EU's Influence on Eastern European Stability in the Context of Ukrainian Crisis}

\author{
Dr. Ömer Uğur (Gümüşhane University, Turkey)
}

\begin{abstract}
The Ukraine crisis that started with the Euromaidan protests in November 2013 appears to be a most important security crises of the post-Cold War security order. Russia's aggression against Ukraine has not just threaten the territorial integrity or sovereignty of the EU's largest neighbour, but also it has led to a rivalry between the former Cold War enemies again and even it led to the start of a period that may cause to conflict between them. The EU's approach that established the Free Trade Area between the EU and Ukraine did not give any chance of talking to third country or organizations such as the Eurasian Union. Therefore, Russia worked hard to influence on Ukraine to abandon to sing the agreement and this happened to see Ukraine's choice as a zero-sum game.

In order to understand the effect of crisis on the EU and Russia, it have to be analysed the economic sanctions imposed by the EU against Russia to resolve the crisis through diplomatic and economic means. Thus, it is necessary to look at the economic relations between Russia and the EU and this data will be obtained in Eurostat.

As a result, economic sanctions helped to move the conflict from the military to the diplomatic levels. Indeed, Russia has seen that European unity gave rise to a significant impact on its economy. Also, the EU realized that the sanctions is the most powerful tool in the hands of the EU in absence of military power.
\end{abstract}

\section{Giriș}

Kasım 2013 tarihinde Maidan ya da göstericilerin yeni taktığı adıyla Euromaidan protestolarıyla başlayan ve Kırım'ın Rusya tarafından ilhak edilmesi ile doruğa çıkan Ukrayna krizi, Sovyetler Birliği’nin dağılmasıyla oluşan Soğuk Savaş sonrası düzenin en önemli güvenlik krizini ortaya çıkarmıştır. Ukrayna'daki Rusya'nın saldırgan tutumu, sadece Avrupa Birliği'nin (AB) en büyük komşusunun toprak bütünlüğünü tehdit etmekle kalmamış, aynı zamanda Soğuk Savaş sonrası Avrupa'da tesis edilen barış ve istikrarı tehdit eden bir durumu ortaya çıkarmıştır. Zira Rusya'nın Kırım’ı ilhak etmesi ve Ukrayna'daki istikrarsızlı̆̆ı arttıran eylemleri, Soğuk Savaş sonrası Avrupa barışı ve refahına katkı sağlayan Batılı ülkeler ve Rusya arasındaki yoğun siyasi diyalogun ve çok yönlü ekonomik ilişkilerin derinden sarsılmasına neden olmuştur. Bu durum ise eski Soğuk Savaş düşmanları arasında yeniden bir rekabetin ve hatta çatışmanın oluşmasına zemin hazırlamıştır. Batılı ülkelerin ve Rusya'nın Soğuk Savaş benzeri bir şekilde AB'nin yakın bir coğrafyasında karşı karşıya gelmiş olması, son kuşak genişlemeler sonucu değişen sınır ve komşularından dolayı en fazla $A B$ ve $A B$ üyesi ülkelerinin etkilenmesine neden olmuştur.

Ukrayna krizi, AB'nin Doğu Avrupa'daki ve Avrasya'daki çıkarlarını barışçıl yollarla sürdürebilmesi ve kıtanın diğer büyük gücü olan Rusya ile karşılıklı faydaya dayanan ilişkilerini devam ettirebilmesi açısından büyük bir dış politika sorunu haline dönüşmüştür. Rusya'nın işbirliği yapılar bir ülke konumundan, bölgesel istikrarı, komşularının toprak bütünlüğünü ve küresel barışı ciddi anlamda tehdit eden bir ülke konumuna gelmesi, AB'nin Rusya'ya karşı uzun yıllardır izlediği dış politikanın değişmesine neden olmuştur. Bu bağlamda AB, Sovyetler Birliği’nin çöküşünden bu yana Avrupa güvenliği ve istikrarına ilk defa doğrudan bir tehdit oluşturan Rusya'ya karşı hem caydırıcılık, hem de işbirliği esaslarına dayanan bir dış politikayı ön plana çıkarmaya çalışmıştır. Başka bir deyişle, Avrupa güvenliği varsayımlarının ve normlarının Rusya tarafından aşındırıldığı bu süreçte $A B$, kıtanın istikrarı yeniden sağlayabilmek için elindeki en güçlü seçenek olarak gördüğü ekonomik ve sivil gücü Rusya'ya karşı izlenecek dış politikanın temel yapı taşı haline getirmiştir. Bu çalışmada, AB'nin Ukrayna krizinden sonra Rusya'ya karşı değişen dış politikası ele alınarak, bu politikanın Ukrayna krizine olan etkileri incelenecektir. Bunu yaparken, AB'nin ekonomik gücünün Doğu Avrupa ve Avrasya üzerinde yeniden hegemonya mücadelesi içerisine giren Rusya karşısında etkinliği tartışılacaktır. Böylece, AB'nin ekonomik gücünün Rusya gibi son dönemde agresif bir dış politika izleyen bir ülke karşısında ne kadar başarılı olduğu gösterilerek, Doğu Avrupa ve Avrasya'nın istikrarına olan katkısı ortaya konacaktır.

\section{Ukrayna Krizi}

2004 yılına kadar Rusya ve Batı arasında denge politikası izlemeyi tercih eden Ukrayna, 2004 yılındaki Turuncu Devrim ile Batı yönlü bir politika oluşturmayı öncelikli hale getirerek açık bir şekilde Batı yanlısı bir pozisyon almayı tercih etmiştir. Fakat Turuncu Devrim sonrası ülkedeki siyasi ve ekonomik istikrarı sürekli kılacak uzun soluklu reformların hayata geçirilememesi ve AB'nin Ukrayna'ya üyelik perspektifi yerine ikili ilişkileri geliştirmeyi önermesi, Ukrayna'da 2013 sonrası ortaya çıkacak siyasi krizin fitilini ateşlemiştir. AB'nin bu tutumu, 
Turuncu Devrim sonrası ülke içi siyasi dengelerin yeniden değişmesine neden olmuştur. Neticede Turuncu Devrim ile yüzünü Batı'ya dönen Ukrayna, 2010 yılında yapılan seçimlerde Rus yanlısı Viktor Yanukoviç'in devlet başkanı seçilmesiyle tekrar Rusya ve AB'nin arasında sıkışıp kalacağı bir politik durumun içine düşerek uluslararası bir krize dönüşecek olan seçim yapma sürecine girmiştir (Kuzio, 2012, s.13-14).

2010 sonrasında Ukrayna, bir yandan AB ile Doğu Ortaklığı kapsamında daha yakın işbirliği öngören Ortaklık Antlaşması müzakerelerini devam ettirirken diğer yandan Rusya ile ilişkilerini düzelterek Rus ekonomisine büyük ölçüde bağımlı olan ülke ekonomisini güçlendirmeyi amaçlamıştır. Böylece Ukrayna, hem AB'nin hem de Rusya'nın sunmuş olduğu ekonomi, ticaret ve enerji firsatlarından yararlanma imkânına kavuşacağını düşünmüş̧ür (Kuzio, 2012, s. 14). Ancak Turuncu Devrim'den çıkardığı derslerle Rusya, AB'nin daha aktif bir Doğu politikası izlemesini olumlu karşılamamıştır. Hatta Sovyet sonrası coğrafyada Batı kökenli kurumların etkisini azaltacak ve kendi etkinliğini arttıracak bir politika izlemeye başlamıştır. Bu durum ise Ukrayna'nın $\mathrm{AB}$ ve Rusya arasında kurmak istediği denge politikasını imkânsız hale getirdiği gibi, 2013 sonrasında meydana gelecek krizinin temel nedenini oluşturmuştur. Çünkü Yanukoviç'in, devlet başkanı olduktan sonra her ne kadar NATO üyeliğinden vazgeçerek Rus yanlısı bir politika takip etse de 2008 yılında AB ve Ukrayna arasında başlayan Ortaklık Antlaşması müzakerelerini sürdürmesi, Ukrayna ile Rusya'yı karşı karşıya getirmiştir. Ukrayna'nın AB ile Ortaklık Antlaşması'nı imzalaması durumunda Rus öncülüğündeki Gümrük Birliğine katılmasını engellenecek ve Ukrayna'nın Rusya ile ilişkilerini aynı düzeyde tutamayacak olması Rusya'nın büyük tepkisini çekmiştir. Bu da Ukrayna'yı AB ve Rusya arasında bir seçim yapmaya zorlamışıtır (House of Lord, 2014, s. 54).

Bu durum karşısında Yanukoviç, AB ile Ortaklık Antlaşması'nın imzalanması sonucu Rusya ile bozulacak ilişkilerin ortaya çıkaracağı ekonomik kayıpların yanında, Ortaklık Antlaşması'nın Ukrayna'ya kısa vadede ekonomik bir yarar getirmeyeceğini dikkate alarak yeni bir arayış içerisine girmiştir (Demir, 2014, s. 170). Bu arayış bağlamında, Ukrayna, Rusya ve AB'nin içinde olduğu bir komisyon oluşturulması teklifinde bulunmuştur. $\mathrm{Bu}$ şekilde hem $\mathrm{AB}$ ile entegrasyon sürecini devam ettirmeyi hem de Rusya'yı yok saymamak ve karşısına almamak için Ukrayna'ya bir manevra alanı oluşturmayı amaçlamışıtır. Rusya bu öneriye olumlu karşlık vermiş̧ olsa da, Avrasya Birliği üyelerinin çoğunun -Rusya hariç hepsi- Dünya Ticaret Örgütü üyesi olmaması nedeniyle $\mathrm{AB}$, bu tür bir uzlaşının iki düzey arasındaki ticari işbirliğini olumsuz etkileyeceğini ileri sürerek sıcak bakmamıştır (House of Lord, 2015, s. 45-46). AB'nin bu kararı karşısında Ukrayna devlet başkanı Yanukoviç, AB ile süregelen Ortaklık Antlaşması'nın Ukrayna'ya büyük ekonomik yükümlülükler getireceğini belirterek AB'nin hiç beklemediği şekilde Ortaklık Antlaşması'nı imzalamaktan vazgeçmiştir (H. Özdal, 2013, s. 13).

Ortaklık Antlaşması'nı imzalamayarak Ukrayna'nın Turuncu Devrim'den beri devam ettirdiği Batı'ya dönük politikalarını terk eden Yanukoviç, ülke içindeki Avrupa yanlılarının büyük tepkisini çekmiştir (Arman ve Mengüaslan, 2015, s. 74). Bu tepki kısa sürede büyük bir protestoya dönüşmüş ve Kiev'de binlerce insan Maidan meydanında toplanarak hükümet karşııı gösteri yapmışlardır. Maidan'da başlayan protestolar önceleri AB ile askıya alınan anlaşmanın yeniden müzakere edilmesine yönelik olsa da daha sonra Rus yanlısı bir tutum takınan devlet başkanı Yanukoviç'in istifa etmesini sağlamaya yönelik bir hal almıştır (Özdal, v.d, 2014, s. 11). Gösterilerin şiddetlenmesi ve can kayıplarının artması, Yanukoviç'in 22 Şubat 2014'te ülkeyi terk ederek Rusya'ya kaçması neden olmuştur. Bunun üzerine Ukrayna Parlamentosu, Yanukoviç'i görevinden azletmiş ve yeni seçimlerin Mayıs ayında yapılmasına karar vermiştir. Yanukoviç'in görevden uzaklaştırılması ve sonrasında Batı yanlısı bir hükümetin kurulması, gösterilerin tansiyonunu düşürmüş ve ülke yeni bir seçim dönemine girmiştir.

Ukrayna'da Euromaidan gösterileri ile başlayan iktidar karşııtı halk hareketi, ülkedeki siyasi ve ekonomik istikrarı altüst etmiştir. Ayrıca Kırım'ın Rusya tarafından ilhak edilmesi ve Rusya'nın kışkırtması ile ülkenin özellikle doğusunda yaşayan Rus kökenli vatandaşların başlatmış oldukları ayrılıkçı hareketler, krizin uluslararasılaştırmıştır (Demir, 2014; Trenin, 2014; MacFarlane ve Menon, 2014). Özellikle bağımsız bir devletin toprak bütünlüğünün parçalanacak şekilde tehlikeye düşürülmesi sadece bölgede etkili olmamış, aynı zamanda soğuk savaş sonrası gündeme gelen Avrupa güvenlik krizini de ortaya çıkarmıştır. Nitekim Kırım'ın ilhakı, soğuk savaş sonrası dönemde Avrupa'nın esasen istikrarlı ve güvenli olduğu ve Rusya'nın bir düşmandan çok müttefik olabileceği düşüncesine de büyük zarar vermiştir (Larrabee v.d., 2015, s. 1). Bu düşünce, Rusya'nın Kırım'ı ilhak etmesinden sonra ülkenin güneyinde ve doğusundaki ayrılıkçı gurupları doğrudan ve dolaylı yollarla desteklemesi ile daha da pekişmiştir. Bununla birlikte Rusya'nın Ukrayna sınırı boyunca askeri yığınak yapması ve askeri tatbikatların sayısını çoğaltması, Ukrayna üzerinde psikolojik baskının artmasına ve Ukrayna'nın doğusunun daha da istikrarsızlaşmasına neden olmuştur. $\mathrm{AB}$ ve $\mathrm{ABD}$, Rusya'nın bölgeyi daha fazla istikrarsızlaştırmasına yönelik adımları atmasını engellemek için diplomatik yolları kullanarak sorunu müzakere ile çözmeye çalışmışlardır (Demir, 2014, s. 179).

$\mathrm{Ne}$ var ki Batı'nın Ukrayna'daki krizi tırmandırmamak için izlemiş olduğu yol, Rusya'yı daha da cesaretlendirerek bölgedeki Rus etkinliğinin artmasına neden olmuştur. Artan uluslararası baskılara rağmen Putin, Doğu Ukrayna'daki ayrılıkçı gruplara verdiği desteği geri çekmek yerine, gizlice bölgeye Rus askerlerini, zırhlı personel taşıyıcıları, tankları ve füze rampalarını konuşlandırarak -elbette herhangi bir Rus simgesi olmadan- yeni dönemde Rusya'nın Batı'ya karşı izleyeceği dış politikayı deklare etmiştir. Rusya'nın bu hamlesi, aynı zamanda bölgedeki Rus yanlısı ayrılıkçı grupların Ukrayna'nın başlatmış olduğu askeri müdahalelere karşı başarılı olmasını sağlamıştır. Bu gelişmeler çerçevesinde Ağustos 2014'te büyük ölçüde düzenli Rus askeri gücünün de etkisiyle 
Ukrayna devlet başkanı Petro Poroshenko, Belarus'un başkenti Minsk’te ayrılıkçı gruplarla yapılan görüşmeler sonucu ateşkes yapmaktan başka çare bulamamıştır.

\section{Ukrayna Krizi'nin AB'nin Rusya ile İlişkilerine Etkisi}

Ukrayna'da meydana gelen bu gelişmeler, şüphesiz 2004 sonrası AB'nin son kuşak genişlemeleri sonucu değişen sınırlarından ve komşularından dolayı en fazla $\mathrm{AB}$ ve $\mathrm{AB}$ üyesi ülkeleri ve onların dış politikalarını etkilemiştir (Vitkus, 2015; Larsen, 2014). Rusya'nın Kırım yarımadasını ilhakı ve Doğu ve Güney Ukrayna bölgelerindeki siyasi istikrarsızlıklar AB'nin soğuk savaş sonrası Avrupa'da üretmiş olduğu güvenlik sistemini tehlikeye düşürmüştür. Bu bağlamda, $\mathrm{AB}$ ve $\mathrm{AB}$ üyesi ülkelerin Ukrayna Krizi çerçevesinde belirlemiş oldukları ortak tutum, AB'nin soğuk savaş sonrası Rusya ile ilgili işbirliğine dayalı politikalarının tersine, Rusya'nın saldırganlığını sınırlandıracak bir dış politikaya evrilmiştir (Schmidt-Felzmann, 2014; 2015; Trenin, 2014; Larsen, 2014; Larrabee v.d. 2015). Krizin başlangıcında AB üyesi ülkeler ekonomik ve siyasi ilişkilerinden dolayı Rusya ile restleşmek istemeseler de Rusya'nın agresif yaklaşımları karşısında AB düzeyinde belirli kararların alınması kaçınılmaz olmuştur (Larsen, 2014, s. 32).

Rusya'nın 2000'li yıllardan sonra yeniden güçlenmesiyle, ulusal çıkarları açısından vazgeçilmez olarak gördüğü yakın çevresini kontrol etme düşüncesini hayata geçirmek için AB dâhil Batı'nın varlığını bölgede engellemeye çalışmıştır (Zhussipbek, 2011). Ukrayna Krizi'ne neden olan temel faktör de Ukrayna'yı Batı'dan uzaklaştırarak Rusya'ya yakınlaştırma politikasının bir neticesidir. Dolayısıyla AB ve Rusya'nın mevcut ilişkilerini radikal bir şekilde değiştiren şey aslında bu ikilinin bölgedeki jeopolitik rekabetinin bir ürünüdür (Trenin, 2014, s. 4). AB, kendi çevresinde bir istikrar kuşağı oluşturmayı amaçlasa da Rusya'nın bunu bir rekabet olarak algılaması ve bu doğrultuda stratejiler geliştirmesi, AB'nin Ukrayna Krizi'nden sonra Rusya'ya karşı izleyeceği dış politikasının değişmesine neden olacak bir durumu ortaya çıkarmıştır.

Ukrayna Krizi, AB ve Rusya'yı karşı karşıya getirmiştir. Ukrayna Krizi’nin erken evresinde AB üyesi ülkeler, Rusya ile olan ekonomik ilişkilerinden dolayı açık bir çatışmadan uzak kalmaya çalışsalar da Rusya'nın Kırım'ı ilhak etmesi ve Doğu Ukrayna'daki siyasi istikrarsızlığı körüklemesi, AB'nin uluslararası sahnede Rusya'ya karşı birleşik ve güçlü bir aktör olarak ön plana çıkmasını gerekli kılmıştır (Speck, 2014; Larrabee v.d. 2015; Larsen, 2014; Vitkus, 2015). Speck'in (2014) de vurguladığı gibi, AB aslında hiçbir zaman Rusya ile karşı karşıya gelmek istememiştir, ancak Ukrayna'daki durum, AB'nin geri adım atamayacağı kadar hassas bir hal almıştır. Zira Rusya'nın Ukrayna'daki istikrarsızlığı arttıran eylemleri, AB'nin iki hayati çıkarını doğrudan etkilemeye başlamıştır. Bunlardan birincisi, AB'nin doğu sınırlarında dost ülkeler halkası yaratarak bölgede istikrarı ve barışı tesis etme politikasını tehlikeye düşürmesidir. İkincisi ise Rusya'nın, AB için bir tabu olan Avrupa sınırlarının güç kullanarak değiştirilmesi ilkesini çiğnemiş olmasıdır (Speck, 2014; Larrabee, 2015, s. 24). AB dış politikasının temelinde yer alan bu ilkelerin Kırım'ın ilhakıyla ihlal edilmiş olması, bir kırılma noktasıdır (MacFarlane ve Menon, 2014; Larsen, 2014; House of Lord, 2014; Schmidt-Felzmann, 2014; 2015).

Sovyetler Birliğinin çöküşünden beri, Avrupa güvenliği ve istikrarını doğrudan tehdit eden en önemli gelişmeyi oluşturan Ukrayna Krizi sonrası AB’nin Rusya'ya karşı izlediği dış politika, hem caydırıcılık hem de işbirliği esaslarından hareketle belirlenmiştir (Vitkus, 2015; Speeck, 2014; Larsen, 2014). AB'nin, Rusya'nın eylemlerini engelleyebilmek için öncelikle caydırıcılık silahını kullanması gerekmiştir. Avrupa güvenliğine dair varsayımların, normların ve kurumların aşındığı bir süreçte, AB'nin kıtada yeniden istikrarı sağlayabilmesi için ekonomik caydırıcılıktan başka seçeneği kalmamıştır (Chivvis, 2015, s. 41). Aynı zamanda AB'nin, Ukrayna'daki eylemleri nedeniyle Rusya'yı tamamen dışlayacak bir politika izlemesinin bölgedeki çatışmaları daha fazla tırmandıracağını düşünmesi, işbirliği süreçlerinin gerekliliğini ortaya koymuştur. AB'nin caydırıcılığın yanında, diplomasiyi ve sivil gücü etkinleştirmesi, Ukrayna Krizi sonrası ABD’nin bütün dikkatini Avrupa'ya çevirmesiyle iki nükleer güç arasında yeni bir soğuk savaşın başlayacağı endişesinden kaynaklanmıştır (Chivvis, 2015, s. 41). Hâlbuki AB'nin asıl amacı, Rusya'yı da içeren bir Avrupa siyasi ve güvenlik sistemini inşa edecek süreçleri yeniden başlatabilmektir. AB, Ukrayna Krizi'nden dolayı Rusya'nın gerekli oranda -özellikle ekonomik anlamdacezalandırılmasını öngörmüş, ama askeri müdahalelerle marjinalleşmesinin önüne geçerek onu Avrupa sistemin içinde tutmayı amaçlamıştır.

\section{Ekonomik Yaptırımların Uygulanması}

Rusya'nın, Ukrayna'nın egemenliğine saygı duymaması ve soğuk savaştan sonra inşa edilen Avrupa barışını tehlikeye düşürmesi karşısında $\mathrm{AB}$, Rusya ile olan diplomatik girişimleri konusunda bir dizi uygulamaların yanında, ekonomik yaptırımlar ve kısıtlamaları da yürürlüğe koymaya başlamıştır (EEAS, 2015). Krizin ilk evresinde $A B$, Rusya ile başlatmış olduğu vize ve ortaklık anlaşması müzakerelerini askıya aldığını açıklamıştır (Vitkus, 2015, s. 8). Bu şekilde AB, Ukrayna'daki durum karşısında kınama açıklamasının ötesine geçecek politikalar izleyeceğinin işaretlerini vermiştir. Nitekim AB, Kırım’ın Rusya tarafından ilhak edilmesi ve sonrasında M17 sefer sayılı uçağın düşürülmesiyle Rusya'ya karşı o güne kadar görülmemiş düzeydeki ekonomik yaptırımları karara bağlamıştır. AB'nin uyguladığı yaptırımlar gereği, Rus bankalarının Avrupa sermaye piyasalarına erişimlerinin engellenmesi, Rusya'nın silah satışı yapması, petrol ve doğalgaz sektöründe ileri teknolojiler 
kullanması ve Avrupa Yatırım Bankası ile Avrupa İmar ve Kalkınma Bankasının Rusya'da yeni finansman faaliyetlerini askıya alması gibi önemli kararlar alınabilmiştir (EEAS, 2015).

Yaptırım ve kısıtlamalar ekseninde şekillenen süreç, AB’nin dış politikasında önemli bir değişim yaşandığına işaret etmektedir (Vitkus, 2015, s. 9). AB Gürcistan Savaşı'nda bile Rusya'ya karşı herhangi bir ekonomik yaptırım uygulamadan ilişkilerini 'her zamanki gibi' devam ettirmeye özen göstermiş, fakat Ukrayna' da sergilediği tavırla başta Rusya olmak üzere birçok ülkeyi şaşırtmıştır. Çünkü Rusya, AB’nin kendi içindeki bölünmelerden dolayı bu tür kararları alabilmesini çok mümkün görmemiştir. Ancak Güney Osetya ve Abhazya'dakinin aksine Rusya'nın Ukrayna'daki müdahalesini kabullenemeyen $\mathrm{AB}$ ve $\mathrm{AB}$ üyesi ülkeler, en uygun yanıtın yaptırımlar olduğu üzerine uzlaşma sağlayabilmişlerdir (Schmidt-Felzmann, 2015, s. 124-25). Nitekim yaptırımlar, AB'nin Rusya'ya karş1 olan tepkisinin tanımlanmasındaki zorlayıcı seçenekler arasında bütün üye ülkelerin ortak paydasını oluşturmuştur (Galbert, 2015, s. 3). Görüldüğü gibi AB, Rusya'nın Ukrayna müdahalesine karşı genel olarak askeri seçenekleri gündemine almamıştır. Aslında bu seçenek, sadece AB'nin değil, askeri bir güç olan ABD'nin dahi gündemine girmemiştir. $\mathrm{Bu}$ konu, $\mathrm{AB}$ üyesi ülkeler arasında önemli görüş ayrılıklarına neden olmuştur. Ancak AB'nin Rusya'ya yönelik tepkisinde askeri bileşeni devre dışı bırakan yaptırımları, üye ülkeler arasındaki çelişen ya da çekişen hedeflerin uzlaştırılması için önemli bir rol oynamıştır (Vitkus, 2015; Galbert, 2015; Schmidt-Felzmann, 2015).

Burada dikkat edilmesi gereken en önemli nokta, 2014 yılından sonra AB düzeyinde hayata geçirilen uygulamaların, Rusya'yı AB'den ve dünyadan tamamen izole etmemesi eğilimidir. AB'nin bu yaklaşımı, üye ülkeler arasındaki farklılıkları azaltmak ve kendi çıkarlarını korumakla yakından ilgilidir. Rusya'nın Ukrayna müdahalesi sonrası üye ülkeler arasında önemli dış politika önceliklerinin ortaya çıkması, AB'yi yaptırım kararlarını alırken üye ülkeler arasındaki 'tek sesliliğe' zarar vermeyecek şekilde hareket etmeye zorlamıştır (Galbert, 2015, s. 6-7). Bu nedenle AB düzeyindeki uzlaşma sınırlı olmuştur. AB düzeyindeki ekonomik yaptırımlar, Rusya'yı dışarda bırakmanın aksine, Rus ekonomisi üzerinde hedeflenen etkiyi elde edebilmek için uygulamaya konmuştur. Zira Rus ekonomisi ile dünya ekonomisinin entegrasyonu büyük oranda sağlanmıştır. Ayrıca $A B$ ve Rusya arasındaki güçlü ekonomik ilişkiler düşünüldüğünde Rusya'nın, İran ve Kuzey Kore gibi Batı'dan kolayca yalıtılabilmesi mümkün gözükmemektedir (Galbert, 2015, s. 6-7). Bunun da ötesinde AB'nin birçok ülkesinin enerji yönünden Rusya'ya bağımlılığı, AB'yi olumsuz etkileyecek bir durumu ortaya çıkarmaktadır. AB hedeflenen ekonomik yaptırımların gerekliliğini kabul etmekle birlikte, Rusya ile iletişim kanallarının açık tutulmasını ve ekonomik ilişkilerin devam ettirilmesini ilkece benimsemiştir.

Rusya üzerinde uygulanan yaptırımlar ne $\mathrm{AB}$ ve $\mathrm{AB}$ ülkelerini ne de dünya uluslararası finans ve küresel enerji arzını istikrarsızlaştıracak kararları içermektedir. AB'nin temel amacı, Ukrayna Krizi'nin askeri alandan, ekonomik ve diplomatik alana çekilerek müzakereler yoluyla çözülmesini sağlamaktır (Secrieru, 2015, s. 41). Böylece Rusya, haddinden fazla cezalandırılmamış ya da Fransa Devlet Başkanı Françis Hollande'ın da belirtiği gibi, AB'nin karşısında dizlerinin üzerine çökmeye zorlanmamıştır (BBC, 2015). Kaldı ki AB, diğer uluslararası sorunlar konusunda Rusya'ya ihtiyacı olan bir aktördür ve dolaysıyla onu tamamen izole ederek aslında uluslararası sorunlar karşısında kendi aktörlüğünü zedeleyecektir. Sonuç olarak AB'nin uyguladığg yaptırımların başarılı olup olmadığı ayrı bir tartışma konusu olmakla birlikte AB'nin, Rusya'yı müzakere masasına çekme stratejisindeki başarısı takdire değerdir. Zira Almanya ve Fransa'nın öncülüğünde Rusya ve Ukrayna'nın Minsk’te bir araya getirilerek ateşkes anlaşmasının imzalanması, AB'nin çatışmaları askeri alandan diplomatik alana çekebildiğini göstermektedir.

\section{Ekonomik Yaptırımların Ukrayna Krizindeki Etkisi}

AB'nin bir dış politika aracı olarak ekonomik yaptırımları uluslararası krizlerde sıklıkla kullandığı görülmektedir (K. Smith, 2014; Keukeleire ve Delreux, 2014; Bindi, 2010). Ancak bu aracın başarısı, yaptırımların uygulandığı ülkenin $\mathrm{AB}$ ekonomisine olan bağımlığına göre değişmektedir. Eğer yaptırım uygulanan ülke AB'nin ekonomisine yüksek oranda bağımlılık gösteriyorsa AB'nin uygulayacağı yaptırımlar başarılı olabilmektedir. Buna karşın bağımlılık göstermiyor ya da daha az bağımlık gösteriyorsa, bu durumda ekonomik yaptırımların başarısı sinırlanmaktadır (Keukeleire ve Delreux, 2014). Bunun yanında ekonomik yaptırım uygulanacak ülke $A B$ ekonomisine bağımlık göstermesinin yanında AB ülkeleri de aynı şekilde yaptırım uygulanan ekonomiye bağımlılık göstermesi durumunda, AB'nin ekonomik yaptırımları başarı ya da başarısızlık gösterebilmektedir.

Bu bağlamda Ukrayna Krizi'nde Rusya ile olan ekonomik ilişkiler AB’nin kapsamlı dış politika kararları almasını engellediği görülmüştür (Vitkus, 2015, s. 9). Zira soğuk savaşın sona ermesinde bu yana, AB ve Rusya ekonomik olarak yoğun bir ilişki söz konusudur. Nitekim Rusya AB'nin üçüncü büyük ticari ortağı (\%8.4 toplam dış ticaretin) iken AB ise Rusya'nın en önemli ticari ortağı (\%48 toplam dış ticaretin) konumunda yer almaktadır (European Parliament, 2015). Aşağıdaki tabloda da görülebileceği gibi, krizinden önce AB ve Rusya arasındaki toplam ticaret hacmi yıllık 326 milyar Euro civarındaydı. Bu miktarın 206 milyar Euro’su AB ülkelerinin Rusya'ya yapmış oldukları ihracatı kapsamaktayken 120 milyar Euro'luk kısmı ise Rusya'nın AB ülkelerine yapmış olduğu ihraç miktarını oluşturmuştur. Dolayısıyla AB, Rusya'ya yönelik ekonomik yaptırım kararlarını alırken bu durum göz önüne almış ve Rusya’ya karşı sınırlı yaptırım kararı üzerinde uzlaşıya varılabilmiştir. 


\begin{tabular}{|l|c|c|c|c|c|c|}
\hline & \multicolumn{2}{|l}{ İhracat } & \multicolumn{2}{l|}{ Itthalat } \\
\cline { 2 - 8 } & $\begin{array}{l}\text { Yaptırımdan } \\
\text { önce }\end{array}$ & \multicolumn{2}{l}{ Yaptırımdan sonra } & \multicolumn{2}{l|}{$\begin{array}{l}\text { Yaptırımdan } \\
\text { önce }\end{array}$} & \multicolumn{2}{l|}{ Yaptırımdan sonra } \\
\cline { 2 - 8 } & 2013 & 2014 & 2015 & 2013 & 2014 & 2015 \\
\hline Avusturya & 3.069 & 2.153 & 2.069 & 4.307 & 3.987 & 2.607 \\
\hline Belçika & 9.992 & 10.637 & 8.315 & 5.113 & 4.091 & 3.040 \\
\hline Bulgaristan & 4.782 & 3.963 & 3.157 & 582,9 & 526,8 & 396,8 \\
\hline Hırvatistan & 1.069 & 857,2 & 432,5 & 282,2 & 274,6 & 198,6 \\
\hline Kibris & 52.814 & 28,6 & 120,8 & 24,2 & 14,3 & 8,9 \\
\hline Çek Cum. & 5.383 & 4.147 & 3.201 & 4.474 & 4.105 & 2.864 \\
\hline Danimarka & 949,9 & 942,2 & 1.335 & 1.562 & 1.153 & 744,9 \\
\hline Estonya & 840,4 & 873,3 & 801,5 & 1.411 & 1.186 & 773,6 \\
\hline Finlandiya & 10.485 & 8.576 & 5.951 & 5.358 & 4.638 & 3.158 \\
\hline Fransa & 10.262 & 9.909 & 6.230 & 7.720 & 6.808 & 4.535 \\
\hline Almanya & 39.127 & 36.205 & 27.035 & 35.789 & 29.230 & 21.802 \\
\hline Yunanistan & 6.606 & 4.831 & 3.436 & 406,1 & 356,8 & 213,4 \\
\hline Macaristan & 6.395 & 5.404 & 3.278 & 2.526 & 2.069 & 1.505 \\
\hline İrlanda & 140,7 & 214,7 & 149,4 & 632,5 & 718,4 & 365,9 \\
\hline İtalya & 20.197 & 17.275 & 14.259 & 10.771 & 9.502 & 7.108 \\
\hline Letonya & 1.087 & 1.039 & 1.054 & 1.759 & 1.605 & 1.243 \\
\hline Litvanya & 7.368 & 5.347 & 4.297 & 4.869 & 5.080 & 3.139 \\
\hline Luxemburg & 2,3 & 12,9 & 6.933 & 156,2 & 128,9 & 112,4 \\
\hline Malta & 7,8 & 15,2 & 73,1 & 35,6 & 3,4 & 3,2 \\
\hline Hollanda & 28.973 & 25.052 & 17.909 & 7.956 & 6.610 & 4.824 \\
\hline Polonya & 18.654 & 17.060 & 12.616 & 8.112 & 7.006 & 5.130 \\
\hline Portekiz & 1.000 & 710,8 & 636,9 & 263,1 & 204,1 & 157,9 \\
\hline Romanya & 2.360 & 2.289 & 2.002 & 1.382 & 1.451 & 989,9 \\
\hline Slovakya & 6.064 & 4.779 & 3.434 & 2.554 & 2.130 & 1.527 \\
\hline Slovenya & 464,1 & 428,1 & 256,5 & 1.189 & 1.128 & 861,1 \\
\hline İspanya & 8.103 & 5.945 & 3.322 & 2.812 & 2.582 & 1.671 \\
\hline İsveç & 5.550 & 6.212 & 4.207 & 2.727 & 2.426 & 1.570 \\
\hline Britanya & 7.965 & 7.457 & 6.122 & 4.666 & 4.177 & 3.330 \\
\hline AB-28 & 206.956 & 182.371 & 135.716 & 119.450 & 103.202 & 73.886 \\
\hline
\end{tabular}

Tablo 1: AB Üye Ülkelerinin Rusya ile Yaptı̆̆ İhracat ve Itthalat Rakamlarl (2013-2015, Milyon Euro). Kaynak: European Commission: Market Access Database, Statistics, 2016.

2014 yılından beri Rusya’ya karşı sınırlı bir ekonomik yaptırım uygulanmasına rağmen, AB ülkeleri bu süre içinde ciddi anlamda ekonomik kayıplar yaşamışlardır. Eurostat'ın 2015 verileri göre, AB ve Rusya arasındaki toplam ticaret 2013 yılındaki ticaret hacmine göre 100 milyardan fazla bir düşüş yalamış ve 209 milyar Euro civarında gerçekleşmiştir (Eurostad, 2016). Halbuki kriz öncesi AB ve Rusya arasındaki ticaret hacmi 326 milyar Euro seviyelerindeydi. Bu anlamda, $\mathrm{AB}$ ve Rusya arasındaki ticarete büyük bir düşüş yaşanmıştır. AB büyük bir ekonomik kayıp yaşamasına rağmen, henüz Ukrayna Krizi’nde istenilen başarılı sağlanamamıştır. Yukarı da belirtildiği gibi, AB'nin uygulamış olduğu ekonomik yaptırımların başarı olabilmesi, o ülkenin AB ekonomisine bağımlı olması sonucu mümkün olabilmektedir. Bu çerçevede Rusya’nın AB ekonomisine yüksek oranda (\%48 oranında) bağımlılık göstermesi, AB yaptırımların başarılı olmasını kuvvetlendirmiştir (Galbert, 2015, s. 5-6). Buna karşılık aynı şekilde AB'nin de yaptırım uygulanan ekonomiye bağımlı olması, yaptırımların başarısını sınırlandırmıştır. Nitekim birçok AB ülkesinin -özellikle Almanya'nın- Rus ekonomisiyle yoğun ticari ilişkileri olması, AB'nin ekonomik yaptırım aracını başarılı bir şekilde kullanmasını engellemiştir. Çünkü Rusya mevcut ekonomik ilişkiler çerçevesinde AB'nin kendine yönelik kapsamlı ekonomik yaptırımlar uygulamayacağının farkındadır. Zira bu durumda AB de katlanılması mümkün olmayan bir ekonomik kayıpla karşı karşıya kalması muhtemel hale gelmektedir. Bundan dolayı, dış politika alında elindeki en güçlü silahı olan ekonomik yaptırımları AB, Rusya'ya karşı tam olarak kullanamamıştır. Bu ise Ukrayna Krizi'nde bir çözümün oluşmasını engellemiştir. Gerçi uygulanan ekonomik yaptırımlar krizin daha fazla tırmanmasının önüne geçebilmiştir. Ancak kesin bir sonucu ulaşılması konusunda yeterli olmamıştır (Speck, 2015b).

Öte yandan AB, Rusya'nın Ukrayna'daki krizi derinleştirmesi durumunda, Rusya'yı ekonomik yaptırımların kapsamını genişletmekle tehdit etmektedir (Forsberg, 2016, s. 28). Böyle bir durum Rusya'yı ekonomik olarak zor durumda bırakacağı gibi, AB ülkeleri içinde ekonomik olarak katlanılması zor bir durumu ortaya çıkaracaktır. Dolayısıyla Almanya ve Fransa başta olmak üzere AB'nin Rusya'ya daha fazla yaptırım uygulanması sıcak bakmamaktadırlar (Galbert, 2015, s. 14-15). Nitekim AB'nin önemli ülkelerinden biri olan Fransa'nın uzun 
zamandadır ekonomik yaptırımların kaldırılması konusundaki düşüncesi son dönemde AB'nin diğer önemli ülkesi olan Almanya tarafında da destek görmeye başlamıştır. Gerçekten de Almanya Rusya'nın Ukrayna'daki krizi tırmandırmaması ve ayrılıkçı grupları desteklemeyi bırakması karşısında ekonomik yaptırımları sonlandırabileceği sinyalini vermektedir. Öyle ki Angela Merkel 2015 Davos Zirvesinde Ukrayna'da tekrar barışın tesis edilmesi karşılığında Rusya'ya, Ukrayna Krizi'nin çıkmasına neden olan Lizbon'dan Vladivostok'a uzanan bir AB serbest ticaret anlaşmasının teklif etmiştir (Telegraph, 2015). Bu bağlamda, Almanya ve Fransa, Rusya'ya karşı daha fazla ve kapsamlı ekonomik yaptırımları uygulanma konusunda isteksizlik gözükmektedirler. Buna rağmen, bütün üye ülkeler, AB dış politikasının tutarlılığı için Rusya'ya karşı mevcut yaptırımları uygulamaya devam etmektedirler.

Sonuç olarak AB'nin Rusya’ya karşı uygulayacağı ekonomik yaptırımların bir sınırı olduğu görülmüştür. AB ülkeleri daha kapsamlı bir ekonomik yaptırımı, özellikle 2008'den beri devam eden ekonomik kriz sonrası, üstlenmesi söz konusu değildir. AB üyesi ülkeler zaten ekonomik yaptırımlara karşı olduğu için daha kapsamlı ekonomik yaptırımlara destek vermeyecektir. Özellikle Ukrayna krizinde AB'yi liderlik eden Almanya'nın Rusya ile olan yoğun ekonomik ilişkilerinden dolayı daha fazla bir ekonomik kayba katlanması zor gözükmektedir. Bundan dolayı AB'nin Rusya'ya karşı daha kapsamlı dış politikasına destek vermemeleri kuvvetle muhtemeldir. Öte yandan Rusya'nın da bu koşullar altında AB'nin uygulayacağı daha kapsamlı bir ekonomik yaptırım kaldırması mümkün değildir. AB bir dış politika aracı olarak ekonomik yaptırımları Ukrayna Krizi'ni sonlandırmayı başaramamış olsa bile krizin daha da büyümesine en engel olmayı başarmıştır. Krizi askeri düzeyden, diplomatik ve ekonomik düzeye taşımayı başarmıştır.

\section{Sonuç}

Rusya karşı ekonomik ağırlıklı bir dış politikanın belirlenmiş olması, AB'nin Ukrayna krizinde etkili bir aktör olamayacağı tartışmalarına neden olmuştur. Ancak AB'nin dış politikasının kurumsal yapısı düşünüldüğünde bir ulus devletin sahip olduğu diş politikanın özelliklerine sahip olmadığı görülmektedir. Nitekim Maastricht Antlaşmasıyla AB'nin ortak politikalarından biri haline gelen dış politika, üye ülkelerin ulusal çıkarları ve egemenlik haklarını koruyabilmek için kendi kontrollerinde olacak şekilde hükümetlerarası nitelikte oluşturulmuştur. Dahası AB düzeyinde oluşturulan ortak dış politikada güvenlik ve savunma konularına sınırlı düzeyde yer verildiği görülmektedir. Dolayısıyla, AB düzeyinde Ukrayna krizinde Rusya’ya karşı belirlenen dış politikanın kapsamlı ve sert güç unsurlarına yer vermesinin beklenmesi AB diş politikasının kurumsal yapısı açısından çok mümkün gözükmemiştir. Yine de, AB'yi üyesi ülkeler arasında Rusya'ya karş1 'tek sesliliğin' sağlanmış olması AB'nin Ukrayna krizinde önemli bir aktör haline gelmesini sağlamıştır. Elbette AB'nin Rusya'ya karşı ekonomik yaptırımları uygulamaya koyması ve üye ülkelerin bu yaptırım kararlarına bağlılık göstermesi Ukrayna krizini sonlandırmaya yetmemiştir. Fakat Ukrayna krizinde Rusya'ya rağmen, üye ülkelerin $A B$ düzeyinde ortak tutumlar belirleyerek tutarlı politikalar üretebilmeleri, üye ülkelerin ulusal dış politikaları arasındaki yakınlaşmayı göstermesi açısından önemlidir.

Soğuk Savaş sonrası düzenin en önemli güvenlik krizini ortaya çıkaran Ukrayna Krizi'ne karşı AB'nin ekonomik yaptırımları öncelediği, askeri seçenekleri ise gündeme dahi almadığı görülmektedir. Her ne kadar Doğu Avrupalı üye ülkeler askeri seçenekleri gündeme getirse de, üye ülkelerin çoğu Rusya'ya karşı askeri seçeneklerin kullanılmasına kesin olarak karşı çıkmışlardır. Bunun temel nedeni AB ülkelerinin tarihsel deneyimleri ve Avrupa bütünleşmesini doğrudan etkileyecek büyük bir savaştan kaçınılmak istenmesinden kaynaklanmıştır. Bu bağlamda Rusya'ya karşı askeri seçeneklerin kullanılmasının Avrupa'yı derinden etkileyecek türden bir savaşı tetikleyeceğinden korkulmuştur. Özellikle nükleer bir güç olan Rusya ile yaşanacak bir savaşın herkes için kötü sonuçlar ortaya çıkaracağı düşünülmüştür. $\mathrm{AB}$, Rusya gibi nükleer bir askeri güçle ne pahasına olursa olsun karş1 karşıya gelmek istememiştir. AB askeri kapasiteye sahip olmasa bile NATO ve ABD aracılığıyla Rusya'yla mücadele edebilecek durumda olmasına rağmen, askeri seçeneğin hiçbir şekilde $A B$ 'ye fayda getirmeyeceğini görülmüştür. Rusya ile askeri bir mücadelenin AB'yi iki türlü olumsuz yönde etkileme potansiyeli belirmiştir. Bunlardan birincisi, AB'nin askeri yöntemleri kullanması durumunda -ki Rusya'ya karşı AB'nin böyle bir kapasitesi söz konusu değildir- Rusya'nın nükleer güç dahil olmak üzere bütün askeri kapasitesini kullanmasına yol açacağı düşünülmüştür. Böyle bir durum ise İkinci Dünya Savaşı’ndan beri Avrupa'da inşa edilmeye çalışılan barış ve istikrarı sonlandıracak bir gelişme olacaktır. İkincisi ise bir şekilde Ukrayna Krizi'nde Rusya askeri müdahalelerle engellenmiş olsa bile, bu kez Rusya'da bir ekonomik ve siyasi çöküşe neden olacağı, bunun ise Avrupa bütünleşmesini için yeni tehditlerin Rusya topraklarında ortaya çıkmasından korkulmuştur. Soğuk savaşın sona ermesinden bu yana Avrupalı bütünleşmesine zarar verebilecek gelişmeleri bertaraf edebilmek için ekonomik ve siyasi yollara başvurulurken, Ukrayna Krizi'nde askeri yöntemlere başvurulması AB'nin uzun yıllardır izlemiş olduğu stratejiye bu anlamda aykırılık arz etmiş olacaktı. Askeri kapasite yetersizliği ve sahip olduğu sivil ve ekonomik güç ilkeleri AB'nin Ukrayna Krizi’nde izlediği dış politikanın temel dinamiği meydana getirmiştir. Askere kapasite yetersizliği askeri açıdan AB'nin etkili bir aktör olmasını sınırlandırsa da sahip olduğu ekonomik güç ve sivil güç Ukrayna Krizi'nin büyümesi engellemiştir. 


\section{Kaynakça}

- Arman, M. R. \& Aslan, H. 2015. Avrupa Komşuluk Politikası Çerçevesinde Ukrayna Krizi, İçinde, U. B. Yıldız (Ed.), Avrupa Birliği’nin Dış İlişkileri: Bölgesel Politikalar, Bölgeler ve Uluslararası Aktörlerle İlişkiler (ss. 59-82). Ankara: Nobel Yayınları.

- BBC, 2015. France Seeks End to Russia Sanctions over Ukraine. http://www.bbc.com/news/world-europe30679176 adresinden 16/04/2016 tarihinde alındı.

- Chivvis, C. 2015. Deterrence in the New European Security Context. İçinde, Riccardo Alcaro (Ed.), WestRussia Relations in Light of the Ukraine Crisis (ss. 33-45). Roma: Edizioni Nuova Cultura.

- Demir, S. 2014. Ukrayna Krizi: Yeni Küresel Politik Düzenin Başlangıcı. İçinde, H. Çomak, C. Sancaktar \& Z. Yıldırım (Eds.), Uluslararası Politikada Ukrayna Krizi (ss. 169-190). İstanbul: Beta Yayınları.

- European Commisson, 2016. An overview of trade flows in goods between EU and non-EU countries. http://madb.europa.eu/madb/statistical_form.htm adresinden 15/05/2016 tarihinde alındı.

- European Parliament, 2015. Economic impact on the EU of sanctions over Ukraine conflict.http://www.europarl.europa.eu/RegData/etudes/BRIE/2015/569020/EPRS_BRI(2015)569020_EN.p df adresinden 25/05/2016 tarihinde alınd1.

- European Union External Action, 2015. EU relations with Russia.http:// eeas.europa.eu/russia/about/index_en.htm adresinden 12/05/2016 tarihinde alındı.

- Forsberg, T. 2016. From Ostpolitik to 'frostpolitik'? Merkel, Putin and German foreign policy towards Russia. International Affairs. 92(1), 21-42.

- Galbert, S. 2015. A Year of Sanctions against Russia-Now What? AEuropean Assessment of the Outcome and Future of Russia Sanctions. Washington: Center for Strategic \&InternationalStudies.

- House of Lord, 2014. The EU and Russi: Before and Beyond the Crisis in Ukraine. London: the Authority of the House of Lords

- Keukeleire, S. \& Delreux, T. (2014). The Foreign Policy of the European Union. 2nd ed., Basingstoke: Palgrave Macmillan.

- Kuzio, T. 2012. Ukraine's relations with the West since the Orange Revolution. European Security, 24(3), 395-413.

- Larrabee, S. F., Wilson, A. P. \& Gordon, J. 2015. Ukrainian Crises and European Security: Implication for the United States and US Army. Santa Monica: RAND Corporation.

- Larsen, H. B. L. 2014. Great Power Politics and the Ukrainian Crisis: NATO, EU and Russia after 2014, Copenhagen: DIIS, Danish Institute for International Studies. Report 2014: 18. https://www.diis.dk/files/media/publications/import/rp182014_lindboe nato_forweb.pdf adresinden 25/05/2016 tarihinde alındi.

- MacFarlane, N. \& Menon A. (2014). The EU and Ukraine. Survival, 56(3), 95-101.

- Özdal, B. 2013. Avrupa Birliği Siyasi Bir Cüce, Askeri Bir Solucan mı?.Bursa: Dora Yayınc1lık.

- Özdal, H. 2013. AB ve Rusya Arasında Ukrayna: Hayaller ve Gerçekler. Uluslararası Stratejik Araştırmalar Kurumu. Analiz No 26, 1-15.

- Özdal, H., Özertem, H. S., Has, K. \& Yegin, M. 2013. Ukrayna Siyasi Krizinde Rusya ve Batı'nın Tutumu.Uluslararası Stratejik Araştırmalar Kurumu, Analiz No: 28, 1-22.

- Schmidt-Felzmann, A. (2015). Facing the Kremlin: Better Brave, Than Sorry!. İçinde, A. Spruds \& K. Bukovskis (Eds.). Towards Reassurance and Solidarity in the Euro-Atlantic Community. Riga Conference Papers 2015(pp.120-129). Riga: Latvian Institute of International Affairs.

- Schmidt-Felzmann, A. 2014. Is the EU's Failed Relationship with Russia the Memeber States Fault? L'Europe en Formation, 14(374), 40-60.

- Secrieru, S. 2015. Have Eu Sanctions Changed Russia's Behaviour In Ukraine? İçinde, I. Dreyer ve J. L. Cabrera (Eds). On target? EU sanctions as security policy tools (ss. 39-48). Paris: EU Institute for Security Studies.

- Speck, U. 2015. German Power and the Ukraine Conflict, Carnegie Europe http://carnegieeurope.eu/2015/03/26/german-power-and-ukraine-conflict adresinden 19/04/20156 tarihinde alınd.

- Telegraph, 2015. Ukraine crisis: Angela Merkel 'offers Russia free trade deal for peace.http://www.telegraph.co.uk/news/worldnews/europe/ukraine/11365674/Ukraine-crisis-AngelaMerkel-offers-Russia-free-trade-deal-for-peace.html adresinden 27/05/2016 tarihinde alındı.

- Trenin, D. 2014. The Ukraine Crises and the Resumption of Great-Power Rivalry. Moscow: Carnegie Moscow Center.

- Vitkus, G. 2015. Towards Stronger Normative Power: The Nature of Shift in EU Foreign Policy in the Context of the Crisis in Ukraine. European Integration Studies. 9, 8-19.

- Zhussipbek, G. 2011. Avrupa Birliği İle Rusya Federasyonu Arasındaki “Stratejik Ortaklığın” Analizi. Uluslararası Hukuk ve Politika, 7(25), 47-85. 


\title{
Orta Asya Entegrasyon Süreçlerine "Büyük Güçlerin" Etkisi The Impact of the "Big Powers" to the Integration Processes in Central Asia
}

\author{
Ediliia Abdykadyrova (Kyrgyz-Turkish Manas University, Kyrgyzstan)
}

\begin{abstract}
It has been over 20 years since the Soviet Union collapsed. Despite that the post-Soviet countries were not able to build strong economic structure, which would be competitive in the international arena. They failed to implement the economic integration among themselves using communication that they had during the Soviet Union time. There have been various attempts to change the situation, but efforts were not successful due to various obstacles. Among these obstacles take place the influence of America, Russia and China, which are considered as great powers and which are pay great attention to Central Asia. This issue attracts attention due to the fact that the problems associated with the integration of the Central Asian countries still exists and that any integration process in the region does not achieve success without the involvement of other external forces. In this paper basic information about the integration processes between the Central Asian countries and their results will be analyzed. In addition, the attitudes of the Central Asian countries towards integration as well as economic and political influence of the great powers to the integration processes in the region will be examined.
\end{abstract}

\section{Giriş}

Geçmişte uluslararası sistemin en önemli aktörlerinden biri olan, Soğuk Savaş döneminin iki kutuplu sisteminde, kutuplardan birinin lideri olan Sovyetler Birliği bir devlet için kısa olan ömründe dünya tarihinde önemli rol oynamıştır. Bu birliğin yıkılması yeni bağımsız devletlerin ortaya çıkmasına neden olmuştur.

Sovyetler Birliği'nin çökmesi siyasi alandaki değişiklikler yanında ekonomik alanı da etkiledi. Örneğin, Sovyetler Birliği'nin dağılmasının ardından Orta Asya bölgesinde ekonomik boşluk oluşmuştur. Bu boşluğun doldurulmasına yönelik yeni ekonomik işbirliği ve entegrasyon girişimleri oldu. Ancak bu devletler arasında Sovyetler Birliği döneminde merkezi hükümet tarafından oluşturulan ekonomik bağımlılık ve var olan ekonomik ağlar her geçen gün zayıfladı ve dolaysıyla aralarındaki entegrasyonu gerçekleştiremediler. Bunu değiştirmek için Orta Asya ülke liderleri tarafından ortaya atılan çeşitli çabalar yer almış fakat başarılı bir sonuca ulaşılmamıştır. Çabaların başarılı olmadıklarının sebepleri arasında hem kendiliğinden kaynaklanan faktörlerin hem de büyük güçlerin etkisi önemli rol oynamaktadır.

Orta Asya bölgesi jeopolitik ve jeoekonomik açıdan çok önemli bir bölge olarak sayılmaktadır. Bu bölge ABD, Rusya ve Çin gibi büyük güçlerin ilgi çektiği ve rekabet alanı olduğu bir toprak parçasıdır. Orta Asya bölgesinin, özellikle güvenlik sorunları açısından önemi büyüktür. Çünkü Orta Asya devletleri uluslararası terorizm, ayrılıkçılık ve nükleer silahları bulunduran İran, Afganistan ve Pakistan gibi ülkelerle sınırı vardır. Bunun dışında işgücünün ucuz olması, doğal ve enerji kaynaklarının bol olması gibi büyük devletlerin ilgisini arttırmaktadır. Bu nedenle Orta Asya bölgesindeki entegrasyon süreci büyük güçlerin etkisi altında kalmıştır.

Orta Asya'da entegrasyon süreci bu bölge devletlerinin bağımsızlıklarını kazandığı döneme rastgelmektedir. Yani, bu devletler hem iç siyasi gelişmelerle hem de entegrasyon süreciyle aynı anda uğraşmışlar. Orta Asya devletlerinin her birinde ulus-devlet inşası, ulusal para, semboller ve dil, örf ve adetler gibi milli değerlerin yeniden canlandırılması gibi bir süreç yaşanıyordu. Bununla birlikte beş ülkenin cumhurbaşkanları üst düzey zirvelerde toplanarak Orta Asya Birliğinin inşasını planlıyor ve hayata geçirmeye çalışıyorlardı. Ancak tüm bu girişimler olumlu sonuç vermediğinden dolayı entegrasyon sürecine Rusya öncülük yapmaya girişmiştir ve bugüne kadar etkinliğini korumaktadır. Bunun yanında Çin Orta Asya’nın jeopolitik ve güvenlik anlamda çok büyük öneme sahip olduğundan ve ekonomik anlamda büyük bir pazar olarak kabul edildiğinden dolayı bu bölgeye ilgi duymaktadır. Amerika ise Çin ve Rusya'nın artan etkisini sınırlamak, Orta Asya devletlerinin Rusya'dan bağımsız olarak kendi politikalarını teşvik etmelerini ve anti-Amerikan niteliğinde ortaya çıkan Rusya ve Çin arasındaki ittifakın oluşturulmasını engellemek amacıyla Orta Asya'da kendi etkisi korumaya çalışmaktadır.

Böylece, Orta Asya ülkeleri arasındaki entegrasyon konusundaki sorunların devam ettiğinden ve söz konusu bölgedeki herhangi bir entegrasyon sürecinin başka dış güçlerin katılımı olmadan başarı elde etmediğinden dolayı bu konu ilgi çekmektedir. Genel olarak bu çalışmada Orta Asya bölgesi ile ve bölgede yer alan devletler arasındaki entegrasyon süreçleri ile ilgili temel bilgiler verilerek sonuçlar analiz edilecektir. Entegrasyon süreçlere yönelik Orta Asya ülkelerin tutumları ve entegrasyon süreçleri doğrultusundaki dönemin büyük güçlerin siyasal ve ekonomik etkileri konu içerisinde alınarak bölgedeki durum incelenmiş ve Orta Asya bölgesinde entegrasyon konusunda neler yapılmış, niçin Orta Asya devletleri kendi aralarında entegrasyon girişimlerinde başarılı olamadılar, başarısızlığın nedenleri nelerdir, büyük güçlerin çıkarları nelerdir, büyük güçler hangi durumlarda bölgesel entegrasyonları destekleyip hangi durumlarda karşı çıkıyorlar gibi sorulara cevaplar aranmıştır. Çalışma 
üç ana bölümden oluşmaktadır. Birinci kısım entegrasyon süreçleri ile ilgili literatür inceleme kısmıdır. İkinci kısımda Orta Asya'da bulunan devletler arasındaki entegrasyon süreçlerinin arka planı incelenerek başarılı bir entegrasyon girişimine dönüşmeyen süreçler örnek olarak verilecektir. Son kısımda ise Orta Asya'daki entegrasyon süreçlerin başarısızlığının nedeni olarak bugün büyük güçler olarak tanımlanan ABD, Rusya ve Çin'in etkisi ele alınacaktır ve sonradan da sonuç kısmı oluşturulacaktır.

Dolaysıyla, çalışmada ABD, Rusya, Çin birbirlerinin ve diğer bölgesel güçlerin konumunun güçlenme olasılığııı ortadan kaldırmak amacıyla, ikili ve çok taraflı formatlarda Orta Asya cumhuriyetleri ile işbirliği konusunda kendi çıkarlarına yönelik entegrasyon modellerini teşvik edeceklerdir olarak ifade edilen geçici tez kabul edilmektedir. Bunun yanında çalışma sırasında ulaşılmış hipotezler şunlardır: SSCB'nın dağılmasının ardından Orta Asya ülkelerinin kendi aralarında başarılı bir entegrasyon girişiminde bulunamamasının ana nedeni başka güçlerin bu bölgeye ilişkin kendi çıkarların var olmasıdır; eğer bölgesel entegrasyon büyük gücün çıkarına ise destekler çıkarına değil ise karşı çıkar ve farklı metodlarla engellemeye çalışır; büyük güç kendisinin içinde olduğu bir entegrasyon ister; kendisi için önemli olan bir bölgede başka gücün egemen olmasına engel olur.

\section{Orta Asya'da Entegrasyon Süreçleri ile İlgili Literatür Taraması}

SSCB'nin dağılmasıyla ve dolaysıyla Soğuk Savaş'ın sona ermesi ile beraber uluslararası ilişkiler alanında değişiklikler yer almıştır. Yeni bağımsız ülkelerin ortaya çıkmasıyla farklı politikalar uygulanmaya başlandı. Günümüzde uluslararası ilişkiler uluslararası ekonomik, siyasi ve kültürel işbirliğinin genişletilmesi ve derinleştirilmesi ile ve aynı zamanda küreselleşme sürecin yoğunlaşması ile karakterize edilen yeni bir döneme girmiştir. Bu çerçevede de uluslararası toplumda kimilerince küreselleşmenin oluşumunu engellemek amacıyla, kimilerince ise onun gelişmesine katkı sağlamak amacıyla farklı entegrasyon girişimleri bulunmaya başladı. Bu entegrasyon girişimleri daha çok bölgesel seviyede gelişmiştir. Bu anlamdaki entegrasyonu açıklarsak devletlerin ortak kurumlar ve kurallar aracılığıyla aralarındaki işbirliğini yükseltmek için bir anlaşma içine girme sürecidir. Genellikle ulusal hükümetler tarafından geniş sosyo-politik ve güvenlik hedeflerine ulaşmak için kabul edilen ticari çıkarlar odaklı bir siyasi ekonomik girişim şeklini almış olmasına rağmen anlaşmanın amaçları ekonomik amaçlardan başlayarak siyasi ya da çevresel amaçlar kadar değişebilir.

Böylece uluslararası entegrasyon girişimleri insanlığın tarihinde her zaman yer almıştır, ancak farklı şekillerde ortaya çıkmıştır. Örneğin İmperializm adı ile bilinen ve büyük devletlerin zorlayıcı emperyal niyetler sayesinde ortaya çıkan süreçler. Bu süreç XX yüzyılın ortalarına kadar sürmüş, fakat II Dünya Savaşın sona ermesiyle ve Batı Avrupa devletlerinin bir arada toplanarak ve barışın sağlanması için sadece işbirlik girişiminde bulunmadan bir örgütün kurulması (Avrupa Birliği) ile bu durum değişmiştir. Ondan sonra ise Avrupa Birliği'nin başarısı dünyanın başka bölgelerinde bulunan devletlerin de bir bölgesel entegrasyon girişimlerinde bulunmasını teşvik etmektedir. Bu çerçevede Avrupa dişındaki bölgesel entegrasyonu sağlamak amacıyla kurulan çeşitli girişimler arasında Güney Doğu Asya Ülkeleri Birliği (ASEAN), Afrika Birliği (AU) ve güney Amerika'daki MERCOSUR vb. yer almaktadır. Bunların yanında 1990'larda bağımsız olarak ortaya çıkan Orta Asya devletleri kendi aralarında Soviyet Birliği zamanında var olan bağı kaybetmemek ve ortalarında oluşan ekonomik boşluğu doldurabilmek amacıyla bütünleşme, entegrasyon girişimlerinde bulunmuşlardır. Fakat bu girişimler başarılı bir sonuca ulaşmamışlardır.

Aleksandr Libman ile Evgeniy Vinokurov Orta Asya'daki bölgesel entegrasyonu ekonomik anlamda ele alarak bölgedeki karşılıklı iktisadi dayanışma kapsamında entegrasyon süreci incelemektedir. Onlar Orta Asya toprakları üzerindeki entegrasyon sürecini bölge içerisinde bulunan ülkelerin siyasi ekonomilerinde var olan çeşitli özel aktörler tarafından kurulan ekonomik ağların etkilediğini dikkate almışlar. Benzer şekilde bölgesel entegrasyon girişimlerinde gayri resmi ticari ağların etkisini belirlemektedirler (Libman ve Vinokurov, 2011). Necla V. Geyikdağı'ya göre Orta Asya ülkeleri kolay bir şekilde ülkelerin tüketicileri, işletmeler ve hükümetleri için önemli yararlar getirecek olan ortak pazar olarak entegrasyon sürecine girebildiklerini belirlemektedir (Geyikdağı, 2008). Kimi akademisyenlere göre, örneğin Alison ve Jonson, Kazantsev, Troitskiy vb., Orta Asya devletlerin kendi aralarında işbirlik yapmaya motivasyonu olmadığından $\mathrm{ABD}$, Rusya, $\mathrm{AB}$, Çin gibi daha büyük bir gücün müdahalesi Orta Asya'nın entegrasyonu için vazgeçilmez bir koşuldur. Alternatif olarak, Koraboyev adlı bir yazar Orta Asya'nın statik bir bölge olmadığını belirterek söz konusu bölgenin entegrasyon sürecine kolay bir şekilde adım atabildiğini iddia etmektedir (İrnazarov ve Salmanov, 2012). Diğer araştırmacılar ise Orta Asya bölgesinde entegrasyonun gerekliliği konusunda ters görüşleri paylaşıyorlar. R. Alşanov ve A. Aşımbaev tarafindan Orta Asya ülkelerin küresel ekonomik ve siyasi alanda topluca hareket etmeden bireysel ve özerk bir şekilde hareket ettiklerini belirlenmiştir ve dolaysıyla aralarında herhangi bir entegrasyon hakkında söz edilemez (Alşanov ve Aşımbaeva, 2006). Benzer bir görüşü G.Saidazimova da ifade etmektedir. Ona göre Orta Asya ülkeleri aralarında iç ve dış politikalarını konularında anlaşmadan siyasi, ekonomik, mali, askeri vs. anlamda dünya toplumuna hızlı ve karlı bir giriş yapma ve yabancı yatırımları çekme doğrultusunda mücadele etmektedirler (Saidazimova).

Böylece, araştırmacılarının bir kısmı Orta Asya bölgesindeki entegrasyon girişimlerine taraftar olarak onların bölgede yer alan ülkelerin gelişmesine katkıda bulunacaklarına inanmaktadırlar. Diğer bir kısmı ise devletler 
arasında gerçek bir entegrasyonun gerçekleşemeyeceğini belirtmektedirler, gerçekleşirse bile dış güçler tarafindan etkileneceğine dikkat etmektedirler.

\section{Orta Asya'da Yer Alan Entegrasyon Süreçlerin Arka Planı}

Uluslararası arena Sovyetler Birliği’nin dağılmasıyla bağımsız yeni 15 cumhuriyetin kurulmasına sahne olmuştur. Kafkasya, Baltık ve Orta Asya bölgelerinde yeni devletlerin ortaya çıkışı küreselleşme, demokratikleşme ve bölgeselleşme süreçlerine rastgelmiştir. 1991 yilında Orta Asya bölgesinde yer alan Kazakistan, Kırgızistan, Özbekistan, Tacikistan ve Türkmenistan egemenliği elde etmişler ve bağımsız devletler olarak dünyaya tanıtılmaya başlamışlar. Orta Asya devletlerin dünyada cereyan eden değişiklilere ve yeni süreçlere katılmaları kendi devletlerinde milli kimlik inşası süreciyle paralel olarak gelişmiştir.

Orta Asya bölgesi ortak din, dil ve tarihe sahip olan bir bölgedir. Buna ek olarak bölgedeki tüm ülkelerin Sovyetler Birliğinin çatısı altında 70 yılık bir dönemde beraber yaşaması, onların benzer kültürel değerler ve düşünce yapılarına sahip olmalarını sağlamıştır. Bunun yanı sıra, Orta Aysa cumhuriyetleri arasında sıkı ekonomik bağ söz konusuydu. Böylece, Sovyetler Birliğ̣i'nin dağılmasından sonra Orta Asya bölgesinin gelişimi ve dünyada kendi yerini belirlemesi için uygun olan entegrasyon modellerin aranması bölgenin kalkınma stratejisinin önemli bir unsuru olmuştur. Bunun doğrultusunda 1990'larda başlayarak Orta Asya devletleri bölgede birleşme ve entegrasyon sürecini gerçekleştirmek amacıyla üst düzey zirve toplantılarını başlatmışlardır.

Orta Asya bölge üzerinde yer alan beş devlet arasındaki entegrasyon doğrultusunda ilk ilişkiler Sovyetler Birliğı’’nin dağılmasından önce başlamıştır. Bölge liderleri ortada var olan Aral meselesi ve su paylaşımı gibi problemleri çözmek amacıyla kendi aralarında toplantılar yapmışlardır. "Bu dönemde bölgesel sorunlara ve Moskova kaynaklı meselelere çözüm aramak için Orta Asya Cumhuriyetlerinin liderleri arasında zirve toplantılarının yapılması yaygın bir uygulama idi” (Karasar ve Kuşkunmayev, 2009). Bu bağlamda Orta Asya devletleri arasında 23 Haziran 1990 tarihinde Almatı'da ilk "entegrasyon toplantısı" gerçekleşmişti. Genel olarak ekonomik konulara dikkat eden bu toplantı ilk defa bölge devletlerinin Moskova'dan bağımsız olarak politika yürütmeye başladıkları açısından çok önemliydi. İkinci toplantı 15 Ağustos 1991'de Taşkent'te gerçekleşti, bir sonraki ise Sovyetler Birliği'nin dağılmasından sonra Aşkabat'ta yer aldı (Karasar ve Kuşkumbayev, 2009). Bu toplantıda Kazakistan cumhurbaşkanı Nursultan Nazarbayev ilk defa Merkezi Asya Birliği ve Türk Birliği’nin kurulması ile ilgili fikrini orta atmışıı (Saidazimova). Cumhurbaşkanların bir araya gelerek yaptıkları zirvelerin sonucunda Merkezi Asya Ekonomik Birliği kuruldu. 1993 yılında Minsk zirvesinde Kazakistan cumhurbaşkanı Nazarbayev Avrasya Ekonomik Birliği fikrini ilk defa diğer liderlerle paylaşmıştır (Karasar ve Kuşkumbayev, 2009). Kazak Avrasyacılığı olarak adlandırılan bu yaklaşım Kazak dış politikasının o dönemdeki çok önemli konsepti haline dönüşmüştür. Ama Orta Asya bölgesinin Kırgızistan dışındaki diğer devlet başkanları tarafindan olumsuz karşılanmıştır. Hatta Özbek lideri Kerimov bu fikre tamamen karşı olduğunu ve entegrasyonun Avrasyacılık yönde gelişmesi kendi bağımsızlıklarını zedeleyeceğini vurgulamıştır. Bundan dolayı Özbekistan Cumhurbaşkanı Kerimov 1995 yılında 'Türkistan Ortak Evimiz' projesini Özbek kamuoyu ve siyasetçilerine sunmuştur (Karasar ve Kuşkumbayev, 2009). Daha sonra bu proje zirve toplantılarında gündeme gelmiştir. Kerimov'un bu projesinin asıl amacı Orta Asya devletlerinin entegrasyon ve birleşme sürecine Rusya'yı katmamak ve sadece beş ülkenin oluşturduğu bir birlik kurmaktı. Çünkü Rusya'yı bölge lideri konumunda kabul etmek istememekteydi..

Özbek ve Kazak liderlerinin Orta Asya'daki entegrasyon ile ilgili sunduğu projelerden esinlenerek Kırgızstan'ın ilk cumhurbaşkanı Askar Akayev 1997 yılında 'İpek Yolu' projesini ortaya atmışıır. Akayev dönemi dış politikasında bu proje ana doktrine dönüşmüş ve siyasi elit arasında hız kazanmıştır. ‘İpek Yolu’ projesinin asıl amacı tarihi İpek Yolunun canlandırılması ve ittifaklar aracıllğıyla güvenlik ve ticaret alanlarında bütünleşme sağlamaktı. Akayev'e göre bu proje devletler arası ticari ilişkileri arttıracaktı. Bununla birlikte bölgede barış ve istikrarın sağlanması kolaylaşacaktı. Ancak Akayev'in İpek Yolu projesi diğer ülke liderleri tarafindan ciddi olarak algılanmadığı için sadece devletin dış politikasındaki doktrin olarak kaldı. Aynı dönemde Kırgız siyasi eliti tarafından Orta Asya'da entegrasyonun sağlanması için enerji ve su kaynaklarının adil paylaşımının bir gerekçe olduğu Kırgız siyasi eliti tarafından kamuoyuna sunulmuştur.

Orta Asya devletlerinin entegrasyonu için girişimlerde bulunan üç devlet dışında kalan Tacikistan ile Türkmenistan ayrı bir konumda yer almaktadır. Çünkü bu devletler bölgedeki entegrasyon sürecine katılmaktan ve herhangi bir projeler ortaya koymaktan vazgeçerek kendi ülkelerine dönük bir politika izliyorlard. Tacikistan Orta Asya entegrasyon sürecine en son katılan ülkedir. Tacikistan Türkmenistan'a nazaran entegrasyon sürecine katılmış sayılmaktadır. Çünkü 1994 yılına kadar yapılan tüm zirvelerde ve toplantılarda yer almıştır (Karasar ve Kuşkumbayev, 2009). Ama kazak ya da Özbek liderleri gibi özel bir projeleri sunmamıştır. Bunun sebebi de Tacikistan'da yaşanan iç savaştır. 1998 yılına kadar Tacik hükümeti bölgedeki entegrasyon faaliyetlerinden tamamen uzaklaşmış. Ancak ülkede iç savaşın bitmesi ve istikrarın sağlanmasıyla tekrar bölge devletlerin zirve toplantılarında yer almaya başlamıştır.

Türkmenistan Sovyetler Birliği'nin dağılmasından sonra hemen kendi ülkesinin siyasi ve ekonomik yapısının güçlenmesi doğrultusunda çabalar göstermeye başlamıştır ve dolaysıyla Orta Asya'da yer alan entegrasyona 
mesafeli kalmıştır. 1996 yılına kadar devletlerin zirve toplantılarına katılmış ve entegrasyon ile ilgili diğer liderlerin görüşlerine de destek sağlamamıştır. Bu dönemden itibaren uluslararası tarafsızlık statüsünü ilan ederek tarafsız politika izlemeye başlamıştır. Böylece Tacikistan ile Türkmenistan faklı sebeplerden dolayı entegrasyon sürecine mesafeli kalmışlardır. Demek ki Orta Asya bölgesindeki entegrasyon sürecinin tamamlanması için çaba gösteren Kazakistan ile Özbekistan devletleriymiş. Buna ek olarak Kırgızistan'ın tüm zirvelere katılarak ve diğer liderlerin projelerini destekleyerek aktif bir şekilde yer aldığ 1 da görülmektedir.

Bölgesel zirvelerin sonucunda 1994 yılında Orta Asya Ekonomik Birliği kurulmuştur. 4 sene geçtikten sonra bu birlik Orta Asya Ekonomik Topluluğuna dönüşmüştür (Erol ve Şahin, 2013). Orta Asya Ekonomik Topluluğu'n kuruluşu Orta Asya devletlerinin entegrasyon sürecindeki girişimlerinin sonuncudur. Çünkü bundan sonra kurulan birlikler ve yapılan platformlar Rusya'nın öncülüğünde yapılmaya başlanmıştır. 1990'ların sonunda Rusya'da yaşanan ekonomik kriz Orta Asya Ekonomi Topluluğu'nu etkileyerek onun gelişmesini durdurmuştur. Krizden dolayı ortaya çıkan zararları kaldırmak amacıyla Orta Asya ülkeleri birbirlerine karşı daha korumacı tedbirler almaya başlamıştırlar (Purtaş, 2008). Bunun sonucunda da topluluğa üye-ülkelerin birbirlerine olan güven düzeyinin azaldığından Orta Asya Ekonomi Topluluğu işlevsiz bir hale düşürmüştür.

Böylece 1999 yılından sonraki dönem Orta Asya bölge devletler merkezli entegrasyon sona ermiştir. 2000 yılında Rusya, Belarus, Kazakistan, Tacikistan ve Kırgızstan arasında Avrasya Ekonomik Topluluğu kurulmuş (Karasar ve Kuşkumbayev, 2009). 2001 yılında ise Avrasya Ekonomik Topluluğu ile Orta Asya Ekonomik Topluluğu birleşmiştir. Bunun sonucunda Avrasya Ekonomik Topluluğu genişlemiş ve Rusya önderliğinde bir entegrasyon platformuna dönüşmüştür.

Orta Asya'da entegrasyon sürecinin ilk yıllarında bölge devletlerinin aktif bir şekilde girişimlerde bulunması görülmektedir. Ama bölge devletlerinin başkanlarının entegrasyon konusunda fikir ayrılıkları ve bölge dışı güçlerin etkileri sebebiyle önceden iyi bir şekilde gelişmeye başlayan bölge merkezli entegrasyon çabaları başarısız olarak çöküntüye uğramıştır.

\section{Orta Asya Entegrasyon Süreçleri ve Büyük Güçler}

Orta Asya bölge merkezli entegrasyon sürecinin sonunda bölge devletlerinin arasında bir birliğin kurulması farklı sebeplerden dolayı gerçekleşmemiştir. Neden Orta Asya bölge merkezli entegrasyonun başarılı olmadı̆̆ hem araştırmacıların hem de kamuoyunun ilgisini çekmektedir. 2000 yılına kadar bölge merkezli entegrasyon çabaları sona erip entegrasyon sürecinin yeni sayfası açılıyordu. Merkezi Asya Ekonomik Topluluğunun Avrasya Ekonomik Topluluğuna dönüşmesinden sonra Orta Asya ülkelerinin liderleri tarafından entegrasyon ile ilgili ses gelmedi. Bunun sebepleri arasında bölge devletlerinin milli kimlik inşaası doğrultusunda politika izlemeleri, entegrasyon konusunda fikir ayrılığın olması, söz konusu topraklar üzerinde yer alan Tacikistan ve Türkmenistan gibi ülkelerin entegrasyon konusundan uzaklığı ve içe dönük politika sürdürmeleri vb. yer almaktadır. Fakat bunların arasında en önemli engel olarak uluslararası alanda önemli onuma sahip olan büyük güçlerin etkisi öne çıkmaktadır. Şimdiki zaman uluslararası alanda güçlü devlet olarak kabul edilen ABD, Çin ve Rusya bugün önemli bölgelerin sirasında yer alan Orta Asya bölgesine dikkat etmektedir.

1999 yılına kadar birleşme ve entegrasyon yolunda çeşitli girişimlerde bulunmalarına rağmen sonunda Rusya'nın bu sürece katılması ve diğer bölge dışı aktörlerin söz konusu topraklara ilgi duyması Orta Asya devletlerinin kendi aralarında birlik kurmalarına büyük bir engel oluşturmuştur. Soviyetler Birliği’nin mirasçısı olan Rusya ayrı bir bölge olarak ortaya çıkan Orta Asya ile pek ilgilenmemiştir. Onu sadece dağılan bir birliğin parçası olarak algılamış. Bu da genel olarak 1990'ların başında Rusya dış politikasında Atlantikçi akımların egemen olduğundan dolayıdır. Fakat zaman geçtikçe Moskova Orta Asya'nın önemini anlayarak önceden ayrılan bağları yeniden kurmaya çalışmaya başladı. Bunun önünde de siyasi amaçlar gelmektedir, ekonomik amaçlar ise arka planda kalmaktadır. Rusya'nın temel amacı bölgede kendi hegemonyasını oluşturmak ve başta ABD ile Çin olan dış aktörlerin etkisini sınırlamaktır (Malaşenko, 2013). Rus çıkarları ilk olarak onun bölge üzerinde kendi etkisini koruma isteğine dayanmaktadır. Buna ek olarak Rusya eskiden Sovyetler Birliği’ne ait olan alanı kendi himayesi altında tutmaya çalışmaktadır ve böylece kendini güçlü devletler sırasına sokmak istemektedir. Çünkü ancak söz konusu topraklar üzerinde Rusya bir lider haline gelmektedir. Dolaysıyla Rusya kurum içerisinde baş röle sahip olan Avrasya Ekonomik Birliği gibi örgütler ve diğer tedbirler aracılığıyla Orta Asya'ya yakınlaşmakta ve aralarındaki bağımlılıkları daha da yükseltmekte. Orta Asya'da ekonomik anlamda diğer bölge ülkelere kıyasla daha iyi gelişmiş Kazakistan gibi ülkelerle işbirlik girişimlerinde bulunarak ilişkilerini daha yüksek seviyeye getirmektedir. Kısacası, Rusya Orta Asya bölge devletlerinin kendisinin bulunduğu ve önemli rol oynadığı herhangi bir kurumlarla entegrasyon sürecine girmelerine yönelik siyaset yürütmektedir.

Çin açısından Orta Asya, Çin'in siyasî, güvenlik, enerji ve ekonomik çıkarlarını ilgilendiren bir bölge olarak ve böylece ulusal çıkarları doğrultusunda kapsamlı politikaları yürütmüştür. Güvenlik açısından Orta Asya bölgesinin istikrarı, Çin'in Doğu Türkistan bölgesi ile ilişkili olduğu için ülke güvenliğini doğrudan ilgilendirmektedir. Ekonomik açıdan, Orta Asya bölgesi zengin hammaddelere sahip olduğundan dolayı ve Çin malları için bir pazar olarak algılanması Çin'i bölge ülkeleriyle ticari ve ekonomik işbirliğine çekmektedir. Zamanla bölgeye batılı güçlerin dikkat çekmeye başladığını fark ederek ve aynı zamanda Rusya'nın bölge üzerinde kendi etkisini koruma 
yönünde bölge devletleri ile sıkı ilişkilerini kurmaya devam etmesini görerek gerekli tedbirler almaya başlamıştır. Dolaysıyla jeopolitik ve jeoekonomik önemi olan Orta Asya bölgesine yönelik, Çin bir bölgesel teşkilat olarak Şanghay Beşlisi ve Şanghay İşbirliği Örgütü’nü oluşturmuştur. Bu örgüt çerçevesinde Çin ekonomik ve güvenliğe ilişkin girişimlerle Orta Asya bölgesini, Çin'in milli çıkarının olduğu bölgelerden biri olarak görmüş ve etki alanı hâline getirme çabalarını göstermiştir.

Günümüzde güçlü devlet olarak algılanan diğer bir ülke ABD’dir. ABD’nin de Orta Asya bölgesine yönelik kendi çıkarları vardır. Genel olarak, ABD çıkarları Çin'in genişlemesini önlenmek, bölgesel etkileşimlerden İran'1 dışlama, Orta Asya devletlerinin Rusya’ya olan bağımlılığını zayıflatma ve ulusaşırı tehditlere engel olma üzerinde oluşmaktadır. Bölgenin enerji kaynak potansiyeli ise Amerika için ikincil bir roldeydi (Troitskiy, 2007). Bu çıkarlar stratejik nitelik taşıyarak ABD'nin küresel güvenlik çıkarları ve endişelerinden türetilmiştir. Bu çıkarlar doğrultusunda ABD Orta Asya bölgesinde kendi nüfuzunu arttırmak ve sosyo-politik süreçleri koordine edebilmek amacıyla demokrasinin gelişmesine katkıda bulunan farklı uluslararası örgütler aracılığıyla kendi çeşitli sivil toplum örgütlerini kullanmaktadır. 2001 yılın 11 Eylül olaylarından sonra terorizme karşı mücadele politikası nedeniyle Kırgizistan ve Uzbekistan'da askeri üsler açılmış ve böylece bölgede Amerikan varlığ yükselmiştir. Ancak sonraki zamanlarda çoğunlukla Irak'taki başarısızlığı nedeniyle ABD bölgedeki pozisyonunu kaybetmeye başladı. Askeri üsler tamamen kapatıldı. Fakat bu durum ABD'nin tamamen Orta Asya bölgesinden çekileceği ve bölgedeki çıkarlarından vazgeçeceği anlamına gelmemektedir. ABD'nin Orta Asya'da Rusya ve Çin'in olduğu gibi kendi çıkarları doğrultusunda faaliyet eden özel bir bölgesel organı ya da kurumu yoktur. Ama bu yönde de bir deneme yaptıkları hakkında söz edilebilir. Hilari Clinton'un ilk defa Hindistan'ın Chennai şehrinde yaptığı konuşmasında "Yeni İpek Yolu" adı altındaki proje hakkında bilgi vermiştir. Proje Afganistan üzerinden geçen ve Güney Asya ile Orta Asya pazarlarını bağlayacak olan ticaret ve ulaşım koridorlar ağların oluşturulmasını öngörmektedir. Bu girişim aynı zamanda denize erişimi olmayan Orta Asya ülkelerine dış pazarlara yol açacaktır (Regnum, 2015). Fakat bu projeyi gerçek bir bölgesel entegrasyon stratejisi olarak algılamak doğru olmaz. Buna rağmen ABD yönlü uluslararası kuruluş ve şirketler aracılığıyla kendi politikalarını koordine edebilirler ve böylece ABD’nin rolü azalsa da kaybolmamıştır.

Böylece Orta Asya bölgesi küresel güvenlik haritasının bir parçası haline gelmiş oluyor ve dünya büyük güçleri bölge ülkelerin kendi arasında birleşerek ortak politikalar üzerinde beraber hareket etmesine karşı çıkmaktadır.

\section{Sonuç}

Sovyetler Birliği'nin dağılmasıyla uluslararası sistem yeni devletlerin doğmasına sahne olmuştur. Bağımsızlığa kavuşan yeni devletlerin kimlik inşa süreci dünyada cereyan eden globalleşme, demokratikleşme ve bölgeselleşme süreçlerine paralel gelişmiştir. Orta Asya bölgesinde yer alan devletler de kendi aralarında bir entegrasyon sürecini gerçekleştirmek amacıyla farklı girişimlerde bulunmuşlardır. Ancak baları elde edememişlerdir. Bunu temel sebepleri arasında da bölge devletleri arasındaki entegrasyon süreçlerine Rusya, Çin ve ABD gibi büyük güçlerin karışmasıdır.

Rusya günümüzde çok önem veren Avrasya Ekonomik Birliğinin kapılarını Orta Asya ülkelerine açmaktadır ve böylece bütünleşme süreci tam olarak Orta Asya bölgesi ile ilgilidir ve Rusya'nın bu süreç içinde diğerlerine göre daha etkili olduğu açıktır. Dolaysıyla Rusya'nın Orta Asya bölgesindeki entegrasyon süreçleri etkileyerek Soviyet Birliği'nin dağılmasından sonra kaybeden eski topraklar üzerinde hegemon olma düşüncelerin varlığı hakkında söz edilmektedir. Bunun yanı sıra, Çin Orta Asya'nın jeopolitik ve güvenlik anlamda çok büyük öneme sahip olduğundan dolayı bu bölgeye ilgi duymaktadır. Buna ek olarak Çin'in ilgisini ekonomik alanda görebiliriz, Orta Asya onlar için büyük bir pazardır. Bunun üzerinde Rusya ile beraber ortaya attığı Şanhay İşbirliği Örgütü ve diğer girişimler çerçevesinde Orta Asya ülkeleri ile ilişkilerini sürdürmektedir. Amerika ise Çin ve Rusya'nın artan etkisini sınırlamak, Orta Asya devletlerinin Rusya'dan bağımsız olarak kendi politikalarını teşvik etmelerini ve anti-Amerikan niteliğinde ortaya çıkan Rusya ve Çin arasındaki ittifakın oluşturulmasını engellemek amacıyla Orta Asya'da kendi etkisi korumaya çalışmaktadır. Amerikan etkisi demokrasinin gelişmesine yönelik yapılan sosyal ve siyasal projeleri ve kurumları destekleyerek, çeşitli kurum ve hareketleri finansman ederek gerçekleştirilmektedir.

Bölgedeki durumu ve koşulları aynı zamanda Rusya, Çin ve ABD gibi ülkelerin bölgedeki etkisini dikkate alarak bölge ülkelerin işbirliği konusunda problemlerin olduğunu görebiliriz. Şimdi Orta Asya ülkeleri arasında dış aktörlerin katılımı olmadan başarılı bir entegrasyon mümkün değildir.

Entegrasyon girişiminde bulunan ülkeler arasındaki işbirlik ülkelerin yaşam standartlarını iyileştirmek için, çevre, enerji vs. problemlerin çözümü için optimal bir politikadır. Ancak, emperyal politikalar yanlısı olan daha güçlü aktörlerin işe karıştığında gerçek ve eşit ortaklar arasındaki bir entegrasyondan söz edilemez.

\section{Kaynakça}

- Adingün, Balım, 2010. Bağımsızlıklarının Yirminci Yılında Orta Asya Cumhuriyetleri Türk Dili Halklar-Türkiye İlişkileri, Atatürk Kültür merkezi. 
- Akiner, 2007. "Regional cooperation in Central Asia". School of Oriental and African Studies, University of Oriental Studies.

- Dadabayev, 2006. "Towards Post-Soviet Central Asian Regional Integration". Akashi Shoten

- Demir, 1998. Tarihten Günümüze Rus Yayılmacılığı ve Yeni Kurulan Devletler, Ötüken Yayınevi.

- Demirtepe, 2012. Orta Asya'da Siyaset ve Toplum: Demokrasi, Etnisite ve Kimlik, USAK Yayınları.

- Demirdağ, Karadeli, 2006. Geçmişten Günümüze Orta Asya ve Kafkasya, Palme Yayıncılık.

- Dikkaya, 2009. Orta Asya ve Kafkasya, Dönüșüm Süreci ve Uluslararası Ekonomi Politik, Beta Yayınları.

- $\quad$ Erol, Şahin, 2013. "Bağımsızlıklarının 20. Yılında Orta Asya ve Kafkasya'daki Türk Cumhuriyetlerinin Entegrasyon Süreci (1991 - 2011)". Karadeniz Araştırmaları, Sayı 37, s.111-136.

- Geyikdagi, 2007. "Regional Integration in Central Asia", Journal of Asia-Pacific Business.

- Haluk, 2011. Orta Asya TürkCumhuriyetlerinde Siyasal Hayat ve Kurumlar, USAK Yayınları.

- İnazarov, Salmanov, 2012. "Regional İntegration in Central Asia: Measuring the Perceptions of Economic Actors in Uzbekistan and Kazakhstan", Norwegian Institute of International Affairs (NUPI), Regional Competence - Building for Think-Tanks in the South Caucasus and Central Asia.

- Karasar, Kuşkumbayev, 2009. "Türkistan Bütünleşmesi: Merkezi Asya'da Birlik Arayışları, 19912001", Ötüken Yayınevi.

- Libman, 2011. "Is it really different? Patterns of regionalization in post-Soviet Central Asia", PostCommunist Economies.

- Matveeva, 2007. "Return to Heartland: Russia's Policy in Central Asia", The International Spectator: Italian Journal of International Affairs.

- Purtaş, 2008. “Orta Asya'nın Bütünlüğü Sorunsalı ve Bölgesel Entegrasyon Girişimleri”. Orta Asya ve Kafkasya Güç Politikası. 1 Baskı. Tasarım Yayınları.

- Sadri, 2007. "Integration in Central Asia: From theory to policy", Central Asian Survey.

- Swanstroem, 2003. "Chinese Business Interests in Central Asia: A Quest for Dominance”. CACI Analyst.

- Troitskiy, 2007. "US Policy in Central Asia and Regional Security”, Global Society.

- Wang, 2014. "The Effects of Regional Integration in Central Asia”, Emerging Markets Finance and Trade.

- Алшанов, Ашимбаев, 2006. По материалам научно-практической конференции "Социальнополитические портреты государств Центральной Азии". http://www.apn.kz/publications/article263.htm.

- Братерский, 2007. “Политика США в Центральной Азии и интересы России”, Центральная Азия и Кавказ, №4 (52).

- Винокуров, Либман, Максимчук, 2010. “Динамика интеграционных процессов в Центральной Азии”, Евразийская Экономическая Интеграичия, Выпуск №2 (7).

- Гусев. "Интеграционные процессы в Центральной Азии”.

- Корабоев, 2010. "От региональной интеграции Центральной Азии к Евразийскому интеграционному пространству: меняющаяся динамика постсоветского регионализма". Евразийская экономическая интеграция, №3 (8).

- Малашенко, 2013. “Интересы и шансы России в Центральной Азии”. Pro et Contra, http://carnegieendowment.org/files/ProEtContra_58_21-34.pdf.

- Саидазимова. "Интеграция в Центральной Азии: реалии, вызовы, возможности". CA\&CC Press, http://www.ca-c.org/journal/cac-09-2000/10.Saidazim.shtml. 


\title{
Çin’in Kültürel Diplomasisinin “Çin Tehdidi” Algısının Kırılmasındaki Önemi The Importance of Cultural Diplomacy in Breaking the
Perception of "China Threat"
}

\author{
Dr. Cemre Pekcan (Çanakkale Onsekiz Mart University, Turkey)
}

\begin{abstract}
Cultural diplomacy, which is accepted as a sub-branch of public diplomacy, is described as 'the exchange of ideas, information, art, and other aspects of culture among nations and their peoples in order to foster mutual understanding' by Milton C. Cummings. Although this term has been used in international relations for centuries, its acceptance as a theory is a relatively new concept. Cultural diplomacy, as a component of both public diplomacy and also Joseph Nye's 'soft power', includes movies, music, dance, exhibitions, various education and exchange programs, literature and cultural programs. In today's world, China, a super power with its growing economy, started to feature its soft power, public and cultural diplomacy to break the perception of 'China threat' theory which shortly claims that the rising power would eventually challenge the hegemon power and war will be inevitable. The aim of this study is to put forward Chinese efforts in promoting cultural diplomacy to break the perception of 'China threat' theory by analyzing the elements of China's cultural diplomacy, which are basically; Confucius Institutes, marketing Chinese cultural products, series of cultural programs and foreign aid.
\end{abstract}

\section{Giriş}

Genellikle Profesör Joseph Nye'ın 'yumuşak güç' kavramının ve aynı zamanda da kamu diplomasisinin bir alt dalı veya unsuru olarak kabul edilen kültürel diplomasi, her ne kadar yüzyıllardır uluslararası ilişsilerde kullanılan bir olgu olsa da, bunun bir teori olarak kabulü görece yenidir.

Dünyada başat güç konumunda olan ABD'nin, 1930'lu yıllardan bu yana diğer devletlerle ilişkilerini güçlendirmek ve dünyadaki imajının olumlu yönde gelişmesi adına yoğun bir şekilde kullandığı kültürel diplomasinin en önemli unsurları; film, müzik, dans, çeşitli sergiler, çeşitli eğitim ve değişim programları, edebiyat ve kültürel programlardır.

Günümüzde özellikle ekonomik alandaki gelişimiyle süper güç konumuna gelen Çin, son dönemlerde oldukça tartışılan ve Organski, Mearsheimer, Huntington gibi siyaset bilimcilerin teorilerine dayandırılan 'Çin tehdidi' algısına bir son vermek istemektedir. Bu amaçla Çin, yumuşak güç, kamu diplomasisi ve kültürel diplomasi gibi unsurları ön plana çıkarmaya başlamıştır. Çin'in binlerce yıllık kültürel mirası da kültürel diplomasiyi ön plana çıkarmasına imkân sağlamaktadır. Yükselişinin barışçıl yollarla olacağını iddia eden Çin, özellikle de 1989 Tiananmen Meydanı Olayları'ndan sonra dünyadaki imajını düzeltme yoluna gitmiştir. Bu bağlamda Çin'in kültürel diplomasisinin en önemli unsurları; dünyanın dört bir yanına kurulan Konfüçyüs Enstitüleri, Çin külttürünü yansıtan şeylerin pazarlanması, çeşitli kültürel programlar ve yabancı ülkelere yapılan yardımlardır. Bu çerçevede çalışmada, Çin'in kültürel diplomasi alanında attığı önemli adımlar ve bunların Çin tehdidi algısının kırılması üzerindeki etkileri analiz edilmeye çalışılmaktadır.

\section{Kültürel Diplomasi Kavramı}

Temel olarak, diyalog ve müzakere gibi şiddet içermeyen yollarla uluslararası ilişkileri yönetme sanatı olarak tanımlanabilecek olan diplomasi, günümüzde ülkelerin politik amaçlarına ulaşmak için kullandıkları etkili bir araçtır. Cull'un tanıma göre ise diplomasi; uluslararası çevrenin/sistemin idare edilebilmesi ya da yönetilebilmesi için, uluslararası bir aktör tarafından uygulanan savaş haricindeki mekanizmalardır (Cull, 2009). Diplomasinin bir alt dalı olan kamu diplomasisi ise, 'uluslararası bir aktörün, uluslararası çevreyi/sistemi, yabancı halkla bă kurarak yönetme girişimidir' (Cull, 2009). Kısacası bir ülkenin hükümetinin, diğer ülkenin insanlarıyla iletişimidir.

Nicholas J. Cull, kamu diplomasisinin en önemli unsurlarının; dinleme, savunma, kültürel diplomasi, değişim, uluslararası yayıncılık ve aynı zamanda psikolojik savaş olduğunu ifade etmiş̧tir (Cull, 2009). Bu bağlamda kamu diplomasisinin bir unsuru olarak görülen kültürel diplomasiyle ilgili, net bir şekilde uzlaşılmış bir tanım olmasa da, kültürel diplomasi konusunda uzmanlaşan kişilerin yaptığı ve genel kabul gören bazı tanımlar mevcuttur. Örneğin; Amerikan siyaset bilimci Milton C. Cummings' in tanımına göre kültürel diplomasi; 'uluslar ve toplumlar arasındaki fikir, bilgi, sanat ve kültürün diğer unsurlarının, ortak bir anlayış geliştirmek amacıyla, karşılıklı değişimini’ ifade eder (Cummings, 2003). Kültürel Diplomasi Enstitüsü’nden Kültürel Diplomasi Akademisi Başkanı Dr. Emil Constantinescu ise külttürel diplomasiyi; 'ilişkileri güçlendirmek, sosyokülttürel ilişkileri artırmak veya ulusal çıkarları desteklemek amacıyla; fikirlerin, değerlerin, geleneklerin ve kültürün veya kimliğin diğer öğelerinin değişimine dayanan ve bundan faydalanan bir hareket ya da davranış biçimi' olarak tanımlamaktadır 
(Chakraborty, 2013). Bir başka tanıma göre de kültürel diplomasi, 'kültürün çeşitli unsurlarının, yabancı halkları, kanaat önderlerini ve hatta yabancı liderleri etkilemesidir' (Lenczowski, 2009). Bu unsurlar, sanat, eğitim, fikir, tarih, bilim, tıp, teknoloji, din, gelenekler, davranış şekilleri, ticaret, yardım, spor, dil, profesyonel meslekler, hobiler, medya v.b. gibi kültürün birçok farklı özelliğini kapsar (Lenczowski, 2009). Ancak bazen, örneğin bir devletin, kendi dilini, siyasal görüşünü ya da politikasını tüm dünyaya anlatmaya ya da empoze etmeye çalıştığ1 durumlarda, kültürel diplomasi karşılıklılıktan ziyade tek taraflı bir durum da olabilir (Cummings, 2003). Kısaca kültürel diplomasi yalnızca karşılıklı anlayışa dayanmaz, ulusal güvenliğin ve ulusal çıkarların korunması amacı da vardır. Bu yüzden Lenczowski'ye göre kültüre diplomasi, genel olarak ulusal güvenlik politikasının, özelde ise kamu diplomasisinin bir unsurudur (Lenczowski, 2009).

Günümüzde hem kamu diplomasisi hem de kültürel diplomasi, Harvard Profesörü Joseph Nye tarafindan ortaya atılan 'yumuşak güç' kavramının unsurları olarak görülmektedir. Nye tarafından 'çekici güç' olarak tanımlanan 'yumuşak güç' kavramı kısaca; kültür, politik değerler ve dış politikasıyla, bir diğer deyişle sert güç ve ekonomik yaptırımlar kullanmadan, bir ülkenin diğer ülkelerin tercihlerini etkileyebilmesi anlamına gelir (Nye, 2004).

Yumuşak güç ve kamu diplomasisiyle birlikte anılan kültürel diplomasi, yeni bir kavram gibi görünse de, aslında uzun yıllardır uluslararası ilişkilerde kullanılan bir unsurdur. Kültürel diplomasi alanındaki uzmanların vurguladıkları temel noktalar ise şunlardır:

- Kültürel diplomasi, hükümetlerin, kişiden kişiye iletişim üzerine kurulu ve tarafsız bir karşılıklı anlayış ve 'güven temeli' oluşturmalarını sağlar. Politika yapıcıları da bu güven esasına dayanarak politik, ekonomik ve askeri anlaşmalar yaparlar.

- Kültürel diplomasinin, gençlere, elit zümrenin dışındakilere ve geleneksel elçilik çemberinin dışındaki diğer dinleyicilere ulaşma yeteneği vardır. Kültürel değişimde eğitim faktörü ise kültürel diplomasinin başarılı olması için oldukça önemlidir.

- Kültürel diplomasi, kamu sektörü, özel sektör ve sivil toplumla uygulanabilir.

- Kültürel diplomasinin, bir ülkedeki insanları, dünyadaki diğer insanların kültür ve yaşam tarzlarının etkisi altında bırakmasına yönelik programlarının, özellikle uluslararası işler üzerinde büyük etkisi vardır.

- Kültürel diplomasi programları, farklı ülkelerdeki insanları birbirine karşı beslediği sebepsiz nefretin, cehaletin ve yanlış anlamaların üstesinden gelinmesini sağlar.

- Son olarak kişiler arasında etkileşimi artırmayı hedefleyen kültürel diplomasi programları, uluslararası sivil işbirliğinin yoğunlaşmasına da katkıda bulunur (Koev, 2013).

Dünyada başat güç konumunda olan ABD, 1930’lu yıllardan bu yana diğer devletlerle ilişkilerini güçlendirmek ve imajının olumlu yönde gelişmesi adına kültürel diplomasisini yoğun bir şekilde kullanmaktadır.

ABD’nin kültürel diplomasi alanındaki ilk girişimi 1930 yılında, Nazi Almanyası'nın Latin Amerika'daki 'kültürel saldırısı'na karşı olmuştur. Amerika'daki Alman aktivistler, kültür işleri yetkilileri tarafından 'iyi bir şekilde örgütlenmiş, maddi açıdan desteklenmiş, ABD'nin Latin Amerika ülkeleriyle kültürel ilişkilerini zayıflatma ve ABD'yi bölgede gözden düşürme amacıyla hareket eden kişiler' olarak tanımlanmışlardır. ABD, bu kişilere karşı, 1936'da Buones Aires’te düzenlenen bir barış konferansında Amerika kıtasındaki ülkelerin kültürel ilişkilerinin güçlendirilmesini öneren bir sözleşme teklif etmiştir. Ülkeler arasında profesör, öğretmen, öğrenci gibi değişimlerin yapılmasını, resmi olmayan örgütlerle daha yakın ilişkiler kurulmasının teşvik edilmesini ve bu sayede kamuoyunun fikirlerine etki edebilmeyi öngören sözleşme, ABD’nin kültürel diplomasisinin ana hatlarını oluşturmuştur (Cummings, 2003).

Amerika, kültürel diplomasinin altın çağını 1950-75 yılları arasında yaşamıştır. Bu dönemde Amerika'nın en iyi aktör, müzisyen, yazar, sanatçı ve dansçıları hükümet tarafından yurt dışına gönderilmiş, Amerika'daki özgürlük ve eşitliği yaymak amacıyla 89 ülkede 100den fazla gösterim yapılmıştır (Schneider, 2003).

9/11 saldırılarından sonra, ABD Dışişleri Bakanlığı diğer ülkelerdeki tüm büyükelçiliklere ve kültür merkezlerine Joel Meyerowitz tarafından çekilmiş fotoğrafların koleksiyonunu göndermiştir. Yıkım, kurtarma ve iyileşmenin her aşamasını gösteren ve bu sayede Amerika'nın kırılgan tarafını yansıtan fotoğraflar insanlarda empati ve sempati duyguları uyandırarak Amerika’yla ilgili fikirlerinin değişmesine yol açmıştır (Schneider, 2003). Örnekten de anlaşıldığı gibi kültürel diplomasi, sanatsal ve kültürel etkinliklerin paylaşılması yoluyla da etkili bir atmosfer oluşturabilmekte ve kişilerin bir ülke hakkındaki önyargısını kırarak, farklı bir izlenim oluşturulmasını sağlayabilmektedir.

Günümüzde Çin, gecikmeli de olsa yumuşak gücün, kamu diplomasisinin ve dolayısıyla kültürel diplomasinin önemini anlayarak, hem Batı'da oluşan 'Çin tehdidi' algısını kırmak, hem de dünyadaki imajını güçlendirmek adına bu konuda önemli adımlar atmıştır. Çin'in kültürel diplomasi alanındaki girişimlerinden önce 'Çin tehdidi' algısının kökenlerine değinmek gerekecektir. 


\section{3 'Çin Tehdidi' Algısının Kökenleri}

1949’da kurulan Çin Halk Cumhuriyeti, Mao’nun ölümünden sonra başa geçen Deng Xiaoping’in özellikle ekonomi alanında yaptığı reformlarla birlikte dış dünyaya açılmış ve muazzam bir ekonomik başarı elde etmiştir. Ekonomik reformlarla birlikte yıllık ortalama \%9-\%10'luk bir büyüme hızıyla Çin, dünyanın en hızlı büyüyen ekonomisi haline gelmiştir. Çin'in bu hızlı büyümesi başta ABD olmak üzere birçok güçlü devleti endişelendirmiş ve 'Çin tehdidi' başlıklı yazılar ve makaleler yazılmasına neden olmuştur.

'Çin tehdidi' teorisi (Zhongguo weixie lun), ilk olarak 1990'ların başında, Güney Kore, Japonya ve ABD tarafından dile getirilmiştir. Özellikle, 25 Şubat 1992'de Çin Ulusal Halk Kongresi’nin, Doğu ve Güney Çin Denizleriyle ilgili çıkardığı kanun ve bu denizlerdeki hak iddiası, Çin'in yayılmacı bir politika izlediği ve bölgede hegemon bir güç olmak istediği şeklinde yorumlanarak 'Çin tehdidi' teorisine zemin hazırlamıştır (Ateba, 2002).

'Çin tehdidi' teorisinin ya da söyleminin dayandığ profesörlerinden Abramo Fimo Kenneth Organski’nin 1958'de yayınladığı Dünya Politikası (World Politics) adlı kitapta detaylı bir şekilde açıkladığı güç geçişi teorisidir (power transition theory). Bu teoriye göre; uluslararası sistemde devletler hiyerarşik olarak dört farklı gruba ayrılmıştır: Başat güç, büyük güçler, orta büyüklükteki devletler ve küçük devletler. Bu hiyerarşiye göre, statükodan memnun olmayan yükselen güçler, eninde sonunda hegemon güce baş kaldıracaktır (Organski, 1968).

'Çin tehdidi' teorisinin dayandığı bir diğer kaynak da neo-realizmin temsilcilerinden John J. Mearshimer'in 'The Tragedy of Great Power Politics' (Büyük Güç Politikalarının Trajedisi) isimli kitabında açıkladığı 'saldırgan realizm'dir (offensive realism). Saldırgan realizme göre devletler nasıl hayatta kalabilecekleriyle ilgilenirler ve bir devletin nihai hedefi, uluslararası sistemde hegemon güç olmaktır. Bunun için de güce sahip olmak gereklidir ve hayatta kalabilmek için daha fazla güce sahip olma isteği, devletleri saldırganlığa iter (Mearsheimer, 2001). Mearsheimer'ın teorisine göre uluslararası sistemin üç özelliği vardır. Birincisi; temel aktör olan devletler anarşik bir sistemde hareket ederler, yani üstlerinde herhangi bir otorite yoktur. İkincisi; her büyük gücün saldırgan bir askeri kapasitesi vardır, yani birbirlerine zarar vermek için imkânları vardır. Üçüncüsü; hiçbir devlet diğerlerinin niyetini ya da gelecek planlarını tam olarak bilemez. Bu yüzden de hayatta kalmanın tek yolu rakiplerinden daha fazla güce sahip olmaktır (Mearsheimer, 2004).

Samuel Huntington'ın Medeniyetler Çatışması isimli tezi de 'Çin tehdidi' teorisini desteklemektedir. Gelecekte savaşların politik sistemler yüzünden değil, ideoloji ve medeniyetler yüzünden olacağını iddia eden Huntington'a göre, Batı medeniyetinin karşısında Konfüçyüsçülük ve İslam yer almaktadır. Çin de, tarih, kültür ve gelenekleri nedeniyle Doğu Asya'da hegemonya arayışında olacaktır (Jing, 2013).

Kuram Çin'e uyarlandığında, ekonomik ve askeri anlamda giderek büyüyen Çin’in, daha fazla güçlendikçe, statükodan memnun olmayacağı, eninde sonunda ABD hegemonyasına baş kaldıracağı ve bunun da savaşa neden olabileceği düşünülmektedir. Çin'in yükselişi konusunda da Mearsheimer, bu etkileyici ekonomik yükseliş devam ettiği takdirde, Çin ve ABD’nin yoğun bir güvenlik rekabetine gireceklerini ve bunun da bir savaş potansiyeli içerdiğini dile getirmektedir. Mearsheimer'a göre, böyle bir durumda, Çin'in yükselişinden rahatsız olan Hindistan, Japonya, Singapur, Güney Kore, Rusya ve Vietnam da Çin’i çevrelemek için ABD’nin yanında yer alacaklardır (Mearsheimer, 2005).

Çin'in resmi gazetesi People's Daily (Renmin Ribao), Çin tehdidi teorisine ilk olarak 1992 yılında cevap vermiş ve ABD'nin bu teoriyi, Tayvan'a silah satmak için bahane olarak kullandığını ifade etmiştir. Bunun sebebi de ABD’nin Tayvan'a savaş uçağı satmaya karar vermesi ve Ross Munro tarafından 'Çin tehdidi' teorisiyle ilgili yazılan bir makaledir. Ancak 1996 ve sonrasında Çin'in tehdit teorisine karşı cevapları daha sert olmaya başlamıştır (Yee ve Feng, 2002). Çin, bu teorinin ırkçı bir yaklaşım olduğunu, ABD ve Batılı devletlerin kaynaklarını paylaşmak istemediği ve Soğuk Savaş mantalitesini devam ettirdikleri için olduğunu iddia etmektedir (Lai, 2011). Konuyla ilgili 1997'de Çin Cumhurbaşkanı Jiang Zemin; Çin'in ekonomik kapasitesinin ve Çin tehdidi teorisinin abartıldığını, bunların temelsiz olduğunu, Çin'in reform ve modernleşmesinin uzun bir istikrar ve barış dönemine ihtiyacı olduğunun ve hatta güçlense bile diğer ülkeleri tehdit etmeyeceğini ifade etmiştir (Yee ve Feng, 2002). Jiang Zemin'den sonra başa gelen Hu Jintao da 2011 yılında Washington'da yaptığı bir toplantıda; barışçıl gelişim çizgisine bağlı kalacaklarını, herhangi bir silah yarışına girmeyeceklerini, hiçbir ülke için askeri bir tehdit olmadıklarını, Çin'in hiçbir zaman yayılmacı bir politika izlemeyeceğini dile getirmiştir (CBS News, 2011). Son olarak Hu Jintao'dan sonra başa gelen Xi Jinping de Hindistan'a yaptığı bir ziyaret esnasında; dünyanın Çin'in gelişiminden faydalanması gerektiğini, Çin'in barışçıl gelişime bağlı olduğunu ve savaşçı devletlerin yok olmaya mahkûm olduklarını belirtmiştir (The Economic Times, 2014).

Görüldüğü gibi Çin, 'Çin tehdidi’ algısını kırabilmek için çeşitli girişimlerde bulunmaktadır. Bunların başında da; barış ve uyumu vurgulayan Konfüçyüs değerlerinin ön plan çıkarılması, 'barışçıl gelişim', 'uyumlu dünya', 'uyumlu toplum' gibi dış politika ilkelerinin oluşturulması ve her firsatta hegemon güce baş kaldırmayacağını dile getirmesi gelmektedir. Tüm bu girişimleri yanı sıra, tehdit algısını kırma konusundaki en önemli adımlardan ya da unsurlardan biri de kültürel diplomasinin etkin bir şekilde kullanılmasıdır. 


\section{4 Çin'in Kültürel Diplomasisi}

Kültür, Amerika’yla karşılaştırıldığında, Çin’in diplomasi alanında yeni yeni kullanmaya başladığı bir unsurdur. Çin'in binlerce yıllık bir medeniyet olması ve kendine has eşsiz kültürü de kültürel diplomasi alanında Çin'i avantajlı kılmaktadır. Yumuşak gücün öneminin farkına varan ve özellikle yumuşak gücün kültür unsurunun üzerinde duran Çin, bu konuda önemli adımlar atmaya başlamıştır. Öyle ki, Çin'in Kültür Bakanı Sun Jiazheng (孙家正), kültürün ekonomi ve politikadan sonra Çin diplomasisinin üçüncü sütunu olduğunu ifade etmiştir. Politbüro Daimi Komitesi'nde kültür işleriyle ilgili Li Changchun ise, Çin'in ülkelerarası kültürel değişimde büyük marka isimleri oluşturmayı ve kültürel ürünlerin ticaretindeki büyük açıkları azaltmayı hedeflemesi gerektiğini belirtmiştir (Hongyi, 2012).

Kültürel gücünün farkında olan Çin, 2010 yılında düzenlenen 16. Ulusal Kongre'de Çin'in kültürel sisteminde bazı reformlar yapılmasıyla ilgili bir karar almıştır. Hu Jintao Kongre'de kültürel sistemin derinleştirilmesinin önemini ve geliştirilmesinin önemini vurgulamıştır (China.org, 2010). Konuyla ilgili Şangay Sosyal Bilimler Akademisi'nin düzenlediği bir forumda, uluslararası ilişkiler uzmanları Çin’in kendi kültürünün çekiciliğinden faydalanması ve bu sayede çeşitli kültürel değişim programlarıyla yumuşak gücünün etkisini artırması gerektiğini ifade etmişlerdir. Bu bağlamda uzmanlar Çin'in, geleneksel kültürünün yeniden canlandırılmasını, özellikle sosyal uyuma vurgu yapılarak uluslararası öğrencilerin cezbedilmesinin ve yurt dışında Konfüçyüs enstitüleri kurmaya devam edilmesinin gerekliliği üzerinde durmuşlardır (Hongyi, 2012).

Bu çerçevede Çin'in yumuşak güç unsurlarından daha etkin bir şekilde faydalanabilmek amacıyla, 2012 yılında Pekin'de, kar amacı gütmeyen ulusal çaplı bir kuruluş olan Çin Kamu Diplomasisi Derneği kurulmuştur. Şu anki başkanı eski Dışişleri Bakanı ve Büyükelçi Li Zhaoxing olan derneğin amacı; Çin'in kamu diplomasisini geliştirmek, Çin ve diğer ülkeler arasında ortak anlayış ve dostluğu güçlendirmek, Çin’e medeni, demokratik, açık, yenilikçi bir imaj kazandırmak ve Çin'in barışçıl gelişimine uygun bir uluslararası çevreye imkân sağlamaktır (China Public Diplomacy Association, 2016). Çin’in kültürel diplomasisinin en önemli unsurları, giriş bölümünde de belirtildiği gibi; dünyanın dört bir yanına kurulan Konfüçyüs Enstitüleri, Çin kültürünü yansıtan şeylerin pazarlanması, çeşitli kültürel programlar ve yabancı ülkelere yapılan yardımlardır.

Çin'in kültürel diplomasisinin unsurlarından başında, Almanya'nın Goethe Enstitüsü, Fransa'nın Alliance Francaise'1 veya Türkiye'nin Yunus Emre Enstitülerine benzer Konfüçyüs Enstitüleri gelmektedir. 2004 y1lında ilk olarak Güney Kore'nin Seoul şehrinde kurulan bu enstitüler, 2014 yılı itibariyle 123 ülkeye yayılmış ve sayıları 465'e çıkmıştır. Bunların 97'si ABD'de, 149'u Avrupa'da yer almaktadır (Tiezzi, 2014). Çin dil ve kültürünün teşvik edilmesi amacını güden ve Çince'nin Yabancı Dil Olarak Öğretilmesi için Çin Ulusal Ofisi (Chinese National Office for Teaching Chinese as a Foreign Language), bir diğer adıyla Hanban tarafindan yönetilen Konfüçyüs Enstitüleri, Çin Milli Eğitim Bakanlığı'na bağlı ve kar amacı gütmeyen kuruluşlardır.

Sayısı giderek artan bu enstitüler, Çin'in propaganda aracı oldukları gerekçesiyle birçok kişi tarafindan eleştirilmektedirler. Temelde amacı Çin dili eğitimi olan Konfüçyüs Enstitüleri'nin eleştirildiği en önemli konu, Çin hükümeti tarafından desteklenen bu enstitülerde ifade özgürlüğünün yeterince olmamasıdır. Özellikle ABD'de bazı akademisyenler, bu enstitülerde Tibet, Dalay Lama, Tiananmen gibi bazı hassas konuların konuşulmamasını ifade özgürlüğüne aykırı bularak ve bunların Çin Komünist Partisi'nin politik amaçlarının bir propagandası olduğunu ifade ederek, enstitülerin kapatılmasını istemiştir. Nitekim ABD’de iki üniversitede Konfüçü̈s Enstitüsü kapatılmıştır. Çin, suçlamaları redderek, bu karara karşı olduğunu ifade etmiş ve enstitülerin Çin-ABD ortak projesi olduğunu, her iki tarafın seçme hakkı olduğunu, tüm sınıfların ve kültürel etkinliklerin açık ve şeffaf olduğunu belirtmiştir (Foster, 2014).

Enstitüleri propaganda aracı olduğunun düşünenler kadar, bu eleştirileri fazla abartılı bulan ABD’li akademisyenler de vardır. Örneğin George Washington Üniversitesi profesörlerinden Edward A. McCord, The Diplomat'taki bir yazısında, enstitülere yönelik bu eleştirilerin yeterli kanıt içermediğini savunmaktadır. McCord'a göre bu eleştirileri yapanlar, örneğin Tayvan konusunda, ABD’nin Tayvan’ın Çin'in bir parçası olduğunu kabul ettiğini unutmaktadırlar. Bunun yanı sıra, diğer hassas konuların enstitü programında yer almaması da, enstitülerin amacı dil ve kültür eğitimi olduğu için, oldukça normal bir durumdur (McCord, 2014).

Konfüçyüs enstitüleri konusunda çeşitli eleştiriler yapılmakla ve birçok farklı görüş öne sürülmekle birlikte, bunlar ister kültürel diplomasi, ister yumuşak güç unsuru, ister propaganda aracı olsun, bu enstitülerin Çin dil ve kültürünü yaymadaki önemi yadsınamaz.

Yine eğitimle bağlantılı olarak, Çin, karşılıklı değişim programlarına ve öğrencilerin yurt dışında eğitim görmelerine de öncelik vermektedir. Çin Milli Eğitim Bakanlığı'na göre; 1978-2003 yılları arasında yurt dışında eğitim gören Çinli ögrrenci sayısı toplamda 700,200 olup, bunlar dünyanın tüm bölgelerinde toplamda 108 farklı ülkede, farklı disiplinlerde eğitim görmüşlerdir. 2003 yılında yurtdışında eğitim gören Çinli öğrenci sayısı ise 117,300'dür (Ministry of Education of the PRC, 2016).

Project Atlas'ın istatistiklerine göre, yurtdışında eğitim gören Çinli öğrenci sayısı 2005-2006'da 417,351; 20062007'de 421,148; 2007-2008'de 144,000; 2008-2009'da 820,000; 2010-2011'de 339,700 ve 2014'te 459,800'dür. En fazla gidilen ülkelerin başında ABD, Avustralya, Birleşik Krallık, Güney Kore, Japonya, Almanya ve Kanada 
gibi ülkeler gelmektedir (Project Atlas, 2016). 2015 yılında ise 523,700 öğrenci yurtdışında eğitim görmüştür. Bunların 25,900'ü Çin hükümeti tarafından, 16,000'i kendi işverenleri tarafından finanse edilmiş, 481,800'ü ise eğitim ücretlerini kendileri karşılamışlardır (The State Council of the PRC, 2016).

Çin Milli Eğitim Bakanlığı'nın istatistiklerine göre Çin'de eğitim gören yabancı öğrenci sayısı, 2014 yılında 377,054 iken, bu sayı 2015 yılında 397,635'e çıkmıştır. Çin'de eğitim gören öğrenciler başlıca Güney Kore, ABD, Tayland, Hindistan, Rusya, Pakistan, Japonya, Kazakistan, Endonezya ve Fransa'dan gelmektedirler (Ministry of Education of the PRC, 2016).

Çin’in kültürel diplomasi unsurlarından ikincisi Çin kültürünü yansıtan şeylerin pazarlanmasıdır ki bunun başında da Çin yemekleri gelmektedir. Çin’in kültürünü yayma konusunda önemli bir unsur olan Çin mutfağı, aynı zamanda yemek diplomasisi (culinary diplomacy) olarak da ifade edilmektedir. Küreselleşmenin de etkisiyle birçok ülkede birçok farklı devletin yemekleri yenebilmekte, bu sayede insanlar farklı kültürler hakkında bilgi sahibi olabilmektedirler. Çin mutfağı, dünya genelinde giderek yayılmakta ve açılan restoran sayısı da hızla artmaktadır. Özellikle 20. yüzyılla birlikte ABD'de açılan Çin restoranı sayısında patlama olmuştur. Çin-Amerikan Restoran Derneği'ne göre, ABD'de şu an 45.000'den fazla Çin restoranı bulunmaktadır ki bu rakam tüm McDonalds, KFC, Pizza Hut, Taco Bells ve Wendy's'in toplamından daha fazladır (Rude, 2016). Bir diğer araştırmaya göre de, ABD’de öğle yemeği için Çin restoranlarını tercih eden kişi sayısı 2009 yılında 40 milyon, 2013 'te 36 milyon, 2015'te de 35 milyon civarındadır (Statista, 2015).

Üçüncü kültürel diplomasi unsuru, Çin tarafından düzenlenen çeşitli kültürel programlardır. Çin'in kültürel mirasını sergilemek ve dünyadaki imajını ve Çin algısını olumlu yönde geliştirmek için yaptığı en önemli etkinliklerden biri 2008 Pekin Olimpiyatları'dır. Olimpiyatların açılış ve kapanış seremonilerinde Çin tarih ve kültürel mirası, Çin'in tanınmış yönetmenlerinden Zhang Yimou tarafından harmanlanarak yüksek bir teknolojiyle sunulmuş ve büyük ilgi çekmiştir. Olimpiyatlarda ayrıca Çin kültürünün en temel unsuru olan uyum kavramı, Konfüçyüs’ten zaman zaman alıntı yapılarak vurgulanmıştır. Toplamda yaklaşık 50 milyar dolarlık yatırım yapılan Olimpiyatlar, Çin'in hem ekonomik gücünün sergilendiği hem de imajı konusunda dünyaya önemli sinyaller verdiği bir etkinlik olmuştur (Preuss, 2007). Olimpiyatlardan sonraki en önemli etkinlik ise 2010'da Şangay'da düzenlenen Expo'dur. İçine altyapı da dâhil edildiğinde Çin'in Expo için harcadığ bütçenin 58 milyar dolar civarında olduğu tahmin edilmektedir (Blanchard, Master, 2010). Expo'ya 200'den fazla yurtdişından devlet başkanlarını da içeren önemli grup katılmıştır. Çinli liderler tarafından özel olarak karşılanan VIP misafirler, Çin'e kamu diplomasisini geliştirmek adına pek çok firsat yaratmıştır (d'Hooghe, 2015). Kısacası, Beijing Olimpiyatlarından hemen 2 yıl sonra yapılan Expo, 190 ülkeyi, 50'den fazla Sivil Toplum Kuruluşunu ve çok sayıda çok uluslu şirket ve kuruluşu bir araya getirmiştir (Winter, 2014). Expo, aynı Olimpiyatlar gibi, düzeniyle ve organizasyonuyla Çin'in dünyaya bakış açısını yansıtan, Çin toplum ve kültüründe uyumun önemini vurgulayan ve Çin'in dünyadaki imajını olumlu yönde etkileyen bir etkinlik olmuştur.

Çin'in önemli kültürel diplomasi unsurlarından biri de diğer ülkelere yaptığı yardımlardır. Çin'in, 2010-2012 yılları arasındaki dış yardımı 14,41 milyar dolardır. Bu yardımların, 31'i Asya, 51'i Afrika, 9'u Okyanusya, 19'u Latin Amerika ve Karayipler, 12'si de Avrupa'ya yapılmıştır (The State Council of the PRC, 2014). Görüldüğü gibi özellikle Afrika, Çin'in yardımda bulunduğu bölgelerin başında gelmektedir. Aslında Çin'in Afrika'ya ilgisinin temelinde artan enerji ihtiyacı için pazar sağlamak yatmaktadır. 1956'da Mısır'la diplomatik ilişki kurulmasıyla başlayan ilişkiler, 1978 sonrası reformlarla birlikte ivme kazanmıştır. Çin ve ABD, Afrika’yla ilişkilerinde farklı bir yol izlemektedirler. Çin, Afrika'daki ülkelerin içişlerine karışmama prensibiyle hareket ederken, $\mathrm{ABD}$, bu ülkeler üzerinde bir yönetim kurmaya ve bunları demokratikleştirmeye çalışmaktadır. Çin'in içişlerine karışmama ve eşitlik prensibi, Afrika'daki ülkelerin Çin'e saygı duymasını sağlamış ve 1971'de Çin'in BM'deki yerini almasında 26 Afrika ülkesinin oyu etkili olmuştur (Li, 2007).

Çin, Afrika'ya yaptığı yatırımlarla, buradaki ülkelerle ilişkilerini daha da geliştirmek istemektedir. Çin'in Afrika'ya yardım programının en önemli başarısı ilk olarak 1963 yılında Cezayir'e gönderilmeye başlanan tıbbi ekiplerdir. Çin, 2005 yılının sonunda, 47 Afrika ülkesine 15,000'den fazla tıbbi personel göndermiş ve 170 milyon hastayı iyileştirdiklerini iddia etmiştir.(Shinn, 2009). Bunun yanısıra, Çin hükümeti kıtada on bir tane Ticareti Geliştirme Merkezi kurmuş ve Çin firmaları Afrika'yı bir ticaret ve yatırım merkezi olarak görmeleri için teşvik edilmişlerdir. 2007 yılı itibariyle 800'ün üzerinde Çin firması 49 Afrika ülkesinde faaliyet göstermekte ve bunların 480'i Afrikalı firmalarla ortak teşebbüste bulunmaktadır (Alden, 2007). Çin'in Afrika'ya yatırım projeleri Büyük Nil Petrol Şirketi, Zimbabwe'deki maden işletmeciliği, Angola'da yeni bir ulusal demir yolu hattının inşaası gibi pek çok alandaki projeleri kapsamaktadır. Bunun yanısıra Çin'in devlet kontrolündeki bankaları Afrika'da giderek daha önemli bir rol oynamaya başlamıştır. Örneğin 2007'de Çin'in Sanayi ve Ticaret Bankası Johannesburg'daki Standard Bank’ın \%20 hissesini 5.5 milyar dolara satın almıştır (Shinn, 2009). Tüm bu yatırımların yanı sıra, Afrika ülkeleriyle Çin arasında birçok kültürel ve eğitimle ilgili değişim program yer almaktadır. Kültürel Mirası Korunması Konusunda Çin-Afrika Forumu, Çin-Afrika Kültür Sanayisi oturumu, Afrika Sanat Festivali, ÇinAfrika Kültürel Ortaklık Programı gibi kültürel alandaki işbirliği projelerinin yanında, çevrenin korunması, bilim, sanat, teknoloji, eğitim, insan kaynakları, sağlık vb. birçok konuda işbirliği devam etmektedir (Ministry of Foreign Affairs of the PRC, 2015). 


\section{Sonuç ve Değerlendirme}

1978'de başlattığ1 ekonomik reformlarla önemli bir dönüşüm geçiren ve ekonomik anlamda hıla büyüyen Çin, uluslararası sistemde giderek büyük bir güç haline gelmiş ve Çin'in bu gücü, Batı'da bir 'Çin tehdidi' algısına neden olmuştur. $\mathrm{Bu}$ Çin tehdidi algısının köklerinde ise Organski, Mearsheimer ve Huntington gibi siyaset bilimcilerin teorileri yatmaktadır. 'Çin tehdidi' algısını kırmak veya yıkmak için Çin, yumuşak gücünü ön plana çıkarmaktadır. Yumuşak güç unsurları içerisinde de kültürel diplomasi büyük önem taşımaktadır.

Uzun yıllardır kullanılmasına rağmen, yeni yeni teorileşen kültürel diplomasi kavramının birçok tanımı olmakla birlikte temelde sanat, eğitim, fikir, tarih, bilim, tıp, teknoloji, din, gelenekler, davranış şekilleri, ticaret, yardım, spor, dil, profesyonel meslekler, hobiler, medya v.b. gibi kültürün birçok farklı özelliğini kapsamaktadır. Çin'in kültürel diplomasisinin en önemli unsurları ise, Konfüçyüs Enstitüleri, Çin kültürünü yansıtan şeylerin pazarlanması, çeşitli kültürel programlar ve yabancı ülkelere yapılan yardımlardır. Bazı akademisyenler, Çin'in yumuşak gücünü, kamu diplomasisi yoluyla yayması için önünde bazı engeller olduğunu düşünmektedir. Bunlardan biri, Çin'in tek parti hükümeti olması dolayısıyla medya, kültürel kuruluşlar ve hükümet arasında mesafe bulunmaması ve dolayısıyla otoriter bir devlet olduğu algısıdır. Diğeri ise Çin hükümetinin, ulusal kanalı olan CCTV, Xinhua Haber Ajansı ve Çin sineması üzerindeki kontrolü nedeniyle bunların uluslararası etkiye sahip olamamasıdır (Flew, 2014). Ancak yine de Çin, bu algıya rağmen, yukarıda belirtilen kültürel diplomasi unsurlarıyla bu algıyı değiştirmeye çalışmaktadır.

Çin dil ve kültürünün yaygınlaştırılması amacını taşıyan ve 123 ülkeye yayılmış olan Konfüçyüs Enstitüleri, Çin'e karşı algının değişmesinde oldukça önemli rol oynamaktadır. Her ne kadar bunlar bazı akademisyenler tarafından eleştirilse de, akademik kuruluşların ve akademisyenlerin kültürel diplomasideki önemi yadsınamaz. $\mathrm{Bu}$ enstitülere Konfüçyüs isminin verilmesi de, Çin'in son dönemde barışçıl gelişimini vurgulamak amacıyla Konfüçyüs değerlerini vurgulaması ve Konfüçyüs'ü Çin'in binlerce yıllık medeniyetinin önemli bir unsuru olarak görmesiyle ilgilidir. Kısaca, Konfüçyüs Enstitüleri, Konfüçyüs değerlerine yapılan vurguyla, Çin'in son dönemde ortaya attı̆̆ı 'uyumlu dünya', 'uyumlu toplum', 'barışçıl gelişim' gibi dış politika ilkeleriyle uyum göstermektedir ve 'Çin tehdidi’ algısının kırılması için belki de en etkili role sahiptir.

Her ülkede sayısı giderek artan Çin restoranlarının yanı sıra, Çin'in ev sahipliği yaptığı Pekin Olimpiyatları ve Şangay Expo'su gibi önemli etkinlikler de 'Çin tehdidi' algısının yıkılmaya çalışıldığı programlar olmuştur. Bu etkinliklerde Çin, medeniyetinin tüm ihtişamını gözler önüne sererek milyonlarca ziyaretçi çekmiş ve barışçıl gelişimini ve hegemonya savaşına girmeyeceğini vurgulamıştır.

Çin, ekonomik olarak güçlendikçe, dış ülkelere yaptığı yardım ve yatırımlar da artmaktadır. Yardım ve yatırım yaptığı ülkelerin içişlerine karışmama prensibini benimseyen Çin'in bu tutumundan dolayı, yardım yaptığı ülkeler Çin'i tercih etmektedir. Bu nedenle ABD, kendi pazar alanına rakip olduğu düşüncesiyle Çin'i tehdit olarak algılamaktadır. Çin'in Afrika ülkelerine karşı tutumu, BM'de birçok Afrika ülkesinin desteğini kazanmasıyla sonuçlanmıştır. Yine bu tutum nedeniyle, yardım yaptığı ülkelerde 'Çin tehdidi' algısında kırılma görülmektedir. Konuyla ilgili, 'yumuşak güç’ kavramının yaratıcısı olan Nye’a göre Çin’in, yumuşak gücünü artırmak için özellikle Latin Amerika ve Afrika'daki programlara milyon dolarlar harcaması, yumuşak gücünün en güzel örneğidir. Bunun yanı sıra, 2008 Pekin Olimpiyatları ve 2010 Şangay Expo'su 70 milyondan fazla ziyaretçi çekerek Çin'in yurtdışındaki itibarını artırmıştır ancak, örneğin olimpiyatlar sonrası insan hakları aktivistlerine karşı uygulanan sıkı baskılar ve Expo sonrası Nobel Barış Ödülü’nü kazanan Liu Xiaobo'nun hapse atılması, Çin'in başarılarını sekteye uğratmıştır (Nye, 2012).

Sonuç olarak Çin, 'Çin tehdidi’ algısını kırabilmek için kültürel diplomasiye büyük önem vermekte ve yukarıda ifade edilen kültürel programlarla bu algıyı değiştirmeye çalışmaktadır. Özellikle de Konfüçyüs Enstitüleri, dış ülkelere yapılan yardımlar ve kültürel ve eğitimle ilgili değişim programları, bu algıyı kırma yolunda atılan en önemli adımlardır. Diğer taraftan, Çin'in otoriter bir devlet olarak görülmesi, insan hakları gibi konulardaki eksiklikler ve Doğu ve Güney Çin denizlerindeki tutumu, 'Çin tehdidi' algısının yıkılmasını zorlaştıran nedenlerdir. Çin, tehdit algısını kırabilmek için, barış ve uyuma vurgu yapmaya devam etmeli, insan hakları konusunda önemli adımlar atmalı ve medya ve kültürel kuruluşlar üzerindeki devlet otoritesi algısını azaltmaya çalışmalıdır.

\section{Kaynakça}

- Alden, 2007. China in Africa, Zed Books LTD., London,UK

- Ateba, 2002. "Is the Rise of China a Security Threat?”, Polis, 9, Numero Special.

- Blanchard and Master, 2010. "China puts power on show at World Expo", The China Post, April 30, http://www.chinapost.com.tw/business/asia/asia-china/2010/04/30/254528/China-puts.htm (23.05.2016).

- CBS News, 2001. "Hu Jintao: China Not a Threat to US Power”, January 20, http://www.cbsnews.com/news/hu-jintao-china-not-a-threat-to-us-power/ (20.05.2016).

- Chakraborty (ed.), 2013. "Cultural Diplomacy Dictionary, Academy for Cultural Diplomacy”, http://www.cd-n.org/content/pdf/Cultural_Diplomacy_Dictionary.pdf 
- China Public Diplomacy Association, http://www.chinapda.org.cn/eng/xhgk/xhjj/ (19.05.2016).

- China.org.cn, 2010. “General Information on the Reform of the Cultural System”, August 20, http://www.china.org.cn/china/2010-08/20/content_20756529.htm (23.05.2016)

- Cull, 2009. Public Diplomacy: Lessons From the Past, Figueora Press, LA, USC Center on Public Diplomacy.

- Cummings, 2003. "Cultural Diplomacy and the United States Government: A Survey”, Center for Arts and Culture, http://www.americansforthearts.org/sites/default/files/MCCpaper.pdf (16.03.2016).

- D’Hooghe, 2015. China's Public Diplomacy, Koninklijke Brill, Netherlands.

- Flew, 2014, "Confucius Institutes and the Network Communication Approach to Public Diplomacy", the IAFOR Journal of Asian Studies, 1, no.1, p.1-18.

- Foster, 2014. "China soft power set back as US universities shut second Confucius Institute in a week", 01. Oct. 2014, The Telegraph, http://www.telegraph.co.uk/news/worldnews/northamerica/usa /11133921/Chinasoft-power-set-back-as-US-universities-shut-second-Confucius-Institute-in-a-week.html (14.07.2015)

- Hongyi, 2012. “China’s Cultural Diplomacy: Going for Soft Power”, in China's Soft Power and International Relations, eds. Hongyi Lai, Yiyi Lu, Routledge.

- Jing, 2013. "Chinese and Western Interpretations of Peaceful Development: A Clash of Rules and Rule", (MA Thesis), Aalborg University, Denmark, MA Thesis.

- Koev, 2013. "The Role of Cultural Diplomacy for Intensifying the Cross Border Cooperation within Danube Region", Journal of Danubian Studies and Research, 3, no.3, p.59-68.

- Lai, 2011. The United States and China in Power Transition, Strategic Studies Institute (SSI).

- Lenczowski, 2009. “Cultural Diplomacy, Political Influence and Integrated Strategy”, in Strategic Influence: Public Diplomacy, Counter Propaganda and Political Warfare, ed. J. Michael Waller, Institute of World Politics Press.

- Li, 2007. "China and Africa: Policy and Challenges, China Security, 3, no.3, p. 69-93.

- McCord, 2014. "Confucius Institutes: Hardly a Threat to Academic Freedoms”, The Diplomat, March 27, http://thediplomat.com/2014/03/confucius-institutes-hardly-a-threat-to-academic-freedoms/ (14.07.2015)

- Mearsheimer, 2001. The Tragedy of Great Power Politics, New York: Norton.

- Mearsheimer, 2004. "Why China’s Rise Will Not Be Peaceful?”, http://mearsheimer.uchicago. edu/pdfs/A0034b.pdf (20.05.2016).

- Mearsheimer, 2005. "The Rise of China will not be Peaceful at all”, http://mearsheimer.uchicago. edu/pdfs/P0014.pdf (20.05.2016).

- Ministry of the Education of the People's Republic of China, "China Relases Report on Foreign Students for 2015”, 20.04.2016, http://en.moe.gov.cn/News/Top_News/201604/t20160420_239196.html (18.05.2016).

- Ministry of the Education of the People's Republic of China, "The Overall Situation of Studying Abroad", http://www.moe.edu.cn/publicfiles/business/htmlfiles/moe/s3917/201007/91574.html (18.05.2016).

- Ministry of the Foreign Affairs of the People's Republic of China. 2015, "The Forum on China-Africa Cooperation Johannesburg Action Plan (2016-2018)", http://www.fmprc.gov.cn/mfa_eng/zxxx _662805/t1323159.shtml (24.05.2016)

- Nye, 2004. Soft Power: The Means to Success in World Politics, New York: Public Affairs.

- Nye, 2012. “China’s Soft Power Deficit”, The Wall Street Journal, May 8, 2012, http://www.wsj.com/articles/SB10001424052702304451104577389923098678842 (19.05.2016).

- Organski, 1968. World Politics, Alfred A Knopf, 2nd edition.

- Preuss, 2007. "Signalling Growth: China’s Major Benefit from Staging the Olympics in Beijing 2008”, Harvard Asia Pacific Review, 9, no.1, p. 41-45.

- Project Atlas, China’s Students Oversees, http://www.moe.edu.cn/publicfiles/business/htmlfiles /moe/s3917/201007/91574.html (18.05.2016).

- Rude, 2016. "A Very Brief History of Chinese Food in America”, February 8, Time, http://time.com/4211871/chinese-food-history/ (23.05.2016).

- Schneider, 2003. "Diplomacy ThatWorks: Best Practice in Cultural Diplomacy”. Cultural Diplomacy Research Service, Center for Arts and Culture. Washington, DC.

- Shinn, 2009. "Africa: the US and China Court the Continent”, Journal of International Affairs, Spring/Summer, 62, No. 2, p. 37-53. 
- Statista, 2015. "Number of people who visited any Chinese restaurant for lunch within the last 30 days in the United States (USA) from autumn 2009 to spring 2015 (in millions)", The Statictics Portal, http://www.statista.com/statistics/231192/people-who-visited-any-chinese-restaurant-for-lunch-usa/ (23.05.2016).

- The Economic Times, 2014. "China’s President Xi’s India Visit: Stronger China Not a Threat to Anyone”, September 18, http://articles.economictimes.indiatimes.com/2014-09-18/news/54068017_1_south-asiaworld-affairs-china-president-xi (20.05.2016).

- The State Council of the People's Republic of China, 2014. "China's Foreign Aid", http://english.gov.cn/archive/white_paper/2014/08/23/content_281474982986592.htm (24.05.2016).

- The State Council of the People's Republic of China, "More Chinese Students Study Abroad in 2015", http://english.gov.cn/state_council/ministries/2016/03/17/content_281475309293312.htm (18.05.2016).

- Tiezzi, 2014. “The Future of China’s Confucius Institutes”, The Diplomat, September 30, 2014, http://thediplomat.com/2014/09/the-future-of-chinas-confucius-institutes/ (17.05.2016)

- Winter, 2014. "Cultural Diplomacy, Cosmopolitanism and Global Hierarchy at the Shanghai Expo", Space and Culture, 18, no.1, p. 39-54.

- Yee ve Feng, 2002. “Chinese Perspectives of the China Threat: Myth or Reality?", in; The China Threat: Perceptions, Myths and Reality, (Yee, Storey eds.), Routledge. 


\title{
Orta Asya'da Oluşturulan Ekonomik ve Siyasi Entegrasyonlar Kapsamında Türkiye Özbekistan İlişkileri
}

\section{Turkey and Uzbekistan Relations within the Scope of Economic and Political Integration of Central Asia}

\author{
Prof. Dr. S. Ridvan Karluk (Anadolu University, Turkey) \\ Assoc. Prof. Dr. Ayşen Hiç Gencer (Istanbul Aydın University, Turkey)
}

\begin{abstract}
Following the dissolution of Soviet Union, Uzbekistan declared its sovereignty on $20^{\text {th }}$ June 1990 and its independency on $1^{\text {st }}$ September 1991. Turkey was the first country recognizing Uzbekistan on $16^{\text {th }}$ December 1991. Among the Central Asian countries, Uzbekistan is the country, having the most crowded Turkish population. On the date of $4^{\text {th }}$ March 1992, the diplomatic relation between Turkey and Uzbekistan established and more than 90 bilateral agreements and protocols signed with the Republic of Uzbekistan. The fact that both countries' people share the same culture and language (Uzbek-Chagatai Turkish) effected Turkey to be the first country recognizing the Republic of Uzbekistan. Uzbekistan is an important country for Turkey with its geopolitical location in Central Asia, deep rooted history, economic potential and the connections between Turkish and Uzbek people. The Prime Minister Erdogan and President Kerimov emphasized the necessity of improving the Turkish - Uzbek relations in the opening of Sochi 2014 Winter Olympics. The Uzbekistan visit of the Foreign Minister Ahmet Davutoğlu between $10^{\text {th }}$ and $12^{\text {th }}$ July 2014 , started a new period in bilateral relations. As a result of this visit, improvement in relations that has slow downed after 2003 is expected to happen. In this paper, the Uzbekistan and Turkey relations is analyzed both in the scope of integration in Central Asia and parties and the measures will be asserted to improve the relations that has slow downed after 2003.
\end{abstract}

\section{Giriş}

Özbekistan; tarihi ve kültürel birikimi, stratejik konumu, doğal kaynakları ve 31 milyon nüfusu ile bölgesel barış ve istikrar için önemli bir ülkedir. Özbekistan'da 450 Türk şirketi; dokuma, taahhüt, gıda, otelcilik, inşaat malzemeleri, plastik, ilaç ve hizmetler sektörlerinde faaliyet göstermektedir. Türk şirketlerinin Özbekistan'daki yatırım tutarı 1 milyar dolar civarındadır. Şirketlerin yıllık ortalama ihracatı 300 milyon dolar olup, 50 bin kişiyi istihdam etmektedirler. Türkiye'de Özbek sermayeli 114 şirket bulunmaktadır. Türkiye, Özbek vatandaşlarının turizm amaciyla en fazla tercih ettikleri ülkeler arasındadır. Uygulanan vize muafiyetinin de etkisiyle Türkiye'ye ilgi giderek artarak son üç yılda 143 bine ulaşmıştır. Türk Havayolları ile Özbekistan Havayolları'nın İstanbulTaşkent arasında her gün tarifeli seferleri vardır.

Türkiye, Özbekistan'ın bağımsızlığı tanıyan ilk ülkedir. Türk ve Özbek halkları arasındaki bă̆, yüzyıllar öncesine dayanır. Bağımsızlıktan sonra ülkeler arasında bazı yanlış anlamalar olmuş olsa da bu durum geçmişte kalmıştır. Bunun en önemli göstergesi TİKA’nın Özbekistan'daki faaliyetleridir. TİKA, kurulduğu 1992 yılından bu yana Özbekistan'da sağlık, restorasyon, tarımsal kalkınma, maliye ve turizm alanlarında projelerini arttırarak sürdürmektedir (TİKA, 2013). TİKA'nın Özbekistan'da gerçekleştirdiği projelerin toplam değeri 2015 y1lında 21 milyon dolara ulaşmıştır. 2016 yılında gerçekleştirilmesi planlanan projelerle bu tutarın 25 milyon dolara çıkması öngörülmektedir.

TİKA projeleri kapsamında Türkiye ve Özbekistan Sağlık Bakanlıkları, Türkiye İnterplast Derneği ve Özbekistan Sağlam Evlat Vakfı işbirliğginde 2009-2015 yıllarında gerçekleştirilen plastik cerrahi operasyonlarda yaklaşık 1.500 hasta muayene edilerek, 0-20 yaş arası toplam 580 kişiye yönelik plastik cerrahi operasyon gerçekleştirilmiştir. Taşkent'te Orta Asya'nın ilk Kemik İliği Nakil Merkezi kurulması, ilgili Özbek kurumları işbirliğiyle bazı devlet okullarında bilgisayar sınıfı oluşturulması, Özbek polis ve sağlık personeline hizmet içi eğitim verilmesi, Özbekistan' daki merkezlerden uzak bölgelerde ve kırsal kesimde yaşayan halka kaliteli sağlık hizmeti sunulması amacıyla iki adet mobil klinik araç sağlanması, TİKA tarafından Özbekistan'da gerçekleştirilen önemli projelerdir. TİKA'nın Özbekistan'daki faaliyetlerinin artmasına paralel olarak Türkiye Özbekistan ilişkileri giderek gelişecektir (TİKA, 2016).

Türkiye'nin 2004 yılından bugüne kadar Özbekistan'a yapmış olduğu resmi kalkınma yardımlarının toplam tutarı 75 milyon dolar civarındadır. Bölgelerinde önemli iki ülkenin bundan sonra ekonomik ve siyasi ilişkilerini geliştirmeleri, hem taraflara ve hem de bölgenin diğer ülkelerine ve bölge barışına hizmet edecektir.

\section{2 Özbekistan'In Temel Özellikleri}

Özbekistan, 447.400 km²'lik yüzölçümüne sahip, Orta Asya'nın en önemli ülkelerindendir. 2016 y1lında nüfusu 31 milyon 576 bin olup toplam nüfus içinde aktif nüfus 13.5 milyondur (Gender Statistics of Uzbekistan, 2016). 
Dünya Bankası'nın 2014 yılı verilerine göre milli geliri 62.4 milyar dolardır (World Bank, 2016). 2013 yılında kişi başına düşen gelir dolar cinsinden 1.541 dolar, (Uzbekistan - Adjusted net national income per capita) 2014'de satın alma gücü paritesine göre (PPP) ise 5.316 dolardır (Uzbekistan: GDP per capita, PPP). Ülke nüfusunun yüzde 80'ini Özbekler, 5,5'ini Ruslar, yüzde 5'ini Tacikler, yüzde 3'ünü Kazaklar, yüzde 2.5'ini Karakalpaklar ve yüzde 1.5'ini Tatarlar oluşturur (Türksoy, 2016). Ülkede yüzde 3,5 oranında Ortodoks nüfus yaşamaktadır. Özbekistan, diğer Orta Asya Türk Cumhuriyetlerine göre en kalabalık Türk nüfusuna sahip ülkedir (Uluslararası Politika Akademisi, 2014).

Özbekistan'da 12 il, 1 özerk cumhuriyet (Karakalpakistan Cumhuriyeti) ve 1 bağımsız şehir (Taşkent) vardır. Başkanlık sistemiyle yönetilen Özbekistan Cumhuriyeti’nin Cumhurbaşkanlığını, bağımsızlığından bu yana İslam Kerimov yürütmektedir. 2015 yılında yapılan Cumhurbaşkanlığı seçimlerinde oyların yüzde 90'nı alan Kerimov, yeniden seçilmiştir (The Guardian, 2016). Yasama yetkisi iki kamaradan oluşan Ali Meclis'tedir. Meclis'te beş siyasi parti temsil edilmektedir.

Özbekistan bağımsızlığını kazandıktan sonra büyük bir büyüme hızına ulaşmıştır. 1990-2000 yıları arasındaki büyüme hızı yüzde -0.2 iken bu hız 2000-2009 döneminde yüzde 6.9, 2009-2013 döneminde ise yüzde 8.2'ye ulaşmıştır (WB, 2015). 2015 yılında 139,600 kişi ülkeye, 168,600 kişi de ülke dışına göç etmiştir. Aktif nüfus 13.7 milyona, çalışan nüfus 13,1 milyona ulaşmıştır. Nüfusun yüzde 82,2'si özel sektörde çalışmaktadır. Kayıtlı işsiz sayısı 709,400, işsizlik oranı yüzde 5,2'dir. Ülke ekonomisinde 1 Ocak 2016 tarihi itibariyle ticari tüzel kişi sayısı 278 bindir. Bunun yüzde 92,6’1 (257 bin) faaliyetlerini sürdürmektedir. 2015 yılında GSYH 171,369 trilyon sum olarak gerçekleşmiştir. 2015 yılında diş ticaret hacmi yüzde 10 oranında azalarak 25,283 milyar dolar olmuştur. Bunun 12,868 milyar doları ihracat, 12,415 milyar doları ithalattır (uzdaily.uz, 2016).

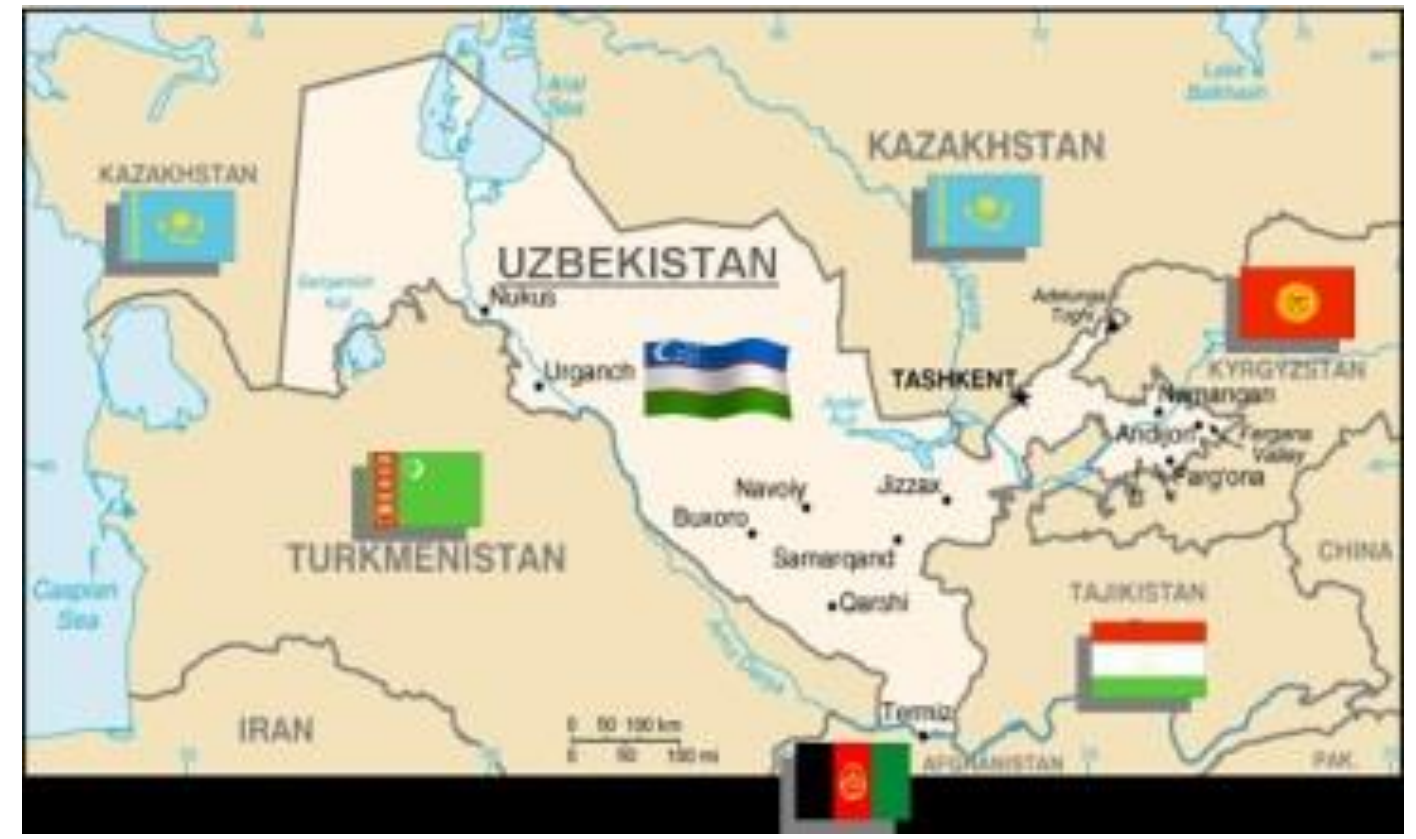

\section{3 Özbekistan'ın Yakın Komşuları ve Bölge Ülkeleri ile İlişsileri}

Tarihi, kültürü, dini alışkanlıkları ve nüfusuyla Orta Asya’nın en önemli ülkesi konumundaki Özbekistan; Bağımsız Devletler Topluluğu (CIS) Avrasya Ekonomik Topluluğu, (EurAsEC) Ekonomik İşbirliği Kuruluşu (ECO), Şanghay İşbirliği Kuruluşu (SCO), Türksoy ve Türk Dili Konuşan Ülkeler İşbirliği Konseyi (TK, Özbekistan, 2016) üyesidir. Avrasya Ekonomik Topluluğu'na 7 Ekim 2005 tarihinde katılmış, 2008'de üyeliğini askıya almıştır. Birlik, Rusya'nın Orta Asya'daki ekonomik ayağı olarak değerlendirilebilir. Özbekistan, Şanghay İşbirliği Kuruluşu'nda gözlemci ülke statüsünde olup, ortak askeri tatbikatlara katılmamaktadır. Kasım 2009'da Orta Asya Birleşik Enerji Sistemi Projesi’nden, 1999'da Moskova'nın önderliğindeki Bağımsız Devletler Topluluğu bünyesindeki Kolektif Güvenlik Anlaşması Kuruluşu'ndan ayrılmıştır. Bunun sebebi, Kuruluş’un üye ülkelere askeri müdahale yapabilmesi ve bunun Özbekistan'ın anayasasına aykırı olmasıdır.

2006 yılında Kuruluşa yeniden üye olurken, Haziran 2012'de Kuruluş'tan ayrılınca Rusya'dan uzak durmak isteyen eski Sovyetler Birliği ülkeleri Gürcistan, Ukrayna, Azerbaycan ve Moldova'nın 1997'de kurdukları GUAM'a (sonraki adıyla Demokrasi ve Ekonomik Kalkınma Kuruluşu: ODED) katılmıştır. Fakat Aralık 2005'te GUAM'dan çıkmıştır. Bu zikzaklı politikanın sebebi, Andican olaylarında Batılıların Özbekistan'a yönelik insan hakları ve demokrasi baskısından kurtulmaktı. Andican Olayları'ndan sonra 29 Temmuz 2005 tarihinde Özbekistan ABD’nin Karşi-Hanabad Askeri Üssü’nü 6 ay içeresinde boşaltmasını istemiştir. 


\section{4 Özbekistan Ekonomisinde Yapısal Dönüşüm ve 2030 Yılı Hedefleri}

Cumhurbaşkanı İslam Kerimov ülkenin sosyo-ekonomik gelişmesi kapsamında 2015 sonuçları ve 2016 Ekonomi Programı'nın öncelikleriyle ilgili olarak Bakanlar Kurulu'nda Özbekistan ekonomisi ile ilgili önemli açıklamalarda bulunmuştur. Kerimov, ülkede iş adamlarının işlerini bürokrasiye takılmadan gerçekleştirebilmesi için 40'dan fazla hukuki düzenlemede değişiklik yapıldığını açıklamıştır. Ekonomide özel mülkiyet ile iş adamlarının haklarının korunmasına, yargının da güçlendirilmesine önem verilmiştir. Vergi ve gümrük mevzuatının ihlal edilmesi sebebiyle girişimcilerin mülkine el konulmasının, ancak yargı kararıyla olmasını öngören düzenlemeler yapılmıştır.

Özbekistan, sahip olduğu pamuk gibi yerüstü, altın, uranyum, doğalgaz ve petrol gibi yeraltı zenginlikleri sayesinde Orta Asya'nın ekonomik yönden güçlü bir ülkesidir. 2015 yılında GSYH yüzde 8, sanayi sektörü yüzde 8 , köy işletmeleri yüzde 7, inşaat alt sektörü yüzde 18 oranında büyümüştür. Son yıllarda sanayi sektörüne yönelik yatırım teşvikleri arttırılmış, 2015 'de 15.8 milyar dolar yatırım teşviki verilmiştir. Tüm yatırımların yüzde 67.1 'i sınai inşaata yöneliktir. 2015 yılında 7.4 milyar dolar değerinde 158 üretim tesisinin yapımı tamamlanmıştır. Yüzde 60'1 kırsal kesimde olmak üzere 980 bin kişiye istihdam imkanı yaratılmıştır.

Gelir dağılımında eşitsizliği gösteren Gini katsayısı 2000 yılında 0,390, 2015 yılında ise 0.280'dir. Gelir dağılımdaki adaletsizlik azaldığg için iç tüketim talebi artarak perakende ticaret hacmi yüzde 15 'e, 100 aileye düşen otomobil adedi 42'ye ulaşmış, otomobil sahibi ailelerin sayısı beş yıl öncesine göre 1,5 kat artmıştır. Yıllık bütçe fazlası 2015 yılında GSYH'nın yüzde 0.1'i, enflasyon oranı da yüzde 5.6 olarak gerçekleşmiştir. GSYH'da küçük işletme ve özel girişimciliğin payı 2000 yılında yüzde 31'den 2015 yılında yüzde 56.7'e çıkmıştır. Küçük işletmeler ve özel girişimcilerin üretimlerinin büyük kısmı tarımsal ürünler olup, nüfusun yüzde 77’i bu sektörde istihdam edilmektedir. Özbekistan'ın en önemli dış ticaret ortağı Rusya'dır (\%24,5). Daha sonra Çin (\%12), Kazakistan $(\% 6,1)$ ve Güney Kore $(\% 5,2)$ gelmektedir.

2010 yılında hizmetler sektörünün GSYH içindeki payı yüzde 49 iken, 2015 y1lında yüzde 54.5'e çıkmıştır. Sektörde ülke nüfusunun yarısından fazlası istihdam edilmektedir. Banka ve sigorta, kiralama, danışmanlık ve diğer hizmetler alt sektörleri hızla gelişmekte ve 80 bin küçük işletme (tüm işletmelerin \% $\% 0^{\prime} i$ ) faaliyet göstermektedir. Bankacılık sektöründe toplam sermaye 2014 yılına göre yüzde 23.3'e artarak 7.8 trilyon Özbek somuna ulaşmış, sermaye yeterlilik seviyesi yüzde 24'e olarak gerçekleşmiş, kamu borcunun GSYH'ya oranı yüzde 18,5 olmuştur. Dünya Bankası'na göre 2014-2015 dönem sonuçları ve 2016-2017 dönemi büyüme beklentileri esas alındığında Özbekistan, dünyada hızlı gelişen beş ülke arasındadır.

2016 yılında GSYH'nın yüzde 7,8 oranında büyümesi, üretimin sanayide yüzde 8,2, tarımda yüzde 6,1 oranında artması, perakende ticaretin yüzde 14, hizmetler sektörünün yüzde 17,4 oranında gelişmesi, enflasyonun yüzde 56,5 seviyesinde tutulması, halkın reel gelirlerinin yüzde 9,5 oranında çoğalması hedeflenmiştir. Ekonomideki yapısal değişiklikler için 17,3 milyar dolar tahsis edilmiştir. Bunun 4 milyar doları yabancı sermaye yarımlarından sağlanacaktır. 2016 yılında kamu harcamalarından sosyal harcamalara yüzde 59,1, eğitime yüzde 33,7, sağlık hizmetlerine yüzde 14 oranında pay ayrılacaktır.

Uluslararası Finans Kurumu (International Finance Corporation: IFC) ve Dünya Bankası (World Bank: WB) tarafından 2003 yılından bu yana yayınlanan İş Yapma Endeksi raporları; (Doing Business) ekonomiler üzerinde ülkelerin yatırım ortamını etkileyebilecek şirket kuruluşu, vergi politikaları, istihdam, lisans alma süreci, yatırımcıların korunması gibi çeşitli göstergeleri temel alarak karşılaştırmalı değerlendirmeler sunmaktadır. Raporlarda; işletmeyi kurma ve devam ettirme konularında devletin koyduğu şartları yerine getirme, dış ticaret, vergi ödeme ve işletmeyi kapatma gibi işlemlerin süre ve maliyetleri ortaya konmaktadır.

Ekim 2015'te yayınlanan Rapor'a göre Özbekistan bir yılda 16 basamak yükselerek 87'nci sırada yer almıştır (Türkiye 55 'nci sıra). Özbekistan; yeni iş imkanlarını destekleme kriterlerine göre 42, yapılan sözleşmelerin hayata geçirilmesinin sağlanmasında 32, ekonomik olarak batık işletmelerin iflas sisteminin verimliliği konusunda 75 'nci sıradadır. Küçük işletmelere kredi sağlanması kriterine göre Özbekistan son üç yılda 154'ncülükten 42'nci sıraya yükselmiştir. Özbekistan, son yıllarda girişimci iş adamlarının faaliyetleri için iyi iş ortamın oluşturulması alanında başarılı sonuçları elde eden ilk on ülke arasındadır (WB, Doingbusiness, 2016).

Özbekistan 2015 yılında Birleşmiş Milletler Gıda ve Tarım Örgütü (FAO) üyeleri arasında gıda güvenliğinin sağlanmasında Birleşmiş Milletler Binyıl Kalkınma Hedeflerine ulaşmada ödül alan 14 ülke arasındadır (UN, Millennium Development Goals, 2015). 2014 y1lında ülkede 7.5 milyon ton buğday ve 3 milyon ton pamuk, 12.5 milyon ton sebze ve patates, 1.8 milyon ton kavun, 1.5 milyon ton üzüm, 2.7 milyon ton meyve üretilmiştir. Sebze meyve depolama kapasitesi 832 bin tona çıkarılarak fiyatlarda istikrar sağlanmıştır. 2015 yılında arazilerinin iyileştirilmesi sonucunda ek olarak 17,5 bin tarım çiftliği kurulmuş ve yaklaşık 250 bin kişi için istihdam yaratılmıştır. Çiftliklere arazi tahsisinde yeni bir süreç başlatılarak yetki İlçe Belediye Başkanından (Hokim rayona) alınarak çiftçilerin Bölge Konseyi ile Arazi Verme Komisyonları'nın raporlarına dayanılarak İlçe Meclisi (Kengaş) üyelerine verilmiştir.

Tarım sektöründe 2020 yılına kadar aşamalı olarak ham pamuk üretiminin düşürülmesi ve devlet alımının 3 milyon 350 bin tondan 3 milyon tona azaltılması planlanmıştır. Böylece hem iç piyasadaki dokuma sanayiin 
hammadde ihtiyacı karşılanacak, hem de dünya piyasalarına pamuk elyafı ve türevlerinin tedarikçiliğine devam edilecektir. 350 bin tonluk pamuk üretimi azaltılarak 170,500 hektarlık sulanan tarım arazisi serbest bırakılacaktır. $\mathrm{Bu}$ toprakların verimlilikleri düşük olup, 1 hektar pamuk rekoltesi 12-15 kental (100 kg) kadardır. Oysa ülke genelinde 1 hektarın ortalama rekoltesi 26,1 kentaldir. Tarım sektöründe ekim alanlarının iyileştirilmesi sonucunda 2020 yılına kadar tahıl üretimi yüzde 16,4 artışla 8,5 milyon tona ulaşacaktır. Patates üretiminde yüzde 35, diğer sebzelerde yüzde 30 , meyve ve üzümde yüzde 21,5, et üretiminde yüzde 26,2, sütte yüzde 47,5, yumurtada yüzde 74,5 kat artış öngörülmektedir.

Özbekistan Ekonomi Bakanlığı verilerine göre 2016 yılının ilk çeyreğinde Özbekistan'da 53,100 ton sebze üretilmiştir. Geçen yıldan kalan ürünlerle birlikte yıl başından sonra 95,100 ton meyve ve sebze ihracatı yapılmıştır. Tarım alanının geliştirilmesi ve reformları programına uygun olarak cari yılda pamuk ekilecek alanlar 30,500 hektar azaltılmıştır. Bu yıl 172,600 hektar alana sebze, 86,300 hektar alana patates ve 26,300 hektar alana bahçe ürünleri ekilmiş, 5,200 hektar alanda yeni meyve bahçeleri oluşturulmuş, 5,700 hektar alan yeniden yapılandırılarak 3,200 hektar alanda üzüm bağları kurulmuş, 163 hektar alanda 4.264 sera oluşturulmuştur. Meyve ve sebzelerin depolanması için 10,500 ton kapasiteli 16 yeni soğuk hava deposu inşa edilmiştir.

Özbekistan'ın sosyal göstergeleri de hızla iyileşmektedir. Alınan önlemler sonucunda son beş yılda 100 bin canlı doğumda anne ölümleri 23,1'den 19'a, beş yaştan küçük çocukların ölümü 14,8'den 13,9'a, yeni doğan bebeklerin ölümü 11'den 10,7'ye düşmüş ve Birleşmiş Milletler Binyıl Kalkınma Hedeflerine ulaşılmıştır. Özbekistan GSYH'nın yüzde 10 ile yüzde 12'i eğitim harcamalarına ayırmaktadır. Bu oran, ülkenin sürdürülebilir kalkınmasını sağlamak için UNESCO'nun önerdiği (\%6-7) oranın iki katıdır. ABD'li araştırma şirketi Gallup'un 148 ülkeyi kapsayan 2015 yılı Küresel Mutluluk Endeksinde Türkiye, Bangladeş ve Sırbistan'la birlikte sondan üçüncü olurken Özbekistan 2013 yılındaki 60'ncılıktan, iki yıl sonra 44'ncü sıraya yükselmiştir.

Ekonomide yapısal değişikler kapsamında özelleştirme konusuna büyük önem verilmektedir. Bu süreçte ilke olarak hidrokarbon hammaddeleri, değerli metaller, uranyum çıkarma ve işleme, demiryolları ile otoyollar, hava taşımacılı̆̆ı, enerji üretimi ve kamu hizmetleri alanındaki tekeller özelleştirme dışında bırakılmıştır. Bununla beraber liberal ekonomiye geçişle birlikte devlet varlıklarının kitle satışı için gerekli altyapı da oluşturulmuştur. Bu kapsamda 506 kamu tesisinin 1 milyon Özbek somu karşılığında satışı gerçekleştirilmiş, yaklaşık 22 bin yeni istihdam yaratılmış, 245 verimsiz kuruluş kapatılmış, 319 kullanılmayan kamu işletmelerinin özelleştirilmesi için envanter işlemi tamamlanarak açık artırma ile satışı yapılmıştır. Yabancı yatırımcılara satılmak üzere $378 \mathrm{kamu}$ kuruluşu açık artırma yoluyla satışa çıkarılmıştır. Bunlar arasında Nevaiazot, Ferganaazot, Urgenç Ekskavatör, Kızılkumsement, Jizzak Akü Fabrikası, Alokabank, Turonbank, Uzagrosugurta şirketleri vardır. Satışa çıkarılan şirketlerinin 52'si özel mülkiyete geçmiş, kamuya ait Kukon Yoğ-Moy A.Ş.'nin hisseleri 2.5 milyon dolara satılmıştır.

Özbekistan ekonomisi 2030 yılına kadar 2 kat büyüyecektir. Bu amaçla sanayi sektörünün GSYH'daki payı 2015 yılında yüzde 33,5'ten yüzde 40'a çıkarılacak, tarımın payı ise yüzde 16,6'dan yüzde 8-10'a indirilecektir. Ayrıca, enerji tasarruflu modern teknolojilerinin yaygın kullanılması sağlanarak enerji yoğunluğunun iki kat azaltılması amaçlanmıştır. 2030 yılında yüksek katma değerli ürünlerin üretilmesi sonucunda petro-kimya ürünlerinin üretiminin 3,2 kat, demir ürünlerinin 2,3 kat, demir dışı madenlerin 2,2 kat ve kimya sanayi ürünleri üretiminin 3,2 kat arttırılması öngörülmüştür. Pamuk elyafı ile ekolojik dokuma ve lif sanayi ürünlerinin üretilmesi 5,6 kat, meyve-sebze ürünlerinin ise 5,7 kat arttırılması hedeflenmiştir (Özbekistan Cumhuriyeti Ankara Büyükelçiliği, 2016).

\section{5 Özbekistan'ın Dış Ticaret Politikası}

Sovyetler Birliği dağıldıktan sonra küresel dünya ekonomisi ile entegrasyona önem veren Özbekistan'ın Dünya Ticaret Kuruluşu'na (WTO) üyelik sürecini hızlandırması, bu yoldaki siyasi iradesini göstermesi gerekmektedir (WTO, 2016). WTO üyeliği Özbekistan ekonomisinin hassas sektörler için bazı riskleri de beraberinde getirebilir. Üyeliğin ülkenin ekonomik ve sosyal hayatında olumsuz sonuçları da olabilir. Ancak üyelik, Özbekistan'a ekonomisinin hangi alanlarının zayıf olduğu ve rekabeti dayanıksızlığını belirleme konusunda yardımcı olabilir.

WTO üyesi olmayan Özbekistan dış ticaret rejiminde; serbest dolaşım, ihracat, re-import, re-export, geçici ithalat, serbest bölge, gümrük bölgesi dışı işleme, gümrük bölgesinde işleme, gözetim altında imha, devlet lehine ithali reddetme, tarife dışı kontrol uygulamaları vardır. Belirli malların dış ticareti hükümetin belirlediği kurumların izni ile mümkündür. Dış ticaret kalemleri üzerinde miktar kısıtlamaları (kota) vardır. İthalatın hükümet garantisi altındaki kredilerle finanse edilmesi ve yüzde 50 den fazla devlet hissesi bulunan şirketlerce yapılmasında zorunlu ekspertiz gereklidir. Mücevher, askeri malzeme, ham petrol, altın, metaller, pamuk ipliğinin ihracatında ihracat sözleşmesinin kayda alınması zorunludur. Diğer ürünlerin dış ticaretinde sözleşmelerin gümrüğe ve ilgili bankaya ibraz edilmesi yeterlidir. 26 Nisan 2010 tarihinde alınan bir kararla, bazı ithal malların (televizyon, buzdolabı, klima, ütü, yatak ve nevresim takımı, tekstil ve deri ürünleri) gümrükleme işlemlerinin yapıldığı tarihten sonra bir yıl içinde satılması zorunlu hale getirilmiştir.

Özbekistan'ın gümrük vergileri nominal bazda yüzde 5 - 30 arasındadır. İthalat sirasında referans fiyat uygulaması da yapılarak ithal edilen ürünlerden normal gümrük ve katma değer vergilerinin (tüm ithalatta KDV 
yüzde 20'dir) dışında ek bir vergi de (Aksiz Vergisi: Bandrol) alınmaktadır. Ayrıca ithal edilen ürünün beyan edilen fiyatıyla emsal oluşturan fiyat arasında fark varsa, bu da tahsil edilmektedir. Gümrük vergisi uygulamasında sık değişen mevzuat ve gümrüğe göre değişebilen uygulamalar sebebiyle sorunlar yaşanmaktadır. Geçmişte Türkiye'de de uygulanan bandrol, ithal edilen bazı ürünlerden alınan bir çeşit vergidir. Özbekistan'da üretilen ürünlerde koruma amaçlıdır. Lüks tüketime konu olan ürünlerin ithalini zorlaştırmayı hedeflemekte, yüzde 5'ten başlayarak ürün cinsine göre değişmektedir. Bazı özel imtiyazlı kamu şirketleri ile toplam çalışan sayısının yüzde 50'den fazlasında engelli-özürlü personel istihdam eden şirketler ithalatta KDV muafiyetinden yararlanmaktadır. Sabit sermaye yatırım malları da KDV'den muaftır. Tüketim mallarının Özbekçe olarak etiketlenme zorunluluğu bulunmaktadır (Ekonomi Bakanlığı, 2016).

\section{Türkiye - Özbekistan İlişkileri}

Özbekistan Cumhuriyeti, Sovyet Sosyalist Cumhuriyetleri Birliği’nin dağılmasından sonra 20 Haziran 1990 tarihinde egemenliğini, 1 Eylül 1991'de bağımsızlığını ilan etmiş, 29 Aralık 1991 tarihinde düzenlenen halkoylaması sonucunda bağımsızlık ilanı onaylanmıştır. Türkiye, 16 Aralık 1991 tarihinde Özbekistan'ın bağımsızlığını tanıyan ilk ülke olmuş, 4 Mart 1992 tarihinde iki ülke arasında diplomatik ilişki kurulmuştur. Taşkent’teki ilk Büyükelçilik aynı yılın Nisan ayında, Özbekistan'ın Ankara Büyükelçiliği ise Ocak 1993'te açılmıştır. İlişkilerin hukuki temelini oluşturmak amacıyla 100'e yakın ikili anlaşma ve protokol imzalanmıştır. Türkiye ve Özbekistan arasındaki ilişkilerin kökü Türkistan dönemine kadar gerilere gider. Özbekistan Cumhuriyeti'nin bağımsızlığını kazanmasından sonra Özbekistan ve Türkiye arasındaki ilişkiler ticari, ekonomik ve mali alanlarda hızla gelişmiştir.

Cumhurbaşkanı İslam Kerimov’un Türkiye’yi ilk ziyaretinin ardından Haziran 1992- Kasım 1999 tarihleri arasında ilişkiler hızla gelişmiştir. Türkiye'den Cumhurbaşkanı seviyesinde ilk ziyaret 8'nci Cumhurbaşkanı merhum Turgut Özal tarafından Nisan 1993 tarihinde gerçekleşmiştir. Bunu Mart 1999'da merhum Cumhurbaşkanı Süleyman Demirel'in, Ekim 2000'de 10'ncu Cumhurbaşkanı Ahmet Necdet Sezer'in ziyaretleri izlemiştir. Daha sonra Başbakanlar seviyesinde Süleyman Demirel (1992), Abdulhaşim Mutalov (1992), Tansu Çiller (1995), Mesut Yılmaz (1998) ve Recep Tayyip Erdoğan (2003) olmak üzere altı temas gerçekleşmiştir (Dışişleri Bakanlığı, 2016). 2003'den sonra 2014 yılına kadar taraflar arasında fazla bir temas olmamıştır.

Kopuklukta tarafların birbirlerini yanlış anlamaları büyük rol oynamıştır. Türkiye, Özbek muhalifleri barındırmakla suçlanmış, muhalif liderlerden Muhammed Salih 1993 yılı ilkbaharında dönemin Cumhurbaşkanı Turgut Özal'ın davetiyle Türkiye'ye gelmiş ve bir süre kaldıktan sonra Türkiye'den ayrılmak zorunda kalmıştır. 16 Şubat 1999 tarihinde Cumhurbaşkanı Kerimov’a yönelik bombalı suikasta Türk vatandaşlarının da katıldığ suçlaması ilişkileri kopma noktasına getirmiş, Özbekistan Türkiye'de eğitim gören Özbek öğrencileri geri çekmiştir. Ayrıca, Kerimov'a yapılan bombalı eylemi gerçekleştirenler arasında yer alan Ayberg İbrahimov’un iki ülke arasında yapılan suçluların iadesi anlaşmasına rağmen Özbek yönetimine verilmemesi, Özbekistan'a göre Türkiye'nin Özbekistan'ı uluslararası arenada yalnız bırakması, 12-13 Mayıs 2005 tarihlerinde Andican'da yaşanan olaylardan sonra BM'nin Özbekistan'a yönelik kabul ettiği eleştiri raporuna Türkiye'nin destek vermesi kopukluğun sebepleri arasında sayılabilir. Batılıların insan hakları ve demokrasi baskısından dolayı Özbekistan Moskova ve Pekin'e dönüş yapmış, Andican olaylarından sonra 29 Temmuz 2005 tarihinde Özbekistan ABD’nin Karşi-Hanabad Askeri Üssü'nü 6 ay içeresinde boşaltmasını istemiştir.

Dönemin Dışişleri Bakanı Ahmet Davutoğlu'nun ifadesiyle iki ülke arasında yanlış anlaşılmalardan kaynaklanan bir durağanlık yaşanmıştır. Gerginliğin giderilmesi için dönemin Dışişleri Bakanı Ahmet Davutoğlu Eylül 2012'de New York'ta Özbekistan Dışişleri Bakanı Kamilov ile görüşmüştür. Özbekistan, 2012-2013 yıllarında BM Genel Kurulu toplantılarında Dışişleri Bakanları seviyesinde yapılan görüşmeler sonrasında 2014 Ocak ayında Türkiye'nin Güvenlik Konseyi adaylığına desteğini açıklamıştır. Dönemin Başbakanı Erdoğan 7 Şubat 2014 tarihinde 2014 Kış Olimpiyat Oyunları açılış töreni için geldiği Soçi'de İslam Kerimov’la görüşmüş, ikili ilişkilerin durumu ele alınmıştır. Görüşme, Başbakan Erdoğan'ın 2003 yılında Özbekistan'a yaptığı ziyaretten sonra iki ülke arasında üst seviyede yapılan ilk temas olmuştur.

Taraflar arasında Mayıs 2014’te Şanghay'da yapılan Asya'da İşbirliği ve Güven Arttırıcı Önlemler Konferansı (AİGK/CICA) 4. Devlet ve Hükümet Başkanları Zirvesi'nde bir görüşme gerçekleşmiştir. Dışişleri Bakanı Davutoğlu'nun 10-12 Temmuz 2014 tarihlerindeki Özbekistan ziyareti, ikili ilişkiler açısından bir dönüm noktası olmuştur. 10 Temmuz'da Özbekistan Dışişleri Bakanı Abdülaziz Kamilov ile bir araya gelen Davutoğlu'nun İlişkilerin son yıllarda istenilen düzeyde olmaması hepimizi üzmüş̧ür. İnşallah mevcut siyasi irade önümüzde bir yol açar'açıklamasına cevap veren Kamilov, bu ziyaretin sadece ikili ilişkilerin gelişmesi için bir firsat değil, aynı zamanda tarihi öneme sahip olduğunu ifade etmiştir. Aynı gün Davutoğlu'nu kabul eden Kerimov, bu görüşmenin Özbekistan ile Türkiye arasındaki ilişkilerin gelişmesi bakımından iyi bir fırsat olduğunu açıklamış, iki ülke arasında geçmişte yaşanan hataların yinelenmemesi gerektiğini belirtmiştir. Davutoğlu da görüşmeyle ilgili olarak Özbekistan ve Türkiye işbirliği içinde olursa Asya istikrara kavuşur. Bu da bütün dünya için müjde olmalıdır" demiştir. 


\section{Sonuç}

Türkiye ve Özbekistan, bölgelerinde güçlü ve etkili iki devlettir. Farklı siyasi ve ekonomik kuruluşlara üye olsalar da tarihten gelen çok kuvvetli bağları vardır. Anadolu Türkçesi ile Özbek Türkçesi birbirine çok yakındır. Orta Asya, dünya medeniyetine büyük iz bırakan düşünür, edebiyatçı ve devlet adamlarıyla çok zengin bir coğrafyadır. Türk diline hizmet eden büyük şair Ali Şir Nevai ve Orta Çağ'da Babür İmparatorluğu'nun kurucusu ve ilk hükümdarı Babür Şah, Türk dünyası açısından önemli iki şahsiyettir. Bu coğrafyada doğan Ali Şir Nevai bu yıl 575, Babür Şah ise 533 yaşına basmıştır.

Özbek şair ve devlet adamı Nevai, Sultan Hüseyin Baykara döneminde vezirlik yapmış, görevinden istifa ettikten sonra 30'a yakın eser yazmıştır. Yaşadığı dönemde Fars dili kullanılırken eserlerini Türkçe yazmıştır. Özbekistan'da adını taşıyan şehir, metro ve sanat yapıtlarının yanı sıra Taşkent, Aşkabat, Bakü, Almatı ve Oş şehirlerinde heykelleri vardır. Babür Şah, 1483 yılında Andican kasabasında dünyaya gelmiştir. Çağatay Türkçesi ile kaleme aldığı ve yaptıklarını kronolojik olarak anlattığı Babürname, Türk edebiyat tarihinin nesir türündeki başyapıtlarından biridir. Ali Şir Nevai ve Babür Şah; hem Türkiye, hem Özbekistan ve hem de Türk dünyasının ortak değerleridir.

Özbekistan'ın Orta Asya'daki jeostratejik konumu ve küresel güçler ile yakın ilişki kurması, ABD-Özbekistan yakınlığı, bölgedeki diğer güçleri rahatsız etmektedir. ABD’nin Afganistan'dan çekilmesiyle birlikte Rusya'nın Orta Asya'da etkisini arttırmaya çalışması, Özbekistan'ı rahatsız etmektedir. Orta Asya'daki Çin-Rusya rekabetinde bölge ülkelerinin tercihleri önemlidir. Kazakistan ve Kırgızistan, Rusya'nın oluşturduğu Avrasya Birliği'ne üye olarak diğer Orta Asya Cumhuriyetlerinden farklı bir tercih yapmışlar, Özbekistan ise bu konuda çekimser kalmıştır. Özbekistan'ın büyük önem verdiği, "egemenlik her şeyden üstündür" ilkesi doğrultusunda Türkiye Özbekistan ilişkileri hızla gelişebilir. Ülkeye büyük yatırım yapan Çin, Japonya ve Güney Kore'nin Özbekistan ile sıcak ilişkiler içinde olmaları, Türkiye açısından önemlidir.

Sovyet döneminden kalma Özbekistan, Tacikistan ve Kırgızistan arasındaki “anklav” sorununun (bir ülkenin başka bir ülke tarafından kuşatılmış toprak parçası) giderilmesi, (Özbekistan-Kırgızistan Sınır Problemi, 2016) Kazakistan-Özbekistan, Kırgızistan-Özbekistan ve Tacikistan-Özbekistan arasında yaşanan su sorunun çözümlenmesi, bölge ülkeleri arasındaki bağı arttıracaktır. Özbekistan İslami Hareketi, İslami Cihat Birliği ve Hizb-ut Tahrir gibi örgütlerin faaliyetleri Özbekistan demokrasisine bir tehdittir. Ayrıca nüfusunda çok sayıda ulusun bulunması ve bu etnik grupların çoğunun komşu ülkelerin ana topluluğu ile aynı olmasının yarattığı sınır ötesi etnik sorunlar da Özbekistan demokrasinin gelişimine engel olmaktadır.

Türkiye ve Özbekistan, geçmişten kaynaklanan yanlış anlamalara son vererek her iki ülkenin de çıkarları doğrultusunda hareket etmelidir. Özbekistan Cumhurbaşkanı İslam Kerimov’un da belirttiği gibi Türkiye ve Özbekistan'1 yolundan saptırmaya çalışanlar, pusuda bekleyip onlara arkadan saldıranlar olabilir. Bu sebeple Türk ve Özbek halkları doğru bildikleri yolda ilerlemelidir. Özbekistan Cumhurbaşkanı Kerimov çok haklıdır: "Kervan tehlikesiz olmaz." (Kerimov, 2014). Kerimov, 22-24 Aralık 1991 tarihlerinde Türkiye'yi ziyaretinde şunları söylemiştir: ' 'Ĕger Türkiye bize destek olursa, Özbekleri bundan sonra kimse boyunduruk altına alamaz. Atatürk ilkeleri bizim Özbekistan'da yapmak istediklerimizle paraleldir, ben Atatürk'e hayranım ve O'nun Türkiye'de başardıklarını Orta Asya halklarının da başaracağını ümit ediyorum. Ben Türk Halklarının birliği düşüncesini savunuyorum. Bu birlik mutlaka gerçekleşmelidir. Politik bir birlikten ziyade ekonomik bir birlik kurulabilir. Bunun adına Türk Ortak Pazar'ı da diyebilirsiniz."

Erk Partisi lideri Muhammet Salih'in Türkiye’ye gelmesiyle başlayan ve Özbek yönetiminin iki ülke arasında öğrenci değişimini öngören anlaşmayı durdurmasına kadar uzanan gelişmeler, Özbekistan ve Türkiye gibi köklü tarihi geçmişe sahip, üstelik aynı kültürel değerlerden beslenmiş ilişkileri kesintiye uğratmamalıdır. Özbekistan ve Türkiye, aralarındaki sorunları çözmek için daha fazla çaba harcamalıdır. Kerimov'un, 'Orta Asya Cumhuriyetler Birliği'nin sağlanabilmesi tarihin dayattı̆̆ bir zorunluluktur.” görüşü çok önemlidir. Ankara'da 30-31 Ekim 1992 tarihinde Cumhurbaşkanı Turgut Özal, Başbakan Süleyman Demirel ve Özbekistan Cumhurbaşkanı İslam Kerimov'un da katılımıyla gerçekleştirilen Türk Zirvesi'nde Başbakan Süleyman Demirel, '’Bu zirve ile Türk Dünyası Adriyatik kıyısından Çin Seddi’ne kadar uzanmıştır. Yeni bir alem meydana çıkmıştır, yeni bir coğrafya şekillenmektedir. Bunun hazzını duyun.” demiştir ama bu isteğin arkası gelmemiştir. Taraflar arasındaki son temaslardan sonra ilişkilerin gelişmemesi için bir sebep kalmamıştır. Bölgedeki istikrarsızlıklara karşı Türkiye ve Özbekistan’ın işbirliğini arttırması, hem taraflar ve hem de bölge güvenliği açısından çok önemlidir.

\section{Kaynakça}

- $\quad$ ALJAZEERATURK, 2014, “Türkiye-Özbekistan ilişkilerinin yeni dönemi," 14 Temmuz 2014. http://www.aljazeera.com.tr/gorus/turkiye-ozbekistan-iliskilerinin-yeni-donemi. Erişim: 12.03.2016.

- DIŞIŞLERİ BAKANLIĞI, 2016, “Türkiye - Özbekistan Siyasi İlişkileri,” http://www.mfa.gov.tr/turkiyeozbekistan-cumhuriyeti-siyasi-iliskileri.tr.mfa. Erişim: 15.03.2016.

- $\quad$ EKONOMİ BAKANLIĞI, 2016, http://www.ekonomi.gov.tr/portal/faces/home/disIliskiler/ulkeler/ulkedetay $/ \%$ C3\%96zbekistan;jsessionid=vyYWK_oCuqDWzYBkG3racuV8oNyhauBeuEeJJYnMQZ7tpaugANr!-977844698?_adf.ctrl- 
state $=$ yiau3cfb_318\&_afrLoop $=311515165927647 \& \_$afrWindowMode $=0 \& \_$afrWindowId $=$null $\# ! \% 40 \% 40$ \%3F_afrWindowId\%3̄Dnull\%26_afrLoop\%3D311515165927647\%26_afrWindowMode\%3D0\%26_adf.ctrl -state\%3D13jf3utq10_4. Erişim: 11.03.2016.

- Erkin, 2016, “Türkiye-Özbekistan ilişkilerinin yeni dönemi,” http://www.aljazeera.com.tr/gorus/turkiyeozbekistan-iliskilerinin-yeni-donemi. Erişim: 12.05.2016.

- GENDER STATISTICS OF UZBEKISTAN, 2016, http://gender.stat.uz/en/mainindicators/labor/economically-active-population/172-number-of-economically-active-population-2007-2010. Erişim: 21.03.2016.

- GENDER STATISTICS OF UZBEKİSTAN, 2016, http://gender.stat.uz/en/about-gender-statistics/generalinformation. Erişim: 17.03.2016.

- HABERRUS, 2014, "Erdoğan Soçi’de Özbekistan lideri Kerimov’la görüştü," http:/haberrus.com/politics/2014/02/10/erdogan-socide-ozbekistan-lideri-kerimovla-gorustu.html. Erişim: 07.03.2016.

- Kadiroğlu, 2010, “Türkiye Özbekistan İlişkileri İlerleme Raporu,” 29.01.2010. http://www.turkbirdev.org/dilturkce/makaleler_detay.asp?makaleNo=63\&makaleBasligi=T\%DCRK\%DDYE $\% 20 \%$ D6ZBEK $\%$ DDSTAN \%20\%DDL\%DD\%DEK\%DDLER\%DD\%20\%DDLERLEME\%20RAPORU Erişim: 12.03.2016.

- Kerimov, 2014, Yenilmez Güç Yüksek Maneviyat, Öncü Basımevi, Ankara.

- Muradova, "Türkiye ve Özbekistan Arasındaki Sosyo - Ekonomik İşbirliği," TASAM, 2010.http://www.tasam.org/tr-TR/Icerik/4447/turkiye_ve_ozbekistan_arasindaki_sosyo__ekonomik_isbirligi. Erişim: 28.03.2016.

- ÖZBEKİSTAN CUMHURIYYTİ ANKARA BÜYÜKELÇİLİ̆̈̇, 2016, http://www.uzembassy.org.tr/. Erişim: 17.05.2016.

- Rotar, 2016, “Uzbekistan and Kyrgyzstan Heighten Tensions in Violent Local Border Dispute,” Eurasia Daily Monitor,10. http://www.ecoi.net/local_link/237021/346017_en.html. Erişim: 21.03.2016.

- THE GUARDIAN, 2016. "Islam Karimov re-elected Uzbekistan's president in predicted landslide," http://www.theguardian.com/world/2015/mar/30/islam-karimov-re-elected-uzbekistans-president-inpredicted-landslide. Erişim: 27.04.2016.

- TİKA, 2016, “Türkiye_Orta_Asya_ve_Kafkasların_Tıp_Egitimi_Merkezi_Olacak," http://www.tika.gov.tr/tr/haber/turkiye_orta_asya_ve_kafkaslarin_tip_egitimi_merkezi_olacak-4636 Türkiye, Erişim: 21.05.2016.

- TİKA, Faaliyet Raporu 2013. http://www.tika.gov.tr/upload/oldpublication/faaliyet-raporu-2013.pdf. Erişim: 29.05.2016.

- TURKISH WEEKLEY, 2016, “Turkey-Uzbekistan: Strengthening Cooperation and Achieving Progress," November 2008. http://www.turkishweekly.net/2008/11/07/news/turkey-uzbekistan-strengtheningcooperation-and-achieving-progress/ tarihi bağ. Erişim: 30.03.2016.

- TÜRK DİLİ KONUŞAN ÜLKELER İŞBİRLİĞİ KONSEYİ, 2016, (Türk Keneşi) Özbekistan, http://www.turkkon.org/tr-TR/ozbekistan/610/614. Erişim: 09.03.2016.

- TÜRKİYE CUMHURİYETİ DIŞİŞLERİ BAKANLIĞI TAŞKENT BÜYÜKELÇİLİĞİ, 2016, “Türkiye Özbekistan İlişkileri,” 15.02.2016. http://taskent.be.mfa.gov.tr/ShowInfoNotes.aspx?ID=250287. Erişim: 19.03.2016.

- TÜRKSOY, 2016, http://www.turksoy.org/tr/members/uzbekistan. Erişim: 11.03.2016.

- TÜRKSOY, 2016, Özbekistan Cumhuriyeti. http://www.turksoy.org/tr/members/uzbekistan. Erişim: 21.04.2016.

- ULUSLARARASI POLİTİKA AKADEMİİ, 2014, “Türk-Özbek İlişkileri ve Yeni Gelişmeler,” http://politikaakademisi.org/2014/04/11/turk-ozbek-iliskileri-ve-yeni-gelismeler/. Erişim: 11.03.2016.

- UN, 2015, Millennium Development Goals: 2015 Progress Chart. http://www.un.org/millenniumgoals/2015_MDG_Report/pdf/MDG\%202015\%20rev\%20(July\%201).pdf. Erişim: 04.03.2016.

- UZBEKİSTAN TODAY, 2016, “Tashkent meeting was held in a friendly atmosphere," http://ut.uz/en/politics/tashkent_meeting_was_held_in_a_friendly_atmosphere. Erişim: 22.05.2016.

- UZBEKİSTAN, 2016, “Adjusted net national income per capita," http://www.indexmundi.com/facts/uzbekistan/adjusted-net-national-income-per-capita 
- UZBEKISTAN, 2016, GDP per capita, PPP, http://www.theglobaleconomy.com/Uzbekistan/GDP_per_capita_PPP/. Erişim: 11.05.2016.

- UZDAILY.uz, 2016, https://www.uzdaily.uz/sections-mid-1.htm. Erişim: 28.04.2016.

- WORLD BANK, Doingbusiness 2016. http://www.doingbusiness.org/ /media/GIAWB/Doing\%20Business/Documents/AnnualReports/English/DB16-Chapters/DB16-Mini-Book.pdf. Erişim: 02.03.2016.

- WORLD BANK,2016, http://databank.worldbank.org/data/reports.aspx?Code=NY.GDP.MKTP.CD\&id=2ddc971b\&report_name=G ender_Indicators_Report\&populartype=series. Erişim: 19.03.2016.

- WORLD BANK, 2015, World Development Indicators, s. 86.

- WTO, Uzbekistan, 2016. https://www.wto.org/english/thewto_e/acc_e/a1_ouzbekistan_e.htm. Erişim: 11.05.2016.

- http://www.doingbusiness.org/rankings

- http://www.uzembassy.org.tr/index.php?lang=tr

- http://www.uzembassy.org.tr/index.php?lang=tr

- https://www.gov.uz/en

- https://www.uzdaily.uz/

- https://www.wto.org/english/thewto_e/acc_e/a1_ouzbekistan_e.htm

- http://www.gundem.be/tr/dunya/ozbekistan-kirgizistan-sinir-problemi 


\title{
Gelişen Ülkelerde Çevresel Bozulma, Gelir Ve Enerji Tüketimi İlişkisi
}

\section{The Nexus between Environmental Degradation, Income and Energy Consumption in Emerging Countries}

\author{
Assoc. Prof. Dr. Cengiz Aytun (Çukurova University, Turkey) \\ Assoc. Prof. Dr. Cemil Serhat Akın (Mustafa Kemal University, Turkey) \\ Assoc. Prof. Dr. Neşe Algan (Çukurova University, Turkey)
}

\begin{abstract}
Today, especially in developing countries, environmental pollution threatens human life. Environmental quality is one of the most important sources of human welfare. Therefore, it is becoming increasingly important to understand the relationship between environmental degradation, income and energy consumption. The aim of this study is to investigate the nature of relationships among the carbon dioxide emissions, economic growth and energy consumption for emerging economies. For this purpose, Environmental Kuznets Curve hypothesis have been tested for 10 emerging economies for the years from 1980 to 2010. Data were brought together from the World Bank development indicators database. In order to test of Environmental Kuznets Curve hypothesis IPS panel unit root, Pedroni panel cointegration and FMOLS estimation methods are used. Results indicate that energy consumption has a positive and significant effect on carbon dioxide emissions. Results indicate that energy consumption has a positive and significant effect on carbon dioxide emissions. The findings also show that per capita GDP follows an inverted U-shape pattern associated with the Environmental Kuznets Curve hypothesis. This situation validates the policies which assert that environmental pollution decreases with income growth.
\end{abstract}

\section{Giriş}

Gelişmiş ya da gelişmekte olan bütün ülkeler için enerji vazgeçilmez bir üretim girdisi olup bir taraftan üretime katkı sağlarken diğer taraftan da ekonomik gelişmeyi de desteklemektedir (Uçan, vd, 2014). Ancak, enerji kullanımının bu katkıları ile birlikte çevresel bozulmaya neden olduğu göz ardı edilmemelidir. Ekonomik gelişme sürecinde enerji ve doğal kaynaklara olan talebin artması çevresel bozulmanın en büyük sebeplerinden biridir. Ekonomik gelişme ve çevre ilişkisi üzerine yapılan çalışmaların önemli bölümünde Çevresel Kuznets Eğrisi(ÇKE)nden yararlanıldığı, kullanılan yöntemlerin de benzerlikler gösterdiği görülmektedir.

S. Kuznets (1955) çalışmasında, ülkelerin kalkınma sürecinde başlangıçta kalkınma ile birlikte gelir eşitsizliğinin artacağını ancak ileriki aşamalarda ekonomik gelişme devam ettikçe gelir eşitsizliğindeki artma eğiliminin duracağını ve sonrasında ise azalacağına vurgu yapmaktadır. Kişi başına gelirden hareketle kalkınma sürecinde büyüme ve gelir eşitsizliği arasında önce artan sonra azalan bir eğilim gösteren eğri ters U şeklinde olup "Kuznets Eğrisi” olarak literatürde yerini almıştır. Söz konusu ilişkinin geçerliliği çeşitli çalışmalarda ampirik olarak sorgulanmıştır. Genel olarak literatürde ters U şeklindeki ilişkinin varlığı yönünde bir uzlaşı sağlandığ 1 görülmekle birlikte ilişkinin olmadığı yönünde de sonuçların bulunduğu görülmektedir (Morrison, 1999; Schultz, 1998; Fields ve Jakupsen,1993; Williamson, 1997). Kuznets'in yapmış olduğu çalışma, gelir ile kalkınma bileşenlerinden gelir dağılımı hakkında çıkarsamalar yapılmasına imkân sağlarken, kalkınma iktisadına yapmış olduğu katkı bununla sınırlı kalmamıştır. Özellikle çevresel kalitenin sürdürülebilmesi için Kuznets eğrisi sık sık çalışmalara ilham kaynağı olmuştur. Standart Kuznets Eğrisindeki gelir dağılımı ekseni, çevresel bozulma (kirlenme) ile yer değiştirdiğinde yeni eğri Çevresel Kuznets Eğrisi (ÇKE) olarak adlandırılmaktadır.

Ekonomik büyümenin çevre üzerine etkileri 1990'lı yıllardan itibaren artan bir şekilde ilgi odağı haline gelmiş ve konuyla ilgili yapılan çalışmalar hızla artmıştır. 1980'li yıllarla birlikte ülkelerin ekonomik büyüme performanslarına bağlı olarak enerji tüketimleri de artmış, bu durum küresel ısınma sorununa dikkatleri çekmiştir. Yenilenebilir enerji kaynakları yerine petrol, doğalgaz gibi fosil yakıtların kullanılması, orman yangınları, ev ve tesislerden çıkan dumanlar vb küresel ısınmaya neden olmaktadır. Doğanın dengesini bozan faaliyetlerin başında ise birincil enerji kaynağı olarak kullanılan fosil yakıtlar gelmektedir. Fosil yakıt kullanımı özellikle $\mathrm{CO}_{2}$ gazının salınımına neden olmaktadır. $\mathrm{CO}_{2}$ gazı toplam sera gazı emisyonunun \%60'ını oluşturmaktadır (IEA, 2013). $\mathrm{CO}_{2}$ düzeyindeki artışının önde gelen nedeni, özellikle üretim sürecinde kullanılan enerji miktarındaki artışlardır.

Ekonomik büyüme ve $\mathrm{CO}_{2}$ emisyonu arasındaki etkileşim daha çok ÇKE hipotezi aracılığı ile kurulmaktadır. Bu eğrinin oluşumunda üç ayrı etkileşim mekanizması işlemektedir. Bunlar ölçek etkisi, kompozisyon etkisi ve teknoloji etkisidir (Brock and Taylor, 2004). Ölçek etkisi ile artan üretim hacmi daha fazla enerji ihtiyacı doğurmaktadır. Özellikle az gelişmiş toplumlarda üretim miktarındaki artış birincil amaç olmaktadır. Bu amaçla artan enerji tüketimi fosil yakıt tüketimini artırmakta ve fosil yakıt tüketimi de $\mathrm{CO}_{2}$ salınımını artırarak çevreyi olumsuz yönde etkilemektedir. Kompozisyon etkisinde; üretilen ürünlerin kompozisyonunda yapılan değişikliklere dikkat çekilmektedir. Ülkeler gelişmenin ilk aşamalarında çevreye daha çok zarar veren ürünleri 
üretmektedirler. Belirli bir gelir düzeyinden sonra toplumsal bilinç artmaktadır. Temiz bir çevre yaşam kalitesinin önemli unsurlarından biri olarak algılanmaya başlanmaktadır. Bu süreçte özellikle sivil toplum örgütleri tarafından yapılan baskılar sonucu ülkenin üretim kompozisyonu daha az çevre kirletici ürünlere kaymaktadır. Teknoloji etkisinin ise çevresel bozulma üzerine beklenen etkisi negatiftir (Kumbaroglu, vd, 2008). Teknolojik gelişmelerle birlikte doğal kaynaklar yerine kullanılabilecek yapay ürünler üretilebilmekte ve üretim sonrası oluşan çevresel atıklar doğaya daha az zararlı biçimde imha edilebilmektedir. Teknolojik ilerleme ve etkin kaynak kullanımı çevresel bozulmayı azaltabilmektedir (Ma ve Stern, 2007).

Günümüzün ekonomik politikaları, büyüme odaklı oluşturulmakta ancak yaratılan gelirin bölüşümü konusunda önerilerde bulunmamaktadır. Artan gelirin uzantısı olarak refah düzeyi yükselen ülkelerde temiz teknoloji kullanımı yaygınlaşmakta, çevresel duyarlılık artmakta iken, çevresel tahribat yaratan sektörlerde üretimlerini ve ihracatlarını artırmaya yönelen gelişmekte olan ülkelerin çevresel zararları artmaktadır. Aynı zamanda gelişmiş ülkelerde tüketicilerin çevre duyarlılıklarında, çevreye ilişkin yasal düzenlemelerin sayısında ve yaptırımlarda da artış gözlenmektedir. $\mathrm{Bu}$ gelişmeler çevresel tahribat yaratan sanayilerin maliyetlerinde artış yaratarak bu sanayilerin gelişmiş ülkelerde faaliyetlerini önemli ölçüde sınırlamaktadır. Ancak bu sanayiler için çevre konusunda yasal düzenlemelerin çok sıkı uygulanmadığı gelişmekte olan ülkeler cazip bir ortam yaratmakta ve gelişmiş ülkeler üretim tesislerini gelişmekte olan ülkelere taşımaktadır. Gelişmekte olan ülkelerin bu sanayi kolları için kirlilik sığınağ 1 (cenneti) haline gelmesi literatürde "kirlilik sığınağı (ya da cenneti) hipotezi”" (Pollution Haven Hypothesis) olarak yer almaktadır. Gelişmiş ülkeler çevresel bozulmaya sebebiyet veren tesislerini doğrudan yabancı sermaye yatırımı şeklinde gelişmekte olan ülkelere taşıyarak kirlilik cennetleri yaratmaktadır (Chew, 2009). Gelişmekte olan ülkeler aleyhine oluşan bu gelişmelerin bu ülkelerin çevresel bozulma sürecine yoğun bir şekilde maruz kalmalarına neden olması, bu ülkelerde uygulanacak çevre politikalarının önemini daha da arttırmaktadır.

Çalışmanın uygulama kısmında yatay kesit gözlemleri zaman serileri ile birleştiren panel veri analizi yöntemi tercih edilmiştir. Panel veri analizi yöntemi sayesinde elde edilen bulgular zaman ve kesit etkisini dikkate almakta ve analize dahil olan değişsenler arasında doğrusallık daha az olmaktadır (Kennedy, 2006). Analiz sürecinde LLC (Levin, vd, 2002) ve IPS (Im, vd, 2003) birim kök testleri uygulanmış, eşbütünleşme testinde Pedroni'nin (1999; 2004) yöntemi takip edilmiştir. Modelin tahmininde FMOLS tahmincisi (Pedroni, 2000) kullanılmıştır. Elde edilen bulgular çerçevesinde "Çevresel Kuznets Eğrisi Hipotezi”nin incelenen gelişmekte olan ülkeler için geçerli olduğunu desteklemektedir. Aynı zamanda enerjiye olan talebindeki artışın çevresel bozulmayı artırdığı, üretim sürecinde ihtiyaç duyulan enerji ihtiyacının özellikle birincil enerji kaynağı olan fosil yakıtlarla karşılandığı sonucuna ulaşılmıştır. Bu bulgular yenilenebilir enerji kaynaklarına yönelimin bu ülkeler açısından hayati bir önem taşıdığını da desteklemektedir. Çalışmanın sonraki bölümünde ilgili literatürde yapılmış çalışmalar, üçüncü bölümde analize dahil edilen veriler e model, dördüncü bölümde ise kullanılan metod hakkında bilgiler yer almaktadır. Çalışma bulguların yer aldığı bölümü takiben sonuç bölümü ise genel değerlendirme çerçevesinde politika önerileri ile sonlandırılacaktır.

\section{Literatür}

Literatürde Çevresel Kuznets eğrisi hipotezinin test edilmesinde Denklem 1'deki model yaygın olarak kullanılmaktadır. Söz konusu model formuna kirliliğe sebep olan çok çeşitli faktörler dahil edilebilmektedir.

$$
y_{i t}=\alpha_{i}+\beta_{1 i} x_{i, t}+\beta_{2} x^{2}{ }_{i, t}+\beta_{3} z_{i, t}+\varepsilon_{i, t}
$$

Denklem 1'deki i ve t sırası ile ülkeleri ve zaman indislerini ifade etmektedir. y çevresel bozulmayı temsil eden bir göstergeyi, x geliri, z ise çevresel bozulmaya sebep olan diğer değişkenleri temsil etmektedir (Aytun, 2014a). Dinda (2004). Çevre ile gelir arasındaki olası ilişki biçimlerini $\beta$ katsayılarının anlamlılığına göre sınıflandırmaktadır. Buna göre $\beta_{1}=\beta_{2}=0$ ise $\mathrm{x}$ ile y arasında ilişki yoktur. $\beta_{1}>0$ ve $\beta_{2}=0$ ise $\mathrm{x}$ ile y arasında monoton artan bir fonksiyonel ilişki vardır. $\beta 1<0$ ve $\beta 2=0$ ise $\mathrm{x}$ ile y arasında monoton azalan bir fonksiyonel ilişki vardır. $\beta_{1}>0$ ve $\beta_{2}<0$ ise $\mathrm{x}$ ile y arasında (ÇKE hipotezini destekler nitelikte) ters $\mathrm{U}$ şeklinde bir fonksiyonel iliş̧ki vardır. $\beta_{1}<0$ ve $\beta_{2}>0$ ise $x$ ile y arasında $U$ şeklinde bir fonksiyonel ilişki vardır.

Fonksiyonel yapıya ilişkin ampirik literatür incelendiğinde uygulanan yöntem, zaman dilimi ve ülke gruplarına göre bulguların farklılaştığg göze çarpmaktadır. ÇKE hipotezinin Grossman ve Krueger (1991) tarafından ilk defa test edilmesinden bu güne bilim dünyasının çevreye duyarlılığı daha da artmıştır. Bu duyarlılığın bir sonucu olarak ÇKE hipotezi çeşitli faktörler de modele dahil edilerek yaygın olarak test edilmektedir (Aytun, 2014a). Ampirik literatür incelendiğinde panel veri analizine ilişkin araç seti geliştikçe tek ülkeli çalışmalardan ziyade panel veri analizine bir yöneliş olduğu görülmektedir. Tablo 1'de ÇKE hipotezinin testine ilişkin yapılmış çalışmalardan seçilmiş örnekler sunulmaktadır.

Öncü çalışmalar ele alındığında bu çalışmaların çevresel bozulmaya sadece gelir düzeyinin etkilerini hesaba kattığ1 görülmektedir (Galeotti ve Lanza, 2005; Holtz-Eakin ve Selden, 1995; Richmond ve Kaufmann, 2006). Sonraki dönem araştırmalarda gelir düzeyine ek olarak açıklayıcı değişken olarak enerji tüketiminin de kullanılmaya başladığı görülmektedir (Narayan ve Narayan, 2010; Omri, 2013). Son dönemlerdeki bazı çalışmalar 
ise çevresel bozulmaya kurumsal faktörleri de dahil etmeye başlamıştır. Akın (2014) BRICS ülkeleri için yapmış olduğu uygulamada özellikle kurumsal kalitenin çevresel bozulmaya etkilerini araştırmıştır. Elde ettiği bulgulara ters U biçimindeki Çevresel Kuznets Eğrisi hipotezini desteklerken, kurumsal kalite ile çevresel bozulma arasında negatif yönlü bir ilişkinin olduğu sonucuna ulaşılmıştır. Finansal serbestleşme CO2 salınımını negatif yönde, kişi başına düşen gelirin, dış ticarete serbestliğinin ve enerji tüketiminin artması ise çevresel bozulmaya pozitif yönde etki etmektedir. Devletin üretim sürecinde müdahil olarak yaratılan negatif dışsallıkları firmalara yüklemesi firmaları çevreye duyarlı daha yüksek teknolojiler kullanmaya zorlamakta, bu sayede kaynakların daha etkin kullanımı çevresel bozulmanın daha az gerçekleşmesini katkı sağlamaktadır (Lee ve Kim 2009).

\begin{tabular}{|c|c|c|c|}
\hline Çalışma & Metot & $\begin{array}{l}\text { Coğrafi-Zaman } \\
\text { Boyutu }\end{array}$ & Sonuç \\
\hline $\begin{array}{l}\text { Holtz-Eakin ve } \\
\text { Selden (1995) }\end{array}$ & Panel sabit etkiler & $\begin{array}{l}130 \text { ülke } \\
1951-1986 \\
\end{array}$ & $\begin{array}{l}\text { Monoton artan } \\
\text { eğri }\end{array}$ \\
\hline $\begin{array}{l}\text { Galeotti ve Lanza } \\
(2005)\end{array}$ & $\begin{array}{l}\text { Lineer ve log-lineer modellerin } \\
\text { karşılaştırılması }\end{array}$ & $\begin{array}{l}108 \text { ülke } \\
1971-1995\end{array}$ & $\begin{array}{l}\text { Ters U şeklinde } \\
\text { eğri }\end{array}$ \\
\hline $\begin{array}{l}\text { Richmond ve } \\
\text { Kaufman (2006) }\end{array}$ & $\begin{array}{l}\text { Panel birim kök, Pedroni } \\
\text { eşbütünleşme, Panel sabit ve rassal etk. }\end{array}$ & $\begin{array}{l}36 \text { ülke } \\
1973-1997\end{array}$ & $\begin{array}{l}\text { ÇKE hipotezi } \\
\text { geçersiz. }\end{array}$ \\
\hline Ang (2007) & ARDL sinır testi, VECM & $\begin{array}{l}\text { Fransa } \\
1960-2000\end{array}$ & $\begin{array}{l}\text { Ters U şeklinde } \\
\text { eğri }\end{array}$ \\
\hline $\begin{array}{l}\text { Apergis ve Payne } \\
(2010)\end{array}$ & $\begin{array}{l}\text { Panel birim kök, Pedroni } \\
\text { eşbütünleşme, Panel FMOLS ve } \\
\text { VECM }\end{array}$ & $\begin{array}{l}\text { Bağımsız devletler } \\
\text { topluluğu } \\
1991-2005\end{array}$ & $\begin{array}{l}\text { Örnekleme göre } \\
\text { sonuçlar } \\
\text { değişmektedir }\end{array}$ \\
\hline $\begin{array}{l}\text { Jalil ve Mahmud } \\
\text { (2009) }\end{array}$ & ARDL sinır testi ve VECM & $\begin{array}{l}\text { Çin } \\
1975-2005\end{array}$ & $\begin{array}{l}\text { Ters U şeklinde } \\
\text { eğri }\end{array}$ \\
\hline $\begin{array}{l}\text { Lean ve Smyth } \\
(2010)\end{array}$ & $\begin{array}{l}\text { Johansen Fisher panel eşbütünleşme, } \\
\text { VECM }\end{array}$ & $\begin{array}{l}\text { ASEAN üyesi } 5 \text { ülke } \\
1980-2006\end{array}$ & $\begin{array}{l}\text { Ters U şeklinde } \\
\text { eğri }\end{array}$ \\
\hline Wang, vd. (2011) & $\begin{array}{l}\text { Panel birim kök, Pedroni } \\
\text { eşbütünleşme, Panel FMOLS ve } \\
\text { VECM }\end{array}$ & $\begin{array}{l}\text { Çin'de } 28 \text { il } \\
1995-2007\end{array}$ & U şeklinde eğri \\
\hline Özcan (2013) & $\begin{array}{l}\text { Yatay kesit bağımlılık ve heterojenliği } \\
\text { dikkate alan panel birim kök, } \\
\text { eşbütünleşme ve Panel FMOLS ve } \\
\text { VECM }\end{array}$ & $\begin{array}{l}12 \text { orta doğu ülkesi } \\
1990-2008\end{array}$ & $\begin{array}{l}\text { Ülkelere göre } \\
\text { sonuçlar } \\
\text { değişmektedir }\end{array}$ \\
\hline Aytun (2014a) & $\begin{array}{l}\text { Panel birim kök, Pedroni } \\
\text { eşbütünleşme, Panel FMOLS }\end{array}$ & $\begin{array}{l}5 \text { ayr1 gelir } \\
\text { gurubunda } 83 \text { ülke } \\
1981-2010\end{array}$ & $\begin{array}{l}\text { ÇKE hipotezi } \\
\text { geçersiz. }\end{array}$ \\
\hline Akın (2014) & $\begin{array}{l}\text { Panel sabit etkiler, rassal etkiler } \\
\text { tahmincileri ile model tahmini }\end{array}$ & $\begin{array}{l}\text { BRICS ülkeleri } \\
\text { 2001-2011 }\end{array}$ & $\begin{array}{l}\text { Ters U şeklinde } \\
\text { eğri }\end{array}$ \\
\hline Aytun (2014b) & $\begin{array}{l}\text { Panel birim kök, Pedroni } \\
\text { eşbütünleşme, Panel FMOLS ve } \\
\text { VECM }\end{array}$ & $\begin{array}{l}10 \text { Gelişen Ülke - } \\
1971-2010\end{array}$ & $\begin{array}{l}\text { Ters U şeklinde } \\
\text { eğri }\end{array}$ \\
\hline $\begin{array}{l}\text { Erataş ve Uysal } \\
\text { (2014) }\end{array}$ & $\begin{array}{l}\text { Panel, Westerlund ECM Panel } \\
\text { Eşbütünleşme }\end{array}$ & $\begin{array}{l}\text { BRICT } \\
1992-2010\end{array}$ & $\begin{array}{l}\text { ÇKE eğrisi N } \\
\text { şeklinde }\end{array}$ \\
\hline Narayan (2010) & $\begin{array}{l}\text { Panel eşbütünleşme ve Panel Uzun } \\
\text { dönem tahmin teknikleri }\end{array}$ & $\begin{array}{l}43 \text { gelişmekte olan } \\
\text { ülke } \\
1980-2004\end{array}$ & $\begin{array}{l}\text { Ülkelerin } \\
\text { \%35'inde ÇKE } \\
\text { geçerli. }\end{array}$ \\
\hline $\begin{array}{l}\text { Robalino-Lopez, } \\
\text { vd. (2015) }\end{array}$ & Eşbütünleşme Teknikleri & $\begin{array}{l}\text { Venezuela } \\
1980-2025\end{array}$ & $\begin{array}{l}\text { ÇKE hipotezi } \\
\text { geçersiz. }\end{array}$ \\
\hline Li, vd. (2016) & PST Regresyon modeli & $\begin{array}{l}\text { Çin -30 Eyalet } \\
\text { 1997--2010 }\end{array}$ & $\begin{array}{l}\mathrm{CO}_{2} \text { için } \mathrm{ÇKE} \\
\text { geçersiz. } \mathrm{SO}_{2} \text { için } \\
\text { ÇKE geçerli. }\end{array}$ \\
\hline
\end{tabular}

Tablo 1. Çevresel Kuznets Ĕgrisini Test Eden Seçilmiş Ampirik Çalışmalar Kaynak: Wang, vd. (2011); Aytun (2014a)

Aytun (2014b) önceki çalışmalardan farklı olarak farklı eğitim seviyelerinin karbondioksit salınımına olan etkisini araştırmış, çalışmada elde edilen bulgular çevresel Kuznets eğrisi hipotezinin geçerli olduğunu desteklemiştir. Eğitim düzeyine ilişkin sonuçlar da bu hipotezi desteklemektedir. Buna göre ortaöğrenim düzeyi artarken karbondioksit salınımı da artmakta olduğu, yükseköğrenim düzeyinin artmasının ise karbondioksit salınımına azaltıcı etkisi yarattığı sonucuna ulaşılmıştır.

Ekonometrik yöntemlerdeki gelişmeler ÇKE hipotezinin de tekrar bu yöntemlerle test edilmesine yol açmıştır. Ancak panel veri analizindeki gerek heterojenitenin gerekse yatay kesit bağımlılığının dikkate alındığı çalışmalar 
(Apergis ve Payne, 2010; Ozcan, 2013; Wang, vd, 2011) konuya genel bir açıklama getirememiştir. Bu anlamda elde edilen bulguların uygulanan yönteme, coğrafi ve zaman boyutuna göre farklılaştığı görülmektedir. Gerçekleştirilecek uygulama ile gelişen ülkeler için literatüre ampirik katkı sağlanması amaçlanmaktadır.

\section{Veri ve Model}

$\mathrm{Bu}$ çalışmada çevresel Kuznets eğrisi hipotezi test edilmek üzere Dünya Bankasının Dünya Kalkınma Göstergeleri veri tabanından elde edilen seriler kullanılmıştır (World Bank, 2016). Seriler 1980-2010 dönemi için 10 gelişen ülkeyi içerecek şekilde bir araya getirilmiştir. Gelişen ülkeler olarak Brezilya, Çin, Macaristan, Meksika, Malezya, Türkiye, Güney Afrika, Mısır, Endonezya ve Hindistan'a ait veriler kullanılmıştır. Kullanılan seriler ve serilerin elde edildiği kaynak Tablo 2'de sunulmaktadır. Ek olarak serilere ilişkin tanımlayıcı istatistikler ise Tablo 3 'te verilmiştir.

\begin{tabular}{|lll|}
\hline SERI & SERIYE ILIŞKIN AÇIKLAMA & KAYNAK \\
\hline CO2 & Kişi başına CO2 emisyonu (metrik ton) & WDI $^{\mathrm{a}}$ \\
\hline GDP & Kişi başına Gayrisafi Yurtiçi Hasıla (2005 yılı sabit fiyatlarıyla - USD) & WDI $^{\mathrm{a}}$ \\
\hline ENR & Kişi başına enerji kullanımı (kg olarak petrole eşdeğer) & WDI $^{\mathrm{a}}$ \\
\hline
\end{tabular}

Tablo2. Serilere Ilişskin Açılamalar ve Kaynaklar Kaynak: ${ }^{a}$ The World Bank World Development Indicators

\begin{tabular}{|l|l|l|l|l|l|}
\hline & Gözlem & Ortalama & Standart Hata & Minimum & Maksimum \\
\hline CO2 & 309 & 3.549957 & 2.645075 & 0.498710 & 10.35715 \\
\hline GDP & 309 & 3866.384 & 2861.662 & 220.4417 & 11533.82 \\
\hline ENR & 309 & 1311.877 & 796.4798 & 293.5117 & 2961.354 \\
\hline
\end{tabular}

Tablo 3. Tanımlayıcı Istatistikler

Çevresel Kuznets Eğrisi hipotezinin testinde zaman serisi analiz araçlarının yanısıra panel veri analizi araçları da kullanılabilmektedir. Bu çalışmada Denklem 2'de ifade edilmiş olan model panel veri araçları ile analiz edilecektir. Söz konusu model çevresel bozulma ile gelir arasındaki ilişkiyi test etmek üzere yaygın olarak kullanılmaktadır (Dinda, 2004).

$$
C O 2_{i t}=\alpha_{i}+\beta_{1 i} G D P_{i, t}+\beta_{2} G D P^{2}{ }_{i, t}+\beta_{3} E N R_{i, t}+\varepsilon_{i, t}
$$

Çalışmada çevresel bozulma göstergesi olarak kullanılan karbondioksit emisyonu düzeyini açıklamak üzere Apergis ve Payne (2010) ve Aytun (2014a) tarafından kullanılan panel veri analizi yaklaşımı izlenecektir. Modelde karbondioksit salınımının uzun dönemdeki en önemli açıklayıcı değişkenleri olarak kişi başına gelir ve enerji tüketimi düzeyleri kullanılmıştır.

Buna göre Denklem 2'de i indisi ülkeleri, t indisi zamanı ifade etmektedir. Uygulamada çevresel bozulma (CO2), gelir düzeyi (GDP) ve enerji tüketimi (ENR) serilerinin seviye değerleri kullanılmıştır. Modeldeki $\beta_{1}$ ve $\beta_{2}$ katsayıları gelir düzeyinin karbondioksit salınıma etkisini temsil etmektedir. $\beta_{3}$ katsayısı ise enerji tüketiminin karbondioksit emisyonuna olan uzun dönemli etkisini göstermektedir. Denklem 2'de $\beta_{1}$ katsayıs1 pozitif ve $\beta_{2}$ katsayısı negatif işaretli ise GDP ile CO2 arasında (ÇKE hipotezini destekler nitelikte) ters U şeklinde bir fonksiyonel ilişki vardır. Ek olarak literatürde enerji tüketiminin karbondioksit salınımını arttırdığı genel olarak kabul edilmektedir. Bu nedenle $\beta_{3}$ katsayısının işaretinin pozitif olması beklenmektedir (Apergis ve Payne, 2010; Dinda, 2004; Wang, vd, 2011).

\section{Metod}

Panel veri analizinin ardında yatan temel varsayım bütün bireylerin havuzlanarak (bir araya getirilerek) model parametrelerinin tek bir birey gibi ortak olarak tahmin edilebileceğidir. Verilerin bu şekilde bir araya getirilmesi yatay kesitler ve zaman serileri arasındaki önceden gözlenemeyen değişimleri ortaya çıkararak çeşitli avantajlar sağlamaktadır (Asteriou ve Hall, 2007). Bu avantajlardan birincisi özellikle yatay kesit verilerde açıklanamayan, farklı birey parametreleri arasındaki heterojenliği göz önünde bulundurabilmesidir. İkincisi; farklı bireylere, firmalara, ülke ya da şehirlere ait etkilerin heterojen olduğunu ayırt edebilmesidir. Üçüncü olarak panel veri; yatay kesit ve zaman serisi analizi enformasyonunu birleştirerek değişkenler arasında daha az doğrusal bağlantı, daha fazla serbestlik derecesi ve etkinlik sağlamaktadır. Dördüncü olarak, panel veri dinamik uyarlamaları açıklamada daha yeteneklidir. Yatay kesit verileri dinamik dönüşümler hakkında hiçbir şey söyleyemez. Panel veri analizi bu dinamik tepkileri mevcut bilgiyi kullanarak çok uzun zaman serilerine ihtiyaç duymaksızın açıklayabilmektedir. Beşinci ve son olarak, panel veri analizi saf zaman serisi ya da saf yatay kesit verilerle kolayca ölçülemeyen etkileri belirleme ve ölçme kabiliyetine sahiptir. Üretim fonksiyonlarının analizinde, ölçek ekonomilerinin etkilerinin teknolojik ilerlemeden ayırt edilmesi bu duruma örnek olarak verilebilir (Baltagi, 2005; Kennedy, 2006).

Uygulamada öncelikle birim kök testleri ile serilerin durağanlıkları araştırılacaktır. Ardından eşbütünleşme testleri uygulanıp eşbütünleşik seriler için model katsayıları tahmin edilecektir. 
Panel veri analizlerinde serilerin durağanlıklarının ilk aşamada araştırılması gerekmektedir. Bu çalışmada LLC (Levin, vd, 2002) ve IPS (Im, vd, 2003) panel birim kök testleri seçilerek uygulanmıştır. LLC ve IPS testleri Denklem 3'teki gibi ifade edilen birinci dereceden otoregresif bir denkliği temel almaktadırlar.

$$
\mathrm{Y}_{i t}=\rho_{\mathrm{i}} \mathrm{Y}_{i t-1}+\Gamma_{\mathrm{it}} \theta_{\mathrm{it}}+\varepsilon_{i t}
$$

$\Gamma_{\text {it }}$ modeldeki sabit etkileri ve trend katsayılarını, $\rho_{\mathrm{i}}$ otoregresif katsayıy1, $\varepsilon_{i t}$ hata terimini ifade etmektedir. Bu modelde $\rho_{\mathrm{i}}$ 'nin 1'e eşit olması Y'nin bugünkü değerlerinin tamamen geçmiş değerlerinden etkilendiği anlamına gelmektedir. LLC testinde $\mathrm{H}_{0}$ hipotezi serilerin ortak bir otoregresif parametreye sahip olduğunu $\left(H_{0}: \rho_{\mathrm{i}}=\rho=1\right)$ öne sürmektedir. IPS testi ise zaman serisinde kullanılan ADF testinin panel veriye uyarlanmış bir versiyonudur. Birimler arasındaki heterojenlik göz önünde bulundurularak her bir birim için ayrı ayrı birim kök test edilir $\left(H_{0}: \rho_{\mathrm{i}}=1\right)$. Panel için elde edilen test istatistiği bireylere özgü istatistiklerin ortalamasıdır (Baltagi, 2005). Gerçekleştirilen Monte Carlo simülasyonları IPS testinin LLC testinden daha güçlü olduğunu ortaya koymaktadır (Tatoğlu, 2012).

Makro ekonomik serilere ilişkin araştırmalarda seriler seviye değerlerinde durağan değilken doğrusal bileşimleri durağan olabilmektedir. Bu nedenle serilerin birinci dereceden durağan olduklarının tespitinden sonra aralarında bir eşbütünleşme ilişkisinin olup olmadığı araştırılmalıdır. Bu çalışmada Pedroni (1999; 2004) tarafından geliştirilen panel eşbütünleşme testi uygulanacaktır. Bu testte birimlere özgü sabit ve trend etkileri ayrı ayrı göz önünde bulundurularak heterojenliğe olanak tanınmaktadır. Pedroni $(1999 ; 2004)$ birden fazla açıklayıcı değişkenli paneller için geliştirdiği eşbütünleşme testinde iki gurupta yedi adet test istatistiği geliştirmiştir. İlk dört test istatistiği gurup-içi (within-dimension) istatistikler olarak adlandırılmaktadır. Bunlar sırasıyla varyans oranı, nonparametrik PP (Philips ve Perron) tipi $\rho$, nonparametrik PP tipi t ve Dickey Fuller (DF) tipi t istatistikleri olarak adlandırılırlar. Bu dört istatistik hesaplanırken eşbütünleşme modeline ait otoregresif katsayılar ( $\phi i)$ homojen kabul edilerek havuzlanmaktadır. İkinci guruptaki üç test istatistiği ise guruplar-arası (between-dimension) istatistikler olarak adlandırılmaktadır. Üç istatistik de hesaplanırken her bir birim için oluşturulan eşbütünleşme modeline ait otoregresif katsayılar heterojen kabul edilir. Her iki gurup için $\mathrm{H}_{0}$ hipotezi "panel için eşbütünleşme yoktur" şeklindedir. Alternatif hipotezler ise homojenliği varsayan gurup-içi testlerde "panel için eşbütünleşme vardır" şeklinde iken, heterojenliği varsayan guruplar-arası testlerde "bazı birimler (i) için eşbütünleşme yok iken, diğer birimler için vardır” şeklindedir. Test istatistikleri asimptotik olarak standart normal dağılıma sahiptir.

Panel veri analizinde eşbütünleşik heterojen serilere ilişkin tahminde Fully Modified OLS (FMOLS) yaygın olarak kullanılmaktadır (Pedroni, 2000). Panel FMOLS tahmincisi her bir zaman serisi için Denklem 2'den elde edilen sonuçlar $\beta_{F M i}^{*}$ kullanılarak $\hat{\beta}_{G F M}^{*}=N^{-1} \sum_{i=1}^{N} \beta_{F M i}^{*}$ elde edilmektedir.

\section{Bulgular}

Tablo 4'te gelişmekte olan 10 ülke için yapılan LLC (Levin, vd, 2002) ve IPS (Im, vd, 2003) panel birim kök testi sonuçları yer almaktadır. LLC testinde serilerin ortak bir otoregresif parametreye sahip olduğu hipotezi $\left(H_{0}: \rho_{\mathrm{i}}=\rho=1\right)$ test edilmiştir. IPS testinde ise birimler arasındaki heterojenlik göz önünde bulundurularak her bir birim için ayrı ayrı sıfır hipotezi $\left(H_{0}: \rho_{\mathrm{i}}=1\right)$ test edilmiştir. LLC ve IPS test sonuçlarına göre CO2, GDP ve ENR serilerinin seviyede birim kök içerdikleri görilmektedir. Serilerin birinci farkları alındığında ise her iki testte de sıfır hipotezi \%1 anlamlılık seviyesinde reddedilmektedir. Elde edilen bulgulara dayanarak serilerin birinci dereceden durağan olduklarına karar verilmiştir.

\begin{tabular}{|c|c|c|}
\hline Seriler & $\begin{array}{c}\text { LLC } \\
(\text { Levin, vd, 2002) } \\
\left(H_{0}: \rho_{\mathrm{i}}=\rho=1\right)\end{array}$ & $\begin{array}{c}\text { IPS } \\
\text { IPS (Im, vd, 2003) } \\
\left(H_{0}: \rho_{\mathrm{i}}=1\right) .\end{array}$ \\
\hline $\mathrm{CO} 2$ & 0.14033 & $3.82541^{\mathrm{a}}$ \\
\hline GDP & 5.36783 & 4.78446 \\
\hline $\mathrm{GDP}^{2}$ & 8.45227 & 6.10510 \\
\hline ENR & 3.57874 & 1.12923 \\
\hline$\triangle \mathrm{CO} 2$ & $-9.75965 * * *$ & $-11.5037 * * *$ \\
\hline$\Delta \mathrm{GDP}$ & $-7.78767 * * *$ & $-7.24903 * * *$ \\
\hline$\Delta \mathrm{GDP}^{2}$ & $-4.11700 * * *$ & $-5.36945 * * *$ \\
\hline$\Delta \mathrm{ENR}$ & $-5.43338 * * *$ & $-8.69625 * * *$ \\
\hline \multicolumn{3}{|c|}{$\begin{array}{l}\text { Not: *** } \mathrm{p}<0.01, * * \mathrm{p}<0.05,{ }^{*} \mathrm{p}<0.1 \text { Optimal gecikme } \\
\text { uzunluğu Schwarz bilgi kriterine göre belirlenmiştir. Test } \\
\text { istatistiğinin yanında a indisinin olmas sabitli modeli, } \\
\text { olmaması sabit ve trendli modeli ifade etmektedir. Spektral } \\
\text { tahmin sürecinde bant genişliği Newey-West ile tespit } \\
\text { edilmiş ve Bartlett kerneli kullanılmıştır. }\end{array}$} \\
\hline
\end{tabular}

Tablo 4. LLC ve IPS Panel Birim Kök Testi Sonuçları 
Serilerin birinci dereceden durağan olduklarına karar verilmesinden sonra Pedroni (1999; 2004) panel eşbütünleşme testi gerçekleştirilmiştir. Tablo 5'te yer alan Pedroni (1999; 2004) panel eşbütünleşme testi sonuçlarına göre Gurup içi Panel- $\rho$, Panel-PP ve Panel-ADF testlerinde $\mathrm{H}_{0}$ hipotezi reddedilmiştir. Guruplar-arası test istatistiklerine bakıldığında ise Group - PP ve Group - ADF testlerinde $\mathrm{H}_{0}$ hipotezi reddedilmektedir. Genel bir bakış ile gerçekleştirilen testler seriler arasında eşbütünleşme ilişkisi olduğuna yönelik güçlü kanıt oluşturmaktadır. Sonuç olarak gelişen 10 ülke için bir araya getirilen serilerin eşbütünleşik olduğuna karar verilmiştir.

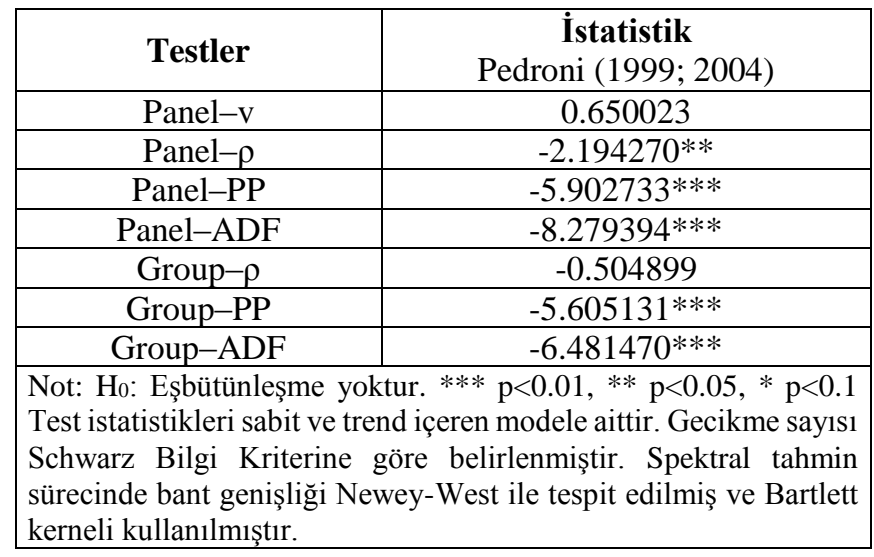

Tablo 5. Pedroni Eşbütünleşme Testi Sonuçları

Çevresel Kuznets Eğrisinin varlığına yönelik oluşturulan model (Denklem 2) Fully Modified OLS (FMOLS) tahmincisi (Pedroni, 2000) ile tahmin edilmiştir. Tablo 6'da raporlanan sonuçlara göre $\beta_{1}$ katsayısının pozitif ve anlamlı iken $\beta_{2}$ katsayısının negatif ve anlamlı olduğu görülmektedir. Özetle, karbondioksit emisyonu (CO2) ile gelir düzeyine (GDP) ilişkin bulguların Çevresel Kuznets Eğrisi hipotezini desteklediği görülmektedir. Bulgular söz konusu 10 gelişen ülke için gelişmenin ilk aşamalarında gelir artışının çevresel bozulmayı arttırdığını ancak belirli bir aşamadan sonra bu etkinin ortadan kalkarak tersine döndüğünü göstermektedir. ÇKE hipotezi çevre kirliliğine karşı hiçbir şey yapmamanın en iyi politika olduğunu ima etmektedir. Bu anlamda gelir artışı ile otomatik olarak çevre kirliliğinin azalacağını öne süren ÇKE hipotezi gelişen 10 ülke örneklemi için desteklenmektedir.

Uygulamada ek olarak elde ettiğimiz bir bulgu ise enerji tüketimi ile karbondioksit salınımına ilişkindir. Enerji tüketimine ilişkin $\beta_{3}$ katsayısının literatürle uyumlu bir şekilde pozitif ve anlamlı olduğu görülmektedir. Buna göre gelişen 10 ülkede kişi başına bir kilogram petrole eşdeğer tüketim yapılmasının karbondioksit emisyonunu 0.002455 metrik ton arttırdığı görülmektedir.

\begin{tabular}{|l|c|}
\hline $\mathrm{CO} 2$ & FMOLS \\
\hline$\left(\beta_{1}\right) \mathrm{GDP}$ & $0.000426 * * *$ \\
\hline$\left(\beta_{2}\right) \mathrm{GDP}{ }^{2}$ & $-1.36 \mathrm{E}-08^{*}$ \\
\hline$\left(\beta_{3}\right) \mathrm{ENR}$ & $0.002455^{* * *}$ \\
\hline Sonuç & $\begin{array}{c}\beta_{1}>0 \text { ve } \beta_{2}<0 \\
\text { ÇKE hipotezi geçerli }\end{array}$ \\
\hline Not: $* * * \mathrm{p}<0.01, * * \mathrm{p}<0.05,{ }^{*} \mathrm{p}<0.1$ \\
\hline
\end{tabular}

Tablo 6. FMOLS Tahmin Sonuçları

\section{Sonuç}

Kuznets 1955 yılındaki temel eserinde ülkelerin kalkınma sürecinde yaşadıkları gelir dağılımı değişmelerine dikkat çekmiştir. Kuznets'e göre ülkelerde gelişme sürecinin ilk aşamalarında gelir dağılımı bozulmakta, ancak belirli bir aşama sonrası gelir dağılımı düzelmeye başlamaktadır. Kuznets'in çalışması ile kalkınmanın bir boyutu olarak gelir dağılımı adaletine dikkat çekilmiştir. Bu durum araştırmacılara benzer süreçlerin kalkınmanın çevre boyutunda da geçerli olup olmadığını araştırma konusunda ilham vermiştir. Standart Kuznets Eğrisi bu bakış açısı ile Çevresel Kuznets Eğrisine dönüşmüştür. Gelişen ülkelerde sanayileşmenin getirdiği çevresel sorunlar bu sorunlara müdahale edip etmeme konusunda kararsızlığa yol açmaktadır. Kuznets'in hipotezinin çevre kirliliği boyutunda geçerli olması, aktif politikaları gereksiz kılmaktadır. Bu anlamda ülkeler milli gelirlerini adım adım yükselttikçe çevresel bozulma önce artacak bir aşamadan sonra azalmaya başlayacaktır. Günümüzde özellikle gelişen ülkelerin ciddi çevre sorunlarıyla karşı karşıya olduğu düşünülürse ÇKE hipotezinin bu ülkelerin uygulayacakları çevre politikaları açısından önemi daha iyi anlaşılmaktadır. Araştırmada bu nedenle gelişen 10 ülkenin 1980-2010 dönemi verileri kullanılmıştır. Serilerin birinci dereceden durağan olduklarının tespit 
edilmesinden sonra serilerin eşbütünleşik olduğu görülmüştür. Eşbütünleşik serilere ilişkin model Panel Fully Modified OLS tahmincisi ile tahmin edilmiştir. Bulgular gelişmekte olan ülkeler örneklemi için Çevresel Kuznets Eğrisi hipotezinin geçerli olduğuna işaret etmektedir. Böylesi bir durum gelir düzeyinin artması ile çevresel bozulmanın giderek azalacağı görüşünü desteklemektedir. Gelişen ülkelerde uzun dönemde fosil kaynak kullanımını azaltılarak çevresel kirliliği ve fosil kaynaklara olan bağımlılığın azaltılması olasıdır. Çevresel kirliliği azaltacak sürdürülebilir bir büyüme performansı için yenilenebilir enerji politikaları oluşturularak, bu ülkelerin gelişmiş ülkelerin kirlilik sığınakları haline gelmemesi konusunda hassasiyet gösterilmesi gerekmektedir. Çalışmamızda ek olarak çevresel bozulmaya etkisi olabilecek kurumsal ve sosyo-ekonomik faktörlerin de araştırılması gelecek çalışmalara öneri olarak sunulmaktadır.

\section{Kaynakça}

- Akın, 2014. "Kurumsal Kalitenin Çevre Üzerine Olan Etkileri: BRICS Ülkeleri Üzerine Bir Uygulama”, Uluslararası Alanya İsletme Fakültesi Dergisi, 6(2), 1-8.

- Ang, 2007. "CO2 emissions, energy consumption, and output in France" Energy Policy, 35(10), 4772-4778.

- Apergis ve Payne, 2010. "The emissions, energy consumption, and growth nexus: Evidence from the commonwealth of independent states", Energy Policy, 38(1), 650-655.

- Asteriou ve Hall, 2007. Applied econometrics : A modern approach using eviews and microfit. Palgrave Macmillan, New York.

- Aytun, 2014a. "Çevresel Kuznets Eğrisi Hipotezi: Panel veri Analizi”, Akademik Bakış, (44), p. 1-14.

- Aytun, 2014b. "Gelişen Ekonomilerde Karbondioksit Emisyonu, Ekonomik Büyüme ve Eğitim Arasındaki İlişki: Panel Veri Analizi”, The Journal of Academic Social Science Studies, (27), 349-362.

- Baltagi, 2005. Econometric Analysis of Panel Data (3rd ed.). John Wiley \& Sons, Chichester.

- Brock ve Taylor, 2004. "Economic Growth and the Environment: A Review of Theory and Empirics", NBER Working Paper Series, Working Paper no: 10854

- Chew, 2009. "Foreign Direct Investment, Pollution and Economic Growth: Evidence form Malaysia". Applied Economics, 41, 1709-1716

- Dinda, 2004. "Environmental Kuznets Curve Hypothesis: A Survey”, Ecological Economics, 49(4), 431455.

- Erataş ve Uysal, 2014. "Çevresel Kuznets Eğrisi yaklaşımının BRICT Ülkeleri kapsamında Değerlendirilmesi”, Iktisat Fakültesi Mecmuası, 64(1), 1-25.

- Fields ve Jakubson, 1994. New Evidence on the Kuznets Curve, Cornell University, Ithaca NY.

- Grossman ve Krueger, 1991. "Environmental Impacts of a North American Free Trade Agreement" (Working Paper No. 3914). National Bureau of Economic Research.

- Galeotti ve Lanza, 2005. "Desperately seeking environmental Kuznets", Environmental Modelling \& Software, 20(11), 1379-1388.

- Holtz-Eakin ve Selden, 1995. "Stoking the fires? CO2 emissions and economic growth", Journal of Public Economics, 57(1), 85-101.

- IEA, 2013. CO2 Emissions From Fuel Combustion Highlights. IEA Publications, Paris.

- Im, Pesaran ve Shin, 2003. "Testing for unit roots in heterogeneous panels", Journal of Econometrics, 115(1), 53-74.

- Jalil ve Mahmud, 2009. "Environment Kuznets curve for CO2 emissions: A cointegration analysis for China", Energy Policy, 37(12), 5167-5172.

- Kennedy, 2006. Ekonometri Kılavuzu (Ş. Açıkgöz \& M. Sarımeşeli, Trans.). Gazi Kitabevi, Ankara.

- Kumbaroglu, Karali ve Arikan, 2008. "CO2, GDP and RET: An Aggregate Economic Equilibrium Analysis for Turkey”, Energy Policy, 36, 2694-2708.

- Kuznets, 1955. "Economic Growth and Income Inequality”, The American Economic Review, 45(1), 1-28.

- Lean ve Smyth, 2010. "CO2 emissions, electricity consumption and output in ASEAN", Applied Energy, 87(6), 1858-1864.

- Lee ve Kim, 2009. "Both institutions and policies matter but differently for different income groups of countries: determinants of long-run economic growth revisited", World Development, 37(3), 533-49.

- Levin, Lin ve Chu, 2002. "Unit root tests in panel data: asymptotic and finite-sample properties", Journal of Econometrics, 108(1), 1-24. 
- Li, Yan, An, Chen ve Shen, 2016. "The coordination between China's economic growth and environmental emission from the Environmental Kuznets Curve viewpoint". Natural Hazards, 1-20. http://doi.org/10.1007/s11069-016-2314-0

- Ma ve Stern, 2007. "China's Carbon Emissions 1971-2003”, Rensselaer Working Papers in Economics, Rensselaer Polytechnic Institute, Department of Economics Number 0706.

- Morrisson, 2000. "Historical Perspectives on Income Distribution: The Case of Europe," in Atkinson and Bourguignon, eds., Handbook of Income Distribution. Elsevier, Amsterdam

- Narayan ve Narayan, 2010. "Carbon dioxide emissions and economic growth: Panel data evidence from developing countries”, Energy Policy, 38(1), 661-666.

- Omri, 2013. "CO2 emissions, energy consumption and economic growth nexus in MENA countries: Evidence from simultaneous equations models", Energy Economics, 40, 657-664.

- Ozcan, 2013.'The nexus between carbon emissions, energy consumption and economic growth in Middle East countries: A panel data analysis”, Energy Policy, 62, 1138-1147.

- Pedroni, 1999. "Critical Values for Cointegration Tests in Heterogeneous Panels with Multiple Regressors", Oxford Bulletin of Economics and Statistics, 61(S1), 653-670.

- Pedroni, 2000. "Fully modified OLS for heterogeneous cointegrated panels", B. H. Baltagi (Ed.), Advances in Econometrics (Vol. 15, s. 93-130). Bingley: Emerald.

- $\quad$ Pedroni, 2004. "Panel Cointegration: Asymptotic and Finite Sample Properties of Pooled Time Series Tests With an Application to the PPP Hypothesis", Econometric Theory, 20(03), 597-625.

- Richmond ve Kaufmann, 2006. "Is there a turning point in the relationship between income and energy use and/or carbon emissions?”, Ecological Economics, 56(2), 176-189.

- Robalino-Lopez, Mena-Nieto ve Garcia-Ramos, 2015. "Studying the relationship between economic growth, CO2emissions, and the environmental Kuznets curve in Venezuela (1980-2025)", Renewable and Sustainable EnergyReviews, 41, 602-614.

- Schultz, 1998. "Inequality in the Distribution of Personal Income in the World: How it is Changing and Why", Journal of Population Economics, 11(3), 307-44.

- Tatoğlu, 2012. İleri Panel Veri Analizi. Beta Yayıncılık, İstanbul.

- Uçan, Arıŏlu ve Yücel, 2014. "Energy Consumption and Economic Growth Nexus: Evidence from Developed Countries in Europe", International Journal of Energy Economics and Policy, 4(3), 411-419.

- Wang, Zhou, Zhou ve Wang, 2011. “CO2 emissions, energy consumption and economic growth in China: A panel data analysis”, Energy Policy, 39(9), 4870-4875.

- Williamson, 1997. “Globalization and inequality, past and present”, The World Bank Research Observer, 12(2), 117-135.

- World Bank, 2016. World Development Indicators, http://databank.worldbank.org/data/ (Erişim: 20.03.2016)

Bu çalışma Çukurava Üniversitesi Bilimsel Araştırma Projeleri birimi tarafından desteklenmiştir. Proje no: SBA2016-7001 


\title{
Türk Sosyal Güvenlik Hukuku'nda Sigortalı Lehine Yorum İlkesi Principle of Interpretation in Favor of the Insuree in Turkish Social Security Law
}

\author{
Asst. Prof. Dr. Nurgül Emine Barın (Afyon Kocatepe University, Turkey)
}

\begin{abstract}
One of the major problems encountered in the implementation of the rule of law is in the absence of the meaning of law or what it wants to tell is not clearly defined, the true meaning is revealed through interpretation. In labor law and social security law; Although the review will benefit from the rules for the common law, workersinterpretation in favor of the insuree is effective. This policy is considered as one of the fundamental policies of the Labour and Social Security Law. Located between the basic policies of business law, the protection of the workers, which is a consequence of the interpretation in favor of the insuree policy, shows itself in the form of interpretation in favor of the insuree in the social security law. One factor for necessity of supporting interpretation in favor of the insuree is, social security right is among the basic human rights. In particular, the interpretation of legislation related to the social security right by constitutional guarantee, it is important to keep in mind this basic policy. The overall purpose of the social security law is to benefit from this right by more people, namely the expansion of the scope. In this study, the place of interpretation in favor of the insuree and limitations related to this interpretation will be examined in the light of samples of Supreme Court Decisions and regarding substance of the Constitution and laws.
\end{abstract}

\section{Giriş}

Yorum en genel tanımıyla kanunun gerçek anlam ve kapsamını belirleme faaliyetidir (Gözler, K. 2013:126). Soyut olan hukuk kuralının somut olaya uygulanabilmesi için, o hukuk kuralının anlamının tam olarak belirlenebiliyor olması gerekmektedir. Eğer ki hukuk kuralının anlamı belirsiz ise, bu durumda yoruma başvurmak kaçınılmaz hale gelmektedir. Dworkin'e (1982:181) göre yorum; yasal bir analiz tekniği olarak ortak hukuka yabancı olmayan bir kavramdır (common law-Ortak hukuk; 11.yüzyılda Ingiltere'de gezici yargıçlar tarafindan geliştirilmiştir. Daha sonra İngiliz Kolonisi olan yerlere yayılmış ve bugün Amerika Birleşik Devletleri, Kanada, Irlanda, Singapur, Pakistan, Hindistan, Gana, Yeni Zelanda, Güney Afrika, Çin (Hong Kong), Avustralya ve hatta Kuzey Kıbrıs Türk Cumhuriyeti gibi pek çok ülkenin hukuk sistemini şekillendirmiştir. Bu sistem esas olarak, örf ve adet hukukuna dayanır. Roma Hukukundan farklı olarak ortak hukuk, özel hukuk-kamu hukuku ayrımına yer vermez. Ortak hukuk sisteminde kanun koyucu yargıçtır, Dönmez B, 2013). Yorum fikri, konuşmacının anlam veya niyetiyle olan bağ azalmadığı sürece, hukuk önermelerinin gerçek değeri veya doğasının bir gereği olarak görülmemelidir (Dworkin R, 1982:181). Dolayısıyla, yazılı veya sözlü kuralların yorumunda dikkat edilmesi gereken ilk nokta, anlamı noktasında yaşanan bir belirsizliğin var olmasıdır. Yorumlama, özellikle yasal metinler üzerinde sık sık çıkan anlaşmazlıklarda, metni anlamayı mümkün kılmaktadır (Patterson, D. 2003:6).

Medeni Kanun'un 1. maddesinde " Kanun, sözüyle ve özüyle değindiği bütün konularda uygulanır" ifadesi kullanılmaktadır. Buradan da anlaşılacağı üzere, kanun uygulanırken sadece metin üzerinden hareket edilmeyecek, kanunun özü (ruhu) de dikkate alınacaktır. Daha açık bir ifadeyle kanunun amacı da anlamının belirlenmesindeki temel unsurlardan birisi olmaktadır. Sosyal güvenlik hukukunda, hukuk kurallarının gerçek anlamının belirlenmesi yönünde yoruma başvururken, bu hukuk dalının kendine özgü özelliklerinin de dikkate alınması önem arz etmektedir. İnsan Hakları Evrensel Bildirgesi'nin 22. maddesinde "Herkes, toplumun bir ferdi olarak sosyal güvenlik hakkına sahiptir; sosyal güvenlik, bireyin onuru, kişiliğinin geliştirilmesi için kaçınılmaz ekonomik, sosyal ve kültürel hakların tatmin edilmesi temeline dayanır" denilerek, sosyal güvenlik politikalarının temelinde kişiliğin geliştirilmesi ve hatta sonucunda insan mutluluğunun temininin amaçlandığını vurgulamaktadır (Güzel A. ve Okur A.R., 1996:6). T.C. Anayasası'nın Sosyal güvenlik hakkı başlığı altındaki 60 maddesinde de " Herkes, sosyal güvenlik hakkına sahiptir. Devlet, bu güvenliği sağlayacak gerekli tedbirleri alır ve teşkilatı kurar" denilerek bu hak temel haklar arasında sayılmış ve devlet bu konuda görevli kılınmıştır. Sosyal güvenliğin tanımına bakılacak olursa; bireylerin istekleri ve iradeleri dışında uğrayacakları tehlikelerin zararlarından kurtarılma garantisi olarak tarif edilebilen sosyal güvenlik, tehlike meydana gelmeden önce bu garantinin varlığına dayalı soyut bir tatmin duygusunu, tehlike meydana geldikten sonra ise tehlikenin zararlarını ortadan kaldırmaya yönelik somut tedbirler bütünü olarak ortaya çıkmaktadır (Alper Y, 1999:4).

İş ve Sosyal Güvenlik Hukukunun temel ilkelerinden birisi de, işçi-sigortalı lehine yorum ilkesidir. İş hukukunun temel prensipleri arasında yer alan işçinin korunması ilkesinin bir sonucu olan işçi lehine yorum ilkesi (bu konuda ayrıntılı bilgi için bkz: Keskin N, 2002), sosyal güvenlik hukukunda kendini sigortalı lehine yorum şeklinde göstermektedir. Sosyal güvenlik hukukunda genel amaç, bu haktan olabildiğince fazla kesimin yararlanabilmesi yani kapsamının genişletilmesidir. Diğer bir ifadeyle bu hukukun uygulanmasında esas alınacak temel ilkelerden birisi de şartlar elverdiği ölçüde sigortalı lehine yorum yapılmasıdır. Bu çalışmada bu ilkeden hareketle öncelikle, 
yorum türleri ve yöntemleri, yorumda kullanılan kurallara değinilecektir. Daha sonra da sigortalı lehine yorumun sosyal güvenlik hukukundaki yeri ve uygulanması değerlendirilecektir.

\section{Hukukta Yorum}

Bir hukuk kuralının anlamı şüpheye yer vermeyecek şekilde net ve açıksa bu durumda o kuralın yorumlanmasına ihtiyaç duyulmamaktadır. Ancak, hukuk kuralının ne demek istediğinin anlaşılamadığı durumlarda soyut olan kuralın somut olaya uygulanabilmesi için yoruma başvurmak kaçınılmaz hale gelmektedir. Bu bağlamda başvurulabilecek farklı yorum türleri, yöntemleri vardır. Ayrıca yorum yapılırken başvurulacak mantık kuralları da konunun önemli bir boyutunu oluşturmaktadır.

\subsection{Yorum Türleri}

Yorum türlerini, yorumu yapan makamlara göre dört başlık altında toplamak mümkündür. Bunlardan ilki yasama yorumudur. Kanun koyucunun mevcut bir kanun hükmünün uygulama bakımından nasıl ele alınması ve nasıl algılanması gerektiğini ifade ettiği bağlayıcı nitelikteki bu yorum türüne, 1982 Anayasasına göre Türk hukuk sisteminde izin verilmemektedir (Çomaklı Ş.E. s:2). Bir diğer yorum türü yargı yorumudur ki, hukuk kuralını uygulayacak olan yarg1 organı tarafindan yapılan yorumdur. Yarg1 yorumunda hakim, ya mevcut hukuk kuralını olaya uygulayarak yorum yapacaktır ya da olaya uygulanacak bir hukuk kuralının olmadığı veya mevcut olmakla birlikte hakimin değerlemesine bırakıldığı bazı durumlarda hukuk yaratma ve takdir yetkisinin kullanarak uyuşmazlığı çözecektir (Keskin N. 2002:17). Yargısal yorum; mahkemelerin, önlerindeki uyuşmazlığa uygulayacakları hukuk kuralına anlam kazandırma eylemleri olarak da ifade edilebilir. Durağan, katı kurallar arasına sıkışmış yasaların, olaylara, yaşama uygulanışı olarak nitelendirilebilir. Yasalar, yorum sayesinde farklı olaylara yeni koşullar altında uygulanarak canlılık kazanacaklardır. Mahkemenin vermiş olduğu karar, hukuk ve insanlar arasında köprü kuran bir yorum şeklidir (Fiss O.M., 1982:740). Bu nedenle yasaların somut olaylara uygulanabilmesi için yorum kaçınılmaz hale gelmektedir (Can H. ve Güner S. 2006:195). Üçüncü yorum türü ise, bilim adamlarının bir yasanın anlamını yorumlama anlamında yaptıkları fikri çalışmaları içeren bilimsel yorumdur (Bayraklı.H.H., 2009:35). Bilimsel yorum soyut ve genel bir nitelik taşımaktadır. Medeni Kanunu'nun 1 maddesinde "Hâkim, karar verirken bilimsel görüşlerden ve yargı kararlarından yararlanır" denilerek bilimsel yoruma yer verilmiştir. Son yorum türü de, yürütme ve idare tarafindan, kanunla verilen yetkileri kullanırken, kuralın yorumlanması şeklinde karşımıza çıkan idari yorumdur. İdari yorumun sonucu; tüzük, yönetmelik, genelge, kararname şeklinde ortaya çıkmaktadır. Anayasa'nın 125 maddesinde, "İdarenin her türlü eylem ve işlemlerine karşı yargı yolu açıktır" diyerek idari yorumun hukuki sonuçlarına ilişkin yargı yoluna başvurulabileceğini vurgulamıştır.

\subsection{Yorum Yöntemleri}

Bir hukuk kuralının anlamını belirleme konusunda, hâkimin başvurabileceği farklı yorum yöntemleri vardır. Bunlardan hangisinin uygulanacağı konusunda yasalarda belirgin bir açıklık bulunmamaktadır. Bu yorum yöntemlerini şu şekilde sıralamak mümkündür.

Sözel yorum; hukuk kuralının anlamının, metinde kullanılan sözcük ve deyimlere dilbilgisi kurallarının uygulanması suretiyle belirlenmesidir (Önen M. 2005:101). Bir metin kendini, kendi adına konuşur" fikri, metinsel (sözel) yorum yaklaşımının bir ifadesidir (Metin, S.). Yoruma, Medeni Kanun'un 1. maddesinde de ifade edildiği gibi sözüyle başlamak gerekmektedir. Bu yöntemin eleştirilen yönü, kanun koyucunun kullandığı sözcüklere aşırı değer vermesi ve bu sözcüklerin titizlikle ve doğru bir şekilde seçildiğini varsaymasıdır.

Tarihsel yorumda; kanun koyucunun kanunu koyarken izlediği amaç araştırılır. Bunun içinse; kanunun sözleri yeterli değildir. Kanunun hazırlık çalışmalarına, yani komisyon ve parlamentoda yapılan görüşme ve tartışmalara ve kanunun gerekçesine bakılmalıdır. Ancak, toplumsal yaşam değişim halindedir. Kanunun yapıldığı zaman hakim olan anlayışa göre toplumun ihtiyaçlarını karşılamak her zaman doğru olmaz. Diğer yandan, kanun bir defa kabul edildikten sonra hukuken kendi geçmişinden kopmakta ve bağımsız bir varlık niteliği kazanmaktadır (Gözler K. 1998:168).

Amaçsal yorum yönteminde hukuk kuralları, uygulandığı zamanın gereklerine ve anlayışına göre yorumlanmaktadır. Yasaları hazırlayan, onu yürürlüğe koyanların bir amacı, bir yorumu vardır. Ama yasa, usulüne göre yürürlüğe konulduktan sonra hazırlayanların görüşünden, anlayışından farklı, bağımsız nitelik kazanmaktadır. Bağımsız niteliği olan yasanın, uygulandığı zamanın gereklerine ve anlayışına uygun olarak yorumlanması yerinde olacaktır (Can H. ve Güner S. 2006:?).

Mantıki yorum yönteminde, ele alınan hükmün, kanunun sistematiğine göre bulunduğu yeri, diğer hükümlerle ilişkisi ve kanunun genel amacı ve yönü dikkate alınmak suretiyle varılacak mantıksal sonucu saptayan bir yorum gerçekleştirilmektedir. Mantıksal yorum ile "hükmün özü" ortaya çıkarılmakta ve böylece sözel yorumun eksikliği ya da yanlışlığ giderilmeye çalışılmaktadır (Önen M. 2005:101). Kavramcı yorum yöntemine göre; bir hukuk kuralını yorumlarken sosyal gerçeklikten veya somut gerçeklikten ziyade, hukuk normunun soyut içeriğinden hareket etmek gerekmektedir. Hukuk normunun içeriği ise hukuk biliminin geliştirdiği “kavram”lar ile belirlenmektedir (Gözler K. 1998:170). 
Son yorum yöntemi de menfaatler içtihadıdır. Menfaatler içtihadı, 1900 yılında Alman Medeni Kanununun kabulünden sonra Alman hukukçuları tarafından geliştirilmiş bulunan bir yöntemdir. Buna göre, her hukuku uyuşmazlığında bir menfaat (çıkar) uyuşmazlığı bulunmaktadır. Yorumcunun görevi, somut olayı yani menfaatler çatışmasını bir karara bağlayarak menfaatler arasında dengeyi sağlamaktır (Güriz A. 1999:62).

\subsection{Yorumda Yararlanılan Mantık Kuralları}

Bir hukuk kuralının anlamını belirlemede yararlanılan temel mantık kuralları şunlardır. Kıyas (benzetme); kanunda belirli bir fiili durum için konulmuş bulunan kuralın, o duruma benzeyen fakat hakkında hüküm bulunmayan başka bir duruma da uygulanmasıdır. Evleviyet (öncelikle uygulama) kuralının temelinde, çoğun içinde azın da bulunacağı veya bütün için doğru olan şeyin parçalar için de doğru olacağı, daha önemli bir durum için kabul edilen bir hükmün daha az önemli bir durum için de uygulanması gerektiği fikri vardır(Gözler K. 1998:173). Aksi ile kanıt uygulamada kıyasa benzemektedir. Kıyasta mevcut hukuk kuralı benzer durumlar için uygulanırken, aksi ile kanıt da hukuk kuralı tamamen zıt bir sonuç doğuracak şekilde hakkında hüküm bulunmayan duruma uygulanmaktadır (Keskin N. 2002:14).

\section{Sosyal Güvenlik Hukukunda Sigortalı Lehine Yorum İlkesi ve Uygulanması}

İş Hukukunun Sanayi devrimiyle birlikte bir bilim dalı olarak ortaya çıktığını söylemek çok da yanlış olmayacaktır. Özellikle olumsuz çalışma koşulları sonucu ortaya çıkan ilk hukuk kurallarının işçiyi koruma yönünde düzenlemeler içerdiği görülmektedir. İş hukukunun işçiyi koruma amacının bir yansıması olan işçi lehine yorum ilkesi Türk Hukukunda bir ilke olarak kabul görmektedir (Bu konuda, bkz. Yarg. İçt.Bir.K. 18.06.1958 gün ve E.20/K.9, R.G. 30.09.1958, s.10020; Yarg.HGK 25.01.1978, E.3435/K. 23, (Keskin N. 2002:38 ); Yarg.9.H.D. 13.04.2000 T. E.1676/K.5056). Hatta Fransız Hukuku'nda "şüpheden işçi yararlanır" şeklinde bir düzenleme getirilmiş̧tir ki bu da işçiyi koruma amacının bir sonucudur (İş Hukuku ve Sosyal Güvenlik Hukuku Akademik Forumu 2014:38).

Sosyal devlet; bireylere belirli bir sosyal güvenlik hakkı ve asgari gelir düzeyi öngören, sağlık ve refah hizmetlerinden serbestçe yararlanma ve belirli bir yaşa kadar eğitim olanağı sunan, bir takım sosyal riskleri önleyici tedbirler alan devlet anlayışıdır (Çakır, Y.2011:87). Sosyal devlet olmanın bir gereği ve sonucu da, sosyal güvenlik hakkının tüm bireylere sağlanması ve güvence altına alınmasıdır. Dolayısıyla, hukuk kuralı uygulanırken anayasada güvence altına alınan en temel haklardan biri olan sosyal güvenliğin esas ilkelerinden (sosyal güvenliğinin kapsamının ve uygulama alanının kişiler ve riskler açısından genişletilmesi) hareket ederek sigortalı lehine yoruma başvurulması yanlış olmayacaktır. Bu kapsamda, yorum yöntemi seçilirken tek bir yorum yönteminden hareket etmek yerine; bu hukuk dalının genel niteliği ve amacı da göz önüne alınarak yoruma başvurmak saha sağlıklı sonuçlar verecektir. Değişik tarihlerde verilen yargı kararlarına bakıldığında; sigortalı lehine yorum ilkesinin uygulamaya geçirildiği görülmektedir. Yargıtay Hukuk Genel Kurulu 1990 yılında verdiği bir kararda (Yarg.H.G.K 14.2.1990 E. 1989/10-391 K. 1990/83); "Kanunun çok açık olmasına karşın yine de kuşkulu bir durumun varlığı iddia edildiği taktirde şüphenin sigortalının lehine yorumlanacağı ise iş ve sosyal güvenlik hukukunun temel ilkelerindendir" diyerek bunu vurgulamıştır.

Yargıtay 10 Hukuk Dairesi 2011 yılında verdiği bir karara (Yarg. 10.H.D. 17.03.2011 E. 2010/9386 K. 2011/3728) ilişkin şu tespitlerde bulunmuştur. "506 Sayılı Kanun m. 53 uyarınca malüliyet aylığı bağlanabilmesi için; sigortalının çalışma gücünün en az 2/3'ünü yitirdiğinin kanıtlanması gereklidir. Mahkemece alınan, Sosyal Sigortalar Yüksek Sağlık Kurulu raporunda ve Adli Tıp İhtisas Dairesi'nin raporunda; davacının çalışma gücünün 2/3'ünü yitirmediği tespit edilmiștir. Bu sebeple 506 Sayılı Kanun hükümlerine göre davacının maluliyet aylığ kazanması koşulları oluşmamıştır. Mahkemenin kararı, bu yönden doğru bulunmaktadır. Ancak davacının talep tarihinden sonra 1.10.2008 tarihinde yürürlüğe giren 5510 Sayılı Kanun hükümlerinde; maluliyet sigortası yönünden sigortalılar lehine getirilmiş hükümler de bulunmaktadır. Bu kanundaki söz konusu hükümlerin, sigortalılar lehine olması sebebiyle uyuşmazlığın çözümünde 5510 Sayılı Kanun hükümlerinin de ayrıca değerlendirilmesi gereklidir" . Yargı organı bu gerekçeyle sigortalı lehine karar vermiştir.

Yargitay 10.Hukuk Dairesi verdiği diğer bir kararda (Yarg.10.H.D. 25.02.2010 E. 2009/8312K. 2010/2516); "Sosyal güvenlik hukukunun özel ve kamusal niteliği itibarıyla ve 5510 sayılı Kanunda, anılan hükümle getirilen, sigortalıların lehine olan bu borçlanma hakkının, Kanunun yürürlüğünden önceki doğum olaylarına uygulanmasını engelleyen bir düzenlemenin olmadığı gözetildiğinde, 5510 sayılı Kanunun yürürlük tarihinden önce meydana gelmiş doğum olaylarına da uygulanabileceğini kabul etmek gereklidir. Zira maddi hukukun her zaman, hayatın değişen sosyal akışı içinde gelişen tüm olayları ve ayrıntıları kurallaştırma gücüne sahip olmadığını da dikkate alıp, çıkarlar dengesi ve adalet duygularını gözeterek toplumun gereksinmelerini karşılamakla yükümlü bulunan yargı organları, sigortalıların lehine hükümler içeren düzenlemelerin yürürlüğe girdiği durumlarda, kanun koyucunun amacını da göz önünde bulundurarak, söze oranla öze üstünlük tanıyan bir yorumla sonuca varmalıdır" ifadesini kullanmıştır. Yargıtay; askerlikte geçen sürelerin borçlanılmasına ilişkin verdiği kararında (Yarg.10.H.D. 11.4.1988 E. 1988/2355 K. 1988/2165), kişinin askerlik sırasında hava değişimi nedeniyle geçen sürelerin de er olarak silah altında geçen süreler olarak kabulü ve borçlanılmasının sigortalı lehine yorum kuralı sonucu olacağı ortadadır diyerek yasa metnindeki "er olarak silah altında geçen süreler" sözcükleri yorumlanırken, sigortalı lehine 
yorum kuralından hareketle geniş yorumlu-sonuca gidilmesi gerekirken, dar yoruma tabi tutulup sadece askerlikten sayılan sürelerin er olarak silah altında geçen süre olarak kabulü isabetsizdir şeklinde karar vermiştir.

Yargıtay 10.Hukuk Dairesi 2004 yılında verdiği bir kararda (Yarg.10.H.D.18.3.2004 E. 2003/6953K. 2004/2074), sosyal güvenlik ve sigortalı lehine yorumla ilgili olarak şu temel noktalara dikkat çekmiştir. Öncelikle belirtmek gerekir ki, Anayasamızın 2. maddesi "Türkiye Cumhuriyeti'nin sosyal bir hukuk devleti" olduğunu işaret etmekte, 60. maddesinde ise "Herkes sosyal güvenlik hakkına sahiptir." Denilmek suretiyle "hiç kimsenin sosyal güvenlik hakkından mahrum edilemeyeceği vurgulanmaktadır. Öte yandan, 506 sayılı Yasa'nın 6. maddesi de "sigortalı olmak hak ve yükümünden kaçınılamaz ve vazgeçilemez" olduğunu hükme bağlamaktadır. İşte bütün bu yasal düzenlemelerle, "sosyal güvenlik" konusunun kamusal niteliği ön plana çıkartılmakla birlikte, özünde huzurlu bir toplum oluşturulması, milli dayanışmanın sağlanması, eşitlik ve adalet ilkeleri çerçevesinde insan haklarına saygılı ve bireylerin yaşam koşullarının iyileştirilerek insanca yaşam olanaklarının hazırlanması görevi cümlesinden olarak, toplumun olabildiğince kapsamlı biçimde sosyal güvenceye kavuşturulması, diğer bir anlatımla geniş halk kitlelerinin Devlet'in koruması (sosyal güvenlik şemsiyesi ) altında toplanmasının amaçlandığını söylemek yerinde olur. Diğer taraftan İş ve Sosyal Güvenlik Kanunları'nın (vaz'ındaki ) çıkartılmasındaki asıl etkenlerden biri de çalışma hayatının düzenlenmesi yanında, işverenler karşısında güçsüz ve zayıf durumda bulunan, çalışanların haklarının güvence altına alınması amacına yöneliktir. Öyle ise, bu sosyal amaçlara ulaşılmasında yasaların genişletici yorumla ele alınması, bu çevrede, çalışanlar lehine hareket edilerek, yok edici ve yıkıcı değil fakat yapıcı yaklaşımlar içinde olunması, sosyal güvenlik hukukunun evrensel ilkelerindendir.

Yargitay 10. Hukuk Dairesi bir kararında (Yarg.10.H.D. 13.10.2004 E. 2004/4836 K. 2004/9206), "Anılan dönemdeki yasal boşluğun, sigortalı lehine olan eski düzenlemedeki 3 tam yıl prim ödeme süresi gözetilerek yargıç tarafından doldurulması sosyal güvenlik hukukunun temel yaklaşım gereklerinden olduğu...." ifadesiyle yasada boşluk olması durumunda, sigortalı lehine eski yasa hükmünün uygulanması esasını benimsemiştir. Aynı yönde eski tarihli bir kararında da (Yarg.21.H.D. 29.12.2004 E.2004/12248 K.2004/12413), " Söz konusu bu yasal boşluk sigortalı lehine doldurulmalıdır" diyerek aynı yönde karar aldığı görülmektedir.

Yargitay bir kararında da (Yarg.10.H.D. 11.11.2008 E. 2008/13916 K. 2008/14584), "sosyal güvenlik kurallarının niteliği dikkate alındığında, sigortalının lehine olan düzenlemeye üstünlük tanınması gerektiği ve halen süregelen uyuşmazlıklar bakımından yeni yasal düzenlemenin geriye doğru yürüyeceği sonucuna varılır" diyerek yasaların geriye yürümesi konusunda da sigortalı lehine yorum ilkesinden hareket etmiştir.

Yargı kararlarına bakıldığında görülmektedir ki, sigortalı lehine yorum ilkesi sosyal güvenlik hukukuna ilişkin yargılamanın temel ilkelerinden birisini oluşturmaktadır.

\section{Sosyal Güvenlik Hukukunda Sigortalı Lehine Yorum İlkesinin Sınırları}

Sosyal güvenlik hukukunda uygulanan sigortalı lehine yorum ilkesi sınırsız bir ilke olarak görülmemelidir. Hukuk kuralının yer aldığı metin hiçbir kuşkuya yer vermeyecek şekilde açık ve netse illa ki yoruma başvurmak yanlış sonuçlara götürebilecektir. Yargıtay Hukuk Genel Kurulu bu yönde verdiği bir kararda (Yarg.H.G.K. 8.3.2006 E. 2006/21-15 K. 2006/58), "... iş ve sosyal güvenlik hukukuna hakim prensip olan; işçi ve sigortalı lehine yorum ilkesinden söz edilerek, yasalarda açıkça belirtilen tanımların dışına çıkılmasına imkan bulunmamaktadır..." diyerek açık ifadelerin bulunduğu durumlarda sigortalı lehine yorum ilkesinden hareket etmeyi yerinde bulmadığına dikkat çekmektedir.

Bu konudaki diğer bir tartışmalı sınırlama da, T.C. Anayasası'nın 65. maddesinde yer almaktadır. Maddede " Devlet, sosyal ve ekonomik alanlarda Anayasa ile belirlenen görevlerini, bu görevlerin amaçlarına uygun öncelikleri gözeterek mali kaynaklarının yeterliliği ölçüsünde yerine getirir" ifadesine yer verilmektedir. Burada öncelikle, Anayasa da devletin temel ilkeleri arasında sayılan sosyal devlet olma niteliğinin gözden kaçırmamak gerekmektedir. T.C.Anayasasının 2. maddesinde "Türkiye Cumhuriyeti........ sosyal bir hukuk devletidir" denilmiştir. 5. maddede ise; " Devletin temel amaç ve görevleri,........... kişilerin ve toplumun refah, huzur ve mutluluğunu sağlamak; kişinin temel hak ve hürriyetlerini, sosyal hukuk devleti ve adalet ilkeleriyle bağdaşmayacak surette sınırlayan siyasal, ekonomik ve sosyal engelleri kaldırmaya, insanın maddi ve manevi varlığının gelişmesi için gerekli şartları hazırlamaya çalışmaktır" ifadesiyle devletin temel amacının bireylerin huzur ve mutluluğunu sağlamak ve bunun önündeki engelleri kaldırmak olduğu vurgulanmıştır. Dolayısıyla sosyal güvenlik hakkının da sosyal devlet olma ilkesinin bir gereği olarak devlet tarafından sağlanması ve güvence altına alınması gerekmektedir. Küreselleşme süreci ile birlikte sosyal devlet kavramındaki yıpranmalar, sosyal devlet ilkesinin önemini yitirdiğine mi işaret etmektedir? Konuya bu açıdan bakıldığında, sosyal devletin vazgeçilmezliği tartışmasızdır. Değişen koşullar karşısında, sosyal devlet ilkesinin korunması ve bu koşullara ayak uydurabilecek şekilde düzenlenmesi önem arz etmektedir (İş Hukuku ve Sosyal Güvenlik Hukuku Akademik Forumu, 2014:10,11).

Bu bağlamda 65. Maddede; devletin sosyal ve ekonomik görevlerini yerine getirirken, bu görevlerin amaçlarına göre öncelikleri belirleyerek mali kaynaklarının yeterliliği ölçüsünde hareket etmesi gerektiği vurgulanmaktadır. Sosyal güvenliğin genel amacı göz önüne alındığında, bu hakkın kullanımına ilişkin uyuşmazlıklarda 65 . 
maddenin bir bahane olarak kullanılması çok da yerinde olmayacaktır. Anayasa Mahkemesi'nin; yataklı tedavi kurumlarında sağlık yardımlarının altı ayla sınırlandırılmasına ilişkin bir kuralı iptal ederken dayandığı gerekçe şudur. "... henüz tedavisi süren kişinin yaşama hakkını, hayatını beden ve ruh sağlığı içinde sürdürme hakkının özünü zedelediğinden Anayasa'nın 17. ve 56. maddelerine aykırıdır. Öte yandan sosyal güvenlik hakk1 "yaşama, maddi ve manevi varlığını koruma hakkı" ile bağlantılı olduğundan, sağlık yardımlarının yataklı tedavi kurumlarında altı ayı geçemeyeceğine ilişkin kural; Anayasanın 65. maddesi kapsamında değerlendirilemez". Anayasa mahkemesi hakların bütünlüğü ilkesinden hareketle doğru bir sonuca varmıştır (İş Hukuku ve Sosyal Güvenlik Hukuku Akademik Forumu, 2014:11).

\section{Sonuç}

Hukuk kuralının anlamını belirleme konusunda yoruma başvurmanın kaçınılmaz olduğu durumlarda, özellikle sosyal güvenlik hukuku alanında göz önünde bulundurulması gereken temel ilkelerden birisi de sigortalı lehine yorumdur. Sosyal güvenlik hukukunda yoruma başvururken elbette genel hukuk hükümlerinden yararlanılacaktır. Ancak, sosyal güvenliğin kişinin maddi ve manevi bütünlüğünü risklere karşı korumak amaçlı bir bilim olduğu düşünüldüğünde; hedefinin hem kapsamını hem de uygulama alanını genişletmek olduğu ortaya çıkmaktadır. Ayrıca sosyal güvenlik hakkının anayasal güvence altına alındığı da gözden kaçırılmaması gereken önemli noktalardan birisidir. Sosyal güvenliğin bu özellikleri sonucunda, insan refah ve huzurunu korumak ve geliştirmeye yönelik çözümler üreten bu bilim dalında sigortalı lehine yorumun yargı kararlarında da belirgin bir şekilde ortaya çıktığı gözlemlenmektedir.

Sosyal güvenlikte sigortalı lehine yorum ilkesi kabul görse de, sınırsız bir uygulama alanının var olduğundan söz etmek mümkün değildir. Özellikle somut olaya uygulanacak hukuk kuralının anlamı konusunda bir tereddüt yok ise, net ve açık bir şekilde anlaşılabiliyorsa, sigortalı lehine yorum adı altında hukuk kuralına yeni ve bambaşka bir anlam yüklemek doğru olmayacaktır. Ayrıca yorum yapılırken anayasanın temel ilkelerine aykırılık oluşturacak sonuçlara varılmaması gerekmektedir. Sigortalı lehine yorum konusunda tartışma yaratan diğer bir sınırlama da T.C. Anayasası'nın 65. maddesiyle getirilmiştir. Uygulamada çeşitli tartışmalara yol açan bu madde hükmünü, sosyal güvenliği sınırlayıcı, hedef ve amacını ortadan kaldıran bir hüküm şeklinde değerlendirmek yanlış sonuçların ortaya çıkmasına neden olabilecektir. Dolayısıyla sosyal güvenlik hakkının önemi ve önceliği dikkate alınarak hükmü değerlendirmek yerinde olacaktır.

Sonuç olarak; hukuk sisteminin önemli sorunlarından birisi olan yorum kavramı sosyal güvenlik hukukunda; bilim dalının niteliği gereği farklı bir boyutla, sigortalı lehine yorum şeklinde karşımıza çıkmaktadır. Çalışmamızda; sosyal devlet ilkesinin en temel özelliklerinden birisi olan sosyal güvenlik hakkının uygulanması şeklinde de adlandırabileceğimiz bu yorum şekli ve uygulanması konusunda bir değerlendirme yapılmaya çalışılmıştır.

\section{Kaynakça}

- Aktaş, S. 2011. "Hukukta Yorum Çabaları” http://www.erzincan.edu.tr/birim/HukukDergi/makale/2011 2.1.pdf erişim tarihi 10.05.2015

- Alper, Y. 1999. “Türkiye'de Sosyal Güvenlik ve Sosyal Sigortalar (SSK, BA ğ-KUR)” eBook Collection (EBSCOhost), EBSCOhost erişim tarihi 13.05.2015.

- Bayraklı H.H. 2009. Hukukun Temel Kavramları, 2. bası, Afyon.

- Can H. ve Güner S. 2006. Hukukun Temel Kavramları, Arıkan Basım Yayım Dağıtım, İstanbul. Hiperkitap (eBook Collection), EBSCOhost erişim tarihi 14.05.2015.

- Çakır Y, 2011. "Sağlık Hizmetlerinde Katılım Payı Uygulaması ve Bu Uygulamanın Sosyal Devlet İlkesi ve Sosyal Güvenlik Hakkı Bakımından İncelenmesi”, Sayıştay Dergisi, 80, Ocak-Mart. s.85-105.

- Çomaklı, Ş.E. Hukukun Temel Kavramları http://atauzem.atauni.edu.tr/dosya/ortak/materyal/Hukukun\%20Temel\%20Kavramlar\%C4\%B1 \%C3\%9Cnite\%202.pdf erişim tarihi 14.05.2015

- Dönmez B, 2013, “İngiliz Ceza Hukukunun Tarihi Gelişim Süreci ve Kaynakları”,

- $\quad$ http://66.221.165.115/cgi-bin/highlt/hebb/highlight.cgi?file=hebb/files/makale-burcudonmez-

- $\quad$ 1.htm\&query=common law\#fm erişim tarihi 13.05.2015.

- Dworkin R, (1982) “Law as Interpretation, Critical Inquiry”, Vol. 9, No. 1, The Politics of Interpretation , September, The University of Chicago Press Stable p. 179-200.

- $\quad$ http://www.jstor.org/stable/1343279 erişim tarihi 06.05.2015

- $\quad$ Fiss O.M., 1982. “Objectivity and Interpretation”, Stanford Law Review, Vol. 34, No. 4 , pp. 739-763

- Gözler, K. 1998. Hukukun Genel Teorisine Giriş: Hukuk Normlarının Geçerliliği ve Yorumu Sorunu, US-A Yayıncılık, Ankara, 
- Gözler, K. 2013. İngilizce Karşılıklarıyla Hukukun Temel Kavramları, Ekin Basım Yayın, Bursa.

- Güzel A. ve Okur A.R. 1996. Sosyal Güvenlik Hukuku, Yenilenmiş 5.bası, İstanbul.

- Güriz A. (1999), Hukuk Başlangıcı, Siyasal Kitapevi, Ankara.

- İş Hukuku ve Sosyal Güvenlik Hukuku Akademik Forumu (2014), Legal Hukuk Kitapları Serisi:285, Legal Yayıncılık, İstanbul.

- Keskin, N. (2002) Türk İş Hukuku'nda İşçi Yararına Yorum İlkesi ve Uygulanması, Yayınlanmamış Doktora Tezi, Anadolu Üniversitesi Sosyal Bilimler Enstitüsü, Eskişehir.

- Metin, S. , Hukuk Normunun Yorumu,

- http://66.221.165.115/cgi-bin/highlt/hebb/highlight.cgi?file=hebb/files/kitap-sevtapmetin1.htm\&query=MEDENİ HUKUK\#_Toc275435907 erişim tarihi 14.05.2015

- Önen, M, (2005), Hukuka Giriş, İstanbul, Arıkan Basım Yayım Dağıtım.

- Patterson, D. (2003) "Interpretation in Law" http://www.trinitinture.com/documents/patterson.pdf erişim tarihi 03.05.2015

- $\quad$ Yarg.9.H.D. 13.04.2000 T. E.1676/K.5056 (Kazancı Hukuk Veritaban1, 2015)

- $\quad$ Yarg.H.G.K 14.2.1990 E. 1989/10-391 K. 1990/83 (Kazancı Hukuk Veritaban1, 2015)

- $\quad$ Yarg. 10.H.D. 17.03.2011 E. 2010/9386 K. 2011/3728 (Kazanc1 Hukuk Veritaban1, 2015)

- Yarg.10.H.D. 25.02.2010 E. 2009/8312K. 2010/2516 (Kazanc1 Hukuk Veritaban1, 2015)

- Yarg.10.H.D. 11.4.1988 E. 1988/2355 K. 1988/2165 (Kazanc1 Hukuk Veritaban1, 2015)

- Yarg.10.H.D18.3.2004 . E. 2003/6953K. 2004/2074 (Kazanc1 Hukuk Veritaban1, 2015)

- $\quad$ Yarg.10.H.D. 13.10.2004 E. 2004/4836 K. 2004/9206 (Kazancı Hukuk Veritaban1, 2015)

- $\quad$ Yarg.21.H.D. 29.12.2004 E.2004/12248 K.2004/12413 (Kazancı Hukuk Veritaban1, 2015)

- Yarg.10.H.D. 11.11.2008 E. 2007/13916 K. 2008/14584 (Kazanc1 Hukuk Veritaban1, 2015)

- Yarg.H.G.K. 8.3.2006 E. 2006/21-15 K. 2006/58 (Kazancı Hukuk Veritaban1, 2015) 


\title{
Türkiye'de Mülteci Sorunu ve Mültecilerin Çalışma ve Sosyal Güvenlik Hakları
}

\section{Refugee Question and The Right to Work and Social Security of Refugees in Turkey}

\author{
Prof. Dr. İbrahim Aydınlı (Ankara Sosyal Bilimler University, Turkey)
}

\begin{abstract}
Turkey faces various problems because of her distinctive geo-strategic importance have made her a transit country. The most important of those are migrations towards Europe due to socio-economic disasters like starvation, poverty or unemployment as well as geopolitical disasters like war or internal turmoils. Although the political and economic dimensions of migration are prominent, these are not the focus of this study. The issue in here is to identify whether immigrants, whose number has almost reached almost five millions as wars and political chaos within neighbouring countries have forced a huge number of people to flee to Turkey, have right to work and social security according to the Turkish law. In this vein, the paper aims to clarify the content of the right to work and social security for immigrants in the long-term, instead of the short-term social assistances in accordance with human rights and social policy implementation in Turkey. For doing so, the paper firstly deals with Turkey's commitment to the international law. Secondly, it analyzes the regulations related to the right to work and social security within the national law. Finally, the paper discusses the problems occur during the implementation of law and regulations and suggests solutions for overcoming such problems.
\end{abstract}

\section{Giriş ve Özet}

Türkiye sahip olduğu jeostratejik öneminden dolayı her zaman geçiş bölgesi olarak değişik sorunlarla karşılaşmaktadır. Bu sorunlardan en önemlileri; açlık, işsizlik vs gibi sosyo-ekonomik afetler ile birlikte savaş, iç karışıklık gibi jeopolitik ya da sosyal afetlerin doğurduğu Avrupa yönlü göçlerdir. Elbette bu tür afetlerin nedenini sadece krizlerin ortaya çıktığı topraklarda aramamak gerekir. Söz konusu sosyal ve ekonomik sorunların ortaya çıkmasında dünya üzerinde ekonomik bakımdan etkili olan ülkelerin rolü inkar edilemez.

Burada inceleme konusu yaptığımız “göç”ün ekonomik ve siyasi yönü ağır basmaktadır. Ancak bu çalışmadaki amacımız meselenin siyasi ve ekonomik yönünü birebir incelemek değildir. Burada ki temel sorun; ortaya çıkan iç savaş, karışıklıklar gibi krizlerin toplumsal hareketlenme (göç) sonucunu doğurması neticesinde, takriben 3 milyonu Suriyelilerin oluşturduğu 4 milyona yaklaşan mültecinin Türk hukuku içinde çalışma hakkı ve sosyal güvenlik haklarının olup olmadığını tespit etmektir.

$\mathrm{Bu}$ bağlamda varmak istediğimiz hedef mültecilere insan hakları ve sosyal politika yönünden yapılan yardımlardan çok onlar için daha uzun vadeli olan çalışma ve sosyal güvenlik haklarını belirlemektir. Bu konuda öncelikle Türkiye'nin uluslararası mevzuat ile bağlığı ele alınacak, sonra da milli hukuktaki çalışma ve sosyal güvenlik haklarına ilişkin düzenlemelere bakılacak ve sonunda da, bu konuda mevzuatın uygulanmasında karşılaşılan sorunlar ve çözüm önerileri sunulacaktır.

\section{Yabancı Kişi ve/veya mülteci}

\subsection{Uluslararası Hukukta Mülteci Kavramı}

Mülteci kavramından önce mültecilerin kaynağını oluşturan göç hareketinin ne anlama geldiğini öncelikle inceleyecek olursak; Göç(Migration): Genel olarak uluslararası bir sınırı geçerek ya da bir devlet içinde yer değiştirmek anlamına gelmektedir. Bir başka ifadeyle; süresi, yapısı ve nedeni ne olursa olsun insanların yer değiştirdiği nüfus hareketlerinin tümüne göç denmektedir. Söz konusu göç kavramının içine; mülteciler, yerinden edilmiş kişiler, yerinden çıkarılmış kişiler ve ekonomik göçmenler de girmektedir.( PERRUCHOUD, Richard; Uluslararası Göç Örgütü Yayınları, Cenevre, 2009, Editör: Doç.Dr. Bülent Çiçekli).

Mülteci kavramı ise 1967 Protokolü ile değişik Mültecilerin Hukuki Statüsüne İlişkin 1951 Sözleşmesi, 1A(2) maddesinde Mülteci: “ Irkı, dini, tabiiyeti belirli bir sosyal gruba mensubiyeti ve siyasi görüşleri yüzünden haklı bir zulüm korkusu nedeniyle vatandaşı olduğu ülkenin dışında bulunan ve söz konusu korku yüzünden, ilgili ülkenin korumasından yararlanmak istemeyen kişi” şeklinde tanımlanmıştır (PERRUCHOUD, Göç Terimleri Sözlüğü, (Editör: Doç.Dr. Bülent Çiçekli).

\subsection{Türk Vatandaşlık Kanunu’nda Yabancı ve/veya Mülteci Kavramı}

Mülteci kavramını da içine alan ve ondan daha geniş bir kavram olan yabancı kavramı 5901 sayılı Türk Vatandaşlığı Kanunu'nda "Yabancı: Türkiye Cumhuriyeti Devleti ile vatandaşlık bağı bulunmayan kişiyi, ifade eder.” (5901/m.3/d) şeklinde düzenlenmiştir (Kanun için bkz; Resmi Gazete Tarihi: 12.06.2009Sayısı: 27256). 
Kanuni düzenlemeden yola çıkarsak yabancı gerçek kişiler; milletlerarası hukukta bir ülkenin siyasi sınırları içinde bulunan ancak o ülkenin vatandaşı olmayan ya başka ülkenin vatandaşlığında olan ya da vatansız olan veya mülteci kişiler olarak tanımlanabilir. Bu anlamda vatansız (heimatloss); hiçbir devletin vatandaşlığında olmayan kişiler iken Mülteci; Vatandaşı olduğu ülkeyi siyasi olaylar nedeniyle iradi ya da gayri iradi terketmiş olup sığındığı ülkenin ya da terkettiği ülkesinin dışında başka bir ülkenin de vatandaşlığına geçmemiş kişilerdir ( ÇELIKEL; Aysel; Yabancilar Hukuku, 6. Bası 1993, İstanbul, s.18,19).

\subsection{Sosyal Güvenlik Hukuku Açısından Mülteci Kavramı}

Çalışma hukuku ve sosyal güvenlik hukuku açısından da yabancı kavramının içine mülteci ve vatansızlar da girmektedir. Ülkemiz tarafından 29.8.1961 tarihinde 359 sayılı kanunla onanmış olan Mültecilerin Hukuki Durumuna Dair 1948 tarihli Birleşmiş Milletler Sözleşmesinin 24. maddesinde; “..çalışma ve sosyal güvenlik mevzuatı açısından mülteciler ile ülke vatandaşlarının durumu birbirinden farksızdır.” hükmü düzenlenmiştir.

Bu konuda Sosyal Sigorta İşlemleri Yönetmeliğinin 9. maddesinin 2 fikrasının ç bendinde "Aşağıda belirtilenler de Kanunun 4 üncü maddesi birinci fikrası (a) bendi kapsamında sigortalı sayılırlar. "Mütekabiliyet esasına dayalı olarak sosyal güvenlik sözleşmesi yapılmış ülkelerin uyruğunda olanlar hariç, yabancı uyruklu, uyruksuz, göcmenler ve sığınmacı kișiler ile uluslararası sosyal güvenlik sözleşmesi imzalanmış ülke sigortalılarından, sözleşmede belirlenen istisna hâlleri dışında çalışmalarını hizmet akdine tabi sürdürenler." şeklinde yapılan düzenleme ile yabancı kavramından ne anlaşılması gerektiği geniş bir şekilde ele alınmıştır. Gerçekten de 5510 sayılı kanunun 60. maddesinde genel sağlık sigortası kapsamında olanlar arasında 2013 değişikliği öncesi "mülteciler ve vatansızlar" kavramı yer almakta idi. Kanun koyucu 2013 yılında yaptığı kanun değişikliği ile bunun yerine aynı anlama gelen bu kişileri (Değişik: 4/4/2013-6458/123 md.) "Uluslararası koruma başvurusu veya statüsü sahibi (mülteci) ve vatansız olarak tanınan kişiler," olarak nitelemiştir.

Göçmen ve azınlık statüsündeki kişiler bakımından ülkemizde uluslararası hukukta azınlıklarla beraber göçmenler de yabancı statüsünde kabul edilmiştir. Bir başka anlatımla ülke vatandaşı ile aynı durumda olduğu söylenebilir. Mülteci, göçmen; kendi ülkesini terkederek başka bir ülkeye yerleşmek için gelen kişilerdir.

Türk hukukunda ayrıca kimlerin göçmen kabul edileceği 5543 sayılı İskan Kanunu'nun 3. maddesinde “Türkiye'ye yerleşmek amacıyla gelen, Türk soyundan olan ve Türk kültürüne bağll olma şartlarını taşlyan kişiler” olarak düzenlenmiştir (Kanun için bkz; Resmi Gazete Tarihi: 26.09.2006 Sayısı: 26301). Azınlıklar ise bulundukları ülkenin vatandaşı olan ancak dil din ve ırk bakımından nüfusun çoğunluğundan farklı olan kişilerden oluşmaktadır (ÇELIKKEL, s.21,22.).

Mülteci ise göçmenlerden farklıdır. Buna göre mülteci; Vatandaşı olduğu ülkeyi siyasi olaylar nedeniyle iradi ya da gayri iradi terketmiş olup sığındığı ülkenin ya da terkettiği ülkesinin dışında başka bir ülkenin de vatandaşlığına geçmemiş kişilerdir (ÇELİKEL, s.19.).

\subsection{7 sayılı Kanuna göre Türk Çalışma Hayatında Yabancıların Çalışma Hakkı ve Mültecilere Getirilen İstisna}

4817 Sayılı Yabancıların Çalışma İzinleri Hakkında Kanun'da mülteci tanımı yapılmamış olmasa da yabancı kavramı tanımlanırken mülteci kavramının da bunun içinde olduğu anlaşılmaktadır. Bundan dolayı kural olarak yabancıların çalışma hakları ve buna ilişkin çalışma izinleri mülteciler içinde geçerlidir(m.3). Ancak bu konuda mültecilere tanınan istisnai durum önem arzetmektedir. Söz konusu istisnai hükümlere değinmeden önce yabancıların bağımlı ya da bağımsız olarak Türkiye 'de çalışabilmelerine ilişkin 4817 Sayılı Yabancıların Çalışma İzinleri Hakkında Kanundaki düzenlemelere değinelim. Öncelikle 4817 sayılı Kanunun 35. Maddesiyle “11.6.1932 tarihli ve 2007 sayılı Türkiye'deki Türk Vatandaşlarına Tahsis Edilen Sanat ve Hizmetler Hakkında Kanun yürürlükten kaldırılarak yabancıların Türkiye'deki çalışma hakları önemli ölçüde genişletilmiştir(ÇELIK, Nuri; İş Hukuku Dersleri, 26. Bası, 2013, s.126).

4817 Sayılı Yabancıların Çalışma İzinleri Hakkında Kanun'a göre Türkiye’deki yabancı kişiler “Türkiye’nin taraf olduğu ikili ya da çok taraflı sözleşmelerde aksi öngörülmedikçe, yabancıların Türkiye'de bağımlı veya bă̆ımsız çalışmaya başlamadan önce izin almaları gerekir.” (m.4) İzinler süreli ve süresiz çalışma izni olarak iki şekilde verilebilir. Süreli izinler "Türkiye’nin taraf olduğu ikili ya da çok taraflı sözleşmelerde aksi öngörülmedikçe süreli çalışma izni iş piyasasındaki durum, çalışma hayatındaki gelişmeler, istihdama ilişkin sektörel ve ekonomik konjonktür değişiklikleri dikkate alınarak, yabancının (...)hizmet akdinin veya işin süresine göre, belirli bir işyeri veya işletmede ve belirli bir meslekte çallşmak üzere en çok bir yıl geçerli olmak üzere verilir." (m.5/1).

Bundan sonra ise "Bir yıllık kanuni çalışma süresinden sonra, aynı işyeri veya işletme ve aynı meslekte çalışmak üzere çalışma izninin süresi üç ylla kadar uzatılabilir.” (m.5/2)Bu süre dolduktan sonra ise "Üç yıllık kanuni çalışma süresinin sonunda, aynı meslekte ve dilediği işverenin yanında çalışmak üzere, çalışma izninin süresi altı yıla kadar uzatılabilir. Türkiye'ye çalışmak üzere gelen bir yabancının beraberinde veya daha sonra getirmiş olduğu eş ve bakmakla yükümlü olduğu çocuklarına da, yabancının kendisi ile birlikte en az beş yıl kanuni ve kesintisiz ikamet etmiş olmaları kaydıyla süreli çalışma izni verilebilir. Bakanlık, süreli çalışma izninin coğrafi geçerlilik alanını genişletebilir veya daraltabilir."(m.5/3,4,5) 
Bağımlı çalışmalar için süresiz çalışma izni kanunun 6. maddesinde “Türkiye’nin taraf olduğu ikili ya da çok taraflı sözleşmelerde aksi öngörülmedikçe Türkiye'de en az sekiz yıl kanuni ve kesintisiz ikamet eden veya toplam altı yıllık kanuni çalışması olan yabancılara, iş piyasasındaki durum ve çalışma hayatındaki gelişmeler dikkate alınmaksızın ve belirli bir işletme, meslek, mülkî veya coğrafi alanla sınırlandırılmaksızın süresiz çalışma izni verilebilir." şeklinde düzenlenmiştir.

Kanunun 7. maddesinde bağımsız çalışma izni Bă̆ımsız çalışma izni "Bağımsız çalışacak yabancılara, Türkiye'de en az beş yıl kanuni ve kesintisiz olarak ikamet etmiş olmaları koşuluyla Bakanlıkça bağımsız çalışma izni verilebilir.” şeklinde düzenlenmiştir.

İzinlerin verilmesi veya uzatılması başlıklı kanun maddesinde yabancıların nereye ne şekilde başvurabilecekleri düzenlemiştir. Buna göre;” (Değişik: 28/1/2010-5951/8 md.)(Değişik birinci fikra: 4/4/2013-6458/123 md.) "Yabancılar, ilk çalışma izni başvurularını bulundukları ülkelerdeki Türkiye Cumhuriyeti konsolosluklarına yapar. Konsolosluk, bu başvurularl doğrudan Bakanlı̆̆a iletir. Bakanlık, ilgili mercilerin görüşlerini alarak 5 inci maddeye göre başvuruları değerlendirir; durumu uygun görülen yabancılara çalışma izni verir. Yabancılar, konsolosluklardan almış oldukları çalışma izinlerinde belirtilen süre kadar Türkiye'de kalıp çalışabilir. Türkiye'de geçerli ikamet izni olan yabancılar veya bunların işverenleri başvurularını Bakanlı̆̆a yurt içinden de yapabilir.'(m.12/1,2) Kanunun 15, 16 ve 17. maddelerinde izin taleplerinin reddi ve iptali izin belgelerinin geçerliliği kaybetmesi ve bunlara karşı yargı yolu ayrıntılı bir şekilde düzenlenmiştir. Yabancıların çalışmasına yönelik bildirim yükümlülüğü ile bunun Bakanlık ve SGK müfettişlerince denetlenmesi ve kanundaki özellikle bildirim yükümlülüğüne uyulmadığında ya da çalışma izni olmadan ya da süresi dolmasına rağmen çalışan yabancıya ve çalıştıran işverene değişik rakamlarda para cezasının getirildiği görülmektedir.(m.18,19,20,21).

Yabancıların Çalışma İzinleri Hakkında Kanunun 8. maddesinde istisnai haller düzenlenerek özellik gösteren bazı kişilere bu Kanunda öngörülen sürelere tâbi olmaksızın çalışma izni verilebileceği düzenlenmiştir. Buna göre

“Türkiye’nin taraf olduğu ikili ya da çok taraflı sözleşmelerde aksi öngörülmedikçe;.......

- 2510 sayılı İskân Kanununa göre muhacir, mülteci veya göçebe olarak kabul edilen yabancılara,

- (Ek: 4/4/2013-6458/123 md.) Uluslararası koruma başvurusunda bulunan ve İçişleri Bakanlığınca şartlı mülteci statüsü verilen yabancl ve vatansız kişilere, ” bu Kanunda öngörülen sürelere tâbi olmaksızın çalışma izni verilebilmektedir(4817/m.8/d-1).

Mültecilere tanınan bu istisnai durum ve kolaylık Yabancıların Çalışma İzinleri Hakkında Kanunun Uygulama Yönetmeliğinde düzenlenmiştir (Resmi Gazete Tarihi: 29.08.2003 Resmi Gazete Sayıs1: 25214).

Çalışma izni bakımından aranan ikamet belgesi ve çalışma izni bakımından iki önemli kolaylık ve istisna tanınmıştır. Buna göre; “İçişleri Bakanlı̆̆ınca mülteci veya sı̆̆ınmacı statüsü verilmiş yabancılardan ikamette süre koşulu aranmaz. Bu statüde bulunanların çalışma izin talepleri değerlendirilirken Yönetmeliğin 13 üncü maddesinin dördüncü fikrasında belirtilen hususlar dikkate alınmaksızın çalışma izin işlemlerinin en kısa sürede neticelendirilmesi için gerekli tedbirler alınır.” (Yön. 7 /4) (Ek fikra: RG-21/1/2010-27469). “2510 sayılı İskan Kanununa göre muhacir, mülteci veya göçebe olarak kabul edilen yabancıların çalışma izni talebinde bulunmaları halinde, Bakanlığa başvuru sırasında durumlarını belgelemek koşuluyla çalışma izinleri istisnai olarak verilebilir.” (Yön.m. 49)

\subsection{8 sayılı Yabancılar ve Uluslararası Koruma Kanununa göre Çalışma ve Sosyal Güvenlik Hakkı a) 6458 Sayılı Kanun Dönemi Öncesi}

Mültecilerin çalışma ve sosyal güvenlik haklarına ilişkin bir çok husus 6458 sayılı kanun öncesinde 1950 yılında çıkarılmış olan 5682 sayılı Pasaport Kanunu ve 5683 sayılı Yabancıların Türkiye'de İkamet ve Seyahatleri Hakkında Kanunlarla belirlenmeye çalışılmıştır.

Uluslararası Koruma (iltica) açısından; Türk hukukundaki ilk düzenleme; 1994 Yönetmeliği olarak bilinen “Türkiye’ye İltica Eden veya Başka Bir Ülkeye İltica Etmek Üzere Türkiye'den İkamet İzni Talep Eden Münferit Yabancılar İle Topluca Siğınma amacıyla Sinırlarımıza Gelen Yabancılar ve Olabilecek Nüfus Hareketlerine Uygulanacak Usul ve Esaslar Hakkında Yönetmelik”tir. Söz konusu yönetmelikle, bireysel ve kitlesel olarak sığınma amacıyla Türkiye'ye gelen yabancılara uygulanacak usul ve esaslar belirlenmiş ve bu konuda görevli kuruluşların görev ve yetkileri hükme bağlanmıştır.

2013 yılında çıkarılarak yürürlüğe sokulan 6458 sayılı kanuna kadar göçmenlerle ilgili birçok hüküm farklı kanunlarda kısmen ve dağınık olarak düzenlenmiştir. Bu yüzden yeknesak bir kanuni düzenleme eksikliği çoğunlukla idari düzenlemelerle karşılanmaya çalışılmıştır. Bu durumda farklı farklı uygulamaları doğurmuştur.

\section{b) 6458 Sayılı Kanun Dönemi}

Ülkemizde mültecilerle ilgili ilk defa geniş ve uygulamada birlik sağlayan hukuki düzenleme 4/4/2013 tarihli 6458 sayılı Yabancılar ve Uluslararası Koruma Kanunu kendini göstermiştir.

6458 sayılı Yabancılar ve Uluslararası Koruma Kanunu ana amaçlarından ilki, yabancıların Türkiye'ye girişleri, Türkiye'de kalışları ve Türkiye'den çıkışları; Türkiye'den uluslararası koruma talep eden yabancılara sağlanacak korumanın kapsamı ve uygulanmasına ilişkin usul ve esasları belirlemektir. İkinci amaç ise idari olarak; kanunun 
uygulanmasını sağlayacak olan İçişleri Bakanlığına bağlı Göç İdaresi Genel Müdürlüğünün kuruluş, görev, yetki ve sorumlulukları da aynı kanun içinde düzenlenerek uygulama birliği sağlanması amaçlanmıştır.

\section{c) 6458 Sayılı Kanunda Geçici Koruma Sistemi}

6458 sayılı kanunda en önemli kurum geçici koruma sistemidir. Özellikle göç hareketlerinin toplu akın şeklinde olmasına yönelik olarak acil çözümler bulmak üzere geliştirilen bir koruma şeklidir. Geçici korumanın asıl işlevi; kitleler halinde ülke sınırlarına ulaşan kişilere, bireysel statü belirleme, belirli haklar sağlamayı hedefleyen pratik ve tamamlayıcı bir çözüm sağlamaktır (JASTRAM; Kate, Mültecilerin Korunması: Uluslararası Mülteci Hukuku Rehberi, 2001, s.127; ÇiÇEKLİ Bülent; Açıklamalı Göç ve İltica Hukuku Terimleri Sözlüğü, Nisan 2013, s.36).

Ülkemizde ilk defa 6458 sayılı kanunla getirilen geçici koruma Suriyeli mültecilere uygulanmaya başlamıştır. Gerçekten de; Suriye'den Türkiye'ye yönelik ilk kitlesel nüfus hareketi Suriye'de yaşanan insani krizin büyümesi sonucunda 300-400 kadar Suriye vatandaşı 29.04.2011 tarihinde Hatay ili Yayladağı ilçesindeki Cilvegözü sınır kapısına gelmeleri ile başlamıştır. Ülkemiz 2011 yılından 2013 yürürlüğe koyduğu 6458 sayılı yasaya kadar Suriye'deki durumun giderek ağırlaşması ve sığınmacıların ülkelerine güvenli bir şekilde dönüşlerinin imkansız olması nedeniyle Suriyeli sığınmacılara hiçbir ön ya da ana şart aranmadan geçici koruma sağlanmıştır.

\section{d) 22.10.2014 tarihli Geçici Koruma Yönetmeliği}

2013 yılında çıkarılan 6458 sayılı Yabancılar ve Uluslararası Koruma Kanunu'na dayanarak geçici korumaya iliş̧kin iş ve işlemlerin nasıl yapılacağına iliş̧kin Bakanlar Kurulu tarafindan bir yönetmelik düzenlenmiş̧ir. 22.10.2014 tarihli Geçici Koruma Yönetmeliğinin temel amac1; 4/4/2013 tarihli ve 6458 sayılı Yabancılar ve Uluslararası Koruma Kanunun 91. maddesi çerçevesinde, uluslararası koruma talebi bireysel olarak değerlendirmeye alınamayan ve ülkesinden ayrılmaya zorlanmış, ayrıldığı ülkeye geri dönemeyen, kişilere geçici koruma sağlamaktır. Bu nedenle acil ve geçici koruma amacıyla kitlesel olarak sınırlarımıza gelen veya sınırlarımızı geçen yabancılardan, sağlanabilecek geçici koruma işlemlerinin usul ve esasları bu yönetmelikte düzenlenmiştir. Ayrıca yönetmelikte geçici koruma sağlanan bu kişilerin Türkiye'ye kabulü, Türkiye'de kalışı, hak ve yükümlülükleri, Türkiye'den çıkışlarında yapılacak işlemleri, kitlesel hareketlere karşı alınacak tedbirler ve buna özgü ulusal ve uluslararası kuruluşlar arasındaki işbirliği konuları hükme bağlanmıştır.

\section{e) Geçici Koruma Yönetmeliğinde Mültecilere Sağlanan Sosyal ve Sağlık Hizmetleri}

Geçici Koruma Yönetmeliğinde mültecilere sağlanan hizmetlerden en önemlileri aşağıdaki gibi belirlenmişsir. Buna göre;

i. Geçici Barınma Merkezlerine Sevk İşlemleri, Bu yönetmelik kapsamındaki yabancılar AFAD tarafindan bildirilecek kapasite bilgisi de göz önünde bulundurularak sevk merkezinden doğrudan veya illere yerleştirildikten sonra valiliklerle eşgüdüm içerisinde Genel Müdürlükçe uygun görülecek geçici barınma merkezine en kısa sürede yönlendirilir(Yön.m.23).

ii. Geçici Koruma Kimlik Belgesi: Kayıt işlemleri tamamlananlara, valilikler tarafından geçici koruma kimlik belgesi düzenlenir.(Yön.m22)

iii. Geçici Korunanlara İllerde Kalma Hakkı Verilmesi: Kamu düzeni, kamu güvenliği, ya da kamu sağlığı yönüyle herhangi bir sakınca görülmediği hallerde geçici korunanların, Genel Müdürlükçe belirlenen illerde kalmalarına izin verilebilir.(Yön.m.24)

iv. Sosyal ve Sağlık Hizmetleri: Bu yönetmelik kapsamındaki yabancılara; sağlık, eğitim, iş piyasasına erişim, sosyal yardım ve hizmetler ile tercümanlık ve benzeri hizmetler sağlanabilir (Yön.m.26).

v. Sağlık Hizmetleri: Temel ve acil sağlık hizmetleri ile bu kapsamdaki tedavi ve ilaçlardan hasta katılım payı alınmaz.( Yön.m.27-b).

vi. Eğitim Hizmetleri: Bu yönetmelik kapsamındaki yabancıların eğitim faaliyetleri, geçici barınma merkezlerinin içinde ve dışlında Milli Eğitim Bakanlığının kontrolünde ve sorumluluğunda yürütülür (Yön.m.28)

vii. İş Piyasasına Erişim Hizmetleri: Geçici koruma kimlik belgesine sahip olanlar, Bakanlar Kurulunca belirlenecek sektörlerde, iş kollarında ve coğrafi alanlarda çalışma izni almak için Çalışma ve Sosyal Güvenlik Bakanlığına başvurabilir (Yön.m.29-2) .

viii. Sosyal Yardım ve Hizmetler: Bu yönetmelik kapsamındaki yabancılardan ihtiyaç sahibi olanların, sosyal hizmetlere erişimleri Bakanlık ve Aile ve Sosyal Politikalar Bakanlığı tarafından belirlenen usul ve esaslara göre sağlanır(Yön.m.30-2).

ix. Hizmetleri: $\mathrm{Bu}$ yönetmelik kapsamındaki iş ve işlemlerde yabancıyla tercüman olmaksızın istenilen düzeyde iletişim kurulamadığında tercümanlık hizmetleri ücretsiz olarak sağlanır (Yön.m.31)

x. Geçici Barınma Merkezlerinde Sağlanacak Hizmetler: Geçici barınma merkezlerinde bulunanlara beslenme, barınma, sağlık, sosyal yardım, eğitim ve benzeri hizmetler imkanlar ölçüsünde sağlanır (Yön.m.40). 
xi. Gönüllü Geri Dönüş: $\mathrm{Bu}$ yönetmelik kapsamındaki yabancılardan gönüllü olarak ülkesine dönüş yapacaklara gerekli kolaylık gösterilir ve imkanlar ölçüsünde destek sağlanabilir (Yön.m.42).

xii. Üçüncü Ülkeye Çıkış ve Yerleştirme: Bu yönetmelik kapsamındaki yabancıların, geçici veya daimi olarak üçüncü ülkeye çıkışları Genel Müdürlüğün iznine tabidir.(Yön.m.44).

xiii. Özel İhtiyaç Sahipleri: Bu yönetmelik kapsamındaki yabancılardan özel ihtiyaç sahibi olanlara sağlanacak başta sağlık hizmetleri, psiko-sosyal destek, rehabilitasyon olmak üzere, her tür yardım ve destek imkanlar ölçüsünde öncelikli ve bedelsiz olarak sağlanır(Yön.m.48).

Geçici koruma uygulamasını yönetmeliğin 12. Maddesine göre; Geçici korunanların;

a) Kendi isteğiyle

b) Üçüncü bir ülkenin korumadan faydalanması

c) Üçüncü bir ülkeye insani nedenler veya yeniden yerleştirme kapsamında kabul edilmesi ya da üçüncü bir ülkeye çıkış yapması

d) Ölmesi

Hallerinde geçici koruma sona erer. Bakanlar Kurulu, sonlandırma kararıyla birlikte;

a) Geçici korumayı tamamen durdurarak geçici korunanların ülkesine dönmesine,

b) Geçici korunanlara, koşullarını taşıdıkları statünün toplu olarak verilmesine ya da uluslararası koruma başvurusunda bulunanların başvurularının bireysel olarak değerlendirilmesine

c) Geçici korunanların, Kanun kapsamında belirlenecek koşullarda Türkiye'de kalmalarına izin verilmesine karar verilebilir.

15.01.2015 Tarihli Geçici Koruma Sağlanan Yabancıların Çalışma İzinlerine Dair Yönetmeliğe göre; getirilen hükümler aşağıdaki gibi düzenlemiştir.

f) Geçici Koruma Yönetmeliğinde Mültecilerin Çalışma Hakları

i. Çalışma İzni Zorunluluğu: Geçici koruma sağlanan yabancılar, çalışma izni olmaksızın Türkiye'de çalışamaz veya çalıştırılamaz (Yön.m.4)

ii. Çalışma İzni Şartları:) Geçici koruma sağlanan yabancılar, geçici koruma kayıt tarihinden altı ay sonra çalışma izni almak için Bakanlığa başvuruda bulunabilir (Yön.m.5/ 12).

Mevsimlik tarım veya hayvancılık işlerinde çalışacak geçici koruma sağlanan yabancılar çalışma izini muafiyeti kapsamındadır. Bakanlığa çalışma izin başvurusu için; sağlık meslek mensuplarının Sağlık Bakanlığından, eğitim meslek mensuplarının ise Milli Eğitim Bakanlığından veya Yükseköğretim Kurulu Başkanlığından ön izin almaları gerekir. Yön. m.6/3)

iii. İkamet İli Zorunluluğu: Geçici koruma sağlanan yabancılara çalışma iznine başvuru hakkı verilmesinde, Geçici Koruma Yönetmeliğinin 24 üncü maddesi uyarınca yabancının kalmasına izin verilen iller esas alınır (Yön.m.7/1)

iv. Yerli - Yabancı Çalıştırma Oranı: Çalışma izni başvurularının değerlendirilmesinde, işyerinde çalışan Türk vatandaşı sayısı üzerinden sektör ve illere göre açık iş ve işe yerleştirmeler dikkate alınarak Bakanlıkça, geçici koruma sağlanan yabancı istihdamı kotası değişen oranlarda uygulanabilir. Üçüncü fikra hükmü saklı kalmak üzere, çalışma iznine başvurulan işyerinde çalışan geçici koruma sağlanan yabancı sayısı, işyerinde çalışan Türk vatandaşı sayısının yüzde onunu geçemez (Yön.m.8)

v. Ücretlendirme: Geçici koruma sağlanan yabancılar a asgari ücret in altında ücret ödenemez (Yön.m.10)

vi. Çalışma İzni İptali: Kamu düzeni, kamu güvenliği ya da kamu sağlığı yönüyle çalışma izni verilmesinde sakınca görüldüğünün İçişleri Bakanlığınca bildirildiği illerde çalışma izni verilmesi, Bakanlıkça durdurulur.(Yön.m.7-2) Geçici Koruma Yönetmeliği kapsamında geçici koruması sonlandırılan veya iptal edilen yabancıların almış olduğu çalışma izinleri iptal edilir (Yön.m.13/3).

\section{Sonuç}

Yukarıdaki tüm bu açıklamalardan anlaşıldığı kadarıyla ülkemizin göçler sonucu Türkiye topraklarında bulunan mültecilere karşı uluslararası hukuktan kaynaklanan yükümlülüğünü sadece geçici koruma ile yetinmeyip mültecilere çalışma hakkı ve sosyal güvence sağlayarak yerine getiren ender ülkelerdendir. Gerçekten de Avrupa ülkelerinin sınırlarına dayanan sadece binlerle ifade edilen mültecilere karşı bir politika dahi belirleyemediği böyle bir durumda ülkemizin tek başına mültecilerin barınma ve iaşe gibi tüm zaruri ihtiyaçları yanında çalışma hakları ile beraber sosyal güvenliklerini de mevzuat güvencesi ile beraber sağlamış olması gıpta edilecek bir durumdur. 


\section{KAYNAKÇA}

- ÇELIK, Nuri; İş Hukuku Dersleri, 26. Bas1, 2013

- ÇELIKEL; Aysel; Yabancılar Hukuku, 6. Bası 1993, İstanbul.

- JASTRAM; Kate, Mültecilerin Korunması: Uluslararası Mülteci Hukuku Rehberi,

- Çİ̧EKLİ, Bülent; Açıklamalı Göç ve İltica Hukuku Terimleri Sözlügü, Nisan 2013.

- PERRUCHOUD, Richard; Uluslararası Göç Örgütü Yayınları, Cenevre, 2009, (Editör:

Doç.Dr. Bülent Çiçekli)

- HTTP://WWW.GOC.GOV.TR/icerik6/gecici-koruma

\section{TABLOLAR}

\section{Geçici Koruma Kapsamındaki Suriye'lilerin İstatistikleri}

\section{Geçici Koruma Kapsammdaki Suriyelilerin İllere Göre Dağlımı}

\begin{tabular}{|c|c|c|c|}
\hline \multicolumn{4}{|c|}{ 05.05.2016 TARIHI ITIBARIYLE GEÇICI KORUMA KAPSAMINDAKI SURIYELILER } \\
\hline ADANA & 150.835 & KAHRAMANMARAS & 84.250 \\
\hline ADIYAMAN & 24.282 & KARABÜK & 267 \\
\hline AFYON & 3.196 & KARAMAN & 408 \\
\hline AĞRI & 832 & KARS & 121 \\
\hline AKSARAY & 931 & KASTAMONU & 567 \\
\hline AMASYA & 164 & KAYSERI & 50.023 \\
\hline ANKARA & 59.714 & KIRIKKALE & 448 \\
\hline ANTALYA & 153 & KIRKLARELI & 2.070 \\
\hline ARDAHAN & 57 & KIRȘEHIR & 536 \\
\hline ARTVIN & 42 & KiLis & 128.488 \\
\hline AYDIN & 6.527 & KOCAELI & 23.253 \\
\hline BALIKESIR & 1.655 & KONYA & 69.040 \\
\hline BARTIN & 26 & KÜTAHYA & 273 \\
\hline BATMAN & 18.026 & MALATYA & 18.090 \\
\hline BAYBURT & 26 & MANISA & 5.644 \\
\hline BILECIK & 485 & MARDIN & 97.383 \\
\hline BINGOL & 697 & MERSIN & 139.363 \\
\hline Bituis & 549 & MUĞLA & 8.173 \\
\hline BOLU & 870 & MUȘ & 728 \\
\hline BURDUR & 7.841 & NEVSSEHIR & 4.880 \\
\hline BURSA & 97.212 & NiĞDE & 2.543 \\
\hline ÇANAKKALE & 3.362 & ORDU & 606 \\
\hline ÇANKIRI & 268 & OSMANIYE & 40.602 \\
\hline ÇORUM & 1.261 & RizE & 512 \\
\hline DENIZLI & 6.286 & SAKARYA & 5.829 \\
\hline DIYARBAKIR & 29.134 & SAMSUN & 3.248 \\
\hline DÜZCE & 443 & SIIRT & 2.839 \\
\hline EDIRNE & 6.511 & SiNOP & 69 \\
\hline ELAZIর̄ & 4.603 & SIVAS & 1.378 \\
\hline ERZINCAN & 163 & ŞANUIURFA & 399.208 \\
\hline ERZURUM & 452 & ŞIRNAK & 14.764 \\
\hline ESKIŞEHIR & 1.649 & TEKIRDAĞ & 5.282 \\
\hline GAZIANTEP & 323.687 & TOKAT & 634 \\
\hline GIRESUN & 132 & TRABZON & 1.651 \\
\hline GUMMUSSHANE & 55 & TUNCELI & 100 \\
\hline HAKKARI & 951 & USSAK & 1.062 \\
\hline HATAY & 383.660 & VAN & 1.531 \\
\hline IĞDIR & 77 & YALOVA & 2.462 \\
\hline ISPARTA & 6.154 & YOZGAT & 2.763 \\
\hline ISTANBUL & 392.642 & ZONGULDAK & 284 \\
\hline İZMir & 91.385 & GENEL TOPLAM & 2.748 .367 \\
\hline
\end{tabular}




\title{
Türkiye'de İpoteğe Dayalı Menkul Kıymetlerle İlgili Son Gelişmeler
}

\section{Recent Development Related to Mortgage Backed Securities in Turkey}

\author{
Prof. Dr. Mustafa Topaloğlu (Beykent University, Turkey)
}

\begin{abstract}
While mortgage backed securities are extremely important for prospering economies especially, these securities are kinds of securities capital market instruments that show increase significantly for last 30 years. These make it convenient for development of the capital market and consumers to obtain housing cost-efficiently, in that these securities provide effective fund flow from different and new financing trough. All over the world mortgage based securities are issued by two securitization ways that: the first one is off-balance sheet securitization, mortgage backed securities which are common on countries, are dominated by Anglo-Saxon financing system and another one is in the balance sheet securitization, mortgage bond system is common in Continental Europe. In the context of the Turkey practice of mortgage backed securities is enforced by Mortgage Code numbered 5582, dated 2007. And then this matter is reconverted by Capital Market Code numbered 6362 and its relevant secondary regulation.
\end{abstract}

\section{Türk Hukukunda İpoteğe Dayalı Menkul Kıymetlerin Yasal Düzenlenişi}

Türkiye'de kurumsal bir yapıya sahip konut finansman sisteminin oluşturulması amacıyla Sermaye Piyasası Kurulu tarafından "Konut Finansman Sistemine İlişkin Kanun Tasarısı Taslağı hazırlanmıştır. Söz konusu Taslak, Bakanlar Kurulu'nda görüşülmüş ve 26.09.2005 tarihinde kanun tasarısı haline getirilmiştir. En son olarak da "Konut Finansman Sistemine İlişkin Çeşitli Kanunlarda Değişiklik Yapılması Hakkında Kanun Tasarısı” adıyla 01.12.2005 tarihinde Türkiye Büyük Millet Meclisi Başkanlığına arz edilmiştir.

Kamuoyunda "mortgage" yada "tutsat" yasası olarak bilinen bu tasarı 21.02.2007 tarih ve 5582 sayılı Konut Finansmanı Sisteminde Değişiklik Yapılması Hakkında Kanunla kabul edilerek yasalaşmıştır. 5582 sayılı Kanun, 06.03.2007 tarih ve 26454 sayılı Resmi Gazete'de yayımlanarak bu konuda ümitlerin kesildiği bir anda yürürlüğe girmiştir.

5582 sayılı Kanunla getirilen Tutsat sisteminin temel esprisi, konut finansmanından kaynaklanan alacakları menkul kıymetleştirmek yoluyla Batılıların “mortgage money- tutsat parası) dedikleri ayrı bir fon yaratmaktır. Yaratılan bu para yada fon tekrar konut sahibi olmak isteyen tüketiciye tutsat kredisi olarak verilerek sisteme geri dönmektedir. Üstelik Tutsat Kanunu yürürlüğe girmeden önce, bankalar yabancı finans kurumlarından yada mevduat faizinden sağladıkları kredileri konut kredilerinin finansmanında kullanmaktaydılar. Tutsat sisteminden menkul kıymetleştirme yoluyla sağlanan fon, sendikasyon kredisi yada mevduat faizinden sağlanan fondan daha düşük maliyetli olduğu için göreceli olarak tutsat kredilerinin faiz oranları klasik konut kredilerinin faizinden daha düşük olması beklenmektedir. Sistem bu şekilde çalıştığı zaman daha uzun vadeli ve daha düşük faizle kredi verilebilecek; belki o zaman "kira öder gibi ev sahibi olma" hayali gerçekleşebilecektir (Önal ve Topaloğlu, 2007).

Öte yandan tutsat kredilerinin 15-20 yıl vadeli olması Türk menkul kıymet piyasasında bu kadar uzun vadeli yatırım aracı ihracına olanak verecektir. Uzun vadeli yatırım yapmak isteyen yatırımcılar güvenli bir yatırım enstrümanını seçme şansına sahip olacaklardır. Yine söz konusu menkul kıymetler emeklilik fonları ve yabancı yatırımcıları yatırım yapmak üzere ülkemize çekebilecektir.

5582 sayılı Kanunun gerekçesinde açıklandığı üzere, konut finansmanına ilişkin alacakların menkul kıymetleştirmesi özellikle Kıta Avrupa'sında kullanılan menkul kıymet türü olan teminatlı tahvil "covered bond" ve ipoteğe dayalı menkul kıymet "mortgage based securities" aracılığıyla gerçekleştirilecektir. 5582 sayılı Kanun bu amaçla, "ipotek teminatlı menkul kıymet" ve "ipoteğe dayalı menkul kıymet" adıyla iki yeni menkul kıymet tipi öngörülmüştür (Berkant, 2005). Aşağıda ayrıntılı olarak belirtileceği üzere Kurul kaydına alınmak suretiyle ihraç edilecek bu iki yeni menkul kıymet türü, Medeni Kanun'da öngörülen senedi ve irad senedinden tamamen farklıdır (Günver, 1994; Çetin, 2004).

5582 Sayılı Kanun daha sonra 6362 sayılı Kanunla değiştirilmiştir. 6362 sayılı yeni Sermaye Piyasası Kanunu 58.maddesinde varlığa ve ipoteğe dayalı menkul kıymetleri aynı maddede düzenlemiştir. Bu beraberlik SPK Tebliğlerinde de devam etmiş, Varlık Finansmanı Fonlarına ve Varlığa Dayalı Menkul Kıymetlere İlişkin Esaslar Hakkında Tebliğ (Seri: III, No: 35) ile Konut Finansmanı Fonlarına ve İpoteğe Dayalı Menkul Kıymetlere İlişkin Esaslar Hakkında Tebliği (Seri: III, No: 34) yürürlükten kaldırılarak bunların yerine 09.01.2014 tarih ve 28877 sayılı Resmi Gazete'de Seri:III, No:58.1 sayılı Varlığa veya İpoteğe Dayalı Menkul Kıymetler Tebliği yürürlüğe konulmuştur. 


\section{2 İpoteğe Dayalı Menkul Kıymetler}

\section{1 İpoteğe Dayalı Menkul Kıymet Kavramı}

6362 sayılı Sermaye Piyasası Kanunu'nda kavram tanımlarıyla ilgili 3.(i) maddesinde yer alan hükümde "İpotekli sermaye piyasası aracı: İpotek teminatlı menkul kıymetler, ipoteğe dayalı menkul kıymetler, ipotek finansmanı kuruluşları tarafından ihraç edilen pay dışındaki sermaye piyasası araçları ve konut finansmanından kaynaklanan alacaklara dayalı olarak veya bu alacakların teminatı altında ihraç edilen diğer sermaye piyasası araçlarını " ifade eder, şeklinde bir tanım yapılmıştır. Bu tanımda ipoteğe dayalı menkul kıymetler bir sermaye piyasası aracı olarak gösterilmiş̧tir. Aynı tanımda yer alan ipoteğe dayalı menkul kıymetler, 6362 sayılı Sermaye Piyasası Kanunun 58.maddesinde ayrıntılı olarak düzenlenmiştir.

Her ikisi de teminat havuzuna dayalı olarak çıarılan İpoteğe dayalı menkul kıymetlerle ipotek teminatlı menkul kıymetler arasında bundan başka farklar da vardır. Bu farklardan en önemlisi, bir borçlanma senedi niteliğinde olan ipotek teminatlı menkul kıymetler, ihraçının tekeffülü altında bulunması dolayısıyla bilanço içi menkul kıymetleştirme kategorisine girmektedir. İpoteğe dayalı menkul kıymetlerde ise teminat havuzu ihraççının malvarlığı ve dolayısıyla bilançosu dışına çıkarılmaktadır. İpoteğe dayalı menkul kıymet hamilleri, alacak hakkından ziyade teminat havuzunda yer alan varlıkların inançlı mülkiyet esaslarına göre maliki olmakta ve temerrüt yada erken ödeme gibi bütün riskleri kendi üzerine almaktadır (Doğru, 2007).

Sermaye Piyasası Kurulu tarafından hazırlanan Seri:III, No:58.1 sayılı Varlığa veya İpoteğe Dayalı Menkul Kıymetler Tebliğinin 17. maddesinde ipoteğe dayalı menkul kıymetlerin sahiplerine konut finansman fonu portföyünde bulunan varlıkların nakit akımlarına katılma hakkı vereceği belirtilmektedir. İpoteğe dayalı menkul kıymetler, sahiplerine alacak hakkı değil, ABD'deki ödeme aktarmalı (pass-through) menkul kıymetlerde olduğu gibi teminat havuzundaki faiz ve anapara ödemelerinden oluşan nakit akımlarına katılma hakkı vermektedirler (Alp, 2000; Handersen ve Scott, 1988; Yalçıner, 2006; Doğru 2007).

Yatırım fonu katılma belgelerinin uygulamada her an paraya çevrilebilir ve geri satılabilir olduğu kabul edilmektedir. Yatırım fonu katılma belgesi sahibinin istediği zaman katılma belgesine iade ederek fondaki portföy payını istemesinin hukuki dayanağı inançlı mülkiyet anlaşmasının bir gereğidir (Nomer, 2002; Destanoğlu, 2004). Ancak nitelikleri gereği uzun vadeli yatırım aracı olan ipoteğe dayalı menkul kıymetlerin her an paraya çevrilmeleri mümkün değildir. Zira ipoteğe dayalı menkul kıymet sahibine teminat havuzundaki uzun döneme yayılan faiz ve ana para nakit akımlarından ödeme yapılmaktadır. Buna karşılık, ViDMK Tebliğinde Doğrudan aktarım usulünde, fon portföyünde yer alan varlıklardan elde edilen, ödeme planına bağlı olan veya olmayan nakit akımları bu sonra fon bünyesinde bekletilmeksizin doğrudan, dolaylı aktarım usulünde ise, söz konusu nakit akımları, bu belirlenen vadelerde yatırımcılara aktarılacağı öngörülmüştür (m.17.(3)). Bu nedenle, istenildiği zaman VIDMK'ların Fon'a iade edilerek portföy payının talep edilmesi mümkün değildir (Topaloğlu, 2009).

\section{2 İpoteğe Dayalı Menkul Kıymetlerin İhraç Esasları}

VIDMK, izahname veya ihraç belgesi SPK'ya sunularak onay alındıktan sonra ihraç edilebilir. Hatta SPK'den gerekli izin alınarak fon içtüzüğünün ticaret siciline tescilinden itibaren en geç altı ay içinde, VIDDKK ihraç belgesi onay başvurusunu SPK'ya iletilmesi zorunludur. Bu süre içinde başvuru yapılmaması veya ihraçtan vazgeçilmesi halinde, fon içtüzüğü kurucu tarafından ivedilikle ticaret sicilinden terkin edilir (VIDMK Tebliği m.7).

VIDMK halka arz edilerek veya nitelikli yatırımcılara satılmak üzere veya birim nominal değeri asgari 100.000 TL tutarında olmak kaydıyla tahsisli olarak ihraç edilebilir. Hatta SPK'dan alınacak bir ihraç tavanı dahilinde halka arzedilmeksizin özel yatırımcılara satılabileceği gibi, yurtdışında bir borsada da ihraç edilebilir (VIDMK Tebliği m.7).

VIDMK ihracını takiben yatırımcılardan toplanan paralarla çerçevesinde fon portföyü oluşturulur. VIDMK ihracı kapsamında yatırımcılara yapılacak ödemeler, fon portföyünde yer alan varlıklardan elde edilen nakit akımlarından karşılanır. Nakit akımlarının karşılanmasına yönelik olarak ihraç öncesinde kısmen veya tamamen garanti veya 5684 sayılı Sigortacılık Kanununda tanımlanan sigorta şirketleri tarafından sigorta teminatı verilebilir ( ViDMK Tebliği m.17).

VIDMK, tertipler halinde ihraç edilir. Aynı tertip içerisinde varlıkların vadesi, ödeme zamanı, tasfiye prosedürüne ilişkin haklar ve kredi riski gibi kriterlerle farklı haklara sahip olan VIDMK dilimleri oluşturulabilir. Halka arz edilecek her tertip veya dilimler SPK'nın yetkilendirdiği derecelendirme kuruluşları tarafından derecelendirmeden geçirilmesi ve derecelendirme notu alması zorunlu tutulmuştur ( VIDMK Tebliği m.17).

\section{Konut Finansman Fonu}

İpoteğe dayalı menkul kıymetler konut finansman fonları tarafindan ihraç edilirler. Sermaye Piyasası Kanununun 58 (1) maddesinde konut finansmanı kavramı tanımlanmıştır.

Konut finansman fonları da konut finansmanı amacıyla verilen ipotekli konut kredilerini bir havuzda toplayarak ipoteğe dayalı menkul kıymet ihraç etmektedirler. Esas olarak bir yatırım fonu prensipleriyle çalışan konut finansman fonları yukarıda kısmen değinildiği gibi bazı farklılıklar da taşımaktadır. 


\subsection{Konut Finansman Fonlarının Kuruluşu ve Hukuki Yapısı}

Konut finansman fonu, Sermaye Piyasası Kanunu'na eklenen 58.maddesi ile düzenlenmiş ve SPK tarafindan konut finansman fonlarına ilişkin VİDMK Tebliğinde şekilde hükümler sevk edilmiştir. Buna göre, konut finansman fonu, Buna göre, konut finansmanı fonu, ipoteğe dayalı menkul kıymetler karşılığında toplanan paralarla, ipoteğe dayalı menkul kıymet sahipleri hesabına; varlık finansmanı fonu, varlığa dayalı menkul kıymetler karşılığında toplanan paralarla, varlığa dayalı menkul kıymet sahipleri hesabına inançlı mülkiyet esaslarına göre fon iç tüzüğü ile kurulan ve tüzel kişiliği olmayan mal varlığıdır (m.58 (1)).

$\mathrm{Bu}$ tanımdan aynen yatırım fonlarında olduğu gibi konut finansman fonlarının da temelinde inançlı mülkiyet esaslarına dayanan bir sözleşme bulunmaktadır.(Makaracı, 2009). Hukuki temeli oluşturan bu inanç sözleşmesiyle yatırımcı (inanan) hissesine sahip olduğu havuzdaki alacak varlığının yönetimini fon kuruluna (inanılan) bırakmaktadır (Tanör, 1999; Adıgüzel, 2007). Fon kurucusu aslında mülkiyeti yatırımcılara ait ipotekli kredilerden oluşan alacak varlıklarının maliki gözükmektedir. Ancak kurucunun bu mülkiyet hakkı, yatırımcılar (ipoteğe dayalı menkul kıymet sahipleri) hesabınadır ve Fon içtüzüğü ve müşterek yatırım sözleşmesinde belirlenen kurallarla sınırlandırılmıştır. Buna göre, Fon kurulu ipoteğe dayalı menkul kıymet sahiplerini koruyacak şekilde fonu yönetmek ve temsil etmek durumundadır.

Fon içtüzüğü, ipoteğe dayalı menkul kıymet sahipleri, kurucu ve fon kurulu arasında fon portföyünün inançlı mülkiyet esaslarına ve vekalet akdi hükümlerine göre yönetimini konu alan iltihaki bir sözleşmedir (VİDMK Tebliği m.5). Aynı maddeye göre, Fona ilişkin içtüzük standardı Kurulca belirlenir. Fon içtüzüğünde bulunması gereken asgari unsurlar VİDMK Tebliğinin ekinde gösterilmiştir.

Fon içtüzüğü Kurulca uygun görüldükten sonra kurucunun merkezinin bulunduğu yer ticaret sicilinde tescil ve Türkiye Ticaret Sicili gazetesinde ilan edilir. Fon içtüzüğünün ticaret sicilinde tescil edildiği anda fonun kuruluş işlemleri tamamlanmış olur (VİDMK Tebliği m.4 ).

Konut finansman fonları süreli veya süresiz olarak kurulur. Fon, VİDMK ihracı amacı dışında kurulamaz ve kullanılamaz (VIDDK Tebliği m.4 (2)). Konut finansman fonları yatırım fonlarından farklı olarak risk yönetimi şeklinde değil de doğrudan yada dolaylı aktarım usulüyle yönetilir. Fon doğrudan aktarım veya dolaylı aktarım usullerinden biri ile yönetilir. Doğrudan aktarım usulünde, fon portföyünde yer alan varlıklardan elde edilen, ödeme planına bağlı olan veya olmayan nakit akımları gerekli kesintiler yapıldıktan sonra fon bünyesinde bekletilmeksizin doğrudan yatırımcılara aktarılır. Dolaylı aktarım usulünde ise, söz konusu nakit akımları, gerekli kesintiler yapıldıktan sonra belirlenen vadelerde yatırımcılara aktarılana kadar, izahnamede veya ihraç belgesinde belirtilen esaslar çerçevesinde fon bünyesinde bekletilebilir (VIDMK Tebliği m.17).

Konut finansman fonu tüzel kişiliğe sahip değildir. Bilanço dışı menkul kıymetleştirme olduğu için fonun malvarlığı kurucunun ve portföyde yer alan ipotekli konut kredilerini veren kuruluşun malvarlığından ayrıdır. Bu nedenle fona ve fondan yapılacak her türlü ödeme ve harcama için bir banka nezdinde kurucunun hesaplarından ayrı olarak fon adına hesap açılır (VİDMK Tebliği m.11).

\subsection{Konut Finansman Fonun Organizasyonu}

Kurucu tarafindan kurulan konut finansman fonun organizasyonu, fon kurulu ve fon operasyon sorumlusu, fon denetçisi, hizmet sağlayııı ve saklayıcıdan oluşur.

Kurucu, SPK’dan izin almak suretiyle konut finansman fonunun kuruluşunu gerçekleştiren kurumlardır. Bankalar, finansal kiralama ve finansman şirketleri, ipotek finansman kurumları ve VİDMK tebliğindeki gerekli nitelikleri taşıyan aracı kurumlar kurucu olabilirler. Kurucuların kendi özel mevzuatlarına yada sermaye piyasası mevzuatına aykırılıktan dolayı faaliyetlerinin bir ay veya daha fazla süreli geçici durdurulmamış olması gerekir (VIDMK Tebliği m.8). Konut finansman fonunda müşterek yatırım sözleşmesi ve fon içtüzüğü kurucu tarafından hazırlanır. Fonun kuruluş aşamasında yatırımcıların katılımını sağlamak için izahname ve sirküler hazırlamak görevi de kurucuya aittir. Fon kurulu kurucu tarafından atanır ve atanan bu kurul ile kuruluş aşamasında portföy yönetim sözleşmesi imzalanır (Adıgüzel, 2007).

Fon kurulu, ihraç edilen ipoteğe dayalı menkul kıymetlerin sahiplerinin haklarını koruyacak şekilde fonu temsil eden ve yöneten organdır. Fon portföyüne alınan varlıkların kayıtlarının doğruluğundan ve bu varlıkların korunması ve saklanmasından fon kurulu sorumludur (Sermaye Piyasası Kanunu m.58 (3).). Kurucu, her fon için 3 kişiden oluşan bir fon kurulunu yönetim kurulu kararıyla atar. Fon kurulu üyelerinden en az birinin Kurulun kurumsal yönetime ilişkin düzenlemelerinde sayılan nitelikleri taşıyan bağımsız üye olması ve en az bir üyenin de Sermaye Piyasası Faaliyetleri İleri Düzey Lisansı belgesine sahip olması zorunludur. Aynı kurucu tarafından birden fazla sayıda fon kurulması halinde, fon kurulları aynı kişilerden oluşabilir (VİDMK Tebliği m.11).

Fon kurulu aşağıdaki hususlardan sorumludur;

-Fon içtüzüğü değişikliklerinin ve ihraca ilişkin belgelerin hazırlanması, tescili ve ilanı,

-Fon portföyünün oluşturulması, değerlenmesi ve fon varlıklarının mevzuat çerçevesinde korunması, saklanması, kaydedilmesi, kayıtların doğru olarak tutulması ve izlenmesi, bunlara ilişkin belge düzeninin kurulması ve bilgi ve belgelerin muhafazası, 
-Fonun yatırımcıların hak ve menfaatlerini koruyacak şekilde, ilgili mevzuat, fon içtüzüğü, izahname, ihraç belgesi ve ihraca ilişkin diğer belgelerde belirtilen ilke ve yöntemlere uygun olarak temsili, yönetimi ve denetiminin gözetimi,

-Bankalar nezdinde fon adına hesap açtırılması, yatırımcılara ödemelerin doğru olarak yapılması ile fondan yapılan diğer harcamaların bu Tebliğ hükümlerine uygunluğu,

-Yatırımc1 raporlarının hazırlanması ve sunulması,

-Hizmet sağlayıcı tarafından verilen hizmetin uygun bir şekilde yapılmasının sağlanması ve hizmet sağlayıcının hizmet sözleşmesinde belirlenen yükümlülüklerini yerine getirmemesi halinde değiştirilmesi,

Fon kurulu bu görevleri bizzat kendisi yerine getirebileceği gibi, kendi sorumluluğu saklı kalmak kaydıyla her bir fon için operasyon sorumlusu atayabilir. Fon operasyon sorumlusu olabilmek için kurucu ve fon kurulu üyesi olabilmek için aranan şartları taşımak gereklidir. Ayrıca, bankalar, aracı kurumlar ve portföy yönetim şirketleri kurucu için aranan şartları taşımaları kaydıyla operasyon sorumlusu görevini üstlenebilirler (VIDMK Tebliği m.11).

Konut finansman fonlarında fona ait bilgilerin güvenilirliğini, faaliyetlerin mevzuata, sözleşmelere, içtüzüğe uygun yürütülmesini sağlayacak, hata, hile ve usulsüzlüklerin önlenmesini ve tespitini temin edecek, yazılı bir iç kontrol sistemi oluşturulması zorunludur.

Fon iç kontrol sistemi asgari olarak;

-VİDMK'nın ihraç tarihinde ve fonun faaliyet süresince Kanuna, VİDMK Tebliğine, fon içtüzüğüne ve izahname, ihraç belgesi veya ihraca ilişkin diğer belgelere uygunluğunu,

-Hizmet sağlayıcının görevinin VIDMK Tebliği ve hizmet sözleşmesi hükümlerine uygun olarak yapılmasını,

-Fon hesaplarından yatırımcılara ve ilgili kişilere yapılan ödemelerin VİDMK Tebliği hükümlerine uygunluğunu,

-Fon varlıklarının VIDMK Tebliği hükümleri çerçevesinde yönetimini, fona ilave edilmesini veya fondan çıkarılmasını,

-Fon varlıklarının kurucunun ve kaynak kuruluşların malvarlığından ayrı olarak muhafazasını, saklanmasını ve VİDMK Tebliğ uyarınca muhasebe, belge ve kayıt düzeninin etkin bir şekilde işlemesini, Fon içtüzüğü, izahname, ihraç belgesi ve ihraca ilişkin diğer belgeler veya Kurul düzenlemesiyle getirilebilecek diğer yükümlülüklerin yerine getirilmesini,

sağlayacak şekilde oluşturulur.

Fon iç kontrol sistemin işleyişini denetlemek için fon denetçisi atanması zorunlu tutulmuştur. Fon kurulu üyelerinin sahip olması gereken nitelikler denetçi için de aranmaktadır. Denetçi, fon kurulu tarafından atanır ve fon kuruluna karşı sorumludur. Fon kurulu gerekli gördüğü takdirde mevcut denetçiyi değiştirebilir.

Fon denetçisi tarafından yapılan tespitleri ve denetleme sonuçlarını ihtiva eden raporlar yılda en az bir kere fon kurulunun bilgisine sunulur. Fon kurulu rapor sonuçlarına ilişkin olarak alınacak tedbirleri karara bağlar. Bu raporların en az beş yıl süre ile saklanması zorunludur.

Fon denetçisi, görevini ifası sırasında herhangi bir ihlal veya aykırılığın varlığını tespit etmesi halinde hazırlayacağı denetim raporunu en kısa sürede fon kuruluna sunar ve aynı gün bir örneğini SPK'ya gönderir.

Fon denetçisi, ipotekli konut kredilerine ilişkin belgeler, fonun bağımsız denetim raporları ve hizmet sağlayıcısı tarafından hazırlanan raporlar dahil fonun tüm defter, kayıt ve belgelerine her an erişebilmelidir (VİDMK Tebliği m.12).

Konut finansman fonlarının organizasyonunda ipotekli konut kredilerinin günlük idaresinden sorumlu bir hizmet sağlayıcısı bulunur. Hizmet sağlayıcısının Kurucu için aranan nitelikleri haiz olması gereklidir.

Hizmet sağlayıcısının sorumlulukları Fon Kurulu ile aralarında akdedilen yazılı bir hizmet sözleşmesiyle belirlenir. Hizmet sağlayıcısının sorumlulukları asgari olarak aşağıdakileri kapsar:

- Fon portföyünde yer alan varlıklara ilişkin ödemelerin zamanında tahsil edilmesi ve fon hesabına aktarılması

-Fon portföyünde yer alan varlıklara ilişkin sigorta, vergi ve benzeri idari işlemlerin yerine getirilmesi,

-Borçluların ödeme kabiliyetlerinin gözetimi ile ödemelerin geç yapılması veya hiç yapılmaması halinde borçluya gerekli ihtarların yapılması,

-Alacaklardan kaynaklanan tüm nakit akımlarına ilişkin bilgilerin, ödeme zamanlarını ve bakiye bilgisini de gösterecek şekilde aylık olarak fon kuruluna raporlanması,

-Hizmet sözleşmesinde belirtilmesi halinde, donuk alacak niteliğindeki varlıklar için gerekli takip işlemlerinin yürütülmesi ve elde edilen gelirlerden fon payına düşen kısmının fon hesabına aktarılması.

Fon kurulu ile yapılan sözleşme çerçevesinde Fona aktarılmak üzere hizmet sağlayıcısı nezdinde bekletilen nakit, hizmet sağlayıcısının kendi hesaplarından ayrı olarak Fon adına açılan bir banka hesabına aktarılır. 
Hizmet sağlayıcısının sözleşmeyle belirlenen yükümlülüklerini yerine getirmemesi veya faaliyet izninin iptali halinde, sözleşme fon kurulu tarafindan sona erdirilir ve önceden belirlenmiş başka bir başka bir hizmet sağlayıcısı atanır ve SPK'ya bilgi verilir.

Sözleşmenin sona ermesini müteakip hizmet sağlayıcısı ipotekli konut kredilerine ilişkin elektronik veya kağıt ortamında tutulan tüm defter, belge ve kayıtları ile ipotekli konut kredilerine ilişkin tüm nakit ve banka hesaplarını mahsup veya kesinti yapmaksızın fon kuruluna veya yerine geçecek olan hizmet sağlayıcısına devreder (VİDMK Tebliği m.13).

Konut Finansman Fonunun portföyündeki ipotekli konut kredileri dışındaki varlıklar, yapılacak bir sözleşme çerçevesinde saklayıcı nezdinde saklanır. Saklama sözleşmesi ardiye sözleşmesi niteliğindedir (Erdoğan, 1990).

\subsection{Konut Finansman Fonu Portföyünün Oluşturulması}

VİDMK Tebliği, daha önceki yürürlükten kalkan IDMK Tebliğinden farklı olarak fon portföyüne dahil olacak varlıkların kapsamını genişletmiştir. Özellikle ipotek teminatlı ticari kredilerin de fon portföyüne dahil olmalarını sağlayarak VİDMK'lara daha kapsamlı bir menkul kıymet olmalarının yolunu açmıştır. Böylece ticari mortgage uygulaması Türk Sermaye Piyasasına bir bakıma girmiş olmaktadır (Reinhard, 2010).

VİDMK Tebliğinde, fona dahil edilebilecek varlıkları şu şekilde gösterilmiştir.

-Bankaların ve finansman şirketlerinin, ilgili sicilde ipotek tesis edilmek suretiyle teminat altına alınmış, konut finansmanından kaynaklanan alacakları,

- Konut finansmanından kaynaklanmak kaydıyla, finansal kiralama sözleşmelerinden doğan alacaklar,

- Bankaların, finansal kiralama şirketleri ve finansman şirketlerinin ilgili sicilde ipotek tesis edilmek suretiyle teminat altına alınmış ticari kredi ve alacakları,

- Toplu Konut İdaresi Başkanlığının konut satışından kaynaklanan taksitli ve sözleşmeye bağlanmış alacakları,

- Türev araçlardan kaynaklanan haklar ve yükümlülükler.

Konut finansmanından kaynaklanmakla birlikte ipotek tesis edilmek suretiyle teminat altına alınmamış olan kredilerden kaynaklananlar, SPK tarafından uygun görülen nitelikte başka bir teminata bağlanmış olan kredilerin de fon portföyüne dahil edilmesinin yolu açılmıștır (VIDMK Tebliği m.15). Ancak bu uygulama, münhasıran ipotek teminatına bağlı olan ipoteğe dayalı menkul kıymetlerin temel niteliğine aykırı düştüğü kanaatindeyiz. Bu yolun açılması fonun teminat havuzunun güçlü bir teminat olan ipotekten oluşması fikrini zedeleyebilir ve muhtemel yatırımcılarda güvensizliğe yol açabilir. Bu bakımdan SPK'nın ipotek dışında diğer teminatlara izin verme hususunda çok titiz davranması ancak ticari işletme rehni, mevduat veya banka teminat mektubu gibi güçlü teminatları kabul etmesi yerinde olacaktır.

Fona devredilecek banka kredilerinin Bankalarca Kredilerin ve Diğer Alacakların Niteliklerinin Belirlenmesi ve Bunlar İçin Ayrılacak Karşılıklara İlişkin Usul ve Esaslar Hakkında Yönetmelik uyarınca birinci sınıf olarak nitelenen bir alacak olması lazımdır.

Finans kuruluşlarınca verilecek kredilerle finansal kredi alacaklarına Finansal Kiralama, Faktoring ve Finansman Şirketlerinin Muhasebe Uygulamaları ile Finansal Tabloları Hakkında Yönetmelik hükümleri uyarınca özel karşılık ayrılmamış olması şarttır.

Söz konusu alacakların teminatını oluşturan taşınmazların ise;

- Taşınmazın Türkiye Cumhuriyeti sınırları içinde olması,

- Taşınmaza ilişkin kanuni zorunluluklardan kaynaklanan sigorta yükümlülüklerinin yerine getirilmiş olması,

- Kredinin kullandırılması veya alacağın oluşumu aşamasında taşınmazın piyasa değerinin BDDK veya Kurulca listeye alınmış değerleme kuruluşlarınca tespit edilmiş olması, zorunlu tutulmuştur.

Fon portföyünün kur ve faiz oranı riskinden korunması amacıyla yapılan swap, forward, future ve opsiyon sözleşmelerine türev araçlar denilmektedir. Söz konusu türev araçlardan kaynaklanan hak ve alacaklar bir limit dahilinde fon portföyüne dahil edilebilir. Buna göre fonun portföyüne dahil edilen türev araçlardan kaynaklanan haklar, riske maruz tüm varlıkların kalan toplam anapara nominal değerini; yükümlülükler, ihraç edilen riske maruz ipoteğe dayalı menkul kıymetlerin kalan toplam anapara nominal değerini aşamaz.

Türev aracın borsalarda alım satıma konu olması veya karşı tarafının, bir banka, kredi kuruluşu, sigorta şirketi veya merkezi takas kuruluşu olması şarttır. Bunların kredi derecelendirme kuruluşlarınca belirlenen derecelendirme notunun yatırım yapılabilir seviyenin en yüksek ilk üç kademesine denk gelen uzun vadeli derecelendirme notuna sahip olması gerekir (VIDMK Tebliği, m.16).

\section{4 İpotekli Konut Kredisinin Fon Portföyüne Devri}

Fon, kredi veren finansman kuruluşunun bilançosunda yer alan ipotekli konut kredisini söz konusu kredi verenle imzalanacak bir sözleşme çerçevesinde portföye dahil etmek üzere devralır. Bundan başka, Fon, Toplu Konut İdaresi Başkanlığının alacaklarını da portföye dahil etmek üzere devralabilir. Söz konusu devir sözleşmeleri alacağın temliki hükümlerine tabiidir (Doğru, 2007). 
Devir sonucunda ilgili kredinin sahipliğiyle ilgili tüm haklar fona geçer. Kredinin fon portföyüne devri tarihinden önceki yapılan işlemlerden dolayı ortaya çıkabilecek mali yükümlülükler fon portföyünden karşılanamaz. Başka bir deyişle fon özellikle bağlı kredilerde kredi veren finansman kuruluşunun Tüketicinin Korunması Hakkındaki Kanundan kaynaklan sorumluluğu üzerine almamaktadır. Bu yükümlülüklerle ilgili hukuki anlaşmazlıklarda taraf sıfatı kaynak kuruluşa ait olup, Fon taraf gösterilemez ( VİDMK Tebliği m. 21).

İpotekli konut kredilerinin teminatı olan konutlara ilişkin tapu sicilinde beyanlar hanesine, ilgili kredinin fona devredildiği hususu kaydedilir. Bundan başka Kurul, ipotekle teminat altına alınmış bir konut kredinin fon portföyüne devredilmesi halinde, ipoteğin veya mülkiyetin; fon hesabına, kurucu adına tapuya tescil ettirilmesini zorunlu tutabilir (6362 sayılı Sermaye Piyasası Kanunu m.58 (5)). Yürürlükten kalkan 2949 sayılı Sermaye Piyasasının 38/B maddesi ile verilmiş tescili zorunlu tutma yetkisini SPK kullanmamış ve mülga İDMK Tebliğinde böyle bir hükme yer vermemişti. Bu kez SPK yeni VIDMK Tebliğinin 17 (5) maddesinde fona devredilen alacağın teminatını oluşturan taşınmazın veya ipoteğin fon adına tescilini zorunlu tutmuştur. Ancak, ilgili tapu sicilinde tescilin mümkün olmaması halinde varlığın fona devredildiği hususu tapu sicilinin beyanlar hanesinde gösterilir.

\subsection{Fon Portföyünü Koruyucu Hükümler}

Yukarıda da belirtildiği gibi, konut finansman fonları, özel amaçlı kuruluş diyebileceğimiz ABD'deki "Trust" lar, Türkiye'deki "yatırım fonlarına” benzer şekilde yapılandırılmıştır (Topaloğlu, 2006; Makaracı, 2007). Bu nedenle Fon üzerinde ipoteğe dayalı menkul kıymet sahipleri dışındaki vergi, SSK, işçi ve diğer üçüncü kişilerin de alacağı bulunabilir (Doğru, 2007). Sermaye Piyasası Kanunu m.58 (2)'de Bu alacakların talebiyle iflasın açılması halinde fon portföyüne dahil alacakların iflas masasına girmesi, yatırımcılar için çok büyük bir güvensizlik oluşturacaktır. İşte bu amaçla fon malvarlığının ihraç edilen ipoteğe dayalı menkul kıymetler itfa edilinceye kadar, başka bir amaçla tasarruf edilemeyeceği, rehnedilemeyeceği, teminat gösterilemeyeceği, kamu alacaklarının tahsili amacı da dahil olmak üzere haczedilemeyeceği, ihtiyati tedbir kararı verilemeyeceği ve iflas masasına dahil edilemeyeceği hükmüne yer verilmiştir. Bu suretle kanunen temlik yasağı konularak, Tebliğ ile temlikin yasaklanamayacağı eleştirileri karşılanmıştır (Ayhan, 1993).

Sermaye Piyasası Kanunu 58(2) maddesi fon malvarlığının teminat gösterilemeyeceği veya rehenedilemeyeceği yasağına istisna da getirmiştir. Buna göre, B fonların mal varlığı, fon hesabına olması ve fon iç tüzüğünde hüküm bulunması şartıyla kredi almak, türev araç işlemleri, açığa satış işlemleri veya fon adına taraf olunan benzer nitelikteki işlemlerde bulunmak amacıyla teminat gösterilmesi veya rehnedilmesi mümkündür.

Genel olarak menkul kıymetleştirmede; alacakların ödenmemesi, likidite riski, erken ödeme riski, çeşitli finansal ve hukuki riskler söz konusudur (Topaloğlu, 2006; Eriş, 2008). Birtakım güvenceler (credit enhancement) yoluyla bu riskler ortadan kaldırılmaya ve azaltılmaya çalışılmaktadır. Aynı düşünceyle ipotekli konut kredilerinden elde edilen nakit akımlarının, ipoteğe dayalı menkul kıymet sahiplerine yapılacak olan ödemeler ile fon varlıklarından yapılabilecek diğer harcamaları karşılayamama riskine karşı, ipoteğe dayalı menkul kıymet sahiplerinin haklarının korunabilmesi amaciyla;

- Fon kurulu ile kurucu ve/veya üçüncü bir taraf arasında sigorta, garanti, teminat mektubu veya diğer bir garanti yöntemi kullanılmasını teminen sözleşme yapılabilir,

- Farklı haklara sahip değişik dilimlerde VİDMK ihraç edilebilir,

- Varlıkların fonun toplam yükümlülüklerini aşan kısmı, hizmet sözleşmesi ile belirlenecek oran veya miktarda bu amaçla oluşturulacak yedek hesaplara aktarılabilir.

Bunlara ek olarak, izahnamede ve ihraç belgesinde açıklanmak kurucu veya kaynak kuruluş fon portföyünün kalitesinin artırılması amacıyla VIDMK dilimlerinden satın alabilir (VİDMK Tebliği, m.19).

\section{6 İpotekli Konut Kredilerinin Fon Portföyünden Çıkarılması veya Değiştirilmesi}

Bazı hallerde fon potföyündeki varlıkların değiştirilmeleri veya çıkarılmaları söz konusu olabilir. Varlıkların fon portföyünden çıkarılması veya değiştirilmesi için fon kurulunun kararı şarttır.

Fona devredilen varlıkların Kanun, Tebliğ, Fon içtüzüğü ve izahnamede belirtilen niteliklere uygun olmadığ 1 sonradan anlaşılabilir. Uygun olmadığı anlaşılan bu varlıkları fona devreden kaynak kuruluş on gün içinde yenileriyle değiştirmek zorundadır. Değiştirilen varlıkların da Fon içtüzüğünde ve izahnamede belirtilen niteliklere uygun nitelikte olması gereklidir.

Garanti verilmesi veya garanti sözleşmesinin işletilmesi bazı hallerde fon portföyünden bazı varlıkların çıkarılma ihtiyacını ortaya çıkarabilir. Böyle bir durumda portföydeki varlıklar, izahname veya ihraç belgesinde belirtilen esaslar çerçevesinde söz konusu fon portföyünden çıkarılabilir veya değiştirilebilir.

Bu sayılan haller dışında, ipotekli konut kredileri, fon portföyüne ilave edilemeyeceği gibi, fondan çıkarılması da mümkün değildir (VİDMK Tebliği m.20).

\subsection{Konut Finansman Fonunun Geri Ödeme Güçlüğüne Düşmesi}

SPK, Fon kurulunun kendine verilen görevleri gereği gibi yerine getirmemesi sonucu fonun geri ödeme güçlüğüne düştüğünü tespit ettiğinde fon kurulu üyelerinin değiştirilmesini talep edebilir. SPK'dan bu yönde talep alan fon kurucusu, fon kurulu üyelerini değiştirmek zorundadır. 
Geri ödeme güçlüğünün devamı halinde SPK, fonun başka bir kurucuya devredilmesine karar verebilir. Kurul fonun başka bir kurucuya devredilmesine karar verebilir. Ancak ilk kurucunun, garanti vermiş olması halinde, ihraç edilen VIDMK'nın geri ödemelerinin fon malvarlığından karşılanamayan kısmının tam ve zamanında yapılmasına ilişkin yükümlülüğü devam eder.

SPK, atanacak yeni kurucuya hizmetleri karşılığında fon malvarlığından yapılacak ödemeleri belirlemeye yetkilidir (VIDMK Tebliği m.27).

\subsection{Konut Finansman Fonunun Sona Ermesi}

Konut finansman fonunun infisah ve fesih diyebileceğimiz iki şekilde sona ermesi söz konusu olabilir.

Konut finansman fonları süreli yada süresiz oluşturulabilir. Fonun içtüzüğünde bir sure konulmuşsa bu sürenin dolmasiyla fon kendiliğinden sona erer veya infisah eder.

Fon süresiz olarak kurulmuş ise, fonun sona ermesi için yatırımcılara karşı bütün yükümlülüklerin ifa edilmiş olması gerekir. Fon kurulu, yatırımcılara karşı fonun yükümlendiği bütün ifaların tamamlandığını gösteren belgelerle SPK'ya sona erme talebiyle başvurur. SPK'nın yapacağı incelemede sunulan belgeler doğru ve yeterli görülürse fonun sona ermesine yada feshine karar verir.

Fon hakkında sona erme kararının verildiği tarihten itibaren artık ipoteğe dayalı menkul kıymet ihraç edilemez (VİDMK Tebliği m.28).

\section{Sonuç}

İpoteğe dayalı menkul kıymetler, ipotekle teminat altına alınmış alacakların menkul kıymetleştirilmesinde kullanılan bir sermaye piyasası aracıdır. 6362 sayılı Sermaye Piyasası Kanunu ipoteğe dayalı menkul kıymetlerin kurulacak konut finansmanı fonları aracılığıyla ihracını öngörmektedir. Konut finansman fonu, ihraç edilen ipoteğe dayalı menkul kıymetler karşılığında toplanan paralarla, ipoteğe dayalı menkul kıymetler hesabına inançlı mülkiyet esaslarına göre oluşturulan malvarlığıdır. Fon malvarlığına devredilen menkul kıymetlerin nakit akımlarından elde edilen gelirler, yatırımcılara ait olmaktadır. Konut finansmanı fonlarının tüzel kişiliği yoktur ve bilanço dışı olduğu için fonu oluşturan kurucunun malvarlığından ayrıdır. Fon malvarlığının ihraç edilen ipoteğe dayalı menkul kıymetler itfa edilinceye kadar, başka amaçla tasarruf edilmesi, haciz ve tedbire konu olması yada iflas masasına girmesi yasaktır. Fon kurulu, ihraç edilen ipoteğe dayalı menkul kıymetlerin sahiplerinin haklarını koruyacak şekilde fonu vekalet sözleşmesi hükümlerine göre temsil eder ve yönetir. Kurucular ayrıca garanti vermedikçe, ihraç edilen sermaye piyasası araçlarının geri ödemelerinin fon malvarlığından karşılanmayan kısmından sorumlu değildir.

İpoteğe dayalı menkul kıymetler en son olarak ikincil mevzuat olarak 09.01.2014 tarih ve 28877 sayıl1 Resmi Gazete'de yayımlanan Seri:III, No:58.1 sayılı Varlığa veya İpoteğe Dayalı Menkul Kıymetler (VIDMK) Tebliği ile düzenlenmiştir. VIDMK Tebliği, yürürlükten kalkan eski Seri: III, No: 34 sayılı İDMK Tebliğinden farklı olarak, fona dahil varlıklardan elde edilen nakit akımlarının bekletilmeksizin doğrudan aktarım yanında ayrıca bu nakit akımlarının belirli bir sure bekletildikten sonra belirlenen vadede yatırımcılara aktarılmalarına imkan tanıyan dolaylı aktarım usulünü de kabul etmiştir.

Yeni VIDMK Tebliği ile bankaların ipotek teminatlı ticari kredilerinin de fona varlık olarak girmesi kabul edilerek bir bakıma ticari mortgage uygulaması da başlatılmıştır. VIDMK'lara daha geniş bir hacim ve işlerlik sağlayacak bu yeni uygulamayı isabetli bulmaktayı.

Bunun yanında, aynı Tebliğde ipotek teminatı olmayan banka kredilerinin de fona dahil edilebilmeleri yönünde yeni hükümler sevkedilmiştir. İpotek teminatlı menkul kıymetlerin niteliği ile bağdaşmayan bu yöndeki hükümler fonun teminat havuzuna duyulan güveni sarsma endișesini bizde yaratmaktadır. Bu nedenle fona ipotek teminatsız varlık girişine ancak istisnai hallerde ve çok güçlü diğer teminatlara sahip olması halinde izin vermek uygun olur.

\section{Kaynakça}

- $\quad$ Adigüzel, B., 2007. "5582 Say1l1 Kanun ile Getirilen Konut Finansman Sisteminde Yeni Sermaye Piyasas1 Araçları”, Legal Mali Hukuk Dergisi, S.29, Mayıs 2007, s.1099-1130.

- Alp, A., 2000. Modern Konut Finansmanı, SPK Yayınları No:51, Ankara.

- Ayhan, R., 1993. Türk Hukukunda Menkul Kıymetleştirme Kavramı ve Varlığa Dayalı Menkul Kıymetler, Ankara.

- Berkant, Z. N., 2005. “Türkiye’de Konut Finansmanında Rollerin Paylaşımı”, Konut Finansmanı ve Türkiye 2 Konferansı, Swiss Hotel İstanbul - Türkiye 17 Kasım 2005.

- Çetin, S.H., 2004. İpotekli Borç Senedi ve İrad Senedi, Bilge Yayınevi, Ankara.

- Doğru, H., 2007. Menkul Kıymetleştirme \& Mortgage, Doğru Hukuk Yayınları, İstanbul.

- $\quad$ Erdoğan, İ., 1990. Ardiye Sözleşmesi, Selçuk Üniversitesi Hukuk Fakültesi Yayınları, Konya. 
- Eriş, M.H., 2008. Bireysel Krediler Kapsamında İpotekli Konut Kredileri ve İşlevsellik Koşulları, Arıkan Basım Yayım Dağıtım, İstanbul.

- Günver, O.R., 1994. Sermaye Piyasası Aracı Olarak İpotekli Borç Senedi ve İrat Senedi, Bankalar Birliği Yayını, Yayın No:185, Ankara.

- Handersen, J. ve Scott, J.P., 1988. Securitization, Woodhead Faulkner, New York.

- $\quad$ Nomer, N. F., 2002. "Yatırım Fonlarında Katılma Belgesi Sahibi ile Kurucu Arasındaki Hukuki İlişki ve Katılma Belgesi Sahibinin Hukuki Durumu”, Prof.Dr. Ömer Teoman'a 55.Yaş Günü Armağanı, C.I, Beta Yayınevi, İstanbul, s. $595-622$.

- Önal, Y.B, ve Topaloğlu, M., 2007. İpotekli Konut Finansmanı ve Hukuku - Mortgage (Tutsat), Karahan Kitabevi, Adana.

- Makaracı, A., 2007. Konut Finansman Sisteminde İhraç Edilen Menkul Kıymetler ve Teminatları, XII Levha Yayıncılık, İstanbul.

- Reinhard, M., 2010. Commercial Mortgages 101, AMACOM Publishing, New York.

- Tanör, R., 1999. Türk Sermaye Piyasası - Taraflar, 2.Bası, C.I, Beta Yayınevi, İstanbul.

- Topaloğlu, M., 2006. “ABD Mortgage Uygulamas1 ve İpotekli Konut Finansmanına İlişkin Kanun Tasarısının Değerlendirilmesi”, Prof.Dr.Fikret EREN'e Armağan, Yetkin Yayınları, Ankara, s.843-876.

- Topaloğlu, M., 2007. İpoteğe Dayalı ve İpotek Teminatlı Menkul Kıymetler, Karahan Kitabevi, Adana.

- Topaloğlu, M., 2009. “Türk Hukukunda İpoteğe Dayalı ve İpotek Teminatlı Menkul Kiymetler”, Prof.Dr.Ali Naim INAN’a Armă̆an, Seçkin Kitabevi, Ankara.

- Yalçıner, K., 2006. İpotek Karşılığı Menkulleştirilmiş Krediler, Gazi Kitabevi, Ankara.

- Yıldız Destanoğlu, B., 2004. Yatırım Fonu Katılma Belgeleri, Banka ve Ticaret Hukuku Araştırma Enstitüsü Yayınları, Ankara. 


\title{
Vergilemede Adalet Açısından Türkiye’nin Dolaysız ve Dolaylı Vergileme Politikası
}

\section{Turkey's Direct and Indirect Taxation Policy in terms of Tax Justice}

\author{
Prof. Dr. Sabahat Binnur Çelik (Beykent University, Turkey)
}

\begin{abstract}
Public finance is a branch of science which examines the activities' economic and finance aspects of the public sector. Public finance has three main objectives such as keeping the economy in balance, providing justice in the distribution of income and providing the economic development / growth. State has to create and apply some finance and economic policies according to those objectives. State can use mainly three tools which are public incomes (mostly taxes), public expenditures and public debt for to keep and to protect the economy in balance. While keeping and protecting the economy in balance, state must consider "justice" in every chosen policy. This work's subject is examining the taxation policy according to the types of taxes from the view of "justice in taxation" in Turkey. In order to reach a successful comment about this subject, we will consider the rate of direct and indirect taxes to total tax revenue. If there isn't justice in taxation, this means that state couldn't apply appropriate policies in a successful way or didn't apply them because of its other purposes. We know that in this century the state is intrusive, effective and very powerful, so we can easily claim that state has responsibility from the lack of justice in taxation. It should not be forgotten that, ensuring "justice in taxation" is so important principle that, Turkish Constitution edited it as an order.
\end{abstract}

\section{Giriş}

Kamu maliyesinin; ekonomik dengenin sağlanması, gelir dağılımında adaletin sağlanması ve ekonomik kalkınma / büyüme ve gelişmenin sağlanması olmak üzere üç temel amacı vardır. Devletin görevi, sayılan bu üç temel amaç doğrultusunda ekonomik/mali politikalara yön vermektir. Devlet, ekonomik/mali politikalara yön verirken, kamu gelirlerini (içlerinde en büyük paya sahip olan vergileri), kamu giderlerini ve kamu borçlanmasını araç olarak kullanır ve uygulayacağı politikalara göre bir bütçe düzenlemesi yapar. Devlet, bu uygulamalarının yanında özel sektörle ilgili olarak çeşitli özendirici ve düzenleyici politikalar da uygulayarak ekonomide kendi programına uygun sonuçlar almayı hedefler. Örnek olarak; işsizlik sigortası yapılmasını zorunlu tutarak veya özendirerek enflasyonist ortamda talep artışını azaltır, ürünün bol olduğu yıllarda talep fazlasını piyasadan çekip, ürünün kıt olduğu yıllar piyasaya sürerek ürün fiyatlarının aşırı yükselmesini engelleyerek arz/talep dengesini oluşturmaya çalışır, halkın atıl birikimlerinin bankacılık sektörünü kullanarak (altın hesap açılarak eldeki altının harcanmasını engelleyip bir süreliğine de olsa bağlanması gibi) ekonomiye aktarılmasını özendirip talep baskısını azaltmaya çalışır. Günümüz devletinin müdahaleci ve çok güçlü olduğu göz önünde bulundurulduğunda, devletin ekonomik ve mali amaçlarına ulaşmak için elindeki araçları uygulama olanağı olduğu gerçektir.

Ülkemizde ekonominin dengede olmadığı bilinmektedir. Ekonomik denge, fiyat dengesinin, istihdam seviyesinin ve dış ticaretin dengede olmasını belirtir (Pehlivan,2002). Fiyat dengesinden kasıt ise, ortalama fiyat düzeyinde aşağıya veya yukarıya doğru keskin hareketlerin olmamasıdır (Akdoğan, 2011). Ülkemizde fiyat dengesinin olmadığı, enflasyonist bir seyir gerçekleştiği bilinmektedir. Enflasyon, toplam talebin toplam arzdan fazla olması sonucunda genel fiyat seviyesinin artması olarak tanımlanır. Enflasyon kavramının iki temel özelliğinden birisi fiyatlarda hissedilir düzeyde artışın olması, diğeri ise, fiyat artışlarının sürekli olmasıdır (Pehlivan,2002). Enflasyonla mücadelede en etkin maliye önlemleri, gelir cephesinde yer alır (Due, 1967). Kamu gelirleri içinde en önemli payı vergiler oluşturduğuna göre, enflasyonla mücadelede en önemli aracın vergiler olduğu açıkça anlaşılmaktadır.

Çalışma konumuz, enflasyonist koşullarda olan ülkemizde, devletin vergileme tercihinin, vergilemede adalet ilkesine uygun olup olmadığının belirlenmesidir.

\section{Türkiye'nin Dolaysız Ve Dolaylı Vergileme Tercihi}

Vergiler değişik kriterlere göre ayırıma tabi tutulabilirler. Örneğin; dolaysız/dolaylı olmalarına göre, konularına göre veya kişisel ve objektif olmalarına göre ayırım yapılabilir.

Vergilerin, vergilemede adalet ilkesine uygun olup olmadığını bize gösteren en önemli ayırım, vergilerin tiplerine göre yapılan dolaysı/dolaylı vergi ayırımdır.

\subsection{Dolaysız ve Dolaylı Vergi Ayırımı}

Vergilerin dolaysız ve dolaylı ayırımında kullanılan kriterlerden birisi verginin yansıması, ikincisi ise, vergi konusunun sürekliliği ve mükellefinin önceden belli olmasıdır (Nadaroğlu, 1989, Akdoğan, 2011). 
Yansıtılamayan (vergi mükellefinin vergiyi ödedikten sonra, ödediği tutarı başkasına yükleyememesi, yaptığı ödeme tutarı kadar kendi iktisadi değerlerinde azalmanın olması hali) veya zor yansıtılan vergiler dolaysız, kolay yansıtılan vergiler dolaylı vergiler sayılır. Bu kritere göre, örneğin gelir ve kurumlar vergisi dolaysız, katma değer vergisi, gümrük vergisi dolaylı vergi sayılmaktadır.

Vergi konusunun sürekli olması ve mükellefinin önceden belli olması kriteri ise, bazı vergilerin genellikle yıllık olarak, periyodik şekilde ve devamlılık gösteren mal, gelir veya gelir getiren faaliyetler üzerinden alınıyor olmasını ifade eder. Bu vergilerde, vergi idaresi, mükelleflerin kimler olduğunu önceden bilir. Konusu belli ve mükellefleri önceden bilinen vergiler, dolaysız vergilerdir. Bu kritere göre, ülkemizde dolaysız vergilerin örnekleri; gelir vergisi, kurumlar vergisi, motorlu taşıtlar vergisi ve emlak vergisi olmaktadır. Dolaylı vergilerde ise, vergi konusu sürekli değildir ve vergi mükellefinin kim olacağı vergi idaresi tarafindan önceden bilinmez. Bu kritere göre, ülkemizde dolaylı vergilerin örnekleri; katma değer vergisi, gümrük vergisi, özel tüketim vergisi olmaktadır.

\subsection{Dolaysız ve Dolaylı Vergilerin Türkiye Uygulamasında Görünümü}

Ülkemizde, dolaysız vergilerden gelir vergisi ve kurumlar vergisi, dolaylı vergilerden katma değer, özel tüketim ve gümrük vergilerinin tahakkuk tutarları göz önünde bulundurulduğunda, dolaysız ve dolaylı vergilerin toplam vergi gelirleri içindeki tutarları Tablo 1 de net olarak görülebilmektedir. Ülkemizde, son on yılın verilerine göre dolaylı vergiler tutarı, toplam vergi gelirleri tutarı içinde en büyük paya sahip olmuştur.

\begin{tabular}{|l|c|c|c|c|c|c|c|c|c|c|}
\hline & $\mathbf{2 0 0 6}$ & $\mathbf{2 0 0 7}$ & $\mathbf{2 0 0 8}$ & $\mathbf{2 0 0 9}$ & $\mathbf{2 0 1 0}$ & $\mathbf{2 0 1 1}$ & $\mathbf{2 0 1 2}$ & $\mathbf{2 0 1 3}$ & $\mathbf{2 0 1 4}$ & $\mathbf{2 0 1 5}$ \\
\hline Merkezi Yönetim Gelirleri & 216 & 242 & 274 & 291 & 355 & 428 & 511 & 591 & 661 & 758 \\
\hline Vergi Gelirleri & 164 & 188 & 212 & 225 & 273 & 332 & 367 & 423 & 471 & 549 \\
\hline $\begin{array}{l}\text { Gelir Ve Kazanç } \\
\text { Üzerinden Alınan Vergiler }\end{array}$ & 50 & 61 & 72 & 79 & 88 & 109 & 121 & 131 & 153 & 174 \\
\hline - Gelir Vergisi & 36 & 43 & 51 & 54 & 60 & 72 & 82 & 93 & 109 & 128 \\
\hline - Kurumlar Vergisi & 14 & 18 & 21 & 24 & 29 & 38 & 38 & 38 & 43 & 47 \\
\hline Ötv, Kdv, Gv Toplamı & 94 & 103 & 113 & 116 & 151 & 185 & 201 & 240 & 260 & 307 \\
\hline Katma Değer Vergisi & 55 & 60 & 67 & 69 & 88 & 113 & 120 & 145 & 157 & 186 \\
\hline - Dahilde Alınan Kdv & 29 & 34 & 37 & 42 & 52 & 64 & 70 & 82 & 93 & 111 \\
\hline - İthalde Alınan Kdv & 25 & 26 & 30 & 26 & 36 & 49 & 50 & 63 & 64 & 74 \\
\hline Özel Tüiketim Vergisi & 38 & 40 & 43 & 45 & 60 & 68 & 75 & 90 & 97 & 113 \\
\hline Gümrük Vergileri & 2 & 2 & 3 & 2 & 3 & 5 & 5 & 5 & 7 & 8 \\
\hline
\end{tabular}

Tablo 1: Dolaysız ve Dolaylı Vergilerin Toplam Merkezi Yönetim Gelirleri İçindeki Tutarları Kaynak: Kamu Hesapları Bülteni, Veriler Tahakkuk Tutarlarıdır (milyar TL)

Tablo 2 de ise, Tablo 1 de yer alan dolaysız ve dolaylı vergilerin toplam merkezi yönetim vergi gelirleri içindeki pay1 \% olarak görülmektedir. Bu tablodan çıkan sonuç, ülkemizde son on yılda toplam merkezi yönetim vergi gelirleri içinde dolaysız vergilerin payının \% 30 civarında seyrettiği, dolaylı vergilerin ise \% 50 nin üzerinde olduğudur. Bu verilere göre, ülkemizde vergi yükünün ağırlıklı olarak dolaylı vergilere dayandığı görülmektedir.

\begin{tabular}{|l|c|c|c|c|c|c|c|c|c|c|}
\hline \multicolumn{1}{|c|}{ Gelirin Çeşidi } & $\mathbf{2 0 0 6}$ & $\mathbf{2 0 0 7}$ & $\mathbf{2 0 0 8}$ & $\mathbf{2 0 0 9}$ & $\mathbf{2 0 1 0}$ & $\mathbf{2 0 1 1}$ & $\mathbf{2 0 1 2}$ & $\mathbf{2 0 1 3}$ & $\mathbf{2 0 1 4}$ & $\mathbf{2 0 1 5}$ \\
\hline $\begin{array}{l}\text { Gelir Ve Kazanç Üzerinden Alınan } \\
\text { Vergiler }\end{array}$ & 30 & 33 & 34 & 35 & 32 & 33 & 33 & 31 & 32 & 32 \\
\hline - Gelir Vergisi & 22 & 23 & 24 & 24 & 22 & 22 & 22 & 22 & 23 & 23 \\
\hline - Kurumlar Vergisi & 8 & 9 & 10 & 11 & 11 & 11 & 10 & 9 & 9 & 8 \\
\hline Kdv, Ötv, Gümrük V & 57 & 55 & 53 & 52 & 55 & 56 & 55 & 57 & 55 & 56 \\
\hline Katma Değer Vergisi & 33 & 32 & 32 & 31 & 32 & 34 & 33 & 34 & 33 & 34 \\
\hline Özel Tüketim Vergisi & 23 & 21 & 20 & 20 & 22 & 20 & 21 & 21 & 21 & 21 \\
\hline Gümrük Vergileri & 1 & 1 & 1 & 1 & 1 & 1 & 1 & 1 & 1 & 2 \\
\hline
\end{tabular}

Tablo 2: Dolaysız ve Dolaylı Vergilerin Toplam Vergi Gelirleri İçindeki Payı (\%) Kaynak: Kamu Hesapları Bültenindeki Veriler Kullanılarak Hesaplanmıştır

\section{Dolaysız ve Dolaylı Vergilerin Vergilemede Adalet İlkesine Uygunluğu}

Vergilemede adalet ilkesi en geniş biçimde, vergi yükünün mükellefler arasında adil bir biçimde dağıtılması (Akdoğan, 1980) olarak tanımlanabilir. Vergilemede adalet ilkesine göre vergileme, mükellefin ödeme gücü ile uyumlu olmalıdır. Vergilemenin, mükellefin ödeme gücüne uygun olmasını sağlamak için ise, vergiler şahsileştirilmelidir, artan oranlılık, en az geçim indirimi ve ayırma ilkesi uygulanmalıdır.

Vergiler şahsileştirilmesi, vergileme sırasında mükelleflerin şahsi ve ailevi durumlarının vergi tutarının belirlenmesinde etkin olması anlamına gelir. Bu uygulama ancak dolaysız vergilerde yer alabilir, çünkü dolaysız 
vergilerde kimin, ne zaman mükellef olacağı önceden bilinmektedir. Bu açıdan dolaysız vergilerin, dolaylı vergilere göre daha adil oldukları açıktır.

Vergilemede adalet ilkesi açısından, vergi tarifesinin artan oranlı olması önemli bir göstergedir. Artan oranlı tarife yapısı dolaysız vergilerde uygulanmaktadır. Gelir vergisi örneğinde olduğu gibi, geliri az olan mükellef, geliri kendisininkinden daha fazla olana göre daha az vergi öder. Oysa dolaylı vergilerde, örneğin katma değer vergisinde, farklı gelir düzeylerindeki mükellefler aynı tutarda harcama yaptıklarında, aynı tutarda vergi öderler. $\mathrm{Bu}$ durumda, ödenen vergi tutarını gelire oranlarsak, geliri az olanın, geliri fazla olana oranla daha çok vergi ödemiş olduğu gerçeğine ulaşırız. Bu sonuç bize, dolaysız vergilerin artan oranlı tarife yapısıyla, vergilemede adalet ilkesine daha uygun olduğunu göstermektedir.

En az geçim indirimi uygulaması, en anonim tanımıyla, kişinin kendisini ve ailesini asgari düzeyde geçindirebilecek tutarın vergi dışı bırakılmasını ifade eder. Bu uygulama da yine dolaysız bir vergi tipi olan gelir vergisinde yer almaktadır, bu nedenle dolaysız vergi uygulaması vergilemede adalet ilkesine daha uygun olmaktadır.

Ayırma ilkesi, gelirin yapısal özelliğinin göz önünde bulundurularak, emekle elde edilen gelirlerin, sermayeden elde edilen gelirlere oranla daha az vergilendirilmesinin sağlanmasıdır. Ayırma ilkesi, dolaysız vergi tipi olan gelir vergisinde uygulanmaktadır. Bu ilkeye karşı görüşler olsa da, bizim de paylaştığımız çoğunluk görüşü, ayırma ilkesinin vergilemede adaleti sağladığına yöneliktir.

\section{Sonuç}

Ülkemizde, toplam merkezi yönetim gelirlerinin büyük kısmının vergilerden oluştuğu Tablo 3'de görülmektedir. Kamu giderlerini karşılamak amacıyla toplanan vergilerin, vergide adalet ilkesine uygun olması, toplumun vergi ödemeye yönelik istek ve bilincini artıracaktır. Bu sonuç ise, devletin kamu hizmetlerini zamanında ve yeterli düzeyde gerçekleştirmesine neden olacaktır. Vergide adalet ilkesine uygun olan vergileme, sebepleri yukarıda açıklandığı üzere, dolaysız vergilerin dolaylı vergilere oranla daha fazla oranda olmasıdır. Oysa ülkemizde bunun tam tersi bir uygulama sürmektedir ve bu dağılım, gelişmiş ülkelerle de uyumlu değildir. OECD üyesi ülkelere baktığımızda, dolaylı vergi yükünün en yüksek olduğu ülke Türkiye'dir. Türkiye'yi, Şili, Macaristan, Estonya ve Yeni Zelanda izlemektedir (OECD Tax Database - OECD, oecd.org) .

\begin{tabular}{|l|c|c|c|c|c|c|c|c|c|c|}
\hline Yillar & $\mathbf{2 0 0 6}$ & $\mathbf{2 0 0 7}$ & $\mathbf{2 0 0 8}$ & $\mathbf{2 0 0 9}$ & $\mathbf{2 0 1 0}$ & $\mathbf{2 0 1 1}$ & $\mathbf{2 0 1 2}$ & $\mathbf{2 0 1 3}$ & $\mathbf{2 0 1 4}$ & $\mathbf{2 0 1 5}$ \\
\hline Vergi Gelirleri (\%) & 76 & 78 & 77 & 77 & 77 & 78 & 72 & 72 & 71 & 72 \\
\hline
\end{tabular}

Tablo 3: Vergi Gelirlerinin Merkezi Yönetim Gelirleri İ̧̧indeki Payı(\%) Kaynak: Kamu Hesapları Bültenindeki Veriler Kullanılarak Hesaplanmıştır

Dolaylı vergilerin, vergi adaleti açısından en olumsuz yanı, mükellefin vergi ödeme gücünün varlı̆̆ı aranmaksızın vergi ödemek zorunda kalmasıdır. Bu olumsuzluk bilhassa zorunlu tüketim mallarının alımında ortaya çıkmaktadır (Akdoğan, 2011). Zorunlu tüketim malı alan dar ve orta gelirliler ile zenginler aynı oranda özel tüketim vergisi ve katma değer vergisi ödemektedirler. Dolaylı vergilerin toplam vergi gelirleri içindeki payının yüksek olması, vergi yükünün daha düşük gelir grupları tarafından karşılanmasına neden olmaktadır.

Dolaylı vergilerin vergi adaleti açısından haksızlık yarattığının yanı sıra yararlı tarafları da bulunmaktadır. En yararlı tarafi, enflasyonla mücadelede verdiği olumlu sonuçlardır. Bilinmektedir ki, en fazla etki eden antienflasyonist maliye önlemleri, gelir cephesinde (bilhassa dolaylı vergilerde) bulunmaktadır (John F. Due, 1967). Dolaylı vergiler fiyata yansıdıkları için tüketicinin mal satın almasını caydırarak toplam talebi kısar ve antienflasyonist bir etki yaratır. Ayrıca, dolaylı vergilerin toplanması kolay ve ucuzdur, üstelik vergi fiyatın içinde gizli olduğu için mükellef vergi ödediğini hissetmez ve vergiye direnç oluşmaz (Akdoğan, 2011). Böylelikle devlet dolaylı vergilere yüklenerek enflasyonla mücadelede daha hızlı ve etkin sonuç alır. Ülkemizde enflasyonun son beş yıllık seyrine baktığımızda, 2011 yılında 10,61, 2012 yılında 7,31, 2013 yılında 7,75, 2014 yllında 7,24 ve 2015 yılı itibariyle \% 9,58 oranlarını görmekteyiz (TCMB). Bu gerçek, bize vergi sistemimizin dolaylı vergiye ağırlık vermesinin nedenini açıklayabilir. Ancak, enflasyonla mücadele ederken, enflasyonun etkileri altında ezilen ve vergi ödeme gücü düşük olan toplum kesiminin fedakarlığının, zengin kesiminkine oranla fazla olması kabul edilemez. Bir ülkede enflasyon varsa, devlet, maliye politikası araçlarını başarıyla uygulayamamış veya başka amaçlarıyla çatıştı̆̆ için uygulamamıştır. Başka ifade ile devletin enflasyonun varlığından sorumluluğu bulunmaktadır. Enflasyonla mücadelede sadece vergi politikaları uygulanması da yetmez, devletin kamu harcamalarını da kısması gerekir, para politikalarını da mali politikalar ile uyumlu şekilde gerçekleştirmesi gerekir. Ayrıca, enflasyonla mücadelede, halkın güven duyduğu bir idarenin ve bunu sürdürecek gerçek bir demokratik rejimin varlığının da gerekli olduğu gözden uzak tutulmaması gereken bir gerçektir (Erginay, 1987).

Vergilemede adaletin sağlanmasının, Türk Anayasasında bir emir olarak düzenlenecek kadar önemli bir ilke olduğu unutulmamalıdır. Anayasamızın 73. maddesinde yer alan "vergi yükünün adaletli ve dengeli dağılımı, maliye politikasının sosyal amacıdır" ifadesi, devlete, vergi dağılımının adil yapılması görevini yüklemektedir. Devletin bu görevini yerine getirmesi açısından, yapılacak reformların başında, toplam vergi gelirleri içinde 
dolaysız vergilerin payının yükseltilmesi gelmektedir. Bunun için de, dolaysız vergilerin oranlarının yükseltilmesi değil, vergi kayıp ve kaçaklarının en aza indirilmesi yolu tercih edilmelidir. Ülkemizde, kayıt dışı ekonominin \% 27, kayıt dışı istihdamın ise \% 40 civarında olduğu tahmini göz önünde tutulduğunda, kayıt dışı olan bu alanların kayda alınmasıyla ilave vergi gelirleri elde edilerek, sosyal güvenlik primlerinin de dahil olduğu dolaysız vergi gelirleri artacaktır ve dolaysız/dolaylı vergi dağılımı, dolaysız vergiler lehine düzelecektir (T.C. Kalkınma Bakanlığı, Vergi Özel İhtisas Raporu).

Bu yüzyılda, devletin, müdahaleci, etkin ve çok güçlü olduğunu biliyoruz, bu nedenle, kolaylıkla devleti, vergilemede adaleti sağlayamamış olmasından dolayı sorumlu tutabiliriz.

\section{Kaynakça}

- Akdoğan, 1980. Gelir Vergisi Açısından Vergi Adaletine Teknik Bir Yaklaşım. Ankara İktisadi Ve Ticari İlimler Akademisi Yayın No: 137, Ankara.

- Akdoğan, 2011. Kamu Maliyesi. Gazi Kitabevi, Ankara.

- $\quad$ Akif Erginay, 1987, Kamu Maliyesi, Turhan Kitabevi, Ankara.

- Due. (Çevirenler, Sevim Görgün ve İzzettin Önder), 1967, Maliye. Fakülteler Matbaası, İstanbul.

- Kamu Hesapları Bülteni, http://www.maliye.gov.tr/Sayfalar/AnaSayfa.aspx, istatistikler

- Nadaroğlu, 1989, Kamu Maliyesi Teorisi, Okan Dağıtımcılık, Yayımcılık, İstanbul,

- OECD Tax Database - OECD, oecd.org

- Pehlivan, 2002, Kamu Maliyesi, Derya Kitabevi, Trabzon.

- TCMB, (http://www.tcmb.gov.tr/wps/wcm/connect/TCMB+TR/TCMB+TR/Main+Menu/Para+

- Politikasi/Fiyat+ Istikrari/Tuketici+Fiyatlari)

- T.C. Kalkınma Bakanlığı, Onuncu Kalkınma Planı, 2014/2018, Vergi Özel İhtisas Raporu, Ankara, 2014 


\title{
Tazminat Uyuşmazlıklarının İdari Yargı Öncesi Sulh Yoluyla Çözümü
}

\section{The Settlement of Compansation Disputes through Peace before Administrative Judiciary}

\author{
Assoc. Prof. Dr. Gürsel Özkan (Danıştay, Turkey)
}

\begin{abstract}
According to the Article 13 of the Law No. 2577, even though one must apply to the authorities as a preliminary condition of court case before filing a fully judicial lawsuit in terms of the administrative action, Article 13 of Law No. 2577 with its current form does not provide a contribution to the provision of the pre-trial dispute resolution. The Decree Law No. 659 set up the way for application which would also include the compensation claims arising from administrative actions that were designed according to The Article 13 of Law No. 2577. In this arrangement, the preference is left to the person concerned to make a choice either to refer to peace or not to against losses arising from administrative processes; one is not given the chance to eliminate the loses by means of peace during the process of law after administrative process is cancelled by law; this also prevents us to come to the desired objective because it doesn't provide adequate legal assurance to the top executives and members of the legal disputes commission for their business and operations.
\end{abstract}

\section{Giriş}

Bireysel hak ve özgürlüklerin idareye karşı korunması hukuk devleti ilkesinin bir gereğidir. Bunun için idari işlem ve eylemlerin hukuka uygunluğunun sağlanması amacıyla bu faaliyetlerin etkin bir şekilde denetiminin yapılması gerekmektedir. İdari faaliyetlerin hukuk sınırları içerisinde gerçekleşip gerçekleşmediğinin denetlenmesi idare içinde yapılacak denetimden ziyade esas itibariyle idari yargı tarafindan yapılmaktadır. İdare karşısında bireyin korunması, hukuk devleti ilkesinin gereği olarak iyi yönetim hakkının kabulünü gerektirmiştir. Yönetimin ilgilileri yargıya başvurmak zorunda bırakmadan uzlaşmak suretiyle hukuka uygun olarak idari faaliyetleri yürütmesi, günümüz demokratik hukuk devletlerinin ulaşı̆̆̆ son aşamayı ifade etmektedir. İdari uyuşmazlıkların idari yargıya başvurulmadan idare içinde çözüme kavuşturulması, diğer bir deyişle uyuşmazlıkların kaynağında doğmadan çözüme kavuşmasının önemi kuşkusuzdur. Yine idarenin verdiği zararlardan sorumlu tutulması da hukuk devleti ilkesinin gereklerinden birini oluşturmaktadır.

Bu kapsamda, 2011 yılında yürürlüğe giren 659 sayılı KHK ile ilgililerin idari işlem ve eylemlerden kaynaklanan zararlarının sulh yoluyla tazmin edilebilmesini idareden isteyebilme imkânı getirilmiştir. Bu Kararnameyle idareye uğranıldığı ileri sürülen zararın tazmin edilmesi istemiyle yapılan başvurunun incelenmesinin usul ve esasları ayrıntılarıyla düzenlenmiş̧ir. Ancak idari işlemlerden kaynaklanan zararlara karşı sulh yoluna başvuruda bulunulmasının ilgililerin tercihine bırakılması, idari işlemin yargı kararı ile iptal edilmesi sonrasında kanun yolu aşamasındaki süreçte zararın sulh yoluyla giderilebilmesine imkân tanınmaması, üst yönetici ile hukuki uyuşmazlıkları değerlendirme komisyonu üyelerine yapmış oldukları iş ve işlemlerden dolayı yeterli yasal güvence sağlanamaması nedenleriyle beklenen amacın elde edilmesi mümkün olamamıştır.

İdari eylem veya işlemlerden kaynaklanan zararların sulh yoluyla tazmin edilememesi halinde uyuşmazlığın açılacak tam yargı davası yoluyla giderileceği açıktır. Bu davalarda, idari yargı yerlerince hak ihlaline sebep olan eylem veya işlem, bütün yönleriyle değerlendirilecek, olayda idarenin sorumluluk sebepleri araştırılacak, idarenin sorumluluğunun saptanması halinde, bilirkişi incelemesi ve diğer araştırmalar yapılarak tespit edilen maddi zarar ile takdir edilen manevi zararın idarece tazminine karar verilecektir. İptal davalarından farklı olarak tam yargı davalarında, idarenin sorumluluk sebebi ile bu sorumluluğun gereği olarak idarenin ödeyeceği zararın miktarı tamamen idari yargı yerince belirlenmektedir. Tam yargı davalarında kusur oranının ve zarar miktarının davanın başında belirsiz oluşu, zarar ve tazminat miktarı üzerinde tarafların müzakeresine imkan tanımaktadır. Bu özellik tam yargı uyuşmazlıklarında alternatif çözüm yöntemlerinin uygulanmasını mümkün kılmaktadır.

İdari Yargılama Usulü Kanunu'nun (IYUK) 13. maddesinde, idari eylemler bakımından tam yargı davası açmadan önce dava şartı olarak idareye, başka bir ifade ile sulh yoluna başvurma zorunluluğu bulunmakta ise de mevcut haliyle IYYUK' nun 13. maddesi hükmü uyuşmazlıkların sulh yoluyla çözümüne bir katkı sağlamamaktadır. Yapılması gereken ön karar aşamasına (zararların sulh yoluyla karşılanmasına) işlerlik kazandırmak, tazminata ilişkin taleplerin dava aşamasına taşınmaksızın idare içerisinde uzlaşma ile çözüme kavuşturulmasını gerçekleştirmektir. Yine yargı yerlerince iptal edilen idari işlemler nedeniyle ortaya çıkan zararların da, idarelerce kendiliğinden tazmin edilmesinin önemi açıktır. Bu nedenle mahkeme kararına gerek kalmaksızın, bu tür işlemlerden kaynaklanan zararların da idarece hesaplanarak ödenmesi gerektiği kuşkusuzdur. 


\section{2 İdarenin Sorumluluğu ve Tazminat Uyuşmazlıkları}

Anayasanın 125. maddesinin son fikrasında, "İdare, kendi eylem ve işlemlerinden doğan zararları ödemekle yükümlüdür.” hükmü yer almıştır. Anayasanın 125. maddesinin yanında 40 ve 129. maddelerinde de devletin sorumluluğuna ilişkin hükümler getirilmiştir. Bu düzenlemelerde sorumluluğun dayanağı olarak herhangi bir ilke öngörülmemiştir. Belirtildiği gibi idarenin sorumluluğu ilkesine yer verilmiş ancak bu sorumluluğun temeli ve kaynağı düzenlenmemiş, yine bu sorumluluğun sebebinin hizmet kusuru mu, yoksa kusursuz sorumluluk mu olduğuna dair bir açıklık getirilmemiştir. Bu nedenle 125. madde idarenin sorumluluğu anlamında genel bir hüküm olup, her iki sorumluluk sebebinin anayasal dayanağını oluşturmaktadır.

Anayasanın 129/5. maddesinde düzenlenen, "Memurlar ve diğer kamu görevlilerinin yetkilerini kullanırken işledikleri kusurdan doğan tazminat davalarl, kendilerine rücu edilmek kaydıyla ve kanunun gösterdiği şekil ve şartlara uygun olarak, ancak idare aleyhine açılabilir.” şeklindeki hüküm, idarenin hizmet kusurunun söz konusu olduğu durumlarda uygulanabilmektedir.

İdarenin sorumluluğunun kabulü konusunda, hukuk devleti ilkesinden hareketle kurum ve kuralların uygulanmasında ortaya çıkan temel sorun, hangi şartların gerçekleşmesi halinde idarenin sorumluluğunun söz konusu olabileceğidir.

Öncelikle idarenin kusurlu olmasında, bir kamu hizmeti etkinliğinin idarenin sorumluluğunu doğuracağının kabulü gerekmektedir. Böyle bir durumda idarenin kusur sorumluluğundan (hizmet kusurundan dolayı sorumluluğundan) söz edilebilir. Diğer belirli bazı istisnai ve sınırlı durumlarda ise idarenin kusurlu olması aranmaksızın sorumluluğu yoluna gidilmektedir. Böyle bir durumda da idarenin kusursuz sorumluluğunun bulunduğu açıktır (Atay ve Odabaşı, 2010).

Sorumlulukta esas alınan kusur kavramı, kişinin temkinli, dikkatli ve kurallara riayet ediyor olması gerekliliğinden kaynaklanmaktadır. Dolayısıyla özel hukukta kusur genellikle, işlem veya eylemin arkasında bir tüzel kişilik olsa dahi, bir kişinin kusuru olarak dikkate alınmaktadır. İdarenin sorumluluğu konusunda söz konusu olan kusur ise kişilerde aranan sübjektif nitelikteki kusur olmayıp, kişilerin dışında kalan ve her kamu hizmetinin kuruluşu ve işleyişi ile ilgili olan objektif nitelikte bir kusurdur.

Hizmet kusuru, kamu hizmetlerinin hukuksal yapısından kaynaklanan devletin borcu niteliği taşımaktadır. Devlet, kamu hizmetlerini ilgili oldukları alan itibariyle şartlara en uygun ve ihtiyaçları karşılamada da en üst düzeyde gerçekleştirmek için kesintisiz ve istikrarlı bir şekilde kamu hizmetinden yararlananlara sunmak, onların hizmetine hazır bulundurmakla yükümlü bulunmaktadır. Bu yükümlülüğün gereği gibi veya hiç yerine getirilmemesi hizmet kusurunu oluşturmaktadır.

İdarenin tüzel kişiliklerden oluşan bir cihaz niteliği taşıması nedeniyle idare adına karar alan görevli veya görevlilerin diğer bir ifadeyle kişi veya kurulların kusuru bu sorumluluğun esasını oluşturmakta, hizmet kusuru oluşabilmesi için kusurun kişiselleştirilebilecek bir nitelik taşıması gerekmektedir. Kusur; kamu hizmetlerini yerine getirmek görevi olan idarenin; kuruluş, işleyiş ve etkinliklerinde görülen eksiklik, hata, aksaklık, standartlara uymama, düzensizlik, boşluk ve bozukluktur (Duran, 1974). Bu anlamda kusur, özel hukuktaki anlamından uzaklaşarak nesnelleşen, anonim bir niteliğe bürünmektedir. $\mathrm{Bu}$ da, hizmet kusurunun bağımsız bir karakteri olduğunu göstermektedir.

Hizmet kusurundan kaynaklanan sorumluluk, doğrudan doğruya idarenin sorumluluğunun dayanağını oluşturmaktadır. İdare kendi idari kusuru nedeniyle doğrudan sorumluluk taşımakta (Duran, 1974), idarenin personeli aracılığı ile ve görev kusurları nedeniyle dolaylı şekilde sorumluluğu hizmet kusuru olarak değerlendirilmemektedir.

Bütün bunlardan sonra denilebilir ki hizmet kusuru, idarenin görmekle yükümlü olduğu herhangi bir kamu hizmetinin ya kuruluşunda, tanzim ve tertibinde veya teşkilâtında, bünyesinde, personelinde yahut işleyişinde gereken emir, direktif ve talimat verilmemesi, gözetim, denetim, teftişin yeterli yapılmaması, hizmete tahsis olunan araçların yetersiz, elverişsiz, kötü olması, gereken önlemlerin alınmaması, geç, zamansız hareket edilmesi, ilh... şeklinde ortaya çıkan- bir takım aksaklık, aykırılık, bozukluk, düzensizlik, eksiklik, sakatlık göstermesidir (Sarıca 1949). Tazminat uyuşmazlıklarında idarenin sorumluluğu kapsamında hizmet kusurunun özellikleri belirlenirken; bağımsız nitelik taşıması, aslî bir sorumluluk nedeni oluşturması, anonim karakter göstermesi, genel nitelikte ve olaylara göre değişken olması esas alınmaktadır (Armağan 1997).

Hizmet kusurunun uygulanmasında tazminat uyuşmazlıkları diğer bir ifadeyle tam yargı davaları söz konusu olmaktadır. Tam yargı davalarının, Borçlar Hukukunun haksız fiilden kaynaklanan tazminat davaları ve sebepsiz zenginleşmeden kaynaklanan istirdat davalarından genel olarak bir farkı bulunmamaktadır. Aradaki fark sadece, sorumluluğun dayandığı kuralların tabi olduğu hukuk kurallarında söz konusu olmaktadır(Candan 2012) . Tam yargı davalarında kişinin bir hakkının ihlal edilmiş olması gerekmektedir. Maddi veya manevi zarar, mamelekte azalma, destekten yoksun kalınan para, vücut bütünlüğünde oluşan bir zarar, oluşan sakatlık nedeniyle işgücü kaybı ya da ölüm hak ihlali niteliğindeki durumlara birer örnek oluşturmaktadır.

Tam yargı davaları sübjektif nitelikte davalardır. Dolayısıyla kişisel bir hakkı ihlal edilenler ancak bu davayı açabilecektir (Çağlayan 2015). Nitekim IYUK' nun 2/(1)-b maddesinde, "kişisel hakk doğrudan muhtel olanlar", 
1n bu davayı açabileceği açıkça ifade edilmiştir. Dolayısıyla tam yargı davası açabilmek için, "menfaat ihlali" yeterli olmayı, "hak ihlali"gerekmektedir.

İdari eylem; idarenin iş, hareket, ameliye ve çalışmalarıdır. Yani idarenin bir idari işlem veya sözleşmenin uygulanması şeklinde olmayan, her türlü faaliyetini yahut hareketsiz kalmasını ifade etmektedir. Kanunun lafżından da anlaşılacağı üzere; tam yargı davasının açılabilmesi için, öncelikle ortada bir idari eylem bulunmalıdır. Burada söz konusu olan eylem, bir idari işlem ya da sözleşmenin uygulanması şeklinde olmayan eylemlerdir. Çünkü idari işlemin uygulanması şeklinde olan eylemler, idari işlemin bir sonucudur ve idari işleme uygulanan kurallara tabidir. IYYUK'nun 13. maddesinde sözü edilen idari eylemden kasit ise idari işlem yahut idari sözleşmeden tamamen ayrı olan, idarenin her türlü faaliyeti, fiziki anlamda gördüğü iş, ameliye yahut çalışmalardır.

\section{Sulh Başvurusu}

Türk Hukuk Lügatinde sulh, "karşılıklı feragat ve müsaade arzularının tesiri altında yapılmış ve yine karşılıklı anlaşmaya dayanan ivazlı bir akittir ki, mevcut bir ihtilafı ortadan kaldırır veya muhtemel bir ihtilafın önüne geçer" (Lügat 1998) şeklinde tanımlanmıştır. Başvuru ise "bir şahsın, herhangi bir dilekte bulunmak üzere, devlet makamına başvurması (Duran 1946)" anlamına gelmektedir. Başvuru terimi, bir hukuk öznesinin diğer bir hukuk öznesine dilek, istek, talep, arz, rica itiraz veya şikâyetlerini iletmesidir (Yıldırım 2006).

İdareden bir talepte bulunmak, hak ve özgürlüklere yönelik her hangi bir arzu, dilek veya şikâyeti idareye bildirmek ve bir haksızlı̆ıın veya zararın yahut haksız bir uygulama veya işlemin etkilerinin giderilmesi amacıyla idareden istemde bulunmak veya zararın giderilmesini talep etmek, diğer bir ifadeyle yükümlendirici bir işlemin kaldırılması, geri alınması veya iptal edilmesi isteminde bulunmak veya yararlandırıcı bir işlem tesis edilmesi talebinde bulunmak idari başvuruyu ifade etmektedir (Özkan 2014).

Yetkili makamlara başvuruyu düzenleyen Anayasanın 40. ve 74. maddesinde yetkili makamlara gecikmeksizin işlem yapma ve cevap verme yükümlülüğü getirilmesi, anayasa koyucunun hak arama özgürlüğüne verdiği önemi ortaya koymakla birlikte yetkili kurumlara da başvuruların sürüncemede bırakılmaması ödevi yüklemektedir.

Hak arama özgürlüğü, haklarının ihlal edildiğini ileri süren bireylerin, ihlalin durdurulması ve olumsuz etkilerinin giderilmesi amacıyla yetkili makamlara başvurma hakkını vermektedir. Bu nedenle hak arama özgürlüğünü yalnızca mahkemelere başvurma hakkıyla sınırlamamak gereklidir. Çünkü ihlalin niteliği de göz önüne alındığında, ihlalin olumsuz etkilerinin giderilmesi yolunda bir karar verebilecek idari makama da başvuru yapılabilecektir. Nitekim Anayasanın 40. maddesi ile "Anayasa ile tanınmış hak ve hürriyetleri ihlal edilen herkes, yetkili makama geciktirilmeden başvurma imkânının sağlanmasını isteme hakkına sahiptir.” hükmü bu durumu destekler nitelikte olan temel normlardandir.

Meydana gelen hak ihlalinin giderilmesi talebinin idari makamca çözüme kavuşturulmaması durumunda hak arama özgürlüğünün "mahkemeye başvurma hakkı" olarak dava açmak suretiyle kullanılması gerekmektedir. Nitekim Anayasanın "Hak Arama Hürriyeti" başlıklı 36. maddesinde; "Herkes, meşru vasıta ve yollardan faydalanmak suretiyle yargı mercileri önünde davacı veya davalı olarak iddia ve savunma ile adil yargılanma hakkına sahiptir. " hükmüne yer verilerek mahkemeye erişim hakkı düzenlenmiştir. Yine Anayasanın "Yargı Yolu" başlıklı 125. maddesinde; idarenin her türlü eylem ve işlemlerine karşı yargı yolu açık olduğu belirtilerek idari eylem ve işlemler bakımından mahkemeye erişim hakkı özel olarak düzenlenmiştir.

Bu düzenlemelerden de anlaşıldığı üzere, hak ihlalinin giderimi, idari makamdan istenebilecekse de, burada esas görev mahkemeye düşmektedir. Çünkü idarenin doğduğu ileri sürülen ihlale yaklaşımı ile mahkemenin bakış açısının aynı nitelikte olmadığı bilinmektedir. Dolayısıyla hak ihlaline uğradığını ileri süren bireye idari makam ile mahkemenin sunduğu hukuki tatmin aynı nitelikte değildir.

659 sayılı Genel Bütçe Kapsamındaki Kamu İdareleri ve Özel Bütçeli İdarelerde Hukuk Hizmetlerinin Yürütülmesine İlişkin Kanun Hükmünde Kararname, genel bütçe kapsamındaki kamu idareleri ve özel bütçeli idarelerin hukuk hizmetlerinin etkili, verimli ve usul ekonomisine uygun şekilde yerine getirilmesi ve bu hizmetlerin yürütülmesinde uygulama birliğinin sağlanması ve idarenin taraf olduğu uyuşmazlıklarda sulh usulüne yönelik usul ve esasların belirlenmesi amacıyla çıkarılmıştır. Sulh başvurusu, 659 sayılı KHK ile IYYUK' nun 13. maddesinde yer verilen idari eylemlerden doğan tazminat taleplerini de içerecek şekilde idareye yapilacak bir başvuru yolu olarak öngörülmüştür. Bu başvuru yolunda, idari faaliyetler nedeniyle zarara uğradığını düşünen kişilerin idari yargı yoluna gitmeden önce sulh yoluna müracaat edebilmesi düzenlenmiş̧tir. Sulh yoluna gidilmesinde uyuşmazlığın idari işlem ya da eylemden doğmuş olması dikkate alınmaksızın her iki durumda da idareye müracaat edilerek zararın karşılanmasının istenilebileceği kabul edilmiştir. Diğer bir ifadeyle sulh yoluyla tazminat taleplerinin ç̧̈zümünde idarenin eylem ya da işlemlerinden doğan tazminat taleplerinin yargı yoluna gidilmeden karşılanması amaçlanmıştır.

\section{1 İdari Uyuşmazlıklarda Sulhe Başvurulması}

Kamu kurum ve kuruluşlarının yetkilileri ileride herhangi bir sorumlulukla karşılaşmamak düşüncesiyle, hukuk müşavirlerini gereksiz yere dava açmaya veya açılmış olan davaları sonuna kadar sürdürmeye zorlamakta olduğu 
bilinmektedir. Yine uzlaşma girişiminde bulunulmaması veya uzlaşma için gerekli çaba gösterilmemesi nedeniyle uyuşmazlıklar dava olarak yargı aşamasına taşınmaktadır.

Kamu idaresinin kaynaklarının tedbirli kullanılması ve idarenin sorumluluğunun yerine getirilmesi ile bireylerin haklarını idari süreçlerde aramasını sağlayabilecek yargılama dışı alternatif çözüm yöntemleri bulunmaktadır. Özellikle son yıllarda idari uyuşmazlıkların çözümünde önemli bir gelişme gösteren yargılama dişı çözüm yöntemleri (Özbek 2005), ABD başta olmak üzere Avrupa Birliği ülkelerinde olduğu gibi ülkemiz bakımından da önemli bir seçenek haline gelmiş bulunmaktadır.

Alternatif uyuşmazlık çözüm yöntemleri, belirtildiği gibi tarafların üzerinde "serbestçe tasarruf edebilecekleri" ve "kamu düzeninden sayılmayan (Bulur 2007)" işlerden kaynaklanan uyuşmazlıklar bakımından uygulama alanı bulabilecek niteliktedir. Alternatif uyuşmazlık çözüm yollarında niteliği gereği, yargı dışı yöntemlere başvuru yoluyla yani tarafların bir araya gelip iletişim kurup, müzakerelerde bulunmak suretiyle, uyuşmazlığın yargıya başvurulmadan yargı yoluna gitmeden çözülebilmesi amaçlanmaktadır. Yargısal çözüm seçeneği tercih edildiğinde, hukuk devletinde, hak arama özgürlüğü, tüm mekanizmalarıyla birlikte, uyuşmazlığı çözmek suretiyle karara bağlamak sonucunu doğuracak şekilde zaten devreye girecektir. Belirtilmesi gerekir ki alternatif uyuşmazlık çözümünde yargısal yahut mahkeme dışı çözüm yollarına başvuru konusunda, aralarında uyuşmazlık bulunanlar, tam bir özgürlüğe diğer bir ifadeyle tam bir serbestiye sahip bulunmaktadır. İstenilmesi halinde ilgililerin idare ile çözüm yolunu seçmek, uzlaşma suretiyle uyuşmazlığı çözüme kavuşturmak, istenmemesi durumunda ise başlangıçta yargı yolunu tercih etmek seçeneğine sahip mekanizmaların hukuk sistemi tarafından kurulmuş olması gerekmektedir.

02.11.2011 tarihli Resmi Gazetede yayımlanan 659 sayılı Kanun Hükmünde Kararname (KHK) ile idari uyuşmazlıkların yargı dışı yollarla çözümlenmesine ilişkin önemli düzenlemeler yapılmıştır. 659 sayılı KHK'nin 9, 10, 11 ve 12. maddelerindeki sulh hükümleri, KHK kapsamındaki idarelerin taraf oldukları adli ve idari uyuşmazlıkların sulhen çözümünü düzenlemiştir. Sulhun, alternatif uyuşmazlık çözümünde olduğu gibi tarafların üzerinde "serbestçe" tasarruf yetkisine sahip olduğu hak ve menfaatlere ilişkin olması esas alınmış, sulh akdinin konusunu, tarafların sözleşme ile düzenleme, üzerinde tasarruf etme erkine sahip oldukları iş ve işlemlerin oluşturması kabul edilmiştir. Bu kapsamda; sebepsiz zenginleşmeden, haksız fiilden, özel hukuk sözleşmelerinden, hizmet kusuru ve kusursuz sorumluluk hallerinden kaynaklanan alacak ve borçlar hakkında sulh anlaşması yapılabilmesi mümkün kılınmış, kamu hukukundan doğan vergi, ceza v.s. hak ve menfaatlere ilişkin konular sulh kapsamı dışında bırakılmıştır. Sulh anlaşmasının geçerli ve hüküm ifade eden bir anlaşma olarak varlık gösterebilmesi için, içeriği itibarıyla emredici hukuk kurallarına ve kamu düzenine uygun olması, ayrıca akdin konusunun fiilî veya hukukî açıdan imkânsız bulunmaması gerekmektedir. Çünkü sulh, tek taraflı bir işlem olmayıp, anlaşma hükmündedir. Her anlaşma gibi sulh için de, öncelikle tarafların sulh koşullarında mutabakata varmış olmaları gerekmektedir.

İdari işlemler dolayısıyla haklarının ihlal edildiğini iddia edenler idareye başvurarak, uğramış oldukları zararın sulh yoluyla giderilmesini dava açma süresi içinde isteyebilirler. İdari eylemler nedeniyle hakları ihlal edilenlerce, idari dava açmadan önce İYUK'nun 13. maddesinin birinci fikrası uyarınca yapılan başvurular da sulh başvurusu olarak değerlendirilerek 659 sayılı KHK' da yer alan hükümler çerçevesinde incelenmesi gerektiği düzenlenmiş, sulh başvurusu idari işlemlerden kaynaklanan zararların tazmini yanında, IYYUK'nun 13. maddesi kapsamında düzenlenmiş bulunan idari eylemlerden doğan tazminat taleplerini de içerecek şekilde kabul edilmiştir.

Sulh yoluna gidilmesinde uyuşmazlığın idari işlem ya da eylemden doğmuş olması durumu IYYUK kapsamında değerlendirildiğinde, idari eylemden kaynaklanan zararların karşılanması talebiyle idareye yapılan sulh başvurusu IYYUK' nun 13. maddesi kapsamındaki bir başvuru olarak kabul görmekte iken, idari işlemden kaynaklanan başvurunun IYYUK' nun 11. maddesi kapsamında idareden; tesis edilmiş bir işlemin geri alınması, kaldırılması veya yeni bir işlem tesisinin talep edilmesi mahiyetindedir. Her iki durumda da idareye müracaat edilerek zararın karşılanması istenebilmekte, idari işlemlerden kaynaklanan zararlarda sulh yoluna başvuru, ilgililerin tercihine birakılmakta zorunlu bir başvuru yolu olarak kabul edilmemektedir.

659 sayılı KHK'nin 12. maddesinde, idarelerin taraf oldukları idarî uyuşmazlıkların sulh yoluyla hâlli, uzlaşma ve vazgeçme yetkileri düzenlenmiştir. Buna göre, idari işlemler dolayısıyla haklarının ihlâl edildiğini iddia edenler idareye başvurarak, uğramış oldukları zararın sulh (uzlaşma) yoluyla giderilmesini, dava açma süresi içinde isteyebilirler. İdarî eylemler nedeniyle hakları ihlâl edilenlerce, idarî dava açmadan önce İYUK 13/(1). maddesi uyarınca yapılan başvurular da (ön karar) sulh başvurusu olarak kabul edilmekte ve bu maddede yer alan hükümler çerçevesinde incelenmektedir. Sulh başvurusunun, belli bir konuyu ve somut bir talebi içermek suretiyle yapılması gerekmektedir. Başvurunun konusu, zarara yol açan olay ve nedenleri, zararın idari eylem veya işlemden doğup doğmadığı ve meydana geliş şekli, idarenin tazmin sorumluluğunun bulunup bulunmadığı, zararın miktarı ve ödenecek tazminat tutarının hukuki uyuşmazlık değerlendirme komisyonunca belirlenmesi yapılacaktır. Hukuki uyuşmazlık değerlendirme komisyonunun inceleme sonunda hazırlayacağı raporun 659 sayılı KHK'nin 11. maddesi uyarınca karar vermeye yetkili mercilere sunulması, bu mercilerin sulh başvurusunu kabul etmesi hâlinde başvuru sahibine, hazırlanan sulh tutanağının imzalanması için en az onbeş günlük süre verilmesi öngörülmektedir. Tazminat miktarı ve ödeme şekli üzerinde idare ve istemde bulunanın sulh olmaları (uzlaşmaları) hâlinde buna ilişkin bir tutanak düzenlenecek ve taraflarca imzalanacaktır. İmzalanan sulh tutanağı, ilam hükmünde sayılacaktır. 


\subsection{Genel Olarak Uyuşmazlıkların Yargı Dışı Çözümü}

Uyuşmazlık çözümünde kullanılan dava dışı usullere genel olarak alternatif uyuşmazlık çözümü (Alternative Dispute Resolution, ADR) adı verilmekte, uyuşmazlıkların çözümü için mahkemeler tarafından yürütülen dava yoluna alternatif olarak işleyen, genellikle tarafsız ve bağımsız bir üçüncü kişinin katılımını ve yardımını gerektiren usuller topluluğu olarak tanımlanmaktadır (Özbek 2013).

Amerika Birleşik Devletlerinde doğan ve gelişen alternatif uyuşmazlık çözüm yolları, 1970 yılında tahkim ve arabuluculuk programlarıyla federal bölge mahkemelerinin uygulamasına girmiş, 1980 yılında kısa yargılama ve ön tarafsız değerlendirme gibi yeni usuller kullanılmaya başlanmış, 1990 yılında Medeni Yargı Reformu Kanunu'yla öngörülen altı temel dava yönetim ilkesinin içinde yer almış ve 1998 yılında ise yasalaşan Alternatif Uyuşmazlık Çözüm Kanunu'yla federal hukuk politikası haline gelmiştir. Son yıllarda Kıta Avrupası ülkelerinde de uygulama alanı bulmaya başlamıştır (Tanrıver 2006).

Alternatif uyuşmazlık çözüm yolları, "bağımsız, tarafsız ve objektif bir üçüncü kişinin, aralarında uyuşmazlık bulunan tarafları bir araya getirerek, ortaklaşa bir çözüm bulmaları konusunda iletişim kurmalarını sağladığı ve aralarındaki uyuşmazlığı ya kendi kendilerine çözmeleri için onlara yardımcı olduğu ya da somut olayın özelliklerine göre onlara üzerlerinde fikir birliğine varabilecekleri çözüm önerileri sunduğu; tamamen gönüllülük esasına göre işlerlik kazanan ve yargılamaya göre seçimlik bir yol olarak uygulama alanı bulan uyuşmazlık çözüm yolları bütünüdür (Özbek 2005)" şeklinde açıklanabilir.

Uyuşmazlıkları çözüme kavuşturma işlevi, esasında devletin işidir ve devlet bu işlevini, yargı yetkisini kullanmak suretiyle yerine getirmektedir. Alternatif uyuşmazlık çözüm yolları ise uyuşmazlıkların çözümünde, yargısal yolların yanında yer alan ve ilgililerin talepleri halinde işlerlik kazanan, esas itibariyle, ilişkilerin koparılmadan sürdürülmesini ve "adil bir karardan" ziyade, "her iki tarafı da tatmin edici” bir çözüme ulaşılmasını hedefleyen yöntemler bütünü anlamına gelmektedir. Bir başka ifadeyle alternatif uyuşmazlık çözümleri, devlete ait yargı yetkisinin mutlak egemenliğine halel getirmeden işlerlik kazanan ve uygulama alanı bulan ek yöntemler bütünü olarak nitelendirilebilir (Pekcanıtez 2005).

Belirtilmesi gerekir ki alternatif uyuşmazlık çözüm yöntemlerinin işlerlik kazanacağı alanlar, "kamu düzeninden sayılmayan ve tarafların üzerinde serbestçe tasarrufta bulunabileceği işlerden kaynaklanan" uyuşmazlıklardır. Yargının işleyişini düzenleyen usul hukuku düzenlemelerinde de, zaten tarafların bu tür uyuşmazlıklarda sulh olabilmesine olanak tanınmakta ve hatta hâkime kimi durumlarda idareye, bu bakımdan tarafları uzlaşmaya yahut sulh olmaya teşvik etme bir ödev olarak yüklenmektedir.

Yarg1 yükünün ve yargı giderlerinin giderek artması, yargının yavaş işleyişi ve bunların getirdiği olumsuzlukların çözümüne yönelik arayışlar; uyuşmazlıkların dava yolu ile çözümü yerine, tarafların kendi iradeleri ile uzlaşarak uyuşmazlığa son vermeleri, toplumsal barışın korunması açısından da tercih sebebi sayılmaktadır. Alternatif uyuşmazlık çözümü, yargıyı daha da etkili kılmak, nitelikli ve önemine uygun uyuşmazlıkları çözerek karara bağlamak işlevini güçlendirmek, basit ve yargılama niteliğinde olmayan muhakeme yapmayı gerektirmeyen uyuşmazlıkları yargı dışında çözmek amacı taşımaktadır.

Her şeyden önce uyuşmazlık çözümünde, yargının yanı sıra, tarafların her ikisinin de tatmin edilmesini ve bu suretle optimal bir çözümün üretilmesini temel alan başka uyuşmazlık çözüm yollarının işlerlik kazanabileceği, hukuksal barışın daha kalıcı ve daha etkin bir biçimde bu yollarla sağlanmasının da mümkün olduğunun kamuoyuna anlatılması gerekmektedir.

İletişim tıkanıklığı veya kopukluğunun yaşandığ1 ve uzlaşma kültürünün yeterince gelişmediği toplumlarda, eğitim araçlarından ve medyadan yararlanmak suretiyle, iletişim tıkanıklı̆̆ının ve kopukluğunun giderilmesine uygun ortam yaratılmak ve bireylerin birbirleriyle iletişim kurmak, gerekiyorsa tarafsız ve objektif üçüncü bir kişinin yardım veya desteğini alarak bir araya gelmek suretiyle, kendi sorunlarını kendilerinin çözebileceği bilincinin oluşturulması gerektiği ortadadır. Bu anlamda, özellikle yargı ile karşılaştırıldığında, sağladığı avantajlar da açıkça ortaya konulmak ve ön plana çıkarılmak suretiyle, uyuşmazlık çözümünde, yargı dışı çözümün amaca en uygun ve en ideal yöntem olduğu yönünde kamuoyunda bir bilinç oluşturulması gerekmektedir. Alternatif uyuşmazlık çözüm yollarının belli başlı olanları, müzakere, tarafsız ön değerlendirme, vakıaların tespiti, kısa duruşma, uzlaştırma ve arabuluculuktur (Özbek 2013).

\section{3 Ön Karar Alma Zorunluluğu ve Sulh Başvurusu}

Hukuka uygun davranmak zorunluluğunun bulunması tek başına idareyi hukuk içinde tutmaya yetmemektedir. Aynı zamanda idarenin hukuka uyma istek ve iradesinin de bulunması gerekmektedir. İdarede hukuka aykırılığı giderme isteğinin bulunması, idari başvuru yollarının yasal olarak düzenlenmediği durumda etkili sonuç doğuramayacaktır. Hukuka aykırılığın idare içinde giderilebilmesi diğer bir ifadeyle idari faaliyetlerin yargı yoluna başvurulmadan hukuka uygun hale getirilmesi veya idarenin verdiği zararın tazmin edilmesi için, bir yol ve yöntemin varlığının gerekliliği kuşkusuzdur. Dolayısıyla yargı yolu son güvence olup, ilgililer hemen yargı yoluna itilmemelidir.

Dava açmak için zorunlu olan idari başvurular, yasa koyucu tarafından dava açmanın ön koşulu olarak öngörülmüşlerdir. Bir başka deyişle idare aleyhine dava açabilmek için öncelikle idareye başvuruda bulunulup, idareden alınacak karardan sonra dava açmak gerekmektedir. Nitekim IYUK' nun 13. maddesi uyarınca, idari 
eylemlerden hakları zarar görenlerin, idare aleyhine tam yargı davası açmadan önce idareye başvurmaları zorunludur. Belirtmek gerekir ki idari başvuruyu dava açılması öncesinde bir ön koşul olarak belirleyen düzenlemelerin varlığı durumunda, İYUK'nun 11. maddesindeki kuralın uygulanması söz konusu olmayacaktır. Bu durumlarda, dava açmadan önce tüketilmesi zorunlu bir başvuru süreci söz konusu olacaktır

Dava açmadan önce tüketilmesi gereken zorunlu idari başvuru yollarının ortak amacı idari yargıya başvurmadan önce idare ile bir uzlaşma ortamı aranarak şayet uzlaşma olmazsa, idarenin olumsuz tutumunu belgeleyen bir ön karar elde etmektir. Bu anlamda başvuru nedeninin idari eylem veya idari işlem olmasının, hiç bir önemi bulunmamaktadır. IYYK' nun 13. maddesine göre, idari eylem nedeniyle hakları ihlal edilenlerin, dava açmadan önce idareye başvurmaları ve bu başvuru sonucunda bir "ön karar” almaları gerekmektedir. Ön karar başvurusuyla amaçlanan, idareye başvurarak muhtel olunan hakkın yerine getirilmesini mahkeme kararına ihtiyaç duymadan, sulh yoluyla sağlamaktır. Ancak uygulamada, ön karar başvurusu üzerine idarelerce kusurun kabul edildiği, dolayısıyla tazmin talebinin karşılandığına rastlanmamaktadır.

659 sayılı KHK'de idarelerin taraf oldukları uyuşmazlıkların, ihtilaflı tarafların hak ve menfaatlerinin dengeli olarak değerlendirilerek, adil ve hakkaniyete uygun olarak çözümlenmesi öngörülmüştür. Bu amacı yerine getirebilmek için, hukuk danışmanlığı işlevi kapsamında hukuk birimlerine, anlaşmazlıkları önleyici hukukî tedbirleri zamanında alma ve uyuşmazlıkların sulh (uzlaşma) yoluyla çözümü konusunda görüş verme görev ve yetkisi verilmiştir (659 sayılı KHK uyarınca çıkarılan, Hukuki Uyuşmazlık Değerlendirme Komisyonunun Çalışma Usul ve Esasları Hakkında Yönetmelik 4. 7. 2012 tarih ve 28343 sayılı Resmi Gazete'de yayınlanmıştır).

659 sayılı KHK uyuşmazlık çözümünde önce uzlaşmaya (sulhe) başvurulmasını, bundan sonuç alınamadığı takdirde, son çare olarak dava açılması esasını benimsemiştir. Bu düzenlemeye göre asıl olan, dava açılmadan önce sulh (uzlaşma) teklifinde bulunulması olup, uyuşmazlığın dava veya icra takibi konusu olması dahi, sulh teklifinde bulunmaya engel oluşturmamaktadır (Özbek 2012). Getirilen bu düzenlemede, sulh kararının verilmesi sürecinde ilgili idari birimlerin katılımı sağlanarak, sağlıklı bir karar verilmesi amaçlanmıştır (Çolak 2013). Ancak 659 sayılı KHK kapsamında yapılan sulh başvurularından kabul olunana rastlanılmamıştır. Dolayısıyla sulh başvurusu müessesesinin uygulaması gerçekleştirilememiş, işlerliği sağlanamamıştır.

\section{Sulh Başvurusunun Zorunlu İdari Başvuru Yolu Olarak Yeniden Düzenlenmesi Gerekliliği}

Sulh başvurusunun "zorunlu idari başvuru yolu olarak" düzenlenmesi gerekli bulunmaktadır. 659 sayılı KHK'nin yürürlüğe girmesinden itibaren yaklaşık beş yıl geçmesine rağmen, gerek idarelerce, gerekse vatandaşlarca uyuşmazlıkların sulh yoluyla çözümüne ilişkin hükümlerin etkin bir şekilde uygulanmadığı görülmektedir.

Sulh başvurusunu uygulamak amacıyla idareler bünyesinde kurulacak olan hukuki uyuşmazlık değerlendirme komisyonlarında görev yapacak üyelerin sürekli hale getirilmesi de sistemin işlerliği bakımından önemli olmaktadir.

Yine KHK kapsamına giren idari uyuşmazlıklarda sulh yoluna başvurulmasının "zorunlu” hale getirilmesi de ayrıca üzerinde değerlendirme yapılmasını gerektirmektedir. 659 sayılı KHK' de yapılacak değişiklik ile idareler tarafından tesis edilen bir idari işlem nedeniyle haklarının ihlal edildiğini iddia eden kişilerin açtıkları iptal davasının sonuçlanmasından sonra tam yargı davası açmadan önce sulh yoluna başvurmalarının da "zorunlu" tutulması gerekmektedir.

659 sayılı KHK'de yer alan mevcut düzenlemede, idaredeki uzlaşma ile görevli kamu görevlilerinin uzlaşma ile ilgili görevlerinden dolayı hukuki güvencelerinin bulunmaması ve mali sorumluluk kaygısı kamu görevlilerinin insiyatif almasını güçleştirmekte olduğunun da bilinmesi gerekmektedir.

Uzlaşma bilincinin yeterince oluşmadığı ve uzlaşmaya varmada genel bir isteksizliğin geçerli olduğu ülkemizde, öncelikle uyuşmazlıkların yargı dışı mekanizmalar ile çözümüne işlerlik kazandırmak, öncelikle bu yollara başvurulmasının zorunlu tutulmasını gerektirmektedir. Ancak başvurunun etkili olması, idare içinde işleyen süreçte uyuşmazlığın çözüme kavuşturulmasının sağlanması halinde sistemin benimsenmesi mümkün olabilecektir. Aksi halde, getirilecek olan yasal zorunluluğun, yarardan çok sakınca yaratacağı söylenebilir. Bu anlamda getirilecek olan yasal bir zorunluluk, hak arama özgürlügüne müdahale olarak dahi algılanabilecek (Ildır, 2003) ve özellikle iş yükünün fazlalığı sebebiyle yargılama sürecinin ağır işlediği ülkemizde, uyuşmazlık çözüm sürecinin daha da uzamasına neden olunabilecektir.

Alternatif uyuşmazlık çözümleri konusunda kamuoyunun bilinçlendirilmesi ve bu yolların, yargının yerine ikame edilmek istenen yollar olmadığının sürekli bir biçimde altı çizilerek, yararları da açıkça ortaya konulmak suretiyle, bu yollara başvurulmasının özendirilmesine ve teşvik edilmesine uygun bir ortamın oluşturulması gerekmektedir. Alternatif uyuşmazlık çözüm mekanizmalarının özüne de uygun olarak, taraflar kendiliğinden bu mekanizmaları işletmek için istekli hale getirilmek suretiyle birçok sorun yargı önüne taşınmadan çözüme kavuşturularak, yargının iş yükünün de önemli ölçüde azalması sağlanacaktır. 


\section{Değerlendirme ve Sonuç}

Medeni yargıda ve ceza yargısında olduğu gibi, idari yargıda da etkinliğin artırılarak mahkemelerin daha verimli çalışabilmesi için idari yargıdaki iş yükünün azaltılması gerektiği kuşkusuzdur. Bu amaçla kullanılabilecek en etkili yöntem de hiç şüphesiz ki uyuşmazlıkların yargı dışı yollarla çözümünün sağlanmasıdır. Bu yolla yargının iş yükü hafiflemekle kalmayacak, dostane çözüm imkânı, idare ile vatandaşın mücadeleci bir usulde karşı karşıya gelmelerini de önleyecektir. Böylece idarenin vatandaş nezdinde saygınlığg korunacak; bundan da önemlisi, idarenin vatandaşla ilişki ve işbirliği içinde bulunması demokratik bir ortamı geliştirecek ve idarenin hukuka saygılı davranma konusunda daha duyarlı olmasını sağlayabilecektir.

İdari davalarda, genellikle kamu gücünün dava konusu uyuşmazlıkta etkinliğinin bulunup bulunmadığının belirlenmesi önem taşımaktadır. Çünkü idarenin taraf olduğu uyuşmazlıklarda sorumluluk hukuku kapsamında tazminat taleplerine ilişkin uyuşmazlıklar (özellikle sağlık mevzuatından kaynaklanan tazminat talepleri), ihale hukuku uyuşmazlıkları, idari yaptırımlar, belediye mevzuatı, imar ve çevre hukuku uyuşmazlıkları, disiplin hukuku, not tespit işlemleri gibi pek çok idari uyuşmazlık, idari başvuru süreci içinde dava yoluna gidilmeksizin çözülme potansiyeline sahip bulunmaktadır.

Burada hangi uyuşmazlıkların yargı dişı çözümünün gerekliliğinin saptanmasında; ölçü olarak, "bir uyuşmazlıkta hâkimin o uyuşmazlığa yargısal bir müdahalesine gerek olup olmadığı" kriteri esas alınabilir.

Yargı dışı uyuşmazlık çözüm yolu, özellikle idarenin sahip olduğu bürokratik kültüründen kaynaklanan takdir yetkisini kullanmaktan kaçınmak suretiyle tüm uyuşmazlıkları "yargı kararı getir o zaman gereğini yapalım" şeklindeki tavrı nedeniyle etkili olamamaktadır. Nitekim 659 sayılı KHK, sulh başvurusunu bir kurum olarak düzenlemiş olmasına rağmen belirtilen bürokratik kültür nedeniyle işlevsiz bırakılmıştır. Türk kamu yönetiminin bürokratik işleyişi, iletişimde tek yönlülüğü esas almaktadır. İletişim daima idareden halka doğru olmakta, kapalılık toplumsal istekler doğrultusunda idareyi hareket etmekten yoksun bırakmaktadır. İletişim devrelerinden yoksun kalan idare, aldığı kararların etkisini algılayamamakta, dolayısıyla etkinliğini ve verimliliğini kaybetme riskiyle karşı karşıya kalmaktadır (Özkan, 2001). Tek taraflı emretme mantığına ve otoritenin üstünlüğüne dayanan anlayışın, yerini iki taraflılık ve karşılıklılık esasına göre işleyen bir modele bırakması artık bir zorunluluktur. Bu modelde ilişkiler, eşitlik düzeyine gelecek, birey artık egemenlik altında olmaktan çıkacak ve yönetimle ilişkilerinde bir taraf, bir aktör statüsüne kavuşacaktır. Böylelikle yukarı doğru iletişim kanalı sadece idarenin istediği zaman değil, bireyin talep ve beklentilerini yönetime iletmek istediği her zaman çalışacaktır.

Uyuşmazlıkların yargı dışı çözümünde bir diğer hususta, idare ile uzlaşma sonucunda alınan kararın uygulanıp uygulanmayacağına ilişkin idareye yönelik duyulan güven eksikliği oluşturmaktadır. Çünkü geleneksel uygulama da idarenin yeniliklere kapalı olması ve eski alışkanlıklarını sürdürmekte ısrarlı davranması nedeniyle anlaşılan tazminat miktarının ödenmesi konusunda hakim kararı istenmeye devam edeceğine ilişkin tutumu ilgililerin bu yola başvurmada çekimser kalmasına yol açabilecektir.

Uyuşmazlıkların yargı dışı yollarla çözümünün sağlanmasında, bu yolların tercih edilme nedeninin özellikle yargının iş yükünün azaltılması amacı taşındığına yönelik değerlendirmelerden kaçınılması, insana değer verilerek idare tarafından artık ciddiye alınma aşamasına geçildiği, hukukun tam olarak uygulanmak istendiği ve herkese adaletli davranma erdeminin önemi üzerinde durulması gerekmektedir.

\section{Kaynakça}

- $\quad$ Atay, E. E., ve Odabaşı, H., 2010. Teori ve Yargı Kararları Işığında İdarenin Sorumluluğu ve Tazminat Davaları, Seçkin Yayınevi, Ankara, 59 s.

- Bulur, A., 2007. “Alternatif Uyuşmazlık Çözüm Yolları ve Arabuluculuk Yöntemi ”, Ankara Barosu Dergisi, Y1l:65, Say1:4, 31 s.

- Çolak, N.İ., 2013. “İdari Uyuşmazlıklarda Alternatif Çözüm Yolları”, Danıştay ve İdari Yargı Günü 144. Yıl Sempozyumu, 11 Mayıs 2012 Ankara, Danıştay Başkanlığı Yayını, 104-105 s.

- Duran, L., 1946. “İdari Müraacatlar ve Bunların Karşısında, İdarenin Sükutu Meselesi ”, İstanbul Üniversitesi Hukuk Fakültesi Mecmuası, Cilt: 12, Sayı: 1, 132-134 s.

- Duran, L., 1974. Türkiye İdaresinin Sorumluluğu, Sorumluluğun Temeli ve Sebepleri Sorumluluğa Yol Açan Olgular, Ankara, 26 s.

- Sarıca, R., 1949. “Hizmet Kusuru ve Karakterleri”, İstanbul Üniversitesi Hukuk Fakültesi Mecmuası, Cilt: $\mathrm{XV}, 858 \mathrm{~s}$.

- Armağan, T., 1997. İdarenin Sorumluluğu ve Tam Yargı Davaları, Seçkin Yayınevi, Ankara, 17-18 s.

- Candan, T., 2012. Açıklamalı İdari Yargılama Usulü Kanunu, 5. Baskı, Adalet Yayınları, Ankara, 170 s.

- Çağlayan, R., 2015. İdari Yargılama Hukuku, Seçkin Yayınevi, Ankara, 534 s.

- Tanrıver, S., 2006. "Hukuk Uyuşmazlıkları Bağlamında Alternatif Uyuşmazlık Çözüm Yollan ve Özellikle Arabuluculuk”, TBB Dergisi, Sayı:64, 151 s. 
- $\quad$ Türk Hukuk Lügatı, Başbakanlık Basımevi, 4. Baskı, Ankara, 305 s.

- Yıldırım, R., 2006. İdari Başvurular, Mimoza Yayınları, İkinci Baskı, Konya, 9 s.

- Ildır, G., 2003. Alternatif Uyuşmazlık Çözümü, Ankara, 48 s.

- Özbek, M., 2005. “Türk Hukukunda ve Mukayeseli Hukukta İdari Uyuşmazlıkların Çözümünde Yargılama Dışı Usuller”, TBB Dergisi, Sayı 56, 90-99 s.

- Özbek, M., 2012. Kamu İhale Hukuku Uyuşmazlıklarında Alternatif Çözüm Yolları (İhale Hukukunda Uygulamada Yaşanan Sorunlar ve Çözüm Yolları, Ankara, 169-188 s.

- Özbek, M., 2013. Alternatif Uyuşmazlık Çözümü, Yetkin Yayınları, Ankara, s???

- Özkan, G., 2001. Demokratik Yönetime Geçiş 21. Yüzyıl Türkiyesi İçin Bir Kanun Önerisi, Tutibay Yayınları, Ankara, $67 \mathrm{~s}$.

- Özkan, G., 2014. “4734 sayılı Kamu İhale Kanunu’nda Öngörülen Zorunlu İdari Başvuru Yolları”, Türkiye Adalet Akademisi Dergisi, Say1:17, Y11: 5, 69 s.

- Pekcanıtez, H., 2005. “Alternatif Uyuşmazlık Çözümleri”, Hukuki Perspektifler Dergisi, 12-16 s. 


\title{
Türk Ticaret Kanunu'nda Haksız Rekabet Suçu Unfair Competition Offence in the Turkish Commercial Code
}

\author{
Prof. Dr. Çetin Arslan (Hacettepe University, Turkey) \\ Ph.D. Candidate Didar Özdemir (Hacettepe University, Turkey)
}

\begin{abstract}
The competition is the key element of the free market economy because the prices cannot be determined according to the supply and demand equilibrium when there is no competition or the competition is violated by conducts against good faith. In this regard, the fraudulent acts between providers and customers and unfair commercial applications constitute tortious acts. The aim of the articles embodying unfair competition of the Turkish Commercial Code (TCC) dated 13.01.2011 and numbered 6102 is to maintain fair, untainted competition for the good of all parties (art. 54/2). The acts and commercial applications against good faith are determined in the article 55 of the TCC in order to protect the competition system. According to the article 62 of the TCC entitled "Criminal Acts", performing one of these acts intentionally; giving wrong or deceptive information about his personal situation, goods, products, commercial activity and work intentionally in order to make his own offer preferred; deceiving employees, administrators and other assistants to obtain the production and commercial secrets of the employer or clients; not preventing the unfair competition acts of the workers, employees or administrators during their work or not correcting the declarations contrary to facts constitute the unfair competition offence. In our study, at first the notion of unfair competition, then the unfair competition offence especially focusing on the controversial points- will be examined.
\end{abstract}

\section{Giriş}

Rekabet, serbest piyasa ekonomisinin nirengi noktasıdır. Zira rekabetin bulunmadığı, dürüstlük kurallarına aykırı davranışlarla ihlal edildiği bir ortamda fiyatların arz ve talep dengesiyle oluşması mümkün değildir. Bu bağlamda tedarik edenlerle müşteriler arasındaki ilişkileri etkileyen hileli hareketler ile haksız ticari uygulamalar hukuk düzeni tarafından kabul görmeyen haksız fiillerdir. 13.01.2011 tarihli ve 6102 sayılı Türk Ticaret Kanunu (TTK)'nda düzenleme altına alınan haksız rekabet hükümlerinin amacı bütün katılanların menfaatine, dürüst ve bozulmamış rekabetin sağlanmasıdır (md. 54/2). Rekabet düzenini korumak amacıyla TTK'nın 55. maddesinde dürüstlük kuralına aykırı davranışlar ve ticari uygulamalar sayılmaktadır. TTK'nın "cezayı gerektiren fiiller" başlıklı 62. maddesine göre, bu davranışlardan birini kasten gerçekleştirmek; kendi icap ve tekliflerinin rakiplerininkine tercih edilmesi için kişisel durumu, ürünleri, iş ürünleri, ticari faaliyeti ve işleri hakkında kasten yanlış veya yanıltıcı bilgi vermek; çalışanları, vekilleri veya diğer yardımcı kimseleri, çalıştıranın veya müvekkillerinin üretim veya ticaret sırlarını ele geçirmelerini sağlamak için aldatmak; çalıştıranlar veya müvekkillerden, işçilerinin veya çalışanlarının ya da vekillerinin, işlerini gördükleri sırada cezayı gerektiren bir haksız rekabet fiilini işlediklerini öğrenip de bu fiili önlememek veya gerçeğe aykırı beyanları düzeltmemek haksız rekabet suçunu oluşturacaktır. "Tüzel kişilerin cezai sorumluluğu” başlıklı 63. maddeye göre ise, tüzel kişilerin işlerini görmeleri sırasında bir haksız rekabet fiili işlenirse 62. madde hükmü, tüzel kişi adına hareket eden organın üyeleri veya ortakları hakkında uygulanacaktır. Haksız rekabet fiilinin bir tüzel kişinin faaliyeti çerçevesinde işlenmesi hâlinde, tüzel kişi hakkında bunlara özgü güvenlik tedbirlerine de karar verilebilecektir. Çalışmamızda, öncelikle haksız rekabet kavramı üzerinde kısaca durulacak, daha sonra haksız rekabet suçu -özellikle sorunlu noktalara ağırlık verilmek suretiyle- genel olarak irdelenecektir.

\section{Haksız Rekabet Düzenlemeleri}

Haksız rekabet, rakipler arasında veya tedarik edenlerle müşteriler arasındaki ilişkileri etkileyen aldatıcı veya diğer şekillerdeki dürüstlük kurallarına aykırı davranışlar ve ticari uygulamalar olarak tanımlanabilir (Örs, 1958; Erdil, 2012). Haksız rekabet hükümleri, günümüz serbest piyasa ekonomisi bakımından gösterdiği öneme binaen birçok mevzuatta yer almaktadır. İlk olarak, 07.12.1994 tarihli ve 4054 sayılı Rekabetin Korunması Hakkında Kanun "mal ve hizmet piyasalarındaki rekabeti engelleyici, bozucu veya kısıtlayıcı anlaşma, karar ve uygulamaları ve piyasaya hâkim olan teşebbüslerin bu hâkimiyetlerini kötüye kullanmalarını önlemek, bunun için gerekli düzenleme ve denetlemeleri yaparak rekabetin korunmasını sağlamak" amacına hizmet etmekte (md. 1) ve "Türkiye Cumhuriyeti sınırları içinde mal ve hizmet piyasalarında faaliyet gösteren ya da bu piyasaları etkileyen her türlü teşebbüsün aralarında yaptığı rekabeti engelleyici, bozucu ve kısıtlayıcı anlaşma, uygulama ve kararlar ile piyasaya hâkim olan teşebbüslerin bu hâkimiyetlerini kötüye kullanmaları ve rekabeti önemli ölçüde azaltacak birleşme ve devralma niteliğindeki her türlü hukuki işlem ve davranışlar, rekabetin korunmasına yönelik tedbir, tespit, düzenleme ve denetlemeye ilişkin işlemler"i kapsamına almaktadır (md. 2). Ayrıca, 11.01.2011 tarihli ve 6098 sayılı Türk Borçlar Kanunu (TBK) da 57. maddesinde adi işler bakımından haksız rekabeti düzenlemekte ve "Gerçek olmayan haberlerin yayılması veya bu tür ilanların yapılması ya da dürüstlük kurallarına aykırı diğer 
davranışlarda bulunulması yüzünden müşterileri azalan veya onları kaybetme tehlikesiyle karşılaşan kişi, bu davranışlara son verilmesini ve kusurun varlığı hâlinde zararının giderilmesini isteyebilir.” hükmünü içermektedir (Baştürk, 2011).

Ticari işler bağlamında haksız rekabet, Türk Ticaret Kanunu’nun “Ticari İşletme” başlıklı birinci kitabının dördüncü kısmında, madde 54 ve devamında düzenlenmektedir (Poroy ve Yasaman, 2010). TTK md. 54/2'ye göre "Rakipler arasında veya tedarik edenlerle müşteriler arasındaki ilişkileri etkileyen aldatıcı veya dürüstlük kuralına diğer şekillerdeki aykırı davranışlar ile ticari uygulamalar haksız ve hukuka aykırıdır.” Bu ifadeden hareketle haksız rekabet, rakipler ya da tedarik edenlerle müşteriler arasındaki ilişkileri etkileyen aldatıcı veya dürüstlük kuralına aykırı davranış veya ticari uygulamalar olarak tanımlanabilir.

TTK md. 55'te dürüstlük kuralına aykırı davranışlar ve ticari uygulamalar 6 bent halinde ve 21 davranış sayılmak suretiyle gösterilmektedir. Fakat dikkat edilmelidir ki bu sayım sınırlı değildir (Baştürk, 2011). Ekonomik hayatın gelişimine paralel olarak haksız rekabet teşkil eden davranışların da değişmesi sebebiyle, örnekleyici sayım haksız rekabetle hukuki mücadelede etkili bir yol gibi görünse de, TTK md. 62/1-a'da 55. maddede sayılan fiiller suç olarak tanımlandığından, bu yöntem suçta ve cezada kanunilik, belirlilik ve öngörülebilirlik ilkelerini ihlal etmektedir. Ayrıca 55. maddede kullanılan "özellikle” ibaresi, ceza hukukunun temel ilkelerinden olan kıyas yasağına aykırıdır.

\section{Türk Ticaret Kanunu'nda Düzenlenen Haksız Rekabet Suçu}

TTK md. 62'de “ceza sorumluluğunu gerektiren fiiller” başlığı altında haksız rekabet suçu oluşturan davranışlar dört bent halinde düzenlenmektedir. İlk bentte TTK md. 55'te yer alan fiillere atıf yapılmış, (b) bendinde kendi icap ve tekliflerinin rakiplerininkine tercih edilmesi için kişisel durumu, ürünleri, iş ürünleri, ticari faaliyeti ve işleri hakkında kasten yanlış veya yanıltıcı bilgi vermek, (c) bendinde çalışanları, vekilleri veya diğer yardımcı kimseleri, çalıştıranın veya müvekkillerinin üretim veya ticaret sırlarını ele geçirmelerini sağlamak için aldatmak, (d) bendinde ise çalıştıranlar veya müvekkillerden, işçilerinin veya çalışanlarının ya da vekillerinin, işlerini gördükleri sırada cezayı gerektiren bir haksız rekabet fiilini işlediklerini öğrenip de bu fiili önlememek veya gerçeğe aykırı beyanları düzeltmemek suç olarak vazedilmiştir.

Dikkat edilmelidir ki TTK md. 62 söz konusu fiiller "daha ağır cezayı gerektiren başka bir suç oluşturmadığı takdirde" uygulanabilen bir hükümdür. Diğer bir ifadeyle, TTK md. 62 hükmü tali normdur (İtişgen, 2016). Sayılan davranışlar başka bir suçun unsurlarını oluşturduğu ve bu suç TTK md. 62'ye göre daha ağır bir cezayı gerektirdiği takdirde o suçtan hüküm kurulur. Söz konusu davranış başka bir suçu meydana getirmekle birlikte, o suçun yaptırımı TTK md. 62'ye göre daha hafif bir yaptırım getiriyorsa bu durumda yine haksız rekabet suçundan dolayı ceza uygulanır.

\section{Haksız Rekabet Suçuyla Korunan Hukuki Değer}

Haksız rekabet suçuyla dürüst rekabet ortamının, dürüstlüğe aykırı davranış ve uygulamalar ile zarara uğrayan rakiplerin ticari itibar ve saygınlığının, tüketici ve müşterilerin haklarının korunduğu, bu sebeple çok hukuki konulu bir suç tipi olduğu söylenebilir (Aydın, 2008).

\section{Haksız Rekabet Suçunun Unsurları}

\subsection{Kanuni Unsur}

TTK md. 62’ye göre, “a) 55 inci maddede yazılı haksız rekabet fiillerinden birini kasten işleyenler,

b) Kendi icap ve tekliflerinin rakiplerininkine tercih edilmesi için kişisel durumu, ürünleri, iş ürünleri, ticari faaliyeti ve işleri hakkında kasten yanlış veya yanıltıcı bilgi verenler,

c) Çalışanları, vekilleri veya diğer yardımcı kimseleri, çalıştıranın veya müvekkillerinin üretim veya ticaret sırlarını ele geçirmelerini sağlamak için aldatanlar,

d) Çalıştıranlar veya müvekkillerden, işçilerinin veya çalışanlarının ya da vekillerinin, işlerini gördükleri sırada cezayı gerektiren bir haksız rekabet fiilini işlediklerini öğrenip de bu fiili önlemeyenler veya gerçeğe aykırı beyanları düzeltmeyenler,

Fiil daha ă̆ır cezayı gerektiren başka bir suç oluşturmadığı takdirde, 56 ncı madde gereğince hukuk davasını açma hakkını haiz bulunanlardan birinin şikâyeti üzerine, her bir bent kapsamına giren fiiller dolayısıla iki yıla kadar hapis veya adli para cezasiyla cezalandırllırlar."

\subsection{Maddi Unsurlar}

\section{i. Konu}

Haksız rekabet, aldatıcı veya dürüstlük kuralına aykırı surette ekonomik rekabetin suiistimalidir (Poroy ve Yasaman, 2010). Bu tanımdan hareketle, haksız rekabet suçunun konusunu genel anlamda dürüst rekabetin egemen olduğu ekonomik düzenin teşkil ettiği söylenebilir (Erdoğan, 2013). 


\section{ii. Fail}

TTK'da düzenlenen haksız rekabet hükümleri ticari işler bakımından uygulama alanı bulduğundan bu suçun faili ancak tacir olabilir. Tüzel kişilerin iradi hareket etme yeteneği bulunmadığından fail olmaları söz konusu değildir. Diğer bir ifadeyle ancak gerçek kişiler bir suçun faili olabilirler (Özgenç, 2015; Koca ve Üzülmez, 2013). Zira Türk ceza hukukunda tüzel kişilerin suç faili olamayacağı, ceza sorumluluklarının kabul edilmesinin ceza sorumluluğunun şahsiliği ilkesine aykırı olacağı ifade edilmektedir (Erman, 1976; Özgenç, 2002; Dursun, 2006; Mahmutoğlu, 2003).

Ticaret şirketleri adına ve faaliyetleri esnasında suç işlenmesi durumunda ise, tüzel kişinin yetkili organ veya temsilcisinin cezai sorumluluğu gündeme gelir (Kangal, 2003). Organ kurul halinde karar almışsa, karara olumlu oy kullanmış üyeler sorumlu olacak; toplantıya katılmamış ya da katılmakla birlikte olumsuz oy kullanmış üyelerin sorumluluğuna gidilemeyecektir. Fakat bu üyelerin kararın alınmasını önleme yükümlülükleri kanunda ya da esas sözleşmede öngörülmüş ise, bu durumda kararın alınmasını önlemeyen üyelerin ihmali suretle suça katıldıklarını söylemek mümkündür (Dursun, 2006).

Bununla birlikte, esas sözleşmede temsil organının üyeleri arasında görev dağılımı yapılması da mümkündür. Görev dağılımının bulunduğu bu gibi durumlarda, her bir üye kendisine verilen temsil yetkisi oranında sorumlu olacaktır ve eylem ya da işlemin ayrıntılarını bilen ve oluşumunda rolü bulunan temsilcilerin cezai sorumluluğuna gidilecektir. 26.09.2004 tarihli ve 5237 sayılı Türk Ceza Kanunu (TCK)’nun suça iştirake ilişkin hükümleri (TCK md. 37-40) bir tarafa bırakıldığında, suç oluşturan eylem ya da işlem hangi temsilcinin görev tanımında yer alıyorsa o temsilcinin cezai sorumluluğu tartışılacaktır (Erman, 1976; Gülhan, 2007).

\section{iii. Mağdur}

Haksız rekabet suçunun geniş anlamda mağduru toplumu oluşturan herkestir. Dar anlamda ise, dürüstlüğe aykırı davranış ve uygulamalar ile zarara uğrayan tüzel kişiler, tüketici ve müşteriler suçun mağduru olmaktadırlar.

\section{iv. Hareket, Netice ve Nedensellik Bağı}

TTK m. 62'nin (a) bendinde 55. maddede yazılı haksız rekabet fiillerinden birini kasten işlemek, (b) bendinde kendi icap ve tekliflerinin rakiplerininkine tercih edilmesi için kişisel durumu, ürünleri, iş ürünleri, ticari faaliyeti ve işleri hakkında kasten yanlış veya yanıltıcı bilgi vermek, (c) bendinde çalışanları, vekilleri veya diğer yardımcı kimseleri, çalıştıranın veya müvekkillerinin üretim veya ticaret sırlarını ele geçirmelerini sağlamak için aldatmak ve (d) bendinde çalıştıranlar veya müvekkillerden, işçilerinin veya çalışanlarının ya da vekillerinin, işlerini gördükleri sırada cezayı gerektiren bir haksız rekabet fiilini işlediklerini öğrenip de bu fiili önlemeyenler veya gerçeğe aykırı beyanları düzeltmemek suç olarak düzenlenmektedir.

TTK md. 55'te haksız rekabet halleri altı bent halinde gruplandırılmış, her bir bendin altında sözü geçen haksız rekabet haline örnek verilmiştir. İlk bentte, dürüstlük kuralına aykırı reklamlar ve satış yöntemleri ile diğer hukuka aykırı davranışlar, (b) bendinde sözleşmeyi ihlale veya sona erdirmeye yöneltmek, (c) bendinde başkalarının iş ürünlerinden yetkisiz yararlanmak, (d) bendinde üretim ve iş sırlarını hukuka aykırı olarak ifşa etmek, (e) bendinde iş şartlarına uymamak, (f) bendinde ise dürüstlük kuralına aykırı işlem şartları kullanmak haksız rekabet teşkil eden fiil olarak gösterilmektedir. Dikkat edilmelidir ki, TTK md. 55'teki sayım sınırlı değildir (Arkan, 2011). Diğer bir ifadeyle, yalnızca TTK md. 55'te sayılan hareketler değil, bu maddede sayılmamakla birlikte TTK md. 54'ün kapsamına giren benzer hareketler de haksız rekabet teşkil eder.

Doktrinde TTK md. 62/1-a atfiyla uygulanan 55. maddedeki hareketlerin seçimlik hareketler mi olduğu yoksa ayrı suçlar mı teşkil ettiği tartışmalıdır. Bir görüşe göre, 55. maddede sayılan hareketlerin tamamı seçimlik hareketlerdir (Aydın, 2008; Baştürk, 2011). Diğer bir görüş ise, TTK md. 55'te yer alan hareketlerin seçimlik hareket olduğunu, “dürüstlük kurallarına aykırı reklam vermek” ve “dürüstlük kurallarına aykırı satıs yöntemleri kullanmak" ş̧eklinde iki ayrı suçun ve 12 bent şeklinde sayılan hareketlerin üç farklı suç oluşturduğunu ileri sürmektedir (Erdoğan, 2013). Kanımızca, TTK md. 62'de dört bent halinde düzenlenen ve yukarıda sayılan TTK md. 55'in altı bendini de kapsayan fiiller haksız rekabet suçunun seçimlik hareketleridir. Dolayısıyla birinin işlenmesiyle suç oluşacak, birden fazlasının gerçekleştirilmesi durumunda ise suçların çokluğu sonucu doğmayacaktır. Ancak bu durum TCK'nın 62. maddesi gereğince temel cezanın belirlenmesinde alt sınırdan uzaklaşma gerekçesi teşkil edebilecektir.

Haksız rekabet suçu neticesi harekete bitişik, diğer bir ifadeyle neticesiz suçlardır. TTK md. 62'de sayılan hareketlerin gerçekleştirilmesiyle rekabet düzeninin bozulduğu ve neticenin gerçekleştiği kabul edilmektedir. Neticesiz suçlar olduğundan nedensellik bağlantısının ayrıca incelenmesine gerek bulunmamaktadır.

\subsection{Manevi Unsur}

Hukuki açıdan haksız rekabetin oluşabilmesi için failin kusuru aranmamakta, dürüstlük kuralına aykırı davranış veya uygulamasının bulunması yeterli kabul edilmektedir. Kusur, yalnızca tazminat sorumluluğu bakımından aranan bir koşuldur (Erdil, 2012; Karahan, 2011; Arkan, 2011). Öte yandan, ceza hukukunda objektif sorumluluk kabul edilmemekte, failin suç teşkil eden fiilinden sorumlu tutulabilmesi için kasten veya en azından taksirle hareket etmesi gerekmektedir. TCK md. 22/1'in "Taksirle işlenen fiiller, kanunun açıkça belirttiği hallerde 
cezalandırllır." düzenlemesi gereğince, haksız rekabet suçu ancak kasten işlenmeleri halinde cezalandırılabilir. Zira suçun taksirli hali düzenlenmemiştir

\subsection{Hukuka Aykırılık Unsuru}

Bir fiilin suç teşkil edebilmesi için tipe uygun, kusurlu bir davranış olmasının yanında aynı zamanda hukuka aykırı olması gerekir. Suç teşkil eden fiiller kural olarak hukuka aykırıdırlar.

TCK'da düzenlenen hukuka uygunluk nedenleri kanunun hükmü, meşru savunma, hakkın kullanılması ve ilgilinin rızasıdır. Genel hukuku uygunluk nedenleri niteliği uygun düştüğü ölçüde haksız rekabet suçu bakımından da uygulama alanı bulacaktır. Kanımızca kanunun hükmü ve meşru savunma hukuka uygunluk sebeplerinin bu suç bakımından uygulanması mümkün değildir. Fakat doktrinde hakkın kullanılması ve ilgilinin rızası hukuka uygunluk nedenlerinin uygulanabileceği ifade edilmektedir (Erdoğan, 2013; Aydın, 2008).

\section{Yaptırım}

\subsection{Cezai Yaptırım}

Haksız rekabet suçunun yaptırımı iki yıla kadar hapis veya adli para cezasıdır. Hapis cezası ile adli para cezası alternatif yaptırımlar olarak düzenlenmektedir (İtişgen, 2016). TCK md. 49/1'e göre, süreli hapis cezası kanunda aksi belirtilmeyen hallerde bir aydan az olamayacağından haksız rekabet suçu için bir aydan iki yıla kadar hapis cezasina hükmedilebilir.

TCK md. 52/1'e göre, adlî para cezası, beş günden az ve kanunda aksine hüküm bulunmayan hallerde yedi yüz otuz günden fazla olmamak üzere belirlenen tam gün sayısının, bir gün karşıllğğ olarak takdir edilen miktar ile çarpılması suretiyle hesaplanan meblağa tekabül etmektedir. TTK md. 62 hükmünde adli para cezasının miktarı gösterilmediğinden esasında bu 5 ila 730 gün olarak anlaşılmalıdır. Öte yandan, adlî para cezasının seçimlik ceza olarak öngörüldüğü suçlarda bu cezaya ilişkin gün biriminin alt sınırı, o suç tanımındaki hapis cezasının alt sınırından az; üst sınırı da, hapis cezasının üst sınırından fazla olamaz (TCK md. 61/9). Sonuç olarak, haksız rekabet suçu için verilebilecek adli para cezasının alt sınırı otuz gün, üst sınırı ise 730 gündür (İtişgen, 2016).

\subsection{Tüzel Kişilere Özgü Güvenlik Tedbirleri}

TTK md. 63, "Tüzel kişilerin işlerini görmeleri sırasında bir haksız rekabet fiili işlenirse 62 nci madde hükmü, tüzel kişi adına hareket eden veya etmesi gerekmiş olan organın üyeleri veya ortakları hakkında uygulanır." düzenlemesini içermektedir. Bu hükme göre, tüzel kişi faaliyeti esnasında, tüzel kişi yararına olarak tüzel kişinin organının üyeleri ya da ortaklarının haksız rekabet suçunun işlemesi halinde TTK md. 62 hükmü onlar hakkında uygulanacaktır. Esasında böyle bir düzenlemeye ihtiyaç yoktur çünkü ceza hukuku bakımından ancak gerçek kişiler fail olabilir ve tüzel kişi yararına suç işlenmesi halinde organ veya temsilcilerin cezai sorumlulukları doğar. Bununla birlikte, düzenlemenin "Haksız rekabet fiilinin bir tüzel kişinin faaliyeti çerçevesinde işlenmesi hâlinde, tüzel kişi hakkında bunlara özgü güvenlik tedbirlerine de karar verilebilir." kısmı yerindedir. Zira TCK md. 60/4 gereğince, tüzel kişiler hakkında güvenlik tedbiri uygulanabilmesi için bu konuda açık hüküm bulunmalıdır.

Tüzel kişiler hakkında uygulanabilecek güvenlik tedbirleri TCK md. 60'a göre, iznin iptali ve müsaderedir. Fakat bu tedbirlerin uygulanmasının işlenen fiile nazaran daha ağır sonuçlar ortaya çıkarabileceği durumlarda, TCK md. 60/3'e dayanarak hâkim bu tedbirlere hükmetmeyebilir (Öztürk ve Erdem, 2014).

\section{Soruşturma ve Kovuşturma}

TTK md. 62'de haksız rekabet suçunun "56 ncı madde gereğince hukuk davasını açma hakkını haiz bulunanlardan birinin şikâyeti üzerine” soruşturulup kovuşturulacağı öngörülmektedir. TTK md. 56'da hukuk davası açabilecek kişiler, haksız rekabet sebebiyle müşterileri, kredisi, meslekî itibarı, ticari faaliyetleri veya diğer ekonomik menfaatleri zarar gören veya böyle bir tehlikeyle karşılaşabilecek olan kimse, ekonomik çıkarları zarar gören veya böyle bir tehlikeyle karşılaşabilecek müşteriler, ticaret ve sanayi odaları, esnaf odaları, borsalar ve tüzüklerine göre üyelerinin ekonomik menfaatlerini korumaya yetkili bulunan diğer meslekî ve ekonomik birlikler ile tüzüklerine göre tüketicilerin ekonomik menfaatlerini koruyan sivil toplum kuruluşlarıyla kamusal nitelikteki kurumlardır (Baştürk, 2011).

TCK md. 73/1'e göre, "Soruşturulması ve kovuşturulması şikâyete bağlı olan suç hakkında yetkili kimse altı ay içinde şikâyette bulunmadı̆̆ takdirde soruşturma ve kovuşturma yapılamaz." Haksız rekabet suçu da TTK m. 56'da sayılan kişilerin ve yukarıda sayılan fiili ve failin kim olduğunu bildiği veya öğrendiği günden itibaren (TCK md. 73/2) altı ay içinde şikâyette bulunması ile soruşturulup kovuşturulur.

\section{Zamanaşımı}

TTK md. 60 "56 ncı maddede yazılı davalar, davaya hakkı olan tarafin bu hakların doğumunu öğrendiği günden itibaren bir yıl ve her hâlde bunların doğumundan itibaren ü̧ yıl geçmekle zamanaşımına uğrar. Şu kadar ki, haksız rekabet fiili aynı zamanda 26/9/2004 tarihli ve 5237 sayll Türk Ceza Kanunu gereğince daha uzun dava 
zamanaşımı süresine tabi olan cezayı gerektiren bir fiil niteliğinde ise, bu süre hukuk davaları için de geçerli olur. ” düzenlemesini getirmektedir.

TCK md. 66/1-e hükmü beş yıldan fazla olmamak üzere hapis veya adlî para cezasını gerektiren suçlarda sekiz yıl dava zamanaşımı süresi öngörmektedir. Haksız rekabet suçunun yaptırımı iki yıla kadar hapis veya adli para cezasıdır. Seçimlik cezaları gerektiren suçlarda zamanaşımı bakımından hapis cezası esas alınır (TCK m. 66/3). Dolayısıyla dava zamanaşımı süresi TCK md. 66/1-e'ye göre sekiz yıl olmaktadır (Öztürk ve Erdem, 2014). Bu süre, TTK md. 60’ta öngörülen üç yıllık süreden uzun olduğundan, aynı hükmün ikinci cümlesi gereğince sekiz yıllık zamanaşımı süresi esas alınır.

\section{Sonuç}

Haksız rekabet suçu TTK'da düzenlenen ticari suçlardandır. TCK'nın “Ekonomi, Sanayi ve Ticarete İlişkin suçlar" bölümünde düzenlenmediğinden esasında özel bir ekonomik suç normu teşkil etmektedir. Düzenleme TTK'nın haksız rekabet bölümünde yer alması sebebiyle konu itibariyle bütünlük arz etmekte, yaptırımı TTK m. 62'de öngörüldüğünden, TCK'nın bir normuna atıf yapılmadığından eksik norm özelliği göstermemektedir. Öte yandan ceza ve ceza muhakemesinin genel hükümleri bu suç bakımından da uygulanmaktadır.

TTK md. 62'nin atfiyla uygulanan TTK md. 55'te dürüstlük kuralına aykırı davranış ve uygulamaların sınırlı surette sayılmayarak örnekler verilmek suretiyle başlıca davranışların öngörülmesi ceza hukukunun temel prensiplerinden olan kanunilik ilkesini ihlal emektedir. Ayrıca, örneklere dayanarak TTK md. 54 kapsamına girecek benzer davranışların da haksız rekabet kabul edilerek cezalandırılması kıyas yasağına aykırılık teşkil edecektir.

\section{Kaynakça}

- $\quad$ ARKAN, 2011. Ticari İşletme Hukuku, 15. Baskı, Banka ve Ticaret Hukuku Araştırma Enstitüsü, Ankara.

- $\quad$ AYDIN, 2008. Türk Ticaret Kanunu'nda Haksız Rekabet Suçları, Yetkin, Ankara.

- BAŞTÜRK, 2011. “Türk Ticaret Kanununda Bilişim Yoluyla Haksız Rekabetin Hukuki - Cezai Sonuçları”, Türkiye Adalet Akademisi Dergisi, 1(6).

- DURSUN, 2006. Ekonomik Suçlar ve Bankacılık Suçları Bağlamında Bankacılık Düzenine Karşı İşlenen Suçlar, Seçkin, Ankara.

- $\quad$ ERDİL, 2012. Haksız Rekabet Hukuku, Vedat, İstanbul.

- ERDOĞAN, 2013. "Yeni Türk Ticaret Kanunu'nda Haksız Rekabet Suçu”, Ipek Yolu Canlanıyor, Türk-Çin Hukuk Zirvesi, Adalet Yayınevi, Ankara.

- $\quad$ ERMAN, 1976. Ticari Ceza Hukuku- Genel Kısım, Matematik Araştırma Enstitüsü Matbaası, İstanbul.

- GÜLHAN, 2007. Anonim Şirket Yönetim Kurulu Üyelerinin Hukuki ve Cezai Sorumlulukları, SPK Yeterlilik Etüdü, İstanbul.

- İTIŞGEN, 2016. “Türk Ticaret Kanununda Düzenlenen Gerçek Dışı veya Yanıltıcı Açıklamada Bulunma Suçu”, Türkiye Barolar Birliği Dergisi, 122.

- KANGAL, 2003. Tüzel Kişilerin Ceza Sorumluluğu, Seçkin, Ankara.

- $\quad$ KARAHAN, 2011. Ticari İşletme Hukuku, 20. Baskı, Mimoza, Ankara.

- $\quad$ KOCA ve ÜZÜLMEZ, 2013. Türk Ceza Hukuku Genel Hükümler, 6. Baskı, Seçkin, Ankara.

- MAHMUTOĞLU, 2003. Ekonomik Suçlar Bağlamında Kredi Hukukundan Kaynaklanan Suç ve İdari Suçlar, Seçkin, Ankara.

- $\quad$ POROY ve YASAMAN, 2010. Ticari İşletme Hukuku, 13. Bası, Vedat, İstanbul.

- $\quad$ ÖRS, 1958. Türk Hususi Hukukunda Haksız Rekabet, Ankara.

- ÖZGENÇ, 2015. Türk Ceza Hukuku Genel Hükümler, 11. Bası, Seçkin, Ankara.

- ÖZGENÇ, 2002. Ekonomik Çıkar Amacıyla İşıenen Suçlar, Seçkin, Ankara.

- $\quad$ ÖZTÜRK ve ERDEM, 2014. Uygulamalı Ceza Hukuku ve Güvenlik Tedbirleri Hukuku, 14. Bası, Seçkin, Ankara. 


\title{
Yatırım Projelerinin Değerlendirilmesi: Türk Çimento Sektöründen Bir Örnek
}

\section{Evaluation of Investment Projects: A Case from Turkish Cement Sector}

\author{
Miyase Karabulut (Türk Hava Yolları, Turkey) \\ Asst. Prof. Dr. S1tkı Sönmezer (Beykent University, Turkey) \\ Asst. Prof. Dr. Vedat Zeki Yenen (Beykent University, Turkey) \\ Zeynep Emir (Beykent University, Turkey)
}

\begin{abstract}
Capital budgeting is crucial for firms that have projects to evaluate especially when the projects are mutually exclusive or financing is scarce. The aim of the study is to determining the most widely used methodologies in capital budgeting decisions and their effectiveness. A qualitative research will provide cement sector specific examples in assessing industry projects and compares the methods of Net Present Value, İnternal rate of Return, Pay-back period, discounted pay-back period and MIRR. Each method is briefly discussed and its drawbacks and advantages are mentioned in detail. Other sectors are also examined in terms of capital budgeting. Our preliminary results indicate that net present value method dominates capital budgeting decisions in the sectors under study.
\end{abstract}

\section{Giriș}

Sermaye bütçelemesi son yıllarda çok önemli bir konu haline gelmiştir. Akademik alanda firmaların stratejik kararlarını olumlu yönde etkileyecek ve şekillendirecek birçok çalışmalar yapılmaktadır. Dünya ve ülke ekonomilerinin büyümesi ile birlikte firmalar bu büyümeye ayak uydurmak amaciyla kendi sistemlerini güçlendirmek ve yenilemek için çeşitli yatırım kararları almaktadır. Sermaye bütçelemesi kapsamında karar verilen yatırım projeleri çok büyük sermaye ile gerçekleştiği için mali ve ekonomik açıdan stratejik öneme sahip olup, alınması ve planlanması zor kararlardır. Yatırım projelerinin etkin bir şekilde incelenerek, değerlendirilmesi ve analiz edilmesi işletmelerin idame, ikame, sürdürülebilir büyüme ve karlılık hedeflerine ulaşmasını sağlayacaktır. Fakat alınacak yanlış bir karar, firmanın büyük sermaye kaybına neden olacaktır. Sermaye bütçelemesine ilişkin uygulamalar aynı zamanda hissedarların sermayelerini arttırmak için de yapılmaktadır. Bu kararların çerçevesi maddi ve maddi olmayan duran varlık kalemleri olup uzun vadeli varlıklardan oluşmaktadır. Şirketlerin yatırım kararları almalarındaki en büyük sebep etkili rekabet edebilmek, kontrollü büyümek ve pazarın dışında kalmamaktır.

Sermaye bütçelemesi oluştururken her bir yatırımın getirisi çok iyi değerlendirilmelidir. Bu yüzden sermaye bütçelemesi hesaplama tekniklerinin giderek önemi artmıştır. Hesaplama geleneksel ve indirgenmiş nakit akım teknikleri kullanılmaktadır

İndirgenmiş nakit akışı yaklaşımında bir varlığa ait beklenen getiri bulunurken nakit akımlara ait gelecekteki riski yansıtacak bir iskonto oranı kullanılarak bugünkü değere indirgemesi yapılmaktadır. Bu yöntem nakit akışlarının değerlendirilmesinde kârın bulunması açısından daha gerçeğe yakın bir ölçüt olarak kabul edilmektedir.

Bazı firmalar yatırım projelerini değerlendirirken ayrıntılı analize gerek görmeden kendi tecrübelerine göre karar alırken bazı firmalar paranın zaman değerini dikkate alan ve almayan yöntemlere göre hesaplayıp, projelerini kendi öncelik sıralamalarına göre kabul veya ret kararı almaktadırlar.

Bu bildirinin amacı, bahsi geçen yöntemleri karşılaştırmak ve firmaların her hangi bir yöntemi tercih sebeplerini ortaya koymaktır. Çimento sektöründe faaliyet gösteren bir firma özelinde tercih edilen yöntem incelenmiştir ve tercih nedenleri tartışılmıştır.

\section{Literatür Taraması}

Miller ve Mao (1969), indirim olmayan sermaye bütçelemesi yöntemleri ve özellikle geri ödeme süresi (PP) üzerine çalışmalar yapmışlardır. Petty ve Chandra (1975), Porwal (1976), Schall, Sundem ve Geijsbeck (1978) ve Bhattacharya (1979), indirgenmiş nakit akışı (DCF) yöntemleri, özellikle IRR yöntemi üzerine çalışmalar yapmışlardır. Pandey (1989) yapmış olduğu çalışmada en popüler yöntemin önce PP sonra IRR yöntemi olduğunu bulmuştur. Ken Leonore ve U.Rao Cherukuri (1991) yapmış olduğu çalışmada büyük ABD şirketlerinin en çok IRR ve NPV yöntemlerini tercih ettiği sonucuna varmışlardır. Petry ve Sprow (1993) firmaların yaklaşık \% 90 NPV ve IRR kullanırken yaklaşık \%60 oranlı ikinci yöntem olarak PP yöntemini kullandığını belirtmişlerdir. Babu ve Sharma (1995)'ın çalışmasında davalı şirketlerin \% 70’i DCF teknikleri kullandığ 1 görülmektedir. Dhanker (1995) benzer çalışmasında şirketlerin \% 16`sı DCF teknikleri, \% 33 PP ve muhasebe getiri oranı (ARR) 
kullandığını belirtmiştir. Jog ve Srivastava (1995) ve Pike (1996) çalışmalarında Kanada ve İngiltere şirketlerinde PP en çok tercih edilen yöntem olduğunu bulmuşlardır.

Cherukuri (1996) Hong Kong, Malezya ve Singapur'dan seçilmiş 300 üst sivil toplum şirketleri üzerine yapılan çalışmaya göre \% 51 IRR, \% $30 \mathrm{NPV}$ ve \% 38 PP ve ARR yöntemi kullandıklarını bulmuștur. 74 Hint şirketi üzerine yapılan ankette ise yatırım değerlendirmesinde \%51 IRR yöntemini kullandığını belirlemiștir. ChadwellHatfield, Patricia, Goitein, Bernard, Horvath, Philip, Webster, Allen (1997) yapmış oldukları çalışmalarda, şirketlerin \% 70 IRR ve \% 84 NPV tercih ettiklerini belirtmişlerdir (Verna, Gupta ve Batra 2009, ss.2-3). Biddle Bowen ve Wallaca (1997) 733 işletme üzerine 1983-1994 dönemini kapsayan çalışmalarında, hisse senedi getirilerini açıklama düzeyi en yüksek performans ölçütünün, kazançlara dayalı ölçütler olduğunu ve bunu önce EVA sonra ise faaliyetlerle ilgili nakit akımlarının takip ettiğini belirlemişlerdir (Akyüz 2013, s.371.).

1990 yıllarda Stanley Block (1997), küçük işletmeler üzerine yapmış olduğu çalışmada, \% 42,7 PP ve \% 22,4 ARR'in en popüler olduğunu ortaya koymuşlardır. Jain ve Kumar (1998), Hindistan'da Bombay Menkul Kıymetler borsasındaki 96 sivil hükümet şirketleri ve Güney Doğu Asya'da beş şirket üzerine yapılan çalışmada bu şirketlerin \% 80'ni en çok NPV ve IRR daha sonra PP tercih ettiğini belirtmişlerdir. Graham ve Harvey (2001), büyük şirketler üzerine yapılan araştırmalarda, yatırım tutarı ve borç oranı yüksek projelerde CEO'ların IRR yerine iskonto oranı kullanıldığı için NPV yöntemini daha çok tercih ettiklerini göstermişlerdir. Ryan ve Ryan (2002), Fortune 1000 şirket üzerine yaptıkları çalışmada, NPV en popüler ve tercih edilen yöntem sonra IRR yönteminin takip ettiğini belirtmiştir. Büyük şirketler ise sermaye bütçelemesinde NPV ve IRR tercih etme eğilimindedir (Verna, Gupta ve Batra 2009, s.3.).

Aynı şekilde Brealey ve Myers (2002) yapmış olduğu çalışmalarında IRR ve NBD yönteminin en kolay ve yaygın olarak kullanılan teknikler olduğunu belirtmiş̧ir (Espınoza ve Morris 2013, s.471.).

Parkash Singh ve Gaur (2004), çalışmasında projeleri kabul/red etmek için IRR ve NPV göre karşılaştırmalı hesaplama yapmışlardır. Bu hesaplamaya göre NPV'nin en iyi yöntem olduğunu belirtmişlerdir. Holmen (2005), İsviçre firmaları üzerine yaptıkları çalışmada büyük işletmelerin NPV, küçük işletmelerin ise IRR yöntemlerini tercih ettiğini belirtmişlerdir. Truong, Peat ve Partington (2007), Avustralya'da işletmelerde yapmış oldukları ankette ise en çok NPV, IRR ve PP tercih edilen yöntemlerdir. Brijlal, Pradeep (2008), Güney Afrika The Westwrn Cape Eyaleti'nde farklı sektörlerde yaptıkları çalışmada kü̧̈ük, orta ve büyük ölçekli şirketlerin en çok PP ve NPV tercih ettiklerini belirtmişlerdir (Verna, Gupta ve Batra 2009, ss.3-4.).

Sharma ve Kumar (2010) , 1994-2008 yıllar arası EVA ile ilgili yayınlanmış 12 çalışmayı inceleyip bir sınıflandırma yapmıştır. Bu çalışmada literatürdeki EVA hızlı bir şekilde geniş bir alanda uygulanarak 7 alt temel oluşturulmuştur.(Fındık 2013, s.93.).

\section{Yöntemler}

Sermaye bütçelemesi kararlarında yöntemler paranın zamanını dikkate alanlar ve paranın zaman değerini dikkate almayanlar diye ikiye ayrılmıştır.

i. Paranın zaman değerini dikkate almayan yöntemler;

Geri ödeme süresi (PP); bir yatırıma ait başlangıç maliyetini kurtarmak için gereken süreyi ifade etmektedir. Sermaye bütçelemesi kararlarında geri ödeme süresi kuralı, bağımsız projelerde hesaplanan geri ödeme süresinden daha az süreye sahip olanları kabul edebileceğini belirtmektedir (Wang 2010, s.50.)

Kârlılık Oranı; basit anlamıyla bu yöntem yatırım yapacak işletmeye ait hesaplanmış olan yıllık net kârın yatırım tutarına oranlanması olup yatırımın sağlayabileceği en yüksek yıllık kârın yatırım tutarına oranı ve ortalama net kârın ortalama yatırım tutarına oranı olarak iki şekilde uygulanmaktadır (Öztürk, Top ve Pehlevan 2015, ss.3132.).

ii. Paranın zaman değerini dikkate alan yöntemler;

İç Getiri Oranı (IRR); yatııma ait nakit giriş ve çıkışlarını birbirine eşitleyen iskonto oranını deneme yanılma yöntemi kullanarak bulmaktadır (Türko 1999, s.328.).

Düzeltilmiş iç getiri (MIRR); bir yatırımının bugünkü değerini, nakit girişlerinin yatııımın ömrünün sonundaki gelecekteki değere eşitleyen iskonto tutarı olup paranın zaman değerini dikkate aldığı için IRR yöntemine göre daha gerçekçi bir hesaplama yapmaktadır (Eroğlu 2016, ss.12-13.).

Fayda-maliyet analizi (FI), yapılacak yatırımlar arasından işletmeye getirisi en yüksek olan yatırımı tespit etmek için, yapılan tüm maliyetler ve sağlanacak faydaların değerleri analiz edilerek çıkan sonuçlara göre karşılaştırma yapılıp ekonomik değeri en yüksek olan yatırımın seçilmesi sağlayan bir yöntemdir (Ergen 2008, s.116.).

Net bugünkü değer (NPV) yöntemi; bir yatırıma ait nakit girişleri ve çıkışları arasındaki fark olup net finansal fayda tahmin edilmeye çalışılmaktadır. Pozitif NPV yatırımın olumlu olduğunu gösterirken negatif NPV ise mali kayba neden olacağını göstermektedir. Ayrıca hesaplamada kullanılan iskonto oranı ise yatırımın kârlı olup olmaması açısından etkili olmaktadır (Pradas, Ullah ve Soucase 2015, s.577.). 
NPV analizinde nakit akışlarının tahmininde uygun bir iskonto oranı kullanılarak beklenen getiri hesaplanmaktadır. Bu hesaplamalar yapılırken değerlendirmede kullanılacak nakit akışlarının sınırlı olması, beklenen nakit akımlarının getirisinin tahminine engel olmaktadır ve doğru bir bilgi edinilmesi mümkün olmamaktadır (S.Armstrong 2015, s.19.).

Ekonomik Katma Değer (EVA), bir şirketin mevcut iş potansiyeli için bir ölçüm aracı olup özellikle sermayenin maliyeti ve birçok muhasebe değişikliklerini dikkate alarak ekonomik katma değer yaratmaktadır. Bununla birlikte muhasebe kârı ekonomik kâra dönüştürerek EVA'ya ulaştırmaktadır (Ray 2012, ss.261-262.).

EVA’nın temel yaklaşımı, işletmeye değer yaratma olup hissedar değerinin yaratılmasında en iyi ölçüm yöntemidir. EVA ölçümlemesini belirleyen işletmelerde ürün, hizmet ve müşterilerinin maliyetlerini belirlemek için faaliyet tabanlı maliyetleme yöntemi yapmaktadır. Yeterli performans göstermeyen birimlerin belirlenmesinde de yardımcı olmaktadır. Bunu yaparken işletme bölümlerinin ayrı ayrı yarattığı değerlerin belirlenmesini sağlamaktadır. İşletme hedeflerine yönelik olarak çalışan personelin performansının değerlendirilmesini de sağlamaktadır. Hissedarlarının zenginliğini dikkate alan EVA, daha yüksek pazar fiyatı için yönetimi öngörür ve daha fazla kâr elde etmesini sağlar. Tüm bunları yaparken işletmeye ait finansal raporlamaları baz alarak hesaplamalar yapmakta olduğu için daha güncel ve gerçekçi hesaplama yapmaktadır (Fındık 2013, ss.95-96.).

\section{Sektör Uygulaması ve Karşılaştırma Analizi}

Yatırımın Konusu $\quad$ : Bir çimento fabrikasında çimento değirmeni yatırımı

Amaç : Üretilecek çimento tipini değiştirerek KÇ (Katkılı Çimento) tipi çimento yerine TÇ (Traslı Çimento) 32.5 tipi çimento üreterek katkı oranını CC/CK=1.30 dan 1.50 ye çıkarmak ve üretim kapasitesini 65 ton/h'ten 75 ton/h'e yükseltmek.

Bütçe : 2,4 MUSD harcama planlanmaktadır.

\section{PARAMETRELER}

Klinker (Yarı Mamul ) Fiyatı (USD/ton): 24

$\begin{array}{ll}\text { Katkı Maliyeti (USD/ton) } & : 10 \\ \text { Kontribüsyon/Katkı payı (USD/ton) } & : 1,40\end{array}$

Kontribüsyon $=($ Klinker Fiyatı USD/ton - Katkı Maliyeti USD/ton $) /$ Katkı Maliyeti USD/ton

Yıllık Satış Miktarı (ton) $\quad: 500.000$

Maliyet Düşüşü / Tasarruf (USD) : 700.000

Maliyet Tasarrufu $=$ Kontribüsyon * Yıllık Satış Miktarı

Yatırım Tutarı (USD) $\quad: 2.400 .000$

Amortisman Süresi (yıl) $\quad: 10$

Y1llı Amortisman Tutarı $=$ Yatırım Tutarı $/$ Amortisman Süresi $=240$

İskonto Faktörü : :\%9

Yıllık Yatırım Maliyeti : :\%11

Faiz ve Vergi Öncesi Kâr/Zarar = = Brüt Faaliyet K/Z - Amortisman Gideri

$=700-240: 460(1$ yil için $)$

Vergi ( Nakit Çıkışı) = Faiz ve Vergi Öncesi Kâr /Zarar * Vergi Oranı

Net Nakit Girişi ve Çıkışı (USD) = = Nakit Girişıleri - Nakit Çıkışları

$=700-92=608($ Y $1111 \mathrm{k})$

Yukarıda verilmiş olan parametrelere baz alınarak paranın zaman değerine dikkate alan yöntemlere göre hesaplama yapılmaktadır.

$$
\begin{gathered}
\text { i. } \quad \text { İç Getiri Oranı (IRR) Yönetimi }=\% 22 \\
\mathrm{C}=\mathrm{A} \frac{(1+r)^{n}-1}{r(1+r)^{n}} \quad 2.400=608 * \frac{(1+I R R)^{10}-1}{I R R *(1+I R R)^{10}}
\end{gathered}
$$


ii. Düzeltilmiş İç Getiri Oranı (MIRR) Yöntemi = \% 15

$2400^{*}(1+\text { MIRR })^{10}=608(1+0,09)^{1}+608(1+0,09)^{2}+\ldots \ldots \ldots+608(1+0,09)^{10}$

iii. Kârııık Endeksi (PI) - Fayda Maliyet Oranı Yöntemi = \% 63

Kârlılık Endeksi (PI) = İskonto Edilmiş Nakit Giriş Toplamı / Nakit Çıkışı

iv. $\quad$ Net Bugünkü Değer (NPV) Yöntemi = $1502 \mathrm{K \$}$

Yıllık Net Bugünkü Değer (NPV) = Nakit Girişleri - Nakit Çıkışları

İskonto Edilmiş NPV $=$ Yıllık NPV * İndirgeme Oranı

NPV Bugünkü Değeri = İskonto Edilmiş Değerlerin Toplamı

v. Ekonomik Katma Değer (EVA) Yöntemi $=1311 \mathrm{K \$}$

Yıllık Ekonomik Katma Değer = NOPAT - Yıllık Yatırım Maliyeti

$\begin{array}{ll}\text { NOPAT } & =\text { EBİT }- \text { Vergi }(\% \text { 20) } \\ \text { EBİT (Faiz Öncesi Kâr/Zarar }) & =\text { Brüt Faaliyet K/Z }- \text { Amortisman Gideri } \\ \text { Yatırım Maliyeti } & =\text { Dönem Başı Yatırım Tutarı * Yatırım Maliyet Oranı } \\ \text { Yıllık EVA } & =\text { NOPAT }- \text { Yıllık Yatırım Maliyeti } \\ \text { Bugünkü EVA } & =\text { Yıllık Ekonomik Katma Değer * İndirim oranı }\end{array}$

\begin{tabular}{|l|c|}
\hline HESAPLAMA YÖNTEMLERİ & Karlılık Oran \\
\hline İç Getiri Oranı (IRR ) & 0,22 \\
\hline Düzeltilmiş İç Getiri Oranının Bugünkü Değeri(MIRR ) & 0,15 \\
\hline Kârlılık Endeksi (PI) & 1,63 \\
\hline
\end{tabular}

Tablo 1. IRR, MIRR ve PI Yöntemlerinin Karşılaştırmalı Analiz Tablosu

Tablo 1'de IRR, MIRR ve PI sonuçlara göre; yapılacak çimento değirmen yatırımının hesaplama sonuçlarını yüzdesel olarak ortaya koymuştur. Bu sonuçlara göre, her üç yöntem için yatırımın getirisi kârlı olup kabul edilebilir bir yatırım projesidir. MIRR ve PI yöntemlerinde, piyasaya göre belirlenmiş bir iskonto oranı olan \% 9 dikkate alınarak hesaplanırken, IRR yöntemi iç getiri oranını dikkate almadığından daha kolay hesaplama yapmaktadır. Bu yüzden sermaye maliyetinin hesaplanmasının mümkün olmadığı durumlarda en çok IRR yöntem kullanılmaktadır. MIRR yöntemi IRR göre hesaplanması daha zor olduğu için daha az tercih edilmektedir. Fakat IRR yöntemine göre ise daha gerçekçi bir hesaplamaya sahiptir.

\begin{tabular}{|c|c|c|c|c|c|c|c|c|c|c|c|c|}
\hline $\begin{array}{l}\text { Hesaplama } \\
\text { Yöntemleri }\end{array}$ & $\begin{array}{l}\text { Nakit } \\
\text { Çıkışı }\end{array}$ & $\Xi$ & $\stackrel{\sim}{\Xi}$ & $\stackrel{m}{\equiv}$ & $\stackrel{ \pm}{\Xi}$ & $\stackrel{n}{z}$ & $\stackrel{b}{z}$ & $\frac{1}{7}$ & $\stackrel{\infty}{\nexists}$ & $\frac{\partial}{2}$ & $\stackrel{\ominus}{\Xi}$ & 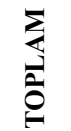 \\
\hline NPV & -2400 & 558 & 512 & 469 & 431 & 395 & 363 & 333 & 305 & 280 & 257 & 1502 \\
\hline EVA & - & 95 & 110 & 121 & 130 & 136 & 141 & 144 & 145 & 145 & 144 & 1311 \\
\hline
\end{tabular}

Tablo 2. NPV ve EVA Yöntemlerinin Karşılaştırmalı Analiz Tablosu

Tablo 2'de çimento değirmen yatırımında EVA ve NPV yöntemlerine göre yapılan hesaplamada hemen hemen birbirine yakın değerler bulunmuştur EVA yönteminde, yatırımın değerlendirilmesinde sermayenin maliyeti dikkate alınarak hesaplama yapılmıştır. NPV yönteminde ise değerlemede nakit girişleri ve nakit çıkışları kullanılmıştır. EVA yönteminde dönemsel sermaye maliyeti dikkate alınarak hesaplama yapılmakta ve dönemsel ekonomik katma değerin net bugünkü değerini görmemize olanak sağlamaktadır. Ayrıca hesaplamada birçok faktörü dikkate aldığı için daha detaylı hesaplamaya imkân sağlamaktadır. Fakat bu kadar detaylı olarak hesaplamalar yapmak, yatırımcıları bu detay bilgileri elde etme bakımından zorlayabilmektedir. NPV yönteminde sermaye maliyetini hesaplamaya katmadan nakit giriş ve çıkışlarını belli bir indirgeme oranı dikkate alınarak hesaplandığı için EVA’ya göre daha kolay hesaplandığı için daha çok tercih edilmektedir.

\section{Sonuç}

Günümüzde şirketler, pazar odaklı yönetim anlayışı yerine maliyet odaklı yönetim anlayışını göre hareket etmektedir. Bu anlayış ise değer odaklı performans ölçüm sistemlerinin ortaya çıkmasına neden olmaktadır. 
Performans hesaplamalarında doğru hesaplama yapılabilmesi için sermayenin maliyeti dikkate alınması gerekmektedir. Değer tabanlı performans ölçümlerinde en kolay ve etkin analiz imkânı olan yöntem EVA yöntemidir. EVA kaynakların doğru ayrılmasına, işletmelerin kendilerini başka şirketlerle kıyaslama yapmasına, sermaye maliyetlerini açıklayarak yatırım kararlarına odaklanmayı sağlamaktadır.

EVA, sermayenin maliyetini dikkate alarak hesaplama yaptığı için dönemsel ekonomik katma değerin net bugünkü değerinin görülmesine imkân sağlamaktadır. Bu nedenle, şirketlerin stratejik kararları açısından gelecekteki beklentilerinin dönemsel etkilerini görmesi, diğer kararların alınması açısından da etkili olmaktadır. EVA yöntemi, yapmış olduğu hesaplamalarda "Sermayenin Değeri Nedir" diye yargılayarak yöneticilere etkinlik ve verimliliği işaret etmektedir. Bu yöntem, evrensel olup mali tablolar grubundaki bilanço ve gelir tablosuna göre hesaplama yaptığı için güncel, doğru ve güvenilir hesaplama yapmaktadır.

EVA yöntemi, yatırımları daha detaylı değerlendirebildiğinden işletmenin tüm organizasyonu ve bölümleri için hesaplama yapılarak birimlerin ve çalışanların performansları açısından şirkete olan katma değerini hesaplayabilmektedir.

Net Bugünkü Değer Yönteminin beklenilen ilgiyi görmemesinin nedeninin yatırım büyüklüğü ve getiri ilişkisinde zayıf kalması olarak açıklanabilir.

\section{Kaynakça}

- Armstrong, 2015. "Using Real Option Analysis To Improve Capital Budgeting Decisions When Project Cash Flows Are Subject To Capacity Constraint." Academy of Accounting and Financial Studies Journal (Utah Valley University), 19, s. 19-25.

- $\quad$ Akyüz, 2013. "Ekonomik Katma Değer (EVA) ve Pazar Katma Değer (MVA) analizi: IMKB'de İşlem Gören Seramik İşletmelerinde Bir Uygulama.", Süleyman Demirel Üniversitesi İktisadi ve İdari bilimler Fakültesi Dergisi, 18, s. 339-356.

- Dağlı,H., Eyüboğlu,K. ve Sevim, U., 2013. "Yurtdışında Sermaye Bütçelemesi Uygulamaları: Türk İnşaat Firmaları Örneği." Atatürk Üniversitesi İktisadi İdari Bilimler Dergisi, s. 93-108.

- $\quad$ Ergen, 2008. "Kamu Kesimi Yatırım Projelerinin Değerlendirilmesinde Fayda-Maliyet Analizi Tekniği ve Türkiye'de Uygulanabilirliği." Ç.Ü. Sosyal bilimler Enstitüsü Dergisi, 2, s. 115-132.

- Eroğlu, 2016. Sermaye Bütçelemesi. http://cevdetkizil.brinkster.net/cevdetchess/tr/admin/editor/sayfalar/sermayebut27092007.pdftarih=27.09.20 07. (03.17.2016).

- Espinoza ve Morris, 2013. "Decoupled NPV: a simple, improved method to value infrastructure

- $\quad$ investments." Construction Management and Economics, s. 471-496.

- Fındık, 2013. "Finansal Performansın Değer Odaklı Ölçülmesi: ekonomik Katma Değer Yaklaşımı." Akademik Araştırmalar ve Çalışmalar Dergisi, 5, s. 90-105.

- Hatipoğlu ve Yener, 2013. "Firma Değerlemesinde İndirgenmiş Nakit akımları Yöntemi: BIST Elektrik Endeksinde Bir Uygulama." Eskişehir Osmangazi Üniversitesi İIBF Dergisi, 8, s. 7-29.

- Mbabazize ve Daniel, 2014. "Capital Budgeting Practices In Developing Countries: A Case Of Rwanda.", Researchjournali's Journal of Finance, 2, s. 2348-2363.

- Öztürk, Z., Top, M., ve Pehlivan, O., 2015. "Sağl1k Sektöründe Yatırım Projelerinin Değerlendirilmesi." Uluslararası Sağlık Yönetimi ve Stratejik araştırma Dergisi, 1, s. 2149-2161.

- $\quad$ Pradas, I.G., Ullah, S. ve Soucase, B.M., 2015. "Sustainable Development with Renewable Energy in India and Pakistan." International Journal Of Renewable Energy Research, 5, s. 570-580.

- $\quad$ Ray, 2012. "Efficacy of Economic Value Added Concept in Business Performance Measurement." Advances in Information Technology and Management (AITM) (World Science Publisher/Shyampur Siddheswari Mahavidyalaya, University of Calcutta, India.), 2, s. 260-267.

- Türko, 1999. Finansal Yönetim. 1. Baskı, Erzurum: Alfa Yayınları.

- Verna, S., Gupta, ve S., Batra, R., 2009. "A Survey Of Capital Budgeting Practices In Corporate India." The Journal of Business Perspective, 13, s. 1-17.

- Wang, 2010. Implementing Capital Budgeting For The Multinational Corporation. Ed: P.J.W Pelle. Nelson Mandela Metropolitan University. 


\title{
Yeşil Pazarlamada Sürdürülebilirlik ve Dünya'dan Bir Örnek: Tchibo
}

\section{Sustainability in Green Marketing and an Example from the World: Tchibo}

\author{
Asst. Prof. Dr. İsmail Erkan Çelik (Beykent University, Turkey) \\ Ph.D. Candidate Öznur Akman (Beykent University, Turkey) \\ Ph.D. Candidate Ayben Ceyhan (Beykent University, Turkey) \\ Asst. Prof. Dr. Vedat Akman (Beykent University, Turkey)
}

\begin{abstract}
Companies are expected to seek solutions towards global environmental problems threatening the quality of life in the world today and the society which they are a part have expectations towards it. As a result, they need to behave in a way responsible for the environment as a member of the society and give density to social activities integrating awareness to green marketing and sustainability. They need to develop community awareness both economic and social wise. In this study, along with developing social responsibility and sustainability issues and green marketing to be discussed will be presented with related example from Tchibo.
\end{abstract}

\section{Giriş}

İşletmeler kuruldukları andan itibaren kurum içinde yer alan bireylere olduğu kadar topluma karşı da sorumlulukları başlar. Bu nedenle özellikle büyük işletmeler toplumun beklentilerine cevap vermek amacıyla, değer ölçütlerine uygun politikalar belirleyerek faaliyetlerini sürdürürler.

İnsanlar çevreden elde ettikleri kaynaklar ile yaşamlarını ve hayatlarını sürdürürken, işletmeler de çevreden elde ettikleri kaynaklarla üretimleri sürdürürler. İşletmeler ürettikleri mal ya da sundukları hizmetle kazanç elde ederken aynı zamanda toplumun beklenti ve gereksinimlerine duyarlı olmakta ve bu yönde faaliyetler geliştirmektedirler.

Sosyal sorumluluk faaliyetlerine önem veren, doğaya saygılı ve kamuya karşı hassasiyet gösteren işletmeler her zaman toplumda iyi bir imaja sahip olmuştur. Bu durum da yeşil pazarlama ve sonrasında sürdürülebilirlik kavramlarını ortaya çıkarmıştır.

Günümüzde gelişen çevre bilinci, toplumdaki bireylerin yaşam tarzları ve tüketim alışkanlıklarını olumlu yönde değiştirmiştir. Toplumun tüketici konumunda gösterdikleri bu özen, işletmeleri üretim süreçlerinde, iş yapış biçimlerinde ve kurumsal sosyal sorumluluk çalışmalarında çevreye karşı daha duyarlı olmaya teşvik etmektedir. Son yıllarda sürdürülebilirlik kavramının önem kazanmasıyla, işletmeler sürdürülebilir yeşil pazarlama projelerine daha çok yatırım yapmaya başlamıştır.

\section{Yeşil Pazarlamadaki Temel Kavramlar ve Yaklaşımlar}

\section{1 Çevre Sorunları ve Yaklaşımlar}

Çevre koruma konusunda atılan ilk adımlar 1970’lerde başlamıştır. O dönemde çevre koruması ile ilgili çalışmalar kirliliğin önlenmesi yönünde olmuştur. Bu amaçla geliştirilen teknolojiler, kirletici faktörlerin havaya, suya ya da toprağa karışmadan önce başvurulan teknolojilerden oluşmuştur. Bu teknolojiler için de yüksek enerji ve malzemeye gereksinim duyulduğu için üretim sistemlerinin geliştirilmesinde ve iyileştirilmesinde etkili olamamıştır.

1980' ler de geliştirilen “çevre yönetimi” yaklaşımı ile işletmeler üretim ve ürünlerini etkili çevre ve enerji performanslarını artıracak şekilde tasarlamaya başlamışlardır. "Endüstriyel ekoloji” nin gelişmesiyle de üretim aşamaları incelenmiş ve atıkların girdi olarak geri döndürülmesi, söz konusu ürünün çevresel etkileri düşünülerek yeniden tasarlanmıştır.

1990’lar da geliştirilen “Toplam Kalite Yaklaşımı” ile işletmeler çevre eğitimi, ölçümleri ve yönetim stratejilerinin belirlenmesini benimsemişlerdir. Bu yaklaşım ile atıkların azaltılması, enerji verimliliği ve malzemelerin yeniden kullanılması ve geri kazanımı alanlarında çalışmalar geliştirilmiştir. Son dönemde ise bu yaklaşıma bir yenisi “Temiz Üretim” eklenmiştir.

\subsection{Sosyal Sorumluluk}

Artık işletmelerin devamlılığını sürdürebilmeleri için sadece kar elde edebiliyor olması yeterli değildir. İşletmenin hedef kitlesinde olan tüketiciler, kurumun topluma ve aynı zamanda doğaya karşı sorumluluklarını yerine getirmesini beklemektedir. 
Firmaların performansına sosyal sorumluluk kampanyalarının etkisi ve firmaların sosyal sorumluluk kampanyalarına katlana bilirliği konusu irdelendiğinde farklı görüşler bulunmaktadır. Bunlar içerisinde öne çıkanlar:

- Firmaları sosyal sorumluluk harcamaları, sosyal açıdan daha az sorumluluk alan rakiplerine karşı dezavantajlı duruma sokmaktadir,

- Sosyal sorumluluk faaliyetlerine yapılan beklenmedik harcamalar çok düşüktür ve sonuç olarak bu harcamalar çalışanların moral-motivasyonunu ve verimliliğini yükseltmektedir,

- Firmalar sosyal sorumluluk çalışmalarına önemli miktarlar harcansa bile bu harcamaları başka alanlarda ki harcamaları azaltarak telafi edebilmektedirler (Uslu, vd, 2008).

Kurumsal sosyal sorumluluk, kar amacı gütmeyen bir kavram olduğundan işletmeler bu faaliyetlerini topluma fayda sağlama, doğayı ya da doğal kaynakları koruma amacıyla gerçekleştirerek hem tüketicilerinin beklentilerini gerçekleştirerek, onlara ulaşmış hem de kurum imajını güçlendirmiş olurlar.

\subsection{Sürdürülebilirlik}

Küresel ısınma, kentleşme, çevre kirliliği, doğal kaynakların azalması gibi çeşitli nedenler sonucunda, toplumun hayatta kalabilmesi için ihtiyacı olan her şeyi bilinçli tüketmesi, doğayı ve doğal kaynakları koruması, çevreye daha duyarlı olması gereği doğmuştur. Günümüzde bu duyarlılığın “sürdürülebilir” olması önem kazanmıştır.

Artık birçok büyük ölçekli işletme, hem kurum içi hem de kurum dişında sürdürülebilir faaliyetlere önem vermektedir. Çalışanlarına karşı olan sürdürülebilir insan kaynaklarının yanı sıra çevreye ve tüketicilerine karşı olan sorumluluklarını da sürdürülebilir bir şekilde yerine getirmektedirler. Tarım ve turizm alanında sürdürülebilir modeller yaratarak yerel kalkınmaya destek olan, verimlilik projesiyle her sene daha az enerji ve su kullanan, doğaya salınan gaz miktarı ve atıkları en alt seviyeye indiren, ürünlerini geri dönüşümlü ambalajlar içinde piyasaya süren ve çevreye duyarlı ürünler üreten birçok kurumsal işletme sürdürülebilirlik kavramını artık bir kurum anlayışı haline getirmiş ve vizyonuna dahil etmiştir. Yine birçok işletme sürdürülebilirlik projelerini sivil toplum kuruluşları işbirliği ile sürdürmektedir.

\subsection{Yeşil Pazarlama}

Kavram olarak "Yeşil Pazarlama", Amerikan Pazarlama Birliğinin (AMA) 1975 yılında düzenlediği 'çevreyle ilgili pazarlama' konulu bir seminerde ilk defa ele alınılmış ve tartışılmıştır. Amerikan Pazarlama Derneği’ne göre yeşil pazarlama:

- Çevre açısından güvenli olduğu düşünülen ürünlerin pazarlanması (perakende tanımı).

- Fiziksel çevre üzerindeki olumsuz etkilerini en aza indirmek için ya da kalitesini artırmak için tasarlanan ürünlerin geliştirilmesi ve pazarlanması (sosyal pazarlama tanımı).

- Organizasyonların ürünleri ekolojik kaygılara duyarlı ve hassas olacak üretme, tutundurma, ambalajlama ve geri çağırma çabaları (çevre tanımı) (American Marketing Association, 2016).

Genel olarak yeşil pazarlama; enerji ve doğal kaynak tüketiminin olumsuz yanlarına 1şık tutan, kamuoyunu bu konuda bilinçlendiren, sürdürülebilirliği ön planda tutan, pazardaki gelişmelerle uyumlu pazarlama anlayışıdır.

\subsection{Yeşil Tüketici}

Tüketiciler açısından çevrecilik, ürünlerden ve üretim süreçlerinden kaynaklanan çevresel zararların artması sonucu daha önemli bir konu haline gelmiştir. Yeşil tüketiciler, çevreye karşı duyarlı olan ve çevreye zarar vermeyen ürünleri satın alan kişilerdir.

Yeşil ürün ve hizmet pazarını dört dilime ayırabiliriz: Trend belirleyiciler, değer arayanlar, standartları izleyenler ve temkinli alıcılar ve aşağıdaki Tablo 1' de detaylandırılmıştır. Trend belirleyiciler erken pazarı oluştururken değer arayanlar ile standartları izleyenler ana akım piyasasını oluşturur, temkinli alıcılar ise arkadan gelenlerdir. Her dilimin ürünün sağlayacağı fayda konusunda farklı görüşleri olduğu için her birine yönelik pazarlama yaklaşımı farklı olmak zorundadır (Kotler, vd, 2010). 


\begin{tabular}{|c|c|c|c|c|}
\hline \multicolumn{5}{|c|}{ Tüketici Dilimlemesi } \\
\hline & $\begin{array}{l}\text { Trend } \\
\text { Belirleyiciler }\end{array}$ & Değer Arayanlar & $\begin{array}{l}\text { Standartları } \\
\text { İzleyenler }\end{array}$ & Temkinli Alıcı \\
\hline Dilim Profili & $\begin{array}{l}\text { - Doğa aşıkları ya } \\
\text { da vizyon sahibi } \\
\text { çevreciler } \\
\text { - Yeşil ürün } \\
\text { kullanmak için } \\
\text { duygusal ya da } \\
\text { manevi } \\
\text { motivasyon } \\
\text {-Yeşil inovasyon } \\
\text { yoluyla rekabet } \\
\text { avantajı arayışı }\end{array}$ & $\begin{array}{l}\text {-Çevresel } \\
\text { pragmatist } \\
\text { - Yeşil ürünleri } \\
\text { kullanmak için } \\
\text { akılcı motivasyon } \\
\text {-Verimliliği } \\
\text { artırmak ve } \\
\text { maliyet tasarrufu } \\
\text { için yeşil ürün } \\
\text { kullanımı }\end{array}$ & $\begin{array}{l}\text {-Çevre } \\
\text { konusunda } \\
\text { muhafazakarlık } \\
\text { - Yeşil ürünlerin } \\
\text { kitlesel kullanıma } \\
\text { ulaşmasını bekler } \\
\text { - Standart hale } \\
\text { gelmiş yeşil } \\
\text { ürünleri kullanır }\end{array}$ & $\begin{array}{l}\text {-Çevre } \\
\text { konusunda } \\
\text { şüphecidir } \\
\text { - Yeşil ürünlere } \\
\text { inanmaz }\end{array}$ \\
\hline $\begin{array}{l}\text { Dilimi } \\
\text { Hedeflemek İçin } \\
\text { Konumlanma }\end{array}$ & $\begin{array}{l}\text { Eko-avantaj } \\
\text { Rekabet avantajı } \\
\text { için yenilikçi } \\
\text { ürün }\end{array}$ & $\begin{array}{l}\text { Eko-verimlilik } \\
\text { Daha az etkiyle } \\
\text { daha çok değer } \\
\text { yaratmak }\end{array}$ & $\begin{array}{l}\text { Eko-standart } \\
\text { Kitlesel kullanımı } \\
\text { olan ürün }\end{array}$ & İzlemeye değmez \\
\hline
\end{tabular}

Tablo 1: Yeşil Pazarın Dört Dilimi Kaynak: Pazarlama 3.0

\section{Yeşil Pazarlama Yaklaşımının Aşamaları}

Yeşil pazarlamanın bir işletme içerisindeki aşamaları:

- Yeşil hedefleme: Bu aşamada, çevreci tüketiciler için yeşil ürünler tasarlanır. Örneğin, alternatif yakıt teknolojisi ile çalışan otomobiller, çevreye zarar vermeyen ürünler gibi.

- Yeşil stratejilerin geliştirilmesi: Bu aşamada çeşitli stratejiler geliştirilir. Örneğin, daha az atık çıkarmak, enerji verimliliğini arttırmak gibi önlemler alınır.

- Yeşil uyum: Bu aşamada, yeşil olmayan, yani çevre dostu olmayan, ürünlerin üretimi durdurularak sadece yeşil ürünler üretilir.

- Yeşil sorumluluk: Bu aşamada işletme yeterince sosyal sorumluluk ve yeşil pazarlama bilincine ulaşmıştır.

\section{Yeșil Pazarlama Stratejileri}

Yeşil pazarlama da ürünün sadece üretimi değil, aynı zamanda ömrünü tamamladığında da ne olacağı konusu irdelenmiştir. Kısaca, ürünün üretimi, dağıtımı, tüketimi sonrasında da çevreye zarar vermeden yok edilmesi konusu yeşil pazarlamanın konusu olmuştur ve bu doğrultuda pazarlama stratejileri geliştirilmiştir. Yeşil pazarlama sahip olduğu bu sorumlulukları yerine getirirken pazarlama karması elemanlarını da bu bilinçle kullanmaktadır. Aşağıda yeşil pazarlama doğrultusunda pazarlama karmasında geliştirilecek stratejiler incelenmiştir.

\subsection{Sürdürülebilir Yeșil Ürün}

İşletmeler üretim sürecinde, kullandıkları hammadde ve enerji kullanımı sonucunda ürün ile birlikte çevreye zararlı atıklar da ortaya çıkarmaktadırlar. Sürdürülebilir işletmelerin çevreye karşı olan bu zararlı etkileri yok etmeleri gerekmektedir. Bunun için de çevreye duyarlı yeşil ürün üretmeleri gerekmektedir.

Pazarlama faaliyetleri süresince yeşil ürünler sürdürülebilir süreçlerden geçerler. Yeşil ürün stratejisinde ürünler 4S (satisfaction, sustainability, social acceptibility, safety) ile formüle edilen tüketicinin istek ve ihtiyaçlarını karşılama, sürdürülebilirliği sağlama, sosyal kabul görme ve güvenilir olma dikkate alınarak üretilirler (Erbaşlar, 2008). Bu formülde ifade edilenler;

- Tatmin; tüketicilerin gereksinimlerinin ve isteklerinin karşılanması,

- Sürdürülebilirlik; ürünün enerji ve kaynakların devamlılığını gerçekleştirmesi,

- Sosyal Kabul; ürünün veya işletmenin çevreye zarar vermediğinin toplum tarafindan kabul edilmesi,

- Güvenilirlik; ürünün tüketicilerin sağlığını ve güveliğini riske sokmamasıdır.

Yeşil işletmecilik anlayışına göre, ürünlerin üretim öncesi ve sonrası geçirdiği tüm aşamalarda çevre bilinci ile hareket edilmelidir ve ayrıca aşağıdaki unsurlara dikkat edilmelidir (Ay ve Yılmaz, 2004):

- Üretim girdilerinin çevre dostu olması,

- Üretim sürecindeki çevre koruma duyarlılı̆̆1,

• Ürünün ambalajlanması, depolama ve taşıma süreçlerindeki çevre duyarlılığı,

· Ürünün tüketim sürecindeki çevre dostu özellikleri.

\subsection{Yeşil Fiyat}

İşletmelerin yeşil strateji uygulamaları ilk etapta ek maliyetlerin doğmasına neden olacaktır. Doğacak olan bu ek maliyetler tüketiciye şeffaf bir şekilde aktarılarak onların desteği alınabilir. Ayrıca, çevrenin sürdürülebilirliğine 
katkı sağlayan ürün üretimi ile sağlanan tasarrufun tüketiciye aktarımı doğru şekilde yapılırsa tüketicinin desteği alınabilir.

Ürüne olan talebin fiyata duyarlı olduğu bir durumda daha düşük bir fiyat, tüketiciyi "yeşil ürün” ü alma konusunda teşvik edecektir. Fiyatta herhangi bir değişiklik yapılmadığı durumlarda, ürünün çevreci özellikleri ön plana çıkarılmalıdır. Ürün fiyatının daha yüksek olduğu durumlarda ise, ürünün promosyonuna ve tutundurma çabalarına önem verilmelidir.

\subsection{Yeşil Dağıtım}

Daha az nakliye çevreye daha az zarar vermek demektir. Bu nedenle milyonlarca tüketiciye ulaşmak için çok sayıda tedarikçi ile çalışan ve kilometrelerce yol yapmak durumunda kalan markalar dağıtım ve nakliye optimizasyonu yaparak hem karbon salınımını azaltıyor hem operasyonel maliyetlerini aşağı çekiyorlar. Tablo 2' de ülkemizde son dönemde hangi şirket yeşil dağıtım için ne yaptı sorusunun cevabı yer almaktadır (Capital GreenBusines, 2015).

\begin{tabular}{|c|c|}
\hline Boyner & $\begin{array}{l}2013 \text { yılında izledikleri sosyal uygunluk projesi kapsamında 2012-2013 } \\
\text { karşılaştırmasında metrekare başına düşen tüketimde \%12,15, birim } \\
\text { emisyondaki, değişimde ise } \% 22,46 \text { oranında azalma sağladı. }\end{array}$ \\
\hline CarreforuSA & $\begin{array}{l}\text { Tedarikçilerin direkt dağıtım yerine depolara teslimat yapmasını sağlıyor. } \\
\text { Onlardan gelen malları konsolide ederek tek bir araçla marketlere iletiyor. }\end{array}$ \\
\hline Dimes & $\begin{array}{l}\text { Tüm tırlar Euro } 5 \text { motor ile donatıldı. Diren Makine (DIMAK) Ar-Ge } \\
\text { bünyesinde } 2 \text { yıl önce, elektrik enerjisi ile desteklenen hibrid araç geliştirmesi } \\
\text { projesiyle yakıttan \%20 tasarruf sağladı. }\end{array}$ \\
\hline G1da 360 & $\begin{array}{l}\text { Rota optimizasyonu yaparak ve filosunda } 5 \text { yaş altı araçlar kullanarak yakıt } \\
\text { tüketiminde \% } 10 \text { tasarruf sağladı. Şirket içinde } 8.500 \text { ton atık kağıdı geri } \\
\text { dönüştürerek } 1.800 \text { ağacı kurtardı. }\end{array}$ \\
\hline Migros & $\begin{array}{l}\text { Son } 5 \text { yıldır taze gıdaları mağazalarına doğrudan sevk ederek } 30 \text { kat daha az } \\
\text { gidiş-geliş yapıyor. Lojistik masraflarını azaltmak için } 2 \text { yıl önce meyve ve } \\
\text { sebze ürünlerinde katlanabilir kasa uygulamasına geçti. }\end{array}$ \\
\hline Proctor\&Gamble & $\begin{array}{l}\text { Nakliye ağını ağırlıklı olarak raylı sistem ve deniz ulaşımı üzerine kuruyor. } \\
\text { Yıllık bazda } 650 \text { adet daha az tır sevkiyatı gerçekleştirdi. } 800.000 \mathrm{~km} \text { daha az } \\
\text { yol yapıldı. } 1.000 \text { ton daha az karbon salınımı gerçekleştirildi. }\end{array}$ \\
\hline Unilever & $\begin{array}{l}\text { Nakliyelerinin çoğunu yüksek tonaj verimliliği ve ton başına düşük karbon } \\
\text { salınımı sağlayan modern tırlara kaydırıyor. Trafikteki araç sayısı \%25 yıllık } \\
\% 14 \text { oranında karbon salınım miktarını azalttı. }\end{array}$ \\
\hline Y1ldız Holding & $\begin{array}{l}\text { 2010'da geleneksel kanala dağıtım yapan } 4 \text { şirket Horizon Gıda altında } \\
\text { birleşerek yıllık } 0 \text { milyon kilometre ve } 4,7 \text { milyon litrelik yakıt tasarrufu, } 11 \\
\text { milyon kili karbon salınımı tasarrufu sağladı. }\end{array}$ \\
\hline
\end{tabular}

Tablo 2: Hangi Şirket Yeşil Dağıtım İçin Ne Yaptı? Kaynak: Capital Greenbusines

Yeşil dağıtımda başarılı olabilmek için hem işletmenin lojistik biriminin hem de dağıtım kanallarının yeşil pazarlama politikasını benimsemiş olması gerekir.

\subsection{Yeşil Tutundurma}

Yeşil pazarlama kar amacı gütmediği gibi, işletmelerin reklam ve diğer tutundurma faaliyetlerine bütçe ayırması gerekmektedir. Bir işletmenin tüketiciye mesajını iletebilmesinin en doğru ve etkili yolu tutundurma araçlarından reklam ve halkla ilişkileri kullanmasıdır. İşletmeler tüketicilere, çevreyi ve doğal kaynakları koruma konusundaki duyarlılıklarını ve yeşil pazarlama faaliyetlerini bu tutundurma araçlarıyla aktarmalıdır. Bu süreçte bir sivil toplum kuruluşu ile ilerlemeleri tüketici algısında daha etkili olacaktır.

$\mathrm{Bu}$ tutundurma faaliyetlerinde mesajı tüketicinin anlayabileceği dilden iletebilmek ve beklentilerini karşılayıcı nitelikte olması son derece önemlidir. Burada verilmesi gereken mesajlar; ürünlerin çevreye duyarlılı̆̆ı, insan sağlığına uygunluğu, pazardaki aynı standarttaki diğer ürünlerden çevreci ürün olma özelliği açısından farklılıkları olmalidir.

\section{5 “Sürdürülebilir İşsletme" Anlayışında Dünyadan Bir Örnek: Tchibo}

1949 yılında kurulan ve dünya genelinde faaliyet gösteren en büyük Alman perakende şirketlerinden biri olan Tchibo, 2006 yılından itibaren kendisini sürdürülebilir bir şirket olarak konumlandırmıştır. Bu konuda pek çok alanda aktif olarak yer almakta ve faaliyetlerini sürdürmektedir.

Tchibo, "Tchibo Joint Forces” projesi ile üreticilere sürdürülebilir bir geçim kaynağı sunmaktadır. Girişimcilik konusunda harekete geçmelerini ve verimliliklerini artırmayı sağlamak üzere bilim adamları, eğitmenler, ihracatçılar ve satıcılar, standart kuruluşları, devlet kurumları ve sivil toplum örgütleri ile işbirliği içinde çalışmaktadır. Tchibo'nun işbirliği içinde olduğu, uluslararası alanda kabul görmüş olan standart kuruluşları 
arasında Rainforest Alliance, Fairtrade, UTZ Certified ve AB mevzuatı kapsamında BIO organik gıda etiketinin arkasında olan örgütler bulunmaktadır. Ayrıca Tchibo, kahve yetiştiricilerini organize etmek ve sürdürülebilir kahve yetiştiriciliğ̈inin faydaları konusunda farkındalıklarını artırmak üzere 4C Birlik Davranış Kuralları’ nın temel standartlarını benimsemiş bir şirkettir.

Tchibo, üretim tesislerindeki çalışma koşullarında sürekli iyileştirme sağlamak için 2007 yılından günümüze WE Yeterlilik Programı'nı (Worldwide Enhancement of Social Quality) uygulamaktadır. Bu program; üretim tesislerindeki çalışma koşullarının iyileştirilmesi için eylem planlarının ortaklaşa geliştirilmesi ve uygulamaya sokulması amacıyla çalışanlarını, alıcılarıyla bir araya getirmektedir. Şu ana kadar 320 üretici yeterlilik tedbirlerinin bir parçası olmuş ve WE programını tamamlamıştır.

Tchibo, tropik ormanlardan elde edilen sert keresteden üretilen bahçe mobilyaları için Orman Koruma Konseyi (Forest Stewards-hip Council-FSC ${ }^{\circledR}$ ) onaylı ahşap kullanmaktadır. 2013 yılından beri Türkiye ve Tchibo'nun yer aldığı ülkelerin büyük bir çoğunluğunda; dergiler, kataloglar ve tanıtım materyalleri sadece $\mathrm{FSC}{ }^{\circledR}$ onaylı kağıt kullanılmaktadır. Tekstil ürünlerinde ise sürdürülebilir kaynaklardan elde edilen organik pamuk kullanılmaktadır. Tchibo aynı zamanda Cotton made in Africa (CmiA) üyesidir. Bu oluşumun ürettiği pamuğu temin ederek pamuk yetiştiricilerini desteklemektedir.

Almanya'daki tüm Tchibo tesislerinde sürdürülebilir enerjiye geçilmiştir. Tchibo, 2010 yılından bu yana müşterilerine, "Power" etiketi kapsamında kendi çevreci enerji ürünü olan "Tchibo Green Energy" yi sunmaktadır.

Tchibo’ nun 2006 yılında başlattığı Sürdürülebilirliğe Yönelik Lojistik (LOTOS) projesi, nakliye süreçlerinin verimliliğini artırarak nakliyeyle ilgili karbon emisyonlarını yüzde 30'un üzerinde azaltmıştır.

Ayrıca WWF-Türkiye ve Tchibo işbirliği ile İstanbul ve Ankara'da bulunan birer mağazası çevreye duyarlı olarak hizmete açıldı. Çevre standartlarına uygun aydınlatma sistemi, ısıtma-soğutma sistemleri, atık yönetimi ve kâğıt tüketimi konusundaki tasarruflarıyla doğanın korunmasına katkıda bulunmaktadır.

\section{Sonuç}

$\mathrm{Bu}$ çalı̧̧mada sosyal sorumluluk, sürdürülebilirlik ve yeşil pazarlama konuları teorik olarak incelenmiş ve yeşil pazarlama stratejileri kapsamında pazarlama karması irdelenmiştir.

Çevre sorunlarının artması ve buna bağlı olarak toplumda da her bir bireyin çevreye olan duyarlılığının artması, işletmeleri de doğal olarak bu konuda sorumlu davranmaya yöneltmiştir. Tüketiciler, işletmelerden üretim ve hizmet faaliyetlerinde çevreye karşı duyarlı hareket etmelerini beklemektedir.

Günümüzde yoğun rekabet ortamındaki işletmeler, pazarlamayı araç olarak kullanarak rakiplerine göre farklılık yaratmaya çalışmaktadırlar. İlişkisel pazarlama yoluyla tüketicileriyle rakiplerine göre daha iyi iletişim kurabilen işletmeler, yeşil ürünlerini ve hizmetlerini sosyal sorumluluk anlayışı ve uygulamaları ile sunabilir ve diğer işletmelere göre daha fazla rekabet avantajı sağlayabilirler.

"Daimi olma yeteneği”" olarak adlandırılan sürdürülebilirlik işletmelerin faaliyetlerini yönlendirmede süreklilikleri için önem kazanmıştır. Yenilenebilir enerji kaynaklarının ve doğal enerjinin kullanımı, doğanın ve doğal kaynakların korunması ülke ekonomisinin gelişimine katkı sağlar ve bunun sonucunda sağlıklı toplumlar oluşur. Artık işletmelerin kısa dönemli değil, uzun dönemli karlılıklarını sürdürebilmek için sürdürülebilirliğe önem vermeleri gerekmektedir.

Dünya'da ve Türkiye'de bilinirliği yüksek ve "sürdürülebilir işletme" olma anlayışına sahip güçlü bir kurum olan Tchibo, hem yeşil ürünler üreterek mağazalarında kullanmakta ve aynı zamanda bu ürünleri tüketiciye sunmakta, hem de birçok topluluk ve kuruluşla işbirliği yaparak üretici ve tüketicileri de sürdürülebilirliğe teşvik etmektedir. Bu anlamda Tchibo, yeşil pazarlamada sürdürülebilirliği etkili ve başarılı bir şekilde uygulayan ve istikrarlı bir şekilde sürdüren örnek bir işletmedir.

\section{Kaynakça}

- American Marketing Association, 2016. Online Dictionary, https://www.ama.org/resources/Pages/Dictionary.aspx?dLetter=G

- Ay ve Yılmaz, 2004. "Yeşil pazarlama ve Serel Seramik A.Ş’ nin yeşil uygulamaları", Celal Bayar Üniversitesi Sosyal Bilimler Enstitüsü Dergisi, 2, p.17.

- Capital GreenBusiness, 2015. 22, p:4, 7, 10-11,

- Erbaşlar, 2008. "Yeşil pazarlama”, Paradoks Ekonomi, Sosyoloji ve Politika Dergisi, 1, p.1-12.

- Kotler, Kartajaya ve Setiawan, 2010. "Pazarlama 3.0”, Sippaş GYO Kitapları, p.175.

- Uslu, Baş̧ı ve Gambarov, 2008. “Türkiye'de Tüketicilerin Sosyal Sorumluluk Kampanyalarına ve Sosyal Açıdan Sorumlu Şirketlere Karşı Tutumu, İşletmecilikte Yeni Gelişmeler ve Firsatlar: Muhan Soysal İşletmecilik Konferansı Kitabı”, Kuzey Kıbrıs: ODTÜ, 3-6 Eylül, p.180 


\title{
Bir Fizikçinin Gözüyle Ekonomi Bilimine Termodinamik Bir Bakış
}

\section{Economic Science Considering with a Thermodynamic Perspective of a Physicist's Point of View}

\author{
Asst. Prof. Dr. Nergin Günay (Beykent University, Turkey)
}

\begin{abstract}
Economy is a discipline by means of its structure which closely interests all humanities live non-stop whether they are directly related or not which in a relationship with mathematic as calculations, psychology as searching investor behaviors, sociology as searching social events, philosophy as structural reviews of the created environment and many kind of disciplines more. In this study based on a survey of the relevant literature, the common features of economy with physics is a supporter in the recent years are revealed. Concept passed into world literature as Econophysics or alias Econphysics is defined. Econophysics is a study field tries to find solutions to economic problem by using physical methods. The main tool is used by the econophysics are statistical and probability methods are taken from statistical physics frequently. Information related to implementation of the laws of thermodynamics which is the branch dealing with the energy and physical energy exchange economic problems are given. The laws of thermodynamics have a very general validity and they do not change depending on the characteristics of the studied system. In this regard, how thermodynamic physics are applied into economics practices are given in detail.
\end{abstract}

\section{Ekonofizik Hakkında Bilmemiz Gereken Bazı Şeyler}

Ekonomi ve fizik bilim dallarının etkileşimi çok eskiye dayanmakta olup, ekonofizik ismi altında ayrı bir disiplin olarak ortaya çıkması oldukça uzun bir süreçte gerçekleşmiştir velev ki, bu kavramın doğuşu oldukça yenidir: Fizikçi H. Eugene Stanley tarafından 1995 yılında Kalküta, Hindistan'da düzenlenen bir konferansta ortaya atılmış olan ekonofizik kavramı "ekonomik konuları incelerken fizik teorilerini ve yöntemlerini kullanan bir araştırma alanı" olarak tanımlanabilir.

\section{Ekonomi: Biraz Fizikten Zarar Gelmez}

Ekonomi ve doğa bilimlerinin ilişkisi üzerine Philip Mirowski'nin yazdığı "More Heat Than Light, Economics As Social Physics: Physics as Nature's Economics" isimli eserde, yazar beşeri/sosyal bilimlerin, doğa bilimlerinde gözlemlenen gelişmelerden öykülenerek, yöntemsel izinden gittiğini söylemektedir (Mirowski, 1989). Çalışmanın bu bölümünde, ekonomi biliminin özellikle metodolojik açıdan yakın bir ilişki içinde olduğu fizik bilim dalı ile ilişkisi üzerine literatürde yapılan çalışmalar derlenmiştir.

Ekonomi ve fizik bilimlerinin geçirdiği tarihsel süreçlerde yakın benzerlikler bulunmaktadır. Ünlü fizik, astronomi ve matematik bilimcileri, Nicolaus Copernicus (Kopernik) (1473-1543), Galileo Galilei (1564-1642), Johannes Kepler (1571-1630) ve Isaac Newton (1643-1727) ile gelişen süreçle, evren hakkında bütüncül ve determinist bir görüş benimsendi. Fizikteki bu gelişmelerden etkilenen ekonomi de bu yönde kendini düzenlemeye çalışıı̧tır. Mekanik ekonomi, Newton'un klasik mekaniği üzerine neredeyse ondan bir yüzyıl sonra inşa edilmiştir (Sebba, 1953).

18. yüzy1l sonlarında ve 19. yüzyılda, Joseph-Louis Lagrange (1736-1813), William Rowan Hamilton (18051865) ve diğer bilim insanlarının çalışmaları, Newton'un teorilerini analitik mekaniğin modern anlatımına dönüştürmüştür ve bu durum ekonomistlerin gözünden kaçmamış, ekonominin matematiksel olarak şekillenmesinde kullanılmıştır (Burda, vd, 2003).

1776'da yayınlanan "The Wealth of Nations (Ulusların Zenginliği)" isimli eseri ile genellikle başladığı kabul edilen klasik ekonominin kurucusu olan Adam Smith (1723-1790)'in modeli mekanikteki denge fikri üzerine kurulmuştur (Sebba, 1953). Newton fiziğini insanoğlunun en büyük keşfi olarak nitelendiren Adam Smith ve döneminin sosyal bilimcileri, insanları ve toplumları yönlendiren doğal yasaların varlığına inanmışlar ve bu yasalara uyulması halinde, toplumsal mutluluğun sağlanacağını düşünmüşlerdir (Paya, 1994).

Aslında bir ahlak filozofu olan Adam Smith, 1759'da yayınlanan "Theory of Moral Sentiments (Ahlaki Duygular Teorisi)" isimli eserinde bu yöntemi ahlak felsefesine uygulamıştır. Ahlaki Duygular Teorisi'nin birleştirici kavramı olan eşanlamlı olarak "duygu birliği" diye kullanılan "sempati" kavramı, kendisini bir başkasının yerine koyarak belirli durumlarda onun ne yapabileceğini düşünebilme kapasitesidir. Bu temel ilke Ulusların Zenginliği'ndeki kişisel çıkar kavramıdır. Newton mekaniğindeki yerçekimi kavramı Smith'in eserinde sempati adını verdiği duyguya karşılık gelirken, Ulusların Zenginliği eserinde iktisadi düzende kişisel çıkar kavramına karşı1lk gelmektedir (Gordon, 1991). 
Doğada insan iradesi dışında, evrensel yasalar dahilinde kendi kendine işleyen bir düzen varsa doğanın bir parçası olan insanda da böyle bir "doğal düzen"in olması gerektiğinden yola çıkan Adam Smith'in, her iki eserinde de kullandığı meşhur görünmez el paradigmasına göre, toplumdaki her birey, kendi çıkarları için çalışanlar bile, farkında olmaksızın toplumun çıkarına hizmet ederler.

Smith'in Newton'un astronomi sistemini de incelediği Astronomi Tarihi diye bilinen "The Principles Which Lead and Direct Philosophical Enquires: Illustrated by the History of Astronomy" isimli çalışmasında geçen hayali makine ya da sistem metaforu karmaşık bir düzeni anlamaya yönelik hayali bir imgelem olarak kullanılmaktadır (Kapucu, 2010).

Fiziki bir sistemin belli bir zamandaki durumunu, yani konumunu ve hızını biliyorsak, diğer herhangi bir zamandaki durumunu da kesin olarak belirleyebileceğimizi söyleyen Newton mekaniği (Ruelle, 1998) Adam Smith'in yanı sıra David Ricardo (1772-1823), John Stuart Mill (1806-1873), Jean-Baptiste Say (1767-1832), Thomas Robert Malthus (1766-1834) ve Karl Marx (1818-1883) gibi diğer klasik ekonomistleri de derinden etkilemiştir.

Klasik ekonomistlerden Mill'in öldüğü 1873 yılına kadar hakimiyetini sürdüren klasik ekonominin yerini bıraktığı neoklasik ekonomi genel denge kuramı üzerine inşa edilmiştir. Bu akımın kurucusu olarak görülen Alfred Marshall (1842-1924)'ın kısmi denge analizinin yanında genel bir denge olması gerektiği görüşü 19. yüzyıl ekonomistleri Antoine Augustin Cournot (1801-1877) ve Jules Dupuit (1804-1866)'e kadar götürülüyor olsa da, bu düşünceyi bugün anlaşıldığı biçimiyle ortaya koyup, formülize eden Leon Walras (1834-1910)'dır. Genel denge teorisinin kurucusu olan Walras, klasik mekanikteki statik denge teorisinden ve Fransız fizikçi Louis Poinsot (1777-1859)'un 1803 yılında yayınlanan "Eléments de Statique" adlı eserinden etkilenmiştir (McKenzie, 2002).

Walras 1874 yılında "Éléments d'économie politique pure (Salt Politik İktisadın Unsurları)" isimli eserinde, analizini serbest rekabet, üretim faktörlerinin tam hareketliliği, fiyat esnekliği varsayımları altında, çok yönlü ve çok emtialı değişime genişletmiş ve bu sınırlayıcı varsayımları kullanarak, ekonomiyi temsil eden bilinmeyen sayısının denklem sayısına eşit olduğu eş zamanlı denklem sistemleri kurarak, serbest piyasa sisteminin, bütün emtialarda arzın talebe eşit olduğu bir genel dengeye ulaşması gerektiği sonucuna varmıştır (Skousen, 2001).

Fizik bilimini ekonomiyle eşleştirmeye çalışan, Leon Walras, William Stanley Jevons (1835-1882), Irving Fisher (1867-1947), Vilfredo Pareto (1848-1923) gibi ekonomistler, maddesel noktaları ekonomideki ajanlarla yer değiştirip, potansiyel enerjiye benzer fayda kavramını ortaya atmışlar ve sonra da en az eylem ilkesine benzeyen bir sistem geliştirmişlerdir (Burda, vd, 2003). En az eylem ilkesi, temelleri Pierre Louis Maupertuis (1698-1759) tarafından ortaya atılan ve İngiliz matematikçi Hamilton'un elinde son şeklini almış olan, bir cismin bir noktadan diğerine gitmek için olası yörüngeler içinden eylem artışının en az olacağı yörüngeyi kullanacağını söyleyen ilkedir (Özmutlu, 2007).

19. yüzyılda en parlak dönemine ulaşmış olan, determinist Newton mekaniği, 1900 yılında Max Planck (18581947)'1n kuantum teorisi ve 1905 yılında Albert Einstein (1879-1955)'1n özel görelilik teorisi ile derinden sarsılmış, yerini belirsizlik ilkesiyle her ölçümün, her meselenin bulanık bir hal aldığı kuantum teorisine veya enerjinin bağımsız enerji paketleri ile yayıldığını kabul eden teoriye bırakmıştır. Louis de Broglie (1892-1987), Erwin Schrödinger (1887-1961), Paul Dirac (1902-1984) ve Werner Heisenberg (1901-1976) gibi birkaç matematikçi fizikçi tarafından geliştirilen kuantum teorisinin, en önemli sonuçlarından biri, 1927 yılında Heisenberg tarafından teklif edilmiş olan, enerjinin bağımsız kuantumlar ile hareket ettiğinin farzedilmesi halinde, zaman ve enerji gibi birbirlerine sürekli olarak etki eden bazı değişken çiftlerinin tam kesinlikle belirlenemeyeceğini ispatlaması olmuştur. Belirsizlik ilkesine göre, değişkenlerden biri ne kadar kesin olarak belirlenirse, diğerinin alacağı değerler dizisi o kadar büyük olacaktı, yani bir parçacığın konumundan ne kadar emin olursak, momentumundan o kadar emin değilizdir.

Fizik teorisinde bu gelişmeler yaşanırken, ekonomiye mikro temeller çerçevesinde (bireyler ve aileler) yaklaşan neoklasik ekonomi, 1930'larda yerini John Maynard Keynes (1883-1946)'in klasiklerin genel denge analizlerine karşı çıkan, ekonominin eksik istihdam seviyesinde dengeye gelebileceğini ve devletin ekonomiye müdahale edebileceğini savunan makro ekonomik (uluslar ve hükümetler için geçerli olan) modeline bırakmıştır. 1936'da "The General Theory of Employment, Interest and Money (İstihdam, Faiz ve Paranın Genel Teorisi)" isimli çalışmasıyla ekonomide yeni bir çığır açan Keynes, ekonomiyi geçmişin değiştirilemeyip, geleceğin belirsiz olduğu durumları göz önüne alarak incelemiştir.

\section{Termodinamik Hakkında Konuşmamız Gerekiyor}

Yunanca therme (1S1) ve dynamis (güç) kelimelerinden türemiş olan termodinamik terimi ilk olarak Lord Kelvin adıyla tanınan William Thomson (1824-1907) tarafindan 1849'da yapılan bir yayında kullanılmıștı (Thomson, 1849). Bazı Türkçe kaynaklarda 1sıl devingi olarak da geçen termodinamik ile ilgili literatürdeki çalışmalara bakıldığında, farklı araştırmacılar tarafından yapılan birçok tanım olduğu görülmektedir: 
- Isı ile ilgili olaylar, sistemin bir durumdan başka bir duruma geçmesi sırasında yapılan enerji aktarılmaları ve enerji aktarılmaları ile sistemin ölçülebilen büyüklükleri arasındaki ilişkiler, termodinamik adı altında incelenir (Halliday ve Resnick, 1998).

- Termodinamik, fiziğin enerji ve enerjinin şekil değiştirmesi ile uğraşan koludur (Çetinkaya, 1999).

- Genel olarak termodinamik, maddenin durumları katı, sıvı, gaz ve bunların birbirlerine dönüşümleriyle ilgilidir (Serway ve Beichner, 2002).

- Termodinamik, enerji ve enerji dönüşümlerini, entropiyi ve maddenin fiziksel özellikleri arasındaki bağıntıları inceleyen fiziksel bir bilim dalıdır (Yamankaradeniz, 2004).

Termodinamikte enerji çözümlemesi yapılırken yapılan çözümleme için bir sistem yani büyüklüğüne bakılmaksızın üzerinde inceleme yapmak üzere sınırlanan belirli bir kütle veya evren parçası tanımlanır. Sistemi çevreleyerek saran, sistemin dışında kalan kütle veya daha büyük evren parçası da sistemin çevresidir ve sistemi çevresinden ayıran, sabit veya hareketli olabilen, gerçek veya hayali yüzey ise sistemin sınırıdır. Sistemin tipi çevre ile arasındaki sınıra bağlı olarak tanımlanabilir. Buna göre, termodinamik sistemlerde, sistem ile çevre arasında kütle girişi ve çıkışı olmakla birlikte enerji alışverişi de varsa sistem açık sistem (kontrol hacmi), sistem ile çevre arasında kütle girişi veya çıkışı olmayan; fakat enerji, iş veya 1sı alışverişi olan sistem kapalı sistem (kontrol kütlesi), sistem ile çevre arasında kütle ve enerji alışverişi yoksa sistem izole sistem olarak adlandırılır. Açık ve kapalı sistemlere uygulanan termodinamik bağıntılar farklıdır.

Enerji, dönüşümü ve madde ile etkileşimi ile ilgilenen temel bir bilim dalı olan termodinamiğin sıfırınc1, birinci, ikinci ve üçüncü yasaları olarak bilinen dört temel yasası bulunmaktadır.

Sadece birbiri ile etkileşen fakat dünyanın geri kalan kısmı ile etkileşmeyen, sıcaklıkları farklı iki cisim yalıtılmış kabın içine konulursa, birbirleriyle temasta olmasalar bile aralarında bir enerji alışverişi olur. Termodinamiğin sıfırıncı kanununa (denge kanununa) göre, iki cisim birbirleriyle ısıl dengede ise, yani aralarında ısıl süreç yolu ile artık enerji değiş tokuşu olmuyorsa, bu iki cismin sıcaklığı aynıdır.

1850'lere kadar, termodinamik ve mekanik, iki farklı bilim dalı olarak görülüyor ve enerjinin korunumunun da yalnızca bazı belirli mekanik sistemleri açıklayabileceği düşünülüyordu. 19. yüzyılın ortalarına gelindiğinde, İngiliz James Joule (1818-1889) ve diğer bilim insanları, deneysel olarak 1sı vererek veya bir sistem üzerinde iş yaparak bir sisteme enerji verilebileceği veya sistemden enerji alınabileceğini gösterdiler. Hiçbir enerji şeklinin yok edilemeyeceği, fakat birbirine dönüştürülebileceği olarak bilinen termodinamiğin birinci yasası (enerjinin korunumu yasas1), her ne kadar daha önce, 1847'de, Alman fizikçi Hermann von Helmholtz (1821-1894) tarafından ifade edilmiş ise de, Rudolf Clausius (1822-1888) ve Lord Kelvin bu ilkeye daha derin bir anlam kazandırmışlardır.

$\delta Q$ sisteme eklenen diferansiyel miktardaki ısı artışı miktarını ve $\delta \mathrm{W}$ çevre tarafından sistem üzerine yapılan işi temsil etmek üzere, gidilen yola bağlı olmayan sadece sistemin başlangıç ve son hallerine bağlı olan sistemin iç enerjisindeki $\mathrm{dE}$ değişimi, $\mathrm{dE}=\delta \mathrm{Q}+\delta \mathrm{W}$ bağıntısıyla verilir. Eğer bu bir hal fonksiyonu olmasaydı bu durumda farklı yollardan gitmek ve dönmek suretiyle yoktan enerji yaratılabilir ve kanun ihlal edilebilirdi. Ayrıca sisteme 1S1 girişinin (+), sistemden 1Sı çıkışının (-) ve sistem tarafından yapılan işin (+), sistem üzerine yapılan işin (-) alındığı biçimindeki işaret kabulünü belirtmektedirler.

Termodinamiğin birinci kanunu 1sı veya işin hangisinin iç enerjide bir değişmeye sebep olacağına bakmaz, bunların sonuçları arasında herhangi bir ayrım yapmaz; bu nedenle ikisi arasındaki önemli ayrım bu kanundan görülmez. Aslında enerjinin korunumu yasasının iç enerjiyi de kapsayacak şekilde genelleştirilmesi olan termodinamiğin ikinci kanunu, bir sistemin iç enerjisindeki değişimin; 1sı, iş veya her ikisi tarafından enerji transferi sonucunda meydana gelebileceğini ifade eden, mikroskobik ve makroskobik nicelikler arasında ilişki kuran, aynı zamanda felsefi bir öneme de sahip olan evrensel bir yasadır.

İkinci yasaya göre, termodinamik bir çevrim gerçekleştirerek çalışan, düşük sıcaklıktaki bir cisimden aldığı 1sıyı yüksek sıcaklıktaki bir cisme aktarmak dışında hiçbir enerji etkileşiminde bulunmayan bir ısı makinesi yapmak mümkün değildir. Entropi adı verilen yeni bir terimin tanımına yol açan bu yasa, sadece süreçlerin yönünü belirlemekle sınırlı kalmaz, enerjinin niteliğinin de nasıl azaldığını ifade eder: Doğada gerçekleşen her süreçte bir miktar ısı enerjisi açığa çıkar ve boşa gider; çünkü işin tamamı ısıya dönüştürülebilirken, ısının tamamı işe dönüştürülemez. Makro düzeyde, yararlı iş yapmak için kullanılamayan bir enerji ölçüsü, mikro düzeyde ise düzensizliğin bir ölçüsü olan entropi (S), enerjinin tersine korunan bir özellik değildir ve artma eğilimindedir $\left(\Delta \mathrm{S}_{\text {evren }} \geq 0\right)$. Termodinamikte anlaşılması en zor olan kavramlardan biri olan entropi, aynı derecede anlaşılması zor olan tersinmezlik kavramını, aynı zamanda entropinin bir hal fonksiyonu olarak kabul edilmesi ve düzensizlikle eşdeğer olarak tanımlanması gibi sorunlu konuları da içerir.

Termodinamiğin üçüncü yasası ise hal fonksiyonu olarak kabul edilmesine rağmen entropinin tanımlanabilmesi için mutlak bir referans noktası oluşturmaktadır.

Entropinin olasılığa dayalı anlamını ilk vurgulayan bilim adamlarından biri olan Ludwig Boltzman, 1877 yılında, bir sistemin girebileceği mikroskopik durumların sayısına (W) bağlı olarak entropiyi tanımlamıştır: $\mathrm{S}=$ $\mathrm{k} \log \mathrm{W}$. Burada k Boltzmann sabiti $\left(1.38065 \times 10^{-23} \mathrm{JK}^{-1}\right)$ 'dir. Boltzmann bu formülü gazların yapısında atomların 
bulunduğu varsayımından hareketle geliştirmiştir ve entropi ölçüsünü termodinamik sistemdeki gazların mikro durumlarının olasılık dağılımlarını tahmin etmek için kullanmıştır.

\section{Olağan Termodinamiğin Ekonomi Hakkında Bize Söyledikleri}

Matematik, fizik ve bilgi biliminde kullanılan entropi terimi ile ilgilenen ilk ekonomistler, 1974 y1linda Nicholas Georgescu-Roegen (1906-1994), daha sonra 1994 yllinda Duncan K. Foley (1942-...) ile Juergen Mimkes (1939...) ve 2001 yılında Adrian A. Drăgulescu ve Victor M. Yakovenko olmuştur (Mimkes, 2006).

1971 yılında yayınlanan "The Entropy Law and the Economic Process (Entropi Kanunu ve Ekonomik Süreç)" isimli çalışmasında, termoekonominin de kurucusu sayılan Nicholas Georgescu-Roegen (1906 -1994), Newton mekaniğini esas alan neoklasik ekonominin, kaynakların sınırlı olduğunu kabul etmekle birlikte, kaynakların kıt olduğunu kabul etmediğini ve ekonomik süreçlerde kullanılabilir enerjinin geri kazanılamaz biçimde yok olduğunu yani termodinamiğin ikinci yasasına göre entropik bir doğası olduğu söylemektedir (Georgescu-Roegen, 1971).

2006 yılında Mimkes, termodinamik yasaları ekonomi için üretmiştir: Termodinamiğin birinci yasası ekonomide üretimin sermaye dengesine, termodinamiğin ikinci yasası ise, bir sistem fonksiyonuna (üretim veya fayda fonksiyonuna) karşlık gelmektedir. Girdiler ve çıktı arasındaki ilişkiyi gösteren emtiaların sayısına bağlı üretim fonksiyonu, stokastik sistemlerde, $\mathrm{S}\left(\mathrm{N}_{\mathrm{k}}\right)=\ln \mathrm{P}\left(\mathrm{N}_{\mathrm{k}}\right)$ şeklindeki entropi denklemi ile verilmektedir. Üretim ve ticaret süresince emtiaların ve paranın dağılımındaki değişimleri karakterize eden entropi kavramı üretim ve ticarette büyük bir öneme sahiptir. Emtiaların satışı (dağılımı) entropideki bir artışa eşittir. Satış sonucunda emtiaların dağılımı dengeye ulaşmakta, her bir birim aynı sayıda emtiaya sahip olduğunda olasılık ve entropi maksimum olmaktadır. Emtiaların ticareti genellikle dengeye ulaşıldığında sona ermektedir. İş ve üretim her zaman entropi azalmasına eşlik etmektedir. Buna göre, entropinin artışı $(\Delta S>0)$, emtia veya para gibi dağıtım unsurlarına uymakta ve düzensizlik yaratmakta iken, entropi azalışı $(\Delta S<0)$, emtia ve para unsurlarını toplamaya uymakta ve düzen yaratmaktadır (Mimkes, 2006).

Fiyat değişimlerinin temel belirleyicisinin para arzı olup, fiyat düzeyinin parasal bir olgu olduğu varsayan, geçmişi 16. yüzyıla dayanan miktar teorisini ilk olarak bilimsel düzeyde inceleyen Amerikalı ekonomist Fisher, M V = P T mübadele denklemini kullanmaktadır. Burada, P ödemelere temel oluşturan işlemlerin ortalama fiyatını (fiyatlar genel düzeyi), T para ile yapılan tüm işlemleri (işlem hacmi), M para miktarını, V paranın işlem dolaşım hızını (buradaki hız (velocity) terimi fizikten alınan bir terimdir) göstermektedir. Bu denkleme göre, ekonomide gerçekleşen tüm mübadelelerin parasal değeri, para arzı ile paranın kaç kez el değiştirdiğini gösteren dolaşım hızının çarpımına eşittir (Aktan, 2000). Bu denklemin teorik içerik kazanması, para arzından fiyatlar genel düzeyine doğru hareket eden fonksiyonel bir ilişki ortaya çıkması, kısa dönemde para arzındaki değişimler karşısında paranın dolaşım hızı ve işlem hacminin sabit olması, para arzının dışsal olması, nedenselliğin yönünün soldan (MV) sağa (PT) hareket etmesi varsayımlarını gerekli kılmaktadır.

Fisher'ın denklemi, termodinamikteki sadece teoride olan ideal gazların durumları hakkında bilgi veren ideal gaz yasasına benzetilmektedir (Maslov, 2010). 1662 yılında İngiliz Fizikçisi Robert Boyle, vakum odasında yaptı̆̆ deneylerde, bir gazın basıncının hacmiyle ters orantılı olarak değiştiğini, 1802 yılında Fransız Jacques A. Charles ve Joseph Louis Gay-Lussac ise düşük basınçlarda bir gazın hacminin sıcaklıkla orantılı olduğunu deneysel olarak buldular. İdeal gaz yasası olarak anılan bir miktar gazın durumunun basıncı, hacmi ve sıcaklı̆ğıa göre belli olacağını söyleyen bu denklem şöyledir: P V $=\mathrm{n} R \mathrm{~T}$. Burada $\mathrm{P}$ basınç, V hacim, $\mathrm{n}$ gazın mol sayısı, R evrensel gaz sabiti $(8.3145 \mathrm{~J} /(\mathrm{mol} . \mathrm{K}))$ ve T'de sıcaklıktır. İstatistiksel mekanik terimleriyle bu denklem: $\mathrm{P} \mathrm{V}=\mathrm{Nk} \mathrm{T}$ şeklinde yazllır.

1965 y1lında başlayan araştırmalara dayanan, 1973 yılında Fischer Sheffey Black (1938-1995) ve Myron Scholes (1941-...) (Black ve Scholes, 1973) ve aynı y1l Robert Cox Merton (1944-...) (Merton, 1973) isimli ekonomistlerce yapılan çalışmalarda bir opsiyonu alırken veya satarken ödenen, tahsil edilen miktarın uygun olup olmadığını hesaplayan bir opsiyon fiyatlama tekniği olan analitik bir model geliştirilmiştir. Ürünün nakit hesabında kısa pozisyon, alım opsiyonu hesabında uzun pozisyon tutarak risksiz faiz oranında getiri elde eden bir portföy kurma düşüncesine dayanan bu model ile Scholes ve Merton 1997 yılında ekonomi alanında Nobel ödülü almışlardır, ödülün verilmesinden iki yıl önce kanser yüzünden vefat eden Black ise ne yazık ki ödülü alamamıştır.

Hisse senedi fiyatlarının tesadüfi olarak yani log-normal dağılacağını ve hisse getirisinin varyansının sabit olduğunu varsayan Black-Scholes Modeli'nde hisse senedinin fiyatı: $d S=\mu S d t+\sigma S d z$ stokastik sürecini izlemektedir. Burada $\sigma$ ürünün fiyat değişkenliğini (volatilite) ve $\mu$ ise vade içindeki ortalama getiriyi (hisse senedi sürüklenme oranını) ifade eden sabit değerlerdir, dS fiyattaki değişim, $\mathrm{dt}$ vade, $\mathrm{dz}$ ise 0 ile 1 arasındaki rassal değerdir.

Hisse ve opsiyon için piyasadaki ideal şartları tanımlayıp, bu varsayımlar ile opsiyon fiyatlama modelinin değişken olarak sadece hisse senedi fiyatı ve zamana bağlı olmasını sağlayan Black ve Scholes'in hisse senedi açısından bir opsiyonun değerini belirleyen bu formülüne aslında fizikte çok önemli olan Brownian Hareketi'nin hisse fiyatlarına ve finansal hareketlere uyarlanması sonucu ortaya çıkmıştır. 
Brownian hareketi, İskoç botanikçi Robert Brown (1773-1858) tarafından gözlenmiş olan, su içindeki çiçek tozlarının düzensiz hareketlerine verilmiş olan bir isim olup (Karatzas ve Shreve, 1988), normal dağılım özelliğine sahip, Martingale bağımlılığı olan ve bazı kısımlarda heterojen özellikler gösteren stokastik bir süreçtir (Spanos, 1999). 1923'de ABD'li matematikçi Nobert Wiener (1894-1964), Brownian hareketin matematiksel temellerini oluşturmuş ve bu süreçler onun adına izafeten Wiener süreci olarak adlandırılmıştır: $d x=a d t+b d z$. Burada a ve b sabit sayıdır, adt terimi x'in zaman başına beklenen drift oranına sahip olduğunu göstermektedir. bdz terimi x'in takip ettiği patikaya noise ya da değişkenlik eklemek olarak düşünülebilir yani bu süreç b $b^{2}$ varyans oranına (yani zaman başına varyans) sahiptir.

Ekonomik olguları açıklarken termodinamik kavramların kullanılması örneğin, entropi yasasının birer yansıması olan ekonomik süreçlerin temel mekanik olmayan doğası ve ekonomide önemli ilkelerden biri olan kıtlık kavramı, termoekonomi adı altında yeni bir alt bilim dalının oluşmasını neden olmuştur. Termoekonomi, kullanılabilir enerjinin ne kadarının gerçek işe dönüştürüldüğünü hesaplamak, 1sıl sistemlerin tamamında verimsizliğin potansiyelini tespit etmek, sistemlerin verimli çalıştırılması ve geliştirilmesine yönelik değiş̧ik senaryolar üzerinde durarak, maliyetleri en aza indirmek için analizler yapmayı kapsamaktadır.

\section{Sonuc}

Ekonomik olguları bilim paradigmasına uygun olarak üreterek, bu paradigmanın geliştirdiği yöntemleri kullanma yoluna giden ekonofizik yaklaşımı üzerine yapılan araştırmaların derlendiği bu çalışmanın son bölümünde, bir doğa bilimi olan fizik ve sosyal bir bilim olan ekonominin etkileşimini eleştiren çalışmalara yer verilmiştir.

1944 yılında yayınlanan, Karl Paul Polanyi (1886-1964)'nin “The Great Transformation (Büyük Dönüşüm)” isimli eserinde yazar, klasik ekonominin temel prensiplerinden biri olan doğal düzenin savunduğu temel ilkelere -görünmez el paradigması, piyasaların kendi kendini düzenlediği anlayışı, ekonomi politikasının uygun şartların oluşmasını sağlayacağı için serbestçe uygulanması (laissez faire, laissez passer: bırakınız yapsınlar, bırakınız geçsinler)- karşı çıkmış ve kendi kurallarına göre işleyen piyasa sisteminin çökmeye mahkum olacağını söylemiştir. Polanyi’ye göre, ekonomik ilişkileri toplumsal ilişkilerden kopararak soyut matematiksel bir analiz haline getirme çabası doğru değildir (Polanyi, 1944).

2007 yılında yayınlanan, Vural Fuat Savaş’ın "Varsayalım Ki” İktisat isimli eserinde yazar, ekonominin sosyal bir bilim olup, ekonominin konusunu oluşturan insanın içinde yaşadığı ortamın devamlı olarak değişme halinde olduğuna değinmektedir ve bu temel özelliği nedeniyle, ekonominin doğal bilimlere özenmesinin ve onlarınkine benzer kesin ve sayısal yasalara sahip olmasının söz konusu olmayacağını söylemektedir (Savaş, 2007).

\section{Kaynakça}

- Aktan, C. C. 2000. Politik İktisat - Monetarizm ve Rasyonel Beklentiler Teorisi. Anadolu Matbaacılık, Ankara.

- Birner, J. 2002. A Conservative Approach to Progress in Economics. S. Boehm, C. Gehrke, H. D. Kurz ve R. Sturn içinde, Is There Progress in Economics? Knowledge Truth and The History of Economic Thought (s. 65-88). Edward Elgar Publishing Limited, Cheltenham.

- Black, F., ve Scholes, M. 1973. "The Pricing of Options and Corporate Liabilities", The Journal of Political Economy, 81(3), p. 637-654.

- $\quad$ Burda, Z., Jurkiewicz, J., ve Nowak, M. A. 2003. "Is Econophysics a Solid Science?", Acta Physica Polonica B, 34(1), p. 87-131.

- Çengel, Y. A., ve Boles, M. A. 1996. Mühendislik Yaklaşımıyla Termodinamik. (T. Derbentli, Çev.) Literatür Yayıncılık, İstanbul.

- Çetinkaya, S. 1999. Termodinamik. Nobel Yayın Dağıtım, Ankara.

- Georgescu-Roegen, N. 1971. The Entropy Law and the Economic Process. Harvard University Press, Cambridge.

- Gordon, S. 1991. The history and philosophy of social science. Routledge, London.

- Guillen, M. 2006. Dünyayı Değiştiren Beş Denklem. (G. Tanrı̈ver, Çev.) Tübitak Popüler Bilim Kitapları, Ankara.

- $\quad$ Halliday, D., ve Resnick, R. 1998. Fiziğin Temelleri 1, Mekanik ve Termodinamik. (C. Yalçın, Çev.) Arkadaş Yayınevi, Ankara.

- Kapucu, H. 2010. Politik İktisat ve Adam Smith. Yön Yayınları, İstanbul.

- Karatzas, I., ve Shreve, S. E. 1988. Brownian Motion and Stochastic Calculus. Springer Verlag, New York. 
- Maslov, V. P. 2010. "Thermodynamic Equations of State with Three Defining Constants", Mathematical Notes, 87(5), p. 728-737.

- McKenzie, L. W. 2002. Classical General Equilibrium Theory. MIT Press, Cambridge.

- Merton, R. C. 1973. "Theory of Rational Option Pricing", The Bell Journal of Economics and Management Science, 4(1), p. 141-183.

- Mimkes, J. 2006. A Thermodynamic Formulation of Economics. B. Chakrabarti, A. Chakraborti, ve A. Chatterjee içinde, Econophysics and Sociophysics Trends and Perspectives (s. 1-33). Wiley-VCH Verlag GmbH \& Co., Weinheim.

- Mirowski, P. 1989. More Heat Than Light, Economics As Social Physics: Physics as Nature's Economics. Cambridge University Press, Cambridge.

- $\quad$ Özmutlu, E. 2007. "En Az Eylem İlkesi", Kaygı: Uludağ Üniversitesi Fen Edebiyat Fakültesi Felsefe Dergisi, 8, p. 173-179.

- $\quad$ Paya, M. M. 1994. Para Teorisi ve Para Politikası. Filiz Kitabevi, İstanbul.

- Polanyi, K. P. 1944. The Great Transformation. Farrar \& Rinehart, New York.

- Ruelle, D. 1998. Rastlantı ve Kaos. (D. Yurtören, Çev.) Tübitak Yayınları, Ankara.

- Savaş, V. F. 2007. "Varsayalım Ki" İktisat. Nobel Yayın Dağıtım, Ankara.

- Sebba, G. 1953. "The Development of the Concepts of Mechanism and Model in Physical Science and Economic Thought", American Economic Association, 43(2), p. 259-268.

- Serway, R. A., ve Beichner, R. J. 2002. Fen ve Mühendislik için Fizik 1. (K. Çolakoğlu, Çev.) Palme Yayıncılık, Ankara.

- $\quad$ Skousen, M. 2001. The Making of Modern Economics: The Lives and Ideas of the Great Thinkers. M.E. Sharpe, Inc., New York.

- Spanos, A. 1999. Probability Theory and Statistical Inference: Econometric Modeling with Observational Data. Cambridge University Press, Cambridge.

- $\quad$ Thomson, W. 1849. "XXXVI.-An Account of Carnot's Theory of the Motive Power of Heat; with Numerical Results deduced from Regnault's Experiments on Steam", Transactions of the Royal Society of Edinburgh, 16(5), p. 541-574.

- Yamankaradeniz, R. 2004. Mühendislik Termodinamiğinin Temelleri Cilt 1. Nobel Yayın Dağıtım, Ankara. 


\title{
Potansiyel Yönetici Adaylarının Kurumsal Sosyal Sorumluluğa İlişkin Görüş ve Algılamalarının Belirlenmesi Üzerine Bir Araştırma
}

\section{A Research to Determine the Opinions and Perceptions of Potantial Manager Candidates toward Corporate Social Responsibility}

\author{
Ph.D. Candidate Erhan Boğan (Sakarya University, Turkey) \\ Ph.D. Candidate Saadet Zafer Kavacık (Akdeniz University, Turkey) \\ Prof. Dr. Mehmet Sarışıık (Sakarya University, Turkey)
}

\begin{abstract}
In recent years, corporate social responsibility, which comprises economic, legal, ethical and philanthropic responsibilities, has become important concept to build good relations between business and stakeholders and to gain competitive advantage over its rivals. Moreover, it has a positive impact on stakeholder's (for example; employees, customers, investors) attitudes and behaviors toward business. The main aim of this study is to determine opinions and perceptions of students who study management license toward corporate social responsibility. The research data is gathered from final year students of Alanya Alaaddin Keykubat University, Faculty of Management with a used scale. 251 surveys are used in the research. The findings obtained from research have put forth that management faculty students who are future manager candidates are in opinion and perception of covering respectively economic, philanthropic, legal and ethical responsibilities in their decisionmaking activities. In addition, the students have listed the company's four most important stakeholders as community, customers, employees and shareholders. Also corporate social responsibility has been emerged by students as a definition of benefit society, compliance with ethical values, volunteer activities and respect for social values.
\end{abstract}

\section{Giriș}

Kurumsal sosyal sorumluluk (KSS)- Corporate Social Responsibility (CSR) kavramı son zamanlarda akademik çalışmalarda sıkça çalışılan konulardan biri haline gelmiştir. KSS kavramına ilişsin ilk tanım denemesi Bowen (1953) tarafından yapılmıştır. Toplum odaklı bir anlayış çerçevesinde yapılan tanımda, toplumun değerlerine ve beklentileriyle örtüşecek faaliyetlerden bahsedilmektedir. Kotler ve Lee'nin (2006) "isteğe bağlı iş uygulamaları ve kurumsal kaynakların katkıları aracılığıyla toplumun refahını iyileştirmek için üstlenilen yükümlülük”, Hophins'in (2003) “işletmenin paydaşlarına karşı ahlaki ve sorumlu şekilde davranması” ve Dünya Sürdürülebilir Kalkınma Konseyinin (www.wbcsd.org) ise "işletmelerin topluma karşı ahlaki davranışları" olarak tanımladığı KKS, günümüzde işletmelerin karşı karşıya kaldığı önemli bir kavramdır. İşletme kararlarını etkileyen ya da alınan kararlardan etkilenen tarafların çıkarlarını göz önünde bulundurulması gerektiğine dayanan KSS, işletmeler için stratejik bir avantaj sağlayabilmektedir. Ayub (2008) tarafından hazırlanan 'Türkiye'de KSS Değerlendirme Raporu'na göre, Türkiye'de yer alan çokuluslu şirketler, sivil toplum kuruluşları ve tüketiciler, şirketler üzerinde birer güç oluşturarak KSS faaliyetlerinin önemli bir ivme kazanmasını sağlamıştır. Bunun yanında, uluslararası arenada faaliyet gösteren Enron, Tyco ya da WorlCom gibi şirketlerde meydana gelen kurumsal skandallar, KSS kavramının önemini daha da artırmıştır (Windsor, 2006).

Kurumsal sosyal sorumluluk kavramının önemi gereği birçok yönetim ve pazarlama araştırmalarına konu olmuştur. Bu noktada KSS ve işletme performansı (Cochran ve Wood, 1984; Tsoutsoura, 2004; Kang ve diğ., 2010; Inoue ve Lee, 2011; Wang, 2014;), çalışan tutum ve davranışları (Bramer, vd., 2007; Kim, vd., 2010; Park ve Levy, 2014; Çalışkan ve Ünüsan, 2011; Farooq, vd., 2014), müşteri memnuniyeti, müşteri sadakati, satın alma davranış1 (Lee ve Heo, 2009; Perez ve Del Bosque, 2015; Liu ve Zhou, 2009; Sen ve Bhattacharya, 2001), potansiyel kalifiyeli elemanların işletmeyi tercih etme sebebi (Bhattacharya, vd., 2008; Turban ve Greening, 1997; Greening ve Turban, 2000), yatırımcıların yatırım yapma kararı verme (Albinger ve Freeman, 2000; Stone, 2001) gibi konularla ilişkisi farklı sektörlerde araştırmalara konu olmuştur.

KSS kavramının öneminin giderek artmasıyla özellikle işletmecilik alanında eğitim gören öğrencilerin bu kavrama yönelik tutumları araştırılmaya başlanmıştır (Bkz. Özalp, vd.,2008; Ibrahim, vd., 2006; Ibrahim ve Angelidis, 1999; Burton ve Geharty,1999; Arlow, 1991). Tüm bu durumların muhtemel bir yansıması olarak, iş etiği kavramı gelişmiş ülkelerde olduğu gibi ülkemizde üniversite düzeyinde işletmecilik alanındaki müfredat programının temel ders konularından birisi haline gelmiştir. Böylelikle, KSS kavramını içerisinde barındıran iş etiği kavramı (Cornelius vd., 2007), potansiyel yönetici olarak nitelendirilebilen işletme fakültesi öğrencilerinin, gelecekte işletmeleri ile karar alma politikalarında önemli bir yer teşkil edeceği düşünülmektedir. 
Yeung (2004)'e göre, iş yaşamında artan karmaşıklıklar sebebiyle, eğitmenler öğrencilere sadece öğrencilere teknik yetenekler ve bilgiyi aktarmakla sorumlu olmayıp, öğrencilerin ahlaki farkındalıklarının artmasına da yardımcı olmalıdırlar. Çünkü günümüzde mükemmel yetenek ve bilgiyle donanımlı olan liderlerin değil, yüksek ahlaki değerlere sahip olan liderlerin başarılı olabileceği düşüncesi hâkimdir (Butcher, 1997; Akt. Yeung, 2004). Yeh (2012)'e göre, işletmelerin çalışanlarına verdikleri eğitim programlarında daha çok işin yapısı ile alakalı teknik bilgilerin yer aldığı görüşü hâkimdir. Bu yüzden öğrencilerin çalışma hayatında yer almadan önce iş ahlaki, etik, sosyal sorumluluk gibi konuları öğrenmiş olması gerekmektedir (Jaszay, 2002). Çünkü iş etiği kavramı işletmelerin başarısı için önemli bir kavramdır (Yeh, 2012). Bu noktada, öğrencilerin karakterlerinin şekillenmesinde önemli yere sahip olan üniversiteler, öğrencilere sosyal sorumluluk, iş ahlakı, sürdürülebilirlik gibi ahlaki değerleri içerisinde barındıran dersleri vererek, gelecekte öğrencilerin karar alma süreçlerinde bu ahlaki değerleri göz önünde bulundurmalarını sağlamaktadır (McKercher, vd., 2014; Ibrahim, vd., 2006). Bunun yanı sıra, geleceğin yöneticilerinin karar alma süreçlerinde ne tür sosyal sorumluluk alanlarına yöneleceklerine dair yeterince araştırma yapılmamıştır (Arlow, 1991). Bu çalışmanın temel amacı da lisans düzeyinde eğitim gören, son sınıf İşletme Fakültesi öğrencilerinin KSS kavramına yönelik tutumlarını belirlemektir. Böylelikle, geleceğin potansiyel yöneticileri olan öğrencilerin alacakları stratejik kararlarda hangi sorumluluklarının daha ön planda olacağı belirlenebilecektir.

\section{Kurumsal Sosyal Sorumluluk}

Kurumsal sosyal sorumluluk (KSS), işletmelerin toplumun yaşam kalitesini artırma, daha sağlıklı bir çevre meydana getirme ve işletme karar ve politikalarında tüm paydaşların çıkarlarını dengelemesi gerektiğini öngören önemli bir kavramdır. Bu kavramın temeli, işletmelerin sorumluluklarını bütüncül bir kapsamda ele alma ve yürütülen faaliyetlerle toplum, çevre, tüketiciler, çalışanlar, hissedarlar ve işletmelerin diğer paydaşlarına faydalı olmaya dayanmaktadır (Brockett ve Rezaee, 2012). İşletmelerin temel amacı kar elde etme olmasına rağmen, işletmeler karar ve politikalarında sosyal ve çevresel stratejik yatırımlara yer vererek toplumun yaşam kalitesini arttırabilmektedir. Bu durum, işletmelere uzun dönemde rekabet avantajı sağlamakta (Commission of the European Communities, 2001) ve hatta işletmelerin sürdürülebilirliğine de önemli katkı sağlamaktadır (Brockett ve Rezaee, 2012).

Literatürde, işletmelerin toplum ve çevreye karşı sürdürülebilir ya da ahlaki davranışlarını ifade eden KSS, kurumsal vatandaşlık, kurumsal sürdürülebilirlik ve işletme sosyal sorumluluğu gibi kavramlar mevcuttur. KSS kavramı birçok araştırmacı tarafından farklı şekillerde açıklanmış ve kavramın kapsamı gittikçe değişmektedir. Örneğin; 1960'lı yılların başında KSS, şirketlerin gönüllü faaliyetleri ile aynı anlamda kullanılmaktaydı. Bu faaliyetlerin temel amacı, sosyal sorunları hafifletmekti. Ancak günümüzde, KSS işletmeler için temel bir faaliyet olarak değerlendirilmiş ve işletme faaliyetlerinde ve stratejilerinde kendine yer bulmuştur (De Grosbois, 2012).

Archie Carroll (1999) tarafından “Kurumsal Sosyal Sorumluluğun Babası” olarak nitelendirilen Bowen (1953)'e göre KSS, işletmelerin hem kendi amaçlarına hem de toplumsal değerler ve beklentilere uygun politikalar belirleme ve uygulama, karar verme ve faaliyetleri yerine getirmeyle toplumun yaşamını iyileştirmeye ilişkin yükümlülüklerinin bütünüdür. Sosyal sorumluluk kavramının tanımlanmasında öncülerden olan Davis (1967)'e göre sosyal sorumluluk "bireysel hareketlerin sosyal sistem içerisinde bütüncül bir şekilde ele alınması ve bu hareketlerin sorumluluğunun üstlenilmesi” anlamını taşımaktadır. Bir başka tanımlamaya göre KSS “işletmelerin kendi çıkarlarını koruduğu gibi toplumsal refahı koruma ve yükseltme amacına uygun faaliyetleri yapma yükümlülüğüdür" (Davis ve Blomstrom, 1975). Bu tanımlamada KSS iki önemli yönüne vurgu yapılmaktadır. Birincisi toplumsal refah korumak ikincisi ise geliştirmektir. Toplumsal refahı korumak, işletme faaliyetlerinin toplum üzerinde olumsuz etkilerin ortadan kaldırılmasını; toplumsal refahı geliştirmek ise, topluma fayda sağlayacak faaliyetlerin yürütülmesini vurgulamaktadır. Bir diğer önemli tanım ise McGuire (1963) tarafından yapılmış olup, buna göre KSS kavramı işletmelerin sadece ekonomik ve yasal yükümlülüklerini yerine getirmesi değil, işletmelerin bu sorumlulukların ötesinde yükümlülüklerini ifade etmektedir.

\section{Kurumsal Sosyal Sorumluluk Piramidi}

KSS kavramının gelişimine en önemli katkılardan birini sağlayan Carroll geliştirmiş olduğu sosyal sorumluluk piramidiyle, işletmelerin sorumluluklarını ekonomik, yasal, etik ve gönüllü sorumluluk olmak üzere dört başlık altında ele almıştır. Carroll (1991)'a göre, aslında işletmeler belirtilen bu sorumlulukların hepsini belirli ölçülerde yerine getirse de, son yıllarda işletmelerde etik ve gönüllü sorumluluklar daha fazla ön plana çıkmaktadır (Carroll, 1991).

\subsection{Ekonomik Sorumluluk}

İşletmeler toplumun istek ve ihtiyaçlarına uygun mal ve hizmet üreten ve bunu belirli bir fiyat karşılığında satan ekonomik kuruluşlardır. İşletmelerin var olması, ekonomik kazanç elde etmesine bağlıdır. Dolayısıyla ekonomik sorumluluk işletmelerin temel birinci sorumluluğu olup, bu sorumluluk yerine getirilmedikçe diğer sorumluluklardan bahsetmek oldukça güçtür. Hisse başına maksimum kazanç, verimlilik, piyasada rekabet edebilir 
bir pozisyona sahip olmak ve kar odaklı olmak işletmelerin ekonomik sorumluluğunu ön planda tutan önemli kavramlardır (Carroll, 1991; Carroll, 2004).

\subsection{Yasal Sorumluluk}

İşletmeler için ekonomik kazanç elde etmek önemli olduğu kadar bu ekonomik kazancın hukuki düzenlemelere uygun olması da bir o kadar önemlidir. İşletme yöneticileri, karar alma ve alınan kararların faaliyete geçirilmesinde ulusal ve mahalli idarelerce düzenlenen yasal hükümleri göz önünde bulundurmakla yükümlüdür (Carroll, 1991; Carroll, 2004). İşletme ve işletmenin faaliyetlerini sürdürdüğü ülke arasındaki sosyal sözleşme ülkeden ülkeye değişkenlik göstermektedir. Bunun sonucu olarak yasal sistemler ve beklentiler de değişkenlik göstermektedir. Farklı ülkelerde faaliyet gösteren küresel bir işletmenin faaliyetlerini gerçekleştirirken uyması gerektiği yasal düzenlemelerde değişmektedir. Bu noktada, faaliyet sürdürülen ülkedeki ya da bölgedeki yasal düzenlemelerin takip edilmesi büyük önem arz etmektedir (Carroll, 2004).

\subsection{Etik Sorumluluk}

İşletmelerin etik sorumlulukları, paydaşları tarafından genel kabul gören ancak yasalarda yer almayan normlar, standartlar ve beklentiler olarak karşımıza çıkmaktadır. Etik sorumluluklar, paydaşların ahlaki haklarını koruma, bu haklara saygı duyma, müşterilere, çalışanlara, hissedarlara ve topluma karşı adalet ve saygı çerçevesinde hareket etme gibi normları, beklentileri ve standartları kapsamaktadır. İşletmelerin alacağı karar ve yürüteceği faaliyetlerin, toplumun değer yargılarıyla bağdaşmayan ve toplumsal sorunlara neden olabilecek şekilde olmaması işletmelerin etik sorumluluklarındandır (Carroll, 1991; Carroll, 2004). İşletmenin kurumsal imajının güçlendirilmesi ya da olası bir itibar zedelenmesine karşı işletmelerin doğru işi yapması kurumsal sosyal sorumluluğun etik boyutunu oluşturmaktadır (Carroll, 2004). Ancak şunu belirtmek gerekir ki; etik sorumluluklar kültürden kültüre değişkenlik göstermekte olup (Parry ve Proctor-Thomson, 2002; Carroll, 2004) bu noktada işletme paydaşları beklentilerinin ve değer yargılarının araştırılması büyük öneme sahiptir.

\subsection{Gönüllü Sorumluluk}

Gönüllü sorumluluklar, toplum tarafından işletmeyi iyi bir kurumsal vatandaş olarak ön plana çıkaran, toplum yararına yapılan vicdani sorumluluklardır. Bu faaliyetler genel olarak toplumun yaşam kalitesinin artmasına yardımcı olabilecek faaliyetlerdir. Gönüllü sorumluluklara örnek olarak, işletmenin sanat, eğitim, spor gibi toplumsal faaliyetlere maddi ve manevi destek sağlaması örnek olarak gösterilebilir (Carroll, 1991). Bu sorumluluklar işletmenin toplumundan aldığını tekrar topluma geri vermesi ve bunun sürdürülebilir bir şekilde yürütülmesini kapsamaktadır. Bu sorumlulukların yerine getirilmemesinin herhangi bir yasal müeyyidesi yoktur. Yasal ve etik sorumlulukta olduğu gibi gönüllü sorumluluklar da ülkeden ülkeye değişkenlik göstermektedir. Örneğin Finlandiya' da işletmenin gönüllü sorumluluklarını yerine getirmesi konusunda halk bir beklenti içerisinde değildir. Çünkü bu sorumluluk devletin işletmelerden elde ettiği vergilerle, devlet eliyle yerine getirilmesi gereken bir sorumluluk alanıdır (Carroll, 2004).

\section{Metodoloji}

Bu bölümde, lisans eğitimi gören 4.sınıf öğrencilerinin potansiyel bir yönetici bakış açısıyla KSS kavramına yönelik tutumlarının belirlenmesine ilişkin araştırmanın amacı, yöntemi, kapsamı, sınırlılıkları ve bulgular yer almaktadir.

\subsection{Araștırmanın Amacı}

Bu çalışmanın temel amacı yönetici adayı olarak lisans öğrenimi gören İşletme Fakültesi 4.sınıf öğrencilerinin KSS kavramı ve içeriğine yönelik görüş ve algılamalarını belirlemektir. Ayrıca işletmelerin KSS konusunda paydaşların önem sırasının belirlenmesi de bu çalışmanın amaçları arasında yer almaktadır.

\subsection{Araștırmanın Yöntemi}

Araştırma verilerini elde etmek için kullanılan ölçek Carroll'un (1991) "The Pyramid of Corporate Social Responsibility: Toward the Moral Management of Organizational Stakeholders" ve Aşcıgil'in (2004) "Perceptions on Corporate Social Responsibility: A Survey on Turkish Managers" başlıklı çalışmalarından uyarlanmıştır. Anket formu demografik özellikleri belirlemeye yönelik ifadeler ile KSS kavramı ve uygulamalarına ilişkin ifadelerden oluşmaktadır.

\subsection{Araştırmanın Kapsamı ve Sınırları}

Araştırma evrenini işletme fakültelerinin son sınıf öğrencileri oluştururken çalışma evrenini Alanya Alaaddin Keykubat Üniversitesi İşletme Fakültesi'nde eğitim öğretim gören 4. sınıf öğrencileri oluşturmaktadır. Fakültede 2014-2015 eğitim öğretim yılı itibariyle kayıtlı öğrenci sayıları sırasıyla; İşletme bölümünde 188, Turizm İşletmeciliği bölümünde 210 ve Uluslararası Ticaret bölümünde ise128'dir. Toplam 4. Sinıf öğrenci sayısı 526'dır. Bu öğrencilerin 300'üne kolayda örnekleme yoluyla ulaşılmış olup doldurulan anketlerin 251'i değerlendirmeye uygun bulunmuştur (eksik, hatalı ve gelişigüzel doldurulduğuna inanılan 29 anket araştırmaya dahil edilmemiştir). Araştırmanın sınırlıkları arasında sadece bir üniversitede yapılmış ve son sınıf öğrencilerinin dahil edilmiş olmasıdır. Araştırmaya 4. Sınıf öğrencilerinin dahil edilmesinin nedeni öğrencilerin önceki dönemlerde KSS kavramını doğrudan ya da dolaylı olarak içeren İşletme Bilimine Giriş, Yönetim ve Organizasyon, Stratejik 
Yönetim, Sürdürülebilir Turizm, Halkla İlişkiler ve özellikle de İş Etiği gibi teorik derslerde görerek kavramın bilincinde olmaları ve mesleki hayata geçme aşamasının göreceli olarak daha yakın bir sürede gerçekleşebilecek olmasıdır. Anket formları 2015 yılı Şubat ayı içerisinde bırak-topla işlemiyle doldurulması sağlanarak toplanmıştır.

\section{Bulgular}

Çalışmaya katılan öğrencilere ilişkin demografik bulgular Tablo 1'de sunulmuştur. Çalışmaya katılan öğrencilerin \% 43’ü kızlardan oluşmakta olup \% 43’ü Turizm İşletmeciliği bölümünde öğrenimlerini sürdürmektedir. Öğrencilerin \% 85'i staj veya kısa süreli çalışma deneyimine sahip olduklarını ve bu deneyimi öğrencilerin sırasıyla turizm endüstrisinde, banka, ticaret, sigorta vb. gibi iş yerlerinde elde ettiklerini belirtmişlerdir. İş deneyimi konusunda öğrencilerin \% 19'u 37 haftadan fazla, \% 42'si ise 12 haftaya kadar olduğunu belirtmişlerdir.

\begin{tabular}{|c|c|c|c|c|c|}
\hline Değişken & Faktör & f & $\%$ & Toplam & Toplam \% \\
\hline \multirow{2}{*}{ Cinsiyetiniz } & Kadın & 107 & 43 & \multirow{2}{*}{251} & \multirow{2}{*}{100} \\
\hline & Erkek & 144 & 57 & & \\
\hline \multirow{3}{*}{ Bölümünüz } & İşletme & 85 & 34 & \multirow{3}{*}{251} & \multirow{3}{*}{100} \\
\hline & Turizm İşletmeciliği & 109 & 43 & & \\
\hline & Uluslararası Ticaret & 57 & 23 & & \\
\hline \multirow{2}{*}{ İş Tecrübeniz } & Var & 214 & 85 & \multirow{2}{*}{251} & \multirow{2}{*}{100} \\
\hline & Yok & 37 & 15 & & \\
\hline \multirow{3}{*}{ Çalıştığınız Sektör } & Turizm & 139 & 55 & \multirow{3}{*}{251} & \multirow{3}{*}{100} \\
\hline & Diğer & 67 & 27 & & \\
\hline & Cevapsiz & 45 & 18 & & \\
\hline \multirow{5}{*}{ Çalışma Süreniz } & $1-12$ hafta & 105 & 42 & \multirow{5}{*}{251} & \multirow{5}{*}{100} \\
\hline & 13-24 hafta & 27 & 11 & & \\
\hline & $25-36$ hafta & 28 & 11 & & \\
\hline & 37 haftadan fazla & 47 & 19 & & \\
\hline & Cevapsiz & 44 & 18 & & \\
\hline
\end{tabular}

Tablo 1: Demografik Bulgular Özelliklere İlişkin Bulgular

Tablo 2'de araştırmaya katılan öğrencilerin KSS kavramını nasıl algıladıklarına ilişkin bulgular yer almaktadır. Öğrencilerin büyük kısmı (\% 77) KSS kavramını "topluma fayda sağlamak” olarak tanımlarken en düşük katılımla (\%38) "Verimliliği arttırmak” olarak açıklamaktadırlar.

\begin{tabular}{|l|c|c|l|r|r|}
\hline \multicolumn{1}{|c|}{ Değişken } & F & \% & \multicolumn{1}{|c|}{ Değişken } & f & \% \\
\hline Hayırseverlik & 112 & 45 & Toplumsal değerlere saygı duymak & 155 & 62 \\
\hline Gönüllü faaliyetler & 159 & 64 & Yasalara uygunluk & 106 & 42 \\
\hline Tüm paydaşların çıkarlarını korumak & 91 & 36 & Topluma fayda sağlamak & 192 & 77 \\
\hline Ahlaki değerlere uygunluk & 171 & 68 & İşletme için değer yaratmak & 126 & 50 \\
\hline Verimliliği arttırmak & 96 & 38 & Diğer & 2 & 1 \\
\hline
\end{tabular}

Tablo 2. Katılımcıların KSS Kavramına İlişkin Algıları ve Paydaşların Önem Derecesi

Tablo 3 'te KSS bağlamında bir işletmenin sorumlu olduğu paydaşların önem derecelerine göre (1; kesinlikle önemsiz - 9; kesinlikle önemli) sıralamalarına ilişkin bulgular yer almaktadır. Katılımcı öğrenciler en önemli paydaş olarak toplumu ve en düşük ortalamaya sahip paydaş olarak ise sivil toplum kuruluşlarını işaret etmektedirler. 


\begin{tabular}{|c|c|c|c|c|c|c|c|c|c|c|c|c|c|c|c|c|c|c|c|}
\hline \multirow{2}{*}{ Değişken } & \multicolumn{2}{|r|}{1} & \multicolumn{2}{|c|}{2} & \multicolumn{2}{|c|}{3} & \multicolumn{2}{|c|}{4} & \multicolumn{2}{|c|}{5} & \multicolumn{2}{|c|}{6} & \multicolumn{2}{|c|}{7} & \multicolumn{2}{|c|}{8} & \multicolumn{2}{|r|}{9} & \multirow{2}{*}{ A.O. } \\
\hline & $\mathrm{f}$ & $\%$ & $\mathrm{f}$ & $\%$ & $\mathrm{f}$ & $\%$ & $\mathrm{f}$ & $\%$ & $\mathrm{f}$ & $\%$ & $\mathrm{f}$ & $\%$ & $\mathrm{f}$ & $\%$ & $\mathrm{f}$ & $\%$ & $\mathrm{f}$ & $\%$ & \\
\hline Toplum & 51 & 27 & 36 & 19 & 21 & 11 & 22 & 12 & 24 & 13 & 12 & 6 & 6 & 3 & 6 & 3 & 9 & 5 & 6,60 \\
\hline Müşteriler & 31 & 17 & 49 & 26 & 34 & 18 & 20 & 11 & 17 & 9 & 11 & 6 & 6 & 3 & 12 & 6 & 7 & 4 & 6,46 \\
\hline $\begin{array}{l}\text { İşletme } \\
\text { Çalışanları }\end{array}$ & 36 & 19 & 22 & 12 & 20 & 11 & 28 & 15 & 35 & 19 & 14 & 8 & 18 & 10 & 11 & 6 & 3 & 2 & 6,12 \\
\hline Hissedarlar & 20 & 11 & 16 & 9 & 33 & 18 & 22 & 12 & 21 & 11 & 26 & 14 & 20 & 11 & 15 & 8 & 14 & 8 & 5,26 \\
\hline Devlet & 13 & 7 & 17 & 9 & 22 & 12 & 26 & 14 & 23 & 12 & 35 & 19 & 16 & 9 & 18 & 10 & 17 & 9 & 4,91 \\
\hline Çevre & 9 & 5 & 27 & 14 & 14 & 8 & 20 & 11 & 23 & 12 & 20 & 11 & 20 & 11 & 43 & 23 & 11 & 6 & 4,64 \\
\hline Rakipler & 14 & 8 & 11 & 6 & 21 & 11 & 25 & 13 & 15 & 8 & 18 & 10 & 25 & 13 & 23 & 12 & 35 & 19 & 4,35 \\
\hline Tedarikçiler & 2 & 1 & 6 & 3 & 12 & 6 & 16 & 9 & 12 & 6 & 29 & 16 & 54 & 29 & 38 & 20 & 18 & 10 & 3,63 \\
\hline $\begin{array}{l}\text { Sivil } \\
\text { Toplum } \\
\text { Kuruluşları }\end{array}$ & 10 & 5 & 5 & 3 & 10 & 5 & 9 & 5 & 19 & 10 & 21 & 11 & 20 & 11 & 22 & 12 & 71 & 38 & 3,25 \\
\hline
\end{tabular}

Tablo 3: Önemine Göre Paydaşların Siralanmasina İlişkin Frekans ve Yüzde Bulguları

Tablo 4'te, Tablo 5'te belirtilen ölçeğe ve faktörlere ilişkin güvenilirlik analizi bulguları yer almaktadır. Güvenilirlik analizinde Cronbach Alpha $(\alpha)$ değeri $0.60 \leq \alpha<0.80$ olması halinde ölçek oldukça güvenilir, 0.80 $\leq \alpha<1.00$ olması halinde ölçek yüksek derecede güvenilir bir ölçektir sonucu elde edilmektedir (Kayış, 2010:405). Ölçeğe ilişkin güvenilirlik analizi sonucunda Cronbach Alpha değerinin 0.92 olduğu bulgusu elde edilmiştir. Bu durumda ölçek yüksek derecede güvenilir bir ölçek iken faktörler oldukça güvenilir olarak yorumlanabilmektedir.

\begin{tabular}{|lccc|}
\hline Değişken & $\begin{array}{c}\text { Faktör Değişkeni } \\
\text { Sayısı }\end{array}$ & $\begin{array}{c}\text { Cronbach } \\
\text { Alpha }\end{array}$ & Güvenilirlik Düzeyi \\
\hline Ekonomik & 5 & 0.797 & Oldukça Güvenilir \\
\hline Yasal & 4 & 0.724 & Oldukça Güvenilir \\
\hline Etik & 5 & 0.781 & Oldukça Güvenilir \\
\hline Gönüllü & 2 & 0.677 & Oldukça Güvenilir \\
\hline Ölçek & $\mathbf{1 6}$ & $\mathbf{0 , 9 2}$ & Yüksek Derecede Güvenilir \\
\hline
\end{tabular}

Tablo 4: Faktörlere İlişkin Güvenilirlik Analizi Bulguları

Tablo 5'te yer alan bulgulara göre, öğrencilerin stratejik kararlarda, en fazla ekonomik ve gönüllü sorumluluğa, daha sonra etik ve son olarak da yasal sorumluluğa yer verdikleri belirlenmiştir. 


\begin{tabular}{|c|c|c|}
\hline Değişken & a.o. & s.s. \\
\hline Ekonomik Sorumluluk & 3,94 & $\mathbf{0 , 8 9}$ \\
\hline $\begin{array}{l}\text { Bir yönetici, işletme ile ilgili kararlar alırken mutlaka, mümkün olan en yüksek } \\
\text { kârı hedeflemelidir. }\end{array}$ & 3,77 & 1,31 \\
\hline $\begin{array}{l}\text { Bir yönetici, işletme ile ilgili kararlar alırken mutlaka, uzun vadede başarılar } \\
\text { elde etmek için planlama yapmalıdır. }\end{array}$ & 4,33 & 1,26 \\
\hline $\begin{array}{l}\text { Bir yönetici, işletme ile ilgili kararlar alırken mutlaka, etik konulara öncelik } \\
\text { verilmesinden dolayı ekonomik performansın olumsuz yönde etkilenmesine } \\
\text { hiçbir zaman müsaade etmemelidir. }\end{array}$ & 3,55 & 1,21 \\
\hline $\begin{array}{l}\text { Bir yönetici, işletme ile ilgili kararlar alırken mutlaka, her zaman işletmenin } \\
\text { ekonomik performansını geliştirmelidir. }\end{array}$ & 3,94 & 1,12 \\
\hline $\begin{array}{l}\text { Bir yönetici, işletme ile ilgili kararlar alırken mutlaka, üretim maliyetlerini } \\
\text { yakından takip etmelidir. }\end{array}$ & 4,12 & 1,11 \\
\hline Yasal Sorumluluk & 3,77 & 0,9 \\
\hline $\begin{array}{l}\text { Bir yönetici, işletme ile ilgili kararlar alırken mutlaka, çalışanların kanunların } \\
\text { çizdiği çerçeve içinde davranmalarını sağlamalıdır. }\end{array}$ & 3,93 & 1,17 \\
\hline $\begin{array}{l}\text { Bir yönetici, işletme ile ilgili kararlar alırken mutlaka, performansı arttırmak } \\
\text { uğruna bile olsa kanunları zorlayan yorumlamalardan kaçınmalıdır. }\end{array}$ & 3,62 & 1,20 \\
\hline $\begin{array}{l}\text { Bir yönetici, işletme ile ilgili kararlar alırken mutlaka, sözleşmelerden doğan } \\
\text { yükümlülüklerini göz ardı etmekten kaçınmalıdır. }\end{array}$ & 3,53 & 1,34 \\
\hline $\begin{array}{l}\text { Bir yönetici, işletme ile ilgili kararlar alırken mutlaka, düzenleyici kanun ve } \\
\text { yönetmeliklerle tanımlanan prensiplere her zaman uymalıdır. }\end{array}$ & 4,00 & 1,08 \\
\hline Etik Sorumluluk & 3,85 & 0,9 \\
\hline $\begin{array}{l}\text { Bir yönetici, işletme ile ilgili kararlar alırken mutlaka, sosyal sorunların / } \\
\text { problemlerin çözülmesine yardım etmelidir. }\end{array}$ & 4,12 & 1,08 \\
\hline $\begin{array}{l}\text { Bir yönetici, işletme ile ilgili kararlar alırken mutlaka, etik ilkelere saygının, } \\
\text { ekonomik performansa göre öncelikli olarak ele alınmasını sağlamalıdır. }\end{array}$ & 3,77 & 1,22 \\
\hline $\begin{array}{l}\text { Bir yönetici, işletme ile ilgili kararlar alırken mutlaka, işletmenin toplumda } \\
\text { "sadece kâr sağlamanın" ötesinde bir rol üstlenmesini sağlamalıdır. }\end{array}$ & 3,97 & 1,26 \\
\hline $\begin{array}{l}\text { Bir yönetici, işletme ile ilgili kararlar alırken mutlaka, herkes tarafından kabul } \\
\text { edilmiş etik ilkelere bağlı olmalıdır. }\end{array}$ & 3,78 & 1,19 \\
\hline $\begin{array}{l}\text { Bir yönetici, işletme ile ilgili kararlar alırken mutlaka, işletmenin, amaçlarına } \\
\text { ulaşması uğruna etik ilkelerden ödün vermekten kaçınmalıdır. }\end{array}$ & 3,59 & 1,31 \\
\hline Gönüllü Sorumluluk & 3,94 & 1 \\
\hline $\begin{array}{l}\text { Bir yönetici, işletme ile ilgili kararlar alırken mutlaka, işletme kaynaklarının bir } \\
\text { kısmını yardım faaliyetlerine ayırmalıdır. }\end{array}$ & 3,97 & 1,16 \\
\hline $\begin{array}{l}\text { Bir yönetici, işletme ile ilgili kararlar alırken mutlaka, toplum ile ilgili } \\
\text { sorunların yönetimine katılmalıdır. }\end{array}$ & 3,90 & 1,11 \\
\hline
\end{tabular}

Tablo 5: KSS kavramına ilişkin faktörler ve faktör değişkenlerinin ă̆ırlıklı ortalama ve standart sapma dă̆llımları

Öğrencilerin KSS kavramına ilişkin tutumları ile cinsiyetleri arasında farklılık olup olmadığını belirlemek için yapılan t- Testi analizinde, öğrencilerin cinsiyetlerine göre kurumsal sosyal sorumluluğa ilişkin tutumlarının farklılaşmadığı bulgusu elde edilmiştir. Benzer şekilde öğrencilerin KSS kavramına ilişkin tutumları ile bulundukları bölüm arasında farklılık olup olmadığını belirlemek için yapılan varyans analizinde, öğrencilerin öğrenim gördükleri bölüm ile kurumsal sosyal sorumluluğa ilişkin tutumlarının farklılaşmadığı bulgusu elde edilmiştir. 


\section{Sonuç}

Araştırmanın sonucunda, öğrencilerin karar alma süreçlerinde KSS alt boyutlarından sırasıyla ekonomik ve gönüllü sorumluluk, etik ve yasal sorumlulukları ön planda tuttukları ortaya çıkmıştır. Dolayısıyla KSS kavramı kapsamında ilk yapılan önemli saptama ekonomik sorumluluk üzerine olmuştur. Bu durum, Carrroll (1991)'un "ekonomik sorumluluk yerine getirilmedikçe diğer sorumluluklardan bahsetmek güçtür "ifadesini desteklerken İbrahim vd. (2006)'nin yaptıkları çalışmada elde edilen sonuçla da önemli benzerlikler taşımaktadır. İbrahim vd'nin. (2006) yaptıkları çalışmada muhasebe öğrencilerinin gelecekte karar alma faaliyetlerinde sırasıyla ekonomik, yasal, etik ve gönüllü sorumlulukları içerisinde barındıracak tutum içerisinde oldukları sonucu ile öğrencilerin sektörde muhasebe alanında faaliyet gösteren yöneticilere oranla etik ve gönüllü sorumlulukları daha fazla dikkate aldıkları belirlenmiştir. İşletme ile ilgili kararlar alınırken kaynakların bir kısmını yardım faaliyetlerine aktarma, toplumsal sorunların çözümüne aktif bir şekilde katılmayı ifade eden gönüllü sorumlulukların geleceğin yöneticileri tarafindan önemsendiği görülmektedir. Bu durumun muhtemel sebebi olarak, son yıllarda sürdürülebilirlik, iş etiği, toplum ve işletme gibi ahlaki değerleri içeren derslerin üniversite müfredatlarında yer alması gösterilebilir.

Yönetici adaylarının işletmenin en önemli paydaşları olarak sırasıyla toplum, müşteriler, işletme çalışanları ve hissedarları benimsemeleri, gelecekte alınacak kararlarda ekonomik kaygıların yanı sıra diğer paydaşların çıkarlarının da göz önünde bulundurulacağını göstermektedir. Bunun yanı sıra, KSS kavramının tanımlanmasına ilişkin verilen cevaplarda 'topluma fayda sağlamak', 'ahlaki değerlere uygunluk', 'gönüllü faaliyetler', 'toplumsal değerlere saygl duymak' olarak tanımlanan kavramın öğrenciler tarafından anlaşıldığı ve benimsendiği söylenebilir.

Arlow (1991) öğrencilerin sosyal sorumluluk kavramına yönelik tutumlarını araştırması sonucunda elde ettikleri bulgularda, kadın katılımcıların erkeklere göre ahlaki sorumlulukları daha fazla ön planda tuttukları belirlenmiştir. Ayrıca, Ibrahim ve Angelidis (1991) yaptıkları çalışmada, erkeklerin kadınlara göre ekonomik sorumluluğu ön planda tuttukları, kadınların ise erkeklere oranla gönüllü sorumluluklara daha fazla yer verme eğiliminde oldukları belirlenmiştir. Burton ve Geharty (1999) erkek ve kadınların KSS kavramına yönelik tutumlarını belirlemede, erkeklerin sırasıyla ekonomik, etik, yasal ve gönüllü sorumluluk; kadınların ise sırasıyla etik, yasal, ekonomik, gönüllü sorumluluğu ön planda tuttukları belirlenmiştir. Aksine, bu araştırmada ise öğrencilerin cinsiyetlerine göre KSS tutumlarının farklılık göstermediği sonucuna ulaşılmıştır. Benzer şekilde öğrencilerin bulundukları bölüm ile de tutumları arasında anlamlı bir farklılık ortaya çıkmamıştır.

Araştırma sonucunda elde edilen bulguları genelleyebilmek için, ülke genelinde farklı İşletme ve İktisadi ve İdari Bilimler Fakültelerinde daha fazla örnekleme ulaşılmalıdır. Ayrıca, potansiyel yöneticiler olarak değerlendirilen öğrenciler ile farklı sektörlerde aktif bir şekilde yönetici kademesinde yer alan yöneticilerin de KSS kavramına ilişkin tutumları araştırmalı ve öğrencilerle mukayese edilmelidir. Böylece geleceği günümüzden ne derece farklılaştıracak kararların alınacağı tahmin edilebilir. Araştırmacılara bu önerilerin ötesinde, ülkemizde yer alan üniversite ve hatta orta öğretim müfredatlarında dahi iş etiği, KSS, sürdürülebilirlik, işletme ve toplum gibi derslerin yer alması sağlanmalıdır. Böylece öğrencilerin gelecekte karar alma faaliyetlerinde tüm paydaşların çıkarlarını dengeleyebilecek bir tutum içerisinde olmaları sağlanabilecektir.

\section{Kaynakça}

- Albinger, Freeman, 2000. "Corporate Social Performance and Attractiveness as An Employer to Different Job Seeking Populations”, Journal of Business Ethics, 28(3), p. 243-253.

- Arlow, 1991. "Personal Characteristics in College Students' Evaluations of Business Ethics and Corporate Social Responsibility", Journal of Business Ethics, 10(1), p. 63-69.

- Aşçıil, 2004. "Perceptions on corporate social responsibility: A survey on Turkish managers", In IABPAD Conference Proceedings, January, New Orleans.

- Ayub, 2008. “Türkiye'de Kurumsal Sosyal Sorumluluğu Değerlendirme Raporu”, KSS Derneği, Mart, Ankara.

- $\quad$ Bhattacharya, Sen, Korschun, 2008. "Using Corporate Social Responsibility to Win the War for Talent”, MIT Sloan Management Review, 49(2),

- Brammer, Millington, Rayton, 2007. "The Contribution of Corporate Social Responsibility to Organizational Commitment”, The International Journal of Human Resource Management, 18(10), p. 17011719.

- Bowen, (1953). "Social Responsibilities of Businessman”, New York: Harper and Row.

- Brockett, Rezaee, 2012. “Corporate Sustainability; Integrating Performance and Reporting”, John Wiley\&Sons, Canada

- Burton, ve Hegarty, 1999. "Some Determinants of Student Corporate Social Responsibility Orientation", Business and Society, 38(2), p.188-205. 
- Butcher, 1997. “The Need for Ethical Leadership”, Executive Speeches, 11(5), p. 83-86.

- Çalışkan, Ünüsan, 2011. "Hotel Employee Perceptions of Corporate Social Responsibility and Its Effects on Job Satisfaction and Intention to Stay", Anatolia: Turizm Arastirmalari Dergisi, 22(2), p. 154-166.

- Carroll, 1999. “Corporate Social Responsibility: Evolution of A Definitional Construct”, Business and Society, 38(3), p. 268-295.

- Carroll, 2004. "Managing Ethically with Global Stakeholders: A Present and Future Challenge", The Academy of Management Executive, 18(2), p. 114-120.

- Carroll, 1991. "The Pyramid of Corporate Social Responsibility: Toward the Moral Management of Organizational Stakeholders", Business Horizons, 34(4), p. 39-48.

- Cochran, Wood, 1984. “Corporate Social Responsibility and Financial Performance”, Academy of Management Journal, 27(1), p. 42-56.

- Commission of the European Communities, "Promoting a European Framework for Corporate Social Responsibility", COM (2001) 366 Final, Brussels.

- Cornelius, Wallace, Tassabehji, 2007. “An Analysis of Corporate Social Responsibility, Corporate Identity and Ethics Teaching in Business Schools”, Journal of Business Ethics, 76(1), p. 117-135.

- Davis, 1967. "Understanding the Social Responsibility Puzzle”, Business Horizons, 10(4), p. 45-50.

- Davis, Blomstrom, 1975. "Business and Society: Environment and Responsibility”, 3rd Edition, New York: McGraw-Hill.

- De Grosbois, 2012. “Corporate Social Responsibility Reporting by The Global Hotel Industry: Commitment, Initiatives and Performance”, International Journal of Hospitality Management, 31(3), p. 896905.

- $\quad$ Farooq, Farooq, Jasimuddin, 2014. "Employees Response to Corporate Social Responsibility: Exploring the Role of Employees' Collectivist Orientation”, European Management Journal, 32(6), p. 916-927.

- Greening, Turban, 2000. “Corporate Social Performance as a Competitive Advantage in Attracting a Quality Workforce", Business and Society, 39(3), p. 254-280.

- Hopkins, 2003. The Planetry Bargain. Earth-scan: UK.

- Ibrahim, Angelidis, 1991. "Effects of Board Members' Gender on Level of Involvement in Strategic Management and Corporate Social Responsiveness Orientation”, Proceedings of The Northeast Decision Sciences Institute, p. 208-210.

- Ibrahim, Angelidis, Howard, 2006. "Corporate Social Responsibility: A Comparative Analyses of Perceptions of Practicing Accountants and Accounting Students", Journal of Business Ethics, 66(2-3), p. 157-167.

- Inoue, Lee, 2011. "Effects of Different Dimensions of Corporate Social Responsibility on Corporate Financial Performance in Tourism-Related Industries”, Tourism Management, 32(4), p. 790-804.

- Jaszay, 2002. "Teaching Ethics in Hospitality Programs", Journal of Hospitality and Tourism Education, $14(3)$, p. 57-59.

- $\quad$ Kang, Lee, Huh, 2010. "Impacts of Positive and Negative Corporate Social Responsibility Activities on Company Performance in the Hospitality Industry", International Journal of Hospitality Management, 29(1), p. $72-82$.

- Kayış, 2006. “Güvenirlik analizi”. Ş. Kalaycı (der.), SPSS Uygulamalı Çok Değişkenli İstatistik Teknikleri, Ankara: Asil Yayın, p. 404-409.

- Kim, Lee, Lee, Kim, 2010. “Corporate Social Responsibility and Employee-Company Identification”, Journal of Business Ethics, 95(4), p. 557-569.

- Kotler, Lee, 2006. “Kurumsal Sosyal Sorumluluk” (S. Kaçamak, Çev.), MediaCat, İstanbul.

- Lee, Heo, 2009. “Corporate Social Responsibility and Customer Satisfaction among US Publicly Traded Hotels and Restaurants”, International Journal of Hospitality Management, 28(4), p. 635-637.

- Liu, Zhou, 2009. "Corporate Social Responsibility and Customer Loyalty: A Conceptual Framework”, In Service Systems and Service Management, 2009. ICSSSM'09. 6th International Conference on (p.794798). IEEE.

- McGuire, 1963. "Business and Society”, New York: McGraw-Hill.

- McKercher, Mackenzie, Prideaux, Pang, (2014). "Is The Hospitality and Tourism Cirriculum Effective in Teaching Personal Social Responsibility?”, Journal Hospitality and Tourism Research, 38(4), p. 431-462. 
- $\quad$ Özalp, Tonus, Sarıkaya, 2008. "İktisadi ve İdari Bilimler Fakültesi Öğrencilerinin KSS Algılamaları Üzerine Bir Araştırma”, Anadolu Üniversitesi Sosyal Bilimler Dergisi, 8(1), p. 69-84.

- Park, Levy, 2014. "Corporate Social Responsibility: Perspectives of Hotel Frontline Employees”, International Journal of Contemporary Hospitality Management, 26(3), p. 332-348.

- Parry, Proctor-Thomson, 2002. "Perceived Integrity of Transformational Leaders in Organisational Settings", Journal of Business Ethics, 35(2), p. 75-96.

- Pérez, Rodríguez del Bosque, 2015. "Corporate Social Responsibility and Customer Loyalty: Exploring the Role of Identification, Satisfaction and Type of Company", Journal of Services Marketing, 29(1), p. 15-25.

- Sen, Bhattacharya, 2001. "Does Doing Good Always Lead to Doing Better? Consumer Reactions to Corporate Social Responsibility”, Journal of Marketing Research, 38(2), p. 225-243.

- Stone, 2001. "Corporate Social Responsibility and Institutional Investment”, Business and Society, 40(1), p. 112-117.

- Turban, Greening, 1997. “Corporate Social Performance and Organizational Attractiveness to Prospective Employees", Academy of Management Journal, 40(3), p. 658-672.

- Tsoutsoura, 2004. “Corporate Social Responsibility and Financial Performance. Center for Responsible Business"

- Wang, 2014. "Do Ethical and Sustainable Practices Matter? Effects of Corporate Citizenship on Business Performance in the Hospitality Industry", International Journal of Contemporary Hospitality Management, 26(6), p. 930-947.

- WBCSD (World Business CouncilForSustainable Development), www.wbscd.org/work-program/businessrole/previous-work/corporate-social-responsibility.aspx, Erişim Tarihi: 18.08.2015.

- Windsor, 2006. “Corporate Social Responsibility: Three Key Approaches”, Journal of Management Studies, 43(1), p. 93-114.

- Yeh, 2012. “Hotel General Managers' Perceptions of Business Ethics Education: Implications for Hospitality Educators, Professionals, and Students", Journal of Human Resources in Hospitality and Tourism, 11(1), p. 72-86.

- Yeung, 2004, "Hospitality Ethics Curriculum: An Industry Perspective”, International Journal of Contemporary Hospitality Management, 16(4), p. 253-262. 


\title{
Şehir Markalamasında Duygusal Yaklaşım: Deneyimsel Pazarlama
}

\section{An Emotional Approach to City Branding: Experiential Marketing}

\author{
Asst. Prof. Dr. Alparslan Özmen (Afyon Kocatepe University, Turkey)
}

\begin{abstract}
Nowadays, transportation, communication, technology and scientific developments are rapidly changing all areas. Consumers have been changed by the intensification of rivalry. Businesses have to produce proper products and services by giving more attention to changing consumer demands and needs against this rivalry. So, the experience economy is seen to take the place of the service economy. In this context, marketing strategies rather than selling products and services varies as to ensure consumer experience. Thus, the experience economy is starting with proposing products and services as a theater or visual art. Service here; to put on the stage is to create unforgettable moments and memories for customers. Today consumers are looking for features that address to their emotions and feelings. In this sense, experience takes the place of the functional value by providing mental, emotional, cognitive, behavioral and relational values. Consumption experience, is composing the focal point of the experiential approach, creating fantasies, emotions and entertainment. From this point they entered rivalry and began branding in cities. Therefore, all the dynamics of the city is necessary to make a difference by staging features that the experiential marketing has revealed. With which properties cities must be at the forefront, they should be identified and tried to be marketed. Experiential marketing will create an unforgettable experience by making the biggest help for city branding. By taking experiential marketing, the study will attempt to evaluate its effect to city branding with making conceptual analysis in the theoretical structure framework.
\end{abstract}

\section{Giriş}

Günümüzde küreselleşen dünyada pek çok durum gibi pazarlarda hızlı bir şekilde değişmektedir. 21. yüzyıla girdiğimiz bu dönemde ulaştırma, iletişim, teknoloji ve bilimsel gelişmeler her girdiği alanı hızla değişime uğratmaktadır. Bu anlamda iş dünyası da varlığını sürdürebilmek için çalışma koşullarını yeniden düzenlemektedir. Pazardaki rekabet yoğunlaşmış ve tüketiciler de değişime uğramıştır. İşletmelerin yaşamlarını sürdürebilmelerinin yanı sıra pazardaki değişiklikleri de göz önünde bulundurmaları gerekmektedir.

$\mathrm{Bu}$ itibarla pazarlama alanındaki değiş̧iklikleri de ele almak gerekmektedir. Geleneksel pazarlama yaklaşımından yeni pazarlama yaklaşımlarına doğru bir gelişme söz konusudur. Ürün ve hizmetlerin özellik ve faydaları üzerine odaklanan geleneksel pazarlama yaklaşımında, geleneksel pazarlamacılar tüketicilerin ürün ve hizmeti değerlendirirken onların sağladıkları toplam faydayı değerlendirdiklerini söylemektedirler. Geleneksel pazarlama da marka ya da ürün rekabette ön plandadır. Geleneksel pazarlama, tüketicilerin rasyonel karar aldığını analitik, nicel ve nitel yöntemlerle değerlendirilen, rekabetin sınırlı olduğu, ürün özellikleri ve faydalara odaklanan bir yaklaşımdır (Babacan, Onat, 2002:11-19). Görüldüğü gibi geleneksel pazarlama yaklaşımı, tüketicilerin rasyonel karar alan ve faydaya odaklanan bireylerden oluştuğunu ve dar kapsamlı bir rekabete odaklandığı görüşü üzerinde durur (Schmitt, 1999a:53-67). Geleneksel pazarlamanın bu dar kalıbı rekabette işletmelere bir sınır getirmektedir. Ayrıca bu değişiklik göstermeyen yöntemlerden sıkılan postmodern tüketici sürekli yenilik arayışındadır (Varinli, 2012:149). Bu bağlamda işletmeler, yeni teknikler geliştirerek bu duruma karşllık vermeleri gerekmektedir. Bunu karşılayabilecek yeni tekniklerden birisi de "deneyimsel pazarlama"dır.

Son yıllarda çok ön planda olan deneyimsel pazarlamanın odak noktası, tüketim öncesi, tüketim sırasında ve tüketim sonrasında yaratılacak, tüketiciye seslenen duygu ve düşüncelerdir. Tüketicilerin duygularına seslenmek, işletme ve işletmenin markasına olan katkılarında önemini göstermektedir. Deneyimsel pazarlamanın bir markaya yapılan pazarlama yatıım getirisi en yüksek yöntem olduğunu araştırmalar ortaya koymaktadır (Varinli, 2012:150). Dolayısıyla Deneyimsel Pazarlama, işletmelere müşteri deneyimi yaratma üzerine kurulan yapıdaki bir araçtır.

\section{Deneyim Ekonomisi}

Günümüzde hizmet ekonomisinin yerini deneyim ekonomisi almaya başlamıştır. 21. yüzyılda pazarlama stratejileri ürün ve hizmet satmaktan, tüketici deneyimi sağlamaya yönelik olarak değişmektedir. Günümüze kadar dört ekonomik sunu bulunmaktadır. Bunlar; emtia, mal, hizmet ve deneyimdir. Her biri farklı olmakla birlikte bir sonraki aşamaya geçişte ekonomik değer katarak gelişme sürecini sürdüreceğini göstermektedir.

Deneyim ekonomisi kavramının öncüleri Pine ve Gilmore'dur. Pine ve Gilmore (1998:98) işletmelerin müşteri odaklı bir yönetim anlayışını ele alırken ekonomik değer dizisinde özelliği olan mal üretimine geçerek ve 
ürünlerini hizmetlerle destekleyerek farklılık yaratmaya çalışmışlardır. Ayrıca işletmeler "ekonomik değerin arttırılması" yolu ile deneyim yaratma sürecine geçildiğini işaret ederek deneyiminde ürün ve hizmetler gibi değerlendirilmesi gerektiğini söylemiş ve sonuçta farklılık yaratmak gerektiği için deneyim pazarlamalarını ifade etmektedirler. Buradan, ekonomik değerin doğasında ve metadan mala, oradan hizmete ve deneyime ulaşan doğal gelişim sürecini izlemektedir. Bu anlamda, deneyim ekonomisinin yükselişinin nedenlerinden biri de refahın artması olarak görülebilir (Pine, Gilmore, 1999:9).

Deneyim ekonomisi, bir tiyatro veya görsel sanatlar gibi ürün ve hizmetleri sunmayla ortaya çıkar. Burada hizmet, sahnelenmek ürün ise, sahne dekorasyonu olarak değerlendirilip müşteriler için unutulmaz anlar ve anılar yaratmaktadır (Günay, 2008:65). Diğer yandan emtia ekonomiyi temsil edip değişme özelliğine sahiptir. Ayrıca ürün somut, hizmet soyut, deneyim ise sürekli hatırlanacak bir anı özelliğine sahiptir. Deneyimde müşteri, konut olarak ifade edilirken her bir müşteri farklı deneyimler elde etmekte ve hissettikleri de birbirinden farklı olmaktadır. Bu anlamda her bir müşteri için farklı deneyimler ortaya konulmaktadır (Pine, Gilmore, 1999:13).

\section{Deneyimsel Pazarlama}

Son yıllarda deneyimsel pazarlamanın önem kazanmasıyla birlikte pazarlama ve tüketici araştırmaları, genelde tüketici deneyimini ve hazcı tüketimi araştırmaktadır (Hirschman, Hollbrook, 1982). Buradan hareketle hazcı deneyimle şekillenen deneyim özelliğinin ortaya çıkması aslında pazarlamanın geleneksel faydalarının artık tüketicilerin ihtiyaçlarını karşılayamama gibi bir durum sonucudur (Schmitt, 1999a:53-67). Günümüzde tüketiciler satın aldıkları ürünlerde ve hizmetlerde kendi zevklerine ve yaşam biçimlerine uygun estetik ve tasarım gibi birçok önemli özellik aramaktadır. $\mathrm{Bu}$ anlamda müşteri deneyimleri, deneyimsel pazarlamanın odak noktasını oluşturmaktadır. Deneyimler; zihinsel, duygusal, bilişsel, davranışsal ve ilişkisel değerler sağlayarak fonksiyonel değerlerin yerini almaktadırlar (Kabadayı, Alan, 2014:203-217). Bu yaklaşım tüketicileri sadece rasyonel karar vericiler değil aynı zamanda duygusal karar vericiler olarak da görmektedir (Schmitt, 1999a:53-67). Müşteri deneyimi kavramı, ürünlerin fonksiyonel ve duygusal yönlerinin birlikte düşünülmesi ile tasarlanarak ortaya çıkmaktadır (Berry, Carbone, Haeckel, 2002:85-89). Müşteri deneyimi oluşturularak müşteri sadakati yaratılabilir. Dolayısıyla müşteriler ve müşterilerin yaşadığı deneyimler markaları yaratmaktadır (Crosby, Johnson, 2007:2028).

Uluslararası Deneyimsel Pazarlama Birliği'ne (IXMA) göre, "deneyimsel pazarlama, müşterilere duyusal yollar aracılığıyla markalar, ürünler ve hizmetler ile ilişki kurma ve etkileşime girme firsatı vermektedir. Bu bağlamda, deneyimsel pazarlama satışların artmasını sağlayan, marka imajı ile farkındalığını artıran, mevcut müşterilerin marka, ürün ve hizmet ile deneyimlerini anlatmaktadır (Varinli, 2012:152).

Tüketim deneyimi, fanteziler, duygular ve eğlenceler deneyimsel yaklaşımın odak noktasını oluşturmaktadır. Deneyimlerden sadece müşteriler yararlanmaz, aynı zamanda işletmeler ve insanlardan oluşmakta ve iş ilişkisi ortamları da deneyimler için bir sahne sağlamaktadır (Pine, Gilmore, 1999:8). Deneyim yaratan işletmeler yenilikçi işletmeler olmakta ve yarattıkları yeni deneyimlerle müşterilerin ürün veya hizmetle ilgili sürece de katılmalarını sağlamaktadır (Gilmore, Pine, 2002:5).

İşletmeler deneyim sağlarken sahte vaatlerden kaçınarak gerçekçi olmalıdırlar. İşletmeler ne ürettiğini, nasıl ürettiğini, kendilerinin ne olduğunu tüketicilere aktarması ve bir deneyim olarak yaşatması için pazarlama stratejisi olarak mekan oluşturmayı kullanabilirler (Pine, Gilmore, 2008:23). Burada önemli olan işletmelerin üretim süreçlerini, bilgi ve deneyimlerini tüketicilerle paylaşarak ve tüketicilere farklı deneyimler yaşatarak mümkün olabilir.

\section{Deneyimsel Pazarlamada Müşteri Deneyimleri}

İşletmelerin son günlerde küresel pazarlarda başarı kazanabilmesi için bilgi teknolojilerini, pazarlama iletişim kanallarını ve markalaşmayı kullanarak müşterilerin istediği deneyimleri yaratma ve sunma becerileri burada etkili olacaktır. Artık ürünün üzerine marka adı koymak, logo yaratmak, reklam yapmak işletmeler için yeterli değildir. Burada önemli olan iletişim araçlarını bütüncül bir şekilde kullanıp marka ile ilişkilendirmek gerekmektedir. Tüm bunlar müşterilerin önemsediği deneyimler yaşamları ile örtüşecek bir biçimde olmalıdır (Schmitt, 1999b:11).

Deneyimsel pazarlamanın temelinde beş ayrı deneyim bulunmaktadır. Bunlar; algılamak, hissetmek, düşünmek, harekete geçmek ve ilişki kurma deneyimleridir. İşletmeler bu deneyimleri uyumlu bir şekilde kurarak başarılı olabilirler (Schmitt, 1999b:63-69).

1-Algılamak: Duyulara ilişkin deneyimlerdir. Bir ürüne karşı duyulan heyecana, ürünün müşteri tarafından cazip ve güzel bulunması algılama faktörüdür. Pazarlama yöneticilerinin müşterilerle temas noktasında alg1 deneyimlerini arttırması gerekmektedir. Bu anlamda tüketicilerde görme, dokunma, duyma, tatma ve koklama yolu ile duyusal deneyimler oluşturulmalıdır.

2-Hissetmek: Müşterinin hizmet aldığı ortamdaki duyguları, ruh hali veya hoş duygular uyandıran bir ürün alırken hissettikleri olarak açıklanabilir. Müşterilerde duygusal deneyimler yaratılmalıdır. Müşterilerle empati kurularak hangi uyarıcıların hangi duyguyu oluşturmak için kullanılması gerekliliği düşünülerek güçlü duygular 
oluşturulmaya çalışılmalıdır. Bu anlamda müşterinin hoş duygular uyandıran bir ürün veya hizmet satın aldığı ortamdaki hissettikleri, duyguları ve ruh halidir.

3-Düşünmek: Düşünmek, algıların oluşturduğu kavramların ve kavramları temsil eden sözcüklerin birbirini çağırmasına dayanmaktadır. Düşünce faktörü, sorun çözücü deneyimleri kavramayı yaratmayı amaçlayıp, müşterileri yaratıcı olmaya yönlendirerek onları düşünmeye yöneltmektedir. Bu bağlamda, çeşitli kanallardan yararlanılarak verilen mesajlarla tüketicilerin işletme ve markası ile ilgili farklılığını görerek düşünmesi sağlanmalıdır.

4-Harekete Geçme: Bu deneyim, duyusal, duygusal, bilişsel ve ilişkisel deneyimlerin bütünüdür. Harekete geçme eylemi, bedensel deneyimleri, yaşam biçimlerini ve karşılıklı ilişkileri etkilemeyi amaçlamaktadır. Bu eylem, müşterilerin fiziksel deneyimlerini kuvvetlendirerek, yaptıkları işlerin alternatif yollarını göstererek, alternatif yaşam biçimlerini ve etkileşimleri tanıtarak müşterilerin yaşamlarını zenginleştirir. Harekete geçme eylemi, tüketici davranışları, yaşam biçimleri ve kültürel özelliklerle ilgilidir.

5-İlişki Kurmak: İlişki deneyiminde, duyusal, duygusal, düşünsel ve davranışsal deneyimler ile ilgili olup ait olma duygusunu yaratmak amaçlanır. Bu deneyimde müşterilerin kendilerini bir grubun parçası olarak hissetmesini sağlamak ve ait olma duygusunu oluşturmayı hedeflemektedir.

$\mathrm{Bu}$ deneyimleri geleneksel pazarlama ile yaratmak mümkün değildir. Geleneksel pazarlama da tüketiciler rasyonel karar vermektedirler. Geleneksel pazarlama ürünün fonksiyonel özellikleri ve yararlarını dikkate alır. Tüketicilerin ürünün bu özelliklerini gözeterek satın alma kararı vereceğini varsaymaktadır. Oysa ki deneyimsel pazarlama daha farklı şeyleri yaşamakla oluşmaktadır. Bu beş farklı deneyim sağlayan unsurlar kullanılarak yaratılabilir.

\section{Deneyimsel Pazarlama Yaklaşımında Şehir Markalaması}

Günümüzde markaların işletmeler ve ürünleri açısından büyük önemi bulunmaktadır. Ancak markaların sadece işletmeler ve ürünleri açısından önemi olmamakta daha geniş bir alanı kapsayan önemi bulunmaktadır. Ayrıca son y1llarda firmalar, ürünler ve hizmetlerin yanında ülkeler, şehirler ve insanlarda birer marka haline gelmiştir. Küreselleşen dünya'da artık şehirlerde kendi aralarında rekabet etmektedir. Bunun içinde kişilerde oluşturdukları algılarla bu rekabeti gerçekleştirmektedirler. Sahip olunan imaj ve algıyla marka şehirler kişilerin dikkatini çekebilmekte ve cazibe merkezi olabilmektedir.

Şehirlerin uluslararası bir marka olma çabası bir anlamda ekonomik nedenlere dayanmaktadır. Şehirler uluslararası bir kimlik yaratarak çekim merkezi olarak yatırımları kendilerine çekmek için bunu küresel bir ekonomik kalkınma stratejisi haline getirmiştir (Paul, 2004:575). Şehrin pazarlanması sayesinde şehirlerin bir marka olması, o şehrin ürettiği ürün ve hizmetlerinin hedef kitle tarafından daha çok istek duyulduğu görülmektedir (Kavaratzis, Ashworth, 2008:16). Buradan hareketle kentsel ekonomilerin refaha ve zenginliğe ulaşmaları yani kalkınmaları gerekmektedir. Bu bağlamda, gerekli eylemlerin stratejik bir şekilde yapılması gerekir. Burada bir şehrin koşullarını, belli başlı fırsatlarını, güçlü ve zayıf yönlerini ortaya koymaya gereksinim bulunmaktadır. Bir şehrin markasının güçlü bir marka haline gelebilmesi için o şehirde marka olmayı destekleyecek değerlerin ve niteliklerin bulunması gerekir. Şehirlerin marka haline getirilmesi gerektiğinde şehrin tarihi, coğrafi, kültürel, ekonomik özellikleri önemli birer marka oluşturma koşullarıdır (Özkul, Demirer, 2012:157-181).

Ülgen ve Mirze (2006:116), etkili bir şehir analizi yapılabilmesi için firmalara yönelik saptamaların şehre uyarlanmasıyla ilgili beş temel konunun öneminden bahsetmektedir. Bunlar;

- Şehrin varlık ve yeteneklerinin belirlenmesi

- Bu varlık ve yeteneklerin taklit edilip edilemeyen yeteneklerden olup olmadığının belirlenmesi

- Varlık ve yeteneklerinin diğer şehirlerin sahip oldukları varlık ve yetenekler ile karşılaştırılarak üstün ve zayıf yönlerinin belirlenmesi

- Şehrin potansiyellerinin diğer şehirlerle kıyaslanması ve

- Kritik başarı faktörlerinin belirlenmesi

Şehir markalamasından önce şehrin dış çevre ve iç çevre analizi yapılarak şehrin stratejik amaçlarının belirlenmesi gerekmektedir. Şehre yönelik diş çevre analizine, öncelikle şehrin içinde bulunduğu mevcut pazar ve rekabet yapısının incelenmesiyle başlanması gerekir. Ayrıca ulusal ve uluslararası çevrelerde meydana gelen değişiklikler tahmin edilmelidir. Özellikle şehri etkileyeceğini düşündüğümüz kişi ve kuruluşlardaki değişimleri de gözlemlemek gerekmektedir. Şehrin iç yapısına ilişkin analizler yapılırken bazı alanlarda incelemeler yapılmalıdır. Bunlar;

- Şehrin üst yönetiminin stratejik şehir yönetimiyle ilgili bilgi, eğitim, yetenek ve yaklaşımlarının belirlenmesi

- Şehrin yapısının ve kültürünün benimsenmesi

- Şehrin bilgi ve iletişim teknolojilerinin belirlenmesi

- Şehrin fiziksel yeterliliğinin belirlenmesi 
- Şehrin finansal durumunun ve potansiyelinin belirlenmesi gibi incelemelerin yapılması gerekmektedir. $\mathrm{Bu}$ incelemelerden amaç şehrin güçlü ve zayıf yönlerini belirleyerek başarılı bir markalama yapmak içindir. Bunun yanında şehre ilişkin paydaş analizinin yapılması gerekmektedir. Şehre iliş̧in hizmetlerinden yararlanan paydaşların taleplerinin de bilinmesi gerekir. Paydaşlar, "kuruluşun ürün ve hizmetleri ile ilgisi olan kuruluştan doğrudan veya dolaylı, olumlu ya da olumsuz yönde etkilenen veya kuruluşu etkileyen kişi, grup veya kurumlardır" (DPT, 2006). Bu tanımı şehirler için ele aldığımızda; şehirden etkilenen veya şehri etkileyen kişi, grup veya kuruluşlardır. Şehirdeki kuruluşlar, şirketler, şehirle ilgili hizmet yürüten birimler olabilir. Bu sayede paydaşlarla etkili bir iletişim kurarak, görüş ve beklentileri saptayarak paydaşlarında şehre katkı sağlaması amaçlanır.

Başarılı bir şehir pazarlaması ve markalaşması için yerine getirilmesi gereken koşullar bulunmaktadır. Vizyon, işbirliği, şehir imajı, liderlik ve stratejik analiz gibi başarı ölçütleri şehir pazarlamasının ve markasının toplum tarafından benimsenmesi için önemlidir (Metaxas, 2002). Şehir pazarlaması ve markalaması, şehrin rekabet koşullarının artması, yatırımları çekmesi, imajının yükselmesi ve şehir kimliğinin kurulması gibi farklı amaçların birleşmesi ile birlikte oluşmaktadır. Örgütsel bir düzeyde stratejik bir araç olan şehir markalama, bir şehrin geleceğindeki vizyonu için gerekli olan görev tanımlarını ortaya koymalıdır. Bu görev tanımlamalarına baktığımızda sorunlarla, amaçlarla, firsatlarla ve konumlarla ilgili güçlü bir bağlantı oluşturup bunlarla beraber hareket edilmesi gereken bir süreci anlatmaktadır. Ayrıca markalaşmış örgütlerin değer yönüyle bakıldığında da ne kadar önemli katkılar sağladığı ortadadır.

Aaker (2007:25) markayı, "bir veya bir grup satıcının mallarını veya hizmetlerini saptamaya ve bu malları ya da hizmetleri rakiplerinkinden farklılaştırmaya yarayan ayırt edici bir isim veya semboldür" şeklinde tanımlamaktadır. Ayrıca marka ismi, semboller ve logolar, markayı çağrıştıran kimlik unsurları ve marka imajını tüketici belleğinde şekillendiren unsurlar marka bileşeni olarak ele alınabilir. Bu bağlamda marka, hedef tüketicide olumlu bir alg1 yaratmak için ortaya konan somut ve soyut özelliklerin bütünüdür (Yükselen, Güler, 2009:17). Son zamanlarda giderek yaygınlaşan şehir markalaşması, şehirlerin rekabet düzeyini ve marka bilinirliliğini arttırması bakımından önemli bir hale gelmiştir. Bu bakımdan ortaya çıkan yeni ekonomik düzende marka, şehirler ve ülkelere, yatırımcılar, turistler, ziyaretçiler ve nitelikli iş gücü için rekabet etme ve ihraç ürünlerine bir değer kazandırma sağlamaktadır. Bu anlamda şehirler açısından markalamanın ne kadar önemli olduğu bilinçli ve etkili bir markalamanın zorunluluk haline geldiği şu koşullardan görülebilir (Hanna and Rowley, 2008:63):

1. Uluslararası medyanın artan gücü

2. Uluslararası seyahat maliyetinin düşmesi

3. Tüketicilerin harcama gücünün artması

4. Sunulan hizmetler açısından şehirlerarası benzerliklerin artması

5. Nitelikli insan kaynağı için artan rekabet

6. İnsanların farklı kültürlere olan ilgisinin artması

Şehir markalamasında da konumlandırma kavramı önemidir. Trout ve Rivkin (1999:12), "konumlandırmayı her zaman ürüne yaptığınız bir şey olarak değil, zihne yaptığınız bir şey olarak tanımladık" şeklinde açıklamışlardır. Şehrin konumlandırılması, şehrin müşterisi olabilecek kişilerin zihninde şehre ait özel yerin saptanıp pazarlama iletişimi sayesinde zihne şehrin yerleştirilmesi anlamına gelmektedir. Başarılı ve güçlü bir şehir markası meydana getirmenin belki en temel koşulu markanın rakiplerinden farklılaştırılmasıdır.

Pazarlamada uzun dönemde rekabet avantajı elde etmenin en önemli unsurlarından biri farklılaşmadır. Ancak küreselleşmeyle birlikte şehirlerin birbiriyle benzerliğinin kültürel, sosyal, ekonomik ve siyasi etkileşimin etkisiyle artması farklılaşmayı zorlaştırmaktadır. Özellikle somut değerler üzerindeki benzerlikler daha fazladır. Bu bağlamda şehirlerin daha kalıcı ve daha güçlü marka kimliğine sahip olabilmeleri için soyut değerlere daha fazla önem vermeleri gerekmektedir. Dolayısıyla, şehirler için bir marka kimliğinin oluşturulması da önemli olduğundan, rekabet avantajı sağlamak isteyen şehirler için soyut değerleri ortaya koyarak farklılaşmak bir zorunluluktur.

Aaker (2009:84) marka stratejistlerinin marka kimliğini yaratmak ve korumak için önem verdikleri marka çağrışımları kümesi olarak ele almaktadır. Bu çağrışımlar, markanın temsil ettiğini olayları yansıtır ve müşterilere verilmiş bir sözdür. Marka kimliği, fonksiyonel, duygusal veya kişisel faydaları içeren değer önermesi yaratarak marka ile müşteri arasında bir ilişki kurmaya yardımcı olmalıdır. Bir imaj oluşturma sürecinin aktif ve önemli bir kısmını marka kimliği oluşturmaktadır (Rainisto, 2003:47). Şehre karakterini veren farklılaştırılmış özellikler bütünü olarak şehir marka kimliği ortaya çıkmaktadır. Şehir kimliğine, şehrin topografik, demografik, iklim ve yönetim özellikleri gibi sosyal ve mekansal boyutları arasındaki etkileşim farklılaşma yaratarak eşsiz bir karakter vermektedir. Marka yöneticilerinin bir şehrin nasıl algılanmasını istediğini ve şehir pazarlama planı içinde yer alan planlı eylemlere dönüştürmesi ve bu sayede şehir kimliğini yaratmak ve sürdürmek istediği eşsiz marka çağrışımları seti olarak tanımlanabilir. Bu bağlamda bu çağrışımlar, şehrin nasıl konumlandığını ve şehrin müşterilerine ne tür vaatleri olduğunu içermektedir (Deffner ve Liouris, 2005:5; Rainisto, 2003:73). Görüldüğü gibi marka kimliği, şehri temsil ettiği için bu kimlik, ne olmakla yani müşterilere neler yapılabileceğiyle ilgilidir. Keller (1998:131-134), marka kimliğinin elemanlarının seçiminde şu ölçütlerin dikkate alınması gerektiğini 
söylemiştir. Hatırlanabilir olmalı, betimleyici, inandırıcı, ilginç anlamlar içermeli ve her koşula göre kullanılabilir olması gerekmektedir.

Markalamanın temel amacı olumlu ve güçlü bir marka imajı oluşturmaktır. Bu anlamda başarılı bir şehir marka imajı oluşturmak gerekmektedir. Bir marka imajı, genelde anlamlı biçimde oluşturulmuş bir çağrışımlar kümesidir (Aaker, 2007:131) şeklinde açıklanmaktadır. Marka imajı, kişilerin bir marka hakkındaki izlenim, duygu, düşünce, inanç ve çağrışımlarının bütünü olarak ele alınabilir. Şehirler bir marka olarak ortaya çıkmasalar bile insanların düşüncelerinde olumlu ya da olumsuz bir imaja sahiptir. Dolayısıyla şehir için yeni bir imaj ortaya koymaktansa var olan olumlu imajı güçlendirmeye, olumsuz imajı ise olumlu olarak değiştirmeye çalışmak daha doğru olur (Asworth, Voogd, 1994:128).

Ürünlerin, hizmetlerin ve insanların imajlarını etkileyen bir takım unsurlar olduğu gibi şehirlerin imajlarını da etkileyen bir takım unsurlar bulunmaktadır. Bu unsurlar gezip görülebilecek turistik alanlar, eğlence ve dinlence alanları, ulaşım ağı, tarihi, kültürel, sosyal, finansal ve doğal güzellikler gibi özellikler şehir imajına katkı sağlamaktadır. Şehir imajı kavramı, insanların şehre ilişkin algılama ve izlenimlerinden oluştuğundan şehir markası yaratma sürecinde stratejik bir öneme sahiptir. Hedef kitle üzerinde olumlu olması istenilen imajın yaratılması rekabet avantajı ve sürdürülebilir bir gelişme sağlamaktadır.

\section{6 Şehir Markalamasında Deneyimsel Pazarlama}

Bir şehrin marka şehir olabilmesinden söz edebilmenin yolları bulunmaktadır. Eğer bir şehir yerli ve yabancı turist çekebiliyorsa, o şehir hakkında konuşulduğunda şehre ait bir özellik, bir sosyolojik durum veya herhangi bir olay ortaya çıkabiliyorsa o şehrin markalaşması hakkında söz etmek mümkündür.

Burada önemli olan o şehrin güzelleşmesi ve dünyaca ilgi çekebilmesi için o kentin ileri gelenleri plan ve projeler yaparak şehri markalaştırmak isteyebilirler. Ancak marka şehir olma iddiası şehirden başlamalıdır. Burada şehri markalaştırmaya çalışmak kırsaldan ziyade şehirden başlamalıdır. Çünkü şehirlerin markalaşmasının birçok avantajları vardır. Bunları şu şekilde sıralayabiliriz:

- Havaalanları şehirlerde bulunmaktadır.

- Turistik oteller şehirlerde bulunur.

- Gece ve sosyal hayat şehirde daha zengindir.

- Resmi kurumların çoğu şehirlerdedir.

Marka şehir olma dışarıdan yatırımcı, alıcı ve turist çekmek için önemlidir. Marka şehirler farkındalık yaratarak buna ulaşabilirler. Ancak burada önemli olan şehirlerde yaşayanlarında buna katkıda bulunmaları gerekmektedir. Onlara daha yüksek yaşam kalitesi sunarak ve bunun önemini anlatarak dünyadaki diğer marka şehirlerle rekabet edilmesi gerekliliğini anlatmak gerekmektedir.

Günümüzde ise pazarlama, sadece ürün veya hizmetlerin üretilmesi ile ilgilenmemekte bunun yanında bireylerle, şirketlerle, kurumlarla, düşünceler, şehirler vs. birçok olayla ilgilenmektedir. Artık şehirler de kaynaklarını daha etkili kullanmak, yaşanabilir mekanlar yaşatmak, cazibe merkezi haline dönüşebilmek amacıyla pazarlamayı kullanmaktadır. Şehre ziyaretçi sayısının artması, yatırım isteklerinin teşvik edilmesi ve şehirde yaşayanların sorunlarının anında çözümlenerek bir değer ortaya konması şehrin pazarlanabilir olması anlamına gelmektedir (Deffner vd., 2005:1).

Bu sürecin başarılı yürütülebilmesi şehri farklı kılmakta ve şehirle ilgili haberlerin olumlu olmasına ve şehirde yaşayanların gelirlerinde bir artışa neden olmaktadır. Bu anlamda şehir markalaması yaparken deneyimsel pazarlamayı kullanarak şehri farklılaştırmak mümkündür. Schmitt (1999a:53) pazarlamacıların tüketicileri için yaratabileceği beş tip deneyim modülünden söz etmektedir. Bunlar; duyusal deneyimler, duygusal deneyimler, yaratıcı bilişsel deneyimler, davranışlar ve hayat biçimi ve de bir kültür bağlantılı olan sosyal kimlik deneyimleridir. Schmitt (1999a:53), deneyimsel pazarlamanın nihai amacının bütünsel deneyimler yaratmak olduğunu savunmaktadır. Dünyanın bir evrime doğru gittiğini ve bu evrimin pazarlamayı da değiştireceğini anlatmaktadır. Bu evrim, tüketicilerin kim olduklarını ve kullandıkları ürünler sayesinde kim olmayı istediklerini ortaya çıkarmalarını ve tüketim aracılı̆̆ıyla zevk, eğlence ve fantezi arama isteğidir (Holbrook ve Hirschman, 1982:132).

Günümüzde sadece fonksiyonel faydalar sağlayan ürün ve hizmetler sunmak ve bunları iletişim aracılığıyla desteklemek yeterli değildir. Bu yeni devrimci yaklaşım Pine ve Gilmore (1998) tarafından deneyim ekonomisi, Schmitt (1999a) tarafindan ise deneyimsel pazarlama olarak ifade edilmektedir. Schmitt'e (1999a:57) göre marka uzmanları unutulmaz ve denemeye değer marka deneyimleri ile sonuçlanan duyusal, duygusal ve bilişsel çağrışımların kaynağı olan markanın özünü gözönüne almamaktadır. Aslında tüketicilerin istediği, duygularını harekete geçiren, duygularına dokunan ve uyarıcı etkisi olan ürünler, iletişim ve pazarlama kampanyalarıdır. Bu bağlamda deneyimsel pazarlama, aldıkları her üründe tüketicileri markaya duygusal anlamda bağlayıp ilgi uyandırmayı ve unutulmaz deneyimler sunmayı amaçlamaktadır (Gortes, 2004:41). Dolayısıyla geleceği düşünen şirketler ve kurumlar odaklarını kaynak ve kapasite yönetiminden, değer yaratmanın öncül koşulu olan tüketici deneyimlerini yönetmeye doğru değiştirmeleri gerekmektedir. 
Schmitt (2003:230) deneyimsel pazarlamanın bir sonucu olarak deneyimsel markalar yaratmak ve bu markaları yönetebilmek için kurallar belirlemiştir.

1. Deneyimleri planlamak gerekmektedir. Burada amaç, yaratıcı olmak, sürpriz yapmak ve merak ettirmek gerekmektedir.

2. Öncelik müşterinin yaşayacağı deneyime verilmelidir.

3. Markanıza farklılık yaratacak bir nesne bulunmalıdır.

4. Duyuları uyaran, duygu yaratan, yaşam biçimleri ile ilişkilendirilecek, sosyal kimlik sağlayacak deneyimler yaratın.

Buradan hareketle şehir markalaması yaparken duyuları, duyguları, düşünceyi, hareketi ve ilişkiyi içine alan bir deneyim yaratarak yoğun rekabet içinde şehri diğer rakip şehirlere karşı farklılaştırabilir.

\section{Sonuç}

Günümüzde şehirler markalaşarak uzun dönemde kar elde edeceklerine ve yeni müşterilere ulaşabileceklerinin farkına varmışlardır. Bu anlamda rekabet avantajı sağlayabilmeleri için farklı olmaları gerektiğini görmüşlerdir. Ancak bu farklılık müşteriler tarafindan anlaşıldığında ve kabul edildiğinde bir anlam kazanmaktadır.

Markaların birbirine çok benzemesi, şehirlerin farklılık yaratmak ve rekabet avantajı elde etme adına müşterilerine eşsiz bir deneyim yaşatmaya ve müşteri tatmini yaratmaya zorlamaktadır. Bu bağlamda deneyimsel pazarlama kavramı, şehir markalamasında müşterilere sürekli olarak hatırlayacağı deneyimler yaşatarak şehirleri rekabet ortamında ön plana çıkaran bir pazarlama stratejisi olarak görülebilir.

\section{Kaynakça}

- $\quad$ Aaker, D., 2007. Marka Değeri Yönetimi, Çev.Ender Orfanlı, MediaCat, İstanbul.

- Aaker, D., 2009, Güçlü Markalar Yaratmak, Çev. Erdem Demir, MediaCat, İstanbul.

- Ashworth, G.J, Voogd, H., 1994. “Marketing and Place Promotion”, in Gold, J.R. \& Ward, S.W. (Eds). Place Promotion, the Use of Publicity and Marketing to Sell Towns and Regions, John Wiley \& Sons, Chichester.

- $\quad$ Babacan, M., Onat, F. 2002. "Postmodern Pazarlama Perspektifi", Ege Akademik Bakış, 2(1), s.11-19.

- $\quad$ Berry, L.L., Carbone, L.P., Haeckel, S.H., 2002, "Managing the Total Customer Experience, MIT Sloan Management Review, 43(3), p. 85-89.

- Crosby, L., Johnson S., 2007, "Experience Required", Marketing Management, July/August, p.20-28.

- Deffner, A., Liouris, C., 2005, “City Marketing: A Significant Planning Tool For Urban Develeopment In A Globalised Economy", 45th Congress of the European Regional Science Association, Vrije Universty, Amsterdam, p. 23-27 August 2005.

- $\quad$ DPT. 2006, Kamu İdareleri İçin Stratejik Planlama Kılavuzu 2. Sürüm. http://www.yapi.hacettepe.edu.tr/dosyalar/stratejik_planlama_klavuzu.pdf. (21.12.2015).

- $\quad$ Gilmore, J.H., Pine, J.B. 2002, "Customer Experience Places: The New Offering Frontier", Strategy and Leadership, V.30, N.1, p. 4-11.

- Gortes, R., 2004, “Create emotional connections with customers”, Caribbean Business, 30th. September, p.41.

- Günay N., 2008, "Hizmet Pazarlamasından Deneyimsel Pazarlamaya: Bir Güzellik Merkezinde Uygulama", Nevşehir Üniversitesi, IIBF, 13. Ulusal Pazarlama Kongresi Kitabı, 25-29 Ekim 2008, Nevşehir.

- Hanna, S., \& Rowley, J., 2008, "An Analysis of Terminology Use in Place Branding", Place Branding and Public Diplomacy, Vol:4, No:1, p.61-75.

- Hirschman E.C., Holbrook, M.B., 1982, "Hedonic Consumption: Emerging Concepts, Methods and Propositions", Journal of Marketing, 48 (3), p. 92-101.

- Kabadayı E.T., Alan A.K., 2014, "Deneyimsel Pazarlama: Pazarlamadaki Artan Önemi", İsletme Araştırmaları Dergisi, 6/1, s.203-217.

- $\quad$ Karavatzis, M., Ashworth G.J., 2007, "Partners İn Coffeeshops, Canals And Commerce: Marketing The City Of Amsterdam", Cities, Vol:24, No:1, p:16-25.

- Kavaratzis, M., Ashworth, G.J., 2008, "Place marketing: how did we get here and where are we going?", Journal of Place Management and Development, Vol. 1, p.150 - 165.

- $\quad$ Keller, K. L., 1998. Strategic Brand Management: Building, Measuring and Managing Brand Equity. Prentice Hall, New Jersey. 
- Metaxas, T., 2002, "Place/City Marketing As A Tool For Local Economic Development And City’s Competitiveness: A Comparative Evaluation Of Place Marketing Policies In European Cities", Paper presented to the EURA Conference Urban and Spatial European policies, Turin, 18-20 April 2002.

- $\quad$ Özkul, E., Demirer, D., 2012, "Şehirlerin Turistik Markalaşmasında Kalkınma Ajanslarının Rolü, Bölge Planları Üzerine Bir Doküman İncelemesi", Işsletme Araştırmaları Dergisi, 4/4, s.157-181.

- Paul, D. E., 2004. "World cities as hegemonic projects: the politics of global imagineering in Montreal", Political Geography, Cilt No: 23.

- $\quad$ Pine, J.B., Gilmore J.H., 1998, "Welcome to the Experience Economy", Harvard Business Review, JulyAugust, p.97-105.

- Pine, J.B., Gilmore J.H., 1999, İş Hayatı Bir Tiyatro ve de Her Şirket Bir Sahne, Çev. Levent Cinemre, Boyner Holding Yayınları, İstanbul.

- $\quad$ Pine J.B., Gilmore, J.H. (2008), "Keep It Real: Learn to Understand, Manage and Excel at Rendering Authenticity", Marketing Management, January- February, p.18-24.

- $\quad$ Rainisto, K., 2003, "Success Factors of Place Marketing: A Study of Place Marketing Practices in Northern Europe and the United States", Helsinki University of Technology, Finland. Doctoral Dissertations.

- $\quad$ Schmitt B.H., 1999a, "Experiential Marketing", Journal of Marketing Management, V.15, p.53-67.

- Schmitt B.H., 1999b, Experiential Marketing: How to Get Customers to Sense, Feel, Think, Act, Relate, The Free Press, New York.

- Schmitt, B. H., 2003, "10 Rules Create and Manage Experiental Brands", http://www.exgroup.com/thought_leadership/articles/10_rules_to_experiential_brands.pdf. (18.05.2016).

- Trout, J., Rivkin S., 1999, Yeni Konumlandırma, Çev. Ahmet Gürsel,Profilo Yayınları, İstanbul.

- Ülgen, Hayri, Mirze, S. Kadri, 2006, İşletmelerde Stratejik Yönetim, Literatür

- Yayıncilık, İstanbul.

- Varinli İ., 2012, Pazarlamada Yeni Yaklaşımlar, Detay Yayıncılık, Ankara.

- Yükselen C., Güler E. G., 2009, Antakya Marka Kent, Detay Yayıncılık, Ankara. 


\title{
Türkiye ve Avrasya Ülkeleri Arasındaki Dış Ticaret İlişkisi: Ampirik Bir Çalışma
}

\section{Foreign Trade Relations between Turkey and the Eurasian Countries: An Empirical Study}

\author{
Ph.D. Candidate Tacinur Akça (İstanbul University, Turkey)
}

\begin{abstract}
The Eurasian Countries incorporates many economic and cultural wealth. The Eurasian countries have attracted attention all over the world with its rich oil and natural gas reserves and geopolitical situation. Due to the increasing importance of the Eurasian countries, as well as being an alternative to a political foreign policy and it has created an economically viable alternative in terms of foreign trade for Turkey. The importance of exports is increasing for the development of Turkey and Eurasia cannot be neglected as an important issue. History of the republic's foreign policy is focused on establishing good relations with the West. Of the Soviet Union collapsed and the Cold War ended after the opening of the new Turkish foreign policy became inevitable to be based in Central Asia and the Caucasus, Turkey aimed to be active in this region.

The main purpose of our study was that Turkey's foreign trade with The Eurasian Countries is to reveal the relationship. The interest in the region began in the beginning of 1990, the economic policies implemented by Turkey has tried to analyze using relevant data. İn our study, in order to analyze the economic relationship between our countries and Eurasian Countries, Turkey's import and export figures which were explained in the form of tables with the countries concerned. We will concentrate on the major Eurasian countries, especially in our work we focus on Russia, Azerbaijan, Turkmenistan, Uzbekistan, Tajikistan, Kazakhstan, Kyrgyzstan, Georgia, Ukraine and Moldova.
\end{abstract}

\section{Giris}

Avrasya ülkeleri büyük imkânlara sahip oldukları ham petrol, doğal gaz, endüstriyel hammaddeler yanında sınırlı sayıda sanayi ürünleri ihraç edebilecek durumdadırlar. İthal edilen başlıca ürünler başta temel besin maddeleri olmak üzere genel olarak tüketim mallarıdır. Türkiye ile Avrasya ülkelerinin, üretim yapıları, ihracat potansiyelleri ve ithal etmek istedikleri maddeler bakımından karşılaştırıldığında birbirlerini tamamladıkları söylenebilir (Akdiş, 1999). Özellikle soğuk savaş sonrasında Türk Dış politikasında Avrasya yeni bir alternatif olarak ortaya çıkmıştır (Tellal, 2010). Avrasya ülkelerinin sahip olduğu zengin doğal kaynak rezervleri, bilhassa jeopolitik konumu Avrupa ve ABD'nin bu bölgeye olan üzerine çekmiştir (Şanlı, 2007). Türkiye açısından Asya'nın önemi, başta ekonomik ve ticari nedenlere dayanmakla birlikte İslam ve Türk dünyasının tamamına yakınını barındırmasıyla özel bir yere sahiptir (Ekşi, 2010:399). Avrasya Ülkeleri ile Türkiye arasındaki ekonomik ve ticari ilişkiler 1992 sonrası başlamış bugüne kadar artan bir hızla gelişme göstermiştir (Solak, 2003; Yüksel:2010).

Türkiye 2000'li yıllara ağır ekonomik krizler eşliğinde girmiştir. Ak Parti ile yeni bir döneme giren Türkiye Kafkasya-Orta Asya ile olan ilişkilerini yeniden yoğunlaştırmıştır (Denizhan, 2010). Türk dış politikasının ana eksenleri değişmiş değildir ve Türkiye'nin Batı bağlantısı devam etmektedir. Özellikle Soğuk Savaş sonrasında Sovyetler Birliğgi'nin yıkılmasından sonra, Türk dış politikasında yeni seçenek Avrasya Ülkeleri olmuştur (Erel, 2010). Avrasya, Türkiye için siyasi bir dış politika seçimi olmasından öte, dış ticareti açısından giderek artan öneminden dolayı ekonomik bir zorunluluk haline gelmiştir. Bilhassa, Türkiye için Avrasya ihracata dayalı gelişimine katkı sağlaması açısından stratejik bir öneme sahiptir. Öncelikle, Avrasya Türkiye'nin enerji ihtiyacını karşılamaya yönelik petrol ve gaz üreticisidir ve Türkiye'nin ihracatında sağlıklı bir yapı kazandırabilecek gelişmekte olan pazarlardandır (Bilgin, 2005). Türkiye'nin önündeki en önemli ekonomik tehdit önemli ölçüde elektrik ürettiği doğal gazın yüksek fiyatlı olmasıdır ve doğal gaz fiyatlarının yüksekliği Türkiye'nin yüksek fiyatı enerji kullanmasını beraberinde getirmektedir. Bu durum Türkiye açısından ihracata yönelen ürünler için önemli bir maliyet dezavantajı oluşturmaktadır (Bilgin, 2005:104).

Bu makale, özellikle Sovyetler Birliği'nin dağılmasını izleyen süreçte Türkiye ile seçilmiş Avrasya Ülkeleri arasındaki ekonomik ve ticari ilişkiler incelemeyi amaçlamaktadır. Makalenin birinci kısmında Türkiye ve Avrasya ülkeleri arasındaki ekonomik ilişkilerin düzeyi anlatılmaya çalışılmıştır. İkinci kısımda ise, Türkiye ve Avrasya Ülkeleri arasındaki dıș ticaretin son on yıldaki seyri ilgili dış ticaret verileri ile açıklanmaya çalışılmıştır.

\section{Türkiye ile Avrasya Ülkeleri Arasındaki Ekonomik İlişkiler}

Türkiye ve Rusya arasında Soğuk Savaş dönemi boyunca yaşanan inişli çıkışlı siyasi dönemler ekonomik ilişkilerin de seyrini etkilemiştir ve ekonomik ilişkiler genelde siyasi ilişkilerin paralelinde bir gelişme göstermiştir. 
Türkiye'nin önemli bir ticaret ortağı olan Rusya ile ekonomik ilişkiler 1990 sonrasında Birliğin dağılmasıyla birlikte artarak devam etmiştir (Sapmaz, 2008). Türkiye ve Rusya'nın, ticari ve ekonomik ilişkilerinin gelişmesindeki en önemli avantajı coğrafi olarak yakın iki ülke olmasıdır. Rusya'nın 1998'de yaşadığı ekonomik kriz sonrası, Türkiye ile olan dış ticaret hacmi önemli ölçüde daralmıştır. 2000 sonrası dönemde ise iki ülke arasındaki ticaret yeniden ivme kazanmıştır (Ekonomi Bakanlığı, 2016). 2015 yılında Rus ekonomisinin \% 4 civarında daralmasıyla birlikte Türkiye ile ikili ticaret, bu durumdan nasibini alarak gerilemeye başlamıştır. Rusya ile Türkiye arasında 24 Kasım 2015 tarihinde uçak krizi meydana gelmiştir. Bu durum sonrasında Rusya, Türkiye'ye karşı birçok ekonomik tedbir uygulamaya başlamıştır. Tarım ürünlerimize ithalat yasağı koyması, Türk mallarının gümrüklerde olağandışı kontrollere tabi tutulması, Türk vatandaşlarının istihdam edilmelerine kısıtlama koyması, 1 Ocak 2016 tarihinden itibaren vize muafiyet anlaşmasını tek taraflı olarak askıya alması dış ticaretin daha da daralmasına neden olduğu gibi, Rusya' daki yatırım ve müteahhitlik hizmetlerinde durağanlığa yol açmıştır (Moskova Büyükelçiliği, 2016).

Azerbaycan'ın bağımsızlığını kazanması akabinde uluslararası toplumla birleşmek için yoğun ilişkiler içerisine girdiği ilk ülkelerden biri Türkiye olmuştur (Kalaycı, 2013:47). Azerbaycan dış ticaret politikasında en belirleyici unsur enerjidir. Petrol ve doğalgaz Azerbaycan'ın ihracatında yüzde 90 paya sahiptir. İthalatında ise yüzde 80 civarında mamul maddeler yer almaktadır. Türkiye'nin Azerbaycan'a ihracatı; ihraç ürünlerinin bu ülkede tanınmaya başlaması, Azerbaycan'ın en önemli ticaret partnerlerinden biri olan İran'ın ihraç ürünlerinin Türk ihraç ürünlerine kıyasla düşük kalitede olması, Azerbaycan-Rusya Federasyonu arasındaki Kuzey Kafkas demiryolunun kapalı olması, Türk şirketlerinin Azerbaycan piyasasında şube açmak suretiyle Türkiye'den ithalat yapması ve bu malları iç piyasada pazarlaması gibi nedenlerle 1993 yılından bu yana yükselme eğilimi göstermektedir. Ancak, yüksek gümrük vergisi oranları nedeni ile iki ülke dış ticareti potansiyelinin gerisinde kalmaktadır (Ekonomi Bakanlığ 1 2016). Azerbaycan ekonomisinde en önemli sektör olan enerji sektöründe son yıllarda ülkemiz aktif bir politikalar izlemekte ve bu kapsamda Türkiye, hem Azerbaycan petrol ve doğalgaz rezervlerinin araştırılması, geliştirilmesi ve işletilmesinde hem de söz konusu rezervlerin dünya piyasalarına nakline yönelik projelerde önemli rol oynamaktadır (Mikail, 2007). Azerbaycan genellikle 2000'li yıllara kadar sermaye ithal eden taraf olarak görünse de, 2000'li yıllardan itibaren aynı zamanda sermaye ihraç eden tarafa da dönüştüğü söylenebilir. Türkiye'ye yapılan yatırımların genelde enerji sektörüne aktarılması da Türkiye ekonomisinin bu sektörünün güçlenmesine yardım edecek niteliktedir. Son yıllarda Türkiye, Azerbaycan ekonomisine doğrudan yatırım yapmakla birlikte, aynı zamanda milyarlarca dolar hacminde müteahhitlik hizmetleri de gerçekleştirmiştir (Bağırzade, 2014).

Türkiye ile Türkmenistan arasındaki ticari ilişkiler, özellikle müteahhitlik alanında 2008 yılında rekor seviyelere ulaşan taahhütlerle birlikte hızlı bir artış ivmesi kazanmıştır. İnşaat alanında büyük oranda Türk menşeli malzemelerin kullanılması, Türkiye'den yapılan ihracatı artırmıştır. Bununla birlikte, piyasada Türk mallarının kalitesi nedeniyle artan talebe bağlı olarak giyim ve gıda sektöründe mal hareketleri de artmıştır. Ayrıca, bavul ticareti olarak da adlandırılan yolcu beraberi ticarette de büyük bir yoğunluk gözlemlenmektedir (Ekonomi Bakanlığı, 2016).

Özbekistan'ın 1991 yılında bağımsızlığını tanıyan ilk ülke Türkiye olmuştur. Türk ortaklı şirketler başta tekstil sektörü olmak üzere, otomotiv, gıda, deri, temizlik malzemeleri ve diğer sektörler üzerine kurulmuştur. Önceki yıllarda ülkemiz yatırımlarının ABD, İngiltere, Almanya, Güney Kore ve Çin'den sonra altıncı sırada yer almaktadır (Dışişleri Bakanlığı, 2016). Türkiye ve Özbekistan arasındaki ticari ve ekonomik ilişkilerle ilgili, bir takım siyasi gerginliklerden ötürü olumlu gelişmelerden söz etmek pek mümkün olmamaktadır. Buna rağmen 2000 sonrası dönemde Türkiye-Özbekistan arası ticaret hacmi yıllar itibarıyla istikrarlı biçimde artış göstermektedir. Her iki ülkenin de yüksek üretim ve tüketim düzeyine sahip olması, kültürel yakınlıklar ve son yıllarda gerçekleşen siyasi sıcak temaslar ileri ki dönemlerde, ticari ve ekonomik ilişkilere pozitif olarak yansıyacaktır (Karyımşakov, 2013).

Orta Asya Türk Cumhuriyetleri içinde Kazakistan hâlihazırda en elverişli iş ortamını sağlayan ülkelerden biridir. Fakat ülkede çok çeşitli firsatlar bulunmakla birlikte, bürokrasinin fazla olması, yasal altyapının henüz tamamlamamış olması bundan dolayı da mevzuatın çok sık değişikliklere uğraması ve uluslararası iş kültürünün henüz yeterince yerleşmemiş olması gibi var olan zorluklar iş ortamını elverişsiz hale getirmektedir. Ülkede üretilen mallar ihtiyacı karşılayacak yeterlilikte değildir bu yüzden ülkeye ihracat gerçekleştiren ya da ihracatta bulunmayı hedefleyen Türkiye'deki üretici firmaların rekabetin yoğun olduğu bu pazarda uzun vadede kalabilmek için üretim faaliyetine geçmeleri gerekebilecektir. Kazakistan ithalata bağımlı bir dış ticaret yapısına sahip bir ülke olmasından dolayı, üretimde çeşitliliğin sağlanması için özellikle tüketim malları üretimini teşvik edici yönde uygulamalar yürütmektedir. Taşımacılıkla ilgili yaşanan sorunlar Türkiye-Kazakistan ticari ilişsilerinin gelişimini olumsuz yönde etkilemektedir. İki ülke arasındaki uzaklık nedeni ile taşımacılık maliyetleri ülkeye ihracat sırasında ortaya çıkan maliyetlerin önemli bir bölümünü oluşturmaktadır. Kazakistan'ın geniş topraklara sahip olması nedeni ile ülke içi taşımacılık da fiyatlandırmada büyük paya sahiptir. Ülke içi taşımacılık, ülkenin çok geniş topraklara sahip olması, kentlerin birbirine çok uzak mesafelerde konumlanması ve karayollarında tesis bulunmaması nedeni ile zordur. Türkiye açısından Kazakistan'ın uzak bir pazar olması ve ayrıca ülke içindeki taşımacılığın da zor olması büyük bir problem teşkil etmektedir. Bunlara ilaveten Gümrük Birliğgi Anlaşması'na 
taraf ülkelere sağlanan söz konusu avantaj ülkemiz ürünlerinin rekabet edebilirliğini olumsuz yönde etkilemektedir (Ekonomi Bakanlığı, 2016). Türkiye ile Kazakistan arasında dış ticaret ilişkileri 1992 yılından itibaren hız kazanmış ve iki ülke arasında dış ticaret hacmi yıllar itibariyle artış göstermiştir (Solak, 2003).

Kırgızistan ve Türkiye arasında, ekonomik ilişkilerin geliştirilmesi amacıyla, 1995 yılında bir anlaşma imzalanarak ticari ve ekonomik işbirliği komisyonu kurulmuştur ve periyodik toplantılarla belirli programlar uygulanmaktadır. 2002 yılında iki ülke arasında aynı amaçlarla uzun vadeli bir program kabul edilmiştir (Karyımşakov, 2013). Türkiye Kırgızistan ile ticaret hacminin arttırmak için öncellikli olarak taşıma maliyetlerinin azaltılması ile ulaştırma koşullarının iyileştirilmesi, karayolunun yanı sıra alternatif ulaşım araçları kullanılması gerekmektedir. Bununla birlikte gümrük işlemlerindeki kayıt dışı harcamaların azaltılması, ticaret hacmini arttırılması için önemli bir etken olacağı düşünülmektedir (Ekonomi Bakanlığı, 2016).

Bağımsızlığını kazanmasından sonra özellikle 2000'li yıllardan itibaren Gürcistan ile Türkiye arasındaki ekonomik ilişkiler ivme kazanmıştır. Türkiye-Gürcistan arasındaki ticaret sürekli bir artış eğilimi göstermesine rağmen iki ülke arasındaki dış ticaret rakamları ve Türkiye'nin Gürcistan'daki yatırımlarının miktarı potansiyelin çok altındadır. Türk firmalarının Gürcistan faaliyetlerindeki temel sıkıntısı ise finansman sorununun olmasıdır. Ayrıca Gürcistan'da modern bankacılık sisteminin yerleşmemiş olması nedeniyle nakit hareketlerinde ve akreditif işlemlerinde sorunlarla karşılaşılmaktadır. Bunun yanında kambiyo mevzuatının yetersizliği para transferlerinde zorluklara neden olmaktadır. Ticari konuları ilgilendiren mevzuatın pek çok konuda henüz tam olarak netlik kazanmamış olması ve sıklıkla değiştirilmesi gibi nedenlerden dolayı Türkiye ve Gürcistan arasındaki ticari ilişkilerin gelişimini olumsuz yönde etkilemektedir (Ekonomi Bakanlığı, 2016).

Türkiye ve Ukrayna arasındaki ticaret hacmi 2008 Krizine kadar artış göstermiştir. Türkiye’nin elverişli coğrafi konuma sahip olması bununla birlikte Ukrayna'ya ulaşımının uygun ve gelişmiş durumda bulunması, iki ülke arasındaki ticaretin gelişmesine büyük katkı sağlamaktadır (Ukrayna Ankara Büyükelçiliği, 2016). Ukrayna Devlet Başkanı Viktor Poroşenko ve Cumhurbaşkanı Recep Tayyip Erdoğan arasında Mart 2016'da düzenlenen ortak basın toplantısında, iki ülke arasında gerçekleştirilecek olan serbest ticaret anlaşmasının, 2016 yılının sonuna kadar sonuçlandırılması öngörülmüştür. Ayrıca yapılan basın toplantısında 2023 yılına kadar ikili ticaret hacminin 20 milyar dolara çıkarılması gibi hedeflerden söz edilmiştir. Özellikle Türkiye ve Rusya arasında var olan sorunlardan dolayı Ukrayna ile ilişkiler büyük bir önem arz etmektedir.

Türkiye'nin Tacikistan ile olan ekonomik ve ticari ilişkileri diğer Avrasya ülkelerine kıyasla düşük seviyelerde kalmaktadır. Tacikistan doğal kaynaklara sahip olmasına rağmen dağlık bir konumdadır. Uzun yıllar süren iç savaş, ulaşımın oldukça güç olması ve bürokratik engeller ekonomik ilişkilerin önünde engel teşkil etmektedir. Türkiye ile Tacikistan arasındaki taşımacılık, diğer ülkeler üzerinden yapılmasından dolayı transit ülkelerde yaşanan sorunlar ticareti olumsuz yönde etkilemektedir (Ekodialog, 2016). Rusya'yı etkisi altına alan ekonomik krizden en çok etkilenen ülkelerden biri de Tacikistan olmuştur. Ülke ekonomisinin büyük ölçüde tarıma dayalı olması endüstrinin gelişmemesine neden olmuştur. Tüm bu gelişmeler Türkiye ve Tacikistan arasındaki ekonomik ve ticari ilişkilerin kısıtlı kalmasına neden olmaktadır (Akçalı, 2005).

Avrasya Ülkelerinin çok zengin kaynaklara sahip olmalarına karşı, kişi başına gelirin düşük olması ve kaynaklarını iyi işletememiş olmaları ticaret potansiyellerini düşürmektedir (Alagöz, vd, 2004). Türkiye ile dış ticaretleri genel olarak çok düşük düzeylerde kalmıştır. Ancak genel olarak değerlendirdiğimizde 2003-2008 döneminde düşük düzeyde de olsa artışlar gözlemlenmiştir. 2009 sonrası dönemde özellikle küresel krizin etkisiyle, bu ülkelerde hem ihracat hem de ithalatta azalmalar yaşanmıştır. 2008 Krizi sonrası dünya piyasalarında petrol ve doğal gaz fiyatlarındaki düşme nedeniyle, çoğu Avrasya ülkesinde ihracat gelirlerini azaltmış ve büyüme oranlarını düşürmüştür. Buna rağmen yaşanan krizin, Avrasya Ülkelerinin Türkiye ile olan ticari ilişkilerini fazla etkilemediğini söyleyebiliriz (Narin ve Marşap, 2010). Türkiye ve Avrasya Ülkeleri arasındaki dış ticaret verilerini incelendiğimizde, özellikle bağımsızlık sonrası dönemde, Türk Cumhuriyetleri arasındaki ticari ilişkilerin her yıl daha da geliştiğini söyleyebiliriz (Bağırzade, 2009).

\section{Türkiye ve Avrasya Ülkeleri Arasındaki Dıș Ticaret Değerleri}

\begin{tabular}{|l|l|l|l|l|l|l|l|l|l|l|}
\hline & $\mathbf{2 0 1 5}$ & $\mathbf{2 0 1 4}$ & $\mathbf{2 0 1 3}$ & $\mathbf{2 0 1 2}$ & $\mathbf{2 0 1 1}$ & $\mathbf{2 0 1 0}$ & $\mathbf{2 0 0 9}$ & $\mathbf{2 0 0 8}$ & $\mathbf{2 0 0 7}$ & $\mathbf{2 0 0 6}$ \\
\hline İhracat & 144 & 158 & 152 & 152 & 135 & 114 & 102 & 132 & 107 & 86 \\
\hline İthalat & 207 & 242 & 252 & 237 & 241 & 186 & 141 & 202 & 170 & 140 \\
\hline
\end{tabular}

Tablo 1. Yillar İtibariyle Türkiye'nin İhracat ve İthalat Miktarlarl (Milyon \$) Kaynak: TÜIK 


\begin{tabular}{|l|c|c|c|c|c|c|c|c|}
\hline & \multicolumn{4}{|c|}{ İhracat } & \multicolumn{4}{c|}{ İthalat } \\
\hline Ülkeler/Yllar & $\mathbf{2 0 1 5}$ & $\mathbf{2 0 1 4}$ & $\mathbf{2 0 1 3}$ & $\mathbf{2 0 1 2}$ & $\mathbf{2 0 1 5}$ & $\mathbf{2 0 1 4}$ & $\mathbf{2 0 1 3}$ & $\mathbf{2 0 1 2}$ \\
\hline Rusya & 3589 & 5945 & 6994 & 6680 & 20400 & 25293 & 25064 & 26625 \\
\hline Azerbaycan & 1899 & 2876 & 2961 & 2587 & 232 & 291 & 334 & 340 \\
\hline Ukrayna & 1121 & 1730 & 2191 & 1830 & 3448 & 4272 & 4515 & 4392 \\
\hline Türkmenistan & 1858 & 2231 & 1957 & 1480 & 557 & 623 & 653 & 303 \\
\hline Gürcistan & 1109 & 1444 & 1246 & 1254 & 223 & 232 & 201 & 180 \\
\hline Kazakistan & 750 & 978 & 1039 & 1068 & 1390 & 2453 & 3106 & 3371 \\
\hline Özbekistan & 1115 & 603 & 562 & 450 & 134 & 780 & 815 & 813 \\
\hline Kirgizistan & 295 & 421 & 388 & 257 & 77 & 66 & 37 & 45 \\
\hline Tacikistan & 162 & 277 & 283 & 235 & 203 & 161 & 371 & 345 \\
\hline Moldova & 202 & 287 & 276 & 224 & 217 & 247 & 261 & 135 \\
\hline
\end{tabular}

Tablo 2. Türkiye'nin Ülkeler Ittibariyle Yapılan İhracat ve Itthalat Miktarları (Milyon \$) Kaynak: TÜIK, T.C. Ekonomi Bakanlığ

\begin{tabular}{|l|c|c|c|c|c|c|c|c|c|c|}
\hline Ülkeler & $\mathbf{2 0 1 5}$ & $\mathbf{2 0 1 4}$ & $\mathbf{2 0 1 3}$ & $\mathbf{2 0 1 2}$ & $\mathbf{2 0 1 1}$ & $\mathbf{2 0 1 0}$ & $\mathbf{2 0 0 9}$ & $\mathbf{2 0 0 8}$ & $\mathbf{2 0 0 7}$ & $\mathbf{2 0 0 6}$ \\
\hline Rusya & 2,5 & 3,8 & 4,6 & 4,4 & 4,4 & 4,1 & 3,1 & 4,9 & 4,4 & 3,8 \\
\hline Azerbaycan & 1,3 & 1,8 & 2,0 & 1,7 & 1,5 & 1,4 & 1,4 & 1,3 & 1,0 & 0,8 \\
\hline Ukrayna & 0,8 & 1,1 & 1,4 & 1,2 & 1,3 & 1,1 & 1,0 & 1,7 & 1,4 & 1,3 \\
\hline Türkmenistan & 1,3 & 1,4 & 1,2 & 1,0 & 1,1 & 1,1 & 1,0 & 0,5 & 0,31 & 0,33 \\
\hline Gürcistan & 0,8 & 0,9 & 0,8 & 0,8 & 0,8 & 0,7 & 0,7 & 0,8 & 0,6 & 0,5 \\
\hline Kazakistan & 0,5 & 0,6 & 0,7 & 0,7 & 0,7 & 0,7 & 0,6 & 0,68 & 1,00 & 0,82 \\
\hline Özbekistan & 0,8 & 0,4 & 0,3 & 0,3 & 0,3 & 0,2 & 0.3 & 0,25 & 0,20 & 0,22 \\
\hline Kirgizistan & 0,2 & 0,3 & 0,2 & 0,2 & 0,1 & 0,1 & 0,1 & 0,14 & 0,16 & 0,15 \\
\hline Tacikistan & 0,1 & 0,2 & 0,2 & 0,2 & 0,1 & 0,1 & 0,1 & 0,1 & 0,1 & 0,1 \\
\hline Moldova & 0,1 & 0,2 & 0,2 & 0,1 & 0,2 & 0,1 & 0,1 & 0,2 & 0,1 & 0,1 \\
\hline
\end{tabular}

Tablo 3. Avrasya Ülkeleri ve Türkiye Arasında Yapılan İhracatın Toplam İçindeki Payı (\%) Kaynak: TÜİK, T.C. Ekonomi Bakanliğg

\begin{tabular}{|l|c|c|c|c|c|c|c|c|c|c|}
\hline Ülkeler & $\mathbf{2 0 1 5}$ & $\mathbf{2 0 1 4}$ & $\mathbf{2 0 1 3}$ & $\mathbf{2 0 1 2}$ & $\mathbf{2 0 1 1}$ & $\mathbf{2 0 1 0}$ & $\mathbf{2 0 0 9}$ & $\mathbf{2 0 0 8}$ & $\mathbf{2 0 0 7}$ & $\mathbf{2 0 0 6}$ \\
\hline Rusya & 9,8 & 10,4 & 10,0 & 11,3 & 9,9 & 11,6 & 13,8 & 15,5 & 13,8 & 12,8 \\
\hline Kazakistan & 6,8 & 10,1 & 7,0 & 8,7 & 8,5 & 7,5 & 7 & 9,2 & 7,6 & 7,1 \\
\hline Özbekistan & 0,6 & 3,2 & 3,2 & 3,4 & 3,3 & 4,6 & 3 & 2,8 & 3,6 & 2,2 \\
\hline Türkmenistan & 2,7 & 2,6 & 2,6 & 1,3 & 1,3 & 0,2 & 0,2 & 0,19 & 0,14 & 0,14 \\
\hline Ukrayna & 1,7 & 1,8 & 1,8 & 1,9 & 2,0 & 2,1 & 2,2 & 3,0 & 2,7 & 2,2 \\
\hline Tacikistan & 1 & 0,7 & 1,5 & 1,5 & 1,4 & 1,5 & 0,8 & 0,7 & 0,8 & 0,8 \\
\hline Moldova & 0,1 & 0,1 & 0,1 & 0,5 & 0,5 & 0,6 & 0,6 & 0,3 & 0,3 & 0,2 \\
\hline Kirgizistan & 0,4 & 0,3 & 0,1 & 0,2 & 0,2 & 0,1 & 0,2 & 0,2 & 0,2 & 0,2 \\
\hline Azerbaycan & 0,1 & 0,1 & 0,1 & 0,1 & 0,1 & 0,1 & 0,61 & 0,46 & 0,19 & 0,27 \\
\hline Gürcistan & 0,1 & 0,1 & 0,1 & 0,1 & 0,1 & 0,2 & 0,2 & 0,3 & 0,2 & 0,2 \\
\hline
\end{tabular}

Tablo 4. Avrasya Ülkeleri ve Türkiye Arasında Yapılan İthalatın Toplam İçindeki Payı (\%) Kaynak: TÜIK, T.C. Ekonomi Bakanlı̆̆l

ABD’de yaşanan 2008 küresel mali kriz nedeni ile Rusya ve Türkiye arasındaki dış ticaret hacmi 2009 yılında $\% 39$ oranında azalarak, hem ihracatta hem de ithalatta gerilemeler yaşanmıştır. Türkiye'nin Rusya'ya olan ihracatı $\%$ 51, ithalatı ise \% 37 oranında düşmüştür. 2010 yılında Rusya'ya olan ihracat $\% 45$ oranında ithalat ise $\% 10$ oranında artmıştır. 2011 yılında Rusya'ya yapılan ihracat 2010 yılına göre \% 29,5 oranında, ithalat ise \% 11 oranında artmıştır. Ülkeye ihracatımız 2012 yılında 2011 yılına göre \% 11,5, ithalatımız ise bir önceki yıla göre \% 10,8 artmıştır. 2013 yılında ihracatımız 2012 yılına kıyasla \% 4,2 artarken, ithalatımız ise \% 5,9 oranında daralmıştır. 2014 yılında Rusya'ya yapılan toplam ihracat, ülke ekonomisindeki yavaşlama ve Rublenin değer kaybına bağlı olarak ithalatın daralması nedeni ile \% 14,6 oranında düşüş yaşamıştır (Ekonomi Bakanlığı, 2016). 2015 yılı itibariyle Rusya, Türkiye'nin toplam ihracatında 2. Sıradadır ve Rusya'ya ihracatımızda yıllar itibariyle son on yılda en düşük seviyelere gelerek 2015 yılında \%2,5 olarak gerçekleşmiştir. En çok İhracat yaptığımız kalemler; turunçgiller, binek otomobilleri ve diğer motorlu araçlar, domates ve karayolu taşıtları için aksam, parça ve aksesuarlardır. Türkiye'nin ithalat yaptığı ülkeler arasında Rusya 3.Sırada yer almaktadır. Rusya'ya olan ithalatta, ihracatta da olduğu gibi 2015 yılında son on yılda en düşük seviyelerinden birini alarak yaklaşık \%10 civarında kalmıştır. Rusya'dan en çok ithal ettiğimiz kalemler ise petrol yağları, buğday ve mahlût, işlenmemiş alüminyum ve petrol gazlarıdır. 
Azerbaycan, 2015 yılı ihracatımızda son yılların en düşük payını alarak \%1,3 olarak gerçekleşmiştir. Azerbaycan'dan yaptığımız ithalat ise 2015 yılında ve önceki yıllarda yaklaşık \%0,1'lik bir oran ile düşük seviyelerde kalmaktadır. Türkiye'nin Azerbaycan'a olan ihracatındaki başlıca kalemler; makineler ve mekanik cihazlar ve yedek parçaları, demir ve çelikten eşyalar, elektrikli makine ve cihazlar ve yedek parçaları, mobilya, otomotiv, optik alet ve cihazlar, motorlu kara taşıtları ve yedek parçaları, mineral yakıtlar, petrol ve türevleridir. Türkiye'nin Azerbaycan'dan yaptığı başlıca ithalat kalemleri ise; işlenmiş alüminyum, kabuklu meyveler, asiklik alkoller vb.dir.

Türkiye'nin Ukrayna'ya yapmış olduğu ihracat ve ithalat rakamlarına baktığımızda, yıllar itibariyle azalan bir seyir izleyerek 2015 yılında yaklaşık \%1'lik bir değer almıştır. Ukrayna'ya yapmış olduğumuz başlıca ihracat kalemleri ise, tekstil elyafı ve mamulleri, sebzeler, meyveler ve mamulleri, giyim eşyası ve aksesuarlarıdır. Ukrayna'dan yapılan ithalatta ise yıllar itibariyle aynı seviyelerde kalarak 2015 yılında yaklaşık \%2 olarak gerçekleşmiştir ve ithal edilen başlıca ürün grupları demir ve çelik, bitkisel yağlar, gübrelerdir.

Türkmenistan 2015 ve 2014 yılları toplam ihracatımızda son yılların en yüksek seviyesiyle \%1,4olarak gerçekleşmiştir. Başlıca ihraç kalemleri sırasıyla, metallerden nihai ürünler, elektrikli makine ve cihazlardır. Türkmenistan'a gerçekleştirilen ithalat son yıllara kıyasla en yüksek artışını göstererek 2015 yılında yaklaşık \%3 olmuştur. Türkmenistan'dan yapılan en çok ithalat ürünleri, tekstil elyafı ve mamulleri, tekstil lifleri, taşkömürü katranı ve ham petrolden üretilen ürünlerdir.

2015 yılında, Özbekistan'a olan ihracatımız yaklaşık \%1 ile son yılların en yüksek seviyesine ulaşmıştır. En çok ihraç ettiğimiz ürünler ise tekstil elyafı ve mamuller, İthal belirli sanayi kollarında kullanılan makine ve cihazları ve kara ulaşım araçlarıdır. Özbekistan'dan Türkiye'ye yapılan ithalat değeri 2015 yılında yok denecek kadar düşük seviyelerde kalmıştır. En çok ithal ettiğimiz başlıca ürünler ise demir dışı metaller, mamulleri, taşkömürü katranı ve ham petrolden ürünlerdir.

Tacikistan ve Türkiye arasındaki dış ticaret ilişkileri sınırlı düzeyde kalmıştır. Türkiye'nin Tacikistan’a olan ihracatımız 2015 yılında \%0,1 olarak gerçekleşmiştir. En çok ihracat malı elyafı ve mamulleridir.2015'de Tacikistan'dan yapılan toplam ithalatımız yaklaşık olarak \% 1 ,'dir ve en çok ithal edilen ürün ise demir dışı metaller ve mamulleridir.

Son on yılda Kazakistan'a yapılan ihracat 2015 yılında düşüş gösterse de çok fazla değişkenlik göstermemiştir ve\%0,6 olarak gerçekleşmiştir. En çok ihraç mallarımız ise çeşitli mamul eşyaları, giyim eşyası ve aksesuarlarıdır. Rusya'dan sonra en çok ithal ürün satın aldığımız Avrasya ülkesidir ve bu oran 2015 yılında düşüş yaşayarak yaklaşık \% 7 olarak gerçekleşmiştir. Başlıca ithal edilen ürün grupları arasında taşkömürü katranı ve ham petrolden ürünler yer almaktadır.

Kırgızistan'a olan ihracat değerlerimiz son yıllarda ortalama olarak aynı değerlerde kalarak 2015 yılında \%0,2 olarak gerçekleşmiştir ve başlıca ihracat malları giyim eşyası ve aksesuarları, tekstil elyafı ve mamulleridir. 2015 yılında Türkiye'nin Kırgızistan'dan yaptığı toplam ithalatımız son yıldaki en yüksek seviyesindedir ve \%0,4 değerindedir. İthal edilen mallar arasında sebzeler, meyveler ve mamuller yer almaktadır.

Gürcistan'a ihracatımız son yıllarda aynı değerlerde kalarak son yıllarda ortalama olarak \%1dolaylarındadır. Gürcistan'a yaptığımız en çok ihraç ürünleri ise demir-çelik ve metallerden nihai ürünlerdir. Gürcistan'dan yapılan mal ithalatı düşük seviyelerde kalmıştır. Başlıca ithal edilen ürünler; metal cevherleri, kırıntı, döküntü, hurdaları, giyim eşyası ve aksesuarlarıdır.

Moldova'ya yapılan ihracat yıllar itibariyle ortalama olarak bir değişiklik göstermeyip ortalama \%0,1'lerde kalmıştır. Başlıca en çok ihracat mallarımız ise tekstil elyafı ve mamulleri, sebzeler, meyveler ve mamulleridir. Moldova'dan 2015 yılında yaptığımız toplam ithalatımız \%0,1 seviyesindedir. En çok ithal edilen ürünler ise yağlı tohumlar ve meyvelerdir.

\section{Sonuç}

Sovyetler Birliğgi'nin dağılması sonrasında Avrasya Ülkeleri ile yapılan toplam ihracat ve ithalat değerleri düzenli bir artış göstermiştir. Ekonomik ilişkilerin olumlu gitmesine rağmen istenilen seviyenin çok altında kalmaktadır ve şüphesiz ki bu oranlar oldukça yetersizdir. Özellikle 1990 sonrası dönemde Türkiye'nin Avrasya ile olan ekonomik ilişkilerin önü açılmıştır önemli bir ivme kazanmıştır. Avrasya ülkelerinin ihtiyacı olan mal ve hizmetler Türkiye tarafından rahatlıkla karşılanabilecekken, Türkiye'nin ihtiyacı olan birçok mal bu ülkelerden temin edilebilir. Türkiye'nin en önemli ekonomik problemlerinden bir tanesi de cari açık problemidir. Cari açığın en önemli nedenlerin biri ise Türkiye'nin büyük ölçüde yapmış olduğu enerji ithalatıdır. Avrasya Ülkelerinin çoğu zengin enerji kaynaklarına sahiptir. Bu bağlamda Avrasya Ülkeleriyle enerji ihtiyacı karşılamaya yönelik yapılacak işbirlikleri Türkiye'ye ekonomik kazançlar sağlayacaktır.

Avrasya ülkeleri 1990 sonrası dönemde, bağımsızlıklarının hemen ardından, Türkiye ile olan dış ticaret hacimlerinde ilk yıllara kıyasla 2000'li yıllarda önemli ölçüde ilerlemeler kaydetmiştir fakat bu ilerlemenin henüz istenen düzeyde gerçekleşmediğini söyleyebiliriz. Özellikle 2015 yılında Rusya ile yaşanan siyasi gerginliklerin önümüzdeki süreçte de devam edeceği öngörülmektedir. Bu bağlamda, komşu ülkeler bazında Türkiye'nin önünde 
diğer Avrasya ülkelerinin önemi ekonomik açıdan daha da önemli hale gelmiştir diyebiliriz. Çoğu Avrasya ülkesiyle bulunan gerek kan bağımız gerekse kültürel yakınlıklarımız, bu ülkelerle olan ilişkilerimizin, daha da olumlu ilerlemelerin gerçekleşmesi bağlamında önem arz etmektedir. Türkiye'nin önümüzdeki süreçte izleyeceği ekonomi politikalarında bu husus önemli bir etkendir ve diğer yandan bu yöndeki çalışmalar sürdürülmeye devam edilmektedir.

\section{Kaynakça}

- Akçalı, 2005. "Bağımsızlıktan Günümüze Türkiye-Tacikistan İlişkileri”, Uluslararası İlişkiler Dergisi, Cilt:2, Say1: 5, s.138.

- Akdiş, 1999. "Orta Asya Türk Cumhuriyetleri İle Olan Ekonomik Sosyal Kültürel İlişkiler-Bölgeye Yabancı İlgisi ve Beklentiler”, Dış Ticaret Müsteşarlığg, Dış Ticaret Dergisi, Yıl:14, Sayı: 4, s.1.

- Alagöz, Yapar, Uçtu, 2004. “Türk Cumhuriyetleri İle İlişkilerimize Ekonomik Açıdan Bir Yaklaşım”, Selçuk Üniversitesi Sosyal Bilimler Enstitüsü Dergisi, Sayı: 12, s.61.

- Bağırzade, 2009. “Türk Cumhuriyetleri Arasında Ticari İşbirliği: Mevcut Durum Ve Perspektifler”, 9.Türk Dünyası Ekonomi Bilişim ve Kültür Forumu, s.45.

- Bağırzade, 2014. “Azerbaycan-Türkiye Ortak Ekonomik Projeleri Ve Bölgesel Yansımaları”, Ekoavrasya Dergisi, sayı:26, s.4.

- Bilgin, 2007. “Türkiye'nin İhracata Yönelik Ekonomi Politikalarında Avrasya’nın Stratejik Önemi”, Türkiye'nin Avrasya Macerası 1989-2006, Derleyen: Mustafa Aydın, Nobel Yayınları, Ankara, s.74.

- DEMIRAĞ, 2016. Soğuk Savaş Sonrası Türkiye'nin Orta Asya Siyasetinde Geldiği Son Nokta, www.jeopolitik.org/index2.php?option=com_content\&do pdf $=1 \&$ id $=22$

- $\quad$ Denizhan, 2010. “Türkiye'nin Kafkasya ve Orta Asya Politikası ve TİKA”, Sosyal ve Beşeri Bilimler Dergisi, Cilt:2 Sayı:1, s.17.

- Dişişleri Bakanlığı, 2016. Özbekistan Ülke raporu, http://www.mfa.gov.tr/ozbekistan-cumhuriyetiekonomisi.tr.mfa

- $\quad$ Ekodialog, 2016. Türkiye - Tacikistan Ticareti, http://ekodialog.com/Konular/Avrasya\%20Ulkeleri/turkiye_tacikistan_ticareti.html

- Ekonomi Bakanlığı, 2016. Dış İlişkiler, https:/www.ekonomi.gov.tr/portal/faces/home/disIliskiler/ulkeler/ulke masalari

- $\quad$ Ekşi, 2010. “Türkiye’nin Asya Politikası”, 5.Uluslararası Türk-Asya Kongresi, s.397.

- Erel, 2010. “Türk Dış Politikasında Avrasyacılık”, Yeni Dönemde Türk Dış Politikası, Editörler: Osman Bahadır Dinçer, Habibe Özdal, Hacali Necefoğlu, Usak Yayınları, Ankara, s. 101.

- Kalaycı, 2013. "Kafdağı'nın Önündeki Ekonomi: Modernleşen Azerbaycan”, Avrasya Etüdleri Dergisi, Sayı:44, s.27.

- Karyımşakov, 2013. “Türkiye ve Kırgızistan Arasındaki Ekonomik İlişkiler: 20 Yı1 İşbirliği ve Gelecek İçin Öngörüler”, Türkiye Türk Cumhuriyetleri İlişkileri, Editörler: Haydar Çakmak ve Mehmet Seyfettin Erol, Barış Kitap, Ankara, s.126.

- Mikail, 2007. “Türkiye Azerbaycan İlişkileri”, Uluslararası Asya ve Kuzey Afrika Çalışmaları Kongresi, s.1063.

- Moskova Büyükelçiliği, 2016. Türkiye-Rusya Ekonomik İlişkileri, http://moskova.be.mfa.gov.tr/ShowInfoNotes.aspx?ID=219659

- $\quad$ Narin, Marşap, 2010. "Küresel Kriz Sonrası Türk Cumhuriyetleri Ekonomileri ve Türkiye ile Ticari İlişkileri”, Uluslararası Avrasya Ekonomileri Konferansı Beykent Üniversitesi, s.5.

- Sami, Ceylan, 1995. "Değişen Uluslararası Dengeler Karşısında Türkiye ile Türk Cumhuriyetleri Arasındaki İşbirliğini Geliştirmenin Önemi”, Çerçeve Dergisi, Sayı:13, s.50

- Sapmaz, 2008. Rusya'nın Trans Kafkasya Politikası ve Türkiye’ye Etkileri, Ötüken Yayınları, İstanbul.

- Selvi, 2016. Türkiye-Azerbaycan-Gürcistan İlişkilerinde Ermenistan Faktörü, http://www.satemer.sakarya.edu.tr/pdf/azerbaycan.pdf

- Solak, 2003. "Türkiye-Orta Asya Cumhuriyetleri Dış Ticaret İlişkilerinin Gelişimi”, Marmara Üniversitesi I.I.B.F Dergisi, Cilt: 18, Say1:1, s. 69.

- TÜİK, 2016. Dış Ticaret İstatistikleri, https://biruni.tuik.gov.tr/disticaretapp/menu.zul

- Ukrayna Ankara Büyükelçiliği, 2016. Ukrayna İle Türkiye Arasında Ticari Ve Ekonomik İşbirliğgi, http://turkey.mfa.gov.ua/tr/ukraine-tr/trade

- Yüksel, 2010. "Sovyet Sosyalist Cumhuriyetler Birliği Sonrası Türkiye Ve Orta Asya Türk Cumhuriyetleri Arasında Ekonomik, Siyasal Ve Kültürel İlişkiler”, www.okanyuksel.com.tr 


\title{
İhracata Dayalı Büyüme: Teknolojik Bakış The Export-Led Growth: A Technological View
}

\author{
Prof. Dr. Harun Bal (Çukurova University, Turkey) \\ Asst. Prof. Dr. Hakkı Çiftçi (Çukurova University, Turkey) \\ Asst. Prof. Dr. Erhan İşcan (Çukurova University, Turkey) \\ Ph.D. Candidate Duygu Serin (Çukurova University, Turkey)
}

\begin{abstract}
The details of the impact of exports on economic growth have been one of the most important topics in the literature. Numerous studies asserted that open economies grow faster than the closed ones because of the effect of the exports on GDP and increase of productivity and efficiency through foreign competition. Concurrently, these studies indicated that there are strong correlation exists between exports and economic growth. On the other hand, high share of production of technology in today's economies is the key for sustainable and high rates of growth and the relationship between technology exports and economic growth has been a topic of interest among economists. Many studies in the literature published on export-led hypothesis in recent years but only few studies addressed the technological issues. Therefore, the purpose of this study is to examine the impact of technology exports on economic growth of selected OECD countries using dynamic panel method. We established the model by using the yearly data of 2003-2015 periods for selected OECD countries provided by OECD. Stat. As a conclusion, it is revealed that technology exports have positive and statistically significant impact on economic growth. These results implied that high-tech exports led to growth in selected OECD countries. These results suggested that promoting the production of technology is one the drivers of the economic growth.
\end{abstract}

\section{Giriş}

İhracat döviz kazancı sağlaması nedeniyle ülkelerin gelişimlerini hızlandırarak ekonomik büyümenin motoru olmaktadır. İhracat ve büyüme ilişkisi incelenmesi gereken bir konu olması nedeniyle ekonomistler arasında önemli bir tartışma konusudur. Ticaretin ekonomik büyümeyi arttırdığı düşüncesi klasik ve neo-klasik dönem iktisatçılarına kadar uzanan eski bir konudur. İhracata dayalı büyümeyi savunanlar argümanlarını Doğu Asya ülkelerinin başarılı gelişimini ve ihracata dayalı sanayileşme stratejisi yoluyla yeni sanayileşmiş ülkelerin (NIC) önemli ölçüde büyümesini örnek vererek desteklediler (Alkhateeb, vd, 2016).

Ülkelerin nitelikli ihracat yapısı daha güçlü büyüme performansı sağlamaktadır. İhracatın büyüme mekanizmasını nasıl etkilediği üzerinde durulması gereken önemli bir konudur. İhracatın büyümeyi hızlandırmasını sağlayan birçok olası neden vardır. İlk olarak, rekabetçi dünya pazarında ürünlerin ihraç edilmesi için ihracatçılar rekabetçi fiyatlar belirlemek zorundadır. Bu durum yeni ve yenilikçi teknolojileri benimsemeye zorlamaktadır. İkincisi, ihracatçı firmalar tarafından yeni teknolojilerin benimsenmesi, diğer yerli firmaların da taklit etmesine neden olarak verimlilik düzeyinde artış sağlamaktadır. Bütün bu çabalar ekonomik kaynakların daha iyi kullanımına neden olmakta ve ekonomik büyüme hızını arttırmaktadır. Üçüncüsü, ihracata dayalı büyüme stratejisi yavaş yavaş ekonominin serbestleşmesinin önünü açarak kaynakların verimli piyasalarda tahsis edilmesini sağlamaktadır. Dördüncüsü, ihracat pazar büyüklüğünü genişletmektedir. Genişleyen pazar payı firmaların büyük ölçekte üretim yapmasını sağlar ve ölçek ekonomilerinden fayda sağlamasına neden olur. Beşinci ve son olarak, ihracat yabancı sermayenin satın alınmasını sağlayan dövizin ülke içine girmesini sağlayarak ülkenin üretkenlik kapasitesini arttırmaktadır (Alkhateeb, vd, 2016).

İhracat-büyüme arasındaki ilișki ihracata dayalı büyümenin yanı sıra büyümeye dayalı ihracat şeklinde de olabilir. Şöyle ki, ekonomik büyümede artış, verimlilik ve etkinlik artışı sağlayarak uluslararası piyasalarda daha rekabetçi ihracatın yapılmasına neden olur. İhracat başarısı için ülkelerin ne ihraç ettikleri konusu da önemlidir. Hangi ürünlerin ihraç edilmesi için alınan karar üretim maliyetlerine, hedefe ulaşım için gerekli maliyetlere, pazar yapısına, tüketici tercih ve gelirlerine bağlıdır (Santos, vd, 2013).

Yeni malların üretimi tüketimi ve gelişimi ilk olarak genellikle gelişmiş ülkelerde ortaya çıkmakta ve daha sonra daha az gelişmiş ülkelere kaymaktadır (Stokey, 1991). Grossman ve Helpman (1991) gelişmiş ülkelerin teknolojik avantaj elde ettiğini ifade etmektedir. Buna göre, nitelikli işgücü ve üstün teknolojiye sahip gelişmiş ülkeler daha fazla bilgi ve becerinin aktarılmasını sağlamakta ve bu nedenle daha yüksek ekonomik büyüme göstermektedir. Dahası, teknoloji gibi daha yüksek sofistike içeren ürünlerin ihraç edilmesi ülkelerin daha verimli yönetim yapılarını uyararak yenilik ve gelişmelerin önünü açmaktadır.

İhracat başarısı genellikle ülke piyasalarının rekabet gücü ölçümü olarak kabul edilmektedir. Teknoloji üreten piyasalar talebin yüksek gelir esnekliği ve verimliliği arttırması nedeniyle diğer piyasalara göre daha hızlı büyüme göstermektedir (Mani, 2000). Yüksek ve sürdürülebilir ekonomik büyümeye ulaşmak için yollar bulmak günümüz ekonomilerinin temel konularından biridir. Gelişmiş ve yeni gelişmekte olan ülkeler sanayileşme yoluyla 
verimlilikte artışlar, hizmet sektöründe gelişmeler, teknolojik etkinlik ve beşeri sermaye birikimi ile daha yüksek ekonomik büyüme hedeflerine ulaşmıştır. Ticaretin bir parçası olan ihracat özellikle gelişmekte olan ekonomiler için yüksek ve sürdürülebilir ekonomik büyümenin önemli bir bileşeni olarak kabul edilmektedir. Bu yüzden, 1980'lerdan beri birçok gelişmekte olan ülke hızlı büyüme yolundaki durgun ekonomilerinin gelişim göstermesi amacıyla ihracata dayalı büyüme stratejilerini benimsemiştir (Shafiullah, 2016). Aynı zamanda Sürdürülebilir ekonomik büyüme sağlanması için daha yavaş büyüyen ürünler yerine teknoloji ihracatına ağırlık verilmelidir (Mani, 2000).

Birçok ülke resesyonun üstesinden gelmek için ihracatı arttırma yolunu tercih etmiştir. İhracatın artması için politikalar ve stratejiler en dinamik bileşen olan teknoloji ihracatına odaklanmıştır. Bilimsel araştırmalar teknoloji ihracatının temel bileşenleri üzerinde durmakta ve politika yapıcıları bunun başarmak için son derece etkili politika arayışını sürdürmektedir. Teknoloji ihracı yapan firma ve piyasaların bilimsel gelişmeye ve teknolojik uzmanlaşmaya dayalı olmaları ve genellikle yüksek araştırma ve geliştirme (AR-GE) harcaması yapmaları gibi ortak özellikleri vardır. Teknoloji ürün ihracatı genellikle AR-GE içerikli ürünler olarak tanımlandığı için, AR-GE ve inovasyon teknoloji ihracatının ana bileşenleri olarak düşünülmektedir (Sandu ve Ciocanel, 2014).

İhracat, ulusal ekonominin başarısını belirleyen önemli bir göstergedir. Bireylerin belirli yada daha yüksek bir yaşam standardına sahip olmasını sağlarken aynı zamanda başarılı piyasalarda yer alan ürünleri dünyaya ihraç etmek sağlıklı ekonomi için gerekli koşullardır. Eğer artan ihracat bir ülkenin ekonomisini güçlendiriyorsa, o zaman teknoloji ihracatının arttırılması önemli bir politika hedefi olmalıdır. Birçok ülke artık teknolojiye dayalı sanayileşme stratejileri izlemektedir. Günümüz dünyasında teknoloji rekabetinde yer alabilmek için yatırım rejimlerinin ve ticaret serbestleşmesinin yanı sıra işgücü, sermaye ve teknolojinin de gelişme göstermesi gerekmektedir. Çünkü teknoloji ürün ihracatı yüksek katma değer sağladığı için ihracatın ithalatı karşılama oranını yükselterek, dış ticaret dengesini olumlu yönde etkilemektedir. Aynı zamanda ihracatın artması GSYİH'da artış sağlayarak, ekonomik büyümeyi de hızlandırmaktadır.

Bu nedenlerden dolayı 1960'ların başından bu yana politika yapıcılar ve akademisyenler ihracat ve ekonomik büyüme arasındaki ilişkiye büyük bir ilgi göstermiştir. Bununla birlikte, bilim adamları arasında hala devam eden bir tartışma söz konusudur. İhracata dayalı büyüme hipotezini doğrulamak amacıyla hem teorik hem ampirik çok fazla çalışma olmasına rağmen daha dar bir kalıp olan teknoloji ihracatının ekonomik büyüme üzerine etkisini inceleyen çok az çalışma vardır. Dolayısıyla bu çalışmada, ihracatın ekonomik büyüme üzerine etkilerinin ele alınmasının yanı sıra literatürde çok fazla irdelenmeyen teknoloji ihracatı ve ekonomik büyüme arasındaki ilişkiler dinamik panel veri tekniği ile analiz edilmektedir. Çalışmanın diğer bölümlerinde sırasıyla teknoloji ihracatı ve ekonomik büyüme arasındaki ilişkinin incelendiği literatür, daha sonra kullanılan yöntem ve veriler hakkında bilgi verilerek uygulama sonuçları ifade edilmiştir.

\section{Literatür}

1970'li yıllardan beri yaklaşık son kırk yıldır ihracat ülkelerin büyümesi için önemli bir araç olarak kabul edilmektedir. Dünya Bankası ve IMF, ülkeleri ihracata yönelik sanayileşme stratejisi benimsemesi ve ekonomilerini ticarete açma konusunda teşvik etmektedir. Bununla birlikte, birçok ülkenin bu sanayileşme stratejisi ile ekonomik büyüme sağlaması her ülke de aynı sonuç gerçekleşeceği anlamına gelmemektedir. Dahası, bu strateji birçok ekonomist tarafından sorgulanmaktadır. İhracatın ekonomik büyüme üzerine etkisinin olup olmadığına yönelik ampirik çalışmalar yapılmaya devam etmektedir. Literatürde ihracatın ekonomik büyümeyi teşvik ettiği yönünde çalışmalar olmasının, yanı sıra ekonomik büyümenin ihracatı teşvik ettiği yönünde çalışmalar da mevcuttur. Bazı çalışmalarda tek yönlü ilişki bulunmasına rağmen, ihracat ve ekonomik büyüme arasında herhangi bir ilişkinin olmadığını tespit eden çalışmalarda vardır. Bu çalışmaların değerlendirilmesi aşağıda yer almaktadir.

Balassa (1978) çalışmasında 11 gelişmekte olan ülkeyi ele alarak ihracatın ekonomik büyüme üzerine etkisini analiz etmiştir. Analizinde ihracatın \%1 artış göstermesinin ekonomik büyümede \%0.04 artış sağlayacağı tespit edilmiştir. Tyler (1981) ihracat ve ekonomik büyüme arasındaki ilişkiyi incelemek amacıyla 55 gelişmekte olan ülkeyi ele almıştır. Çalışmada toplam ihracatta ortaya çıkan \%1'lik artış ekonomik büyümede \%0.057 artış sağladığı bulgusuna ulaşılmıştır. Kwasifosu (1990) ihracatın ekonomik büyüme üzerine etkisini 28 Afrika ülkesi ile Afrika dışı ülkeler arasında karşılaştırma yaparak incelemiştir. Çalışma sonucunda ihracatın \% 1 artış göstermesi Afrika ülkelerinde \%0.123, Afrika dışı ülkelerde \%0.149 artış sağladığı bulgusuna ulaşılmıştır.

Jung ve Marshall (1985) çalışmasında ihracatın ekonomik büyüme üzerine etkisini Granger nedensellik analizi yöntemini kullanarak 37 gelişmekte olan ülkeyi incelemiştir. Analiz sonucunda ele alınan ülkeler arasında yalnızca dört ülkenin ihracatı ekonomik büyüme üzerinde pozitif etkisi olduğu saptanmıştır. Rana (1985) 14 gelişmekte olan ülkeyi analiz ettiği çalışmasında ihracatın ekonomik büyüme üzerine pozitif katkısı olduğunu tespit etmiştir. Bu sonuçlar ihracatın yayılım etkisi yoluyla ekonomik büyüme hızını arttırdığı yönündedir. Helpman ve Krugman (1985) benzer çalışmalar yaparak ihracattan ekonomik büyümeye tek yönlü ilişki olduğunu tespit etmiştir. Çalışma sonucunda, ihracatın yayılım etkisi ile ihracat yapılan sektörler dışında, yerli sanayiyi olumlu yönde etkilendiği 
ifade edilmiştir. Örneğin, ihracattan elde edilen döviz ile firmalar makine ithalatı yaparak modern teknolojileri satın alma imkanına sahiptir. Bu durum emek verimliliğini arttırmakta ve ekonomik büyümeyi hızlandırmaktadır.

El-Sakka vd. (2000) çalışmasında yıllık veri kullanarak Suudi Arabistan açısından 1970-1999 dönemi için nedensellik analizi yaparak ele almıştır. Çalışmada, ihracattan büyümeye tek yönlü bir ilişki olduğu tespit edilmiştir. Wernerheim (2000) çalışmasında ihracat ve büyüme arasındaki ilişkiyi eşbütünleşme ve nedensellik analizi yaparak test etmiştir. Analiz sonucunda ihracatın büyümeyi pozitif yönde etkilediği tespit edilmiştir. Hatemi (2002) bu konuyu 1960-1999 yılları için genişletilmiş nedensellik yöntemi ile Japonya açısından analiz etmiştir. Çalışma sonucunda ihracat ve ekonomik büyüme arasında pozitif ilişki tespit edilmiştir. Ayrıca, Japonya'nın ekonomik büyümesi için ihracatın zorunlu bir bileşen olduğu ifade edilmiştir. Tsen (2007) analizine yerel talebi ve yatırımları da dahil ederek 1968-2004 dönemi için Orta Doğu ülkelerini ele almıştır. Çalışmada ihracat ve ekonomik büyüme arasında çift yönlü ilişki olduğu tespit edilmiştir. Söz konusu ülkelerin ekonomik büyümesi için ticaretin serbestleşmesi gerektiği ifade edilmiştir. . Mishra (2011), ihracata dayalı ekonomik büyüme hipotezini Hindistan açısından 1970-2009 dönemi için araştırmıştır. Çalışmasında birim kök ve eşbütünleşme analizi yaptıktan sonra, Hindistan için ihracata dayalı ekonomik büyüme yerine büyümeye dayalı ihracat stratejisinin etkili olduğunu tespit etmiştir. Tingvall ve Ljungwall (2012), Çin için ihracata dayalı büyüme stratejisini meta analizi yaparak ele almıştır. Analiz sonucunda ihracattan büyümeye nedensellik ilişkisi olduğu tespit edilmiştir. Ayrıca bu ilişkinin diğer geçiş ülkelerine göre daha güçlü olduğu ifade edilmiştir. Agrawal (2014), çalışmasında liberalleşme sonrası Hindistan da ihracat ve ekonomik büyüme arasında çift yönlü ilişki olduğunu tespit etmiştir. Abbas (2012) çalışmasında Pakistan açısından ihracat ve ekonomik büyüme arasında ilişkiyi Johansen eşbütünleşme yöntemi ile 1975-2010 dönemi için ele almıştır. Analizinde ihracat ve ekonomik büyüme arasında hem kısa hem uzun dönemde ilişki olduğu tespit etmiştir.

Literatürde hem zaman serisi hem de veri kesit boyutlarını ele alan panel eşbütünleşme çalışmaları da vardır. İhracata dayalı ekonomik büyüme hipotezini inceleyen bu çalışmaların sonuçları farklılık göstermektedir. Bahmani-Oskooee vd. (2005) ile Reppas ve Christopoulos (2005) çalışmasında uzun dönem nedensellik analizini kullanarak ekonomik büyümeden ihracata tek yönlü ilişki olduğunu tespit ederken; Parida ve Sahoo (2007) ihracat artışının ekonomik büyümede artışa neden olduğunu ifade etmiştir. Benzer şekilde, Jun (2007) analizinde ihracatın ekonomik büyüme üzerine uzun dönem etkisi olduğunu tespit etmiştir. Pazim (2009) panel veri analiz tekniğini kullanarak ihracat ve büyüme ilişkisini analiz etmiştir. Analiz sonucunda ele aldığı Afrika ülkeleri için ihracatın ekonomik büyüme üzerine pozitif etkisi olduğunu ifade etmiştir. Bu sonuçlar benzer örneklemi ele alan Fosu (1990) ve Ukpolo (1994) ile paralellik göstermektedir. Tekin (2012) regresyon analizi ile en az gelişmiş 18 ülkeyi ele alarak ihracata dayalı büyüme hipotezini destekler sonuçlar bulmuştur. Foster (2006) eşik regresyon tekniği ile bir grup Afrika ülkesi için ihracatın ekonomik büyümeye pozitif ve anlamlı etkisi olduğunu tespit etmiştir. Ek olarak Galimberti (2009) ile Seabra ve Galimberti (2012) ihracat ve büyüme ilişkisini incelediği çalışmalarında benzer sonuçlara ulaşmıştır. Mehrara ve Firouzjaee (2011) çalışmasında ihracat ve ekonomik büyüme arasında çift yönlü nedensellik ilişkisi tespit etmiştir.

Montobbio ve Rampa (2005), yapısal ayrıştırma tekniğini kullanarak 1985-1998 döneminde dokuz gelişmekte olan ülke için teknolojik performans ve ihracat arasındaki ilişki araştırılmıştır. Analizde bir ülkenin artan teknolojik firsatlara sahip endüstrilerde ilerlemesi durumunda yüksek teknoloji sektörlerinde ihracat kazançları sağlanabileceği tespit edilmiştir. Belay (2005) faktör analizi ve panel regresyon yöntemi ile dünyada yüksek teknolojili ürün ihracatının \%97'sini kapsayan 55 gelişmiş ve gelişmekte olan ülkede yüksek teknolojili ürün ihracatının unsurları incelenmiştir. Analizde ülkelerin teknolojik yapısının yüksek teknolojili ürün ihracatının artmasına fayda sağladığını sonucuna ulaşılmıştır. Lee ve Hong (2010), 71 ülkeyi ele aldığı çalışmasında, 19702004 döneminde, yüksek teknolojili ürün ihracatı yapan ülkelerin ekonomik büyümesinin düşük teknolojili ürün ihracatı yapan ülkelerden daha hızlı olduğu sonucuna ulaşmıştır. Kılavuz ve Topçu (2012), yüksek ve düşük teknolojili ürün ihracatı ile ekonomik büyüme arasındaki ilişkiyi incelemiştir. Çalışma gelişmekte olan 22 ülke için 1998-2006 dönemi verileriyle panel veri analizi yöntemi kullanılmıştır. Yüksek teknolojili ürün ihracatının, ekonomik büyümeyi pozitif ve istatistiki olarak anlamlı olarak etkilediği tespit edilmiştir.

\section{Yöntem ve Veri Seti}

Teknoloji ihracatı ve ekonomik büyüme arasındaki ilişki dinamik panel veri analizi tekniği olan Sistem Genelleştirilmiş Momentler Metodu kullanılarak test edilmiştir. Çalışmada seçilmiş 10 OECD üyesi ülkenin 20032015 yılları arası yıllık verileri kullanılmıştır. Yapılan analizlerin sonuçlarını daha doğru bir şekilde değerlendirebilmek amacıyla ele alınan ülkeler dünyada teknoloji ihracat alanında en gelişmiş ülke grubudur. Söz konusu ülkeler şu şekildedir: Almanya, Amerika, Çek Cumhuriyeti, Fransa, Hollanda, İngiltere, İtalya, Japonya, Kanada, Kore, Macaristan, Meksika, Polonya'dır. Uygulamada Ekonomik Kalkınma ve İşbirliği Örgütü (OECD) veritabanlarından elde edilen veriler kullanılmıştır. Teknoloji ihracatının ekonomik büyüme üzerindeki etkisini açıklamak üzere oluşturulan model şu şekildedir:

$$
\operatorname{Lgdp}_{i, t}=\alpha_{0}+\beta_{1} \operatorname{Lgdp}_{i, t-1}+\beta_{2} \operatorname{Lexp}_{i, t}+\varepsilon_{i, t}
$$


Modelde, i ve t sırasıyla ülke ve zaman periyodunu, $\boldsymbol{\alpha}_{\mathbf{0}}$ sabit terimi ve $\varepsilon_{\mathbf{i}, \mathbf{t}}$ hata terimini ifade etmektedir. Çalışma kapsamında kullanılan değişenler Tablo 1'de yer almaktadır. Değişkenlerin isimlerinin önünde yer alan "L" ise, değişkenlerin logaritmik dönüşümlerinin yapılmış olduğunu ifade etmektedir.

\begin{tabular}{|l|l|}
\hline Değişkenin Adı & Tanımlayıc Bilgi \\
\hline Büyüme (Lgdp) & $\begin{array}{l}\text { Ekonomik büyümeyi temsil edebilmek amacıyla GSYİH ekonometrik } \\
\text { modelin bağımlı değişkenidir. }\end{array}$ \\
\hline İhracat (Lexp) & $\begin{array}{l}\text { Bilgisayar, elektronik ve optik gibi teknoloji ürünleri ihracatını ele alan } \\
\text { göstergedir. }\end{array}$ \\
\hline
\end{tabular}

Tablo 1. Analizde Yer Alan Değişkenler Listesi

Çalışmada kullanılan değişkenlere ait veri setlerinin logaritmik dönüşümleri yapılmış ve reelleştirilmiştir. Daha sonra dinamik panel veri analizi yöntemi ile tahmin edilmiştir. Dinamik modeller uygulama kolaylığ ve modellerin tahmin edilmesi için gereken araç değişkenlere kıyasla basit varsayımlara dayandığından literatürde çok sık karşılaşılmaktadır. Arellono ve Bover (1995) ve Blundell ve Bond (1998) zaman boyutu kısa olan panel veriler için fark veya düzey GMM'in tutarlı ve etkin sonuçlar elde edilemeyeceğini ifade ederek hem fark hem de düzey denklemlerinin birleştirilmesiyle tahmin gücü daha yüksek olan Sistem-GMM yöntemini geliştirmişlerdir. GMM yöntemleri bir aşamalı ve iki aşamalı olmak üzere ikiye ayrılmaktadır. Bir aşamalı tahminde hata terimlerinin zaman içinde ve gruplar arasında sabit varyanslı olduğu varsayılmaktadır. İki aşamalı tahmincide ise, hata terimlerinin sabit varyanslı olmadığı kabul edilmektedir. İkinci aşamada birinci aşamadan elde edilen hata artıkları da kullanılmakta bu nedenle iki aşamalı tahmin asimtotik olarak daha güçlü sonuçlar vermektedir (Khadraoui, 2012). Bu yüzden analizde diğer GMM yöntemleri ile karşılaştırıldığında daha iyi bir tahmin edici olan iki aşamalı Sistem-GMM tekniği kullanılmıştır.

\section{Uygulama Sonuçları}

Modele ilişkin iki aşamalı Sistem-GMM analizi tahmin sonuçları Tablo 2'de yer almaktadır.

\begin{tabular}{|l|l|}
\hline Değişkenler & Katsayılar \\
\hline$L g d p_{i, t-1}$ & $\begin{array}{l}.9847903 \\
(0.000)^{*}\end{array}$ \\
\hline Lexp & \\
& 3.190755 \\
& $(0.000)^{*}$ \\
\hline Wald Testi & $\chi^{2}(2)=8961.71$ \\
& {$[0.0000]^{*}$} \\
\hline Sargan Testi & $\chi^{2}(76)=12.86591$ \\
& {$[1.0000]$} \\
\hline Spesifikasyon Testleri & \\
\hline AR(1) & -2.6324 \\
\multicolumn{2}{|l|}{} \\
\hline AR(2) & {$[0.0085]^{*}$} \\
& -1.7683 \\
& {$[0.0770]$} \\
\hline
\end{tabular}

Tablo 2. Modelin GMM Tahmin Sonuçları

* \%1 düzeyindeki anlamlılıkları ifade etmektedir. Parantez içindeki değerler standart sapmaları, köşseli parantezler ise testlerin olasılık değerlerini göstermektedir.

Teknoloji ihracatının ekonomik büyüme üzerine olan etkisini analiz eden dinamik panel veri analizi sonuçlarına göre, bağımlı değişkenin gecikmesinin pozitif ve istatistiksel açıdan anlamlı olduğu görülmektedir. Aynı zamanda bilgisayar, elektronik ve optik gibi teknoloji ürünleri ihracatını kapsayan göstergenin (Lexp $\mathbf{p}_{\text {it }}$ ) ekonomik büyüme üzerine etkisinin pozitif ve anlamlı olduğu tespit edilmiştir. Bu bulgu ülkelerin teknoloji ihracatında \%1'lik artış olmasının ekonomik büyüme üzerinde 3.19 oranında artış yaratacağının bir göstergesidir. Böylelikle, önceki bölümde bahsedilen literatüre paralel olarak ülkelerin teknoloji ihracatı ekonomik büyüme artışını destekler niteliktedir. Bu nedenle ülkelerin teknoloji ihracatına yönelmeleri ve bu strateji ile ekonomik büyüme artışı sağlanacağı görülmektedir. Wald testi, modelde kullanılan değişkenlerin bir bütün olarak anlamlı olup olmadığını test etmektedir. Modelde hesaplanan Wald testi olasılık değerine bakıldığında model bir bütün olarak anlamlı bulunmuştur. Modelde kullanılan araç değişkenlerin uygun olup olmadığının analizi için Sargan testinin yapılması gerekmektedir. Sargan testinin olasılık değeri beklenen şekilde araç değişkenlerin içsellik sorunu taşımadığını ve araç değişkenlerin tam ve doğru olduğunun göstergesidir. Dinamik panel veri analiz tekniği olan Sistem-GMM yönteminde birinci dereceden otokorelasyon olması modelin kendi yapısı gereği sıklıkla karşılaşılan bir durum olduğundan önem arz etmemektedir. Ancak tahmin sonuçlarının tutarlı ve etkin olması için modelin ikinci dereceden otokorelasyon sorununun olmaması gerekmektedir. Tabloya bakıldığında modelde beklenildiği gibi 
birinci dereceden otokorelasyon bulunduğu ancak ikinci dereceden otokorelasyon olmadı̆̆ı görülmektedir. Dolayısıyla Sistem-GMM tahmin sonuçları etkin ve tutarlıdır.

\section{Genel Değerlendirme}

Son yıllarda ihracatın ekonomik büyüme üzerine olan etkisi önemli bir tartışma konusu olmaktadır. Bu nedenle çalışmada teknoloji ihracatının ekonomik büyüme üzerine etkisi seçilmiş OECD ülkeleri için dinamik panel veri analizi tekniği olan Sistem-GMM yöntemi ile incelenmiştir. Çalışma sonuçları literatürle uyumlu olarak, teknoloji ihracatının ekonomik büyümeyi destekleyen bileşenlerden biri olduğu sonucuna ulaşılmıştır. İhracat ekonomik büyümenin motoru olması dolayısıyla ülkelerin ihracat kompozisyonları da önem arz etmektedir. Şöyle ki, daha sofistike ve yüksek kaliteli ürünler olan teknoloji ihracatı yüksek katma değer sağlaması nedeniyle bu teknolojilerin iyileştirilmesi ve benimsenmesi gerekmektedir. Bu şekilde hem dış ticaret dengesi pozitif etkilenmekte hem de ekonomik büyümede artış sağlanmaktadır. Politika yapıcılarının teknoloji ihracatını teşvik etmesi ve uygulanan politikaların ekonomik büyümeyi ve gelişmeyi hızlandırması yönünde ihracat artışını hedeflemesi gerekmektedir.

\section{Teşekkür}

Bu çalışma Çukurova Üniversitesi Bilimsel Araştırma Projeleri Koordinasyon Birimince Desteklenmiştir.

\section{Kaynakça}

- Abbas, S. (2012). Causality between Exports and Economic Growth: Investigating Suitable Trade Policy for Pakistan. Eurasian Journal of Business and Economics, 5(10), 91-98.

- Agrawal, P. (2014). The Role of Exports on India’s Economic Growth. Institute of Economic Growth working paper No.345. Retrieved from http://www.iegindia.org/workpap/wp345.pdf

- $\quad$ Alkhateeb, T. T. Y., Mahmood, H., \& Sultan, Z. A. (2016). The Relationship between Exports and Economic Growth in Saudi Arabia. Asian Social Science,12(4), 117.

- Arellano, M., \& Bover, O. (1995). Another look at the instrumental variable estimation of error-components models. Journal of econometrics, 68(1), 29-51.

- Bahmani-Oskoee, M. and Alse, J., 1994. Export Growth and Economic Growth: an application of cointegration and error -correction modeling. The Journal of Developing Areas 27, 535-42.

- Balassa, B. (1978), 'Exports and Economic Growth: Further Evidence', Journal of Development Economics, vol. 5, pp. $181-189$.

- Belay, Seyoum; (2005), "Determinants Of Levels Of High Technology Exports: An Empirical Investigation", Advances İn Competitiveness Research, 13(1), Pp.64-79.

- $\quad$ Blundell, R., \& Bond, S. (1998). Initial conditions and moment restrictions in dynamic panel data models. Journal of econometrics, 87(1), 115-143.

- $\quad$ East Countries. Journal of Economic Cooperation, 28(2), 57-82.

- El-Sakka, M. I., \& N. H. (2000). Exports and Economic Growth: The Arab Experience. The Pakistan Development Review, 9(2), 153-169.

- Foster, N., 2006. Exports, growth and threshold effects in Africa. Journal of Development Studies 42, 10561074.

- Fosu, A. K., 1990. Exports and economic growth: the African Case. World Development, Vol. 18, No. 6 pp. 831-35.

- Galimberti, J.K., 2009. Conditioned export-led growth hypothesis: a panel threshold regression approach. MPRA Paper.

- Grossman, G.M. and Helpman, E. (1991), “Trade, Knowledge Spillovers, and Growth”, European Economic Review, 35 (3): 517-526.

- Hatemi, J. A. (2002). Export Performance \& Economic Growth Nexus in Japan: A Bootstrap Approach. Japan and World Economy, 14, 25-33. http://dx.doi.org/10.1016/S0922-1425(01)00071-8

- Helpman, E., \& Krugman, P. R. (1985). Market structure and foreign trade. MIT press, Cambridge, MA.

- Jun, S., 2007. Bi-directional relationships between exports and growth: a panel cointegration analysis. Journal of Economic Research 12:133-171.

- Jung, W., \& Marshall, P. (1985). Exports, Growth and Causality in Developing Countries. Journal of Development Economics, 18, 1-12. http://dx.doi.org/10.1016/0304-3878(85)90002-1 
- Khadraoui, N. (2012). Capital Movements and Economic Growth Fluctuations: The Threshold Effect of Financial Development. International Journal of Economics and Finance, 4(4), p193.

- Kilavuz, E. ve Topçu, A. (2012), "Export and Economic Growth in the Case of the Manufacturing Industry: Panel Data Analysis of DevelopingCountries", International Journal of Economics and Financial Issues, 2(2), 201-215.

- Lee, J-W. ve Hong, K. (2010), “Economic Growth in Asia: Determinants and Prospects.” Manila: Asian Development Bank Economics Working Paper Series, No. 220.

- Mani, S. (2000). Exports of high technology products from developing countries: is it real or a statistical artifact?. United Nations University, Institute for New Technologies.

- $\quad$ Mehrara, M., Firouzjaee, B.A., 2011. Granger causality relationship between export growth and GDP growth in developing countries: panel cointegration approach. International Journal of Humanities Social Science 1,223-231.

- Mishra. P. K. (2011). The Dynamics of Relationship between Exports and Economic Growth in India. International Journal of Economic Sciences and Applied Research, 4(2), 53-70.

- Montobbio, Fabio And Francesco Rampa; (2005), “The Impact Of Technology And Structural Change On Export Performance İn Nine Developing Countries”, World Development, 33(4), Pp.527-547.

- Parida, P.C., Sahoo, P., 2007. Export-led growth in South Asia: a panel cointegration analysis. International Economics Journal 21:155-175.

- $\quad$ Pazim, K. H., 2009. Panel data analysis of export-led growth hypothesis in BIMP-EAGA Countries. University Library of Munich, Germany

- Rana, P. B. (1985). Exports and Economic Growth in the Asian Region. (ADB Economic Staff Paper No. 25.).

- $\quad$ Reppas, P., Christopoulos, D., 2005. The export-output growth nexus: evidence from African and Asian countries. Journal of Policy Modeling 27, 929-940.

- $\quad$ Sandu, S., \& Ciocanel, B. (2014). Impact of R\&D and Innovation on High-tech Export. Procedia Economics and Finance, 15, 80-90.

- Santos, P. G., Ribeiro, A. P., \& Carvalho, V. M. (2013). Export-led Growth in Europe: Where and What to Export (No. 479). Universidade do Porto, Faculdade de Economia do Porto.

- Seabra,F., Galimberti, J.K., 2012. Conditioned export-led growth hypothesis: a panel threshold regression approach. Revista de Economia 38,7- 24.

- Shafiullah, M., \& Navaratnam, R. (2016). Do Bangladesh and Sri Lanka Enjoy Export-Led Growth? A Comparison of Two Small South Asian Economies.South Asia Economic Journal, 17(1), 114-132.

- Stokey, N. (1991), “The Volume and Composition of Trade Between Rich and Poor Countries,” Review of Economic Studies, 58: 63-84.

- $\quad$ Tekin, R.B., 2012. Economic growth, exports and foreign direct investment in least developed countries: a panel granger causality analysis. Economic Modelling 29, 868-878.

- Tingvall, P. G., \& Ljungwall, C. (2012). Is China different? A meta-analysis of export-led growth. Economic Letters, 115, 177-179. http://dx.doi.org/10.1016/j.econlet.2011.11.028

- Tsen, W. H. (2007). Exports, Domestic Demand and Economic Growth: Some Empirical Evidence of Middle

- $\quad$ Tyler, W.B. (1981), 'Growth and Export Expansion in Developing Countries', Journal of Development Economics, vol. 9, pp. 121 - 30.

- Ukpolo, V., 1994. Export Composition and growth of selected low-income African countries: evidence from time-series data. Applied Economics 26, 445-449

- Wernerheim, C., Micheal., 2000. Cointegration and causality in the exports-GDP nexus: the postwar evidence for Canada. Empirical Economics. 25, 111-125. 


\title{
Türkiye'nin Merkezi ve Doğu Avrupa Ülkelerine İhracat Artışında Yaygın ve Yoğun Ticaretin Rolü
}

\section{The Role of Extensive and Intensive Margins in Export Growth of Turkey to Central and Eastern European Countries}

\author{
Ph.D. Candidate Gizem Akbulut (Gümüşhane University, Turkey)
}

\begin{abstract}
In the recent years, Central and Eastern Europe Countries-10 (CEEC-10) countries are implementing policies for developing in international trade relations and these countries are relatively small and open economies. On the other hand, they increase both provide a dynamic increase in exports and export market share, to facilitate the European Union (EU) and their activities to integrate into world trade. The purpose of this study, with CEEC-10 of Turkey's sectoral export growth rates decomposes into extensive and intensive margins. Also intensive margin decomposes into price and quantity components. By building on the methodology pioneered by Feenstra (1994) and Hummels and Klenow (2005) and then "the decomposition of export growth rates" method developed by Bingzhan (2011). Intensive margin is the growth in products that were exported in both periods. Extensive margin is the growth in product variety or new trade partners. In the empirical part of the study were used the BACI international trade database from CEPII. The database provides the export values and quantities for Turkey to CEEC-10 at the Harmonized System's (HS96) six-digit level over period 2006 to 2013. Foreign trade activities of countries are an important channel both to gain of international qualification and to the realization of economic growths and/ or in terms of sustainability of the current growth rates. According to results of a study, with CEEC10 Turkey's export is mainly explained generally by the quantity growth rather than price growth. In other words, export growth carries with the low added value product.
\end{abstract}

\section{Giriş}

Türkiye, 1980 'li yıllarda dış ticarette ithal ikamesi yerine ihracatı teşvik etmeye yönelik politikalar uygulamaya başlamasıyla birlikte ihracatı giderek artmıştır. Türkiye'nin ihracatının artmasında ticaret yaptığı ülke ve/veya ülke gruplarının da payı oldukça önemlidir. Türkiye'nin ticaret yaptığı ülke ve/veya ülke grupları yıllar itibariyle değişmesine rağmen özellikle 1996 yllında Gümrük Birliğinin yürürlüğe girmesiyle birlikte Avrupa Birliğine (AB) üye ülkelerin Türkiye'nin ihracatındaki önemi artmıştır.

Merkezi ve Doğu Avrupa (MDA) ülkeleri geleneksel olarak emek yoğun endüstrilere sahip ülkeler olmakla birlikte sermaye yoğun endüstriler yönünden dezavantajlı konumundadır. 1989-1995 döneminde yapılan reformlarla MDA ülkelerinin ticareti konusunda önemli değişiklikler yapılmıștır (Ghatak, Silaghi ve Daly, 2009). MDA ülkelerinde merkezi olarak planlanan ekonomik reformların çökmesi ve ardından yaşanan ekonomik liberalleşme süreci, iktisadi açıdan ve dolayısıyla dış ticareti açısından da önemli dönüşümleri beraberinde getirmiştir. Buna ilave olarak Avrupa Birliği anlaşmaları, bu ülkelerin reformları için belirleyici bir gelişmedir (Caetano ve Galego, 2006). 2. Dünya savaşının ardından Sovyet Rusya'nın Avrupa'nın doğu bölgesini işgal etmesiyle birlikte MDA ülkeleri Batı Avrupa'nın standartlarına erişebilmek için yaptıkları faaliyetlerden en önemlisi AB'ye entegre olma çabalarıdır. 2004 yılında 8 MDA ülkesinin (Çek Cumhuriyeti, Estonya, Macaristan, Letonya, Litvanya, Polonya, Slovakya ve Slovenya) AB'ye katılmasının ardından Bulgaristan ve Romanya'nın da katılmasıyla birlikte toplamda 10 ülke olmuştur. Bu noktada MDA-10 ülkelerinin aynı zamanda $\mathrm{AB}$ üye ülkeleri olması Türkiye'nin bu ülkelere yaptığı ticaretin artması açısından oldukça önemlidir.

Şekil 1'de 2006-2013 döneminde Türkiye'nin MDA-10 ülkeleriyle yaptı̆̆ toplam ihracat değerleri yer almaktadır. Genel olarak rakamlarla değerlendirmek gerekirse; Türkiye'nin 2006 yllında sınır komşularından biri olan Bulgaristan'a ihracatı yaklaşık 1 milyar 406 milyon \$ iken 2013 yılında 2 milyar 019 milyon \$'a yükselmiştir. 6 fasıllı ürün kategorisinde ise Bulgaristan Türkiye'den daha çok mineral yakıtlar, demir ve çelik, yenilebilir sebze ve meyveler, bakır ve bakır eşya gibi ürünleri ithal etmektedir. MDA-10 ülkeleri içerisinde Türkiye'nin en fazla ihracat yaptığı ülkelerin başında Romanya gelmektedir. 2006 yılında yaklaşık 2 milyar 503 milyon \$ iken 2013 y1lında 2 milyar 528 milyon \$'a olmuştur. Diğer ülkeler içerisinde 2006 y1lında gerçekleşen Türkiye'nin Romanya'ya yüksek düzeydeki ihracatı, 2013 yılında da devam etmiștir. 6 fasıllı ürün kategorisinde daha çok demir ve çelik, motorlu kara taşıtları ve yenilebilen meyveler, kabuklu yemişler, turunçgil ve kavun kabuğu gibi ürünleri ihraç etmektedir. 2006-2013 döneminde MDA-10 ülkeleri içerisinde en az ihracat yaptığımız ülke ise Letonya'dır. 2006 yılında yaklaşık 68 milyon \$ gerçekleşen ihracat artarak 2013 yılında yaklaşık 98 milyon \$ olmuştur. 


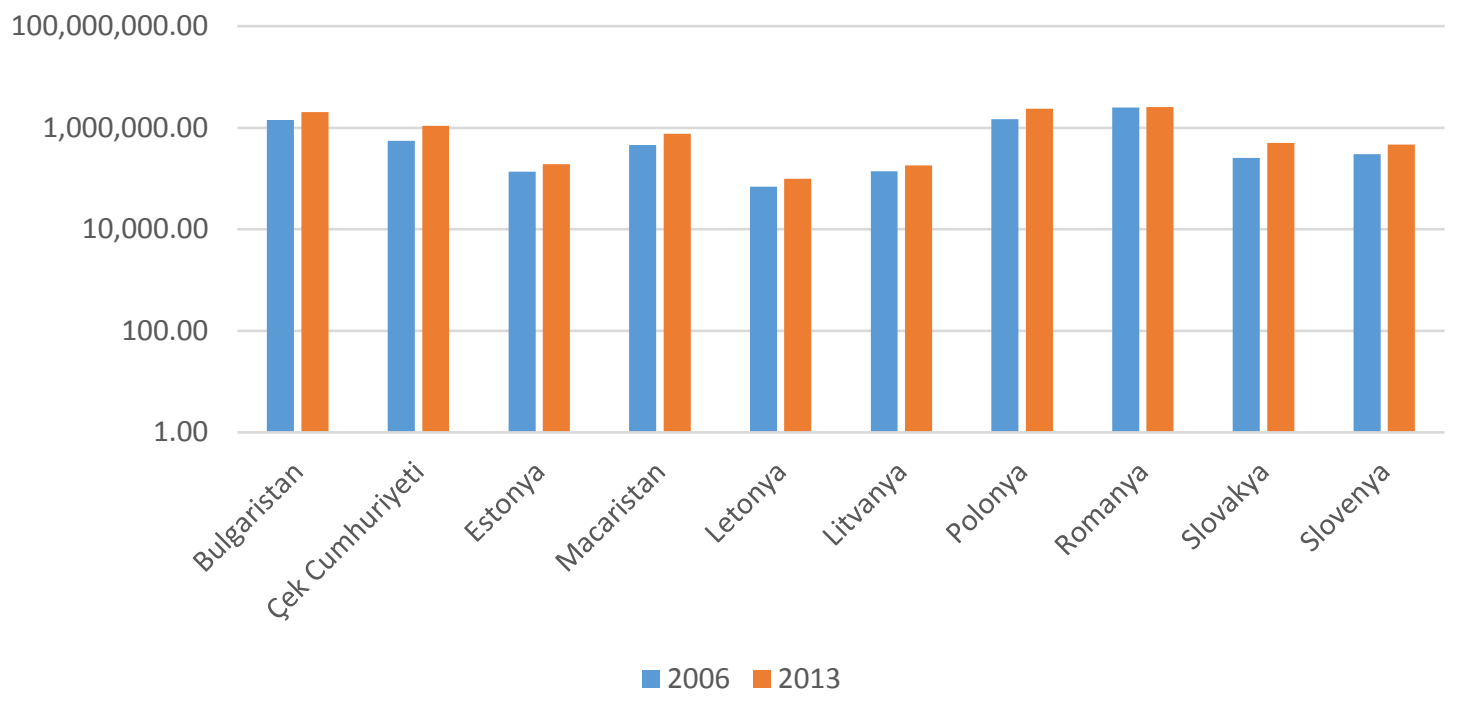

Şekil 1. 2006-2013 Döneminde Türkiye'nin MDA-10 Ülkelerine ihracatının Gelişimi Kaynak: BACI, 2016.

Genel olarak ülkelerin ihracat artışlarını inceleyen pek çok çalışma olmasına rağmen ihracat artışının kaynaklarını araştıran çalışmalar son yıllarda dikkat çekmektedir. Ülkelerin ihracat artışlarının dinamikleri çeşitli şekillerde olabilmektedir. İhracat artışlarının bir kısmı ülkelerin mevcut ticaret ilişkisinde bulunduğu ülkelere fiyat veya miktardaki artış olarak adlandırılan yoğun ticaret ile ilişkilendirilirken bir kısmı da yeni ticaret ortaklıkları ve/veya yeni ürünlerin ihracatındaki artış olarak ifade edilen yaygın ticaret ile ilişkilendirilmektedir. Dolayısıyla çalışmaların amaçlarına uygun bir yaygın ve yoğun ticaret kavramlarının tanımının yapılması ve yöntemin seçilmesi önemli bir noktadır. MDA-10 ülkelerinin aynı zamanda $\mathrm{AB}$ üye ülkeleri olması Türkiye'nin ihracatındaki önemini ortaya koymaktadır. Bu noktada çalışmanın amacı 2006-2013 döneminde Türkiye'nin MDA-10 ülkelerine yaptığı ihracat artışııı dinamiklerini incelemeye yöneliktir. Amiti ve Freund (2007) çalışmasından yola çıkarak Bingzhan (2011) tarafından geliştirilen "ihracat artı̧s oranlarının ayrıştırılması" yöntemi kullanılarak Türkiye'nin ihracat artışının dinamikleri incelenmiştir.

\section{Literatür Araştırması}

İhracat artışını, yaygın ve yoğun ticaret olarak dinamiklerine ayrıştırarak inceleyen çalışmalar son yıllarda giderek artmaktadır. Feenstra (1994)Feenstra (1994)Feenstra (1994)Feenstra (1994)Feenstra (1994) tarafindan ortaya atılan ve daha sonra Hummels ve Klenow (2005) tarafından geliştirilen yaygın ve yoğun ticaret değerleri, Hummels ve Klenow (2005) çalışmasında "ihracat paylarını ayrıştırma yöntemi" ile incelenmiştir. Öncü niteliğinde olan Hummels ve Klenow (2005) tarafından yapılan çalışmanın amacı, 1995 yılında 126 ihracatçı ülkenin 59 ithalatçı ülkeye yaptığı yaygın ve yoğun ticaretin önemini ortaya koymaktır. Ayrıca çalışmada yoğun ticaret fiyat ve miktar olarak bileşenlerine ayrıştırılarak da incelenmiştir. Çalışmanın veri seti Harmonize Sisteme (HS) göre sınıflandırılan 6 basamaklı ürün kategorisinde yer alan yaklaşık 5000 ürünü kapsamaktadır. Çalışmanın sonucuna göre daha büyük ekonomiye sahip olan ülkelerin ihracat artışının yaklaşık \%60'ı yaygın ticaret ile gerçekleşmektedir. Diğer taraftan yoğun ticaret artışı ise fiyattan ziyade miktar artışı ile desteklenmektedir. Hummels ve Klenow (2005) öncülüğünde ortaya atılan yöntem daha sonra referans niteliğinde pek çok araştırmacı tarafindan geliştirilmiştir.

Geçiş ekonomilerini inceleyen Kandogan (2006) çalışmasında 1992-1999 dönemine ilişkin eski sosyalist ülkelerden Merkezi ve Doğu Avrupa Ülkelerinin (CEECs) ve Bağımsız Devletler Topluluğunun (CIS) ihracatları yaygın ve yoğun ticaret açısından karşılaştırılarak incelenmiştir. Hummels ve Klenow (2005) yöntemi kullanılarak yapılan analizin sonucuna göre yoğun ticaretteki artı̧ CIS ülkelerinin ihracatındaki artışta daha önemlidir. Diğer taraftan CEECs ülkelerinin ihracat artışında ise yaygın ticaret çok daha fazla bir öneme sahiptir.

Yaygın ve yoğun ticareti inceleyen literatürdeki önemli çalışmalardan biri de Amiti ve Freund (2007) tarafından yapılmıştır. Çalışmada, 1992-2006 dönemleri arasında Çin'in ihracatının yaklaşık \%450 arttığı vurgulanarak ihracat artışı yaygın ve yoğun ticaret olarak ayrıştırılmıştır. HS- 6 basamaklı ürün kategorisinde gerçekleştirdiği ihracat artışının hemen hemen tamamını yoğun ticaretteki artış ile sağlamaktadır. Yani ihracat artışı aynı çeşitteki ürünlerin daha fazla ihraç edilmesiyle gerçekleşmektedir. Diğer taraftan HS-10 basamaklı ürün bazındaki ihracat artışının ise yaklaşık \%5-15'i yoğun ticaretteki artıştan kaynaklanmaktadır.

Besedes ve Prusa (2007) çalışmalarının amacı yaygın ve yoğun ihracattaki performanslarına bağlı olarak ülkelerin ihracat artışlarını araştırmaya ve karşılaştırmaya yöneliktir. Çalışmanın veri seti 1975-2003 döneminde 46 ülkenin 181 ülkeye olan SITC Rev.1'de yer alan 4 basamaklı imalat sanayi ürünlerinin ihracatını kapsamaktadır. 
Çalışmanın sonucuna göre ihracat artışı yaygın ticaretten ziyade yoğun ticaretteki artış ile gerçekleşmektedir. Özellikle gelişmekte olan ülkeler açısından yoğun ticaretin önemi vurgulanmaktadır. Eğer gelişmekte olan ülkeler, yoğun ticaret yoluyla performanslarını geliştirebilirlerse önemli ölçüde daha yüksek bir ihracat artışı gerçekleştireceklerdir.

Amurgo-Pacheco (2008) çalışmasında ise 1990-2005 döneminde 24 gelişmiş ve gelişmekte olan ülkenin ihracat çeşitlendirmesinde yaygın ve yoğun ticaretin rolü araştırılmıştır. Farklı bir bakış açısı ile ihracat çeşitlendirmesi coğrafik ve ürün çeşitlendirmesi olmak üzere 2 kritere göre incelenmiştir. Çalışmanın sonucuna göre ihracat artış1 daha çok yoğun ticaretteki artış ile açıklanmaktadır. Bununla birlikte ülkelerin coğrafik çeşitlendirme yoluna gitmesi, ürün çeşitlendirmesinden daha fazla dinamik bir artış yaratmaktadır.

Yaygın ve yoğun ticareti inceleyen çalışmalardan biri de Bingzhan (2011) tarafından geliştirilmiştir. Çalışmada ticaret artışı; yaygın, fiyat ve miktar olmak üzere 3 kısma ayrıştırılarak incelenmiştir. 2001-2007 döneminde Çin'in 140 ülke ile yaptığı ihracat bu 3 dinamiğe göre hesaplanmıştır. Hummels ve Klenow (2005) tarafından geliştirilen yöntem, Bingzhan (2011) çalışmasının amacına göre yeniden yorumlanmıştır. Çalışmanın sonucunda literatürdeki pek çok çalışmanın bulgularını destekler niteliktedir. Çin'in toplam ihracat artışının yaklaşık \%70'i yoğun ticaretteki artış ile gerçekleşmektedir. Bu bulgunun da ötesinde yoğun ticaretteki artış, fiyat artışından daha çok miktar artışından kaynaklanmaktadır.

Türkiye'nin ihracatının büyüme dinamiklerini araştıran Türkcan ve Pişkin (2012) çalışmasında, yaygın ve yoğun ticaret değerleri Amiti ve Freund (2007) tarafından ortaya atılan ve Bingzhan (2011) tarafından geliştirilen yöntem ile hesaplanmıştır. Çalışmanın ampirik kısmında 1997-2008 dönemine ilişkin Türkiye'nin karşılıklı ihracat ilişkisinde bulunduğu 197 ülkeye olan 6 fasıllı ürün kategorisinde gerçekleştirdiği ihracatı incelenmiştir. Çalışmanın sonucuna göre Türkiye'nin toplam mallardaki ihracat artışının yaklaşık \%96 oranında yoğun ticaret ile gerçekleşmektedir. Yoğun ticaretinin de önemli bir kısmı miktar artışı yoluyla olmaktadır.

Ekmen-Özçelik ve Erlat (2013) çalışmasında Amiti ve Freund (2007) tarafından geliştirilen yöntem kullanılmıştır. Çalışmada Avrupa Birliği (AB)-15 pazarında Türkiye'nin ihracat artışında yaygın ve yoğun ticaretin görece önemleri incelenmiştir. SITC Rev.3 de yer alan ürünler bazında incelenen çalışmanın sonucuna göre Türkiye'nin ihracat artışı yaygın ticaretten ziyade yoğun ticaretteki artış ile gerçekleşmektedir.

Literatürde yapılan çalışmalar genel olarak değerlendirildiğinde yaygın ve yoğun ticaret değerleri, yönteme, çalışmanın amacına, ülke grubuna ve ürün kategorilerine göre farklı şekillerde yorumlanmaktadır. Bu bağlamda çalışmalarının bir kısmı (Hummels ve Klenow (2005)) ihracat artışının yaygın ticaret ile gerçekleştiğini öne sürerken bir kısım çalışmalar da (Besedes ve Prusa (2007); Bingzhan (2011)) yoğun ticaretin önemine vurgu yapmaktadir.

\section{Veri Seti ve Yöntem}

Türkiye'nin MDA-10 ülkeleriyle gerçekleştirdiği ihracat artışının dinamiklerini inceleyen çalışmanın ampirik kısmında 2006-2013 dönemine ait HS' ye göre kategorize edilmiş 6 fasıllı ürün grubuna ilişkin CEPII veritabanından elde edilen BACI veri seti kullanılmıştır. Feenstra (1994) ve Hummels ve Klenow (2005) öncülüğünde Bizngzhan (2011) tarafından geliştirilen ihracat büyüme oranlarının ayrıştırılması yöntemi kullanılmıştır. Bingzhan (2011) çalışmasına dayalı olarak bu çalışmada yaygın ve yoğun ticaret değerlerinin toplam ihracata olan katkı oranlarını ayrıştırabilmek için t+1 ve t dönemlerindeki $I_{j m t+1}$ ve $I_{j m t}$ ürün kategorilerinin ihracat paylarını tespit etmek amacıyla aşağıdaki hesaplama yapılmaktadır:

$$
E X R_{j m}=\frac{\sum_{i \in I_{j m t+1}} x_{j m i t+1}}{\sum_{i \in I_{j m t}} x_{j m i t}}
$$

$I_{j m t+1}, \mathrm{t}+1$ döneminde $\mathrm{j}$ ülkesinden $\mathrm{m}$ ülkesine ihraç edilen ürün kategorilerini, $I_{j m t}$ ise $\mathrm{t}$ döneminde $\mathrm{j}$ ülkesinden m ülkesine ihraç edilen ürün kategorilerini göstermektedir. $x_{j m i t+1}$ ve $x_{j m i t}$ sırasıyla $\mathrm{t}+1$ döneminde $\mathrm{j}$ ülkesinden $\mathrm{m}$ ülkesine ihraç edilen i ürünün ihracat değerini, $\mathrm{t}$ döneminde $\mathrm{j}$ ülkesinden $\mathrm{m}$ ülkesine ihraç edilen $\mathrm{i}$ ürününün ihracat değerini temsil etmektedir. Denklem 1 'de hesaplanan toplam ihracatı yaygın ve yoğun ticaret değerlerine göre ayrıştırarak denklem 2'deki gibi tekrar yazılabilmektedir:

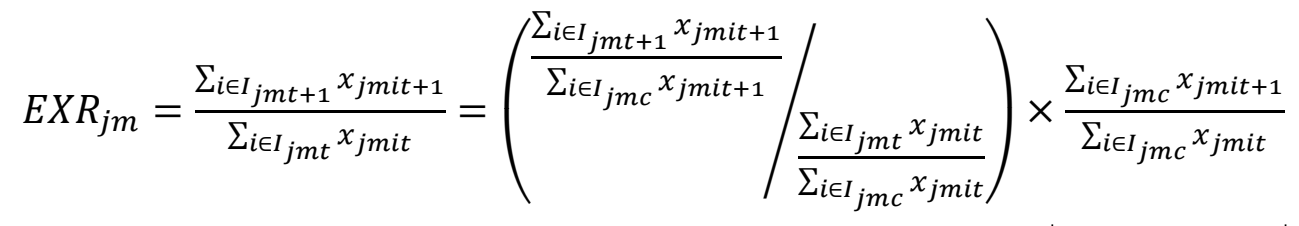

$$
\begin{aligned}
& \bigsqcup_{\mathrm{A}}
\end{aligned}
$$

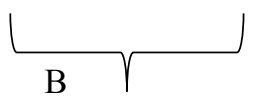

Denklem 2'deki A kısmı toplam ihracat artışına yaygın ticaretin, B kısmı ise yoğun ticaretin görece katkısını temsil etmektedir. $\mathrm{t}+1$ ve $\mathrm{t}$ dönemlerinde $\mathrm{j}$ ülkesinden $\mathrm{m}$ ülkesine ihraç edilen ürünlerin çeşitliliğinde artış olursa 
yaygın ticaret (EM) değeri birden büyük olacaktır. Bununla birlikte her iki dönemde de ortak ihraç edilen ürünlerin $\left(I_{j m c}\right)$ sayısında $\mathrm{t}$ dönemine göre $\mathrm{t}+1$ döneminde bir artış söz konusu olursa yoğun ticaret (IM) değeri birden büyük değer alacaktır.

İhracat artış oranına katkısı açısından Bingzhan (2011) çalışmasında yoğun ticaret değeri, fiyat ve miktar olarak ikiye ayrılmaktadır. Hummels ve Klenow (2005) çalışmasında da belirtildiği üzere fiyat, ürün kalitesi ile ilişkilendirilmektedir. Yani ürünlerin fiyatlarının artması daha kaliteli ürünlerin ihraç edildiği şeklinde yorumlanmaktadır. Bu bağlamda yoğun ticaret değeri aşağıdaki gibi ifade edilmektedir:

$$
\frac{\sum_{i \in I_{j m c}} x_{j m i t+1}}{\sum_{i \in I_{j m c}} x_{j m i t}}=\frac{\sum_{i \in I_{j m c}} p_{j m i t+1} q_{j m i t+1}}{\sum_{i \in I_{j m c}} p_{j m i t} q_{j m i t}}=\prod_{i \in I_{j m c}}\left(\frac{p_{j m i t+1}}{p_{j m i t}}\right)^{w_{j m i}} \times \prod_{i \in I_{j m c}}\left(\frac{q_{j m i t+1}}{q_{j m i t}}\right)^{w_{j m i}}
$$

Denklem 3 'te yer alan $w_{i}$, t döneminde j ülkesinden m ülkesine ihraç edilen i ürün kategorisinin payının $\left(S_{j m i t}\right)$, $\mathrm{t}+1$ döneminde $\mathrm{j}$ ülkesinden $\mathrm{m}$ ülkesine ihraç edilen $\mathrm{i}$ ürün kategorisinin payının $\left(S_{j m i t+1}\right)$ logaritmik ortalamalarını vermektedir. Bu logaritmik ortalamalar aşağıdaki gibi hesaplanarak $w_{i}$ değeri elde edilmektedir.

$$
\begin{gathered}
s_{j m i t}=\frac{p_{j m i t} q_{j m i t}}{\sum_{i \in I_{j m c}} p_{j m i t} q_{j m i t}} \\
s_{j m i t+1}=\frac{p_{j m i t+1} q_{j m i t+1}}{\sum_{i \in I_{j m c}} p_{j m i t+1} q_{j m i t+1}} \\
w_{i}=\frac{\frac{s_{j m i t+1}-s_{j m i t}}{\operatorname{lns} s_{j m i t+1}-\ln s_{j m i t+1}}}{\sum_{s_{j m i t+1}-s_{j m i t}}}
\end{gathered}
$$

Yaygın ticaret ile fiyat ve kalite olarak bileşenlerine ayrıştırılan yoğun ticaretin ihracat artışına görece katkılarını hesaplayabilmek için formül daha detaylı olarak aşağıdaki gibi yazılabilmektedir:

$$
\begin{aligned}
& E X R_{j m}=\frac{\sum_{i \in I_{j m t+1}} x_{j m i t+1}}{\sum_{i \in I_{j m t}} x_{j m i t}}=E M_{j m} \times P_{j m} \times Q_{j m}
\end{aligned}
$$

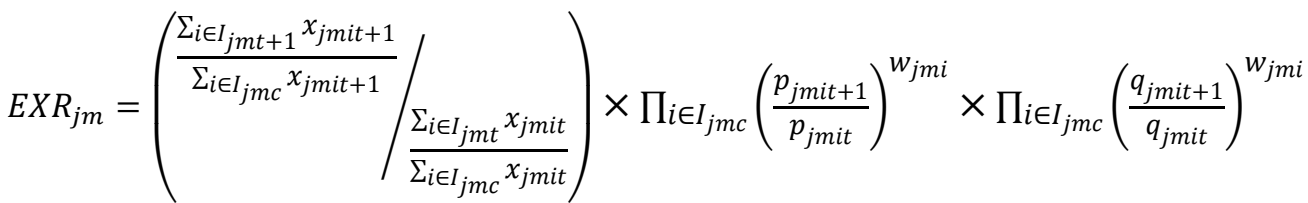

Yaygın ve yoğun ticaret artış oranı olarak toplam ihracat artış oranına katkısını hesaplayabilmek amacıyla her bir bileşenin doğal logaritması alındıktan sonra ele alınan yıl sayısına bölerek 100 ile çarpılmaktadır:

$$
\begin{aligned}
& g_{E M_{j m}}=100 \times\left(\frac{\ln \left(E M_{j m}\right)}{(t+1)-(t)}\right) \\
& g_{E X R_{j m}}=g_{E M_{j m}}+g_{P_{j m}}+g_{Q_{j m}}
\end{aligned}
$$

Denklem (8)'de ifade edildiği gibi fiyat ve miktar artışının toplam ihracat artışına olan katkısı da aynı şekilde hesaplanmaktadır. Denklem (9) ise her bir bileşenin artış oranlarının toplamı, toplam ihracat artış oranını vermektedir. Yaygın ticaret artış oranının, fiyat artış oranının ve miktar artış oranının toplam ihracat artış oranına katkısı ise aşă̆ıdaki gibi hesaplanmaktadır:

$$
\begin{aligned}
& r_{E M_{j m}}=100 \times\left({ }^{g_{E M_{j m}}} / g_{E X R_{j m}}\right) \\
& r_{p_{j m}}=100 \times\left({ }^{g_{p_{j m}} / g_{E X R_{j m}}}\right) \\
& r_{Q_{j m}}=100 \times\left(^{g_{Q_{j m}} / g_{E X R_{j m}}}\right)
\end{aligned}
$$

2006-2013 döneminde Türkiye’ nin MDA-10 ülkeleriyle gerçekleştirildiği ihracat artışının, yaygın ve yoğun ticaret (fiyat ve miktar) dinamiklerinin yukarıdaki denklemlerde ifade edildiği gibi hesaplanmasında kullanılan veri setinin niteliği oldukça önemlidir. Çalışmada kullanılan BACI veri seti, hem fiyatı hem de miktarı aynı birimler üzerinden hesapladığı için ülkeler ve ürünler arası karşılaştırma yapabilme avantajı sağlamaktadır. Bu doğrultudan hareketle çalışmada, BACI veri setinden elde edilen HS-96 6 fasılllı ürün kategorisindeki ihracat verileri kullanılarak denklemlerdeki formüllere göre hesaplamalar yapılmıştır. 


\section{Bulgular}

İhracat artış oranlarını ayrıştırma yöntemiyle hesaplanan toplam ihracat, yaygın ticaret ve fiyat ve miktar olarak bileşenlerine ayrıştırılan yoğun ticaret değerleri tablo 1'de yer almaktadır. Tablonun ilk 4 sütunu sırasıyla toplam ihracat (EX), yaygın ticaret (EM), fiyat $(\mathrm{P})$ ve miktar $(\mathrm{Q})$ bileşenlerini göstermektedir. Devam eden sütunlarda ise sırasıyla bileşenlere ilişkin artış oranlarının değerleri ve toplam ihracat artışı içerisindeki payları yer almaktadır.

2006-2013 döneminde Türkiye'nin Bulgaristan'a olan ihracat artış oranı \%5.16'dır. Toplam ihracat artışının $\% 0.59$ 'u miktar artışı ile gerçekleşirken \%3.67'si fiyat artışı ile gerçekleşmektedir. Çek Cumhuriyetinin \%2'lik ihracatının \%4,60'ı yaygın ticaret ile \%36'sı fiyat bileşeni ve \%59'u miktar bileşeni ile açıklanmaktadır. Bulgaristan'ın aksine Çek Cumhuriyeti olan ihracat artışı miktarsal artış ile desteklenmektedir. Türkiye'nin Estonya ile gerçekleştirdiği ihracat artışı \%4,86 iken yaygın ticaretinde \%3,19'luk bir azalma meydana gelmiştir. Toplam ihracat artışının oldukça önemli bir kısmı da miktar artışı ile gerçekleşmektedir.

Türkiye'nin Macaristan'a toplam ihracatı \%1,65 iken yaygın ticaret \%1'dir. Yoğun ticaret fiyat ve miktar bileşenlerine ayrılarak değerlendirildiğinde fiyat artışı \%6,19, miktar artışı ise \%1,05 olarak ihracat artışını desteklemektedir. Macaristan'ın aksine Letonya'ya yapılan ihracat artışının \%5,96'u miktar artışı ile açıklanmaktadır.

Litvanya'ya gerçekleşen ihracatta \%3,74'lük artışın \%1,34'ü yaygın ticaret artış1, \%3,67'si fiyat artışı ve \%1,17'si miktar azalışı ile açıklanmaktadır. Aynı şekilde Litvanya ticaretine paralel olarak Slovenya'ya yapılan ticaretin de \%4,87'si yaygın ticaretteki artış, \%2,77'si fiyat artışı ve \%1,59'u miktar azalış ile gerçekleşmektedir.

\begin{tabular}{|l|c|c|c|c|c|c|c|c|c|c|c|}
\hline Ülkeler & EX & EM & $\mathbf{P}$ & $\mathbf{Q}$ & $\mathbf{g E X}$ & $\mathbf{g E M}$ & $\mathbf{g P}$ & $\mathbf{g Q}$ & $\mathbf{r E M}$ & rP & rQ \\
\hline Bulgaristan & 1,44 & 1,07 & 1,29 & 1,04 & 5,16 & 0,90 & 3,67 & 0,59 & 17,52 & 71,02 & 11,46 \\
\hline Çek Cumh. & 1,98 & 1,03 & 1,28 & 1,49 & 9,74 & 0,45 & 3,55 & 5,74 & 4,60 & 36,43 & 58,97 \\
\hline Estonya & 1,41 & 0,80 & 1,07 & 1,65 & 4,86 & $-3,19$ & 0,93 & 7,11 & $-65,60$ & 19,23 & 146,36 \\
\hline Macaristan & 1,65 & 1,00 & 1,54 & 1,08 & 7,19 & $-0,05$ & 6,19 & 1,05 & $-0,71$ & 86,16 & 14,55 \\
\hline Letonya & 1,43 & 1,17 & 0,80 & 1,52 & 5,14 & 2,28 & $-3,10$ & 5,96 & 44,48 & $-60,40$ & 115,93 \\
\hline Litvanya & 1,30 & 1,09 & 1,29 & 0,92 & 3,74 & 1,24 & 3,67 & $-1,17$ & 33,18 & 98,12 & $-31,30$ \\
\hline Polonya & 1,62 & 1,08 & 1,21 & 1,24 & 6,90 & 1,09 & 2,69 & 3,12 & 15,74 & 38,98 & 45,28 \\
\hline Romanya & 1,10 & 0,95 & 1,13 & 1,03 & 1,38 & $-0,80$ & 1,70 & 0,49 & $-58,02$ & 122,73 & 35,28 \\
\hline Slovakya & 1,96 & 1,03 & 1,32 & 1,43 & 9,62 & 0,48 & 4,01 & 5,13 & 5,01 & 41,66 & 53,34 \\
\hline Slovenya & 1,53 & 1,41 & 1,21 & 0,89 & 6,06 & 4,87 & 2,77 & $-1,59$ & 80,47 & 45,71 & $-26,18$ \\
\hline
\end{tabular}

Tablo 1. Türkiye'nin MDA-10 Ülkeleri ile Gerçekleştirdiği İhracat Artışının Dinamikleri, 2006-2013. Hesaplamalar Yazar Tarafindan Yapılmıştır.

Polonya ile gerçekleşen ihracatın \%1,08'i yaygın ticaret, yoğun ticaretin ise $\% 1,21$ 'i fiyat bileşeni ve \%1,24'ü miktar bileşeni ile açıklanmaktadır. Slovakya da benzer şekilde ticaret artışının \%0,48'i yaygın ticaretteki artış, yoğun ticaretteki artışın \%4,01'i fiyat artışı ve \%5,13'ü miktar artış1 ile gerçekleşmektedir. Son olarak Romanya ile yapılan ihracat artışının dinamiklerine bakıldığında Bulgaristan, Macaristan, Litvanya ve Slovenya ile paralel bir seyir izlediği görülmektedir. Yıllık \%1,38 ihracat artış1, \%0,8 yaygın ticarette azalış, \%1,70 fiyat artış1 ve \%0,49 miktar artışı ile açıklanmaktadır.

Genel olarak değerlendirildiğinde, Türkiye'nin Estonya ve Letonya ile yaptığg ihracatın oldukça önemli bir kısmı miktarsal artışa bağlı olarak yoğun ticaret artışı ile gerçekleşmektedir. Aynı şekilde Çek Cumhuriyeti, Polonya ve Slovakya ile de yine miktar artışı yoluyla ticaret artışını desteklemektedir. Bulgaristan (\%71,02), Romanya $(122,73)$, ve Macaristan $(86,16)$ ve Litvanya $(98,12)$ ticaretinde ise en dikkat çekici nokta yüksek oranda gerçekleşen fiyat artışlarıdır. Yani diğer ülkelere kıyasla daha kaliteli ürünler ihraç edilmektedir. Slovenya $(\% 45,71)$ da görece olarak daha düşük olmasına rağmen ticarete artışının büyük bir kısmını fiyat artışı ile sağlamaktadır. Kısaca Türkiye ilgili ülkelere ihracat artışını yaygın ticaretten ziyade yoğun ticaret ile gerçekleştirmektedir. Yoğun ticaret artışının da \%60'ını fiyat artışı ile \%40’ını ise miktar artışı ile desteklemektedir.

\section{Sonuç}

Türkiye'nin en fazla ihracat yaptığı ülkelerin başında AB üye ülkeleri gelmektedir. MDA ülkelerinin AB'ye üye olmasıyla birlikte Türkiye açısından bu ülkelerle yapılan ticari ilişkiler önem kazanmıştır. Bu bağlamda çalışmanın amacı 2006-2013 döneminde Türkiye'nin MDA-10 ülkelerine yaptığı ihracatta yaygın ve yoğun ticaretin rolünü incelemektir. Literatürde yaygın ve yoğun ticaret kavramları çeşitli şekillerde ifade edilmektedir. Bu çalışmada yaygın ticaret yeni ürünlerin ihraç edilmesiyle gerçekleşen ihracat artışı olarak tanımlanırken yoğun ticaret, mevcut ürünlerin ihraç edilmesiyle ortaya çıkan ihracat artışı olarak tanımlanmıştır. Ayrıca yoğun ticaret, fiyat ve miktar olarak da bileşenlerine ayrılmıştır. Çalışmanın analizinde Amiti ve Freund (2007) tarafından ortaya atılan ve 
Bingzhan (2011) tarafından geliştirilen "ihracat artış oranlarını ayrıştırma” yöntemi uygulanmıştır. Analizin sonucu elde edilen bulgulara göre Türkiye, MDA-10 ülkeleriyle yaptığı ihracat artışını yaygın ticaretten ziyade yoğun ticaret ile desteklemektedir. Yani ürün çeşitliliğiyle gerçekleşen ihracatın toplam ihracat içerisindeki payı daha düşüktür. Bu durumun sebepleri arasında Türkiye'nin nitelikli işgücüne sahip olmaması, ihracatta düşük teknolojili üretimin yapılması, lojistik, bilgi ve iletişim altyapısının yetersiz olması gibi faktörleri saymak mümkündür. Diğer taraftan yoğun ticaret fiyat ve miktar olarak bileşenlerine ayrıldığında Türkiye'nin ihracat artışı miktar artışından daha çok fiyat artışı ile gerçekleşmektedir. Bu şekilde sağlanan fiyat artışı, Türkcan ve Pişkin (2012) çalışmasında da ifade edildiği gibi, ihraç edilen ürünlerdeki katma değer artışını göstermektedir. Ancak sürdürülebilir bir ekonomik büyümeyi desteklemesi için fiyattaki yani kalitedeki artışın süreklilik arz etmesi gerekmektedir. Türkiye, hem gelişmiş ülkelerin standartlarını yakalayabilmesi hem de daha nitelikli ürünler ihraç ederek rekabet ortamında tercih edilen ülke konumuna gelebilmesi için teknolojik altyapıyı geliştirmesi, beşeri sermayeye ağırlık vermesi, Araştırma ve Geliştirme (AR-GE) harcamalarını teşvik etmesi ve nitelikli eğitime önem vermesi gerekmektedir. Diğer taraftan da dünya pazarında rakip ülkelerle rekabet edebilmek için ürün çeşitliliğini arttırıcı yönde politikalar uygulamalıdır.

\section{Kaynakça}

- Amiti, M, Freund, C. (2007). An anatomy of China's trade growth. Paper presented at the Trade Conference, IMF.

- Amurgo-Pacheco, A. (2008). Patterns of export diversification in developing countries (4473. bs): World Bank Publications.

- $\quad$ Besedes, T, Prusa, T J. (2007). "The Role of Extensive and Intensive Margins and Export Growth". NBER Working Paper Series, 13628.

- $\quad$ Bingzhan, S. (2011). "Extensive margin, quantity and price in China's export growth". China Economic Review, 22(2), 233-243.

- Caetano, J, Galego, A. (2006). "tradE flowS among cEEc and Eu countriES: what arE thE futurE pErSpEctivES?". rEviSta dE Economía mundial(15), 65-87.

- $\quad$ Ekmen-Özçelik, S, Erlat, G. (2013). "What Can We Say About Turkey and its Competitors in the EU Market? An Analysis by Extensive and Intensive Margins". Topics in Middle Eastern and African Economies, 15(1), 186-210.

- Feenstra, R C. (1994). "New product varieties and the measurement of international prices". The American Economic Review, 157-177.

- $\quad$ Ghatak, S, Silaghi, M I P, Daly, V. (2009). "Trade and migration flows between some CEE countries and the UK". The Journal of International Trade \& Economic Development, 18(1), 61-78.

- Hummels, D, Klenow, P J. (2005). "The variety and quality of a nation's exports". American Economic Review, 704-723.

- Kandogan, Y. (2006). "The reorientation of transition countries' exports: Changes in quantity, quality and variety". Intereconomics, 41(4), 216-229.

- Türkcan, K, Pişkin, E. (2012). "Türkiye İhracatının Büyüme Dinamiği: Yoğun ve Yaygın Ticaretin Rolü". Paper presented at the International Conference on Economics, İzmir, Türkiye. 


\title{
Türkiye ve Orta Asya Türk Ülkeleri Arasında Endüstri İçi Ticaretin Düzeyi ve Sektörel Rekabet Gücünün Belirlenmesi Determination of the Level of Intra Industry Trade and Sectoral
Competition Power between Turkey and Central Asian Turkic
Countries
}

\author{
Assoc. Prof. Dr. Sabri Azgün (Atatürk University, Turkey) \\ Asst. Prof. Dr. Ziya Çağlar Yurttançıkmaz (Atatürk University, Turkey) \\ Prof. Dr. Mine Gerni (Marmara University, Turkey) \\ Prof. Dr. Selahattin Sarı (Beykent University, Turkey)
}

\begin{abstract}
In terms of Intra-industry trade, international investments, technology transfer and capital movements, has increased the interdependence of countries and increasingly have similar economic structures of countries. Intraindustry trade, is of goods and services with the same or similar factor intensity in production or, two-way trade of goods and services that are close substitutes for each other as the demand side. Intra-industry trade, is extremely important in terms of the determination of competitive aspects and of foreign exchange earnings of the country and industry. The aim of this study is to determine the level of intra-industry trade between Turkey and The Turkic Central Asian countries and productive product and sectors to be advantageous in Turkey's intra-industry trade. In this study, Using The Balassa and Grubel-Lloyd index of Intra-1ndustry trade measurement methods will be analyzed the development of intra-industry trade between Turkey and The Turkic Central Asian countries for the period 1995-2013 and highly competitive industry and products will be determined on the basis of foreign trade data in STIC 9 digit.
\end{abstract}

\section{Giriş}

Bir birine benzer olmayan ya da tamamen farklı sektörler arasında gerçekleşen dış ticaret endüstriler arası ticaret ifade edilmekte ve gerekçesini geleneksel klasik dış ticaret teorisinden almaktadır. Ülkelerin gelişmişlik düzeyleri arasındaki fark ne kadar artarsa endüstriler arası ticareti düzeyinin de yükselmesi beklenir. Endüstri içi ticaret ise bir ülkenin aynı endüstriye ait malları hem ihraç ve hem de ithal etmesi olarak tanımlanır. Üretim ve tüketim kalıpları birbirlerine benzeyen ülkeler arasında sanayi mallar ticaretinin yüksek miktarda olmakta ve bu ticaretin önemli bir kısmının da aynı endüstrideki malların iki yönlü ticareti (endüstri-içi ticaret) şeklinde gerçekleşmektedir. Endüstri-içi dış ticaret aynı endüstri grubunda bulunan; ancak dış görünüş, kalite, kullanım özellikleri ve marka açısından bazı farklılıklar gösteren malların aynı zamanda ihraç ve ithaline dayanan bir dış ticaret türüdür.

Endüstri içi dış ticaret düzeyi ülkenin kişi başına milli geliri, ülkenin coğrafi olarak büyüklüğü, bölgesel birleşme hareketlerine katılımı ve ürün farklılaştırma derecesi ile birlikte artmakta ve faktör donanımı farklılığının artması, dış ticaret üzerindeki engellerin artması ve ürün standartlaştırma derecesiyle birlikte azalmaktadır.

Bu çalışmada Türkiye ve orta Asya Türk cumhuriyetleri arasında endüstri içi ticaret düzeyi mal grupları itibariyle belirlenmeye ve Türkiye ile söz konusu ülkeler arasındaki dış ticarette rekabet gücü yüksek sektörler ortaya konmaya çalışılacaktır. Çalışma, beş bölümden oluşmaktadır. Birinci bölüm çalışmanın giriş bölümüdür. İkinci bölümde endüstri içi ticarette literatüründeki temel gelişmeler verilmektedir ve bu gelişmeleri yönlendiren literatür özeti verilmektedir. Üçüncü kesimde uygulamaya temel teşkil eden Balassa (1961) ve Ballasa (1966) endeksleri sunulmuştur. Dördüncü bölümde analiz, bulgular verilmekte ve son bölüm ise sonuç kısmıdır.

\section{Endüstri İçi Ticarette Temel Ayrımlar ve Literatürdeki Gelişmeler}

Endüstri-içi ticaretin ölçülmesine yönelik çalışmalar endüstri-içi ticaret literatüründe en önemli gelişmelerin yaşandığı Alan olarak değerlendirilebilir. Endüstri içi ticareti ölçmeye dönük çalışmalar 1960'lara kadar geriye gitmektedir. 1960'lı yıllarda Verdoorn, Michealy, Kojima, Balassa ve Grubel- Lloyd gibi iktisatçılar endüstri-içi ticareti ölçmeye yönelik çaba içerisine girmişler. Endüstri içi ticaretin düzeyi ve rekabet gününü ölçmeye dönük Balassa $(1965,1966)$ ve Grubel-Lloyd $(1971,1975)$ endüstri-içi ticaret hesaplamalarında en sık başvurulan endeksler olarak karşılaşılmaktadır.

Endüstri içi ticaretteki ölçmeye yönelik çalışmaların üç temel üç kategoride gelişme gösterdiği ifade edilebilir. Birincisi, dış ticaret dengesizliği durumunda endeks değerinin hatalı olacağ ve bu eksikliği gidermeye dönük çalışmalar. Ekonomide dış ticaret dengede değilse, hesaplanan endeks değeri olması gerekenin altında olacaktır. Dış ticaret açığı durumunda, dengesizlik durumunda her bir endüstrideki ihracat ithalatı karşılayamadığından, dış 
ticaretin yapısı ne olursa olsun (tamamı endüstri içi ticarette olsa bile), endeks her durumunda yüz değerinin altında olacaktır. Bu durumdan diş ticaret dengesizliğini dikkate alan (Grubel- Lloyd. (1971) Akiuno (1978) ve Glejser, Goossens ve Eede (1979) Loertcscher ve Wolter (1980) tarafından yeni endeksler geliştirilmiş ve/veya mevcut geliştirilmiş endeksler revize edilmiştir.

İkincisi, Endüstri içi ticaret literatüründeki diğer bir ayrım marjinal endüstri içi ticaretin ölçümüne dönük çalışmalardır. Grubel-Lloyd ve Balassa endeksleri endüstri-içi ticareti sadece belirli bir yıl için ölçtüğünden statik niteliktedirler. Gerçi farklı yıllara ait endüstri-içi ticaret endeksleri hesaplanarak bir değerlendirme yapmak mümkün olsa da dış ticaretteki yapısal değişmeler (dış ticaret akımlarındaki ve dış ticaret bileşimindeki değişme) hakkında değerlendirme yapmak zordur. Bu zorluğu gidermek için dinamik ölçme tekniklerine ihtiyaç olduğu noktasından hareketle marjinal endüstri-içi ticaret endeksleri geliştirilmiştir. Dış ticaretin liberalleştirilmesi ve diş ticarette meydana gelen yapısal değişimler dolayısıyla, her hangi bir endüstri için koruma oranındaki değişmenin, söz konusu endüstri için hesaplanan endüstri içi ticaret düzeyine ve diğer endüstrilerin endüstri içi düzeyine etkileri marjinal endüstri içi ticaret olarak tanımlanır. Marjinal endüstri içi ticaret; Hamilton ve Kniest (1991), (Greenaway, Hire, Milner ve Eliot (1994) ve (Brülhart, 1994) . Menon ve Dixon (1997) çalışmalarıyla endüstri içi ticaretteki değişimi ölçmek için literatürde yer alan ve literatüre yön veren temel çalışmalar olarak ifade edilebilir.

Üçüncüsü, Endüstri-içi ticaretin ölçülmesine yönelik diğer önemli bir gelişme de hiç kuskusuz ki yatay ve dikey endüstri-içi ticaretin hesaplanmasına yönelik atılan adımlardır. Çünkü gerek Grubel -Lloyd ve Balassa endeksleri endeksi gerekse marjinal endüstri-içi ticaret endeksleri dış ticarete konu olan malların dikey ya da yatay olarak farklılaştığıyla ilgilenmemektedir. Hâlbuki yatay ve dikey endüstri-içi ticaretin ölçülmesine yönelik çalışmalar da malların farklılaştığı noktasından hareket edilmektedir. Endüstri içi ticaret literatürdeki son ayrım yatay ve dikey endüstri içi ticaretin ölçümüdür. Endüstri-içi ticaret yatay ve dikey endüstri-içi ticaret olmak üzere iki temel kategoriye ayrılır. Benzer malların mübadelesi yatay endüstri-içi ticaret; daha yüksek derecede proses edilmiş çıktılar için girdi mübadelesini dikey endüstri-içi ticaret olarak ifade edilebilir. Yatay endüstri içi ticaret ürünlerde uzmanlaşmayla ölçek ekonomisinden faydalanmak suretiyle benzer faktör donanımlarına sahip ülkelerde uluslararası ticareti mümkün kılarken, dikey endüstri içi ticaret özellikle işgücü niteliği veya ar-ge harcamaları gibi faktör donanımı farklılıklarına sahip ülkelerdeki uluslararası ticaret yapısını yansıtabilir. Örneğin montaj amacı için ucuz niteliksiz işgücünden veya ar-ge için uzmanlaşmış personelden faydalanmak üzere ülkeler arasında üretimin dikey uzmanlaşması karşılaştırmalı üstünlüklerle şekillenebilmektedir. Yatay endüstri içi ticaret, daha çok benzer faktör donanımlarına sahip ülkeler arasında gerçekleșen iki yönlü ticaret şeklidir. Benzer faktör donanımına sahip ülkelerin gelir düzeyleri de birbirine benzer olacağından aynı malın farklılaşmış çeşitlerine olan talep, farklı faktör donanımlarına sahip ülkelere göre daha yüksek olacaktır. Ülkelerin gelir seviyeleri bir birine ne kadar yakınsa, yatay endüstri içi ticarette o kadar yüksek olacaktır. Ayrıca yatay endüstri içi ticaretin mal farklılaştırması ve ölçek ekonomileri ile de pozitif yönlü bir ilişkisinin olduğu kabul edilmektedir. Endüstride faaliyet gösteren firma sayısı ve firmaların üretim ölçeği artıkça yatay endüstri için ticarette artacaktır.

Dikey endüstri içi ticaret, farklı kalitelerdeki malların eşanlı dış ticaretidir. Dikey endüstri içi ticarette malların kalitelerinin üretimde kullanılan emek/sermaye oranına bağlı olarak belirlenmekte ve aynı emek/ sermaye oranına sahip malların kalitelerinin aynı olduğu ifade edilmektedir. Dikey endüstri içi ticaret, geleneksel faktör donatım modellerinden hareketle, sermaye yoğun ülkelerin daha kaliteli, emek yoğun ülkelerin daha düşük kaliteli mallar üreteceği görüşüne dayanmaktadır. Yatay ve Dikey Endüstri içi ticaretin ölçümüne dönük çalışmalar endüstri içi ticaret literatürünün en güncel alanıdır. Çünkü yatay ve dikey endüstri içi uzmanlaşma sektörel düzeyde ekonomik gelişme ve rekabet gücündeki değişimin de temel göstergesidir. (Falvey, 1981 (Abd- El Rahman, 1991) (Aturupane, Djankow ve Hoekman, 1997) Greenway, Hilne ve Milner, 1995) (Falvey, 1981), (yatay ve dikey endüstri içi ticaret ayrımını modellerken benzer mal veya mal grupları arasındaki farklılıkları dikkate almışlar ve söz konusu çalışmaları temel alarak (Ferto ve Hubbart, 2002), (Cabrish ve Segnana, 2003) ve (Şimşek, 2005) yatay ve dikey endüstri içi ticareti çeşitli ülkeler için araştırmışlardır.

Bu çalışmanın amacı Balassa(1965) açıklanmış karşılaşmalı üstünlükler endeksi ve Balassa (1966) endüstri içi ticaretin düzeyini belirlediği endekslerle Türkiye Ve Orta Asya Türk Cumhuriyetleri arasındaki endüstri içi ticaretin düzeyini belirlemek ve rekabet gücü yüksek sektörleri mal ticareti açısından belirlemektir. Güran (1990) Türkiye ve Avrupa birliği ülkeleri arasındaki dış ticareti rekabet gücü açısından açıklanmış karşılaştırmalı üstünlükler endeksi yardımıyla sektörel boyutta rekabet gücünü araştırmaktadır. Araştırmada tekstil sektörünün yüksek rekabet gücüne sahip olduğu bulgularına ulaşılmıştır. Çoban ve Kök (2005) Türkiye ile Avrupa birliği ülkeleri arasındaki tekstil sektörünün rekabet gücünü açıklanmış karşılaştırmalı üstünlükler endeksi yardımıyla araştırmışlardır. Çalışmada tekstil sektöründe Türkiye'nin rekabet gücü açısından oldukça iyi durumda olduğu sonucuna ulaşılmıştır. Yılmaz (2003) Avrupa birliği ülkelerinden Çek Cumhuriyeti, Bulgaristan ve Romanya ve Macaristan ile Türkiye arasındaki dış ticareti dış ticareti açıklanış karşılaştırmalı üstünlükler indeksi yardımıyla analiz etmişlerdir. Türkiye'nin genel olarak emek yoğun sektörlerde karşılaştırmalı üstünlüğe sahip oldukları bulgularına ulaşılmıştır. Çek cumhuriyeti ise sermaye yoğun katma değeri yüksek ürünlerde diğer ülkelere göre rekabet gücü yüksektir Aydın (2008) Türkiye'nin AB ve AB dışı ülkelereler ile endüstri içi dış ticaret düzeyindeki gelişmeleri ve Türkiye'nin Endüstri içi ticaretinin belirleyicilerini analiz etmektedir. Türkiye'nin diş ticaret ortakları arasındaki dış ticaret dengesizliği, kalkınma düzeyi, dış açıklık ile endüstri içi ticaret arasında negatif 
ilişki bulunmaktadır. Türkiye ile dış ticaret ortakları arasındaki coğrafi uzaklıkta endüstri içi ticaret düzeyini düşürmektedir. Avrupa Birliği ile yürütülen bütünleşme sürecinin endüstri içi ticaret düzeyini artırdığ1 sonucuna varılmıştır. Doğrudan yabancı sermaye yatırımlarının da endüstri içi ticareti düzeyinin artmasına yol açtığı sonucuna varılmıştır. Çakmak (2005) Türkiye'nin tekstil ve hazır giyim sektörü ve söz konusu sektörün alt sektörlerinin rekabet gücünü Balassa'nın açıklanmış karşılaştırmalı üstünlük endeksi ve Wollrath'ın endeksleri ile araştırmaktadır. Araştırma sonuçlarına göre, Türkiye Tekstil ve hazır giyim sektöründe dünyada rekabet gücü oldukça yüksektir. Altay ve Gürpınar (2008) Türkiye için mobilya sektörünü açıklanmış karşılaştırmalı üstünlükler, ihracat ve ithalat avantaj endeksleri ile rekabet gücü açısından analiz etmişlerdir. Türkiye'nin dünya karşı mobilya sektöründe rekabet avantajına ancak Avrupa Birliğine karşı ise rekabet açısından dezavantajlı olduğu sonucuna ulaşılmıştır. . Yurttançıkmaz (2013) Türkiye ve Avrupa birliği arasındaki endüstri içi ticaretin düzeyini ve rekabet gücü yüksek sektörleri 1995-2009 dönemi için araştırmaktadır. Ekonomik entegrasyon süreci ile birlikte, endüstri içi ticaretin düzeyinin arttığı ve rekabet gücü açısından sanayi malları, makina ulaşım araçları sektöründe, Türkiye'nin rekabet gücü artarken, rekabet gücünün göreceli yüksek olduğu tekstil sektöründe rekabet gücünün nispi olarak gerilediği sonucuna varılmıştır.

\section{Endüstri İçi Ticareti Düzeyinin ve Rekabet Gücü Açısından Ölçümü}

Endüstri-içi ticaret, faktör girdileri ve tüketim açısından birbirine yakın ikame malların eşanlı ithalat ve ihracatı veya Üretim, tüketim veya her ikisinde de yakın ikamesi bulunan aynı endüstriye ait malların hem ihraç hem de ithal edilmesine endüstri-içi ticaret olarak ifade edilebilir. Dolayısıyla, Endüstri-içi ticaret, benzer faktör yoğunluklarına sahip mallar arasında gerçeklesen ticaret şeklidir. Her hangi bir ekonomi için Endüstri içi ticaret rekabet gücü ve endüstri içi ticaretin düzeyi başta olmak üzere çeşitli açılardan ölçülebilmektedir. Çalışmada Balassa (1965- 1996) çalışmalarıyla, sırasıyla ülkenin endüstri içi ticarette rekabet gücü ve endüstri içi ticaretin düzeyini ölçmektedir.

\subsection{Rekabet Gücünün Ölçümü}

Balassa (1965) ülkelerin dış rekabet gücünün ölçümünde kullanılan Açıklanmış Karşılaştırmalı Üstünlükler (Revealed Comparative Advantage) (RCA) yöntemini ortaya koymaktadır. Açıklanmış Karşılaştırmalı Üstünlükler dış rekabet gücü ölçüm yöntemi, üretim faaliyetlerinin yanı sıra fiyat dışı faktörlerin de analize dahil edilmesini gerektirir. Analiz yaparken, ihracat iç üretimle ve ithalatta iç tüketimle ilişkilendirilir. Açıklamalı karşılaştırmalı üstünlükler yaklaşımı uygulamada, faktör getirileri veya faktör yoğunluklarının rolünü belirlemede bir araç olarak kullanılmaktadır. i ülkesinin j malına (veya mal grubuna) ait RCA endeks genellikle malın ülke toplam ihracatı içindeki payının dünya toplam ticareti (veya bölge toplam ticareti) içindeki payına oranlanması ile ölçülmektedir.

$$
R C A_{i j}=\frac{\left(X_{i j} / X_{i t}\right)}{\left(X_{w j} / X_{w t}\right)}
$$

Burada $X_{i j}$ ve $X_{w j}$ i ülkesinin j malı ihracatını ve dünya (veya bölge) j malı ihracatını gösterirken $X_{i t}$ ve $X_{w t}$ ülkenin toplam ihracatını ve dünya toplam (veya bölge toplam) ihracatını göstermektedir. Açıklanmış karşılaştırmalı üstünlüklerde "bir "den küçük bir değer ülkenin ilgili malda (endüstri de), açıklanmış karşılaştırmalı üstünlükler bakımından dezavantajlı olduğu, "bir"den büyük bir değer ise ülkenin o malda açıklanmış karşılaştırmalı üstünlüğe sahip olduğu şeklinde yorumlanmalıdır.

\subsection{Endüstri İçi Ticaret Düzeyinin Ölçümü}

Ekonomiler arasında yapılan dış ticaretin daha çok endüstri içimi yoksa endüstriler arası şeklinde olduğunu belirlemeye dönük bir endekstir. Balassa (1966) Avrupa Birliği (o zaman ki ismiyle Avrupa Topluluğu) ülkeleri arasındaki dış ticaretin endüstri içi yoksa endüstriler arası nitelikte olduğunu belirlemeye yönelik bir çalışmasının sonucunda ortaya çıkmıştır. Balassa (1966)'nın ortaya koyduğu endeks diğer geliştirilen endekslere temel teşkil etmesi bakımından önemlidir. Balassa Endeksi şöyle ifade edilebilir.

$$
I I T_{j}^{B}=\frac{1}{N} \times \sum \frac{\left|X_{j}-M_{j}\right|}{X_{j}+M_{j}}
$$

$I I T_{j}^{B}=$ Endüstri içi ticaret değerini

$X_{j}=\mathrm{j}$ endüstrisi (veya mal grubu) ihracat değerini

$M_{j}=\mathrm{j}$ endüstrisi (veya mal grubu) ithalat değerini

$N=$ İncelenen endüstri (veya mal gurubu) sayısını ifade eder.

Balassa endeksi, dış ticaret açığının (veya fazlasının) mutlak farkını toplam dış ticarete oranını alarak ve söz konusu oranın aritmetik ortalamasını almaktadır. Endüstri içi ihracat ve ithalat değerlerinin eşit halinde endeks 
değeri sıfır'a yakınsayacaktır. Ekonomi dış ticarette sadece bir ya da birkaç ürün ya da sektör ihracatında yoğunlaşırsa endeks değeri bir 'e yakınsar. Endeks değerinin sıfır'a yakın olması yüksek derecede endüstri-içi uzmanlaşma, endeks değerinin bir' yakın olması ise yüksek derecede endüstriler arası uzmanlaşmayı tanımlamaktadır. Balassa endeksinin, ilk bakışta esas itibariyle endüstriler-arası dış ticaret hakkında bilgi verdiği görülürken, aynı zamanda endüstri- içi ticaret için de aynı şekilde açıklayıcı olmaktadır. Endeks hesaplanırken veya yorumlanırken endeksteki $1 / \mathrm{N}$ parametresi dikkate alınmazsa, belirli mal grubu ya da sektör düzeyinde belirli bir ülke ya da bölge ile yapılan ticarette endüstri içi ticaret düzeyi elde edilir. Eğer endeks hesaplanırken, 1/n göz önünde bulundurursa, o zaman belir bir ülke ya da bölge ile tapılan ticarete belir bir dönem için incelen mal grupları ya da sektör için ortalama endüstri içi ticaret düzeyi elde edilmiş olur. Endüstrilerin dış ticaretteki ağırlıklarını dikkate almadan tüm endüstrilere eşit ağırlık vermesi, toplam dış ticaretin dengede olmaması durumu için bir düzeltme öngörmemesi yönleriyle eksikliği bulunmaktadır (Grubel and Lloyd, 2003: 250).

\section{Analiz ve Bulgular}

Çalışma 1995-2014 dönemi için Türkiye ve Orta Asya Türk cumhuriyetleri (Azerbaycan, Türkmenistan, Özbekistan ve Kırgızistan) arasında mal ticaretini rekabet gücü ve endüstri içi ticaretin düzeyi açısından karşılaştırmaktadır. Veriler UNCTAT (United Nations Conference on Trade and Development) dan elde edilmiştir. Türkiye ile Türk Cumhuriyetleri arasındaki mal ticareti rekabet gücü açısından ölçülürken, bu ülkeler mal grupları düzeyinde toplulaştırılmıştır. Bir başka ifadeyle Orta Asya Türk Cumhuriyetleri tek bir bölge olarak kabul edilmiştir. Bu ülkelerle endüstri içi ticaretin düzeyi mal ve rekabet gücü analiz edilirken, Standart Uluslararası Ticaret Sınıflaması sistemi (SITC) sisteminde en yüksek toplulaştırma düzeyi bir basamaklı ayrım esas alınmıştır. Bir basamaklı temel düzey esas alındığından mal grupları itibariyle her hangi bir toplulaştırmaya başvurulmamıştır. Standart Uluslararası Ticaret Sinıflaması sistemi (SITC) inde mal grupları dokuz kategori olarak tasnif edilmektedir. Bu kategoriler ekte Tablo 1'de verildiği üzere; 0: canlı hayvanlar ve gıda maddeleri, 1: içki ve tütün 2: Akaryakıt hariç yenilmeyen hammaddeler, 3: mineral yakıtlar, yağlar ve alkali ürünler, 4: hayvansal, bitkisel katı ve sıvı yağlar, mumlar, 5: Başka yerde belirtilmeyen kimyasal sanayi ürünleri, 6: Başlıca sınıflara ayrılan işlenmiş mallar, 7: makine ve taşıt araçları, 8: çeşitli mamul eşya, 9: STIC'da sınıflandırılmamış eşyalar olarak tasnif edilmiştir.

Türkiye ile Orta Asya Türk cumhuriyeti mal ticareti Rekabet gücü açısından Balassa (1965) açıklanmış karşılaştırmalı üstünlükler endeksi yardımıyla analiz edilmiş ve analiz sonuçları ekteki Tablo 2'de sunulmuştur. Açıklanmış karşılaştırmalı rekabet gücü endeksinin "bir”den büyük olması söz konusu endüstri de (veya mal grubu) rekabet gücünün yüksek olduğunu göstermektedir. Türkiye; 5: Başka yerde belirtilmeyen kimyasal sanayi ürünleri, 6: Başlıca sınıflara ayrılan işlenmiş mallar, 7: makine ve taşıt araçları, 8:çeşitli mamul eşya mal gruplarında Orta Asya Türk cumhuriyetlerine karşı rekabet gücü açısından avantajlı durumdadır. Söz konusu sektörler itibariyle 1995-2014 arasında rekabet gücü Türkiye açısından nispi olarak azalmakla birlikte, 6: Başlıca sınıflara ayrılan işlenmiş mallar sektörü hariç Türkiye bu ülkelere karşı rekabet gücü avantajını korumaktadır. Orta Asya Türk Cumhuriyetleri; 0: canlı hayvanlar ve gıda maddeleri, 1: içki ve tütün 2: akaryakıt hariç yenilmeyen hammaddeler, 3: mineral yakıtlar, yağlar ve alkali ürünler, 4: hayvansal, bitkisel katı ve sıvı yağlar, mumlar ve 9: STIC'da sınıflandırılmamış eşyalar açısından Türkiye'ye karşı, rekabet gücü açısından avantajlı durumdadırlar.

Söz konusu sektörler itibariyle 1995-2014 arasında Türkiye açısından rekabet gücü nispi olarak azalmakla birlikte, 9: STIC'da sınıflandırılmamış eşyalar sektörü hariç Orta Asya Türk Cumhuriyetleri, Türkiye'ye karşı rekabet gücü avantajını korumaktadır. Rekabet gücü açısından, genel olarak değerlendirildiğinde, işlenmiş ürünler bir başka ifadeyle yüksek katma değeri ürünlerde Türkiye'nin rekabet gücü avantajı, düşük katma değerli ürünlerde ise Orta Asya Türk Cumhuriyetlerinin rekabet Avantajı söz konusudur. Ancak, zamanla, katma değeri yüksek ürünler de Orta Asya Türk cumhuriyetlerinin rekabet gücünde nispi artış olduğu görülmektedir.

Türkiye ile Orta Asya Türk cumhuriyetleri arasındaki endüstri içi ticaretin düzeyi, bir basamaklı mal grupları bazında analiz edilmiştir. Balassa (1966) endeksi 1995-2013 dönemi için yapılan hesaplamalar sonucu elde edilen endeks değerleri ekte Tablo 3'de sunulmuştur. Türkiye ile Türk Cumhuriyetleri arasındaki mal ticareti endüstri içi ticaretin düzeyi belirlenirken, bu ülkeler bir basamaklı mal grupları düzeyinde toplulaştırılmıştır. Bir başka ifadeyle Orta Asya Türk Cumhuriyetleri tek bir bölge olarak kabul edilmiştir. 0: canlı hayvanlar ve gıda maddeleri sektöründe dönemin başında, ticaretin niteliği endüstri içi tarzda olmakla birlikte, dönemin sonralarına doğru endüstriler arası nitelik kazandığg görülmektedir. 1: içki ve tütün, 4: hayvansal, bitkisel katı, sıvı yağlar ve mumlar sektörlerinde, 7: makine ve taşıt araçları ve 8: çeşitli mamul eşya sektörlerinde bütün dönem itibariye istikrarlı bir biçimde, dış ticaret endüstri içi ticaret şeklinde gerçekleşmektedir. 6:Başlıca sınıflara ayrılan işlenmiş mallar sektörlerinde söz konu bölge ile yapılan ticaret endüstriler arası biçiminde gerçekleşmekte ve dönem boyunca endüstriler arası ticaret niteliğini korumaktadır. Söz konusu sektörde endüstriler arası ticaret oranı \% 90’ların üzerindedir. 2: ve 3: sektörlerinde dönemin başında endüstriler arası ticaret düzeyi \% 1 in altına iken, dönemin sonlarına doğru endüstriler arası ticaret düzeyi yaklaşık \%25'ler düzeyine yükselmiştir. 5: başka yerde belirtilmeyen kimyasallar ve sanayi ürünleri bütün dönem itibariyle istikrarlı olup, endüstri içi ticaret düzeyi \%25'ler düzeyindedir. 9: STIC'da sınıflandırılmamış eşyalar kategorisi endüstri içi ticaret açısından en istikrarsız 
görünüm arz etmektedir. 1997-2007 dönemi itibariyle endüstri içi ticaret düzeyi\%100’ler düzeyinde iken, daha sonraki yıllarda endüstriler arası ticaret düzeyinin artarak, 2012 yılında \%96'Lara ulaşmıştır.

Hesaplanan hem açıklanmış karşılaştırmalı üstünlükler endeksi, hem de endüstri içi düzeyi endeks değerleri birlikte değerlendirildiğinde, genel olarak Türkiye'nin rekabet gücünün göreceli olarak imalat sanayi ürünlerinde yüksek olduğu, ancak birincil ve işlenmiş tarımsal ürünlerde ise rekabet gücünün düşük olduğu görülmektedir. Türkiye ile Orta Asya Türk Cumhuriyetleri arasındaki dış ticaret genel olarak endüstriler arası dış ticaret şeklinde gerçekleşmektedir.

\section{Sonuç}

Endüstri içi ticaret, ekonomide rekabetçi bir yapının oluşturulması ve dolayısıyla uluslararası dış ticaret kazançlarının maksimize edilmesi, rekabetçi dış ticaret politikalarının oluşturulması bakımından son derece önemlidir. Dünyada meydana gelen ticaret şekillerindeki değişimler, Endüstri içi ticaretin gelişmekte olan ülkelerde artmasına yol açmıştır. Bir ülkenin aynı malın değişik türlerini neden hem ihraç hem de ithal ettiğini açıklamak üzere geliştirilen modele göre, ülkelerin faktör donatımları birbirine benzer nitelikte ise, dış ticaret daha çok endüstri içi ticaret şeklinde gerçekleşecektir.

Endüstri içi ticaretteki ölçmeye yönelik çalışmalar üç temel üç kategoride gelişme göstermektedir. Birincisi, dış ticaret dengesizliği durumunda endeks değerinin hatalı olacağı ve bu eksikliği gidermeye dönük çalışmalar tarzında gelişmektedir. İkincisi, dış ticaretin liberalleştirilmesi ve dış ticarette meydana gelen yapısal değişimler dolayısıyla, her hangi bir endüstri için koruma oranındaki değişmenin, söz konusu endüstri için hesaplanan endüstri içi ticaret düzeyine ve diğer endüstrilerin endüstri içi düzeyine etkilerinin analizine dönük teorik ve ampirik çalışmalar, marjinal endüstri içi ticaret olarak ifade edilmektedir. Üçüncüsü, endüstri içi ticaret literatürdeki son ayrım yatay ve dikey endüstri içi ticaretin ölçümüdür. Endüstri-içi ticaret yatay ve dikey endüstriiçi ticaret olmak üzere iki temel kategoriye ayrılır. Benzer malların mübadelesi yatay endüstri-içi ticaret; daha yüksek derecede proses edilmiş çıktılar için girdi mübadelesini dikey endüstri-içi ticaret olarak ifade edilebilir. Dikey endüstri içi ticaret, farklı kalitelerdeki malların eşanlı dış ticaretidir. Dikey endüstri içi ticarette malların kalitelerinin üretimde kullanılan emek/sermaye oranına bağlı olarak belirlenmekte ve aynı emek/ sermaye oranına sahip malların kalitelerinin aynı olduğu ifade edilmektedir. Dikey endüstri içi ticaret, geleneksel faktör donatım modellerinden hareketle, sermaye yoğun ülkelerin daha kaliteli, emek yoğun ülkelerin daha düşük kaliteli mallar üreteceği görüşüne dayanmaktadır.

1990’lı yıllarda Sovyetler Birliği’nin çöküşü ile birlikte Orta Asya Türk Cumhuriyetleri bağımsızlıklarını kazanmışlardır. Türkiye'nin Orta Asya Cumhuriyetleri ile ticareti bu ülkelerin bağımsızlıklarınım kazanması ile birlikte gelişme göstermektedir. Türkiye İle Bölge arasında gerçekleşen ticaret; rekabet gücü ve endüstri içi ticaretin düzeyi açısından Balassa (1965) açıklanmış karşılaştırmalı üstünlükler endeksi ve Balassa(1966) endüstri içi ticaret düzeyi ölçüm endeksi ile değerlendirilmiştir. Türkiye; 5-8: imalat sanayi mal gruplarında Orta Asya Türk cumhuriyetlerine karşı rekabet gücü açısından avantajlı durumdadır. Türkiye tarımsal (0-4) mal gruplarında ise başlangıçta rekabet gücü açısından avantajlı durumda iken bu üstünlük zamanla Orta Asya Türk cumhuriyetlerine geçmektedir. Orta Asya Türk cumhuriyetleri ile yapılan dış ticaret, 6 (Materyale Göre Başlıca Sınıflara Ayrılan İşlenmiş Mallar) sektörü hariç endüstriler arası dış ticaret şeklinde gerçekleşmektedir. Genel olarak Türkiye'nin İmalat sanayi sektörlerinde rekabet gücünün göreceli olarak yüksek olduğu, bununla birlikte tarım ve gıda ürünlerinde rekabet gücünün düşük olduğu görülmektedir. Bir materyale göre işlenmiş mallar sektörü hariç ticaret endüstriler arası niteliktedir.

Ekler

\begin{tabular}{||l||l||}
\hline \hline 0 & (Canlı Hayvanlar ve Gıda Maddeleri) \\
\hline 1 & (İçki ve Tütün) \\
\hline 2 & (Akaryakıt Hariç Yenilmeyen Hammaddeler) \\
\hline 3 & (Mineral Yakıtlar, Yağlar ) \\
\hline 4 & (Hayvansal, Bitkisel Katı ve Sıvı Yağlar, Mumlar) \\
\hline 5 & (Kimyasallar Ve İlişkili Mallar) \\
\hline 6 & (Materyale Göre Başlıca Sınıflara Ayrılan İşlenmiş Mallar) \\
\hline 7 & (Makineler ve Taşıı Araçları) \\
\hline 8 & (Çeşitli Mamul Eşya) \\
\hline 9 & (SITC'de Sınıflandırılmamış Eşyalar) \\
\hline \hline
\end{tabular}

Tablo 1: Uluslararası Standart Sanayi Mal Sinıflaması Sistemi 


\begin{tabular}{|c|c|c|c|c|c|c|c|c|c|}
\hline RCA & 0 & 1 & 2 & 3 & 4 & 5 & 6 & 7 & 8 \\
\hline 1995 & 2.535 & 2.876 & 0.018 & 0.004 & 3.805 & 1.706 & 1.019 & 2.007 & 3.434 \\
\hline 1996 & 1.490 & 2.016 & 0.065 & 0.066 & 2.231 & 1.351 & 1.234 & 1.768 & 2.333 \\
\hline 1997 & 1.232 & 1.204 & 0.050 & 0.127 & 1.735 & 1.135 & 1.153 & 1.448 & 1.903 \\
\hline 1998 & 1.352 & 1.282 & 0.054 & 0.091 & 1.706 & 1.267 & 1.326 & 1.856 & 2.179 \\
\hline 1999 & 1.585 & 0.811 & 0.067 & 0.113 & 1.893 & 1.356 & 1.412 & 1.475 & 2.248 \\
\hline 2000 & 1.044 & 1.022 & 0.087 & 0.172 & 1.594 & 2.021 & 1.366 & 1.760 & 2.231 \\
\hline 2001 & 1.103 & 0.201 & 0.105 & 0.137 & 0.554 & 2.076 & 1.479 & 1.932 & 1.891 \\
\hline 2002 & 1.101 & 0.254 & 0.132 & 0.102 & 0.467 & 1.884 & 1.475 & 1.817 & 1.866 \\
\hline 2003 & 0.914 & 0.346 & 0.179 & 0.075 & 0.338 & 1.652 & 1.228 & 1.825 & 2.249 \\
\hline 2004 & 0.915 & 0.572 & 0.200 & 0.056 & 0.454 & 1.656 & 1.369 & 1.639 & 2.525 \\
\hline 2005 & 1.081 & 0.510 & 0.313 & 0.054 & 0.290 & 1.948 & 1.375 & 1.204 & 2.639 \\
\hline 2006 & 0.751 & 0.698 & 0.198 & 0.047 & 0.277 & 1.786 & 1.156 & 1.630 & 2.464 \\
\hline 2007 & 0.588 & 0.724 & 0.169 & 0.034 & 0.467 & 2.141 & 1.100 & 2.303 & 2.912 \\
\hline 2008 & 0.490 & 0.576 & 0.294 & 0.055 & 0.790 & 1.967 & 1.173 & 2.197 & 2.813 \\
\hline 2009 & 0.559 & 0.543 & 0.371 & 0.051 & 0.173 & 1.752 & 1.131 & 2.120 & 2.478 \\
\hline 2010 & 0.444 & 0.473 & 0.234 & 0.064 & 0.505 & 2.068 & 1.068 & 1.973 & 2.765 \\
\hline 2011 & 0.394 & 0.715 & 0.280 & 0.058 & 0.713 & 1.843 & 0.953 & 2.316 & 2.767 \\
\hline 2012 & 0.380 & 0.420 & 0.199 & 0.063 & 0.494 & 1.814 & 0.933 & 2.096 & 2.585 \\
\hline 2013 & 0.363 & 0.427 & 0.210 & 0.075 & 0.596 & 1.692 & 0.962 & 2.030 & 2.192 \\
\hline 2014 & 0.386 & 0.447 & 0.204 & 0.068 & 0.480 & 1.627 & 0.945 & 1.715 & 2.150 \\
\hline
\end{tabular}

Tablo 2: Türkiye-Orta Asya Türk Cumhuriyetleri Mal ticareti Açıklanmış Karşılaştırmalı Üstünlük Endeksleri (1995-2014)

\begin{tabular}{|l|l|l|l|l|l|l|l|l|l|}
\hline EIT & 0 & 1 & 2 & 3 & 4 & 5 & 6 & 7 & 8 \\
\hline 1995 & 0.024 & 0.002 & 0.012 & 0.000 & 0.000 & 0.245 & 0.977 & 0.015 & 0.003 \\
\hline 1996 & 0.009 & 0.000 & 0.057 & 0.527 & 0.000 & 0.216 & 0.783 & 0.013 & 0.018 \\
\hline 1997 & 0.011 & 0.000 & 0.061 & 0.685 & 0.003 & 0.231 & 0.875 & 0.036 & 0.015 \\
\hline 1998 & 0.160 & 0.000 & 0.071 & 0.428 & 0.008 & 0.151 & 0.998 & 0.029 & 0.007 \\
\hline 1999 & 0.083 & 0.041 & 0.090 & 0.167 & 0.018 & 0.252 & 0.955 & 0.048 & 0.005 \\
\hline 2000 & 0.349 & 0.041 & 0.084 & 0.195 & 0.634 & 0.114 & 0.822 & 0.068 & 0.016 \\
\hline 2001 & 0.236 & 0.189 & 0.121 & 0.624 & 0.000 & 0.100 & 0.863 & 0.098 & 0.061 \\
\hline 2002 & 0.740 & 0.000 & 0.147 & 0.466 & 0.000 & 0.423 & 0.938 & 0.045 & 0.026 \\
\hline 2003 & 0.964 & 0.000 & 0.235 & 0.296 & 0.000 & 0.419 & 0.958 & 0.055 & 0.096 \\
\hline 2004 & 0.638 & 0.015 & 0.201 & 0.181 & 0.000 & 0.575 & 0.873 & 0.035 & 0.043 \\
\hline 2005 & 0.491 & 0.009 & 0.345 & 0.123 & 0.069 & 0.423 & 0.745 & 0.022 & 0.039 \\
\hline 2006 & 0.662 & 0.001 & 0.258 & 0.118 & 0.000 & 0.382 & 0.631 & 0.024 & 0.077 \\
\hline 2007 & 0.835 & 0.001 & 0.254 & 0.115 & 0.000 & 0.282 & 0.712 & 0.010 & 0.044 \\
\hline 2008 & 0.595 & 0.000 & 0.385 & 0.080 & 0.000 & 0.388 & 0.844 & 0.007 & 0.022 \\
\hline 2009 & 0.747 & 0.003 & 0.491 & 0.111 & 0.000 & 0.173 & 0.996 & 0.018 & 0.017 \\
\hline 2010 & 0.815 & 0.001 & 0.294 & 0.055 & 0.000 & 0.177 & 0.851 & 0.010 & 0.016 \\
\hline 2011 & 0.694 & 0.001 & 0.374 & 0.129 & 0.000 & 0.235 & 0.835 & 0.003 & 0.010 \\
\hline 2012 & 0.969 & 0.002 & 0.392 & 0.173 & 0.016 & 0.239 & 0.928 & 0.006 & 0.004 \\
\hline 2013 & 0.521 & 0.002 & 0.291 & 0.207 & 0.014 & 0.190 & 0.972 & 0.003 & 0.005 \\
\hline 2014 & 0.505 & 0.012 & 0.268 & 0.230 & 0.000 & 0.303 & 0.892 & 0.003 & 0.005 \\
\hline
\end{tabular}

Tablo 3: Türkiye-Orta Asya Türk Cumhuriyetleri Arasında Mal Ticareti Endüstri İçi Ticaret Düzeyleri (1995- 


\section{Kaynakça}

- $\quad$ Abd El Rahman, K. (1991) "Firms' Competition and National Comparative Advantages as Joints Determinants of Trade Composition" Weltwirtschaftliches Archiv 127(1), 83-97

- $\quad$ Altay, B., Gürpınar, K. (2008) “Açıklanmış Karşılaştırmalı Üstünlükler Ve Bazı Rekabet Gücü Endeksleri: Türk Mobilya Sektörü Üzerine Bir Uygulama”, Afyon Kocatepe Üniversitesi İktisadi Ve İdari Bilimler Dergisi, 10(1), 257-274

- $\quad$ Aturupane, ., Djankow S., ve Hokeman, B. (1997) "Determinants of Intra Industry Trade Between East and Weast Europe”, World Bank, Development Research Group, Policy Research Working Paper : 1850

- Aydın, A. (2008) "Endüstri İçi Ticaret ve Türkiye: Ülkeye Özgü Belirleyicilerin Tespitine Yönelik Bir Araştırma”, Marmara Üniversitesi İktisadi ve İdari Bilimler Fakültesi Dergisi, 25(2), 881-916.

- Balassa, B., (1966), "Tariff Reductions and Trade in Manufactures among the Industrial Countries”, American Economic Review, 56(3), 466-473.

- Balassa, B., Bauwens, L. (1987)” Intra Industry Specialization İn A Multi-Country And Multi Industry Framework", The Economic Journal, 97(338), 923- 939.

- Brülhart, M. (1994), "Marginal Intra-Industry Trade: Measurement and Relevance for the pattern of Industrial Adjustment” 130(3 ), 600-613.

- Bülhart, M. (1994), "Marginal Intra-Industry Trade: Measurement and Relevance for the pattern of Industrial Adjustment” 130(3 ), 600-613.

- Çakmak, Ö.A.(2005)” Açıklanmış Karşılaştırmalı Üstünlükler Ve Rekabet Gücü: Türkiye Tekstil Ve Hazır Giyim Endüstrisi Üzerine Bir Uygulama” Ege Akademik Bakış Dergisi, 5(1), 65-76.

- CÇoban, O. Kök, R.(2005) “Türkiye Tekstil Endüstrisi Ve Rekabet Gücü: AB Ülkeleriyle Karş1laştırmalı Bir Analiz Örneği (1989-2001)” iktisat, işletme ve finans dergisi, 20(228), 68-81.

- Falvey, R.(1981) “Commercial Trade Policy and Intra Industry Trade”, Journal of International Economics, 11(4), 495-511.

- Greenaway,D., Hine, R.C., Milner, C., (1995), "Vertical and Horizantal Intra Industry Trade : Across Industry Analysis For United Kingdom”, The Economic Journal , 105 (433), 1505-1518.

- Greenaway,D., Hine, R.C., Milner,C., and Elliott, R. (1994), “Adjustment and the measurement of marginal intra-industry trade", Weltwirtschaftliches Archiv, 130(2), 418-427.

- Grubel, H.G., Lloyd, P.J, (2003), Intra-Industry Trade, UK: Edward Elgar Publishing Limited.

- Güran, N. (1990) Dışa Açılma Sürecinde Türkiye Ekonomisinin Rekabet Gücü, Avrupa Topluluğu İle İlişkiler Başkanlığı, Ankara.

- Hamilton, C., and Kniest, P. (1991), "Trade Liberalisation, Structural Adjustment and Intra-Industry Trade: A Note." Weltwirtschaftliches Archiv, 127(2), 356-367.

- Herbert Glejser, Karel Goossens and M.Vanden Eede (1982), "Inter-industry versus Intra-Industry Specialization in Exports and Imports(1959-1970_1973)",Journal of International Economics, 12 (3-4), 363369.

- $\quad$ Lancaster, K.(1980), “Intra-Industry Trade Under Perfect Monopolisitic Competition, Journal of International Economics, 10(2), 151-175.

- Loertscher, Rudaolp and Wolter Frank (1980), "Determinants of Intra- Industry Trade: Among Countries and Across Industries", Weltwirtschafliches Archiv, 116(2), 280-293.

- Yllmaz, B.(2003) "Turkey’s Competitiveness in the European Union: A Conparision with Five Candidate Countries and the EU”, Ezoneplus Working Paper N0:12.

- Yurttançıkmaz, Z.Ç. (2013) “Türkiye’nin AB Pazarından Endüstri İçi Ticaret Açısından Avantajlı Olduğu Ürünlerin Belirlenmesi”, Cumhuriyet Üniversitesi İktisadi ve İdari Bilimler Dergisi, 14(1), 1-22. 


\title{
Selçuklu Deniz Ticaretinin Anadolu Ekonomisinin Dünya Ekonomisine Entegrasyonundaki Rolü
}

\section{Role of Seljuk Maritime Trade on the Integration of Anatolian Economy with World Economy}

\author{
Assoc. Prof. Dr. Ayşe Dudu Kuşçu (Konya Necmettin Erbakan University, Turkey)
}

\begin{abstract}
It was not only Turkish history to be changed when Seljuk conquered Anatolia but also the destiny of Anatolia changed. Anatolia that was the center of east - west and north - south trade since Assyria trade colonies was lost its commercial importance during the conquer by Turks, long time ago. Before Seljuk, the region was a part of the Byzantine Empire and it lost its commercial activities. It was a long time for Seljuk to revitalise the Anatolian trade. The war in Myriokephalon reduced the problems of Turkish Seljuk and enabled the establishment of a strong state in Anatolia. Myriokephalon War deeply impacted Byzantine and the Seljuk Sultan Kılıç Arslan focused on to develop the economy of the county and made very important achievements. He was the first who tried to conquer Antalya that is a port city. Kılıç Arslan and succeeding Sultans of Seljuk State followed the same path. Izeddin Keykavus conquered Sinop. Alâeddin Keykubâd conquered Alanya, so Seljuk had its third port city. The volume of domestic and international trade of Seljuk made it very powerful economy of the region. In this study, the factors which made for Seljuk to conquer these port cities in the Black Sea and Mediterranean easy, and the contribution of maritime trade to Seljuk economy, with reference to the sources form the era.
\end{abstract}

\section{Fethinden Myryakefalon Savaşı'na Kadar Anadolu}

XI. Yüzyılda Türkler tarafından fethedilmeden önce, Anadolu coğrafyasına baktığımızda; karşımıza çıkan manzara oldukça şaşırtıcı bir görünüm arz eder. Pek çok medeniyete ev sahipliği yapan ve eski dünya kıtaları dediğimiz üç kıtanın kavşak noktasında bulunan coğrafya, bu dönemde Bizans İmparatorluğu'nun hakimiyeti altındadır. Ancak Bizans'ın içinde bulunduğu siyasî, askerî ve ekonomik istikrarsızlığa paralel olarak eski önemini ve canlılığını yitirmiş, demografik açıdan da oldukça azalmıştır (1).

Selçuklu Türkleri, Anadolu'yu fethedince, siyasî hakimiyeti ele geçirdikleri gibi bölgenin demografik açıdan da Türkleşmesini sağlamışlardır. Soydaşlarının Anadolu'da yeni bir devlet kurduğunu duyan Türk kitleleri, akın akın Anadolu'ya gelmeye ve burada yerleşmeye başlamışlardır. Anadolu'da siyasî, askerî ve nüfus bakımından üstünlüğünü Türklere kaptıran Bizans, Türkleri Anadolu'dan atmak için yüzyılı aşkın bir süre mücadele etmiş, hattâ bu mücadeleyi tek başına yürütemeyeceğini anlayıp bütün Hristiyan dünyasını da bu amacına dahil ederek Haçlı Seferleri'nin başlamasını sağlamıştır.

Bu sebeple ilk Selçuklu sultanlarının öncelikli hedefi, Anadolu'da kurmuş oldukları yeni devletlerini, Bizans ve Haçlı tehlikesine karşı korumak ve savunmak olmuştur. Ancak onlar, yalnızca Bizans ve Haçlılar'ın oluşturduğu tehlike ile değil, aynı zamanda kendilerini rakip gören soydaşları Danişmendlilerle uğraşmak zorunda kalmışlardır.

\section{Siyasî ve Ekonomik Alanda Bir Deha; Sultan II. Kılıç Arslan}

Bizans'ın Türkleri Anadolu'dan atma girişimleri, 1176 yılında Türkler'in kesin zaferiyle sonuçlanan Myriokephalon Savaşı ile son bulmuştur. Bu savaştan sonra Bizans, Türklere karşı taarruz durumundan savunma durumuna geçmiş ve Anadolu'nun bir Türk yurdu haline geldiğini kabullenmek zorunda kalmıştır. Haçlı Seferleri ise, 1096 yılında başlayan ilk sefer haricinde, Türkiye Selçukluları için çok büyük tehlike oluşturmamıştır. Fakat ilk seferde, Selçuklu Devleti'nin başkenti İznik dahil olmak üzere Marmara bölgesinde ele geçirilen bütün yerler kaybedilmiştir. Buna rağmen Selçuklular, çabuk toparlanabilmiş ve gerek siyasî anlamda gerekse fetihlerde ilerlemeye devam etmişlerdir. 1188 yılında gelişen III. Haçlı Seferi, Anadolu üzerinden yapılan son sefer olmuştur. $\mathrm{Bu}$ sefer de Selçuklular için o derece etkili olmamıştır. Kısacası XII. Yüzyılın son çeyreğinden 1243 yılındaki Moğol istilâsına kadar Selçuklu Devleti’ni ciddi anlamda tehdit edecek büyük bir tehlike kalmamıştır.

Bizans’ın Selçuklu Devleti üzerine yaptığı son büyük taarruzu teşkil eden Myriokephalon Savaşı, Selçuklu Devleti için siyasî, ekonomik ve kültürel anlamda bir dönüm noktasını oluşturmuştur. Bu tarihten sonra savaşın galibi olan Selçuklu sultanı II. Kılıç Arslan (1155-1192), çok önemli siyasî ve ekonomik politikalar geliştirerek devletin yükselme dönemine girişinde öncü bir rol oynamıştır. Siyasî üstünlüğün Türkler'e geçmesini sağlayan Kılıç Arslan, Selçuklu hakimiyeti altında Anadolu'da Türk birliğini sağlama politikasını başlatarak bir yandan soydaşlarından gelebilecek tehlikeleri bertaraf ederken, diğer yandan da devletin iç ve dış düşmanlarının birlikte hareket etmesi ihtimalini ortadan kaldırmak istemiştir.

Siyasî alanda bu gibi önemli politikaların temelini atan II. Kılıç Arslan, ekonomik alanda da çok önemli politikaların mimarı olmuştur. Sahip olduğu liderlik vasıfları, Onun kısa sürede Anadolu ekonomisinin 
geliştirilmesinde ticaretin temel faaliyet alanı olması gerektiğini anlamasını sağlamıştı. Bu çerçevede ticarî amaçlı fetihlere öncelik verdi. 1180 yılından sonra Batı Anadolu'da pek çok şehri fetheden II. Kılıç Arslan, önemli bir liman şehri olan Antalya'yı da kuşatmış fakat alamamıştı. Bunun yanı sıra ülkede ticaretin gelişmesini sağlayacak alt yapı çalışmalarını başlattı. İlk Selçuklu kervansarayı kendisi tarafından Aksaray'a bir konak (yaklaşık 35-40 km) mesafede yaptırılmıştı (2). Kılıç Arslan bunlardan başka payitaht Konya'nın yakınında bulunan Aksaray şehrini askeri bir üs ve karargâh olarak inşâ ederken bu şehre yerleştirilmek üzere Azerbaycan'dan ilim ve sanat erbab1 ile birlikte tüccarlar da getirtmişti (3). Siyasî ve ekonomik alanda bir deha olarak niteleyebileceğimiz II. Kılıç Arslan'ın asıl dehası; edindiği bu ticari politikayı oğulları ve torunlarına miras olarak bırakması oldu.

\section{II. Kılıç Arslan'ın Mirası; Ticarî Amaçlı Fetihler}

1204 yılında Latinler'in İstanbul'u ele geçirmesiyle sonuçlanan IV. Haçlı Seferi, Bizans İmparatorluğu'nun parçalanarak biri İznik’te, diğeri Trabzon'da olmak üzere iki ayrı krallığın kurulmasına sebep olmuştu (4). Bizans'ın parçalanıp siyasî otoritesini kaybetmesi, milletlerarası ticaretin güvenliğini ortadan kaldırmıştı. Karadeniz ve Akdeniz sahillerinde ticaret yapan tüccar, meydana gelen kargaşa ortamından faydalanarak soygun yapanlara hedef olmaktan kurtulamıyor ve ağır zararlara uğruyordu. Bu sebeple 1205 yılında ikinci kez Selçuklu tahtına geçen I. Gıyâseddin Keyhüsrev, bölgedeki en güçlü siyasî otoriteyi temsil ettiğinden özellikle Müslüman tüccarın şikayet makamı haline gelmişti. Bu arada İtalyan asıllı Aldo Brandini adlı biri, Bizans'ın içine düştüğü durumdan faydalanarak Antalya'yı ele geçirmiş ve şehirdeki ticarî faaliyetleri kontrolü altına almıştı. Ancak şehirdeki mücadele ve kaos ortamı devam etti. Akdeniz'in en önemli liman şehrinde emniyet ve asayişin olmayışı, şehirde yaşayanları rahatsız ettiği gibi Mısır ve Avrupa'dan gelen tüccar taifesinin de emniyetini ortadan kaldırmıştı. Bu sebeple soygun olayları arttı. Babası II. Kılıç Arslan'ın ticaret politikasını devam ettiren I. Gıyaseddin Keyhüsrev, kendisine gelip mallarının soyulduğunu arz eden tüccarı bahane ederek Antalya üzerine yürüdü. 5 Mart 1207 de Antalya Türkler'in eline geçti.

Akdeniz'in en önemli liman şehri ve ticari üssü olan Antalya'nın ele geçirilmesiyle Selçuklular'ın ticaret algıSı, köklü bir değişikliğe uğradı. Artık Selçuklu Devleti, Baharat yolunun önemli bir kavşağında söz sahibi olabilecek, Akdeniz ticaretine katılma firsatı elde edebilecek, ayrıca Anadolu'nun kuzey-güney ticareti bu liman şehri üzerinden daha güvenli ve yoğun bir şekilde yapılabilecekti. İthalat ve ihracatın artması, Selçuklu ticari hayatını daha da canlandıracak, böylelikle devlet ekonomisi güçlenecekti.

Antalya'nın Selçuklular tarafından fethinin bu ticarî ve ekonomik öneminin yanı sıra siyasî ve askeri önemi de mevcuttu. Bu tarihten sonra Selçuklu Devleti, Akdeniz'e kıyısı olan devletlerce siyasî muhatap olarak alınacak ve otoritesini daha da güçlendirecekti. Nitekim Prof. Osman Turan, Selçuklular'ın Hristiyan devletlerle ilk ticaret anlaşmalarının Antalya'nın fethinden sonra yapıldığını belirtir (5). Şehrin askerî önemine gelince; Antalya'nın fethi bir bakıma güneyde Anadolu'nun tabii sınırlarına ulaşmak anlamına geliyordu. Bu durum aynı zamanda ülkenin denizden gelebilecek tehlikelere karşı tedbirli olmasını da zaruri kılmıştı. Bu sebeple Gıyaseddin Keyhüsrev, Antalya'da deniz kuvvetleri için askeri bir üs de oluşturdu (6).

Antalya'nın fethinden sonra Sultan I. Gıyaseddin Keyhüsrev, ticareti himaye amaçlı çok önemli politikalar geliştirdi. O'nun, karada ve denizde soyguna uğrayan veya herhangi bir şekilde zarar gören tüccarın mallarını devlet hazinesinden tazmin etme uygulaması, çağına göre çok ileri bir anlayışın ürünü idi (7). Ayrıca bazı ticarî vergilerin kaldırılması Anadolu'nun milletlerarası bir ticaret ve transit merkezi olmasını sağladı (8).

I.Gıyaseddin Keyhüsrev, 1211 yılında öldü. O’nun ölümü üzerine oğulları I. İzzeddin Keykâvus ve Alâeddin Keykubâd arasında yaşanan taht mücadeleleri sırasında yaşanan kargaşa ve otorite boşluğu sebebiyle Antalya elden çıktı. Ancak İzzeddin Keykâvus (1211-1219), kardeşiyle girdiği taht mücadelesini kazanıp Selçuklu tahtına oturunca, babasının ve dedesinin politikasını devam ettirip ticarî amaçlı fetihlere öncelik verdi. Kıbrıs kralı Hugue ve Venedikliler ile karşılıklı ticareti düzenleyen bir anlaşma yaptıktan sonra Karadeniz tarafına yöneldi. Amacı Akdeniz'den sonra Karadeniz'de de ticarî bir üs elde edip ticarî üstünlüğü ele geçirmekti. Bu çerçevede Samsun ve Sinop gibi iki önemli liman şehrinin Selçuklu Devleti’ne kazandırılmasını zarurî görüyordu. Aksi halde Selçuklular'ın doğu-batı ve güney-kuzey ticaretinin kontrolünü ele geçirmeleri, yeni vatanlarını dünya ticaretinin tercih edilen mekanı haline getirmeleri, bir başka ifadeyle dünya ticaretiyle entegrasyon sağlamaları mümkün değildi. Üstelik Latinlerin Bizans İmparatorluğu'na vurdukları ağır darbeden sonra Karadeniz ticareti, dünya ülkeleri için eskisi kadar emniyetli gözükmüyordu. Tarihî İpek yolunun uzantısı olan bölgede, ortaya çıkan otorite boşluğu, ticaret kervanlarının akışını olumsuz yönde etkilemiş, bölge ticarî cazibesini kaybetme noktasına gelmişti.

Bütün bunların yanı sıra Bizans'ın devamı niteliğindeki İznik Laskaris hanedanlığı ve Trabzon'daki Komnenoslar, Karadeniz ticaretinde söz sahibi olmak, bir bakıma Bizans'ın yerini almak istiyorlardı. Bu sebeple topraklarına yakın olan Samsun ve Sinop'u ele geçirmeyi hedefliyorlardı (9). İki Rum devletinin menfaatlerinin çatışma noktası haline gelen Karadeniz ticaret yolu, zaman zaman şiddetli mücadelelerin yaşandığı ve asayişin bozulduğu, sıkça tıkanan bir yol olmuştu. Nihayet Selçuklu toprakları kuzeyden tehdide uğruyordu. Bu şartlar altında I. İzzeddin Keykavus’un Karadeniz’e yönelmesi oldukça tabii gözüküyordu. Dönemin kaynaklarından İbn Bibi, Keykavus'un Sivas’ta iken birdenbire Karadeniz üzerine harekete geçme sebebini, sınır muhafızlarından 
habercilerin gelip Canik tekfuru veya Trabzon Rum İmparatoru'nun kendi ülkesinde cinayetler işlediğini, hattâ kendi ülkesi sınırlarını aşarak Türk topraklarına tecavüz edip haddini aştığını, bu yüzden de sultanın Sinop üzerine yöneldiğini kaydeder (10).

Kanaatimizce İzzeddin Keykavus oldukça isabetli bir zamanlama ile Karadeniz’e yönelmişti. Çünkü aynı sıralarda Trabzon Rum İmparatoru Kir Aleksios da Sinop taraflarına yönelmiş bulunmaktaydı. Keykavus, Sinop hakkında gerekli ön istihbaratı topladıktan sonra şehri kuşattı. Yanında daha önce Türkmenler tarafından esir edilen Trabzon Rum İmparator Kyr Aleksios da bulunduğu halde şehri ele geçirdi.1 Kasım 1214'te "galip sultan" unvanıyla Sinop'a giren İzzeddin Keykavus, sekiz ay kadar şehirde kalıp burada idarî, askerî, sosyal, ekonomik ve demografik pek çok düzenlemeler yaptı. Şehrin valiliğine Ermeni asıllı bir dönme olan Hetum'u tayin etti. Bunun sebebi muhtemelen Hetum'un yabancı dil bilmesi ve bölgeye gelen yabancı tüccar ile iyi geçinebileceği kanaati idi. Keykâvus ayrıca, ülkenin pek çok yerinde görevli valilere birer ferman göndererek memleketin her köşesinden akıl, dirayet, mal ve serveti ile meşhur kimselerin seçilip Sinop şehrine gönderilmesini talep etti (11). Böylelikle buradaki ticaretin Türk burjuvazisinin eline geçmesi hedeflenmişti.

Sinop şehrinin imar ve iskanı bu şekilde düzenlendi. Ayrıca burada bir de askerî üs oluşturuldu. Selçuklular, Sinop'un fethiyle Karadeniz ticaretinde önemli bir konum elde etmişlerdi. Sinop'un fethinden on iki yıl gibi kısa bir süre sonra Sultan Alâeddin Keykubad (1220-1237) döneminde Karadeniz ticaretine hakim olma konusunda önemli bir adım daha atıldı. 1223 yılı başlarında, Moğollar'ın Kırım sahilinde büyük ticaret şehri olan Suğdak’1 işgal etmeleri, bu sebeple şehir halkının perişan olması ve Keykubâd'ın kendi vassalı olan Rumların bu bölgeye yerleşmek istemeleri üzerine Selçuklular'ın ilk deniz aşırı seferi olan Suğdak Seferi gerçekleştirildi. Uc beyi Hüsameddin Çoban komutasında gerçekleştirilen bu sefer sonucunda; bölgedeki Rus Knezlikleri, Selçuklu hakimiyetini tanıdılar. Suğdak şehrinin idaresi Selçuklular'a geçti. Selçuklular, siyasi ve ekonomik bakımdan Karadeniz'in en önemli gücü haline geldi.

İzzeddin Keykavus, Sinop'un fethinden sonra 1207 y1lında Selçuklu hakimiyetine alınan fakat 1211 yılında kardeşi ile giriştiği taht mücadelesi sırasında tekrar elden çıkan Antalya'yı 1216 yılında geri aldı. Böylelikle Akdeniz'de Selçuklu hakimiyeti yeniden güçlendi. İzzeddin Keykavus da "Sultanü’l-Bahreyn” (iki deniz sultanı) unvanını ald1.

1219 yılı sonlarında İzzeddin Keykavus’un ölümü üzerine Selçuklu tahtına kardeşi Alâeddin Keykubad geçti. Keykubad, babası I. Gıyaseddin Keyhüsrev ve ağabeyi İzzeddin Keykavus’un ticari politikasını devam ettirdi. Onun döneminde yapılan ticarî amaçlı fetihler ve alt yapı faaliyetleri babası ve kardeşinin yaptıklarını gölgede bıraktı. O tahta geçtikten iki ay sonra Venediklilerle ticarî bir anlaşma yaptı (12). Bu anlaşma babası ve ağabeyi dönemlerinde yapılan anlaşmaların devamı niteliğinde idi. Bunun yanısıra 1223 yılında Akdeniz'in önemli bir liman şehri olan Alaiye, yani bu günkü Alanya alındı (13). Keykubad Alaiye'de bir tersane yaptırdı. Bu tersane hem savunma hem de ticarî amaçlı idi. Nitekim Alaiye, bir süre sonra Akdeniz ticaretinde çok önemli bir noktaya geldi. W. Heyd, Alaiye hakkında şunları söyler: "Ortaçağda buraya Candelore adını verirlerdi. Gerçek bir Türk ticaret şehri idi, buraya Mısır'dan, İskenderiye'den ve Suriye'den birçok tüccar gelirdi. Mısır kereste ihtiyacını buradan sağlardı. Buradan yüklenen balyalar, İskenderiyye, Dimyat ve Mısır'ın diğer limanlarına gönderilirdi. Doğal olarak Kıbrıs adasının da komşu oluşu çok sıkı ilişkilere vesile oluyordu (14).

Yine Heyd'in verdiği bilgilere göre, 1289 yılında bir Ceneviz gemisinin şeker, keten ve biber yüküyle İskenderiyye-Alaiye seferi yaptı̆̆ı, bir diğerinin de İbn Batuta'yı Suriye'nin Lazkiye limanından Alaiye'ye getirdiği tespit edilmiştir (15).

Buradan da açıkça anlaşılıyor ki, Selçuklular'ın, Antalya, Sinop ve Alaiye gibi liman şehirlerini fethetmeleri, uzun bir süredir devam eden ülke içindeki ticaretin artık dünyaya açılmasını sağlamıştı. II. Kılıç Arslan döneminden beri sultanlar, ileri gelen devlet adamları ve emirler tarafından bilinçli bir şekilde yaptırılan kervansaraylar, ülkeyi doğudan batıya, güneyden kuzeye adeta bir ağ gibi sarmış, liman şehirlerinin fethinden sonra bu kervansaraylar, artık sadece iç ticarete değil aynı zamanda ülke dışından gelenlere de hizmet eder duruma gelmişlerdi (16).

\section{Liman Şehirlerinin Ele Geçirilmesinden Sonra Başlayan Dışa Açılma}

Selçuklu Devleti’nin Antalya'nın fethinden hemen sonra Kıbrıs Krallığı ve Venedikliler ile karşılıklı ticareti düzenleyen anlaşmalar yaptığını yukarıda belirtmiştik. Sonraki dönemlerde Latinler, Pisalılar ve Akdeniz'e komşu diğer devlet ve milletlerle de ticaret anlaşmaları yapıldı. Nitekim Kıbrıs kralı Henri'ye ait 1236 tarihli ferman Marsilya, Monpellier ve diğer Provence halklarının daha önce olmasa bile Alâeddin Keykubad zamanında Anadolu'da ticaret yaptıklarını ortaya koymaktadır (17).

Selçuklu limanlarına getirilen veya transit olarak geçirilen mallardan da ortalama \% 2 civarında bir gümrük vergisi alınmaktaydı (18). İzzeddin Keykavus, Kıbrıs Kralı ile yaptığı anlaşmada gümrük vergisi nispetini tayin etmeksizin, sadece mutad olan diğer vergilerin alınmasını emretmiştir ki, bunun aynı nispette olduğu muhakkaktır. Bundan bir asır sonra Kıbrıslıların Antalya'da ithal ve ihraç malları için \%2, muayene için çuval başına yarım akçe ödediklerini, Floransalı Bardi kumpanyasının ihraç malları için herhangi bir vergi ödememeleri konusunda imtiyaz aldıkları bilinmektedir (19). 
Deniz ticaretinin gelişmesi ve dışa açılma, Anadolu'da şehirlerin büyümesine ve bu şehirlerde birtakım Venedik ve Ceneviz kolonilerinin kurulmasına (20) sebep olduğu gibi imalat sanayisinin gelişmesine de katkıda bulunmuştu. Özellikle ihraç edilen malların ham madde olarak ihracının yanı sıra mamul madde olarak ihracı da söz konusuydu. $\mathrm{Bu}$ sebeple mamul madde elde edebilecek imalathaneler liman şehirlerinde veya onların yakınlarında kurulmuştu. Örneğin Alaiye'nin fethinden sonra şehrin yanıbaşındaki düzlükte bir şeker imalâthanesi yaptırılmıştı (21). Büyük ihtimalle Mısır'dan getirilen veya yörede yetiştirilen şeker kamışından şeker imal ediliyordu.

Selçuklular döneminde Anadolu'dan ne alınıp ne satıldığı konusunda yeterli bilgiye sahip değiliz ancak, XIV. Yüzyıl Anadolusu hakkında çok değerli bilgiler veren İbn Battûta, Antalya'da yetiştirilen ve Mısır'a ihraç edilen bademden söz eder (22), yine Denizli'de dokunan altın işlemeli pamuk kumaşların dünyaca meşhur olduğunu belirtir (23). Bilindiği gibi İbn Battuta'nın Anadolu’yu seyahat ettiği yıllar, Selçuklu Devleti'nin yıkılıp Anadolu'da Türk Beylikleri’nin kurulduğu dönemdir. Beylikler büyük ihtimalle teşkilat ve kültürde olduğu gibi ekonomik faaliyetlerinde de Selçuklu geleneğini devralmışlar ve onu büyük bir başarı ile devam ettirmişlerdir. Bu analitik metottan yola çıktığımızda safran, susam, bal, balmumu, kitre zamkı, meşe mazısı, şam üzümleri, Kütahya şapı, kırmızı maroken, halı, buğday, koyun ve at Selçuklular'ın ihraç kalemleri arasındaydı. Bunlar Rodos, Kıbrıs, Sakız Adası, Ceneviz, Mısır, Bizans ve Karadeniz'in Kuzeyindeki devletlere satılıyordu. Faruk Sümer, Erzurum bölgesinden Azerbaycan'a koyun satıldığını, ayrıca Konya’nın meşhur Kamereddin kayısıları çok lezzetli olduğu için Misır ve Suriye'de aranan mallar arasında olduğunu nakleder (24).

Buna karşılık kumaş, sabun, kalay, kurşun ve Kıbrıs'ın sofra takımları Selçuklu'nun ithal ettiği emtiadandı. Kürk, keten ve köle ticareti de Yabanlu Pazarı gibi Anadolu'nun belli başlı pazarlarında yapılan ticaretin en önemli unsurlarındandı (25). Bunları muhtemelen Rus ve Kıpçak tacirler getiriyordu (26). Kaldı ki, daha sonraki dönemlerde Mısır'da kendi adlarıyla anılacak olan bir devlet kuran Memlükler'in, başlarına geçen hükümdarların bile Anadolu'da satıldığını dönemin kaynaklarından açıkça öğrenebiliyoruz. Yine Faruk Sümer, Mısır'dan Alaiye limanına baharat, çivit, keten ve şeker, Irak ve İran'dan atlas ve sakarlat denilen işlemeli kumaşlar, mücevher ve kağıt getirildiğini, Hindistan'dan ise, dibâ, kılıç, zırh ve ilaç olarak kullanılan otlar ve baharat getirildiğini belirtir (27).

Esasen Selçuklular döneminde Anadolu'ya gelen yabancı seyyahların verdiği bilgiler Anadolu'daki ticarî faaliyetler açısından çok değerlidir ancak bu konu başlı başına kıyaslı bir şekilde ele alınmalıdır. 1271 yılında Anadolu'dan geçen Marco Polo, Akdeniz kıyısında Ayas denilen bir kasaba bulunduğunu, buranın önemli bir ticaret merkezi olduğunu, Venedik ve Cenevizli tacirlerin mal almak için buraya geldiklerini belirtir. Marco Polo ayrıca Anadolu'da pek çok büyük şehrin varlığından, burada yetiştirilen at ve sığırlardan ve dünyaca ünlü halılardan bahseder (28). Arap coğrafyacısı İbn Said'in de Aksaray'da dokunup dünya pazarlarında çok beğenilen halıların dünyada eşi benzeri olmadığını kaydetmesi Marco Polo’yu teyit eder (29).

Seyyah Rahip Simon de Saint Qentin ise, Türkiye sultanlığının çok ünlü ve zengin bir sultanlık olduğunu burada çok sayıda gümüş, bakır ve şap madeninin bulunduğunu, ayrıca Fransa ve İngiltere'de satılık kölelerin giydiği başlıkların (bonet) buradan temin edildiğini bildirmesi dikkat çekicidir (30). VII. Haçlı Seferi (1248-1252)'ne katılan Joinvilli ise, "Konya yani Selçuklu sultanının Müslüman hükümdarlar arasında en zengin sultan” olduğunu bildirir. O’nun sultanın zenginliği hakkındaki anlattıkları da oldukça kayda değerdir. Joinville, sultanın denizde iken şarap taşınmasında kullanılan üç dört ölçü şarap alabilecek büyüklükteki toprak küplere, altınlarının büyük bir kısmını eriterek doldurduğunu ve sonra da onları kırdırarak altın külçelerinin küp şeklinde kalmasını sağlayarak bunları kalelerinden birisinde muhafaza ettiğini belirtir (31). Bu durum abartılı bile olsa, Selçuklu Devleti'nin zenginliği hakkında fikir vermesi bakımından önemlidir. Anlaşılan o ki, Selçuklular'ın zenginliği bu dönemde Avrupa'da adeta efsaneleşmiştir. Belki de bu sebeple Selçuklu tarihçisi Prof. M. Altay Köymen, bu dönemde Anadolu'nun o zamanın dünyasının en zengin ülkesi olduğunu ve Selçuklular'ın güçlü bir medeniyet oluşturup İtalya'dan çok önce “Türk Rönesans”ını oluşturduklarını iddia eder (32).

\section{Sonuç}

Selçuklu sultanları Anadolu hakimiyetini tam olarak elde ettikten sonra Anadolu'nun jeostratejik yapısına uygun ekonomik politikalar geliştirmekte son derece başarılı olmuşlardır. İyi bir ticaret alt yapısı oluşturmuşlardır. İlk defa denizle tanışmalarına rağmen, limanların ve deniz ticaretinin önemini çabuk kavramışlar ve buna yönelik siyasi politikalar geliştirip, ikili veya çoklu anlaşmalar yapmışlardır. Böylelikle ülkenin Akdeniz ve Karadeniz ticaretinde önemli bir aktör durumuna gelmesini sağlayıp, Anadolu ekonomisini dünya ekonomisi ile entegre etmeyi başarmışlardır. Bu durum Selçuklu ekonomisini oldukça güçlendirmiş ve bu sayede devlet Moğol İstilasına kadar Orta Doğu'nun en önemli siyasî ve ekonomik gücü haline gelmiştir. 


\section{Kaynakça}

${ }^{1}$ Bizans döneminde Anadolu'nun eski ticarî önemini yitirme sebepleri hakkında ayrıntılı bilgi ve yorum için bkz. O. Turan, "Selçuklu Türkiyesi ve Dünya Ticareti”, Türk Yurdu Der. (Y1l: 1960), S. 50, c. X, s.5-7.

${ }^{2}$ Osman Turan, Selçuklular Zamanında Türkiye, İstanbul, 1993, III. Bask1, s.234

${ }^{3}$ O. Turan, Türkiye Selçukluları Hakkında Resmi Vesikalar, Ankara, 1988, II. Baskı, s.121; O.Turan, "Kılıç Arslan II", I.A.c.VI, s.701.

${ }^{4}$ Bizans İmparatorluğu, daha sonra VIII. Mihail Paleologos (1259-1282) tarafindan yeniden ihya edilecektir.

${ }^{5}$ O. Turan, Resmi Vesikalar, s. 124.

${ }^{6}$ O. Turan, Selçuklular Zamanında Türkiye, s.285.

7 İktisat tarihinde "sigorta benzeri faaliyetler" olarak değerlendirilen benzeri uygulamalar, ticareti teşvik için daha önce Roma ve Müslüman Doğu'da uygulanmışsa da, bu şekilde her ne sebeple olursa olsun zarar gören mal sahibinin mallarının devlet tarafından karşılanması söz konusu olmamıştır. XIV. Yüzyılda günümüz anlamında sigortacılığın ilk örnekleri diyebileceğimiz hukuki akd ve mukaveleye dayanan sigorta müessesesi gemici ve tüccar İtalyan Cumhuriyetlerine dayandırılmaktadır. Fakat bu konuda Selçuklu Devleti uygulamasının etkisini ciddi anlamda araştırmak gerekir. O. Turan, Resmi Vesikalar, s.128; Ayrıca bu konuda bkz. Sinan Kuşçu,

Sigorta Talep Teorisi ve Türkiye Uygulaması, Erzurum, 1996

${ }^{8}$ O.Turan, Selçuklular Zamanında Türkiye, s.285.

${ }^{9}$ Komnenoslar'dan I. Aleksios (1204-1222) ve kardeşi David IV. Haçli Seferi'nden sonra Trabzon merkez olmak üzere bütün orta ve doğu Karadeniz şeridini ele geçirmekle kalmamışlar Sivas’1 Karadeniz'e bağlayan ticaret yolunu da kontrolü altına almışlardı. Salim Koca, Sultan I. İzzeddin Keykâvus, Ankara, 1997, TTK. Yay., s.29. ${ }^{10}$ İbn Bibi, el-Evamirü'l Ala'iye-fi'l-Umuri'l-Ala'iye (Selçukname) (Ter.Mürsel Öztürk), Ankara, 1996, s.168169.

${ }^{11}$ Salim Koca, Sultan I. İzzeddin Keykâvus, s.35.

${ }^{12}$ O. Turan, Selçuklular Zamanında Türkiye, s.395; Faruk Sümer, "Selçuklular Devrinde Ticaret”, Türk Dünyası Araştırmaları Der. (1993), S. 83, s,12.

${ }^{13}$ İbn Bibi, el-Evamirü'l Ala'iye-fi'l-Umuri'l-Ala'iye (Selçukname), s. 268.

${ }^{14}$ W. Heyd, Yakın- Doğu Ticaret Tarihi, (Ter. E. Ziya Karal), Ankara,2000, II. Baskı, s. 611; İbn Battûta, Ebû Abdullah Muhammed, İbn Battûta Seyahatnâmesi, (Ter. A. Sait Aykut), İstanbul, 2000, c.I, s.402.

${ }^{15}$ W. Heyd, Yakın- Doğu Ticaret Tarihi, s.610; İbn Battûta, İbn Battûta Seyahatnâmesi, c.I, s.400.

${ }^{16}$ Selçuklu kervansarayları hakkında ayrıntılı bilgi için bkz. K. Erdmann, Die Anatolische Karavansaray des 13. Jahrhunderts, I, II, Berlin 1961.

${ }^{17}$ O.Turan, Resmi Vesikalar, s.124-125; Bu konuda ayrıca bkz. Melek Delilbaşı, “Anadolu Selçukluları ve Beylikler Döneminde Batı ile Ticarî İlişkilere Genel Bir Bakış”, Tarihte Türk Devletleri, II, Ankara, 1987, s.481489.

${ }^{18}$ O.Turan, Resmi Vesikalar, s.125; O. Turan, "Selçuklu Türkiyesi ve Dünya Ticareti”, s. 6.

${ }^{19}$ O. Turan, Resmi Vesikalar, s. 125.

${ }^{20}$ O. Turan, "Selçuklu Türkiyesi ve Dünya Ticareti", s. 6.

${ }^{21}$ İsmail Hakkı Konyalı, Alanya, (Alaiye), İstanbul, 1946, s.165-198; Salim Koca, Anadolu Beylikleri Tarihi, Ankara, 2012, s.72.

${ }^{22}$ İbn Battûta, İbn Battûta Seyahatnâmesi, s.403.

${ }^{23}$ İbn Battûta, İbn Battûta Seyahatnâmesi, s.408.

${ }^{24}$ Faruk Sümer, "Selçuklular Devrinde Ticaret", s.14.

${ }^{25}$ W. Heyd, Yakın- Doğu Ticaret Tarihi, s.608; Bu konuda bkz. Faruk Sümer, Yabanlu Pazarı, İstanbul, 1985.

${ }^{26}$ Faruk Sümer, "Selçuklular Devrinde Ticaret", s.13.

${ }^{27}$ Faruk Sümer, "Selçuklular Devrinde Ticaret", s.13.

${ }^{28}$ Marco Polo, Marko Polo Seyahatnamesi, (Yayına haz. Filiz Dokuman), Tercüman 1001 Temel Eser, c.I, s.1920.

${ }^{29}$ Faruk Sümer, "Selçuklular Devrinde Ticaret", s.11.

${ }^{30}$ Simon de Saint Quentin, Bir Keşiş’in Anılarında Tatarlar ve Anadolu, Antalya, 2006, s. 49-50.

${ }^{31}$ Jean de Joinville, Bir Haçlının Hatıraları, (Çev. Cüneyt Kanat), Ankara, 2002, s. 83.

${ }^{32}$ M. Altay Köymen, “Selçukluların Kendilerine Mahsus İktisadî Siyasetleri Var mıydı?”, Millî Kültür, Aralık 1979 , s.67. 
- Delilbaşı, 1987. "Anadolu Selçukluları ve Beylikler Döneminde Batı ile Ticarî İlişkilere Genel Bir Bakış”, Tarihte Türk Devletleri, II, Ankara.

- Erdmann, 2000. Die Anatolische Karavansaray des 13. Jahrhunderts, I, II, Berlin 1961.

- Heyd, 2000. Yakın- Doğu Ticaret Tarihi, (Ter. E. Ziya Karal), Ankara, II. Baskı.

- İbn Battûta, 2000. Ebû Abdullah Muhammed, İbn Battûta Seyahatnâmesi, (Ter. A. Sait Aykut), İstanbul.

- İ̉bn Bibi, 1996. el-Evamirü'l Ala'iye-fi’l-Umuri’l-Ala'iye (Selçukname), (Ter.Mürsel Öztürk), Ankara.

- Jean de Joinville, 2002. Bir Haçlının Hatıraları, (Çev. Cüneyt Kanat), Ankara.

- Koca, 1997. Sultan I. İzzeddin Keykâvus, Ankara, TTK. Yay.

- Koca, 2012. Anadolu Beylikleri Tarihi, Ankara.

- Konyal1, 1946. Alanya, (Alaiye), İstanbul.

- Köymen, 1979. “Selçukluların Kendilerine Mahsus İktisadî Siyasetleri Var mıydı?”, Millî Kültür,( Aralık).

- Kuşçu, 1996. Sigorta Talep Teorisi ve Türkiye Uygulaması, Erzurum.

- Marco Polo, Marko Polo Seyahatnamesi, (Yayına haz. Filiz Dokuman), Tercüman 1001 Temel Eser.

- Simon de Saint Quentin, 2006. Bir Keşiş’in Anılarında Tatarlar ve Anadolu, Antalya.

- Sümer, 1985. Yabanlu Pazarı, İstanbul.

- $\quad$ Sümer, 1993. “Selçuklular Devrinde Ticaret”, Türk Dünyası Araş. Der. (Yı1:1993), S. 83.

- Turan, 1993. Selçuklular Zamanında Türkiye, İstanbul, III. Bask1.

- Turan, 1988. Türkiye Selçukluları Hakkında Resmi Vesikalar, Ankara, II. Bask1.

- Turan, "Kılıç Arslan II”, İ.A., c.VI.

- Turan, 1960. "Selçuklu Türkiyesi ve Dünya Ticareti”, Türk Yurdu Der. (Y11: 1960),S. 50., c.X. 


\title{
1990-2015 Yılları Arasında Bin Yıl Kalkınma Hedefleri ve Yoksulluk: Türkiye Örneği
}

\section{Poverty and The Millennium Development Goals Between 1990- 2015: The Case of Turkey}

\author{
Hüseyin Çelik (Çukurova University, Turkey) \\ Ph.D. Candidate Ahmet Duran Çelik (Mustafa Kemal University, Turkey) \\ Prof. Dr. Mahir Fisunoğlu (Çukurova University, Turkey)
}

\begin{abstract}
As a definition; poverty is a situation that people's basic needs are not being met to sustain their life which is many countries facing today. In recent years, fighting against poverty has become one of the most important issues in the world. One of the steps taken by the United Nations to fight agains poverty is Millennium Development Goals. In 2000, a millennium development meeting took place with many countries' participation in New York. During the meeting, many goals were set such as eliminating poverty and famine, decreasing child death, providing primary education for all and dealing with epidemic diseases. In this study, progress level of The Millennium Development Goals, the steps which have taken and their effects were examined in Turkey. Data was collected from UNDP and TSI (Turkish Statistical Institute). The millenium development goals globally has been reached at a certain level between 1990 and 2015. Today, primary school accessibility level is around 90\% in developing countries. Eventhoug poverty was reduced by half, there are still 1,2 billion people who live in extreme poverty. In Turkey, there have been promising developments towards Millennium Development Goals. While level of people who live under extreme poverty line (1\$ per day) was $0,2 \%$ in 2002 , this rate was decreased to $0 \%$ by 2006 . The poverty rate (below 4,3 \$ per capita per day) in 2014 was 1,62\%, and primary school enrollment rate was $99 \%$. In addition to this, mother and children death rate was largely decreased.
\end{abstract}

\section{Giriș}

Günümüzde insanlığın birçok ortak sorunu vardır. Bu sorunlarından belki de en önemlisi yoksulluktur. Bugün pek çok ülke az ya da çok bu sorunla karşı karşıya olup, Dünya'da bir milyardan fazla insan günlük 1 ABD dolarının altında bir gelir düzeyi ile yaşamaktadır. Bu durum birçok ülkeyi çeşitli önlemler almaya zorlamıştır. Bu önlemlerden biri de Bin Y1l Kalkınma Hedefleridir. Birleşmiş Milletler tarafindan yoksullukla mücadele için konulan bu hedefler arasında ilk sırada aşırı yoksulluk yer almaktadır. Bu hedefler 1990-2015 yıllarını kapsamaktadır ve 2015 yılında Birinci Bin Yıl Kalkınma hedefleri sona ermiştir.

Küresel açlık, hedef tarih olan 2015'ten önce yarı yarıya azaltılmıştır. Gelişmekte olan bölgelerdeki çocukların \% 90’ı şimdi ilkokul eğitimi almaktadır ve ilkokula giden kız ve erkek çocuklarının sayısındaki eşitsizlik azaltılmıştır. Tüm sağlık göstergelerindeki ilerlemenin yanı sıra, sıtma ve tüberküloza karşı mücadelede de kayda değer bir ilerleme görülmüştür. Bir çocuğun beş yaşından önce ölme olasılığı son yirmi yılda yaklaşık yarı yarıya azalmıştır. Diğer bir deyişle bu durum, her gün 17 bine yakın çocuğun kurtarıldığı anlamına gelmektedir. İyileştirilmiş su kaynaklarına erişimi olmayan insan sayısını yarı yarıya indirme hedefine de ulaşılmıştır (UNDP, 2016).

Bu Hedefler doğrultusunda Türkiye'de de önemli aşamalar kaydedilmiştir. Aşırı yoksulluk sınırı olarak belirlenen günlük 1 doların altında yaşayanların oranı 1994'te nüfusun \%1.1'i, 2002'de \%0.2'si iken 2006 yılında bu oran sıfırlanmıştır. Kişi başı günlük harcaması, cari satın alma gücü paritesine (SGP) göre 2,15 doların altında kalan fert oranı 2011 yılında \%0,14 iken, bu oran 2012 yılında \% 0,06 olarak tahmin edildi. Yoksulluk sinırı, cari SGP' ye göre 4,3 dolar olarak alındığında ise 2011 yılında \%2,79 olan yoksulluk oranı, 2014 y1lında \%1,62 olmuştur. Bunun yanında gıda yoksulluğu oranı da görece düşük bir seviyede seyretmektedir. Ayrıca, ilköğretime kayıtta cinsiyet eşitliğini hemen hemen sağlanmış ve çocuk ve anne ölümlerinin azaltılmasında önemli ilerlemeler kaydedilmiştir. İlköğretime kayıt oranı \%98.7 olan Türkiye, 'Herkes için evrensel ilköğretimi sağlamak' hedefini 2015 yılından önce büyük oranda tamamlamış olup, 15-24 yaş grubundaki okuma yazma oranı \% 97’ye ulaşmıştır (UNDP, 2016).

Bu çalışmada, yoksulluk kavramı ele alınmış ve Bin Yıl Kalkınma Hedeflerinin neler olduğuna değinilmiştir. Ayrıca bu hedefler doğrultusunda Türkiye'de yürütülen faaliyetler incelenmiştir. Türkiye'de Bin Yıl Kalkınma Hedeflerinin ne ölçüde başarılı olduğunun belirlenmesi amacıyla özellikle yoksulluktaki gelişmeler TÜİK ve UNDP verileri ışığında incelenmiştir. Son olarak da İnsani Gelişme Endeksine yer verilmiştir. 


\section{Yoksulluk Kavramı}

21. Yüzyılda, dünya üzerindeki insanların refah içinde yaşamaları ve bunun devamlılık arz etmesi büyük önem taşımaktadır. Ancak dünyanın birçok ülkesinde insanlar refah içinde yaşamak bir yana, gıda yoksunluğundan dolayı yaşamlarını kaybetmektedirler. Yoksulluk insanoğlunun yüz yüze kaldığı en büyük sorunlardan biridir.

Oldukça karmaşık bir olgu olan yoksulluğun birden fazla tanımı vardır. Yoksulluk genel anlamıyla, 'bireylerin yaşamlarını devam ettirebilmesi için gerekli temel ihtiyaçlarını karşılayamama durumu” olarak tanımlanmaktadır (İbrişim,2008). Birleşmiş Milletler tarafından yayınlanan 1997 İnsani Gelişme Raporu'nda yoksulluk, "'insanların kabul edilebilir yaşam koşullarında hür, haysiyetli, kendine ve başkalarına saygıll, uzun, sağllklı ve yaratıcı bir hayat sürdürebilmeleri için gerekli insani gelişmenin en temel unsuru olan firsatlar ve seçeneklerden mahrum olmaları" şeklinde tanımlanmaktadır. Dünya Bankası 2000'li yıllardan itibaren yoksulluk kavramına yeni bir boyut kazandırarak; ' 'kırllganlık, savunmasızlık, söz hakkı olmama, güçsüzlük” şeklinde tanımlamıştır.

Yoksulluk özellikle az gelişmiş ülkelerin sorunu olmakla birlikte gelişmiş ülkelerde de görülebilmektedir. Türkiye gibi gelişmekte olan ülkeler açısından da yoksulluk gözardı edilmemesi ve önüne geçilmesi gereken bir sorun haline gelmektedir.

\section{Bin Yıl Kalkınma Hedefleri}

Günümüzde yoksullukla mücadele için yürütülen birçok çalışma vardır. Bu çalışmalardan bir tanesi de Bin Y1l Kalkınma Hedefleridir. Bu hedefler, Birleşmiş Milletler tarafından 2000 yılında New York'ta gerçekleştirilen zirvede, 189 ülke tarafından imzalanan Bin Yıl Bildirisinde yer alan ve 2015 yılına kadar ulaşılması beklenen amaçlardan oluşmaktadır. Birçok ülke ve uluslararası kuruluş bu hedefleri benimsemiş ve bu doğrultuda ortak çalışmalar yapmıştır.

Bin Yıl Kalkınma Hedefleri, yoksulluk ve açlığın ortadan kaldırılması, tüm insanların temel eğitim haklarından yararlanması, cinsiyet eşitsizliğinin azaltılması, çocuk ölümlerinin önlenmesi, anne sağlığının iyileştirilmesi, salgın hastalıklarla mücadele gibi küresel sorunlara çözüm aramaktadır. Bahsi geçen amaç ve hedefler Tablo 1'de ayrıntılı olarak görülmektedir.

\begin{tabular}{|c|c|c|c|}
\hline \multirow{2}{*}{ 1.Amaç } & \multirow{2}{*}{$\begin{array}{l}\text { Aşırı yoksulluğu ve açlığı ortadan } \\
\text { kaldırmak. }\end{array}$} & 1.Hedef & $\begin{array}{l}1990 \text { ile } 2015 \text { arasında geliri } 1 \text { ABD \$'in altında olan } \\
\text { insanların oranını yarıya indirmek. }\end{array}$ \\
\hline & & 2.Hedef & $\begin{array}{l}1990 \text { ile } 2015 \text { yılları arasında aç insan sayısını yarıya } \\
\text { indirmek. }\end{array}$ \\
\hline 2.Amaç & $\begin{array}{l}\text { Evrensel olarak ilköğretim } \\
\text { düzeyinin sağlanması. }\end{array}$ & 3.Hedef & $\begin{array}{l}2015 \text { yılına kadar tüm kız ve erkek çocuklarının } \\
\text { ilköğretimlerinin tamamlanmasını sağlamak. }\end{array}$ \\
\hline 3.Amaç & $\begin{array}{l}\text { Cinsiyet eşitliğinin sağlanması ve } \\
\text { kadınların güçlendirilmesi. }\end{array}$ & 4.Hedef & $\begin{array}{l}2005 \text { yılında ilk ve orta öğretimde cinsiyet ayrımına } \\
\text { son verilmesi; eğitimin tüm seviyelerinde bu hedefin } \\
\text { sağlanması. }\end{array}$ \\
\hline 4.Amaç & Çocuk ölümlerinin azaltılması. & 5. Hedef & $\begin{array}{l}1990 \text { ile } 2015 \text { yılları arasında beş yaşına ulaşmadan } \\
\text { ölen çocukların sayısının 2/3 oranında azaltılması. }\end{array}$ \\
\hline 5.Amaç & Anne sağlı̆̆ının iyileştirilmesi. & 6. Hedef & $\begin{array}{l}\text { Anne ölüm oranlarının } 1990 \text { ile } 2015 \text { yılları arasında } \\
\text { 3/4 oranında azaltılması. }\end{array}$ \\
\hline \multirow{2}{*}{ 6.Amaç } & \multirow{2}{*}{$\begin{array}{l}\text { HIV/Aids, sitma ve diğer } \\
\text { hastalıklarla mücadele. }\end{array}$} & 7. Hedef & $\begin{array}{l}\text { HIV/Aids salgınının } 2015 \text { yılında durdurulması ve } \\
\text { salgının azaltılması. }\end{array}$ \\
\hline & & 8. Hedef & $\begin{array}{l}\text { Sitma ve diğer önemli hastalıkların salgınının } 2015 \\
\text { yılında durdurulması ve sonra salgının azaltılması. }\end{array}$ \\
\hline \multirow{3}{*}{ 7.Amaç } & \multirow{3}{*}{$\begin{array}{l}\text { Çevrenin sürdürülebilirliğinin } \\
\text { sağlanmasi. }\end{array}$} & 9. Hedef & $\begin{array}{l}\text { Sürdürülebilir kalkınma prensiplerinin ülke } \\
\text { politikalarında ve programlarında uygulanması ve } \\
\text { doğal kaynakların kaybının azaltılması. }\end{array}$ \\
\hline & & 10. Hedef & $\begin{array}{l}\text { Temiz su kaynaklarına ve temel sağlık önlemlerine } \\
\text { sahip olmayan insanlarının oranının } 2015 \text { yılına kadar } \\
\text { yarıya azaltılması. }\end{array}$ \\
\hline & & 11. Hedef & $\begin{array}{l}\text { Gecekonduda yaşayan en az } 100 \text { milyon insanın } \\
\text { yaşamlarında } 2020 \text { yılında kadar önemli ilerlemeler } \\
\text { sağlanması. }\end{array}$ \\
\hline 8.Amaç & $\begin{array}{l}\text { Kalkınma için küresel ortaklıklar } \\
\text { geliştirmek. }\end{array}$ & 12. Hedef & $\begin{array}{l}\text { Açık, kurallara bağlı, tahmin edilebilir, ayrımcılık } \\
\text { içermeyen ticaret ve finans sistemleri geliştirmek. }\end{array}$ \\
\hline
\end{tabular}

Tablo 1. Bin Yıl Kalkınma Amaç ve Hedefleri Kaynak: UNDP 


\subsection{Bin Yıl Kalkınma Hedefleri Kapsamında Türkiye'de Kaydedilen İlerlemeler}

Yoksulluk oranı gelişmekte olan ülkelerde oldukça yüksektir. Bu ülkelerde yaşayan insanlar yoksullukla büyük bir mücadele içerisindedir. Aşırı yoksulluk içinde yaşayan bu insanlar için Bin Yıl Kalkınma Hedefleri büyük önem arz etmektedir. Bu hedefler daha uzun soluklu ve sağlıklı bir yaşam için önemlidir. Türkiye'de yoksullukla mücadele eden ülkelerden biridir. Bu anlamda Bin Yıl Kalkınma Hedefleri doğrultusunda Türkiye'de ortak faaliyetler yürütülmüştür. UNDP, politika ve projelerde özellikle kadının her alanda etkinliğinin artırılmasına ve cinsiyet eşitliğinin sağlanmasına büyük önem vermektedir. UNDP, bu alanlarda ilerleme kaydedebilmek ve Türkiye'nin kalkınmasına katkıda bulunabilmek için, hükümet, yerel yönetimler, sivil toplum örgütleri, üniversiteler ve özel sektörle ortak çalışmalar yürütmektedir.

\begin{tabular}{|l|c|c|c|c|c|c|c|c|c|}
\hline Y1l & 2006 & 2007 & 2008 & 2009 & 2010 & 2011 & 2012 & 2013 & 2014 \\
\hline $\begin{array}{l}\text { Yoksul Sayıs } \\
\text { (Bin kişi) }\end{array}$ & 12.550 & 11.165 & 11.580 & 12.097 & 12.025 & 11.670 & 12.000 & 11.140 & 11.335 \\
\hline
\end{tabular}

Tablo 2. Türkiye'de Eşdeğer Hane Halkı Kullanılabilir Kişi Gelirine Dayalı Yoksul Kişi Sayısı (2006-2014) Kaynak: $T \ddot{U} \dot{I} K$

Türkiye'deki yoksul kişi sayısı Tablo 2'de görülmektedir. TÜİK verilerine göre 2006'da Türkiye'de yoksul kişi sayısı 12.500 kişidir. 2010 yılında bu sayı 12.025 kişi iken 2014 yılında bu sayı 11.335 kişidir. Bu veriler 1şığında yoksul kişi sayısında çok büyük bir düşüş yaşanmadığı ve Bin Yıl Kalkınma Hedeflerinin kısmen başarılı olduğu görülebilmektedir.

\begin{tabular}{|l|c|c|c|c|c|c|c|c|}
\hline Y11 & 2002 & 2003 & 2004 & 2005 & 2006 & 2007 & 2008 & 2009 \\
\hline $\begin{array}{l}\text { Yoksulluk Oran1 } \\
(\%)\end{array}$ & 26,96 & 28,12 & 25,60 & 20,50 & 17,81 & 17,80 & 17,11 & 18,08 \\
\hline
\end{tabular}

Tablo 3. Yoksulluk Sınırı Yöntemine Dayalı Yoksulluk Oranı (2002-2009) Kaynak: TÜIK

Türkiye'de yoksulluk sınırı yöntemine göre yoksulluk oranı 2002'de \% 26,96 iken 2009 yılında bu oran \% 18,08'e düşmüştür (Tablo 3).

\begin{tabular}{|l|l|l|l|l|l|l|l|l|}
\hline Y11 & 2002 & 2003 & 2004 & 2005 & 2006 & 2007 & 2008 & 2009 \\
\hline $\begin{array}{l}\text { Gida Yoksulluk } \\
\text { Oranı (\%) }\end{array}$ & 1,35 & 1,29 & 1,29 & 0,87 & 0,74 & 0,48 & 0,54 & 0,48 \\
\hline
\end{tabular}

Tablo 4. Türkiye’de Yoksulluk Sınırı Yöntemlerine Dayalı Gıda Yoksulluğu Oranı (2002-2009) Kaynak: TÜIKK

Türkiye'de gıda yoksulluğu da var olan bir diğer yoksulluk türüdür. Gıda yoksulluğu, bir ülkedeki hane halkı ya da bireylerin yaşamını sürdürebilmek için alması gereken en az kaloriyi içerecek gıda mallarına erişememesi durumudur. TÜİK verilerine göre 2002 yılında bu oran \% 1,35 iken 2006 y1lında \% 0,74'e düşmüştür. 2009 y1lına gelindiğindeyse bu oran \% 0,48 olmuştur. Verilerden anlaşılmaktadır ki, Türkiye'de gıda yoksulluğu oranlarında 2002-2009 yılları arasında dalgalanmalar yaşanmış olsa da genel olarak düşük bir seviyede seyretmektedir (Tablo 4).

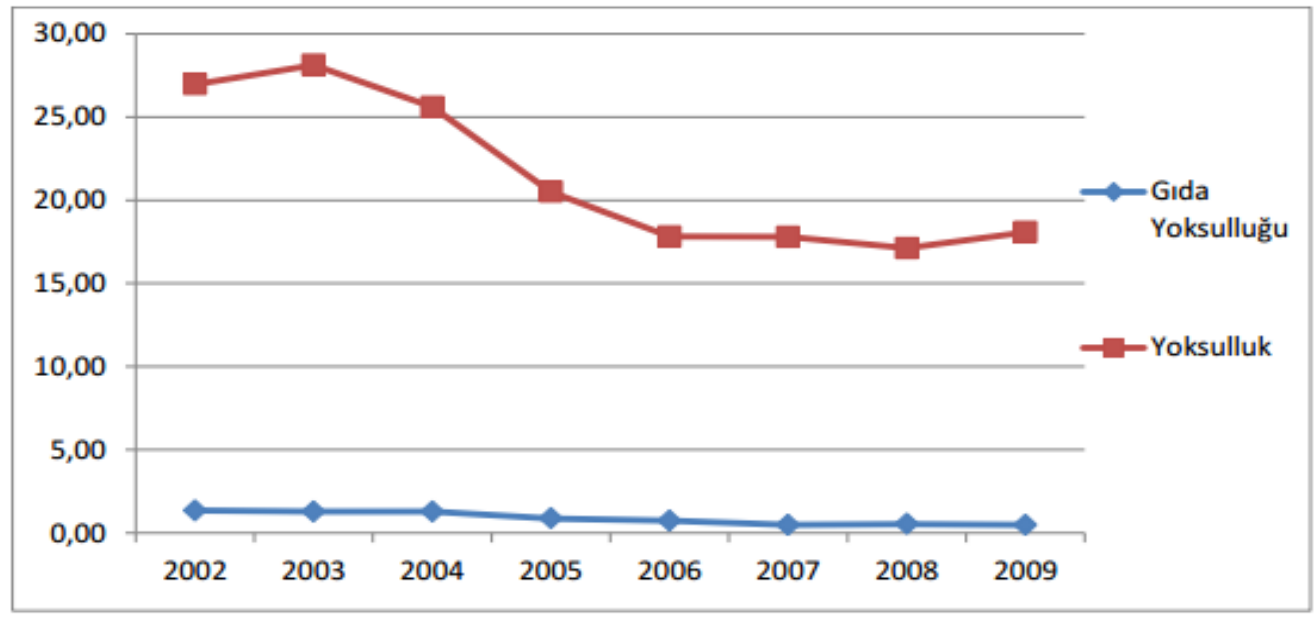

Şekil 1. Türkiye'de Gıda Yoksulluğu Ve Yoksulluk Oranları (2002-2009) (Tablo 3 ve 4'deki veriler kullanılarak oluşturulmuştur) 
Şekil 1'de Türkiye'deki gıda yoksulluğu ve yoksulluk oranları grafik olarak verilmiştir. Şekil incelendiğinde, iki yoksulluk türünün de 2002-2009 yılları arasında azalan bir eğilim içinde olduğu görülmektedir. 2009'da gıda yoksulluğu \% 0,48 ve yoksulluk oranı \% 18,08'dir.

\begin{tabular}{|c|c|c|c|c|c|c|c|c|c|c|c|c|c|}
\hline Yil & ণ̊ & ֻి & $\underset{ণ}{\stackrel{Ð}{~}}$ & $\stackrel{n}{8}$ & ஓ̊ & 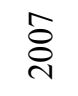 & $\stackrel{\infty}{\stackrel{\sim}{\circ}}$ & ஓి & $\stackrel{\circ}{\stackrel{0}{\sigma}}$ & 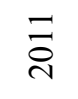 & $\frac{\sim}{\stackrel{\sim}{\sim}}$ & $\stackrel{m}{\stackrel{n}{0}}$ & $\underset{\sim}{\stackrel{\nabla}{~}}$ \\
\hline $\begin{array}{l}\text { Kişi Yoksulluk } \\
\text { Oranı (\%) }\end{array}$ & 30,3 & 23,7 & 20,8 & 16,3 & 13,3 & 8,41 & 6,83 & 4,35 & 3,66 & 2,79 & 2,27 & 2,06 & 1,62 \\
\hline
\end{tabular}

Tablo 5. Satın Alma Gücü Paritesine Dayalı Kişi Başına Günlük Geliri 4,3 \$’in Altında Olanlar (2002-2014) Kaynak: TÜIK

Tablo 5'de görüldüğü üzere, Türkiye'de günlük geliri 4,3 \$' in altında olan kişi oranı yıllar itibari ile azalmıştır. Kişi yoksulluk oranı 2002'de \% 30,3 iken 2014'de bu oran \% 1,62'ye gerilemiştir. Bu olumlu bir ilerleme kaydedildiği anlamına gelmektedir.

\begin{tabular}{|c|c|c|c|c|c|c|c|c|c|c|c|c|c|}
\hline Yil & ชิ & ஜ̊ & ঠ্ণ & $\stackrel{\overbrace{}}{8}$ & ஓ̊ & 옹 & $\stackrel{\infty}{\stackrel{8}{0}}$ & 용 & $\stackrel{\circ}{\stackrel{0}{\circ}}$ & $\overline{\bar{\nu}}$ & $\frac{\sim}{8}$ & $\stackrel{m}{\stackrel{n}{2}}$ & 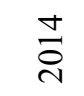 \\
\hline $\begin{array}{l}\text { Kişi Başı } \\
\text { GSYİH (\$) }\end{array}$ & 3,492 & 4,565 & 5,775 & 7,036 & 7,597 & 9,247 & 10,444 & 8,561 & 10,003 & 10,428 & 10,459 & 10,822 & 10,395 \\
\hline
\end{tabular}

Tablo 6. Cari Fiyatlarla Kişi Başı GSYİH (2002-2014) Kaynak: TÜIK

Türkiye'de kişi başına gelirde yaşanan artış açık bir şekilde gözlenebilmektedir. Kişi başına gelir 2002 yılında 3,492 \$ dolar iken 2010 yılında 10,003 \$ ve 2014 yılına gelindiğinde ise 10,395 \$'a ulaşmış olup, 2002 ve 2014 yılları arasında yaklaşı1k 3 kat artmıştır (Tablo 6).

\subsection{UNDP ve Türkiye Ortak Faaliyetleri}

Son yıllarda UNDP ve Türkiye yoksullukla mücadele ve sürdürülebilir kalkınma anlamında birçok faaliyet yürütmektedir. Bunlardan bazıları aşağıda yer almaktadır:

- Kadının sosyal yaşama katılımını güçlendirmek amacıyla Şubat 2016'da UNDP ve GAP idare başkanlığı ortak çalışmasıyla eğitimler verilmiştir.

- “Lice Organik Tarımın Geliştirilmesi” projesi, Diyarbakır Büyükşehir Belediyesi tarafından organik tarımı desteklemek ve yaygınlaştırmak amacıyla GAP Bölge Kalkınma İdaresi ve Karacadağ Kalkınma Ajansı mali desteği ve UNDP teknik işbirliği ile yürütülmektedir.

- “Her Damla Değer Katar”, UNDP ve Coca-Cola’nın su ortaklığı konusunda oluşturduğu bir inisiyatiftir. Projenin vizyonu; sosyal ve ekonomik kalkınma açısından birincil derecede önemli olan suya ve hijyene erişimin geliştirilmesi, böylelikle Binyıl Kalkınma Hedefleri’ne ulaşılmasının desteklenmesidir.

- Birleşmiş Milletler Uluslararası Mayın Bilincini Geliştirme Günü nedeniyle, Milli Savunma Bakanlığg ve Birleşmiş Milletler Kalkınma Programı (UNDP) Türkiye'nin doğu sınırlarının mayınlardan temizlenmesi ve sınır denetiminin arttırılması konusunda kapsamlı bir projenin ilk adımları atılmıştır.

- UNDP ve Galatasaray spor kulübü 2016'nın Nisan ayında 2030 yılına kadar yoksulluğu sona erdirmeyi amaçlayan bir anlaşma imzalamıştır (UNDP, 2016).

\section{4 İnsani Gelişme Endeksi ve Türkiye}

İnsani gelişme endeksi Amartya Sen'in Kapasite Yaklaşımına dayanmaktadır. Öncelikle Kapasite Yaklaşımının ne olduğuna değinmek gerekirse; kapasite, bir insanın ne olabileceğini veya ne yapabileceğini içeren bir kavramdır: iyi beslenebilmek, ölümden kaçabilmek, okuyabilmek ve yazabilmek, haberleşebilmek, toplum içinde bulunabilmek, utanmadan insanlar arasında bulunmak anlamlarına gelmektir (Kabaş,2006).

UNDP tarafindan bu yaklaşım baz alınarak hazırlanan İnsani Gelişme Endeksi, insan yaşamı için gerekli üç unsurun yoksunluğu olarak tanımlanır. Bu üç unsur şunlardır:

- Yaşam süresi.

- Yaşam kalitesi.

- Bilgi seviyesi. 


\begin{tabular}{|l|c|c|c|c|}
\hline Yıllar & $\begin{array}{c}\text { Doğumda } \\
\text { ortalama yaşam } \\
\text { beklentisi (Yıl) }\end{array}$ & $\begin{array}{c}\text { Okula devam } \\
\text { süresi beklentisi } \\
\text { (Yıl) }\end{array}$ & $\begin{array}{c}\text { Ortalama } \\
\text { okula gitme } \\
\text { süresi (Yıl) }\end{array}$ & ÍGE değeri \\
\hline $\mathbf{1 9 9 0}$ & 64,3 & 8,9 & 4,5 & 0,576 \\
\hline $\mathbf{1 9 9 5}$ & 67,0 & 9,6 & 4,8 & 0,604 \\
\hline $\mathbf{2 0 0 0}$ & 70,0 & 11,1 & 5,5 & 0,653 \\
\hline $\mathbf{2 0 0 5}$ & 72,5 & 11,9 & 6,0 & 0,687 \\
\hline $\mathbf{2 0 1 0}$ & 74,2 & 13,9 & 7,2 & 0,738 \\
\hline $\mathbf{2 0 1 1}$ & 74,4 & 14,4 & 7,4 & 0,751 \\
\hline $\mathbf{2 0 1 2}$ & 74,7 & 14,5 & 7,6 & 0,756 \\
\hline $\mathbf{2 0 1 3}$ & 75,0 & 14,5 & 7,6 & 0,759 \\
\hline $\mathbf{2 0 1 4}$ & 75,3 & 14,5 & 7,6 & 0,761 \\
\hline
\end{tabular}

Tablo 7. Türkiye'nin İGE eğilimleri (1990-2014) Kaynak: Insani Gelişme Raporu, 2015

2015 yılına ait İnsani Gelişme Raporuna göre Türkiye'nin İGE değeri 0,761 olmuştur. Bu değerle Türkiye, yüksek insani gelişme kategorisinde ve 188 ülke ve bölge arasında 72. sırada yer almıştır. Tablo 7'de Türkiye'nin 1990-2014 yılları arasında her bir İGE göstergesi açısından kaydettiği ilerlemeye yer verilmiştir. Doğumda ortalama yaşam beklentisi 1990 yılında 64,3 iken 2014'de 75,3 yıla yükselmiştir. Okula devam süresi beklentisi 1990'da 8,9 iken 2014'de 14,5 yıla yükselmiştir. Ortalama okula gitme süresi 1990'da 4,5 y1l iken 2014'de 7,6 yıla yükselmiştir. İGE değeri 1990 yılında 0,576 iken 2014 yılında bu oran 0,761 olmuştur. Verilerden anlaşılacağı üzere, İGE göstergeleri açısından yıllar itibariyle olumlu artışlar gerçekleşmiştir.

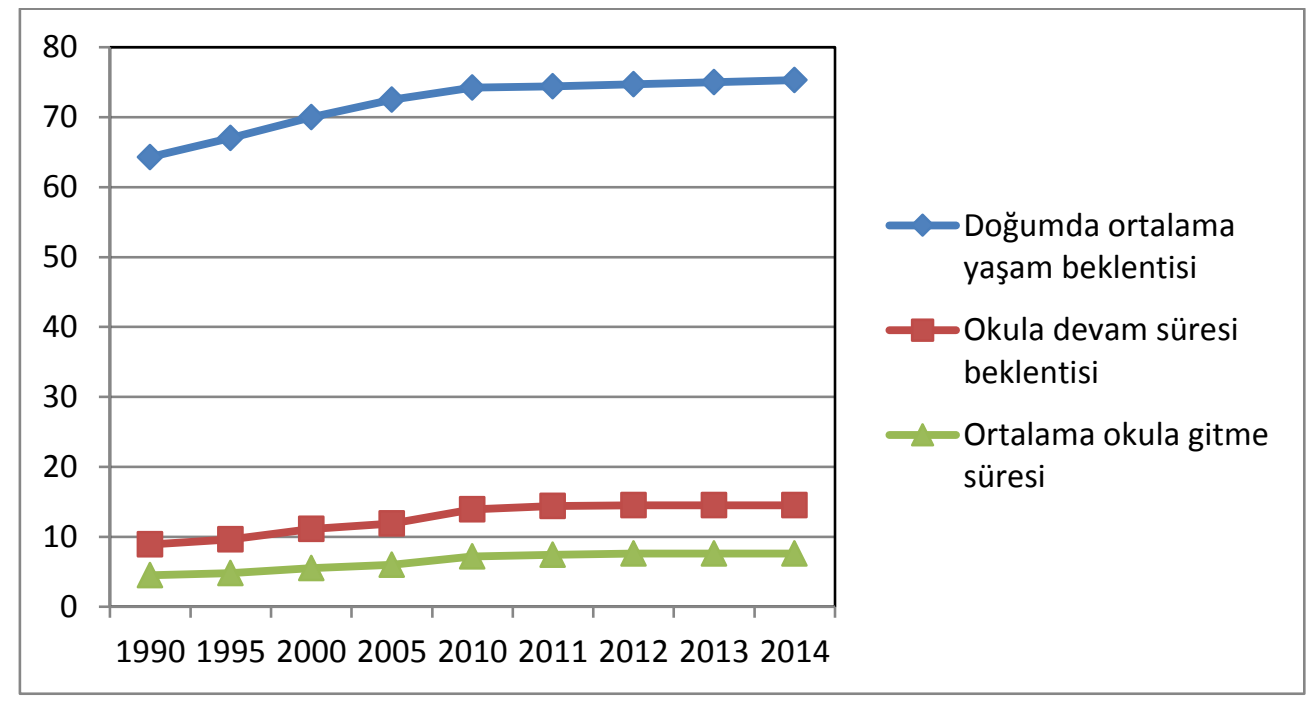

Şekil 2. Türkiye’nin bazı IGGE oranları (1990-2014) (Tablo 7'deki veriler kullanılarak hazırlanmıştır)

Şekil 2. incelendiğinde 1990-2014 yılları arasında ortalama okula gitme süresi ve okula devam süresinde 2011 2014 yılları arasında çok belirgin bir artış gözlenmemektedir. Bunula beraber, doğumda ortalama yaşam süresinde yıllar itibariyle önemli bir artış yaşanmıştır.

\begin{tabular}{|l|l|c|c|c|c|}
\hline & $\begin{array}{c}\text { IGE } \\
\text { değeri }\end{array}$ & $\begin{array}{c}\text { İGE } \\
\text { Sıralaması }\end{array}$ & $\begin{array}{c}\text { Doğumda Ortalama } \\
\text { Yaşam Beklentisi (Yıl) }\end{array}$ & $\begin{array}{c}\text { Okula Devam Süresi } \\
\text { Beklenmesi (Yıl) }\end{array}$ & $\begin{array}{c}\text { Ortalama Okula } \\
\text { Gitme Süresi (Yıl) }\end{array}$ \\
\hline Türkiye & 0,761 & 72 & 75,3 & 14,5 & 7,6 \\
\hline Sırbistan & 0,771 & 66 & 74,9 & 14,4 & 10,5 \\
\hline Azerbaycan & 0,751 & 78 & 70,8 & 11,9 & 1,2 \\
\hline $\begin{array}{l}\text { Avrupa ve } \\
\text { Orta Asya }\end{array}$ & 0,748 & - & 72,3 & 13,6 & 8,0 \\
\hline $\begin{array}{l}\text { Yüksek } \\
\text { İGE }\end{array}$ & 0,744 & - & 75,1 & 13,6 & 8,2 \\
\hline
\end{tabular}

Tablo 8. Türkiye 'nin 2014 İGE Göstergelerinin Seçilmiş Ülkeler Ve Ülke Gruplarıyla Karşılaştırılması Kaynak: Insani Gelişme Raporu, 2015

Tablo 8'e göre Türkiye'nin 2014 yılında 0,761 düzeyinde ölçülen İGE değeri, yüksek insani gelişme kategorisindeki ülkeler için ortalama 0,744 olarak ölçülen ve ayrıca Avrupa ve Orta Asya ülkelerinin 0,748 olarak 
ölçülen insani gelişme değerinin üzerindedir. Avrupa ve Orta Asya ülkeleri arasında 2014'teki İGE sıralaması ve nüfus büyüklüğü anlamında Türkiye’ye yakın ülkeler, sırasıyla Sırbistan ve Azerbaycan olmuştur.

\section{Sonuç}

Bu çalışmada, karmaşık bir kavram olmasından ötürü, yoksulluğun tanımlanmasında birden fazla ölçütten yararlanılmış olup, yoksulluğun dünya genelindeki en önemli sorunların başında geldiğine ve yoksullukla mücadele yöntemlerinden biri olan Bin Yıl Kalkınma Hedefleri'ne değinilmiştir. Ayrıca bu hedefler doğrultusunda Türkiye'deki yoksulluğun ne durumda olduğu incelenmiştir.

Türkiye'de gıda yoksulluğu yıllar itibariyle düşüş eğiliminde olsa da yoksulluk sınırı yöntemine göre yoksulluk oranı halen \% 18 gibi nispeten yüksek bir orandadır ve konunun halen ciddiyetini koruduğuna işaret etmektedir. Satın alma gücü paritesine göre günlük geliri 4,3 \$'ın altında olan kişi oranı 2014'de \% 1,62'dir ve olumlu bir seviyede olduğu gözlenmektedir. Gelir durumuna bakıldığındaysa 2014 yılında kişi başına GSYIH 10,395 \$'dır.

Sürdürülebilir ilerlemeyi sağlama yolunda karşılaşılan zorlukları ölçmede önemli bir gösterge olan İnsani Gelişme Endeksi açısından Türkiye olumlu bir seviyeye ulaşmışıı. Türkiye, İGE sıralamasında 72. sıradadır.

UNDP ve Türkiye, Bin Yıl Kalkınma Hedefleri kapsamında çeşitli ortak faaliyetler yürütmektedir. Özellikle cinsiyet eşitsizliğini ortadan kaldırmak, kadının toplumdaki etkinliğini artırmak, organik tarımı geliştirmek gibi çalışmalara ağırlık verilmiştir.

Bin Yıl Kalkınma Hedefleri kapsamında yoksullukla mücadele anlamında dünya ve Türkiye'de olumlu gelişmeler yaşanmışıtır. Ancak Dünya'da hala aşırı yoksulluk içinde yaşayan insanların sayısı azımsanamayacak kadar fazladır. Yoksulluğun önüne geçebilmek için daha çok uluslararası anlaşmalara ve organizasyonlara ihtiyaç vardır. 2015-2030 yılları arasında uygulanacak olan İkinci Bin Yıl Kalkınma Hedefleri kuşkusuz bu faaliyetler arasında en önemlilerinden biridir ve küresel yoksulluğu belli bir oranda azaltması umut edilmektedir.

\section{Kaynakça}

- İbrişim, 2008. "Yoksulluk, Yoksulluğun Ölçülmesi ve Türkiye Üzerine Analizi", Yüksek Lisans Tezi, p. 98.

- Kabaş, 2010. Gelişmekte Olan Ülkelerde Yoksulluğun Nedenleri ve Yoksullukla Mücadele Yolları. Nobel Kitabevi, Adana.

- Kabaş, 2006. "A. Sen'in Kapasite Yaklaşımına Göre Türkiye'de Yoksulluğun Boyutları", Ekonomik Yaklaşım, 17, p. 77.

- TÜIK, 2016. Yoksulluk istatistikleri, http://www.tuik.gov.tr/PreTablo.do?alt_id=1013

(Erişim Tarihi: 23.04.2016)

- UNDP, 2016. Türkiye hakkında, http://www.tr.undp.org/content/turkey/tr/home/countryinfo/ (Erişim Tarihi: 27.03.2016)

- UNDP, 2016. 2015 İnsani gelişme raporu, http://www.tr.undp.org/content/turkey

(Erişim Tarihi: 19.05.2016) 


\title{
Sosyal Sermaye, Duygu ve Motivasyon Temelinde Çalışanların Bilgi Paylaşma Niyetinin Belirleyicileri \\ Determinants of Employees' Knowledge Sharing Intention through Perspectives of Social Capital, Emotion and Motivation
}

\author{
Assoc. Prof. Dr. Canan Nur Karabey (Atatürk University, Turkey)
}

\begin{abstract}
The aim of this study is to investigate the factors that determine employee's knowledge sharing intention through the perspectives of social capital, emotion and motivation. The impacts of individual factors, namely social capital, enjoyment in and fear for knowledge sharing, sense of belonging and knowledge sharing self-efficacy on employee's intention to share knowledge with colleagues are examined. In order to test the hypotheses regarding the relationships among aforementioned variables, data were gathered through question forms from 267 employees working at two shopping malls in a province of Turkey. First, confirmatory factor analysis was applied to data on LISREL 8.7 software. Second, the validity of the measurement model was examined and last, anticipated relationships among variables were investigated through path analysis in structural equation modelling. The results stated that fear for sharing knowledge affected intention negatively while enjoyment in sharing knowledge and knowledge sharing self-efficacy affected intention positively. Also, relational capital was not found to impact intention to share knowledge via fear and enjoyment. On the other hand, sense of belonging impacted intention merely through enjoyment in sharing knowledge.
\end{abstract}

\section{Giriş}

Bu araştırmanın amacı sosyal sermaye, duygu ve motivasyon kavramlarını temel alarak çalışanın bilgi paylaşma niyetini belirleyen unsurları araştırmaktır. Çalışanın sosyal sermayesinin, bilgi paylaşmadan duyduğu zevk ve korkunun, aitlik duygusunun ve bilgi paylaşmaya ilişkin özyetkinliğin bilgisini iş arkadaşlarıyla paylaşma niyetine etkisi incelenmektedir.

Sosyal sermaye, bireyin sahip olduğu ilişkiler şebekesi aracıllğıyla edindiği gerçek ve potansiyel kaynakların tümünü ifade eder (Nahapiet ve Ghoshal, 1998). Sosyal sermayenin yapısal boyutu sosyal bağların sayısını ve şebekedeki kişilerin karşıllıklı bağlantılı olma düzeyini gösterirken, ilişkisel boyut bu bağların getirdiği güven gibi soyut değerleri içerir. Aitlik duygusu, çalışanın örgüt üyeleriyle birliktelik ya da yakınlık duygusunu ne ölçüde hissettiğini belirtir (Goh ve Sandhu, 2013). Özyetkinlik; kişinin bir işi yapma konusunda kendi yetkinliğine olan inancını ve ortaya çıkabilecek zorluklarla ne kadar iyi mücadele edebileceğine ilişkin düşüncesini gösterir (Bandura, 1982). Bilgi paylaşma çeşitli sosyal öğrenme türlerini içerdiğinden, bilgi paylaşmaya ilişkin öz yetkinlik kişinin bilgi paylaşma uygulamaları üzerindeki kontrolünü yansıtır (Kuo ve Young, 2008). Bilgi paylaşmaktan duyulan zevk içsel motivasyonla ilgilidir ve içsel motivasyon bir faaliyeti maddi olmayan faydalar için, örneğin faaliyeti gerçekleştirme sürecinin zevki için yerine getirme isteğini belirtir (Hau vd., 2013). Bilgi paylaşmaktan duyulan korku ise çalışanın değerli bilgiler vermesine karşılık çok az bilgi alacağı ve örgütteki konumunun zayıflayacağı konusundaki endişesini gösterir (Renzl, 2008). Bilgi paylaşma niyeti ise çalışanların örgütle ilgili bilgi ve uzmanlıklarını diğerlerine aktarma niyetidir (Tohidinia ve Mosakhani, 2010).

\section{Teorik Çerçeve}

Bilgi paylaşımının gerçekleşmesi için güçlü bireysel motivasyona ihtiyaç vardır. Aktarılacak bilginin türünden bağımsız olarak motivasyon çalışanların bilgilerini paylaşmalarını etkileyen en önemli unsurlardan biridir. Özellikle rasyonel eylem teorisi bilgi paylaşma gibi sosyal etkileşimleri karşılıklı sosyal değişim (değiş-tokuş) olarak görür (Scott, 2000). Karşlıklı sosyal değişimin parasal (bonus, terfi vb.) ya da parasal olmayan (zevk, karşl1ıklılık vb.) faydaları olabilir. Bir çalışanın bilgi paylaşmadan elde edebileceği en önemli faydalar örgütsel ödüller, karşıllıklılık ve zevktir.

Çalışanların içsel ve dışsal motivasyonları bilgi paylaşma niyetlerinin gelişmesinde etkilidir. Dışsal olarak motive edilmiş çalışanlar bilgilerini paylaşmaları sayesinde edinecekleri fayda ve ödüller ile motive olur. İçsel motivasyon bir faaliyeti maddi olmayan yararlar için, örneğin faaliyeti yerine getirme sürecinin verdiği zevk için yapma isteğini ifade eder. Bilgi yönetimi ile ilgili geçmişteki çalışmalar bir işi yapmaktan duyulan zevki hayati bir içsel motivasyon unsuru olarak görmüştür (Hau vd., 2013). İçsel olarak motive olan çalışanlar bilgi paylaşmaya katılmaktan doğan zevk ve eğlence duygusundan etkilenirler. Zevk bilgiyi sağlayan kişi ile onun benliği arasındaki karşılıklı değişim ilişsisine dayanan bir tür teşvik edici olarak bilgiyi sağlayan kişiden doğar. Geçmişteki çalışmalar içsel motivasyonun bilgi paylaşımı üzerinde olumlu etkilerinin olduğunu göstermiştir. Örneğin Tissen vd. (1989) işin kendisinden kaynaklanan içsel ödüllerin çalışanları bilgi paylaşmaya yönelttiğini öne sürmüştür. Wasko ve Faraj (2005) zevkin elektronik uygulama şebekelerinde bilgi sağlama ile olumlu yönde ilişkili olduğunu 
ampirik olarak göstermiştir. Zevk çalışanları bilgi paylaşmaya teşvik etmede önemli bir unsur olarak kabul edilmiştir (Lin, 2007). Cabrera vd.'ye göre (2006) bilgilerini paylaşmaları yönünde daha fazla içsel ödüller algılayan çalışanlar bilgi paylaşımına katılmaya daha eğilimlidir. Lin (2007) ve Hung vd. (2011) çalışanların başkalarına yardım etmekten duyduğu zevkin, bilgi paylaşmaya yönelik tutumlarını ve davranışsal niyetlerini önemli ölçüde etkilediğini göstermiştir (aktaran Hau vd., 2013). Bu görüşlerden hareketle aşağıdaki hipotez geliştirilmiştir:

$\mathrm{H}_{1}$ : Çalışanın bilgi paylaşmaktan duyduğu zevk arttıkça bilgi paylaşma niyeti de artar.

Örgütteki değerini kaybetme korkusu bilgi paylaşmanın önündeki temel engellerden biridir. Örneğin sömürülme korkusu, bireylerin değerli bilgiler vermeye karşılık çok az şey kazanma konusunda endişe duydukları bir durumu yansıtır. Bireyin sahip olduğu benzersiz değeri kaybetme korkusu ile bilgi paylaşma davranışı arasındaki ilişki dikkate alındığında, şu nokta göz önünde bulundurulmalıdır: bilgi vermek bireyin başkalarına oranla sahip olduğu benzersiz değeri kaybetmesine sebep olabilir ve faydalar bilgiyi sağlayan dışındaki herkes için doğabilir. Bilgi paylaşımı sosyal ikilem olarak bilinen belli bir sosyal durum kullanılarak da ifade edilebilir. Sosyal ikilemler paradoksal durumları gösterir. Bireysel rasyonellik bireysel çıkarları en yükseğe çıkarmayı isterken kolektif (ortaklaşa, bütüncül) irrasyonelliğe yol açabilir. Eğer bireyler bir işbirliği ilişkisi içinde kaybetmekten endişe duyarsa, bilgi paylaşmaktan kaçınırlar (Renzl, 2008). Renzl (2008) kişinin değerini kaybetme korkusunun takım içindeki ve takımlar arasındaki bilgi paylaşımını azalttığını ampirik olarak göstermiştir. Yukarıdaki açıklamalardan hareketle aşağıdaki hipotez ortaya atılmıştır:

$\mathrm{H}_{2}$ : Çalışanın bilgi paylaşmaktan duyduğu korku arttıkça bilgi paylaşma niyeti azalır.

Bilgi paylaşma süreci yalnızca bir kişinin bilgisini diğerine aktarması olarak görülmemeli, bunun yerine katılımcıların belli olaylara anlam yüklediği paylaşılan bir bilgi üretme süreci olarak görülmelidir. Bu yaklaşımın merkezinde grup üyeleri arasındaki sosyal dinamikler yer alır. Bilgi paylaşımı temelde kişilerarası ve grupça ilişkiler tarafından belirlenir. Çalışanların sosyal ilişkilerde başkalarına nasıl bağlandığı temelde ne ölçüde ve hangi yollarla bilgi alabileceklerini ve bilgi sağlayabileceklerini belirler (van den Hoff ve Huysman, 2009). Çalışanın sosyal sermayesi arttıkça bilgi paylaşma niyetinin de artması beklenir; çünkü sosyal şebekeler ihtiyaçları ve soruları olan kişilere erişimi sağlar ve üyeler arasında ortak bir çıkar duygusu ve güven geliştirerek diğerlerinin sahip olduğu bilginin değerini takdir etme iklimi oluşturur. Sosyal sermayenin yapısal boyutu kimin hangi yollarla ulaşılabilir olduğunu gösteren şebeke bağlantılarını içerir ve bu boyuttaki unsurlar şebeke örüntüsünü (şebekedeki bireylerin birbirine bağlanma şeklini), yoğunluğu ve hiyerarşiyi ortaya koyar. İlişkisel boyut ise etkileşimler esnasında insanlar arasında oluşan güven düzeyini ortaya koyar. Oluşan normlar, zorunluluklar, güven ve özdeşleşme şebekedeki bireylerin ortak amaçlara yönelik farkındalığını artırır. Sosyal şebeke kişilerarası temas için çok sayıda firsat sunar. İnsanlar fikirlerini ve kaynaklarını yakın bir ilişski geliştirdikleri kişilerle paylaşma konusunda daha olumlu hislere sahip olurlar. Ayrıca iş arkadaşlarıyla daha geniş bir sosyal şebekeye sahip olan çalışanlar bilgilerini paylaşma konusunda daha fazla sosyal baskı hissederler; çünkü iyi bir ilişki iş arkadaşlarının bireye ilişkin yüksek davranışsal beklentiler içine girmesine yol açar (Chow ve Chan, 2008). Özetlemek gerekirse, sosyal sermayenin bilgi paylaşımına şu yollarla katkıda bulunduğu söylenebilir: ihtiyaçları veya soruları olan bireylere ulaşmayı sağlayarak; ortak bir çıkar duygusu oluşturarak, karşılıklı güven ve başkalarının bilgisinin değerini takdir etme iklimi sağlayarak; diğerlerinin bilgisini anlamaya yardımcı olan ortak bir yeteneği paylaşarak ve tüm bilgilerin doğru yorumlanmasını ve değerlendirilmesini sağlayarak (van den Hoff ve Huysman, 2009). Sosyal sermayenin iki alt boyutu olan yapısal ve ilişkisel sermayenin bilgi paylaşma niyeti üzerindeki etkisi karşılaştırılmalıdır; çünkü bunlar birbirinden bağımsız etkilere sahip olabilir. Sosyal sermayenin bilgi paylaşmadan duyulan korkuyu azaltarak ve zevki artırarak bilgi paylaşma niyetini artırması beklenir. Sosyal sermayesi yüksek kişiler bilgi paylaşmaktan daha az korku duyacak, daha fazla zevk alacak ve böylece bilgi paylaşma istekleri artacaktır. Dolayısıyla aşağıdaki hipotezler geliştirilmiştir:

$\mathrm{H}_{3}$ : Çalışanın yapısal sermayesi arttıkça bilgi paylaşmaktan duyduğu zevk artar.

$\mathrm{H}_{4}$ : Çalışanın yapısal sermayesi arttıkça bilgi paylaşmaktan duyduğu korku azalır.

$\mathrm{H}_{5}$ : Çalışanın ilişkisel sermayesi arttıkça bilgi paylaşmaktan duyduğu zevk artar.

$\mathrm{H}_{6}$ : Çalışanın ilişkisel sermayesi arttıkça bilgi paylaşmaktan duyduğu korku azalır.

Genel itibariyle öz-yetkinlik; kişinin belirli bir işi yapma konusunda kendi yetkinliğine (yeterliliğine) dair inancını, ileride ortaya çıkması muhtemel zorluklarla mücadele için gereken faaliyetleri ne kadar iyi yapabileceğine ilişkin düşüncesini gösterir (Bandura, 1982). Cabrera vd. (2006), Lin (2007) ve Hsu vd. (2007) bilgi paylaşma öz yetkinliğinin bilgi paylaşmanın öncülü olduğunu göstermiştir. Ayrıca BP Amoco'da bireylere bilgi yönetim sistemlerini kullanma konusunda koçluk etme ve onları yetiştirme yoluyla onların bilgi paylaşma görevlerini yerine getirme yeteneklerine duydukları inanç güçlendirilmiş ve böylece bilgi paylaşma uygulamalarında başarı sağlanmıştır (Husted ve Michailova, 2002). Buna karşılık, kendine güven eksikliği çalışanın bilgi yönetimini günlük iş yükü ile bütünleştirmede başarısız olmasına sebep olur (KPGM, 2000'den aktaran Kuo ve Young, 2008). Kuo ve Young (2008) özyetkinliğin bilgi yönetimi uygulamasını doğrudan etkileyen önemli bir unsur olduğunu göstermiştir. Yani yüksek özyetkinlik sahibi bireyler bilgi paylaşmanın önündeki engellerin üstesinden gelmeye daha fazla eğilimlidir. Ye vd., (2006) ve Tohidinia ve Mosakhani (2010) bilgi 
paylaşma bağlamında öz yetkinliğin bilgi paylaşmaya yönelik tutumu olumlu etkilediğini ortaya koymuştur. Bu görüşlerden yola çıkılarak aşağıdaki hipotez geliştirilmiştir:

$\mathrm{H}_{7}$ : Çalışanın bilgi paylaşmaya ilişkin özyetkinliği arttıkça bilgi paylaşma niyeti de artar.

Örgüte aidiyet duygusu hissetmenin de bilgi paylaşmaktan duyulan korkuyu azaltarak ve zevki artırarak bilgi paylaşma niyetini güçlendirmesi beklenir; çünkü çalışan kendisini örgütün diğer üyeleriyle bağlantılı algıladığında, örgütteki benzersiz değerini kaybetme korkusunu daha az yaşar. Aitlik duygusu ayrıca çalışanın iş arkadaşlarıyla daha çok bilgi paylaşmak zorunda olduğunu hissetmesine yol açarak bilgi paylaşma niyetini destekler (Goh ve Sandhu, 2013). Bu düşünceler doğrultusunda aşağıdaki hipotezler geliştirilmiştir:

$\mathrm{H}_{8}$ : Çalışanın örgüte aidiyet duygusu arttıkça bilgi paylaşmaktan duyduğu zevk artar.

$\mathrm{H}_{9}$ : Çalışanın örgüte aidiyet duygusu arttıkça bilgi paylaşmaktan duyduğu korku azalır.

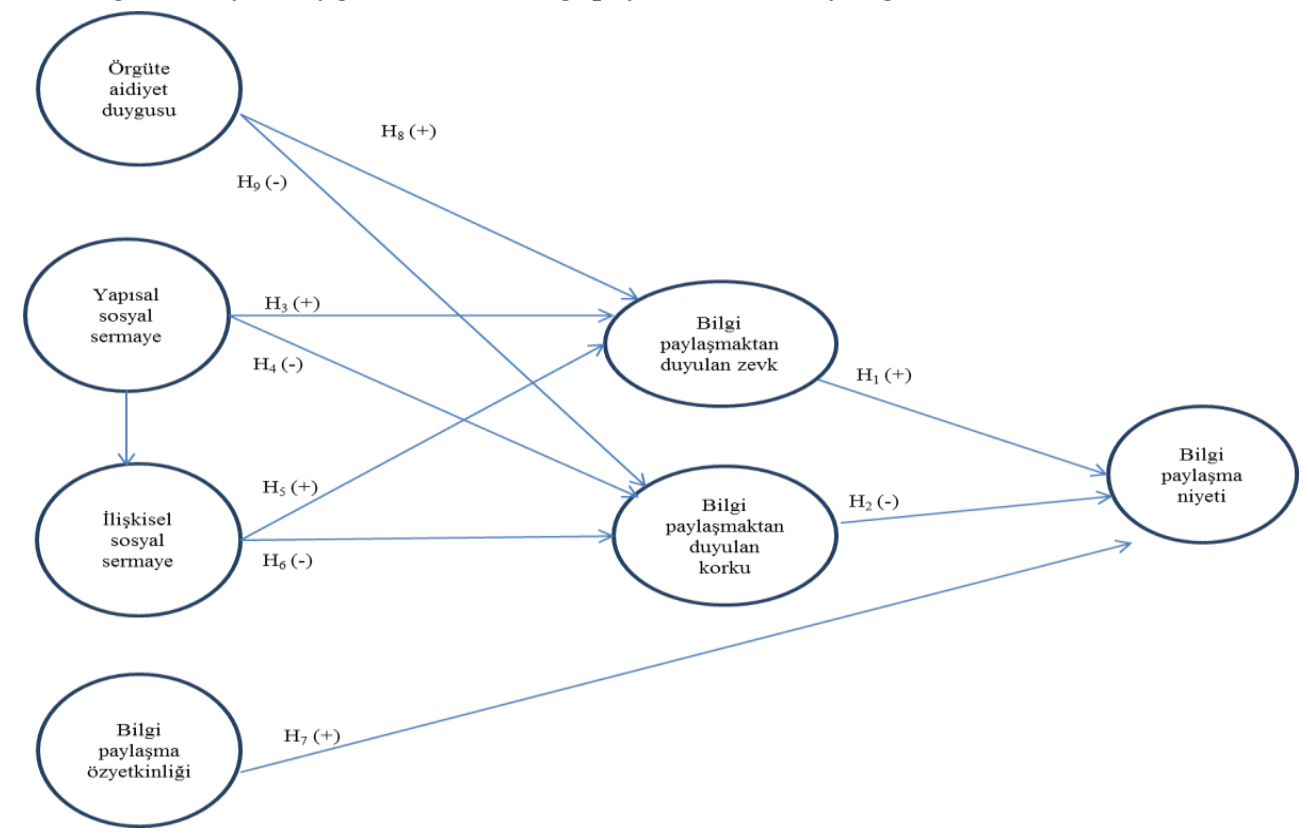

Şekil 1. Araştırma Modeli

\section{Araştırma Yöntemi}

Öne sürülen hipotezleri test etmek için bir ilimizde faaliyette bulunan iki alışveriş merkezindeki işletmelerde çalışan 267 kişiden yüz yüze anket uygulaması yoluyla veri toplanmıştır. Elde edilen veriler LISREL 8.7 programı aracılığıyla analize tabi tutulmuştur. Öncelikle oluşturulan ölçüm modeline doğrulayıcı faktör analizi uygulanmış, ölçüm modelinin geçerliliği ve güvenilirliği incelenmiş ve daha sonra yapısal eşitlik modeliyle yol analizi yapılarak değişkenler arasında öngörülen ilişkilerin bulunup bulunmadığı test edilmiştir. Kullanılan ölçeklere ilişkin bilgiler Tablo 1'de verilmiştir:

\begin{tabular}{|l|l|l|}
\hline Ölçek & Madde sayısı & Kaynak \\
\hline Bilgi paylaşma niyeti & 5 & Bock vd., 2005 \\
\hline Bilgi paylaşmaktan duyulan zevk & 3 & Wasko ve Faraj, 2005 \\
\hline Bilgi paylaşmaktan duyulan korku & 5 & Wasko ve Faraj, 2005; Renzl, 2008 \\
\hline Bilgi paylaşma özyetkinliği & 5 & Bock vd., 2005 \\
\hline Örgüte aidiyet duygusu & 4 & Bock vd., 2005 \\
\hline Yapısal sosyal sermaye & 7 & van den Hoff ve Huysman, 2009 \\
\hline İlişkisel sosyal sermaye & 5 & van den Hoff ve Huysman, 2009 \\
\hline
\end{tabular}

Tablo 1. Araştırmada Kullanılan Ölçekler

\section{Bulgular}

Araştırmaya katılan çalışanlara ilişkin demografik bulgular şöyle özetlenebilir: Cevaplayıcıların \% 45,6'sı kadın (120 kişi), \% 54,4’ü erkektir (143 kişi). Cevaplayıcıların \% 63,1’i 25 veya altı yaşlarda iken 26-30 yaş grubundaki çalışanların oranı \% 21,3'tür. Araştırmanın aktif bedensel çalışmayı gerektiren perakende hizmet sektöründe yapıldığı dikkate alındığında genç çalışanların niçin böyle yüksek bir orana sahip olduğu anlaşılmaktadır. Yönetsel pozisyon açısından durum incelendiğinde, cevaplayıcıların \% 28,1'inin yönetsel görevi olduğu görülmektedir. Eğitim düzeyine bakıldığında, yüksekokul/üniversite mezunlarının oranının \% 66,5 olduğu görülmektedir. 
Çalışma süresine bakıldığında ise bulundukları örgütte 1- 4 yıldır çalışanların oranı \% 46,8 iken, 1 yıldan az süredir çalışanların oranı \% 41,8'dir. Dolayısıyla cevaplayıcıların bulundukları örgütteki çalışma süresi oldukça kısadır.

Verilerin analizinde öncelikle oluşturulan ölçüm modeli bir bütün olarak doğrulayıcı faktör analizine tabi tutulmuş ve modelin yapı geçerliliği ve güvenilirliği incelenmiştir. Ölçüm modelinin geçerlilik ve güvenilirliğine ilişkin başlica göstergeler Tablo 2'de özetlenmiştir:

\begin{tabular}{|c|c|c|c|c|c|c|}
\hline Kavram & Gösterge & $\begin{array}{l}\text { Standardize } \\
\text { faktör yükü }\end{array}$ & $\stackrel{\text { t }}{\text { değeri }}$ & $\begin{array}{c}\text { Birleşik } \\
\text { güvenilirlik }\end{array}$ & $\begin{array}{c}\text { Ortalama } \\
\text { Açıklanan } \\
\text { Varyans } \\
\end{array}$ & $\begin{array}{l}\text { Cronbach } \\
\text { alfa }\end{array}$ \\
\hline \multirow{4}{*}{$\begin{array}{l}\text { Bilgi paylaşma niyeti } \\
(\mathrm{N})\end{array}$} & N1 & 0,82 & 17,37 & 0,886 & 0,66 & 0,892 \\
\hline & $\mathrm{N} 2$ & 0,92 & 24,95 & & & \\
\hline & N3 & 0,88 & 20,94 & & & \\
\hline & N4 & 0,61 & 10,78 & & & \\
\hline \multirow{4}{*}{$\begin{array}{l}\text { Bilgi paylaşmaktan } \\
\text { duyulan korku }(\mathrm{KO})\end{array}$} & KO1 & 0,74 & 14,68 & 0,874 & 0,64 & 0,866 \\
\hline & $\mathrm{KO} 2$ & 0,82 & 17,12 & & & \\
\hline & KO3 & 0,88 & 18,22 & & & \\
\hline & KO5 & 0,74 & 13,86 & & & \\
\hline \multirow{3}{*}{$\begin{array}{l}\text { Bilgi paylaşmaktan } \\
\text { duyulan zevk }(\mathrm{Z})\end{array}$} & $\mathrm{Z} 1$ & 0,86 & 18,19 & 0,912 & 0,77 & 0,914 \\
\hline & $\mathrm{Z2}$ & 0,91 & 22,27 & & & \\
\hline & $\mathrm{Z3}$ & 0,87 & 18,63 & & & \\
\hline \multirow{4}{*}{$\begin{array}{l}\text { Örgüte aidiyet } \\
\text { duygusu (AIT) }\end{array}$} & AIT1 & 0,86 & 20,60 & 0,922 & 0,75 & 0,924 \\
\hline & AIT2 & 0,86 & 16,58 & & & \\
\hline & AIT3 & 0,88 & 18,85 & & & \\
\hline & AIT4 & 0,86 & 17,71 & & & \\
\hline \multirow{3}{*}{$\begin{array}{l}\text { Yapisal sermaye } \\
\text { (YS) }\end{array}$} & YS2 & 0,75 & 12,01 & 0,814 & 0,60 & 0,816 \\
\hline & YS5 & 0,75 & 12,79 & & & \\
\hline & YS6 & 0,81 & 15,16 & & & \\
\hline \multirow[t]{4}{*}{ İlişkisel sermaye (IS) } & IS1 & 0,59 & 9,54 & 0,814 & 0,53 & 0,799 \\
\hline & IS2 & 0,77 & 13,63 & & & \\
\hline & IS3 & 0,83 & 17,14 & & & \\
\hline & IS5 & 0,69 & 11,07 & & & \\
\hline \multirow{3}{*}{$\begin{array}{l}\text { Bilgi paylaşmaya } \\
\text { iliş̧kin özyetkinlik } \\
\text { (ÖZ) }\end{array}$} & ÖZ1 & 0,87 & 18,61 & 0,852 & 0,66 & 0,848 \\
\hline & ÖZ2 & 0.74 & 1216 & & & \\
\hline & ÖZ3 & 0,82 & 16,77 & & & \\
\hline
\end{tabular}

Tablo 2. Ölçüm Modeline Ait Başlıca Değerler

Tablo 2'deki değerlere göre her bir değişkeni ölçen ölçeğin Cronbach alfa değeri 0,70'in üzerinde olduğundan ölçeklerin yüksek içsel tutarlılığa sahip olduğu söylenebilir (Hair vd., 1998). Yakınsama geçerliliği için her bir maddenin faktör yüklerinin anlamlı ve 0,50 'den yüksek olması, bütünleşik güvenilirliğin 0,60'dan yüksek olması (Bagozzi ve Yi, 1988) ve ortalama açıklanan varyansın (Average Variance Extracted-AVE) tüm kavramlar için 0,50'den yüksek olması gerekir. Bu modelde tüm faktör yükleri ve bütünleşik güvenilirlikler kabul edilebilir aralıktadır ve $\mathrm{p}=0,01$ önem düzeyinde anlamlıdır.

Ayrışma geçerliliğini test etmek için Fornell and Larcker'ın yaklaşımından yararlanılmıştır (Fornell and Larcker, 1981). Bu yaklaşımda her bir kavram için ortalama açıklanan varyans değerinin karekökünün, bu kavram ile diğer kavramlar arasındaki korelasyondan yüksek olması gerekir. Ayrışma geçerliliğine ilişkin değerler Tablo 3 'te gösterilmiştir: 


\begin{tabular}{|l|c|c|c|c|c|c|c|}
\hline & $\mathbf{1}$ & $\mathbf{2}$ & $\mathbf{3}$ & $\mathbf{4}$ & $\mathbf{5}$ & $\mathbf{6}$ & $\mathbf{7}$ \\
\hline 1-Bilgi paylaşma niyeti & 0,81 & & & & & & \\
\hline 2-Bilgi paylaşmaktan duyulan korku & $-0,382$ & 0,80 & & & & & \\
\hline 3-Bilgi paylaşmaktan duyulan zevk & 0,493 & $-0,216$ & 0,88 & & & & \\
\hline 4-Örgüte aidiyet duygusu & 0,485 & $-0,248$ & 0,419 & 0,87 & & & \\
\hline 5-Yapısal sermaye & 0,472 & $-0,308$ & 0,376 & 0,638 & 0,77 & & \\
\hline 6-İlişkisel sermaye & 0,465 & $-0,256$ & 0,298 & 0,661 & 0,702 & 0,73 & \\
\hline 7-Bilgi paylaşmaya ilişkin özyetkinlik & 0,492 & $-0,283$ & 0,426 & 0,628 & 0,545 & 0,564 & 0,81 \\
\hline
\end{tabular}

Tablo 3. Ayrışma Geçerliliği Göstergeleri*

* Köşegende italik olarak gösterilen değerler Açıklanan Ortalama Varyans'ın karekökü olup, köşegenin altındakiler ise her bir değişkenin diğer değişkenle arasındaki ilişkiyi gösteren korelasyon katsayısıdır.

Tablo 3'e göre ölçüm modelindeki değişkenler ayrışma geçerliliği sergilemektedir.

Ölçüm modelinin ayrışma ve yakınsama geçerlilikleri ile değişkenlerin güvenilirlikleri ortaya konduktan sonra yol analizi yapılmıştır. Değişkenlerin dağılımı normal dağılıma uymadığı için yol analizinde asimptotik kovaryans matrisinden yararlanılmış ve tahmin yöntemi olarak maximum likelihood (en yüksek olabilirlik) kullanılmıştır. Yol analizine ilişkin uyum indeksleri Tablo 4'te özetlenmiştir:

\begin{tabular}{|c|c|c|c|}
\hline Kisaltma & Anlamı & Modele ait değer & Kabul değeri \\
\hline$\chi^{2}$ & Ki kare & 289,07 & - \\
\hline $\mathrm{Sd}$ & Serbestlik derecesi & 260 & - \\
\hline$\chi^{2} / s d$ & Ki kare/ serbestlik derecesi & 1,112 & $\begin{array}{l}\leq 2^{\mathrm{a}}, \leq 5^{\mathrm{b}} \text { (a: çok iyi uyum, b: } \\
\text { iyi uyum) }\end{array}$ \\
\hline $\mathrm{p}$ & Önem düzeyi & 0,104 & $0,05 \leq$ \\
\hline RMSEA & Yaklaşık Hataların Ortalama Karekökü & 0,021 & $0,05<($ tolerans 0,08$)$ \\
\hline CFI & Artmalı Uyum İyiliği İndeksi & 1,00 & $0,90 \leq$ \\
\hline NNFI & Normlaştırılmamış Uyum İyiliği İndeksi & 1,00 & $0,90 \leq$ \\
\hline AGFI & Düzeltilmiş İyilik Uyum İndeksi & 0,86 & $0,90 \leq$ \\
\hline
\end{tabular}

Tablo 4. Araştırma Modeline Ait Uyum İndeksleri

Tablo 4'e göre oluşturulan araştırma modelinin kabul edilebilir uyum sergilediği görülmektedir. Modeldeki denklemlere ait regresyon katsayıları ise Tablo 5 'te gösterilmiştir:

\begin{tabular}{|c|c|c|c|c|}
\hline Yol & Hipotez & $\begin{array}{c}\text { Yol } \\
\text { katsayısı }\end{array}$ & $\begin{array}{c}t \\
\text { değeri }\end{array}$ & Sonuç \\
\hline $\mathrm{ZE} \rightarrow \mathrm{NI}$ & $\mathrm{H}_{1}$ & 0,30 & 4,38 & Kabul edildi \\
\hline $\mathrm{KO} \rightarrow \mathrm{NI}$ & $\mathrm{H}_{2}$ & $-0,30$ & $-4,77$ & Kabul edildi \\
\hline $\mathrm{YS} \rightarrow \mathrm{ZE}$ & $\mathrm{H}_{3}$ & 0,46 & 2,67 & Kabul edildi \\
\hline $\mathrm{YS} \rightarrow \mathrm{KO}$ & $\mathrm{H}_{4}$ & $-0,44$ & $-2,42$ & Kabul edildi \\
\hline $\mathrm{IS} \rightarrow \mathrm{ZE}$ & $\mathrm{H}_{5}$ & $-0,26$ & $-1,48$ & Reddedildi \\
\hline $\mathrm{IS} \rightarrow \mathrm{KO}$ & $\mathrm{H}_{6}$ & 0,046 & 0,25 & Reddedildi \\
\hline ÖZ $\rightarrow$ NI & $\mathrm{H}_{7}$ & 0,35 & 4,99 & Kabul edildi \\
\hline $\mathrm{AIT} \rightarrow \mathrm{ZE}$ & $\mathrm{H}_{8}$ & 0,37 & 2,95 & Kabul edildi \\
\hline $\mathrm{AIT} \rightarrow \mathrm{KO}$ & $\mathrm{H}_{9}$ & $-0,052$ & $-0,40$ & Reddedildi \\
\hline
\end{tabular}

Tablo 5. Hipotez Testi Sonuçları

Tablo 5'e göre bilgi paylaşmaktan duyulan zevk arttıkça bilgi paylaşma niyeti artmakta, korku arttıkça ise niyet azalmaktadır. Ayrıca yapısal sermaye bilgi paylaşmaktan duyulan zevki artırarak ve korkuyu azaltarak niyeti olumlu yönde etkilemektedir. Bilgi paylaşmaya ilişkin özyetkinlik de bilgi paylaşma niyetini artırmaktadır. Örgüte aidiyet duygusu ise zevk üzerinden bilgi paylaşma niyetini olumlu yönde etkilemektedir.

\section{Sonuç ve Değerlendirme}

Çalışanın bilgi paylaşmaktan duyduğu zevk arttıkça ve korkusu azaldıkça bilgi paylaşma niyeti artmaktadır. Dolayısıyla bir örgütte çalışanların işe ilişkin değerli bilgilerini iş arkadaşlarıyla paylaşması isteniyorsa, bilgi paylaşmaktan zevk duyacakları bir ortamın mutlaka oluşturulması gerekir. Başka bir ifadeyle, çalışanlar bilgi paylaşarak içsel ödüllere ulaşabilmeli, yani kendilerini değerli, önemli ve örgüte katkı sağlayan bireyler olarak görebilmelidir. Sahip olduğu bilgiyi paylaştığında örgütteki değerinin azalacağından endişelenen ve yalnızca bu bilgileri alan tarafın avantajlı olacağını, kendisinin ise dezavantajlı duruma düşeceğini düşünen bireyler bilgilerini paylaşmak istemeyecektir. 
Çalışanın yapısal sermayesi arttıkça, bilgi paylaşmaktan duyduğu korku azalmakta, zevk artmakta ve bunun sonucunda da bilgi paylaşma niyeti yükselmektedir. Başka bir ifadeyle, hangi iş arkadaşlarının hangi bilgilerle ilgilendiğini bilen, kendi işini ilgilendiren bilgilere kimlerin sahip olduğu bilen ve iş arkadaşları tarafından da ne tür bilgilere sahip olduğu bilinen çalışanlar bilgilerini paylaşmaktan korkmamakta ve zevk almaktadır. Böylece bu çalışanların bilgi paylaşma niyeti de artmaktadır. Bu çalışmada çalışanın ilişkisel sermayesinin bilgi paylaşmaktan duyduğu korkuyu ve zevki anlamlı derecede etkilemediği görülmüştür. Başka bir ifadeyle, çalışanın iş arkadaşlarına güvenme ve kendisini onlara bağlı hissetme düzeyi, bilgi paylaşmaya ilişkin korku ve zevk duygularını etkilememektedir. Bu bulgu ilişkisel sermayenin sübjektif norm gibi başka değişkenler aracılığıyla bilgi paylaşma niyetini etkileyebileceği düşüncesini akla getirmektedir.

Çalışanın bilgi paylaşma konusunda kendisini yeterli görme düzeyi, yani öz yetkinliği arttıkça bilgi paylaşma niyetinin de arttığı gözlenmektedir. Bu yüzden yöneticiler çalışanların bilgi paylaşma özyetkinliğini artırmak amacıyla katılımcı yönetim uygulamasına gidebilir ve onlara yönetsel destek sağlayabilir. Özellikle bilgi paylaşma konusunda özyetkinliği düşük bireylere yönelik destekleyici bir yaklaşım yararlı sonuçlar verebilir.

Çalışanın örgüte aidiyet hissetme düzeyi arttıkça bilgi paylaşmaktan duyduğu zevk de artmakta ve bu da sonuçta bilgi paylaşma niyetinin artmasına yol açmaktadır. Ancak aidiyet duygusunun bilgi paylaşmaktan duyulan korkuyu anlamlı düzeyde etkilemediği de bu çalışmada belirlenmiştir. Bu noktada örgüt yönetimlerine çalışanların aidiyet duygusunu besleyecek uygulamalara yönelmeleri önerilebilir.

Bu çalışmanın sonuçları çalışanların işle ilgili bilgilerini paylaşmalarını teşvik etmek açısından sosyo-psikolojik unsurların büyük önem taşıdığını ortaya koymaktadır. Günümüzde örgütler bilgi paylaşımını teşvik etmek amacıyla işle ilgili bilgi-iletişim teknolojilerini yüksek maliyetlerle de olsa örgüte kazandırmaktadır. Bilginin toplanması, ilgili birim ya da kişilere aktarılması, korunması vb. konularda teknolojik altyapı önemli bir kolaylaştırıcı görevi görmektedir; fakat bilgi yönetim sürecindeki tüm aşamalarda temel aktörün çalışanlar olduğu gerçeği gözden kaçırılmamalıdır. Çalışanların bilgilerini iş arkadaşlarıyla paylaşma konusunda duydukları istek, yani bilgi paylaşma niyeti özellikle yeni ve değerli bilgilerin üretilmesi açısından hayati bir role sahiptir. Dolayısıyla bu isteği artırmak amacıyla yönetim örgüt iklimine olumlu yönde etkilerde bulunmaya çalışmalıdır.

Her çalışma gibi bu çalışmanın da bazı sınırlılıkları mevcuttur. Birincisi, yapılan alan araştırması yalnızca bir ilde ve perakende sektöründe çalışan personel üzerinde gerçekleştirilmiştir. Dolayısıyla ulaşılan bulgular yalnızca ilgili grup için geçerlidir. Gelecekteki araştırmaların çalışanlar arası bilgi paylaşımının daha önemli olduğu ve belli bir örgütte çalışma süresinin nispeten uzun olduğu sektörlerde gerçekleştirilmesi, bilgi paylaşımını etkileyen sosyo-psikolojik değişkenleri daha iyi anlamak açısından yararlı olacaktır. İkincisi, gelecekteki çalışmalarda cinsiyet, işteki pozisyon, eğitim vb. değişkenlerin bağımsız değişkenlerin etkisini biçimlendirici (moderator) bir rol oynayıp oynamadığı incelenebilir. Ayrıca örgütsel ve kişilerarası bağlamla ilgili başka değişkenler de araştırmalara dâhil edilmelidir. Yine bir toplumun kültürel değerlerinin, yani ulusal kültürün örgütsel yönetim teorilerini şekillendirdiği dikkate alındığında (Hofstede, 1994), gelecekteki çalışmalara ulusal kültüre ait değerlerin dâhil edilmesi ve farklı kültürel ortamlarda karşılaştırmalı çalışmaların yapılması motivasyonel ve bilişsel unsurların oldukça etkili olabildiği bilgi paylaşma olgusunun doğasını açıklamaya katkıda bulunabilir. Örneğin toplulukçu yönelim ve iç grup/ dış grup algısı gibi kültürel niteliklerle ilgili değişkenler çalışmalarda ele alınabilir. Üçüncüsü, boylamsal ve çalışanın bilgi paylaşma düzeyini mümkünse objektif verilerle de ölçmeye imkân verecek şekilde tasarlanacak araştırmalar yardımıyla çalışanın aktif bilgi paylaşma davranışını incelemek literatüre önemli bir katkı sağlayabilir.

\section{Kaynakça}

- Bagozzi, R. P., Yi, Y., 1988, “On the Evaluation of Structural Equation Model”, Journal of Academy of Marketing Science, 16(1), p. 74-94.

- $\quad$ Bandura, A., 1982. "Self-Efficiency Mechanism in Human Agency”, American Psychologist, 37 (2), p.122147.

- $\quad$ Bock, G. W., Zmud, R. W., Kim, Y. G., \& Lee, J. N., 2005. "Behavioral Intention Formation in Knowledge Sharing: Examining the Roles of Extrinsic Motivators, Social-Psychological Forces, and Organizational Climate", MIS Quarterly, 29(1), pp. 87-111.

- Cabrera, A., Collins, W. C., Saldago, J. F., 2006. "Determinants of Individual Engagement in Knowledge Sharing", International Journal of Human Resource Management, 17(2), p. 245-264.

- Chow, W., S., Chan, L. S., 2008. "Social Network, Social Trust and Shared Goals in Organizational Knowledge Sharing”, Information \& Management, 45, p. 458-465.

- $\quad$ Fornell, C., \& Larcker, D.F., 1981. "Structural Equation Models with Unobservable Variables and Measurement Errors”, Journal of Marketing Research, 18(2), p. 39-50.

- $\quad$ Goh, S., Sandhu, M., 2013. “Affiliation, Reciprocal Relationships and Peer Pressure in Knowledge Sharing in Public Universities in Malaysia”, Asian Social Science, 9(7), p. 290-298. 
- Hair, J., Anderson, R., Tatham, R., \& Black, W., 1998. Multivariate Data Analysis. Prentice-Hall, Englewood Cliffs, NJ.

- Hau, Y. S., Kim, B., Lee, H., Kim, Y., 2013. “The Effects of Individual Motivations and Social Capital on Employees' Tacit and Explicit Knowledge Sharing Intentions”, International Journal of Information Management, 33, p. 356-366.

- Hofstede, G., 1994. “Management Scientists Are Human”, Management Science, 40(1), p. 4-13.

- Hsu, M., Ju, T.,Yen, C., \& Chang, C., 2007. "Knowledge Sharing Behavior in Virtual Communities: The Relationship Between Trust, Self-Efficacy, and Outcome Expectation", Journal of Human-Computer Studies, 65, p. 153-169.

- Hung, S. Y., Durcikova, A., Lai, H. N., \& Lin, W. M., 2011. "The Influence of Intrinsic and Extrinsic Motivation on Individuals' Knowledge Sharing Behaviour", International Journal of Human-Computer Studies, 69, p. 415-427

- Husted, K., \& Michailova, S., 2002. "Diagnosing and Fighting Knowledge Sharing Hostility”, Organizational Dynamics, 31(1), p. 60-73.

- $\quad$ Kankanhalli, A., Tan, B. C. Y., \& Wei, K. K., 2005. “Contributing Knowledge to Electronic Knowledge Repositories: An Empirical Investigation”, MIS Quarterly, 29, p. 113-143.

- $\quad$ Lin, H. F., 2007. "Effects of Extrinsic and Intrinsic Motivation on Employee Knowledge Sharing Intentions", Journal of Information Science, 33, p. 135-149.

- KPMG Consulting, 2000. Knowledge Management Research Report 2000, http://www.kpmg.nl.

- Kuo, F., Young, M., 2008. “A Study of the Intention-Action Gap in Knowledge Sharing Practices”, Journal of the American Society for Information Science and Technology, 59(8), p. 1224-1237.

- Kwok, S. H., \& Gao, S., 2005. “Attitude toward Knowledge Sharing Behaviour”, Journal of Computer Information Systems, 46, p. 45-51.

- Nahapiet, J.; Ghoshal, S., 1998. "Social Capital, Intellectual Capital, and the Organizational Advantage”, The Academy of Management Review, 23(2), p. 242-266.

- $\quad$ Renzl, B., 2008. "Trust In Management and Knowledge Sharing: The Mediating Effects of Fear and Knowledge Documentation”, Omega, 36, p. 206-220.

- Scott, J., 2000). "Rational Choice Theory", in G. Browning, A. Halcli, \& F. Webster (Eds.), Understanding contemporary society: Theories of the present. Sage Publications, London, p. 126-138.

- $\quad$ Seba, I., Rowley, J., \& Lambert, S., 2012. "Factors Affecting Attitudes and Intentions towards Knowledge Sharing in the Dubai Police Force", International Journal of information Management, 32, p. 372-380.

- $\quad$ Tissen, R., Andriesson, D., \& Deprez, L. F., 1998. Value-Based Knowledge Management. Addison-Wesley Longman, Amsterdam.

- Tohidinia, Z., Mosakhani, M., 2010. "Knowledge Sharing Behaviour and Its Predictors”, Industrial Management \& Data Systems, 110(4), p. 611-631.

- Van den Hoof, B., Huysman, M. 2009. "Managing Knowledge Sharing: Emergent and Engineering Approaches", Information and Management, 46, p.1-8.

- Wasko, M. M., \& Faraj, S., 2005. "Why Should I Share? Examining Social Capital and Knowledge Contribution in Electronic Networks of Practices", MIS Quarterly, 29, p. 35-57.

- $\quad$ Ye, S., Chen, H. and Jin, X., 2006, “An Empirical Study of What Drives Users to Share Knowledge in Virtual Communities”, in Lang, J., Lin, F. and Wang, J. (Eds), Knowledge Science, Engineering and Management, Springer, Berlin, p. 563-75. 


\title{
Enformasyon Yoksulluğu: Yeni İletişim Teknolojilerinin Yaygınlaştırılması Yoluyla Yoksulluğun Azaltılması The Poverty Information: Reduction of Poverty through the Dissemination of New Communication Technologies
}

\author{
Asst. Prof. Dr. Barış Yıldız (Gümüşhane University, Turkey)
}

\begin{abstract}
Communication Technologies is considered to be an effective method for the elimination of the development gap between countries and disparities and inequalities between individuals. This idea is accepted by all scholars of the information society. Information and communication technologies can be used as a means to poor people, who is exposed to social exclusion, make their voices heard. It is also observed that the people socialized over time, increased the quality and level of sharing and found efficient and entertaining communication possibilities with people who they don't know. Because of that, it has a vital importance of information and communication technologies. Because it allows people take steps from social exclusion to social inclusion. The studies done by Goodman on South Africa, by Jensen on China and by Bhavnani on Thailand, Indonesia and Malaysia shows that new media helps to reduce impact of poverty and breaks the cycle of poverty. It has also been obtained successful results in breaking the cycle of poverty when new media Technologies are provided in India, Brazil and Nepal. The aim of this study is to examine how the poverty information can be reduced and how people living in poverty can be get out of this cycle by providing information and communication technologies. It will first attempt to define new media explaining poverty information. The impact of these tools on cycle of poverty will be shown. As a result, it will be analyzed how information technologies contribute to fight against poverty by country examples.
\end{abstract}

\section{Giriş}

Ülkeler birçok bakımından farklılıklara sahiptirler. Bu farklılıklar yoksulluğun nedeni olan faktörlerin de ülkelere ve hatta aynı ülke içerisinde bölgelere göre değişiklik göstermesine neden olabilmektedir. Ayrıca bir ülke için yoksulluğun nedeni olan herhangi bir faktör diğer başka faktör ve nedenlerinde ortaya çıkışına neden olabilir, yoksulluk olgusunun etkisi genişleyebilir ve baş edilmesi çok daha zor bir hal alabilir. Bu açılardan bakıldığında yoksulluk genel olarak ekonomik bünyedeki yetersizlik, gelir dağılımındaki adaletsizlik, hızlı nüfus artışı, göçler, doğal afetler ve yetersiz istihdam imkânı gibi durumların sonucu olarak ortaya çıkabilmekte ve hatta bu nedenlerin ortaya çıkmasında kendisi bir neden olabilmektedir. Az gelişmiş ve gelişmekte olan ülkelerin ve özellikle alt gelir grubundaki insanların teknolojik gelişmelere ayak uyduramamasının da yoksulluğu arttırdığı söylenebilir.

Yoksullukla mücadeleye yönelik politikaların ise kısa sürede sonuçlandırılması mümkün değildir. Ancak planl, programlı ve uzun soluklu olarak yürütülen politikalar sonucunda yoksulluğa karşı verilen savaş anlamlı olur. Yeni iletişim araçlarına ulaşımın arttırılıp enformasyon yoksulluğunun azaltılması yoksullukla savaşta kullanılabilecek uzun soluklu argümanlardan biridir. Öte yandan yoksulların bu teknolojilerden önce gıda ve ilaca ihtiyacı olduğu kabul edilmektedir. Ama iletişim teknolojilerine sahip olmanın her ikisine de sahip olmayı kolaylaştırdığına dair çalışmalar vardır (Guest, 2002: 230). Ayrıca az gelişmiş ülkelerdeki sermaye birikiminin emek ve teknolojik yeniliklerden bağımsız olarak etkinlik sağlamasının zor olacağı da söylenebilir.

Buna göre yeni iletişim teknolojileri hem kurulmaları sırasında yaratıkları katma değer hem de kullanıcılarına sağladıkları enformasyon ile emeğin bir ürünü olarak ekonomik büyüme sürecine doğrudan ya da dolaylı olarak olumlu etki edebilir. Yoksulların ulaşılabilirlik imkânlarının arttırılarak yeni teknolojileri kullanabilmesi onların yardımlara ulaşmasını, teknoloji kullanan işyerlerinde istihdamlarını, kendilerine uygun işleri takip edebilmelerini ve kendilerini daha rahat ifade edip işbirliği içinde olup birbirlerine destek vermelerini de katkı yapacaktır. Bunlara ilaveten iletişim teknolojileri ülkeler arasındaki ekonomik ve kültürel açıkların azalmasına, az gelişmiş ülkelerin seslerini duyurmalarına, yoksulluğun görünür olmasına, yeni teknolojilerin tanınmasına, eğitimden sağlığa birçok alanda bölgesel farklılıkların ortadan kalkmasına ve beşeri sermayenin gelişmesine yardımcı olarak da yoksullukla mücadeleye katkıda bulunabilmektedir. Kısacası digital devrimin zenginleri daha zenginleştirdiği gerçeğinin yanında yoksullara da yardım edebileceği düşünülmektedir.

\section{Yoksulluğun Kavramsal Çerçevesi}

Yoksul olarak adlandırılan kesim her ülkenin gelişmişlik ve dolayısıyla gelir düzeyine olarak birbirlerinden farklılıklar gösterir. Örneğin; İngiltere'de en yoksul olarak değerlendirilen \%10 ile daha az gelişmiş ya da gelişmekte olan biri diğer ülkenin yoksulların gelirleri birbiri ile aynı değildir. Bunun nedeni yoksulluk sınırı ve yoksulluğun ölçülmesi için kullanılan tekniklerin ülkelerin farklı durumlarının dikkate alınarak farklı biçimlerde hesaplanmasıdır. Ayrıca yoksulluk konusunda çok fazla çalışma yapan Dünya Bankası gibi örgütlerin özellikle 
yoksul ülkelerde yoksulluğun değerlendirilmesinde, gelire odaklandığı görülmektedir. Bu da gelirin ön planda olduğu mutlak yoksulluk kavramını ortaya çıkarmıştır (Durgun, 2011: 143-144).

Zengin ve yoksul arasındaki uçurumun, kalkınmakta olan ülkelerde daha fazla açıldığı görülmektedir. Sanayi toplumlarında da durum göründüğünden daha kötüdür (Wendpanga, 2011). Ancak buna rağmen Amerikalıların bir yıllık kolalı içecek tüketim harcamalarının, nüfusu 100 milyonu aşkın Bangladeş' in GSMH' nın neredeyse iki katına ulaşması; bir Kanadalı'nın bir Etiyopya'lının tükettiğinden 436 kat fazla enerji tüketmesi; Hollanda'nın kendi yüz ölçümünde üretilen ürünün 14 katı ürünü tüketmesi; nüfusu dünyanın \%4.48'ini oluşturan ABD'nin, dünya kaynaklarının \%30'unu tüketmesi gibi örnekler sanayi toplumlarının durumlarının yine de az gelişmiş veya gelişmekte olan ülkelere göre daha iyi olduğunu göstermektedir. Ayrıca Dünya nüfusunun gelir dilimde en üstte yer alan \%20'lik kesiminin toplam dünya hasılasının \%84' ünü, en altta yer alan \%20'lik kesimin ise \%1, 4'ünü elde ediyor olması da adaletsizliği çok net bir biçimde ortaya koymaktadır (Şenses, 2009: 20; Ilgar ve Lefilleul, 2011: 74).

Uluslararası alanda Dünya Bankası, IMF ve Birleşmiş Milletler Kalkınma Programı (UNDP) gibi kurumlar yoksulluk konusunda en çok çalışma yapan örgütlerdir. Dünya Bankası yoksulluğu gelir yetersizliği, maddi imkânsızlıklar yüzünden kaynaklara ve üretime ulaşamama ve böylece belirlenen bir standart asgari yaşama ulaşamama hali olarak tanımlamaktadır (Worldbank, 1990: 26). Dünya Bankası'nın bu tanımı yoksulluğu daha çok gelir boyutu içine hapsetmiş ve sosyal boyutları ile yoksulluğun sebep ve sonuçları üzerinde durmamıştır (Uzun, 2003:156). Dünya Bankası'nın yoksullukla ilgili 1990 yılında yayınladığı rapor ise gelir, tüketim gibi geleneksel tanımlamaları aşmış; eğitim, sağlık ve toplumsal yaşama dair diğer bazı unsurları da yoksulluk tanımlamaları içine dâhil etmiştir. Zaman içinde savunmasızlık, kırılgan olmak, söz hakkı olmamak, risklerle karşı karşıya olmak ve güçsüzlük gibi diğer birçok etmende yoksulluk tanımlamalarına dâhil edilerek günümüze kadar farklı yoksulluk tanımları yapılmıştır (Coşkun ve Tireli, 2008: 35).

Dünya Bankası ekonomistlerinden Lipton (1997: 1001) ise yoksulluğu kişi başına özel tüketimin belirli bir düzeyin altında kaldığı durum olarak tanımlamaktadır. Benzer bir biçimde Alagh (1992:109) yoksulluk için mutlak asgari refah düzeyinin altında kalma durumu ve yaşamda kalabilmek için gerekli mal ve hizmetlere olan ihtiyaçların karşılanamamasıdır tanımı yapmaktadır.

Yoksulluğa bakış açıları ve ortaya çıkmasına neden olan unsurlar yoksulluğun değişik görünümlerinin tanımlanmasına neden olmuştur. Yoksulluğun değişik türleri olmasına rağmen hepsinin ortak noktası mutlak ve göreli yoksulluk üzerinden doğmasıdır. Yaşam için gereksinim duyulan beslenme, giyim, barınma, sağlık, temiz içme suyu, bilgiye erişim gibi temel bir mal sepetini satın almadaki yetersizlik mutlak yoksulluk olarak tanımlanmaktadır. Böyle bir sepeti finanse etmek için gerekli gelir kaynağından yoksun olan bireyler ya da hane halkları da yoksul ve zayıf olarak nitelendirilmektedir (Awad ve Israeli, 1997: 5). TÜIK'e (2016) göre göreli yoksulluk ise, toplumu oluşturan bireylerin, tespit edilmiş genel bir toplumsal ortalama refah düzeyinin belli bir miktar altında olmasidır.

Yoksulluğun günümüzün en önemli toplumsal sorunlardan birisi haline gelmesine neden olan faktörlerden bir diğeri ise yoksulların yaşadıkları sosyal dışlanma süreci ile yakından ilgilidir. İleri teknolojilerin getirdiği yüksek yaşam standartlarının etkisi ile toplumda ekonomik, sosyal, kültürel ve mekânsal anlamda yaşanan ayrışmalar ve eşitsizlikler, bireyler arasındaki toplumsal bağı zedelemektedir. Bu gibi faktörler bazı temel hak ve özgürlüklerin kullanımı kisitlama, toplumsal karar alamda etkin olamama ve kamusal hizmetlerden yararlanamama gibi sosyal dışlanma durumlarını ortaya çıkarabilmektedir. Bu süreç, yoksulluğa zemin hazırlayarak bireylerin kendilerini topluma ait olma duygularını zayıflatmakta ve özellikle savunmasız kesimleri daha dar bir çevreye mahkûm ederek problemin çözümünü zorlaştırmaktadır. Ortaya çıkan bilgi eksikliği ise yoksulların daha korunmasız ve görünmez olmalarına neden olan bu faktörlerin etkisini arttırmaktadır (COMCEC, t.y.:1).

Yoksulluğa neden olan faktörlerin isabetli bir şekilde tespit edilmesi önemlidir. Çünkü yoksulluğu bir tek nedene bağlı olarak açıklamak zordur. Örneğin kişilerin gelirlerinde meydana gelen azalmalar çok farklı nedenlerin birbirleriyle ilişkili tepkimeleri sonucu yoksulluğu ortaya çıkarmış olabilir. İşsiz birinin eğitim sebebiyle mi işsiz olduğu veya zaten yoksul bir aileden geldiği için eğitimi alamadığından dolayı $\mathrm{m}$ işsiz olduğunun tespit edilmesi çok güçtür. Teknolojik gelişmelerden bilgisayar kullanımının eğitimsiz kişiler arasındaki işsizliği arttırdığı ve dolayısıyla gelir azalmasına neden olarak yoksulluk olgusunu ortaya çıkardığı ileri sürülebilir. Böyle bir nedenin yarattığı sorun konuyu daha karmaşık hale getirebilmektedir. Görüldügü gibi nedenlerin tespit edilmesi ile mücadele araçlarının seçilmesi arasında doğru yönlü bir ilişki vardır. Yoksulluğun türüne göre doğru araçların seçilerek ve kullanımlarının zamanlaması iyi tespit edilerek mücadeleye başlamak gerekmektedir (Sarısoy ve Koç, 2010:329). Hedefleme mekanizmalarının da doğru tespit edilerek mücadeleye dâhil edilmesi bu araçların etkinliğinin arttırılmasına katkı yapacaktır.

Yoksulluğun kaynaklarını genel olarak şu şekilde sayabiliriz; Doğal afetler; Savaş, İç Çatışma ve Terörizm; Adil Olmayan Gelir Dağılımı; Kaynak Dağılımındaki Çarpıklıklar, Kaynakların kötü idare edilmesi ve planlamaya ilişkin problemler; Ekonomik Krizler; Küreselleşme; Küresel Sermaye Hareketliliğindeki Değişmeler; Sağlık Koşulları; Eğitim İmkânlarından Mahrum Kalmak ve Düşük eğitim düzeyi; Ekonomik Gelişmeler; Kültürel İhtiyaçların Karşılanamaması; Vasıfsız İşgücü, işsizlik, emeğin yeterli düzeyde nitelikli olmaması; Yetersiz işte 
çalışma; Düşük ücretli işler; Çalışamayacak durumda olan özürlü sayısının fazla olması; Toprağın eşitsiz paylaşımı, yanlış tarımsal politikalar, israf ve Miras yoluyla elde edilen gelirler; Enflasyon; Adaletsiz vergi sistemi; Yüksek faiz ve rant ekonomisi; Sosyal Dışlanma; Teknolojik gelişmelere ayak uyduramama ve iletişim araçlarına ulaşamama.

Yoksulluk görüldüğü gibi çeşitli nedenlere bağlı olarak ortaya çıkmaktadır. Buda yoksullukla mücadele araçlarının çeşitlenmesene neden olmuştur. Yoksullukla mücadelede kullanılan araçlar en genel biçimiyle doğrudan mücadele araçları ve dolaylı mücadele araçları olarak ikiye ayırabiliriz. Doğrudan mücadele araçları kamusal mali tedbirler, mikrokredi ve sivil toplum kuruluşlarının çabaları şeklinde sınıflandırılabilir. Dolaylı mücadele araçları ise yoksulluk yanlısı büyüme politikalarıdır. Yoksulluğun azaltılması için uygulanacak kamusal mali tedbirler kamusal sosyal harcamalar ve kamusal gelirler kapsamında değerlendirilmektedir. Kamusal sosyal harcamalar kamusal sosyal yardım ve hizmetler, sosyal sigortalar, vatandaşlık geliri uygulamaları, sosyal konut politikaları, proje destekleri, aktif istihdam politikaları ve elektrik-su-gaz'la ilgili kamu kolaylıklarından oluşmaktadır. Kamusal gelirler ile yoksullukla Mücadelede etmek ise bazı özel vergisel düzenlemeler sayesinde olmaktadır (Y1ld1z, 2013).

Dolaylı müdahale aracı olan büyüme ve özelliklede yoksulluk yanlısı büyüme, büyümenin nimetlerinden herkesin faydalanmasını sağlayıp, yoksulluğu azaltan reformlar belirleyip uygulamaktır. Ancak bu tarz bir büyümenin daha yüksek okuma yazma ve hesap yapma düzeyi ve temel eğitim, genel sağlik hizmetlerinin iyileştirilmesi, toprak reformlarının tamamlanması gibi yeterince destekleyici bir toplumsal arka plan aracılığı ile gerçekleşmesi halinde faydalı olabileceği ifade edilmektedir (Kirmanoğlu, 2005:27).

\section{Enformasyon Yoksulluğu}

Enformasyon (information), başkaları tarafından belirli bir amaç için düzenlenen, sadece düzenleyen için anlam taşıyan, çalışanlara ve yöneticilere değişik ağ bağlantıları, internet vb. şekillerde ulaşan ve bu kişilere olayları yorumlamak için bakış açısı kazandıran şekillendirilmiş veri (data) olarak tanımlanabilir. Bilgiye (knowledge) ulaşmak için gerekli olan bir unsur olan enformasyon, bu özelliği ile veri ile birlikte bilginin oluşmasında ve kaybolmamasında esas etkendir. Veri-enformasyon-bilgi sürecinde enformasyon olmadan bilgi elde etmek zordur (Güçlü ve Sotirofski, 306: 354). Enformasyon yoksulluktan kurtulmak için gerekli olan bilginin girdisi durumundadir.

Enformasyonun teknolojik yapılarca ve iletişim araçları ile iletildiği günümüzde, herkese eşitçe ulaşıp ulaşmadığ 1 ve sonuçta insanların bu olguyu kendi yaşamlarını daha iyi hale getirebilmek için kullanıp kullanamadığı sorunları enformasyon zengini ve enformasyon yoksulu kavramlarını ortaya çıkarmıştır. Burada enformasyonun ortaya çıkışı ve insanlara dağılımı konusunda ciddi gelişmeler olduğu kabul edilmektedir. Ancak yeni iletişim araçlarının herkes tarafından eşit bir biçimde kullanılmasında ve sonuçta enformasyonun yayılmasında ortaya büyük farklılıkların çıkmasına vurgu yapılmaktadır. Enformasyon zenginleri hem internet ve cep telefonu gibi iletişim teknolojileri vasıtasıyla, hem de yazılı ve görsel medya araçları vasıtasıyla enformasyona kaliteli ve ucuz erişim sağlayanlardır. Bunlar daha çok gelişmiş kapitalist ülkelerde ve gelir dağılımını ciddi bozukluk gösterdiği az gelişmiş ve gelişmekte olan ülkelerdeki üst gelir grubundaki kişileridir. Enformasyon yoksulları ise bu erişimi enformasyon zenginleri kadar kaliteli ve ucuz sağlayamamakta ve üstelik erişimlerinin önünde siyasi, ekonomik ve kültürel baskı ile karşı karşıya kalmaktadırlar. Bu durum karşısında bireyler enformasyona ulaşmak için gerekli yetenek, beceri ve maddi imkânlara da sahip olamamakta ve dolayısıyla yoksullar daha da kırılgan olmaktadır. Enformasyon yoksulluğu ise daha çok az gelişmiş ve gelişmekte olan ülkelerdeki ve gelişmiş ülkelerde en alt gelir grubunda yer alan daha az sayıdaki insanlar üzerinde negatif etkiler olarak kendini göstermektedir (Başaran ve Taşdemir, 2011).

\section{Yoksulluğun Azaltılması İçin Yeni İletişim Teknolojileri Kullanımının Etkileri}

Bilgi ve iletişim teknolojileri, 20. yy’ın son çeyreğinden itibaren ciddi gelişme göstererek, iletişim alanının yanı sıra diğer birçok alandaki gelişmelere de önemli destek olmuş ve bilginin işlenmesi, toplanması, depolanması, iletilmesini sağlayan altyapıların kurulmasına da yardım etmiştir (TÜBİTAK, 2004:18). Yeni İletişim Teknolojileri ise, hem kullanıcılar arasındaki, hem de kullanıcılar ile enformasyon arasındaki karşılıklı iletişimi, içlerinde bulunan mikro-işlemcilerle sağlayan veya geliştiren; mikro elektronik ve veri iletiminin yanında, cep telefonları, kablolu televizyonlar, bilgisayarlar, faks ve on-line veri tabanları gibi teknolojileri içeren iletişim araçlarıdır. İletişim teknolojilerinin öneminin artmasında belki de en önemli katkı internet teknolojisinin gelişmesidir. Bugün ticaret, pazarlama, bilgi ve tanıtım gibi katma değeri yüksek alanların geliştirilmesine çaba sarf edildiğinde internete dayalı teknolojiler öncelikli hedef olmaktadır. Yeni iletişim teknolojileri zaman bakımından yeni değildir. Yeni iletişim teknolojileri, bugüne kadarki iletişim ortamına katkıda bulunan bilim alanlarının karşısına konuldukları için yenidirler (Başaran, 2002; Yeşilorman ve Koç, 2014: 118). Ayrıca bir toplum tarafindan yeni ulaşılabilir oldukları anda da o toplum veya grup içinde yeni iletişim teknolojisi olarak adlandırılmaktadırlar.

Bireyler sadece gelir düzeyi ile ilgili değil, kullanım sağlayan altyapının yetersiz olması; bu ürünlere sahip olamama ve bu teknolojileri kullanabilmek için gerekli bilgi ve beceriye sahip olmama gibi diğer birçok etmenden 
ötürü de bu teknolojilerinden ya minimum düzeyde yararlanmakta ya da hiç yararlanamamaktadırlar (Kalaycı, 2013:156). Bu durum, rekabet edebilmek açısından dezavantajlı olan ülkeleri olumsuz etkilemektedir.

Bilgi ve iletişim teknolojileri bireyleri iki şekilde etkileyerek eşitsizlikleri arttırabilir. i) iyi eğitimli kişilerin yeni teknolojileri daha iyi kullanabilmesi bu kesimlerin yüksek düzeyde ücret almasını sağlayarak eğitimsiz işgücüne olan talebin düşmesine ve dolayısıyla ücretlerinin düşmesine neden olur. ii) bu teknolojiler değişik alanlarda işgücünün makine ile ikamesine neden olarak işsizliği arttırabilir ve ücretlerin aşağ doğru seyretmesine neden olabilir. Yapılan birçok çalışmanın sonucuna göre bu teknolojilerin ücret eşitsizliklerinin artmasına neden olabilecek faktörlerden biri olduğu tespit edilmiştir (Öztürk, 2005: 113).

$\mathrm{Bu}$ teknolojilerde yaşanan hızlı gelişme, bilgilerin toplumun tüm kesimleri arasında paylaşılmasına imkân tanımakta ve bilginin yayılma hızı ve kapasitesini etkilemektedir. Uluslararası ve ulusal rekabette üstünlük yeni iletişim teknolojilerini yoğun olarak kullananlardadır. Dünya iletişimini herkes için daha erişilebilir ve ucuz hale getiren yeni iletişim teknolojilerinin ortaya çıkardığı bilgi ekonomisinin ise gelişmişlik farklarını kapatarak dünya ülkelerini eşitlediği ve bilgi-işlem operatörü, sistem analisti, veri giriş uzmanı gibi birçok yeni iş ve mesleği ortaya çıkarak istihdama katkı sağladığı görülmektedir (Kevük, 2006, 340-343). Yeni iletişim teknolojileri iktisadi yapıda özellikle yeni istihdam biçimleri ve yeni işler gibi iki konu ile ön plana çıkmaktadır. Ayrıca geleneksel iletişim araçlarında yeterince görünür ve öngörülebilir geliri olamayan grupların eğitim, örgütlenme ve kamuoyunda yer alma gibi konularda yeni iletişim araçlarından yararlandığı ifade edilmektedir (Başaran, 2002; UNCTAD, 2010 : 8; Özdemir, 2014:160-161).

Yoksulluk birçok unsurun yanında iletişim imkânları gibi belirli bir yaşam standardından da mahrum olmaktır. Bilgi ve iletişim yoksulluğu, yoksulluğun nedenlerinden ancak bir boyutu oluşturabilir ancak diğer tüm boyutları da etkileyebilir (Barja ve Gigler, 2007: 15). Dolayısıyla yoksul bireyleri yeni iletişim araçlarına kavuşturmak yoksullukla mücadelede bir araç olarak kullanılabilir. Bilgi ve yeni iletişim teknolojileri sektörünün gelişimi, bu sektörün GSYH'ya yapacağı doğrudan katkının yanı sıra, diğer sektörlerin gelişimi için de kritiktir.

Bilgi ve yeni iletişim teknolojileri sonucu ortaya çıkan ürünler ve hizmetler diğer sektörleri de etkileyerek; tüm ekonomik sistem için yeni sistemlerin, ürünlerin, hizmetlerin, tedarik zincirinin ortaya çıkmasına neden olabilir. Ayrıca tüm üretim ve satış sürecinde maliyet avantajı sağlayabilen bu teknolojiler, verimliliğin artmasına ve yeni pazarlara girişe de katkıda bulunabilirler (Kalkınma Bakanlığı, 2014: 220).

İnternete ve mobil telefon hatları daha geniş bir yayılma gösterirse bilgi ve iletişim teknolojilerinde farklı türde birleşmelerle yeni firsatlar açabilir. Kablosuz bağlantı gibi yeni radyo formatları aracılığı ile etkileşimli iletişim kırsalda yeniliklere yol açar ve farklı teknolojilerin kombinasyonu interneti daha erişilebilir ve uygun fiyatlı yapar. Benzer şekilde bazı toplum bilgi merkezleri tarafından çift simli cep telefonları ile bilgi aramaları için SMS tabanlı hizmetler verilmektedir. Geleneksel teknolojilerin bile sağlayacağı roller olabilir. Örneğin Sahra-altı ülkeler radyo sahiplik ve kullanılabilirlik açısından yoksulluların en yüksek erişime sahip olduğu araçtır. Burada radyo bilgiye ulaşımda bir yöntem olarak hala bazı avantajlara sahiptir. Nispeten ucuz olan radyo sinyal ile uzak coğrafi bölgelere ulaşabilir, eğitim düzeyi ya da okuryazarlık düzeyi ne olursa olsun radyo erişimi olan herkes bilgiye nüfus edebilir. Bölgeye özgü bilgi vermek için kullanılabilir, yerel dillerde yayın yapılarak daha çok kişi tarafindan kullanılması sağlanabilir. Radyonun ana dezavantajı tek yönlü iletişim sağlaması olsa da radyo merkezli girişimler kırsal yoksullukla mücadelede kullanılmaya devam edebilir (UNCTAD, 2010: 7).

Yeni iletişim araçlarının tarımda kullanımı kırsaldaki yoksulluğun büyük bir kısmını oluşturan küçük çiftçilere bazı avantajlar kazandırmaktadır. Bu avantajlar özetle şunlardır; i) Gelen lojistik: Belirli ürünler için tohum kaynağı ve satın alınması ile ilgili bilgiler. ii) Operasyonlar: Tohumlama, ekim, hazırlanması, büyüme ve hasat ile ilgili bilgiler. iii) Pazarlama-satış: Çıktı için müşteri belirlemeye yarayan yardımcı bilgiler. Müşteriyi belirlemek ne zaman ve hangi pazarda satın almak ve satmayı bilmek çiftçi için önemlidir. iv) Giden lojistik: Ambalajlama, depolama ve taşımaya ilişkin bilgiler. v) Satış sonrası servis: Müşterilerden geri bildirimle ilgilidir. vi) Destek faaliyetleri: Tarımsal yaygınlaştırma hizmetleri, kredi ve sigorta erişimi konusunda bilgiler (UNCTAD, 2010: 67). Guest (2002)'e göre örneğin Bangladeş sahillerindeki birçok balıkçı köyünde, sadece bir tek gönüllü, internete bağlanarak Amerikan Deniz Kuvvetlerinin web sayfasına girerek hava durumuna öğrenip hoparlörler vasıtasıyla bütün köylülere duyuru yaptığı vakit, küçük tahta kayıklı balıkçılar için yaklaşmakta olan bir firtınanın önceden bilinmesi sağlanabilir ve bu haber hayatta kalmak için önemli olacaktır. Ayrıca internet vasıtasıyla yakaladıkları balıkların fiyatlarını öğrenerek komisyoncu ile kendi lehlerine daha iyi bir pazarlık yapma şansı yaratabilirler hatta internetten bakacakları uydu görüntüleri sayesinde, denizdeki balık kümlerinin dolaştıkları yerleri görüp gelirlerinin artırma şansı yakalayabilirler.

Günümüzde gelişmiş ülkeler eğitim, sağlık, kamu hizmetleri ve ticaret gibi her alanda bu teknolojileri kullanmaktadır. Yoksulluğun en önemli mücadele araçlarından biri olan eğitimde bu teknolojilerin kullanılması ile sanal eğitim başlatılarak öğrencinin sadece bilgiyi alması değil, aynı zamanda bilgiyi kendisinin arayıp bulması, bunu günlük hayatta kullanılabilecek seviyeye getirmesi ve ondan yararlanması sağlanmıştır (Karasar, $2004: 117$ ve 120). Eğitim yanında sağlık hizmetlerinde de mobil telefon gibi teknolojilerin kullanılması, ortaya çıkabilecek faydalardan toplumun her kesiminin faydalanmasını sağlayacaktır. Ayrıca kamusal sosyal harcamalar içerisinde 
yer alan aktif istihdam politikaları kapsamında verilen mesleki eğitim faaliyetlerinde de yeni iletişim teknolojilerinin önemi doğrultusunda eğitimler verilmektedir.

2010-2011'de yayınlanan "Küresel Bilgi Teknolojisi Raporu” bu teknolojilerin yoksullukla mücadeledeki önemine vurgu yapmış, küçük ve orta ölçekli işletmelerin yoksullarla etkileşimine dikkat çekerek özellikle bu kesimlerde kullanımının yoksullar için gelir akımı yaratabileceği ifade edilmiştir. Ayrıca çok daha fazla çeşidi olan güvenli iş alanlarının yaratılabileceği ifade edilmiştir. Bu etkilerin oluşabilmesi için gerekli olan altyapı yatırımlarına önem verilmesi sonucunda ise düşük gelir grupları bilgi ve iletişim teknolojilerini kullanma konusunda ilerleme kaydedebilecektir ( İSTKA, 2012: 8).

UNCTAD (2010: 10-11) tarafından bilgi ve iletişim teknolojilerinin işletmeler ve yoksullar arasındaki ilişkilerde kavramsallaştırılması şu şekilde ifade edilmiştir;

İlk ayrım yoksulluk içeren bir ülkedeki bilgi ve iletişim teknolojileri kullanımının ekonomik ve ekonomik olmayan tipleri arasında yapılabilir. Ekonomik olmayan kullanım sağlık, eğitim ve diğer sosyal boyutlarıyla ilgili olabilir. Ekonomik açıdan tüketiciler, çalışanlar, tedarikçiler ve girişimciler gibi yoksulları içerebilir ve bazı tür finansal işlemleri yapmak için bilgi ve iletişim teknolojileri kullanılabilir.

İkinci ayrım bilgi ve iletişim teknolojilerinin yoksullar tarafından dolaylı ve doğrudan kullanımı arasında yapılabilir. Dolaylı kullanım geniş ve büyük ölçeklidir. Ancak dolaylı kullanımın yoksulluğa etkisi belirsiz biçimlerde olur. Örneğin dolaylı ekonomik olmayan kullanımda bilgi ve iletişim teknolojileri bir organizasyonu etkileyecek biçimde kamu sektörü veya uluslararası alanda iç kullanımı içerebilir. Fakat yoksul tarafından bilgi ve iletişim teknolojilerinin direkt kullanımına yol açmaz. Örneğin sağlık bakanlığı bünyesinde politika oluşturmaya yardımcı olmak için bilgi ve iletişim teknolojileri kullanılmaz. Dolaylı ekonomik kullanımı, yoksul topluluklara satılan malların üretim maliyetini düşürmek için bir teşebbüs tarafından bilgi ve iletişim teknolojileri kullanımına başvurulabilir. Alt gelirli pazarlara tedarik (arz) ve dağıtımı geliştirmek için büyük firmaların bilgi ve iletişism teknolojileri kullanımı buna bir örnek olabilir. Bu durumda yoksullar daha iyi bir şekilde arzdan ve düşük fiyatlardan dolaylı olarak yararlanabilir.

Bilgi ve iletişim teknolojilerinin üreticileri ya da kullanıcıları olarak yoksulların katılımı, bireyde geçim üzerinde potansiyel olarak derin bir etkiye sahiptir. Doğrudan bilgi ve iletişim teknolojileri kullanımını üç ana kategoride belirtmek mümkündür. Bunlar;

i) İşletmelerde doğrudan bilgi ve iletişim teknolojileri kullanımı: Çalışan yoksul insanlar veya kendisine yetecek kadar geçimi bulunanlar veya bilgi ve iletişim teknolojileri sektörü dışındaki büyüme odaklı işletmeler tarafından bilgi ve iletişim teknolojileri kullanımını içerir. Örneğin, müşterileri ile irtibatta mikro girişimciler tarafından cep telefonu kullanabilir. Çiftçiler hava tahminlerini almak için yerel radyoyu kullanabilir.

ii) Bilgi ve iletișim teknolojileri sektörüne doğrudan katılım: İşçi ya da girișimci gibi yoksulları içeren bilgi ve iletişim teknolojileri ile ilgili mal ve hizmet üretimi yeni gelir getirici geçimler oluşturabilir. Örneğin, büyük bilgi ve iletişim teknolojileri üreticisi firma ya da Telekom şirketlerinde yoksul insanların istihdama dâhil olarak üretime katılması yeni gelir getirici durumlardır. Yol kenarlarında telefon görüşmeleri satan insanlar, büfelerde dijital fotoğraf sağlayan PC, e-bilet ve e-devlet hizmetleri gibi bilgi ve iletişim teknolojilerine dayalı serbest mesleklerin oluşturulması yeni gelir getirici durumlar yaratabilir.

iii) Doğrudan bilgi ve iletişim teknolojileri kullanımının diğer türleri: Bunlar yoksul bir topluluktan bir kullanıcıyı kapsayan tipik bir bilgi ve iletişim teknolojisi ile etkin bilgi akışı, işlem ya da ekonomik olmayan bir şey olabilir. Örneğin yoksul bir tüberküloz hastasına ilacı için SMS ile hatırlatma yapılabilir. Diğer ekonomik kullanımları ise; kentsel göçmenlerin kırsal akrabalarına mobil para havalesi yapılabilir.

\section{Yoksullukla Mücadelede Yeni İletişim Teknolojileri Kullanımı Ülke Kanıtları}

Bilgi teknolojilerine ulaşacak imkânı bulamayan yoksul veya eğitimsiz kesimlere bu teknolojilerin ulaştırılması ve İnternet uygulamalarının yaygınlaştırılması için kayda değer çabalar harcanmaktadır. Hindistan, Brezilya ve Laos gibi sosyo-ekonomik şartların geniş kitleleri bu teknolojilerden uzak tuttuğu ülkelerde geliştirilen çeşitli projeler, bu konudaki kararlılığın göstergesi sayılır. Örneğin Brezilya'daki bir proje kapsamında; akademisyenler tek işlevi internete bağlanmak olan "Computador Popular" adında bir masa üstü bilgisayar geliştirdiler. Bu bilgisayarda, internette sörf için gerekli olmayan CD ve disket (floppy) sürücüsü bulunmamaktadır. Sadece internet için gerekli donanıma sahip olan "Computador Popular", 250 dolar gibi birçok kimsenin alabileceği bir fiyattan satıldı. Vatandaşların \%95'inin internete bağlanmasını hedef olarak belirleyen Brezilya Hükümeti, bu makineleri dahi alamayacak durumdaki kişiler için ise ayda 15 dolar geri ödemeli bir kredi programı uyguladı. Diğer taraftan üreticilerin önerilerini izlemeye alınarak, üretim öncelikleri belirlenmeye başlanmıştır. Hükümetin, yoksul kesime internet erişim imkânı sunma projesi bu projenin bir başka ayağını oluşturmuştur (Active Academy Araştırma Merkezi, 2004:1). 
Hindistan, yoksullara internet erişimi sağlanması konusunda çalışmaların yapıldığı bir diğer ülkedir. Simputer, 1999 yılında planlanıp 2004 yılında faaliyete başlayan, bilgi teknolojileri açısından, gelişmekte olan ve gelişmiş ülkeler arasındaki farkı kapatabilmek amacı ile fakir ve eğitimde geri kalmış sıradan insanları hedefleyen düşük maliyetli, ucuz ve dayanıklı bir cep bilgisayarı geliştirme projesidir. Proje ile mikro bankacılık, büyük veri toplama, tarımsal bilgi gibi farklı sektörlerde işlemlerin uygun bir fiyata yapılacağı ümit edilmişti. Bu cep bilgisayarında dokunmatik ekran, modem, ses sistemi, sabit disk yerine flaş bellek ve lisans ücretinden tasarruf etmek için Linux (açık-kaynak) işletim sistemini kullanılmıştır. Bu bilgisayar, elektriğin bile olmadığı bölgelerde yanındaki kolun çevrilmesiyle şarj olmakta ve kablo altyapısı yokluğundan kablosuz internet erişimini kullanmaktadır. AMD, eBay, Google, Marvell, News Corporation, Nortel Networks ve Red Hat gibi sponsor firmaların her birinin en az 2 milyon dolar verdiği para ile ilerleyen proje daha üretime geçmeden birçok ön sipariş almayı başarmıştı. Simputer daha çok tapu ve kadastro işlemlerinin dijital ortama aktarılması gibi alanlarda kamu kurumlarında kullanılmıştır. Ancak 100 dolarlık bilgisayar olarak tanıtılan cihaz 150 dolara ulaşarak fiyat konusunda rekabetçi bir yapıya ulaşamamıştır. Bazı insanlar için çok pahalı olabileceğinden, smart kart sistemi ile birçok kişi tarafından ortak kullanıma imkân tanınmasına rağmen dizüstü bilgisayar fiyatlarının düşüşüyle iyice zorda kalınarak bir süre sonra bilgisayarın pazarlaması durmuştur (Mandal, 2015: 158; Radikal, 2006; Simputer, 2004).

Laos'taki Jhai Foundation'ın geliştirdiği "Remote IT Village" projesindeki öncelikli hedef, kırsal kesimdeki ailelerin çocuklarına bilgisayar ve eğitimi vererek, çiftçiler ve kırsal kesimdeki küçük işletmelerin İnternet imkânlarından yararlanmalarını sağlamak. Bu proje sayesinde, çiftçilerin organik tarım yoluyla ürün fazlası sağlayabilecekleri, bunun yanı sıra piyasa fiyatlarını da takip ederek, ürünlerinin daha etkin şekilde pazarlayabilecekleri belirtiliyor. Kablosuz İnternet bağlantısının kullanıldığı projede, kablosuz ağ, köylülerin malı olup, kullanıcılara sağlanan destekler için çok düşük ücretler alınıyor (Active Academy Araştırma Merkezi, 2004:2).

Pakistan, Tayland ve Çin gibi ülkelerde yapılan bazı araştırmalarda mobil telefonların taksici, sokak satıcısı ve küçük esnaf gibi belli bir işyeri olmadan çalışanlar tarafından müşterilere ulaşmada kullanıldığı tespit edilmiştir. Hindistan'da özellikle günlük olarak yakalanan balık miktarının bilinememesi, hava durumu tahminlerinin öğrenilememesi gibi eksik bilgi nedeniyle balıkçılık sektöründe fiyatlara yansıyan sorunların çözümünde de bilgi akışı sağlayan mobil telefonların kullanıldığı görülmektedir. Aynı şekilde Tanzanya'da da balıkçılar mobil telefonlar aracılığı ile balık piyasası hakkında bilgi edinerek pazarlık güçlerinin arttırabilmişlerdir. Malezya, Tayland ve Endonezya gibi ülkeler de ise, doğal afetlerden etkilenen yoksul kesimlere afet sonrası süreçte ulaşmada mobil telefonların önemli roller üstlendiği görülmüştür (Ergül ve diğerleri, 2010:141).

Yoksul birisine cep telefonu satmak, uzak bir köye ankesörlü telefon kurmaktan çok daha ucuz ve süratli bir iştir. Cep telefonları şirketleri peşin tahsilat yapabildiklerinden ötürü batık paraların peşinde koşmak için zaman ve para harcamak zorunda da değillerdir. Bangladeş’te kırsalda yaşayan kadınlar fiyatı belki bir evin yıllık geliri kadar olan cep telefonu almak için yerel bir kredi bankası olan Grameen Bankası'ndan kredi kullanabilmektedirler. Grameen Bank'a göre Bangladeş’te 2008 yılı sonuna kadar köylerde telefonu olan 300.000'den fazla kadın vardı. Kredi kullanan bu kadınların \%50'si aldıkları kredileri geri ödeyebilmiştir. Çünkü köyde telefonu olan kadınlar diğer köylülere telefonu kullandırarak kişi başı gelirlerini ek gelir yaratarak neredeyse iki katına çıkarmıştır. Burada uygulanan projenin bazı aşamalarında bu kadınlar kendi hanelerinin \%24'üne denk gelen yılda yaklaşık ortalama 300 dolar ek gelir elde etmişlerdir. Ayrıca bazen bir telefon görüşmesi uzun ve pahalı bir seyahatinde yerini alabilmektedir. Bir araştırmaya göre telefon sayesinde aylık gelirlerde genel olarak \%3 ile \%10 arasından bir tasarruf sağlandığı tespit edilmiştir. Benzer gelişmeler Gana ve Uganda dâhil olmak üzere diğer bazı ülkelerde de görülmüştür (UNCTAD, 2010: 56; Guest, 2002: 231).

Türkiye'de bilgi ve iletişim teknolojileri donanımına sahiplik ve erişim açısından kırsal ve kentsel kesimler arasında büyük bir açık bulunmaktadır. Kentlerde yaşayanların neredeyse yarısı internet erişimine sahipken, bu oran, kırsal kesimde ancak dörtte bire yaklaşmaktadır. Türkiye genelinde 2015 yılı Nisan ayında internet erişimine ve genişbanta sahip hanelerin oranı sırasıyla \%69,5 ve \%67,8 olmuştur. Buna göre hanelerin \%37,4'u ADSL, kablolu internet, fiber gibi sabit, \%58,7'si ise mobil genişbant bağlantı ile internete erişim sağlamıştır. 2015 yılı Nisan ayında hanelerin \%96,8'inde cep telefonu veya akıllı telefon bulunurken, \%29,6'sinda ise sabit telefon bulunmaktadır (TÜİK, 2015). "Bilgi ve İletişim Teknolojileri Gelişmişlik Endeksi”nin 2013 yılı verilerine göre Türkiye, 166 ülkeli listede 68. sırada yer almaktadır. Türkiye'nin bilgi ve iletişim teknolojileri pazarı, katma değer üretimine ve yüksek teknoloji geliştirilmesine değil tüketime dönük olarak faaliyet göstermektedir (Saran, 2015).

Türkiye'de bu alanda gereken gelişim yakalayabilmek ve ilgili endekste yukarılara çıkabilmek için 2010 y1lında başlatılan Fatih Projesi kapsamında öğrencilere tablet; okullara ise bilgisayar, projeksiyon ve akıllı tahta dağıtımları yapılmaktadır. Proje kapsamında etkileşimli tahtalar toplam 114.921 adet sınıfa yerleştirilmiş; 20.269 okula çok fonksiyonlu yazıcı dağıtımı yapılmış; toplam 81 ildeki meslek liseleri hariç 3.516 lisede genişbant hızlı internet altyapısı kurulumları tamamlanmıştır. 2016 yılının Ocak ayında 10.600.000 tablet bilgisayarın dağıtımı planlanmıştır. Yapılan çalışmalarla 4.000 okula uydu ve 35.684 okula ADSL bağlantısı ile internet erişim imkânı sağlanmaktadır. Öğrenciler için Eğitim Bilişim Ağı uygulaması geliştirilmiştir. Bu uygulama ile öğrencilerin güvenli bağlantılara ulaşmasını ve derslerine daha etkili katılmasını sağlamak için 150.000'e civarında eğitsel 
dijital içerik geliştirilmiştir. Bu portalı kullanan 2.000.000 civarından kayıtlı kullanıcı bulunmaktadır. Çalışmalar kapsamında 100’e yakın yazılımın geliştirilmesi tamamlanmıştır (Türkkan ve Çiftçi, 2015: 63). Türkiye'de, Aile ve Sosyal Politikalar Bakanlığı tarafından, kadınlar ve çocuklar için internet kullanımının yaygınlaştırılması için tespit edilen bir gelirin altındaki yoksul ailelere belli miktarda bedava internet verilmesi projesi gündeme alınmıştır. Aktif istihdam politikaları çerçevesinde de bilgi ve iletişim teknolojilerine dönük mesleki eğitimler verilmekte ve programlar uygulanmaktadır.

\section{Sonuç}

Yoksulluğun günümüzde sadece asgari bir tüketimden ve harcamadan mahrumiyet olmadığı, içinde sağl1k, eğitim, sosyal sermaye, ulaşım ve iletişim imkânları gibi yaşam için önemli olabilecek unsurlardan da mahrum kalmak olduğu kabul edilmektedir. Yoksulluk problemi kısa vadeli olan kısmi yardımlarla çözülmeye çalışılarak ertelenmektedir. Oysaki sorun göründüğünden daha derin ve süreklilik arz etmektedir. Buda problemin daha başka çözümler üretilerek halledilmesini gerekli kılmaktadır. Günümüzde eğitim, iş arama ve bulma, üretim, tüketim gibi ekonomik ve sosyal içerikli pek çok işlemin artık elektronik ağlar üzerinden yürütüldüğü görülmektedir. Ancak, yoksulluk içinde yaşayanların karşılaştıkları sorunlar bu tür gelişmelerin yoksullar tarafından kullanımını kısıtlamakta ve sosyal dışlanma olgusunu daha ağır yaşamalarına neden olmaktadır.

Yeni iletişim teknolojilerinin sağladığı imkânlarla: ekonomik büyüme sürekli hale getirilebilir; verimlilik artışı yaratılabilir; yeni enerji kaynaklarının kullanımı arttırılarak çevresel koşullardan en fazla etkilenen yoksulların lehine olacak şekilde karbon emisyonları azaltılabilir; ihraçta sektöründeki rekabet gücü artırılabilir ve böylece yoksulların yaşam standartları yükseltilip sosyal içerilmelerine katkı yapılarak katılımcı olmaları sağlanıp, mücadele örülebilir (Karagöz, 2007: 216). Bilgi ve iletişim teknolojilerinin sosyal dişlanmaya maruz kalan yoksulların, seslerini duyurmalarını ve görülebilir olmalarını sağlayarak da sosyal içermeye katkı yaptıkları saptanmıştır. Bilgi ve iletişim teknolojilerinin kalkınma politikalarına girmesini sağlamak ve bölgesel ve alt bölgesel düzeylerde bunların transferini ve kullanımını sağlamak için bu konularda insan kaynağını geliştirmek gereklidir. Bu sebeple yoksullara uygulamalı eğitim desteği sağlanması ve böylece becerilerin geliştirilmesi konularına yeni iletişim teknolojilerinin katkı yapabileceği ifade edilmektedir. Zamanında ulaşılan her bilginin çok yaralı olacağı gerçeğinden hareketle bilgi ve iletişim teknolojileri, azgelişmiş ülkelerin sağlık alanındaki yenilikleri ve gelişmeleri takip etme şansını arttırıp salgın hastalık gibi bir felaketin yayılmasını engelleme ve felaket risklerinin azaltılması konularına da katkıda bulunabilir (Aykan, 2009: 66). Toplumsal eşitsizlik temelinde kadınların, çocukların ve yaşlıların daha güçlü kılınmasına dair çabalara yönelik sosyal kampanyaların bu kesimlere ulaştırılmasında ve yoksullara dönük mücadele yollarının tanıtılmasında iletişim teknolojilerinin yaşamsal yeri olduğu belirtilmektedir.

Yeni iletişim teknolojilerinin insani gelişmeyi üç farklı biçimde etkileyebileceğini ve böylece insanlığa yaraşır bir toplum inşa edilmesi için adımlar atılabileceğini söyleyebiliriz. Bunlar (Najam, 2012); i) insanların yetkinliklerini, yaratıcılıklarını ve bilgi düzeylerini arttırmak, ii) ekonomik büyüme sağlayan üretkenliği arttırmak ve iii) az miktarda yatırımla geniş iş imkânları yaratmaktır.

Günümüz bilgi toplumunda ülkelerin yeni iletişim teknolojilerine ulaşamadıkları için geri kalmadığı; ülkelerin geri kaldıkları için bu teknolojiye ulaşamadıklarına dair görüşlerde vardır. Bu düşünceyi destekleyen görüşe göre yeni iletişim teknolojileri azgelişmiş ve gelişmekte olan bölgelerde yaşamını sürdüren yoksulların bile lazım olan bir bilgiye artık çok düşük maliyetle ve oldukça rahat ulaşmasına yardımcı olabilir. Bu bilgilere geçen yüzyılda gelişmiş ülkelerdeki en zengin insanların bile ulaşması mümkün değildi (Stiglitz, 2002:26). Ancak internet ve benzeri teknolojilerin dezavantajlı kesimlerin günlük yaşamında var olan eşitsizliklerin giderilmesine, daha iyi bir yaşam sürmelerine olan katkısına ve alt gelir grubundaki insanların bunlara nasıl ulaşabileceğine dair konuların çalışılmaya devam etmesi gerekmektedir.

\section{Kaynakça}

- Active Academy Araştırma Merkezi, 2004. "Bilişim Yoksulluğuna Çare Aranıyor”, Activeline Dergisi, Şubat, p.1-3.

- $\quad$ Alagh, K. Y.,1992. “ Growth Performance Of The Indian Economy 1950-89 Problem of Employment and Poverty”, Developing Economies, 30(2), p. 97-116.

- Aykan, K., 2009. "Birleşmiş Milletler Asya ve Pasifik Ekonomik ve Sosyal Komisyonu (UNESCAP)", Uluslararası Ekonomik Sorunlar, 34, p.58-62.

- Awad, Y. ve Israeli, N., 1997, "Poverty and Income Inequality: An International Comparison, 1980s and 1990s", Luxembourg Income Study Working Paper Series, Working Paper No. 166, p.2-38.

- Barja, G., Gigler, B. S., 2007. "The Concept of Information Poverty and How to Measure It in The Latin American Context" Digital Poverty, 11.

- Başaran, F., 2002. “Internet: Yönelimler, Olas1lıklar”, https://bianet.org/bianet/print/12678-internetyonelimler-olasiliklar (Erişim Tarihi: 16.04.2016). 
- Başaran, F., Taşdemir, B. 2011. Enformasyon Toplumu Teorilerinin Eleştirisi, http://acikders.ankara.edu.tr/ pluginfile.php $/ 440 / \mathrm{mod}$ resource/content $/ 2 /$ Enformasyon $\% 20$ Toplumu $\% 20$ Teorilerinin $\% 20 \mathrm{Ele} \% \mathrm{C} 5 \% 9$ Ftiri si\%20PDF\%20belgesi.pdf .

- COMCEC (t.y.), "Yoksulluğun Önlenmesinde Mikrokredi Uygulamaları ve Türkiye”, OIC/COM CEC/23-07/CR(1), http://www.comcec.org/EN/belge/arsiv/pdf/TURKEY\%2023-07\%20CR (1)TR.pdf (24.11.2015).

- Coşkun, S. ve Tireli, M., 2008 Avrupa Birliğinde Yoksullukla Mücadele Stratejileri ve Türkiye, Nobel Yayın Dağıtım, Ankara.

- Durgun, Ö., 2011. “Türkiye'de Yoksulluk ve Çocuk Yoksulluğu Üzerine Bir İnceleme”. Bilgi Ekonomisi ve Yönetimi Dergisi, 6(1), p.143-154

- $\quad$ Ergül, H., ve diğerleri, 2010. "Eski Yoksulluk, Yeni Medya: Yoksullukla Baş Etmede Yeni Medya Nasıl Kullanılıyor (Mu)?”, Uluslararası Yoksullukla Mücadele Stratejileri Sempozyumu Deneyimler ve Yeni Fikirler Bildiriler Kitabı, Sydgm Yayınları, İstanbul, p.133-144.

- Guest, R., 2002. “Teknoloji ve Yoksulluk”, Liberal Düşünce, Kış-Bahar, p.219-247.

- Güçlü, N., Sotirofski, K. 2006. “Bilgi yönetimi” Türk Eğitim Bilimleri Dergisi,4(4), p.351-373.

- Ilgar, R. ve Lefilleul, N. J., 2011, “Az Gelişmiş Ülkelerin Coğrafî Koşullarının Zorladığı Mekâna Bağlı Kalkınma Girişimleri”, CÜ Sosyal Bilimler Dergisi, 35(2), p.73-91.

- IISTKA, 2012. Kâr Amacı Gütmeyen Kuruluşlara Yönelik Bilgi Ve İletişim Teknolojileri Odaklı Ekonomik Kalkınma Mali Destek Programı, 2012 Yılı Teklif Çağrısı Başvuru Rehberi.

- Kalaycı, C. 2013. "Dijital Bölünme, Dijital Yoksulluk ve Uluslararası Ticaret” Atatürk Üniversitesi İktisadi ve İdari Bilimler Dergisi, 27(3),p.145-162.

- Karagöz, K., 2007. "Bilgi İletişim Teknolojilerindeki Gelişmenin İhracata Etkisi: Türkiye İçin Ampirik Bir Analiz" Maliye Dergisi, 153, p.214-223.

- Karasar, S. 2004. "Eğitimde Yeni İletişim Teknolojileri-Internet ve Sanal Yüksek Eğitim.”, TOJET: The Turkish Online Journal of Educational Technology, , 3(4), p.117-125.

- Kalkınma Bakanlığı, 2014. Onuncu Kalkınma Planı (2014-2018) 2015 Yılı Programı, Ankara.

- Kevük, S. 2006.”Bilgi Ekonomisi”, Journal of Yaşar University 1(4), p.319-350.

- Kirmanoğlu, H.,2005. “Amartya Sen’in Özgürlük Ve Kalkınma Üzerine Düşüncelerine Bir Bakış”, İstanbul Üniversitesi İktisat Fakültesi Maliye Araştırma Merkezi Konferansları 47. Seri, p.22-30.

- Lipton, M.,1997, "Poverty-Are There Holes in The Consensus?”, World Development, p.1000-1012

- Mandal, N. (2015), "A Present Scenario of E-Information Service in Rural India." "Knowledge Librarıan" an International Peer Reviewed Bılıngual E-Journal of Library and Informatıon Sclence, 2(6), p.149-176.

- Najam, S. (01.05.2012). “Teknoloji Yoluyla İnsani Gelişme”, UNDP Türkiye, http://www.tr.undp.org /content/turkey/tr/home/presscenter/news-from-new-horizons/2012/06/human-development-throughtechnology.html (Erişim Tarihi: 24.04.2016).

- Ö̈zdemir-Yücesan, G. 2014. "Hırsız Zamanlar, İstilacı Mekânlar”: 21. Yüzyılda Yeni İletişim Teknolojileri, İş ve İstihdam.”, VI. Sosyal İnsan Hakları Ulusal Sempozyumu Kitabı, p.157-167.

- Öztürk, A. G. D. L. 2005. "Türkiye'de Dijital Eşitsizlik: Tübitak-Bilten Anketleri Üzerine Bir Değerlendirme.”, Erciyes Üniversitesi İktisadi ve İdari Bilimler Dergisi, 24(24), p.111-132.

- Radikal, 20.11.2006. 100 Dolarlık Umut Suya Düştü, http://www.radikal.com.tr/ek_haber.php?ek=sa\& haberno=3228 (Erişim tarihi: 12.04.2016).

- Sarısoy, İ. ve Koç, S., 2010. "Türkiye'de Kamu Sosyal Transfer Harcamalarının Yoksulluğu Azaltmadaki Etkilerinin Ekonometrik Analizi”, Maliye Dergisi, 158 (Ocak-Haziran), p.326-348.

- Saran, U. (01.09.2015), “Türkiye Bilim Toplumu Olmaya Ne kadar Yakın?”, AljazeeraTurk, http://www.aljazeera.com.tr/gorus/turkiye-bilgi-toplumu-olmaya-ne-kadar-yakin (Erişim Tarihi: 27.03.2016)

- Simputer, 2004. What is a Simputer?, http://www.simputer.org/simputer/about/ (Erişim tarihi: 16.05.2016).

- Stiglitz, Josph E. 2002. Küreselleşme Büyük Hayal Kırıklı̆̆ı, Çev: Arzu Taşçığlu, Deniz Vural, Plan B Yayınevi, İstanbul.

- Şenses, F., 2009. Küreselleşmenin Öteki Yüzü Yoksulluk, İstanbul: İletişim Yayınları.

- $\quad$ TÜBİTAK, 2004. Ulusal Bilim ve Teknoloji Politikaları 2003-2023 Strateji Belgesi, Türkiye Bilimsel ve Teknik Araştırma Kurumu, Ankara.

- TÜİK, 2016. Yoksullukla İlgili Tanımlar, http://www.tuik.gov.tr/MicroVeri/GYKA_2011/turkce/metaveri/ tanim/yoksullukla-ilgili-taniimlar/index.html (Erişim Tarihi: 22.05.2016) 
- TÜİK, 2015. “Hanehalkı Bilişim Teknolojileri Kullanım Araştırması, 2015”, Haber Bülteni, Sayı: 18660.

- Türkkan, G. ve Çiftçi, M., 2015, “Fatih projesi Nedir?” Yiğitek Dergisi, 12 (Ocak), p.62-64.

- UNCTAD, 2010. Information Economy Report 2010, ICTs, Enterprises and Poverty Alleviation, UNITED NATIONS PUBLICATION, Switzerland.

- $\quad$ Uzun, M. A., 2003. "Yoksulluk Olgusu ve Dünya Bankası”, Cumhuriyet Üniversitesi, İktisadi ve İdari Bilimler Dergisi, 4 (2), p.155-173.

- Yeşilorman, M., Koç, F. 2014. "Bilgi Toplumunun Teknolojik Temelleri Üzerine Eleştirel Bir Bakış” Firat University Journal of Social Sciences/Sosyal Bilimler Dergisi, 24(1), p.117-133.

- Yıldız, B. (2013), Dünyada ve Türkiye'de Yoksullukla Mücadelede Uygulanan Mali Tedbirler ve Türkiye Analizi, Karadeniz Teknik Üniversitesi Sosyal Bilimler Enstitüsü, Yayınlanmamış Doktora Tezi, Trabzon.

- $\quad$ Wendpanga, S. E., 08.10.2011. “Zengin - yoksul uçurumu büyüyor”, (Çev.Aydın Üstünel), Çelik Akpınar (Ed.), Deutsche Welle, http://www.dw.de/dw/article/0,,15445171,00.html.

- Worldbank, 1990. World Development Report, Oxford University Pres, New York. 


\title{
Türkiye'de Neoliberal Ekonomi Politikaları Sürecinde Gelir Bölüşümü ve İktisadi Büyüme İlişkisinin Analizi Analysis of Income Distribution and Economic Growth Relation
in Process of Neoliberal Economic Policies in Turkey
}

\author{
Prof. Dr. Ahmet Incekara (Istanbul University, Turkey) \\ Ph.D. Candidate Betül Mutlugün (Istanbul University, Turkey)
}

\begin{abstract}
Income inequality has long been the economic, social, political and moral concern for many countries. Attaining more fair income distribution along with economic growth and development has started to gain importance. But in spite of the vast literature on income distribution and economic growth, there remains disagreement on the effect of income inequality on economic growth. With the transformation process as a result of neoliberal policies implemented since the late 1970's, unequal distribution of income became more apparent in terms of economic and social issues. In this study, the effect of neoliberal economic policies on income inequality and economic growth has been analyzed in the context of social classes.
\end{abstract}

\section{Giriş}

Son yıllarda gelir ve servet eşitsizliği ile ilgili endişelerin ortaya çıkmasıyla birlikte gelir dağılımına ilişkin çalışmaların artmasına rağmen, bölüşüm problemleri yeni değildir. Sanayi devriminden bu yana küresel düzeyde gelir eşitsizliği artan bir trend sergilemektedir. Şekil 1'e göre, gelişmiş kapitalist ülkelerde nüfusun en zengin \%1'lik kesiminin toplam gelirden aldığı pay sanayi devriminden 1914 yılına kadar tarihi zirvesini yaşarken, 19141945 yılları arasında gelir eşitsizliği artmaya devam etmiştir. İkinci dünya savaşından sonra 1950'ler ve 1960’lı yılların başında ve 1980'li yıllara kadar gelir eşitsizliği dramatik bir azalma göstermiştir. İşsizlik oranının doğal işsizlik oranına yaklaştığı, yüksek büyüme oranlarının gerçekleştiği ve sosyal alandaki problemlerin tartışma konusu olmadığı bu dönemde gelir dağılımı adaleti ve eşitsizlik sorunları iktisadi tartışmaların gündeminde yer almamıştır. Dönemin optimist ortamında, büyüme ve istihdam politikalarından düşük gelir grubuna mensup ekonomik birimlerin fayda sağlayabileceği ve gelirin yeniden dağıtımı politikalarının maliyetinin iktisadi etkinliği azaltıcı yönde etki yapacağı iddia edilmiştir. Bunun sonucunda, etkinlik-eşitlik çelişkisi bağlamında bir tercih problemi ortaya çıkmıştır. 1930'lu ve 1940’lı yıllarda hüküm süren ve neoklasik ekolden ilerleyen refah iktisatçılarının önerilerine uygun olarak, eşitlikten ziyade iktisadi etkinliğin arttırılması yönünde çaba gösterilmiştir.

20. yüzyılın son çeyreğinden bu yana ise, ulus devletlerin uluslararası sermaye ve emperyalizmin amaçlarına hizmet etmek doğrultusunda küreselleşme sürecine uyum sağlayabilmesi için neoliberal iktisadın ekonomi politikalarına yön verdiği görülmektedir. M. Friedman'ın oluşturduğu Chicago okulunun ve F. A. Hayek'in öncüleri olduğu neoliberal iktisadın temel çıkış noktası iktisadi özgürlüklerdir. 1989 yılında neoliberalizmin politika ayağını oluşturan Washington Uzlaşısı ile küreselleşmeye uyum için gereken şartlar belirlenerek politikalar formüle edilmiş ve daha sonra bu politika önerileri neoliberal iktisadın kalkınma reçetesine dönüşmüştür. Neoliberal iktisat politikaları "Chicago Oğlanları” olarak da bilinen Friedman'ın öğrencileri tarafından ilk defa 1973 'te darbe ile başa gelen Pinochet döneminde Şili'de uygulanmaya başlanmış ve Şili ekonomisi piyasa temelli yapısal bir dönüşüm geçirmiştir. 1980'lerde ve 1990'lı yılların başında ise neoliberal iktisat politikaları, Latin Amerika ülkeleri ve Türkiye'nin de içinde bulunduğu birçok gelişmekte olan ülkede yaygın olarak benimsenir hale gelmiştir.

Neoliberal iktisat analizlerinde temel olarak bireysel özgürlük ve girişimciliği esas almakta, serbest piyasa ekonomisi ve uluslararası mal ve sermaye akımlarının serbestisini benimsemektedir. Buna göre, ekonomilerin dışa açılması, dünya ekonomisiyle bütünleşmesi ve yeniden yapılanma sürecine girmeleri sonrasında uzun dönemde ekonomiler hızlı büyüme oranlarını yakalayacak ve bu büyüme toplumun bütün kesimlerinin gelirinde bir artış şeklinde kendini gösterecek, yoksulluk oranı gerileyecektir. Neoliberal teoriye göre, eşit olmayan getiriler beşeri ve fiziki sermayeye daha çok yatırım yapılmasını teşvik edeceği ve dolayısıyla büyümeyi arttıracağı için, iktisadi eşitsizlikler "kabul edilebilir" olarak nitelendirilmektedir. Bazı gruplar büyümenin nimetlerinden diğerlerinden daha fazla faydalansa bile, sonunda herkes karlı çıkacaktır (Greenwood ve Holt, 2010: 403). Buna "aşağı damlama etkisi" denmektedir. 


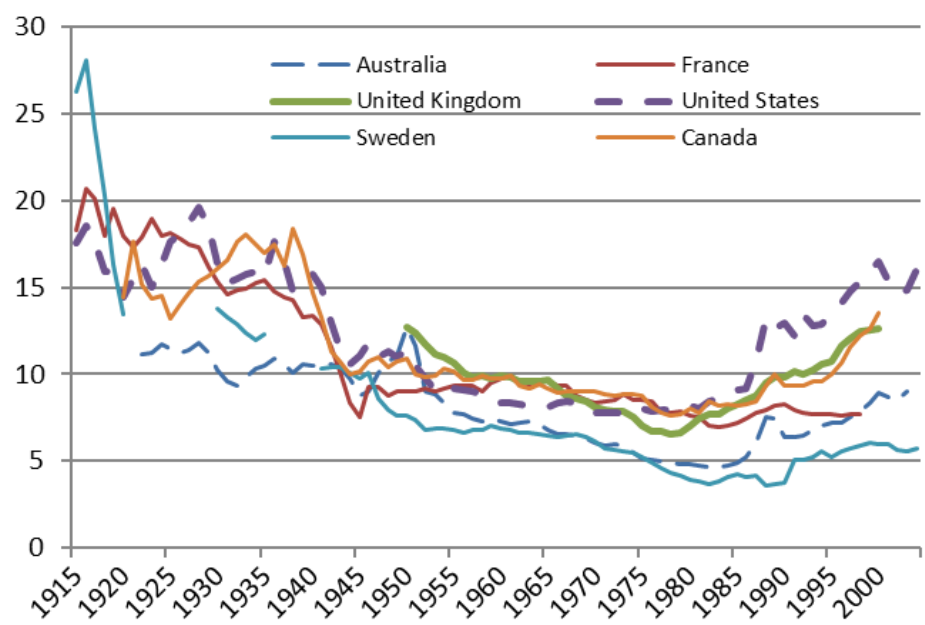

Şekil 1. Nüfusun En Yüksek Gelirli \%1'lik Kesiminin Gelirden Aldı̆̆̊ Pay Kaynak: OECD Statlinks.

Ancak, neoliberal ekonomi politikalarının etkilerinin hissedilmeye başlandığı 21. yüzyılın sonlarına doğru birçok ülkede zengin ve fakir arasındaki uçurum gittikçe artmaya devam etmektedir. Türkiye'nin de aralarında bulunduğu OECD ülkelerinde 1980'lerde nüfusun en yüksek gelire sahip \%10'luk dilimi en düşük gelirli \%10'luk diliminden 7 kat daha fazla kazanmaktayken, 1990'lar ve 2000'lerde bu değer sırasıyla 8 ve 9 katına çıkmıştır. Bugün ise en zengin \%10'luk dilim, en fakir \%10'luk dilimin gelirinden 9.6 kat daha fazla kazanmaktadır. Gelir eşitsizliğini ölçmek için kullanılan ve değeri 0 ile 1 arasında değişen GINI katsayısının OECD ülkelerinde 2013 yılının ortalama değeri 0.315 iken, bu değer Türkiye'de 0.4 düzeyini aşmış ve 0.5 düzeyine yaklaşmıştır (Şekil 2). Türkiye, Meksika ve Şili'den sonra OECD ülkeleri arasında en yüksek gelir eşitsizliğine sahip 3. ülke konumundadır. Son yıllarda giderek artan eşitsizlikler, aşağı damlama etkisinin iddia edilen olumlu etkilerinin gerçekçi olmadığına dair görüşlerin güçlenmesine zemin oluşturmuştur.

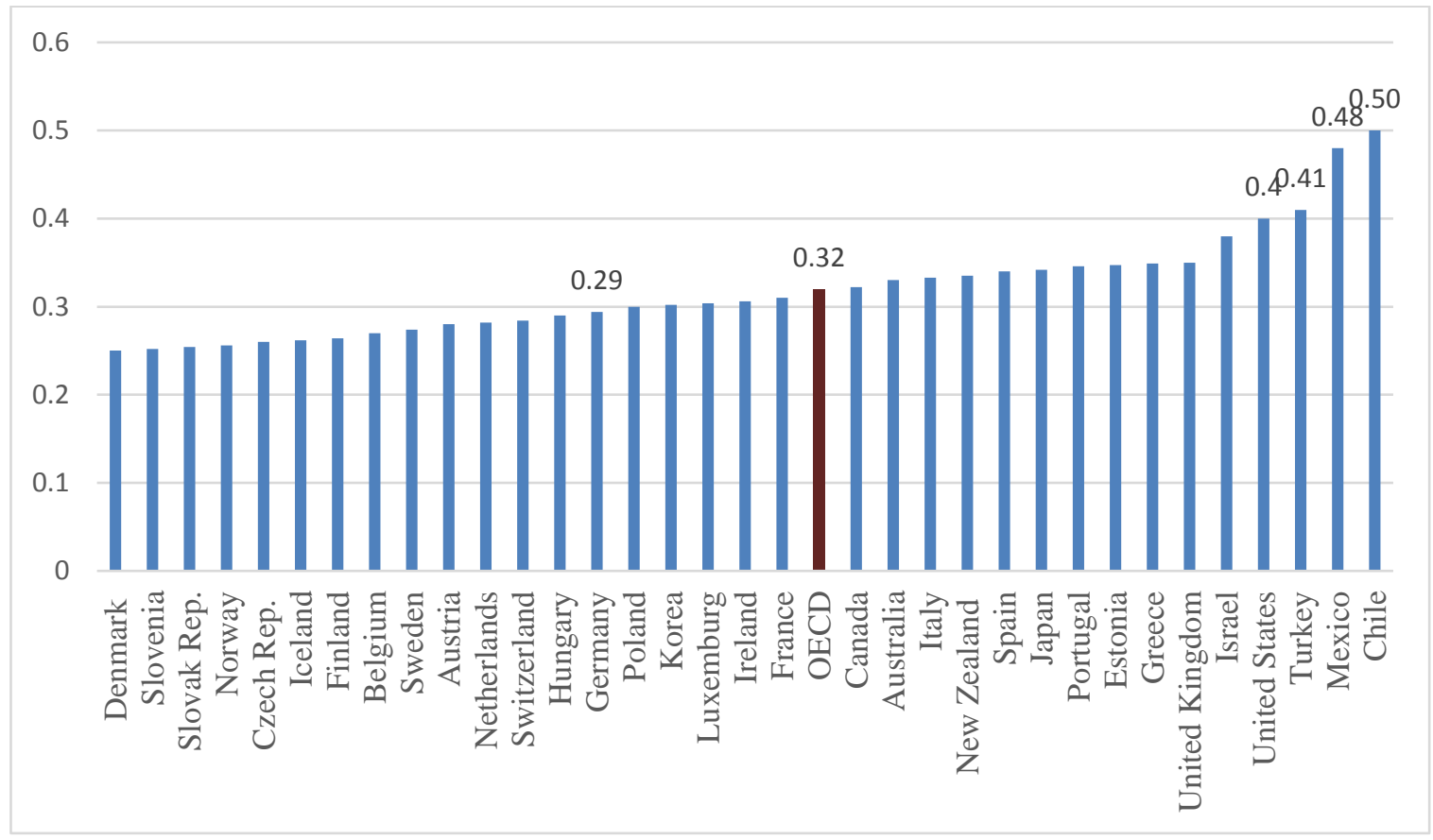

Şekil 2. 2013 Yllı OECD Ülkeleri GINI Katsayısı Kaynak: OECD

Neoliberal politikaların gelir eşitsizliği ve büyümeye olan etkisinin yönüyle ilgili olarak birbirine zıt görüşlerin ortaya atılması, konunun ülke bazında ve her ülkenin kendi dinamikleri çerçevesinde değerlendirilmesi gerekliliğini ortaya çıkarmaktadır. Bu çalışmanın 2. kısmında neoliberal politikaların bölüşüm ve büyümeye olan etkilerinden bahsedilecek, literatürde konuyla ilgili teorik görüşlere yer verilecektir. 3. kısımda ise Türkiye'de 1980’li yıllardan sonra uygulanmaya başlanan dışa açılma politikalarının gelir dağılımı ve büyümeyi nasıl etkilediği analiz edilecektir. 


\section{Büyüme, Gelir Eşitsizliği ve Neoliberalizm}

1971 'de uluslararası para sisteminin sona ermesi ve 1973'te Petrol Krizi ile birlikte 1980'li yıllarda gelişmiş ülkeler stagflasyon yaşarken, gelişmekte olan ülkeler de ödemeler dengesi açığı ve borç krizi ile karşı karşıya kalmıştır. Yeni bir iktisadi problem olarak algılanabilecek stagflasyonun çözümü için ise mevcut paradigmanın bir çözüm önerisi bulunmadığından, neoliberal iktisat politikaları devreye girmiştir. Ancak, neoliberal iktisadi söylemlerin iktisat teorisinde yeni bir iktisadi gelişme olduğu söylenemez, zira neoliberal iktisadın politika önerileri incelenince, Klasik liberalizmden öz olarak farklı olmadığı açıkça görülecektir.

Neoklasik iktisat teorisinin söylemlerini temel alan neoliberalizm, tam rekabet varsayımı altında üretim faktörlerinin üretime marjinal katkıları çerçevesinde getiri elde edeceğini iddia etmektedir. Bu bağlamda, gelir bölüşümündeki değişimler, ekonominin teknolojinin yarattığı yapısal değişimlere veya arz ve talep şokları sonucunda yeni piyasa dengesine etkin uyum sağlamasının doğal bir sonucudur (Fiorentini, 2015:120). Neoliberal iktisadın savunucuları gelir dağılımındaki değişimleri hiçbir zaman bir problem olarak algılamamışlar, yetenek ve eğitim bakımından eşit olmayan işçilerin farklı ücret almalarının doğal olduğunu söyleyerek eşitsizliklerin bir dereceye kadar kabul edilebilir olduğunu ifade etmişlerdir. Bu durumda, işsizlerin veya en düşük gelir grubuna mensup bireylerin mevcut durumu, bu kesimlerin aylak olması temelinde açıklanmaktadır. Dolayısıyla, gelir dağılımı ve bölüşüm konuları neoklasik iktisadın ilgi alanına girmemektedir.

Neoliberalizmin en temel öğesi, piyasanın iktisadi faaliyetlerde hakim rol oynamasıdır. Bunun için bireysel girişimcilik serbestleşmeli, mülkiyet hakları güvence altına alınmalı ve dünya ticaretinin önündeki her türlü engel ortadan kaldırılmalıdır. Bu yolla kaynak dağılımında etkinlik sağlanacaktır. Serbest piyasa ekonomisinin işleyişiyle ilgili gereken koşulların yaratılması için ise devlet gereken kurumsal yapıyı yasal önlemler ile oluşturmalıdır. Devlet bunun dışında piyasaya müdahalede bulunmamalıdır, çünkü devlet piyasa sinyallerini zamanında değerlendirecek kabiliyete sahip değildir. Ayrıca, devlet güçlü çıkar gruplarının etkisinde kalarak, ekonomiye yanlı ve isabetsiz müdahalelerde bulunabilmektedir (Harvey, 2005: 2). Dolayisiyla, devletin ekonomik faaliyetlerdeki rolünün azaltılarak devlet müdahalesinin ortadan kaldırılması sayesinde piyasa başarısızlıklarının önüne geçilmiş olunacaktır.

Devlet, piyasada karı düşürecek her türlü girişimi ortadan kaldırmaya yönelik müdahalede bulunmalıdır. Kamu İktisadi Teşekkülleri (KIT) ise dış açıklar, borçlanma ve dolayısıyla da borç krizinin sorumlusudur (Yıldırım, 2011:75). KİT'lerin üretim maliyetleri yüksek olduğundan yurtiçi rekabeti ve uluslararası rekabet gücünü azaltarak cari açık verilmesine sebep olmaktadır. Bu nedenle, devlete ait her türlü işletme ve bankanın devlet tekelinden çıkarılıp özelleştirilerek özel yatırımcılara satılması gerekmektedir. Dolayısıyla, rekabetin önünde bir engel teşkil eden devletin ekonomideki rolü, denk bütçe, özelleştirme ve deregülasyon politikalarıyla azaltılmaya çalışılmalıdır (Harvey, 2005:65). Kamu sektörü istihdam yaratmak amacıyla iktisadi faaliyetlerde bulunmamalıdır, çünkü bu durum büyüme hızının düşmesine ve ödemeler dengesi krizlerinin ortaya çıkmasına yol açmaktadır (Johnston, 2007: 227). Kamu harcamaları yoluyla sosyal hizmetler ve yardımların sağlanmasına yönelik harcamalar azaltılmalı ve kamu harcamalarının öncelikli alanları yeniden düzenlenerek bu harcamalar uzun dönemde iktisadi büyümeyi arttıracak eğitim, sağlık ve altyapı sektörlerine kaydırılmalıdır. Buna karşın, özel sektöre yönelik yardımlar ve vergi kolaylıkları sağlanmalıdır. Vergi reformu yapılmalı ve hükümet vergi tabanını genişletmelidir.

Neoliberal görüşün argümanlarına göre, eşitsizlik ve büyüme arasında pozitif yönlü bir ilişki mevcuttur. Ekonomide yatırımları gerçekleştiren kesim, sermayenin büyük bölümünü elinde tutan en zengin kesimdir. Aynı zamanda, bu sınıf marjinal tasarruf eğilimi en yüksek olan sınıftır. Alt gelir gruplarının marjinal tasarruf eğilimi düşük, marjinal tüketim eğilimi yüksek olduğundan, eşitsizlik en yüksek gelir grubunun gelirini arttıracak, bu durum daha fazla tasarruf ve yatırım yapmalarını sağlayarak ekonomik büyümeyi hızlandıracaktır. Artan büyümeden toplumun en düşük gelirli kesimi de artan kamusal hizmetler sayesinde faydalanacaktır. Ayrıca, eşitsiz bir toplum çalışma dürtüsünü kamçllayacak, yetenek geliştirmeyi ve daha riskli projeler üstlenmeyi teşvik edecektir, çünkü bu faaliyetlerde bulunmanın sağlayacağı marjinal fayda, gelir eşitsizliği yüksek olduğu sürece fazladır. Bu nedenle neoliberal politikalar zenginden yoksula gelir transferine karşı çıkmaktadırlar, çünkü yüksek sosyal yardımlar bir yandan insanların çalışma güdülerini engellemekte, diğer yandan artan oranlı vergiler yatırımları caydırmaktadır (Johnston, 2007: 226).

Neoliberalizmin bir diğer temel ilkesi ise serbest dünya ticaretinin önündeki tüm engellerin ortadan kaldırılması ve karşılaştırmalı üstünlüklerin ilkelerine göre hareket edilmesidir. Uluslararası mal ve sermaye akımlarının serbestisi ve teknoloji transferi yoluyla kaynak dağılımında etkinlik ve verimlilik artışları sağlanacak ve ekonomik büyüme olumlu etkilenecektir. Merkez ve çevre ülkeler arasındaki uluslararası ekonomik işlemler ve teknoloji transferinin iktisadi anlaşmalarla hızlandırılması, çevre ülkelerin de zenginleşmesini sağlayacaktır (Akalın, 2009:18). Graff vd. (2003), gelişmekte olan ülkelerde teknoloji transferleri yoluyla gıda üretimi ve kırsal kesimde gelir artışı kaydedildiğini iddia etmektedir.

Giriş bölümünde bahsedildiği gibi, neoliberal iktisat, yukarıdaki argümanlar eşliğinde aşağı damlama etkisi sayesinde eşitsizliği yatırım ve tasarruflar ile çalışma güdülerini teşvik eden bir olgu olarak görmektedir. Ancak, son dönemlerde yatay kesit veri yöntemi, panel veri analizi ve ülke grupları bazında yapılan ampirik çalışmaların sonuçlarına göre, gelir eşitsizliğinin büyüme üzerindeki etkisi güçlü ve negatiftir. Literatürde tüketim yetersizliğine 
dayanan modellere ve Hobson, Keynes ve Sismondi’ye göre, gelir eşitsizliğindeki büyük uçurumlar ve adaletsiz gelir bölüşümü, zenginlerin gelirlerinin büyük kısmını harcamayarak tasarruf etmesi ve yatırım yapmamasına sebep olmaktadır. Zira Hobson'ın çalışmalarında ifade ettiği gibi, kapitalistlerin geliri çok yüksek olduğundan, büyük miktarda tasarruf yapmaktadırlar. Kapitalistlerin amacı sadece tüketimde bulunmak değil, aynı zamanda tasarruf ve yatırım yaparak daha fazla servet biriktirmektir. Servet birikimi de ancak tüketim mallarına yeterli talep olduğunda gerçekleşir. Eğer gelir eşitsizliği artar ve ücretin payı düşerse, ücretin marjinal tüketim eğilimi fazla olduğundan, efektif talep düşecek ve büyüme yavaşlayacaktır.

Aşağı damlama etkisi yoluyla eşitsizliğin büyümeyi negatif etkilemesinin sebeplerinden biri de, bölüşüm en yüksek gelir grupları lehine değiştikçe ve bu gruplar ekonomide ve politikada daha etkili olmaya başladıkça, toplumun genel refahı için yapılacak olan kamu harcamalarına daha az destek vermek istemeleridir (Glaeser, Scheinkman ve Schleifer, 2003). Yüksek gelir grupları kamusal mal ve hizmetlerden yararlanmaya gerek görmedikleri ve tüm ihtiyaç duydukları mal ve hizmetleri özel olarak satın alabildikleri için, artan oranlı vergilerden de kaçınmak istemektedirler (Greenwood ve Holt, 2010: 405).

Neoliberal politikaların önerisine göre, yabancı portföy yatırımları finansal piyasaların gelişmesine katkıda bulunarak büyümeyi sağlamaktadır. Finansal serbestleşme, ekonomik büyüme üzerindeki olumlu etkisi, kredi hacminin genişlemesine yardımcı olması ve finansal hizmet kalitesini arttırması nedeni ile yoksulluğu azaltıcı etkide bulunabilmektedir (Yanar ve Şahbaz, 2013:58). Ancak, yabancı sermayenin kriz dönemlerinde ülkeyi hızla terk etmesi ve hızlı büyüme balonları krizin derinleşmesine ve yoksulluğun artmasına neden olabilmektedir (Arestis ve Caner, 2009; Caner, 2007: 7). Benzer şekilde, merkez-çevre ülkelerin arasında giderek artan dünya ticaretinin az gelişmiş ve gelişmekte olan ülkeleri kalkındıracağını iddia eden neoliberal görüşe karşı, Culpeper (2002), teknoloji transferlerinin sermaye yoğun üretime yol açması ve emek tasarrufunda bulunması sebebiyle, dışa açılma politikalarının gelişmekte olan ülkelerde vasıfsız işgücünün gelirinde azalmaya neden olduğunu vurgulamıştır.

Ayrıca, gelir dağılımı salt iktisadi yönden incelenmesi gereken bir konu olmayıp, sosyal olgulara ve normatif yargılara da yer veren bir alandır. Artan eşitsizlikler sonucu bozulan sosyal uyum, kendini toplumun tüketim kalıplarında değişme olarak göstermektedir. En yüksek gelirli kesimin geliri arttıkça sosyal statü amacıyla daha çeşitli mal ve hizmetleri tüketmeye başlamakta, bu da yüksek gelirli kesimin tüketimini referans alan orta gelirlilerin mevcut orta sınıf yaşam standartlarını arttırmaktadır (Frank, 1999). Bu durum, orta gelirlilerin orta sınıf yaşam standartlarına uyum sağlamasını giderek zorlaştırmaktadır.

\section{Türkiye'de Neoliberal Politikaların Bölüşüme Etkileri ve Büyüme}

1970’li yıllara kadar uygulanan ithal ikameci politikaların yarattığı ödemeler dengesi açığ problemi, dışa bağımlılığın artması, yüksek enflasyon, maliye disiplininin olmayışı ve istikrarsız makroekonomik gidişat Türkiye ekonomisinde yeni iktisat politikası arayışlarını gündeme getirmiştir. 24 Ocak 1980 yılında yürürlüğe konan istikrar tedbirleri ile Türkiye 1980'li yıllarda dışa dönük ve ihracata dayalı büyüme stratejisi benimsemiş, mevcut konjonktüre uygun olarak uygulanan neoliberal politikalar büyüme, istihdam ve bölüşüm ilişkilerinin belirlenmesinde önemli ölçüde rol oynamıştır. 24 Ocak kararları ile birlikte faiz kontrolleri kaldırılmış, döviz ticareti serbestleştirilmiş, sermaye hareketleri 1989 yılında tamamen serbest bırakılmış ve 1996 yılında AB ile Gümrük Birliği anlaşmasıyla dış ticaret serbest hale getirilmiştir (Arın, 2007: 462).

\subsection{0-1989 Yılları Ticari Serbestleşme Dönemi}

1980'li yıllarda dışa açılmak ve dış sermayeyi yurtiçine çekebilmek için ihracatı özendirmeye yönelik yoğun vergi teşvikleri, firmaların maliyetlerini düşürmek üzere düşük ücret politikası eşliğinde uygulanmıştır. Bu yolla ihracat artışı ve ekonomik büyüme sağlanmak istenmiştir. Bu dönemde emek piyasasının esnekleştirilmesi ve ücretlerin baskılanmasını amaçlayan neoliberal politikalar sonucunda reel ücretler aşınırken reel kârlar artışa geçmiştir (Şekil 3). Neoliberal politikaların hissedilmeye başlandığg 1983 yılında reel ücretler 1977 yılına göre \%27 azalırken, çiftçilerin reel ücretleri \%40 gerilemiştir. Memurların 1979 yılındaki maaş düzeyleri ise 1989 sonunda yarıdan fazla azalmıştır. 1980 yılında \%100'ü aşan enflasyon oranı ve \%1 oranında küçülen bir ekonomiyi devralan neoliberal politikalar sonucunda 1980-1988 yılları arasında büyüme oranı ortalama \%4,9 olarak gerçekleşmiştir (Şekil 4). Ancak yine de serbest piyasa ekonomisinin iktisadi büyümeyi arzu edilen düzeye ulaştırmakta başarısız olduğu söylenebilir. Zira gerçekleşen büyüme ihracat teşviklerinin başarısı sonucu verimlilik ve ihracat artışıyla değil, ücretlerin baskılanması yoluyla üretim maliyetlerinin düşmesi ve iç talebin baskılanmasıyla gerçekleşmiştir. Ayrıca 1980 öncesi kapasite kullanım oranının düşük olması ve 1980'den sonra sanayi kapasite kullanım oranlarının artması da bu büyümenin gerçekleşmesinde bir etkendir. Dolayısıyla, ihracat teşvikleri ve reel ücretleri düşürmeye yönelik politikalar ile desteklenen dışa açılma politikası başarılı olamamıştır (Şekil 4). Kamunun faiz ödemelerinden ötürü artan borç yükünün karşılanması ve enflasyonist eğilimler, yüksek gelir grubundan ziyade orta ve alt gelir grubuna vergi yükü olarak yansıdığından, gelir dağılımı daha da bozulmuştur (Kazgan, 1989:6,7). 


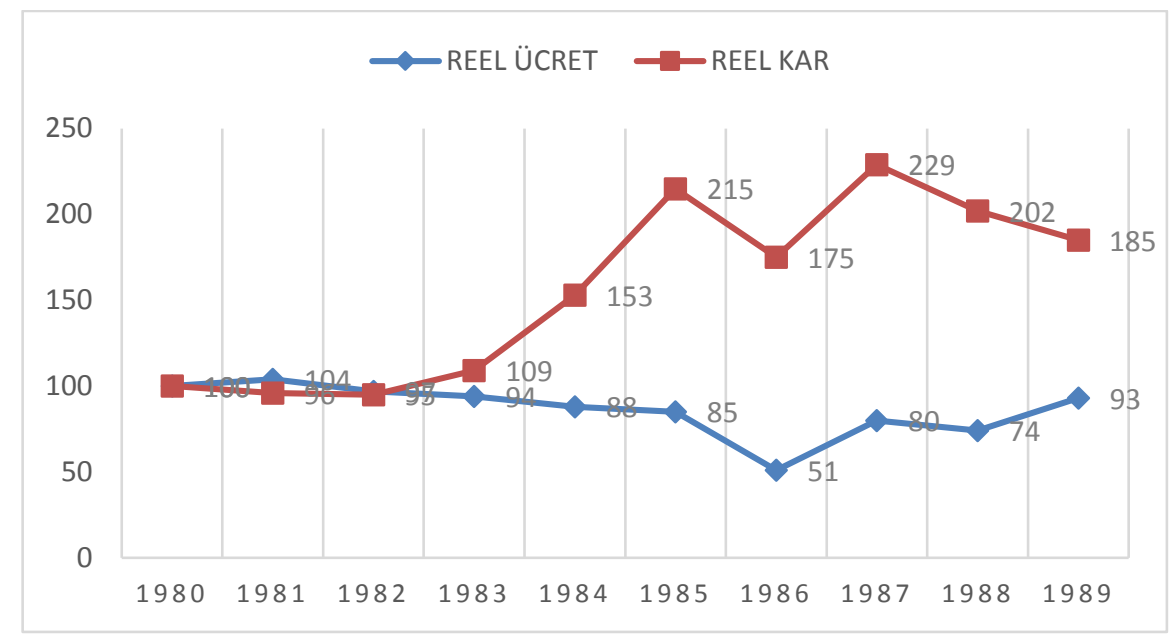

Şekil 3. 1980-89 Yılları Arası İmalat Sanayi Ücret ve Kar (1980=100) Kaynak: E. Yeldan, 1994

1980 sonrası Türkiye'de uygulanan özelleştirmeler sonucunda hem kamunun ekonomideki rolünün azaltılması, hem de sermayenin devlet kontrolünden çıkarılarak tabana yayılması beklenmiştir. Ancak, özelleştirmeler ve KİT'lerin satışı sonucu sermaye tekellerde toplanmış, bu da 1980 döneminde özel işletmelerin kâr oranlarının artmasına dolaysız veya dolaylı bir katkı sağlamıştır (Sönmez, 1994: 42). Özelleştirmelerden işgücü piyasaları olumsuz etkilenmiş, neoliberal dönüşüm sürecinde sendikalar işlevsizleşerek pazarlık gücü azalmış, taşeronlar yaygınlaşmış ve ücretler düşmüştür.

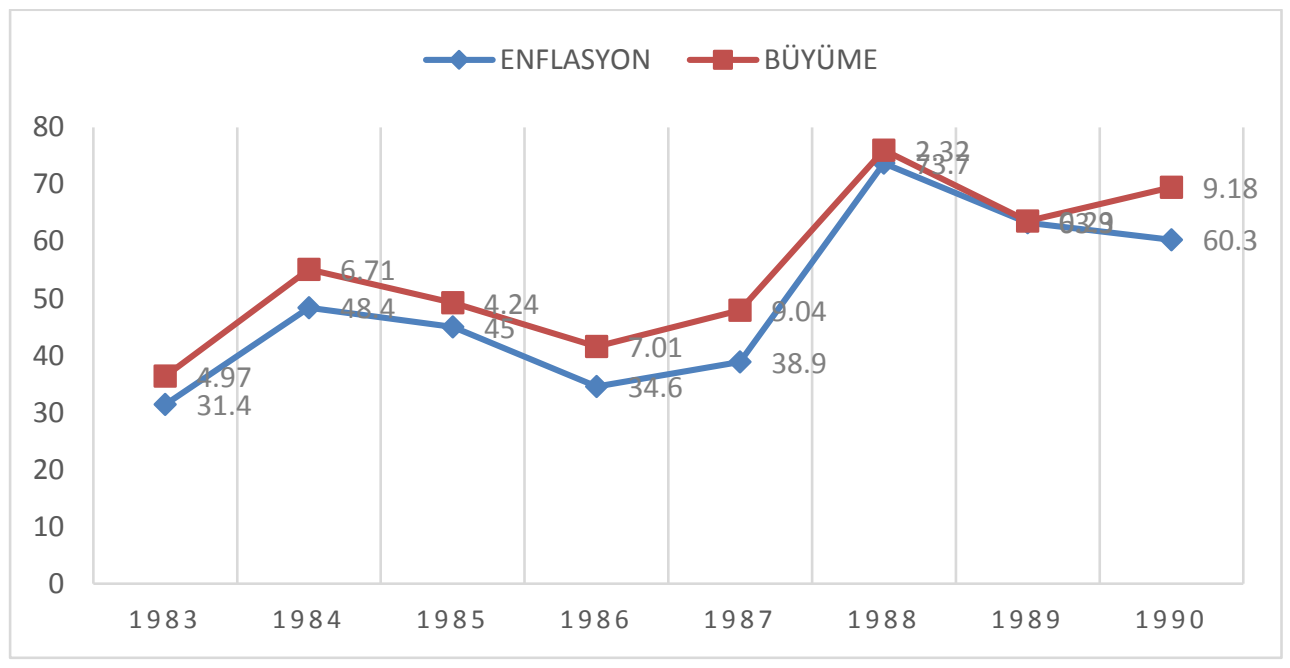

Şekil 4. 1983-1990 Yılları Arası Enflasyon ve Büyüme Oranları Kaynak: TÜIK

1980’li yıllarda Türkiye'de özel sermayenin önünü açmak için özel sektöre yönelik yardımlar kapsamında vergi sisteminde değişikliklere gidilmiştir. Kurumlar vergisinde şirketler lehine bir dizi istisna ve muafiyet getirilirken, 1985 yılı başında katma değer vergisinin kabulü ile vergiler tüketiciler üzerine yıkılmış ve vergi sistemi adaletsiz bir yapı kazanmıştır (Çelik, 2004:80). Neoliberal politikaların uygulanmaya başlanmasından itibaren vergi gelirlerinde dolaylı vergilerin arttırılıp dolaysız vergilerin azaltılması gelir dağılımının bozulmasında önemli bir rol oynamıştır. Çünkü dolaylı vergiler tüketim üzerinden alınan gelir düzeyinden bağımsız vergiler olup, vergi yükünün düşük gelir gruplarına kaydırılmasına sebep olmaktadır. Türkiye'de 1980 yılında dolaylı vergilerin toplam vergiler içerisindeki payı \%37 iken, 2013'te \%69'a yaklaşmıştır. Bu oran, 2013'te Avrupa Birliği ülkelerinde sadece \%27'dir. Türkiye'de dolaylı vergilerin milli gelir içindeki payı 1960 yılında \%35 civarında iken, 1988 yılında \%55 seviyesine yükselmiştir (Ekonomi Forumu, 1990: 7-8). Dolaylı vergilerin payının giderek artması, marjinal tüketim eğilimi yüksek olan orta ve düşük gelir gruplarının kullanılabilir gelirini azaltarak tüketim harcamalarını düşürmesine ve talebin azalarak ekonomide daraltıcı bir etki yaratmasına sebep olduğu söylenebilir.

Türkiye'de tahsil edilen gelir vergisi esas olarak ücretli kesimden alınan vergiler üzerine dayanmaktadır. 2015'te ücret dışı gelirlerden alınan beyana dayanan gelir vergisi tahsilatı \%1 iken, gelir vergisi tevkifatı yoluyla doğrudan ücretliler tarafından ödenen vergilerin toplam vergi gelirleri tahsilatına oran $\% 21$ 'dir. Öte yandan, gelir vergisi artan oranlı bir vergidir ve Türkiye'de vergi dilimleri enflasyon oranından daha yüksek oranda arttırıldığından, ücretli kesim daha üst oranlardan vergi ödemek zorunda kalmaktadır (Çelik, 2004:77-78). Bölüşümü etkilemekte 
kullanılan en önemli araç olan vergi politikalarının, Türkiye'de neoliberal politikalarla birlikte değişen vergi sistemi yoluyla gelir dağılımını ücret gelirleri aleyhine bozduğu sonucuna varılabilir.

\begin{tabular}{|l|c|c|c|}
\hline & $\mathbf{1 9 9 4}$ & $\mathbf{2 0 0 2}$ & $\mathbf{2 0 0 3}$ \\
\hline Ücretli maaşlı & $35,1 \%$ & $50,1 \%$ & $52,8 \%$ \\
\hline Yevmiyeli & $6,0 \%$ & $3,3 \%$ & $3,5 \%$ \\
\hline Toplam İş Gücü & $41,1 \%$ & $53,4 \%$ & $56,3 \%$ \\
\hline Kendi hesabına çalışan & $37,7 \%$ & $29,7 \%$ & $25,1 \%$ \\
\hline İşveren & $21,2 \%$ & $16,9 \%$ & $18,6 \%$ \\
\hline $\begin{array}{l}\text { Kişi Baş̧ına İş̧veren Gelirinin Kişi } \\
\text { Başına İgücü Gelirine Oranı }\end{array}$ & 4,4 & 3 & 2.7 \\
\hline
\end{tabular}

Tablo 1: DİE Gelir Dă̆llımı Anketlerine Göre Gelirin Fonksiyonel Dă̆ılımı Kaynak: DİE 1994, 2002 ve 2003 Gelir Dă̆llımı Anketleri

Neoliberal politikaların uygulanmaya başlandığı 1980'li yıllarda bölüşüm ücretli kesimin aleyhine, sermayenin ise lehine gerçekleşmiş, 1980 sonrası refah artışı vadeden neoliberal politikalar iktisadi ve sosyal anlamda başarılı olamamıştır. 1979 yılında maaş ve ücretlilerin milli gelirden aldıkları pay \%32,8'den 1985'te \%19,7'ye, 1988 y1lında ise \%14'e gerilemiştir (Sönmez, 2001: 174-76). Uygulanan politikalar rantiyeler, özel sermaye sahipleri ve ihracatçıların çıkarlarına uygun şekillenirken, köylülere verilen destekler 1980 yılı öncesine göre ciddi oranda azalmış, reel ücretler ise dramatik biçimde gerilemiş, devlet sosyal yardımları azalttığından yoksulluk artmıştır. Diğer yandan, Tablo 1 ve Tablo 2'de gösterilen ve Devlet İstatistik Enstitüsü (DİE) tarafindan anket yöntemiyle hesaplanan hane halkı kullanılabilir gelir verilerine göre, en yüksek \%20'lik gelir grubunun milli gelirden aldığ 1 pay 1983 yılından sonra genel bir azalış gösterirken, en düşük \%20'lik gelir grubunun milli gelirden aldığı payda iyileşme gerçekleşmiştir. Bu veriler yukarıda aynı dönemde emek aleyhine bölüşüme işaret eden ve kullanılabilir gelirin GSYİH üzerinden hesaplanma yöntemiyle elde edilen veriler ile karşılaştırıldığında, tersi bir sonuç ortaya çıkarmaktadır. Kaynakta kesinti ile vergi ödeyen ücret geliri elde eden kesimden ziyade, özellikle beyana dayalı vergi ödeyen faiz, rant ve kar sahibi kesimlerin vergilendirilmemiş gelirini saklama eğilimi içinde olması, ücretli kesimin gelirden aldığı payın artmış, diğer gelir kesimlerinin payının ise azalmış gözükmesine sebep olmaktadır (Çelik, 2004:71). Ayrıca, anketlerin saptadığı kullanılabilir gelirin gerçek kullanılabilir gelire oranının düşük olması ve anket kapsamının düşük gözlem içermesi de anketlerin güvenirliğini zedelemektedir.

\begin{tabular}{l|llllllllll} 
& $\mathbf{1 9 6 3}$ & $\mathbf{1 9 6 8}$ & $\mathbf{1 9 7 3}$ & $\mathbf{1 9 7 8}$ & $\mathbf{1 9 8 3}$ & $\mathbf{1 9 8 6}$ & $\mathbf{1 9 8 7}$ & $\mathbf{1 9 9 4}$ & $\mathbf{2 0 0 2}$ & $\mathbf{2 0 0 3}$ \\
\hline $\mathbf{5 . ~ \% 2 0}$ & 4,5 & 3,0 & 3,5 & 2,9 & 2,7 & 3,9 & 5,2 & 4,9 & 5,3 & 6 \\
$\mathbf{4 . ~ \% 2 0}$ & 8,5 & 7,0 & 8,0 & 7,4 & 7,0 & 8,4 & 9,6 & 8,6 & 9,8 & 10,3 \\
$\mathbf{3 .} \% \mathbf{2 0}$ & 11,5 & 10,0 & 12,5 & 13,0 & 12,6 & 12,6 & 14,1 & 12,6 & 14 & 14,5 \\
$\mathbf{2 .} \% \mathbf{2 0}$ & 18,5 & 20,0 & 19,5 & 22,1 & 21,9 & 19,2 & 21,2 & 19,0 & 20,8 & 20,9 \\
$\mathbf{1 .} \% \mathbf{2 0}$ & 57,0 & 60,0 & 56,5 & 54,7 & 55,8 & 55,9 & 49,9 & 54,9 & 50,1 & 48,3 \\
GINI & 0,55 & 0,56 & 0,51 & 0,51 & 0,52 & 0,50 & 0,43 & 0,49 & 0,44 & 0,42
\end{tabular}

Tablo 2. DİE Anketlerine Göre Bireysel Gelir Dă̆ılımı (1963-2003) Kaynak: DPT, 2007, s.204.

Öte yandan, bu dönemde gelir dağılımını iyileştirmeye yönelik bir takım uygulamalar da gerçekleşmiştir. Hane halkının konut ihtiyacını gidermeye yönelik düşük faizli krediler yoluyla toplu konut uygulaması, zorunlu tasarruflar için devlet katkısı, ücretlilere vergi iadesi, Sosyal Yardımlaşma ve Dayanışmayı Teşvik Fonu uygulaması ile düşük gelir gruplarına bir miktar transfer gerçekleştirilmiş, 1984’ten sonra sendikal hakların tekrar tanınmaya başlanmıştır (Cicioğlu, 2013: 34).

\subsection{9-2001 Yılları: Finansal Serbestleşme, 1994 ve 2001 Krizi}

1989 yılında sermaye hareketlerinin serbestleştirilmesi ve 1990'da TL'nin konvertibl olmasıly 1980'li yılların nispeten kontrol altına alınan neoliberal dönemi köklü bir şekilde değişmiş ve Türkiye, neoklasik argümanlara dayanan denetimsiz bir neoliberal döneme geçiş yapmıştır. Rekabet gücünün öneminin arttı̆ğ, bireysel özgürlüklerin temel alındığı, üretime marjinal katkı çerçevesinde bölüşüm anlayışından ötürü gelir eşitsizliğini doğal olarak nitelendiren neoklasik piyasa anlayışı ekonomiye ve topluma bu dönemde egemen olmuştur.

$\mathrm{Bu}$ dönemde, neoliberal öğretinin aksine devletin iktisadi faaliyetlerdeki rolünün arzu edilen düzeyde azaltılamaması ve sosyal hizmetlerin sunulmaya devam etmesi sonucu kamu açıkları giderek artış göstermiştir. Kamu açıklarının finansmanı için bir yandan dolaylı vergiler arttırılmaya devam ederken, diğer yandan iç borçlanmaya gidilmesi yüksek yurtiçi faize sebep olmuştur. Faizlerin yükselmesinden ötürü özel sektörü korumak amacıyla vergi indirimleri yapılması ve buna karşılık dolaylı vergilerin arttırılması gelir dağılımının ücretli kesim aleyhine bozulmasına sebep olmuştur. Finansal serbestleşmeyle birlikte finans kapitalle bütünleşen Türkiye ekonomisinde sıcak para girişleri neticesinde faiz ödemeleri giderek artmış ve milli gelirin önemli bir kısmı finans 
kesimine transfer edilmiştir. Diğer yandan, 1989 yılından itibaren izlenen politikalar reel ücretleri artışa geçirmiştir. Ücret, maaş ve köylü gelirlerinin artması hem iç talebi arttırarak ihraç fazlasının yurtiçinde satılmasına, hem de kamu açıklarının büyümesine neden olmuş ve bu gelişmeler 1994 krizine yol açmıştır (Boratav, 1997: 210).

“1990’lar boyunca sürdürülen dışa bağımlı, yapay büyüme stratejisinin ve çarpık toplumsal bölüşüm ve birikim mekanizmalarının tıkanmış olmasının" ekonominin daralmasına neden olması üzerine 1998 Temmuzunda IMF ile imzalanan Yakın İzleme Anlaşması, ücretlerin baskılanması, deregülasyon, sosyal güvenlikte emeklilik yaşının yükseltilmesi, mevcut tarımsal destekleme araçlarının kaldırılması gibi gelir dağılımı adaletini bozacak yeni dönüşümler önermekteydi (Yeldan, 2004: 159). Ancak, 1994 krizini ortaya çıkaran politikalara devam edilmesi üzerine Kasım, Aralık 2000-Şubat, Mart 2001 bankacılık ve döviz kuru krizleri ile karşı karşıya kalınmıştır (Kibritçioğlu, 2001: 4). 2001 yılında \%6,6'dan \%8,5'e yükselen işsizlik oranı ve 1998'den itibaren uygulanan politikalar eşliğinde sosyal güvenlik harcamalarının ve transfer ödemelerinin daha da azaltılması yoksullaşmayı da beraberinde getirmiş, ekonomi 2001 yılında $\% 9,5$ oranında küçülmüştür. 2000 yılında özel sektör işgücünün GSMH'dan aldığı pay \%24 iken, 2001'de \%16,6'ya inmiştir (Sönmez, 2004: 175).

\begin{tabular}{c|cccc} 
& $\mathbf{1 9 9 5 - 2 0 0 0}$ & $\mathbf{2 0 0 1}$ & $\mathbf{2 0 0 2 - 2 0 0 7}$ & $\mathbf{2 0 0 8 - 2 0 1 1}$ \\
\hline GSYH BÜYÜME (1998=100) (\%) & 4,7 & $-9,5$ & 6,8 & 3,5 \\
ENFLASYON (1994=100) (\%) & 69,5 & 68,5 & 12,8 & 8,1 \\
FAİZ ORANLARI & 74,4 & 62,5 & 26 & 17,6
\end{tabular}

Tablo 3. Türkiye'nin Temel Makroekonomik Göstergeleri Kaynak: TCMB, Elektronik Veri Dağıtım Sistemi

2001 krizi reel gelirlerde aşınmanın yaşandığı, istihdam ve talebin daraldığı, üretim ve tüketimin azalarak ekonominin küçüldüğü bir dönemi temsil etmektedir. Birbiri ardına yaşanan krizler devlet gelirlerini azaltırken, devletin genelde sosyal refahı, özelde ise gelir dağılımını düzeltici ve yoksulluğu azaltıcı politikalar uygulama imkânını daraltmıştır (DPT: 2004, 153). Krizlerin ücretlerde yarattığı dramatik düşüşler, 1970'li yıllardaki düşüşlerden daha büyük oranda gerçekleşmiş, 1987 yılında 0,43 olan GINI katsayısı, 1994 yılında 0.49'a yükselmiştir (Tablo 2). Türkiye'de en yoksul yüzde 20'lik gelir grubu 1987 yıllında milli gelirden \%5,24 pay alırken, finansal serbestleşme sonrası 1994 yılında \%4,86 pay almıştır. Tablo 2'ye dikkat edilirse, 2, 3, 4 ve 5. en düşük gelir gruplarının hepsinin payı finansal serbestleşmeyle birlikte azalırken, en zengin yüzde $20^{\prime}$ lik gelir grubunun payı ise 1987-1994 arasında \%49,9'dan \%54,9'a yükselmiştir. Dolayısıyla, yukarıda bahsedilen finansal serbestleşme ücretli kesim aleyhine sonuçlar doğurmuş, sıcak para akımları ise sermaye sahibi sınıfın faiz gelirlerini arttırarak gelir eşitsizliğini derinleştirmiştir. Bu anlamda neoliberal politikaların tam serbestleşme önerisi bir yandan gelir dağılımını bozucu ve yoksullaştıııcı etkiler yaratırken, diğer yandan Türkiye'de yaşanan krizlerin temel sebebini oluşturmuş, ekonominin daralmasına ve sosyal alanda uyumsuzluklara neden olmuştur.

\subsection{Krizi Sonrası Dönem}

1990'lı yıllarda yaşanan ekonomik istikrarsızlıklar ve krizlerin ardından 2002 yılında “Gü̧̈lü Ekonomiye Geçiş Programı" ile gelen reformlarla 1980 sonrasında başlayan liberalleşme ve yapısal uyum politikalarına devam edilmiştir. 2001 yılında yaklaşık \%9,5 oranında küçülen ekonomi, 2002-2007 döneminde ortalama $\% 7$ oranında büyümüş̧ür (Tablo 3). Düşen enflasyon ve faiz oranlarıyla birlikte 2002-2007 döneminde gelir eşitsizliğinde göreli bir iyileşme kaydedilmiş ve yoksulluk azalmıştır (Tablo 4). Milli gelir içerisinde sosyal harcamaların ve transfer ödemelerinin payı artırılmış, asgari ücret reel olarak yükselmiştir. Türkiye'de 2002 yılında en zengin yüzde 20'lik grubun yıllık kullanılabilir gelirden aldığı pay, en yoksul yüzde 20'lik grubun aldığı payın yaklaşık 9,5 katı iken, 2003 yllinda bu oran 8,1, 2004 yılında ise 7,7 seviyesine düşmüştür (DPT, 2006: 42).

Tablo 4'e göre 2002-2008 yılları arasındaki GINI katsayısı düşmüş ve gelir eşitsizliği azalmış, ancak 2007 yılından sonra gelir eşitsizliğinde anlamlı bir iyileşme olmamıştır. 1994, 2001 ve 2008 krizlerinin maliyeti ise emek geliri elde edenlere yüklenmiş, kriz yıllarında sermaye geliri artmıştır. 2002-2007 döneminde düşen işsizlik, enflasyon ve faiz oranları, ortalama $\% 6,8$ oranında iktisadi büyüme (Tablo 3) ve makroekonomik istikrarın gelir eşitsizliğinin bu dönemde azalma eğilimi göstermesinin nedeni olduğu söylenebilir. Ancak, bu dönemde büyüme artışının gelir eşitsizliğini azaltıcı rol oynamasında neoliberal önerinin aksine devletin iktisadi faaliyetlerden tamamen çekilmemesi ve piyasayı düzenleyici ve kontrol edici mekanizmaları harekete geçirmesinin de büyük etkisi vardır. 2008-2011 yılı ortalama \%3,5 oranı ile nispeten düşük büyüme oranları kaydeden Türkiye ekonomisinde gelir eşitsizliğinin yatay bir seyir izlediği ve yapısal bir karakter gösterdiği ifade edilebilir (TÜSİAD, 2014: 114). 


\begin{tabular}{|c|c|c|c|c|c|c|c|c|c|c|}
\hline & ֻั & હ્ণ & ষ্ণ & ஜ̊ & ஓ્ণ & હ) & $\underset{\overbrace{}}{\stackrel{\infty}{ٍ ̆ 丶 ~}}$ & & 육 & 륵 \\
\hline \multicolumn{11}{|l|}{ HBA } \\
\hline En Yoksul \%20 & 5,3 & 5,6 & 5,4 & 5,4 & 6 & 6 & 5,9 & 5,8 & 6,3 & 6,1 \\
\hline Íkinci \%20 & 9,8 & 10,1 & 10,3 & 10,8 & 11,3 & 11,3 & 10,9 & 11 & 11,3 & 11,1 \\
\hline$\ddot{U}$ çüncü \%20 & 14,1 & 14,4 & 15,3 & 15,9 & 16,2 & 16,3 & 16 & 15,8 & 15,8 & 15,8 \\
\hline Dördüncü \%20 & 20,9 & 20,9 & 21,9 & 22,8 & 22,4 & 22,7 & 22,6 & 22,2 & 22,1 & 22,1 \\
\hline En Zengin \%20 & 49,8 & 48,9 & 47 & 45,1 & 44,1 & 43,7 & 44,7 & 45,3 & 44,4 & 44,8 \\
\hline \multicolumn{11}{|l|}{ GYKA } \\
\hline En Yoksul \%20 & - & - & - & 5,3 & 6,1 & 6,1 & 5,9 & 6,2 & 6,2 & - \\
\hline Ikinci \%20 & - & - & - & 10,2 & 10,8 & 10,6 & 10,5 & 10,9 & 10,8 & - \\
\hline$\ddot{U}$ çüncü \%20 & - & - & - & 15 & 15,5 & 15,3 & 15,3 & 15,5 & 15,4 & - \\
\hline Dördüncü \%20 & - & - & - & 22,1 & 21,8 & 22,1 & 21,7 & 22 & 21,9 & - \\
\hline En Zengin \%20 & - & - & - & 47,4 & 45,8 & 45,8 & 46,6 & 45,4 & 45,8 & - \\
\hline GINI & 0,44 & 0,42 & 0,4 & 0,38 & - & 0,41 & 0,41 & - & - & - \\
\hline
\end{tabular}

Tablo 4. Hane Halkı Bütçe Araştırması (HBA) ve Gelir ve Yaşam Koşulları Araştırması (GYKA) Anketlerine Göre Hane Halkı Gelir Gruplarının Toplam Gelirden Aldıkları Paylar (\%) Kaynak: TÜIK Ham Verileriyle TÜSİAD Tarafindan Oluşturulmuştur (TÜSİAD 2014, 77)

\section{Sonuç}

Neoliberal iktisadın temel argümanları, kaynak dağılımında piyasanın temel rolü üstlenmesi, devletin iktisadi faaliyetlerdeki rolünün büyük oranda azaltılması ve dünya ekonomisine giderek artan bir uyum süreci çerçevesinde şekillenmektedir. Bu sayede hızlı ve etkin büyüme gerçekleşecek, önceki iktisadi modellerin neden olduğu durgunluk ve canlanma dönemlerinin birbiri ardına sürekli olarak gerçekleştiği iktisadi yapı terkedilecektir. Özel kesime sağlanan vergi kolaylıkları ve desteklerle yatırımlar artarak büyüme gerçekleşecek, bu büyümeden toplumun düşük gelire sahip katmanları da faydalanacaktır. Buna aşağı damlama etkisi denmektedir. Büyüme ve eşitsizlik arasındaki ilişkiyi inceleyen çalışmaların argümanlarına göre, yeniden dağıtım politikaları iktisadi etkinliği bozmakta ve büyümeyi negatif etkilemekte, eşitsizlik çalışma dürtüleri ve toplam yatırımları teşvik etme yoluyla büyümeye katkı sağlamakta ve ayrıca büyüme de eşitsizliği tetiklemektedir. Gelir ve servet eşitsizliğinin büyüme üzerine etkisi pozitif yönlü olarak gerçekleşmektedir. Neoliberal politikalar stagflasyonun sebebini işgücü piyasasının esnek olmamasına ve artan oranlı vergilerin yatırımları caydırmasına bağlamaktadır.

Türkiye'de 1980 yılından itibaren küreselleşme sürecine uyum sağlayabilmek için neoliberal politikalar uygulanmış, ticaret ve finans serbestleştirilmiş, özel kesim vergi kolaylıklarıyla desteklenirken, ücretli kesimin aleyhine vergi ve transfer politikaları uygulanmış ve özelleştirmelere hız verilmiştir. Bu dönemde devletin ekonomideki rolü bir dönem azaltılsa da, kamu harcamaları neoliberal politikalar sürecinde artarak devam etmiştir. Türkiye'de küreselleşme sürecinde önce ihracata yönelimi özendirmek amacıyla verilen ihracat teşvikleri, daha sonra finansal serbestleşme sürecinde kamu açıklarını kapamak amacıyla yüksek reel faizle kamu iç borçlanmasıyla büyük borç yükü yaratılması gelir dağılımının daha da bozulmasında belirleyici bir rol oynamıştır (Şenses, 2004).

Türkiye'de 1980 y1lından itibaren gelir dağılımında ciddi bir iyileşme gözlenmemektedir. Hatta 1978-1987 periyodunda büyüme artmasına rağmen gelir dağılımı daha da bozulmuş, 1994 yılında gerçekleşen krizin maliyeti ise ücretli kesime yüklenmiştir. 2002-2007 döneminde uygulanan güçlü ekonomiye geçiş programı döneminde artan büyüme oranları eşliğinde gelir dağılımında TÜİK anketlerine göre göreli bir iyileşme sağlansa da, gelişmiş ülkelerle karşılaştırıldığında Türkiye gelir eşitsizliği en yüksek ülkeler arasında yer almaktadır. 2013 yılında OECD ortalama GINI katsayısı 0.32 iken, Türkiye 0.41 oranı ile gelir eşitsizliği en yüksek 3. ülkedir. Ayrıca, TÜIKK anketlerinin aksine, GSYİH'den elde edilen farklı gelir gruplarının milli gelirden aldıkları paya göre, 1980'lerden itibaren ücretli kesimin gelirden aldığı pay sürekli bir azalış gösterirken, faiz, rant ve karın aldığı pay artış göstermektedir. TÜİK anketlerine göre, özellikle 2007 periyodundan sonra günümüze kadar gelir eşitsizliğindeki değişim 0’a yakındır. Bu da gelir eşitsizliğinin toplumun dinamikleri çerçevesinde kalıcı bir yapı sergilediğini ve gelir eşitsizliğini azaltmak ve artan büyüme oranlarından toplumun tüm kesiminin faydalanmasını sağlamak için vergiler ve transfer harcamaları yoluyla müdahale edilmesi gerektiğini ortaya çıkarmaktadır. Kapitalizmin istikrarsız bir görünüm sergilediği ve müdahale edilmediği zaman büyümenin gelir eşitsizliğini azaltmayacağı Türkiye'nin neoliberal politika uygulamaları sürecinde tecrübe edilmiştir. Sosyal devlet anlayışı ile uygulanacak politikalar emek gelirlerinde iyileşme sağlayacak, gelir dağılımı adaleti gerçekleşecek ve büyüme artacaktır. Zira 
1989 yılından sonra ücretli kesimin önceki dönemdeki kayıplarını telafi etmesi ve reel ücretlerin 1994 krizine kadar artışa geçmesi neoliberal politikaların olumlu sonuçlarından ortaya çıkmamış, devletin ekonomiye müdahalesi yoluyla, diğer bir deyişle kamu ve sosyal harcamalar ile transfer ödemelerini arttırması yönünde uyguladığı sosyal politikalar sayesinde gerçekleşmiştir.

Sonuç olarak, neoliberal argümanın aksine, Türkiye'de gelir eşitsizliği ve büyüme arasında pozitif yönlü bir ilişki gerçekleşmemiş, diğer bir ifadeyle artan gelir eşitsizliği arzu edilen büyüme performansının yakalanmasına yardımcı olmamış, gerçekleşen düşük büyüme oranları ise ücretli kesimin durumunu daha da kötüleştirmiştir.

\section{Kaynakça}

- Akalın, 2009. Neoliberal iktisadın gelişimi üzerine kısa bir not. Neoliberal İktisadın Marksist Eleştirisi, 921, Kalkedon Yayınları.

- Arestis ve Caner, 2009. "Financial Liberalization and The Geography of Poverty", Cambridge Journal of Regions, Economy and Society, Vol. 2, No. 2, pp. 229- 244.

- Arın, 2007. Türkiye’de Mali Küreselleşme ve Mali Birikim ile Reel Birikimin Birbirinden Kopması. Köse, Şenses ve Yeldan, (eds). Küresel Düzen: Birikim Devlet ve Sınıflar. ss. $569-610$ ( İçinde). İstanbul: İletişim. 4. Bask1.

- Boratav, 1974. Türkiye'de Devletçilik. Ankara: Gerçek Yayınevi.

- Caner, 2007. "Finansal Serbestleşme ve Yoksulluk İlişkisi Üzerine”, İktisat, İşletme ve Finans, Vol. 22, No. 254, ss. 5-17.

- Cicioğlu, 2013. “Türkiye’de 1980 Sonrası Gelir Dağılımıını Ekonomi Politikaları ve Krizler Bağlamında Değerlendirilmesi”, HAK-IŞ Uluslararası Emek ve Toplum Dergisi, Cilt 2, Sayı: 4.

- Culpeper, 2002. “Approaches to Globalisation and Inequality within the International System”, Paper prepared for UNRISD Project on Improving Knowledge on Social Development in International Organisation, September 2002, Erişim:

http://www.unrisd.org/80256B3C005BCCF9/(httpAuxPages)/B8D267D84E8E6A66 C12570AE002F994E/\$file/culpeper.pdf (Erişim: 07.07.2013)

- CÇelik, 2004. “AB Ülkeleri ve Türkiye’de Gelir Eşitsizliği: Piyasa Dağılımı-Yeniden Dağılım”, Çalışma ve Toplum, 3.

- Devlet Planlama Teşkilatı (DPT), 2004. Sekizinci Beş Yıllık Kalkınma Planı 2005 Yılı Programı. DPT, Ankara.

- Devlet Planlama Teşkilatı (DPT), 2006. Dokuzuncu Kalkınma Planı (2007-2013), Taslak Program.

- Devlet Planlama Teşkilatı (DPT), 2007. Dokuzuncu Kalkınma Planı (2007-2013), 2007 Yılı Programı, DPT, Ankara.

- Ekonomi Forumu, 1990. Türkiye’de Gelir Dağılımı, Friedrich Ebert Vakfi.

- Fiorentini, 2015. "Neoliberal Policies, Income Distribution Inequality and the Financial Crisis", Forum for Social Economics, 44 (2), pp. 115-132.

- Frank, 1999. Luxury Fever: Money and Happiness in an Age of Excess. New York: The Free Press.

- Glaeser, Scheinkman ve Shleifer, 2003. "The injustice of inequality”, Journal of Monetary Economics, 50(1), pp. 199-222.

- Greenwood ve R. Holt, 2010. “Growth, Inequality and Negative Trickle Down”, Journal of Economic Issues, 44(2), pp. 403-410.

- Harvey, 2005. A Brief History of Neoliberalism. New York: Oxford University Press.

- Hobson, 1938. Imperialism: A study. Spokesman Books.

- Johnston, 2007. “Yoksulluk ve Bölüşüm: Yeniden mi neoliberal Gündemde?” (çev: Ş. Başlı ve T. Önel). Saad-Filho, A. ve Johnston, D. (eds.). Neoliberalizm: Muhalif bir seçki. (ss. 225-235) içinde. İstanbul: Yordam Kitap.

- Kibritçioğlu, 2001. "Causes of inflation in Turkey: A literature survey with special reference to theories of inflation”, UIUC Working Paper, 01-0115.

- $\quad$ OECD, Statlinks, (http:// dx.doi.org/10.1787/420757184562).

- OECD, Statlinks, http://www.oecd.org/social/income-distribution-database.htm

- Sönmez, 1994. Kriz, Devlet Müdahalesi ve Özelleştirme, Özelleştirme Tartışmaları, Derleyen: Aykut Polatoğlu, Bağlam Yayıncılık, İstanbul.

- Sönmez, 2001. Gelir Uçurumu. İstanbul: Om Yayınevi. 
- Sönmez, 2004. 2001 Krizi, IMF ile İlişkiler ve Gelir Bölüşümü. Gülten Kazgan’a Armağan, Türkiye Ekonomisi (s. 341-365). içinde İstanbul: Bilgi Üniversitesi Yayınları.

- Şenses, 2004. “Neoliberal Küreselleşme Kalkınma için Bir Fırsat mı, Engel mi?”, Working Paper In Economic, 4(09).

- TCMB, Elektronik Veri Dağıtım Sistemi, http://evds.tcmb.gov.tr/cbt.html

- TÜSİAD, 2014. Türkiye'de Bireysel Gelir Dağılımı Eşitsizlikleri: Fonksiyonel Gelir Kaynakları ve Bölgesel Eşitsizlikler, Yayın No: TÜSİAD-T/2014-06/554.

- $\quad$ Yanar ve Şahbaz, 2013. “Gelişmekte olan Ülkelerde Küreselleşmenin Yoksulluk ve Gelir Eşitsizliği Üzerindeki Etkileri”, Eskişehir Osmangazi Üniversitesi IIBF Dergisi, 8(3), pp. 55-74.

- Yeldan, 1994. Türkiye Ekonomisinde Krizin Oluşumu 1990-1993, Ankara, Teksir Yayınevi.

- Yeldan, 2004. Küreselleşme Sürecinde Türkiye Ekonomisi, Bölüşüm, Birikim ve Büyüme. İstanbul: İletişim Yayınları.

- Yıldırım, 2011. "Neoliberal İktisat Politikalarının Türkiye'de Orta Sınıfa Etkisi”, Doktora Tezi, Abant İzzet Baysal Üniversitesi Sosyal Bilimler Enstitüsü İktisat Anabilimdalı 


\title{
Türkiye'de Çocuk Yoksulluğu Child Poverty in Turkey
}

\author{
Assoc. Prof. Dr. Özlem Durgun (Istanbul University, Turkey)
}

\begin{abstract}
Poverty is one of the biggest problems in developing countries. Poverty is general scarcity or the state of one who lacks a certain amount of material possessions or money. Poverty issue is examined on a sector and national levels. Addition it is examined in households and gender level in many countries. When these studies are examined, the most affected segments of poverty are women and children. In our study: The relationship between the woman poverty rates and female labour force participation rates were examined in Turkey. Poor children do not only occur in developing countries. In developed countries and in countries with high income levels, poor children are likely to occur. Adults' poverty is possible to solve in time with employment, aids and donations. However, child poverty continues in the future. Unfortunately, aid to households are not enough. So the problem must be clearly demonstrated and implemented specific policies for children. Child is the social structure of the subject. Damage to children will be create a domino effect in the future. Consequently, it should be recognized and taken measures taken in advance.
\end{abstract}

\section{Giriș}

Yoksulluk Gelişmekte olan ülkelerde tüm gelişmelere rağmen en büyük sorunlarının başında gelmektedir. Yoksulluk, asgari yaşam standardını sürdürebilmesi için temel ihtiyaçları karşılayan gelire sahip olunmaması durumu olarak tanımlanmaktadır. Yoksulluk konusu, birçok ülkede sektörel ve ulusal düzeyde incelenmesinin yanı sıra hane halkı ve toplumsal cinsiyet düzeylerinde de incelenmektedir. Bu çalışmalar genel olarak incelendiğinde Yoksulluktan en fazla etkilenen kesim kadınlar ve çocuklardır. Yoksul çocuklar sadece gelişmekte olan ülkelerde görülmez. Yoksul çocuk gelişmiş ülkelerde ve gelir düzeyi yüksek ailelerde de ortaya çıkma ihtimali vardır. Yetişkin yoksulluğunu istihdam artışı, yardım ve hibelerle zaman içinde çözmek mümkündür. Ancak çocuk yoksulluğu ileriki dönemlerde de devam etmektedir. Maalesef hanehalkına yapılan yardımlar yeterli gelmemektedir. Bu yüzden sorun net olarak ortaya konmalı ve çocuklara yönelik özel politikalar uygulanmalıdır. Çocuk toplumsal yapının öznesidir. Ona gelecek zarar domino etkisi yaratacaktır. Bu yüzden önceden fark edilmeli ve önlem alınmalıdır.

$\mathrm{Bu}$ çalışmada kavramsal olarak yoksulluk tanımlandıktan sonra çocuk yoksulluğu açıklanacaktır. Genellikle düşük gelire sahip hanehalkı çocukları yoksul kabul edilerek daha yüksek gelirli ailelerde ve toplumlarda çocuk yoksulluğu ihmal edilmektedir. Çalışmanın amacı gelişmiş ülkelerde de rastlanılan çocuk yoksulluğu sorununu ortaya koyarak Türkiye'de bu sorunun varlığını ortaya koymaktır. Hanehalkına yapılan yardımların çocukların yoksulluğu üzerinde bir etkisi olmadığını veya düşük olduğunu göstermektir. Türkiye'de yapılan çalışmalar maalesef ekonometrik model kullanılacak kadar uzun bir zaman serisine sahip değildir. Resmi istatistik kurumu tarafından yapılan çalışma düzenli bir hale getirilmelidir.

Türkiye en gelişmiş yirmi ülke arasında olduğuna göre çocuk yoksul sayısının da bu ülkeler kadar düşük olması beklenmektedir. Göreli yoksulluğun gelişmiş ülkelere nazaran daha yüksek bir orana sahip olması nedeniyle yoksullukla mücadele programları uygulanmalıdır. Çocuk yoksulluğu gelecek nesillere aktarıma neden olduğundan dolayı bu sorununla baş edebilmek için yoksul çocuklar sorunu çözülmelidir. Çözmek için de sorunun varlığı ortaya konmalıdır. Gelişmiş ülkelerde çeşitli aile tiplerinde çocuk yoksulluğu büyük bir sorun oluşturmaya başlamıştır. Türkiye'de ise kendine özgü bir program uygulaması gereklidir. Türkiye'de nüfus artış politikası teşvik ederken yeni nesil yoksul yaratmaya neden olunmamalıdır. Bu makalede yıllar itibarıyla çeşitli istatistiklerden hanehalkı ve yoksul çocuk arasındaki ilişki ortaya konmaya çalışılmıştır.

\section{Kavramsal Çerçeve}

Yoksulluk kavramı sadece gıda veya üretim yetersizliği ile ilişkilendirilebilecek tek yönlü bir kavram değildir. Sadece maddi kriterlerin altında olmakla ilişkilendirildiğinde gelişmiş ülkelerde hiç rastlanılmaması gerekirdi. Gelişmiş ülkelerde yetkin uygulanan sosyal politikalar sayesinde azaltılmasına rağmen yoksulluk çeşitli şiddette değişik şekillerde ortaya çıkmaktadır. Bu nedenle yoksulluğun tek bir tanımını yapmak mümkün değildir. Literatür incelendiğinde farklı yoksulluk tanımlarıyla karşılaşılır. Ülkeler arasındaki gelişmişlik farklarına bağlı olarak yoksulluk da değişmektedir. Az gelişmiş ülkelerde yoksulluk büyük bir sorun olarak ortaya çıkmaktadır. Bu ülkelerde yoksulluk daha çok açlık, barınma ve güvenlik sorunu olarak ortaya çıkmaktadır. Ülke geliştikçe insanlar arasındaki yaşam standardı farklılığına dönüşmektedir. Yoksulluğun çok boyutluluğu sınırlarını net olarak çizmeyi zorlaştırmaktadır. 
Yapılan çalışmalar incelendiğinde, ihtiyaç, yaşam standardı, kaynak yetersizliği, temel güvenlik eksikliği, yetki eksikliği, çoklu yoksulluk, yoksun bırakma, eşitsizlik, sınıf, bağlılık ve kabul edilmeyen ekonomik güçlük olarak on bir tane anlam kümesini içermektedir (Ak, 2016).

Mutlak yoksulluk, maddi kriterleri dikkate alarak açlık sınırının altında, gelir dağılımının tabanında yaşayan insan grubunu göstermektedir. Mutlak yoksullar yaşamını sürdürecek asgari bir gelire sahip değillerdir. Bu nedenle asgari ihtiyaçlarını da sağlayamazlar. Yeterli mal ve hizmetten yararlanamazlar.

Göreli Yoksulluk, iyi yaşam standardının ülkeden ülkeye hatta zamana göre değişmesi nedeniyle özellikle gelişmiş ülkelerde mutlak yoksulluk oranını karşılayacak bir ölçü olmaması nedeniyle geliştirilmiştir. Toplumun genel düzeyine göre belli bir sınırın altında gelir veya harcamaya sahip olan birey veya hanehalkı göreli olarak yoksul kabul edilmektedir (Özcan, 2016). Dolayısıyla yoksullukta tek ölçme yöntemi ve yaklaşımının olmaması yoksulluğun kavranmasını güçleştirmektedir. Tüm bu karmaşanın yanında aile fertlerinin yoksulluklarının birbirinden farklı olması da büyük bir sorundur. Aynı hane halkı içinde bireylerin bazıları yoksulluk sorunu yaşamazken daha güçsüz bireyler yoksulluk sorunuyla karşılaşmaktadırlar.

BM Kalkınma Programına göre yoksulluk insan yaşamını etkileyen çok boyutlu bir kavramdır. BM kalkınma programının yayınladığı endeks de bu nedenle "çok Boyutlu Yoksulluk Endeksi Verileri" olarak adlandırılmaktadır. BM’e göre yoksulluk gelişmekte olan ülkelerde azalmasına rağmen halen kader olarak kabul edilmekte, kanıksanarak içselleştirilmektedir. Bir kültür olarak kabul edilerek gelecek nesillere aktarılmaktadır (UNDP 2014). Burada çocuk yoksulluğu önem kazanmaktadır. Çocuklar yoksullukla beraber büyüdüğünde bunu kabullenmekte veya kabul etmek zorunda kalmaktadır. Yoksulların çocukları daha kötü beslenme, barınma gibi nedenlerle sağlık sorunlarıyla yaşamaktadır. Ayrıca yaşıtlarıyla aynı eğitimi almadıklarından istihdama dahil olamamakta ve gelecek nesilde de yoksulluk sorunu devam etmektedir. Çocuk yoksulluğu sorunu sadece gelişmekte olan ülkelerde değil gelişmiş ülkelerde de karşılaşılan büyük bir sorundur. Gelişmiş ülkelerdeki refah oranlarının yüksekliğine rağmen sosyal politikaların çocuklara ulaşamaması ve yardımların yeterli gelmemesi, aile içinde dengeli dağıtılmaması gibi nedenlerle çocuk yoksulluğu sorunu yaşanmaktadır.

Gelişmekte olan ve ya az gelişmiş ülkelerle ilgili yoksulluk sorunu hakkında çalışmalar yapılırken gelişmiş ülkelerdeki sorun gözardı edilmektedir. Bu ülkelerde mutlak yoksulluk sorunu çözülmesine rağmen göreli olarak yoksulluk sorunu devam etmektedir. Ayrıca çocukların yoksulluğu tüm nüfusla karşılaştırıldığında daha yüksek çıkmaktadır.

\section{Gelişmiş Ülkelerde Göreli Yoksulluk Sorunu}

Çok boyutlu bir sorun olan yoksulluk gelişmiş ülkelerde de büyük bir sorun teşkil etmektedir. Bölüşüm ve dağıtım mekanizmaları dengeli olmadığında gelir artıcı politikalar yoksulluk sorununu çözmemektedir. Özellikle üst üste yaşanan krizlerle birlikte çocuklar yoksulluktan etkilenmişlerdir. Bu sorunu ortaya koymak amacıyla Unicef "Ekonomik Durgunluk Dönemi Çocukları" isimli raporu yayınlamıştır. Raporda gelişmiş ülke olarak Avrupa Birliği ve OECD ülkeleri olmak üzere 41 ülke incelenmiştir. 2008 yılından beri devam eden krizin etkileri gelişmiş ülkelerde çocuk yoksulluk oranını yükseltmiştir. Rapora göre 41 ülkeden 23 tanesinde çocuk yoksulluğu yükselmiştir. Daha az gelir daha az koruma toplam yoksulluk oranından daha yüksek oranda çocuk yoksulluğu ile karşılaşılmasına neden olmuştur. Özellikle tek ebeveynli ailelerde sorunlar daha fazla büyümüştür. Bu nedenle OECD de "Hayat Nasıl? Refah Ölçümleme 2015" isimli raporunda 34 üye ülkeyi incelemiştir. Yayınlanan raporda çocuk yoksulluğu ile ilgili bir bölüm yayınlamıştır. Rapora göre ekonomik kriz sonrası yaşanan eşitsizliklerden en çok çocukların etkilendiğini göstermektedir. OECD ülkelerindeki her 7 çocuktan biri yoksuldur. Kriz öncesine göre çocuk yoksulluğu 2/3 artmıştır.

\begin{tabular}{|l|l|l|}
\hline Ülkeler & Tüm Nüfus & Çocuk (0-17Yaş) \\
\hline Avusturya & 0,08 & 0,8 \\
\hline Belçika & 0,10 & 0,13 \\
\hline Kanada & 0,12 & 0,14 \\
\hline Danimarka & 0,06 & 0,04 \\
\hline Finlandiya & 0,07 & 0,04 \\
\hline Fransa & 0,08 & 0,11 \\
\hline Yunanistan & 0,14 & 0,18 \\
\hline İtalya & 0,13 & 0,18 \\
\hline Meksika & 0,20 & 0,25 \\
\hline İspanya & 0,15 & 0,21 \\
\hline Amerika & 0,17 & 0,21 \\
\hline Türkiye & 0,19 & 0,28 \\
\hline Almanya & 0,09 & 0,09 \\
\hline
\end{tabular}

Tablo1: Medyan Gelirin \%50 sine Göre Gelişmiş Ülkelerde Göreli Yoksulluk Oranı Kaynak: OECD Economic and Social Statistics, 2014 
Yoksulluk oranları ülkeden ülkeye farklılık göstermektedir. Yukarıdaki tabloya göre ülkelerin tün nüfus yoksulluk oranlarını ve çocukların yoksulluk oranlarını karşılaştırmaktadır. Danimarka yoksulluk oranı olarak en düşük değere sahiptir. Ama ekonomik ve teknolojik olarak dünyanın en gelişmiş ülkeleri olarak kabul etmek hatalı olur. Danimarka ve Finlandiya'yı diğer ülkelerden ayıran özellik sadece düşük oranlara sahip olması değildir. Aynı zamanda tüm yoksulluk oranından daha düşük çocuk yoksulluğuna sahip olmalarıdır. Almanya ve Avusturya da aynı oranda iken diğer ülkelerde çocuk yoksulluk oranı tüm yoksulluk oranından daha yüksektir. Türkiye OECD ortalaması olan \%11'in çok üzerinde yoksulluk oranına sahiptir. Çocuk yoksulluğu açısından en yüksek orana sahip OECD ülkesidir. Dolayısıyla çözüm bekleyen önemli sorunlardan birisidir.

Gelişmiş ve zengin ülkeler olarak kabul edilen OECD ülkelerinin ortalamaları incelendiğinde çocuk yoksulluğuyla karşılaşılmaktadır. 15 yaşından küçük çocukların \%7,9'unun evinde 10 adetten az kitap bulunmaktadır. 15 -19 yaş grubundaki çocukların \%6,9'u eğitim almamaktadır. Ergen yaştaki çocukların \%12,9'u tek ebeveynli olarak yaşamaktadır. Aileleriyle sadece haftada bir iki kez beraber aynı masada yemek yiyen 15 yaşından büyük çocukların sayısı \%80'lere varmaktadır. Bu çocukların \%31'i son iki ay içinde zorbalıkla karşılaşmışlardır. Erken gebelik yaşayan 15-19 yaş arasındaki çocuk sayısı \%16'ya ulaşmıştır (UNICEF, 2015a).

Gelişmekte olan ülkelerde sorun daha vahimdir. \%33,9 çocuk beş kişiden fazla kişiyle tek bir odada yaşamaktadır. \%30,7'sinde tuvalet, \%21'inde temiz su yoktur. \%13 çocuk hiç okula gitmemektedir. Hiç televizyon, radyo, gazete ve telefonu olmayan çocukların oranı \%16,1'dir. Açlık sınırının altında yaşayan çocuk sayısı $\% 16,1$ 'dir (Gordon, 2005).

\section{Türkiye'de Yoksulluk}

OECD ülkeleri içinde en yüksek yoksulluk oranına sahip Türkiye uygulanan politikalar sayesinde yoksulluk sorunuyla mücadelede başarılı sonuçlar elde etmiştir. Mutlak yoksulluk sorununu büyük ölçüde çözülmüştür. Ekonomik büyüme ve sosyal politikalar sayesinde mutlak yoksulluk sıfıra yaklaşmıştır. Günlük 1 doların altında yaşayan aşırı yoksul oranı 1994'de \%1,1 iken 2006 yılında sıfıra düştü. Bu nedenle, fert yoksulluk oranlarının TÜ̇iK tarafından hesaplanması, 2009 yılı yoksulluk araştırmasıyla son bulmuştur. Açlık sınırının altında kalanlar için endeks oluşturmak istatistiki açısından geçersiz hale gelmiştir. TÜİK 4.3 doların altında yaşayan yoksullarla ilgili çalışmalara ise devam etmektedir. Bu rakam da 2014 yılında 1.62’ye gerilemiştir. Mutlak yoksul sayısı 20 milyondan 1.25 milyona düşmüştür (TUIK, 2014a). Türkiye'de yaşanan başarı gelişmekte olan ülkelerin başarılarıyla benzer özellik göstermektedir. Gelişmekte olan 107 ülkede yoksulluk oranı 1990 y1lından günümüze yarı yarıya yaklaşık \%30'lara inmiştir (ILO, 2014). Ancak Türkiye ekonomik büyüklük olarak OECD ülkeleri arasında ilk 20'de yer almaktadır. Bu nedenle gelişmiş ülkelerdeki yoksulluk oranlarını dikkate alarak çalışma yapılmalıdır. Bu nedenle medyan geliri dikkate alan göreli yoksulluk endeksleri kullanılmalıdır.

\begin{tabular}{|l|c|c|c|c|c|c|c|c|c|}
\hline & 2006 & 2007 & 2008 & 2009 & 2010 & 2011 & 2012 & 2013 & 2014 \\
\hline Yoksul Sayıs1 & 12548 & 11163 & 11580 & 12097 & 12025 & 11670 & 11998 & 11137 & 11332 \\
\hline Yoksulluk Oranı & 18,6 & 16,3 & 16,7 & 17,1 & 16,9 & 16,1 & 16,3 & 15,0 & 15,0 \\
\hline Yoksulluk Açı̆̆1 & 31.7 & 26,4 & 25,6 & 28,0 & 26,6 & 26,3 & 26,9 & 26,0 & 24,4 \\
\hline
\end{tabular}

Tablo 2: Eşdeğer Hanehalkı Kullanabilir Fert Gelirine Göre Hesaplanan Yoksul Sayıları, Yoksulluk Oranı ve Yoksulluk Açı̆̆l (Medyan gelir \%50) Kaynak: TÜIKKb.

Göreli yoksulluk medyan gelirin \%50'si dikkate alındığında 2006 yılında \%18,6 iken 2007 ve 2008 yıllarında düşmeye başlamıştır. Ancak 2009'da \%17,1'e yükselmiştir. Dada sonra tekrar düşüş trendine girerek 2014 y1lında \%15'e düşmüştür. Yoksulluğun derecesini gösteren yoksulluk açı̆̆ı rakamları 2006 y1lında \%31,7'den düşmeye başlamıştır. 2009 yılındaki yükselişin ardından 2014 yılında \%24,4'e inmiştir. Mutlak yoksulluk ile karşılaştırıldığında daha düşük bir başarı gösterilmiştir. Açlık sınırında yaşayan yoksullarla ilgili sağlanan başarı göreli yoksullukta sağlanamamıştır. Göreli yoksulluk daha ayrıntılı incelenerek özel politikalar uygulanmalıdır.

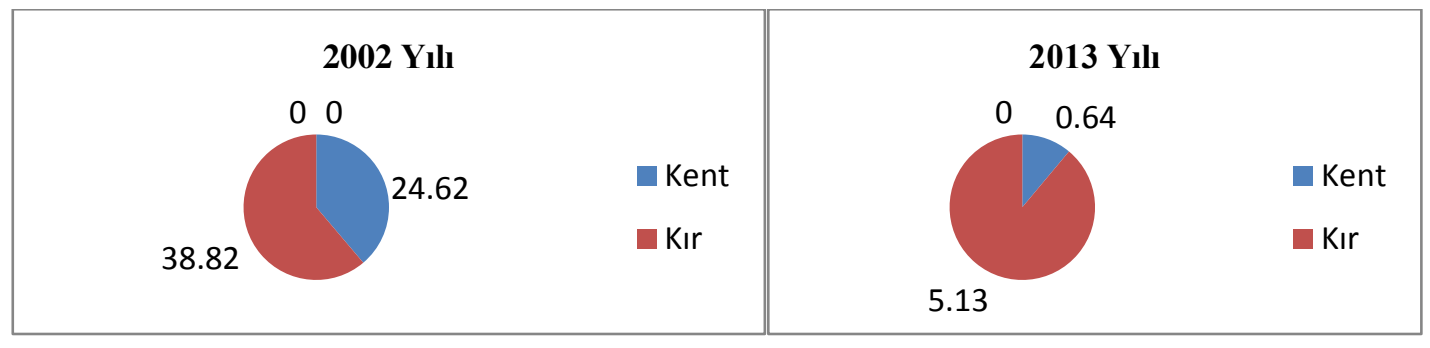

Şekil 1: Fert Yoksulluk Oranı 2013 Kaynak: TÜIK 2015 a

Türkiye'de yoksulluk sınırı yöntemlerine göre fert yoksulluk oranları, Kişi başı günlük 4,3 doların altında yaşamak zorunda kalanlar incelendiğinde 2002 yılında \%30,30 iken gerek GSYH' da büyüme gerek kişi başına gelirin artmasıyla 2013 yılında 2,06'ya düşmüştür. Ancak kent kır ayrımı göz önüne alındığında kentteki yoksullukla mücadelede kazanılan başarının kırsalda aynı başarıyı gösteremediği görülmektedir. Kentte sıfıra 
doğru yaklaşan oran kırsalda hala yüksektir. 2010 yılında metodolojik değişim yapılmadan önceki tarihe bakarsak harcama esaslı göreli yoksulluk 2002 yılında kentte 11,33 iken kırsalda 19,86 olarak gerçekleşirken son açıklanan tarih olan 2009 yılında kentte 6,59'a düşmüştür. Aynı tarihte kırsaldaki harcama esaslı göreli yoksulluk hızla yükselerek 34,20'ye yükselmiştir. Kırsalda iyileşme yerine daha da kötüleşme yaşanmış ve yoksulluk hızla artmıştır. Kırsaldaki yoksullaşma kent ile olan farkın derinleşerek büyümesine neden olmuştur. 2010 y1lı sonrası yeni yöntemle hesaplamalarda da kent kır ayrımı açıkça görülmektedir.

Cinsiyet, yaş, eğitim düzeyi ve hanehalkı gibi faktörler yoksullukla karşılaşılma riskini etkilemektedir. Örneğin, kadınların yoksullukla karşılaşma riski gelişmiş ülkelerde bile erkeklerden daha yüksektir. AB genel ortalamasında kadın yoksulluğu riski erkek yoksulluğundan \%3daha fazladır. Hele aile reisi kadın olan tek ebeveynli çocuklu ailelerde yoksulluk riski \%35'lere, İngiltere ve Hollanda gibi zengin ülkelerde bu oran \%50'ye ulaşmaktadır. Ayrıca hanehalkı tipi bakımından 65 yaş üstündeki yetişkinlerden oluşan ailelerde de yoksulluk riski yükselmektedir (Öztürk ve Çetin, 2009).

Birleşmiş Milleteler 1994 yılından başlayarak her yıl mayıs ayında Uluslararası Aile Gününü kutlamaktadır. Türkiye'de buna istinaden TÜİK olarak 2012 yılından itibaren aile ile ilgili çalışmalar yayınlamaya başlamıştır. Türk aile yapısı 2015 yılında yaptığı açıklamaya göre bir önceki yıl \%8,6 olan tek kişilik hane halkı oranı \%8,9'a yükselmiştir. Tek ebeveyni anne olanların büyük çoğunluğunu kadınlar oluşturmaktadır. Erkekler sadece \%15 civarındadır. Üç kuşağ1 da içeren geniş hane halkı oranı da \%13,5'den \%13.1'e düşmüştür TÜİK, 2015c).

Tüm hanehalklarının yaklaşık 5'de biri yoksulluk sınırının altında yaşamaktadır. Hanehalkı tipine göre yoksulluk oranı incelendiğinde yoksulluk ve çocuk arasındaki ilişki kuvvetlenmektedir. 25 yaşından küçük olan ve ekonomik açıdan pasif olarak ailesiyle yaşayan çocukları bağımlı çocuk olarak adlandırdığımızda, bağımlı çocuğu olan hanehalklarının yoksulluk oranı \%27,7'ye çıkmaktadır. Çocuksuz ailelerdeki oran ise \%7'ye inmektedir. Çocuklu ve çocuksuz hanehalkları arasında yoksulluk açısından büyük bir uçurum oluşmaktadır. Çocuklu ailelerde de yoksulluk oranı aşağıdaki tabloda verilmiştir.

\begin{tabular}{|l|c|c|c|c|c|c|}
\hline Yıllar & $\begin{array}{c}\text { Bağımlı } \\
\text { çocuğu } \\
\text { olan hane } \\
\text { halk1 }\end{array}$ & $\begin{array}{c}\text { Tek Yetişkinli } \\
\text { En az Bir } \\
\text { Bağımlı } \\
\text { Çocuğu Olan } \\
\text { Hanehalkı }\end{array}$ & $\begin{array}{c}\text { İki Yetişkinli } \\
\text { En az Bir } \\
\text { Bağımlı } \\
\text { Çocuğu Olan } \\
\text { Hanehalkı }\end{array}$ & $\begin{array}{c}\text { İki Yetişkinli } \\
\text { En az İki } \\
\text { Bağımlı } \\
\text { Çocuğu } \\
\text { Olan } \\
\text { Hanehalk1 }\end{array}$ & $\begin{array}{c}\text { İki Yetişkinli } \\
\text { En az U̧ç ve } \\
\text { Fazla Bağımlı } \\
\text { Çocuğu Olan } \\
\text { Hanehalkı }\end{array}$ & $\begin{array}{c}\text { Hanehalk1 Tipi } \\
\text { Belirlenemeyen }\end{array}$ \\
\hline 2006 & 21,3 & 29,8 & 6,5 & 11,2 & 37,4 & 17,3 \\
\hline 2007 & 19,2 & 19,0 & 5,2 & 8,9 & 34,5 & 15,1 \\
\hline 2008 & 20,1 & 24,2 & 5,5 & 9,5 & 36,8 & 6,2 \\
\hline 2009 & 20,6 & 25,8 & 6,9 & 9,7 & 38,5 & 19,3 \\
\hline 2010 & 20,3 & 22,5 & 6,1 & 9,1 & 37,6 & 15,4 \\
\hline 2011 & 19,4 & 27,2 & 6,0 & 7,8 & 36,4 & 10,9 \\
\hline 2012 & 19,7 & 23,4 & 4,8 & 8,8 & 37,8 & 21,3 \\
\hline 2013 & 18,3 & 21,4 & 4,4 & 7,8 & 36,4 & - \\
\hline 2014 & 18,4 & 23,6 & 4,1 & 7,9 & 35,8 & 4,0 \\
\hline
\end{tabular}

Tablo 3: Hane Halkı Sayına Göre Yoksulluk Oranı Kaynak: TÜIK 2015d

2006 yılında bağımlı çocuğu olan hanehalkı \%21,3’ten 2014 yılına geldiğinde 18,4'e düşmüştür. Bu düşüş mutlak yoksulluk oranındaki başarı kadar olmasa da düşüş trendinde olması iyidir. Tek yetişkinli en az bir çocuğu olan hanehalkında yoksulluk oranı daha yüksektir. Ancak AB ortalamasının \%35'lere çıktığı bir durumda 2006 yılındaki \%29,8'lik oran yüksek kabul edilmemelidir. Gerçi bu oran zaman içinde dalgalanmalar göstermesine rağmen son yıllarda \%23,6'ya inmiştir. Tek ebeveynli ve çocuklu ailelerde yoksullukla karşılaşma riski azalmıştır. Hanehalkları genel olarak incelendiğinde en düşük yoksulluk oranına sahip aile tipi iki ebeveynli tek çocuklu ailelerdir. Çocuk sayısı ikiye çıktığında yoksulluk oranı da iki katına çıkmaktadır. İki çocuklu ailelerdeki yaklaşık $\% 8$ 'lik oran çocuk sayısı nispeten makul düzeydedir. Çocuk sayısı üçe çıktığında tek çocukluklara göre yoksulluk oranı yaklaşık 9 katına çıkmaktadır. Çocuk sayısı arttıkça yoksul sayısı radikal bir şekilde artmaktadır. Çocuk yoksulluğu dikkate değer rakamlara yükselmektedir. Kalabalık ailelerle yoksulluk arasında çok sıkı bir ilişki vardır. Tek ebeveyni aileler bile çok çocuklu ailelerden daha iyi durumdadır.

TÜİK 2014 verilerine göre hanehalkı büyüklüğü açısından bölgeler arasında da büyük farklılıklar vardır. Türkiye ortalaması 3,6 iken, en yüksek olduğu iller Şırnak 7,3; Hakkâri 6,6 ve Urfa 6,1olmak üzere doğuda toplanmıştır. Batı bölgelerde ise hanehalkı büyüklükleri Türkiye ortalamasının altında kalmaktadır. Çanakkale 2.7iken Balıkesir ve Eskişehir 2,9 kişilik aile büyüklüğüne sahiptir. Bu verilere göre yoksulluk doğuda büyük bir sorun olarak bulunmaktadır. Ancak sorunun en büyük kısmı kalabalık ailelerde yetişen çocukların büyük bir kısmının da yoksul çocuklardan oluşması nedeniyle gelecek dönemlerde de sorunun devam etmesidir. Batı ve doğu arasında büyük farklılık farklı sorunları da beraberinde getirecektir.

Makroekonomik istikrar ve büyüme, çocukların yoksulluğunu çözen bir politika olmaktan çıkmaktadır. Ailelerin refah düzeyindeki artış çok çocuklu ailelere yansımamaktadır. Bölgeler arasındaki fark açılmaktadır. Türkiye 
genelinde çocuk yoksulluğu oranı \%44,3'e çıkmıştır. Kısaca her iki çocuktan biri yoksuldur (Kabaş ve Kandır, 2015).

\section{Türkiye'de Çocuk Yoksulluğu}

0-17 yaş grubu çocuklar tüm dünyanın yaklaşık \%30'unu oluşturmaktadır. 1945'lerde bu oran \%45'ler civarında idi. Azalan çocuk nüfusunun 2075 yılında \%17,6 düşeceği tahmin edilmektedir. Bu azalmada kentleşme, kadının aktif çalışma hayatı gibi etmenlerin yanında son yıllarda sık yaşanan krizlerin yarattığı yoksulluk da etken olmuştur. Yoksulluğun tüm ülkelerde hatta gelişmiş ülkelerde bile artışı büyük bir sorun haline getirmiştir. Hane içindeki yoksulluk bireylere farklı derecede etki etmiştir. Gelir getiren yetişkinler daha az etkilenirken çocuklar yoksulluktan en çok etkilenen kesim olmuşlardır. Yoksul çocuklar yoksulluğu gelecek nesillere taşıdıklarından dolayı ayrıca incelenmeli ve önlem alınmalıdır. Bu konuda UNICEF tarafından yapılan çocuk yoksulluğu çalışmasına göre 2008 krizinden 2014'e kadar 2,6 milyon çocuk daha yoksullaşmıştır. Çocuk yoksulluğu, başta en yüksek artışın İzlanda olduğu devamında Yunanistan ve İrlanda'nın geldiği araştırmaya konu olan ülkelerde yoksul çocuk oranları \%29ile 41 arasında değişerek 76,5 milyona yükselmiştir (UNİCEF, 2014b).

\begin{tabular}{|l|c|c|c|c|c|c|c|c|}
\hline \multirow{3}{*}{ Türkiye } & & 2007 & 2008 & 2009 & 2010 & 2011 & 2012 & 2013 \\
\cline { 2 - 9 } & Erkek & 32,0 & 33,3 & 32,9 & 32,6 & 31,4 & 32,8 & 32,0 \\
\cline { 2 - 9 } & $\mathrm{K} 1 \mathrm{z}$ & 33,6 & 34,8 & 35,7 & 34,9 & 33,2 & 32,7 & 33,1 \\
\hline \multirow{2}{*}{$\begin{array}{l}\text { Yaş } \\
\text { grubu }\end{array}$} & $0-5$ & 32,8 & 32,9 & 33,4 & 31,7 & 30,6 & 31,6 & 30,1 \\
\cline { 2 - 9 } & $6-13$ & 33,6 & 35,5 & 36,1 & 35,0 & 33,4 & 33,6 & 33,9 \\
\cline { 2 - 9 } & $14-17$ & 31,1 & 32,4 & 33,8 & 34,2 & 32,4 & 32,9 & 33,6 \\
\hline
\end{tabular}

Tablo 4: Cinsiyet ve Yaş Grubuna Göre Yoksul Çocuk Sayısı ve Yoksulluk Oranı, Kaynak: TÜIK 2014

Türkiye son 20 yılda büyümüş ve kişi başına düşen milli gelirde artış sağlamıştır. Ekonomik büyüklük olarak OECD ülkeleri arasındaki yerini almış ve 17.lige kadar yükselmiştir. Ancak yoksulluk gibi önemli göstergelerde hele çocuk yoksulluğu gibi önemli bir oranda aynı başarıyı yakalayamamıştır. Ülke nüfusu genç olmasına rağmen bu kesimin GSYH' dan aldığı pay küçük kalmıştır. 2008- 2012 yılları arasındaki nüfus artışına rağmen bütçede GSYH ile orantılı olarak bir artış yaratılmamıştır.

2013 yılı itibariyle Türkiye nüfusunun \%29,7'i çocuklardan oluşmaktadır. Ab ülkeleri ile karşılaştırıldığında en yüksek çocuk nüfusuna sahip ülkedir. En az çocuk sayısına sahip Almanya (\%16)'nın yaklaşık iki katına sahiptir. Çocuk nüfusu Fransa'da \%22,2, İngiltere'de \%21,2, İsveç'te \% 20,2, Yunanistan'da \%17,6 ve İtalya'da \%16,8 olarak gerçekleşti (TÜIKK, 2015c). Türkiye'de her üç kişiden birisi çocuktur. Yüksek çocuk nüfusuna rağmen 2010 y1lında çocuklara yönelik harcamaların GSYH'ya oranı \%3,59 iken bir sonraki yıl \%3,4'e düşmüştür. Eğitim harcamalarını çıkarırsak oran 2010 yılında \%1,21 iken 2011 'de bu oran \% 1,11 olarak gerçekleşmiştir. GSYH oranı zaten gelişmiş ülkelere kıyasla düşükken yıldan yıla daha da düşmüştür. GSYH büyürken yaşanan düşüşler çocuk yoksulluğunda etken faktörlerden birisidir. Gelecek nesillere yoksulluğun aktarılmaması için GSYH' dan çocuklara aktarılan pay GSYH'nın artışından büyük veya en azından aynı düzeyde olması gerekir (Durmuş, vd, 2013: 45). TÜİK verilerine göre eşdeğer hanehalkı kullanılabilir medyan gelirin \%60 kabul edersek, yoksul çocukların yoksul fertler içindeki oranı \% 44,3 'tür. Bu oranın yüksekliği gelecek nesillere yoksulluğun taşınacağının önemli bir göstergesidir.

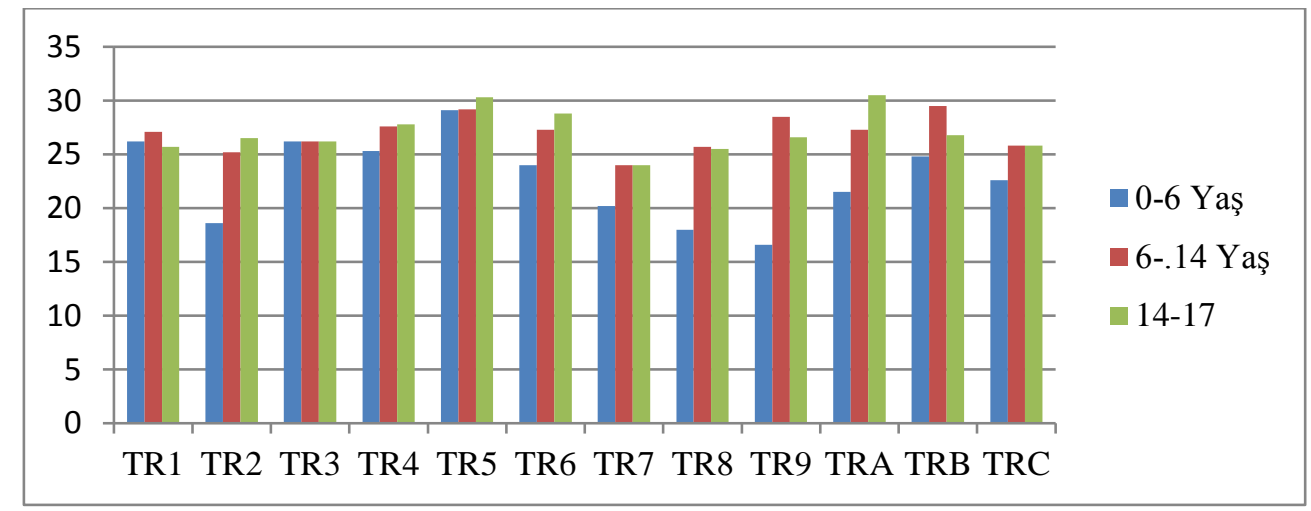

Şekil 2: IBBS 1. Düzey'e Göre Yoksul Çocuk Sayısı ve Yoksulluk Oranı, (Medyan Gelir \%60) Kaynak: TÜIK Çocuk İstatistikleri

Şekil 2'ye göre 0-6 yaş grubunda Batı Marmara \%18.6'lık oranla en düşük yoksulluk grubunu oluşturmaktadır. Aynı yaş grubunda Batı Anadolu ve İstanbul en yüksek orana sahiptir. 6-14 Yaş grubunda en yüksek yoksulluk Ortadoğu Anadolu ve Doğu Karadeniz'de iken en düşük Orta Anadolu'da yaşanmaktadır. Kuzeydoğu Anadolu 1417 yaş grubunda ve tüm yaş grupları içinde en yüksek yoksulluk oranıyla \%30,5'e, onu çok yakından takip eden Batı Anadolu \%30,3 çıkmaktadır. Kısaca en fakir bebekler batıda doğmakta, gençlerin en fakirleri ise Kuzeydoğu ve Batı Anadolu'dan çıkmaktadır. 
Türkiye 16 yaş altındaki nüfusun yoksullukla karşılaşma riski \%30,2 ile OECD ülkeleri arasındaki kötü konumu ile toplumsal olarak büyük bir sorun yaşamaktadır. Hanehalkıyla beraber değerlendirilen bu yoksulluk oranı aslında gerçeği yansıtmamaktadır. Gelir azaldığında yoksul olarak tanımladığımız çocuklar aslında daha çok etkilenmektedirler. Yoksul çocuklar hane içinde daha yoksullaşmaktadır. Aslında yoksul çocuk sayısının daha yüksek olduğu kabul edilmeli ve yeniden tanımlanmalıdır. Bu ortamdaki çocuklar yetersiz beslenmekte ve salıksız şartlarda yetersiz eğitim alarak büyümektedirler. Dolayısıyla bedensel ve zihinsel olarak yüksek gelirli aile çocuklarında geri kalmaktadırlar. Yetişkin olduklarında yetersizlikleri nedeniyle yoksul olarak hayatlarını sürdürmek zorunda kalmaktadırlar. Tüm bu gelişme de kuşaklar arası bir kısır döngüye dönüşmektedir. Sorun daha büyüyerek ve derinleşerek ülke genelini etkiler hale gelmektedir. Dünya Bankasının raporuna göre nesiller arası firsat grupları karşılaştırıldığında düşük firsat grubuna sahip yoksul çocukların oranı yüksek firsat grubuna sahip çocukların yaklaşık 16 kat fazlasıdır (Kahraman ve Gül, 2015).

Az gelişmiş ülkelerde tuvaletin ev içinde veya dişında kullanımı bir yoksulluk göstergesi olarak kullanılmaktadır. En az bir çocuğa sahip ailelerde 2011 yılında yapılan istatistiğge göre konut içinde tuvaleti olmayan illerde en yüksek oran \%52,4 ile Iğdır, \%50 ile Kars, \% 41,8 ile Ağrı ve Ardahan'dır. Türkiye genelinde \%7,4'ünün tuvaleti konut içinde değildir. Kısaca Doğu Anadolu'da her iki çocuktan biri güvenli barınma sorunu yaşamaktadır. Bu nedenle çocuklarda sık sık ev kazaları görülmektedir. 1-17 yaş grubu çocuklarda ölüm nedenleri arasında ilk sırada dışsal yaralanmalar ve zehirlenmeler gelmektedir. Bu yaş grubu içinde en fazla ölüm oranına 5-14 yaşta rastlanılmaktadır (TÜİK, 2014).

Bedensel ve zihinsel gelişim için barınma yanında çocuk gelişimi için iyi beslenme de gereklidir. Sağlıklı gelişemeyen çocuk hem ailesine ekonomik olarak ek yük getirir hem de gelecek nesilde yoksulluk sarmalından kurtulamaz. Çeşitli ülkelerde yapılan çalışmalarda diyabet, obezite ve hipertansiyon gibi sürekli hastalıklar yoksul aile çocuklarında daha çok görülmektedir (Şener ve Ocakçı, 2014). 7-8 yaş grubu çocuklarda TÜİK tarafindan yapılan çalışmaya göre kilolu çocukların Türkiye genelindeki oranı \% 7,5 çıkmıştır. Şişman çocukların \%10,3’ü kentte yaşayan erkek çocuklardır. Kentli kızlar \%6,5'lik bir orana ulaşırken kırsal alanda kilolu çocuk sayısı azdır. Beden kitle endeksi gözönüne alındığında sonuçlar daha kötü çıkmaktadır. Her dört çocuktan biri normal beden kitle endeksine sahip değildir, kilolu veya obezdir.

\begin{tabular}{|c|c|c|c|c|c|c|c|c|}
\hline & & \multicolumn{3}{|l|}{ Erkek } & \multicolumn{3}{|l|}{$\mathrm{K}_{1 \mathrm{Z}}$} \\
\hline & & Toplam & Toplam & Kent & Kir & Toplam & Kent & Kir \\
\hline \multirow[t]{3}{*}{ Ağırlık } & Zayıf & 2,3 & 2,3 & 1,8 & 4,2 & 2,3 & 2,0 & 3,3 \\
\hline & Normal & 90,2 & 88,6 & 87,8 & 92,9 & 91,9 & 91,5 & 93,7 \\
\hline & Kilolu & 7,5 & 9,1 & 10,3 & 3,0 & 5,9 & 6,5 & 2,9 \\
\hline \multirow[t]{3}{*}{ Uzunluk } & Bodur & 2,4 & 2,2 & 1,6 & 5,6 & 2,6 & 1,8 & 6,0 \\
\hline & Normal & 95,3 & 94,8 & 95,0 & 93,9 & 95,8 & 96,3 & 93,7 \\
\hline & Uzun & 2,2 & 3,0 & 3,4 & 0,5 & 1,6 & 1,9 & 0,2 \\
\hline \multirow[t]{4}{*}{ Beden Kitle } & Zayıf & 2,1 & 2,2 & 2,1 & 2,4 & 1,9 & 1,9 & 1,3 \\
\hline & Normal & 75,5 & 74,5 & 72,9 & 82,8 & 76,5 & 74,6 & 85,0 \\
\hline & Kilolu & 14,2 & 13,3 & 13,7 & 11,1 & 15,0 & 16,0 & 10,5 \\
\hline & Obez & 8,3 & 10,0 & 11,2 & 3,7 & 6,6 & 7,4 & 3,1 \\
\hline
\end{tabular}

Tablo 5: Çocukların (7-8Yaş) Boy ve Kilo Dă̆ılımı Kaynak: TÜIKK 2014

Bu kadar yüksek yoksulluğun olduğu Türkiye'de çocukların suça bulaşması da kaçınılmazdır. Güvenlik birimine gelen çocuk sayısı 2011 yılında 204.040'den, 2013'de 273.571'e çıkmıştır. Suça sürüklenme hızla artmaktadır. 2011 yılında 84.916 iken rakam 115.439'a yükselmiştir Ceza alarak hüküm giyen 161.711 çocuk en çok hırsızlık, yağma ve yaralama suçlarını işlediler (TÜİK, 2014).

Yoksullukla bağlantılı olarak çocuk istihdamının yüksekliği de çözülmesi gereken bir sorundur. Türkiye'de her iki çocuktan birisi ev işlerinde çalıştırılmaktadır. Hatta 2006 ile 2012 yılı ile karşılaştırıldığında oranın \%4,5'den 49,2'ye yükseldiği görülmektedir. Aynı yıllarda ekonomik işlerde çalışan çocukların oranı \%5,9 olarak gerçekleşmiştir. Erkeklerde dışarıda çalışma oranları \%8'lere kadar çıkarken kızlarda evde çalışma oranı daha yüksektir.

Çocuk yoksulluğu eğitimde de sorun yaratmaktadır. Türkiye'de halen 1.297 .000 çocuk okula gitmemektedir. Oransal olarak \%8,5'dir. 15-17 yaş grubunda her dört çocuktan birisi okula gitmemektedir. Kırsal alanda sorun daha büyümekte gençlerin $\% 40^{\prime}{ }_{1}$ okula gitmemektedir. Kırsal alanda her iki kız çocuğundan birisi okula gitmemektedir. Türkiye genelinde çocuklar 14 yaşına kadar tarımsal alanda çalışmakta, 14 yaş sonrasında \% 80 'lere varan oranda sanayi veya hizmet sektöründe çalışmaktadır. Her iki çocuktan biri aileye gelir desteğinde bulunmak için çalışmaktadır. İş ve meslek öğrenmek amacıyla çalışanların oranı \%15'lerde kalmaktadır (TÜİK, 2014).

Çocuklar kültürel faaliyetlerde de bulunmamaktadır. Türkiye'de günlük gazete alan çocuklu aileler sadece 2013 yılı itibarıyla \%4'tür. Yine çocuklu ailelerin \%2,5'i sinema, tiyatro, maç gibi alışkanlıkları vardır. \%96 gazete okumayan ve \%97,5 kültürel faaliyetlerde bulunmayan ailelerde çocukların geleceğe hazırlanması mümkün değildir. 


\section{Sonuç}

Eğitim almayan çocukların yoksulluk kısır döngüsünü kırması imkânsızdır. Özellikle kırsal alanda okutulmayan kızlar yoksul çocuklar yetiştirerek yoksulluğun gelecek dönemlerde devam etmesine neden olmaktadırlar. Türkiye genelinde okutulmayıp çalışmak zorunda kalan çocuklar gelecek neslin de yoksul adaylarıdır. Uzun dönemde ortaya çıkan maliyeti çocuklar ödemektedir.

Yoksul çocukların sadece okula gitmesi yeterli değildir. Onlara yardımcı olacak rol model büyükleri yoktur. Ayrıca beslenme yetersizlikleri nedeniyle gelişimleri geri kalmıştır. Genellikle çok çocuklu ailelerin çocukları oldukları için ilgi ve takip de yoktur. Dolayısıyla suça sürüklenme ihtimalleri yüksektir. Okulu terk etmeleri için zaman içinde kendiliğinden ortaya çıkan bu nedenler ortadan kaldırılmalıdır.

Şu anki yoksulluk gelecek dönemin yoksulluk nedeni olmamalıdır. Çocuklarda okullaşma belirli sürelerde belirli yerlerde tutulma olarak kabul edilmemelidir. Yoksulluk etkilerini azaltıcı veya önleyici aktivitelere yer verilmelidir. Bu amaçla çocuk yoksulluğu tespit edilip çocuğa yönelik politikalar uygulanmazsa gelecekte daha kötü sorunlarla karşılaşılır. Bu nedenle çocuklar GSYH'dan nüfuslarıyla orantılı olarak pay almalıdır.

\section{Kaynakça}

- Ak Muammer, “Toplumsal Bir Olgu Olarak Yoksulluk”, Akademik Bakış Dergisi, Sayı 54, Nisan 2016.

- Durmuş Gözde, Ayşe Beyazova ve Nurhan Yentürk, 2013, "Sivil Toplum Kuruluşları İçin Çocuğa Yönelik Harcamaları İzleme”, Uluslararası Katılımlı Sosyal Hizmet Sempozyumu 2013 Türkiye’de Çocuğun Refahı ve Korunması ‘Kapsayıcı Bir Yaklaşım Arayışı’ Sempozyum Bildirileri, 28-30 Kasım, Kocaeli, ss. 44-56.

- Gordon, David, 2005. Child Poverty In the Developing World, The Policy Press, Bristol, İngiltere.

- ILO (International Labour Organisation), 2014. Indonesia: Labour and social trends update, Geneva: ILO.

- Kabaş, Tolga ve Ediz Deniz Kandır, 2015. "Türkiye’de Yoksulluğun Azaltılmasında Demografik Kazancın Önemi." Türkiye Dördüncü Nüfusbilim Konferans1 Hacettepe, Ankara: 67.

- Kahraman, Fatih, and Songül Sallan Gül, 2015. "Türkiye'de Çocuk Yoksulluğu: Gaziantep Üzerine Bir Araştırma" Hitit Üniversitesi Sosyal Bilimler Enstitüsü Dergisi 8.1 ss 344-372.

- OECD, 2014, (Organisation for Economic Co-operation and Development) OECD Factbook, Economic, Environmental and Social Statistics, pp. 67.

- $\quad$ Özcan, Süleyman Emre, 2016. "Yoksulluk Göstergesi Olarak Hoşnutsuzluk Endeksi, Türkiye İçin Bir Deneme" Dumlupınar Üniversitesi Sosyal Bilimler Dergisi, Say148, ss.294-313.

- Öztürk Mustafa, Başak Işıl Çetin, 2009.“Dünya'da ve Türkiye’de Yoksulluk ve Kadınlar”, Journal of Yasar University, 3(11), 2661-2698.

- Şener Dilek Konuk, Ayşe Ferda Ocakçı, 2014. "Yoksulluğun Çocuk Sağlığı Üzerine Çok Boyutlu Etkileri”, Ankara Sağlık Hizmetleri Dergisi, Cilt 13, S.1, 57-68.

- $\quad$ TÜİK (Türkiye İstatistik Kurumu), 2015a. Gelire Dayalı Yoksulluk İstatistikleri, 2006-2013.

- TÜİK (Türkiye İstatistik Kurumu) 2015b. Gelir ve Yaşam Koşulları Araştırmas1, 2006-2014 Eşdeğer Hanehalkı Kullanabilir Fert Gelirine Göre Hesaplanan Yoksul Sayıları, Yoksulluk Oranı ve Yoksulluk Açığı.

- $\quad$ TÜİK (Türkiye İstatistik Kurumu) 2015c. Haber Bülteni, İstatistiklerle Aile 201422 Nisan 2014, say1:18624, 05 May1s.

- $\quad$ TÜİK (Türkiye İstatistik Kurumu), 2015d. Eşdeğer hanehalkı kullanılabilir fert gelirine ve hanehalkı tipine göre yoksul sayıları ve yoksulluk oranı 2006-2014.

- $\quad$ TÜİK (Türkiye İstatistik Kurumu), 2014. İstatistiklerle Çocuk, Yayın No:4372, Ankara

- UNDP (United Nations Development Programme), 2014. Human Development Report 2014, http://www.undp.org/content/turkey/tr/home/library/human_development/hdr-2014.html.

- UNICEF (United Nations Children's Fund) 2015a. https://www.unicef.org.nz/_data/assets/pdf_file/0003/5475/ChildPoverty_Bklt_ebook.pdf, 07 Aug 2015.

- UNICEF (United Nations Children's Fund) 2015b. "Child Poverty up by 2.6m in Rich World”, http://www.unicef-irc.org/ article/1069. 


\title{
Almanya'daki Türk Göçmen Kadınların İşçileșme Süreci ve Gelecek Beklentileri \\ The Future Expectations and Laboration of Migrant Women From Turkey in Germany
}

\author{
Prof. Dr. Nuray Gökçek Karaca (Anadolu University, Turkey) \\ Asst. Prof. Dr. Erol Karaca (Anadolu University, Turkey)
}

\begin{abstract}
This study sought to investigate future expectations and laboration of the migrant women from Turkey in Germany. The research was carried out with 570 migrant women from Turkey in Germany in 2012-2013. The data were collected by using a questionnaire developed by the researcher based on a literature review. Data were analyzed with factor analysis by using the statistical package SPSS. According to the research results, a significant number of women said that they are housewives but not working. This result points out the continuity of perception and evaluation of being a housewife "as not a profession and form of labor". The data about women except from housewives reveals the difficulties in their labor life and also the effectiveness of informal networks on laborization process. Overwhelming majority of these women have experienced various jobs and indicated lower and inadequate wages as the reason of these experiences. In addition, the most effective means in the process of finding jobs is the circle of acquaintances rather than job-creating agencies, trainings and employment tests. As a result of the inadequacy of formal structure, a significant number of women has to work with low wages and not obtained sufficient social benefits. In spite of the difficulties faced by women in their laborization process, a great majority of women have the social security right. The presence of social security, however, could not prevent feeling insecure about their future and negative evaluation about their economic conditions.
\end{abstract}

\section{Giriș}

Literatürde tam bir kavram birliğinden söz edebilmek mümkün değilse de insanlık tarihi kadar eskiye dayanan bir insanlık fenomeni olan göçü, insanların daha iyi hayat şartlarına kavuşmak üzere geçici bir süre için veya kalıcı olarak bir yerden bir yere gitmesi şeklinde tanımlamak mümkündür. Göç olgusunun gerçekleşme biçimine göre göç "ulusal göç" ve "uluslararası göç"; göçmenlerin kendi ülkelerini terk etme ve gittikleri ülkeyi tercih etme nedenlerine göre göç "ekonomik göç” ve "ekonomik olmayan göç” şeklinde ikili bir ayırıma tabi tutulabilir.

Göç konusunda gelişen bir literatür bulunmasına rağmen, göçün nedenleri hala oldukça sınırlı düzeyde bilgiye sahip olunan bir alan olma özelliğini korumaktadır. Göçün tanımlanmasında olduğu gibi, literatürde göçün sebepleri konusunda da tam bir görüş birliğinden söz etmek mümkün değildir. Böyle olmakla birlikte günümüzde savaşların, doğal afetlerin, nüfus artışının, dinsel, kültürel, ekonomik (küresel ticaretin), siyasi (insan hakları ve demokratikleşme), jeopolitik (sınır bölgelerinde sığınmacı olma zorunluluğu) ve ailevi faktörlerin göçe neden olduğu genel kabul görmektedir (Werner, 1996; Gençler, 2002).

Literatür incelendiğinde, işgücü piyasası dengesinin ve uyum dinamiklerinin tartışılması açısından göçün belirleyicisi olan faktörlerin, göç etmeyi teşvik eden etkiler olarak "itici faktörler" ve "çekici faktörler" şeklinde ikili bir ayırıma tabi tutulduğu görülmektedir. İtici faktörler, göç etmek yönündeki ilgiyi ve isteği etkileyen arz yanlı faktörlerdir. Çekici faktörler ise, bunlar da göç alan (kabul eden) ülkede göçmenlere yönelik talebi etkileyen talep yanlı faktörlerdir (Visco, 2000: 11; Coppel-Dumont-Visco, 2003: 11).

Olayın arz yönünde, göç edilen ve terkedilen ülkeler arasındaki nispi gelir eşitsizliklerinin, göçü teşvik edici, başka bir deyişle artırıcı yönde etkileyen önemli bir faktör olduğu geniş kabul görmektedir. Elbette, bu faktör mevcut göç hareketlerini büyük ölçüde açıklamaktan uzaktır. Çünkü göç olgusu aynı zamanda, göç nedeniyle ortaya çıkması beklenen maliyet (ulaşım ve yerleşim maliyetleri gibi) ve faydalar kadar, göç edilen ülkenin göçmen politikasına da bağlıdır. Ekonomik olmayan faktörler de aynı şekilde önemlidir. Bir başka ülkede yaşamak amacıyla göç etmenin getirdiği psikolojik baskı ile dil ve kültürel farklılıklar, göç edilecek olan ülkenin tercih edilmesi, başka bir ifadeyle hangi ülkeye göç edileceğinin belirlenmesi kadar, göç etme kararının alınmasını da güçleştirmektedir. Ayrıca daha önce göç edenlerin yerleşim tarzları, aileyi yeniden birleştirmeye yönelik programlar yoluyla ve göç edilen ülkeye son olarak gidenlerin, geldikleri ülke ile olan etkileşimleriyle ortaya çıkan göçmen dinamikleri de göç etme kararının verilmesinde rol oynamaktadır (Werner, 1994: 147-164; CoppelDumont-Visco, 2003: 13; Vishwanath, 1991; Burda, 1995).

Talep yönünden ise, göç alan pek çok ülkede göçmen işçilere duyulan ihtiyacın önemine dikkat çekilmektedir. Bazı Avrupa ülkeleri yabancı işgücünü yeniden eğiterek (iş eğitimi), ithalata rakip (ithal ikameci) endüstriler ile hizmet sektöründe söz konusu olan işgücü açığını geleneksel şekilde karşılamışlardır. Bu durum, özellikle işgücü kıtlığının (açığının), başka bir deyimle emek arzındaki daralmanın yaygın şekilde yaşandığı 1950’lerin ortalarından 1970'li yılların başlarına dek görülmüş, Almanya, Fransa ve İngiltere gibi ülkeler, göçü arttırmaya 
yönelik özendirici politikaları aktif olarak uygulamışlardır. Bu talep yanlı göçlerin önemi, resesyona ve işsizliğin artmasına yol açan 1973'teki birinci petrol şokunun ardından azalmıştır. Daha sonra teknolojik ilerlemeler nedeniyle emek talebinin nitelikli işgücüne kayması, göç alan ülkelerde niteliksiz işgücüne yönelik talebin azalmasına neden olmuştur.

Türkiye'de uluslararası göç istatistikleri konusunda veri kaynakları; nüfus sayımları, sınır istatistikleri, idari kayıtlar ve araştırmalardır. İdari kayıt olarak, oturma izinleri, sığınmacı ve mülteci kayıtları ile pasaport ve yasa dışı göç bilgileri Emniyet Genel Müdürlüğü tarafından, çalışma izinleri ve yurt dişında yaşayan Türk vatandaşlarına ait bilgiler Çalışma ve Sosyal Güvenlik Bakanlığı tarafindan, vatandaşlık bilgileri Nüfus ve Vatandaşlık İşleri Genel Müdürlüğü tarafından derlenmektedir. TÜİK Başkanlığı tarafından yapılan nüfus sayımlarıyla yurt dışından Türkiye'ye göç eden nüfusun büyüklüğü ve niteliği ile ilgili bilgiler derlenmektedir. Türkiye'de Uluslararası göç verilerinin derlenmesine ilişkin düzenli bir kayıt sistemi bulunmamaktadır. Bununla birlikte, ilgili kurumlar idari çalışmaları doğrultusunda bazı verileri derlemektedirler. $\mathrm{Bu}$ veriler, göç istatistiklerinin karşılaştırılabilirliği ve ölçülebilirliği açısından uluslararası tanımlamalara ve sınıflamalara uygun değildir. Böyle olmakla birlikte uluslararası göç bakımından Türkiye’nin başka ülkelerle karşılaştırmasının yapılabilmesi açısından önemli olan uluslararası göç istatistiklerinin kapsamını; "yurt dışından gelenler, yurt dışına gidenler, oturma ve çalışma izni alan yabancılar, sığınmacı ve mülteciler, yasa dışı göç edenler, vatandaşlığa girenler, vatandaşlıktan çıkanlar, yabancı nüfus ve yurt dışında yaşayan Türk vatandaşlarına ilişkin bilgilerin oluşturduğunu bilmekte yarar vardır.

Çalışma ve Sosyal Güvenlik Bakanlığı verileri yurt dışına gönderilen işgücü göçü akımının 2010 yılından 2011 y1lına yurt dışı iş gücü akımının \% 2 artarak 53.800'e yükseldiğini göstermektedir (International Migration Outlook, 2013). Türkiye'de uluslararası boyutta ilk göç hareketi 1950'li ve 60'lı yıllarda Almanya'ya yoğun olmak üzere doğudan batıya doğru gerçekleşmiştir. Temel nedeni ise ekonomik sorunlardan kaynaklıdır. Bugün Türkiye'nin nüfusunun \% 6'sının dünyanın farklı ülkelerinde yerleşmiş olduğu görülmektedir (İçduygu, 2009). Dünya Bankası (2011) verilerine göre Türkiye'nin yurtdışındaki toplam göçmen sayısı: 4.261 milyon, yurtdışındaki göçmenlerin toplam nüfustaki payı \% 5,6'dır. Türkiye’nin en çok göç verdiği ülkeler ise Almanya, Fransa, Hollanda, Avusturya, ABD, Bulgaristan, Belçika, Suudi Arabistan, Birleşik Krallık, İsviçre'dir (World Bank, 2011). Yukarıda değinildiği üzere 1960’ların başından itibaren düzenli olarak göç alan bir ülke olan Almanya, göç dalgasının büyümesi nedeniyle yeni göçmenlik yasalarını uygulamaya koyarak Almanya’ya göçü yavaşlatmıştır. Bu doğrultuda Türkiye'den Almanya'ya yönelen göç hareketi de yavaşlamıştır. Buna rağmen aileyi yeniden birleştirmeye yönelik programlar yoluyla özellikle evliliğe bağlı göç hareketi varlığını korumuştur. Nitekim Türk vatandaşı kadınların evlilik yoluyla Almanya’ya göçü hala devam etmektedir.

Almanya’ya göç öncesi yaşadıkları yerlerde iş yaşamına ve sosyal yaşama katılımları son derece sınırlı olan Türk göçmen kadınların Almanya'da ekonomik nedenlere bağlı olarak iş yaşamına katılımlarında ciddi düzeyde bir artış görülmektedir. Göreli olarak Türkiye ile karşılaştırıldığında sosyal yaşama katılımları da Türkiye'den farklıdır. Türkiye'nin farklı bölgelerinden gelen ve farklı yaşam kültürüne sahip olan Almanya'ya evlilik yoluyla göç eden kadınların yerleştikleri kentlerdeki konumları da oldukça karmaşık ve çok boyutlu bir değişim sürecini beraberinde getirmiştir.

Bu çalışmanın amacı, göreli olarak Türkiye ile karşılaştırıldığında gerek sosyal yaşamda ve gerekse iş yaşamında daha fazla rol almaya başlayan, Almanya'daki Türk göçmen kadınların işçileşme süreçlerini incelemek ve gelecek beklentilerini değerlendirmektir. Bu amaç doğrultusunda aşağıdaki sorulara cevap aranmıştır:

- Almanya'daki Türk göçmen kadınların işçileşme süreçleri nasıldır?

- Almanya'daki Türk göçmen kadınların gelecek bağlamında göçten beklentileri nelerdir?

- Almanya'daki Türk göçmen kadınların gelecek beklentisi nasıldır?

\section{Yöntem}

Almanya'daki Türkgöçmen kadınların işçileşme süreçlerini incelemek ve gelecek beklentilerini değerlendirmek amacıyla yapılan bu çalışma, karşılaştırmalı türden ilişkisel tarama modelindedir. Ayrıca alan yazın taraması ve belge incelemesi ile yürütülen bu çalışmada, Çalışma ve Sosyal Güvenlik Bakanlığı'nın işgücü istatistiklerinden yararlanılmıştır.

\subsection{Evren ve Örneklem}

Türkiye'den Almanya'ya göç edenlerin Almanya'daki 16 eyalete göre dağılımları incelendiğinde, Almanya'nın hemen hemen her eyaletindeki nüfus içerisinde önemli bir paya sahip oldukları görülmektedir. Bununla birlikte Türkiye'den Almanya’ya göç edenler, daha yoğun bir şekilde sırasıyla Kuzey Ren Westfalya, Baden Württemberg ve Bavyera eyaletlerinde yaşamaktadırlar. Yoğunluk kategorisinde ise, ilk üç sırayı Bremen, Berlin ve Kuzey Ren Westfalya eyaletleri yer almaktadır. Ayrıca söz konusu nüfusun belirtilen eyaletlerde sanayinin yoğun olduğu kentlerde yaşadığı da bilinmektedir (Suğanlı, 2003: 16-18). Bu durum, çalışmanın yukarıda belirtilen beş eyaletteki sanayinin yoğun olduğu kentlerde yürütülmesini anlamlı kılmaktadır. Araştırmanın evrenini Türkiye'den Almanya'ya evlilik yoluyla göç eden 16 eyaletteki kadınlar oluşturmaktadır. Örneklem oluşturulurken ilk aşamada, 
yukarıda değinildiği üzere, Türkiye'den Almanya'ya göç eden nüfusun yoğunlukta bulunduğu eyaletler sıraya konarak, yoğunluk kategorisi kriterine göre sıralama baz alınarak beş eyalet seçilmiştir. Daha sonra seçilen her eyaleti temsilen, Türkiye'den Almanya'ya göç eden nüfusun yoğun olarak yaşadığı sanayileşmiş bir il baz alınarak, projenin Köln, Stutgart, Münih, Bremen ve Berlin şehirlerinde yürütülmesi kararlaştırılmıştır.

Almanya'nın örnekleme dahil edilen beş kentinde yaşayan ve kendilerine kartopu örneklemi yoluyla ulaşılan, araştırmaya dâhil edilen Türk göçmen kadınların Almanya'da yaşadıkları kentlere göre dağılımı şöyledir:

\begin{tabular}{|c|c|c|}
\hline Almanya'da Yaşadıkları Yer & $\mathbf{N}$ & $\%$ \\
\hline 1) Köln & 172 & 30.18 \\
\hline 2) Stuttgart & 150 & 26.32 \\
\hline 3) Bremen & 109 & 19.13 \\
\hline 4) Münih & 53 & 9.29 \\
\hline 5) Berlin & 86 & 15.08 \\
\hline Toplam & 570 & 100 \\
\hline
\end{tabular}

Tablo 1. Almanya'daki Türk Göçmen Kadınların Yaşadıkları Kentlere Göre Dă̆ılımı

Katılımcıların yaşa göre dağılımları incelendiğinde, çoğunluğunun 41-45 yaş aralığında, en az katılımcının ise 20-25 ve 71-75 yaş aralığında olduğu gözlenmiştir. Bu bulgu, araştırmaya dâhil edilen kadınların önemli bir çoğunluğunun 45 yaşın altında olduğunu göstermektedir. Dolayısıyla araştırmaya dâhil edilen kadınların tamamının aktif nüfus içerisinde yer aldığı söylenebilir.

Araştırmaya dâhil edilen göçmen kadınların \%89.83'ünün evli, \%7.54'ünün boşanmış ve \%2.63'ünün ise dul olduğu görülmektedir. Bu bulguya göre araştırma kapsamındaki göçmen kadınların büyük çoğunluğu evlidir.

Araştırmaya dâhil edilen göçmen kadınların eğitim durumları incelendiğinde, \%40’ının lise, \%24.57'sinin ortaokul, \%22.28'inin ilkokul ve \%11.05'inin ise yüksekokul/fakülte mezunu olduğu görülmektedir. Bu durum, araştırmaya dâhil edilen kadınların büyük bir çoğunluğunun (\%86.85) lise ve daha alt derece okullardan mezun olduklarını; yüksek lisans ve doktora mezunu oranının ise son derece düşük olduğunu ortaya koymaktadır.

Ayrıca katılımcılardan Almanca dilini az bilenlerin çoğunlukta hiç bilmeyenlerin ise azınlıkta olduğu gözlenmiştir. Zira Almanya'daki Türk göçmen kadınların yarıdan fazla çoğunluğunun (\%56) Almanca dil düzeyinin çok düşük düzeyde olduğu ve yine \%1.80’lik bir oranının da Almancayı hiç bilmediği; Almanca okuyorum ve yazıyorum diyenlerin oranın çok düşük düzeyde olduğu saptanmıştır. Araştırma bulgularına göre, araştırmaya dâhil edilen kadınlardan sadece \%28.79'i Almancayı iyi bildiklerini ifade etmektedir. Bu bulgular, genel olarak Almanya'daki Türk göçmen kadınların Almanca yeterliklerinin düşük olduğunu ortaya koymaktadır. $\mathrm{Bu}$ sonuca göre Almanca yetersizliğinin Almanya'daki Türk göçmen kadınların çalışma yaşamına girişlerini zorlaştıran önemli bir nedeni olabileceği çıkarsamasında bulunulabilir.

Araştırmaya dâhil edilen Almanya’ya göç ederek Köln, Stutgart, Münih, Bremen ve Berlin şehirlerinde ikamet eden 570 kadının yarıdan fazla çoğunluğunun (\%68.07) il ve kasaba/ilçe merkezinde, geriye kalanların ise önemli bir çoğunluğunun (\%26.67) köyde doğdukları görülmektedir. Bu bulgu, araştırmaya dâhil edilen kadınların hem köy ve hem de kent kökenli olduğunu ortaya koymaktadır.

Almanya'daki Türk göçmen kadınların doğdukları ile göre dağılımı incelendiğinde, hemen hemen Türkiye' nin tüm illerine dağıldıkları görülmektedir. Böyle olmakla birlikte, araştırmaya dahil edilen kadınların önemli bir çoğunluğu sirasıyla Malatya ( $n=66)$, Ankara $(n=46)$, İstanbul $(n=31)$, Kayseri $(n=29)$, Konya $(n=28)$, Sivas $(n=26)$, İzmir ( $n=18)$, Tunceli $(n=16)$, Çorum $(n=13)$, Adana, Zonguldak ve Kırşehir $(n=12)$, Antalya, Bursa ve Diyarbakır $(\mathrm{n}=11)$ ve Yozgat $(\mathrm{n}=10)$ ilindendir.

\subsection{Veriler ve Toplanması}

Araştırmanın amaçları, Almanya'daki Türk göçmen kadınların çalışma yaşamına girişte karşılaştıkları sorunlar ile bu sorunları etkileyen faktörlerin belirlenmesine yönelik ölçme araçları kullanılmasını gerektirmektedir. Sosyal ve ekonomik yaşama katılım konusunda erkek ve kadın arasında eşitliğin sağlanabilmesi ve kadınların işgücüne katılımının artırılmasına dönük politikaların geliştirilebilmesi için önem taşımasına rağmen, Türkiye'den Almanya'ya göç eden kadınların çalışma yaşamına girişte karşılaştıkları sorunların ve bu sorunları etkileyen faktörlerin ölçek yoluyla belirlenmesine yönelik çalışmalar çok sınırlıdır. Toplumsal cinsiyet eşitliğinin son derece önem kazandığı günümüz açısından Almanya' daki Türk göçmen kadınların çalışma yaşamına girişte karşılaştıkları sorunların ve bu sorunları etkileyen faktörlerin belirlenmesine dönük ölçme araçlarının geliştirilmemiş olması önemli bir eksikliktir. Bu eksikliğin giderilmesi amacıyla literatür taramasına dayalı olarak Gökçek Karaca ve Karaca tarafından "Göç Beklentisi Ölç̧eği” (GBÖ) ve "Çalışma Yaşamına Katılıma Yönelik Tutum Ölçeği” (ÇYKYTÖ) geliştirilmiştir. Araştırma verileri, geçerlik ve güvenirlik çalışmaları yapılarak araştırmacılar tarafından geliştirilen bu iki ölçek ile toplanmıştır. 


\section{Bulgular ve Yorumlar}

\subsection{Almanya'daki Türk göçmen kadınların İşçileşme Süreci}

Çalışmanın bu bölümünde araştırmaya dâhil edilen Almanya'daki Türk göçmen kadınların meslek, mesleki kıdemleri (hizmet süreleri), ücret karşılılığı çalışmaya Almanya'da başlayıp başlamama durumu, farklı işler yapıp yapmama durumu, farklı işler yapma nedenleri, yapılan işi öğrenme biçimi, işsizlik deneyimi, iş bulma yöntemi, çalıştıkları işyerinde hizmet süresi, iş ve/veya işyeri değiştirip değiştirmeme durumu, sigortalı olarak çalışıp çalışmama durumu, sosyal yardım alıp almama durumu, sendikaya üye olup olmama durumu, ücret düzeyine ilişkin bulguları yorumlanmıştır.

\subsection{1. İşçileşme Sürecinin Değerlendirilebilmesi Açısından Esas Alınan Ölçütler Meslek}

Araştırmaya dâhil edilen Almanya'daki Türk göçmen kadınların mesleğe göre dağılımı Tablo 2'de verilmiştir.

\begin{tabular}{|c|c|c|}
\hline Meslek & $N$ & $\%$ \\
\hline 1) $\dot{I}_{s ̧ c ̧ i}$ & 250 & 43.90 \\
\hline 2) Memur & 29 & 5.10 \\
\hline 3) Serbest Meslek & 24 & 4.20 \\
\hline 4) Esnaf & 40 & 7.00 \\
\hline 5) Ev Hanımı & 219 & 38.40 \\
\hline 6) $\dot{I}_{\text {Şsiz }}$ & 8 & 1.40 \\
\hline Toplam & 570 & 100 \\
\hline
\end{tabular}

Tablo 2. Almanya'daki Türk Göçmen Kadınların Mesleğe Göre Dă̆ılımı

Tablo 26 incelendiğinde, araştırmaya dâhil edilen Almanya'daki Türk göçmen kadınların \%43.90'ının işçi, \%38.40'1nın ev hanımı, \%'sinin esnaf, \%5.10'unun memur, \%4.20'sinin serbest meslek erbabı olduğu görülmektedir. Bu durum, araştırmaya dâhil edilen çalışan kadınların önemli bir çoğunluğunun (\%49) bağımlı çalışan (işçi ve memur) olduğunu, buna karşın bağımsız çalışanların (serbest meslek erbabı ve esnaf) sayısının da azımsanmayacak oranda (11.20) olduğunu ortaya koymaktadır. Ayrıca araştırma bulgularına göre, Almanya'daki Türk göçmen kadınların önemli bir kısmının da $(n=8)$ işsiz olduğu görülmektedir. Bu sonuçlar, araştırmaya dahil edilen Almanya'daki Türk göçmen kadınların önemli bir kısmının (n=343) bağımlı veya bağımsız çalıştı̆̆ını, çalışmayan 8 işçi de dahil önemli bir kısmının da çalışmadığını $(\mathrm{n}=227)$ ortaya koymaktadır.

Mesleki Kıdemleri (Hizmet Süreleri)

Araştırmaya dâhil edilen Almanya'daki Türk göçmen kadınların mesleki kıdemlerine göre dağılımı Tablo 3'te verilmiştir.

\begin{tabular}{|c|c|c|c|}
\hline Mesleki Kıdem & $N$ & \multicolumn{2}{|c|}{$\%$} \\
\hline 1) $0-1 y l l$ & 11 & 3.13 & 1.93 \\
\hline 2) $1-5 y l l$ & 158 & 45.02 & 27.72 \\
\hline 3) $5-10 y a l$ & 107 & 30.48 & 18.77 \\
\hline 4) $10-15 \mathrm{yll}$ & 44 & 12.54 & 7.72 \\
\hline 5) 15 yll ve üzeri & 31 & 8.83 & 5.44 \\
\hline Toplam & 351 & 100 & 61.58 \\
\hline 6) Çalışmıyorum & 219 & & 38.42 \\
\hline Toplam & 570 & & 100 \\
\hline
\end{tabular}

Tablo 3. Almanya'daki Türk Göçmen Kadınların Mesleki Kıdemlerine Göre Dağılımı

Tablo 3 incelendiğinde, araştırmaya dâhil edilen 351 kadının yarısından fazlasının (\%78.63) mesleki kıdem süresinin 10 yıldan daha düşük olduğu, 15 yıl ve üzerinde mesleki kıdeme sahip kadın sayısının ise azımsanmayacak oranda (\%8.83) olduğu görülmektedir. Kuşkusuz bu durum da, Almanya'ya geliş tarihinde olduğu gibi, araştırmanın konusunu Almanya'ya göç eden kadınların çalışma yaşamına girişte karşılaştıkları sorunların oluşturmasına bağlı olarak, göreli olarak çalışmanın daha genç kadınlar üzerine odaklanmasından kaynaklanmaktadır.

\section{Ücret Karşılı̆̆ı Çalışmaya Almanya'da Başlayıp Başlama Durumu}

Araştırmaya dâhil edilen Almanya'daki Türk göçmen kadınların ücret karşılılığg çalışmaya Almanya'da başlayıp başlamama durumuna göre dağılımı Tablo 4'te verilmiştir. 


\begin{tabular}{|c|c|c|c|}
\hline $\begin{array}{c}\text { Ücret Karşıllı̆̆ı Çalışmaya } \\
\text { Almanya'da Başlama Durumu }\end{array}$ & $N$ & \multicolumn{2}{|c|}{$\%$} \\
\hline 1) Evet & 291 & 82.91 & 51.10 \\
\hline 2) Hayır & 60 & 17.09 & 43.30 \\
\hline Toplam & 351 & 100 & 94.40 \\
\hline 3) Çalışmıyorum & 219 & & 5.60 \\
\hline Toplam & 570 & & 100 \\
\hline
\end{tabular}

Tablo 4. Almanya'daki Türk Göçmen Kadınların Ücret Karşılı̆̆ı Çalışmaya Almanya'da Başlayıp Başlamama Durumuna Göre Dağılımı

Tablo 4 incelendiğinde, araştırmaya dâhil edilen Almanya'daki Türk göçmen kadınlardan işsiz olduğunu ifade eden 8 kadın da dâhil çalışan 351 kadının çok büyük bir çoğunluğunun (\%82.91) ücret karşılığı çalışmaya Almanya'da başladıkları, buna karşın \%17.09'luk azımsanamayacak bir kesiminde ücret karş1lığı çalışmaya Türkiye'de başladıkları görülmektedir.

\section{Farklı Işsler Yapıp Yapmama Durumu}

Araştırmaya dâhil edilen Almanya'daki Türk göçmen kadınların farklı işler yapıp yapmama durumuna göre dağılımı Tablo 5 'te verilmiştir.

\begin{tabular}{|c|c|c|c|}
\hline Farklı İşler Yapıp Yapmama Durumu & $N$ & \multicolumn{2}{|c|}{$\%$} \\
\hline 1) Evet & 142 & 40.46 & 24.91 \\
\hline 2) Hayır & 209 & 59.55 & 36.67 \\
\hline Toplam & 351 & 100 & 61.58 \\
\hline 3) Çalışmıyorum & 219 & & 38.42 \\
\hline Toplam & 570 & & 100 \\
\hline
\end{tabular}

Tablo 5. Almanya'daki Türk Göçmen Kadınların Farklı İşler Yapıp Yapmama Durumuna Göre Dağılımı

Tablo 5 incelendiğinde, araştırmaya dâhil edilen Almanya'ya evlilik yoluyla göç eden işsiz olduğunu ifade eden 8 kadın da dâhil çalışan 351 kadının yarısından fazlasının (\%59.55), yaptıkları işin dışında farklı işler yapmadıkları, \%40.46'sının ise yaptıkların işin dışında farklı işleri tecrübe ettikleri görülmektedir. Araştırmaya dahil edilen kadınların neredeyse yarıya yakının farklı işler tecrübe etmesi, onların iş ve işyeri değiştirme hareketliliğinin yüksek olduğunu göstermektedir. Söz konusu durumun kadınların eğitim düzeyi ve buna bağlı olarak yaptıkları işin niteliğinden kaynaklandığı söylenebilir.

\section{Farklı İşler Yapma Nedenleri}

Araştırmaya dâhil edilen Almanya'daki Türk göçmen kadınların farklı işler yapma nedenlerine göre dağılımı Tablo 6'da verilmiştir.

\begin{tabular}{|c|c|c|}
\hline Farklı İşler Yapma Nedenleri & $N$ & $\%$ \\
\hline 1) Ücret düşüklüğ̈̈ ve yetersizliği & 80 & 56.34 \\
\hline 2) $\dot{I}_{s ̧ s i z l i k}$ & 11 & 7.74 \\
\hline 3) Issyerinin kapanması & 9 & 6.34 \\
\hline 4) İşverenle anlaşamama & 2 & 1.41 \\
\hline 5) $\dot{I} \sin$ zorluğ $u$ & 7 & 4.93 \\
\hline 6) Yer değişikliği & 6 & 4.23 \\
\hline 7) Dil sorunu & 7 & 4.93 \\
\hline 8) Diğer nedenler & 9 & 6.34 \\
\hline 7) Cevap Yok & 11 & 7.74 \\
\hline Toplam & 142 & 100 \\
\hline
\end{tabular}

Tablo 6. Almanya'daki Türk Göçmen Kadınların Farklı Işsler Yapma Nedenlerine Göre Dă̆glımı

Tablo 6'ya göre araştırmaya dâhil edilen ve farklı işler yaptığını ifade eden 142 kadının, farklı işler yapmalarının nedenlerine göre dağılımı incelendiğinde, daha çok ücret düşüklüğü ve yetersizliği nedeniyle (\%56.34) farklı işler yaptıkları anlaşılmaktadır. Tablo 30'da görüleceği üzere, araştırmaya dahil edilen kadınların ücret düşüklüğü ve yetersizliğine ilaveten işsizlik, işyerinin kapanması, dil sorunu, işin zorluğu, yer değişikliği, işverenle anlaşamama ve diğer kişisel nedenlerle de farklı işler yaptıkları görülmektedir. 


\section{Yaptlan İsi Öğrenme Biçimi}

Araştırmaya dâhil edilen Almanya'daki Türk göçmen kadınların yaptıkları işi öğrenme biçimine göre dağılımı Tablo 7'de verilmiștir.

\begin{tabular}{|c|c|c|c|}
\hline Yaptıkları İşi Öğrenme Biçimi & $N$ & \multicolumn{2}{|c|}{$\%$} \\
\hline 1) Çalışma sırasında & 276 & 78.63 & 48.42 \\
\hline 2) Ĕ̈itimini alarak & 75 & 21.37 & 13.16 \\
\hline Toplam & 351 & 100 & 61.58 \\
\hline 3) Çalışmıyorum & 219 & & 38.42 \\
\hline Toplam & 570 & & 100 \\
\hline
\end{tabular}

Tablo 7. Almanya'daki Türk göçmen kadınların Yaptıkları Işsi Öğrenme Biçimine Göre Dă̆ılımı

Tablo 7 incelendiğinde, araştırmaya dâhil edilen Almanya'ya göç eden ve işsiz olduğunu ifade eden 8 kadın da dahil çalışan 351 kadının büyük bir çoğunluğunun (\%78.63), yaptıkları işi çalışma esnasında öğrendiği, buna karşın yaptıkları işin eğitimini alan kadınların sayısının da azımsanmayacak oranda (\%21.37) olduğu görülmektedir.

\section{İssizlik Deneyimi}

Araştırmaya dâhil edilen Almanya'daki Türk göçmen kadınların işsizlik deneyimine göre dağılımı Tablo 8'de verilmiştir.

\begin{tabular}{|c|c|c|c|}
\hline İsssizlik Deneyimi & $N$ & \multicolumn{2}{|c|}{$\%$} \\
\hline 1) Evet & 177 & 50.43 & 31.05 \\
\hline 2) Hayır & 174 & 49.57 & 30.53 \\
\hline Toplam & 351 & 100 & 61.58 \\
\hline 3) Çalışmıyorum & 219 & & 38.42 \\
\hline Toplam & 570 & & 100 \\
\hline
\end{tabular}

Tablo 8. Almanya'daki Türk Göçmen Kadınların Isssizlik Deneyimine Göre Dă̆ılımı

Tablo 8 incelendiğinde, araştırmaya dâhil edilen Almanya’ya göç eden ve işsiz olduğunu ifade eden 8 kadın da dâhil çalışan 351 kadının işsizlik deneyimine sahip olup olmamalarına göre dağılımları incelendiğinde; hemen hemen yarısının (\%50.43) bir yıldan kısa süreli ve bir yıldan uzun süreli işsizlik yaşadığı, \%49.57'sinin ise hiç işsiz kalmadığı görülmektedir. Ancak kısa sürelerle işsiz kalanların sayısı (15), uzun süre işsiz kalanlara (152) göre daha yüksektir. İşsiz kalanların eğitim düzeylerinin düşüklüğü ve cinsiyetleri işsizlik sürelerini uzattığ1 ve tanıdıklarının az olması nedeniyle iş bulma imkânlarının kısıtlı olduğu tahmin edilmektedir. Zira Tablo 33 'te de görülebileceği üzere, araştırmaya dâhil edilen kadınların çok büyük bir çoğunluğunun çalıştıkları işleri, tanıdıkları aracılığıyla buldukları görülmektedir.

\section{İş Bulma Yöntemi}

Araştırmaya dâhil edilen Almanya'daki Türk göçmen kadınların çalıştıkları işi bulma yöntemine göre dağılımı Tablo 9'da verilmiştir.

\begin{tabular}{|c|c|c|}
\hline İş Bulma Yöntemi & $N$ & $\%$ \\
\hline 1) Bizzat başvuru ile & 50 & 14.25 \\
\hline 2) Tanıdık vasıtasıyla & 206 & 58.70 \\
\hline 3) İş Bulma Kurumu vasıtasılyla & 21 & 5.98 \\
\hline 4) İsyerinin aileye ait oluşu & 13 & 3.70 \\
\hline 5) İş ilanlart yoluyla & 19 & 5.41 \\
\hline 6) Sinav yoluyla & 3 & .85 \\
\hline 7) Staj vasitasıyla & 2 & .57 \\
\hline 8) Cevap yok & 37 & 10.54 \\
\hline Toplam & 351 & 100 \\
\hline
\end{tabular}

Tablo 9. Almanya'daki Türk Göçmen Kadınların Çalıştıkları İşi Bulma Yöntemi Göre Dă̆ılımı

Tablo 9 incelendiğinde, araştırmaya dâhil edilen Almanya'ya göç eden ve işsiz olduğunu ifade eden 8 kadın da dâhil çalışan 351 kadının yarısından fazlasının (\%58.70), tanıdıkları vasıtasıyla, \%14.75'inin bizzat başvuruyla, 
\%5.98'inin İş Bulma Kurumu vasıtasıyla, \%5.41'inin iş ilanları yoluyla iş bulduğu görülmektedir. Küçük bir oran (\%1.42) olmakla birlikte sınav ve staj yoluyla işe yerleşenlere de rastlanmaktadır.

\section{Çalıştıkları İsyerindeki Hizmet Süresi}

Araştırmaya dâhil edilen Almanya'daki Türk göçmen kadınların çalıştıkları işyerindeki hizmet süresine göre dağılımı Tablo 10'da verilmiştir.

\begin{tabular}{|c|c|c|}
\hline Çalıştıkları İşyerindeki Hizmet Süresi & $N$ & $\%$ \\
\hline 1) 1 yıldan daha kısa süreli & 20 & 5.70 \\
\hline 2) $1-5 y l l$ & 137 & 39.03 \\
\hline 3) $6-10 y u l$ & 110 & 31.34 \\
\hline 4) $11-15 y u l$ & 39 & 11.11 \\
\hline 5) 15 yıldan daha uzun süreli & 45 & 12.82 \\
\hline Toplam & 351 & 100 \\
\hline
\end{tabular}

Tablo 10. Almanya'daki Türk Göçmen Kadınların Çalıştıkları İşyerindeki Hizmet Süresine Göre Dağılımı

Tablo 10 incelendiğinde, araştırmaya dâhil edilen Almanya’ya göç eden ve çalıştığını ifade eden 351 kadının çok büyük bir çoğunluğunun (\%76.07) çalıştıkları işyerindeki hizmet süresinin 10 yıldan daha düşük olduğu ve 10 yıldan daha düşük hizmet süresine sahip olanların yaklaşık olarak yarısını 5 yıl ve 5 yıldan daha düşük hizmet süresine sahip olanların oluşturduğu, 10 yıl ve üzerinde hizmet süresine sahip kadın sayısının ise azımsanmayacak oranda (\%23.93) olduğu görülmektedir. Kuşkusuz bu durum da, Almanya’ya geliş tarihinde olduğu gibi, araştırmanın konusunu Almanya'ya evlilik yoluyla göç eden kadınların çalışma yaşamına girişte karşılaştıkları sorunların oluşturmasına bağlı olarak, göreli olarak çalışmanın daha genç kadınlar üzerine odaklanmasından kaynaklanmaktadır.

\section{İş ve/veya İşyeri Değiştirip Değiştirmeme Durumu}

Araştırmaya dâhil edilen Almanya'daki Türk göçmen kadınların iş ve/veya işyeri değiştirip değiştirmeme durumuna göre dağılımı Tablo 11 'de verilmiştir.

\begin{tabular}{|c|c|c|}
\hline $\begin{array}{l}\text { İş ve/veya İşyeri Değiştirip } \\
\text { Değiştirmeme Durumu }\end{array}$ & $N$ & $\%$ \\
\hline 1) Evet & 185 & 52.71 \\
\hline 2) Hayır & 158 & 45.01 \\
\hline 3) Cevap Yok & 8 & 2.28 \\
\hline Toplam & 351 & 100 \\
\hline
\end{tabular}

Tablo 11. Almanya'daki Türk Göçmen Kadınların İş ve/veya İşyeri Değiştirip Değiştirmeme Durumuna Göre Dă̆llımı

Tablo 11 incelendiğinde, araştırmaya dâhil edilen Almanya'ya göç eden ve çalıştığını ifade eden 351 kadının yarısından fazlasının çalıştıkları iş ve/veya işyerini değiştirip değiştirmedikleri sorusuna "evet" cevabı verdikleri, buna karşın azımsanmayacak bir oranının da (\%45.01) "hayır" cevabı verdikleri görülmektedir. Bu durum, araştırmaya dâhil edilen Almanya' daki Türk göçmen kadınlardan çalışanların önemli bir çoğunluğunun çalıştıkları iş ve/veya işyerini değiştirdiklerini ortaya koymaktadır.

Araştırmaya dâhil edilen Almanya'daki Türk göçmen kadınlardan iş ve/veya işyeri değiştirdiğini ifade edenlerin iş ve/veya işyeri değiştirme sıklıklarına göre dağılımı Tablo 12'de gösterilmiştir.

\begin{tabular}{|c|c|c|}
\hline İş ve/veya İşyeri Değiştirme Sıklıkları & $\mathbf{N}$ & $\%$ \\
\hline 1) 1 & 15 & 8.10 \\
\hline 2) 2 & 67 & 36.22 \\
\hline 3) 3 & 37 & 20.00 \\
\hline 4) 4 & 33 & 17.84 \\
\hline 5) 5 & 12 & 6.49 \\
\hline 6) 5'den fazla & 21 & 11.35 \\
\hline Toplam & 185 & 100 \\
\hline
\end{tabular}

Tablo 12. Almanya'daki Türk Göçmen Kadınların İş ve/veya İşyeri Değiş̧tirme Sıklıklarına Göre Dağılımı

Tablo 12 incelendiğinde, araştırmaya dâhil edilen Almanya'ya göç eden ve iş ve/veya işyeri değiştirdiğini ifade eden kadınların çok büyük bir çoğunluğunun (\%91.90) iki ve daha fazla sıklıkta ve hatta \%35.68'inin ise dört ve 
daha fazla sıklıkta değiştirdiği görülmektedir. Bu sonuç, araştırmaya dâhil edilen Almanya'daki Türk göçmen kadınların iş ve/veya işyeri değiştirme sıklıklarının yüksek düzeyde olduğunu ortaya koymaktadır.

Diğer göçmen işçiler gibi Almanya'daki Türk göçmen kadınların çalışma yaşamında karşılaştığı önemli sorunlardan biri, iş veya işyeri değiştirme zorunluluğudur. Araştırmaya dâhil edilen kadın işçilerinden sadece \%8.10'unun (15) hep aynı iş ve/veya işyerinde çalışması bu durumu kanıtlar niteliktedir.

İşyeri değiştirme sayısı bakımından en uç örneği 7 işyeri değiştirdiğini belirten 5 kişi oluş̧urmaktadır. Beşten fazla işyeri değiştirdiğini söyleyen 14 kişinin büyük çoğunluğu 6 işyeri değiştirmiştir.

Türk göçmen işçilerin sıklıkla işyeri değiştirmek zorunda kalmaları, çalıştıkları işyerlerindeki hizmet sürelerinin kısa oluşu ile de desteklenmektedir. Nitekim Tablo 34'de görülebileceği üzere araştırmaya dâhil edilen Almanya'ya göç eden ve çalıştı̆ııı ifade eden kadınların \%76.07'si $(\mathrm{n}=267)$ çalıştıkları iş ve/veya işyerinde en fazla 10 yıllık hizmet süresine sahipken, $\% 23.93$ 'ü $(n=84)$ ise 10 yıl ve üzerinde hizmet süresine sahiptir. Bu sonuç da, hemen hemen her göçmen iş̧̧inin sıklıkla iş ve işyeri değiştirdiğini göstermektedir. Bu durum, araştırmaya dâhil edilen Almanya'ya göç eden ve çalıştığını ifade eden kadınların iş güvencesi ve sosyo-ekonomik güvencelerden yoksun olmaları ile açıklanabilir.

Araştırmaya dâhil edilen Almanya'daki Türk göçmen kadınlardan iş ve/veya işyeri değiştirdiğini ifade eden ve yukarıda iş ve/işyeri değiştirme sıklıkları verilen kadınların iş ve/veya işyeri değiştirme nedenlerine göre dağılımı ise Tablo 13 'te verilmiştir.

\begin{tabular}{|c|c|c|}
\hline İş ve/veya İşyeri Değisştirme Nedenleri & $N$ & $\%$ \\
\hline 1) Ücret düşüklüğ̈̈ ve yetersizliği & 95 & 51.35 \\
\hline 2) İssten çıkarılma & 20 & 10.81 \\
\hline 3) İsyerinin devri, iflast ya da kapanması & 9 & 4.86 \\
\hline 4) İsveren ya da arkadaşlarla anlaşamama & 5 & 2.70 \\
\hline 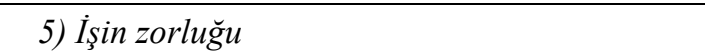 & 15 & 8.11 \\
\hline 6) Yer değişikliği & 9 & 4.86 \\
\hline 7) Dil sorunu & 10 & 5.41 \\
\hline $\begin{array}{l}\text { 8) Diğer nedenler (emeklilik, ulaşım zorluklarl, } \\
\text { sağllk sorunları, işten duyulan memnuniyetsizlik, } \\
\text { kendini geliş̧tirme isteği, daha iyi iş bulma isteği }\end{array}$ & 11 & 5.95 \\
\hline 7) Cevap Yok & 11 & 5.95 \\
\hline Toplam & 185 & 100 \\
\hline
\end{tabular}

Tablo 13. Almanya'daki Türk Gö̧̧men Kadınların İş ve/veya İşyeri Değiştirme Nedenlerine Göre Dağılımı

Tablo 13'e göre araştırmaya dâhil edilen Almanya'ya göç eden ve iş ve/veya işyeri değişstirdiğini ifade eden 185 kadının hemen hemen yarısının (\%51.35) ücret düşüklügü ve yetersizliği nedeniyle çalıştıkları iş ve/veya işyerini değiştirdikleri, bunun dışında işten çıkarılma, işyerinin devri, iflası ya da kapanması, işveren ya da arkadaşlarla anlaşamama, işin zorluğu, yer değişikliği, dil sorunu, emeklilik, ulaşım zorlukları, sağlık sorunları, işten duyulan memnuniyetsizlik, kendini geliştirme isteği ve daha iyi iş bulma isteği gibi durumların da iş ve/veya işyeri değiştirme bakımından önemli nedenler olduğu görülmektedir.

Tablo 6 ve Tablo 13 incelendiğinde araştırmaya dâhil edilen Almanya'ya göç eden ve iş ve/veya işyeri değiştirdiğini ifade eden 185 kadının, 43'ünün işini değiştirmeksizin farklı işyerlerinde çalıştıkları, buna karşın 142 kadının farklı işler yapmak üzere işyerlerini değiştirdiği sonucuna ulaşılmaktadır. Farklı işler yaptığını ifade eden 142 kadının, farklı işler yapmalarının nedenlerine göre dağılımı incelendiğinde, daha çok ücret düşüklüğü ve yetersizliği nedeniyle (\%56.34) farklı işler yaptıkları anlaşılmaktadır. Daha önce değinildiği üzere, araştırmaya dahil edilen kadınların ücret düşüklüğü ve yetersizliğine ilaveten işsizlik, işyerinin kapanması, dil sorunu, işin zorluğu, yer değişikliği, işverenle anlaşamama ve diğer kişisel nedenlerle de farklı işler yaptıkları görülmektedir.

\section{Sigortalı Olarak Çalışıp Çalışmama Durumu}

Araştırmaya dâhil edilen Almanya'daki Türk göçmen kadınların sigortalı olarak çalışıp çalışmama durumuna göre dağılımı Tablo 14'te verilmiştir.

\begin{tabular}{|c|c|c|}
\hline $\begin{array}{c}\text { Sigortalı Olarak Çalışıp Çalışmama } \\
\text { Durumu }\end{array}$ & $N$ & $\%$ \\
\hline 1) Evet & 323 & 92.02 \\
\hline 2) Cevap Yok & 28 & 7.98 \\
\hline Toplam & 351 & 100 \\
\hline
\end{tabular}

Tablo 14. Almanya'daki Türk göçmen kadınların Sigortalı Olarak Çalışıp Çalışmama Durumuna Göre Dağılımı 
Tablo 14 incelendiğinde, araştırmaya dâhil edilen Almanya’ya göç eden ve çalıştığını ifade eden 351 kadının hemen hemen tamamına yakınının (\%92.02) sigortalı olarak çalıştığı, sigortasız çalıştı̆̆ını ifade eden kadına hiç rastlanmadığı görülmektedir. Bu durum, Almanya'da çalışma ilişkileri sisteminin güçlü bir yapıya sahip olması ile açıklanabilir.

\section{Sosyal Yardım Alıp Almama Durumu}

Araştırmaya dâhil edilen Almanya'daki Türk göçmen kadınların sosyal yardım alıp almama durumuna göre dağılımı Tablo 15’te verilmiştir.

\begin{tabular}{|c|c|c|}
\hline Sosyal Yardım Alıp Almama Durumu & $N$ & $\%$ \\
\hline 1) Evet & 98 & 17.20 \\
\hline 2) Hayır & 422 & 74.00 \\
\hline 6) Cevap yok & 50 & 8.80 \\
\hline Toplam & 570 & 100 \\
\hline
\end{tabular}

Tablo 15. Almanya'daki Türk Göçmen Kadınların Sosyal Yardım Alıp Almama Durumuna Göre Dăğlımı

Tablo 15 incelendiğinde, araştırmaya dâhil edilen Almanya'daki Türk göçmen kadınların çok büyük bir çoğunluğunun (\%74) sosyal yardım almadıklarını beyan ettikleri, buna karşın sosyal yardım alan kadınların sayısının da azımsanmayacak oranda (\%17.20) olduğu görülmektedir. Sosyal yardım alanların oranının belirtilen rakamın çok üzerinde olabileceği tahmin edilmektedir. Zira kadınların sosyal yardım aldıklarını beyan etmede güçlük çektikleri gözlemlenmiştir.

\section{Sendikaya Üye Olup Olmama Durumu}

Araştırmaya dâhil edilen Almanya'daki Türk göçmen kadınların sendikaya üye olup olmama durumuna göre dağılımı Tablo 16'da verilmiştir.

\begin{tabular}{|c|c|c|}
\hline Sendikaya Üye Olup Olmama Durumu & $N$ & $\%$ \\
\hline 1) Sendikaya Üye Olanlar & 78 & 22.22 \\
\hline 2) Sendikaya Üye Olmayanlar & 234 & 66.67 \\
\hline 6) Cevap yok & 39 & 11.11 \\
\hline Toplam & 351 & 100 \\
\hline
\end{tabular}

Tablo 16. Almanya'daki Çalışan Türk Göçmen Kadınların Sendikaya Üye Olup Olmama Durumuna Göre Dağılımı

Tablo 16 incelendiğinde, araştırmaya dâhil edilen Almanya’ya göç eden ve çalıştığını ifade eden 351 kadının önemli bir çoğunluğunun (\%66.67) sendika üyesi olmadığı, buna karşın sendikaya üye olan kadınların sayısının da azımsanmayacak oranda (\%22.22) olduğu görülmektedir. Almanya'ya evlilik yoluyla göç eden çalışan kadınların işçi sendikalarına üye olmamaları/olamamaları, tüm göçmen işçiler açısından olduğu gibi Almanya'daki göçmen işçilerinin sorunlarının da sendikalar tarafından yeterince benimsenmemesi ve göçmen işçilerin işçi sendikalarının ilgi alanı dışında kalması ile açıklanabilir (Gökçek Karaca, 2005).

Göçmen işçilerin yurt dışında olmaları dolayısıyla göç veren ülkedeki sendikaların onlara ulaşma zorlukları ve hizmet verme konusunda yaşanan güçlükler, göçmen işçilerin sendikalara katılımının teşvik edilmesini zorlaştırmaktadır. Aynı şekilde göçmen işçilerin çeşitli sektörlerde, farklı işverenler için çalışmaları, dil ve kültür sorunları da göç alan ülkedeki sendikaların göçmen iş̧̧ilere temasa geçebilmesini güçleştirerek onların sendikalara katılımının teşvik edilmesini zorlaştırmaktadır (Erkul, 1965, 146-148). Göçmen işçilerin genellikle iyi bir eğitim almamış olmaları, sendikalar konusunda bilgi sahibi olmamaları, sendikaya üye olmalarının gerekli olduğuna inanmamaları gibi nedenler de göçmen işçilerin sendikalara katılımının teşvik edilmesini zorlaştırmaktadır. Özellikle göçmen işçilerin düzensiz bir durumda olmaları halinde ise, göçmen işçilerin sendikalara katılımının teşvik edilmesi daha da zorlaşmaktadır. Ayrıca göç alan ülkelerde sendikalara katılımı engellemek amacıyla izlenen kısıtlayıcı politikalar ve uygulamalar, işverenler tarafından yapılan yoğun baskılar da, büyük miktarlarda göç maliyetlerine katlanmak zorunda kalan göçmen işçileri, işlerini kaybetme korkusuyla sendikalara katılma konusunda son derece kısıtlı bir hareket alanı bırakmaktadır. Aynı zamanda sınırlı kaynaklara sahip olan sendikalar da üyelerinin göçmen işçilere yönelik hizmetlerin genişletilmesinden duydukları rahatsılık nedeniyle göçmen işçilerle sınırlı düzeyde ilişki kurabilmektedirler.

\section{Ücret Düzeyi}

Araştırmaya dâhil edilen Almanya'daki Türk göçmen kadınlardan çalışanların ücret düzeyine göre dağglımı Tablo 17'de verilmiştir. 


\begin{tabular}{|c|c|c|}
\hline$\ddot{U}$ cret Düzeyi & $\mathbf{N}$ & $\%$ \\
\hline 1) $1.800 €^{*}$ ve altı & 300 & 85.47 \\
\hline 2) $1.801-3000 €$ & 45 & 12.82 \\
\hline 3) $3.001 €$ ve üzeri & 6 & 1.71 \\
\hline Toplam & 351 & 100 \\
\hline
\end{tabular}

Tablo 17. Almanya'daki Türk göçmen kadınlardan Çalışanların Ücret Düzeyine Göre Dă̆llımı

* Almanya'da asgari ücret uygulamasına dahil edilen işkolları dikkate alınarak, ortalama saatlik asgari ücretin $8 €$ olduğundan hareketle, tam süreli çalışan iş̧̧inin aylık olarak $1800 €$ ücret alacağı varsayılmıştır.

Tablo 17 incelendiğinde, araştırmaya dâhil edilen Almanya'ya göç eden ve çalıştığını ifade eden 351 kadından, elde ettikleri ücretin miktarını beyan edenlerin önemli bir çoğunluğunun, ücret gelirinin asgari ücret düzeyinde olduğu görülmektedir. Gelir düzeyi 3001 €'nun üzerinde olan 6 kişiden 4 'ünün işyeri sahibi oldukları saptanmıştır.

\subsection{2. İşçileşme Sürecinin Dĕgerlendirilmesi}

Yukarıda belirtilen esaslar çerçevesinde Almanya'daki Türk göçmen kadınların işçileşme sürecine ilişkin özellikleri şu şekilde özetlenebilir:

- Katılımcıların çoğu ilk iş hayatına Almanya'da başlamıştır.

- Sadece 142 katılımcı ilk işinin ve şu anki işinin dışında Almanya'da farklı işlerde çalışmıştır.

- 271 katılımcı şu an çalıştığı işinden önce iş arayıp bulamadığ1 dönemler olmamıştır.

- Yaklaşık 200 katılımcı herhangi bir sigortaya sahip değildir.

- Sigortaya sahip olmayan katılımcıların sadece 98 'i sosyal yardım almaktadır.

- Katılımcıların büyük bir çoğunluğu sendikaya üyedir. Aynı zamanda 273 katılımcı sendikaya üye olmanın gerekli olduğunu savunmaktadır.

- Katılımcıların çoğu Türkiye'de bıraktıkları yerden eğitimlerine devam etmek istememektedirler.

\subsection{Gelecek Beklentisi}

\subsubsection{Göçten Beklentiler}

Araştırmaya dâhil edilen Almanya'daki Türk göçmen kadınların göçe ilişkin beklenti düzeylerine ait betimsel istatistikler ise, Tablo 18'de verilmiştir.

\begin{tabular}{|c|c|c|}
\hline Göçe İlişkin Beklenti Düzeyi & Ort. & Mod \\
\hline 1. Almanya'da Türkiye'ye göre beni daha iyi bir geleceğin beklediğine inanıyorum. & 3.00 & 2.00 \\
\hline 2. Almanya'da Türkiye’ye göre daha iyi bir iş bulabileceğimi düşünüyorum. & 3.00 & 2.00 \\
\hline $\begin{array}{l}\text { 3. Almanya'da işim çok iyi olmasa da, Türkiye’ye göre daha yüksek ücret alacă̆ımı } \\
\text { düşünüyorum. }\end{array}$ & 4.00 & 4.00 \\
\hline 4. $\quad$ Almanya'da ne iş yaparsam yapayım sosyal haklarımın korunacağına inanıyorum. & 4.00 & 4.00 \\
\hline 5. $\quad$ Almanya'da siyasal haklarımın kısıtlanmayacağına inanıyorum. & 3.00 & 4.00 \\
\hline $\begin{array}{l}\text { 6. Almanya'da hiç çalışmasam bile maddi açıdan bir yoksunluk yaşayacă̆ımı } \\
\text { düşünmüyorum. }\end{array}$ & 4.00 & 4.00 \\
\hline 7. Almanya'daki yaşam olanakları beni cezbediyor. & 3.00 & 2.00 \\
\hline 8. $\quad$ Almanya'daki çalışma koşulları beni cezbediyor. & 3.00 & 2.00 \\
\hline 9. Almanya'daki istikrar ortamı beni cezbediyor. & 3.00 & 2.00 \\
\hline 10. Almanya'daki çalışma olanakları beni cezbediyor. & 3.00 & 2.00 \\
\hline $\begin{array}{l}\text { 11. Almanya'da mesleki terfi ve liyakat bakımından ayırımcılığa maruz kalmayacağımı } \\
\text { düsünüyorum. }\end{array}$ & 3.00 & 1.00 \\
\hline
\end{tabular}

Tablo 18. Almanya'daki Türk Göçmen Kadınların Göçe İlişkin Beklenti Düzeyleri

Tablo 18'de görülebileceği üzere, araştırmaya dâhil edilen Almanya'daki Türk göçmen kadınların göçe ilişkin beklenti ifadelerine katılma düzeylerinin düşük olduğu görülmektedir. Bu bulgu, araştırmaya dâhil edilen Almanya'daki Türk göçmen kadınların Almanya'ya göç etmelerinde, Türkiye’ye göre Almanya'nın çekiciliğinin ve Almanya'nın sosyal, ekonomik ve siyasal haklar bakımından gelişmişliğinin çok etkili olmadığını ortaya koymaktadır. Bu sonuca göre, araştırmaya dâhil edilen Almanya'daki Türk göçmen kadınların göç kararı almalarında kendilerinin belirleyici olmadığı ve evliliğin doğal bir sonucu olarak Almanya'ya göç etmek zorunda kaldıkları söylenebilir. 
Tablo 18'de görülebileceği üzere, araştırmaya dâhil edilen Almanya'daki Türk göçmen kadınların göçe ilişkin beklenti ifadelerinden göreli olarak en çok katıldıkları üç ifade sırasıyla şunlardır:

- “Almanya'da ne iş yaparsam yapayım sosyal haklarımın korunacağına inanıyorum”

- “Almanya'da işim çok iyi olmasa da, Türkiye'ye göre daha yüksek ücret alacağımı düşünüyorum”

- “Almanya'da hiç çalışmasam bile maddi açıdan bir yoksunluk yaşayacağımı düşünmüyorum”.

Yine Tablo 45'de görülebileceği üzere, araştırmaya dâhil edilen Almanya'daki Türk göçmen kadınların göçe ilişkin beklenti ifadelerinden göreli olarak en az katıldıkları üç algı ifadesi ise sırasıyla şunlardır:

- "Almanya'da mesleki terfi ve liyakat bakımından ayırımcılığa maruz kalmayacağımı düşünüyorum."

- "Almanya' daki çalışma koşulları beni cezbediyor"

- "Almanya'daki çalışma olanakları beni cezbediyor".

Tablo 18'de de görülebileceği üzere, araştırmaya dâhil edilen Almanya'daki Türk göçmen kadınların gerek "Türkiye ile Karşılaştırıldığında Almanya'yı Çekici Kılan Nedenlere” ve gerekse de "Sosyal, Ekonomik ve Siyasal Haklar Bakımından Almanya'nın Gelişmişliğine” yönelik beklenti ifadelerine katılma düzeyleri düşüktür. Böyle olmakla birlikte araştırmaya dâhil edilen Almanya'daki Türk göçmen kadınların "Sosyal, Ekonomik ve Siyasal Haklar Bakımından Almanya'nın Gelişmişliğine” yönelik beklenti ifadelerine katılma düzeyleri “Türkiye ile Karşılaştırıldığında Almanya'yı Çekici Kılan Nedenlere” yönelik beklenti ifadelerine katılma düzeylerinden daha yüksektir.

\subsubsection{Gelecek Beklentisi}

Araştırmaya dâhil edilen Almanya'daki Türk göçmen kadınların geleceğe güvenle bakıp bakmama durumuna göre dağılımı Tablo 19'da verilmiştir.

\begin{tabular}{|c|c|c|}
\hline Geleceğe Güvenle Bakıp Bakmama Durumu & $N$ & $\%$ \\
\hline 1) Geleceğe güvenle bakanlar & 313 & 54.90 \\
\hline 2) Geleceğe güvenle bakmayanlar & 244 & 42.80 \\
\hline 6) Cevap yok & 13 & 2.30 \\
\hline Toplam & 570 & 100 \\
\hline
\end{tabular}

Tablo 19. Almanya'daki Türk Göçmen Kadınların Geleceğe Güvenle Bakıp Bakmama Durumuna Göre Dă̆llımı

Tablo 19 incelendiğinde, araştırmaya dâhil edilen Almanya'daki Türk göçmen kadınların yarıdan fazlasının (\%54.90) geleceğe güvenle baktığı, buna karşın \%42.80'inin ise geleceğe güvenle bakmadıkları görülmektedir. Bu durum, Almanya’ya evlilik yoluyla göç eden kadınların önemli bir kısmının gelecekten endişeli olduğunu ortaya koymaktadir.

\section{Sonuç}

Araştırma sonuçlarına göre, araştırmaya dâhil edilen Almanya'daki Türk göçmen kadınlar işçileşme süreci açısından şu özellikleri göstermektedir:

- Araştırmaya dâhil edilen kadınların önemli bir çoğunluğu (\%49) bağımlı çalıșandır (ișçi ve memur). Buna karşın bağımsız çalışanların (serbest meslek erbabı ve esnaf) sayısı da azımsanmayacak orandadır (11.20). Ayrıca araştırma bulgularına göre, Almanya'daki Türk göçmen kadınların önemli bir kısmının da işsiz olduğu ve daha çok kendilerini ev hanımı olarak ifade ettiği görülmektedir.

- Araştırmaya dâhil edilen işsiz olduğunu ifade eden 8 kadın da dahil çalışan 351 kadının çok büyük bir çoğunluğunun (\%78.63) mesleki kıdem süresinin 10 yıldan daha düşük olduğu, 15 yıl ve üzerinde mesleki kıdeme sahip kadın sayısının ise azımsanmayacak oranda (\%8.83) olduğu görülmektedir.

- Araştırmaya dâhil edilen 351 çalışan kadının çok büyük bir çoğunluğunun (\%82.91) ücret karşılığı çalışmaya Almanya'da başladıkları, buna karşın \%17.09'luk azımsanamayacak bir kesiminde ücret karşılığı çalışmaya Türkiye'de başladıkları görülmektedir.

- Araştırmaya dâhil edilen 351 çalışan kadının yarısından fazlasının (\%59.55), yaptıkları işin dıșında farklı işler yapmadıkları, \%40.46'sının ise yaptıkların işin dışında farklı işleri tecrübe ettikleri görülmektedir.

- Araştırmaya dâhil edilen ve farklı işler yaptığını ifade eden 142 kadının, daha çok ücret düşüklüğü ve yetersizliği nedeniyle (\%56.34) farklı işler yaptıkları saptanmıştır. Ayrıca ücret düşüklüğü ve yetersizliğine ilaveten Almanya'daki Türk göçmen kadınların işsizlik, işyerinin kapanması, dil sorunu, işin zorluğu, yer değişikliği, işverenle anlaşamama ve diğer kişisel nedenlerle de farklı işler yaptıkları görülmektedir.

- Araştırmaya dâhil edilen 351 çalışan kadının büyük bir çoğunluğunun (\%78.63), yaptıkları işi çalışma esnasında öğrendiği, buna karşın yaptıkları işin eğitimini alan kadınların sayısının da azımsanmayacak oranda (\%21.37) olduğu görülmektedir. 
- Araştırmaya dâhil edilen 351 çalışan kadının hemen hemen yarısının (\%50.43) bir yıldan kısa süreli ve bir yıldan uzun süreli işsizlik yaşadığ $1, \% 49.57$ 'sinin ise hiç işsiz kalmadığı görülmektedir.

- Araştırmaya dâhil edilen 351 çalışan kadının yarısından fazlasının (\%58.70), tanıdıkları vasıtasıyla, \%14.75'inin bizzat başvuruyla, \%5.98'inin İş Bulma Kurumu vasıtasıyla, \%5.41'inin iş ilanları yoluyla iş bulduğu görülmektedir. Küçük bir oran (\%1.42) olmakla birlikte, Almanya’ya evlilik yoluyla göç eden kadınlardan sınav ve staj yoluyla işe yerleşenlere de rastlanmaktadır.

- Araştırmaya dâhil edilen 351 çalışan kadının çok büyük bir çoğunluğunun (\%76.07) çalıştıkları işyerindeki hizmet süresinin 10 yıldan daha düşük olduğu ve 10 yıldan daha düşük hizmet süresine sahip olanların yaklaşık olarak yarısını 5 yıl ve 5 yıldan daha düşük hizmet süresine sahip olanların oluşturduğu, 10 yıl ve üzerinde hizmet süresine sahip kadın sayısının ise azımsanmayacak oranda (\%23.93) olduğu görülmektedir.

- Araştırmaya dâhil edilen kadınlardan çalışanların önemli bir çoğunluğunun iş ve/veya işyeri değiştirme sıklıklarının yüksek düzeyde olduğu görülmektedir. Diğer göçmen işçiler gibi Almanya'ya evlilik yoluyla göç eden kadın göçmen işçilerin de çalışma yaşamında karşılaştığı önemli sorunlardan biri, iş veya işyeri değiştirme zorunluluğudur. Araştırmaya dâhil edilen kadın işçilerinden sadece \%8.10'unun (15) hep aynı iş ve/veya işyerinde çalışması bu durumu kanıtlar niteliktedir.

- Araştırmaya dâhil edilen iş ve/veya işyeri değiştirdiğini ifade eden 185 kadının hemen hemen yarısının (\%51.35) ücret düşüklüğü ve yetersizliği nedeniyle çalıştıkları iş ve/veya işyerini değiştirdikleri, bunun dışında işten çıkarılma, işyerinin devri, iflası ya da kapanması, işveren ya da arkadaşlarla anlaşamama, işin zorluğu, yer değişikliği, dil sorunu, emeklilik, ulaşım zorlukları, sağlık sorunları, işten duyulan memnuniyetsizlik, kendini geliştirme isteği ve daha iyi iş bulma isteği gibi durumların da iş ve/veya işyeri değiştirme bakımından önemli nedenler olduğu görülmektedir.

- Araştırmaya dâhil edilen çalıştığını ifade eden 351 kadının hemen hemen tamamına yakınının (\%92.02) sigortalı olarak çalıştığı, sigortasız çalıştığını ifade eden kadına hiç rastlanmadığı görülmektedir.

- Araştırmaya dâhil edilen kadınların çok büyük bir çoğunluğunun (\%74) sosyal yardım almadıklarını beyan ettikleri, buna karşın sosyal yardım alan kadınların sayısının da azımsanmayacak oranda (\%17.20) olduğu görülmektedir.

- Araştırmaya dâhil edilen çalıştığını ifade eden 351 kadının önemli bir çoğunluğunun (\%66.67) sendika üyesi olmadığı, buna karşın sendikaya üye olan kadınların sayısının da azımsanmayacak oranda (\%22.22) olduğu görülmektedir.

- Araştırmaya dâhil edilen 351 çalışan kadının çok büyük bir çoğunluğunun, ücret gelirinin asgari ücret düzeyinde olduğu görülmektedir.

Araştırma sonuçlarına göre, araştırmaya dâhil edilen Almanya'daki Türk göçmen kadınların, yarıdan fazlasının (\%54.90) geleceğe güvenle baktığı, buna karşın \%42.80'inin ise geleceğe güvenle bakmadıkları; göçe ilişkin beklenti ifadelerine katılma düzeylerinin düşük olduğu görülmektedir. Bu bulgu, araştırmaya dâhil edilen Almanya'ya evlilik yoluyla göç eden kadınların Almanya'ya göç etmelerinde, Türkiye'ye göre Almanya'nın çekiciliğinin ve Almanya'nın sosyal, ekonomik ve siyasal haklar bakımından gelişmişliğinin çok etkili olmadığını ortaya koymaktadir.

Bu sonuçlar Almanya'daki Türk göçmen kadınların ev kadınlığını meslek olarak görmeme eğiliminin ve algısının sürekliliğine işaret etmektedir. Çalıştığını belirten kadınlara ilişkin veriler, göçmen kadınların çalışma yaşamında karşılaştıkları sorunları ve işçileşme süreçlerinde enformel ilişki ağlarının etkinliğini ortaya koymaktadır. Zira işçi olduklarını belirten kadınlar büyük oranda farklı işleri de tecrübe etmişler ve iş değişikliğinin gerekçesi olarak ücret düşüklüğü ve yetersizliğine işaret etmişlerdir. Buna ek olarak, kadınların iş bulma süreçlerinde en etkili aracın İş Bulma Kurumu, staj ya da sinavdan ziyade tanıdıklar olduğu da görülmektedir. Formel yapıdaki yetersizliğin bir sonucu olarak bu kadınların çoğu düşük ücretlerle çalışmakta ve herhangi bir sosyal yardım almamaktadır. Kadınların işçileşme süreçlerinde karşılaştıkları tüm bu sorunlara rağmen, önemli bir kısmı sosyal güvenlik hakkına sahiptir. Fakat sosyal güvencenin varlığı, kadınların ekonomik durumlarına ilişkin olumsuz değerlendirme yapmalarına ve geleceğe yönelik güvensiz bir bakış taşımalarına engel olamamıştır. 


\section{Kaynakça}

- Burda, M. (1995). Migration and the Option Value of Waiting. CEPR Discussion Paper, No.1229.

- Coppel, J. D., J-C and Visco, I. (2001), Trends in Immigration and Economic Consequences, OECD Economics Department Working Papers No:284, Web: http://www.oecd.org/dataoecd/29/30/1891411.pdf (Erişim Tarihi: 15.11.2007).

- Gençler, 2002. Yabancı Kaçak İş̧̧ilik Gerçeği ve Türkiye Örneği, İş Hukuku ve İktisat Dergisi, TÜHİS Yayınları, 17 (3), 28-46.

- Gençler, 2004. Avrupa Birliği'nin Göç Politikası, Sosyal Siyaset Konferansları Dergisi, 49, 173-197.

- http://iudergi.com/index.php/sosyalsiyaset//article/viewFile/461/416

- International Migration Outlook, 2013. http://www.keepeek.com/Digital-Asset-Management/oecd/socialissues-migration-health/international-migration-outlook-2013_migr_outlook-2013-en\#page1

- İçduygu, 2009. International Migration and Human Development in Turkey, Human Development Research Paper 2009/52. http://hdr.undp.org/sites/default/files/hdrp_2009_52.pdf

- The Migration and Remittances Factbook, World Bank, 2011. http://siteresources.worldbank.org/INTLAC/Resources/Factbook2011-Ebook.pdf

- Suğanlı, Mehmet (2003). Almanya'da Yaşayan ve Türkiye Cumhuriyet Merkez Bankasında Hesabı Bulunan Türklerin Sosyo-Ekonomik Yapısı ve İşçi Dövizleri, Ankara: TCMB Uzmanlık Yeterlilik Tezi.

- Vishwanath, T. (1991). Information Flow, Job Search and Migration. Journal of Development Economics, Vol.36, No.2.

- Visco, I. (2000). Immirgation, Development and the Labour Market. Migration:Scenarios for The 21st Century (International Conference), Rome, 12-14 July, Web: http://www.oecd.org/pdf/M000080000/M00008031.pdf (Erişim Tarihi: 2.03.2003).

- Werner, H. (1994). Reginal Economic Integration and Migration: The European Case. The Annals of The American Academy of Political and Social Sciences, Volume 534, 147-164.

- Werner H, 1996. Reginal Economic Integration and Migration: The European Case. The Annals of The American Academy of Political and Social Sciences, Vol. 534, 147-164. 


\title{
Almanya'daki Türk Göçmen Kadınların Çalışma Yaşamına Katılım Konusundaki Tutumlarını Belirlemeye Yönelik Ölçek Çalışması
}

\section{The Study of the Scale to Determine Attitudes on Labor Force Participation of Turkish Migrant Women in Germany}

\author{
Asst. Prof. Dr. Erol Karaca (Anadolu University, Turkey) \\ Prof. Dr. Nuray Gökçek Karaca (Anadolu University, Turkey)
}

\begin{abstract}
This study sought to develop a Likert type scale which is valid and reliable in order to investigate attitudes on labor life participation of the migrant women. The research was carried out with 570 Turkish migrant women in Germany, living in Cologne (172), Stuttgart (150), Bremen (109), Munich (53) and Berlin (86), Germany, in 20122013. The data were collected by using a questionnaire consisting of two sections, developed by the researchers to determine attitudes on labor life participation of migrant women. The first part is the form related to demographic and personal information, consisting of items about the gender, age, marital status, status, if they find their income level sufficient, if they look at the future with confidence and perceptions about being unionized. The second part includes 15 expressions related to attitudes on labor life participation of migrant women on a 5-point Likert-type scale consisting of 5 choices, from $1=$ Strongly Disagree to $5=$ Strongly Agree. Data which were collected through that The Attitude Scale on Labor Life Participation were analyzed with factor analysis by using the statistical package SPSS. The findings of the study revealed that the scale was valid and reliable.
\end{abstract}

\section{Giriş}

Günümüzde kadınlar diğer alanlara göre en çok ekonomik yaşama katılım konusunda ayırımcılığa maruz kalmaktadır. Kadın göçmenler yaşanan bu ayrımcılığı çok daha ciddi boyutta yaşamakta, yaşadıkları ülkenin vatandaşlarının sahip oldukları kültürel, sosyal ve ekonomik haklardan yararlanamamaktadırlar. Kuşkusuz kadınların çalışma yaşamına katılım konusunda ayrımcılığa maruz kalmasının en önemli nedenlerinden biri, kadını ekonomide erkeklerle aynı mesleki firsatlardan ve eşit ücret alma hakkından yararlanmaktan alıkoyan sosyokültürel engellerin varlığını sürdürmesidir. Gerçekten de kadınların yaptığı işin, aileye destek olmak için yapılan bir çalışma olduğu yolundaki geleneksel anlayış, kadınlara ekonomik büyüme dönemlerinde gereksinim duyulan ve gerileme dönemlerinde bir kenara itilen, yedek işgücü niteliği kazandırmaktadır.

Almanya'daki Türk göçmen kadınların çalışma yaşamına girişlerini sadece izlenilen ayırımcılık politikaları etkilememekte, bunun yanında tüm dünya ülkelerinde olduğu gibi, Almanya'da da kadınların çalışma yaşamına girişlerini zorlaştıran etkenlere ilaveten Türkiye'den gelen kadınlara özgülenebilecek başkaca faktörlerin de çalışma yaşamına girişi zorlaştırdığı tahmin edilmektedir. Türkiye'den Almanya'ya göç edenlerin cinsiyete göre dağılımı incelendiğinde, Almanya'da çalışan Türkiyeli göçmenlerin sayısı 458.243 iken, bu rakamın içinde çalışan kadınların oranı \%29 olması, Türkiye'den Almanya'ya göç eden kadınların çalışma yaşamına girişte isteksiz oldukları şeklinde yorumlanabileceği gibi, çalışma yaşamına girişte erkeklerle karşıslaştırılamayacak boyutta zorluklar yaşadıkları şeklinde de açıklanabilir.

Sosyal ve ekonomik yaşama katılım konusunda erkek ve kadın arasında eşitliğin sağlanabilmesi ve kadınların işgücüne katılımının artırılmasına dönük politikaların geliştirilebilmesi için önem taşımasına rağmen, Türkiye'den Almanya'ya göç eden kadınların çalışma yaşamına girişte karşıllaştıkları sorunların ve bu sorunları etkileyen faktörlerin ölçek yoluyla belirlenmesine yönelik çalışmalar çok sınırlıdır. Toplumsal cinsiyet eşitliğinin son derece önem kazandığı günümüz açısından Türkiye'den Almanya'ya göç eden kadınların çalışma yaşamına girişte karşılaştıkları sorunların ve bu sorunları etkileyen faktörlerin belirlenmesine dönük ölçme araçlarının geliştirilmemiş olması önemli bir eksikliktir. Bu eksikliğin giderilmesi için yapılan bu çalışmanın amacı, Türkiye'den Almanya'ya göç eden kadınların çalışma yaşamına girişte karşılaştıkları sorunların ve bu sorunları etkileyen faktörlerin saptanabilmesi için bir tutum ölçeği geliştirmektir.

\section{Yöntem}

Almanya'daki Türk göçmen kadınların çalışma yaşamında karşılaştıkları sorunları ve bu sorunlara etki eden faktörleri belirlemek için bir tutum ölçeği geliştirmek amacıyla yapılan bu çalışma, karşılaştırmalı türden ilişkisel tarama modelindedir (Karasar, 2000). 


\subsection{Evren ve Örneklem}

Almanya'nın örnekleme dahil edilen beş kentinde yaşayan ve kendilerine kartopu örneklemi yoluyla ulaşılan, araştırmaya dâhil edilen Türk göçmen kadınların Almanya'da yaşadıkları kentlere göre dağılımı şöyledir:

\begin{tabular}{|l|c|c|}
\hline Almanya'da Yaşadlklarl Yer & $N$ & $\%$ \\
\hline 1) Köln & 172 & 30.18 \\
\hline 2) Stuttgart & 150 & 26.32 \\
\hline 3) Bremen & 109 & 19.13 \\
\hline 4) Münih & 53 & 9.29 \\
\hline 5) Berlin & 86 & 15.08 \\
\hline Toplam & 570 & 100 \\
\hline
\end{tabular}

Tablo 1. Almanya'yadaki Türk Göçmen Kadınların Yaşadıkları Kentlere Göre Dağıllımı

\subsection{Veriler ve Toplanması}

Araştırma verilerinin toplanmasında alanyazın taramasına dayalı olarak 2013 yılında Karaca tarafindan geliştirilen "Kadınların Çalışma Yaşamına Katılımlarına Yönelik Tutum Ölçeği” (KÇYKYTÖ) ile kullanılmıştır (Karaca, 2013).

\subsection{Kadınların Çalışma Yaşamına Katılımlarına Yönelik Tutum Ölçeği’nin Geçerlik ve Güvenirlik Çalışması}

KÇYKYTÖ’nün göçmen kadınların çalıșma yaşamına katılım konusundaki tutumlarını ne ölçüde saptayabildiğini görmek için öncelikle ön deneme grubu üzerinde çalışma yapılmıştır. Bu kapsamda ön deneme çalışması, Almanya'ya göç etmiş Köln'de yaşayan 43 Türk göçmen kadına uygulanmıştır.

Ön deneme grubuna uygulanıp son şekli verilen 15 maddelik KÇYKYTÖ, araştırmaya dâhil edilen 610 kişiye uygulanmıştır. Ancak daha önce değinildiği üzere, 40 anket yönergeye uygun şekilde doldurulmadığından analiz dışında tutulmuștur. Uygulama sonrası, ölçeğin yapı geçerliğini test etmek için, analize dâhil edilen 570 kişiden elde edilen veriye faktör analizi uygulanmıştır.

\subsubsection{Faktör Analizi}

Faktör analizi, ölçme aracının yapısını aynı yapıyı ya da niteliği ölçen değişkenleri bir araya toplayarak ölçmeyi az sayıda faktör ile açıklamayı amaçlayan istatistiksel tekniktir (Büyüköztürk, 2002, s.117; Ülkü ve Koç, 1978, s.197; Balcı, 1997, s.298). Faktör analizine çok çeşitli amaçlarla başvurulabilir (Baykul, 2000, s.389): Bu araştırmada faktör analizi ölçeğin yapısını belirlemek amacıyla yapılmıştır.

Faktör analizinde aynı yapıyı ölçmeyen maddelerin ayıklanmasında; maddelerin yer aldıkları faktördeki yük değerlerinin.45'in üstünde olmasına dikkat edilmiştir. Bu ölçütlere göre, Temel Bileşenler Analizi Uygulanan 15 maddeden faktör yükü .45'in altında olan 16. madde ölçekten çıkartılmış ve 14 madde kalmıştır.

Faktör analizinde faktör yük değeri .45'in üstünde olan maddeler alınmış ve bu ölçüte göre, 14 maddenin birinci faktörde yer aldığı ve birinci faktör yük değerlerinin .47 ile .76 arasında değiştiği gözlenmektedir. Bu durum KÇYKYTÖ'nün genel bir faktöre sahip olduğunu göstermektedir. Temel Bileşenler Analizinde birinci faktörün açıkladığı varyansın $\% 43.82$ olması da bunun bir göstergesidir.

Ölçekte bulunan maddelerin ayırt ediciliğini değerlendirmek amacıyla yapılan madde analizi sonuçları incelendiğinde madde-toplam korelasyon katsayısı .42 ile .68 arasında değişmektedir. Bu bulgu, 14 alg1 ifadesinin her birinin ayırt edici özelliğe sahip olduğunu göstermektedir. Tüm ölçeğin güvenirlik katsayısı Cronbach $\alpha=.89$ olarak bulunmuştur. Bu değerler ölçeğin güvenilir olduğunun bir göstergesi olarak yorumlanabilir.

KÇYKYTÖ üç faktörlü olduğu için, faktörlerin kendileriyle yüksek ilişki veren maddeleri bulmaları ve daha kolay yorumlanabilmeleri amacıyla varimax tekniği uygulanarak rotasyon işlemi yapılmıştır (Büyüköztürk, 2002, s.120). Rotasyon işlemi sonrasında aynı yapıyı ölçmeyen maddelerin ayıklanmasında; maddelerin yer aldıkları faktördeki yük değerlerinin yüksek olmasına ve maddelerin tek bir faktörde yüksek, diğer faktörlerde ise düşük yük değerine sahip olmasına dikkat edilerek, maddelerin faktör yüklerinin en az .45 ve tek faktör altında yer alması (maddenin iki ayrı faktör altında yüksek faktör yükü alması durumunda farkın en az .10 olması) ölçütleri (Büyüköztürk, 2002, s.118, 119) esas alınmıştır. Bu ölçütlere göre, varimax rotasyon Uygulanan 14 maddeden varyansları düşük olan ve faktör yükleri .45'in altında olan 5., 6. ve 7. maddeler ölçekten çıkartılmış ve geriye 11 madde kalmıștır.

Ölçekte kalan 11 maddenin faktörlere göre dağılımı Tablo 2'de verilmiştir. 


\begin{tabular}{|l|c|}
\hline \multicolumn{1}{|c|}{ Faktörler } & \multicolumn{1}{c|}{ Maddeler } \\
\hline $\begin{array}{l}\text { 1. Faktör: Çalışma Yaşamına Katılımı Zorlaştıran Kişisel ve } \\
\text { Çalışma Koşullarından Kaynaklanan Nedenler }\end{array}$ & $8,9,10,11,12,13$ ve 14 \\
\hline 2. Faktör: Çalışma Yaşamına Katılım İsteğini Olumsuz \\
Etkileyen İçsel ve Dışsal Nedenler
\end{tabular}

Tablo 2. ÇYKYTÖ'de Kalan 11 Maddenin Faktörlere Göre Dă̆ılımı

KÇYKYTÖ’nün faktör yapılarını incelemek amacıyla uygulanan varimax rotasyon sonucu ölçekteki maddelerin madde-toplam korelasyon katsayıları, temel bileşenler analizi sonuçları ve faktörlerdeki yük değerleri Tablo 3 'te verilmiştir.

\begin{tabular}{|c|c|c|c|c|c|c|}
\hline \multirow[b]{2}{*}{$\begin{array}{l}\stackrel{0}{Z} \\
\stackrel{\pi}{\mathscr{H}} \\
\tilde{n}\end{array}$} & \multirow[b]{2}{*}{ 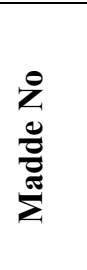 } & \multirow[b]{2}{*}{ 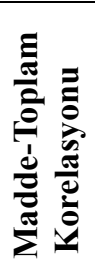 } & \multirow[b]{2}{*}{ 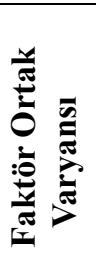 } & \multirow[b]{2}{*}{ لَّ } & \multicolumn{2}{|c|}{ Rotasyon Sonrası Yük Değeri } \\
\hline & & & & & Faktör-1 & Faktör-2 \\
\hline 1 & M1 & .54 & .86 & .65 & .07 & .92 \\
\hline 2 & M2 & .55 & .81 & .66 & .12 & .89 \\
\hline 3 & M3 & .58 & .55 & .68 & .34 & .66 \\
\hline 4 & M4 & .52 & .44 & .61 & .31 & .58 \\
\hline 5 & M8 & .43 & .45 & .51 & .67 & -.02 \\
\hline 6 & M9 & .57 & .62 & .63 & .79 & .04 \\
\hline 7 & M10 & .66 & .59 & .74 & .71 & .29 \\
\hline 8 & M11 & .67 & .60 & .76 & .68 & .38 \\
\hline 9 & M12 & .66 & .58 & .75 & .66 & .38 \\
\hline 10 & M13 & .64 & .59 & .74 & .70 & .32 \\
\hline 11 & M14 & .60 & .50 & .68 & .65 & .28 \\
\hline
\end{tabular}

$$
\begin{aligned}
& \text { Açıklanan Varyans } \\
& \text { Toplam = \% 59.83 } \\
& \text { Faktör-1 = \% } 45.73 \\
& \text { Faktör-2 = \% } 14.10 \\
& \text { Cronbach } \alpha=.87
\end{aligned}
$$

Tablo 3. Varimax Rotasyon Sonucu ÇYKYTÖ’deki Maddelerin Madde-Toplam Korelasyon Katsayılarl, Temel Bileşenler Analizi Sonuçları ve İki Faktördeki Yük Değerleri

\subsubsection{Madde Analizi}

Ölçekte bulunan maddelerin ayırt ediciliğini değerlendirmek amacıyla yapılan madde analizi sonuçları incelendiğinde, madde-toplam korelasyonlarının .43 ile .67 arasında yüksek düzeyde olduğu görülmektedir. Bu bulgu, 11 tutum ifadesinin her birinin ayırt edici özelliğe sahip olduğunu göstermektedir. Tüm ölçeğin güvenirlik katsayısı Cronbach $\alpha=.87$ olarak bulunmuştur. Bu değerler ölçeğin güvenilir olduğunun bir göstergesi olarak yorumlanabilir.

\subsubsection{Almanya'daki Türk Göçmen Kadınların Çalışma Yaşamına Katılıma Yönelik Tutumlarının Çeşitli Değişkenler Bakımından Analizi}

Geçerlik ve güvenirlik çalışması kapsamında madde analizi ve faktör analizi dışında ayrıca KÇYKYTÖ’nün yapı geçerliğini test etmek için ki-kare testi kullanılarak Almanya'daki Türk göçmen kadınların çalışma yaşamına katılıma yönelik tutumlarının çeşiti değişkenler bakımından farklılık gösterip göstermediği de saptanmaya çalışılmıştır. Ki-kare testi yapılırken, beklenen değeri 5 'ten küçük olan gözenek sayısının toplam gözenek sayısının \%20'sini aştığı durumlarda, gözeneklerdeki gözlem sayılarını ve bunun sonucu olarak beklenen değerleri artırabilmek için beklenen değerin düşük olduğu satır/sütun düzeylerinde birleştirme yapılmıştır (Büyüköztürk, 2002: 142). Bu gereklilik doğrultusunda, göçten beklenti ifadeleri ile çalışma yaşamına girişte karşılaşılan sorun ifadelerine verilen tepki kategorilerinden (Kesinlikle katılıyorum, katılıorum, kararsızım ve katılmıyorum) "kesinlikle katılmıyorum" tepki kategorisi bir önceki kategori olan "katılmıyorum" kategorisi ile birleştirilerek, beklenen değeri 5 ’ten küçük olan gözenek sayısının \%20'nin altına düşürülebileceği öngörülmüştür. 
Yaş Bakımından: Almanya'daki Türk göçmen kadınların çalışma yaşamına katılıma yönelik tutumlarının yaşa göre farklılık gösterip göstermediği ya da yaş ile ilişkili olup olmadığına ilişkin ki-kare testi sonuçları Tablo 4’te gösterilmiştir.

\begin{tabular}{|c|c|c|c|c|c|}
\hline Mad. No & Yaş & Katılmıyorum & Kararsızım & Katılıyorum & Toplam \\
\hline 1 & \multicolumn{5}{|c|}{$\chi^{2}=1.46$} \\
\hline 2 & \multicolumn{5}{|c|}{$\chi 2=5.51$} \\
\hline 3 & \multicolumn{5}{|c|}{$\chi 2=1.41$} \\
\hline 4 & \multicolumn{5}{|c|}{$\chi 2=4.34$} \\
\hline \multirow[t]{5}{*}{5} & $25-35$ yaş & 58 & 35 & 49 & 142 \\
\hline & 36-45 yaş & 78 & 54 & 100 & 232 \\
\hline & $\begin{array}{c}46 \\
\text { üzeri }\end{array}$ & 52 & 33 & 105 & 190 \\
\hline & Toplam & 188 & 122 & 254 & 564 \\
\hline & \multicolumn{5}{|c|}{$\chi 2=15.02 \quad \mathrm{sd}=4 \quad \mathrm{p}=.005^{*}$} \\
\hline 6 & \multicolumn{5}{|c|}{$\chi 2=8.72 \quad \mathrm{sd}=4 \quad \mathrm{p}=.069$} \\
\hline 7 & \multicolumn{5}{|c|}{$\chi 2=8.25$} \\
\hline 8 & \multicolumn{5}{|c|}{$\chi 2=6.66$} \\
\hline \multirow[t]{5}{*}{9} & $25-35$ yaş & 65 & 42 & 35 & 142 \\
\hline & 36-45 yaş & 112 & 68 & 52 & 232 \\
\hline & $\begin{array}{c}46 \text { yaş ve } \\
\text { üzeri }\end{array}$ & 81 & 42 & 67 & 190 \\
\hline & Toplam & 258 & 152 & 154 & 564 \\
\hline & \multicolumn{5}{|c|}{$\chi 2=10.03 \quad \mathrm{sd}=4 \quad \mathrm{p}=.040 * *$} \\
\hline 10 & \multicolumn{5}{|c|}{$\chi^{2}=5.63 \quad \mathrm{sd}=4 \quad \mathrm{p}=.228$} \\
\hline \multirow[t]{5}{*}{11} & $25-35$ yaş & 61 & 32 & 49 & 142 \\
\hline & $36-45$ yaş & 94 & 42 & 96 & 232 \\
\hline & $\begin{array}{c}46 \\
\text { üzeri }\end{array}$ & 54 & 14 & 122 & 190 \\
\hline & Toplam & 209 & 88 & 267 & 564 \\
\hline & \multicolumn{5}{|c|}{$\chi 2=37.57$} \\
\hline
\end{tabular}

Tablo 4. Yaş Bakımından Almanya'ya Evlilik Yoluyla Göç Eden Kadınların Çalışma Yaşamına Katılıma Yönelik Tutumlarına İlişkin Ki-Kare Testi Sonuçları

Tablo 4 incelendiğinde, yaş bakımından kadınların ölçekteki "5., 9. ve 10." maddeler hariç, diğer maddelerin tamamında yer alan ifadelere katılma düzeylerinde, anlamlı $(p<.01$ ve $p<.05)$ bir farklılık çıkmamıştır. Sonuçlara göre, araştırmaya dahil edilen kadınların yaş bakımından sadece "Yeterli düzeyde Almanca bilmememin işe girişimi zorlaştırdığını düşünüyorum”, "Çalışırsam, aileme yeterince zaman ayıramayacağımı düşünüyorum” ve "Getirisi yüksek işler için niteliklerimin uygun olmadığını düşünüyorum" ifadelerine katılma düzeylerinde anlamlı bir farklılık olduğu görülmektedir. Sonuçlara göre, yaşı daha büyük olan kadınlar, "Almanca bilmemenin işe girişimi zorlaştırdığını düşünüyorum” ifadesi ile "Getirisi yüksek işler için niteliklerimin uygun olmadığını düşünüyorum" ifadesine, yaşı daha küçük olan kadınlardan daha yüksek düzeyde katılmakta iken; yaşı daha küçük olan kadınlar ise, "Çalışırsam, aileme yeterince zaman ayıramayacağımı düşünüyorum” ifadesine yaşı büyük olan kadınlardan daha yüksek düzeyde katılmaktadır. Bu sonuç, göreli olarak yaş büyüdükçe, kadınların işe giriş veya çalışma bakımından aileye zaman ayıramama endişesini önemli bir neden olarak görmediklerini ancak yaşa rağmen hala Almanca bilmemeyi işe girişi ve çalışmayı zorlaştıran önemli bir neden olarak gördüklerini ortaya koymaktadır.

Medeni Durum Bakımından: Almanya'daki Türk göçmen kadınların çalışma yaşamına katılımına yönelik tutumlarının evli olup olmamaya göre farklılık gösterip göstermediği ya da evli olup olmama ile ilişkili olup olmadığına ilişkin ki-kare testi sonuçları Tablo 5'te gösterilmiştir. 


\begin{tabular}{|c|c|c|c|c|c|}
\hline Mad. No & Yaş & Katılmıyorum & Kararsızım & Katılıyorum & Toplam \\
\hline 1 & \multicolumn{5}{|c|}{$\chi 2=5.44$} \\
\hline 2 & \multicolumn{5}{|c|}{$\chi^{2}=3.52$} \\
\hline \multirow[t]{4}{*}{3} & Evli & 273 & 128 & 111 & 512 \\
\hline & $\begin{array}{c}\text { Evli } \\
\text { Olmayanlar }\end{array}$ & 37 & 6 & 15 & 58 \\
\hline & Toplam & 310 & 134 & 126 & 570 \\
\hline & \multicolumn{5}{|c|}{$\chi 2=6.22$} \\
\hline 4 & \multicolumn{5}{|c|}{$\chi^{2}=1.10$} \\
\hline 5 & \multicolumn{5}{|c|}{$\chi 2=2.41$} \\
\hline 6 & \multicolumn{5}{|c|}{$\chi 2=4.80$} \\
\hline 7 & \multicolumn{5}{|c|}{$\chi 2=3.60$} \\
\hline 8 & \multicolumn{5}{|c|}{$\chi 2=1.02$} \\
\hline \multirow[t]{4}{*}{9} & Evli & 222 & 144 & 146 & 512 \\
\hline & $\begin{array}{c}\text { Evli } \\
\text { Olmayanlar }\end{array}$ & 38 & 8 & 12 & 58 \\
\hline & Toplam & 260 & 152 & 158 & 570 \\
\hline & \multicolumn{5}{|c|}{$\chi 2=10.77 \quad \mathrm{sd}=2 \quad \mathrm{p}=.005 *$} \\
\hline 10 & \multicolumn{5}{|c|}{$\chi 2=3.50$} \\
\hline 11 & \multicolumn{5}{|c|}{$\chi 2=1.62$} \\
\hline
\end{tabular}

Tablo 5. Evli Olup Olmama Bakımından Almanya'ya Evlilik Yoluyla Göç Eden Kadınların Çalışma Yaşamına Katılımına Yönelik Tutumlarına İlişkin Ki-Kare Testi Sonuçları

Tablo 5 incelendiğinde, evli olup olmama bakımından kadınların ölçekteki “3. ve 9.” maddeler hariç, diğer maddelerin tamamında yer alan ifadelere katılma düzeylerinde, anlamlı $(\mathrm{p}<.01$ ve $\mathrm{p}<.05)$ bir farklılık çıkmamıştır. Sonuçlara göre, evli olan kadınlar, "Çok istememe rağmen, çocuklarımın bakımını üstlendiğim için çalışamıyorum" ifadesine, evli olmayan kadınlardan daha düşük düzeyde katılmakta iken; evli olmayan kadınlar ise, "Çalışırsam, aileme yeterince zaman ayıramayacağımı düşünüyorum" ifadesine evli olan kadınlardan daha düşük düzeyde katılmaktadır. Bu sonuç, çocuklar da dahil evli kadınların evli olmayan kadınlara göre çalışmaya daha çok ihtiyaç duyduklarını ve evlilikte dahil her ne olursa olsun çalışma konusunda istekli olduklarını ortaya koymaktadır.

Eğitim Düzeyi Bakımından: Almanya'daki Türk göçmen kadınların çalışma yaşamına katılımına yönelik tutumlarının eğitim düzeyine göre farklılık gösterip göstermediği ya da eğitim ile ilişkili olup olmadığına ilişkin ki-kare testi sonuçları Tablo 6'da gösterilmiştir. 


\begin{tabular}{|c|c|c|c|c|c|}
\hline Mad. No & Eğitim Düzeyi & Katılmıyorum & Kararsızım & Katılıyorum & Toplam \\
\hline \multirow[t]{6}{*}{1} & İlkokul & 93 & 22 & 12 & 127 \\
\hline & Ortaokul & 94 & 25 & 21 & 140 \\
\hline & Lise & 127 & 79 & 22 & 228 \\
\hline & $\begin{array}{c}\text { Yüksek OkulFakültel } \\
\text { Lisansüstü }\end{array}$ & 67 & 0 & 4 & 71 \\
\hline & Toplam & 381 & 126 & 59 & 566 \\
\hline & \multicolumn{5}{|c|}{$\chi 2=51.70 \quad \mathrm{sd}=6 \quad \mathrm{p}=.000^{*}$} \\
\hline \multirow[t]{6}{*}{2} & İlkokul & 95 & 18 & 14 & 127 \\
\hline & Ortaokul & 87 & 27 & 26 & 140 \\
\hline & Lise & 127 & 79 & 22 & 228 \\
\hline & $\begin{array}{c}\text { Yüksek OkulFakültel } \\
\text { Lisansüstü }\end{array}$ & 67 & 1 & 3 & 71 \\
\hline & Toplam & 376 & 125 & 65 & 566 \\
\hline & \multicolumn{5}{|c|}{$\chi 2=58.23 \quad \mathrm{sd}=6 \quad \mathrm{p}=.000 *$} \\
\hline \multirow[t]{6}{*}{3} & İlkokul & 72 & 20 & 35 & 127 \\
\hline & Ortaokul & 72 & 31 & 35 & 140 \\
\hline & Lise & 106 & 82 & 37 & 228 \\
\hline & $\begin{array}{c}\text { Yüksek OkulFakültel } \\
\text { Lisansüstü̈ }\end{array}$ & 59 & 0 & 40 & 71 \\
\hline & Toplam & 309 & 133 & 124 & 566 \\
\hline & \multicolumn{5}{|c|}{$\chi^{2}=54.74 \quad s d=6 \quad p=.000^{*}$} \\
\hline \multirow[t]{6}{*}{$\overline{4}$} & İlkokul & 76 & 27 & 24 & 127 \\
\hline & Ortaokul & 78 & 40 & 22 & 140 \\
\hline & Lise & 120 & 88 & 20 & 228 \\
\hline & $\begin{array}{c}\text { Yüksek OkulFakültel } \\
\text { Lisansüstü }\end{array}$ & 63 & 3 & 5 & 71 \\
\hline & Toplam & 337 & 158 & 71 & 566 \\
\hline & \multicolumn{5}{|c|}{$\chi^{2}=51.70 \quad s d=6 \quad p=.000^{*}$} \\
\hline \multirow[t]{6}{*}{5} & ílkokul & 24 & 20 & 83 & 127 \\
\hline & Ortaokul & 38 & 30 & 72 & 140 \\
\hline & Lise & 81 & 69 & 78 & 228 \\
\hline & $\begin{array}{c}\text { Yüksek OkuVFakültel } \\
\text { Lisansüstü }\end{array}$ & 45 & 4 & 22 & 71 \\
\hline & Toplam & 188 & 123 & 255 & 566 \\
\hline & \multicolumn{5}{|c|}{$\chi^{2}=69.36 \quad s d=6 \quad p=.000^{*}$} \\
\hline \multirow[t]{6}{*}{6} & İlkokul & 28 & 14 & 85 & 127 \\
\hline & Ortaokul & 40 & 29 & 71 & 140 \\
\hline & Lise & 65 & 80 & 83 & 228 \\
\hline & $\begin{array}{c}\text { Yüksek OkuVFakültel } \\
\text { Lisansüstü }\end{array}$ & 40 & 8 & 23 & 71 \\
\hline & Toplam & 173 & 131 & 262 & 566 \\
\hline & \multicolumn{5}{|c|}{$\chi^{2}=65.79 \quad s d=6 \quad p=.000^{*}$} \\
\hline
\end{tabular}




\begin{tabular}{|c|c|c|c|c|c|}
\hline Mad. No & Eğitim Düzeyi & Katılmıyorum & Kararsızım & Katılıyorum & Toplam \\
\hline \multirow[t]{6}{*}{7} & İlkokul & 37 & 47 & 43 & 127 \\
\hline & Ortaokul & 59 & 46 & 35 & 140 \\
\hline & Lise & 80 & 97 & 51 & 228 \\
\hline & $\begin{array}{c}\text { Yüksek OkulFakültel } \\
\text { Lisansüstü̈ }\end{array}$ & 48 & 10 & 13 & 71 \\
\hline & Toplam & 224 & 200 & 142 & 566 \\
\hline & \multicolumn{5}{|c|}{$\chi^{2}=37.763 \quad s d=6 \quad p=.000^{*}$} \\
\hline \multirow[t]{6}{*}{8} & İlkokul & 43 & 50 & 34 & 127 \\
\hline & Ortaokul & 51 & 53 & 36 & 140 \\
\hline & Lise & 89 & 100 & 39 & 228 \\
\hline & $\begin{array}{c}\text { Yüksek OkulFakültel } \\
\text { Lisansüstü }\end{array}$ & 50 & 9 & 12 & 71 \\
\hline & Toplam & 233 & 212 & 121 & 566 \\
\hline & \multicolumn{5}{|c|}{$\chi^{2}=37.26 \quad s d=6 \quad p=.000^{*}$} \\
\hline \multirow[t]{6}{*}{9} & ílkokul & 50 & 25 & 52 & 127 \\
\hline & Ortaokul & 59 & 39 & 42 & 140 \\
\hline & Lise & 99 & 79 & 50 & 228 \\
\hline & $\begin{array}{c}\text { Yüksek OkulFakülte/ } \\
\text { Lisansüstü } \\
\end{array}$ & 52 & 8 & 11 & 71 \\
\hline & Toplam & 260 & 151 & 155 & 566 \\
\hline & \multicolumn{5}{|c|}{$\chi^{2}=42.64 \quad s d=6 \quad p=.000^{*}$} \\
\hline \multirow[t]{6}{*}{10} & İlkokul & 50 & 38 & 39 & 127 \\
\hline & Ortaokul & 63 & 35 & 42 & 140 \\
\hline & Lise & 109 & 72 & 47 & 228 \\
\hline & $\begin{array}{l}\text { Yüksek OkulFakültel } \\
\text { Lisansüstü }\end{array}$ & 55 & 4 & 12 & 71 \\
\hline & Toplam & 277 & 149 & 140 & 566 \\
\hline & \multicolumn{5}{|c|}{$\chi^{2=36.07} \quad s d=6 \quad p=.000^{*}$} \\
\hline \multirow[t]{6}{*}{11} & İlkokul & 34 & 23 & 70 & 127 \\
\hline & Ortaokul & 40 & 27 & 73 & 140 \\
\hline & Lise & 79 & 36 & 113 & 228 \\
\hline & $\begin{array}{c}\text { Yüksek OkulFakültel } \\
\text { Lisansüstü }\end{array}$ & 56 & 3 & 2 & 71 \\
\hline & Toplam & 209 & 89 & 268 & 566 \\
\hline & \multicolumn{5}{|c|}{$\chi 2=64.34 \quad \mathrm{sd}=6 \quad \mathrm{p}=.000^{*}$} \\
\hline
\end{tabular}

Tablo 6. Eğitim Düzeyi Bakımından Almanya’ya Evlilik Yoluyla Göç Eden Kadınların Çalışma Yaşamına Katılımına Yönelik Tutumlarına İlişkin Ki-Kare Testi Sonuçları

Tablo 6 incelendiğinde, eğitim düzeyi bakımından araştırmaya dahil edilen Almanya'ya evlilik yoluyla göç eden kadınların ölçekteki maddelerin tamamında yer alan ifadelere katılma düzeylerinde, anlamlı $(p<.01 \mathrm{ve} p<.05)$ bir farklılık çıkmıştır. Sonuçlara göre, eğitim düzeyi daha yüksek olan kadınlar, çalışma yaşamına katılıma yönelik tutum ifadelerine, eğitim düzeyi daha düşük olan kadınlardan daha düşük düzeyde katılmaktadırlar. Bu sonuç, göreli olarak işe girişi ve çalışmayı zorlaştıran nedenlerin eğitim düzeyi daha yüksek olan kadınlar üzerinde daha etkili olduğunu ve eğitim düzeyi yüksek olan kadınların iş bulmada daha çok zorluk yaşadığını ortaya koymaktadır. Nitekim tüm dünya ülkelerinde olduğu gibi Almanya'da da eğitimli işsizlik oranının yüksek olduğu bilinmektedir.

Almanca Dil Düzeyi Bakımından: Almanya'daki Türk göçmen kadınların çalışma yaşamına katılıma yönelik tutumlarının Almanca dil düzeyine göre farklılık gösterip göstermediği ya da Almanca dil düzeyi ile ilişkili olup olmadığına ilişkin ki-kare testi sonuçları Tablo 7'de gösterilmiştir. 


\begin{tabular}{|c|c|c|c|c|c|}
\hline Mad.No & $\begin{array}{c}\text { Almanca Dil } \\
\text { Düzeyi }\end{array}$ & Katılmiyorum & Kararsızım & Katılıyorum & Toplam \\
\hline \multirow[t]{5}{*}{1} & $\begin{array}{c}\text { Hiç bilmeyenler/ } \\
\text { Biraz bilenler }\end{array}$ & 229 & 53 & 47 & 329 \\
\hline & Iyi bilenler & 93 & 63 & 8 & 164 \\
\hline & $\begin{array}{c}\text { Almanca okuyup } \\
\text { yazanlar }\end{array}$ & 57 & 10 & 4 & 71 \\
\hline & Toplam & 379 & 126 & 59 & 564 \\
\hline & \multicolumn{5}{|c|}{$\chi 2=42.70$} \\
\hline \multirow[t]{5}{*}{2} & $\begin{array}{l}\text { Hiç bilmeyenler } \\
\text { Biraz bilenler }\end{array}$ & 222 & 54 & 53 & 329 \\
\hline & İyi bilenler & 93 & 62 & 9 & 164 \\
\hline & $\begin{array}{c}\text { Almanca okuyup } \\
\text { yazanlar }\end{array}$ & 59 & 9 & 3 & 71 \\
\hline & Toplam & 374 & 125 & 65 & 564 \\
\hline & \multicolumn{5}{|c|}{$\chi^{2}=45.73 \quad s d=4 \quad p=.000^{*}$} \\
\hline \multirow[t]{5}{*}{3} & $\begin{array}{c}\text { Hiç bilmeyenler } \\
\text { Biraz bilenler }\end{array}$ & 186 & 59 & 84 & 329 \\
\hline & Iyi bilenler & 78 & 64 & 22 & 164 \\
\hline & $\begin{array}{c}\text { Almanca okuyup } \\
\text { yazanlar }\end{array}$ & 41 & 11 & 19 & 71 \\
\hline & Toplam & 305 & 134 & 125 & 564 \\
\hline & \multicolumn{5}{|c|}{$\chi^{2}=32.68 \quad s d=4 \quad p=.000^{*}$} \\
\hline \multirow[t]{5}{*}{4} & $\begin{array}{l}\text { Hiç bilmeyenler/ } \\
\text { Biraz bilenler }\end{array}$ & 207 & 78 & 44 & 329 \\
\hline & Iyi bilenler & 87 & 66 & 11 & 164 \\
\hline & $\begin{array}{c}\text { Almanca okuyup } \\
\text { yazanlar }\end{array}$ & 40 & 14 & 17 & 71 \\
\hline & Toplam & 334 & 158 & 72 & 564 \\
\hline & \multicolumn{5}{|c|}{$\chi^{2}=26.35$} \\
\hline \multirow[t]{5}{*}{5} & $\begin{array}{c}\text { Hiç bilmeyenler } \\
\text { Biraz bilenler }\end{array}$ & 79 & 59 & 191 & 329 \\
\hline & Iyi bilenler & 80 & 57 & 27 & 164 \\
\hline & $\begin{array}{c}\text { Almanca okuyup } \\
\text { yazanlar }\end{array}$ & 26 & 8 & 37 & 71 \\
\hline & Toplam & 185 & 124 & 255 & 564 \\
\hline & \multicolumn{5}{|c|}{$\chi^{2}=81.89$} \\
\hline \multirow[t]{5}{*}{6} & $\begin{array}{c}\text { Hiç bilmeyenler } \\
\text { Biraz bilenler }\end{array}$ & 97 & 60 & 12 & 329 \\
\hline & İyi bilenler & 2 & 62 & 50 & 164 \\
\hline & $\begin{array}{c}\text { Almanca okuyup } \\
\text { yazanlar }\end{array}$ & 21 & 9 & 41 & 71 \\
\hline & Toplam & 170 & 131 & 263 & 564 \\
\hline & \multicolumn{5}{|c|}{$\chi^{2}=35.42$} \\
\hline \multirow[t]{5}{*}{7} & $\begin{array}{c}\text { Hiç bilmeyenler } \\
\text { Biraz bilenler }\end{array}$ & 122 & 105 & 102 & 329 \\
\hline & İyi bilenler & 72 & 76 & 16 & 164 \\
\hline & $\begin{array}{c}\text { Almanca okuyup } \\
\text { yazanlar }\end{array}$ & 29 & 19 & 23 & 71 \\
\hline & Toplam & 223 & 200 & 141 & 564 \\
\hline & \multicolumn{5}{|c|}{$\chi^{2}=31.02$} \\
\hline
\end{tabular}




\begin{tabular}{|c|c|c|c|c|c|}
\hline Mad.No & $\begin{array}{c}\text { Almanca Dil } \\
\text { Düzeyi }\end{array}$ & Katılmıyorum & Kararsızım & Katılıyorum & Toplam \\
\hline \multirow[t]{5}{*}{8} & $\begin{array}{l}\text { Hiç bilmeyenler/ } \\
\text { Biraz bilenler }\end{array}$ & 126 & 109 & 94 & 329 \\
\hline & İyi bilenler & 73 & 79 & 12 & 164 \\
\hline & $\begin{array}{c}\text { Almanca okuyup } \\
\text { yazanlar }\end{array}$ & 32 & 24 & 15 & 71 \\
\hline & Toplam & 231 & 212 & 121 & 564 \\
\hline & \multicolumn{5}{|c|}{$\chi^{2}=31.31$} \\
\hline \multirow[t]{5}{*}{9} & $\begin{array}{l}\text { Hiç bilmeyenler/ } \\
\text { Biraz bilenler }\end{array}$ & 145 & 67 & 117 & 329 \\
\hline & İyi bilenler & 74 & 70 & 20 & 164 \\
\hline & $\begin{array}{c}\text { Almanca okuyup } \\
\text { yazanlar }\end{array}$ & 36 & 15 & 20 & 71 \\
\hline & Toplam & 255 & 152 & 157 & 564 \\
\hline & \multicolumn{5}{|c|}{$\chi^{2}=43.29 \quad s d=4 \quad p=.000^{*}$} \\
\hline \multirow[t]{5}{*}{10} & $\begin{array}{l}\text { Hiç bilmeyenler } \\
\text { Biraz bilenler }\end{array}$ & 147 & 88 & 94 & 329 \\
\hline & Iyi bilenler & 95 & 44 & 25 & 164 \\
\hline & $\begin{array}{l}\text { Almanca okuyup } \\
\text { yazanlar }\end{array}$ & 32 & 19 & 20 & 71 \\
\hline & Toplam & 274 & 151 & 139 & 564 \\
\hline & \multicolumn{5}{|c|}{$\chi^{2}=12.46$} \\
\hline \multirow[t]{5}{*}{11} & $\begin{array}{l}\text { Hiç bilmeyenler/ } \\
\text { Biraz bilenler }\end{array}$ & 106 & 39 & 184 & 329 \\
\hline & Iyi bilenler & 68 & 31 & 65 & 164 \\
\hline & $\begin{array}{l}\text { Almanca okuyup } \\
\text { yazanlar }\end{array}$ & 35 & 18 & 18 & 71 \\
\hline & Toplam & 209 & 88 & 267 & 564 \\
\hline & \multicolumn{5}{|c|}{$\chi 2=28.67 \quad$ sd $=4$} \\
\hline
\end{tabular}

Tablo 7. Almanca Dil Düzeyi Bakımından Almanya'ya Evlilik Yoluyla Göç Eden Kadınların Çalışma Yaşamına Katılıma Yönelik Tutumlarına İlişkin Ki-Kare Testi Sonuçları

Tablo 7 incelendiğinde, Almanca dil düzeyi bakımından araştırmaya dahil edilen Almanya'ya evlilik yoluyla göç eden kadınların ölçekteki maddelerin tamamında yer alan ifadelere katılma düzeylerinde, anlamlı $(\mathrm{p}<.01 \mathrm{ve}$ $\mathrm{p}<.05)$ bir farklılık çıkmıştır. Sonuçlara göre, Almanca dil düzeyi daha düşük olan kadınlar, çalışma yaşamına katılıma yönelik tutum ifadelerine, Almanca dil düzeyi daha iyi olan kadınlardan daha yüksek düzeyde katılmaktadırlar. Bu sonuç, göreli olarak işe girişi ve çalışmayı zorlaştıran nedenlerin eğitim düzeyi daha yüksek olan kadınlar üzerinde olduğu gibi, Almanca dil düzeyi daha yüksek olan kadınlar üzerinde de daha etkili olduğunu ve dil düzeyi yüksek olan kadınların iş bulmada daha çok zorluk yaşadığını ortaya koymaktadır.

\section{Sonuc}

Bu çalışmada, Almanya'daki Türk göçmen kadınların çalışma yaşamına katılıma yönelik tutumlarını saptamaya yönelik geçerli ve güvenilir bir ölçek geliştirilmeye çalışılmıştır. Ölçeğin geliştirilmesinin ilk aşamasında kadınların çalışma yaşamına, işgücüne katılımı ve karşılaştıkları sorunlara ilişkin alan yazın incelenmiş, ardından kadınların çalışma yaşamına katılımlarına ilişkin veri toplama araçları gözden geçirilmiştir. Bir sonraki aşamada ise hazırlanan ölçek dil bakımından alan uzmanları tarafından incelenmiş, kapsam geçerliliği açısından ise üniversitelerde görev yapan alan uzmanlarını görüşlerine başvurulmuştur. Uzman görüşleri doğrultusunda ise ölçeğe son şekli verilmiştir.

Araştırma bulguları, “Kadınların Çalışma Yaşamına Katılımlarına Yönelik Tutum Ölçeği” (KÇYKYTÖ)'nin 11 maddeden oluşan, "Çalışma Yaşamına Katılımı Zorlaştıran Kişisel ve Çalışma Koşullarından Kaynaklanan Nedenler” ve "Çalışma Yaşamına Katılım İsteğini Olumsuz Etkileyen İçsel ve Dışsal Nedenler" şeklinde iki faktörlü bir ölçek olduğunu ortaya koymaktadır.

Araştırma kapsamında elde edilen sonuçlar, KÇYKYTÖ’nin çalışma grubundan elde edilen veriler için geçerli ve güvenilir olduğunu göstermektedir. Bu araştırmanın kapsamadığı, Almanya'nın farklı kentlerinde ya da 
Türkiye'den göç alan diğer ülkelerde yaşayan evli ya da evli olmayan Türkiye'den göç etmiş tüm kadınlar bakımından güvenirlik ve geçerlik çalışmalarının yinelenmesi ve yapılan analizlerin karşılaştırılması özellikle faktör yapı geçerliğini belirlenebilmesi açısından önemlidir. Bu bakımdan KÇYKYTÖ kullanılarak araştırmalar yapılmalı ve elde edilen sonuçlar bu araştırmanın sonuçları ile karşılaştırılmalıdır. Ayrıca KÇYKYTÖ’nün yapı geçerliğini test etmek açısından Almanya'daki Türk göçmen kadınların çalışma yaşamına katılıma yönelik tutumlarının sosyal yardım alıp almama, ekonomik durum algısı, gelecek beklentisi gibi değişkenler bakımından da farklılık gösterip göstermediğinin araştırılmasında yarar vardır. Bu çalışmanın göçmen ve çalışma yaşamı ile alan yazına ve konu ile ilgilenen akademisyenlere katkı sağlayacağı umulmaktadır.

\section{Kaynakça}

- Balcı, A. (1997). Sosyal Bilimlerde Araştırma Yöntem, Teknik ve İlkeler (Gözden geçirilmiş ve ilave edilmiş 2. baskı). Ankara: 72 TDFO Bilgisayar-Yayıncılık.

- Baykul, Y. (2000). Eğitimde ve Psikolojide Ölçme: Klasik Test Teorisi ve Uygulaması. Ankara: ÖSYM Yayınları.

- Büyüköztürk, Şener (2002), Veri Analizi El Kitabı (1. Bask1), Ankara: Pegem A Yayıncılık.

- Karaca, E. (2013). Investigation of the Reliability and Validity of Attitude Scale on Labor Force Participation of Women with A Structral Equation Model. International Conference on Eurasian Economies, St. Petersburg, Russia.

- Karasar, N. (2000). Bilimsel Araştırma Yöntemi. 10. Baskı. Ankara: Nobel Yayın ve Dağıtım.

- Ülkü, S. ve Koç, N. (1978). Faktör Analizi Yetenekleri Sınıflama (Ayırtetme). A.Ü. Eğitim Fakültesi Dergisi $10(1-2), 25-34$. 


\title{
Ekonomik Büyüme ve Göç İlişkisi: Gelişmekte Olan Ülkelere Dayalı Bir Analiz
}

\section{Economic Growth-Migration Nexus: An Analysis Based on Developing Countries}

\author{
Asst. Prof. Dr. Haktan Sevinç (Iğdır University, Turkey) \\ Asst. Prof. Dr. Eda Bozkurt (Atatürk University, Turkey) \\ Asst. Prof. Dr. Serkan Künü (Iğdır University, Turkey) \\ Ph.D. Candidate Demet Eroğlu Sevinç (Iğdır University, Turkey)
}

\begin{abstract}
Relations between migration and economic growth have been shaped around both positivist and Non-positivist ideas in the economic literature. Approaches based on the Positivist argument mostly views the effect of migration on economic growth through the lens of human capital and brain drain while Non-positivist argument approaches the issue in terms of the negative effects of unqualified labor. On the other hand, increasing migration at the international level has been gaining importance since immigrants create socio-economic problems in both their native and destination countries. In this study, effects of migration, which constitutes and important problem both at the national and the international level, on economic growth were investigated in the light of these approaches. Relations between migration and economic growth in the developing countries were researched through panel data methods. According to the findings of the study, migration has a negative effect on economic growth. Therefore, it can be said that immigration of qualified human capital and brain drain has important consequences for the economic development of countries. This situation undoubtedly implies implementation of policies which directly affects the amount of investment to human capital.
\end{abstract}

\section{Giriş}

Göç ve ekonomik büyüme/kalkınma arasındaki ilişki uzun süredir birçok ekonomist ve politikacı tarafından analiz ediliyor olsa bile söz konusu değişkenler arasındaki ilişkinin yönü ve boyutu net olarak ortaya konmamıştır. $\mathrm{Bu}$ duruma sebep olarak göç veren ile göç alan ülkelerde göç olgusunun zit etkiler oluşturması en temel faktör olarak ön plana çıkmaktadır. Şöyle ki; göç veren bir ülkede görece kalifiye emek gücünün göçmesi bu ülkede kalifiye beşeri sermayenin azalmasıyla verimlilik düşüşlerine yol açabilmektedir. Ortaya çıkan söz konusu düşüş dolayısıyla da ekonomik büyüme/kalkınma sekteye uğrayabilmektedir. Diğer taraftan kalifiye olmayan emek gücünün göçmesi ise göç veren ülkede emeğin marjinal ürününü arttırarak ekonomik büyüme üzerinde olumlu etkilerde bulunabilecektir. Göç alan ülkelerde ise süreç tersine işleyebilecek ve doğal işsizlik düzeyi üzerinde bir göç akımı ülkedeki işsizlik oranlarını aşırı bir şekilde yükseltebilecektir.

Söz konusu bu teorik bilgiler ışığında kalifiye işgücünün büyüme üzerine olumlu yöndeki etkisine dayalı birçok teori ortaya çıkmış ve emeğin verimliliğine yönelik çeşitli değerlendirmeler yapılmıştır. Ayrıca göçmenlerin göç ettikleri ülkelerin ekonomilerine yönelik muhtemel etkilere dayalı çok daha fazla net görüş ve teori varken, kendi ülkelerinin ekonomilerine yönelik göçün etkilerine dayalı teori ve görüş nispeten daha azdır. Bu minvalde göç olgusu azgelişmiş ve gelişmekte olan ülkelere dövize dayalı bir sermaye hareketliliği katarak iç piyasalardaki likiditeyi arttırmaktadır. Gelişmiş ülkelerde ise emeğe dayalı endüstrilerde ihtiyaç duyulan emek faktörüne nispeten bir maliyette bulunulmadan veya daha düşük maliyetlerle sahip olunmasına katkı sunmaktadır. Böylece gelişmekte olan ülkelerdeki nitelikli işgücü göçünün artmasına yol açarak bu ülkeler için bir dezavantaj oluştururken, gelişmiş ülkeler içinse bir avantaj oluşturmaktadır. Nitelikli emek gücünün hareketliliği ise beyin göçü kapsamında değerlendirilmekte ve göç alan ülke için en çok arzu edilen göç şekli sayılmaktadır.

Diğer taraftan söz konusu bu durumu Neoklasik kuram; işgücü, düşük gelirli ülkelerden/bölgelerden yüksek gelirli ülkelere/bölgelere yönelerek kişi başına gelirin net iç göç alan ülkelerde/bölgelerde zamanla azalmasına, net iç göç veren ülkelerde/bölgelerde ise zamanla artmasına yol açar şekilde açıklamaktadır. İşgücünün bir ülkeden/bölgeden diğerine göçü ile birlikte ülkelerarası/bölgelerarası gelir farklılıkları zaman içinde kaybolacak, sonucunda ise göç yavaşlayacak ve en nihayetinde duracaktır. Bu bakış açısına göre göç, ülkelerarası/bölgelerarası gelir yakınsamasını hızlandıran bir olgu durumundadır (Kırdar ve Saraçoğlu, 2012: 2).

Bu bağlamda çalışmanın amacı; ekonomik büyüme ve göç olgusu arasındaki ilişkiyi Türkiye'nin de dahil olduğu gelişmekte olan ekonomiler özelinde araştırmaktır. Panel veri analizine dayalı olan çalışmanın zaman boyutunu ise 1962-2012 dönemine ait 5 yıllık veriler oluşturmaktadır. Çalışma ekonomik büyüme ve göç ilişkisine yönelik bazı teorik bilgilerin verildiği giriş kısmı ile başlamakta ve konuyla ilgili literatür özetinin verildiği ikinci bölümle devam etmektedir. Üçüncü bölüm; veriler, yöntem ve araştırma bulgularının verildiği ampirik analiz kısmından oluşmaktayken, son bölüm ise çalışmaya ait genel bir değerlendirilmenin yapıldığı ve analiz sonuçlarının yorumlandığı kısımdan oluşmaktadır. 


\section{Literatür}

Zlotnik (1998), 1965-1996 yılları arasında uluslararası göç ile ilgili genel bir değerlendirme yapmıştır. Uluslararası göçün karmaşık ve değişik bir olgu olduğunu, uluslararası düzeyde kapsamlı veri olmamasına rağmen 1965'den bu yana göçün giderek artan bir oranda arttığını, uluslararası göçün küresel ekonomik değişimde en önemli faktörlerinden biri olduğunu ifade etmiştir.

Chen (2005), ABD ve Filipinler için stokastik dinamik modelle kaynak ülke açısından göçün ekonomik büyüme üzerine etkilerini araştırmıştır. Uluslararası göçün doğurganlık ve eğitim harcamalarını etkilediği için ekonomik büyümeyle ilişikli olduğunu tespit etmiştir. Ayrıca kısa dönemde meydana gelen bir beyin göçü ile uzun dönemde yüksek beşeri sermaye niteliğindeki işçilerin göç etmesinin ekonomik büyümeye zarar verebileceğini vurgulamıştır.

Morley (2006), Avustralya, Kanada ve ABD’de 1930-2002 döneminde sınır testi yöntemiyle göç ve ekonomik büyüme arasındaki ilişkiyi araştırmıştır. Araştırma sonuçlarına göre uzun dönemde ekonomik büyümeden göçe doğru nedensel bir ilişki olup tersi söz konusu değildir. Bu ülkelerde göçü kontrol etmek için kullanılan kanunların tamamen başarılı olmadığına karar verilmiştir.

Bozdağ ve Atan (2009), Türk işçilerinin, Avrupa Birliği üyesi yedi ülkenin ve Norveç'in milli gelirlerine olan katkılarını 1995-2006 yılları arasında Veri Zarflama Analizi, Potansiyel İyileştirmeler Analizi ve Malmquist Endeks ile incelemişlerdir. Araştırma sonuçlarına göre toplam işgücü ve sermaye faktörlerinin üretime olan katkıları açısından etkinlikleri en yüksek ülkeler, İsveç ve Norveç’tir. Yerli ve yabancı emek olarak ayrım yapıldı̆̆ında en etkin ülke Finlandiya'dır.

Maria ve Lazarova (2012), 130 gelişmekte olan ülkede 1990-2000 dönemi için regresyon ve simülasyon analizleriyle göç, beşeri sermaye ve ekonomik büyüme ilişkisini araştırmışlardır. Göçün beşeri sermayenin hem düzeyinde hem de bileşiminde istatistiki olarak anlamlı etkisi söz konusudur. Ayrıca bu durumunda büyüme üzerinde etkili olduğu görülmüştür. Yetenekli insanların göçü sebebiyle nüfusun \%70’i daha düşük büyümeye maruz kalmaktadır. Teknolojik gelişmişlik düzeyi düşük ülkelerde kayıplar daha da fazladır.

Martin (2012), Meksika-ABD ve Türkiye-Avrupa ülkeleri için göç ve ekonomik kalkınma arasında karşılaştırmalı deskriptif bir araştırma yapmıştır. Yazara göre formel işlerde çalışan nüfusun çok küçük bir kısmı göç etmektedir. Bu sebeple Meksika ve Türkiye hükümetlerinin ve olası bu ülkelerden gelen göç ile başetmesi gereken Amerika ile Avrupa hükümetlerinin göç etme gereksinimini durduracak bir kalkınma sağlaması gerekmektedir. Bunu sağlamanın yolu, tarım sektörünü bırakan ve istihdama yeni katılacak işgücü ile enformel istihdamda olan ve hiç istihdamda olmayanlar için ayrıca istihdam piyasasına yeni girenler için uygun işler sağlayacak ekonomik büyümenin istikrarla sürdürülmesidir.

Boubtane vd. (2014), 22 OECD ülkesi 1986-2006 GMM ile ekonomik büyüme ve göç arasındaki ilişkiyi araştırmışlardır. Göçmenler tarafından oluşturulan beşeri sermayenin ekonomik büyümeyi olumlu etkilediği sonucuna ulaşılmışlardır.

Karaca ve Saruç (2014), Avrupa Birliği'ne aday tüm geçiş ekonomileri ile Türkiye'de göç olgusunu teorik düzeyde araştırmışlardır. Avrupa Birliği'ne aday tüm geçiş ekonomileri ile Türkiye'nin transit geçiş ülkesi olduğunu, işçi gelirleri alıcı ülkenin döviz kazanımının arttırdığını, gelir seviyesinin de yükselttiğini ancak ekonomik kalkınmaya ne ölçüde katkısı olduğunun belirsiz olduğunu ifade etmişlerdir. Aday geçiş ekonomileri ve Türkiye'de işçi dövizi girişinin milli gelir içindeki payı ne olursa olsun, büyüme ve refahı tek başına arttıramayacağı, ancak diğer sosyal ve ekonomik ölçütlerle birlikte kalkınmaya katkısı olacağını ifade etmişlerdir.

Yukarıda verilen literatür özeti ışığında ekonomik büyüme ve göç ilişkisine yer verilen çalışmaların hem sınırlı sayıda olduğu hem de ekonometrik tekniklere fazlaca yer verilmediği görülmektedir. Bu sebeple ortaya konan bu çalışmanın gerek teorik gerekse ampirik yönünle söz konusu literatüre katkı oluşturacağı söylenebilir.

\section{Ampirik Analiz}

\subsection{Veriler ve Yöntem}

Araştırmada 1962-2012 dönemi için beş yıllık ortalama verilerle Türkiye'nin de içinde yer aldiğ gelişmekte olan ülkelerde ekonomik büyüme ve göç ilişkisi araştırılmıştır. Uygulanacak panel veri analizlerinde ekonomik büyümeyi temsilen Y; gayri safi yurtiçi hasıladaki yıllık büyüme oranı, göçü temsilen $\mathrm{M}$; net göçün nüfusa oranı değişkenleri kullanılmıştır. İlgili veriler Dünya Bankası veri tabanından elde edilmiştir.

Ekonomik büyüme ve göç arasındaki ilişkinin incelenmesinde ele alınan veri seti yatay kesit boyutu $(\mathrm{N}=18)$, zaman boyutundan ( $\mathrm{T}=11$ ) büyük olduğu için, $\mathrm{N}>\mathrm{T}$ durumuna uyan dengeli panel verileri içermektedir. Çalışmada ilk olarak homojenlik testiyle panel veri modellerindeki $\beta$ eğim katsayılarının yatay kesitler arasında farklı olup olmadığ Test S; Swamy test istatistiği ve k; bağımsız değişken sayısı olmak üzere $Y_{i t}=\alpha_{i+} \beta_{i} X_{i t}+\varepsilon_{i t} \quad i=1 \ldots \ldots N$, $\mathrm{t}=1 \ldots \ldots$. T şeklinde hesaplanmaktadır. $\mathrm{H}_{0}: \beta_{\mathrm{i}}=\beta$ Eğim katsayıları homojendir (bütün $\beta_{\mathrm{i}}{ }^{\prime}$ ler için) ve $\mathrm{H}_{1}: \beta_{\mathrm{i}} \neq \beta$ Eğim katsayıları homojen değildir (en az bir i için) şeklindedir. 
Homojenlik testlerinin ardından birim kök ve eş-bütünleşme testlerinin seçiminde önemli olan yatay kesit bağımlılı̆̆ (cross-section dependence) incelemesi yapılmıştır. Pesaran (2004) tarafından geliştirilen $\mathrm{CD}_{\mathrm{LM}}$ testi eşitlik (1) deki gibi hesaplanmaktadır (Pesaran, 2004:9).

$$
\operatorname{CDLM}=\sqrt{\frac{2 \mathrm{~T}}{\mathrm{~N}(\mathrm{~N}-1)}}\left(\sum_{\mathrm{i}=1}^{\mathrm{N}-1} \sum_{\mathrm{j}=\mathrm{i}+1}^{\mathrm{N}} \sqrt{\mathrm{T}_{\mathrm{ij}} \hat{\rho}_{\mathrm{ij}}}\right) ; \mathrm{N}(0,1) \text { ve } \mathrm{N} \rightarrow \infty
$$

Çalışmada yatay kesit bağımlılığı varlığını reddeden boş hipotez reddedildiği için İkinci Nesil Birim Kök Testlerinden Pesaran'ın CADF Testine (Cross-Sectionally Augmented Dickey Fuller-CADF) yer verilmiştir. Pesaran'ın CADF Testi, standart ADF birim kök testinin bireysel serilerin birinci farkları ve gecikme seviyelerinin yatay kesit ortalamalarına göre genişletilmiş halidir (Pesaran, 2007:267). $\mathrm{H}_{0}$ : $\beta_{\mathrm{i}}=0$ Birim kök vardır ve $\mathrm{H}_{1}$ : $\beta_{\mathrm{i}}<0$ Birim kök yoktur şeklindeki hipotezlerin test edildiği CADF Testinde kullanılan temel denklem $y_{i t}=\left(1-\phi_{i}\right) \mu_{i}+$ $\phi_{i} y_{i, t-1}+u_{i t}$ olup $i=1, \ldots, N ; t=1, \ldots, T$ ve $u_{i t}=\gamma_{i} f_{t}+\varepsilon_{i t}$ 'dir. $f_{t}$, gözlemlenemeyen ortak etkileri, $\varepsilon_{i t}$ ise bireysel spesifik hataları göstermektedir. $\phi_{i}=1$ olması durumunda $\mathrm{H}_{0}: \beta_{\mathrm{i}}=0$ (tüm i’ler için) şeklindedir. Bu durumda CADF Testi'nde kullanılan denklem şu şekilde ifade edilmektedir.

$\Delta \mathrm{y}_{\mathrm{it}}=\alpha_{\mathrm{i}}+\beta_{\mathrm{i}} \mathrm{y}_{\mathrm{i}, \mathrm{t}-1}+\varepsilon_{\mathrm{it}}$

(2) nolu denklemde $\alpha_{\mathrm{i}}=\left(1-\phi_{\mathrm{i}}\right) \mu_{\mathrm{i}}, \beta_{\mathrm{i}}=-\left(1-\phi_{\mathrm{i}}\right)$ ve $\Delta \mathrm{y}_{\mathrm{it}}=\mathrm{y}_{\mathrm{it}}-\mathrm{y}_{\mathrm{it}-1}$ 'dir. Böylece denklem $Y_{i, t}$ 'nin gecikmeli birinci farklarının ilave edildiği genişletilmiş regresyon denklemine dönüşmekte ve tahmin edilmektedir. CADF ile her bir yatay kesite ait değerin durağanlığını tespit etmek güçtür. CADF regresyonu tahmin edildikten sonra $\mathrm{H}_{0}$ hipotezinin geçerliliği panelin geneli için CIPS (Cross-Sectionally Augmented IPS) istatistiği ile test edilebilmektedir. CIPS $=\mathrm{N}^{-1} \sum_{\mathrm{i}=1}^{\mathrm{N}} \mathrm{CADF}_{\mathrm{i}}$ şeklinde ifade edilen CIPS istatistiğinde, gecikmeli değişkenlerin $\mathrm{t}$-istatistiklerinin ortalamaları $\left(C A D F_{i}\right)$ alınmaktadır. CADF testinde CIPS istatistiğinin kullanılmasının temel nedeni, her bir yatay kesite ait birim kök test istatistiklerinin ortalaması alınarak panelin geneli için birim kök testi yapılabilmesidir (Pesaran, 2007:267-268). Birim kök sınamasının ardından Westerlund tarafından 2008 yılında geliştirilen Durbin-Hausmann Eş-Bütünleşme Testi'nin kullanılması kararlaştırılmıştır. Ayrıca çalışmada eşbütünleşme katsayılarının tahmini için Pesaran (2006) tarafından geliştirilen T $>$ N ve NT $>$ T durumuna uyan Ortak İlişkili Etkiler (Common Correlated Effect-CCE) tahmin yöntemi kullanılmıştır. Serilerin heterojen olmasını ve yatay kesit bağımlılığı göz gönünde bulunduran ve aynı zamanda değişkenlerin durağanlığı hakkında herhangi bir kısıtlama öngörmeyen Durbin-Hausmann Eş-Bütünleşme Testi'nde, eş-bütünleşmenin varlığ panel ve grup boyutu olmak üzere iki şekilde ele alınmaktadır. Durbin-Hausman panel testinde otoregresif parametrenin, $\mathrm{H}_{0}$ : Eşbütünleşme yoktur ve $\mathrm{H}_{1}$ : Eş-bütünleşme vardır şeklindeki hipotezler altında tüm kesitler için aynı olduğu varsayımı yapılmaktadır. Bu varsayım altında boş hipotezin reddedilmesi, bütün kesitler için eş-bütünleşmenin varlığına işaret etmektedir. Grup testinde ise otoregresif parametrenin kesitler arasında farklılaşmasına izin verilmektedir. Testte boş hipotezin reddedilmesi, en azından bazı kesitler için eş-bütünleşme ilişkisinin varlığına işaret etmektedir (Bayar vd., 2011:15). Durbin-Hausmann Testi ile eş-bütünleşme ilişkisinin tespit edilmesi durumunda, değişkenlerin uzun dönem eş-bütünleşme katsayıları tahmin edilebilmektedir. Bu amaçla kullanılan CCE tahmincisi aşağıdaki eşitlik ile ifade edilmektedir.

$$
y_{i t}=\alpha_{i}^{\prime} d_{t}+\beta_{i}^{\prime} x_{i t}+e_{i t} i=1 \ldots \ldots . . N, \quad t=1 \ldots \ldots T
$$

(3) nolu eşitlikte $e_{i t}=\gamma_{i}^{\prime} f_{t}+\varepsilon_{i t}$ şeklindedir. Yatay Kesit Bağımlılığı Altında Ortalama Grup Etkileri (Common Correlated Mean Group Effects-CCMGE) ve Havuzlanmış Ortak İlişkiler (Common Correlated Effects PooledCCEP) tahmincisi kullanılmaktadır (Pesaran,2006:982).

Son olarak, bu çalışmada yapılan panel veri analizlerinde Gauss 10 ve Eviews 9 ekonometrik analiz paket programları kullanılmıştır.

\subsection{Araştırma Bulguları}

Araştırma yapılan ilk test homojenlik testi olup sonuçları Tablo 1 yardımıyla görülmektedir. Analiz sonuçlarına göre eğim katsayılarının heterojen olduğunu söylemek mümkündür. Böylece her kesit için yapılacak eşbütünleşme testinin geçerli ve güvenilir olduğu tespit edilmiş olmaktadır.

\begin{tabular}{|l|c|c|}
\hline Test & Test İstatistiği & p Değerleri \\
\hline Delta_tilde_adj & 1.290 & 0.098 \\
\hline
\end{tabular}

Tablo 1. Homojenlik Testi Sonuçları

Tablo 2'de homojenlik testinin ardından yapılan yatay kesit bağımlılı̆̆ araştırmasına ilişkin bulgular yer almaktadır. Buna göre birimler arasında yatay kesit bağımlılığın olmadığını ileri süren $\mathrm{H}_{0}$ hipotezi \% 1 önem düzeyinde modelde reddedilmiştir. Ülke grupları itibariyle paneli oluşturan kesitler arasında yatay kesit bağımlılık bulunduğu için ülkelerden birinde meydana gelen beklenmeyen bir olay diğerlerini de aynı şekilde etkileyebilmektedir.

\begin{tabular}{|l|c|c|}
\hline Test & Test İstatistiği & p Değerleri \\
\hline Panel için cd LM (Pesaran 2004 CD) & 4.174 & 0.000 \\
\hline
\end{tabular}

Tablo 2. Yatay Kesit Bă̆ımlılı̆̆ı Test Sonuçları 
Yatay kesit bağımlılı̆̆ı dikkate alan CADF-CIPS birim kök testine ait sonuçlar Tablo 3'de verilmiştir. Değişkenlerin düzey değerlerine göre yapılan CADF Testi sonucunda elde edilen CIPS istatistiklerine göre hem Y hem de $\mathrm{M}$ değişkeni durağan değildir. Bu nedenle değişkenlerin farkları alınarak CADF-CIPS birim kök testi tekrar yapılmıştır. Her iki değişkenin birinci fark değerleri ile [I(1)] durağan hale geldikleri, yani birim kök içermedikleri tespit edilmiştir.

\begin{tabular}{|c|c|c|c|c|c|c|c|c|}
\hline \multirow{3}{*}{ Ülkeler } & \multicolumn{4}{|c|}{ Seviye } & \multicolumn{4}{|c|}{ Fark } \\
\hline & \multicolumn{2}{|c|}{$\mathbf{Y}$} & \multicolumn{2}{|c|}{ M } & \multicolumn{2}{|c|}{$\mathbf{Y}$} & \multicolumn{2}{|c|}{ M } \\
\hline & Stat. & $\begin{array}{c}\text { Lag } \\
\text { Length }\end{array}$ & Stat. & $\begin{array}{c}\text { Lag } \\
\text { Length }\end{array}$ & Stat. & $\begin{array}{c}\text { Lag } \\
\text { Length }\end{array}$ & Stat. & $\begin{array}{c}\text { Lag } \\
\text { Length }\end{array}$ \\
\hline Cezayir & $-6.809^{b}$ & 2 & -0.133 & 2 & $-259.964^{a}$ & 2 & -0.692 & 2 \\
\hline Belize & $-4.288^{c}$ & 2 & -3.960 & 2 & $-4.926^{\mathrm{a}}$ & 2 & -1.294 & 2 \\
\hline Botsvana & -1.912 & 2 & -1.045 & 2 & 1.132 & 2 & -1.662 & 2 \\
\hline Çin & $-4.945^{b}$ & 2 & -0.627 & 2 & -1.970 & 2 & -0.410 & 2 \\
\hline Kolombiya & -0.705 & 2 & 1.447 & 2 & -0.805 & 2 & 0.509 & 2 \\
\hline Kosta Rika & 0.154 & 2 & -1.427 & 2 & -0.411 & 2 & -1.385 & 2 \\
\hline $\begin{array}{l}\text { Dominik } \\
\text { Cum. }\end{array}$ & -0.291 & 2 & -0.677 & 2 & -0.559 & 2 & -0.735 & 2 \\
\hline Ekvator & -1.389 & 2 & -1.914 & 2 & -1.438 & 2 & $-14.989^{a}$ & 2 \\
\hline Gabon & -2.529 & 2 & -3.802 & 2 & $-12.506^{\mathrm{a}}$ & 2 & -1.121 & 2 \\
\hline İran & -1.327 & 2 & -3.521 & 2 & -0.965 & 2 & -2.787 & 2 \\
\hline Malezya & -1.753 & 2 & -2.526 & 2 & -2.992 & 2 & -3.811 & 2 \\
\hline Meksika & -2.889 & 2 & -1.064 & 2 & $-4.519^{c}$ & 2 & $-14.770^{\mathrm{a}}$ & 2 \\
\hline Panama & -0.422 & 2 & -1.604 & 2 & $-4.245^{c}$ & 2 & -0.417 & 2 \\
\hline Paraguay & -0.041 & 2 & -0.509 & 2 & -0.606 & 2 & 1.515 & 2 \\
\hline Peru & -1.507 & 2 & -3.908 & 2 & $-4.505^{\mathrm{c}}$ & 2 & $-33.045^{a}$ & 2 \\
\hline $\begin{array}{l}\text { Güney } \\
\text { Afrika }\end{array}$ & -2.482 & 2 & 0.465 & 2 & $-12.296^{\mathrm{a}}$ & 2 & 0.019 & 2 \\
\hline $\begin{array}{l}\text { St. Vincent ve } \\
\text { Grenad. }\end{array}$ & $-6.228^{b}$ & 2 & -3.793 & 2 & $-5.038^{\mathrm{b}}$ & 2 & -1.739 & 2 \\
\hline \multirow[t]{2}{*}{ Türkiye } & $-5.171^{b}$ & 2 & -0.296 & 2 & $-16.786^{\mathrm{a}}$ & 2 & 1.226 & 2 \\
\hline & \multicolumn{2}{|c|}{ CIPS: -2.474 } & \multicolumn{2}{|c|}{ CIPS:-1.605 } & \multicolumn{2}{|c|}{ CIPS: $\mathbf{- 1 8 . 5 2 2 ^ { \mathrm { a } }}$} & \multicolumn{2}{|c|}{ CIPS: $-4.199^{\mathrm{a}}$} \\
\hline
\end{tabular}

Not: CADF istatistiği kritik değerleri, Pesaran (2007) Tablo 1c, s.276; -7.50, -4.89 ve -3.99 olmak üzere a;\%1, b;\%5 ve c;\%10 anlamlılık düzeylerini göstermektedir. CIPS istatistiği kritik değerleri, Pesaran (2007) Tablo 2c s.281; -3.46, -3.02 ve -2.82 olmak üzere a; $\% 1, \mathrm{~b} ; \% 5$ ve c; $\% 10$ anlamll1ık düzeylerini göstermektedir.

Tablo 3. CADF ve CIPS Birim Kök Testi Düzey Sonuçlarl

Çalışmada homojenlik, yatay kesit ve birim kök testi sonuçları, serilerin heterojen olduğuna, yatay kesit bağımlılık içerdiğine ve birinci fark cinsinden durağan olduklarına işaret etmektedirler. Bu duruma uygun olarak yapılan Durbin-Hausmann Eş-Bütünleşme Testi'nin sonuçları Tablo 4'te görülmektedir. Durbin-Hausmann EşBütünleşme Testi sonuçlarına göre, otoregresif parametrenin tüm kesitler için aynı olduğu varsayımı altında hem grup hem de panel istatistikleri \%1 önem düzeyinde anlamlıdırlar. Boş hipotezin reddedilmesi, panelde yer alan bütün kesitler için eş-bütünleşmenin var olduğunu göstermektedir. Yani ekonomik büyüme ve göç arasında eşbütünleşik ilişkilerin varlığından söz edilebilmektedir.

\begin{tabular}{|l|c|c|}
\hline Test & Test İstatistiği & p Değerleri \\
\hline dh_g & 6.261 & 0.000 \\
\hline dh_p & 8.725 & 0.000 \\
\hline
\end{tabular}

Tablo 4. Westerlund (2008) Durbin-Hausmann Test Sonuçları

Eşbütünleşme ilişkisinin varlığının ardından değişkenlerin uzun dönem eş-bütünleşme katsayıları tahmin edilmiştir. Tablo 5 CCE tahmincisinin panel ve yatay kesit birimler için hesaplanan regresyon katsayılarını göstermektedir. Tablo 5 'te yer alan sonuçlara göre, elde edilen ampirik bulgular sonucunda ekonomik büyüme ve göç arasında doğru yönlü bir ilişki vardır. Göçte meydana gelen \%1'lik artış, ekonomik büyümeyi \%3.32 artırmaktadır. 


\begin{tabular}{|l|c|c|}
\hline Yatay Kesit & Katsayı & t istatistiği \\
\hline Cezayir & 11.511 & $5.437^{\mathrm{a}}$ \\
\hline Belize & -0.239 & $-1.636^{\mathrm{c}}$ \\
\hline Botsvana & 1.635 & $2.422^{\mathrm{a}}$ \\
\hline Çin & 36.906 & $2.159^{\mathrm{b}}$ \\
\hline Kolombiya & -1.356 & -1.053 \\
\hline Kosta Rika & -0.372 & $-1.617^{\mathrm{c}}$ \\
\hline Dominik Cum. & 10.890 & $3.858^{\mathrm{a}}$ \\
\hline Ekvator & 2.812 & $4.117^{\mathrm{a}}$ \\
\hline Gabon & -2.185 & $-2.142^{\mathrm{b}}$ \\
\hline Iran & -1.985 & $-2.902^{\mathrm{a}}$ \\
\hline Malezya & 0.264 & 0.364 \\
\hline Meksika & -0.902 & $-1.563^{\mathrm{c}}$ \\
\hline Panama & -0.940 & -0.760 \\
\hline Paraguay & 1.519 & $2.103^{\mathrm{b}}$ \\
\hline Peru & 2.701 & $2.369^{\mathrm{a}}$ \\
\hline Güney Afrika & 0.241 & 0.755 \\
\hline St. Vincent ve Grenadinler & -0.271 & -0.459 \\
\hline Türkiye & -0.296 & $-1.333^{\mathrm{c}}$ \\
\hline Panel & 3.329 & $1.531^{\mathrm{c}}$ \\
\hline $\begin{array}{l}\text { Not: İstatistik değerleri } 2.32,1.65 \text { ve } 1.28 \text { olmak üzere a; } \% 1, \mathrm{~b} ; \% 5 \mathrm{ve} \mathrm{c} ; \% 10 \text { anlaml111k düzeylerini } \\
\text { göstermektedir. }\end{array}$ & \\
\hline
\end{tabular}

Tablo 5. CCE Tahmincisinin Yatay Kesit ve Panelde Hesaplanan Regresyon Katsayıları

\section{Sonuç}

Ekonomik büyüme ve kalkınma; gelişmiş, gelişmekte olan ve azgelişmiş tüm ülkeler için çok önemli bir hedef olmakla birlikte büyüme ve kalkınma sürecinin hangi enstrümanlar tarafından belirlendiği geçmişten bu yana birçok araştırmacı ve politikacı için en önemli sorulardan biri olmuştur. Bu bağlamda ekonomik büyüme üzerinde göç olgusunun etkisi de birçok teori ve teorisyen tarafından irdelenmiştir. Söz konusu değişkenler olan ekonomik büyüme ve göç olgusu arasındaki ilişkinin boyutu ülkelerin aldığı ve verdiği göçün miktarına ve niteliğine bağl1 olmakla birlikte genel görüş, nitelikli sermaye göçü alan ülkelerin ekonomik büyümesinin artacağı ve niteliksiz sermaye göçü alan ülkelerin ise ekonomik büyüme sürecinden olumsuz etkileneceği yönündedir. Fakat diğer taraftan nüfus artış hızı düşük veya negatif olan gelişmiş ülkelere doğru gerçekleşen kalifiye olmayan beşeri sermaye akımlarının da söz konusu ülkelerin ekonomik büyümesini olumlu yönde etkileyebileceği yönünde görüşler de mevcuttur. Bununla birlikte göç veren ülkeler için azalan işgücüyle birlikte emeğin marjinal verimliliğinin artması da mümkün olabilmektedir. Bu bağlamda ekonomik büyüme ve göç arasındaki ilişkiler ve ekonomik büyümeye göçün muhtemel etkileri ortaya konan bu çalışmanın da konusunu oluşturmaktadır.

Panel veriye dayalı analizin ilk kısmında panelin bütünündeki homojenlik, yatay kesit ve birim kök testleri analiz edilmiş ve ortaya çıkan analiz bulguları serilerin heterojen olduğuna, yatay kesit bağımlılık içerdiğine ve birinci fark cinsinden durağan olduklarına işaret etmiştir. Ortaya çıkan bu sonuçlar ışı̆̆ında gerçekleştirilen panel ve yatay kesit katsayı sonuçlarına göre ise Cezayir, Botsvana, Çin, Dominik Cumhuriyeti, Ekvator, Paraguay ve Peru'da ekonomik büyüme ile göç arasında istatistiki olarak anlamlı ve pozitif ilişkiler bulunmaktadır. Belize, Kosta Rika, Gabon, İran, Meksika ve Türkiye gibi diğer ülkelerde ise ekonomik büyüme ve göç arasındaki ilişkinin yönü negatif olmakla beraber istatistiki açıdan anlamlı çıkmaktadır.

Tüm bu sonuçlar birlikte değerlendirildiğinde ülkeler arasındaki göçün niteliği (kalifiye veya kalifiye olmayan emek gücünün göç etmesi) belli olmamakla birlikte, panelin tümünde ve genel olarak araştırılan ülkelerin büyük bir çoğunluğunda (18 ülkenin 13'ünde) ekonomik büyüme ve göç arasında anlamlı bir ilişki tespit edilmiştir. Diğer taraftan ekonomik büyüme ve göç arasındaki ilişkilerin anlamlı bulunduğu ülkelerin 7'sindeki katsayılar pozitifken, 6'sında ise negatiflik söz konusudur. Bu durum katsayıların pozitif olduğu ülkelerde görece kalifiye olmayan emek gücünün göç etmiş olabileceği şeklinde yorumlanabileceği gibi, katsayıların negatif olduğu ülkelerde ise görece kalifiye olan emek gücünün göç ediyor olabileceği şeklinde yorumlanabilir. Ayrıca göç yalnızca ekonomik yani tek boyutlu bir olgu olmadığ için sosyal yönü dahil olmak üzere farklı bakış açılarını içinde barındıran politika ve yaklaşımlara ihtiyaç olduğu unutulmamalıdır. 


\section{Kaynakça}

- Bayar, G., Güloğlu, B. ve Tokpunar, S., "Sanayi Sektörü İstihdamının Temel Belirleyicileri ve Dış Ticaret, Türkiye Örneği”, Ekonomik Yaklaşım Kongreler Dizisi, 2011, 15.

- Boubtane, E., Dumont, J.C. ve Rault, C., Immigration and Economic Growth in the OECD Countries, 19862006, IZA Discussion Paper Series, (Working Paper No:8681), Germany, 2014.

- Bozdoğan, E. G. ve Atan, M. (2009) “Avrupa Ülkelerine Göç Eden Türk İşçilerin İktisadi Etkinliğe Katkısı”, Gazi Üniversitesi İktisadi ve Ídari Bilimler Fakültesi Dergisi, 11(1), 159-180.

- Chen, H.J. (2006) “International Migration and Economic Growth: A Source Country Perspective", J Popul Econ, 19, 725-748.

- Gökçek Karaca, N. ve Saruç, S., "Türkiye ve Avrupa birliğine Aday Geçiş Ekonomilerinde Uluslararası Göç Trendleri”, International Conference On Eurasian Economies, 2014.

- Kırdar, M.G. ve Saracoğlu, D.Ş. (2012) “İç Göç, Bölgesel Yakınsama Sorunu ve Ekonomik Büyüme: Türkiye Örneği”, Türkiye Ekonomi Kurumu, TEK Tartışma Metni, 2012/75.

- Maria, C. D. ve Lazarova, E.A. (2012) "Migration, Human Capital Formation, and Growth: An Empirical Investigation”, World Development, 40(5), 938-955.

- Martin, P. L. (2012) “Göç, Ticaret ve Kalkınma: Meksika-ABD ve Türkiye-Avrupa Karş1laştırması”, Migration Letters, 9(4), 401-414.

- Morley,, B. (2006) “Causality Between Economic Growth and Immigration: An ARDL Bounds Testing Approach”, Economics Letters 90 (2006) 72-76.

- $\quad$ Pesaran, M. H., General Diagnostic Tests for Cross Section Dependence in Panels, (Working Paper No:0435), University of Cambridge, Cambridge 2004.

- $\quad$-----------, (2006) "Estimation and Inference in Large Heterogeneous Panels wiht A Multifactor Error Structure", Econometrica, 74(4),967-1012.

- $\quad$-----------, (2007) “A Simple Panel Unit Root in the Presence of Cross-Section Dependence”, Journal of Applied Econometrics, 22(2007), 265-312.

- Pesaran, M. H. ve Yamagata, T., (2008) “Testing Slope Homogeneity in Large Panels”, Journal of Econometrics, 142(2008), 50-93.

- Zlotnik, H. (1998) “International Migration 1965-96: An Overview”, Population and Development Review, 24(3), 429-468. 


\title{
Orta Gelir Tuzağının Belirleyenleri: Türkiye Örneği The Determinants of Middle Income Trap: The Case of Turkey
}

\author{
Prof. Dr. Harun Bal (Çukurova University, Turkey) \\ Assoc. Prof. Dr. Neşe Algan (Çukurova University, Turkey) \\ Ph.D. Candidate Müge Manga (Çukurova University, Turkey) \\ Ph.D. Candidate Esra Ballı (Çukurova University, Turkey)
}

\begin{abstract}
The term "middle income trap" was firstly used in the World Bank's Report titled "An East Asian Renaissance Ideas for Economic Growth" (2007), which then swiftly gained wide currency. According to this report, some countries that failed to align themselves with the requirements of changes and diversification of 21 st century would remain in their respective income bracket. As long as the labor force of a given middle income country is not gradually transferred from the agriculture sector operating with low levels of productivity into the manufacturing sector which produces high added value products thanks to innovation-based practices, it will be losing its competitive edge as compared advanced countries, leading it to reach a plateau at its given level of income. This study is dedicated to determining whether or not Turkey do suffer from middle income trap, and examining the factors responsible for such trap, if they do so. This study also analyzes the primary causes behind middle income trap by utilizing both social and economic data these countries such as real GDP, inflation, good and services export to GDP, agriculture sector to GDP, Gini coefficient and age dependency ratio utilizing Vector Error Correction Model.
\end{abstract}

\section{Giriș}

2000'li yıllarda gündeme gelen Orta Gelir Tuzağı kavramı büyüme ve kalkınma literatüründe yeni tartışmaları gündeme getirmiştir. Orta gelir tuzağı, ilk kez Dünya Bankası için Indermit Gill, vd. (2007) tarafından hazırlanan "An East Asian Renaisance Ideas for Economic Growth" başlıklı raporunda yer almış ve hızlı bir şekilde yaygınlık kazanmıştır. Bu rapora göre, gelişmekte olan orta gelir sınıfındaki ülkeler 21. Yüzyılda ekonomi dünyasında oluşan değişim ve çeşitliliğe ayak uyduramayacak ve orta gelir sınıfında kalmaya devam edeceklerdir. Diğer bir ifade ile raporda, orta gelir tuzağı orta gelire ulaşan ülkelerin düşük gelirli ülkelerle yüksek gelirli ülkeler arasına sıkışıp kalacağı ifade edilmektedir. Düşük gelirli ülkeler düşük emek maliyeti avantajını kullanarak, ucuz maliyetli emek yoğun ürünlerle gelişmiş ülkelerle rekabet edebilirler. Orta gelirli ülke kavramı, işgücünün aşamalı olarak düşük verimliliğe sahip tarım sektöründen, inovasyon destekli katma değeri daha yüksek olan imalat sektörüne kaymaması sebebiyle rekabet gücü düşen ve mevcut gelir grubunda kalmaya devam eden ülke olarak tasvir edilebilir. Orta gelir tuzağının değerlendirmesi aşamasında üç temel kriter kullanmaktadır. Bunlar;

- Kişi başına gelir düzeyinin 15.839 \$ (2005 sabit fiyatlarıyla) düzeyine yükselmesi

- Kişi başına gelir düzeyinin ABD kişi başı gelir düzeyinin \%58'inin üzerine düzeyine ulaşılması,

- Ülkenin imalat sanayisinin ulusal gelir içindeki payının \%23 düzeyine ulaşması şeklinde ifade edilebilir (Eichengreen vd, 2011). Bahsi geçen bu kriterler orta gelir için eşik değerleri olarak kabul edilebilmektedir.

Bununla birlikte ABD kişi başına düşen milli gelir düzeyine göre orta gelir tuzağı kavramını açıklayan birçok farklı yaklaşım bulunmaktadır. Robertson ve Ye (2013)'e göre, orta gelir tuzağına yakalanmış olan ülkelerin milli gelir düzeylerinin ABD kişi başına düşen gelirinin \%8-36 arasında bulunduğunu, Woo (2012)'de ise, ABD kişi başına gelir düzeyinin \%20-55 düzeyleri arasında olduğu ifade edilmektedir.

Orta gelir tuzağının oluşumunu açıklamak amacıyla Aoki (2011), Çin, Japonya ve Kore'nin büyüme dönemlerini belirli safhalara ayırma yolunu seçmiştir. Maltusyen evresi (M-evre) olarak ifade edilen ilk evrede gelir düzeyi düşük, tarım sektörünün istihdamda önemli paya sahip ve yapısal bir dönüşüm söz konusudur. İkinci evre olarak ifade edilen G-evresinde; hükümetin dahil olduğu endüstriyel birikim, çocuk ölümlerinde düşüş ve doğum oranlarında artış oluşmaktadır. Kuznets evresi (K-evresi) olarak ifade edilen üçüncü evre ise, işgücü göçünün sebep olduğu kalkınmada oluşan yapısal değişimin meydana geldiği evredir. Dördüncü evre ise, beşeri sermayedeki gelişmelere bağlı olarak toplam faktör verimliliğinin arttı̆ğ sürdürülebilir büyüme adına önemli gelişmelerin oluştuğu $H$ - evresidir. Beşinci $P D$-evresi ise, post-demografik evre olarak ifade edilen, düşük doğurganlığın oluştuğu ve nüfusun yaşlandığı dönemdir. Aoki (2011)'e göre eğer ülkeler bu evrelerden geçip, yüksek gelir düzeyine ulaşmada sorun yaşarlarsa bu durumda orta gelir tuzağına yakalanma durumu ile karşılaşacaklardır.

Bir başka çalışmada, Tho (2013), Güneydoğu Asya Ülkeleri Birliği (ASEAN) ülkelerinden yola çıkarak orta gelir tuzağından kaçış ve bu ülkelerin yüksek gelir elde etmesi yönünde değerlendirmeler yapmıştır. Tho (2013)'te ekonomik gelişim süreci, A- B aralığı olarak ifade edilen yoksulluk tuzağı, B-C aralığı olan yoksulluk tuzağından çıkış ve C-E aralığı olan orta gelir tuzağı şeklinde işlemektedir. Bu çalışmada, A- B aralığının geleneksel bir toplumu temsil ettiği B-C aralığının oldukça uzun zaman alan sanayi ve hizmet sektörünün payının artması ile gerçekleşecek bir süreç olduğu ifade edilmektedir. C-E aralığı ise ülkenin orta gelir düzeyinde sıkıştığı bölümdür. 
Ayrıca bu çalışmada ülkenin orta gelir grubundan (C-E aralığı), yüksek gelir grubuna ulaşması için emeğin verimliliğin artması, sanayi yapısındaki gelişmelerin büyümeyi pozitif yönde etkileyecek şekilde gelişmesi gerektiği ifade edilmektedir ( Koçak ve Bulut, 2014).

Orta gelir tuzağının nedenleri üzerine farklı yaklaşımlar bulunmaktadır. Ancak genel olarak yapılan çalışmalarda orta gelir tuzağının asıl sebebi olarak verimlilikteki düşüş gösterilmektedir. Zeng ve Feng (2014), orta gelir tuzağı sebebi olarak yüksek yenilikçi ekonomiler ile düşük gelirli ekonomilerin rekabet edememesi, Chen ve Dai (2014)'te ise azgelişmiş ülkelerin gelişimlerinin ilk evresinde taklit yoluyla yenilik yaptıkları ancak bu yeniliklerin gelir düzeylerini sadece belirli bir düzeye kadar yükselttiği ve ülkelerinin orta gelir düzeylerinde tıkandığg ifade edilmiştir (Koçak ve Bulut, 2014). Orta gelir tuzağının ne için meydana geldiğini açıklayan Solow, Maltusyen Tuzak ve Lewis'in İkili Dual Yapı Modellerine göre ise, uzun dönemli büyümeyi belirleyen temel değişkenin teknoloji olduğu ifade edilmektedir. Latin Amerika ve Doğu Asya ülkelerinin orta gelir tuzağına yakalanma nedenleri ve tuzaktan kurtulma önerileri üzerine birçok çalışma yapılmıştır. Genel olarak ifade edilmek gerekirse Kharas ve Kohli (2011), Carnovale (2012), Paus (2012), Woo (2012) gibi orta gelir tuzağının nedenleri üzerine yapılmış olan çalışmalarda, beşeri sermayeden, Ar-Ge harcamalarına yargı ve basın özgürlüğünden ülkede uygulanan siyasal rejime kadar-kısacası ülkenin her alanda- dünya genelinde oluşan yapısal dönüşüme ayak uyduramaması sebep olarak gösterilmektedir (Bozkurt, vd., 2014).

Orta gelir tuzağının ölçümüne yönelik farklı yaklaşımlar mevcuttur. Eichengreen, vd., (2012), tarafından ortaya atılan ve Hausmann, vd (2005) tarafindan geliştirilen yöntem üzerinden oluşturulan büyümede yavaşlama yaklaşımına göre, büyümede yavaşlama oluşmadan önceki yedi yıllık dönemdeki ortalama büyüme oranı \%3,5'e eşit veya daha fazla olmalı $\left(g_{t, t-n}, \geq 0.035\right)$, büyümede yavaşlamanın oluştuğu yıldan sonraki yedi yıllık dönemde

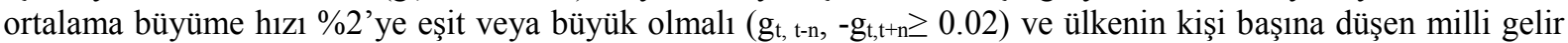
düzeyi 10.000 \$'dan büyük olması ( $\mathrm{y}_{\mathrm{t}}>10.000$ \$) kriterleri geçerlidir. Bir başka yaklaşımda, Woo (2012), çalışmasında Woo (2011)'de ifade edilen yakalama endeksi (CUI) kavramı kullanılarak 1960-2008 dönemi için ülkeler ABD’nin kişi başına gelir düzeyine göre orta-düşük-yüksek gelirli olarak ülkeler şeklinde sınıflandırılmıştır. CUI değişkenin belirlediği kriterlere göre, CUI $>\% 55$ ise ülke yüksek gelirli, \%55>CUI $>\% 20$ orta gelirli, CUI $>\% 20$ ise ülke düşük gelirli ülke olarak gruplandırılmıştır. Ülkelerin orta gelir tuzağında bulunup bulunmadığını test eden bir başka çalışmada Felipe vd, (2012), ülkeler kişi başına GSYİH düzeylerine göre dört farklı sınıflandırmaya tabi tutulmuştur (1990-PPP \$). Bu sınıflandırmaya göre, 2.000 \$ altı gelir grubuna sahip ülkeler düşük gelirli, 2.000 \$-7.250 \$ gelir grubu düşük orta gelirli ülkeler, 7.250\$- 11.750 \$ düzeyinde kişi başına gelire sahip ülkeler yüksek orta gelirli, 11.750 \$ kişi başına gelire sahip ülkeler ise yüksek gelirli ülkeler şeklinde gruplandırılmıştır. Ayrıca bu çalışmada ülkenin düşük orta gelir düzeyli ülke olarak kabul edilebilmesi için en fazla bu grupta 28 yıl, yüksek orta gelir düzeyinde bir ülke olarak kabul edilmesi için ise en az 14 yıl geçirmesi gerektiği belirtilmiştir.

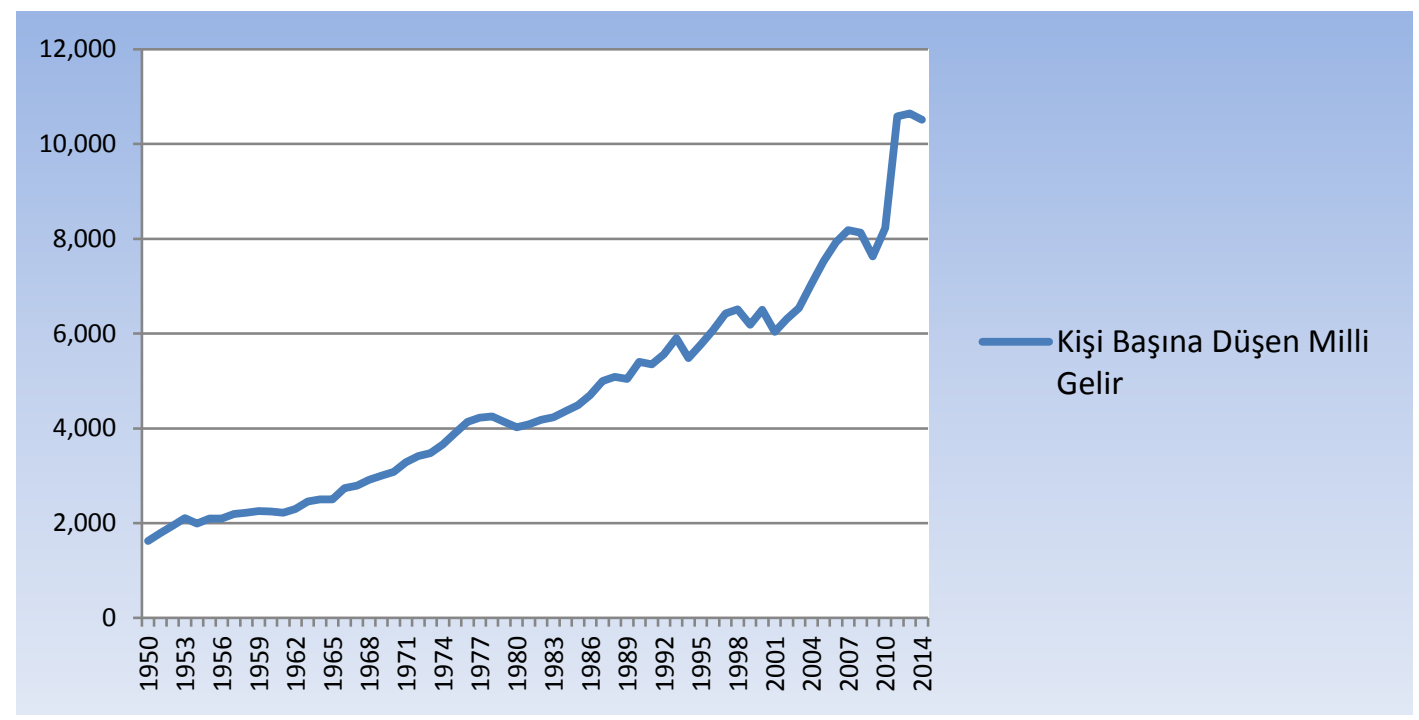

Şekil 1: Türkiye'deki 1950-2014 Yılları Arasındaki Kiş̧i Başına Düşen Milli Gelirin Seyri Kaynak: (Maddison ve Worldbank Veri Tabani)

1950-2014 yılları arasında Türkiye'deki kişi başına düşen gelir düzeyi Felipe vd, (2012) çalışmasında yer alan yaklaşıma göre incelendiğinde Türkiye 1955 yılında 2.093 \$ kişi başına düşen gelir düzeyi ile düşük orta gelirli ülke konumuna ulaşmış ve bu trendini 2005 yılına kadar devam ettirmiştir. Türkiye'nin düşük orta gelir düzeyinden yüksek orta gelir düzeyine geçişi 50 yıllık bir zaman diliminde gerçekleşmiştir. Felipe vd (2012) yaklaşımına göre Türkiye 2005-2014 yılı arasında yüksek orta gelir düzeyini korumakta ve grupta Türkiye'nin yüksek orta gelir tuzağına düşmemesi için toplamda dört yılı bulunmaktadır. Ayrıca Felipe vd, (2012)'deki yaklaşıma göre bir ülkenin yüksek orta gelir tuzağından kurtulabilmesi için kişi başına düşen gelir artış hızının ortalama en az \%3,5 
olması gerektiği ifade edilmiştir. Türkiye'nin 2005-2014 yılları arasında kişi başına düşen gelir artış hızı ortalama \%3'lerde seyretmiştir. Bu sebeple, Felipe vd, (2012)'ye yaklaşımına göre Türkiye'nin, 2005-2014 yılları arasında yüksek orta gelir tuzağında bulunan bir ülke konumunda olduğu açıkça ifade edilebilir.

Şekil 1'de yer alan kişi başına düşen GSYİH düzeyindeki gelişim seyrine bağlı olarak Tho (2013)'nun orta gelir tuzağı yaklaşımı Türkiye için ele alındığında, ekonominin gelişim süreci içerisinde orta gelir tuzağını belirttiği gelir düzeyine 2010'lu yıllarda ulaşıldığı ve günümüze kadar bu düzeyde kaldığını görmek mümkündür.

Diğer bir tanımlamaya göre orta gelir tuzağında olan ülkenin kişi başına gelir düzeyinin ABD'de kişi başına düşen gelir düzeyinin \%20'si oranında olması (yaklaşık 10.000 \$) ülkenin orta gelir tuzağında olması anlamına geldiğinden hareket edildiğinde ise, Türkiye'nin orta gelir tuzağına çok yakın olan bir ülke konumunda olduğu söylenilebilir.

\begin{tabular}{|c|c|c|c|}
\hline Yillar & TR KBGSYH (US\$) & ABD KBGSYH (US\$) & TR/ABD*100 \% \\
\hline 2000 & 4.147 & 35.252 & 11,76 \\
\hline 2001 & 3.002 & 36.065 & 8,32 \\
\hline 2002 & 3.519 & 36.950 & 9,52 \\
\hline 2003 & 4.535 & 38.325 & 11,83 \\
\hline 2004 & 5.791 & 40.401 & 14,33 \\
\hline 2005 & 7.040 & 42.629 & 16,51 \\
\hline 2006 & 7.626 & 44.750 & 17,04 \\
\hline 2007 & 9.245 & 46.467 & 19,9 \\
\hline 2008 & 10.272 & 46.901 & 21,9 \\
\hline 2009 & 8.528 & 45.461 & 18,76 \\
\hline 2010 & 10.017 & 46.811 & 21,4 \\
\hline 2011 & 10.363 & 48.328 & 21,44 \\
\hline 2012 & 10.457 & 49.802 & 21 \\
\hline 2013 & 10.975 & 52.980 & 20,7 \\
\hline 2014 & 10.515 & 54.629 & 19,2 \\
\hline
\end{tabular}

Tablo 1: Türkiye KBGSYH oranının ABD KBGSYH'ya oranı (TR/ABD*100\%) Kaynak: Eğilmez (2012) ve Worldbank Veri Tabanı

Tablo 1 de görüldüğü üzere Türkiye 2000'li yıllarda itibaren orta gelir tuzağına yakalanma durumu belirsiz bir süreç izlemiş ve özellikle son yıllarda Türkiye orta gelir tuzağına oldukça yakın bir görünüm sergilemiştir.

$\mathrm{Bu}$ çalışmada, giriş bölümünde orta gelir tuzağı ile ilgili genel bilgiler verilmiş, çeşitli yaklaşımlar çerçevesinde Türkiye'nin orta gelir tuzağında olup olmadığı üzerine genel değerlendirmeler yapılmaktadır. Ampirik analiz bölümünde Türkiye'nin gelir düzeyini etkileyen demografik ve ekonomik bazı değişkenler ile gelir düzeyi arasındaki ilişki VECM modeli, Etki- Tepki analizi ve Varyans Ayrıştırması 1şı̆̆ında incelenmekte ve analiz sonuçları verilmektedir. Sonuç bölümünde ise analiz kısmında elde edilen bulguların ışı̆̆ında orta gelir tuzağından çıkış üzerine çeşitli öneriler sunulmaya çalışılmıştır.

\section{Literatür Taraması}

Literatürde Türkiye'deki orta gelir tuzağını araştıran birçok çalışma bulunmaktadır. Bu çalışmalarda genel olarak Türkiye'nin orta gelir tuzağında bulunup bulunmadığı ve gelir düzeyini etkileyen çeşitli değişkenler üzerine değerlendirmeler yapılmıştır. Tasar vd. (2016), çalışmasında Türkiye'nin orta gelir tuzağında olup olmadığını 1960-2014 yılları için Robertson ve Ye (2013) birim kök testleri kullanılarak analiz edilmiş ve Türkiye'nin orta gelir tuzağında olmadığı sonucuna ulaşmışlardır. Bir başka çalışmada, Raiser vd. (2016) Polonya ve Türkiye'yi karşılaştırmalı olarak incelemiş, orta gelir tuzağı ile ilgili olarak Polonya'nın, Türkiye'ye nazaran daha yüksek oranda büyüme düşüşü yaşadığını ve Polonya'nın ekonomik kuruluşlarının Türkiye'den daha iyi bir konumda bulunduğunu ifade etmişlerdir. Ayrıca bu çalışmada makroekonomik politikalar açısından Türkiye'de daha büyük oranda dengesizlikler bulunduğu şeklinde bir değerlendirme yapmışlardır. Öztürk (2015), orta sınıf ile ekonomik büyümedeki duraklama ile orta gelir tuzağı üzerinde orta sınıfın rolünün incelendiği 1980-2012 yılları esas alınarak Türkiye'nin dahil olduğu 76 ülke üzerine yaptığı çalışmasında, büyümeyi belirleyen faktörler arasında inovasyon, verimlilik ve doğrudan yabancı yatırımların etkili olduğunu ve orta gelir tuzağının önlenmesinde orta sınıfın önemli bir rol oynadığını sonucuna ulaşmıştır. Şahin vd. (2015), Türkiye'de orta gelir tuzağı bağlamında kişi başına düşen gelirin belirleyicilerini Johansen eşbütünleşme ve Granger nedensellik yöntemleriyle 1980-2013 yıllarını esas alarak incelenmiştir. Yapılan analizde, ihracat ile kişi başına düşen gelir arasında çift yönlü bir nedensellik olduğu sonucuna ulaşılmıştır. Nişancı vd. (2015), 1980-2013 yıllarını esas alarak yapmış oldukları çalışmada, Türkiye ekonomisinin Dünya Bankası'nın belirttiği gibi 2005 yılında üst-orta gelir grubuna geçemediği ve Türkiye'nin orta gelir grubunda ortalama kalma süresinin 14 yıl olduğu dikkate alındığında Türkiye'nin orta gelir tuzağında bulunduğu sonucuna ulaşmışlardır. Yılmaz (2015), Türkiye'nin beşeri sermayesi ile orta gelir tuzağında bulunmayan seçilmişülkelerin beşeri sermayesini karşılaş̧ırmış ve orta gelir tuzağından çıkabilmek için 
Türk eğitim sisteminin kritik önem taşıdı̆̆ını ileri sürmüştür. Beşeri sermayenin yüksekliği, inovatif ve rekabetçi verimlilik kapasitesi ile orta gelir tuzağının aşılabileceğini vurgulamıştır.

Uyanık (2015), çalışmasında Türkiye'de işgücünün niteliği ve görece düşük ücret profilli iktisat politikasını ele aldığı çalışmasında, hedef sektör ve ürünler belirlendiğinde bununla ilgili olarak da beşeri sermayenin geliştirilmesi ile Türkiye'nin orta gelir tuzağından kurtulabilme şansına sahip olacağını vurgulamıştır. Bunun için önermiş olduğu sektörler arasında ilaç, kozmetik ve tohum sektörleri bulunmaktadır. Alçın ve Güner, B. (2015), Türkiye'nin orta gelir tuzağına düşme nedenleri ve çıkış politikalarını inceledikleri çalışmalarında toplam faktör verimliliğinde artış, inovasyon, beşeri sermayenin yükseltilmesi ve uzun dönemli teknoekonomik politikaların uygulanmasının Türkiye'nin orta gelir tuzağından çıkışı için önem arz ettiğini vurgulamışlardır.

Koçak ve Bulut (2014), Türkiye'nin orta gelir tuzağında olup olmadığını Lee ve Strazicich (2003) ve Carrion-iSilvestre, J.L., Kim, D. ve Perron, P. (2009) birim kök testleri ile test etmiş ve Türkiye'nim orta gelir tuzağında yer almadığı sonucuna ulaşmışlardır. Bozkurt vd. (2014) Türkiye'nin yüksek gelir düzeyine sahip ülkelere yakınsayıp yakınsamadığını, çeşitli yakınsama analizi ve ARDL ile inceledikleri çalışmalarında Türkiye'nin yüksek gelirli ülkelere yakınsadığı sonucuna ulaşmışlardır. Dalgıç vd. (2014) 1990-2013 yıllarını esas alarak Türkiye dahil 56 ülke üzerine yapmış oldukları çalışmalarında, teknolojik, makroekonomik faktörler ve kurumların orta gelir tuzağından çıkış için ne kadar etkili olduğunu test etmiş ve teknolojinin yükseltilmesi, katma değeri yüksek ürünlerin ihracatının Türkiye'nin gelişmiş ülkelerin gelir seviyesini yakalamada kritik bir role sahip olduğunu vurgulamışlardır. Atalay (2015)’ göre orta gelir tuzağında bulunan ülkeler ekonomik büyümelerini gerçekleştirebilmeleri için beşeri sermayelerini güçlendirmelilerdir. Beşeri sermayeyi güçlendirmek aynı zamanda belirli sosyal ve ekonomik maliyetleri de beraberinde getirecektir. Bu nedenle bu durumda olan ülkeler beşeri sermayelerinin güçlendirirken aynı zamanda istihdam arttırıcı politikalar izlemelilerdir. Çaşkurlu ve Arslan (2014)'te orta gelir tuzağından çıkış reçetelerinden birinin sektör seçimi ile ilgili olduğunu ileri sürmüşlerdir. Bu seçimde ele alınması gereken kriterin hedef alınacak sektörün küresel yapıya eklemlenebilmesi olduğu ifade edilmiştir. Buna göre bu çalışmada Türkiye için demiryolu sektörünü orta gelir tuzağından çıkış için geliştirilmesi gereken sektör olarak belirlemişlerdir. Demiryolu sektörü sunulan hizmet ve geliştirilecek teknoloji ile üretilecek makine, donanım ve yan sanayi ürünlerinin gelişmesini sağlayacaktır.

Yapılan çalışmalarda Türkiye'nin orta gelir tuzağında bulunup bulunmadığı üzerine genel bir fikir birliği bulunmamaktadır. Bunun en temel sebeplerinden birinin orta gelir tuzağının sınanmasında farklı yaklaşımların olmasından kaynaklandığı düşünülmektedir. Ancak, yapılan çalışmaların dikkat çekici olan diğer bir yönü Türkiye'deki orta gelir tuzağından çıkış için inovasyon, beşeri sermaye ve teknolojik gelişmelerin desteklenmesi gerektiği yönündedir.

\section{Ampirik Analiz}

Çalışmada, Türkiye'nin orta gelir tuzağı bağlamında kişi başına gelir düzeylerini etkileyen bazı değişkenlerine yer verilmiştir. Çalışmanın analiz kısmında VECM yönteminden faydalanılarak 1980-2014 yılları için Türkiye'deki GDP ile enflasyon (ENF), GDP'deki ihracatın (EXP) -tarımın payı (TAR), Gini katsayısı (GINI) ve yaş bağımlılık oranı (AGE) değişkenleri arasındaki ilişki incelenmiştir. Değişkenlerin seçiminde Egawa (2013), çalışması takip edilmiştir. Çalışmanın yöntem kısmında VECM (Vektör Hata Düzeltme Modeli) ve bu modele bağlı Varyans ayrıştırması ve Etki-tepki analizi yöntemi kullanılmıştır. Kısıtlı bir VAR modeli olan Hata Düzeltme Modelinde Engle-Granger (1987) değişkenler arasında uzun dönemli bir ilişki çıkması durumunda kısa dönemde değişkenler arasındaki dengesizliklerin giderilmesi için kullanılabilecek bir hata düzeltme modelinin olduğunu savunmuştur.

Genel hatlarıyla Vektör Hata Düzeltme Modeli (VECM),

$$
\begin{aligned}
& \Delta Y=\beta_{0} \sum_{i=1}^{n}+\beta_{1 i} \Delta X_{t-i}+\sum_{i=1}^{n} \beta 2 \mathrm{i} \Delta Y_{t-i}+\beta_{3 i} E C T_{t-1}+\epsilon_{t} \\
& \Delta X=\alpha 0+\sum_{i=1}^{n} \alpha 1 \mathrm{i} \Delta Y i-1+\sum_{i=1}^{n} \alpha 2 \mathrm{i} \Delta X_{1-i}+\alpha_{3 i} E C T_{t-1}+\epsilon_{t}
\end{aligned}
$$

şeklinde ifade edilebilir. (1) numaralı modelde yer alan $\Delta$, ilk farkı, $u_{t-1}$, modelde yer alan kalıntı değerinin bir dönem gecikmelisi yani denge hata teriminin görgül tahminini, $\in$ ise kabul edilen varsayımlar dahilinde hata terimini göstermektedir. Oluşturulan regresyon, $Y_{t}$ 'deki değişmeyi, $X_{t}$ 'deki değişmeye ve bir önceki dönemin dengeleme hatasına bağlar. Buradaki, $\Delta X_{t}, \Delta Y_{t}$ 'deki kısa dönem bozucu etkisine ulaşırken, hata düzeltme terimi, uzun dönem dengesine doğru olan yuvarlamalara ulaşmaya çalışır. Bu aşamada modelde yer alan $\alpha_{2}$, istatistiksel olarak anlamlı ise, $Y_{t}$ 'de bir dönemdeki dengesizliğin ne kadarının diğer dönemde düzeltildiğini belirtir (Gujarati; Şenesen vd, 1999:729). Yani hata düzeltme mekanizmasında hata teriminin gecikme katsayısı negatif ve istatistiksel olarak anlamlı ise hata düzeltme modeli anlamlı olduğu söylenilebilir (Ay ve Özşahin, 2007: 9).

Çalışmanın analiz kısmında öncelikle Türkiye için birim kök testi uygulanmıştır. Birim kök testi olarak Tablo 2'de seriler için uygulanan birim kök testi sonuçları gösterilmiştir.

Yapılan birim kök testi sonucunda değişkenlerin, fark değerinde I(1) durağan yani birinci dereceden bütünleşik olduğu söylenilebilir. Modellerde yer alan değişkenlerin tamamının birinci düzeyde durağan olması bu değişkenler için eşbütünleşme testi yapılabileceğini göstermektedir. Uygulanan model için otokorelasyon ve değişen varyans 
sorunu yaratmayan uygun gecikme uzunluğu SC kriterine göre 2 olarak belirlenmiştir. VAR(2) olarak hesaplanan eşbütünleşme testi sonuçları Tablo 3'te gösterilmiştir.

\begin{tabular}{cccl}
\hline \hline & \multicolumn{3}{c}{ ADF TESTI் } \\
\hline Değişkenler & & & $\begin{array}{l}\text { Fark } \\
\text { Trendsiz }\end{array}$ \\
GDP & $-6.705(1)$ & $\Delta$ GDP & $-6.897(1)$ \\
Gİİ & $-0.875(0)$ & $\Delta$ GİNİ & $-5.274(1)$ \\
Tarım (\%) & $-2.410(0)$ & $\Delta$ Tarım & $-5.917(1)$ \\
EXP (\%) & $-1.766(0)$ & $\Delta$ EXP & $-5.917(1)$ \\
ENF & $-3.317(0)$ & $\Delta$ ENF & $-5.851(1)$ \\
AGE & $0.1175(0)$ & $\Delta$ AGE & $-4.187(\mathrm{I})$ \\
\hline
\end{tabular}

Tablo 2. Birim Kök Testi Sonuçları

\begin{tabular}{lccccc}
\hline \hline $\begin{array}{c}\text { Sifır } \\
\text { hipotez }\end{array}$ & $\begin{array}{c}\text { Öz } \\
\text { Değerler }\end{array}$ & $\begin{array}{c}\text { İz } \\
\text { Değerler }\end{array}$ & $\begin{array}{c}\text { 0.05 Kritik } \\
\text { Değerler }\end{array}$ & $\begin{array}{c}\text { Maksimum } \\
\text { Öz Değerler }\end{array}$ & $\begin{array}{c}\text { 0.05 Kritik } \\
\text { Değerler }\end{array}$ \\
$\mathrm{r}=0$ & 0.8128 & 171.90 & 95.753 & 53.6212 & 40.077 \\
$\mathrm{r} \leq 1$ & 0.7877 & 118.28 & 69.818 & 49.5951 & 33.876 \\
$\mathrm{r} \leq 2$ & 0.5800 & 68.687 & 47.856 & 27.7610 & 27.584 \\
$\mathrm{r} \leq 3$ & 0.4431 & 40.926 & 29.797 & 18.7351 & 21.131 \\
$\mathrm{r} \leq 4$ & 0.3737 & 22.191 & 15.494 & 14.9751 & 14.264 \\
$\mathrm{r} \leq 5$ & 0.2018 & 7.21609 & 3.8414 & 7.216090 & 3.84146 \\
\hline
\end{tabular}

Tablo 3: Yapılan Eşbütünleşme Testi Sonuçları

İki gecikmeli bir VAR modeli uygulamasıyla elde edilen sonuçlara göre, $\% 5$ anlamlılık düzeyinde " $H_{0}$ : Eşbütünleşme yoktur. " hipotezi reddedilmiş ve değişkenler arasında eşbütünleşme vektörünün varlığı tespit edilmiştir. Yapılan test sonuçlarına göre, iz değere ve maksimum öz değere göre vektörünün varlığı tespit edilmiştir. Değişkenler arasında eşbütünleşme varlığının tespiti uzun dönemde değişkenler arasında ilişki olduğunu göstermektedir. Standart testler sonucunda, uygulanan VECM ile hesaplanan ve normalleştirilen katsayılar Tablo 4'te gösterilmiştir.

\begin{tabular}{llllll}
\hline \hline GDP & GINI & TAR & EXP & ENF & AGE \\
\hline 1000000 & 0.357 & -0.278 & -0.101 & 0.1137 & 0.2517 \\
& $(0.106)$ & $(0.327)$ & $(0.091)$ & $(0.015)$ & $(0.201)$ \\
& {$[-3.35]$} & {$[-0.850]$} & {$[-1.110]$} & {$[7.368]$} & {$[1.248]$} \\
\hline
\end{tabular}

Tablo 4. Normalize Edilmiş Denklem Sonuçları

Türkiye için hesaplanan eşbütünleşme analizi ile elde edilen uzun dönem esneklikleri;

$$
L n G D P=0.513-0.357 \operatorname{Ln} G I N I+0.278 L n T A R+0.101 \operatorname{LnEXP}-0.113 E N F-0.257 L n A G E
$$

VECM analizi sonuçlarına göre, hata terimi katsayısının negatif ve anlamlı olması sebebiyle hata düzeltme modelinin uygulanmasının anlamlı olduğu sonucuna ulaşılabilir. Türkiye için yapılan uygulama sonucunda hata düzeltme katsayısı -1.34 olarak hesaplanmıştır. Elde edilen sonucun negatif ve istatistiksel olarak anlamlı çıkması kullanılan hata düzeltme mekanizmasının işlediğini ve herhangi bir dönemde oluşacak bir dengesizliğin yaklaşık olarak bir yıl içerisinde dengeye geleceğini göstermektedir. Uygulanan analiz sonuçlarına göre, GINI katsayısı negatif, tarım (TAR) ve GDP'deki ihracatın payı değişkeni (EXP) ile GDP değişkeni arasında pozitif yönlü, enflasyon ile GDP değişkeni arasında ise negatif yönlü, yaş bağımlılık oranı ile negatif yönlü ilişkisi mevcuttur.

Değişkenlere uygulanan kısa dönemli şokların hangi dönemlerde, ne kadarlık bir düzeyde ve hangi yönde etkili olduğunun analiz edilmesi amacıyla Etki-Tepki ve Varyans Ayrıştırması analizleri uygulanacaktır. Yapılan EtkiTepki analizi sonuçları Şekil 2'de gösterilmiştir.

Şekil 2(a) GDP'nin, GDP'de oluşan bir birimlik pozitif şok karşısındaki tepkisini göstermektedir. Şekil 2(b) ise GINI katsayısındaki bir birimlik şok karşısındaki GDP'nin tepkisini göstermektedir. GDP, GINI katsayısındaki bir birimlik şok karşısında dalgalı, pozitif ve dengeye yönelen bir seyir izlemiştir. Şekil 2(c) tarım değişkenin bir birimlik değişimin GDP'de oluşturacağı etkiyi göstermektedir. GDP, tarım sektörüne dönemler itibariyle negatif yönlü tepki vermiştir. Şekil 2(d) ise, GDP'nin ihracattaki gelişmede oluşabilecek bir birimlik pozitif şok karşısındaki tepkisini göstermektedir. GDP ilk dönemlerde ihracattaki gelişmeye negatif daha sonraki dönemlerde ise pozitif yönde tepki göstermiştir. Şekil 2(e) ise, GDP'nin enflasyonda oluşacak bir birimlik şok karşısında 
negatif yönde tepki göstereceği açıkça görülmektedir. Şekil 2(f) ise, GDP'nin yaş bağımlılık oranı değişkenindeki bir birimlik değişme karşısındaki tepkisini göstermektedir. Yaş bağımlılık oranı ile GDP değişkeni arasında beklentilere uygun olarak pozitif yönlü ilişki çıkmıştır.

(a)

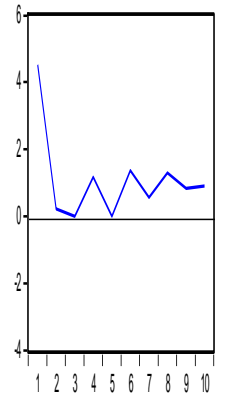

(b)

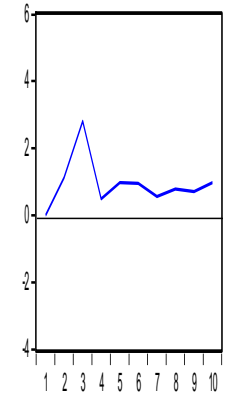

(c)

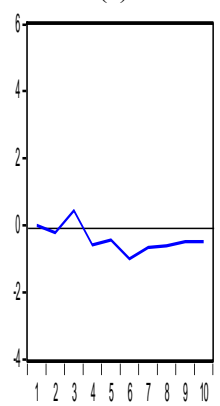

(d)

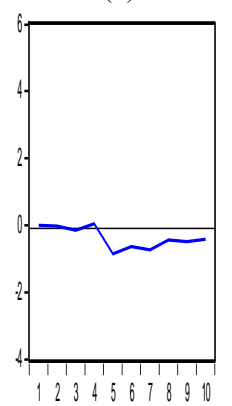

(e)

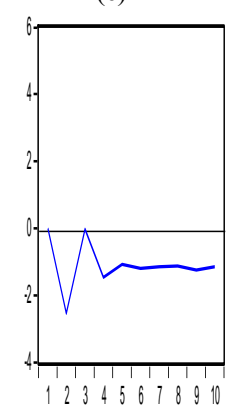

(f)

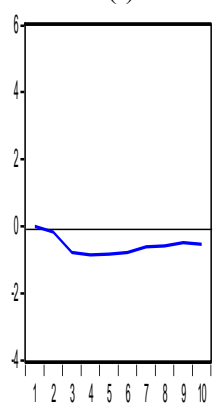

Şekil 2: Etki-Tepki Analizi Sonuçları

Çalışmanın analiz kısmında yer alan diğer bir test ise, dinamik bir modeldeki değişkenlerden herhangi birinde oluşan bir birimlik şokun yüzdesel olarak diğer değişkenlerde yaratacağı değişimi göstermek amaciyla kullanılan Varyans Ayrıştırması testidir. Tıpkı Etki-tepki analizinde olduğu gibi özellikle politik önerilerde bulunma amacıyla sıkça kullanılmaktadır. Varyans Ayrıştırması testi, modelde yer alan değişkenlerin sıralamasından yüksek düzeyde etkilenmektedir. Bu sebeple modeldeki değişkenler iktisadi kuramlara ve yapılan Granger nedensellik testi sonucuna göre dışsaldan içsele doğru GINI, tarım, ihracat, enflasyon, age şeklinde sıralanmıştır. Yapılan Varyans Ayrıştırması sonuçları Tablo 5'te gösterilmiştir.

\begin{tabular}{cccccccc}
\hline \hline Period & S.E. & GDP & GiNi & TAR & TiCARET & ENF & AGE \\
\hline \hline 1 & 4.515372 & 100.0000 & 0.000000 & 0.000000 & 0.000000 & 0.000000 & 0.000000 \\
2 & 5.315503 & 72.34325 & 4.438311 & 0.186682 & 0.000857 & 22.92288 & 0.108025 \\
3 & 6.074041 & 55.40279 & 24.60464 & 0.654242 & 0.065887 & 17.55642 & 1.716016 \\
4 & 6.456355 & 52.26591 & 22.33525 & 1.413198 & 0.063150 & 20.66282 & 3.259672 \\
5 & 6.744115 & 47.90102 & 22.58929 & 1.741238 & 1.694623 & 21.53526 & 4.538570 \\
6 & 7.193298 & 45.77308 & 21.56242 & 3.487349 & 2.270595 & 21.75775 & 5.148805 \\
7 & 7.416356 & 43.62221 & 20.85381 & 4.053758 & 3.125841 & 22.84173 & 5.502662 \\
8 & 7.709925 & 43.18952 & 20.30787 & 4.364142 & 3.227627 & 23.25252 & 5.658324 \\
9 & 7.930748 & 41.91771 & 19.96228 & 4.506226 & 3.434327 & 24.44265 & 5.736804 \\
10 & 8.166308 & 40.78014 & 20.24027 & 4.625123 & 3.494725 & 25.00083 & 5.858908 \\
\hline \hline
\end{tabular}

Tablo 5: Varyans Ayrıştırması Testi

Türkiye için yapılan varyans ayrıştırması sonuçlarına göre, GDP 5. dönemde \%22.58 ile en fazla GINI katsayısından, ikinci olarak \%21.53 ile enflasyon değişkeninden, \%4.53 ile yaş bağımlılık değişkeninden, \%1.74 ile tarımdan ve \%1. 69 oranında ihracat etkilenmiştir. Değişkenler arasında oluşan etki sıralaması dönemler itibariyle aynı düzeyde kalmıştır. Değişkenler arasındaki mevcut sıralama dönemler itibariyle aynı şekilde kalmıştır.

\section{Sonuç}

Orta gelir tuzağı, son dönemlerde ismi sıkça kullanılan bir kavram olarak 2000'li y1llarda literatüre geçmiștir. Türkiye'nin orta gelir tuzağında bulunup bulunmadığı üzerine bir görüş birliği sağlanamamıştır. Yaşar ve Gezer (2014), Nişancı vd. (2015) gibi bazı çalışmalarda Türkiye'nin orta gelir tuzağında bulunduğu desteklenirken, Koçak ve Bulut (2014) ve Bozkurt vd. (2014) gibi çalışmalarda Türkiye'nin orta gelir tuzağında bulunduğu ve bu seyirde gelir düzeyinin devam etmesi durumunda orta gelirde uzun süre kalma olasılığının yüksek olduğu ifade edilmiştir. Bu çalışmada öncelikle Türkiye'nin yıllar itibariyle GSYİH oranındaki değişmelerden faydalanılarak Felipe (2012)'deki yaklaşımına göre Türkiye'nin 1955 yılında düşük orta gelirli ülke konumuna yükseldiği ve bu sürecin 2005 yılına kadar devam ettiği görülmektedir. 2005 yılında Türkiye yüksek orta gelirli ülke konumuna yükselmiş ve bu Türkiye'nin bu grupta bir ülke olarak kabul edilmesi için dört yıllık bir süresinin kaldı̆̆ görülmektedir. Felipe (2012)'deki yaklaşıma ek olarak genel bazı oranlardan faydalanılarak Türkiye'nin aslında tarihsel süreçte birçok kere orta gelir tuzağına düştüğünü ve son altı yıllık süreçte orta gelir tuzağı etrafında dolaştığı sonucuna ulaşılmıştır.

Bununla birlikte literatürde yer alan birçok çalışmadan farklı olarak bu çalışmada Türkiye'nin gelir düzeyeni etkileyen bazı demografik ve ekonomik değişkenlere yer verilerek orta gelir tuzağı tehlikesi içinde olan 
Türkiye'nin gelir düzeyini en çok etkileyen değişkenlerin neler olabileceği hususunda bazı değerlendirmeler yapılmıştır. Yapılan değerlendirmeleri desteklemesi açısında Vektör Hata Düzeltme Modeli (VECM), Etki- Tepki analizi ve Varyans Ayrıştırması testleri uygulanmıştır. Yapılan çalışmada, 1980-2014 yılları için Türkiye'deki GDP ile enflasyon (ENF), GDP'deki -tarımın payı (TAR) ve İhracat (EXP), Gini katsayısı (GİNi) ve yaş bağımlılık oranı (AGE) değişkenleri arasındaki ilişki incelenmiştir. Yapılan çalışmada mevcut yıllarda Türkiye'deki GDP oranını en fazla etkileyen değişkenin gelir dağılımındaki adaleti temsil eden GİNİ katsayısının etkilediği sonucuna ulaşılmıştır. Bu durum Türkiye'nin orta gelir tuzağından kaçış stratejisi olarak gelir dağılımındaki adaleti sağlayıcı politika önlemleri alması gerektiğini vurgulamaktadır. GDP'deki tarım sektörünün payı ile GDP arasındaki ilişki beklentilerin aksine pozitif yönde çıkmıştır. Bu sonuç belki de Türkiye'nin henüz tarım-sanayi ve hizmet sektörü dönüşümüne hazır olmadığını ifade etmektedir. Bu açıdan bakıldığında tarımın GDP'yi pozitif destekleyen bir olgu olması tarım sektöründe de iyileşmelerin yapılması gerektiğimi göstermektedir. Genel olarak ifade edilmesi gerekirse daha düşük bir yaş bağımlılık oranı, GDP'de daha yüksek bir ihracat oranı, daha istikrarlı ve daha düşük bir enflasyon her ülkenin ekonomik gelişiminde itici güç olduğu gibi Türkiye için de bu durum geçerli olacaktır. Aynı zamanda Türkiye2nin kişi başına gelir açısından yüksek gelir grubuna geçiş yapabilmesi için şuanda bulunduğu gruptaki rakiplerinden daha yüksek ve istikrarlı bir büyüme hızına ulaşması gerekmektedir. Bu sebeple bu koşulların istenilen düzeyde tutulması için yapılması gerekenler bir taraftan ekonomik büyümeyi sağlarken diğer taraftan da Türkiye'yi orta gelir tuzağı tehlikesinden uzak tutabilecektir.

\section{Kaynakça}

- Alçın, S., \& Güner, B. 2015. “Orta Gelir Tuzağı: Türkiye Üzerine Bir Değerlendirme”. Marmara University Journal of Economic \& Administrative Sciences, 37(1), s.27-45

- Aoki, M. 2011, “The Five Phases of Economic Development and Institutional Evolution in China, Japan and Korea", ADBI Working Paper Series, 340, Asian Development Bank Institute, Tokyo.

- Ay, A. \& Özşahin, J. 2007. “J Eğrisi Hipotezinin Testi: Türkiye Ekonomisinde Reel Döviz Kuru ve Diş Ticaret Dengesi İlişkisi”. Uludă̆ Üniversitesi İktisadi ve İdari Bilimler Fakültesi Dergisi, 26(1), s.1-23

- Atalay, R. 2015. "The Education and the Human Capital to Get Rid of the Middle-income Trap and to Provide the Economic Development”. Procedia-Social and Behavioral Sciences, 174, p: 969-976.

- Bozkurt, E., Bedir, S., Özdemir, D., \& Çakmak, E. 2014. “Orta Gelir Tuzağı ve Türkiye Örneği”. Maliye Dergisi, (167), s.22-39.

- Carnovale, M. 2012. “Developing Countries and the Middle-Income Trap: Predetermined to Fall?” New York University May.

- Chen, C. \& Dai, L. 2014, "The Middle Income Trap, Branching Deregulation, and Political Influence”, 26 Eylül, New Jersey, http://www.princeton.edu.tr

- Çaşkurlu, E., \& Arslan, C. B. 2014. “Orta Gelir Tuzağından Çıkışa Odaklanma: Ürün Tuzağı (Ürün Boşluğu) ve Demiryolu Taşımacılık Sektörü”. Maliye Dergisi,167, s. 71-92.

- Dalgıç, B., İyidoğan, P. V., \& Balıkçığlu, E. 2014. “Orta Gelir Tuzağından Çıkışta Hangi Faktörler?”. Maliye Dergisi, (167), s. 116-125.

- Egawa, A. 2013. "Will income inequality cause a middle-income trap in Asia," Bruegel Working Paper, 2013/06

- Eğilmez, M. 2012, “Orta Gelir Tuzağ1 ve Türkiye” 16.12.2012, http://www.mahfiegilmez.com, (Erişim Tarihi: 10.05.2016).

- $\quad$ Eichengreen, B., Park, D. \& Shin, K. 2011, "When Fast Growing Economies Slow Down: International Evidence and Implications for China”, NBER Working Paper Series, 16919, National Bureau of Economic Reseaarch, March.

- $\quad$ Eichengreen, B., Park D. \& Shin K., 2012, "When Fast Growing Economies Slow Down: International Evidence and Implications for China," Asian Economic Papers, 11, p.42-87.

- $\quad$ Engle, R. F. \& Granger, C. W. 1987. Co-integration and Error-correction: Representation, Estimation and Testing. Econometrica, 55, p: 251-276.

- Felipe, J., Abdon, A. \& Kumar, U. 2012, “Tracking the Middle-Income Trap: What Is It, Who Is in It, and Why?", Levy Economics Institute of Bard College Working Paper, 715, Levy Economics Institute of Bard College, New York.

- Gill, I. S., Kharas, H. J., \& Bhattasali, D. 2007. An East Asian renaissance: ideas for economic growth. World Bank Publications.

- Gujarati, N. D. 1999. Temel Ekonometri, Şenesen, Ü. ve Şenesen, G. (Çev.), Literatür Yayıncılık, İstanbul, s.729. 
- Hausmann, R., Pritchett L., \& Rodrik D. 2005, "Growth Accelerations," Journal of Economic Growth, 10, p.303-329.

- $\quad$ Kharas, H. \& Kohli, H. 2011, "What is the Middle Income Trap, Why Do Countries Fall into it, and How Can it Be Avoided?”, Global Journal of Emerging Market Economies, 3(3), p. 281-289

- Koçak, E., \& Bulut, Ü. 2014. "Orta gelir tuzağı: teorik çerçeve, ampirik yaklaşımlar ve Türkiye üzerine ekonometrik bir uygulama”. Maliye Dergisi, 167, s. 167-01.

- Maddison, A. 2010, Statistics on World Population, GDP and per capita GDP, 1- 2008 AD. Historical Statistics, http://www.ggdc.net/maddison/maddisonproject/data.htm (Erişim tarihi: 10.05.2016)

- Nişanc1, M., Gerni, M., Türkmen, A. \& Emsen, Ö. S. 2015. "Türkiye Ekonomisinin Orta Gelir Tuzağına Düşüp Düşmediğine Dair Tartışma: Kur Değerlenmesi Çerçevesinde Bir Bakış”, International Conference on Eurasian Economies, 2015 s: 232-242

- Özturk, A. 2015. "Examining The Economic Growth and The Middle-Income Trap from The Perspective of The Middle Class". International Business Review. IBR: 1208, p.1-13

- Paus, E. 2012, "Confronting the Middle Income Trap: Insights from Small Latecomers", Studies in Comparative International Development, 47(2), p. 115-138.

- $\quad$ Raiser, M., Wes, M., \& Yilmaz, A. 2016. "Beyond Convergence: Poland and Turkey en route to high income". Central Bank Review, 16(1), p.7-17.

- Robertson, P.E. ve Ye, L. 2013, “On the Existence of a Middle Income trap", University of Western Australia Economics Discussion, Paper, 13-12, Australia.

- S Şahin, İ., Başer, K., \& Karanfil, M. 201). “Orta Gelir Tuzağı Üzerine Ampirik Bir Çalışma: Türkiye Örneği (1980-2013)”. Uluslararası Alanya İşletme Fakültesi Dergisi, 7(2), s.225-235

- Tasar, I., Gültekin, E., \& Acci, Y. 2016. “Is Turkey in a middle income trap?”, Journal of Applied Research in Finance and Economics, 1(1), p.36-41.

- Tho, T.V. 2013, “The Middle-Income Trap: Issues for Members of the Association of Southeast Asian Nations", ADBI Working Paper, 421, Asian Development Bank Institute, Tokyo.

- Uyanık, C. C. 2015. “Orta Gelir Tuzağı ve Türkiye'nin Konumu Açısından Bir Değerlendirme”, Sosyoekonomi, 23(26), s. 175-186

- Woo, W.T. 2012, "China Meets the Middle-Income Trap: The Large Potholes in the Road to Catching-up", Journal of Chinese Economic and Business Studies, 10(4), p. 313-336

- Worldbank, 2016, World Development Indicators, http://databank.worldbank.org/data/home.aspx (Erişim Tarihi: 05.05. 2016)

- Yaşar, E., \& Gezer, M. A. 2014. “Türkiye’nin Orta Gelir Tuzağına Yakalanma Riski ve Bu Riskten Kurtulma Önerileri”. Maliye Dergisi, (167), s. 126-148.

- Y1lmaz, G. 2015. “Turkish middle income trap and less skilled human capital”. Iktisat Isletme ve Finans, 30(346), p. 9-36.

- Zeng, J. \& Fang, Y. 2014, "Between Poverty and Prosperity: China’s Dependent Development and the 'Middle-Income Trap"', Third World Quarterly, 35(6), p.1014-1031

Bilgi notu: Bu çalışma Çukurova Üniversitesi Rektörlüğü Bilimsel Araştırma Projeleri Birimi tarafindan SBA2016-5965 Kodlu Proje İle desteklenmiştir. 


\title{
Emek Verimliliğinin Belirleyen Demografik Unsurlar: Seçilmiş Ülkeler Üzerine Analizler (1960-2010) \\ The Determinants of Labor Productivity: Analyses on Chosen Countries (1960-2010)
}

\author{
Prof. Dr. Murat Nişancı (Erzincan University, Turkey) \\ Ph.D. Candidate Aslı Cansin Doker (Erzincan University, Turkey) \\ Ph.D. Candidate Adem Türkmen (Erzincan University, Turkey) \\ Prof. Dr. Ömer Selçuk Emsen (Atatürk University, Turkey)
}

\begin{abstract}
Discussions on economic productivity, in micro analysis aspects there is direct causal relationship between increases or decreases in the production and productivity, whereas it can be said that productivity is based on economic recession or growth in macro analysis aspects. In the literature, while Classical theoreticians is attributed that the source of growth is the marginal productivity of capital, neoclassic school claims that marginal productivity difference provide benefit the country from behind for realization of the convergence hypothesis. Furthermore, increasing efficiency and as the factors this increase efficiency human capital, learning by doing concepts and technology are focused in the endogenous growth theories. In this study, human capital, physical capital per worker, exports per worker, gender differences, fertility, life expectancy and dependent population ratio were determined as determinants of labor productivity. In respect to labor productivity, variables are divided to three main groups in order to economic demographic and social and psychological factors. The variables are placed with taking five years average due to the fact that those variables' effects reveal themselves more clearly in the long term. In the paper, it was investigated by panel data analysis considering groups of developed and developing countries between 1960 and 2010 period. In this context the degree of efficiency may well be discussed with parameters of selected variables for productivity of labor. Additionally, within framework of descriptive statistics the differences and similarities between countries were interpreted for political recommendations to developing countries how to increase productivity for catching developed countries' growth trend.
\end{abstract}

\section{Giriş}

İktisadın tanımı ile özdeşleşmiş "kaynakların kıt oluşu” sorunu iktisatçıların geçmişten bugüne daima ilgisini çekmiş ve sürekli tartışmalara konu olmuştur. Veri teknoloji ve yetersiz imkânların ortaya çıkardığı bu sorun özellikle üretim faktörlerinin yetersizliği açısından bakıldığında, ekonomilerin gelişmişlik düzeylerindeki farklılıkların da nedeni olarak ortaya çıkmaktadır. Gelişme farklılı̆̆ını gidermede, üretim faktörlerinin nicel eksikliğini azaltan bir etken olarak ortaya çıkan verimlilik, aynı zamanda bu faktörlerin nitelik boyutuna temas etmektedir. Böylece genelde iktisat literatüründe ve özelde de büyüme ve kalkınma literatüründe önemli bir yer tutmaktadir.

Verimlilik (prodaktivite) kelimesinin iktisat yazınında bir yer bulması ise fizyokratların bu konudaki görüşleri ile başlamıştır. Fizyokrat iktisatçılardan Le Littré kelimeyi tanımlarken, üretebilme kabiliyeti ya da hassasiyeti olarak ifade ederken, F. Quesnay verimliliği tarımda refahın kaynă̆ı olarak nitelendirmiştir. Klasik iktisatçılardan A. Smith işgücü ve işbölümü arasındaki uzmanlaşma ilişkisi ile verimliliği günümüze kadar taşımıştır (Kök ve Deliktaş, 2003). Üretim sürecinde maliyetlemeyi emek-değer teorisine dayandıran Klasik iktisatçılar için üretim sürecinde emeğin rolü ve üretimde harcanan zaman -ki harcanan zamandaki farklılıklar daha sonra verimlilik ölçütü olarak kabul edilecektir- önemli bir yer tutmaktadır. Verimlilik üzerine teorik tartışmalar devam ederken, halihazırda verimlilik en genel kalıpla tanımlanır hale gelmiş ve üretim sürecinde ortaya çıkan ürün (çıktı) ile o üretimi gerçekleştiren üretim faktörleri (girdi) arasındaki ilişki şeklinde tanımlanır olmuştur.

Diğer taraftan verimlilik girdi ve çıktı tanımlamalarının değişimine paralel olarak farklı tanımlamalar da bürünebilmektedir. Örneğin Prokopenko (1992) verimliliğin çıktı ile çıktıyı elde etmek için harcanan zaman arasındaki ilişki olarak ifade edilebileceğini belirtmekte ve zamanın evrensel bir ölçü birimi olmasından dolayı daha iyi sonuç vereceğini kabul etmektedir. Bu tanımlamaya göre harcanan zamandaki farklılıklar, verimlilik farkları olarak kabul edilmektedir.

Verimlik ise kendi içinde toplam ve kısmi verimlilik olarak ikiye ayrılmakla birlikte teoride marjinal ve ortalama verimlilikten de bahsedilmektedir. Toplam faktör verimliliği tüm üretim faktörlerinin verimliliğini ifade ederken, emek verimliliği (kısmi verimlilik) üretimde kullanılan girdilerden sadece emeğin verimliliğini ele almaktadır. Emek verimliliği makro manada ölçülürken, ülke toplam üretiminin emek miktarına veya çalışılan saate bölünmesi ile bulunmaktadır. Machlup (1972), bu teknik tanımın dolayısıyla emek verimliliğinin, sadece emeği ilgilendiren bir yapı gibi görünmesine rağmen, verimliliğe etki edebilecek tüm faktörlerin etkisinden oluştuğunu ifade etmiştir. $\mathrm{Bu}$ manada verimliliğe etki eden faktörlerin bilinmesi özellikle gelişmekte olan ülkelerin ileriye doğru üretim, 
büyüme ve kalkınma stratejileri açısından büyük önem arz etmektedir. Emek verimliliği incelenirken, kullanılan sayısal değişkenlerin dışında emeğin çalışma ortamı, hayat standartları, bilgiye/eğitime ulaşabilirliği, aile yaşamı gibi birçok etmen mikro manada verimlilik üzerinde ciddi farklılıklar yaratmaktadır. Değişen üretim süreci ve üretim ilişkileri emek verimliliğine verilen önemi arttırmış ve bu tip mikro değişkenler ya da daha da toplulaştırılmış şekilde makro değişkenlerin verimlilik üzerindeki etkilerinin araştırılması konusuna ilgiyi cezbetmiştir. İçsel büyüme modelleri bu verimlilik farklılıklarını büyüme formlarına dahil ederken, beşeri sermaye kavramından faydalanmışlardır. Buna ilaveten Galbraith (1969) kavramı biraz daha geliştirerek entelektüel sermaye kavramını literatüre kazandırmıştır. Gerek beşeri sermaye olsun, gerek entelektüel sermaye kavramları olsun özünde emek verimliliğini ifade etmekte ve özellikle gelişmekte olan ülkelerin gelişmiş ülkeleri yakalama potansiyeli açısından üzerinde yoğunlukla çalışılması gereken kavramlar olarak öne çıkmaktadırlar. Verimliliğin beşeri sermaye boyutundan etkilenebilirliğine dair düşünce ve buna paralel olarak beşeri sermayeyi etkileyen unsurlar ve özellikle bu unsurların büyüme üzerine etkilerine dair çalışmalara literatürde bolca rastlamak mümkündür. Bunlardan başlıcaları Barro (2001), Becker vd. (1994), Romer (1990), Benhabib ve Spiegel (1994), Stockey (1990) vb. şeklinde sıralanabilir. Bu çalışmalarda genel olarak beşeri sermaye ve verimlilik artışlarının büyüme üzerinde ciddi etkilere sahip olduğu yönünde bulgulara ulaşılmıştır. Ancak, verimliliğin belirleyicilerine dair çalışmalar ise literatürde yer almakla birlikte sayılarının oldukça az olduğu gözlenmektedir.

Verimlilik ekonomilerin büyüme ve kalkınmalarında etkili iken, tek başına emeğin verimliliğinin nicel olarak büyüme üzerindeki etkilerinin incelenmesi yetersiz kalmaktadır. Bu manada emek verimliliğinin belirleyicilerinin hem mikro manada hem de makro manada incelenmesi önem kazanmaktadır. Bu çalışmada temel amaç emek verimliliğinin seçilmiş makro belirleyicilerinin gelişmiş gelişmekte olan ve az gelişmiş ülke gurubundan oluşan 34 ülkelik gurupta test edilmesidir. Seçilmiş makro belirleyiciler ekonomik, demografik ve sosyal olmak üzere üç gurupta toparlanmıştır. Ekonomik belirleyicileri zımnen ifade etmek için kişi başı ihracat ve kişi başı sermaye birikimi değişkenleri kullanılmış ve teorik beklentiye uygun olarak bu değişkenlerin emek verimliliği üzerinde pozitif etkileri olacağı düşünülmüştür. Demografik ve sosyal değişkenler olarak, kaba doğum oranı, nüfus bağımlılık oranı ve yaşam beklentisi değişkenleri seçilmiştir. Yaşam beklentisinin emek verimliliği ile pozitif ilişkisi beklenirken, bağımlılık oranı ve doğum oranının verimlilik üzerindeki etkilerine dair literatür çeşitlilik göstermekle beraber doğum oranındaki artışın verimliliği düşüreceğine dair beklenti verimliliğin en basit formülü haline gelmiştir. Ayrıca beşeri sermayeyi ifade etmesi açısından 2. düzey okullaşma oranı verimliliği artırması beklenen bir unsur olarak modele dahil edilmiştir. Özellikle demografik değişkenlerdeki etkilerin uzun sürelerde ortaya çıkacağı düşünüldüğünden, çalışmada 1960-2000 yılları arasını içeren veri seti 5 yıllık ortalamalar şeklinde kullanılmıştır.

\section{Literatür Araştırması}

Smith iktisadi büyümenin en önemli lokomotifinin iş bölümü olduğunu ileri sürerken, emek verimliliğine işaret etmektedir. Emek verimliliğinin en önemli belirleyicisi olarak iş bölümü ve uzmanlaşmayı göstermektedir (Smith, 1776). Sanayi Devriminden sonraki süreçten günümüze ise işbölümü ve uzmanlaşmanın belirleyiciliğine teknolojinin de eklendiği söylenilebilir. Ayrıca emek verimliliğinin belirleyici unsurlarından biri de üretim sürecine katılan sermaye miktarındaki artıştır. Diğer bir ifadeyle teknolojik gelişmelerin ve sanayileşmenin üretimdeki emek faktörünün verimliliği noktasında etkin olmasını sağlayacak önemli bir unsur, sermaye faktöründeki artış olacaktır (Tanyeri, 1984).

Literatürde yer alan birçok çalışma neo klasik okulun ekonomik büyüme modellerinde faktör bileşimi, yatırım, okullaşma oranı ve nüfus ile açıklamaya çalışmışlardır. Fakat faktör bileşimini model içerisinde gösteriminin bu değişkenler ile ifade edilmesi yetersiz kalabilmektedir. Büyüme modellerinin faktör bileşimlerinde elde edilmesi zor olan değişkenler ise beşeri sermaye ve fiziki sermayedir. Ülkeler arasındaki verimlilik analizlerinde farklılıkları ortaya koyan çalışmalarda (Acemoglu vd. 2001) ise kurumların önemi vurgulanmıştır. Uzun dönem verimlilik analizini ele alan çalışmasında Feyrer (2007), demografik değişkenlerin verimlilik analizinde kullanılması gereken değişkenlerden olduğuna temas etmiştir. Mikro iktisadi analizlerde deneyim, eğitim ve işgücü piyasası yapısında önem arz etmektedir. İşgücü piyasasındaki demografik değişimler beşeri sermayenin yapısını deneyim faktörü çerçevesinde değiştirebilmektedir. Literatürde yer alan demografik yapı ve işgücü çalışmalarında ise bağımlılık oranı dikkat çekmektedir. Bloom vd. (2001) ve Kögel (2001) bağımlılık oranı ile toplam verimlilik ve büyüme arasında anlamlı bir ilişki olduğunu ortaya koymuşlardır.

Feyrer (2007) çalışmasında işçi başına düşen çıktı miktarını fiziki sermaye, beşeri sermaye ve verimliliğin bir göstergesi olarak kabul ederek, bağımsız değişkenleri işgücünün yaş gruplarına göre ağırlıklandırılmış halleri ve bağımlılık oranı olarak modellemiştir. Çalışmada verimlilik modellemesi için Solow artığı hesaplanmış ve bağımsız değişkenlerle modellenmiştir. Verimlilik ile işgücü demografik değişkenlerinin güçlü bir korelasyona sahip olduğu ve zengin- fakir ülkeler arasındaki verimlilik farkının demografik yapı farklılığından kaynaklandığı ileri sürülmüştür. 
Beşeri sermayenin büyüme üzerindeki etkilerini araştıran çalışmalarda [Nelson and Phelps (1966); Lucas (1988); Rebelo (1992); Mulligan and Sala-i-Martin (1992)], beşeri sermayeyi etkileyen faktörler arasında okullaşma oranını önemli derece de etkin kabul etmişlerdir.

Barro (2001) beşeri sermaye ve ekonomik büyüme adlı çalışmasında, 1960 ile 1985 yılları arasında 22 OECD ülkesi, 14 Ortadoğu ve Kuzey Afrika ülkesi, 27 Sahra ülkesi, 23 Latin Amerika ülkesi 10 Pasifik ülkesi ve 7 Asya ülkesinde okullaşma oranları ve büyümeleri arasındaki ilişkiyi incelemiştir. Çalışmada bağımlı değişken olarak büyüme belirlenirken, bağımsız değişkenler olarak okullaşma, açıklık ve kamı eğitim harcamaları, doğurganlık oranı, kayıt dışı işlemler ve tarife oranları alınmıştır. Beşeri sermayenin etkileri incelenirken, 5 yıllık ortalama veriler kullanılmıştır. Eğitim ve beşeri sermayenin makroekonomik alandaki etkilerinin uzun dönemde ortaya çıkacağı göz önüne alınmıştır. Eğitiminin beşeri sermaye üzerinde pozitif etkileri gözlemlenirken, doğurganlığın negatif etkileri bulunmuştur.

Mincer (1981), çalışmasında beşeri sermayenin eğitim, deneyim ve mobilite ile geliştiğini; dolayısıyla fiziki sermaye ile koordineli olarak üretimin bir faktörü olduğunu belirtmiştir. Okul öncesi eğitim ve kadınların eğitim oranının yetişkin işçilerin verimliliği üzerinde pozitif etkilerinin varlığını ortaya koymuştur. Beşeri sermayenin ekonomik ve demografik değişimlerin nedeni ve sonucu olabileceğini belirtmiştir. İşgücü arzındaki yaş, cinsiyet dağılımı ve eğitimin işgücü verimliliğini etkileyeceğini öne sürmüştür.

Gust ve Marquez (2002), bilgi teknolojilerinin adaptasyon süreçlerini üretim verimliliği açısından, 13 sanayileşmiş ülke için 1992 ile 1999 yılları arasında incelemiştir. Yapılan çalışmada panel veri teknikleri kullanılmış ve işgücünü ve sermaye faktörünün teknoloji adaptasyonu sürecinde verimlilik analizleri yapılmıştır. Faktör verimliliğinin bilgi teknolojileri harcamaları ve işgücü oranlarıyla ilişkili olduğu sonucuna varılmıştır. İşgücü faktörü açısından bu adaptasyon sürecinde eğitim faktörünün önemi vurgulanıştır

Belorgey vd. (2004), çalışmalarında işçi başına verimliliği etkileyen faktörleri 25 OECD ülkesi için 1992 ile 2002 yılları arasındaki ilişkiyi incelemişlerdir. Çalışmada işçi başına verimlilikteki artış hızı, yani büyüme bağımlı değişken olarak belirlenmiş ve bağımsız değişkenler olarak, bilgi ve iletişim teknoloji harcamalarının ve üretiminin milli gelir içerisindeki payı, çalışma saatleri, üretim kapasiteleri, çalışmaya hazır işgücü oranları ve yatırımların oranı modelle dahil edilmiştir. GMM yöntemi ile tahmin edilen modele göre, çalışma saatleri ile verimlilik arasında pozitif ve anlamlı bir ilişki bulunurken; hazır işgücü oranları ile verimlilik arasında negatif yönlü bir ilişki bulunmuştur. Bilgi ve iletişim teknolojilerine yapılan harcamaların ve üretimin işçi başına verimliliği arttıran önemli bir faktör olduğu bulgular arasındadır.

Guellec ve Potterie (2001) yayınladıkları çalışmalarında ise araştırma ve geliştirme harcamalarının toplam faktör verimliliği üzerine etkilerini belirlemek amacıyla yaptıkları analizde 1980 ile 1998 yılları arasında 16 OCED ülkesindeki çoklu faktör verimliği modellemesiyle Solow artığı modelini kullanarak yeni teknolojilerin etkilerini incelemiştir. Çalışmada kullanılan demografik değişkenler literatürde sıklıkla kabul edilen bağımlılık oranı, doğurganlık oranı, eğitime katılım oranı ve yaşam beklentisi olarak belirlenmiştir. Aynı zamanda makro ekonomik kontrol değişkenler ise kişi başına düşen sermaye birikimi, kişi başına düşen ihracat modele dahil edilmiştir.

Literatür özetlerinde ekonomik büyüme/gelişme unsuru açısından tek boyutlu bakış açılarından ziyade, daha girift bakış açılarının görece daha yüksek açıklama gücü içerdiği kabul edilmektedir. Büyüme/gelişme boyutunun verimlilik temelli olarak ele alınması perspektifinde bunun ekonomik unsurların yanı sıra demografik ve sosyal unsurlar ile beşeri sermaye boyutunu da içerdiği dikkat çekmektedir. Çalışmada teorik ve uygulamalı literatürden hareketle ekonomik unsurlar olarak sabit sermaye stoku ve dışa açıklık; demografik unsurlar olarak yaş bağımlılığı ve yaşam beklentisi; beşeri sermaye unsuru olarak da ortaöğretim mezunlarının toplam nüfus içindeki payları verimliliğin belirleyicisi olarak modellenmesi düşünülmektedir.

\section{Veri Seti ve Amprik Sonuçlar}

Çalışmada 34 ülkeye ait 1960 ile 2010 yılları arasındaki işgücü verimliliğini etkileyen demografik faktörler panel veri analizi ile incelenmiştir. Değişkenler teorik olarak uzun dönemde değişim gösterdikleri için beşer yıllık ortalamalarıyla modele dahil edilmiştir. Analiz sürecinde model spesifikasyonu değişkenlere ait serpilme diyagramlarından yararlanılarak belirlenmiştir. Değişkenlerden yaşam beklentisi, kişi başına düşen ihracat ve işgücü başına düşen verimlilik oran değişimi olmadığı için grafiksel analizde logaritmik seyir gösterdiği için logaritmaları alınarak modele eklenmiştir. Eğitime katılım oranı veri setleri 15 yaş üstü ve 25 yaş üstü olarak Barro(2015) elde edilmiş ve ayrı ayrı modele dahil edilmiştir. Modelin spesifikasyonu;

$\log Y_{i t}=\beta_{1} \log X_{1 i t}+\beta_{2} \log X_{2 i t}+\beta_{3} \log X_{3 i t}$

Ekonomik değişkenlerle verimlilik analizine ait model spesifikasyonu;

Inproduct $=\beta_{1}$ Ingross fixed $+\beta_{2}$ exports

Demografik değişkenlerle verimlilik analizine ait model spesifikasyonu;

Inproduct $=\beta_{1}$ agedep $+\beta_{2}$ education $15+\beta_{3}$ lifeexpect 
Model tahmininde sırasıyla havuzlanmış model, sabit etkiler modeli ve tesadüfi etkiler modelleri elde edilerek karşılaştırmaları yapılmıştır. Yatay kesit bağımlılığı ve model üstünlük testleri yapılarak model seçimine gidilmiştir. Çalışmada yapılacak olan analizlerde kullanılan değişkenler, hesaplamaları ve tanımları Tablo 1'de verilmiştir. Tablo 1'de yer alan değişkenlerden yaş bağımlılığıyla doğurganlık oranı arasında yüksek korelasyondan ötürü yaş bağımlılı̆̆ın modelleme de yer almasına karar verilmiştir. Eğitim göstergesi olarak okullaşma oranı ile 15 yaş üstü eğitime devam eden nüfusun oranı dikkate alınmıştır. Çalışmada model spesifikasyonu kararı serilere ait grafiksel analiz ve teorik beklentiler dikkate alınarak karar verilmiştir.

\begin{tabular}{|l|l|l|l|}
\hline $\begin{array}{l}\text { Verinin } \\
\text { kısaltması }\end{array}$ & Kullanılan Verinin Adı & Kaynağı & $\begin{array}{l}\text { Hesaplama } \\
\text { Yöntemi }\end{array}$ \\
\hline Ingrossfixed & $\begin{array}{l}\text { Kişi başı brüt sabit Sermaye } \\
\text { stoku (Sabit 2005\$) }\end{array}$ & $\begin{array}{l}\text { Dünya Bankası WDI Nisan 2000 } \\
\text { ve Aralık 2015 arşiv verileri }\end{array}$ & $\begin{array}{l}\text { Brüt sabit sermaye } \\
\text { stoku/nüfus }\end{array}$ \\
\hline lnexports & $\begin{array}{l}\text { Kişi başı Mal ve Hizmet İhracat1 } \\
\text { (Sabit 2005\$) }\end{array}$ & $\begin{array}{l}\text { Dünya Bankası WDI Nisan 2000 } \\
\text { ve Aralık 2015 arşiv verileri }\end{array}$ & $\begin{array}{l}\text { Mal ve Hizmet } \\
\text { İhracatı /nüfus }\end{array}$ \\
\hline Fertility & Doğurganlık Oranı & $\begin{array}{l}\text { Dünya Bankası WDI Nisan 2000 } \\
\text { ve Aralık 2015 arşiv verileri }\end{array}$ & \\
\hline lnlifeexpect & $\begin{array}{l}\text { Doğumdan toplam yaşam } \\
\text { beklentisi (Y1) }\end{array}$ & $\begin{array}{l}\text { Dünya Bankası WDI Nisan 2000 } \\
\text { ve Aralık 2015 arşiv verileri }\end{array}$ & \\
\hline Agedep & $\begin{array}{l}\text { Nüfus Bağımlılı Oranı } \\
\text { (Çalışma yaşındaki Nüfus } \\
\text { içindeki pay \%) }\end{array}$ & $\begin{array}{l}\text { Dünya Bankası WDI Nisan 2000 } \\
\text { ve Aralık 2015 arşiv verileri }\end{array}$ & \\
\hline Inproduct & $\begin{array}{l}\text { Geary Khamis SGP ile } \\
\text { dönüştürülmüş çalışan işçi } \\
\text { başıa emek verimliliği (sabit } \\
\text { 1990 \$) }\end{array}$ & $\begin{array}{l}\text { Total Economy Conferance Emek } \\
\text { ve İstihdam verileri }\end{array}$ & $\begin{array}{l}\text { GSYIHH/ emeğin } \\
\text { toplam çalışma saati }\end{array}$ \\
\hline Education15 & $\begin{array}{l}\text { Ortaokulu tamamlayan 15 yaş } \\
\text { üstü nüfusun 15 yaş üstü toplam } \\
\text { nüfus içindeki payı }\end{array}$ & $\begin{array}{l}\text { Barro- Lee Eğitime erişim verileri } \\
1950-2010\end{array}$ & \\
\hline Education25 & $\begin{array}{l}\text { Ortaokulu tamamlayan 25 yaş } \\
\text { üstü nüfusun 15 yaşüstü toplam } \\
\text { nüfus içindeki payı }\end{array}$ & $\begin{array}{l}\text { Barro- Lee Eğitime erişim verileri } \\
1950-2011\end{array}$ & \\
\hline Enrolment & Ortaokul okullaşma oranı & $\begin{array}{l}\text { Barro- Lee Eğitime erişim verileri } \\
1950-2012\end{array}$ & \\
\hline
\end{tabular}

Tablo 1. Verilerin Tanımları ve Hesaplanma Yöntemlerine İlişkin Bilgiler

Çalışmada kullanılan değişkenlerden, okullaşma oranı, yaş bağımlılığı, yaşam beklentisi, eğitime katılan nüfus, doğurganlık oranı ve okullaşma oranı demografik faktörleri göstermekte iken; kişi başına düşen ihracat ile sermaye birikimi stoku ekonomik faktörleri göstermektedir. Model spesifikasyonunda ekonomik ve demografik değişkenler ilk aşamada havuzlanmış, sabit etkiler ve tesadüfi etkiler olarak ayrı ayrı modellenmiştir. Çalışmaya dahil edilen 34 ülke grubu Tablo 2'de sunulmuştur.

\begin{tabular}{|c|c|c|c|c|c|c|c|c|c|}
\hline Sira & Ülkeler & & Sira & Ülkeler & Sira & Ülkeler & Sira & Ülkeler \\
\hline 1 & Argentina & & 10 & Denmark & & 19 & Luxembourg & 27 & Portugal \\
\hline 2 & Australia & & 11 & Finland & 20 & Malaysia & 28 & Spain \\
\hline 3 & Austria & 12 & France & 21 & Mexico & 29 & Sweden \\
\hline 4 & Belgium & 13 & Greece & & 22 & Netherlands & 30 & Switzerland \\
\hline 5 & Bolivia & 14 & Iceland & 23 & New Zealand & 31 & Thailand \\
\hline 6 & Brazil & 15 & India & 24 & Norway & 32 & Turkey \\
\hline 7 & Canada & 16 & Ireland & & 25 & Peru & 33 & United Kingdom \\
\hline 8 & Chile & 17 & Italy & & 26 & Philippines & 34 & United States \\
\hline 9 & China & 18 & Japan & & & & \\
\hline
\end{tabular}

Tablo 2. Analizde Kullanılmak Üzere Seçilmiş Ülkeler

Analize konu olan modeller arasında seçilmiş ülkeler için ilk aşamada demografik değişkenler üzerinden havuzlanmış model tahmin sonuçları elde edilmiştir. Havuzlanmış model tahmini, yatay kesitler, yani seçilen ülkeler arasında herhangi bir farkın olmadığını varsayarak veri setini genel olarak ele almaktadır (Yerdelen, 2012). $\mathrm{Bu}$ nedenle sabit etkiler ve tesadüfi etkiler modelleri de tahmin edilmiş ve modellere ilişkin istatistiki bulgular Tablo 3 'te gösterilmiştir. 


\begin{tabular}{|l|c|c|c|}
\hline DEĞiŞKENLER & $\begin{array}{c}\text { Havuzlanmış } \\
\text { Model }\end{array}$ & $\begin{array}{c}\text { Sabit Etkiler } \\
\text { Modeli }\end{array}$ & $\begin{array}{c}\text { Tesadüifi } \\
\text { Etkiler } \\
\text { Modeli }\end{array}$ \\
\hline Education15 & $0.0109514 * * *$ & $0.0169309 * * *$ & $0.0161417 * * *$ \\
\hline Lnlifeexpect & $4.164695 * * *$ & $1.556884 * * *$ & $1.782314 * * *$ \\
\hline Agedep & -0.0027861 & $-0.0065583 * * *$ & $-0.006466 * *$ \\
\hline Constant & $-7.879854 * * *$ & $3.308225 * * *$ & $2.36087 * *$ \\
\hline F-statistics & $221.97 * * *$ & $176.17 * * *$ & $560.32 * * *$ \\
\hline $\mathbf{R}^{2}$ & 0.6497 & 0.6082 & 0.6186 \\
\hline \multicolumn{2}{|r|}{ HausmanTest } & Prob>chi2 $2=0.0000$ \\
\hline
\end{tabular}

Not: *** ve ** işaretleri sırasıyla $\% 1$ ve $\% 5$ 'te anlamlılığı göstermektedir.

\section{Tablo 3. Demografik ve Beşeri Sermaye Değişkenlerine Ait Model Tahmin Sonuçları}

Panel veri analizinde serilerin zaman boyutunun yatay kesit boyutundan büyük olduğu durumlarda analizlerden önce serilere ait birim kök ve durağanlık sınamalarının yapılması gereklidir (Yerdelen, 2012). Çalışmada kullanılan değişkenlere ait seriler 5 yıllık ortalamalardan oluştuğu için, serinin yatay kesit boyutu zaman boyutundan daha büyük durumdadır ( $\mathrm{t}=11, \mathrm{n}=34)$. Bir diğer test edilmesi gereken temel varsayım ise modellere ait kalıntıların yatay kesitler arasındaki bağımlılı̆̆ın test edilmesidir. Yatay kesit bağımlılığın test edilmesinde $t>n$ durumda bu varsayımın geçerliliğinin test edilmesi için geliştirilmiş olan Paseran testi veri seti uygun olmadığı için kullanılmamıştır. Demografik ve beşeri sermaye değişkenlerine ilişkin model tahmin sonuçlarından seçilen değişkenlerin bağımlı değişkeni açıklama gücü sırasıyla $0.64,0.61$ ve 0.62 şeklindedir. Seçilen değişkenlerin model içerisindeki birlikte anlamlılığı tüm modellerde uygunluk göstermiştir. Parametre tahmincilerinin teorik beklentiyle örtüştüğü dikkat çekmektedir. Yapılan Hausman testi sonuçlarına göre sabit etkiler modelinin tesadüfi etkiler modeline göre daha güçlü olduğuna işaret etmektedir. Havuzlanmış model tahmin sonuçlarında yaş bağımlılığı değişkeninin iktisadi teoriyi desteklediği fakat istatistiki açıdan anlamsız olduğu tespit edilmiştir. Buna göre model seçim kriterleri dikkate alındığında, sabit etkiler modelinin diğer iki modele göre üstün olduğu sonucuna varılmıştır. Sabit etkiler modeline göre yaş bağımlılığının işgücü başına düşen verimlilik üzerinde negatif etkisinin olduğu görülmektedir. Bu sonuç Feyrer (2007) çalışmasının sonuçlarıyla da örtüşmektedir. Diğer yandan yaşam beklentisi ve eğitimin verimlilik üzerinde pozitif bir korelasyona sahip olduğu ve iktisadi teoriyi desteklediği görülmektedir. Barro (2002) çalışmasındaki eğitime katılan nüfusun beşeri sermaye üzerindeki olumlu etkileri bulgusuyla analiz sonucu örtüşmektedir.

Ekonomik göstergeler ile tahmin edilen modellere ilişkin bulgular ise Tablo 4'te gösterilmiştir. Demografik değişkenlerde olduğu gibi ekonomik göstergelerde havuzlanmış model, sabit etkiler ve rassal etkiler modellemeleriyle tahmin edilmiştir.

\begin{tabular}{|l|c|c|c|}
\hline DEĞIŞKENLER & $\begin{array}{c}\text { Havuzlanmış } \\
\text { Model }\end{array}$ & $\begin{array}{c}\text { Sabit Etkiler } \\
\text { Modeli }\end{array}$ & $\begin{array}{c}\text { Tesadüfi Etkiler } \\
\text { Modeli }\end{array}$ \\
\hline Lnexports & $0.1208375 * * *$ & $0.2433107 * * *$ & $0.238394 * * *$ \\
\hline Lngrossfixed & $0.3740438 * * *$ & $0.2968353 * * *$ & $0.2937009 * * *$ \\
\hline Constant & $6.164563 * * *$ & $5.840404 * * *$ & $5.900354 * *$ \\
\hline F-statistics & $1361.51 * * *$ & $1492.08 * * *$ & $3126.08 * * *$ \\
\hline $\mathbf{R}^{2}$ & 0.8832 & 0.8753 & 0.8755 \\
\hline \multicolumn{3}{|r|}{ HausmanTest } & \multicolumn{2}{|c|}{ Prob>chi2 $=0.0000$} \\
\hline
\end{tabular}

Not: *** işareti \%1'de anlamlılı̆̆ göstermektedir.

\section{Tablo 4. Ekonomik Değişkenlere Ait Model Tahmin Sonuçları}

Tahmin sonuçlarına göre modellemede kullanılan değişkenlerin verimliliği açıklama gücü sırasıyla $0.88,0.87$ ve 0.86 'dır. Değişkenlerin birlikte anlamlılıklarına F-testi yardımıyla bakıldığında, seçili değişkenlerin birlikte anlamlı olduğu yani modelin tanımlama gücünün yüksek olduğu görülmektedir. Hausman testi ile sabit etkiler ve tesadüfi etkiler modelleri arasındaki sınama sonucu sabit etkiler modelinin rassal etkiler modeline göre daha üstün olduğu kabul edilmiştir. Buna göre, tüm değişkenlere ait parametreler 0,01 anlamlılık düzeyinde istatistiksel açıdan anlamlıdır ve ekonomik teoriyi destekleyen sonuçlar vermektedir. İşgücü başına verimliliğin kişi başına ihracat ve sermaye birikimi arasında pozitif bir korelasyona sahip olduğu gözlemlenmiştir.

Çalışmanın ekonometrik analizinde kullanılan değişkenler içinde birbirinin ikamesi olan değişkenler arasında modellerin açıklama gücü ve istatistiksel üstünlüklere göre seçimler yapılmıştır. Hem demografik hem de ekonomik değişkenlerin birlikte ele alınarak tahmin edilen modellere ait sonuçlar Tablo 5 'te yer almaktadır. Education15 değişkeni ile enrolment değişkeninin analiz sonuçları aynı yönde ve miktarda ilişkiyi gösterdiği için modellemede Education15 tercih edilmiştir. Enrolment değişkeninin model sonuçları ek kısımda belirtilecektir. 
Aynı şekilde Education25 değişkeninin modele dahil edilmemesinin nedeni Education15 değişkeninin söz konusu değişkeni içermesi olarak belirtilmelidir.

\begin{tabular}{|c|c|c|c|}
\hline DEĞİŞKENLER & $\begin{array}{c}\text { Havuzlanmış } \\
\text { Model }\end{array}$ & $\begin{array}{l}\text { Sabit Etkiler } \\
\text { Modeli }\end{array}$ & $\begin{array}{c}\text { Tesadüfi } \\
\text { Etkiler Modeli }\end{array}$ \\
\hline Lnexports & $0.1045578 * * *$ & $0.3049343 * * *$ & $0.2830375 * * *$ \\
\hline Lngrossfixed & $0.4031333 * * *$ & $0.3231196^{* * *}$ & $0.3173372 * * *$ \\
\hline Education15 & $0.0066738 * * *$ & -0.0001931 & 0.0009789 \\
\hline Lnlifeexpect & 0.3294163 & -0.0157242 & 0.0199638 \\
\hline Agedep & $0.0093112 * * *$ & $0.0093909 * * *$ & $0.3049343 * * *$ \\
\hline Constant & $3.963705 * * *$ & $4.687691 * * *$ & $4.758303 * * *$ \\
\hline F-statistics & $624.35 * * *$ & $949.94 * * *$ & $3779.21 * * *$ \\
\hline $\mathbf{R}^{2}$ & 0.8974 & 0.8739 & 0.8775 \\
\hline \multicolumn{2}{|c|}{ HausmanTest } & \multicolumn{2}{|c|}{ Prob $>$ chi $2=0.0000$} \\
\hline
\end{tabular}

Not: *** işareti \%1'de anlamlılı̆̆ göstermektedir

Tablo 5. Demografik ve Ekonomik Değişkenlerin Birlikte Yer Aldı̆̆ Model Tahmin Sonuçları

Çalışmada işgücü başına verimlilik analizinde bağımsız değişken grupları olarak ekonomik ve demografik değişken kullanılmıştır. Tablo 5 'te yer alan bu iki grubunda dahil olduğu modellerin açıklayıcılık oranları sırasıyla $0.89,0.87$ ve 0.88 şeklindedir. Analize konu olan değişkenlerden yaş bağımlılığı ve yaşam beklentisinin verimlilik üzerindeki etkilerinin yönlerinin değiştiği gözlemlenmektedir. Yapılan Hausman test sonucuna göre sabit etkiler modelinin rassal etkiler modeline göre daha üstün olduğu reddedememektedir. Sabit etkiler modeli, verimlilik analizinde seçilen ülkeler arasında zamana ve birime göre değiştiğini fakat dışşal ölçülemeyen hataların etkili olmadığını ifade etmektedir. Grafiksel analizler sonucu verimliliğin zaman boyutu süresince artan bir trende sahip olduğu gözlemlemektedir. Çalışmada yer alan ülke gruplarına bakıldığında, gelişmiş, gelişmekte olan ve az gelişmiş ülke gruplarının her birinden örnekler bulunmaktadır. Grafiksel analizler yardımıyla, sermaye birikimi ve verimlilik trendi değişkenleri üzerinden bakıldığında, Çin'in artış trendi diğer ülkeler nazaran daha etkileyicidir. Gelişmiş ülkelerdeki sermaye birikiminde durağanlık gözlemlenirken, gelişmekte olan ülkelerde bu oranın yavaşta olsa artı̧̧ gösterdiği gözlemlenmektedir.

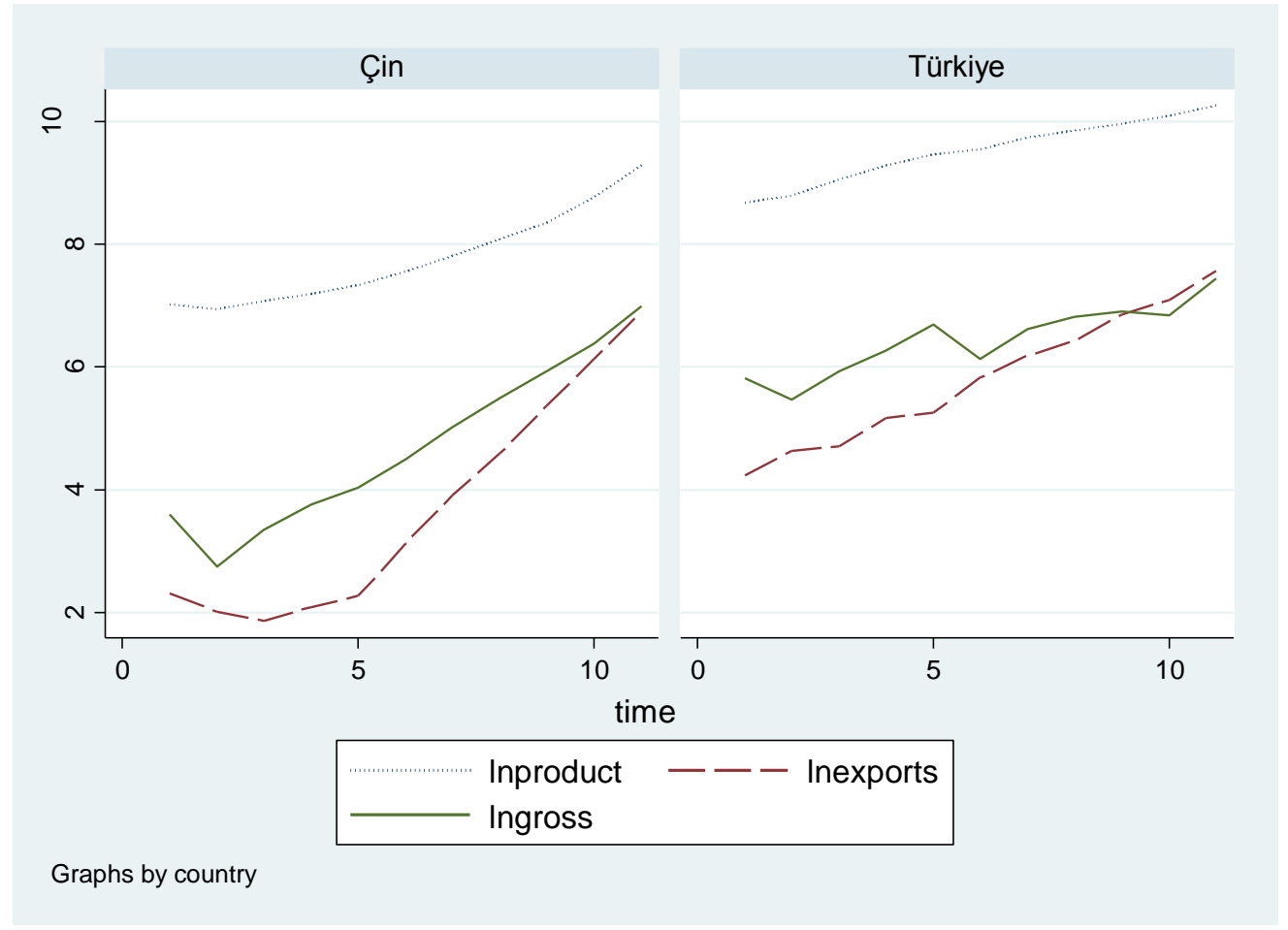

Grafik 1. Çin ve Türkiye'ye Ait Ekonomik Göstergelerin Grafiksel Gösterimi 
Grafik 1'de Çin ve Türkiye'nin verimlilik, ihracat ve sermaye birikimi değişkenlerinin zaman içerisindeki hareketi incelenmiş ve Çin'in büyüme trendinin daha öncede belirtildiği gibi daha hızlı olduğu gözlemlenmektedir. Gelişmiş ülkelere ait grafikler incelenmiş ve gerek sermaye birikiminde, gerekse diğer değişkenlerde durağan bir gelişme gözlemlenmiştir. Demografik değişkenler üzerinden yapılan grafiksel analiz yardımıyla Çin ve Türkiye özelinde verimlilik değişkeninin artış trendine karşılık nasıl bir seyir izlediği ortaya konulmaya çalışılmıştır.

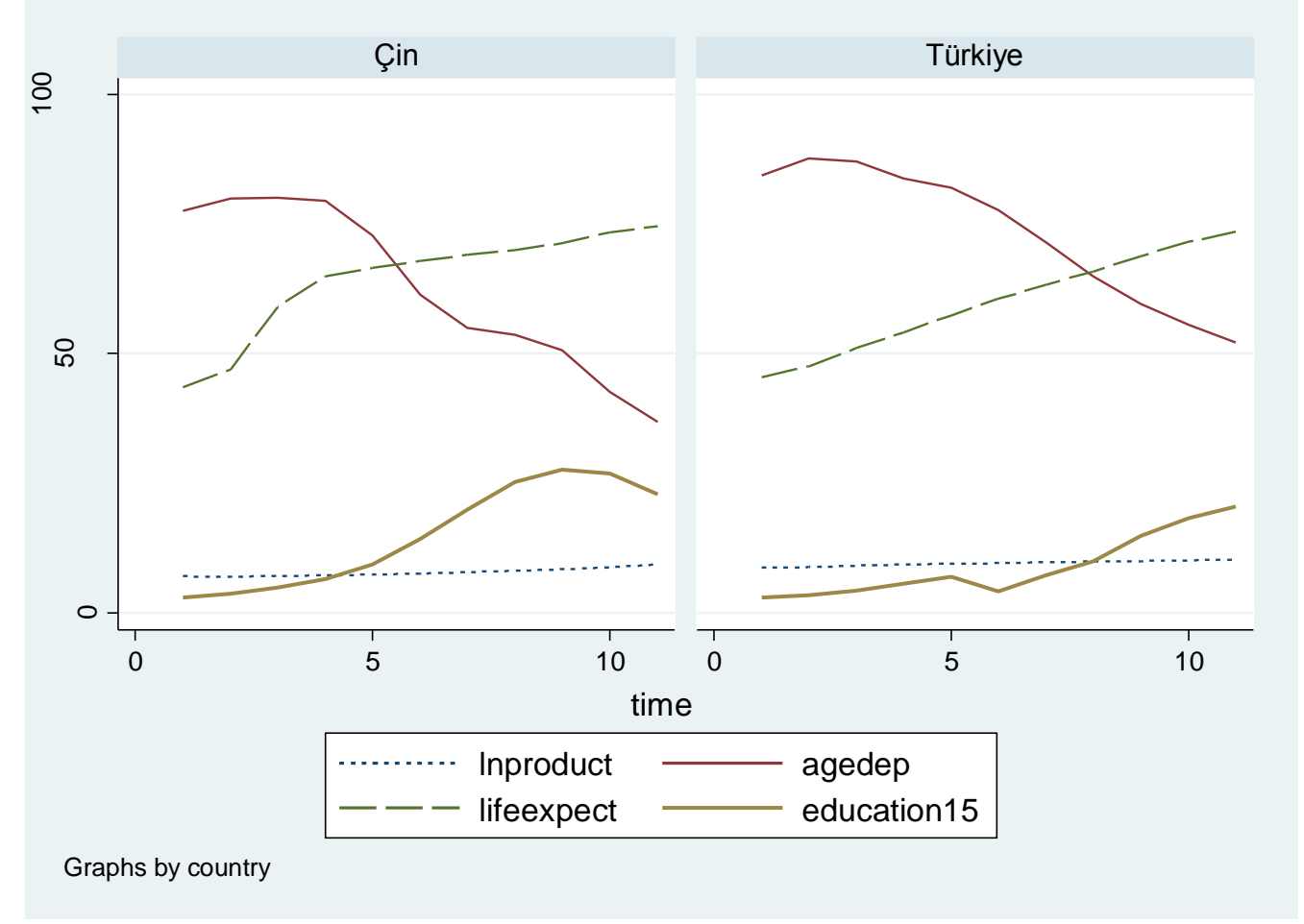

Grafik 2. Demografik Değişkenler ve Verimliliğin Çin ve Türkiye Grafikleri

Grafik 2'de Çin'de ki yaş bağımlılığın oldukça hızla bir biçimde düşüş trendinde olduğu gözlemlenirken, yaşam beklentisinin tersi yönde arttığ 1 teorik beklentiye uyumlu bir biçimde gözlemlenmektedir. Eğitimine katılan nüfus payının Türkiye'ye nazaran daha hızlı bir artış gösterdiği fakat son on yılda düşme eğilimine girdiği gözlenmektedir.

\section{Sonuç ve Politik Önermeler}

Verimliliğin ekonomik büyüme üzerine etkilerine ilişkin yaygın literatüre karşılık, verimliliği belirleyen unsurları alan çalışmaların oldukça zayıf olduğu dikkat çekmektedir. Çalışmada uygun veri setine sahip 34 gelişmiş, gelişmekte olan ve az gelişmiş ülkede verimliliği belirleyeceği literatürde ortak bir konsensüs ile belirlenmiş verilerle analizler yapılmıştır. Bu çerçevede ekonomik değişkenlerden sermaye birikimi ve ihracat değişkenlerinin verimlilik üzerine çok kuvvetli etkilerinin olduğu gözlenmiştir. Diğer taraftan beşeri sermaye ve demografik boyutu temsilen alınan değişkenlerden eğitimin pozitif ve istatistiki açıdan anlamlı etkilerinin olduğu gözlenirken, yaşam beklentisi ve yaş bağımlılığının ise negatif etkilerinin olduğu görülmüştür. Demografik değişken olarak kullanılan yaşam beklentisinin ve bunun tetiklediği yaş bağımlılı̆̆ının artmasının verimliliği adeta zorlayıcı unsur olarak azalttığı dikkat çekmektedir. Diğer bir ifadeyle özellikle yaşam sürelerinin giderek artması ile birlikte çalışan nüfus üzerine sıkıştırma etkilerinin ortaya çıkması, ekonomilerde verimliliği azaltıcı ve büyümeyi durağanlığa sevk etmesi kaçınılmaz gözükmektedir.

Elde edilen bulgular değerlendirildiğinde, dünya nüfusundaki yaşlanmaya paralel olarak verimlilik ve büyümede durağanlıklar ve hatta düşüşlerin kaçınılmaz hale geleceği gözlenmektedir. Bunun aşılabilirliğinde nüfus artış hızını yükseltici politika uygulamalarına gidilmesinin elzem olacağı düşünülebilir. Ancak, kalkınma ve demografi ilişkileri incelendiğinde, çocuk edinme eğiliminin kalkınmışlığa paralel olarak düştüğü olağan süreç olarak kabul edilmektedir. Dolayısıyla tersine dönene nüfus piramidine karşı, evlenme ve çocuk edinme eğilimini artırıcı politikaların belki uzun vadede bu kısır döngünün aşılabilirliğini mümkün kılsa da, cari durum dikkate alındığında, fiziki sermaye birikimini artırıcı politika önlemlerine ilaveten, beşeri sermayeyi geliştirici politika uygulamalarına ağırlık verilmesinin durağanlığı aşmaya yardımcı olacağı söylenebilir. Diğer taraftan emekliliğin/yaş bağımlılığının minimize edilmesi yönündeki uygulamaların da verimlilikte durağanlığı aşıcı önlemler olarak görüleceği ileri sürülebilir. Bu bağlamda emeklilerin çalışanlar üzerindeki yüklerini azaltıcı olacak şekilde evde üretim ya da hobi şeklinde görülecek üretsel faaliyetlerde bulunmaya teşvik edici önlemlerin alınması ve yaşam 
sürelerindeki uzamayı da dikkate alacak şekilde emeklilik yaşının uzatılmasının üretimi-büyümeyi destekleyeceği düşünülebilir.

Bu çalışmada verimliliğin ekonomik, demografik ve beşeri sermaye boyutuna ilaveten Acemoğlu'nun kurumsal yapılara vurgu yapan bakış açısını da modelleyen çalışmalarla desteklenmesi gerektiği ilgiye değer görülebilir. Dolayısıyla demokratik yapıları gelişen ülkelerin kurumsallaşarak girişim öğesinin adeta yaşama alanı bulacağı düşünülebilir. Ayrıca kurumsallaşan ekonomilerin iç yatırım iklimindeki gelişmelere bağlı olarak dış yatırımcılar için de cazibeli hale gelmesi kuvvetle muhtemeldir. Bu nedenle sermaye birikimi ve dışa açıklık değişkenlerine ilaveten yabancı sermaye yatırımlarının da modellenmesi ve bunun demokratikleşme ve girişim ölçütleri ile beslenmesinin daha kuvvetli sonuçlar vereceği düşünülebilir. Dolayısıyla daha genişletilmiş modellerden hareketle hangi boyuta ağırlık verilmesi gerektiği noktasında fikir sahibi olunması mümkün olacaktır.

\section{Kaynakça}

- Acemoglu, Daron, Simon Johnson, and James A. Robinson (2001), "The Colonial Origins of Comparative Development: An Empirical Investigation”, American Economic Review, 91(5): 1369-1401.

- Barro, Robert J., and Jong-Wha Lee (1994), "Sources of Economic Growth", Carnegie-Rochester Conference Series on Public Policy, 40: 1-46.

- Barro, Robert and Jong-Wha Lee, 2013, "A New Data Set of Educational Attainment in the World, 1950 2010." Journal of Development Economics, vol 104, pp.184-198.

- Barro, Robert J. (2001), "Human capital and growth", The American Economic Review, 91(2): 12-17.

- Becker vd.,(1994), "Human capital, fertility, and economic growth", Human Capital: A Theoretical and Empirical Analysis with Special Reference to Education (3rd Edition). The University of Chicago Press, 323350.

- Belorgey (2004), "Determinants of Productivity per Employee: an Empirical Estimation Using Panel Data" Banque De France, Economic Analysis and Research Division

- Benhabib, Jess, and Mark M. Spiegel (1994), "The Role of Human Capital in Economic Development Evidence from Aggregate Cross-Country Data", Journal of Monetary economics, 34(2): 143-173.

- Bloom vd. (2001) “Economic Growth and the Demographic Transition”, NBER working paper 8685.

- Galbraith (2015), The new industrial state, Princeton University Press.

- Feyrer (2007), Demographics and Productivity, The Review of Economics and Statistics, 89(1): 100-109.

- Guellec ve Potteri, (2001), “The Internationalization of Technology Analyzed with Patent Data", Research Policy, 30: 1253-1266.

- Gust and Marquez (2002), "International Comparisons of Productivity Growth: The Role of Information Technology and Regulatory Practices”, International Finance Discussion Papers,727,Board of Governors of Federal Reserve System, New York.

- Kogel, Tomas (2001), "Youth Dependency and Total Factor Productivity”, MPIDR Working Paper No. WP 2001-030.

- KÖK, DELIKKTAŞ (2003), Endüstri İktisadında Verimlilik Ölçme ve Strateji Geliştirme Teknikleri, Dokuz Eylül Üniversitesi İ̈BF Yayını, Yayın Karar No: 25-8/1, İzmir

- Krugman, (1980), "Scale Economies, Product Differentiation, and the Pattern of Trade", American Economic Review, 70, p. 950.

- Krugman, (2010), "The New Economic Geography, Now Middle-Aged”, in Proceedings of AAG 2010 Meeting, p. 348.

- Lucas, Robert E (1988), "On the Size Distribution of Business Firms", The Bell Journal of Economics, 9:2 (1978), 508-523. , "On the Mechanics of Economic Development," Journal of Monetary Economics 22, 3-42.

- Lucas, R E. (1988), “On the Mechamcs of Development Planning”, Jortrturl ofMottetan Econotrtics, 22: 3 42.

- Machlup, F. (1972), The Production and Distribution of Knowledge in the United States, Princeton, NJ: Princeton University Press. https://archive.org/details/productiondistri00mach

- Mincer, Jacob, Human Capital and Economic Growth (November 1981). NBER Working Paper No. w0803. Available at SSRN: http://ssrn.com/abstract=256899

- Mulllgan, C. B and X. Sala-i-Martin, "Some Emplncal Evldence on Two-Sector Models of Endogenous Growth", unpubllshed manuscnpt, University of Chicago, June 1992.

- Nelson, Richard, and Edmund Phelps (1966), "Investment in Humans, Technological Diffusion, and Economic Growth", American Economic Review, 56: 69-75. 
- Prokopenko, Joseph. Productivity management: A practical handbook. International Labour Organization, 1992.

- Rebelo, S. (1991), “Long-Run Pollcy Analysis and Long-Run Growth”, Journal of Polrricol Econont 99: 500-21.

- $\quad$ Romer, Paul M. (1990), Human Capital And Growth: Theory And Evidence”, Carnegie-Rochester Conference Series on Public Policy. Vol. 32. North-Holland.

- $\quad$ Smith, 1776. Ulusların Zenginliği, (Çev. Haldun Derin), İstanbul: İş Bankası Kültür Yayınları, 2006.

- Stokey, Nancy L. Human Capital, Product Quality, and Growth, No. w3413. National Bureau of Economic Research, 1990.

- Tanyeri, 1984. Fiyat Teorisi, Ölçek Ekonomileri ve Teknolojik Gelişme, Ankara: Hacettepe Üniversitesi İktisadi ve İdari Bilimler Fakültesi.

- Total Economy Database, https://www.conference-board.org/data/economydatabase/

- Yerdelen, İleri Panel Veri Analizi, (1. Baski), Beta Basım Yayım Dağıtım, İstanbul, 2012.

- Yerdelen, Panel Veri Analizi, (1. Baskı), Beta Basım Yayım Dağıtım, İstanbul, 2012.

- World Bank, (2010). Net Migration Statistics, http://data.worldbank.org/indicator/SM.POP.NETM

- World Bank, World Development Indicators Archive http://databank.worldbank.org/data/reports.aspx?source=WDI-Archives

(Beta), 


\title{
Türkiye'de İç Göçün Belirleyicileri Determinants of Internal Migration in Turkey
}

\author{
Assoc. Prof. Dr. Rüştü Yayar (Gaziosmanpaşa University, Turkey) \\ Meltem Uçgunoğlu (Gaziosmanpaşa University, Turkey) \\ Ph.D. Candidate Yusuf Demir (Cumhuriyet University, Turkey)
}

\begin{abstract}
Migration is defined as movement of population from one place to another. If population moves within the country, it is identified as internal migration, vice versa if population moves out of country, it is identified as emigration. Thanks to economic policies implemented in 1980's in Turkey, there has been structural transformation. With the beginning of intensive migration from rural areas to urban places, this movement has brought some problems. In this paper, firstly internal migration phenomenon will be explained theoretically and will be presented in terms of Turkey side with various statistics. Some factors which are thought as having an impact on emergence of internal migration that heads to serious problems and reached serious dimensions in Turkey will be estimated with regression model. Economic reasons of migration will be discussed with driving and attractive forces. And with this approach, it is planned as the migration rate will be added to regression model as dependent variable and income, education, unemployment and health will be added to model as independent variable. Social and economic policies will be proposed in order to provide solutions of problems about internal migration.
\end{abstract}

\section{Giriș}

Göç olgusu kişilerin ikamet ettikleri yeri bırakıp geçici bir süre veya sürekli olmak üzere farklı bir coğrafyaya yerleşmesi olarak tanımlanabilir. Bu kavram sosyal, ekonomik ve siyasal pek çok farklı süreci kapsar. Türkiye gibi gelişmekte olan ülkelerde yaşanan göç; hızlı nüfus artışı, sanayileşme hareketleri, kentleşme, tarımda makineleşme, bölgelerarası dengesizlikler ile bağdaştırılabilir.

Aynı ülkenin farklı bölgelerinde görülen eşitsizlik “bölgesel dengesizlik” olarak tanımlanabilir. Gelişmekte olan ülkelerde adı sıkça anılan bölgesel dengesizlik kavramı gelişmiş ülkelerde de kendini göstermektedir. Bununla birlikte bölgesel gelişmişlik farkları ekonomik, sosyal ve kültürel sorunları da beraberinde getirmektedir. Ülkeler nasıl kendi arasında gelişmiş, az gelişmiş ve gelişmekte olan ülkeler olarak kategorize ediliyorlarsa, bir ülkenin bölgeleri arasında da coğrafi, iktisadi, sosyal ve kültürel bakımlardan farklılıkların bulunması söz konusu ülkeye ait bu bölgelerin gelişmiş, az gelişmiş bölgeler diye de nitelendirilmesine neden olmaktadır. Bu farklılıklar sonucunda oluşan bölgesel dengesizlik iç göçlerin sebebi olabileceği gibi sonucu da olabilmektedir. Özellikle dünyada olduğu kadar Türkiye’de bölgesel gelişmişlik farklarının dengeli bir yapıya kavuşturulması, bölgesel kalkınmanın hızlandırılması ve sürdürülebilir dengeli bir kalkınmanın sağlanması için çeşitli politikalar uygulanmıştır. Bu politikalar arasında iç göçü engellemeye yönelik çalışmalarda söz konusu olmuş fakat uygulanan politikalarla istenilen başarıya ulaşılmamıştır. İç göçler birçok sorunları beraberinde getirmektedir. Özellikle engellenemeyen kentleşme problemlerini kaçınılmaz kılmaktadır. Bu sebeple içgöçlerin sebepleri ve belirleyicilerini araştırmak önemlidir. Çalışmanın amacı Türkiye'de bölgesel dengesizliğin nedenlerinden birisi olan iç göçün gelişimini belirleyerek, net göç hızına etki edebileceği düşünülen faktörleri tespit etmektir. Türkiye'de iç göç olgusunun belirleyicilerinin neler olduğu saptanmaya çalışılmıştır. Çalışmanın uygulama kısmında zamana ilişkin veri yetersizliğinden dolayı yatay kesit verileri kullanılmıştır.

Çalışmanın giriş bölümünü takip eden ikinci bölümünde Türkiye'de bölge ve bölgesel dengesizlik kavramları üzerinde durulmaktadır. Üçüncü bölümde teorik çerçevede iç göç olgusu incelenmiştir. Dördüncü bölümde ise, iç göç olgusu çoklu regresyon analizi ile incelenerek; net göç hızını açıkladığı düşünülen değişkenler arasında matematiksel bir model oluşturulmaya çalışılmıştır.

\section{Türkiye'de Bölge ve Bölgesel Dengesizlik Kavramları}

Etimolojik kökleri Latince "region: çevre-alan" anlamına gelen bölge kavramı literatürde tam olarak açıklığa kavuşmamış, sınırları oldukça güç çizilebilen bir kavram olmakla birlikte; yaşanan kavram kargaşasının en büyük nedeni çeşitli amaçlara yönelik çeşitli bölge ölçeklerinin kullanılmasıdır (Ildırar, 2004; Gündüz, 2006). Bölge tanımlanmasında kullanılan başlıca ölçütler; coğrafi, kültürel, etnik, kentsel ve yönetseldir. Hem siyasi hem de politika açısından bölge kavramı yaygın olarak kullanılmakta olup, kavram üzerinde siyaset bilimi, kamu politikası, sosyoloji ve ekonomi gibi disiplinler daha çok durmaktadır. Bu bağlamda, bölge kriterleri geniş bir yelpazede tanımlanmakla birlikte ortak ölçütler mekansal ve coğrafi değiş̧kenleri içermektedir (McCall, 2010; Ildirar, 2004). 
Türkiye'de ise bölge kavramına bakış açısı dönemsel olarak farklılıklar göstermektedir. Bölge yönetimine ilişkin ilk düzenleme 1913 yılında çıkarılan “İdare-I Umumiye-I Vilayet Kanun-u Muvakkatı'nda yer almıştır. 1921 Anayasası'nda Türkiye'nin illere ve ilçelere ayrıldığı belirtilirken, 1924 Anayasası'na göre “Türkiye, coğrafi durumu ve ekonomik ilişkileri bakımından illere, iller ilçelere, ilçeler bucaklara bölünmüştür ve bucaklar da kasaba ve köylerden meydana gelmektedir" ifadesi kullanılmıştır. 1961 Anayasası'nda il sistemi genel çatısını korumuştur fakat il içinde "yetki genişliğine sahip kuruluşlar meydana getirilebilir" hükmüyle bölgesel kuruluşların oluşumu söz konusu olmuştur. 1982 Anayasası'nda ise 1961 Anayasası ile benzerlik göstermektedir ve bölgesel düzeyde örgütlenmeye olanak tanımaktadır (Sert, 2012).

Dünya bütününde zaman ve mekan yönünden farklılık gösteren ekonomik gelişmeler, her ülkenin coğrafi sınırları içinde bölgeler arasında da ortaya çıkmaktadır (Açma,1991). Bir ülkenin bölgeler arasında görülen nüfus, tarımsal yapı, gelir dağılımı, mali piyasalar, ulaşım ve haberleşme imkanlarında farklılıklar bölgesel dengesizlik olarak tanımlanabilir (Şahinkaya, 1992). Sanayi Devrimi’nin bir ülkenin tüm bölgelerinde eş anlı olarak başlamamış olmasından dolayı bölgesel dengesizliğin nedeninin ve başlangıcının “Sanayi Devrimi”ne uzandığını söylemek mümkündür (Özel, 2009). Bölgesel dengesizlik olgusu sadece gelişmekte olan ülkelerle sınırlı kalmamış, 1929 Dünya Ekonomik Bunalımı akabinde yüzünü gelişmiş ülkelerde de göstermeye başlamıştır (Göktürk, 2006). Gelişmiş ülkelerde ve gelişmekte olan ülkelerde çehresini farklı olarak gösteren bölgesel dengesizlik; gelişmiş ülkelerde, eşitsiz dağılım sonucunda kapitalizmin iç dinamiklerince; gelişmekte olan ülkelerde ise, ekonomik bağımlılıkları söz konusu olduğu için dış dinamiklerce belirlenmiştir (Özel, 2009).

Ülkemizde bölgelendirme konusuna yönelik farklı kurumlarca ve değişik yaklaşımlarla çalışmalar yapılmıştır (Özçağlar, 2003). Cumhuriyet'in kurulması ile Türkiye'de bölgesel politikalar sadece ekonomik gelişmelerin 1şı̆̆ında değil, aynı zamanda Avrupa ülkelerinin deneyimlerinden etkilenilerek oluşturulmuştur (Göymen, 2004:1).

1968 yılından günümüze, bölgelerarası sosyo-ekonomik gelişmişlik endeks çalışması DPT tarafından bölgelerarası sosyo-ekonomik gelişmişlik farklarının azaltılması amacıyla yapılmaktadır. Endeks çalışması ilk olarak 1970 yılında yapılmış olup, belirli dönemlerde tekrarlanan endeks çalışmasının sonuncusu Kalkınma Bakanlığı Bölgesel Gelişme ve Yapısal Uyum Genel Müdürlüğü tarafından 2011 yılında yapıllmıştır.

\begin{tabular}{|c|l|}
\hline 1963 & $\begin{array}{l}\text { İlk İller: İstanbul, Ankara, İzmir, Adana, İçel } \\
\text { Son İller: Mardin, Van, Muş, Adıyaman, Bingöl, Hakkâri }\end{array}$ \\
\hline $\mathbf{1 9 7 0}$ & $\begin{array}{l}\text { İlk İller: İstanbul, Ankara, İzmir, Adana, Kocaeli } \\
\text { Son İller: Adıyaman, Ağrı, Mardin, Muş, Bingöl, Hakkâri }\end{array}$ \\
\hline $\mathbf{1 9 9 5}$ & $\begin{array}{l}\text { İlk İller: İstanbul, Ankara, İzmir, Kocaeli, Bursa } \\
\text { Son İller: Bitlis, Ardahan, Bingöl, Ağrı, Şırnak, Muş }\end{array}$ \\
\hline $\mathbf{2 0 0 3}$ & $\begin{array}{l}\text { İlk İller: İstanbul, Ankara, İzmir, Kocaeli, Bursa, Eskişehir, Tekirdağ } \\
\text { Son İller: Ardahan, Van, Bingöl, Hakkâri, Şırnak, Bitlis, Ağrı, Muş }\end{array}$ \\
\hline 2011 & $\begin{array}{l}\text { İlk İller: İstanbul, Ankara, İzmir, Kocaeli, Antalya, Bursa, Eskişehir ve Muğla } \\
\text { Son İller: Ardahan, Bingöl, Şanlıurfa, Mardin, Van, Bitlis, Siirt, Şırnak, Ağrı, Hakkâri ve Muş }\end{array}$ \\
\hline
\end{tabular}

Tablo 1: Yıllara Göre Türkiye'de İllerin Sosyo-Ekonomik Gelişmişlik Sıralaması Kaynak: Elmas, 2001; Dinçer ve vd.,2003; SEGE,2011.

Tablo 1 incelendiğinde Türkiye'de belirtilen yıllar itibariyle illerin sosyo-ekonomik gelişmişlik sıralamasında çok fazla fark olmadığı görülmektedir. İstanbul, Ankara ve İzmir'in sıralamaları değişmemiştir. İlk iller; İstanbul, Ankara, İzmir, Kocaeli, Antalya, Bursa, Eskişehir ve Muğla iken, son iller; Ardahan, Bingöl, Şanlıurfa, Mardin, Van, Bitlis, Siirt, Şırnak, Ağrı, Hakkari ve Muş’tur. Nitekim bölgeleri merkez-çevre olmak üzere ikiye ayıran "Merkez Çevre" modelini de göz önüne alırsak İstanbul ve Ankara’nın birer merkez olarak gelişmesi işgücünün, sermayenin ve teknolojinin dişarı çıkmasına neden olmuş Kocaeli ve Eskişehir'in gelişmesine olanak sağlamıştır.

Türkiye'de uygulanan politikaları Planlı Dönem Öncesi (1923-1960) ve Planlı Dönem Sonrası (1960-...) olarak incelemek mümkündür. Planlı Dönem Öncesi'nde göze çarpan noktalar;

1923-1930 yıllarını kapsayan birinci liberal dönemde özel sektörün gelişimi hedeflenmiş olup, yabancı sermayenin ülkeye girmesine izin verilmemiştir. Fakat kalkınma ve sanayileşme için gerekli olan sermaye ve girişimciliğin yetersiz kalması arzulanan ivmenin yakalanmasına engel oluşturmuştur. 1929 Büyük Buhran sonucunda ise Türkiye'de kapalı bir ekonomi modeli uygulanmış; devletçi, müdahaleci ve korumacı politikalar ön plana çıkmıştır (Karaarslan, 2008). 1930-1950 Devletçilik dönemi ile sanayileşme ve kalkınma stratejileri yer almadığı gibi bu dönemde devlet eliyle kurulan işletmeler özel sektöre devredilmiştir. 1950-1960 Dönemi'nde ise 1930-1950 Dönemine tezat olan düşünce anlayışı ile devletin rolü hem ulusal hem de bölgesel bazda tartışılmış olup, başlangıçta devletin rolünün daraltılması hedeflenmiş fakat söz konusu olan hedef gerçekleştirilememiştir (Karaçay ve Erden, 2004).

Planlı Dönem Sonrası'nda (1960-...) 10 adet Kalkınma Planı oluşturulmuştur. Türkiye'de bölgesel kalkınmaya yönelik bakış açısı ve uygulamaya konulan kalkınma planlarında genel olarak kullanılan ortak kavram bölge planlaması, bölgelerarası dengesizliğin giderilmesi ve dengeli bölgesel gelişme düzeni oluşturulmasıdır. Bunun için hedefler arasında iç göçlerin engellenmesi de vardır. 


\section{3 İç Göç Olgusu: Teorik Çerçeve}

Coğrafi mekân değiştirme süreci olarak görülen göçün nedenleri ve sonuçları düşünüldügünde bireylerin ve toplumun üzerinde büyük değişiklikler yarattığı yadsınamaz bir gerçektir ( Yenigül, 2005). Yıldırım’a göre, göç olgusu insanlık tarihi kadar eskidir çünkü eski dönemlerde ilkel kabileler beslenip barınabilmek için kendilerine uygun, ihtiyaçlarını karşılayacakları yerler aradıkları için sürekli hareket halindedirler (Yıldırım, 2004). Şen ise göçü, toplumsal ve ekonomik değişimlere bağlı olarak ortaya çıktığından bir sonuç, toplumsal ve ekonomik değişimlere katkıda bulunması dolayısıyla da bir nedendir (Şen, 2014).

\begin{tabular}{|c|c|c|c|}
\hline Yazar & Yayın Yılı & Yöntem & Sonuç ve Açıklamalar \\
\hline $\begin{array}{l}\text { Yamak ve Yamak } \\
\text { (Türkiye'de Gelir } \\
\text { Dağılımı ve İç Göç) }\end{array}$ & 2000 & İstatistiksel & $\begin{array}{l}\text { 1980-1990 verileri kullanılmıştır. Gelir } \\
\text { dengesizliğinin net göç üzerinde ciddi bir } \\
\text { etkisinin olduğu ve net göç alan illerin } \\
\text { yüksek gelir düzeylerinden dolayı aldıkları } \\
\text { sonucuna varılmış olup ayrıca kişi başına } \\
\text { düşen ortalama gelir düzeyinin Türkiye } \\
\text { ortalamasına yakınsaması durumunda bu } \\
\text { illerin net göç oranının \% } 25 \text { oranında bir } \\
\text { azalma göstereceği sonucuna varılmıştır. }\end{array}$ \\
\hline $\begin{array}{l}\text { Pazarlıŏlu } \\
\text { (İzmir Örneğinde İç } \\
\text { Göçün Ekonometrik } \\
\text { Analizi) }\end{array}$ & 2002 & $\begin{array}{l}\text { İki Değişkenli } \\
\text { (Bivariate } \\
\text { Probit Model) }\end{array}$ & $\begin{array}{l}\text { Çalışmada İzmir’e göç etmede en önemli } \\
\text { faktörün ekonomik nedenler olduğu } \\
\text { sonucuna varılmış. Göç edenler eğitim } \\
\text { seviyelerinin düşük olmasından dolayı } \\
\text { yaşam seviyesini yükseltememiştir. }\end{array}$ \\
\hline $\begin{array}{l}\text { HÜNEE } \\
\text { (Türkiye'de Göç ve } \\
\text { Yerinden Olmuş Nüfus } \\
\text { Araştırması) }\end{array}$ & 2006 & $\begin{array}{l}\text { Nitel ve Nicel } \\
\text { Araştırma }\end{array}$ & $\begin{array}{l}\text { Araştırma sonucunda göç etme süreci } \\
\text { kişilerin istekleri dişında baskı ve talepler } \\
\text { nedeniyle gerçekleşmektedir. }\end{array}$ \\
\hline $\begin{array}{l}\text { Bahar ve Bingöl } \\
\text { (Türkiye'de İç Göç } \\
\text { Hareketlerinin İstihdam } \\
\text { ve İşgücü Piyasalarına } \\
\text { Etkileri) }\end{array}$ & 2010 & - & $\begin{array}{l}\text { Çalışmada Türkiye'de bulunan emek arzı } \\
\text { fazlalığı, talebini bulamamakta ve bu } \\
\text { nedenden dolayı insanlar göç } \\
\text { etmektedirler. Göç edenler istihdam } \\
\text { olanaklarına ulaşmasına rağmen, bulunan } \\
\text { işlerin marjinal verimlilikleri düşüktür. }\end{array}$ \\
\hline $\begin{array}{l}\text { Aşkın ve Vd. } \\
\text { (Kırsal Göçün } \\
\text { Ekonometrik Analizi: } \\
\text { Yeşilyurt İlçesi Örneği) }\end{array}$ & 2011 & $\begin{array}{c}\text { Bivariate Probit } \\
\text { Model }\end{array}$ & $\begin{array}{l}\text { Araştırma verilerine göre, kırsal göçün } \\
\text { nedenleri kentin çekici faktörleri ile } \\
\text { birlikte ve ondan daha güçlü olarak kırın } \\
\text { itici faktörlerinden kaynaklandığı } \\
\text { sonucuna varılmıştır. }\end{array}$ \\
\hline $\begin{array}{l}\text { Başel } \\
\text { (Türkiye'de Nüfus } \\
\text { Hareketleri ve İç Göçün } \\
\text { Nedenleri) }\end{array}$ & 2012 & - & $\begin{array}{l}\text { Türkiye'de iç göçün artma nedenini kırın } \\
\text { nüfus artışı ile bağlantılı olarak kırın } \\
\text { nüfusunu besleyememesine bağlanmıştır. } \\
\text { Türkiye'deki göçlerin en önemli nedeninin } \\
\text { bölgesel dengesizlik olduğu } \\
\text { savunulmuştur. }\end{array}$ \\
\hline $\begin{array}{l}\text { Kırdar ve Saraçoğlu } \\
\text { (İç göç, Bölgesel } \\
\text { Yakınsama Sorunu ve } \\
\text { Ekonomik Büyüme: } \\
\text { Türkiye Örneği) }\end{array}$ & 2012 & $\begin{array}{l}\text { En Küçük } \\
\text { Kareler } \\
\text { Yöntemi ve } \\
\text { Araç Değişken } \\
\text { Yöntemi }\end{array}$ & $\begin{array}{l}1975 \text { ve } 2000 \text { yıllarına ait veriler } \\
\text { kullanılmıştır. Çalışmada belli koşullar } \\
\text { altında iller arasında yakınsama olduğu } \\
\text { sonucuna varılmıştır. Fakat bu } \\
\text { yakınsamanın hızlanmasında iç göçün } \\
\text { herhangi bir yardımı yoktur. }\end{array}$ \\
\hline
\end{tabular}

Tablo 2: Litaratür Taraması

Tablo 2 Litaratür taraması sonucunda iç göç konusunda yapılan çalışmalarda genel olarak ulaşılan sonuç; iç göç olgusunun ekonomik faktörler ve kentin çekiciliği nedeniyle gerçekleştiğidir.

Dünyada ise iç göçle ilgili çalışmalar incelendiğinde teorik göç literatürünün makro ve mikro teorilerin $1 s ̧ ı \breve{g} 1$ altında açıklandığı görülmektedir. Makro düzeyde göç veren ve alan bölgelerin sosyo-ekonomik koşulları incelenmektedir. Buna göre, faktörler göç kararının verilmesine neden olan faktörleri, kırsal alan dışına iten itici faktörler ve kentsel alanlara çeken çekici faktörler olmak üzere ikiye böler (Sarjahpeyma, 1984). Makro teorilerden olan ve göç konusunda ilk teorik çalışmasını oluşturan Ravenstein'e göre; göç ekonomik ve sosyal açıdan yetersiz olan yerlerden daha iyi yerlere doğru bir akım olup, çıkış noktasından varış noktasına bir akım oluşturduğu gibi 
karşı bir akımda oluşturabilir. Göçmenler ise genellikle kırsal alanlarda yaşarlar. Kadın göçmenler kısa mesafeleri tercih ederken, erkek göçmenler uzak mesafeleri tercih etmektedirler (Topbaş, 2007). Türkiye'de en fazla göç alan bölge olan İstanbul kadın göçünün de yaşandığı en yoğun bölgedir. İstanbul'u Batı Anadolu, Doğu Marmara ve Ege Bölgeleri takip etmekte olup; buralarda da kadın göçünün sayısı erkek göçünü aşmaktadır. En az göç alan bölge ise, Kuzeydoğu Anadolu olup, Ortadoğu Anadolu, Doğu Karadeniz ve Güneydoğu Anadolu olarak sıralanmaktadır (TUİK). Kadınların daha fazla göç etmesinin nedeni "bağlantılı göçtür". Bağlantılı göç ailenin herhangi bir nedenle göç eden erkek üyelerini takip eden kadınların hareketini tanımlayan bir olgudur. Aynı bağlamda, yine ağırlıklı olarak kadınlara özgü başka bir göç nedeni olan "evlilik göçünü” ele almak mümkündür. Bağlantılı göç ya da evlilik göçü kadınlar açısından önemli bir göç nedeni olsa da, birey olarak kendilerine ait itme-çekme nedeniyle kadınlar ailenin erkek bireylerinden bağımsız olarak hareket edebilirler (İlkaracan ve İlkaracan, 1998).

Makro teorilere tezat olarak mikro modelde, göç kararı toplam değişkenlere bağlı olmayıp, bireyin kazanacağı net kazanç algısına bağımlıdır ve bu nedenle birey hür iradesi ile ne zaman ve nereye göç edeceğine karar vermektedir (Sarjehpeyma, 1984). Neo-Klasikler'in göç kararına ilişkin oluşturdukları mikro modeller arasında yer alan “Todaro Modeli”nden sonra, bireylerin kentsel işsizliğe rağmen göçü, beklenen gelirlerini yükseltme amacı ile yaptıkları kabul edilir. Kente göç kararı beklenen geliri yükseltmek amacıyladır ve beklenen gelirde reel gelir ve bir iş bulma gibi iki değişkene bağlıdır (Çelik, 2005).

Göç olgusunun bölgelerarası gelir farklılıklarını azaltmak gibi pozitif bir sonucu olduğu varsayımıyla hareket eden Neo-Klasiklerin aksine Sarjehpeyma kır-kent göç sürecini inceleyen araştırmacıların önemli bir yanılg1 içerisinde olduklarını iddia etmektedirler. Sarjehpeyma'ya göre, göç kırsal ve kentsel alanlarda farklılıkları daha çok arttırarak çekici faktörlerinde etkisi ile daha fazla göç verilmesine neden olmaktadır. Itici ve çekici faktörlerin neden olduğu göç süreci bölgesel dengesizliklere neden olduğu gibi gidilen yerde toplumsal ve politik problemlerin yaşanmasına da neden olmaktadır (Sarjehpeyma, 1984).

Lee tarafından 1966 yılında "Bir Göç Teorisi” adlı makalede göçün itici ve çekici nedenleri ortaya atılmıştır (Çağlayan, 2006; Erçevik, 2013). Yaklaşımda insanları kırsal alanlardan iten "itici faktörler" ile kentsel alanların cazibesini arttıran "çekici faktörler” üzerinde durulur (Çelik, 2005). Teoriye göre, göç; tarım toplumundan sanayi toplumuna geçişle birlikte topraktan kopuş süreci olarak yaşanmaya başlanmıştır. Teoriyi Türkiye açısından değerlendirecek olursak, 1945-1950 yılları arasında tarım ürünlerinde görülen fiyat artışları ve kırlarda toprağa dayalı işlerden kopuş, kentlerde ise sanayi ve hizmet sektörü için ciddi bir işgücü göç olgusunun gelişmesine neden olmuştur. Kentleşme tarihinin başlangıç noktası olan 1950'li yıllarda günümüzde metropol olarak tanımlanan İstanbul ve Ankara çekim merkezleri olarak görülmüştür (Öztürk ve Altuntepe, 2008). Yine 1980'li yıllar tarımda meydana gelen olumsuzluklar sonucunda metropol iller göç almaya devam etmişlerdir. Bu yıllarda, kentlerden kırlara yaşanan yoğun göç akımının en büyük nedeni ülkede uygulanan yeni liberal ekonomik politikalar olup, tarımda liberalizasyon ve devlet desteklerinin azalması da göç olgusunun gerçekleşmesini tetiklemiştir (Aşkın ve vd., 2013).

Cumhuriyetin kuruluş yıllarında köylerde yaşayan nüfusun oranı yıllar itibariyle köyden kente göçler nedeniyle değişmiştir. Türkiye'deki iç göç hareketleri ilk zamanlar devlet tarafından desteklenmesine rağmen, kentsel bölgelerde yaşanan sosyal problemler göçün bir problem olarak algılanmasına yol açmış ve kırdan kente göçün engellenmesi için Güneydoğu Anadolu Projesi ve Doğu Anadolu Projesi gibi birçok plan ve program hazırlanmıştır (Koçak ve Terzi, 2012).

\begin{tabular}{|c|c|c|c|c|c|c|}
\hline Yıllar & $\begin{array}{c}\text { Toplam } \\
\text { Nüfus (bin) }\end{array}$ & $\begin{array}{c}\text { Kent Nüfusu } \\
\text { (bin) }\end{array}$ & $\begin{array}{c}\text { Kent Nüfus } \\
\text { Oranı }\end{array}$ & $\begin{array}{c}\text { Kır Nüfusu } \\
\text { (bin) }\end{array}$ & $\begin{array}{c}\text { Kır Nüfus } \\
\text { Oranı }\end{array}$ & $\begin{array}{c}\text { Kentleşme Hızı } \\
\text { (Yüzde) }\end{array}$ \\
\hline $\mathbf{1 9 8 0 - 1 9 8 5}$ & 44.737 & 16.065 & 35,9 & 28.672 & 64,1 & 3,9 \\
\hline $\mathbf{1 9 8 5 - 1 9 9 0}$ & 50.664 & 23.238 & 45,9 & 27.426 & 54,1 & 7,7 \\
\hline $\mathbf{1 9 9 0 - 1 9 9 5}$ & 56.473 & 28.958 & 51,3 & 27.515 & 48,7 & 4,5 \\
\hline $\mathbf{2 0 0 0 - 2 0 0 7}$ & 67.804 & 38.661 & 57,0 & 29.515 & 48,7 & 4.5 \\
\hline $\mathbf{2 0 0 7 - 2 0 0 8}$ & 70.586 & 47.608 & 67,4 & 22.978 & 32,6 & 3,0 \\
\hline $\mathbf{2 0 0 8 - 2 0 0 9}$ & 71.517 & 49.514 & 69,2 & 22.003 & 30,8 & 4,0 \\
\hline $\mathbf{2 0 0 9 - 2 0 1 0}$ & 72.561 & 50.873 & 70,1 & 21.688 & 29,9 & 2,7 \\
\hline $\mathbf{2 0 1 0 - 2 0 1 1}$ & 73.722 & 52.340 & 72,3 & 21.382 & 29,0 & 2,9 \\
\hline $\mathbf{2 0 1 1 - 2 0 1 2}$ & 74.724 & 53.631 & 86,7 & 21,093 & 28,2 & 2,5 \\
\hline $\mathbf{2 0 1 2 - 2 0 1 3}$ & 75.627 & 54.705 & 87.2 & 20.922 & 27,7 & 2,0 \\
\hline $\mathbf{2 0 1 3 - 2 0 1 4}$ & 76.667 & 66.488 & 86,7 & 10.179 & 100,0 & 21,5 \\
\hline $\mathbf{2 0 1 4 - 2 0 1 5}$ & 77.696 & 67.720 & 87,2 & 9.976 & 12.8 & 1,9 \\
\hline
\end{tabular}

Tablo 3: 1980-2014 Yılları İtibariyle Kırsal Kentsel Nüfus Kaynak: Kalkınma Bakanlığı, 2015.

Tablo 2'de 1980-2014 yılları itibariyle kırsal-kentsel nüfus oranlarından göreceğimiz gibi 1980 y1lından sonra kent nüfus oranı sürekli bir artış göstermiş olup, 2013 yılında \%21,5 kentleşme oranı ile kent nüfus oranı rekor bir 
seviyeye ulaşmıştır. Bu durum ise, 6360 sayılı Yeni Büyükşehir Belediyesi Kanunu ile yeni büyükşehirler tanımlanmış olması ve bazı idari sınırların değiştirilmesinden kaynaklanmaktadır.

Türkiye'de göç hareketlerini 1923-1950 Dönemi’nde yaşanan ekonomik amaçlı iç göç hareketleri, 1950-1960 Dönemi'nde kırsal alandan kentsel alana kırın iticiliğinden dolayı yaşanan iç göç hareketleri, 1960-1980 Dönemi'nde kentin çekiciliğinin neden olduğu iç göç hareketleri ve 1980-1990'lı yılları içinde modernleşme temelinde toplumsal hareketliğin artması sonucu yaşanan iç göç hareketleri olmak üzere dört kısma ayrılabilir.

1923-1950 Dönemi’nde önemli bir göç hareketi yaşanmamıştır. Devlet memurlarının tayini çerçevesinde gerçekleşen göç hareketleri söz konusudur (Erçevik,2013). 1950 yilına kadar il içi göç ve mevsimlik işçi göçü söz konusu iken, bu yıllarda başlayan ekonomik canlanma ile iller arası iç göç hareketleri yoğunlaşmıştır (Bülbül ve Köse,2010). 1950'li yıllarda artan nüfus sonucunda toprağın bireyler arasında paylaştırıldığı, ölüm ve doğum oranlarının yüksek olduğu, göçün olmadığı geleneksel köy toplumlarında yaşam döngüleri toprakla ve devletle var olan dengeler çerçevesinde sürmüştür (Akşit,1997). Ancak söz konusu denge, 1945-1950 yılları arasında Türkiye'de doğal nüfus artış hızı, 2. Dünya Savaşı'nı izleyen yıllarda tarım ürünlerinde görülen fiyat artışları ve bu fiyat artışları neticesinde doğal olarak küçük toprak sahibi köylüleri arazilerini genişletmeye ve işgücü oluşturacak çocuklarını yöneltmesi; Marshall Planı ile Batı'dan gelen maddi katkılarında etkisiyle hızlanan kapitalistleşme, kırlarda toprağa dayalı işlerden kopuş, kentlerde ise sanayi ve hizmet sektörü için ciddi bir işgücü gereksinimi yaratmıştır (Erçevik, 2013; Vergin, 1986).

1950’li yıllar, Türkiye'de kentleşme tarihinin başlangıç noktasıdır. Etkileri günümüzde de devam eden köylerden kentlere doğru olan göçün başladığı, doruklarına ulaştığı ve sonra yavaşladığı dönemdir (İçduygu ve Ünalan,1997). $\mathrm{Bu}$ dönemde, günümüzde metropol olarak tanımladığımız İstanbul'un tüm Karadeniz illeri ve Doğu Anadolu illerinden; Ankara'nın ise İç Anadolu ve Doğu Anadolu illerinden gelen göçlerin çekim merkezi olmasıdır. Ege ve Akdeniz Bölgesi'ndeki iller daha az göç almakla birlikte bu dönemde göçle tanışmışlardır (Ercevik,2013). 19601980 yılları arasında köylerde meydana gelen dönüşüm nedeniyle kent nüfusunda artış görülmüştür. Göç olgusunun gelişmesindeki nedenler ise; kır-kent gelir farklarının artışı, kentlerin ekonomik ve toplumsal çekiciliğinin yükselmesidir. Göçler 1960’lı yılların sonları ile 1980 yılların başlarında tarımda meydana gelen piyasalaşma sonucunda olmuştur (İçduygu ve Ünalan, 1997). 1980'li ve 1990'lı yıllarda modernleşmenin "küreselleşme" olgusu ile anılmaya başlanması, ekonomik serbest piyasa ekonomisi iç göçü tetikleyen unsurlar arasındadır (Erçevik,2013). Yaşanan iç göçler kentsel ağırlıklı olup, nedenleri arasında yatırım özendirici politikalar, eğitim örgütlenmesinin kentsel alanlarda yoğunlaşması, köyle kent arasında ara engellerin oluşması sayılabilir (Peker,1999). 1980'li yıllardan itibaren kentlerden kırlara yoğun göç akımı gerçekleşmiştir. Bunun en büyük nedeni ise, ülkede uygulanan yeni liberal ekonomik politikalar olup, tarımda liberalizasyon, devlet desteklerinin azalması da göç olgusunun gerçekleşmesini tetiklemiştir (Aşkın ve vd., 2013).

\section{4 İç Göçün Nedenlerinin Çoklu Regresyon Analizi ile İncelenmesi: Türkiye Örneği}

Ülke sınırları içindeki, belirli bir alana diğer alanlardan gelen göç alınan göç olurken, ülke sınırları içindeki belirli bir alandan diğer alanlara giden göç verilen göçtür.

Net göç, bir ilin aldığı göçten verdiği göçün çıkartılmasıyla hesaplanmaktadır.

Net göç hızı ise, her il için net göçün ilgili ilin toplam nüfusuna bölünmesi ile bulunmaktadır. Bir ile ait net göç hızının negatif değere sahip olması o ilin göç verdiğini, pozitif olması ise göç aldığını göstermektedir.

Son yıllarda özellikle bazı illerde yoğun bir şekilde göçlerin yaşanması bu konuda araştırma yapmayı kaçınılmaz kılmıştır.

Bu çalışmadaki amaç, iller bazında elde edilen net göç hızını açıkladığı düşünülen değişkenler arasında matematiksel bir model oluşturmaktır. Başka bir ifadeyle, Türkiye'de net göç hızını hangi faktörlerin ne yönde etkilediğini belirlemektir. Bu amaca ulaşmak için çeşitli fonksiyonel formlar denenmiş ancak en uygun fonksiyonun doğrusal form olduğu sonucuna ulaşılmıştır.

Bir değişkeni etkileyen iki ve daha fazla bağımsız değişken arasındaki neden- sonuç ilişkilerini doğrusal bir modelle açıklamak ve bu bağımsız değişkenlerin etki düzeylerini belirlemek için yararlanılan yönteme çoklu doğrusal regresyon analizi denir.

$Y$ bağımsız değişkeni $X_{i}$ ler de bağımsız değişkenleri göstermek üzere çoklu regresyon ilişkisi genel olarak;

$Y=b_{0}+b_{1} X_{1}+b_{2} X_{2}+\cdots+b_{k} X_{k}+u$ şeklinde gösterilir.

Tek veya birden fazla bağımsız değişkenli regresyon analizlerinde oluşturulan modellerin anlamlı sonuçlar vermesi ve yorumlamalar yapılabilmesi için bir takım varsayımların geçerli olması gerekmektedir. Bu varsayımlar; - Regresyon tahmin hatalarının arasında bağımlılık yani otokorelasyon olmaması,

- Regresyon tahmin hatalarının varyanslarının eşit olması yani eşit varyanslılık şartının sağlanması,

- Regresyon tahmin hatalarının dağılımının normal dağılıma uygun olması,

- Bağımsız değişkenler arasında çoklu doğrusal bağlantı olmaması gerekmektedir.

Çalışmada kullanılan veriler 2014 yılına ait yatay kesit verileridir. Net göç hızının modellenmesinde kullanılan değişkenlere ilişkin açıklamalar Tablo 4'de verilmiştir. 


\begin{tabular}{|c|c|c|c|c|c|c|c|}
\hline Değişkenler & Kodu & Birim & Kaynak & $\begin{array}{c}\text { Beklenen } \\
\text { işaret }\end{array}$ & Açıklama & Ort. & $\begin{array}{r}\text { Std. } \\
\text { Sapma }\end{array}$ \\
\hline Net Göç Hızı & NGH & $\%$ & TÜİK & Bağımlı & $\begin{array}{l}\text { Her il için net göçün ilgili ilin toplam } \\
\text { nüfusuna bölünmesi ile bulunmaktadır, }\end{array}$ & $-3,56$ & 13,26 \\
\hline İşsizlik Oranı & İŞZLKO & $\%$ & TÜİK & + & $\begin{array}{l}\text { IBBS2 ( } 26 \text { bölge birimi) düzeyinde } \\
\text { verilmiş olmasından dolayı IBBS3 ( } 81 \\
\text { il) düzeyine dağıtılmıştır, }\end{array}$ & 8,89 & 4,71 \\
\hline Doktor Say1s1 & DRSAY & $\begin{array}{l}\text { Mutlak } \\
\text { Kişi Sayıs1 }\end{array}$ & TKHK & + & İlde yüz bin kişiye düşen doktor sayısı, & 56,22 & 19,39 \\
\hline $\begin{array}{l}\text { Okur-Yazar } \\
\text { Nüfus Oran1 }\end{array}$ & OKRNÜF & $\%$ & TÜİK & + & İldeki okur-yazar nüfus oran1, & 92,29 & 4,23 \\
\hline $\begin{array}{l}\text { Yoksulluk } \\
\text { Oranı }\end{array}$ & YKSLO & $\%$ & TÜİK & + & $\begin{array}{l}\text { Eşdeğer hane halk1 kullanılabilir } \\
\text { medyan gelirin \% } 60 \text { kriterine göre, } \\
\text { IBBS } 2 \text { ( } 26 \text { bölge birimi) düzeyinde } \\
\text { verilmiş olmasından dolayı IBBS3 ( } 81 \\
\text { il) düzeyine dağıtılmıştır, }\end{array}$ & 16,80 & 2,70 \\
\hline $\begin{array}{l}\text { Nüfus Artış } \\
\text { Hızı }\end{array}$ & NÜFAHZ & $\%$ & TÜİK & + & $\begin{array}{l}\text { İldeki bir önceki yıla göre nüfus } \\
\text { miktarındaki değişme, }\end{array}$ & 8,56 & 14,39 \\
\hline $\begin{array}{l}\text { Marmara } \\
\text { Bölgesi }\end{array}$ & MAR & $\begin{array}{l}\text { Marmara } \\
\text { Bölgesi=1; } \\
\text { değilse } 0\end{array}$ & & + & İl Marmara Bölgesi'nde & 0,14 & 0,34 \\
\hline Ege Bölgesi & EGE & $\begin{array}{l}\text { Ege } \\
\text { Bölgesi=1; } \\
\text { değilse } 0\end{array}$ & & + & İl Ege Bölgesi’nde & 0,09 & 0,28 \\
\hline $\begin{array}{l}\text { Akdeniz } \\
\text { Bölgesi }\end{array}$ & AKDNZ & $\begin{array}{l}\text { Akdeniz } \\
\text { Bölgesi=1; } \\
\text { değilse } 0\end{array}$ & & + & İl Akdeniz Bölgesi'nde & 0,09 & 0,28 \\
\hline $\begin{array}{l}\text { İç Anadolu } \\
\text { Bölgesi }\end{array}$ & İÇANDL & $\begin{array}{l}\text { İç Anadolu } \\
\text { Bölgesi=1; } \\
\text { değilse } 0\end{array}$ & & - & İl İç Anadolu Bölgesi’nde & 0,19 & 0,40 \\
\hline $\begin{array}{l}\text { Karadeniz } \\
\text { Bölgesi }\end{array}$ & KRDNZ & $\begin{array}{l}\text { Karadeniz } \\
\text { Bölgesi=; } \\
\text { değilse } 0\end{array}$ & & - & İl Karadeniz Bölgesi’nde & 0,21 & 0,41 \\
\hline $\begin{array}{l}\text { Doğu Anadolu } \\
\text { Bölgesi }\end{array}$ & DANDL* & $\begin{array}{l}\text { Doğu } \\
\text { Anadolu } \\
\text { Bölgesi }=1 \\
\text { değilse } 0\end{array}$ & & - & İl Doğu Anadolu Bölgesi’nde & 0,17 & 0,38 \\
\hline $\begin{array}{l}\text { Güney Doğu } \\
\text { Anadolu } \\
\text { Bölgesi }\end{array}$ & GDANDL & $\begin{array}{l}\text { Güneydoğ } \\
\text { u Anadolu } \\
\text { Bölgesi }=1 \text {; } \\
\text { değilse } 0\end{array}$ & & - & İl Güneydoğu Anadolu Bölgesi’nde & 0,12 & 0,33 \\
\hline
\end{tabular}

Tablo 4: Değişskenlerin Tanımlayıcı İstatistikleri

Büyük bir göç nedeni olarak görülen GSMH değerine ulaşılamadığı için Satın Alma Gücü Paritesi kullanılmadan Türkiye için hesaplanan gelire dayalı göreli yüzde yoksulluk sınırına göre medyan gelirin \%60'ına göre bölgesel yoksul sayıları değişken olarak kullanılmıştır. İşsizlik oranı ve yoksul sayıları IBBS2 (26 bölge birimi) düzeyinde verilmiş olmasından dolayı IBBS3 (81 il) düzeyine dağıtılmıştır.

Marmara Bölgesi, Ege Bölgesi, Akdeniz Bölgesi, İç Anadolu Bölgesi, Doğu Anadolu Bölgesi, Güneydoğu Anadolu Bölgesi nitel değişken olduğu için çalışmada kukla değişken olarak modele katılmıştır. İlin bulunduğu bölge 1 olarak alınmış, bulunmaması hali ise 0 olarak kabul edilmiştir.

Yapılan regresyon analizi sonuçları Tablo 5'de verilmiştir. Belirlilik katsayısı $\left(\mathrm{R}^{2}\right)$ birden çok bağımsız değişkenli modellerde, bağımlı değişkende meydana gelen değişmelerin, modeldeki bağımsız değişkenler tarafından açıklanabilen oranını verir. $\mathrm{R}^{2}$ büyüdükçe, $\mathrm{Y}^{\prime}$ deki değişimin bağımsız değişkenleri ile açıklanan yüzdesi de büyür ve regresyon doğrusunun gözlemlere uyumu artmaktadır. Net göç hızını açıklamada kullanılan değişkenler, net göç hızının \%92'sini açıkladığı ifade edilebilir.

F istatistiği regresyon modelinin anlamlılı̆̆ını bir bütün olarak test etmede kullanılır. Başka bir ifadeyle, F testi bağımlı değişken ile bağımsız değişken içeren parametreler arasında sıfırdan farklı bir ilişkinin olup olmadığını araştırır. Varyans analizi sonucuna göre, regresyon modeli \%1 önem seviyesinde anlamlı bulunmuştur.

t testi regresyon modelindeki bağımlı değişken ile bu değişkeni açıklayan bağımsız değişkenler arasındaki ilişkiyi gösteren parametrelerinin tek tek test edilmesinde kullanılır. Modele katılan değişkenlerden yüz bin kişiye düssen doktor sayısı (DRSAY), yoksulluk oranı (YKSLO) ve ilin Güneydoğu Anadolu Bölgesi'nde olması (GDANDL) değişkenleri istenilen önem seviyesinde (en fazla \%10) anlamlı bulunamamıştır. 


\begin{tabular}{lclccc}
\hline \multicolumn{1}{c}{ Değişken } & Katsayı & Std. hata & t-Değeri & $\begin{array}{c}\text { Önem } \\
\text { seviyesi }\end{array}$ & VIF \\
\hline İŞZLKO & & & & & \\
DRSAY & $\mathbf{- 0 , 3 0 9 5 2 6}$ & $\mathbf{0 , 1 3 8 9 4 6}$ & $\mathbf{- 2 , 2 2 7 6 7 3}$ & $\mathbf{0 , 0 2 9 2}$ & $\mathbf{2 , 1 1 3}$ \\
OKRNÜF & 0,031949 & 0,025759 & 1,240287 & 0,2191 & 1,233 \\
YKSLO & $\mathbf{0 , 3 9 3 5 8 7}$ & $\mathbf{0 , 1 5 0 6 2 1}$ & $\mathbf{2 , 6 1 3 1 0 6}$ & $\mathbf{0 , 0 1 1 0}$ & $\mathbf{2 , 0 0 9}$ \\
NÜFAHZ & $-0,061434$ & 0,236713 & $-0,259530$ & 0,7960 & 2,018 \\
MAR & $\mathbf{0 , 7 9 2 3 7 1}$ & $\mathbf{0 , 0 3 8 7 2 0}$ & $\mathbf{2 0 , 4 6 4 0 0}$ & $\mathbf{0 , 0 0 0 0}$ & $\mathbf{1 , 5 3 3}$ \\
EGE & $\mathbf{6 , 5 4 0 5 6 0}$ & $\mathbf{2 , 2 0 8 2 8 0}$ & $\mathbf{2 , 9 6 1 8 3 5}$ & $\mathbf{0 , 0 0 4 2}$ & $\mathbf{2 , 8 6 4}$ \\
AKDNZ & $\mathbf{6 , 7 5 3 5 9 8}$ & $\mathbf{2 , 1 8 9 5 1 6}$ & $\mathbf{3 , 0 8 4 5 1 7}$ & $\mathbf{0 , 0 0 2 9}$ & $\mathbf{1 , 8 9 4}$ \\
IÇANDL & $\mathbf{3 , 9 7 3 8 5 9}$ & $\mathbf{2 , 1 2 7 7 5 2}$ & $\mathbf{1 , 8 6 7 6 3 3}$ & $\mathbf{0 , 0 6 6 1}$ & $\mathbf{1 , 7 8 9}$ \\
KRDNZ & $\mathbf{3 , 4 3 1 6 1 6}$ & $\mathbf{1 , 8 8 7 3 2 4}$ & $\mathbf{1 , 8 1 8 2 4 4}$ & $\mathbf{0 , 0 7 3 4}$ & $\mathbf{2 , 6 8 9}$ \\
GDANDL & $\mathbf{6 , 7 4 8 9 8 4}$ & $\mathbf{1 , 8 2 8 9 2 6}$ & $\mathbf{3 , 6 9 0 1 3 6}$ & $\mathbf{0 , 0 0 0 4}$ & $\mathbf{2 , 7 7 6}$ \\
C & $-2,281719$ & 2,425533 & $-0,940708$ & 0,3501 & 3,186 \\
\hline R-squared & $-48,26317$ & 14,29527 & $-3,376164$ & 0,0012 & \\
Adjusted R-squared & 0,920563 & Mean dependent var & $-3,555556$ & \\
S.E. of regression & 0,907899 & S.D. dependent var & 13,25747 & \\
Sum squared resid & 4,023387 & Akaike info criterion & 5,758079 & \\
Log likelihood & 1116,947 & Schwarz criterion & 6,112812 & \\
F-statistic & $-221,2022$ & Hannan-Quinn criter & 5,900403 & \\
Prob(F-statistic) & 72,69233 & Durbin-Watson stat & 2,261061 & \\
\hline & 0,000000 & & & & \\
\hline
\end{tabular}

Tablo 5: Regresyon Analizi Sonuçları

Otokorelasyon, zaman içinde ya da mekân içinde sıralanan gözlem dizilerinin birimleri arasındaki ilişkidir. Regresyon katsayılarının yorumlanabilmesi için modelde otokorelasyon (ardışık bağımlılık) olmaması gerekir. Çünkü bu durumda F ve t testi anlamlılığını kaybeder. Otokorelasyon durumunu ortaya çıkarmada Durbin-Watson $d$ istatistiği ve Breusch-Godfrey Serial Correlation LM testleri kullanılmış ve otokorelasyon problemine rastlanılmamıştır (Tablo 6).

Değişen varyans hata teriminin varyansının tüm gözlemler için aynı olmaması durumudur. Değişen varyans durumunda parametre tahmincilerinin varyansları olduğundan büyük çıkar. Bunun sonucunda $t$ testi sonucu olduğundan küçük bulunur. Yani anlamlı bir katsayının anlamsız olarak yorumlanması muhtemeldir. Değişen varyans problemi White nR-kare testi ile araştırılmış ancak modelde böyle bir problemin varlığına rastlanılmamıştır (Tablo 6).

\begin{tabular}{lrlr}
\hline Heteroskedasticity Test: White & & & \\
F-statistic & 2,179260 & Prob. F(56,24) & 0,0194 \\
Obs*R-squared & 67,68845 & Prob. Chi-Square(56) & 0,1361 \\
Scaled explained SS & 65,66438 & Prob. Chi-Square(56) & 0,1768 \\
Breusch-Godfrey Serial Correlation LM Test & 0,913174 & Prob. F(2,67) & 0,4062 \\
F-statistic & 2,149382 & Prob. Chi-Square(2) & 0,3414 \\
Obs*R-squared & & & \\
Normality Test & 1,562355 & Probability & 0,457867 \\
\hline Jarque-Bera &
\end{tabular}

Tablo 6: Hata Terimlerine Illişkin Testler

Bir regresyon modelinde açıklayıcı değişkenlerin tümü veya bir kısmının aralarında tam veya tama yakın bir doğrusal ilişkinin olmasına çoklu doğrusal bağlantı (multicollinearity) adı verilir. Açıklayıcı değişkenler arası mükemmele yakın bir ilişki En Küçük Kareler (EKK) metodunu kullanılmaz hale getirir. Çoklu doğrusallığın olduğu durumlarda parametreleri tahmin etmek imkânsızlaşır ve kesin tahminlerde bulunmak zorlaşır. Modelde çoklu doğrusal bağlantı araştırılmış ve bunun için Varyans Artış Faktörü (VIF) değerleri hesaplanmış ve Tablo 5'de verilmiştir. Tablo incelendiğinde, VIF değerlerinin hepsi 10'dan daha küçük olduğu görülmektedir. Bu durumda çoklu doğrusal bağlantı probleminin olmadığı söylenebilir.

Aralık tahmini ve regresyon katsayılarının testlerinin yapılabilmesi için hata terimlerinin dağılımının normal dağılıma uyması gerekir. Modeldeki hata terimlerinin normal dağılımı Jarque-Bera testi ile incelenmiş ve hata terimlerinin normal dağıldığı tespit edilmiştir (Tablo 6).

Net göç hızını açıkladığı düşünülen değiş̧kenlere ilişkin regresyon analiz sonuçları kısaca aşağıda özetlenmiştir.

İşsizlik oranı (İŞZLKO) değişkeninin katsayı işareti negatif olup \%5 önem düzeyinde anlamlıdır. Beklentilerin aksine işsizlik oranının artması net göç hızını azaltıcı yönde etkilemektedir. Gelişmiş iller kalifiye iş gücü için 
çekim merkezi konumundadır. Bir ilin sosyo-ekonomik gelişmişlik düzeyi arttıkça kalifiye iş gücünü barındırma oranı da artmakta ve buna paralel olarak illerde yeteri kadar kalifiye iş gücünün olması iş bulma olanağını sınırlandırmaktadır. Bu yüzden işsizlik oranının net göç hızını etkileyen temel bir faktör olmadığı sonucuna varmak mümkündür.

Okuryazar nüfus oranı (OKRNÜF) modele katılmış ve katsayı işareti pozitif olarak belirlenmiştir. Diğer değişkenler sabitken okuryazar nüfus oranında \% 1artış net göç hızını \%0,39 artıracaktır.

Modele dahil edilen nüfus artış hızı (NÜFAHZ) değişkeninin katsayı işareti pozitif olup \%1 önem seviyesinde istatistiksel olarak anlamlı bulunmuştur. Nüfusun artmasının göçü de hızlandırdığı söylenebilir.

Türkiye yedi farklı coğrafi bölgeye ayrılmıştır. Her bölge birbirinden farklı gelişmişlik düzeyindedir. Gelişmişlik farklıllğ 1 göçü de beraberinde getirecektir. $\mathrm{Bu}$ sebeple modele kukla değişken olarak katılan bölge değişkenlerinden Güney Doğu Anadolu Bölgesi'ne ilişkin değiş̧en anlamlı değişken diğerlerinin hepsi istenilen önem düzeyinde anlamlı bulunmuştur. Anlamlı bulunan değişkenlerin hepsinin de katsayı işareti pozitiftir. Doğu Anadolu Bölgesi temel alındığında, ilin Marmara, Ege, Akdeniz, İç Anadolu veya Karadeniz Bölgesi'nde olmasının net göçü artırıcı etki yaptı̆̆ı söylenebilir.

\section{Sonuç ve Değerlendirme}

En genel tanımıyla göç; ekonomik, siyasi ya da sosyal nedenlerle bireylerin veya toplulukların oturdukları yerleşim yerini bırakıp yerleşmek için başka bir bölge ya da ülkeye gitmeleridir. İç göç hareketinin nedenleri arasında ilk olarak düşünülen ekonomik faktörler olsa da; sosyal, siyasal ve coğrafi nedenlerden dolayı da iç göç olgusu gerçekleşmektedir. Bu göç nedenlerini genel itibariyle itici ve çekici güçler olarak ifade edebilir.

Kırsal alanlarda birçok yönden sahip olunamayan ve hiçbir şekilde olunamayacağ düşünülen "itici" olarak adlandırılan olanaklara, kentsel alanlarda sahip olacakları düşüncesi ile kentin "çekici" 1şıklarına kapılan insanlar tarafindan göç olgusu gerçekleştirilmektedir. Bireyler özgür iradeleri ile seçim yaparak, kentli olma düşüncesiyle kırsal alanda yaşamaya bir tepki niteliğinde göçü gerçekleştirirler. Böylelikle gerek kırsaldaki işsizlik, sanayileşme ile tarımsal yapıda yaşanan olumsuz değişimler göçün itici faktörlerini oluştururken, kentsel alanlarda ki ilerlemeler, kentte yaşamanın cazibeli oluşu, olanakların sınırsız olduğu düşüncesi gibi çekici faktörlerin birleşmesiyle yaşanan önemli bir demografik süreç olan iç göç olgusunun ekonomik olduğu kadar sosyal bir değişim olduğunu da kanıtlamaktadır.

Türkiye'de 1920 'lerden sonra yaşanan göç hareketleri ekonomik kalkınma, sanayileşme ve modernleşme sonucunda yaşanmıştır. 1950 yılına kadar ekonomik canlanma ile iller arası iç göç hareketleri yoğunlaşmıştır. 1950'li yıllarda hızlanan iç göç, daha çok ülkede kırsal alanlardaki dönüşümün ivme kazanması ile kırın iticiliği şeklinde açıklanabilir. 1960-1980 döneminde yaşanan göçler ise, kenti çekiciliği şeklindedir. 1980-1990'lı yıllar içinde iç göç olgusu ve süreçleri modernleşme temelindeki toplumsal hareketliğin artması ile yeni bir döneme girmiştir. 1980'li yıllar tarımda meydana gelen olumsuzluklar sonucunda metropol iller göç almışlardır. 1980 sonrası dönem ise nüfusun çoğunluğunun kentlerde yaşadığı bir dönem olmuş ve kırdan kente göç olgusu söz konusu olduğu gibi, kentten kente de göç olgusu yaşanmıştır.

Regresyon analizi sonucunda; kullanılan on bir değişkenden sekizi istenilen önem seviyesinde anlamlı bulunmuştur. Bu değişkenlerden işsizlik oranı hariç diğer değişkenlerin net göç hızını pozitif yönde etkiledikleri tespit edilmiştir. Özellikle Doğu Anadolu Bölgesi temel alındığında diğer bölgelerin göç alan bölgeler olduğu söylenebilir.

Nitekim bölgesel dengesizliğin bir sonucu olarak gerçekleşen iç göç olgusunun en önemli nedenlerinden biri olarak sosyo-ekonomik şartlar düşünülecek olursa; Türkiye'de yedi bölgenin sosyo-ekonomik gelişmişlik sıralamasında, ilk sırada Marmara ve Ege Bölgeleri yer alırken, son sıraları Güney Doğu ve Doğu Anadolu Bölgeleri oluşturmaktadır. Modelimiz sonucunda da İç Anadolu, Doğu Anadolu ve Güney Doğu Anadolu Bölgeleri'nde herhangi bir ilde yaşama olasıllığının göç verme olasılığını artırdığı sonucuna varmış bulunmaktayız. Ayrıca 2013-2014 yılları verilerin baktığımızda en fazla göç alan bölgeler İstanbul, Batı Anadolu, Doğu Marmara ve Ege Bölgeleri iken, en fazla göç veren bölgeler Kuzeydoğu Anadolu, Ortadoğu Anadolu, Doğu Karadeniz ve Güneydoğu Anadolu Bölgeleridir. Bu da kırsal alanının iticiliğinin, kentsel alanın çekiciliğinin bir göstergesidir.

Türkiye'de iç göçü engellemek için farklı politika uygulamaları yaparak, göç veren bölgelere yönelik teşvik projeleri artırılmalıdır. Bölgesel dengesizliklerin neden olduğu göç hareketi devam ettiği müddetçe bölgesel gelişme ve gelir farklılıkları artma eğilimi gösterecektir. Sonuç olarak, göç alan bölgelerde yaşanan olumsuzluklar artarken, göç veren bölgelerde kayıplar söz konusu olacaktır. 


\section{Kaynakça}

- Açma,1991. "Gelişmiş Ülkelerin Azgelişmiş Bölgelerini Geliştirmeyi Amaçlayan Politikaların İncelenmesi ve GAP Örneği, İstanbul Ticaret Odası, Yayın No:7 p.7.

- Akşit,1997. İç Göçlerin Nesnel ve Öznel Toplumsal Tarihi Üzerine Gözlemler: Köy Tarafından Bir Bakış, Ahmet İçduygu ve Diğerleri (Der.), Türkiye'de İçgöç,: Türkiye Ekonomik ve Toplumsal Tarih Vakfi Yayınları, İstanbul.

- Aşkın ve vd.,2013. "Kırsal Göçün Ekonometrik Analizi: Yeşilyurt İlçesi Örneği” Cumhuriyet Üniversitesi İ.I.B.F. Dergisi, Cilt:14, Sayı:2, p.231.

- Bahar ve Bingöl, 2010. “Türkiye’de İç Göç Hareketlerinin İstihdam ve İşgücü Piyasalarına Etkileri”, Süleyman Demirel Üniversitesi, İktisadi ve İdari Bilimler Fakültesi Dergisi, C.14,Sayı:2,p.43

- Başel,2007. “Türkiye'de Nüfus Hareketlerinin ve İç Göçün Nedenleri”, Sosyal Siyaset Konferansları Dergisi, Say1:53, p.516

- Bülbül ve Köse,2010. “Türkiye'de Bölgelerarası İç Göç Hareketlerinin Çok Boyutlu Ölçekleme Yöntemi İle İncelenmesi”, İstanbul Üniversitesi İşletme Fakültesi Dergisi, Cilt/Vol:39, Say1/No:1,p.75-94.

- C Çelik,2005. “İç Göçler: Teorik Analiz” Ç.Ü. Sosyal Bilimler Enstitüsü Dergisi, Cilt:14, Sayı:2, p.174.

- CCağlayan,2006. “Göç Kuramları, Göç ve Göçmen İlişkisi”, Muğla Üniversitesi, Sosyal Bilimler Enstitüsü Dergisi, Sayı:17, p.69

- Dinçer ve vd., 2003. “ IIllerin ve Bölgelerin Sosyo-Ekonomik Gelişmişlik Sıralaması Araştırması”. Devlet Planma Teşkilatı Yayın No DPT 2671, Ankara.

- Elmas,2004. “Cumhuriyetin İlanından Günümüze Türkiye’de Bölgesel Politikalar” Ekonomik Yaklaşım, Say1:50, Cilt:15, p.115

- Erçevik,2013. “Türkiye'deki İç Göçlerin Nedenlerinin Log Lineer Analizi İle İncelenmesi, Yüksek Lisans Tezi, Marmara Üniversitesi, Sosyal Bilimler Enstitüsü, İstanbul, p.11.

- Göktürk,2006. Bölgesel Dengesizliğe Küreselleşme-Yerelleşme Penceresinden Bir Bakış, Arı,A (Der) Bölgesel Kalkınma Politakalar ve Yeni Dinamikler, Derin Yayınları, İstanbul.

- Göymen,2004. “Türkiye'de Bölge Kavramı ve Politikaların Gelişimi”, AB ve Türkiye'de Yönetişim Uluslararası Konferans1, İstanbul: Pendik Belediyesi Yayınları, October 2004, p:13

- Gündüz,2006. Bölgesel Kalkınma Politikası, Ekin Kitapevi, Bursa.

- Hünefee, 2006. “Türkiye’de Göç ve Yerinden Olmuş Nüfus Araştırması”, Hacettepe Üniversitesi Nüfus Etütleri Enstitüsü, Yayın no.NEE-HÜ.06.01, Ankara.

- Ildırar,2004. Bölgesel Kalkınma ve Gelişme Stratejileri, Nobel Yayınları, Ankara.

- İçduygu ve Ünalan,1997. Türkiye'de İç Göç Sorunsal Alanları ve Araştırma Yöntemleri, Ahmet İçduygu ve Diğerleri (Der), (1998), Türkiye'de İçgöç: Türkiye Ekonomik ve Toplumsal Tarih Vakfı Yayınları, İstanbul

- İlkaracan ve İlkaracan,1998. “1990’lar Türkiye’sinde Kadın ve Göç” 75 Yılda Köylerden Şehirlere, İstanbul: Tarih Vakfi Yayınları, p:305

- Karaarslan,2008. “Avrupa Birliği ve Türkiye'de Bölgesel Politikalar ve Kalkınma Ajansları” Yüksek Lisans Tezi, Ankara Üniversitesi Sosyal Bilimler Enstitüsü, Ankara.

- Karaçay-Çakmak ve Erden,2004. "Yeni Bölgesel Kalkınma Yaklaşımları ve Kamu Desteklemeke Politikaları: Türkiye'den Bölgesel Panel Veri Setiyle Ampirik Bir Analiz”, Gazi Üniversitesi İktisadi ve İdari Bilimler Fakültesi Dergisi, 6/3 (2004), p:77-96

- Kalkınma Bakanlığı, 2015. "Ekonomik ve Sosyal Göstergeler 1950-2014" Temmuz.(http://www.kalkinma.gov.tr/Lists/Yaynlar/Attachments/654/Ekonomik\%20ve\%20Sosyal\%20G\% C3\%B6stergeler_1950_2014.pdf)

- Kırdar ve Saraçoğlu,2012. "İç Göç, Bölgesel Yakınsama Sorunu ve Ekonomik Büyüme: Türkiye Örneği'Türkiye Ekonomi Kurumu, Tartışma Metni 2012/75.

- Koçak ve Terzi,2012. “Türkiye'de Göç Olgusu, Göç Edenlerin Kentlere Olan Etkileri ve Çöüm Önerileri, Kafkas Üniversitesi İ̈BF Dergisi, Cilt:3 Sayı:3,p:7.

- McCall,2010. "What do we mean by Regional Development", Institute for Regional Development Cradle Coast Campus University of Tasmania, p.5.

• Özçağlar,2003. “Türkiye'de Yapılan Bölge Ayrımları ve Bölge Planlama Üzerindeki Etkileri” Ankara Üniversitesi, Coğrafi Bilimler Dergisi,1 (1), p:3 
- Ö̈zel,2009. “Avrupa Birliği’ne Uyum Sürecinde Türkiye’de Bölgelerarası Dengesizlik ve Yeni Yönetsel Birim Arayışları”, Ankara Üniversitesi, Siyasal Bilgiler Fakültesi Dergisi, Sayı:64,p.166.

- Öztürk ve Altıntepe, 2008. “Türkiye’de Kentsel Alanlara Göç Edenlerin Kent ve Çalışma Hayatına Uyum Durumları: Bir Alan Araştırması” Journal of Yaşar University p.1588.

- Pazarlığlu, 2007. "İzmir Örneğinde İç Göçün Ekonometrik Analizi”, Yönetim ve Ekonomi Dergisi, Cilt: 14 Sayı: 1, p: 121.

- Peker,1999. Türkiye'de İçöçün Değişen Yapısı, Oya Baydar (Der), 75 Yılda Köylerden Şehirlere, İstanbul: Tarih Vakfi Yayınları.

- Sarjahpeyma,1984. “The Economic Impact of Internal Migration: Iran as Special Case”, Unpublishet PhD Thesis, The University of Oklahoma.

- Sert,2012. "Bölge, Türkiye’de Bölge Kavramı ve Kalkınma Ajanslarının Yapısı” Kilis Üniversitesi, Sosyal Bilimler Enstitüsü Dergisi, Sayı:4, p.119.

- Sege,2011. “ IIllerin ve Bölgelerin Sosyo-Ekonomik Gelişmişlik Sıralaması Araştırması. http://www.ab.gov.tr/files/ardb/evt/2_turkiye_ab_iliskileri/2_2_adaylik_sureci/2_2_8_diger/tckb_sege_2013 .pdf)

- Şahinkaya,1993. “Türkiye’de Bölgesel Gelişmişlik Düzeyi ve Kalkınmada Öncelikli Yöreler Üzerine Bazı Gözlemler” Mülkiyeliler Birliği Dergisi, C.XVII, Ankara, p.151.

- S Şen,2014. “Türkiye’de İç Göçlerin Neden ve Sonuç Kapsamında İncelenmesi”, Çalışma ve Toplum Dergisi, Say1:40, p.232.

- Topbaş,2007. "İç Göçün Belirleyicileri Üzerine Ekonometrik Bir Model Çalışması 2000 Türkiye Örneği, Karadeniz Teknik Üniversitesi Sosyal Bilimler Enstitüsü, Doktora Tezi.

- TUIK, http://www.tuik.gov.tr/VeriBilgi.do?alt_id=1067

- Vergin,1986. "Hızlı Şehirleşmenin Sosyolojik ve Siyasal Sonuçları, SİSAV (Der.), Hızlı Şehirleşmenin Yarattığı Ekonomik ve Sosyal Sorunlar", SİSAV Yayınları, İstanbul

- Yamak ve Yamak,1999. “Türkiye’de Gelir Dağılımı ve İç Göç”, Dokuz Eylül Üniversitesi Sosyal Bilimler Enstitüsü Dergisi,1(1),p:16-28.

- Yıldırım,2004. “Kentleşme ve Kentleşme Sürecinde Göçün Suç Olgusu Üzerindeki Etkileri”, Yüksek Lisans Tezi, Ankara Üniversitesi, Sosyal Bilimler Enstitüsü, s.31. 


\title{
Düzgün İş Endeksi Çerçevesinde OECD Ülkeleri İçinde Türkiye'nin ve Diğer Ülkelerin Düzgün İş Yapılarının Karşılaştırmalı Analizi
}

\section{A Comparative Analysis of Turkey's and Other OECD Countries' Decent Work Structures}

\author{
Assoc. Prof. Dr. Elif Haykır Hobikoğlu (Istanbul University, Turkey) \\ Prof. Dr. Ahmet İncekara (Istanbul University, Turkey)
}

\begin{abstract}
This study examines all the efforts paid since the year 2000 for improving the working conditions of decent work which is a concept that has been in use by the International Labour Organization. A comparative analysis of Turkey's and other OECD counties' decent work structures is presented in our study which has been conducted by looking at such indicators as wages paid for labour, working conditions, social security rights, union rights, income security, annual leave durations, existence of social dialogue, labour participation rates, social assistance, social protections, the state of human development index.
\end{abstract}

\section{Giriș}

2000 yılından bu yana Uluslararası Çalışma teşkilatı tarafından kullanılmaya başlan bir kavram olan düzgün iş emek kullanımında çalışma koşullarının iyileştirilmesine yönelik çalışmaların tümünü içermektedir. Çalışmamız da emeğin karşılığı alınan ücret, çalışma koşulları, sosyal güvenlik hakları, sendikal haklar, gelir güvencesi, yıllık izin süreleri, kıdem tazminatı, sosyal diyalogun varlığı, işgücüne katılma oranı, sosyal yardım, sosyal korumalar, insanı gelişme endeksi göstergelerinin gelişmişliği, sendikalaşma oranları gibi unsurların ön plana alınarak yapıldığ düzgün iş endeksinde, OECD ülkeleri içinde Türkiye'nin ve diğer ülkelerin düzgün iş yapıları incelenerek karşılaştırmalı bir analizi yapılmıştır.

Literatüre İngilizce bir kavram olarak giren ' decent work”, emeğin var olma koşullarını etkinleştirmek, çalışma koşullarının iyileştirilmesi, emek karşılığ korunduğu, kabul edilebilir çalışma koşullarının içinde olmak, beşeri sermayenin değer algısının yükseltildiği koşulları ifade etmek için kullanılmaktadır. Temel kriterlerin oluşup oluşmadığı noktasında ölçümlenen düzgün iş kavramı, gelir güvencesi, sosyal güvenlik kapsamında olma, sendikal hakların varlığı, işçi ve işveren örgüt yöneticilerinin ve temsilcilerinin temel ekonomik ve sosyal politikaların belirlenmesinde uygulanmasındaki katılımlarının derecelerini ve birlikte iş yapabilirliklerini gösteren sosyal diyalog şartlarının emek piyasasında var olup olmaması gibi konumlandırmalar dâhilinde incelenmektedir.

Düzgün iş temel hak ve standartların emek piyasasında uygulamasını gösteren, istihdam, gelir paylaşımı ve ekonomik firsatları değerlendirmede cinsiyet farklılığının düzeyini gösteren, sosyal diyalogun iletişim aracıyla emek piyasasının tüm paydaşlarını katılım platformunda eşdeğer kılındığı ve sosyal Güvenliğin en etkin şekilde uygulama alanını genişleten kavramsal bir çerçeveyi içermektedir.

\section{Düzgün İş Göstergeleri Çerçevesinde Düzgün İş Endeksi ve Temel Özellikleri}

Düzgün iş performansının belirlenmesinde istihdam boyutu, istihdam oranı, işgücüne katılım oranı, ücretli çalışanların toplam istihdama oranı, işsizlik oranı, gelir dağılımı adaleti, çalışma saatleri, yıllık ücretli izin hakkı, işçi sağlığı, işyeri doktoru istihdamı, işçi sağlığ oluşan fiziksel ve duygusal zorlukları telafi yöntemlerinin varlığı, işyerinde iletişim kalitesi ve gelişim olanaklarının varlığı gibi ölçütler kullanılmaktadır.

Düzgün iş performansı sosyal diyalog boyutunu, çalışanların yönetim kararlarına katılım oranları, işbirliği, emek piyasasını oluşturan farklı çıkar grupları arasında adil bir çözüm mekanizmasının hukuksal ve demokratik bir alt yapısının olması, grev hakkının olası, toplu pazarlık haklarını varlığı, çalışanların sendikaya üyelik oranı kapsamaktadır ve kullanılmaktadır, çeşitli çıkar gruplarının çıkar çatışmalarını barışçı yollarla çözmesi ve devletin de mekanizmaya destek vermesi ile ilgilidir. İlk akla gelen uygulama alanı toplu pazarlık olsa da bundan daha geniş bir anlam taşımaktadır

Düzgün iş performansının belirlenmesinde kullanılan sosyal güvenlik boyutu ise mesleki hastalık ve kaza durumlarında sağlık imkanlarına ulaşabilme yeteneği, yaşlılık halinde bakım ihtiyacı, hane halkı gelirinin yoksulluk boyutunun üstünde olup olmaması, devlet kamu harcamaları içinde sosyal güvenlik harcamalarının payı, sosyal güvenlik hizmetlerinin yaygınlığı, sosyal güvenlik kapsamında olan çalışanların tüm çalışanlara oranı, aktif sigortalıların istihdam edilen nüfusa oranı, sosyal güvenlik harcamalarının GSMH içindeki oranı, işsizlik sigortası 
uygulaması ve oranlarını içermektedir. . Bu boyutun ölçümünde, genellikle yapılan harcamalar esas alınmaktadır. Oysa GSMH içindeki harcama oranına bakılarak Türkiye ile diğer ülkelerin mukayese edilmesi hatalı sonuçlar doğurabilir. Çünkü Türkiye, görece genç bir ülkedir. Mukayese yapılan Avrupa ülkeleri kadar sağlik ve sosyal güvenlik harcaması yapması doğal değildir. Dolayısıyla, sosyal güvenliğin kapsamına bakılması daha yararlı sonuçlar doğurabilir. Türkiye'de ILO'nun 9 temel sosyal sigorta kolundan sadece aile yardımları sigorta kolu uygulanmamaktadır.

Düzgün iş performansının belirlenmesinde temek hak ve özgürlükler çerçevesinde irk, cinsiyet, fiziksel özellik gibi konularda ayrımcılığa ne oranda tutulduğuyla ilintilendirilen mesleki ayrımcılığın istihdam sürecini etkileyip etkilemediği ile ölçülmektedir. Kadınların işgücüne katılım oranı, yüksek ücretli işlerde kadınların çalışma oranı, üst kademe de çalışan kadınların oranı, girişimci kadınların oranı önemli göstergelerdir.

Sosyal ve Ekonomik boyutu ölçümlemek için enflasyon oranı ile reel ücret düzeyinin belirlenmesi, kayıt dişılığın ekonomik sistem içindeki boyutu, ekonomik büyümeyi büyük oranda etkileyen endüstrilerde çalışanların çalışma koşullarının diğer endüstri çalışanlarının koşullarının karşılaştırılması

\section{Düzgün İş Endeksi Çerçevesinde OECD ülkeleri ve Türkiye Analizi}

Dharam Ghai tarafından geliştirilen bir yöntem olan düzgün iş sıralaması ile ülkelerin düzgün iş göstergeleri çerçevesinde sıralaması ve karşılaştırılması yapılmıştır (Gai:2003). Bu yöntem ülkelerin düzgün iş performanslarının karşılaştırılması açısından önemlidir.

Richard Anker tarafından geliştirilen düzgün iş ölçme yönteminde ise endeksi oluşturan göstergeler sosyo ekonomik boyutuyla ülkelerin ekonomik verilerini kapsamlı bir şekilde değerlendiren bir yöntem oluşturmuştur.

\begin{tabular}{|l|l|}
\hline Norveç & 1 \\
\hline İsviçre & 2 \\
\hline Avustralya & 3 \\
\hline Japonya & 4 \\
\hline Yeni Zelanda & 5 \\
\hline Almanya & 6 \\
\hline Hollanda & 7 \\
\hline Avusturya & 8 \\
\hline Danimarka & 9 \\
\hline ABD & 10 \\
\hline İzlanda & 11 \\
\hline İsveç & 12 \\
\hline İngiltere & 13 \\
\hline İsrail & 14 \\
\hline Finlandiya & 15 \\
\hline İrlanda & 16 \\
\hline Meksika & 17 \\
\hline Estonya & 18 \\
\hline Şili & 19 \\
\hline Slovenya & 20 \\
\hline Belçika & 21 \\
\hline Fransa & 22 \\
\hline İspanya & 23 \\
\hline Portekiz & 24 \\
\hline Slovakya & 25 \\
\hline Polonya & 26 \\
\hline Macaristan & 27 \\
\hline Yunanistan & 28 \\
\hline TÜRKIYE & 29 \\
\hline & 30 \\
\hline & \\
\hline & \\
\hline
\end{tabular}

Tablo 1. Düzgün Işs Göstergelerinden İstihdam Koşullarının Ülke Stralaması Kaynak: OECD and World Labour Report'dan Yararlanılarak Hazırlanmıştır.

Düzgün iş esas itibariyle, çalışma koşullarından istihdam edilebilirliğe, iş-yaşam dengesinden sosyal güvenliğe, temel çalışan haklarından iş sağlığı ve güvenliği önlemlerine kadar pek çok konuyu kapsamına alan çok boyutlu bir kavramdır. İstihdam koşulları incelendiğinde Türkiye 29. Sırada bulunmaktadır. İstihdam koşullarını en yüksek dereceden karşılayan ülke ise Norveç ve İsviçre'dir. 


\begin{tabular}{|l|l|}
\hline Fransa & 1 \\
\hline Danimarka & 2 \\
\hline Belçika & 3 \\
\hline Finlandiya & 4 \\
\hline İsveç & 5 \\
\hline İtalya & 6 \\
\hline Avusturya & 7 \\
\hline İspanya & 8 \\
\hline Almanya & 9 \\
\hline Portekiz & 10 \\
\hline TÜRKIYE & 11 \\
\hline Yunanistan & 12 \\
\hline Hollanda & 13 \\
\hline İngiltere & 14 \\
\hline Slovenya & 15 \\
\hline Lüksemburg & 16 \\
\hline & 17 \\
\hline İrlanda & 18 \\
\hline Norveç & 19 \\
\hline Yeni Zelanda & 20 \\
\hline & 21 \\
\hline Çek Cum & 22 \\
\hline Polonya & 23 \\
\hline ABD & 24 \\
\hline Avustralya & 25 \\
\hline İsviçre & 32 \\
\hline Slovakya & 27 \\
\hline Kanada & 28 \\
\hline İzlanda & 29 \\
\hline Estonya & 30 \\
\hline İsrail & 31 \\
\hline Şili & \\
\hline Kore & 32 \\
\hline & 13 \\
\hline & 12 \\
\hline
\end{tabular}

Tablo 2. Düzgün Işs Göstergelerinden Sosyal Güvenlik Koşulları Dahilinde Sosyal Koruma Stralaması Kaynak: OECD and World Labour Report'dan Yararlanılarak Hazırlanmıştır.

Düzgün is göstergelerinden sosyal güvenlik dahilinde sosyal korunma başarısı konusunda Fransa 1. sırada iken Türkiye diğer göstergelere oranla yüksek bir etkiye sahip olarak 11. sıradadır. Sosyal güvenlik politikalarının yasalarla etkin bir korumaya sahip olduğu fakat bu yasaların işlerliğinin arttırılmasına yönelik çalışmaların yapılması önem arz etmektedir.

ILO tarafından 1952 yılında yayınlanan sosyal güvenlikle ilgili sözleşmede edilen 102 sayılı "Sosyal Güvenliğin Asgari Normları Sözleşmesi”"nde koruma garantisi içine alınması gereken tehlikeler iş kazaları ve meslek hastalığı, hastalık, analık, malûllük, yaşlılık, ölüm, işsizlik ve aile gelirinin yetersizliği ve son olarak eklenen yaşlılık halinde bakım ihtiyacı olarak belirlenmiştir. Bu sözleşmenin ülkeler tarafından kabul edilmesi bir ülkede sosyal güvenlik sisteminin oluşturulmuş sayılabilmesi için, en az biri iş kazası ve meslek hastalıkları, yaşlılık, malûllük ve ölüm sigortalarından biri olmak üzere dokuz sosyal güvenlik tehlikesinden en az üç tanesinin oluşturulması gerekmektedir. Sosyal güvenlik çeşitli tehlikeler atlatarak, muhtaç duruma düşen işçilerin ve işçi ailelerinin uğradıkları bu tehlikelerin yaşattığı maddi manevi negatif etkilerden arındırılarak, insan onuruna yaraşır, asgari bir hayat standardına kavuşturulması olarak tanımlanmaktadır (Alper,2000). 


\begin{tabular}{|l|l|}
\hline İzlanda & 1 \\
\hline İsveç & 2 \\
\hline Danimarka & 3 \\
\hline Finlandiya & 4 \\
\hline Norveç & 5 \\
\hline Belçika & 6 \\
\hline Lüksemburg & 7 \\
\hline İtalya & 8 \\
\hline Irlanda & 9 \\
\hline Avusturya & 10 \\
\hline & 11 \\
\hline Kanada & 12 \\
\hline İngiltere & 13 \\
\hline Yunanistan & 14 \\
\hline Yeni Zelanda & 15 \\
\hline Portekiz & 16 \\
\hline Almanya & 17 \\
\hline Hollanda & 18 \\
\hline Avustralya & 19 \\
\hline Japonya & 20 \\
\hline İsviçre & 21 \\
\hline Çek Cum & 22 \\
\hline Şili & 23 \\
\hline Macaristan & 24 \\
\hline Meksika & 25 \\
\hline Polonya & 26 \\
\hline Slovenya & 27 \\
\hline Kanada & 28 \\
\hline İzlanda & 29 \\
\hline Kore & 30 \\
\hline Fransa & 31 \\
\hline Estonya & 32 \\
\hline TÜRKİYE & 33 \\
\hline & \\
\hline & \\
\hline
\end{tabular}

Tablo 3. Düzgün İş Göstergelerinden İşçi İşveren İletişim ve Ortak Katılım Dâhilinde Sosyal Diyalog Ülke Sıralaması Kaynak: OECD and World Labour Report'dan Yararlanılarak Hazırlanmıştır.

ILO işçi ve işveren uyuşmazlıklarının da sosyal diyalog çözümünü kullanarak ülkelerdeki işçi ve işveren sosyal temsilcileri ile toplumdaki diğer organize çıkar grupları arasında karşılıklı etkileşim ve fayda dahilinde sosyal politikaların belirlenmesini sağlamaktadır (Işı̆̆ıçok, 1999).

Düzgün iş sisteminde sosyal diyalog olarak belirtilen işçi ve işveren iletişim ve ortak katılım konusunda İzlanda uyguladığı barışçı ve uzlaşmacı politikalarla birinci sırada iken, Türkiye sosyal diyalog konusunda 33. sırada yer almaktadır. Tarafların karşılıklı haklarını koruma ile uyumlanmış sistemlerin uygulanması ve tarafların birbirini dinleme ve ortak çıkarlarda entegrasyon kültürünün artmasına yönelik politika ve uygulamalarla Türkiye'de üst sıralara doğru yükselme eğilimi gösterecektir. 


\begin{tabular}{|l|l|}
\hline Norveç & 1 \\
\hline İzlanda & 2 \\
\hline Avusturya & 3 \\
\hline Almanya & 4 \\
\hline Avustralya & 5 \\
\hline Kanada & 6 \\
\hline Japonya & 7 \\
\hline Finlandiya & 8 \\
\hline Danimarka & 9 \\
\hline Yeni Zelanda & 10 \\
\hline İsrail & 11 \\
\hline Kore & 12 \\
\hline İngiltere & 13 \\
\hline Hollanda & 14 \\
\hline Lüksemburg & 15 \\
\hline ABD-Estonya & 16 \\
\hline Meksika & 17 \\
\hline Slovakya & 18 \\
\hline Slovenya & 19 \\
\hline-------- & 20 \\
\hline Polonya & 21 \\
\hline TÜRKIYY & 22 \\
\hline Şili & 23 \\
\hline İtalya & 24 \\
\hline İspanya & 25 \\
\hline Yunanistan & 26 \\
\hline & \\
\hline
\end{tabular}

Tablo 4 Düzgün Işş Göstergelerinden Kadın İşgücünün Işsizizlik Oranı Ülke Sıralaması Kaynak: OECD and World Labour Report'dan Yararlanılarak Hazırlanmıştır.

Kadın işgücü işsizlik oranı dikkate alındığında Norveç ilk sırada iken Türkiye sırlamada 22. sırada yer almaktadır.

Kadının işgücün katılım oranının azlığı ekonomiler açısından arzu edilmeyen ve atıl bir kaynak olarak görülen bir durumdur.

Kalkınma Bakanlığı İşgücü piyasasının etkinleştirilmesi programı eylem planı çerçevesinde 2013'te \%30.8 olan kadının işgücüne katılım oranının 2018'de \%34,9 çıkarmayı öngörmektedir. Bakanlık kadınların işgücüne ve istihdama katılımının artması için: kaliteli, hesaplı ve kolay erişilebilir kreş imkanlarının yaygınlaştırılması, kadınların çocuklarını bırakabileceği oyun odalarının yaygınlaştırılması, doğum izinlerinden sonra ebeveynlere çocuklarının ilkokula başlama yaşına kadar kısmi sureli çalışma hakkı tanınması gibi konularda etkin politikalar geliştirmesini öngörmektedir (Kalkınma Bakanlığı,2015:1,4).

Kadınların işgücüne katılım oranı önemli ekonomik göstergeler arasındadır ve bu oran OECD ülkelerine nazaran Türkiye'de düşük seviyededir. Kadın istihdamına yönelik engelleri kaldırmaya yönelik politikalar son yıllarda büyük etkinlik kazanmıştır.

Kadınlar için iş gücü piyasasında eşitlik sağlayıcı politikaların hayata geçirilmesi ile kadınları iş gücü piyasasından alıkoyan en önemli sebeplerin tespit edilip bu noktalarda çözüm geliştirici istihdam politikalarının hayata geçirilmesi önem arz etmektedir.

\section{Sonuç}

Düzgün iş performansının yüksek olması bir ülkenin ekonomik kalkınmışlığının ve refah düzeyinin önemli bir göstergesidir bu nedenledir ki bu sıralamada üst sıralarda olmak ekonomik etkinliğin ve çalışanların mutluluğunun toplumun refah seviyesinin yüksek olmasının sonucunu da oluşturmaktadır.

Düzgün iş performansı açısından İskandinav ülkelerinin ilk sıralarda olduğunu görmekteyiz.

Türkiye Sosyal güvenlik ve sosyal koruma alanında görece olarak diğer göstergelere oranla daha yüksek bir performans sergilemiştir. 
İşsizlik sorununun Türkiye'de yüksek bir seyir izlemesi eğitim yetenek emek talebi üçgeninin dengesinin sağlanması ile oluşacaktır. Yetenek ve istek temelli tasnif edilecek eğitim çağındaki çocuk ve gençlerin kategorize edilerek eğitim sisteminin yapısal sorunlarını çözecek temelden eğitim sisteminin değişimini gerektiren yetenek temelli çoklu zeka sisteminin geliştirilmesi istihdam sorununun çözülmesi için altyapı oluşturacaktır.

\section{Kaynakça}

- Anker Richard, 2003 Measuring Decent Work with Statistical Indicators, International Labour Review, Vol 142, NO:2,

- $\quad$ Alper, Yusuf, 2000, Türkiye'de Sosyal Güvenlik ve Sosyal Sigortalar (SSK, BAĞ-KUR), Genişletilmiş 3. Baskı, Alfa Basım Yayım Dağıtım Ltd. Şti, Bursa.

- Ghai Dharam, 2002, Decent Work: Concepts, Models and Indicators, International Institute for Labour Studies, Dicussion Paper 139, Geneva

- Gahi, Dharam, (2006). "Decent Work: Universality and Diversity”, Decent Work: Objectives and Strategies içinde, ILO, Geneva.

- Işı̆̆ıçok, Özlem, 1999, "Sosyal Diyalog, Temel Nitelikleri ve Türkiye’de Sosyal Diyaloğa İlişkin Genel Bir Değerlendirme”, İş Güç: Endüstri İlişkiler ve İnsan Kaynakları Dergisi, 1(1), ss. 1-6.

- Kalkınma Bakanlığı, İşgücü Piyasasının Etkinleştirilmesi Programı Eylem Planı 2014-2018, Ocak 2015, www.kalkinma.gov.tr 


\title{
G-20 Ülkelerinde İşsizlik ve Askeri Harcamalar Arasındaki İlișkiler
}

\section{The Relationships between Military Expenditures and Unemployment in G-20 States}

\author{
Asst. Prof. Dr. Ahmet Fatih Aydemir (Atatürk University, Turkey) \\ Asst. Prof. Dr. Dilek Özdemir (Atatürk University, Turkey) \\ Dr. Burhan Kabadayı (Erzincan University, Turkey) \\ Prof. Dr. Ömer Selçuk Emsen (Atatürk University, Turkey)
}

\begin{abstract}
The effects of the military expenditure on the economic growth and consequently on the employment has been the primary topic of the discussing in the literature of economics. Considering that the military expenditures generally emerge as a sub-item of the public spending, it has been asserted by the liberal approach that the principle of the non-productiveness of the public sector would be even more applicable in the military expenditures. None the less, using the military spending as a tool to lead an economy that feature underemployment constitutes the positive aspect of the views to the military expenditure and this is also the case of the prediction of the Keynesian economy. In this study, the effects of the military expenditure on the unemployment, which is a reflection of the effects of the economic growth, are analyzed as the subject matter. The findings revealed that the military spending has positive effects on the unemployment in some G20 states while it also has negative effects in some and has neutral effects in others. In addition, it is further indicated that the positive effects are experienced in relatively advanced economies, the negative effects emerge in relatively less developed economies, and the countries with abundant natural resources experience neutral effects.
\end{abstract}

\section{Giriş}

İç ve dış güvenlik unsurunun sağlanamadığı toplumlarda üretim için uygun iklimin inşa edilememesine bağlı olarak büyümede düşüşlerin yaşanmasının kaçınılmazlığının da ötesinde ülkenin yok olması kuvvetle muhtemeldir. Dolayısıyla iç ve dış çatışma ortamının varlığı göz önünde bulundurulduğunda, birçok ülke gelirlerinin önemli bir miktarını savunma harcamalarına tahsis ederler. Zira bir ülkedeki politik istikrar yerli ve yabancı yatırımcıları cezbetme ve böylece ekonomik büyümeyi tetiklemede önemli bir unsur konumundadır. Bu noktada savunma harcamaları politik istikrarı beslemesinin yanı sıra toplam talepte artışlar, altyapıda gelişmeler, istihdam yaratma vb. unsurlarla da ekonomik büyüme üzerine pozitif etkiler yaratabilmektedir. Diğer taraftan yatırımları dışlama etkisi, üretken faaliyetlerde kesintiye yol açmalar ve artan kamu borcu vb. unsurlara yol açması nedeniyle savunma harcamaları ekonomik büyüme üzerine negatif etkiler de doğurabilir (Selvanathan ve Selvanathan, 2014: 69). Özellikle üretken olmayan, yani reel üretimi etkilemeyen bu türden harcama kalemlerindeki artışların belirli bir süre sonra ekonomik büyümeyi olumsuzlaştırdığı; örneğin Dünya Bankası ve IMF raporlarında askeri harcamaların iki katına çıkarılmasının gelir seviyesi üzerine \%20'lik azaltıcı etkiler doğurduğu ileri sürülmektedir (Olofin, 2012: 122). Savunma harcamalarının ekonomik büyümeyi negatif etkileyeceğine dair bakış açısı daha çok Klasik okul kökenli iken; askeri harcamaların ekonomik büyümeyi pozitif etkileyeceğine dair bakış açısı ise Keynesyen düşünce menşeilidir. Klasik okul ve kurucusu Adam Smith toplumları üretken emek ve üretken olmayan emek şeklinde tasnif ederken, üretken emek unsurunu reel üretime doğrudan katkı yapan emek olarak tanımlamakta; üretken olmayan emeği ise askeri ve polis gücü olarak nitelendirmektedir. Keynesyen düşüncede özellikle ekonominin yaygın olarak eksik istihdamda bulunduğu durumlarda, toplam talep üzerinde meydana getirilecek pozitif şokların büyüme ve istihdamda pozitif etkiler yaratacağı açıktır. İçsel büyüme teorilerinden özellikle Barro'nun perspektifinde kamu harcamalarının uzun dönemli büyüme oranı üzerine önemli bir etkisinin olduğu kabul edilir. Harcamanın etkisi ise hükümet müdahalesinin hacmine ve kamu harcamalarının farklı bileşenlerine bağlıdır. Diğer bir ifadeyle kamu harcamalarının farklı türleri ekonomik büyüme üzerine heterojen etkilere sahiptir. Örneğin kamu altyapı yatırımları, Ar-Ge ve kamu eğitimi, ekonomik büyüme üzerine pozitif etkileri olan kamu malları olarak addedilir. Diğer taraftan temelde üretken olmayan harcama kalemlerinden kamu harcamalarındaki artışların ekonomik büyümede bir azalama anlamına geldiği; adeta bu tür harcama kalemlerindeki artışlar büyümeyi o ölçüde negatif etkilediği ileri, sürülmektedir. Kamu aynı zamanda savunma harcamalarının finansmanında da önemli bir role sahiptir. İçsel büyüme teorileri "u eğrisi” şeklinde bağlantıların olduğuna dair kestirimde bulunarak, ekonomide askeri harcamaların payı ile uzun dönemli ekonomik büyüme arasındaki ilişkinin şekli hususunda bir zemin sunar (Korkmaz, 2015: 274).

Özetle teorik düzeyde askeri harcamalar ile ekonomik büyüme arasındaki ilişkilerde olumlu ya da olumsuz bakış açılarının koşula bağlı olarak işlediği dikkate çekmektedir. Teorik düzeyde belirgin olmayan bu sonuca benzer bir 
şekilde ampirik literatürde de askeri harcamalar ile ekonomik büyüme arasındaki ilişkiler oldukça tartışmalı bir konudur. Askeri harcamalar ve büyüme olgusu literatürde ilk olarak Benoit $(1973,1978)$ tarafindan yapılan çalışmayla adeta mihenk taşı olmuştur. Daha sonrasında ise özellikle Ram (1995) ile Sandler ve Hartley (1995) ile ilgi çekmeye başlamıştır. İktisat literatüründe harcama ve ekonomik büyüme ilişkilerini yoğun bir şekilde ele alan literatür zenginliğine karşılık, kısmen de olsa askeri harcama ve işsizlik boyutuna yoğunlaşan çalışmalar da bulunmaktadır. Çalışmaların bir kısmında işsizlik oranları bağımlı değişken olarak ele alınmakta ve askeri harcamalar ile ekonomik büyüme birlikte bağımsız değişken olarak modelleyen çalışmalarda Okun Kanununun test edilmesi yoluna gidilmiştir. Bir kısım çalışmalarda ise istihdamın belirleyicileri arasında askeri harcamalar modellenmektedir. Bu çalışmada askeri harcamalar ve işsizlik boyutunun ele alınması G20 ülkeleri nezdinde araştırılması planlanmıştır. Böylece ele alınan ülkeler özelinde askeri harcamaların işsizliği azaltması, yani Keynesyen iktisat mekanizması içerisinde bulunması ya da işsizlik üzerinde etkisinin olmaması ve hatta artırması da Klasik iktisat mekanizması çerçevesinde çalışan bir ekonominin varlığı ortaya konulmaya çalışılacaktır. Bu çerçevede çalışmanın ikinci kısmında askeri harcamalar ile işsizlik ilişkileri teorik düzeyde ele alınacak ve üçüncü kısımda da uygulamalı araştırmalardan bir özet sunulacaktır. Dördüncü kısımda ise hem teorik hem de uygulamalı literatürden hareketle model belirlemesi ve uygulamaya yer verilecektir. Beşinci ve son kısımda da çalışmadan elde edilen bulgular değerlendirilerek politika önermesi yapılacaktır.

\section{Askeri Harcamalar ve İşsizlik İlişskileri}

Askeri harcamalara atfedilen birbirine taban tabana zit iki etkiden bahsedilmektedir. Birincisi askeri harcamalar sonucu ortaya çıkan negatif etkilerdir ki, buna aynı zamanda dışlama (crowding-out) etkisi adı verilir. Dışlama etkisi kaynakların tam ve etkin kullanımı durumunda, savunma harcamalarındaki artışlar diğer ekonomik faaliyetleri olumsuz yönde etkileyebilmekte; fırsat maliyeti yaklaşımı altında kaynakların (başta yatırımlar olmak üzere tüketim ve tasarrufların) etkin alanlardan etkin olmayan alanlara kaymasına vurgu yapılmaktadır. İkincisi de askeri harcamaların üretimi destekleyen arz boyutunu dikkate alır. Buna göre arz yanlı yaklaşımda savunma amaçlı gerçekleştirilen Ar-Ge'ler verimlilik üzerine negatif etkisi olmaması koşuluyla büyümeyi teşvik edeceği ileri sürülmektedir ki, buna da harekete geçirme (spin-off) etkisi adı verilir (Morales-Ramos, 2002: 366-367).

Literatürde askeri harcamaların istihdamı etkileyebilmesinin koşulu ise birkaç kanalla ortaya çıkabilmektedir. Birincisi, "verimliliği artırma etkileri”dir. Askeri harcamalarda bulunma gereği savunma amacıyla kullanılan araç ve gereçlerin üretimi (veya diğer ülkelerden ithalatı), araç ve gereçlerin tamiri ve işlerlik maliyetleri, Ar-Ge faaliyetleri için harcamalar ile savunma alanında kullanılan askeri ve sivil personelden müteşekkil olabilir (Korkmaz, 2015: 273). Bu noktada askeri sektörlerde genişleme değişik yollardan emek verimliliğini etkileyebilmektedir; bunlara örnek olarak, askeri harcamalardan özel sektöre teknoloji yayılmaları, dış askeri tehditlerden kaynaklanan vatandaşların can ve mal güvenliğinin sağlanmasına bağlı olarak uygun üretim ikliminin oluşturulması, vatandaşlara pozitif dişsallıklar sağlayan askeri altyapı inşaatlar vb. şeklinde sıralanabilir. Dolayısıyla emek verimliliğinde sağlanacak iyileşmelere bağlı olarak emeğe olan talep artar ve bu durum da işsizlik üzerinde azaltıcı etkiler yaratır. İkincisi, olumlu etkilerinin aksine, askeri harcamaların vergi bozucu etkileri de bulunabilir. Askeri harcamalar vergiler ağırlaştırılarak finanse edilmeye gereksinim duyabilir. Şayet vergi yükü işveren üzerindeyse emek talebi azalabilir; buna karşılık vergi yükü işçilerin üzerindeyse, bu kez de emek arzı azalabilir. Ayrıca bu tür vergi yüklerinin, kamuda etkinsizlik veya yolsuzluğa bağlı olarak oldukça ağır yansımaları olabilir. Üçüncüsü, “yeniden dağıtım etkileri”dir. Örneğin askeri sektördeki daralmalar, askeri sektörden özel sektöre doğru işçilerin hareket etmesine yol açabilir. Bu türden yeniden paylaşım etkileri kolay olmayabilir; böylece askeri sektörlerdeki daralmalar fraksiyonel işsizliğe yol açabilir. Dolayısıyla pozitif ve negatif etkileri dikkate alındığında, işsizliğin askeri harcamalarda değişikliklere nasıl tepki vereceği hususu açık olarak belirlenemez (Tang vd., 2009: 253-254). Askeri harcamaların istihdam ya da tersi ifadesiyle işsizliğe etkileri ele alınırken; ekonomik büyüme ve işsizlik arasındaki değiş-tokuş ilişkisine, yani Okun Kanunu’na atıfta bulunmak mümkündür. Doğal olarak GSYİH büyüme oranı değişkenlerden biri olarak modele dahil edilir. Zira ekonomik büyüme emek gücüne duyulan gereksinimi artırır; yani ekonomideki gelişmeler emek arzındaki fazlalıkları emerek işsizlik oranlarında azalışlara yol açar. Askeri harcamaların artmasının atıl emeği massederek işsizliği azaltabileceğine dair bakış açısı teorik düzeyde ispatlanabilir konumdadır ve bu durum da askeri harcamalar ile istihdam arasında pozitif bir ilişkinin varlığı ile ifade edilir. Ancak, ampirik düzeyde teori ile örtüşen bulgulara rastlanılmasına karşılık, bazen de negatif bir ilişkinin varlığını ortaya koyan sonuçlarla da karşılaşılır. Literatürde ortaya çıkan çelişkili sonuçlar, ekonomik kalkınma ile işsizlik arasındaki etkileşimin varlığını belirsiz hale getirdiği söylenebilir (Qiong ve Junhua, 2015: 499). Diğer taraftan işsizliğin askeri harcamaların belirleyicisi olması halinde ters nedensellik söz konusu olacaktır. Şöyle ki, Abell (1990, 1992) ekonomik istikrar endişesi dışında savunma harcamaları işsizlik oranlarında değişikliklere duyarlı olabileceğini kabul eder. Ayrıca askeri harcamalar organize olmuş emeğin istihdamında ve monopolcü sermayenin kazançlarını sağlamlaştırmada karşı konjonktür mekanizması olarak da kullanılabilir. Bu argümanlar askeri harcamalar ile işsizlik arasında iki yönlü ilişkinin olabileceğini de ima eder. Askeri harcamalar ile işsizliğin özellikle birinciden ikinciye doğru olacak şekilde birçok kanaldan birbirlerinin etkilediği varsayımı altında, bu iki değişken arasındaki karşılıklı bağımlılığı analiz etmek için ileri derecede ekonometrik modeller tesis etmek oldukça güçtür (Tang vd., 2009: 254). 


\section{Askeri Harcamalar ile İşsizlik Üzerine Literatür Araştırması}

Askeri harcamalar ile ekonomik büyüme üzerine yapılan çalışmalarda tam bir konsensüsün sağlanamamasına benzeri durum askeri harcamalar ile işsizlik arasında da görüldüğünü ileri sürmek mümkündür. Diğer bir ifadeyle askeri harcamaların verimsizliğine atıf yapılarak ekonomide askeri harcamaların işsizliği azaltmadığı gibi, üretken yatırımlarda yarattığı dışlama etkileri ile ekonomik büyümeyi ve dolayısıyla işsizliği artıracağını ileri süren çalışmalar söz konusudur. Klasik orijinli bu çalışmalarda ekonominin tam istihdamda denge düzeyini bozacak her türlü verimsizliğin büyümeyi ve istihdam yapısını olumsuzlaştıracağı ileri sürülmektedir. Özellikle ekonomi tam istihdam dengesinde iken, üretken olmayan alanlara yapılacak kaynak transferinin belki istihdamda değişiklik yaratmayacağı; ancak üretken olmayan alanlara kaynak aktarımıyla birlikte ekonominin potansiyellerini sekteye uğratacağı ileri sürülmektedir. Keynesyen iktisatta ise ekonomisinin eksik istihdamda bulunduğu durumda askeri alanda harcama genişlemeci politika uygulamalarının pozitif talep şoklarına yol açarak hem istihdam hem de milli gelir düzeyinde olumlulaşmayı tetikleyeceği ileri sürülür. İçsel büyüme teorisyenleri de klasik iktisat bakış açısında kamuyu verimsiz addederken, kamunun özellikle eğitim ve sağlık alanında yapacağı atılımların büyümeyi besleyeceğini kabul ederler. Ancak, kamunun iç ve dış güvenlik ile adalet ve diplomasi fonksiyonlarının işlemediği bir yapıda reel ekonomi için uygun iklimin sağlanamamasının olumsuz yansımaları zımnen de olsa büyüme üzerine negatif yansımalar doğuracağı kabul edilir. Dolayısıyla askeri harcamalar bulunulan jeo-politik konum gereği hem gelir hem de istihdam etkileri yaratabilir. Aşağıdaki tabloda askeri harcamalar ile işsizlik/istihdam üzerine yapılmış çalışmalar ve özetleri bulunmaktadır.

\begin{tabular}{|c|c|c|c|c|}
\hline Yazar(lar) & Veri Dönemi & Veri & Yöntem & Bulgu \\
\hline $\begin{array}{l}\text { Hooker ve } \\
\text { Ross (1994) }\end{array}$ & $\begin{array}{l}\text { 1963-1992; } \\
\text { ABD eyaletler }\end{array}$ & $\begin{array}{l}\text { İşsizlik oranları; GSYİH } \\
\text { içerisinde savunma } \\
\text { harcamalarının payı, } \\
\text { Resesyon yılları gölge } \\
\text { değişkeni }\end{array}$ & $\begin{array}{l}\text { EKK } \\
\text { tahminleri }\end{array}$ & $\begin{array}{l}\text { Eyaletten eyalete değişse de askeri } \\
\text { harcamaların işsizlik üzerine } \\
\text { negatif etkileri }\end{array}$ \\
\hline Paul (1996) & $\begin{array}{l}\text { 1962-1988; } 18 \\
\text { OECD ülkesi }\end{array}$ & $\begin{array}{l}\text { İşsizlik oranı, Savunma } \\
\text { harcamalarının reel büyüme } \\
\text { oranı, Savunma dışındaki } \\
\text { harcamaların reel büyüme } \\
\text { oranı }\end{array}$ & $\begin{array}{l}\text { VAR } \\
\text { modeline } \\
\text { bağl1 } \\
\text { Granger } \\
\text { Nedensellik } \\
\text { testleri }\end{array}$ & $\begin{array}{l}\text { OECD ülkelerinde savunma } \\
\text { harcamaları ile işsizlik arasında } \\
\text { ortak bir bulgudan ziyade ülkelere } \\
\text { özgü bulgular elde edilmiş; sadece } \\
\text { Norveç’te çift, Danimarka'da } \\
\text { savunma harcamaları ile işsizlik } \\
\text { arasında tek yönlü ilişki }\end{array}$ \\
\hline $\begin{array}{l}\text { Dunne ve } \\
\text { Watson } \\
(2000)\end{array}$ & $\begin{array}{l}\text { 1963-1990; } \\
\text { Güney Afrika }\end{array}$ & $\begin{array}{l}\text { İstihdam, Üretim, Reel } \\
\text { ücretlerin logaritması, Askeri } \\
\text { yükün GSYİH'ya oranı }\end{array}$ & $\begin{array}{l}\text { ARDL } \\
\text { yaklaşımı; } \\
\text { Otoregresiv } \\
\text { dağıtılmış } \\
\text { gecikme } \\
\text { modeli }\end{array}$ & $\begin{array}{l}\text { Askeri harcamalardaki artışlar } \\
\text { dışlama etkisi yapmakta; bu da } \\
\text { üretim ve istihdam üzerine olumsuz } \\
\text { yansımalarda bulunmakta }\end{array}$ \\
\hline $\begin{array}{l}\text { Yildırım ve } \\
\text { Sezgin (2003) }\end{array}$ & $\begin{array}{l}\text { 1950-1997; } \\
\text { Türkiye }\end{array}$ & $\begin{array}{l}\text { Toplam istihdamın } \\
\text { logaritmas1, Reel ücretler, } \\
\text { Reel askeri harcamalar }\end{array}$ & $\begin{array}{l}\text { ARDL } \\
\text { yaklaşımı }\end{array}$ & $\begin{array}{l}\text { Hem kısa hem de uzun dönemde } \\
\text { askeri harcamaların istihdam } \\
\text { üzerine negatif etkileri }\end{array}$ \\
\hline $\begin{array}{l}\text { Huang ve Kao } \\
(2005)\end{array}$ & $\begin{array}{l}\text { 1966-2002; } \\
\text { Tayvan }\end{array}$ & $\begin{array}{l}\text { Özel sektörde istihdam, Yıllık } \\
\text { savunma harcamaları, Reel } \\
\text { GSYİH, Ortalama aylık reel } \\
\text { maaşların logaritmik farkları }\end{array}$ & $\begin{array}{l}\text { ARDL } \\
\text { yaklaşımı }\end{array}$ & $\begin{array}{l}\text { Savunma harcamaları uzun } \\
\text { dönemde istihdama pozitif, kısa } \\
\text { dönemde ise negatif etkili; GSYİH } \\
\text { üzerine ise pozitif etkili }\end{array}$ \\
\hline $\begin{array}{l}\text { Tang ve diğ. } \\
\text { (2009) }\end{array}$ & $\begin{array}{l}\text { 1988-2004; } 46 \\
\text { gelişmiş ve } \\
\text { gelişmekte olan } \\
\text { ülke }\end{array}$ & $\begin{array}{l}\text { Askeri harcamaların } \\
\text { GSYIH'ya oranı, işsizlik } \\
\text { oranları, fert başına GSYİH }\end{array}$ & $\begin{array}{l}\text { Granger } \\
\text { panel } \\
\text { nedensellik }\end{array}$ & $\begin{array}{l}\text { Askeri harcamaların işsizliği } \\
\text { artırıcı etki (OECD dışındakiler ile } \\
\text { orta ve düşük gelirli ülkelerde) }\end{array}$ \\
\hline $\begin{array}{l}\text { Malizard } \\
(2014)\end{array}$ & $\begin{array}{l}\text { 1975-2008; } \\
\text { Fransa }\end{array}$ & $\begin{array}{l}\text { İşsizlik oranları, GSYİH'nın } \\
\text { reel büyüme oranı, savunma } \\
\text { harcamaları ile savunma } \\
\text { dışında yapılan harcamaların } \\
\text { GSYİH'ya oranı }\end{array}$ & $\begin{array}{l}\text { ARDL } \\
\text { yaklaşımı }\end{array}$ & $\begin{array}{l}\text { Uzun ve kısa dönemde askeri olan } \\
\text { ve olmayan harcamaların işsizlik } \\
\text { üzerine pozitif, ancak askeri } \\
\text { olmayan harcamaların pozitif } \\
\text { etkileri daha zayıf; büyüme ise } \\
\text { negatif etkili }\end{array}$ \\
\hline $\begin{array}{l}\text { Qiong ve } \\
\text { Junhua (2015) }\end{array}$ & 1991-2013; Çin & $\begin{array}{l}\text { İşsizlik oranları, GSYİH } \\
\text { büyümesi, Askeri } \\
\text { harcamaların GSYİH'ya oranı } \\
\text { ve askeri olmayan } \\
\text { harcamaların GSYİH'ya oranı }\end{array}$ & $\begin{array}{l}\text { ARDL } \\
\text { yaklaşımı }\end{array}$ & $\begin{array}{l}\text { Uzun ve kısa dönemde işsizlik } \\
\text { üzerine ekonomik büyüme ve } \\
\text { askeri olmayan harcamalar negatif; } \\
\text { askeri harcamalar ise pozitif etkili }\end{array}$ \\
\hline $\begin{array}{l}\text { Korkmaz } \\
(2015)\end{array}$ & $\begin{array}{l}\text { 2005-2012; } 10 \\
\text { Akdeniz ülkesi }\end{array}$ & $\begin{array}{l}\text { Askeri harcamaların GSYİH } \\
\text { içerisindeki payı, Yıllık reel } \\
\text { büyüme oran1, İşsizlik } \\
\text { oranları }\end{array}$ & $\begin{array}{l}\text { Panel veri } \\
\text { dinamik } \\
\text { sabit etkiler } \\
\text { modeli }\end{array}$ & $\begin{array}{l}\text { Askeri harcamalar GSYİH'dan } \\
\text { negatif ve işsizlikten pozitif } \\
\text { etkilenmekte }\end{array}$ \\
\hline
\end{tabular}

Tablo 1: Savunma Harcamaları ile İssizlik/İstihdam İlişkileri 


\subsection{Pozitif İlișki Yakalayan Çalışmalar}

Buna göre Smith (1977), 8 ülke üzerine yaptığı analizlerde askeri harcama ile işsizlik arasında pozitif bir ilişki yakalamıştır. Abell (1990), savunma harcamalarının ABD'de işsizliğin nedensel ilişkisinin olduğunu göstermiştir. Hooker ve Knetter (1997), ABD'deki 50 eyalet üzerine yaptığı panel veri analizlerinde askeri tedarik amaçlı harcamaların istihdam etkileri olduğunu ve dolayısıyla istihdam artışında askeri harcamaların önemli etkilerinin olduğunu tespit etmiştir. Barker vd. (1991), İngiltere için askeri harcamalardaki kesintilerin ekonomik yansımalarını incelemiş ve bu türden kesintilerin işsizlikte önemli bir azalışa ve çıktıda/üretimde artışa yol açtığını tespit etmişlerdir.

\subsection{Herhangi Bir İlișki Yakalayamayan Çalıșmalar}

Chaster (1978), 9 ülkeye ilişkin işsizlik verilerinin kullanarak yaptı̆̆ı analizlerde askeri harcamalar ile işsizlik oranları arasında belirgin bir ilişki yakalayamamıştır.

Dunne ve Smith (1990), askeri harcamaların işsizliğin nedeni olmadığını veya tersi askeri harcamaların 11 OECD ülkesinin 9'u dışında işsizlik üzerine önemli bir etkisinin bulunmadığını ortaya koymuşlardır.

Dunne ve Watson (2005), 9 OECD ülkesinde imalat sanayi verilerini kullanarak CES üretim fonksiyonu tahmin etmişler ve 1966-2002 dönemi için istihdam üzerine askeri sektörün önemli bir etkisinin olmadığını ortaya koymuşlar, ancak Soğuk Savaş dönemi için anlamlı ilişkiler yakalamışlardır.

Paul (1996), askeri harcamalar ve askeri olmayan harcamalar ile işsizlik arasında 1962-1988 dönemi için 18 OECD ülkesinde homojenitenin olmadığını ortaya koymuştur.

Payne ve Ross (1992), ABD'de savunma harcamaları ile işsizlik oranları arasında herhangi bir nedensel ilişkinin olmadığını ortaya koymuşlardır.

\subsection{Negatif İliş̧ki Yakalayan Çalışmalar}

Yildirim ve Sezgin (2003), Türkiye'de hem kısa hem de uzun dönemde askeri harcamaların istihdamı negatif yönde etkilediğini tespit etmişlerdir.

Huang ve Kao (2005), Tayvan üzerine yaptıkları çalışmada savunma harcamalarının kısa dönemde ekonomik büyümeyi negatif etkilediğini, ancak uzun dönemde pozitif etkilerinin olduğunu tespit etmişlerdir.

Wing (1991), savunma harcamalarının 1979 ve 1980 arasında Endonezya'da istihdamda gözle görülebilir artışa yol açtığını belirlemiştir.

\section{Veri, Yöntem ve Uygulama}

Yaygın literatür askeri harcamalar ile ekonomik büyüme ilişkilerine yoğunlaşırken, kısmen de olsa bunun dolaylı etkilerini ele alan çalışmalar da bulunmaktadır. Dolaylı etkiler arasında askeri harcamaların işsizlik üzerine etkileri yer almaktadır. Literatürde askeri harcamaların verimsizliğine atfen, işsizlik üzerine etkilerinin olmadığı yönünde araştırmalar yoğunlukta iken, işsizliğin çağın en önemli sorunları arasında sayılan işsizliğin askeri harcamalar ile ötelenebileceği de düşünülmektedir. Dolayısıyla yaygın işsizlik sorununa karşı bir tür işsizlik ile mücadele aracı olarak askeri harcamalarda bulunma yoluna gidildiği bir politika aracı olarak ileri sürülebilir.

Çalışmada panel veri analizi kullanılarak G20 ülkelerinde 1990-2014 döneminde askeri harcamalar ile işsizlik arasındaki ilişki incelenmiştir. Oluşturulması planlanan modelin matematiksel formu aşağıdaki şeklide ifade edilebilir.

$$
\mathrm{U}=\mathrm{f}(\mathrm{M})
$$

Burada eşitliğin sağında yer alan-bağımlı değişken işsizlik oranları (U) iken, bağımsız değişken askeri harcamaların GSYIH içerisindeki payı (M)'dır. Matematiksel bu eşitlik de ekonometrik formda aşağıdaki biçimde tanımlanabilir:

$$
\mathrm{U}=\beta 0+\beta 1 \mathrm{Mit}+\varepsilon i \mathrm{t}
$$

(2) nolu eşitlikte i ülkeyi-yatay kesit boyutunu ve t de zaman boyutunu göstermektedir. $\beta 0$ sabit terimi $\beta 1$ eğim katsayısını ve eit de hata terimini ifade eder. Çalışmada analizde kullanılan askeri harcamaların GSYİH içindeki payları ve işsizlik oran verileri Dünya Bankası ve Quandl veri tabanından alınmıştır. Analiz için Gauss-9 programı kullanılmıştır.

\subsection{Durağanlık Araştırması}

Çalışmada, ekonometrik analizlerde öncelikle serilerin durağanlığının araştırılması gerekir. Durağanlık sınmaları öncesinde de paneli oluşturan ülkeler arasında yatay kesit bağımlılı̆̆ın (YKB) olup olmadığı incelenmelidir. YKB varlığı ilk kez Breusch-Pagan (1980) tarafindan geliştirilen (Lagrange Multiplier-CDLM1 testi) ve CDLM2 testiyle incelenmiştir. Seriler için birim kök testi olarak yatay kesit bağımlılığı dikkate alan ikinci kuşak birim kök testlerinden, Pesaran (2006) tarafindan geliştirilen CADF (Cross-Sectionally Augmented Dickey Fuller) testi kullanılmıştır. Seriler arasında eş-bütünleşme ilişkisinin varlığı; Westerlund (2008) Durbin H testi ile eş-bütünleşme katsayısının homojenliği, başka bir değişle açıklayıcı değişkenlerin katsayılarının yatay kesitten (ülkeden) yatay kesite (ülkeye) değişip değişmediği; Pesaran ve Yamagata(2008) tarafindan geliştirilen Slope Homogeneity Testi ile incelenmiş̧ir. Uzun dönem bireysel eş-bütünleşme katsayıları Pesaran (2006) tarafindan 
geliştirilen ve yatay kesit bağımlılığını göz önünde bulunduran CCE (Common Correlated Effects: Ortak İlişkili Etkiler) yöntemiyle, panelin geneline ait uzun dönem eş-bütünleşme katsayısı yine Pesaran (2006) tarafindan geliştirilen ve yatay kesit bağımlılığını göz önünde bulunduran CCMGE (Common Correlated Mean Group Effects: Yatay Kesit Bağımlılığı Altında Ortalama Grup Etkileri) yöntemiyle tahmin edilmiştir.

Seriler arasında YKB varken, bu durum dikkate alınmadan analiz yapılması elde edilecek sonuçları önemli ölçüde etkilemektedir (Breusch ve Pagan, 1980; Pesaran, 2004). Bu nedenle analize başlamadan önce serilerde ve eş-bütünleşme denkleminde YKB'nin varlığının test edilmesi gerekmektedir. YKB'nin yapılacak birim kök ve eşbütünleşme testleri seçilirken göz önünde bulundurulması yapılan analizin sonuçlarını sapmalı ve tutarsız hale getirecektir. Yatay kesit bağımlılı̆ğ test etmek için kullanılan yöntemler, Breusch-Pagan (1980) CDLM1, Pesaran (2004) CDLM2, Pesaran vd. (2004) CDLM ve Pesaran vd. (2008) CDLMadj testleridir. CDLM1 ve CDLM2 testleri $\mathrm{T}>\mathrm{N}$ koşulunda, CDLM testi $\mathrm{N}>\mathrm{T}$ koşulunda ve CDLMadj testi ise her iki koşulda da yatay kesit bağımlılığı olup olmadığını test eden tahmincilerdir.

Bu çalışmada yatay boyut 19 ülke ve zaman boyutu da 25 yıl olduğu için Breusch-Pagan (1980) LM1 testi ve Pesaran (2004) CDLM2 testi kullanılmıştır. Yatay kesit bağımlılığı araştıran sonuçlar Tablo 2'de verilmiştir.

\begin{tabular}{|l|l|l|l|l|l|l|}
\hline \multirow{2}{*}{ CD Testleri } & \multicolumn{2}{l}{} & \multicolumn{2}{l|}{$\mathrm{M}$} & \multicolumn{2}{l|}{$\begin{array}{l}\text { Modelde yatay kesit } \\
\text { bağımlılık }\end{array}$} \\
\cline { 2 - 7 } & Sabitli & $\begin{array}{l}\text { Sabitli } \\
\text { trendli }\end{array}$ & Sabitli & $\begin{array}{l}\text { Sabitli } \\
\text { trendli }\end{array}$ & $\begin{array}{l}\text { İstatistik } \\
\text { Değeri }\end{array}$ & Olas1lik \\
\hline \multirow{2}{*}{ LM1(Breusch, Pagan 1980) } & $\begin{array}{l}257.088 \\
0.000\end{array}$ & $\begin{array}{l}294.085 \\
0.000\end{array}$ & $\begin{array}{l}305.556 \\
0.000\end{array}$ & $\begin{array}{l}326.853 \\
0.000\end{array}$ & 605.579 & 0.000 \\
\hline \multirow{2}{*}{ LM2 (Pesaran 2004) } & 4.655 & 6.656 & 7.276 & 8.428 & 23.499 & 0.000 \\
& 0.000 & 0.000 & 0.000 & 0.000 & \\
\hline
\end{tabular}

Tablo 2: Yatay Kesit Bă̆ımlılık Test Sonuçları

CDLM1 ve CDLM2 testlerinin sonuçlarına göre, yatay kesit bağımlılık yoktur şeklinde olan H0 hipotezi istatistiki olarak anlamlı şekilde reddedilmekte ve hem serilerde hem de modelde yatay kesit bağımlılığı olduğuna karar verilmektedir. YKB'nin varlığı söz konusu olduğundan, bu durumu dikkate alan birim kök testleri, ikinci kuşak panel birim kök testleri olarak adlandırılmaktadır. M ve U değişkenleri için paneli oluşturan ülkeler arasında YKB tespit edildiği için serilerin durağanlığı ikinci kuşak birim kök testlerinden CADF testi (Pesaran 2007) ile incelenmiştir. CADF ile paneli oluşturan serilerdeki her bir yatay kesit biriminde (her bir ülke için) birim kök testi yapılabilmektedir. Böylece serilerin durağanlığı, hem panelin geneli için hem de her bir yatay kesit için ayrı ayrı hesaplanabilmektedir. Her ülkenin zaman etkilerinden farklı etkilendiğini varsayan ve mekânsal otokorelasyonu dikkate alan $\mathrm{CADF}$ testi, $\mathrm{T}>\mathrm{N}$ ve $\mathrm{N}>\mathrm{T}$ durumunda kullanılmaktadır. $\mathrm{Bu}$ test istatistiği değerlerini, Pesaran (2007)'nin CADF kritik tablo değerleriyle karşılaştırarak, her ülke için durağanlık test edilmektedir. Her bir yatay kesite (ülkelere) ait birim kök test istatistiklerinin ortalaması alınarak panelin geneli için birim kök test istatistiği olan CIPS (Cross-Sectionally IPS) elde edilebilir (Pesaran, 2007). Paneli oluşturan her ülke için birim kök istatistiği (CADF) ve panelin geneli için test istatistiği (CIPS) ve Pesaran (2007) tarafından hesaplanan kritik değerler Tablo 3'de verilmiştir.

\begin{tabular}{|c|c|c|c|c|c|c|}
\hline \multirow{3}{*}{$\frac{\text { Değişkenler }}{\mathrm{M}}$} & \multicolumn{3}{|l|}{ Sabit } & \multicolumn{3}{|l|}{ Sabit ve Trend } \\
\hline & \multirow{2}{*}{ CİPS İstatistiği } & \multicolumn{2}{|c|}{ Kritik Değer } & CİPS İstatistiği & \multicolumn{2}{|c|}{ Kritik Değer } \\
\hline & & $\% 1$ & $-2,38$ & $-3,191$ & $\% 1$ & $-2,88$ \\
\hline $\mathrm{U}$ & -2.285 & $\% 5$ & $-2,20$ & $-2,423$ & $\% 5$ & $-2,72$ \\
\hline$\Delta \mathrm{U}$ & -2.790 & $\% 10$ & $-2,11$ & $-3,229$ & $\% 10$ & $-2,63$ \\
\hline
\end{tabular}

Tablo 3: CADF Birim Kök Test Sonuçları

Tablodaki sonuçlar incelendiğinde, panelin geneli için M değişkeninin düzeyde durağan olduğu gözükürken. U değişkeninin birinci farkı alındığında durağan hale geldiği görülmüştür.

\subsection{Eş-bütünleşme Analiz Sonuçları}

Çalışmanın bu aşamasında, M ile U serileri arasındaki ilişki eş-bütünleşme ile analiz edilmiştir. Serilerde ve eşbütünleşme denkleminde yatay kesit bağımlılığı tespit edildiği için, panelde eş-bütünleşmenin varlığı, Westerlund (2008) Durbin-H yöntemi ile test edilmiştir. Bu yöntem; bağımlı değişken I(1) olmak şartıyla, bağımsız değişkenlerin I(1) veya I(0) olmasına da izin vermektedir (Westerlund, 2008). Testin H0 Hipotezi eş-bütünleşme ilişkisi yoktur şeklindedir. Westerlund (2008) Durbin-H yönteminde, eş-bütünleşme ilişkisinin varlığı, gurup ve panel boyutunda ayrı ayrı test edilmektedir. Westerlund (2008) Durbin-H panel eş-bütünleşme testinde, otoregresif parametrenin bütün kesitler için aynı olduğu kabul edilmektedir. Bu varsayım altında, H0 hipotezi reddedildiğinde, bütün kesitler için eş-bütünleşme ilişkisinin var olduğu kabul edilmektedir. Westerlund (2008) Durbin-H gurup testinde ise otoregresif parametrenin kesitler arasında farklılaşmasına izin verilmektedir. Bu testte, $\mathrm{H} 0$ hipotezinin reddedilmesi, en azından bazı kesitler için eş-bütünleşme ilişkisinin varlığını ifade etmektedir (Bayar vd., 2011: 15). Westerlund (2008) Durbin-H testi yapılmış ve Tablo 4 'teki sonuçlar elde edilmiştir. 


\begin{tabular}{|l|c|c|}
\hline Durbin- H Testleri & Durbin-H Hes. Değ. & Olasıllk Değeri \\
\hline Durbin-H Gurup İstatistiği & -0.664 & 0.747 \\
\hline Durbin-H Panel İstatistiği & 2.073 & 0.019 \\
\hline
\end{tabular}

Tablo 4: Westerlund (2008) Durbin-H Testi Sonuçları

Test sonucuna göre panelde eş-bütünleşme ilişkisi varken, gurup istatistiğinde eş-bütünleşme ilişkisinin bir kısım ülkeler özelinde olmadığı görülmektedir.

\subsection{Eş-bütünleşme Katsayısının Homojenliğinin Test Edilmesi (Slope Homogeneity Tests)}

Diğer taraftan eş-bütünleşme denkleminde eğim katsayısının homojen olup olmadığını, yani yatay kesitler arasında fark olup olmadığını belirlemeye yarayan bir testtir. Pesaran ve Yamagata (2008) homojenliği test edebilmek için büyük örneklemler için $\widetilde{\Delta}$, küçük örneklemler için $\tilde{\Delta}_{a d j}$ test istatistikleri geliştirilmişlerdir. H0 hipotezi eğim katsayıları homojendir şeklindedir. Homojenlik test istatistikleri de Tablo 5 'te verilmiştir.

\begin{tabular}{|c|c|c|}
\hline & Test İstatistiği & Olasılık Değeri \\
\hline$\widetilde{\Delta} T e s t i$ & 17.106 & 0.000 \\
\hline$\widetilde{\Delta}_{a d j}$ Testi & 18.187 & 0.000 \\
\hline
\end{tabular}

Tablo 5: Homojenlik Testi Sonuçları

Tablo 5'te yer alan sonuçlara göre tahmin edilen olasılık değeri \%1 düzeyinde anlamlıdır ve H0 hipotezi reddedilir. Dolayısıyla eş-bütünleşme denkleminde eğim katsayılarının heterojen olduğuna karar verilmiştir.

\subsection{Eş-bütünleşme Katsayılarının Tahmini}

Denklemin uzun dönem katsayılarını tahmin etmek için de Pesaran (2006) tarafından geliştirilen ve yatay kesit bağımlılı̆̆ı göz önünde bulunduran Ortak İlişkili Etkiler Modeli (Common Corelated Effects Model-CCE) kullanılmıştır. CCE modeli de $\mathrm{N}>\mathrm{T}$ ve $\mathrm{N}<\mathrm{T}$ durumlarında kullanılabilen bir tahmincidir. Ayrıca yatay kesit birimleri için ayrı ayrı uzun dönem denge katsayılarını hesaplayabilen bir tahminci olduğundan her bir ülke için ekonomik ilişkilerin yönü hakkında yorum yapılabilmektedir (Pesaran 2006). CCE tahmin sonuçları Tablo 6'da yer almaktadır. (*) katsayının \%5 anlamlılık düzeyinde istatistiki olarak anlamlı olduğunu ifade etmektedir.

\begin{tabular}{|l|c|c|}
\hline Ülke & $\begin{array}{c}\text { Uzun Dönem Eş-bütünleşme } \\
\text { Katsaylları }\end{array}$ & t İstatistiği \\
\hline Arjantin(*) & 13.272 & 3.785 \\
\hline Avustralya(*) & 10.453 & 2.906 \\
\hline Brezilya(*) & 0.572 & 2.685 \\
\hline Kanada(*) & 6.364 & 4.803 \\
\hline Çin & 0.964 & 1.340 \\
\hline Fransa $\left(^{*}\right)$ & 3.588 & 3.270 \\
\hline Almanya & 2.589 & 0.776 \\
\hline Hindistan(*) & 2.300 & 2.500 \\
\hline Endonezya(*) & -5.320 & -4.286 \\
\hline İtalya $\left(^{*}\right)$ & -7.444 & -3.007 \\
\hline Japonya(*) & 16.066 & 5.440 \\
\hline Güney Kore & -1.355 & -1.261 \\
\hline Meksika(*) & 7.595 & 3.430 \\
\hline Rusya & 0.139 & 0.526 \\
\hline Suudi Arabistan & -0.018 & -0.165 \\
\hline Güney Afrika(*) & -5.762 & -3.715 \\
\hline Türkiye(*) & -2.098 & -3.383 \\
\hline İngiltere(*) & 4.449 & 3.545 \\
\hline ABD(*) & 2.747 & 5.594 \\
\hline CCMGE & 2.584 & 1.82 \\
\hline
\end{tabular}

Tablo 6: CCE Testi Sonuçlart

Tablodan elde edilen sonuçlara göre Arjantin, Avusturalya, Brezilya, Kanada, Fransa, Hindistan, Japonya, Meksika, İngiltere ve ABD'de askeri harcamalar ile işsizlik arasında pozitif yönlü bir ilişki söz konusu iken, Endonezya, İtalya, Güney Afrika ve Türkiye'de ise ilişkinin yönü negatiftir. Dolayısıyla ilk gurupta yer alan ülkelerde askeri harcamaların "dışlama etkisi”nin işlediği; buna karşılık ikinci gurupta yer alan ülkelerde ise "harekete geçirme etkisi”nin çalıştığı düşünülebilir. Çin, Almanya, Rusya ve Suudi Arabistan için ise istatistiki açıdan anlamlı bir ilişki elde edilememiştir. Bu ülkelerin ise daha çok kaynak zengini ülkeler olduğu dikkat çekmektedir. G20 ülkeleri üzerine yapılan analizler sonucu elde edilen bu bulgular gelişmekte olan ülkelerde yapılan askeri harcamaların teknolojik gelişme, altyapı ve beşeri sermaye birikimi alanında katkı sağlayarak 
büyümeyi pozitif etkileyip işsizliği azalttı̆̆ı düşünülebilir. Ya da savunma sanayi araştırma ve geliştirme yatırımları, silah teknolojisindeki yenilikler özel sektör üretimi üzerinde pozitif etki yaratarak büyümeye ve istihdam oranlarına katkı sağladığı düşünülebilir. Dolayısıyla çalışma bu kısımda Keynesyen yaklaşımı desteklerken, gelişmiş ülkelerde ise askeri harcamaların işsizliği pozitif etkilediği görülmektedir.

\section{Genel Değerlendirme ve Sonuç}

Askeri harcamalar ile işsizlik arasındaki ilişkilerin dönemden döneme ve ülkeden ülkeye farklılıklar sergileyebileceğine dair bir literatürün var olduğu bilinmektedir. Askeri harcamaların kaynakların üretken olan ve dolayısıyla reel üretimden çekilerek üretken olmayan bir alana kanalize edildiği savı daha çok Klasik iktisadın en önemli önermelerindendir. Dolayısıyla Klasiklerde kaynakların etkin olmayan bir alana yönlendirilmesinin üretimi-büyümeyi etkilemeyeceği ve hatta olumsuzlaştıracağı; tam istihdamdaki bir ekonomi için ise istihdam konumunu değiştirmeyeceği ileri sürülmektedir. Diğer bir ifadeyle işgücü unsuru üretken olan alanlardan üretken olmayan alanlara yönlendirilmiş olacaktır. Buna karşılık, ekonominin genelde eksik istihdamda olduğu savını ileri süren Keynesyenlerde ise askeri harcamalarda bulunmakla toplam talepte bir genişleme sağlanacağından, toplam talep genişlemesi de ekonomiyi eksik istihdamdan tam istihdama taşımış olacaktır.

$\mathrm{Bu}$ çalışmada yapılan analizlerde olası tam istihdam düzeyinde bulunduğu düşünülebilecek ülkelerde askeri harcamaların kaynakların etkinliğini bozarak işsizlik oranlarını artırdığı gibi bir sonuç elde edilmiştir. İşsizlik ile askeri harcamalar arasında pozitif ilişkilerin gözlendiği ülkeler Arjantin, Avusturalya, Brezilya, Kanada, Fransa, Hindistan, Japonya, Meksika, İngiltere ve ABD’dir. Genelde ekonomide işsizlik oranlarının doğal işsizlik düzeyinde bulunduğu söylenebilecek bu ülkeler için Klasiklerin öngörüsünün işlediği ileri sürülebilir. Diğer taraftan Türkiye, Güney Afrika, İtalya ve Endonezya'da ise askeri harcamaların işsizliği azalttığına dair bulgular elde edilmiştir. Bu guruptaki ülkelerde ise yaygın bir eksik istihdam yapısının mevcudiyetinden bahsedilerek, Keynesyenlerin bakış açısının geçerliliğinden bahsedilebilir. Son olarak Çin, Almanya, Rusya ve Suudi Arabistan için ise anlamlı bulguların elde edilememesi, genelde doğal kaynak zenginliğinin yapılan askeri harcamaların işsizlik üzerine ne lehte ne de aleyhte bir bulgu vermediği söylenebilir. Özetle askeri harcamalar ile işsizlik arasındaki ilişkilerde ülkeye özgü bulguların varlığı hem teorik hem de uygulamalı literatürle de örtüşmektedir. Ancak G20 özelinde yapılan analizlerin ülkelerin alt gruplar şeklinde tasnif edilerek yapılmasının bu savı destekleyip desteklemediği inceleme konusu yapılabilir.

\section{Kaynakça}

- Bayar, Güzin, Bülent Güloğlu ve Selman Tokpunar (2011), “Türkiye Ekonomisi’nin Dinamikleri: Politika Arayışları", Ekonomik Yaklaşım Kongresi, 22-23 Aralık.

- Breusch, Trevor Stanley and Adrian Rodney Pagan (1980), “The Lagrange Multiplier Test and its Applications to Model Specification in Econometrics", The Review of Economic Studies, Econometrics Issue, 47 (1): 239-253.

- Dunne, Paul and Duncan Watson (2000), "Military Expenditure and Employment in South Africa", Defence and Peace Economics, 11 (4): 587-596.

- Hooker, Mark and Michael Knetter (1994), "Unemployment Effects of Military Spending: Evidence from a Panel of States”, NBER Working Paper, No. 4889.

- Huang, Jr-Tsung and An-Pang Kao (2005), “Does Defence Spending Matter to Employment in Taiwan?", Defence and Peace Economics, 16 (2): 101-115.

- Korkmaz, Suna (2015), "The Effect of Military Spending on Economic Growth and Unemployment in Mediterranean Countries", International Journal of Economics and Financial Issues, 5 (1): 273-280.

- Malizard, Julien (2014), "Defense Spending and Unemployment in France", Defence and Peace Economics, 25 (6): 635-642.

- Morales-Ramos, Eduardo (2002), “Defence R\&D Expenditure: The Crowding-out Hypothesis”, Defence and Peace Economics, 13 (5): 365-383.

- Qiong, Li and Hu Junhua (2015), “Military Expenditure and Unemployment in China”, Procedia Economics and Finance, 30: 498-504.

- Olofin, Olabode Philip (2012), "Defense Spending and Poverty Reduction in Nigeria", American Journal of Economics, 2 (6): 122-127.

- Paul, Satya (1996), “Defence Spending and Unemployment Rates”, Journal of Economic Studies, 23 (2): 44-54.

- Pesaran, M. Hashem (2006), "Estimation and Inference in Large Heterogeneous Panels with a Multifactor Error Structure”, Econometrica, 74 (4): 967-1012. 
- Pesaran, M. Hashem (2007), “A Simple Panel Unit Root Test in The Presence of Cross Section Dependence”, Journal of Applied Econometrics, 22: 265-312.

- Pesaran, M. Hashem and Takashi Yamagata (2008), “Testing Slope Homogeneity in Large Panels”, Journal of Econometrics, 142: 50-93.

- Selvanathan, Saroja and Eliyathamby A. Selvanathan (2014), "Defence Expenditure and Economic Growth: A Case Study of Sri Lanka Using Causality Analysis”, International Journal of Development and Conflict, 4: 69-76.

- $\quad$ Tang, Jenn-Hong, Cheng-Chung Lai and Eric S. Lin (2009), "Military Expenditure and Unemployment Rates: Granger Causality Tests Using Global Panel Data", Defence and Peace Economics, 20 (4): 253-267.

- Westerlund, Joakim (2008), "Panel Cointegration Tests of the Fisher Effect”, Journal of Applied Econometrics, 23: 193-233.

- Yıldırım, Julide and Selami Sezgin (2003), "Military Expenditure and Employment in Turkey”, Defence and Peace Economics, 14 (2): 129-139. 


\title{
Kırsal Alanlarda Sürdürülebilir Kalkınma İçin Göçün Önlenmesinde Yaygın Formal Ĕ̆itim Önerisi: Bir Pilot Araştırma Common Formal Education Proposal in Preventing Immigration
for Sustainable Development in Rural Areas: A Pilot Study
}

\author{
Assoc. Prof. Dr. Lutfiye Özdemir (İnönü University, Turkey)
}

Ph.D. Candidate Orhan Polat (İnönü University, Turkey)

\begin{abstract}
This study was conducted to determine the effect of training in the prevention of migration as an obstacle for sustainable rural development. In this context, the causes of migration from rural areas to the cities were investigated and evaluated the educational status of people living in the villages. For this purpose, research has been implemented in rural part of Turkey's Central Anatolia, Mediterranean and Black regions. Research data were collected by applying a questionnaire to the region inhabitants. A total of 123 questionnaires were evaluated. On statistical analysis, Cronbach's alpha value was found to be .833 . Consequently, accessed findings are: 1) People living in region have low educational levels. 2) None of the participants had received any training related to agriculture in high school. 3) The proportion of participants receiving vocational training in related to agriculture, except for state schools is low. 4) Lack of education is one of the important reasons of the migration from rural to urban areas. 5) If enough agricultural education is given to region habitants, natural resources to ensure the survival of future generations are protected.
\end{abstract}

\section{Giriş}

Kırsal alanlarda sürdürülebilir kalkınmanın sağlanabilmesi için köylerden kentlere olan göçlerin önlenmesi önemli konulardan biridir. Çünkü kırsal kesimlerden kentlere olan göçler, tarımsal faaliyetleri ve dolayısıyla sürdürebilir kalınmayı olumsuz etkileyebilmektedir. Kırsal kesimlerden kentlere olan göçlerin çok çeşitli sebepleri bulunmaktadır. Bu bağlamda araştırma, sürdürülebilir kırsal kalkınma engeli olarak görülen göçün önlenmesinde eğitimin etkisini belirlemek amacıyla yapılmıştır. Araştırmada öncelikle kırsal alanlardan kentlere yapılan göçlerin nedenleri araştırılmış ve köylerde yaşayan insanların eğitim durumları değerlendirilmiştir.

Kapsamlı literatür taraması sonucunda göçlerin temel nedenlerinden birinin formal (resmi) tarım eğitimi eksikliği ve köylerdeki okulların kapatılması sonucu uygulanan taşımalı eğitim sistemi olduğu tespit edilmiştir. Göç, tarım faaliyetlerini sekteye uğratarak kırsal alanlarda sürdürülebilir kalkınmayı engellemektedir. Devlet, Birleşmiş Milletler (BM), Avrupa Birliği (AB) ve Dünya Bankası (DB) kaynaklı sürdürülebilir kırsal kalkınma çalışmalarında eğitim eksikliği, yaygın ve formal (resmi) olmayan "proje tipi” eğitimlerle giderilmeye çalışılarak kırsal kalkınma hedeflenmiş ancak bu çalışmaların sonuçları da kısa süreli (proje süresi kadar) olmuştur. Sonuç olarak ülkemizde son yüzyılda kırsal alanda sürdürülebilir bir kalkınma gerçekleştirilememiş ve yapılan çalışmalar başarısızlıkla sonuçlanmıştır. Bu nedenle günümüzde kırsal kesimlerden kentlere olan göç hala devam etmektedir.

\section{Literatür Taraması}

Sürdürülebilirlik; ekonomik gelişmenin ve kalkınmanın, doğal kaynakları tüketmeden ve doğanın kurulu dengesini bozmadan gelecek nesillere ihtiyaçlarını karşılayabilecek ve kalkınmalarına imkân sağlayabilecek şekilde bugünün ve yarının kalkınmasının tasarlanması ve uygulanmasıdır. Dar anlamda diğer bir ifadeyle organizasyonlarda sürdürülebilirlik ise; organizasyon ile çevresi arasındaki ilişkilerin sürekliliğini sağlayabilecek şekilde bir ahenk içinde olması anlamını taşımaktadır (Koçel, 2015). Sürdürülebilirlik kavramı sosyal, ekonomik, çevresel ve tarımsal sürdürülebilirlik olmak üzere dört unsuru kapsamaktadır. Sosyal sürdürülebilirlik, toplumun manevi yapısının birbiri ile dinsel ve kültürel etkileşimlerle sürdürülmesi ve yenilenmesidir. Ekonomik sürdürülebilirlik ise, maddi sermayenin (yapı, hammadde, enerji, doğal kaynaklar vb.) devamlılığıdır (Altınok vd., 2015). Çevresel sürdürülebilirlik de; doğal kaynakların ölçülü bir biçimde kullanılarak, bugün ve gelecekte kaliteli yaşamın ve gıda üretiminin devam ettirilmesidir (The EU Eplained, 2014). Son olarak tarımsal sürdürülebilirlik; ekonomik ve çevresel sürdürülebilirlik ile doğrudan ilişkili olup doğal kaynakların bozulmasına neden olmadan, insan sağlığını tehlikeye atmadan tarımsal faaliyetlerin planlanması, uygulanması ve denetlenmesidir (Kırımhan, 2005). Kalkınma; gelişme süreci ve eylemidir, büyüme ve ilerleme olarak da ifade edilebilir. BM'de yapılan çalışmalarda sürdürülebilir kalkınma; bugünün ihtiyaçlarını gelecek nesillerin yaşam kabiliyetini bizden şikâyet etmeyecek şekilde karşılayarak gelişmek olarak tanımlanmaktadır (WCED, 1987; Strange ve Bayley, 2008). Tarımsal sürdürülebilirliğin ana konuları; devlet müdahalesi, küresel bir bakış açısı, temel kaynakların yönetimi (toprak kullanımı, su yönetimi, alternatif kimyasalların kullanımı, ormanlaştırma ve tarım, su kültürü), üretim ve verimlilik (teknolojik temelli, insan kaynakları, girdilerin verimliliği) ve tarafsızlıktır. Tarımsal sürdürülebilirliğin sağlanmasında kaynak yönetimini ve üretimi ile verimliliği gerçekleştirecek olan güç insandır. Geleneksel tarım 
anlayışından teknolojik tarım anlayışına geçiş insan kaynaklarını geliştirmeden imkansızdır. Bunun için de eğitim gereklidir. Düşük bilinç düzeyi kırsalda yaygındır. Araştırmacılar eğitimde reformlar gerçekleştirerek, kırsal alanda yaşayanlar ve tarım için ihtiyacı karşılayacak çözümler üretmelidirler. Bu eğitim reformu, sürdürülebilir tarım için toprak, su ve ormanların etkili bir şekilde kullanımasını içermelidir. Ayrıca bu eğitim reformu yalnızca kırsal alanda yaşayan erkekleri değil kadınları da kapsamalı ve desteklemelidir (WCED, 1987). AB Sürdürülebilir Kalkınma Stratejisi; çevrenin korunması, sosyal uyumun ve refahın sağlanması, ekonomik potansiyelin çevresel ve sosyal yeniliklerle yükseltilmesi, kaynakların etkili bir şekilde kullanılması ve yönetilmesi sağlanarak toplumların sürdürülebilir üretkenlikleriyle yaşam kalitesinin uzun dönemli olarak sürdürülebilmesini sağlamak için eylemlerin geliştirilmesi ve belirlenmesi amacını taşımaktadır. Eğitim ve uygulama, sürdürülebilir kırsal kalkınma açısından kritik öneme sahiptir ve $A B$ Komisyonu 2020'ye kadar eğitimde işbirliğini sağlamayı hedeflemektedir (EC, 2016; EUR-Lex, 2016). BM ve AB'ye göre sürdürülebilir kalkınma için; insan kaynaklarının ekonomik, çevresel, sosyal ve tarımsal sürdürülebilirlik konusunda eğitilmeleri bir zorunluluktur (UN, 1992). İklim değişikliğinin olumsuzluklarının giderilmesi, ormanların azalmasının engellenmesi, yeni tarımsal metotlar geliştirilmesi gibi yöntemlerle çevresel zararların azaltılması uygulamalarının gerçekleşmesi halinde sürdürülebilir kırsal kalkınmanın hızlı artış potansiyeline sahip olabileceği değerlendirilmektedir (IISD, 2010). Kırsal alan; Ulusal Kırsal Kalkınma Stratejisi’nde (UKKS) (2014-2020) “nüfusu 20 binden düşük olan yerleşim yerleri” olarak ifade edilmektedir. Kalkınma, ekonomik, sosyal ve insan kalkınması olarak üç boyutta ele alınmaktadır. Ekonomik kalkınma; insanların refahını ve mutluluğunu artırmak için onların ihtiyaç duydukları mal ve hizmetlerin gelişmiş bir ekonomik yapı içerisinde üretilerek karşılanmasıdır. Sosyal kalkınma ise; insanların sosyal yaşamlarının iyileştirilmesi için sağlık, eğitim, altyapı, kent ve çevre sorunları gibi hizmet yönlü alanlardaki gelişme olarak ifade edilmektedir. İnsan kalkınması da; insanların kişisel ve toplumsal olarak sahip oldukları potansiyellerini kalkınma için kullanmaları ve ülkenin gelişmesinde yapıcı rol oynanmasıdır. Bu bağlamda eğitim, öncelikle insan kalkınmasında ve sonrasında sosyal ve ekonomik kalkınmada önemli bir yere sahiptir. Kalkınma alanlarına göre kırsal, kentsel, bölgesel, ülkesel ve küresel kalkınma olarak ayrılabilir. Bu araştırmanın konusunu oluşturan kırsal kalkınma, düşük nüfus yoğunluğuna sahip yaşam ve çalışma alanlarında, mevcut doğal kaynakların istismar edilmeden, uygulanabilir ve sürdürülebilir şekilde değerlendirilerek, hayat standartları ve gelir düzeylerinin yükseltilerek sosyal refahın artırılmasıdır. Kırsal alan çoğunlukla tarımsal faaliyetlerin iyileştirilmesi olarak düşünülmektedir (İrmiş ve Eroğlu, 2015). Kırsal kalkınma; kırsalda yaşayan insanların ekonomik ve sosyal refah ile birlikte yaşam kalitesini artırma süreci olarak ifade edilmektedir. Kırsal alandaki temel ekonomik faaliyet tarıma dayalıdır (UKKS 2014-2020). Kırsal alanın tarımla ilişkilendirilmesinin sebebi tarımın tanımından anlaşılmaktadır. Tarım; "bitkisel ve hayvansal ürünlerin üretilmesi, kalite ve verimlerinin yükseltilmesi, uygun koşullarda korunması, işlenip değerlendirilmesi ve pazarlanması"dır (Büyük Türkçe Sözlük, 2016c). Tanımdan da anlaşıldığı gibi, tarım, kırsal alanda üretilen hem hayvansal hem de bitkisel kaynaklı ürünlerin üretilmesini, kalite ve verimin yükseltilmesini ve üretilen bu ürünlerin özelliklerini kaybetmeden muhafaza edilmesini, işlenmesini ve pazarlanmasını kapsamaktadır. Tüm bu faaliyetleri oluşturan bitkisel ve hayvansal ürünlerin üretimi, yalnız kırsalda yapılabildiğinden tarım ve kırsal alan birbiri ile doğrudan ilişkilidir. Tarımın kalkınması kırsal alanın kalkınması demektir. İrmiş ve Eroğlu'na (2015) göre; kırsal alan kalkınması için; kırsal alan turizm, organik tarım, halıcılık, el sanatları, geleneksel üretim konuları gibi kültürel ve sanatsal üretim ile bu alandaki istihdam, eğitim ve sağlığın iyileştirilmesi oldukça önemli konular kabul edilmektedir (Işık ve Baysal, 2011'dan Aktaran). Dünya Bankası'nın 2008 yılı Dünya Kalkınma Raporu'nda kırsal kalkınmanın önündeki en büyük engelin göç olduğu, göç engellenmedikçe kalkınmanın mümkün olmadığı belirtilmektedir. Kırsal kalkınma için eğitimlerle kabiliyetlerin geliştirilmesi gerektiği vurgulanmaktadır. Aynı raporda göçün, eğitimlerle kabiliyetlerin geliştirerek yoksulluğun azaltıldığı refahın artırıldığı çeşitli ülkelerden örneklerle gösterilmiştir.

Eğitimler; resmi eğitimde temel eğitimin kalitesinin geliştirilmesi, meslek eğitimlerinin ve yüksek eğitimin düzenlenmesi şeklinde olmuştur. Resmi olmayan eğitimlerde Sivil Toplum Kuruluşları'nın (STK) ikinci şans eğitimleri ile kabiliyet kazanmaları amaç edinilmiştir. Tüm eğitimlerin nitelikleri, geleneksel yöntemlerden ziyade günümüz piyasalarına uygun sorgulayıcı, yenilikçi tarımsal eğitimlerin yanında işletmecilik ve girişimcilik eğitimlerini de kapsamaktadır (World Development Report, 2008, 2007). Kırsal kalkınmayı gerçekleştirebilmede en önemli faktör, devamlığı olan insan kaynağıdır. Kırsal alanda kalkınmanın sürdürülebilirliği gençlerle sağlanabilmektedir. Oysa ki, gençler, kırsal alandan kentlere göç etmektedirler. İște bu sebepten dolayı göç, kırsal kalkınmanın önündeki en önemli engellerden biri olarak görülebilir. Çünkü göç, kırsal alanda emek ve sermaye gibi üretimin ana kaynaklarının kaybedilmesine neden olabilmektedir. Genç ve nitelikli iş gücünün kırsal alandan göçü ise hem üretim faktörlerinin kaybına hem de kırsal alanda yaşlı nüfusun oluşmasına yol açmaktadır (T.C. Kalkınma Bakanlığı, 2016). BM'de yapılan çalışmalarda demografik değişikliklere yani göçlere; çevresel faktörler, yoksulluğun azaltılması, güvenlik ihtiyacı, sağlık, kaliteli yaşam, gelir seviyesini artırma isteği, okula erişim/gitme, mesleki eğitim, kişisel istekler ve kendini güçlendirme/gerçekleştirme gibi ihtiyaçların neden olduğu sonucuna ulaşılmıştır (UN, 1992). Ayrıca AB uzmanlarınca AB'nin kurumsal kapasitesinin geliştirilebilmesi için LEADER programı eğitimi saha ziyaretlerinden/çalışmalarından ve kırsal kesimlerde yaşayanlarla yüzyüze yapılan görüşmelerden kırsal alanlardan göçün sosyal nedenlerinden birinin de; 1997 yılında uygulanmaya başlanan 8 yıllık kesintisiz eğitim ile birlikte köylerdeki ilkokulların kapatılması sonucu uygulanan taşımalı eğitim sistemi olduğu ifade edilmiştir. Taşımalı eğitim uygulaması ile hali hazırda birçok bölgede, tüm öğrenciler (ilkokul, 
ortaokul ve lise) eğitimini genellikle ilçe merkezindeki okullarda almaktadırlar. Gençler küçük yaştan itibaren 12 yıl boyunca ilçe merkezinde eğitim aldıktan sonra kırsal alanda yaşamın iyi olmadığını, okulların kapatıldığını, sosyal imkânların yetersiz olduğunu düşünerek kırsal alanda yaşamak istememektedirler. Kırsaldan göçün başka ekonomik ve sosyal nedenleri ise; tarım arazilerinin küçük olması, üreticilerin çoğunun tarımı bir meslek olarak görmemesi, tarımsal deneyim süresinin az olması ve gençlerin tarımsal faaliyetlerden uzaklaşmasıdır (Yavuz vd., 2015). Tan ve diğerlerine (2015) göre; göçün engellenmesi ve kırsal kalkınmanın sağlanması için, kırsal alanlardaki üreticilerin, tarım destekleri ve politikaları konusunda bilinç düzeylerinin yükseltilmesi ve çiftçi eğitimlerinin geliştirilmesi gerekmektedir. Kırsal alanda mevcut durum değerlendirildiğinde, ülkemizdeki zayıflıklar; tarımsal eğitim, yayım, örgütlenme ve işbirliği konularındaki yetersizlikler kırsal kalkınmayı engellemektedir. $\mathrm{Bu}$ durumun düzeltilmesi için üreticilerin örgütlenme ve mesleki-teknik bilgi düzeyinin yükseltilmesi gerekmektedir (T.C. Kalkınma Bakanlığı, 2016). 2011 yılında Türkiye İstatistik Kurumu (TÜİK) tarafından yapılan çalışmaya göre ülke genelinde; 2.207 .844 kişinin göç ettiği, göç etme nedenlerinin ise; \% $\% 1,5$ oranında aile fertlerinden birine bağl1 göç etme, $\% 22,6$ oranında eğitim, \%13,4 oranında tayin/iş değişikliği, \%12,2 oranında iş aramak/bulmak, \%7,5 oranında evlilik/boşanma, \%1 oranında sağlık ve $\% 1,8$ oranında diğer nedenler olduğu tespit edilmiştir (TÜİK, 2016a). Göç etme nedenleri incelendiğinde; aile fertlerinden birine bağlı göç etme, eğitim ve iş arama/bulma nedenlerinin kırsal alandan göç nedenleri ile örtüştüğü görülmektedir. Bu oran \% \%, 3 oranına denk gelmekle beraber genel olarak her göç eden dört kişiden üçünün bu sebeplerden birine bağlı olarak göç ettiği sonucu çıkmaktadır. 2014-2015 döneminde ise toplam 2.720.438 kişi çeşitli nedenlerle göç etmiştir. Bu sonuçlara göre, 2011 yılına göre 2015 yılında göç eden insan sayısı yaklaşık 500.000 kişi artmıştır. Ülkemizde illerin aldığı göç ile verdiği göç oranlarına göre (-\%28,6 ile -15,8 oranları arasında) en çok göç veren iller sırasıyla; Kars, Ağrı, Yozgat, Muş, Bayburt, Şırnak, Ardahan, Bitlis, Çankırı, Siirt, Hakkâri, Iğdır, Van ve Erzurum'dur. İllerin aldığı göç ile verdiği göç oranlarına göre (+\%22,6 ile 5 oranları arasında) en çok göç alan iller sırasıyla; Tekirdağ, Karabük, Gümüşhane, Kocaeli, Antalya, Yalova, Ankara, Kastamonu, Eskişehir, Bolu, Sakarya, Bursa, Kırklareli, Denizli, Bilecik ve İzmir'dir (TÜİK, 2016b). Ülke genelinde gerçekleşen bu göçler incelendiğinde, genel olarak göçün az gelişmiş veya gelişmekte olan illerden daha gelişmiş illere yapıldığı görülmektedir. Geçmişten günümüze gerçekleştirilen kırsal kalkınma stratejilerinin başarısız olduğu mevcut durumda hala kalkınamamış kırsal alanlardan ve önlenemeyen göçten anlaşılmaktadır. Başarısızlıklardan çıkarılan sonuç "mevcut uygulamaların" yeterli başarıya ulaştıramadığıdır. Bunun için öncelikle kırsal alanda değişimi yapacak olan insan kaynağı incelenmelidir. Ülkemizdeki kırsal alanlarda yaşayan ve büyüyen insanların aldıkları eğitim sistemindeki mevcut uygulamayı ve kırsal alanda kalkınmayı sağlamış ülkelerin eğitim sistemlerindeki mevcut uygulamayı inceleyerek ve karşılaştırarak tüm ülkeyi kapsayan yaygın yeni bir formal (resmi) eğitimle desteklenmiş bir kırsal kalkınma programının oluşturulması gerekmektedir.

\section{Eğitim ve Tarım Eğitimi}

Teknoloji yoğun ürünler ve İnternet ile küreselleşen iletişim; hem bilgiye erişimi hızlandırmış hem de bilginin yenilenme süresinin azalmasına neden olmuştur. Bilginin yenilenme süresinin azalmasını sağlayan bu etkenler değişimi de zorunlu kılmıştır. Bu nedenle değişime neden olan bilginin doğruluğu ve güvenirliği, tüm bilimsel alanlarda olduğu gibi sosyal bilimlerde de önemlidir. Koçel (2015) bilgi üretiminde, bilgi-insan ilişkisi, sağlıklı ve güvenilir bilgi konularına dikkat çekerken, İnam (2015) da "Epistemiyatri Kapısını Açarken” adlı makalesinde, bilgi sağlığını (veya epistemiyatri), içinde yaşanılan ve küçüldüğü söylenen dünyanın sorunu olarak belirtirken "bilgi sağlığı" ve "bilgi doğruluğu” kavramlarının önemini vurgulamaktadır. Drucker (2016), geçmiş zamanlarda insanların 18-19 yaşına kadar öğrendiği bilgilerle hayatları boyunca mesleklerini sürdürebildiklerini ancak günümüzde ise bir konuda bilgi ve uzmanlığa sahip olan bir kişinin bilgisinin dört veya beş yılda yetersiz hale geldiğine dikkat çekerek, kişilerin ve organizasyonların sürekli olarak kendilerini yenilemek zorunda olduklarını ifade etmektedir. Doğru ve sağlıklı bilgiler özel veya resmi eğitim ile insanlara aktarılmaktadır. Bunun için devlet yapılanmalarında eğitim-öğretim veren kurum/kuruluşlar oluşturulmuştur veya oluşturulmasına müsaade edilmiştir. Bir ülkenin sürdürülebilir kırsal kalkınmasında en önemli unsur "insan”dır. İnsan aldığı eğitimlerle kendini bilgi ile donatırken içinde bulunduğu ortam ve koşullarda en iyi şekilde hayatını sürdürebilmek için kendini donattığı bu bilgilerden faydalanmaktadır. Bu nedenle insanın yaşadığı ortamda varlığını sürdürebilmesi için bilgiye ihtiyacı vardır ve bilgiyi ya da bilgiye erişimi eğitimle edinmek zorundadır. Ülkelerin ise eğitimöğretim veren kurum/kuruluşlarının ve bu kurum/kuruluşlarda eğitim veren insanlarının, verilen bilgileri çağın gereklerine göre yenilemeleri ve geliştirmeleri gerekmektedir. Bu yenileme ve geliştirmeyi yaparken kurduğu eğitim modelleri ve sonuçlarını da -odağında insan, etrafında çevresi- olacak şekilde sık sık yeniden değerlendirmelidir. Bu kapsamda 1997 yılında Türkiye'de eğitim sistemi, "8 yıllık kesintisiz zorunlu eğitim" temel alınarak yeniden yapılandırılmıştır. Bu yapılandırma sonucunda kırsal alanlarda bulunan birçok ilkögretim okulu kapatılmış ve yakında bulunan şehir merkezlerine veya öğrenci sayısı çok olan diğer alanlarda bulunan ilköğretim okullarına taşımalı eğitim başlamıştır. AB uzmanlarınca, AB Kurumsal Kapasitenin geliştirilmesi için LEADER Programı eğitimi saha ziyaretleri ile çalışmaları ve kırsal kesimlerde yaşayan insanlarla yapılan yüz yüze görüşmeler sonucunda; taşımalı eğitimin kırsalda yaşayan gençlere, küçük yaştan itibaren eğitim süresi boyunca şehir hayatının kolaylıklarını gösterdiği, kırsal alanda yaşamın iyi olmadığı, okulların kapatıldığı, sosyal 
imkânların yetersiz olduğunu hissettirdiği ve bunun neticesinde kırsal alanlarda/köylerde yaşanmaması yönünde bir algı oluşturarak kırsalda yaşamayı istememeye ve tarım ile ilgili faaliyetlerden uzaklaştırmaya sebep olduğu sonucuna ulaşı1mıştır.

Yapılan araştırmalarda kırsal alanlarda yaşayanlara tarım eğitimi verilmesi gerektiği sonucuna ulaşılmıştır (WCED, 1987; EC, 2016; EUR-Lex, 2016; UN, 1992; IISD, 2010; World Development Report 2008, 2007; İrmiş ve Eroğlu, 2015; Yavuz vd., 2015; Tan vd., 2015; T.C. Kalkınma Bakanlığ1, 2016). Cumhuriyet döneminden bugüne kadar uygulanan formal (resmi) mesleki eğitim sisteminde; kırsal alanlarda yaşayanların yaptıkları işleri kapsayan bir mesleki eğitimin (tarım eğitiminin) doğrudan işi yapacaklara verilmediği tespit edilmiştir. Bu nedenlerle mevcut tarım eğitim sisteminin, sürdürülebilir ülke kalkınmasını destekleyecek şekilde yeniden organize edilerek çağdaş yönetim teknikleri ile yönetilmesi bir zorunluluk oluşturmaktadır. Geçmişten günümüze kırsal alanda yaşayanlara verilen resmi eğitimler incelendiğinde, Ziraat Talimhanesi, Ziraat Mektebleri, Numune Tarlası ve Çoban Mektebi ile Köy Enstitüleri göze çarpmaktadır. 1847 yılında ziraat üretim tekniklerinin geliştirilmesi ve tarımda verimliliğin artırılması maksadıyla, İstanbul'da Ayamama Çiftliği'nde Ziraat Talimhanesi kurulmuştur. Ancak yapılan ekimlerin başarısız olması ve taşraya gidecek öğrenci yetiştirilememesi sebebiyle 1851 'de kapatılmıştır. 1891 ve 1892 yıllarında açılan İstanbul Halkalı Hamidiye Ziraat Mektebi, Bursa Hamidiye Ziraat Mektebi ve 1898 yılında açılan Ankara Numune Tarlası ve Çoban Mektebi ile çiftçilerin devrin yenilikleri ile tanıştırılması, ziraat üretim tekniklerinin geliştirilerek tarımda verimliliğin artırılması hedeflenmiştir (Keskin, 2010). Daha sonra bu okullardan bazıları zamanla yüksekokula ve Ziraat Fakültesi/Enstitüsüne dönüştürülmüştür. 1937'de Köy Eğitmenleri Kanunu'nda 'Nüfusları öğretmen gönderilmesine elverişli olmayan köylerin eğitim ve öğretim işlerini görmek, Ziraat işlerinin fennî bir şekilde yapılması için köylülere rehberlik etmek üzere köy eğitmenleri istihdam edileceği”" ve "Köy eğitmenlerinin, Maarif ve Ziraat vekillikleri tarafindan; ziraat işleri yaptırılmaya elverişli okul veya çiftliklerde açılan kurslarda yetiştirileceği” belirtilmektedir (Resmi Gazete, 2016a). Bu kanunun gereği olarak 17 Nisan 1940 yılında çıkarılan 3803 sayılı Köy Enstitüleri Kanunu göze çarpmaktadır. 3803 Sayılı Köy Enstitüleri Kanunu’nda "köy öğretmeni ve köye yarayan diğer meslek erbabını yetiştirmek üzere ziraat işlerine elverişli arazisi bulunan yerlerde, Maarif Vekilliği'nce köy enstitüleri” açılacağ1 belirtilmektedir (Resmi Gazete, 2016b). Bu iki kanunla Türkiye'de kırsal alanda ilk kez tarım eğitimi düzenlenmeye çalışılmıştır. Enstitülerin ilk resmî eğitim programı 1943 yılında yayımlanmış ve programa ilkokulu bitiren çocukların sınavla alınacağı, karma eğitim uygulanacağı, beş yıl sürecek eğitim zamanının yarısı kültür derslerine, dörtte biri tarım dersleri ve çalışmalarına, dörtte biri de sanat ya da teknik derslere ve çalışmalara ayrılacağı belirtilmiştir. Zamanla köy enstitülerinin sayıları 21'i bulmuştur ve 1946'ya kadar bu enstitülerde 16.400 kadın ve erkek öğretmen ile 7.300 sağlık memuru ve 8.756 eğitmen yetiştirilmiştir (toplam 25.156) ve 1954 y1lında köy enstitüleri ilköğretim okulları ile birleştirilerek kapatılmıştır (Milli Eğitim Bakanlığı, 2016). 1945 yılı genel nüfus sayımına göre belde ve köylerde yaşayan insan sayısı 14.103.072 iken il ve ilçelerde yaşayan nüfus sayısı 4.687.102'dir. Toplam ülke nüfusu ise 18.790.174 kişidir (TÜİK, 2016c). Eğitilen bu kişilerin ülke genelindeki belde ve köylere eşit olarak dağıtıldığı varsayıldığında, 560 kişiye 1 eğitim almış kişi düşmektedir. Köy Enstitüleri'nde verilen eğitimler, eğitici eğitimleriydi. Ülke genelinde işi yapacaklara doğrudan verilen mesleki bir eğitim olmamış ve tüm ülkeyi kapsayan yaygın formal (resmi) eğitime dönüştürülememiştir. 1937 ile 1945 yılları arasında köy enstitülerinin açıldığı iller şunlardır: Adana/Düziçi, Adapazarı/Arifiye, Ankara/Hasanoğlan, Antalya/Aksu, Aydın/Ortaklar, Balıkesir/Savaştepe, Diyarbakır/Dicle, Erzurum/Pulur, Eskişehir/Çifteler, Isparta/Gönen, İzmir/Kızılçullu, Kars/Cılavuz, Kastamonu/Gölköy, Kayseri/Pazarören, Kırklareli/Kepirtepe, Konya/İvriz, Malatya/Akçadağ, Sivas/Yıldızeli, Samsun/Ladik, Trabzon/Beşikdüzü ve Van/Ernis (1948). Bu enstitülerde verilen ders müfredatı Tablo 1'de sunulmaktadır (Altunya, 2016).

\begin{tabular}{|c|c|c|c|c|c|}
\hline \multicolumn{6}{|c|}{ Köy Enstitüleri Ders Müfredatı } \\
\hline \multicolumn{2}{|r|}{ Kültür Dersleri } & \multicolumn{2}{|r|}{ Ziraat Ders ve Çalıșmaları } & \multicolumn{2}{|r|}{ Teknik Dersler ve Çalışmalar } \\
\hline 1. & Türkçe & 1. & Tarla Ziraat1 & 1. & Köy Demirciliği (nalbantlık, motorculuk) \\
\hline 2. & Tarih & 2. & Bahçe Ziraat1 & 2. & Köy Dülgerliği (marangozluk) \\
\hline 3. & Coğrafya & & $\begin{array}{l}\text { Fidancılık, Meyvecilik ve Sebzecilik } \\
\text { Bilgisi }\end{array}$ & 3. & Köy Yapıcılığı \\
\hline 4. & Yurttaşlık Bilgisi & 4. & Sanayi Bitkileri Ziraatı & & (a) Tuğlacılık ve Kiremitçilik \\
\hline 5. & Matematik & 5. & Zooteknik & & (b) Taşçılık \\
\hline 6. & Fizik & 6. & Kümes Hayvanları Bilgisi & & (c) Kireçcilik \\
\hline 7. & Kimya & 7. & Arıcılık, İpek Böcekçiliği & & (d) Duvarcilık ve Sivacilık \\
\hline 8. & Tabiat ve Okul Sağlık Bilgisi & 8. & Balıkçılık ve Su Ürünleri Bilgisi & & (e) Betonculuk \\
\hline 9. & Yabanc1 Dil & 9. & Ziraat Sanatları & 4. & Kızlar İçin Köy Ev ve Eı Sanatları \\
\hline 10. & El Yazıs1 & & & & (a) Dikiş-Biçki, Nakış \\
\hline 11. & Resim-İş & & & & (b) Örücülük ve Dokumacılık \\
\hline 12. & $\begin{array}{l}\text { Beden Eğitimi ve Ulusal } \\
\text { Oyunlar }\end{array}$ & & & & (c) Ziraat Sanatları \\
\hline 13. & Müzik & & & & \\
\hline 14. & Askerlik & & & & \\
\hline 15. & Ev İdaresi ve Çocuk Bakımı & & & & \\
\hline 16. & \multicolumn{5}{|c|}{$\begin{array}{l}\text { Öğretmenlik Bilgisi: (a) Toplumbilim, (b) İş Eğitimi, (c) Çocuk ve İş Ruhbilimi, (d) İş Eğitimi Tarihi, (e) Öğretim Metodu ve } \\
\text { Tatbikat }\end{array}$} \\
\hline 17. & Zirai İşletmeler Ekonomisi ve K & oope & eratifçilik & & \\
\hline
\end{tabular}

Tablo 1. Köy Enstitüleri Ders Müfredatı Kaynak: Köy Enstitüsü Sistemine Toplu Bir Bakış 
2012-2013 eğitim ve öğretim yılında, MEB’e bağlı 4 adet Anadolu tarım meslek lisesinde 714 öğrenci (409 Erkek, $305 \mathrm{Kız}$ ); 20 tarım meslek lisesinde 3.044 öğrenci (2.520 Erkek, $524 \mathrm{~K}$ 1z) olmak üzere 306 öğretmen (195 Erkek, $111 \mathrm{~K} 1 \mathrm{z}$ ) ve 170 derslik bulunmaktaydı (Milli Eğitim İstatistikleri Örgün Eğitim 2012-2013). Günümüzde ise Tablo-2'de belirtilen yerlerdeki tarım ile ilgili meslek liseleri ve çok programlı liselerde; hayvan sağlığı ve yetiştiriciliği (hayvan yetiştiriciliği, veteriner sağlık) ve tarım (bahçe bitkileri, tarla bitkileri, süs bitkileri, peyzaj, tarım alet ve makineleri) alanlarında eğitimler verilmektedir (Mesleki ve Teknik Ĕgitim Programlar ve Öğretim Materyalleri, 2016).

\begin{tabular}{|c|c|c|c|c|c|c|c|c|c|}
\hline $\begin{array}{l}\text { İl } \\
\text { SN } \\
\end{array}$ & $\begin{array}{l}\text { İlçe } \\
\text { SN. }\end{array}$ & İl & İlçe & Dal & $\begin{array}{l}\text { İ } \\
\text { SN. }\end{array}$ & $\begin{array}{l}\text { İlçe } \\
\text { SN. }\end{array}$ & İl & İlçe & Dal \\
\hline 1 & 1 & AMASYA & MERKEZ & BB, TB, TAM, SB, HSY, VS & 21 & 34 & KIRKLARELİ & MERKEZ & TAM \\
\hline 1 & 2 & AMASYA & SULUOVA & HSY, VS & 22 & 35 & KIRȘEHIR & KAMAN & BB, TB, TAM, HSY, VS \\
\hline 2 & 3 & ANKARA & ALTINDAĞ & SB & 23 & 36 & KONYA & ÇUMRA & BB, TB, TAM, SB \\
\hline 2 & 4 & ANKARA & YENIMAHALLE & SB & 23 & 37 & KONYA & EREĞLI & HSY, VS \\
\hline 3 & 5 & ANTALYA & AKSU & $\mathrm{BB}, \mathrm{P}, \mathrm{SB}$ & 23 & 38 & KONYA & HÜYÜK & BB \\
\hline 3 & 6 & ANTALYA & KAȘ & BB & 23 & 39 & KONYA & KARAPINAR & HSY, VS \\
\hline 4 & 7 & ARDAHAN & GÖLE & HSY, VS & 23 & 40 & KONYA & KARATAY & HSY, VS \\
\hline 4 & 8 & ARDAHAN & HANAK & HSY, VS & 23 & 41 & KONYA & KULU & BB, TB, TAM, HSY, VS \\
\hline 5 & 9 & AYDIN & GERMENCIK & HSY, VS & 23 & 42 & KONYA & SELÇUKLU & $\mathrm{BB}, \mathrm{P}, \mathrm{SB}$ \\
\hline 5 & 10 & AYDIN & NAZILLII & BB & 23 & 43 & KONYA & SEYDIŞEHIR & BB, HSY, VS \\
\hline 6 & 11 & BALIKESIR & IVRINDİ & BB & 23 & 44 & KONYA & YUNAK & TB, SB \\
\hline 6 & 12 & BALIKESIR & MANYAS & HSY, VS & 24 & 45 & KÜTAHYA & ÇAVDARHISAR & BB, TB, HSY \\
\hline 7 & 13 & BAYBURT & DEMİRÖZÜ & HSY, VS & 25 & 46 & MALATYA & BATTALGAZİ & BB, TB, TAM, SB, HSY, VS \\
\hline 8 & 14 & BURDUR & KEMER & HSY, VS & 26 & 47 & MANISA & KÖPRÜBAȘI & TB \\
\hline 8 & 15 & BURDUR & TEFENNI & BB, TB, SB, HSY, VS & 26 & 48 & MANISA & SARIGÖL & BB, SB \\
\hline 9 & 16 & BURSA & İNEGÖL & $\mathrm{BB}, \mathrm{TB}, \mathrm{SB}$ & 27 & 49 & MERSIN & ERDEMLİ & $\mathrm{BB}, \mathrm{TB}, \mathrm{SB}$ \\
\hline 9 & 17 & BURSA & OSMANGAZİ & BB, TB, P, TAM, SB, HSY, VS & 27 & 50 & MERSIN & MEZİTLİ & $\mathrm{P}$ \\
\hline 10 & 18 & ÇANKIRI & MERKEZ & BB, TB, TAM, SB, HSY, VS & 27 & 51 & MERSIN & SILİFKE & $\mathrm{P}$ \\
\hline 11 & 19 & DENIZLII & SARAYKÖY & BB & 28 & 52 & MUĞLA & FETHIYE & $\mathrm{BB}, \mathrm{P}, \mathrm{SB}$ \\
\hline 12 & 20 & DIYAARBAKIR & BİSMILL & HSY & 28 & 53 & MUĞLA & KÖYCEĞİZ & $\mathrm{P}$ \\
\hline 12 & 21 & DIYARBAKIR & ÇÜNGÜŞ & BB & 28 & 54 & MUĞLA & MENTEŞE & $\mathrm{P}, \mathrm{SB}$ \\
\hline 13 & 22 & EDİRNE & İPSALA & TAM & 29 & 55 & RIZE & ÇAYELİ & $\mathrm{P}, \mathrm{SB}$ \\
\hline 13 & 23 & EDİRNE & KEŞAN & TAM & 30 & 56 & SAMSUN & BAFRA & $\mathrm{BB}, \mathrm{TB}, \mathrm{SB}$ \\
\hline 14 & 24 & ERZINCAN & MERKEZ & BB, SB, HSY, VS & 30 & 57 & SAMSUN & TEKKEKÖY & HSY, VS \\
\hline 15 & 25 & ESKIŞEHIR & MAHMUDİYE & TB, TAM, HSY, VS & 31 & 58 & SIVAS & SUŞEHRİ & BB, TB, TAM, HSY, VS \\
\hline 15 & 26 & ESKIŞEHIR & ODUNPAZARI & $\mathrm{P}$ & 32 & 59 & ŞANLIURFA & AKÇAKALE & $\mathrm{BB}, \mathrm{TB}, \mathrm{TAM}, \mathrm{SB}$ \\
\hline 16 & 27 & ISPARTA & ŞARKIKARAAĞAÇ & HSY, VS & 32 & 60 & ŞANLIURFA & CEYLANPINAR & BB, TB, HSY, VS \\
\hline 17 & 28 & İSTANBUL & ÜSKÜDAR & HSY, VS & 32 & 61 & ŞANLIURFA & HALİLIYE & BB \\
\hline 18 & 29 & İMIR & BAYINDIR & $\mathrm{P}, \mathrm{SB}$ & 32 & 62 & ŞANLIURFA & VİRANŞEHİR & BB, TB, P, HSY, VS \\
\hline 18 & 30 & İZMIR & ÖDEMIŞ & SB, BB & 33 & 63 & TEKİRDAĞ & HAYRABOLU & TAM \\
\hline 19 & 31 & KARS & MERKEZ & TAM & 34 & 64 & VAN & TUŞBA & HSY, VS \\
\hline 19 & 32 & KARS & SELIM & HSY & 35 & 65 & YALOVA & MERKEZ & $\mathrm{P}, \mathrm{SB}$ \\
\hline 20 & 33 & KASTAMONU & AĞLI & HSY, VS & 36 & 66 & ZONGULDAK & ÇAYCUMA & BB \\
\hline
\end{tabular}

BB: Bahçe Bitkileri; TB: Tarım Bitkileri; TAM: Tarım Alet ve Makineleri; SB: Süs Bitkileri; HSY: Hayvan Să̆lı̆̆l ve Yetiștirme, VS: Veteriner Sağllk; P: Peyzaj

\section{Tablo 2. Tarım ve Hayvan Sağlı̆̆ı/Yetiştiriciliği Alanı Olan Okullara Ait Bilgiler Kaynak: Meslekî ve Teknik Eğitim Genel Müdürlüğ̈̈}

Tablo 2. incelendiğinde, 36 ilde ve illerin merkez ilçeleri dâhil olmak üzere 66 ilçede bulunan okullarda "tarım bölümü’ne ait eğitim programları uygulanmaktadır. Ülkemizde; 81 il, 919 ilçe, 32.012 mahalle (büyükşehir yasasına göre büyükşehirlere bağlı köyler mahalle olmuştur), 18.330 köy, 26.043 bağlı mezra (küçük yerleşim yeri), 30 Büyükşehir Belediyesi, 51 İl Belediyesi, 519 Büyükşehir İlçe Belediyesi, 400 İlçe Belediyesi ve 397 Belde Belediyesi olmak üzere toplam 1.397 adet belediye bulunmaktadır (Türkiye Mülki İdare Bölümler Envanteri, 2016). Ülke nüfusu 78.741.053 ve belde/köy nüfusu 6.217.919'dur (TÜİK, 2016d). Ülkemizde 2014 ve 2015 yıllarında nitelikli tarım, ormancılık ve su ürünlerinde çalışanların ortalama yıllık sayısı sırasıyla 4.324.000 kişi ve 4.235.000 kişidir (TÜİK, 2016e). Eldeki bulgular değerlendirildiğinde, sürdürülebilir kırsal kalkınma için formal tarım eğitiminin tüm ülkeye yayılması şarttır; ancak ülkemizde 919 ilçe olmasına rağmen sadece 66 ilçede tarım ile ilgili eğitim verilmekte ve 853 ilçede ise tarım ile ilgili eğitim verilmemektedir. Dolayısıyla bu ilçelere bağlı köylerde ve daha küçük yerleşim yerlerinde yaşayanlara tarım ile ilgili eğitim de verilmemektedir. Avrupa Birliği'nde tarımsal mesleki eğitiminin "ortak tarım politikasının uygulanmasında mesleki eğitim alanında etkili çabaların koordinasyonu” için gerekli olduğu, 1961 yılında Avrupa Ekonomik Topluluğu'nun (AET) “Ortak Mesleki Eğitim Politikasının Uygulanması için Genel Prensipler” isimli komisyon çalışmasında belirtilmektedir. 1964 yılında ise AET mesleki eğitimi, tarım ve diğer alanlar olmak üzere ikiye bölmüştür. Tarım işçilerinin mesleki eğitim almalarının büyük önem taşıdığı belirtilmiştir. 1967 yılında ise tarımsal mesleki eğitime ilişkin prensipler belirlenmiştir. AB ülkelerinde üyeliğin koşulu olarak tarımsal mesleki eğitim uygulanmaktadır (Panorama, 2004). Ülkemizde ise henüz yaygın formal (resmi) eğitimle desteklenmiş bir kırsal kalkınma programının olmadığı ve bunun sürdürülebilir kırsal kalkınma açısından bir engel oluşturabileceği sonucuna ulaşılmıştır. Çünkü hali hazırda ülkemizde adı tarım öğretmenliği olan branş öğretmenliği yoktur ve bu konuda öğretmen yetiştirecek bir yükseköğretim programı bulunmamaktadır (Öğrenci Seçme ve Yerleştirme Sınavı Kılavuzu, 2016). Tarım öğretmenliği adı altında çeşitli ülkelerde yükseköğretim programları 
uygulanmaktadır. Örneğin, ABD'de 1887 yılında "Hatch Act" adı ile bilinen yasa ile tarımsal araştırma/uygulamaların yapılmasının ve 1917 yılında "Smith-Hughes Act" olarak bilinen yasa ile tarımsal mesleki eğitim verilmesinin temeli atılmıştır. Günümüzde ise ABD’de lise seviyesinde tarımsal mesleki eğitim verilmesine devam edilmektedir. Bununla birlikte tarımsal eğitimi verecek öğretmenlerin yetiştirilmesine devam edilmektedir. Örneğin Minesota Üniversitesi'nde lisans düzeyinde verilen “Tarım Öğretmenliği” programına ait eğitim müfredatı Tablo-3'de sunulmaktadır.

\begin{tabular}{|c|c|c|}
\hline \multicolumn{3}{|c|}{ TARIM EĞITIMİ-MINESOTA ÜNIVERSITESİ, FEN FAKÜLTESI TARIM ÖĞRETMENLİĞİ [LİSANS] } \\
\hline \multicolumn{3}{|c|}{ PROGRAM GEREKSINIMLERİ [120.5 KREDİ] } \\
\hline GENEL KÜLTÜR EĞITTIMII [35] & GIDA, TARIM VE DOĞA BÍLIMLERİ \& [39] & MESLEKİ [41.5] \\
\hline Temel Bilgiler & Displinlerarası Öğrenme [3] & Tarım Eğitimi [28] \\
\hline Güzel Sanatlar [3] & CFAN 1501-Biyoteknoloji, İnsan ve Cevre & AFEE 1001-Tarım Eğitimine Giriș \\
\hline Biyoloji [4] (laboratuvar zorunlu) & Hayvan Bilimi [7] & AFEE 1002-Tarım Mesleğinde Kariyer Planlaması \\
\hline AGRO 1101-Bitki Besin Sistemleri Biyolojisi & ANSC 1101-Hayvan Bilimine Giriș & AFEE 2096-Mesleki Staj (Uygulama) \\
\hline veya BIOL 1009-Genel Biyoloji & Tarım ve Ekonomi Uygulamaları [6] & AFEE 2421-Gıda, Tarım ve Çevre İçin Mesleki İletișim \\
\hline Tarihsel Bakıș [3] & APEC 1101-Mikro Ekonomi İlkeleri & AFEE 5111W-Tarım Öğretmenliğinde Öğretim Metodları \\
\hline Literatür [3] & Gida Bilimi [3] & AFEE 5112-Tarım Öğretmenliği Müfredat Programı \\
\hline Matematiksel Düsünce [3] & FSCN 1102-Gida: Güvenlik, Risk ve Teknoloji & AFEE 5114-Tarım Öğretmenliği Semineri \\
\hline MATH 1031-Cebir ve olasilik & Veya ANSC 1511-Hayvansal Ürünlerin Muhafazas1 & AFEE 5116-Tarımsal Deneyim Programları Paylaşımı \\
\hline Fizik Bilimi [4] (laboratuvar zorunlu) & Doğal Kaynaklar [3] & AFEE 5118-Geleceğin Çifçileri Yönetim ve Danışmanlı̆̆ \\
\hline CHEM 1015-Kimyaya Giriș (Ders) & Bitki Bilimi [6] & AFEE 5697-Öğretmenlik Stajı: Okul ve sınıf \\
\hline CHEM 1017-Kimyaya Giriș (Laboratuvar) & CFAN 3001-Zararlılar ve Bitki Koruma & AFEE 5698-Öğretmenlik Staj1 \\
\hline Sosyal Bilimler [3] & Veya ENT 4015-Süs ve Çim Entomolojisi & Eğitim [13.5] \\
\hline PSTL 1281-Psikolojinin İlkeleri & Toprak Bilimi [4] & $\begin{array}{l}\text { OLPD 5000, 5010, 5020-Okul Kültürü ve İletişim CI 5163, 5164- } \\
\text { Çocuk ve Ergen Gelişimi. }\end{array}$ \\
\hline Veya PSY 1001-Psikolojiye Giriș & SOIL 2125-Temel Toprak Bilimi & CI 5307-Teknoloji Öğrenme ve Öğretme \\
\hline Belirlenen Temalar & Teknoloji [6] & CI 5452-Alan İçerikleri ve Okuma \\
\hline Toplumsal Yaşam ve Etik [3] $F S C N 1102$ & AFEE 2051-Mevcut Teknik Yeterlilikler & EPSY 5015, 5016-Öğretmenlik Öğrencilerinin Şartları \\
\hline ABD'de Sosyal Adalet ve Çeşitlilik [3] & AFEE 3112-Yap1 ve İnşaat Teknolojileri & PUBH 3005-Alkol ve Uyuşturucu Fonu \\
\hline Çevre [3] & & SEÇMELİ DERSLER [5 KREDİ] \\
\hline SOIL 2125-Temel Toprak Bilimi & & \\
\hline Küresel Bakış Açıları [3] & & \\
\hline APEC 1101-Mikro Ekonomi Illkeleri & & \\
\hline Teknoloji ve Toplum [3] & & \\
\hline CFAN 1501-Biyoteknoloji, Insan ve Çevre & & \\
\hline Nitelikli Yazma & & \\
\hline
\end{tabular}

Tablo 3. Tarım Öğretmenliği (Lisans Düzeyi) Eğitim Programı Kaynak: Agricultural Education (Teacher Licensure)

Tablo 3'de görüldüğü gibi, ülkemizde yükseköğretim düzeyinde; ziraat mühendisi, gıda mühendisi, makine mühendisliği, işletme (pazarlama vb.) ve veterinerlik eğitimi almış bireylerin öğretmenlik eğitimini almalarına müteakip "tarım öğretmenliği” kavramını oluşturacağı değerlendirilmektedir. Ayrıca yükseköğretim düzeyinde üniversitelerde kırsal kalkınmanın en etkin öğesi olan "tarım öğretmenliği” bölümünün oluşturulmasına ihtiyaç olduğu görülmektedir. Gerek ilköğretimde uygulanan taşımalı eğitim sisteminin gerekse mesleki anlamda verilmesine ihtiyaç duyulan tarım eğitiminin, kırsal alanda sürdürülebilir bir kalkınmayı sağlayacak şekilde ilköğretimden yükseköğretime kadar her seviyede bir bütün halinde sistem yaklaşımı ile ele alınıp en kısa sürede yeniden oluşturularak, uygulamaya geçirilmesine ihtiyaç vardır.

\section{Araştırmanın Soruları ve Amacı}

Bu çalışmanın üç temel sorusu vardır: 1) Kırsal alanlardan kentlere olan göçlerin nedenleri nelerdir? 2) Kırsaldan kente göçte var olan eğitim sisteminin etkileri nelerdir? 3) Kırsal alanlarda yaşayan ve çiftçilik yapan insanlara tarımla ilgili teknik eğitimlerin verilmesinin ve var olan eğitim sisteminde değişiklikler yapılmasının göçlerin önlenmesi üzerinde bir etkisi var mıdır? Oluşturulan bu üç temel soru bağlamında araştırmanın amacı: Kırsal alanlarda sürdürülebilir kalkınma için göçün önlenmesinde bir yaygın formel eğitim önerisinde bulunmaktır.

\section{Yöntem}

\subsection{Araştırmanın Örneklemi ve Veri Toplama Yöntemi}

Bu araştırma, İç Anadolu Bölgesi’nden Ayaş ilçesinde ve Beypazarı ilçesinin Macun ve Karaşar köylerinde; Akdeniz Bölgesi’nden Hatay Arsuz ilçesinin Karahüseyinli köyünde ve Karadeniz Bölgesi’nden Bolu Kıbrısçık ilçesinin Yazıca ve Köseler köylerinde yapılmıştır. Ayrıca Güneydoğu Anadolu Bölgesi'nden Diyarbakır ili kırsalında yapılmak üzere anketler gönderilmiş, fakat güvenlik nedeniyle izin alınamamıştır. Anketörler vasıtasıyla uygulanan anketlerden 150 tanesi geri dönmüştür. Ancak toplanan anketlerin sadece 123 adedi değerlendirilebilir nitelikte olduğu için istatistiki değerlendirmeye alınarak programa yüklenmiştir. Belirtilen bölgelerin başka kırsal kesimlerinde de yapılması devam eden bu araştırma, bir pilot uygulama olup, erişilen verilerin değerlendirilmesi sonucunda anket daha da geliştirilerek Türkiye'nin diğer bölgelerinde tarımsal ihracatın fazla olduğu iller seçilerek uygulama alanı genişletilecektir. $\mathrm{Bu}$ çalışmadaki değerlendirmeler toplanan veriler bağlamında gerçekleştirilmiştir. Sonuç olarak araştırmanın örneklemi; İç Anadolu Bölgesi’nde 52 anket, Akdeniz Bölgesi'nde 31 anket ve Karadeniz Bölgesin'nde de 40 anket olmak üzere toplam 123 anketten oluşmaktadır. 
Araştırmada veri ve bilgi toplamada anketörler vasıtasıyla yüzyüze anket yöntemi kullanılmıştır. Anket formu araştırmacıların kendileri tarafından kapsamlı literatür taraması sonucunda edindikleri bilgiler bağlamında hazırlanmış olup, toplam yirmibeş sorudan oluşmaktadır. Birinci bölünde daha çok demografik niteliklerle ilgili açık uçlu toplam sekiz soru bulunmakta; devamında göçün nedenleri ve tarımsal teknik eğitimle ilgili beşli likert ölçeğine göre hazırlamış olan toplam onyedi soru yer almaktadır.

\subsection{Araştırmada Kullanılan Analiz Yöntemi}

Araştırmada toplanan verilerin analizinde SPSS 22.00 programı kullanılmıştır. Öncelikle araştırmada kullanılan ölçeğin güvenilirliğini belirleyebilmek için Cronbach analizi yapılmıştır. Verilerin analizinde frekans ve yüzde dağılımlarıyla birlikte ortalama ve standart sapma gibi tanımlayıcı istatistiki yöntemlerden yararlanılmıştır.

\section{Araştırma Bulguları}

Kırsal alanlarda yaşamakta olan köy sakinleri üzerinde yapılmış bulunan bu araştırmada katılımcıların cinsiyetlerine göre dağılımlarında; \%74'ünün erkeklerden \%26'sının ise kadınlardan oluştuğu bulunmuştur. \%98.4'ü evli \%1.6'sı ise bekar olan katılımcıların yaş dağılımına bakıldığında; \%6.5'inin 30 ve altı yaş grubunda bulunduğu, \%26.8'inin 31-49 yaş grubunda yer aldığ1, \%47.2'sinin ise 50-69 yaş grubu arasında olduğu ve son olarak \%19.5'inin 70 ve üzeri yaş grubunda bulunduğu saptanmıştır. Kısal alanlardaki yaşam süreleri değerlendirildiğinde; katılımcıların \%25.2'sinin 1-40 yıldır köylerde yaşadıkları, \%44.7'sinin 41-60 yıldır ve \%30.1'inin ise 61-80 yıldır kırsalda yaşam sürdürdükleri saptanmıştır. Kırsal alanlardaki yaşamları boyunca çiftçilik deneyimlerinin ne olduğu sorulduğunda; katılımcıların \%21.1'i 1-20 yıl süresince çiftçilik yaptıklarını, $\% 46.3$ 'ü 21-40 yıldır ve \%32.5'i de 41 yıldan daha uzun süredir çiftçilik tecrübelerinin bulunduğunu belirtmişlerdir.

Eğitim düzeyine göre katılımcıların \%6.5'i okur-yazar, \%68.3'ü ilk öğretim, \%23.6’1 orta ve lise eğitim düzeyinde ve \%1.6'sı da (biri önlisans diğeri lisans eğitimli 2 kişi) lisans ve önlisans eğitimli kişilerden oluşmaktadır. Bu bağlamda araştırmanın yapıldığı kırsal alanlarda yaşayanların \%68.3 gibi büyük bir oranının oldukça düşük eğitimli bir grubu oluşturduğu ve üniversite mezunu katılımcı sayısının oldukça düşük olduğu söylenebilir. Katılımcıların tamamı okullarda lise düzeyinde tarımla ilgili hiçbir mesleki eğitim almadıklarını belirtmişlerdir. "Devlet okullarının dışında tarımla ilgili bir mesleki eğitim aldınız mı?” sorusuna ise sadece üç kişi 'evet' yanıtını vermiş geri kalan \%97.6'sı ise bir mesleki eğitim almadıklarını belirtmişlerdir. Eğitimle ilgili olarak erişilen bu bulgulardan da görüldüğü gibi, kırsal alanlarda yaşayan insanların eğitim düzeyleri düşük olmakla birlikte bu eksikliği giderebilmek amacıyla sonradan alınabilecek/veya alınması gerekli eğitimlerin de temin edilmediği söylenebilir. Oysa ki, kırsal alanlarda sürdürülebilir kalkınma için eğitimin önemi yadsınamaz.

Demografik verilerden elde edilen bu bulguların ötesinde kırsal alanlardaki göçlerin nedenleri ve çözümleri hakkında ulaşılan bulguların güvenirliliğini saptayabilmek amacıyla yapılan analiz sonucunda; Cronbach Alpha değerinin .833 olduğu bulunmuştur. Ölçekte yer alan tüm değişkenler, madde silindiğinde, güvenirlik katsayındaki değişmeye bakılmak amacıyla güvenirlik analizine tabi tutulmuştur. İncelenen madde ölçekten çıkarıldığında, geriye kalan diğer maddeler için güvenirlik katsayısının hesaplanması, ölçeğin güvenirliğindeki değişmeleri incelemek bakımından önemlidir. Eğer bir madde ölçekten çıkarıldığında alpha katsayısı, ölçeğin tümü için hesaplanan alpha katsayısına göre artış gösterirse, o maddenin güvenirliği azaltan bir madde olduğu söylenebilir ve bu maddenin ölçekten çıkarılması önerilir. Eğer bir madde ölçekten çıkarıldığında alpha katsayısı, ölçeğin tümü için hesaplanan alpha katsayısından küçük çıkarsa, o maddenin ölçekte kalması gerektiği düşünülür. Her faktör için ayrı ayrı madde silindiğinde güvenirlik katsayısı hesaplanmış ve 14. (insanlar hastalıklarından dolayı göç ediyorlar), 15. (şehirde yaşamanın kolaylıkları insanları göç ettiriyor), 21. (sağlık alt yapısı gelişirse, insanlar göç etmezler), 22. ( kırsal alanlarda insanlar arasında işbirliği yapılmaktadır) ve 24. (şu ana kadar geliştirilen kırsal kalkınma projelerinin başarıya ulaşma derecesi nedir?) maddelerin güvenirliliği azaltan maddeler olması sebebiyle ölçekten çıkarılmıştır. Belirtilen maddeler çıkarıldıktan sonra ölçekte kalan maddeler bağlamında kırsal alanlardaki göçlerin nedenleri Tablo 5'de verilmiştir. 


\begin{tabular}{|c|c|c|}
\hline İfadeler & Ortalama & Std. Sapma \\
\hline \multicolumn{3}{|l|}{ Kırsal Alanlardan Göçün Nedenleri } \\
\hline 9) Köylerde ilkokullar kapatıldıktan 452sonra çocukların eğitimi için şehirlere göç artmıştır & 4.5285 & .66929 \\
\hline 10) Tarımsal mesleki eğitim verilmediğinden verimli/kazançlı bir tarım yapılamıyor & 4.5447 & .69249 \\
\hline 11) Verimli tarım yapılamadığından insanlar yoksulluktan/işsizlikten göç ediyor & 4.4472 & .85126 \\
\hline $\begin{array}{l}\text { 12) Bilinçsiz, tarım ile gelecek nesillerin yaşayabilmesi için gerekli olan doğal kaynaklar } \\
\text { (toprak, su, orman ve çevre) yok ediliyor }\end{array}$ & 4.7398 & .49319 \\
\hline $\begin{array}{l}\text { 13) Gençler küçük yaşlardan itibaren ilçe merkezlerinde okuduğu için kırsalda yaşamayı } \\
\text { tercih etmiyorlar }\end{array}$ & 4.3740 & .78300 \\
\hline \multicolumn{3}{|l|}{ Kırsal Alanlardan Göçüm Çözümleri } \\
\hline 16) Köyde okul açılırsa ve kaliteli eğitim verilse, insanlar göç etmez & 4.2520 & .91967 \\
\hline $\begin{array}{l}\text { 17) Kırsal alanlarda tarımsal eğitimler verilirse, insanlar tarımdan daha çok kazanç elde } \\
\text { ederler }\end{array}$ & 4.5122 & .61891 \\
\hline $\begin{array}{l}\text { 18) Kırsal alanlarda tarımsal eğitimler verilirse, gelecek nesillerin yaşayabilmeleri için } \\
\text { gerekli doğal kaynaklar korunur }\end{array}$ & 4.5366 & .78189 \\
\hline $\begin{array}{l}\text { 19) Gençler küçük yaşlardan itibaren tarımsal faaliyetlerden uzaklaşmazsa şehirlere göç } \\
\text { etmezler }\end{array}$ & 4.3008 & .85828 \\
\hline 20) Kırsal alanlarda sosyal hayat gelişirse, insanlar göç etmezler & 4.4878 & .72841 \\
\hline 23) Kırsal alanlarda tarımsal eğitimler verilirse, işsizlik azalır & 4.3821 & .78428 \\
\hline
\end{tabular}

Tablo 5. Kırsal Alanlardaki Göçün Nedenleri ve Çözüm Yöntemleri

Tablo 5'te görüldüğü gibi, katılımcıların araştırmacılar tarafından belirtilen göç nedenlerine katılım düzeylerinin yüksek olduğu belirtilebilir. Katılımcıların tüm maddelere katılım düzeyleri "katılıyorum" (4) seçeneğinin üzerindedir. Köylü katılımcıların en yüksek katılımı "bilinçsiz tarım ile gelecek nesillerin yaşayabilmesi için gerekli olan doğal kaynaklar (toprak, su, orman ve çevre) yok ediliyor” ifadesine verdikleri görülmektedir. Bunu katılım düzeyi 4.54 ile "tarımsal mesleki eğitim verilmediğinden verimli/kazançlı bir tarım yapılamıyor" düşüncesi takip etmektedir. Göçü önlemeye yönelik çözüm ifadelerine bakıldığında, "kırsal alanlarda tarımsal eğitimler verilirse, gelecek nesillerin yaşayabilmeleri için gerekli doğal kaynaklar korunur" ifadesine katılımcıların en yüksek düzeyde katılım sağladıkları görülebilir. Bunu 4.51 katılım düzeyi ile "kırsal alanlarda tarımsal eğitimler verilirse, insanlar tarımdan daha çok kazanç elde ederler" ifadesi yer almaktadır. Bu ifadelerin aynı zamanda birinci ve ikinci derece önem arz eden göç nedenleri için çözüm önerileri olduğu belirtilebilir. Sonuç olarak kırsal alanlardan göçün önemli nedenlerinden birinin de eğitim olduğu söylenebilir.

\section{Sonuç}

Geçmişten günümüze gerçekleştirilen sürdürülebilir kırsal kalkınma stratejilerinin yeterli başarıya ulaşamadı̆̆ı, mevcut durumda hala kalkınamamış kırsal alanlardan ve kırsal kesimlerden kentlere gerçekleşen önlenemeyen göçlerden anlaşılmaktadır. Önlenemeyen göçlerin kaynaklarını açığa çıkarabilmek ve çözümler üretebilmek ve dolayısıyla sürdürülebilir kırsal kalkınmayı sağlayabilmek amacıyla gerçekleştirilen bu araştırma; İç Anadolu, Akdeniz ve Karadeniz olmak üzere üç farklı bölgede 123 katılımcı ile anketörler vasıtasıyla yüzyüze yapılan anket ile gerçekleştirilmiştir. Araştırma sonucunda demografik niteliklerle ilgili şu bulgulara ulaşılmıştır: 1) Araştırmanın uygulandığı kırsal kesim insanlarının eğitim düzeyleri düşüktür. 2) Katılımcıların tamamı okullarda lise düzeyinde tarımla ilgili hiçbir mesleki eğitim almamışlardır. 3) Devlet okullarının dışında tarımla ilgili olarak mesleki eğitim alan katılımcıların oranı düşüktür.

Kırsal alanlardan kentlere olan göçlerin nedenleri önem derecelerine göre şunlardır: 1) Bilinçsiz tarım ile gelecek nesillerin yaşayabilmesi için gerekli olan doğal kaynaklar (toprak, su, orman ve çevre) yok ediliyor. 2) Tarımsal mesleki eğitim verilmediğinden verimli/kazançlı bir tarım yapılamıyor. 3) Köylerde ilkokullar kapatıldıktan sonra çocukların eğitimi için kentlere göç artmıştır. 4) Verimli tarım yapılamadığından insanlar yoksulluktan/işsizlikten göç ediyor. 5) Gençler küçük yaşlardan itibaren ilçe merkezlerinde okuduğu için kırsalda yaşamayı tercih etmiyorlar.

Kırsal alanlardan kentlere olan göçlerin çözümleri ise önem derecelerine göre şunlardır: 1) Kırsal alanlarda tarımsal eğitimler verilirse, gelecek nesillerin yaşayabilmeleri için gerekli doğal kaynaklar korunur. 2) Kırsal alanlarda tarımsal eğitimler verilirse, insanlar tarımdan daha çok kazanç elde ederler. 3) Kırsal alanlarda sosyal hayat gelişirse, insanlar göç etmezler. 4) Kırsal alanlarda tarımsal eğitimler verilirse, işsizlik azalır. 5) Gençler küçük yaşlardan itibaren tarımsal faaliyetlerden uzaklaşmazsa, şehirlere göç etmezler. 6) Köyde okul açılırsa ve kaliteli eğitim verilse, insanlar göç etmezler.

Erişilen bu bulgulardan da görüldüğü gibi, önlenmekte güçlük çekilen göçlerin bir kısmının taşımalı eğitimin kırsalda yaşayan gençlere, küçük yaştan itibaren eğitim süresi boyunca kent yaşamının kolaylıklarını gösterdiği, kırsal alanda yaşamın iyi olmadığı, okulların kapatıldığı, sosyal imkânların yetersiz olduğunu hissettirdiği ve bunun neticesinde kırsal alanlarda/köylerde yaşamaması yönünde bir algı oluşturarak kırsalda yaşamayı istememeye ve tarım ile ilgili faaliyetlerden uzaklaştırmaya sebep olduğu sonucuna ulaşılmıştır. Kırsaldan göçe neden olan bir diğer unsurun da tarım eğitimi eksikliğinin olduğu görülmektedir. Cumhuriyet döneminden bugüne 
kadar uygulanan formal (resmi) mesleki eğitim sisteminde; kırsal kesimlerde yaşayanların yaptıkları işleri kapsayan bir mesleki eğitimin (tarım eğitiminin) doğrudan işi yapacaklara verilmediği tespit edilmiştir. Bu nedenlerle mevcut tarımsal eğitim sisteminin, sürdürülebilir kırsal kesimi destekleyebilecek şekilde yeniden organize edilerek çağdaş yönetim teknikleri ile yönetilmesi bir zorunluluk oluşturmaktadır. Ülkemizde kırsal alanlarda yaşayan ve büyüyen insanların aldıkları mevcut eğitim sisteminin kırsal alanda kalkınmayı sağlamış ülkelerin eğitim sistemleri ile karşılaştırılarak tüm ülkeyi kapsayan yaygın bir formal (resmi) eğitimle desteklenmiş bir kırsal kalkınma programının oluşturulması sonucuna ulaşılmıştır. Sürdürülebilir kırsal kalkınma için çevresel, ekonomik, sosyal ve tarımsal yönden insanların bilinç düzeylerinin yükseltilmesi gerekmektedir. Eğer bu bilinç düzeyi yükseltilemezse hem ülkemizin hem de dünyanın ihtiyaçlarımızı ve yaşam kabiliyetimizi sürdürülebilir kılması imkânsızlaşabilir. Bu nedenle ülkemizin tamamını kapsayacak şekilde ilköğretimden yükseköğretime kadar her düzeyde sürdürülebilir bir kırsal kalkınmayı öncelikli kılacak eğitimi yeniden yapılandırmak ve yaygın formal (resmi) eğitimle desteklenerek "tarım eğitimi eksikliğini”" ve "taşımalı eğitim sisteminin olumsuzluklarını" kaldırarak kırsal kesimlerden kentlere olan göçleri engellemek suretiyle sürdürülebilir kırsal kalkınmayı sağlayabilecek bir öneri oluşturulmuştur. Geçmişten günümüze kadar yapılan çalışmalarda sorunlar tespit edilmiş ancak sorunlar projelerle çözülmeye çalışılmıştır. Sorunu oluşturan ana sebepler ve bu sebeplerin nasıl ortadan kaldırılacağı ve uygulamasının nasıl olacağı tam olarak belirlenememiştir. Oysa ki, gelişmiş ülkelerde kırsal kesimlerde gerçekleştirilen kalkınmaya yönelik proje tipi çalışmalar, temel resmi eğitime ek olarak yapılan destekleyici çalışmalardır. Ülkemizde de bu yöndeki çalışmalar gelişmiş ülkelerde yapılan uygulamalara benzer şekilde destekleyici çalışma olarak gerçekleştirilmelidir. Sürdürülebilir kırsal kalkınma için yaygın formal eğitimle desteklenmiş kırsal kalkınma programı önerisi, şu adımlardan oluşmaktadır.

1. İlkokul seviyesinde verilen derslere tarımla ilgili derslerin de konulması ve bu derslerin daha ziyade öğrencilere toprakta uygulamalı öğretilmesi,

2. Lise seviyesindeki eğitimin ise; Türkiye'de her ilçede (919 ilçede) bulunan meslek, teknik veya çok programlı liselerde "bitkisel ve hayvansal ürünlerin üretilmesi, kalite ve verimlerinin yükseltilmesi, uygun koşullarda korunması, işlenip değerlendirilmesi ve pazarlanması konularını içeren bilgilerin ve yapı/inşaat/makine teknolojileri, girişimcilik, mikro ekonomi gibi tarımla uğraşanların kırsalda ihtiyacı olan konuları kapsayan ve bölgenin özelliklerine göre de gerekli bilgilerin” öğretildiği tek alanlı tarım bölümünün açılarak verilmesi (şu an Türkiye'de çiftçilik yapanlara yönelik resmi (formal) bir mesleki eğitim verilmemektedir)

3. Sürdürülebilir kalkınmayı sağlamış ülkelerdeki gibi ülkemizdeki üniversitelerde de "tarım öğretmenliği" branşının oluşturulması ve "tarım öğretmenliği” bölümünün açılması önerilmektedir. Liselerdeki tarım bölümünden mezun olan öğrencilerin lisans eğitimine "tarım öğretmenliğgi” bölümünden devam etmesi teşvik edilmelidir.

Bu tür bir uygulamanın pilot uygulama olarak tarımın daha yoğun olduğu ve tarımsal kazancın artma fırsatının bulunduğu il ve ilçelerde yapılması ve bu uygulama için $\mathrm{AB} / \mathrm{BM}$ ve devletin fon/kaynaklarından desteklenmesi önemlidir. Böylece kırsal alanların daha etkin ve verimli işletilmesi için profesyonel iş gücü oluşturulabilecek ve kırsal alanlar cazip hale getirilerek kentlerden kırsal alanlara göçler sağlanabilecektir. Yeni iş sahalarının oluşması ardı sıra kırsal alanlarda eğitim kurumlarının da açılmasında etkili güç olacaktır.

\section{Kaynakça}

- Agricultural Education (Teacher Licensure), 2016. University of Minnesota, http://aged.cfans.umn.edu/programs/licensure

- Altınok, Fırat, Soyu, 2015. "Küresel İklim Değişikliği Sorununun Çözümü İçin Yeni Bir Sürdürülebilir Kalkınma Anlayışı”, International Conference on Eurasian Economies, s. 623.

- Altunya, 2016. Köy Enstitüsü Sistemine Toplu Bir Bakış. Tarih ve Siyaset Serenti, 12.03.2012.

- Büyük Türkçe Sözlük, 2016a. Sürdürülebilir Kalkınma. http://tdk.gov.tr/index.php?option=com_bts\&view= bts\&kategori1 $=$ veritbn\&kelimesec $=294311$

- Büyük Türkçe Sözlük, 2016b. Sürdürülebilir Büyüme. http://tdk.gov.tr/index.php?option=com_bts\&view= bts\&kategori1 $=$ veritbn\&kelimesec $=294310$

- Büyük Türkçe Sözlük, 2016c. Tarım. http://www.tdk.gov.tr/index.php?option=com_bts\&arama=kelime\&guid $=$ TDK.GTS.56f835cc8acfa7.61756333

- Drucker, 2016. "The New Society of Organizations". Harvard Business Review. September-October 1992, https://hbr.org/1992/09/the-new-society-of-organizations

- EUR-Lex (Access to European Union Law), 2016. 2009 Review of the European Union Strategy for Sustainable Development. http://eur-lex.europa.eu/legal-content/EN/TXT/?uri=CELEX:52009DC0400

- European Commission (EC), 2016. Sustainable Development. http://ec.europa.eu/environment/eussd/

- İnam, 2015. Epistemiyatri Kapısını Açarken, Online yayınlar, http://phil.metu.edu.tr/ahmetinam/epistemiatri.htm

- International Institute for Sustainable Development (IISD), 2010. Sustainable Development: From Brundtland to Rio 2012. United Nations Headquarters, New York 
- İrmiş, Eroğlu, 2015. "Bir Kırsal Kalkınma Modeli Olarak Geleneksel Üretimi Yeniden Canlandırma Örneği: Yeşilyuva Ayakkabı Üretimi”, International Conference on Eurasian Economies, s. 689-698.

- Keskin, 2010. "Osmanlı İmparatorluğu'nda Modern Ziraat Eğitiminin Yaygınlaşması: Ankara Numune Tarlası ve Çoban Mektebi.” OTAM (Ankara Üniversitesi Osmanlı Tarihi Araştırma ve Uygulama Merkezi Dergisi),28. S-087-106. http://dergiler.ankara.edu.tr/dergiler/19/1664/17759.pdf

- Kırımhan, 2005.Organik Tarım Sistemleri ve Çevre. Turhan Kitabevi Ofset Matbaacılık Tesisleri.Ankara.

- Koçel, 2015. İşletme Yöneticiliği. Beta, İstanbul.

- Meslekî ve Teknik Eğitim Genel Müdürlüğ̈̈, 2016. Okul arama, http://mtegm.meb.gov.tr/TR/okullar.asp?PAGE=Liste

- Mesleki ve Teknik Eğitim Programlar ve Öğretim Materyalleri, 2016. Alan/Dal. http://www.megep.meb.gov.tr/Default.aspx?page=alanDal

- Milli Eğitim Bakanlığı, 2016. Köy enstitüleri, http://www.meb.gov.tr/meb/hasanali/egitimekatkilari /koy_enstitu.htm

- Milli Eğitim İstatistikleri Örgün Eğitim, 2012-2013. Milli Eğitim Bakanlığı. Ankara.

- OECD, 2004. Measuring Sustainable Development: Integrated Economic, Environmental and Social Frameworks. OECD Publications. Paris. France

- Öğrenci Seçme ve Yerleştirme Sınavı Klavuzu, 2016. ÖSYM. Ankara.

- Panorama, 2004.Towards A History Of Vocational Education And Training (VET) in Europe in A Comparative Perspective Proceedings of The First International Conference Volume II, 2002. Florence, Office for Official Publications of The European Communities, Luxembourg.

- Resmi Gazete, 2016a. Kanun No: 3238, Köy Eğitmenleri Kanunu. Resmi Gazete Say1: 3639. 24 Haziran 1937.https://www.tbmm.gov.tr/tutanaklar/KANUNLAR_KARARLAR/kanuntbmmc017/kanuntbmmc017/ka nuntbmmc01703238.pdf

- Resmi Gazete, 2016b. Kanun No: 3803, Köy Enstitüsü Kanunu. Resmi Gazete Sayıfa: 13682. 22 Nisan 1940. http://www.resmigazete.gov.tr/arsiv/4491.pdf

- Strange, Bayley, 2008. Sustainable Development. Linking Economy, Society, Environment. OECD.

- T.C. Kalkınma Bakanlığı, Kurumsal ve Stratejik Yönetim Dairesi Başkanlığı, 2016. Ulusal kalkınma stratejisi (2005-2009), http://www.sp.gov.tr/upload/xSPTemelBelge/files/3chYO+KirsalKalkinmaStrateji.pdf

- Tan, Hasdemir, Everest, 2015. "Türkiye'de Tarımsal Destekleme Politikaları", International Conference on Eurasian Economies 2015, s. 266-270.

- The EU Explained, 2014. Agriculture. European Commission Directorate -General for Communication Citizens information 1049 Brussels Belgium, Manuscript updated in November 2014, Luxembourg: Publications Office of the European Union.

- Türkiye İstatistik Kurumu (TÜIKK), 2016a. İstatistiksel Tablolar ve Dinamik Sorgulama, Göç Etme Nedenine Göre Göç Eden Nüfus ve Oran1, 2 Ekim 2011, http://www.tuik.gov.tr/PreIstatistikTablo.do?istab_id=1491

- Türkiye İstatistik Kurumu (TÜIK), 2016b. İstatistiksel Tablolar ve Dinamik Sorgulama. İllerin alddı̆̆ göç, net göç ve net göç hızı, 1980-2015. http://www.tuik.gov.tr/PreIstatistikTablo.do?istab_id=163

- Türkiye İstatistik Kurumu (TÜIK), 2016c. Y1llara ve cinsiyete göre il/ilçe merkezleri ve belde/köyler nüfusu, 1927-2015, www.tuik.gov.tr/PreIstatistikTablo.do?istab_id=1587

- Türkiye İstatistik Kurumu (TÜIK), 2016d. İstatistiksel Tablolar ve Dinamik Sorgulama, Y1llara ve cinsiyete göre il/ilçe merkezleri ve belde/köyler nüfusu, Genel Nüfus Sayıları 1927-2015. http://www.tuik.gov.tr/PreIstatistikTablo.do?istab_id=1587

- Türkiye İstatistik Kurumu (TÜIK), 2016e. İstatistiksel Tablolar ve Dinamik Sorgulama, 15+ yaştaki nüfusun işgücü durumu, http://www.tuik.gov.tr/PreTablo.do?alt_id=1007

- Türkiye Mülki İdare Bölümler Envanteri, 2016. Mülki idare birimleri, https://www.eicisleri.gov.tr/Anasayfa/MulkiIdariBolumleri.aspx

- Ulusal Kırsal Kalkınma Stratejisi (2014-2020), 2014. Yüksek planlama kurulunun 31.12.2014 tarihli 2014/45 sayıl1 kararı, Resmi Gazete Sayı: 29274, (21.02.2015).

- United Nations (UN), (1992). Sustainable Development Agenda 21. United Nations Conference on Environment \& Development Rio de Janerio, Brazil. https://sustainabledevelopment.un.org/ content/documents/Agenda21.pdf (01.06.2016).

- World Commission on Environment and Development (WCED), 1987. Our Common Future, From One Earth to One World. Oslo. http://www.un-documents.net/our-common-future.pdf (31.05. 2016).

- World Development Report 2008, (2007). Agriculture for Development. The World Bank. Washington DC.

- Yavuz, Miran, Özüdoğru, 2015. “Türkiye'de Tahıl Üreticilerinin Tarımsal Amaçları ve Üretimlerini Sürdürme Eğilimleri”, International Conference on Eurasian Economies 2015. 


\title{
Çalışma Hayatında Yaşanan Dönüşüm ve Çalışan Yoksulluğu Transformation in Working Life and Working Poverty
}

\author{
Asst. Prof. Dr. Gülşen Sarı Gerşil (Celal Bayar University, Turkey)
}

\begin{abstract}
Although it has taken into account that globalization has been increasing the enrichment all over the world consider, its emerging and growing poverty size is also engrossing. Because, changes in the labor market is steadily worsening and becoming a chronic state with globalization. Due to unfavorable conditions in working life, working who have got a job or routinely work and get steady income have also been facing with the risk of poverty besides the increase in unemployment is seen. The ones who fall into poor condition despite working have become so visible that "Working Poverty" has taken part in serious issues in international organizations. According to the ILO, "all working who live in a poor family" are referred as the ones working poorly. In general, the working Poverty is that the income earnt by employee cannot meet his needs and he has barely met even his basic needs or cannot. Transformations in the changing socio-economic structure with neo-liberal economy, causes such as flexible working practices experienced in the labor markets, increase in unregistered employment, lack of social protection and decline in unionization rates, gaps in wage levels lead to the increase in the working poor in Turkey and in the world. In this study, by making conceptual evaluation of the working poverty and considering data both published by international organizations (ILO, UN, Eurostat, OECD), and also published for Turkey (TEO, TSI), the dimensions of working poverty will be evaluated.
\end{abstract}

\section{Giriş}

Tüm Dünya'da arka arkaya krizlerin ortaya çıkması ve küreselleşme süreciyle birlikte uygulanan neo-liberal politikaların etkisi ve teknolojik gelişmeler işgücü piyasalarında köklü değişikliklere yol açmıştır. Esnek çalışma uygulamaları, taşeronlaşma, göç, kayıtdışı istihdam vb. faktörler emeğin değerini düşürmüştür. Bu durum, çalışanın elde ettiği gelirle geçinememesi ve yoksulluğa düşmesine yol açmıştır. Yoksulluk gözle görülür hale gelmiş ve tüm ülkelerin en öncelikli sorunları arasında yer almıştır. Yoksulluk algısı ülkelerin sosyo-ekonomik ve kültürel yapılarına göre farklılıklar göstermektedir.

Amerika'da yoksulluk uzun yıllar boyu çalışmak istemeyen insanların utancı olarak ifade edilmiştir. Temel düşünce kişilerin çalışamaması sonucunda yoksulluğa düşmesinin kaçınılmaz olmasıdır. Bu bağlamda insanlar çalışırlarsa bu riskle karşı karşıya kalmayacaklardır. Amerika'nın işgücü piyasaları Avrupa ülkelerinden farklı özellikler taşımaktadır. Bu nedenle, işsizlik politikaları başarılı görülebilir çünkü istihdam yaratma kapasiteleri oldukça iyidir. Ancak ücret gelirlerinde artış sağlayamamaları nedeniyle çalışanların ülke gelirinden aldıkları payın düşmesine ve gelir eşitsizliğine yol açmaktadır. Bu durum uzun vadede düşük ücretli istihdamının artmasına ve çalışan yoksulluğuna neden olmuştur.

Yapılan son araştırmaların küreselleşme süreciyle birlikte dünya da genel olarak zenginlik ve refahta artış gerçekleştiği yönündedir. Ancak yine bazı araştırmalar bu zenginlik ve refaha rağmen yoksullukta da ciddi artışlar olduğu yönündedir. Bu durum göstermektedir ki elde edilen zenginlik ve refah adil paylaşılamamaktadır. Yoksulluk kavramının farklılıklar göstermesi ve yeni yoksulluk kavramlarının ortaya çıktığı görülmektedir. Bu kavramlar arasında "çalışan yoksulluğu" tanımlanarak nedenleri, boyutları ve sonuçları ile değerlendirilmeye çalışılacaktır.

\section{Kavram Olarak Yoksulluk, "Çalışan Yoksulluğu”}

\subsection{Genel Olarak Yoksulluk}

Günümüz dünyasında yoğun olarak tartışılan sorunların başında yoksulluk gelmektedir. Tartışmaların temelini, yoksulluğun kavramlaştırılması ve ölçülerek belirlenmesi ile yoksullukla mücadele etmenin yolları oluşturmaktadır. Küreselleşme süreciyle birlikte artış gösteren "küresel yoksulluk" genel olarak küresel bir sorun olarak algılanmaya ve bununla ilgili mücadelenin uluslararası stratejilerle ve uluslar üstü kuruluşların katkılarıyla çözülmesi gerekliliğidir.

Çalışan yoksul kavramsal olarak ele alındığında hem çalışma hem de yoksulluk çerçevesinde değerlendirilmesi mümkündür. Çalışan yoksul tanımlanacak olursa, öncelikle yoksulluğun ele alındığı ve farkı yoksulluk kıstasları ve buna ilişkin farklı değerlendirmeler sözkonusu olacaktır. Bu bağlamda, yoksulluğun ekonomik gelir ve tüketim harcamalarının yanısıra Semanta Sen'in yapılabilirlik ölçütleri önemli ölçüde dikkate alınmaktadır. Kişilerin yaşamını sürdürebilmeleri, asgari temel ihtiyaçlarını karşılayabilmesi ve ya minimum kalori miktarı için gereken tüketim harcamaları için hesaplama öngörülmektedir.

Bu çerçevede, yaşayabilmek anlamında en düşük gıdanın ekonomik değeri yoksulluğun belirlenmesinde bir sınır kabul edilmekte ve bu sınırın altında kalanlar yoksul olarak nitelendirilmektedirler (Şenses, 2003). Bu yaklaşım 
mutlak yoksulluk olarak ifade edilmekte ve gelişmemiş ülkelerde yaygın olarak görülürken, gelişmiş ülkelerde daha çok göreceli yoksulluk sözkonusu olmakla birlikte ABD yoksulluk kavramında halen mutlak yoksulluğu dikkate almaktadır (Seçer, 2007).

Heterojen bir özelliği bulunan yoksulluk, dünya genelinde bölgelere ve ülkelere göre farklı biçimlerde kendini gösterebilmektedir. Yapılan bazı araştırmalarda yoksulluğun kentsel, kırsal veya coğrafi açılardan ele alınarak boyutlarının belirlenmesine çalışılmaktadır (Ersoy, 1985). Kırsalda yaşanan yoksulluğun, Kentlerde yaşanan yoksulluğa göre daha yoğun olduğu bazı araştırmalarda ortaya çıkmıştır (Ecevit ve Ecevit, 2002).

Multidisipliner yoksulluk kavramı farklı bakış açıları nedeniyle farklı yaklaşımları beraberinde getirmektedir. Bazı yaklaşımlara göre yoksulluk, "sistemin yapısından ve işleyişinden kaynaklanan güç ve servet dağılımındaki eşitsizliğin bir sonucu" olarak görülürken; bazıların da ise, "yoksul olarak tanımlanan kişilerin, eğitimsizlik, beceri ve kapasite gibi bireysel nitelik ve yeteneklerinin düşüklüğü nedeniyle ortaya çıkan firsatlardan yararlanamama durumu" olarak tanımlamaktadır. Bu iki yaklaşım da yoksulluğu, onu doğuran nedenler üzerinden tanımlamaya yöneliktir (Gündoğan, 2008).

Yoksulluk ülkelerin sosyo ekonomik yapıları açısından farklı tanım ve ölçümlere sahip bulunmakla birlikte genel uygulama mutlak ve göreceli yoksulluk dikkate alınarak belirlenmektedir. Mutlak yoksulluk, gerek haneler gerekse de bireyler açısından yukarıda da değinildiği üzere asgari yaşam standartlarının sağlanamaması ve belirlenen yoksulluk sınırının altında kalınmasıdır. Bu çerçevede, mutlak yoksulluğun devletlerin refah politikaları ülke gelirinin dağılımı ve tüketim harcamalarının belirlenmesi açısından değerlendirildiği ve uygulandığ yoksulluk kavramıdır. Sonuç olarak, amaçlanan bireylerin fiziksel ihtiyaçlarının karşılanması ve yaşamlarını sürdürebilmeleridir. Göreli yoksulluk ise, Bir ülkede belirlenen ortalama refah düzeyi açısından bireylerin sözkonusu bu refah düzeyinin altında kalmasıdır. Yani toplumun kültürel yapısına göre bireylerin yaşam standartlarının göreli olarak karşılaştırılmasıdır. Göreli yoksulluk, gelişmiş ülkelerde görülmekle birlikte, gelişmemiş ülkelerde kalkınma göstergesidir (İçli, 2009).

Ínsani Yoksulluk, Birleşmiş Milletler Kalkınma Programı (UNDP) tarafından 1997 İnsani Gelişme Raporu ile ilk kez söz edilmiştir. İnsani yoksulluk, "gelir yoksulluğu ile ilişkili bulunmasına rağmen ondan farklıdır. Gelir yoksulluğu ölçümleri mutlak gelir üzerine odaklanırken, insanî yoksulluk kavramı, okur-yazarlık, yetersiz beslenme, kısa yaşam süresi, ana-çocuk sağlığının yetersizliği, önlenebilir hastalıklara yakalanmak gibi temel insanî yeteneklerden yoksun olmak biçiminde" tanımlanabilir. Tanımdan da anlaşılacağı üzere, insanın temel yeteneklerini devam ettirebilmesi, üretim, hizmet ve destek unsurların ( sağlık hizmetleri başta olmak üzere, su kaynağına, eğitime, enerjiye ulaşamamak, iletişim kuramamak vb.) olmaması veya sınırlandırılması insani yoksulluk boyutu olarak değerlendirilmektedir. Aynı raporda, "insani yoksulluğu ölçmek amacıyla İnsani Yoksulluk Endeksi (Human Poverty Index) geliştirilmiştir. Bu endeks gelişmekte olan ülkeler için üç kriterden yola çıkarak hesaplanmaktadır" (Memiş, 2014). "Yaşam süresi: 40 yaşın altındaki nüfus yüzdesi Eğitim: Okuma yazma bilmeyen nüfus yüzdesi, Makul bir yaşam standardı (Sağlıklı içme suyuna sahip olmayan nüfus yüzdesi, temel Sağlık imkânlarından yoksun nüfus yüzdesi, 5 yaşın altında olan ve yeterli beslenemeyen, bu yüzden ciddi düzeyde düşük kilolu olan çocukların nüfus yüzdesinden oluşmaktadır)” (UNDP, 1997 İnsani Gelişme Raporu).

\begin{tabular}{lccccc}
\hline Bölgeler & $\mathbf{1 9 8 7}$ & $\mathbf{1 9 9 3}$ & $\mathbf{2 0 0 2}$ & $\mathbf{2 0 0 5}$ & $\mathbf{2 0 1 0}$ \\
\hline Doğu Asya ve Pasifik & 81,59 & 75,76 & 51,93 & 39,03 & 29,73 \\
Avrupa ve Orta Asya & 6,33 & 9,18 & 7,92 & 4,6 & 2,35 \\
Güney Amerika ve Karaipler & 22,35 & 21,72 & 22,23 & 16,69 & 10,37 \\
Orta Doğu ve Kuzey Afrika & 26,14 & 22,13 & 19,73 & 17,37 & 12,04 \\
Güney Asya & 84,48 & 82,67 & 77,41 & 73,36 & 66,71 \\
Sahra Altı Afrika & 74,29 & 78,12 & 76,11 & 74,08 & 69,87 \\
Üst Orta Gelir Grubu & 58,53 & 55,31 & 38,03 & 27,61 & 19,46 \\
Türkiye & 7,68 & $9,84(2)$ & 9,57 & 6,87 & 4,71 \\
\hline
\end{tabular}

Tablo 1: Dünyanın Farklı Bölgelerinde Yoksulluk Oranları, Kaynak: Word Bank

(1) Günde 2 dolardan az gelirle geçinen nüfusun toplam nüfusa oranı.

(2) 1994 yılına ait veridir.

Tablo 1'de, yoksulluk oranları ele alınan bölgelerde yıllar itibarıyla düşüş göstermektedir. Bunun yanında, Doğu Asya ve Pasifik bölgesi 2000 yılı öncesinde yakın değerler aldığı Güney Asya ve Sahra altı Afrika bölgelerine kıyasla daha fazla düşüş göstermiştir. Tüm yıllar itibarıyla en düşük yoksulluk oranına sahip bölge ise Avrupa ve Orta Asya olmaktadır. Türkiye ise Avrupa ve Orta Asya bölgesinin biraz üzerinde, ancak diğer bölgelere kıyasla 
düşük yoksulluk oranına sahiptir. Benzer şekilde, Türkiye'nin yoksulluk oranı, dâhil olduğu üst, orta gelir grubu ülkelerinin ortalama değerinden de düşüktür.

Dünyada genel kabul görmüş olan yoksulluk parametreleri, "satın alma gücü paritesine göre hesaplanan günlük 1,25 dolar ya da 2 doların altında gelirle hayatını sürdürmek zorunda kalan insanları yoksul olarak kabul eden Dünya Bankası'nın yöntemidir. Buna göre günlük 1,25 dolar, açlık sınırını ifade etmektedir. Bu sınır sadece insanın yaşamını sürdürebilmesi için gerekli olan asgari gıda ihtiyacını belirlemektedir. 2 dolarlık seviye ise temel ihtiyaçlar olarak ifade edilen sadece gıda değil, aynı zamanda ısınma, giyinme, bir hanede oturma, kısacası asgari sosyal yaşam hakkına sahip olmanın en düşük düzeyini göstermektedir" (World Bank). Tablo 1'de Dünya'da farklı yoksulluk seviyeleri görülmektedir.

\begin{tabular}{llll}
\hline & \multicolumn{2}{c}{ DÜNNYA NÜFUSU $(\%)$} & \\
\hline Bir Günde Elde & $(\$)$ & Kişi & Nüfus (\%) \\
Edilen Gelir (\$) & & Sayısı(Milyon) & \\
$\mathbf{1 \$}$ & 1\$'dan Az & 880 & 14 \\
& 1\$'dan Çok & 5.580 & 86 \\
$\mathbf{1 , 2 5 \$}$ & 1,25\$'dan Az & 1.400 & 22 \\
& 1,25\$'dan Çok & 5.060 & 78 \\
$\mathbf{1 , 4 5 \$}$ & 1,45\$'dan Az & 1.720 & 27 \\
& 1,45\$'dan Çok & 4.740 & 73 \\
$\mathbf{2 \$}$ & 2\$'dan Az & 2.600 & 40 \\
& 2\$'dan Çok & 3.860 & 60 \\
$\mathbf{2 , 5 \$}$ & 2,5\$'dan Az & 3.140 & 49 \\
& 2,5\$'dan Çok & 3.320 & 51 \\
$\mathbf{1 0 \$}$ & 10\$'dan Az & 5.150 & 80 \\
& 10\$'dan Çok & 1.310 & 20 \\
\hline
\end{tabular}

Tablo 2: Dünya'da Farklı Yoksulluk Seviyeleri (2005 Yılı Satın Alma Gücü Paritesine Göre) Kaynak: Global Issues, Social, Political, Economic and Environmental Issues That Affect Us All

Tablo 2'de bir günde dolar cinsinden elde edilen gelir dikkate alınarak dünyada farklı yoksulluk seviyeleri verilmiştir. Buna göre; "1 doların altında gelire sahip olanlar dünya nüfusunun \%14’ünü (880 milyon kişi), 1,25 doların altında gelire sahip olanlar \%22'sini (1 milyar 400 milyon kişi), 1,45 doların altında gelire sahip olanlar \%27'sini (1 milyar 720 milyon kişi), 2 doların altında gelire sahip olanlar \%40’ını (2 milyar 600 milyon kişi), 2,5 doların altında gelire sahip olanlar \%49'unu (3 milyar 140 milyon kişi), 10 doların altında gelire sahip olanlar da \%80'ini (5 milyar 150 milyon kişi)" oluşturmaktadır.

\section{2 Çalışan Yoksulluğu}

Yoksulluk konusunda yapılan araştırmaların büyük çoğunluğu işgücü piyasalarında ekonomik olarak aktif olmayan kesimler yani istihdam edilemeyen işsizler üzerinde yoğunlaşmaktadır. Ancak bazı akademik araştırmaların çalışan yoksullara dikkat dikkat çektiği görülmektedir. Bu çerçevede, çalışan yoksullukla kıyaslanabilir durumlara bakıldığında; benzer işi yapan kişilerin çalışma performansları karşılaştırılarak düşük performansla çalışana daha düşük ücret ödenmesi, süreklilik özelliği olmayan kısa süreli işler nedeniyle düzensiz çalışma süreleri, terfi alamama, niteliksiz işlerde çalışma, sosyal yardımlarda yararlanamama, tam zamanlı çalışmakla birlikte çalışma koşullarının kötü olması vb. çalışan yoksulluğunu da beraberinde getirmektedir (Scholtens, 2002).

Çalışan yoksul her ne kadar istatistiki açıdan ifade edilebilir olsa da, sosyo ekonomik boyutları dikkat çekmektedir. Bu çerçevede, dünya genelinde yoksul bir hanede doğan ve yaşayan çalışanlar "çalışan yoksul” olarak değerlendirilmektedir. Buda göstermektedir ki, yoksulları çalışan yoksullardan ayır edici iki faktör bulunmaktadır. İlki çalışan kavramı olup, ikincisi de, ekonomik gelirin belirlenen yoksulluk sınırının altında gelire sahip bir hane halkı içinde yaşamaktır (EUROFOUND, 2013). Gelir düzeyinin belirlenen yoksulluk sınırının altında bulunması ve çalışan yoksullun hanehalkı içinde toplanan bu gelirden eşit yaralanamaması, bazı sorunlara yol açmaktadır. Özellikle hanehalkı içinde yaşayan kadın ve çocukların sosyo kültürel nedenlerden dolayı bundan olumsuz etkilendikleri görülmektedir. Bu durum çalışan yoksulun toplumda sosyal dişlanmayla karşı karşıya kalmasına neden olmaktadır (Erdoğdu, Kutlu, 2014).

İstihdam ve yoksulluk kavramları her ne kadar farklı kavramlarmış gibi görünse de, aslında birbirlerini tamamlayan sosyal ve ekonomik adaletsizliklerin önemli unsurlarını oluşturmaktadırlar. Bazen istihdamın genel yapısı ve niteliği, adaletsizliği ve yoksulluğu besleyen bir unsur haline dönüşebilmektedir. Küresel ekonomik yapıda işgücü piyasalarına göre esnek istihdam şekli ile yoksulluk kavramının farklı boyutları ile karşılaşılmaktadır.

Yeni bir kavram olarak ortaya çıkan çalışan yoksullar incelendiğinde benzer özellikler ortaya çıkmaktadır. Yapılan araştırmalar küreselleşme olgusunun olumlu ve olumsuz yönlerine vurgu yapmaktadır. Küreselleşme 
süreciyle birlikte benimsenen neo-liberal politikalar, enformel istihdamı arttırarak düşük ücretli, düzensiz, örgütsüz ve güvencesiz istihdamın yayılmasına yol açmış, diğer yandan ise kayıtlı istihdamı daraltarak (Chen, vd., 2005: 6) beraberinde çalışan yoksulların ortaya çıkmasına neden olmuştur (Suğur vd., 2010).

\begin{tabular}{|c|c|c|c|}
\hline Ülke & Kaynak & Çalışma Tanımı & Yoksulluk Eşiği \\
\hline AB & Eurostat & $\begin{array}{l}\text { Asgari } 15 \text { saat istihdam edilmek } \\
\text {-Önceki yılda en sık görülen faallik } \\
\text { durumu }\end{array}$ & $\begin{array}{l}\text { Düşük gelir çizgisi: ortalama } \\
\text { hanehalkı gelirinin \% } \\
60 \text { 'ından daha azına eşit } \\
\text { (Göreli parasal yoksulluk) }\end{array}$ \\
\hline Fransa & $\begin{array}{l}\text {-Ulusal İstatistik ve } \\
\text { Ekonomi Enstitüsü } \\
\text {-Akademik } \\
\text {-Sosyal Dışlanma } \\
\text { Ulusal Eylem Planı }\end{array}$ & $\begin{array}{l}\text {-işgücü piyasasında asgari } 6 \text { ay geçiren } \\
\text { kişiler (çalışarak veya iş arayarak) } \\
\text {-asgari } 6 \text { ay çalışan kişiler } \\
\text {-bir yıl boyunca asgari } 1 \text { ay is sahibi } \\
\text { olanlar }\end{array}$ & $\begin{array}{l}\text { Düşük gelir çizgisi: ortalama } \\
\text { hanehalkı gelirinin \% } \\
\text { 50'sinden daha azına eşit } \\
\text { (Göreli parasal yoksulluk) }\end{array}$ \\
\hline Belçika & Ulusal Eylem Planı & $\begin{array}{l}\text {-işgücü piyasasında asgari } 6 \text { ay geçiren } \\
\text { kişiler (çalışarak veya iş arayarak) } \\
\text {-asgari } 6 \text { ay çalışan kişiler }\end{array}$ & $\begin{array}{l}\text { Düşük gelir çizgisi: ortalama } \\
\text { hanehalkı gelirinin \% } \\
60 \text { ’ından daha azına eşit } \\
\text { (Göreli parasal yoksulluk) }\end{array}$ \\
\hline İsviçre & $\begin{array}{l}\text {-Federal İstatistik } \\
\text { Bürosu } \\
\text {-Akademik }\end{array}$ & $\begin{array}{l}\text {-çalışma saatlerine bakılmaksızın tüm } \\
\text { faal bireyler veya } \\
\text {-tam zamanlı çalışan tüm bireyler } \\
\text { (haftada } 36 \text { saat veya üstü) } \\
\text {-haftada asgari } 40 \text { saat kazançlı bir } \\
\text { faaliyeti olan birey }\end{array}$ & $\begin{array}{l}\text { Yaşam için gerekli asgari } \\
\text { gelire, ortalama kira ve temel } \\
\text { sağlık sigortası priminin } \\
\text { eklenmesiyle hesaplanan } \\
\text { yoksulluk çizgisi }\end{array}$ \\
\hline \multirow[t]{4}{*}{ ABD } & Nüfus Dairesi & $\begin{array}{l}\text { Aile üyelerinin çalışma saatlerinin } \\
\text { toplam } 1750 \text { saate eşit veya fazla } \\
\text { olması ( } 44 \text { hafta) }\end{array}$ & \\
\hline & & & $\begin{array}{l}\text { Federal Yoksulluk Çizgisi } \\
\text { (Mutlak parasal yoksulluk) }\end{array}$ \\
\hline & $\begin{array}{l}\text { İşgücü İstatistikleri } \\
\text { Dairesi }\end{array}$ & $\begin{array}{l}\text { İşgücü piyasasında (çalışarak veya iş } \\
\text { arayarak) asgari yılın } 6 \text { ayını geçiren } \\
\text { ( } 27 \text { hafta) bireyler }\end{array}$ & \\
\hline & Araştırmacılar & $\begin{array}{l}\text { Asgari yarı zaman çalışan yetişkinler } \\
\text { (yaklaşık } 1000 \text { saat) }\end{array}$ & $\begin{array}{l}\text { Federal Yoksulluk Çizgisinin } \\
\% \text { 125- \% } 150 \text { - \% 200’ünden } \\
\text { az gelir ((Mutlak parasal } \\
\text { yoksulluk) }\end{array}$ \\
\hline \multirow[t]{3}{*}{ Kanada } & $\begin{array}{l}\text { Ulusal Refah } \\
\text { Konseyi }\end{array}$ & $\begin{array}{l}\text { Toplam aile gelirinin \% 50'sinden } \\
\text { fazlasının ücretler, maaşlar veya kendi } \\
\text { hesabına çalışmadan elde edilmesi }\end{array}$ & $\begin{array}{l}\text { İstatistik Kanada'nın düşük- } \\
\text { gelir sınırı (LICO) } \\
\text { (Mutlak parasal yoksulluk) }\end{array}$ \\
\hline & $\begin{array}{l}\text { Sosyal Gelişme } \\
\text { Konseyi }\end{array}$ & $\begin{array}{l}49 \text { hafta tam zamanlı (haftada asgari } \\
30 \text { saat) veya kısmi süreli çalışan } \\
\text { yetişkinler }\end{array}$ & $\begin{array}{l}\text { Sosyal Gelişme Konseyi } \\
\text { göreli düşük kazanç çizgisi } \\
\text { (Göreli parasal yoksulluk) }\end{array}$ \\
\hline & $\begin{array}{l}\text { Politika Araştırma } \\
\text { Ağ1 }\end{array}$ & Tam zamanlı/ Tam yıl çalışanlar & $\begin{array}{l}\text { Göreli düşük-gelir çizgisi: } \\
\text { y1lda } 20.000 \text { \$ dan az (Göreli } \\
\text { parasal yoksulluk) }\end{array}$ \\
\hline Avustralya & $\begin{array}{l}\text { Sosyal Politika } \\
\text { Araştırma Merkezi }\end{array}$ & $\begin{array}{l}\text { Çalışma saatlerine bakılmaksızın tüm } \\
\text { faal bireyler }\end{array}$ & $\begin{array}{l}\text { Henderson mutlak yoksulluk } \\
\text { çizgisi } \\
\text { (Mutlak parasal yoksulluk) }\end{array}$ \\
\hline
\end{tabular}

Tablo 3: Literatürde Çeşitli Çalışan Yoksul Tanımlamaları, Kaynak: Peña-Casas, Latta, 2004.

ABD dışında başka ülkelerde de çalışan yoksul tanımlarının yapıldığı görülmektedir. Örneğin İsviçre Federal İstatistik Bürosu, "Çalışma saatlerine bakılmaksızın tüm faal bireyler, yaşam için gerekli asgari gelirin, ortalama kira ve temel sağlık sigortası priminin eklenmesiyle hesaplanan yoksulluk çizgisinin altında kalması halinde" 
çalışan yoksul olarak kabul etmektedir. Çeşitli ülkelerde kullanılan çalışan yoksul tanımları aşağıdaki tablo 3'de verilmiştir.

Uluslararası Çalışma Örgütü (ILO) çalışan yoksulları, "benzer şekilde çalışan ve yoksul hane halkına üye olan kimseler olarak tanımlamaktadır" (Majid, 2001). Dünya İstihdam Raporunda ise, "çalışan yoksul hem kabul edilen bir yoksulluk sınırı altında olan, hem de işgücü piyasasına katılan bireyler" olarak tanımlanmaktadır. Bu da göstermektedir ki, yapılan tanım her ne kadar yoksulluk istatistiklerine dayansa da, ülkelerin demografik özellikleri farklılık göstermektedir. Örneğin, çalışma çağındaki nüfus (15-65 yaş arası), işgücü piyasasına dahil olma oranları ve işsizlik oranlarının yanısıra iş yasaları vb. farklılıklar göz ardı edilemez (Kapsos, 2005).

\section{3 Çalışan Yoksulluğun Boyutları}

Küresel sorunların başında gelen yoksulluk tüm ülkelerin çözüm üretmek amacıyla üzerinde çalıştığı konuların başında yer almaktadır. Uluslarüstü kuruluşlar tarafından yoğun olarak tartışılan yoksulluk verilerine bakıldığında Dünya Bankası verilerine göre; "günlük geliri 1.25\$'ın (satın alma gücü paritesine göre) altında olan nüfusun Dünya nüfusuna oranı 1981 yılında \%52, 1990 yılında \% 43 ve 2011 yılında \%’ 17 dir. Bu da Dünya'da yaklaşık 1 milyarın üstünde insanın yoksulluk ile mücadele ettiğini göstermekte olup bu nüfusun büyük çoğunluğu Sahara Afrikası ve Güney Asya ülkelerinde yaşamaktadır”. Yoksulluk Türkiye açısından da önemli sorunlar arasında yer almaktadır. TÜİK (Türkiye İstatistik Kurumu) tarafından belirlenen "4 kişilik bir aile için yoksulluk sınırı 4.963 lira olup, yaklaşık 11 Milyon kişi bu sınırın altında yaşamaktadır” (Duran, 2015).

\subsection{Türkiye'de Çalışan Yoksulluğu}

Küreselleşme ile birlikte emeğin değersizleştirilmesi nedeniyle düşük ücretle çalışan bireylerin gelirleri belirlenen mutlak yoksulluk sınırının altında kalması, çalışan yoksulların ortaya çıkmasına yol açmıştır. Tüm dünyada hızla artan çalışan yoksullar daha çok az gelişmiş ülkelerde yoğunlaşmaktadır. Bilimsel çalışmalar çözüm üretilmemesi halinde çalışan yoksulların ülkeler açısından ciddi sorunlar yaratabileceği yönünde sonuçlar açıklamaktadır. Türkiye'nin sosyo-kültürel yapısındaki değişim ve dönüşüm nedeniyle geleneksel dayanışmanın azalması, yoksullar açısından olumsuz sonuçların ortaya çıkmasına neden olmaktadır. İşgücü piyasalarına giremeyen ya da düşük ücret nedeniyle toplumsal dışlanmaya maruz kalabilen bireylerin sayısı artmakta ve toplumda farklı tabakalaşmalar ortaya çıkmaktadır (UNDP, 2005). Türkiye'de yoksulluk oranları incelendiğinde, kadınların kayıtdışı istihdamı nedeniyle çoğunlukla da ücretsiz aile işçisi olarak çalışmaları yoksulluktan en çok etkilenen (\% 32.03) kesimi oluşturduklarını ve yine (\% 28.56) en çok yevmiyeli olarak çalışanlar yani niteliksiz işgücü ve göçmenlerin etkilendiği görülmektedir (TUIK, 2008).

Son zamanlarda yoksulluğu toplumsal cinsiyet temelinde ele alan ve kadın yoksulluğuna dikkat çeken çalışmalar kadının hem evde hem de çalışma hayatında erkeğe göre yoksulluğu daha derin yaşadı̆̆ koymaktadır. Bunun yanı sıra işgücü piyasaları açısından dezavantajlı gruplar arasında bulunan yaşlılar, çocuklar, engelliler, farklı etnik kökene sahip olanlar, göç edenler vb. yoksulluk çerçevesinde ele alan çalışmaların arttığı görülmektedir. Bu bağlamda ilk kez ABD yapılan çalışmalarda çalışan yoksulluğu kavramı literatürde yer almıştır.

\begin{tabular}{lllll}
\hline Çeşitli Yıllar & $\mathbf{2 0 0 6}$ & $\mathbf{2 0 1 2}$ & $\mathbf{2 0 1 4}$ & $\mathbf{2 0 1 8 * *}$ \\
\hline İşgücüne Katılım Oranı ( \%) & 46.3 & 50.0 & 51,0 & 53.8 \\
Kadınların İşgüicüne Katılım Oranı( \%) & 23.6 & 29.5 & 30,1 & 34.9 \\
İstihdam (milyon) & 20.4 & 24.8 & 26.1 & 29.9 \\
İşsizlik Oranı( \%) & 10.2 & 9.2 & 10,7 & 7.2 \\
Genç İşsizlik Oranı( \%) & 19.1 & 17.5 & 19,4 & 13.0 \\
Kayıt Dışı İstihdam( \%) & 47.0 & 39.0 & 35.1 & 30.0 \\
İşKUR’a Kayıtlı İşsizlerin Yerleştirilme Oranı( \%) & 12.3 & 23.5 & 25,5 & 50.0 \\
\hline
\end{tabular}

Tablo 4. Türkiye Içcin Kilit Işsücü Piyasası Göstergeleri, Kaynak: 2006 Ve 2012 Yılı Verileri TÜIKK ve Türkiye IŞ Kurumuna (İ̧KUR) Aittir. 2013 Ve 2018 Yılı Verileri Onuncu Kalkınma Planı Tahminleridir.

* Kadınların işgücüne katılma oranı ve kayıt dışı istihdam oranı: Kasım 2014'e (son mevcut veri noktası) kadarki ayların ortalamasıdır. IŞKUR verileri yıllıktır. Diğer satırlar Kasım 2014 itibariyle mevsimsel olarak düzeltilmiş değerleri göstermektedir.

**Plan hedefi

Kentsel yoksulluğun en önemli kaynağını çoğunlukla kayıtdışı sektörde çalışanlar oluşturmaktadır. Kayıtdışı sektör genellikle sosyal güvencesiz ve düşük ücretler nedeniyle yoksulluk kavramıyla özdeşleşmektedir. Kayıtdışı işler çoğunlukla eğitimsiz ve nitelik gerektirmeyen sık sı işe giriş ve çıkışa elverişli olması nedeniyle işgücü piyasalarına girmesi zor olan dezavantajlı gurupları (kadınlar, çocuklar, göç edenler, öğrenciler, emekliler, özürlüler vb.) kapsar. Kayıtdışı sektörlerde sendikal örgütlenme yoktur. Düşük sermaye ve basit teknoloji ile üretim yapılan merdiven altı işleri kapsamaktadır (Ersoy, 2000). Kayıtdışı sektör Türkiye'de istihdamı genişletmekle birlikte çalışma hayatında kuralsızlaştırmayı ve emeğin istismarını da doğurmaktadır. 
Türkiye'de orta vadede genç işsizliğini azaltmak ve kadınların işgücü piyasalarına girmesini sağlamak kadın ve genç istihdamın arttırılması hedeflenmektedir. Bu bağlamda devletin ciddi politika uygulamaları olumlu sonuçlar vermiştir. Ancak buna rağmen Tablo 4'de de görüleceği üzere, çalışma çağı nüfusu (15-65 yaş arası) büyük oranda (yaklaşık \% 50) istihdam edilememektedir. Bunun nedeni, OECD verilerine incelendiğinde; Türkiye kadın istihdamında OECD ortalamasının (\% 65) oldukça altında kalmaktadır ki buda \% 30 oranında kadın istidamı ile açıklanabilir. Yine genellikle kadın ağırlıklı olmakla birlikte gençlerin hemen hemen \% 35'i işgücüne dahil olmadığı gibi eğitimde almamaktadır. Bu oran OECD ortalaması açısından en yüksek aktif olmayan genç nüfusudur. 2014 yılı genç işsizlik oranı \%19.4 gibi oldukça düşündürücü bir orana sahiptir. Ayrıca istihdam edilen gençlerin \% 48 ise kayıtdışı sektörde çalışmaktadır. Kayıt dışı istihdam oranı genel nüfus içinde \% 35 olarak görülmektedir.

Adil gelir dağılımının sağlanması, yoksulluk sorununun çözülmesinde oldukça önemlidir. Bu kapsamda, uygulanan politikalar sonuç vermiş ve Türkiye'de günlük geliri 4,3 doların altında kalan nüfusun oranı, 2006 yılında \% 13,3 seviyesinden 2011'de \% 2,8'e düşmüş, gelir dağılımında sağlanan eşitliğin yansıması Gini katsayısını 2006 yılını 0,40 seviyesinden 2011'de 0,38'e düşürmüştür (Tablo 5).

\begin{tabular}{lllll}
\hline & $\mathbf{2 0 0 6}$ & $\mathbf{2 0 1 1}$ & $\mathbf{2 0 1 3}$ & $\mathbf{2 0 1 8}$ \\
\hline Gini Katsayısı* & 0,40 & 0,38 & 0,37 & 0,36 \\
Kişi Başı Günlük4,30 Doların Altındaki Nüfus Oranı (\%)*** & 13,3 & 2,8 & 2,3 & $<1,0$ \\
Göreli Yoksulluk (\%)*** & 25,0 & 22,6 & 22,0 & 19,0 \\
\hline
\end{tabular}

Tablo 5: Türkiye’de Kişi Başına Düşen Gelirin Nüfus İçindeki Oranı. Kaynak: 2006-2011 Yılı Verileri TÜİK ve Aile ve Sosyal Politikalar Bakanlı̆̆ına Aittir. 2013 ve 2018 yılı verileri Onuncu Kalkınma Planı Tahminidir.

(*) 2006 ve 2011 yılı rakamları TÜIKK Gelir ve Yaşam Koşulları Araştırmaları

(**) 2006 ve 2011 yılı rakamları TÜIK 2011 Yoksulluk Çalışması

(***)2006 ve 2011 yll rakamları TÜIK 2006 ve 2011 Gelir ve Yaşam Koşulları Araştırmaları (Göreli yoksulluk hesaplanırken eşdeğer hane halkı kullanılabilir geliri medyan değerinin yüzde 60' l yoksulluk sinırı olarak alınmıştır.)

\subsection{Dünya'da Çalışan Yoksulluğu}

Günümüzde çalışma hayatına ilişkin asgari ücretler, sosyal koruma uygulamaları ve örgütlü dayanışma mücadelesinin sosyal politika aracıyla etkisizleştirilmesi ve ikinci dünya savaşı sonrasında uygulanan liberal politikalar sonucunda sağlanan hızlı büyüme ve tam istihdam düzeyinin büyük ölçüde gerçekleştirilmesi çalışma ve yoksulluk kavramının ayrışmasına yol açmış ve çalışan yoksulluk kavramı ortaya çıkmıştır. "Kapitalizmin altın çağı boyunca, çalışan yoksulluğu kavramı bir oximorona dönüşürken” (Shipler, 2005), yoksulluk sınıfsal boyuttan gerilerken, bireysel ve kültürel dönüşümlerle ön plana çıkmıştır (Erdoğdu, Kutlu, 2014).

İşü̈cü piyasa dengeleri, istihdamın genel yapısı demoğrafik özellikler ülkeler açısından benzer özelliklere sahip değildir. Bu nedenle çalışan yoksulluğunun kaynakları ve etkilerinin ülkelere göre farklılık göstermesi son derece doğaldır. Türkiye'de kayıt dışı istihdam OECD ülkelerinin ortalamasının oldukça üstünde olması nedeniyle "çalışan yoksullar" işgücü piyasalarının en belirgin özellikleri arasında yer almaktadır. OECD ve AB ülkelerinin bütününe bakıldığında Türkiye, çalışan yoksulluğu oranının en yüksek olduğu ülkelerin başında gelmektedir (Şekil 1). TÜİK verileri açısından son dönemlerde Türkiye'de çalışan yoksulluğunun azaldığı görülmekle birlikte, OECD ve AB ülkeleri açısından bir kıyaslama yapıldığında yine çalışan yoksul oranı yüksektir. Bu anlamda, önceki yıllara göre kısmen azaldığı ifade edilebilir.

OECD ülkeleri açısından çalışan yoksulluğu ortalaması \% 7,3 oranına sahipken, Türkiye'de bu oranın \% 17,2 olduğu Şekil 1'de görülmektedir. Aynı şekilde Türkiye ve AB ülkeleri 2002-2003 yılları için kıyaslandığında, çalışan yoksulluk oranının \% 23 olduğu görülmektedir. 2002-2003 y1lları içinde çalışan yoksulluğu açısından Türkiye'ye en yakın oranlara sahip olan ülkeler; Romanya \% yüzde 14, Yunanistan \% 13,5 dir. Çalışan yoksulluğu oranının kısmen azaldığı İrlanda, Estonya veya Hollanda gibi bazı istisna ülkeler dışında, çalışan yoksulluğu oranı AB ülkelerinde sabit kalmış veya yükselmiştir. 


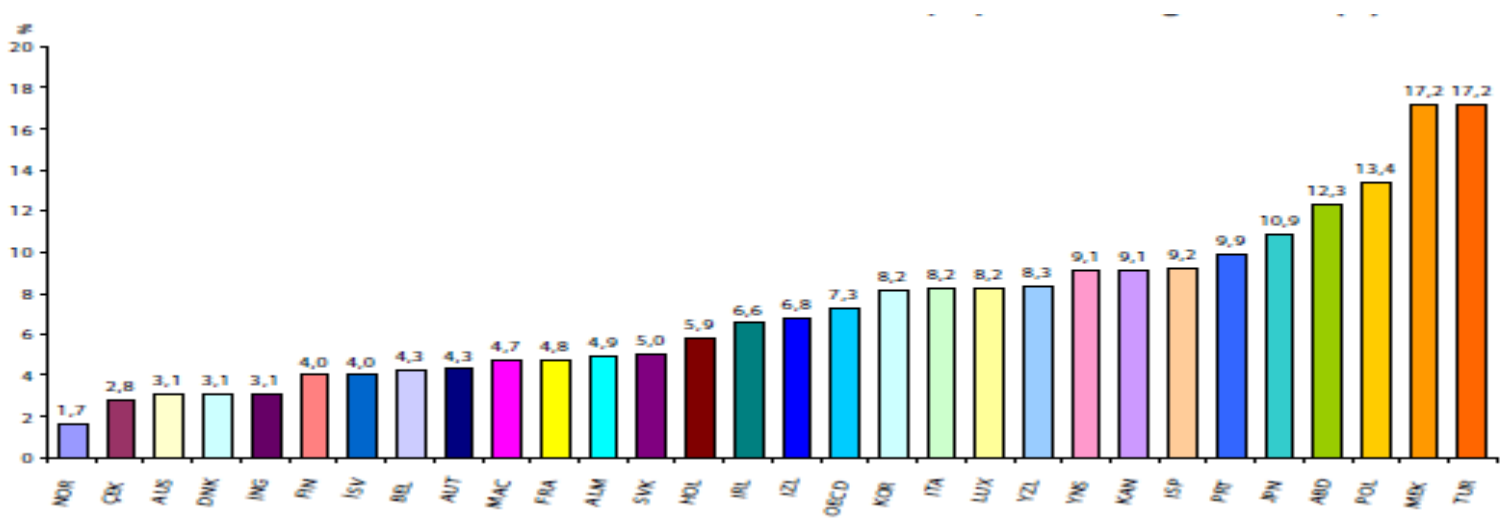

Şekil 1: 2000 ’li Yılların Ortalarında OECD Ülkelerinde Çalışan Yoksulluğu Oranları (\%) Kaynak: OECD, OECD Employment Outlook 2009-Tackling the Jobs Crisis, OECD, 2009, s.180.

\section{4 Çalışan Yoksulluğunu Azaltmaya ve Önlemeye Yönelik Uygulamalar}

İstihdam, yoksulluğun azaltılması ve önlenmesi için en önemli araçlar arasındadır. Uygun bir işte istihdam yani çalışma hakkının temel hak ve özgürlükler bağlamında geliştirilmesi daha adil bir gelir dağılımı çerçevesinde ekonomik büyümenin sağlanması genel anlamda yoksullukla mücadelede oldukça etkili olacaktır. Günümüz dünyasında pek çok kişi hem kendi hem de ailesinin geçimini sağlayabilmek ve yoksulluktan kurtulmak istemektedirler. Ancak, düşük verimli işler ve düşük ücretler nedeniyle bunu başaramamaktadırlar (ILO, 2002a).

İşü̈cü piyasasında yer alan yoksulları, çalışan yoksullar ve işsiz yoksullar olarak iki kategoride belirlemek mümkündür (Osmani, 2002). İşgücü piyasalarına giremeyen işsizler, genellikle yoksullukla eş anlamlı ifade edilmektedir. Bununla birlikte, kişinin istihdam edilmesi onu yoksulluktan kurtaramayabilir. Çünkü en az işsizlik kadar önemli bir sorun haline gelen diğer bir olguda çalışan yoksullar sorunudur. Küreselleşme süreciyle birlikte hızla büyüyerek yaygınlaşan ve emeğin değersizleştirilerek uygulanan düşük ücret, insanları hızla yoksulluğa "çalışan yoksulluğuna" doğru itmektedir. Bu durum çalıştığı halde elde ettiği gelirle ihtiyaçlarını sağlayamayan ve gittikçe yoksullaşan bireyler doğurmaktadır. Tüm dünyada farklı boyutlarda büyük ölçekte çalışan guruplar çalışmaları karşılığında elde ettikleri gelirle geçinememekte ve çalışan yoksullar olarak tanımlanmaktadırlar (Sengenberger, 2001).

\subsection{Pasif İşgücü Piyasası Politikaları}

Türkiye'de kayıt dışı istihdam son derece yaygınlaşmış ve çalışanlar, düşük ücret, sosyal korumasız, geçici işlerde ve olumsuz çalışma koşulları çerçevesinde işgücü piyasasına girmektedir (Sugur ve Nichols, 2005). Türkiye'de kayıt dışı istihdamın en yüksek olduğu kesim, ücretsiz aile işçisi olarak çalışan kadın ve çocuklardan sonra yevmiyeli olarak çalışanlardır (Akyıldız, 2006). Ülkemizde tarım sektörü başta olmak üzere kayıtdışı isthdamın oldukça yaygın olduğu göz önüne alınacak olursa, sektördeki daha çok gelenekçi bir yapının olması çalışma koşulları açısından olumsuzlukların bulunduğu gerçeğini de ortaya koymaktadır. Her ne kadar ekonomik açıdan yaşanan değişim ve dönüşümler sektörler arasında önemli geçişleri ortaya çıkarsa da, çalışan açısından kayıtdışılık devam etmektedir. Bu durumda göstermektedir ki, kayıtdışı istihdamla mücadele kaçınılmazdır. Bu mücadele çalışan yoksulluğu açısından dolaylı da olsa pasif işgücü piyasası politikalarını da içermektedir.

Pasif işgücü piyasası politikalarının amacı, işsizliği azaltmaktan ziyade, düşük istihdamın neden olduğu gelir kaybı veya gelirsizlik nedeniyle bireysel ya da hanehalkı düzeyinde ki, yoksulluk oranının artmasını önlemektir. Ayrıca kısa çalışma ödeneği vb. pasif istihdam politikaları, kişinin işsiz kalmasıyla birlikte belirli süre geçici bir gelirle desteklenmesi açısından oldukça önem taşımaktadır (İŞ-KUR, 2013). Çalışan yoksulluğuna yönelik bir önlem olarak İşsizlik Sigortası, uygulanmaktadır. İşsizlik sigortası, “Türkiye’deki işsizlik ödeneği alma süresi, yatırılan prim gün sayısına göre değişkenlik göstermekte ve en fazla 300 gün ödeme yapılmaktadır. İşsizlik Sigortasının uygulamaya başlanmıştır” (İŞ-KUR, 2014). AB ülkeleri ile karşılaştırıldığında, ülkemizde işsizlik sigortası uygulamasından yararlanabilmek için düzenlenen şartların daha ağır olmasıdır. Yani, Türkiye'de, işsizlik sigortasından yararlanabilmek koşulları, diğer ülkelerle karşılaştırıldığında örneğin, istihdam edilme süresinin daha fazla olması, işsizlik sigortası fonu iştirak gün süresinin uzunluğu vb. koşullar bulunmaktadır. Uygulama açısından kişinin kendisinin işten ayrılması halinde de işsizlik sigortasından yararlanılamaması sonucunu doğurmaktadır (Sürücü, 2014).

Bir diğer Pasif istihdam politikası, Kısa Çalışma Ödeneği, genel ekonomik, sektörel veya bölgesel kriz ile zorlayıcı sebeplerle işyerindeki haftalık çalışma sürelerinin geçici olarak en az üçte bir oranında azaltılması veya süreklilik koşulu aranmaksızın işyerinde faaliyetin tamamen veya kısmen en az dört hafta süreyle durdurulması hallerinde, işyerinde üç ayı aşmamak üzere (Bakanlar Kurulu kararı ile 6 aya kadar uzatılabilir.) sigortalılara çalışamadıkları dönem için gelir desteği sağlayan bir uygulamadır (4857 sayılı İş Kanunu'nun 65md.). İşçinin kısa çalışma ödeneğine hak kazanabilmesi için, kısa çalışmanın başladığı tarihten önceki; son 120 gün içinde prim 
ödeyerek sürekli çalışmış olması ve son üç yıl içinde en az 600 gün işsizlik sigortası primi ödemiş olması gerekir (Demir, 2014). En fazla kısa çalışma ödeneği, 2008 ekonomik krizinden sonra 2009 yılında 190.223 kişiye toplam 162 milyon 506 bin TL ödeme yapılmış; bu miktar 2013 yılında ise 824 bine düşmüştür (IŞ̧-KUR, 2014).

Pasif politikalar içerisinde yer alan, Ücret Garanti Fonu, İşsizlik Sigortası Fonu kapsamında oluşturulan ve hizmet akdine tabi olarak çalışan işçileri, işverenin; konkordato ilan etmesi, işveren için aciz vesikası alınması, iflası veya iflasın ertelenmesi, nedenleri ile işverenin ödeme güçlügüne düştüğü hallerden korumak ve işçilerin iş ilişkisinden kaynaklanan üç aylık ödenmeyen ücret alacaklarını karşılamak amacıyla oluşturulmuş bir pasif istihdam aracıdır". Fon, 4447 sayılı İşsizlik Sigortası Yasası'na göre "sigortalı sayılan kişileri hizmet akdine tabi olarak çalıştıran işverenin konkordato ilan etmesi, işveren için aciz vesikası alınması, iflası, iflasın ertelenmesi nedenleri ile işverenin ödeme güçlügüne düştüğü hallerde geçerli olmak üzere, işçilerin iş ilişkisinden kaynaklanan üç aylık ödenmeyen ücret alacaklarını karşılamak amacı”yla düzenlenmiştir. Burada İşçinin en az bir yıl aynı işyerinde kıdemi olması gerekmektedir (Ücret Garanti Fonu Yönetmeliği). 2009 tarihi itibariyle, ödemeler toplamı 77 milyon 475 bin TL dir. Aralık 2013 ayına kadar söz konusu fondan 5 bin 653 kişi yararlanmıştır (IŞS-KUR, 2014).

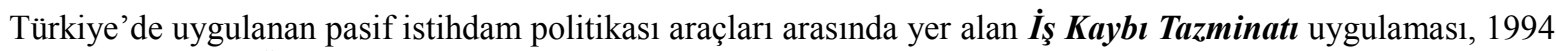
yılında çıkarılan “Özelleştirme Uygulamalarının Düzenlenmesi”yle ilgili, devlete ait işletmelerde çalışıp özelleştirme nedeniyle işten çıkartılan, işletmelerin küçültülmesi veya faaliyetlerinin kısmen veya tamamen durdurulması, süreli veya süresiz kapatılması veya tasfiye edilmesi sonucu iş kaybı tazminatı almaya hak kazanan sigortalı işçilere, diğer tazminatların yanısıra, özelleştirme fonundan karşılanan bir ödeme türüdür(4046 sayılı yasaya). Tazminat tutarı, günlük net asgari ücretin iki katıdır. Bu tazminat türünü hak edenlerden, iş sözleşmesinin sona erdiği tarihte, iş sözleşmesi aynı işveren ile kesintisiz 550 gün devam edenlere çalışma süresine bağlı olarak 90 gün, 1.100 güne kadar hizmeti olanlar için 120 gün, 1.650 güne kadar hizmeti olanlar için 180 gün ve 2.200 güne kadar hizmeti olanlar için ise 240 gün ödeme yapılmaktadır (İŞ-KUR, 2014). Pasif işgücü piyasası politikaları, iş sözleşmesinin feshinin yanı sıra işyeri ve işgücü piyasası dinamiklerinin, çalışanı yoksullaştırma riskine karşı, alınması gereken koruyucu önlemlerdir. Ancak Türkiye'de başta işsizlik sigortası olmak üzere hemen hemen pasif istihdam politikaların tamamı bu önlemlerden yararlanma koşulları bakımından oldukça sert ve kısıtlayıcı, ödenek miktarları açısından ise yetersiz görülmektedir.

\subsection{Aktif İşgücü Piyasası Politikaları}

Aktif istihdam politikalarına yönelik uygulamaları iki kategoride ele almak mümkündür. Bunlar, işsizlerin tamamına yönelik uygulanan programlar ile işgücü piyasalarına girmesi güç olan dezavantajlı guruplara (gençler, engelliler, kadınlar, yaşlılar ve uzun süreli işsizler, göçmenler) yönelik programlardır (Uşen, 2007). Aslında aktif istihdam politikaları, esnek çalışma uygulamalarının hukuki düzenlemelerinin yapılarak yaygınlaştırılması, işgücünün niteliğinin arttırılmasına yönelik eğitim programları, etkin bilgilendirme ve geri bildirim, işçi ve işverenin karşılaşmalarını sağlayacak aracılık ve işe yerleştirme, ayrıca okullarla işyerleri arasında staj uygulamaları ile gençlere çalışma hayatına ilişkin kazanımların sağlanacağı programların uygulanması, istihdam/iş yaratmaya yönelik mesleki eğitim programları, işsizliğin yoğun olduğu bölgelerde işyerlerinin mali bakımdan vergi indirimleri vb. ücret ve istihdam sübvansiyonları ile desteklenmesi, girişimciliğe ve inovasyon yönelik özendirici politika ve uygulamalar vb. araçlarla hayata geçirilmesidir (Uşen, 2007). Açıklamalar çerçevesinde Türkiye'de işgücü piyasasındaki düşük istihdam düzeyi özelliklede düşük ücretli istihdam düzeyi enformel sektörün giderek genişlemesi nedeniyle çalışan yoksulluğunun çözülmesini mümkün kılmamaktadır. Türkiye ekonomisinin işgücü piyasalarını genişletmek suretiyle üretkenliği arttıracak politikalara ihtiyacı bulunmaktadır. Formel ekonomideki istihdamda kadınların işgücü piyasasına girmesini sağlayacak düzenlemelerin acil olarak hayata geçirilmesi önemlidir.

Yapılan düzenlemeler ile İŞKUR, Türkiye'de aktif istihdam politikalarının yasal uygulayıcısı haline gelmiştir (Aktif İşgücü Hizmetleri Yönetmeliği’nin 2.md.). Türkiye açısından istihdamın artırılması, işgücünün niteliklerinin geliştirilmesi ve sanayinin talep ettiği mesleklere yönelik nitelikli işgücü ihtiyacının karşılanabilmesi amacıyla İŞKUR tarafından Aktif İşgücü Piyasası Programları kapsamında mesleki eğitim ve rehabilitasyon faaliyetleri düzenlenmektedir. Bu kapsamında; mesleki eğitim kursları, işbaşı eğitim programları, Toplum Yararına Programlar ve girişimcilik eğitim programları düzenlenmektedir. Ayrıca özel politika gerektiren gruplara yönelik yapılan proje ve geliştirilen politikalarla işgücü piyasasına dahil olmada görece güçlük çekenlere yönelik özel uygulamalar yürütülmektedir (İŞKUR, 2013 a).

Daha öncede değinildiği üzere kırsal alanda yaşanan yoksulluğun boyutları kentsel alanlara göre çok daha fazladır. Bu nedenle Kırsalda tarım sektöründe istihdam edilen işçilerin göç ve olumsuz ekonomik yapıdan dolayı son derece düşük ücretlerle çalışmaları ve çalışan yoksulluğunun en dibe vuran kesimini oluşturdukları görülmektedir. Türkiye'de tarım sektöründe istihdam her ne kadar düşse de hala önemini korumaktadır. Bu bağlamda, tarımda verimliliğin ve formel istihdamın arttırılmasına yönelik stratejiler geliştirilerek tarım sektörünün ayağa kalkması sağlanmalıdır.

Son olarak çalışan yoksulluğun yalnızca işgücü piyasası ve sosyal koruma odaklı önlemlerle çözülmesini beklemek gerçekçi olmayacaktır. Türkiye'deki çok çocuklu hane halkı yapısı ekonomik yapı ve işgücü piyasası 
koşulları ile uyumlu değildir ve yoksulluğun önemli bir kaynağıdır. Bu anlamda çok çocuklu aile yapısının birey hak ve özgürlükleri temelinde ekonomik, sosyal, sağlık ve eğitim politikaları aracılığıyla dönüştürülmesi hedeflenmelidir (Kapar, 2010).

\section{Sonuç}

TÜİK verilerine dayalı yapılan bilimsel çalışmalar, Türkiye'nin yoksulluk boyutlarını ortaya sermektedir. Yapılan araştırmalar cinsiyet bağlamında kadınların erkeklere oranla yoksulluktan daha fazla etkilendiklerini göstermektedir. Yoksulluğu, yaşlılar, çocuklar, engelliler, farklı toplumsal kökenliler vb. farklı toplumsal kategoriler çerçevesinde ele alan çalışmalar da, bu kişilerin işgücü piyasalarına girişleri zor olması nedeniyle daha fazla yoksulluk riskiyle karşı karşıya kaldıklarını göstermektedirler. Türkiye'de çalışan yoksulların genel yapısı, kayıtdışı istihdamın yaygın olduğu sektörler başta olmak üzere düşük ücretli (yevmiyeli) kendi hesabına çalışan ve ücretsiz aile işçisi, tarım ve inşaat işlerinde, niteliksiz işlerde, küçük ölçekli işletmelerde çalışanlar, nüfusu fazla ailelerde yaşayanlar ve kadın çalışanlar ile işgücü piyasalarına girmesi zor olan dezavantajlı gruplar şeklinde ifade edilebilir. Yine yapılan çalışmalarda, hizmet sektöründe çalışan yoksulların ev hizmetleri kapsamında çocuk-yaşlı bakımı ile günlük ev işlerinde çalıştıkları ve bu işlerin genel özellikleri ele alındığında sosyal güvencesiz ve düşük ücretli işler olduğu görülmektedir (Yılmaz, 2010).

Formel istahdama dahil olamadığı için enformel sektörde işgücü piyasasına dahil olan kesimin sosyal koruma kapsamına alınmasına ilişkin politikaların ve yasal düzenlemelerin yapılması gerekir. Türkiye'de gerçek anlamda yoksulluk sınırlarının belirlenerek kavramın ülke sosyo-ekonomik koşullarının dikkate alınmak suretiyle uygulanabilir çözümler üretilmelidir. Çalışan yoksulların ve enformel çalışma koşullarının varlığı sosyal güvenlik yapısının yeniden ele alınmasını zorunlu hale getirmiştir. Pasif istihdam politikaları çerçevesinde, sosyal yardım ve sosyal hizmet uygulamalarının çalışan yoksulları da kapsayacak biçimde tekrar düzenlenmesi gerekmektedir. Aksi takdirde düşük gelirli çalışan yoksulların içinde bulundukları zorluklar ve yoksunluklar gözardı edilmiş olacaktır. Günümüzde yoksulluğun çok farklı boyutları bulunmaktadır. Yeni yoksulluk kavramları arasında gözle görülebilir hale gelen çalışan yoksulluğunun düşük gelirli çalışan kesimleri de kapsadığı unutulmamalıdır. Aynı zamanda işgücü piyasasında önemli bir yer tutan düşük ücretli, güvencesiz, geçici veya ücretsiz istihdamın azaltılması sağlayacak politikalar uygulanmalıdır. Diğer yandan, asgari ücret ve özellikle ücret gelirinin vergilendirilmesi, sosyal güvenlik kesintileri gibi kamu nitelikli politikalarda çalışan yoksullar yararına ve bu hanelerin harcanabilir gelirlerini arttırıcı düzenlemeler yapılmalıdır. Sosyal güvenlik sistemi, sosyal koruma açığını ortadan kaldıracak şekilde düzenlenmelidir (Kapar, 2010). Çalışan yoksulluk sorununun çözümünde üretilecek politikaların bu çerçevede düzenlenmesi çok önemlidir.

\section{Kaynakça}

- Akyıldız, 2006. Türkiye’de istihdamın analitik dinamiği, Ankara: Asil Yayın Dağıtım, s.143.

- Chen, Vanek, Lund, Heintz, Jhabvala, ve Bonner, 2005. Progress of the World's

Women 2005: Women, Work and Poverty,.UNIFEM (United Nations Development Fund For Women).

- Demir, 2014. İş Hukuku Uygulamalaması, Legal Yayınevi, İzmir

- Duran, 2015. “Türkiye'de Yoksulluğa Bölgesel Bir Bakış”, İktisadi Ve İdari Bilimler Fakültesi Dergisi, 30, Say1:2, s.88.

- Dünya Bankası Grubu - Türkiye İşbirliği, 2015. Ülke Programının Görünümü Nisan file://C:/Users/izmir/Desktop/\%C4\%B0\%C5\%9Fg\%C3\%BCc\%C3\%BC\%20Piyasalar\%C4\%B1.pdf Ecevit ve Ecevit, 2002. Kırsal Yoksullukla Mücadele: Tarımda Mülksüzleşme ve Aile Emeğinin Metalaşması. Yoksulluk, Şiddet ve İnsan Hakları, ed. Yasemin Özdek TODAİE Yay.

- Erdoğdu, Kutlu, 2014. “Dünyada ve Türkiye'de Çalışan Yoksulluğu:İşgücü Piyasası ve Sosyal Koruma Politikaları Bağlamında Bir Değerlendirme" Çalışma ve Toplum, 2, s.66

- $\quad$ Ersoy, 1985. Göç ve Kentsel Bütünleşme, A.Ü. SBF ve BYYO Basımevi, Ankara

- Eurofound (2010) Working Poor in Europe, Luxembourg: European Foundation for the Improvement of Living and Working Conditions, http://www.Eurofound.europa.eu/pubdocs/2010/25/en/1/E F1025EN.pdf.

- Eurofound, 2013. Wages: A working conditions and industrial relations perspective, Ireland: Eurofound

- Global Issues, Social, Political, Economic and Environmental Issues That Affect Us All, http://www.globalissues.org/article/26/poverty-facts-and-stats Erişim: 28.05.2016. (Tablo "Percent of People in the Wold of Diffirent Poverty Levels" grafiğindeki verilere göre hazırlanmıştır.)

- Gündoğan, 2008. “Türkiye'de Yoksulluk Ve Yoksullukla Mücadele”, Ankara Sanayi Odasl(ASO), cak/Şubat

- ILO (2002a), Global Employment Agenda, Discussion Paper, International Labour Office, Geneva.p.2

- ILO, 2011. Key Indicators of the Labour Market, 7th edition, Geneva: ILO. 
- $\quad$ ILO, 2012. Global Employment Trends 2012, Geneva: ILO.

- İçli, 2009. “Çalışan Yoksullar: Denizli Örneğinde Uygulamalı Bir Araştırma”, VI. Ulusal Sosyoloji kongresi, Ekim, s.153-155

- İ̧̧-KUR, 2013. 7. Genel Kurul Çalışma Raporu, Ankara: İş-Kur.

- $\quad$ İŞ-KUR, 2014. İşsizlik Sigortası Fonu Bülteni, Ocak http://www.iskur.gov.tr/kurumsalbilgi/yayinlar.aspx\#dltop

- Kalkınma Bakanlığı, 2013. Onuncu Kalkınma Planı 2014-2018, Ankara

- Kalkınma Bakanlığı, http://www.kalkinma.gov.tr/Lists/Ekonomik\%20ve\%20Sosyal\%20Gstergeler/Attachm

- Kapar, 2010.'Türkiye'de Çalışan Yoksullar”, (ASO)Ankara Sanayi Odası Yayın Organı, Kasım - Aralık 2010, s.52-63

- Kapsos, 2005.Estimating growth requirements for reducing working poverty: Can the world havle working poverty by 2015?, World Employment Report 2004-05: Employment, productivity and poverty reduction. Geneva, ILO, , s.2.

- Majid, 2001. "The size of the working poor population in developing countries", Employment Paper 2001/16. ILO: Geneva, s.2.

- Osmani, 2002. Exploring The Employment Nexus: Topics in Employment and Poverty, A report Prepared for the Task Force on the Joint ILO-UNDP Programme on Employment and Poverty, UNDP, New York, ILO, Geneva.p.4

- Peña-Casas, Latta, 2004. Working poor in the European Union, European, Foundation for the Improvement of Living and Working Conditions, s.7

- Scholtens, 2002. Literatüre Review on the Working Poor, Grand Valley State University Community Research Institute. p.2.

- Suğur, Suğur, Şavran ve Çetin, 2010. "Hizmet Sektöründe Çalışan Yoksulların Geçim Stratejileri ve Sosyal İlişki Ağları: Eskişehir Örneği”, İ̧̧ GÜÇ Endüstri İlişkileri ve İnsan Kaynakları Dergisi, Ocak/Jaunary 2010 - 12 - S: 01

- $\quad$ Sugur, ve Nichols, 2005. Turkey: The development of white goods in the 'EU periphery'. (Eds: T. Nichols \& S. Cam). Labour in a global world: Case studies from the white goods industry in Africa, South America, East Asia and Europe (pp. 144-172). New York, NY: Palgrave Macmillan, p.154

- Seçer, 2007. “Amerika Birleşik Devletlerinde Çalışan Yoksullara Yönelik Sosyal Refah Politikaları”, Kamu$\dot{I}_{s} ;$ 9, S: 2

- Sengenberger, 2001.Decent Work: The International Labour Organization, Agenda, Dialogue + Cooperation 2/2001.p.43

- Sürücü, 2014. İşsizlik, İşsizlikle Mücadelede Pasif İstihdam Politikalari: Almanya Ve Türkiye Örnekleri, Yurt Dişi İşçi Hizmetleri Uzmanlik Tezi, Çalişma Ve Sosyal Güvenlik Bakanliği Dış İlişkiler Ve Yurt Dışı İşçi Hizmetleri Genel Müdürlüğü.

- $\quad$ Shipler, 2005. The Working Poor: Invisible in America, UK: Vintage.

- Şenses, 2003. Küreselleşmenin Öteki Yüzü: Yoksulluk. İletişim Yayınları, s.63.

- TUIK, 2008 Hanehalkı fertlerinin işteki durumuna göre yoksulluk oranları, Türkiye, http://www.tuik.

- TURK İŞ 2007 www.turkish.org.tr/source.cms.docs/turkis.org.tr.ce/indexasp?wslt =CD5EE825-6253-4E90A592-24CFE24A1F1

- UNDP, 1997 İnsani Gelişme Raporu

- UNDP, 2005. United Nations Human Development Report, Human Development Index http://www.undp.org.tr/gov.tr/Preistatistiktablo.do?istab

- Uşen, 2007. “Aktif Emek Piyasası Politikaları”, Çalışma ve Toplum, 2007/2, 65 - 94.

- Ücret Garanti Fonu Yönetmeliği, 28.06.2009 tarih ve 27272 sayılı Resmi Gazete. http://www.mevzuat.gov.tr/Metin.Aspx?MevzuatKod=7.5.13170\&MevzuatIliski=0\&sour ceXmlSearch=ücret\%20garanti\%20fonu

- Word Bank, http://data.worldbank.org/topic/poverty

- Yılmaz, 2010. Risk Kapıyı Kırınca Kentlerde Yoksulluk, Dayanışma, Güven ve Güvenlik, İstanbul: Libra. 


\title{
Hemşirelerin Örgütsel Bağlılık Düzeyinin ve İş Doyumunun Beklenen Personel Devir Hızı Üzerine Etkisi
}

\section{The Effect of Organizational Commitment and Job Satisfaction of Nurses on Anticipated Turnover}

\author{
Asst. Prof. Dr. Irfan Özcan (Akdeniz University, Turkey) \\ Asst. Prof. Dr. Gökhan Aba (Bandırma Onyedi Eylül University, Turkey) \\ Prof. Dr. Metin Ateş (İstanbul Aydın University, Turkey)
}

\begin{abstract}
Today, there is an intense competition regarding the provision of private health services. In the context of such competition, it is important to provide that health personnel commit to their jobs and have job satisfaction in order for hospitals to thrive. However, perceptions and cognitions related to leaving employment are affected due to the specific features of health services and due to the heavy workload of personnel. The current study was conducted in order to determine the effect of organizational commitment and job satisfaction on employee turnover rates among health personnel. A total of 415 nurses who were employed in 5 private hospitals located in Istanbul completed questionnaires. In the study, expected employee turnover, organizational commitment, and job satisfaction scales were administered. Data was analyzed using the SPSS 17.0 software. It was found that expected employee turnover levels showed significant differences according to the demographic features of the nurses. In addition, employee turnover rates were negatively related to organizational commitment and job satisfaction. According to this, employee turnover levels decrease as organizational commitment and job satisfaction increase. Based on these results, it is recommended that hospital administrations should place importance on programs that aim to increase organizational commitment and job satisfaction among nurses in order to reduce employee turnover rates.
\end{abstract}

\section{Giris}

Günümüzde özel sağlık hizmeti veren kuruluşlarının sayısının hızla artması sonucu özel sağlık kurumları arasında yoğun rekabet yaşanmaktadır. Bununla birlikte, hasta beklentilerinde meydana gelen değişimler ve sağlık hizmetleri talebindeki artış, mevcut iş yükünün de artmasına neden olmuştur. Bu rekabet ve yoğun iş temposu ortamı, çalışanların iş bırakma algı ve düşüncelerini de etkilemeye başlamıştır.

Bu çalıșmada, hemşirelerin işten ayrılma niyetlerini etkileyen iş doyumu ve örgütsel bağlılık faktörleri üzerinde durulmuştur. Hızla değişen ve gelişen sağlık sektöründe, iş doyumu ve örgütsel bağlılık kavramları, işletmeler için oldukça önemli bir konu haline gelmiştir. Çünkü çalışanların sadakatinin ve sorumluluk bilincinin artması, dolayısıyla uyumlu ve üretken çalışabilmeleri, büyük ölçüde örgütsel bağlılığına ve iş doyumunun yüksek olmasına bağlıdır. İş doyumu ve işletmeye bağlılığı yüksek olan bireylerin, hasta memnuniyetinin sağlanmasında, hizmet kalitesinin artmasında ve işletmenin başarılı olmasında önemli bir katkı sağladığı bilinmektedir

Hem mevcut hemşire sayısının yetersiz olması hem de turnover oranlarının yüksek olması, hastane yöneticilerine yeni hemşire arayışlarına itmekte ve mevcut elemanlarını işte tutma çabalarını gerektirmektedir. Yeni hemşirelerin kısa sürede tedarik edilmesi ve daha maliyetli olması göz önünde tutulduğunda, mevcut personelin işte tutulması için iş doyumlarının ve örgütsel bağlılıklarının artırılması daha da önemli hale gelmektedir.

\section{Personel Devri}

Personel devri kısaca, bir işletmedeki işten ayrılmalar ve işe yeni katılmalardır. Bu durum, insan kaynakları açısından önemli bir gösterge niteliğindedir (Tuna, 2007). Belli bir dönemde, bir örgüt veya bölümde meydan gelen personel işe giriş-çıkış hareketlerinin oluşturduğu bir durumdur (Acar, 2008). Bir örgütte belirli bir dönemde işten ayrılan veya uzaklaştırılan toplam personel sayısının aynı döneme ait çalıştırılan ortalama personel sayısına bölümünün yüzdesel ifadesi olarak tanımlanmaktadır (Ünsalan ve Şimşeker, 2006). Personel devri, kendisini mutsuz ve baskı altında çalıştığını hisseden çalışanların, bu ortamdan ve baskıdan kurtulma için başvurduğu çözüm yollarından bir tanesidir. Kısaca personel devri, çalışanların, bir işletmede herhangi bir sebeple işten ayrılmaları veya işten uzaklaştırılmalarıdır (Met ve Sarıŏlan, 2010).

Personel devri, insan kaynakları açısından önemli bir konu olduğundan, personel devrine sebep olan faktörlerin bilinmesinde fayda vardır. Genel olarak değerlendirildiğinde, personel devri, gönüllü veya gönülsüz olmak üzere iki sebepten ortaya çıkmaktadır (Tuna, 2007). Çalışan, kendi isteğiyle işten ayrılmaya karar verdiğinde gönüllü personel devri; işten ayrılma kararı işletme tarafından verildiğinde ise gönülsüz personel devri olmaktadır. Gönülsüz personel devri genellikle hastalık, sakatlık gibi nedenlerle çalışanın iş göremez duruma gelmesi 
sebebiyle ortaya çıkar. Gönüllü personel devri ise genel olarak yöneticilerin yaklaşımları veya işletmeden kaynaklanan diğer faktörlerden ortaya çıkar (Eronat, 2004).

Personel devrin yüksek veya düşük olması, örgütsel faaliyetler ile yakından ilişkilidir. Personel devrinin yüksek olması, işletmeler için ek maliyet unsuru olmaktadır. Bu maliyetler; yeni işe alım, duyuru, personel eğitimi gibi unsurlardan oluşmaktadır. Bir personelin işten ayrılmasının işletmeye maliyeti, mevcut personelin elde tutulmasından daha yüksek olduğu bilinmektedir (Tuna, 2007).

Örgüt içinde bir işe ya da birime yerleştirilen personel, tüm iş yaşamı süresince nadiren aynı iş ve birimde çalışırr. Örgütsel zorunluluklar ve bireysel istek ve gereksinimler sonucu bir işten diğerine geçerler ya da geçmek zorunda kalırlar. Bu geçişler, hiyerarşide üst basamaklara ya da alt basamaklara olabileceği gibi aynı düzey içinde de gerçekleşebilir. Personelin örgüt içindeki tüm yer ve iş değişiklikleri personel hareketliliği kapsamına girer. Personel hareketliliği nedeniyle personel yöneticileri mevcut personel kaynaklarını örgüte en fazla katkı yapacak şekilde geliştirmeleri gerekmektedir.

Günümüzde hastaneler, kaynak kıtlığı ya da hatalı insan gücü politikaları sebebiyle hemşire yetersizliği sorunu ile karşı karşıyadır. Günümüzde mesleğe yeni başlayan hemşirelerin mesleği bırakma niyetleri, mevcut hemşirelerin işe devamlılığının ve örgütsel bağllılklarının sağlanamaması ve farklı mesleklere yönelmeleri sonucu hemşire yetersizliği ortaya çıkmıştır. Bu sonuç sadece belli ülkelerin ya da bölgelerin yaşadığı sorunlar olmaktan çıkmış ve araştırmacılar konuyu "hemşirelerin dünya çapında yetersizliği" şeklinde ifade etmişlerdir. İşten ayrılmalar, dünyada ve Türkiye'de hemşire sayısındaki yetersizliğin en önemli nedenlerinden biri olduğu belirtilmektedir (Yaprak ve Seren, 2010).

\section{3 Örgütsel Bağlılık}

Örgütsel bağlılık kavramı literatürde farklı şekillerde tanımlanmıştır. Bir tanımda; kişilerin işletmeyle girdiği kimliksel birlik ve beraberlik ile bağlılığın bileşimi şeklinde ifade edilirken, başka bir tanımda, kişinin çalıştığı kurum ile kurduğu kimliksel beraberlik düzeyi ve içinde bulunduğun işletmenin aktif bir üyesi olmaya devam etme arzusu olarak tanımlanmıştır (Yenihan, 2014). Örgütsel bağlılık düzeyinin yüksek olması, çalışan performansı, iş doyumu ve verimlilik üzerinde olumlu etki yarattığı; bununla beraber devamsızlık ve işten ayrılma oranlarını da azalttığı belirtilmektedir (Top, 2012).

Türkiye'de ve diğer ülkelerde, hemşirelerin örgüte bağlılıklarını ve ilgili etmenleri inceleyen çalışmalar yapılmakta ve hemşirelerin kurumlarına /bağlı çalışanlar olmalarını arttırmaya yönelik stratejiler tartışılmaktadır. Türkiye'de yapılan çalışma sonuçları hemşirelerin örgütlerine orta ya da düşük düzeyde bağlılık duyduklarını göstermektedir. Hemşire devir hızları, gelişmiş ülkelerin verileri ile karşılaştırıldığında oldukça yüksek olduğu görülmektedir (Eren ve Demirgöz Bal, 2015).

\section{4 İş Doyumu}

Çalışma yaşamı boyunca, çalışanların elde ettikleri deneyimler, bireyin işe yönelik duygusal ve bilişsel tutumun da etkilemektedir. Bu deneyim sürecinde, oluşabilecek olumsuz izlenimler, çalışanların işe ve işletmeye yönelik memnuniyetlerini etkilemekte ve mutsuz çalışanlar ortaya çıkmaktadır. İstenilen durum, çalışanların iş hayatında mutluluğa ulaşmaları ve yaptıkları işten doyum almalarının sağlanmasıdır (Eğinli, 2009).

İş doyumu/doyumsuzluğu, bir işletmede çalışan bireylerin işine, çalışma ortamına ve çalışma arkadaşlarına yönelik duygu, düşünce ve davranışlarının bir ürünü olarak tanımlanabilmektedir (Çetinkaya Ulusoy ve Ecevit Alpar, 2013).

Çalışan doyumu, bir çalışanın işine yönelik olumlu ya da olumsuz duygularının toplamı, iş doyum derecesini belirlemektedir. Başka bir ifadeyle iş doyumu, çalışanların işten elde ettikleri maddi kazanç ile çalışanın birlikte çalıştı̆̆ iş arkadaşları ile arasındaki uyumdur (Karakuş, 2011).

Türkiye'de ve dünyada, işten ayrılmaların yoğun olarak görülmesinin nedeninin, iş doyumu ve örgütsel bağlılıktaki olumsuz sonuçlar olduğu belirtilmektedir. Yapılan çalışmalarda, hemşirelerin iş doyumlarının ortalamanın biraz üzerinde ya da düşük düzeyde olduğu belirtilirken, yurtdışında yapılan çalışmalarda da benzer sonuçların bulunduğu belirtilmektedir (İntepeler, vd, 2014). Çalışma ortamında, hemşirelerin iş stresi düzeyinin artması ve daha düşük takım çalışması düzeyi, daha düşük iş doyum ve daha yüksek personel devrine sebep olmaktadır. Yapılan çalışmalar, iş doyumu ile işten ayrılma niyeti arasından anlamlı bir ilişkinin olduğunu göstermektedir (Kohler, 2010).

İş doyumu, hemşirelerin çalışma yaşamında en sık araştırılan konuların başında gelmektedir. Bu çalışmalardan elde edilen ortak sonuç, hemşirelerin iş doyumlarının düşük seviyelerde olduğudur. 


\section{Yöntem}

$\mathrm{Bu}$ çalışmanın amacı, sağlık hizmetleri sunumunda çalışan hemşirelerin personel devir hızına etki edebilecek örgütsel bağlılık ve iş doyumu değişkenlerinin beklenen personel devir hızı üzerindeki etkilerini belirlemek ve bu doğrultuda çözüm önerileri getirmektir.

Araştırmada veri toplama aracı olarak anket kullanılmıştır. Araştırmanın evrenini İstanbul'da A sınıfı bir hastanede görev yapan hemşireler oluşturmaktadır. Araştırmada örneklem hesaplanmamış, hastanede çalışan tüm hemşireler çalışma kapsamına alınmak istenmiştir. Araştırmaya katılmayı kabul eden 500 hemşire üzerinde soru formu uygulanmış ve 415 kullanılabilir soru formu elde edilmiştir.

Araştırmacı tarafından oluşturulan soru formu dört kısımdan oluşmaktadır. Birinci kısımda tanımlayıcı bilgiler, ikinci kısımda Beklenen Personel Devri Ölçeği, üçüncü kısımda Örgütsel Bağlılık Ölçeği ve son kısımda ise İş Doyumu Ölçeği yer almıştır.

Hinshaw and Atwood tarafından 1984'de geliştirilen Beklenen Personel Devri Ölçeği (ATS: Anticipated Turnover Scale) sağlık çalışanlarının işlerine gönüllü olarak son verme niyetlerini, yani çalışanlarda gönüllü iş bırakma düşünce olasılığını ölçmektedir. Toplam 12 maddeden oluşan ölçekte, altı pozitif ve altı negatif madde bulunmaktadır. Toplam puanın yüksek olması, işten ayrılma niyetlerinin yüksek olduğunu göstermektedir. Ölçeğin güvenirliği 0,870 olarak yüksek bulunmuştur.

Hastanede çalışan işgücünün hastaneye bağlılığını belirlemeye yönelik ve Lyman W. Porter, Wiliam J. Crampon ve Frank J.Smith (1976) tarafından geliştirilen "Örgütsel Bağlılık" anket formu ve TUSSIDDE (Türkiye Sanayi Sevk ve İdare Enstitüsü) tarafından geliştirilip uygulanan “Çalışan Memnuniyeti” anket formlarından derlenen 16 adet soru bulunmaktadır. Ölçeğin genel güvenirliği 0,821 'dir. Ortalama puanlar hastaneye bağl1lık seviyesini göstermektedir. Ortalama puanı arttıkça örgütsel bağlılık düzeyinin arttığını göstermektedir. İş doyumunu belirlemeye yönelik, Arthur. H Brayfield ve Harold F. Rothe (1965) tarafindan geliştirilen İş Doyumu ve TUSSIDE tarafından geliştirilen "Çalışan Memnuniyeti" anketi sorularının derlenmesiyle oluşturulmuş 18 sorudan oluşmaktadır. Soruların ortalama puanı iş doyum seviyesini göstermektedir. Ölçeğin ortalama puanı arttıkça iş doyumunun arttığını göstermektedir. Ölçeğin genel güvenirliği 0,833’tür.

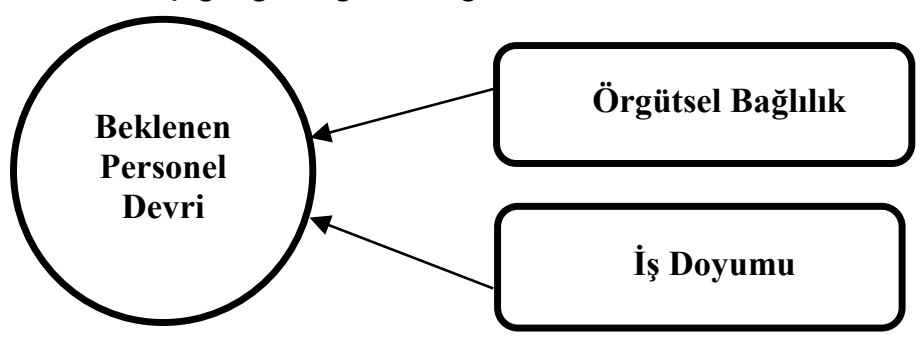

Şekil 1. Araştırma Modeli

Verilerin analizi için, SPSS (Statistical Package for Social Sciences) for Windows 17.0 programı kullanılmıştır. Verilerin analizinde, tanımlayıcı istatistiklerden, korelasyon ve regresyon analizlerinden faydalanılmıştır.

\section{Bulgular}

Tablo 1'de hemşirelere ilişkin tanımlayıcı istatistiklere yer verilmiştir. Buna göre, hemşirelerin \% 45,3'ünün sağlık meslek lisesi mezunu oldukları, \% 66,3'ü klinik hemşire olarak çalıştıkları, \% 48,9'unun 23-27 yaş aralığında yer aldıkları, \% 58,8'inin hem mesaide çalıştıkları, hem de nöbet tuttukları, \% 41,9'unun mesleki deneyimlerinin 1-5 yıl aralığında yer aldığ,$\%$ 42,2'sinin bu kurumda çalışma sürelerinin 1-5 yıl arasında olduğu, \% 63,9'unun bu kurumun ilk çalışma yeri olmadığı ve \% 58,8'inin bekâr olduğu tespit edilmiştir (Tablo 1). 


\begin{tabular}{|c|c|c|}
\hline & $\mathrm{n}$ & $\%$ \\
\hline \multicolumn{3}{|l|}{ Eğitim Durumu } \\
\hline Sağlık meslek lisesi & 188 & 45,3 \\
\hline Ön lisans & 35 & 8,4 \\
\hline Lisans & 161 & 38,8 \\
\hline Yüksek lisans/doktora & 31 & 7,5 \\
\hline \multicolumn{3}{|l|}{ Görev Yaptığı Yer } \\
\hline Hemşire (koord./md.) & 3 & 0,7 \\
\hline Hemşire (yrd/supervisor) & 9 & 2,2 \\
\hline Sorumlu hemşire & 61 & 14,7 \\
\hline Klinik hemşiresi & 275 & 66,3 \\
\hline Poliklinik hemşiresi & 23 & 5,5 \\
\hline Diğer & 44 & 10,6 \\
\hline \multicolumn{3}{|l|}{ Yaş } \\
\hline $18-22$ & 41 & 9,9 \\
\hline $23-27$ & 203 & 48,9 \\
\hline $28-32$ & 120 & 28,9 \\
\hline $33-37$ & 26 & 6,3 \\
\hline 38 ve üzeri & 25 & 6,0 \\
\hline \multicolumn{3}{|l|}{ Çalışma Şekli } \\
\hline Sürekli gündüz & 148 & 35,7 \\
\hline Sürekli gece & 23 & 5,5 \\
\hline Mesai+Nöbet & 244 & 58,8 \\
\hline
\end{tabular}

\begin{tabular}{lcc}
\hline & $\mathrm{n}$ & $\%$ \\
\hline Mesleki Deneyim Süresi & & \\
\hline 1 yıldan daha az & 46 & 11,1 \\
1-5 yıl arası & 174 & 41,9 \\
6-11 yıl arası & 127 & 30,6 \\
12-17 yıl arası & 56 & 13,5 \\
18 yıl ve üstü & 12 & 2,9 \\
\hline Kurumda Çalışma Süresi & & \\
\hline 1 yıldan daha az & 145 & 34,9 \\
1-5 yıl arası & 175 & 42,2 \\
6-11 yıl arası & 83 & 20,0 \\
12-17 yıl aras1 & 12 & 2,9 \\
\hline
\end{tabular}

\begin{tabular}{lcc}
\hline $\begin{array}{l}\text { Kurumda İlk Çalışma } \\
\text { Olup Olmama Durumu }\end{array}$ & & \\
\hline Evet & 150 & 36,1 \\
Hayır & 265 & 63,9 \\
\hline Medeni durum & & \\
\hline Evli & 165 & 39,8 \\
Bekâr & 244 & 58,8 \\
Boşanmış & 6 & 1,4 \\
\hline
\end{tabular}

Tablo 1. Tanımlayıcı Bilgilere Yönelik Bulgular

Araştırmaya katılan sağlık çalışanlarının beklenen personel devri, çalışılan hastaneye bağlılık ve iş doyumu ortalamaları incelendiğinde; beklenen personel devri ortalaması 3,495 $\pm 0,930$; çalışılan hastaneye bağlılık ortalaması 3,457 $\pm 0,531$ ve iş doyumu ortalaması 3,358 $\pm 0,535$ olarak bulunmuştur (Tablo 2).

\begin{tabular}{lccccc}
\hline & $\mathbf{N}$ & Ort. & S.s & Min. & Max. \\
\hline Beklenen personel devri & 415 & 3,495 & 0,930 & 1,500 & 6,667 \\
Çalışılan hastaneye bağlılık & 415 & 3,457 & 0,531 & 1,625 & 4,875 \\
İş doyumu & 415 & 3,358 & 0,535 & 1,056 & 4,556 \\
\hline
\end{tabular}

Tablo 2. Beklenen Personel Devri, Örgütsel Bağlılık ve İş Doyumu Ortalamaları

Çalışılan hastaneye bağlılık ile beklenen personel devri arasındaki ilişskinin belirlenebilmesi için yapılan korelasyon analizi sonucunda, puanlar arasında \%52,2 düzeyinde negatif yönlü anlamlı ilişki tespit edilmiştir $(\mathrm{r}=$ $0,522 ; \mathrm{p}=0,001<0,05)$. Buna göre çalışılan hastaneye bağlılık puanı arttıkça beklenen personel devri puanı azalmaktadır. İş doyumu ile beklenen personel devri arasındaki ilişkiyi belirlemek üzere yapılan korelasyon analizi sonucunda ise, puanlar arasında \%50,1 negatif yönlü anlamlı ilişki bulunmuştur $(r=-0,501 ; p=0,001<0,05)$. Buna duruma göre iş doyumu puanı arttıkça beklenen personel devri puanı azalmaktadır (Tablo 3).

\begin{tabular}{cccc}
\hline & & Örgütsel bağlılık & İş doyumu \\
\hline \multirow{3}{*}{ Beklenen personel devri } & $\mathrm{r}$ & $-0,522$ & $-0,501$ \\
& $\mathrm{p}$ & $\mathbf{0 , 0 0 1}$ & $\mathbf{0 , 0 0 1}$ \\
& $\mathrm{N}$ & 415 & 415 \\
\hline
\end{tabular}

Tablo 3. Beklenen Personel Devri Düzeyi, Örgütsel Bağlılık ve İş Doyumu Arasındaki İlişki

Örgütsel bağlılığın beklenen personel devri üzerine etkisi istatistiksel açıdan anlamlı olduğu tespit edilmiştir $(\mathrm{F}=154,585 ; \mathrm{p}=0,001<0,05)$. İş doyumunu beklenen personel devri üzerine etkisini test etmek için yapılan regresyon modelinde de istatistiksel olarak anlamı sonuçlar elde edilmiştir $(F=138,293 ; \mathrm{p}=0,001<0,05)$. (Tablo 4). 


\begin{tabular}{|c|c|c|c|c|c|c|c|}
\hline $\begin{array}{l}\text { Bağımlı } \\
\text { değişken }\end{array}$ & Bağımsız değişken & $\mathbf{B}$ & $\mathbf{t}$ & $\mathbf{p}$ & $\mathbf{F}$ & $\begin{array}{l}\text { Model } \\
\text { (p) }\end{array}$ & $\mathbf{R}^{2}$ \\
\hline \multirow{3}{*}{$\begin{array}{l}\text { Beklenen } \\
\text { personel } \\
\text { devri }\end{array}$} & Sabit & 6,656 & 25,876 & 0,001 & \multirow[b]{2}{*}{154,585} & \multirow[b]{2}{*}{0,001} & \multirow[b]{2}{*}{0,271} \\
\hline & $\begin{array}{l}\text { Çalışılan hastaneye } \\
\text { bağl1lık }\end{array}$ & $-0,914$ & $-12,433$ & 0,001 & & & \\
\hline & $\begin{array}{l}\text { Sabit } \\
\text { İs doyumu }\end{array}$ & $\begin{array}{c}6,415 \\
-0,870\end{array}$ & $\begin{array}{c}25,510 \\
-11,760\end{array}$ & $\begin{array}{l}0,001 \\
0,001\end{array}$ & 138,293 & 0,001 & 0,249 \\
\hline
\end{tabular}

Tablo 4. Örgütsel Bağlllık ve İş Doyumunun Beklenen Personel Devri Üzerine Etkisi

\section{Tartışma ve Sonuç}

Özel hastanelerde çalışan hemşirelerin örgütsel bağlılık ve iş doyumu düzeyinin beklenen personel devri üzerine etkisinin araştırıldığı bu çalışmada, 415 hemşire çalışma kapsamına alınmıştır. Elde edilen bulgulara bakıldığında, hemşirelerin beklenen personel devri, örgütsel bağlılık ve iş doyumu arasında istatistiksel açıdan anlamlı ilişkiler saptanmıştır. Buna göre, hemşirelerin örgütsel bağlılık ve iş doyumu düzeyleri azaldıkça işten ayrılma niyetleri artmaktadır. Bununla birlikte, örgütsel bağlılık ve iş doyumu faktörlerinin, beklenen personel devri üzerinde etkili olduğu tespit edilen diğer bir durumdur. Başka bir ifadeyle, hemşirelerin örgütsel bağl1lık düzeyi ve iş doyumları arttıkça hemşire devir hızları da düşmektedir. Bu durumun, literatürde yer alan birçok çalışmadan elde edilen sonuçlar ile benzer nitelikte olduğu tespit edilmiştir (Duygulu ve Korkmaz, 2008; De Gieter, vd, 2011; Lum, vd, 1998; Shader, vd, 2001; Al-Hussami, vd, 2013; Yasmin ve Marzuki, 2015; Kohler 2010; Almalki, vd, 2012; Tao, vd, 2015; Hudgins, 2016; Asegid, 2014).

Sonuç olarak hastanelerin başarıya ulaşabilmesi için hem çalışanların işe bağlılığının ve yaptıkları işten doyum almalarının sağlanması hem de mevcut personelin elde tutulması ve işten ayrılma niyeti var ise buna iten sebeplerin ortaya konması ve çözülmesi gerekmektedir. Bu durum, hasta açısından verilen hizmetlerin bütünlüğünün ve sürekliliğinin sağlanması, kurumsal açıdan ise maliyetler (yeni personelin işe alınması, duyuru, eğitim, işe alınan tecrübesiz çalışanın yaratacağı maliyetler vb) önemli bir etken haline gelmiştir. Hastane ve hemşirelik hizmetleri yöneticilerinin bu konuda duyarlılık göstermesi ve iyileştirici/geliştirici önlemler alması gerekmektedir.

\section{Kaynakça}

- Acar AC, 2008. İnsan Kaynakları Planlaması İşgören Seçimi. 3 baskı, Beta Basım Yayın, İstanbul.

- Al-Hussami M, Darawad M, Saleh A, Hayajneh FA, 2013. Predicting Nurses' Turnover Intentions by Demographic Characteristics, Perception of Health, Quality of Work, and Work Attitudes. 1st Annual International Interdisciplinary Conference, AIIC 2013, 24-26 April, Azores, Portugal.

- Almalki M, FitzGerald G, Clark M, 2012. "The Relationship between Quality of Work Life and Turnover Intention of Primary Health Care Nurses in Saudi Arabia", BMC Health Services Research, 12(314), 1-11.

- Asegid A, Belachew T, Yimam E, 2014. "Factors Influencing Job Satisfaction and Anticipated Turnover among Nurses in Sidama Zone Public Health Facilities, South Ethiopia”, Nursing Research and Practice, 2014, 1-26.

- Brayfield A, Rothe H, 1965. “An Index of Job Satisfaction”. Studies in Personnel and Industrial Psychology. Homewood, Illinois: Sixth Printing, the Dorsey Press Inc.

- C Çetinkaya Ulusoy E, Ecevit Alpar, Ş, 2013. "Hemşirelerde Meslektaş Dayanışması ve İş Doyumu ile İlişkisi”, F.N. Hem. Derg, 21(3), 154-163.

- De Giether S, Hofmans J, Pepermans RG, 2011. "Revisiting The Impact of Job Satisfaction and Organizational Commitment on Nurse Turnover Intention: An Individual Difference Analysis", International Journal of Nursing Studies, 48, 1562-1569.

- Duygulu S, Korkmaz F, 2008. "Hemşirelerin Örgüte Bağlılığı, İş Doyumları ve İşten Ayrılma Nedenleri”, C. Ü. Hemşirelik Yüksekokulu Dergisi, 12(2), 9-20.

- Eğinli AT, 2009. "Çalışanlarda İş Doyumu: Kamu ve Özel Sektör Çalışanlarının İş Doyumuna Yönelik Bir Araştırma”, Atatürk Üniversitesi İktisadi ve İdari Bilimler Dergisi, 23(3), 35-52.

- Eren H, Demirgöz Bal M, 2015. "Hemşirelikte Örgütsel Bağlılık”, Sağlık ve Hemşirelik Yönetimi Dergisi, 1(2), 44-50.

- $\quad$ Eronat Z, 2004. “İşletmelerde İş Tatmini ve İşgücü Devir Hızı Problemlerinin Çözümünde Bir Faktör olarak İletişim; KOBİ'lerde Ampirik Bir Uygulama”. Yayımlanmamış Yüksek Lisans Tezi, Ankara Üniversitesi Sosyal Bilimler Enstitüsü, Ankara.

- Hinshaw AS, Atwood JR, 1985. Anticipated Turnover Among Nursing Staff Study: Final Report. National Institutes of Health, National Center for Nursing Research, Bethesda, MD. 
- Hudgins TA, 2016. "Resilience, Job Satisfaction And Anticipated Turnover In Nurse Leaders", Journal of Nursing Management, 24, E62-E69

- $\quad$ İntepeler ŞS, Güneş N, Bengü N, Yılmazmış, F, 2014. "Bir Üniversite Hastanesinde Çalışan Hemşirelerin İş Doyumu ve Kurumsal Bağlılıklarındaki Değişim”, DEUHYO ED, 7(1), 2-6.

- Karakuş H, 2011. "Hemşirelerin İş Tatmin Düzeyleri: Sivas İli Örneği”, Dicle Üniversitesi Sosyal Bilimler Enstitüsü Dergisi, 3(6), 46-57.

- Kohler M, 2010. "Exploring the Relationships among Work-Related Stress, Quality of Life, Job Satisfaction, and Anticipated Turnover on Nursing Units with Clinical Nurse Leaders". Graduate Theses and Dissertations (http://scholarcommons.usf.edu/etd/3648, 05.05.2016)

- Lum L, Kervin J, Clark K, Reid F, Sirola W, 1998. "Explaining Nursing Turnover Intent: Job Satisfaction, Pay Satisfaction, or Organizational Commitment?”, Journal of Organizational Behavior, 19, 305-320.

- Met ÖL, Sarığlan M, 2010. “Otel İşletmeleri Yiyecek-İçecek Ünitelerinde İşgören Devri Üzerine Görgül Bir Araştırma”. Adıyaman Üniversitesi Sosyal Bilimler Dergisi, 5, 200-213.

- Shader K, Broome ME, Broome CD, West ME, Nash M, 2001. "Factors Influencing Satisfaction and Anticipated Turnover for Nurses in an Academic Medical Center", J Nurs Adm, 31(4), 210-6.

- Tao H, Ellenbecker CH, Wang Y, Li Y, 2015. "Examining Perception of Job Satisfaction and Intention to Leave Among ICU Nurses in China”, International Journal of Nursing Science, 2, 140-148.

- Top M, 2012. "Hekim ve hemşirelerde örgütsel bağl1lık, örgütsel güven ve iş doyumu profili”, İstanbul Üniversitesi İsletme Fakültesi Dergisi, 41(2), 258-277.

- Tuna M. (2007). "Personel Devir Oranı Analizi: Ankara’da Yer Alan Yıldızlı Otel İşletmelerinde Bir Uygulama”, Anatolia: Turizm Araştırmaları Dergisi, 18(1), 45-52.

- Ünsalan E, Şimşeker B, 2006. İnsan Kaynakları Yönetimi, Detay Yayıncılık, Ankara.

- Yaprak E, Seren Ş, 2010. "Hemşirelerin İşten Ayrılma Niyetleri ve Örgüt İkliminin Hemşire İstihdamına Etkisi”, Hemşirelikte Eğitim ve Araştırma Dergisi, 7(1), 28-33.

- Yasmin K, Marzuki NA, 2015. "Impact of Organizational Commitment on Intention to Quit Among Psychaitric Nurses: Evidence from Pakistan”, International Journal of Learning \& Development, 5(4), 89102.

- Yenihan B, 2014. “Örgütsel Bağlılık ve İş Tatmini Arasındaki İlişki”, Karabük Üniversitesi Sosyal Bilimler Enstitüsü Dergisi, 4(2), 170-178. 


\title{
Türkiye'de Sağlık Sektörü ve Sağlık Harcamalarının Büyüme Üzerindeki Etkisinin 2000-2014 Yılları için Analizi
}

\section{Evaluating the Effects of Health Sector and Health Expenditures on Economic Growth for Turkey between the years 2000-2014}

\author{
Asst. Prof. Dr. Müjgan Hacıoğlu Deniz (İstanbul University, Turkey) \\ Assoc. Prof. Dr. Kutluk Kağan Sümer (İstanbul University, Turkey)
}

\begin{abstract}
This study provides general information about the health economics and the health care expenditures in addition to its relations with economic growth and development. Specifically, this research focuses on the relation between health expenditures such as investments in medical sector, drugs etc. and economic growth in Turkey. Determining the structure of health expenditures and identifying the factors that influence such expenditures; "Child-Infant Mortality Rate", "Life Expectancy at Birth and "Gross Mortality Rate are vitally important in terms of improvement of health indicators. Gross National Product per Capita and health expenditures per capita were considered as basic economic indicators as well. In this research, Turkey's Gross National Product per capita in years between 2000-2014 and changes in basic health indicators of Turkey were analyzed and evaluated together. It also examined if a close relation exists between the expenditures for drugs and the total health expenditures within the whole system.
\end{abstract}

\section{Giris}

Sağlık ekonomisi alanında şimdiye kadar yapılan çalışmalarda genel olarak gözlenmiştir ki, ekonomik göstergelerde meydana gelen iyileşmeler ve sağlık sektörüne yapılan yatırım ve harcamalardaki artış sağlık göstergelerini de pozitif yönde etkilemiştir. Bu çalışmada da temel olarak ülke ekonomisindeki olumlu gelişmeler ve sağlık ekonomisine yapılan yatırımlar ile sağlık göstergelerinde meydana gelen değişimlerin birbirlerini ne ölçüde etkilediği belirlenmeye çalışılmıştır. Tespitte bulunurken yararlanılan en yaygın gösterge, Gayri Safi Yurtiçi Hasıla - (GSYH - Gross Domestic Product, GDP) ve Kişi Başına Düşen Gayrı Safi Yurtiçi Hasıla (Per Capita Income) iken kullanılan en yaygın sağlık göstergeleri Doğumda Yaşam Beklentisi (Life Expectancy from Birth), Bebek-Çocuk Ölüm Hızı ve Kaba Ölüm Oranı olmuştur. Bu bildiride amaçlanan da, sağlık hizmetlerine yapılan harcamalar ve sağlık sektörü ile genel ülke ekonomisi arasındaki ilişkinin değerlendirilmesi ve sağlik harcamalarının ekonomi üzerindeki etkilerinin varsa tespit edilmesidir. Aynı şekilde, yapılan sağlık harcamalarının kapsamı; ne kadarı kamu eliyle yapılmakta, ne kadarı özel sektör yatırımı ve ne kadarlık kısmı koruyucu hekimlik veya aile hekimliğine harcanıyor ve ne kadar oranda ayakta tedavi masraflarına giden bir sağlı harcaması var. $\mathrm{Bu}$ gibi ayrıntılı kalemler bazında harcama oranları incelenerek, TÜIKK verilerine (tablolar ve yıllık raporlar) dayanarak ekonomik büyüme ve sağlık ekonomisine yapılan yatırım ve harcamalar arasındaki ilişki değerlendirilmeye çalışılacaktır. Bununla birlikte, sağlık ve ilaç sektöründe yapilan harcamalar ve bunun arkasındaki nedenlerle beraber son dönemde yapılan yatırımların sonucunda sağlık alanında elde edilen çıktıların belirlenmesi amaçlanmıştır. Sağlık hizmetleri kavramı ile ne kastedilmektedir ve sağlık sektörü denince ne tür hizmetler bu sektörün kapsamına girmektedir, kısaca bu konuda bilgi vermek faydalı olacaktır.

Yine sağlık harcamalarının Türkiye'de nasıl gerçekleştiğinin daha iyi anlaşılabilmesi için Türkiye'de son dönemde yapılan hastane yatırımları ve gerek aile hekimliği sistemine geçilmesi ile ortaya çıkan yeni sağlık sistemi hakkında genel bilgi verilerek ilgili tablolardan yararlanılarak genel bir değerlendirmede bulunulacaktır. Sağlık harcamalarını etkileyen önemli bir diğer faktör de, sağlık hizmetlerinin ne şekilde ve kim tarafından finanse edildiğidir. Sağlık finansmanının önemli sorunlarından biri maliyetleri kontrol altına almak olduğundan, ödeme yöntemleri üzerinde önemle durulması gereken konulardan biridir. Çalışmada kısa da olsa finansman yöntemleri hakkında bilgi verilecektir. Bu genel değerlendirmenin akabinde, Türkiye'de 2000 yllından beri gerçekleştirilen sağlı harcamaları devletin resmi kurumlarından ve TÜİK'den elde edilen veriler doğrultusunda irdelenecektir. Daha sonra yıllar itibariyle Türkiye'de sağlı alanında gerçekleştirilen reformlar hakkında kısa bir bilgi verilerek akabinde Türkiye ile gelişmiş ülkeler arasındaki sağllk harcamaları farkının ne ölçüde ve yönde değiştiği tespit edilmeye çalışlacaktır. Bu amaçla, Türkiye ile OECD ülkelerine ait sağlık sektör verileri karşılaştırılacaktır. Araştırmaya ilişkin veriler, kamu ve özel kurum ve kuruluşların veri bankaları ve raporlarından elde edilerek incelemeye tabi tutulacaktır. Sonuç bölümünde ise bu çalışmanın bütününden elde edilen tespitler ve varılan sonuçlar değerlendirilerek; yaklaşık son on beş yıllık dönem için kısa bir çıkarımda bulunulacaktır.

\section{Sağlık Kavramına İktisadi Bakış}

Sağlık kavramı insan yaşamını yalnızca birey olarak değil, aynı zamanda toplumsal hayat ve ekonomik etkileri açısından da etkilemektedir. Öncelikle sağlıklı bir birey olmak, fiziksel ve ruhsal sağlığa sahip olmak, mutlu ve 
üretken bir vatandaş olmanın ilk şartıdır. Nitekim 'Sağlıklı olmak, temel bir ihtiyaçtır ve onsuz diğer mal ve hizmetlerin de anlamı yoktur" (Sophia Witter, 2002: s.4). Dolayısıyla, sağlık kavramının önemi tartışılamaz ve sağlığın vazgeçilmez bir servet olması temel özelliğidir (WHO, 1981: 19). Sağlık kavramı göreceli bir kavramdır ve kişiden kişiye değişen çok farklı tanımları olmasına rağmen en yaygın ve kabul göreni Dünya Sağlık Örgütü (WHO)'nün 1948 yılında yaptığı tanımdır: 'Sağlık yalnızca hastalık ya da sakatlığın olmayışı değil, bedence, ruhça ve sosyal yönden tam iyilik durumudur." (Akın, 2007: 5).

Bir devlet ve ülke yönetimi açısından sağlıklı bir topluma sahip olmanın yansıra onun sürdürülebilir kılmak da önemlidir. Sağlıklı bir toplumdan bahsedebilmek için de o ülkedeki ekonomik yapının ve sosyolojik çevrenin de sağlık sistemini desteklemesi gerekmektedir. Nitekim ekonomi yönetimi sağlık hizmetlerinin finansmanı için kaynak bulmaya çalışırken, özel idare ve yerel yönetimler de çevre şartlarının insan sağlığı üzerindeki olumsuz etkilerinin azaltılması için gerekli önlemleri almakla görevlidir.

\subsection{Sağlık Hizmeti ve Genel Özellikleri}

Sağlık sektörü genel itibariyle, sağlığın elde edilmesi, korunması ve devamlılığının sağlanması amacıyla sağlıkla ilgili mal ve hizmet üreten bütün kurum ve kuruluşların oluşturduğu yapı olarak tanımlanmaktadır. Aynı şekilde, sağlık sektörünü oluşturan aktörlerin hepsinin birlikte sağlık odaklı gerçekleştirdiği faaliyetler bütününe sağlık hizmetleri denmektedir. Bu bağlamda, sağlık hizmetlerinin üç boyutu vardır; birincisi koruma boyutu, ikincisi tedavi boyutu ve son olarak da rehabilitasyon boyutudur. Sağlık hizmetlerini bu şekilde sınıflandırmak sistemin verimliliğini sağlarken bu sayede devlet ekonomik kaynakların gereksiz kullanımını da önlemek istemektedir. Sağlık hizmetlerinin temel girdileri; insan kaynakları, sermaye, teknoloji, hammadde yani sağlık ekipmanları ve aletleri olarak sıralanabilir. Sağlık sisteminin çıktıları ise, ortalama yaşam süresinin uzatılması, hayatta kalma, hastalıkların tedavisi ve bu konuyla ilişkili gelişmelerdir (Akın, 2007: 6-7).

Sağlık iktisadi bir mal değilken sağlık hizmetleri iktisadi bir mal-hizmet-dir. İktisat biliminde rekabetçi piyasalar yaklaşımına göre piyasa başarısızlığının varlığı yani kaynakların etkin tahsisinin yapılamaması piyasanın etkin işleyişini engellemektedir. $\mathrm{Bu}$ durum piyasaların işleyişine müdahalenin gerekçesini oluşturur. Sağlık hizmetlerinin sunulduğu piyasanın etkin işleyişini engelleyen ve etkin kaynak tahsisini önleyen nedenler olarak belirtilen faktörler piyasa aksaklıklarına neden olurlar. Bu nedenlerden dolayı rekabetçi piyasalar, sağlık hizmetleri için etkin çalışmaz ve bu koşullarda devlet sağlık hizmetlerinin sunulduğu piyasalara müdahale etmek durumunda kalır ve tam rekabet piyasası olmadığı bir yerde farklı bir piyasa tipi ortaya çıkar. Sağlık malı/hizmetleri yarı kamusal mal ve hizmetler kategorisine girmektedir.

Önemli bir nokta da, sunulan sağlık hizmeti sonucunda ortaya çıkan faydanın sadece bireye özel olmayıp topluma da sosyal bir fayda sağlamakta olmasıdır. Sağlık hizmetlerinden elde edilen bireysel fayda pazarlanabilir iken bu hizmetlerin sağladığı sosyal fayda ise pazarlanamaz. Mal ve hizmet üretmek isteyen bir üretici yalnızca pazarlayabileceği özel faydayı dikkate alarak hareket eder ancak sağlık sektöründe bu durum farklılaşmaktadır. Özetle, toplumun genel itibariyle daha sağlıklı bir yapıya kavuşması, bir üretim faktörü olan emeğin verimliliğinin artmasına neden olur. Sağlık hizmetlerinin faydası da sonuç olarak, bireyin dışına taşar ve topluma yayılır (Tokalaş, 2006: 16-17).

\subsection{Să̆lık Ekonomisi Kavramı}

Sağlık hizmetleri piyasanın doğurduğu rekabet ortamında yalnızca özel sektör kuruluşlarınca değil, özel hastahane ve merkezlerin yanısıra kamu sektörünce de finanse edilip üretilmesini sağlar. Devlet sosyal devlet olmasının gereği olarak toplum sağlığını korumak için sağlık hizmetlerini tümden özel sektöre ve serbest piyasa koşullarına bırakamaz ve koruyucu devlet ilkesi sebebiyle temel sağlık hizmetlerinin sunulması, sağlı harcamalarının finansmanı ve sağlığın denetlenmesi gibi görevler üstlenir.

Sağlık ve sağlık hizmetleri ve dolayısıyla sağlık ekonomisi gelişmekte olan ülkeler açısından her geçen gün daha fazla önem arz etmeye başlamıştır. Bunun nedenleri şöyle sıralanabilir; ulusal ve bireysel düzeyde artan sağlık harcamaları, ekonomik yapıdaki gelişme ve değişimler, tıp teknolojisindeki hızlı gelişmeler ve demografik yapıdaki değişim. Sağlı ekonomisinin cevap aradığı temel sorun veya sorunlar aşağıdaki gibi sıralanabilir; ' 'kaynaklar koruyucu hekimlik için mi yoksa hastane hizmetleri için mi daha çok harcanmalı, kaynaklar kanser tedavisi için mi yoksa kanser tarama programları için mi ayrılmalı?” gibi soruların cevabını aramaktadır. Sağlık hizmetlerinden kimler yararlanmalı yada böyle bir soru gereksiz midir? Sağlık alanında hangi tıbbi mal ve hizmetler üretilmelidir gibi sorular sağlık ekonomisinin yanıt aradığı belli başlı sorulardır. Sağlık harcamaları son yıllarda artıyor bunun sebepleri nelerdir ve finansmanı kim tarafından sağlanmalıdır da bir diğer önemli husustur.

Sağlık hizmetlerinin üretiminin tamamıyla piyasa koşullarına bırakılmayışı yalnızca ekonomik nedenlerle yani piyasa başarısızlığından ve etkin kaynak tahsisi olmayışından değil sağlıklı bir yaşamın bir insan hakkı ve anayasal bir hak olmasından dolayıdır (Çilingiroğlu, 2001: 1592). Sağlık alanında da kaynaklar sınırlı olduğu için eldeki kaynaklar doğru kullanılmalı, minimum kaynak ile maksimum çıktı sağlanmalı, kullanılan birim kaynak başına en fazla yarar sağlayan işlerin yapılmasına öncelik verilmelidir. İşte tüm bu tercihleri yapabilmek, kaynak israfının önlenmesi ve sağlık hizmetlerinin etkin bir şekilde yapılmasını sağlayabilmek için sağlık ekonomisine ve rehberliğine ihtiyaç vardır. 
Sağlık ekonomisi de her türlü sağlık hizmeti üretmek için kullanılan kaynakların en verimli ve etkin şekilde kullanılmasını amaçlamaktadır. Denilebilir ki, sağlık ekonomisi genel ekonomi biliminin kurallarını sağlık sektörüne uygulanmasıyla ve ekonomi teorilerinin, yöntemlerinin ve analiz tekniklerinin sağlı alanına uyarlanması ile ortaya çıkan uygulamalı bir alt daldır. Toplum sağlığını maksimize etme amacına ulaşmada sağlığa ayrılan kaynakların nasıl tahsis edileceği sorusuna cevap ararken, devletin piyasadaki rolünü, sağlık hizmetlerinin sunum ve finansman türlerini, bütçelendirme ile sağlık planlamasını, aynı şekilde sistemin bir bütün olarak sorgulanmasını da içermektedir. Uygulama açısından toplumların ve toplumu oluşturan fertlerin sağlıklarını korumak, sağlık koşullarının bozulması durumunda tedavilerini yapmak, hastalıklarından tamamen kurtulamayıp sakat kalanların başkalarına bağımlı olmadan yaşayabilmelerini sağlamak ve toplumların sağlık düzeylerini yükseltmek için yapılan planlı çalışmalarda ekonomi biliminin teorilerinin ve metodolojisinin sağlık sektörüne adapte edilmesini içerir (Bekir, 2003: 1).

\subsection{Sağlık Sektörü ile Ekonomik Büyüme İlișkisi}

Bir toplumun iş gücü verimliliğini ve beşeri sermayesinin niteliğini etkileyen ve şekillendiren iki temel unsur o toplumdaki mevcut eğitim ve sağlık sistemidir. Bir ülkenin eğitim politikaları kadar sağlık politikaları ve sağlığa ayırdığı bütçe de o toplumun sağlık düzeyini diğer bir ifadeyle beşeri sermayenin gelişimini ve ülke ekonomisine olan katkısını belirler. Buradan ülkelerin ekonomik gelişmişlik düzeyleri ile sağlık sektörlerinin yapısı ve dolaylı olarak sağlığa ayırdığı bütçe arasında yakın ve karşılıklı bir nedensellik ilişkisi bulunduğunu iddia edebiliriz. Ekonomik gelişmesini belli bir seviyeye ulaştırabilmiş toplumlarda sağlık için ayrılan kaynaklar arttığı gibi, bireylerin sağlık konusunda farkındalıkları da artmaktadır. Aynı şekilde denebilir ki, sağlık hizmetlerinin gelişimi de ekonomik gelişimi hızlandırmaktadır (Mazgit, 1998). Toplumların yaşam kalitelerinin yüksek olması, sağlık hizmetlerinin toplumun geniş kesimlerine ulaşabilmesi beraberinde iş gücü katılımı ve işçi verimliliğini de artırmakta ve ülkenin üretim kapasitesini de olumlu etkilemektedir. Özetle toplumun sağlık düzeyinin yükselmesi toplam çıktıyı dolayısıyla ekonomik büyümeyi olumlu etkilediğine dair birçok görüş bulunmaktadır.

Akın (2007) belirtmiştir ki; bir toplumdaki sağlık hizmetleri, eğitim düzeyi ve nüfus yapısı ile ekonomik ve sosyal kalkınma düzeyi arasında yakın bir ilişki bulunmaktadır. Toplumun sağlık düzeyini yükselten sağlık hizmetlerine yapılan yatırımlar, daha başarılı ve eğitim için sağlıklı bir nüfus yapısını getirir, bu da verimlilik ve üretim artışını hızlandırır. Sağlık hizmetlerine erişimin kolaylaşması ve daha sağlıklı bir toplum yapısı kalkınmayı engelleyen nüfus baskısını da eritir. Karşılıklı olarak, sağlıklı toplum için daha fazla kaynak ayrılması ve bu kaynakların etkin kullanımı ekonomik ve sosyal kalkınmaya da katkıda bulunur. Eğitim düzeyi yükselen toplum, sağlık göstergelerinde meydana gelen iyileşmelerle birlikte nitelikli işgücü olarak kalkınmada yer almaktadır. Verimlilik ve üretim artışı gelir artışını, gelir artışı da ekonomik ve sosyal kalkınmayı yükseltir. Gelişmiş toplumlar sağlık hizmetleri için diğer ülkelere oranla daha fazla kaynak tahsis ederek toplumun refah ve sağlık düzeyinin üst seviyeye çıkmasını ve bu düzeyin devamlılığını amaçlarlar.

\subsection{Kiși Başına Düşen GSYİH ile Temel Sağlık Göstergeleri Arasındaki İlişki}

Kişi başına düşen gelirin yükselmesi ve GSMH'daki artışlar çoğu zaman ekonomik anlamda büyümeyi ifade eder. Fakat gerçek anlamda büyümeden daha doğru bir tanımla kalkınmadan bahsedebilmek için sayısal değerlerin ve rakamların yanısıra birçok sosyal göstergenin beraberce incelenmesi ve değerlendirilmesi gerekir. Bunlar, beslenme, istihdam, eğitim düzeyi ve tüm dünyada gittikçe önem kazanan sağlıkla ilgili göstergelerdir. Son çeyrek yüzyılda ekonomik kalkınma gerçekleşirken insani faktörlerle ekonomik faktörler arasındaki ilişkinin boyutları da önem kazanmıştır. İnsani göstergeler içerisinde sağlık göstergeleri, ekonomik kalkınmayla daha yakın ilişki içerisinde olduğu gerçeğine dayanarak diğer göstergelere oranla daha fazla önem atfedilmeye başlanmıştır. Bir toplumun sağlık düzeyi ortaya konurken dünya genelinde kabul görmüş, doğumda yaşam beklentisi, bebek ölüm oranları, çocuk ölüm oranları ile kaba ölüm oranları gibi göstergeler kullanılmaktadır. Diğer yandan toplumun ekonomik durumunu ortaya koymak için ülkenin milli geliri (GSYİH) ve tüketim harcamaları kullanılmaktadır. Bugüne kadar yapılan araştırmalar göstermiştir ki, gelir ve tüketim harcamaları tek başına bir ülkenin ekonomik durumunu ortaya koymak için yeterli bir ölçüt değildir ve son dönemde genel sağlık göstergeleri ile ekonomik göstergeler birlikte değerlendirilmeye başlanmıştır. Dünya Sağlık teşkilatı (WHO)'na göre, bir ülkede sağlık harcamalarına ayrılan pay o ülkenin yıllık GSMH'nın en az yüzde 5'i kadar olması gerekmektedir. Gelişmekte olan ve az gelişmiş ülkelerde ekonomik kaynakların daha da kıt olması sağlık hizmetlerine ayrılan bütçenin de daha etkin kullanımı gerektirirken, yapılan harcamaların sağlık çıktılarının da daha dikkatli analiz edilmesini gerektirir. Aşağıda Tablo 2'de dünya genelinde ülkelerin sağlık harcamalarının GSYİH'ları içerisindeki yüzdeleri yer almaktadır. Gelişmiş ülkeler diğer ülkelere göre daha yüksek rakamlarda sağlı harcaması gerçekleştirmesi sebebiyle, bu harcamalarının etkin dağılımı ile bu alanda yapılan reformlar konusunda diğer az gelişmiş ülkeler tarafından takip edilir ve model olarak alınırlar. 


\begin{tabular}{|c|c|c|c|c|c|c|}
\hline Country & 1960 & 1970 & 1980 & 1990 & 2000 & $2009^{\circ}$ \\
\hline Australia & & & 6.3 & 6.9 & 8.3 & 8.5 \\
\hline Austria & 4.3 & 5.2 & 7.5 & 8.4 & 9.9 & 11.0 \\
\hline Belgium & 3.9 & 6.3 & 7.2 & 8.6 & 10.4 & 10.9 \\
\hline Canada & 5.4 & 6.9 & 7.0 & 8.9 & 8.8 & 11.4 \\
\hline Czech Republic & & & & 4.7 & 6.5 & 8.2 \\
\hline Denmark & & & 8.9 & 8.3 & 8.3 & 11.5 \\
\hline Finland & 3.8 & 5.5 & 6.3 & 7.7 & 7.0 & 9.2 \\
\hline France & 3.8 & 5.4 & 7.0 & 8.4 & 9.6 & 11.8 \\
\hline Germany & & 6.0 & 8.4 & 8.3 & 10.3 & 11.6 \\
\hline Greece & & 5.4 & 5.9 & 6.6 & 7.8 & 9.7 \\
\hline Hungary & & & & & 6.9 & 7.4 \\
\hline Iceland & 3.0 & 4.7 & 6.3 & 7.8 & 9.5 & 9.7 \\
\hline Ireland & 3.7 & 5.1 & 8.3 & 6.1 & 6.3 & 9.5 \\
\hline Italy & & & & 7.7 & 8.1 & 9.5 \\
\hline Japan & 3.0 & 4.6 & 6.5 & 6.0 & 7.7 & 8.1 \\
\hline Korea & & & 3.4 & 4.0 & 4.6 & 6.9 \\
\hline Luxembourg & & 3.1 & 5.2 & 5.4 & 5.8 & 7.8 \\
\hline Mexico & & & & 4.8 & 5.6 & 6.4 \\
\hline Netherlands & & & 7.4 & 8.0 & 8.0 & 12.0 \\
\hline New Zealand & & 5.2 & 5.9 & 6.9 & 7.7 & 10.3 \\
\hline Norway & 2.9 & 4.4 & 7.0 & 7.6 & 8.4 & 9.6 \\
\hline Poland & & & & 4.8 & 5.5 & 7.4 \\
\hline Portugal & & 2.5 & 5.3 & 5.9 & 8.8 & 10.2 \\
\hline Slovak Republic & & & & & 5.5 & 9.1 \\
\hline Spain & 1.5 & 3.5 & 5.3 & 6.5 & 7.2 & 9.5 \\
\hline Sweden & & 6.8 & 8.9 & 8.2 & 8.2 & 10.0 \\
\hline Switzerland & 4.9 & 5.4 & 7.3 & 8.2 & 10.3 & 11.4 \\
\hline Turkey & & & 3.3 & 3.6 & 4.9 & 6.2 \\
\hline United Kingdom & 3.9 & 4.5 & 5.6 & 6.0 & 7.2 & 9.8 \\
\hline United States & 5.1 & 7.0 & 8.7 & 11.9 & 13.2 & 17.4 \\
\hline
\end{tabular}

a 2009 or most recent year. OECD data for the United States may differ slightly from values reported by the Centers for Medicare and Medicaid Services.

Source: Organization for Economic Cooperation and Development (OECD) Health Care Data, June 2011.

\section{Tablo 1. OECD Ülkelerinin Yıllar İtibariyle Să̆lık Harcamalarının GSYiH İçerisindeki Oranı Kaynak: OECD Sağllk Hizmetleri Verisi, Haziran 2011}

Gelişmiş ülkelerde gelir artışı ve sağlıktaki iyileşmelere paralel olarak doğumda beklenen yaşam süresi yıllara göre artış göstermektedir. Örneğin, 1994- 2005 yılları arasında OECD ülkelerinin KBDGSYIH'ları ortalama olarak \% 45 artarken doğumda yaşam beklentisi de söz konusu yıllar arasında \%2.9 artış göstermiştir (OECD Health Data 2005). Dünya genelinde makro açıdan ülkelerin sağlık durumlarını ortaya koymada kullanılan en önemli göstergelerden biri de bebek ölüm oranlarıdır (DPT, 2006: 201). Aynı zamanda bebek ölüm hızı göstergesi insani gelişimin bir göstergesi olarak da kullanılmaktadır. Nitekim Dünya Sağlık Örgütü (WHO), Birleşmiş Milletler Kalkınma Programı (UNDP) ve OECD gibi uluslararası kuruluşlar ve örgütler de bebek ölüm oranlarına dair göstergeleri diğer gelişmişlik göstergeleriyle beraber sıkça kullanmaktadırlar ve raporlarında yer vermektedirler.

Az gelişmiş ülkelerde, toplumda büyük kayıplara neden olan bulaşıcı hastalıklar ve enfeksiyon hastalıklarına karşı harcama yapmak mevcut toplum için faydalı iken aynı zamanda gelecek nesillerin de sağlık durumlarında iyileşmelere neden olacaktır. Ülkelerin zaman içerisinde üretimlerinde dolayısıyla gelirlerinde meydana gelen artışlar ülkede yaşayan bireylerin daha rahat yaşam sürmelerini sağlayacak hizmetlerin taleplerinde de artış getirir. Artan gelirle beraber sağlık harcamasının artmasının nedenlerinden biri de kamu sağlık hizmetlerinin dışında özel sağlık hizmetlerine doğru yönelimin artmasıdır. İnsanlar gelir düzeyleri ve paralelinde yaşam standartlarının yükselmesiyle birlikte daha kaliteli hizmet arayışına girmektedirler. Kapitalist sistemde yeterli geliri olan kişiler daha iyi bir sağlık hizmetini özel sektörden talep etmektedirler ve özel sektör de bu hizmeti kar amacı güderek sunmaktadır. Sonuçta kişisel gelirin artması, yaşam standartlarının yükselmesi, gerek kamu kesimi, gerekse özel 
kesim tarafından verilen sağlık hizmetlerine olan talebi artırmaktadır ve bu da nihayetinde sağlık harcamalarını artırmaktadır.

\section{Türkiye' de Sağlık Sistemi ve Sağlık Harcamaları}

Türkiye'de sağlık sistemi hizmet arz edenler ve hizmet talep edenler açısından önemli çeşitlilik arz etmektedir. Bu da sağlık sektöründe hem özel hem de kamu kesiminin hizmet arz ettiği anlamına gelirken, hizmet alanlar açısından da sağlık sigortası güvencesi kapsamında olanlar ve olmayanlar diye iki kısma ayrılması demektir. Atasever'e göre (2014) sağlık harcamalarının finansmanı sağlayanlar açısından 2002-2013 döneminde en önemli artış, SGK'nın harcamalarında yaşanmıştır. Yine Atasever, Türkiye Sağlık Hizmetlerinin Finansmanı ve Sağlık Harcamalarının Analizi kitabında: '2002 yılına oranla 2013 yılında SGK'nın sağlık harcamalarında 5,2 kata yakın artış, olmuştur. Bu artışın en önemli sebepleri olarak, SSK hastanelerinin Sağlık Bakanlığına devrini, özel hastanelerin SGK'lılara açılmasını, ilaca ve diğer sağlık hizmetlerinde erişimin kolaylaştırılması" olduğunu belirtmiştir.

Özetle, Türk sağlık sektörüne yön veren temel aktör olarak Sağlık Bakanlığı gözükse de, üniversiteler ve diğer devlet kurumları ile özel sağlık kuruluşları hep birlikte Türkiye'deki sağlık sektörünün karmaşık bir yapı oluşturmasına ve sağlık harcamalarının çeşitlenerek artış göstermesine katkı yapmaktadırlar.

Türkiye genelinde 2003 yılında başlatılan "'Sağlıkta Dönüşüm Programı" ile ülkenin sağlık sisteminin ana finansman modeli olarak sosyal sigorta modeli büyük oranda korunmuştur. Sağlıkta Dönüşüm Programı'nın temel hedeflerinden biri sağlık harcamalarının kontrol altına alınması olarak belirtilmişti; nitekim yapılan sağlık yatırımları ve yapılan harcamaların maliyet-etkinliğini artırmak ve ilaç harcamalarından ziyade koruyucu hekimliğe ve aile hekimliğini desteklemek hedeflendi (Sağlık Bakanlığı, 2003). Sağlık Bakanlığı 2013 Faaliyet Raporu'na göre cari harcamalar arasından kamu kesimi kişisel sağlık harcamaları, ilaç ve tedavi harcamalarını içermektedir. Kamu kesimi kolektif sağlık harcamaları ise koruyucu sağlık ve temel sağlık harcamaları ile sağlık yönetimi kapsamında yer alan personel ve diğer cari harcamaları içermektedir. Tüm bunlara sağlık yatırımları da ilave edilmektedir. Kamusal sağlık harcamalarının GSYİH içindeki payının artışının büyük oranda kamunun kişisel sağlık harcamalarındaki artıştan kaynaklandığı bir gerçektir. Başka bir ifadeyle, kamusal sağlık harcamalarındaki artış maalesef büyük ölçüde ilaç ve tedavi harcamalarındaki artıştan kaynaklanmaktadır. 20022013 döneminde sağlık harcamalarının finansmanı sağlayanlar açısından en önemli artış, SGK'nın harcamalarında yaşanmıştır.

\begin{tabular}{|l|c|c|c|c|c|}
\hline Y1llar & $\begin{array}{c}\text { Kamu Sağlık } \\
\text { Harcaması }\end{array}$ & $\begin{array}{c}\text { Özel Sağlık } \\
\text { Harcaması }\end{array}$ & $\begin{array}{c}\text { Toplam Sağlık } \\
\text { Harcamas1 }\end{array}$ & $\begin{array}{c}\text { Kamu Sağlı } \\
\text { Harcamalarının Pay1 } \\
(\%)\end{array}$ & $\begin{array}{c}\text { Özel Sağlik } \\
\text { Harcamalarının Pay1 } \\
(\%)\end{array}$ \\
\hline 2002 & 13.270 & 5.504 & 18.774 & 70,7 & 29,3 \\
\hline 2003 & 17.462 & 6.817 & 24.279 & 71,9 & 28,1 \\
\hline 2004 & 21.389 & 8.632 & 30.021 & 71,2 & 28,8 \\
\hline 2005 & 23.987 & 11.372 & 35.359 & 67,8 & 32,2 \\
\hline 2006 & 30.116 & 13.953 & 44.069 & 68,3 & 32,2 \\
\hline 2007 & 34.530 & 16.374 & 50.904 & 67,8 & 27,0 \\
\hline 2008 & 42.159 & 15.580 & 57.740 & 73,0 & 19,0 \\
\hline 2009 & 46.890 & 11.021 & 57.911 & 81,0 & 21,4 \\
\hline 2010 & 48.482 & 13.196 & 61.678 & 78,6 & 20,4 \\
\hline 2011 & 54.580 & 14.028 & 68.607 & 79,6 & 20,8 \\
\hline 2012 & 58.785 & 15.404 & 74.189 & 79,2 & 21,5 \\
\hline 2013 & 66.228 & 18.162 & 84.390 & 78,5 & \\
\hline
\end{tabular}

Tablo 2. Kamu ve Özel Să̆llk Harcamaları, (2002-2013), (milyon TL) Kaynak: TÜIK, Sağlık Harcamalarının Finansmanı Sağlayanlara Göre Dă̆ılımı, (2002-2013), Dönemi, Ankara 2014 


\section{Ekonometrik Model}

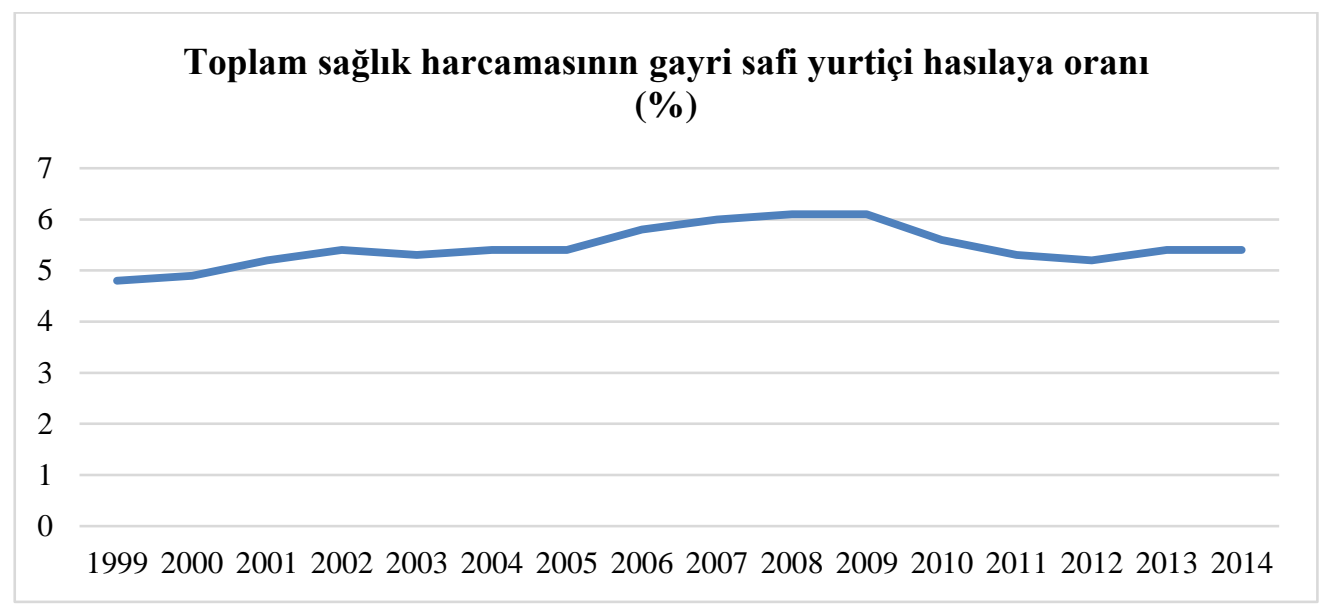

Şekil 1. Toplam Sağlık Harcamasının Gayri Safi Yurtiçi Hasılaya Oranı

Log (GSYIH)'ın Phillips-Perron Durağanlık Testi

Null Hypothesis: LOG (GSYIH) has a unit root

Exogenous: None

Bandwidth: 0 (Newey-West automatic) using Bartlett kernel

\begin{tabular}{llcc}
\hline \hline & Adj. t-Stat & Prob.* \\
\hline \hline Phillips-Perron test statistic & 0.068746 & 0.6894 \\
\hline Test critical values: & 1\% level & -2.728252 & \\
& 5\% level & -1.966270 & \\
& $10 \%$ level & -1.605026 & \\
\hline \hline
\end{tabular}

\section{$\Delta \log (G S Y I H)$ 'ın Phillips-Perron Durağanlık Testi}

Null Hypothesis: D(LOG(GSYIH)) has a unit root

Exogenous: None

Bandwidth: 0 (Newey-West automatic) using Bartlett kernel

\begin{tabular}{llll}
\hline \hline & Adj. t-Stat & Prob. ${ }^{*}$ \\
\hline \hline & & & \\
\hline \multirow{2}{*}{ Phillips-Perron test statistic } & -7.913780 & 0.0000 \\
\hline Test critical values: & 1\% level & -2.740613 & \\
& 5\% level & -1.968430 & \\
& $10 \%$ level & -1.604392 & \\
\hline \hline
\end{tabular}

Birinci Mertebeden durağandır. 


\section{Log(TSH)'In Phillips-Perron Durağanlık Testi}

Null Hypothesis: LOG(TSH) has a unit root

Exogenous: None

Bandwidth: 2 (Newey-West automatic) using Bartlett kernel

\begin{tabular}{llll}
\hline \hline & Adj. t-Stat & Prob. ${ }^{*}$ \\
\hline \hline & & & \\
\hline \multirow{2}{*}{ Phillips-Perron test statistic } & 2.977117 & 0.9978 \\
\hline Test critical values: & 1\% level & -2.728252 & \\
& 5\% level & -1.966270 & \\
& $10 \%$ level & -1.605026 & \\
\hline \hline
\end{tabular}

\section{$\Delta \log (\mathrm{TSH})$ 'ın Phillips-Perron Durağanlık Testi}

Null Hypothesis: D(LOG(TSH)) has a unit root

Exogenous: None

Bandwidth: 2 (Newey-West automatic) using Bartlett kernel

\begin{tabular}{|c|c|c|c|}
\hline & & Adj. t-Stat & Prob.* \\
\hline \multicolumn{2}{|c|}{ Phillips-Perron test statistic } & -3.577177 & 0.0016 \\
\hline Test critical values: & $\begin{array}{l}1 \% \text { level } \\
5 \% \text { level } \\
10 \% \text { level }\end{array}$ & $\begin{array}{l}-2.740613 \\
-1.968430 \\
-1.604392\end{array}$ & \\
\hline
\end{tabular}

\section{Birinci Mertebeden durağandır.}

Dependent Variable: LOG(TSH)

Method: Least Squares

Date: 05/16/16 Time: 16:26

Sample: 19992014

Included observations: 16

\begin{tabular}{lllll}
\hline \hline Variable & Coefficient & Std. Error & t-Statistic & Prob. \\
& & & & \\
\hline \hline & & & & \\
C & 8.467665 & 9.386650 & 0.902097 & 0.3823 \\
LOG(GSYIH) & 0.059887 & 0.282411 & 0.212056 & 0.8351 \\
& & & \\
\hline \hline & & & \\
R-squared & 0.003202 & Mean dependent var & 10.45760 \\
Adjusted R-squared & -0.067998 & S.D. dependent var & 0.868411 \\
S.E. of regression & 0.897450 & Akaike info criterion & 2.737951 \\
Sum squared resid & 11.27584 & Schwarz criterion & 2.834524 \\
Log likelihood & -19.90361 & Hannan-Quinn criter. & 2.742896 \\
F-statistic & 0.044968 & Durbin-Watson stat & 0.077795 \\
Prob(F-statistic) & 0.835119 & & \\
& & & \\
\hline
\end{tabular}

Sonuç olarak GSYİH’daki artış oranı ve sağlık harcamaları arasında bir ilişki bulunmamıştır.

\section{Değerlendirmeler ve Sonuç}

Bu çalışmada, Türkiye'de sağlık sektöründe yapılan harcamalar ve ekonomik büyüme arasında herhangi bir ilişki olup olmadığını analiz edebilmek için önce sağlığın bir hizmet olarak ekonomideki yeri ve sağlık harcamalarının niteliği üzerinde kısa bir değerlendirme yaptık. Daha sonra Türkiye'deki sağlık sektörünün yapısı üzerinde durularak; sağlık ile ekonomi arasındaki ilişki, belli başlı uluslararası örgütler tarafından tüm dünyada 
gelişmişlik göstergesi olarak kabul edilen sağlık göstergeleri bazında değerlendirilmeye çalışılmıştır. Zaman içerisinde sağlıklı bir toplumu ifade eden kriterler ile ekonomik göstergeler arasındaki ilişkinin ne yönde geliştiği incelenmiş ve karşıllıklı etkileşimleri analiz edilmeye çalışılmıştır. Diğer bir ifadeyle, ülke genelinde daha sağlıklı bir toplum yapısına sahip olma yolunda son yıllarda önemli gelişme kaydederken Türkiye ekonomisinin bundan nasıl etkilendiği ve aynı şekilde, kişi başına düşen milli gelir ve diğer makro verilerde yaşanan olumlu gelişmeler sonucunda sağlık göstergelerinin ne yönde etkilendiği veriler bazında değerlendirilmeye çalışılmıştır. $\mathrm{Bu}$ araştırmaların sonucunda doğumda yaşam beklentisi ile kişi başına düşen gelir arasında pozitif yönlü bir ilişkinin olduğu belirlenirken, Türkiye'de yıllar itibariyle kişi başı gelir ve sağlık sistemine ayrılan pay arttıkça bebek ölüm hızı, çocuk ölüm hızı ve kaba ölüm oranı arasında negatif yönlü bir ilişki gözlemlenmiştir.

Belirtilmelidr ki, dünya genelinde olduğu üzere Türkiye'de de kamunun sağlık harcamalarının GSYİH'ya oranı her geçen yıl artmaktadır. Ancak, Kamunun sağlık harcamalarının GSYİH'ya oranı yalnızca reform sürecinde değil, 'Sağlıkta Dönüşüm Programı' uygulamaya geçirilmeden önceki dönemde de ciddi artış, göstermiştir. Yine Türkiye'deki kamusal sağlık harcamalarının oranı kendisiyle yakın milli gelir seviyesine sahip diğer ülkelere göre daha yüksek seyretmektedir, bu da kamu sektörünün Türk Sağlık Sistemi içerisindeki belirleyici rolüne işaret etmektedir. Son olarak çalışmamızda kurulan ekonometrik modelde, 'Phillips-Perron Durağanlık Testi' kullanılarak Türkiye'deki sağlık harcamaları 1999-2014 dön1e46+ mi için analiz edilmiş ve sağlık sektöründeki yatırımlar ile ekonomik büyüme arasında bir ilişki bulunamamıştır. Kısaca, ele alınan dönem için incelenen veriler göstermiştir ki, Türkiye'de yapılan sağlık harcamaları ve ekonomik büyüme arasında anlamlı bir ilişki yoktur.

\section{Kaynakça}

- Ağırbaş, İ., Tatar, M. 2001 "Sağlık Hizmetlerinde Ekonomik Değerlendirme Teknikleri”, Yeni Türkiye Dergisi, Sağlı Özel Sayısı 2 Yı1 7, Sayı 40

- Arslanhan Memiş, S. 2012. "Son Dönemdeki Harcamalarının Analizi”, Değerlendirme notu. Ankara: Türkiye Ekonomi Politikaları Araştırma Vakfi.

- Atasever, Mehmet, Türkiye Sağık Hizmetlerinin Finansmanı ve Sağlık Harcamalarının Analizi 20022013.

- Belek, İ., Dünya Genelinde Sağlı Harcamalarının GSYİH İçerisindeki Yüzdesi Kaynak, Sağlık Sistemleri Hangi Dinamiklerle Gelişiyor ve Nasıl Gruplanıyor?, Toplum ve Hekim, Kasım 1994 - Şubat 1995, Cilt. 9, s.64, s.15, OECD Health Data 2006.

- Charles, E. Phelps, Health Economics, Addison Wesley, 2002.

- CCaışkan, Z. (2008), 'Sağlık Ekonomisi: Kavramsal Bir Yaklaşımı”, Hacettepe Üniversitesi İktisadi ve İdari Bilimler Fakültesi Dergisi, Cilt 26, Say1 2, s. 29-50.

- Çilingiroğlu, Nesrin, "Ekonomik Kalkınma ve Sağlık Ekonomisi”, Yeni Türkiye, Sayı 40, 2001, s.1592

- Çilingiroğlu, Nesrin, Sağlık Ekonomisi, Yayımlanmamış Halk Sağllğı Ders Notları, Hacettepe Üniversitesi, Halk Sağlığı Anabilim Dalı, Kasım 2003, s. 11

- Folland, S., Goodman, A. C., Stano, M. (1997), The Economics of Health and Health Care, New Jersey: Prentice Hall, 1997.

- Işık, Abdülkadir (1998); "Sağlık Ekonomisi, Finansmanı ve Ekonometrik Bir Analiz Çerçevesi”, Yayınlanmamış Doktora Tezi, Marmara Üniversitesi SosyaBilimler Enstitüsü, İstanbul.

- Işık, Abdülkadir ve diğerleri 1997, Sağık Ekonomisinin Kapsamı ve Tarihsel Gelişimii, Ankara.

- Kasım 2015; Türkiye'de Sağık Harcamalarına Tarihsel Bir Bakış, Volkan Yılmaz ve Nurhan Yentürk İstanbul Bilgi Üniversitesi Sivil Toplum Çalışmaları Merkezi)

- Mazgit, İsmail, “Ekonomik Kalkınma Sürecinde Türkiye'de Sağlık Sektörünün Yeniden Yapılanması”, Yayınlanmamış Doktora Tezi, Dokuz Eylül Üniversitesi Sosyal Bilimler Enstitüsü, İzmir, 1998.

- Tokalaş, Sevinç, (2006) 'Kamu Sağlık Hizmetlerinin Satın Alınması”, Yüksek Lisans Tezi, İstanbul.

- Sağlık Bakanlığı Sağlıkta Dönüşüm Programı, 2013. Sağlık İstatistikleri Yıllığı. Ankara. Sosyal Güvenlik Kurumu 2014. 
İş Sağlığı ve Güvenliği Uygulamalarının Sağlık Çalışanları Tarafından Değerlendirilmesi: Bir Özel Hastane Örneği Occupational Health and Safety Practices Evaluation by Health
Workers: An Example of Private Hospital

\author{
Selin Dayan (Beykent University, Turkey) \\ Assoc. Prof. Dr. Volkan Öngel (Beykent University, Turkey)
}

\begin{abstract}
The aim of this study is to identify distribution of occupational diseases and related health complaints among health workers and also to detect employee apprehensions about availability of occupational health and safety issues in the workplace. The application area of this study is a private hospital subservient in Istanbul and accredited by JCI. Within the framework of this study, a survey which contains 8 queries about demographic and personal features, 12 queries about occupational diseases and related complaints and 24 queries about occupational health and safety issues is applied to health staff employed in variable departments and positions in this hospital. The reliability coefficient of this survey is found .816 (Cronbach's Alpha). In the conclusion of this study; it is detected that the employee's perception about the occupational health and safety issues in the workplace has a positive aspect. Moreover, arm and leg pains (\%65.6), over-fatigue (\%64.1), insomnia (\%59.7) and presence of venous varicosises $(\% 54.2)$ were the most determined diseases and complaints, which are considered as workoriginated among healthcare workers. In accordance with findings, the privileged improvements about the problems in occupational health and safety issues in this hospital have been presented.
\end{abstract}

\title{
1 Giriş
}

Çalışmanın Amacı: Sağlık kurumları ve özellikle hastanelerdeki çalışma alanları iş sağlığı ve güvenliği bakımından önemli riskler taşımaktadır. İlgili kurumlarda hizmet veren sağlık çalışanları ise bu riskler karşısında tehlike altındadır. İş Sağlığı ve Güvenliği'ne ilişkin işyeri Tehlike Sınıfları Tebliği’nde hastanelerin yüksek riskli grupta yer alması, hastanelerde iş sağlığı ve güvenliği (İSG) uygulamalarının önemini ön plana çıkarmıştır. Çalışmada, sağlık çalışanlarında olabilecek meslek hastalıkları ve şikayetlerin dağılımı ile kurumdaki iş sağlığı ve güvenliği uygulamalarının mevcudiyetine yönelik çalışan algılarının tespit edilmesi amaçlanmıştır.

Çalışmanın Önemi: Sağlık en önemli hizmet sektörlerinden birisi olarak doğrudan insan hayatı ile ilişkilidir. Sağlık çalışanlarının kendilerini güvenli bir çalışma ortamında hissetmeleri iş verimi ve verilen hizmet kalitesinin arttırılması açısından önem taşımaktadır. Sağlık çalışanlarının İSG uygulamalarına ilişkin konularda görüşlerinin alınması, hastanelerdeki iş sağlığı ve güvenliğine yönelik uygulamaların yetersiz kaldığı alanlar mevcut ise belirlenmesi, belirlenen alanlardaki risklerin en aza indirilmesi ve bu alanlarda etkin korunma sistemlerinin geliştirilmesini sağlayacaktır.

Kullanılan Metod ve Teknikler: İstanbul ili Avrupa yakasında faaliyet gösteren bir özel hastanenin 500 sağlık çalışanına anket dağıtılmıştır. Dağıtılan anketlerin 370 adeti geriye toplanabilmiştir. Çalışmanın analizinde 343 anket değerlendirmeye alınmıştır. 27 anket cevaplarındaki tutarsızlıklar ve eksiklikler sebebiyle çalışma dışarısında bırakılmıştır. Yapılan anket ile çalışanların iş sağlığı ve güvenliği uygulamalarının mevcudiyetine yönelik algıları ölçülmeye çalışılmıştır.

Karşılaşılan Zorluklar ve Sınırlamalar: Araştırmanın yalnızca bir özel hastane baz alınarak yürütülmesi ve gerçekleştirilen anket uygulamasına hekimlerin az sayıda katılımı araştırmanın sınırlılığıdır.

\section{2 İş Sağlı̆̆ı Ve Güvenliği}

İş sağlığı kavramı; çalışanların fiziksel, mental ve duygusal iyilik hallerinin sağlanması için işyeri politika ve programlarının oluşturulması, geliştirilmesi ve devamlılığının sağlanması olarak tanımlanmaktadır (IAPA, 2007). İş güvenliği ise, yapılan iş esnasında çalışanların karşı karşıya geldikleri tehlikelerin bertaraf edilmesi ya da azaltılması için işverenin sorumluluğunda olan teknik kurallar bütünüdür (Köseoğlu, 2005).

\section{Sağlık Çalışanlarının İş Sağlığı Ve Güvenliği}

Dünya Sağlık Örgütü’ne göre sağlık çalışanı “toplumun sağlığını iyileştirme, koruma ve geliştirme işiyle uğraşan tüm insanlar” olarak tanımlanmıştır (Oğan, 2014). Uluslararası Çalışma Örgütü sağlık alanında çalışanları; doktorlar, diğer profesyonel meslekler (diş hekimi, eczacı, psikolog), hemşire, ebe ve sağlık memuru, diğer sağlık elemanları (EEG, EKG, radyoloji, odyoloji teknisyeni) ve diğer çalışanlar (sekreter, diyetisyen, güvenlik görevlileri vb.) olarak sınıflandırmıştır (Karaca, 2013). Sağlık sektörü en hızlı büyüyen sektörlerdendir. Sağlık çalışanları, işyerlerinde iğne batması, sırt ağrıları, lateks alerjisi, şiddet ve stres gibi çok geniş yelpazeli tehlikelerle 
yüzyüzedir. Her ne kadar sağlık çalışanlarının bu gibi tehlikelere maruziyeti azaltılabilir ve hatta önlenebilirse de çalışanların işyerlerinde yaralanma ve hastalanmaları devam etmektedir. Bütün endüstriyel sektörler arasında sağlık sektörü, ölümcül olmayan mesleki kaza ve hastalıklar bakımından diğer sektörlerden daha fazla vaka sayısına sahiptir (CDC, 2016).

Sağlık çalışanlarının sağlığını etkileyen tehlike ve riskler literatürde; kimyasal, fiziksel, biyolojik, ergonomik ve psikososyal olarak gruplandırılmıştır. Sağlık çalışanlarının çalışma koşulları sebebiyle risk altında kaldıkları en önemli etkenlerden biri biyolojik olanlardır. Biyolojik ajanlar birçok infeksiyon hastalı̆ı̆ının sebebi olarak gösterilirler (Taşçıŏlu, 2007). Hastaların kan veya kanla kontamine vücut sıvılarıyla temas halinde HIV (Human Immunodeficiency Virus), Hepatit B (HBV), Hepatit C (HCV), Hepatit D virüsleri başlıca bulaşan virüslerdir (Akova, 2016). Omaç ve arkadaşlarının Malatya İl merkezinde çalışan hemşireler üzerine yapmış oldukları bir çalışmada, son üç ay içerisinde en az bir defa kesici delici yaralanma ile karşılaşmış olup, hepatit B aşısı yaptırma oranlarının düşük olduğu belirlenmiş̧tir (Omaç, vd, 2010). İnci ve arkadaşlarının 2007-2008 yılları arasında HBV, HCV ve HIV seropozitifliğini araştırmak amacıyla yaptıkları bir çalışmada, sağlık çalışanlarının üçünde $(\% 1,0)$ HBsAg, bir (\%0.34) kişide anti-HCV pozitifliği olduğu tespit edilmiştir. HIV Ag/Ab ise çalışma kapsamındaki tüm sağlık çalışanlarında negatif olarak belirlenmiştir (İnci, vd, 2009). Tüberküloz, suçiçeği, kabakulak, difteri, kızamık, kızamıkçık, boğmaca, meningokok, parvovirüs B19, influenza, virüsler ve brusella bakterileri solunum yolu ile bulaşabilmektedir (Saygun, 2012). Tüberküloz riski, sağlık çalışanlarının tümünü etkilemekle birlikte özellikle göğüs hastalıkları, laboratuvar, morg gibi birimlerde istihdam edilenlerde daha yüksektir (Özkara, 2003).

Sağlık çalışanları çalışma ortamı kaynaklı birçok kimyasal risk etkeni ile karşı karşıya kalabilmektedir. Bu kimyasallar; anestezik maddeler, sitotoksik maddeler ve sterilizasyonda kullanılan maddeler olarak sıralanabilir. Bunlar, sık kullanılmaları ve etkileri nedeniyle çalışan sağlığının korunması açısından oldukça önemlidir (TTB, 2008). Ameliyathanelerde hastalara anestezi verilirken cihazlardan, maskelerden, hortumlardan sizan ve hastanın soluması gibi durumlardan dolayı ameliyathane odasına uçucu anestezik gazlar küçük miktarlarda yayılmaktadır. Atık olarak etrafa yayılan nitrozoksit ve halotan, enfluran, sevofluran gibi halojenli anestezik maddeler sağlik çalışanları tarafından solunmaktadır. Çalışanların maruz kaldığı bu atık anestezik maddeler, baş ağrısı, halsizlik, bulantı, baş dönmesi, bilinç bozuklukları, karaciğer ve böbrek hastalıkları gibi sıkıntılara yol açmaktadır (NIOSH, 2007). Kimyasal sterilizasyon amaçlı kullanılan gluteraldehit, formaldehit ve etilen oksit gibi maddeler de ameliyathanelerde sıklıkla kullanılan maddelerdir. Havalandırma koşulları iyi olmadığında fazla miktarda glutaraldehidin, ciddi deformasyonlara sebep olabilir. Formaldehit kullanımı ise deri hassasiyeti, gözde ve solunum yollarında iritasyon, öksürük ve baş ağrısı, hatta yüksek dozda maruz kalındığında ölüme bile yol açabilmektedir. Etil oksit yanıcı olmasının yanında, konsantrayonu \% 3'e ulaştığında patlayıcı bir gazdır ve kanserojen olduğunu gösteren çalışmalar mevcuttur (Aslan ve Öntürk, 2011). Çalışma ortamında kullanılan bir diğer kimyasal madde antineoplastik ajanlardır. Antineoplastikler içerisinde kemoterapi ilaçları ve sitotoksik ilaçlar sıklıkla kullanılmaktadır. İlaçları hazırlayan eczacılar ve hem hazırlayıp hem de hastaya uygulayan hemşireler en yüksek maruziyet riskine sahip çalışan gruplarıdır. Yapılan çalışmalarda kimyasal ajanlara mesleki maruziyet, cilt döküntüleri, alerjik reaksiyonlar, saç kaybı gibi akut etkiler, kadın çalışanlarda düşük doğum ağırlıklı bebek, malformasyon gibi üreme problemlerine yol açtı̆̆ görülmüştür (NIOSH, 2012).

Sağlık çalışanlarının sağlığını tehdit eden fiziksel etkenler arasında radyasyon, elektrik, gürültü, kötü havalandırma, aydınlatma düzeyi gibi risk etmenleri sıralanabilir (TTB, 2008). Vehid ve arkadaşlarının Cerrahpaşa Tıp Fakültesi'nin çeşitli ünitelerinde mevcut gürültü düzeyleri ve kaynaklarını saptamak amacıyla yapmış oldukları çalışmada, saptanan gürültü düzeyinin WHO tarafindan tavsiye edilen en yüksek değerden yüksek olduğu sonucuna varmışlardır (Vehid, vd, 2010). Gürültünün çalışan sağlığı üzerine; geçici veya kalıc işitme kaybı ile fiziksel, yorgunluk, uyku bozukları, baş ağrıları, dolaşım semptomları gibi fizyolojik, davranış bozuklukları, sinirlenme, genel rahatsızlık ve sıkılma gibi psikolojik etkileri vardır (Parlar, 2008).

Sağlık kurumlarında radyasyon, hastalıkların tanı ve tedavisinde kullanılır. Bu durum, radyasyona maruz kalan sağlık çalışanları için mesleki bir sağlık riski oluşturmaktadır. Mesleki maruziyetin en yaygın olduğu radyoloji çalışanlarında, kısa süreçte yüksek miktarda ya da uzun süreçte düşük miktarlarda aldıkları radyasyona bağlı akut veya kronik etkiler görülmektedir. Radyasyonun kronik etkileri, ışınlamadan uzun zaman sonra ortaya çıkan ve çoğunlukla ölümcül olabilen hastalıkları kapsamaktadır (Yaşar, 2012). Radyasyonun akut etkileri ise, iç kanama, yorgunluk, ateş, bulantı, kusma, ishal, sıvı elektrolit dengesizliği, zihin bulanıklığı, nöbet gibi bulgulara yol açabilir (Toplan, 2016). Serhatlıoğlu ve arkadaşları tarafından Fırat Üniversitesi Tıp Fakültesi Radyodiagnostik Anabilim Dalı'nda gerçekleştirilen bir araştırmada iyonize radyasyona uzun dönem maruz kalan radyoloji çalışanlarında CD4+ T lenfositleri, total immunoglobülinler (IgA, IgG, IgM), C3 ve C4'ün azaldığı, biyokimyasal olarak serum trigliserit düzeyleri ve serum paraoksonaz aktivitesinin anlamlı şekilde yükselmiş olduğu saptanmıştır (Serhatlıŏglu, vd, 2004). Ergonomik olmayan çalışma ortamı, çalışanlarda çeşitli sağlık problemlerine yol açmaktadır. Çalışanların uygun olmayan postürde malzeme, eşya ve hasta taşıması çeşitli kas iskelet sistemi hastalıklarına yol açmaktadır (Emiroğlu, 2012). Kas iskelet sistemi hastalıkları arasında bel ağrısı oldukça sık görülmektedir. Bel ağrısı vb. rahatsızlıkların görülmesinde yineleyen hareketler ve zorlanmalar önemli etkenlerdir. Yineleyen hareketler ve zorlanmalar neticesinde kaslarda, eklemlerde, tendonlarda hasarlar meydana gelmekte ve çeşitli klinik tablolar ortaya çıkabilmektedir (Bilir, 2007). İlçe'nin yapmış olduğu bir araştırmada, Yoğun Bakım 
Ünitesi'nde görevli hemşirelerin 1/5'inde tanı konmuş kas iskelet hastalığının olduğu ve \% 71.1 'inin çalıştıkları son hafta süresince bel ağrısı yaşadıkları tespit edilmiştir. Hasta taşınması esnasında görevli kişilerden destek almayanlarla ve çoğunlukla ayakta çalışanlarda kas-iskelet hastalığı görülme arasında anlamlı bir farkın olduğu istatistiksel olarak ortaya konulmuş ve. Yoğun Bakım Üniteleri'nin ergonomik faktörler açısından riskli olduğu tespit edilmiştir (İlçe, 2007). Güler ve arkadaşlarının yapmış oldukları bir çalışmada, hemşirelerin \% 63.3'ünde ergonomik koşullara bağlı yani çalışma ortamı kaynaklı kas iskelet sistemi rahatsızlığı olduğu ve bu rahatsızlıklar içerisinde en çok alt ekstremitelerde ağrı yaşadıkları belirlenmiştir (Güler, vd, 2015).

Sağlık sektörü çalışanlarının tümünde psikososyal risk faktörleri görülebilir; buna hemşireler, doktorlar, temizlik görevlileri ve hatta teknik servis çalışanları da dahildir. Zaman baskısı, katı hiyerarşik düzen, ödül sisteminin eksikliği, yetkin olmayanın önderliği, doğru bilginin eksikliği, idari personelin destek yetersizliği, vardiyalı çalışma, gece çalışması, düzensiz çalışma saatleri gibi işle ilgili yüklenmeler, sosyal çatışma, mobing, şiddet ve ayrımcılık, çalışma organizasyonlarının ideal olmayışı bilinen psikososyal riskler arasında yer almaktadır (European Comission, 2010).

Akca ve arkadaşlarının, özel bir sağlık kuruluşunda çalışan personelin şiddetle karşılaşma sıklığının belirlenmesi amacıyla yapmış oldukları çalışmada, sağlık çalışanlarının \% 24,2'sinin şiddete maruz kaldığı saptanmıştır (Akca, vd, 2014). Çamcı ve Kutlu'nun sağlık çalışanlarına yönelik yaptıkları başka bir çalışmada, son bir yılda şiddete maruz kalma oranlarının \%72,4, en çok maruz kaldıkları şiddet türününse sözel şiddet olduğu belirlenmiştir (Çamcı ve Kutlu, 2011).

Literatüre bakıldığında sağlık çalışanları içerisinde en çok hemşirelerin mobinge maruz kaldığ belirlenmiştir (Karakaş ve Okanlı, 2013). Dikmetaş ve arkadaşlarının yapmış olduğu bir çalışmada mobing düzeyinin, duygusal tükenme, duyarsızlaşma ve kişisel başarıyı anlamlı şekilde etkilediği belirlenmiştir (Dikmetaş, vd, 2011). Günüşen ve Üstün'ün, hemşire ve hekimlere yönelik yapılan tükenmişlik araştırmalarını inceleyerek yaptıkları çalışmada, tükenmişliği artıran faktörleri, çalışma saatlerinin fazlalığı, nöbetler, iş yükünün fazlalığı, işyeri memnuniyetsizliği, rol çatışması ve belirsizliği, hasta sayısı, yoğun bakım ve acil servislerde çalışma olarak saptamışlardır (Günüşen ve Üstün, 2010).

\section{Materyal ve Yöntem}

Araştırma çalışma ortamından kaynaklanan risk etmenleri karşısında tehlike altında kalan sağlık çalışanlarında olabilecek meslek hastalıkları ve şikayetlerin dağılımı ile kurumdaki iş sağlığı ve güvenliği uygulamalarının mevcudiyetine yönelik çalışan algısının tespit edilmesi amacıyla tanımlayıcı olarak yapılmıştır. Araştırmanın evrenini, İstanbul ili içerisinde ikamet eden ve hastalar ile doğrudan ilişki içinde olan yaklaşık 900 sağlık çalışanına sahip özel bir hastanede farklı departman ve branşlarda çalışan 21 doktor, 228 hemşire, 94 diğer sağlık personeli oluşturmaktadır. Diğer sağlık personeli grubu; biyolog, kimyager, eczacı, laboratuvar teknikeri, anestezi teknikeri, radyoloji teknikeri ve acil tıp teknisyenlerini içermektedir.

Araştırma için etik kurul onayı ve ilgili kurumun yazılı izni alınmıştır. Anket uygulamasından önce katılımcılara bilgi verilmiş ve gönüllü olan kişilere anket yöneltilmiştir. Anketler, 2015 Mart ayı içerisinde elden doldurtulmaya başlanmış olup iki aylık bir süre içerisinde tamamlanmıştır. Yöneltilen anket "Bir Ölçek Geliştirme Çalışması: Hastanede Çalışan Sağlık Personeli İçin İş Güvenliği Ölçeği” (Öztürk ve Babacan, 2012) isimli çalışmadaki anketten uyarlanmış demografik ve bireysel özelliklere ait 8 soru (yaş, cinsiyet, medeni durum, eğitim durumu, pozisyon, hastanedeki çalışma deneyimi, mesleki çalışma deneyimi ve hastanedeki çalışma birimi), mesleki hastalık ve şikayetlere ait 1 bölüm 12 soru, ISG uygulamalarına ait 6 bölüm 24 sorudan oluşmaktadır. Anketin demografik veriler haricindeki soruları için, “(1) Kesinlikle Katılmıyorum” ile “(5) Kesinlikle Katılıyorum” arasındaki değerleri içeren 5'li likert ölçeği kullanılmıştır. A Bölümü’nde yer alan "Mesleki Hastalıklar ve Şikayetler” başlığı için “(1) Kesinlikle Katılmıyorum” çalışan açısından en olumlu durumu ifade ederken, "(5) Kesinlikle Katılıyorum” ise en olumsuz durumu ifade etmektedir. Anketteki İSG uygulamalarına ait diğer başlıktaki sorular için “(1) Kesinlikle Katılmıyorum” çalışan açısından en olumsuz durumu ifade ederken, "(5) Kesinlikle Kat1liyorum” ise en olumlu durumu ifade etmektedir.

\section{Bulgular}

\subsection{Sağlık Çalışanlarının Demografik Özelliklerine Ait Bulgular}

Araştırmaya katılan sağlık çalışanlarının; hastanedeki çalışma birimi, pozisyon, hastanedeki çalışma deneyimi, mesleki çalışma deneyimi, eğitim durumu, medeni durum, cinsiyet ve yaş bilgileri aşağıdaki başlıklarda detaylı olarak karşılaştırılmıştır.

\subsection{1. Çalışma Birimi}

Araştırmaya katılan 343 sağlık çalışanının poliklinik, servis ve diğer birimler olmak üzere detaylı dağılımları Tablo 1'de sunulmuştur. 


\begin{tabular}{|c|c|c|c|c|}
\hline \multirow{17}{*}{ 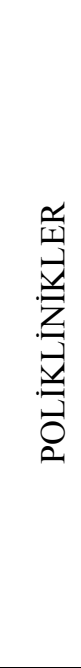 } & Hastanedeki Çalıșma Birimi & $\mathrm{N}$ & Yüzde & Kümülatif Yüzde \\
\hline & A ğız ve Diş Sağlı̆ğ Kliniği & 6 & 1,7 & 14 \\
\hline & Check Up Polikliniği & 8 & 2,3 & 30,3 \\
\hline & Dermatoloji Polikliniği & 2 & 0,6 & 30,9 \\
\hline & Gastroenteroloji Polikliniği & 12 & 3,5 & 34,4 \\
\hline & Genel Cerrahi Polikliniği & 1 & 0,3 & 34,7 \\
\hline & Göğüs Hastalıkları Polikliniği & 2 & 0,6 & 35,3 \\
\hline & Göz Polikliniği & 3 & 0,9 & 36,2 \\
\hline & Kardiyoloji Polikliniği & 12 & 3,5 & 41,4 \\
\hline & Kulak Burun Boğaz Polikliniği & 2 & 0,6 & 60,9 \\
\hline & Medikal Onkoloji Polikliniği & 15 & 4,4 & 65,3 \\
\hline & Nükleer Tıp ve Moleküler Görüntüleme Polikliniği & 11 & 3,2 & 68,5 \\
\hline & Ortopedi ve Travmatoloji Polikliniği & 2 & 0,6 & 74,3 \\
\hline & Pediatri Polikliniği & 3 & 0,9 & 75,2 \\
\hline & Üroloji Polikliniği & 2 & 0,6 & 89,5 \\
\hline & Radyasyon Onkolojisi Polikliniği & 8 & 2,3 & 81 \\
\hline & TOPLAM & 89 & 26 & \\
\hline \multirow{6}{*}{ 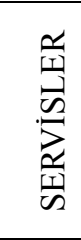 } & Acil Servis & 33 & 9,6 & 12,2 \\
\hline & Yetişkin Yatan Hasta Servisi & 23 & 6,7 & 100 \\
\hline & Pediatri Servisi & 12 & 3,5 & 78,7 \\
\hline & Kardiyoloji Servisi & 20 & 5,8 & 47,2 \\
\hline & Onkoloji Servisi & 18 & 5,2 & 73,8 \\
\hline & TOPLAM & 106 & 30,8 & \\
\hline \multirow{10}{*}{ 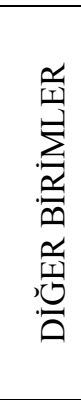 } & Ameliyathane & 32 & 9,3 & 23,3 \\
\hline & Yenidoğan Yoğun Bakım Ünitesi & 13 & 3,8 & 93,3 \\
\hline & Koroner Yoğun Bakım Ünitesi & 23 & 6,7 & 60,3 \\
\hline & Acil Laboratuvar & 9 & 2,6 & 2,6 \\
\hline & Klinik Laboratuvar & 22 & 6,4 & 53,6 \\
\hline & Transfüzyon Merkezi & 5 & 1,5 & 88,9 \\
\hline & Kardiyoloji İşlem Bölümü & 6 & 1,7 & 37,9 \\
\hline & Radyoloji & 22 & 6,4 & 87,5 \\
\hline & Bebek Odas1 & 16 & 4,7 & 28 \\
\hline & TOPLAM & 148 & 43,1 & \\
\hline \multicolumn{2}{|c|}{ GENEL TOPLAM } & 343 & 100 & \\
\hline
\end{tabular}

Tablo 1. Ankete Katılan Çalışanların Hastanedeki Çalışma Birimlerine Göre Dağılımı

\subsubsection{Pozisyon}

Tablo 2'de görüldüğü üzere katılımcıların 228'i hemşire, 21'i doktor ve 94'ü de diğer sağlık personelidir. Bu ankete hemşireler tarafından yoğun katılımın nedeni, hastane içerisinde hemşire populasyonun doktor ve diğer sağlık personeline oranla daha fazla olmasıdır.

\begin{tabular}{|l|c|c|c|}
\hline & N & Yüzde (\%) & Kümülatif Yüzde \\
\hline Diğer Sağlık Personeli & 94 & 27,4 & 27,4 \\
\hline Doktor & 21 & 6,1 & 33,5 \\
\hline Hemșire & 228 & 66,5 & 100 \\
\hline Toplam & 343 & 100 & \\
\hline
\end{tabular}

Tablo 2. Ankete Katılan Çalışanların Hastanedeki Pozisyonlarına Göre Dă̆ılımı

\subsubsection{Hastane Çalışma Deneyimi}

Tablo 3'te verilen ankete katılan personelin hastanedeki çalışma deneyimi incelendiğinde 137 kişinin $(\% 39,9)$ bir yıldan daha az süredir hastanede çalıştığı görülmektedir. Bunun sebebi, anketin uygulandığı özel hastanenin yetkin personellerinin çoğunluğunu yeni açtığı kurumda görevlendirmesidir. Tecrübeli personelin kaydırılması nedeniyle yeni alımlar artmıştır. 1-5 yıl arası hastanede çalışan personel sayısı ise 100 kişi $(\% 29,2)$ ile ikinci sırada yer almaktadir.

\begin{tabular}{|l|l|c|c|}
\hline & N & Yüzde (\%) & Kümülatif Yüzde \\
\hline 1 Y1ldan Az & 137 & 39,9 & 39,9 \\
\hline 1-5 Y1l & 100 & 29,2 & 69,1 \\
\hline 6-10 Y11 & 42 & 12,2 & 81,3 \\
\hline 11-15 Y1l & 30 & 8,7 & 90,1 \\
\hline 15 Y11 Üzeri & 34 & 9,9 & 100,0 \\
\hline Toplam & 343 & 100 & \\
\hline
\end{tabular}


Tablo 3. Ankete Katılan Çalışanların Hastanedeki Çalışma Deneyimlerine Göre Dă̆ılımı

\subsubsection{Mesleki Çalışma Deneyimi}

Tablo 4'te verilen katılımcıların mesleki çalışma deneyimleri analiz edildiğinde, en yoğun grubun 116 kişi ile $(\% 33,8)$ 1-5 yıl arası tecrübeli çalışanların olduğu, 78 kişi $(\% 22,7)$ ile ikinci yoğun grubun ise 1 yıldan az mesleki tecrübesi olan kişiler olduğu görülmektedir.

\begin{tabular}{|l|l|c|c|}
\hline & N & Yüzde (\%) & Kümülatif Yüzde \\
\hline 1 Y1ldan Az & 78 & 22,7 & 22,7 \\
\hline 1-5 Y1l & 116 & 33,8 & 56,6 \\
\hline 6-10 Y1l & 48 & 14,0 & 70,6 \\
\hline 11-15 Y1l & 39 & 11,4 & 81,9 \\
\hline 15 Y1l Üzeri & 62 & 18,1 & 100,0 \\
\hline Toplam & 343 & 100,0 & \\
\hline
\end{tabular}

Tablo 4.Ankete Katılan Çalışanların Mesleki Çalışma Deneyimlerine Göre Dă̆ılımı

\subsubsection{Cinsiyet}

Tablo 5'te görüldüğü üzere ankete katılan sağlık çalışanlarının \% 78,1'ini $(\mathrm{n}=268)$ kadınlar oluştururken, \% 21,9’u ( $\mathrm{n}=75)$ erkek çalışanlardan oluşmaktadır. Bu durum kurum bünyesinde çalışan personel dağılımına uygundur.

\begin{tabular}{|l|l|c|c|}
\hline & $\mathrm{N}$ & Yüzde (\%) & Kümülatif Yüzde \\
\hline Kadın & 268 & 78,1 & 78,1 \\
\hline Erkek & 75 & 21,9 & 100,0 \\
\hline Toplam & 343 & 100,0 & \\
\hline
\end{tabular}

Tablo 5. Ankete Katılan Çalışanların Cinsiyetlerine Göre Dă̆ılımı

\subsubsection{Yaş}

Tablo 6'da görüldüğü üzere, kurum genelindeki dağılıma uygun olarak ankete katılan 343 çalışanın 218 tanesi 21-30 yaş aralığındadır. Sonraki yoğun grup ise 81 çalışan $(\% 23,6)$ ile 31-40 yaş arası çalışanlar olmaktadır. Katılımın gençlerde daha fazla olmasının sebepleri, sorgulama, takip etme, öğrenmeye ve kendilerini geliştirmeye açık olmaları, mevcut olumsuz koşulların düzeltilmesi konusunda bilinçli yaklaşmaları olarak düşünülmektedir. İleriki yaşlarda öğrenmeye kapalı olma, mevcut koşulları kabullenme gibi durumların ortaya çıktığı düşünülmektedir.

\begin{tabular}{|l|l|c|c|}
\hline & N & Yüzde (\%) & Kümülatif Yüzde \\
\hline 20 Yaş Alt1 & 5 & 1,5 & 1,5 \\
\hline 21-30 Yaș & 218 & 63,6 & 65,0 \\
\hline 31-40 Yaș & 81 & 23,6 & 88,6 \\
\hline 41-50 Yaș & 34 & 9,9 & 98,5 \\
\hline 51 Yaș Üzeri & 5 & 1,5 & 100,0 \\
\hline Toplam & 343 & 100,0 & \\
\hline
\end{tabular}

Tablo 6. Ankete Katılan Çalışanların Yaşlarına Göre Dağılımı

\subsection{7. Ĕ̆itim Durumu}

Tablo 7'de verilen katılımcıların eğitim durumu incelendiğinde 161 kişilik lisans mezunları \%49,6 ile anketin en yoğun grubunu oluşturmaktadır. Sonraki gruplar ise sırası ile \% 20,7 (n=71) ile ön lisans, \% 15,2 (n=52) ile yüksek lisans, \% $14(\mathrm{n}=48)$ ile lise ve \%3,2 $(\mathrm{n}=11)$ ile doktora olmaktadır.

\begin{tabular}{|l|l|c|c|}
\hline & $\mathrm{N}$ & Yüzde (\%) & Kümülatif Yüzde \\
\hline Lise & 48 & 14,0 & 14,0 \\
\hline Ön Lisans & 71 & 20,7 & 34,7 \\
\hline Lisans & 161 & 46,9 & 81,6 \\
\hline Yüksek Lisans & 52 & 15,2 & 96,8 \\
\hline Doktora & 11 & 3,2 & 100,0 \\
\hline Toplam & 343 & 100,0 & \\
\hline
\end{tabular}

Tablo 7. Ankete Katılan Çalışanların Ĕ̌itim Durumlarına Göre Dă̆ılımı

\subsubsection{Medeni Durum}

Tablo 8'de görüldüğü üzere katılımcıların \% 68,8'i $(\mathrm{n}=236)$ bekar çalışanlardır. Evli çalışanların oranı ise \% $31,2$ ( $n=107)$ 'dir. Bekar çalışan sayısı, evli çalışan sayısının iki katından fazladır. Sağlık sektöründe 24 saat çalışma esası ve vardiya sistemi olduğundan bu fiziksel zorluklar çalışan kompozisyonunun bekar çalışan ağırlıklı olmasını 
gerektirmektedir. Kıdemli çalışanlarda gündüz mesai yapma oranı arttığından bu çalışanlar arasında evli olma oranının daha yüksek olması beklenmekte ve yine buna benzer şekilde gece mesai, yoğun çalışma temposu içinde yer alan çalışanlar içinde bekar olma oranının daha yüksek olması beklenmektedir.

\begin{tabular}{|l|l|c|c|}
\hline & $\mathrm{N}$ & Yüzde (\%) & Kümülatif Yüzde \\
\hline Bekar & 236 & 68,8 & 68,8 \\
\hline Evli & 107 & 31,2 & 100,0 \\
\hline Toplam & 343 & 100,0 & \\
\hline
\end{tabular}

Tablo 8. Ankete Katılan Çalışanların Medeni Durumlarına Göre Dă̆ılımı

\subsection{Sağılı Çalışanlarının Hastane'deki İş Sağlığı ve Güvenliği Uygulamalarını Değerlendirme” Anketi’ne Ait Yanit Analizi \\ 5.2.1.Mesleki Hastalıklar ve Şikayetler}

Kurumdaki mesleki hastalık ve şikayetlerin dağılımı aşağıdaki tabloda en yüksek düzeyden en düşüğe doğru sıralanmıştır.

\begin{tabular}{|c|c|c|}
\hline A. MESLEKİ HASTALIKLAR VE ŞİKÂYETLER & Kişi Sayısı & Oran $(\%)$ \\
\hline A7. Kol ve Bacak Ağrılarından Șikayet Mevcuttur & 225 & $65,60 \%$ \\
\hline A3. Aşırı Yorgunluk Mevcuttur & 220 & $64,14 \%$ \\
\hline A4. Uykusuzluk Sorunu Mevcuttur & 205 & $59,77 \%$ \\
\hline A1. Varis Mevcuttur & 186 & $54,23 \%$ \\
\hline A8. Zihinsel Yorgunluk / Koordinasyon Eksikliği Görülmektedir & 168 & $48,98 \%$ \\
\hline A6. Sindirim Sistemi İle İlgili Yakınmalar Görülmektedir & 160 & $46,65 \%$ \\
\hline A2. Ruhsal Sorunlar Yaşanmaktadır & 154 & $44,90 \%$ \\
\hline A5. Bel F1tığ 1 vb. Hastalıklar Görülmektedir & 148 & $43,15 \%$ \\
\hline A12. Yumuşak Doku Travması Görülmektedir & 112 & $32,65 \%$ \\
\hline A9. Alerjik Sorunlar Görülmektedir & 98 & $28,57 \%$ \\
\hline A10. Çalıșanlar Arasında Solunum Yolu Hastalıkları Görülmektedir & 97 & $28,28 \%$ \\
\hline A11. Enfeksiyona Bağlı Hastalıklar Görülmektedir & 52 & $15,16 \%$ \\
\hline
\end{tabular}

Tablo 9. Çalışma Koşullarına Bağlı Mesleki Hastalık ve Şikayetlerin Oran Tablosu

Tablo 9'a göre çalışanların \%65,60 '1 ile en yoğun olarak kol ve bacak ağrılarından şikayet mevcut iken buna yakın bir oran olan $\% 64,14$ ile aşırı yorgunluk şikayeti izlemekte ve sonrasında ise $\% 59,77$ ile uykusuzluk sorunu görülmektedir. Yine çalışanların \%54,23 ünde varis şikayeti mevcuttur. Diğer şikayetler ise sırası ile zihinsel yorgunluk, sindirim sistemi yakınmaları şeklinde sıralanmaktadır.

\subsection{2.İş Sağlığı ve Güvenliği Uygulamalarının Mevcudiyetine Yönelik Hipotez Testleri}

Yapılan ankette kurumdaki iş sağlığı ve güveliği uygulamalarını tespit etmeye yönelik 6 başlık altında toplam 24 soru sorulmuştur. Çalışanların iş sağlığı ve güvenliği uygulamalarına yönelik verdiği cevapları incelendiğinde tüm sorular için“(3) Kararsızım” yanıtının alınması $(3 * 24=72)$ kurumda iş sağlığı ve güvenliği açısından ne olumlu ne de olumsuz bir uygulamanın olmadığını göstermektedir. 72 puandan daha büyük değerler kurumda iş sağlığı ve güvenliği uygulamalarının sağlık çalışanları tarafından doğrudan ve pozitif yönde algılanmakta olduğunu ifade etmektedir.

\begin{tabular}{|l|c|c|c|c|c|c|}
\hline & $\mathrm{N}$ & Aralık & Minimum & Maksimum & Ortalama & Std. Sapma \\
\hline $\begin{array}{l}\text { İSG Uygulamalarının Mevcudiyetine } \\
\text { Yönelik Puan Toplamı }\end{array}$ & 343 & 72 & 48 & 120 & 93,53 & 12,810 \\
\hline
\end{tabular}

Tablo 10. İşS Sağlığı ve Güvenliği Uygulamalarının Mevcudiyetine Yönelik Tanımlayıcı İstatistikler

Tablo 10'da iş sağlığı ve güvenliğine ait soruların tamamına yanıt veren 343 çalışan olduğu ve bu çalışanların genel puan toplamı kriteri adına ankette aldıkları puanların 48 ile 120 arasında değiştiği, ortalamasının 93,53, standart sapmasının ise 12,810 olduğu görülmekte olan tanımlayıcı istatistikler verilmiştir. Tablo 10 'da sunulan istatistiki verilerin anlamlı bir farklılık oluşturup oluşturmadığına yönelik aşağıdaki hipotezler kurulmuş ve test edilmiştir.

Ho: "Kurumdaki iş sağlığı ve güvenliği uygulamaları sağlık çalışanları tarafından doğrudan ve pozitif yönde algilanmaktadır."

$\mathbf{H}_{\mathrm{a}}$ : "Kurumdaki iş sağlığı ve güvenliği uygulamaları sağlık çalışanları tarafindan doğrudan ve pozitif yönde algilanmamaktadir."

$\mathrm{Bu}$ şekilde oluşturulmuş olan ana hipotez için çalışanların ortalama genel puanları toplamı “(3) Kararsızım” durumu ifade eden 24 soruya da 3 seçeneği ile yanıt vermeleri durumunda alacakları 72 puana göre değerlendirilmiştir. 


\begin{tabular}{|l|c|c|c|c|c|c|}
\hline & \multicolumn{2}{|l}{ Test Değeri $=72$} & Ortalama Fark & \multicolumn{2}{l|}{ Farkların \%95 Güven Aralı̆ $\breve{g}_{1}$} \\
\cline { 2 - 7 } & $\mathrm{t}$ & $\mathrm{df}$ & Sig. & Alt & Üst \\
\hline $\begin{array}{l}\text { GENEL PUAN } \\
\text { TOPLAMI }\end{array}$ & 31,124 & 342 &, 000 & 21,528 & 20,39 & 22,67 \\
\hline
\end{tabular}

Tablo 11. Tek Örnek T Testi

Tablo 11 'de verilen T testi sonucuna göre t değeri 31,124, sig değeri (p-değeri) .000'dır. Sig değerinin 0.05 'den küçük olması sebebiyle kurumdaki iş sağlığı ve güvenliği uygulamalarının mevcudiyeti sağlık çalışanları tarafından doğrudan ve pozitif yönde algılanmaktadır. Diğer bir ifade ile $\mathrm{H}_{0}$ hipotezi reddedilemez.

\section{Sonuç}

Sağlık çalışanlarının iş sağlığı ve güvenliği uygulamalarının mevcudiyetine yönelik algılarının pozitif yönde olduğu hipotez testleri ile ortaya konmuştur. Çalışanların iş sağlığı ve güvenliği uygulamalarının mevcudiyetine yönelik puan ortalamaları 93,53 ile kararsızlı̆̆ ifade eden 72 puan ortalamasına göre pozitif yönde seyretmekte ancak maksimum seviye olan 120 puana göre değerlendirildiğinde kurumda İSG uygulamaları açısından iyileştirmelerin yapılabileceği alanlar olduğu ve bu alanlardaki iş süreçlerin iyileştirilmesi gerektiği tespit edilmiştir. Sağlık çalışanlarının mesleklerinden kaynaklı olduğunu düşündüğü hastalık ve şikayetler içerisinde kol ve bacak ağrıları $(\% 65,6)$, aşırı yorgunluk $(\% 64,1)$, uykusuzluk $(\% 59,7)$ ve varis mevcudiyeti $(\% 54,2)$ ilk sıralarda yer almaktadır.

Sağlık çalışanlarının sağlıklarını korumak ve geliştirmek amacıyla, öne çıkan sorunlara yönelik iyileştirmeler için ilgili birimlerdeki iş süreçlerinin incelenerek bu süreçlere yönelik ergonomik ve psikososyal iyileştirmeler yapılması, çalışanların bu yöndeki şikayetlerini azaltıcı çözümler üretilmesini ve kurumdaki mevcut iş sağlığı ve güvenliği uygulamalarına yönelik görüşlerin olumlu yönde artışını sağlayacaktır.

Yorgunluk, kol ve bacak ağrıları, varis ve uykusuzluk şikayetlerinin iyileştirilmesi için çalışma alanlarında ergonomik sandalye, koltuk, seçimi ile hastane genelinde yaygınlaştırılması, hastaların taşınması veya kaldırılması esnasında çalışan gücü yerine yardımcı alet kullanımının yaygınlaştırılması, rotasyonlu çalışma shifti oluşturulması ve iş yüküne göre çalışma saatlerinin yeniden düzenlenmesi, sürekli ayakta ve ağır işlerde çalışanların farklı rollerde görevlendirilmesi, egzersiz eğitimlerinin verilmesi, işyükünün adaletli dağılımı, gece nöbetinde çalışan kişiler için ergonomik düzenlenmiş dinlenme alanları, hemşireler için sağlanan lojman hizmetinin büyütülerek daha fazla kişiyi kapsaması ve hastaneye yakın konumlandırılması alınabilecek önlemler arasında olabilir.

*Çalışma Dayan, 2016. İş sağlığı ve güvenliği uygulamalarının sağlık çalışanları tarafından değerlendirilmesi: Bir özel hastane örneği isimli tezi esas alınarak hazırlanmıştır.

\section{Kaynakça}

- Akca, vd, 2014. "Sağlık Çalışanlarına Uygulanan Şiddet: Özel Bir Tıp Merkezi Örneği”, Ankara Sağlık Hizmetleri Dergisi, C.13, S. 1, s.1.

- Akova, 2016. "Sağlık Personeline Kan Yoluyla Bulaşan İnfeksiyon Hastalıkları ve Korunmak için Alınacak Önlemler",http://www.hastaneinfeksiyonlaridergisi.org/managete/fu folder/1997-02/html/1997-1-2-083090.htm.

- $\quad$ Aslan ve Öntürk, 2011. "Güvenli Ameliyathane Ortamı; Biyolojik, Kimyasal, Fiziksel ve Psikososyal Riskler, Etkileri ve Önlemler”, Maltepe Üniversitesi Hemşirelik Bilim ve Sanatı Dergisi, C. 4, S. 1, s.135.

- Bilir, 2007. Mesleksel Kas İskelet Sistemi Hastalıkları, İş Sağlığı ve Güvenliği Dergisi, Çalışma ve Sosyal Güvenlik Bakanlığı Yayını, S. 34, s. 10-13.

- C Çamcı ve Kutlu, 2011. “Kocaeli’nde Sağlık Çalışanlarına Yönelik İşyeri Şiddetinin Belirlenmesi”, Psikiyatri Hemşireliği Dergisi, C.2, S.1, s.9.

- Centers for Disease Control and Prevention (CDC), 2016, Healthcare Workers, http://www.cdc.gov/niosh

- $\quad /$ topics/healthcare/.

- Dikmetaş, vd, 2011. “Asistan Hekimlerin Tükenmişlik ve Mobbing Düzeylerinin İncelenmesi”, Türk Psikiyatri Dergisi, S.22, s.1.

- Emiroğlu, 2012. "Sağlık Sektöründe Mesleki Riskler ve Hukuksal Düzenlemeler", Türk Tabipleri Birliği, Mesleki Sağlık ve Güvenlik Dergisi, s.21-22.

- European Comission, 2010. "Psychosocial Risks", Occupational Health and Safety Risks in The Healthcare Sector, s.173. 
- Güler, vd, 2015. "Hastane Ergonomik Koşullarının Hemşirelerin Mesleki Kas İskelet Sistemi Rahatsızlıkları Üzerine Etkisi”, International Anatolia Academic Online Journal, Scientific Science, C. 3 S. 1, s.1-7.

- Günüşen ve Üstün, 2010. “Türkiye’de İkinci Basamak Sağlık Hizmetlerinde Çalışan Hemşire ve Hekimlerde Tükenmişlik: Literatür İncelemesi”, [Elektronik versiyonu], Dokuz Eylül Üniversitesi Hemşirelik Yüksekokulu Elektronik Dergisi, S.3, C.1, s.40, .http://www.academia.edu/2573645/T\%C3\%BCrkiyede_ikinci basamak sa $\% \mathrm{C} 4 \% 9 \mathrm{Fl} \% \mathrm{C} 4 \% \mathrm{~B} 1 \mathrm{k}$ hizmetler inde $\% \mathrm{C} 3 \% \mathrm{~A} 7 \mathrm{al} \% \mathrm{C} 4 \% \mathrm{~B} 1 \% \mathrm{C} 5 \% 9 \mathrm{Fan}$ hem $\% \mathrm{C} 5 \% 9$ Fire ve hekimlerde t $\% \mathrm{C} 3 \% \mathrm{BCkenmi} \% \mathrm{C} 5 \% 9 \mathrm{Flik}$ lit erat $\% \mathrm{C} 3 \% \mathrm{BCr}$ incelemesi.

- $\quad$ İlçe, 2007. Yoğun Bakım Ünitelerinde Ergonomik Faktörlerin İncelenmesi, Yayınlanmamış Doktora Tezi, Ege Üniversitesi, s.141.

- IInci, vd, 2009. "Hastane Çalışanlarında HBV, HCV ve HIV Seropozitifliğinin Araştırılması”, Türk Hijyen ve Deneysel Biyoloji Dergisi, C. 66, S. 2, Ankara, s.59.

- Industrial Accident Prevention Association (IAPA), 2007. Glossary of Occupational Health \& Safety Terms, s.20, http://www.iapa.ca/pdf/iapa_glossary.pdf.

- Karaca, 2013. Sağlık Çalışanlarında İş Sağlığı ve Güvenliği, Yayınlanmamış Yüksek Lisans Tezi, Beykent Üniversitesi, Sosyal Bilimler Enstitüsü, İstanbul.

- Karakaş ve Okanlı, 2013. "Hemşirelik ve Mobing”, Gümüşhane Üniversitesi Sağlık Bilimleri Dergisi, C.2, S.4, s.562.

- Köseoğlu, 2005. “İş Sağlığı ve Güvenliği Nedeniyle İşin İdarece Durdurulması ve İş yerinin Kapatılması”, İş Güç Endüstri İlişkileri ve İnsan Kaynakları Dergisi, C.7 S.1, s.14.

- National Institute for Occupational Safety and Health (NIOSH), 2007. Occupational Hazards in Hospitals "Waste Anesthetic Gases", s.1-2, http://www.cdc.gov/niosh/docs/2007-151/pdfs/2007-151.pdf.

- National Institute for Occupational Safety and Health (NIOSH), 2012. Occupational Exposure To Antineoplastic Agents and Other Hazards Drugs, http://www.cdc.gov/niosh/topics/antineoplastic/default.html.

- Oğan, 2014. “Sağlık Çalışanları İçin İşçi Sağlığı ve Güvenliği”, Türk Tabipleri Birliği, 1. Baskı, Ankara, s.10.

- Omaç, vd, 2010. "Malatya Merkez Hastanelerinde Çalışmakta Olan Hemşirelerde Mesleki Kesici Delici Yaralanma ve Hepatit B Bağışıklanma Durumları”, İnönü Üniversitesi Tıp Fakültesi Dergisi, S. 17(1), s.19.

- Özkara, 2003. Sağlık Kurumlarında Tüberküloz Bulaşması ve Korunma, 21. Yüzyılda Tüberküloz Sempozyumu, $\quad$ s.244, $\quad$ http://www.klimik.org.tr/wp-content/uploads/2012/02/982011125349Seref_Ozkara.pdf.

- Öztürk ve Babacan, 2012. "Bir Ölçek Geliştime Çalışması: Hastanede Çalışan Sağlık Personeli İçin İş Güvenliği Ölçeği”, Hemşirelikte Eğitim Ve Araştırma Dergisi, Karadeniz Teknik Üniversitesi C.9, S.1, s.3642.

- Parlar, 2008. "Sağlık Çalışanlarında Göz Adı Edilen Bir Durum: Sağlıklı Çalışma Ortamı”, TAF Preventive Medicine Bulletin, C. 7, S.6, s.550.

- Saygun, 2012. "Sağlık Çalışanlarında İş Sağlığı ve Güvenliği Sorunları”, TAF Preventive Medicine Bulletin, S. (11)4, s.376.

- Serhatlığlu, vd, 2004. "İyonizan Radyasyonun Radyoloji Çalışanlarının Bağışıklık Düzeyleri ve Kan Biyokimyası Üzerine Etkileri”, Tanısal ve Girişimsel Radyoloji Derneği Yayını, S.10, s.97.

- Taşçıŏlu, 2007. Lüleburgaz Devlet Hastanesi ve Lüleburgaz 82. Y1l Devlet Hastanelerinde İş ve Çalışma Ortamından Kaynaklanan Riskler ve Bu Riskleri Hemşirelerin Algılama Düzeylerinin Saptanması, YayınlanmamışYüksek Lisans Tezi, Trakya Üniversitesi, s.17.

- Toplan, 2016. İyonizan Radyasyonun Biyolojik Etkileri, s.458, http://194.27.141.99/dosya-depo/dersnotlari/serife-selmin-toplan/011\%20iyonizan\%20Radyasyonun\%20Biyolojik\%20Etkileri Prof.\%20Dr.pdf.

- Türk Tabipler Birliği (TTB), 2008. Sağlık Çalışanlarının Meslek Riskleri, Türk Tabipler Birliği Yayınları, Birinci Bask1, Ankara, s.11.

- Yaşar, vd, 2012. “İyonize Radyasyonun Yaşam Kalitesi Üzerine Etkisi”, Smyrna Tıp Dergisi, S. 3, s.19.

- Vehid, vd, 2010. "Hastane Ortamı Gürültü Düzeyi ve Nedenleri”, 13. Ulusal Halk Sağlığı Kongresi, Bildiri Özetleri Kitabı, İzmir, s.96. 


\title{
Sağlık Kurumlarında Yönetim ve Estetik Tıp Merkezlerindeki Stratejik Hedefler
}

\section{Aesthetic Medicine Center: Strategic Objectives of Management in Health Institutions}

\author{
Ph.D. Candidate Gülay Tamer (İstanbul Gelişim University, Turkey)
}

\begin{abstract}
Healthcare is the world's largest industries today. Incorrect decisions which have been taken in any industrial enterprise would impact year-end balance sheet or in worst case scenario, temporary economic downturns. However, mistakes which are made in the management of health industries would end up lowering quality of human life which could give rise to deterioration of the welfare society. Management philosophy of the health care institutions has a direct impact to solution of health issues. Therefore, their approach of management play an important role in the development of quality of life. Knowledge and individual skills of those involved in the management of health managers at different levels of organization is crucial for the future of the company and consequentially for welfare of nation. In this study; Aesthetic Medicine which is one of the most exclusive and ever-developing areas of health institutions has been analyzed. These institutions aim to enhance their social perception by improving their appearance with noninvasive aesthetic treatments and by providing preventive treatments to maintain their youthful appearance. The frequency of the applied treatments in aesthetic medical institutions varies according to their clients' economic welfare, socio-cultural evolution of their society, sex, age range and many other sociological parameters. In order to meet the expectations in health institutions, it is crucial to determine the correct customer profile by utilizing present opportunities of the sector. This study is prepared to present an approach to create sectoral innovation by drawing attention to self-renewing business growth methods for aesthetic medicine management.
\end{abstract}

\section{Giriş}

Günümüzde; sağlık sektöründe toplumun sağlığına hizmet etmek amacıyla kullanılan teknoloji, tedavi yöntemlerindeki yenilikler, ileri uzmanlığa sahip personelin bir arada çalışması, toplumun ihtiyaç beklentilerindeki yükselme, kullanılan kaynakların artması ve yönetim hizmetinin profesyonel yöneticiler tarafından sağlanması yani kısaca etkililik ve kalite, sağlık sektöründe hizmet veren kuruluşların en öncelikli kriterleridir.

Sağlık işletmelerinde dünya standartlarında hizmet sunulma gerekliliği, hizmet kalitesinde yükselme, her alanda kullanılan kaynakların teknolojilerinin değişmesi gibi durumlar kaynakların yönetimini koordine edebilen profesyonellerce yönetilmesini zorunlu hale getirmektedir. Sektörde her alanda faaliyet gösteren kuruluşlarının modern yönetim sistemlerine göre yönetilmeleri ve verilen hizmetlerin kalitesini arttırabilmek için, var olan problemleri çözümlenmesi ve bilgi akışının iyi sağlandığı iyi bir ekip çalışması büyük önem arz etmektedir. Sağlık hizmetlerinde yönetimin başında eskiden olduğu gibi başhekimler, değişik uzmanlığa sahip tıp doktorları değil yönetim alanında etkin uzman yöneticilere yer verilmektedir. Bu profesyonellerin yetiştirilmesinde lisans ve lisansüstü formal eğitimler ve belirli aralıklarla yapılacak sürekli eğitim sağlayan kurs, seminer, hizmet içi eğitimler olabilmektedir. Hizmetlerin çeşitliliği bireylerin beklentileri, kültür, ekonomik özellikler toplumdan topluma farklılık gösterebilmekte ve birçok sektörde hızlı bir değişim ve gelişim sergilemektedirler. Toplumun yaşam kalitesinin arttırmak amacıyla sağlık hizmetlerinde zorunlu kriterler vardır. Her sektörde olduğu gibi sağlık sektöründe de artan rekabet koşulları devamlılık sağlayabilmek adına sağlık kuruluşlarının gelişmiş dünya ülkelerinin hizmet kalitesini ölçü alıp sektörel yenilik ve inovasyon konuları ile ilgili araştırmalar yapmaları zorunlu hizmet anlayışı olmaktadır (Akyüz, 2001).

\section{Sağlık Kurumlarında Yönetim ve Stratejik Planlama}

Toplum sağlığını koruyabilmek, gelecekte de sağlıklı bir nesil oluşturabilmek için önceden koruyucu tedbirlerin alması, hastalık hali oluştuğunda da her bireye gereken bakım ve tedavi hizmetlerinin sağlanması devletlerin zorunlu görevidir (Ekici, 2007).

Sağlık hizmetlerinde yönetim anlayışı; Bireylere, toplumlara ya da kurumlara, sağlığın korunması ve herhangi bir hastalık durumu oluştuğunda tıbbi tedavi ve bakım ile iyi bir ortamda hizmet verebilmek için, yapılacak işleri ve kullanılacak ekipmanları ihtiyaçlar ve talepler doğrultusunda, planlama, örgütleme yönlendirme, denetleme ve koordine etmeyi sağlamaktadır.

Sağlık sektöründe verilen tedavi ve bakım hizmetlerini, hastanın önceden deneme imkânı bulunmadığı için, hasta-doktor ilişkisi tamamıyla güven duygusu içinde kurulmuştur. Bu güven unsuru tıp mesleği prensipleri ile de uyum içindedir. Tıp mesleğinde kâr maddi olarak değil, kişinin sosyal sorumluluklarını yerine getirmesi, 
mesleğinde başarı performansı, bilime ve tıp mesleğine katkıları, yayınları gibi değişkenlerle ölçülmektedir. Bu nedenle gerek hastane yöneticileri, doktorlar ve diğer sağllk personeli için insan sağlı̆̆ına hizmet esas olup pazarlama, satış konularına duygusal anlamda uzak kalmaktadırlar (Can, 2001).

\subsection{Sağlık Kurumlarında Yönetimin Temel İlkeleri ve Kurumsal Amaçlar}

Sağlık kuruluşlarında verilecek hizmet kapsamını bireylerin genel sağlık gerekliliklerine göre belirlemek,

Kurumsal plan, program, organizasyon ve çalışma stratejilerini belirlemek,

Tedavi ve bakım hizmetlerini sunacak profesyonel ve etkin ekibi oluşturmak,

Tedavi ve bakım hizmetlerini teknolojinin en yeni teçhizat ve ekipman ile sağlamak,

Sektördeki tedavi ve bakım hizmetlerindeki yetki ve uygunluk standartları korumak,

Yüksek nitelikteki tedavi hizmetlerini, katlanabilir maliyetlerle ihtiyaç sahiplerinin hizmetine sunmak,

Toplumun sağlığının korunması da gerekli olan tedbirlerin alınmasını sağlayarak ekonomik ve sosyal kalkınmaya destek sağlamak v.b.

Sağlık sektöründe hizmet veren kurumların kurumsal amaçlarının yanında toplum sağlı̆̆ını korumak gibi önemli temel ilkeleri bulunmaktadır (Bush, 1995).

\subsection{Sağlık Kuruluşlarında Hizmet Yaklaşımları}

Sağlık kurumlarındaki verilen hizmet yaklaşımlarında, sorunların çözümünde ve işletmenin imajının belirlenmesinde hasta memnuniyeti büyük öneme sahiptir. Bireylerin kurum hakkındaki görüşlerini anlamak için hizmeti sunan uzman personel tarafından sağlanan hizmetin önemi ve kapsamı kadar bu tür işletmelerde tedavi ve bakım uygulamalarını gerçekleştirebilmek için kullanılan alet ve ekipman, finansman gibi mevcut kaynakları etkili ve verimli bir şekilde kullanmak sağlık kurumlarının en önemli yaptırımlarıdır.

Hizmet sektöründeki yer alan işletmelerin hizmet kalitesindeki başarısı ve verimlilik düzeyi, çalışanların yetkinlikleri ve performans kriterleri ile doğrudan doğruya ilişkilidir ve sağlıkla ilgili artan bilinç sayesinde hastalar tüm hizmetlerden eşitlik içinde faydalanma, kurumunu seçme ve değiştirme, kendisine uygulanacak tedavi hakkında yeterli bilgi isteme, sürekli hizmet alma hakkı, mahremiyet, tedavi hizmetini reddetme ve durdurma, saygı ve kabul görme, şikayetçi olma ve dava açma gibi hakları vardır.

Sağlık kurumlarından hizmet alma ihtiyacı ve zorunluluğu ile gelen hastaların öncelikleri, beklentileri açık ve net olarak anlaşılmalı, bu beklentilere gerçekçi çözümler üretilerek, tedavi ve bakım hizmetinin kapsamıyla ilgili açık ve net doğru bilgilendirmenin yapılarak tüm detaylarıyla hizmet sahiplerine açıklanmalı, sonuçlar hakkında bilgilendirme sağlanıp hastanın uyumuna destek sağlanmalıdır (Hansen, 2011).

\subsection{Sağlık İşletmelerinde Kontrol}

Sağllk sektöründe verilen hizmetin yeterli ve etkili bir şekilde yerine getirilebilmesi için belli ölçülere, standartların gerekliliği vardır. Sağlığın korunması, iyileştirilmesi adına gerekli önlemlerin alınmasında ve hastalık söz konusu olduğunda amaçlanan sonuçlara ulaşmak amaciyla kullanılan teknik ve yeterlilikleri bu ölçüler ışığında incelenerek yapılan sonuçlar değerlendirilmeye alınır. Kontrol işlevi ile verilen tedavi ve bakım hizmetlerinin verimini arttırma, fayda seviyesini yükseltme değerleme için birimlerin, arasındaki bilgi akışının yeterli seviyede olması ve tüm birimlerin birçoğuna yardımcı olacak kayıt ve istatistiklerin düzenli, güvenilir şekilde tutulmaları ve arşivlenmeleri de gerekmektedir. Kurumlarda sunulan hizmet kalitesinin değerlendirilmesi için yeterli ve güvenilir verilere sahip olmayan birimlerin etkili ve yeterli çalışması ve sağlıklı kararlar alması mümkün değildir. Hizmet kuruluşlarında kalite kontrolü değerlemenin sağlıklı olması açısından çok büyük öneme sahiptir. Sağlık kurumlarında verilen tedavi uygulamalarının ulaştığı sonuç, yani gerçekleşen son durum belirlenemez ise yapılması zorunlu kriterlerle yapılan tedavilerin sonuçlarının karşılaştırma olasılığı yeteri kadar olamaz. Bu gerekçelerden dolayı gerçekleşen sonuçların etkinliğinin ve kalitesinin belirlenmesi zorunluluğu vardır (Rajnandını, 1999).

\subsection{Sağlık Hizmetlerinde Kalite Anlayışı}

Sağlık kuruluşlarında hizmet kalitesi Kriterleri:

Ortam, malzeme, teçhizat, ekipman, uzmanların bilgi ve tecrübeleri konusunda yetkin ve etkinli olmaları,

Tehlike ve risk oluşturmamak,

Her an ulaşılabilir ve kesintisiz hızlı hizmet sunmak,

Hastanın istek ve ihtiyaçlarını anlamak ve her an ilgili, yardıma hazır olmak,

Kurumun güven verici olması ve iyi imaj sergilemesi, hasta memnuniyeti sağlamak için sağlık hizmetlerinde kalite kriterleridir.

Sağlık hizmetlerinde kalite sağlama ve hasta mutluluğu için birimlerin, birbirleriyle uyum içinde çalışmaları ve birbirleriyle sürekli iletişim kurmaları gerekmektedir (Sabuncuoğlu;1997). 


\section{Sektörel Analiz}

\subsection{Estetik Tıp Merkezlerinin Temel Özellikleri}

Zaman içerisinde giderek önemli hale gelen güzellik kavramı, başlangıçtaki çok küçük uygulamalarla kişilere hizmet verirken artık çok farklı tedavi ritüelleriyle ve yeni tedavi ve bakım uygulamalarıyla küreselleşen dünya da ekonomik, teknolojik, toplumsal, kültürel, yapılarda meydana gelen hızlı ve sürekli gelişme ve değişmeler, Estetik Tıp Sektöründe de hizmet veren merkezlerin yapılarında önemli değişimlerin yaşanmasına neden olmuş ve her geçen gün yeni uygulamalarla faaliyetler vererek kişilerin mutluluğuna hizmet eden ve aranılan bir sektör haline gelmiştir. Önceki yıllarda sayıları çok az olan estetik merkezleri, sadece büyük şehirlerde hizmet veriyorlardı. Ekonomik sosyo kültür seviyesi yüksek, görsel mesleği olan kişilerin ihtiyaç duyduğu, çoğunluğunu bayan çok az sayıda erkekten oluşmaktayken, son on yılda bu sektöre duyulan ihtiyaç hızla arttırmıştır. Buna bağlı olarak bu alanda açılan merkezlerin sayısı her geçen gün hızla artmakta böylece önceleri sadece sağlık eğitimi aldıktan sonra konusunun uzmanları tarafından işletilen bu sağlık sektörüne, bazı girişimciler de katılarak, pazardan pay almaya başlamışlardır. İletişim kanallarını iyi kullanabilen girişimciler pazarlama mantı̆̆ı ile hareket ederek sektörü, farklı bir pazar haline dönüşmektedirler. Bu sektöre de taleplerin sayıları değişik ölçeklerde her geçen gün yıldan yıla artmaktadır. Önceleri sadece kaymak tabaka diye tanımladığımız sosyo-kültürel seviyesi yüksek kişilerin hizmet aldığı sektörden çıkıp artık her türlü sosyo kültürel kesimden bireylerin hizmetinde olup müşteri yelpazesini çeşitlendirmektedir (Ünal, 2012).

\subsection{Bireyler Estetik Tip Merkezlerine Neden İhtiyaç Duyar?}

Kişinin hayata bakış açısı, iş yaşamındaki pozisyonu, idealindeki görünümü, toplumda öbür bireylerde bıraktığ ilk izlenim, hatta aynadaki yansıması çoğu zaman bireyin estetik ve güzellik merkezlerinden hizmet alma ihtiyacını doğurur. Demografik faktörler de kişilerin tüketim davranışlarını etkilemektedir. Nüfus sayısı, cinsiyeti, yaşı, gelir, eğitim, meslek dağılımı konum ve zaman boyutu itibariyle kişilerin tercihlerinde belirleyici faktörler olmaktadır. Medyada gördükleri kişileri sürekli genç görüp, kendinde yaşa, yıpranmaya bağlı hissettiği fiziksel değişikliklerden hoşnut olmaması, çevresinde bazı kişilerin öncü olup onlara rol model olması da kişilerin( estetik ve kozmetik merkezlerine olan )ihtiyaç hissetmelerin de rol oynamaktadır. Ülkemizde; son on yıla kadar sadece kadınların ihtiyaç hissettiği bu tür uygulamalara erkekler nasıl anlaşılırım korkusuyla ya gizli gizli giderken; artık erkekler de bakımlı, genç ve dinamik görüntüye sahip olabilmek için rahatlıkla bu tür sağlık kuruluşlarına gelebilmektedirler (Erdoğdu, 2013).

\section{- $\quad$ Estetik Tıp Merkezlerinden Kişisel Beklentiler}

Danışmanlık almak için,

Depresyonlarını iyileştirmek için,

Dünyanın herhangi bir yerinde gerçekleştirilen bilimsel estetik faaliyetlerinden haberdar olmak ve bu hizmetlere imkanlar ölçüsünde sahip olmak,

Fiziki görünüşlerini daha iyi hale getirmek,

Görünümü değiştirmek, farklı bir imaj a sahip olmak için,

Hayatlarında değişiklik yapmak için,

İlgi ihtiyacı için,

Psikiyatrik bozukluklar nedeniyle,

Sosyal çekiciliklerinde ciddi değişiklikler yapmak için,

Sosyalleşme ihtiyacı için,

Var olan durumlarını koruyarak, geleceğe karşı daha dinç, daha bakımlı ve prezantasyonu yüksek daha çekici görünümüne sahip olmak,

Yapılan bazı hataların düzeltilmesini sağlamak için,

Tüm nedenlere karşın kişilerin kişiler estetik tıp merkezlerinden hizmet almaya geliş motivasyonun anlaşılması oldukça karmaşıktır.

\section{- Estetik ve Güzellik Sektöründe Hizmet Veren Kuruluşların Sınıflandırılması}

Medikal estetik hastaneleri, Medikal estetik poliklinikleri; Estetik ve plastik cerrahi uzmanlarının özel muayeneleri, Alternatif Tıp Merkezleri, Akupunktur merkezleri, Güzellik salonları, Kuaförler, Bioenerji ve yoga merkezleri, Spor salonları, Otellerin SPA Merkezleri, Ayak Sağlığı merkezleri, Manikür \& pedikür salonları, Kaplıca ve Hamamlar, Aktarlar, Kozmotologlar, Kozmetik Ürün Merkezleri, Anti-aging ilaç firmaları v.b. sektöre hizmet veren kuruluşlardır.

\subsection{Estetik Tıp merkezlerindeki Tedavi Türleri}

Kilo kontrolü (kilo verdirmek, kilo alma, hamile, çocuk, sporcu beslenmesi, anti-aging beslenme gibi kişiye özel programlar1),

Cilt yenileme, anti-aging bakım ve tedavi uygulamaları, 
Cilt problemlerini çözme (kırışıklık, akne, leke, iz, sarkma, v.b),

Damar ve k1lcal damar problemleri,

Lazer tedavileri ve bakımları gibi uygulamalar Estetik Tıp Merkezlerinde uygulanmaktadır.

\subsection{Tedavi Öncesinde Yapılması Gerekenler}

Öncelikle kişilerin beklentilerini dinlemek endişelerini göze almak kişilere hangi uygulamalara ihtiyaçlarının olduğunu açıklayarak tedavi planı yapılmalıdır. Ne sıklıkta hastayı görebileceğimiz belirlenmeli hastayı motive etmeli, takiplerinin iyi yapılması sağlanmalıdır.

Hastaya ne kadar zamandandır bu tedaviyi düşündüğü hakkında ve neden bizi tercih ettiği varsa endişe duyduğu noktalar hakkında bilgi verilmeli mutlaka sistemli olunmalı. Sistemli bir kurum sistemli bir tedavi protokolu her zaman pozitif sonuçlar doğurmaktadır.

Örneğin hastalar telefon üç kez çaldığı halde cevap alamadığı merkezlere çok iyi hizmet verilse bile güvensizlik duyarlar. İşletme sistemi tedavi güvenirliliği kadar müşteriler açısından önem arz etmektedir (Öztürk,1994).

\section{- Uygulama Öncesi Davranışsal Yaklaşımlar}

Hastanın beklentilerinin açık ve net olarak anlaşılması,

Bu beklentilere gerçekçi çözümler üretilmesi,

Konuyla ilgili açık, net ve doğru bilgilerin verilmesi,

Yapılacak uygulamaya ilişkin detayların tanımlanması,

Gerekli ise hasta için psikiyatrik yardımın önlenmesi gerekmektedir.

\section{- Tedavi Sonrasında Yapılması gerekenler}

Yapılan tedavinin sonuçlar konusunda hastanın uyumuna yardımcı olunmalı,

Gerekli durumlarda sonuçlara tekrar müdahale konusunda istekli davranmalı ve tekrar geliş konusundaki açık kapı olduğu vurgulanmalı,

Sorunları olan hastalar için memnuniyetsiz oldukları konularla ilgili gerekli destekler sağlanmalıdır.

Hastaların iyi uygulanan tedavi sonrasında duygusal durumları yükselmektedir.

İyi uygulamalar, güvenli sonuçlar daha gerçekçi söylemler hastalarda merkeze bağlılığı güçlendirmektedir

Medikal tıp merkezlerinde hizmet alan hastalar kendilerine daha çok zaman ayıran merkezlere daha fazla güven duymaktadırlar ayrıca bir başkasını görüp karar vermek kişilerin tavsiyesi hastaya gösterilen ilgi profesyonellik hasta memnuniyet anket uygulaması tedavi sonrası bakım kontrolleri hasta memnuniyeti açısından önemlidir. Gerçekçi olmayan vaatlerde bulunmak her zaman hastalar için hayal kırıklığı merkezler için müşteri kaybı oluşmaktadır. Öncelikle hastalarla iyi bir konsültasyon yapıp hastaya özel oldukları hissi yaratılmalıdır. Tazelenmiş ve dinlenmiş görünmek iyi yaşlanmak zarif ve sofistike sonuçlar güvenli tedavilerle sağlanmaktadır. Hastalara mutlaka bilimsel yayın göstererek güven sağlanmalı hizmet kalitesi açısından uygulama sonrası kontroller mutlaka yapilmalıdir.

\subsection{Estetik Tıp Sektörlerinin Sistematik Yapısı}

Estetik ve Güzellik sektöründe hizmet veren kuruluşların her danışanını hizmet hakkında bilgilendirmek, kullanılan ürünlerle ilgili aydınlatmak, yeniliklerle ilgili bilgilendirmek gibi yükümlülükleri vardır, çünkü farklılıkları ortaya koymaları, yeniliğin kabulünü (psikolojik ve davranışsal) sağlamalıdırlar, mal ve hizmeti satın alınmasını sağlarken hizmet verilen merkezinde benimsenmesi sağlanmalıdır. Böylece hizmet satın alan ile hizmet veren merkezin bağlılığ sağlanmalıdır. Kişilerin güvenini kazanmak maddi kazanç elde etmekten daha önemlidir, çünkü aynı zamanda hizmet sunulan bireylerin çevresindeki kişilerin merkeze gelmesi sağlanarak sunulan hizmetin ve kalitesinin daha çok bireye ulaşmasını sağlamaktadır.

Güzellik merkezlerinden hizmet almaya gelen kişiler yapılan uygulamalardan memnun kaldığında sürece sürekli müşteri konumuna gelip, çevresine de tavsiye edebiliyorlar, güven duygusuyla uzmanlarını değiştirmiyorlar. Bazen belli yerler belli sosyal kesimin uğrak yeri olabiliyorlar. Gittikleri klinikte medyatik kişileri görebilmek, onların yaptırabildiği işlemleri yaptırabilmek, kendini o gruba aitmiş gibi görmek isteğinde olan kişilere de çoğunlukla rastlanmaktadır. Bu sektöre yıldan yıla artan taleple değişik ölçekte sayıları her geçen gün artan önceleri sadece kaymak tabaka diye tanımladığımız sosyo-kültürel seviyesi yüksek kişilerin hizmet aldığ sektörden artık her kesimden bireyler hizmet almakta bu da müşteri yelpazesini çeşitlendirmektedir. Bu doğrultuda farklı talepleri olan kişilerin sayısı hızla çoğalmaktadır. Kişiler bazen ekonomik olarak ulaşamadıkları bazı uygulamalara, daha ucuz olarak elde edebilmek adına bazı kontrolsüz cihazlarla ve ürünlerle sağlıklarını riske atmaktadırlar. Hiçbir sağlık kuruluşu standartlarından ödün vermemelidir, bu nedenle belli bedeller ödeyerek elde ettiği sarf ürünleri; daha ucuza hizmet verme adına malzeme ve cihazlardan tasarruf edememektedir. Bu nedenlerden dolayı tüketicilerde ekonomik olarak daha ulaşabilir seçenekleri riskli de olsa tercih edebilmektedirler (Karaman, 2010). 


\author{
3.6 Estetik Tıp Merkezlerindeki Hizmetlerin Değerlendirilmesi \\ Hizmetten genel olarak faydalanma, \\ Eşitlik içinde hizmete ulaşma, \\ Bilgilendirme, \\ Kuruluşu seçme ya da değiştirme, \\ Bilgi isteme, \\ Mahremiyet, \\ Riza ve izin, \\ Güvenlik, \\ Reddetme ve durdurma, \\ Ritüellerini yerine getirme, \\ Sayg1 görme, kabul görme, \\ Rahatlık bulma ve sürekli hizmet hakkı, \\ Müracaat, şikayet ve dava hakkı en önemli konulardır.
}

\title{
- Performans kriterleri
}

Hizmet almaya gelen kişilere değer verir, haklarını korur,

Ekip çalışmasına önem verir, ekibinde çalışanların verimini artırmak üzere çalışanın memnuniyetine ağırlık verir, etkin ve güvenli çalışma ortamı yaratır,

Sağlığın korunması, iyileştirilmesi doğrultusunda çalışır,

Değişen teknolojiyi takip eder, yeni gelişmelerin uygulanmasını sağlamak için çaba gösterir.

\subsection{Estetik Tip Merkezlerinde Vizyon}

Estetik \&Güzellik sektöründe sürekli büyümeyi sağlamak ve önde gelen firmalar arasında yer almak,

Doğru ve karlı alanlara yatırım yapılması ve bu alanlarda etkinliğin artırılmasını sağlamak,

Yüksek standartlarda Hizmet kalitesinin artırılmasını sağlamak,

Kaliteden ödün vermeksizin müşteri memnuniyetinde yüksek performans sağlayarak sağlık, merkezlerinin karlılığını artırmak hedeflenmiştir (Doğan, 2002).

\section{- $\quad$ Estetik Tıp Merkezlerinde Misyon}

Müşteri memnuniyetini en üst seviyeye taşımak, profesyonel ekibi ile her daim müşterilerin ilk tercihi haline getirmek,

Merkezlerde çalışanlarının ve hizmet alanlarının performanslarını artırmak üzere faaliyet göstermek,

İnsanların hayal ettikleri sonuçlara en iyi şekilde ulaşmalarını sağlamak,

Güzellik sektörüne de hizmet veren diğer önde gelen kuruluşlarla rekabet edebilecek etkinliğe ulaşmak.

\subsection{Estetik Tıp Merkezlerindeki Stratejik Hedefler}

Plastik cerrah, Dermatolog, medikal estetik hekimi, Beslenme uzmanı, Hemşire, Güzellik uzmanı, Halkla ilişkiler uzmanından oluşan ekibin ortak çalışması ile oluşturulan stratejik hedefler, Mesul Müdürün onayına sunulur. Yapılan öneriler tartışılır ve onaylanan hedeflerin en kısa zaman içerisinde uygulanması yönünde çalışmalar başlatılır. Yılsonlarında faaliyetler itibariyle ulaşılan sonuçlar izlenir ve hedeflere ulaşma derecesi ölçülür.

İşletmelerinin uzun süreli olmalarında: iyi belirlenmiş vizyon \& misyonun yanında günün getirdiği fırsatları iyi değerlendirmek, her zaman yeniliklere, değişimlere uyum sağlayabilme gerekliliğini, standartları iyi belirlenmiş işletmeler firsatlara ve tehditlere karşı da güçlü stratejik yönetimler uygulayarak geleceğe daha umutlu, güvenli, olabilmek adına her geçen gün kapasitelerini genişleterek rakiplerine karşı farklı stratejik gelişimler uygulamalarının zorunluluğu kaçınılmaz olduğunu düşünmektedir (Yıldırım, 2000).

\section{Kişisel Yorum}

Estetik tıp sektöründe son yıllarda çok fazla sayıda yeni tedavi yöntemleri uygulamaya sunuldu. Bu yenilikler hem sektörü ve sektöre bağlı hizmet veren kuruluşların dinamiklerini kökten değiştirdi. Türkiye'de ve dünyada sadece kadınların ihtiyaç hissettiği düşünülmekte; ya da görsel mesleği olanların, maddi gücü olan kişilerin sahip olabileceği uygulamalar olarak düşünülmekte iken ve oldukça çok dar bir çerçevede hizmet veren güzellik ve bakım sektörü devasa sınırlara ulaştı. Sektör çalışanlarının tedavi ritüellerini bilinçli reklam ve tanıtımları sayesinde lüks tüketim gibi algılanan ve gizli olarak yaptırılan uygulamalar artık bir gereksinim olarak algılanmaya başlandı. Sektördeki bu hızlı gelişmeler daha kapsamlı hizmet veren merkezlerin oluşmasına olanak sağladı. Günümüz de artık cinsiyet farkı gözetmeden kişiler bu tür koruyucu bakımlara gereksinim duymaktadırlar. Tedavi 
talebi ile merkezlerden hizmet almaya gelen bireyler arasında çok bilinçli ne istediğini ve neye gereksinimini olduğunu farkında olan bilinçli kişiler kadar, birçoğu da istediği uygulamayla ilgili hiç bir fikri olmadan değişik taleplerle müracaat etmektedirler. Bazen medyanın dayatmaları ya da arkadaş ve sosyal çevrelerinin telkiniyle bu tür merkezlere gelmektedirler.

Günümüzde genç, çekici ve canlı bir izlenim uyandıran kişilerin mesleki başarılarının daha yüksek olduğu ispatlanmış durumdadır. Bu sebeple birçok yönetici, dış görünüşlerine önceki yıllara nazaran çok daha önem veriyor ve estetik tıp merkezlerinden tedavi ve bakım hizmetleri alma talebinde bulunuyorlar.

Estetik Tıp Merkezlerinden hizmet alan orta yaştaki yönetim ve insan kaynaklarında görev yapan kişiler daha çok yüzle ilgili estetik uygulamaları tercih ediyor. Çünkü yaşa bağlı deformasyonların artmasıyla yorgun ifade prezantasyonu etkilediğinden daha kalıcı işlemlere olan talepleri artabiliyor. Dolayısıyla kariyer için estetik tıp sektörüne başvuranların sayısını günümüzde hızla artmaktadır.

Gelişen ve değişen sosyo-ekonomik ve teknolojik ortamda, yeni açılan Estetik tıp merkezlerinin, poliklinik ve estetik hastanelerinin sayısı hızla artmakta, yeni açılan klinik ve salonlar halen hizmetlerine devam eden kurumlar için rekabet açısından ciddi bir tehdit oluşturmaktadır. Günümüzde estetik\& güzellik sektöründe işinin en iyisi olmanın artık yetersiz kaldığı düşünülmektedir. Bunun yanı sıra sadece teknolojik imkanlar ve başarılı uzmanların yeterli olmayıp iyi bir ekip çalışmasına da çok büyük ihtiyaç vardır. Bu noktada merkezde hizmet veren tüm çalışanların eğitimlerinin sürekliliğinin sağlanması ve bilgilerinin güncel tutulması gerekmektedir (Tunçer, 2012).

Beklentiler:

Estetik tıp merkezlerindeki tedavi ve bakım hizmetlerinin sürekliliği ve devamlılığına hizmet etmek,

"Güzellik ve bakım merkezlerinden hizmet alan müşterilerin profilini belirlemeye yönelik kişiye özel hizmet kalitesi sağlanarak hizmet talebi ile gelen bireylere daha iyi kalitede hizmet sunabilmek için neler yapılabilir?" sorusuna cevap aramak,

Merkezlerdeki müşteri profili belirlenerek (hangi yaş, eğitim, sosyal durum ve gelir düzeyleri) hangi tür hizmetlere daha fazla gereksinim duyulduğunu belirlemek, merkezlerden tedavi hizmeti alan kişilerin beklentilerini öğrenmek hizmet kalitesini kişilerin beklentilerinin üzerinde sunmak için çok gereklidir.

Hangi tedavi ve uygulamalarının daha sık talep edildiği durumları belirlemek,

Tedavi uygulama çeşitliliğini belirlemek,

Yapılan hizmetlere ilave olarak yeni uygulamaları hizmete sunmak,

Fazla talep görmeyen işlemleri uygulamadan çıkarabilmek,

Bireylerin gereksinim duyduğu tedavi ve bakım koşulları sağlayarak rakiplere göre üstünlük sağlayabilmek,

Mevcut durum analizi yapmayı, hem de geleceğe yönelik planlama yapmayı hedeflemek,

Aynı iş kolundaki çerçeveyi netleştirme, ilgili piyasadaki dinamikleri ve iş görme koşullarını daha net olarak tanımak,

Hedef kitleyi netleştirerek etkinliği ve verimliliği arttırmak,

Bu sektördeki rakiplere yol göstermek ve Sektörel inovasyon sağlamak gibi beklentiler mevcuttur.

\section{Kaynakça}

- Açıkalın Aytaç, (2000)"İnsan Kaynağının Yönetimi Geliştirilmesi, "Pegem Yayıncılık, Ankara,

- Aktan Coşkun Can. (2006) "Stratejik Yönetim ve Stratejik Planlama, Kamu Mali Yönetiminde Stratejik Planlama ve Performans Esaslı Bütçeleme Sistemi”, Seçkin Yayınları, Ankara,

- Akyüz, Ömer Faruk.(2001)” Değişim Rüzgârında Stratejik Insan Kaynakları Planlaması”, Sistem Yayınc1lik, İstanbul

- Argon Türkan ve Altay Eren. (2004)” İnsan Kaynakları Yönetimi”, Nobel Yayınları, Ankara,

- Balcı Asım.(2003) “Kamu Yönetiminde Çağdaş Yaklaşımlar”, Seçkin Yayıncılık, Ankara,

- Baltaş Acar. (2002)” Ekip Çalışması ve Liderlik”, Remzi Kitabevi Yayını, İstanbul,

- Başaran İbrahim Ethem.(1982) “Örgütsel Davranışın Yönetimi”, A.Ü.E.F. Yayını, Ankara,

- Benlıgıray Serap.(2007) “Ücret Yönetimi”, Beta Basım Yayım, İstanbul,

- Berberoğlu Güneş.(2002)“Yönetim ve Organizasyon”, Anadolu Üniversitesi Yayınları, Eskişehir,

- Bloom Benjamin.(1979) “İnsan Nitelikleri ve Okulda Öğrenme”, Çev. Ali Özçelik, ÖSYM Yayınları, Ankara,

- Bursalığlu Ziya.(1994) “Okul Yönetiminde Yeni Yapı ve Davranı”s, Pegem Yayın, Ankara,

- Bush Tony.(1995)“Theories of Educational Management”, P.C.P Publishing Ltd, Leicester,

- Can Halil.(2001) “Kamu ve Özel Kesimde İnsan Kaynakları Yönetimi”, Siyasal Kitabevi, Ankara, 
- Ciulla Joanne.(2014) “The Heart of Leadership”, Quorum Books, London, pp. 61-62

- Demirci Çiğdemç(200)“Motivasyonun Önemi, Alfa Basım Dağıtım”, İstanbul,

- Ekıı Memduh.(2007) “Geleceği Planlamada Stratejik Yönetim”, A-C Yayınevi, Ankara,

- Erçetin Şule.(2000) “Lider Sarmalında Vizyon”, Nobel Yayın Dağıtım, Ankara,

- Eren Erol.(2008) " Örgütsel Davranış ve Yönetim Psikolojisi”, Beta Yayınları, İstanbul,

- Eren Erol. (2005) "Stratejik Yönetim ve İşletme Politikası”, Beta Yayınları, İstanbul, ss. 19-25.

- Ergin Canan. (2003) "Insan Kaynakları Yönetimi Psikolojik Yaklaşım”, Academy Plus Yayınevi, Ankara,

- Ersen Haldun. (1996) "Toplam Kalite ve İnsan Kaynakları Yönetimi İlişkisi: Verimli ve Etkin Olmanın Yolu”, Yön Matbaacılık, İstanbul,

- Ertürk Mümin. (2011) “Işsletme Biliminin Temel Illkeleri”, Beta Yayınları, İstanbul,

- Fındıkçı İlhamı. (2009) “Insan Kaynakları Yönetim”, Alfa Yayınları, İstanbul,

- Gemici Tahir. (2007) “Stratejik Yönetim”, Gazi Kitapevi Yayınları, Ankara,

- Geylan Ramazan. (2004) “Insan Kaynakları Yönetimi”, Eskişehir Anadolu Üniversitesi Yay., Eskişehir,

- Greenberg Jerald. (1993) “Behavior In Organization”, Prentice Hall, Boston

- Güney Salih. (2015) “Liderlik”, Nobel Yayın Dağıtım, İstanbul, ss. 29-30.

- Gürüz Demet Ve Gaye Özdemir Yaylacı. (2007) “İletişim Gözüyle İnsan Kaynakları Yönetimi”, Media Cat., İstanbul,

- Hatıpoğlu Zeyyat. (2012) “Insan Kaynaklarl Yönetimi, Uygulamalı”, Beta Basım Yayım, İstanbul

- Heller Robert. (1989) “The Leaders And Shapers Of Europe's Quality Revolution”, The Oualitv Makers, Londra,

- Kahraman Yavuz. (2001) “Yönetişim Ve Yönetim Ekseninde Kamu Yönetimi”, Ekin Basım Yayım,

- Karabay Melisa Erdilek. (2015) "Iş̧letmelerde Etik Ve Etik Liderlik Sigortacılık Sektöründe Bir Araştırma" Beta Basım Yayım, İstanbul, Ss. 56-57.

- Karaman Ahmet. (2005) “Vizyon Yönetimi, Nasıl Ve Niçin?”, Iq Yayıncılık, İstanbul,

- Karaman Füsun. (2010) “Işsletmelerde Motivasyon Ve Verimlilik”, Etap Yayınevi, Ss. 94-95

- Kaynak Turgay. (1998) “İnsan Kaynakları Yönetimi”, İstanbul Üniversitesi İşletme Fakültesi Yayın, İstanbul,

- Kılıç Mustafa.(2009) “Yönetim Ve Organizasyon” Örgütsel Çatışma Ve Çatışma Yönetimi”, Nobel Yayın Dağıtım, Ankara,

- Koçel Tamer. (2005) “İşletme Yöneticiliği”, Arıkan Basım Yayım Dağıtım Ltd. Şti., İstanbul

- $\quad$ Kutal Gülten Ve Ali Rıza Büyükuslu. (1996) “Endüstri İlişkileri Boyutunda Çok Uluslu Şirketler Ve İnsan Kaynă̆ı Yönetimi Teori Ve Uygulama”, Der Yayınları, İstanbul.

- Lyon David. (2007) “Postmodernity”, Open University Press, Buckingman.

- Mirze Kadri Ve Hayri Ülgen. (2004) “İşletmelerde Stratejik Yönetim”, Literatür Yayıncılık, İstanbul.

- Neale Margaret. (1990) “Organizational Behavior Management Challenge” The Dryden Pres., Usa, 62-63.

- Ö̈zen Hüseyin Ve Azmi Yalçın. (2010) ” Insan Kaynakları Yönetimi Stratejik Bir Yaklaşım”, Nobel Kitapevi, Adana.

- Sabuncuoğlu Zeyyat. (2000) “Insan Kaynakları Yönetimi”, Ezgi Kitapevi, Bursa.

- Sullivan Gordon And Michael Harper. (1997) "Umut Bir Yöntem Olamaz”, Çev., Ayşe Bilge Dicleli, Boyner Holding Yayınları, İstanbul.

- Tannenbaum Robert Vd. (1961) “Leadership And Organizations, A Behavioral Science Approach”, Mcgraw Hill Pub., Columbia .

- Tortop Nuri. (1999) “Yönetim Bilimi, Yarg1 Yayınevi”, Ankara.

- Tutum Cahit. (1979) “Personel Yönetimi”, Doğan Basımevi, Ankara.

- Uğur Adem. (2008) “Insan Kaynakları Yönetimi” Sakarya Yayıncılık, Sakarya.

- Uysal Gürhan. (2002) “Insan Kaynakları Yönetimi”, İibf Yayınları, Samsun.

- Üzzün Cengiz. (2000) "Stratejik Yönetim Ve Halkla İlişkiler”, Dokuz Eylül Yayınları, İzmir.

- Yüksel Öznur. (2007) “Insan Kaynakları Yönetimi”, Gazi Kitapevi, Ankara. 
- Zaleznık Abraham. (1999) “Yönetici Ve Lider, Birbirinden Farklı Mıdır?, Liderlik”, Çev, Meral Tüzel, Optimist Yayınları, İstanbul.

- Aksu Müge. (2003) “Liderlik Yaklaşımları Ve Dönüştürücü Liderlik Üzerine Bir Araştırma”, Kadir Has Üniversitesi Sosyal Bilimler Enstitüsü, İşletme Bölümü, İstanbul, (Yayımlanmamış Yüksek Lisans Tezi).

- Aydın Ebru. (2007) “Örgütlerde Kariyer Yönetimi Uygulamaları”, Pamukkale Üniversitesi Sosyal Bilimler Enstitüsü, Denizli, (Yayınlanmamış Yüksek Lisans Tezi).

- Derıngöl Halil. (2005) “Tarihsel Gelişimi İçinde İnsan Kaynakları Yönetimi Anlayışı, Amaçları Ve Fonksiyonları Üzerine Çukurova Bölgesinde Faaliyet Gösteren İşletmelerde Bir Araştırma”, Adana, (Yayımlanmamış Yüksek Lisans Tezi).

- Dilsiz Ahmet. (2010) "Kamu Yönetiminde Performans Değerlendirme Ve 360 Derece Bildirim Yöntemiyle Bir Uygulama”, Sosyal Bilimler Enstitüsü, Kırıkkale Üniversitesi, Kırıkkale, (Yayınlanmış Yüksek Lisans Tezi).

- Dinç Emrullah. (2007) “360 Derece Performans Değerlendirme Sistemi Ve Bir Uygulama”, Uludağ Üniversitesi S.B.E., Bursa, 2005, (Yayımlanmamış Yüksek Lisans Tezi).

- Erdoğan Murat, "Performans Yönetim Sisteminin Çalışan Davranışları Üzerindeki Etkisine Yönelik Bir Araştırma”, Maltepe Üniversitesi S.B.E., İstanbul, (Yayımlanmamış Yüksek Lisans Tezi).

- Erdoğdu Emel. (2013) "İnsan Kaynakları Yönetiminde Personel Seçimi Ve Psikoteknik Testlerin Önemi”, Atılım Üniversitesi Sosyal Bilimler Enstitüsü İşletme Yönetimi Ana Bilim Dalı, (Yayınlanmamış Yüksek Lisans Tezi).

- Ertaş Aysel. (1996) “Hastanelerin Kurumsallaşma Düzeyine Yönelik Bir Araştırma”, İşletme Fakültesi, İstanbul Üniversitesi, İstanbul, (Yayınlanmamış Doktora Tezi).

- Güven Tahir. (2000) "Vizyoner Liderlik Ve Takım Oluşturmada Liderin Vizyonunun Rolü”, Gazi Üniversitesi Sosyal Bilimler Enstitüsü, Ankara, (Yayımlanmamış Yüksek Lisans Tezi).

- SSevik Mehmet Emin. (2006) "Yeniden Yapılandırma Sürecinde Gelir İdaresinin Analizi, Sosyal Bilimler Enstitüsü”, Sakarya Üniversitesi, Sakarya, (Yayınlanmamış Yüksek Lisans Tezi).

- Turhan Muhammed. (2007) “Genel Ve Mesleki Lise Yöneticilerinin Etik Liderlik Davranışlarının Okullardaki Sosyal Adalet Üzerindeki Etkisi”, Fırat Üniversitesi, Sbe, Eğitim Bilimleri Anabilim Dalı, Elazı̆̆ , (Yayımlanmamış Doktora Tezi).

- Yılmaz Naciye Tuba. (2009) " Personel Seçim Problemine Analitik Hiyerarşi Yöntemi İle Bir Yaklaşım”, Marmara Üniversitesi, Sosyal Bilimler Enstitüsü, Ekonometri Anabilim Dalı, İstanbul, (Yayınlanmamış Yüksek Lisans Tezi).

- Bırgen Tahsin. ( 1994) “İnsan Kaynaklarının Gelişimi Ve Eğitiminin Önemi”, Önce Kalite Dergisi, Kalder Yayın1, 28-57.

- Covin Jeffrey Vd. (1994) "Strategic Process Effects On The Entrepreneurial Orientation-Sales Growth Rate Relationship“, Entrepreneurship Theory And Practice, 47-92.

- Çavdar Hava Ve Mehmet Çavdar. (2010) “İşletmelerde İş Gören Bulma Ve Seçme Aşamaları”, Deniz Harp Okulu Deniz Bilimleri Ve Mühendisliği Dergisi, İstanbul, 79-93.

- Doğan Selen. (2002) "İşletmelerde Vizyon Ve Misyon Bildirisi Geliştirme Ve Önemi Üzerine Bir Araştırma”, Amme İdaresi Dergisi, 143-174.

- Elbeyi Pelit. (2003) "Hizmet İşletmelerinde İş Gören Motivasyonunun Önemi Ve Verimliliğe Etkisi”, Standart Dergisi, Ankara, 49-64.

- Fiol Marlene. (2015) “Thought Worlds Colliding, The Role Of Contradiction İn Coorporate Innovation Processes," Entrepreneurship, Theory \& Practice, 61-97.

- Gatıgnon Hubert. (1997) “Strategic Orientation Of The Firm New Product Performance,” Journal Of Marketing Research, 77-90.

- Hansen Duane. (2011) "Ethical Leadership: A Multifoci Social Exchange Perspective”, The Journal Of Business Inquiry, 41-55.

- Herdman Justin. (2012) "Liderlik Ve Yönetim: Teori Var Pratik Yok?", Hemşirelikte Eğitim Ve Araştırma Dergisi, 14-48.

- Kağnıcıŏglu Deniz. (2001) “İnsan Kaynakları Yönetimi Ve Değişen Endüstri İlişkileri”, Anadolu Üniversitesi Sosyal Bilimler Dergisi, İstanbul, 4-20.

- Karıp Emin. (1998) “Dönüşümcü Liderlik”, Kuram Ve Uygulamada Eğitim Yönetimi Dergisi, 433-475.

- Kaya Harun. (2008) “Kamu Ve Özel Sektör Kuruluşlarının Örgütsel Kültürünün Analizi Ve Kurum Kültürünün Çalışanların Örgütsel Bağlılığına Etkisi, Görgülü Bir Araştırma”, Maliye Dergisi, 135-170. 
- Kocabaş İbrahim Ve Ramazan Erdem. (2003) "Yönetici Adayı Öğretmenlerin Kişisel Zaman Yönetimi Davranışları", Fırat Üniversitesi Sosyal Bilimler Dergisi, 203-240.

- Konovsky Mary. (2000) 'Understanding Procedural Justice And Its Impact On Business Organizations”, Journal Of Management, 32-56.

- Laub Jack. (1999) “Assessing The Servant Organization, Development Of The Servant Organizational Leadership “Assessment Sola Instrument, Dissertation Abstracts International, 19-55.

- Muter Şener. (2000) “Endüstri İlişkileri Açısından İnsan Kaynaklarının Önemi”, İşveren Dergisi, 65-98.

- Rajnandını Pillai. (1999) "Leadership And Organizational Justice, Similarities And Differences Across Cultures". Journal Of International Business Studies, 763-764.

- Rown Michael. (2009) "Ethical Leadership: A Review And Future Directions", The Leadership Quarterly, 595-616.

- Sarıtepecı Mustafa Ve Hasan Çakır. (2014) "Harmanlanmış Öğrenmenin Öğrencilerin Sosyal Bilgiler Dersine Yönelik Motivasyon Ve Tutumlarına Etkisinin İncelenmesi”, Pamukkale Üniversitesi, Ĕ̆itim Fakültesi Dergisi, 105-149.

- Schubert Elizabeth. (2002) 'Perceptions Of The Ethical Work Climate And Covenanta Relationships", Journal Of Business Ethics, Ss. 63-95, S. 82.

- Tatum Charles. (2014) "Making Just Decisions: Organizational Justice, Decision Making, And Leadership", Management Decision, 310-329.

- $\quad$ Tezel Naki. (2002) “Liderlik Yaklaşımları Ve Türk Kamu Yönetiminde Liderlik Araştırmaları”, Türk İdare Dergisi, Balıkesir, 218-254.

- Tunçer Polat. (2012) “Değişen İnsan Kaynakları Yönetimi Anlayışında Kariyer Yönetimi”, On Dokuz Mayıs Üniversitesi Eğitim Fakültesi Dergisi 203-233.

- Ünal Mesud. (2012) "Bilgi Çağında Değişim Ve Liderlik", Marmara Üniversitesi İ.I.B.F. Dergisi, Ss. 44-75, S. 51.

- Yıldırım Sema. (2000) "Stratejik Yönetim Planlaması, 2000’li Yı1larda İşletmeler İçin Yeni Bir Açılım”, Amme Idaresi Dergisi, Ankara, 101-159.

- Yıldız Mehmet. (2002) “Liderlik Yaklaşımları Ve Türk Kamu Yönetiminde Liderlik Araştırmaları”, Türk Idare Dergisi, 218-250. 


\title{
Türkiye’de Çevre Amaçlı Tarım Arazilerini Koruma Programı Uygulamaları
}

\section{Implementation of Environmentally Based Agricultural Land Protection Program in Turkey}

\author{
Dr. Mehmet Hasdemir (Ministry of Food, Agriculture and Livestock, Turkey) \\ Mine Hasdemir (Agricultural Economy and Policy Development Institute, Turkey)
}

\begin{abstract}
Agriculture, which includes many aspects like vegetative and animal production by utilization of soil and water resources and enhancement of efficiency and quality, has been considered the most environmentally-friendly sector up to date and meets nutritional demand of one fifth of world population. On the other hand, due to utilization of intensive input for maximization of yield per unit area of land, agriculture has become a sector which may also result negative impacts on the environment. For this reason, environmentally-friendly agricultural policies have started to be implemented in many countries besides the implementation of policies based on increased agricultural production. In this context, Environmentally Based Agricultural Land Protection (ÇATAK) Program has started to be implemented in Turkey since 2006 for protection of soil and water quality, prevention of erosion and mitigation of agriculture-derived negative impacts. The Program is executed by the Ministry of Food and Agriculture. Within this scope, environmentally-friendly practices are being supported by awarding grants to the beneficiary farmers. This study aims to address the extent to which implementation of ÇATAK Program has contributed to land protection based on a review of environmentally-friendly agricultural practices and beneficiary activities. Additionally, the place of environmental subsidy is assessed within the agricultural funding scheme being implemented in Turkey.
\end{abstract}

\section{Giris}

Çevreyi oluşturan temel unsurlar dikkate alındığında hava, toprak ve su ekolojik bir denge içindedir. Canlılar bu ortamda yaşamlarını doğal olarak sürdürmektedirler. Ancak dışarıdan yapılan müdahaleler bu doğal dengeyi bozmakta ve tüm canlıları olumsuz etkilemektedir. Çevre sorunları ortaya çıkışı birden bire olmamaktadır. Zaman içerisinde oluşan kirlenme doğanın kendini yenileme özelliğinden dolayı fark edilmemekte, fakat süreç içerisinde kirlenmenin veya müdahalenin doğanın kendini yenileme yeteneğinin üzerine çıkması, çevrenin hızla bozulmasına neden olmaktadır. Bu nedenle kirlenme ortaya çıkmadan, çevre kirlenmesine neden olan faktörlerin tespit edilerek gerekli tedbirlerin alınmasına ihtiyaç duymaktadır.

Toprak ve su kaynaklarını kullanarak bitkisel ve hayvansal ürünler elde etmek, verimliliği ve kaliteyi artırmak gibi pek çok çalışmaları içeren tarım, geçmişten bugüne çevre ile en fazla uyum içerisinde olan bir sektör olarak dünya nüfusunun besin ihtiyacını karşılamaktadır. Ancak geçmişte çevreyi koruyan ve çevre için kurtarıcı bir faaliyet olarak görülen tarım, birim alandan elde edilen verimi artırmaya dayalı yoğun girdi kullanımı sonucu çevre üzerinde olumsuz etkileri olabilen bir sektör halini almıştır.

1960-1970’lerde hızla artan dünya nüfusunun gıda ihtiyacının karşılanması için tarım politikalarının ana hedefi olan yeşil devrim; yüksek verimli çeşitlerin yanı sıra gübre ve ilaç gibi girdilerin yoğun tüketilerek, birim alandan sağlanan verimi artırmaya öncelik vermiştir. Özellikle gelişmekte olan ülkelerde bu amaçla kimyasal gübre ve tarım ilaçlarının kullanımının teşvik edilmesi ulusal politika haline gelmiştir. Ancak aradan 20 yıl geçtiğinde ortaya çıkan çevre kirliliği ve sağlık sorunları ile ilişkilendirilmesi sonucunda, birçok ülkede girdi kullanımının yoğun olduğu geleneksel tarımsal üretim tekniklerine alternatif olabilecek çevre dostu üretim tekniklerinin arayışı başlamış, sürdürülebilirliğin sağlanması ana hedef haline gelmiştir (Anonim, 2005a).

Küresel iklim değişikliği yanında tarım ve gıda piyasalarında yaşanan dalgalanmalar sektörü önemli ölçüde etkilemektedir. Dünya genelinde kişi başına düşen tarım arazisi ve su başta olmak üzere doğal kaynaklar azalmaktadır. Geçtiğimiz dönemde tarımsal üretim yıllık ortalama \%2 artış göstermiştir. Gelecek on yılda ise bu artışın yavaşlayarak, ortalama \%1,7 olacağı öngörülmektedir. Yaşanan bu gelişmeler, tarımsal üretimde başta su ve toprak olmak üzere mevcut kaynakların etkin kullanımını sağlayacak planlamaları zorunlu kılmaktadır (Anonim, 2014).

Küresel su tüketimi son yıllarda giderek artmaktadır. Endüstriyel, evsel ve tarımsal sulama için çekilen toplam su miktarı 1900'lü yıllarda $580 \mathrm{~km}^{3}$ düzeyinde iken, 2010 yılında $3.900 \mathrm{~km}^{3}$ 'ün üzerine çıkmıştır. Sulama için enerji tüketimi de gittikçe artmaktadır. Küresel bazda 1990 yılında $35.981 \mathrm{mln} \mathrm{kWh}$ olan sulama amaçlı su tüketimi, 2000 yılında 130.786 mln kWh'ye, 2014 yılında ise $325448 \mathrm{mln}$ kWh'ye yükselmiştir. Dünyadaki toplam tatlı su tüketiminin \%70'i tarımsal amaçlıdır. Toplam ekili alanların \%20'sinde sulu tarım yapılmasına rağmen, küresel üretiminin \%40’1 sulu alanlardan elde edilmektedir (FAO, 2015). Bu durum, hem küresel bazda 
hem de tarım sektörü özelinde suyu önemli kılmaktadır. Bu nedenle kuraklığın etkisinin arttığı günümüzde su kullanımına ilişkin politikalar içerisinde tarım sektörü öne çıkmaktadır.

Dünya nüfusundaki artışa karşılık kişi başına düşen tarım arazilerinin azalması ve tarımsal büyüme hızının yavaşlamasına rağmen son yıllarda küresel gübre tüketimi artmaktadır. Birim alanda kullanılan azot miktarı 2000 yılında 64,9 kg/ ha iken 2014 yılında 85,8 kg/ha'a yükselmiştir. Aynı dönemde fosfor tüketimi de 25,9 kg/ha' dan $33,2 \mathrm{~kg} / \mathrm{ha}$ 'a yükselmiştir. Benzer bir şekilde potasyum kullanımı da 18,2 kg/ha'dan 20,4 kg/ha'a çıkmıştır (FAO, 2015).

Tarımsal üretimin en önemli girdileri olan su ve gübre kullanım düzeyi dikkate alındığında, sektörün sürdürülebilirliğine yönelik politikaların oluşturulmasında su ve gübre kullanımını azaltacak, mevcut kaynakların kullanımının etkinliğini artıracak politikalar öncelikli olarak yer almak durumundadır. Ayrıca uygun toprak işleme teknikleri, çayır ve meraların korunması, erezyonun önlenmesi, zirai ilaçların doğru kullanımı ile çevre, insan ve hayvan sağlığına zarar vermeyen bir tarımsal üretimin yapılmasına ihtiyaç duyulmaktadır. Tüm bu hususlarda çiftçilerde davranış değişikliğinin oluşturulmasına yönelik en önemli araçlardan biri de tarımsal desteklemelerdir.

Çevre sorunlarının birey tarafindan risk olarak algılanması ve tehdit olarak görülmesi, çevreye yararlı davranışları motivasyonu açısından oldukça önemlidir (Erten, 2004). Çevre sorunlarıyla mücadelenin ve sürdürülebilir bir yaşamı sağlamanın en temel ve yararlı yolu da kişilerin davranışlarını, tutumlarını değiştirmektir (Talas ve Karataş, 2012). Çiftçilerin tarımsal faaliyetlerinin çevreye zarar vermeden sürdürülmelerine yönelik tutum ve davranışların desteklenmesini amaçlayan bir destekleme mekanizması, çevre politikaları açısından büyük önem arz etmektedir.

\section{2 Çevre Amaçı Tarım Arazilerini Koruma Programı}

Önemli toprak-su kaynaklarına ve benzersiz biyolojik çeşitliliğe sahip Türkiye'de toprak ve su kaynaklarının korunması, geliştirilmesi, ulusal ve uluslararası politikalara uygun olarak verimli kullanılması yalnızca günün gereksinimleri değil, gelecek kuşakların refahı ve mutluluğu için de önemlidir. Doğal kaynakların korunması, ulusal savunma stratejisinin ayrılmaz bir parçasıdır. Toprak, su ve genetik varlıklar, geçmişten geleceğe ulusun ve insanlığın ortak değerleri ve sorumluluğudur (Anonim, 2005a).

$\mathrm{Bu}$ amaçla 25.7.2005 tarihinde yürürlüğe giren Çevre Amaçlı Tarımsal Arazilerin Korunması (ÇATAK) Programını Tercih Eden Üreticilerin Desteklenmesine Dair 2005/9230 Nolu Bakanlar Kurulu Kararı, Türkiye'de tarımsal faaliyetlerin çevre üzerine olan etkilerinin azaltılması yönünde yapılan çalışmalar açısında bir dönüm noktası oluşturmuştur. 2005/9230 Nolu Bakanlar Kurulu Kararı ile hassas bölgelerdeki bozulma ve kirlenme tehdidi altındaki ekolojik dengenin yeniden tesisi ve sürdürülebilirliği için tarımsal üretim ile iştigal eden üreticilerin desteklenmesine başlamıştır (Anonim, 2005b).

Toprak ve su kalitesinin korunması, doğal kaynakların sürdürülebilirliği, erozyonun önlenmesi ve tarımın olumsuz etkilerinin azaltılmasına yönelik olan ÇATAK Programını tercih eden üreticilerin desteklenmesine ilişkin çalışmalar Gıda Tarım ve Hayvancılık Bakanlığı'nca yürütülmektedir. ÇATAK uygulamalarının 2006-2008 yılları arasındaki finansman ihtiyacı, Dünya Bankası tarafından finanse edilen Türkiye Tarım Reformu Uygulama Projesi'nin yarı dönem değerlendirme görüşmeleri sonrasında 11.03.2005 tarihinde Türkiye Cumhuriyeti Hükümeti ile Dünya Bankası tarafından imzalanan İkraz Anlaşması ile karşılanmıştır. Bu yeni ikraz anlaşmasının gereği ÇATAK, Türkiye Tarım Reformu Uygulama Projesi’nin alt bileşenlerinden biri olarak yürürlüğe girmiştir. Ancak, pilot olarak uygulanmaya başlayan ÇATAK, süreç içerisinde sadece dış kaynaklarla yürütülen bir proje olmaktan çıkıp, tarımsal desteklemelerin önemli bir unsuru haline gelmiştir. 2006-2008 yılları arasında dış kaynaklar ile 4 pilot ilde başlatılan program, 2009 yılından itibaren iç kaynaklarla finanse edilmeye başlanmıştır.

\subsection{Programın Yasal Dayanağı}

Çevre Amaçlı Tarımsal Arazilerin Korunması Programını Tercih Eden Üreticilerin Desteklenmesine Dair ilk Bakanlar Kurulu Kararı olan 2005/9230 Sayılı Karar, 31.08.2005 tarihli ve de 25922 sayılı Resmi Gazete'de yayımlanarak yürürlüğe girmiştir. Buna bağlı olarak uygulama esaslarıyla ilgili Yönetmelik de 31.08.2005 tarihli ve de 25922 sayılı Resmi Gazete'de yayımlanmıştır (Anonim, 2005b).

Çevre amaçlı uygulamaların desteklenmesine yönelik politika değişikliğinin en önemli dayanağı 2006-2010 yılları arasında yapılacak tarımsal desteklemeleri düzenleyen Tarım Stratejisi Belgesi'dir. 30.11.2004 tarih ve 2004/92 Sayılı Yüksek Planlama Kurulu Karrı ile yayımlanan Tarım Stratejisi Belgesi'nin 1. Maddesinde; kaynakların etkin kullanımı ilkesi çerçevesinde ekonomik, sosyal, çevresel ve uluslararası gelişmeler boyutunu bütün olarak ele alan örgütlü, rekabet gücü yüksek, sürdürülebilir bir tarım sektörünün oluşturulması temel amaç olarak belirlenmiştir. Bu temel amaç doğrultusunda tarım stratejisi belgesi, 2006-2010 yılları arasında, Avrupa Birliğine uyumu da gözeterek, tarım sektörü ile ilgili kesimlerin karar almalarını kolaylaştırmak, sektörün kalkınma hedef ve stratejileri doğrultusunda geliştirilmesini sağlamak ve 2004 sonuna kadar çıkarılacak Tarım Çerçeve Kanunu ile bu kanuna dayalı olarak hazırlanacak ikincil mevzuatın temelini oluşturmak için hazırlanmıştır (Anonim, 2004). 
2006-2010 yılları arasında yapılacak desteklemeleri düzenleyen Tarım Stratejisi belgesinin 4. maddesinde ÇATAK desteklemelerine yer verilerek, destekleme uygulamaları bu çerçevede yürütülmüştür. Daha sonra 18.04.2006 tarihinde yayımlanan 5488 Sayılı Tarım Kanunu ile tarımsal destekleme araçları yeniden düzenlenmiştir. 5488 Kanunun 19. maddesi (f) bendinde ÇATAK Programı desteklerine yer verilerek ÇATAK desteklemeleri yasa ile düzenlenmiştir. Buna göre ÇATAK Programının hangi arazilerde uygulanacağı, sözleşmelerin kapsamı, ödemelerin süresi ve ödeme miktarları Tarımsal Destekleme ve Yönlendirme Kurulunun teklifi üzerine Bakanlar Kurulu tarafından belirlenmektedir. Bakanlar kurulu kararı ile ilan edilen illerde belirlenen ÇATAK uygulama alanlarında başvuruda bulunan çiftçilere, 3 yıl süre ile her yıl için ayrı ayrı destekleme ödemesi yapilmaktadir.

5488 Kanunun 19. maddesi (f) bendi çerçevesinde, Tarımsal Destekleme ve Yönlendirme Kurulunun teklifi üzerine, 27/10/2008 tarihli ve 2008/14268 sayılı Bakanlar Kurulu Kararı ile Çevre Amaçlı Tarımsal Arazilerin Korunması Programını Tercih Eden Üreticilerin Desteklenmesine İlişkin Karar yayımlanmıştır. Bu karara dayanılarak ÇATAK Programını tercih eden üreticilerin desteklenmesinde görev alacak kurum ve kuruluşların belirlenmesi ile desteklemeye ilişkin usul ve esaslara uygulama tebliği ile düzenlenmektedir. Halen ÇATAK programı 1 Mart 2016 tarihli ve 29670 Resmi Gazete'de yayımlanan 2006/9 Sayılı Uygulama Tebliği çerçevesinde yürütülmektedir (Anonim, 2016a).

\subsection{Programın Uygulama Kategorileri}

ÇATAK Programının uygulandığı illerde; programın uygulanacağı alanların önceliğini ve çerçevesini belirlemeye ilişkin çalışmalar il ÇATAK uygulama komisyonu tarafından yürütülmektedir. İl ÇATAK uygulama komisyonu ÇATAK programı kapsamında çalışmaların yürütülmesinden ve bu çalışmalar sırasında ortaya çıkacak problemlerin çözümünden yetkili ve sorumludur. Komisyon, İl/ilçe ÇATAK uygulama birimleri tarafından yapılan faaliyetlerin izleme ve değerlendirmesini yapmaktadır (Anonim, 2016a).

ÇATAK programı kapsamında destekleme yapılacak alanlarda farklı kategorilerde belirlenen uygulamalara 3 yıl süre ile ödeme yapılmaktadır. ÇATAK programının uygulandığı 2006-2008 yılları arasında 3 ayrı kategoride destekleme yapılmıştır. 14 Kasım 2008 tarihli ve 27054 sayılı Resmî Gazete'de yayımlanan 27.10.2008 tarihli ve 2008/14268 sayılı Bakanlar Kurulu Kararı çerçevesinde, daha önce 3 kategoride uygulanan ÇATAK Programının I. ve III. kategorileri birleştirilerek 2009 yılından itibaren 2 kategoride uygulanmaya başlanılmıştır. 2011 yılından itibaren ise toprak işlemesiz tarım (minimum işlemeli tarım) ayrı bir kategori haline getirilerek halen uygulama aşağıdaki kategorilerde gerçekleştirilmektedir.

a) Birinci kategori (30 TL/da/yıl): Tek yıllık bitkilerin üretildiği alanda minimum işlemeli tarımın yapılması,

b) İkinci kategori (60 TL/da/yıl): Toprak ve su yapısının korunması ile erozyonun önlenmesi amaciyla; setleme, teraslama, canlı veya cansız perdeleme, taş toplama, açık drenaj uygulaması, jips uygulaması, kükürt veya kireç uygulaması, malçlama, ahır veya çiftlik gübresi ile gübreleme, yeşil gübreleme, aşırı otlatmanın engellenmesi, çok yıllık buğdaygiller veya yonca hariç çok yıllık baklagiller ile alanı kaplama gibi tedbirlerden her yıl en az iki uygulamanın yapılması veya bu tedbirlerin en az biriyle birlikte arazinin boş bırakılması uygulaması.

c) Üçüncü kategori (135 TL/da/yıl): Çevre dostu tarım teknikleri ve kültürel uygulamalardan oluşan ve aşağıda belirtildiği şekilde gruplandırılan uygulamalardan birisinin tatbik edilmesi:

1) Tarımsal girdilerin çevreye duyarlı bir şekilde kullanımını sağlamak üzere; su tüketimini asgariye indirecek uygun basınçlı sulama sistemleri ile birlikte entegre ürün yönetimi genel prensiplerinde gübre ve bitki koruma ürünlerinin kullanılması.

2) Organik tarım veya iyi tarım uygulamalarının, bu kategori veya diğer kategorilerde yer alan tedbirlerden en az biri ile birlikte uygulanması.

3) Kapalı drenaj sisteminin, bu kategori veya diğer kategorilerde yer alan tedbirlerden en az biri ile birlikte uygulanmasi.

Uygulama Tebliğine göre birinci kategoride yer alan minimum işlemeli tarım; çevreye duyarlı üretimin yapılması amacıyla toprak ve su kalitesinin arttırılması için anıza doğrudan ekim yapılmasını sağlayan minimum veya sıfır toprak işlemesinin yapıldığı tarımsal üretim faaliyetleri olarak tanımlanmaktadır. Uygulamada bu kategori anıza doğrudan ekim şeklinde yürütülmektedir.

Organik tarım ve iyi tarım uygulamaları (İTU), Gıda Tarım ve Hayvancılık Bakanlığı tarafından yetkilendirilen kontrol ve sertifikasyon kuruluşları ile sözleşme yaparak ilgili mevzuatlar çerçevesinde yürütülmektedir. İyi Tarım Uygulamaları Hakkında Yönetmeliğe göre İTU; "tarımsal üretim sistemini sosyal açıdan yaşanabilir, ekonomik açıdan karlı ve verimli, insan sağlığını koruyan, hayvan sağlığı ve refahı ile çevreye önem veren bir hale getirmek için uygulanması gereken işlemleri” olarak tanımlanmaktadır (Anonim, 2010b). 5262 Sayılı Organik Tarım Kanunu göre de organik tarım faaliyetleri; "toprak, su, bitki, hayvan ve doğal kaynaklar kullanılarak organik ürün veya girdi üretilmesi ya da yetiştirilmesi, doğal alan ve kaynaklardan ürün toplanması, hasat, kesim, işleme, tasnif, ambalajlama, etiketleme, muhafaza, depolama, taşıma, pazarlama, ithalat, ihracat ile ürün veya girdinin tüketiciye ulaşıncaya kadar olan diğer işlemler” olarak tanımlanmaktadır (Anonim, 2010a). 


\subsection{Programın Uygulama Alanı}

ÇATAK program uygulaması, çeşitli nedenlerle toprak yapısının ve su kalitesinin değiştiği gözlenen ve tedbir alınmadığı takdirde yakın gelecekte çevre açısından olumsuz etkilere sahip olabilecek, ülke genelindeki bölgeleri kapsayacak şekilde, bütçe imkânları da göz önüne alınarak genişletilmektedir.

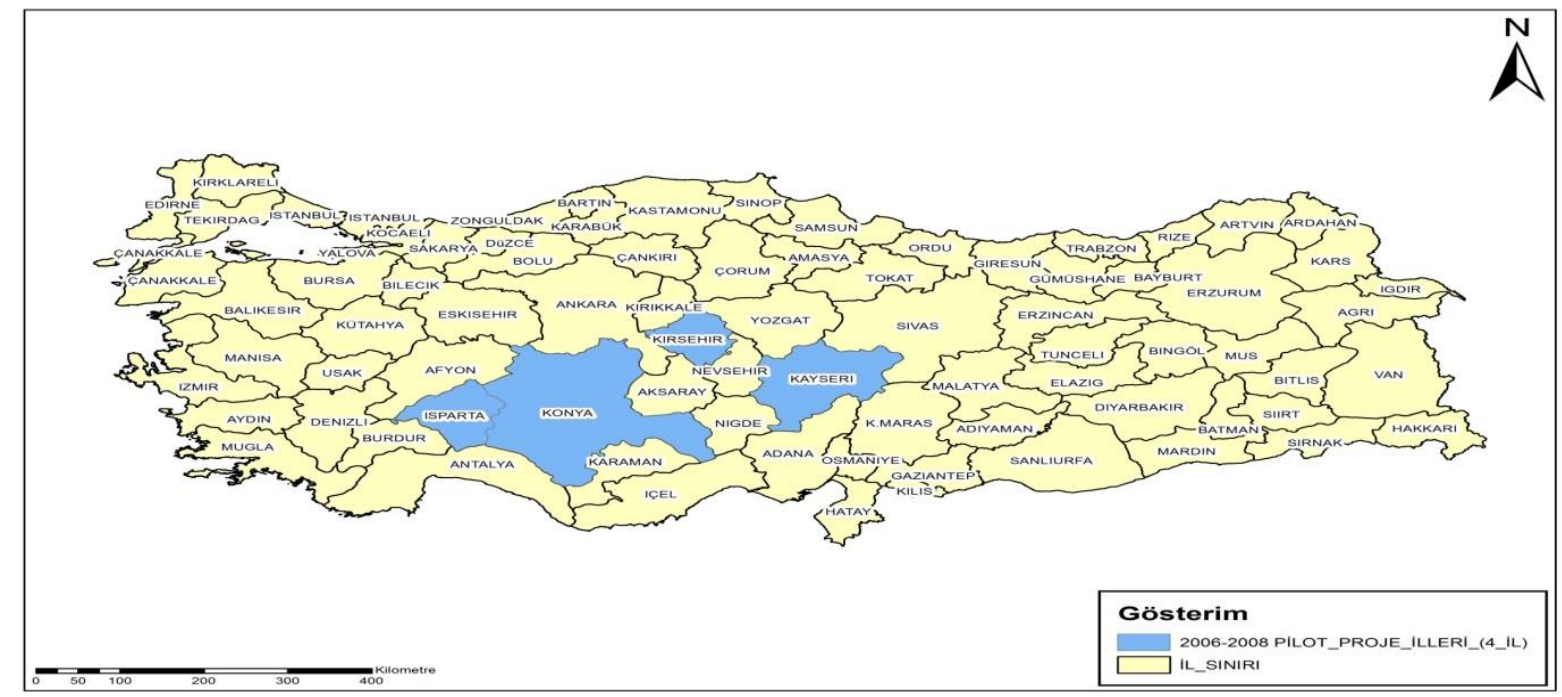

Şekil 1. ÇATAK Programı 2006-2009 Pilot Uygulama Illeri Kaynak: Anonim, 2016 b.

Program, ilk olarak 2006 yılında Kırşehir, Isparta, Konya ve Kayseri'den oluşan 4 ilde pilot olarak uygulanmaya başlanılmıştır (Şekil 1). Uygulama esasları gereği, ÇATAK programının yürütüleceği illerde hassas alanlar belirlenmektedir. Desteklemelerde, bu alanlarda tarımsal faaliyet yapan çiftçilere yöneliktir. Uygulamanın başlatıldığı 2006 yılındaki hassas alanlar ise Kırşehir İli Seyfe Gölü, Kayseri İli Sultan Sazlığı, Konya İli Ereğli Sazlıkları ve Isparta İli Kovada Gölü çevreleridir. ÇATAK uygulamasının yapıldığı dört bölgenin de ortak özelliği, bu bölgelerin sulak alanlar olmasıdır. Aynı zamanda Uluslararası Öneme Sahip Sulak Alanların Korunması Sözleşmesi olarak bilinen Ramsar Sözleşmesiyle korunmuş alanlar içerisine girmektedir.

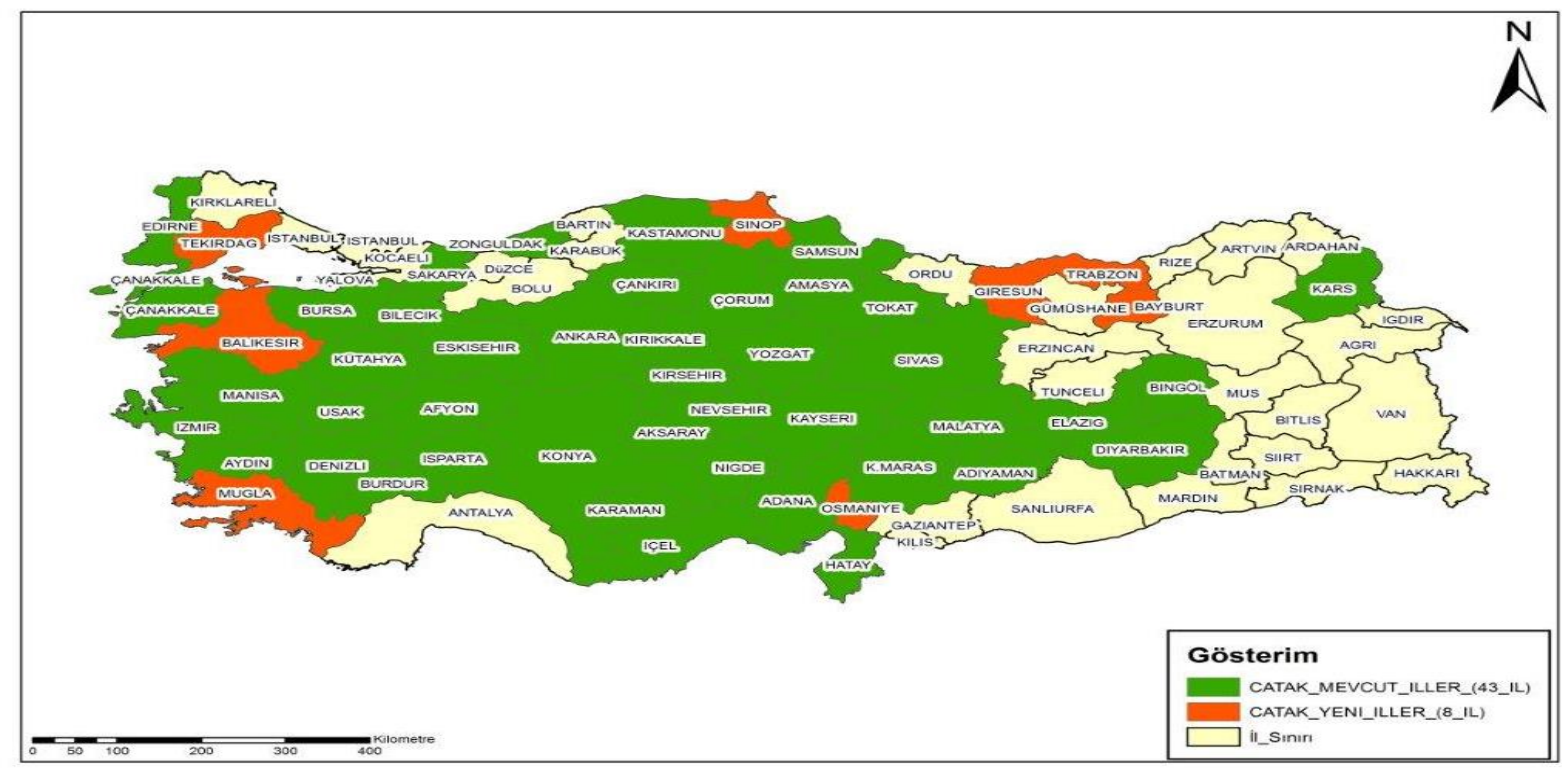

Şekil 2. ÇATAK Programı 2015 Uygulama İlleri Kaynak: Anonim, $2016 b$.

2009 yılından itibaren ÇATAK uygulaması kademeli olarak genişletilmeye başlatılmıştır. 2009 yılında ilave 5 il kapsama dahil edilmiş, 2010 yılında 10 il, 2011 yılında 6 il, 2012 yılında 2 il, 2012 yılında 3 il, 2014 yılında 13 il ve 2015 yılında 8 il programa dahil edilmiş olup halen 51 ile ÇATAK programı yürütülmektedir (Şekil 2).

2016/9 sayılı ÇATAK Uygulama Tebliği'nin 5. Maddesine göre Bakanlar Kurulunca belirlenen illerde uygulama alanları aşağıdaki şekilde belirlenmektedir.

a) ÇATAK programının uygulanacağı alanların önceliğini ve çerçevesini belirlemeye ilişkin çalışmalar il ÇATAK uygulama komisyonu tarafından yürütülmekte, 
b) İl ÇATAK uygulama komisyonu tarafindan il/ilçe ÇATAK uygulama birimlerinin görüşleri dikkate alınarak, bozuk vasıflı orman alanları ve boş orman toprakları haricindeki hassas bölgelerde mahallinde ayrıntılı etüt, değerlendirme ve tespitler yapılmakta,

c) İl ÇATAK uygulama komisyonunun teklifi ve Bakanlığın uygun görüşü alınarak hassas bölgelerde belirlenen uygulama alanı mahallinde ilan edilmektedir.

Uygulama Tebliğine göre hassas alan ise mevcut yapısal dengede, çeşitli nedenlerle toprak yapısının ve su kalitesinin değiştiği gözlenen ve tedbir alınmadığı takdirde yakın gelecekte çevre açısından olumsuz etkilere sahip olabilecek bölgeler olarak tanımlanmaktadır (Anonim, 2016a).

\subsection{Program Kapsamında Yapılan Desteler}

ÇATAK programına başvuran çiftçilerle üç yıllık hibe sözleşmesi yapılmak suretiyle üç ayrı kategoride çiftçiler desteklenmektedir. Yıllık destekleme miktarı birinci kategori için $30 \mathrm{TL} / \mathrm{da}$, ikinci kategori için $60 \mathrm{TL} / \mathrm{da}$ ve üçüncü kategori için 135 TL/da olarak belirlenmiştir. 2006-2008 yılları ile 2009 ilk ödemesi Dünya Bankası'ndan sağlanan dış kaynak ile karşılanırken, 2009 yılı ikinci dönem ödemesinden itibaren ÇATAK programı desteklerinin tamamı Türkiye Cumhuriyeti Bütçesinden sağlanan iç kaynaktan finanse edilmiştir.

2006 yılında 4 ilde toplam 469 üretici ÇATAK Programı kapsamında hibe sözleşmesi imzalayarak destekten yararlanırken, iç kaynaktan desteklemenin başladığı 2009 yılında 9 ilde 1881 üretici, 2014 yılında 43 ilde 15.430 üretici ve 2015 yılında 51 ilde 22.628 üretici ÇATAK Programı kapsamında desteklenmiştir (tablo1).

\begin{tabular}{|l|c|l|c|}
\hline Yll & Il Saylsl & Uygulamaya Dahil Edilen Iller & Üretici Saylsl \\
\cline { 1 - 2 } 2006 & \multirow{2}{*}{4} & Kırşehir, Isparta, Konya, Kayseri & 469 \\
\cline { 1 - 2 } 2007 & 9 & Kahramanmaraş, Karaman, Canakkale, Niğde, Nevşehir & 1.508 \\
\cline { 1 - 2 } 2008 & 19 & $\begin{array}{l}\text { Adana, Amasya, Aksaray, Burdur, Denizli, Mersin, Samsun, } \\
\text { Sivas, Bilecik, Diyarbakır }\end{array}$ & 1.484 \\
\hline 2009 & 25 & Ankara, Aydın, Tokat, Manisa, Çorum, Edirne & 2.940 \\
\hline 2010 & 27 & Adıyaman, İzmir & 4.648 \\
\hline 2011 & 40 & Eskişehir, Hatay, Zonguldak & 6.568 \\
\hline 2012 & 43 & $\begin{array}{l}\text { Afyonkarahisar, Bingöl, Bursa, Çankırı, Elazığ, Kars, Kastamonu, } \\
\text { Kurıkale, Kütahya, Malatya, Sakarya, Uşak, Yozgat }\end{array}$ & 15.430 \\
\hline 2013 & 51 & $\begin{array}{l}\text { Balıkesir, Bayburt, Giresun, Muğla, Osmaniye, Sinop, Tekirdağ, } \\
\text { Trabzon }\end{array}$ & 22.628 \\
\hline 2015 & &
\end{tabular}

Tablo 1. ÇATAK Programinin Uygulandığ İl ve Üretici Sayısl Kaynak: Anonim, $2016 b$.

ÇATAK programı kapsamında üretici sayısı ve il sayısındaki artışa bağlı olarak uygulama alanında hızlı bir şekilde artmıştır. 2006 yllında 4 ilde toplam 1.726 ha alanda başlamış olan program, 2009 yilında 4.752 ha alana, 2014 yllında 50.559 ha alana ve 2015 y1lında 77.847 ha alana ulaşmıştır. Uygulamayı yapan ve hibe sözleşmesi imzalayan çiftçilere 2006 yılında yaklaşık 1,43 milyon TL destekleme ödemesi, 2009 yılında 5,06 milyon TL, 2014 yllında 52,89 milyon TL ve 2015 yilında 81,20 milyon TL destekleme ödemesi yapılmıştır. ÇATAK programının uygulamaya başladığı 2006-2015 yılları arasında üreticilere yapılan destekleme tutarı toplam 232.559.062 TL'ye ulaşmıştır (Tablo 2).

ÇATAK destekleri, diğer destekleme ödemelerinden farklı şekilde yürütülmekte olup Gıda Tarım ve Hayvancılık Bakanlığı tarafindan illere tahsis edilen uygulama alanı çerçevesinde yürütülmektedir. Bu nedenle başvuran üreticilerin, tüm işletmesinin desteklenmesinden ziyade, ÇATAK uygulama birimi tarafindan uygun görülen hassas alanlarda yer alan ve desteklenmesi uygun görülen tarım arazileri desteklenmektedir. Bu çerçevede çiftçi başına ÇATAK kapsamında desteklenen ortalama alan 2006 yılında 36,80 da, 2015 yılında ise 34,40 da olarak gerçekleşmiştir. Çiftçi başına ortalama destekleme alanı programın başladığı ilk yılda, en düşük alan ise 25,26 da ile 2009 yılında yaşanmıştır (Şekil 3).

\begin{tabular}{|c|c|c|}
\hline$Y_{l} l$ & Uygulama Alanı (ha) & Destekleme Ödemesi Miktarl (TL) \\
\hline 2006 & 1.726 & 1.434 .000 \\
\hline 2007 & 4.041 & 2.605 .000 \\
\hline 2008 & 4.063 & 4.630 .000 \\
\hline 2009 & 4.752 & 5.061 .922 \\
\hline 2010 & 8.808 & 10.347 .256 \\
\hline 2011 & 14.414 & 16.128 .359 \\
\hline 2012 & 21.804 & 23.182 .680 \\
\hline 2013 & 33.172 & 35.084 .038 \\
\hline 2014 & 50.559 & 52.890 .491 \\
\hline 2015 & 77.847 & 81.195 .316 \\
\hline & TOPLAM & 232.559 .062 \\
\hline
\end{tabular}

Tablo 2. ÇATAK Programinın Uygulama Alanı ve Ödeme Miktarı Kaynak: Anonim, $2016 b$. 
Uygulama sonuçlarına incelendiğinde çiftçi başına ortalama destekleme tutarının yıllar itibariyle değişkenlik gösterdiği görülmektedir. Çiftçi başına en yüksek ortalama destek tutarı 2013 yılında 3.816 TL olarak gerçekleşmiştir. En düşük ortalama destek ise 2007 yılında 1.727 TL olarak gerçekleşmiştir. 2015 yılı itibariyle çiftçi başına ortalama destek 3.588 TL'dir (Şekil 3).

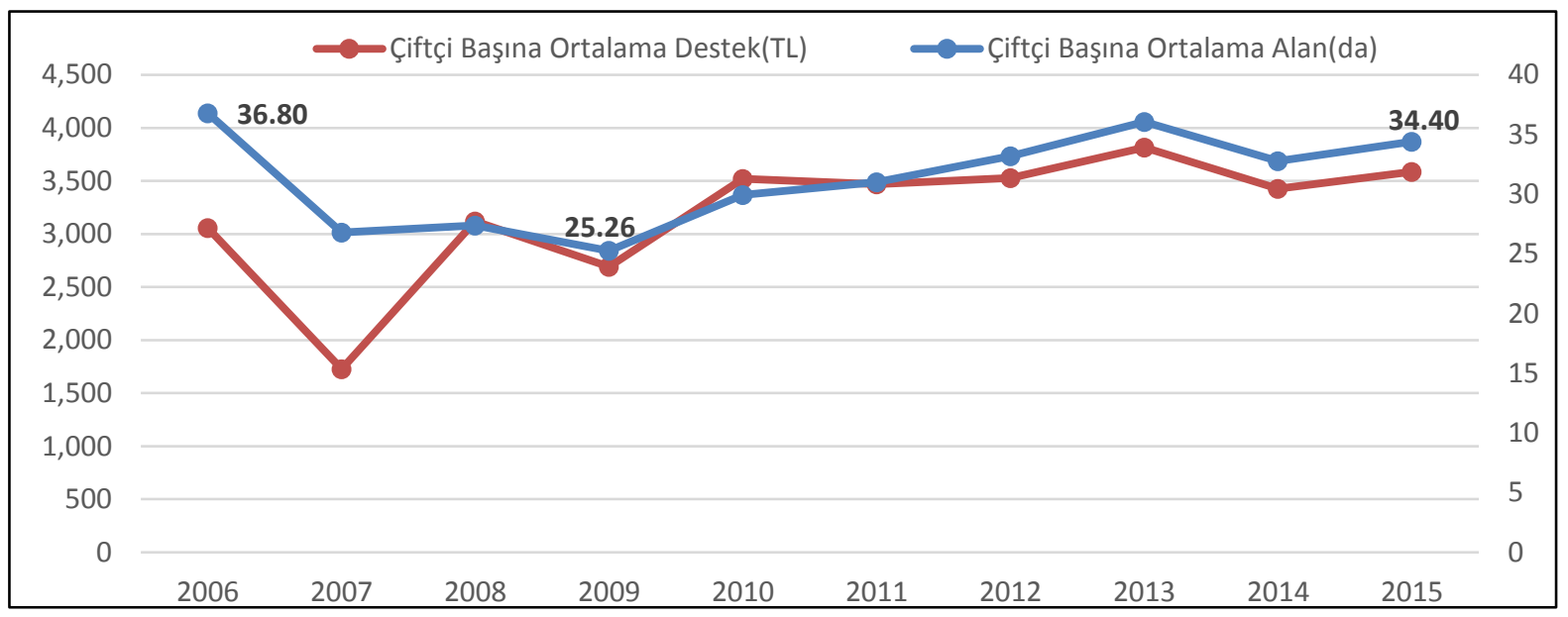

Şekil 3. Uygulama Sonuçlarına Göre Çiftçi Başına Ortalama Alan ve Destekleme Miktarı

ÇATAK kategorilerinin farklı miktarlarda desteklenmesi, uygulama sonuçlarını da etkilemektedir. Uygulama sonuçlarına göre en fazla destekleme üçüncü kategori üzerinden yapılmıştır. 2013-2015 yılları arasında üretici sayısına göre birinci kategori \%2, ikinci kategori \%39 ve üçüncü kategori \%59'dur. Uygulama alanına göre de birinci kategori \%3, ikinci kategori \%37 ve üçüncü kategori \%60’dır (Şekil 4).

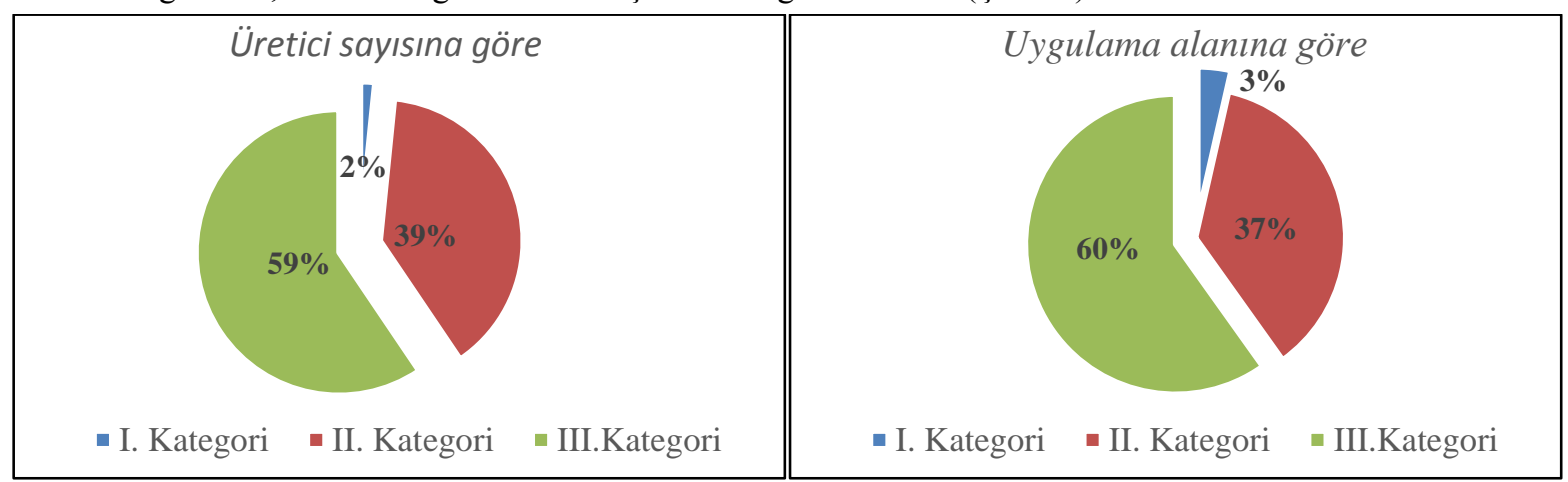

Şekil 4. 2013-2015 Yılları Arasında Uygulama Kategorilerine Göre ÇATAK Destekleri Kaynak: Anonim, $2016 b$.

\section{Sonuç}

Üretimini artırmaya odaklanan politikaların uygulandı̆̆ı yirminci yüzyıl tarım sisteminin öncelik ve hedeflerinde değişikliğe gidilmesine ihtiyaç bulunmaktadır. Ancak bu öncelik ve hedeflerin değişmesini sağlayacak sistemin ana unsuru ve karar vericisi olan çiftçilerin, bu yeni hedefleri benimsemesi hiçte kolay olmamaktadır. Bir yandan çevre kirliliğini önlemek, diğer yandan tarım topraklarının verimliliğini koruyarak, bitkisel ve hayvansal ürünler elde etme çabaları dünya devletlerinin tarım politikalarında zorunlu değişimler yaşanmasına neden olmaktadır.

İktisadi bir faaliyetin icrasını içeren ve çiftçilerin geçim kaynağı olan tarım sektörünün, ekonomik açıdan karlı ve verimli aynı zamanda sosyal açıdan yaşanabilir olması gerekmektedir. Çiftçilerin üretim süreçlerinde kimyasalları kullanmamaları, doğal kaynakları korumaları ve geliştirmeleri gibi çevreci yaklaşımlarda bulunarak kısa dönemde kar etmeyi istemek yerine, uzun dönemde sürdürülebilirliği hedeflemeleri için mevcut üretim yöntemlerinde değişikliğe gitmeleri gerekmektedir. Bu değişiklikler ise mevcut gelir düzeylerinde düşüşlere neden olabilmekte, bu durum çevre dostu tarım uygulamalarının benimseme sürecini uzatabilmektedir. Çiftçilerde çevreyi korumak amacıyla istenilen bu davranış değişikliğini sağlayacak en önemli araçlardan biri de tarımsal desteklerdir. Bu doğrultuda ÇATAK, Türkiye'de tarım çevre ilişkileri açısından önemli bir araçtır.

Programın uygulama sonuçları çiftçilerin birim alandan daha yüksek destekleme aldıkları üçüncü kategoriye yöneldiğini göstermektedir. Program amaçlarına bakıldığında toprak ve su kaynaklarının korunmasına yönelik spesifik tedbirleri içeren ikinci kategori ile koruyucu toprak işlemeyi destekleyen birinci kategoriye olan başvurunun oransal olarak daha düşük kaldığı görülmektedir. Bu çerçevede, 2016 yılında ÇATAK Uygulama Tebliği'nde yapılan değişiklik ile üçüncü kategori desteklerinden yararlanan üreticilere, diğer kategorilerden de 
bir uygulama yapma seçeneğinin getirilmesinin olumlu sonuçlar doğuracaktır. Tarımsal destekleme araçlarını düzenleyen 5488 sayılı Tarım Kanunu'nda birçok destekleme araçları bulunmaktadır. Bu destekler içerisinde yer alan ÇATAK programı, fark ödemesi desteği, telafi edici ödemeler veya tarım sigortaları desteklerinden farklı amaçlara sahiptir. ÇATAK destekleri, çiftçilere gelir transferi veya sübvansiyondan ziyade çevre amaçlı uygulamaları yaygınlaştırmak ve benimsetmek üzere çiftçilerde bir davranış değişikliği oluşturma amacındadır. $\mathrm{Bu}$ nedenle, desteklerin yanında çiftçilerin benimseme sürecini hızlandıracak eğitim ve yayım çalışmalarına ihtiyaç duyulmaktadır. Çiftçilerin sorunlarını doğru tespit ederek, tarımsal faaliyetlerinin çevre üzerindeki etkileri azaltmayı sağlayacak doğru tedbirlerin seçimi konusunda eğitim ve yayım çalışmalarına önem verilmelidir.

\section{Kaynakça}

- Anonim, 2004. Tarım Stratejisi Belgesi. 30 Kasım 2004 tarih ve 2004/92 Sayılı Yüksek Planlama Kurulu Kararı. Ankara.

- Anonim. 2005a. II. Tarım Şurası Sonuç Raporu. Tarım ve Köyişleri Bakanlığı. Ankara.

- Anonim, 2005b Çevre Amaçlı Tarımsal Arazilerin Korunması Programını Tercih Eden Üreticilerin Desteklenmesine Dair 2005/9230 sayılı Bakanlar Kurulu Kararı. 31 Ağustos 2005 tarihli ve 25922 sayılı T.C. Resmi Gazete

- Anonim, 2006. 5488 Sayılı Tarım Kanunu. 25 Nisan 2006 tarihli ve 26148 sayılı T.C. Resmi Gazete

- Anonim, 2008.Çevre Amaçlı Tarımsal Arazilerin Korunması Programını Tercih Eden Üreticilerin Desteklenmesine İlişkin Karar. 14 Kasım 2008 tarihli ve 27054 sayılı T.C. Resmi Gazete

- Anonim, 2010a. Organik Tarımın Esasları ve Uygulanmasına İlişkin Yönetmelik. 18 Ağustos 2010 tarihli ve 27676 sayılı T.C. Resmi Gazete.

- Anonim, 2010b. İyi Tarım Uygulamaları Hakkında Yönetmelik. 7 Aralık 2010 tarihli ve 27778 sayılı T.C. Resmi Gazete.

- Anonim, 2014. Onuncu Kalkınma Planı, Bitkisel Üretim Özel İhtisas Komisyonu Raporu, Kalkınma Bakanlığg, Ankara.

- Anonim, 2016a. Çevre Amaçlı Tarım Arazilerini Koruma Programını Tercih Eden Üreticilerin Desteklenmesine Dair Kararın Uygulanmasına İlişkin 2006/9 Sayılı Uygulama Tebliği. 1 Mart 2016 tarihli ve 29670 say1lı T.C. Resmi Gazete.

- Anonim, 2016b. Bitkisel Üretim Verileri. Gıda Tarım ve Hayvancılık Bakanlığı Bitkisel Üretim Genel Müdürlüğü. www. tarim.gov.tr. Erişim tarihi: 25.05.2016

- Erten, S., 2004. Çevre Eğitimi ve Çevre Bilinci Nedir, Çevre Eğitimi Nasıl Olmalıdır. Çevre ve İnsan Dergisi, Çevre ve Orman Bakanlığ 1 Yayın Organı. Sayı 65/66. 2006/25 Ankara

- FAO, 2015. Statistical Pocketbook 2015, World Food and Agriculture. Food and Agriculture Organızatıon of the United Nations, Rome 2015.

- Hasdemir, M., Hasdemir, M., 2012. Çevre Amaçlı Tarım Arazilerini Koruma Programı ve Bu Programı Uygulamada Görevli Personellerin Çevre Duyarlılıkları. Türkiye 10. Ulusal Tarım Ekonomisi Kongresi Bildiriler Kitab1, 2, 0, s. 1276- 1283.

- Talas, M. ve Karataş, A., 2012. Çevre Bilincinin Geliştirilmesinde Topluma Hizmet Uygulamaları Dersinin Önemi: Niğde Üniversitesi Sınıf Öğretmenliği Programı Örneği” Journal of World of Turks.. ZfWT Vol. 4, No. 1 


\title{
Geri Dönüşümün Ekonomi Üzerine Etkileri, İnşaat Sektöründe Atık Lastik Kullanımı Örneği \\ The Effects of Recyling on Economy: The Case of Usage of Scrapped Tires in Construction Industry
}

\author{
Ph.D. Candidate Hümeyra Tosun (Aksaray University, Turkey) \\ Asst. Prof. Dr. Fatih Kürşat Fırat (Aksaray University, Turkey)
}

\begin{abstract}
Today, rapidly industrialization and an accompanying increase of the world population cause diminishing of the limited amount of natural resources. The purpose of this study is to examine the recycling applications in the construction industry and to investigate the contribution of scrapped tires to construction industry and national economy. The construction industry is one of the fields that has the largest raw material consumption. Due to the high demand for the construction materials recycling is often employed and provide a significant economic contribution. Today, scrapped tires both exist abundantly and are currently worthless wastes. This wastes not only pollute the environment but also cause negative effects on the human healthy. Because of this reason, old tires are either reduced to certain dimension or melted in the recycling plants. The new products that therefore emerges is added in to the hot mix asphalt and then used in highway constructions, which are a significant capital expenditure for the national economy. As a result of this study, it is reveal that recycling in the construction industry has very significant positive contribution to natural environment and the existing recycling resources are not well-utilized. Moreover, the applications that have been done so far provided significant contributions to the national economy. Consequently, recycling studies should be speeded up and governmental supports should be put into practice.
\end{abstract}

\section{Giriş}

Nüfus yoğunluğunun gün geçtikçe artıyor olması kaynaklar açısından değerlendirildiğinde ciddi anlamda yetersizlik söz konusu olmaktadır. Yaşam için gerekli olan herşeyin üretime için bir kaynağın var olması gerekliliği kaynakların azalmasına ve hatta bazılarının yok olmasına sebebiyet vermektedir. Bu esnada devreye girebilecek en güçlü yöntem olan geridönüşüm faktörü her alanda cankurtaran vazifesi üstlenmektedir. Sınırlı olarak nitelendirilen kaynakları tam ve etkili bir biçimde kullanmak ülke ve hatta dünya ekonomisi içerisinde en önemli unsur halini almıştır.

Çevre, insanların ve diğer canlıların yaşamları boyunca ilişkilerinin sürdürüldüğü mutualist olarak etkileşim içerisinde bulundukları bir ortamdır. Zamanla bu etkileşim insanlar için bir yıkım ortaya çıkarmakta ve bu yıkımı onarma görevi sosyal bir varlık olan insana düşmektedir (Fırat ve Soyu, 2014). Çevre ve şehircilik bakanlığının atık yönetimi yönetmeliğine göre hedef;

a) İnsan sağlı̆̆ını olumsuz yönde etkileyen atıkların bu zararı en aza indirgeyecek şekilde uzaklaştırılması,

b) Atıkların geri dönüşüm ve geri kazanımla değerlendirilerek uygulanabilir bir atık yönetimi sistemi oluşturulması,

c) Sağlı̆̆ olumsuz etkilemeyecek şekilde, oluşturulan bu yönetmelik çerçevesinde ürünlerin dikkatli bir şekilde piyasaya sunulup denetlenmesi'dir (Atık Yönetimi Yönetmeliği, 2015).

$\mathrm{Bu}$ amaçları nitelendiren bir örnek olan atık lastiklerin yol inşaatında kullanımı ekonomik açıdan ciddi ölçüde katkı sağlamaktadır. Yol yapımında kullanılan temel madde olan bitü, “doğal kökenli hidrokarbonların bir karışımı veya pirojenik kökenli hidrokarbonların karışımı yada bunların her ikisinin bir kombinasyonu olup çok defa bunların gazı sıvı, yarı katı ve katı olabilen, metal-dışı türevleri ile bir arada bulunan, yapıştırıcı özellikleri olan ve karbon disülfürde tamamen çözünen madde" olarak tanımlanır (Orhan, 2012).

Büyümeye bağlı olarak güvenilir, konforlu ve uzun ömürlü yolların yapılması talebi standartı yüksek yol yapımı adımını başlatmış ve günümüzde kullanılan Bitümlü Sıcak Karışım (BSK) kaplamalı yolları oluşturmuştur. Yol kaplamasının daha uzun ömürlü olabilmesi için bitümün içerisine çeşitli katkı maddeleri ilave edilmektedir. Modifiye bitüm olarak isimlendirilen bu işleme piyasada bulunan birçok katkı maddesi ilave edilmiş fakat bazılarından olumlu sonuçlar alınırken bazılarından da alınamamıştır. Bu olumlu sonuç alınan katkılardan biri, parçalanılarak belirli bir granülometreye getirilip bitümün içerisine ilave edilen atık lastiklerdir (Deniz ve Sönmez, 2005). Günümüz dünyasında bir çöp niteliği taşıyan bu lastiklerin kullanımı geri dönüşüm mekanizmasının en canlı örneklerinden biri olup, ülke ekonomisinin farkedilebilir bir oranda katkı sağlamaktadır. 


\section{Geri Dönüşüm}

İnsanlar tarafından tüketilen maddelerin sonucu olarak ortaya çıkan atıkların çeşitli fiziksel ve kimyasal işlemlerle yeni bir hammaddeye dönüştürülüp yeniden üretim için kullanılması işlemi geri dönüşüm olarak açıklanmaktadır. Başka bir deyişle kullanılmış ve faydalılığını yitirerek çöp niteliğine erişmiş maddelerin çeşitli yöntemlerle yeni bir madde ortaya çıkarıp faydalı fonksiyon yüklenmiş hale getirilmesi de geri dönüşüm olarak isimlendirilmiştir.

Ekonomik zorluklarla yüzyüze gelen ve kalkınma döngüsü durumu içinde olan ülkelerin kaynaklardan uzun sürede ve maksimum etki kapsamında yararlanabilmeleri için çöp niteliği taşıyan atık madde israfını engellemeleri, ekonomik açıdan araştırıp analiz ederek kullanım sahalarını bulmaları gerekmektedir. Ülkemizde de hızla artan nüfus artışıla birlikte atık miktarı ve ayrıca ambalajlı ürün kullanımı da fazlalaşmış böylece geri kazanım ekonomik açıdan etkili bir değer haline gelmiştir (Gurer vd, 2004).Yine Çevre ve Şehircilik Bakanlığının Atık yönetimine ilişkin genel ilkeler şunlardır:

a) Üretilmiş atıkların tehlike durumunu göz önünde bulundurarak;

1) Daha sağlıklı ve temiz alternatifler oluşturarak doğal kaynakların tahribatını en aza indirgemek,

2) Ürünleri, doğa tahribatını ve insan sağlı̆̆ını minimum etkileyecek şekilde tasarlamak ve piyasaya sunmak,

3) Yeniden kullanıma endeksli yeni tasarımlar ile zararlı etkileri en aza indirgemek hedeflenmiştir.

b) Atık madde üretiminin engellenemez olduğu yerlerde ise atık maddelerden ikincil ham madde üretimi esaslı çalışmalar yaparak geri kazanım sağlamak amaçlanmıştır..

c) Öncesinde yapılan geri dönüşüm çalışmaları örnek gösterilerek toplumda geri dönüşümün faydalılığ 1 bilincini benimsetmek hedeflenmiştir,

d) ç) Atık maddelerin işlenmesi ve taşınması esnasında doğal ortama ve insanlığa hasar oluşturmayacak teknikler kullanmak amaç edinilmiştir (Çevre ve Şehircilik Bakanlığı, 2015).

Geri dönüşülebilecek olarak belirlenen atık maddeler ilk olarak kaynağından düzgün bir şekilde çıkartılıp ürün geri alımı aşamasında ürünlerin kullanılabilir parçaları alınmaktadır. Ürünlerin bileşimini oluşturan parçalar gruplandırılarak atık maddeler arasında materyale göre (cam, kağıt, alüminyum, plastik, piller, motor yağı, akümülatörler, beton, organik atıklar ve elektronik atıklar) değerlendirme yapılmaktadır. Geri kazanılan bu gruplandırma yapılan ürünlerde, geri dönüştürülecek malzemeler çeşitli tekniklerle değiştirilerek (kimyasal veya fiziksel) yeni bir ürün oluşturulmaktadır. Bu sayede geri dönüştürülen atık maddeler tekrardan faydalı hale getirilerek ekonomik olarak değerli duruma getirilmektedir (Guide vd, 1999).

Yapılan araştırmalardan elde edilen neticelere göre, katı atıklar ciddi manada birer sorun niteliği taşımaktadır ve çözüm için iyi bir yönetim planının oluşturulması gerekmektedir. Bunun için de ilk olarak bu konudaki mevcut yasal düzenlemelerin daha düzgün bir şekilde uygulanması şarttır. Bunun yolu da topluma farkındalık bilincinin işlenmesinden geçmektedir (Coşkun ve Öztürk, 2012).

Bazı ülkelerin örnek geri dönüşüm politikalarına bakacak olursak;

- İngiltere'de 1992 y1lı Mart ayında yayımlanan "Integrated Solid Waste Management Business Plan" (Birleşik Katı Atık Yönetimi İş Planı) ile evsel atıkların 2000 yılına kadar \% 50 lik kısmının geri kazanımı amaçlanmıştır.

- Almanya' da 1991' de Ambalaj Atıklarının Önlenmesi Tüzüğü yürürlüğge sokularak atıkların doğaya zararını en aza indirgemek hedeflenmiştir.

- Hollanda' da bazı atık kategorilerinde, yeniden işleme oranları çok yüksektir. Örneğin, 1985 yılında, tüketilen kağıdın \%50'si, demir ve çeliğin \%56'sı, alüminyumun \% 54'ü geri dönüştürülmüştür. Camın da tekrardan kullanımı oranı oldukça yüksektir. Yakma yöntemi ile bu rakamlar aşağılara düşebileceği gibi, geri kazanımın henüz yeni başlama seviyelerinde olduğu plastik gibi malzemelerde, geri kazanım çabalarının tamamen durmasına da yol açabilir (Diaz ve Gouleke, 1986).

- Türkiye' de katı atıklarla ilgili ilk kanuni yönetmelik 1991 yılında Çevre Bakanlığı tarafından çıkarılmıştır. Bu yönetmelik içecek ve temizleme maddelerinin plastik ve metal kökenli ambalajlarının geri kazanılmasını gerektirmektedir. Yönetmelikte belirlenen ilk hedef plastiklerin \%25' inin, metal kökenli ambalajların \% 15 , inin geri kazanılmasıdır. Bu ambalajları üreten ve kullanan firmalar örgütlenerek ÇEVKO Vakfını kurmuşlardır (Katı Atıkların Kontrolü Yönetmeliği, 1991).

Atık Yönetimi, tehlikeli ve tehlikesiz tüm atık maddelerin en aza indirgenmesi ve zararlı etkilerinden dolayı ortamdan uzaklaştırılmasını çeşitli aşamalarla işleyen bir yönetimdir. Doğal kaynakların korunmasının yanısıra ve kaynakların verimliliği açısından geri dönüşüme çok fazla değer yüklenmiştir. Buna ilaveten ciddi oranlarda enerji tasarrufu da yine geri dönüşümle olmaktadır. Bütün bu işlemlerin eksizsiz bir şekilde uygulanmasıyla hem ekonomik katkı hem de doğa tahribatını engelleyici bir çözüm oluşturulmaktadır. Geri dönüşüm vasıtasıyla maliyetler azalacak ve bu sayede fiyatlar da bu durumdan olumlu yönde etkilenecektir. Bu durum aynı zamanda toplumsal bir sorun haline gelmiş çevre kirliliğinin azaltarak insanlık için daha temiz, huzurlu bir ortam imkanı sağlayacaktır. En nihayetinde hem şu anki hem de gelecekteki insanlığa sınırlı olan kaynaklardan daha fazla 
kullanım yüzdesi sağlayarak daha huzurlu rahat bir yaşam imkanı sunacaktır. Tablo 1'de alüminyum, bakır, demirçelik, kurşun, çinko, kağıt ve plastiğin geri kazanımın sağlamış olduğu enerji tasarrufu oranları görülmektedir. Buna göre alüminyum \% 95 ile en yüksek enerji tasarrufu, çinko ise \% 60 ile en düşük enerji tasarrufu sağlayan malzeme olarak gösterilmektedir (Furat ve Akbaş, 2015).

\begin{tabular}{|c|c|}
\hline Metal/Malzeme & Enerji Tasarrufu \\
\hline Alüminyum & 95 \\
\hline Bakır & 85 \\
\hline Demir-Çelik & 74 \\
\hline Kurşun & 65 \\
\hline Çinko & 60 \\
\hline Kağıt & 64 \\
\hline Plastik & $>80$ \\
\hline
\end{tabular}

Tablo 1: Birincil Kaynaklara Kıyasla Geri Kazanımın Sağladı̆̆ı Enerji Tasarrufu Kaynak (Fırat ve Akbaş, 2015).

\section{Atık Lastiklerin Geri Dönüștürülmesi}

Yaşanılabilir bir çevre ve kaynakların korunduğu bir dünya oluşturabilmek için, birçok atık malzemenin yanısıra atık lastik malzemenin de ülke ekonomisine sağladığı katkıdan dolayı geri kazanımı çok önem taşımaktadır. Bu malzemelerin kullanılabilir hale getirilebilmesi için çeşitli işlemlerden geçerek yeni kullanım içim hazır hale gelmesi gerekmektedir. Atık lastiklerin kullanılma alanlarının bütünleştiği malzeme uyumuyla ilişkisine göre çeşitli deneylerle veya gözlemlerle incelenip belirlenmesi gerekmektedir (Vatan, 2002).

Çevre açısından oldukça dayanıklı yüksek molekül yapılı polimer bağlarla bağlanmış kauçuklardan üretilmiş olan lastikler, kullanım ömürlerini tamamladıktan sonra çevrede zor ortadan kalkacak atıklar oluşturmaktadır (Gönüllü, 2004).Türkiye de ömrünü tamamlamış lastiklerin kontrol yönetmeliğine göre amaç;

a) Atık maddelerin doğaya vermiş olduğu tahribatı önlemek için doğrudan yada işlemlerden geçerek ortama birakılmasının engellenmesi,

b) Ömrünü tamamlamış lastiklerin atık maddelerin yeniden kullanılması için gerekli tüm düzenlemelerin ve tasarım tekniklerinin oluşturulması,

c) İthalat ve ihracat ile ilgili tüm idari hususların tespit edilmesidir (Resmi Gazete, 2006).

Günümüzde oldukça fazla sayıda otomobil lastiği üretilmektedir. Bu da eskimiş lastiklerin ne olacağı konusunu düşündürmeye başlatmış ve insan ve doğa için tehlike niteliği taşıyan bu atıkların geri kazanım yöntemlerini araştırmak için bir sebep oluşturmuştur.

Eski lastikler, yakıldığında oluşturduğu yüksek enerji çıktısından dolayı yakılabilir yada ham maddesi olan kauçukları yeniden kullanabilmek için kimyasal işlemlerden geçirilebilir; ama lastiğin içinde yer alan çelik ve diğer bileşenler bu durumun oldukça fazla maliyetli olmasına sebebiyet vermektedir. Ölçümlere göre atık lastiklerin $28,000 \mathrm{~kJ} / \mathrm{kg}$ ile $35,000 \mathrm{~kJ} / \mathrm{kg}$ arasında bir 1 sıl değere sahip olduğu bilinmektedir. Uygun ortamda ve tekniklerle, atık lastiklerin yakılarak, 1sı enerjisi elde edilmesi gereken yerlerde kullanılabilmektedir (Sugözü ve Mutlu, 2009). Lastiklerin yakılması sonucu atmosfere fazlasıyla zararlı bileşikler salınmaktadır. Atmosfere salınan bu bileşenler; karbon siyahı ve oksitleri, uçucu ve yarı uçucu organikler, çok halkalı hidrokarbonlar, yağlar, kükürt oksitleri, nitrosaminler, uçucu küller ve $\mathrm{As}, \mathrm{Cd}, \mathrm{Cr}, \mathrm{Pb}, \mathrm{Zn}, \mathrm{Fe}$ ve diğerleridir. Çeşitli doğal afetler ve yangınlar ile atmosfere salınan bu gazlar ve maddeler su ve toprağın kirlenmesine sebebiyet vererek insan sağlığını olumsuz yönde etkilemektedir (Çevre ve Şehircilik Bakanlığı, 2012). Bu durumda ülkeler tarafından daha duyarlı davranma ve yapıcı çözümler ortaya çıkarma zorunluluğu ortaya çıkmaktadır. Türkiye'de de tehlikeli atık geri kazanımını/bertarafını yapan tesislerin lisans alması zorunlu hale getirilmiştir. 


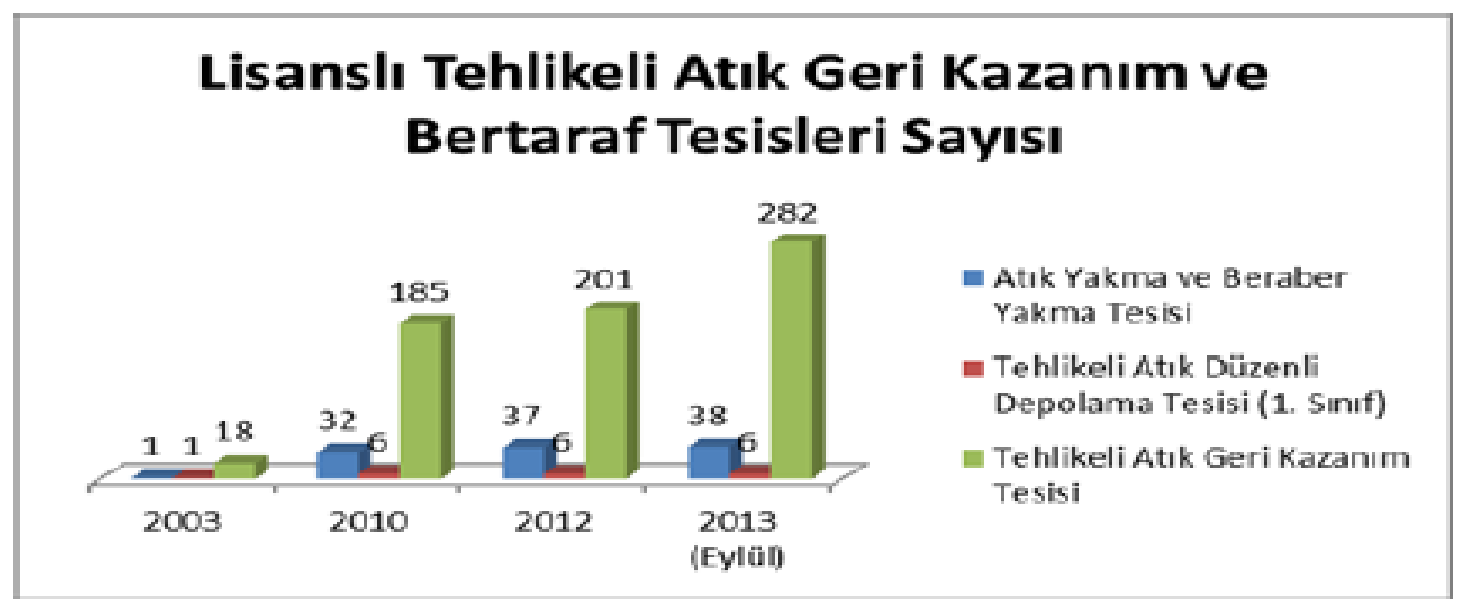

Şekil 1: Yıllara Göre Tehlikeli Atık Lisansı Alan Tesis Sayılarının Dă̆ıllımı Kaynak: Çevre ve Şehircilik Bakanlı̆̆ (ÇSB), 2013

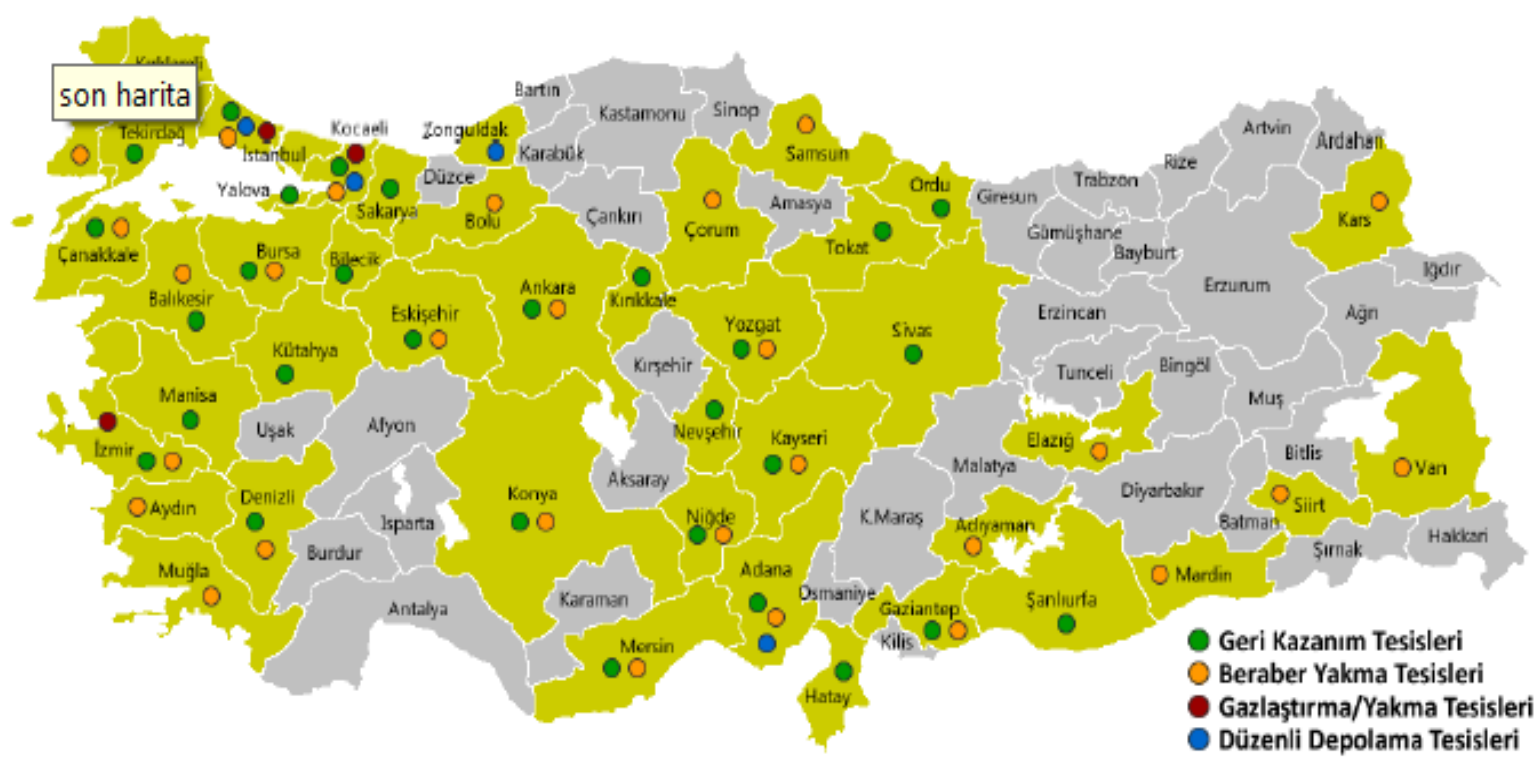

Şekil 2: 2010 Yllı Lisanslı Geri Kazanım/Bertaraf Tesislerinin Dağılımı Kaynak: Çevre ve Şehircilik Bakanlı̆̆ı (ÇSB), 2012-

Lastik Sanayicileri Derneğiecnin 2010 yılında elde ettiği verilere göre Türkiye"de yıllık yaklaşı olarak 180,000 ton ömrünü tamamlamış lastik oluşmaktadır ve yönetmeliğe göre ömrünü tamamlamış atık lastiklerin; doğayı tahrip edecek bir biçimde bırakılmasının engellenmesi ve çeşitli geri dönüşüm yöntemlerinin oluşturulması amaçlanmıştır. Ayrıca yönetmeliğe göre her yıl üretilen belli sayıda lastik, üreticileri tarafından toplanmalıdır ve toplanan ömrünü tamamlamış lastiklerin akıbeti hakkında bilgi taahhütünde bulunulmalıdır (Karabörk ve Akdemir, 2011).

Türkiye'de mevcut 35-40 milyon ton dolaylarında lastik üretim alanı bulunmakta ve lastik üretiminde kullanılan hammaddelerin tamamı ithal edilmektedir. Ögütülmüş taşıt lastikler malzeme geri kazanımı ve enerji geri kazanımı olarak kullanılmaktadır. Ömrünü tamamlamış lastiklerin malzeme olarak geri kazanımında kimyasal olarak "piroliz" işlemi kullanılmaktadır. Piroliz işlemine göre; atık lastikler öğütülerek içindeki bileşenler (pirolitik yağ ve gazlar, is karası, çelik tel) ortaya çıkmaktadır. Bu bileşenlerden pirolitik yağlar yakıt olarak direkt olarak elektrik üretimde kullanılmaktadır. Bu işlemin diğer bileşeni olan is karası kauçuk bazlı ürünler için hammadde olarak kullanılmaktadır. Pirolitik gazlar ise gaz olması dolayısıyla yanıcı özelliğe sahip olmasıyla enerji verici olarak kullanılabilmektedir.

Atık taşıt lastikleri aynı zamanda öğütüldükten sonra atık lastiklerin boyutları daha da minimize edilerek parça, granül, toz üretilmektedir. Bu üretilen malzemeler; çim sahalarda döşeme, yol inşaatında kaplama ve çeşitli oyun okul sahalarında vb yerlerde kullanılabilmektedir (LASDER, 2012). 
Türkiye'de her yıl yaklaşık 200.000 ton ömrünü tamamlamış lastik ortaya çıkmaktadır. Bir lastiğin geri dönüşüme gönderilmesiyle kullanılabilecek fazla rakamlarda ürün elde edilebilir. $\mathrm{Bu} 200.000$ ton ömrünü tamamlamış lastiğin geri kazanımı sonucunda yaklaşık olarak 146.000 ton kauçuk granülü ve 38.000 ton çelik geri kazanılmaktadır. 200.000 ton ömrünü tamamlamış lastiğin piroliz işlemi sonucunda; yaklaşık 80.000.000 litre pirolitik yağ, 60.000 ton karbon siyahı ve 30.000 ton pirolitik gaz geri kazanılmaktadır (ÇŞB, 2012-3).

Avrupa Birliği kullanılmış lastik yönetiminde aşağıdaki tavsiyelerde bulunmuştur

- 2000 senesinde kullanılmış lastiklerin yaklaşık \% 100“ë toplanmalı

- 2000 senesinde kullanılmış lastiklerin tonca ağırlığının minimum \%25 $\%$ i tekrar kaplanmalı

- 2000 senesinde kullanılmış lastiklerin tonca ağırlı̆̆ının minimum \%65 i geri kazanılmalı

- 2000 senesinin sonunda enerji geri kazanımı olmadan atık lastik yakmaya ve düzenli depolamaya götürmeye son verilmeli (European Commission (EC), 1993).

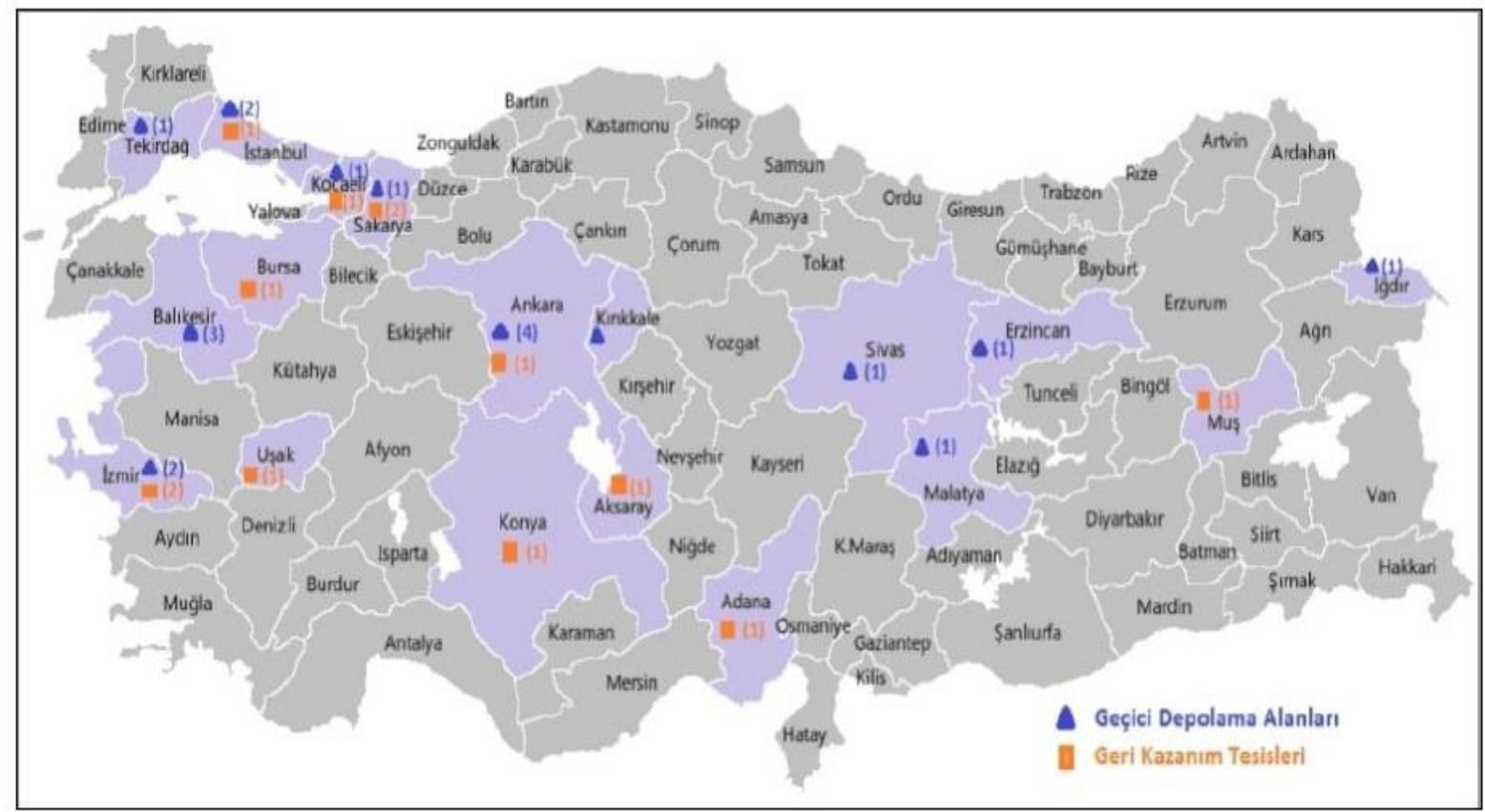

Şekil 3: Lisanslı ÖTL Geri Kazanım Tesisleri ve Geçici Depolama Alanları Kaynak: Çevre ve Şehircilik Bakanliğl (ÇŞB), 2012-1

Granül kauçuğun dane boyutları $0.85 \mathrm{~mm}$ ile $9.5 \mathrm{~mm}$ arasında olmaktadır. Bunun yanında, uygulanacağı yere göre boyut küçültme yapılabilir. Granül lastik üretimi, granül makinesi yada öğütme değirmeni makineleriyle yapılmaktadır. Granül makinesi, öğütme değirmenine göre daha düzgün şekilli ve küçük yüzey alanına sahip parçacıklar üretmektedir ve manyetik ayırıcılar yardımıyla, çelik teller granül lastik içerisinden ayrıştırılmaktadır. Ayrıca granül lastik parçaları içerisindeki cam fiberler hava püskürten ayırıcılar yardımıyla toplanmaktadır. Granül lastik parçaları, çift çevrimli manyetik ayırmaya maruz bırakıldıktan sonra, çeşitli boyutlarda sınıflandırılmış şekilde belirli ağırlıklarda hizmet için piyasaya sürülmektedir (Yeşilata vd, 2007).

\section{Atık Lastiklerin Yol Üstyapısına ve Ekonomiye Olan Katkısı}

Karayolu üstyapı kaplamaları yolun diğer tabakalarına oranla maliyetin çok büyük bir kısmını oluşturmaktadır. Ayrıca üstyapı kaplamalarının performansı tabakada uygun bitüm sınıfının kullanılmasına bağlıdır. Daha önce de tanımından bahsedildiği üzere ham petrolün damıtılması sonucu arta kalan yüksek kaynama noktalı hidrokarbonlardan oluşan bitüm, kalitesiyle yol kalitesi arasında doğru orantılı bir ilişki mevcuttur. Nitekim kaplama tabakalarında yüksek sıcaklık ve ağır trafik yükü etkisi altında tekerlek izinde oturma ve kusma, ortalama sıcaklıkta yorulma çatlağı, düşük sıcaklıklarda ise termal bir çatlama şeklinde, üstyapıların performansını en fazla etkileyen ve oldukça sık görülen bozulmaların oluşmasında bitümlü bağlayıcıların özellikleri en temel olarak belirlenen sebeplerdendir. Bitümün özelliklerinin tekerlek izinde oturma üzerindeki etkisi \%40, yorulma çatlağ oluşumu üzerindeki etkisi \%60, termal çatlak oluşumu üzerindeki etkisi ise \%90 gibi yüksek bir oranda görülmektedir (Dinç ve Yazıcı, 2000). Netice olarak karayolu üstyapılarının mevcut iklim ve trafik koşullarına göre performansı, yani en az bakım ve onarım maliyetleri ile en uzun vadede ve konforlu bir şekilde hizmet verebilme kabiliyetleri, önemli derecede bu koşullara uygun sınıfta bitümün kullanılmasına bağlı olmaktadır.

Yol kaplamasında görülen bozulmalar yorulmayla açıklanmıştır. Kaplama tabakası farklı şiddet ve frekanslarla tekrarlanan tekerlek yükleri etkisi altında kalmaktadırlar. Yorulma, bir malzemenin tekrarlı yükler altında, statik dayanımının altındaki zorlamalarda süregelen hasara uğraması olarak açıklanmaktadır. Kırılma çoğunlukla çekme 
gerilmesinin en yüksek olduğu kaplama tabakasının tabanından başlayarak yukarıya doğru ilerler. Tekrarlı yüklerin etkisiyle oluşan yorulma, yükleme özellikleri, iklim şartları, çevre etkileri, karışım özellikleri vb birçok faktöre bağlıdır. Hveem (1955), kaplamadaki bozulmanın yorulma ile olabileceği hipotezini sunan ilk bilim adamlarından birisi olmuştur. Dünyada bitümlü karışımların yorulma davranışına etkisi üzerine fazlasıyla yapılmış çalışma bulunmaktadır (Çelik, 2001). Fakat öğütülmüş atık lastiklerle modifiye edilmiş bitümlerin yorulma davranışıyla olan ilişkisi üzerine ilk çalışma Esch (1982) tarafından yapılmıştır ve bitümlü karışım içerine öğütülmüş lastik parçacıkların ilavesi yapılmış olan çalışmasında, kaplamaların yorulma davranışının normal bitümlü karışımlara oranla on kat daha iyi olabileceğini belirtmiştir.

Bitüm cinsi yorulma süresinde fazlasıyla etki göstermektedir. Çelik (2000) tarafından yapılmış olan çalışmada kiriş numunelerinin yorulma sürelerinin tespiti için sabit basınç deneyi yöntemi kullanılmıştır ve asfalt betonunun yorulma davranışına öğütülmüş lastik parçacıklarıyla modifiye edilmiş bitümüm ile farklı bağlayıcı oranlarının (optimum bağlayıcı oranının \% 0,5 üstü ve \% 0,5 altı) etkisi incelenmiştir. Bitümün otomobil lastiği ile modifikasyonu, asfalt betonunun yorulma süresini ciddi oranlarda artırmış olduğu gözlemlenmiştir. \% 5 oranında az bir ögütülmüş lastik katkısı, 50 penetrasyon bitüm için yorulma süresini iki kat artırırken 100 penetrasyon bitümle yapılan modifikasyon sonucu yorulma süresini yirmi üç kat artırdığı sonucuna ulaşılmıştır (Çelik, 2001).

Atık lastiklerden öğütülmüş kauçuk, bitümlü bağlayıcıyı modifiye etmek için kullanılarak bağlayıcının viskositesini artırmış olur. Bu işlem asfalt çimentosuyla \%18-25oranlarında karıştırılarak gerçekleştirilir. Bu proses ıslak yöntem olarak adlandırılır ve $0,6 \mathrm{~mm}-0,15 \mathrm{~mm}$ arasındaki büyüklüklerdeki öğütülmüş kauçuk tanecikleri kullanılır (Epps,1994).Lastikle modifiye bitümlü bağlayıcılar olarak isimlendirilir. Asfalt kauçuk bağlayıcıları, sıcak asfalt karışımlı (HMA) kaplamalarda kullanılır. Yüzeysel kaplamalarda basınç yutucu membran (SAM), basınç yutucu membran ara tabakası (SAMI) olarak kullanılabilir. Araştırmalara göre öğütülmüş lastik parka katkılı kaplamaların normal asphalt beton kaplamalarına göre elastik özelliğinin daha fazla olduğu gözlenmiştir. Bu eklenen lastik parçalarının don kabarması sonucu oluşan çatlama riskini minimize ettiği sıcaklığın etkisiyle kaplamanın yumuşamasını ve genleşmeyi azaltarak kaplamaların bozulmasını engellediği görülmüştür (Çă̆lar, 2007).

\section{Sonuç}

Hükümet ve ilgili tüm kesimlerin geri dönüşüm politikasını içselleştirerek ulusal ve bölgesel inovasyon sistemlerine işlerlik kazandırarak doğru yaklaşımların belirlenip geri dönüşüm konusunda hızlı bir şekilde inovasyon çalışmalarının yapılması gerekmektedir. Geri dönüşümü etkin kullanan bir kalkınma ve büyümeyi hedeflemesi gereken Türkiye'nin kendi geri dönüşüm sistemini belirlemesi bu konuda tüm aktörlerinin bulunduğu bir yapı oluşturması ve geliştirilmesi gerekmektedir.

Bu çalışmada özel olarak ele alınan atık lastiklerin geri dönüşümünden elde edilen kauçuk granüllerin birçok kullanım alanı olduğu gibi çalışmamızda bahsettiğimiz yol üstyapı kaplamasında parçalanarak belirli bir granülometriye getirilip bitüm içerisine eklenerek oluşturulan yol asfaltında kullanımı, yolun dayanım performansına olan katkısından dolayı bozulmaları azaltarak bakım onarım maliyetini düşürür ve ayrıca normal asfalt kaplamalarından daha az kalınlık ve maliyette yapılmasını sağlar. Bu da ülke ekonomisine ve dünya ekonomisine yüksek oranlarda katkı anlamına gelmektedir. Ayrıca ömrünü tamamlamış lastiğin geri dönüşümünden sonra kauçuk granülden başka çelik, pirolotik yă̆, karbon siyahı ve pirolotik gaz maddeleri elde edilmektedir ki buda ekonomiye belirli bir oranda katkı sağlar.

Sonuç olarak atık lastikler geri dönüşümünde mutlaka değerlendirilmesi gereken malzemelerin başında gelmektedir. Atık lastiklerin geri dönüşümde kullanılması, hem bu lastiklerin gelişigüzel bir şekilde çevreye bırakılması yada yakılmasıyla oluşan çevresel sorunların önlenmesini hem de ülke kaynaklarının korunması ve ülke ekonomisine olan katkısının artmasını sağlamaktadır

\section{Kaynakça}

- Çelik, O., N., 2001.,"Öğütülmüş Atık Otomobil Lastiğiyle Modifiye Edilmiş Bitümler ile Yapılan Asfalt Betonun Yorulma Davranışı”, Turk J Engin Environ Sci 25 (2001), 487 .

- Çağlar, G., A., 2007. ,"Endüstriyel Atık Malzemelerin Karayollarında Kullanımı”, İTÜ Fen Bilimleri Enstitüsü, 2007.

- Çevre ve Şehircilik Bakanlığı, 2015. Atık Yönetimi ve Yönetmeliği, Resmi Gazate, Sayı: 29314

- Dinç, E., Yazıc1, A., 2000),"Superpave Bitüm Deneyleri ve Agrega Gradasyonu”, 3. Asfalt Sempozyumu, Ankara, 16-17, 161-1721

- Epps, Jon A., 1994. "Uses of Recycled Rubber Tires in Highways, University ofNevada", Transportation Research Board, Washington.

- European Commission (EC), 1993, "Proposal from the working group to theEuropean Commission for a recommendation on the prevention recovery and disposal of used pneumatic tyres"EC, Brussele. 
- $\quad$ Fırat, K., F., Akbaş, F., 2015. "İnşaat EndüstrisindeGeri Dönüşüm Çalışmalarının Geliştirilmesi ve Ekonomi Üzerine Etkileri” International Conference on Eurasian Economies, 2015.

- $\quad$ Firat, E., Soyu, E., 2014. "Davranışsal ekonomi çerçevesinde geridönüşümün değerlendirilmesi “, 14. Ulusal İşletmecilik Kongresi, 2015.

- Gürer, C., vd, 2004. “İnşaat Endüstrisinde Geri Dönüşüm ve Bir Hammadde Kaynağı Olarak Farklı Yap1 Malzemelerinin Yeniden Değerlendirilmesi”,5 Endüstriyel Hammaddeler Sempozyumu, 13-14 Mayıs 2004, İzmir, Türkiye.

- Guide Jr. V.D.R. Jayaraman, V., Srivastava, R., 1999. “The Effect Of Lead Time Variation On The Performance Of Dsassembly Release Mechanisms”, Computers \& Industrial Engineering, 36, ss. 320-3345.

- Gönüllü, M.T., 2004.,"Atık Lastiklerin Yönetimi", Katı Atık Geri Dönüşüm Teknolojileri Semineri, İSO, İstanbul.

- Karabörk, F., Akdemir, A., 2011."Atık Taşıt Lastiklerinin Devulkanizasyonla Geri Kazanımı”, Electronic Journal of Vehicle Technologies (EJVT) Vol: 3, No: 3, 2011 (21-35)

- $\quad \mathrm{KGM}($ Karayolları Genel Müdürlüğü), www.kgm.gov.tr,(14.04.2016)

- Karacasu, M., Bilgiç, Ş., 2009. "Atık Lastik Katkısının Sıcak Asfalt Özelliklerine Etkisi”, Journal of Engineering and Architecture Faculty of Eskişehir Osmangazi University, Vol: XXII, No:2, 2009.

- Katı Atık Yöntem Yönetmeliği, Çevre ve Şehircilik Bakanlığı http://www.csb.gov.tr/, (25.04.2016).

- Limbachiya, Mukesh C., 2004. "Used/Post-Consumer Tyres”, Thomas Telford Publish, Kingston University-London, September.

- Lastik Sanayicileri Derneği, www.lasder.org.tr, (21.04.2016).

- Orhan, F., 2012. Bitümlü karışımlar Laboratuvar Çalışmaları, Karayolları Genel Müdürlüğü, Araştırma Geliştirme Dairesi Başkanlığı Üstyapı Geliştirme Şubesi Müdürlüğü Ankara 2012.

- Öztürk, M., Coşkun, H., 2012. “Katı Atık Yönetimi Konusunda Hatay İlinde İnşaat Sektörü Paydaşlarının Algilamaları:Hatay İli Örneği”, e-Journual of New World Sciences Academy 2012,volume:7, number:1A0302.

- Ömrünü Tamamlamış Lastiklerin (ÖTL) Kontrolü Yönetmeliği, Resmi Gazete (Tarih: 25/11/2006, Say1: 26357)

- Sugözü, İ., Mutlu İ., 2009. “Atık Taşıt Lastikleri ve Değerlendirme Yöntemleri” Electronic Journal of Vehicle Technologies Vol: 1, No: 1, 2009.

• Vatan, C., 2002.. "Plastik Malzemelerin Geri Dönüşümü :Otomotiv Endüstrisinden Örnerkler”, İTÜ Fen Bilimleri Enstitüsü, Yüksek Lisans Tezi.

- Yeşilata, B., vd., 2007."Atık taşıt lastiklerinin geri kazanımı ve yalıtımamaçlı kullanımı”, MMO tesisat mühendisliği dergisi, 102, 64-7. 


\title{
Türkiye'de Uygulanan Tarımsal Belgelendirme Programları ve Bu Programların Çevresel Sürdürülebilirliğe Olan Etkileri
}

\section{Agricultural Certification Programs Implemented in Turkey and the Extent of their Contributions to Environmental Sustainability}

\author{
Dr. Mehmet Hasdemir (Ministry of Food, Agriculture and Livestock, Turkey) \\ Dr. Füsun Zehra Özkan (Turkey)
}

\begin{abstract}
The negative impacts of global-scale developments and consumption habits on the environment are increasing each day. In this context, studies are conducted worldwide by many institutions and non-governmental organizations to support environmental policies. Additionally, certification programs are being executed by conformity assessment bodies to mitigate the impacts of production processes on the environment. These management systems or certification programs are either used on a voluntary basis or made mandatory by company policy, national or international regulations. The certification programs were firstly started to be used in industry and service sectors and are currently being used in agriculture sector. The certification programs used in agriculture sector aim to ensure an environmentally-friendly agricultural production process and improve consumer trust and satisfaction. This study aims to address the extent to which implementation of ISO/IEC 17065 Standard based organic and good agricultural practices and GLOBALG.A.P. certification programs and ISO 14001 Management System Standard have contributed to environmental sustainability in Turkey.
\end{abstract}

\section{Giriş}

Birim alandan elde edilen üretim miktarını artırmaya dayalı politikalar ile geçtiğimiz yüzyılda tarımsal üretim miktarında önemli artışlar yaşanmıştır. Yeşil devrim olarak algılanan süreçte, insanlık modern olarak tanımladı̆̆ metotları kullanmak suretiyle, gıda ihtiyaçlarını karşılamada önemli bir başarı kazanmıştır. Mevcut ihtiyaçların giderilmesi adına doğaya meydan okuyarak elde edildiği zannedilen kazanımlar, ilerleyen yıllarda bir yanılgı olarak görülmüş ve bu durum doğanın yok olması tehlikesiyle karşı karşıya kalan insanlık için bir paradoks oluşturmuştur. Bir yandan büyük insan kitlelerini beslemek için doğadan alabileceğinin en fazlasını alma ve bu amaçla her türlü modern teknikleri kullanma, diğer yandan bu tekniklere karşı direnemeyen doğanın yok olması sonucu insanlığın kendini besleyecek tek kaynağını kaybetme tehlikesinin olduğunu fark etme, bu paradoksu ortaya çıkarmıştır.

Bunun yanında, kırdan kente göç ve yüksek gelir gruplarının tüketim alışkanlıklarının değişmesi, insanlığın gıda ediniminden saklamaya, beklentiden tüketime kadar pek çok aşamada gıda alışkanlıklarını değiştirmiştir. Binlerce yıllık gıda temin ve tüketim alışkanlıklarının hızla değişiyor olması, gıdanın riskli bir konuma gelmesine neden olmuştur. Kırsalda yaşarken tükettiği gıdanın bizzat üreticisi olan veya üreticisini tanıyan insan, şehirleşme ile birlikte modern olarak tanımlanan usullerde kendisine sunulan binlerce çeşit ürüne mevsim farkı gözetmeksizin ulaşmaya başlamıştır (Anonim, 2010a). Bu gelişmeler doğrultusunda tüketiciler, kendilerine sunulan gıdanın güvenilir olması yanında çevre, insan ve hayvan sağlığına zarar vermeden üretilmesi ve bununda kendilerine sunulacak delillerle ispat edilmesini talep etmektedir. Tüketicilerin bu talebi, geçmişte sanayi ve hizmet sektöründe başlayan belgelendirme faaliyetlerinin, tarım sektöründe de yaygınlaşmasına neden olmaktadır.

Uygun teknolojileri kullanarak çevre, insan ve hayvan sağlığına zarar vermeyen bir tarımsal üretimin yapılmasının yanında doğal kaynakların korunması, tarımda izlenebilirlik ve sürdürülebilirlik ile gıda güvenliğinin sağlanmasını amaçlayan iyi tarım uygulamaları ile organik tarım gibi belgelendirme programları günümüzde ortaya çıkan paradokslara çözüm üretecek bir modeli tarım sektörüne sunmaktadır. Bununla birlikte yönetim sistemleri belgelendirmesi, tarımsal üretimin belirlenen standartlara uygun olarak gerçekleştirilmesine imkân tanımaktadır.

\section{Yönetim Sistemlerinin Belgelendirmesi}

Uygunluk değerlendirme kavramı belgelendirme, muayene ve test faaliyetlerini kapsayacak şekilde üç ana başlık altında değerlendirilmektedir. Uygunluk değerlendirme, ISO/IEC 17000:2004 Uygunluk değerlendirmesi Terimler, tarifler ve genel prensipler standardı kapsamında ilgili ürün, hizmet, proses, sistem, kuruluş veya kişinin ilgili ulusal / uluslararası standard şartları veya yönetmeliklere göre uygunluk seviyesini göstermek üzere bir araç olarak tanımlanabilir (Anonim, 2004).

Uygunluk değerlendirme faaliyetleri içinde belgelendirme faaliyeti incelendiğinde ise yine üç ana faaliyet başlı̆̆ görülmektedir. Bunlar; ürün/ proses/hizmet belgelendirme, yönetim sistemlerinin belgelendirilmesi ve 
personel belgelendirme faaliyetleri olarak özetlenebilir. Uygunluk değerlendirmesi her alanda ilgili standardlar esas alınarak gerçekleştirilmektedir.

132 Sayılı Kuruluş Kanunu ile her türlü madde ve mamuller ile usul ve hizmet standardlarının hazırlanması görevi ülkemizde Türk Standardları Enstitüsü’ne (TSE) verilmiştir. Standard “imalatta, anlayışta, ölçme ve deneyde bir örneklik" olarak tanımlanmaktadır. Standardizasyon ise "belirli bir faaliyetle ilgili olarak ekonomik fayda sağlamak üzere bütün ilgili tarafların yardım ve işbirliği ile belirli kurallar koyma ve bu kuralları uygulama işlemi” şeklinde tanımlanmaktadır (TSE, 2016).

Standardların hazırlanmasında ülkelerin şartları, can ve mal güvenliği, ulusal ve uluslararası mevzuatlar, üretim teknolojileri, tüketici sorunları, kalite ve çevre konularına öncelik verilmektedir. Bu öncelikler içerisinde hazırlanan standartlar, kaynakların optimum kullanılması ve üretim faaliyetlerin çevreye duyarlı bir şekilde yürütülmesine doğrudan katkı sağlamaktadır. Ayrıca kaynakların etkin kullanılması ile kayıpların ve atıkların asgariye indirilmesi, verimliliğin artırtılması ve bu üretimin sistemleri konusunda bireylerin bilinçlendirmesi dolaylı olarak çevrenin korunmasına önemli katkılar sağlamaktadır.

Belgelendirme faaliyeti içinde yer alan yönetim sistemlerinin belgelendirilmesi, ilgili yönetim sistemi standardları kapsamında gerçekleştirilmektedir. Uluslararası Standard Organizasyonu (ISO) tarafından yayınlanan yönetim sistemi standardları genel olarak, bir yönetim sistemini kurmak ve işletmek için izlenmesi gereken bir model sağlamaktadır. Yönetim sistemi standardları da ISO tarafından yayımlanan diğer tüm standardlar gibi uzmanların mutabakatının bir sonucudur. Küresel bazda ortaya çıkan yönetim tecrübelerini ve ilgili alanda ortaya konulan iyi uygulama sonuçlarını içermektedir.

Bu standartlar, büyük ya da küçük ürün ya da hizmet üreten, faaliyet alanı ne olursa olsun herhangi bir sektördeki kuruluşa uygulanabilmektedir. Etkili bir yönetim sistemi uygulamanın kuruluşlara olan faydaları genel olarak; kaynakların daha verimli kullanılmasını sağlamak, gelişmiş bir risk yönetim metodolojisine sahip olmak, hizmetler veya ürünler için artan müşteri memnuniyetinin sürekli olarak sağlanması şeklinde özetlenebilmektedir. ISO tarafından yayımlanan yönetim sistemi standardları konularına göre 8 ana grupta hazırlanmaktadır. Bu gruplar kalite, emniyet ve güvenlik, genel yönetim, sağlık ve medikal, çevre ve enerji, endüstri, hizmetler, bilgi teknolojileri olarak siralanmaktadır (ISO, 2016).

Akreditasyon kuruluşları yönetim sistemleri belgelendirmesi konusunda ISO/IEC 17021:2011 ve ISO 170211:2015standardlarına göre akreditasyon hizmeti sunmaktadırlar. Bu kapsamda Türk Akreditasyon Kurumu (TURKAK) tarafindan ISO 14001 Çevre Yönetim Sistemleri için de akreditasyon hizmeti verilmekte olup TURKAK'dan akredite olan belgelendirme kuruluşları tarafindan ise ISO 14001 Çevre Yönetim Sistemi standardının şartlarını taşıyan kuruluşların yönetim sistemleri belgelendirilmektedir. ISO 14001 standardına göre belgelendirilmek isteyen bir kuruluş, bu standardın şartlarını yerine getirdiği bir çevre yönetim sistemini kurmak ve uygulamaktan sorumludur (TÜRKAK, 2016).

\subsection{ISO 14001:2015 Çevre Yönetim Sistemi Belgelendirme Faaliyeti}

Sürdürülebilir kalkınma, şeffaflık ve hesap verebilirlik için sosyal beklentiler, artarak sıkılaşan mevzuat, kirlilikten kaynaklanan çevre üzerinde artan baskı, kaynakların verimsiz kullanımı, uygunsuz atık yönetimi, iklim değişikliği, ekosistemin değersizleşmesi ve biyoçeşitliliğin kaybedilmesi ile günümüzde giderek artmıştır. Bu durum da kuruluşları, sürdürülebilirliğin çevre boyutuna katkı sağlamak amacıyla çevre yönetim sistemlerini uygulamak suretiyle çevre yönetimine sistematik bir yaklaşım benimsemeye itmiştir (Anonim, 2015). Bu amaçla çevre yönetimi için sistematik bir yaklaşım benimseyen, çevreye duyarlı kuruluşlar tarafından ISO 14001 Çevre Yönetim Sistemi standardları uygulanmaktadır. Tüm yönetim sistemi standardlarında olduğu gibi genel olarak uygulamada gönüllülük yaklaşımı olsa da, çevre konusunda bilinçli müşterilerin talepleri veya ulusal/bölgesel mevzuatların ve düzenleyici kuruluşların yaptırımları ile ISO 14001 kapsamında belgelendirme sektörel bazda zorunlu olabilmektedir. ISO 14001 Standartları, dünyada en fazla bilinen ve en yaygın kullanılan Çevre Yönetim Sistemi Standartlarıdır.

ISO 14001:2015 Çevre yönetim sistemleri - Şartlar ve kullanım kılavuzu standardı Uluslararası Standard Organizasyonu (ISO) ISO/TC 207 “Çevre Yönetimi Teknik Komitesi” tarafından hazırlanmıştır. ISO 14001:2015 standardının temel amaçları, 'kuruluşlara çevreyi korumak ve sosyo ekonomik ihtiyaçlarla denge içerisinde değişen çevre şartlarına tepki vermek için bir çerçeve sağlamaktır. Bu Standard uygulayıcı kuruluşlara, kendi yönetim sistemleri için belirledikleri hedeflenen çıktılarına erişmek için şartları belirlemekte olup, çevre yönetimi için sistematik bir yaklaşım sağlayarak, sürekli başarı ve sürdürülebilir kalkınmaya katkı için imkân sağlamaktadır. Bu kapsamda uzun süreli başarıyı ve sürdürülebilir kalkınmaya katkıyı sağlamak üzere;

- Olumsuz çevresel etkilerin önlenmesi veya hafifletilmesi ile çevrenin korunmasi,

- Çevresel şartların potansiyel olumsuz etkilerinin kuruluş üzerinde hafifletilmesi,

- Kuruluşa uygunluk yükümlülüklerinin yerine getirmesinde yardım edilmesi,

- Çevresel performansin artmasi,

- Çevresel etkilerin, yaşam döngüsü içerisinde istem dışı şekilde artmasını önleyebilecek bir yaşam döngüsü yaklaşımı kullanarak, kuruluşun ürün ve hizmetlerinin; tasarımının, imalatının, dağıtımının, tüketiminin ve elden çıkarılmasının kontrol edilmesi veya etkilemesi, 
- Kuruluşun pazardaki pozisyonunu güçlendiren çevresel olarak sağlam alternatiflerin sonuçları olabilecek finansal ve operasyonel faydalar sağlanması,

- İlgili taraflarla çevre bilgilerinin paylaşılması’ hususlarında şartları kapsamaktadır.

Standard 'bir kuruluşun, çevresel performansını arttırmak için kullanabileceği bir çevre yönetim sistemi için şartları kapsamaktadır. Bu standardın, sürdürülebilirliğin çevre boyutuna katkı sağlayan, çevre sorumluluklarını sistematik bir yaklaşımla yönetmeyi amaçlayan kuruluşlar için kullanımı amaçlanmıştır (Anonim, 2015).

Standardın tarihsel gelişimi incelendiğinde;

- 1992: BS 7750 Standartları

- TS 9719 (Çevre Yönetim Sistemleri- Genel Özellikler)

- 1996: ISO 14001 Standard1

- 1997: TS EN ISO 14001 Standard 1

- 2004: ISO 14001 ve ISO 14004'ün ikinci revizyonlarının yayınlanması

- 2015: ISO 14001 Standard1

ISO 14001:2015 standardı Haziran 2015 yayınlanmış olup, uygulayıcı kuruluşların bu yeni versiyona geçişi için 3 yıllık bir geçiş süreci planlanmıştır. Standardın 2004 baskısında da olduğu gibi ISO 14001:2015 kuruluşların; çevreye, kendine ve ilgili taraflara değer katan, kendi çevre yönetim sisteminin amaçlanan çıktılarına ulaşmasına yardım edecek bir sistem kurulmasını öngörmektedir. Kurulan çevre yönetim sisteminin çıktıları ise kuruluşun kendi oluşturduğu çevreye ilişkin politikaları ile uyumlu olarak, çevre performansının artırılmasını, uygunluk yükümlülüklerinin (yasal şartlar, ulusal/uluslararası/bölgesel düzenlemeler, paydaş/müşteri vb. ilgili tarafların şartları gibi) yerine getirilmesi, çevreye ilişkin hedeflenenlere ulaşma olarak standarda açıklanmaktadır. ISO 14001:2015 standardı aşağıda belirtilen 10 ana başlıktan oluşmaktadır.
1) Kapsam
2) Atıf yapılan standard ve/veya dokümanlar
3) Terimler ve tarifler
4) Kuruluşun bağlamı
5) Liderlik
6) Planlama
7) Destek
8) Operasyon
9) Performans değerlendirme
10) İyileştirme

ISO 14001 standardında, çevrenin artık sadece kuruluşun fiziksel sınırları için değil ürünün tedarik zinciri için düşünülmesi gerektiği vurgulanarak, kuruluşların sahip olduğu "çevre ile etkileşime giren veya girebilen faaliyet veya ürün ya da hizmetlerinin bir unsuru olan" çevre boyutlarının belirlenmesi ve değerlendirilmesinde yaşam döngüsü ve katma değer perspektifi özellikle vurgulanmaktadır. Ayrıca, kuruluşların ürün veya hizmetlerinden kaynaklı çevresel etkilerinin ve istenmeyen sonuçlar oluşmasının önlenmesinde, yaşam döngüsü perspektifini kullanarak tasarım, imalat, dağıtım, tüketim, geri dönüşüm gibi tüm aşamaların dikkate alınması gerekliliği belirtilmektedir. Çevresel etki ise standarda "kısmen veya tamamen, bir kuruluşun çevre boyutlarından kaynaklanan, çevreye yaptığı olumlu veya olumsuz herhangi bir değişiklik” şeklinde tanımlanmaktadır. Bu bağlamda uygulayıcı kuruluşlar tüm uygun kontrolleri hammadde alımından ürünün bertarafina kadarki süreçte sağlamalıdırlar.

ISO 14001 standardının belgelendirmesinde, ilgili standardın yukarıda verilen şartları ile uygunluk yükümlülüklerini (yasal şartlar, ulusal/uluslararası/bölgesel düzenlemeler, paydaş/müşteri vb. ilgili tarafların dikkate alınan şartları gibi) uygulama durumu dikkate alınmaktadır.

\section{3 Ürün Belgelendirme}

Ürün belgelendirme, belirlenen bir norm veya standartlara üretimin yapıldığının tescil edilmiş halidir. Ürün belgelendirmenin nihai amacı, ilgili tüm taraflara bir ürün belirtilen şartları yerine getirdiğine ilişkin güvence vermektir. Belgelendirmenin değeri; belirtilmiş olan şartların karşılandığının, yeterliliğe sahip üçüncü bir tarafça gösterilmesine duyulan güven ve inancın derecesidir.

Belgelendirme faaliyeti içinde yer alan ürün belgelendirme, genel olarak tüketiciler için istenen şartlara uygun ürüne ulaşımı amaçlarken, üreticiler için de yasal şartlar dahil ilgili tarafların şartlarını karşılayan üretim sisteminin oluşturulması ve uygulanması bilincinin yerleşmesini amaçlamaktadır (Anonim, 2013). İlgili standartlar kapsamında belgelendirme için esas alınan şartların üreticiler ve tüketiciler dahil olmak üzere tüm ilgili taraflara katma değer sağlayacak ve çevreye olan zararları minimize edecek kriterler içermesi amaçlanmaktadır.

Ürün, bir prosesin sonucudur. Bitkilerin büyümesi veya diğer doğal kaynakların oluşumu gibi doğal proseslerin çıktıları da ürün olarak tanımlanmaktadır. Ürünlerin belgelendirilmesi ise üçüncü taraf uygunluk değerlendirme faaliyetleri kapsamında ele alınmaktadır. Uygunluk Değerlendirmesi faaliyetleri kapsamında ürünlerin 
belgelendirilmesi; Ürün Proses Ve Hizmet Belgelendirmesi Yapan Kuruluşlar İçin Şartlar ISO/IEC 17065: 2012 standardı ile düzenlenmiştir.

ISO/IEC 17065:2012 standard1, Avrupa Standardizasyon Komitesi (CEN) tarafindan onaylanan ve Aralık 2012'de TS EN ISO/IEC 17065: 2013 numaralı Türk standardı olarak kabul edilen EN ISO/IEC 17065: 2012 standardı esas alınarak, Türk Standardları Enstitüsü Mühendislik Hizmetleri İhtisas Kurulu'na bağlı TK29 Yönetim Sistemleri Teknik Komitesi marifetiyle Türkçeye tercüme edilmiş, TSE Teknik Kurulu'nun 10 Nisan 2013 tarihli toplantısında kabul edilerek yayımına karar verilmiş̧tir. ISO/IEC 17065:2012 standardı aşağıdaki sekiz ana başlıklardan oluşmaktadır (Anonim, 2013).

1) Kapsam,

2) Atıf yapılan standard ve/veya dokümanlar,

3) Terimler ve tarifler,

4) Genel şartlar,

5) Yapısal şartlar,

6) Kaynak şartları,

7) Proses şartları,

8) Yönetim sistemi şartları.

ISO/IEC 17065:2012 standardı kapsamında "genel şartlar' incelendiğinde; belgelendirme kuruluşlarının yapısal statüsü ile belgelendirme faaliyetine yönelik olarak müșteriler ve belgelendirme kuruluşu arasında imzalanan ve belgelendirme faaliyetlerinin sağlaması için yasal geçerliliği olan sözleşme şartlarının tanımlandığı görülmektedir. Genel şartlar ayrıca belgelendirme kuruluşu tarafindan kullanılan lisanslar, belgeler, uygunluk işaretlerinin sahipliği, kullanımı ve gösterimi kapsamında oluşturulan kontrol mekanizmasını dikkate almaktadır. Genel şartlar ile tarafsızlık ve gizlilik ilkeleri kapsamında sistemin yönetilmesi için güçlü bir yapı oluşturulmuştur.

Yapısal şartlar maddesi ile belgelendirme kuruluşunun organizasyon yapısı, bu organizasyon yapısı altında çalışan kurullar vb. ilgili organlar için gerekli şartlar tanımlanmaktadır. Kaynak şartları maddesi ile belgelendirme kuruluşu personeli, personelin ilgili standard ve yönetmeliklere göre yetkinliği, yetkinliğin değerlendirilmesi ve izlenmesi ile kuruluş tarafından kullanılması planlanan iç ve dış kaynakların yönetimi için şartlar belirlenmiştir. Yönetim sistemi maddesi ile bu standardı uygulayan belgelendirme kuruluşları tarafindan ISO/IEC 17065:2012 standardının ve ilgili belgelendirme programının yerine getirilmesi için politikaların ve hedeflerin oluşturulması, dokümante edilmesi ve uygulanması için şartlar belirlenmiştir.

Proses şartları maddesi ile iyi tarım uygulamaları, organik tarım veya GLOBALGAP gibi belgelendirme programlarına yönelik olarak başvurunun alınmasından itibaren bağımsız denetim faaliyetleri, ilgili taraflara yönelik olarak belgelerin hazırlanması, ilgili belgelendirme programı şartlarına göre izleme ve kontrollerin yapılması, bu sistemde üretilmiş çıktılara yönelik olarak direk veya dolaylı kullanıcıların itiraz ve şikâyetlerinin ele alınması, gerekli kayıtların tutulması gibi tüm kesimler için güven sağlamaya yönelik faaliyetler tanımlanmaktadır.

Ürün belgelendirmesinin uygulama kuralları, prosedürleri ve yönetimi, belgelendirme programı aracıllı̆ıyla şart koşulmaktadır. Ürün belgelendirme programları, başlangıç deneyini veya muayeneyi ve bunların tedarikçilerinin kalite yönetim sistemlerinin değerlendirilmesini ve sonrasında, kalite yönetim sistemini ve üretimden ve piyasadan alınan numunelerin deney veya muayenelerini esas alan gözetimi içerebilmektedir (Anonim, 2013).

Türkiye'de uygulanan tarımsal ürün belgelendirmesi programlarından organik tarım, iyi tarım uygulamaları ve GLOBALGAP yönetmelikleri, belgelendirme sürecine ilişkin kontrol ve sertifikasyon sisteminin usul ve esaslarını düzenlemektedir. Bu düzenlemeler aynı zamanda ISO/IEC 17065:2012 standardının 7. Maddesinde düzenlenen proses şartlarına ilişkin kuralları da içermektedir.

\section{1 İyi Tarım Uygulamaları Belgelendirmesi}

Türkiye'de İTU belgelendirilmesi, ilk olarak EUREPGAP Protokolü ile başlamıştır. Özellikle Avrupa ülkelerine yönelik ihracat yapan yaş meyve sebze sektöründe, iyi tarım uygulamaları yapan üreticiler 2003 yıllndan itibaren EUREPGAP kapsamında belgelendirilmekte olup bu durum ülke içerisinde iyi tarım uygulamalarının yaygınlaşmasına ve yasal düzenlemelerin yapilmasına neden olmuştur. Sektöre yaşanan bu gelişmeler doğrultusunda 08.09.2004 Tarihinde İyi Tarım Uygulamalarına İlişkin Yönetmelik 25577 Sayılı Resmi Gazetede yayımlanarak yürürlüğe girmiştir (Hasdemir, 2009). Daha sonra 07.12.2010 tarihli ve 27778 sayılı Resmi Gazete yayımlanan İyi Tarım Uygulamaları Hakkında Yönetmelik ile 2004 yılında yayımlanan ilk yönetmelik yürürlükten kaldırılmıştır. İTU kapsamında yapılan belgelendirmeler halen 2010 yılında yayımlanan Yönetmeliğe göre yürütülmektedir.

Türkiye'de İTU'ya ait üretim verileri Tablo 1'de verilmiştir. Bu tablo incelendiğinde 2015 yllı itibariyle 61 ilde 344.396 ha alanda 39.740 üreticinin iyi tarım uygulamaları yaptığı görülmektedir. Yıllar itibariyle üretici sayısında ve üretim alanında dalgalanmalar yaşanmakta birlikte, son yıllarda üretici sayısı ve üretim alanı önemli ölçüde artmıştır. Özelikle 2014 yılında, bir önceki yıla göre üretici sayısında \%161,1' lik bir artış yaşanmıştır. 2015 yılında ise üretici sayısı bir önceki yıla oranla \%86,29 artmıştır (Anonim, 2016). 


\begin{tabular}{|l|c|c|c|c|}
\hline & Il Sayısı & Üretim Alanı (da) & $\ddot{\text { Uretici Sayısı }}$ & $\begin{array}{c}\text { Uretici Sayısındaki } \\
\text { Değişim (\%) }\end{array}$ \\
\hline 2007 & 18 & 5.361 & 651 & - \\
\hline 2008 & 19 & 6.023 & 822 & 26.27 \\
\hline 2009 & 42 & 170.280 & 6.020 & 632.36 \\
\hline 2010 & 49 & 78.174 & 4.540 & -24.58 \\
\hline 2011 & 49 & 49.963 & 3.042 & -33.00 \\
\hline 2012 & 47 & 83.717 & 3.676 & 20.84 \\
\hline 2013 & 56 & 98.510 & 8.170 & 122.25 \\
\hline 2014 & 53 & 214.771 & 21.332 & 161.10 \\
\hline 2015 & 61 & 344.396 & 39.740 & 86,29 \\
\hline
\end{tabular}

Tablo 1. Türkiye'de İyi Tarım Uygulamaları Üretim Verileri Kaynak: Anonim, 2016.

İyi Tarım Uygulamaları Hakkında Yönetmeliğe göre İTU; “tarımsal üretim sistemini sosyal açıdan yaşanabilir, ekonomik açıdan karlı ve verimli, insan sağlı̆̆ını koruyan, hayvan sağlığı ve refahı ile çevreye önem veren bir hale getirmek için uygulanması gereken işlemleri” olarak tanımlanmıştır.

ITU belgelendirme süreci kontrol ve sertifikasyon aşamalarından oluşmaktadır. İyi Tarım Uygulamaları Hakkında Yönetmeliğin 6. Maddesi kontrol ve sertifikasyon işlemlerini açıklamaktadır. Buna göre tarımsal ürünlerin kontrol ve sertifikasyonu, bireysel sertifikasyon ve grup sertifikasyonu olmak üzere iki şekilde yapılabilmektedir. Gerçek veya tüzel kişilerin malik veya kiracılık sıfatıyla tasarrufu altında bulunan alanlarda üretim yapmaları halinde, bireysel sertifikasyon yapılmaktadır. Bireysel sertifikasyonda, sertifikasyon kapsamındaki ürünün üretiminin yapıldığı tüm alanlar, yılda en az bir kez kontrol ve sertifikasyon kuruluşları tarafından kontrol edilmektedir. Üretici örgütü veya müteşebbis çatısı altında sözleşmeyle bir araya gelen üreticilerin malik veya kiracılık sifatıyla tasarrufu altında bulunan alanlarda üretim yapması halinde, grup sertifikasyonu yapılmaktadır. Üretici örgütleri veya müteşebbisler yılda en az bir kez kontrol ve sertifikasyon kuruluşları tarafından kontrol edilmektedir. Bu kontrollerde, kalite yönetim sistemi ile gruba dahil üreticilerden örnekleme yöntemi ile seçilenlerin tüm üretim alanları kontrol edilmektedir. Örnekleme yöntemi ile kontrol edilecek üretici sayısı; her alt kapsam için üretim sistemleri dikkate alınarak, gruba dahil üretici sayısının ayrı ayrı kareköklerinin toplamının alınması ile belirlenmektedir.

Kontrol faaliyetleri sonucunda, İyi Tarım Uygulamaları Hakkındaki Yönetmeliğe uygunluğu belirlenen tarımsal ürün, üretici veya üretici grubu adına ürün sertifikası düzenlenmektedir. Kontrol ve sertifikasyonunca düzenlenen sertifikanın geçerlilik süresi, düzenlendiği tarihten itibaren en fazla on iki aydır. Sertifikanın onaylanması yetkisi, Gıda Tarım ve Hayvancılık Bakanlığı tarafından ilgili kontrol ve sertifikasyon kuruluşu adına yetkilendirilmiş sertifikere aittir.

Bir üretici veya üretici grubu adına sertifika düzenlenebilmesi için Bakanlıkça belirlenen birinci derece kontrol noktalarının tamamına, ikinci derece kontrol noktalarının en az yüzde doksan beşine ve taraflar arasında yapılan sözleşme esaslarına uyulması gerekmektedir. Yapılan kontrollerde, birinci derece kontrol noktalarının her hangi birine veya ikinci derece kontrol noktalarının yüzde beşinden fazlasına uymayanlara düzeltici faaliyet talebinde bulunarak sırasıyla uyarı ve askıya alma yaptırımları uygulanır. Buna rağmen uygunsuzlukların kapatılmaması durumunda, sertifika iptal edilerek üretici on iki ay süre ile sistem dışına çıkarılır.

\subsection{Organik Tarım Belgelendirmesi}

Organik tarım, geçmişte insanlığın yaptığı yanlış uygulamalar sonucunda bozulan doğal dengenin yeniden tesisini öngören ve bu amaçla bitki, hayvan ve insan ile birlikte toprak, su ve diğer faktörleri bütünsel bir yaklaşımla ele alarak planlayan, doğal girdileri kullanan bir üretim sistemidir. Bu sistem sadece organik ürünlerin üretimi ve tüketiciye ulaştırılmasından ibaret değildir. Günümüzde organik tarım sistemi, sürdürülebilir bir ekosistem, tüm canlılar için hakkaniyet, sosyal adalet ve beşeri ilişkiler anlayışı ile birlikte organik yaşam olarak algılanmaktadır. Dünyada yaşanan bu gelişim ve değişimler, ülkemizi de büyük ölçüde etkilemektedir. Türkiye'de organik ürünlerin üretimi ve tüketiminde önemli artışlar yaşanmaktadır (Hasdemir ve Bayaner, 2009).

Günümüzde pek çok ülkede organik tarım için mevzuatlar oluşturularak uygulanmaktadır. Türkiye'de organik tarım faaliyetleri 1980 yılında başlamış olup, 1991 yılından itibaren 2092/91 sayılı Avrupa Birliği Organik Tarım Yönetmeliği esas alınarak gerçekleştirilmiştir. Bu alanda ilk mevzuat düzenlemesi, 1994 yılında, Tarım ve Köyişleri Bakanlığı tarafından "Bitkisel ve Hayvansal Ürünlerin Ekolojik Metotlarla Üretilmesine İlişkin Yönetmelik" adı altında 18.12.1994 tarihli ve 22145 sayılı Resmi Gazete'de yayınlanarak yürürlüğe girmiştir. 2004 yılında, 5262 Sayılı "Organik Tarım Kanunu” 03.12.2004 tarihli ve 25659 sayılı Resmi Gazete'de yayımlanarak yürürlüğe girmiştir. Türkiye'de organik ürünlerin belgelendirilmesi, çeşitli değişiklikler yapılmakla birlikte halen 5262 Sayılı Kanuna dayanılarak hazırlanan ve 18.08.2010 tarihli 27676 sayılı Resmi Gazete'de yayımlanan "Organik Tarımın Esasları ve Uygulanmasına İlişkin Yönetmelik” çerçevesinde yürütülmektedir.

Türkiye'de gerçekleştirilen organik tarım üretim verileri tablo 2'de görülmekte olup son y1llarda önemli artışlar yaşandığı görülmektedir. 2004-2010 yılları arasında çiftçi sayısı 5,6 kat, yetiştiricilik alanı 4,5 kat artış 
göstermiştir. 2014 yılı itibariyle geçiş dönemi dahil toplam 60.797 çiftçi 491.977 ha alanda organik yetiştiricilik yapılmaktadır. Üretim miktarı 1,6 milyon tonu geçmiştir (Anonim, 2016).

\begin{tabular}{|c|c|c|c|c|c|c|}
\hline & $\begin{array}{c}\text { Ürün } \\
\text { Sayısı }\end{array}$ & $\begin{array}{c}\text { Çiftçi } \\
\text { Sayısı }\end{array}$ & $\begin{array}{c}\text { Yetiştiricilik } \\
\text { Alanı (ha) }\end{array}$ & $\begin{array}{c}\text { Doğal Toplama } \\
\text { Alanı (ha) }\end{array}$ & $\begin{array}{c}\text { Toplam Üretim } \\
\text { Alanı (ha) }\end{array}$ & $\begin{array}{c}\text { Üretim } \\
\text { Miktarı (ton) }\end{array}$ \\
\hline 2004 & 174 & 12.751 & 108.598 & 100.975 & 89.827 & 377.616 \\
\hline 2005 & 205 & 14.401 & 93.134 & 110.677 & 203.811 & 421.934 \\
\hline 2006 & 203 & 14.256 & 100.275 & 92.514 & 192.789 & 458.095 \\
\hline 2007 & 201 & 16.276 & 124.263 & 50.020 & 174.283 & 568.128 \\
\hline 2008 & 247 & 14.926 & 109.387 & 57.496 & 166.883 & 530.225 \\
\hline 2009 & 212 & 35.565 & 325.831 & 175.810 & 501.641 & 983.715 \\
\hline 2010 & 216 & 42.097 & 383.782 & 126.251 & 510.033 & 1.343 .737 \\
\hline 2011 & 225 & 42.460 & 442.581 & 172.037 & 614.618 & 1.659 .543 \\
\hline 2012 & 204 & 54.635 & 523.627 & 179.282 & 702.909 & 1.750 .127 \\
\hline 2013 & 213 & 60.797 & 461.395 & 307.619 & 769.014 & 1.620 .387 \\
\hline 2014 & 208 & 71.472 & 491.977 & 350.239 & 842.216 & 1.642 .235 \\
\hline
\end{tabular}

Tablo 2. Türkiye'de Organik Tarım Üretim Verileri Kaynak: Anonim, 2016.

Organik Tarımın Esasları ve Uygulanmasına İlişkin Yönetmeliğin amacı; ekolojik dengenin korunması, organik tarımsal faaliyetlerin yürütülmesi, organik tarımsal üretimin ve pazarlamanın düzenlenmesi, geliştirilmesi, yaygınlaştırılmasına ilişkin usul ve esasları belirlemektir. Yönetmeliğe göre organik tarım faaliyeti yapan gerçek veya tüzel kişi müteşebbis olarak tanımlanmakta olup müteşebbis, organik tarım faaliyetini bireysel olarak yapabildiği gibi üretici grubu ile de yapabilmektedir. Organik tarım faaliyetleri, müteşebbis ile yetkilendirilmiş kuruluş arasında imzalanan sözleşmeye dayalı olarak yürütülmektedir.

Organik Tarım Yönetmeliği yetkilendirilmiş kuruluşu; kontrol ve sertifikasyon kuruluşu, kontrol kuruluşu veya sertifikasyon kuruluşu olarak Bakanlık tarafından yetki verilmiş gerçek veya tüzel kişiler olarak tanımlamaktadır. Bu çerçevede organik tarım belgelendirilmesi de ITTU belgelendirmesinde olduğu gibi Gıda Tarım ve Hayvancılık Bakanlığınca yetkilendirilmiş kuruluşlar tarafından gerçekleştirilmektedir.

Organik tarım belgelendirmesi kontrol ve sertifikasyon süreci olmak üzere iki aşamadan oluşmaktadır. Kontrol süreci Yönetmeliğin 36. Maddesinde tanımlanmıştır. Organik Tarım Yönetmeliğine göre yetkilendirilmiş kuruluşlar, organik tarım faaliyetinin risk analizine göre bulunan kritik kontrol noktalarını dikkate alarak bir kontrol planı hazırlamalı, risk analizi sonucu haberli veya habersiz y1llık kontrol ve ziyaretlerin yoğunluğunu belirlemelidir. Buna doğrultuda, tüm müteşebbislere yılda en az bir defa kontrol ziyareti yapılmaktadır.

Organik ürünlerin sertifikasyonuna ilişkin kurallar, Organik Tarım Yönetmeliğinin 37. Maddesinde düzenlenmiştir. Buna göre sertifikasyon; bütün kontrol yöntemlerinin uygulanması sonucu işletmenin, ürünün ve girdinin geldiği aşamanın belgelendirilmesidir. Sözleşme yapılan müteşebbise yetkilendirilmiş kuruluş tarafindan yapılacak ilk kontrole müteakip uygun görülmesi halinde yetkilendirilmiş kuruluş tarafindan organik tarım müteşebbis sertifikası düzenlenmektedir. Daha sonra Yönetmelik hükümlerine uygun olarak üretilen ürünlere, ürün sertifikası verilmektedir. Sertifika onaylama yetkisi, ITTU'da olduğu gibi Gıda Tarım ve Hayvancılık Bakanlığ tarafından yetkilendirilmiş sertifikere aittir.

Organik tarım belgelendirilmesinde İTU'dan farklı olarak ilk yıl her ürüne organik sertifikası düzenlenememektedir. Organik tarım yapılan alanlar, hayvanlar, arılar ve su ürünleri geçiş sürecine alınmaktadır. Bitkisel üretimde organik tarıma başlanmasından on iki ay sonra elde edilen ürünler geçiş süreci ürünü olarak değerlendirilmektedir. Geçiş süreci ürünü, "Organik tarım geçiş süreci ürünüdür" etiketiyle pazarlanabilmektedir.

\subsection{GLOBALGAP Belgelendirmesi}

Avrupa ülkelerindeki yaş meyve-sebze pazarının önemli bir kısmına hakim büyük perakendeci kuruluşlar, tüketicilerin güvenli gıda taleplerini karşılamak üzere 1997 yılında EUREP (Euro Retailer Producer Group) adı altında bir araya gelmişlerdir. 1999 yılında ise bu organizasyon, öncelikle yaş meyve sebzede iyi tarım uygulamalarının (GoodAgriculturalPractices: GAP) esasları belirleyerek, EUREPGAP adı altında yayınlamıştır. Avrupa ülkelerinde başlatılan bu uygulama ilerleyen yıllarda dünya genelinde genişlemiş, sonrasında ChileGAP, ChinaGAP, KenyaGAP, MexicoGAP, JGAP (Japon) ve ThaiGAP gibi farklı organizasyonların oluşması ile dünya geneline yayılmıştır. Bu gelişmelerin sonucunda, EUREPGAP isim değişikliğine giderek 7 Eylül 2007 tarihinde kendi ismini GLOBALGAP olarak değiştirmiştir. Bu tarihten itibaren EUREPGAP, GLOBALGAP olarak tanımlanmaktadır.

GLOBALGAP belgelendirmesi; gıda güvenliği ve izlenebilirlik, çevre (biyolojik çeşitlilik dahil), işçi sağlığ1, güvenliği ve refahı, hayvan refahı, entegre ürün yönetimi (ICM), entegre haşere kontrolü (IPC), kalite yönetim sistemi (QMS) ve tehlike analizi ve kritik kontrol noktaları (HACCP) kavramlarını kapsamaktadır. Aynı zamanda iş performansını artırarak, yaşamsal kaynakların israfını azaltır ve gelecek nesiller için en iyi uygulamaları yapılandırmak için tarımsal üretime genel bir yaklaşım getirmektedir. GLOBALGAP aynı zamanda Entegre Çiftlik 
Güvencesi Standardı (IFA) olup, tüm tarım, su ürünleri yetiştiriciliği, hayvancılık ve bitkisel üretimi kapsamaktadır (GLOBALGAP, 2014).

GLOBALGAP belgelendirmesi, FoodPLUSGmbH tarafindan yetkilendirilen belgelendirme kuruluşları tarafindan yapılabilmektedir. Bu kuruluşunlar belgelendirme faaliyetlerinde, GLOBALGAP tarafindan oluşturulan kontrol noktaları ve uygunluk kriteri kullanılmaktadır.

Kontrol Noktaları ve Uygunluk Kriterleri; uygunluğu doğrulamak üzere denetlenen bireysel veya grup üreticiler tarafından uygulanması gereken tüm kontrol noktaları ve uygunluk kriterlerini içermektedir. Bu doküman, kontrol noktaları, uygunluk kriterleri ve her noktada ihtiyaç duyulan uygunluk derecesi ile her alan ve alt-alanları içeren birimlere ayrılmıştır. Uygunluk dereceleri, majör zorunluluk (mutlak zorunlu), minör zorunluluk (zorunlu) ve tavsiye şeklindedir (Anonim, 2014).

Kontrol Listesi; kontrol noktaları ve uygunluk kriterlerindeki kontrol noktalarına cevap vermektedir. Bundan dolayı modüler yapıda oluşturulmuştur. GLOBALGAP'de dört tip kontrol listesi bulunmaktadır. Bunlar;

- Üreticileri kontrol etmek için kullanılan kontrol listesi,

- Üretici grubu kalite yönetim sistemlerini ve çoklu üretim alanlarına sahip olan bireysel üreticilere ait kalite yönetim sistemlerinin denetiminde kullanılan kontrol listesi,

- Onaylanmış kontrol listesi veya eşdeğerlpropramçeklistleri,

- Belgelendirme kuruluşlarınca yapılan habersiz denetimlerde kullanılan kontrol listesinden oluşmaktadır.

\section{Tarımsal Belgelendirme Programları ve Çevresel Sürdürülebilirlik İlişkisi}

Öncelikleri ve istekleri her geçen gün değişen toplulukların ihtiyaçlarını karşılama çabası içerisinde olan tarım sektörü, tüketicilerin, dış pazarların ve düzenleyici kuruluşların talepleri doğrultusunda ürünlerini belgelendirmektedir. Satın alma gücüne göre değişen tüketici talepleri ise belgelendirme programlarının amaçlarını ve kapsamını değiştirmektedir. Güvenilir gıdaya erişim yanında, bu gıdanın üretilme süreçlerinde çevreye zarar verilmeden üretilmesi her geçen gün daha da önemli hale gelmektedir. Bu nedenle tarımsal belgelendirme programları; çevre, insan ve hayvan sağlı̆ı̆na zarar vermeden üretimin yapılmasını sağlayacak kriterlerden oluşmaktadır.

Organik Tarımın Esasları Ve Uygulanmasına İlişkin Yönetmeliğin 1. Maddesinde bu Yönetmeliğin amacı; "ekolojik dengenin korunması, organik tarımsal faaliyetlerin yürütülmesi, organik tarımsal üretimin ve pazarlamanın düzenlenmesi, geliştirilmesi, yaygınlaştırılmasına ilişkin usul ve esasları belirlemek" olarak tanımlanmışıır. Bu tanımlamadan da anlaşılacağı üzere organik tarımda üretimi artırmaya dayalı bir yaklaşımdan ziyade, çevrenin korunması öne çımaktadır. Ancak tüm bu amacın yanında üretimin sürdürülebilirliği esastır. $\mathrm{Bu}$ doğrultuda, üretimin devamını sağlamak üzere gerektiğinde uygun girdilerin ve yöntemlerin kullanılmasına izin vermektedir.

İyi Tarım Uygulamaları Hakkında Yönetmeliğin 1. Maddesinde ise Yönetmeliğin amacı; “çevre, insan ve hayvan sağlığına zarar vermeyen bir tarımsal üretimin yapılması, doğal kaynakların korunması, tarımda izlenebilirlik ve sürdürülebilirlik ile güvenilir ürün arzının sağlanması için gerçekleştirilecek iyi tarım uygulamalarının usul ve esaslarını düzenlemek" olarak tanımlanmıştır. İyi tarım uygulamaları belgelendirmesini düzenleyen bu Yönetmelik, güvenilir ürünün elde edilmesine odaklanırken, bu ürünün elde edilmesini sağlayacak sistemde sürdürülebildiğin oluşması için aynı zamanda çevreye duyarlı bir üretim yapılmasını amaçlamaktadır. İyi tarım uygulamalarında çevreyi etkileyebilecek bir müdahalenin kararı, ekonomik zarar eşiği dikkate alınarak entegre mücadele prensiplerinde uygulanabilmektedir. İyi Tarım Uygulamaları Hakkında Yönetmeliğe göre entegre mücadele; "kültür bitkilerinde zararlı türlerin popülasyon dinamikleri ve çevre ile ilişkilerini dikkate alarak, uygun olan mücadele metotlarını ve tekniklerini uyumlu bir şekilde kullanarak, bunların popülasyonlarını ekonomik zarar seviyesinin altında tutan zararlı yönetimi sistemi” olarak tanımlanmaktadır. Bu çerçevede iyi tarım uygulamalarında, çevresel sürdürülebilirlik yanında ekonomik sürdürülebilirliğin de öne çıktı̆̆ı görülmektedir.

GLOBALGAP belgelendirmesi, entegre ürün yönetimi prensiplerinde iyi tarım uygulamaları esasına dayanmaktadır. GLOBALGAP belgelendirmesi için üreticilerin uyması gereken koşullar, kontrol noktaları ve uygunluk kriteri olarak GLOBALGAP tarafından yayımlanmaktadır. Yaş meyve ve sebze kapsamında yapılan bir GLOBALGAP V5 belgelendirmesinde 218 kontrol noktası bulunmakta olup bu kontrol noktalarında 4 ana öncelik bulunmaktadır. Bunlar sırasıyla 99 kontrol noktası ile gıda güvenliği, 69 kontrol noktası ile çevre, 28 kontrol noktası ile işçi sağlığı, güvenliği ve refahı, 22 kontrol noktası ile izlenebilirliktir (Şekil 1). 

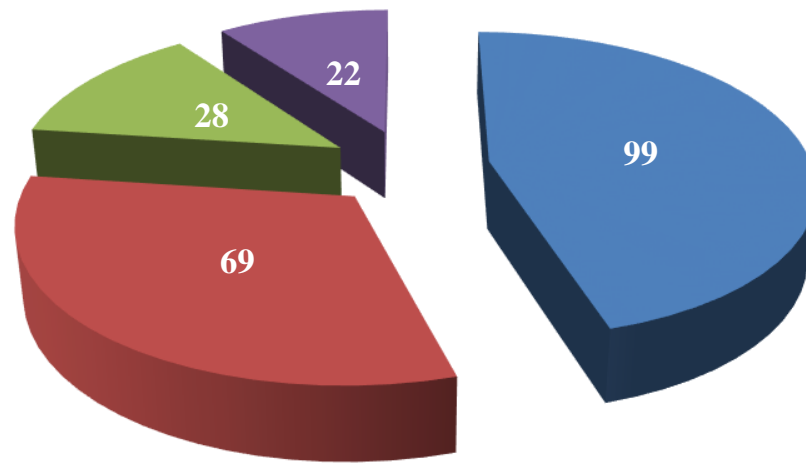

- Glda güvenliği

- Çevre

- $\dot{I}_{s c ̧ i}$ sağlı $\breve{g} l$, güvenliğ $i$ ve refahı

- Izlenebilirlik

Şekil 1. GLOBALGAP kontrol noktalarının dă̆ılımı Kaynak: GLOBALGAP, 2014.

GLOBALGAP kontrol noktalarının dağılımını gösterir Şekil 1'de görüldüğü üzere, kontrol noktalarının büyük bir çoğunluğu gıda güvenliği ile ilgilidir. Kontrol noktaları içerisinde ikinci sırada çevre ile ilgili kontrol noktaları gelmektedir. Çevre ile ilgili kontrol noktaları içerinde, doğrudan çevre koruyucu tedbirler yanında, üretim kararının verilmesinden hasada kadar geçen süreçte risk analizlerini esas alan kontrol noktaları bulunmaktadır. Böylece tarım işletmelerinde, kriz yönetiminden ziyade risk yönetimine ve kaynakların en uygun şekilde kullanımına imkân tanınmaktadır.

\section{Sonuç}

Ekonomik, sosyal ve kültürel alanda yaşanan gelişmeler, tarımsal üretim sistemlerini önemli ölçüde etkilemektedir. Bir tarafta gelirlerini artırmak isteyen üretici kitlesine karşılık, diğer tarafta sağlıklı ürünlere ulaşma amacındaki tüketiciler yer almaktadır. Hem üreticilerin üretimlerine devam etmeleri için hem de tüketicilerin taleplerinin sürekli karşılanması için doğal kaynakların sürdürülebilir kullanımına ihtiyaç duyulmaktadır. Tarımsal üretimde çevresel sürdürülebilirliğin en önemli unsurları, toprak ve su başta olmak üzere doğal kaynakların sürdürülebilir kullanımı ile çevreye zarar vermeyen üretim teknikleridir. Ekonomik sürdürülebilirlik için de ekonomik açıdan karlı ve verimli bir tarımsal üretime ihtiyaç duyulmaktadır. Bu nedenle ekonomik ve çevresel sürdürülebilirlik için, kaynak kullanımından ürünün piyasaya arzına kadar geçen yaşam döngüsünü içerisine alan yönetim sistemi veya ürün belgelendirmesi faaliyetlerinin önemi gittikçe artmaktadır.

Bir yönetim sistemi belgelendirmesi olan ISO 14001:2015 Çevre Yönetim Sistemi standardı, tarım dahil tüm üretim süreçlerinin çevreye duyarlı ve çevrenin korunmasına yönelik tedbirlere öncelik verecek bir şekilde yapılmasına imkan sağlayacak bir sistem önermektedir. Ayı zamanda çevre koruma algısını, üretim sahasının dışına çıkararak, tedarik zincirine kadar genişletmekte ve yaşam döngüsü perspektifini ön plana çıkartmaktadır. Bu durum işletmelerde çevreye bakış açısından yaşam döngüsü ve katma değer perspektifi oluşturmaktadır. İTU, organik tarım ve GLOBALGAP ise ürüne odaklanan ürün belgelendirme programları olmakla birlikte, ürünün üretim süreçlerinde çevre, insan ve hayvan sağlığına zarar vermeyen uygulamaların yapılmasını gerekli kılmaktadır. Tüm bu süreçler birlikte ele alındığında yönetim sistemleri belgelendirmesi ve ürün belgelendirmesi programları tarımsal üretimin sürdürülebilirliğine önemli katkılar sağlamaktadır.

Yönetim sistemleri belgelendirmesi ve ürün belgelendirmesi programlarının tarım sektöründe gelişmesi, yaygınlaşması ve tüm taraflarca kabul görmesi için de sisteme olan güvenin devam ettirilmesi gerekmektedir. Belgelendirmenin nihai amacı tüm taraflara güvence vermektedir. $\mathrm{Bu}$ nedenle, belirtilen belgelendirme programları, tarafsızlık ve bağımsızlık ilkesi çerçevesinde üçüncü taraf yetkin kuruluşlarca yürütülmektedir. Tüm bu sistemin gönüllülük ilkesi çerçevesinde yürütüldüğü dikkate alındığında, hem bağımsızlığın ve tarafsızlığın sağlanması, hem de yetkinliğin ortaya konulmasında, resmi otoritelerin yanı sıra akreditasyon kurumlarına ihtiyaç duyulmaktadır. Ülkemizde bu alanda hizmet veren TÜRKAK-Türk Akreditasyon Kurumu, yönetim sistemleri ve ürün belgelendirmesi alanlarında gerçekleştirdiği akreditasyon faaliyetleri ile ulusal ve uluslararası boyutta bu sistemlerin tüm taraflar açısından güvenilirliğine ve tanınmasına katkı sağlamaktadır.

Bununla birlikte yönetim sistemleri ve ürün belgelendirmesi kapsamlarında, farklı ülkeler ve farklı organizasyonlar tarafından yürütülen programların çeşitliliği ve sayısındaki artış, hem üretici hem de tüketici boyutunda karışıklıklara, zaman ve para kayıplarına neden olabilmektedir. Bu sebeple programlar arasında eşdeğerliğe ihtiyaç duyulmaktadır. Entegre ürün yönetimi prensiplerine dayanan iyi tarım uygulamalarında, ulusal mevzuata göre İyi Tarım Uygulamaları Hakkındaki Yönetmeliğe göre yapılan belgelendirme ile FoodPLUSGmbH tarafından yürütülen GLOBALGAP'e göre yapılan belgelendirmeler arasında eşdeğerlik anlaşmaları henüz bulunmamaktadır. Aynı şekilde ülkemiz mevzuatına göre uygulanan organik tarım belgelendirmesi ile Avrupa Birliği, ABD veya Japonya gibi ülkelerin mevzuatlarına göre yürütülen belgelendirme programları arasında da eşdeğerlik söz konusu değildir. Bu durumda üreticiler, hedef pazarlarına göre benzer programlar için ayrı ayrı 
sertifikalara ihtiyaç duymaktadırlar. Eşdeğerlik anlaşmalarının yapılması, ulusal mevzuata göre düzenlenen İTU veya organik tarım sertifikaların ülke sınırları dışında da geçerli olmasını yanında üreticilere ekonomik açıdan önemli katkılar sağlayacaktır.

Çevrenin korunması kapsamında gerçekleştirilen ulusal ve uluslararası protokoller ve ülkesel/yerel düzenlemeleri kapsayan tüm faaliyetlerin yanı sıra biz tüketicilerin bilinçlendirilerek çevreye duyarlı standardlar dikkate alınarak üretilen ürünlere ve sunulan hizmetlere olan talebin arttırılması da dünyamızda yaşayan tüm canlıların yeryüzündeki varlığını sürdürebilmesi için temel şarttır. Tüm bu çalışmalar ile gelecek kuşaklara bırakacağımız en önemli mirasın yaşanabilir bir dünya olduğunu vurgulanırken, üretim faaliyetleri için çevreye, doğaya ve tüm canlıların yaşam döngüsüne duyarlı kuruluşların ürün ve hizmetlerini tercih ederek desteklemek birey olarak hepimizin temel görevidir.

\section{Kaynakça}

- Anonim, 2004. ISO/IEC 17000:2004- Uygunluk Değerlendirmesi - Terimler, Tarifler ve Genel Prensipler

- Anonim, 2010a. Anonim. 2010. Stratejik Plan. Türkiye Cumhuriyeti Tarım ve Köyişleri Bakanlığı, Ankara.

- Anonim, 2010b. Organik Tarımın Esasları ve Uygulanmasına İlişkin Yönetmelik. 18 Ağustos 2010 tarihli ve 27676 sayılı T.C. Resmi Gazete.

- Anonim, 2010c. İyi Tarım Uygulamaları Hakkında Yönetmelik. 7 Aralık 2010 tarihli ve 27778 sayılı T.C. Resmi Gazete.

- Anonim, 2013. TS EN ISO/IEC 17065 Uygunluk Değerlendirmesi; Ürün Proses Ve Hizmet Belgelendirmesi Yapan Kuruluşlar İçin Şartlar. Türk Standardları Enstitüsü Mühendislik Hizmetleri İhtisas Kurulu TK29 Yönetim Sistemleri Teknik Komitesi.

- Anonim, 2015. ISO 14001:2015 Çevre Yönetim Sistemleri -Şartlar ve Kullanım Kılavuzu. Uluslararası Standard Organizasyonu Çevre Yönetimi Teknik Komitesi.

- Anonim, 2016. Bitkisel Üretim Verileri. Gıda Tarım ve Hayvancıllk Bakanlığı Bitkisel Üretim Genel Müdürlügüü. www. tarim.gov.tr. Erişim tarihi: 25.05.2016

- GLOBALGAP, 2014. GLOBALGAP Entegre Çiftlik Güvensesi Standardı V5. www.globalgap.org. Erişim tarihi: 25.05 .2016

- Hasdemir, M. 2009. Dünya'da ve Türkiye'de İyi Tarım Uygulamaları. Standard Ekonomik ve Teknik Dergi, Y11:48, Say1: 565, Ankara.

- Hasdemir, M. ve Bayaner, A., 2009. Dünya'da Ve Türkiye'de Organik Tarıma Bakış. Standard Ekonomik ve Teknik Dergi, Yıl 48, Sayı 567, Ankara

- Hasdemir, M. ve Özkan, F.Z. 2015. Tarım Ürünleri Belgelendirmesi Yapan Kuruluşların Akreditasyon Standartlarında Yaşanan Değişimin Sektörel Etkileri. Çanakkale Onsekiz Mart Üniversitesi Ziraat Fakültesi Dergisi (COMU J. Agric. Fac.) 2015: 3 (1): 133-142

- ISO, 2016. Yönetim Sistemi Standartları. Uluslarası Standard Organizasyonu.www.iso.org. Erişim tarihi:25.05.2016

- TSE, 2016. Standard Hizmetleri. Türk Standartlar Enstitüsü. www.tse.org.tr. Erişim tarihi: 25.05.2016

- TÜRKAK, 2016. Sistem Organizasyon Başkanlığı. Türk Akreditasyon Kurumu.www.turkak.org.tr. Erişim tarihi:25.05.2016 


\title{
Kooperatif Ortaklarının Kooperatif Yönetimine Katılma Durumları ve Eğilimleri: Tarım Kredi Kooperatifleri Balıkesir Bölge Birliği Örneği
}

\section{Cooperative Members' Participation Status and Trends to Cooperative Management: Case of Regional Union of Agricultural Credit Cooperative in Balıkesir}

\author{
Dr. Bengü Everest (Çanakkale Onsekiz Mart University, Turkey) \\ Prof. Dr. Murat Yercan (Ege University, Turkey)
}

\begin{abstract}
Cooperatives are organizations that are managed by partners. The behavior and approaches of the partners related to cooperative management affect the success of the cooperative. This study aimed to determine the following; level of awareness about the cooperative management of members, tasks take trends in the cooperative management who didn't take task in the cooperative management, members participate in the cooperative management. The data were obtained by face-to-face interviews with the 367 cooperative members in Balıkesir, Bursa and Çanakkale province. Participation of members in the cooperative management of the situation revealed non-parametric statistical methods, logistic regression analysis method and fuzzy paired comparison method were used. 56,25\% of the members think as, "states should be effective in reaching decisions on the cooperative". According to logistic regression analysis young partners tend to think that way than older partners. Only $20 \%$ of members who didn't take task in the cooperative management, want to take task in the cooperative management in future. These members follow-up agricultural meetings and use internet for reach agricultural information. $45 \%$ of members joined last cooperative management meeting. According to fuzzy paired comparison method, the most influential factor in the choose management decision is "to trust management candidate".
\end{abstract}

\section{Giriș}

Son günlerde önemi üzerinde daha fazla konuşulan kooperatifler dünya genelinde hemen hemen her alanda faaliyet göstermektedirler. Kooperatifler ortakları tarafından yönetilen girişimler olup bir araya gelen insanların kendi kendilerine yardım etmeleri prensibine göre çalışırlar. Kooperatiflerin faaliyetlerini daha başarılı bir şekilde gerçekleştirmeleri direkt kooperatif ortakları ile ilgilidir. Kooperatiflerde başarının sağlanmasında ortakların ilk rolü gerçekleştirdikleri faaliyeti profesyonelce yapmalarıdır. Örneğin tarımsal kooperatiflerde ortaklar tarımsal faaliyet uygulamalarında ne kadar güçlü/etkili olursa bu durum üreticilerin ortağı oldukları kooperatifi o kadar olumlu yönde etkileyecektir. Ancak bu başarı tek başına kooperatifin de başarılı olacağı anlamına gelmez. Ortakların bireysel başarılarının kooperatif başarısını artırması için ortaklar kooperatiflerine sıkıca bağlı olmalı ve ortakların kooperatifçilik bilinçleri yüksek olmalıdır. Ortaklar kooperatiflerine ne kadar fazla sahip çıkarlarsa kooperatifler de o kadar güçlenecektir.

Ortakların kooperatiflerine olan bağlılıklarını ortaya koymada, ortakların kooperatif yönetimine olan katkısını ve katılımını ele almak değerlendirilecek unsurlardan biridir. Dolayısıyla ortakların kooperatif yönetimine katılma durumlarının ve katılmayı isteme eğilimlerinin bilinmesi önemlidir. Buradan yola çıkarak bu araştırmada Tarım Kredi Kooperatifi ortaklarının kooperatif yönetimine katılma durumları ve bunu etkileyen faktörleri belirlemek amaçlanmıştır.

Ayrıca kooperatif yönetimine ilişkin diğer araştırmacılar tarafindan yapılmış çalışmalara kısaca yer vermenin faydalı olacağı düşünülmektedir. Örneğin Özdemir (1996), Tekirdağ ilinde kooperatif ortağı 225 çiftçi ile anket çalışması yapmıştır. Araştırmada ortakların kooperatif yönetimine katılmaları, genel kurula katılım, genel kurulda konuşma durumları, yönetim ve denetim kuruluna aday olma durumları, yönetim kurulu kararlarını takip etme durumları ele alınmıştır. Gray and Kraenzle (1998), süt kooperatifine katılımı etkileyen faktörleri analiz etmişlerdir. Kooperatife katılım, kooperatif toplantılarına katılım, kooperatifte görev alma, diğer çiftçilerin kooperatife katılmasını sağlamak ile olmaktadır. Ortakların toplu eylem yapmaları, çiftçilikte mesleki doyum, kooperatif operasyonlarından memnuniyet, kooperatif ortakları arasında eşitlik olması, kooperatif menfaatlerine göre karar verme özellikleri kooperatif katılımında önemli faktörler olarak bulunmuştur. Ertan ve Turan (2001), Gülbirlik ortaklarını kooperatif-ortak ilişkisi yönünden analiz etmişlerdir. Çalışmada ortakların genel kurul toplantılarına katılma durumları, kooperatif yönetimine yapılan atamalar ve kooperatif yönetimi hakkındaki görüşleri ele alınmıştır. Bilgin vd. (2005), Tariş ortaklarıyla yürüttükleri çalışmada kooperatif ortaklarının kooperatif yöneticilerine ve birbirlerine yönelik duygusal ve bilişsel güvenlerini incelemişlerdir. Duygusal ve bilişsel güven kooperatife olan bağlılığ artırmaktadır. Yöneticilere bilişsel güvenin artmasında etkili olabilecek faaliyetleri yapmaları tavsiye edilmiştir. Östergerb et al., (2007), çalışmalarında 60 yaşından büyük çiftçilerin 
kooperatif yönetimine katılmayı 60 yaşından küçük çiftçilere göre daha fazla önemsediklerini bulmuşlardır. Loursen et al., (2008), modern Danimarka kooperatifleri arasında tarım kooperatiflerine olan ortak katılımı ve kooperatiflerin organizasyon karakterini ele aldıkları çalışmalarında kooperatife olan toplam bağımlılığın kooperatiften memnuniyet üzerinde bir etkiye sahip olduğunu bulmuşlardır. Tan and Everest (2010), çalışmalarında Çanakkale ilinde süt konusunda faaliyet gösteren kooperatif yöneticilerinin profillerini ortaya koymuşlardır. 191 kooperatif yöneticisi ile anket çalışması yapılmış ve kooperatif yöneticilerinin sosyo-ekonomik yönleri incelenmiştir. Çalışmada kooperatif yöneticilerinin ortaklara tarımsal konularda eğitim programları hazırlamaları ile yöneticilerin yöneticilik deneyimleri ve tarımsal aktiviteleri takip etmeleri arasında istatistiksel olarak anlamlı ilişkiler bulunmuştur. Xiang and Sumelius (2010), Finlandiya'da çiftçilerin kooperatif yönetimine katılmalarında etkili olan faktörlerin analizini yapmışlardır. Çalışma Finlandiya'ya özgü süt kooperatifine ortak 200 çiftçi ile yapılan anket çalışmasının verilerine dayanmaktadır. Çalışmada ortakların motivasyonları ile isteklilikleri ve çiftçilerin davranışları; çiftçilerin kişisel özellikleri, aile özellikleri, diğer üyelerin tutumları, güven faktörü ve çiftçilerin ihtiyaçlarını açıklayan faktörler ele alınarak değerlendirilmiştir. Didier et al., (2012), çalışmalarında kooperatiflerde ortakların güvenleri ve yönetime katılmaları arasındaki ilişkiyi ele almışlardır. Kooperatif ortağı çiftçilerin yönetime katılma davranışları açıklanırken iki kavram dikkate alınmıştır: Güven ve örgütsel bağlılık. Çalışma Fransız tarımsal kooperatiflerinden seçilmiş 259 kooperatif ortağı ile yürütülmüştür. Çalışmada ortakların kooperatife olan duygusal bağlılıklarının kooperatife güvenmekte ve yönetime katılmakta etkili olduğu sonucuna varılmıştır. Espallardo et al., (2012), yapmış oldukları araştırmada çiftçilerin tarımsal pazarlama kooperatifine ortak olmada memnuniyetlerini ve kooperatif ortaklı̆̆ına devam etme niyetlerini ele almışlardır. Çalışma taze meyve ve sebze pazarlayan kooperatifin 321 ortağı ile yapılan anket çalışmasına dayanmaktadır. Araştırmada fiyatların çiftçilerin kooperatif ortağı olarak kalmalarında doğrudan önemli bir etkiye sahip olmadığı ve ortakların kooperatiften memnun oldukları bulunmuştur. Zakic et al., (2013), Sırbistan'da tarımsal kooperatif ortaklarının önemli konuları algılamalarını araştırmışlardır. Çalışma 11 kooperatifin 228 ortağı ile yürütülmüş ve ortakların liderlik, motivasyon, bilgi düzeyi ve deneyim konuları ele alınmıştır. Araştırmaya göre başarılı bir kooperatif için ve kooperatifin gelişmesi için kooperatif ortaklarının liderlik algısı önemli ve gereklidir. Ayrıca çalışmada kooperatif ortaklarının kooperatifle daha sıkı çalışmak istedikleri tespit edilmiştir.

\section{Materyal ve Yöntem}

Araştırmanın ana materyalini Tarım Kredi Kooperatifleri Balıkesir Bölge Birlıği’ne bağlı Balıkesir, Bursa ve Çanakkale illerindeki Tarım Kredi Kooperatifleri ortaklarından anket yoluyla elde edilen birincil nitelikli veriler oluşturmaktadır. Büyük Ölçekli (A Ölçekli), Orta Ölçekli (B Ölçekli), Küçük Ölçekli (C Ölçekli) ve Çok Küçük Ölçekli (D Ölçekli) kooperatifler ayrı ayrı her il için sıralanarak ilk sıradaki kooperatif, orta sıradaki kooperatif ve son sıradaki kooperatif gayeli olarak seçilmiştir. Seçilen bu kooperatif ortakları araştırmanın popülasyonunu oluşturmaktadır. Örnek hacmi aşağıdaki formüle göre belirlenmiştir (Miran, 2010).

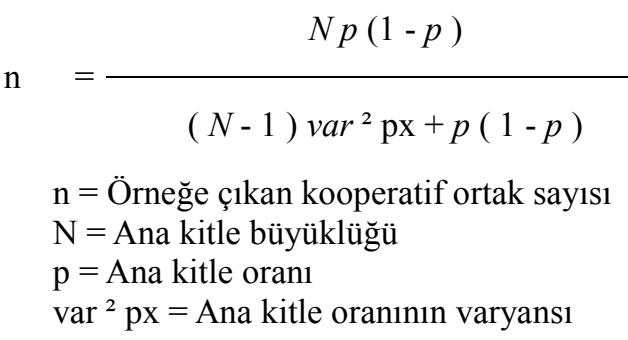

Araştırmada en yüksek örnek hacmine ulaşmak için 0.10 hata payı ve \%95 güven aralığı ile çalışılmış ve örnek hacmi toplam 367 olarak belirlenmiştir. Araştırmada ortakların sosyo-ekonomik durumlarını ve kooperatif yönetimine katılma durumlarını ortaya koymak amacıyla temel tanımlayıcı istatistikler kullanılmıştır. Ortakların kooperatif yönetimine katılmalarında etkili olan faktörler lojistik regresyon yöntemi ile analiz edilmiştir. Ortakların kooperatif yöneticilerini seçerken dikkat ettikleri hususların belirlenmesinde bulanık eşli karşılaştırma (BEK) yönteminden yararlanılmıştır. Bulanık eşli karşılaştırma sonucu verilerin yorumlanmasında Friedman ve Kendall's W testleri kullanılmıştır.

\section{Araştırma Bulguları ve Tartışma}

Çiftçilerin \%55,31'i 55 yaşın altındadır. Yaşı 56-65 arası olanların oranı \%28,07 ve yaşı 65'den büyük olanların oranı \%16,62 olarak bulunmuştur. Çiftçilerin eğitim durumlarının ilkokul seviyesinde yı̆̆ıldığı görülmektedir $(\% 69,48)$. Ortaokul mezunu olanların oranı \%11,99, lise mezunu olanların oranı \%15,80 ve üniversite mezunu olanların oranı \% 1,63 olarak belirlenmiştir. Çiftçilerin yaklaşık yarısının $(\% 49,59)$ mesleki deneyim süresi 30 yılın altındadır. Çiftçilerin \%27,52'sinin çiftçilik deneyim süresinin 31-40 y1l arasında olduğu, \%22,89'unun çiftçilik deneyim süresinin 40 yıldan fazla olduğu görülmüştür. Çiftçilerin yıllık tarımsal gelir aralıklarında ilk sırayı $\% 45,78$ 'lik oranla 10001-25000 TL gelir aralığ almaktadır. Bunu \%29,16'lık oranla 25001-50000 TL gelir aralığ $\% 14,71$ 'lik oranla $<10000$ TL gelir aralığı, \%6,54'lük oranla 50001-100000 TL gelir aralığı ve \%3,81'lik oranla 
>100001 TL gelir aralığı takip etmektedir. Çiftçilerin \%63,76’sının tarım dışı gelirinin bulunduğu, \%36,24'ünün tarım dış1 geliri bulunmadığı görülmüştür. Çiftçilerin tarım kredi kooperatifine ortaklık yılı en az 1 yıl ve en çok 60 yıl olup ortalama 17 yıl olarak tespit edilmiştir. Kooperatifi ziyaret sıklı̆̆ında ilk sırayı \%31,88'lik oranla "Ayda bir defa ziyaret edenler" almaktadır. Araştırma bölgesinde çiftçilerin \%45,50'sinin son bir yıl içinde yapılan tarımsal toplantılara katıldığı, \%54,50'sinin katılmadığı tespit edilmiştir. Çiftçilerin \%96,19 gibi büyük bir çoğunluğunun tarımsal gazete, dergi gibi bir yayına üye olmadığı belirlenmiştir. Balıkesir, Bursa ve Çanakkale illerindeki çiftçilerin yaklaşık \%30’nunun tarımsal bilgilere ulaşmada interneti kullanabildiği görülmüştür (Tablo 1).

\begin{tabular}{|c|c|c|}
\hline Yaș grupları & Sayı & $\%$ \\
\hline$\leq 35$ & 17 & 4,63 \\
\hline $36-45$ & 64 & 17,44 \\
\hline $46-55$ & 122 & 33,24 \\
\hline $56-65$ & 103 & 28,07 \\
\hline$>65$ & 61 & 16,62 \\
\hline \multicolumn{3}{|l|}{$\operatorname{Min}=24$, Mak $=85$, Ort $=53$, S. Sapma $=11$} \\
\hline Eğitim seviyesi & Sayı & $\%$ \\
\hline Okuryazar & 4 & 1,09 \\
\hline İlkokul & 255 & 69,48 \\
\hline Ortaokul & 44 & 11,99 \\
\hline Lise & 58 & 15,80 \\
\hline Üniversite & 6 & 1,63 \\
\hline Çiftçilik deneyimi (yıl) & Sayı & $\%$ \\
\hline$<=10$ & 18 & 4,90 \\
\hline $11-20$ & 63 & 17,17 \\
\hline $21-30$ & 101 & 27,52 \\
\hline $31-40$ & 101 & 27,52 \\
\hline$>=41$ & 84 & 22,89 \\
\hline \multicolumn{3}{|l|}{ Min $=1$, Mak=70, Ort $=33$, S. Sapma $=13$} \\
\hline Yıllık tarımsal gelir aralığı (TL) & Sayı & $\%$ \\
\hline$<10000$ & 54 & 14,71 \\
\hline $10001-25000$ & 168 & 45,78 \\
\hline $25001-50000$ & 107 & 29,16 \\
\hline $50001-100000$ & 24 & 6,54 \\
\hline$>100001$ & 14 & 3,81 \\
\hline Tarım dışı gelir varlığı & Sayı & $\%$ \\
\hline Var & 234 & 63,76 \\
\hline Yok & 133 & 36,24 \\
\hline Kooperatife ortaklık yılı & Sayı & $\%$ \\
\hline $1-10$ & 132 & 35,97 \\
\hline $11-20$ & 122 & 33,24 \\
\hline $21-30$ & 77 & 20,98 \\
\hline $31-40$ & 31 & 8,45 \\
\hline$>=41$ & 5 & 1,36 \\
\hline \multicolumn{3}{|l|}{ En küçük $=1$ En büyük $=60$ Ortalama $=17,02$ Std. Sapma $=11,04$} \\
\hline Kooperatifi ziyaret sıklığı & Sayı & $\%$ \\
\hline Haftada bir defa & 98 & 26,70 \\
\hline Ayda bir defa & 117 & 31,88 \\
\hline Birkaç ayda bir defa & 53 & 14,44 \\
\hline Nadiren & 99 & 26,98 \\
\hline Son bir yılda tarımsal toplantılara katılma durumu & Sayı & $\%$ \\
\hline Katılan & 167 & 45,50 \\
\hline Kat1lmayan & 200 & 54,50 \\
\hline Herhangi bir tarımsal yayına üyelik durumu & Sayı & $\%$ \\
\hline Üye & 14 & 3,81 \\
\hline Üye değil & 353 & 96,19 \\
\hline Tarımsal bilgiye ulașmada internetten faydalanma durumu & Sayı & $\%$ \\
\hline Faydalanan & 110 & 29,97 \\
\hline Faydalanmayan & 257 & 70,03 \\
\hline
\end{tabular}

Tablo 1. Kooperatif Ortaklarına Ait Genel Özellikler 
Çiftçilerin kooperatif yönetimine katılmalarını tespit etmek amacıyla çiftçilerin yönetim kurulu üyesi, denetçi ya da temsilci görevlerinin olup olmadığı ya da geçmişte bu görevlerden birinde yer alıp almadıkları ya da ileride böyle bir isteklerinin olup olmadığı ele alınmıştır. Kooperatiflerin yönetiminde yer alan çiftçiler diğer çiftçilere göre kooperatif sorunları ile daha yakından ilgilenirler ve kooperatifin gelişmesi için daha fazla çaba harcarlar. Dolayısıyla çiftçilerin kooperatif yönetiminde görev almış olmaları ya da görev almak istemeleri kooperatifi sahiplenme durumları ile ilgili bilgi vermektedir. Araştırma bölgesindeki çiftçilerin \%10,90'ının anket yapılan dönemde kooperatif yönetiminde yönetim kurulu üyesi, denetçi ve temsilci gibi görevleri olduğu bulunmuştur. Kooperatif yönetiminde anket yapılan dönemde herhangi bir görevi olmayan çiftçilerin geçmişte kooperatif yönetiminde görevlerinin olup olmadığı araştırılmıştır. Buna göre kooperatif yönetiminde anket yapma döneminde görevi olmayan çiftçilerin \%11'i daha önce kooperatif yönetiminde görev almıştır. Buna karş1lık çiftçilerin \%89'u daha önce kooperatif yönetiminde hiç görev almamıştır. Daha önce kooperatif yönetiminde hiç tecrübesi olmayan çiftçilerin \%20,62'si kooperatif yönetiminde görev almak istemekte, buna karşılık çiftçilerin \% 79,38 'i kooperatif yönetiminde görev almak istememektedir. Daha önce kooperatif yönetiminde hiç görev almamış ve bundan sonra da görev almayı düşünmeyen çiftçilerin \%51,52'si yöneticilik yapmanın zor bir iş olduğunu düşünmekte, \%38,96's1 zamanı olmadığ1 için ve \%9,52'si yaşlı olduğu için kooperatif yönetiminde görev almayı düşünmemektedir (Tablo 2).

Kooperatif ana sözleşmeleri kooperatifle ilgili, kuruluş, çalışma konuları, ortaklık şartları, kooperatif sermayesi, ortakların sorumlulukları, kooperatif organları seçimi ve sorumlulukları gibi konularla ilgili kararları içeren önemli bir belgedir. Çiftçiler ortağı oldukları kooperatifleri daha yakından tanırlarsa kooperatifi daha fazla sahipleneceklerdir. Bir kooperatifi daha iyi tanıyabilmek için kooperatifle ilgili tüm konuların yer aldığı kooperatif ana sözleşmesini okumak gerekmektedir. Araştırmada çiftçilere ortağı oldukları tarım kredi kooperatiflerine ait kooperatif ana sözleşmesini daha önce okuyup okumadıkları sorulmuştur. Araştırma bölgesindeki çiftçilerin \%26,98'i kooperatif ana sözleşmesini okumuş, \%73,02'si okumamıştır. Ana sözleşmeyi okumayan çiftçilerin \%56,34'ü ana sözleşmeyi okumaya gerek duymadığı için okumadığını, \%24,25'i ana sözleşmenin çok uzun ve yazılarının çok küçük olması sebebiyle okumadığını, \%8,21'i zamanı olmadığı için okumadığını ve \%11,19'u ana sözleşme eline geçmediği için okumadığını ifade etmiştir (Tablo 2).

Ortakların kooperatif toplantılarını takip etmeleri ve toplantılara aktif olarak katılmaları, ortakların kooperatif yönetimine katılmaları ile ilgili önemli bir göstergedir. Araştırmada çiftçilere ortakları olduğu tarım kredi kooperatiflerinin son yapılan genel kurul toplantısına katılıp katılmadıkları sorulmuştur. Araştırma bölgesindeki çiftçilerin \%45,50'si son yapılan genel kurul toplantısına katılmışken, \%54,50'si katılmamıştır. Toplantıya katılmayan çiftçilerin \%42'si zamanı olmadığı için, \%21'i toplantıdan haberi olmadığı için, \%7'si yeni ortak olduğu için, \%8'i toplantıları sevmediği için ve \%4,5'i kooperatife borcu olduğu için son yapılan genel kurul toplantısına katılmamıştır. Toplantılara katılmayanların \% 17,5'i ise katılmama nedenini belirtmemiştir. Kooperatif toplantılarına katılmayanların \%20'si toplantı kararlarını daha sonra takip ederken, \%80'i alınan kararları takip etmemektedir (Tablo 2). 


\begin{tabular}{|c|c|c|}
\hline Kooperatif yönetiminde görev alma durumu & Sayı & $\%$ \\
\hline Görevli olanlar & 40 & 10,90 \\
\hline Görevli olmayanlar & 327 & 89,10 \\
\hline Kooperatif yönetiminde görevi olmayanların geçmişte görevi & Sayı & $\%$ \\
\hline Görevli olanlar & 36 & 11,00 \\
\hline Görevli olmayanlar & 291 & 89,00 \\
\hline İleride kooperatif yönetiminde görev alma isteği & Sayı & $\%$ \\
\hline İsteyenler & 60 & 20,62 \\
\hline İstemeyenler & 231 & 79,38 \\
\hline Kooperatif yönetiminde görev almak istememe nedenleri & Sayı & $\%$ \\
\hline Yöneticilik zor iş & 119 & 51,52 \\
\hline Zamanım yok & 90 & 38,96 \\
\hline Yaşliyım & 22 & 9,52 \\
\hline Kooperatif ana sözleșmesini okuma durumu & Sayı & $\%$ \\
\hline Okuyan & 99 & 26,98 \\
\hline Okumayan & 268 & 73,02 \\
\hline Kooperatif ana sözleșmesini okumama nedenleri & Sayı & $\%$ \\
\hline Gerek duymadim & 151 & 56,34 \\
\hline Çok uzundu ve yazılar küçüktü & 65 & 24,25 \\
\hline Zamanım yoktu & 22 & 8,21 \\
\hline Elime geçmedi & 30 & 11,19 \\
\hline Son yapılan kooperatif genel kurul toplantısına katılma durumu & Sayı & $\%$ \\
\hline Katılan & 167 & 45,50 \\
\hline Katılmayan & 200 & 54,50 \\
\hline Kooperatif genel kurul toplantısına katılmama nedenleri & Sayı & $\%$ \\
\hline Zamanım yoktu & 84 & 42,00 \\
\hline Haberim olmadi & 42 & 21,00 \\
\hline Yeni ortak & 14 & 7,00 \\
\hline Toplant1lar1 sevmiyorum & 16 & 8,00 \\
\hline Kooperatife borcum var & 9 & 4,50 \\
\hline Cevap yok & 35 & 17,50 \\
\hline Toplantıya katılmayanların alınan kararları takip etme & Sayı & $\%$ \\
\hline Takip eden & 40 & 20,00 \\
\hline Takip etmeyen & 160 & 80,00 \\
\hline
\end{tabular}

Tablo 2. Kooperatif Ortaklarının Kooperatif Yönetimine Katılmaları

Araştırmada kooperatif yönetiminde hiç görev almamış çiftçilerin, ilerleyen yıllarda kooperatif yönetiminde görev alma isteklerini etkileyen faktörler Lojistik Regresyon ile analiz edilmiştir. Modelin bağımlı değişkeni, çiftçilerin kooperatif yönetiminde yönetim kurulu, denetçi ya da temsilci olarak görev alma istekleridir. Çiftçilerin kooperatif yönetiminde görev almak istemeleri 1, görev almak istememeleri 0 olarak kabul edilmiştir. Kooperatif yönetiminde görev almak istemede etkili olabilecek açıklayıcı değişkenler yaş (yıl), eğitim seviyesi (1: Okur-yazar, 2: İlkokul, 3: Ortaokul, 4: Lise, 5: Üniversite, 6: Lisansüstü), kooperatife ortaklık yılı, tarımsal toplantılara/eğitimlere katılma durumu (1: Katılan, 0: Katılmayan), tarımsal yayınlara üye olma durumu (1: Üye, 0: Üye değil), internet kullanma durumu (1: Kullanan, 0: Kullanmayan), kooperatif kararlarında yetkili olan kişiler (1: Kooperatif yönetim kurulu, 2: Kooperatif müdürlüğ̈̈), kooperatifi demokratik bulma (1: Demokratik, 0: Demokratik değil), kooperatif eğitimi alma (1: Alan, 0: Almayan), kooperatif ana sözleşmesini okuma (1: Okuyan, 0: Okumayan), genel kurul toplantılarına katılma (1: Katılan, 0: Katılmayan), yıllık tarımsal gelir düzeyi (1: $<10000$ TL, 2: 10000-20000, 3: 20000-50000, 4: 50000-100000, 5: >100000), tarım diş1 gelir varlığ (1: Olan, 0: Olmayan) ve kooperatifi ziyaret sıklığıdır (1: Nadiren, 2: Birkaç ayda bir, 3: Ayda bir, 4: Haftada bir) Modelin çözümlenmesinden sonra istatistiki açıdan anlamlı çıkan değişkenler açıklanmıştır (Tablo 3).

Model genel olarak anlamlı çıkmıştır $\left(X^{2}: 47.6598\right.$, p: 0.0000). Analiz sonucuna göre tarımsal toplantılara katılma durumu, internet kullanma durumu, tarım dışı gelir varlığı ve kooperatifi ziyaret sıklığı kooperatif yönetiminde görevi olmayan çiftçilerin kooperatif yönetiminde rol alma isteklerinde etkili faktörler olarak bulunmuştur.

Çiftçilerin tarımsal toplantılara katılma durumları ile kooperatif yönetiminde görev alma istekleri arasındaki ilişki pozitif yönlü olup toplantılara katılma \%5 için anlamlıdır. Tarımsal toplantılara katılan çiftçilerin (çiftçilerin $\% 45,50$ ’si), kooperatif yönetiminde görev alma isteği eğilimleri \%12 daha fazladır (Tablo 3).

Çiftçilerin bilgiye ulaşmak amacıyla internet kullanmaları ile ileride kooperatif yönetiminde görev alma istekleri arasındaki ilişki pozitif yönlüdür. İnternet kullanan çiftçilerin $(\% 29,97)$ kooperatif yönetiminde görev alma isteği eğilimleri, internet kullanmayan çiftçilere göre \%11 daha fazladır (Tablo 3). 
Çiftçilerin tarımsal faaliyet dışında ilave bir gelirlerinin olması ile kooperatif yönetiminde görev alma istekleri arasındaki ilişki negatif yönlüdür. Tarım dışı geliri olmayanların (çiftçilerin \% 036,24 ’ü) kooperatif yönetiminde görev alma isteği eğilimleri \%16 daha fazladır (Tablo 3).

Çiftçilerin kooperatif yönetiminde görev alma istekleri ile anlamlı bir ilişki bulunan bir diğer değişken çiftçilerin kooperatifi ziyaret sıklığı olup değişkenler arasındaki ilişki negatif yönlüdür. Yani kooperatifi daha sık ziyaret edenlerin kooperatif yönetiminde görev alma isteği eğilimleri zayıftır (Tablo 3).

\begin{tabular}{|c|c|c|c|c|}
\hline Değișkenler & Katsayı & Std. Hata & p-Değeri & Ĕğim \\
\hline Sabit & -2.88067 & 1.46693 & 0.04956 & \\
\hline Yaş & 0.011336 & 0.0183704 & 0.53718 & 0.0015133 \\
\hline Eğitim & 0.111847 & 0.209255 & 0.59299 & 0.0149311 \\
\hline Ortaklik Y1lı & -0.00256873 & 0.0177798 & 0.88513 & -0.000342913 \\
\hline Tarımsal Toplantılara Katılım & 0.878018 & 0.35959 & $0.01462 * *$ & 0.122579 \\
\hline Tarımsal Yayın Üyeliği & -0.91481 & 0.799338 & 0.25243 & -0.091244 \\
\hline İnternet Kullanma & 0.772393 & 0.387839 & $0.04642 * *$ & 0.114561 \\
\hline Koop. Kararlarında Yetkili Olan Kişiler & -0.0167198 & 0.334934 & 0.96019 & -0.00223201 \\
\hline Kooperatifi Demokratik Bulma & -0.521425 & 0.332696 & 0.11705 & -0.0709078 \\
\hline Koop.Eğitimi Alma & -0.0754722 & 0.477539 & 0.87442 & -0.00990771 \\
\hline Ana Sözleşmeyi Okuma & 0.241733 & 0.385953 & 0.53110 & 0.0336031 \\
\hline Genel Kurul Toplantılarına Katılma & -0.219644 & 0.360903 & 0.54279 & -0.0287546 \\
\hline Tarımsal Gelir & -0.203824 & 0.187101 & 0.27599 & -0.0272095 \\
\hline Tarım D1ş1 Gelir Varlı̆̆1 & -1.1397 & 0.363067 & $0.00169 * * *$ & -0.167828 \\
\hline Kooperatifi Ziyaret S1klığ1 & -0.52216 & 0.152255 & $0.00060 * * *$ & -0.0697058 \\
\hline $\mathrm{X}^{2}$ & \multicolumn{4}{|c|}{47.6598 (p: 0.0000$)$} \\
\hline
\end{tabular}

Tablo 3. Kooperatif Yönetiminde Görev Alma İsteğini Etkileyen Faktörler

Çiftçilerin kooperatif ana sözleşmesini okumaları üzerinde etkili olan faktörlerin analizinde modelinin bağımlı değişkeni, çiftçilerin kooperatif ana sözleşmesini okuma durumlarıdır. Kooperatif ana sözleşmesini okuyanlar 1, okumayanlar 0 olarak kabul edilmiştir. Kooperatif ana sözleşmesini okumada etkili olabilecek açıklayıcı değişkenler yaş (yıl), eğitim seviyesi (1: Okur-yazar, 2: İlkokul, 3: Ortaokul, 4: Lise, 5: Üniversite, 6: Lisansüstü), kooperatife ortaklık yılı, tarımsal toplantılara/eğitimlere katılma durumu (1: Katılan, 0: Katılmayan), tarımsal yayınlara üye olma durumu (1: Üye, 0: Üye değil), internet kullanma durumu (1: Kullanan, 0: Kullanmayan), kooperatifi ziyaret sıklığı (1: Nadiren, 2: Birkaç ayda bir, 3: Ayda bir, 4: Haftada bir), kooperatif kararlarında yetkili olan kişiler (1: Kooperatif yönetim kurulu, 2: Kooperatif müdürlüğü), kooperatif eğitimi alma (1: Alan, 0: Almayan), kooperatif yönetiminde görevi olma durumu (1: Olan, 0: Olmayan), yıllık tarımsal gelir düzeyi (1: $<10000$ TL, 2: 10000-20000, 3: 20000-50000, 4: 50000-100000, 5:>100000) ve tarım dışı gelir varlığıdır (1: Olan, 0: Olmayan). Modelin çözümlenmesinden sonra istatistiki açıdan anlamlı çıkan değişkenler açıklanmıştır (Tablo 4).

Model genel olarak anlamlı çıkmıştır ( $X^{2}: 35.3043$, p: 0.0004). Analiz sonucuna göre tarımsal toplantılara katılma durumu çiftçilerin kooperatif ana sözleşmesini okuma üzerinde pozitif yönde etkilidir. Toplantılara katılma \%1 için anlamlı olup, tarımsal toplantılara katılan çiftçilerin (çiftçilerin \%45,50'si) kooperatif ana sözleşmesini okuma eğilimi, toplantılara katılmayan çiftçilere göre \%20 daha fazladır (Tablo 4).

\begin{tabular}{|c|c|c|c|c|}
\hline Değișkenler & Katsayı & Std. Hata & p-Değeri & Ĕğim \\
\hline Sabit & -1.79707 & 1.12979 & 0.11169 & \\
\hline Yaş & -0.00343322 & 0.0149262 & 0.81808 & -0.000641106 \\
\hline Eğitim & 0.137183 & 0.164309 & 0.40377 & 0.0256171 \\
\hline Ortaklık Y1lı & -0.00588416 & 0.0137837 & 0.66946 & -0.00109879 \\
\hline Tarımsal Toplantılara Katılım & 1.08035 & 0.264562 & $0.00004 * * *$ & 0.205107 \\
\hline Tarımsal Yayın Üyeliği & 0.379306 & 0.60124 & 0.52812 & 0.0768008 \\
\hline İnternet Kullanma & -0.491717 & 0.321775 & 0.12648 & -0.08717 \\
\hline Kooperatifi Ziyaret Siklığı & 0.144167 & 0.118518 & 0.22383 & 0.0269211 \\
\hline Kooperatif Kararlarında Yetkili Olan Kişiler & 0.0705875 & 0.255083 & 0.78199 & 0.0131812 \\
\hline Koop. Eğitimi Alma & 0.50798 & 0.311773 & 0.10324 & 0.10207 \\
\hline Kooperatif Yönetiminde Görevi Olma & 0.516267 & 0.386878 & 0.18206 & 0.105603 \\
\hline Tarımsal Gelir & 0.124933 & 0.139361 & 0.37000 & 0.0233296 \\
\hline Tarım D1ş1 Gelir Varlığ1 & 0.101899 & 0.292328 & 0.72741 & 0.0188956 \\
\hline$X^{2}$ & \multicolumn{4}{|c|}{$35.3043(\mathrm{p}: 0.0004)$} \\
\hline
\end{tabular}

Tablo 4. Kooperatif Ana Sözleşmesini Okumayı Etkileyen Faktörler 
Çiftçilerin kooperatif genel kurul toplantısına katılmaları üzerinde etkili olan değişkenlerin analizinde bağımlı değişken çiftçilerin kooperatif genel kurul toplantısına katılma durumlarıdır (1: Katılanlar, 0: Katılmayanlar). Bağımlı değişkenin açıklanmasında kullanılan bağımsız değişkenler yaş (yıl), eğitim seviyesi (1: Okur-yazar, 2: İlkokul, 3: Ortaokul, 4: Lise, 5: Üniversite, 6: Lisansüstü), kooperatife ortakl1k yıl1, tarımsal toplantılara/eğitimlere katılma durumu (1: Katılan, 0: Katılmayan), tarımsal yayınlara üye olma durumu (1: Üye, 0: Üye değil), internet kullanma durumu (1: Kullanan, 0: Kullanmayan), kooperatifi ziyaret sıklığı (1: Nadiren, 2: Birkaç ayda bir, 3: Ayda bir, 4: Haftada bir), kooperatif eğitimi alma (1: Alan, 0: Almayan), kooperatif kararlarında yetkili olan kişiler (1: Kooperatif yönetim kurulu, 2: Kooperatif müdürlüğ̈), kooperatif yönetimiyle olan ilişki (1: Güçlü, 2: Geliştirilebilir, 3: Zayıf), kooperatif yönetim kurulu çalışmalarından memnun olma (1: Memnun, 0: Memnun değil), kooperatif müdürlüğü çalışmalarından memnun olma (1: Memnun, 0: Memnun değil), yıllık tarımsal gelir seviyesi ve tarım dışı gelir varlığıdır (1: Olan, 0: Olmayan) (Tablo 5).

Modelin çözümlenmesinden sonra istatistiki açıdan anlamlı çıkan değişkenler açıklanmıştır. Model genel olarak anlamlı çıkmıştır ( $X^{2}$ : 94.7, p: 0.0000). Analiz sonucuna göre çiftçilerin kooperatif genel kurul toplantısına katılmalarında etkili olan değişkenler kooperatife olan ortaklık yılı, tarımsal toplantılara katılma durumu ve çiftçilerin kooperatif yönetiminde yönetim kurulunun ya da kooperatif müdürlüğünün etkili olduğunu düşünmeleridir (Tablo 5).

Kooperatif ortaklık yılı \%5 için anlamlı olup ortaklık y1lı ile kooperatif yönetim kurulu toplantılarına katılma arasındaki ilişki pozitif yönlüdür. Kooperatife olan ortaklık yılının on yıl artması kooperatif genel kurul toplantılarına katılma eğilimini \%7 artırmaktadır (Tablo 5).

Çiftçilerin tarımsal eğitimlere katılma durumları ile kooperatif yönetim kuruluna katılmaları arasında da pozitif yönlü bir ilişki olup, tarımsal toplantılara katılma \%1 için anlamlıdır. Tarımsal toplantılara katılanların kooperatif genel kurul toplantılarına katılma eğilimi \%20 daha fazla bulunmuştur (Tablo 5).

Çiftçilerin kooperatif yönetiminde yönetim kurulu ya da kooperatif müdürlüğünün daha etkili olduğunu düşünmeleri ile kooperatif yönetim genel kurul toplantılarına katılmaları arasındaki ilişki pozitif yönlüdür. Kooperatif yönetiminde kooperatif müdürlüğünün daha fazla etkili olması gerektiğini düşünenlerin kooperatif genel kurul toplantılarına katılma eğilimi \%44 daha fazla bulunmuştur (Tablo 5).

\begin{tabular}{|c|c|c|c|c|}
\hline Değișkenler & Katsayı & Std.Hata & p-değeri & Ĕgim \\
\hline Sabit & -0.855287 & 1.26391 & 0.49860 & \\
\hline Yaș & -0.0068528 & 0.0143542 & 0.63307 & -0.0017009 \\
\hline Eğitim & -0.179384 & 0.170477 & 0.29269 & -0.0445235 \\
\hline Ortaklık Y1lı & 0.0276674 & 0.0129463 & $0.03259 * *$ & 0.0068671 \\
\hline Tarımsal Toplantılara Katılım & 0.850456 & 0.2597 & $0.00106 * * *$ & 0.2086 \\
\hline Tarımsal Yayın Üyeliği & 0.289119 & 0.636348 & 0.64958 & 0.0721302 \\
\hline İnternet Kullanma & 0.00569457 & 0.312787 & 0.98547 & 0.00141354 \\
\hline Kooperatifi Ziyaret Siklığ1 & 0.0400755 & 0.113233 & 0.72340 & 0.00994681 \\
\hline Koop. Eğitimi Alma & -0.143461 & 0.331758 & 0.66543 & -0.0354386 \\
\hline Koop. Kararlarında Yetkili Olan Kişiler & 1.92302 & 0.302279 & $<0.00001 * * *$ & 0.441453 \\
\hline Kooperatif Yönetimiyle Olan İlişki & -0.18522 & 0.216275 & 0.39177 & -0.0459719 \\
\hline Koop. Yönetim Kurulundan Memnun Olma & 0.283678 & 0.386553 & 0.46303 & 0.0697767 \\
\hline Kooperatif Müdürlüğünden Memnun Olma & 0.256433 & 0.420049 & 0.54154 & 0.0629393 \\
\hline Tarımsal Gelir & -0.038748 & 0.139381 & 0.78101 & -0.00961731 \\
\hline Tarım Dıș1 Gelir Varlığ & 0.00152358 & 0.287589 & 0.99577 & 0.000378147 \\
\hline $\mathrm{X}^{2}$ & \multicolumn{4}{|c|}{$94.7(\mathrm{p}: 0.0000)$} \\
\hline
\end{tabular}

\section{Tablo 5. Kooperatif Genel Kurul Toplantısına Katılmayı Etkileyen Faktörler}

Kooperatif ortaklarının kooperatif yönetimine katılmalarında yönetici, denetçi ve temsilci seçimlerinde etkili olan faktörler Bulanık Eşli Karşılaştırma ile ele alınmıştır. Ortaklara kooperatif yöneticilerinin seçiminde 3 amaç sunulmuş ve bu amaçlar arasında eşli karşılaştırmalar yapmaları sağlanmıştır. Ortakların bu amaçlara verdikleri ağırlıklar bulanık eşli karşılaştırma yöntemiyle belirlenmiştir. Daha sonra uygun istatistiki testler yapıılmıştır. Çiftçilerin kooperatifte yönetim kurulu, denetçi ve temsilci seçim amaçlarında etkili olan faktörlerin; adaya duyulan güven, adayın daha önce kooperatif organlarında görev almış olma durumu yani tecrübe ve adayın eğitim seviyesi olabileceği kabul edilmiştir. Bulanık eşli karşılaştırma yöntemi sonuçlarına göre çiftçiler kooperatif yönetimine katılırken kooperatif yöneticileri seçiminde en önemli faktör "Ortakların adaya duydukları "güven"dir. Çiftçiler için kooperatif yöneticileri seçiminde en fazla etkili olan ikinci faktör "Adaya kooperatif yönetimi tecrübe durumu"dur. Yönetici seçiminde çiftçiler için önemli olan üçüncü faktör ise "Adayların eğitim seviyesi” olarak tespit edilmiştir. Bulanık eşli karşılaştırma yöntemi için Friedman testi değerlendirildiğinde yöntemin istatistiki açıdan anlamlı olduğu görülmüştür. Buradan şu sonuç çıkarılabilir: bazı amaçlar diğerlerinin üzerinde tercih edilmektedir. Diğer bir anlatımla çiftçilerin kooperatif yöneticileri seçim amaçları arasında fark bulunmuştur. 
Kendall's W değeri 0.21 bulunmuştur. Buradan yola çıkarak amaç sıralamada çiftçiler arasındaki uyumun zayıf olduğunu söylemek mümkündür. Yani çiftçiler kooperatif yöneticisi seçimlerinde farklı açılardan değerlendirme yapmaktadirlar (Tablo 6).

\begin{tabular}{|l|c|c|c|c|}
\hline Amaçlar & Ortalama & Std. Sapma & Minimum & Maksimum \\
\hline Güven & 0,60 & 0,26 & 0,00 & 1,00 \\
\hline Tecrübe & 0,45 & 0,23 & 0,00 & 1,00 \\
\hline Eğitim & 0,29 & 0,27 & 0,00 & 1,00 \\
\hline Friedman testi $p<0.01$ için anlamlıdır \\
\hline \multicolumn{4}{|l|}{ Kendall's W = 0.21 }
\end{tabular}

Tablo 6. Bulanık Eşli Karşılaştırma Yöntemine Göre Çiftçilerin Kooperatif Yöneticileri Seçiminde Etkili Olan Amaçları

\section{Sonuç ve Öneriler}

Elde edilen bulgular genel olarak toparlanacak olursa ortakların kooperatif yönetimi ile ilgili bilinç düzeylerinde eğitim düzeyleri, hane nüfusları, kooperatife olan ortaklık yılları, tarımsal toplantılara katılma durumları, internet kullanma durumları, tarım dışı gelir durumları, kooperatifi ziyaret sıklıkları ve kooperatif konusunda eğitim almış olmaları etkili faktörler olarak bulunmuştur. Dolayısıyla bölgede kooperatif bilincinin geliştirilmesi çalışmalarında çiftçilerin bu özellikleri göz önünde tutulmalıdır. Bölgede kooperatifçilik bilincinin geliştirilmesi için şunlar tavsiye edilmektedir: Kooperatif bilincini geliştirecek broşür, dergi, gazete, kitap gibi basılı yayım materyalleri çiftçilerin kolaylıkla ulaşabilecekleri şekilde yaygınlaştırılmalıdır. Kooperatif yönetimine aday olacak kişilerin belirli bir kooperatif eğitimini alması gerekmektedir. Böylece en azından kooperatifçilik yöneticiliği yapacakların kooperatifçilik bilinci daha gelişmiş olacaktır. Bölgede internet kullanımının yaygınlaştırılması faydalı olacaktır. Ortakların kooperatif yönetim kurulu toplantılarına katılmaları ve kooperatif ana sözleşmesinin okunması için kooperatif yönetimleri çaba göstermelidir.

\section{Kaynakça}

- Bilgin, N., Ergun, E. ve Aydınlı, H., İ., 2005, "Tarımsal Kooperatiflerde Etik ve Güvenin Ortakların Performansı Üzerindeki Etkileri”, Üçüncü Sektör Kooperatifçilik Dergisi. p. 50. Sayı: 148. ISSN: 1300-1469.

- $\quad$ Didier, V., B., Henninger, M., C. And Akremi, A., E., 2012, “The Relationship Between Members' Trust and Participation in the Governance of Cooperatives: The Role of Organizational Commitment", International Food and Agribusiness Management Review, 75 p. Volume 15, Issue 1.

- Ertan, A. ve Turan, A., 2001, “Gülbirlik Ortaklarının Kooperatif Ortak İlişkisi Yönünden Analizi”, Süleyman Demirel Üniversitesi İktisadi ve İdari Bilimler Fakültesi Dergisi, C:6, s: 2. s. 29-43.

- Espallardo, M., H., Lario, N., A. and Mata's, G., M., 2012, "Farmers' Satisfaction and Intention to Continue Membership in Agricultural Marketing Co-operatives: Neoclassical Versus Transaction Cost Considerations", European Review of Agricultural Economics, pp. 1-22, doi: 10.1093/erae/jbs024.

- Gray, T. and Kraenzle, C., A., 1998, "Member Participation in Agricultural Cooperatives: A Regression and Scale Analysis", Rural Business-Cooperative Service Research Report, 165 p.

- Laursen, C., V., Karantininis, K., and Bhuyan, S., 2008, "Organizational Characteristics and Member Participationin Agricultural Cooperatives: Evidence from Modern Danish Cooperatives”, Paper Submitted To The Seminar: The Role of The Cooperatives in The European Agro-Food System 28th-30th May, Bologna.

- Miran, B., 2010, Temel İstatistik. ISBN:975-93088-0-0. s.142. İzmir.

- Österberg, P., Hakelius, K. And Nilsson, J., 2007, Members' Perception of their Participation in the Governance of Cooperatives: The Key to Trust and Commitment in Agricultural Cooperatives. Department of Economics, Swedish University of Agricultural Sciences, Uppsala, Sweden.

- Özdemir, G., 1996, Tekirdağ İlinde Tarımsal Kooperatiflerde Kooperatif Ortak İlişkileri. Ankara Üniversitesi Fen Bilimleri Enstitüsü Tarım Ekonomisi Anabilim Dalı. Doktora Tezi.

- Tan, S. and Everest, B., 2010, "The Examination of the Manager Profile of Dairy Agricultural Development Cooperatives: The Case of Canakkale Province", Journal of Animal and Veterinary Advances, 9 (24): 30213025 p.

- Tarım Kredi Kooperatifleri Balıkesir Bölge Müdürlüğü, 2012, Balıkesir Bölge Birliği Verileri. "İllere ve Ölçeklerine Göre Kooperatiflerin Dağılımı”. Balıkesir.

- Xiang, L., Y. and Sumelius, J., 2010, "Analysis of the Factors of Farmers' Participation in the Management of Cooperatives in Finland”, Journal of Rural Cooperatıon, 38(2): 134-155 p. ISSN 0377-7480.

- Zakic, N., Vukotic, S., Laketa, M. and Laketa, L., 2013, “Agrıcultural Co-Operatives: Researching Members' Perception of Important Issues of Co-Operatives on The Example of Serbia”, The Journal of Animal \& Plant Sciences, 23(1): 2013, 290-297 p. ISSN: 1018-7081. 


\title{
Çevre Dostu Ürünlere Ödeme İsteğini Etkileyen Faktörlerin Belirlenmesi: Türkiye'den Deneysel Bulgular
}

\section{Identifying the Factors Affecting the Willingness to Pay for Environmentally Friendly Products: Empirical Evidence from Turkey}

\author{
Assoc. Prof. Dr. Rüştü Yayar (Gaziosmanpaşa University, Turkey)
}

\begin{abstract}
The use of resources for sustainable growth is extremely important in the fight against famine. It should not pollute the environment for sustainable production. Therefore, the consumption of environmentally friendly products is the most important step in the sustainable production. The aim of the study was to determine factors affecting the willingness of consumers to pay more for environmentally friendly products. The willingness of consumers to pay more was analyzed in terms of socio-economic and demographic characteristics of consumers. The study was interviewed with 479 consumers living the city center of Ankara. In the study, ordered probit regression models were estimated. According to the study, there were statistically significant between the willingness of consumers to pay more environmentally friendly products with gender and education level. At the same time, of the variable used in regression model, early majority, late majority, laggards, risk averse and risk moderate were statically significant.
\end{abstract}

\section{Giriş}

İnsanların ihtiyaçları sonsuz ancak bunları karşılayacak kaynaklar yetersizdir. Sonsuz ihtiyaçların karşılanmasında kıt olan kaynakların aşırı kullanımı bir takım çevre sorunlarını beraberinde getirmektedir. Son yıllarda çevre kirliliğinin artması, insanların güvenli ve temiz bir çevrede yaşam sürdürebilmelerini tehdit eden bir boyuta getirmiştir. Bu sorun ülkeleri ve toplumları, ulusal ve uluslararası düzeyde üretime yönelik alanlarda ortak çözümler üretme çabasına yöneltmiştir. Aşırı üretim ve tüketim çevresel problemlerin ortaya çıkmasını kaçınılmaz kılmaktadır. Günümüzde üretim daha çok tüketici tercihleri doğrultusunda şekillenmektedir. Dolayısıyla çevresel problemlerin çözümünde tüketici tercihlerinin önemli bir etkiye sahip olduğu söylenebilir.

Tüketicilerin satın alma davranışları çevresel problemler üzerinde doğrudan etkilidir. Tüketicilerin çevreye zarar vermeyen ürünleri (çevre dostu) tercih edip diğer alternatiflerden vazgeçmesi ve geri dönüşümlü ambalajlar kullanması çevreye önemli katkılar sağlayacaktır. Çevrecilik için yapılacak ürün politikalarında tüketici kilit rolde düşünülmelidir. Çünkü söz konusu ürünlerdeki değişiklikler tüketim kalıplarının değişmesine ve tüketicilerin sorumluluklarının artmasına sebep olabilecektir (Çabuk ve ark, 2008: 85).

Tüketiciler daha az kirlilik yaratan, atıkları azaltan, daha fazla geri dönüşüm sağlayan yenilenebilir kaynakların üretimde daha fazla kullanımını ve ürünlerin ekosistem için daha güvenli olmasını talep etmektedirler. Tüketicilerin çevrenin korunması konusunda gittikçe daha fazla bilinçlenmeleri şirket yöneticileri ve özellikle pazarlama yöneticileri için daha fazla önemsenmesi gereken bir konu haline gelmektedir. Günümüzde sayıları giderek artan çevre bilincine sahip tüketicilerin özelliklerinin belirlenmesi ve davranışlarının değerlendirilmesi işletmelere, çevresel duyarlılıklarını planlamada ve bu çabayı ürün yapılarına, üretim sistemlerine ve pazarlama yönetimlerine yerleştirmede önemli katkılar sağlayacaktır (Karaca, 2013: 99). Bu çalışma ile tüketicilerin çevreye dost ürünlere fazladan ödeme yapma durumlarının tüketicilerin hangi özelliklerine göre farklılık gösterdiğini tespit etmek amaçlanmıştır.

Tüketimin sürdürülebilir olabilmesi için ürünün çevre dostu olması önemlidir. Hussein ve Cankül (2010) çevre dostu ürünü, çevreyi kirletmeyen, doğal kaynakları daha az tüketen, geri dönüştürebilen veya koruyabilen ürün şeklinde tanımlamışlardır. Çevre dostu ürünler üzerine yerli ve yabancı literatürde birçok çalışma yapıldığı tespit edilmiştir. Bu çalışmalardan bazıları aşağıda özetlenmiştir.

Kızıloğlu ve arkadaşları (2013) bu çalışmayı üniversite öğrencilerinin yeşil gıda ürünleri hakkında bilgi tutum ve görüşlerini belirlemek ve bu ürünlere fazladan ödeme isteklerinin olup olmadığını tespit etmek amacıyla yapmışlardır. 238 öğrenciden derlenen verilere faktör analiz uygulanmıştır. Araştırma sonuçları doğrultusunda, öğrencilerin yeşil gıda ürününe karşı tutumlarını; beslenme, sağlık, çevre bilinci ve bilinçlendirme diye dört faktöre yüklendiği sonucuna ulaşılmıştır. Öğrencilerin \%50'si yeşil gıda ürünlerine normal değerinden \%5 daha fazla ödemeye istekli oldukları tespit edilmiştir. Öğrencilerin çevreyi ve sağlıklarını korumaya karşı istekli oldukları belirlenmiştir. Bu sonuçlara göre göre, yeşil gıda ürünlerinin reklamının daha fazla yapılarak üretici firmaların politikalarını bu yönde geliştirmesi önerilmiştir.

Yılmaz ve Arslan (2011) üniversite öğrencilerinin çevresel duyarlılıklarını, çevreyi koruma vaatlerini ve çevre dostu tüketim davranışlarını; öğrencilerin cinsiyetlerine, ailelerinin yaşadığı yere ve anne-baba eğitim düzeyine 
göre incelemişlerdir. Çalışma sonucuna göre, öğrencilerin cinsiyetlerinin, ailelerinin yaşadıkları yerin ve özellikle annelerinin eğitim düzeylerinin çevresel duyarlılıklarını ve davranışlarını etkilediği tespite dilmiştir. Araştırmaya katılanların çevresel duyarlılıklarının yüksek olduğu fakat çevre dostu tüketim davranışlarının ise ortalamaya yakın düzeyde kaldığını tespit etmişlerdir.

Karabaş ve Gürler (2012) Samsun il merkezindeki tüketicilerin organik ürünlere yönelik davranışlarını ve organik ürünleri tercih etmelerinde etkili olan faktörleri belirlemeyi amaçlayan bir çalışma yapmışlardır. 478 tüketiciden derlenen verilerin regresyon analizi yapılmışlardır. Araştırma sonuçlarına göre, organik ürünlere ulaşabilme kolaylığı, eşin eğitim düzeyi, organik ürünlere fazladan ödeme yapmayı kabul etme, gıda maddelerinin sağlığa olan etkilerini önemseme, organik tarım konusunda tam bilgi sahibi olma ve aileye gelir getiren kişi sayısındaki bir birimlik artışın organik ürün tüketimini arttırdığını tespit etmişlerdir. Öte yandan; organik tarımın en önemli unsuru olan kontrol ve sertifikasyonla ilgili olarak, tüketici bilincinin oluşmadığ sonucuna varılmıştır.

Sarıkaya (2007) çalışmasında, organik ürünlerin pazarlanmasında organik ürünleri kullanan tüketicilerin organik ürünlere yönelik tutumlarını ve tercihleri etkileyen faktörlerin incelemiştir. Araştırma bulgularına göre, tüketicilerin organik ürün satın alma davranışları ve tutumları açısından dört boyutun öne çıktığı tespit edilmiştir.

Bunlar; sorumluluk, güven, değer ve faydadır. Tüketicilerin organik ürün tercihlerinin demografik özelliklere bağlı olarak değişkenlik gösterdiği sonucuna ulaşmıştır.

Karaca (2013) çalışmasında, çevre bilincini ve çevreye duyarlı ürünleri kullanma eğilimlerini belirlemek amacıyla Sivas ilinde yaşayan 362 kişiye yüz yüze anket uygulanmıştır. Bireylerin demografik özellikleri ile çevre bilinci ve çevreye duyarlı ürün bilinci arasında istatistiki açıdan fark olup olmadığının analizinde t testi uygulanmış ve ayrıca likert ölçekli sorular için faktör analizi ile soruların gruplama biçimleri araştırılmıştır. Çalışmada, Sivas ili halkının çevreye bilinçli ve çevre dostu ürünleri kullanmaya duyarlı oldukları sonucuna varılmıştır.

Özdemir, Karaaslan ve Altuntaş (2010) çalışmalarında, Kırşehir, Ankara ve İstanbul' da yaşayan bireylerin satın alma tercihlerinde çevreci olan ürün ve işletmeleri tercih etme düzeyleri ölçmüşlerdir. Şehir, eğitim, yaş ve cinsiyet bazında tüketicilerin çevreci tüketim anlamında aralarında farklılığın olup olmadığı incelenmiştir. Araştırma sonucuna göre; Kırşehir'de yaşayan tüketicilerin pek çok ifade de çevrecilik açısından büyük şehirlerde (Ankara ve İstanbul) yaşayanlara göre daha duyarlı oldukları ortaya çıkmıştır. Yaş, cinsiyet ve eğitim değişkenlerine göre de gruplar arasında çevreci tüketim açısından anlamlı farklılıklar bulunmuştur.

Royne, Levy ve Martinez (2011) çalışmalarında tüketicilerin çevre dostu ürünlere fazladan ödeme isteklerini etkileyen faktörleri araştırmışlardır. Çalışma sonuçlarına göre bireylerin çevre dostu ürünlere fazladan ödeme isteğinin demografik gruplara farklılık gösterdiği tespit edilmiştir. Bireylerin önemli bir kısmının atık endişesi yüzünden çevre dostu ürünlere daha fazla ödemeye istekli oldukları belirlenmiştir. Gelecek nesillere sağlıklı bir çevre bırakmak için farklı özellikteki gruplara çevre dostu ürünleri satın almaları konusunda eğitim verilmesi gereğine işaret edilmektedir.

Tsen, Phang, Hasan ve Buncha (2006) çalışmalarında tüketicilerin yeşil ürünlere fazla ödeme isteğinde değer yargılarının, tutumlarının ve davranışlarının nispi etkisini belirlemeye çalışmışlardır. Araştırmada yeşil ürünlere ödeme istekliliğini belirlemede tüketicilerin tutumlarını açıklayan faktörler ilk sırada yer alırken bunu tüketicilerin davranışlarını açıklayan faktörler takip etmiştir. Yeşil ürünlere ödeme isteğini açıklamada toplumsallık duygusu istatistiki olarak önemli bulunmuştur.

\section{Veri ve Yöntem}

Çalışmada kullanılan veriler anket yöntemiyle sağlanmış birincil verilerdir. Çalışmada çoktan seçmeli sorulara yer verilmiştir. Veriler 2015 yılı Nisan ve Haziran aylarını kapsamaktadır. Veriler Ankara ili kentsel alandaki on sekiz yaş üzerindeki 600 tüketiciden derlenmiş ancak bunlardan 479 tanesi uygun bulunmuştur. Anket uygulamasında kolayda örnekleme yöntemi tercih edilmiştir. Soruların geçerliliğini test etmek amacıyla Ankara kent merkezinde 30 katılımcı ile yüz yüze görüşme yapılarak gerekli düzeltmeler yapılmıştır. Anket formunun hazırlanmasında literatürde daha önce bu konuya benzer çalışmalardan yararlanılmıştır (Togay ve Akın, 2015).

Modelde yer alan değişken isimleri ve tanımlayıcı istatistikler Tablo 1'de verilmiştir. Katılımcılardan sağlanan verilere ilişkin tanımlayıcı istatistiklerin açıklanması kısaca şu şekildedir: Katılımcıların \%49'u erkek ve \%51'i kadınlardan oluşmaktadır. Katılımcıların aylık ortalama geliri, sosyal sorumluluk düzeyi sırasıyla 1501-2250 TL arasında, orta düzeyde olduğu belirlenmiştir. Araştırmaya katılanların önemli bir bölümü yenilikleri geç benimsediği (\%65) ve önemli bir bölümünün ise orta ve düşük düzeyde risk alanlardan (\%79) oluştuğu tespit edilmiştir.

Tüketicilerin çevre dostu ürünlere fazladan ödeme yapma durumlarını belirlemede kullanılan cevap seçenekleri normal fiyatının yüzde belirli bir oranı kadar fazla olacağı için sıralı formda oluşmaktadır. Sıralı şekilde derlenen cevapların modellenmesinde literatürde oldukça geniş bir kullanım alanı bulan Sıralı Probit Modeli kullanılmaktadır. Sıralı probit modeli iki sonuçlu probit model gibi gözlemlenemeyen (gizli) değişkenli regresyon modeli olarak oluşturulur (Maddala, 1983; Long, 1997). Aşağıdaki regresyon denklemi göz önünde bulundurulursa; 
$y^{*}=x^{\prime} \beta+\varepsilon$.

Burada $y^{*}$ gözlemlenemeyen değişkendir ve bu çalışma için aşağıdaki gibi tanımlanır (Greene, 2012: 787).

$$
\begin{aligned}
& y=0 \text { şayet } y^{*} \leq 0 \\
& y=1 \text { şayet } 0<y^{*} \leq \mu_{1} \\
& y=2 \text { şayet } \mu_{1}<y^{*} \leq \mu_{2} \\
& y=3 \text { şayet } \mu_{2}<y^{*} \leq \mu_{3} \\
& y=4 \text { şayet } \mu_{3}<y^{*} \leq \mu_{4} \\
& y=5 \text { şayet } \mu_{4}<y^{*} \leq \mu_{5} \\
& y=6 \text { şayet } y^{*} \leq \mu_{5}
\end{aligned}
$$

Eşik değerlerini gösteren $\mu^{\prime}$ ler sıralı probit model ile tahmin edilecek olan bilinmeyen parametrelerdir. Siralı probit modelde hataların normal dağıldığı varsayımı ile çalışmadaki yedi farklı seçenek için aşağıdaki olasılıklar elde edilebilir (Greene, 2012: 788).

$$
\begin{aligned}
& \operatorname{Prob}(y=0 \mid x)=\Phi\left(-x^{\prime} \beta\right), \\
& \operatorname{Prob}(y=1 \mid x)=\Phi\left(\mu_{1}-x^{\prime} \beta\right)-\Phi\left(-x^{\prime} \beta\right), \\
& \operatorname{Prob}(y=2 \mid x)=\Phi\left(\mu_{2}-x^{\prime} \beta\right)-\Phi\left(\mu_{1}-x^{\prime} \beta\right), \\
& \operatorname{Prob}(y=3 \mid x)=\Phi\left(\mu_{3}-x^{\prime} \beta\right)-\Phi\left(\mu_{2}-x^{\prime} \beta\right), \\
& \operatorname{Prob}(y=4 \mid x)=\Phi\left(\mu_{4}-x^{\prime} \beta\right)-\Phi\left(\mu_{3}-x^{\prime} \beta\right), \\
& \operatorname{Prob}(y=5 \mid x)=\Phi\left(\mu_{5}-x^{\prime} \beta\right)-\Phi\left(\mu_{4}-x^{\prime} \beta\right), \\
& \operatorname{Prob}(y=6 \mid x)=1-\Phi\left(\mu_{5}-x^{\prime} \beta\right) .
\end{aligned}
$$

Denklem 3'de $\Phi$ normal dağılım gösteren kümülatif olasılık fonksiyonudur. Olasılıkların pozitif olması için $0<\mu_{1}<\mu_{2}<\mu_{3}<\mu_{4}<\mu_{5}<\mu_{6}$ olmalıdır. Model en çok olabilirlik metodu ile çözülür. Sıralı probit modelde bağımsız değişkenlerinin marjinal etkileri katsayılara eşit olmayacaktır. Fonksiyonda yer alan değişkenlerin marjinal etkileri de hesaplanabilmektedir.

Regresyon modelinin bağımlı değişkeni, tüketicilerin çevre dostu ürünlere fazla ödeme isteklilikleri ile ilgilidir. AR değeri düşük cep telefonlarına fazla ödeme isteklilikleri ile ilgilidir. Tüketicilerin çevre dostu ürünler için fazladan ödeme isteği, "hiç", “\%10 fazla, "\%20 fazla", \%30 fazla", "\%40 fazla", "\%50 fazla" ve "\%50 den fazla" şeklinde sınıflandırılmıştır. Çalışmada kullanılan değişkenlerin tanımı ve değişkenlere ilişkin açıklayıcı istatistikler Tablo 1'de verilmiştir.

Tablo incelendiğinde, katılımcıların \%49,06'sı bayan, ortalama yaş grubu 26-35 yaş, \%43,63'ü evli ve ortalama aylık gelir grubu 1501-2250 TL olarak belirlenmiştir. Katılımcıların ortalama eğitim düzeyi ön lisanstır. Katılımcıları diğer bazı özellikleri: ortalama sosyal sorumluluk seviyeleri fazla, \%32,57'si yenilikleri en son benimsemekte, $\% 42,80$ 'i orta düzeyde ve $\% 36,12$ 'si ise düşük düzeyde risk alıcıdır.

Tüketicilerin çevre dostu ürünlere fazladan ödeme isteklerinin, sosyo ekonomik ve demografik özelliklere göre farklılık göstereceği çalışmanın temel hipotezi olarak kabul edilmiştir. Bazı temel açıklayıcı değişkenlerin katsayılarına ilişkin beklentiler aşağıdaki gibi özetlenmiştir:

Yaş (YAŞ) değişkenin katsayı işaretinin pozitif olması beklenmektedir. Yaş arttıkça tüketicilerin çevre dostu ürünlere fazladan ödeme isteklerinin artacağı beklenmektedir. Bireyler yaşlandıkça sağlıklarına daha fazla dikkate edecekleri, bilinçli olmaları sebebiyle gelecek nesillere daha yaşanabilir dünya bırakmak isteyecekleri ve bu sebeple daha yüksek fiyat ödeme isteğinde olacakları beklenmektedir.

Eğitim (EĞTM) değişkeninin işaretinin pozitif olması beklenmektedir. Eğitim düzeyi yüksek tüketicilerin bilinçli bir şekilde çevreye daha duyarlı olacağı ve dolayısıyla çevre dostu ürünlere fazladan ödeme isteğinde olacakları düşünülmektedir.

Aylık ortalama gelir (AGLR) değişkeninin katsayı işaretinin pozitif olacağı beklenmektedir. Tüketicilerin gelir düzeyi arttıkça, daha sağlıklı, kaliteli ve güvenli ürünleri tercih etmeleri beklenmektedir. Gelir düzeyi ile üstün mallar talebi arasında doğru yönlü bir ilişki bulunmaktadır.

Cinsiyet (CNS) ve medeni durum (MDRM) değişkenlerinin katsayılarının işaretlerinin negatif olması beklenmektedir. Bayanların erkeklere göre, evli olanların diğerlerine göre sağlık konusunda daha duyarlı olabileceği düşünülmektedir.

Tüketicilerin risk tutumları çevre dostu ürünler için fazladan ödeme isteklerini etkileyebilecektir. Risk değişkeni ile çevre dostu ürünlere fazladan ödeme isteği arasında negatif bir ilişkinin olacağı varsayılmıştır. Daha az risk almayı seven tüketicilerin çevre dostu ürünlere fazladan ödeme isteklerinin daha fazla olacağı düşünülmektedir. Kukla değişken tuzağından kaçınmak için RISK1 değişkeni temel kategori olarak alınmıştır.

Rogers (1995) tüketicilerin yenilikleri benimseme durumlarını beş kategoride sınıflandırmıştır. Bu kategorilerin tanımlamaları Tablo 5'de verilmiştir. Yenilikleri benimseme kategorileri ile fazladan ödeme isteği arasındaki 
ilişkiyi test etmek amacıyla dört değişken (YNLK2, YNLK3, YNLK4 ve YNLK5) sıralı probit regresyon modeline dâhil edilmiştir. Kukla değişken tuzağından kurtulmak için YNLK1 değişkeni referans kategori olarak alınmıştır. Yenilikleri benimseme ile çevre dostu ürünlere fazladan ödeme isteği arasında pozitif yönlü bir ilişkinin olabileceği varsayılmıştır.

Ailedeki çocuk sayısı (ÇOCSAY) değişkeni modele katılmış olup katsayı işaretinin pozitif olması beklenmektedir. Ailelerin çocuk sahibi olmaları çevreye olan duyarlılıklarını artıracağı düşünülmektedir. Bu sebeple çevre dostu ürünleri tercih edecekleri beklenmektedir.

Sosyal sorumluluk düzeyi (SOSSOR) değişkenin katsayı işaretinin pozitif olması beklenmektedir. Sosyal sorumluluğu yüksek olan tüketicilerin çevre dostu ürünlere daha fazla ödeme yapma isteğinde olacakları düşünülmektedir.

\begin{tabular}{|c|c|c|c|}
\hline Değişkenler & Değişkenlerin tanımı & Ortalama & $\begin{array}{l}\text { Standart } \\
\text { sapma }\end{array}$ \\
\hline$F \ddot{O I}$ & $\begin{array}{l}\text { Tüketicilerin çevre dostu ürünlere fazladan ödeme yapma isteği }(\text { hiç }=0 ; \% 10=1 ; \\
\% 20=2 ; \% 30=3 ; \% 40=4 ; \% 50=5 ; \% 50 \text { ve daha fazla }=6)\end{array}$ & 2,3841 & 1,5384 \\
\hline CNS & Cinsiyet durumu (bayan=0; erkek $=1$ ) & 0,4906 & 0,5004 \\
\hline$Y A S$ & Yaş durumu $(18-25$ yaş $=1 ; 26-35$ yaş $=2 ; 36-50$ yaş $=3 ; 51$ ve üstü yaş $=4)$ & 2,1273 & 1,0240 \\
\hline MDRM & Medeni durumu (evli=1; değilse $=0$ ) & 0,4363 & 0,4965 \\
\hline$E \breve{G} T M$ & $\begin{array}{l}\text { Eğitim düzeyi (okur-yazar değil=1; okur-yazar=2; ilkokul=3; ortaokul=4; lise }=5 \text {; } \\
\text { ön lisans=6; yüksek lisans ve üstü }=7 \text { ) }\end{array}$ & 5,7265 & 1,5478 \\
\hline$A G L R$ & $\begin{array}{l}\text { Aylık ortalama gelir }(750 \mathrm{TL} \text { den az }=1 ; 750-1500 \mathrm{TL}=2 ; 1501-2250 \mathrm{TL}=3 ; 2251- \\
3300 \mathrm{TL}=4 ; 3301 \mathrm{TL} \text { ve üstü }=5)\end{array}$ & 2,5449 & 1,1987 \\
\hline SOSSOR & Sosyal sorumluluk düzeyi (çok az=1; az=2; orta $=3 ;$ fazla $=4 ;$ çok fazla $=5)$ & 3,1378 & 0,9755 \\
\hline$Y N L K 1^{*}$ & Yenilikleri ilk benimseme (yeniliklere hemen uyum sağlama $=1$; değilse $=0$ ) & 0,0334 & 0,1799 \\
\hline$Y N L K 2$ & $\begin{array}{l}\text { Yenilikleri çok geçmeden benimseme (yeniliklere çok geçmeden uyum sağlama=1; } \\
\text { değilse }=0 \text { ) }\end{array}$ & 0,0522 & 0,2227 \\
\hline$Y N L K 3$ & $\begin{array}{l}\text { Yenilikleri ilerleyen zamanda benimseme (yeniliklere ilerleyen zamanda uyum } \\
\text { sağlama }=1 \text {; değilse }=0 \text { ) }\end{array}$ & 0,2651 & 0,4419 \\
\hline YNLK4 & $\begin{array}{l}\text { Yenilikleri toplumun yarısının uyumundan sonra benimseme (yeniliklere toplumun } \\
\text { yarısının uyumundan sonra uyum sağlama }=1 ; \text { değilse }=0 \text { ) }\end{array}$ & 0,3236 & 0,4683 \\
\hline YNLK5 & Yenilikleri en son benimseme (yeniliklere en son uyum sağlama=1; değilse $=0$ ) & 0,3257 & 0,4691 \\
\hline RISK1* & Risk alıcı (risk alıcı ise $=1$; değilse $=0$ ) & 0,2109 & 0,4083 \\
\hline RISK2 & Orta düzeyde risk alıcı (orta düzeyde risk alıcı ise $=1$; değilse $=0$ ) & 0,4280 & 0,4953 \\
\hline RISK3 & Düşük düzeyde risk alıcı (düşük düzeyde risk alıcı ise $=1$; değilse $=0$ ) & 0,3612 & 0,4808 \\
\hline ÇOCSAY & $\begin{array}{l}\text { Ailedeki çocuk sayısı (çocuk yok=0; Bir çocuk=1; İki çocuk=2; İkiden fazla } \\
\text { çocuk=3) }\end{array}$ & 1,7516 & 1,0702 \\
\hline
\end{tabular}

*Referans kategori olarak alınmıştır.

\section{Tablo 1. Tanımlayıcı Ístatistikler}

Çalışmada, tüketicilerin çevre dostu ürünler için fazla ödeme istekleri sosyo-ekonomik ve demografik faktörlere göre analiz edilmiştir. Deneysel model aşağıdaki gibi belirlenmiştir:

$$
\begin{aligned}
& F \mathrm{ÖI}_{i}=\propto_{0}+\propto_{1} \text { CNS }_{i}+\propto_{2} Y A S_{i}+\propto_{3} \text { MDRM }_{i}+\propto_{4} \text { ĔGTM }_{i}+\propto_{5} \text { AGLR }+\propto_{6} \text { SOSSOR }_{i}+\propto_{7} Y N L K 2_{i} \\
& +\propto_{8} Y N L K 3_{i}+\propto_{9} Y N L K 4_{i}+\propto_{10} Y N L K 5_{i}+\propto_{11} R \dot{\mathrm{I} S K} 2_{i}+\propto_{12} R \dot{\mathrm{I} S K 3_{i}}+\operatorname{CCOCSAY}_{i}+\varepsilon_{i}
\end{aligned}
$$

Bağımlı değişken olan çevre dostu ürünlere fazladan ödeme yapma isteği yedi farklı seçenekte kategorize edilmiştir. Çevre dostu ürünlere fazladan ödeme yapama isteğinin hangi faktörlere göre farklılık göstereceğini açıklayabilmek için bağımlı değişkenin değer aralığı \%0 ile \%50 arasında geniş tutulmuştur. Çevre dostu ürünlere fazladan ödeme isteğini etkileyen değişkenlere ait sıralı probit model sonuçları Tablo 2' de ve değişkenlere ilişkin marjinal etkiler ise Tablo 3'de verilmiştir. Modelin oluşturulmasında çoklu doğrusal bağıntı problemini ortadan kaldırmak için YNLK1 ve RİSK1 değişkenleri modelden çıkartılmıştır. Sıralı probit modeli en çok olabilirlik yöntemine göre bütünüyle istatistiksel olarak anlamlı bulunmuştur $(p<0,0000)$. Modelde tahmin edilen eşik değerler, tüketicinin fayda fonksiyonu ile fazladan ödeme isteği arasındaki sayısal ilişkiyi ifade etmektedir. Eşik değerler pozitif ve $\mu_{1}<\mu_{2}<\mu_{3}<\mu_{4}<\mu_{5}$ olmalıdır. Modelin eşik değerleri pozitif ve 0,01 düzeyinde istatistiksel olarak anlamlı bulunmuştur. Bu sonuç bağımlı değişken kategorilerinin uygun şekilde düzenlendiğini, tüketicilerin sosyo-ekonomik/demografik özelliklerinin çevre dostu ürünlere fazladan ödeme yapma isteği etkilerinin yüksek olduğunu göstermektedir.

Modele katılan on üç değişkenden yedisi istenilen önem seviyesinde istatistiki olarak anlamlı bulunmuştur. İstenilen önem düzeyinde anlamsız bulunan bağımsız değişkenlerin yorumlanmasından kaçınılmıştır. 


\begin{tabular}{|c|c|c|c|c|}
\hline Değișkenler & Katsayılar & Standart hata & t hesap & Önem düzeyi \\
\hline Sabit & $-0,5248$ & 0,4214 & $-1,245$ & 0,2130 \\
\hline CNS & $-0,4934^{* * *}$ & 0,1125 & $-4,385$ & 0,0000 \\
\hline$Y A S$ & 0,0922 & 0,0685 & 1,347 & 0,1779 \\
\hline$M D R M$ & $-0,1065$ & 0,1229 & $-0,867$ & 0,3857 \\
\hline ĔGTM & $0,1081^{* * *}$ & 0,0404 & 2,675 & 0,0075 \\
\hline$A G L R$ & 0,0380 & 0,0523 & 0,728 & 0,4669 \\
\hline SOSSOR & $0,0869^{*}$ & 0,0502 & 1,730 & $\mathbf{0 , 0 8 3 7}$ \\
\hline$Y N L K 2$ & 0,3331 & 0,3494 & 0,953 & 0,3404 \\
\hline$Y N L K 3$ & $0,7613^{* *}$ & $\mathbf{0 , 3 1 8 0}$ & 2,394 & 0,0167 \\
\hline YNLK4 & $1,0264^{* * *}$ & $\mathbf{0 , 3 2 4 3}$ & 3,165 & 0,0015 \\
\hline YNLK5 & $1,0446^{* * *}$ & 0,3194 & 3,270 & 0,0011 \\
\hline RISK2 & 0,1900 & 0,1335 & 1,356 & 0,1752 \\
\hline RISK3 & $0,4744^{* * *}$ & 0,1395 & 3,401 & 0,0007 \\
\hline$C ̧ O C S A Y$ & 0,0580 & 0,0455 & 1,275 & 0,2023 \\
\hline$\mu_{1}$ & 1,0170 & 0,0921 & 11,046 & 0,000 \\
\hline$\mu_{2}$ & 1,9386 & 0,1059 & 18,311 & 0,000 \\
\hline$\mu_{3}$ & 2,6354 & 0,1150 & 22,917 & 0,000 \\
\hline$\mu_{4}$ & 2,9291 & 0,1200 & 24,419 & 0,000 \\
\hline$\mu_{5}$ & 3,3671 & 0,1302 & 25,867 & 0,000 \\
\hline Gözlem sayıs1 & 479 & & Log likelihood & $-777,3968$ \\
\hline Ki-kare & 110,6134 & & Önem seviyesi & 0,0000 \\
\hline
\end{tabular}

Tablo 2. Stralı Probit Model Sonuçları

Modele katılan cinsiyet (CNS) değişkeninin işareti negatif olup \%1 önem düzeyinde istatistiki açıdan anlamlı bulunmuştur. Tüketicinin erkek olması çevre dostu ürünlere fazladan ödeme yapma isteğini azaltıcı etki yapacağ söylenebilir. Cinsiyetin erkek olması ile çevre dostu ürünlere hiç ödememe, $\% 10$ fazla ödeme ve $\% 20$ fazla ödeme olasılı̆̆ sırasıyla $\% 5, \% 11$ ve $\% 2$ düzeyinde artarken, $\% 30$ fazla ödeme, $\% 40$ fazla ödeme, \%50 fazla ödeme ve $\% 50$ 'den fazla ödeme olasılığı sırasıyla $\% 7, \% 3, \% 4$ ve $\% 4$ düzeyinde azalmaktadır.

\begin{tabular}{|c|c|c|c|c|c|c|c|}
\hline Değişkenler & \begin{tabular}{l}
\multicolumn{1}{c}{$Y=00$} \\
(\%0 fazla \\
ödeme) \\
\end{tabular} & $\begin{array}{c}\mathrm{Y}=01 \\
(\% 10 \text { fazla } \\
\text { ödeme }) \\
\end{array}$ & $\begin{array}{c}\mathrm{Y}=02 \\
\text { (\%20 fazla } \\
\text { ödeme) } \\
\end{array}$ & $\begin{array}{c}Y=03 \\
\text { (\%30 fazla } \\
\text { ödeme) } \\
\end{array}$ & $\begin{array}{c}\mathrm{Y}=04 \\
(\% 40 \text { fazla } \\
\text { ödeme }) \\
\end{array}$ & $\begin{array}{c}\mathrm{Y}=05 \\
\text { (\%50 fazla } \\
\text { ödeme) } \\
\end{array}$ & $\begin{array}{c}Y=06 \\
(\% 50 ' d e n \\
\text { fazla ödeme })\end{array}$ \\
\hline Sabit & 0,0570 & 0,1183 & 0,0234 & $-0,0744$ & $-0,0361$ & $-0,0431$ & $-0,0450$ \\
\hline CNS & $\mathbf{0 , 0 5 3 5}$ & 0,1112 & $\mathbf{0 , 0 2 2 0}$ & $-0,0699$ & $-0,0339$ & $-0,0405$ & $-0,0423$ \\
\hline$Y A S ̧$ & $-0,0100$ & $-0,0208$ & $-0,0041$ & 0,0131 & 0,0063 & 0,0076 & 0,0079 \\
\hline$M D R M$ & 0,0116 & 0,0240 & 0,0047 & $-0,0151$ & $-0,0073$ & $-0,0088$ & $-0,0091$ \\
\hline EĞTM & $-0,0117$ & $-0,0244$ & $-0,0048$ & $\mathbf{0 , 0 1 5 3}$ & 0,0074 & $\mathbf{0 , 0 0 8 9}$ & $\mathbf{0 , 0 0 9 3}$ \\
\hline$A G L R$ & $-0,0041$ & $-0,0086$ & $-0,0017$ & 0,0054 & 0,0026 & 0,0031 & 0,0033 \\
\hline SOSSOR & $-0,0094$ & $-0,0196$ & $\mathbf{- 0 , 0 0 3 9}$ & 0,0123 & 0,0060 & $\mathbf{0 , 0 0 7 1}$ & 0,0075 \\
\hline$Y N L K 2$ & $-0,0362$ & $-0,0751$ & $-0,0148$ & 0,0472 & 0,0229 & 0,0274 & 0,0286 \\
\hline YNLK3 & $-0,0826$ & $-0,1716$ & $-0,0339$ & 0,1079 & $\mathbf{0 , 0 5 2 3}$ & 0,0626 & $\mathbf{0 , 0 6 5 3}$ \\
\hline YNLK4 & $-0,1114$ & $-0,2313$ & $-0,0457$ & 0,1455 & 0,0706 & 0,0843 & $\mathbf{0 , 0 8 8 0}$ \\
\hline YNLK5 & $-0,1134$ & $-0,2354$ & $-0,0465$ & 0,1481 & 0,0718 & 0,0858 & 0,896 \\
\hline RISK2 & $-0,0196$ & $-0,0408$ & $-0,0081$ & 0,0257 & 0,0124 & 0,0149 & 0,0155 \\
\hline RISK3 & $-0,0515$ & $-0,1069$ & $-0,0211$ & 0,0672 & 0,0326 & $\mathbf{0 , 0 3 9 0}$ & 0,0407 \\
\hline ÇOCSAY & $-0,0063$ & $-0,0063$ & $-0,0026$ & 0,0082 & 0,0040 & 0,0048 & 0,0050 \\
\hline
\end{tabular}

\section{Tablo 3. Sirall Probit Modelin Marjinal Etkileri}

Modele katılan tüketicinin eğitim seviyesi değişkeninin (EĞTM) katsayı işareti beklendiği gibi pozitif olup, \%1 önem seviyesinde istatistiksel olarak anlamlıdır. Tüketicilerin eğitim seviyeleri yükseldikçe çevre dostu ürünlere fazla ödeme yapma isteklilikleri artış göstermektedir. Eğitim seviyesi bir birim arttığında, çevre dostu ürünlere fazladan hiç ödememe, $\% 10$ daha fazla ödeme ve $\% 20$ daha fazla ödeme olasılıklarının sırasıyla, $\% 1, \% 2$ ve $\% 0,5$ azaldığı söylenebilir. Buna karşın, çevre dostu ürünlere $\% 30, \% 40, \% 50$ ve $\% 50$ den daha fazla ödeme olasılıklarının ise sırasıyla \%2, \%0,7 \%0,9 ve \%0,9 oranında arttığı belirlenmiştir. Eğitim seviyesi yüksek olan tüketicilerin çevre konusunda daha duyarlı oldukları söylenebilir.

Tüketicilerin sosyal sorumluluk düzeyleri ile çevre dostu ürünlere fazladan ödeme istekleri arasında doğru yönlü bir ilişkinin olduğu tespit edilmiş ve regresyon katsayısı istenilen önem seviyesinde istatistiksel olarak anlamlı bulunmuştur. Sosyal sorumluluğu yüksek tüketicilerin çevre dostu ürünlere fazladan ödeme isteklerinin yüksek olduğu marjinal sonuçlardan görülmektedir.

Yenilikleri benimseme değişkeni ve risk alma değişkenlerinin katsayı işaretleri pozitif olup, istatistiksel olarak anlamlıdır. Tüketicilerin yenilikleri benimseme davranışı azaldıkça çevre dostu ürünlere fazladan ödeme isteği 
artmaktadır. Diğer taraftan tüketicilerin risk alma düzeyleri azaldıkça çevre dostu ürünlere fazladan ödeme isteği artmaktadir.

\section{Sonuç}

Bu çalışma ile tüketicilerin çevre dostu ürünleri satın alırken daha fazla ödeme yapmaya istekliliğini etkileyen faktörlerin belirlenmesi amaçlanmıştır. Çalışmada Ankara ili kentsel alanında yaşayan on sekiz yaş ve üzerindeki 479 tüketiciden 2015 yılı Nisan ve Haziran dönemi için anket yoluyla elde edilen veriler kullanılarak sıralı probit regresyon analizi yapılmıştır.

Katılımcıların \%49,06’sı bayan olduğu, ortalama yaş grubunun 26-35 yaş aralığında olduğu bulunmuştur. Tüketicilerin \%32,57'si yenilikleri en son benimsemekte, \%42,80'i orta düzeyde ve \%36,12'si ise düşük düzeyde risk alıcıdır. Regresyon modelinde yer alan değişkenlerden; cinsiyet, eğitim düzeyi, sosyal sorumluluk seviyesi, yenilikleri ilerleyen zamanda benimseme, yenilikleri toplumun yarısının uyumundan sonra benimseme, yenilikleri en son benimseme ve düşük düzeyde risk alma değişkenleri istenilen önem seviyesinde istatistiksel olarak anlamlı bulunmuştur. Sıralı probit analizi ile tüketicilerin çevre dostu ürünleri satın alırken daha fazla ödeme yapmaya istekliliğini etkileyen faktörler sıralanmıştır. Tüketicilerin ortalama olarak çevre dostu ürünlere \%20 den daha fazla ödeme isteğinde oldukları belirlenmiştir.

$\mathrm{Bu}$ çalışmanın hem tüketiciler hem de üreticiler için bir bilgi seti olabileceği düşünülmektedir. Tüketicilerin çevre ve sağlık konusunda giderek bilinçlenmeleriyle çevre dostu ürünlere olan talepleri daha da artacaktır. Üreticilerin çevre dostu ürün fiyatları üzerinde etkili olan ve olmayan faktörleri dikkate alarak planlamalarını bu doğrultuda yapmaları hem kendileri için hem de dünya doğal kaynaklarının etkin kullanılması için son derece önem arz ettiği söylenebilir.

\section{Kaynakça}

- Çabuk, S., Nakıboğlu, B. ve Keleş, C. 2008. “Tüketicilerin Yeşil (Ürün) Satın Alma Davranışlarının SosyoDemografik Değişkenler Açısından İncelenmesi”, Ç.Ü. Sosyal Bilimler Enstitüsü Dergisi, Cilt: 17, Sayı: 1, s.85-102.

- Greene, W. H. 2012. Econometric Analysis, 7th ed., New Jersey: Prentice Hall, USA.

- Husseın, A.T. ve Cankül, D. 2010. "Üniversite Öğrencilerinin Yeşil Pazarlama Faaliyetleri Kapsamında Çevreye İlişkin Davranışlarını Belirlemeye Yönelik Bir Araştırma”, Gazi Üniversitesi Ticaret Ve Turizm Ĕgitim Fakültesi Dergisi, Sayı: 1.

- $\quad$ Karabaş, S. ve Gürler, A.Z. 2012. “Organik Ürün Tercihinde Tüketici Davranışları Üzerine Etkili Faktörlerin Logit Regresyon Analizi İle Tahminlenmesi”, Adlyaman Üniversitesi Sosyal Bilimler Enstitüsü Dergisi, Yıl: 5 Say1: 10, s.129-156.

- Karaca, Ş. 2013. "Tüketicilerin Yeşil Ürünlere İlişkin Tutumlarının İncelenmesine Yönelik Bir Araştırma”,

- Ege Akademik Bakış, Cilt: 13, Sayı: 1, s.99-111.

- Kızıloğlu, R., Kızılaslan, H. ve Gökçe, C. 2013. “Gaziosmanpaşa Üniversitesi Ziraat Fakültesi Öğrencilerinin Yeşil Gıda Ürünleri Hakkındaki Bilgi, Görüş ve Tutumları Üzerine Araştırma”, Gaziosmanpaşa Bilimsel Araştırma Dergisi, Cilt: 6, s.19-30.

- Long, J. S. 1997. Regression Models for Categorical and Limited Dependent Variables, London: SAGE Publications, UK.

- Maddala, G. S. 1983. Limited-dependent and Qualitative Variables in Econometrics, New York: Cambridge University Press, USA.

- Özdemir, H.Ö., Karaaslan, M.H. ve Altuntaş, B. 2010. Tüketicilerin Çevreci İşletmelere ve Ürünlere Karş1 Tutumları: Ankara, İstanbul ve Kırşehir İllerinde Bir Uygulama, e-Journal of New World Sciences Academy, Cilt:5, Say1:4, s.353-366.

- $\quad$ Rogers, E. M. 1995. Diffusion of Innovations, 4th ed., New York: The Free Press, Simon \& Structure Inc., NY 10020, USA.

- $\quad$ Royne, M. B., Levy, M. and Martinez, J. 2011. "The Public Health Implications of Consumers' Environmental Concern and Their Willingness to Pay for an Eco-Friendly Product", The Journal of Consumer Affairs, Volume: 45, Number: 2, p.329-343.

- Sarıkaya, N. 2007. "Organik Ürün Tüketimini Etkileyen Faktörler ve Tutumlar Üzerine Bir Saha Çalışması”, Kocaeli Üniversitesi Sosyal Bilimler Enstitüsü Dergisi, Cilt: 14, Say1: 2007/2, s.110-125.

- Togay, Z.T. ve Akın, N. 2015. Veri toplama aşamasında katkı sağlamışlardır.

- Tsen, C. H., Phang, G., Hasan, H. ve Buncha, M. R. 2006. "Going Green: A Study of Consumers' Willingness to Pay for Green Products in Kota Kinabalu”, International Journal of Business and Society, Volume: 7, Number: 2, p.40-54.

- Yılmaz, V. ve Arslan, T. 2011. "Üniversite Öğrencilerinin Çevre Koruma Vaatleri ve Çevre Dostu Tüketim Davranışlarının İncelenmesi”, Anadolu Üniversitesi Sosyal Bilimler Dergisi, Cilt: 11, Sayı: 3, s.1-10. 


\title{
Kırgızistan'da Mikro Finans Uygulamasının Yoksulluk Üzerindeki Etkisi
}

\section{The Impact of Microfinance on Poverty: Evidence from Kyrgyzstan}

\author{
Ph.D. Candidate Kadyrbek Sultakeev (Kyrgyzstan-Turkey Manas University, Kyrgyzstan) \\ Assoc. Prof. Dr. Metin Bayrak (Kyrgyzstan-Turkey Manas University, Kyrgyzstan)
}

\begin{abstract}
Nowadays, the microfinance market is growing rapidly. Microfinance is becoming more common in the Kyrgyzstan market, complementing the traditional banking segment. However, how much microfinance affected the poverty is a subject for debate. Giving low income household money may lift them out of poverty for a short period of time but when the credit is spent borrowers fall back into poverty. The aim of the study was to analyze the impact of microfinance practices on poverty in Kyrgyzstan. The data were obtained from 521 microfinance clients in all districts and two largest cities. These are: Chuy, Naryn, Talas, Jalal Abad, Osh, Batken districts and Osh and Bishkek cities. A logit regressional analysis was used to determine the variables that affected poverty in Kyrgyzstan.
\end{abstract}

\section{Giriş}

Dünyada bütün ülkelerde yoksulluk çözülmesi gereken sosyal ve ekonomik sorun olmuştur. Bu çerçevede Birleşmiş Milletler Örgütü Milenyum Kalkınma Hedefleri’ne göre aşırı yoksulluğu ve açlığı ortadan kaldıracak politikalara önem vermektedir.

Yoksullukla mücadele eden politikalar içerisinde başta mikrokredi uygulaması başarılı bir program olarak bilinmektedir. Bundan dolayı, dünyada Birleşmiş Milletler Örgütü 2005 yılın 'mikrokredi yılı' olarak kabul etmiştir (Morduch, 2002).

Mikrofinans piyasası ne kadar gelişmiş olsa da yoksulluk oranı azalmamaktadır. Mikrokredinin yoksulluk üzerindeki etkisi üzerinde çalışmalar değişik sonuçları vermektedir (Coleman, 1999 ve Khandker, 2003).

Kırgızistan'da mikrofinans sistemi hakkında çalışmalara (Djuraev, 2008; Jeenalieva, 2008; Temirbekova, 2012 , Davlesov ve Ibraev, 2014;) girmektedir. Bu araştırmalar betimsel istatistik analizleri içermektedir. Ancak yoksulluk üzerindeki mikrofinansın etkilerini analiz eden empirik araştırmalara sadece Angioloni v.b., 2013; Sultakeyev, 2012 çalışmaları girmektedir. Angioloni v.b., 2013 çalışmasında mikrokredinin aile refah düzeyi üzerindeki etkisini ölçmüştür. Ekonometrik analizlerin sonucu mikrokredinin cinsiyet üzerinde ve refah üzerinde etkisi olmamıştır. Bu çalışmanın eksik yönü kredi değişken yerine borç değişkeninin kullanılması kredi hakkında tam doğru sonuçları vermemektedir. Konu ile ilgili bir diğer çalışmada (Sultakeyev, 2012) kredinin kar üzerindeki etkisini incelemiştir ve sonuç olarak \%3 oranında bir etki olduğunu savunmuştur. Çalışmanın eksik yönü araştırma sadece iki bölgede gerçekleşmiştir ve değişken olarak yoksulluk ele alınmamıştır.

Bu çalışmanın amacı mikrokredinin yoksulluk üzerindeki etkisini bulmak ve bu etkiyi arttırmak için devletin ne yapması gerektiği önerileri sunmaktır. Bu amaç çerçevesinde birinci olarak, yoksul ve yoksul olmayan mikrofinans kullanıcıları üzerinde bireysel, aile ve bölgesel farklılıkların etkisini ölçmektir. Daha doğrusu, mikrokredi kullanıcılarının yoksul olma olayına yaş, eğitim, cinsiyet, aile, ek gelir, iş-tecrübesi, kredi amacı, işi büyüyenler ve krediyi ödemede zorlanmayanlar, paralel kredi ve faiz oranı değişkenlerin etkileri ölçenecektir.

Çalışma giriş, yöntem, analiz ve sonuç kısımdan oluşmaktadır. Çalışmanın giriş bölümünde mikrofinansın önemi, gelişimi, mikrokredi piyasasındaki problemler ele alınmıştır. Yöntem bölümünde ise araştırmanın yöntemi açıklanmıştır. Araştırmanın modeli, alanı, ana kütle, örnek kütle seçimi ve veri analizi yorumlanmıştır. Analiz kısmında ise Logit regresyon sonuçları, mikrokredi kullanıcılarının betimsel istatistikleri yorumlanmıştır. Son bölümde araştırmanın sonuçları incelenmiştir.

\section{Kırgızistan'da Mikrofinans ve Gelişimi}

Kırgızistan ekonomisi ağırlıklı olarak tarıma dayalı olmasından dolayı çiftçilik, hayvancılık amaçlı kredilere ihtiyacı olan insanların sayısı çoktur. Kırgızistan'da 3.8 milyon işgücü nüfusun 700 bininin sabit işleri bulunmakta ve nüfusun 900 bini diğer ülkelerde çalışmaktadır. Diğer 2,2 milyon kişinin ise sürekli ve istikrarlı bir işi yoktur. Dolayısıyla bu kesimin geçimlerini sürdürebilmesi için kendi işlerini kurmaları zorunlu olmaktadır. Ancak kendi işlerini başlatabilmeleri için finansal kaynaklara ihtiyaçları bulunmaktadır. Son 15-20 yıldan beri yukarıda belirtilen durumun varlığı nedeniyle mikrokrediye aşırı talep bulunmaktadır. Fakat bu aşırı talebi mikrokredi arzı karşılayamamaktadır. Talebin fazla olması ve arzın az olması faiz oranlarının yüksek olmasına neden olmaktadır. Ayrıca 2002 yılında rekabetçi piyasa oluşturma amacıyla kabul edilen Mikrokrediler Hakkında Kanunda 
'mikrokredi kuruluşları faiz oranlarını kendileri belirler' maddesi, mikrokredi kuruluşlarının keyfi faiz oranı uygulamalarına yol açmıştır. Bilindiği gibi mikrokredinin temel amacı, yoksul insanlara kredi imkanları sunarak kendi işlerini kurmalarına yardımcı olmaktır. Bu bağlamda, sektörün gelişmesinde uluslararası kurumların da katkısı büyüktür. Bu kurumlar arasında Dünya Bankası, Asya Kalkınma Bankası, Avrupa gelişme ve kalkınma bankası, IMF, IFC, OSCE, USAİD, TIKKA ve TASİS gibi uluslararası kuruluşlar vardır.

2002 yılında kabul edilen 'Mikrokrediler Hakkında Kanun' (23 Haziran 2002 y1l 124 sayıl1) mikrokredi veren işletmelerin daha düzenli çalışmasını sağlamıştır. Ayrıca bu işletmeler Merkez Bankasının düzenleme ve denetimine tabidir. Kanun, mikrokredi işletmelerinin tanımı, sınıflandırılması, lisans alma süreci ve denetlenmesi hakkında ayrıntıları ihtiva etmektedir. Bu kanun çerçevesinde mikrofinans işletmeleri 3'e ayrılmaktadır. Bunlar;

1. Mikrofinans İşletmesi: Uluslararası, ulusal veya yerel kuruluşlardan sağlanan fon ya da özsermayeyi tüzel ve gerçek kişilere mikrokredi ve diğer hizmetleri verme hakkına sahip olan ve hukuki organizasyon açısından anonim şirkettir. Bu tür işletmenin başka bir özelliği de mevduat toplama hakkına sahip olmasıdır.

2. Mikrokredi İşletmeleri: Uluslararası, ulusal veya yerel kuruluşlardan sağlanan fon ya da özsermayeyi tüzel ve gerçek kişilere mikrokredi olarak sunan ve Merkez Bankasından sertifika alan, hukuki açıdan herhangi bir işletme niteliğinde olan kuruluşlardır.

3. Mikrokredi Acenteleri: Uluslararası, ulusal veya yerel kuruluşlardan sağlanan fon ya da özsermayeyi tüzel ve gerçek kişilere mikrokredi olarak sunan, ticari olmayan işletme türüdür.

4. 1990 yılında bağımsızlığını kazanan Kırgızistan'ın mikrofinans ve mikrokredi sistemi, yapılan birçok değişiklikler olmuştur. 2015 yılının başında 5 mikrofinans işletmesi, 143 mikrokredi işletmesi, 54 mikro kredi acentesi, 128 kredi birliğinden oluşmaktadır (Tablo 1).

\begin{tabular}{lcccccccccc}
\hline & 2006 & 2007 & 2008 & 2009 & 2010 & 2011 & 2012 & 2013 & 2014 & 2015 \\
\hline Mikrofinans İşletmesi & 1 & 2 & 2 & 4 & 4 & 4 & 4 & 4 & 4 & 5 \\
Mikrokredi İşletmesi & 57 & 103 & 170 & 226 & 246 & 340 & 242 & 208 & 203 & 143 \\
Mikrokredi Acentesi & 89 & 127 & 119 & 129 & 130 & 110 & 74 & 65 & 65 & 54 \\
Kredi Birlikleri & 308 & 272 & 248 & 238 & 229 & 197 & 183 & 153 & 150 & 128 \\
\hline
\end{tabular}

Tablo 1. Kirgızistan'da Mikro Finans Kurumlarının Dă̆ılımı

Tablo 1'de mikro finans kurumlarının sayısı 2011 yılına kadar hızlı artmış, 2011 yılından sonra ise düşme eğilimine girmiştir. Buna 2011 ve 2012 yıllarında mikrokredi faiz oranlarının yüksek olmasından dolayı müşteri tepkileri ve Kırgız Cumhuriyeti Merkez Bankasının mikrofinans kurumlarını sıkı kontrol altına alması neden olmuştur. Düzenleyici (regülatör) yetkisine sahip olan Merkez Bankası 2012 yılından sonra Mikrokredi Kuruluşlarından her üç ayda bir periyodik düzenleyici rapor istenmeye başlamıştır. Ayrıca kanunun 2. maddesinin gereklerine aykırı faaliyetler için birçok mikrokredi kurumlarına uyarı gönderilmiştir. Bu uyarı örneğin Kırgızistan'ın en büyük MKK olan "Mol-Bulak Finans" şirketine de gönderilmiştir. Uyarı gereklerine uygun olarak, Mol-Bulak Finans şirketi 2017 yılına kadar faiz oranlarını optimize etmek için faiz oranlarını tedrici olarak azaltacağına dair bir plan sunmuştur. Ancak 2013 yılın 2. çeyreğinde Mol-Bulak Finans şirketinin, planda belirlenen performans düzeyine ulaşamadığı ve ağırlıklı ortalama faiz oranları bir önceki döneme göre arttığı için faaliyeti geçici olarak durdurulmuştur. Ayrıca 2013 yılında mikrokredi kurumlarının sayısındaki azalmaya 'faiz oran tavanı uygulama kanunu' nun yürürlüğe girmesi de neden olmuştur.

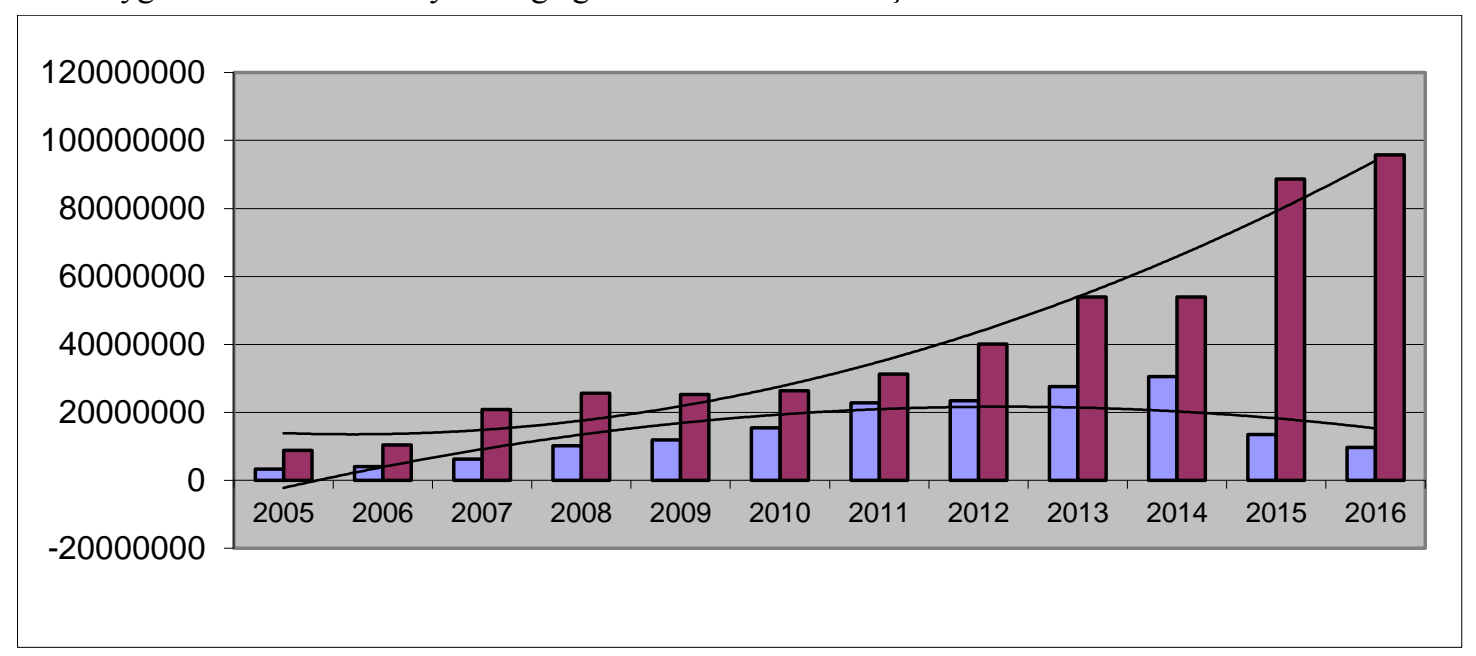

Grafik 1. Banka ve Mikrokredi Kuruluşların Kredi Portföyü

Grafik 1'de mikrokredi kurumları (mavi renkte) ve ticari bankaların kredi portföyü (kırmızı renkte) verilmiştir. Şekil 1'de 2008 yılında mikro kredi kurumları 6167144000 som iken 2011 yılında 22755380000 som kadar hızlı (\%) artış olmuştur. Ancak banka portföyü 2008 yılında 20797600000 iken 2011 yılı 31217100000 kadar 
(\%) bir artış olmuştur. Artış her iki sektörde de olmuştur. Fakat mikrokredi sektöründeki artış banka sektörüne göre çok fazla olmuştur. Sebebi ise mikrokrediye olan talebin aşırı derecede yüksek olması, mikrokredi kanunlarının liberal olmasıdır. Çünkü KC Merkez Bankası mikrofinans piyasasının canlandırmak ve rekabetçi piyasa oluşturmak için mikrokredi sektörünü 2012 yılına kadar serbest bırakmıştır. Ancak 2013 yıllından başlayarak mikrokredi sektöründe gelişme azalmaya başlamıştır. Çünkü bu yıllarda mikrokredi piyasasının en büyükleri olarak bilinen Bay-Tüşüm, Finka ve Kompanion mikrofinans işletmeleri ticari banka olmalarından dolayı mikrokredi piyasasının kredi portföyü azalmıştır ve banka sektörünün kredi portföyü artmıştır.

\section{Yöntem}

Çalışmanın amacına ulaşmak için araştırma alanı, araştırma birimleri, örnekkütle seçimi ve veri analizi yapılmıştır.

\subsection{Araştırma Alanı}

Araştırma alanları ülkenin 7 bölgesinde ve iki büyük şehrinde gerçekleşmiştir. Bunlar sırasıyla: Çüy bölgesi, Isık Göl bölgesi, Narın bölgesi, Talas bölgesi, Celal Abad bölgesi, Oş bölgesi, Batken bölgesi, Oş şehri ve Bişskek şehri.

\subsection{Araştırma Birimleri (Evren):}

Kırgızistan'da mikro kredi kullanan müşterilerdir. Müşterilerin sayısı Kırgızistan Milli İstatistik Komitesi’nin istatistik verileri esas alınmıştır. Kırgızistan Milli İstatistik Komitesi’nden alınan bilgilere göre, Kırgızistan'ın yedi bölgesinde ve iki büyük şehrinde toplam 456587 müşteri bulunmaktadır. Aşağıdaki tabloda mikro kredi müşterileri sayı olarak bölgelere göre sıralanmış ve böylece araştırma birimleri (evren) ile ilgili çalışma tamamlanmıştır (bkz. Tablo 2).

\begin{tabular}{ll}
\hline Araştırma Alanı & Toplam \\
\hline Batken Bölgesi & 32908 \\
Jalalabat Bölgesi & 82944 \\
Isık-Köl Bölgesi & 47015 \\
Narın Bölgesi & 38053 \\
Oş Bölgesi & 74679 \\
Talas Bölgesi & 30494 \\
Çüy Bölgesi & 72716 \\
Bişkek şehri & 60711 \\
Oş şehri & 17067 \\
\hline Toplam & 456587
\end{tabular}

Tablo 2. Kırgızistan'da Mikro Kredi Müşterilerinin Bölgelere Göre Dă̆ılımı (Anakütle)

\section{3 Örneklem:}

Belirlenen listelerden, \%95 güven aralığı ve 0,05 hata payı ile basit tesadüfi örnekleme yöntemine göre örnek seçilmiştir. Evrendeki birim sayısı bilindiği zaman tesadüfi örnekleme yöntemi aşağıda gösterilen formül ile hesaplanmıştır:

$$
n=\frac{\pi(1-\pi) * Z^{2}}{(p-\pi)^{2}}
$$

$\mathrm{N}$ : evren birim sayıs1,

n: örneklem büyüklüğü,

$\mathrm{Z}: \alpha=0.05$ için 1,96 değeri,

$\pi$ : Evrendeki X'in gözlenme oranı, Tahmin edilen ve İstenen özellik Oranı

$(1-\pi)$ : X'in gözlenmeme oranı,

$(\mathrm{p}-\pi)$ : örneklem hatası, hata payı.

Formül (1)'e göre örneklem sayısı $n=\frac{0,5^{*} 0,5^{*} 1,96^{2}}{0,05^{2}}=384,16 \quad$ olarak hesaplanmıştır.

Bölgelere göre örneklem sayıları her bölgedeki işletmelerin oransal ağırlığı dikkate alınarak hesaplanmıştır. Örneklem sayıları Tablo 3'te verilmektedir.

(Örnek kütle)

Araştırma Alanı Toplam




\begin{tabular}{ll}
\hline Batken Bölgesi & 28 \\
Jalalabat Bölgesi & 70 \\
Isık-Köl Bölgesi & 40 \\
Narın Bölgesi & 32 \\
Oş Bölgesi & 63 \\
Talas Bölgesi & 26 \\
Čüy Bölgesi & 61 \\
Bişkek şehri & 51 \\
Oş şehri & 14 \\
\hline Toplam & 384
\end{tabular}

Tablo 3. Müssterilerin Bölgelere Göre Örneklem Dağılımı

\section{Bulgular}

$\mathrm{Bu}$ kısımda anket sonuçları yer almaktadır. Sonuçlara dayanan bulgular ve yorumlar yapılmıştır. Yapılan örneklem büyüklüğü hesaplamasında elde edilen değer, \% 10 hata payılla ve \% 99 güven aralığılyla Cronbach alfa katsayısı 0,780 olarak ölçülmüştür. Yapılan testin güvenilirlik analizinde Bu katsayı ölçeğin oldukça güvenilir olduğunu ispatlamıştır.

\subsection{Verinin Ekonometrik Modeli}

Yoksulluk üzerinde bireysel, aile ve mikrofinans ile ilgili olan faktörlerin etkisini ölçmek için en çok atıf alan araştırmaların birinde Chowdhury v.d. (2002) logit regresyonu kullanmıştır. Model aşağıda gösterilmiştir.

Prob $(\mathrm{P}=1)=f(\mathrm{XP}, \mathrm{XH}, \mathrm{XV})$

Burada;

«P» bağımlı değişken, «1» olarak kodlanmışsa yoksul, «0» ise yoksul değil,

«XP» Mikrokredi programının değişkenlerinin vektörü

«XH» Ailenin ve bireyin sosyal-ekonomik değişkenlerinin vektörü

«XV» bölge değiş̧kenleri vektörü

Chowdhury v.d. (2002) bu model ile objektif ve subjektif yoksulluk üzerindeki mikrofinansın etkisini ölçmüştür.

Bu çalışmanın ekonometrik modeli,

$\operatorname{Ln}(\mathrm{p} /(1-\mathrm{p}))=\mathrm{B} 0+\mathrm{B} 1 \mathrm{X} 1+\mathrm{B} 2 \mathrm{X} 2++\ldots+\mathrm{B} 9 \mathrm{X} 9$

Ekonometrik modelin bağımlı değişkeni

Modelin bağımlı değişkeni ( $\mathrm{P}=1)$ olarak insanın yoksul olma olasılı̆̆ını aldık. Yoksul olma durumu olarak insanın yaşaması için en gerekli olan bir aylık asgari ücreti kabul ettik. 2014 yılı asgari ücret miktarı aylık olarak 4891 som. Demek kimin aylık geliri 4891 somdon küçük ise yoksul (1), büyük ise yoksul değil (0).

Ekonometrik modelin bağımsız değişkenleri

«XP» Mikrokredi programının değişkenlerinin vektörunda aşağıdaki değişkenler istatiksel olarak önemli çıkmıştır.

1. Kredi miktarı

2. Kredi süresi

3. Kredi amac1

4. Krediyi kolay ödeyenler

5. Paralel kredi almayanlar

6. Kredi faiz oranı

«XH» Aile ve bireyin sosyo-ekonomik değişken vektörunda aşağıdaki değişkenler istatiksel açıdan önemli olarak çıkmıştır.

1. Yaş

2. Aile durumu

3. Ek geliri olmayanlar

4. İş tecrübesi

«XV» bölge farklılıkları vektöründe il, şehir ve köy, uzaklık ve bağl1lı gibi değişkenler anlamsız çıktığından modelde yer almadi.

Logit Regresyon Modeli ve Sonuçları 


\begin{tabular}{lcccc}
\hline Bağımsız Değişkenler & Sabit katsayı & Standart Hata & Anlamlılık & Exp(B) \\
\hline Sabit & 1,131 &, 465 & $(, 015)^{* * *}$ & 3,098 \\
Yaş (60) & 1,693 &, 271 & $(, 000)^{* * *}$ & 5,435 \\
Aile &,- 566 &, 268 & $(, 035)^{* *}$ &, 568 \\
Ek geliri olmayanlar & 1,452 &, 258 & $(, 000)^{* * *}$ & 4,272 \\
Tecrübe &,- 964 &, 268 & $(, 000)^{* * *}$ &, 381 \\
Kredi miktarı &, 000 &, 000 & $(, 040)^{* *}$ & 1,000 \\
Kredi süresi &,- 040 &, 015 & $(, 007)^{* * *}$ &, 960 \\
Krediyi amaçlı kullananlar &,- 365 &, 223 & $(, 102)^{*}$ &, 694 \\
Krediyi kolay ödeyenler &,- 374 &, 221 & $(, 091)^{*}$ &, 688 \\
Paralel kredi almayanlar &,- 711 &, 275 & $(, 010)^{* * *}$ &, 491 \\
Faiz oranı 35-40 &, 445 &, 232 & $(, 055)^{* *}$ & 1,561 \\
\hline (***) anlaml1\% 1\% & & &
\end{tabular}

$(* * *)$ anlamlı 1\% düzeyinde, $(* *)$ anlaml $5 \%$ düzeyinde, $(*)$ anlamlı 10\% düzeyinde

Tablo 4. Logit Regresyon Modeli

\subsection{Değişkenlerin yorumlanması}

Yaş (60): Yaşı altmış ve altmış üstü olanlar gençlere göre yoksul olma olassllı̆̆ 5,4 kat büyük.

Aile: Ailesi olan mikrokredi kullanıcıları dul ve ayrılanlara göre yoksul olma olasılığı yüzde 56 azalmaktadır.

Ek geliri olmayan mikrokredi kullanıcıları: Ek geliri olmayan mikrokredi kullanıcıları ek geliri olanlara göre yoksul olma olasılığı 4,2 kat fazla olmaktadır. Mikrokredi alan müşterilerin ek geliri olanlar aylık kredi ödemelerini kolay ödemektedir. Mikrokredi kullanıcılarının ek gelirlerini arttırmak için sosyal işletmelerin kurulması da çok önemli olacaktır. Örneğin bu kurumun müşterilerine yoksulluktan hızlı çıkmaları amacıyla çok ucuz mallar avans olarak verilebilir. Yoksullar bu malların üzerine en fazla \% 75 oranına kadar fiyat uygulayarak piyasaya satabilirler. Günümüzde bu örnek Türkiye'de başarılı şekilde uygulanmaktadır.

Tecrübe: Tecrübesi olan mikrokredi kullanıcıların tecrübesi olmayan mikrokredi kullanıcılarına göre yoksul olma olasılığı yüzde 38 azalmaktadır. Çünkü tecrübesi olmayan mikrokredi kullanıcıları aldıkları krediyi kısa dönemde gelir getirici faaliyetlere kullanmak isterken, girişimcilik ve yetenek eksikliği nedeniyle yanlış mal alımı, satışların azalması vb. sebeplerle yeni bir borç sarmalının içerisine girmektedirler. Bundan dolayı kredi verilmeden önce teknik bilgi ve eğitimler verilmesi, verilen kaynakların hangi amaçlara kullanılacağının tespit edilmesi ve işlerini büyütmek için çeşitli tavsiyelerde bulunulması gerekir. Bu şekilde bir destek sağlanması kişilerin mikro kredi kullanımını daha da etkinleştirir. Böylece mikro kredi hizmetlerinden yararlananlar yatırımlarını daha verimli alanlarda yapma imkânına kavuşurlar ve bu hizmeti sunan kurumlar da kullandırdıkları kredinin faizi ile beraber geri dönüşünü kolaylaştırmış olurlar.

Kredi tutarı: Kredi tutarının bir birim artması yoksulluk olma olasılığını hiç azaltmamaktadır.

Kredi süresi: Kredi süresinin bir aya uzatılması yoksul olma olasılığını yüzde 4 oranında azaltmaktadır. Kredi süresinin uzun olması kaynağın daha çok işte kullanması ve aylık geri ödeme miktarının az oranda olmasıdır. Aylık geri ödeme miktarının az oranda olması ise mikrokrediden kazandıkları gelirin hemen ödenmeyip daha çok işte kullanmasidır.

Krediyi amacına göre kullananlar: Kredi kullananların krediyi amacına göre kullanıp, işleri büyüyenlerin amaç dışı kullananlara göre yoksul olma olasılığı yüzde 69 azalmaktadır. Mikrokredinin amaç dışı kullanıldığında birtakım sorunların da ortaya çıkmasına neden olmaktadır. Bundan dolayı verilen kaynakların hangi amaçlara kullanılacağının tespit edilmesi çok önemlidir. Ayrıca kredi verildikten sonra kredinin nereye harcadığını öğrenmek için monitoring yapılması gerekir. Mikrokredi, mevcut işin büyütülmesi için kullanıldı̆̆ında yoksulların yoksulluktan kurtulmasında çok önemli bir oynayabilir.

Krediyi kolay ödeyenler: Krediyi kolay ödeyenlerin kredi ödemede zorlananlara göre yoksul olma olasıllı̆ yüzde 68 azalmıştır.

Paralel kredi almayanlar: Paralel kredi almayanlar paralel kredi alanlara göre yoksul olma olasıllı̆g yüzde 49 azalmaktadır. Mikro kredi sisteminden yararlanacak fertlerin finansal bilgilerinin geliştirilmesi gerekir. Borçluların mikrofinans kurumların bol olmasından dolayı bir anda aynı iş için üç ve dört mikro kredi kurumundan mikro kredi alabilme olanakları artmaktadır. Çalışmada borçluların dörtte biri (\%25) ikiden fazla kredi aldığı durum tespit edilmiştir (Tablo 36). Bu borç üstü borç mikro kredi kullanıcıların ödeme güçlerini zayıflatmaktadır. Belli bir zaman sonrası müşteri çok miktarda kredi aldığı için pişman oluyor.

Faiz oranı 35-40: Kredi kullananların krediyi yüzde 35-40 civarında faiz oranından alıyorlarsa, onların yoksul olma olasılığı düşük faiz oranından uygulanan kredilere göre 1,5 kat artmaktadır. Mikro kredi faiz oranlarının 
yüksekliği müşterilerin borç ödeme güçlerinin yetersiz olmasına ve sattığı malın fiyatııın yükselmesine neden olmaktadır. Bu da uzun dönemde kredi kullanan kişinin rekabet gücünü zayıflatmaktadır.

\section{Sonuç}

Dünyada mikrofinans piyasası çok gelişmiş olsa da, birçok ülkelerde yüksek faiz oranları nedeniyle etkili olamamaktadır. Kırgızistan'da mikrokredilerin yaygın hale gelerek geleneksel bankacılık sektörünü tamamladığı bilinse de, yoksulluk üzerindeki etkisinin olup olmadığı bilinmemektedir.

Bundan dolayı çalışmanın amacı mikrokredinin yoksulluk üzerindeki etkisini bulmak ve bu etkiyi arttırmak için devletin ne yapması gerektiği önerileri sunmaktır. Bu amaç çerçevesinde birinci olarak, yoksul ve yoksul olmayan mikrofinans kullanıcıları üzerinde bireysel, aile ve bölgesel farklılıkların etkisini ölçülmüştür. Daha doğrusu, mikrokredi kullanıcılarının yoksul olma olayına yaş, eğitim, cinsiyet, aile, ek gelir, iş-tecrübesi, kredi amacı, işi büyüyenler ve krediyi ödemede zorlanmayanlar, paralel kredi ve faiz oranı değişkenlerin etkileri ölçülmüştür.

Çalışmanın amacına ulaşmak için logit regresyonu kullanılmıştır. Çalışmanın sonuçlarına göre mikrokredinin yoksulluk üzerindeki etkisi sıfıra çok yakın bir değer almaktadır. Dolayısıyla Kırgızistan'da uygulanan mikrokredi programlarının yoksulluğu azaltıcı etkisi bulunmamaktadır. Yoksulluğu azaltıcı etkisinin olmamasının birinci sebebi faiz oranlarının yüksek olmasıdır. Müşterilerin genellikle katlanan faiz oranları yüzde 35-40 arasında olmaktadır. Bu orandan alan müşterilerin yoksul olma olasılığı banka faiz oranından uygulanan kredilere göre 1,5 kat artmaktadır. İkinci sebep ek geliri olmayan mikrokredi kullanıcılarıdır. Ek geliri olmayan müşteriler ek geliri olanlara göre yoksul olma olasılığı 4,2 kat fazla olmaktadır. Çünkü ek geliri olan müşteriler aylık kredi ödemelerini kolay ödemektedir. Mikrokredi kullanıcılarının ek gelirlerini artırmak için sosyal işletmelerin kurulması da çok önemli olacaktır. Örneğin bu kurumun müşterilerine yoksulluktan hızlı çıkmaları amacıyla çok ucuz mallar avans olarak verilebilir. Yoksullar bu malların üzerine en fazla $\% 75$ oranına kadar fiyat uygulayarak piyasaya satabilirler. Günümüzde bu örnek Türkiye'de başarılı şekilde uygulanmaktadır. Diğer taraftan müşterilerin ek gelirlerinin olması için devletin kırsal kesimlerde iş olanakların sağlanması da çok önemlidir. Aile üyelerinin devlet ya da özel sektörlerin fabrikalarında, üretimlerinde çalışarak ek ücret kazanması müşterilerin krediyi etkili kullanmasına izin vermektedir. Üçüncü sebep verilen kredi süresinin kısa olmasıdır. Kredi süresinin bir aya uzatılması yoksul olma olasılı̆̆ını yüzde 4 oranında azaltmaktadır. Çünkü kredi süresinin uzun olması aylık geri ödeme miktarının az oranda olması demektir. Bu ise mikrokrediden kazandıkları gelirin hemen ödenmeyip daha uzun süre işte kullanması demektir. Dördüncü sebep müşterilerin paralel kredi kullanmasıdır. Bu da borç üstü borç olarak mikro kredi kullanıcıların üzerine bir yük olarak ödeme güçlerini zayıflatmaktadır. Paralel kredi alanlar paralel kredi almayanlara göre yoksul olma olasılığı yüzde 49 artmaktadır. Mikrokredi programlarının yoksulluğu azaltıcı etkisi bulunmamasının diğer sebeplerine de müşterilerinin yaş durumunu, ailesinin olmaması, iş tecrübesinin olmaması, krediyi amacına göre kullanmaması girmektedir.

\section{Kaynakça}

- Angioloni, S., Kudabaev, Z., Ames, G. C., \&Wetzstein, M. E. (2013). Micro-credit impact in Kyrgyzstan: A study case. Southern Agricultural Economics Association, 23.

- Chowdhury, M. J. A., Amin, S., \&Farha, T. (2012). Access to Credit and Women Entrepreneurship: Evidence from Bangladesh.

- Coleman, B. E. (1999). The impact of group lending in Northeast Thailand. Journal of Development Economics, 60(1), 105-141.

- Djuraev N., (2008). Mikro Kredi Sistemi ve Kırgızistan, Yüksek Lisans Tezi, SBE, KTMÜ

- Jeenbaeva B.J.,(2008).Problemi Razvitya Mikrofinansirovaniya I Mikrokreditovaniya v Perehodniy Period, Tsentr Ekonomicheskih isledovaniy NAN KR.

- Khandker, S. R. (2003). Micro-finance and poverty: evidence using panel data from Bangladesh. World Bank Policy Research Working Paper, (2945).

- Morduch, J., \& Haley, B. (2002). Analysis of the effects of microfinance on poverty reduction (Vol. 1014). NYU Wagner working paper.

- Seyitbekov, T., (2007). "Mikro Finansman'ın Kırgızistan Uygulaması ve Sonuçları (Celalabad Vilayeti Alabuka Bölgesi)", Yüksek Lisans Tezi, Sakarya University, Sosyal Bilimler Enstitüsü

- Sultakeev, K., (2012). “Kırgızistan'da Yoksulluğu Önlemede Mikrokredi Uygulamaları” Yüksek lisans Tezi, Kırgızistan Türkiye Manas Üniversitesi

- Temirbekova N.,(2012). Microfinance in Kyrgyzstan: Facilitating Women's Economic Empowerment, Master thesis, Central European University, Budapest, Hungary

- A. Davlesov, N. Ibraev, 2014: "Kırgız Cumhuriyeti'nde mikrofinans pazarının rolü: umutları ve tehditleri raporu ", Kırgız Stratejik Araştırmalar Ulusal Enstitüsü 24 Temmuz 2013 N 163 Cumhuriyet ", Bişkek 


\title{
Borç Krizinde Kemer Sıkma Politikaları Ne Kadar Başarılı? Austerity Policies in Debt Crisis: The Limits of Success
}

\author{
Prof. Dr. Naci Tolga Saruç (İstanbul University, Turkey) \\ Candan Yılmaz (Gümüşhane University, Turkey)
}

\begin{abstract}
Global financial crisis, emerged in 2008 and deepening thoroughly in 2008, revealed deep cracks in European Union countries -especially peripheral countries. The member of peripheral countries implemented European Union monetary policy have adopted low-cost borrowing as a public income. On the one hand, the global crisis has decreased the amount of funds in the international arena and led to an increase in borrowing costs. On the other hand, those peripheral countries with austerity policies imposed by the Troika faced with the problem of debt. The global crisis, appeared in the US and in a short time affected many countries gave rise to the debt crisis in the EU. The aim of this study is to demonstrate theoretically effects of the global crisis on peripheral countries of the EU. Furthermore, it is to analyze how the EU debt crisis considered the second phase of global crisis developed in member states and what kind of measures was taken for crisis. Eurostat database from 2006 to 2015 are used. EU members met the global financial crisis with high debt have increased in public expenditure in order to mitigate the effects of crisis. In addition to this, member states are deprived from tax income because of using strict austerity policies. In conclusion, it is shown that the austerity policies imposed by EU caused to increased further public debt stock in the member states and it left peripheral members the debt impasse.
\end{abstract}

\section{Giriş}

Serbestleşme olgusunun ivme kazanması ile birlikte, finansal serbestleşmenin itici gücü olan sermayenin mobilitesi artmaktadır. Finansal serbestleşme politikasını benimseyen gelişmekte olan ülkeler aşırı risk üstlenmekte ve uluslararası alanda bulunan sermayenin yönü ve hacminde meydana gelen olağanüstü değişmeler ülkelerin kırılganlıklarını artırmaktadır. Bu ülkelerde risk faktörü arttıkça makroekonomik dengeler bozulmakta ve ülkeler krize sürüklenmektedir. Ancak 2007 yılında dünyayı etkisi altına alan küresel krizi diğer krizlerden ayıran temel unsur gelişmiş bir ülkede ortaya çıkmasıdır. Finansal serbestleşmenin de etkisiyle gelişmiş ülkede ortaya çıkan kriz birçok ülkeyi etkisi altına almıştır. Küresel krizden etkilenen ülkelerde büyüme oranları düşmüş, işsizlik oranları artmış, finansal kurumların birçoğu zarar görmüştür. Küresel krizin ilk aşaması olarak görülen bu dönemde ABD Hükümeti hem toplam talebi canlandırmak hem de büyük miktardaki zararları karşılamak için kamu harcamalarını artırmıştır. Bu dönemde piyasaları canlandırmak amacıyla 2008 yılında 700 milyon dolarlık yardım paketi piyasaya sunulmuş, Federal Açık Piyasa Kurulu yüzde 5.25 düzeyinde olan gösterge faizini yüzde 2'ye indirmiş ayrıca vergi teşvikleri genişletilmiştir. Kısaca ABD Hükümeti, küresel kriz döneminde Keynesyen politikaları uygulamış ve devletin görünür elini yardıma çağırmıştır (Eğilmez, 2015: 106).

Avrupa Birliği'nde de krize karşı genişletici politikalar alınmış ilk olarak iflas eden ülke ekonomilerini kurtarmak adına fon oluşturulmuş ve bu fona 440 milyar Euro kaynak ayrılmıştır. Mayıs 2010 tarihinde, Avrupa Birliği - IMF ortaklığı ile Yunanistan için 110 milyar Euro, Kasım 2010'da İrlanda için 85 milyar Euro ve Nisan 2011'de Portekiz için 78 milyar Euro tutarında kurtarma paketi açıklanmıştır (Yıllmaz, 2013: 129 - 130). Ancak küresel krizin etkilerini hafifletmek adına ard arda açılan yardım paketleri, kısa dönemde etkili olsa da uzun dönemde bütçe üzerinde ağır yük oluşturmuştur (Prinz ve Beck, 2012:5).

Diğer taraftan küresel kriz Avrupa Birliği üyeleri arasında herkesin görebildiği iki temel eksen ortaya çıkarmıştır. İlk eksen, küresel kriz öncesi dönemde ekonomileri istikrarlı tutmayı başararak cari fazla veren "merkez grubu", diğer eksen ise cari açığı hızla artan ve aşırı borçlanan “çevre grubudur”. Merkez grubunda özellikle Almanya, çevre ülkelerin neredeyse toplam cari açığı kadar cari fazla vermiş, düşük enflasyon düşük ücret ve girişken ticaret politikalarıyla merkez-çevre arasındaki uçurumu derinleştirmiştir (Öniş ve Kutluay, 2012: 5). Avrupa Birliği çevre grubunda yer alan ülkeler ise Troyka tarafindan (Avrupa Merkez Bankası, IMF ve Avrupa Komisyonu) dayatılan ancak halkın tepkisine ve sokak gösterilerine de neden olan, kemer sıkma politikalarına yönelmek zorunda kalmışlardır.

Bu çalışmada küresel krizin ikinci aşaması olarak değerlendirilen Avrupa Birliği borç krizinin olumsuz etkilerini bertaraf etmek özellikle birlik içerisinde yer alan ve Tembel Akdeniz olarak nitelendirilen İrlanda, İspanya, İtalya, Yunanistan ve Portekiz ülkelerine dayatılan kemer sıkma politikalarının başarısı ele alınmaktadır.

\section{Küresel Finansal Krizden Avrupa Borç Krizine}

Avrupa Birliği'nin siyasi olarak inşa edilmesi ve genişlemesi daha sonra Euro Alanı'nın oluşturulması ve Euro'nun tek para birimi olarak kullanılmaya başlanmasıyla birlikte faiz oranları düşük seviyelerde seyretmiş ve ekonomide beklentiler olumlu olarak gerçekleşmiştir (Tichy, 2012: 98). Ancak bu süreç özellikle borçlanma 
maliyetlerini düşürmüş ve borçlanma olağan bir kamu geliri olarak görülmüştür. Birliğe katılmadan önce uluslararası alanda rekabet gücünü korumak amacıyla sıklıkla devalüasyon yapan bu ülkeler tek bir para politikası nedeniyle "merkez grubu" ülkelerle aynı politikayı uygulamışlar, ancak ekonomik büyümeyi sağlamak ve iç talebi canlandırmak için kamu harcamalarını artırmışlardır (Yılmaz, 2013: 86). Bu durumda da birlik içinde yer alan ülkelerin borç stokları artmaya başlamıştır.

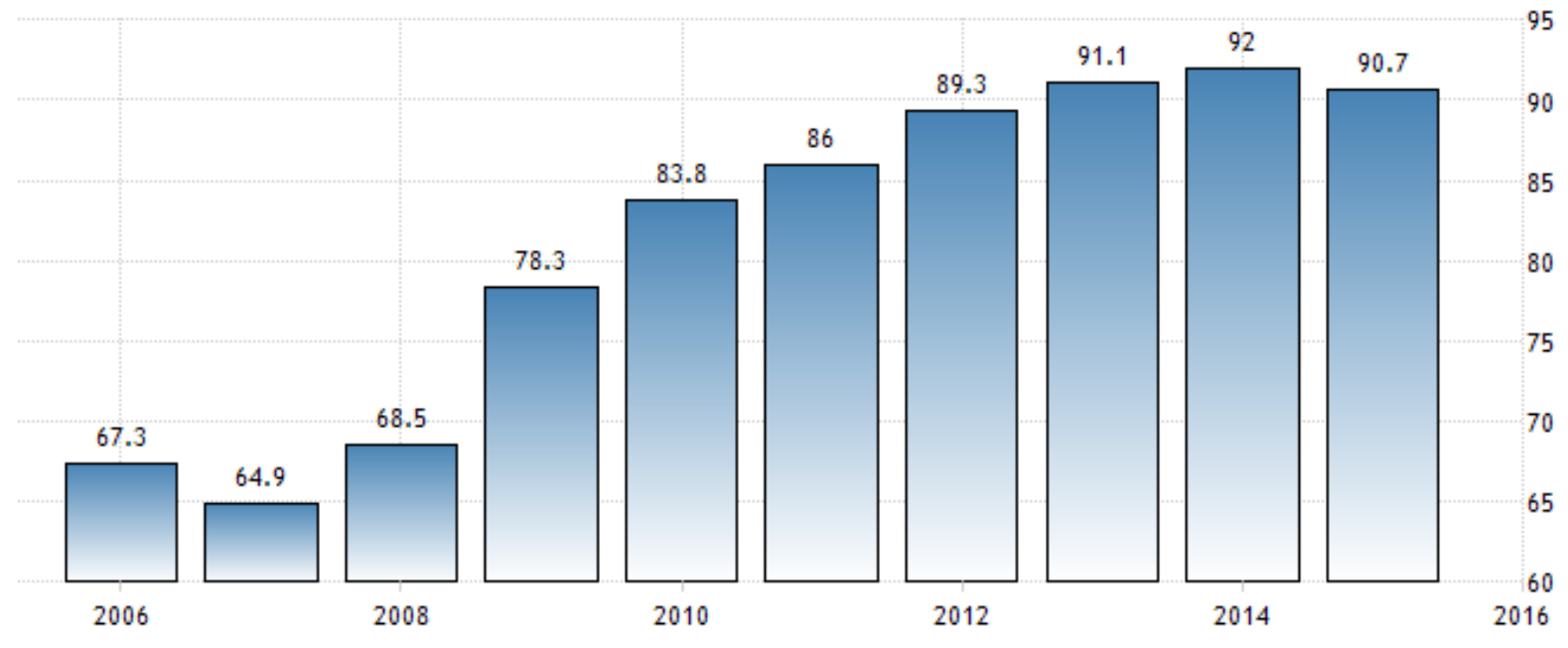

Grafik 1: Avrupa Birliği Kamu Borç Stoku / GSYH Oranı (\%) Kaynak: Eurostat, General Government Debt, 2016.

Grafik 1 Avrupa Birliği kamu borç stokunun GSYH içindeki payını göstermektedir. Öncelikli olarak Avrupa Birliği'nin küresel krizi borçlu olarak karşıladığını söylemek mümkündür. Küresel krizin de etkisiyle kamu harcamaları daha da artırılmış ve ilerleyen yıllarda kamu borç stokunda da artış görülmüştür. Dikkat edilmesi gereken ikinci bir husus ise Avrupa Birliği ortalamasının kamu borç stoku / GSYH oranının \% 60’1 aştığı dolayısıyla Maastrict Kriterlerine uyulmadığıdır.

Avrupa Birliği içinde kamu borç stokunun hızlı biçimde artması ilk bakışta sorun olarak görülmemiştir. Ancak küresel krizin ABD'de ortaya çıkması ve birçok ülkeyi etkisi altına alması ile birlikte Avrupa Birliği krize borçlu olarak girmiştir. Küresel krizin olumsuz etkilerini hafifletmek ve birlik içinde istikrarı tekrar sağlamak için kamu harcamaları artırılmıştır. Bu durumda da birlik içinde yer alan ülkelerin özellikle de "çevre ülkelerin" bütçe dengeleri bozulmuştur (Sandoval ve diğerleri, 2011: 3).

Küresel krizin Avrupa' da borç krizi olarak devam etmesinin nedeni önceleri yüksek kamu borcu olan Yunanistan olarak görülmüştür. Bu dönemde Yunanistan'ın kamu borç stoku \% 120, bütçe açı̆̆ $\% 13$ düzeylerinde gerçekleşmişti ve edinilen bilgilerin şeffaf ve güvenilir olduğuna dair kuşkular bulunmaktaydı. 2010 yılından itibaren merkez grubu ülkeleri Yunanistan üzerine odaklanmış ancak benzer makroekonomik dengesizliklerin İspanya, Portekiz gibi ülkelerde de olduğunu görmüşlerdir (Gros ve Mayer, 2010: 1).

2010 yılından itibaren henüz ekonomilerde cılız bir iyileşmenin görülmesi ancak küresel krizin Avrupa Borç Krizi olarak birlik içinde devam etmesi ve bünyesinde makroekonomik dengesizlikleri barındıran ülkelerin artması Avrupa Birliği'nde yer alan kurumları önlem almaya zorlamıştır. Söz konusu borç krizinin tüm birliğe ulaşmasını önlemek isteyen Troyka (Avrupa Merkez Bankası, IMF ve Avrupa Komisyonu) tarafindan bu dönemde artan bütçe açıkları ve kamu borçları nedeniyle çevre ülkelere, kemer sıkma politikaları önerilmiştir. Önerilen kemer sıkma politikaları, büyük tepkilere rağmen zorunlu reformlar ve harcama kesintilerini içermektedir. Kemer sıkma politikalarının yoğun olarak uygulandığı / uygulatıldığı ülkeler ise Yunanistan, İrlanda, İspanya, İtalya ve Portekiz'dir (Monastiriotis, 2013: 1). 


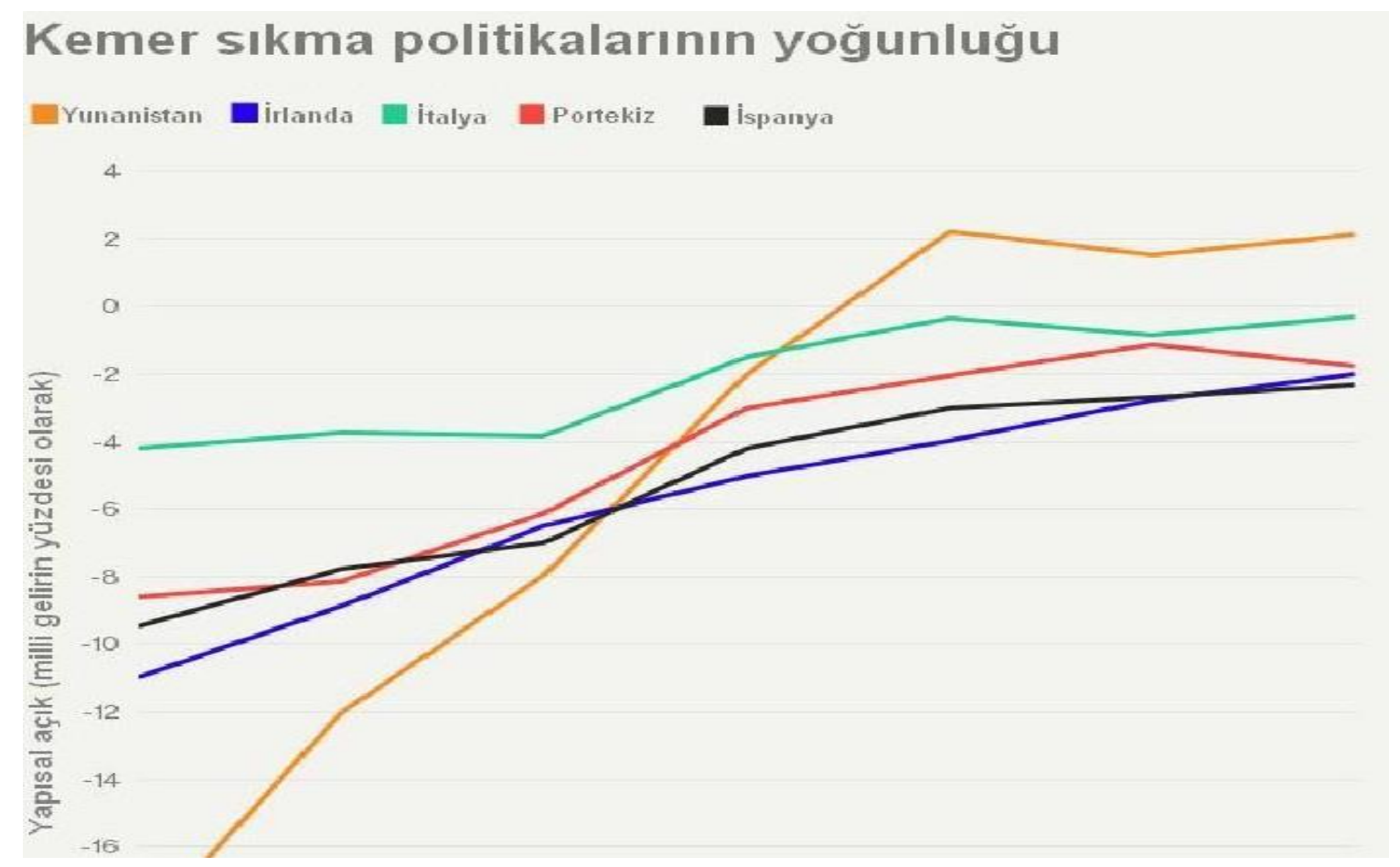

Grafik 2: AB Üyesi Ülkelerde Kemer Sikma Politikalarının Yoğunluğu

Grafik 2'de 2009 - 2015 döneminde AB üyesi ülkelerde uygulanan kemer sıkma politikalarının yoğunluğu görülmektedir. Kemer sıkma politikalarının krizin ilk etkisinin görülmeye başlandığı 2009 yılında İtalya'da yoğun olarak uygulandığı görülmektedir. 2013 yılında ise kemer sıkma politikalarını Yunanistan için yoğun olarak uygulanmıştır. Birlik içinde yer alan İrlanda, Portekiz ve İspanya kemer sıkma politikalarının yoğun olarak uygulandığı diğer ülkelerdir.

Yunanistan; ilk olarak Mart 2010'da 110 milyar Euro yardım paketi almış, 2011 yılında Yunanistan'ın 100 milyar Euro borcu silinmiştir. Şubat 2012'de 130 milyar Euro bir yardım paketi daha hazırlanmıştır (AB Genel Sekreterliği, 2011: 5). Avrupa Birliği tarafından sağlanan yardımlar karşılığında uygulanan kemer sıkma politikaları; vergi oranlarının artırılması, vergi muafiyeti ve istisnalarına sınırlamalar getirilmesi, emeklilik yaşının 65' çıkarılması, , emekli maaşlarında ve kamu işçilerinin ücretlerinde kesintiler yapılması, sosyal yardımların kısılması, kamu kuruluşlarının özelleştirilmesi asgari ücretin \% 22 oranında düşürülmesi, kamu istihdamının \% 22 düşürülerek 150.000 kişi kadar azaltılması gibi düzenlemeleri barındırmaktadır (Hurma, 2013: 24).

İrlanda; 2011 yılı ortalarına kadar kamu finansman dengesinde herhangi bir sorun olmadığını belirtmiş olsa da, ülkenin bankacılık sektöründe var olan yüksek borç yapısı nedeniyle mali yardımlar yapılmıştır. İrlanda borçlanma kriziyle mücadele çerçevesinde kemer sıkma politikalarını uygulamış ve bu politikayı takiben bir taraftan kamu harcamaları kısılmış, diğer taraftan vergi oranları artırılmıştır (Şanlıŏ̆lu ve Bilginoğlu, 2010: 160).

İtalya ise kriz döneminde toplam 40 milyar Euro yardım paketi almıştır. Bu yardımlar karşılığında ise bakanlık harcamalarında ve diğer cari harcamalarda kesintiler yapılması, yerel yönetimlere daha az kaynak transferi gerçekleştirilmesi, emeklilik yaşının yükseltilmesi, kamu sektörü çalışanlarının sayısının düşürülmesi, sağlık yardımlarında kesintilere gidilmesi gibi önlemler alınmıştır (Eraslan ve Timurtaş, 2015: 46).

İspanya'da borç krizine karşı uygulamaya konulan önlemler ise memur maaşlarının 2010 yılında \%5 azaltılması ve 2011 ile 2012 yıllarında ise dondurulması, emekli maaşlarında kesintiye gidilmesi ve emeklilik yaşının yükseltilmesi, kamuda istihdam edilenlerin sayısının azaltılması, siyasi partilere ve sendikalara yapılan desteklerin \%20 oranında düşürülmesi ve vergi oranlarının -özellikle de KDV oranların- artırılması olarak görülmektedir (Hurma, 2013: 25). Krizle birlikte ciddi oranda bozulan İspanya'nın mali yapısını yeniden iyileştirmeye yönelik alınan tedbirler iç talebi daraltmış ve ülkenin büyüme potansiyelini düşürerek yüksek işsizliğe neden olmuştur. Küresel krizin ilk etkilerinin görüldüğü 2008 yılında işsizlik oranı \% 13 seviyelerinde iken bu oran 2012 yılının ilk çeyreğinde \% 24 seviyelerinde gerçekleşmiştir (Korkmaz ve diğerleri, 2013: 121).

Polonya'da da kamu mali disiplinin sağlamak ve yükselen kamu borç stokunu azaltmak için kamu harcamaları kısılmış ve vergi oranları artırılmıştır. İlk olarak özel emeklilik fonlarına yapılan transferleri nominal ücretlerin \%7,3'ü düzeyinden \% 5'i seviyesine indirilmesi, KDV oranlarının artırılması - 1 puanlık -artış, bazı KDV ve ÖTV muafiyet uygulamalarına son verilmesi gibi önlemlerin yanında kamu kesiminde ücretlerin dondurulması (öğretmenler hariç) erken emeklilik planlarının 2009 yılında kaldırılması gibi önlemler alınmıştır (Avrupa Birliği Genel Sekreterliği, 2011: $80-81$ ). 
Uygulanan kemer sıkma politikaları doğası gereği, kamu harcamalarında ve kamu hizmetlerinde keskin bir daralma içermektedir. Bu durumda artan gelir eşitsizliği toplumda huzursuzluğa neden olmaktadır (King, 2012: 4). Ayrıca kemer sıkma politikalarının yoğun olarak uygulandığı ülkelerdeki hükümetler "iyi dönemlerde savurgan harcama yapmakla" suçlanmıştır (BBC, 2012:1). Dolayısıyla ekonomik belirsizlik yerini değişen hükümetlere bırakmıştır. Söz konusu dönemde; Yunan halkı, 25 Ocak 2015'te yapılan erken seçimlerde, Yunanistan krizinin zorlukla kontrol edildiğini ve Almanya liderliğinde uygulanan ve halen devam eden sıkı kemer sıkma politikası önlemlerini “ akılsızca ve Yunanistan’1 yok edici” olarak tanımlayan ve marjinal söylemleri ile öne çıkan Syriza’yı iktidara getirmiştir (Şanlı, 2015: 1 - 9).

Diğer taraftan vergi oranlarında artış yapılmış, artan vergi gelirleri ve daraltılan kamu harcamaları ile bütçe açı ̆̆ / GSYH oranının düşürülmesi hedeflenmiştir. Ancak söz konusu uygulama talebin düşmesine yol açmış bu durumda da hem GSYH oranı düşmüş hem de vergi gelirlerinde azalma meydana gelmiştir. Dolayısıyla hedeflenenin aksine çevre ülkelerinde uygulanan sıkı maliye politikası bütçe açığı / GSYH oranının artmasına ve durgunluğa neden olmuştur.

\begin{tabular}{|c|c|c|c|c|c|c|c|c|c|c|}
\hline Yillar & $\mathbf{2 0 0 6}$ & $\mathbf{2 0 0 7}$ & $\mathbf{2 0 0 8}$ & $\mathbf{2 0 0 9}$ & $\mathbf{2 0 1 0}$ & $\mathbf{2 0 1 1}$ & $\mathbf{2 0 1 2}$ & $\mathbf{2 0 1 3}$ & $\mathbf{2 0 1 4}$ & $\mathbf{2 0 1 5}$ \\
\hline Ülkeler & & & & & & & & & & \\
\hline Euro Area (19) & 45.6 & 44.9 & 46.5 & 50.3 & 50.0 & 48.6 & 49.0 & 48.6 & 48.2 & 47.4 \\
\hline İrlanda & 33.9 & 35.9 & 41.9 & 47.2 & 65.7 & 45.5 & 41.8 & 39.7 & 38.6 & 35.1 \\
\hline İspanya & 38.3 & 38.9 & 41.1 & 45.8 & 45.6 & 45.8 & 48.0 & 45.1 & 44.5 & 43.3 \\
\hline İtalya & 47.6 & 46.8 & 47.8 & 51.2 & 49.9 & 49.1 & 50.8 & 51.0 & 51.2 & 50.5 \\
\hline Portekiz & 45.2 & 44.5 & 45.3 & 50.2 & 51.8 & 50.0 & 48.5 & 49.9 & 51.7 & 48.3 \\
\hline Yunanistan & 45.1 & 47.1 & 50.8 & 54.1 & 52.5 & 54.2 & 55.3 & 62.1 & 50.7 & 55.3 \\
\hline
\end{tabular}

Tablo 1: Kamu Harcamaları / GSYH Oranı (\%) Kaynak: Eurostat, 02.05.2016.

Tablo 1'de kamu harcamaları / GSYH oranının özellikle 2008 ve 2009 yılında arttığı görülmektedir. Bu harcamaların artış hızı ülkeden ülkeye farklılaşmaktadır. Kamu harcamalarındaki artış, kriz nedeniyle artan harcamalara bağlı olarak artmıştır (Lapavitsas vd.,2010: 13). Bu harcamaların artış nedeninin özellikle sosyal politikalardan kaynaklandığı bilinmektedir. 2009 yılından itibaren ise kamu harcamalarının Avrupa Birliği genelinde ve Euro Alanında azalma eğilimi içinde olduğu görülmektedir (Yiğit, 2013: 1).

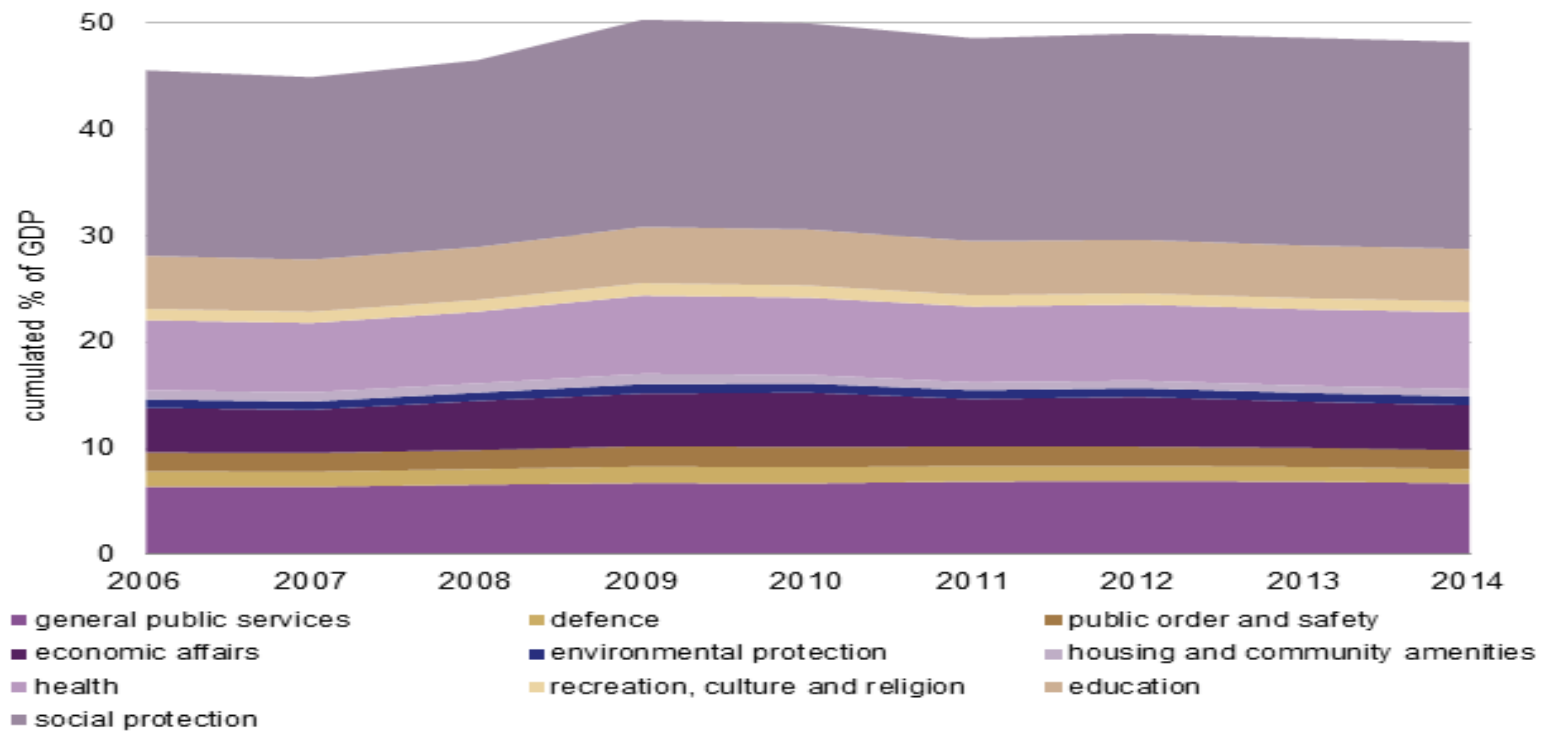

Grafik 3: 2006 - 2014 Döneminde EU (28) Kamu Harcamalarının Bileşenlerinin GSYH Oranı Kaynak: Eurostat, 2016. 


\begin{tabular}{|c|c|c|c|c|c|c|c|c|c|}
\hline Üllar & $\mathbf{2 0 0 6}$ & $\mathbf{2 0 0 7}$ & $\mathbf{2 0 0 8}$ & $\mathbf{2 0 0 9}$ & $\mathbf{2 0 1 0}$ & $\mathbf{2 0 1 1}$ & $\mathbf{2 0 1 2}$ & $\mathbf{2 0 1 3}$ & $\mathbf{2 0 1 4}$ \\
\hline EU (28) & & & & & & & & & \\
\hline Euro Area (19) & 39.3 & 39.3 & 39.2 & 38.5 & 38.5 & 38.9 & 39.6 & 39.9 & 40.0 \\
\hline İrlanda & 32.7 & 32.1 & 30.4 & 29.0 & 28.6 & 28.2 & 29.1 & 29.5 & 30.5 \\
\hline İspanya & 36.7 & 37.1 & 32.9 & 30.6 & 32.1 & 32.0 & 33.0 & 33.8 & 34.4 \\
\hline İtalya & 40.3 & 41.6 & 41.5 & 42.0 & 41.7 & 41.7 & 43.7 & 43.6 & 43.7 \\
\hline Portekiz & 34.8 & 35.0 & 34.9 & 33.4 & 33.7 & 35.5 & 34.5 & 37.2 & 39.9 \\
\hline Yunanistan & 32.7 & 33.5 & 33.7 & 32.9 & 34.2 & 36.1 & 38.3 & 38.3 & 39.0 \\
\hline
\end{tabular}

Tablo 2: Toplam Vergi Gelirleri / GSYH Payı (\%) Kaynak: Eurostat, 2016.

Küresel krizin etkisiyle piyasalarda oluşan durgunluk, GSYH oranlarının düşmesine neden olmuş ve toplanan vergi gelirleri azalmıştır. Özellikle küresel krizin birçok ülkeyi etkisi altına aldığı 2008 yılından itibaren hem Avrupa Birliği ortalamasında hem de kemer sıkma politikalarının uygulandığ ülkelerde vergi gelirlerinin düştüğü görülmektedir. Krizin etkileri hafifletmek amacıyla uygulanan genişletici maliye politikaları ve durgunluk nedeniyle azalan vergi gelirleri ülkelerin borç stoklarını artırmıştır (Contessi ve Li, 2014: 14).

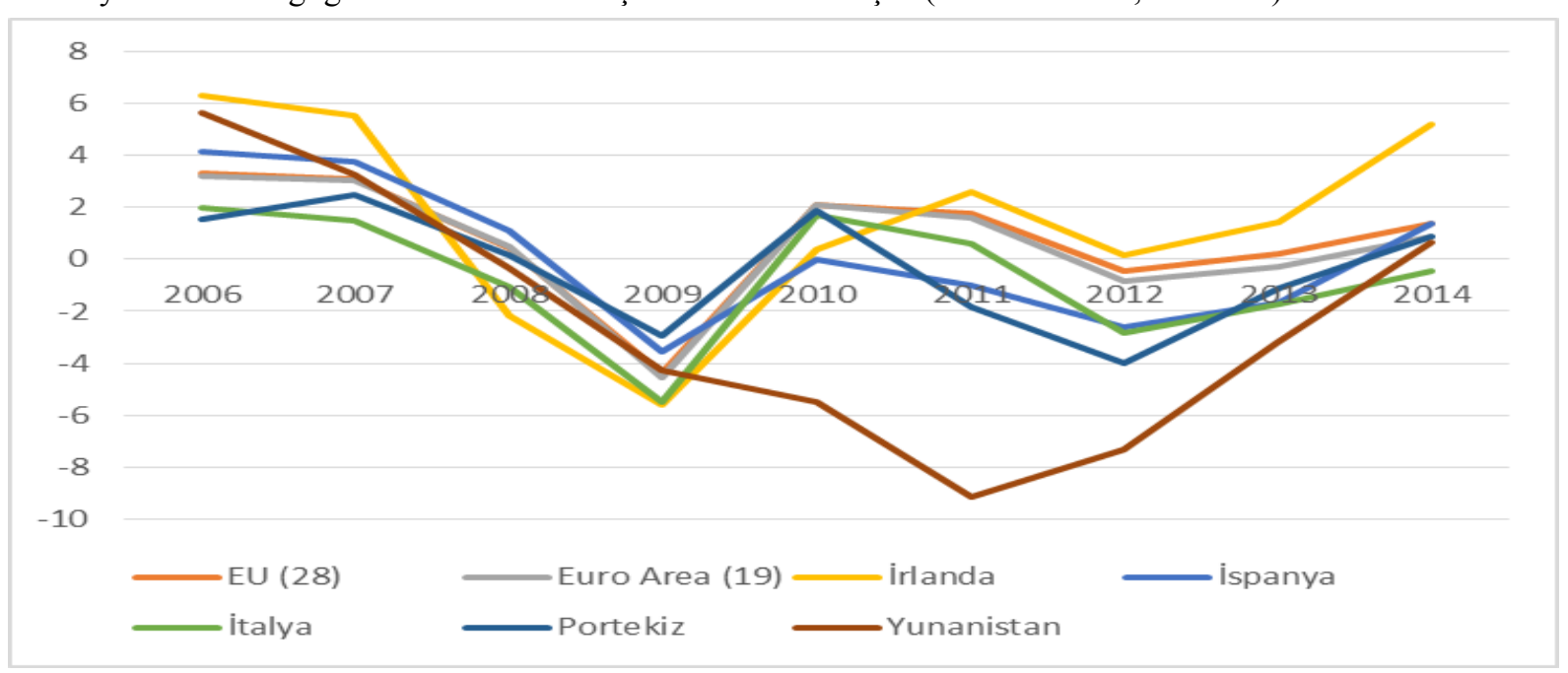

Grafik 4: Büyüme Oranları / GSYH Oranları (\%) Kaynak: World Development Indicators, 2016.

Küresel krizle birlikte 2006 yılında Avrupa Birliği (28) ülkelerinde büyüme oranı yaklaşık \% 3 - 4 seviyelerinde gerçekleşirken 2008 yılında düşme eğilimine girmiştir. Bu dönemde, Euro bölgesi yüzde 4,1 küçülerek tarihinin en büyük daralmasını yaşamıştır (Yılmaz, 2013: 58-59). 2009 yılında meydana gelen şiddetli düşüşün temel nedeni ise özel yatırımlarda meydana gelen azalmadır. Kredi piyasalarının daraldığı ve ekonomide belirsizliğin hakim olduğu ortamda, kapitalist sistem tıkanma yaşamış ve büyüme oranları düşmüştür (Lapavitsas vd.,2010: 37).

2006 - 2007 yıllarında yüzde 6 seviyelerinde büyüme yakalayan İrlanda 2008 yılından itibaren negatif büyümeye geçmiş ve 2009 yılında büyüme oranı - 6 seviyelerinde gerçekleşmiştir. 2010 yılından itibaren ise pozitif büyümeyi yakalamıştır. 2011 yılında yüzde 2 civarında olan büyüme oranı 2012 yılında azalmıştır. 2013 yılından itibaren ise büyüme oranının tekrar artmaya başladığı görülmektedir.

Küresel kriz, uzun süredir önemli ölçüde büyüme yakalayan İspanya ekonomisini de olumsuz etkilemiştir. 2006 - 2007 yıllarında yaklaşık olarak yüzde 4 civarında büyüme kaydeden İspanya 2008 yılından itibaren küçülme dönemine girmiştir. 2009 döneminde - 3 seviyelerinde gerçekleşen büyüme oranı bu dönemden itibaren negative olarak gözlemlenmiştir. 2014 yılından itibaren ise büyüme oranının nispeten artış trendi içinde olduğu söylenebilir.

İtalya 2006 ve 2007 yıllarında yüzde 2 seviyelerinde büyüme oranı kaydetmiş ancak 2008 yılından itibaren söz konusu büyüme oranlarından uzaklaşmıştır. 2008 yılında -1 seviyelerinde olan büyüme oranı 2009 yılında rekor seviyelerde gerçekleşmiş ve -6 olmuştur. 2010 yılında pozitif yönlü bir büyüme olsa da bu büyüme oranı sınırlı kalmış ve bu yıldan itibaren büyüme oranları yüzde $0-1$ aralığında gerçekleşmiştir.

Portekiz, kriz ortaya çıktığında yüzde 3 civarında büyüme oranına sahipken, 2008 yılından son çeyreğiyle beraber küçülmeye başlamış, en büyük küçülme oranı 2009 yılında yüzde 4 civarında gerçekleşmiştir. 2010 yılından itibaren büyüme oranlarında pozitif büyüme sağlanmış olsa da bu başarı uzun sürmemiş ve 2011 ve 2012 yıllarında tekrar küçülme yaşanmış ve büyüme oranı - 4 olarak gerçekleşmiştir. 2013 yılından itibaren büyüme oranlarında artış görülmüş, 2014 döneminde büyüme oranı yüzde 1 civarında gerçekleşmiştir. 
2006 döneminde yüzde 5 seviyelerinde büyüme yakalayan Yunanistan'ın 2007 yılı itibariyle daralma dönemi içinde olduğu gözlemlenebilir. Çalışmada ele alınan ülkeler arasında en yüksek kamu borç stokuna sahip olan Yunanistan, 2009 yılında - 4, 2010 yılında - 6 civarında büyüme gerçekleştirmiştir. 2011 yılında ise - 9 seviyelerinde büyüme oranı yakalamış ve rekor seviyelere ulaşmıştır. 2012 tarihinden itibaren büyüme oranlarında nispeten olumlu gelişmeler görülse de büyüme oranları negatif olarak gerçekleşmiştir. 2014 yılı itibariyle ise büyüme trendi pozitif yönlü olmuş ve yüzde 1 seviyelerinde gerçekleşmiştir.

Doğrudan yabancı sermaye ve büyüme arasındaki ilişki üzerine net bir konsensüs oluşturulamasa da özellikle az gelişmiş ve gelişmekte olan ülkelerin yabancı sermaye kaynaklı büyüdükleri bilinmektedir. Doğrudan yabancı sermaye ile büyüme arasında bir ilişki olup olmadığına ilişkin olarak yapılan çalışmalarda çok farklı sonuçlar bulunmuştur. Bazı araştırmalar doğrudan yabancı sermaye ve büyüme arasında pozitif yönlü ilişki olduğunu (örneğin, Lensink ve Morrissey, 2001; Basu, Chakraborty, Reagle, 2003; Choe, 2003; Hsiao ve Shen, 2003; Vu ve Noy, 2009; Ahmad, 2010) bazı araştırmalar ise doğrudan yabancı sermaye ile büyüme arasında bir ilişki olmadığını (örneğin Carkovic ve Levine, 2002; Choong, Baharumshah, Yusop, Habibullah, 2010; Alagöz vd.2008) bulgulamışlardır. Nitekim söz konusu ülkelerin yabancı sermayeyi cazip hale getirerek büyümek istemeleri yetersiz olan yurtiçi tasarruflar ve kronik hale gelen cari açıktan kaynaklanmaktadır (Seyidoğlu, 2003: 143). Dolayısıyla hem AB hem de AB borç krizinin temel aktörleri olarak görülen İrlanda, İspanya, İtalya, Portekiz ve Yunanistan'a bakıldığında doğrudan yabancı sermaye önem kazanmaktadır. Ancak doğrudan yabancı sermaye hareketlerinin ele alınan ülkeler doğrultusunda farklılaştığı görülmektedir. Küreselleşmenin hız kazanması ile doğrudan yabancı sermaye hareketlerinin de hız kazandığı bilinmektedir. Dolayısıyla Tablo 3'de görüldüğü üzere küresel finansal krizin ilk etkilerinin ortaya çıktığı 2007 yılında doğrudan yabancı sermaye / GSYH oranında artış olmuştur. 2007 yılında hem Avrupa Birliği ve Euro Alanı'nda yabancı sermayenin yoğun olarak geldiği gözlenmektedir. $\mathrm{Bu}$ dönemde gelişmiş ülkelerde yabancı sermaye yatırımlarının azaldığı, gelişmekte olan ülkelerde ise bu payın arttığı görülmektedir. Bölgesel olarak bakıldığında ise AB ilk sırada yer almaktadır. AB'ye en fazla yatırım yapan ülkeler ise Amerika, İsviçre, Kanada, Japonya, Avustralya ve Brezilya olarak siralanmaktadır (European Union Foreign Direct Investment Yearbook 2007). Dolayısıyla finansal krizin ilk aşamasında doğrudan yabancı sermayenin, gelişmiş ülkelerden AB'ye yöneldiğini söylemek mümkündür. İtalya, Yunanistan ve Portekiz'de ise yıllardır süregelen mali istikrarsızlık ve yüksek kamu borç stoku gibi nedenlerle doğrudan yabancı sermaye hareketlerinin genel olarak azalma eğilimi içinde olduğu görülmektedir (Yılmaz, 2013: 59-60).

\begin{tabular}{|c|c|c|c|c|c|c|c|c|c|c|}
\hline Yillar & $\mathbf{2 0 0 6}$ & $\mathbf{2 0 0 7}$ & $\mathbf{2 0 0 8}$ & $\mathbf{2 0 0 9}$ & $\mathbf{2 0 1 0}$ & $\mathbf{2 0 1 1}$ & $\mathbf{2 0 1 2}$ & $\mathbf{2 0 1 3}$ & $\mathbf{2 0 1 4}$ & $\mathbf{2 0 1 5}$ \\
\hline Ëlkeler & & & & & & & & & & \\
\hline Euro Area (19) & 6.92 & 9.51 & 4.60 & 3.01 & 3.91 & 5.70 & 4.21 & 3.95 & 1.70 & - \\
\hline İrlanda & 9.51 & 22.2 & 8.46 & 22.9 & 17.1 & 9.78 & 18.2 & 20.9 & 34.59 & - \\
\hline İspanya & 2.60 & 4.98 & 4.86 & 0.89 & 2.86 & 2.13 & 1.85 & 3.29 & 2.47 & - \\
\hline İtalya & 2.00 & 1.81 & -0.39 & 0.75 & 0.46 & 1.51 & 0.00 & 0.91 & 0.64 & - \\
\hline Portekiz & 6.32 & 2.50 & 2.98 & 2.28 & 3.54 & 4.00 & 10.6 & 4.80 & 5.39 & - \\
\hline Yunanistan & 1.97 & 0.61 & 1.61 & 0.83 & 0.17 & 0.37 & 0.67 & 1.22 & 0.71 & - \\
\hline
\end{tabular}

Tablo 3: Doğrudan Yabancı Sermaye Girişi / GSYH Oranı (\%), Kaynak: The World Bank, World Development Indicators, 02.05.2016.

Küresel krizin ilk aşaması olarak görülen 2007 döneminde AB üyesi ülkelerde doğrudan yabancı sermaye / GSYH oranında artış olduğu gözlemlenmektedir. 2008 ve 2009 dönemlerinde doğrudan yabancı sermaye / GSYH oranı nispeten azalmıştır. Küresel krizin Avrupa Birliği'nde borç krizi olarak nitelendirildiği 2010 döneminde doğrudan yabancı sermaye çıkışı / GSYH oranının arttığı görülmektedir 


\begin{tabular}{|c|c|c|c|c|c|c|c|c|c|}
\hline Yllar & $\mathbf{2 0 0 6}$ & $\mathbf{2 0 0 7}$ & $\mathbf{2 0 0 8}$ & $\mathbf{2 0 0 9}$ & $\mathbf{2 0 1 0}$ & $\mathbf{2 0 1 1}$ & $\mathbf{2 0 1 2}$ & $\mathbf{2 0 1 3}$ & $\mathbf{2 0 1 4}$ \\
\hline EU (28) & 9.25 & 12.27 & 8.64 & 3.99 & 5.14 & 7.09 & 5.76 & 5.61 & 2.56 \\
\hline Euro Area (19) & 10.82 & 12.79 & 8.16 & 5.34 & 6.35 & 8.57 & 7.47 & 7.60 & 4.06 \\
\hline İrlanda & 18.49 & 20.73 & 21.17 & 23.14 & 7.64 & -0.63 & 9.49 & 15.77 & 39.25 \\
\hline İspanya & 8.32 & 9.91 & 4.62 & 1.06 & 2.64 & 3.02 & -0.18 & 1.89 & 3.33 \\
\hline İtalya & 2.18 & 4.17 & 2.81 & 0.83 & 1.44 & 2.27 & 0.32 & 0.94 & 0.95 \\
\hline Portekiz & 4.20 & 3.53 & 2.07 & 1.45 & -1.54 & 6.38 & 2.27 & 3.41 & 3.91 \\
\hline Yunanistan & 1.54 & 1.65 & 0.90 & 0.73 & 0.56 & 0.63 & 0.27 & -0.2 & 0.38 \\
\hline
\end{tabular}

Tablo 4: Doğrudan Yabancı Sermaye Çıkışı / GSYH Oranı (\%), Kaynak: The World Bank, World Development Indicators, 02.05.2016.

Söz konusu dönemde çalışmada ele alınan ülkeler arasında doğrudan yabancı sermaye çıkışı / GSYH oranın en fazla İrlanda'da olduğu görülmektedir. Söz konusu dönemde çalışmada ele alınan ülkeler arasında doğrudan yabancı sermaye çıkışı / GSYH oranın en fazla İrlanda'da olduğu görülmektedir. AB açısından doğrudan yabancı sermaye çıkışı konusu üzerine daha fazla odaklanıldığında söz konusu sermayenin gelişmekte olan ülkeleri tercih ettiği görülmektedir.

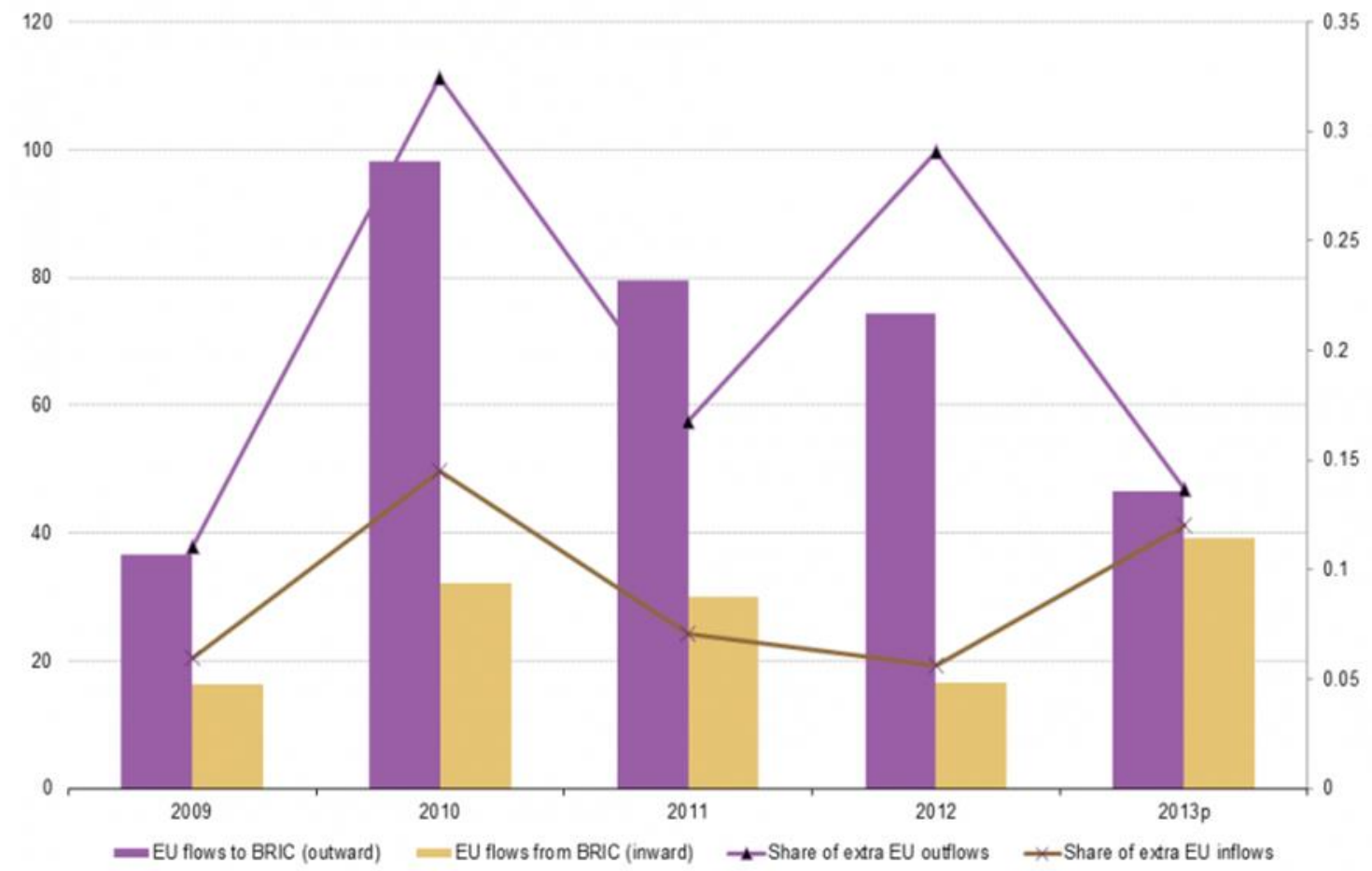

Grafik 5: Doğrudan Yabancı Sermaye Hareketleri, Kaynak: Eurostat.

AB'den çıkan yabancı sermaye, finansal sistemleri ABD ve Avrupa bankacılık sistemiyle daha az bağlantılı olan gelişmekte olan ülkeleri özellikle de pozitif ve nispeten daha yüksek büyüme oranlarına sahip BRICS ülkelerini tercih ettiği bilinmektedir (Karabıyık ve Anbar, 2010: 52). 


\begin{tabular}{|c|c|c|c|c|c|c|c|c|c|c|}
\hline Yillar & $\mathbf{2 0 0 6}$ & $\mathbf{2 0 0 7}$ & $\mathbf{2 0 0 8}$ & $\mathbf{2 0 0 9}$ & $\mathbf{2 0 1 0}$ & $\mathbf{2 0 1 1}$ & $\mathbf{2 0 1 2}$ & $\mathbf{2 0 1 3}$ & $\mathbf{2 0 1 4}$ & $\mathbf{2 0 1 5}$ \\
\hline Ülkeler & & & & & & & & & & \\
\hline EU (28) & -1.6 & -0.9 & -2.4 & -6.7 & -6.4 & -4.5 & -4.3 & -3.3 & -3.0 & -2.4 \\
\hline Euro Area (19) & 1.5 & -0.6 & -2.2 & -6.3 & -6.2 & -4.2 & -3.7 & -3.0 & -2.6 & -2.1 \\
\hline İlanda & 2.8 & 0.3 & -7.0 & -13.8 & -32.3 & -12.6 & -8.0 & -5.7 & -3.8 & -2.3 \\
\hline İspanya & 2.2 & 2.0 & -4.4 & -11.0 & -9.4 & -9.6 & -10.4 & -6.9 & -5.9 & -5.1 \\
\hline İtalya & -3.6 & -1.5 & -2.7 & -5.3 & -4.2 & -3.5 & -2.9 & -2.9 & -3.0 & -2.6 \\
\hline Portekiz & -4.3 & -3.0 & -3.8 & -9.8 & -11.2 & -7.4 & -5.7 & -4.8 & -7.2 & -4.4 \\
\hline Yunanistan & -5.9 & -6.7 & -10.2 & -15.2 & -11.2 & -10.2 & -8.8 & -13.0 & -3.6 & -7.2 \\
\hline
\end{tabular}

Tablo 5: Bütçe Açı̆̆ / GSYH Oranı (\%) Kaynak: Eurostat, Economy and Finance Database, 02.05.2016.

Birlik içinde krize karşı yapılan kamu harcamalarının artması ve durgunluk nedeniyle GSYH'nın azalması ve paralelinde vergi gelirlerinin azalması bütçe açıklarını artırmıştır. Ancak Avrupa Birliği’nde bu durum 2009 yılında Yunanistan'da gerçekleşen genel seçimlerden sonra bütçe açı̆̆ı / GSYH oranının \% 6 değil \% 12.7 olarak açıklanması ile görülmüştür. Yunanistan tarafından Maastrict Kriterleri’nde yer alan bütçe açığı / GSYH \% 3 olması kuralının aşııı ihlal edildiği, ülkede yer alan finansal ve makroekonomik dengesizliklerin olması ve bu durumun çevre ülkelere de yayılması Avrupa Birliği borç krizini siyasi bir krize çevirmiştir (Lane, 2012: 56).

\begin{tabular}{|c|c|c|c|c|c|c|c|c|c|c|}
\hline Yillar & $\mathbf{2 0 0 6}$ & $\mathbf{2 0 0 7}$ & $\mathbf{2 0 0 8}$ & $\mathbf{2 0 0 9}$ & $\mathbf{2 0 1 0}$ & $\mathbf{2 0 1 1}$ & $\mathbf{2 0 1 2}$ & $\mathbf{2 0 1 3}$ & $\mathbf{2 0 1 4}$ & $\mathbf{2 0 1 5}$ \\
\hline Ülkeler & & & & & & & & & & \\
\hline EU (28) & 60.4 & 57.8 & 60.9 & 73.0 & 78.5 & 81.0 & 83.8 & 85.5 & 86.8 & 85.2 \\
\hline Euro Alanı (19) & 67.3 & 64.9 & 68.5 & 78.3 & 83.8 & 86.0 & 89.3 & 91.1 & 92.0 & 90.7 \\
\hline İrlanda & 23.6 & 23.9 & 42.4 & 61.8 & 86.8 & 109.1 & 120.1 & 120.0 & 107.5 & 93.8 \\
\hline İspanya & 38.9 & 35.5 & 39.4 & 52.7 & 60.1 & 69.5 & 85.4 & 93.7 & 99.3 & 99.2 \\
\hline İtalya & 102.6 & 99.8 & 102.4 & 112.5 & 115.4 & 116.5 & 123.3 & 129.0 & 132.5 & 132.7 \\
\hline Portekiz & 69.2 & 68.4 & 71.7 & 83.6 & 96.2 & 111.4 & 126.2 & 129.0 & 130.2 & 129.0 \\
\hline Yunanistan & 103.6 & 103.1 & 109.4 & 126.7 & 146.2 & 172.1 & 159.6 & 177.7 & 180.1 & 176.9 \\
\hline
\end{tabular}

Tablo 6: Kamu Borcu / GSYH Oranı (\%), Kaynak: Eurostat, Government Deficit and Debt, 02.05.2016.

AB ve Euro Alanı ortalamasına bakıldığında kamu borç stoku / GSYH oranının küresel krizin ilk etkilerinin görülmeye başlandığı 2007 yılında arttığı ve bu artışın devam ettiği görülmektedir. Avrupa Birliği kamu borç stoku / GSYH oranına ilişkin en önemli katkı Tembel Akdeniz olarak nitelendirilen İrlanda, İspanya, İtalya Portekiz ve Yunanistan'dan gelmektedir. Bu ülkelerden hareketle en yüksek kamu borç stoku Yunanistan'a aittir. Burada dikkat edilmesi gereken nokta 2006 krizin etkilerinin henüz görülmediği 2006 döneminde İtalya, Portekiz ve Yunanistan'ın kamu borç stokunun milli gelir içindeki payının Maastricht Kriteri’nde yer alan \% 60 oranını aştığıdır. Krizin Avrupa Birliği ülkelerinde milat olarak gösterildiği 2009 yılında kamu borç stokunun milli gelir içindeki payı hızla arttığı ve söz konusu oranın günümüzde de yüksek seviyelerde olduğu görülmektedir.

Küresel krizin Avrupa'ya yayılmasından günümüze kadar Maasticht Kriterleri’nde yer alan bütçe açığının milli gelir içindeki payının yüzde 3 ve borç stokunun milli gelir içindeki payının yüzde 60 olması kriterleri birlik içinde yer alan merkez ülkeler ve çevre ülkeler tarafından birçok kez ihlal edilmiştir. 


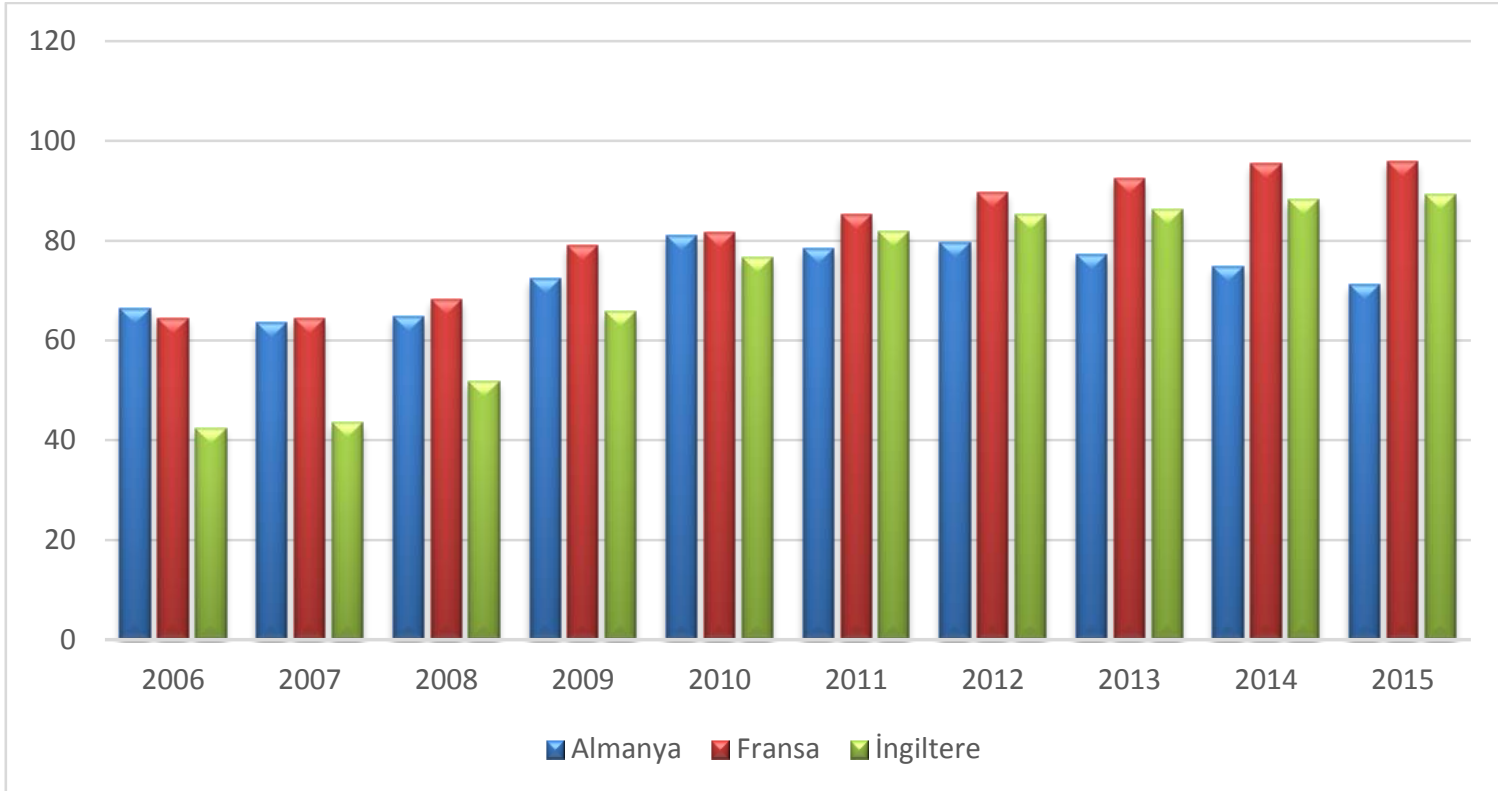

Grafik 6: Kamu Borç Stoku / GSYH Oranı (\%), Kaynak: Eurostat.

2006 ve 2007 yıllarında Avrupa Birliği içinde güçlü ekonomiye sahip Almanya ve Fransa'da kamu borç stoku / GSYH oranının yüzde 60 seviyelerinde olduğu ve Maastricht Kriterleri’nin ihlal edildiği görülmektedir. İngiltere'de ise söz konusu dönemde kamu borç stoku / GSYH oranı yüzde 40 seviyelerinde gerçekleşmiştir. Küresel krizin Avrupa'ya yayıldığ 2009 yılında ise kamu borç stokunda hızlı bir artış gerçekleşmiştir. Bu dönemde birlik içinde merkez grubu olarak adlandırılan Almanya, Fransa ve İngiltere'nin kamu borç stokunun milli gelir içindeki payının hızla yükseldiği görülmektedir. 2009 yılından günümüze gelinceye kadar kamu borç stokunun milli gelir içindeki payının birliğin güçlü ülkelerinin dahi Maastricht Kriterleri’ni sağlayamadığı görülmektedir. Ancak 2011 yılından itibaren Almanya, kamu borç stokunun milli gelir içindeki payı azalma trendi içine girmiştir. Fransa ve İngiltere'nin ise Almanya kadar başarılı olmadığı görülmektedir.

\section{Sonuç}

Avrupa borç krizi, birlik içinde yer alan ülkelerin hem kamu sektörü hem de özel sektörün yüksek seviyelerde borçlanmasının bir sonucudur. Birlik içinde yer alan ve tek para politikası uygulayan üye ülkeler, özellikle merkez grubu içinde yer alan güçlü ekonomik yapısı olan Almanya, Fransa ve İngiltere gibi ülkeler ile aynı politikaları benimsemişlerdir. Bu nedenle özellikle çevre grubu içinde yer alan ve daha zayıf ekonomik yapıları olan ülkeler büyüme oranlarını artırmak ve uluslararası alanda rekabet edebilmek için düşük faizli borçlanmayı politika olarak benimsemişlerdir. Söz konusu çevre ülkelerin aşırı borçlanması, bu ülkelerin borç stoklarını artırmakla kalmamış aynı zamanda yapısal reformları da ötelemiştir.

Yüksek borç stoklarına sahip olan birlik ülkelerinde küresel finansal krizin etkisiyle Keynesyen politikalar uygulamaya konulmuş ve devlet müdahaleleri artmıştır. Keynesyen politikaların özü olan kamu harcamalarının artırılması ve vergi oranlarının düşürülmesi politikası, üye ülkelerin bütçe açıklarını artırmış ve söz konusu ülkelerin daha fazla borçlanmasına neden olmuştur.

Avrupa borç krizinin temel aktörleri olarak görülen ve Tembel Akdeniz olarak nitelendirilen Yunanistan, İrlanda, İtalya, İspanya ve Portekiz birlik içinde en yüksek borç stokuna sahip olan ülkelerdir. Bu nedenle Almanya'nın baskısıyla Troyka tarafından söz konusu ülkelere verilen mali yardımlar karşılığında kemer sıkma politikaları benimsetilmiştir. Uygulanan kemer sıkma politikaları özünde kamu harcamalarının kısılması, ücretlerin dondurulması, sosyal yardımların sekteye uğraması, vergi oranlarının artırılmasıdır ve bu politikayla söz konusu ülkelerin bütçe açıklarının azaltılarak uzun dönemde borç stoklarını azaltmaları hedeflenmiştir. Yapısal reformlardan yoksun bu politikalar, kısa sürede başarılı olsa da uzun dönemde kısılan kamu harcamaları nedeniyle toplam talepte düşüş yaşanmasına ve büyüme oranlarının düşmesine neden olmuştur. Azalan büyüme oranları nedeniyle vergi hasılatında azalma meydana gelmiştir. Bu nedenle azalan vergi gelirleri nedeniyle söz konusu ülkeler tekrar borçlanmaya gitmiş ve borç sarmalı içinde kalmışlardır.

Ayrıca küresel finansal krizden itibaren yanlış ya da eksik politikalar uygulayan $\mathrm{AB}$, ciddi eleştirilere maruz kalmıştır. Uygulanan politikalar hem toplumsal baskıya neden olmuş ve birlik içinde huzursuzluk yaratmış hem de siyasi krize neden olmuştur. Söz konusu dönemde, ortak para biriminin yanlış bir uygulama olduğu, kırılgan ekonomik yapıya sahip ülkelerin birliğe dahil edilmesi ile, birliğin krizlere karşı daha savunmasız olduğu ve uzun dönemde birliğin geleceğine ilişkin endişeler oluşmaktadır. 


\section{Kaynakça}

- Avrupa Birliği Genel Sekreterliği, 2011. Küresel Krizin AB Üyesi Ülke Ekonomilerine Etkileri ve Gelecek Döneme İlişkin Beklentiler, Avrupa Komisyonu Ekonomik ve Mali Konular Genel Müdürlüğü Raporu.

- C. Lapavitsas, A. Kaltenbrunner, G. Lambrinidis, D. Lindo, J. Meadway, J. Michell, J.P. Painceira, E. Pires, J. Powell, A. Stenfors, N. Teles, (2010), "The Eurozone Between Austerity And Default", Research On Money And Finance, p. 1 - 69.

- Contessi, Silvio ve Li Li, 2014. "Debt Crisis In Europe Is Easing, But Stability Remains A Long Way Off", The Regional Economics, p. 14 -15.

- Eğilmez, Mahfi, 2015. Küresel Finans Krizi: Piyasa Sisteminin Eleştirisi, Remzi Kitabevi, 11. Basım, Ankara.

- Eraslan, Cemil ve Timurtaş, M. Emin, 2015. “Avrupa Borç Krizinin Seçilmiş Ülke Örnekleri Üzerindeki Etkileri", Gazi Journal of Economics and Business, s. 17 - 54.

- Eurostat Database, http://ec.europa.eu/eurostat/data/database.

- European Commission, 2007. European Union Foreign Direct Investment Yearbook 2007, http://ec.europa.eu/eurostat/ramon/coded_files/fdi_yearbook_2007.pdf Erişim Tarihi: 16.05.2016.

- Gros, Daniel and Mayer, Thomas, 2010. How To Deal With Sovereign Default In Europe: Create the European Monetary Fund Now!", CEPS Policy Brief, p. 1 - 10.

- Hurma, Emrah, 2013. "Ekonomik Krize Karşı Alınan Önlemler: Yunanistan, İtalya ve İspanya Örnekleri”, TBMM Aylık Bülteni, Sayı:184, s:24-25

- International Money Fund, World Development Indicators, http://www.imf.org/external/pubs/ft/weo/2016/01/weodata/weoselagr.aspx.

- Karabıyık, Lale ve Anbar Adem, 2010. "Küresel Ekonomik Krizin Doğrudan Yabancı Yatırımlar Üzerindeki Etkisi”, Muhasebe ve Finansman Dergisi, V. 46, p. 44 - 57.

- Korkmaz, Adem vd, 2013. "Küresel Ekonomik Krizde Dünyada ve Türkiye'de İşsizlikle Mücadelede

- Uygulanan Politikalar: Başarılı ve Başarısız Ülkeler”, Uluslararası Alanya İşletme Fakültesi Dergisi, C:5, S:1, s. 113-125.

- Lone, R. Philip, 2012. “The European Sovereign Debt Crisis”, Journal of Economics Perspectives, v. 26, N.3, p. $49-68$.

- Monastiriotis, Vassilis, 2013. “Austerity Measures In Crisis Countries: Results And Impact On Mid-Term Development", Intereconomics, p. 3 - 32.

- Prinz Aloys ve Beck Hanno, 2012. "Fighting Debt Explosion in the European Sovereign Debt Crisis", Intereconomics, 3, p. 185-189.

- Sandoval Lazaro, Beltran Erika, Ulziikhutag Sodgerel ve Zorigt Temuun, 2011. "The European Sovereign Debt Crisis: Responses to the Financial Crisis", New Voices in Public Policy, 5, p. 1- 25, ISSN: 1947-2633.

- Şanlı, A. Güldem, 2015. "Yunanistan Avrupa'y1 Kurtarabilir Mi?”, http://docplayer.biz.tr/5101322Yunanistan-avrupa-yi-kurtarabilir-mi.html, Erişim Tarihi: 01.06.2016.

- Şanlığlu, Ömer ve Bilginoğlu, Mehmet Ali, 2010. “Euro Bölgesi’nde Yaşanan Mali Sorunlar Ve Maliye Politikalarinda Uyum Arayışları”, Erciyes Üniversitesi İktisadi ve İdari Bilimler Fakültesi Dergisi, Sayı: 35, s. $149-173$

- Seyidoğlu, Halil, 2003. "Uluslararası Mali Krizler, IMF Politikaları, Az Gelişmiş Ülkeler, Türkiye ve Dönüşüm Ekonomileri”, Doğuş Üniversitesi Dergisi, V. 2, p. 141 - 156.

- Tichy, Gunther, 2012. "The Sovereign Debt Crisis: Causes and Consequences", Austrian Economic Quarterly, 2, 95-107.

- Yılmaz, Elif Binhan, 2013. Küresel Krizin Avrupa'da Borç Krizine Dönüşümü, Derin Yayınları, İstanbul.

- Yılmaz, B. Elif, 2013. "Küresel Krizin PIIGS (Portekiz, İrlanda, İtalya, Yunanistan ve İspanya) Ülkeleri ile Türkiye'nin Makroekonomik Değişkenlerine Yansımaları", Ankara Sanayi Odası Dosya, Kasım - Aralık.

- Yiğit, Dilek, 2013. “Avrupa Birliği’nde Krizin Gölgesindeki Kamu Harcamaları”, Stratejik Düşünce Enstitüsü Dergisi.

- World Bank, World Development Indicators, http://databank.worldbank.org/data/reports.aspx?source=2\&Topic=3. 


\title{
Bazı Geçiş Ekonomisi Ülkelerinde Uygulanan Mikrofinans Sistemi Etkinliğinin Faiz Oranlarına Tesiri
}

\section{Effect of Efficiency on Interest Rate in Microfinance Systems of Some Transition Economies}

\author{
Assoc. Prof. Dr. Metin Bayrak (Kyrgyzstan-Turkey Manas University, Kyrgyzstan) \\ Ph.D. Candidate Kadyrbek Sultakeev (Kyrgyzstan-Turkey Manas University, Kyrgyzstan) \\ Ph.D. Candidate Dastan Aseinov (Kyrgyzstan-Turkey Manas University, Kyrgyzstan)
}

\begin{abstract}
Although the share of microfinance institutions in financial sector of Transition Economies are increasing, the level of interest rates charged by microfinance institutions are very high than normal bank interest rates. Because in these countries the main reasons of high interest rates are operational cost, funding costs, credit risk, inflation and target profit of MFIs. The main purpose of this paper is to analyze the effect of efficiency on interest rate in microfinance system of sampled transition economies. This study uses MIX data that runs from 2000 to 2014 for transition economies countries. The efficiency of microfinance institutions in sampled transition economies measured by applying Stochastic Frontier Approach. The impact of efficiency on interest rate will be analyzed using fixed effects and random effects panel data models.
\end{abstract}

\section{Giriş}

Günümüzde mikrokredi piyasası hızla büyümektedir. Ekonomik büyümeyi teşvik etmek, yoksulluğu azaltmak ve girişimciler için gelir getirici sosyal hedefleri ile başlayan mikro kredi kurumları son zamanlarda karlı hale gelmekte ve dünyada 3.652 mikrokredi kuruluşları 205 milyon yoksul müşteriye ulaştığı söylenmektedir (Maes ve Reed, 2012:3; Schicks,2010:1).

Beck, Demirgüç-Kunt ve Martinez Peria (2008) gelişmekte olan ülkelerde nüfusun \%40 -\%80’i banka hizmetlerini kullanamamaktadır. Bu kesimin mikrofinanstan yararlanması son derece önemlidir.

Ancak yoksulların mikrokrediden yararlanması son derece önemli olmasına rağmen, halen faiz oranlarının yüksek olması toplumda zorunlu başvurulan bir yöntem olduğu görülmektedir.

Mikrokredi kurumları faiz oranlarının yüksek olmasını farklı sebeplere bağlamaktadır. Sebepleri ise kaynakların pahalı olması, işlem maliyetlerinin yüksek olması, kar oranının yüksek tutulması ve geri dönüşüm risk oranının yüksek olmasıdır. Mikro kredi faiz oranlarının yüksek olmasının en önemli sebebi mikrofinans işletmelerinin etkinsiz çalışmalarıdır.

$\mathrm{Bu}$ araştırmanın amacı etkinliğinin mikro kredi faiz oranı üzerindeki etkisi incelenecektir. Çalışmada Mikrofinans Bilgi Değişimi (MIX Market) veri tabanından indirilmiş veri seti kullanılmıştır. Örnek ülkeler olarak seçilmiş 11 BDT ülkesindeki 215 Banka Dışı Finans Kurumuna ait dengesiz panel veri seti kullanılmıştır. MKK'ların maliyet etkinlikleri ölçülerinin hesaplanmasında stokastik sınır analizi yöntemi uygulanmıştır. İkinci aşamasında maliyet etkinliğinin faiz oranı üzerindeki etkisi sabit etkiler modeli ile incelenmiştir.

Çalışma dört bölümden oluşmaktadır. Birinci bölüm giriş, ikinci bölüm literatür analizi, üçüncü bölüm yöntem ve model, dördüncü bölüm analiz ve son bölümde ise sonuç yer almaktadır.

\section{Literatür Analizi}

\subsection{Faiz Oranı Üzerindeki Araştırmalar}

Cotler and Almazan (2013) mikrofinans piyasasında faiz oranını etkileyen faktörleri analiz etmek için 20002008 yıllarını kapsayan 84 ülkenin 1299 mikrofinans kurumlarının verilerini kullanmıştır. Mikrokredi faiz oranı Afrika'da \%42, Amerika'da \%42 ve Asya ülkelerinde \%35 oranında bulunmaktadır. Bu faiz oranına etki eden faktörlerden kaynak maliyeti, mikrokredi kurumlarının etkinliği, karlılık oranı, ortalama kredi büyüklügü (log), ve rekabet değişkenlerini incelemiştir. Araştırma sonuçlarında üç değişken anlamlı çıkmıştır. Bunlar kaynak maliyeti, rekabet ve etkinliktir. Kaynak maliyet ile faiz oranı arasında anlamlı pozitif yönlü ilişki çıkmıştır. Rekabetin sonuçları bölgeden bölgeye göre değişiklik göstermektedir. Asya ülkelerinde rekabetin artması faiz oranını azaltmaktadır, ancak Amerika ülkelerinde faiz oranı değil, onun yerine ortalama kredi büyüklüğ̈̈ azaltmaktadır. Son olarak, mikrokredi faiz oranını düşürmek için etkinliğin artmasıdır. Etkinliği arttırmak için teknoloji kullanımını ve yönetim kalitesini arttırmak gerekir.

Cull, R., \& Demirgüç-Kunt, A. (2006) 49 ülkenin 124 mikrofinans kuruluşlarının verilerini kullanarak firmaların müşterilere yüksek mikrokredi faiz oranı uygulaması yüksek kar elde edip etmediğini incelemiştir. Bağımlı değişken olarak financial self-sufficiency (FSS) oranı ele alınmıştır. Kurumun giderlerini karşılamak için yeterli 
gelir elde etme ölçüsüdür. Çalışmayı güçlendirmek için ayrıca bağımlı değişken olarak operation self-sufficiency (OSS) ve return on assets (ROA) analize tabi tutulmuştur. Bu üç bağımlı değişkenlerin korelasyon katsayısı pozitif ve anlamlı çıkmıştır. Ayrıca bu üç değişkenlerin mikrofinans kurum yaşı ve firma büyüklüğü ile aynı yönlü yüksek ilişki çıkmıştır.

\subsection{Etkinlik Üzerindeki Çalıșmalar}

Mikrofinans faiz oranlarını düşürmek için firmalarının etkin çalışması son zamanlarda önemli olmaya başlamıştır. Bundan dolayın etkinliğin iyi ölçülmesi söz konusu olmaktadır. Etkinlik firmaların girdilerini (personel, aktif, sübvansiyonlar) en iyi şekilde kullanarak en fazla çıktı (kredi miktarı, mali sürdürebilirlik ve daha çok yoksula ulaşabilmek) sağlayabilmek demektir (Balkenhol, 2007).

Annim, (2010) etkinlik için ayrı bir tanım getirmiştir. Personelin zamanı, personel sayısı ve operasyon giderlerinin optimal kombinasyonu ile en çok kredi miktarına, müşteri sayısına özellikle finansal hizmetlerden mahrum kalan kesime kaliteli bir hizmet sunmaktır.

Empirik araştırmalarda etkinlik üzerinde yaygın kullanılan yöntemlerden ikisi çok bilinmektedir. Bunlar parametrik olamayan (veri zarflama yöntemi) ve parametrik (stokastik analiz yöntemidir). Her iki yaklaşımın kendi içinde güçlü ve zayıf yönleri vardır.

Hermes et al., (2009) çalışmasında 1997-2007 yıllara arasındaki 435 mikrokredi kurumun (MixMarket) verilerini kullanarak finansal gelişme ile MFI etkinliği arasındaki ilişkiyi Stokastik sınır modeli yöntemi ile analiz etmiştir. Bağımlı değişken olarak TC (toplam maliyet), bağımsız değiş̧en olarak ücret, depozit için ödenen faiz, aktif mikrokredi kullanıcıların sayısı ve kredi portföyü ve etkinlik dağılımı ele alınmıştır.

Oteng-Abayie, 2013 çalışmasında 2007-2010 yıllar arasında 135 mikrofinans kurumlarının ekonomik etkinliğini Cobb-Douglas Stokastik sınır modeli yöntemi ile analiz etmiştir. Bağımlı değişken olarak (EE) etkinlik dağılımın logaritması alınmıştır. Bağımsız değişken olarak, (ALB) ortalama kredi miktarı, (ASB) ortalama depozite miktarı, (CPB) müşteri başı maliyet, (BPF) personele düşen müşteri sayısı, (personel başına mevduat sahipleri), (AGE) Mikrokredi kurumların çalışma süresi incelenmiş̧ir.

\section{Yöntem ve Model}

MKK'ların maliyet etkinlikleri ölçülerinin hesaplanmasında stokastik sınır analizi yöntemi uygulanmıştır. İkinci aşamasında maliyet etkinliğinin faiz oranı üzerindeki etkisi sabit etkiler modeli ile incelenmiş̧tir.

\subsection{Stokastik Maliyet Sınırı Yaklaşımı}

Bu çalışmada MKK'ların maliyet etkinlik ölçüleri Hermes vd. (2011), Servin vd. (2012) Annim (2012), Abate vd. (2014) izlenerek Aigner vd. (1977) tarafından önerilmiş Stokastik Sınır Yaklaşımına göre hesaplanmıştır. Bu yaklaşıma göre, MKK'ların maliyet etkinliği veri olan girdi fiyatı, çıtı miktarına ve mevcut teknoloji şartlarında faaliyet gösteren MKK'nın gözlemlenen maliyetlerinin tüm MKK'lara ait verilere göre tahmin edilen maliyetlerin etkin sınırına yakınlığı açısından ölçülür. Maliyetlerin etkin sınırı mümkün olan minimum maliyetleri yansıtır.

Gregoire ve Tuya (2006), Annim (2012) izlenerek stokastik sınır Battese ve Coelli (1995) tarafindan önerilen etkinsizlik etkileri modeli uygulanmıştır. Bu modelin temel avantajı, maliyet sınırının ve etkinsizlik denklemlerinin eş anlı olarak tahmin edilebilmesidir. Seçilmiş ülkelerdeki MKK'nın maliyet fonksiyonları translog spesifikasyonuna göre oluşturulmuş model bu şekildedir.

$$
\begin{aligned}
\operatorname{Ln}\left(\frac{\mathrm{TC}_{i \mathrm{it}}}{\left(\mathrm{W}_{3 \mathrm{it}} \cdot \mathrm{TA}_{\mathrm{it}}\right.}\right)= & \alpha+\beta_{1} \operatorname{Ln}\left(\frac{\mathrm{Q}_{1 \mathrm{it}}}{\mathrm{TA}_{\mathrm{it}}}\right)+\gamma_{1} \operatorname{Ln}\left(\frac{\mathrm{W}_{1 \mathrm{it}}}{\mathrm{W}_{3 \mathrm{t}}}\right)+\gamma_{2} \operatorname{Ln}\left(\frac{\mathrm{W}_{2 \mathrm{it}}}{\mathrm{W}_{3 \mathrm{it}}}\right) \\
& +1 / 2\left(\beta_{11} \operatorname{Ln}\left(\frac{\mathrm{Q}_{1 \mathrm{it}}}{\mathrm{TA}_{\mathrm{it}}}\right)^{2}+\gamma_{11}\left(\frac{\mathrm{W}_{1 \mathrm{it}}}{\mathrm{W}_{3 \mathrm{it}}}\right)^{2}+\gamma_{22}\left(\frac{\mathrm{W}_{2 \mathrm{it}}}{\mathrm{W}_{3 \mathrm{i}}}\right)^{2}\right)+\gamma_{12} \operatorname{Ln}\left(\frac{\mathrm{W}_{1 \mathrm{it}}}{\mathrm{W}_{3 \mathrm{it}}}\right) \operatorname{Ln}\left(\frac{\mathrm{W}_{2 \mathrm{it}}}{\mathrm{W}_{3 \mathrm{it}}}\right) \\
& +\varphi_{11} \operatorname{Ln}\left(\frac{\mathrm{Q}_{1 \mathrm{it}}}{\mathrm{TA}_{\mathrm{it}}}\right) \operatorname{Ln}\left(\frac{\mathrm{W}_{1 \mathrm{it}}}{\mathrm{W}_{3 \mathrm{it}}}\right)+\varphi_{12} \operatorname{Ln}\left(\frac{\mathrm{Q}_{1 \mathrm{it}}}{\mathrm{TA}_{\mathrm{it}}}\right) \operatorname{Ln}\left(\frac{\mathrm{W}_{2 \mathrm{it}}}{\mathrm{W}_{3 \mathrm{it}}}\right)+\sum_{\mathrm{c}=1}^{10} \tau_{\mathrm{c}} \mathrm{D}_{\mathrm{c}}+\mathrm{u}_{\mathrm{it}}+v_{\mathrm{it}}
\end{aligned}
$$

$\mathrm{Bu}$ denklemdeki $\ln \mathrm{TC}_{i t}, \ln \mathrm{Q}_{1 \mathrm{it}}, \ln \mathrm{W}_{\text {nit }}$, i. MKK'nın t. dönemindeki (sırasıyla) toplam maliyetini (faiz ve operasyonel giderlerin toplamı), vergi öncesi toplam karını, n. girdisinin fiyatınının doğal logaritmalarını ifade etmektedir.

$\alpha, \beta, \gamma, \varphi$ ise tahmin edilecek parametrelerdir. $v_{\mathrm{i}}$, bağımsız ve simetrik $\mathrm{N}\left(0, \sigma_{\mathrm{v}}^{2}\right)$ dağılım gösteren ve verilerdeki gürültüyü ve genellikle beyaz gürültü şeklinde belirtilen rassal hata terimini (Kumar ve Gulati, 2014:98); $u_{i}$ ise negatif değer almayan ve ortalamasında kesilmiş $\mathrm{N}^{+}\left(\mu, \sigma_{\mathrm{u}}^{2}\right)$ dağılımından türetilen ve asimetrik normal-kesikli normal dağılım gösteren (Kasman, 2003:86) bir taraflı etkinsizliği temsil eder. $D_{c}$ ise, seçilmiş 11 Eski SSCB cumhuriyetleri arasındaki heterojenliğin kapsanması amacıyla oluş̧urulan kukla değişkenlerini temsil etmektedir.

Dualite teoremi, maliyet fonksiyonunda yer alan girdi fiyatlarının doğrusal homojenliğini ve ikinci dereceden parametrelerin simetrik olmasını gerektiğinden dolayı, fonksiyon parametrelerine bu şekildeki şartların sağlanmasını gerektirmektedir: $\sum_{\mathrm{n}=1}^{\mathrm{N}} \gamma_{\mathrm{n}}=1, \sum_{\mathrm{n}=1}^{\mathrm{N}} \sum_{\mathrm{s}=1}^{\mathrm{S}} \gamma_{\mathrm{ns}}=0, \sum_{\mathrm{n}=1}^{\mathrm{N}} \varphi_{1 \mathrm{n}}=0$. Maliyet fonsiyonunda girdi 
fiyatlarındaki doğrusal homojenlik şartı $\mathrm{TC}_{\mathrm{it}}, \mathrm{W}_{1 \mathrm{it}}$ ve $\mathrm{W}_{2 \mathrm{it}}$ 'nin $\mathrm{W}_{3 \mathrm{it}}$ 'e bölünmesi şeklinde dönüşüm ile sağlanmıştır. İlgili parametrelerde $\gamma_{\mathrm{ns}}=\gamma_{\mathrm{sn}}, \beta_{\mathrm{mr}}=\beta_{\mathrm{rm}}$ şeklindeki kısıtın sağlanması ile simetrik şartı yerine getirilmiştir. MKK'ların farklı büyüklükte olmasından kaynaklanan potansiyel değişen varyansın azaltılması çıktıların normalleştirilmesini gerektirmekte. Yazındaki çalışmalarda (Berger and Mester, 1997; Tabak vd., 2014) değişen varyansın (heteroscedasticity) azaltılması amacı ile çıktıları normalleştirme işlemi toplam maliyetlerin ve çıtıların da toplam varlıklara bölünmesi yoluyla sağlanmıştır.

Firmanın göreceli etkinliğinin hesaplanmasında Jondrow vd. (1982) tarafından önerilen $\lambda=\sigma_{u} / \sigma_{v}$ oranı kullanılmıştır.

$$
\lambda^{2}=\sigma_{\mathrm{u}}^{2} / \sigma_{\mathrm{v}}^{2} \geq 0
$$

$\sigma_{v}^{2} \rightarrow+\infty$ ve/veya $\sigma_{u}^{2} \rightarrow 0$ sonucunda, $\lambda^{2} \rightarrow 0$ ise, $\varepsilon_{\text {it }}$ 'nin belirlenmesinde simetrik hata teriminin üstünlüğünün bir göstergesidir. $\lambda=0$ ise, teknik etkinlik sıfıra eşittir; maliyet, üretim, kar hacmi sınırda yer alır (Greene 1993). $\mathrm{Bu}$ durum, deterministik sınır fonksiyonunun EKK ile etkin bir şekilde tahmin edilebilir. $\sigma_{\mathrm{u}}^{2} \rightarrow \infty$ ve/veya $\sigma_{v}^{2} \rightarrow$ 0 sonucunda $\lambda^{2} \rightarrow+\infty$ olması, $\varepsilon_{\text {it }}$ 'nin belirlenmesinde etkinsizlik teriminin üstünlüğünün ve stokastik maliyet sınırı tanımlamasının geçerliliğinin bir göstergesidir. Tanımlanmış maliyet fonksiyonunun parametreleri en çok olabilirlik yöntemi ile tahmin edilmiştir.

MKK'ların girdi ve çıktıları Sealey ve Lindley (1977) geliştirilmiş finansal aracılık yaklaşımına göre belirlenmiştir. Bu yaklaşıma göre MKK'lar fon alıp satan kuruluşlar olarak değerlendirilmektedir. Çıktı olarak müşterilere sağlanan kredilerin portföyü (Q1it), girdilerden emeğin fiyatı personel giderlerinin toplam varlıklara oranı (W1it), kullanılan fonların fiyatı olarak yükümlülüklerle ilgili finansal giderlerin toplam yükümlülüklere oranı (W2it), fiziki sermayenin fiyatı operasyonel giderlerden personel giderlerinin çıkartılmasıyla toplam varlıklara oranı (W2it) kullanılmıştır.

\subsection{Etkinsizlik Etkileri Modeli}

Yazındaki bazı çalışmalar incelenerek belirlenmiş olan değişkenlere göre oluşturulan etkinsizlik etkileri denklemi bu şekilde yazılabilir:

$$
\begin{aligned}
\mu_{\mathrm{i}}=\delta_{0}+\delta_{1} \mathrm{LLR}_{\mathrm{it}} & +\delta_{2} \mathrm{LTA}_{\mathrm{it}}+\delta_{3} \text { WOMAN }_{\mathrm{it}} \\
& +\delta_{4} \mathrm{ALB}_{\mathrm{it}}+\delta_{5} \mathrm{ROA}_{\mathrm{it}}+\delta_{6} \mathrm{DER}_{\mathrm{it}}+\delta_{7} \mathrm{CPB}_{\mathrm{it}}+\delta_{8} \mathrm{AgeY}_{\mathrm{it}}+\delta_{9} \text { AgeM }_{\mathrm{it}} \\
& +\delta_{10} \text { OureachM }_{\mathrm{it}}+\delta_{11} \text { OureachL }_{\mathrm{it}}+\delta_{12} \mathrm{EQR}_{\mathrm{it}}+\delta_{13} \mathrm{OSS}_{\mathrm{it}}
\end{aligned}
$$

$\mu_{\mathrm{i}}$, translog maliyet sınırı fonksiyonunun tahmin edilen parametrelerine göre hesaplanan MMK'ların etkinsizliklerinin kesilmeden önceki ortalamasını yansıtmaktadır.

MKK'ların maliyet etkinsizliğini etkilediği varsayılan değişkenler olarak borç özkaynak oranı (DER) (Bayragi, 2014), aktif karlılığı (ROA) (Singh vd., 2013), MKK’nın büyüklüğünü yansıtan değişken olarak toplam varlıkların doğal logaritması (LTA) (Gregoire ve Tuya, 2006; Kinde, 2012; Abate vd., 2014); MMK'ların operasyonel sürdürebilirliğin bir göstergesi olarak operasyonel yeterlik (OSS) (Annim, 2012; Singh vd., 2013; Bayragi, 2014); operasyonel maliyetlerin aktif borçluların sayısına oranı şeklinde ölçülen borçlu başına gerçekleştirilen maliyetleri (CPB) (Kinde, 2012; Bayragi, 2014); sosyal yardımın (outreach) ters göstergesi olarak borçlu (müşteri) başına ortalama kredi bakiyesinin (bilanço tutarı) kişi başına düşen GSMG'e oranının (ALB) (Ferro vd., 2006; OlivaresPolanco, 2005; Paxton, 2007; Hermes vd., 2011); sosyal yardımın (outreach) diğer bir göstergesi olarak da kadın müşterilere sağlanan kredilerin toplam kredilerdeki oranı(WOMAN) (Hermes vd., 2011; Annim, 2012; Abate vd., 2014; Bayragi; 2014; Bos ve Millone, 2013); yaş1 ve tecrübesi daha çok olan MKK'nın maliyet etkinliğinin daha yüksek olduğu test edilebilmesi için MKK yaşının bir ölçüsü olarak, kuruluşundan itibaren 5-8 yıl, 8 ve üzeri yıl geçen MMK'lar için sırasıyla AgeY ve AgeM kukla değişkenleri oluşturulmuştur (Hermes vd., 2011; Singh vd., 2013; Abate vd., 2014) değişkenleri etkinsizlik etkileri denklemine bağımsız değişkenler olarak dahil edilmiştir. Sosyal yardımın (outreach) diğer bir göstergesi olarak gözlemlenen MKK'nın borçlularının sayısı 10000'den az ise 1; 10000-30000 arasında ise 2; 30000'den fazla ise 3 değerlerini alan Outreach modele dahil edilmiştir.

Bunun dışında, MKK'larının risk alma stratejilerinin etkinsizlik üzerindeki etkisinin hesaba alınabilmesi amacıyla sermayenin toplam varlıklara oranı (EQR) ve kredi kayıpları için ayrılan reservlerin toplam sağlanan kredilere oranı (LLR) modele dahil edilmiştir (Lensink vd., 2008; Hermes vd., 2011). Bazı diğer çalışmalarda risk göstergesi olarak, anaparanın geri ödenmesi vadesinden 30 günden fazla gecikmiş kredilerin oranı (PAR30) (Bos ve Millone, 2013), veya kredi kayıplarının toplam sağlanan kredilere oranını (Bayragi, 2014) kullanılmıştır.

\subsection{Sabit Etkiler Panel Veri Modeli}

Maliyet etkinliğinin faiz oranı üzerindeki etkisinin araştırılmasında geleneksel Sabit Etkiler ve Rassal Etkiler Modelleri uygulanmıştır. Nawaz vd. (2011), Cotler ve Almazan (2013) izlenerek bağımlı değişken olarak belirlenen finansal giderlerin toplam yükümlülüklere oranı şeklinde ölçülen faiz oranını (IR) etkilediği varsayılan bağımsız değişken olarak da MKK'ların finansal maliyet etkinliği ölçüsü (CE) belirlenmiştir.

Diğer bağımsız değişkenler olarak, kredi kayıplarının karşılanması için ayrılan rezervlerin toplam kredi portföyüne oranı (LLR) (Chikalipah, 2012); MKK'nın büyüklüğünü yansıtan değişken olarak toplam varlıkların doğal logaritması (LTA) (Chikalipah, 2012); MKK yaşının bir ölçüsü olarak, kuruluşundan itibaren 1-4 yıl; 5-8 
yıl, 8 ve üzeri yıl geçtiğine göre sırasıyla 1,2 ve 3 değeri alan değişken (AGE1) (Campion vd., 2010; Chikalipah, 2012); aktif karlılık oranı (ROA) (Nawaz vd., 2011; Chikalipah, 2012; Cotler ve Almazan, 2013); MMK'ların operasyonel sürdürebilirliğin bir göstergesi olarak operasyonel yeterlik (OSS) (Campion vd., 2010; Nawaz vd., 2011); sosyal yardımın (outreach) ters göstergesi olarak borçlu (müşteri) başına ortalama kredi bakiyesinin (bilanço tutarı) kişi başına düşen GSMG'e oranının (ALB) (Campion vd., 2010; Nawaz vd., 2011; Janda vd., 2013; Cotler ve Almazan, 2013); sosyal yardımın (outreach) diğer bir göstergesi olarak da kadın müşterilere sağlanan kredilerin toplam kredilerdeki oranı (WOMAN) (Campion vd., 2010; Nawaz vd., 2011; Janda vd., 2013); sosyal yardımın (outreach) diğer bir göstergesi olarak gözlemlenen MKK'nın borçlularının sayısı 10000'den az ise 1; 10000-30000 arasında ise 2; 30000'den fazla ise 3 değerlerini alan değişken (OUTREACH1) modele dahil edilmiştir.

Borçlanma faiz oranı (FR) (Campion vd., 2010; Nawaz vd., 2011; Cotler ve Almazan, 2013); makroekonomik istikrarsızlığın hesaba alınması amacıyla GSYİH'nin büyüme oranı (GROWTH) ve deflatörü (DEFL) değişkenleri de modele dahil edilmiştir (Chikalipah, 2012; Janda vd., 2013).

Bunun dışında personel giderlerinin kredi portföyüne oranı (PEREXP) değişkeni de modele dahil edilmiştir. Bu değişkenin eklenmesinde 1 ABD dolar tutarındaki kredi için gerçekleştirilen personel giderlerinin artması kredilere uygulanan faiz oranlarının artırdığı varsayımı esas alınmıştır.

Belirlenmiş değişkenlere göre oluşturulan sabit etkiler panel veri modeli ve rassal etkiler panel veri modeli bu şekilde yazılabilir:

$\mathrm{IR}_{\mathrm{it}}$

$=\tau_{1} \mathrm{CE}_{\mathrm{it}}+\tau_{2} \mathrm{LLR}_{\mathrm{it}}+\tau_{3} \mathrm{AGE} 1_{\mathrm{it}}+\tau_{4} \mathrm{ROA}_{\mathrm{it}}$

$+\tau_{5}$ ALB $_{\text {it }}+\tau_{6}$ WOMAN $_{\text {it }}+\tau_{7}$ FR $_{\text {it }}+\tau_{8}$ PEREXP $_{\text {it }}+\tau_{9}$ DEFL $_{\mathrm{i}(\mathrm{t}-1)} \tau_{10} \mathrm{GROWTH}_{\text {it }}+\tau_{11} \mathrm{OSS}_{\text {it }}+\tau_{12} \mathrm{LTA}_{\mathrm{it}}$

$+\mu_{\mathrm{i}}+\varepsilon_{\mathrm{it}}$

\subsection{Veri Seti ve Betimsel İstatistikler}

Bu çalışmada Mikrofinans Bilgi Değişimi (MIX Market) veri tabanından indirilmiş veri seti kullanılmıştır. Örnek ülkeler olarak seçilmiş 11 BDT ülkesindeki 215 Banka Dışı Finans Kurumuna ait dengesiz panel veri seti kullanılmıştır. Veri tabanından indirilen veri setinde toplam gözlem sayısı 1160'dir. Fakat modellerin tahmin edilmesi esnasında gözlem kayıplarından dolayı gözlem sayısı 509'a kadar azalmıştır. Ülkelerin listesi ve ülkelere göre gözlemlerin ve Banka Dışı Finans Kurumların sayılarının dağılımı Tablo 1.'de sunulmuştur.

\begin{tabular}{|l|c|c|c|}
\hline Ülke & MKK sayısı & Gözlem sayıs1 & $\begin{array}{c}\text { Toplam gözlem } \\
\text { sayısındaki payı, } \%\end{array}$ \\
\hline Azerbeycan & 22 & 166 & 14.31 \\
\hline Ermenistan & 11 & 78 & 6.72 \\
\hline Gürcistan & 16 & 105 & 9.05 \\
\hline Kazakistan & 46 & 214 & 18.45 \\
\hline Kirgızistan & 16 & 92 & 7.93 \\
\hline Moğolistan & 11 & 54 & 4.66 \\
\hline Moldova & 6 & 33 & 2.84 \\
\hline Özbekistan & 17 & 69 & 5.95 \\
\hline Rusya & 30 & 111 & 9.57 \\
\hline Tacikistan & 39 & 226 & 19.48 \\
\hline Ukrayna & 1 & 12 & 1.03 \\
\hline TOPLAM & 215 & 1160 & 100 \\
\hline
\end{tabular}

Tablo 1. Seçilmiş Ülkelere Göre Örneklem

Stokastik sinır translog maliyet fonksiyonu, Etkinsilik Etkileri denklemi, SEM, REM, VCESEM, PCSE, GLSAR1 ve GLSPSAR1 modellerinde kullanılan değişkenlere ait betimsel istatistikler Ek'teki Tablo E4.'te sunulmuştur.

\section{Analiz}

\subsection{Stokastik Maliyet Translog Sinırı}

Model (1)'de etkinsizlik etkileri denklemindeki değişkenlere ait katsayılardan EQR ve OSS değişkenlerinin katsayılarının pozitif işaretli fakat istatistiki olarak anlamsız olmasından dolayı, bu değişkenlerin modelden çıkartılmasıyla alternatif modeller olarak Model (2) ve Model(3) tahmin edilmiştir.

Akaike ve Bayesçi bilgi kriterlerine göre değerlendirilerek ve LR testi sonuçları esas alınarak Model(3) tercih edilerek, çalışmanın sonraki aşamasında bu modele göre hesaplanmış maliyet etkinlik ölçüleri kullanılmıştır. 


\subsection{Etkinsizlik Etkileri}

Etkinsizliği etkileyen faktörlerden LLR'ın anlamlı ve pozitif işaretli katsayısı esas alınarak MKK'ların kredi portfoyünün kalitesindeki bozulmalardan kaynaklanan kayıp ve giderler MKK'ların maliyetlerinin ve maliyet etkinsizliğinin artmasında önemli bir neden olduğu öne sürülebilir. AgeY ve AgeM değişkenlerinin katsayılarının işareti ve istatistiki anlamlılığı dikkate alınarak MKK'ların faaliyet gösterdiği yıllardır kazandıkları tecrübe ve deneyimleri kullanarak maliyetlerini daha etkin yönetebildikleri öne sürülebilir. Borçlu başına ortalama kredi tutarının kişi başına GSMG'e oranı (ALB) şeklinde ölçülen kredilerin büyüklüğündeki ve bayan borçluların yüzde oranındaki artışların MKK'ların maliyet etkinsizliğini artırdığına dair bulgular elde edilmiştir. Tahmin edilen Outreach değişkenine ait katsayının negatif işaretli olması ölçek ekonomisinin mevcudiyetinden dolayı MKK'lardan kredi almış borçluların sayısının artmasıyla toplam ve ortalama maliyetlerin azalmasının sonucu olabilir.

Varyans parametrelerinin, ayrıca $\lambda$ değerinin istatistiki olarak anlamlı ve sıfırdan uzak olması etkinsizlik teriminin mevcudiyetinin bir işaretidir. Wald testinin sonuçalarına göre model genel olarak anlamlıdır.

\subsection{Etkinlik Skorlar}

Tahmin edilen parametreler kullanılarak MKK'ların maliyet etkinlik ölçüleri hesaplanmıştır. Maliyet etkinlik ölçülerinin betimsel istatistikleri Tablo 2.'de sunulmuştur.

\begin{tabular}{|l|c|c|c|c|c|c|}
\hline Ülke & MKK sayıs1 & $\begin{array}{c}\text { Gözlem } \\
\text { sayıs }\end{array}$ & Ortalama & $\begin{array}{c}\text { std. } \\
\text { Sapmas } 1\end{array}$ & $\begin{array}{c}\text { Minimum } \\
\text { değer }\end{array}$ & $\begin{array}{c}\text { Maksimum } \\
\text { değer }\end{array}$ \\
\hline Azerbeycan & 22 & 92 & 0.825 & 0.130 & 0.362 & 0.975 \\
\hline Ermenistan & 11 & 55 & 0.799 & 0.139 & 0.411 & 0.953 \\
\hline Gürcistan & 16 & 76 & 0.793 & 0.153 & 0.280 & 0.966 \\
\hline Kazakistan & 46 & 58 & 0.752 & 0.157 & 0.255 & 0.958 \\
\hline Kırgızistan & 16 & 50 & 0.764 & 0.171 & 0.156 & 0.970 \\
\hline Moğolistan & 11 & 19 & 0.827 & 0.088 & 0.645 & 0.936 \\
\hline Moldova & 6 & 14 & 0.689 & 0.220 & 0.278 & 0.942 \\
\hline Özbekistan & 17 & 16 & 0.794 & 0.141 & 0.532 & 0.973 \\
\hline Rusya & 30 & 29 & 0.717 & 0.185 & 0.190 & 0.951 \\
\hline Tacikistan & 39 & 91 & 0.820 & 0.130 & 0.385 & 0.965 \\
\hline Ukrayna & 1 & 9 & 0.715 & 0.208 & 0.356 & 0.942 \\
\hline TOPLAM & 215 & 509 & 0.790 & 0.152 & 0.156 & 0.975 \\
\hline
\end{tabular}

Tablo 2. Etkinlik Ölçülerine Ait Betimsel İstatistikler

Tüm MKK'ların ortalama maliyet etkinlik ölçüsü 0,79 düzeyinde hesaplanmıştır. Maliyetlerin yönetimindeki başarısızlığın sonucunda aynı çıktı miktarının üretimi için gerçekleştirilen giderlerin \%79'u yeterli iken, daha fazla maliyet ile üretilmiştir. Bu sonuçlara göre, Moğolistan ve Moldova'daki MKK'lar maliyetlerin yönetiminde sırasıyla en etkin ve en etkinsiz olarak değerlendirilmektedir.

Şekil 1.'de tüm MKK'ları için hesaplanan maliyet etkinlik ölçülerinin ortalamasının yıllara göre değişimi gösterilmiştir.

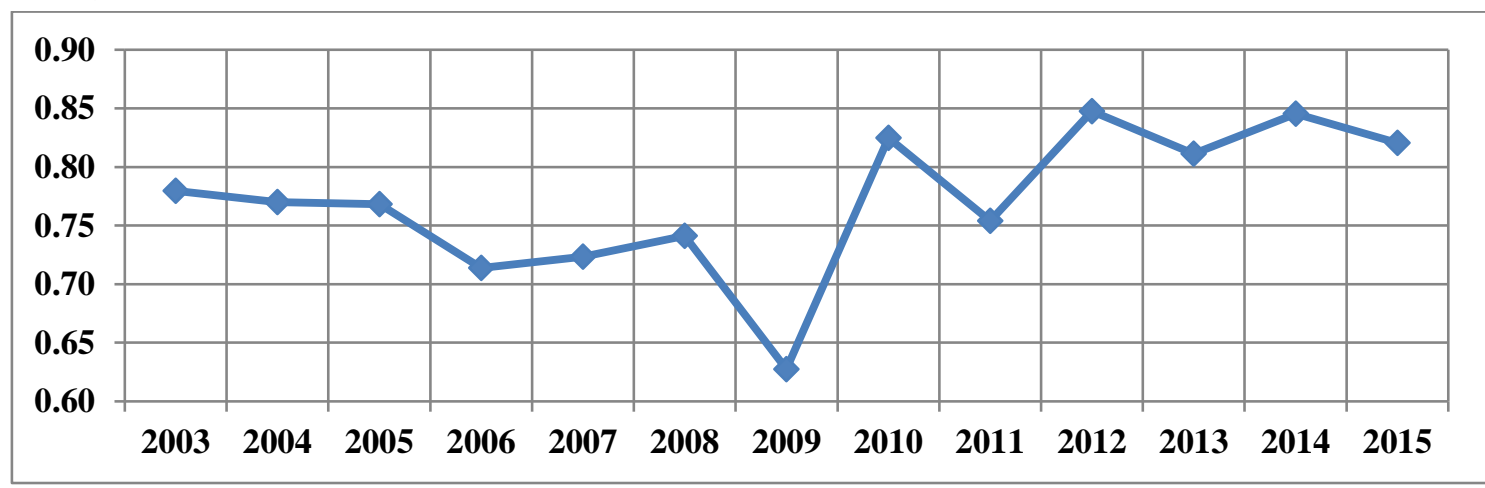

Şekil 1. MKK’ların Ortalama Maliyet Etkinliği Ölçüsünün Yıllara Göre Değişimi

Seçilmiş MKK'ların maliyet etkinliklerinin yıllara göre değişiminde 2007-2008, 2010, 2012, 2014 yıllarında artış, 2003-2006, 2009, 2011, 2013 ve 2015 yıllarında azalma gözlemlenmiştir. 2009 yılındaki keskin azalma Dünya Finansal krizinin etkisinin sonucu olarak değerlendirilebilir.

\subsection{Maliyet Etkinliğinin Faiz Oranı Üzerindeki Etkisi}

Sabit etkiler (SEM) ve rassal etkiler (REM) modelleri tahmin sonuçları Ek'teki Tablo E5'te sunulmuştur. Model tanımlanmasında için gerçekleştirilmiş hausman testi, ve diğer diagnostik testlerin sonuçları Tablo 3 'te sunulmuştur. Hausman testi (Hausman, 1978) sonuçlarına göre sabit etkiler modeli tercih edilmiştir. 


\begin{tabular}{|c|c|c|c|}
\hline Sifir hipotez & Test istatistiği & Ho olasılık değeri & Karar \\
\hline \multicolumn{4}{|l|}{ Hausman testi } \\
\hline $\begin{array}{l}\text { Difference in coefficients not } \\
\text { systematic }\end{array}$ & $\operatorname{chi} 2(12)=28.44$ & Prob $>$ chi2 $=0.0048$ & $\begin{array}{l}\text { Ho red, sabit etkiler } \\
\text { modeli daha uygundur }\end{array}$ \\
\hline \multicolumn{4}{|l|}{ Zaman etkisinin testi } \\
\hline $\begin{array}{l}\text { Zaman kuklasının katsayıları eşanlı } \\
\text { olarak sıfıra eşittir }\end{array}$ & $\mathrm{F}(12,369)=0.84$ & Prob $>F=0.6075$ & Ho red edilemez \\
\hline \multicolumn{4}{|c|}{ Panel veriler için Otokorelasyon (Wooldridge) testi } \\
\hline H0: no first order autocorrelation & $F(1,56)=6.498$ & Prob $>F=0.0136$ & $\begin{array}{l}\text { Ho red, 1. mertebeden } \\
\text { otokorelasyon vardır }\end{array}$ \\
\hline \multicolumn{4}{|c|}{ Sabit etkiler regresyon modeli için gruplara göre değişen varyans testi (Modifiye Wald testi) } \\
\hline $\begin{array}{l}\text { H0: varyans tüm birimler için sabittir, } \\
\left(\text { sigma(id)^ } 2=\operatorname{sigma}^{\wedge} 2\right)\end{array}$ & $\operatorname{chi} 2(114)=8.1 \mathrm{e}+32$ & Prob $>$ chi $2=0.0000$ & $\begin{array}{l}\text { Ho red, değişen varyans } \\
\text { mevcuttur }\end{array}$ \\
\hline
\end{tabular}

Tablo 3. Hausman ve Diagnostik Test Sonuçları

Test sonuçlarına göre tespit edilen değișen varyans ve 1. mertebeden otokorelasyondan dolayı bunlar dikkate alınabilen standart hataları birimlere göre ayarlanmış sabit etkiler modeli (VCESEM) tahmin edilmiştir. Küme dirençli (cluster-robust (VCE)) tahmincileri olarak da bilinen ve Wooldridge (2013), Stock ve Watson (2008)'de tanımlanan bu tahminciler daha tutarlıdır.

Bu çalışmada dengesiz panel veri seti kullanıldığından yatay kesit bağımlılık veya eşzamanlı korelasyonun tespiti için testler uygulanamamıştır.

Fakat, tahmin edilen katsayıların panel içi AR(1) tipi otokorelasyon, ve paneller arası değişen varyans dışında yatay kesit bağımlılığın olduğu duruma karşı dirençliğinin incelenmesi amacıyla panellere göre düzeltilmiş standart hatalar (panel-corrected standard errors) (PCSE) modeli, Genelleştirilmiş EKK (feasible generalized least squares) modellerinden AR(1) katsayısının tüm paneller için genel (GLSAR1) ve her bir panel için ayrı (GLSPAR1) olmak üzere daha 3 modelin sonuçları da sunulmuştur.

Tahmin edilen modellere göre, MKK'larca sağlanan krediler için uygulanan faiz oranlarını en büyük ölçüde personel giderlerinin kredi portfoyüne oranı (PEREXP) etkilediği halde, kredi kayıplarının karşılanması için ayrılan rezervlerin toplam varlıklara oranı (LLR) ve karlılık oranının (ROA) etkilemiştir. Faiz oranlarını pozitif yönde etkileyen diğer değişkenler olarak borçlanma fiyatı (FR) ve bir yıl gecikmeli enflasyon oranı (DEFL) belirtilebilir.

Modeldeki katsayılara göre faiz oranını negatif yönde etkileyen değişkenler MKK'nın yaşı (AGE1) ve kredilerin ortalama büyüklüğü (ALB), ve maliyet etkinliğidir. Maliyet etkinliği (CE) değişkeninin katsayısı negative ve istatistiki olarak anlamlıdır. MKK'ların maliyetlerini etkin kullanan MKK'larca uygulanan faiz oranlarının göreceli daha düşük olduğuna dair bulgular elde edilmiştir. Maliyetlerin \%60-\%70'1 personel giderlerinden oluştuğu ve PEREXP değişkeni ile ilgili bulgular esas alınarak, bazı MKK'ların uyguladıkları faiz oranlarının yüksek olması aşırı ücretlerin belirlenmesinin bir sonucu olduğu belirtilebilir.

\section{Sonuç}

Gelişmekte olan ülkelerde nüfusun \%40 -\%80’i banka hizmetlerini kullanamamaktadır. Bu kesime hizmet etmek için dünyada 3.652 mikrokredi kuruluşları 205 milyon yoksul müşteriye ulaşmıştır. Ancak yoksulların mikrokrediden yararlanması son derece önemli olmasına rağmen, dünyada faaliyet gösteren mikrokredi kurumlarının \%75’i faiz oranlarının yüksek olması nedeniyle toplumda zorunlu başvurulan bir yöntem olduğu görülmektedir.

Mikrokredi kurumları faiz oranlarının yüksek olmasını farklı sebeplere bağlamaktadır. Sebepleri ise kaynakların pahalı olması, işlem maliyetlerinin yüksek olması, kar oranının yüksek tutulması ve geri dönüşüm risk oranının yüksek olmasıdır. Ancak mikro kredi faiz oranlarının yüksek olmasının en önemli sebebi mikrofinans işletmelerinin etkinsiz çalışmalarıdır.

Bu araştırmanın amacı MKK'ların maliyetlerinin etkin kullanmasının mikro kredi faiz oranı üzerindeki etkisinin incelenmesidir. $\mathrm{Bu}$ amaca ulaşmak için Çalışmada Mikrofinans Bilgi Değişimi (MIX Market) veri seti kullanılmıştır ve stokastik sınır analizi yöntemi ile maliyet etkinliğinin faiz oranı üzerindeki etkisi sabit etkiler modeli ile incelenmiştir.

Araştırmanın sonuçlarına göre MKK'ların maliyetlerini etkin kullanmasıyla MKK'larca uygulanan faiz oranları üzerinde etkisi olduğu anlaşılmıştır. Maliyetlerin \%60-\%70'1 personel giderlerinden oluştuğu ve bazı MKK'ların uyguladıkları faiz oranlarının yüksek olması aşırı ücretlerin belirlenmesinin bir sonucu olduğu tespit edilmiştir.

Bundan dolayı mikro kredi faiz oranlarını düşürmek için MKK'ların personel ücretlerine dikkat etmesi ve MMK yöneticilerinin maaşlarının aşırı yüksek tutmaması gerektiği sözkonusudur. 


\section{Kaynakça}

- $\quad$ Abate, G. T., Borzaga, C., \& Getnet, K. (2014). Cost Efficiency and Outreach of Microfinance Institutions: Trade-Offs and The Role of Ownership. Journal of International Development, 26(6), 923-932.

- Annim, S.K., (2010). Microfinance efficiency trade-offs and complementarities.

- Balkenhol B., (2007). Microfinance and public policy: Outreach, performance and efficiency. ILO.

- $\quad$ Beck, T., Demirguc-Kunt, A. and Martinez Peria, M.S., (2008). Services for Everyone? Barriers to Bank Access and Use around the World. World Bank Economic Review, this issue.

- $\quad$ Berger, A. N., \& Mester, L. J. (1997). Inside the black box: What explains differences in the efficiencies of financial institutions? Journal of Banking \& Finance,21(7), 895-947.

- Bos, J. W. B.\& Millone, M. M., (2013). Practice what you preach: Microfinance business models and operational efficiency (No. 067). Maastricht University, Graduate School of Business and Economics (GSBE).

- Campion, A., Ekka, R. K., \& Wenner, M. (2010). Interest rates and implications for microfinance in Latin America and the Caribbean (No. IDB-WP-177en). IDB Working Paper Series.

- Chikalipah, S. (2012). What influences microfinance lending interest rates in Sub-Saharan Africa, unpublished journal Bournemouth University, Bournemouth, UK

- Cotler, P., \& Almazan, D. (2013). The Lending Interest Rates in the Microfinance Sector: searching for its determinants. Journal of CENTRUM Cathedra: The Business and Economics Research Journal, 6(1), 69-81.

- Cull, R., \& Demirgüç-Kunt, A. (2006). Financial performance and outreach: a global analysis of leading microbanks. World Bank Policy Research Working Paper, (3827).

- Ferro Luzzi, G., \& Weber, S. (2006). Measuring the performance of microfinance institutions. Unpublished working paper, Geneva: Uni-versity of Geneva.

- Gonzalez, Adrian, Analyzing Microcredit Interest Rates: A Review of the Methodology Proposed by Mohammed Yunus (February 2010). MIX Data Brief No. 4. Available at SSRN

- Greene, W. H. (1993). The Econometric Approach to Efficiency Analysis. In: Fried HO, Lovell CAK, Schmidt SS (eds.), The Measurement of Productive Efficiency: Techniques and Applications, Oxford University Press, New York, ss. 68-119.

- Gregoire, J. R., \& Tuya, O. R. (2006). Cost efficiency of microfinance institutions in Peru: A stochastic frontier approach. Latin American Business Review,7(2), 41-70.

- Hausman, J. A. 1978. Specification tests in econometrics. Econometrica 46: 1251-1271.

- Hermes, N., Lensink, R. and Meesters, A. (2009). Financial development and the Efficiency of Microfinance Institutions. Online resource available at http://papers.ssrn.com/sol3/papers.cfm

- Hermes, N., Lensink, R. and Meesters, A. (2009). Outreach and Efficiency of Microfinance Institutions, Working paper, University of Groningen.

- Hermes, N., Lensink, R., \& Meesters, A. (2011). Outreach and efficiency of microfinance institutions. World Development, 39(6), 938-948.

- Janda, K., \& Turbat, B. (2013). Determinants of the financial performance of microfinance institutions in Central Asia. Post-Communist Economies, 25(4), 557-568.

- Jondrow, J., Lovell, C. A. Knox, Materov, I. S., Schmidt, P. (1982). On Estimation of Technical Inefficiency in the Stochastic Frontier Production Function Model. Journal of Econometrics 19,233-238.

- Kasman, A. (2003). Banking Efficiency During the Financial Crisis Period. ISE Review, 7, pp. 83-97

- Kinde, B. A. (2012). Financial sustainability of microfinance institutions (MFIs) in Ethiopia. European Journal of Business and Management, 4(15), 1-10.

- $\quad$ KTMÜ BAP Projesi, Kırgızistan'da Mikro Finans Uygulaması Ve Mikro Kredi Faiz Oranlarının Düşürülmesi, 2015

- $\quad$ Kumar, S. ve Gulati, R. (2014). Deregulation and Efficiency of Indian Banks, India Studies in Business and Economics, Springer İndia, Chapter 3, 49-131

- $\quad$ Lensink, R., Meesters, A., \& Naaborg, I. (2008). Bank efficiency and foreign ownership: Do good institutions matter? Journal of Banking and Finance, 32(5), 834-844.

- Maes J.P. and Reed L.R, (2012). State of The Microcredit Summit Campaign

- Olivares-Polanco, F. (2005). Commercializing microfinance and deepening outreach: Empirical evidence from Latin America.Journal of Micro-finance, 7(1), 47-69. 
- $\quad$ Oteng-Abayie, E. F., Amanor, K., \& Frimpong, J. M. (2013). The measurement and determinants of economic efficiency of microfinance institutions in Ghana: A stochastic frontier approach. African Review of Economics and Finance, 2(2), 149-166.

- Paxton, J. (2007). Technical efficiency in a semi-formal financial sector: The case of Mexico.Oxford Bulletin of Economics and Statistics, 69(1), 57-74.

- Schicks J., (2010). Microfinance and over-indebtedness: Understanding its drivers and challenging the common myths, CEB Working Paper 10/048

- $\quad$ Sealey, Jr.C.W., Lindley, J.T., (1977). Inputs, Outputs, and Theory of Production Cost at Depository Financial İnstitutions. Journal of Finance, Vol. 32, pp. 1251-1266.

- Servin, R., Lensink, R., \& Van den Berg, M. (2012). Ownership and technical efficiency of microfinance institutions: Empirical evidence from Latin America. Journal of Banking \& Finance, 36(7), 2136-2144.

- $\quad$ Singh, S., Goyal, S. K., \& Sharma, S. K. (2013). Technical efficiency and its determinants in microfinance institutions in India: a firm level analysis. Journal of Innovation Economics \& Management, (1), 15-31.

- Stock, J. H., and M. W. Watson. 2008. Heteroskedasticity-robust standard errors for fixed effects panel data regression. Econometrica 76: 155-174.

- Tabak, B. M., Cajueiro, D. O., \& Dias, M. V. (2014). The Adequacy of Deterministic and Parametric Frontiers to Analyze the Efficiency of Indian Commercial Banks (No. 350).

- University of Manchester Brooks World Poverty Institute.

- Wooldridge, J. M. 2013. Introductory Econometrics: A Modern Approach. 5th ed. Mason, OH: SouthWestern.

\section{Ekler}

\begin{tabular}{|l|c|c|c|c|c|}
\hline Değişken notasyonu & Gözlem sayısı & ortalama & Standart Sapma & Minimum değer & Maximum değer \\
\hline WOMAN & 646 & 0.474 & 0.192 & 0.004 & 1.000 \\
\hline ABL & 663 & 0.908 & 1.591 & 0.001 & 23.977 \\
\hline ROA & 683 & 0.052 & 0.113 & -0.564 & 0.631 \\
\hline DER & 696 & 5.967 & 61.726 & -27.620 & 1436.600 \\
\hline CPB & 634 & 455.085 & 1010.383 & 0.000 & 15150.990 \\
\hline AgeY & 697 & 0.341 & 0.475 & 0.000 & 1.000 \\
\hline AgeM & 697 & 0.418 & 0.494 & 0.000 & 1.000 \\
\hline Age1 & 697 & 2.175 & 0.796 & 0.000 & 3.000 \\
\hline OutreachM & 697 & 0.162 & 0.369 & 0.000 & 1.000 \\
\hline OutreachL & 697 & 0.089 & 0.285 & 0.000 & 1.000 \\
\hline IR & 697 & 0.374 & 0.160 & 0.000 & 0.988 \\
\hline CE & 508 & 0.791 & 0.152 & 0.154 & 0.975 \\
\hline LLR & 674 & 0.014 & 0.025 & -0.077 & 0.285 \\
\hline FR & 663 & 0.119 & 0.105 & -0.014 & 1.090 \\
\hline PEREXP & 683 & 0.133 & 0.090 & 0.000 & 0.995 \\
\hline DEFL & 696 & 11.163 & 9.064 & -18.930 & 39.178 \\
\hline GROWTH & 697 & 6.566 & 6.015 & -15.136 & 34.500 \\
\hline OSS & 694 & 1.371 & 0.611 & 0.104 & 6.650 \\
\hline
\end{tabular}

Tablo E4. Değişkenlere Ait Betimsel Istatistikler 


\begin{tabular}{|c|c|c|c|c|c|c|c|}
\hline & & SEM & REM & VCESEM & $P C S E$ & GLSAR1 & GLSPSAR1 \\
\hline Değişken & Parametre & \multicolumn{6}{|c|}{ Katsayılar } \\
\hline \multirow[t]{2}{*}{$\mathrm{CE}$} & $\tau_{1}$ & $-0.0866 * * *$ & $-0.0811 * * *$ & $-0.0866^{*}$ & $-0.0646 * *$ & $-0.0673 * * *$ & $-0.0778 * * *$ \\
\hline & & $(-3.60)$ & $(-3.61)$ & $(-2.12)$ & $(-2.40)$ & $(-4.20)$ & $(-6.87)$ \\
\hline \multirow[t]{2}{*}{ LLR } & $\tau_{2}$ & $0.595 * * *$ & $0.663 * * *$ & $0.595 * * *$ & $0.655^{* * *}$ & $0.655^{* * *}$ & $0.621 * * *$ \\
\hline & & $(4.94)$ & $(5.77)$ & $(4.33)$ & $(5.43)$ & $(8.41)$ & $(11.03)$ \\
\hline \multirow[t]{2}{*}{ Age1 } & $\tau_{3}$ & $-0.0149 * *$ & -0.00865 & $\begin{array}{c}- \\
0.015 * * *\end{array}$ & -0.00512 & $-0.00629 *$ & $-0.00980 * * *$ \\
\hline & & $(-2.29)$ & $(-1.50)$ & $(-5.21)$ & $(-0.85)$ & $(-1.91)$ & $(-3.76)$ \\
\hline \multirow{2}{*}{ ROA } & $\tau_{4}$ & $0.593 * * *$ & $0.648^{* * *}$ & $0.593 * * *$ & $0.558 * * *$ & $0.634 * * *$ & $0.651 * * *$ \\
\hline & & $(10.38)$ & $(12.63)$ & $(7.40)$ & $(7.10)$ & $(13.86)$ & $(21.97)$ \\
\hline \multirow[t]{2}{*}{ ALB } & $\tau_{5}$ & $-0.0219 * * *$ & $-0.0128 * * *$ & $0.022 * * *$ & $-0.012 * * *$ & $-0.0158 * * *$ & $-0.0125 * * *$ \\
\hline & & $(-3.93)$ & $(-3.38)$ & $(-4.65)$ & $(-2.73)$ & $(-5.03)$ & $(-5.58)$ \\
\hline \multirow[t]{2}{*}{ WOMAN } & $\tau_{6}$ & $0.0657^{* *}$ & $0.0883 * * *$ & 0.0657 & $0.128 * * *$ & $0.0899 * * *$ & $0.106 * * *$ \\
\hline & & $(2.08)$ & $(3.31)$ & $(1.42)$ & $(4.78)$ & $(5.79)$ & $(9.16)$ \\
\hline \multirow[t]{2}{*}{$\overline{F R}$} & $\tau_{7}$ & $0.104 * * *$ & $0.127 * * *$ & $0.104 * *$ & $0.130 * * *$ & $0.161 * * *$ & $0.109 * * *$ \\
\hline & & $(3.18)$ & $(4.14)$ & $(3.12)$ & $(3.35)$ & $(6.01)$ & (5.15) \\
\hline \multirow{2}{*}{ PEREXP } & $\tau_{8}$ & $0.914 * * *$ & $0.993 * * *$ & $0.914 * * *$ & $0.998 * * *$ & $1.039^{* * *}$ & $0.972 * * *$ \\
\hline & & $(14.55)$ & $(17.87)$ & $(5.11)$ & $(14.19)$ & $(24.64)$ & $(34.09)$ \\
\hline \multirow{2}{*}{ DEFL } & $\tau_{9}$ & $0.000756^{* *}$ & $0.000724 * *$ & 0.000756 & $0.000621^{*}$ & 0.000286 & 0.0000792 \\
\hline & & $(2.15)$ & $(2.12)$ & $(1.30)$ & $(1.68)$ & $(1.40)$ & $(0.55)$ \\
\hline \multirow[t]{2}{*}{ GROWTH } & $\tau_{10}$ & 0.000190 & 0.000110 & 0.000190 & 0.000660 & -0.0000087 & 0.000297 \\
\hline & & $(0.40)$ & $(0.24)$ & $(0.51)$ & $(1.18)$ & $(-0.03)$ & $(1.08)$ \\
\hline \multirow[t]{2}{*}{ OSS } & $\tau_{11}$ & -0.0116 & -0.00559 & -0.0116 & 0.00508 & 0.00222 & -0.00915 \\
\hline & & $(-0.92)$ & $(-0.51)$ & $(-0.70)$ & $(0.32)$ & $(0.25)$ & $(-1.49)$ \\
\hline \multirow[t]{2}{*}{ LTA } & $\tau_{12}$ & 0.000938 & -0.00183 & 0.000938 & 0.00237 & -0.00144 & -0.00164 \\
\hline & & $(0.24)$ & $(-0.61)$ & $(0.38)$ & $(0.70)$ & $(-0.86)$ & $(-1.39)$ \\
\hline \multirow[t]{2}{*}{ Azerbeycan } & $\varsigma_{1}$ & & & & $0.0499 * * *$ & $0.0448 * * *$ & $0.0421 * * *$ \\
\hline & & & & & $(3.36)$ & $(5.58)$ & $(5.91)$ \\
\hline \multirow[t]{2}{*}{ Gürcistan } & $\varsigma_{3}$ & & & & $0.0795 * * *$ & $0.0737 * * *$ & $0.0696^{* * *}$ \\
\hline & & & & & $(5.87)$ & $(9.18)$ & $(9.61)$ \\
\hline \multirow[t]{2}{*}{ Kazakistan } & $\varsigma_{4}$ & & & & $0.0431^{* *}$ & $0.0578 * * *$ & $0.0629 * * *$ \\
\hline & & & & & $(2.38)$ & $(6.10)$ & $(9.92)$ \\
\hline \multirow[t]{2}{*}{ Kırgızistan } & $\varsigma_{5}$ & & & & $0.0662 * * *$ & $0.0550^{* * *}$ & $0.0730^{* * *}$ \\
\hline & & & & & $(4.68)$ & $(6.36)$ & $(9.86)$ \\
\hline \multirow[t]{2}{*}{ Moldova } & $\varsigma_{6}$ & & & & $0.0495^{* *}$ & $0.0635^{* * *}$ & $0.0455^{* *}$ \\
\hline & & & & & $(2.28)$ & $(3.80)$ & $(2.09)$ \\
\hline Moğolistan & $\varsigma_{7}$ & & & & $0.105 * * *$ & $0.0961 * * *$ & $0.0966^{* * *}$ \\
\hline & & & & & $(5.50)$ & $(12.12)$ & $(16.07)$ \\
\hline Rusya & $\varsigma_{8}$ & & & & -0.0151 & -0.00641 & -0.00329 \\
\hline & & & & & $(-0.70)$ & $(-0.54)$ & $(-0.47)$ \\
\hline Tacikistan & $\varsigma_{9}$ & & & & $0.0958 * * *$ & $0.0861 * * *$ & $0.0960 * * *$ \\
\hline & & & & & $(6.50)$ & $(10.17)$ & $(14.32)$ \\
\hline Ukrayna & $\varsigma_{10}$ & & & & 0.0449 & 0.0191 & 0.0364 \\
\hline & & & & & $(0.76)$ & $(0.34)$ & $(0.71)$ \\
\hline Özbekistan & $\varsigma_{11}$ & & & & $0.162 * * *$ & $0.229 * * *$ & $0.288 * * *$ \\
\hline & & & & & $(4.77)$ & $(5.84)$ & $(12.46)$ \\
\hline Sabit & $\tau_{0}$ & $0.293 * * *$ & $0.270 * * *$ & $0.293 * * *$ & 0.0932 & $0.186^{* * *}$ & $0.222 * * *$ \\
\hline & & $(4.38)$ & $(5.10)$ & $(12.56)$ & $(1.48)$ & $(5.75)$ & $(8.67)$ \\
\hline Gözlem sayı & & 507 & 507 & 507 & 507 & 473 & 473 \\
\hline R-kare & & 0.558 & & 0.558 & 0.778 & & \\
\hline Düzeltilmiş & are & 0.413 & & 0.547 & & & \\
\hline AIC & & -1666.4 & . & -1672.4 & . & . & . \\
\hline $\mathrm{BIC}$ & & -1611.4 & . & -1630.1 & . & . & . \\
\hline Wald (Ki-ka & & & $821.0 * * *$ & 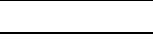 & $1010.4 * * *$ & $2483.3 * * *$ & $5780.2 * * *$ \\
\hline
\end{tabular}

Tablo E5. Sabit Etkiler ve Rassal Etkiler Modelleri Tahmin Sonuçları

Not: bağımlı değişken: IR; * $\mathrm{p}<0.1,{ }^{*} \mathrm{p}<0.05, * * * \mathrm{p}<0.01$ istatistik değerlerin anlamlılık düzeylerini ifade etmektedir; parantez içinde $\mathrm{t}$ istatistik değerleri sunulmuştur 


\title{
Uluslararası Sermaye Hareketlerinin Finansal Krizlere ve Bankalara Etkileri
}

\section{The Effect of International Capital Movements on Financial Crisis and Banks}

\author{
Asst. Prof. Dr. İsmail Erkan Çelik (Beykent University, Turkey) \\ Assoc. Prof. Dr. Kamil Uslu (Kavram MYO, Turkey) \\ Midzhit Hodzhaniyazov (Marmara University, Turkey)
}

\begin{abstract}
International Capital Movements the course of history have changed and improved until today and took its place in the evolving field of finance. In particular, The Industrial Revolution began with the rapid changes seen that right quickly spread from place to place in fluid funds. Globalization has accelerated the rapid development of technical and technological development. Specifically, after 1980, international capital mobility until it is able to confirm it. All the methods developed for removing most important part of the financial restructuring of the financial crisis, banks are minimizing financial risks. The aim of this study is to investigate whether International Capital Movements of the financial crisis and how it affects the works of bank. Banks have become the customers are responsible for implementing various methods to rid the financial crisis. The financial crisis in late 2008 to eliminate the problems that arise hedge to be removed from the market and the fund carries the responsibility with its own more efficient methods.
\end{abstract}

\section{Giriș}

Uluslararası Sermaye Hareketleri tarihi seyri içerisinde günümüze kadar değişerek ve gelişerek finans alanında yerini almıştır. Özellikle sanayi devrimi ile başlayan hızlı değişmeler akışkan fonları bir yerden bir yere doğru hızla yayıldığı görünmektedir. Küreselleşmenin hızla gelişmesi teknik ve teknolojideki gelişmeyi de hızlandırmıştır. Özellikle 1980'lerden sonra Uluslararası Sermayedeki hareketlik bunu teyit edebilmektedir.

Çalışmada Uluslararası Sermaye hareketlerinin banka krizlerini etkileri tarihi bir gelişmesiyle Uluslararası Sermaye hareketlerinin ekonomik istikrar üzerindeki etkisi üzerinde durulmuştur. Burada Uluslararası Sermaye Hareketleri çeşitleri ile finansal krizler üzerindeki etkileri incelenmiştir. Finansal krizlerin özellikleri ve türleri, finansal krizleri modelleri bankaların finansal krizlerden korunma yöntemleri değerlendirilerek teorik bir görüş sunulmuştur. Daha çok literatürdeki verileri değerlendirmesi ile sonuçlanmıştır. Değerlendirmesi ile yeni bir görüş sunulmuştur.

\section{Uluslararası Sermaye Hareketlerinin Tanımı}

Geçmişte olduğu gibi bugünde ulusların birbirlerine ekonomik olarak, ihtiyaçları vardır. Bunların bir kısmı mal ve hizmet akışını gösterirken, bir kısmı da finansal hareketlerdir. Uluslararası Sermaye hareketleri bu yönden önem taşımaktadır. Uluslararası sermayeyi genel olarak, bir ülkenin karşılığını ödemeksizin veya ileri bir tarihte ödemek üzere dış ülkelerden sağlamış olduğu ekonomik kaynaklar olarak tanımlamak mümkündür. Başka bir anlatımla bir ülkenin karşılığını farklı şekillerde ileride ödemek için başka ülkelerden kısa vadede ekonomik gücüne katabileceği, teknolojik ve mali kaynaklardır (İsmail Aydoğuş, 1989, Anadolu Üniversitesi Afyon İ.̇̇.B.F. 15. Kuruluş Yı1ı Armağanı, Türkiye'de 24 Ocak 1980 Sonrası Yabancı Sermaye Yatırımları ve Gelişimi, Eskişehir, ss.229-243). Başka bir deyiş ile Yabancı (uluslararası) sermaye, bir ülkenin sermaye birikimine, o ülkenin kendi sınırları dışındaki farklı bir ülkenin kurum veya vatandaşlarının sahipliği olarak tanımlanabilir.

Resmi sermaye hareketleri; gelişmiş ülkelerin, az gelişmiş ülkelere yaptıkları bağış ve kredi şeklindeki yardımlardır. Yardımlar bağış şeklinde olursa uluslararası bir transfer söz konusu iken kredi şeklinde olursa devletlerarası bir borçlanma söz konusudur. Uluslararası özel sermaye akımlarının, ticari koşullara göre para ve sermaye piyasalarından fon sağlanması en belirgin özellikleridir. Üretime yönelik yardım niteliğinde olmamaları doğrudan yabancı sermaye yatırımlarından, yardım niteliğinde olmamaları nedeniyle de resmi sermaye hareketlerinden ayrilmaktadır.

John Keynes ve Bertil Ohlin'in teorilerinde; sermaye akımlarının temeli atılmıştır. Bir ülkenin üretim faktörlerinden olan sermaye ve emeğin, uluslararası piyasada yer değiştirdiği konusunun sistemleştirilmesi, ilk 1933 yılında Bertil Ohlin tarafından söz edilmiştir. Ohlin, dünya savaşlarından sonra kazanan ülke ile kaybedenin arasında kaybeden ülke tazminat ödemesinden kaynaklı olarak, satınalma gücünde farklılıklar ortaya çıktığından bahsetmiştir. Ödeme yapan tarafın satınalma gücünde zayıflamanın, diğerinde ise artmanın söz konusu olduğunu belirtmiştir (Nurdan Aslan, 1997, Uluslararası Özel Sermaye Akımları: Portföy Yatırımları ve Sıcak Para Hareketleri, Türkmen Kitapevi, İstanbul, s.23.). 
Modern anlamda Uluslararası sermaye hareketleri tarihi günümüze kadar değişiklere uğrayarak, bugünkü anlamda gelişmesine katkıda bulunmuştur. 18.yüzyılın ikinci yarısında Sanayi Devrimi ile başlayan kapitalist üretim biçiminin gelişim süreci içerisinde ele alınabilir. Sanayi devrimini izleyen yıllarda ulusal sınırların dışındaki ekonomik faaliyetler hızlanmıştır. Bu gelişimin arkasında, Avrupa ülkelerinin 18. yüzyılda sömürge altında olan ülkelerinin ucuz hammadde, işgücü ve piyasa firsatlarından faydalanma çabaları yatmıştır. Haberleşme, üretim ve ulaşım teknolojilerindeki yeni olanaklar, üretim ve ticaretin hızla yükselmesine, emisyon sistemlerinin oluşmasına ve ticari senetlerin yaygınlaşmasına yol açmıştır. Ülke ekonomilerin dışa açılması ile büyümeye başlayan ticaret hacmi, gelişmekte olan ülkeler, gelişmiş ülke stoklarına eskisinden daha çok ihtiyaç duymaya başladıkları söylenebilir. Bunun neticesinde, gelişmekte olan ülkelerin çoğu, kendi sermaye hesaplarını ve kambiyo sistemlerini serbestleştirmiş, finansal piyasalarını oluşturup, geliştirmiştir. Büyüyen piyasalar olarak bilinen bu yeni piyasalar, sermaye girişi için cazip firsatlar sunarken, kambiyo sistemlerinin serbestleştirilmesi sermaye giriş çıkışını sağlanmıştır. Bu da yabancı sermaye hareketlerinin hem miktarının, hem de hızının artmasına yardımcı olmuştur.

\section{- Uluslararası Sermaye Hareketlerinin Nedenleri}

Uluslararası sermaye akımlarının son yıllarda hızla artmış olmasının tabii olarak birçok nedeni bulunmaktadır. Bunların bir kısmı iktisadi siyasi, olmakla birlikte, önemli bir kısmı da teknolojik gelişmeye bağlı altyapı hizmetlerindeki yeterliliğe bağlıdır. Bunlar aşağıda sıralanmıştır;

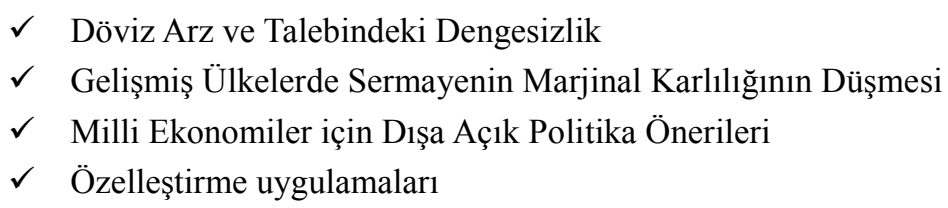

\subsection{Uluslararası Sermaye Hareketlerinin Ekonomik İstikrar Üzerine Etkisi}

Dolaylı sermaye yatırımlarının seyri ile ilgili olarak önem verilen uygulamalardan biri de 1990’lı yıllarda gelişmekte olan ülkelerde çoğalan kısa vadeli borçlardır. Kısa vadeli borçlar içerisinde olan özel sektörün, en çok finansal kurumların payı ciddi miktarda büyüme göstermiştir. Örneğin güneydoğu Asya krizinde özel sektörün yabancı ülkelerden aldıkları kısa vadeli borçlar, önemli nedenlerden biri olarak açıklayabilmektedir. Bununla ilgili 1986-1998 yıllarını ve 33 gelişmekte olan ülkeyi içeren bir çalışmada, ilgili ülke piyasalarında negatif bir gelişme ortaya çıktığında kısa vadeli borçlardaki düşüşün, olumlu bir ekonomik durumun varlığında söz konusu ülkelere verilen kısa vadeli borç miktarına göre iki kat daha hızlı bir biçimde azaldığını ortaya koymaktadır. Yani kısa vadeli yabancı sermaye negatif ekonomik gelişmelere hızlı bir şekilde tepki vermektedir.

Uluslararası sermaye hareketlerinin ekonomik istikrar üzerine etkisi kapsamında değinilmesi gereken hususların başında finansal serbestleşme ve finansal bütünleşme gelmektedir. Finansal bütünleşmeyi işaret eden uygulamaların artması özellikle yirmi birinci yüzyılın başlarında önemli ölçüde olmuştur (Sudi Apak ve Engin Demirel, 2009, Finansal Yönetim, Papatya Yayıncılık, İstanbul, s.44.). Oluşan bu bütünleşik yapının kontrol edilmesi gerekli olmuştur. Bu noktada yapılan kontrollerin etkinliği uluslararası sermaye hareketlerinin ekonomik istikrar üzerinde hangi noktada etkili olduğunu belirleyeceği için önemli bir yere sahiptir denilebilir.

\subsection{Tobin Vergisi Uygulama ve Etkinliği}

1981 y1lında Nobel İktisat ödülünü kazanan James Tobin kısa vadeli spekülatif sermaye hareketlerini önlemek amacıyla tüm döviz işlemlerini kapsayacak genel bir vergi önerisi getirmiştir. Tobin'in kendi ifadesiyle; “Önerim, uluslararası para piyasamızın aşırı derecede hızlı çarklarına biraz olsun kum serpmektireee demiştir.

Tobin vergisinin temelleri Keynes ${ }^{e \text { in }}$ bu konudaki düşüncelerine kadar uzanmaktadır. Keynes, risk ve ilave maliyetlerin uzun dönemli yatırımlara zarar vermeden kısa dönemli parasal akımları azaltabileceğini ve böylece bu vergiler ile spekülatif işlemlerin önlenebileceğini ileri sürmüştür. Keynes, menkul kıymetler piyasasındaki fiyatlamalarda böyle bir vergilemenin sadece kısa vadeli işlemlerden kar elde etmek isteyenleri etkileyeceğini gözlemlemiştir. Örneğin borsa işlemlerine konulacak küçük bir vergi uzun vadeyi değil kısa vadeyi etkileyecektir.

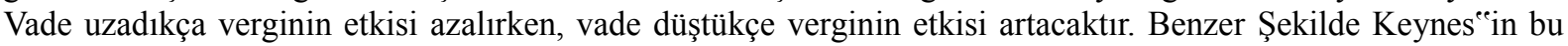
yaklaşımını dışarıdan gelen yabancı sermaye için kullanırsak, kısa vadeli sermaye üzerine konulacak bir vergi, uzun vadeli yabancı sermaye üzerinde önemli bir etki yaratmazken, sadece kısa vadeli yabancı sermayeyi etkileyecektir.

Bazı ülke uygulamalarında, döviz kurunun uygulandığı gelişmiş ve gelişmekte olan ülkelerin piyasalarında çok

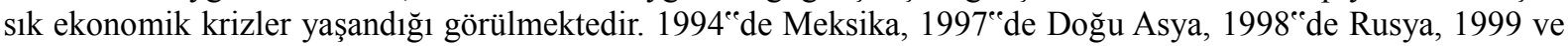
$2002^{\text {ee }} \mathrm{de}$ Brezilya, $2001^{\text {ee }} \mathrm{de}$ Türkiye, $2002^{\text {ee }} \mathrm{de}$ Arjantin ekonomilerinde krizler yaşanmıştır. Son olarak Amerika ${ }^{e e} \mathrm{da}$ başlayan ekonomik kriz bütün dünyayı etkilemiştir.

Tobin vergisi, uluslararası spekülatif işlemlerin sorunlarını önlenebilmek amacıyla önerilen bir politika aracı olarak da açıklanabilir. Başka bir deyişle; Tobin'in söz ettiği, kısa vadeli veya spekülatif işlemelerindeki kar elde etme ihtimalinin bu tür işlemler için küçük oranlı bir işlem vergisi uygulanılması sonucunda artan spekülasyon maliyetleri sonucunda düşmesi şeklinde de tanımlanabilir (Ferit Kula, 2003, "Uluslararası Sermaye Hareketlerinin 
Etkinliği: Türkiye Üzerine Gözlemler", Cumhuriyet Üniversitesi İktisadi ve İdari Bilimler Fakültesi Dergisi, Cilt: 4, Say1: 2, Sivas, ss.143-145.).

\subsection{Uluslararası Sermaye Hareketlerin çeşitleri $>$ Özel Sermaye Hareketleri}

Uluslararası sermaye hareketlerinden özel sermaye hareketleri kendi içerisinde üçe ayrılabilir. Bunlar sırasıyla doğrudan yatırımlar, dolaylı yatırımlar ve diğer yatırımlar şeklinde sınıflandırılmaktadır.

\section{$>$ Doğrudan Yatırımlar}

"Uluslararası doğrudan yatırımlar, ev sahibi ülkeler açısından yurtiçi özel yatırımları tamamlayıcı, yeni iş imkanları ile teknoloji transferine yol açan, ev sahibi ülkede ekonomik büyümeyi sağlayan ve tüm aktörleri harekete geçiren önemli bir sermaye kaynağı olarak görünmektedir" (Hasan Vergil ve Coşkun Karaca, 2010, "Gelişmekte Olan Ülkelere Yönelik Uluslararası Sermaye Hareketlerinin Ekonomik Büyüme Üzerindeki Etkisi: Panel Veri Analizi”, Ege Akademik Bakış Dergisi, Cilt: 10, Sayı: 4, İzmir, s.1210.).

$\mathrm{Bu}$ ifadelerden anlaşlacağı üzere doğrudan yatırımlar, ekonomik sistemin bütününü etkileyecek şekilde ve düzeyde etkilere sahiptir.

\section{$>$ Dolaylı Yatırımlar}

Sermayenin ülkeye girmesinde nakit ya da döviz seçeneklerinin var olması ile birlikte, dolaylı yatırımlardan söz edilmektedir (Can Bakkalcı ve Nilüfer Argın, 2013, "Yabancı Yatırımların İsgü̈cü Piyasalarını Uyarma Süreci Kapsamında Dış Ticaretin İ̧selleştirilmesì", Çalışma İlişkileri Dergisi, Cilt:4, Sayı:1, s.72.). Bu ifadeden yola çıkılmak suretiyle dolaylı yatıımları doğrudan yatırımlardan ayıran en temel özelliğin varlıkların ülkeye giriş biçimi olduğu söylenebilir. Aynı zamanda yapılan yatırımların belirgin niteliklerinin anlaşılmasında önemli rollere sahip olan bu durum, dolaylı yatırımların daha uzun vadeli yatırım olduğunu işaret etmektedir. Doğrudan yatırımlar ile kıyaslandığında dolaylı yatırımların kapsamının nispeten dar olduğu görülmektedir. Bu nedenle yapılacak olan incelemede dolaylı yatırımlara yüzeysel olarak yer verilmesi uygun görülmüştür.

\section{$>$ Diğer Yatırımlar}

Diğer uluslararası sermaye hareketlerine dair bir başka sınıflandırma ise, ticari banka kredileri ve sendikasyon kredileri şeklindedir. Bankaların günümüzde sahip oldukları rollerin giderek artması, ticari banka kredilerinin varlı̆ı̆ını ve rollerini kaçınılmaz hale getirmiştir. Öyle ki gelinen noktada özel işletmelerin yanında hükümetler dahi ticari banka kredisini başvurmaktadır. Bu da ticari banka kredilerinin geldiği noktayı açıklaması bakımından önemlidir.

İlgili literatür incelendiğinde, uluslararası özel sermaye hareketleri kapsamında yer alan diğer yatırımların farklı şekilde sınıflandırılarak incelendiği görülmektedir. Ancak doğrudan yatırımlar ve dolaylı yatırımlar ile kıyaslandığında diğer yatırımların daha az tercih edilen bir yapıda olduğu sonucu elde edilmiştir.

\section{$>$ Resmi Sermaye Hareketleri}

Resmi sermaye hareketleri ile birlikte açıklanmak istenen özel yatırımların yer almadığı uluslararası sermaye hareketleridir. Bu kapsamda değinilmesi gerekenlerin başında ise 1980'li yıllar itibariyle resmi sermaye hareketlerinin özel sermaye hareketlerinden daha düşük düzeyde bir kullanım sıklığına sahip olduğudur. Küreselleşme ile birlikte resmi sermaye hareketlerinin yerini özel sermaye hareketlerine bırakması, yaşanan gelişmeler ve küreselleşmenin hızı göz önüne alındığında olağan karşılanmaktadır.

\section{Finansal Kriz ve Finansal Kriz Tanımı}

Günümüzde en çok finansal açıdan kullanılan kriz tanımının kapsamı finansal unsurlarla sınırlandırılmaktan uzaktır. Genel bir tanıma göre kriz, "beklenmeyen ve önceden sezilemeyen, acele cevap verilmesi gereken, örgütlerin önleme ve uyum mekanizmalarını etkisiz hale getiren, mevcut değer, amaç ve varsayımlarını tehdit eden gerilim durumu" şeklinde açıklanmaktadır. Bu tanımdan hareketle krizin sıra dışı özelliklere sahip bir yapıda olduğu söylenebilir.

Krizin evrensel bir tanımından bahsetmek güçtür. Ancak, krizle ilgili yapılan tanımlar, ortaya çıkması ile birlikte zarar verme ve yok edici yapıda olma nitelikleri konusunda fikir birliğine sahiptir. Bu da krizlerin yolunda giden süreçleri sekteye uğrattığını işaret etmektedir. Kriz, performans başta olmak üzere kurumların yapının bütününe zarar verecek nitelikte etkiler barındırmaktadır (Ali Şahin Örnek, 2007, "Kriz Yönetimi Stratejileri ve Türkiye Bilişim Sektörü Örneği”, Yönetim Bilimleri Dergisi, Cilt: 5, Sayı: 1, s.117.). Dolayısıyla krizin tanımına ilişkin araştırmalarda krizin olumsuz özelliklerine ağırlık verilmesi olağan görünmektedir.

Yapılan tanımlarda krizin olumsuz yönlerine dikkat çekilmiş olsa da kriz kavramı tamamıyla olumsuz veriler bulunduran bir kavram değildir. Öyle ki krizlerle birlikte bir takım firsatların varlığı söz konusu olmaktadır. Bu noktada krizin tehlike ve firsat unsurlarının birleşiminden meydana geldiğini savunan araştırmaların varlığı bilinmektedir (Nihat Gültekin ve Emel Aba, 2011, "Küçük ve Orta Ölçekli Iş̧letmelerde Kriz Yönetimi: Şanlıurfa Örneği”, Girişimcilik ve Kalkınma Dergisi, Cilt: 6, Sayı: 2, Şanlıurfa, s.208.). O halde krizle birlikte karşılaşılması 
muhtemel risklerin yanında bazı fırsatların olduğu, ancak belirtilen firsatların olumlu yansımalarını görebilmek için krizin firsat barındıran yönlerinin doğru analiz edilmesinin gerektiği yorumu yapılabilir.

\subsection{Finansal Krizlerin Özellikleri}

Krizin özelliklerinin bilincinde olunması, herhangi bir risk unsuru ile krizlerin birbirinden ayırt edilebilmesi için gerekmektedir. Krizlere karşı önlem alınmasının ve krize tepki gösterilmesinin zorluğu da bu özelliğe paralel olarak ortaya çıkmıştır. Önceden sezilememesi sebebiyle krizlerin ani değişiklikler meydana getirdiği bilinmektedir ve bu da krizlerin sahip olduğu temel özellikler arasında yer almaktadır. Temel özellikleri kapsayacak şekilde inceleme yapılacak olduğunda krizlerin özellikleri aşağıda sıralandığı gibidir:

- Kriz durumu tahmin edilmekten uzaktır,

- Krizi tahmin etme/önleme mekanizmaları kriz anlarında yetersiz kalmaktadır,

- Örgütün amaçları ve varlıkları, kriz tarafından tehdit edilmektedir,

- İvedi müdahale ihtiyacı vardır,

- Karar verici konumundaki kişi ya da kişilerde gerilime neden olmaktadır,

- Krize müdahale edilebilecek zaman oldukça kısıtlıdır ve

- Kriz, yepyeni ve sıra dışı bir olgudur.

Yukarıda sıralanan özelliklerden de anlaşılacağı üzere krizin çok geniş bir kapsamı bulunmaktadır. Örgütün içerisinde yer aldığı süreçlerin tamamını içerecek şekilde özelliklere sahip olması, krizin özellikleri konusu kapsamında yer verilmesi gereken bir başka husus olarak görünmektedir. Krizlere karşı önlem almak ve krizi doğru şekilde yönetmek için burada sıralanan özelliklerin bilincinde olmak gerekmektedir.

\subsection{Finansal Kriz Türleri}

Finansal ilgili literatür incelendiğinde finansal kriz türlerine ilişkin birçok farklı araştırma yapıldığı ve bunların farklı görünmesiyle, finansal krizleri açıklamaya çalıştığı görülmektedir. Bu araştırmalar ile birlikte ortaya çıkan sınıflandırmalardan bir tanesinde cari hesap krizleri, bilanço krizleri, sirayet krizleri ve irrasyonel spekülasyon olmak üzere dört kriz türünün bir araya gelerek finansal kriz türlerini oluşturduğu sonucu elde edilmiştir.

Finansal kriz türleri; para, borç, sistematik krizler olmak üzere üç başlık altında incelemeye alınabilir. Bu şekilde bir sınıflandırma yapılması halinde sistematik krizler ifadesi dikkat çekmektedir. Çünkü bu krizlerin banka ve para krizlerini de kapsadığı bilinmektedir (Cüneyt Sevim, 2012, Öncü Göstergeler Yaklaşımına Göre Finansal Krizler ve Türkiye Örneği, Bankacılık Düzenleme ve Denetleme Kurumu, Ankara, s.10.). Sistematik finansal krizleri önemli yapanlardan bir tanesi de meydana getirdiği piyasa bozulmaların yüksek düzeyde olmasıdır. Finansal krizin, sahip olduğu etki ölçeği ve etki düzeyi sebebiyle sistematik finansal krizlerin büyük önem sahip olduğu değerlendirmesi yapılabilir.

Finansal kriz türleri özelinde değerlendirme yapılırken, sistemin bütününün göz önünde bulundurulması gerekmektedir. Ancak, bu şekilde finansal kriz türlerinin doğru bir şekilde değerlendirilmesi mümkün olabilecektir. $\mathrm{Bu}$ açıdan değerlendirme yapıldığında finansal kriz türleri şu şekilde sıralanmaktadır:

- Para/döviz krizi,

- Bankacilık krizi,

- Sistematik krizler ve

- D1ş borç krizi şeklindedir.

Yukarıda sıralanan finansal kriz türlerine benzer bir sınıflandırmaya bölüm içerisinde yer verilmiş olup bu sınıflandırmada dış borç krizi de finansal kriz türlerine eklenmiş görünmektedir. Finansal kriz türlerine ilişkin farklı incelemelerin varlığının anlaşılması adına, bu örnek önemli ve açıklayıcı roller üstlenmektedir.

\subsection{Finansal Kriz Göstergeleri}

Finansal krizin göstergeleri, çoğunlukla finansal kriz oluşmadan etkisi gözlenen faktörleri ifade etmektedir. Dolayısıyla krizden krize finansal krizin göstergeleri farklılık gösterebilir. Finansal kriz göstergeleri büyüme oranı, alınan kredi miktarı, borç seviyesi gibi birbirinden farklı değişkenlerden meydana gelebilir. Nasıl ki finansal krizlerin türlerine ilişkin farklı değerlendirme kriterleri bulunmaktaysa, finansal kriz göstergeleri için de birbirinden farklı içeriğe sahip göstergelerden söz edilmesi mümkündür.

Krizlerin oluşum sürecine göre değişmekle birlikte finansal kriz göstergelerinden bazıları öncü gösterge niteliği taşımaktadır. Yani bu göstergeler nispeten önemli göstergeler olarak ele alınabilir. Finansal krizlerin öncü göstergeleri arasında ihracat ve ithalat verileri, hisse senedi fiyatları, reel döviz kuru, cari işlemler açığı ve sermaye girişleri gibi göstergeler yer almaktadır (Mert Ural, 2003, “Finansal Krizler ve Türkiye”, Dokuz Eylül Üniversitesi İktisadi ve İdari Bilimler Fakültesi Dergisi, Cilt: 18, Sayı: 1, İzmir, s.13.). Finansal krizlerin Finansal kriz göstergelerin oluşumunda önemli rol sahibi olmaları sebebiyle öncü göstergeler olarak anılan bu göstergelerin etki düzeyleri, birbirinden farklı olmakla birlikte, her bir finansal kriz için öncü gösterge niteliği taşımadığının bilincinde olmak gerekmektedir. 


\subsection{Finansal Kriz Modelleri}

Finansal krizleri araştıran çok sayıda araştırmanın varlığı, finansal krizleri açıklamaya yönelik olarak ortaya atılan modelleri beraberinde getirmiştir. Her bir finansal kriz modeline yer verilmesi mümkün olmadığ için modelleri sınıflandırma yaparak değerlendirmek uygun görülmüştür. Buna göre finansal kriz modelleri birinci nesil modeller, ikinci nesil modeller ve üçüncü nesil modeller olmak üzere üçe ayrılmaktadır.

Birinci nesil finansal kriz modellerinin ortaya çıkmasında 1970'li ve 1980'li yıllarda meydana gelen krizleri açıklama girişimlerinin önemli rolleri bulunmaktadır. İlgili dönemde Arjantin ve Meksika'da yaşanan krizler özelinde yapılan incelemelerin yoğunluğu görülmekle birlikte dövizdeki istikrarsılıklar ve makro politikalar arasındaki uyumsuzluğun etkileri birinci nesil kriz modellerinde önemli bir yere sahiptir. Finansal kriz modellerinden birinci nesil kriz modellerinin ödemeler dengesini açıklamaya yönelik girişimleri görülmektedir.

Finansal krizlerin ortaya çıktığı dönemde, krizleri açıklamada yeterli olarak görülen birinci nesil finansal kriz modelleri, dünyanın yaşadığı hızlı gelişimle birlikte geçerliliğini yitirmeye başlamıştır. Başka bir deyişle birinci nesil kriz modellerinin krizleri açıklamada yetersiz kalması ile birlikte yeni modellerin ortaya atılması girişimleri söz konusu olmuştur. İkinci ve üçüncü nesil kriz modellerinin varlığının çıkış noktası da burada açıklanan durum olarak görünmektedir. Finansal krizlerin oluşumunda farklı unsurların etkilerinin gözlenmeye başlaması ile finansal krizleri açıklamak adına yeni kriz modelleri ortaya atılmıştır.

İkinci nesil finansal krizlerin ortaya çıkmasının nedeni birinci nesil finansal krizin yeteri kadar finansal krizlerin çözümünde etkin olmadığı ve ilgili mali, idari, siyasi durumlar aynen devam etmesindendir. İkinci finansal kriz modellerinin ortaya çıkması birinci nesil finansal kriz modellerin eksiklerini ortadan kaldırmak içindir. Ancak, birinci finansal kriz modellerinin sorunlarını aynen devam etmesi ikinci finansal kriz modellerinin çıkmasına neden olmuştur (Muhammet Ali Avcı ve Nasuh Oğuzhan Altay, 2013, "Finansal Krizlerin Sinyal Yaklaşımı ile Öngörülmesi: Türkiye, Arjantin, Tayland ve İngiltere İçin Bir Analiz”, Pamukkale Üniversitesi Sosyal Bilimler Enstitüsü Dergisi, Say1: 14, Denizli, s.49.). İkinci finansal kriz modelinin çözümü yeteri kadar etkin olmaması üçüncü nesil finansal krizin çözüm modellerine yönelmiştir.

Yukarıda belirtildiği gibi, ikinci nesil modellerde zayıf makro verilerdeki değişkenler finansal krizi öngörebilmek adına yeterli değildir. Çünkü ikinci nesil modellere göre, bu göstergeler, krizin neden oluştuğuna yeterli düzeyde yanıt verememektedir. Buradan hareketle ikinci nesil finansal kriz modellerine göre, krizlerin neden ortaya çıktığında, finansal krizin kendi kendini besleyen beklentileri, sürü davranışı, bulaşıcı gelişmeler gibi etkileri ile karşılaşılabilmektedir.

Üçüncü nesil finansal kriz modellerinin kapsamı diğer modellere göre daha geniştir. Her iki modelin yetersizliğinin ürünü olması sebebiyle bu durum son derece olağandır. Göstergeler açısından değerlendirilecek olduğunda ise üçüncü nesil krizlerin sermaye piyasasındaki hareketler, mevduat garantileri, bankacılıktaki denetimin yetersiz oluşu, aşırı döviz borcu, faiz farklarının artışı gibi öncü kriz göstergelerini bünyesinde barındırdığı görülebilmektedir.

Örnek olarak, Latin Amerika ve özellikle de Güneydoğu Asya krizinin üçüncü nesil kriz modelleri ile etkileşmiştir. Bu iki kriz özelinde inceleme yapılması ile karşılaşılmaktadır. Yapılan inceleme, üçüncü nesil kriz modellerinin finansal sektör ile bankacılık sektöründeki problemler arasındaki ilişkinin odak noktası olduğunu göstermektedir. Üçüncü nesil modeller şu şekilde özetlenmektedir: "Üçüncü nesil modeller, sermaye giriş ve çıkışlarının serbest olduğu, tam sermaye hareketliliğini içeren bir sektörlü büyüme modeline dayanmaktadır”.

Üçüncü nesil modeller ile değinilmesi gereken hususlardan bir tanesi de krizden etkilenme ile ilgilidir. Üçüncü nesil modellere göre finansal krizlerden yüksek düzeyde etkilenilmesinin sebebi, ekonominin kırılgan olmasıdır. $\mathrm{Bu}$ modele göre birçok farklı kaynağın bir araya gelerek oluşturduğu finansal krizler, yapısal bozulmaları kırılgan ekonomiler üzerinde göstermektedir. Üçüncü nesil finansal kriz modelleri, güneydoğu Asya krizinin yaşandığı ülkeler başta olmak üzere, birçok krizi bu içeriğe göre değerlendirilebilir.

Ahlaki tehlike (Moral Hazard). sorununun olması, üçüncü nesil krizleri diğer krizler modellerinden ayıran unsurlardan bir diğeridir. Ekonomik birimler içerisinde bilginin eşit bir şekilde dağılmaması ve sonrasında bu duruma dayalı olarak ortaya çıkan hatalar, asimetrik bilgi niteliği taşır. Asimetrik bilgilerle birlikte yanlış seçimlerin yapılmasının krizleri tetikleyen bir yapıda olması, üçüncü nesil finansal kriz modellerinin ahlaki tehlike boyutunu işaret etmektedir. Ahlaki tehlike sorunu, finansal piyasada ters seçimleri tetiklemesi sebebiyle üçüncü nesil finansal kriz modelleri içeriğinde oldukça önemli bir yere sahiptir denilebilir.

\subsection{Finansal Krizlerin Sonuçları}

Finansal krizlerin sonuçlarının açıklanmasından önce bu krizlerle birlikte ortaya çıkan etkilerin birbirine bağlı faktörler aracılığıyla ortaya çıktığının bilinmesi gerekir. $\mathrm{Bu}$ da finansal krizlerin sonuçları konusunun incelenmesinde, krizleri ortaya çıkaran faktörlerin etkisini işaret etmektedir. Finansal krizlerin sonuçlarını incelerken bu bilinçte olunması, konu ile ilgili kolaylık sağlayabilecektir. Finansal krizlerin sonuçları, reel sektör özelinde değerlendirilecek olduğunda aşağıda sıralanan sonuçlardan bahsedilebilir. Bunlar; (Nısfet Uzay, 2012, "Finansal Krizin Reel Sektör Üzerindeki Etkileri ve Kriz Sonrası Temel Göstergelerde Değişim: Kayseri Örneği”, Süleyman Demirel Üniversitesi İktisadi ve İdari Bilimler Fakültesi Dergisi, Cilt: 17, Sayı: 2, Isparta, ss.123-124.). 


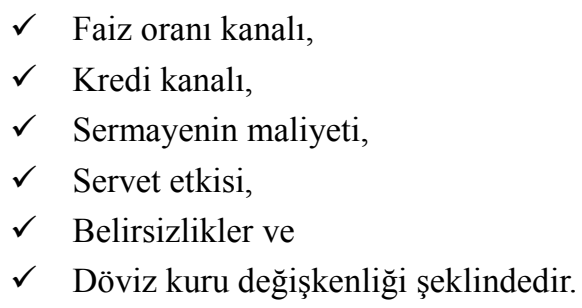

Reel sektör açısından ele alındığında yukarıdaki sonuçları beraberinde getiren finansal krizler, krizin kendisini gösterdiği ölçeğe göre de farklı sonuçlar doğurabilecek bir yapıya sahiptir. Finansal piyasalarda meydana gelen krizin sonuçları arasında; kredi hacminin daralması, faiz oranlarının yükselmesi, emisyon seviyesinin artması, harcama ve talep düzeylerinin düşmesi, üretim ve istihdam oranının azalması, tasarruf ve yatırımların azalması şeklinde sıralanmaktadır. Sıralanan sonuçlar aynı zamanda finansal krizlerin makroekonomik açıdan etkileri olarak da bilinmektedir. Ayrıca finansal krizin sonuçları kapsamında değinilen bu hususların etkisini göstermesinin ekonomik sistemin kırılgan olmasıyla birlikte gerçekleştiği söylenebilir.

Finansal krizlerin sonuçlarının neler olduğu, finansal krizlerin tanımlarında gizlidir. Çünkü finansal krizler tanımlanırken ortaya çıkardığı etkileri işaret eden tanımların varlığı söz konusudur. Bu açıdan değerlendirme yapılacak olduğunda finansal krizlerin sonuçları şu şekildedir: "Finansal kriz; kısa vadeli faiz oranları, varlık fiyatları, ödemelerin bozulması ve iflaslar ile mali kurumların iflası gibi finansal göstergelerin tümünün veya çoğunluğunun ani, keskin ve açık bir biçimde bozulmasıdır" (Fatih Yücel ve Hüseyin Kalyoncu, 2010, "Finansal Krizlerin Öncü Göstergeleri ve Ülke Ekonomilerini Etkileme Kanallart: Türkiye Örneği”, Maliye Dergisi, Say1: 159, Ankara, s.54.). Görüldüğü üzere yapılan bu tanımda finansal krizlerin sonuçları ve etkilerine ilişkin önemli veriler bulunmaktadır.

\section{Finansal Krizlerin Bankaların Sermaye Yapısına Etkisi}

Uluslararası sermaye hareketleri, finansal krizler ve bankacılık sektörü etkileşimi kapsamında bilinmesi gerekenlerin başında, olumsuz etkilerin önüne geçilmesi adına bir takım düzenlemeler yapılması gerektiğidir. Bu düzenlemelerin odak noktası yabancı sermaye bağımlılı̆̆ının azaltılması şeklindedir. Yabancı sermayeye olan bağımlılığın azalması ve daha etkin bir şekilde kullanılmaya başlaması için finansal reformlar yapmak gerekebilir. Dolayısıyla bankacılık sektörünün sermaye yapısının olumsuz etkilerden korunması için bir takım mali reformlara ihtiyaç duyulduğu -sermaye yapısı çok güçlü olmayan ülkeler için çıkarımı yapılabilir.

Günümüzde uluslararası sermaye piyasalarına erişimin kolay olması, bankacılık sektöründe dışa bağımlılığı artırmaktadır. Bu duruma paralel olarak finansal krizlerin yaşanması ile birlikte bankacılık sektörünün sermaye yapısının etkilenme düzeyi yüksek düzeyde olmaktadır. Belirtilen sonucun ortaya çıkmasında bankacılık sektörünün dış yükümlüğünün belirleyici rolleri olduğu bilinmektedir. Ayrıca ekonomik kırılganlık açısından uluslararası sermaye hareketleri ve finansal kriz etkileşiminin bankacılık sektöründe kendisini göstermesi söz konusu olacaktır.

Finansal krizler, bankacılık sektörü üzerinde etkisini gösterirken daraltıcı etkiler ortaya çıkmaktadır (Okşan Kibritçi Artar ve Ayşe Atılgan Sarıdoğan, 2012, “Küresel Finansal Krizin Türkiye’de Bankacılık Sektörü Mali Yapısına Etkileri”, Marmara Sosyal Araştırmalar Dergisi, Sayı: 2, İstanbul, s.4.). Yani finansal bir kriz bankacılık sektörünün sermaye yapısında daraltıcı sonuçlara neden olmaktadır. Ekonomik sistemin sekteye uğramasına neden olan bu husus, sektörel göstergelerin olumsuz yönde seyretmesine neden olacaktır. Ülkelerin bankacılık sektörlerinin ne kadar güçlü bir yapıda olduğu, bankacılık sektörünün sermayesinin ne oranda daralacağı hususunda etkili olacaktır.

Bankacılık sektörünün sermaye yapısı krizden etkilenirken birçok faktörün etkisinde olsa da bu faktörler sınıflandırma yapılmak suretiyle değerlendirmeye alınabilir. Bu şekilde bir yöntem belirlenmesi halinde bankacılık sektörünün sermaye yapısı üzerindeki etkiler aşağıdaki şekilde sıralanmaktadır:

$\checkmark$ Banka şubesi ve personel sayılarının değişimi şeklinde ortaya çıkan etkiler,

$\checkmark$ Aktif/Pasiflerin yapısındaki gözlenen değişmelerin etkileri,

$\checkmark$ Aracılık işlemleri ve bu işlemlerin etkileri,

$\checkmark \quad$ Karlılık üzerine olan etkiler,

$\checkmark$ Özkaynaklar ve mevduatlar gibi konulara yönelik etkiler şeklinde sıralanmaktadır.

Görüldüğü üzere finansal krizlerin bankacılık sektörü üzerindeki etkileri, farklı içerikte konularda meydana gelebilmektedir. Tüm bunlar, finansal krizlerin bankacılık sektörünün sermaye yapısına olan etkilerinin anlaşılması katkıda bulunacak nitelikte ve düzeyde faktörler olarak görünmektedir.

Finansal krizin bankacılık krizi niteliği taşıması ile birlikte bankacılık krizinin sermaye yapısının değişim yaşaması kaçınılmazdır. Ayrıca sermaye yapılarından yaşanan değişimler, reel ekonomiye zarar verecek nitelikte olabilir. Çünkü bankacılık krizlerinin ekonomiye zarar verme düzeyi daha yüksek olacaktır. Bu noktada finansal 
krizin yaşanması sonrasında bankacılık sektörünün sermaye yapısında ani ve beklenmedik değişiklikler yaşanabilir. Belirtilen değişiklikler büyük oranda sermaye daralması olarak ortaya çıkmaktadır.

Uluslararası sermaye hareketlerinin hızlanması, finansal krizlerin bankacılık sektöründeki sermaye yapısına olan etkisini artırmış̧ır. Finansal açıdan istikrarsızlıkların yaşanmasında, uluslararası finans sermayesinin etkilidir (Ekrem Erdem, M. Fatih İlgün ve Cüneyt Dumrul, 2011, "Finansal İstikrarın Bankacllık Sisteminin Borç Verme Politikaları Üzerindeki Etkisi: 2008 Küresel Krizi Çerçevesinde Türkiye Üzerine Bir İnceleme”, Bankacılık ve Finansal Piyasalar Dergisi, Cilt: 5, Sayı: 1, Ankara, s.11.). Sermaye hareketleri ve finansal istikrarsızlık üzerine olan etkilerinin bir sonucu olarak ulusal para birimlerinin önemli ölçüde değer kaybetmesine yol açması ve döviz kurlarının aşırı miktarda dalgalanmasına neden olmaları, bankacılık sektöründe istikrarın yakalanmasının önüne geçen bir süreç niteliği taşımaktadır.

Bankacılık sektöründe sermaye yapısının finansal krizlerden etkilenmesi, kaçınılmazdır. Bu durum özellikle küresel finansal krizle birlikte ortaya çıkan sonuçlar aracılığıyla görülmüş̧ür. Bu kısımdaki inceleme ile birlikte bankacılık sektörünün sermaye yapısının daralması, finansal krizle birlikte ortaya çıkan sonuçlar arasından en çok karşılaşılanı olarak ortaya çıkarılmışıır.

\subsection{Finansal Krizlerin Bankaların Kredi Yapısına Etkisi}

Finansal krizlerin ortaya çıkması ile birlikte birçok sektörde olduğu gibi bankacılık sektöründe de daralmalar meydana gelmektedir. Nitekim finansal krizlerin ortaya çıkması ile birlikte bankacılık sektörü üzerinde temel etkinin kredilerin daralması şeklinde kendisini göstermesi söz konusu olmaktadır. Ekonomi için büyük öneme sahip ekonomik göstergelere sahip olan bankacılık sektöründe, kredilerde daralmaların meydana gelmesi, beraberinde başka etkileri de getirebilir ve bu husus kredi yapısı ile finansal krizi ilişkisi kapsamında son derece önemlidir.

Yaşanan finansal krizler, ekonomik faaliyetlerin durgunlaşmasına yol açabilmektedir. Bu da kredilerin geri ödenmesinde sorunlar yaşanması anlamına gelmektedir. Kredilerin geri ödenmesinde yaşanan sorunlar da bankaların kredi hacimlerinin daralmasına neden olabilir (Ziya Tunç Aloğlu, 2005, Bankacilık Sektörünün Karşılaşıı̆ı Riskler ve Bankacılık Krizleri Üzerindeki Etkileri, Türkiye Cumhuriyet Merkez Bankası Bankacılık ve Finansal Kuruluşlar Genel Müdürlüğü, Uzmanlık Yeterlilik Tezi, Ankara, s.130.). Dolayısıyla finansal krizlerin bankaların ekonomik faaliyetlerini sekteye uğrattığı ve bu sayede bankaların kredi hacmini önemli ölçüde daralttığı anlaşılmıştır. Yani finansal kriz yaşanması, bankalara büyük zararlar verebilecek potansiyele sahip gelişmeleri beraberinde getirmektedir.

Bankacılık sektöründe doğru yapılandırmalarla birlikte finansal krizlerin direkt olarak bankalara ve bankaların kredi yapısına tesir etmesinin önüne geçilebilir. Ancak küreselleşen dünyada bu önlemler sektörün etkilenmesini sadece geciktirebilir. Çünkü tüm sektörlerde yaşanan gelişmelerin birbirlerini etkilemesi, bankacılık sektörünün de etkilenmesini kaçınılmaz kılmaktadır. Küresel düzeyde kredi musluklarının kısılması ve kredi maliyetlerinin artması suretiyle bankacılık sektörü güçlü olsa dahi bankaların kredi yapılarının etkilenmesi söz konusu olabilir. $\mathrm{Bu}$ da yurt içi ve yurt dışı pazarlarda yaşanan daralmaların sonucudur. Verilen örnekten de anlaşılacağı üzere bankaların kredi yapılarının krizden etkilenmesi adına krizin doğrudan bankacılık sektörünü etkilemesi şartı aranmamaktadir.

Çalışmada incelenen krizler arasında en önemlisi olarak görünen küresel finansal kriz özelinde bankaların kredi yapısına olan etkiler incelenecek olduğunda kayda değer düzeyde etkilerin varlığı ile karşılaşılacaktır. Küresel finansal krizle birlikte bankacılık sektörü kredi kalitesinin aşağı yönde seyrettiği görülmektedir. Yine aynı dönemde bankacılık sektöründeki sorunlu kredilerin artması söz konusu olmuştur. Son yıllarda karşılaşılan en büyük krizin bankacılıktaki kredi yapısına etkileri yorumlamak adına bu veriler önemlidir.

Bankacılık krizleri, gelişmiş ve gelişmekte olan ekonomileri ayırt etmeksizin ortaya çıkabilir. Bu da oluşan krizlerin bankacılık sektörüne yansımalarını doğru bir şekilde analiz etmeyi gerektirmektedir. Yaşanan finansal krizler ve sonuçlarının çalışmamızla ilgili sonuçları şu şekilde özetlenmektedir: "Bankacılık sistemine duyulan güven eksikliği ve zayıf bankacılık sisteminin varlı̆̆ı, bankaların zamanla başarısız olmasına neden olurken, sermayesi zayıf olan bankalara da fonlarını genişletme firsatı vermemektedir. Sonuçta bankacılık kredilerinde azalma kaçınılmaz olmakta; banka kredilerindeki daralma ise, diğer kesimlerin sermayelerini küçülterek, firmalar ve hane halklarının yatırım ve tüketimlerini azaltmaktadır". Görüldüğü üzere finansal krizlerden bankacılık krizlerinin yaşanması ile birlikte kredi yapısı başta olmak üzere bankacılık sektörünün tamamen etkilenmesi söz konusu olmaktadır. Finansal krizler ve bankacılık sektörüne olan etkilerin anlaşılması adına, çalışmanın bu kısmında yer verilen ifadeler açıklayıcı roller üstlenmektedir.

\subsection{Bankaların Uluslararası Finansal Krizlerden Korunması ve Alınması Gereken Tedbirler}

Her ne kadar krizleri öngörmedeki güçlük nedeniyle krizlere karşı sağlıklı sonuçlar verecek önlemler almak güç olsa da bankacılık sektöründe yapılacak bazı düzenlemelerle birlikte krizlerin olası etkilerini en aza indirgemek mümkün olabilecektir. Nitekim var olan risklere karşın bankacılıkta risk kavramının önemi giderek artmış olup bankalar riskten kaçınmak için risk yönetim teknikleri ve politikaları geliştirip uygulamaya koymaya başlamışlardır. Şirketlerin ve bankaların yüksek miktarda yabancı para borçlarının olması, gelinen noktada en önemli riskler arasında yer almaktadır.(Tepav, Türkiye Ekonomisi İçin Kriz Önlemleri, (29.03.2016)). Bu nedenle 
finansal krizlerden korunabilmek adına yapılması gerekenlerin başında yabancı para borçlarının kontrol altında tutulması gelmektedir. Aksi takdirde meydana gelecek olası kriz senaryosunda bankacılık sektörünün büyük kayıplar yaşaması muhtemeldir. Dolayısıyla uluslararası finansal krizlerden korunmak isteyen bankaların öncelikle yabancı para borçlarını kontrol etmeleri beklenmektedir.

Günümüz küresel dünyasının koşulları göz önüne alındığında bankaların uluslararası finansal krizlerden kendilerini tam anlamıyla korumalarının mümkün olmadığı söylenebilir. Ancak alınacak olan önlemlerle birlikte sağlam bir sektöre yapı oluşturularak bankacılık sektörünün yaşadığı krizlerden minimum seviyede etkilenmesi sağlanabilir. Küresel düzeyde gerçekleşen krizlerden sektörün korunması hiç de kolay değildir. Ancak yineleneceği üzere alınacak önlemlerle birlikte sektörün göreceği zararın azaltılması mümkün olacaktır. Ayrıca gelecekte yaşanacak olan krizlere karşı da hazırlıklı olunmasını firsat sağlanacaktır. Bu nedenle bankacılık sektöründe finansal krizlerle mücadele edilmesi, korunması ve alınacak olan tedbirler konusunun önemi, son derece büyüktür.

İstikrar, finansal piyasalar için en önemli kavramlardan bir tanesi olarak görünmektedir. Çalışmanın bu kısmına kadar verilen bilgiler de bu ifadeyi destekler nitelikte görünmektedir. Uluslararası krizlerle mücadele edilmesinde bankaların alabileceği önlemlerin bir anlam ifade edebilmesi için istikrarın varlığının şart olduğu göz ardı edilmemelidir. Aksi takdirde ne kadar politika geliştirilip ne kadar önlem alınırsa alınsın, bankaların kendilerini uluslararası finansal krizlerden korumalarını beklemek gerçekçi olmayacaktır.

\section{Sonuç}

Uluslararası sermaye hareketlerinin finansal krizler ve bankalara etkilerini belirlemek amacıyla küreselleşen dünyada uluslararası sermaye hareketlerinin finansal krizler ve bankalara etkilerinin kaçınılmaz olduğu sonucunu ortaya koymuştur. Sermaye hareketlerinin döviz arz-talebi, marjinal kar oranının düşmesi, dışa açık politika, özelleştirme uygulamaları gibi pek çok farklı sebebi olduğu gelmektedir. Uluslararası sermaye hareketlerinin ortaya çıkaracağı etkiler de aynı şekilde oldukça geniş kapsamlıdır. Uluslararası sermaye hareketlerinin ekonomik istikrar üzerine etkileri, bunların başında yer almaktadır. Finansal krizler; para krizi, bankacılık krizi, dış borç krizi ve sistematik kriz gibi krizlerden oluşmaktadır. Bu krizlerin her birisinin farklı göstergeleri bulunmaktadır. Yapılan inceleme sonrasında ulaşılan sonuçlar; faiz oranın artış, hisse senedi fiyatının düşmesi, belirsizliklerin artması, banka paniği, fiyatların artması gibi kriz göstergelerinin varlığını ortaya koymuştur. Ayrıca cari açık, enflasyon, döviz kuru, işsizlik oranı ve borç düzeyi gibi temel makroekonomik hususların finansal krizlerin göstergeleri arasında yer aldığı sonucuna varılmıştır.

Bankaların uluslararası finansal krizlerden korunmak için alabileceği tedbirler özelinde değerlendirme yapılmış ve bankaların krizlerden tamamen korunmalarının mümkün olmadığı sonucu elde edilmiştir. Bankacılık sektörünün finansal istikrar açısından sahip olduğu roller nedeniyle krizlere karşı bankaların alacağı önlemler, son derece önemli bir yere sahiptir. Bu nedenle bankaların finansal krizlere karşı önlem alırken en düşük düzeyde etkilenecek şekilde uygulamalara yönelmesi gerektiği anlaşılmıştır. Uluslararası sermaye hareketleri, finansal krizler ve bankacılık sektörü arasında karşılıklı etkileşimi ortaya çıkaran birçok farklı unsurun varlığını göstermiştir. Yine bu çalışmayla finansal krizlerin sonuçları ve krizlere karşı alınabilecek önlemler gibi önemli konularda açıklayıcı verilere ulaşıldığı düşünülmektedir ve tüm bunlar çalışmanın önemini meydana getirmektedir.

\section{Kaynakça}

- Apak, Sudi ve Demirel, Engin. 2009, ‘'Finansal Yönetim”, İstanbul: Papatya Yayıncılık,

- Aslan, Nurdan. 1997 'UUluslararası Özel Sermaye Akımları: Portföy Yatırımları ve Sıcak Para Hareketleri”, Türkmen Kitapevi, İstanbul,

- Avcı Muhammet Ali ve Altay Nasuh Oğuzhan. 2013, "Finansal Krizlerin Sinyal Yaklaşımı ile Öngörülmesi: Türkiye, Arjantin, Tayland ve İngiltere İçin Bir Analiz”, Pamukkale Üniversitesi Sosyal Bilimler Enstitüsü Dergisi, Say1: 14, 47-58.

- Aydoğuş, İsmail. 1989, “Anadolu Üniversitesi Afyon İ.İ.B.F. 15. Kuruluş Yılı Armağanı”, Türkiye’de 24 Ocak 1980 Sonrası Yabancı Sermaye Yatırımları ve Gelişimi, Eskişehir, 229-243.

- Bakkalcı, A. Can ve Argın, Nilüfer. 2013, "Yabancı Yatırımların İşgücü Piyasalarını Uyarma Süreci Kapsamında Dış Ticaretin İçselleştirilmesi”, Çalışma İlişkileri Dergisi, Cilt: 4, Sayı: 1, 71-97.

- Gültekin, Nihat ve Aba, Emel. 2011, “Küçük ve Orta Ölçekli İşletmelerde Kriz Yönetimi: Şanlıurfa Örneği””, Girişimcilik ve Kalkınma Dergisi, Cilt: 6, Sayı: 2, 205-226.

- Kula, Ferit. 2003, “Uluslararası Sermaye Hareketlerinin Etkinliği: Türkiye Üzerine Gözlemler”, Cumhuriyet Üniversitesi İktisadi ve İdari Bilimler Fakültesi Dergisi, Cilt: 4, Sayı: 2, 141-154.

- Oktar, Suat ve Dalyancı, Levent. 2010, "Finansal Kriz Teorileri ve Türkiye Ekonominde 1990 Sonras1 Finansal Krizler”, Marmara Üniversitesi İktisadi ve İdari Bilimler Fakültesi Dergisi, Cilt: 29, Sayı: 2, 122. 
- Sayılı Murat ve Uyanık Mehmet. 2012, “Küresel Ekonomik Kriz ve Etkileri: Tokat İli Merkez İlçe Glda Sanayi Örneği”, Çankırı Karatekin Üniversitesi Sosyal Bilimler Enstitüsü Dergisi, Cilt: 3, Sayı: 2, 239249.

- Ural Mert. 2003, “Finansal Krizler ve Türkiye”, Dokuz Eylül Üniversitesi İktisadi ve İdari Bilimler Fakültesi Dergisi, Cilt: 18, Sayı: 1, 11-28.

- Vergil, Hasan ve Karaca, Coşkun, 2010, “Gelişmekte Olan Ülkelere Yönelik Uluslararası Sermaye Hareketlerinin Ekonomik Büyüme Üzerindeki Etkisi: Panel Veri Analizi”, Ege Akademik Bakış Dergisi, Cilt: 10, Sayı: 4, 1207-1216. 


\title{
Finansal Varlık Olarak Altının Arz-Talep Dengesinin Kısa ve Uzun Dönem Kantitatif Analizi ve Altın Fiyat Fonksiyonunun Ampirik Olarak Test Edilmesi
}

\section{The Short and Long Term Quantitative Analysis of Supply- Demand Equilibrium of Gold as a Financial Asset and Empirical Testing of Gold Price Function}

\author{
Prof. Dr. Sudi Apak (Esenyurt University, Turkey) \\ Asst. Prof. Dr. Ali Osman Serdar Citak (Medipol University, Turkey)
}

\begin{abstract}
In order to analyze gold as a financial asset requires evaluation both technical features of precious metals and financial markets in the analytical framework. The aim of this study is to analyze the demand and supply functions of gold under the market conditions which are dominated by bullion banks and central bank in both short and long terms. Finally, as first step the mathematical infrastructure of gold price function analyzed and as second step gold price function has been estimated by using econometrical methods. In this study, the one period lagged data of gold price in US dollar and return of US treasury bonds have used for estimating of the model and reached statistically significant results.
\end{abstract}

\section{Giriş}

Dünya altın talebinin coğrafi dağılımında, geleneksel olarak Asya ve Ortadoğu ülkelerinde bir yoğunlaşmanın olduğu görülmektedir. Hindistan ve Pakistan'ın yıllık altın talebi, toplam dünya talebinin beşte birine ulaşmakta, diğer bir beşte bir talep miktarı ise Ortadoğu ülkeleri ve ülkemizden gelmektedir. Altının, yüksek likiditeye sahip bir değer biriktirme aracı olması, finansal piyasaların gelişmemiş olduğu ekonomilerde güven boşluğunu doldurması ve kültürel faktörlerin de etkisiyle yoğun olarak az gelişmiş ve gelişmekte olan ülkelerde talep edildiği gözlenmektedir (Starr ve Tran, 2007).

Altın talebi, kategorik olarak iki bölüme ayrılabilir. İlk kategori kullanım yani tüketim talebi olup, altından mamul veya içeriğinde altın kullanılarak üretilmiş her türlü mal veya emtianın tüketilmesine yönelik taleptir. İkinci talep türü ise, altının bir finansal araç olarak talep edilmesi ve bir yatırım sürecinde değerlendirilmesidir. Bu talep, öncelikle yatırım amaçlı olmak üzere, fon yöneticilerinden, merkez bankalarından, altın bankalarından ve altını finansal varlık olarak değerlendiren hane halkından gelmektedir. Altına yönelik finansal talep, altının geleneksel olarak enflasyona karşı bir koruma aracı şeklinde algılanmasının yarattığı bir talep türüdür (Ghosh, vd, 2004).

Altın arzı, temelde iki kaynaktan beslenmektedir. Herhangi bir zaman noktasında altının fiziki arzı, ilgili dönemde madenlerden üretilen fiziki altın miktarı ile ağırlıklı olarak merkez bankaları ve kısmen de diğer bankalar tarafından piyasaya ödünç olarak verilen altın miktarının toplamından oluşmaktadır.

Dünyadaki toplam global yatırım portföyünün yarısının hisse senetlerinden, yaklaşık \%40’ının sabit getirili menkul kıymetlerden ve \%10 civarında da fiziki ve finansal varlık formunda altından oluştuğu tahmin edilmektedir (Harvey,2013). Ancak, bireysel yatırım portföylerine bakıldığında altının payının, global portföy oranı olan yüzde ondan düzeyinden çok daha düşük düzeyde olduğu görülmektedir. Bu bağlamda altının finansal varlık olarak, portföy çeşitlendirmesinde yeteri kadar etkin bir rol oynayamadığı ileri sürülebilir.

Son yıllarda borsalarda işlem gören altın yatırım fonlarının gelişmesi, bireysel yatırımcılar açısından da altını yatırım yapılabilir bir finansal varlık haline getirmiştir. Özellikle iktisadi gelişmenin hızlı bir ivme gösterdiği Çin, Hindistan ve bazı Güney Doğu Asya ülkelerinde kişi başına düşen milli gelirin artışı ile finansal varlık olarak altına olan yatırımlar da artış göstermiştir (Sazonov ve Nikolaev, 2013).

\section{Kısa Dönemde Altın Arz ve Talebinin Analizi}

Kısa dönemde toplam altın arzı, madenden üretilen altın ile merkez bankaları ve altın bankacılığı faaliyetinde bulunan finansal kurumlar tarafından altın sektörüne ve endüstriye ödünç olarak verilen altının toplamından oluşmaktadır (Ghosh, vd, 2004).

Merkez bankaları ile altın kiralama işlemi yapan altın bankaları (bullion bank), altın külçeleri satarlar ve bu fonlarla tahvil alıp, dönem sonunda söz konusu tahvillerden faiz geliri elde ederler. Diğer yandan da pozisyonlarını risklere karşı korumak için (hedge), altın pozisyonları karşılığında forward sözleşme satın alıp, borcun vadesi geldiğinde altın fiyatını dönem başındaki fiyata sabitleyebilir. 
Merkez bankaları, altın bankaları ve altın üreticileri arasındaki bu işlemler aşağıdaki eşitliğin oluştuğu döneme kadar devam edebilir.

$$
P_{t}\left(1+i_{t}\right)=P_{t}\left(1+R_{g t}\right)\left(1+\pi_{g t}\right)
$$

$i_{t}$ : Bononun $\mathrm{t}$ dönemindeki faiz oranı

$\pi_{g t}:$ Altın fiyatlarındaki beklenen artış

$R_{g t}:$ Altının fiziki faiz oranı

Kısa dönemde, herhangi bir t anında altın arzının bileşenleri, aşağıdaki gibi formüle edilebilir.

$$
S_{t}=S_{p}+S_{c b}
$$

$S_{\mathrm{t}}:$ Toplam arz

$S_{p}:$ Madenden üretilen altın

$S_{c b}:$ Altın sektörüne ve endüstriye ödünç verilen altın

Altın sektörüne ve endüstriye, merkez bankaları ve altın bankacılığı faaliyetinde bulunan finansal kurumlar tarafından ödünç verilen altın, bir dönem sonra altının fiziki faiz oranı kadar artırılarak borç verene ödenecektir. Böylece dönem sonunda sektöre borç verilecek altın stokunda bir artış gerçekleşecektir. Dolayısı ile dönem sonunda geri ödenecek altın miktarı, bir dönem önceki ödünç altın miktarı ile altının fiziki faiz oranının doğrusal bir fonksiyonu olarak aşağıdaki ifade ile tanımlanabilir.

$$
S_{t}^{*}=\left(1+r_{t-1}\right) S_{c b-1}
$$

$\mathrm{S}_{\mathrm{t}}^{*}$ : Dönem sonunda geri ödenen altın miktarı

$\mathrm{r}_{\mathrm{t}-1}$ :Altının fiziki faiz oranının bir dönem önceki değeri

$\mathrm{S}_{\mathrm{cb}-1}$ :Altın sektörüne ve endüstriye ödünç verilen altının bir dönem önceki değeri

Kısa dönemde madenden üretilen altın arzının fonksiyonu, altın fiyatı, altının fiziki faiz oranı ve bir dönem önce madenden çıkarılan ve piyasaya külçe olarak sunulan altının miktarının bir fonksiyonudur.

$$
\begin{aligned}
& S_{t}=f\left(P_{g}, S_{c b-1}, r_{t}\right) \\
& \partial S_{t} / \partial P_{g}>0 \\
& \partial S_{t} / \partial R_{t}>0 \\
& \partial S_{t} / \partial S_{c b-1}<0
\end{aligned}
$$

Altının arzı, altın fiyatı ve altının fiziki faiz oranı ile doğru, bir dönem önceki ödünç miktarı ile ters orantı ilişkisi içindedir.

Altının toplam talebi, fiziki formda ve kullanım amaçlı külçe altın talebi ile finansal varlık olarak altın talebinin toplamından oluşmaktadır.

$$
\begin{aligned}
& D_{g}=D_{u t}+D_{a t} \\
& D_{g}: \text { Toplam altın talebi } \\
& D_{u t}: \text { Altın kullanım talebi } \\
& D_{a t}: \text { Altının finansal varlık olarak talebi }
\end{aligned}
$$

Altının kullanım talebi, altından mamul mal ve hizmetlere yönelik tüketim talebidir. Tüketim talebi altın fiyatları arttıkça azalan bir seyir izlemektedir. Fiyatlarda sert düşmelerin olması halinde talep kısa dönemli olarak bir duraksama göstermekte, ardından ise hızlı bir yükseliş trendine girmektedir. Dolayısı ile altının tüketim talebi ile fiyatı arasındaki ilişkinin ters orantılı bir fonksiyonel bağıntı olduğu görülmektedir.

$$
\begin{aligned}
& D_{u t}=f\left(P_{t}\right) \\
& \partial D_{u t} / \partial P_{t}<0
\end{aligned}
$$

Altına finansal varlık olarak talep, altın $\beta \operatorname{sının(sistematik~riskinin)~negatif~değer~alacağının~beklenmesinden~}$ dolayıdır. Dolayısıyla altının, negatif değerli $\beta$ katsayısı ile menkul kıymetlerden oluşan bir portföyde çeşitlendirme etkisiyle riskin azaltılmasına katkıda bulunacağı beklenmektedir.

Teorik anlamda, altının cari dönem talebinin, $\beta$ nın cari dönem değeri ile ters orantılı, $\beta$ nın bir dönem gecikmeli değeri ile doğru orantılı olarak gerçekleşmesi beklenir. Diğer yandan fiyat modeli içinde getiri (R) parametresinin yer alması ve tahmin modelinde katsayısının negatif işaretli çıkması, beta parametresinin test edilmesi açısından olumlu bir ön işaret olarak yorumlanabilir (Ghosh, vd, 2004). 
Finansal aktif değer olarak altına olan talep fonksiyonun kapalı formu;

$D_{a t}=D_{a}\left(R_{t}, \beta_{g^{t}}, \beta_{g^{t}-1}\right)$

$\partial D_{a t} / \partial R_{t}<0$

$\partial D_{a t} / \partial \beta_{g t-1}>0$

$\partial D_{a t} / \partial \beta_{g t}<0$

Altın talep fonksiyonunun kısa dönem tahmin modeli;

$D_{a t s}=\alpha_{t}+\gamma_{1} R_{t}+\gamma_{2} \beta_{g t}+\gamma_{3} \beta_{g t-1}+u_{t}$

\section{Uzun Dönem Altın Arz ve Talebinin Analizi}

Uzun dönemde, altın üreticileri karlarını maksimize etmeyi amaçlayacakları için, piyasa koşulları üretim ve kiralama sürecinin marjinal maliyetleri birbirine eşitleninceye kadar çalışacaktır. Uzun dönemde, rekabetçi piyasa koşulları altında altın üretiminin marjinal maliyeti altın fiyatına eşit olmak durumundadır.

$$
\begin{aligned}
& P_{t+1}=M C_{g t}\left(1+\pi_{t}\right) \\
& P_{t+1}=P_{t}\left(1+\pi_{t}\right) \\
& M C_{g t+1}=M C_{g t}\left(1+\pi_{t}\right)
\end{aligned}
$$

$\mathrm{MC}_{\mathrm{g}}$ : Altın üretiminin marjinal maliyeti

Yukarıdaki ifade altın fiyatının enflasyon oranı kadar artacağının beklendiğini göstermektedir.

Rekabetçi piyasa koşulları içinde uzun dönemde altınla ilgili üretim ve kiralama süreçlerinin marjinal maliyetleri ile altın fiyatları birbirine eşitleneceğinden aşağıdaki bağıntıya ulaşılacaktır.

$$
\begin{aligned}
& M C_{a}=M C_{b} \\
& P_{t}=M C_{a t}+M C_{b t}
\end{aligned}
$$

Altın üreticisi için bir ons altını $t$ anında merkez bankası veya altın bankalarından borçlanarak elde etmenin marjinal maliyeti, bir ons altını madenden çıkarmanın bugünkü değeri ile altın cinsinden fiziki faiz tutarının toplamına eşittir.

$$
M C_{b t}=\frac{M C_{a t}\left(1+R_{g t}\right)\left(1+\pi_{s t}\right)}{\left(1+R_{t}\right)\left(1+\pi_{t}\right)}
$$

$\pi_{\epsilon}:$ Altının madenden çıkarım maliyetlerindeki artış oranı

$\pi_{\mathrm{t}}$ : Enflasyon oran 1

$\mathrm{R}_{\mathrm{t}}$ : Reel faiz oranı

$\mathrm{R}_{\mathrm{g}}$ : Altının fiziki faiz oranı

Altın üretimindeki maliyet artışı enflasyon oranı kadar olduğu takdirde aşağıdaki fonksiyonel ilişki geçerli olmaktadır.

$$
M C_{a t+1}=M C_{a t}\left(1+\pi_{\varepsilon t}\right)
$$

Uzun dönem analizinde altın üretim maliyetindeki artış enflasyon oranına eşit olacağından;

$$
\pi_{\varepsilon}=\pi
$$

Altın fiyatı da üretimin marjinal maliyetine eşit olacaktır.

$$
P=M C_{a}
$$

Altın fiyatının, üretimin marjinal maliyetinin daha aşağısına düşmesi halinde madenden altın üretim faaliyeti imkansız hale gelecektir. Nitekim özellikle 1999 ve 2000 yıllarında altın fiyatlarının ons başına 200 ABD doları civarında seyretmesi birçok madenin marjinal üretim maliyetini karşılayamaması sonucunu doğurmuş ve madenler kapanma tehlikesi ile karşı karşıya kalmışlardır.

Altının uzun dönem toplam talep fonksiyonu; modelin parametreleri olan, fiyat, reel faiz oranı ve finansal aktif varlık olarak altının beta katsayısı ve bir dönem gecikmeli değeri dikkate alınarak aşağıdaki kapalı fonksiyonel formda ifade edilebilir.

$$
D_{g t}=D_{g}\left(P_{t}, R_{t}, \beta_{g t}, \beta_{g t-1}\right)
$$




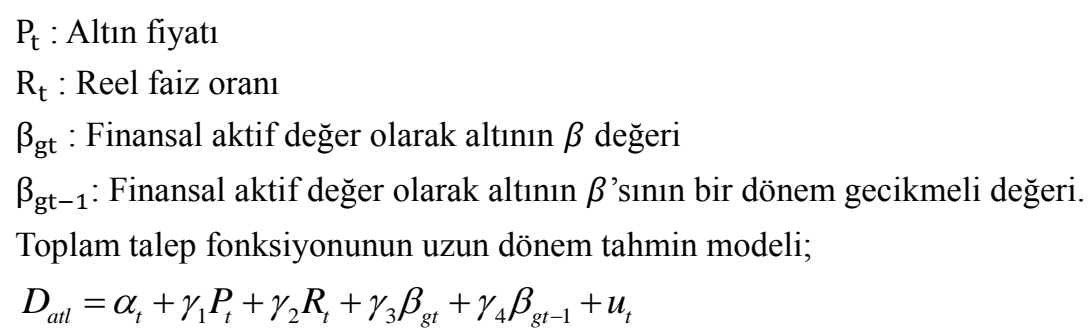

Altının fiyatı, uluslararası ölçekte belirlendiğinden, pozitif eğimli bir talep eğrisinin olması durumunda altın fiyatının artmasına paralel olarak yatırımcının finansal varlık olarak altın talebi de artmaktadır (Sazonov ve Nikolaev, 2013).

\section{Literatür}

Fiyat tahmini, finansal varlıklara ilişkin karar alma sürecinin ayrılmaz bir parçasıdır. Finansal varlık olarak altın fiyatlarındaki değişimi açıklayan modellerin öncü çalışmalarında, altın fiyatlarının makroekonomik değişkenlere ve siyasi gelişmelere duyarlı olduğu şeklinde tezler ileri sürülmüştür. Bu çalışmalarda, makroekonomik değişkenler olarak, döviz kurları, faiz oranı, dünya gayri safi hasılası ve politik riskler dikkate alınmıştır (Abken, 1979 ). Diğer yaklaşımlarda ise, altın fiyatlarını spekülasyon ile açıklamaya çalışmış ve altın fiyatlarındaki değişimin rasyonalitesi üzerine yoğunlaşmıştır (Koutsoyiannis, 1983).

Chappell ve Dowd (1997) çalışmasında, altını enflasyona karşı koruma amacı ile talep edilen bir finansal varlık olarak değerlendirip, altın fiyatlarını, fiyatlar genel seviyesi ile ilişkilendirmiştir. Altının satın alma gücünün korunması yani enflasyona karşı mali tasarrufların korunması, bir ülke içinde endojen satın alma gücünün (domestic purchasing power) yani dolar cinsinden yurt içi satın alma gücünün ve de egzojen satın alma gücünün (external purchasing power) yurt dışı döviz kurları cinsinden tanımlanmış satın alma gücünü koruyup korumadığı Capie, Mills ve Wood'un (2005), çalışmasında test edilmiş ve altının daha çok yurt dışı satın alma gücünü koruduğu tespit edilmiştir.

Chan ve Mountain (1988), zaman serisi verileri kullanarak yaptıkları analizde; altın ile diğer kıymetli madenler fiyatları arasında nedensellik testi yapmışlar, sadece altın ve gümüş fiyatları arasında nedensellik ilişkisine ulaşmışlardır.

Haugom (1991), çalışmasında, altın talebinin gelişmiş ülkelerde, geçmiş dönemlerin talebi ile pozitif, fiyat hareketleri ile ise negatif korelasyon içinde olduğunu göstermiştir. Gelişmekte olan ülkelerde ise talebin, daha çok uluslararası ekonomik ve siyasi gelişmelerden etkilendiği sonucuna ulaşmıştır.

Sjaastad ve Scacciavillani (1996), altın fiyatları ile döviz kurları arasındaki ilişkiyi 1982-90 dönemi için araştırmışlardır. Bu çalışmanın en temel bulgusu Bretton Woods sisteminin ortadan kalkması ile önemli paralar arasındaki kurların dalgalanmasının altın fiyatlarındaki en önemli istikrarsızlık nedeni olduğunun tespitidir.

Taylor (1998) çalışmasında; 1914-1937 ile 1968-1996 yılları arası verileri kullanmış ve kıymetli maden fiyatları ile enflasyon arasındaki ilişkiyi araştırmıştır. Çalışmanın temel bulgusu kıymetli madenlerin 1939 öncesi dönem ile OPEC petrol krizinin yaşandığı 1979 döneminde kısa ve uzun dönemli olarak enflasyona karşı koruma özelliğinin bulunduğu yönündedir.

Cai, Cheung ve Wong (2001), çalışmalarında altına dayalı vadeli sözleşme fiyatlarının, merkez bankası rezervlerinin satış hareketleri, Güney Afrika'ya ilişkin siyasi gelişmeler ve ABD ekonomisinin enflasyon, işsizlik ve faiz oranları gibi makro göstergeleri ile petrol fiyatlarındaki değişmelerden doğrudan etkilendiğini ortaya koymuştur.

Altının fiyat değişimlerini diğer kıymetli madenlerin fiyatlarının bir fonksiyonu olarak açıklayan çalışmalarda mevcuttur. Çalışmada altın fiyatı ile gümüş ve platin fiyatları arasında doğrudan bir açıklayıcılık ilişkisi bulunmamakla birlikte, modele dahil edildiklerinde modelin açıklama gücünü olumlu etkilediği tespit edilmiştir (Du ve Yuchen, 2012).

\section{Ampirik Analizin Yöntemi}

Finansal varlık olarak altın fiyatının tahmin modelinde, altının 1990 yılından itibaren ABD doları cinsinden fiyat verilerinin gecikmeli değerleri kullanılmıştır. Dönem seçiminde külçe formunda fiziki altından, finansal araç olarak altına geçiş trendinin başladığı dönem olarak verilerin doksanlı yılları kapsamasına özen gösterilmişstir. Finansal varlık olarak altın fiyat fonksiyonunda, ABD hazine bonosu getirileri de bir diğer açıklayıcı değişken olarak modele dahil edilmiştir. Modelde tamamen uluslararası piyasalarda oluşan ABD doları cinsinden ifade edilen veriler kullanılmış ve zaman serisi analizi yapılmıştır.

Altın fiyatının oluşumuna ilişkin literatürdeki akademik çalışmalarda, makroekonomik faktörler ile kıymetli madenler piyasalarının endojen verileri bağımsız değişken olarak ele alınmıştır. Çalışmamızda daha önce yapılan 
akademik çalışmalar da dikkate alınarak, çok sayıda açıklayıcı değişken kullanmaktan özellikle kaçınılmıştır. Diğer yandan, zaman serisi formatında sektörel faktör datalarının birbirleri ile trend öğesi içerdikleri ve zaman serisi verileri kullanılarak gerçekleştirilen bir tahmin çalışmasında ekonometrik tahmin hatalarının ortaya çıkma olasılığının artacağı dikkate alınmıştır.

$\mathrm{Bu}$ nedenlerden dolayı çalışmamızda, altın fiyatının bir dönem gecikmeli değeri ile ABD hazine bonolarının getiri oranları bağımsız değişken olarak kullanılmıştır. Dönem gecikmesinin kullanılması, bir dönem önce oluşan altın fiyatlarının makroekonomik faktörlerin ve kıymetli madenler piyasasının diğer parametrelerinin etkisini taşıdığının varsayılmasındandır. Diğer açıklayıcı değişken olan hazine bonosu getirileri altının finansal varlık olarak fiyatına doğrudan katkı yapan bir değişken olmasından dolayı modele dahil edilmiştir.

Literatür çalışmasının muhtelif bölümlerinde atıf yapıldığı üzere, finansal varlık olarak altın talebine ilişkin fiyat değişimlerinin tahmin denklemleri oluşturulurken fiyatın cari ve gecikmeli dönem değerleri, altın piyasasında geçerli olan ödünç oranları veya bunların bir proxy değişkeni olarak enflasyon oranının modellere dahil edildiği özellikle son dönem çalışmalarında görülmektedir. Çalışmamızda enflasyon oranı yerine, enflasyonun etkisini de içeren ve finansal varlık olarak altındaki fiyat değişimlerini daha anlamlı şekilde açıklayacağı beklenilen hazine bonosu getirileri kullanılmıştır.

Modelin oluşturulmasında altın fiyatlarının tahmininde dikkate alınacak gecikme sayısının anlamlı düzeyini tespit etmek için öncelikle iki dönem gecikme ile bir dönem gecikme arasında Akaike ve Schwarz Bilgi kriteri testleri yapılmış ve değerleri minimum olan modelin tek dönem gecikmeli model olduğu sonucuna varılmış ve bu model tercih edilmiştir.

\begin{tabular}{|c|c|c|c|}
\hline Gecikme Sayıs1 & AIC & SC & HQ \\
\hline 0 & 31.34781 & 31.49592 & 31.38506 \\
\hline 1 & -36.68100 & -36.08857 & -36.53201 \\
\hline
\end{tabular}

Tablo1: Model Seçimine İlişkin Bilgi Kriterleri.

Tahminde kullanılan doğrusal modelin kantitatif formu aşağıdaki gibidir.

$$
P_{t}=\alpha_{t}+\gamma_{1} P_{t-1}+\gamma_{2} R_{t}+\varepsilon_{t}
$$

Modelde kullanılan 1990-2014 arası fiyat ve getiri verilerinin logaritma değerleri alınıp, düzeltme yapıldıktan sonra tahmin sürecinde kullanılmıştır. Modelin tahmin sonuçları aşağıda verilmiştir.

\begin{tabular}{|l|c|c|c|c|}
\hline Değişkenler & Katsayılar & Standart Hata & t istatistiği & Kuyruk Olasıllı̆ 1 \\
\hline $\mathrm{C}$ & 165.1187 & 92.06543 & 1.793493 & 0.0873 \\
\hline LOGGP(-1) & 0.911153 & 0.08072 & 11.28664 & 0.0000 \\
\hline LOGR & -24.54885 & 15.52094 & -1.581659 & 0.1287 \\
\hline
\end{tabular}

Tablo 2: Modelin Tahmin Sonuçları.

Modelin tahmin denklemi ve tahmin edilen katsayıları ve düzeltilmiş determinasyon katsayısı aşağıda verilmektedir. Modelin tahmin sonuçlarında, elde edilen katsayı işaretleri teorik beklentilerimizi destekler niteliktedir. Altının bir dönem gecikmeli değerinin cari dönem altın fiyatı üzerindeki etkisinin pozitif olduğu görülmüştür. Buna göre, bir önceki dönemin gerçekleşen fiyatı, bir sonraki dönem fiyatını, fiyat oluşumunu etkileyen tüm makroekonomik faktörlerin etkisini de içeren bir şekilde ve pozitif yönde etkilemektedir doğrultusunda bir yorum yapılabilir.

\begin{tabular}{|l|l|}
\hline$R^{2}$ & 0.936494 \\
\hline Düzeltilmiş $R^{2}$ & 0.930446 \\
\hline F istatistiği & 154.8395 \\
\hline Regresyonun Standart Hatası & 119.8525 \\
\hline Akaike Bilgi Kriteri & 12.52687 \\
\hline Schwarz Kriteri & 12.67413 \\
\hline Durbin-Watson İstatistiği & 0.927053 \\
\hline
\end{tabular}

Tablo 3: Modelin Tahmin Istatistikleri.

Finansal varlık olarak altın fiyatının ABD hazine bonoları getirileri ile karşılaştırılmasında, katsayı işaretinin negatif olduğu yani bono getirilerinin yükselmesi halinde bu durumun altın fiyatlarını olumsuz yönde etkileyeceği sonucu ortaya çıkmaktadır.

Modelin tahmin edilmiş formu aşağıda sunulmuştur. Parantez içi değerler katsayıların standart sapmalarıdır.

$\log P_{t}=165.1187+0.911153 \log G P_{t-1}-24.54885 \log R_{t}$

$$
(92.06543) \quad(0.08072) \quad(15.52094)
$$


Model, F istatistiği değeri dikkate alındığında bir bütün olarak altın fiyatlarını anlamlı bir şekilde açıklamaktadır. Ayrıca modelin determinasyon ve düzeltilmiş determinasyon katsayıları değerlendirildiğinde bağımsız değişkenlerin altın fiyatlarını ve değişimlerini açıklamakta yüksek düzeyde bir açıklama gücüne sahip oldukları söylenebilir.

\section{Sonuç}

Altın global ölçekte, özellikle ekonomik kriz dönemlerinde daima güvenli liman olma özelliğini sürdürmüş, hem bir kıymetli maden olarak fiziki üretim sürecinde hammadde, hem de bir finansal araç olarak bir yatırım enstrümanı şeklinde işlev görmüştür. Altının fiyatlaması da bu bağlamda kendine özgü bir takım özellikler arz etmektedir. Öncelikle madenden çıkarılan altının belirli bir ayarda külçe formuna gelebilmesi için geçen süreçte fiyatlama, tamamen endüstriyel parametrelerle gerçekleştirilen bir fiyatlamadır. Altının madenden çıkarılma maliyeti ve bu sürecin finansman maliyeti, nihai piyasa fiyatını etkileyen en önemli iki faktördür.

Altının finansal varlık olarak fiyatlaması ise fiziki altından çok daha farklı değişkenlerle tanımlanabilir. Finansal varlık olarak altının fiyatlaması üzerine, literatürde yapılan çalışmalarda bağımsız değişken olarak döviz kurları, faiz oranları, dünya gayri safi hasılası ve hatta diğer kıymetli madenlerin fiyatları kullanılmıştır. Konu üzerinde akademik tartışmalar devam etmekte olup, genel kabul görmüş bir fiyatlama modeli üzerinde henüz uzlaşılamamıştır.

$\mathrm{Bu}$ çalışmada finansal varlık olarak altının, fiyat fonksiyonunun tahmin denemesi yapılmış ve altının fiyatlandırma mekanizması bağlamında kantitatif olarak kısa ve uzun dönemde modellemesi gerçekleştirilmiştir. Çalışmada oluşturulan modelin altın fiyatlarını açıklamakta, teorik beklentilere uygun katsayı işaretleri verdiği ve modele ilişkin istatistiklerin de modelin açıklama gücüne ilişkin tatmin edici sonuçlar gösterdiği görülmektedir. Modelde açıklayıcı değişken olarak, altın fiyatlarının bir dönem önceki değeri ile hazine bonosu getirilerinin istatistiksel olarak açıklama gücünün oldukça yüksek olduğu tespit edilmiştir.

\section{Kaynakça}

- Abken, 1979. "The Economics of Gold Price Movements". Federal Reserve Bank of Richmond.

- Cai, Cheung ve Wong, 2001. "What Moves the Gold Market?”, Journal of Futures Markets, 21, 3,p.257-78.

- Capie, Mills ve Wood, 2005. “Gold as a Hedge against the Dollar.” Journal of International Financial Markets, Institutions and Money, 15, 4, p. 343-52.

- Chan ve Mountain, 1988. "The Interactive and Causal Relationships Involving Precious Metal Price Movements", Journal of business and economic statistics, 6, p. 69-77.

- Chappell ve Dowd, 1997. "Simple Model of Gold Standart." Journal of Money, Credit and Banking, 29, p. 94-105.

- Du ve Yuchen, 2012. "Modeling and Forecasting Volatility of Gold Price with Other precious Metal Prices by Univariate GARCH Models", Department of Statistics, Uppsala University.

- Ghosh, vd, 2004. “Gold as an Inflation Hedge?”, University of Stirling, Studies in Economics and Finance, p. 1-25.

- Harvey, 2013. "The Truth about Gold: Why It Should (or Should Not) Be Part of Your Asset Allocation Strategy", Institute Conference Proceedings Quarterly, p. 9-17.

- Haugom, 1991. "The Supply and Demand for Gold”, Ph.D. Dissertation, Simon Fraser University.

- Koutsoyiannis, 1983. "A Short-Run Pricing Model for Speculative Asset, Tested with Data from the Gold Bullion Market”, Applied Economics, 15, p. 563-581.

- Sazonov ve Nikolaev, 2013. "Theoretical Aspects of Investment Demand for Gold”, Investment Management and Financial Innovations, 10, 4, p. 148-155.

- Sjaastad ve Scacciavillani, 1996. "The Price of Gold and the Exchange Rate", Journal of International Money and Finance, 15, p. 879-897.

- Starr ve Tran, 2007. "Determinants of the Physical Demand for Gold: Evidence from Panel Data", American University Department of Economics Working Paper Series, 2007-09. Washington DC.

- Taylor, 1998. "Precious Metals and Inflation", Applied Financial Economics, 8, p. 201-210. 


\title{
Türkiye'de Altın Fiyatlarına Etki Eden Temel Faktörlerin Analizi The Empirical Analysis of the Basic Factors Effecting the Gold Market in Turkey
}

\author{
Prof. Dr. Turgut Özkan (Beykent University, Turkey) \\ Çiğdem Kolay (Beykent University, Turkey)
}

\begin{abstract}
The gold which is the most important metal known since seven thousand years and is located in the first place among the precious metals protects being the saving mean. Gold increasingly preferred in industry due to the technological purposes, and because of its mentioned specifications creates the significant price fluctuations within its specific market structure. In this study, the basic national factors effecting the gold market in Turkey were tested in terms of empiric. Weighted avarage gold prices used as a dependent variable; whereas basket exchange rate, BIST 100 index, deposit interest rate and inflation rate used as an independent variable. The datas related to these variables were dealed on a monthly basis, between the years of January 1999- December 2014. Taking the advantage of the e-views package program, multiple regression model was performed in the analysis. In the final result of the analysis, the impacts of all independent variables but BIST 100 index values, on gold market prices were statistically found to be significant.
\end{abstract}

\section{Giriş}

Altın, çağlar boyunca değerini yitirmemiş, özelliklerinden ötürü dış etkenlere karşı oldukça dayanıklı, hurdası dahi değerli olan kıymetli bir madendir. Üretim hacminin sınırlı olması, inelastik arz yapısı, aynı ya da benzer özelliğe sahip başka bir madenin olmayışı ve merkez bankaları için rezerv aracı olması altını diğer madenlerden ayıran temel özelliklerdir (Kaplan 2004, 11-12).

Yaklaşık 7000 yıl önce kullanılan ilk maden türü olan, yüzyıllarca para ve mücevher yapımında faydalanılan altın, tarihte birçok toplum için zenginliğin ve gücün simgesi, ekonominin başrol oyunculuğu görevini üstlenmiştir. Parlak sarı rengi ile göz alan bu değerli maden türü dayanıklılığından, fiziksel ve kimyasal özelliklerinden dolayı günümüzde gelişen teknoloji ile geniş bir kullanım alanına sahiptir (S. Aslan 1999, 4).

Altının günümüzde önemli bir rezerv aracı olmasının temelinde 19. Yüzyılın ikinci yarısı itibariyle uygulamaya konulan "Altın Standardı Sistemi” yatmaktadır. Altın, uzun dönemler boyunca para olarak kullanıldıktan sonra oluşturulan kağıt para sistemi altın esasına bağlanmıştır (Menase 2009, 10). Klasik altın standardı, gelişmiş ekonomilerde 1880'den 1914'e kadar hüküm sürmüştür. 1944-1973 arası, kısa dönemli dalgalanmalar karşısında sabit kurların korunabilmesini amaçlayan ve doların altına ve diğer para birimlerinin de dolara bağlandığı Bretton Woods Sistemi olarak adlandırılan dönemdir (Öztürk 2002, 98). Bretton Woods Sistemi’nin çökmesi ile bu üçlü arasındaki yüksek korelasyon kopmuş ve ülkeler sabitten dalgalıya doğru geniş bir yelpazede değişik kur sistemleri uygulamaya başlamıştır. Yeni yapı kurlar, altın ve her türlü finansal varlığın, çeşitliliği artan, güçlü risk faktörlerinin etkisinde fiyatlandığı bir dönem yaratmıştır.

Türkiye'de yoğun talep gören hem mal hem finansal varlık olarak kullanılan altın, gelişen finans sektörü ile yatırım aracı olarak da farklı bir boyut kazanmış ve fiziki yatırım araçlarının dışında finansal yatırım aracı olarak da önemli gelişmeler kaydetmiştir.

Türkiye'nin serbest piyasa ekonomisine geçiş politikası kapsamında alınan yapısal değişiklik kararları, altın sektörünün gelişimi açısından önemli sonuçlar doğurmuştur. 1983 ve 1984 yıllarında altın ithalatı belirlenen kurallara uymak kaydı ile serbest bırakılmış ve aynı kararla altın ve döviz kurlarının Türk Lirası karşılığında değerinin belirlenmesi için TCMB'ye yetki verilmiştir. 1984 yılında TCMB bünyesinde Türk Lirası karşılığı altın piyasası kurulmuş ve 1989 yılında döviz karşılığı altın piyasasını açılmıştır. Türk Parası Kıymetini Koruma hakkında 32 sayılı karar ile sermaye hareketleri, 1993 yılında yapılan değişikliklerle de altının fiyatının dünya fiyatlarına paralel olarak serbestçe belirlenmesi ile ithalatı ve ihracatı serbest bırakılmıştır (Öztekin, Tağtekin ve Güvenç 2002, 171-172). Altın Bankacılı̆̆g'nın Türkiye'de başlangıcı olarak kabul edilen 21.03.1993 tarihinde "altın depo" ve "altın kredisi" hesaplarını yasal zemine oturtulmuştur (Çıtak 2004, 130).

26 Temmuz 1995 günü “İstanbul Altın Borsası” çalışmaya başlamış ve böylece altın, ekonominin kurumsal mali değerleri arasında yerini almıştır. 18 Ekim 1996 tarihinde "İstanbul Altın Borsası Vadeli İşlemler ve Opsiyon Piyasası Yönetmeliği” ne dayanarak vadeli işlemler ve opsiyon piyasası, 1996 yılında İstanbul Altın Rafinerisi faaliyete geçmiştir (Halisçelik 1998, 3). 2013 yılında Altın Borsası, BİST (Borsa İstanbul) bünyesine alınmıştır. $\mathrm{Bu}$ düzenlemelerle hem yurt içi altın fiyat ve hacim hareketlerinin kontrolü hem altına dayalı fiziki ve finansal yatırım araçlarının çeşitlendirilmesi hem de altın piyasasının küresel bazda rekabet edebilirliği için gerekli altyapının sağlanması amaçlanmıştır. 
Türkiye'de 6.500 ton altın potansiyelinin henüz 710 tonu üretime hazır rezerv hale getirilmiş olup, keşfedilmeyi bekleyen altın potansiyeli yaklaşık 5.790 ton'dur. Son 10 yılda yaklaşık olarak 82 ton altın üretilmiştir (MTA Raporu, 2011).

Bu çalışmada, Türkiye'de altın ve altın piyasası ile altının piyasa fiyatına etki eden faktörler ampirik olarak incelenmiştir. Konuya ilişkin sınırlı sayıda ve daha dar kapsamlı yapılan araştırmaları nedeni ile bu alanda kapsamın genişletilmesine ve zengin bir tartışma ortamı yaratılarak literatüre katkı da bulunmak amaçlanmıştır. Analizde yer alan değişkenler, Ocak 1999 - Aralık 2014 yılları arasındaki aylık bazda; ağırlıklı ortalama altın fiyatları, enflasyon oranı, BİST 100 endeksi, sepet döviz kuru ve mevduat faiz oranı ile sınırlandırılmıştır. Söz konusu analizde çoklu regresyon modeli uygulanmıştır.

Çalışmanın birinci bölümü giriş bölümü olup, ikinci bölüm Türkiye'de ve diğer ülkelerde yapılmış çalışmaları kapsayan yazın taramasına ayrılmıştır. Üçüncü bölümde, çalışmaya ilişkin veri setinin açıklanmasına ve analizde kullanılan yönteme yer verilmiştir. Dördüncü bölümde, Türkiye'de altın piyasasına etki eden temel ulusal faktörlerin ekonometrik modeller yardımı ile analizi ve analizde elde edilen istatistiksel çıktılar sunulmuştur. Beşinci bölümde analiz bulgularının değerlendirilmesine yer verilmiştir. Altıncı bölüm olan sonuç bölümünde ise analiz sonuçlarının değerlendirilmesi yapılmış ve konuya ilişkin sonraki çalışmalar için önerilerde bulunulmuştur.

\section{Yazın Taraması}

Altın piyasasına ilişkin yazın taramasını Türkiye'nin ve diğer ülkelerin altın piyasasının ve altın fiyatlarına etki eden faktörlerin analiz edildiği çalışmalar olarak iki guruba ayırmak mümkündür. Diğer ülkelerle ilgili yapılan çalışmalarının bir kısmının birden fazla ülkeyi kapsadığ 1 ve daha uzun bir analiz dönemini içerdiği görülmüştür.

Bordo tarafından 1993 yılında yapılan çalışmada, Altın Standardı, Bretton Woods ve diğer parasal rejimler üzerinde durulmuş ve tarihsel bir değerlendirme yapılmıştır. Bu çalışmada 2 sorunun cevabı incelenmiştir. Bu sorulardan ilki; Ekonomik performansta en iyi parasal rejim hangisidir? İkinci soru ise; hangi parasal rejimlerin diğerlerinden daha başarılı olduğu sorusudur. Özellikle, klasik altın standardına dayalı para sistemi neden bir yüzyıl varlığını korumuş; Bretton Woods sistemi neden sadece yirmi beş yıl dayanabilmiş ve neden Avrupa Para Politikaları sadece birkaç yıl başarı göstermiştir? Sonuç olarak, döviz kuru hedef bölgeleri veya olası bilimsel liyakatlere rağmen altının gerçek fiyatını, hedeflemek gibi parasal reform önerileri ancak uluslar kendi ülkeleri içindeki özerkliklerinden vazgeçer ve güvenilir taahhüt yolunu izler ise işe yarayabileceği belirtilmiştir.

Hsieh ve Christina tarafından 2004 yılında yapılan çalışmada, "büyük buhran döneminde Birleşik Devletler Merkez Bankası Altın Standardı tarafından kısıtlanıp kısıtlanmadığı” sorusuna cevap aranmıştır. Para miktarının arttırılması ve devalüasyon beklentileri arasındaki bağlantının incelendiği bu çalışmada, devalüasyon beklentilerini ölçmek için vadeli döviz kuru ve faiz oranları değişkenleri kullanılmıştır. Para miktarının büyük oranda arttırılmasının, yatırımcıları ABD’nin devalüasyon yaşayacağına inandırdığına dair çok az veri edinilmiş, devalüasyon beklentisi ya da spekülatif atak korkusuna dair de çok az kanıt olduğu ileri sürülmüştür. Ayrıca; altın standardı hakkındaki endişelerden çok, kusurlu bir para politikası modeli ve 12 merkez bankası arasındaki uyuşmazlığın FED’in genişleme politikasını 1932 yazında askıya almasında sebep olduğu sonucuna ulaşılmıştır.

Tully ve Lucey (2007) çalışmalarında, GARCH modeli kullanılarak makroekonomik faktörlerin altın piyasası üzerindeki etkilerini araştırmışlardır. 1983-2003 yılları arasındaki aylık nakit ve vadeli altın fiyatları ile önemli ekonomik değişkenler kullanılmıştır. Araştırmanın sonucunda, altın piyasası üzerinde ABD dolarının etkileri olduğu bilgisine ulaşılmıştır.

Do, Mcaleer ve Sriboonchitta tarafından (2009) yapılan çalışmada, borsadaki oynaklıkların uluslararası altın piyasaları üzerindeki etkileri ve ASEAN (Endonezya, Malezya, Filipinler, Tayland ve Vietnam) olarak adlandırılan gelişmekte olan borsaların uluslararası altın piyasalarına etkileri incelenmiştir. Söz konusu çalışmada GARCH modeli uygulanmıştır. Altının, Vietnam ve Filipinler'de hisse senetleri için yedek mal, Endonezya, Tayland ve Malezya hisse senetleri için tamamlayıcı mal olduğu kanısı elde edilmiştir.

Cheng, Su ve Tzou'nun 2009 yılındaki çalışmalarında petrol fiyatlarındaki değişkenliğin altın piyasasına etkileri incelenmiştir. Yapılan ampirik analiz için BHK ve PGARCH modeli kullanılmıştır. Araştırmada 29 Nisan 199820 Temmuz 2006 yılları arasındaki günlük altın ve ham petrol fiyatlarından yararlanılmıştır. Analiz sonucunda altın fiyatlarındaki değişkenliğin yatırımcılar, finansal kurumlar ve vadeli işlem borsası üzerinde etkileri olduğu bulunmuştur.

Ho, Wang ve Liou (2010) tarafından yapılan çalışmada, uluslararası altın endeksleri, vadeli altın işlemleri ve genel ekonomi arasındaki etkileşim incelenmiştir. Ampirik çalışmada Ocak 1998-Eylül 2006 tarihleri arasındaki aylık veriler kullanılmıştır. Değişkenler olarak; AMEX Altın Endeksi, dolar endeksi, CRB Vadeli Endeksi, Dow Jones Ortalama Endeksi, OPEC ham petrol spot, New York altın spot, New York vadeli altın verileri alınmıştır. Bu çalışmada Vektör Hata Düzeltme Modeli (VECM), Granger nedensellik testi gibi çok sayıda zaman serisi yöntemi kullanılmıştır. Araştırma sonucunda, altın vadeli işlem, altın endeksleri ve genel ekonomi arasında uzun dönemde dengeli bir ilişki olduğu sonucuna ulaşılmıştır. 
2012 yılında Sadeghzadeh ve Eren tarafından yapılan çalışmada, Altın fiyatlarındaki değişimin altın madeni sektörü ve altın işleyen firmaların hisse senedi getirilerine etkisi incelenmiştir. Ampirik analizde Temmuz 2011Haziran 2012 tarihleri arasında 365 günlük altın fiyatları ile altın madeni sektörü ve altın işleyen sektörlerin hisse senedi getirileri verileri kullanılmıştır. Bu değişkenler arasındaki ilişki eşbütünsellik analizi ile araştırılmıştır. Yapılan analiz sonucunda; söz konusu değişkenler arasında uzun dönemli ilişkinin olmadığı sonucuna varılmıştır.

Trück ve Liang'ın 2012 yılında yaptıkları çalışmada ise, altın piyasasında dalgalanma modellemesi ve tahmini üzerinde durulmuştur. Analizde kullanılan veriler, 4 Ocak 1999'dan 30 Aralık 2008 tarihine kadar olup, zaman serisi 11 Eylül 2001 dönemini, 2003'te başlayan Irak savaşını ve 2008'deki küresel finansal kriz dönemini kapsamaktadır. Bu çalışmada test edilen Temmuz-Aralık 2008 tarih aralığındaki örneklem dişı dönem finansal piyasaların tarihindeki en dalgalı dönemlerden bir tanesidir. Araştırma sonucunda günlük geri dönüşlerin önceki, hatta gelecekteki dönemlerden belirgin olarak farklılık gösterdiği anlaşılmıştır. Dolayısıyla dikkate alınan örneklem dışı dönemde çok iyi performans gösteren modellerin daha uzun vadelerde ve özellikle piyasa şartları değiştiğinde düşük performans gösterebildiği saptanmıştır. Çalışmada örneklem içi tahminlerde, TARCH sınıfi modellemelerin en iyi sonucu verdiği ifade edilirken, örneklem dışı tahminlerde sonuçların o kadarda keskin, net olmadığı ve kullanılan modelin ayrıntı özelliklerinin modelin performansına karar vermede önemli rol oynadığı ileri sürülmüştür. Genel olarak, kabul edilen bütün kriterlerle ilgili kullanılan modellerin hiç biri belirgin şekilde daha iyi performans göstermezken, çoğu modelin Rassal Yürüyüş Modeli’nden (Random Walk Theory) daha üstün olduğu sonucuna varılmıştır.

Sverdrup, Koca ve Granath tarafından 2012 yılında yapılan çalışmada, Altın piyasası modellemesi, geçmişinin açıklanması ve gelecek senaryolarının fiziksel ve ekonomik tutarlılığının değerlendirilmesi üzerinde durulmuştur. Entegre edilmiş dinamik model kullanılarak 1920-2010 yılları arasındaki altın arz ve fiyatını yeniden yapılandırmak mümkün olduğu savunulmuş ve bu sonuçları 2010-2100 dönemindeki altın fiyatları ve arzına ilişkin tahminde bulunmak için kullanmışlardır. Simülasyon sonuçları göstermiştir ki, piyasa temel olarak arz talep ilişkisi ile yürütülmekte fakat türev ürünler ve spekülasyonlar piyasayı büyük kısa vadeli varyasyonlar oluşturması bakımından önemli ölçüde etkilemektedir. Bu konuda yapılan araştırmalara göre, 1930 ve 1971 yılları arasında fiyatlar ABD ve Birleşik Krallık hükümetleri tarafından belirlenmiştir. 1971'den sonra 1990-2000 yıllarında piyasa işlevsel hale dönüşmüştür. Altın fiyatları önceden belirlenen kurun ileri tarihli kullanılması sebebiyle yapay bir şekilde durgunlaşmış ve ticaretin yönünü değiştirmiştir. Şimdiye kadarki araştırmacıların kullandığı modellere göre yüksek kalitedeki cevherlerin, gelecek 50 yılın temel arzını oluşturacağını, düşük kaliteli mevduatlara yöneliminin, altın piyasasının en önemli kaynağı olacağı öngörülmüştür. Ayrıca; genel fiyatlar emtia fiyatları ile karşılaştırıldığında, azalan türev ürün ticareti sonucu, altın piyasasında bir sıkışma yaşanacağını, vadeli ve türev ürünler ticaretinin piyasayı ve fiyatları neredeyse sabitleyeceğini iddia etmişlerdir. Ancak, kullanılan modelin sonuçları vadeli ve türev ürünler ticaretinin daha az durağanlık yaratacağını ve durgunluğun fiyat dalgalanmalarını arttıracağını ve bu yapının uzun vadeli trendin temel faktörler tarafından belirlenmesini engelleyemeyeceğini göstermiştir

Türkiye Altın Piyasası ve altın fiyatları konusunda yapılan çalışmaların ise oldukça sınırlı olduğu görülmüştür.

1989 yılında Özman tarafından yapılan çalışmada, Türkiye'de altın ticareti konusu incelenmiştir. Çalışmanın sonucunda, altının biriktirilmesinin önlenmesi ve bu paranın yatırımda kullanılması, kaçak altın ticaretinin önlenmesi ve altın piyasasının resmiyet kazanması üzerinde durulmuştur.

1997 yılında Durmuşoğlu tarafından yapılan “Türkiye'de Altın Piyasası” adlı çalışmada, Türkiye'de uluslararası bir altın piyasasının oluşması için önem taşıyan ilgili kurum ve piyasaların hayata geçirilmesinin, İstanbul Altın Borsası'nın gelişim hızını arttıracağı, uluslararası altın arz ve talebinde bulunan kesimlere eksiksiz hizmet verebilen ülkeler karşısında Türkiye'nin rekabet şansının bulunduğu sonucuna ulaşılmıştır.

2008 yılında Poyraz ve Didin tarafından yapılan çalışmada, 1996 - 2005 yılları arasındaki aylık veriler kullanılmıştır. Türkiye'de Altın fiyatlarının döviz kuru, döviz rezervi ve petrol fiyatlarındaki değişime ne derece bağımlı olduğu çoklu faktör modeli yardımıyla tespit edilmiş ve ampirik araştırmada bağımlı değişken olarak altın fiyatları, bağımsız değişkenler olarak ise döviz kuru, döviz rezervi ve petrol fiyatları baz alınmıştır. Yapılan regresyon analizi ve durağanlık testinin sonucunda döviz kuru, döviz rezervi ve petrol fiyatlarının farklı düzeylerde altın fiyatlarını etkilediği bilgisine ulaşılmıştır.

Menase tarafından yapılan çalışmada, Türkiye'de altın fiyatlarının oluşumunu etkileyen faktörler çoklu regresyon analizi ile test edilmiştir. Analizde Ağustos 1995- Aralık 2008 yılları arasında 161 aylık veri seti kullanılmıştır. İstanbul Altın Borsasında belirlenen altın fiyatları bağımlı değişken olarak alınırken bağımsız değişken olarak, TÜFE endeksi, reel mevduat faiz oranları, İMKB-100 endeks değerleri, reel kur endeksi ve Londra altın piyasasında belirlenen altın fiyatları kullanılmıştır. Bu çalışmada, İstanbul Altın Borsasında oluşan altın fiyatlarını, Londra altın piyasasında belirlenen altın fiyatları etkilerken TÜFE, mevduat faiz oranı, reel kur endeksi ve IMKB-100 endekslerinin etkilemediği sonucuna ulaşılmıştır (Menase 2009).

2011 yılında Toraman, Başarır ve Bayramoğlu tarafından yapılan çalışmada, altın fiyatlarını etkileyen faktörler araştırılmıştır. Bağımlı değişken olarak altın fiyatları alınmış ve bağımsız değişken olarak petrol fiyatları, dolar endeksi, Dow Jones Endeksi, ABD enflasyon oranı ve reel faiz oranları kullanılmıştır. Çalışmada Ocak 1992- Mart 
2010 yılları arasında aylık veriler alınarak MGARCH modelleri ile analiz yapılmıştır. Analizin sonucunda; sadece altın getirisi ile dolar getirisinin arasında negatif yönlü olmak üzere anlamlı bir doğrusal ilişkinin olduğu bulunmuş, fakat diğer değişkenler ile altın getirileri arasında anlamlı bir istatistiksel ilişkinin olmadığı görülmüştür.

Topçu ve Aksoy tarafından yapılan ampirik çalışmada, yatırım aracı olarak altının getirisi ile İMKB Ulusal 100 Endeksi, İMKB DİBS Fiyat Endeksi (91 günlük), TÜFE ve ÜFE bazlı hesaplanan enflasyon arasındaki kısa ve uzun dönemli ilişsi incelenmiştir. Çalışmada Ocak 2003- Aralık 2011 tarihleri arasındaki aylık veriler kullanılmıştır. Kısa dönemli ilişkilerin analizinde, tanımlayıcı istatistikler hesaplandıktan sonra korelasyon ve çok değişkenli regresyon analizleri kullanılmış, uzun dönemli ilişkilerin analizi için ise serilerin durağanlık testleri yapılarak eşbütünleşme modelleri arasında yer alan Engle-Granger eşbütünleşme testi, Granger Nedensellik testi ve Johansen eşbütünleşme testleri uygulanmıştır. Yapılan regresyon analizinde altın getirisi ile hisse senedi getirileri arasında negatif, ÜFE bazlı enflasyon ile pozitif ilişki olduğu saptanmıştır. Engle-Granger eşbütünleşme testi kullanılarak altın ile ÜFE ve TÜFE arasında nedensellik ilişkisi tespit edilmiş̧ir. Ayrıca; Granger Nedensellik testi ile DİBS, hisse senedi ve TÜFE'den altına, altından ise ÜFE'ye doğru tek yönlü nedensellik ilişkisi olduğu sonucuna ulaşılmışıtır (Topçu ve Aksoy 2012).

Yüksel tarafından yapılan bir başka ampirik çalışmada, uluslararası finansal krizlerde altın fiyatlarının hareketliliği incelenmiştir. Söz konusu çalışmada GARCH modelinden yararlanılmış ve 1968-2010 yılları arası Londra sabah ve öğlen kotasyon fiyatları ile 1995-2010 yılları arası İstanbul Altın Borsası kapanış fiyatları kullanılmıştır. Çalışmada, uluslararası finansal kriz dönemlerinde altın fiyatlarının hareketliliğinin arttığı konusunda güçlü kanıtlara ulaşılmıştır (Yüksel 2012).

Tokat'ın çalışmasında, altın, döviz ve hisse senedi piyasalarında oynaklık etkileşimi mekanizması incelenmiştir. 03 Ocak 2000-08 Haziran 2012 tarihleri arasındaki 24 ayar gram altın, ABD Dolar-TL döviz kuru, ons altın, ABD Dolar endeksi ve IMKB-100 Endeksi günlük verileri alınmış ve çok değişkenli GARCH modeli uygulanmıştır. Bu çalışma ile tüm parametrelerin heteroskedastik özellik, göstererek kendi geçmiş şoklarından etkilendiği sonucuna varılmıştır (Tokat 2013).

Polat (2013) tarafından yapılan çalışmada, altın fiyatlarını etkileyen faktörlerin tespiti üzerinde durulmuştur. Ampirik analizde Ocak 1988-Mart 2013 yılları arasındaki aylık veriler kullanılmıştır. Bağımlı değişken olarak uluslararası altın fiyatları alınırken, bağımsız değişkenleri döviz kuru, Dow Jones Endeksi, petrol fiyatları, faiz oranı, gümüş fiyatı ve enflasyon oranı oluşturmuştur. Uygulanan ekonometrik yöntemlerin sonucunda altın fiyatını en çok ve pozitif yönde enflasyonun, daha sonra döviz kurunun etkilediği, ancak bu etkinin negatif yönde oluştuğu bilgisine ulaşılmıştır. En az etkileyen faktör Dow Jones Endeksi olurken, faiz oranı dışında diğer faktörlerin altın fiyatına etkisi anlamlı bulunmuştur.

2013 yılında Atay tarafından yapılan ampirik çalışmada ise, Dünya'da ve Türkiye'de altın piyasaları ve Türkiye'de altın fiyatlarını etkileyen faktörler incelenmiştir. Araştırmada Ocak 2003-Haziran 2013 tarihleri arasında aylık veriler kullanılmıştır. Bağımlı değişken olarak Türkiye'deki altının TL/kg cinsinden fiyatı, bağımsız değişkenler olarak BİST 100 Endeksi, mevduat faiz oranı, reel efektif kur endeksi, TÜFE, $\mathrm{M}_{1}$ para arzı ve küresel krizin ülkemize etkilerini temsil eden kukla değişkeni alınmıştır. Yapılan VAR analizlerinin sonucunda, TÜFE’nin Türkiye'deki altın fiyatlarının Granger nedenseli olduğu, Varyans Ayrıştırma Analizi sonucunda altın fiyatlarındaki değişimin \%90'ının altının kendi iç dinamiklerinden ve yaklaşık \%10'unun ise TÜFE'den kaynaklandığı görülmüştür. Etki-Tepki Analizi sonuçlarına göre TÜFE'nin ilk 3 periyod da belirsiz etkisi ve 5. periyodun sonuna kadar sınırlı şekilde pozitif yönlü etkisi olduğu bilgisine ulaşıılmıştır.

\section{Analiz Yöntemi ve Veri Seti}

Analizde altın fiyatları üzerinde etkili olan temel faktörlerle modeller oluşturulmuş ve e-views 7 paket programından yararlanılarak çoklu regresyon modeli kapsamında ekonometrik analizler kullanılmışır. Model oluşturmadan önce değişkenlerin her birine ilişkin bazı tanımlayıcı istatistiki testler uygulanmıştır.

Türkiye'de altın piyasasına ilişkin veriler Ocak 1999 - Aralık 2014 dönemi için inceleme kapsamına alınmış ve bu döneme ilişkin veriler aylık bazda kullanılmıştır. Bunun iki farklı nedeni söz konusudur. Birincisi, bazı değişkenler enflasyon gibi aylık olarak izlenmektedir. İkincisi, altın piyasası gibi piyasalarda hareketlilik çok kısa dönemde gerçekleştiğinden, erişilebilir en kısa vadelerle çalışılması en doğru sonuçları ortaya koyacaktır.

Şekil 1. de görüldüğ̈̈ gibi ampirik çalışmamız için altın piyasasına ilişkin veri olarak ağırlıklı ortalama altın fiyatı dolar/ons cinsinden alınmış ve bu piyasayı etkileyen faktörler olarak enflasyon oranı, sepet döviz kuru, BİST 100 Endeksi ve mevduat faiz oranına ilişkin veriler kullanılmıştır. Enflasyon göstergesi olarak TÜFE, borsa hareketlerinin göstergesi olarak BİST 100 Endeksi, piyasa faiz göstergesi olarak vadeli mevduat faiz oranı, döviz piyasası göstergesi olarak ise sepet döviz kuru verilerinden faydalanılmıştır.

Bu değişkenlere ilişkin verilerden döviz kuru oranları ile enflasyon oranları TCMB Elektronik Veri Dağıtım Sistemi'nden, ağılıklı ortalama altın fiyatları Borsa İstanbul A.Ş. (BİST) elektronik veri sisteminden, mevduat faiz oranı ile BİST 100 Endeksi TÜiK elektronik veri sisteminden sağlanmıştır. 


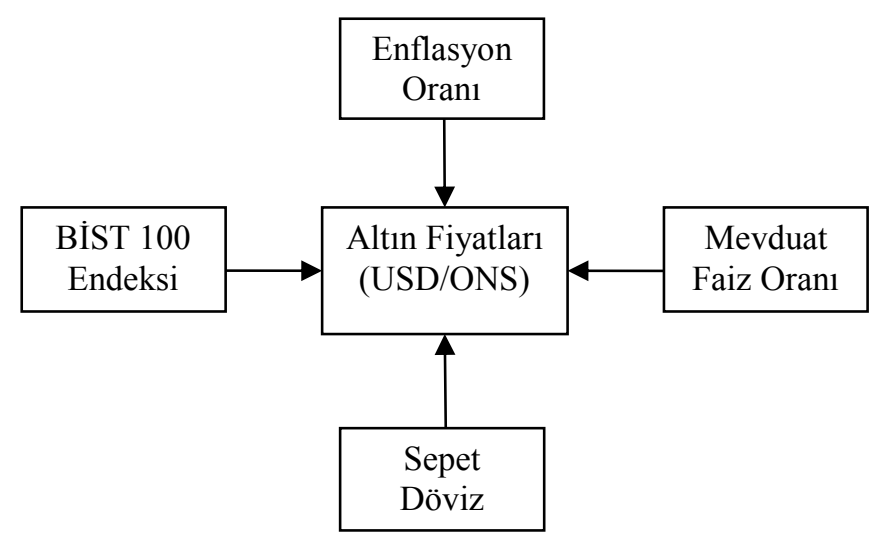

Şekil 1: Altın Piyasasına Etki Eden Temel Faktörler

Model kapsamında kullanılacak değişkenlere ilişkin detaylı açıklamalar aşağıda verilmiştir:

Ağırlıklı Ortalama Altın Fiyatları (Altın): Borsa İstanbul A.Ş. tarafından yayımlanan bu veriler, 1 ons altının dolar cinsinden ağırlıklı ortalama fiyatıdır. Kullanılan veriler aylık bazdadır.

Enflasyon oranı (Enflasyon): Yurtiçi fiyatlarına ilişkin gösterge olarak Tüketici Fiyat Endeksi (TÜFE) bazlı enflasyon oranı kullanılmıştır. Veriler aylık yüzde değişim olarak alınmıştır.

Faiz Oranı (Faiz): Faiz göstergesi olarak aylık ortalama reel vadeli mevduat faiz oranı kullanılmıştır. Enflasyonun etkisinden arındırmak amacıyla reel oranlar veri setine dahil edilmiştir. Bu amaçla 1994=100 ve 2003=100 temel yıllı TÜFE’ye göre mevduat faiz oranlarının reel değerleri hesaplanarak kullanılmıştır.

Döviz Kuru (Kur): Kur göstergesi olarak sepet döviz kuru kullanılmıştır. Bu nedenle, veriler TCMB Elektronik Veri Dağıtım Sistemi'nden günlük bazda dolar ve euro döviz kuru olarak alınmış ve 1 dolar + 1 Euro esasına göre tanımlanan günlük sepet döviz kuru hesaplanmıştır. Günlük sepet kurlarından hareketle ağırlıklı ortalama değerler alınarak, aylık sepet döviz kuru bulunmuştur.

BİST 100 endeksi (BİST): Borsa İstanbul pay piyasası için temel endeks olarak kullanılan aylık bazda verilerden faydalanılmıştır. BİST 100 endeksi olarak tanımlanan bu endeks, ulusal piyasalarda işlem gören şirketlerle, kurumsal ürünler piyasasında işlem gören gayrimenkul yatırım ortakları ve girişim sermayesi yatırım ortaklıkları arasından seçilen en büyük piyasa derinliğine sahip 100 şirketin pay senedinden oluşmaktadır. Aylık ortalama endeks değerleri TÜİK elektronik veri sisteminden alınmıştır.

\section{Analiz ve Analizde Elde Edilen Bulgular}

Zaman serisi analizlerimizdeki modellemelerde kullanılabilmesi için tüm değişkenlerin doğal logaritması alınmış, modelleme aşamasında bu logaritmik veriler kullanılmıştır. Tablo: 1, logaritmik değişkenlere ait tanımlayıcı istatistikleri göstermektedir. BİST 100 Endeksi ve faiz oranı negatif değerler içerdiği için logaritmaları alındığında bazı veri kayıpları söz konusu olmuş ve BİST 100 endeksi için gözlem sayısı 106'ya, enflasyon oranı için 169'a, faiz oranı için 134'e düşmüştür. Tablo: 1'e göre altın bağımlı değişkeninin çarpıklık değerinin $\mathrm{S}>0$ olması nedeni ile sağa, diğer parametrelerin $(\mathrm{S}<0)$ sola çarpık olduğu anlaşılmaktadır. Basıklık değerinin $\mathrm{K}<3$ olduğundan altının normal dağılımdan daha basık, diğer değişkenlerin ise ( K > 3) daha dik olduğu saptanmıştır. $\mathrm{Bu}$ durumda, altın dışındaki diğer parametrelerin kalın kuyruk (fattail) ve pozitif basık (leptokurtic) özelliği taşıdığı görülmüştür.

\begin{tabular}{|l|c|c|c|c|c|}
\hline & Lnaltın & Lnenflasyon & Lnfaiz & Lnkur & InBISST \\
\hline Ortalama & 6,47 & $-0,01$ & $-0,29$ & 0,38 & 1,40 \\
\hline Medyan & 6,46 & 0,17 & $-0,07$ & 0,49 & 1,74 \\
\hline Maksimum & 7,49 & 2,34 & 2,79 & 0,97 & 3,80 \\
\hline Minimum & 5,55 & $-4,60$ & $-4,61$ & $-1,05$ & $-3,91$ \\
\hline Standart Sapma & 0,66 & 1,19 & 1,13 & 0,48 & 1,33 \\
\hline Çarpıklık & 0,05 & $-1,04$ & $-0,82$ & $-1,67$ & $-1,00$ \\
\hline Basıklık & 1,49 & 4,94 & 4,44 & 4,99 & 4,58 \\
\hline Jarque-Bera & 18,39 & 56,49 & 26,40 & 120,78 & 28,76 \\
\hline Gözlem Sayısı & 192 & 169 & 134 & 192 & 106 \\
\hline
\end{tabular}

Tablo 1: Logaritmik Değişkenlere İlişkin Tanımlayıcı İstatistikler

$\mathrm{Bu}$ aşamadan sonra, modellemede kullanılacak değişkenlerin zaman serisi özelliklerinin tespiti yapılmıştır. Zaman serisi tahminlerinde karşılaşılan temel sorun, serilerin zaman içinde durağanlık göstermemesidir. Durağan olmayan bir zaman serisi ile çalışıldığında, modelde yer alan değişkenler arasında gerçekte var olmayan sahte bir 
ilişki söz konusu olmakta ve yanıltıcı sonuçlara ulaşılmaktadır. Bu nedenle, durağanlık koşulunu sağlamayan değişkenler için, veri setini durağan hale getirecek dönüştürmeler uygulanmaktadır.

Durağan olmayan seriler ile ampirik çalışmaların yapılmasının sorunlu olarak görülmesinin nedenlerinden biri, durağan olmayan zaman serileri ile yapılan tahminlerde sahte regresyon sorunun ortaya çıkmasıdır (Granger ve Newbold 1974). Bu sorun sahte regresyon denkleminin açıklama gücünü gösteren $\mathrm{R}^{2}$ değerinin olması gereken değerden çok daha yüksek çıkmasına ve analiz sonuçlarının hatalı olmasına yol açmaktadır. Değişkenler birim kök (Unit Root) içeriyorlarsa (durağan değillerse), "t" ve "F" testleri de geçersiz olmaktadır.

Bu nedenle, değişkenlerin durağan olup olmadıkları incelenerek, durağan olmayan serilerin farkları alınmış ve seriler durağan hale getirilmiştir. Değişkenler durağan hale gelene kadar "d" defa farkı alınmış ve seri I (d) simgesi ile gösterilmiştir. Serilerin durağan olup olmadığının saptanması için Augmented Dickey-Fuller (ADF) (1979, 1981) Testi ile Birim Kök Testi (Unit Root Test) uygulanmıştır. Tablo: 2'de yer alan değerlerden de görüleceği gibi, ADF Test sonuçları $>\% 5$ olduğundan değişkenlerden altın fiyatlarının ve enflasyon oranı değerlerinin birim kök içerdiği anlaşılmıştır. Bu iki seri durağan olmadıklarından, her iki değişkeninde farkları alınarak, durağan hale getirilmişlerdir. Birinci dereceden fark alındığında her iki seri de durağan hale geldiğinden I(1) ile gösterilmişlerdir. Diğer değişkenler de ise birim kök olmadığı görülmüş, bu nedenle herhangi bir dönüşüm yapılmamıştır.

\begin{tabular}{|l|c|c|c|}
\hline \multicolumn{4}{|c|}{ ADF Birim Kök Testi } \\
\hline Değisskenler & Gecikme Değeri & ADF & Sonuç \\
\hline Lnaltin & 0 & $0,82^{*}$ & $\mathrm{I}(1)$ \\
\hline Lnenflasyon & 11 & $0,06^{*}$ & $\mathrm{I}(1)$ \\
\hline Lnfaiz & 10 & 0,02 & $\mathrm{I}(0)$ \\
\hline Lnkur & 6 & 0,04 & $\mathrm{I}(0)$ \\
\hline lnBïST & 0 & 0,00 & $\mathrm{I}(0)$ \\
\hline
\end{tabular}

(*) \%10 ve \%5 önem derecelerinde MacKinnon (1996) kritik değerlerine göre durağanlık yoktur hipotezi reddedilememektedir.

Tablo 2: Logaritmik Değişkenlerin Birim Kök Testleri

Birim kök sorunu ortadan kaldırıldıktan sonra, modelleme aşamasına geçilmiştir. İlk olarak, tüm değişkenler modele dahil edilmiş ve sonuçları incelenmiştir. Çoklu regresyon modeli ile bağımlı değişken olan ağırlıklı ortalama altın fiyatları açıklanmaya çalışılmıştır. Tüm değiş̧kenlerin yer aldığı model aşağıdaki biçimdedir.

$$
\text { dinaltin }_{t}=\beta_{0}+\beta_{1} \text { dlnenflasyon }_{t}+\beta_{2} \text { lnfaiz }_{t}+\beta_{3} \text { lnkur }_{t}+\beta_{4} \text { lnbist }_{t}+\varepsilon_{t}
$$

$\mathrm{Bu}$ modele ilişkin sonuçlar Tablo: 3'de verilmiş̧ir. Tablo: 3 'de de görüldüğü gibi, modelde yer alan bazı değişkenler $\% 5$ anlamlılık düzeyindeki kritik t-tablo değerini geçememiştir. t-istatistiklerine ait olasıllık değerlerine bakıldığında sabit terim, kur ve BIST 100 endeksine ilişkin katsayıların olasılıkları 0.05 değerinden daha büyük değer taşıdıklarından, istatistiki olarak anlamsız oldukları saptanmıştır. Bu nedenle bu değişkenlerin modelden çıkarılması gerektiği anlaşılmıştır. Modele bütün olarak bakıldığında ise F istatistiğine ait olasılık değeri $(0,02)$ 0,05 değerinden daha küçük olduğu için $\mathrm{F}$ istatistiğinin anlamlı olduğu görülmüştür.

\begin{tabular}{|l|c|c|c|c|}
\hline Değiskenler & Katsayı & t-istatistiği & Olasılık değeri & Sonuc \\
\hline Sabit Terim & 0,0083 & 0,810 & $0,42^{*}$ & Anlamsız \\
\hline Enflasyon & 0,0094 & 2,909 & 0,01 & Anlaml \\
\hline Faiz & 0,0085 & 2,151 & 0,04 & Anlamlı \\
\hline Kur & 0,0201 & 1,911 & $0,06^{*}$ & Anlamsız \\
\hline BíST 100 Endeksi & $-0,0014$ & $-0,321$ & $0,75^{*}$ & Anlamsız \\
\hline F-istatistiği & 3,169 & 0,02 & \\
\hline
\end{tabular}

\%5 anlamlılık düzeyine göre, olasılık değerleri 0.05 değerinden daha büyük olduğu için değişkenlerin katsayıları anlamlıdır hipotezi reddedilmektedir.

Tablo 3: Çoklu Regresyon Modeli Katsayı Sonuçları

Modelde yer alan değişkenlerin anlamsızlıklarının nedenini saptamak için değişkenler arasındaki korelasyon ilişsisine bakılmıştır. Korelasyon katsayısı 0 ila 1 arasında değişen bir değere sahiptir ve 0 değerine yaklaştıkça doğrusal ilişki zayıflamakta, 1 değerine yaklaştıkça kuvvetlenmektedir. Tablo: 4, modelde yer alan tüm değişkenlere ilişkin korelasyon tablosunu göstermektedir. Tablo: 4'den de anlaşllacağı gibi, bağımsız değişkenler arasında çoklu regresyon sonucunu etkileyecek derecede kuvvetli bağlantılar söz konusu değildir. Fakat dikkat çekici bir nokta altın fiyatları ile BİST 100 Endeksi arasında görülmektedir. İkili bağlantıya bakıldığında, BİST 100 Endeksi ile altın fiyatları arasındaki ilişkinin çok zayıf olduğu anlaşılmaktadır.

\begin{tabular}{|l|c|c|c|c|c|}
\hline & DInaltın & DInenflasyon & Lnbist & Lnfaiz & Lnkur \\
\hline DInaltın & 1 & 0.335 & -0.020 & 0.154 & 0.096 \\
\hline DInenflasyon & 0.335 & 1 & -0.033 & -0.037 & -0.099 \\
\hline Lnbist & -0.020 & -0.033 & 1 & 0.378 & -0.307 \\
\hline Lnfaiz & 0.154 & -0.037 & 0.378 & 1 & -0.507 \\
\hline Lnkur & 0.096 & -0.099 & -0.307 & -0.507 & 1 \\
\hline
\end{tabular}

Tablo 4: Model Değişkenlere Ait Korelasyon Tablosu 
$\mathrm{Bu}$ nedenle de, zaten modelde anlamsız bulunan BİST 100 endeks değeri modelden çıkarılarak, aşağıda tanımlanan yeni bir model oluşturulmuştur:

$$
\text { dlnaltin }_{t}=\beta_{1} \text { dlnenflasyon }_{t}+\beta_{2} \operatorname{lnfaiz}_{t}+\beta_{3} \operatorname{lnkur}_{t}+\varepsilon_{t}
$$

Tablo: 5'den de görüleceği gibi; t-istatistiklerine ilişkin olasılık değerleri 0,05 değerinden daha küçük olduğundan, yukarıdaki modelde yer alan tüm değişkenlerin istatistiksel olarak anlamlı olduğu anlaşılmıştır.

\begin{tabular}{|l|c|c|c|c|}
\hline Değișkenler & Katsayı & t-istatistiği & Olasılık değeri & Sonuç \\
\hline Enflasyon & 0,010 & 2,941 & 0,004 & Anlamlı \\
\hline Faiz & 0,010 & 2,194 & 0,030 & Anlamlı \\
\hline Kur & 0,020 & 2,289 & 0,024 & Anlamlı \\
\hline
\end{tabular}

Tablo 5: Çoklu Regresyon Modeli Katsayı Sonuçları

Modelin hata terimleri veya artık değerlerinin analiz sonuçları Şekil: 2'de yer almaktadır. Şekil: 2'den de anlaşılacağı gibi, altın fiyatlarına ilişkin gerçek değerlerle model tahminlerine ilişkin değerler arasında genel anlamda bir uyum söz konusudur. Sadece belirli aylarda, artık değerler kabul edilebilir düzeyinin üzerindedir.

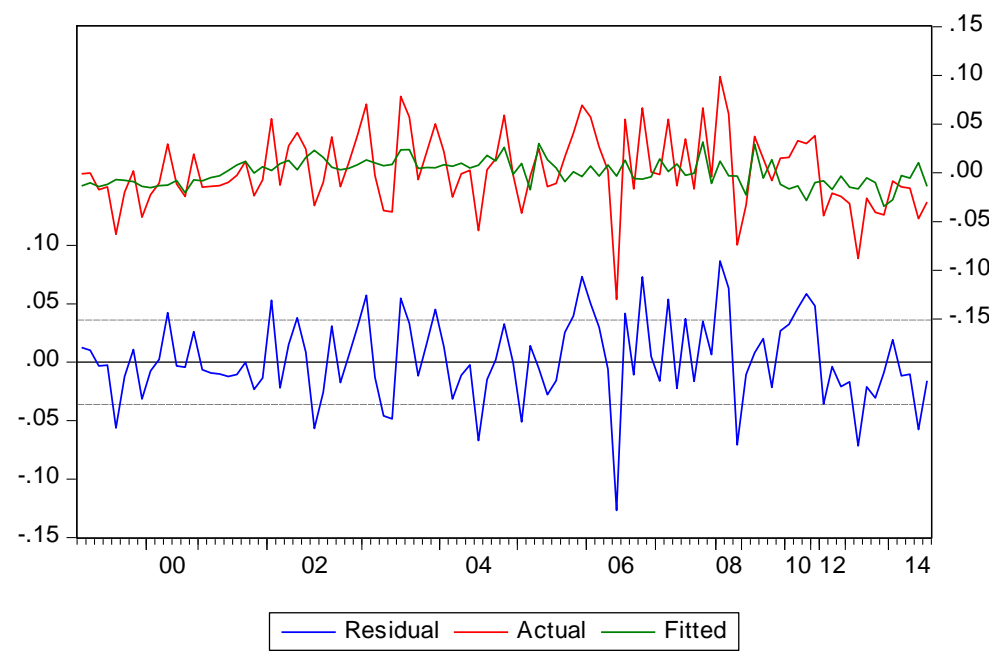

Şekil 2: Artık Değerlerin Analizi

$\mathrm{Bu}$ nedenle, modelde hata terimleri arasında bir seri korelasyon olup olmadığına bakılmıştır. Korelasyonun varlığını saptamak için Breusch-Godfrey Seri Korelasyon Testi kullanılmıştır. Teste göre 0,05 anlamlılık düzeyinde elde edilen $\mathrm{F}=0,246$ değeri kritik tablo değeri olan $\mathrm{F}(2,94)=0,78$ değerinden küçük olduğu için hata terimleri arasında yüksek dereceden seri korelasyon olmadığ 1 anlaşılmıştır. Hata terimlerinin sabit varyanslı (homoskedastik) olup olmadığının kontrolü için de, White'ın Değişen Varyans Testi uygulanmış ve test sonucunda elde edilen $F$ istatistiği $(F=0,41) 0,05$ anlamlılık düzeyinde kritik tablo değeri olan $F(6,92)=0,871$ 'den küçük olduğu için hata terimlerinin sabit varyanslı olduğu anlaşılmıştır. Hata terimlerinin normallik kontrolü JarqueBerra Normallik Testi ile yapılmış ve hata terimlerinin normal dağılmadığı görülmüştür.

Hata terimlerinin normallik testini geçememesinin sebebi Türkiye'deki ekonomik krizler olabileceği yaklaşımı ile incelenen dönemde ekonomik krizlerin etkilerinin yaşandığı aylara ait kukla değişken oluşturulmuştur. Bu nedenle, ekonomik krizlerin yaşandığı 2001 Nisan ayı, 2003 Mayıs ve Haziran ayları, 2008 Eylül ve Ekim ayları ile 2010 Kasım ve Aralık aylarına 1, diğer aylara 0 olacak şekilde bir kukla değişken kullanılmıştır. Kukla değişkenin modele eklenmesi ile model aşağıdaki şekilde ifade edilmiştir:

$$
\text { dlnaltin }_{t}=\beta_{1} \text { dlnenflasyon }_{t}+\beta_{2} \operatorname{lnfaiz}_{t}+\beta_{3} \text { lnkur }_{t}+\beta_{4} \text { kukla }_{t}+\varepsilon_{t}
$$

Tablo: 6 , kukla değişkenin de yer aldığı bu modele ait sonuçları göstermektedir. Tablo: 6'dan da görüleceği gibi; tüm açıklayıcı değişkenler \%5 düzeyinde, anlamlı çıkmıştır. Bu durumda, kullanılan son modelin uygun bir model olduğu anlaşılmıştır. Modele ilişkin hata terimlerinin tekrar analizi yapılarak elde edilen modelin bir sorun taşıyıp taşımadığına bakılmıştır.

\begin{tabular}{|l|c|c|c|l|}
\hline Değişkenler & Katsayı & t-istatistiği & Olasılık değeri & Sonuç \\
\hline Enflasyon & 0,010 & 3,419 & 0,0009 & Anlaml 1 \\
\hline Faiz & 0,006 & 1,771 & 0,0798 & Anlaml \\
\hline Kur & 0,014 & 1,944 & 0,0548 & Anlaml 1 \\
\hline Kukla Değişken & 0,062 & 2,377 & 0,0195 & Anlaml 1 \\
\hline
\end{tabular}

Tablo 6: Çoklu Regresyon Modeli Katsayı Sonuçları

Bu sonuçlardan elde edilen katsayılar kullanılarak, modeli aşağıdaki gibi ifade etmek mümkündür:

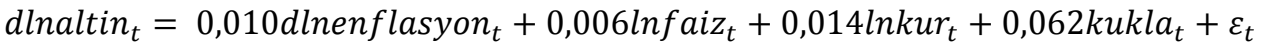


Hata terimlerine ait artık değer analizi yapılarak Şekil: 3 elde edilmiştir. Şekil: 3 'den de anlaşılacağı gibi, altın fiyatlarına ilişkin gerçek değerlerle model tahmin değerleri arasında genel bir uyum olmakla beraber, belirli bazı aylarda model tahmin değerlerinde sapmaların olduğu görülmektedir.

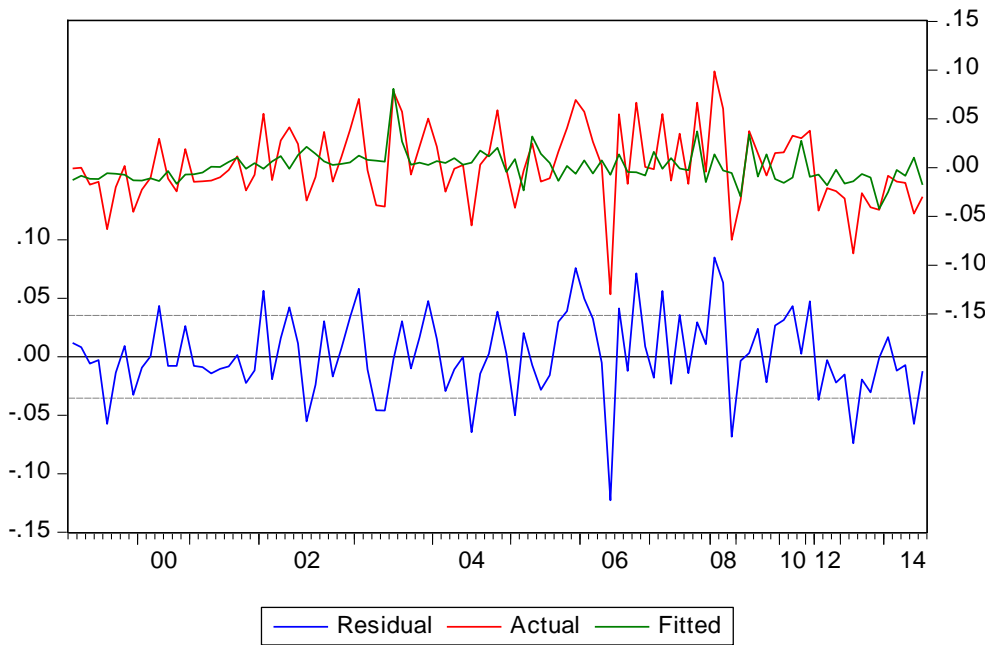

Şekil 3: Artık Değerlerin Analizi

Hata terimlerine ilişkin varsayımların sağlanıp sağlanmadığını saptamak için Breusch-Godfrey Seri Korelasyon Testi yapıldığında, 0.05 anlamlılık düzeyinde hata terimleri arasında seri korelasyon olmadığ görülmüştür. $\mathrm{F}=$ 0,282 değeri kritik tablo değeri olan $\mathrm{F}(2,93)=0,75$ değerinden küçük çıkmıştır.

Modele ilişkin Jarque-Bera normallik testi ile hata terimlerinin normal dağılıp dağılmadığı test edilmiş, \%10 anlamlılık düzeyinde Jarque-Bera test sonuçlarının anlamlı olduğu ve verilerin normal dağıldığı görülmüştür. Son olarak, White'ın Değişen Varyans Testi yapılmış ve $F=0,5728$ değeri kritik tablo değeri olan $F(8,90)=0,7976$ değerinden küçük çıktığı için hata terimleri arasında değişen varyans sorunu olmadığı anlaşılmıştır.

\section{Bulguların Değerlendirmesi}

Çalışmada Türkiye'de dolar/ons cinsinden aylık ortalama altın fiyatlarına (piyasasına) etki edebileceği düşünülen seçilmiş dört temel faktör kullanılmıştır. Kullanılan faktörler; TÜFE bazlı aylık enflasyon, günlük 1 USD + 1 EUR cinsinden hesaplanan aylık ortalama döviz sepet kuru, borsada işlem gören en büyük yüz şirketi kapsayan BISST-100 endeksinin aylık ortalama değerleri ve tüm ticari bankaların aylık vadeli mevduat faiz oranlarından hesaplanan reel aylık ortalama faiz oranıdır. Belirtilen bağımsız değişkenlerle bağımlı değişken olarak öngörülen altın fiyatları arasında modelleme yapılmış, farklı modeller birbirleriyle karşılaştırılarak, ekonometrik olarak anlamlı ve açıklama gücü en yüksek model seçilmiştir.

Modele eklenen ve her biri ulusal ekonominin barometresi olan bağımsız değişkenlerden BİST-100 Endeksi dışında diğer üç faktörün istatistiksel olarak anlamlı oldukları anlaşılmıştır. Kullanılan modellerin bu çıktısı, BİST 100 endeks değerinin Türkiye'deki altın fiyatları üzerinde etkisinin olmadığını göstermiştir. Başka bir deyimle; diğer değişkenlerin anlamlı çıkmasının bir sonucu olarak, 01.1999-12.2014 döneminde Türkiye'deki altın fiyatları üzerinde enflasyonun, sepet döviz kurunun ve aylık vadeli mevduat faiz oranının her birinin etkili olduğu anlaşılmıştır. Modele ayrıca kriz aylarının etkilerinin arındırılmasına yönelik bir kukla değişken eklenmiş ve krizlerin etkisi giderilerek model daha anlamlı hale getirilmiştir.

Modelin açıklama gücü olan $\mathrm{R}^{2}$ değeri \%16.6'dır. Türkiye'deki altın fiyatları üzerinde ulusal faktörlerin hangi düzeyde etkili olduklarını gösteren $\mathrm{R}^{2}$ 'nin modeldeki açıklama gücü çok yüksek değildir. Bu sonucun temel nedeni, -çalışmanın yazın taraması kısmında da belirtildiği gibi- Türkiye'deki altın piyasası ya da fiyatları üzerinde ulusal değişkenlerin yanı sıra (özellikle) Londra ve diğer uluslararası borsalarda oluşan altın fiyatları ile diğer finansal varlıkların fiyat hareketlerinin de etkilerinin olmasıdır. Bu faktörlerin modelde yer almaması, açıklama gücünün nispeten düşük kalmasına yol açmakla birlikte istatistiksel olarak bir sorun oluşturmamaktadır. Çünkü çalışmamızda, sadece ulusal faktörlerin altın fiyatları üzerine etkilerinin incelenmesi amaçlanmıştır.

\section{Sonuç}

Üretim hacminin sınırlı olması, arzının fiyatında meydana gelen değişikliklerden kısa vadede etkilenmemesi, fiziksel ve kimyasal özelliklerinden ötürü yerini dolduracak başka bir materyalin bulunamamış olması ve rezerv aracı olarak kullanılması gibi özellikleri, altını diğer madenlerden ayırmaktadır. En eski kıymetli metal türlerinden biri olan altın, önemli bir endüstri ürünü olmasının yanı sıra bir yatırım aracı olarak küresel ve yerel borsaların en çok işlem gören kıymetli madenleri veya finansal araçları arasındadır. 
Türkiye'de 1980'li yıllardan sonra ekonomi stratejisinin değiştirilerek serbest piyasaya geçiş politikalarının uygulanmaya başlanılması ile altın sektöründe kayda değer gelişmeler yaşanmıştır. Türkiye'deki altın talebinin ana kaynağını tasarruf ve yatırım amaçlı altın oluşturmaktadır. Ayrıca; spekülatif amaçlı, Merkez Bankası ve endüstriyel kaynaklı altın talebi ile düşük işçilik maliyetine dayalı yurt dışının talebi diğer önemli kaynaklardır. Talebe karşı sınırlı da olsa bir altın madenciliğine dayalı arzdan söz etmek mümkündür. Fiziki altın ticaretinin yanında borsada altına dayalı menkul kıymetler işlem görmekte, küçük ve büyük yatırımcının karşısında geniş bir ürün yelpazesi bulunmaktadır.

$\mathrm{Bu}$ çalışmamızda Türkiye'de altın piyasasına etki eden temel faktörler, e-views paket programından faydalanılarak çoklu regresyon modeli yardımı ile incelenmiştir. Çalışmada Ocak 1999 - Aralık 2014 dönemindeki aylık bazlı veriler kullanılmıştır. Modelin bağımlı değişkenini, dolar/ons cinsinden ağırlıklı ortalama altın fiyatları oluşturmuş, bağımsız değişkenler olarak TÜFE bazlı aylık enflasyon oranları, aylık ortalama sepet döviz kurları, aylık ortalama BİST 100 Endeks değerleri ve ortalama aylık vadeli mevduat faiz oranları kullanılmıştır.

Yapılan ekonometrik analizler değerlendirildiğinde; Türkiye'de altın piyasası fiyatları üzerinde enflasyon oranlarının, mevduat faiz oranlarının ve sepet döviz kurlarının istatistiksel olarak anlamlı sonuçlar yarattıkları, fakat BİST 100 endeks değerlerinin piyasa fiyatları üzerinde anlamlı istatistiki etkisinin bulunmadığı bilgisine ulaşılmıştır. Modelin sonuçlarına göre; Ocak 1999 - Aralık 2014 döneminde, herhangi bir " $\mathrm{t}$ " zamanında, altın fiyatları üzerinde enflasyonun etkisi \%1,0, faizin etkisi \%0,6 olmakta, sepet döviz kuru ise altın fiyatlarını \% 1,4 oranında ve pozitif yönde etkilemektedir. Kriz dönemlerinde ise bu parametrelerin etkileri istatistiki olarak anlamsızlaşmakta ve altın fiyatlarının değişkenliği (volatiliteleri) ya da dalga boyu hızla artmaktadır.

Çalışmanın sonuçlarının, literatürde yer alan, Türkiye’yi, diğer ülkeleri ve uluslararası borsaları irdeleyen çok sayıda ampirik çalışmanın ulaştığı sonuçlarla uyumlu olduğu görülmüşsür. Az sayıda çalışmada, sadece borsa endekslerine ilişkin sonuçların farklı olduğu veya endeksin sınırlı da olsa altın fiyatlarını etkilediği görülmüştür.

Analizde elde edilen modelin açıklayıcı gücü olan $\mathrm{R}^{2}$ değeri \%16.6'dır. Modelin önemli çıktılarından birisini oluşturan $\mathrm{R}^{2}$ 'nin açıklama gücünün yüksek olmamasının sebebi; Türkiye'deki altın piyasası fiyatları üzerinde ampirik analizimizde kullanılan bu üç değişkenin dışında başka parametrelerin de etkisinin bulunmasıdır. Diğer ulusal faktörlerin ve kıymetli metallerin yanı sıra uluslararası faizler, kurlar ve altın borsalarındaki fiyat hareketlerinin de modele eklenmesi, başka araştırmaların konusunu oluşturabilir.

\section{Kaynakça}

- Aslan, S. (1999) Altın ve Altına Dayalı İşlemler Muhasebesi, İstanbul Altın Borsası Yayınları, İstanbul.

- Atay, G. (2013) “Dünya'da ve Türkiye'de Altın Piyasaları ve Türkiye'de Altın Fiyatlarını Etkileyen Faktörlerin İncelenmesi”, Yayınlanmamış Yüksek lisans Tezi, T.C. İstanbul Üniversitesi, İstanbul.

- Bordo, M. D. (1993) “The Gold Standard, Bretton Woods and Other Monetary Regimes: An Historical Appraisal", NBER Working Paper Series, No.4310, Cambridge.

- Borsa İstanbul, 2014. Veriler, http://www.borsaistanbul.com/veriler/verileralt/kmtp/piyasa-verileri

- Cheng, W. H., Su J. B. ve Tzou, Y. P. (2009) "Value-at-Risk Forecasts in Gold Market Under Oil Shocks", EuroJournals Publishing, Issue: 4.

- Çıtak, S. (2004) 24 Ayar, Düş Yıldızı Yayınları, Ankara.

- $\quad$ Do, G. Q., Mcaleer, M., ve Sriboonchitta, S. (2009) "Effects of International Gold Market on Stock Exchange Volatility: Evidence From Asian Emerging Stock Markets”, Economics Bulletin, Volume: 29, Issue: 2.

- Durmuşoğlu, A. B. (1997) “Türkiye Altın Piyasası”, Yayınlanmamış Yüksek Lisans Tezi, T.C. İstanbul Üniversitesi, İstanbul.

- Granger, C. W. J., ve Newbold P. (1974) "Spurious Regressions in Econometrics”, Journal of Econometrics, Nottingham.

- Halisçelik, E. (1998) “Kıymetli Madenler Kıymetli Madenler Borsaları”, Etüd Raporu, T.C. Başbakanlık Hazine Müsteşarlığı Hazine Kontrolörleri Kurulu, Ankara.

- Ho, W. R. J., Wang, Y. C. ve Liou, G. J. (2010) “The Interactive Relationship Among International Gold Indices, Gold Futures And The Overall Economy”, African Journal Of Business Management, Vol. 4 (9), Taiwan.

- Hsieh, C. T. ve Christina, D. R. (2004) "Was The Federal Reserve Constrained By The Gold Standard During The Great Depression”, California: University of California, Berkeley.

- Kaplan, K. (2004) Türkiye'de Kuyumculuk ve Altın, İstanbul Ticaret Odası Yayınları, İstanbul.

- Maden Tetkik ve Arama Genel Müdürlüğü (MTA) (2012) Madencilik Sektörü ve Madencilik Raporu,, http://www.mta.gov.tr. 
- Menase, M. (2009) “Altın Piyasası ve Türkiye'de Altın Fiyatlarını Etkileyen Faktörlerin Analizi”, Yayınlanmamış Yüksek Lisans Tezi, T.C. Marmara Üniversitesi, İstanbul.

- Özman, S. (1989) “Türkiye'de Altın Ticareti”, Yayınlanmamış Yüksek Lisans Tezi, T.C. İstanbul Üniversitesi, İstanbul.

- $\quad$ Öztekin, Y., Tağtekin, Ö., ve Güvenç, M. (2002) Tarih Boyunca Türkler'de Altın, İstanbul Altın Borsası Yayınları, İstanbul.

- Öztürk, N. (2002) “IMF'nin Değişen Rolü ve Gelişmekte Olan Ülke Ekonomilerine Etkileri”, Ankara Üniversitesi SBF Dergisi, C. 57, S. 4, s. 98

- Polat, M. (2013) “Altın Fiyatını Etkileyen Faktörlerin Zaman Serisi Analiziyle Tespiti”, Yayınlanmamış Yüksek Lisans Tezi, T.C. Atatürk Üniversitesi, Erzurum.

- Poyraz, E., ve Didin, S. (2008) “Altın Fiyatlarındaki Değişimin Döviz Kuru, Döviz Rezervi ve Petrol Fiyatlarından Etkilenme Derecelerinin Çoklu Faktör Modeli İle Değerlendirilmesi”, Süleyman Demirel Üniversitesi İktisadi ve İdari Bilimler Fakültesi Dergisi, C. 13, S. 2, s. 93 - 104.

- Sadeghzadeh, K., ve Eren, M. (2012) “Altın Fiyatları Değişiminin Altın Madeni Sektörü ve İşleyen Sektördeki Firmaların Hisse Senedi Getirilerine Etkisinin Eşbütünsellik Analizi İle İncelenmesi”, 16. Finans Sempozyumu, Erzurum.

- $\quad$ Sverdrup, H., Koca, D., ve Granath, C. (2012) "Modelling The Gold Market, Explaining The Past and Assessing The Physical And Economical Sustainability Of Future Scenarios”, 30th International Conference of the System Dynamics Society, Switzerland.

- Tokat, H. A. (2013) “Altın, Döviz ve Hisse Senedi Piyasalarında Oynaklık Etkileşimi Mekanizmasının Analizi”, İstanbul Üniversitesi Siyasal Bilgiler Fakültesi Dergisi, No: 48, ss. 151-162.

- Topçu, N., ve Aksoy, M. (2012) “Gelişmekte Olan Ülkelerde Bir Yatırım Aracı Olarak Altın: Türkiye Örneği”, 10. Uluslararası Türk Dünyası Sosyal Bilimler Kongresi.

- Toraman, C., Başarır, Ç. ve Bayramoğlu, M. F. (2011) “Altın Fiyatlarını Etkileyen Faktörlerin Tespiti Üzerine: MGARCH Modeli ile Bir İnceleme”, Uluslararası Alanya İşletme Fakültesi Dergisi, C. 3, S. 1, s. 120.

- Trück, S., ve Liang, K. (2012) "Modelling and Forecasting Volatility in the Gold Market", International Journal Of Banking and Finance, Volume: 9, Issue: 1, Article 3, Australia.

- Tully, E., ve Lucey, B. M. (2007) “A Power GARCH Examination of the Gold Market”, Research in International Business And Finance, Volume: 21, pp. 316-325.

- Türkiye İstatistik Kurumu, 2014. Konularına Göre İstatistikler, http://www.tuik.gov.tr/PreTablo.do?alt_id=1064

- Türkiye Cumhuriyeti Merkez Bankası, 2014. Elektronik Veri Dağıtım Sistemi, http://evds.tcmb.gov.tr/

- Yüksel, B. (2012) “Uluslararası Finansal Krizlerde Altın Fiyatlarının Hareketliliği”, Yayınlanmamış Yüksek Lisans Tezi, T.C. Marmara Üniversitesi, İstanbul. 


\title{
2008 Finansal Krizinin Türk İmalat Firmalarının Finansal Performanslarına Etkileri \\ The Effects of the 2008 Financial Crisis on the Financial Performance of Turkish Manufacturing Companies
}

\author{
Prof. Dr. Reşat Karcıoğlu (Atatürk University, Turkey) \\ Asst. Prof. Dr. Ensar Agırman (Atatürk University, Turkey) \\ Ph.D. Candidate Durmuş Yıldırım (Atatürk University, Turkey)
}

\begin{abstract}
The financial crisis of 2007-2010 also known as the Global Financial Crisis and 2008 financial crisis, was considered by many economists to be the worst financial crisis since the Great Depression of the 1930's. It contributed to the failure of key businesses, declines in consumer wealth estimated in the trillions of U.S. dollars, substantial financial commitments incurred by governments, and a significant decline in economic activity. The financial crisis of 2007/08 which began in the United States had little impact on Turkish economy in the beginning stages. However, as a result of the economic downturn in global economics, Turkish economy has been also affected by its domino effect. The aim of this study is to characterize the impact of the 2008 global financial crisis on the financial performance of manufacturing companies listed on Borsa Istanbul, Turkey. Financial analysis will be conducted on 192 publicly listed manufacturing companies. Twelve financial ratios will be examined to determine the profitability, liquidity, activity, leverage and solvency of these companies over the period between 2006 and 2010. A data envelopment analysis will be applied to measure the performance of manufacturing firms before and after the financial crisis of 2008. Findings of this paper may be used by the managements to mitigate the effects and to enhance future performance of these companies have been uncovered. The analysis and observations will be invaluable to researchers intending to study how the manufacturing industry responds to a future slump in demand.
\end{abstract}

\section{Giris}

2007 yılı Ağustos ayında patlak veren ve Amerikan sub-prime mortgage piyasasındaki çöküş ile birlikte etkisini artıran 2008 finansal krizinin, oluşturduğu domino etkisi ile hemen hemen bütün dünya ülkelerini etkilediği söylenebilir. "Başlangıcından itibaren küresel olma" özelliği ile günümüze kadar yaşanmış olan ekonomik ve finansal krizlerden ayrılan 2008 küresel finansal krizi (Tepav, 2014) birçok ekonomist tarafından 1929 Büyük Buhranından sonra, dünyanın yaşadığı en büyük finansal kriz olarak tanımlanmaktadır (Soros, 2010: 7).

Dünya ekonomi ve finans tarihinde unutulmayacak izler bırakan 2008 küresel finansal krizini, diğer krizlerden ayıran önemli farklılıklarından biri de 2008 finansal krizinden önceki krizlerin genellikle az gelişmiş ve gelişmekte olan piyasa ekonomilerini etkilemiş olmasına rağmen, 2008 küresel finansal krizinin daha çok gelişmiş ülke ekonomilerini etkilemiş olmasıdır. Bu durumun temel nedeni gelişmiş ülke finansal piyasalarında finansal türev ürünlerine diğer ülkelere nazaran daha çok yer verilmesidir (Özkan, 2008: 9).

Başlangıç itibariyle finansal bir çalkantı olarak adlandırılan kriz, sonrasında tam manası ile bir finansal krize dönüşmüş ve bir süre yalnızca finansal kurumları etkilemiştir. Sonrasında giderek daha hızlı bir şekilde diğer sektörlere de yayılan kriz, reel sektörü de etkisi altına almıştır. Dünya ekonomilerinde yaşanan çöküş, yayılma hızı ile benzersiz bir etkiye sahipti öyle ki Eylül 2008'den Ocak 2009 arasındaki dört aylık süre içerisinde dünya ticaretindeki azalış \%30'lara varmıştı, ayrıca dünya ülkelerinin Gayri Safi Yurtiçi Hasıla'larındaki düşüş aynı dönem için \%3 olarak hesaplanmaktayd1 (Bricongne vd. 2012, 134).

Göstergelerde meydana gelen bu düşüşler II. Dünya Savaşından beri yaşanan en büyük daralmayı işaret etmektedir (Dömbekci, 2014: 34). Dünya ekonomilerinde yaşanan bu daralma, uluslararası ticaret mekanizmasının yavaşlamasına, birçok ülke ekonomisinde üretimin daralmasına ve tüm bunların sonucu olarak işsizliğin artmasına neden olmuştur.

Türkiye ekonomisi açısından incelendiğinde, finans sektörünün temel yapı taşları olan bankaların krizden hemen hemen hiç etkilenmedikleri söylenebilir. Zira 2000 - 2001 mali krizlerinde büyük sarsıntılar yaşayan ve böylesi sıkıntıları yeniden yaşamamak adına bankacılıkta yapısal reformlarını tamamlayan Türkiye bankacılık sektörü 2008 finansal krizi karşısında sağlam kalabilmeyi başarmıştır (Afşar; 2011: 169). Bununla birlikte, gelişmiş Avrupa ülkeleri ile yoğun ticari faaliyetler içerisinde bulunan reel sektör temsilcileri krizin oluşturduğu olumsuz koşullardan etkilenmişlerdir. Krizden etkilenen gelişmiş ülke ekonomilerinden gelen talep miktarlarında, 2008 yılı dördüncü çeyreği itibariyle sert düşüşlerin yaşanması, küresel kredi kaynaklarının azalması ve kredi maliyetlerindeki artışlar (Ertuğrul ve dĭg, 2010, 62-63) sonucu, Türkiye ekonomisi içerisinde yer alan firmaların ekonomik ve mali pozisyonlarında da daralmalar meydana gelmiştir. 
Çalışmanın amacı, 2008 küresel finansal krizinin Borsa İstanbul (BIST) İmalat Sektöründe faaliyet gösteren firmaların finansal performansları üzerindeki etkisinin araştırılmasıdır. Çalışma dönemi olarak finansal kriz öncesi ve sonrasını kapsayan 2006-2010 yılları seçilmiştir. Bahsedilen dönemde imalat sanayinde faaliyet gösteren 135 firmaya ait verilere ulaşılmış olup imalat sanayi kendi içinde 8 alt sektöre ayrılarak analize tabi tutulmuştur. Bu bağlamda, çalışma dört ana bölümden oluşmaktadır. İlk bölümde 2008 küresel finansal krizinin firma performansına etkisi ölçen araştırmaların yer aldığı literatür taraması bulunmaktadır. İkinci ve üçüncü bölümlerde veri seti ve çalışmanın bulgularına yer verilmiştir. Çalışma genel bir değerlendirmenin yapıldığı sonuç bölümü ile tamamlanmaya çalışılmıştır.

\section{Literatür}

2008 finans krizinin patlak vermesinden bugüne kadar aradan geçen süre içerisinde küresel finansal krizin dünya ve Türkiye ekonomisi üzerindeki etkisini mikro ve makro bazda ölçen birçok çalışma gerçekleştirilmiştir. Bu çalışmaların temel amaçları arasında krizin oluşturduğu etkileri belirlemeye ve bu etkilerin yayılmasına neden olan çeşitli faktörleri araştırmaya yönelik olanlar olduğu kadar, 2008-2009 krizi boyunca firma performanslarını ölçen çalışmalarda literatürde kendilerine yer edinmektedirler.

Claessens ve diğ. (2011) 42 ülkedeki imalat sanayi sektöründe yer alan firmaların performanslarını inceledikleri çalışmalarında krizin toplam talebi etkilemesinden dolayı firmalar üzerinde çok büyük bir olumsuz etki oluşturduğunu ortaya koymaktadır.

Yunanistan'daki gıda üretim firmalarının 2006 ve 2011 yılları arasındaki performanslarını panel veri analizi ile değerlendirdikleri çalışmalarında Notta ve Vlachvei (2014) kriz öncesi dönemde piyasa payının firma karlılığına pozitif ve istatistiki olarak etki eden tek faktör olduğunu ve firma büyüklüğü ile karlılık arasında doğrusal bir ilişkinin bulunduğunu tespit etmişlerdir. Bununla birlikte, kriz döneminde bu firmaların piyasa paylarının, likidite pozisyonlarının ve kaldıraç derecelerinin karlılıkları üzerinde anlamlı bir etkiye sahip olduklarını ve bu faktörlerin firma karlılıklarında meydana gelen farklılıkları açıkladığını ortaya koymaktadırlar.

Avrupa ve Kuzey Amerika Firmalarının krize karşı tepkilerini 2004 ve 2011 dönemleri arasında iki aşamalı en küçük kareler regresyon modeli ile araştıran Filbeck, Louie ve Zhao (2013) büyük firmaların aktif karlılıklarında kriz sonrası dönemde bir azalmanın meydana geldiğini ve bununla birlikte en büyük firmaların aktif karlılıkların da ise aynı dönemde bir artışın meydana geldiğini ortaya koymaktadırlar. Ayrıca, Kuzey Amerika merkezli şirketlerin Avrupa'ya olan satışlarında istatistiki olarak anlamlı bir azalmanın meydana geldiği ve satışlarını Avrupa dışı pazarlara taşıyabilen şirketlerin aktif karlılıklarında artış meydana gelirken bunu başaramayan şirketlerde azalmaların oluştuğu yine yazarlar tarafindan belirtilmektedir.

Baeka, Kangb ve Park (2004) OLS regresyon yöntemi ile kriz süresince firma değerini tanımlama da kurumsal yönetim ölçütlerinin önemini Güney Kore Borsasında listelenen firmalardan finansal sektörde faaliyet göstermeyen 644 firmayı ele alarak inceledikleri çalışmalarında yüksek yabancı ortaklık oranına sahip şirket hisse senet değerlerinde kriz döneminde çok küçük bir azalmanın meydana geldiğini göstermektedirler. Aynı zamanda yüksek bilgilendirme kalitesine ve alternatif dış finansman kaynaklarına sahip firmaların krizden daha az etkilendiklerini ifade etmektedirler.

Stockholm Borsasında listelenen firmaları parametrik ve yarı parametrik regresyon yöntemleri incelediği çalışmasında Asgharian (2003) kriz dönemlerinde yüksek kaldıraç oranlarına sahip olan firmaların normal dönemden daha düşük satış oranlarına sahip olduklarını tespit etmektedir.

Müslümov ve Karataş (2001) araştırmalarında Asya krizinin Türk imalat sektörü üzerindeki etkilerini İMKB'ye kayıtlı 70 şirketin finansal tablolarını kullanarak ele almışlardır. Araştırma sonuçları tekstil sektörünün krizden etkilendiğini bununla birlikte gida ve çimento sektörlerinin söz konusu krizden etkilenmediğini ortaya koymaktadır.

Aşıkoğlu ve Ögel (2006) 2001 mali krizinin imalat sektörü üzerindeki etkilerini finansal tablolar yardımıyla incelemiş ve uyguladıkları t-testi ve oran analizi sonuçlarına göre firmaların kaynak yapısı içerisinde toplam öz kaynak miktarının azaldığını, kısa vadeli borçlanmaların arttığını ve sonuç olarak borç öz kaynak oranının arttığını tespit etmişlerdir.

Emir, Aslantürk ve Sevim (2011) tarafından gerçekleştirilen araştırmada, 2008 finansal krizinin Borsa İstanbul'da tekstil, gıda, içki ve tütün sektörlerinde işlem gören firmalar üzerinde oluşturduğu etki finansal oranlar aracılığıyla ortaya konulmuştur. Gerçekleştirilen oran analizi ve bağımlı örneklem t-testi sonuçlarına göre tekstil sektörünün 2008 krizinden etkilendiği, bununla birlikte gıda, içki ve tütün sektörünün küresel mali krizden etkilenmediği sonucuna varılmıştır.

Uyar ve Okumuş (2010) 2008 finansal krizinin İMKB üretim sektöründe yer alan 124 firma üzerine olan etkilerini finansal oranlar yardımıyla incelemişlerdir. Çalışma sonuçlarına göre 2008 kriz dönemi süresince firmaların likidite kabiliyetlerinin azaldığ elde etme güçlerinde zayıflamaların meydana geldiğini, tüm bunların sonucu olarak firmaların zarar ettikleri sonucunu ortaya koymaktadırlar. 
Karahan ve Özduran (2012) İMKB'ye kayıtlı 27 tekstil firmasının 2008 finansal krizinden ne ölçüde etkilendikleri sorusuna yanıt aradıkları çalışmalarında, söz konusu firmaların 2006-2010 dönemi arasındaki finansal verilerini incelemişlerdir. Elde ettikleri veri setini t-testi ile analiz eden yazarlar firmaların kriz döneminde likidite problemleri yaşadıklarını ortaya koymaktadırlar. Ayrıca, firmaların borçluluk oranlarında artışlar ve karlılık oranlarında azalışlar meydana gelmesi krizin olumsuz etkileri olarak değerlendirilmiştir.

Gümüş ve Aydemir (2014) tarafindan gerçekleştirilen araştırmada Borsa İstanbul' da işlem görmekte olan Çimento sektörü ve Otomotiv ve Yan Sanayisi sektörlerinde toplam 59 adet firmanın bilançoları incelenmiş ve 2008 finansal krizi öncesi ve sonrasında firma bilançolarının gösterdikleri farklılıklar ortaya konulmuştur. Araştırma sonuçlarına göre sektörlerin krizden farklı derecelerde etkilendikleri, kriz sonrası dönemde kriz öncesi döneme nazaran çok daha kötü bir finansal yapı ile karşı karşıya kaldıkları, ayrıca öz sermaye miktarlarında azalmalar meydana gelirken yabancı kaynak kullanımının arttığı bu durumun da karlılıkları olumsuz etkilediği tespit edilmiştir.

\section{Veri Seti ve Yöntem}

Bu çalışmada, 2008 küresel finansal krizin Borsa İstanbul (BIST) İmalat sektöründe faaliyet gösteren firmaların finansal performansları üzerindeki etkisi araştırılmıştır. Çalışma dönemi olarak finansal kriz öncesi ve sonrasını kapsayan 2006-2010 yılları seçilmiştir. Bahsedilen dönemde imalat sanayinde faaliyet gösteren 135 firmaya ait verilere ulaşılmış olup imalat sanayi kendi içinde 8 alt sektöre ayrılarak analize tabi tutulmuştur. Alt sektörlere ait firma sayıları Tablo 1'de gösterilmiştir.

\begin{tabular}{|l|l|}
\hline İmalat Sanayi Alt Sektörleri & Firma \\
\hline Gida, İçki ve Tütün Sanayi & 22 \\
\hline Dokuma, Giyim Eşyası ve Deri Sanayi & 18 \\
\hline Orman Ürünleri, Mobilya, Kağıt Ürünleri, Basım ve Yayım Sanayi & 15 \\
\hline Petrol, Kimya ve Plastik Sanayi & 19 \\
\hline Taș ve Toprağa Dayalı, Cam, Cam Ürünleri Sanayii & 25 \\
\hline Metal Sanayi & 18 \\
\hline Elektrik Makinaları ve Aygıtları Sanayi & 8 \\
\hline Taşıt Araçları Sanayi & 10 \\
\hline Toplam & $\mathbf{1 3 5}$ \\
\hline
\end{tabular}

Tablo 1: Imalat Sanayi Alt Sektörleri

Çalışmada kullanılan veriler FINNET veri tabanından elde edilmiş olup verilerin analizinde GAMS 23.8.2 programından faydalanılmıştır.

Firmalara ait finansal performansların ölçümünde, çok sayıda girdi ve çok sayıda çıktının olması durumunda doğrusal programlama tabanlı bir etkinlik ölçme tekniği olan Veri Zarflama Analizi (VZA) kullanılmıştır. VZA'da bir karar biriminin göreli etkinliği toplam ağırlıklı çıktılarının toplam ağırlıklı girdilerine oranı olarak tanımlanmaktadır. Doğrusal programlama tabanlı VZA modelinde her bir birim için o birimin etkinliği maksimize edilir. Modelin kısıtları ise bu ağırlıklar diğer karar birimlerine de uygulandığında hiçbir karar biriminin etkinliğinin 1'i geçmemesini sağlayan kısıtlardır (Ulucan 2007). Radyal ve radyal olmayan olmak üzere literatürde iki tür etkinlik ölçüsü vardır. Radyal yaklaşımlar CCR ve BCC modelleriyle ifade edilir. CCR modeli Charnes , Cooper ve Rhodes (1978) tarafından geliştirilen VZA modelidir. Bu modelde karar verme birimlerine ait toplam etkinlik skorları ölçeğe göre sabit getiri varsayımı altında hesaplanmaktadır. Bu modelde toplam etkinlik skoru, teknik etkinlik ve ölçek etkinliği değerlerinin çarpımı sonucu bulunarak yetersiz karar birimlerini tespit etmeye çalışır (Charnes, Cooper et al. 1978). BCC modeli ise Banker, Charnes, Cooper (1984) tarafından geliştirilmiştir (Banker, Charnes et al. 1984). Bu model, CCR'den farklı olarak ölçeğe göre değişken getiri altında teknik etkinliği ölçmektedir. Radyal modellerin zayıf yönü radyal olmayan girdi ve çıktılardaki aylaklıkları ihmal etmesidir. Radyal olmayan Aylak Temelli Model ( Slack Based Model) direkt aylaklıklarla ilgilenir, ancak bu modelin zayıf yönü ise girdi ve çıktıların radyal özelliklerini ihmal etmesidir. SBM radyal olmayan bir etkinlik ölçüsüdür. SBM, CCR etkinlik ölçüsündeki zayıf etkinlik değerlerini yansıttığı gibi etkinsizlik değerlerini de iyi bir şekilde tespit eder. Ayrıca SBM, karar verme birimlerinin etkinliğini tek periyotta ölçen bir modeldir. Çalışmamızda Tone (2001) tarafından geliştirilen SBM ( Slack Based Model - Aylak Temelli Model ) kullanılmıştır. Bu model şu şekildedir: Modelde üretim imkanları kümesi $P$ olarak tanımlanmış olup,

$P=\{((x, y) \mid x \geq X \lambda, y \leq Y \lambda, \lambda \geq 0)\}$

$\lambda, R^{n}$ 'nin içinde negatif olmayan vektördür. DMU $\left(x_{0}, y_{o}\right)$,SBM'deki karar birimlerini tanımlayan bir ifade olarak kabul edilir;

$x_{o}=X \lambda+s^{-}$,

$y_{o}=Y \lambda-s^{+}$,

$s^{-} \in R^{m}$ ve $s^{+} \in R^{s}$ vektörleri aylaklık (slacks) olarak adlandırılıp sırasıyla fazla girdiyi ve eksik çıktıyı gösterir. $X>0$ ve $\lambda \geq 0$ koşullarında $x_{o} \geq s^{-}$. SBM formülü şöyledir (Tone 2001). 
[SBM]

$0 \leq \rho \leq 1$

$$
\begin{gathered}
\text { minimize } \rho=\frac{1-(1 / m) \sum_{i=1}^{m} s_{i}^{-} / x_{i o}}{1-(1 / s) \sum_{r=1}^{s} s_{r}^{+} / y_{r o}} \\
x_{i o}=\sum_{j=1}^{n} x_{i j} \lambda_{j}+s_{i}^{-} \quad i=1, \ldots, m \\
y_{r o}=\sum_{j=1}^{n} y_{i j} \lambda_{j}-s_{r}^{+} \quad \begin{array}{c}
r=1, \ldots, s \\
\lambda_{j}, s_{i}^{-}, s_{r}^{+} \geq 0
\end{array}
\end{gathered}
$$

Çalışmamızda firmaların etkinliklerini ölçmede girdi değişkeni olarak Cari Oran (Dönen Varlıklar/Kısa Vadeli Yabancı Kaynaklar), Alacak Devir Hızı Oranı (Net Satışlar/Ortalama Ticari Alacaklar), Stok Devir Hızı Oranı (Satılan Malın Maliyeti/Ortalama Stok Tutarı), Maddi Duran Varlık Oranı (Maddi Duran Varlıklar/Toplam Aktif), Kaldıraç Oranı (Borçlar/Özsermaye) ve Satışların Maliyeti/Satışlar oranı kullanılmıştır. Çıktı değişkenleri ise Net Kar Marjı (Net Kar/ Satışlar), Aktif Karlılık (Net Kar/ Toplam Aktif), Öz Sermaye Karlılı̆̆ı (Net Kar / Öz Sermaye), Hisse Senedi Piyasa Fiyatı, Hisse Başı Kar olarak belirlenmiştir.

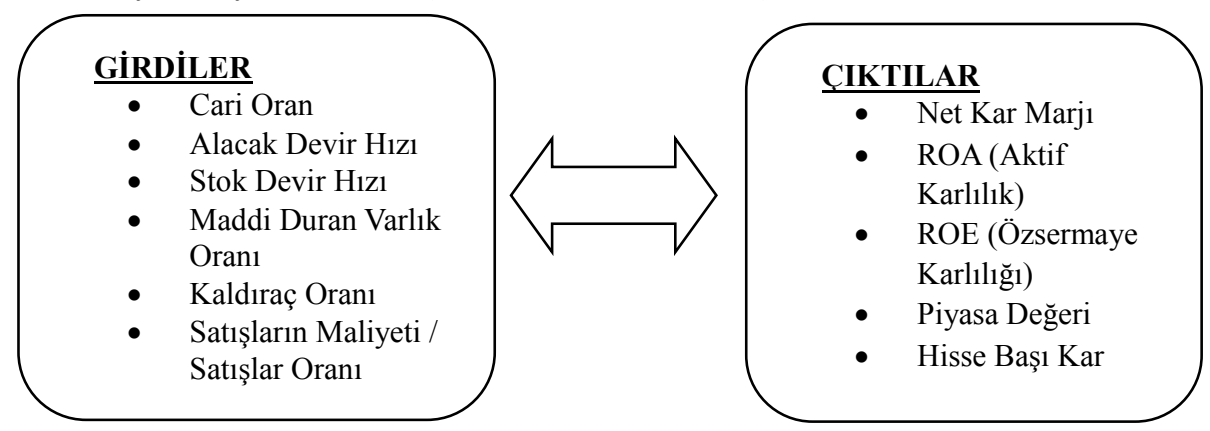

Şekil 1: Aylak Temelli Modelde Kullanılan Girdi ve Çıktılar

Çalışmada kullanılan girdi ve çıktı değişkenlerine ait mali tablo verileri yıllara ait kapanış bilançolarından hesaplanmıştır.

\begin{tabular}{|c|c|c|c|c|c|c|c|c|c|c|}
\hline \multirow[b]{2}{*}{ Oranlar* } & \multicolumn{2}{|c|}{2006} & \multicolumn{2}{|c|}{2007} & \multicolumn{2}{|c|}{2008} & \multicolumn{2}{|c|}{2009} & \multicolumn{2}{|c|}{2010} \\
\hline & & 豙 & 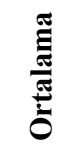 & 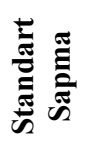 & 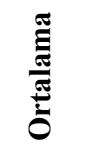 & 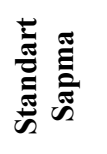 & 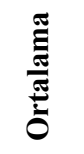 & 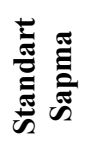 & 䇂 & 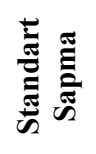 \\
\hline $\mathrm{CO}$ & 2,41 & 2,11 & 2,47 & 2,14 & 2,27 & 2,70 & 2,33 & 2,20 & 2,25 & 2,08 \\
\hline ADH & 1,07 & 0,50 & 1,05 & 0,50 & 1,00 & 0,47 & 0,87 & 0,39 & 0,96 & 0,46 \\
\hline SDH & 7,36 & 12,30 & 7,45 & 11,89 & 6,91 & 10,52 & 7,19 & 9,75 & 7,54 & 10,60 \\
\hline MDV & 0,40 & 0,17 & 0,40 & 0,17 & 0,39 & 0,17 & 0,40 & 0,18 & 0,37 & 0,16 \\
\hline KAL & 0,63 & 3,44 & 0,87 & 2,45 & 1,71 & 4,16 & 0,88 & 2,03 & 2,14 & 16,39 \\
\hline SMS & 0,77 & 0,13 & 0,79 & 0,17 & 0,80 & 0,12 & 0,81 & 0,13 & 0,80 & 0,12 \\
\hline MARJ & 0,03 & 0,24 & 0,03 & 0,38 & $-0,05$ & 0,27 & $-0,04$ & 0,44 & 0,03 & 0,17 \\
\hline ROA & 4,00 & 13,19 & 3,72 & 27,58 & $-1,34$ & 15,66 & 1,09 & 9,83 & 2,85 & 8,40 \\
\hline ROE & 1,00 & 50,48 & 4,68 & 38,53 & $-19,85$ & 77,51 & $-0,07$ & 25,21 & 35,03 & 368,28 \\
\hline PD & 5,12 & 11,94 & 5,55 & 11,39 & 2,98 & 6,68 & 5,66 & 11,45 & 12,42 & 34,66 \\
\hline HBK & 1,71 & 9,57 & 1,63 & 8,48 & 0,55 & 3,77 & 0,11 & 1,57 & 0,57 & 1,92 \\
\hline
\end{tabular}

\section{Bulgular}

Tablo 2'de 2006-2010 yıllarında BIST İmalat Sektörü'nde faaliyet gösteren 135 firmaya ait tanımlayıc1 istatistikler verilmiştir.

Tablo 2: Tanımlayıc İstatistikler *CO: Cari Oran, ADH: Alacak Devir Hızı, SDH: Stok Devir Hızı, MDV: Maddi Duran Varlıklar Oranı, KAL: Kaldıraç Oranı, SMS: Satışların Maliyeti/Satışlar, MARJ: Net Kar Marjı, ROA:

Aktif Karlılık, ROE: Özsermaye Karlılı̆̆ı, PD: Hisse Senedi Piyasa Değeri, HBK: Hisse Başı Kar

Tablo 2 incelendiğinde, kullanılan bütün girdi ve çıktı değişkenlerine ait ortalamalara bakıldığında özellikle finansal krizin başladığı 2008 yılında firma rasyolarında önemli düşüşler gözlenmiştir. Ortalama cari oran 2007 yılında 2,47 iken 2008'de 2,27'ye düşmüştür. Aktif devir hızı ortalama değerleri 2007 yılına göre 2008'de yaklaşık olarak \%5, 2009 yılında ise \%17’lik bir düşüş göstermiştir. Karlılık oranlarına bakıldığında ise kriz döneminin 
etkisi bariz bir şekilde görülmüştür. Aktif karlılık ve öz sermaye karlılığı ortalamaları 2008 yılı için sırasıyla $-1,34$ ve $-19,85$ olarak hesaplanmıştır. Krizin etkisi az da olsa 2009 yılında da etkisini sürdürmüştür. Hisse senetlerine ait ortalama piyasa fiyatları ise 2007 yılına nazaran kriz döneminde \%46'lık bir değer kaybına uğramıştır.

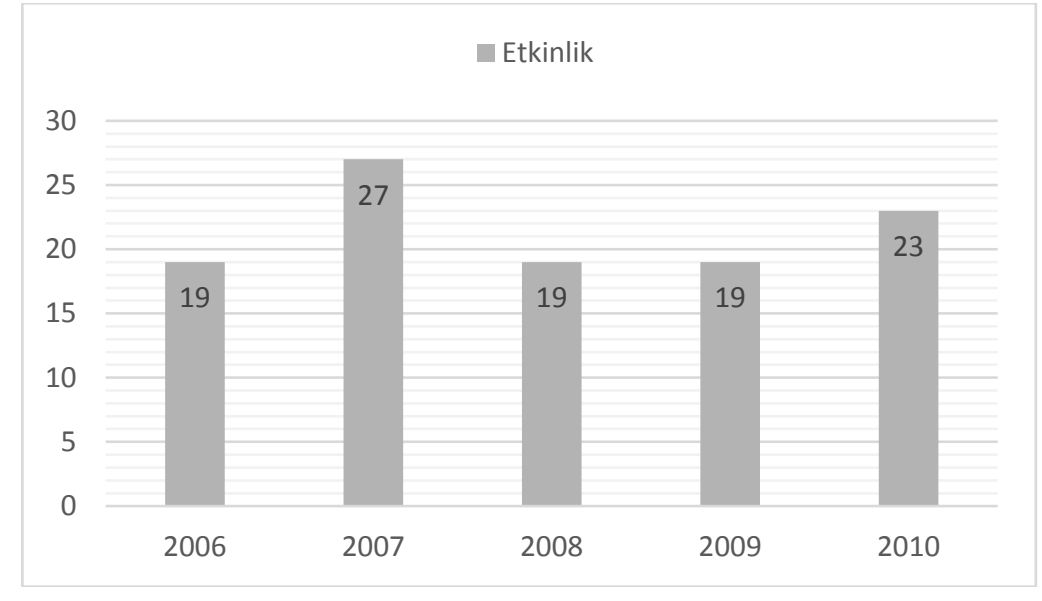

Grafik 1. 2006-2010 Yılları Arası Etkin Firma Sayıları

Grafik 1'de 2006-2010 yıllarını arasında BIST İmalat Sektöründe faaliyet gösteren 135 firmadan kaçının etkin olduğuna dair yıllık etkin firma sayıları verilmiştir. Analizin sonuçlarına göre 2006 yılında 19 firma etkinken 2007 bu rakam 27'ye çıkmış ve 2008 küresel krizinin etkisiyle etkin firma sayısında azalarak 19'a düşmüştür. Krizin etkisi 2009 yılında da devam etmiş, fakat 2010 yılında etkin performans gösteren firma sayısı 23'e çıkmıştır.

\begin{tabular}{|l|c|c|c|c|c|c|}
\hline Sektörler & $\mathbf{2 0 0 6}$ & $\mathbf{2 0 0 7}$ & $\mathbf{2 0 0 8}$ & $\mathbf{2 0 0 9}$ & $\mathbf{2 0 1 0}$ & Ortalama \\
\hline Gıda, İçi ve Tütün Sanayi & 0,18 & 0,33 & 0,13 & 0,46 & 0,37 & $\mathbf{0 , 3 0}$ \\
\hline Dokuma, Giyim Eşyası ve Deri Sanayi & 0,08 & 0,13 & 0,08 & 0,13 & 0,19 & $\mathbf{0 , 1 2}$ \\
\hline $\begin{array}{l}\text { Orman Ürünleri, Mobilya, Kâğıt Ürünleri, } \\
\text { Basım ve Yayım Sanayi }\end{array}$ & 0,18 & 0,28 & 0,22 & 0,17 & 0,26 & $\mathbf{0 , 2 2}$ \\
\hline Petrol, Kimya ve Plastik Sanayi & 0,16 & 0,24 & 0,18 & 0,18 & 0,23 & $\mathbf{0 , 2 0}$ \\
\hline $\begin{array}{l}\text { Taş ve Toprağa Dayall, Cam, Cam Ürünleri } \\
\text { Sanayi }\end{array}$ & 0,38 & 0,43 & 0,33 & 0,26 & 0,21 & $\mathbf{0 , 3 2}$ \\
\hline Metal Sanayi & 0,21 & 0,24 & 0,23 & 0,09 & 0,21 & $\mathbf{0 , 2 0}$ \\
\hline Elektrik Makinaları ve Aygıtları Sanayi & 0,06 & 0,03 & 0,15 & 0,24 & 0,05 & $\mathbf{0 , 1 0}$ \\
\hline Taşıt Araçları Sanayi & 0,50 & 0,30 & 0,20 & 0,22 & 0,30 & $\mathbf{0 , 3 1}$ \\
\hline İmalat Sanayi Tüm Firmalar & $\mathbf{0 , 2 2}$ & $\mathbf{0 , 2 7}$ & $\mathbf{0 , 2 0}$ & $\mathbf{0 , 2 2}$ & $\mathbf{0 , 2 4}$ & $\mathbf{0 , 2 3}$ \\
\hline
\end{tabular}

Tablo 3: Aylak Temelli Model (SBM) Etkinlik Analizi Sonuçları

Tablo 3 ve Grafik 2'de 2006-2010 yıllarında İmalat Sektöründe faaliyet gösteren firmalara ait etkinlik değerleri alt sektörler bazında gösterilmiştir. 


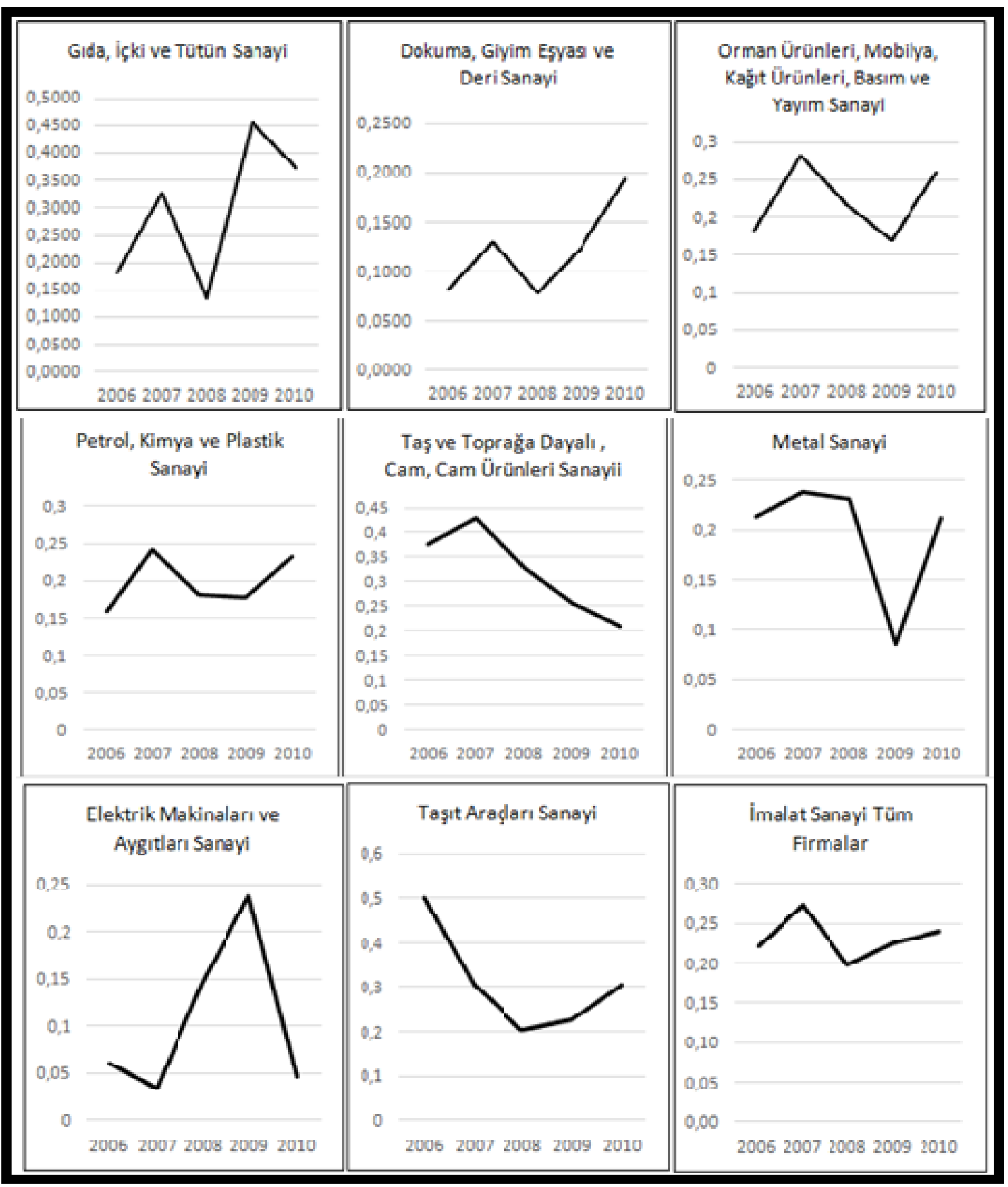

Grafik 2: 2006-2010 Yılları Imalat Sanayi Firma Etkinlikleri

İmalat sektörüne ait tüm firmaların ortalama etkinlik değerlerine Tablo 3'ten bakıldığında 0,27 ile 2007 yılının en etkin yıl olduğu tespit edilmiştir. Küresel finansal krizin başladığı 2008 yılında ise firmaların etkinlik düzeyi 0,20’ye düşmüştür. 2009 ve 2010 yıllarında ise firma etkinlik değerleri yükseliş trendine girmiştir.

İmalat sanayi alt sektörleri incelendiğinde Gıda, İçki ve Tütün Sanayi etkinlik değerleri 2007 y1lına göre kriz döneminde \%60’lık bir düşüş göstermiştir. 2009 yılında ise tekrar yükselişe geçmiştir. Dokuma, Giyim Eşyası ve Deri Sanayi 2008 yılındaki firma etkinlik ortalamaları 0,08 olarak gözlemlenmiştir. 2009 ve 2010 yılı etkinlik değerleri artarak sırasıyla 0,13 ve 0,19'a ulaşmıştır. Orman Ürünleri, Mobilya, Kâğıt Ürünleri, Basım ve Yayım Sanayi firma etkinlikleri 2007 yılında 0,28 iken 2008 yılında \%21'lik bir kayıpla 0,22'ye düşmüş ve krizin etkisi 2009 yılında da devam ederek etkinlik değeri 0,17 olarak gözlemlenmiştir. Petrol, Kimya ve Plastik Sanayi firma etkinlik değerleri 2007'de 0,24 iken 2008 ve 2009 yıllarında 0,18'e düşmüştür. Taş, Toprak ve Cam Ürünleri Sanayi firmalarının etkinlik dereceleri 2007'de 0,43 iken 2008 yılında \%20'lik bir kayıpla 0,33'e gerilemiş, 2009 yılında da azalış devam ederek etkinlik ortalaması 0,26 olarak hesaplanmıştır. Metal Sanayi firmalarının etkinlikleri ise 2009 yılında 0,09'a düşmüştür. Elektrik Makinaları ve Aygıtları Sanayi'de ise firma etkinlikleri 
diğer sektörlerin aksine 2008 ve 2009 yıllarında artarak sırasıyla 0,15 ve 0,24 olarak hesaplanmıştır. Taşıt Araçları Sanayi firmaları etkinlik değerleri 2007 yılında 0,30 iken 2008 yılında \%33 azalışla 0,20 olarak gözlenmiştir. 2009 ve 2010 yılında ise sektördeki ortalama etkinlik değerleri artış göstermiştir.

Alt sektörlerin yıllık ortalama etkinlik değerleri incelendiğinde Taş, Toprak ve Cam Ürünleri Sanayi 0,32 ile en etkin sektör olarak göze çarparken bunu 0,31 ile Taşıt Araçları Sanayi ve 0,30 ile Gıda, İçki ve Tütün Sanayi takip etmektedir. Yıllık ortalama etkinlik değeri en düşük olan sektör ise 0,10 ile Elektrik Makinaları ve Aygıtları Sanayi'dir.

Grafik 2 incelendiğinde, Elektrik Makinaları ve Aygıtları Sanayi hariç 2008 ve 2009 yılını kapsayan kriz döneminde firma etkinliklerinde büyük düşüşler olduğu gözlenmiştir.

\section{Sonuç}

2008 küresel finansal krizinin, Borsa İstanbul (BIST) İmalat sektöründe faaliyet gösteren firmaların finansal performansları üzerindeki etkisini araştırdığımız bu çalışmada; finansal kriz öncesi ve sonrası dönemi kapsayan 2006-2010 yılları arasında imalat sanayinde faaliyet gösteren 135 firmaya ait verilere ulaşılmış olup, imalat sanayi kendi içinde 8 alt sektöre ayrılarak analize tabi tutulmuştur. Bu bağlamda, firmalara ait finansal performansların ölçümünde, çok sayıda girdi ve çok sayıda çıktının olması durumunda doğrusal programlama tabanlı bir etkinlik ölçme tekniği olan Veri Zarflama Analizi (VZA) kullanılmıştır.

Çalışmamızda firmaların etkinliklerini ölçmede girdi değişkeni olarak Cari Oran (Dönen Varlıklar/Kısa Vadeli Yabancı Kaynaklar), Alacak Devir Hızı Oranı (Net Satışlar/Ortalama Ticari Alacaklar), Stok Devir Hızı Oranı (Satılan Malın Maliyeti/Ortalama Stok Tutarı), Maddi Duran Varlık Oranı (Maddi Duran Varlıklar/Toplam Aktif), Kaldıraç Oranı (Borçlar/Özsermaye) ve Satışların Maliyeti/Satışlar oranı kullanılmıştır. Çıktı değişkenleri ise Net Kar Marjı (Net Kar/ Satışlar), Aktif Karlılık (Net Kar/ Toplam Aktif), Öz Sermaye Karlılı̆̆ı (Net Kar / Öz Sermaye), Hisse Senedi Piyasa Fiyatı, Hisse Başı Kar olarak belirlenmiştir.

Analizler sonuçları incelendiğinde, kullanılan bütün girdi ve çıktı değişkenlerine ait ortalamalara bakıldığında özellikle finansal krizin başladığ 2008 yılında firma rasyolarında önemli düşüşler gözlenmiştir. Ortalama cari oran 2007 yılında 2,47 iken 2008'de 2,27'ye düşmüştür. Aktif devir hızı ortalama değerleri 2007 yılına göre 2008'de yaklaşık olarak \%5, 2009 yılında ise \%17'lik bir düşüş göstermiştir. Karlılık oranlarına bakıldığında ise kriz döneminin etkisi bariz bir şekilde görülmüştür. Aktif karlılık ve öz sermaye karlılığı ortalamaları 2008 yılı için sırasıyla -1,34 ve -19,85 olarak hesaplanmıştır. Krizin etkisi az da olsa 2009 yılında da etkisini sürdürmüştür. Hisse senetlerine ait ortalama piyasa fiyatları ise 2007 yılına nazaran kriz döneminde \%46'lık bir değer kaybına uğramıştır.

İmalat sektörüne ait tüm firmaların ortalama etkinlik değerleri gözlemlendiğinde ise 0,27 ile 2007 yılının en etkin yıl olduğu tespit edilmiştir. Küresel finansal krizin başladığı 2008 yılında ise firmaların etkinlik düzeyi 0,20’ye düşmüştür. 2009 ve 2010 yıllarında ise firma etkinlik değerleri yükseliş trendine girmiştir.

Elde sonuçlar yorumlandığında kriz döneminde imalat sanayinde yer alan firmaların borçlarında artış, satışlarında daralma ve karlılık oranlarında etkin bir düşüşün meydana geldiği gözlemlenmektedir. Hemen hemen imalat sanayinin tüm alt sektörlerinde yaşanan cari oran düşüşleri, karlılık rasyolarındaki negatif yönlü eğilimler 2008 finansal krizinin reel sektör üzerindeki olumsuz etkilerini açık bir şekilde ortaya koymaktadırlar. Bununla birlikte, firma etkinliklerinde kriz döneminde ciddi bir düşüş yaşanmasına rağmen, sektör firmaları bu süreci hızlı bir şekilde atlatarak 2009 ve 2010 yıllarında yeniden toparlanma sürecine girmişledir.

\section{Kaynakça}

- Afşar, M., (2011); “Küresel Kriz ve Türk Bankacılık Sektörüne Yansımaları”; Eskişehir Osmangazi Üniversitesi İIBF Dergisi, Ekim 2011, 6(2), 143-171

- Asgharian, H. (2003). “Are Highly Leveraged Firms More Sensitive to an Economic Downturn?”, The European Journal of Finance, 9:3, 219-241, DOI: 10.1080/13518470210132381 http://dx.doi.org/10.1080/13518470210132381

- Aşıkoğlu, R. ve Ögel, S. (2006), “2001 Krizinin İMKB’de Hisse Senetleri İşlem Gören İmalat İşletmelerinin Finansal Yapısı Üzerine Etkileri”, Afyon Kocatepe Üniversitesi İ.İ.B.F Dergisi, Cilt 8, Sayı 2, 1-18.

- Baeka, J., S., Kangb, J., K., ve Park K., S., (2004) “Corporate Governance and Firm Value: Evidence From the Korean Financial Crisis”, Journal of Financial Economics 71 (2004) 265-313

- $\quad$ Banker, R. D., vd. (1984). "Some Models for Estimating Technical and Scale Inefficiencies in Data Envelopment Analysis." Management Science, 30(9): 1078-1092.

- Charnes, A., vd. (1978). "Measuring the Efficiency of Decision Making Units." European Journal of Operational Research 2(6): 429-444.

- Claessens, S., Djankov, S., and Xu, L.C., 2011. "Corporate Performance in the East Asian Financial Crisis”. World Bank Research Observer 15, p 23-46. 
- Dömbekci, B., (2014).” The Effects of 2008 Global Economic Crisis on Borrowing Rates of Manufacturing Companies: Pre-Crisis and Crisis Comparison. Finansal Araştırmalar ve Çalışmalar Dergisi, Cilt: 5 • Say1: 10 • Ocak 2014, ISSN 1309-1123, ss. 33-52. DOI: 10.14784/JFRS.2014104498

- $\quad$ Emir, M., Aslantürk D., ve Sevim U., (2011). "2008 Ekonomik Krizinin Gıda Ve Tekstil Firmaları Üzerine Etkilerinin Finansal Oranlar Yardımıyla Analizi: İMKB’de Bir Uygulama”, Gazi Üniversitesi İktisadi ve İdari Bilimler Fakültesi Dergisi, 13/3. 1-24

- Ertuğrul, C., İpek, E. ve Çolak, Olcay (2010) “Küresel Mali Krizin Türkiye Ekonomisine Etkileri”. Yönelim ve Ekonomik Araştırmalar Dergisi (Cevrimiçi): http://www.bjmer.net/DergiTamDetay.aspx?ID=114\&Detay=Ozet

- Filbeck, G., Louie K. ve Zhao X., (2013). “The Impact of The Euro Crisis On The Financial Performance Of European And North American Firms” International Journal of Finance \& Economics. 19: 173-187. Published online 11 October 2013 in Wiley Online Library (wileyonlinelibrary.com). DOI: $10.1002 /$ ijfe. 1473

- Gümüş F., B. ve Aydemir, L., (2014). “2008 Küresel Finans Krizinin Sektörel Bazda Şirket Mali Tablolarına Etkilerinin Analizi”, İşletme Bilimi Dergisi, Cilt:2 Sayı:1

- Karahan, M. ve Özduran M. (2012). "2008 Küresel Krizi Sonrası Dönemde Tekstil Sektörünün Mali Oranlar Yöntemiyle Finansal Durum Analizi” Sosyal ve Ekonomik Araştırmalar Dergisi, 12(24): 217-239.

- Müslümov, A. ve Karataş, A. (2001), "The Effects of the Assian Crisis to Turkish Manufacturing Industry: The Case of Textile, Food and Cement Industries”, Doğuş Üniversitesi Dergisi, Sayı 4, 91-104.

- Notta, Q. ve Vlachveib, A. (2014). "The Impact of Financial Crisis on Firm Performance in Case of Greek Food Manufacturing Firms" Procedia Economics and Finance, 454 - 460 doi: 10.1016/S22125671(14)00734-5

• Özkan, F. Gülçin (2008). "Küresel Mali Kriz: Makroekonomik Bir Yaklaşım”, http://www.york.ac.uk/depts/econ/documents/misc/financial_crisis_macroeconomic_explanation.pdf (15.03.2010). Erişim Tarihi: 03.03.2016

- Soros. G., (2010); "Finansal Piyasalar İçin Yeni Paradigma” İnklap Kitapevi; ISBN:978-975-10-2812-9; Eylül; 2010

- $\quad$ Tone, K. (2001). "A Slacks-Based Measure of Efficiency in Data Envelopment Analysis." European journal of Operational Research 130(3): 498-509.

- Ulucan, A. (2007). Yöneylem Araştırması İşletmecilik Uygulamalı Bilgisayar Destekli Modelleme Ankara, Siyasal Kitabevi.

- Uyar, A. ve Okumuş, E. (2010), "Finansal Oranlar Aracılığıyla Küresel Ekonomik Krizin Üretim Şirketlerine Etkilerinin Analizi: İMKB’de Bir Uygulama”, Muhasebe ve Finansman Dergisi, Sayı 46, 146 156.

- $\quad$ http://www.tepav.org.tr/upload/files/1271312239r2127.2007_08_Kuresel_Finans_Krizi_ve_Turkiye_Etkiler _ve_Oneriler.pdf. Erişim Tarihi: 11.02.2016 


\title{
Bireysel Emeklilik, Tasarruf Oranı ve Cari Açık Arasındaki İlişkiler: OECD Ülkeleri Üzerine Bir Uygulama
}

\section{The Relationships Between Private Pension System, Saving Rate and Current Deficit: An Application on OECD Countries}

\author{
Prof. Dr. Selim Başar (Atatürk University, Turkey) \\ Ph.D. Candidate Murat Eren (Atatürk University, Turkey) \\ Ph.D. Candidate Gürkan Bozma (Iğdır University, Turkey)
}

\begin{abstract}
Today developed and developing economies have many problems. Some of these problems are created by global conjuncture and the rest of them are originated by problems which can be seen in some specific economies. One of the most important problems of economies is low saving rate. Since low saving rate can cause through to inability to increase investments and inability to reduce current account deficit, to remain below potential growth. The governments which want to increase the level of savings may use the private pension system as a political tool to increase domestic savings and decrease current account deficit. In accordance with this development, the relationships between private pension system, savings rate and current account deficit have been examined by using panel causality test for 14 OECD countries over the period 2005-2014. The findings indicate that developments in the private pension system leads to improvement in the current account balance.
\end{abstract}

\section{Giriş}

Yurtiçi tasarrufların cari açık üzerindeki etkisi, özellikle son çeyrek yüzyılda ekonomik araştırmaların konusunu oluşturmaktadır. Feldstein ve Horioka (1979)'nın gerçekleştirdiği, yurtiçi tasarrufların sermaye akımı üzerindeki etkisini inceleyen çalışma, bu konuda yapılan çalışma sayısının artmasına neden olmuştur. Bu konuda yapılan ampirik ve teorik araştırmalara karşın tasarrufların cari açık üzerindeki etkisi konusunda kesin bir görüş birliğine varılamamıştır.

Yurtiçi tasarruflar, genel ekonomik dengenin oluşmasını sağlayan temel değişkenlerden biridir. Tasarruflar sabit sermaye yatırımları dolayısıyla büyüme için kaynak oluşturmaktadır. Tanım gereği, sermaye akımına kapalı ekonomilerde iç tasarruflar, sabit sermaye yatırımları ve stok değişmelerinin toplamını oluşturmakta, iç tasarruflardaki artış yatırımların artmasına, azalış ise yatırımların azalmasına yol açmaktadır. Sermaye hareketlerine açık ekonomilerde ise iç tasarruflara ek olarak yabancı sermaye girişi olarak kendini gösteren diş tasarruflar da yatırım ve büyüme için kaynak oluşturmaktadır. Bu durumun sonucu olarak, yatırım yapmak için kullanılan iç tasarruflardaki eksiklik dış tasarruflarla karşılanır. Dolayısıyla dış tasarruflar kadar dış açık, yani cari işlemler açığı meydana gelir (Uygur, 2012). Düşük yurtiçi tasarruf oranları, mevcut yatırım harcamalarını gerçekleştirmek için ülkelerin dış tasarruflara daha fazla bağımlı hale gelmelerine, dolayısıyla cari açık sorunuyla karşılaşmalarına neden olmaktadır. Ayrıca dış tasarruflara bağımlılık, ani bir sermaye çıkışı durumunda ekonominin kırılganlığını artırmakta ve ekonominin sürdürülebilir büyümesini tehlikeye sokmaktadır. Özellikle gelişmekte olan ekonomilerin içinde bulunduğu bu durum, dünya ekonomisindeki sürdürülebilir büyümeye de engel olmakta ve küresel krizlere neden olabilmektedir. Bu nedenle iç tasarruflara ilişsin dengesizliklerin azaltılması ve optimum iç tasarruf düzeyine ulaşılması ülke ekonomileri ve dünya ekonomisi için büyük önem arz etmektedir.

Yurtiçi tasarruf oranının artırılması için ön planda tutulan istihdam ve gelirin artırılmasının yanında emeklilik sisteminin tasarruf oranını yükseltecek şekilde organize edilmesi de önem arz etmektedir. Küresel ölçekte gerek ortalama yaşam süresinin ve yaşlı nüfus oranının artmasıyla birlikte gerekse de özellikle gelişmekte olan ülkelerin dıș tasarruf bağımlılığı nedeniyle sosyal güvenlik sistemlerinde kapsamlı reform ihtiyacı ortaya çıkmıștır. Gelişmiș ve gelişmekte olan birçok ülke, kamunun sağladığı emeklilik sistemine (PAYG: pay-as-you-go) ek olarak, zorunlu ve/veya gönüllü emeklilik sistemine geçiş yapmışlardır (Özel ve Yalçın, 2013). Gönüllü emeklilik sistemini benimseyen ülkeler bu uygulama ile işgücü piyasası etkinliğini artırmayı, yerli sermaye birikimini teşvik etmeyi ve bağımlılık oranını düşürmeyi amaçlamışlardır. Ayrıca gönüllülük esasına dayanan emeklilik sisteminin, ülkelerin tasarruf - yatırım dengesi ve dolayısıyla cari açığı üzerinde olumlu etkide bulunacağı düşünülmüştür (Schimmelpfennig, 2000). Uygulanan emeklilik sisteminde meydana gelen değişim, özellikle son çeyrek yüzyılda yoğunlaşmıştır. Bu değişimde ise yaş ortalamasındaki yükselme ve emeklilik süresindeki uzamayla birlikte kamunun sağladığı emeklilik sisteminin devlet bütçesi üzerinde baskı oluşturması etkili olmuştur.

Gerçekleştirilen bu çalışma ile ülkelerin, makroekonomik dengelerinin sağlanmasına engel olan iç tasarruf yetersizliğini gidermek ve/veya gelecekte karşılaşabilecekleri sorunları bertaraf edebilmek için uygulamaya geçirdikleri bireysel emeklilik sistemi (BES), yurtiçi tasarruf oranları ve cari denge arasındaki ilişkiler panel nedensellik analizi ile incelenmektedir. 14 OECD ülkesi verileri ile gerçekleştirilen bu uygulama ile bireysel 
emeklilik sistemi, yurtiçi tasarruf oranı ve cari açık arasındaki nedensellik ilişkileri tespit edilerek uygulanacak makroekonomik politikalara yol göstermek amaçlanmaktadır.

Bu çalışma, girişi takiben üç bölüm ve sonuç bölümünden oluşacaktır. İkinci bölümde, yurtiçi tasarruf düzeyinin belirleyicileri ve bireysel emeklilik sisteminin tarihsel gelişimi üzerinde durulacaktır. Üçüncü bölümde, bireysel emeklilik sistemi, tasarruf düzeyi ve cari denge ile ilgili gerçekleştirilen ulusal ve uluslararası çalışmaların bir özeti verilecektir. Dördüncü bölümde bireysel emeklilik sistemi, yurtiçi tasarruf oranı ve cari denge arasındaki ilişkiler panel nedensellik analizi ile incelenecek, elde edilen ekonometrik bulgular özetlenecektir. Son bölümde ise sonuç ve değerlendirme kısmına yer verilecektir.

\section{Tasarruf Düzeyinin Belirleyicileri ve Bireysel Emeklilik Sistemi}

Tasarruf oranlarının artııılmasının, ekonominin genel dengesinin sağlanmasında ve cari işlemler dengesinin sağlanmasında önemli etkisi bulunmaktadır. Düşük yurtiçi tasarruf oranları, dış finansman imkânları kısıtlı olan şirketlerin yatırımlarının azalmasına (Felstein - Horioka bilmecesi), bu da ekonomik büyümenin yavaşlamasına neden olmaktadır. Ayrıca yurtiçi tasarruf oranının düşük olması, sermaye girişinin yön değiş̧tirmesi veya durması durumunda, yatırımlar azalmakla kalmayacak, beklentiler de olumsuz etkilenerek ekonominin kırılganlığını büyük ölçüde artıracaktır. Dış tasarrufa bağımlılık, sadece sermaye girişinin azaldığı dönemlerde değil arttığı dönemlerde de tehlikeli sonuçlar doğurabilmektedir. Sürekli dış sermaye girişi ulusal para biriminin değerlenmesine neden olmakta, bu da sektörlerin karlılığını ve döviz yükümlülüklerini artırırken, ülkenin rekabet gücünün zayıflamasına neden olacaktır (World Bank, 2013).

Tasarruf oranını etkileyen faktörler üzerine gerçekleştirilen teorik ve uygulamalı çalışmalar, tasarruf oranının muhtemel belirleyicilerinin gelir düzeyi, büyüme, demografik yapı, enflasyon, krediler, reel faiz oranları ve maliye politikası gibi faktörler olduğunu göstermektedir.

- $\quad$ Ekonomik Büyüme ve Kişisel Gelir: Bireylerin gelir düzeyindeki yükselişin tasarruf oranlarına etkisi teorik çerçevede incelendiğinde; sürekli gelir hipotezine göre büyüme oranındaki artış tasarruf oranlarında düşmeye neden olurken, yaşam döngüsü hipotezine göre büyümenin tasarruf üzerindeki etkisi belirsizdir. Yapılan çalışmalar, gelir düzeyindeki artışın tasarruf oranında artışa neden olduğu, ayrıca gelişmekte olan ülkelerde, gelişmiş ülkelere kıyasla meydana gelen artışın daha fazla olduğu sonucuna ulaşmaktadır.

- Demografik Yapı: Çalışmayan nüfusun çalışan nüfusa oranını temsil eden bağımlılık oranındaki yükselme, tasarruf oranlarında düşüşe neden olmaktadır.

- Enflasyon: Teorik olarak incelendiğinde enflasyon oranındaki artış, paranın değerinde azalmaya neden olduğundan tasarruf oranını düşürmesi beklenmektedir. Ayrıca belirsizlik oranı üzerine gerçekleştirilen birçok çalışmada, belirsizlik oranını temsilen enflasyon oranı kullanılmıştır. Ancak elde edilen bulgularda, enflasyon oranı ile tasarruf oranı arasında anlamlı bir ilişkiye rastlanamamıştır.

- Krediler: Kredi hacmindeki genişleme ve kredi kartı sayısında meydana gelen yükselmenin tasarruf oranında azalmaya neden olabilmektedir.

- Reel Faizler: Reel faizlerin tasarruf eğilimi üzerindeki etkisi hususunda kesin bir yargı bulunmamaktadır. Reel faizlerin tasarruf üzerindeki etkisi, gelir ve ikame etkisine göre şekillenmektedir. Reel faiz oranında meydana gelen düşme hane halkının kredi maliyetlerini azaltırken, gelecek dönemlerdeki gelirin bugünkü değerinin artmasını sağlar. Bunun yanında faiz oranlarındaki düşme hanehalkı varlıklarının getirisini azaltmakta ve hanehalkının borçlanma isteğinin azalmasına neden olmaktadır.

- Maliye Politikası: Ricardocu denklik hipotezine göre kamu tasarruflarında meydana gelen bir azalma özel sektör tasarruflarında birebir artışa neden olacaktır. Bu konu üzerine gerçekleştirilen çalışmaların büyük kısmında da hipotezi destekler nitelikte; kamu tasarruflarının hane halkı tasarrufları üzerindeki etkisi negatif bulunmuştur. Ancak çalışma bulgularından elde edilen sonuçlarda, değişkenler arasındaki ilişki, hipotezin ileri sürdüğü gibi birebir olarak değil, kamu tasarrufundaki değişim sonucunda özel tasarruflardaki değiş̧im daha düşük olarak tespit edilmiştir.

Tasarrufu etkileyen faktörler üzerine değinilen özet görüşler dışında, sosyal güvenlik politikaları ve finansal serbestleşme gibi faktörlerin de tasarruflar üzerinde etkide bulunduğu öne sürülmektedir. Buna göre kamunun sağladığı emeklilik sisteminin tasarruflar üzerinde negatif etkide bulunduğu ileri sürülürken, bireysel emeklilik sistemindeki gelişmelerin tasarruflar üzerinde olumlu etkide bulunduğu iddia edilmektedir. Finansal serbestleşmenin tasarruflar üzerindeki etkisi incelendiğinde ise teorik olarak kısa dönemde olumsuz uzun dönemde olumlu etkilerinin bulunması beklenmektedir. Ancak konu ile ilişkin yapılan araştırmalarda herhangi bir kanıtlayıcı sonuca ulaşılamamıştır (Erkiletlioğlu, vd, 2011).

Daha önce de değinildiği gibi özellikle gelişmekte olan ülkelerde iç tasarrufların yetersizliği özellikle gelişmekte olan ülkeleri dış tasarruflara bağımlı hale getirmiştir. Bu durum da, tasarruf sorununa sahip ülkelerin cari açık sorunuyla karşı karşıya gelmelerine ve ülke ekonomisinin iç ve dış şoklara karşı daha kırılgan hale gelmelerine neden olmaktadır. Ekonomilerin dış tasarruflara bağımlı olması ve iktisadi şoklara karşı kırılganlıklarının artması, 
yalnızca o ülke ekonomisini değil küreselleşen dünyada tüm ekonomileri etkilemekte hatta küresel krizlere neden olabilmektedir.

İç tasarruf yetersizliği, yalnızca gelişmekte olan ve cari açık sorunuyla karşı karşıya olan ülkelerde değil, gelişmiş ekonomilerde de problemlere yol açabilmektedir. Dünyada özellikle gelişmiş ekonomilerde genç nüfus oranı düşmekte, çalışmayan nüfusun çalışan nüfusa oranını gösteren bağımlılık oranı yükselmektedir. Bağımlılık oranı yüksek olan ekonomilerde, iç tasarruf oranları düşmekte ve kamunun sağladığı emeklilik sistemi artık yeterli olmamaktadır. Dış tasarrufa bağımlılık ve nüfusun bağımlılık oranının yükselmesi gibi nedenler, ülkeleri emeklilik sistemlerinde düzenlemeye gitmeye mecbur kılmıştır. Emeklilik sistemlerinde yapılan bu düzenleme ile kamunun sağladığı emeklilik sistemine ek olarak çeşitli gönüllü emeklilik sistemleri devreye girmiştir.

Günümüzde emeklilik sistemleri üçe ayrılmaktadır. Bunlardan ilki kamunun sağladığı zorunlu emeklilik sistemi, ikincisi zorunlu özel emeklilik sistemi, üçüncüsü ise gönüllü özel emeklilik sistemidir. Kamunun sağladığı zorunlu özel emeklilik sistemi, yeniden dağılım, tasarruf ve güvence oluşturma gibi işlevleri yerine getirmede yetersiz olduğundan özel emeklilik sistemleri gündeme gelmiştir. Uluslararası kuruluşların önerileri ve bazı başarılı örnek ülke uygulamalarının etkisiyle gelişmekte olan birçok ülke 1990'lı yıllarda yapılan sosyal güvenlik reformları çerçevesinde zorunlu özel emeklilik sistemine geçiş yapmışlardır (Özel ve Yalçın, 2013).

BES'in mikro amacı kişilerin aktif çalışma döneminde tasarruf düzeylerini artırmak ve bu tasarrufların emeklilik döneminde ek gelir olarak kullanılmasını sağlamaktır. BES'in makro amacı ise ekonomiye uzun süreli kaynak temin etmektir (Uyar, 2012).

Son çeyrek yüzyılda özel emeklilik uygulamaları dünya genelinde yaygınlık kazanmıştır. Ülkeler, mevcut kamu emeklilik sistemlerine ek olarak özel emeklilik sistemlerini uygulamaya geçirmişlerdir. Özel emeklilik sistemi uygulaması, birçok ülkede oldukça eskiye dayanmaktadır. Örneğin, İngiltere'de özel emeklilik sistemi 18. yüzyıldan beri uygulamada olmakla birlikte özellikle son 30 yılda reformlarla güncellenmiştir. İngiltere'de uygulanan özel emeklilik sistemi vergi indirimi yoluyla teşvik sağlarken; Amerika uygulaması daha kompleks bir yapıya sahiptir. Bireysel emeklilik sisteminin Amerika uygulaması, işverenin ve devletin de katkı yaptığı bir yapı görünümü sergilemektedir. Kanada da bireysel emekliliğe 20. yüzyılın başında vergi desteği ile başlayan ülkelerden birisidir ve 20. yüzyılın ortalarında gönüllülüğe dayanan özel emeklilik planlarını devreye sokmuştur. Özel emeklilik sistemlerine uzun zamandır yer veren bu gibi ülkelerin yanında Avusturalya, Japonya, İsveç gibi ülkelerde bireysel emekliliğe verilen destek oldukça yenidir (Özel ve Yalçın, 2013).

Tasarruflar ve cari açıkla ilgili gerçekleştirilen çalışma sayısı oldukça fazladır. Ancak çalışmanın amacına uygun olan ve bireysel emeklilik sistemini de konu alan çalışma sayısının oldukça kısıtlı olduğu görülmüştür. Çalışmanın devamında tasarruf oranı, bireysel emeklilik sistemi ve cari açıkla ilgili, konunun sınırları dahilinde bulunan çalışmalara kısaca yer verilecektir.

\section{Tasarruf Oranı, Bireysel Emeklilik ve Cari Açık İlişsisine Yönelik Gerçekleştirilen Çalışmalar}

Daha önceki bölümde değinildiği gibi tasarruflar ile cari açık arasındaki ilişkiyi inceleyen çalışma sayısı oldukça fazladır. Söz konusu iki değişken arasındaki ilişkiyi inceleyen çalışmalardan bir kısmı iki değişken arasında anlamlı ilişkiler tespit ederken; aradaki ilişkinin anlamsız olduğunu tespit eden çalışmalar da bulunmaktadır. Bireysel emeklilik ise her ne kadar uzun zamandır uygulanıyor olsa da bazı gelişmiş ve gelişmekte olan ülkeler için özellikle son çeyrek yüzyılda ön plana çıkmıştır. Bu nedenle bireysel emeklilik sisteminin makroekonomik değişkenlerle olan ilişkisini konu alan çalışma sayısı daha kısıtlıdır.

Murphy ve Musalem (2004), 43 gelişmiş ve gelişmekte olan ülke üzerine gerçekleştirdikleri çalışmalarında, emeklilik sistemindeki birikimin ulusal tasarruflar üzerindeki etkisini incelemişlerdir. Elde edilen bulgulara göre, emeklilik sistemi zorunlu olmak kaydı ile ulusal tasarruflar üzerinde pozitif etkide bulunmaktadır. Ancak emeklilik sisteminin gönüllülüğe dayanması durumunda söz konusu etki ortadan kalkmaktadır. Aghion, Comin, Howitt (2006), yurtiçi tasarrufların ekonomik büyüme üzerindeki etkisini inceledikleri çalışmalarında, az gelişmiş ve gelişmekte olan ülkeler için teknolojik gelişmenin önemli olduğunu ve bu teknolojinin gelişmiş ülkelerden alınması için yurtiçi tasarrufların yüksek olması gerektiğini vurgulamışlardır. Bebczuk ve Musalem (2006), 1980 - 2004 dönemi verileri ile 48 gelişmiş ve gelişmekte olan ülke üzerine gerçekleştirdikleri çalışmalarında, bireysel emeklilik sistemlerinin tasarruf oranı üzerindeki etkisini incelemişlerdir. Çalışmadan elde edilen bulgulara göre, bireysel emeklilik sisteminde meydana gelen bir dolarlık artış, ulusal tasarrufları 20 sent artırmaktadır. Ayrıca emeklilik sisteminin kamusal veya özel olması bu oranı etkilememesine karşın; emeklilik sisteminin ne kadar süredir uygulandığı bu oranı etkilemektedir. Buna göre emeklilik sisteminin uygulandığı yıl sayısı arttıkça tasarruflarda meydana getireceği etki artmaktadır. Yaraşır ve Yılmaz (2011), 1999 - 2007 dönemi verileri ile gerçekleştirilen çalışmada Dinamik Panel Veri Analizi Kullanılmıştır. Özel tasarrufların belirleyicilerini ve belirleyici faktörlerin etkilerinin analiz edildiği çalışmada cari hesap dengesinin özel tasarruflar üzerinde pozitif etkide bulunduğu tespit edilmiştir. Özcan ve Günay (2012), 1975 - 2006 dönemi Türkiye verileri ile gerçekleştirdikleri çalışmalarında, özel tasarruf davranışlarını belirleyen makroekonomik ve sosyal değişkenleri incelemişlerdir. Elde edilen bulgular, dış ticaret açığının tasarrufları azaltıcı etkide bulunduğunu göstermektedir. 
Uyar (2012), 2004 - 2009 dönemi aylık verileri ile Türkiye üzerine gerçekleştirdiği çalışmasında, bireysel emeklilik sisteminin makroekonomik etkilerini inceleyecek bireysel emeklilik verileri ile makroekonomik göstergeler arasındaki ilişkiyi incelemiştir. Elde edilen bulgulara göre BES katılımcı sayısı ile dış ticaret endeksleri arasında herhangi bir ilişki tespit edilememiştir. Brückner ve Pappa (2013), Sahra altı Afrika ülkeleri üzerine gerçekleştirdikleri çalışmalarında, yurtiçi tasarruflar ile cari açık arasındaki ilişkiyi incelemişlerdir. Çalışmadan elde edilen bulgulara göre yurtiçi tasarrufların cari açı üzerindeki etkisi anlamsız olmakla birlikte, ticaret dengesi üzerindeki etkisi pozitif ve anlamlıdır. Özel ve Yalçın (2013), gelişmekte olan 16 ülke üzerine panel veri analizi ile gerçekleştirdikleri çalışmalarında, özel emeklilik uygulamalarının tasarruf oranı üzerindeki etkilerini incelemişlerdir. Elde edilen bulgulara göre, özel emeklilik sistemlerinin tasarruflar üzerinde olumlu etkide bulunduğunu ancak söz konusu etkinin daha ziyade zorunlu özel emeklilik sisteminin bulunduğu ülkelerde geçerli olduğunu vurgulamışlardır.

\section{Veri Seti ve Ekonometrik Yöntem}

Bu çalışmada, 14 OECD ülkesi için 2005-2014 döneminde bireysel emeklilik sistemi, tasarruf ve cari açık arasındaki ilişkiler ele alınmıştır. Değişskenler arasındaki ilişkiler incelemek için, emeklilik sisteminin GSYH'ye \% oranı, tasarruf için tasarrufların GSYH'ye \% oranı ve cari açık için cari açığı GSYH'ye \% oranı kullanılmıştır. Çalışmada kullanılan bireysel emeklilik sistemi ve cari açık verileri OECD Temel Makro Ekonomik Göstergeler'den, tasarruf verileri ise Dünya Bankası Gelişme Göstergeleri'nden alınmıştır.

\begin{tabular}{|l|l|l|}
\hline Değişkenler & \multicolumn{2}{c|}{ Açılamalar } \\
\hline Bireysel Emeklilik & $\%$ GSYIH & OECD-Makro Ekonomik Göstergeler \\
\hline Tasarruf & $\%$ GSYIH & Dünya Bankası \\
\hline Cari Açık & $\%$ GSYIH & OECD-Makro Ekonomik Göstergeler \\
\hline
\end{tabular}

Tablo 1. Değişkenlere Ait Açıklamalar

Çalışmada ele alınan değişkenler arasındaki ilişkinin incelenmesi için Dumitrescu ve Hurlin (2012) tarafından önerilen panel nedensellik testi kullanılmıştır. Ekonometrik yazında, yatay kesit bağımlılığı altında seriler arasındaki nedensellik ilişkisi inceleyen birkaç yöntem bulunmaktadır. Bu yöntemlerden ilki Konya (2006) tarafindan önerilen bootstrapa dayalı panel nedensellik analizidir. Bu yöntem, serilerin durağanlık düzeylerini dikkate almamaktadır. Bir diğer yöntem ise Emirmahmutoğlu ve Köse (2011) tarafından önerilen panel nedensellik analizidir. Bu panel nedensellik analizi, seriler farklı seviyelerde durağan olduğu zaman da kullanılabilmektedir. Dumitrescu ve Hurlin (2012) tarafindan önerilen panel nedensellik testinde ise serilerin aynı seviye durağan olması koşulu bulunmaktadır.

Dumitrescu ve Hurlin (2012) tarafından önerilen panel nedensellik analizi aşağıda çalışmaya uyarlanmış eşitlik üzerinden incelenebilir:

$$
\begin{aligned}
& T A_{i, t}=a_{i}+\sum_{k=1}^{K} \gamma_{i}^{k} T A_{i, t-k}+\sum_{k=1}^{K} \beta_{i}^{k} C A_{i, t-k}+\varepsilon_{i, t} \\
& C A_{i, t}=a_{i}+\sum_{k=1}^{K} \gamma_{i}^{k} C A_{i, t-k}+\sum_{k=1}^{K} \beta_{i}^{k} B \dot{\mathrm{I}} R_{i, t-k}+\varepsilon_{i, t} \\
& T A_{i, t}=a_{i}+\sum_{k=1}^{K} \gamma_{i}^{k} T A_{i, t-k}+\sum_{k=1}^{K} \beta_{i}^{k} B \dot{\mathrm{I}} R_{i, t-k}+\varepsilon_{i, t}
\end{aligned}
$$

Eşitlik (1), (2) ve (3)'te TA, CA, BİR, K, t ve $\varepsilon$ sırasıyla tasarruf oranı, cari açık, bireysel emeklilik, optimal gecikme uzunluğu, zamanı ve hata terimlerini göstermektedir. Seriler arasındaki nedensellik ilişkisini test etmekte kullanılan boş ve alternatif hipotezler aşağıdaki gibidir:

$$
\begin{aligned}
& H_{0}: \beta_{i}^{k}=0 \quad \forall_{i=} 1 \ldots . . N \\
& H_{1}: \beta_{i}^{k}=0 \quad \forall_{i=1} \ldots . N_{1} \\
& H_{1}: \beta_{i}^{k} \neq 0 \quad \forall_{i=} N_{1}+1, N_{1}+2 \ldots \ldots, N
\end{aligned}
$$

Eşitlik 4'teki boş hipotezin kabul edilmesi durumunda CA'dan TA'ya ya da BİR'den CA'ya doğru hiçbir birimde nedensellik ilişkisi olmadığını göstermektedir. Eşitlik (5) ve (6)'da $\mathrm{N}_{1}=0$ olması durumunda bütün birimlerde CA'den TA'ya ya da BİR'den CA'ya doğru nedensellik ilişkisi olduğu ifade edilebilmektedir. Dumitrescu ve Hurlin (2012) tarafından önerilen panel nedensellik testinde boş hipotezin test edilmesi aşağıdaki eşitlik (6)'daki bütün birimlerden elde Wald istatistiklerin aritmetik ortalaması kullanılmaktadır. Daha sonra elde edilen 
$W_{N, T}^{H N C}$ istatistiğinden eşitlik (8) ve (9)'da verilen $Z_{N, T}^{H N C}$ ve $Z_{N}^{H N C}$ istatistikleri elde edilerek boş hipotez ( $H_{0}$ : CA nedeni değildir TA'nın) sınanır.

$$
W_{N, T}^{H N C}=\frac{1}{N} \sum_{i=1}^{N} W_{i, T} \quad \text { (HNC: Homogenous Non Causality) }
$$

Eşitlik (7)'de $\mathrm{W}_{\mathrm{i}, \mathrm{T}}$, her birimin Wald istatistiğini ifade etmektedir. Dumitrescu ve Hurlin (2012), $\mathrm{N}>\mathrm{T}$ olması durumunda $Z_{N}^{H N C}$ istatistiğini ve $\mathrm{N}<\mathrm{T}$ olması durumunda ise $Z_{N, T}^{H N C}$ istatistiğini önermiştir. $Z_{N, T}^{H N C}$ ve $Z_{N}^{H N C}$ istatistikleri eşitlik (8) ve (9)'daki gibi hesaplanmaktadır:

$$
\begin{aligned}
& Z_{N, T}^{H N C}=\sqrt{\frac{N}{2 K}}\left(W_{N, T}^{H N C}-K\right) \\
& Z_{N}^{H N C}=\frac{\sqrt{N}\left(W_{N, T}^{H C}-N^{-1} \sum_{i=1}^{N} E\left(W_{i, T}\right)\right.}{\sqrt{N^{-1} \sum_{i=1}^{N} \operatorname{Var}\left(W_{i, T}\right)}}
\end{aligned}
$$

Dumitrescu ve Hurlin (2012) tarafindan önerilen panel nedensellik testi, zaman boyutunun birim boyutundan büyük $(\mathrm{T}>\mathrm{N})$ ya da küçük olması $(\mathrm{N}>\mathrm{T})$ durumunda bile etkili sonuçlar verebilmektedir (Dumitrescu ve Hurlin, 2012).

$\mathrm{Bu}$ doğrultuda çalışmada ele alınan değişkenler arasındaki nedensellik ilişkilerinin elde edilebilmesi için serilerin durağanlık seviyelerinin test edilmesi gerekmektedir. $\mathrm{Bu}$ amaç doğrultusunda serilerin durağanlık analizleri, Levin, Lin ve Chu (2002) (LLC), Im, Pesaran ve Shin (2003) (IPS), Maddala ve Wu (1999) (FisherADF) ve Breitung (2000) panel birim kök testleriyle yapılmıştır. Tablo 2'de panel birim kök testleri sonuçları görülebilmektedir.

\begin{tabular}{|l|c|c|c|c|c|c|}
\hline Birim Kök Testleri & CA & $\Delta$ CA & TA & $\Delta$ TA & BİR & $\Delta$ BİR \\
\hline LLC & $-6.27^{*}$ & $-11.324^{*}$ & $-4.929^{*}$ & $-12.337^{*}$ & $-3.889^{*}$ & $-13.976^{*}$ \\
\hline IPS & -0.907 & $-1.688^{* *}$ & 0.401 & $-1.886^{* *}$ & 0.8825 & $-1.804^{* *}$ \\
\hline Fisher-ADF & $42.337^{* *}$ & $59.205^{*}$ & 21.745 & $65.305^{*}$ & 18.867 & $62.531^{*}$ \\
\hline Breitung & -0.812 & $-2.476^{*}$ & 0.461 & $-3.618^{*}$ & 2.054 & $-1.742^{* *}$ \\
\hline
\end{tabular}

Not: *,** \%1 ve \%5 anlamlılık seviyesini boş hipotezin reddedildiğini göstermektedir.

Tablo 2. Panel Birim Kök Test Sonuçları

LLC, IPS, Fisher-ADF ve Breitung (2000) panel birim kök testlerinin, her birinin bir diğerine göre üstün yanı bulunmaktadır. Breitung (2000) tarafından önerilen panel birim kök testi, serilerdeki birimler arasında sabit bir otokorelasyon katsayısı (yatay-kesit bağımlılı̆̆1) ve serilerde trendin olması durumunda LLC, IPS ve Fisher-ADF panel birim kök testlerine göre daha güçlüdür (Tatoğlu, 2013). Bu doğrultuda serilerin durağanlık analizleri yapılırken Breitung (2000) tarafından önerilen panel birim kök testi dikkate alınmıştır. Breitung (2000) panel birim kök testi sonuçlarına göre CA, TA ve BİR serilerinin seviye değerinde $\% 1, \% 5$ ve $\% 10$ anlamlılık seviyelerinde durağan olmadığı fakat birinci farklarında sırasıyla \%1, \%1 ve \%5 anlamlılık seviyelerinde durağan olduğu tespit edilmiştir. Diğer bir ifade ile serilerin I(1) seviyesinde durağan olduğu görülmüştür.

Dumitrescu ve Hurlin (2012) tarafından önerilen panel nedensellik testinin diğer bir koşulu olan birimler arasında otokorelasyon olması koşulunun tespit edilebilmesi için Baltagi, Feng ve Kao (2012), Breusch-Pagan (1980) ve Pesaran (2004) tarafından önerilen LM testleri ile Pesaran (2004) tarafından önerilen CD testi kullanılmıştır. Tablo 3 'te yatay kesit bağımlılığı testleri sonuçları görülebilmektedir.

\begin{tabular}{|c|c|c|c|}
\hline $\begin{array}{c}\text { Yatay-Kesit Bağımlılığ } \\
\text { Testleri }\end{array}$ & CA & TA & BİR \\
\hline Breusch-Pagan-LM & $316.302^{*}$ & $270.107^{*}$ & $525.508^{*}$ \\
\hline Pesaran-LM & $15.6627^{*}$ & $12.238^{*}$ & $31.170^{*}$ \\
\hline Baltagi, Feng ve Kao-Lm & $14.8850^{*}$ & $11.460^{*}$ & $30.392^{*}$ \\
\hline Pesaran-CD & $9.99182^{*}$ & $7.915^{*}$ & $13.571^{*}$ \\
\hline
\end{tabular}

Not: * \%1 anlamlılık seviyesini boş hipotezin (yatay-kesit bağımlılı̆̆ı yoktur) reddedildiğini göstermektedir.

Tablo 3. Yatay-Kesit Bă̆ımlılı̆̆l Testleri Sonuçları

Tablo 2'de görülebileceği üzere Baltagi, Feng ve Kao (2012), Breusch-Pagan (1980) ve Pesaran (2004) ve Pesaran (2004) testleri sonucunda boş hipotez (yatay-kesit bağımlılı̆̆ 1 yoktur) bütün seriler için \%1 anlamlılık seviyesinde reddedilerek birimler arasında otokorelasyon olduğu tespit edilmiştir. 
Panel birim kök ve yatay-kesit bağımlılı̆̆ı testleri sonucunda, serilere Dumitrescu ve Hurlin (2012) tarafindan önerilen panel nedensellik testinin uygulanabileceği görülmüştür. Tablo 4’te Dumitrescu ve Hurlin (2012) panel nedensellik testi sonuçları görülebilmektedir.

\begin{tabular}{|l|l|l|l|l|l|l|}
\hline \multirow{2}{*}{$\begin{array}{l}\text { Gecikme } \\
\text { Uzunluğu }\end{array}$} & \multicolumn{6}{|c|}{$Z^{H N C}$} \\
\cline { 2 - 7 } & $\mathrm{CA} \rightarrow \mathrm{TA}$ & $\mathrm{TA} \rightarrow \mathrm{CA}$ & $\mathrm{CA} \rightarrow \mathrm{BI}$ & $\mathrm{BI} \rightarrow \mathrm{CA}$ & $\mathrm{TA} \rightarrow \mathrm{BI}$ & $\mathrm{B} \dot{\mathrm{I}} \rightarrow \mathrm{TA}$ \\
\hline $\mathrm{K}=1$ & 0.829 & 1.459 & $2.079^{* *}$ & 1.587 & 0.589 & 1.233 \\
\hline $\mathrm{K}=2$ & $5.495^{*}$ & 0.274 & $20.980^{*}$ & $1.959^{* *}$ & $3.133^{*}$ & $2.777^{*}$ \\
\hline
\end{tabular}

Not: * ,* sırasıyla \%1ve \%5 anlamlılık seviyesini boş hipotezin reddedildiğini göstermektedir. $Z^{H N C}$ değeri $Z_{N}^{H N C}$ istatistiğini göstermektedir

Tablo 4. Dumitrescu ve Hurlin (2012) Panel Nedensellik Testi Sonuçları

Dumitrescu ve Hurlin (2012), N>T olması durumunda $Z_{N}^{H N C}$ istatistiğini önermiştir. Ampirik bulgular sonucunda bir gecikme için yalnızca cari açıktan bireysel emekliliğe doğru tek yönlü bir nedensellik ilişkisini gösteren boş hipotez \%5 anlamlılık seviyesinde reddedildiği tespit edilmiştir. Diğer taraftan iki gecikme için tasarruftan bireysel emekliliğe ve bireysel emeklilikten tasarrufa doğru nedensel ilişkiyi gösteren boş hipotez \% 1 anlamlılık seviyesinde reddedilmiştir. Diğer bir ifade ile bireysel emeklilik ile tasarruf arasında çift yönlü bir nedensellik ilişkisi vardır. Aynı şekilde, bireysel emeklilikten cari açığa doğru nedensel ilişkiyi gösteren boş hipotez \% 1 anlamlılık seviyesinde; cari açıktan bireysel emekliliğe doğru nedensel ilişkiyi gösteren boş hipotez ise \% 5 anlamlılık seviyesinde reddedilmiştir. Buna göre cari açık ve bireysel emeklilik arasında çift yönlü ilişki vardır. Elde edilen bu sonuçların aksine, iki gecikme için cari açıktan tasarrufa doğru nedensel ilişkiyi gösteren boş hipotez ise \% 1 anlamlılık seviyesinde reddedilmiştir. Değişkenler arasındaki nedensellik ilişkilerini gösteren grafik şu şekilde gösterilebilir.

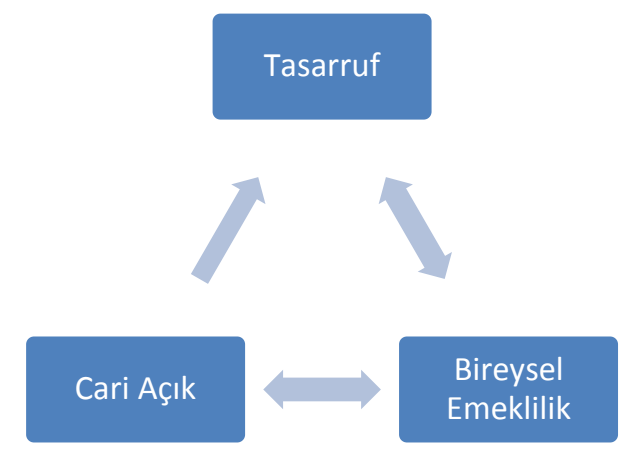

Grafik 1. Seriler Arasındaki Nedensellik İlişkileri

\section{Sonuç}

Bu çalışmada, 2005-2014 dönemi verileri ile 14 OECD ülkesi için bireysel emeklilik, tasarruf ve cari açık arasındaki ilişkiler panel nedensellik analizi ile araştırılmıştır. Çalışmadan elde edilen ampirik bulgulara göre, iki gecikme için tasarruf ve bireysel emeklilik arasında çift yönlü; bireysel emeklilik ile cari açık arasında çift yönlü; cari açıktan tasarrufa doğru tek yönlü nedensellik ilişkilerine rastlanmıştır. Elde edilen bu bulgular, Murphy ve Musalem (2004), Bebczuk ve Musalem (2006), Yaraşır ve Yılmaz (2011), Özel ve Yalçın (2013) ve Özcan ve Günay (2012) ile uyumluluk gösterirken Uyar (2012) ile çelişmektedir.

Elde edilen bulgular ülkeler açısından incelendiğinde ise şu sonuçlar elde edilmiştir; Estonya, İzlanda, Polonya ve Türkiye'de cari açıktan tasarrufa doğru nedensellik ilişkisi bulunurken Çek Cumhuriyeti, Estonya, İspanya ve Türkiye'de Tasarruftan Cari açığa doğru nedensellik ilişkisi bulunmaktadır. Bireysel emeklilik ile cari açık arasındaki ilişkiye bakıldığında; Şili, Çek Cumhuriyeti, Macaristan, İzlanda, İsrail, Polonya ve Slovak Cumhuriyeti'nde nedenselliğin yönü cari açıktan bireysel emekliliğe doğru iken, Şili, Çek Cumhuriyeti, Estonya, Macaristan, İzlanda, İsrail, İtalya, Yeni Zelanda, Polonya, Portekiz, Slovak Cumhuriyeti, İspanya, Türkiye ve Amerika Birleşik Devletleri’nde nedenselliğin yönü bireysel emeklilikten cari açı̆̆a doğrudur. Son olarak Şili, Macaristan, İzlanda ve Türkiye'de tasarruf oranından bireysel emekliliğe doğru nedensellik ilişkisi bulunurken, Şili, Estonya, İzlanda, İsrail, Yeni Zelanda ve Slovak Cumhuriyeti’nde bireysel emeklilikten tasarruf oranına doğru nedensellik ilişkisi bulunmaktadır.

Yurtiçi tasarruf oranının düşüklüğü, ülleleri bulundukları gelişmişlik seviyelerine göre farklı şekillerde etkilemektedir. Ancak genel olarak bakıldığında yurtiçi tasarruflardaki yetersizlik, ülkelerin makroekonomik dengelerinde bozulmalara neden olmaktadır. Gerçekleştirilen bu çalışma ile ülkelerin, makroekonomik dengelerinin sağlanmasına engel olan iç tasarruf yetersizliğini gidermek ve/veya gelecekte karşılaşabilecekleri sorunları bertaraf edebilmek için uygulamaya geçirdikleri bireysel emeklilik sistemi (BES), yurtiçi tasarruf oranları ve cari denge arasındaki ilişkiler panel nedensellik analizi ile incelenmiştir. Elde edilen bulgular tasarruf 
açığının kapatılmasında ve cari dengenin sağlanmasında bireysel emeklilik sisteminin etkili olduğunu göstermiştir. Çalışma bulguları, politika yapıcıların bireysel emeklilik sistemini geliştirmeleri ve tasarruf oranını artırıcı yeni tedbirler geliştirmelerinin, makroekonomik denge açısından önemli olduğunu göstermektedir.

\section{Kaynakça}

- Aghion, P, Comin, D, Howitt, P. (2006). When does domestic saving matter for economic growth? : National Bureau of Economic Research.

- $\quad$ Baltagi, B. H., Feng, Q., and Kao, C. (2012), “A Lagrange Multiplier Test for Cross-sectional Dependence in a Fixed Efects Panel Data Model", Journal of Econometrics, 170, 164-177.

- Bank, W. (2013). Sustaining High Growth: The Role of Domestic Savings Synthesis Report. (66301-TR).

- Bebczuk, R N, Musalem, A. (2006). "Pensions and saving: new international panel data evidence". Documentos de Trabajo.

- Breitung, Jörg (2000). “The Local Power of Some Unit Root Tests for Panel Data,” in B. Baltagi (ed.), Advances in Econometrics, Vol. 15: Nonstationary Panels, Panel Cointegration, and Dynamic Panels, Amsterdam: JAI Press, 161-178.

- Breusch, T., Pagan, A. (1980), “The Lagrange Multiplier Test And İts Application To Model Specifications İn Econometrics”, Reviews of Economics Studies, 47, 239-253.

- Brückner, M, Pappa, E. (2013). "On the Relationship Between Domestic Savings and the Current Account in Poor Countries: Evidence and Theory".

- Dumitrescu, E. I. ve Hurlın, C., (2012), “Testing for Granger noncausality in heterogeneous panels", Economic Modelling, 29(4), 1450-1460.

- Emirmahmutoglu, Furkan and Kose, Nezir (2011), "Testing for Granger Causality in Heterogeneous Mixed Panels", Economic Modelling, 28, SSRN: http://ssrn.com/abstract=1550128.

- $\quad$ Erkiletlioğlu, H, Gül, E, Şat, A G, Çevik, B. (2011). "Türkiye'de Tasarruf Eğilimi". Türkiye İş Bankası A.Ş. Íktisadi Araştırmalar Bölümü.

- Feldstein, M S, Horioka, C Y. (1979). Domestic savings and international capital flows: National Bureau of Economic Research Cambridge, Mass., USA.

- Im, K. S., M. H. Pesaran, and Y. Shin (2003). "Testing for Unit Roots in Heterogeneous Panels", Journal of Econometrics, 115, 53-74.

- $\quad$ Kónya, L. (2006), "Exports and growth: Granger causality analysis on OECD Countries with a panel data approach", Economic Modelling, 23, 978-992.

- Levin, A., C. F. Lin, and C. Chu (2002). "Unit Root Tests in Panel Data: Asymptotic and Finite-Sample Properties", Journal of Econometrics, 108, 1-24.

- Maddala, G. S. and S. Wu (1999), “A Comparative Study of Unit Root Tests with Panel Data and A New Simple Test", Oxford Bulletin of Economics and Statistics, 61, 631-52.

- $\quad$ Murphy, P L, Musalem, A R. (2004). Pension funds and national saving (3410. bs): World Bank Publications.

- Özcan, K M, Günay, A. (2012). Türkiye’de Özel Tasarrufları Belirleyen Unsurlar: Turkish Economic Association.

- $\quad$ Özel, Ö, Yalçın, C. (2013). "Yurtiçi Tasarruflar ve Bireysel Emeklilik Sistemi: Türkiye'deki Uygulamaya İlişkin Bir Değerlendirme". TCMB, Çalışma Tebliği(13/04).

- Pesaran, M. H. (2004) “General Diagnostic Tests for Cross Section Dependence in Panels”, University of Cambridge, Faculty of Economics, Cambridge Working Papers in Economics No. 0435.

- Schimmelpfennig, A. (2000). Pension Reform, Private Saving, and the Current Account in a Small Open Economy: International Monetary Fund.

- Tatoğlu Yerdelen, F. (2013). "İleri Panel Veri Analizi: Stata Uygulamalı." İstanbul: Beta Basım, Yayım, Dağıtım.

- $\quad$ Uyar, H İ. (2012). "Bireysel Emeklilik Sistemi İle Ekonomik Göstergeler Arasindaki İlişkinin İncelenmesi". Mali Cozum Dergisi/Financial Analysis(110).

- Uygur, E. (2012). Türkiye'de Tasarrufların Seyri ve Etkileyen Bazı Unsurlar: Discussion Paper, Turkish Economic Association.

- Yaraşır, S, Yılmaz, B E. (2011). "OECD Ülkelerinde Özel Tasarruflar: Bir Bakış (1999-2007)". Maliye Dergisi, 160. 


\title{
Döviz Kuru, Altın Fiyatları ve Borsa Getirileri Yönünün Yüksek Dereceden Markov Zincirleri Modelleri ile Tahmini
}

\section{Estimation of Direction of Exchange Rate, Gold Price and Stock Market Returns with High Order Markov Chain Models}

\author{
Prof. Dr. Süleyman Bilgin Kılıç (Çukurova University, Turkey) \\ Salih Çam (Çukurova University, Turkey)
}

\begin{abstract}
This study uses a hybrid high order Markov Chains Model to predict direction of exchange rate, gold price and stock market returns with the Artificial Neural Network Algorithm as an estimator of transition probability matrix. Many forecasting techniques are used to examine the direction of returns forecasting in the literature such as Markov Chains Model and Artificial Neural Network Algorithm. In this study, it is aimed to combine these two techniques and to utilize the predict values of the Artificial Neural Network Algorithm for calculate transition probabilities matrix. Calculations show that the hybrid model gives high correct classification probabilities besides of well approximated transition probabilities. Returns series of USD/TRY exchange rate, closing price of Borsa Istanbul Stock Exchange and gold prices cover the period of 01/01/2003 and 31/01/2016. All series are obtained from database of Central Bank of Turkey. As a result, although the transition probabilities almost equal to 0.5 and so estimation of these series are not easy, the transition probabilities and correct classification probabilities gained from the hybrid model provide substantial information related to direction of returns forecasting. Besides, estimated model provide valuable information to individual investors and companies, and could help them to take position against to risks.
\end{abstract}

\section{Giriş}

Etkin piyasa hipotezi Amerikalı ekonomist Fama (1970) tarafından ortaya atıldığından beri birçok araştırmaya konu olmuştur. Fama (1970) göre etkin bir piyasa yeterince büyüktür ve bu piyasada birbirleri ile kar maksimizasyonu için rekabet eden birçok aktör vardır. Dolayısıyla tek bir alıcı veya satıcı piyasada fiyatlama yapamaz. Genel olarak etkin piyasalar zayıf etkin piyasalar, orta etkin piyasalar ve güçlü etkin piyasalar olmak üzere üç şekilde karşımıza çıkmaktadır. Zayıf etkin piyasa hipotezine göre verilerin tarihsel özelliklerinden yola çıkarak gelecek ile ilgili çıkarım yapılamaz. Diğer bir ifade ile teknik analiz yardımı ile uzun dönemde piyasa ortalama getirisinin üstünde bir getiri elde etmek mümkün değildir. Orta etkin piyasa hipotezine göre ise yeni bir bilgi bütün aktörler tarafından hemen elde edilmektedir. Sonuç olarak orta etkin bir piyasada bilgi fiyatlanmıştır ve ortalamanın üstünde getiri sağlamaz. Bu tür bir piyasada ortalamanın üstünde getiri sağlamak için halka açık olmayan (içerden) bilgi sağlanmalıdır. Nihayet güçlü etkin bir piyasada, halka açık bilginin yanında içerden bilgi de ortalamanın üstünde kar sağlamak adına yarar sağlamayacaktır.

Bir piyasanın yeterince büyük olması sadece iç piyasadaki aktör sayılarına bağlı değildir. Küreselleşen piyasalar ile birlikte artan dış ticaret, iç piyasalara yabancı sermaye girişini ve yabancı yatırımcı sayısını arttırmıştır. Dolayısıyla ticaret ilişkilerin olduğu ekonomilerde meydana gelen bir şok direkt olarak iç piyasadaki yabancı yatırımcıları ve döviz kuru üzerinden ihracat yapan yerli yatırımcıları etkilemektedir. Bu noktada hem yabancı yatırımcılar hem de yerli yatırımcılar açısından başta döviz kuru olmak üzere finansal piyasaların gelecek değerlerini öngörebilmek çok önemlidir. Bundan dolayı bu piyasalar ile ilgili ekstra bir bilgi elde edilmesi yatırımcılara avantaj sağlamanın yanında sözü geçen piyasaların doğru bir şekilde tahmin edilmesi hükümetler, şirketler ve yatırımcılara risklere karşı pozisyon alma şansı da tanıyacaktır. Örneğin hükümetler açısından döviz kurunun kısa ve orta vadede nasıl hareket edeceği ile ilgili ekstra bir bilgi, uygulayacakları para politikalarını daha etkin kullanmalarına yardımcı olacaktır. Bireysel bir yatırımcının ekstra bir bilgiye sahip olması ise uzun dönem getirisini ortalama getirinin üstüne çıkartmasını sağlayacaktır. Bu çalışmaya konu olan piyasalar etkin piyasalar ya da etkin piyasalara en yakın piyasalardır. Dolayısıyla bu piyasalarla ilgili doğru ve güçlü tahminler elde etmek karar alıcılara ve yatırımcılara hareket alanı sağlayacaktır.

\section{Literatür}

Markov zincirleri ve yapay sinir ağlarının uygulama alanları oldukça geniştir. Markov zincirleri fizik, internet, istatistik, iktisat, matematiksel biyoloji, müzik ve spor gibi birçok alanda kendine yer bulmuştur. Yapay sinir ağları ise finans, haberleşme, tıp ve ilaç sanayi v.b gibi geniş bir uygulama alanına sahiptir. Özellikle Markov zincirleri modelleri döviz kuru, altın fiyatları ve borsa verileri gibi gelecek değerlerinin tahmin edilmesi güç olduğu değişkenlerde sıklıkla kullanılmıştır. Bu tekniklerin finans alanındaki uygulamalarının birkaçı burada özetlenmiştir. Ryan (1973) borsa hareketlerini Markov zincirleri modellerini kullanarak tahmin etmiştir. Ryan yaptığı analizler sonucunda Markov zincirleri modelinin borsa hareketleri ile ilgili önemli bilgiler verdiğini 
göstermiştir. Engel ve Hamilton (1990) Amerikan dolarındaki ani iniş ve çıkışları Markov zincirleri modellerini kullanarak serinin rastsal bir süreç izleyip izlemediğini başka bir ifade ile serinin Markov zincirleriyle tahmin edilip edilemeyeceğini araştırmıştır. Yapılan analizler doğrultusunda yazar, incelediği dönem çerçevesinde serinin rastsal yürüyüşten daha iyi performans gösterdiğini bulmuştur. McQueen (1991) Markov zincirleriyle 1947-1987 dönemine ait y1llık borsa getirisi serisinin Markov sürecine uyduğunu göstermiştir. Başka bir ifade ile borsa getirilerinin Markov zincirleri modelleriyle tahmin edilebileceği sonucuna varmıştır. Marsh (2000) çalışmasında iki durumlu Markov zinciri modelini üç günlük döviz kuru getiri oranları serisine uygulamış ve serinin Markov sürecine uyduğu sonucuna varmıştır. Marsh analizine Alman Markı, İngiliz Sterlini ve Japon Yenini dahil etmiş ve bu üç döviz kuru serisini üç ayrı dönemler halinde analiz etmiştir. Araştırmac1 1980-1985, 1980-1990 ve $1980-$ 1995 dönemleri olarak ele aldığı serilerin birinci dönemler için en iyi performansı sergilediklerini, dönem aralığı arttıkça Markov zincirlerinin tahmin performansının biraz düştüğünü gözlemlemiştir. Benzer bir çalışma Mills ve Jordanov (2003) tarafindan yapılmış ve 1985-1995 dönemini kapsayan borsa verileri kullanılmıştır. Yazarlar yaptıkları analizler sonucunda Markov zincirlerinin özellikle uzun dönemde daha iyi tahmin performansı sergilediğini sonucuna varmışlardır. Kanas (2003) Amerika borsa verilerini 1872-1999 dönemi için dört faklı tahmin tekniği kullanarak analiz etmiştir. Kanas ikisi parametrik ikisi non-parametrik olan teknikler arasından Markov zincirleri ve yapay sinir ağları algoritmasının en az diğer iki teknik kadar iyi performans gösterdiklerini bildirmiştir. Ayrıca çalışmada dört değerlendirme kriteri uygulanmış ve bu kriterlere göre en iyi performansı Markov zincirleri göstermiştir. Can ve Öz (2009) USD döviz kurunu saklı Markov zincirleri modelini kullanarak tahmin etmişlerdir. 1992-2007 dönemi verileri kullandıkları çalışmalarında araştırmacılar, 2008 yılı için döviz kuru hareketlerini başarılı bir şekilde tahmin etmişlerdir. Aşkın, Güzin ve Gülüzar (2012), altın fiyatlarının getiri yönlerini 2005-2009 yılları arası günlük veriler kullanarak analiz etmişler ve Markov zincirleri modellerinden anlamlı sonuçlar elde etmişlerdir. Ayrıca Kılıç (2013) ve Onalan (2014) çalışmalarında TL/USD döviz kurunu Markov zincirleri yardımıyla tahmin etmiş ve önemli bilgiler elde etmişlerdir. İlarslan (2014) İMKB 10 indeksindeki on bankandan dokuz tanesinin hisse senedi fiyatları hakkında doğru öngörüler yapmıştır

Yukarıda Markov zincirleri ile ilgili literatürdeki çalışmaların bir kısmı özetlendi. Burada ise yapay sinir ağları algoritmasının finansal veriler ile uygulamasını içeren çalışmalar özetlenecektir. Markov zincirleri modellerinde olduğu gibi özellikle döviz kuru ve borsa verilerinin gelecek tahminleri için yapay sinir ağları algoritması oldukça fazla kullanılmıştır. Zhang ve Hu (1998) giriş katmanı ve gizli katmandaki düğüm sayılarının ağın performansı üzerindeki etkisini araştırdıkları çalışmalarında, Pound/USD döviz kuru serisini analiz için kullanmışlardır. Ampirik sonuçlar doğrultusunda yapay sinir ağları algoritmasının araştırmada kullanılan lineer modellerden daha iyi tahmin performansı gösterdiklerini gözlemlemişlerdir. Ayrıca ă̆ performansının verinin sıklığına göre de iyileştiğini bildirmişlerdir. Shin ve Han (2000) Won/USD döviz kuru değerlerini tahmin ettikleri çalışmalarında Genetik algoritma ile Yapay sinir ağları algoritmasını birlikte kullanımının tatmin eden sonuçlar verdiğini göstermişlerdir. Ayrıca Nag ve Mitra (2002) de Genetik algoritma ve Yapay sinir ağları algoritmasını birlikte kullanmış ve çalışmadaki diğer tekniklerden başarılı tahminler ürettiğini gözlemlemişlerdir. Diğer bir çalışmada ise Leung, Chen ve Daouk (2000) Genel regresyon sinir ağları modelini döviz kuru fiyatlarını analiz etmek için kullanmışlar ve bu tekniğin kullanılan diğer tekniklere kıyasla iyi performans sergilediği sonucuna varmışlardır. Kamruzzaman ve Sarker (2003) Avustralya Dolarını beş farklı para birimi karşısındaki değerini Yapay sinir ağları algoritmasıyla tahmin etmiştir. Kamruzzaman ve Sarker çalışmasında Yapay sinir ağları algoritmasını ARIMA modeliyle beş kritere göre karşılaştırmış ve YSA'dan daha başarılı tahminler elde etmiştir. Benzer şekilde Panda ve Narishman (2007) Rupi/USD döviz kurunun haftalık verilerinden yola çıkarak bir hafta sonraki değerini YSA, lineer otoregresif model ve rassal yürüyüş modelleriyle tahmin etmiştir. Yapılan değerlendirmelerden sonra YSA'dan daha doğru tahminler elde etmişlerdir. Gulseren, Kayakutlu ve Daniels (2011) NASDAQ indeksi günlük verilerinin yaklaşık yedi aylık dönemini kapsayan veri setini çok katmanlı Yapay sinir ağları algoritması ve birkaç hibrit modelin çıktıları üzerinden araştırmıştır. Çalışmanın sonucuna göre çok katmanlı Yapay sinir ağları modelinin güçlü tahminler ürettiği gözlemlenmiştir. Borsa getirisi, altın fiyatları getirisi ve faiz getirisi verilerini konu alan çalışmasında Kılıç, Paksoy ve Genç (2014) serilerin YSA modeliyle tahminlerinin önemli bilgiler verdiği sonucuna varmışlardır.

\section{Yöntem}

Bu çalışmada USD/TL döviz kuru, altın fiyatları ve borsa verilerinin günlük getiri oranları kullanılmıştır. Her bir değişkene ait ikinci dereceden ve üçüncü dereceden Markov zincirleri geçiş olasılıkları matrisi hesaplanmıştır. Değişkenlerin üçüncü dereceden geçiş olasılıklarını hesaplamak amacıyla giriş verisi son üç günün getiri yönünün pozitif $(+)$ veya negatif $(-)$ olmasına bağlı olarak $(+++),(++-),(+-+),(-++),(--+),(-+-),\left(+--_{-}\right)$ve $(---)$ olmak üzere sekiz adet Yapay sinir ağı modeli tahmin edilmiştir. Bütün yapay sinir ağları modelleri için yaklaşık yüz deneme yapılmış ve en yüksek performansı gösteren model seçilmiştir. Performans kriteri olarak Yapay sinir ağının toplam doğru tahmin etme başarısı ve getirinin iki yönünü minimum \%50 doğrulukta tahmin etmesi dikkate alınmıştır. İkinci dereceden geçiş olasılıkları matrisini hesaplamak amacıyla ise giriş verisi son iki günün getiri yönünün pozitif $(+)$ veya negatif (-) olmasına bağlı olarak $(++),(+-),(-+)$ ve (- -) olmak üzere dört Yapay sinir ağı modeli tahmin edilmiştir. Aynı şekilde bütün Yapay sinir ağı modelleri için yaklaşık yüz deneme yapılmış ve 
en iyi sınıflama başarısını gösteren ağ yapısı tahmin edici olarak seçilmiştir. Yapay sinir ağları modelleri hesaplanırken $\mathrm{w}$ giriş katmanı ile gizli katman arasındaki ağırlıkları gösteren matris, $\mathrm{v}$ ise gizli katman ile çıkış katmanı arasındaki ağırlıkları gösteren matris olarak hesaplanmıştır. Yapay sinir ağının çıktısı

$$
\hat{Y}_{t}=F_{2}\left[\left(V_{t}^{T} F_{1}\left(W_{t} \cdot X_{t}\right)\right)\right]
$$

olarak gösterilebilir. Burada $X=\left(x_{0}, x_{1}, \ldots ., x_{p}\right)^{T} \in R^{(p+1) x 1}$ yapay sinir ağının giriş verisini temsil ederken $Y=\left(y_{0}, y_{1}, \ldots ., y_{k}\right)^{t} \in R^{(k+1)}, \mathrm{X}$ giriş verisine karşılık ağın çıkış verisini temsil etmektedir. Ayrıca $F_{1}\left(W_{t} \cdot X_{t}\right)$ giriş katmanından gizli katmana aktivasyon fonksiyonudur ve şu şekilde gösterilmektedir.

$$
F_{1}\left(W_{t} X_{t}\right)=\left(F\left(\text { net }_{0(t)}\right), F\left(n e t_{1(t)}\right) \ldots . . F\left(n e t_{q(t)}\right)\right)^{T} \in R^{q+1) x 1}
$$

Burada $\quad n e t_{i(t)}=\sum_{j=0}^{p} w_{i j(t)} . x_{j(t)}, \quad i=0,1, \ldots, q$ 'dir ve $w_{i 0(t)}, \mathrm{t}=1,2, \ldots, \mathrm{q}$ gizli katmandaki düğümlere giden hata terimleridir. $F_{2}\left[\left(V_{t}^{T} F_{1}\left(W_{t} \cdot X_{t}\right)\right)\right]$ fonksiyonu ise gizli katmandaki net girdinin v çıkış katmanı ağılıklarıyla çarpılmasıyla elde edilmiştir (Yu ve diğerleri, 2007, s.28-29). Başka bir ifade ile ağın çıktısıdır. $F_{2}(n e t)$ aktivasyon fonksiyonu oluşturulan Yapay sinir ağı modellerinin performanslarına göre sigmoid fonksiyonu olarak seçilmiş̧ir.

Eşitlik [1]'den elde edilen $\hat{Y}_{t}$ tahmin değerleri geçiş olasılıkları matrisini hesaplamak için kullanılmıştır. Bütün geçiş olasılıkları için $n_{i l \ldots . . i 0}$ yüksek dereceden Markov zincirlerinde geçiş tipinin sayısını, $\hat{p}_{i l \ldots . . . i 0}$ ilgili geçiş olasılığını ve m durum sayısını göstersin. Geçiş olasılıklarının en yüksek olabilirlik (EYO) tahmini şu şekilde hesaplanabilir.

$$
\hat{p}_{i l \ldots \ldots i 0}=\frac{n_{i l \ldots \ldots i 0}}{n_{i l \ldots \ldots i 1}+}
$$

burada $\quad n_{i l \ldots \ldots i 1}+=\sum_{i_{0}=1}^{m} n_{i l \ldots \ldots i 0}$ 'dır ve Yapay sinir ağının tahmin edilmiş değerleridir. Örneğin üç gün boyunca pozitif getiri takip eden bir değişkenin bir adım sonraki getirisinin de pozitif olma olasıllığı pozitif, pozitif, pozitif $(+++)$ devam eden getirilerin sayısının bir sonraki gün pozitif gerçekleşmiş getirilerin sayısına bölünmesiyle bulunmaktadır.

Birinci dereceden Markov sürecinde bir değişkene ait gözlemlerin sadece kendinden bir önceki gözlemden etkilendiğini daha eski gözlemlerden etkilenmediği varsayılmaktadır. Fakat ikinci dereceden ve üçünce dereceden Markov zincirlerinde bu varsayımın biraz gevşetilmesi gerekmektedir.

$$
\begin{gathered}
P\left(X_{t}=i_{0} / X_{0}=i_{t}, \ldots . ., X_{t-2}=i_{2}, X_{t-1}=i_{1}\right)=P\left(X_{t}=i_{0} / X_{t-2}=i_{2}, X_{t-1}=i_{1}\right) \\
P\left(X_{t}=i_{0} / X_{0}=i_{t}, \ldots . ., X_{t-2}=i_{2}, X_{t-1}=i_{1}\right)=P\left(X_{t}=i_{0} / X_{t-3}=i_{3}, X_{t-2}=i_{2}, X_{t-1}=i_{1}\right)
\end{gathered}
$$

Eşitlik [4] ikinci dereceden Markov sürecini gösterirken [5] üçüncü dereceden Markov sürecini göstermektedir. Buna göre üçüncü dereceden Markov zincirinin geçiş olasılığı matrisi $(8 \times 2)$ boyutunda, ikinci dereceden Markov zincirinin geçiş olasıllı̆ı matrisi ise $(4 \times 2)$ boyutunda olacaktır

\section{Uygulama}

Dolar/TL, Borsa İstanbul 100 indeksi ve altın fiyatlarının getirileri için hesaplanan geçiş olasılıkları matrisleri ve her bir Yapay sinir ağı algoritmasının özet bilgileri aşağıdaki tablolarda verilmiştir. Üçüncü dereceden Markov zincirleri için sekiz Yapay sinir ağı modeli tahmin edilmiş olup, bütün modellerin doğru tahmin etme başarıları ilgili tablolarda verilmiştir. Ayrıca bütün Yapay sinir ağlarının hesaplanan ağırlıkları EkA'da verilmiştir. Yapay sinir ağları tasarlanırken gizli katman fonksiyonu toplam fonksiyonu, çıkış katmanı fonksiyonu ise sigmoid fonksiyonu ve ağın eğitiminde Gradient descent metodu kullanılmıştır. Aşağıdaki $P_{\text {altin(getiri })}$ matrisleri altın getirilerinin ikinci (1b) ve üçüncü (1a) dereceden geçiş olasılıklarını göstermektedir. 


$$
\left.\begin{array}{rl|ll}
(+++) & 0,410 & 0,590 \\
& (++-) & 0,553 & 0,447 \\
P_{\text {Altin (getiri) }}= & (+-+) & 0,469 & 0,531 \\
& (-++) & 0,569 & 0,431 \\
& 0,457 & 0,543 \\
& (+--) & 0,471 & 0,529 \\
& (---) & 0,537 & 0,463 \\
0,463 & 0,537
\end{array}\right]
$$

$$
P_{\text {Altin(getiri) }}=\underset{(++)}{(+)}(+)\left[\begin{array}{ll}
0,498 & 0,502 \\
0,538 & 0,462 \\
0,473 & 0,527 \\
0,511 & 0,489
\end{array}\right]
$$

(1b)

Aşağıdaki tablolar Altın getirileri serisiyle ilgili geçiş olasılıkları matrisindeki bütün Yapay sinir ağlarının (YSA) doğru sınıflama başarısını özetlemektedir.

\begin{tabular}{|l|c|c|c|}
\hline Model & $\begin{array}{c}\text { (+) yönü doğru tahmin } \\
\text { etme başarıs }(\%)\end{array}$ & $\begin{array}{c}\text { (-) yönü doğru tahmin } \\
\text { etme başarıs }(\%)\end{array}$ & $\begin{array}{c}\text { Toplam doğru tahmin } \\
\text { etme başarıs1 (\%) }\end{array}$ \\
\hline$(++)$ & 50,4 & 50,7 & 50,6 \\
\hline$(+-)$ & 58,2 & 50,8 & 54,6 \\
\hline$(-+)$ & 51,3 & 56,4 & 54,0 \\
\hline$(--)$ & 52,0 & 50,0 & 51,1 \\
\hline Ortalama & $\mathbf{5 2 , 9 8}$ & $\mathbf{5 1 , 9 8}$ & $\mathbf{5 2 , 5 8}$ \\
\hline
\end{tabular}

Tablo 1. Altın Getirilerine Ait YSA Modelleri Sınıflama Başarıları

\begin{tabular}{|l|c|c|c|}
\hline Model & $\begin{array}{c}(+) \text { yönü doğru tahmin } \\
\text { etme başarısı (\%) }\end{array}$ & $\begin{array}{c}(-) \text { yönü doğru tahmin } \\
\text { etme başarıs1 (\%) }\end{array}$ & $\begin{array}{c}\text { Toplam doğru tahmin } \\
\text { etme başarısı (\%) }\end{array}$ \\
\hline$(+++)$ & 50,0 & 65,7 & 59,0 \\
\hline$(++-)$ & 60,0 & 50,0 & 56,0 \\
\hline$(+-+)$ & 52,2 & 57,9 & 55,2 \\
\hline$(-++)$ & 67,9 & 53,5 & 60,5 \\
\hline$(--+)$ & 50,8 & 59,4 & 55,1 \\
\hline$(-+-)$ & 57,3 & 62,2 & 59,9 \\
\hline$(+--)$ & 60,3 & 54,0 & 57,4 \\
\hline$(---)$ & 60,9 & 69,5 & 65,0 \\
\hline Ortalama & $\mathbf{5 7 , 4 3}$ & $\mathbf{5 9 , 0 3}$ & $\mathbf{5 8 , 5 1}$ \\
\hline
\end{tabular}

Tablo 2. Altın Getirilerine Ait YSA Modelleri Sınıflama Başarıları

Tablo1 ikinci dereceden modellerin başarılarını Tablo2 ise üçüncü dereceden modellerin sınıflama başarısını göstermektedir. Tabloya göre ikinci dereceden YSA'nın ortalama toplam doğru tahmin etme başarısı $\% 52,58$ 'dir. $\mathrm{Bu}$ oran üçüncü dereceden YSA modellerinde \%58,51 düzeyine çıkmaktadır. Ayrıca tek tek bakıldığında ikinci dereceden modellerin en güçlü tahmini $\% 58,2$ olarak gerçekleşmişken üçüncü dereceden modellerin en güçlü tahmini \% 69,5 olarak gerçekleşmiştir. Bu istatistiklerin dışında ikinci dereceden modeller $(+)$ yönlü getirileri $\% 52,98$ oranında, (-) yönlü getirileri 51,98 oranında doğru tahmin etmiş̦tir. Bu oranlar Tablo2'de \%57,43 ve 59,03 olarak gerçekleşmiştir. Borsa İstanbul 100 indeksine ait olasılıklar şu şekilde gerçekleşmiştir.

$$
\left.\begin{array}{rl|ll}
(+++) & 0,494 & 0,506 \\
P_{\text {Bist1 0o(getiri })} & (++-) & 0,417 & 0,583 \\
(+-+) & 0,451 & 0,549 \\
& (-+) & 0,605 & 0,395 \\
& 0,452 & 0,548 \\
& (+--) & 0,548 & 0,452 \\
& (---) & 0,534 & 0,466 \\
0,534 & 0,466
\end{array}\right]
$$

(2a)

$$
P_{\text {Bist100(getiri) }}=\underset{(++)}{(+)}(+)\left[\begin{array}{ll}
0,338 & 0,662 \\
0,495 & 0,505 \\
0,510 & 0,490 \\
0,557 & 0,443
\end{array}\right]
$$

(2a) BİST100 indeksine ait üçüncü dereceden geçiş olasılığı matrisini gösterirken (2b) BİST100 indeksine ait ikinci dereceden geçiş olasıllığı matrisini göstermektedir. 


\begin{tabular}{|l|c|c|c|}
\hline Model & $\begin{array}{c}\text { (+) yönü doğru tahmin } \\
\text { etme başarıs }(\%)\end{array}$ & $\begin{array}{c}\text { (-) yönü doğru tahmin } \\
\text { etme başarı1 }(\%)\end{array}$ & $\begin{array}{c}\text { Toplam doğru tahmin } \\
\text { etme başarı1 (\%) }\end{array}$ \\
\hline$(++)$ & 33,5 & 65,9 & 49,1 \\
\hline$(+-)$ & 52,3 & 53,6 & 52,9 \\
\hline$(-+)$ & 55,0 & 54,0 & 54,5 \\
\hline$(--)$ & 59,3 & 48,7 & 54,6 \\
\hline Ortalama & $\mathbf{5 0 , 0 3}$ & $\mathbf{5 5 , 5 5}$ & $\mathbf{5 2 , 7 8}$ \\
\hline
\end{tabular}

Tablo 3. BIST100 İndeksine Ait İkinci Dereceden YSA Modellerinin Sınıflama Başarlları

\begin{tabular}{|l|c|c|c|}
\hline Model & $\begin{array}{c}(+) \text { yönü doğru tahmin } \\
\text { etme başarıs1 (\%) }\end{array}$ & $\begin{array}{c}\text { (-) yönü doğru tahmin } \\
\text { etme başarısı }(\%)\end{array}$ & $\begin{array}{c}\text { Toplam doğru tahmin } \\
\text { etme başarıs1 (\%) }\end{array}$ \\
\hline$(+++)$ & 51,7 & 53,6 & 52,5 \\
\hline$(++-)$ & 45,2 & 63,3 & 52,8 \\
\hline$(+-+)$ & 50,0 & 62,1 & 54,9 \\
\hline$(-++)$ & 61,6 & 41,1 & 52,7 \\
\hline$(--+)$ & 53,5 & 63,3 & 58,3 \\
\hline$(-+-)$ & 64,5 & 55,7 & 60,3 \\
\hline$(+--)$ & 58,3 & 52,3 & 55,5 \\
\hline$(--)$ & 61,5 & 52,3 & 60,1 \\
\hline Ortalama & $\mathbf{5 5 , 7 9}$ & $\mathbf{5 5 , 4 6}$ & $\mathbf{5 5 , 8 9}$ \\
\hline
\end{tabular}

Tablo 4. BIST100 İndeksine Ait Üçüncü Dereceden YSA Modellerinin Sinıflama Başarıları

Tablo3 ve Tablo4'de sırasıyla BİST100 indeksine ait ikinci dereceden YSA modeli ve üçüncü dereceden YSA modelinin doğru sınıflama başarıları özetlenmiştir. Tahmin edilen geçiş olasılıkları matrislerine göre getirilerin $(+)$ veya (-) olma olasılıkları genel olarak $\% 45-\% 55$ aralığında gerçekleşmiştir. YSA modellerin performanslarına baktığımızda ise üçüncü dereceden modellerin ikinci dereceden modellere kıyasla daha iyi performans gösterdikleri görülmektedir. Üçüncü dereceden modellere göre ekstra \%5,89 oranında bilgiye sahip olmaktayız. İkinci dereceden modellere göre ise bu oran \%2,78 seviyesine düşmektedir. Bütün modeller incelendiğinde (+) yönlü getiri maksimum \%61,6 oranında doğru tahmin edilebilirken (-) yönlü getiri \%65,9 oranında tahmin edilebilmiştir. Son olarak USD/TL döviz kuru serisine ait geçiş olasılıkları matrisleri ve doğru sınıflama başarıları şu şekilde gerçekleşmiştir.

$$
\left.\begin{array}{rl|ll}
(+++) & 0,528 & 0,472 \\
& (++-) & 0,487 & 0,513 \\
P_{U S D / T L(\text { getiri })}= & (-++) & 0,503 & 0,497 \\
& (-++) & 0,503 & 0,497 \\
& (+-) & 0,495 & 0,505 \\
& (--) & 0,446 & 0,554 \\
0,335 & 0,665 \\
0,253 & 0,74,7
\end{array}\right]
$$

$$
P_{\text {USD/TL(getiri) }}=\underset{(++)}{(+)}\left[\begin{array}{lll}
(++) & 0,493 & 0,507 \\
0,133 & 0,867 \\
0,512 & 0,488 \\
0,202 & 0,798
\end{array}\right]
$$

(3b)

(3a) USD/TL döviz kuruna ait üçüncü dereceden Markov zinciri geçiş olasılığı matrisini gösterirken (3b) aynı seriye ait ikinci dereceden Markov zinciri geçiş olasılığ 1 matrisini göstermektedir.

\begin{tabular}{|l|c|c|c|}
\hline Model & $\begin{array}{c}(+) \text { yönü doğru tahmin } \\
\text { etme başarıs }(\%)\end{array}$ & $\begin{array}{c}\text { (-) yönü doğru tahmin } \\
\text { etme başarıs } \mathbf{( \% )}\end{array}$ & $\begin{array}{c}\text { Toplam doğru tahmin } \\
\text { etme başarı1 (\%) }\end{array}$ \\
\hline$(+++)$ & 61,0 & 55,7 & 58,4 \\
\hline$(++-)$ & 49,6 & 51,9 & 50,9 \\
\hline$(+-+)$ & 58,6 & 58,8 & 58,7 \\
\hline$(-++)$ & 56,0 & 54,8 & 55,4 \\
\hline$(--+)$ & 58,6 & 59,5 & 59,0 \\
\hline$(-+-)$ & 51,9 & 60,7 & 57,0 \\
\hline$(+--)$ & 35,2 & 67,7 & 55,0 \\
\hline$(---)$ & 32,4 & 79,9 & 59,9 \\
\hline Ortalama & $\mathbf{5 0 , 4 1}$ & $\mathbf{6 1 , 1 2 5}$ & $\mathbf{5 6 , 7 9}$ \\
\hline
\end{tabular}

Tablo 5. USD/TL Döviz Kuruna Ait Üçüncü Dereceden YSA Modellerinin Sınıflama Başarıları 


\begin{tabular}{|l|c|c|c|}
\hline Model & $\begin{array}{c}\text { (+) yönü doğru tahmin } \\
\text { etme başarıs1 (\%) }\end{array}$ & $\begin{array}{c}\text { (-) yönü doğru tahmin } \\
\text { etme başarıs }(\%)\end{array}$ & $\begin{array}{c}\text { Toplam doğru tahmin } \\
\text { etme başarıs }(\%)\end{array}$ \\
\hline$(++)$ & 55,8 & 54,2 & 55,0 \\
\hline$(+-)$ & 14,2 & 87,4 & 55,3 \\
\hline$(-+)$ & 51,8 & 49,5 & 50,6 \\
\hline$(--)$ & 20,6 & 80,1 & 54,7 \\
\hline Ortalama & $\mathbf{3 5 , 6}$ & $\mathbf{6 7 , 8}$ & $\mathbf{5 3 , 9}$ \\
\hline
\end{tabular}

Tablo 6. USD/TL Döviz Kuruna Ait İkinci Dereceden YSA Modellerinin Sınıflama Başarıları

Tablo4 ve Tablo5 USD/TL döviz kuruna ait ikinci ve üçüncü dereceden YSA modellerin bilgilerini özetlemektedir. Buna göre üçüncü dereceden YSA modelleri ortalama olarak \%56,79 oranında doğru sınıflama yapmıştır. Tablo4'den anlaşılacağı gibi (- - -) modeli (+) yönü çok iyi tahmin edemese de (-) getiriyi \% 79,9 ile diğer modellere kıyasla en iyi tahmin eden model olmuştur. Yine USD/TL döviz kuru tahminin de üçüncü dereceden YSA modelleri ikinci dereceden modellere göre daha iyi sonuçlar vermişlerdir. Yöntem kısmında her bir modelin yaklaşık 100 denemeden sonra seçildiği ve seçim kriterlerinin en yüksek toplam doğru tahmin etme başarısı ile modellerin getiri yönlerini minimum \%50 doğru tahmin etmeleri olarak belirlendiği vurgulanmıştı. Fakat bazı modelleri her iki yönü \%50'den yüksek tahmin edemediği görülmektedir. Bunun sebebi YSA'nın yapılan 100 deneme sonucunda minimum \%50 sınıflama başarısının yakalanamamış olmasıdır. Dolayısıyla bu modeller için sadece en iyi toplam doğru sınıflama başarısı göz önünde bulundurulmuştur.

\section{Sonuç}

Markov zincirleri ve Yapay sinir ağlarının değişkenliği çok fazla olan serilerde lineer modellere kıyasla tahmin gücünün daha iyi olduğu önceki çalışmalardan anlaşılmaktadır. Bu çalışmada YSA ve Markov zincirleri birleştirilerek modellerin tahmin gücünün yanında geçiş olasılıkları matrisine ait her bir olasılığın doğru sınıflama başarısını da görme şansını elde ettik. Böylelikle herhangi bir serinin herhangi bir modeli için bir sonraki getiri yönünün \% kaç olasılıkla (-) ve ya (+) olacağını söylemenin yanında bu gerçekleşecek olasılığın da \% kaç olasılıkla doğru olacağını görebiliyoruz. Örneğin altın fiyatları serisi için son üç günün getirisi (- - -) olduğunda sonraki günün (-) olma olasılı̆̆ $\% 53,7$ ve bu ve eğer ilgili YSA modeli (-) tahmin ediyorsa bu tahmin \% 69,5 olasıllkla doğru olacaktır. Aynı şekilde sonraki günün getirisinin (+) olama olasılığı \%46,3 iken bu olasılığa bağlı modelin (+) tahmini \%60,9 oranında doğru olacaktır. Serilerin tahmin edilme başarılarına bakıldığında en iyi performansın altın fiyatları serisine ait olduğu görülmektedir. Ayrıca altın serisi de dahil olması koşuluyla bütün seriler için üçüncü dereceden YSA modelleri ikinci dereceden YSA modellerinden üstün performans gösterdiği sonucuna da varılabilir. Finansal piyasalar etkin piyasalara en yakın piyasalar olması ya da başka bir ifade ile verilerin tarihsel özelliklerinden yararlanarak gelecek ile ilgili tahmin yapma zorluğu böyle bir sonucu doğurmuş olabilir. Bu doğrultuda iki gecikmenin dahil edildiği modellerin üç gecikme dahil edilen modellere göre daha az bilgi içermesi olağan karşılanabilir. Bunun doğruluğunu görmek adına serilerin birinci dereceden ve dördüncü dereceden YSA modellerine bakılabilir. Ayrıca bütün serilerin ayıca her bir derece için serilerin rassal yürüyüş sergileyip sergilemediği analiz edilebilir.

\section{Kaynakça}

- $\quad$ Aşkın, Güzin ve Gülüzar,2012. Altın Fiyatlarındaki Dağılımların Markov Zinciri ile Analizi: Uzun Erimli Olasılıklar. Erciyes Üniversitesi İktisadi ve İdari Bilimler Fakültesi Dergisi. Sayı 40,ss. 119-142

- Can, T., ve Öz, E. (2009). Saklı Markov modelleri kullanılarak Türkiye’de dolar kurundaki değişimin tahmin edilmesi. Ístanbul Üniversitesi İşletme Fakültesi Dergisi, 38(1), 1-23.

- Guresen, E., Kayakutlu, G., \& Daim, T. U. (2011). Using artificial neural network models in stock market index prediction. Expert Systems with Applications, 38(8), 10389-10397.

- $\quad$ Engel, C., ve Hamilton, J. D. (1990). Long swings in the dollar: Are they in the data and do markets know it?. The American Economic Review, 689-713.

- ILARSLAN, K. (2014). Hisse Senedi Fiyat Hareketlerinin Tahmin Edilmesinde Markov Zincirlerinin Kullanılması: İMKB 10 Bankacılık Endeksi İşletmeleri Üzerine Ampirik Bir Çalışma. Journal of Yasar University, 35(9).

- Kamruzzaman, J., ve Sarker, R. A. (2003, December). Forecasting of currency exchange rates using ANN: A case study. In Neural Networks and Signal Processing, 2003. Proceedings of the 2003 International Conference on (Vol. 1, pp. 793-797). IEEE.

- $\quad$ Kanas, A. (2003). Non-linear forecasts of stock returns. Journal of Forecasting, 22(4), 299-315.

- KILIÇ, S. B. (2013). Predicting the Direction of Gold Price Returns: Integrating Composite Artificial Neural Network Models by Markov Chain Process. Çukurova Üniversitesi İktisadi ve İdari Bilimler Fakültesi Dergisi,17(2). 
- $\quad$ Leung, M. T., Chen, A. S., ve Daouk, H. (2000). Forecasting exchange rates using general regression neural networks. Computers \& Operations Research, 27(11), 1093-1110.

- $\quad$ Malkiel, B. G., ve Fama, E. F. (1970). Efficient capital markets: A review of theory and empirical work. The journal of Finance, 25(2), 383-417.

- Marsh, I. W. (2000). High-frequency Markov switching models in the foreign exchange market. Journal of Forecasting, 19(2), 123-134.

- McQueen, G., ve Thorley, S. (1991). Are stock returns predictable? A test using Markov chains. The Journal of Finance, 46(1), 239-263.

- Mills, T. C., ve Jordanov, J. V. (2003). The size effect and the random walk hypothesis: Evidence from the London Stock Exchange using Markov chains. Applied Financial Economics, 13(11), 807-815.

- $\quad$ Nag, A. K., ve Mitra, A. (2002). Forecasting daily foreign exchange rates using genetically optimized neural networks. Journal of Forecasting, 21(7), 501-511.

- Onalan, O. (2014). Currency exchange rate estimation using Grey Markov Prediction Model. Journal of Economics Finance and Accounting, 1(3), 205-217.

- $\quad$ Paksoy, S., ve Kilic, S. B. (2015). Forecasting the Direction of BIST 100 Returns with Artificial Neural Network Models. International Journal of Latest Trends in Finance and Economic Sciences, 4(3), 7.

- $\quad$ Panda, C., \& Narasimhan, V. (2007). Forecasting exchange rate better with artificial neural network. Journal of Policy Modeling, 29(2), 227-236.

- $\quad$ Ryan, T. M. (1973). Security prices as Markov processes. Journal of Financial and Quantitative Analysis, 8(01), 17-36.

- Shin, T., ve Han, I. (2000). Optimal signal multi-resolution by genetic algorithms to support artificial neural networks for exchange-rate forecasting.Expert Systems with Applications, 18(4), 257-269.

- Yu, L., Wang, S., \& Lai, K. K. (2010). Foreign-exchange-rate forecasting with artificial neural networks (Vol. 107). Springer Science \& Business Media.

- Zhang, G., \& Hu, M. Y. (1998). Neural network forecasting of the British pound/US dollar exchange rate. Omega, 26(4), 495-506. 


\title{
Sermaye Kaçışı ve Geçiş Ekonomileri Capital Flight and Transition Economies
}

\author{
Prof. Dr. Harun Bal (Çukurova University, Turkey) \\ Assoc. Prof. Dr. Neşe Algan (Çukurova University, Turkey) \\ Gamze Leman Ulaştırıcı (Çukurova University, Turkey)
}

\begin{abstract}
Capital flight and calculation methods are one of concepts that could not been arrived at a consensus in economics literature. Capital flight is defined generally as transferring resident assets of countries to abroad. In addition, political and economic uncertainty and including all capital outflows done with speculative aims in this scope is more acceptable and appropriate approach. Definitional-level differences are the fundamental reasons of measuring methods and their results. When examining in terms of developing countries, it has been seen that regarding capital flights which fall in importance and amount relatively between second half of 1990s and 2000s have extended fast from current years. This situation is not different for economies in transition. Currently the analyses regarding capital flights draw attention with its results that support concerns about transition countries. In this context, calculation methods and the results obtained constituted a different research subject for transition economies. Our study has aimed to analyze of capital flight for 1995-2015 period in the context of selected economies in transition. In analyses, World Bank (WDR 1985) calculation method of capital flight was used. The results have differentiated according to calculation methods, also draw attention to significant increases especially in current years and support concerns regarding increase of capital flight. While our study makes political suggestions directed at decreasing capital flights of relevant countries, redraw attention to discussion in this context.
\end{abstract}

\section{Giriş}

Geçiş ekonomileri birçok sebebi olmakla beraber başlangıçtaki hedef ve beklentilerinin yalnızca bir kısmını gerçekleştirebilmişlerdir. Bahsedilen sebeplerin başında kamu ve özel sektörde yaşanan sermaye birikimi problemi gösterilebilir. Sermaye birikimi probleminin sebeplerinden biri ve belki de en önemlilerinden birisi ise Sermaye kaçışlarıdır. Sermaye kaçışı; var olan ekonomik problemleri şiddetlendirmekte ve hali hazırda yetersiz olan sermaye birikimi problemini de derinleştirmektedir. Sermaye kaçışı sadece Geçiş ekonomileri için değil, neredeyse gelişmekte olan ülkelerin tümünün genel bir problemidir. Bununla birlikte bu çalışmada amaç gelişmekte olan ülkelerin tümü değil, önemli bir grubu olarak Geçiş ekonomileri için sermaye kaçışlarının boyutlarına ilişkin analizler yapmaktır. 1995-2015 dönemi için yapılan sermaye kaçışı analizlerinde WDR 1985 yöntemi kullanılmaktadır.

$\mathrm{Bu}$ çalışmanın sonraki bölümlerinde sırasıyla geçiş ekonomilerinde sermaye birikimi sorunu ile sermaye kaçışları ilişkisi, sermaye kaçışlarına ilişkin tanımsal bilgiler ve nedenleri, ölçme yöntemleri ve uygumla bölümü itibariyle de Geçiş ekonomileri örneğinde Sermaye kaçışlarına ilişkin analizler ve elde edilen sonuçlara yer verilecektir. Sonuç bölümünde ise analiz kısmında elde edilen sonuçların ışığında Geçiş ülkelerinde yaşanan Sermaye kaçışlarının boyutları ve bu konuda etkili görülen önemli faktörlere dikkat çekilecektir.

\section{Geçiş Ekonomilerinde Ekonomik Problemler ve Sermaye Birikimi}

1980lerin sonu 1990ların başı itibariyle Doğu Avrupa ve Asya'daki pek çok sosyalist ülke siyasi ve ekonomik yapılarında köklü değişikliklere gitmişlerdir. Siyasi ve ekonomik yapılarını dönüştürmeye yönelik mücadeleye girişmeleri nedeniyle bu ülkeler "Geçiş ülkeleri” olarak adlandırılmıştır. Söz konusu ülkelerde dönüşüm sürecinden kaynaklanan zorlu süreci daha da zorlaştıran önemli bir sebep ise sermaye kaçışları sorunudur (Bkz, Loungani ve Mauro,2000; Buiter ve Szegvari, 2002). Pek çok sosyal, siyasal ve ekonomik problemin temelinde yatan finansman sorunu gelişmekte olan diğer ülkeler kadar Geçiş ekonomileri için de geçerlidir ve bu ülkeler sermaye birikim sürecini desteklemek ve hızlandırmak adına dış finansman çeşitlerini kendilerine çekmek istemektedirler. Sermaye kaçışları bir yandan zorlukla alınabilen dış fonlara talebin artma göstermesine neden olurken, diğer yandan da bu fonların kaçış miktarı kadar bölümünün gelişme sürecinin dışına çıkmasına neden olmaktadır.

\section{Sermaye Kaçışı: Tanım ve Bazı Tahminler}

Sermaye kaçışı kavramı geçmişi gerilere gitmekle birlikte 1970'li yılların sonu ve 1980'li yılların başlarında borç krizleriyle birlikte dikkat çekmeye başlamıştır (Öztürk ve Artan, 2016, s.172). Bu konudaki en önemli faktör ülkelerin sermaye hareketlerine yönelik kısıtlamaları azaltmaları veya kaldırmalarıdır. Bahsedilen faktör, sermaye hareketlerini arttırmakla kalmamış, farklı gelişmişlik seviyelerine sahip ülkelerin aralarında da sermaye 
hareketlerine neden olmuştur. Yalnız burada dikkat çeken konu, gelişmiş ülkelerdeki birey ve kurumların gelişmekte olan ülkelere yönelik yaptıkları fon transferleri sermaye hareketi veya yatırım olarak değerlendirilirken; tam tersi şekilde gelişmekte olan ülkelerden gelişmiş ülkelere doğru hareket eden sermaye "kaçış" olarak adlandırılmasıdır. Bu noktada sermaye kaçışı hakkındaki temel problemlerden biri olarak tanımlama sorunu karşımıza çıkmaktadır. Sermaye kaçışlarını yasal ve yasal olmayan kaçışlar olarak ayırmamız da mümkündür ama bunun sonucunda bir ilave hesaplama problemiyle karşılaşmak ta kaçınılmaz olacaktır. Bazı çalışmalarda sadece yasadışı akışların sermaye kaçışı olarak alınması gerektiğinden bahsedilmektedir. Bununla beraber, kapsamlı bir analiz yasal ve yasadışı kaçışları beraber olarak göz önüne almalıdır. Yasal olmayan bir çıkışın ülkeye yasal yoldan geri dönebileceğini unutmamak gerekir. Khan ve UL Haque (1987)'e göre sermaye kaçışı gelişmekte olan ülkelerden meydana gelen, kısa ve uzun vadeli portföy ya da varlık yatırımlarını içeren özel sektöre ait bütün sermaye çıkışlarıdır. Tornell ve Velasco (1992) sermaye kaçışlarını, fakir ülkelerden zengin ülkelere doğru meydana gelen, beşeri sermaye de dâhil olmak üzere, verimli kaynakların akımı olarak tanımlamaktadır.

Tanımlamalar genellikle iki grup şeklindedir. Bunlardan ilki; uluslararası ticaretin finansmanı, gerçek yatırım imkanlarının değerlendirilmesi, portföy çeşitlendirmesi gibi nedenlerden kaynaklanan normal sermaye akımlarının, yüksek faiz getirisi, devalüasyon beklentileri, vergiden kaçınma ve kriz bekleyişli akımlardan ayrılarak tanımlanmasıdır. Gelir ve kurumlar vergisi oranlarının çok yüksek olduğu durumlarda ithalatçılar gelirlerini yurtdışında saklamayı daha cazip bulacaklardır. Diğer tanımlama ise; az gelişmiş ülkeler için sermaye faktörünün kıtlığını taban almakta ve ülkeden çıkan tüm sermayeyi kaçış olarak değerlendirmektedir (Esen, 1990, s.40). Bu ayrımla beraber gelişmekte olan ülkeler için mantıklı olan tanım; bu ülkelerdeki siyasi ve ekonomik belirsizlikler ve spekülatif amaçlarla yapılan kısa ve uzun dönemli tüm sermaye çıkışlarının kapsam içine alınmasıdır (Khan ve Vihaque,1987, s.3). Tanımlamalardaki bu farklılıklara bağlı olarak farklı formüller ve hesaplama yöntemleri geliştirilmiştir. Son yıllarda döviz kuru, faiz oranı, enflasyon oranı, finansal açıklık gibi ekonomik göstergelerin yanı sıra politik risk, kamulaştırma riski, yolsuzluk, dış karışıklık gibi kurumsal göstergelerin sermaye kaçışlarının belirleyicileri arasında yer aldığı görülmektedir.

Yapılan çalışmaların Afrika ve Latin Amerika ülkeleri üzerinde yoğunlaştı̆̆ı, geçiş ekonomilerinin ise birkaç çalışmada incelendiği ve bu çalışmaların Rusya üzerinde yoğunlaştığı görülmektedir. Abalkin ve Walley (1999), Lougani ve Mauro (2000) ve Kar ve Freitas (2013) bu çalışmaların bazılarıdır. Örnek olarak çok borçlu beş gelişmekte olan ülkenim 1976-1984 döneminde dış borçları 243 milyar dolar artarken, bu ülkelerden dişarıya giden özel sermaye çıkışlarının miktarı aynı dönemde 133 milyar dolar olarak tahmin edilmekteydi (Diwan, 1989, s.121). Diğer bir çalışmada ise Sahra altı Afrika ülkelerinden 25 fakir ülkenin 1996 itibariyle dış borç toplamı 178 milyar dolar iken, sermaye kaçışı 193 milyar dolar (faiz gelirleriyle 285 milyar dolar) olduğu ve bu fakir ülkelerin aslında sermaye kaçışları çerçevesinde net kreditör pozisyonuna dahi geciktiklerinden söz edilmektedir (Boyce ve Ndikumana, 2001, s.27).

Helleneier (2001) ise Rusya Federasyonu için sermaye kaçışlarının yıkıcı etkilerini işlediği çalışmasında, tahmin edilen sermaye kaçış miktarının, toplam dış borç stok miktarına ulaştığını ifade etmektedir. Collier, Hoeffler ve Pattillo (2000) tarafından gerçekleştirilen bir diğer çalışma ise sermaye kaçışını bir portföy oluşturma tercih şekli olarak ele almakta ve özel sektör sermaye birikimin ülke dışında tutulan kısmı olarak hesap etmektedir.

\section{Sermaye Kaçışı: Nedenleri ve Etkileri}

Sermaye kaçışının birçok sebebi vardır. Vergilerde artış beklentileri, devalüasyon riski, finansal baskılar (Bkz. Pakko, 2000), enflasyon, siyasi ve ekonomik istikrarsizlıklar (Bkz. Lensink ve Diğ. 2000; Hermes ve Lensink, 2001), dış teşvikler vb. Sermaye kaçışının nedenlerini Collins (1988) beş ana başlık altında toplamaktadır;

1) Ulusal paranın aşırı değerlenmesi ve devalüasyon beklentisi

2) Ekonomik istikrarsızlık ve sosyal çalkantılar

3) Yüksek enflasyon

4) Düşük iç faiz oranları

5) Aşırı bütçe açıkları ve parasal tabanın genişlemesi

Cuddington (1986) yapmış olduğu çalışmada reel döviz kurunun aşırı değerlenmesiyle, sermaye kaçışı arasında güçlü bir ilişkinin varlı̆̆ını ortaya koymaktadır. Kara para aklayan mekanizmaların varlığı da sermaye kaçışlarını etkileyen bir faktördür. Vergilerin artacağı konusundaki beklentiler de benzer şekilde önemli bir rol oynamaktadır. Ülkede döviz ve sermaye kontrolünün olmaması sermaye kaçışını kolaylaştırır. Bununla beraber döviz giriş çıkışının kontrolü tek başına sermaye kaçışını önleyemez, fakat risk ve işlem maliyetini arttırmak suretiyle kaçışı zorlaştırır. Günümüz dünyasında sermaye çok daha fazla mobildir ve kar ile güvenliği birlikte bulduğu her yere hareket edebilir. Uygun olmayan politika çerçevelerinde ve ekonomik istikrarsızlık durumlarında sermayeyi tutmak çok daha zor olmaktadır. Sermaye kontrolleri sıkılaştırıldığında ise yasal olmayan yollardan çıkışlarda artış gözlenebilir. Sermaye kontrollerinin yoğunluğuna karşın son derece ciddi sermaye kaçışlarıyla karşı karşıya kalan Rusya Federasyonu bu konudaki en uygun örneklerden biridir (Doğanlar ve Özsoylu, 1995).

Sermaye kaçışı ülkelerinin ekonomik dengeleri üzerinde kısa ve uzun dönemli etkilere sahiptir. Kısa dönemde sermaye kaçışının hızla artması ülkede uygulanan faiz oranlarına, döviz fiyatlarına ve ülkenin rezerv 
pozisyonlarına olumsuz etki yapar. Sermaye kaçışı likidite sıkıntısı yaratacağından faizlerin artmasına neden olur. Milli paranın alım gücü düşeceğinden döviz fiyatları artacaktır. Döviz fiyatları sabit tutulmak istenirse döviz rezervlerinde azalma olacaktır. Tüm bunlar ülkenin makroekonomik dengesinde baskı oluşturacak ve sonuç olarak ülke ekonomisini olumsuz olarak etkileyecektir. Uzun dönemdeyse ilk etki dövize yapılan spekülatif yatırımlar nedeniyle üretken sektörlere yapılabilecek yatırımların azalması olacaktır. Yatırımların daha az verimli alanlara kayması, büyüme oranlarını olumsuz etkileyecektir. İkinci olumsuz etki ise vergi alanında ortaya çıkar ki bu da gelir ve servet vergileri hâsılatında azalma olması anlamına gelmektedir. Vergi tabanının daralması ve vergi gelirlerinin düşmesi kamunun borçlanma ihtiyacını arttıracağından, dış borçlarda da artışa neden olacaktır (Doğanlar ve Özsoylu, 1995).

Sermaye kaçışının eşitlik üzerinde negatif etkisi olması bu olgunun sosyal boyutu olarak karşımıza çıkmaktadır. Daha varlıklı kesimin yüksek veri oranlarından kaçması ve bu sırada daha dar gelirli kesimin ise sosyal servis kesintileri ve yüksek vergi oranları ile karşı karşıya kalması sosyal eşitsizliği arttırmaktır. Bunların yanı sıra işsizlik ve yavaş büyümeye sebep olur.

Sermaye kaçışının en önemli sonucu ise, sermaye ithalatçısı olan ülkelerde özel sermaye akışlarının net bakiyesini azaltıcı etki yapmasıdır. Yani, sermaye kaçışı ülkeye gelen sermayeyi etkisiz hale getirmektedir. Dodey'in (1988) çalışması Meksika ve Venezuela için 1974-1982 yılları arasında bu sonucu doğrulayan bulgular elde etmiştir. Bu ülkelerden kaçan sermaye miktarı toplam dış borçların yarısına ve hatta daha fazlasına ulaşmıştır.

\section{Sermaye Kaçışının Ölçülmesi}

Sermaye kaçışının tanımlanmasındaki çeşitlilik, ölçülmesi konusunda da benzer bir çeşitliliğin yaşanmasına sebep olmuştur. Ölçme yöntemleri içinde en yaygın olan ise bu çalışmada da kullanılmış olan, Dünya Bankasının 1985 yılı kalkınma raporuna kullandığı WDR 1985 yöntemidir. Bu yönteme göre;

Sermaye Kaçışı= Gayrisafi Dış Borç Stok Değişimi + Ülkeye Giren Net Doğrudan Yabancı Sermaye Yatırımları + Cari işlemler Bilançosu Açı̆̆ 1 - Resmi Uluslararası Rezerv Stok Değişimi 'dir.

Dünya Bankası'na (1985) göre sermaye kaçışları, yabancı varlıkların nispeten değerini düşüren ve devalüasyon beklentisine neden olan aşırı değerli döviz kuru, belirsizlik yaratan ve reel faiz oranlarını azaltan yüksek ve değişken enflasyon oranı, yüksek enflasyon dönemlerinde negatif reel faiz oranlarına yol açan ve dış borçlanmayı zorlaştıran aşırı korumacı politikalar nedeniyle ortaya çıkan sermaye çıkışlarıdır (World Bank, 1985, s.63-64).

$\mathrm{Bu}$ tanıma göre cari işlemler açığımı finanse etmeyen veya rezerv birikiminde artışa yol açmayan her türlü sermaye girişi daha sonra ülkeyi kaçış şeklinde terk etmektedir. Bunun yansıra WDR 1985 yöntemi, yurtdışına yapılan normal portföy yatırımları ve yanlış faturalandırmaları da ölçüm içine dahil etmektedir. Yanlış faturalandırmanın çıkış noktası ticarete konu olan belgede, dış ticaret partneri ile anlaşmalı olarak, malın değerine ilişkin bilgilerde sahtecilik yapılması ve mal bedelinin düşük ya da yüksek gösterilmesidir (Erbe,1985, s.269). Yanlış faturalandırmanın ölçülmesinde ülkelerin ihracat ve ithalat verileri karşılaştırılmaktadır (Claessens ve Naude, 1993, s.8). Lougani ve Mauro (2000) sermaye kaçışını dar anlamdaki sıcak para tanımları ve geniş anlamdaki kaçış yöntemleriyle ölçmektedir.

1) Sicak Para Yöntemiyle SK 1= Net hata ve noksan + parasal otoriteler, genel hükümet ve bankalar dışındaki birimlerce tutulan portfolyo yatırımı olmayan varlık ve yükümlülükler.

2) Sicak Para Yöntemiyle SK 2= SK 1 + Bankalar tarafından tutulan portfolyo yatırımı olmayan varlık ve yükümlülükler ve net doğrudan sermaye yatırımı

3) Geniş Tanım SK 3= SK 2 + Borçlanma menkul kıymetleri şeklindeki portföy yatırımlarının varlık ve yükümlülüklerinin net artışı

Sermaye kaçının ölçülmesinde kullanılan diğer yöntemler şu şekildedir (Eggerstedt ve Diğ. 1995, s. 224-226);

1) Cuddington: (-) net hata ve noksan + kısa vadeli banka dışı özel sektör dış aktif akışları

2) Alvarez ve Guzman: (-) net hata ve noksan + özel, kamu ve bankacılık sektörü dış aktif akışları- dış aktiflerin dışarıdaki faizleri - altın alış/satış ve rezerv değişimi ile SDR'ler - kamu sektörü dış aktif artışları - bankaların dış aktif artışları

3) Morgan Guaranty Trust: gayrisafi dış borç stok değişimi + ülkeye giren net doğrudan yabancı sermaye + cari işlemler bilançosu açı̆̆ - resmi uluslararası rezerv stokundaki değişimi - parasal otoriteler, ticari bankalar ve diğer bankacılık sektörünün brüt dış aktifleri.

4) Zedillo: borç akışları + net doğrudan sermaye yatırımları + cari işlemler bilançosu fazlası - resmi rezervlerdeki değişim - dişarda elde edilen faiz gelirleri

5) Gurria ve Fadl: borç akışları + net doğrudan yabancı sermaye yatırımları + cari işlemler bilançosu fazlası - resmi rezervlerdeki değişim - dişarıda elde edilen faiz gelirleri - ticari bankalarca tutulan diş aktiflerdeki değişim- kamu sektörünce tutulan dış aktiflerdeki değişim. 


\section{Sermaye Kaçışının Geçiş Ekonomilerindeki Seviyesinin WDR 1985 Çerçevesinde Ölçülmesi ve Sonuçları}

Garibaldi ve Diğ. (2002) geçiş ekonomilerine sermaye girişleri farklılıklarının açıklanmasında en önemli değişkenlerin; makroekonomik istikrar, ekonomik reformlar, ticari liberalizasyon, doğal kaynak zenginliği, özelleştirme, DSYS önündeki engeller, yatırım ve girişimciliği engelleyebilen (yolsuzluk, rüşvet, mülkiyet hakları vb.) devlet yönetiminin düzenleyici uygulamaları olduğunu ortaya koymaktadır. Bu faktörler yatırım ortamındaki farklılıklarla birleştirildiğinde sermaye girişinin ve sermaye kaçışının açıklanmasında önemli hale gelmektedir. Geçiş ekonomilerinden sermaye çıkışlarını araştıran çalışmalarda en önemli faktörler; yatırımcıların güvensizlikleri, kurumsal yap1 ve politikalara güvensizlikler, yönetişim kalitesindeki zaaflar, makroekonomik performansın iyileştirilmesi ve bankacılık ve finans sisteminin güçlendirilmesi olarak belirlenmiştir (Bkz. Loungani ve Mauro, 2000; Buiter ve Szegvari, 2002).

Geçiş ekonomilerinde yaşanan sermaye kaçışları WDR 1985 yöntemiyle ABD doları cinsinden 1995-2015 dönemi için hesaplanmış ve ekte elde edilen \% lik oranlar ülke bazında grafiklerle gösterilmiştir. Bu grafiklerden de görüleceği üzere tüm geçiş ülkelerinden sermaye kaçışının olmasının yanı sıra bazı ülkelere de sermaye girişi gerçekleşmiştir. Hesaplamalarda kullanılan verilerden; sermaye kaçışı yazarlar tarafından hesaplanmış, diğer veriler ise dünya bankası, IMF DOTS ve OECD'den alınmıştır. Verilerin anlamlılık derecesini arttırabilmek amacıyla sermaye kaçışının 1995-2015 dönemi için yıllık değerleri ülkeler için tek tek belirlenmiş ve aynı dönemlere ait yıllık GSYİH değişkenine bölünerek yıllık sermaye kaçışı / GSYİH değerleri tespit edilmiştir.

Burada elde edilen verilere göre, 1995-2015 yılları arasındaki sermaye kaçışı ortalamaları ülkeler bazında ekte verilmiştir. Bu verilere göre; 2015 yılında Arnavutluk'ta \%-3.23, Bulgaristan'da \%15.1, Hırvatistan'da \%0.44, Letonya'da \%14.8, Polonya'da \%-0.4, Slovakya'da \%0.62, Çek Cumhuriyeti'nde \%3.05, Estonya'da \%2.8, Macaristan'da \%9.56, Litvanya'da \%-1.5 ve Rusya Federasyonu'nda \%9.1 sermaye kaçışı olmuştur. Tüm yıllar içinde en büyük sermaye kaçışı 2003 yılında \%25.15 değeriyle Hırvatistan'da gerçekleşmiştir. Ülkeler arasındaki bu farklılıkların temel kaynağı konusunda önceki bölümlerde sıralanan faktörler geçerli olmakla beraber, ülke bazında daha ayrıntılı analizler yapılması, daha anlamlı sonuçlar elde etmek açından gerekli görülmektedir.

\section{Sonuç}

$\mathrm{Bu}$ çalışmanın temel amacı sermaye kaçışlarının kavramsal olarak değerlendirilmesi, ölçme yöntemlerinin açıklanması ve geçiş ekonomilerinden seçilen ülkelerin WDR (1985) metodolojik çerçevesinde sermaye kaçış oranlarının hesaplanmasıdır. Sermaye kaçışı ve hesaplama yöntemleri üzerinde hala bir fikir birliğine varılamamıştır. Bununla beraber, fazlasıyla mobil hale gelen para, finans piyasalarının her geçen gün artan önemi, küreselleşen ve bağlantıların ve erişimlerin arttığı günümüzde, sermaye kaçışı da artan bir öneme sahip olmaktadır.

Geçiş ülkeleri kendi özel durumlarıyla ilgili problemler yaşayan ve genel anlamda sermaye birikimi problemiyle karşı karşıya kalan; bu sebeple diğer gelişmekte olan ülkelere nazaran ayrı bir öneme sahip olan ülkeler grubudur. $\mathrm{Bu}$ ülkelerden sermaye kaçışını araştıran çalışmalarda kaçışı arttıran faktörlerin, güvensizlikler, yönetişim kalitesindeki zaaflar, bankacılık ve finans sistemlerinin güçlendirilmesi konularının altı çizilmektedir. Kaçışa sebep olan konular kadar, Sermaye kaçışının ülkelere verdiği maddi ve manevi zararı da unutmamak gerekmektedir. Bu bağlamda, sermaye kaçışının hesaplanması, var olan durumu göz önüne koymakta kalmayıp, ülkelere sermaye kaçışının sebepleri ve bu kaçışı engellemek için yapılması gereken politikalar hakkında yol gösterici olmasın açısından önemlidir.

Çalışmamız seçilmiş geçiş ekonomileri için sermaye kaçışını ortalama olarak 1995-2005 dönemi için GSYİH'ya oranlayarak tespit etmiş ve göstermiştir. Bu verilere göre; 2015 y1lında Arnavutluk'ta \%-3.23, Bulgaristan'da $\% 15.1$, Hirvatistan'da \%0.44, Letonya'da \%14.8, Polonya'da \%-0.4, Slovakya'da \%0.62, Çek Cumhuriyeti'nde $\% 3.05$, Estonya'da \%2.8, Macaristan'da \%9.56, Litvanya'da \%-1.5 ve Rusya Federasyonu'nda \%9.1 sermaye kaçışı olmuştur. Tüm yıllar içinde en büyük sermaye kaçışı 2003 yılında \%25.15 değeriyle Hırvatistan'da gerçekleşmiştir. Ülkeler arasındaki bu farklılıkların temel kaynağı konusunda önceki bölümlerde sıralanan faktörler geçerli olmakla beraber, ülke bazında daha ayrıntılı analizler yapılması, daha anlamlı sonuçlar elde etmek açından gerekli görülmektedir. 


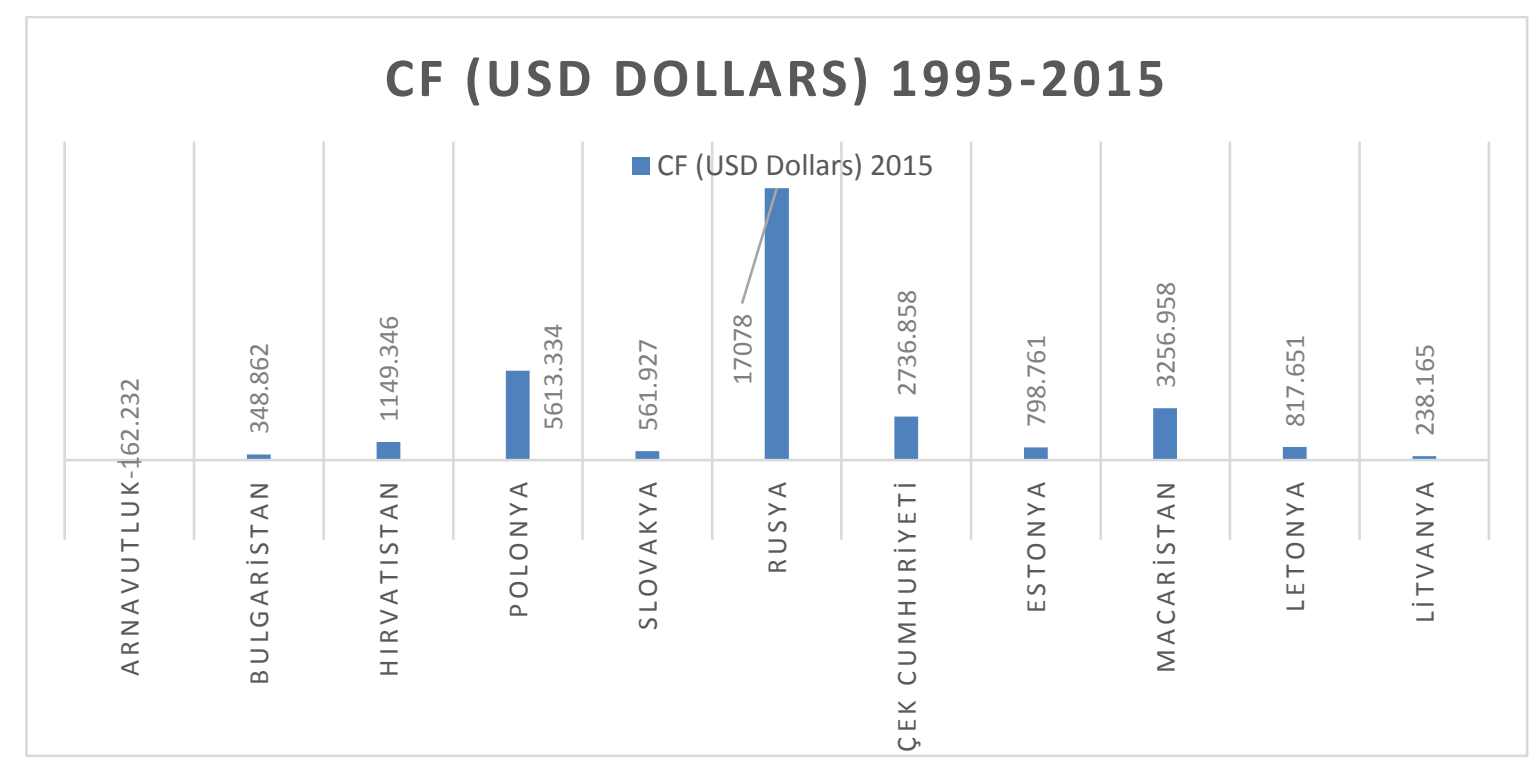

Şekil 1. Geçiş Ekonomilerinde 1995-2015 Yılları Arası Hesaplanan Sermaye Kaçış Miktarları (USD Milyon Dolarl Cinsinden)

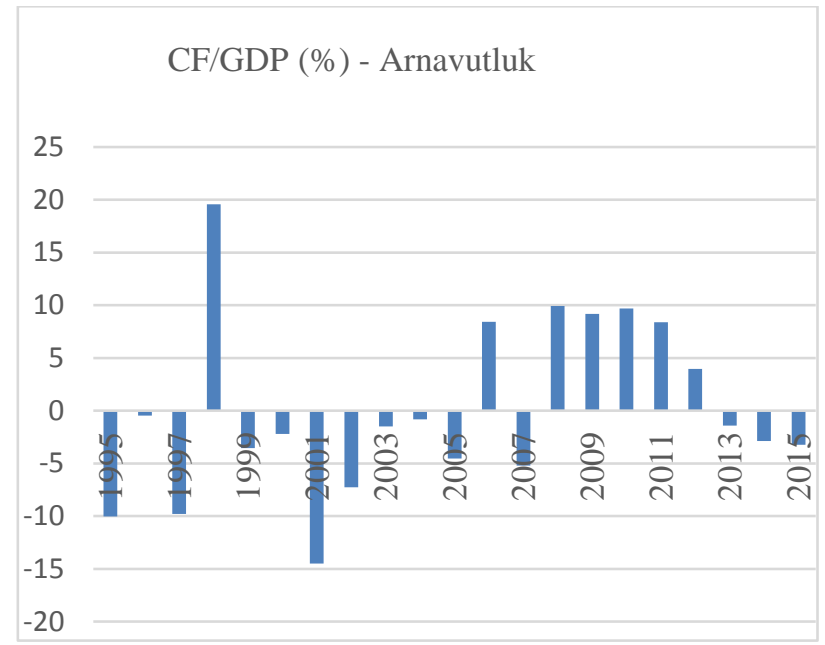

Şekil 2. Arnavutluk Iç̧in WDR (1985) Yöntemiyle 1995-2015 Yılları Arası Hesaplanan Sermaye Kaçış Oranı (Sermaye Kaçışının GSYİH İçindeki Yüzdesi)

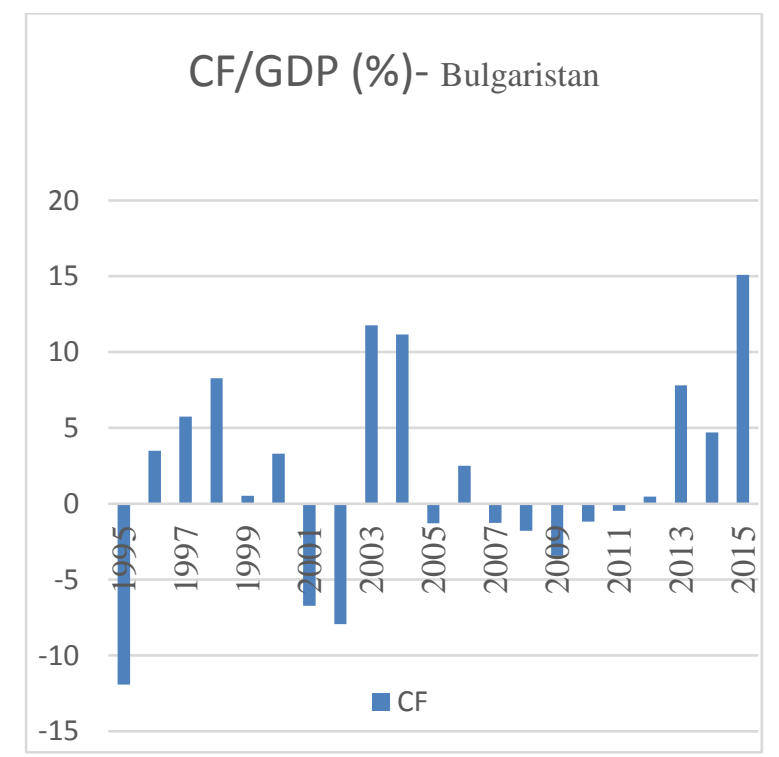

Şekil 3. Bulgaristan İçin WDR (1985) Yöntemiyle 1995-2015 Yılları Arası Hesaplanan Sermaye Kaçış Oranı (Sermaye Kaçışının GSYİH İçindeki Yüzdesi) 


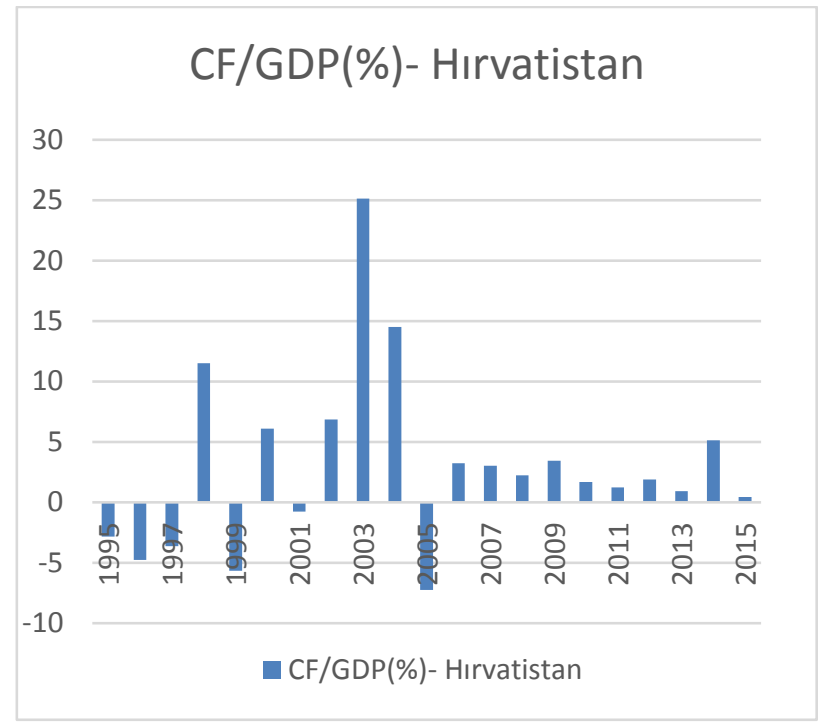

Şekil 4. Hırvatistan İçin Wdr (1985) Yöntemiyle 1995-2015 Yılları Arası Hesaplanan Sermaye Kaçış Oranı (Sermaye Kaçışının Gsyih Iç̧indeki Yüzdesi)

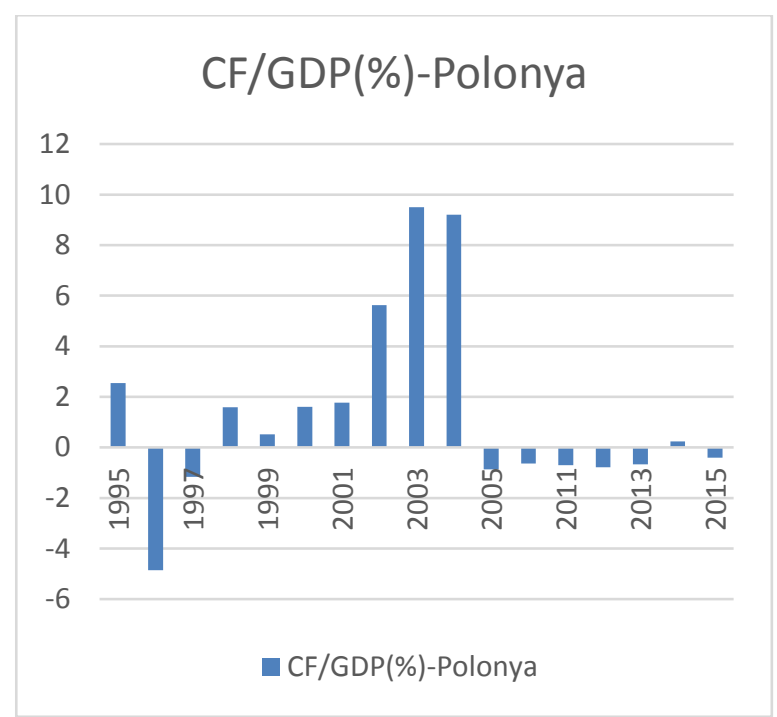

Şekil 5. Polonya İçin WDR (1985) Yöntemiyle 1995-2015 Yılları Arası Hesaplanan Sermaye Kaçış Oranı (Sermaye Kaçışının GSYIH İçindeki Yüzdesi)

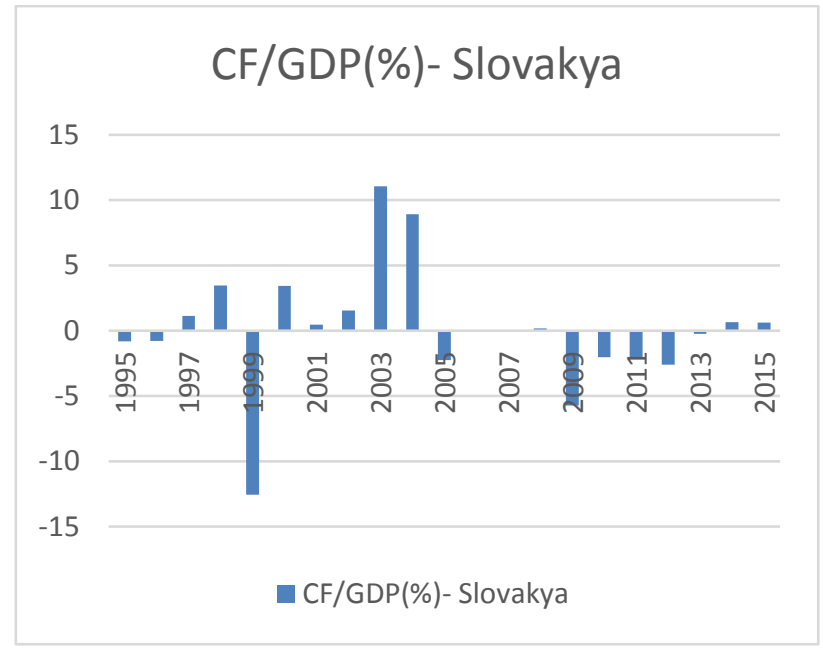

Şekil 6. Slovakya İçin WDR (1985) Yöntemiyle 1995-2015 Yılları Arası Hesaplanan Sermaye Kaçış Oranı (Sermaye Kaçışının GSYIH İçindeki Yüzdesi) 


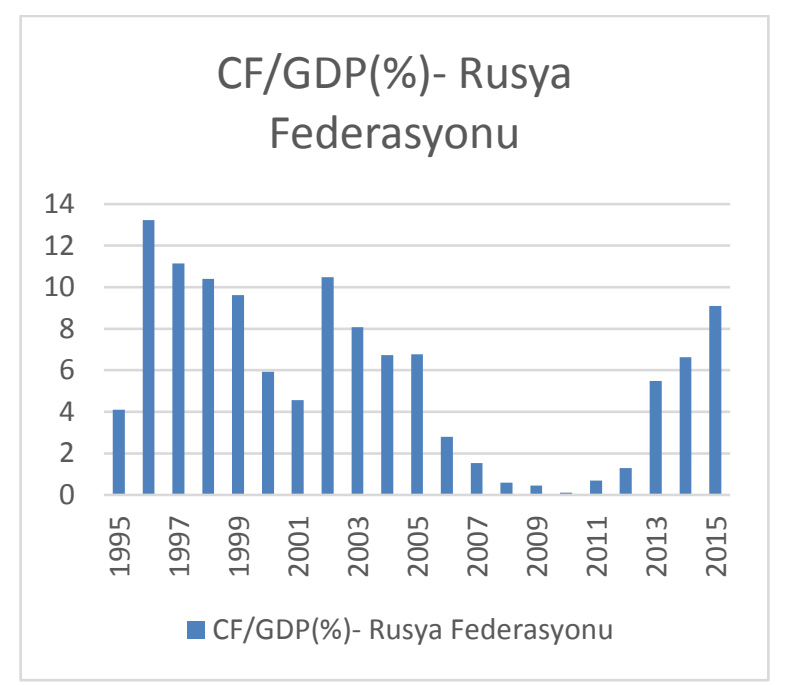

Şekil 7. Rusya Federasyonu İçin WDR (1985) Yöntemiyle 1995-2015 Yılları Arası Hesaplanan Sermaye Kaçış Oranı (Sermaye Kaçışının GSYIH İçindeki Yüzdesi)

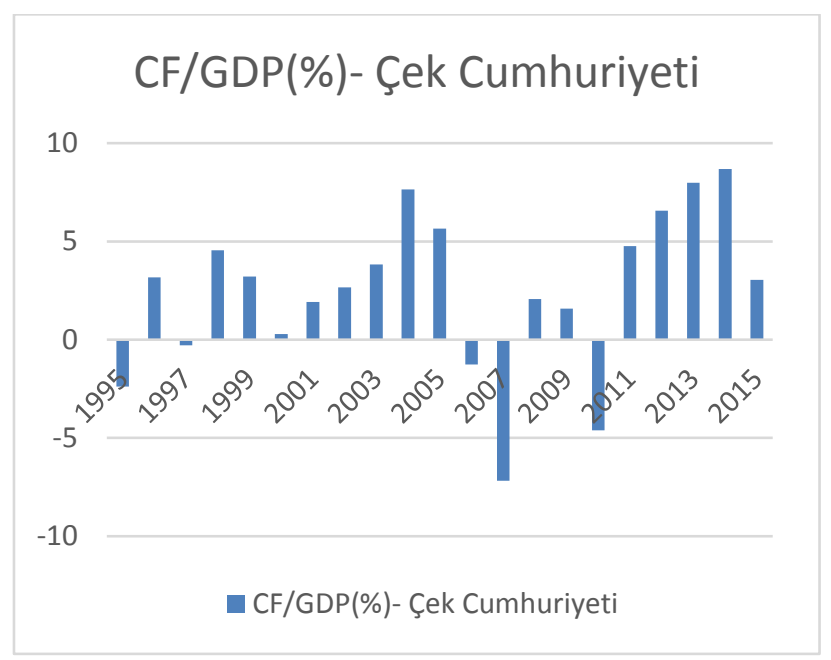

Şekil 8. Çek Cumhuriyeti İ̧̧in WDR (1985) Yöntemiyle 1995-2015 Yılları Arası Hesaplanan Sermaye Kaçıs Oranı (Sermaye Kaçışının GSYİH İçindeki Yüzdesi)

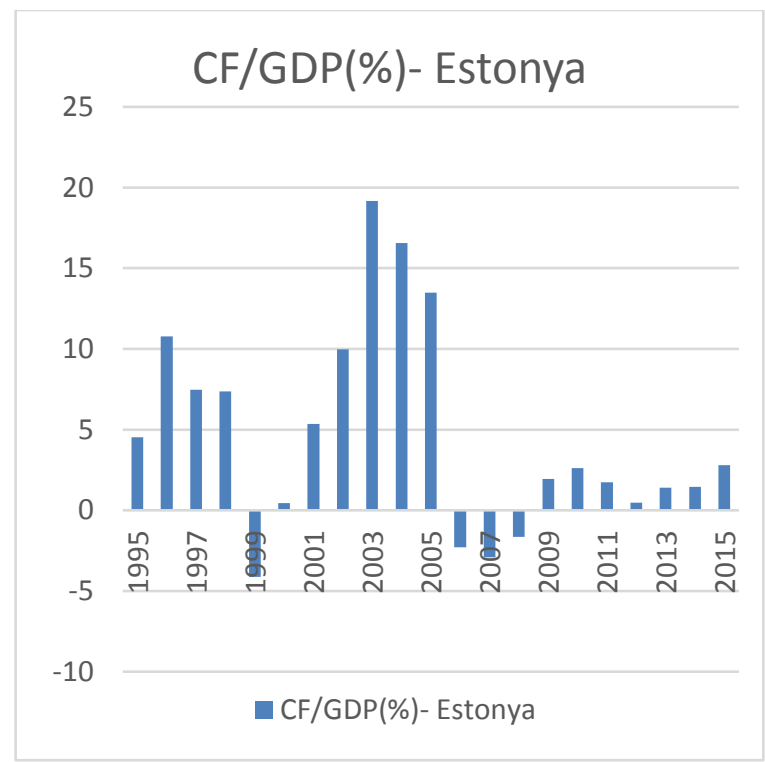

Şekil 9. Estonya İçin WDR (1985) Yöntemiyle 1995-2015 Yılları Arası Hesaplanan Sermaye Kaçı̧ Oranı (Sermaye Kaçışının GSYIH İçindeki Yüzdesi) 


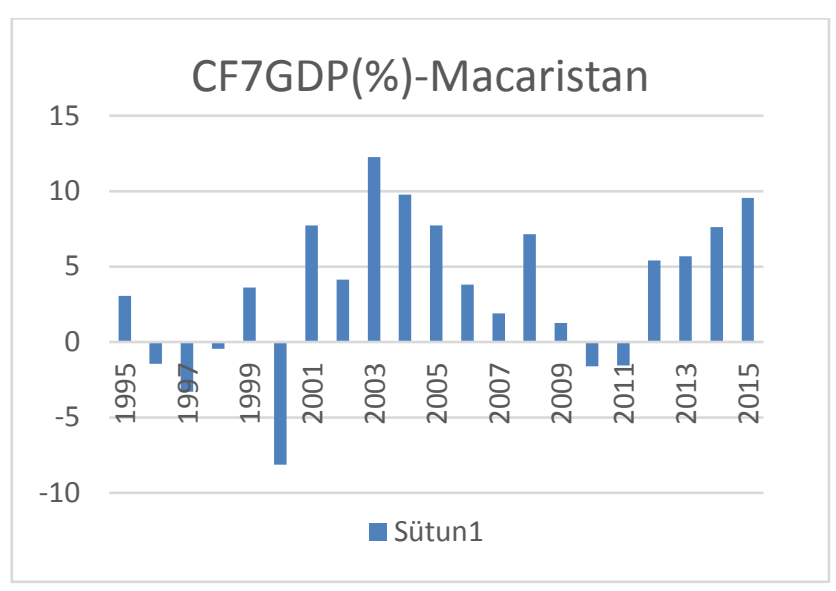

Şekil 10. Macaristan Iç̧in WDR (1985) Yöntemiyle 1995-2015 Yılları Arası Hesaplanan Sermaye Kaçış Oranı (Sermaye Kaçışının GSYIH İçindeki Yüzdesi)

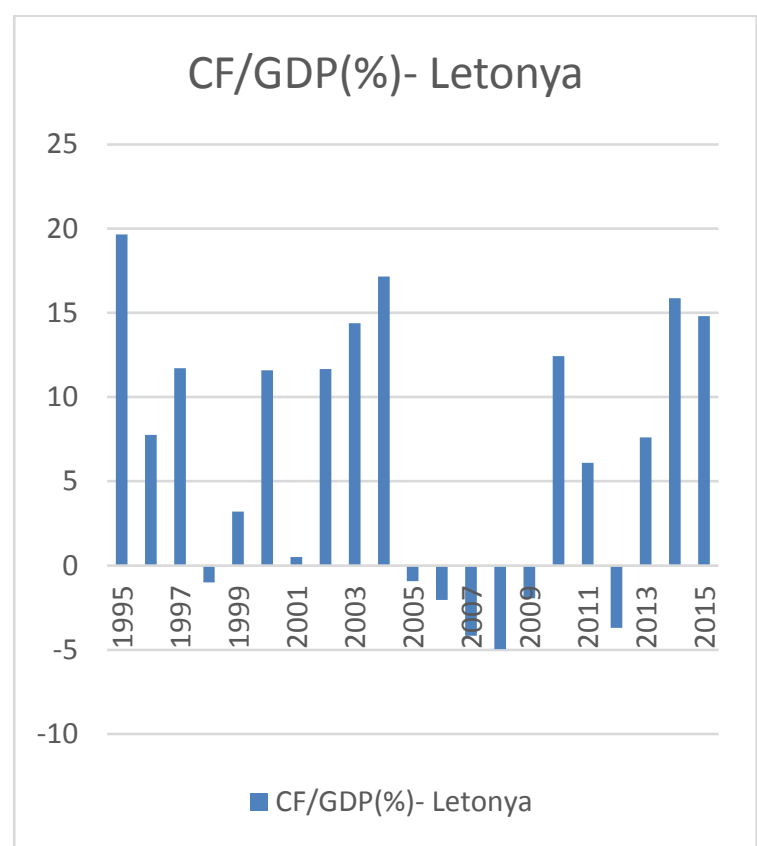

Şekil 11. Letonya Iç̧in WDR (1985) Yöntemiyle 1995-2015 Yılları Arası Hesaplanan Sermaye Kaçıs Oranı (Sermaye Kaçışının GSYİH İçindeki Yüzdesi)

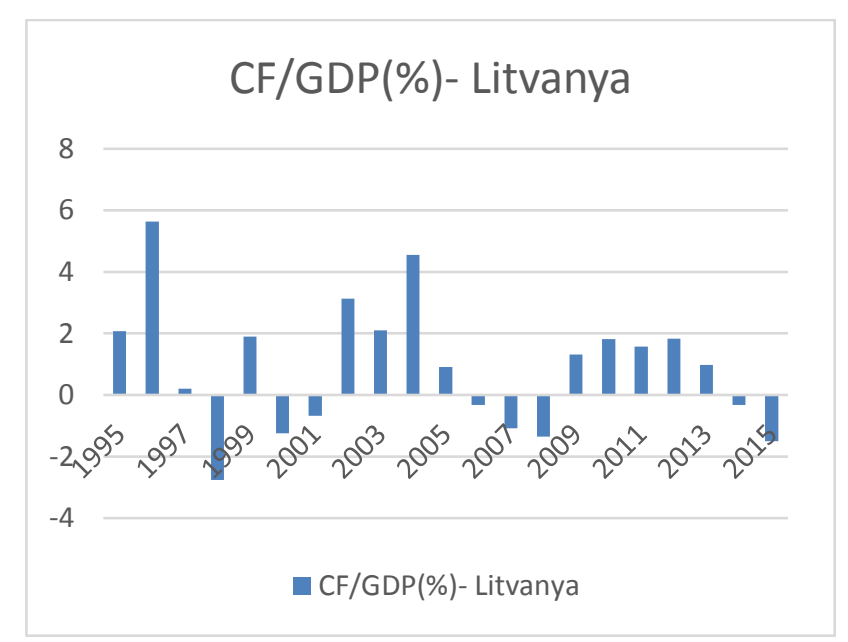

Şekil 12. Litvanya Iç̧in WDR (1985) Yöntemiyle 1995-2015 Yılları Arası Hesaplanan Sermaye Kaçış Oranı (Sermaye Kaçısıııın GSYİH İçindeki Yüzdesi) 


\section{Kaynakça}

- Bal, H. (2003), "Geçiş Ekonomilerinde Ekonomik Performans ve Yatırım İklimindeki Gelişmelere bir Bakış" Manas Üniversitesi Birinci Piyasa Ekonomisine Dönüşüm Sürecinde Geçiş Ekonomileri Uluslararası Sempozyum Bildirileri İçinde, 25 Aralık 2003 Bishkek

- Buiter, W. Ve Szegvari, I. (2002), “Capital Flight and Outflows from Russia”, EBRD Working Papaer No: 73.

- Cuddington, J. (1986), “Capital Flight: Estimates, Issues and Explanations”, Princeton Studies in International Finance, No: 58.

- Cuddington, J. (1987). "Capital Flight, European Economic Review”, 31,382-388.

- Doğanlar, M. Ve Özsoylu, A.F. (1995), "Sermaye Kaçışı: .tanımı, Nedenleri, Ölçülmesi ve Sonuçları”, 4. Ulusal Sosyal Bilimler Kongresi, ODTÜ, 3 Kasım 1995, Ankara.

- Dooley, M. P. (1988), “Capital Flight: A Response to Financial Risks”, IMF Staff Papers, Vol. 35, September.

- $\quad$ EBRD (2003), Transition Report 2003, London, UK.

- EBRD (European Bank For Reconstruction and Development) (2013). Transition Report 2013-Stuck in Transition, http://www.tr.ebrd.com/tr13/images/downloads/357_TR2013v3.pdf, Erişim Tarihi (22.04.2016)

- Esen, Oğuz (1990), "Gelişmekte olan ülkelerden Sermaye Kaçışı”, Banka ve Ekonomik Yorumlar Dergisi, Y11:27, Sayı:5, Mayıs.

- Gibson D. H. Ve Tsakalotos Euclid(1993). "Testing a Flow Model of Capital Flight in Five European Countries". The Manchester School, 61 (2), 144-166

- Harrigan, J., Mavrotas, G., Yusop, Z. (2002). "On The Determinants of Capital Flight: A New Approach". Journal of The Asia Pacific Economy, 7 (2), 203-241.

- Henry, A. W. (2013). "Analysis of the Effects of Capital Flight on Economic Growth: Evidence From Nijerian Economy (1980-2011)". European Journal of Business and Management, 5(17), 21-32.

- Khan M. S. U1 Haque, N. (1987). "Foreign Borrowing and Capital Flight". IMF Staff Papers, Vol. 32, No.4, 606-628.

- Lucas, R.E. Jr. (1990). “Why Doesn’t Capital Flow From Rich to Poor Countries”. American Economic Review, 80, 92-96.

- Pastor, M. JR (1990). "Capital Flight From Latin America”. World Development, 18(1),1-18.

- Quazi, R.M. (2004). “Foreign Aid and Capital Flight in Bangladesh”. Journal of Asia Pacific Economy, 9 (2), 370-393.

- World Bank (1985). World Bank Development Report 1985- International Capital and Economic Development World Development Indicators. 


\title{
Finansal Piyasalara İlişkin Bir Değerlendirme: Avrupa Birliğine Üye Ülke Macaristan ve Aday Ülke Türkiye
}

\section{An Assessment on Financial Markets: European Union Member Country Hungary and Candidate Country Turkey}

\author{
Asst. Prof. Dr. Fatma Gündoğdu Odabaşığlu (Atatürk University, Turkey)
}

\begin{abstract}
With the end of cold war, Central and Eastern European countries who had not participated in the integration of Europe, have applied to become members of European Union. Hungary, a Central European country; applied for membership on December 16, 1991, started full membership negotiations in 1998 and joined the Union on May 1, 2004. Turkey on the other hand, was granted candidacy status during Helsinki European Council Summit Meeting of December 1999, after a 40 years long relationship that started with Turkey's application to join European Economic Community on July 31, 1959. Negotiations for full membership of Turkey were finally started on October 3, 2005 and country entered a new era to adapt EU Acquis. Within this context, this study aims to compare financial markets of EU member state Hungary and candidate state Turkey for the period of 1998 - 2015; to evaluate risks and fragilities related to financial development levels and stability of banking sectors for both countries based on generally accepted financial indicators. In conclusion; Hungary was observed to have significantly less developed capital market compared Turkey over the years, despite having similar ratios in financial deepening during recent years. Findings of this assessment point out an increasing credit risk for banking sector of Hungary, enhanced by the economic crisis of 2008. In comparison, credit risk in banking sector of Turkey has been decreasing over the years. High credit/deposit ratio, is a sign of degradation and can be observed in Hungary's balance sheets, raised for Turkey as well.
\end{abstract}

\section{Giriş}

Finansal piyasalar, fon fazlası bulunan kişi ve kurumlardan, fon açı̆̆ı bulunan kişi ve kurumlara fon aktarımını gerçekleştirme işlevini yerine getirerek, ekonominin sağlıklı işleyebilmesinde büyük bir rol üstlenirler. $\mathrm{Bu}$ rolleriyle, ekonominin bütününde, üretim artışı ve sermayenin etkin dağılımı için önem arz eder; tüketicilerin mal ve hizmet satın alma zamanlamalarını etkileyerek, toplumun ekonomik refahını yükseltirler (Mishkin, 2006). 1990'larda hızlanan finansal küreselleşme sürecinde, sermaye piyasalarının önündeki engellerin kaldırılmasıyla, piyasalarda uluslararası işlemlerin hacminde büyük bir artış gerçekleşmiş ve farklı finansal faaliyet alanları fonksiyonel anlamda bütünleşmiştir. Buna bağlı şekilde, geleneksel bankacılığı, menkul kıymet ve diğer banka dışı işlemlerle birleştiren şirket çeşitleri ortaya çıkmış, finansal yeniliklerle birlikte, olağanüstü büyüklükte bir türev ürünler piyasası oluşmuştur. Bu gelişmeler, piyasaları düzenleme konusunda otoritelerin işini zorlaştırmış ve küresel piyasalar, finansal şokların ülkeler arasında aktarıldığı kanallarla, küresel krizlerin tetikleyicisine dönüşmüşlerdir (Ganiev, 2014).

1989 yılında piyasa ekonomisine geçiş yapan Macaristan'ın, 2004 yılında AB'ne üyeliği, ekonomisinin serbestleşmesi ve dışa açılması sürecine hız kazandırmış ve küresel gelişmelerden giderek artan ölçüde etkilenmiştir. Nitekim 2008 ekonomik krizinin, en büyük pazarı olan AB ülkelerine olumsuz yansımaları, Macaristan ekonomisini sarsmıştır. 1980 sonrasında piyasa ekonomisine geçen ve 2005 yılında $A B$ müktesebatına uyum sürecini başlatan Türkiye'de ise, benzer şekilde, 1994, 2000 ve 2001 krizleri genel olarak, ekonominin dişa açıklığı ve sermaye hareketlerinin serbestliğinden kaynaklanmış ve ekonomide derin izler bırakmıştır.

Bu bağlamda, çalışmada, küresel rekabet ortamında, ekonomilerinin etkin işleyebilmesi açısından, bankacılık sektörü ve menkul kıymetler piyasalarında istikrarın daha da önem kazandığı, Macaristan ve Türkiye için literatürde genel kabul gören göstergelerden hareketle, 1998-2015 dönemi itibariyle, finansal gelişmişlik ve bankacılık sektörü sağlamlık seviyelerinin, risk ve kırılganlıklarının değerlendirilmesi amaçlanmaktadır. $\mathrm{Bu}$ doğrultuda, 2005 yılında $\mathrm{AB}$ müktesebatına uyum sürecini başlatan Türkiye'nin, 2004 yılında AB'ne girmiş olan Macaristan'a kıyasla finansal piyasalar açısından durumu irdelenmektedir. Finansal verilerde standart sağlamak üzere genel olarak, Uluslararası Para Fonu (IMF) ve Dünya Bankası kaynakları kullanılmaktadır.

Bununla beraber, Macaristan için bankacılık sektörü finansal sağlamlık göstergeleri açısından, 2009-2012 yıllarına ait verilere ulaşılamaması; ayrıca, ülkelerin muhasebe, vergi ve denetim sistemlerindeki farklılıklar nedeniyle, kesin bir şekilde karşılaştırılamaması çalışmanın kısıdını oluşturmaktadır.

\section{Genel Bakıș: Macaristan ve Türkiye}

Köklü bir ortak tarihe sahip Macaristan ve Türkiye arasındaki ilişkilerin, genel olarak, dostluk, işbirliği ve karşılıklı çıkarlar temelinde, gelişmekte ve derinleşmekte olduğu, iki ülke arasında önemli bir siyasi sorunun 
bulunmadığı gözlenebilmektedir. İki ülke arasındaki ekonomik ve ticari ilişkiler, özellikle Gümrük Birliği sonrasında hızla artmış olup, Macaristan, Türkiye'yi Doğu'ya açılabileceği bir kapı olarak görmekte; ekonomi ve enerji alanlarındaki ilişkilerini geliştirmeyi amaçlamaktadır (Türkiye Cumhuriyeti Dışişleri Bakanlığı, 2016).

\subsection{Macaristan}

1991 yılında Sovyet Sosyalist Cumhuriyetler Birliği’nin dağılması sonrasında, bağımsızlıklarına kavuşan eski sosyalist ülkelerde, merkezi planlı sistemden piyasa ekonomisi sistemine geçiş şeklinde bir akım başlamıştır. Orta ve Doğu Avrupa ülkelerinin geçiş sürecindeki reformları, diğer ülkelerden farklı olarak iki aşamalı gerçekleşmiştir. İlk aşama (1995 ve 1996 yıllarına kadar) reformları, makroekonomik istikrar, özelleştirme, bankacılık ve finansal sektör gibi temel konulara yönelik uygulanmışken, ikinci aşama reformları 1997'den başlayarak büyük ölçüde, AB'ne üyelik odaklı gerçekleştirilmiştir (European Commission, 2016). Çok sayıda Orta ve Doğu Avrupa ülkesi, Sovyetler Birliği’nin mirasını devralan Rusya Federasyonu'nun yayılmacılığından endişelenerek, güvenlik ortamı ve müttefik arayışıyla AB'ne girmeye hazırlanmıştır (Canbolat, 2002).

Bir Orta Avrupa ülkesi olan Macaristan'da ise; piyasa ekonomisine geçişin ilk adımı, 1 Ocak 1968 tarihli ve "Yeni Ekonomik Mekanizma" olarak adlandırılan reformla başlamıştır. Mekanizma, genelde Macar Sosyalist İşçi Partisi Merkez Komitesi’nce, merkezi planlamada alt kademelerin serbestliğinin artırılması, piyasa ve özel mülkiyet alanının genişletilmesine yönelik olarak uygulanmıştır (Balassa, 1983). Bu gelişmeyi takip eden dönemde; merkezi devlet yapısı eşliğinde, 1980’ler boyunca, ekonominin çeşitli alanlarında, reformlar yapılmış ve piyasa ekonomisine adım adım yaklaşılmıştır. Geçiş sürecinin sorunsuz ve başarılı olmasında etkili olan bu reformlar, diğer Doğu Avrupa ülkelerinin de dikkatlerini çekmiştir (Hare, 1991). 1953'de Stalin'in ölümünden büyük ölçüde etkilenmiş olan Macaristan, siyasi sistem değişikliğine giderek, demokratikleşmeye yönelik önemli aşamalar kaydetmiş ve aslında sosyalist bloktan koparken; Batı Avrupa ile bütünleşme amaçlı siyasi ve ekonomik alt yapı hazırlığı da yapmıştır (Yücel, 2011).

Macaristan bankacılık sektöründe 1987 yılında önemli bir yapısal değişiklik yapılmış, ticari bankacılık ve merkez bankacılığı fonksiyonlarının tek banka tarafından (Macaristan Merkez Bankası -Magyar Nemzeti Bank-) yürütüldüğü, Komünist rejimin tek bankalı sisteminden, fonksiyonların ayrıldığı, piyasa odaklı iki kademeli bankacılık sistemine geçilmiştir. Bu gelişme, diğer Doğu Avrupa ülkeleri ile karşılaştırıldığında Batı Avrupa ile yakın iş ilişkilerini daha erken başlatmış olan Macaristan'da doğrudan yabancı yatırımlar ve yabancı banka sayısının artışına da yol açmıştır (Csizmazia, 2014). Yıllar içerisinde gerçekleştirdiği bu siyasi ve ekonomik dönüşümle, 1989 yılında piyasa ekonomisine geçmiş olan ülkede önemli ekonomik reformlar gerçekleştirilmiştir. Geçiş sürecinde örnek alınabilecek bir başarı sağlanmış ve kısa bir dönemde, küçük ve büyük ölçekli özelleştirme; fiyat, döviz ve ticari serbestleştirme, bankacılık ve banka dışı mali kurumlar reformlarının ilerleme seviyesine ilişkin endekslerde 4,0 ve 4,3 puanlarına ulaşılmıştır. Öte yandan; rekabet politikası, kurumsal reformlar ve altyapı reformları açısından süreç henüz tamamlanamamıştır (European Bank for Reconstruction and Development, 2016). Avrupa İmar ve Kalkınma Bankası (European Bank for Reconstruction and Development -EBRD-) tarafından hazırlanan genel geçiş göstergeleri, özelleştirme, fiyat serbestleştirme, kurumsal yapılandırma, ticaret ve döviz sistemi, rekabet politikası, bankacılık reformu ve faiz serbestleştirme, menkul kıymetler piyasaları ve banka dışı mali kurumlar gibi başlıklarla sınıflandırılmaktadır. Geçişteki ilerlemeler ise, 1 ile $4+$ arasında puanlanmaktadır. 4+ sanayileşmiş bir piyasa ekonomisinin standartlarını temsil etmektedir (European Bank for Reconstruction and Development, 2016).

2004 yılında AB'ne tam üye olan Macaristan, yabancı yatırımcılar için çekim merkezi olmuş, doğrudan sermaye yatırımlarının artışıyla, bölgedeki diğer ülkelere kıyasla, ekonomik başarıyı daha hızlı bir şekilde yakalamıştır (Türkiye Cumhuriyeti Dışişleri Bakanlığı, 2012).

\subsection{Türkiye}

1980’li yıllara oldukça kapsamlı bir ekonomik değişim ve yapısal dönüşüm programı ile girmiş olan Türkiye'de 24 Ocak 1980 Kararları ile temel strateji olarak, piyasa ekonomisi koşullarında kalkınma belirlenmiş ve bu doğrultuda, piyasaların serbestleştirilmesi ve dışa açılmayla ilgili önemli adımlar atılmıştır. Bununla beraber, serbestlik ve dışa açılma için gerekli kurumsal yapı ve düzenleme oluşturulmadan, Türk Parası Kıymetini Koruma Hakkında 07.08.1989 tarihli 32 Sayılı Karar ile finansal piyasaların erken ve aşırı ölçüde serbestleştirilmesi, dış faktörlerin de etkisiyle, ekonomide 1988-1989, 1991, 1994 ve 1998-1999, 2000-2001 yıllarında ciddi bunalımlar yaşanması sonucunu doğurmuştur (Şahin, 2009). Buradan hareketle; kamu bankalarının başı çektiği sağlıksız bir finansal sistem ve diğer yapısal sorunların devam ettiği ekonominin yeniden yapılandırılması ve istikrarın kalıcılığının sağlanması amaçlarıyla, 14 Nisan 2001 'de açıklanan Güçlü Ekonomiye Geçiş Programı uygulanmaya başlanmıştır. Bu Program kapsamında finansal sektörün yeniden yapılandırılması, şeffaflı̆̆ın artırılması, ekonomide rekabet ve etkinliğin artırılması gibi alanlarda düzenlemeler yapılmıştır.

EBRD bünyesinde yayınlanan geçiş raporları itibariyle; Türkiye'de yapısal ve kurumsal değişim göstergeleri açısından, 2008 yılından başlayarak, küçük ölçekli özelleştirme reform endeks puanı 4,0; fiyat, döviz ve ticari serbestleştirme reformları endeks puanı 4,3'e ulaşmış ve reformlar genel olarak tamamlanmıştır. Ancak, kurumsal, altyapı, büyük ölçekli özelleştirme, rekabet politikası, bankacılık ve banka dişı mali kurumlar reformları açısından sürecin devam ettiği gözlenmektedir (European Bank for Reconstruction and Development, 2016). 
Türkiye'nin AB ile ilişkilerine gelindiğinde ise, ilişkilerin Türkiye'nin 1959'da Avrupa Ekonomik Topluluğu'na (AET) tam üyelik başvuru yapmasıyla başladığı bilinmektedir. Türkiye, bu başvuruda, kalkınma düzeyi itibariyle, tam üyelik şartlarını yerine getirebilmede yeterli bulunmamıştır. AET ile 1963 yılında, tam üyelik koşulları gerçekleşinceye kadar geçerliliğini sürdürecek bir ortaklık anlaşması imzalamış olan Türkiye, Topluluğa entegrasyon için hazırlık, geçiş ve nihai dönemden oluşan üç aşamalı bir sürece girmiştir. 1973 y1lında Katma Protokol'ün yürürlüğe girmesiyle hazırlık dönemi tamamlanmış ve geçiş dönemi başlatılmıştır. 70 ve 80’li yıllarda yaşanan ekonomik problemler ve darbenin etkisiyle geçiş döneminde yavaş ilerleme sağlanmış ve 1996'da Türkiye'nin Gümrük Birliği'ne girişiyle son bulmuştur. 10-11 Aralık 1999'da Helsinki'de yapılan Zirvede Türkiye'nin tam üyelik adaylığı tescil edilmiş ve siyasi kriterlerin yeterli ölçüde karşılaması nedeniyle, 17 Aralık 2004 tarihli Brüksel Zirvesinde Türkiye ile müzakerelerin başlatılması önerilmiştir. Böylece, 3 Ekim 2005 tarihinde katılım müzakerelerine başlanmış olup, müktesebat uyum çalışmaları sürdürülmektedir (Türkiye Cumhuriyeti Avrupa Birliği Bakanlı̆̆ 1,2016$)$.

\section{Finansal Piyasalara İlişkin Bir Değerlendirme: Macaristan ve Türkiye}

Finansal istikrar, genel olarak, fiyatlandırma, kaynak dağılımı ve finansal riskleri yönetmeye yönelik mekanizmaların, ekonominin performansına katkıda bulunmak için yeterli düzeyde çalışabildiği durumu ifade etmek için kullanılmakta ve istikrarın sağlanması, ekonomideki kurumların çok daha fazla işbirliği ve uyumunu gerektirmektedir (Schinasi, 2004). Finansal piyasaların küreselleşmesiyle, dış piyasalarda oluşabilen bir dalgalanmanın diğer ülkelere hızla yayılabilmesi, finansal istikrarın önemini daha da artırmaktadır. Gelişmiş finansal piyasalar ve sağlam bir bankacılık sistemi, ekonomilerin, sürdürülebilir büyüme hedeflerine ulaşabilmelerinde anahtar unsurlar olarak kabul edilmektedir (Serdengeçti, 2005).

\subsection{Finansal Gelişmişlik Seviyeleri Açısından}

Finansal yapıyı oluşturan kurum ve araç sayıları ile çeşitliliklerindeki artışı ifade eden finansal gelişmişliğin ölçümünde çok sayıda gösterge kullanılmakla birlikte, iktisat yazınında genel kabul gören göstergelerden birkaçı; geniş tanımlı para arzı (M2), özel sektör kredileri ve menkul kıymetler borsası işlem hacminin GSYİH içerisindeki paylarıdır (Lynch, 1996).

Bu kapsamda, bir finansal derinlik ölçütü olan M2/GSYİH oranı itibariyle, Macaristan'da oranların, genel olarak, Türkiye oranlarından daha yüksek olduğu; bununla beraber, son yıllarda birbirine yaklaştığı ve 2014 yılında Türkiye'de Macaristan’a göre daha yüksek bir seviyeye ulaşıldığı gözlenmektedir.

\begin{tabular}{|l|c|c|}
\hline & Macaristan & Türkiye \\
\hline 1998 & 44,07 & 28,83 \\
\hline 1999 & 45,70 & 39,09 \\
\hline 2000 & 44,95 & 34,50 \\
\hline 2001 & 45,29 & 45,55 \\
\hline 2002 & 45,51 & 39,92 \\
\hline 2003 & 46,11 & 35,20 \\
\hline 2004 & 46,67 & 34,59 \\
\hline 2005 & 50,08 & 40,47 \\
\hline 2006 & 53,03 & 42,31 \\
\hline 2007 & 55,64 & 43,84 \\
\hline 2008 & 57,13 & 48,56 \\
\hline 2009 & 60,97 & 54,63 \\
\hline 2010 & 61,71 & 56,12 \\
\hline 2011 & 63,29 & 54,74 \\
\hline 2012 & 59,32 & 55,36 \\
\hline 2013 & 60,88 & 60,64 \\
\hline 2014 & 58,25 & 60,47 \\
\hline
\end{tabular}

Tablo 1. M2/GSYİH Oranlarl (Yüzde) Kaynak: World Bank

Öte yandan iki ülke için de en yüksek seviyenin yüzde 60'lara ulaşabilmesi ekonomide parasallaşma ve hane halklarının bankacılık sistemini kullanma düzeyleri açısından henüz gelişmiş ülke mali piyasalarının seviyelerine ulaşılamadığına dikkat çekmektedir (bkz. Tablo 1).

Bu gelişmeye paralel bir seyir takip eden, diğer bir finansal gelişmişlik göstergesi, özel sektör kredileri/GSYİH oranıdır. Ulusal ve uluslararası tasarrufların yatırımlara dönüştürülmesinde, finansal aracılık gelişme düzeyini yansıtan oranın, yıllar içerisindeki değişimi itibariyle, Macaristan oranlarının belirgin ölçüde Türkiye oranlarından yüksek olduğu, ancak 2012 yılından başlayarak, Türkiye oranlarının gerisinde kaldığ 1 görülmektedir (Tablo 2). Bu görünümden hareketle; ülke ekonomisinin büyümesi için yatırımların gerekliliği ve yatırımların büyük ölçüde kredilerle finanse edilebilmesi nedeniyle, Macaristan bankacılık sektöründe finansal aracılık faaliyetlerinin Türkiye bankacılık sektörüne göre daha etkin olduğu ileri sürülebilmektedir. 


\begin{tabular}{|l|c|c|}
\hline & Macaristan & Türkiye \\
\hline 1998 & 23,41 & 17,19 \\
\hline 1999 & 25,52 & 16,63 \\
\hline 2000 & 31,91 & 17,75 \\
\hline 2001 & 32,70 & 15,35 \\
\hline 2002 & 34,40 & 14,52 \\
\hline 2003 & 36,52 & 14,55 \\
\hline 2004 & 39,03 & 17,28 \\
\hline 2005 & 43,42 & 22,25 \\
\hline 2006 & 47,59 & 25,94 \\
\hline 2007 & 53,55 & 29,50 \\
\hline 2008 & 59,75 & 32,59 \\
\hline 2009 & 60,34 & 36,48 \\
\hline 2010 & 61,12 & 44,21 \\
\hline 2011 & 59,16 & 49,97 \\
\hline 2012 & 50,90 & 54,40 \\
\hline 2013 & 46,49 & 65,99 \\
\hline 2014 & 43,45 & 70,13 \\
\hline
\end{tabular}

Tablo 2. Özel Sektör Kredileri/GSYIHH (Yüzde) Kaynak: World Bank

Küçük tasarrufların doğrudan doğruya yatırımlara aktarılması işlevini gören, menkul kıymetler borsasının gelişmişlik seviyesinin belirlenmesine ilişkin, menkul kıymetler borsası işlem hacmi/GSYİH oranı (borsa kapitalizasyon oranı) itibariyle ise; verilerine 2002'den başlayarak ulaşılabilen (bu nedenle Türkiye verileri de 2002'den başlatılmıştır) Macaristan için, oranların genel olarak Türkiye'nin gerisinde kaldığı gözlenmektedir (Tablo 3).

\begin{tabular}{|l|c|c|}
\hline & Macaristan & Türkiye \\
\hline 2002 & 19,24 & 15,50 \\
\hline 2003 & 19,60 & 22,57 \\
\hline 2004 & 27,59 & 25,07 \\
\hline 2005 & 28,95 & 33,13 \\
\hline 2006 & 36,55 & 30,30 \\
\hline 2007 & 33,22 & 43,97 \\
\hline 2008 & 11,75 & 16,10 \\
\hline 2009 & 23,15 & 37,70 \\
\hline 2010 & 21,30 & 41,36 \\
\hline 2011 & 13,42 & 25,44 \\
\hline 2012 & 16,32 & 39,96 \\
\hline 2013 & 14,73 & 23,78 \\
\hline 2014 & 10,49 & 27,52 \\
\hline
\end{tabular}

Tablo 3. Menkul Kıymetler Borsası İşlem Hacmi/GSYİH (Yüzde) Kaynak: World Bank

Bununla beraber, 2008 yılında, oranın iki ülkede de büyük ölçüde küresel krizin etkisiyle düşüş gösterdiği dikkat çekmektedir. Macaristan'ın tek borsası Budapeşte Borsası (BSE) olup, Türkiye'nin tek borsası olan Borsa İstanbul ile kıyaslandığında nispeten küçük bir borsadır. BSE, 1990'da kurulmuştur. 2002'de özel bir şirkete dönüştürülen Borsanın çoğunluk hisseleri, 2004'te aralarında Viyana Borsası'nın da bulunduğu Avusturyalı bir şirketler birliğine geçmiş ve 2008'de Viyana Borsası, BSE'nin ana ortağı olmuştur. Borsa işlemleri, hisse senetleri, borçlanma araçları, türev ve emtia olmak üzere dört piyasada gerçekleştirilmektedir (Çikot, 2011).

\subsection{Bankacılık Sektöründe Sağlamlık Seviyeleri Açısından}

Finansal analizin desteklenmesi ve finansal sistemin zayıflıklarının değerlendirilebilmesi amacıyla, IMF tarafindan geliştirilen ve 2005 'ten itibaren yıllık olarak yayımlanan finansal sağlamlık gösterge seti, temel ve önerilen göstergelerden oluşmaktadır (bkz. IMF, 2015). Çalışmada, Macaristan ve Türkiye bankacılık sektörlerine yönelik incelenen temel gösterge değerleri için, 2008-2015 yıllarına ait son üç aylık dönem verileri kullanılmaktadır.

2008 küresel krizi sonrasında, uluslararası finansal düzenlemelerin geliştirilmesi amacıyla, Basel Bankacılık Denetim Komitesi’nce sermaye yeterliliği ve piyasa likidite risklerine ilişkin yeni düzenlemeler içeren Basel III yayımlanmıştır. Yeni düzenlemeler, mevcut eksiklikleri tamamlayan bir ek düzenlemeler seti niteliğindedir. Düzenlemelere geçişlerin 2013'ten başlayarak 2019'a kadar kademeli olarak yapılması planlanmıştır. Basel III' de ana sermaye/risk ağırlıklı varlıklar rasyosuna ilişkin minimum \% 8 ve Tier 1 sermaye/risk ağırlıklı varlıklar rasyosuna ilişkin 2013 için \% 4,5, 2014 için \% 5,5 ve 2015-2019 y1lları için \% 6,0 minimum değerleri 
belirlenmiştir (Bank for International Settlements, 2016). Tier 1, genel olarak, ödenmiş sermaye, dağıtılmamış kar ve yedek akçelerden oluşan çekirdek ana sermayeyi ifade etmektedir.

Sermaye yeterliliği rasyoları açısından Macaristan ve Türkiye bankacılık sektörleri incelendiğinde, Basel standartları kapsamında, sermaye kalitesini de yansıtan ana sermaye/risk ağırlıklı varlıklar ve Tier 1 sermaye/risk ağırlıklı varlıklar rasyolarının, iki ülkede de minimum değerlerin üzerinde seyrettikleri görülmektedir (Tablo 4). Bununla beraber, rasyoların, 2008 yılında Macaristan bankacılık sektörüne kıyasla, Türk bankacılık sektöründe çok daha yüksek bir değere ulaştıkları dikkat çekmektedir.

\begin{tabular}{|l|c|c|c|c|}
\hline Sermaye Yeterliliği & \multicolumn{5}{l|}{} \\
\hline & Macaristan & \multicolumn{3}{l|}{ Türkiye } \\
\hline & $\begin{array}{c}\text { Ana sermaye/risk } \\
\text { ağırlıkl varlıklar }\end{array}$ & $\begin{array}{c}\text { Tier 1 sermaye/risk } \\
\text { ağırlıklı varlıklar }\end{array}$ & $\begin{array}{c}\text { Ana sermaye/risk } \\
\text { ağırlıklı varlıklar }\end{array}$ & $\begin{array}{c}\text { Tier 1 sermaye/risk } \\
\text { ağırlıklı varlıklar }\end{array}$ \\
\hline 2008 & 12,3 & 10,3 & 18,0 & 17,2 \\
\hline 2009 & - & - & 20,6 & 18,6 \\
\hline 2010 & - & - & 19,0 & 17,0 \\
\hline 2011 & - & - & 16,6 & 14,9 \\
\hline 2012 & - & - & 17,9 & 15,1 \\
\hline 2013 & 17,4 & 14,6 & 15,3 & 13,0 \\
\hline 2014 & 16,9 & 13,7 & 16,3 & 13,9 \\
\hline 2015 & 16,6 & 13,4 & 15,6 & 13,2 \\
\hline
\end{tabular}

Tablo 4. Sermaye Yeterliliği Rasyoları Kaynak: IMF

Bankalar, kısa vadeli fonları uzun vadeli fonlar haline dönüştüren kurumlardır. Banka varlıklarının, yükümlülüklerini karşılayamaması durumunda finansal yapıları bozulmakta ve ekonomideki, çok sayıda bankanın likidite sıkışıklığı yaşayarak finansal yapılarının bozulması bankacılık krizlerine neden olabilmektedir. Bu doğrultuda, Basel III' de bankaların, net nakit çıkışlarını karşılayabilecek seviyede yeterli likit varlık stoku bulundurmaları amacıyla, likidite karşılama rasyolarının asgari gereklilik düzeyleri, 2015 yılı için \% 60 ve 2016 yılı için \% 70 olarak belirlenmiştir (Bank for International Settlements, 2016).

Macaristan ve Türkiye bankacılık sektörleri için; likidite riskini yansıtan likidite rasyolarına Tablo 5'de yer verilmektedir. Buna göre; 2008-2015 döneminde, likit varlıklar/toplam varlıklar ve likit varlıklar/kısa vadeli yükümlülükler rasyoları itibariyle, iki ülkenin bankacılık sektörlerinde, likidite seviyelerinin yeterli olduğu, bununla beraber; Türkiye oranlarının Macaristan oranlarından daha yüksek seviyelerde seyretmesi, likidite yönetiminde, beklenmedik panik durumlarının karşılanabilmesi açısından, Türk bankalarının, Macaristan bankalarından daha başarılı oldukları şeklinde değerlendirilebilmektedir.

\begin{tabular}{|l|c|c|c|c|}
\hline Likidite Riski & \multicolumn{5}{l|}{} \\
\hline & \multicolumn{5}{|l|}{ Türkiye } & $\begin{array}{c}\text { Likit } \\
\text { varlıklar/toplam }\end{array}$ & $\begin{array}{c}\text { Likit varlıklar/k1sa } \\
\text { vadeli }\end{array}$ \\
\hline & $\begin{array}{c}\text { Likit } \\
\text { varlklar/toplam }\end{array}$ & $\begin{array}{c}\text { Likit varlıklar/k1sa } \\
\text { vadeli }\end{array}$ & 54,2 & 79,5 \\
\hline 2008 & 18,1 & 35,4 & 57,7 & 84,4 \\
\hline 2009 & - & - & 55,4 & 79,7 \\
\hline 2010 & - & - & 49,7 & 72,0 \\
\hline 2011 & - & - & 50,9 & 76,0 \\
\hline 2012 & - & - & 47,1 & 72,1 \\
\hline 2013 & 32,8 & 57,5 & 53,7 & 77,4 \\
\hline 2015 & 38,0 & 63,5 & 49,5 & 69,6 \\
\hline
\end{tabular}

Tablo 5. Likidite Rasyoları Kaynak: IMF

Önemli bir sistemik risk erken uyarı göstergesi olarak da kabul edilen, takipteki kredilerin izlenme süreci, işlem maliyetlerini artırmakta ve bankaların aktif kalitesini bozmaktadır. Bu durum, bankaların yükümlülüklerini yerine getirebilme güçlerini de zayıflatarak, itibar kaybına neden olmaktadır (Tanınmış Yücememiş ve Sözer, 2011). İki ülkenin bankacılık sektörlerinde, aktif kalitesine ilişkin takipteki krediler/toplam brüt krediler rasyolarına Tablo 6'da yer verilmektedir. Kredi riskini de yansıtan rasyo açısından, 2009 yılına kadar olan dönemde, Macaristan bankacılık sektörü oranlarının, Türkiye bankacılık sektörü oranlarının oldukça gerisinde kalarak, düşük seyrettiği; ancak 2008 krizinin ardından 2014 yılına kadar giderek yükseldiği gözlenmektedir. 


\begin{tabular}{|l|c|c|}
\hline \multicolumn{2}{|l|}{ Aktif Kalitesi } \\
\hline & Macaristan & Türkiye \\
\hline 1998 & 4,90 & 6,70 \\
\hline 1999 & 4,20 & 10,50 \\
\hline 2000 & 3,00 & 9,20 \\
\hline 2001 & 3,60 & 29,30 \\
\hline 2002 & 2,90 & 12,70 \\
\hline 2003 & 2,60 & 11,50 \\
\hline 2004 & 1,80 & 6,50 \\
\hline 2005 & 2,30 & 4,32 \\
\hline 2006 & 2,60 & 3,58 \\
\hline 2007 & 2,30 & 3,32 \\
\hline 2008 & 2,98 & 3,44 \\
\hline 2009 & 8,24 & 4,97 \\
\hline 2010 & 10,04 & 3,49 \\
\hline 2011 & 13,68 & 2,58 \\
\hline 2012 & 16,04 & 2,74 \\
\hline 2013 & 16,83 & 2,64 \\
\hline 2014 & 15,62 & 2,74 \\
\hline 2015 & 12,67 & 2,73 \\
\hline
\end{tabular}

Tablo 6. Takipteki Krediler/Toplam Brüt Krediler Rasyosu Kaynak: IMF

$\mathrm{Bu}$ gelişme parelelinde, Macaristan bankacılık sektöründe kredi riskinin artması nedeniyle, uluslararası kredi derecelendirme kuruluşlarınca (Standard and Poor's, Fitch ve Moody's) ülkenin 2008 sonrası görünümü genel olarak negatife düşürülmüştür. Bu görünüm, 2014 ve 2015 yılları için Standard and Poor's tarafından durağana ve Moody's tarafından 2014 için durağana 2015 için pozitife ve Fitch tarafından 2015 için pozitife yükseltilmiştir (Trading Economics, 2016).

Türkiye'de ise, incelenen dönem itibariyle, 2001 krizinin ardından en yüksek seviyesine ulaşan oranın yıllar içerisinde giderek azaldığı izlenebilmektedir. Sektörün 2001 krizini takip eden ilk birkaç yıl dışında kredi riski taşımadığı gözlenmektedir.

Finansal istikrarsızlığı başlatan önemli etkenlerden biri, banka bilançolarının bozulmasıdır. Bazı ülkelerde, finansal serbestleşmenin ardından banka kredilerinin hızla artışı nedeniyle, riskli kredilerin artması sonucu bilançolar bozulabilmektedir (Goldstein ve Turner, 1996). 1990'larda yaşanmış olan çoğu bankacılık krizinin dişa açılma ve bankacılık sistemlerindeki serbestleşmeden kısa süre sonra oluştuğu gözlenmektedir (Hawkins ve Mihaljek, 2001).

\begin{tabular}{|l|c|c|}
\hline & Macaristan & Türkiye \\
\hline 1998 & 62,55 & 63,23 \\
\hline 1999 & 66,89 & 44,60 \\
\hline 2000 & 83,55 & 54,58 \\
\hline 2001 & 85,12 & 35,89 \\
\hline 2002 & 88,86 & 38,35 \\
\hline 2003 & 105,68 & 44,09 \\
\hline 2004 & 113,34 & 53,42 \\
\hline 2005 & 119,68 & 59,00 \\
\hline 2006 & 122,47 & 66,29 \\
\hline 2007 & 133,37 & 72,06 \\
\hline 2008 & 143,02 & 71,58 \\
\hline 2009 & - & 71,54 \\
\hline 2010 & - & 84,96 \\
\hline 2011 & - & 99,56 \\
\hline 2012 & - & 108,10 \\
\hline 2013 & - & 120,16 \\
\hline
\end{tabular}

Tablo 7. Kredi/Mevduat Rasyosu (Yüzde) Kaynak: World Bank

$\mathrm{Bu}$ doğrultuda, iki ülkenin bankacılık sektörlerinde kredi/mevduat rasyosunun 1998-2013 yılları arasındaki gelişim seyirleri dikkate alındığında; oranın, Macaristan ve Türkiye bankacılık sektörlerinde yıllar içerisinde giderek yükseldiği, ancak Türkiye bankacılık sektörü oranlarının, Macaristan bankacılık sektörü oranlarının oldukça gerisinde kaldığı gözlenmektedir (Tablo 7). Kredi artışlarının mevduat artışıyla karşılanamaması, likidite sorununa neden olabilmekte; oranın yüksekliği, bankaların yurtdışı borçlanmalarını ve dolayısıyla kur riskini yükseltici etkide bulunmaktadır. Bu nedenle, ülke otoritelerince düzenlemeler yapılması gerekebilmekte, oranın, 
Kore denetim otoritesince, 2009 yılında \% 100 veya daha altındaki seviyelerle sınırlandırması örnek verilebilmektedir (Park, vd, 2015).

Bankaların yabancı para cinsinden işlemleri, ulusal paraların yabancı paralar cinsinden değerlerinin değişmesi paralelinde risk içermektedir. Bankaların yabancı para net genel pozisyonu, yabancı para cinsinden toplam varlıklarından, yabancı para cinsinden toplam yükümlülükleri çıkarılarak elde edilmekte; fark, pozitif ise yabancı para pozisyon fazlası, negatif ise yabancı para pozisyon açığının bulunduğu anlamına gelmektedir (Kaplan, 2002). Bankaların acık pozisyonlarını sürekli artırarak yüksek kur riski üstlenmeleri, yurtiçi ve yurt dışı piyasalarda beklenmeyen değişiklikler sonucunda, hem bankacılık kesimi hem de ekonominin geneli için olumsuzluklar yaratabilmektedir. Bu nedenle, ekonomilerde, kur riski yönetimine ilişkin uluslararası düzenlemelere uyum sağlamak amacıyla, bankaların açık pozisyonlarını sınırlayan düzenlemelere gidilmiş; yabancı para net açık pozisyon/sermaye rasyosu sınır değeri, Macaristan bankacılık sektörüne yönelik yapılan düzenlemelerle \% 30; Türk bankacılık sektörüne yönelik yapılan düzenlemelerle \% 20 olarak belirlenmiştir (Canales-Kriljenko, 2004).

$\mathrm{Bu}$ bilgi doğrultusunda; kur riskini de yansıtan yabancı para net açık pozisyon/sermaye rasyosu açısından iki ülke bankacılık sektörleri karşılaştırıldığında, 2008-2015 döneminde; Macaristan bankacılık sektöründe oranın yasal sınırlar içerisinde kalmakla birlikte, diğer yıllara göre 2014'de en yüksek seviyesine ulaştığı gözlenmektedir (Tablo 8). Bu gelişmenin başlıca nedeni; İsviçre Merkez Bankası'nın Frank'ın değerini yükseltmeye yönelik düzenlemeleri ve Macaristan bankacılık sektöründe Frank cinsinden kullandırılan mortgage kredilerinin GSYİH içerisindeki payıdır (Zoltan ve Balazs, 2015).

\begin{tabular}{|l|c|c|}
\hline Kur Riski & \multicolumn{2}{|l|}{} \\
\hline & Macaristan & Türkiye \\
\hline 2008 & 15,3 & $-1,7$ \\
\hline 2009 & - & 0,3 \\
\hline 2010 & - & $-0,1$ \\
\hline 2011 & - & $-1,1$ \\
\hline 2012 & - & 0,0 \\
\hline 2013 & 15,5 & $-3,5$ \\
\hline 2014 & 21,9 & $-2,1$ \\
\hline 2015 & 17,3 & $-0,4$ \\
\hline
\end{tabular}

Tablo 8. Yabancı Para Net Açık Pozisyon/Sermaye Rasyosu Kaynak: IMF

Türk bankacılık sektöründe ise, oranın yasal sınırlar içinde, 2012 yılı dışında hep negatif değerlerde seyrettiği, 2013 yılında en yüksek orana ulaştığı ve 2014'den başlayarak düşüşe geçtiği görülmektedir Bu gelişme, bankalarca yabancı para cinsinden sağlanan fonların bir bölümünün, swap işlemleri aracılığıyla TL'ye çevrilerek kredi olarak kullandırılmasıyla açıklanabilmekte ve kur riskinin yönetilebilir seviyede olduğu izlenimini doğurmaktadır. Geçmişte yaşanan krizler nedeniyle, kur riskinin yönetiminde edinilen tecrübeyle, Türk bankacılık sektöründe, genel olarak bilanço içinde taşınan açık (kısa) pozisyon, bilanço dışında oluşturulan fazla (uzun) pozisyon ile dengelemekte ve önemli tutarda net pozisyon taşınmamaktadır. Bazı dönemlerde negatif, bazı dönemlerde pozitif değerler alan net pozisyon, özkaynaklara oranla yüksek seviyelerde olmamakta ve yasal sınırlar içerisinde kalmaktadır (BDDK, 2012).

Karlılık ve gelir rasyoları açısından iki ülke bankacılık sektörleri karşılaştırıldığında, 2008-2015 döneminde; Macaristan bankacılık sektöründe aktif ve özkaynak karlılık oranlarının, Türkiye bankacılık sektörü oranlarının büyük ölçüde gerisinde kaldığı ve negatif değerlere ulaşan düşüşler gerçekleştiği görülmektedir (Tablo 9). Net faiz gelirleri/brüt gelirler oranları da, Türkiye oranlarının gerisinde ve bu gelişme, aktif kalitesini yansıtan ve 2008 krizinin etkisiyle giderek artan takipteki krediler/toplam brüt krediler oranının yüksekliği ile açıklanabilmektedir. Macaristan bankacılık sektörüne kıyasla, Türk bankacılık sektöründe oldukça yüksek kârlılık oranlarına ulaşılmıştır.

Diğer taraftan; bankaların finansal sıkıntı ve dolayısıyla iflas risklerinin ölçütü olarak kullanılabilen, z-skoru açısından iki ülke bankacılık sektörleri karşılaştırıldığında, Macaristan bankacılık sektörü oranlarının, Türkiye bankacılık sektörü oranlarına göre çok daha yüksek olduğu görülmektedir (Tablo 10). 1999-2013 döneminde, Macar bankalarının iflas riskleri, Türk bankalarının iflas risklerine göre düşük seviyelerde kalmıştır. Türk bankaları, 2001'den başlayarak, iflas risklerini azaltabilmiş ve daha sağlam bir finansal bünyeye sahip olabilmişlerdir. 


\begin{tabular}{|c|c|c|c|c|c|c|}
\hline \multicolumn{7}{|c|}{ Kârlılık ve Gelir } \\
\hline & \multicolumn{3}{|l|}{ Macaristan } & \multicolumn{3}{|l|}{ Türkiye } \\
\hline & $\begin{array}{c}\text { Aktif } \\
\text { Karlılığı }\end{array}$ & $\begin{array}{c}\text { Özkaynak } \\
\text { Kârlılığı }\end{array}$ & $\begin{array}{c}\text { Net Faiz } \\
\text { Gelirleri/Brüt } \\
\text { Gelirler }\end{array}$ & $\begin{array}{c}\text { Aktif } \\
\text { Karlılığ } 1\end{array}$ & $\begin{array}{c}\text { Özkaynak } \\
\text { Kârlılığı }\end{array}$ & $\begin{array}{c}\text { Net Faiz } \\
\text { Gelirleri/Brüt } \\
\text { Gelirler } \\
\end{array}$ \\
\hline 2008 & 1,1 & 16,4 & 65,4 & 2,5 & 20 & 67,3 \\
\hline 2009 & - & - & - & 3,3 & 26,4 & 69,2 \\
\hline 2010 & - & - & - & 3,1 & 23,9 & 62,5 \\
\hline 2011 & - & - & - & 2,2 & 19 & 65,2 \\
\hline 2012 & - & - & - & 2,4 & 19,6 & 64,4 \\
\hline 2013 & 0,2 & 2,3 & 46,6 & 2 & 17,4 & 65,4 \\
\hline 2014 & $-2,2$ & $-20,6$ & 53,6 & 1,7 & 14,7 & 68,1 \\
\hline 2015 & 0,2 & 1,6 & 50,5 & 1,5 & 13,6 & 76,0 \\
\hline
\end{tabular}

Tablo 9. Kârlılık ve Gelir Rasyoları Kaynak: IMF

Genelde; z-skoru, 2.99'dan büyükse sektörün sağlamlığını, 1.81 ile 2.99 arasında değiş̧iyorsa sektörün yeterli sağlamlığa sahip olmadığını ve 1.81' den küçükse sektörün finansal sıkıntı içerisinde bulunduğunu ifade etmektedir (Sebe-Yeboah ve Mensah, 2014). Bu aralıklar, ülkelerin ekonomik koşullarına bağlı farklılıklar gösterebilmektedir.

\begin{tabular}{|l|c|c|}
\hline & Macaristan & Türkiye \\
\hline 1999 & 9,10 & $-0,43$ \\
\hline 2000 & 16,37 & 0,80 \\
\hline 2001 & 17,13 & 1,82 \\
\hline 2002 & 19,19 & 7,94 \\
\hline 2003 & 19,58 & 8,57 \\
\hline 2004 & 19,90 & 11,76 \\
\hline 2005 & 18,55 & 19,57 \\
\hline 2006 & 15,95 & 8,59 \\
\hline 2007 & 16,35 & 10,22 \\
\hline 2008 & 15,67 & 6,70 \\
\hline 2009 & 15,78 & 6,94 \\
\hline 2010 & 19,21 & 5,54 \\
\hline 2011 & 17,26 & 4,52 \\
\hline 2012 & 20,51 & 4,87 \\
\hline 2013 & 16,18 & 3,35 \\
\hline
\end{tabular}

Tablo 10. Z Skoru Kaynak: World Bank

\section{Sonuç}

1998-2015 dönemi itibariyle, Macaristan ve Türkiye için finansal gelişmişlik ve bankacılık sektörü sağlamlık seviyelerinin, risk ve kırılganlıklarının değerlendirilmesinin amaçlandığı bu çalışmada ulaşılan sonuçlar özetle şöyledir:

Finansal gelişmişlik seviyeleri itibariyle bir değerlendirme yapıldığında; M2/GSYİH oranının iki ülkede de en fazla yüzde 60' lara ulaşabilmesi, piyasaların henüz yeterli gelişmişliğe ulaşamadığını göstermektedir. Özel sektör kredileri/GSYİH oranı itibariyle, Macaristan oranlarının belirgin ölçüde, Türkiye oranlarından yüksek olması nedeniyle, Macaristan bankacılık sektöründe finansal aracılık faaliyetlerinin Türkiye bankacılık sektörüne göre daha etkin olduğu ileri sürülebilmektedir. Menkul kıymetler borsası işlem hacmi/GSYİH oranı itibariyle, oranların genel olarak Türkiye'nin gerisinde kaldığı gözlenmektedir. Finansal sağlamlık göstergeleri itibariyle bir değerlendirme yapıldığında, iki ülke için de sermaye yeterliliği ve likidite rasyolarının Basel standartları kapsamında yeterli seviyelerde olduğu görülmektedir. Bununla beraber, likidite rasyolarının Türk bankacılık sektöründe, Macaristan bankacılık sektörü rasyolarına oranla daha yüksek seviyelerde seyretmesi, likidite yönetiminde, Türk bankalarının, Macaristan bankalarına göre daha başarılı oldukları izlenimini doğurmaktadır. Kredi riskini yansıtan takipteki krediler/toplam brüt krediler rasyoları itibariyle, Macaristan bankacılık sektörü oranlarının, 2008 krizinin ardından 2014 yılına kadar giderek yükselmesi, Türkiye'de ise, 2001 krizinin ardından en yüksek seviyesine ulaşan oranın, yıllar içerisinde giderek azalması, Macaristan bankacılık sektörünün incelenen dönemde kredi riski taşıdığına işaret etmektedir. Bu paralelde, kredi/mevduat rasyolarının her iki ülkede de yüksek seviyelerde seyretmesi, finansal istikrarsızlığın nedenlerinden biri olan banka bilançolarında devam edebilecek bozulma şeklinde değerlendirilebilmektedir.

Kur riskini yansıtan yabancı para net açık pozisyon/sermaye rasyosu itibariyle, oranların Macaristan ve Türkiye bankacılık sektörlerinde yasal sınırlar içerisinde kalmış olmaları, kur riskinin iki ülkede de yönetilebilir seviyede 
olduğunu göstermektedir. Karlılık ve gelir rasyoları itibariyle ise, Macaristan bankacılık sektörüne göre, Türk bankacılık sektöründe oldukça yüksek kârlılık oranlarına ulaşıldığı gözlenmektedir.

Sonuç olarak, AB'ne aday ülke Türkiye'nin üye ülke Macaristan'a kıyasla finansal piyasalar açısından durumu irdelendiğinde, incelenen dönem itibariyle, Türkiye ve Macaristan'da finansal gelişmişlik seviyelerinin genel olarak paralellik gösterdiği ve Türkiye'nin son iki yılda Macaristan'ın önüne geçtiği izlenmektedir. Bankacılık sektörü sağlamlık göstergeleri açısından ise, sektörün taşıı̆ı̆ı kredi riskinin büyüklüğü, kredi/mevduat rasyolarının yüksekliği ve sektörde karlılık oranlarının negatif değerlere ulaşması, Türk Bankacılık sektörüne kıyasla daha kırılgan bir yapıya sahip olduğu izlenimini doğurmaktadır.

\section{Kaynakça}

- Balassa, 1983. “The Hungarian Economic Reform, 1968-82”, PSL Quarterly Review, 36, p.165.

- Bank for International Settlements, 2016. Committees and associations, Basel Committee on Banking Supervision, Basel III, https://www.bis.org/bcbs/basel3.htm?m=3\%7C14\%7C572

- Bankacıllk Düzenleme ve Denetleme Kurumu, 2012. Türk Bankacılık Sektörü Kur Riski Değerlendirme Raporu, s. 12.

- Canales-Kriljenko, 2004. "Foreign Exchange Market Organization in Selected Developing and Transition Economies: Evidence from a Survey", IMF Working Paper, 4, pp. 34-35.

- Canbolat, 2002. Avrupa Birliği Uluslararası Bir Sistemin Tarihsel, Teorik, Kurumsal, Jeopolitik Analizi ve Genişleme Sürecinde Türkiye ile İlişsiler, Alfa Basım Yayım Dă̆ııım, İstanbul.

- Claessens and van Horen, 2012. "Foreign Banks: Trends, Impact and Financial Stability", IMF Working Paper, 10, pp. 19-20.

- Csizmazia, 2014. "The Development of the Hungarian Banking Sector Prior to Basel II", International Journal of Knowledge and Innovation in Business, 1, p. 54.

- Çikot, 2011. "Macaristan Sermaye Piyasası", Sermaye Piyasasında Gündem, Sayı 104, s.9.

- De Haan, Oosterloo, Schoenmaker, (2009). European Financial Markets and Institutions, Cambridge University Press.

- European Bank for Reconstruction and Development, 2016. What We Do, EBRD economics, Economic data, http://www.ebrd.com/what-we-do/economic-research-and-data/data/forecasts-macro-data-transitionindicators.html

- European Bank for Reconstruction and Development, 2016. What We Do, EBRD economics, Economic data, Forecasts, data, indicators,

http://www.ebrd.com/cs/Satellite?c=Content\&cid=1395237866249\&pagename=EBRD\%2FContent\%2FCon tentLayout

- European Commission, 2016, International Cooperation and Development, Economic Reforms (Transition to a Market-Based Economy), https://ec.europa.eu/europeaid/economic-reforms-transition-market-basedeconomy_en

- Ganiev, 2014. “Küreselleşme, Finansal Piyasalar ve Kriz”, İktisat Politikası Araştırmaları Dergisi, 1, ss. 122-123.

- Goldstein and Turner, 1999. Yükselen Ekonomilerde Bankacılık Krizleri: Kökenler ve Politika Seçenekleri, (Karacan, Çev.), Dünya Yayıncılık, İstanbul, 1996.

- Hare, 1991. "Hungary: In Transition to a Market Economy", Journal of Economic Perspectives, 5, p. 196.

- Hawkins and Mihaljek, 2001. "The banking industry in the emerging market economies: competition, consolidation and systemic stability - an overview", Bank for International Settlements Paper, 4, p. 7.

- IMF, 2015, Publications, https://www.imf.org/external/np/sta/fsi/eng/fsi.htm

- IMF, 2016. Data, IMF Data, Financial Soundness Indicators (FSIs), http://data.imf.org/?sk=9F855EAEC765-405E-9C9A-A9DC2C1FEE47\&ss=1411569045760

- Kaplan, 2002. Bankacılık Sektörünün Yabancı Para Pozisyon Açı̆̆ı: Türkiye Örneği, Türkiye Cumhuriyet Merkez Bankası Araştırma Genel Müdürlüğü Çalışma Tebliği, No. 1, s. 12.

- Lynch, David (1996), "Measuring Financial Sector Development: A Study of Selected Asia Pasific Countries", The Developing Economies, 34, pp. 7-10.

- Mishkin, 2006, The Economics of Money, Banking and Financial Markets, 8th Edition, Pearson, Addison Weasley. 
- $\quad$ Park, Jun and Lee, 2015. "Evaluation on The Usefulness of The Loan-to-Deposit Ratio Regulation-From The Macroprudential Policy Perspective-“, Bank of Korea, http://www.seacen.org/file/file/2015/PolicySummit/BOKpaper.pdf

- Schinasi, 2004. “Defining Financial Stability”, IMF Working Paper, 187, p. 10.

- Sebe-Yeboah and Mensah, 2014. "A Critical Analysis of Financial Performance of Agricultural Development Bank (ADB, Ghana)”, European Journal of Accounting Auditing and Finance Research, 2, p. 15.

- Serdengeçti, 2005. "Finansal İstikrar Raporu”, Kamuoyu Tanıtımı, Türkiye Cumhuriyet Merkez Bankası, Ankara, s.3.

- Şahin, 2009. Türkiye Ekonomisi, Tarihsel Gelişimi - Bugünkü Durumu, 10. Baskı, Ezgi Kitabevi, Bursa.

- Tanınmış Yücememiş ve Sözer, 2011. "Bankalarda Takipteki Krediler: Türk Bankacılık Sektöründe Takipteki Kredilerin Tahminine Yönelik Bir Model Uygulaması”, Finansal Araştırmalar ve Çalışmalar Dergisi, 3, s. 45.

- Trading Economics, 2016. Indicators, Credit Ratings, http://www.tradingeconomics.com/hungary/rating

- Türkiye Cumhuriyeti Avrupa Birliği Bakanlığı, 2016. TR-AB İlişkileri, http://www.ab.gov.tr/index.php?p=4

- Türkiye Cumhuriyeti Dışişleri Bakanlığı, 2012. Türkiye Cumhuriyeti Budapeşte Büyükelçiliği, Bilgi Notları, Macaristan Ekonomisi ve Dış Ticareti, http://www.budapeste.be.mfa.gov.tr/ShowInfoNotes.aspx?ID=121440

- Türkiye Cumhuriyeti Dışişleri Bakanlığı, 2016. Dış Politika, Bölgeler, Avrupa, Macaristan, TürkiyeMacaristan İlişkileri, http://www.mfa.gov.tr/-turkiye-macaristan-siyasi-iliskileri.tr.mfa

- World Bank, 2016. Data, Indicators, http://data.worldbank.org/indicator/

- World Bank, 2016. World DataBank, Global Financial Development, http://databank.worldbank.org/data/reports.aspx?source=global-financialdevelopment\&Type=TABLE\&preview $=$ on\#

- Yücel, 2011. “Komünizm Sonrası Orta ve Doğu Avrupa Ülkelerindeki Anayasacılık Hareketleri”, Ankara Üniversitesi Hukuk Fakültesi Dergisi, 60, s. 657.

- Zoltan and Balazs, 2015. "Hungary's Orban Makes World's Best Trade on Swiss Franc Loans", Bloomberg, http://www.bloomberg.com/news/articles/2015-01-16/hungary-s-orban-makes-world-s-best-trade-on-swissfranc-loans 


\title{
Terörizmin Finansal Piyasalara Etkisi: Türkiye Örneği Impact of Terrorism on Financial Markets: The Case of Turkey
}

\author{
Assoc. Prof. Dr. Neşe Algan (Çukurova University, Turkey) \\ Prof. Dr. Mehmet Balc1lar (Eastern Mediterranean University, Cyprus) \\ Prof. Dr. Harun Bal (Çukurova University, Turkey) \\ Ph.D. Candidate Müge Manga (Çukurova University, Turkey)
}

\begin{abstract}
This study investigates the impact of terrorism on the Turkish financial market using daily data from Jan 4, 1988 to May 24, 2016. In order to measure the impacts of terrorist attacks in Turkey we test for causality from terrorism index to returns and volatilities of 3 aggregate and 16 sector level stock indices using a recently developed nonparametric causality-in-test test of Balcilar et al. (2016). The results obtained indicate that there is no causality from terrorist activities to stock market returns (1st moment). However, we find significant causality at various quantiles from terrorist activates to volatility (2nd moment) of tourism, food and basic materials sectors.
\end{abstract}

\section{Giriş}

Finansal piyasalar, ülkelerin ekonomik, sosyal ve politik alanlarında yaşanan gelişmelerinden hızlı bir şekilde etkilendiği piyasa türüdür. Belirsizlik finansal piyasaların mevcut durumdan etkilenme derecesini belirleyen önemli bir faktör olup belirsizliği yaratan önemli olgulardan birisi de terörizmdir. Terör ve terörizm ile ilgili olarak birçok tanımlama yapılmıştır. Bunlardan biri Laqueur (1987) tarafından yapılmış ve bu tanımlamada terör; şiddet, kargaşa, strateji amaçlı kullanılan ve insani olmayan güdülerle gerçekleşen eylemler bütünü olarak tanımlanmıştır.

Terör eylemleri toplumda sosyal, psikolojik, siyasal ve ekonomik sonuçlar doğurur. Bu sonuçların bir kısmı dolaylı bir kısmı ise dolaysız etkilerdir. Terörün ekonomik sonuçları, terör eyleminin olmasından hemen sonra ortaya çıkarak etkisini çok kısa vadede gösterirken, orta ve uzun vadede de ekonomi üzerinde olumsuz etkiler yaratmaktadır. Terörün ekonomik etkilerinin ele alındığı çalışmaların birçoğunda terörün doğrudan ekonomik maliyetlerinin kısa dönemde ortaya çıktığı, terörün dolaylı maliyetlerinin ise ülkelere, sektörlere ve zamana göre farklılık gösterebildiği yönündedir. Uluslararası ekonomi açısından terörizm: Fiziksel ve beşeri sermaye stokunda azalışa, yüksek oranda belirsizliğe, üretken olan sektörler yerine güvenlik harcamalarında artışa ve turizm sektörleri gibi spesifik sektörlerin olumsuz yönde etkilenmesine sebep olmaktadır (Abadie ve Gardeazabal, 2005). Terör saldırıları sonucu piyasalarda: terör saldırılarını önlemeye yönelik artan harcamalar üretim maliyetlerinde artışa neden olmakta, havacılık ve hizmet sektörleri talebinde azalmaya neden olmakta ve artan belirsizlik düzeyi, risk primini yükseltmektedir (Frey, Luechinger $v d$. 2007:13).

Terörün ekonomik maliyetiyle ilgili olarak Ekonomi ve Barış Kurumu (IEP) tarafından hazırlanan 2015 yılı raporuna göre, global ekonomide terörizmin ekonomik maliyeti 2013 yılına göre, 20 milyar \$'lik artışla 2014 yılında 52.9 milyar \$ düzeyine yükselmiştir. Ayrıca bu raporda terör eylemlerinin türünün ekonomik maliyeti etkileyen önemli bir faktör olduğu ifade edilmektedir. Daha fazla kişinin ölümüne veya yaralanmasına sebep olan bir terör eylemlerinin ekonomik maliyetinin, kişisel bir saldırı şeklinde gerçekleşen terör eylemlerine göre 32 kat daha fazla yüksek olduğu ifade edilmektedir. Terör olaylarından korunma amacıyla yapılan devlet harcamalarının yaklaşık olarak 117 milyar \$ düzeylerinde olması terörün ekonomik boyutunun önemini açıkça ortaya koymaktadır (IEP, 2015).

Terör eylemlerindeki artış, bilginin de hızlı yayılımı, belirsizliği artırarak risk primlerini yükseltmekte, beklenen gelirlerin azalmasına neden olmaktadır. Ancak finans piyasaları bu tür eylemlerin olumsuz etkilerinden kısa sürede arınabilmektedir.

Türkiye'de terör olayları, birçok etnik örgüt tarafından gerçekleşmektedir. Son dönemlerde artan ve El-Kaide, DHKP/C, PKK/KONGRA-GEL-TAK, KCK gibi birçok örgüt tarafindan Türkiye'de gerçekleştirilen terör eylemleri ile ekonomik yapı arasındaki ilişkinin incelenmesi gereğini ortaya çıkarmaktadır. Grafik 1'de Türkiye'de 2006-2014 yılları arasındaki terör indeksindeki değişmeler yer almaktadır.

Grafik 1'den 1970-2015 dönemi için Türkiye terör indeksi verilmiştir. Bu indeks yazarlar tarafindan ln (e + ölü sayısı + yaralı sayısı + terör olayı sayısı) formülü ile yazarlarca hesaplanmıştır.1970-2015 yılları arasında Türkiye'deki terör eylemlerinin azımsanmayacak boyutta seyrettiği açıkça görülmektedir. Terör indeksinde özellikle 1985 sonrası çok önemli bir artışın gerçekleştiği, en yüksek terör olayı etkisini 1992 de ortaya çıktığı ancak 1992 sonrasında da terör indeksinin yüksek seviyelerde kaldığı gözlenmektedir.

Türkiye'de yaşanan terör eylemlerinin birçoğunun eylem stratejilerinde ekonomik hedeflerin bulunması bu eylemleri daha çok dikkat çeker hale getirmektedir. Terör eylemleri ve teröre hizmet amaçlı atılmış her türlü adım, piyasalarda risk ve belirsizlik unsuru yaratarak finansal piyasaları olumsuz yönde etkilemektedir. Dalgalanma ve oynaklığın en çok yaşandığı finansal piyasaların terör eylemlerinden nasıl etkilendiği bu aşamada özellikle dikkat 
çekmektedir. Bu çalışmada, Türkiye'de yaşanan terör olaylarının finansal piyasalar üzerine olan etkisi incelenmektedir.

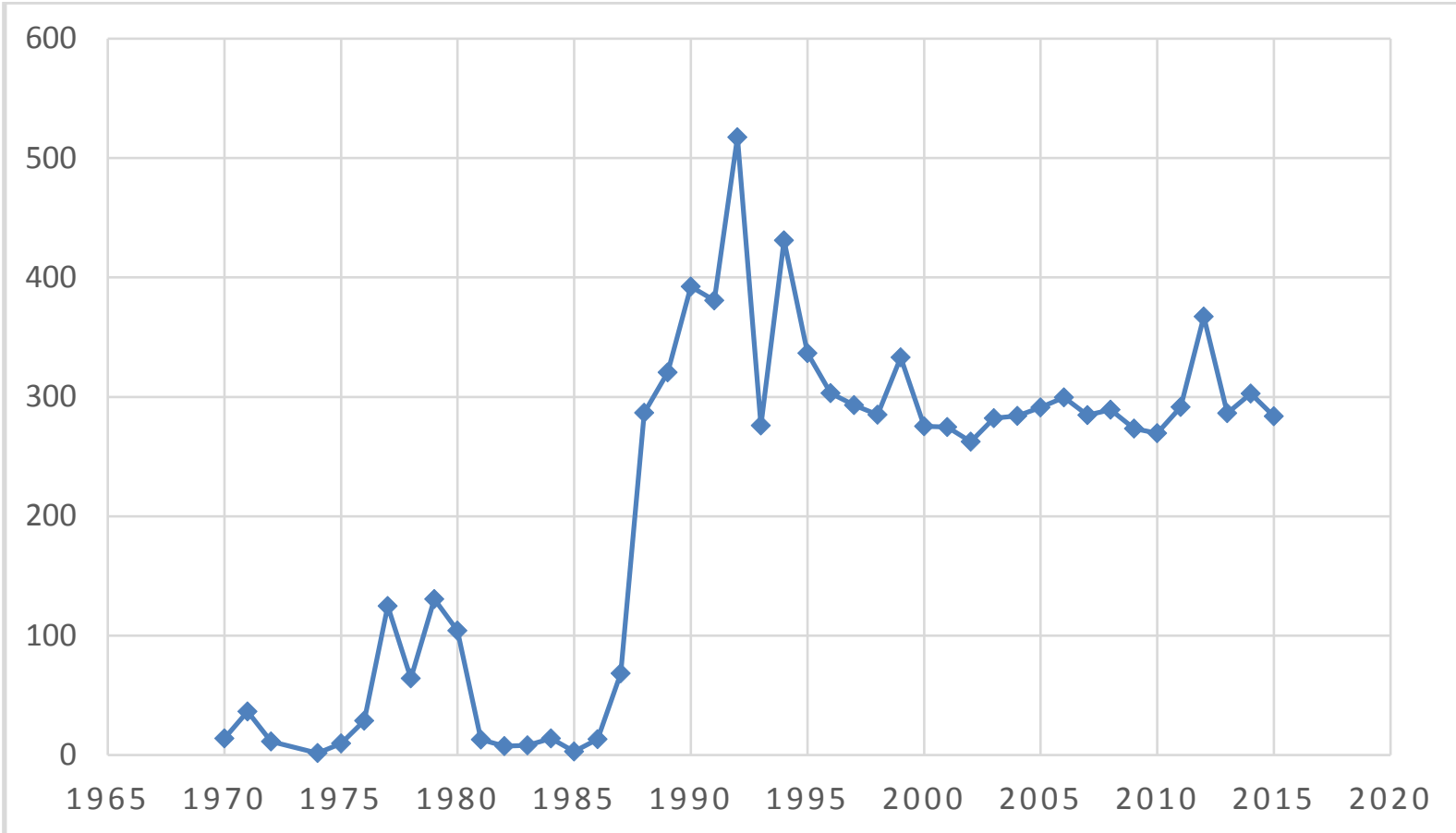

\section{Grafik 1. Türkiye Iç̧in 1970-2015 Dönemi Terör İndeksi}

Literatürde terör eylemlerinin finansal piyasalar üzerine etkisini inceleyen birçok çalışma bulunmaktadır. Olay çalışma yaklaşımını kullanarak Karolyi ve Martell (2005) terör saldırılarının menkul kıymetler piyasasındaki etkileri araştırmış, gelişmiş ve demokratik bir ülkedeki terör eylemlerinin firmaları daha fazla etkilediği sonucuna ulaşmıştır. Bunun yanında, bir firma yöneticisinin zor kullanılarak kaçırılmasının herhangi bir bina veya tesislere gerçekleştirilen bombalı saldırılardan daha büyük bir olumsuz etki yaratacağı bulunmuştur.

Arin vd. (2008), çok değişkenli GARCH modelini Endonezya, İsrail, İspanya, Tayland ve Türkiye üzerine uyguladıkları çalışmalarında terör eylemlerinin menkul kıymetler borsası üzerinde oluşturduğu dalgalanmalarının her ülkede farklı boyutta olduğu sonucuna ulaşmışlardır. 2002.01-2006.12 tarihleri arasında günlük verilerin kullanıldığ çalışmada terör endeksi volatilitesinin borsa getirilerini etkilediğini, İspanya'ya ve İngiltere'nin terör saldırılarına karşı daha dirençli olduğu ve bu ülkedeki yatırımcıların terör saldırılarına karşı daha dayanıklı olduğu sonucuna ulaşmışlardır.

Chulia vd. (2007), çok değişkenli GARCH modelini kullandıkları çalışmalarında terör eylemlerinin ABD ve Avrupa borsaları arasında volatilite aktarımının nasıl etkilendiğini incelemişledir. Elde ettikleri sonuçlara göre, 11 Eylül 2001'de Newyork'ta meydana gelen terör eyleminin Avrupa borsasinda dalgalanmaya neden olurken, 11 Mart 2004 Madrid ve 7 Temmuz 2005'te Londra'da meydana gelen terör eylemlerinin ABD borsasının volatilitesini etkilemediği yönünde sonuçlar elde etmişlerdir.

Finansal piyasalar ve terör olayları ilişkisinin incelendiği bir başka çalışmada, Chen ve Siems (2004), ABD finans piyasasının herhangi bir terör saldırısı sonucu eski haline dönmesi için gerekli olan sürenin 40 gün gibi kısa bir süre iken birçok finansal piyasada bu sürenin çok daha uzun olduğu sonucuna varmışlardır.

İsrail'deki terör atakları üzerine odaklanan Eldor ve Melnick (2004), çalışmalarında Filistin'nin terör eylemlerinin döviz kuru ve borsa piyasaları üzerindeki etkilerini incelemişlerdir. Elde edilen sonuçlara göre, terör saldırılarının İsrail'in borsa ve döviz kuru piyasasında kalıcı etkiler oluşturduğunu ancak yerel terör eylemlerinin İsrail'de herhangi bir etki yaratmadığı sonucuna ulaşmışlardır. Bir başka çalışmada Hon vd. ( 2004), 5 ekonomi üzerine yaptıkları çalışmalarında 11 Eylül saldırılarının hisse senedi piyasaları üzerindeki etkilerini incelemiş ve Avrupa piyasalarına göre ABD piyasalarından çok daha kısa zamanda terör saldırılarının etkilerinin ortadan kalktığı sonucuna ulaşmışlardır.

Eldor $v d$. (2005), 460 terör saldırısı örneklemi üzerinden 2000-2003 yılları arasındaki terör saldırılarının finansal piyasa üzerindeki etkisi incelenmiş ve terör eylemlerinin hisse senetleri üzerinde negatif yönde etkide bulunduğunu ve terör saldırıları ile birlikte yatırımcıların daha farklı yatırım kanallarına kaydı̆̆ ifade edilmiştir. Bir başka çalışmada Eldor $v d$. (2012), İsrail ve Filistin arasındaki çatışmaların finansal piyasalara ve ekonomiye etkisini günlük veriler kullanarak GARCH analizi ile değerlendirmişlerdir. Analiz sonucunda her iki ülkenin hisse 
senetlerinin değer kaybına uğrayarak ekonomisinin zarar gördüğü ancak İsrail Telaviv borsasının Filistin borsasına göre daha çok etkilendiği sonucuna ulaşmışlardır.

Benzer bir şekilde Johnston ve Nedelescu (2005), çalışmalarında düzenleyici bir çalışma yapısının mevcut olduğu finans piyasasının terör eylemlerinin etkilerini hafifletici rol oynayacağını ifade etmişlerdir. Bu sebeple terör saldırıları karşısında piyasanın direncinin artırılması yönünde düzenlemeler yapılması gerektiğini savunmuşlardır. Bir başka çalışmalarında Johnston ve Nedelescu (2006) ABD'de (2001) ve İspanya'da (2004) gerçekleşen terör saldırıları sonucu ortaya çıkan şoklardan sonra hızlı bir şekilde toparlandıkları sonucuna ulaşmışlardır.

Nikkinen $v d$. (2008), 11 Eylül terör saldırılarının 53 finansal piyasa üzerindeki etkilerini incelemiş ve terör eylemlerinin finansal piyasaları global ekonomiyle olan ilişkisi düzeyinde, kısa vadede negatif yönde etkilediği sonucuna ulaşmışlardır.

Chesnesy $v d$. (2011), çalışmalarında 25 ülke ve 11 yıllık zaman aralığındaki terör eylemlerinin hisse senedi, tahvil ve emtia piyasaları üzerindeki etkileri olay çalışması dahilinde GARCH-EVT yaklaşımıyla incelenmiştir. Elde edilen sonuçlar her ülkenin finans piyasasının terör olaylarından farklı boyutta etkilendiğini, en çok etkilenen İsviçre borsasının, en az etkilenenin ise ABD borsasının olduğunu tahmin etmişlerdir. Ayrıca, bu çalışmada parametrik olmayan yöntemin diğerlerine kıyasla terörün finansal piyasalar üzerine etkisinin değerlendirilmesinde daha uygun olduğuna değinmişlerdir. Bir başka çalışmada Drakos (2010), 22 ülkedeki terör olaylarının günlük borsa getirileri üzerindeki etkisini incelemiş ve terör olayları ile borsa getirileri arasındaki ilişkinin negatif yönde olduğunu tahmin etmiştir.

Yıldırım (2012), Türkiye'deki finans sistemi ile terörizm arasındaki ilişkiyi incelediği çalışmasında 2001 Şubat ve 2010 Ocak zaman aralığındaki terör olaylarının etkilerini olay çalışması ve zaman serisi olarak iki farklı yöntemle test etmiştir. Yapılan analizin olay çalışması kısmında sivillere yönelik terör eylemleri ile finansal piyasalar arasında negatif yönlü ilişki tahmin edilirken, zaman serisi analizinde aynı yönlü sonuçların altyapı/tesislere yönelik geçekleşen terör eylemlerinde oluştuğu sonucuna da ulaşılmıştır. Türkiye'de hisse senedi piyasası üzerine yapılan bir başka çalışmada Aksoy (2014), 1996-2007 tarihleri arasında Türkiye'de ve 11 Eylül 2011 tarihinde ABD’de gerçekleşen terör saldırılarının Türk hisse senedi piyasası üzerine etkileri iki farklı yöntemle analiz edilmiştir. Olay etüdü yöntemi ve zaman serisi yöntemi kullanılan çalışmada, çoğu terör olayı için hisse senedi piyasasının terör olayını takip eden günlerde düşmeye devam ettiğini göstermiştir. Zaman serisi analizinde ise Türk Hisse Senedi Piyasasının terör saldırılarına duyarlı olduğu sonucuna ulaşılmıştır. Ayrıca, terör eylemlerinin BIST100 endeksi oynaklığını arttırdığı sonucuna ulaşmışlardır. Ağırman vd. (2014), terör saldırıları ve finansal piyasalar arasındaki ilişki 2003-2011 y1lları itibariyle 35 ülke üzerine panel veri analiz yöntemi ile incelenmiş ve analiz sonuçları, terörist eylemlerin hisse senedi piyasaları üzerine gerçekleşen kısa vadeli olumsuz etkilerinin uzun dönemde piyasa mekanizması tarafından düzeltildiği sonucuna ulaşmışlardır.

Christofis $v d$. (2013) tarafından yapılan çalışmada üç ana terörist saldırının yükselen uluslararası borsalardan biri olan Borsa İstanbul üzerindeki etkisini olay çalışma çerçevesinde incelenmiş ve bu saldırılardan borsa piyasasındaki volatilitenin kısa dönemde anlamlı ancak hızla toparlanarak tepki gösterdiği sonucuna ulaşmışlardır. Bir başka çalışmada Bashir vd. (2013), terörün Pakistan Karaçi Menkul Kıymetler Borsası üzerine etkisi GARCH ve GARCH-EVT modeli kullanılarak 01.2005-12.2010 dönemi analiz edilmiştir. Çalışmada terör eylemlerinin finansal piyasalar üzerinde olumsuz etki yarattığı sonucuna ulaşılmıştır. Karaçi Menkul Kıymetler Borsası üzerine yapılan bir başka çalışmada Suleman (2012), EGARCH modelini kullanarak terör saldırılarının sektör getirileri üzerinde negatif etki yarattığı ve finansal sektör endeksleri üzerindeki volatiliteyi arttırdığı sonucuna ulaşmıştır

Yapılan çalışmalar, üç farklı soru üzerine odaklanmaktadır. Bunlar; terör eylemleri borsa getirilerini nasıl etkiler, menkul kıymetler borsası oynaklığının terör olaylarına nasıl tepki gösterir ve terör eylemleri nedeniyle meydana gelen şoklar nasıl uluslararası boyutta yayılır, şeklinde sıralanabilir. Bu çalışmada Balcılar vd. (2016) tarafından son dönemlerde geliştirilen parametrik olmayan yeni bir parametrik olmayan kantil nedensellik testi ile yukarıda bahsedilen üç farklı soru Türkiye için tekrar ele alınmıştır. Balcılar vd. (2016) tarafindan önerilen parametrik olmayan kantil nedensellik testi Nishiyama $v d$. (2011)'in parametrik olmayan nedensellik testi ve Jeong $v d$. (2012) tarafından geliştirilen parametrik olmayan kantil nedensellik testinin k. sıradan nedenselliğe genelleştirilmesidir. Parametrik olmayan kantil nedensellik testinin üç temel avantajı bulunmaktadır. Bunlar, (i) hisse senedi piyasasındaki dalgalanmaların dağılımının tüm kantiller üzerindeki nedensellik etkilerini test etmek (ii) hem birinci momentin (getiriler) ve hem de ikinci momentin (oynaklık) nedenselliğinin test edilebilmesi ve (iii) birinci ve ikinci momentlerde nedenselliğin doğrusal olmayan, yapısal kırılmalar ve uç değerlerin varlığına karşı dirençli bir istatistik ile sınanabilmesi şeklinde ifade edilebilir.

$\mathrm{Bu}$ çalışmanın giriş bölümünde terör ve borsa üzerine bazı değerlendirmelerde bulunulup terör ve menkul kıymetler borsası üzerine yapılmış bazı çalışmalar ve detayları üzerine değerlendirilmeler yapılmıştır. İkinci bölümde çalışmada kullanılacak olan ekonometrik yöntemin teorik yapısı ve detayları verilmektedir. Üçüncü bölümde yapılan analiz sonucu elde edilen bulgulara ve sonuç bölümünde ise çalışmanın analiz kısmında Türkiye üzerine elde edilen sonuçlar doğrultusunda çeşitli politik önerilerde bulunulmaya çalışılmaktadır. 


\section{Parametrik Olmayan Kantil Nedensellik Testi}

Bu çalışmada kullanılan test, Nishiyama $v d$. (2011), ve Jeong $v d$. (2012), çalışmalarında yer alan parametreler aracılığıyla oluşturulmuş ve Balcılar vd, tarafından ortaya atılmış yeni bir parametrik olmayan nedensellik testidir. Jeong $v d$. (2012)'de $x_{t}$ (terör saldırıları indeksi) $\theta$ 'ınc1 kantilde gecikme vektörü $\left\{y_{t-1}, \ldots, y_{t-p}, x_{t-1}, \ldots, x_{t-p}\right\}$ 'ne göre $y_{t}$ 'nin (hisse senedi getirilerinin) Granger nedeni olmamamsı için

$$
Q_{\theta}\left(y_{t} \mid y_{t-1}, \ldots, y_{t-p}, x_{t-1}, \ldots, x_{t-p}\right)=Q_{\theta}\left(y_{t} \mid y_{t-1}, \ldots, y_{t-p}\right)
$$

olması gerekir. Benzer şekilde $\theta$ 'ınc1 kantilde $\left\{y_{t-1}, \ldots, y_{t-p}, x_{t-1}, \ldots, x_{t-p}\right\}$ 'e göre, $x_{t}, y_{t}$ değişkeninin eğer,

$$
Q_{\theta}\left(y_{t} \mid y_{t-1}, \ldots, y_{t-p}, x_{t-1}, \ldots, x_{t-p}\right) \neq Q_{\theta}\left(y_{t} \mid y_{t-1}, \ldots, y_{t-p}\right)
$$

ise Granger nedenidir. (2) numaralı denklemde yer alan $Q_{\theta}\left(y_{t} \mid \cdot\right), 0$ ile 1 arasında yer alır $t$ değerine bağlıdır ve $y_{t}$ değişkeninin $\theta$ 'ınc1 kantilini ifade etmektedir. Burada $Y_{t-1} \equiv\left(y_{t-1}, \ldots, y_{t-p}\right), X_{t-1} \equiv\left(x_{t-1}, \ldots, x_{t-p}\right)$ ve $Z_{t}=$ $\left(X_{t}, Y_{t}\right)$ şeklinde tanımlanmış olup, $F_{y_{t} \mid Z_{t-1}}\left(y_{t} \mid Z_{t-1}\right)$ ve $F_{y_{t} \mid Y_{t-1}}\left(y_{t} \mid Y_{t-1}\right)$ eşitlikleri sirasıyla $y_{t}$ değişkeninin $Z_{t-1}$ ve $Y_{t-1}$ 'e dayalı koşullu dağılımına ifade etmektedir. $F_{y_{t} \mid Z_{t-1}}\left(y_{t} \mid Z_{t-1}\right)$ 'in tüm $Z_{t-1}$ için $y_{t-1}$ 'demutlak olarak sürekli olduğu varsayılır. Eğer $Q_{\theta}\left(Z_{t-1}\right) \equiv Q_{\theta}\left(y_{t} \mid Z_{t-1}\right)$ ve $Q_{\theta}\left(Y_{t-1}\right) \equiv Q_{\theta}\left(y_{t} \mid Y_{t-1}\right)$ eşitlikleri tanımlanırsa, $F_{y_{t} \mid Z_{t-1}}\left\{Q_{\theta}\left(Z_{t-1}\right) \mid Z_{t-1}\right\}=\theta$ bir olasıllk ile doğrudur. Sonuç olarak hipotez, 1. ve 2. denklemlere yer alan tanımlamalar

$$
\begin{aligned}
& H_{0}: P\left\{F_{y_{t} \mid Z_{t-1}}\left\{Q_{\theta}\left(Y_{t-1}\right) \mid Z_{t-1}\right\}=\theta\right\}=1 \\
& H_{1}: \quad P\left\{F_{y_{t} \mid Z_{t-1}}\left\{Q_{\theta}\left(Y_{t-1}\right) \mid Z_{t-1}\right\}=\theta\right\}<1
\end{aligned}
$$

şeklinde ifade edilen hipotezler dahilinde sınanmaktadır.

Jeong $v d$. (2012) çalışmasında $J=\left\{\varepsilon_{t} E\left(\varepsilon_{t} \mid Z_{t-1}\right) f_{Z}\left(Z_{t-1}\right)\right\}$ mesafe ölçütünü kullanılmıştır. Eşitlikte yer alan $\varepsilon_{t}$, regresyondan elde dilen hata terimini, $f_{Z}\left(Z_{t-1}\right)$ ise $Z_{t-1}$ değişkeninin marjinal olasılık yoğunluk fonksiyonunu ifade etmektedir. Regresyon hatası 3. Denkleme dayalı olarak ortaya çıkmaktadır. Bu denklemde $\mathbf{1}\{\cdot\}$ gösterge fonksiyonu olarak ifade edildiğinde $E\left[\mathbf{1}\left\{y_{t} \leq Q_{\theta}\left(Y_{t-1}\right) \mid Z_{t-1}\right\}\right]=\theta$ veya eş değer bir şekilde, $\mathbf{1}\left\{y_{t} \leq\right.$ $\left.Q_{\theta}\left(Y_{t-1}\right)\right\}=\theta+\varepsilon_{t}$ olacaktır. Jeong et al. (2012), $J \geq 0$ varsayımı altında mesafe ölçütü için

$$
J=E\left[\left\{F_{y_{t} \mid Z_{t-1}}\left\{Q_{\theta}\left(Y_{t-1}\right) \mid Z_{t-1}\right\}-\theta\right\}^{2} f_{Z}\left(Z_{t-1}\right)\right] .
$$

olduğunu ifade etmektedir. $J=0$ eşitliği söz konusu olduğunda, değişkenler arasında nedensellik ilişskisi olmadığını ifade eden $H_{0}$ hipotezi, $J>0$ olması durumunda geçerli olan $H_{1}$ hipotezine karşı sınanmaktadır. Jeong vd. (2012), $J$ için

$$
\hat{J}_{T}=\frac{1}{T(T-1) h^{2 p}} \sum_{t=p+1}^{T} \sum_{s=p+1, s \neq t}^{T} K\left(\frac{Z_{t-1}-Z_{s-1}}{h}\right) \hat{\varepsilon}_{t} \hat{\varepsilon}_{s}
$$

şekirdek yoğunluk tehmincisini kullanmaktadır. $\mathrm{Bu}$ denklemde yer alan $K(\cdot), h$ genişliğinde çekirdek fonksiyonunu, $T$, örneklem boyutunu, $p$, gecikme uzunluğunu, $\varepsilon_{t}$, tahmin edilen regresyon hatasını ifade eder ve

$$
\hat{\varepsilon}_{t}=\mathbf{1}\left\{y_{t} \leq \hat{Q}_{\theta}\left(Y_{t-1}\right)\right\}-\theta
$$

olarak tanımlanır.

Çalışmada kullanılan $y_{t}$ için $\theta$ 'ıncı kantile bağlı parametrik olmayan çekirdek tahmincisini elde etmek için $Y_{t-1}$ bağlı olarak $\hat{Q}_{\theta}\left(Y_{t-1}\right)=\hat{F}_{y_{t} \mid Y_{t-1}}^{-1}\left(\theta \mid Y_{t-1}\right)$ eşitliği kullanılmaktadır. Eşitlikte yer alan $\widehat{F}_{y_{t} \mid Y_{t-1}}\left(y_{t} \mid Y_{t-1}\right)$ Nadarya-Watson çekirdek tahmin edicisi olup

$$
\widehat{F}_{y_{t} \mid Y_{t-1}}\left(y_{t} \mid Y_{t-1}\right)=\frac{\sum_{s=p+1, s \neq t}^{T} L\left(\frac{Y_{t-1}-Y_{s-1}}{h}\right) \mathbf{1}\left(y_{s} \leq y_{t}\right)}{\sum_{s=p+1, s \neq t}^{T} L\left(\frac{Y_{t-1}-Y_{s-1}}{h}\right)}
$$

şeklinde elde eidlir. Burada $L(\cdot)$ kernel çekirdek tahmincisi ve $h$ ise bant genişliğidir.

Jeong $v d$. (2012), çalışmasında yer alan ekonometrik yapı, bu çalışmada 2. moment için genelleştirilmiştir. Bu amaçla Nishiyama $v d$. (2011) tarafından geliştirilen parametrik olmayan kantil nedensellik testine benzer bir yöntem izlenmiştir. Daha yüksek düzeydeki momentler için nedenselliği göstermek amaciyla

$$
y_{t}=g\left(Y_{t-1}\right)+\sigma\left(X_{t-1}\right) \varepsilon_{t}
$$

denklemini ele alalım. Denklemde yer alan $\varepsilon_{t}$, beyaz gürültü sürecini $g(\cdot)$ ve $\sigma(\cdot)$ fonksiyonları, durağanlık için belirli şartları sağlayan bilinmeyen fonksiyonları ifade etmektedir. Bu formülasyon $X_{t-1}$ 'den $y_{t}$ 'ye doğru Granger nedenselliğe izin vermemektedir. Fakat $\sigma(\cdot)$ 'nun doğrusal olmayan genel bir fonksiyonu olması durumunda $X_{t-1}$ 'den $y_{t}^{2}$ 'ye nedenselliğe izin vermektedir. Bu yüzden, varyansta (oynaklıkta) Granger nedensellik için $X_{t-1}$ 'in karesinin alınmasına gerek yoktur. Burada, (9) nolu denklemde yer alan varyans nedenselliği için sıfir ve alternatif hipotezler aşağıdaki gibi tekrar formüle edilmiştir: 


$$
\begin{aligned}
& H_{0}: \quad P\left\{F_{y_{t}^{2} \mid Z_{t-1}}\left\{Q_{\theta}\left(Y_{t-1}\right) \mid Z_{t-1}\right\}=\theta\right\}=1, \\
& H_{1}: \quad P\left\{F_{y_{t}^{2} \mid Z_{t-1}}\left\{Q_{\theta}\left(Y_{t-1}\right) \mid Z_{t-1}\right\}=\theta\right\}<1
\end{aligned}
$$

Sıfır hipotezi için ulaşılabilir test istatistiği 10. denklemden ifade edilmiştir ve 6 ve 8 . denklemde yer alan $y_{t}$ değişkeni yerine $y_{t}^{2}$ (hisse senedi getirisinin karesi ya da oynaklık) değişkenine yer verilmiştir.

Jeong $v d$. (2012) ifade edildiği gibi genel olarak koşullu birinci moment (ortalama) nedensellik ikinci momentte (varyans) nedenselliği de ima eder. Bu sorunu gösterebilmek için

$$
y_{t}=g\left(X_{t-1}, Y_{t-1}\right)+\epsilon_{t} .
$$

denklemini ele alabiliriz. Burada 1. Momentte nedensellğin 2. Momenttede nedensellik anlamına geldiği açıktır. Böylece, daha yüksek mertebeden nedensellik aşağıdaki şekilde test edilebilir:

$$
\begin{aligned}
& H_{0}=P\left\{F_{y_{t}^{k} \mid Z_{t-1}}\left\{Q_{\theta}\left(Y_{t-1}\right) \mid Z_{t-1}\right\}=\theta\right\}=1 \quad k=1,2, \ldots, K, \\
& H_{1}=P\left\{F_{y_{t}^{k} \mid Z_{t-1}}\left\{Q_{\theta}\left(Y_{t-1}\right) \mid Z_{t-1}\right\}=\theta\right\}<1 \quad k=1,2, \ldots, K .
\end{aligned}
$$

(13) nolu denklemden faydalanarak oluşturulan “ $x_{t}, K$ 'ıncı kantile kadar $y_{t}$ 'nin nedenidir" tanımlaması, (6) nolu denklemde her $k$ için hesaplanan test istatistiğine dayandırılabilir. Ancak her $k=1,2, \ldots, K$ değerinin 13. denkleme farklı sıfır hipotezleri ile ele alınması dolayısıyla birlikte değerlendirilmesi oldukça zordur. Çünkü bu hipotezler karş1lıklı olarak birbiriyle ilişkilidir (Nishiyama $v d$. 2011). Bu sorunu tatmin edici bir şekilde gidermek için Nishiyama $v d$. (2011) çalışmasında yer alan ardışık test yöntemi bazı değişikliklerle uyarlanmıştır. İlk olarak birinci momentteki $(k=1)$ düzeyinde nedenselliğin varlığını ifade eden sıfır hipotezinin reddedilmesi, 2. düzeyden de nedenselliğin olmadığını göstermemektedir bundan dolayı $k=2$ düzeyi (2. moment) için test yeniden ardışık olarak yapılır. Sonuç olarak, ortalamada nedenselliği veya varyansta nedensellik veya ortalama ve varyansın her ikisinde de nedenselliği ardışık olarak sınayabiliriz.

Kantil nedensellik testi için yapılan ampirik uygulamada 6. ve 8. denklemlerde yer alan parametrelerden $h$, bant genişliğini, $p$, gecikme uzunluğunu $K(\cdot)$ ve $L(\cdot)$ ise çekirdek tipini seçmek gerekmektedir. Çalışmada belirlenen gecikme uzunluğu Schwarz Bilgi Kriterine (SIC) göre belirlenmiştir. SIC kritiği gecikme uzunluğunun belirlenmesinde tutumlu bir kriter olarak bilinir ve bu yüzden parametrik olamayan yaklaşımlar ile ilgili aşırı parametreleşme problemine karşı dirençlidir. Bant genişliği için en küçük kareler çapraz doğrulama yöntemi kullanılmıştır. $K(\cdot)$ ve $L(\cdot)$, için ise, Gaussçu çekirdeği kullanılmıştır.

\section{Veri ve Bulgular}

Bu çalışmada yapılan ortalamada ve oynaklıkta (varyansta) nedensellik analizi Borsa İstanbul (BIST) içerisinde yer alan günlük hisse senedi getirileri için yapılmıştır. Spesifik olarak terör indeksinin günlük hisse senedi getirileri ve/veya oynaklığı üzerinde Granger nedenselliğe sahip olup olmadığı incelenmiştir. İncelenen BIST getirileri arasında Toplam Piyasa, BIST-100 ve BIST-30 olarak 3 adet genel indeks ve ayrıca Bankacılık, Toplam Piyasa, Havayolları, Temel Materyal, İnşaat, Tüketim Malları, Finans, Kamu Hizmetleri, Finansal Hizmetler, Endüstri, Teknoloji, Gıda, Tüketici Hizmetleri, Seyahat, Perakendecilik, Telekomünikasyon ve Turizm olmak üzere 16 sektör indeksi yer almaktadır. Çalışmada kullanılan günlük veriler 4 Ocak 1988-24 Mayıs 2016 dönemini kapsamaktır. Getiriri serileri Thomson Reuters Datastream veritabanından elde edilmiş olup logaritmik yüzde getiri olarak hesaplanmıştır. Eckstein and Tsiddon (2004) ve Arin vd. (2008) çalışmalarını izleyerek terör indeksi $\ln (e+$ ölü sayısı + yaralı sayısı + terör olayı sayısı) formülü ile yazarlarca hesaplanmıştır. Bu indekse temel olan terör olaylarına ilişkin veriler RAND Database of Worldwide Terrorism Incidents (RDWTI) ve Global Terrorism Database veri tabanlarından elde edilmiş eksik olan kısımlar yazarlarca internet kaynaklarından tamamlanmıştır. Bu çalışmada kullanılan veriler hem alt sektörel düzeyde olması hem de yüksek frekanslı olması nedeniyle diğer çalışmalardan farklılaşmaktadır.

Hem ortalamada (getiri) hem de varyansta (oynaklık) nedensellik testleri için kullanılan parametrik olmayan kantil nedensellik testleri seçilen kantil değerlerinde uygulanabilmektedir. Bu amaçla tüm testler $0.10,0.15, \ldots$, 0.85, 0.90 şeklinde 17 kantil değerinde hesaplanmıştır. Kantil testleri uçlarda yere alan kantillerde duyarlılık göstereceğinden 0.10 'dan daha küçük ve 0.90 'dan daha büyük kantiller için test yapılmamıştır.

Grafik 2 seçilen kantil değerlerinde hesaplanan parametrik olmayan getiri ve oynaklık kantil test sonuçlarını göstermektedir. Grafik 2 her bir getiri serisi için hesaplanan getiri (ortalam) Granger nedensellik testini kalın düz çizgi ile oynaklık (varyans) nedensellik testini kalın kesikli çizgi ile yüzde 5 önem seviyesindeki kritik değeri de ince düz çizgi ile ayrı ayrı panellerde göstermektedir. 
(a) BIST-100

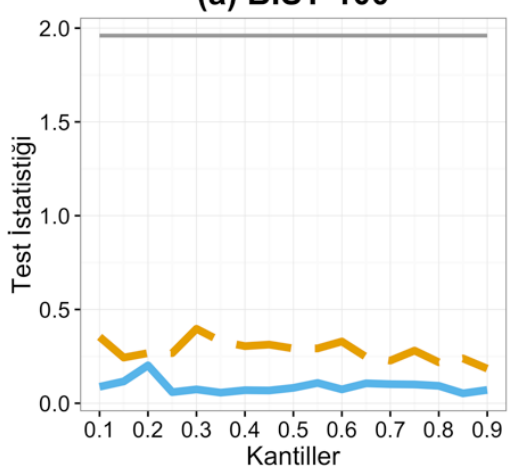

(d) Toplam Piyasa

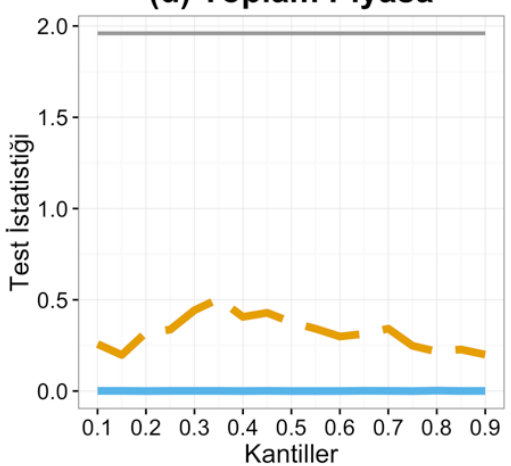

(g) Inşaat

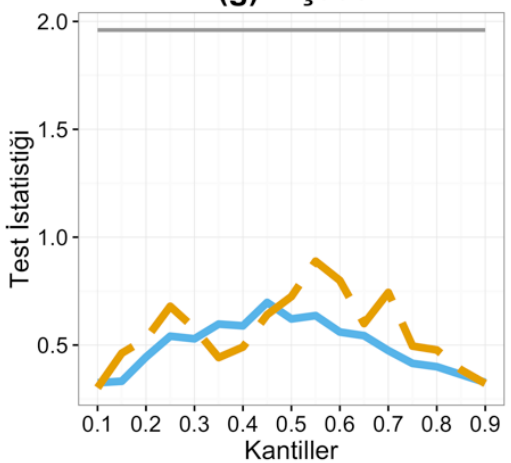

(1) Kamu Hizmetleri

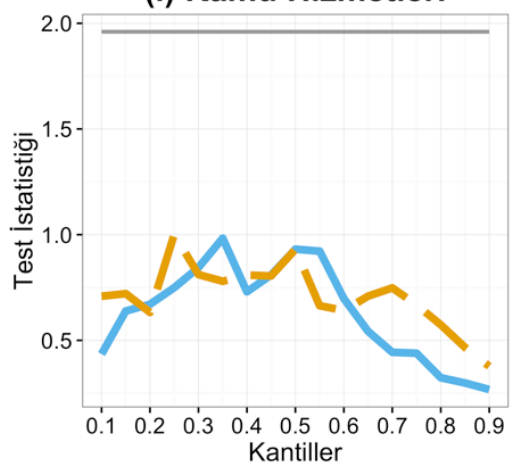

(b) BIST-30

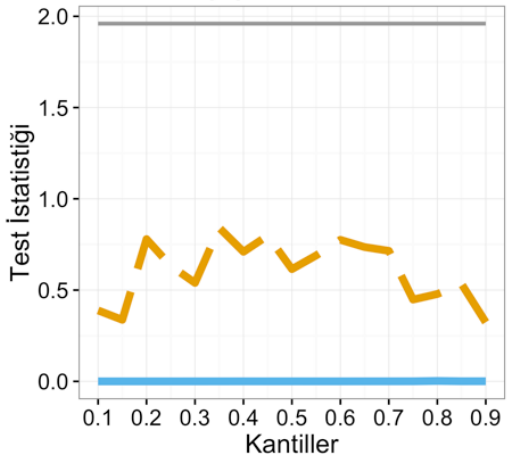

(e) Havayolları

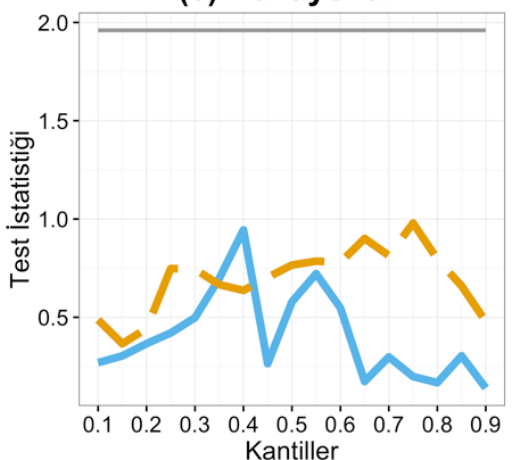

(h) Tüketim Malları

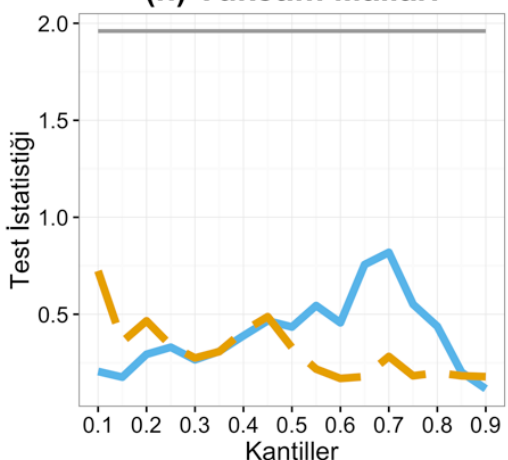

(j) Finansal Hizmetler

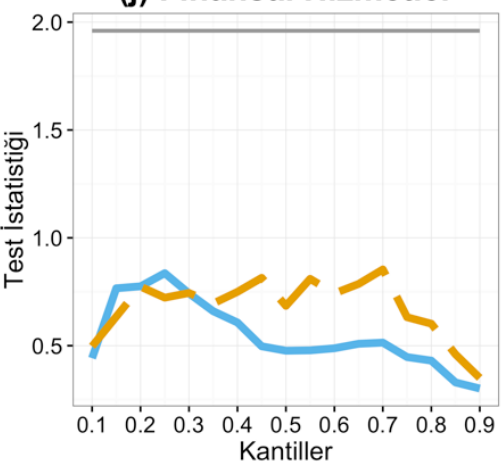

(c) Bankacılık

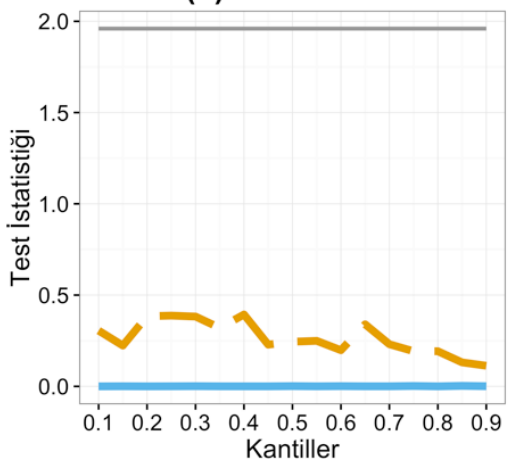

(f) Temel Materyal

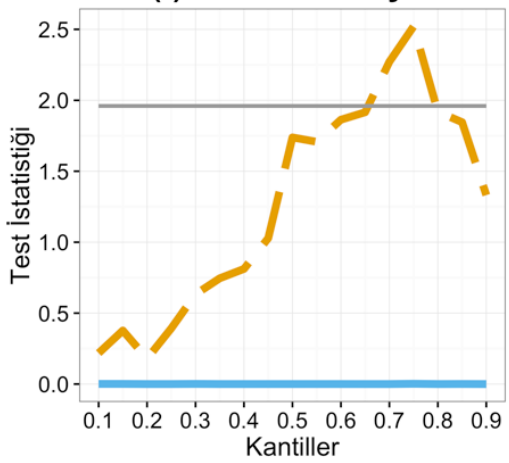

(i) Finans

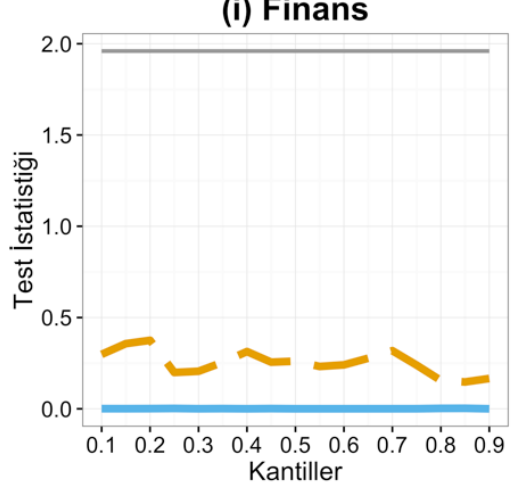

(k) Endüstri

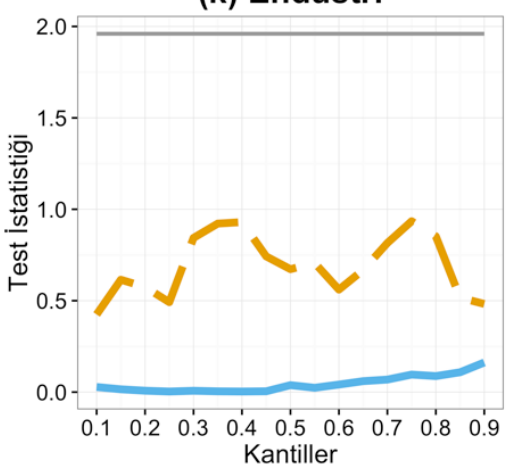

Grafik 2. Parametrik Olmayan Kantil Nedensellik Testleri 
(I) Teknoloji

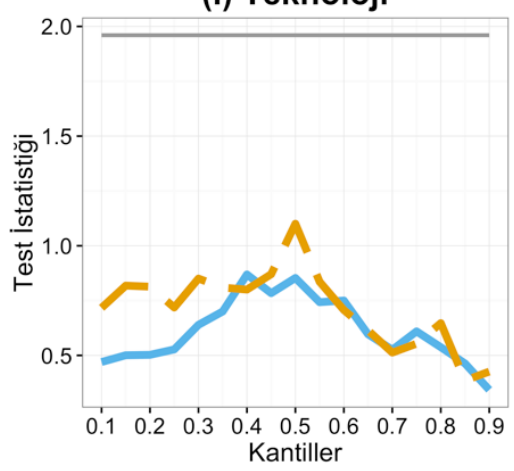

(o) Seyahat

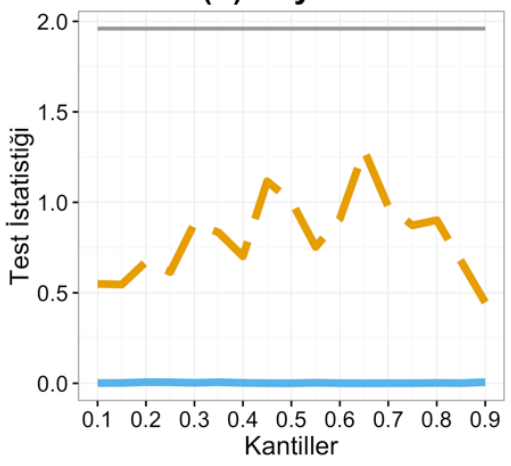

(m) Gıda

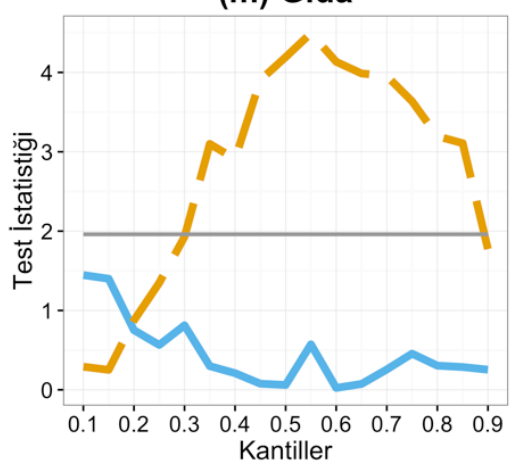

(ö) Perakendecilik

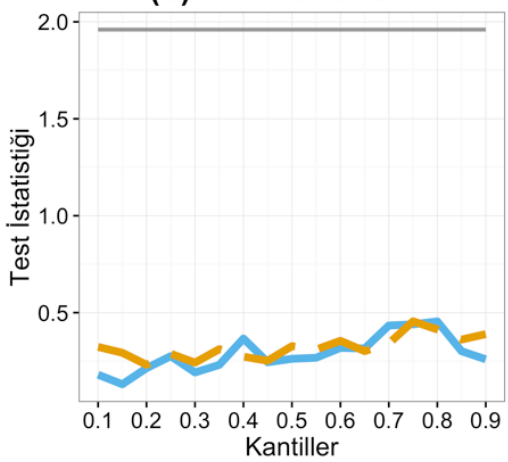

(r) Turizm

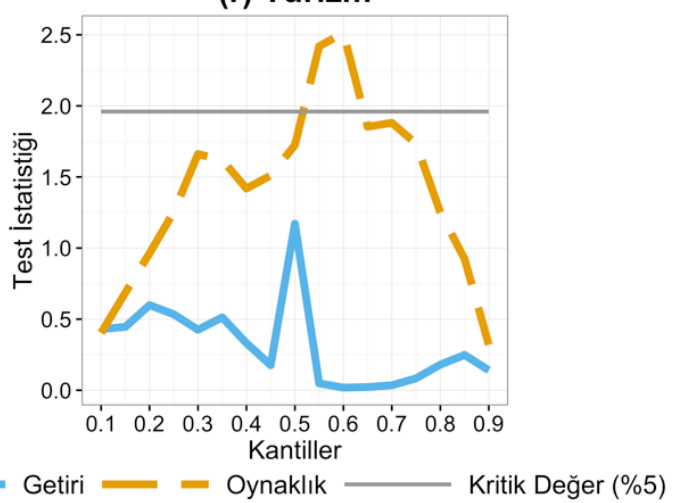

(n) Tüketici Hizmetleri

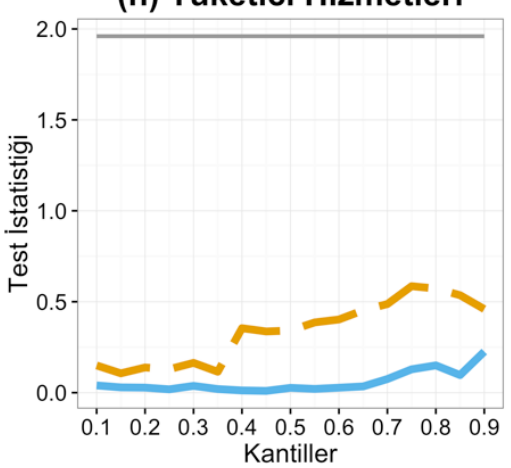

(p) Telekomünikasyon

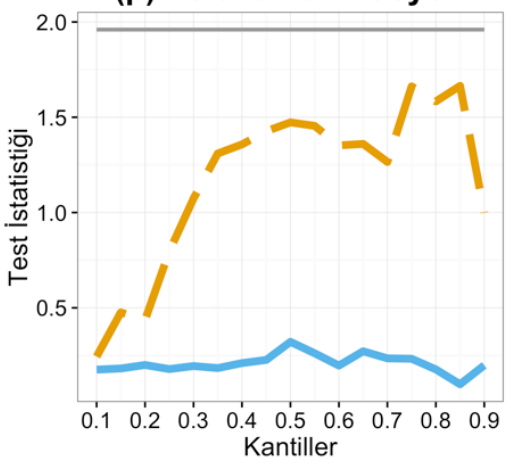

Grafik 2. (devam)

Grafik 2 incelendiğinde ortaya çıkan en önemli bulgu hiçbir getiri serisi terör indeksinin getiriye (ortalama ya da 1. momentte) Granger neden olmamasıdır. Yüksek frekanslı veri kullanılmasına rağmen Türkiye'de terör olayları hisse senetlerinin ortalama getirilerini etkilediğini gösteren bir bulgu elde edilememiştir. Bu durum Turizm, Gıda ve Ulaştırma gibi terör olaylarına daha duyarlı sektörler içinde geçerlidir.

Grafik 2'de yer alan test sonuçları incelendiğinde, terör olaylarının Temel Materyal, Gıda ve Turizm sektörü hisse senetlerinin oynaklığına bazı kantillerde Granger neden olduğu görülmektedir. Spesifik olarak Temel Materyaller için $0.65-0.80$, Gıda için 0.30-0.90, Turizm 0.50-0.65 kantil aralıklarında terör olayları oynaklığa Granger neden olmaktadır. Bu sektörlerden Gıda ve Turizm sektörlerinin özellikle turist ziyaretçi sayına bağlı bağlı sektörler olması dikkat çekicidir. Sonuç olarak, terör olayları Türkiye'de menkul kıymetleri piyasalarında ortalama getiriyi etkilememektedir, ancak turizme bağlı getiriye sahip sektörlerde varlık getirilerinin oynaklığı terör olaylarından etkilenmektedir.

\section{Sonuç}

Finansal piyasalar, ülkelerin ekonomik, sosyal ve politik alanlarında yaşanan gelişmeler ve belirsizliklerden hızlı bir şekilde etkilenen piyasalardır. Belirsizlik, güvensizlik finansal piyasaların mevcut durumdan etkilenme derecesini belirleyen önemli bir faktördür ve belirsizliği yaratan önemli olgulardan birisi de terörizmdir. Terör eylemleri, belirsizlik ve güvensizliği önemli ölçüde artırmakta, toplumda davranış ve beklentilerde değişikliklere neden olarak ülkelerin makroekonomik yapıları üzerinde olumsuzluklar yaratmaktadır. İyi yada kötü haberlere duyarlılığın fazla olduğu piyasalarda oynaklık yüksek olmakta, kötü haberlerin oynaklığı artırmasına karşılık, iyi 
olayların her zaman oynaklık üzerinde fazla etkisi olmadığı yapılan çalışmalarda vurgulanmaktadır. Bu aşamada ülkelerin terör gibi kötü haberlerden etkilenme derecesi önem kazanmaktadır. Bu çalışmada, Türkiye menkul kıymetler piyasasının terör eylemlerine olan tepkisi incelenmektedir. Parametrik olmayan kantil nedensellik testi kullanılan çalışmada Türkiye'deki terör eylemlerinin finansal piyasalar üzerindeki etkileri incelenmektedir. Elde edilen bulgulara göre terör faaliyetlerinin finans piyasası arasında ortalama getiri bakımından nedensellik ilişkisinin olmadığı, ancak gerçekleşen terör faaliyetlerinin finans turizm gibi teröre hassas sektörlerde getiri oynaklığını etkilediği bulunmuştur. Sonuç olarak, terör olayları Türkiye'de turizm, gıda, temel materyaller gibi sektörlerde oynaklığı artırmak suretiyle belirsizliğe neden olmaktadır.

\section{Kaynakça}

- Abadie, A. \& Gardeazabal, J. 2005. "Terrorism and the World Economy”. European Economic Review, 52(1), p. 1-27

- Ağırman, E., Özcan, M., \& Yılmaz, Ö. 2014. "Terörizmin Finansal Piyasalara Etkisi: Ampirik Bir Çalışma". BDDK Bankacılık ve Finansal Piyasalar, 8(2), s. 99-117

- Aksoy, M. 2014. "The Effects of Terrorism on Turkish Stock Market". Ege Akademik Baklş, 14(1), s. 31-41

- $\quad$ Arin, K.P., Ciferri, D., \& Spagnolo, N., 2008. "The price of terror: The effects of terrorism on stock market returns and volatility”. Economics Letters, 101, p. 164-167.

- Balcilar, M., Bekiros, S., \& Gupta, R. (2016). "The role of news-based uncertainty indices in predicting oil markets: a hybrid nonparametric quantile causality method", Empirical Economics. p.1-11

- Bashir, U, Gillani, A H, \& Muhammad, S. 2013. "Influence of Terrorist Activities on Financial Markets: Evidence from KSE”. Financial Assets and Investing, (2), p. 5-13

- Chen, A.H., \& Siems, T.F., 2004. "The effects of terrorism on global capital markets". European Journal of Political Economy, 20, p. 349-366.

- Chesney, M., Reshetar, G., \& Karaman, M. 2011. "The Impact of Terrorism on Financial Markets: An Empirical Study". Journal of Banking and Finance, 35 (2), p.253- 267.

- Christofis, N, Kollias, C, Papadamou, S, \& Stagiannis, A. 2010. “Terrorism and Capital Markets: The Effects of the Istanbul Bombings". Economics of Security Working Paper 31.

- Chuliá, H., Climent, F.J., Soriano, P., \& Torró, H., 2009. "Volatility transmission patterns and terrorist attacks". Quantitative Finance, 9 (5), p. 607-619.

- Drakos, K. 2010. “Terrorism activity, investor sentiment and stock returns". Review of Financial Economics, 19 (3), p.128-135.

- Eckstein, Z. \& Tsiddon, D., 2004. "Macroeconomic Consequences of Terror: Theory and the Case of Israel". Journal of Monetary Economics, 51 (5), p. 971-1002.

- $\quad$ Eldor, R. R., Hauser, S., Kroll, Y., \& Shoukair, S. 2012. "Financial markets and terrorism: The perspective of the two sides of the conflict". Journal of Business Administration Research, 1, p. 18-29.

- Eldor, R.,\& Melnick, R., 2004. "Financial markets and terrorism". European Journal of Political Economy, 20, p. 367-386.

- Frey, B., Luechinger, S., \& Stutzer, A. 2007. "Calculating Tragedy: Assessing the Costs of Terrorism", Journal of Economic Surveys, (21).p: 1-24

- Global Terrorism Datebase, 2016. Global Terrorism Index. https://www.start.umd.edu/gtd/ (Erişim tarihi: 20.03.2016)

- Hon, M.T., Strauss, J., \& Yong, S.Y., 2004. Contagion in financial markets after September 11: myth or reality?, Journal of Financial Research, 27, p. 95-114.

- Institute for Economics Aad Peace (IEP), 2015. Global Terrorism Index- Measuring and Understanding The Impact Of Terrorism, http://economicsandpeace.org/wp-content/uploads/2015/11/Global-Terrorism-Index2015.pdf

- Jeong, K., Härdle, W. K. \& Song, S., 2012. A consistent nonparametric test for causality in quantile. Econometric Theory 28, p. 861-887.

- Johnston, B., \& O. Nedelescu, 2006. "The impact of terrorism on financial markets". Journal of Financial Crime 13, p. 7-25.

- $\quad$ Karolyi, A., \& Martell, R., 2010. Terrorism and the stock market. International Review of Applied Financial Issues and Economics 2, p. 285-314.

- Laqueur, W. 1987. The Age of Terrorism. London: Wei- denfeld and Nicolson.

- Nikkinen, J., Omran, M., Sahlstrom, P., \& Aijo, J. 2008. "Stock Returns and Volatility Following The September 11 Attacks: Evidence from 53 Equity Markets”. International Review of Financial Analysis, 17 (1), p.27-46

- $\quad$ Nishiyama, Y., Hitomi, K., Kawasak, Y., \& Jeong, K., 2011. A consistent nonparametric Test for nonlinear causality - specification in time series regression. Journal of Econometrics, 165, p. 112-127.

- Tahir Suleman, M. 2012. "Stock market reaction to terrorist attacks: Empirical evidence from a front line state". Australasian Accounting, Business and Finance Journal, 6(1), p. 97-110. 


\title{
Rusya Borsası'nın Petrol Fiyatlarına Bağımlılı̆̆ı Dependence on Oil Prices of Russian Stock Market
}

\author{
Asst. Prof. Dr. Dilek Özdemir (Atatürk University, Turkey) \\ Asst. Prof. Dr. Özge Buzdağlı (Atatürk University, Turkey) \\ Ph.D. Candidate Murat Akdağ (Atatürk University, Turkey) \\ Prof. Dr. Ömer Selçuk Emsen (Atatürk University, Turkey)
}

\begin{abstract}
In the period after transition, economically full-liberal policy implementations applied by Russia Federation has been taken attention as cyclical movement. No variations of goods is said to be effective about the main reasons about cyclical movement in liberalisation. As a kind of indicator of the Russian economy, stock market's sensitivity to oil prices analyzed. In this context, especially change of oil prices, exchange rate and money supply effects on Russia are analyzed for the period of 1996M1-2015M12. Stationarity of the series is investigated by Lee ve Strazicich (2003) unit root test with multiple structural breaks, existence of cointegration relation between series is tested by Maki (2012) method of cointegration with multiple structural break, and cointegration coefficients are predicted with Dynamic Ordinary Learst Square-DOLS method. Furthermore, causality relations between series are investigated by Hacker and Hatemi-J (2012) symmetric causality test. As a result, Russian stock market is positively effected by oil prices, real effective exchange rate and real money supply. Also causality tests showed that bidirectional causality relation found on stock market with oil prices and real effective exchange rate, and unidirectional causality from real money supply to stock market.
\end{abstract}

\section{Giris}

Petrolün arz ve talebinin esnekliği düşük bir mal olması nedeniyle fiyatlarında meydana gelen değişmeler hem petrol ihracatçısı hem de petrol ithalatçısı ülkeler açısından önemli bir etkiye sahiptir. Özellikle gelişmekte olan ülkelerin kalkınabilmek ve kalkınmak için de sanayileşmeleri gereği dikkate alındığında, sanayi çarklarının döndürebilirliği büyük ölçüde petrole bağımlı olmalarını kaçınılmaz kılmaktadır. Bu durum da ekonomilerinin kırılganlığını artıran unsurlar arasında görülebilir. Dolayısıyla petrol fiyatlarındaki artışlar petrol ithalatçısı ülkeleri olumsuz yönde etkilerken, ekonomisinde mal çeşitliliği düşük olan petrol ihracatçısı ülkeleri ise kazançlı hale getirmektedir.

Petrol ihraç eden ülkeler arasında bulunan Rusya ise günümüzde Suudi Arabistan ve ABD’den sonra üçüncü büyük petrol üreticisi konumundadır (Dünya Bankası 2015). Diğer taraftan ekonomide yeterli çeşitleme yapamayan ülkelerden olan Rusya'nın ekonomisi petrol fiyatlarına karşı oldukça duyarlıdır. Rusya'nın petrol ihracatına bağımlılığının göstergeleri arasında, petrol fiyatlarında yaşanan şok niteliğindeki düşüşlere paralel olarak 2015'te ortaya çıkan ekonomik daralma ve uygulanan ambargo paralelinde yaşadığı borç krizi gösterilebilir. Diğer taraftan küresel büyümenin beklentilerin altında gerçekleşmesi (2014'te \%2,6'dan, 2015'te \%2,4'e düşmesi) ve petrol fiyatlarındaki düşüşün beklentilerin ötesinde devam etmesi Rus ekonomisinde \%3,7'lik bir GSYİH daralmasıyla sonuçlanmıştır. Rusya'nın halihazırdaki resesyonu ticaretin, para transferinin ve sermaye akımlarının azalması kanalıyla bölgedeki diğer ülkeleri de olumsuz etkilemektedir (Dünya Bankası Rusya Ekonomik Raporu, 2016). Diğer bir ifadeyle yayılma-bulaşma-domino etkileri diye ifade edilen husus, Rusya ile önemli ticareti olan ülkelere de sıçramaktadır. Bu çerçevede Türkiye'nin petrol ve enerji ithalatında en önemli ticari partnerlerinden biri olması nedeniyle Rus ekonomisindeki olumsuz gelişmelerin Türkiye ekonomisi üzerine yansımaları olması kaçınılmazdır.

Petrol fiyatlarındaki düşüşün Rus ekonomisinde yarattığı olumsuz etkiler yalnızca GSYİH daralmasıyla sınırlı kalmamış, diğer makroekonomik göstergelere de negatif yansımıştır. Temel göstergelerden bazılarındaki değişimler Tablo 1'de verilmektedir.

\begin{tabular}{|l|c|c|c|c|}
\hline Temel Makroekonomik Göstergeler & $\mathbf{2 0 1 2}$ & $\mathbf{2 0 1 3}$ & $\mathbf{2 0 1 4}$ & $\mathbf{2 0 1 5}$ \\
\hline M2, \% değişim & 17,9 & 15,4 & 7,3 & 7,2 \\
\hline Nominal döviz kuru Rb/USD (ortalama) & 31,1 & 31,8 & 38,4 & 60,6 \\
\hline Rezervler (altın dahil), milyar \$ & 537,6 & 509,6 & 385,5 & 368,4 \\
\hline Cari açık (milyar \$) & 71,3 & 33,4 & 58,3 & 69,6 \\
\hline Borsa endeksi (RTS) & 1,527 & 1,443 & 791 & 757 \\
\hline
\end{tabular}

Tablo 1. Rusya'nın 2012-2015 Döneminde Temel Makroekonomik Göstergelerindeki Değişmeler Kaynak: Dünya Bankası Rusya Ekonomik Raporu 2016.

Tablo 1'de görüldüğü gibi 2015 y1lındaki olumsuz gelişmeler Rusya'da M2'nin azalmasına, rezervlerde erimeye, cari açı̆̆ın artmasına ve Rb/USD kurunun yükselmesine neden olmuştur. Ayrıca borsa endeksi RTS'de de büyük 
oranda düşüş yaşandığı, dolayısıyla Rus borsasının petrol fiyatlarındaki değişmelerden etkilendiği düşünülebilir. Şirketlerin üretim sürecinde petrolün önemli bir girdi olması nedeniyle, petrol fiyatlarındaki yükseliş üretim maliyetlerini artırarak, şirketlerin kârlılığını azaltan bir unsur olarak görülebilir. Şirketlere ait hisse senedi fiyatları şirketlerin beklenen kârına göre belirlendiğinden, petrol fiyatlarındaki riskler borsada ayrıca fiyatlandırılmaktadır. Bu nedenle petrol şoklarının borsa üzerinde anlamlı etkiye sahip olduğu; petrolün üretim sürecinde girdi veya çıtı olarak kullanılmasına göre fiyatlarındaki artış ya da azalışların hisse senedi fiyatlarını değiştirebildiği ileri sürülebilir (Asteriou vd, 2013). Bu bağlamda Şekil 1'de 1996-2015 dönemi için petrol fiyatları ile borsanın izlediği seyir görülmektedir.

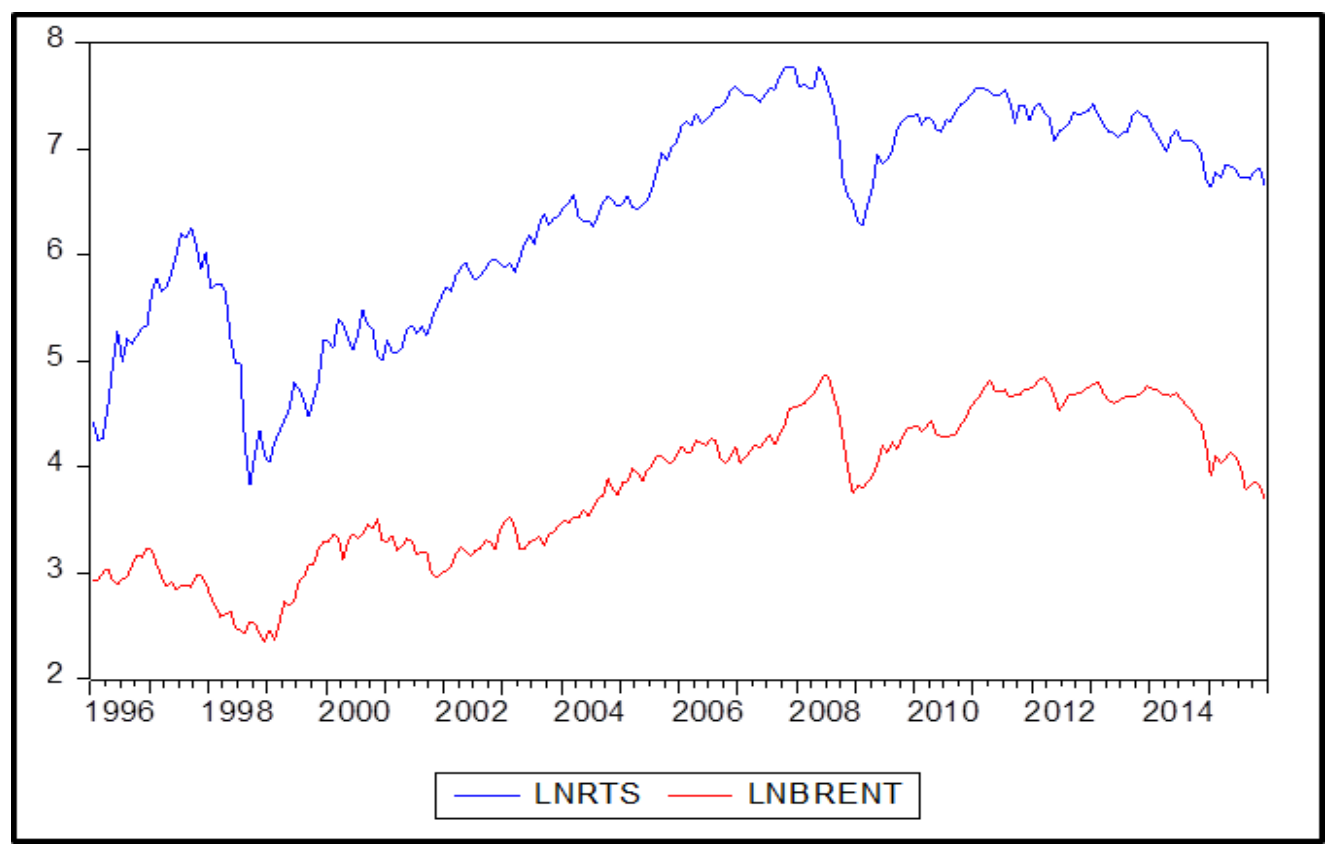

Şekil 1. Borsa ve Petrolün Seyri

Şekil 1' de üst kısımda görülen RTSI ile alt kısımda görülen petrol fiyatlarındaki dalgalanmaların paralellik gösterdiği ileri sürülebilir. Bu kapsamda çalışma, yukarıdaki şekilde gözlenen paralelliğin ekonometrik anlamda tutarlılık arz edip etmediğini amaçlamakta; yani dünyanın en büyük petrol ihracatçısı ülkeleri arasında yer alan Rusya için borsanın petrol fiyatlarına duyarlılığını incelemeyi amaçlamaktadır.

\section{Literatür}

Petrol fiyatlarının borsa üzerindeki etkileri arz ve talep şoklarına, ülkelerin gelişmişlik derecelerine ve petrol ihracatçısı ve ithalatçısı olmasına göre farklılık gösterdiğinden, literatürde petrol fiyatlarındaki değişimlerin borsa üzerine etkileri hususunda tam bir görüş birliğinin bulunduğu söylenemez.

Borsa ve petrol fiyatları arasındaki ilişkileri inceleyen çalışmaların temelinde ise borsa ile para arzı arasındaki ilişkileri ele alan çalışmalar yatmaktadır. Bu çalışmalar arasında Hamburger ve Kochin (1972), Modigliani (1972), Keran (1971) ile Homa ve Jaffe (1971) örnek gösterilebilir (Gupta, 1974). Çalışmada literatür araştırması, genelde borsa ve başta para arzı olmak üzere bir kısım makroekonomik değişkenler boyutuyla ele alan çalışmalar ile özelde petrol fiyatları boyutuyla ele alan çalışmalar ve daha özelde Rusya üzerine yapılan çalışmalardan oluşturulmuştur. Böylece literatürdeki bakış açılarından hareketle Rusya özelinde yapılacak analizler için hem model hem de yöntem arayışına teorik dayanak teşkil ettirtilmeye çalışılmıştır.

Gupta (1974), para arzında gözlenen herhangi bir noktadaki dönüşümün borsa üzerinde ileride yaratacağı etkileri ölçmeyi amaçlamıştır. Bu çerçevede olasılık yaklaşımı kullanılarak para arzındaki t döneminde ortaya çıkacak değişikliklerin borsa değeri üzerine etkilerini araştırmıştır. Aylık veriler ile M2 ve Standard and Poor's'un 425 Endüstriyel indeks değerleri 1948:1-1970:12 veri dönemi için inceleme konusu yapılmıştır. Analiz sonuçlarında M1'e göre M2'nin daha iyi bir sinyalci olduğu tespit edilmiştir.

Goodhart vd. (2003) tarafından yapılan çalışmada Brezilya ve G. Kore'de döviz kuru ve hisse senedinde varlık fiyatları üzerine para politikasının etkileri ele alınmıştır. G. Kore ve Brezilya için 1995-1999 arası dönem, günlük veriler kullanılarak analiz edilmiştir. Serilerdeki oynaklık değerleri GARCH yaklaşımı ile belirlenmiş ve oynaklık serileri VAR modeli ile analize tabi tutulmuştur. Elde edilen bulgularda sıkı para politika uygulamalarının hisse getirileri üzerine avantajlı yansımalarının olduğu ortaya konulmuştur.

Phylaktis ve Ravazzolo (2005) borsa ve döviz kuru arasındaki kısa ve uzun dönemli dinamikleri eş-bütünleşme ve çok değişkenli Granger nedensellik analizleri ile inceleme konusu yapmışlardır. 1980-1998 arası dönem için 
Pasifik Havzası ülkelerde (Hong Kong, Malezya, Singapur, Tayland ve Filipinler) aylık verilerle yapılan analizlerde kontrol değişken olarak da TÜFE alınmıştır. Analiz sonuçlarına göre borsa ile kur arasında pozitif yönlü ilişkilerin olduğu tespit edilmiştir.

Pethe ve Karnik (2000), Hindistan üzerine yaptıkları çalışmada borsa ve makroekonomik değişkenler arasındaki ilişkileri incelemişlerdir. Makroekonomik değişkenler olarak döviz kuru, gecelik faiz oranları, dar anlamda para arzı, geniş anlamda para arzı ve sanayi üretim indeksi alınmıştır. Eş-bütünleşme ve hata düzeltme modelinin kullanıldığı çalışmada aylık veriler ile 1992-1997 arası dönem incelenmiştir. Analiz sonuçlarına göre makroekonomik değişkenler ile borsa arasında kısa dönemde zayıf da olsa ilişkiler ortaya konulurken, uzun dönemde ilişkinin olmadığı gözlenmiştir.

Rahmanov (2007), petrol şoklarının Kazakistan, Rusya ve Ukrayna'da GSYIH, enflasyon, faiz oranı, ücretler ve reel efektif döviz kuru üzerindeki etkisini incelemek amaciyla 1995:Q1-2008:Q2 dönemine ait verilerden yararlanarak VAR analizi yapmıştır. Kazakistan için petrol fiyatlarındaki artışın, enflasyonda artışa neden olduğu, döviz kurunu ve faiz oranını etkilemediği bulgusuna ulaşılmışır. Ukrayna'da petrol fiyatlarındaki artı̧ın, enflasyonda ve ücretlerde artışa neden olduğu, reel döviz kuru ve faiz oranı üzerinde ise anlamlı etkisinin olmadığı görülmüştür. Rusya özelinde ise petrol fiyatlarındaki artışın yalnızca GSYIH'yi pozitif etkilediği, petrol fiyatlarındaki azalışın ücretleri, reel döviz kuru ve enflasyonu azalttığı ortaya konmuştur.

Basher ve Sadorsky (2006) yılındaki çalışmalarında, petrol fiyatları değişiminin 21 gelişmekte olan ülkenin borsalarındaki etkisini incelemişlerdir. 1992:12-2005:10 dönemine ait verilerin kullanıldığı çalışmanın sonuçlarına göre, petrol fiyatlarının gelişmekte olan ülke borsaları üzerinde pozitif ve anlamlı etkiye sahip olduğu görülmüştür.

Asteriou vd. (2013), petrol fiyatlarındaki değişimlerin borsa ve faiz oranları üzerindeki etkilerini petrol ihracatçısı 13 ülke ve petrol ithalatçısı 18 ülkenin 1988:01-2008:12 dönemi için incelemişlerdir. Granger nedensellik ile Johansen eşbütünleşme testi ve hata düzeltme modelinden yararlanarak yaptıkları analiz sonuçlarında petrol fiyatlarındaki dalgalanmaların petrol ithalatçısı ülkelerin borsaları üzerindeki etkilerinin, petrol ihracatçısı ülkelerdekinden daha anlamlı olduğu, ayrıca hem kısa dönemde hem de uzun dönemde petrol fiyatlarının borsa ile etkileşiminin faiz oranlarıyla etkileşiminden daha güçlü olduğu ortaya konmuştur. Son olarak petrol fiyatlarındaki dalgalanmaların gelişmiş ve gelişmekte olan ülkeler açısından farklılık gösterdiği bulgusuna ulaşılmışıır.

Fang ve You (2014), Çin, Hindistan ve Rusya gibi gelişmekte olan ekonomilerde petrol fiyatları ve hisse senedi getirileri arasındaki dinamik etkileşimi araştırmak amacıyla 2001:01-2012:05 dönemine ait aylık verilerle yaptıkları çalışmalarında yapısal VAR (SVAR) yöntemini kullanmışlardır. Analiz sonuçlarında Hindistan'da petrol tüketimindeki artış tarafından tetiklenmediği sürece yükselen petrol fiyatlarının Hindistan ekonomisi üzerinde her zaman negatif etkisinin olduğu bulunmuştur. Ayrıca küresel talepteki artıştan kaynaklanan petrol fiyatları şokunun Çin ekonomisi üzerinde anlamsız bir etkiye sahip olduğu görülmüştür. Küresel talepten kaynaklanan petrol şokunun Rus hisse senedi getirilerinde ise anlamlı bir düşüşe yol açtığı bulgusuna ulaşılmıştır.

Yalçın (2015), çalışmasında petrol piyasasındaki arz ve talep şokları nedeniyle artan petrol fiyatlarının Kazakistan, Rusya ve Ukrayna borsaları üzerindeki etkisini 2000:01-2013:07 dönemi için incelemiştir. 2008 küresel krizi değişkeninin de yer aldığı modelini SVAR yöntemiyle analiz ederek, üç ülkenin borsalarının petrol fiyatları şoklarına verdiği tepkilerin farklılaştı̆ıını ortaya koymuştur. Kazakistan'ın tüketimi tarafindan belirlenmediği sürece petrol fiyatlarının Kazakistan borsasını etkilemediği; Ukrayna'daki petrole özgü talep şokunun Ukrayna Borsası'nı hem örneklem döneminde hem de kriz sonrası dönemde pozitif etkilediği; Rusya'nın petrole özgü talep şokunun Rus Borsası'nı yalnızca kriz sonrası dönemin ilk aylarında anlamlı ve pozitif etkilediği, küresel petrol talebinin ve petrol arzının ise borsa üzerinde anlamlı etkisinin olmadığı sonucuna ulaşılmıştır.

Gay (2008), Brezilya, Rusya, Hindistan ve Çin borsalarının 1999:03-2006:06 yılları arasındaki aylık verileri kullanarak döviz kuru ve petrol fiyatlarıyla olan iliş̧isini ARIMA modeli ile incelediği çalışmasında BRIC ülkelerinin borsaları üzerinde döviz kuru ve petrol fiyatlarının önemli etkisi olmadığını ortaya koymuştur.

Hayo ve Kutan (2005), Rus Borsası'nın günlük getirilerini asimetrik GARCH modeli ile inceledikleri çalışmalarında, Rusya borsasının getirilerinin tahmininde S\&P500 getirileri ve petrol endeksi getirilerinin önemli olduğunu göstermişlerdir.

Jalolov ve Miyakoshi (2005), EGARCH modeli ile 1995-2003 arasındaki aylık verilerle yaptıkları çalışmada, Almanya Borsası'nın aylık Rusya borsasını tahminlemede aralarındaki ticaret ve yatırım nedeniyle daha başarılı olduğunu bulmuşlardır. Bununla birlikte doğalgaz veya petrolün önemsiz olduğunu belirtmişlerdir. Bununla birlikte doğalgaz veya petrolün önemsiz olduğunu belirtmişlerdir.

Saleem ve Vaihekoski (2008), küresel, yerel ve ulusal para risklerinin Rusya borsasında fiyatlandırılıp fiyatlandırılmadığını analiz etmişlerdir. 1995-2006 arası dönem için çoklu GARCH-M yaklaşımının kullanıldığı çalışmada ulusal para riskine yerel, ulusal ve küresel borsaların etkileri incelenmiş; Rusya borsası ile Rus rublesi arasında anlamlı ilişkiler yakalanmıştır. 
Anatolyev (2008) tarafından 1995:01-2004:12 döneminde Rusya Borsasını etkileyen faktörlerin incelendiği çalışmada, temel faktörlerden petrol fiyatları ve yabancı döviz kurlarının etkisinin zayıfladığı, diğer faktörlerden Amerikan hisse senetleri fiyatları ve yerel faiz oranlarının etkisinin arttığı bulgusuna ulaşılmıştır.

Peresetsky (2011), 2000:01-2010:10 dönemi için Rusya borsa endeksi ve petrol fiyatlarını GARCH, TGARCH ve Sıradan En Küçük Kareler modelleri ile incelediği çalışmasında S\&P500 endeksinin tüm örneklem dönemi için, NIKKEI endeksinin ise 2008:08-2009:09 döneminde etkili olduğu bulunmuştur. Ayrıca petrol fiyatlarının 2006 yılına kadar borsa üzerinde etkili olduğu bulgusuna ulaşılmıştır.

Göçer ve Bulut (2015), petrol fiyatlarındaki değişimlerin Rusya ekonomisi üzerindeki etkilerini 1992:Q1 2014:Q4 dönemi için incelemiş̧lerdir. Hacker ve Hatemi-J (2012) simetrik nedensellik testi ve Maki (2012) çoklu yapısal kırılmalı eşbütünleşme testlerinden yararlanarak gerçekleştirdikleri analizlerinde petrol fiyatlarından ihracata, dış ticaret dengesine ve milli gelire doğru nedensellik ilişkilerinin olduğunu tespit etmişlerdir. Ayrıca eşbütünleşme testi sonuçlarında petrol fiyatlarındaki artışın, Rusya'nın ihracatını, dış ticaret dengesini ve milli gelirini arttırdığı ortaya konmuştur.

Literatür özetleri genel olarak borsa endeksi ile para arzı başta olmak üzere reel kur, enflasyon oranı gibi bir kısım makroekonomik değişkenler arasındaki ilişkileri araştırırken, özellikle petrol gelirlerine bağımlılığın yüksek olduğu ülkelerde ise petrol gelirleri ya da petrol fiyatlarının da etkilerini araştırdığı gözükmektedir.

\section{Ampirik Analiz}

$\mathrm{Bu}$ çalışmada petrol ihracatçısı olan Rusya borsası ile petrol fiyatları arasındaki ilişkiler analiz konusu yapılacaktır. Temelde bu iki değişkenler arasındaki ilişkiler incelenirken, aynı zamanda kontrol değişkenler olarak yukarıdaki literatürden hareketle kurdaki ve para arzındaki değişimin etkileri de araştırılmıştır. Öncelikle serilerin durağanlıkları Lee ve Strazicich (2003) çoklu yapısal kırılmalı birim kök testiyle incelenmiştir. Daha sonra seriler arasında eşbütünleşme ilişkisinin olup olmadığının tespiti için Maki (2012) çoklu yapısal kırılmalı eşbütünleşme testi yapılmış ve seriler arasındaki uzun dönem ilişkileri Dinamik En Küçük Kareler (Dynamic Ordinary Learst Square-DOLS) yöntemiyle tahmin edilmiştir. Ayrıca seriler arasındaki Hacker ve Hatemi J (2012) simetrik nedensellik testleri uygulanmıştır.

\subsection{Veri Seti ve Model}

Rusya borsası ile petrol fiyatları, reel efektif döviz kuru ve reel para arzı arasındaki ilişkinin analiz edilmesinde 1996M1:2015M12 dönemine ait veriler kullanılmıştır. Rusya borsasını temsilen RTSI (Russian Trading System Index) brent petrol fiyatları, reel efektif döviz kuru (ABD Doları/Ruble) ve M2 para arzı değişkenleri kullanılmıştır. Değişkenler için Federal Reserve Bank of St. Louis, Rusya Merkez Bankası ve Bloomberg internet sitelerinden faydalanılmıştır. Çalışmada kullanılan değişkenler mevsimsel dalgalanmalar gösterdiği için hareketli ortalamalar yöntemiyle mevsimsellikten arındırılmış ve serilerin doğal logaritması alınmıştır. Çalışmada kullanılan temel model aşağıda belirtilmiştir.

$$
\operatorname{lnRTSI}_{t}=\beta_{0}+\beta_{1} \ln B R E N T_{t}+\beta_{2} \ln R E E R_{t}+\beta_{3} \ln M 2_{t}+\varepsilon_{t}
$$

\subsection{Yapısal Kırılmalı Birim Kök Testi}

Zaman serisi analizlerinde veri döneminde yapısal kırılma varken bu yapısal kırılmaları dikkate almadan birim kök testi yapmak hatalı sonuçlar verebilmektedir (Perron 1989). Yapısal kırılmayı göz önüne alan testler, kırılmanın tek ya da çok olmasına veya kırılma döneminin dışsal ya da içsel olarak belirlenmesine göre sınıflandırılabilir. Çalışmada kullanılan Lee-Strazicich (2003), yapısal kırılmanın içsel ve iki tane olduğu duruma örnektir. Lee-Strazicich test süreci şu şekildedir:

$$
y t=\delta^{\prime} Z t+e t, \quad \text { et }=\beta \text { et }-1+\varepsilon t, \quad \varepsilon 443 t \sim \text { iid } N(0, \sigma 2)
$$

Burada Zt dişsal değişkenler vektörüdür (Lee ve Strazicich, 2003). Lee- Strazicich, B modeli trentde bir kerelik kırılmaya izin vermesi nedeniyle çok fazla anlamlı kabul edilmemekte ve bu nedenle Perron'un ve ZivotAndrews'in aksine Lee-Strazicich (2003) A ve C modelleriyle çalışmaktadır.

Model A düzeyde iki kırılmaya izin verir ve $Z_{t}=\left[1, t, D_{1 t}, D_{2 t}\right]^{\prime}$ şeklinde ifade edilebilir. Burada $t \geq T_{B j}+$ $1, j=1,2$ için $D_{j t}=1$ ve diğer durumlarda ise $D_{j t}=0$ değerini alır. $T_{B j}$ kırılma tarihini gösterir. Model C düzeyde ve trentde iki kırılma içermektedir ve $Z_{t}=\left[1, t, D_{1 t}, D_{2 t}, D T_{1 t}, D T_{2 t}\right]^{\prime}$ şeklinde ifade edilir. Burada $t \geq$ $T_{B j}+1, j=1,2$ için $D T_{j t}=t-T_{b j}$ ve diğer durumlarda ise 0 değerini alır. Model A ve Model $\mathrm{C}$ 'de $\beta$ 'nın değerine bağlı olarak sıfır ve alternatif hipotezler şu şekildedir:

$$
\begin{aligned}
& H_{0}=y_{t}=\mu_{0}+d_{1} B_{1 t}+d_{2} \beta_{2 t}+y_{t-1}+\vartheta_{1 t} \\
& H_{a}=y_{t}=\mu_{1}+\gamma_{t}+d_{1} D_{1 t}+d_{2} D_{2 t}+\vartheta_{2 t}
\end{aligned}
$$


Burada $\vartheta_{1 t}$ ve $\vartheta_{2 t}$ terimleri durağan hata terimlerini; $t=T_{B j}+1, j=1,2$ için $B_{j t}=1$ ve diğer durumlarda $B_{j t}=0$ ve $d=\left(d_{1}, d_{2}\right)$ değerini alır. Model C içinse (3) ve (4) nolu eşitliğe sırasıyla $D T_{j t}$ değerleri eklenmelidir. Burada hem $H_{0}$ altında hem de $H_{a}$ altında kırılmaya izin verdiğinden testin yorumu nettir.

Lee-Strazicich (2003) sürecinde, iki kırılmalı $L M$ birim kök test istatistiği şu şekilde hesaplanabilir:

$$
\Delta y_{t}=\delta^{\prime} \Delta Z_{t}+\phi \tilde{S}_{t-1}+u_{t}
$$

Burada $\tilde{S}_{t}=y_{t}-\widetilde{\Psi}_{x}-Z_{t} \tilde{\delta}$ ve $t=2, \ldots T ; \tilde{\delta}, \Delta y_{t}$ 'nin $\Delta z_{t}$ üzerine regresyonundan elde edilen katsay1ları; $y_{1}$ ve $Z_{1}$, $y_{t}$ ve $Z_{t}$ 'nin ilk gözlemleridir. Bu testte birim kök hipotezi şu şekilde test edilmektedir:

$$
H_{0}: \phi=0 \text { birim kök } \quad H a: \phi<0 \text { yapısal kırılmalı durağanlık }
$$

$L M_{t}$ test istatistiği bu hipotezi test etmek için hesaplanan $L M_{\tau}$ istatistiğidir. Lee-Strazicich (2003) kırılma tarihlerini grid-search süreci kullanarak içsel biçimde tespit etmektedir. Ayrıca kırılmanın ilk gözlemlerde ya da son gözlemlerde olması çok anlamlı olmaması nedeniyle, ilk ve son gözlemlerde belirli bir sınıra kadar dışlamaya gidilir. Örneğin ilk ve son \%5 gözlem çıkarılarak kırılma noktalarını test istatistiğinin minimum olduğu noktalar belirlenir. Bu teste iliş̧in kritik değerler Lee-Strazicich (2003) tarafından üretilmiştir. Hesaplanan test istatistikleri kritik değerlerden küçük olduğunda, $H_{0}$ hipotezi reddedilmekte, diğer bir ifadeyle incelenen serinin durağan olduğu kabul edilmektedir.

\begin{tabular}{|c|c|c|c|c|c|c|}
\hline \multirow[b]{2}{*}{ Değişkenler } & \multicolumn{3}{|c|}{ Model A } & \multicolumn{3}{|c|}{ Model C } \\
\hline & $\begin{array}{c}\text { Test } \\
\text { İstatistiği }\end{array}$ & $\begin{array}{c}\text { Kurılma } \\
\text { Tarihi }\end{array}$ & $\begin{array}{c}\text { Kritik } \\
\text { Değerler }\end{array}$ & $\begin{array}{c}\text { Test } \\
\text { İstatistiği }\end{array}$ & $\begin{array}{l}\text { Kırılma Tarihi } \\
\text { ve } \lambda \text { Değerleri }\end{array}$ & $\begin{array}{c}\text { Kritik } \\
\text { Değerler }\end{array}$ \\
\hline LNRTS & $-2,5714$ & $\begin{array}{l}11.1998 \\
07.2003\end{array}$ & & $-5,0267$ & $\begin{array}{c}06.1998 \\
(\lambda 1: 0,1250) \\
04.2006 \\
(\lambda 2: 0.5083) \\
\end{array}$ & \\
\hline LNBRENT & $-1,8294$ & $\begin{array}{l}11.2002 \\
12.2008\end{array}$ & & $-4,4038$ & $\begin{array}{c}11.2004 \\
(\lambda 1: 0,4458) \\
06.2013 \\
(\lambda 2: 0,8750)\end{array}$ & $\% 1:-6,41$ \\
\hline LNREER & $-1,7736$ & $\begin{array}{l}07.1998 \\
05.2000\end{array}$ & & $-4,8405$ & $\begin{array}{c}11.1998 \\
(\lambda 1: 0,1458) \\
11.2011 \\
(\lambda 2: 0,7958) \\
\end{array}$ & $\begin{array}{l}\% 5:-5,74 \\
\% 10:-5,32\end{array}$ \\
\hline LNM2 & $-1,5850$ & $\begin{array}{l}10.1999 \\
03.2000\end{array}$ & $\begin{array}{l}\% 1:-4,545 \\
\% 5:-3,842\end{array}$ & $-5,1393$ & $\begin{array}{c}08.1998 \\
(\lambda 1: 0,1333) \\
06.2006 \\
(\lambda 2: 0,5260)\end{array}$ & \\
\hline$\triangle L N R T S$ & $-13,0222$ & $\begin{array}{l}04.2008 \\
12.2008\end{array}$ & $\% 10:-3,504$ & $-13,829$ & $\begin{array}{c}07.1998 \\
(\lambda 1: 0,1292) \\
11.1998 \\
(\lambda 2: 0,1458)\end{array}$ & \\
\hline$\triangle L N B R E N T$ & $-13,4803$ & $\begin{array}{l}05.2008 \\
10.2008\end{array}$ & & $-14,6655$ & $\begin{array}{c}03.2008 \\
(\lambda 1: 0,6125) \\
11.2008 \\
(\lambda 2: 0,6458)\end{array}$ & $\begin{array}{l}\% 1:-6,32 \\
\% 5:-5,73\end{array}$ \\
\hline$\triangle R E E R$ & $-10,7154$ & $\begin{array}{l}06.1998 \\
12.1999\end{array}$ & & $-13,9112$ & $\begin{array}{c}07.1998 \\
(\lambda 1: 0,1292) \\
12.1998 \\
(\lambda 2: 0,1500)\end{array}$ & $\% 10:-5,32$ \\
\hline$\triangle L M 2$ & $-13,0391$ & $\begin{array}{l}01.1998 \\
03.1999\end{array}$ & & $-15,0172$ & $\begin{array}{c}06.1998 \\
(\lambda 1: 0,1250) \\
04.1999 \\
(\lambda 2: 0,1667)\end{array}$ & \\
\hline
\end{tabular}

Serilerin durağanlığı Lee-Strazicich(2003) birim kök testi ile incelenmiş ve test sonuçları Tablo 2'de verilmiştir.

Not: Tabloda yer alan kritik değerler Lee ve Strazicich (2003)'den alınmıştır.

Tablo 2. Lee ve Strazicich (2003) Birim Kök Testi Sonuçları

Serilerin düzey değerleri için yapılan testte hesaplanan test istatistikleri \%1 anlamlılık düzeyinde kritik değerlerden büyük olduğundan, $\mathrm{H}_{0}$ hipotezi kabul edilmiş ve yapısal kırılmalar altında serilerin birim kök içerdiği sonucuna varılmıştır. Serilerin birinci farkları alındığında ise hesaplanan test istatistikleri \%1 anlamlılık düzeyinde kritik değerlerden küçük olduğundan, $\mathrm{H}_{0}$ hipotezi reddedilmiş ve serilerin durağan hale geldiği görülmüştür. 


\subsection{Maki (2012) Eșbütünleșme Testi}

Birim kök testi sonuçlarına göre, serilerin tümünün aynı dereceden durağan olması, eşbütünleşme ilişkisinin varlığını araştırmak için sağlanması gereken ilk aşamadır. Birim kök testlerinde olduğu gibi eşbütünleşme ilişkisinde de yapısal kırılmalar eşbütünleşme testinin performansını etkilemektedir. Bu amaçla eşbütünleşme ilişkisi Maki (2012) çoklu yapısal kırılmalı eşbütünleşme testi ile araştırılmıştır. Maki (2012) beş yapısal kırılmayı içsel olarak belirleyen bir eşbütünleşme yöntemidir. Maki (2012), yapısal kırılmaların varlığı durumunda seriler arasında eşbütünleşme ilişkisini test etmek için dört farklı model kullanır:

Model $0=y_{t}=\mu+\sum_{i=1}^{k} \mu_{i} D_{i, t}+\beta^{\prime} x_{t}+u_{t}$,

Model $1=y_{t}=\mu+\sum_{i=1}^{k} \mu_{i} D_{i, t}+\beta^{\prime} x_{t}+$ trend $+u_{t}$,

Model $2=y_{t}=\mu+\sum_{i=1}^{k} \mu_{i} D_{i, t}+\beta^{\prime} x_{t}+\sum_{i=1}^{k} \beta_{i}^{\prime} x_{t} D_{i, t}+u_{t}$

Model $3=\mu+\sum_{i=1}^{k} \mu_{i} D_{i, t}+\beta^{\prime} x_{t}+\sum_{i=1}^{k} \beta_{i}^{\prime} x_{t} D_{i, t}+\gamma$ trend $+\sum_{i=1}^{k} \gamma_{i}$ trend $D_{i, t}+u_{t}$

Model 0, sabit terimde kırılmanın olduğu trendsiz modeli (7 nolu model); Model 1, sabit terimde kırılmanın olduğu trendli modeli ( 8 nolu model); Model 2, sabit terimde ve eğimde kırılmanın olduğu modeli (9 nolu model) ve Model 3, sabit terimde, eğimde ve trendde kırılmanın olduğu modeli (10 nolu model) göstermektedir Şöyle ki, Maki (2012) çalışmasında belirtilen modellerle gauss kodları arasındaki farklılıkları daha sonrasında kendisi ile yapılan yazışmalar sonucunda uyumlu hale getirmiştir. Burada $t=1,2, \ldots, T$ 'dir. $y_{t}$ ve $x_{t}=\left(x_{l t}, \ldots ., x_{m t}\right)$ gözlemlenebilen $I(1)$ değişkenlerini ve $u_{t}$ hata terimini göstermektedir. $D_{i, t}$ kukla değişkenler olup $t>T_{B i}$ iken, 1 değerini, diğer durumlarda 0 değerini almaktadır. Ayrıca $k$ maksimum kırılma sayısını ve $T_{B i}$ kırılma zamanını gösterir. Maki (2012) eşbütünleşme testi, önsel şart olarak belirlenmemiş kırılma sayısının maksimum kırılma sayısına eşit ya da daha küçük olduğunun varsayıldığı Bai ve Perron (1998) tarafindan önerilen yapısal kırılma testine ve Kapetanios (2005) tarafından geliştirilen yapısal kırılmalı birim kök testine dayanır (Maki, 2012). Maki (2012) eşbütünleşme testinin hipotezleri şöyledir:

$$
\begin{aligned}
& H_{0}=\text { Yapısal kırılmlar altında eșbütünleşme yoktur } \\
& H_{\alpha}=\text { Yapısal kırılmlar altında eşbütünleşme vardır }
\end{aligned}
$$

Hipotezleri test etmek için gerekli olan kritik değerler, Monte Carlo simülasyonuyla hesaplanmış ve Maki (2012)'de verilmiştir. Hesaplanan test istatistikleri kritik değerden küçük olduğunda $H_{0}$ reddedilmekte ve seriler arasında eşbütünleşme ilişkisinin var olduğuna karar verilmektedir. Bu çalışmada eşbütünleşme ilişkisi Maki (2012) testi ile incelenmiş ve sonuçlar Tablo 3'de verilmiştir.

\begin{tabular}{|c|c|c|c|c|c|}
\hline & \multirow{2}{*}{$\begin{array}{c}\text { Test } \\
\text { İstatistiği }\end{array}$} & \multicolumn{3}{|c|}{ Kritik Değer } & Yapisal Kurılma Tarihleri \\
\cline { 3 - 6 } & & $\% 1$ & $\% 5$ & $\% 10$ & \\
\hline Model 0 & $-5,148$ & $-6,555$ & $-6,038$ & $-5,773$ & $1997: 05,1998: 07,2008: 03,2008: 09,2011: 07$ \\
\hline Model 1 & $-5,155$ & $-6,784$ & $-6,250$ & $-5,976$ & $1997: 05,1998: 07,2008: 03,2008: 09,2011: 07$ \\
\hline Model 2 & $-6,744 * *$ & $-7,232$ & $-6,702$ & $-6,411$ & $2006: 10,2008: 06$ \\
\hline Model 3 & $-9,667 * * *$ & $-9,428$ & $-8,800$ & $-8,508$ & $1997: 01,1997: 08,1999: 01,2007: 04,2009: 04$ \\
\hline
\end{tabular}

Tablo 3. Maki (2012) Çoklu Yapısal Kırılmalı Eşbütünleşme Testi Sonuçları

Tablo 3'de yer alan Maki Eşbütünleşme testi sonuçlarına göre Model 0 ve Model 1'de eşbütünleşme ilişkisinin olmadığı, Model 2 ve Model 3'de test istatistiği kritik değerlerden küçük olduğundan Ho hipotezi reddedilmiş ve seriler arasında eşbütünleşme ilişkisinin olduğu belirlenmiştir. Model 2'de iki kırılmada, Model 3'de ise beş kırılmada eşbütünleşme ilişkisi bulunmuştur. Sabit terimde, eğimde ve trendde kırılmanın olduğu Model 3 temel alınarak eşbütünleşme ilişkisinin varlığ kabul edilmiş ve kırılma tarihleri uzun dönemli katsayıların tahmininde kukla değişkenler olarak modele dahil edilmiştir.

\subsection{Eşbütünleşme Katsayılarının Tahmini}

Eşbütünleşme katsayıları, seriler arasında eşbütünleşme ilişkisinin varlığını gözönünde bulunduran DOLS yöntemiyle tahmin edilmiştir. Bu yöntemde, StockWatson (1993), OLS (Ordinary Least Square: En Küçük Kareler) tahmincisindeki sapma ve içsellik sorunlarını giderebilmek için, modele açıklayıcı değişkenlerin düzey değerleriyle birlikte, farklarının gecikmelerinin (lag) ve öncüllerinin de (lead) eklenmesini önermiştir. DOLS tahmincisinin kullanılabilmesi için, seriler arasında eşbütünleşme ilişkisinin var olması gerekmektedir. Bu yöntemin en önemli üstün yanlarından birisi; bağımlı değişken I(1) olmak şartıyla, bağımsız değişkenlerden bazılarının I(1), bazılarının I(0) olmasına izin vermesidir.

Tablo 4'deki sonuçlar incelendiğinde Rusya Borsası'nı; petrol fiyatlarındaki \%1'lik artışın \%0.288 oranında, reel efektif döviz kurundaki \%1'lik artışın \%1.299 oranında ve reel para arzındaki \%1'lik artışın ise \%0.56 oranında artırdığı görülmektedir. K1 ve K2 kuklaları istatistiki açıdan anlamlı değilken, K3 kuklasını ifade eden 1999:01 dönemi Rusya'nın 1998'deki borç krizinin borsaya negatif yansıması olarak kabul edilebilir. K4 kuklasını 
ifade eden 2007:04 ise borsayı pozitif etkilediği görülmektedir. 2007 yılında Rusya ekonomisinin \% 8,5 oranında büyümesi, \%3,9 oranında sabit sermeye yatırımlarının artması ve ihracat artışının borsaya olumlu etkisini temsil ettiği söylenebilir. K5 kuklasını ifade eden 2009:04 dönemi ise 2008 küresel finansal krizin yansıması olarak kabul edilebilir.

\begin{tabular}{|c|c|c|c|c|}
\hline & \multicolumn{4}{|c|}{ Bağımlı değişken: LNRTS } \\
\hline Değișkenler & Katsayı & St Hata & $\boldsymbol{t}$ istatistiği & Olasılık değeri \\
\hline $\boldsymbol{c}$ & -2.951 & 1.059 & -2.786 & 0.0058 \\
\hline LNBRENT & 0.288 & 0.133 & 2.156 & 0.0321 \\
\hline LNREER & 1.299 & 0.325 & 3.988 & 0.0001 \\
\hline $\boldsymbol{L N M 2}$ & 0.565 & 0.114 & 4.924 & 0.0000 \\
\hline K1 & 0.157 & 0.114 & 1.376 & 0.1701 \\
\hline K2 & 0.226 & 0.158 & 1.427 & 0.1549 \\
\hline K3 & -0.348 & 0.136 & -2.560 & 0.0111 \\
\hline K4 & 0.425 & 0.151 & 2.818 & 0.0053 \\
\hline K5 & -0.139 & 0.059 & -2.322 & 0.0211 \\
\hline $\boldsymbol{R}^{\mathbf{2}}$ & 0.914 & $\mathbf{R} \mathbf{2}$ & 0.90 & \\
\hline
\end{tabular}

Not: Newey-West standart hataları kullanılmıştır. Kukla değişkenler; K1: 1997:01; K2:1997:08, K3:1999:01, K4:2007:04, K5:2009:04

Tablo 4. Uzun Dönem Eşbütünleşme Katsayıları

\subsection{Simetrik Nedensellik Testi}

Simetrik nedensellik testi öncelikle Hacker ve Hatemi-J (2006) testi ile öne çıkmıştır. Ancak bu testte gecikme uzunluğunun dişsal olarak belirlenmesi bir eksiklik olarak görüldüğünden Hacker ve Hatemi-J (2012) tarafindan yapılan çalışmayla bu eksiklik giderilerek gecikme uzunluğunun içsel olarak belirlenmesi mümkün hale getirilmiştir. Optimal gecikme uzunluğu VAR modelinde boostrap simülasyonu ile tahmin edilmiştir. VAR modelinde Schwarz Bayesian Kriterinin (SBC) minimum olduğu gecikme uzunluğu bulunmaktadır. Schwarz Bayesian Kriteri aşağıda 12 nolu eşitlikte belirtilmiştir.

$$
\left.S B C=\ln \left(\operatorname{det} \widehat{\Omega}_{j}\right)+k\left(\frac{n^{2} \ln T}{T}\right), k=0,1,2, \ldots K\right)
$$

Burada k gecikme uzunluğu, $\widehat{\Omega}_{j}$; varyans kovaryans matrisinin determinantı, $\mathrm{n}$, denklem sayısı ve T ise toplam gözlem sayısıdır. Hacker ve Hatemi-J (2012) simetrik nedensellik testinin boş hipotezi granger nedensellik testlerinde olduğu gibi "birinci değişkenden ikincisine doğru bir nedensellik ilişkisi yoktur" şeklindedir. Hesaplanan Wald istatistik değeri boostrap kritik değerlerden büyükse, nedenselliğin olmadığı boş hipotez reddedilir. Bootstrap kritik değerlerini hesaplamak için bootstrap simülasyonunu 10.000 defa tekrarlamakta ve her bir simülasyonda Wald istatistiğini hesaplamaktadır. Bu çalışmada da simetrik nedensellik testi uygulanmış ve sonuçlar Tablo 5'te sunulmuştur.

\begin{tabular}{|c|c|c|c|c|c|}
\hline \multirow{2}{*}{ Hipotez } & \multirow{2}{*}{$\begin{array}{l}\text { Wald Test } \\
\text { İstatistiği }\end{array}$} & \multicolumn{3}{|c|}{ Kritik Değerler } & \multirow{2}{*}{ Karar } \\
\hline & & $\% 1$ & $\% 5$ & $\% 10$ & \\
\hline $\begin{array}{l}\text { LNRTS=> } \\
\text { LNBRENT }\end{array}$ & $9.871 * * *$ & 9.417 & 6.026 & 4.691 & $\begin{array}{l}\text { Borsadan Petrol Fiyatlarına doğru bir } \\
\text { nedensellik ilişkisi vardır. }\end{array}$ \\
\hline $\begin{array}{l}\text { LBRENT=> } \\
\text { LRTS }\end{array}$ & $14.793 * * *$ & 9.248 & 6.082 & 4.691 & $\begin{array}{l}\text { Petrol Fiyatlarından Borsaya doğru } \\
\text { bir nedensellik ilişkisi vardır. }\end{array}$ \\
\hline $\begin{array}{l}\text { LNRTS=> } \\
\text { LNREER }\end{array}$ & $10.667 * *$ & 14.937 & 9.967 & 7.30 & $\begin{array}{l}\text { Borsadan Reel Efektif Döviz Kuruna } \\
\text { doğru bir nedensellik ilişkisi vardır. }\end{array}$ \\
\hline $\begin{array}{l}\text { LNREER=> } \\
\text { LNRTS }\end{array}$ & $33.872 * * *$ & 10.989 & 6.229 & 4.622 & $\begin{array}{l}\text { Reel Efektif Döviz Kurundan Borsaya } \\
\text { doğru bir nedensellik ilişkisi vardır. }\end{array}$ \\
\hline $\mathrm{RTS}=>\mathrm{M} 2$ & $9.899 *$ & 17.875 & 11.753 & 9.593 & $\begin{array}{l}\text { Borsadan Para Arzına doğru bir } \\
\text { nedensellik ilişkisi vardır. }\end{array}$ \\
\hline M2 =>RTS & $45.868 * * *$ & 11.137 & 6.111 & 4.635 & $\begin{array}{l}\text { Reel Para Arzından Borsaya doğru bir } \\
\text { nedensellik ilişkisi vardır. }\end{array}$ \\
\hline
\end{tabular}

Tablo 5. Simetrik Nedensellik Testi Sonuçları

Tablo 5'te yer alan simetrik nedensellik testi sonuçlarına göre RTSI ile petrol fiyatları, reel efektif döviz kuru ve para arzı ile çift yönlü nedensellik ilişkisi mevcuttur. Simetrik nedensellik testinin boş hipotezinin reddedildiği anlamlılık düzeylerine ve katsayıların büyüklüğüne bakıldığında, reel para arzının, reel efektif döviz kurunun ve 
petrolün borsaya olan etkisinin daha güçlü olduğu söylenebilir. Bu bulgular Rusya Borsası'nın petrol fiyatlarına kura ve para arzına güçlü bir şekilde duyarlı olduğunu göstermektedir.

\section{Sonuç}

Ülke borsalarının başta para arzı olmak üzere bir takım makroekonomik değişkenlerle ilişkisini ele alan yaygın bir literatürün varlığı dikkat çekmektedir. Bu çalışmada önemli bir petrol ihracatçısı olan Rusya'nın borsası ile petrol fiyatları arasındaki ilişkiler analiz konusu yapılmıştır. Rusya borsası ile petrol fiyatları arasındaki ilişkiler incelenirken, çalışmada literatürden hareketle kontrol değişkenler olarak kurdaki ve para arzındaki değişimin etkileri de modele dahil edilmiştir. Kur ve para arzının modele dahilinde, kurun bir tür asimetrik yansımalar sergilemesi ve para arzının da finansal derinleşme göstergesi olarak kabul edilmesi bu düşüncenin temelini oluşturmuştur.

Çalışmadan elde edilen bulgulara göre Rusya Borsası'nı etkileyen değişkenler en güçlüden en zayıfa göre sıralandığında; reel döviz kurunun (\%1.299), reel para arzının (\%0.56) ve petrol fiyatlarının (\%0.288) artırdığ görülmektedir. Dolayısıyla Rusya Borsası ile reel döviz kuru, reel para arzı ve petrol fiyatları arasında pozitif yönlü ilişkilerin olduğu belirlenmiştir. Diğer taraftan Rusya Borsası üzerine bu ülkenin kendine özgü krizi (1998 krizinin 1999:01 döneminde) negatif etkileri ile yüksek büyümesinin (2007:04) pozitif etkileri yakalanmış iken; küresel ekonomik krizin (2008 krizinin 2009:04 döneminde) negatif etkili olduğu gözlenmiştir. Ayrıca yapılan simetrik nedensellik testi sonuçlarına göre RTSI ile petrol fiyatları, reel efektif döviz kuru ve para arzı ile çift yönlü nedensellik ilişkiler yakalanmıştır.

Elde edilen bulgular bir bütün olarak değerlendirildiğinde, Rusya Borsası'nın petrol fiyatlarına, kura ve para arzına güçlü bir şekilde duyarlı olduğu gözlenirken, aynı zamanda dışsal şoklardan da yadsınamadığı dikkat çekmektedir. Petrol gelirlerine yüksek derecede bağımlı bir ekonomi olan Rusya ekonomisinin dişsal unsurlarca belirlenen petrol fiyatlarındaki dalgalanmalara duyarlı bir ekonomik yapısının varlığı, aynı zamanda bu ülkede zımnen "doğal kaynakların laneti argümanı”nın kuvvetli bir şekilde varlığına işaret etmektedir. Rusya'nın halihazırda dünya siyasal yapısında eski Sovyetlerden gelen güçlü askeri yapısını bireysel tüketim ihtiyaçları karşılayacak ölçüde ekonomik yapı ile çeşitlendirememesinin petrole dayalı kırılgan bir ekonomik yapı içerisinde kalmasına yol açtığı söylenebilir.

\section{Kaynakça}

- Anatolyev, S. (2008). A 10-Year Retrospective on the Determinants of Russian Stock Returns. Research in International Business and Finance, 22(1): 56-67.

- Asteriou, D., Dimitras, A., Lendewig, A.(2013). The Influence of Oil Prices on Stock Market Returns: Empirical Evidence from Oil Exporting and Oil Importing Countries, International Journal of Business and Management; 8 (18): 101-120

- Basher, S. A., Sadorsky, P. (2006). Oil Price Risk and Emerging Stock Markets, Global Finance Journal, 17(2), 224-251.

- $\quad$ Fang, Chung-Rou, You, Shih-Yi (2014). The Impact of Oil Price Shocks on The Large Emerging Countries' Stock Prices: Evidence from China, India and Russia, International Review of Economics and Finance, 29: 330-338.

- Gay Jr, R. D. (2008). Effect of Macroeconomic Variables on Stock Market Returns for Four Emerging Economies: A Vector Regression Model for Brazil, Russia, India, and China. ProQuest.

- Goodhart, C., Mahadeva, L., Spicer, J. (2003). Monetary Policy's Effects During The Financial Crises in Brazil and Korea, International Journal of Finance and Economics, 8: 55-79.

- Göçer, İ., Bulut, Ş. (2015). Petrol Fiyatlarındaki Değişimlerin Rusya Ekonomisine Etkileri: Çoklu Yapısal Kırılmalı Eşbütünleşme ve Simetrik Nedensellik Analizi, Çankırı Karatekin Üniversitesi İBF Dergisi, http://dx.doi.org/10.18074/cnuiibf.229, ss.1-28.

- Gupta, M. C. (1974). Money Supply and Stock Prices: A Probabilistic Approach, The Journal of Financial and Quantitative Analysis, 9(1): 57-68.

- Hacker, R.S. ve Hatemi-J, A. (2006). Tests for Causality between Integrated Variables Using Asymptotic and Bootstrap Distributions: Theory and Application, Applied Economics, 38(13): 1489-1500.

- Hacker, R.S. ve Hatemi-J, A. (2012). A Bootstrap Test for Causality with Endogenous Lag Length Choice: Theory and Application in Finance, Journal of Economic Studies, 39(2): 144-160.

- Hayo, B., \& Kutan, A. M. (2005). The Impact of News, Oil Prices, and Global Market Developments on Russian Financial Markets. Economics of Transition, 13(2): 373-393.

- Jalolov, M., Miyakoshi, T. (2005). Who Drives the Russian Financial Markets?, Developing Economies, 43(3): 374-395. 
- Kapetanios, G. (2005). Unit-Root Testing Against The Alternative Hypothesis of up to m Structural Breaks, Journal of Time Series Analysis, 26(1): 123-133.

- Lee, J. ve Strazicich, M.C. (2003). Minimum Lagrange Multiplier Unit Root Test With Two Structural Breaks, The Review of Economics and Statistics, 85(4): 1082-1089.

- Maki, D. (2012). Tests for Cointegration Allowing for an Unknown Number of Breaks, Economic Modelling, 29(5): 2011-2015.

- Peresetsky, A. A. (2011). What determines the Behavior of the Russian Stock Market, MPRA paper, 41508.

- Pethe, A., Karnik, A. (2000). Do Indian Stock Markets Matter? Stock Market Indices and Macro-Economic Variables, Economic and Political Weekly, 35(5): 349-356.

- Phylaktis, K., Ravazzolo, F. (2005). Stock Prices and Exchange Rate Dynamics, Journal of International Money and Finance, 24: 10301-1053.

- Rahmanov, Ramiz (2007). Do Oil Price Shocks Matter for Transition Economies? Evidence from Kazakhstan, Russia and Ukraine, Central European University Department of Economics, pp.1-84.

- Saleem, K., Vaihekski, M. (2008). Pricing of Global and Local Sources of Risk in Russian Stock Market, Emerging Markets Review, 9: 40-56.

- $\quad$ Stock, J. ve Watson, M. W. (1993) “A Simple Estimator of Cointegrating Vectors in Higher Order Integrated Systems" Econometrica, 61(4): 783-820.

- Yalçın, Y. (2015). "Petrol Fiyatı Şoklarının BDT Borsaları Üzerine Etkisi: Rusya, Kazakistan ve Ukrayna”, Gazi Üniversitesi İktisadi ve İdari Bilimler Fakültesi Dergisi, 17(1): 64-81. 


\title{
Türkiye'de Seçimler ve Reel Döviz Kuru Oynaklığı (1992-2014) Elections and the Real Exchange Rate Volatility In Turkey (1992- 2014)
}

\author{
Prof. Dr. Cevat Gerni (Doğuş University, Turkey) \\ Asst. Prof. Dr. Özge Buzdağlı (Atatürk University, Turkey) \\ Asst. Prof. Dr. Dilek Özdemir (Atatürk University, Turkey) \\ Prof. Dr. Ömer Selçuk Emsen (Atatürk University, Turkey)
}

\begin{abstract}
Sudden fluctuations that occur as results of politicians' manipulation on the macroeconomic variables during the election period are called as Political Business Cycle. In recent years, exchange rate also has become an important subject of many studies in this framework. Before the elections, to gain the public's votes, politicians firstly put pressure on the exchange rates to prevent currency depreciation, and then this can lead to manipulative fluctuations. In this respect, during the 1992:01-2014:12 periods in Turkey, the impact of the entire local and general elections on the real exchange rate volatility is examined using E-GARCH method. On the other hand, political variables such as independence of Central Bank, exchange rate regime, the number of representatives of the ruling party in the parliament and coalition are included to the model while the pre and after election period from the 1 st to the 6 th month as dummy variables. Based on the results of the analysis, it can be said that the elections and the political variables affect the real exchange rate and its volatility in Turkey. However, there is no significant evidence whether the politicians act opportunistic behavior to be reelected. Since the uncertainty during the election period cause outflow of the capital and deferral of the investment decisions of the investors until after the election, it may well be said that the politicians fail to influence the real exchange rate for their self-interests.
\end{abstract}

\section{Giriş}

Politika ve ekonomi arasındaki ilişkiler literatürde araştırmacıların uzun yıllardır ilgi gösterdiği bir konudur. Bu ilişki de daha çok "Politik Konjonktür Dalgalanmaları" (PKD) teorileri kapsamında ele alınmaktadır. PKD, öz itibariyle seçimlerin, makroekonomik değişkenler üzerinde meydana getirdiği sistematik ve/veya sistematik olmayan dalgalanmaları ifade etmektedir (Onur, 2001: 159). Sistematik dalgalanmalardan kastedilen, uyarlanmış beklentilere sahip seçmenlerin, seçimi kazanmak isteyen politikacıların faaliyetlerine aldanıp, hata yapmalarıdır. Sistematik olmayan dalgalanmalar ise rasyonel seçmenin, seçimde kime oy vereceğine bilinçli olarak karar vermesinden kaynaklanmaktadır (Onur, 2002: 89). PKD, literatürde iki gruba ayrılarak incelenmektedir. Birincisi, geleneksel PKD olarak tanımlanmakta ve hükümetlerin, makroekonomik koşullara sistematik ve kestirilebilir şekilde etki edebildikleri geleneksel modellere yer vermektedir. İkincisi ise, rasyonel (modern) PKD olarak adlandırılmakta ve özellikle seçmenler ile hükümetler arasındaki asimetrik bilgi avantajını kullanarak, hükümetlerin davranışlarını açıklamada rasyonel beklentilerden ve oyun teorisi unsurlarından yararlanan modelleri kapsamaktadır (Garza, 2006: 5). Her iki grup da kendi içerisinde "fırsatçı" ve "partizan" yaklaşım olmak üzere ikiye ayrılmaktadır.

Diğer taraftan PKD literatüründe politikacıların kendi çıkarları doğrultusunda manipüle ettikleri ekonomik değişkenler incelenirken, genellikle kamu harcamaları, işsizlik, enflasyon, bütçe dengesi, vergi oranları ve faiz oranlarından yararlanıldığı gözlenmektedir. Bununla birlikte yakın geçmişte döviz kuru değişkeninin de analizlerde yer almaya başladığı dikkat çekmektedir. Son politik ekonomik modellerde döviz kuru döngüleri üreten mekanizmalar ise üç çeşittir: (i) firsatçı, (ii) partizan-ideolojik ve (iii) farklı yeterlilik düzeyine sahip politika yapıcıların varlığı (Aboal vd, 2000: 5).

(i) Fırsatçı döngüye göre koltuk heveslisi politikacılar, seçim öncesinde yerli paranın aşırı değerlenmesine ve seçim sonrası ise yerli paranın değer kaybına izin vermektedirler (Stein vd., 2005: 313). Asimetrik bilgi altında fırsatçı hükümetler yeterlilik sinyali vermek için ayarlamaları erteleyerek bugünkü devalüasyon ve yarınki devalüasyon arasındaki değiş-tokuştan (trade-off) faydalanırlar ve dolayısıyla seçilme şanslarını artırırlar (Stein ve Streb, 2004: 120).

(ii) Partizan-ideolojik döngü, politika yapıcının kendi tercih ettiği politika programından sapmasını gerektirmez. $\mathrm{Bu}$ aslında belirli seçmen kesiminin refahı için endişelenen iki çeşit politika yapıcı ya da parti arasındaki tercih uyuşmazlığıdır (Aboal vd., 2000: 5). Örneğin, sol partiler daha yüksek enflasyonla ilişkilendiriliyorsa, muhtemelen bu durum genel döviz kuru zayıflığıyla da ilişkilendirilir. Aynı nedenle, işçi sendikaları, temel sanayi ürünlerinin rekabet gücü üzerindeki etkilerinden ötürü devalüasyona eğilimli olabilirler (Frieden, 1998: 12).

(iii) Bazı modeller, politika yapıcıların sınırı sayıdaki politika araçlarını kullanarak, arzulanan makroekonomik sonuçlar elde etmedeki yeterlilik farklılıkları nedeniyle döviz kuru yörüngeleri üretirler. Yeterli politikacılar, tüketicilerin refahını iyileştiren önemli miktarda kamusal mal temin etmek için daha küçük bir kaynak miktarına 
ve daha küçük bir devalüasyona ihtiyaç duyarlar (Aboal vd., 2000: 5-6). Yetersiz politikacılar ise aynı düzeyde kamusal mal sağlamak için daha yüksek vergilere (örneğin daha yüksek devalüasyona) ihtiyaç duyarlar (Stein ve Streb, 2004: 120). Bu nedenle yetersiz firsatçı politikacılar, yeterli olan politikacıyı taklit etmek için tercih ettikleri devalüasyonun ritmini azaltırlar. Sonrasında seçimi kazandıklarında seçimden önce katlanılan borçları ödemek için devalüasyona ihtiyaç duyarlar (Aboal vd., 2000: 6).

Özetle seçim dönemleri (seçim öncesi ve sonrası) politik belirsizliğin ve dolayısıyla ekonomik kırılganlığın yüksek olduğu dönemlerdir (Bussière ve Mulder, 1999: 8). Seçim kampanyalarının gerçekleştiği dönem boyunca hangi parti veya adayın kazanacağı belirsizdir. Çok partili sistemlerde bu belirsizlik, koalisyonu kimin kuracağı sorunu çözülene kadar, genellikle seçimden sonra bile devam eder. Hükümetin kompozisyonu hakkındaki belirsizlik, ekonomi politikalarında da bir belirsizliğe neden olur. Çünkü rakip partilerin farklı ekonomik görüşleri ve endişeleri vardır. Farklı ekonomi politikaları, yatırımcıların beklenen getirilerini etkileyebilir (Brunner, 2009: 150-151). Diğer taraftan seçimler boyunca yerli paranın anormal değer kaybına uğramasının olası bir açıklaması, seçimsel belirsizliğin kendisinin yerli parada değer kaybına yol açmasıdır. Örneğin, çok uluslu şirketler riski azaltmak için seçim dönemi boyunca bir ülkedeki doğrudan yatırımlarını azaltabilir veya erteleyebilirler. Daha uç durumlarda sermaye çıkışları, kaynakları korumanın bir yolu olabilir. Eğer değer kaybı seçim sonucunun belirsizliğinden kaynaklanmakta ise bu belirsizlik seçimden hemen önce en fazladır ve zafer sahibi belli olur olmaz etkisini yitirmeye başlar (Sibley, 2001: 18-19).

Bu çalışmada Türkiye ekonomisi özelinde döviz kuru oynaklığının seçimler bağlamında ele alınması amaçlanmıştır. Seçim öncesinde iktidarda kalma motifiyle ulusal paranın değerlenmesine göz yuman politikaların temelinde en kaba şekliyle hem yabancı para cinsinden ulusal gelirin suni olarak artırılması hem de ithal girdiye dayalı düşük enflasyon hedefinin gerçekleştirilmesi amaçlanmaktadır. Seçim sonrasında ise ekonominin kendi dinamiklerine dönmesine paralel olarak ulusal paranın görece daha yüksek değer kaybı yaşaması kuvvetle muhtemeldir. Dolayısıyla çalışmada teorik saikle belirtilen kur oynaklığının işleyip işlemediği inceleme konusu yapılmıştır.

\section{Literatür Özeti}

Ekonomideki oynaklıkları siyasal motiflerle gerekçelendiren yaklaşımlardan ilki olan Geleneksel Fırsatçı yaklaşım Nordhaus tarafından ortaya atılmıştır. Bu yaklaşıma göre bütün politikacılar sadece iktidarda kalabilme şanslarını artırmaya çalışırlarken, seçmenlerin miyopik oldukları, yani yalnızca yakın geçmişteki olaylara göre oy verdikleri ileri sürülür (Nordhaus, 1975: 178). Douglas Hibbs'in öncülüğünü yaptığı Geleneksel Partizan yaklaşımda ise partilerin öncelik verdiği ekonomik hedefler ideolojik düşüncelere göre farklılık göstermekte ve dolayısıyla politik dalgalanmalar iktidar partisinin değişmesi nedeniyle yaşanmaktadır (Hibbs, 1977: 1471). Cukierman ve Meltzer (1986), Rogoff (1987) ile Rogoff ve Sibert (1988) tarafından ileri sürülen Rasyonel Fırsatçı yaklaşıma göre hükümetler farklı yeterlilik derecelerine sahip olmakla birlikte, yeterliliklerini seçmenlerden daha iyi bilirler. Dolayısıyla rasyonel seçmen varsayımında bile firsatçı dalgalanmalar yaşanabilir (Alesina, 1989: 63). Alesina (1987) ile Alesina ve Sachs (1988) tarafından ileri sürülen Rasyonel Partizan yaklaşıma göre ideolojik olarak farklı iki parti arasında geçen rekabet, seçim sonuçlarına ilişkin belirsizliği artırmaktadır (Alesina, 1989).

Teorik literatürde oynaklıkların gerekçeleri politik perspektifte sistematik olarak ele alınırken, uygulamalı literatürde oynaklığa yol açan faktörler olarak ekonomik faktörlerin yanı sıra politik faktörleri de içeren çalışmalar ve bunun içerisinde özellikle döviz kuru oynaklığını inceleyen birçok çalışma bulunmaktadır. Bu çalışmalar ortak paydada değerlendirildiğinde, ekonomik faktörlerle birlikte politik faktörlerin de döviz kuru üzerinde etkili olduğu dikkati çekmektedir. Buna göre bazı çalışmalarda (örneğin, Frieden,1998; Jaramillo vd., 1999; Frieden vd., 2000; Stein ve Streb, 2004) politikacıların seçim dönemlerinde firsatçı yaklaşıma uygun döviz kuru politikaları izlediği sonucuna ulaşılmışken, bazı çalışmalarda ise (örneğin, Remmer, 1993; Akalın ve Erkişi, 2007; Demirgil, 2011) politik belirsizliğin ön plana çıkmasına bağlı olarak beklenenin aksi yönde bulgularla karşıllaşılmıştır. Ayrıca politik belirsizliğin döviz kuru oynaklığını arttırdığını ileri süren çalışmalar da (örneğin, Lobo ve Tufte, 1998; Freeman vd., 2000; Brunner, 2009) dikkat çekmektedir.

\section{Uygulama}

Bu çalışmanın amacı, Türkiye'de 1992:01-2014:12 döneminde politik faktörlerin reel döviz kuru oynaklığ1 üzerindeki etkisini incelemektir. Bu çerçevede öncelikle reel döviz kuru oynaklığı modellenmekte, ardından uygun oynaklık modeli içerisinde politik değişkenlerin etkisi tahmin edilmektedir. Ekonometrik analiz için E-views (8.0) ve Gauss paket programlarından yararlanılmıştır.

Analizin ilk aşamasında reel döviz kuru oynaklığı modellenmektedir. Bu amaçla TCMB'nin resmi internet sitesinden elde edilen TÜFE bazlı reel efektif döviz kuru verileri kullanılmıştır. Reel döviz kuru serisi oluşturulurken, 2003 bazlı veriler 1995 bazlı verilere dönüştürülmüş ve daha sonra logaritması alınmıştır. Logaritması alınmış reel döviz kuru serisi "Lkur" olarak adlandırılmıştır. Lkur serisinin durağan olup olmadığının analiz edilmesinden önce serinin görsel olarak incelenmesi yoluna gidilmiş ve bu çerçevede grafiği Şekil 1'de gösterilmiştir. 


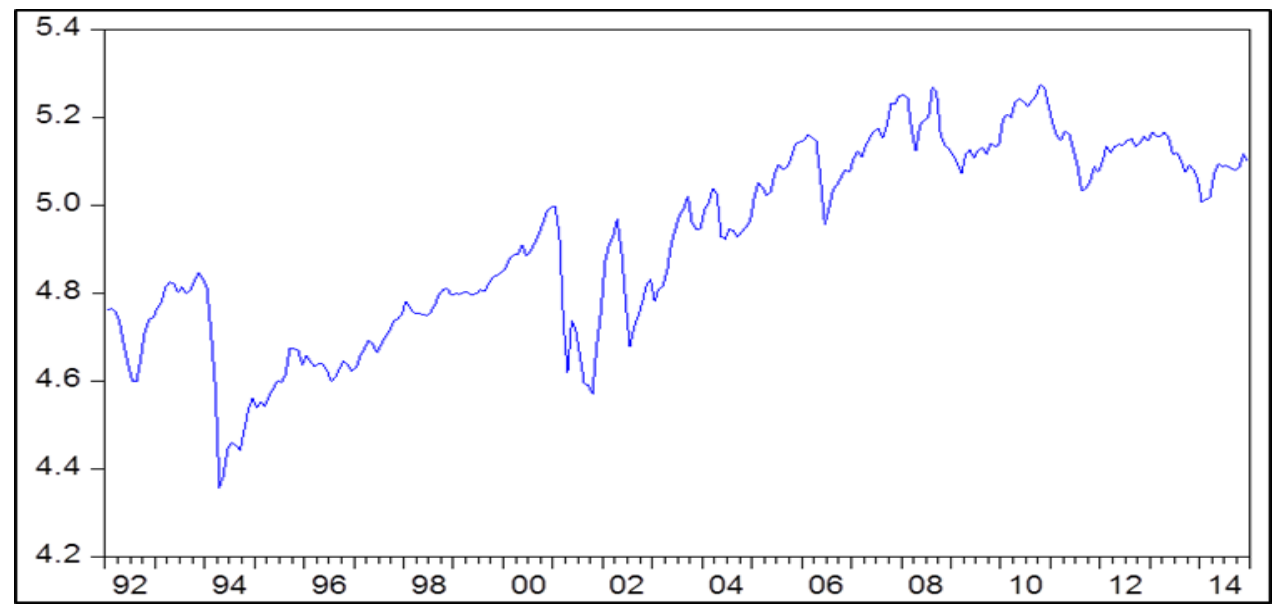

Şekil 1. Lkur Serisinin Grafiği

Şekil 1'de Lkur serisinin 1992:01-2014:12 döneminde izlediği seyir görülmektedir. İncelenen dönemde serinin ani yükselişler ve düşüşler gösterdiği, bunun yanı sıra trende sahip olduğu ve oynaklık sergilediği söylenebilir. Her ne kadar grafiksel gösterim seri ile ilgili olarak bir fikir sahibi olunmasına imkan verse de durağanlık konusunda kesin bir sonuca varılabilmesi için birim kök testlerinden yararlanılması gerekliliği açıktır. Bu çerçevede Lkur serisinin durağanlığının analiz edilmesinde hem geleneksel birim kök testleri hem de yapısal kırılmalı birim kök testleri kullanılmıştır.

\subsection{Geleneksel Birim Kök Testleri}

Çalışmada geleneksel birim kök testleri arasında yer alan ADF, PP, KPSS ve Ng-Perron testlerinden yararlanılmıştır.

- ADF, PP ve KPSS Testi

Lkur serisine ait ADF, PP ve KPSS birim kök testi sonuçları Tablo 1'de verilmişstir.

\begin{tabular}{|l|c|c|c|c|c|c|c|}
\hline \multicolumn{2}{|l|}{$\begin{array}{l}\text { ADF ve PP için temel hipotez: } \\
\text { LKUR serisi birim köke sahiptir. } \\
\begin{array}{l}\text { Temel hipotez: LKUR serisi } \\
\text { durağandır. }\end{array}\end{array}$} & $\begin{array}{c}\text { Sabit } \\
\text { terimli }\end{array}$ & $\begin{array}{c}\text { Sabit terimli } \\
\text { ve trendli }\end{array}$ & $\begin{array}{c}\text { Sabit } \\
\text { terimli }\end{array}$ & $\begin{array}{c}\text { Sabit terimli } \\
\text { ve trendli }\end{array}$ & Sabit terimli & $\begin{array}{c}\text { Sabit } \\
\text { terimli ve } \\
\text { trendli }\end{array}$ \\
\hline & Test istat. & -1.817329 & $-4.45822^{(\mathrm{a})}$ & -1.596904 & $-3.475509^{(\mathrm{b})}$ & $1.67283^{(\mathrm{a})}$ & $0.161803^{(\mathrm{b})}$ \\
\hline \multirow{2}{*}{$\begin{array}{l}\text { Kritik } \\
\text { değerler }\end{array}$} & $\% 1$ & -3.454174 & -3.991904 & -3.453997 & -3.991780 & 0.739000 & 0.216000 \\
\cline { 2 - 8 } & $\% 5$ & -2.871922 & -3.426311 & -2.871845 & -3.426251 & 0.463000 & 0.146000 \\
\cline { 2 - 8 }
\end{tabular}

Not: (c) \%10, (b) \%5, (a) \%1 önem düzeyinde anlaml.

\section{Tablo 1. Lkur Serisi Için ADF, PP ve KPSS Birim Kök Testi Sonuçları}

Tablo 1'de görüldüğü gibi Lkur serisinin ADF ve PP birim kök testi sonuçları hem sabit terimli model hem de sabit terimli ve trendli model için verilmiştir. Ancak, serinin grafiği incelendiğinde, seri trend içerdiğinden, birim kök testi sonuçları sabit terimli ve trendli model için yorumlanmaktadır. Buna göre Lkur serisi, temel hipotezi seride birim kökün olduğu şeklinde kurulan ADF ve PP birim kök testi sonuçlarında, \%1 önem düzeyinde durağan çıkmıştır.

KPSS testinde temel hipotez serinin durağan olduğu şeklinde kurulmaktadır. Bu nedenle temel hipotezin reddedilmesi, serinin birim kök içerdiği anlamına gelmektedir. KPSS testi sonuçlarına göre sabit terimli ve trendli modelde hesaplanan test istatistiği, \%1 önem düzeyinde kritik değerden küçüktür. Dolayısıyla temel hipotez reddedilememekte ve Lkur serisi durağan olarak kabul edilmektedir.

\section{- Ng-Perron Testi}

Ng-Perron testinde yer alan MZa ve MZt testlerinde temel hipotez, serinin birim kök içerdiği şeklindeyken, MSB ve MPT testlerinde temel hipotez, serinin durağan olduğu biçimindedir. Tablo 2'de Lkur serisine ait NgPerron testi sonuçları yer almaktadır. 


\begin{tabular}{|c|c|c|c|c|c|c|c|c|c|}
\hline & \multicolumn{4}{|c|}{ Ng-Perron testi (sabit terimli) } & \multicolumn{4}{|c|}{ Ng-Perron testi (sabit terimli ve trendli) } \\
\hline & & $\mathrm{MZa}$ & $\mathrm{MZt}$ & MSB & MPT & $\mathrm{MZa}$ & $\mathrm{MZt}$ & MSB & MPT \\
\hline & Test istatistiği & -4.2857 & -1.3502 & $0.3151^{\text {(a }}$ & $\begin{array}{c}5.9044^{(\mathrm{a}} \\
\end{array}$ & $-19.41^{(\mathrm{b})}$ & $-3.108^{(\mathrm{b})}$ & $0.1601^{(a)}$ & $4.741^{(\mathrm{a})}$ \\
\hline \multirow{3}{*}{$\begin{array}{l}\text { Kritik } \\
\text { Değerler }\end{array}$} & $\% 1$ & -13.800 & -2.5800 & 0.17400 & 1.78000 & -23.800 & -3.4200 & 0.14300 & $\begin{array}{c}4.0300 \\
0\end{array}$ \\
\hline & $\% 5$ & -8.1000 & -1.9800 & 0.23300 & 3.17000 & -17.300 & -2.9100 & 0.16800 & $\begin{array}{c}5.4800 \\
0 \\
\end{array}$ \\
\hline & $\% 10$ & -5.7000 & -1.6200 & 0.27500 & 4.45000 & -14.200 & -2.6200 & 0.18500 & $\begin{array}{c}6.6700 \\
0\end{array}$ \\
\hline
\end{tabular}

Not: MZa ve MZt için temel hipotez: LKUR serisi birim köke sahiptir. MSB ve MPT için temel hipotez: LKUR serisi durağandır. (c) $\%$ 10, (b) \% 5, (a) \% 1 önem düzeyinde anlaml.

Tablo 2. Lkur Serisi İçin Ng-Perron Testi Sonuçları

Sabit terimli ve trendli modelde MZa, MZt, MSB ve MPT testi sonuçlarına göre Lkur serisi \%5 önem düzeyinde durağan kabul edilmektedir.

\subsection{Yapısal Kırılmalı Birim Kök Testleri}

Lkur serisinin durağanlık analizinde yapısal kırılmalı birim kök testlerinden de yararlanılmışıtır. Bunlardan Zivot-Andrews (1992) birim kök testi tek bir içsel kırılmayı dikkate alırken, Lee-Strazicich (2003) birim kök testi iki içsel kırılmayı dikkate almaktadır.

- Zivot-Andrews (1992) ve Lee-Strazitch (2003) Birim Kök Testi

Zivot-Andrews (1992), tek bir içsel kırılmayı dikkate alan birim kök testidir. Bu testte temel hipotez, serinin birim kök içerdiği şeklinde kurulmuştur. Lkur serisi için Zivot-Andrews (1992) ve Lee-Strazitch (2003) birim kök testi sonuçları Tablo 3’te verilmiştir.

\begin{tabular}{|l|c|c|c|c|}
\hline \multirow{2}{*}{} & \multicolumn{2}{|c|}{ Model A } & \multicolumn{2}{c|}{ Model C } \\
\cline { 2 - 5 } & Test istatistiği & Kırılma tarihi & Test istatistiğ & Kırılma tarihi \\
\hline Lkur (Zivot-Andrews) & $-4.6942(2)$ & $2002: 12$ & $-4.9167(2)$ & $2006: 06$ \\
\hline Kritik değerler \%5 & \multicolumn{2}{|c|}{-4.80} & \multicolumn{2}{c|}{-5.08} \\
\hline Lkur (Lee-Strazitch) & $-4.0480(1)^{*}$ & $2001: 04 / 2003: 04$ & $-5.8604(1)^{*}$ & $1995: 08 / 2008: 02$ \\
\hline Kritik değerler \%5 & \multicolumn{2}{|c|}{-3.84} & 5.71 \\
\hline
\end{tabular}

Not: $\left.{ }^{*}\right) \% 5$ önem düzeyinde anlamlı. Parantez içinde uygun gecikme sayısı gösterilmektedir.

Tablo 3. Lkur Serisi Iç̧in Zivot-Andrews (1992) Birim Kök Testi Sonuçları

Zivot-Andrews (1992) birim kök testi sonuçlarında model A ve model C'ye göre Lkur serisi için hesaplanan test istatistiği kritik değerlerden küçük olduğundan, temel hipotez reddedilememektedir. Diğer bir ifadeyle Lkur serisi düzeyde değil, farkta durağandır.

İki içsel kırılmayı dikkate alan Lee-Strazicich (2003) birim kök testinde temel hipotez, serinin birim kök içerdiği biçimindedir. Tablo 3'teki sonuçlarda, model A ve model C'ye göre Lkur serisi için hesaplanan test istatistiği, kritik değerlerden büyük olduğundan, temel hipotez reddedilmekte, yani serinin durağan olduğuna karar verilmektedir.

- Birim Kök Testlerinin Genel Değerlendirmesi

Lkur serisinin durağanlık analizi için gerçekleştirilen birim kök testleri sonuçları bir bütün olarak değerlendirildiğinde, Zivot-Andrews (1992) birim kök testi dışındaki diğer tüm birim kök testlerinde Lkur serisinin düzeyde durağan olduğu ortaya çıkmıştır. Böylece oynaklık modellerine ilişkin olarak yapılacak tahminlemelerde Lkur serisinin düzeyde durağan olarak alınmasına karar verilmiştir.

\subsection{Oynaklık Modelleri ile Reel Döviz Kuru Oynaklığının Tahmini}

Lkur serisinin durağan olduğuna karar verildikten sonra, serinin tanımlayıcı istatistikleri incelenmiştir. Tablo 4 'te Lkur serisine ait tanımlayıcı istatistikler yer almaktadır.

\begin{tabular}{|l|c|}
\hline \multicolumn{2}{|c|}{$\begin{array}{c}\text { Örneklem: 1992:M01-2014:M12 } \\
\text { Gözlem say1s1: 276 }\end{array}$} \\
\hline Ortalama & 4.921104 \\
\hline Medyan & 4.945207 \\
\hline Maksimum & 5.275100 \\
\hline Minimum & 4.356709 \\
\hline Standart sapma & 0.217620 \\
\hline Eğiklik & -0.313718 \\
\hline Basıklı & 2.002599 \\
\hline Jarque-Bera & 15.96757 \\
\hline Olasılık & 0.000341 \\
\hline
\end{tabular}

Tablo 4. Lkur Serisinin Tanımlayıcı İstatistikleri 
Tanımlayıcı istatistiklerden de görüldüğü üzere, Lkur serisinin basıklık değeri olan 2.002599, normal dağılım için öngörülen 3 değerinin altındadır. Ayrıca, Jarque-Bera testi sonucuna göre "normal dağılım” temel hipotezi reddedilmiş, yani serinin normal dağılım sergilemediği ortaya çıkmıştır. Bu nedenle ARCH modelleri kurulurken, normal dağılım yerine student-t dağılımı tercih edilmiştir (Ertuğrul, 2012: 82).

Box Jenkins yöntemiyle Lkur serisinin ARMA yapısı da incelenmiş ve serinin ARMA $(1,1)$ yapısının uygun olduğuna karar verilmiştir. ARMA $(1,1)$ modelinde hata terimleri arasında otokorelasyon yok olmaktadır.

ARMA $(1,1)$ modelinde ARCH etkisinin varlığını test etmek için ARCH-LM testi uygulanmıştır ve sonuçları Tablo 5 'te gösterilmiştir.

\begin{tabular}{|l|l|l|l|}
\hline Heteroskedasticity Test: ARCH \\
\hline F-statistic & 22.97797 & Prob. F(1,272) & 0.0000 \\
Obs*R-squared & 21.34385 & Prob. Chi-Square(1) & 0.0000 \\
\hline
\end{tabular}

Tablo 5. ARMA $(1,1)$ Modelinde ARCH Testi Sonuçlarl

ARCH-LM testi sonucunda F istatistiğinin olasılık değeri “0” bulunmuştur. Dolayısıyla "ARCH etkisi yoktur” şeklindeki temel hipotez reddedilmiş ve modelde ARCH etkisinin varlığı ortaya konulmuştur.

$\mathrm{Bu}$ çerçevede Lkur serisine ait en uygun oynaklık modelini bulmak için sırasıyla ARCH, GARCH ve E-GARCH modelleri tahmin edilmiştir.

\section{- ARCH Modeli}

ARCH modellerinde hata terimindeki değişen varyans bir sorun olarak görülmez, modellenmesi gereken bir varyans olarak kabul görür. Böylece seride oynaklığın varlığı araştırılabilir.

ARCH sürecinin derecesi belirlenirken, hata teriminin koşullu varyansının kendinden ne kadar önceki hata terimine bağlı olduğuna bakılır. Eğer hata terimi kendinden bir önceki hata terimine bağlıysa, model ARCH (1) şeklinde ifade edilir.

Herhangi bir $\mathrm{y}_{\mathrm{t}}$ serisi için tahmin edilen ARCH (1) modeli aşağıdaki gibidir:

$$
y_{t}=a_{0}+a_{1} y_{t-1}+\varepsilon_{t}
$$

(1) no'lu denklemde koşullu değişen varyans için Engle (1982) tarafından aşağıdaki model sunulmuştur:

$$
\begin{aligned}
& \varepsilon_{t}=v_{t} \sqrt{h_{t}} \\
& h_{t}=\alpha_{0}+\alpha_{1} \varepsilon_{t-1}^{2}
\end{aligned}
$$

(2) no'lu denklem ARCH modeli olarak adlandırılır. $v_{t}$ beyaz gürültü sürecine sahiptir ve $\varepsilon_{t}$ 'den bağımsızdır. Ayrıca $\operatorname{Var}\left(v_{t}\right)=1$ 'dir. Aynı zamanda (2) no'lu denklemde $\alpha_{0}$ ve $\alpha_{1}$ katsayıları ARCH modelinin bilinmeyen parametrelerini temsil eder. ARCH modelinde koşullu varyansın pozitif olma koşulunun sağlanabilmesi için $\alpha_{0}>$ 0 ve $0<\alpha_{1}<1$ olmalıdır (Engle, 1982: 987-992). Lkur serisi için tahmin edilen ARCH modeli aşağıdaki gibidir. Parantez içindeki değerler ilgili parametrenin standart hatasını göstermektedir:

$$
\begin{gathered}
\text { Lkur }_{\mathbf{t}}=\mathbf{5 . 4 0 0 5 7 7}+\mathbf{0 . 9 8 6 9 5 9} \text { Lkur }_{\mathbf{t}-\mathbf{1}}+\boldsymbol{\varepsilon}_{\mathbf{t}}+\mathbf{0 . 2 9 5 9 7 5} \boldsymbol{\varepsilon}_{\mathbf{t}-\mathbf{1}} \\
(0.329287)(0.008235) \\
\mathbf{h}_{\mathbf{t}}=\mathbf{0 . 0 0 0 5 6 5}+\mathbf{0 . 7 0 7 9 8 5} \boldsymbol{\varepsilon}^{\mathbf{t}-\mathbf{1}} \\
\quad(0.000164) \quad(0.254349)
\end{gathered}
$$

Tahmin edilen ARCH(1) modeline ait Akaike(AIC) kriteri -4.275478 ve Schwarz(SC) kriteri ise -4.196567'dir. Modelde $\alpha_{0}$ parametresi 0.000565 olarak hesaplanmış; $\alpha_{0}>0$ koşulu sağlanmıştır. Buna benzer biçimde $\alpha_{1}$ parametresi de 0.707985 olarak hesaplanmış; $0<\alpha_{1}<1$ koşulu sağlanmıştır. Tahmin edilen modelin hata karelerine ARCH-LM testi uygulanmış ve ARCH etkisinin ortadan kalktığı görülmüştür. Böylece takip edilen süreçlere bağlı olarak tahmin edilen modelde ARCH etkisinin yakalanmış olduğu ileri sürülür.

\section{- GARCH Modeli}

GARCH modelinde koşullu varyansın gecikmelerine de yer verildiğinden, GARCH modeli, otoregresif (AR) ve hareketli ortalamalar (MA) özelliklerini birlikte taşımaktadır. GARCH $(\mathrm{p}, \mathrm{q})$ modeli için koşullu varyans denklemi aşağıdaki gibidir:

$$
\begin{aligned}
& \varepsilon_{t}=v_{t} \sqrt{h_{t}} \\
& h_{t}=\alpha_{0}+\sum_{i=1}^{q} \alpha_{i} \varepsilon_{t-i}^{2}+\sum_{j=1}^{p} \beta_{j} h_{t-j}
\end{aligned}
$$

$\operatorname{GARCH}(\mathrm{p}, \mathrm{q})$ modelinde $\mathrm{p}$, varyansın kendi gecikmeli değerleridir ve uzun dönem etkisini yakalar; q ise geçmiş artıkların karesidir ve yüksek sıklık etkisini yakalar. $\alpha_{i} \mathrm{ARCH}$ parametresi ve $\beta_{j}$ ise GARCH parametresi olarak adlandırılır. Modelde ARCH parametresi oynaklığın şoklara verdiği anlık tepkiyi gösterirken, GARCH parametresi oynaklık direncinin derecesini ifade eder. GARCH parametresinin büyük olması oynaklığın kalıcı ve dirençli olduğuna işaret etmektedir.

GARCH modelinde de ARCH modelindeki gibi koşullu varyansın pozitif olma koşulunun sağlanması için benzer kisitlar mevcuttur. Bu kısıtlar; $\alpha_{0}>0, \alpha_{i} \geq 0, \beta_{j} \geq 0, \mathrm{p} \geq 0$ ve $\mathrm{q}>0$ olarak gösterilmektedir (Bollerslev, 
1986: 308-311). Lkur serisi için tahmin edilen GARCH $(1,1)$ modelinin sonuçları aşağıda verilmektedir. Parantez içindeki değerler standart hataları göstermektedir:

$$
\begin{gathered}
\text { Lkur }_{\mathbf{t}}=\mathbf{5 . 2 3 5 4 9 3}+\mathbf{0 . 9 8 3 7 5 2} \text { Lkur }_{\mathbf{t}-\mathbf{1}}+\boldsymbol{\varepsilon}_{\mathbf{t}}+\mathbf{0 . 3 4 0 1 7 6} \boldsymbol{\varepsilon}_{\mathbf{t}-1} \\
(0.194919)(0.00902) \\
\mathbf{h}_{\mathbf{t}}=\mathbf{0 . 0 0 0 1 1 0}+\mathbf{0 . 3 0 8 5 5 6} \boldsymbol{\varepsilon}_{\mathbf{t}-\mathbf{1}}^{\mathbf{0}}+\mathbf{0 . 6 4 4 8 9 4} \mathbf{h}_{\mathbf{t}-1} \\
(5.46 \mathrm{E}-05)(0.115484) \quad(0.096672)
\end{gathered}
$$

Yukarıda hesaplanan GARCH $(1,1)$ modeline ait AIC kriteri -4.280403 ve SC kriteri ise -4.188340'dır. Tahmin sonucunda $\alpha$ parametresi 0.308556 ve $\beta$ parametresi ise 0.644894 olarak bulunmuştur. Modelde durağanlık için aranan $\alpha+\beta<1$ koşulu sağlanmıştır. Ancak, $\alpha+\beta$ toplamının 1'e çok yakın bir değer alması ve $\beta>\alpha$ olması nedeniyle, reel döviz kuru serisinin oynaklığının şoklara dirençlilik gösterdiği, diğer bir ifadeyle şokların oynaklık üzerindeki etkisinin kalıcı olduğu gibi bir sonuç ortaya çıkmaktadır ve bu da oynaklık modellerinin teorisi açısından çok istenilen bir durum değildir. Tahmin edilen modelde kalan ARCH etkisini araştırmak amacıyla ARCH-LM testi yapılmış ve sonuçta ARCH etkisinin ortadan kalktığ́ görülmüştür.

\section{- E-GARCH Modeli}

ARCH ve GARCH modellerinde pozitif ve negatif şokların oynaklık üzerinde aynı etkiyi gösterdikleri kabul edilmektedir. Oysa finansal zaman serilerinde asimetrik etki söz konusudur. ARCH ve GARCH modellerinin bu eksikliklerini gidermek amacıyla Nelson (1991) E-GARCH modelini geliştirmiştir. Modelde koşullu varyansın pozitif olma koşulunun sağlanması için logaritmik bir dönüşüm gerçekleştirilmiştir. E-GARCH modelinde koşullu varyans denklemi aşağıdaki gibidir:

$$
\operatorname{Ln}\left(h^{2}\right)=\alpha_{0}+\alpha_{1}\left|\frac{\varepsilon_{t-1}}{h_{t-1}}\right|+\gamma \frac{\varepsilon_{t-1}}{h_{t-1}}+\beta \ln \left(h^{2}{ }_{t-1}\right)
$$

(4) nolu denklemde $\gamma<0$ ise asimetrik etki vardır; buna karşılık $\gamma=0$ ise asimetrik etki yoktur. $-1<\gamma<0$ ise olumlu şoklar olumsuz şoklara göre oynaklığı daha az etkilemektedir. $\gamma<-1$ ise olumlu şoklar oynaklığı azaltır, olumsuz şoklar oynaklığı arttırır (Nelson, 1991: 350-352). Lkur serisi için tahmin edilen E-GARCH $(1,1)$ modelinin sonuçları aşağıda verilmektedir. Parantez içindeki değerler standart hataları göstermektedir:

$$
\begin{aligned}
& \text { Lkur }_{t}=\mathbf{5 . 1 9 2 9 0 8}+\mathbf{0 . 9 8 4 8 1 4} \text { Lkur }_{\mathrm{t}-1}+\boldsymbol{\varepsilon}_{\mathrm{t}}+\mathbf{0 . 3 5 3 5 1 5} \varepsilon_{\mathrm{t}-1} \\
& (0.179288)(0.008534) \quad(0.060833) \\
& \operatorname{Ln}\left(h^{2}{ }_{t}\right)=\mathbf{- 2 . 1 1 3 5 0 9}+\mathbf{0 . 5 7 0 7 4 1}\left|\frac{\varepsilon_{t-1}}{h_{t-1}}\right|-\mathbf{0 . 2 3 9 2 2 0} \frac{\varepsilon_{t-1}}{h_{t-1}}+\mathbf{0 . 7 5 8 9 7 4 l n}\left(h^{2}{ }_{t-1}\right) \\
& \begin{array}{lll}
(0.641118)(0.157553) & (0.102119) \quad(0.084266)
\end{array}
\end{aligned}
$$

Yukarıda tahmin edilen modelden elde edilen sonuçlara göre " $\gamma$ " parametresi (-0.239220) negatif ve istatistiksel olarak anlamlı bulunmuştur. Dolayısıyla reel döviz kuru oynaklığı üzerinde negatif şokların, pozitif şoklara göre daha fazla etkili olduğu görülmüştür. E-GARCH modeline ait AIC kriteri -4.302587 ve SC kriteri ise 4.197371'dir. Model tahmin edildikten sonra, hata terimlerinde kalan ARCH etkisini araştırmak amaciyla, ARCHLM testi yapılmış ve sonuçta ARCH etkisinin ortadan kalktığı görülmüştür.

- Oynaklık Modellerinin Karşılaştırılması

Lkur serisi için tahmin edilen oynaklık modellerinden hangisinin en başarılı olduğuna karar vermek amacıyla, öncelikle modellere ait AIC ve SC kriterleri açısından değerlendirilmesi yapılmalıdır. Buna göre en küçük AIC ve SC kriterine sahip olan model E-GARCH $(1,1)$ modelidir. Dolayısıyla reel döviz kuru oynaklığının modellenmesinde E-GARCH $(1,1)$ modelinin diğerlerine göre daha uygun olduğuna karar verilir. Ancak, bu modelin başarılı olduğuna karar vermek için hata terimleri arasında otokorelasyonun olmaması ve ARCH etkisinin ortadan kalkmış olması gerekir. Bu işleme bağlı olarak yapılan E-GARCH modeli tahmini sonrasında ARCH etkisinin ortadan kalktığı görülmüştü. Otokorelasyonun ortadan kalkmış olduğu ise hata karelerinin korelogramına bakılarak tespit edilmiştir. Sonuç olarak reel döviz kuru oynaklığının modellenmesinde en başarılı modelin EGARCH $(1,1)$ olduğuna karar verilmiştir.

\subsection{E-GARCH Modelinde Politik Değişkenlerin İncelenmesi}

Çalışmada kullanılan politik değişkenler, tarafımızdan oluşturulan kukla değişkenlerdir ve aşağıda tanitılmaktadir:

Merkez bankasının bă̆ımsızlı̆̆ı (MBBAG): Literatürde bağımsız merkez bankalarının kur oynaklığını azaltıcı yönde etkiye sahip olduğu ileri sürülmekte olduğundan analize dahil edilmiştir. Türkiye Cumhuriyeti Merkez Bankası 25 Nisan 2001 tarihi itibariyle bağımsız hale gelmiştir. Bu nedenle merkez bankası bağımsızlığı kukla değişkeni 1992:01-2001:04 döneminde “0”, 2001:05-2014:12 döneminde ise "1” değerini almıştır.

Koalisyon (KOALISYON): Koalisyon dönemlerinde ekonomik istikrarsızlı̆̆ın ve dolayısıyla kur oynaklığının artması beklendiğinden analizde yer verilmiştir. Bu değişken, Türkiye'de koalisyonların iktidarda olduğu 1992:01 2002:11 döneminde " 1 ", tek partinin iktidarda olduğu 2002:12-2014:12 döneminde ise "0" değerini almıştır.

Íktidarın meclisteki gücü (MECLISTEKIGUC): İktidarın mecliste yüksek milletvekili sayısına sahip olması, ekonomiye yönelik politika kararlarını kendi çıkarları doğrultusunda daha rahat bir şekilde alabilmesine imkan vererek, kur oynaklığını etkilediği düşünülmektedir. 1992:01-2014:12 döneminde iktidarın milletvekili sayısının, 
meclisteki tüm milletvekili sayısına oranlanmasıyla elde edilmiştir. Milletvekili sayılarına ilişkin veriler TBMM'den elde edilmiştir.

Kur rejimi (REJIM): Ülkelerin uyguladıkları farklı kur rejimleri kur oynaklığı üzerinde etkili olmaktadır. Türkiye, 21 Şubat 2001'den itibaren dalgalı kur rejimi uygulamaktadır; önceki dönemde ise zaman zaman kur bantı ve kur baskılaması/sabitlemesi gibi rejimleri uygulamıştır. Bu nedenle REJIMM değişkeni 2001:03-2014:12 dönemi için "1", diğer dönemlerde "0" değerini almaktadır.

Seçim değişkenleri: Seçim öncesi ve sonrası dönemde politikacıların iktidara gelebilmek için firsatçı ya da partizan amaçlarla kur oynaklığını etkileyebildikleri görülmektedir. Türkiye'de 1992:01-2014:12 döneminde gerçekleşmiş olan tüm genel ve yerel seçimler ele alınmış ve seçimlerden önceki ve sonraki 1 ila 6 ay arası için seçim kukla değişkenleri oluşturulmuştur. Örneğin seçim öncesi 1 ay kukla değişkeni, seçimin gerçekleştiği ay ve ondan önceki 1 ay için " 1 ”, seçim sonrası 1 ay kukla değişkeni, seçimin gerçekleştiği ay ve onu takip eden 1 ay için "1" değerini alırken, diğer tüm aylar " 0 " ile sembolize edilmektedir.

E-GARCH(1,1) modelinde yukarıda belirtilen politik değişkenlerin reel döviz kuru oynaklığı üzerindeki etkisi incelenirken seçim değişkenleri, diğer değişkenlerden ayrı biçimde ele alınmış ve modellenmiştir. Tablo 6, seçimler gölge değişkeni dışındaki diğer politik değişkenlere ait tahmin sonuçlarını göstermektedir. Tabloda politik değişkenlerin E-GARCH $(1,1)$ modelinde varyans denklemindeki tahmin sonuçları yer almaktadır.

Tablo 6'da görüldüğü gibi merkez bankası bağımsızlığı (MBBAG) ve kur rejimi (REJiM) değişkenleri, reel döviz kuru oynaklığı üzerinde anlamlı bir etkiye sahip değildir. Koalisyon değişkeninin reel döviz kuru oynaklığını pozitif ve $\% 5$ önem düzeyinde anlamlı şekilde etkilediği bulgusuna ulaşılmıştır. Bu bulgu, beklentilere uygun çıkmıştır. Çünkü Türkiye'de koalisyon dönemleri, siyasi istikrarsızlığın yaşandığı dönemlerdir ve bu istikrarsızlığa bağlı olarak reel döviz kuru oynaklığı artmaktadır. Meclistekiguc değişkeni ise reel döviz kuru oynaklığı üzerinde pozitif ve \%10 önem düzeyinde anlamlı etkiye sahip bulunmuştur. İktidarın meclisteki koltuk oranının artması, kendi amaçlarına uygun politika kararları almasında avantaj sağlayacağından kur oynaklığını arttırmaktadır. Oysa siyasal uyumun ve buna bağlı olarak ortaya çıkacak siyasal istikrarın paralel bir şekilde kur istikrarını sağlayacağı önsel olarak ileri sürülebilir. Ancak, bunun aslında demokratikleşmeden uzak bir motif olarak kur üzerinde olumsuz yönde sinyal oluşturacağına dair bulgu yakalanmıştır.

\begin{tabular}{|l|c|}
\hline \multicolumn{1}{|c|}{ Değişkenler } & Ortalama denklemi \\
\hline $\mathrm{C}$ & $5.069580^{(\mathrm{a})}$ \\
\hline Lkur $_{\mathrm{t}-1}$ & $0.979310^{(\mathrm{a})}$ \\
\hline$\varepsilon_{\mathrm{t}-1}$ & $0.345109^{(\mathrm{a})}$ \\
\hline \multicolumn{2}{|c|}{ Varyans denklemi } \\
\hline$\alpha_{0}$ & $-5.878877^{(\mathrm{a})}$ \\
\hline$\alpha_{1}$ & 0.226807 \\
\hline$\gamma$ & $-0.394538^{(\mathrm{a})}$ \\
\hline$\beta$ & $0.501857^{(\mathrm{a})}$ \\
\hline MBBAG & -1.070971 \\
\hline KOALİSYON & $0.843912^{(\mathrm{b})}$ \\
\hline MECLISTEKİGUC & $2.018723^{(\mathrm{c})}$ \\
\hline REJIM & 1.968769 \\
\hline
\end{tabular}

Tablo 6. Student-t Dă̆ılımında E-GARCH(1,1) Modelinde Varyans Denklemindeki Tahmin Sonuçları

Politik değişkenler E-GARCH $(1,1)$ modelinde ayrıca ortalama denkleminde tahmin edilmiştir. Tablo 7'de ortalama denklemindeki tahmin sonuçları verilmiştir. 


\begin{tabular}{|l|c|}
\hline \multicolumn{1}{|c|}{ Değişkenler } & Ortalama denklemi \\
\hline $\mathrm{C}$ & $4.975817^{(\mathrm{a})}$ \\
\hline Lkur $\mathrm{t}-1$ & $0.966861^{(\mathrm{a})}$ \\
\hline$\varepsilon_{\mathrm{t}-1}$ & $0.379612^{(\mathrm{a})}$ \\
\hline MBBAG & $0.154665^{(\mathrm{a})}$ \\
\hline KOALİSYON & $-0.019665^{(\mathrm{c})}$ \\
\hline MECLİSTEKİGUC & 0.007249 \\
\hline REJiM & -0.011642 \\
\hline \multicolumn{2}{|c|}{ Varyans denklemi } \\
\hline$\alpha_{0}$ & $-4.236527^{(\mathrm{a})}$ \\
\hline$\alpha_{1}$ & $0.515856^{(\mathrm{b})}$ \\
\hline$\gamma$ & $-0.425518^{(\mathrm{a})}$ \\
\hline$\beta$ & $0.455685^{(\mathrm{a})}$ \\
\hline
\end{tabular}

Tablo 7. Student-t Dă̆glımında E-GARCH(1,1) Modelinde Ortalama Denklemindeki Tahmin Sonuçları

Politik değişkenlerin ortalama denklemindeki tahmin sonuçları yorumlanırken, söz konusu değişkenlerin reel döviz kuru oynaklığı üzerindeki etkisi değil, reel döviz kuru üzerindeki etkisi tartışılır. Bu bağlamda meclistekiguc ve rejim değişkenlerinin reel döviz kuru üzerinde anlamlı bir etkisinin olmadığı görülmüştür. Merkez bankası bağımsızlığı değişkeni ise reel döviz kuru üzerinde pozitif ve istatistiksel olarak anlamlı etkiye sahiptir. Diğer bir ifadeyle merkez bankası bağımsızlığı, politik faktörlerden ziyade ekonomik unsurları dikkat alarak reel döviz kurunu arttırmakta ve böylece TL'nin değer kazanmasına sebep olmaktadır. Özellikle 2001 sonrasındaki süreçte merkez bankası özerkliği tesis edilirken, paralelinde dünya ekonomisindeki gelişmeler ve bunun içerisinde finans kapitaldeki genişlemeler Türkiye ekonomisi özelinde kur değerlenme sürecini besleyen unsurlar arasında yer almıştır. Koalisyon değişkeninin ise reel döviz kuru üzerinde negatif ve \%10 önem düzeyinde anlamlı bir etkiye sahip olduğu bulgusu elde edilmiştir. Buna göre koalisyon dönemlerinde reel döviz kurunun (TL'nin) değer kaybettiği söylenebilir.

Seçim değişkenleri E-GARCH(1,1) ile tahmin edilirken, seçim öncesi 1-6 ay arası ve seçim sonrası 1-6 ay arası kukla değişkenleri için toplam 12 model kullanılmıştır. Model 1-6, seçim öncesi değişkenlerin tahmininde, model 7-12 arası seçim sonrası değişkenlerin tahmininde kullanılmıştır. Diğer politik değişkenlerin tahmininde olduğu gibi seçim değişkenleri de E-GARCH(1,1) modelinin hem varyans denkleminde hem de ortalama denkleminde tahmin edilmiştir. Tablo 8'de seçim öncesi değişkenlerinin E-GARCH(1,1) modelinde varyans denklemindeki tahmin sonuçları gösterilmiştir.

\begin{tabular}{|c|c|c|c|c|c|c|}
\hline Modeller/ Değişkenler & Model 1 & Model 2 & Model 3 & Model 4 & Model 5 & Model 6 \\
\hline \multicolumn{7}{|l|}{ Ortalama denklemi } \\
\hline $\mathrm{C}$ & $5.199868^{(\mathrm{a})}$ & $5.192717^{\text {(a) }}$ & $5.192377^{(\mathrm{a})}$ & $5.193262^{\text {(a) }}$ & $5.200502^{\text {(a) }}$ & $5.209660^{(a)}$ \\
\hline Lkur $_{\mathrm{t}-1}$ & $0.984704^{(\mathrm{a})}$ & $0.984361^{(\mathrm{a})}$ & $0.984407^{(\mathrm{a})}$ & $0.984539^{(\mathrm{a})}$ & $0.984405^{\text {(a) }}$ & $0.984435^{\text {(a) }}$ \\
\hline$\varepsilon_{t-1}$ & $0.352255^{(\mathrm{a})}$ & $0.353584^{(\mathrm{a})}$ & $0.354411^{(\mathrm{a})}$ & $0.354510^{(\mathrm{a})}$ & $0.352522^{(\mathrm{a})}$ & $0.351701^{(\mathrm{a})}$ \\
\hline \multicolumn{7}{|l|}{ Varyans denklemi } \\
\hline$\alpha_{0}$ & $-2.16604^{(\mathrm{a})}$ & $-2.159870^{(\mathrm{a})}$ & $-2.18107^{(\mathrm{a})}$ & $-2.14984^{(\mathrm{a})}$ & $-2.16787^{(\mathrm{a})}$ & $-2.266439^{(a)}$ \\
\hline$\alpha_{1}$ & $0.571988^{(\mathrm{a})}$ & $0.569458^{(\mathrm{a})}$ & $0.572117^{(\mathrm{a})}$ & $0.571365^{(\mathrm{a})}$ & $0.572279^{(a)}$ & $0.576260^{\text {(a) }}$ \\
\hline$\gamma$ & $-0.222611^{(b)}$ & $-0.226123^{(\mathrm{b})}$ & $-0.227958^{(\mathrm{b})}$ & $-0.230695^{(\mathrm{b})}$ & $-0.220417^{(b)}$ & $-0.220243^{(\mathrm{b})}$ \\
\hline$\beta$ & $0.754540^{(\mathrm{a})}$ & $0.754725^{(\mathrm{a})}$ & $0.751763^{(\mathrm{a})}$ & $0.755470^{(\mathrm{a})}$ & $0.754854^{(\mathrm{a})}$ & $0.744088^{(a)}$ \\
\hline Seçim öncesi 1 ay & 0.272115 & & & & & \\
\hline Seçim öncesi 2 ay & & 0.167009 & & & & \\
\hline Seçim öncesi 3 ay & & & 0.115484 & & & \\
\hline Seçim öncesi 4 ay & & & & 0.069216 & & \\
\hline Seçim öncesi 5 ay & & & & & 0.122396 & \\
\hline Seçim öncesi 6 ay & & & & & & 0.180455 \\
\hline
\end{tabular}

Tablo 8 Student-t Dă̆ılımında E-GARCH(1,1) Modellerinde Seçim Öncesi Değişkenlerinin Varyans Denklemindeki Tahmin Sonuçları

Tablo 8'de görüldüğü gibi E-GARCH $(1,1)$ modellerinde varyans denklemlerinde seçim öncesi 1-6 ay arasındaki tüm kukla değişkenlerin katsayılarının pozitif olduğu, ancak istatistiki bakımdan anlam taşımadığı sonucuna varılmıştır. Bu bağlamda Türkiye'de seçimlerden önce politikacıların, firsatçı yaklaşıma göre döviz kuru oynaklığını azaltıp, yeniden seçilme şanslarını arttırma çabalarına dair anlamlı bir sinyalin yakalanamadığı söylenebilir. Burada seçmenlerin kur üzerindeki davranışları ile merkez bankası bağımsızlığının etkileri dikkate 
alındığında, genel literatürün aksine Türkiye özelinde, seçimlerden önce kurların siyasetçe baskılanamadığı ileri sürülebilir.

Seçim sonrası değişkenlerinin E-GARCH $(1,1)$ modellerinde varyans denklemlerindeki tahmin sonuçları Tablo 9'da gösterilmektedir.

\begin{tabular}{|c|c|c|c|c|c|c|}
\hline Modeller/ Değişkenler & Model 7 & Model 8 & Model 9 & Model 10 & Model 11 & Model 12 \\
\hline \multicolumn{7}{|l|}{ Ortalama denklemi } \\
\hline $\mathrm{C}$ & $5.23159^{(a)}$ & $5.235599^{(\mathrm{a})}$ & $5.20317^{(\mathrm{a})}$ & $5.19429^{(a)}$ & $5.19704^{(a)}$ & $5.19644^{(\mathrm{a})}$ \\
\hline Lkur ${ }_{t-1}$ & $0.98426^{(a)}$ & $0.984058^{(\mathrm{a})}$ & $0.98415^{(\mathrm{a})}$ & $0.98554^{(\mathrm{a})}$ & $0.98573^{(a)}$ & $0.98559^{\text {(a) }}$ \\
\hline$\varepsilon_{\mathrm{t}-1}$ & $0.34035^{\text {(a) }}$ & $0.338676^{(a)}$ & $0.34782^{\text {(a) }}$ & $0.35544^{\text {(a) }}$ & $0.35569^{\text {(a) }}$ & $0.35651^{\text {(a) }}$ \\
\hline \multicolumn{7}{|l|}{ Varyans denklemi } \\
\hline$\alpha_{0}$ & $-2.8155^{(\mathrm{a})}$ & $-3.42902^{(\mathrm{a})}$ & $-2.7487^{(\mathrm{a})}$ & $-1.8344^{(\mathrm{a})}$ & $-1.7943^{\text {(a) }}$ & $-1.8345^{(a)}$ \\
\hline$\alpha_{1}$ & $0.63767^{\text {(a) }}$ & $0.662000^{(a)}$ & $0.61585^{(\mathrm{a})}$ & $0.54581^{\text {(a) }}$ & $0.54186^{\text {(a) }}$ & $0.54619^{\text {(a) }}$ \\
\hline$\gamma$ & $-0.21447^{(b)}$ & $-0.24960^{(b)}$ & $-0.25109^{(b)}$ & $-0.23659^{(b)}$ & $-0.23626^{(b)}$ & $-0.23613^{(\mathrm{b})}$ \\
\hline$\beta$ & $0.67359^{\text {(a) }}$ & $0.591319^{\text {(a) }}$ & $0.67676^{(\mathrm{a})}$ & $0.79409^{\text {(a) }}$ & $0.79868^{\text {(a) }}$ & $0.79321^{\text {(a) }}$ \\
\hline Seçim sonrası 1 ay & $0.687516^{(\mathrm{c})}$ & & & & & \\
\hline Seçim sonrası 2 ay & & $0.600729^{(\mathrm{c})}$ & & & & \\
\hline Seçim sonras1 3 ay & & & 0.184703 & & & \\
\hline Seçim sonrası 4 ay & & & & -0.093960 & & \\
\hline Seçim sonrası 5 ay & & & & & -0.112402 & \\
\hline Seçim sonrası 6 ay & & & & & & -0.104259 \\
\hline
\end{tabular}

Tablo 9. Student-t Dă̆ılımında E-GARCH(1,1) Modellerinde Seçim Sonrası Değişkenlerinin Varyans Denklemindeki Tahmin Sonuçları

Tablo 9'da seçim sonrası 1 ay ve seçim sonrası 2 ay kukla değişkenlerinin katsayılarının pozitif ve \%10 önem düzeyinde anlamlı olduğu görülmektedir. Bu bulgulara göre seçim sonrası 2 aya kadarki dönemde reel döviz kuru oynaklığı artmaktadır. Bu 2 ay kadarki süreyi kapsayan dönem, yeni hükümetin veya koalisyonun kurulmasına kadarki süreci içerdiğinden, siyasal belirsizliğin devam ettiğini ve bunun da kur oynaklığını arttırdığını söylemek mümkündür. Seçim sonrası 3, 4, 5 ve 6 ay kukla değişkenlerinin ise reel döviz kuru oynaklığı üzerinde anlamlı bir etkiye sahip olmadıkları sonucuna varılmıştır.

Seçim değişkenleri E-GARCH $(1,1)$ modellerinde ortalama denkleminde de tahmin edilmiştir. Model 13-18 arası seçim öncesi 1 ila 6 ay arası kukla değişkenlerin tahmininde, model 19-24 arası ise seçim sonrası 1 ila 6 ay arası kukla değişkenlerin tahmininde kullanılmıştır. Tablo 10'da seçim öncesi kukla değişkenlerin ortalama denklemindeki tahmin sonuçları verilmiştir.

Tablo 10'da seçim öncesi 2 ve 4 ay kukla değişkenlerinin katsayılarının negatif ve istatistiki olarak anlamlı bulunduğu görülmektedir. Bu bulgulara göre seçim öncesindeki 2 ve 4 ayı kapsayan dönemde reel döviz kurunun ve dolayısıyla TL'nin değer kaybettiği söylenebilir. Bu durumun seçimlerin yarattığ kaynaklandığı ve yukarıda da belirtildiği üzere seçmenlerin seçim öncesinde seçim sonuçlarını adeta satın aldıkları gibi bir sonucun ortaya çıktığı düşünülebilir. Politikacıların fırsatçı yaklaşım çerçevesinde reel döviz kurunu baskı altına alamadıkları ve TL'deki değer kaybını önleyemedikleri ortaya çıkmaktadır. Seçim öncesi 1, 3, 5 ve 6 . ay kukla değişkenlerinin katsayıları ise istatistiki bakımdan anlamlı değildir.

\begin{tabular}{|c|c|c|c|c|c|c|}
\hline Modeller/ Değișkenler & Model 13 & Model 14 & Model 15 & Model 16 & Model 17 & Model 18 \\
\hline \multicolumn{7}{|l|}{ Ortalama denklemi } \\
\hline $\mathrm{C}$ & $5.187702^{(\mathrm{a})}$ & $5.195093^{(\mathrm{a})}$ & $5.196565^{(\mathrm{a})}$ & $5.220662^{(\mathrm{a})}$ & $5.196764^{(\mathrm{a})}$ & $5.193981^{(a)}$ \\
\hline Lkur $_{\mathrm{t}-1}$ & $0.985094^{(\mathrm{a})}$ & $0.985372^{(\mathrm{a})}$ & $0.985863^{(\mathrm{a})}$ & $0.985584^{(\mathrm{a})}$ & $0.984552^{(\mathrm{a})}$ & $0.984738^{(a)}$ \\
\hline$\varepsilon \mathrm{t}-1$ & $0.352163^{(\mathrm{a})}$ & $0.373351^{(\mathrm{a})}$ & $0.352871^{(\mathrm{a})}$ & $0.376485^{(\mathrm{a})}$ & $0.359379^{(\mathrm{a})}$ & $0.354519^{(\mathrm{a})}$ \\
\hline Seçim öncesi 1 ay & 0.002790 & & & & & \\
\hline Seçim öncesi 2 ay & & $-0.007415^{(\mathrm{c})}$ & & & & \\
\hline Seçim öncesi 3 ay & & & 0.005655 & & & \\
\hline Seçim öncesi 4 ay & & & & $-0.011654^{(a)}$ & & \\
\hline Seçim öncesi 5 ay & & & & & -0.004459 & \\
\hline Seçim öncesi 6 ay & & & & & & -0.001388 \\
\hline \multicolumn{7}{|l|}{ Varyans denklemi } \\
\hline$\alpha_{0}$ & $-2.160290^{(a)}$ & $-2.121349^{(a)}$ & $-1.834792^{(\mathrm{a})}$ & $-2.350863^{(a)}$ & $-2.394818^{(a)}$ & $-2.194834^{(\mathrm{a})}$ \\
\hline$\alpha_{1}$ & $0.573219^{\text {(a) }}$ & $0.568094^{(\mathrm{a})}$ & $0.553110^{(\mathrm{a})}$ & $0.625030^{(\mathrm{a})}$ & $0.584728^{(\mathrm{a})}$ & $0.578950^{(a)}$ \\
\hline$\gamma$ & $-0.246275^{(b)}$ & $-0.245910^{(\mathrm{b})}$ & $-0.219542^{(b)}$ & $-0.232338^{(b)}$ & $-0.250592^{(a)}$ & $-0.242336^{(a)}$ \\
\hline$\beta$ & $0.752202^{\text {(a) }}$ & $0.758482^{(\mathrm{a})}$ & $0.796633^{(\mathrm{a})}$ & $0.733396^{(\mathrm{a})}$ & $0.721498^{(\mathrm{a})}$ & $0.748670^{\text {(a) }}$ \\
\hline
\end{tabular}

Not: (c) \% 10, (b) \% 5, (c) \% 1 önem düzeyinde anlamlı.

Tablo 10. Student-t Dă̆llımında E-GARCH(1,1) Modellerinde Seçim Öncesi Değişkenlerinin Ortalama Denklemindeki Tahmin Sonuçları 
Seçim sonrası 1 ila 6 ay arası kukla değişkenlerin E-GARCH $(1,1)$ modellerinde ortalama denklemindeki tahmin sonuçları ise Tablo 11'de verilmiştir.

\begin{tabular}{|c|c|c|c|c|c|c|}
\hline Modeller/ Değişkenler & Model 19 & Model 20 & Model 21 & Model 22 & Model 23 & Model 24 \\
\hline \multicolumn{7}{|l|}{ Ortalama denklemi } \\
\hline $\mathrm{C}$ & $5.206287^{\text {(a) }}$ & $5.200820^{(\mathrm{a})}$ & $5.193465^{\text {(a) }}$ & $5.196557^{\text {(a) }}$ & $5.195611^{\text {(a) }}$ & $5.185384^{\text {(a) }}$ \\
\hline Lkur $t-1$ & $0.985765^{(\mathrm{a})}$ & $0.985748^{(\mathrm{a})}$ & $0.985048^{(\mathrm{a})}$ & $0.985458^{(\mathrm{a})}$ & $0.985151^{(\mathrm{a})}$ & $0.984727^{(\mathrm{a})}$ \\
\hline$\varepsilon_{\mathrm{t}-1}$ & $0.360310^{(\mathrm{a})}$ & $0.366297^{(\mathrm{a})}$ & $0.353476^{(\mathrm{a})}$ & $0.360366^{(\mathrm{a})}$ & $0.354675^{(\mathrm{a})}$ & $0.355933^{\text {(a) }}$ \\
\hline Seçim sonrası 1 ay & 0.003340 & & & & & \\
\hline Seçim sonras 2 ay & & -0.004995 & & & & \\
\hline Seçim sonras1 3 ay & & & -0.001900 & & & \\
\hline Seçim sonrası 4 ay & & & & -0.006783 & & \\
\hline Seçim sonras 15 ay & & & & & -0.001541 & \\
\hline Seçim sonrası 6 ay & & & & & & -0.004376 \\
\hline \multicolumn{7}{|l|}{ Varyans denklemi } \\
\hline$\alpha_{0}$ & $-2.370398^{(a)}$ & $-1.717449^{(a)}$ & $-2.108628^{(a)}$ & $-1.815553^{(a)}$ & $-1.950257^{(\mathrm{a})}$ & $-2.181413^{(a)}$ \\
\hline$\alpha_{1}$ & $0.583302^{(\mathrm{a})}$ & $0.535714^{(\mathrm{a})}$ & $0.572518^{(\mathrm{a})}$ & $0.550258^{(\mathrm{a})}$ & $0.561353^{(\mathrm{a})}$ & $0.572607^{\text {(a) }}$ \\
\hline$\gamma$ & $-0.262238^{(b)}$ & $-0.202995^{(b)}$ & $-0.236256^{(b)}$ & $-0.214253^{(b)}$ & $-0.226963^{(b)}$ & $-0.241784^{(\mathrm{b})}$ \\
\hline$\beta$ & $0.724080^{(\mathrm{a})}$ & $0.812412^{(\mathrm{a})}$ & $0.759966^{(\mathrm{a})}$ & $0.799391^{\text {(a) }}$ & $0.781616^{(\mathrm{a})}$ & $0.749836^{\text {(a) }}$ \\
\hline
\end{tabular}

Tablo 11: Student-t Dă̆ıllımında E-GARCH(1,1) Modellerinde Seçim Sonrası Değiş̧kenlerinin Ortalama Denklemindeki Tahmin Sonuçları

Tablo 11'deki sonuçlara göre seçim sonrası kukla değişkenlerin hiçbirinin reel döviz kuru üzerinde istatistiki bakımdan anlamlı bir etkileri bulunamamıştır.

\section{Sonuç}

Literatürde yaygın bir şekilde gözlenen seçim-kur oynaklığı ilişkilerine dair çalışmalardan hareketle Türkiye ekonomisi özeli için araştırılma yoluna gidilmiştir. Bu bağlamda çalı̧̧mada Türkiye için 1992:01-2014:12 döneminde seçimlerin ve politik değişkenlerin reel döviz kuru oynaklığı üzerindeki etkisi incelenmiştir. Seçimlerin ve politik değişkenlerin kur oynaklığı üzerindeki etkisinin incelenmesindeki amaç, politikacıların seçim dönemlerinde yeniden iktidara gelebilmek için döviz kurunu manipüle edip etmediklerinin araştırılmasıdır. Bu bağlamda öncelikle reel döviz kuru oynaklığ ARCH modelleriyle tespit edilmiş ve en başarılı modelin E-GARCH olduğuna karar verilmiştir. Ardından literatürden hareketle seçimlerin ve merkez bankası bağımsızlığı, koalisyon, iktidarın meclisteki koltuk sayısı (meclisteki güç) ve kur rejimi gibi politik değişkenlerin kur oynaklığı üzerindeki etkisi analiz edilmiştir. Söz konusu değişkenler E-GARCH modelinde hem ortalama hem de varyans denkleminde tahmin edilmiştir. Ortalama denklemindeki tahmin sonuçları reel döviz kuru açısından; varyans denklemindeki tahmin sonuçları ise reel döviz kuru oynaklığı açısından yorumlanmaktadır.

Analiz sonuçları genel olarak değerlendirildiğinde, seçimlerin ve politik faktörlerin reel döviz kuru ve reel döviz kuru oynaklığı üzerinde sınırlı da olsa etkili olduğu söylenebilir. Ancak, genel literatürün aksine, politikacıların seçim dönemlerinde firsatçı amaçlarla döviz kurunu manipüle ettiklerine dair anlamlı ve güçlü bir sinyal Türkiye ekonomisi özelinde yakalanamamıştır. Bunun bir nedeni, Türkiye gibi ekonomik ve siyasi istikrarsızlıkların uzun yıllar hüküm sürdüğü bir ülkede, politikacıların sınırlı seçeneklere sahip olmaları nedeniyle, bu tür manipülatif davranışları özellikle döviz kuru bağlamında gerçekleştirmelerinin zorlaşmasıdır. Diğer bir nedeni de seçim dönemlerinin yarattığı belirsizlik ortamının, seçmenler ve yatırımcıların yatırım kararlarını ertelemeleri ve ülkeden sermaye kaçışına neden olması gibi faktörlerin reel döviz kuru oynaklı̆̆ı üzerinde politikacılardan daha fazla etki yapması olabilir. Ayrıca artan küreselleşmeyle birlikte uluslararası ticaretin ve kısa vadeli sermaye hareketlerinin serbestleşmesi, ülkelerin uyguladıkları ekonomi politikalarının birbirlerini daha fazla etkilemesine ve dolayısıyla dış ülkelerde uygulanan bir kur politikasının yurtiçine yansımalarının politikacıların amaçlarını gerçekleştirmeleri önünde bir engel teşkil ettiği söylenebilir.

\section{Kaynakça}

- Aboal, D., Lorenzo, F., Rius, A. (2000). "Is the Exchange Rate Politically Manipulated Around Elections? The evidence from Uruguay". Working Paper 18/00, p. 1-28.

- Akalın, G., Erkişi, K. (2007). "Türkiye'de Seçim Ekonomisi Uygulamalarının Geleneksel Oportünist Seçim Çevrimleri Açısından Değerlendirilmesi”. ZKÜ Sosyal Bilimler Dergisi, 3(5), p.89-116.

- Alesina, A. (1989). "Politics and Business Cycles in Industrial Democracies". Economic Policy, 4 (8), p. 57 98.

- Bollerslev, T. (1986). "Generalized Autoregressive Conditional Heteroskedasticity". Journal of Econometrics, 31, p. 307-327. 
- Brunner, M. (2009). "Does Politics Matter? The Influence of Elections and Government Formation in the Netherlands on the Amsterdam Exchange Index". Acta Politica, 44 (2), p. 150-170.

- Bussière, M., Mulder, C. (1999). “Political Instability and Economic Vulnerability”. IMF Working Paper, 46, p. 1-36.

- Demirgil, H. (2011). "Politik İstikrarsızlık, Belirsizlik ve Makroekonomi: Türkiye Örneği (1970-2006)". Marmara Üniversitesi İ.I.B.F. Dergisi, 31 (2), p. 123-144.

- Engle, R. F. (1982). "Autoregressive Conditional Heteroscedasticity with Estimates of the Variance of United Kingdom Inflation”. Econometrica, 50 (4), p. 987-1007

- $\quad$ Ertuğrul, H. M. Türkiye'de Döviz Kuru Volatilitesi ve Enflasyon İlişkisi. (Yayınlanmamış Doktora Tezi). Ankara: Hacettepe Üniversitesi Sosyal Bilimler Enstitüsü. 2012.

- Freeman, J. R., Hays, J. C., Stix, H. (2000). "Democracy and Markets: The Case of Exchange Rates". American Journal of Political Science, 44 (3), p. 449-468.

- Frieden, J. A. (1998). "The Political Economy of European Exchange Rates:An Empirical Assessment”. Department of Government Harvard University Cambridge, MA 02138, p. 1-62.

- $\quad$ Frieden, J., Ghezzi, P., Stein, E. (2000). "Politics and Exchange Rates in Latin America". Inter-American Development Bank Research Network Working paper, R-421, p. 1-53.

- Garza, C.G. The Political Cycle and The Mexican Economy. (Phd Theses). Instituto Tecnologico y de Estudios Superiores de Monterrey. 2006.

- Hibbs, D. A. (1977). "Political Parties and Macroeconomic Policy". The American Political Science Review, 71 (4), p. 1467-1487.

- Jaramillo, J. C., Steiner, R., Salazar, N. (1999). "The Political Economy of Exchange Rate Policy in Colombia". Banco Interamericano de Desarrollo Documento de Trabajo R-366, p. 1-34.

- $\quad$ Lee, J., Strazicich, M.C. (2003). "Minimum Lagrange Multiplier Unit Root Test With Two Structural Breaks". The Review of Economics and Statistics, 85 (4), p. 1082-1089.

- $\quad$ Lobo, B. J., Tufte, D. (1998). “Exchange Rate Volatility: Does Politics Matter?”. Journal of Macroeconomics, 20(2), p.351-365.

- Nelson, D.B. (1991). "Conditional Heteroskedasticity in Asset Returns: A New Approach”. Econometrica, 59 (2), p. 347-370.

- Nordhaus, W. (1975). “The Political Business Cycle”. The Review of Economic Studies, 42 (2), p. 169-190.

- Onur, S. (2001). "Politik Konjonktür Dalgalanmaları ve Türkiye Uygulaması (1950-2000)”. Süleyman Demirel Üniversitesi İktisadi ve İdari Bilimler Fakültesi Dergisi, 6 (2), p. 157-184.

- Onur, S. (2002). "Politik Bütçe Döngüleri ve Türkiye Ekonomisi (1975-2000)". Uludağ Üniversitesi İktisadi ve Ídari Bilimler Fakültesi Dergisi, (2), p. 85-126.

- Remmer, K. L. (1993). “The Political Economy of Elections in Latin America, 1980-1991”. American Political Science Review, 87 (2), p. 393-407.

- Sibley, M. (2001). "The Impact of Presidential Elections on Currency Values in Latin America”. Multinational Business Review, 9(2), p. 14-19.

- Stein, E. H., Streb, J. M. (2004). "Elections and The Timing of Devaluations". Journal of International Economics, 63, p. 119-145.

- Stein, E. H., Streb, J. M., Ghezzi, P. (2005). "Real Exchange Rate Cycles Around Elections". Economics \& Politics, 17 (3), p. 297-330.

- Zivot, E., Andrews, D.W.K. (1992). "Further Evidence on the Great Crash, the Oil-Price Shock, and the Unit-Root Hypothesis”. Journal of Business \& Economic Statistics, 10 (3), p. 251-270. 


\title{
Döviz Kurunun Çıktı Üzerindeki Etkisi: Geçiş Ülkeleri Örneği The Impact of Exchange Rate on Output: Evidence from Transition Countries
}

\author{
Prof. Dr. Ebru Çağlayan Akay (Marmara University, Turkey) \\ Asst. Prof. Dr. Raziiakhan Abdieva (Kyrgyzstan-Turkey Manas University, Kyrgyzstan) \\ Asst. Prof. Dr. Zamira Oskonbaeva (Kyrgyzstan-Turkey Manas University, Kyrgyzstan)
}

\begin{abstract}
This study investigates the impact of exchange rate on aggregate output for a group of 10 transition economies using panel simultaneous equation model. The model is estimated by generalized two-stage least squares method. The annual data used in the study cover the period from 1998 to 2014 for selected transition countries which are: Azerbaijan, Kazakhstan, Kyrgyzstan, Belarus, Georgia, Moldova, Russia, Tajikistan, Ukraine and Latvia. The result of the study indicates that there is a relationship between exchange rate and macroeconomic variables under consideration. It can be concluded that output effect of exchange rate changes is contractionary in the first year. In the second year this impact is completely reversed. Thus, the impact of exchange rate on output is neutral in the long run. The findings of the study will provide useful information to researchers and policymakers focusing on exchange rate issues in transition countries.
\end{abstract}

\section{Giriş}

Döviz kurunda meydana gelecek değişmeler ülke parasının göreceli olarak değerini değiştirerek, yurtiçi ve yurtdışı fiyatların yapısını önemli ölçüde etkilemektedir. Dış sektörde istikrarın sağlanması açısından döviz kurunun önemli bir araç olarak kullanılabileceği savunulmaktadır. Devalüasyon yani ulusal paranın değer kaybetmesi, bir yandan yurt içinde üretilen malları yurtdışına göre ucuzlatarak ihracatın artmasına, ithalatın azalmasına neden olacak ve dış ticaret dengesinin iyileşmesine olumlu katkıda bulunacaktır. Bu tür gelişmeler ise ekonomi üzerinde genişletici etki yaratacaktır (Bahmani ve Gelan, 2013).

Çalışmamızın amacı, seçilmiş geçiş ülkelerinde (Azerbaycan, Kazakistan, Kırgızistan, Beyaz Rusya, Gürcistan, Moldova, Rusya, Tacikistan, Ukrayna ve Letonya) döviz kurunda meydana gelecek değişimlerin çıktı üzerindeki etkisini inceleyerek, bu ülkeler için döviz kurunun daraltıcı, genişletici veya yansız etkilerden hangisini gösterdiğini ortaya koymaktır. Bu amaç için 1998-2014 dönemine ait yıllık verilere üç denklemden oluşan panel eşanlı modeli uygulanmıştır.

Çalışmada, giriş bölümünün ardından döviz kuru, çıktı ve kamu harcamaları arasındaki ilişki açıklanmıştır. Üçüncü bölümde kullanılan metodoloji ve veri seti tanımlanmıştır. Çalışmamız elde edilen bulgular ve sonuç bölümü ile sona ermektedir.

\section{Döviz Kuru Kavramı ve Döviz Kuru ile Çıktı, Kamu Harcamaları İlişkisi}

Gelişmiş ve gelişmekte olan ülkelerde döviz kurlarında meydana gelen değişmeler temel ekonomik göstergeleri etkileyen en önemli değişkenlerden biri olmuştur. Döviz kuru, çıktı ve "kamunun toplumsal gereksinimleri karşılamak, sosyal ve ekonomik hayata müdahalelerde bulunmak üzere belirli kurallara göre yaptığı harcamalar toplamı" olarak tanımlanan kamu harcamaları arasındaki ilişkiyi ele alacak olursak söz konusu değişkenler arasında etkileşim mevcuttur.

Döviz kuru ve kamu harcamaları arasındaki ilişki iki farklı yaklaşımla açıklanabilir. Bunlardan biri neoklasik modeldir ve kamu harcamalarındaki artışın reel döviz kurunun değer kaybetmesine ve çıktının artmasına neden olacağını öngörmektedir. İleri görüşlü tüketici bu modele göre, kamu harcamalarındaki cari artışın ileride vergilerdeki artış yolu ile finanse edileceğinin farkına varmaktadır. Dolayısıyla cari emek arzının artması ve reel ücretlerin düşmesi beklenmektedir. Sonuç olarak özel tüketim azalarak reel döviz kuru değer kaybederken çıktıda düşüşler meydana gelecektir. Diğer yandan Neo-Keynesgil model kamu harcamalarındaki artışın reel döviz kurunun değer kazanmasına neden olacağını ileri sürmektedir. Kamu harcamalarındaki artış ile beraber çıktı oranında da artışlar meydana gelir. Bu ise emek talebini yükseltir ve reel ücretlerin artmasına sebep olur. Bu nedenle özel tüketim artacak ve reel döviz kuru değer kazanacaktır (Çebi ve Çulha, 2014).

Ampirik çalışmalar döviz kuru ile kamu harcamaları arasındaki ilişkinin iki farklı şekilde olabileceğini göstermektedir. Bazı çalışmalarda kamu harcamalarında meydana gelecek artışın reel döviz kurunun değer kaybetmesine neden olacağı öne sürülürken (Ravn vd. 2000; Kim ve Roubini 2008; Corsetti vd. 2009; Monacelli ve Perotti 2010; Enders vd. 2011), diğerlerinde tam tersine reel döviz kurunun değer kazanacağ1 vurgulanmaktadır (Beetsma vd. 2008; Bénétrix ve Lane (2009a, b) ve Castro ve Fernandez, 2013). 
Döviz kuru ve çıktı arasındaki ilişkiye bakıldığında, döviz kurunun çıktı üzerindeki etkisinin daraltıcı ya da genişletici yönde olabileceği beklenmektedir. Bu değişkenler arasındaki ilişki çift yönlü de olabilir ve çıktı da döviz kurunu açıklayabilir (Odedokun 1997; Kamin ve Klau, 1998). Balassa (1964), Samuelson (1964) ve öncesinde Harrod (1933) tarafindan vurgulanan hipoteze göre reel döviz kurundaki değişimin sebebi sektörler arasındaki verimlilik farklılığından kaynaklanmaktadır. Diğer bir deyişle ticaret ortaklarının çıktı düzeylerine oranla bir ülkenin çıktı düzeyinde, verimlilikten kaynaklanan bir artış meydana gelirse, o zaman reel döviz kuru değerlenecektir.

Çıktı ve kamu harcamaları arasındaki ilişkinin yönü ise iki farklı görüşle açıklanabilmektedir. Keynesyen görüşte kamu harcamaları ile çıktı arasındaki ilişki kamu harcamaları artışından çıktıya doğrudur. Keynesyen görüş efektif talep yetersizliğini ortadan kaldırmak için kamu harcamalarının artırılması gerektiğini ve bu yolla üretim ve istihdam duzeyinin artırılabileceğini ileri sürmektedir. Kamu harcamaları toplam çıktı düzeyini değiştiren dışsal bir değişken olarak ele alınmıştır (Loizides ve Vamvoukas, 2005). Bu nedenle, nedensellik ilişkisinin yönü kamu harcamaları artışından çıktıya doğrudur (Tuna, 2013). Alman iktisatçı Adolph Wagner (1883) tarafından ortaya atılan ve Wagner Yasası olarak ifade edilen yaklaşım kamu harcamaları ile çıktı arasındaki ilişkinin çıktıdan kamu harcamaları artışına doğru olduğuna işaret eder. "Kamu harcamaları artış yasası" şeklinde adlandırılan bu yasaya göre çıktıdaki artış devletin kamusal faaliyetlerini genişletmektedir.

\section{Veri ve Değişkenler}

Bu çalışmada 1998-2014 dönemine ait yıllık veriler kullanılarak geçiş sürecindeki 10 ülke için için döviz kurunun çıktı üzerindeki etkisi incelenmiştir. Bu ülkeler, Azerbaycan, Kazakistan, Kırgızistan, Beyaz Rusya, Gürcistan, Moldova, Rusya, Tacikistan, Ukrayna ve Letonya'dır. Tüm veriler Dünya Bankası veri tabanından temin edilmiştir (World Bank, 2016). Uygulamada kullanılan verilere ilişkin bilgiler Tablo 1.'de özetlenmiştir.

\begin{tabular}{lll}
\hline Değişken & Kısaltma & Tanımlama \\
\hline Döviz kuru & RER & Reel döviz kuru $\left(\mathrm{R}=\mathrm{e}^{*} \mathrm{P}_{\mathrm{d}} / \mathrm{P}_{\mathrm{f}}\right)$ \\
Çıktı & GDP & Sabit 2005 ABD\$ \\
Para arzı & MS & Geniş para arzı (ABD\$ cinsinden) \\
Enflasyon & INF & Tüketici fiyat endeksi (\%) \\
Kamu harcamaları & GEXP & Kamu harcamaları (ABD\$) \\
Kamu gelirleri & GREV & Kamu gelirleri (ABD\$) \\
Dışa açılık oranı & OPEN & (İhracat+İthalat)/GSYİH (\%) \\
\hline Notlar: & \\
(i) e= nominal döviz kurunu, P $_{\mathrm{d}}$ yurtiçi fiyatlar düzeyini ve $\mathrm{P}_{\mathrm{f}}$ ise yurtdışı fiyatlar düzeyini \\
ifade etmektedir. \\
(ii) Çalışmada değişkenler logaritmik formları ile incelenmiştir \\
\hline
\end{tabular}

Tablo 1. Değişken Tanımı

\subsection{Panel Eşanlı Modelleri ve Genelleştirilmiş İki Aşamalı En Küçük Kareler}

İktisadi olaylar her zaman tek bir denkleme indirgenen modeller ile açıklanamayacak kadar karmaşık yapıya sahiptirler. İktisadi olayların birden çok denklem tarafından açıklandığı modellerden biri de eşanlı denklem modelleridir. Tek denklemli modellerde bağımsız değişkenden bağımlı değişkene doğru tek yönlü neden-sonuç ilişkisi varken eşanlı denklem modellerinde değişkenler arasında karşılıklı neden sonuç ilişkisi ortaya çıkmaktadır.

Panel eşanlı modeli,

$$
y_{j}=Y_{j} \beta_{j}+X_{j} \gamma_{j}+u_{j}
$$

şeklinde gösterilebilir. Burada $Y_{j}, N T \times g_{j}$ boyutunda bir matris ve $X_{j}$ ise $N T \times\left(k_{j}+1\right)$ boyutunda bir matristir. Tüm içsel ve dişsal değişkenler $Z_{j}=\left[Y_{j}, X_{j}\right]$ şeklinde, parametreler de $\delta_{j}^{\prime}=\left[\beta_{j}^{\prime}, \gamma_{j}^{\prime}\right]$ şeklinde bir araya getirilerek eşanlı denklem modelinin j. yapısal kalıp denklemi için matris gösterimi,

$$
y_{j}=Z_{j} \delta_{j}+u_{j}
$$

olarak yazılabilir. Birimlerin gözlenemeyen etkisi, hata teriminin bir bileşeni olarak $u_{j}=Z_{\mu} \mu_{j}+v_{j}$ şeklinde denklemde yer almaktadır (Baltagi, 2009).

Panel Eşanlı Modelleri için, Genelleştirilmiş İki Aşamalı En Küçük Kareler tahmincisi,

$$
\delta_{j, G 2 S L S}=\left[Z_{j}^{* \prime} P_{X^{*}} Z_{j}^{*}\right]^{-1} Z_{j}^{* \prime} P_{X^{*}} y_{j}^{*}
$$

olarak elde edilir (Baltagi, 2009). Burada, $Z_{j}^{*}=\Omega_{j j}^{-1 / 2} Z_{j}$ ve $y_{j}^{*}=\Omega_{j j}^{-1 / 2} y_{j}$ varyans kovaryans matrisi kullanılarak dönüşüm yapılmış değişkenlerdir. $P_{X^{*}}=X^{*}\left(X^{*^{\prime}} X^{*}\right)^{-1} X^{* \prime}$ ise şeklindedir. Varyans kovaryans matrisi, $\Omega_{j j}=\sigma_{\mu j j}^{2}\left(I_{N} \otimes J_{T}\right)+\sigma_{v j j}^{2}\left(I_{N} \otimes I_{T}\right)$ ifadesine eşittir. Balestra ve Varadharajan-Krishnakumar, tüm dişsal 
değişkenleri göstermek üzere araç değişken kümesi olarak, $X^{*}=\Omega_{j j}^{-1 / 2} X \quad$ şeklinde varyans kovaryans matrisi ile dönüşüm yapılmış dışsal değişkenlerin parametre tahmininde kullanılmasını önermişlerdir.

\section{Tahmin Sonuçları}

Çalışmada farklı dinamik yapılı modeli uygylayan Eme ve Olugboyega (2012) çalışmasından yararlanarak, ele alınan geçiş ülkeleri için döviz kuru ile çıktı arasındaki ilişki çıktı, döviz kuru ve kamu harcamaları denklemleri şeklinde üç denklemli panel eşanlı modeli ile tahmin edilmiştir. Tahmin edilen panel eşanlı modeli,

Çıktı denklemi: $\quad L G D P_{i t}=\alpha_{0}+\alpha_{1} L M S_{i t}+\alpha_{2} L R E R_{i t}+\alpha_{3} L R E R_{i t-1}+\varepsilon_{i t}$

Döviz kuru denklemi: $L R E R_{i t}=\beta_{0}+\beta_{1} L I N F_{i t}+\beta_{2} L G E X P_{i t}+\beta_{3} L O P E N_{i t}+\beta_{4} L G D P_{i t}+\varepsilon_{i t}$

Kamu harcamaları denklemi: $L G E X P_{i t}=\gamma_{0}+\gamma_{1} L G D P_{i t}+\gamma_{2} L G R E V_{i t}+\varepsilon_{i t}$

şeklindedir. Birinci denklem çıktı denklemidir. Bu denklem için para arzındaki genişlemenin çıktı üzerindeki etkisinin arttıııcı yönde olacağı, yani $\alpha_{1}>0$ olacağı beklenmektedir. Döviz kuru katsayısının ise pozitif ya da negatif değer alacağı beklenmektedir. Katsayı pozitif değer alacaksa devalüasyonun genişletici etki yarattığı, oysaki negatif değer alacaksa daraltıcı etki yarattı̆̆ı söylenebilir.

İkinci denklem döviz kuru denklemidir. Bu denklemde $\beta_{1}$ enflasyon katsayısının pozitif değer alacağı beklenmektedir. $\beta_{2}$ kamu harcamaları katsayısının ya pozitif ya da negatif değer alacağı beklenmektedir. Döviz talebinin artması dövizin fiyatının yükselmesi buna karşılık ulusal paranın değer kaybetmesi demek olacaktır (Drine ve Rault, 2001). Bu nedenle $\beta_{3}$ dışa açıklık oranının ya pozitif ya da negatif değer alacağı öngörülmektedir. Bazı araştırmacılar, ticari serbestleşmeden sonra dışa açıklığın reel döviz kuru üzerinde pozitif bir etkiye sahip olduğunu belirtirken (Edwards, 1993; Hau, 2002); diğerleri ise dışa açıklığın reel döviz kurları üzerinde negatif bir etkiye sahip olduğunu belirtmiştir (Calvo ve Drazen,1998). Balassa-Samuelson hipotezine göre çıktıda meydana gelecek herhangi bir artış reel kurun değerlenmesine neden olacaktır. Dolayısıyla $\beta_{4}$ çıktı değişkeninin negatif değer alacağı beklenmektedir.

Üçüncü denklem ise kamu harcamaları denklemidir. Bu denklemde çıktı $\gamma_{1}$ ve kamu gelirleri $\gamma_{2}$ katsayılarının pozitif değer alacağı öngörülmektedir. Çıktı ile kamu harcamaları arasındaki pozitif yönlü ilişki katsayının birden büyük değer alması halinde Wagner yasası ile açıklanabilmektedir. Yani kamu harcamalarının çıktıdaki artışa göre daha hızlı büyüyeceği ortaya konulacaktır. Kamu gelirleriyle kamu harcamaları arasındaki pozitif yönlü ilişki Friedman (1978) tarafından dile getirilen, vergi-harcama (tax-and spend) hipoteziyle açıklanabilmektedir. Buna göre, kamu gelirlerindeki değişmeler, kamu harcamalarında değişmelere neden olacaktır.

Eşanlı denklem modelinde çıktı (LGDP), reel döviz kuru (LRER), kamu harcamaları (LGEXP) içsel değişken, para arzı (LMS), enflasyon oranı (LINF), dışa açıklık oranı (LOPEN), kamu gelirleri (LGREV) dışsal değişken ve bir dönem gecikmeli reel döviz kuru (LRER $\left.{ }_{t-1}\right)$ ise gecikmeli içsel değişkendir. Ele alınan panel eşanlı modelinin doğru kurulup kurulmadığını belirlemek için ilk olarak belirlenme durumu incelenmiştir. Boy şartı, bir denklemin belirlenebilmesi için gerekli fakat yeterli olmayan şarttır. Bir denklemin bu şarta göre belirlenebilir olması için incelenen denklemde yer almayan değişkenler sayısının $\left(\mathrm{k}_{\mathrm{j}}{ }^{*}\right)$ modelde yer alan içsel değişken sayısının bir eksiğine $\left(\mathrm{g}_{\mathrm{j}}\right)$ eşit veya daha fazla olması gerekir. Rank şartı ise bir denklemin belirlenmiş olması için yeterli şarttır. Bu şarta göre denklemin belirlenebilir olması için, incelenen denklemde bulunmayan diğer denklemlerde bulunan değişkenler matrisinin satır yada sütun rankının g-1'e (rank $\left.\left(A_{j}\right) \geq g-1\right)$ yani modelde yer alan içsel değişken sayısının bir eksiğine eşit olması gerekir (Şükrüoğlu, 2015).

Bunun için modelde yer alan her bir denklem için boy ve rank şartı incelenmiş ve sonuçları sırasıyla Tablo 2.'de verilmiştir.

\begin{tabular}{|c|c|c|}
\hline Denklem & Boy Şartı $\left(k_{j}^{*} \sim g_{j}\right)$ & Karar \\
\hline Çıktı Denklemi & $\mathrm{k}_{\mathrm{j}}^{*}>\mathrm{g}_{\mathrm{j}}$ & Aşırı Belirlenme \\
\hline Döviz Kuru Denklemi & $\mathrm{k}_{\mathrm{j}}^{*}>\mathrm{g}_{\mathrm{j}}$ & Aşırı Belirlenme \\
\hline Kamu Harcamaları Denklemi & $\mathrm{k}_{\mathrm{j}}^{*}>\mathrm{g}_{\mathrm{j}}$ & Aşırı Belirlenme \\
\hline
\end{tabular}

Tablo 2. Boy Şartı

Rank şartını incelemek için denklemlerin hata terimleri sağ tarafta kalacak şekilde düzenlenmesiyle oluşturulan rank şartı inceleme tablosundan yararlanarak, üç denklem için rank şartının inceleneceği $\mathrm{A}_{1}, \mathrm{~A}_{2}$ ve $\mathrm{A} 3$ matrisleri sirasiyla, $A_{1}=\left[\begin{array}{cccc}-\beta_{2} & -\beta_{1} & -\beta_{3} & 0 \\ 1 & 0 & 0 & -\gamma_{2}\end{array}\right], A_{2}=\left[\begin{array}{ccc}-\alpha_{1} & -\alpha_{3} & 0 \\ 0 & 0 & -\gamma_{2}\end{array}\right]$ ve $A_{3}=\left[\begin{array}{ccccc}-\alpha_{2} & -\alpha_{1} & -\alpha_{3} & 0 & 0 \\ 1 & 0 & 0 & -\beta_{1} & -\beta_{3}\end{array}\right]$ olarak belirlenmiştir. Bu denklemler için rank $(\mathrm{A}) \geq \mathrm{g}-1$ eşitsizliğini sağlandığından söz konusu denklemler için rank şartının da sağlandığı görülmüştür. Ayrıntılı sonuçlar, istenildiğinde yazarlardan temin edilebilir. 
Hem boy şartına göre hem de rank şartına göre her bir denklemin belirlendiği görülmüş ve model Genelleştirilmiş İki Aşamalı EKK yöntemi ile tahmin edilmiştir. Tahmin sonuçları Tablo 3.’te yer almaktadır. Ele alınan eşanlı denklem modeli için iki aşamalı grup içi tahminler de yapılmış, katsayıların tümü için istatistiksel anlamlı sonuçlara ulaşılamamış, bu nedenle burada raporlanmamıştır.

\begin{tabular}{|c|c|c|c|}
\hline Değişkenler & Çıktı Denklemi & $\begin{array}{l}\text { Döviz Kuru } \\
\text { Denklemi }\end{array}$ & $\begin{array}{c}\text { Kamu Harcamaları } \\
\text { Denklemi }\end{array}$ \\
\hline LMS & $\begin{array}{l}0.2909 * * * \\
(0.0141)\end{array}$ & & \\
\hline LRER & $\begin{array}{l}-0.3822 * * * \\
(0.0961)\end{array}$ & & \\
\hline $\mathrm{LRER}_{\mathrm{t}-1}$ & $\begin{array}{l}0.2738 * * * \\
(0.0693)\end{array}$ & & \\
\hline LINF & & $\begin{array}{l}1.9891 * * * \\
(0.0683)\end{array}$ & \\
\hline LGEXP & & $\begin{array}{l}-0.2223 * * \\
(0.1157)\end{array}$ & \\
\hline LOPEN & & $\begin{array}{c}-0.2833 * * * \\
(0.1033)\end{array}$ & \\
\hline LGDP & & $\begin{array}{l}-0.7489 * * \\
(0.3176)\end{array}$ & $\begin{array}{l}0.0308 * * \\
(0.0128)\end{array}$ \\
\hline LGREV & & & $\begin{array}{l}1.0026 * * * \\
(0.0044)\end{array}$ \\
\hline Sabit & $\begin{array}{l}17.3910 * * * \\
(0.3418)\end{array}$ & $\begin{array}{l}16.4218 * * * \\
(5.7919)\end{array}$ & $\begin{array}{l}0.7176^{* *} \\
(0.2946)\end{array}$ \\
\hline $\mathrm{R}^{2}$ & 0.8407 & 0.9364 & 0.9208 \\
\hline Wald Testi & $632.61 * * *$ & $1615.58 * * *$ & $53325.78 * * *$ \\
\hline
\end{tabular}

Tablo 3. Genelleştirilmiş İki Aşamalı EKK Tahmin Sonuçları

Panel eşanlı denklem modelindeki her denklem için elde edilen parametre tahminleri,

$L G D P_{i t}=17.3910+0.2909 L M S_{i t}-0.3822 L R E R_{i t}+0.2738 L R E R_{i t-1}$

$L R E R_{i t}=16.4218+1.9891 L_{I N F_{i t}}-0.2223 L G E X P_{i t}-0.2833 L O P E N_{i t}-0.7489 L G D P_{i t}$

$L G E X P_{i t}=0.7176+0.0308 L G D P_{i t}+1.0026 L G R E V_{i t}$

olarak gösterilebilir. Üç model incelendiğinde, modellerin genel olarak anlamlılıklarını sınamak için yapılan Wald testi sonuçlarının anlamlı olduğu görülmektedir. Her üç denklem için belirlilik katsayısı değerleri sırasıyla, $\% 84, \% 93$ ve $\% 92$ olarak bulunmuştur.

Genelleştirilmiş İki Aşamalı EKK tahmin sonuçlarına göre bütün katsayıların istatistiksel olarak anlamlı olduğu görülmektedir. Elde edilen parametre tahminlerini yorumlayacak olursak çıktı denkleminde para arzındaki \% 1' lik artışın \% 0.29 oranında çıktı üzerinde artışa neden olacağı görülmektedir. Döviz kurundaki \% 1'lik artış kısa dönemde çıktı üzerinde $\% 0.38$ oranında daraltıcı etkiye sahipken, bir dönem sonra $\% 0.27$ oranında arttırıcı etkiye sahip olduğu gözlenmektedir. Bu sonuçlara göre, devalüasyonun cari ve gecikmeli etkileri birbirini etkisiz hale getirir ve uzun dönemde devalüasyonun yansız olduğu yani çıktı üzerinde hiç bir etki yaratmadığı ifade edilebilir (Edwards, 1986).

Döviz kuru denklemi incelendiğinde, enflasyon oranındaki \% 1'lik artışın döviz kurunu \% 1.98 oranında artıracağı ve dışa açıklık oranındaki \% 1'lik artışın döviz kurunu \% 0.28 oranında düşüreceği söylenebilir. Kamu harcamalarındaki \% 1'lik artışın döviz kurunun \% 0.22 oranında değer kazanmasına neden olacağı görülmektedir. Diğer bir deyişle kamu harcamaları ve döviz kuru arasındaki ilişkiyi açıklarken Neo-Keynesgil modelin geçerli olduğu kanısına varılabilir. Çıktıdaki \%1'lik artış ise reel kuru \% 0.74 oranında değerlendireceği gözlemlenmektedir. Bu sonuç Balassa-Samuelson hipotezinin geçerli olduğuna işaret etmektedir.

Kamu harcamaları denkleminde ise çıktı ve kamu gelirlerindeki \% 1'lik artışın kamu harcamaları üzerinde sırasıyla \% 0.03 ve \% 1.00 oranında arttırıcı etki yaratacağı görülmektedir. Wagner Yasası'nın geçerli olabilmesi için LGDP değişkeni katsayısının 1'den büyük olması gerekmektedir. Elde edilen sonuca göre $0.03<1$ olduğundan, bulgular doğrultusunda Wagner Yasası desteklenmemektedir. Bu sonuç, geçiş ülkeleri için ele alınan dönemde çıktı ile kamu harcamaları arasında doğrudan bir ilişkinin kurulamadığı sonucunu ortaya koymaktadır. Kamu gelirleriyle kamu harcamaları arasındaki pozitif yönlü ilişki ise vergi-harcama hipoteziyle açıklanabilmektedir. Buna göre, kamu gelirlerindeki değişmeler, kamu harcamalarında değişmelere neden olacaktır. Kamu gelirlerini 
artırmak amacıyla vergilerin artırılması yalnızca harcamaların artmasına neden olacaktır ve sonuçta bütçe açıkları üzerinde olumlu bir etki gerçekleşmeyecektir.

\section{Sonuç}

Geleneksel teoride döviz kurunda meydana gelen değişmelerin (ulusal paranın değer kaybetmesinin) ekonomi üzerinde genişletici etkisinin olduğu öne sürülmektedir. Bu görüşe zit olarak reel döviz kurunun devalüe edilmesinin ise daraltıcı olabileceği yani çıktı üzerinde etkisinin negatif yönde olabileceği de savunulmaktadır. Bu çerçevede, çalışmada döviz kuru ile çıktı arasında gözlemlenecek negatif ya da pozitif yönlü ilişkinin varlığı, geçiş sürecindeki 10 ülke (Azerbaycan, Kazakistan, Kırgızistan, Beyaz Rusya, Gürcistan, Moldova, Rusya, Tacikistan, Ukrayna ve Letonya) için incelenmiştir. 1998-2014 dönemine ait yıllık veriler kullanılarak, üç denklemden oluşan panel eşanlı modeli genelleştirilmiş iki aşamalı en küçük kareler yöntemi ile tahmin edilmiştir.

Çalışmadan elde edilen bulgulara göre, döviz kurunun çıktı üzerinde aynı dönemde negatif etkisi olduğu, bir dönem önceki döviz kurunun etkisinin pozitif olduğu görülmüştür. Buna göre, döviz kurunun çıktı üzerinde kısa dönemde daraltıcı etki, bir dönem sonra ise bu etkinin tersine dönmesi nedeniyle genişletici etki yarattığ bulunmuştur. Uzun dönemde bu pozitif ve negatif etkiler zaman içinde birbirlerini dengeleyeceğinden etkisi nötr olacaktır. Sonuç olarak, geçiş ülkeleri için uzun dönemde döviz kurunun çıktı üzerindeki etkisinin nötr (yansız) olduğu söylenebilir. Bu çalışmadan elde edilen sonuçlar Edwards (1986), Acar (2000) ve Sencicek ve Upadhyaya (2008)'nın çalışmalarıyla örtüşmektedir.

\section{Kaynakça}

- Acar M., 2000. "Devaluation in Developing Countries: Expansionary or Contractionary?” Journal of Economic and Social Research, 2(1), 59-83.

- Balassa, B., 1964. "The purchasing power doctrine: a reappraisal”, Journal of Political Economy, 72, 584596.

- $\quad$ Baltagi, B. H. 2009. A Companion to Econometric Analysis of Panel Data, John Wiley and Sons, Ltd. Publication, England.

- Bahmani-Oskooee. M. ve Gelan A., 2013. “Are Devaluations Contractionary in Africa?” Global Economic Review, 42(1), 1-14.

- $\quad$ Beetsma, R., Giuliodori, M. ve Klaassen, F. 2008. "The effects of public spending shocks on trade balances and budget deficits in the European Union", Journal of the European Economic Association, 6, 414-23.

- Bénétrix, A. S. ve Lane, P. R. 2009a. "The impact of fiscal shocks on the Irish economy", The Economic and Social Review, 40, 407-34.

- Bénétrix, A. S. ve Lane, P. R. 2009b. "Fiscal shocks and the real exchange rate”, IIIS Discussion Paper 286, Institute for International Integration Studies, Dublin.

- Calvo, A.G. ve Drazen, A., 1997. Uncertain Duration of Reform: Dynamic Implications. NBER Working Paper No. 5925.

- Castro, F. ve Fernandez, L. 2013. "The effects of fiscal shocks on the exchange rate in Spain", The Economic and Social Review, 44, 151-80.

- Corsetti, G., Meier, A. ve Müller, G. J. 2009. "Fiscal Stimulus with spending reversals", IMF Working Paper 09/106, International Monetary Fund, Washington, DC.

- Çebi C. ve Çulha A. A., 2014. "The effects of government spending shocks on the real exchange rate and trade balance in Turkey, Applied Economics, 46(26), 3151-3162.

- Drine, İ. ve Rault C., 2001. 'Long-run determinants of real exchange rate : New evidence based on panel data unit root and cointegration tests for MENA countries", ss.1-26.

- Eme A. ve Olugboyega A., 2012. "Exchange Rate and Macroeconomic Aggregates in Nigeria", Journal of Economics and Sustainable Development, 3(2), 93-102.

- Edwards, S., 1986. “Are devaluations contractionary?” Review of Economics and Statistics, 68, 501-508.

- Edwards, S. 1993. “Openness, Trade Liberalization and Growth in Developing Countries”, Journal of Economic Literature, 31(3), 1358-93.

- $\quad$ Enders, Z., Müller, G. J. ve Scholl, A. 2011. "How do fiscal and technology shocks affect real exchange rates? New evidence for the United States", Journal of International Economics, 83, 53-69.

- Friedman, M., 1978. “The Limitations of Tax Limitation”, Policy Review, 5, 7-14.

- Harrod, R., 1933. International Economics. London; Nisbet and Cambridge University Press.

- Hau, H. 2002. "Real Exchange Rate Volatility and Economic Openness: Theory and Evidence", Journal of Money, Credit and Banking, 34(3): 611-30. 
- Kamin, S. B. ve Klau, M., 1998. "Some multi-country evidence on the effect of real exchange rate on output", International Finance Discussion Papers, 611, Board of Governors of the Federal Reserve System, Washington, DC.

- $\quad$ Kim, S. ve Roubini, N., 2008. "Twin deficit or twin divergence? Fiscal policy, current account and real exchange rate in the U.S.”, Journal of International Economics, 74(2), 362-83.

- Loizides J. ve Vamvoukas G., 2005. “Government Expenditure And Economic Growth: Evidence from Trivariate Causality Testing”, Journal of Applied Economics, 8(1), 125-152.

- Monacelli, T. ve Perotti, R. 2010. "Fiscal policy, the real exchange rate and traded goods", The Economic Journal,120(544), 437-61.

- Odedokun, M. O., 1997. “An empirical analysis on the determinants of the real exchange rate in African countries", The Journal of International Trade and Economic Development, 6(1), 63-82.

- Ravn, M. O., Schmitt-Grohé, S. ve Uribe, M., 2007. "Explaining the effects of government spending shocks on consumption and the real exchange rate", NBER Working Paper 13328, National Bureau of Economic Research, Cambridge, MA.

- Samuelson, P. A., 1964. "Theoretical notes on trade problems", The Review of Economics and Statistics, 46, 145-154.

- Sencicek M. ve Upadhyaya, K.P., 2010. “Are devaluations contractionary? The case of Turkey”, Applied Economics, 42(9), 1077-1083, DOI: 10.1080/00036840701721208.

- Şükrüoğlu, D., 2015. Eşanlı Panel Veri Modelleri, Bölüm 4, Stata ile Panel Veri Modelleri kitabı içinde, Editör: Selahattin Güriş, Der Yayınları, İstanbul, 105-146.

- Tuna K., 2013. “Türkiye’de Wagner Kanunu’nun Geçerliliğinin Test Edilmesi “, İşletme ve İktisat Çalışmaları Dergisi1(3), 54-57.

- Wagner A., 1883. “Three Exracts on Public Finance”, in A. R., Musgrave, A. T. Peacock (Ed.), Classics in the Theory of Public Finance, 1967, s. 1-27.

- World Bank, 2016 http://data.worldbank.org/country/ erişim tarihi 12.12.2015 


\title{
Faiz Koridoru Uygulamasının Merkez Bankası Politikalarına Etkisi
}

\section{The Effect of the Interest Rate Corridor Implementation to Central Bank Policies}

\author{
Ph.D. Candidate Mustafa Batuhan Tufaner (Beykent University, Turkey) \\ Assoc. Prof. Dr. Kamil Uslu (Kavram MYO, Turkey) \\ Assoc. Prof. Dr. İlyas Sözen (Beykent University, Turkey)
}

\begin{abstract}
Central banks fulfill missions like financing governments, contributing the improvement of the financial market and implement monetary policy. Because of these important functions, instruments of the central bank has become a subject of ongoing debate over the years. The Central Bank's monetary policies instruments are important in terms of achieving the set macroeconomics targets. In recent years to become a major focus of attention of the interest rate corridor instrument has led to examine the structure of the central banks. The interest rate corridor primarily, provides flexibility advantages through interest rate to the central banks. The opinion that the central banks which have a flexible structure are more successful on ensuring the price stability and implementing macro policies with evading the political effects became stronger. In this context, in this study to examine the contributions of a flexible central bank to price stability and financial stability. In this bulletin different policy instruments of central banks are compared and critically assessed various determinants of central bank flexibility. In addition, comparing of the legislation of major central banks and various interest rate corridor implementations are examined.
\end{abstract}

\section{Giriş}

Merkez bankalarının 2008 Küresel Krizi’ne bağlı olarak, faiz oranlarını esas alan yeni para politikası araçları geliştirdiği ifade edilebilir. Gelişmiş ülke merkez bankaları finansal kırılganlıklara direnç gösterebilmektedir. Finansal risklere hassasiyeti yüksek olan gelişmekte olan ülkelerde ise, geleneksel para politikası araçları yetersiz kalmakta ve merkez bankalarına sınırlı bir uygulama alanı bırakmaktadır. Finansal piyasalardaki hızlı gelişmelere bağlı olarak ortaya çıkan finansal riskler, merkez bankalarını yeni politika araçları kullanmaya yöneltmiştir. Özellikle faiz oranlarındaki volatilite, finansal istikrarı ve fiyat istikrarını önemli ölçüde etkileyebilmektedir. Bu doğrultuda, merkez bankaları geleneksel para politikası araçlarına alternatif olarak faiz koridoru sistemini uygulayabilmektedir.

Bu çalışmada, faiz koridoru uygulamasının merkez bankası politikalarına etkisi incelenmiştir. Çünkü bağımsız merkez bankaları faiz koridorunun çok farklı çeşitlerini uygulamaktadırlar. Çalışma üç ana başlık altında toplanmıştır. Buna göre; çalışmanın giriş bölümünü takip eden ikinci bölümde faiz koridoru uygulamasının genel hatları çizilmiş, etki kanalları üzerinde durulmuş ve optimal faiz koridoru genişliği tartışılmıştır. Üçüncü bölümde faiz koridoru uygulamalarında çeşitli yabancı ülke deneyimleri ele alınmıştır. Dördüncü ve son bölümde ise, TCMB’nin 2008 Küresel Krizi sonrasında uyguladığı faiz koridoru sistemi ayrıntılı olarak incelenmiştir. Bununla birlikte, faiz koridoru taban ve taban oranının yıllara göre değişimi ve bunun TCMB politikalarını nasıl etkilediği ortaya koyulmuştur.

\section{Faiz Koridoru Sisteminin Gelişimi ve Etki Kanalları}

Finansal piyasaların sürekli bir değişim içerisinde olması ve buna bağlı olarak artan finansal riskler, para politikası araçlarına farkı boyutlar kazandırmıştır. Merkez bankaları son dönemlerde finansal istikrarsızlıklarla mücadelede, geleneksel olmayan para politikalarına yönelmişlerdir. Özellikle, faiz koridoru uygulaması 2008 Küresel Krizi'nden itibaren iktisat literatüründe önemli bir yer tutmaya başlamıştır. Finansal piyasalarda meydana gelen bu gelişmeler, faiz koridoru uygulamasını, fiyat istikrarını ve finansal istikrarı temel alan kuramsal araştırmalara yönlendirmiştir. $\mathrm{Bu}$ açıdan, makroekonomik istikrarın önemli bir belirleyicisi haline gelen faiz koridoru sistemi, para politikasının yeni bir aracı olarak uygulamaya konulmuştur.

\subsection{Faiz Koridorunun Tanımı, İșleyişi ve Özellikleri}

Faiz koridoru, merkez bankalarının gecelik borç verme ve borç alma faiz oranları arasındaki fark olarak tanımlanmaktadır. Faiz koridoru uygulamasında üçlü faiz sistemi yer almaktadır. Bunlar; borç verme faiz oranı, borç alma faiz oranı ve politika faiz oranıdır (Vural, 2013, s. 30). Borç verme faiz oranı, merkez bankasının likidite sorunu yaşayan bankalara verdiği kısa vadeli borç için belirlediği faiz oranıdır. Borç alma faiz oranı ise, likidite fazlası olan bankaların faiz getirisi sağlamak amacıyla bu fonlarını merkez bankasına yatırması karşılığında kabul ettiği faiz oranıdır. Politika faiz oranı da genellikle faiz koridorun orta noktasını oluşturmaktadır. 
Faiz koridorunun tavan ve tabanı arasında değişik oranlar belirlemek mümkün olsa da, merkez bankalarının borç verme faiz oranının, borç alma faiz oranından yüksek olması gerekmektedir. Diğer bir ifadeyle, merkez bankaları faiz koridorunu pozitif olarak belirlemektedir. Faiz koridorunun tabanı ve tavanı arasındaki aralık, kredi ve mevduat faizlerinin bir göstergesi olarak kabul edilmektedir. Ekonomik daralma dönemlerinde, bankaların kredi arzındaki azalışına bağlı olarak faiz koridoru genişlemekte, ekonomik genişleme dönemlerinde ise, bankaların kredi arzındaki artışa bağlı olarak faiz koridoru daralmaktadır (Bernanke ve diğerleri, 1996, s. 14). Dolayısıyla, ekonomik genişleme ile faiz koridoru genişliği arasında ters yönlü bir ilişki olduğu ifade edilebilmektedir.

Fon fazlası olan bankaların, fon ihtiyacı olan bankalara, merkez bankası tarafından belirlenen borç alma faiz oranının altındaki bir seviyeden borç vermesi rasyonel değildir. Fon fazlası olanlar bunun yerine merkez bankasına borç vermektedir. Benzer şekilde, fon ihtiyacı olan bankalar da, merkez bankası tarafından belirlenen borç verme faiz oranının üzerindeki bir seviyeden borç alması anlamlı değildir. Bunun yerine, merkez bankasına başvurarak koridorun üst sınırından borçlanmaktadır. Dolayısıyla, faiz koridoru sisteminde piyasa faizi merkez bankası tarafından belirlenen koridorun içinde belirlenmektedir. Bunu sağlayan olgu, merkez bankasının üst sınırdan borç verip, alt sınırdan ise borç almasıdır (Özatay, 2012, s. 427).

Faiz koridoru uygulaması, finansal riskleri ve ekonomideki istikrarsılıkları bertaraf etmeyi amaçlamaktadır. Merkez bankaları bir yandan piyasadaki likidite seviyesini kontrol altında tutarken, diğer yandan değişen koşullara hızlı tepki verme kabiliyeti artmaktadır. Faiz koridoru uygulaması, açık piyasa işlemine ihtiyaç duyulmaksızın, koridorda değişiklik yapılmak suretiyle piyasaya müdahale etme imkanı sağlamaktadır (Duramaz ve Dilber, 2015, s. 33). Merkez bankasının fon piyasasındaki değişikliklerle ilgili tahminleri ne kadar doğruysa, piyasa faizinin politika faizinden sapma eğilimi o ölçüde azalacaktır. Dolayısıyla, meydana gelecek bu sapmaların para politikası duruşu üzerindeki etkisi, şokların büyüklüğü ve sürekliliğinin yanı sıra, faiz koridoru sisteminin eksiksiz tasarlanmasına bağlıdır (Clews ve Diğerleri, 2010, s. 295).

Faiz koridoru ve politika faizi yapılanması, temel olarak üç gruba ayrılabilmektedir. Bunlar; resmi politika faizi olmayan koridor, taban sistemi ve orta-faiz koridor sistemidir (Maehle, 2014, s. 10). Resmi politika faizi olmayan koridorda merkez bankası, bankalararası oranlar için isterse bir iç hedef koyabilmektedir. Taban sisteminde, koridorun tabanını oluşturan merkez bankasının fon sağlama faiz oranı, hem bankalararası faiz oranını hem de politika faiz oranını hedefleme avantajı sağlamaktadır. Orta-faiz koridor sisteminde ise, politika faizi, koridorun orta noktasını oluşturmakta ve politika faizindeki değişiklikler koridorun tavan ve tabanı arasında hareket etmektedir.

\subsection{Faiz Koridoru Politikasının Ortaya Çıkış Süreci}

Merkez bankaları 1980'li yılların sonlarına gelindiğinde, fiyat istikrarını sağlamak amacıyla enflasyon hedeflemesi stratejisi uygulamaya başlamışlardır. Özellikle gelişmiş ülke merkez bankaları, bu rejimi başarılı bir şekilde uygulamış ve beklentilerini yeterince karşılamışlardır. Ancak 2000'li yıllara gelindiğinde, finansal piyasalarda yaşanan gelişmelere bağlı olarak ortaya çıkan finansal riskler ve ardından yaşanan 2008 Küresel Krizi'nin yıkıcı sonuçları, fiyat istikrarı hedefinin yeterli olmadığını göstermiştir. Buna bağlı olarak, merkez bankaları fiyat istikrarının yanı sıra, finansal istikrarı da sağlayacak politika arayışlarına yönelmişlerdir (Gertler ve Karadi, 2011, s. 18). Bu bağlamda, finansal istikrarın sağlanması hususunda önemli bir rol oynayan kısa vadeli faiz oranlarını esas alan faiz koridoru uygulaması, yeni bir politika aracı olarak birçok ülke tarafından kullanılmaya başlanmıştır.

Faiz koridoru uygulamasının ortaya çıkmasında rol oynayan bir diğer etken, geleneksel para politikası araçlarının etkinliğini zaman içinde kaybetmesidir. Örneğin, zorunlu karşılık oranları bankaların kredi kullandırma kapasitelerini sınırlandırmakta ve dolayısıyla diğer finansal kurumlarla rekabet edememesine yol açmaktadır (Bowman ve diğerleri, 2010, s. 1). Bu bağlamda, faiz koridoru uygulaması merkez bankalarının ihtiyaçlarına cevap vermekte yetersiz kalan geleneksel para politikası araçlarının yerini almış ve merkez bankalarına yeni bir perspektif kazandırmıştır.

Faiz koridoru uygulamasını başlatan öncü merkez bankaları, enflasyon hedeflemesi stratejisini de ilk uygulamaya koyan merkez bankalarıdır. Bunlar; Yeni Zelanda, Kanada, İngiltere ve Norveç Merkez Bankalarıdır (Tokucu, 2013, s. 8). Faiz koridorunu ilk uygulamaya başlayan ülkelere bakıldığında, politika faiz oranının koridorun orta noktasında belirlendiği görülmektedir. Bununla birlikte, bu merkez bankaları politika faiz oranına yakın ve oldukça dar bir aralıkta izleyen bir koridor belirlemişlerdir. Örneğin; Kanada gecelik faiz oranlarını politika faizinin 25 baz puan üzerinde ve altında belirlerken, İngiltere ise politika faizi çerçevesinde 100 baz puanlık bir aralık belirlemiştir (Whitesell, 2006, s. 1178). Bu bağlamda, çeşitli ülke merkez bankalarının politika hedefleri doğrultusunda farklı oranlar belirlediği ifade edilebilmektedir.

\subsection{Faiz Koridorunun Etki Kanalları}

Kısa vadeli faiz oranlarının tek araç olarak belirlendiği geleneksel para politikası uygulamalarında, yalnızca fiyat istikrarına odaklanıldığından kredi ve döviz kuru kanallarını ayrı ayrı etkileme amacı güdülmemektedir. Merkez bankaları enflasyon hedeflemesi doğrultusunda kısa vadeli faiz oranlarını arttırmaktadır. Politika faizinde meydana gelen artış, bir taraftan kredi genişlemesini baskılarken diğer taraftan yerli paranın değerlenmesine neden 
olmaktadır. Dolayısıyla, her iki kanal da eşanlı olarak enflasyon oranını düşürücü nitelikte işlemektedir (Kara, 2012, s. 7).

Faiz koridoru uygulamasında ise, fiyat istikrarıyla birlikte finansal istikrar da hedeflediğinden kredi ve döviz kuru kanallarını ayrı ayrı etkileme gereksinimi ortaya çıkmaktadır. Faiz koridoru uygulamasının etki kanallarına bakıldığında, politika faizlerinin ve koridor genişliğinin önemli bir rol oynadığı görülmektedir. Bunun yanı sıra, faiz koridoru sisteminin merkez bankalarının para politikası uygulamalarında sağladığı kolaylıklar, merkez bankalarının hareket kabiliyetini de arttırmaktadır. Bu bağlamda, faiz koridoru uygulamasının başlıca etki kanalları; kredi kanalı ve döviz kuru kanalı olarak iki ayrı grupta incelenebilmektedir.

\subsubsection{Kredi Kanalı}

Merkez bankaları etkin bir likidite yönetimi aracılı̆̆ıyla, likidite ihtiyacının hangi kaynaklardan sağlanacağını belirleyebilmekte ve gecelik faiz oranı seviyesini kontrol altında tutabilmektedir. Böylelikle, merkez bankaları, piyasaya yaptığı fonlamanın günlük ortalama maliyetini ayarlarlayabilmekte ve likidite ihtiyacı olan bankaların marjinal kredi maliyetlerini etkileyebilmektedir ( Duramaz ve Dilber, 2015, s. 33). Dolayısiyla, sermaye akımlarının yoğunlaştı̆ı dönemlerde faiz koridoru aşağı doğru genişletilerek kısa vadeli spekülatif hareketler engellenebilmekte ve ucuz likidite nedeniyle ortaya çıkan kredi genişlemesi baskılanabilmektedir. Aynı şekilde, küresel sermaye hareketlerinin azaldığ 1 ve kur volatilitesinin arttığı dönemlerde faiz koridoru yukarı doğru genişletilmektedir (Serel ve Özkurt, 2014, s. 61).

Merkez bankaları, fonlama faizine dair belirsizlikleri de bir politika aracı olarak kullanabilmektedir. Politika faizinin koridor içerisinde dalgalı bir seyir izlemesine izin verilmesi, fonlama maliyetlerinde belirsizliğe yol açmaktadır. Bu belirsizlik seviyesi, faiz koridorunun genişliği ve kısa vadeli faizlerin öngörülebilirliğiyle orantılıdır. Fonlama maliyetlerindeki belirsizlik ise, bankalar açısından bir risk oluşturmaktadır. Faiz riskindeki artış, maliyet ve likidite yoluyla bankaların kredi verme iştahını azaltmakta ve faiz riskini sınırlamak isteyen bankaların kredi arzını daraltmalarına neden olmaktadır (Binici ve diğerleri, 2013, s. 11). Fonlama maliyetlerindeki belirsizlik, bankaları, kalıcı kaynak sağlama amacıyla mevduat faizlerini yükseltmeye teşvik etmektedir. Bu durumda, kredi faizindeki artış mevduat faizindeki artışı aşacağından, kredi faizi ile mevduat faizi arasındaki fark büyümektedir. Kredi faizlerindeki artışın, mevduat faizindeki artışan fazla olmasının nedeni ise, kredilerin vadesinin daha uzun olması ve belirsizliğe karşı daha duyarlı olmasıdır (Serel ve Özkurt, 2014, s. 61).

Kredi kanalı, merkez bankalarının fonlama miktar ve maliyetlerindeki belirsizlik seviyesini tayin ederek kredi arzını etkilemesine imkan sağlamaktadır. Özellikle faiz koridorunun yukarı doğru genişletilmesi ile likidite yönetiminin eşanlı uygulanması, krediler açısından oldukça etkili olabilmektedir. Bu uygulama, bankaların faiz riski fiyatlaması yaparken faiz koridorunun üst sınırını baz almasına neden olmaktadır. Dolayısıyla, piyasaya fon sağlayıcı konumda bulunan merkez bankaları, kredi faizlerini ve kredi hacmini önemli ölçüde etkileyebilmektedir (Duramaz ve Dilber, 2015, s. 34)

\subsubsection{Döviz Kuru Kanalı}

Faiz koridoru uygulamas1, sermaye hareketlerini etkilemek suretiyle döviz kuru volatilitesinin belirlenmesine yardımcı olmaktadır. Küresel risk iştahında bir azalma olduğunda, özellikle gelişmekte olan ülkelerin birçoğunda sermaye kaçışları hızlanmaktadır. Bu dönemlerde merkez bankaları, sermaye hareketlerinin döviz kuru üzerinde oluşturacağı olumsuz etkiyi hafifletmek amacıyla piyasanın ihtiyaç duyduğu miktarın altında bir fonlama gerçekleştirebilmektedir. Merkez bankalarının beklenenden az seviyede fonlama yapması, finansal kurumların likidite ihtiyaçlarını döviz satımı yoluyla karşılamasına sebep olmaktadır. Dolayısıyla, sermaye kaçışlarının döviz kuru üzerinde oluşturacağı hareketler sınırlandııılmış olmaktadır. Sermaye akımlarının yoğunlaştığı dönemlerde faiz koridoru aşağı yönlü genişletilerek döviz kuru volatilitesi arttırılabilmektedir. Buna karşın, sermaye akımlarının zayıfladığı dönemlerde ise koridor yukarı doğru genişletilerek döviz kuru volatilitesi azaltılabilmektedir (Kara, 2012, s. 11).Faiz koridoru uygulamasının döviz kuru kanalıyla etkilediği bir diğer alan hisse senedi piyasasıdır. Para politikası ile hisse senedi piyasası arasında güçlü ve anlamlı bir ilişkinin bulunması, politika faizinin ve dolayısıyla koridor sisteminin geniş bir etki alanına sahip olduğunu göstermektedir. Ehrmann, Bjørnland, Bohl ve Kholodilin'in ABD ve Euro bölgesi üzerine yaptığı çalışmalar, politika faizi şoklarının hisse senedi piyasalarını negatif yönde etkilediğini göstermiştir (Tetik ve Ceylan, 2015, s. 58). Buna göre, hisse senedi fiyatları, politika faizi beklentilerindeki bir şoka pozitif yönde bir tepki vermektedir. Diğer taraftan, faiz ile döviz kuru arasındaki ilişki bağlamında, politika faizindeki şokların döviz kurunu aynı yönde etkilediği ortaya koyulmuştur.

Merkez bankaları değişen finansal koşullar karşısında faiz koridoru uygulaması aracıllğıyla faiz oranlarını etkileyebilmekte ve böylelikle döviz kuru volatilitesinin azaltılmasına ve makro finansal risklerin sınırlandırılmasına yardımcı olabilmektedir (Yücememiş ve Arıcan, 2015, s. 11). Faiz koridorunun yukarı doğru genişletilmesi döviz kurunu düşürürken, koridorun aşağı doğru genişletilmesi ise döviz kurunu yükseltmektedir. Diğer taraftan, faiz koridoru uygulaması döviz kuru kanalı aracıllğıyla ülkelerin ithalat ve ihracat eğilimlerini de etkileyebilmektedir. Dış ticaret dengesi, ödemeler dengesinin önemli bir kalemini oluşturduğundan döviz kuru kanalı, özellikle gelişmekte olan ülkelerin yaşadığı açık problemleri açısından önem kazanmaktadır. Dolayısıyla, 
faiz koridoru uygulamasının finansal piyasalarla birlikte makro dengelere de önemli ölçüde tesir ettiği ifade edilebilmektedir.

\subsection{Optimal Faiz Koridoru Genişliğinin Belirlenmesi}

Faiz koridorunun genişliği meselesi, finansal istikrar ve fiyat istikrarı açısından önem taşımaktadır. Borçlanma ve mevduat tesisi arasındaki fark, özellikle bankalararası piyasayı ve merkez bankası işlemlerini etkileyebilmektedir. Bununla birlikte, gecelik faiz oranı dengesi ile bankalararası piyasa hacimleri arasındaki değişim, faiz koridorunun genişliğine bağlı olarak belirlenmektedir. Bankalararası borçlanmanın bir işlem maliyetinin olması, bankalararası ortalama fon alışverişi hacminin hem bu işlem maliyetlerine hem de faiz koridorunun genişliğine bağlı olmasına neden olmaktadır. Dolayısıyla, koridorun taban ve tavanı eşit olduğunda, bankalararasında fon alışverişi olmayacaktır. Bankalararası işlem maliyetleri piyasadaki alışveriş hacmini belirlediğinden, fon sağlamanın toplam maliyeti penaltı faiz oranıyla tayin edilmektedir. Merkez bankasından fon kullanmanın maliyeti ise, bankaların bilgi birikimi ve piyasa döneminden ziyade, cari ve beklenen likidite pozisyonuna bağlı olmaktadır (Bindseil ve Jablecki, 2011, s. 18).

Bankalararası borçlanma devir hızının bazı değişkenlere bağlı olduğu söylenebilmektedir. Bunlar; bankalararası şokların başlangıç miktarı, gün sonundaki toplam şokların volatilitesi, faiz koridorunun genişliği ve işlem maliyetlerinin seviyesidir (Bindseil ve Jablecki, 2011, s. 19). Bankalararası borçlanma devir hızı, tüm piyasa işlemlerinin rekabetçi takas faiz oranı üzerinden eşanlı olarak gerçekleşeceği varsayımı altında, bankaların günlük likidite yönetimi sürecinde belirlenmektedir. Dolayısıyla, faiz koridoru genişliğinin bu süreçte önemli bir rol oynadığ ifade edilebilmektedir.

Bankalararası borçlanma devir hızının bir diğer etkisi, merkez bankası bilançosunun büyüklüğüyle ilgilidir. Beklenen merkez bankası bilançosu büyüklüğü, toplam beklenen değere eşit olmaktadır. Merkez bankası bilançoları, faiz koridoru genişliğindeki artış ve likidite şoklarındaki dengeye bağlı olarak küçülebilmektedir. Kriz dönemlerinde bankalararası şokların volatilitesinin yükselmesi, bankalararası piyasa işlemlerini daha maliyetli hale getirmekte ve merkez bankası bilançolarını büyütmektedir. Diğer bir ifadeyle, faiz koridorunun genişliğine bağlı olarak merkez bankaları ile piyasa aracıları arasındaki likidite sağlama paylaşımı artmaktadır. Bu bağlamda, birçok gelişmiş ülke merkez bankasının 2008 Krizi’nin ardından artan kısa vadeli faiz oranı volatilitesini azaltmak amacıyla faiz koridorunu daralttığı söylenebilir (Maehle, 2014, s. 17).

Teminat tutmanın firsat maliyetinin pozitif olması durumunda optimal yaklaşım, pozitif faiz koridoru uygulamasıdır. Optimal faiz koridoru genişliği; ticari şokların doğasına, tercihlere ve üretim teknolojisine bağlı olarak değişebilmektedir. Bu koşullar altında, politika uygulayıcı konumundaki merkez bankalarının önünde iki seçenek bulunmaktadır. Bunlar; bant genişliğini sabit tutarken faiz koridorunu değiştirme veya faiz oranı bandının genişliğini değiştirmedir (Berentsen ve Monnet, 2006, s. 5). Mevduat faiz oranı sabit tutularak borçlanma faiz oranının arttırılması, faiz oranı bandının genişliğinin değiştirilmesine örnek olarak gösterilebilir.

Optimal faiz koridoru, teminat getiri oranının azaldığı ölçüde sağlanabilmektedir. Teminat firsat maliyetinin sıfır olduğu noktada mevduat ve kredi faiz oranları eşit olarak belirleneceğinden, optimal genişlik ayarlanmış olmaktadır. Diğer taraftan, para piyasasındaki kısa vadeli satış sınırlamaları bağlayıcı değilse ve teminat tutmanın firsat maliyeti düşükse gecelik borçlanma oranı, faiz koridorunun orta noktasını oluşturma eğilimindedir. Bu durumda, gecelik borçlanma oranının dalgalanma eğilimi de oldukça azalmaktadır. Koridor sisteminde kısa vadeli satış sınırlamalarının bağlayıcılığı ve teminat tutmanın fırsat maliyeti, para piyasası oranının politika faiz oranının üzerinde olma eğiliminin gerekçesini açıklamaktadır (Berentsen ve Monnet, 2006, s. 6).

Piyasa yanlısı bir merkez bankası normal ekonomik koşullar altında 175 baz puanlık bir koridor tercih edebilmektedir. Yansız ve volatiliteden kaçınan bir merkez bankasının her koridor daraltmada 25 baz puan azaltması halinde, riskten kaçınan bir merkez bankası böyle bir durumda 150 baz puan belirleyecektir. İşlem maliyetlerinin ve likidite şoklarının arttığı bir kriz durumunda ise, tüm merkez bankaları faiz koridoru genişliğini arttıracaklardır. Örneğin, riskten kaçınan ve 875 baz puanlık bir koridor belirleyen bir merkez bankası, yansız tercih ve volatiliteden kaçınma durumunda yalnızca 75 baz puanlık bir dilim kabul etmek durumundadır (Bindseil ve Jablecki, 2011, s. 26).

\section{Faiz Koridoru Uygulamalarında Çeşitli Ülke Deneyimleri}

2008 Küresel Krizi döneminde merkez bankalarının müdahale çeşitlerinin değişmesi, para politikası araçları üzerinde de etkili olmuştur. Para arzının arttırılması, bazı sektörlere doğrudan kredi avantajları sağlanması ve merkez bankalarının son başvuru mercii olma rolünün arttırılması gibi politikalar, faiz koridoru uygulamasını ön plana çıkarmıştır. Bununla birlikte, piyasalarda artan likidite nedeniyle merkez bankalarının politika faiz oranını yönetmekte zorlanmaları ve yeni politika arayışlarına yönelmeleri, koridor sistemi üzerinde daha fazla durulmasına sebep olmuştur. Faiz koridoru uygulamasının esnek bir yapıya sahip olması ve faiz oranlarının kontrolünde kolaylıklar sağlaması, merkez bankalarını bu uygulamaya yöneltmiş ve dolayısıyla faiz koridoru uygulaması birçok merkez bankası tarafından uygulanır hale gelmiştir. 


\subsection{Avrupa Merkez Bankası}

Avrupa Merkez Bankası (AMB), 1998 yılının Haziran ayından itibaren koridor sisteminin uygulanması yönünde çalışmalarını hızlandırmıştır. 1999 yılında Avrupa Para Birliği'ne (Euro) geçilmesiyle birlikte, faiz koridoru sistemi fiilen uygulamaya konulmuştur. AMB'nın faiz koridoru uygulaması, tipik olarak gecelik faiz oranının taban ve tavanından oluşmaktadır. Koridorun tabanını gecelik mevduat faiz oranı oluştururken, koridorun tavanını ise marjinal borç verme oranı oluşturmaktadır. Faiz koridorunun genişliği ve hedef faiz oranı, Avrupa Guvernörler Konseyi tarafından gerçekleştirilen her ayın ilk toplantısında belirlenmekte ve böylelikle para politikası duruşu ortaya konulmaktadır (Kahn, 2010, s. 18).

Euro bölgesinde uygulanan likidite politikası, faiz koridoru sistemiyle entegre bir şekilde yürütülmektedir. AMB, Euro Gecelik Endeks Ortalaması'nı (EONIA) temel politika faizine yakın tutabilmek amacıyla bankacılık sektörüne likidite sağlamaktadır. En önemli likidite karșılıklarını ise, Temel Refinans İșlemleri (MRO) oluşturmaktadır (Nautz ve Offermanns, 2007, s. 288-289). Temel Refinansman Oranı, aynı zamanda AMB'nın temel politika faiz oranıdır. Bununla beraber, ince ayar işlemleri özellikle tesis döneminin son gününde anlık olarak gerçekleştirilmektedir.

AMB, kurulduğu tarihten itibaren faiz koridoru oranlarında birçok değişiklik yapmış ve bazı dönemlerde simetrik bazı dönemlerde ise asimetrik faiz koridoru uygulamasını benimsemiştir. Küresel Kriz öncesinde banka faiz oranları normal seviyenin oldukça üzerinde olduğundan, AMB ile olan fon alışverişleri sınırlı tutulmuştur $\mathrm{Bu}$ dönemde, kredi ve mevduat faiz oranları, temel refinansman işlemlerinin minimum teklif oranı etrafinda 100 baz puan civarında belirlenmiştir. 9 Ekim 2008 tarihine gelindiğinde ise, piyasa faiz oranlarındaki farklılıkları sınırlandırmak amacıyla koridor genişliği gösterge politika faizi etrafında yaklaşık 50 baz puan daraltılmıştır. 2009 yılında krizin etkilerinin azalmasının ardından faiz koridoru genişletmiş ancak, aynı yıl içerisinde $\% 1$ olan gösterge politika faizinin indirilmesiyle birlikte koridor tekrar 75 baz puan daraltılmıştır (Bowman ve diğerleri, 2010, s. 9).

AMB 2014 yılının Haziran ayından itibaren borç alma faiz oranını ilk defa negatife çekmiştir. Faiz koridoru genişliği 16 Mart 2016 tarihli son AMB toplantısının ardından (borç alma faizi $\%-0,4$ ve borç verme faizi \%0,25) 65 baz puan olarak belirlenmiştir (AMB, 2016). Negatif faiz oranı uygulamasındaki temel amaç, yatırımlar yerine harcamaları teşvik etmek ve böylece ekonomik aktiviteyi canlandırmak olmuştur. Diğer yandan kısa ve uzun vadeli likidite desteğinin yükseltilmesinin finansal istikrara katkı sağlayacağını düşünen AMB, gecelik faiz oranının koridor tabanına yaklaşmasına geçici olarak izin vermiştir. Dolayısıyla mevduat faiz oranı, geçmiş dönemlere kıyasla daha belirgin bir rol oynamaya başlamıştır (Bernhardsen ve Kloster, 2010, s. 18).

\section{2 İngiltere Merkez Bankası}

İngiltere Merkez Bankası (IMB), enflasyon hedeflemesi stratejisini ilk uygulayan merkez bankalarından biridir. Fiyat istikrarı ile birlikte finansal istikrarı eşgüdümlü olarak hedefleyen İMB, 2001 yılının Haziran ayından itibaren faiz koridoru sistemini uygulamaya başlamıştır. Bununla birlikte mevduat faiz oranı, Sterlin Gecelik Endeks Ortalaması'nın (SONIA) tabanı olarak tayin edilmiştir (Bowman ve diğerleri, 2010, s. 14). Bu tarihten 2005 yılına kadar politika faizi olarak resmi repo faiz oranı kullanılmış ve koridor genişliği 200 baz puan olarak belirlenmiştir. Koridor uygulamasının temel amacı hem tesis döneminde hem de tesis döneminin son gününde faiz volatilitesini azaltmak olmuştur. Bu çerçevede bankaların rezerv hedef zorunluluğunun bulunmaması, ince ayar işlemleri ve koridorun daraltılması gibi faktörlerin, piyasa faiz oranlarının politika faizine yakın bir seyir izlemesini sağladığı söylenebilmektedir.

IMB 2006 yılının Mayıs ayında para politikası uygulamasını geliştirmek amacıyla operasyonel yapısını yeniden düzenlemiştir. Yeni yapı içerisindeki faiz koridorunda, bankalar her ay kendi rezerv hedeflerini belirlemiş ve rezerv dengeleri, bu hedefler etrafında nispeten dar bir alana sıkışmıştır. Diğer taraftan, rezerv miktarı yeterli olmayan bankaların cezalandırılmasını önlemek amacıyla yüksek borç verme faiz oranı uygulanırken, rezerv fazlası olan bankaların ödüllendirilmesi amacıyla düşük borç alma faiz oranı uygulanmıştır (Clews ve diğerleri, 2010, s. 297).

2008 Krizi'nin başlangıcıyla birlikte İMB da diğer merkez bankaları gibi rezervlerini finansal varlık alımına yönlendirmiş ve bir parasal genişleme dönemi başlatmıştır. Ekonominin canlandırılması amacına yönelik olarak alınan bu karar, bankalararası faiz oranının politika faiz oranından sapmasına ve bankaların rezerv hedeflerinden uzaklaşmasına neden olmuştur. Bununla birlikte. piyasada yaşanan likidite bolluğu, piyasa faiz oranlarını politika faizinin altına çekmiş ve hedeflenen piyasa faiz oranı gerçekleştirilememiştir.

Belirlediği hedeflere ulaşmakta zorlanan İMB, 2012 yılının Aralık ayında, taban sistemi olarak nitelenen faiz koridoru uygulamasına geçmiştir. İMB, taban sisteminin uygulamaya konulmasıyla birlikte likidite yönetimi ile para politikasını birbirinden ayırabilmiştir. Taban sisteminin yanı sıra yüksek olan toplam rezerv miktarı, gecelik faiz oranındaki volatilitenin azaltılmasına önemli bir katkıda bulunmuştur. Diğer yandan, bu durum, günlük likidite ihtiyaçlarını etkin bir şekilde yönetmeyi amaçlayan bankaların para piyasasındaki ticari rezerv tutma isteğini önemli ölçüde azaltmıştır (Jackson ve Noss, 2015, s. 8). 2009'dan bu yana para piyasası faaliyetlerindeki azalmanın bir nedeni de taban sistemi uygulamasına bağlanabilmektedir.

\subsection{Kanada Merkez Bankası}

Kanada Merkez Bankası'nın (KMB) temel para politikası; düşük ve istikrarlı enflasyon oranı, finansal sistemin istikrarı, ulusal paranın güvenliği ve kamu gelir ve borçlarının etkin yönetiminin bileşiminden oluşmaktadır. 
Enflasyon hedeflemesi stratejisini ilk uygulayan merkez bankalarından biri olan KMB, aynı zamanda saf koridor sistemini de ilk uygulayan merkez bankaları arasında yer almaktadır. 1990'ların sonunda Kanada Ödemeler Birliği (The Canadian Payments of Association-CPA) tarafından oluşturulan Yüksek Hacimli Transfer Sistemi (The Large Value Transfer System -LVTS), koridor uygulamasının temellerini oluşturmuştur. Bu sistem aracılığıyla, yüksek hacimli ödemelerin transfer işlemleri sağlanmış ve operasyonel yapının çerçevesi inşa edilmiştir.

KMB'nın koridor tavanını Banka Oranı (Bank Rate) olarak adlandırılan bankalara borç verme faiz oranı oluştururken, koridor tabanını ise merkez bankasının mevduat fazlası olan finansal kurumlara ödediği borç alma faiz oranı oluşturmaktadır. Koridor 50 baz puan genişliğinde olup, koridorun orta noktasında ise, gecelik faiz oranları için belirlenen (hedef) politika faiz oranı yer almaktadır. Mevcut piyasa koşulları ve enflasyon görünümü esas olduğundan İMB, koridorun konumunu ile genişliğini belirlemekte ve kararını her yıl belirli tarihlerde duyurmaktadır (Zhang, 2012, s. 4).

KMB, gerekli gördüğü durumlarda politika hedeflerinin desteklenmesi amacıyla hedef oranında açık piyasa işlemleri yapabilmektedir. Munzam karşılığın olmaması ise, katılımcıların gün sonunda dengeye ulaşmalarını amaçlamaktadır. Bu açıdan Kanada faiz koridoru uygulaması, gecelik faiz oranının politika faizine yakın tutulması ve piyasaya likidite sağlama hususunda, rezerv onarımına ilişkin idari yükümlülükler dayatılmaksızın oldukça etkili olduğunu göstermektedir. Dolayısıyla, Kanada uygulamasında, gecelik faiz oranı ile hedef faiz oranı arasındaki fark, munzam karşılık ile faiz koridorunu bir arada benimseyen diğer ülkelerden oldukça düşüktür.

KMB, 2008 Küresel Krizi sırasında para piyasalarında meydana gelen gerginliğe, gecelik faiz oranı için belirlenen hedef oranı birkaç kez düşürerek cevap vermiştir. Gecelik likidite talebinin yükselmesi ise, KMB'ın ödemeler dengesi seviyesini dönemsel olarak yükseltmesine neden olmuştur. Finansal karışılığın dinmesinin ardından para piyasasındaki genel durumda gözle görülür bir iyileşme yaşanmıştır. Düşük faiz koşulları altında piyasaların etkin işleyişini sürdürmesi için gecelik faiz oranı tabanı 25 baz puan olarak belirlenmiştir. Bununla beraber, hedef faiz oranının sağlamlaştırılması için normal koşullarda 25-50 milyon \$ olarak belirlenen ödemeler dengesi seviyesi günlük hedefi, 3 milyar \$ olarak belirlenmiştir (Zhang, 2012, s. 7).

KMB, para politikalarının etkin bir şekilde yürütülmesi ve finansal risklerin kontrol altına alınması amacıyla faiz koridoru uygulaması ile birlikte LVTS ağını da izlemektedir. Bu sistem içerisinde, kurumların gün içerisindeki nihai ödemelerindeki belirsizliklerin azaltılabilmesi, finansal istikrara katkı sağlayabilmektedir. Bunun yanı sıra, politika faizlerinin ekonomik faaliyet düzeyini etkilemek için kullanılabilmesi de fiyat istikrarına katkıda bulunabilmektedir. Böylece, hem fiyat istikrarı hem de finansal istikrar hedefi sağlanmış olmaktadır.

\subsection{Japonya Merkez Bankası}

Japonya Merkez Bankası (JMB) 2001 yılının Mart ayında Tamamlayıcı Kredi Tesisi (Complementary Lending Facility) sistemini uygulamaya başlamış ve 25 baz puanlık bir faiz oranı belirlemiştir. Bu sistem sayesinde, kredi talepleri uygun teminatlar ile güvence altına alınmış ve katılımcılara kullandırılan krediler için resmi iskonto oranı uygulanmıştır. Bununla birlikte, kredi vadesi bir gecelik olmasına karşın, beş iş gününe kadar uzatılabilmesine izin verilmiştir. Resmi iskonto oranının, gecelik faiz oranı (overnight call rate) için belirlenen işlem hedefinden yüksek olması, gecelik faiz oranı üzerinde bir tavan oluşturmuştur (Friedman ve Kuttner, 2010, s. 42).

JMB, teminat sisteminde de önemli değişikliklere gitmiştir. İlk başlarda, senet satın alma işlemleri için kullanılan teminatlar ile fon tesisi için kullanılan teminatlar birbirinden ayrılmıştır. Ancak, 2001 yılının Aralık ayına gelindiğinde, katılımcıların kullandığı teminatların daha etkin bir şekilde yönetilebilmesi için bu iki sistem aynı havuzda birleştirilmiştir (Blenck ve diğerleri, 2001, s. 30). Bununla birlikte JMB, finansal sistemin istikrarı için gerekli gördüğü durumlarda, katılımcılara uygun teminatlar karşılığında kredi vermiştir. Dolayısıyla, JMB'nın temel para politikasının açık piyasa işlemleri olduğu ifade edilebilmektedir.

2008 Krizi'nin etkileri, JMB'nın para politikasını ve araçlarını da etkilemiştir. Teminatlandırılmamış gecelik faiz oranı için belirlenen hedef 30 baz puana düşürülmüştür. JMB bu durum karşısında, geçici bir önlem olarak Tamamlayıcı Mevduat Tesisi (Complementary Deposit Facility) sistemini uygulamaya koymuş ve faiz oranını 10 baz puan olarak belirlemiştir. 19 Aralık toplantısında alınan bu kararın ardından faiz oranı için belirlenen hedef, koridorun taban seviyesi olarak kabul edilmiştir (Bowman ve diğerleri, 2010, s. 10). Yaşanan krizin bir diğer etkisi, JMB'nın politika faiz oranlarını sıfıra indirmesi olmuştur. $\mathrm{Bu}$ değişiklikle beraber, JMB faiz oranları etkilenmeksizin rezerv kaynak miktarını değiştirme imkanına sahip olmuştur.

JMB'nın para politikası uygulamalarına bakıldığında, 1990'ların başından geleneksel olmayan para politikası araçlarına yöneldiği görülmektedir. İlk başlarda parasal genişleme politikalarına yönelen JMB, daha sonra faiz koridoru taban sistemi uygulamaya başlamıştır. 1995 yılında ortaya çıkan banka başarısızlıkları, JMB'nın sürekli faiz indirimine gitmesine yol açmış ve nihayet 1999 yılında faiz oranları sıfıra indirilmiştir. Faiz politikasına paralel olarak, menkul kıymet kredileri genişletilmiş ve Japon firmalara fon sağlanması hususunda sınırlı bir program izlenmiştir. 2008 Krizi'nin ardından faiz koridorunun tabanı sıfır olarak belirlenmiş ve faiz koridoru zamanla daraltılmıştır. Özellikle mevduat tesisinin etkin bir şekilde yönetilmesinin, etkili bir taban sisteminin ortaya çıkmasına katkıda bulunduğu söylenebilmektedir. 


\section{TCMB'nin Faiz Koridoru Uygulamaları}

2008 Küresel Krizi, diğer ülke merkez bankalarında olduğu gibi TCMB’nin para politikalarını da etkilemiştir. TCMB, nihai para politikası amacı olarak belirlediği fiyat istikrarı ve finansal istikrara ulaşabilmek açısından 2010 yılından itibaren araç değişikliğine gitmiştir. Bu bağlamda, geniş faiz koridoru ve aktif likidite politikasının birlikte kullanıldığı bir para politikası stratejisi tasarlanarak uygulamaya konulmuştur (Kara, 2015, s. 2).

TCMB'nin uygulamaya koyduğu faiz koridoru sisteminde koridorun tavanını gecelik borç verme faizi, koridorun tabanını ise gecelik borç alma faizi oluşturmaktadır. Bununla birlikte, koridor tabanı ile tavanı arasında kalan politika faizi ise, bir hafta vadeli repo faiz oranı ile belirlenmektedir. Daha önce pasif bir rol oynayan koridor uygulaması, yapılan değişiklikle birlikte politika faizi etrafında asimetrik bir şekilde oluşturulmuş ve daha aktif bir politika aracı olarak kullanılmaya başlanmıştır (Oktar ve Yurdabak, 2015, s. 5). Dolayısıyla, TCMB'nin faiz oranları üzerindeki manevra alanı genişlemiş ve gecelik borçlanma, borç verme ve haftalık repo faiz oranlarının birbirinden farklı amaçlarla kullanılabilmesi olanaklı hale gelmiştir.

TCMB'nin temel fonlama aracı bankalara teminat karşılığında sağlanan bir hafta vadeli repo ihaleleri olsa da, TCMB para piyasalarını çeşitli vadelerde fonlama imkanına sahiptir. Bunlar; bir hafta ve bir ay vadeli repo ihaleleri, gecelik repo imkanı ve geç likidite penceresi aracılığıyla gerçekleştirilmektedir. TCMB, miktar ihalesi kapsamında her gün saat 10:00'da ihale miktarını duyurmakta ve bankalar bu miktarın \%20'sini aşmayacak biçimde tekliflerini iletmektedir (Küçük ve diğerleri, 2015, s. 5). Teklif miktarının, ihale miktarını aşması durumunda ise, her banka kendi teklif miktarı oranında borçlanmaktadır. $\mathrm{Bu}$ ihalede uygulanan faiz oranı, TCMB'nin politika faizi olarak belirlediği bir haftalık repo faiz oranıdır. Diğer yandan, TCMB bir hafta vadeli repo ihaleleri ve piyasanın uzun dönem likidite beklentilerini iyileştirebilmek amaciyla daha uzun vadeli repo ihaleleri de fonlayabilmektedir.

2011 yılında Avrupa ekonomisindeki belirsizliklerin artması, TCMB'nin politika çerçevesini etkilemiştir. Sermaye akımlarının sınırlanması, döviz kurundaki aşırı değerlenmenin önlenmesi, yurtiçi kredilerin ve talebin kontrol altına alınması gibi hedefler faiz koridorunun aşağı doğru genişletilmesine neden olmuştur. Böylelikle, gecelik piyasa faiz oranlarının politika faiz oranlarını aşmasına izin verilmiş ve spekülatif sermaye girişlerinin azaltılması sağlanmıştır. 2012 yılının sonlarına doğru küresel risk iştahının iyileşmesiyle birlikte, piyasaya verilen likidite miktarı arttırılmış ve kısa vadeli faizlerin koridor tabanına yakın bir noktada seyretmesi mümkün hale getirilmiştir. Bununla birlikte, TCMB kısa vadeli sermaye akımlarının finansal istikrar üzerinde oluşturabileceği riskleri sınırlamak amacıyla, politika faizini kademeli olarak azaltmıştır (Özhan ve diğerleri, 2013, s. 85).

TCMB 2013 yılında, enflasyon hedeflemesi ve finansal istikrar doğrultusunda parasal sıkılaştırma politikasına yönelmiştir. Bu politikanın etkinliğini arttırmak amacıyla, gecelik borç verme faiz oranı arttırılarak faiz koridoru yukarı doğru genişletilmiştir. Etkin likidite yönetimi ise, kısa vadeli faizlerin koridorun üst sınırına yakın bir noktada oluşmasını sağlamıştır. Ancak, 2014 yılında piyasalarda risk algısını olumsuz yönde etkileyen gelişmelerin ortaya çıkması, operasyonel çerçevenin sınırlanmasıyla neticelenmiştir. Bu doğrultuda, 28 Ocak 2014 tarihli PPK (Para Politikası Kurulu) kararı ile bir hafta vadeli repo faiz oranı \%4,5’ten \%10'a çıkarılmış ve bankalararası gecelik faiz oranlarının faiz koridorunun tavanı olan \%12'ye yakın bir seviyede oluşması hedeflenmiştir (Yücememiş ve diğerleri, 2015, s. 465).

TCMB, 24 Mart 2016 tarihli PPK toplantısında, politika faiz oranının \% 7,5 düzeyinde sabit tutulmasına karar vermiştir. 21 Nisan 2016 tarihli son PPK toplantısında ise, borç alma faiz oranını \% 7,25 ve borç verme faiz oranını \%10 olarak belirlemiştir (TCMB, 2016). Dar ve asimetrik bir faiz koridoru uygulaması tercih eden TCMB, politika faizini koridor tabanına yakın bir seviyede tutmuştur. Finansal piyasaların gelişmesi dolayısıyla, faiz oranları da bu değişime uyumlu hale getirilmiş ve döviz ve kredilerdeki volatilite azaltılmaya çalışılmıştır. Bununla beraber, kısa vadeli spekülatif sermaye hareketleri ve makro finansal risklerin sınırlandırılması amaçlanmıştır.

TCMB tarafından uygulanan faiz koridoru sisteminin, döviz kurları ve kredilerdeki volatiliteyi azalttığ görülmektedir. Bu bağlamda, son dönemde meydana gelen gelişmelerin, TCMB'nin geniş faiz koridoruna olan ihtiyacını azalttığı söylenebilmektedir. Bunun en temel nedeni, küresel volatilite ve risklerin azalması ile küresel finansal piyasalarda yaşanan iyileşmelerdir. Cari dengedeki iyileşme ve enerji fiyatlarında meydana gelen düşüş de, döviz talebini kademeli olarak azaltarak bu süreci desteklemektedir. Bunun yanı sıra, Ağustos ayında yayımlanan yol haritasında belirtilen politika araçlarının etkin bir şekilde uygulanması da, bu ihtiyacı ortadan kaldıran bir diğer neden olarak ifade edilebilmektedir.

\section{Sonuç}

2008 Küresel Krizi, ülkeleri ekonomik yapılarına göre çeşitli şekillerde etkilemiştir. Krizden etkilenen ülkeler ve politika yapıcılar, krize yönelik yeni ekonomi politika arayışlarına yönelmişlerdir. Finansal sistemde meydana gelen gelişmelerin genel ekonomik istikrarı büyük ölçüde etkileyebilmesi, faiz oranlarının daha önemli bir hale gelmesine neden olmuştur. 1998 yılında AMB tarafindan uygulanmaya başlayan faiz koridoru uygulaması, krizin çözümüne katkıda bulunacak bir sistem olarak görülmüş ve birçok ülke tarafından kriz süresince ve ardından etkin bir politika aracı olarak uygulanagelmiştir. 
AMB, Kanada, İngiltere ve Japonya faiz koridorunu 2008 Krizi’nden önce kullanmaya başlarken, TCMB ise 2008 Krizi sonrasında uygulamaya koymuştur. AMB, Kanada, İngiltere ve Japonya'nın krizle birlikte taban sistemini uygulamasına geçtiği görülmüştür. TCMB ve diğer merkez bankalarının ise, politika faiz oranlarını koridorun merkezine yakın tutmaya yönelik bir politika izlediği ifade edilebilmektedir. Bununla birlikte, TCMB'nin son dönemde politika faiz oranını koridor tabanına yakın bir seviyede belirlemeye çalışmıştır. Dolayısıyla, faiz koridoru sisteminin de diğer para politikası araçları gibi ülkelerin hedef ve ekonomik koşullarına göre farklı şekillerde uygulanabildiği söylenebilmektedir.

Faiz koridoru sistemi, gelişmekte olan ülkelerde uygulanmaya devam ederken gelişmiş ülkelerde ise negatif faiz uygulamasına geçilmesinden dolayı, faiz koridoru uygulaması terk edilmeye başlanmıştır. Gelişmekte olan ülkelerde enflasyon oranlarının dünya ortalamasının üzerinde olması nedeniyle, faiz koridoru uygulaması bu ülkeler için geçerliliğini korumaktadır. Ayrıca, koridor sistemi bu ülke gruplarının tüketim harcamalarını dengeleyebilmektedir. Ancak, gelişmiş ülkelerde tüketim harcamalarının düşük olması ve sermaye yatırımlarına bağımlılığın düşük olması, ülke büyümelerini iç tüketim harcamalarıyla destekleme düşüncesiyle negatif faiz uygulamasını ön plana çıkarmaktadır.

Faiz koridoru uygulamasının, merkez bankalarına birçok açıdan avantaj sağladığı ifade edilebilmektedir. İlk olarak, merkez bankaları faiz koridoru uygulamasıyla birlikte, geleneksel para politikalarına oranla piyasalara daha hızlı ve etkin bir şekilde müdahalede bulunma imkanı sağlamıştır. Dolayısıyla, ani ve beklenmedik ekonomik şoklar karşısında esnek davranabilme kabiliyeti gelişmiş ve diğer değişkenlerin bu şoklardan etkilenmesinin önüne geçilmeye çalışılmıştır. Kredi ve döviz kuru kanalıyla döviz kuru volatilitesi ve sermaye hareketleri kontrol altında tutulabilmektedir. Diğer taraftan, ödemeler dengesi aracılığıyla makroekonomik dengeler, hedefler doğrultusunda ayarlanabilmektedir. Bu açıdan, krize doğru yol alan süreçler içerisinde faiz koridoru uygulamasının etkinliği daha fazla hissedilebilmektedir. Dolayısıyla, bu yeni para politikası aracının aynı hedefe yönelik diğer para politikası araçlarıyla eşgüdümlü bir şekilde uygulandığında, merkez bankası politikalarının etkinliğini arttırdığı söylenebilmektedir.

\section{Kaynakça}

- Vural Umut, 2013. “Geleneksel Olmayan Para Politikalarının Yükselişi”, TCMB Uzmanlık Yeterlilik Tezi, ss. 1-109.

- Bernanke Ben, Mark Gertler ve Simon Gilchrist, 1996. "The Financial Accelerator and the Flight to Quality”, The Review of Economics and Statistics, Vol. 78, No. 1, ss. 1-15.

- Özatay Fatih, 2012. "Para Politikasında Yeni Arayışlar ve TCMB”, TEPAV, ss. 1-17.

- Duramaz Selim ve İlkay Dilber, 2015. "Küresel Kriz Sürecinde Para Politikasında Yeni Bir Araç Olarak Faiz Koridoruna Genel Bir Bakış", Maliye Araştırmaları Dergisi, Cilt. 1, Sayı. 1, ss. 29-38.

- Clews Roger, Chris Salmon ve Olaf Weeken, 2010. “The Bank’s Money Market Framework”, Quarterly Bulletin. Research and Analysis, ss. 292-301.

- Maehle Nils, 2014. "Monetary Policy Implementation: Operational Issues for Countries with Evolving Monetary Policy Regimes", IMF Working Paper, No. 14, ss. 1-66.

- Gertler Mark ve Peter Karadi, 2011. "A Model of Unconventional Monetary Policy”, Journal of Monetary Economics, No. 58, ss. 17-34.

- Bowman David, Etienne Gagnon ve Mike Leahy, 2010. "Interest on Excess Reserves as a Monetary Policy Instrunment: The Experience of Foreign Central Banks”, Board of Guvernors of the Federal Reserv System. International Finance Discussion Papers, No. 996, ss. 1-47.

- Tokucu Erkan, 2013. "Para Politikalarının Uygulanmasında Faiz Koridoru Sistemi ve Kanada, İngiltere ve Yeni Zelanda Deneyimleri”, Finans Politik \& Ekonomik Yorumlar, Cilt. 50, Say1. 581, ss. 7-24.

- Whitesell William, 2006. "Interest Rate Corridors and Reserves", Journal of Monetary Economics, No. 53, ss. 1177-1195.

- Kara Hakan, 2012. “Küresel Kriz Sonrası Para Politikası”, TCMB Çalışma Tebliği, No. 12/17, ss. 1-25.

- Serel Alpaslan ve İsmail Cem Özkurt, 2014. "Geleneksel Olmayan Para Politikası Araçları ve Türkiye Cumhuriyet Merkez Bankası”, Yönetim ve Ekonomi Araştırmaları Dergisi, Sayı. 22, ss. 56-71.

- Binici Mahir ve diğerleri, 2013. "Faiz Koridoru bir Makro İhtiyati Araç Olabilir mi?”, TCMB Ekonomi Notlarl, Say1. 20, ss. 1-16.

- $\quad$ Tetik Metin ve Reşat Ceylan, 2015. "Faiz Koridoru Stratejisinin Hisse Senedi Fiyatları ve Döviz Kuru Üzerine Etkilerinin İncelenmesi”, Business and Economics Research Journal, Vol. 6, No. 4, ss. 55-69.

- Arıcan Erişah ve Başak Tanınmış Yücememiş, 2015. "Para Politikaları Işığında Türk Bankacılık Sektörü Genel Değerlendirmesi”, İktisadi Araştırmalar Vakfi, ss. 1-12. 
- $\quad$ Bindseil Ulrich ve Juliusz Jablecki, 2011. "The Optimal Width of the Central Bank Standing Facilities Corridor and Banks' Day-to-Day Liquidity Management”, ECB Working Paper Series, No. 1350, ss. 1-34.

- Berentsen Aleksander ve Cyril Monnet, 2006. "Interest Rate Policy in a Channel System”, Federal Reserve Bank of Philadelphia Working Paper, No. 08-7, ss. 1-42

- Kahn George A., 2010. "Monetary Policy under a Corridor Operating Framework", Federal Reserve Bank of Kansas City Economic Review. Fourth Quarter, Vol. 95, No. 4, ss. 5-34.

- Nautz Dieter ve Christian J. Offermanns, 2007. "The Dynamic Relationship Between the Euro Overnight Rate, the ECB's Policy Rate and the Term Spread”, International Journal of Finance And Economics, 12, ss. 287-300.

- Bernhardsen Tom ve Arne Kloster, 2010. “Liquidity Management System: Floor or Corridor?”, Norges Bank. Staff Memo, No. 4, ss. 1-31.

- Jackson Cristopher ve Joseph Noss, 2015. “A Heterogeneous Agent Model for Assessing the Effects of Capital Regulation on the Interbank Money Market under a Corridor System”, Bank of England Staff Working Paper, No. 548, ss. 1-28.

- Zhang Nellie, 2012. "Estimating the Demand for Settlement Balances in the Canadian Large Value Transfer System”, Bank of Canada Working Paper, No. 15, ss. 1-40.

- Friedman Benjamin M ve Kenneth N. Kuttner, 2010. "Implementation of Monetary Policy: How Do Central Banks Set Interest Rates?”, NBER Working Paper Series, No. 16165, ss. 1-94.

- Blenck Denis ve diğerleri, 2001. "The Main Features of the Monetary Policy Frameworks of the Bank of Japan, the Federal Reserve and the Eurosystem", BIS Papers, No. 9, ss. 23-56.

- Kara Hakan, 2015. "Faiz Koridoru ve Para Politikası Duruşu”, TCMB Ekonomi Notları, Sayı. 13, ss. 1-12.

- Oktar Suat ve Kamil Yurdabak, 2015. "2008 Küresel Kriz Sonrası Türkiye Cumhuriyet Merkez Bankas1 Para Politikası Uygulamaları”, Akademik Hassasiyetler Dergisi, Say1. 4, ss. 1-34.

- Küçük Hande ve diğerleri, 2015. "Interest Rate, Liquidity Management, and the Overnight Spread”, Contemporary Economic Policy, No. 12165, ss. 1-16.

- Özhan Galip Kemal ve diğerleri, 2013. "Unconventional Monetary Policy and Its Reflections on the Global Economy", Think Tank 20: The G-20 and Central Banks in the New World of Unconventional Monetary Policy Report, ss. 81-87.

- Yücememiş Başak Tanınmış, Ufuk Alkan ve Canan Dağıdır, 2015. "Yeni Bir Para Politikası Aracı Olarak Faiz Koridoru: Türkiye'de Para Politikası Kurulu Faiz Kararlarının Enflasyon Üzerindeki Etkisi”, Finansal Araştırmalar ve Çalışmalar Dergisi, Cilt. 7, Sayı. 13, ss. 449-478.

- TCMB, 2016. Faiz Oranlarına İlişkin Basın Duyurusu, http://www.tcmb.gov.tr/wps/wcm/connect/tcmb+tr/tcmb+tr/main+menu/duyurular/basin/2016/duy2016-19\#, 15.05.2016. 


\title{
Kredi Balonlarının Ekonomik İstikrarsızlık Üzerine Etkisi: 1998 - 2016 Dönemi Türkiye Örneği \\ The Effect of the Credit Bubbles on Economic Instability: The Sample of Turkey in 1998 - 2016 Period
}

\author{
Asst. Prof. Dr. Özge Korkmaz (Bayburt University, Turkey)
}

\begin{abstract}
A country having a stable economy is directly related with its financial stability. Especially in recent years, we face the incurring debts as the most important problem of the individuals and countries, these problems must be taken into consideration, and the influence of indebtedness on economic stability must be investigated. In other words, the source of the excessive indebtedness, which directs the economic stability, must be defined well. For this purpose, in the study, the credit bubbles have been considered as the factors triggering the indebtedness, and the effects of the credit bubbles on economic instability in Turkey has been investigated. For this purpose, first of all, the dates when the credit bubbles were incurred were determined, and then the factors influencing the economic instability have been examined. In this study, the three-month data of the 1998:01-2016:01 period for Turkey, the economic instability indicators, and the credit bubbles have been considered. By using the Sup ADF (SADF) and Generalized Sup ADF (GSADF) tests, the credit bubbles were determined.
\end{abstract}

\section{Giriș}

Finansal istikrar kavramı, finansal sistemin ana ekonomik fonksiyonlarını etkin şekilde yerine getirdiği durağan bir ortam olarak tanımlanmaktadır (Deutsche, 2003:8). Bir diğer ifadeyle, finansal sistemdeki istikrar, kaynakların bölüştürülmesi, risklerin dağıtılması ve ödemelerin gerçekleştirilmesi eylemlerinin yerine getirilmesi ile ilişkilidir. Ekonomik istikrar kavramı ise, genel ekonomik faaliyetlerde aşırı daralma ve genişleme gibi bir dalgalanmanın olağanüstü, sürpriz ve beklenmeyen bir biçimde görülmemesi olarak tanımlanmaktadır. Benzer şekilde ekonomik istikrarsızlık kavramı, ekonomideki gelişmelerin beklenen ve istenen seviyede devam etmemesi olarak ifade edilebilmektedir.

Ekonomik istikrarın sağlanması ve korunması ülkelerin sürdürmüş olduğu politikaların devamlılı̆̆ı için oldukça önemlidir ve iktisat literatüründe ekonomik istikrar göstergesi olarak birçok değişken ele alınmaktadır. Ekonomik istikrar denildiği zaman ilk akla gelen kavram, fiyat istikrarıdır ve ekonomik istikrar göstergesi olarak enflasyon oranları dikkate alınabilmektedir. Benzer şekilde ekonomik istikrar göstergesi olarak gayri safi yurt içi hasıla tutarı da ele alınmaktadır. Her iki göstergeye de yön verebilen bir diğer unsur ise finansal kesimde ortaya çıkan aşırı borçlanma oranlarıdır. Borçlanma oranlarının aşırı olması durumunda ekonomik istikrarın sağlanabilmesi oldukça güçtür. Dolayısıyla ekonomik istikrara yön veren aşırı borçlanmanın ana kaynağı belirlenmelidir. Bu doğrultuda çalışmada kredi balonlarının borçlanmayı tetikleyen bir unsur olduğu düşünülmüş ve Türkiye'de kredi balonlarının ekonomik istikrarsızlık üzerindeki etkisi ortaya konulmak istenmiştir.

Çalışmada Türkiye için 1998:01-2016:01 dönemi dikkate alınmış, SADF ve Genelleştirilmiş SADF testleri aracilığıyla kredi balonlarının oluştuğu tarihler tespit edilmiştir. Ayrıca çalışmada M2 para arzı, finansal istikrarsızlık, ekonomik istikrarsızlık, tüketici fiyat endeksi, üretici fiyat endeksi, toplam kredi hacmi, gayri safi yurt içi hasıla, interbank faiz oranı ile kredi balonları değişkenlerinden ve regresyon analizinden yararlanılmıştır.

\section{Literatür}

2008 krizi ile birlikte birçok ülke için ekonomik istikrarın sağlanması önemli bir hedef haline gelmiştir. Ekonomik istikrarın sağlanması hususu üzerine yazılan birçok çalışmanın literatürde yer aldığı söylenebilmektedir. Dolayısı ile literatür incelemesinde bir sınırlama getirilmiş ve sadece ampirik açıdan ekonomik istikrar kavramını ele alan çalı̧̧malara yer verilmiştir.

Barros vd. (2000) yoksulluk ve eşitsizlik ile enflasyon ve büyüme arasındaki ilişkiyi araştırmışlardır. 1984-1998 yılları için yoksulluk, eşitsizlik, işsizlik oranı ve enflasyon oranı değişkenleri kullanılmış ve regresyon analizi yönteminden yararlanmışlardır. Çalışmanın sonucunda işsizlik ile yoksulluk ve eşitsizlik arasında negatif ilişki olduğu bulunmuştur. Ayrıca enflasyonun hızlandığı dönemlerde enflasyonun ve işsizliğin yoksulluk ve eşitsizliği pozitif olarak etkilediği görülmüştür.

Ismihan ve diğerleri (2005), 1963-1999 dönemleri için Türkiye'de makroekonomik istikrarsızlık, kamu ve özel sermaye oluşumu ve ekonomik büyüme arasındaki ilişkiyi incelemişlerdir. Çalışmada reel GSYİH, reel özel sabit yatııımlar, reel kamu sabit yatırımlar ve makroekonomik istikrarsızlık değişkenleri kullanılmış ve eşbütünleşme ve vektör otoregresif modelden (VAR) yararlanılmıştır. Çalışma sonucunda, kronikleşen ve artan makroekonomik istikrarsızlığın sermaye oluşumunu ve ekonomik büyümeyi olumsuz yönde etkilediği bulunmuştur. Aynı zamanda, 
kronik makroekonomik istikrarsızlığın kamu yatırımları için önemli bir engel olduğu, uzun dönemde kamu ve özel yatırımlar arasındaki bütünleşmeye zarar verdiği görülmüştür.

Folawewo ve Osinubi (2006) enflasyon ve döviz kuru istikrarsızlığının kontrolünde para politikasının etkinliğini araştırmışlardır. 1980-2000 dönemi için enflasyon oranı, reel devlet kredi değeri, Merkez bankası rezervlerinin toplam yurtiçi kredilere oranı, tüketici fiyat endeksi, nominal efektif döviz kuru ve reel efektif döviz kuru değişkenleri kullanılmış ve Johansen eşbütünleşme ve regresyon analizlerinden yararlanılmıştır. Çalışmanın sonucunda enflasyon-vergi oranının belirlenmesi yoluyla bütçe açığının finansmanını etkilemede para politikasının başarısının enflasyon ve reel döviz kurunu etkilediği görülmüştür.

Huang ve Meng (2007), momopolistik rekabet ve kuadratik fiyat uyarlamaları altında sermaye oluşumu ve makroekonomik istikrarsızlık arasındaki ilişkiyi genel denge modeli çerçevesinde incelemişlerdir. Çalışma sonucunda katma değerli üretim maliyetinde sermayeye yapılan ödemelerin payındaki artışın ve fiyatlarda meydana gelen jumpların makroekonomik istikrarsızlığı arttırdığı görülmüştür.

Jalab, Gbakou ve Sandretto (2008), 1970-2005 dönemi için Orta Doğu ve Kuzey Afrika ülkelerinde doğrudan yabancı yatırımın ekonomik büyüme üzerindeki etkisini incelemişlerdir. Çalışmada dinamik panel veri analizi, GMM ve 2 Aşamalı EKK yöntemlerinden yararlanılmıştır. Çalışmada kişi başına ekonomik büyüme oranı, dışa açıklık, enflasyon ve doğrudan yabancı yatırım değişkenleri kullanılmıştır. Çalışma sonucunda doğrudan yabancı yatırımların ekonomik büyüme üzerinde etkisinin olmadığı görülmüştür. Aynı zamanda, doğrudan yabancı yatırımın büyüme etkisinin dışa açıklık ve kişi başına gelire bağlı olmadığı bulunmuştur. Bununla birlikte, doğrudan yabancı yatırımın ekonomik büyüme üzerindeki pozitif etkisinin enflasyon oranına bağlı olduğu tespit edilmiştir.

Cömert ve Olçu (2010), 2002-2008 dönemi için Merkez Bankası para politikasının makroekonomik istikrarsılılk üzerindeki etkisini ele almışlardır. Çalışmada TCMB faiz yumuşatma eğiliminin para politikasının temel belirleyicisi olduğu ifade edilmiştir. Çalışmada kısa dönem faiz oranı, reel döviz kuru oranı, enflasyon oranı, çıktı açığı, beklenen ve hedeflenen enflasyon arasındaki fark ve FED faiz oranı değişkenleri kullanılmıştır. EKK ve GMM yöntemlerinden yararlanılmıştır. Çalışma sonucunda para politikasını temsil eden kısa dönem faiz oranı ve FED faiz oranındaki artışın ekonomik istikrarsızlığı arttırdığı, buna karşın reel döviz kurundaki değer artışının ise ekonomik istikrarsızlığı azalttığı bulunmuştur.

Karagöz ve Ergün (2010), çalışmalarında Türkiye'de 1987-2010 dönemi için ekonomik istikrarsızlı̆ı̆n kaynaklarını incelemişlerdir. Çalışmada üç aylık veri setinden; toptan eşya fiyat endeksi, üretim düzeyi, para arzı, mevduat faiz oranı, reel döviz kuru değişkenlerinden ve ARDL-Sınır testi yaklaşımından yararlanılmışıı. Analiz sonucunda GSMH, reel döviz kuru, faiz oranı ve para arzı değişkenlerinin ekonomik istikrarsızlık göstergesi olan enflasyon oranını anlamlı olarak etkilediği gözlenmiştir. GSMH ile reel döviz kuru değişkenlerinin ekonomik istikrarsızlığı azalttığı, faiz oranı ve para arzı değişkenlerinin ise ekonomik istikrarsızlığı arttırdığı tespit edilmiştir.

Berument, Dincer ve Mustafaoglu (2011) , 1987-2007 dönemi için makroekonomik istikrarsılılk ile toplam faktör verimliliği arasındaki ilişkiyi incelemişlerdir. Çalışmada enflasyon oranı, dışa açıklık oranı ve finansal piyasa derinliği makroekonomik istikrarsızlık ölçütleri olarak kullanılmıştır. Çalışmada VAR-GARCH yönetiminden yararlanılmıştır. Çalışma sonucunda dışa açıklık ve finansal piyasa derinliğinin toplam faktör verimliliğini azalttığı, buna karşın enflasyondaki oynaklığın ise toplam faktör verimliliğini arttırdığı bulunmuştur.

Jalil, Harun ve Mat (2012) adem-i merkeziyetçiliğin makro ekonomik istikrarsızlık üzerindeki etkisini analiz etmişlerdir. 1972-2001 dönem için 62 ülke ile yapılan panel veri analizi yönteminden yararlanılmıştır. Adem-i merkeziyetçiliğin ölçümü olarak alt yönetim harcamalarının toplam devlet harcamaları içindeki yüzdesi ve alt yönetim gelirlerinin toplam devlet gelirleri içindeki yüzdesi kullanılmıştır. Makro ekonomik istikrarsızlı̆̆ın göstergesi olarak ise enflasyon oranı ve bütçe açığı düzeyi kullanılmıştır. Çalışma sonucunda adem-i merkeziyetçiliğin enflasyon oranında azalmaya yol açtığını, bununla birlikte, adem-i merkeziyetçilik ile bütçe açığı arasında herhangi bir korelasyon olmadığı görülmüştür. Aynı zamanda adem-i merkeziyetçiliğin enflasyon üzerindeki etkisinin algılanan yolsuzluk düzeyine bağlı olduğu görülmüştür.

Meeks, Nelson ve Alessandri (2013), toplam faaliyetin, kredi arzının ve kredi yayılmasının konjonktür hareketleri ve finansal şoklara tepkisini genel denge modeli çerçevesinde analiz etmişlerdir. Çalışmanın sonucunda finansal kurumlar arasındaki etkileşimler ve yayılma etkisinin kredi dinamiklerini etkilediğini, finansal bir şoku takiben sadece seküritizasyon piyasalarında amaçlanan stabilizasyon politikasının makroekonomik istikrarsızlık üzerinde anlamlı bir etkiye sahip olmadığı görülmüştür.

\section{Veri Seti ve Yöntem}

Çalışmada E-Views 9 programından ve STATA 13 programından yararlanılmıştır. Çalışmada kullanılan tüm değişkenlere ait bilgiler Tablo 1'de sunulmuştur. 


\begin{tabular}{|l|l|}
\hline Değişkenler & Açıklama \\
\hline FI & Toplam kredi hacminin GSYİH'ye oranı \\
\hline EI & Reel GSYİH'nın 6 çeyreklik hareketli standart sapması \\
\hline GSYIH & GSYİH'nın doğal logaritması \\
\hline TUFE & Tüketici fiyat endeksinin doğal logaritmasının birinci devresel fark1 \\
\hline UFE & Üretici fiyat endeksinin doğal logaritmasının birinci devresel fark1 \\
\hline LM2 & M2 Para arzının doğal logaritması \\
\hline İHR & Ulusal para cinsinden ihracat tutarının doğal logaritması \\
\hline İTH & Ulusal para cinsinden ithalat tutarının doğal logaritması \\
\hline RDK & ABD doları cinsinden reel döviz kuru \\
\hline TKR & Toplam kredi tutarının doğal logaritması \\
\hline D & Yapısal kırılmaların var olduğu tarihi gösteren kukla değişken \\
\hline FAIZ & Interbank faiz oranı \\
\hline BALON & Kredi balonlarının var olduğu tarihi gösteren kukla değişken \\
\hline
\end{tabular}

Tablo 1: Çalışmada Kullanılan Değişkenler

Tablo 1'de gösterilen FI ve EI değişkenleri literatürden hareketle elde edilmiştir ve çalışmada finansal istikrarsızlık değişkeni FI ve ekonomik istikrarsızlık değişkeni EI kısaltması ile gösterilmiştir. Çalışmada kullanılan değişkenler TCMB elektronik veri dağıtım sistemin (EVDS)'den ve Federal Reserve Bank (FRED Database) internet sitesinden elde edilmiştir. Çalışmada, mevsimselliğin doğrusal olarak ayrıştırıldığı hareketli ortalama yöntemine dayanan Census X12 yöntemi ile seriler mevsimsellikten arındırılmıştır.

Finansal balonların bulunması amacıyla son zamanlarda kullanılmaya başlayan sağ kuyruklu birim kök testlerinde biri olan SADF ve Genelleştirilmiş SADF testlerinde sıfır ve alternatif hipotezlerin formülasyonu ve regresyon modelinin spesifikasyonu önemlidir (Philips, Shi and Yu, 2014: 316). En çok kullanılan sağ kuyruklu birim kök testlerinden biri olan SADF (sup ADF) testi, Philips, Wu ve Yu (2011) tarafından önerilmiştir. SADF testi ADF modelinin tekrarlayan tahminine dayanır ve karşılık gelen ADF istatistik dizisinin alt değeri olarak elde edilir (Philips, Shi and Yu, 2013: 8) ve aşağıdaki otoregresif spesifikasyon en küçük kareler ile tahmin edilir.

$$
x_{t}=\mu_{x}+\delta x_{t-1}+\sum_{j=1}^{J} \emptyset_{j} \Delta x_{t-j}+\varepsilon_{x, t}, \varepsilon_{x, t} \sim N I D\left(0, \sigma_{x}^{2}\right)
$$

Gecikme parametresi J'nin verilen bazı değerleri için, burada NID bağımsız ve normal dağılımı göstermektedir. Birim kök testinde sıfır hipotezi $H_{0}=\delta=1$ ve sağ kuyruklu alternatif hipotezi $H_{1}=\delta>1$ 'dir. Tekrarlamalı regresyonlarda, yukarıdaki model her geçişte bir gözlem arttırılan örnek verinin, alt kümelerini kullanarak tekrar tekrar tahmin edilir.

$$
\sup _{r \in\left[r_{0}, 1\right]} A D F_{r} \rightarrow \sup _{r \in\left[r_{0}, 1\right]} \frac{\int_{0}^{r} \widetilde{W} d W}{\left(\int_{0}^{r} \widetilde{W}^{2}\right)^{1 / 2}}
$$

Burada W standart Brownian hareketi ve $\widetilde{W}(r)=W(r)-\frac{1}{r} \int_{0}^{1} W$ küçültülen Brownian hareketini göstermektedir (Philips, Wu and Yu, 2011: 206-207). Genelleştirilmiş ADF (GADF) testi de SADF testi ile benzerlik göstermektedir. Genelleştirilmiş ADF, SADF testi gibi alt örneklerde ADF testinin tekrarlamalı olarak çalışmasına bağlıdır. Ancak Genelleştirilmiş ADF testi, SADF testine göre çok daha geniştir ve bu test en büyük ADF istatistiği olarak ifade edilmektedir. GADF testi aşağıdaki formül aracılığıyla hesaplanmaktadır (Philips, Shi and $\mathrm{Yu}, 2013: 10)$.

$$
\operatorname{GSADF}\left(\boldsymbol{r}_{0}\right)=\underset{\substack{r_{2} \in \\ r_{1} \in\left[0, r_{2}-r_{1}\right]}}{\sup }\left\{A D F_{\left.r_{1}, 1\right]}^{r_{2}}\right\}
$$

Çalışmada kredi balonlarının ortaya çıktığı tarihler SADF ve Genelleştirilmiş SADF testleri aracılığıyla araştırılmıştır.

\section{Bulgular}

Çalışmada ilk olarak toplam kredilerden hareketle, kredi balonlarının var olup olmadı ̆̆ belirlenmek istenmiştir. $\mathrm{Bu}$ amaçla SADF ve Genelleştirilmiş SADF testlerinden yararlanılmıştır. Elde edilen sonuçlar Tablo 2'de sunulmuştur. SADF ve GSADF testlerine ilişkin grafikler ise Şekil 1'de gösterilmiştir.

Balonların meydana geldiği dönemleri belirlemek amacıyla, SADF ve GSADF istatistikleri her bir gözlem için 1000 replikasyonlu Monte Carlo simülasyonundan elde edilen \%95 kritik değer ile karşılaştırılmıştır.

Şekil 1'de tüm dönem boyunca date-stamping strateji sonuçları gösterilmektedir ve Şekil 1'e göre, Türk kredi piyasasında balonların varlığı görülmektedir. 


\begin{tabular}{|c|c|c|}
\hline & SADF & GSADF \\
\hline KREDİ & $5.848353^{* * *}$ & $5.848353^{* * *}$ \\
\hline $90 \%$ kritik değer & 1.041980 & 1.998844 \\
\hline $95 \%$ kritik değer & 1.348546 & 2.311151 \\
\hline $99 \%$ kritik değer & 1.891039 & 3.011358 \\
\hline $\begin{array}{l}*{ }^{* *} \text { ve }^{* * *} \text { sırasıyla } 0.10,0.05 \text { ve } 0.01 \text { düzeyinde istatistiksel olarak } \\
\text { anlamlılığ1 ifade etmektedir. }\end{array}$
\end{tabular}

Tablo 2: SADF ve GSADF Test Sonuçları

SADF test

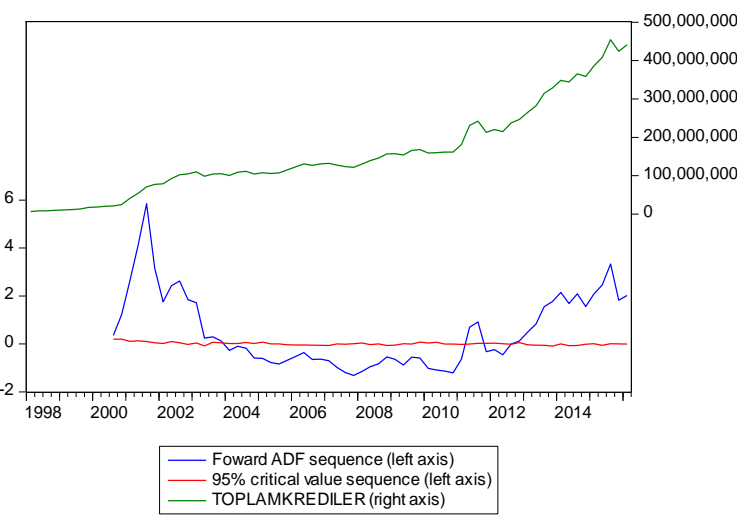

GSADF test

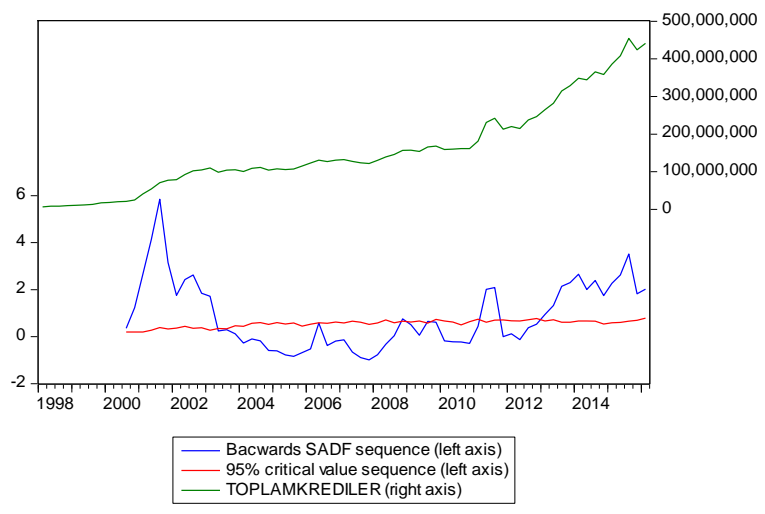

Şekil 1. Türk Kredi Piyasasında Date-Stamping Balon Dönemleri

Çalışmada analizin güvenilir sonuçlar verebilmesi için serilerin birim kök içerip içermediğinin araştırılması gerekmektedir. Dolayısı ile kredi balonlarının belirlenmesinin ardından, sahte regresyon sorunundan kaçınmak amacıyla, serilerin durağan oldukları seviye/farklar araştırılmak istenmiştir. Çalışmada yapısal kırılmaları dikkate alan Zivot-Andrews birim kök testinden yararlanılmıştır. Serilerin düzey değerleri için Zivot-Andrews birim kök test sonuçları Tablo 3 'te rapor edilmiştir.

\begin{tabular}{|c|c|c|c|c|c|c|}
\hline \multirow[b]{2}{*}{ Değişkenler } & \multicolumn{2}{|c|}{ Sabit Terimli } & \multicolumn{2}{|c|}{ Trendli } & \multicolumn{2}{|c|}{ Sabit Terimli ve Trendli } \\
\hline & Test İstatistiği & $\begin{array}{c}\text { Kırılma } \\
\text { Tarihi }\end{array}$ & Test İstatistiği & $\begin{array}{c}\text { Kırılma } \\
\text { Tarihi }\end{array}$ & Test İstatistiği & $\begin{array}{c}\text { Kurılma } \\
\text { Tarihi }\end{array}$ \\
\hline FI & $-3.6540(5)$ & $2000: 03$ & $-3.5049(5)$ & 2001:02 & $-3.6266(5)$ & $2000: 03$ \\
\hline EI & $-3.9169(4)^{*}$ & 2003:01 & $-48.6861(1)^{* * *}$ & 2007:01 & $-8.6057(1)^{* * *}$ & 2007:04 \\
\hline GSYIH & $-9.3752(0)^{* * *}$ & 2013:01 & $-5.4855(0)^{* *}$ & 2001:04 & $-6.7669(0)^{* * *}$ & 2001:01 \\
\hline TUFE & $-6.7341(6)^{* * *}$ & 2002:04 & $-5.7407(0)^{* * *}$ & 2004:03 & $-7.9706(3)^{* * *}$ & 2003:02 \\
\hline UFE & $-8.3570(3)^{* * *}$ & 2003:01 & $-6.4032(2)^{* * *}$ & 2005:04 & $-8.0968(3)^{* * *}$ & 2003:01 \\
\hline LM2 & $-5.8052(0)^{* * *}$ & 2005:04 & $-4.4179(1)^{* *}$ & 2002:04 & $-6.0895(0)^{* * *}$ & 2000:04 \\
\hline$\dot{\mathrm{I} H R}$ & $2.3680(0)$ & 2003:02 & $-3.5077(5)$ & 2008:01 & $-3.8334(2)$ & 2010:01 \\
\hline İTH & $-3.5461(1)$ & 2003:02 & $-3.6996(1)$ & 2008:01 & $-3.7138(1)$ & 2008:03 \\
\hline RDK & $-2.5807(1)$ & 2014:03 & $-2.5882(1)$ & 2013:02 & $-2.5345(1)$ & 2014:01 \\
\hline TKR & $-6.7521(5)^{* * *}$ & 2000:04 & $-5.4211(5)$ & 2001:02 & $-6.6595(5)$ & 2000:04 \\
\hline FAIZ & $-6.3805(0)^{* * *}$ & 2002:03 & $-6.3669(0)^{* * *}$ & 2005:04 & $-6.6001(0)^{* * *}$ & 2003:02 \\
\hline
\end{tabular}

Tablo 3: I(0) İçin Zivot-Andrews Birim Kök Testi Sonuçları

Tablo 3 incelendiğinde, gayri safi yurt içi hasıla, ekonomik istikrarsızlık, interbank faiz oranı, toplam kredi hacminin ve M2 para arzı değişkenlerinin düzey değerlerinde durağan olduğu ancak finansal istikrarsızlık, reel döviz kuru değişkenlerinin ve ihracat ile ithalat oranlarının durağan olmadığı gözlenmiştir. Durağan olmayan değişkenlerin birinci devresel farklarında durağan olup olmadıkları araştırılmış ve elde edilen sonuçlar Tablo 4 'te gösterilmiştir.

Çalışmada yapısal kırılmaların kredi balonlarının ortaya çıktığı tarihleri tam olarak içermediği dikkat çekmektedir. Dolayısı ile çalışmada yapısal kırılmaların ekonomik istikrarsızlık üzerindeki etkilerinin ayrıca ele alınması gerektiği düşünülmüş ve bu doğrultuda yapısal kırılmaların olduğu tarihlere 1, olmadığı tarihlere 0 değeri verilerek "D” kukla değişkeni oluşturulmuştur. 


\begin{tabular}{|c|c|c|c|c|c|c|}
\hline & \multicolumn{2}{|c|}{ Sabit Terimli } & \multicolumn{2}{|c|}{ Trendli } & \multicolumn{2}{|c|}{ Sabit Terimli ve Trendli } \\
\hline Değişkenler & Test İstatistiği & $\begin{array}{c}\text { Kırılma } \\
\text { Tarihi }\end{array}$ & Test İstatistiği & $\begin{array}{c}\text { Kurılma } \\
\text { Tarihi }\end{array}$ & Test İstatistiği & $\begin{array}{c}\text { Kırılma } \\
\text { Tarihi }\end{array}$ \\
\hline FI & $-8.2634(0)^{* * *}$ & 2001:01 & $-6.6635(0)^{* * *}$ & 2004:02 & $-8.3071(0)^{* * *}$ & 2002:01 \\
\hline İHR & $-7.8746(0)^{* * *}$ & 2009:02 & $-5.5343(4)^{*}$ & 2003:03 & $-8.1357(0)^{* * *}$ & 2009:02 \\
\hline İTH & $-6.3743(0)^{* * *}$ & 2008:04 & $-5.5738(0)^{* * *}$ & 2003:04 & $-6.7955(0)^{* * *}$ & 2008:04 \\
\hline RDK & $-7.3302(0)^{* * *}$ & 2001:02 & $-6.8055(0)^{* * *}$ & $2007: 03$ & $-7.6596(0)^{* * *}$ & 2001:02 \\
\hline
\end{tabular}

\section{Tablo 4: I(1) İçin Zivot-Andrews Birim Kök Testi Sonuçları}

Çalışmada ekonomik istikrarsızlığı etkileyen faktörler regresyon analizi aracılığıyla belirlenmek istenmiştir. Regresyon modellerinde birden fazla bağımsız değişkenin ele alınması durumunda değişkenler arasında ilişki olabilmektedir. Bir diğer ifadeyle, modelde çoklu doğrusal bağlantı sorunu ile karşılaşıla bilinmektedir. Bu sorunun ortaya çıkmaması adına bağımsız değişkenler arasında yüksek korelasyona sahip değişkenler belirlenerek modelde aynı anda dikkate alınmamalıdır. Bu doğrultuda korelasyon matrislerinden yararlanılmıştır ve elde edilen sonuçlar Tablo 5'te sunulmuştur.

\begin{tabular}{|c|c|c|c|c|c|c|}
\hline & DFI & EI & GSYİH & TUFE & UFE & LM2 \\
\hline DFI & 1 & & & & & \\
\hline EI & 0.0958 & 1 & & & & \\
\hline GSYİH & -0.1133 & $-0.9240^{* * *}$ & 1 & & & \\
\hline TUFE & 0.1871 & $0.8359^{* * *}$ & $-0.8464^{* * *}$ & 1 & & \\
\hline UFE & $0.2469^{* *}$ & $0.6637^{* * *}$ & $-0.6803^{* * *}$ & $0.8985^{* * *}$ & 1 & \\
\hline LM2 & -0.0621 & $-0.9223^{* * *}$ & $0.9841^{* * *}$ & $-0.8106^{* * *}$ & $-0.6620^{* * *}$ & 1 \\
\hline DİHR & -0.1090 & 0.0166 & -0.0346 & -0.0125 & 0.1391 & -0.0841 \\
\hline DíTH & $-0.4296^{* * *}$ & -0.0185 & 0.0201 & -0.1421 & -0.0643 & -0.0371 \\
\hline DRDK & $0.4243^{* * *}$ & 0.0795 & -0.0080 & $0.2654^{* *}$ & $0.4453^{* * *}$ & 0.0205 \\
\hline TKR & -0.0697 & $-0.8835^{* * *}$ & $0.9768^{* * *}$ & $-0.8031^{* * *}$ & $-0.6218^{* * *}$ & $0.9449^{* * *}$ \\
\hline FAIZ & $0.2268^{*}$ & $0.8396^{* * *}$ & $-0.8688^{* * *}$ & $0.7743^{* * *}$ & $0.6288^{* * *}$ & $-0.8534^{* * *}$ \\
\hline & \multicolumn{2}{|c|}{ DİHR } & DİTH & DRDK & TKR & FAIZ \\
\hline DİHR & \multicolumn{2}{|c|}{1} & & & & \\
\hline DİTH & \multicolumn{2}{|c|}{$0.6000^{* * *}$} & 1 & & & \\
\hline DRDK & \multicolumn{2}{|c|}{$-0.3308^{* * *}$} & $-0.5852^{* * *}$ & 1 & & \\
\hline TKR & \multicolumn{2}{|c|}{-0.0139} & 0.0088 & 0.0455 & 1 & \\
\hline FAIZ & \multicolumn{2}{|c|}{0.0044} & -0.1166 & 0.1130 & $-0.8268^{* * *}$ & 1 \\
\hline
\end{tabular}

Tablo 5: Korelasyon Matrisi

Korelasyon matrisi sonuçlarından hareketle, çalışmada araştırılmak istenen modeller şu şekilde oluşturulmuştur:

MODEL 1: EI=f (DFI, DİHR,LM2)

MODEL 2: $\mathrm{EI}=\mathrm{f}(\mathrm{DI} T H, \mathrm{BALON}, \mathrm{FAIZ})$

MODEL 3: $E I=f(D R D K, D, T K R)$

MODEL 4: $U F E=f(B A L O N, D R D K, F A I Z)$

MODEL 5: $U F E=f(D I H R, T K R)$

MODEL 6: UFE $=f(D F I$, DITH, LM2)

MODEL 7: UFE=f (GSYİH, D)

MODEL 8: $T U F E=f(B A L O N, D R D K, F A I Z)$

MODEL 9: $T U F E=f(D I H R, ~ T K R)$

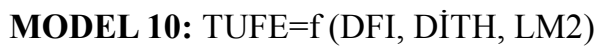

MODEL 11: TUFE=f (GSYİH, D)

Çalışmanın bu aşamasında yukarıda ifade edilen modellerin En Küçük Kareler Yöntemi (EKKY) aracılığıyla tahminine geçilmiştir. Bilindiği üzere regresyon modellerinde EKKY varsayımlarının sağlanması durumunda modelden elde edilen bilgilerin güvenilir ve tutarlı olduğu söylenebilmektedir. Bu nedenle modellerde 
otokorelasyon sorunu Breusch-Godfrey LM sınaması ile farklı varyans sorunu Breusch-Pagan-Godfrey sinamas1 ile ve hata terimlerinin normal dağılıp dağılmadığı ise Jarque-Bera (JB) testi ile araştırılmıştır. Elde edilen Diagnostik test sonuçları Tablo 6'da raporlanmıştır.

\begin{tabular}{|c|c|c|c|c|c|c|}
\hline \multirow{2}{*}{ MODELLER } & \multicolumn{2}{|c|}{ Jarque-Bera } & \multicolumn{2}{|c|}{ Breusch-Pagan-Godfrey } & \multicolumn{2}{|c|}{ Breusch-Godfrey LM } \\
\hline & $\begin{array}{c}\text { İstatistik } \\
\text { Değeri }\end{array}$ & $\begin{array}{c}\text { Olasılık } \\
\text { Değeri }\end{array}$ & $\begin{array}{c}\text { İstatistik } \\
\text { Değeri }\end{array}$ & $\begin{array}{c}\text { Olasilhk } \\
\text { Değeri }\end{array}$ & $\begin{array}{c}\text { İstatistik } \\
\text { Değeri }\end{array}$ & $\begin{array}{c}\text { Olasilık } \\
\text { Değeri }\end{array}$ \\
\hline MODEL 1 & 1.6656 & 0.4348 & 11.1323 & $0.0110^{* *}$ & 51.7828 & $0.0000^{* * *}$ \\
\hline MODEL 2 & 73.8053 & $0.0000^{* * *}$ & 31.6375 & $0.0000^{* * *}$ & 15.3634 & $0.0005^{* * *}$ \\
\hline MODEL 3 & 2.8157 & 0.2446 & 4.1229 & 0.1273 & 51.7719 & $0.0000^{* * *}$ \\
\hline MODEL 4 & 79.6294 & $0.0000^{* * *}$ & 32.6461 & $0.0000^{* * *}$ & 13.6883 & $0.0011^{* * *}$ \\
\hline MODEL 5 & 539.1797 & $0.0000^{* * *}$ & 1.7571 & 0.4154 & 13.2832 & $0.0013^{* * *}$ \\
\hline MODEL 6 & 321.5805 & $0.0000^{* * *}$ & 10.9011 & $0.0123^{* *}$ & 3.3102 & 0.1911 \\
\hline MODEL 7 & 509.2836 & $0.0000^{* * *}$ & 4.6759 & $0.0965^{*}$ & 9.3790 & $0.0092^{* * *}$ \\
\hline MODEL 8 & 123.8163 & $0.0000^{* * *}$ & 35.2718 & $0.0000^{* * *}$ & 10.7015 & $0.0047^{* *}$ \\
\hline MODEL 9 & 261.7995 & $0.0000^{* * *}$ & 1.0863 & 0.5809 & 28.4150 & $0.0000^{* * *}$ \\
\hline MODEL 10 & 26.9796 & $0.0000^{* * *}$ & 12.2517 & $0.0056^{* * *}$ & 19.1964 & $0.0001^{* * *}$ \\
\hline MODEL 11 & 180.5495 & $0.0000^{* * *}$ & 4.2357 & 0.1203 & 20.8158 & $0.0000^{* * *}$ \\
\hline
\end{tabular}

Tablo 6: Diagnostik Test Sonuçları

Diagnostik test sonuçlarını gösteren Tablo 6 incelendiğinde, otokorelasyon sorununun Model 6 hariç tüm modeller için geçerli olduğu gözlenmiştir. Aynı zamanda Model 1 ve Model 3 hariç diğer tüm modellerde hata terimlerinin normal dağılıma sahip olmadığı sonucuna varılmıştır. Bir diğer ifadeyle, "Hata terimleri normal dağılım göstermektedir" ifadesinin geçerliliği sadece Model 1 ve Model 3 için söylenebilmektedir. Ayrıca Model 3, Model 5, Model 9 ve Model 11 hariç tüm modellerde farklı varyans sorunun var olduğu tespit edilmiştir. Bu bulgulardan hareketle, tahmincilerin güvenilir sonuçlar verebilmesi amaciyla, dirençli standart hatalardan elde edilen tahminciler ile çalıssılmıştır ve edilen model sonuçları sırasıyla Tablo 7'de, Tablo 8'de, Tablo 9'da, Tablo 10 'da ve Tablo 11'de sunulmuştur.

İlk olarak ekonomik istikrarsızlığı etkileyen faktörler Model 1, Model 2 ve Model 3 aracılığıyla araştırılmış ve elde edilen bulgular sırasıyla Tablo 7'de ve Tablo 8'de gösterilmiştir.

\begin{tabular}{|c|c|c|c|c|}
\hline \multicolumn{5}{|c|}{ MODEL1 } \\
\hline \multicolumn{5}{|c|}{ Bağımlı Değișken: EI } \\
\hline Değişkenler & Katsayı & Robust Standart Hata & t-istatistik Değeri & Olasılık Değeri \\
\hline Sabit Terim & 0.3783 & 0.02158 & 17.5300 & $0.0000^{* * *}$ \\
\hline DFI & 0.0146 & 0.0170 & 0.8600 & 0.3930 \\
\hline DIHR & -0.0237 & 0.0258 & -0.92 & 0.3600 \\
\hline LM2 & -0.0176 & 0.0215 & -15.98 & $0.0000^{* * *}$ \\
\hline \multicolumn{3}{|c|}{$\mathrm{R}^{2}=0.8468$} & \multicolumn{2}{|c|}{$F=88.33\left(0.0000^{* * *}\right)$} \\
\hline
\end{tabular}

Tablo 7: Model 1 Sonuçlarl

Model 1 incelendiğinde, ihracat oranının ve finansal istikrarsızlı̆̆ı ekonomik istikrarsızlı üzerinde anlamlı bir etkisi olmadığı sadece para arzının ekonomik istikrarsızlı̆̆ etkilediği gözlenmiş̧tir. Bu doğrultuda para arzındaki bir artışın, ekonomik istikrarsızlığı 0.0176 oranında azalttığı ve bu oranın oldukça düşük olması nedeniyle, para arzının ekonomik istikrarsızlık üzerinde çok büyük bir etkisi olmadığı söylenebilmektedir.

Model 2 incelendiğinde, ithalat oranın, kredi balonlarının ve interbank faiz oranını ekonomik istikrarsızlık üzerinde anlamlı etkisi olduğu görülmektedir. Model 2'de, kredi balonlarındaki artışın ekonomik istikrarsızlığı azalttığı; ithalat oranlarındaki artışın ve interbank faiz oranlarındaki artışın ise ekonomik istikrarsızlığı arttırdığı belirlenmiştir. Faiz oranındaki artış ekonomik istikrarsızlığı 0.0007 kadar; ithalat oranındaki artış ise 0.0308 kadar ekonomik istikrarsızlığı arttırmakta iken; kredi balonlarındaki artış 0.0124 kadar ekonomik istikrarsızlı̆̆ azaltmaktadır. Model 3'teki bulgulardan hareketle ise, döviz kurundaki artışın ekonomik istikrarsızlığı arttırdığı ve toplam kredi hacmindeki artışın ekonomik istikrarsızlı̆̆ azalttığı söylenebilmektedir. Aynı zamanda yapısal kırılmaların ekonomik istikrarsızlık üzerinde herhangi bir anlamlı etkiye neden olmadığ Tablo 8'den görülmektedir. Bu bulgularda dikkat çeken iki husus vardır: bunlardan ilki faiz oranının etkisinin yok denecek kadar az olmasıdır. Bir diğer dikkat çeken nokta ise, kredi balonlarının ve toplam kredi hacminin ekonomik istikrarsızlık üzerinde azaltıcı etkisinin var olduğunun gözlenmesidir. Dolayısı ile bu bulgular değerlendirildiğinde, kredi kullanım oranlarındaki artı̧ın kredi balonlarının ortaya çıkmasına neden olabileceği ve böylece piyasada 
yeniden bir yapılanma olabileceği düşünülmektedir. Dolayısı ile kredi balonları ile ortaya çıkan kırılganlığın piyasada bir toparlanma yaratabileceği ve bu durumun ekonomideki istikrarsızlığın azalmasına yol açabileceği akla gelmektedir. Tüm bu varsayımların yanı sıra, Model 2 ve Model 3 'teki değişkenlerin katsayıları itibariyle ekonomik istikrarsızlık üzerinde çok büyük etkilere sahip olmadıkları da göz ardı edilmemelidir.

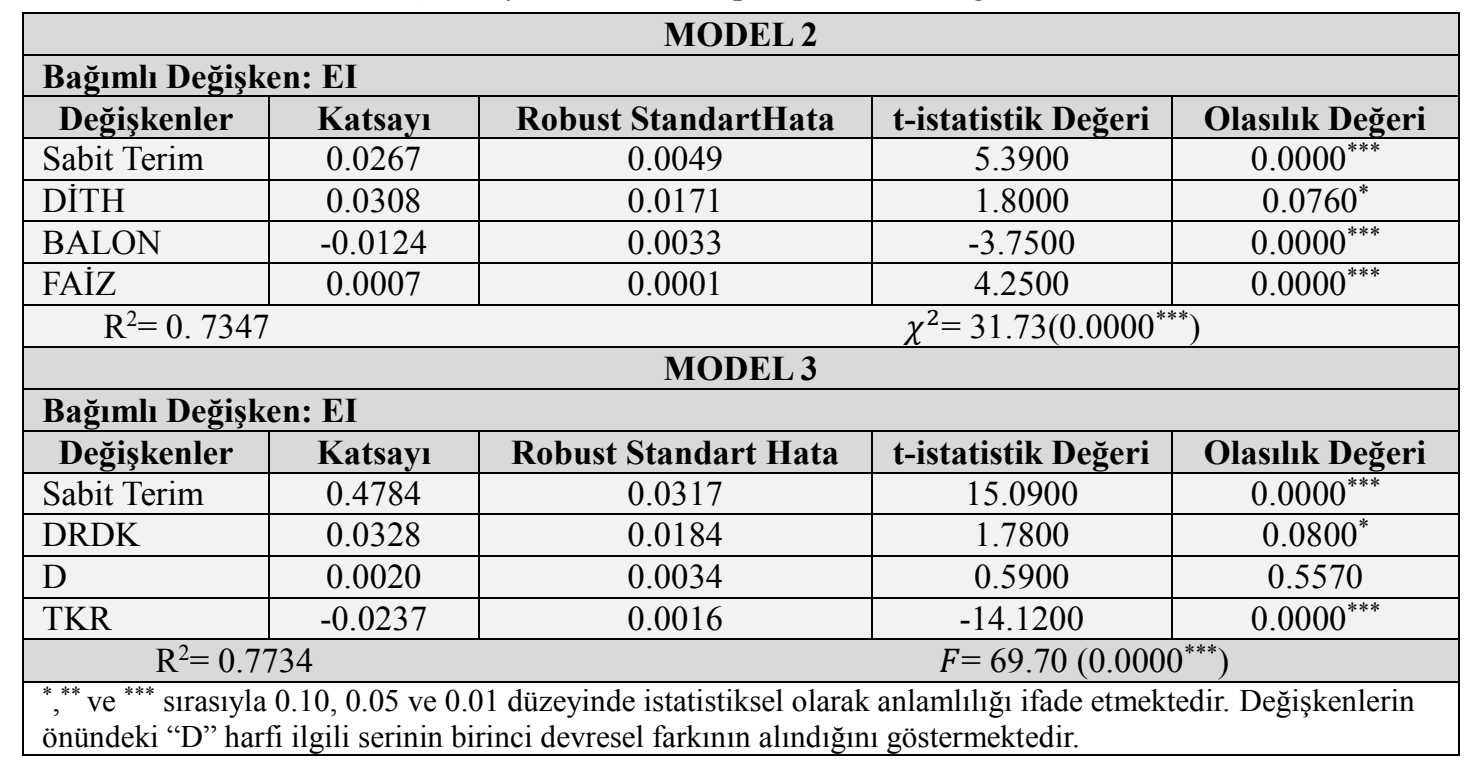

Tablo 8: Model 2 ve Model 3 Sonuçlart

Çalışmanın bu kısmında üretici fiyat endeks değerinden hareketle hesaplanan enflasyon oranı, ekonomik istikrarsızlık göstergesi olarak ele alınmış ve ilgili değerin bağımlı değişken olduğu modeller tahminlenmiştir. Elde edilen tahmin sonuçları Tablo 9'da ve Tablo 10'da verilmiştir.

\begin{tabular}{|c|c|c|c|c|}
\hline \multicolumn{5}{|c|}{ MODEL 4} \\
\hline \multicolumn{5}{|c|}{ Bağımlı Değişken: UFE } \\
\hline Değişkenler & Katsayı & Robust Standart Hata & t-istatistik Değeri & Olasılık Değeri \\
\hline Sabit Terim & 0.0101 & 0.0126 & 0.8000 & 0.4250 \\
\hline BALON & -0.0072 & 0.0115 & -0.6300 & 0.5332 \\
\hline DRDK & 0.1921 & 0.0977 & 1.9700 & $0.0530^{*}$ \\
\hline FAIZ & 0.0019 & 0.0126 & 0.8000 & $0.0050^{* * *}$ \\
\hline \multicolumn{5}{|l|}{$\mathrm{R}^{2}=0.5406$} \\
\hline
\end{tabular}

Tablo 9: Model 4 Sonuçları

Model 4 sonuçları incelendiğinde, reel döviz kurundaki artışın üretici fiyat endeksinden hareketle hesaplanan enflasyon oranını 0.1921 oranında arttırdığı ve interbank faiz oranlarındaki artışın enflasyon oranını 0.0019 oranında arttırdığı söylenebilmektedir. Bu bağlamda çalışmada kredi balonlarındaki artışın enflasyon oranı üzerinde herhangi anlamlı bir etkisi olmadığı tespit edilmiştir.

Çalışmada üretici fiyat endeksinden hareketle hesaplanan enflasyon oranının bağımlı değişken olarak ele alındığı Model 5, Model 6 ve Model 7 için elde edilen bulgular Tablo 10'da sunulmuştur.

Model 5 sonuçları ele alındığında ise, hem ihracat oranının hem de toplam kredi hacminin enflasyon oranı üzerinde anlamlı bir etkiye neden olduğu gözlenmiş ve ihracat oranındaki artışın enflasyonu pozitif yönde; toplam kredi hacmindeki artışın ise enflasyonu negatif yönde etkilediği belirlenmiştir. Aynı zamanda ihracatın etkisinin toplam kredi hacminden daha fazla olduğu tespit edilmiştir.

Model 6'ya ait bulgular incelendiğinde, para arzının ve finansal istikrarsızlığın enflasyon oranı üzerinde anlamlı bir etkiye sahip oldukları görülmüştür. Finansal istikrarsızlıktaki artışın enflasyonu 0.1818 oranında arttırdığı ancak para arzındaki bir artışın ise 0.0241 oranında enflasyonu azalttı̆̆ 1 sonucuna varılmıştır.

Yapısal kırılmaların enflasyon oranı üzerinde herhangi bir anlamlı etkisi olmadığı Model 7'den hareketle söylenebilmektedir. Ayrıca bu modelde gayri safi yurt içi hasıla oranındaki bir artışın enflasyonu 0.0390 kadar azalttığ 1 belirlenmiştir. 


\begin{tabular}{|c|c|c|c|c|}
\hline \multicolumn{5}{|c|}{ MODEL 5} \\
\hline \multicolumn{5}{|c|}{ Bağımlı Değişken: UFE } \\
\hline Değişkenler & Katsayı & Robust Standart Hata & t-istatistik Değeri & Olasılık Değeri \\
\hline Sabit Terim & 0.6426 & 0.0781 & 8.2300 & $0.0000^{* * *}$ \\
\hline DİHR & 0.1050 & 0.0527 & 1.9900 & $0.0500^{* *}$ \\
\hline TKR & -0.0325 & 0.0040 & -7.9900 & $0.0000^{* * *}$ \\
\hline \multicolumn{3}{|l|}{$\mathrm{R}^{2}=0.4036$} & \multicolumn{2}{|l|}{$\chi^{2}=31.88\left(0.0000^{* * *}\right)$} \\
\hline \multicolumn{5}{|c|}{ MODEL 6} \\
\hline \multicolumn{5}{|c|}{ Bağımlı Değişken: UFE } \\
\hline Değișkenler & Katsayı & Robust Standart Hata & t-istatistik Değeri & Olasılık Değeri \\
\hline Sabit Terim & 0.5019 & 0.0694 & 7.2300 & $0.0000^{* * *}$ \\
\hline DFI & 0.1818 & 0.0906 & 2.0100 & $0.0490^{* *}$ \\
\hline DİTH & 0.0002 & 0.0899 & 0.0000 & 0.9970 \\
\hline LM2 & -0.0241 & 0.0034 & -7.0400 & $0.0000^{* * *}$ \\
\hline \multicolumn{3}{|l|}{$\mathrm{R}^{2}=0.6959$} & \multicolumn{2}{|c|}{$\chi^{2}=73.2457\left(0.0000^{* * *}\right)$} \\
\hline \multicolumn{5}{|c|}{ MODEL 7} \\
\hline \multicolumn{5}{|c|}{ Bağımlı Değişken: UFE } \\
\hline Değişkenler & Katsayı & Robust Standart Hata & t-istatistik Değeri & Olasılık Değeri \\
\hline Sabit Terim & 0.7794 & 0.1009 & 7.7200 & $0.0000^{* * *}$ \\
\hline $\mathrm{D}$ & -0.0009 & 0.0109 & -0.0900 & 0.9320 \\
\hline GSYİH & -0.0390 & 0.0052 & -7.4100 & $0.0000^{* * *}$ \\
\hline \multicolumn{2}{|c|}{$\mathrm{R}^{2}=0.8517$} & \multicolumn{3}{|c|}{$\chi^{2}=93.94\left(0.0000^{* * *}\right)$} \\
\hline
\end{tabular}

Tablo 10: Model 5, Model 6 ve Model 7 Sonuçlarl

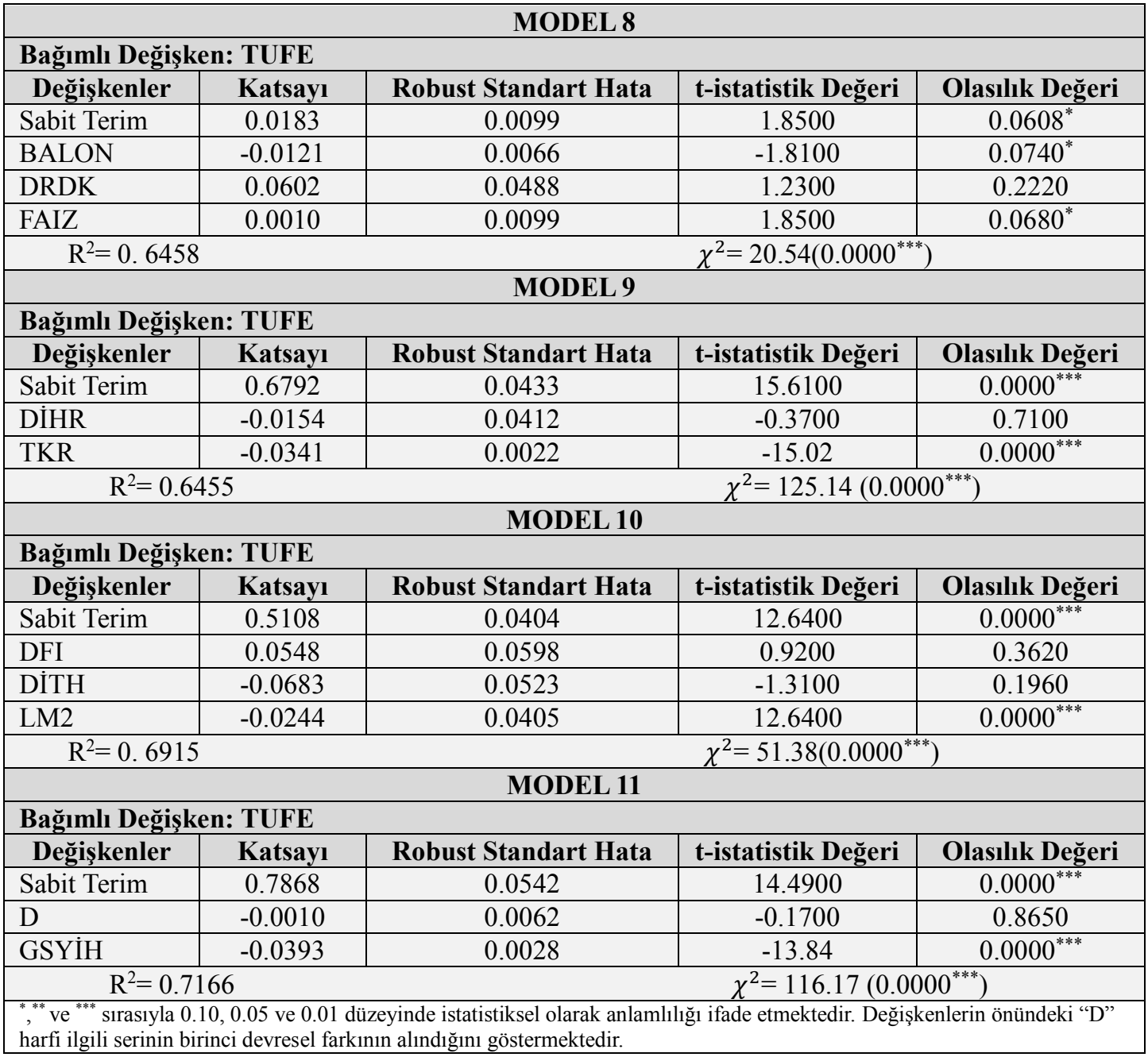

Tablo 11: Model 8, Model 9, Model 10 ve Model 11 Sonuçlart 
Buraya kadar tahminlenen tüm modeller birlikte ele alındığında en yüksek açıklama oranının Model 7 ve akabinde Model 1'de olduğu tespit edilmiştir. Aynı zamanda Model 4, Model 5, Model 6 ve Model 7 birlikte ele alındığında enflasyon oranı üzerinde en fazla etkiye ilk olarak reel döviz kurunun; ikinci olarak finansal istikrarsızlık değişkeninin ve ardından da ihracat oranının geldiği söylenebilmektedir. Her üç değişkenin de enflasyonu arttırdığı da dikkat çeken bir diğer noktadır. Dolayısı ile enflasyonla mücadele programlarında bu değişkenlerin etkisinin dikkate alınması gerektiği düşünülmektedir.

Çalışmada son olarak tüketici fiyat endeks değerinden hareketle hesaplanan enflasyon oranı, ekonomik istikrarsızlık göstergesi olarak ele alınmış ve bu doğrultuda model tahminleri yapılmıştır. İlgili model sonuçları ise Tablo 11'de sunulmuştur.

Tablo 11 incelendiğinde, tüketici fiyat endeksinden hareketle hesaplanan enflasyon oranını kredi balonlarının, interbank faiz oranının, toplam kredi hacminin, para arzının ve gayri safi yurt içi hasıla oranının anlamlı olarak etkilediği sonucuna varılmıştır. Bu bağlamda Model 8'e ait bulgulardan hareketle, kredi balonlarındaki artışın enflasyon oranını 0.0121 kadar azalttığı ve interbank faiz oranındaki artışın enflasyon oranını 0.0010 kadar arttırdığı söylenebilmektedir. Ayrıca Model 8'de reel döviz kurunun enflasyon oranını anlamlı olarak etkilemediği gözlenmiştir. Benzer şekilde Model 9'da ihracat oranının enflasyon oranı üzerinde anlamlı bir etkisi olmadığ görülmüştür. Aynı zamanda Model 9'da toplam kredi hacmindeki artışın enflasyon oranını 0.0341 kadar azalttığı belirlenmiştir. Model 10 incelendiğinde, para arzındaki artışın enflasyon oranı üzerinde azaltıcı bir etkisi olduğu saptanmıştır. Bir diğer ifadeyle, para arzındaki artış, enflasyon oranını 0.0244 oranında azaltmaktadır. Model 10'da finansal istikrarsızlık ve ithalat oranının enflasyon oranını; Model 11'de ise yapısal kırılmaların enflasyon oranını anlamlı olarak etkilemediği tespit edilmiştir. Son olarak Model 11'de gayri safi yurt içi hasıla oranındaki artışın enflasyon oranını 0.0393 kadar azalttığı gözlenmiştir.

Çalışmada EI, UFE ve TUFE değişkenlerinin ekonomik istikrarsızlık göstergesi olarak ele alındığı 11 model içerisinde en fazla ve en az etkiye sahip değişkenlere ilişkin bilgiler sunulmak istenmiştir. Söz konusu özet bulgular Tablo 12'de verilmiştir.

\begin{tabular}{|l|c|c|}
\hline Bağımlı Değişken & En Az Etkileyen Değişken & En Fazla Etkileyen Değişken \\
\hline EI & FAIZ (+) & RDK (+) \\
\hline UFE & FAIZ (+) & RDK (+) \\
\hline TUFE & FAIZ (+) & GSYİH (-) \\
\hline
\end{tabular}

Tablo 12: Ekonomik İstikrarsızlık Göstergelerini En Az ve En Fazla Etkileyen Değişkenler

Tablo 12 incelendiğinde, ekonomik istikrarsızlık göstergesi olarak ele alınan EI, UFE ve TUFE değişkenlerini en az etkileyen değişkenin interbank faiz oranı olduğu söylenebilmektedir. Çalışmada interbank faiz oranı ile ekonomik istikrarsızlık arasında pozitif yönlü bir ilişki olduğu ve dolayısı ile interbank faiz oranındaki artışın ekonomik istikrarsızlığı arttırdı̆̆ı saptanmıştır.

Ekonomik istikrarsızlık göstergesi olarak ele alınan EI ve UFE değişkenlerini en fazla etkileyen değişkenin reel döviz kuru olduğu Tablo 12'den görülmektedir. Ayrıca çalışmada reel döviz kurundaki artışın ekonomik istikrarsızlığı arttırdığı sonucuna ulaşılmıştır. TUFE değişkenin ekonomik istikrarsılık göstergesi olarak ele alındığı durumda ise gayri safi yurt içi hasıla oranının ekonomik istikrarsızlığı en fazla etkileyen unsur olduğu belirlenmiştir. Dolayısı ile gayri safi yurt içi hasıla oranındaki artışın ekonomik istikrarsızlığı azalttığı Tablo 12'den hareketle söylenebilmektedir.

Tablo 12'deki bulguların çalışmanın özetini sunması nedeniyle oldukça önemlidir. Bir diğer ifadeyle, bu bulguların politika yapıcılara yol gösterebilecek bir nitelikte olduğu söylenebilmektedir. Dolayısı ile politika yapıcıların burada söz edilen sonuçları dikkate alarak yeni yapılacak olan ekonomik istikrar politikaları oluşturması gerektiği düşünülmektedir.

\section{Sonuç}

Çalışmada kredi balonlarının ve yapısal kırılmaların ekonomik istikrarsızlık üzerinde etkisi olup olmadığını belirlemek ve ekonomik istikrarsızlığı etkileyen faktörlerin ortaya konulmasını sağlamak amaçlanmıştır. Bu bağlamda Türkiye için 1998:01-2016:01 dönemleri ile M2 para arzı, finansal istikrarsızlık, ekonomik istikrarsızlık, tüketici fiyat endeksi, üretici fiyat endeksi, toplam kredi hacmi, gayri safi yurt içi hasıla, interbank faiz oranı ile kredi balonları değişkenlerinden yararlanılmıştır. Kredi balonlarının varlığı SADF ve GSADF testleri aracılığıyla tespit edilmiştir. Çalışmada ekonomik istikrarsızlığı etkileyen faktörler ise regresyon analizi aracılığıyla araştırılmıştır.

Çalışmada ekonomik istikrarsızlığı etkileyen faktörler ayrı ayrı ele alınmak istenmiş ve bu amaçla 11 model oluşturulmuştur. Ekonomik istikrarsızlığı ve üretici fiyat endeksinden hareketle hesaplanan enflasyon oranını en fazla etkileyen unsurun reel döviz kuru olduğu gözlenirken; tüketici fiyat endeksinden hareketle hesaplanan enflasyon oranını en fazla gayri safi yurt içi hasıla oranının etkilediği gözlenmiştir. Aynı zamanda çalışmada faiz oranının ekonomik istikrarsızlık üzerinde pozitif yönlü ve en az etkiye sahip değişken olduğu saptanmıştır. 


\section{Kaynakça}

- Barros, Ricardo P. ve diğerleri (2000). Poverty, Inequality and Macroeconomic Instability. IPEA discussion paper, No:93.

- Berument, Hakan; Dincer, N. Nergiz; Mustafaoglu, Zafer (2011). Total Factor Productivity and Macroeconomic Instability. The Journal of International Trade and Economic Development, 20(5), 605-629.

- Cömert, Hasan ve Olçu, Gökçe A. (2010). Interest Rate Smoothnig and Macroeconomic Instability Under Post-Capital Account Liberalization Turkey. Canadian Journal of Development Studies, 3(4), 459-482

- Deutsche, Bundesbank (2003), Report on the Stability of the German Financial System, Monthly Report, (December), Frankfurt.

- Folawewo, Abiodun O.; Osinubi, Tokunba S. (2006). "Monetary Policy and Macroeconomic Instability in Nigeria: A Rational Expectation Approach", J. Soc. Sci., 12(2), pp. 93-100.

- Harvey, David; Leybournei Stephen ve Sollis,Robert (2013). "Recursive Right-Tailed Unit Root Tests for an Explosive Asset Price Bubble". Journal of Financial Econometrics, vol: 0, no:0, 1-22.

- Huang, Kevin X.D ve Meng, Qinglai (2007). Capital and Macroeconomic Instability in a Discrete-Time Model with Forward-Looking Interest Rate Rules. Journal of Economic Dynamics and Control, 31, 28022826

- Ismihan, Mustafa; Ozcan, Kivilcim M.; Tansel, Aysit (2005). The Rolde of Macroeconomic Instability in Public and Private Capital Accumulation and Growth: The Case of Turkey 1963-1999. Applied Economics, 37, pp.239-251

- Jalab, Mustapha S.; Gbakou, Monnet B. P.; Sandretto, Rene (2008). Foreign Direct Investment, Macroeconomic Instability and Economic Growth in MENA Countries. Centre National de la Recherche Scientifique Documents De Travail Working Papers, W.P.08-17

- Jalil, Ahmad Z. A.; Harun, Mukaramah; Mat, Siti H. C. (2012). Macroeconomic Instability and Fiscal Decentralization: An Empirical Analysis. Prague Economic papers, 2, 150-165.

- Karagöz, Kadir ve Ergün, Suzan (2010), “Türkiye'de Ekonomik İstikrarsızlığın Kaynakları: Ekonometrik Bir Değerlendirme", Süleyman Demirel Üniversitesi İktisadi ve İdari Bilimler Fakülte Dergisi, C:15, S.2,169-185.

- Meeks, Roland; Nelson, Benjamin ve Alessandri, Piergiorgi (2013). Shadow Banks and Macroeconomic Instability. Temi di Discussione Working Papers.

- Philips, Peter C.B.; Wu, Yangru; Yu, Jun (2011). "Explosive Behavior In The 1990s NASDAQ: When Did Exuberance Escalate Asset Values?", International Economic Review, 52 (1).

- Philips, Peter C.B.; Shi, Shuping; Yu, Jun (2013), “Testing For Multiple Bubbles: Historical Epısodes of Exuberance and Collapse In The S\&P 500", Cowles Foundation Discussion Paper No. 1914

- Philips, Peter C.B.; Shi, Shuping; Yu, Jun (2014), "Specification Sensitivity in Right-Tailed Unit Root Testing For Explosive Behavior", Oxford Bulletin of Economics and Statistics, 76, 3 (2014). 


\title{
Kurgizistan'da Vergi Bilinci Tax Consciousness in Kyrgyzstan
}

\author{
Asst. Prof. Dr. Raziiakhan Abdieva (Kyrgyzstan-Turkey Manas University, Kyrgyzstan) \\ Tolkun Cumakunova (Kyrgyz Turkish Manas University, Kyrgyzstan)
}

\begin{abstract}
Taxes are the main financial resource of government. Performance of tax system depends on the willingness of taxpayers to pay taxes or tax morale. Government can use deterrence instruments as tax penalty and size of detection. But socio-psychological factor as tax consciousness play one of the main role in the tax behavior. Tax consciousness means that taxpayer is aware about taxes that paid, knows what taxes are and how tax revenue is used. So tax consciousness is important in the forming of tax behavior and also in the improving democracy by increasing public control on public finance.

In transition economies as Kyrgyzstan government needs more financial resources to implement economic and social reforms, to decrease poverty and achieve sustainable development. Nowadays government seeks ways to increase tax revenue. In this paper author aim to analyze tax consciousness of taxpayers in Kyrgyzstan using the questionnaire conducted in 2013 in the capital city of Kyrgyzstan in Bishkek. Factors that affect tax consciousness will be analyzed with probit model.
\end{abstract}

\section{Giriş}

Günümüz dünya ülkelerinde kamu giderlerini karşılamak için en önemli kaynak vergi gelirleridir. Vergi, kamu harcamalarını finanse etmek amacı ile devletin hukuki zorunluluk altında, yasayla belirtilen kurallara göre karşılıksız, mükelleflerin gelir ve malları üzerinden alınan iktisadi değerdir. Dolayısıyla devletin toplumsal ihtiyaçlarını karşılamada en önemli gelir kaynağı olan verginin önemi yüksektir.

Ancak vergilemenin başarılı olabilmesi için devlet tarafından konulan vergisel ödevlerin vatandaşların ne kadar doğru ve titizlikle yaptıklarına veya yapma isteklerine bağlıdır. Mükelleflerin vergi yükümlülüklerini iyi bilmeleri ve doğru yerine getirmeleri ile vergi sistemi etkin çalışabilmektedir. Bu durumda mükelleflerin vergileri anlama ve vergileri gönüllü olarak ödeme, diğer bir değişle, vergi bilinçleri ve vergi kültürünün önemi öne çıkmaktadır.

Çalışmamızın amacı Kırgızistan'da mükelleflerin vergiyi nasıl algıladıklarını ve vergi bilincini incelemektir. Giriş bölümünü izleyen ikinci bölümde vergi bilinci kavramı ve vergi bilincini etkileyen faktörler araştırılmıştır. Üçüncü bölümde veri ve betimsel istatistikler sunulmuştur. Dördüncü bölümde model ve ampirik sonuçlar ve beşinci bölümde de sonuç ve değerlendirme yazılmıştır.

\section{Vergi Bilinci Kavramı ve Vergi Bilincini Etkileyen Faktörler}

Literatürde vergi bilinci üzerinde uzlaşmış bir tanım mevcut değildir. Dornstein'e (1987) göre vergi bilinci, verginin farkında olunması olarak tanımlanmışsa; Torgler'e (2005) göre mükellefin vergiyi ödeme konusundaki içsel motivasyonu olarak; Narta (2007), Edizdoğan, Çetinkaya ve Gümüş’e (2010) göre ise bireylerin gelirlerinden veya servetlerinden devletin yerine getirmekte yükümlü olduğu kamu hizmetlerinin gerçekleştirilmesi için kanunda belirtilen usul, esas ve oranlara göre katkıda bulunmaları gerektiğini fark etme yeteneği olarak; Savaşan ve Odabaş ise (2005) birey kullandığı kamusal mal ve hizmet ile ödediği verginin ilişkilendirilmesi olarak; Demir'e (2016) göre vergi ile ilgili bireylerin sahip oldukları farkındalık düzeyi olarak; Akdoğan'a (2005) göre ise kamu hizmetlerinin gerçekleştirilmesi için vergini önemseyen bireyler vergi ile ilgili ödevlerini yerine getirmedeki istekliliklerinin düzeyi olarak tanımlamaktadırlar.

Şener (1997) ise vergi bilinci sadece vergiyi ödeme bilinci olarak algılanmaması gerektiğini, bunun yanı sıra mükelleflerin ödediği vergilerin nerelere harcandığının denetimini ifade eden bir kavram olarak da değerlendirilmesi gerektiğini belirtmektedir. Edizdoğan v.d.(2010) Şener'in düşüncelerine katılarak vergi bilincini mükelleflerin ödediği vergilerin nasıl harcandığını bilmeleri olarak da açıklamaktadırlar. Yeşilyurt (2015) vergi bilincini kendi tanımlamasında verginin gerekliliğine inanma, bunun kamu hizmetlerin sürdürülmesi için önemli faktör olduğu kavrama ve devletin yapmış olduğu harcamaları vatandaşlar ile paylaşma durumu olarak belirtmektedir. Bunun yanı sıra Kalafat (2016) ise mükelleflerin vergilemede var olan ilgileri ve motivasyonları, vergi konusunda yükümlü olduğu ödevleri kanunlara göre yerine getirmede gösterdikleri gayretleri ve vergi idaresine karşı olan tutum biçimleri olarak tanımlamaktadır.

Bu kapsamda vergi bilinci bireylerin vergiyi algılamaları ve bunu davranışlarına olumlu ya da olumsuz şekilde yansıtmaları olarak tanımlayabiliriz. Yukarıda da belirtildiği gibi çeşitli kaynaklarda vergi bilincinden söz edildiğinde ve çoğunda olumlu algılama olarak tanımlar yapılmaktadır (Ömürbek, vd, 2007; Hazman, 2009; Taytak, 2010; Egeli, Diril, 2014; Yeşilyurt, 2015). Oysa vergi bilinci yukarıda da bahsedildiği gibi mükelleflerin vergiyle ilgili sahip oldukları farkındalık düzeyidir (Demir, 2016). Verginin neden ödendiğinin farkındalığına 
vurgu yapılmış olması vergi bilincinin doğru bir tanımının yapılması için gereklidir. Mükellef her zaman vergi karşısında aynı reaksiyonu göstermemesinden dolayı vergi bilinci, mükellefin vergi ödeme konusundaki içsel motivasyonu olarak tanımlanmaktadır (Hazman, 2009). Böylece, genel olarak vergi bilinci vatandaşların ödediği verginin farkında olmaları, bu vergilerin niçin ödendiğini bilmeleri ve vergi gelirlerinin nasıl harcandığına ilgi göstermeleri ve sonuçta verginin gerek olup olmadıkları ile ilgili görüşleri denilebilir.

Vergi bilinci mükellefin vergileri nasıl algıladıklarını, vergi ile ilgili tutum ve davranışlarını ve son olarak vergi kültürünün düzeyini etkileyebilmektedir. Diğer bir değişle, vergi bilinci vergi kültürünün ilk aşaması sayılabilir. Demek, mükellefin vergi yükümlülüklerini yerine getirmesi ile ilgili aldığı kararları ve yaptığı davranışları onun vergi bilinci ve vergileri algılamalarına bağlıdır denilebilir.

Mükelleflerin vergi bilinci pozitif olan ülkelerde mükellefler vergi borçlarını dürüst ve doğru bir şekilde öderler ve vergiye karşı olumsuz bir davranış göstermezler. Fakat vergi bilincini düşük veya olmayan gelişmekte olan ülkelerde mükellefler vergiyi devlet tarafından zorla alınan yük olarak algılayıp daha çok vergiden kaçınma ve vergi kaçırma gibi olumsuz davranışlarda bulunurlar. Böylece, vergi bilinci düzeyi ülkenin kamu gelirleri açısından önem arzetmektedir.

Genel olarak gelişmiş ülkelerde vergi bilinci gelişmekte olan ülkelere göre daha olumlu algılanır. Vergi bilincinin daha yüksek olumlu algılanması için ülkeler farklı faaliyetlerde bulunurlar. Örnek olarak Türkiye'de vergi bilincinin gelişmesi için vergilerin yükümlü psikolojisine uygun bir biçimde hazırlanması önemli bir etken olarak kabul edilir. İlkokul, ortaokullarda bile verginin ödenmesi toplum için daha önemli olduğunu anlatırlar. Böylece bireyler küçükken vergi hakkında bilgilendirilmiş olur ve vergiden kaçınma, vergi kaçakçıllı̆̆1 gibi olumsuz düşüncelerden uzak kalır. Fakat öyle olsa bile Türkiye'de vergi bilinci ve vergi ahlakının gelişmiş ülkelere göre yetersiz olduğunu söyleyebiliriz. Çünkü devletin güçlenmesi ile toplumda oluşacak vergi bilinci arasında doğru orantılı bir ilişki vardır. Toplumda vergi bilinci ne kadar arttırılsa, devletin gücü ve devletin sağlayacağı imkanlar (daha iyi eğitim, daha iyi sağlık hizmeti gibi) da o oranda arttırılmış olacaktır (Taytak, 2010).

Vergi bilincini etkileyen faktörleri sosyal-demografik, siyasal ve ekonomik olarak ayırabiliriz. Sosyaldemografik faktörlere mükellefin cinsiyeti, yaşı, eğitim ve gelir seviyesi, medeni durumu v.s. etkileyebilmektedir. Siyasi faktörler olarak mükellefin vergi sistemi, vergi idaresi ve vergi müfettişleri ile ilgili görüşleri, devlete ve hükümete olan güveni, kamu hizmetlerinin yeterliliği ve kalitesi sayılabilir. Ekonomik faktörlere ise vergi oranları, vergi denetiminin sıklığı ve vergi cezalarının ağırlığı gibi faktörler girebilir. Çalışmamızda vergi bilincini etkileyen sosyal-demografik ve siyasi faktörler analiz edilecektir.

\section{Veri ve Betimsel İstatistikler}

Çalışmada Kırgızistan'ın başkenti olan Bişkek şehrinde 2013 yılında 400 kişiden toplanan anket verileri kullanılmıştır. Katılımcıların \%39,3’ü (157 kişi) erkek, \% 60,7’si (243 kişi) bayandır; yüzde 66,3\%'ü evli ve \% 32,3'ü bekardır.

Yaşına göre dağılımına bakıldığında \% 39’u 16-29 yaş arası, \% 42,8’i 30-49 yaş arsı, \% 16,8'I 50-69 yaş arası ve \% 1,2'si de 70 yaştan büyük olanlardır. Eğitim durumuna göre katılımcıların \%8,5'i ortaokul mezunu, \% 18.8 'i meslek yüksekokul mezunu, \% 73,2'si üniversite mezunu ve \% 4,8'i de yüksek lisans ve daha üst düzeyde eğitimli olanlardır. Aylık ortalama gelirinin seviyesine baktı̆̆ımızda katılımcıların \% 11,5'inin ortalama aylık geliri 5000 soma kadar, \% 31,5'inin ise 5000-10 000 som aras1, \% 23'ünün geliri 10 001-15 000 som aras1, \% 19,5'inin 15 000 - 25000 som arası ve \% 11,5'inin de aylık ortalama geliri 25000 somdan yukarı olduğunu belirtmişlerdir.

\section{Ampirik Sonuçlar}

Vergi bilincini etkileyen demografik ve siyasi faktörler probit modeli ile incelenmiştir. Modelde vergi bilincini bildiren bağımlı değişken olarak ankette verilen aşağıdaki soru alınmıştır:

'Sizce vergiler gerekli midir?'

\subsection{Vergi Bilincini Etkileyen Demografik Faktörlerle İlgili Model ve Sonuçları}

Aşağıdaki tabloda vergi bilincini etkileyen demografik faktörlerle ilgili modelde yer alan bağımsız değişkenlerin açıklamaları verilmiştir.

\begin{tabular}{|c|c|}
\hline Değişkenler & Açıklama \\
\hline Cinsiyet & Eğer erkek ise 1, aksi halde 0. \\
\hline Yaş & Eğer yaş1 50-69 yaş arası ise 1, aksi halde 0. \\
\hline Ĕgitim Seviyesi & Ĕger üniversite mezunu ise 1, aksi halde 0. \\
\hline Geliri & Eğer aylık ortalama geliri 25 000 som ve fazla ise 1, aksi halde 0 \\
\hline
\end{tabular}

Tablo 1: Vergi Bilincini Etkileyen Demografik Faktörlerle İlgili Modelde Yer Alan Bă̆ımsız Değişkenler 


\begin{tabular}{|l|c|c|}
\hline Değişkenler & Katsayı & Marjinal Etki \\
\hline Cinsiyet & $0.3169 * *$ & $0.0679 * * *$ \\
\hline Yaş & $0.3814 * *$ & $0.0904 * *$ \\
\hline Eğitim Seviyesi & $-0.4362 * * *$ & $-0.1006^{* * *}$ \\
\hline Geliri & $-1.0417 * *$ & $-0.1315 * * *$ \\
\hline
\end{tabular}

Tablo 2: Probit Modelinin Sonuçlarl
LR chi2 (4) $=22.16(0.000) \quad$ Pseudo R2 $=0.0669$
Log likelihood = - 154.49685

Marjinal etki Vergi Bilinci değişkeninin 0 ve 1 arasındaki değişimine göre hesaplanmıştır.

Not: *, ** ve *** $10 \%, 5 \%$ ve $1 \%$ düzeyinde anlamlllık derecesini göstermektedir.

Probit modelinde elde edilen katsayılar direkt yorumlanamamaktadır. Bu katsayıları yorumlayabilmek için marjinal etkileri hesaplanmıştır. Model sonuçlarına göre mükelleflerin erkekler bayanlar göre \% 6.8 oranında daha çok verginin gerek olduğunu düşünmektedirler. 50-69 yaş arasındaki mükellefler diğerlerine göre \% 9'a daha çok verginin gerekli olduğunu düşünmektedirler. Böylece, yaş ile vergi bilinci arasında pozitif ilişki bulunduğu söylenebilir.

Üniversite mezunu olanların vergi bilinci diğerlerine göre \% 10 oranında düşük olduğu tespit edilmiştir. Üniversite mezunları diğer eğitim seviyesindekilere göre vergileri gerekli saymamaktadırlar. Bu şaşırtıcı sonucun nedeni üniversite mezunlarının devletin ve hükümetin performansı, kayıt dışı ekonomi, vergilerin nasıl harcandığ ve kamu hizmetlerinin kalitesi hakkında daha çok bilgisi olduğu için vergi bilinçleri negatif olabilir.

Gelir düzeyi en yüksek olan ortalama geliri 25001 somdan yukarı olan mükelleflerin de vergi bilincinin diğer gelir gruplarına nazaran \% 13 oranında düşük olduğu görülmektedir. Diğer bir değişle, geliri en yüksek olan gruptakiler vergilerin gerekliliğini daha az hissetmektedirler.

\subsection{Vergi Bilincini Etkileyen Siyasi Faktörlerle İlgili Model ve Sonuçları}

Aşağıdaki tabloda vergi bilincini etkileyen siyasi faktörlerle ilgili modelde yer alan bağımsız değişkenlerin açıklamaları verilmiştir.

\begin{tabular}{|l|l|}
\hline Değişkenler & Açıklama \\
\hline Vergi sistemi hakkında bilgisi & Eğer ise vergi sistemi hakkında tam bilgiye sahipse 1 , aksi halde 0. \\
\hline Vergi sisteminin adaletliliği & Eğer vergi sistemini adaletli sayıyor ise 1, aksi halde 0. \\
\hline Vergi Mevzuatı & Eğer vergi mevzuatı zor ve karmaşı ise 1, aksi halde 0. \\
\hline Devlete Olan Güvenin Yüksek Olması & Eğer devlete olan güveni yüksek ise 1, aksi halde 0 \\
\hline Devlete Olan Güvenin Düşük Olması & Eğer devlete olan güveni düşük ise 1, aksi halde 0 \\
\hline
\end{tabular}

Tablo 3: Vergi Bilincini Etkileyen Siyasi Faktörlerle İlgili Modelde Yer Alan Bă̆ımsız Değişkenler

\begin{tabular}{|l|c|c|}
\hline Değişkenler & Katsayı & Marjinal Etki \\
\hline Vergi sistemi hakkında bilgisi & $0.6515^{* *}$ & $0.1705^{* *}$ \\
\hline Vergi sisteminin adaletliliği & $1.2549 * * *$ & $0.4031^{* * *}$ \\
\hline Vergi Mevzuatı & $-0.5960^{*}$ & $-0.0904 * * *$ \\
\hline Devlete Olan Güvenin Yüksek Olması & $0.9564 * * *$ & $0.2864 * *$ \\
\hline Devlete Olan Güvenin Düşük Olması & $-0.7936 * * *$ & $-0.1203 * * *$ \\
\hline
\end{tabular}

\section{Tablo 4: Probit Modelinin Sonuçları}

LR chi2 (5) $=37.97(0.000) \quad$ Pseudo R2 = $0.1147 \quad$ Log likelihood $=-146.59065$

Marjinal etki Vergi Bilinci değişkeninin 0 ve 1 arasındaki değişimine göre hesaplanmıştır.

Not: *,** ve *** $10 \%, 5 \%$ ve $1 \%$ düzeyinde anlamlılık derecesini göstermektedir.

Vergi bilincini etkileyen siyasi faktörlerle ilgili probit modeli sonuçlarına göre vergi sistemi hakkında tam bir bilgiye sahip olanlar diğerlerine göre vergileri \% 17 oranında daha çok gerekli olarak saymaktadırlar. Özellikle vergi sistemini adaletli sayanlar diğerlerine göre vergi bilinci \% 40 oranında daha yüksektir. Bununla birlikte devlete güveni yüksek olan katılımcılar da vergileri diğerlerine göre \% 29 oranında gerekli bir unsur olarak kabul etmektedirler.

Vergi mevzuatını zor ve karmaşık olarak sayanların vergi bilinci diğerlerine göre $\% 9$ oranında düşüktür. Vergi sistemini adaletli saymayanlar ise vergilerin gerekliliğini \% 12 oranında daha az hissetmektedirler.

\section{Sonuç ve Değerlendirme}

Vergi bilinci mükelleflerin vergi yükümlülüklerini tam ve doğru bir şekilde gönüllü olarak yerine getirmelerini etkileyen önemli etkenlerdendir. Vergi bilincinin yüksek olması devletin vergi yönetimi ile ilgili harcamalarını da azaltarak kamu gelirlerinin sürekliliğini ve yeterliliğini sağlamaktadır. 
Çalışmada piyasa ekonomisine geçiş sürecinde olan Kırgızistan'da vergi bilinci ve etkileyen faktörler probit modeli ile incelenmiştir. Ampirik çalışmaların sonuçlarına göre erkeklerin ve büyük yaştakilerin vergi bilinci daha yüksek olduğu, üniversite mezunu olanların ve geliri yüksek olanların da vergi bilincinin düşük olduğu tespit edilmiştir.

Vergi bilincini etkileyen siyasi faktörlere gelince, vergi sistemi hakkında tam bir bilgiye sahip olanların, vergi sistemini adaletli sayanların ve devlete güveni yüksek olanların vergi bilinçleri önemli derecede yüksek olduğu açıklanmıştır. Diğer taraftan devlete güveninin düşük olanların ve vergi mevzuatını zor ve karmaşık olarak sayanların vergi bilinci düşük olduğu belirlenmiştir.

Yukarıdaki sonuçlar çerçevesinde Kırgızistan'da mükelleflerin vergi bilinçlerini arttırmak için vatandaşlara vergi sistemi hakkında bilgilerin yaygınlaştırılması, halka vergi kanununun basit bir şekilde anlatılması, devlete olan güvenin arttırılması gerekmektedir. Mükelleflerin vergi sisteminin adaletliliği hakkında düşünceleri de önemli bir etken olduğundan, bu yönde de çalışmalar yapılmalıdır. Bununla birlikte genç yaştakilerin karşılaştırmalı olarak vergi bilinçleri daha az olduğu için okullardan itibaren vergi bilincinin oluşmasının sağlanması gerekmektedir.

\section{Kaynakça}

- $\quad$ Akdoğan, A. 2005. Kamu Maliyesi, Gazi Kitabevi, 9.Bask1, Ankara., s.180.

- Demir, İ.C. 2016. "Vergi Bilincinin Oluşumunda Eğitimin Rolü: İlköğretim Öğrencileriyle Ampirik Bir Çalışma”, Celal Bayar Üniversitesi İIBF, Yönetim ve ekonomi Dergisi, Y1l:2016, Cilt:23, Say1:1, s.128.

- Dornstein, M. 1987. "Taxes: Attitudes and Perceptions and Their Social Bases", Journal of Economic Psychology, S.8, 55-76.

- $\quad$ Edizdoğan N., Çetinkaya Ö. ve Gümüş E. 2010. Kamu Maliyesi. Ekin Basım Yayın., Bursa. s.202.

- $\quad$ Egeli, H., Diril, F. 2014, "Vergi Bilincinin Oluşumunda Bilişim Teknolojilerinin Rolü: İzmir İli İçin Bir Uygulama”, Sosyo-Ekonomi Dergisi, S. 2, s.35.

- Hazman, G. G. 2009," Vergi Bilincini Etkileyen Muhtemel Dişsal Etkenlerin Lojistik Regresyon Analizi Ile Tespiti”, Akademik Incelemeler Dergisi, 4 (1), s.53-54.

- Kalafat, T. 2016. "Mali Sosyolojisi Açısından Vergi Bilinci ve Vergi Ahlakı”, Vergi Müfettişi (Eski Maliye Müfettişi), http://www.vergivizyon.net/mali-sosyoloji-acisindan-vergi-bilinci-ve-vergi-ahlaki/ 20/05/2016

- Narta, M. E. 2007. Vergi Bilinci, http://www.maliye.gov.tr/defterdarliklar/duzce/vergi_haftasi/vergi\%20bilinci.htm

- Ömürbek, N., Çiçek, H. G. ve Çiçek, S. 2007, "Vergi Bilinci Üzerine Bir İnceleme: Üniversite Öğrencileri Üzerinde Yapılan Anketin Bulguları”, Maliye Dergisi, Sayı 153, Temmuz-Aralık 2007, s. 104

- Savaşan, F. ve Odabaş, H. 2005. "Türkiye’de Vergi Kayıp ve Kaçaklarının Nedenleri Üzerine Ampirik Bir Çalışma”, Selçuk Üniversitesi IİBF, Sosyal ve Ekonomik Araştırmalar Dergisi, Y1l 5, S. 10, s. 1-28.

- Şener, A. 1997, "Verginin Önemi, Vergi Bilincinin Topluma Yay1lması ve Vergilerle İlgili Son Düzenlemeler”, Yaklaşım Dergisi, Yı1:5, Sayı:52., s.8-9.

- Taytak, M. (2010). “İlköğretim II. Kademe Öğrencilerinde Vergi Bilincinin Tespiti: Amprik Bir Araştırma”, Maliye Dergisi, S:158, s.498.

- Torgler, B. 2005., “Tax Morale and Direct Democracy”, Europen Journal of Political Economy, Vol.21, s.525-531.

- Yeşilyurt, Ş. 2015. "Vergi Bilincinin Vergi Ahlakı Üzerindeki Etkisi: Maliye ve İlahiyat Bölümü Öğrencileri Örneği”, Mustafa Kemal Üniversitesi Siyasal Bilgiler Fakültesi, Mustafa Kemal Üniversitesi Sosyal Bilimler Enstitüsü Dergisi. Y11:2015, Cilt:12, .say1:32, s.38. 


\title{
Bir Mali Politika Aracı Olarak Çevre Vergileri: Baltık Ülkeleri Örneği
}

\section{Environmental Taxes as a Fiscal Policy Instrument: The Case of the Baltic States}

\author{
Dr. Hilal Görkem (Çanakkale Onsekiz Mart University, Turkey)
}

\begin{abstract}
The aim of this study is to evaluate environmental taxation in the Baltic States (Estonia, Latvia, Lithuania). First, environmental policies and environmental tax reforms of these countries will be generally overviewed. After addressing the legal regulations related environmental taxation, the composition of environmental taxes, the share of environmental taxes in total tax revenue and GDP will be put forward. In the light of these indicators, the situation of the Baltic countries in EU will be assessed. The reports of the European Commission, Eurostat database, and OECD Database on instruments used for environmental policy are the main data sources used in the study. According to Eurostat data for 2014, energy taxes take the largest share from environmental taxes in EU. While Lithuania has the highest share of energy taxes $(93,78 \%)$ in EU, Estonia has the lowest share of transport taxes $(2,12 \%)$. Latvia ranks fifth in terms of the share of environmental taxes in total tax revenue $(9.16 \%)$. Estonia is among in top ten countries with a share of $8,22 \%$. The share of Lithuania $(6.06 \%)$ remains slightly below average.
\end{abstract}

\section{Giriş}

1993 ’te Jacques Delors'un "Büyüme, Rekabetçilik ve İstihdam Üzerine Beyaz Kitap"1, hem çevre korumay1 hem de büyüme ve istihdamı teşvik ederek çifte yarar elde etme imkanı sunan "çevresel vergi reformu" kavramını gündeme getirmiştir (European Commission (DG TAXUD), Eurostat, 2008:99). Çevresel vergi reformunun temelinde yatan unsur, çevreye zararlı mal ve faaliyetler üzerine konan vergi araçlarından elde edilen gelirlerle emek vergilemesi üzerindeki vergi yükünün azaltılması ve ortaya çıkacak olan gelir kaybının finanse edilmesidir (European Commission (DG TAXUD), Eurostat, 2003:22).

1990'lı yıllarda çevresel vergi reformları, Danimarka, Almanya, İtalya, Hollanda, Avusturya, İsveç, Finlandiya ve İngiltere gibi ülkelerde uygulanmaya başlanmıştır (European Commission (DG TAXUD), Eurostat, 2003:22). $\mathrm{Bu}$ öncü ülkeleri takip eden diğer öne çıkan ülkeler ise 1997 'de enerji ürünleri üzerine bir karbon vergisi koyan Slovenya, 2008 yılına kadar kişisel gelir vergisindeki kesintileri finanse etmek için özel tüketim vergisi artı̧̧larını kullanan Estonya ile 2008'de çevresel vergi reformu başlatan Çek Cumhuriyeti olarak sayılabilir (European Commission (DG TAXUD), Eurostat, 2010: 149. AB ülkeleri çevre vergi reformları hakkında detaylı bilgi için bknz Speck ve Jilkova, 2009; Ekins, 1999).

Bu çalışmada örnek olarak 3 Baltık ülkesinin seçilmesinin nedeni, bu ülkelerin coğrafi olarak birbirlerine yakın ve benzer koşullara sahip olmaları, yüzölçümü ve nüfus olarak benzer büyüklükte olmaları, ortak bir politik ve ekonomik geçmişe sahip olmaları olarak sıralanabilir. SSCB'nin dağılmasıyla birlikte bağımsılıklarını kazandıktan sonra görece kısa bir süre içinde geçiş ekonomisinden yüksek gelirli ülke konumuna geçmiş olmaları, 2003 'ten itibaren ve özellikle 2004'te AB'ye katılmalarını takiben GSYIH'lerindeki büyük artış sonucu "Baltık Mucizesi", "Baltık Kaplanları" (Dudzińska, 2013; Mezö ve Bagi, 2012) gibi sıfatlarla anılmaları, özellikle diğer Avrupa ülkelerine göre başta Estonya olmak üzere krizden çıkmada gösterdikleri iyi performans (Dudzińska, 2013) bu üç Baltık ülkesinin incelenmesini daha önemli hale getirmektedir. AB ülkeleri içinde izledikleri çevre vergi politikaları ile farklı ve öne çıkan özellik gösterip göstermedikleri belirlenmeye çalışılacaktır.

Bu amaçla 1995-2014 dönemi verileri kullanılarak, 20 yıl içinde 3 Baltık ülkesinde çevre vergilerine ilişkin eğilimler ve gelişim belirlenerek mevcut durum ortaya konacaktır. Çevre vergilerine ilişkin kullanılacak temel göstergeler, toplam çevre vergi gelirleri, çevre vergi gelirlerinin bileşimi (enerji, ulaşım, kaynak ve kirletme vergileri), çevre vergi gelirlerinin toplam vergi gelirleri içindeki payı ile GSYIH içindeki payıdır. Eurostat çevre vergi gelirleri verileri kullanılmıştır. Ülkelerdeki vergileme ile ilgili yasal düzenlemeler ve reformlar için başvurulan temel veri kaynakları Avrupa Komisyonu'nun "Tax Reforms in EU Member States" raporları, bu raporlara dayanan "Taxation Reforms Database "(2010-2015), Avrupa Komisyonu'nun "Taxation Trends in the European Union" raporları ile "OECD Database on instruments used for environmental policy"dir.

\section{Baltık Ülkelerinde Çevre Vergilemesine İlişkin Düzenlemeler}

\subsection{Estonya}

1980'lerden itibaren bağımsız bir çevre politikasına sahip olan Estonya'da, 1990'lı yıllarda çevre mevzuatını oluşturan çok sayıda yasa ve düzenlemenin yapıldığı ve özellikle 1992'den sonra bunların hızla arttı̆̆ı 
görülmektedir (European Parliament, 1998a:3). Çevre mevzuatına çerçeve sağlayan Çevre Koruma Kanunu (1990) ile birlikte doğal kaynakların kullanımı ve çevre kirliliği (zararlı maddelerin suya veya havaya boşaltımı ve atık maddelerin atılması) için vergi ve harçlar getirilmiştir (European Parliament, 1998a:3). Estonya'da 1991'den beri çevre harçları alınmaktadır (Estonian Environment Agency, 2014:193; Kraav E ve Lüpsik 2007a).

1990’lı yıllarda çevre vergilemesi ile ilgili diğer başlıca düzenlemeler şu şekilde sıralanabilir (European Parliament, 1998a, OECD, 2016): 1991 tarihli atık bertaraf, su kirletme, hava kirletme, madencilik ve su çıkarma harçları, Atık Kanunu (1992), 1993 tarihli hava kirliliği uymama ücretleri (air pollution non-compliance fees) ve balıkçılık harcı (fishing charge), 1993 tarihli Yakıt Tüketim Vergisi, 1983'te kurulan Estonya Çevre Fonu'nun reforme edilmesi (1994), atık bertarafı uymama ücretleri, su kirliliği uymama ücretleri (1994), Motorlu Taşıtlar Tüketim Vergisi (1995), doğa koruma uymama ücretleri (1995), Ambalaj Tüketim Vergisi (1997).

2000'li yıllara gelindiğinde ilk 10 yılda öne çıkan iki düzenlemeden söz edilebilir: 2003 yılında motorlu taşıtlar tüketim vergisinin kaldırılması (OECD, 2016) ve 2005 yılında Çevresel Vergi Reformu'nun (Ekolojik Vergi Reformu) başlatılması (Kraav ve Lüpsik 2007a, 2007b). Motorlu taşıtlar tüketim vergisinin kaldırılmasıyla birlikte, araç vergilemesinde bir düşüş yaşanırken (European Commission (DG TAXUD), Eurostat, 2005:127), 2004 yılında ağır yük taşıtları vergisi getirilmiştir (OECD, 2016). 2005 Çevresel Vergi Reformu ile ülkenin çevre kalitesinin arttırılması, sürdürülebilir kalkınmanın sağlanması ve istihdam üzerindeki vergi yükünün hafifletilmesi amaçlanmıştır (Kraav ve Lüpsik 2007a). Bu amaçla çevreye zararlı mal ve hizmetler üzerindeki vergilerin arttırılıp, gelir vergisinin azaltılacağı şekilde vergi sisteminin yeniden düzenlenmesi öngörülmektedir (Kraav ve Lüpsik 2007a).

2000’li yıllarda genel olarak özel tüketim vergilerinde ve harçlarda oran artışları yapıldığı görülmektedir. Özellikle enerji ürünlerindeki vergi oranları AB'ye üyelikten sonra aşama aşama arttırılmıştır. Avrupa Komisyonu'nun 2004 "Structures of the taxation systems in the European Union” raporunda Estonya'nın 1 Mayıs 2004 'ten itibaren dizel yakıt ve petrol üzerindeki özel tüketim vergisi oranlarını önemli ölçüde arttırdığı belirtilmiştir (European Commission (DG TAXUD), Eurostat, 2004:154). 2005 yılında çevre harçları için yapılan yasal düzenlemeyle, 2006-2009 dönemi için harçlar belirlenmiştir (GIZ, 2014:22). 2008 yılında elektrik tüketim vergisi konmuş (OECD, 2016), 2008-2009 döneminde yeşil vergi reformunun bir parçası olarak elektriğin yanı sıra doğal gaz, kok kömürü ve kömür üzerinden yeni tüketim vergileri alınmaya başlanmıştır (Poltimäe 2014: 66; European Commission (DG TAXUD), Eurostat, 2010:187). 1 Ocak 2008'de özel tüketim vergisi oranları kurşunsuz benzin için \%25 ve dizel için \%35 arttırılmış, böylece $\mathrm{AB}$ minimum düzeyine ulaşılmıştır (European Commission (DG TAXUD), Eurostat, 2009:153). AB minimum oranlarını karşılayan tüketim vergisi oranlarında da artışa gidilebildiği görülmektedir. Aynı dönemde hafif ısıtma yağından alınan ÖTV'nin yaklaşık \% 40 oranında arttırılması böyle bir uygulamadır (European Commission (DG TAXUD), Eurostat, 2009:153).

2009 yılında Çevre Harçları Yasası'nda yapılan değişiklikle, çevre harç oranları enflasyona göre yeniden belirlenmiş ve buna göre 2010'dan sonra harç oranları arttırılmıştır (GIZ, 2014:22). 2009'da yakıt üzerindeki özel tüketim vergisi \%10-127 arttırılmıştır (European Commission (DG TAXUD), Eurostat, 2010:33). Kurşunsuz benzin, dizel, kok kömürü ve kömür, doğal gaz ve elektrik üzerindeki özel tüketim vergileri hem 2009 'da hem 2010'da arttırılmıştır (European Commission (DG TAXUD), Eurostat, 2013:75). 2010 yılında elektrik özel tüketim vergisi \%40 arttırılmıştır (European Commission (DG ECFIN-DG TAXUD), 2011:40). Ocak 2011'de 1s1 üretiminde kullanılan bitümlü şist (oil shale) üzerine konulan özel tüketim vergisi $(0,15 € / G J)$ (European Commission (DG TAXUD), Eurostat, 2013:74), Ocak 2013'te \%100 arttırılmıştır (European Commission (DG TAXUD), Eurostat, 2014:76). Oran artışlarının yanı sıra bazı muafiyet ve istisnaların kaldırıldığı görülmektedir. 2011 yılında biyoyakıt ÖTV muafiyetine, 2012'de ise ormancılık, inşaat, madencilik ve sabit motorlar için kullanılan gaz yağı (gas oil) üzerindeki azaltılmış oran uygulamasına son verilmiştir (European Commission (DG TAXUD), Eurostat, 2014: 76).

1 Ocak 2015'ten itibaren yürürlüğe giren düzenlemeyle biyogaz için tüketim vergisi kaldırılırken (European Commission (DG TAXUD), Eurostat, 2015:40); diğer, uyumlaştırılmamış tüketim vergileri kapsamında, 1 Ocak 2015 'te yürürlüğe girmek üzere, oran artışı uygulamalarına gidilmiştir: 1. Özel işaretli yakıt için (specially marked fuel) uygulanan azaltılmış vergi oranının kaldırılması. 2. 2015-2017 için yıllık \%20 oranında doğal gaz tüketim vergisinde artış (European Commission (DG TAXUD), Eurostat, 2015:40). Aynı tarihte 1991 tarihli atık bertaraf, su kirletme, hava kirletme, madencilik ve su çıkarma harçlarında, 1993 tarihli hava kirliliği uymama ücretlerinde, 1994 tarihli atık bertarafı uymama ücretleri ile su kirliliği uymama ücretlerinde oran artışları yapılmıştır (OECD, 2016). Ayrıca 1997 tarihli ambalaj tüketim vergisinde düzenleme yapılmış ve ödeme detaylarında ayarlama yapılmıştır (OECD, 2016)

Estonya'da mevcut çevre vergi ve harçları şu şekilde gruplanabilir (Hogg vd., 2016): 1. Enerji: yakıt ve elektrik özel tüketim vergileri 2. Ulaşım: araç tescil harcı, ağır yük taşıtları vergisi. 3. Kirletme ve kaynak: atık bertaraf harc1, hava kirletme harc1, su kirletme harcı, su çıkarma harcı, ambalaj özel tüketim vergisi, madeni kaynaklar çıkarma harcı, balıkçılık, avlanma ve orman kesimi harçları. 


\subsection{Letonya}

Letonya'da 1959 ve 1968 'te çevre korumayla ilgili ilk çerçeve yasalar çıkarılırken (European Parliament, 1998b:3), esas olarak çevre ile ilgili yasal düzenlemelerin 1990'larda yoğunlaştı̆̆ görülmektedir. 1991'de çevre korumayla ilgili revize edilmiş yeni bir çerçeve yasa kabul edilmiş ve çevre koruma 1991 yılında anayasaya konmuştur (European Parliament, 1998b:3).

1995 yılında Doğal Kaynak Vergisi Kanunu ile atık bertarafı, hava ve suya yayılan emisyonlar gibi çevre kirliliğine sebep olan faaliyetler, çevreye zararlı mal ve ürünler (yağlar, piller, ozon tabakasına zararlı ürünler, lastik, bilişim ve elektronik ürünler), ambalaj ve radyoaktif maddelere yönelik bir doğal kaynak vergisi getirilmektedir (GIZ, 2014:26). Ayrıca 2004'ten itibaren araçlar da bu verginin kapsamına alınmıştır (GIZ, 2014:26). 1990'lı yıllarda çevre vergilemesi ile ilgili diğer başlıca düzenlemeler şu şekilde sıralanabilir (European Parliament, 1998b:3; OECD, 2016): 1990'da doğal kaynakların korunması için bir vergi konmuştur. Enerji kullanımı vergisi (1996), su kirliliği uymama ücretleri (1991), yıllık motorlu taşıt harcı (1994), 1995'te hava emisyon harcı, radyoaktif madde ithalat harcı, ozon tabakasını incelten maddeler üzerine konan harç, çevreye zararlı ürünler harcı, malzeme çıkarma harcı, ambalaj ve tek kullanımlık sofra eşyası harcı, atık bertaraf harcı, su çıkarma harcı, su atığı harcı, 1997 Yakıt Tüketim Vergisi, 1999 Motorlu Taşıtlar Tüketim Vergisi.

2003/96/EC Konsey Direktifi'nin öngördüğü minimum vergi oranlarına ulaşmak için, Tüketim Vergisi Kanunu'nda petrol ürünleri için vergi oran artışını getiren değişiklikler sırasıyla 1 Mayıs 2004, 1 Ocak 2005,1 Ocak 2007 ve 1 Şubat 2009'da yürürlüğe girmiştir (European Commission (DG TAXUD), Eurostat, 2005:161, European Commission (DG TAXUD), Eurostat, 2007: 177, European Commission (DG ECFIN-DG TAXUD), 2009: 74). 1 Ocak 2007 itibarıyla ağır yakıt, kurşunlu benzin ve gaz yağı için (ulaşım yakıtı olarak kullanılması dışında) (European Commission (DG TAXUD), Eurostat, 2007: 177), 2008 yılı başında madeni yağlar için (European Commission (DG TAXUD), Eurostat, 2008: 167), 1 Şubat 2009'dan itibaren kurşunsuz benzin, gaz yağ1 ve parafin/kerosen için $\mathrm{AB}$ minimum düzeyine ulaşılmıştır (European Commission (DG ECFIN-DG TAXUD), 2009:37).

1 Mayıs 2010 itibarıyla 1sınma ve ulaşım için kullanılan doğal gaz üzerinden özel tüketim vergisi alınmaya başlanmıştır (European Commission (DG TAXUD), Eurostat, 2010: 219). 2010' da \%5 ve üzeri biyoyakıt içeren yakıtların, fosil yakıtlara göre daha düşük oranda vergilendirilmesi düzenlemesi getirilirken, otomobil ve motosikletler üzerindeki verginin hesaplanmasında motor hacminin yanısıra sera gazı emisyonu da göz önüne alınacak hususlardan biri olarak kabul edilmiştir (European Commission (DG ECFIN-DG TAXUD), 2010: 41). Ayrıca 2010 döneminde yıllık araç vergisi oranları iki katına çıkarılmıştır (European Commission (DG ECFINDG TAXUD), 2010: 41).

2010'da otomobil ve motosikletler için yıllık bir harç getirilmiş, 2011'de biyoyakıt içeren yakıtlar için özel tüketim vergisinde daha düşük oran uygulaması kaldırılmıştır (European Commission, 2016). Aynı yıl, motorlu taşıtlar vergisinin yapısı, üç unsuru (araç brüt ağırlığı, motor kapasitesi ve maksimum motor gücü) dikkate alacak şekilde değiştirilerek lüks ve çevre dostu olmayan güçlü araçların vergi yükü arttırılmıştır (European Commission (DG ECFIN-DG TAXUD), 2012:29, 41).

2011'de vergi oranlarında artışların yanı sıra bazı muafiyet ve istisnalar kaldırılarak vergi tabanı genişletilmiştir (European Commission, 2016): Petrol üzerindeki tüketim vergileri Haziran 2011'den itibaren arttırılmıştır. Temmuz 2011'den itibaren, elektrik üretmek için kullanılan doğal gaz üzerindeki tüketim vergisi muafiyeti kaldırılmış, tarımda kullanılan dizel yakıt için özel tüketim vergisi muafiyetleri azaltılmıştır. 1 Şubat 2012'den itibaren tüketim vergi tabanı belirli motor yăğ gruplarını dahil ederek genişletilmiştir (European Commission, 2016, European Commission (DG ECFIN-DG TAXUD), 2013:33).

2014 yılında enerji ile kaynak ve kirletme vergilerinde artışlar yapıldığı görülmektedir. Ocak 2014 itibarıyla LPG, tarım ve sanayide kullanılmayan doğalgaz ve diğer gazlı hidrokarbonlar üzerindeki özel tüketim vergileri arttırılmıştır (European Commission, 2016, European Commission (DG ECFIN-DG TAXUD), 2014:36). Yeraltı kaynakları, depolama sahalarında evsel atıkların bertarafı, çevreye zararlı mallar, ambalaj, eski ve hurda araçlar, hava kirliliği ve suya kirletici emisyonlar üzerindeki doğal kaynaklar vergisi oranları arttırılmıştır (European Commission, 2016, European Commission (DG ECFIN-DG TAXUD), 2014:36). Ayrıca, havai fişek ve toplam kurulu gücünün 2 mega wattan düşük olduğu hidroelektrik santrallerinde elektrik üretimi için su kaynaklarının kullanımı da doğal kaynaklar vergisi kapsamına alınmıştır (European Commission (DG TAXUD), Eurostat, 2014:108).

1 Ocak 2014-31 Aralık 2017 dönemi için, zorunlu tedarik usulleri aracılığıyla elektrik satma hakkı verilmiş olan elektrik üreticilerine yönelik "sübvansiyonlu elektrik vergisi” uygulamaya geçmiştir (European Commission (DG TAXUD), Eurostat, 2014: 108). Üretim sürecinde kullanılan enerji kaynaklarına göre \%5, \%10 ve \%15 olmak üzere 3 çeşit vergi oranı söz konusudur (European Commission (DG TAXUD), Eurostat, 2014: 108). 1 Ocak 2015 'ten itibaren yürürlüğe giren enerji vergileri ile ilgili düzenlemeyle Letonya'da B30 biyoyakıt için oran artışına gidilmiştir (European Commission (DG TAXUD), Eurostat, 2015:74).

Letonya'da mevcut çevre vergileri şu şekilde gruplandırılabilir (Hogg vd.,, 2016): 1. Enerji: yakıt ve elektrik özel tüketim vergileri, sübvansiyonlu elektrik vergisi. 2. Ulaşım: otomobil tescil vergisi, motorlu taşıtlar vergisi, 
şirket otomobili vergisi (1 Ocak 2011'den beri). 3.Kirletme ve kaynak: doğal kaynaklar vergisi (atık bertaraf vergisi (landfill tax), su çıkarma vergisi, agrega vergisi (aggregates tax), hava kirletme vergisi, su kirletme vergisi, ambalaj vergisi, çevreye zararlı mallar vergisi, kömür, kok kömürü ve linyit satışı üzerine ek vergi, jeolojik yapılara doğal gaz ve sera gazı pompalama vergisi).

\subsection{Litvanya}

İlk Doğa Koruma Kanunu'nun 1959’da kabul edildiği Litvanya'da, 1992 yılında ise Çevre Koruma Kanunu kabul edilmiştir (United Nations, 1999:185). Özellikle 1990’lı yıllarda çevre ile ilgili mevzuatta önemli yasal düzenlemelerin yapıldığı görülmektedir. 1991 tarihli Devlet Tabiat Kaynakları Vergi Kanunu, kaynak kullanıcılarına vergi ödeme yükümlülüğü getirmiş, Petrol ve Gaz Kaynaklarının Kullanımına İlişkin Kanun (1992), petrol ve gaz piyasa fiyatları üzerine \% 20 bir vergi öngörürken, Çevre Kirletme Harçları Kanunu (1991) ise su kirletici 51 kimyasal, hava kirletici 91 kimyasal ve hava kirletici 9 toz bileşeni için vergi oranlarını belirlemektedir (United Nations, 1999: 23-24). 1991 yılında çevreye ilişkin birçok harç uygulamaya geçmiştir (OECD, 2016): hava ulaşımı için hava kirletme harcı, mobil kaynaklar/yakıtlar için hava kirletme harcı, sabit kaynaklar için hava kirletme harcı, su kirletme harcı, ticari balıkçılık harçları (2007'de kaldırılmıştır), ağaç kesme harçları, avlanma sahaları kullanım harcı, kentsel atık kullanıcı harcı, su çıkarma harcı, mineral çıkarma harçları, atıksu kullanıcı harcı, su temini kullanıcı harcı, hava emisyon uymama ücretleri, su kirliliği uymama ücreti, atık bertarafı uymama ücretleri. 1993 'te ağaç kesme uymama ücretleri, 1996'da doğa koruma uymama ücreti, 2003'te ambalaj harcı ve atık ile ilgili ürün harçları getirilmiştir (OECD, 2016).

1990’lı yıllarda çevre vergilemesi alanında uygulamaya konan diğer öne çıkan vergiler, motorlu taşıtlar ithalat vergisi (1993), yakıt tüketim vergisi (1994), ağır yük taşıtları vergisidir (1995) (OECD, 2016). 2002 yılında daha önceden lüks otomobiller üzerine konmuş olan tüketim vergisinin yerine geçmek üzere, şu an yürürlükte olmayan araç işlem vergisi getirilmiştir (OECD, 2016).

1 Temmuz 2002'de yürürlüğe giren Özel Tüketim Vergisi Kanunu'nun yeni versiyonuna (European Commission (DG TAXUD), Eurostat, 2004: 184) göre yakıt tüketim vergisi oranlarında revizyon yapılmıştır (OECD, 2016). 2003 'te petrol ve doğal gaz kaynakları vergisinde değişiklik yapılmış, buna göre satış fiyatının \%2-\%20'si arasında farklılaştırılmış vergi oranları ile daha esnek bir vergileme sistemi getirilmiştir (OECD, 2016). AB üyeliğini (1 Mayıs 2004) takiben, $A B$ minimum oranlarına ulaşmak için tüketim vergisi oranları (geçiş dönemine izin verilen petrol, benzin, kömür, kok kömürü, linyit, elektrik ve sigara gibi ürünler hariç) arttırılmaya başlamıştır (European Commission (DG TAXUD), Eurostat, 2008: 171).

Ekonomik krizle mücadele tedbirleri kapsamında 1 Ocak 2009'da yürürlüğe giren vergi kanunları değişiklikleriyle yakıt üzerindeki tüketim vergileri arttırılmıştır: kurşunsuz petrol üzerindeki \%34; kurşunlu benzin üzerindeki \%37, dizel yakıt ve kerosen üzerindeki \%20, petrol gazı ve gaz hidrokarbonlar üzerindeki \%143 yükseltilmiştir (European Commission (DG ECFIN-DG TAXUD), 2009:74). Motor yakıtı olarak kullanılan gaz yağ1 üzerindeki özel tüketim vergisi 1 Ocak 2011 itibarıla, \%10'un üzerinde, 1 Ocak 2013 itibarıla ise \%9,3 arttırılmıştır (European Commission, 2016, European Commission (DG ECFIN-DG TAXUD), 2013:34). Litvanya'da 1 Temmuz 2015'ten itibaren yürürlüğe giren enerji tüketim vergilerindeki düzenlemeye göre, zirai faaliyetler için kullanılan gaz yağı üzerine minimum bir özel tüketim vergisi konmuştur (European Commission, 2016).

Haziran 2009'da, mobil kaynaklardan hava kirliliği için, Ocak 2010'da su, toprak ve havaya sabit kirlilik kaynaklarından gelen emisyonlar için, Ocak 2012'de ambalaj ve diğer ürünler için kirletme vergisi oranları güncellenmiştir (Hogg vd., 2016:538). 1 Ocak 2016 itibarıyla yürürlüğe girmek üzere Kasım 2014'te atık bertarafı vergisi düzenlemesi getirilmiştir (Hogg vd., 2016:538). Vergi oranları, atık türüne göre değişmektedir: Zararsız atık, katı atık için ve zararlı atık için oranlar, sırasıyla 21,72 €/ton, 7,24 €/ton, 47,79 €/ton (2020 itibarıyla bu oranlar sirasıyla 44,89 €, 30,41 € ve 70.96 €'ya ulaşacaktır.) (Hogg vd., 2016: 413, 538).

Litvanya'da mevcut çevre vergi ve harçları şöyle gruplandırılabilir: (Hogg vd., 2016): 1. Enerji: yakıt ve elektrik özel tüketim vergileri, 2.Ulaşım: motorlu taşıtlar ithalat vergisi, ağır yük taşıtları vergisi, 3. Kirletme ve kaynak: atık bertarafi vergisi, kirletme vergisi (su, toprak ve havaya sabit kirlilik kaynaklarından yayılan emisyonlar, mobil kaynaklardan havaya yayılan emisyonlar, ambalaj ve diğer zararlı ürünler üzerinden vergi alınır), üreticiler ve iç piyasaya belirli mallar koyan ithalatçılar tarafından ödenen, mallar ve ambalaj maddeleri üzerinde bir vergi, doğal kaynak çıkarma vergisi, petrol ve doğal gaz çıkarma vergisi, kereste satışından elde edilen gelirden zorunlu kesintiler, su çıkarma harçları, su temini kullanıcı harçları, av alanları vergisi.

\section{Baltık Ülkelerinde Çevre Vergi Gelirlerinin Gelişimi}

Baltık ülkeleri çevre vergi gelirlerinin 1995-2014 dönemindeki gelişimi, toplam çevre vergi gelirleri, çevre vergi gelirlerinin bileşimi, toplam vergi gelirleri (sosyal güvenlik primleri dahil) ve GSYİH içindeki payları esas alınarak incelenmiştir (Baltık ülkelerinde çevre vergileri hakkında diğer çalışmalar için bknz. Štreimikiené, 2015, Kurtinaitytė Venediktovienė,vd., 2014, Speck, vd., 2006 ). Eurostat (2016) “Çevre Vergi Gelirleri” verileri kullanılmıştır. AB-28'e ilişkin veriler 2002'den itibaren mevcut olduğundan, AB-28 karşılaştırmalarında 2002 ve sonrası baz alınmıştır. 


\subsection{Toplam Çevre Vergi Gelirleri}

Litvanya'nın toplam çevre vergi gelirleri 2014 yılına kadar Baltık ülkeleri arasında en yüksek değere sahiptir (bknz Tablo1). 2014'te birinciliği Letonya almıştır. Litvanya'nın çevre vergi gelirleri 2005'e kadar artış trendi göstermiştir. 20 yıllık sürede 3 kere azalma eğilimine giren çevre vergi gelirlerindeki hem miktar hem oransal olarak en büyük azalış 2006'da gözlenmiştir (\%9,99'luk bir düşüş ile çevre gelirleri 48,1 milyon € azalmıştır). Toplam çevre vergi gelirleri, 2005'te bir önceki yıla göre \%2,13'lik bir düşüşle 10,46 milyon $€$, 2010'da ise \%5,63'lük bir düşüş ile 30,56 milyon $€$ azalmıştır. 2005 ve 2006 yıllarındaki azalış, ulaşım vergi gelirlerindeki azalıştan, 2010'daki azalış, enerji ve kirletme/kaynak vergi gelirlerindeki azalıştan kaynaklanmıştır (2006'da ayrıca kirletme vergi gelirlerinde bir önceki yıla göre 0,36 milyonluk bir gelir azalışı yaşanmıştır.) (Tablo 2). Oransal olarak en büyük artış \%54,52 ile 1997 yılında yaşanırken, bunu \%33,25 ile 1998, \%29,07 ile 1996 yılları izlemiş̧tir. 1997'de ulaşım ve enerji vergi gelirleri \%50'nin üzerinde, kirletme/kaynak vergileri ise \%40'a yakın oranda artmıştır. 1996 'da oransal olarak en çarpıcı artış $(\% 79,58)$ kirletme/kaynak vergilerinde görülmüştür. Enerji vergi gelirlerinde \%30,17, ulaşım vergi gelirlerinde ise \%24,91 oranında artış görülmüştür. 1995 'te uygulamaya geçen ağır yük taşıtları vergisinin ulaşım gelir artışında rol oynadığı söylenebilir. 1998'deki artışın neredeyse tamamı enerji vergi gelirlerindeki artıştan kaynaklanmaktadır (Tablo 2).

Estonya'nın toplam çevre vergi gelirleri, dönem boyunca 3 ülke arasında en düşük değere sahiptir. 1999 (-\%4,97) ve $2013(-\% 0,90)$ yıllarındaki az miktardaki düşüşler dışında 20 yıllık süreçte artış eğilimi gözlenmektedir. Oransal olarak en büyük artış 1996'da yaşanmıştır $(\% 105,66)$. Bir önceki yıl 25,61 milyon $€$ olan toplam çevre vergi gelirleri, iki katının biraz üzerinde artarak 52,67 milyon €’a ulaşmıştır. Artış büyük ölçüde enerji vergi gelirlerindeki artıştan kaynaklanırken, ulaşım vergi gelirleri \%62,03 oranında artmıştır. Bunda 1995 tarihli motorlu taşıtlar tüketim vergisinin etkisi açıktır. Oransal olarak ikinci büyük artış \%41,15 ile 2001'de gerçekleşirken, bunu \%39,94 ile 1998 yılı (27,23 milyon €) izlemiştir.

Letonya'da 1999'da 18,29 milyon €,2001'de 1,98 milyon €, 2009'da 17,54 milyon € düşüş olmak üzere 20 yıllık dönemde üç kez toplam çevre vergisi gelirlerinde azalma görülmüştür. 1999 ve 2001 'deki düşüşler enerji vergi gelirlerindeki düşüşlerden kaynaklanırken, 2009'daki düşüşte enerji vergilerindeki düşüşün de payı olmakla birlikte, büyük ölçüde ulaşım vergilerindeki düşüşün etkisi olmuştur. Oransal olarak en büyük artışların yaşandığ 1 yıllar $1996(\% 74,01), 1997(\% 60,56)$ ve $1998(\% 56,94)$, yıllarıdır. 1996 yılındaki artışta, bir önceki yıla göre \%77,53 artış kaydeden enerji vergi gelirleri dikkat çekmektedir. 1997'de kirletme ve kaynak vergileri bir önceki yıla göre \%461,94'lük çarpıcı bir artış göstermiştir (bknz Tablo 2). 1995 tarihli Doğal Kaynaklar Vergisi’nin etkisinin 1997 yılında kendisini belirgin şekilde gösterdiği söylenebilir.

\begin{tabular}{|l|l|l|l|l|}
\hline Y1 & AB 28 & Estonya & Letonya & Litvanya \\
\hline 1995 & $:$ & 25,61 & 40,74 & 95,99 \\
\hline 1996 & $:$ & 52,67 & 70,89 & 123,89 \\
\hline 1997 & $:$ & 68,18 & 113,82 & 191,43 \\
\hline 1998 & $:$ & 95,41 & 178,63 & 255,08 \\
\hline 1999 & $:$ & 90,67 & 160,34 & 302,67 \\
\hline 2000 & $:$ & 104,39 & 193,6 & 305,77 \\
\hline 2001 & $:$ & 147,35 & 191,62 & 349,94 \\
\hline 2002 & $264.591,28$ & 154,59 & 217,62 & 425,93 \\
\hline 2003 & $270.930,89$ & 164,53 & 238,57 & 461,84 \\
\hline 2004 & $282.004,96$ & 203,87 & 287,45 & 491,98 \\
\hline 2005 & $288.518,05$ & 255,72 & 346,45 & 481,52 \\
\hline 2006 & $296.552,24$ & 295,95 & 385,25 & 433,42 \\
\hline 2007 & $304.584,37$ & 355,68 & 437,21 & 507,56 \\
\hline 2008 & $297.826,66$ & 382,46 & 449,44 & 533,52 \\
\hline 2009 & $289.672,43$ & 415,93 & 431,9 & 542,78 \\
\hline 2010 & $303.392,34$ & 431,6 & 432,8 & 512,22 \\
\hline 2011 & $316.592,37$ & 454,26 & 497,6 & 527,68 \\
\hline 2012 & $327.129,45$ & 489,06 & 537,61 & 548,13 \\
\hline 2013 & $331.851,56$ & 484,64 & 558,21 & 572,34 \\
\hline 2014 & $343.640,99$ & 533,05 & 630,13 & 618,95 \\
\hline
\end{tabular}

Tablo 1. 1995-2014 Toplam Çevre Vergi Gelirleri, Milyon Euro Kaynak: Eurostat

\section{2 Çevre Vergi Gelirleri Bileşimi}

2014 'te $A B$ çevre vergileri içinde en büyük payı \%76,5 ile enerji vergileri alırken, ulaşım vergileri \%19,9, kirletme ve kaynak vergileri ise \%3,6'llk pay almıştır (Eurostat, 2016) Letonya'da enerji vergileri \%78,6, ulaşım vergileri \%18, kirletme/kaynak vergileri \%3,4; Litvanya'da enerji vergileri \%93,8, ulaşım vergileri $\% 3,5$, kirletme/kaynak vergileri \%2,7; Estonya'da enerji vergileri \%87, ulaşım vergileri \%2,1, kirletme/kaynak vergileri $\% 10,9$ paya sahiptir (bknz Tablo2). Baltık ülkelerinde de vergi bileşiminden en büyük payı AB'deki gibi enerji 
vergileri almaktadır. Üç ülkede de enerji vergi gelirlerinin aldığı pay, AB-28 oranının üzerindedir. Özellikle Litvanya'nın \%90'un üzerindeki payı çarpııı bir örnek oluşturmaktadır. Toplam çevre vergi gelirleri içinde enerji vergilerinin en yüksek olduğu $\mathrm{AB}$ ülkesi, Litvanya'dır. Letonya'daki ulaşım vergileri payı $\mathrm{AB}-28$ 'in biraz altındayken, Estonya ve Litvanya en düşük ulaşım vergileri payına sahiptir. Estonya'da kirletme/kaynak vergileri, $\mathrm{AB}$ payının çok üzerindedir (3 katı). $\mathrm{AB}$ genelinin aksine, kirletme/kaynak vergileri enerji vergilerinden sonra bileşimden en çok payı almaktadır.

\begin{tabular}{|l|c|c|c|c|c|c|c|c|c|}
\hline & \multicolumn{2}{|l}{ Estonya } & \multicolumn{2}{l|}{ Letonya } & \multicolumn{2}{l|}{ Litvanya } \\
\hline Y11 & Enerji & Ulaşım & $\begin{array}{c}\text { Kirletme/ } \\
\text { Kaynak }\end{array}$ & Enerji & Ulaşım & $\begin{array}{c}\text { Kirletme/ } \\
\text { Kaynak }\end{array}$ & Enerji & Ulaşım & $\begin{array}{c}\text { Kirletme/ } \\
\text { Kaynak }\end{array}$ \\
\hline 1995 & 16,2 & 5,61 & 3,81 & 38,54 & 0 & 2,20 & 56,42 & 37,65 & 1,91 \\
\hline 1996 & 38,84 & 9,09 & 4,74 & 68,42 & 0 & 2,47 & 73,44 & 47,03 & 3,43 \\
\hline 1997 & 53,23 & 8,35 & 6,59 & 98,7 & 1,24 & 13,88 & 113,11 & 73,6 & 4,72 \\
\hline 1998 & 79,75 & 8,47 & 7,18 & 159,89 & 2,46 & 16,28 & 173,33 & 77,25 & 4,5 \\
\hline 1999 & 72,52 & 10,32 & 7,83 & 140,15 & 3,12 & 17,07 & 220,09 & 70,49 & 12,09 \\
\hline 2000 & 76,06 & 13,05 & 15,28 & 156,46 & 18,61 & 18,53 & 216,91 & 82,91 & 5,95 \\
\hline 2001 & 111,39 & 14,59 & 21,37 & 153,57 & 19,23 & 18,82 & 249,9 & 90,14 & 9,9 \\
\hline 2002 & 116,69 & 15,42 & 22,48 & 174,27 & 24,23 & 19,12 & 303,27 & 111,12 & 11,54 \\
\hline 2003 & 133,9 & 3,8 & 26,83 & 197,21 & 25,54 & 15,82 & 328,55 & 122,32 & 10,98 \\
\hline 2004 & 173,76 & 7,11 & 23 & 238,44 & 35,97 & 13,04 & 332,91 & 142,76 & 16,31 \\
\hline 2005 & 215,88 & 7,91 & 31,93 & 290,81 & 40,27 & 15,37 & 364,36 & 99,97 & 17,19 \\
\hline 2006 & 243,11 & 9,31 & 43,53 & 319,71 & 49,2 & 16,34 & 393,87 & 22,72 & 16,83 \\
\hline 2007 & 291,62 & 9,49 & 54,57 & 361,83 & 59,92 & 15,46 & 459,35 & 29,87 & 18,34 \\
\hline 2008 & 320,26 & 7,47 & 54,73 & 382,84 & 52,64 & 13,96 & 498,12 & 14,6 & 20,81 \\
\hline 2009 & 355,97 & 6,42 & 53,54 & 379,7 & 40,9 & 11,3 & 513,13 & 11,54 & 18,11 \\
\hline 2010 & 378,95 & 7,45 & 45,2 & 358,78 & 60,73 & 13,29 & 492,23 & 12,62 & 7,37 \\
\hline 2011 & 395,74 & 9,84 & 48,68 & 390,91 & 91,06 & 15,63 & 497,11 & 14,26 & 16,31 \\
\hline 2012 & 431,91 & 10,79 & 46,36 & 425 & 94,2 & 18,41 & 515,93 & 15,39 & 16,82 \\
\hline 2013 & 420,94 & 10,94 & 52,76 & 435 & 102,88 & 20,33 & 537,71 & 15,62 & 19 \\
\hline 2014 & 463,78 & 11,31 & 57,96 & 495,29 & 113,71 & 21,13 & 580,48 & 21,81 & 16,65 \\
\hline
\end{tabular}

*Letonya'ya ait kirletme ve kaynak vergi gelirleri Eurostat'ta mevcut olmadiğ için, toplam çevre vergi gelirlerinden enerji ve ulaşım vergi gelirleri çıkarılarak hesaplanmıştır.

\section{Tablo 2. 1995-2014 Çevre Vergi Gelirleri Bileşimi (Milyon Euro) Kaynak: Eurostat}

Estonya'nın 20 yıllık dönem boyunca çevre vergi gelirleri bileşimine bakıldığında enerji vergilerinin payının $\% 63,26$ ile $\% 88,31$ arasında seyrettiği görülmektedir. 1995 'te $\% 21,91$ olan ulaşım vergilerinin payı, 2014'te $\% 2,12$ 'dir. 2003 'te $\% 9,97$ 'den $\% 2,31$ 'e keskin bir düşüş $(-\% 75,36)$ yaşanmıştı. Bu motorlu taşıtlar tüketim vergisinin kaldırıldığı yıldır. Ağır yük taşıtları vergisinin getirildiği 2004 yılında ise ulaşım vergi gelirlerinde $\% 87,11$ 'lik büyük bir artış yaşanmıştır. 2008 ve 2009 yıllarında ulaşım vergilerinde sırasıyla $\% 21,29, \% 14,06$ oranlarında azalma görünürken, 2010 yılında tekrar artışa geçmiştir $(\% 16,04)$. Kirletme ve kaynak vergilerinin toplam payına bakıldığında, $\% 7,53$ ila $\% 16,31$ arasında seyrettiği izlenmektedir. Dönem başında $\% 14,88$ olan oran, 2014 'te $\% 10,87$ 'dir. Toplam çevre vergileri bileşiminde 2000 yllına kadar ulaşım vergileri, bileşimden aldığ pay olarak 2.siradayken, 2000 'den itibaren kirletme ve kaynak vergileri 2 .sıraya yerleşmiştir.

Letonya'da enerji vergilerinin payı \%77,93 ile \%96,52 arasında değişmektedir. Dönem başında enerji vergilerinin payı \%94,60 iken, 2014'te \%78,60'tır. 1997 yllına kadar ulaşım vergileri sıfır iken, 1997'de \%1,09 pay almaktadır. 2014 'te bu oran $\% 18,05$ olmuştur. 1999 'da $\% 1,95$ olan ulaşım vergileri payı, 2000 'de $\% 9,61$ 'e sıçramıştır. Bunda, 1999 'da motorlu taşıtlar tüketim vergisinin konmasının etkisi olduğu öne sürülebilir. Letonya'nın kirletme ve kaynak vergilerinin bileşimdeki payı 1995'te \%5,4 iken, 2014 yılında \%3,35'e gerilemiş̧tir. En yüksek oran 1997 yllına aittir $(\% 12,19)$.

Litvanya'da 1995 'te $\% 58,78$ olan enerji vergi gelirlerinin payı 2014 'te $\% 93,78$ 'e ulaşmıştır. 2006 yılında önemli bir artı̧̧ göze çarpmaktadır. Bir önceki yı1 \%75,67 olan pay, \%90,87’ye çıkmıştır. Bunda ulaşım vergi gelirlerindeki \%77,27'lik büyük azalışı önemli etkisi vardır. 2006'dan itibaren enerji vergilerinin payı \%90'ın üzerinde seyretmiştir. Ulaşım vergi gelirlerinin payı dönem başında $\% 39,22$ iken 2005 'te bu pay $\% 20,76$ 'ya düşmüştür. 2006'da bu pay keskin bir düşüşle \%5,24'e inmiştir. 2008'den itibaren \%2-\%3 bandında seyretmiştir. Litvanya'da kirletme/kaynak vergi gelirlerinin payı, \%1,44 ile \%3,99 arasında yer almışıtır. Ulaşım vergi gelirlerinin payının büyük düşüş gösterdiği 2006 ve sonrası kirletme/kaynak vergileri payı ulaşım vergileri ile birbirine yakın oranlarda seyretmiştir.

\section{3 Çevre Vergi Gelirlerinin Toplam Vergi Gelirleri İçindeki Payı}

2014 yılı Eurostat verilerine göre toplam vergi gelirleri içinde çevre vergilerinin payı bakımından Letonya $\% 9,16$ ile $\mathrm{AB}$ ülkeleri içinde 5.sırada yer alırken, Estonya $\% 8,22$ ile ilk 10 da yer almaktadır. Litvanya ise $\% 6,06$ ile AB28 'in biraz altında kalmıştır. 3 Baltık ülkesi içinde genel olarak 2005'e kadar Litvanya liderken (1998 yılı hariç), 
2005 'ten itibaren Letonya ve Estonya arasında birincilik değişmiştir. Litvanya 2005'ten itibaren (2009 hariç) genel bir düşüş trendine girmiştir. 2002 ve 2003 yıllarında Estonya AB-28'in biraz altında seyrederken, 2006-2008 arasında ve 2011 'den itibaren Litvanya AB-28'in altında kalmıştır. Letonya ise AB-28'in oldukça üzerinde bir yüzdeye sahiptir.

Letonya'da 1996'da \%59,1'lik belirgin bir artış vardır. Bu çevre vergi gelirlerinin ikiye katlandığ bir yıldır. Çevre vergi gelirlerinde en büyük artışların olduğu yıllardan biri olan 1998'de \%36,51'lik belirgin bir artış var. 2009 yılına gelindiğinde \%27,55'lik artışla çevre vergilerinin pay1 \%6,57'den \%8,38'e yükselmiştir. 1999'da vergi gelirlerinin düşüşü ile birlikte \%17,03 azalma söz konusudur. Dönem içindeki oransal olarak en büyük azalışların yaşandığı diğer yıllar 2006 ve 2007'dir (sırasıyla -\%14,11 ve -\%12,03). Letonya'da çevre vergilerinin toplam vergi gelirlerinden aldığı payın en yüksek olduğu yıl 2014'tür.

Estonya'da çevre vergilerinin toplam vergi gelirlerinden aldığı payda 1996 yılında \%68,16 oranında büyük bir artış olmuştur. Dikkat çekici artışların yaşandığı diğer yıllar, $2001(\% 27,81)$ ve 1998 'dir $(\% 25,34)$. Bunlar, toplam çevre vergi gelirlerinde oransal olarak en büyük artışların görüldüğü yıllardır. 2002'de \% -8,36'l1k bir azalış yaşanırken, ikinci büyük azalış -\% 7,51 ile 1999'da, üçüncüsü ise -\%6,07 ile 2013'te görülmüştür. 1999 ve 2013 yılları toplam çevre vergi gelirlerinde azalmanın görüldüğü yıllardır. Estonya'da çevre vergilerinin toplam vergi gelirlerinden aldığı payın en yüksek olduğu yıl 2010'dur.

Litvanya'da 2009'da çevre vergilerinin payı \%24,62'lik bir artışla \%6,58'e yükselmiştir. İkinci büyük artıŞ 1999'da (\%15,98) olmuş, bir önceki yıl \%7,76 olan oran \%9'a yükselmiştir. 1998'de \%13,12'lik bir artış yaşanmıştır. Litvanya'da çevre vergilerinin toplam vergi gelirlerinden aldığ payın en yüksek olduğu yıllar 2002 ve 2003 'tür. 2003 'ten itibaren genel olarak azalma trendinde olduğu görülmektedir (2009 ve 2014 hariç). En büyük azalışların görüldüğü yıllar 2000 (-\%11,67), 2005 (-\%15,64) ve 2006’dır (-\%23,94).

\begin{tabular}{|l|l|l|l|l|l|l|l|}
\hline Y1l & AB 28 & Estonya & Letonya & Litvanya & \multicolumn{3}{|l|}{ AB 28 Ülkeleri İçindeki Siralama } \\
\cline { 6 - 8 } & & & & & Estonya & Letonya & Litvanya \\
\hline 1995 & $:$ & 2,45 & 3,22 & 6,77 & 27 & 26 & 14 \\
\hline 1996 & $:$ & 4,12 & 5,12 & 6,88 & 26 & 23 & 14 \\
\hline 1997 & $:$ & 4,46 & 6,41 & 6,86 & 27 & 17 & 16 \\
\hline 1998 & $:$ & 5,59 & 8,75 & 7,76 & 21 & 10 & 14 \\
\hline 1999 & $:$ & 5,17 & 7,26 & 9 & 27 & 16 & 8 \\
\hline 2000 & $:$ & 5,43 & 7,63 & 7,95 & 24 & 12 & 8 \\
\hline 2001 & $:$ & 6,94 & 7,13 & 8,72 & 17 & 15 & 5 \\
\hline 2002 & 6,6 & 6,36 & 7,66 & 9,68 & 22 & 11 & 5 \\
\hline 2003 & 6,64 & 6,09 & 8,25 & 9,67 & 24 & 11 & 5 \\
\hline 2004 & 6,61 & 6,7 & 8,88 & 9,21 & 21 & 8 & 6 \\
\hline 2005 & 6,43 & 7,54 & 9 & 7,77 & 14 & 7 & 12 \\
\hline 2006 & 6,19 & 7,14 & 7,73 & 5,91 & 15 & 9 & 23 \\
\hline 2007 & 5,99 & 6,97 & 6,8 & 5,76 & 13 & 16 & 22 \\
\hline 2008 & 5,85 & 7,33 & 6,57 & 5,28 & 10 & 16 & 25 \\
\hline 2009 & 6,14 & 8,37 & 8,38 & 6,58 & 9 & 8 & 19 \\
\hline 2010 & 6,16 & 8,77 & 8,69 & 6,37 & 6 & 7 & 21 \\
\hline 2011 & 6,17 & 8,59 & 8,85 & 6,12 & 9 & 6 & 22 \\
\hline 2012 & 6,15 & 8,56 & 8,53 & 6,02 & 5 & 6 & 21 \\
\hline 2013 & 6,13 & 8,04 & 8,52 & 5,98 & 10 & 8 & 19 \\
\hline 2014 & 6,15 & 8,22 & 9,16 & 6,06 & 10 & 5 & 20 \\
\hline
\end{tabular}

Tablo 3. 1995-2014 Çevre Vergi Gelirlerinin Toplam Vergi Gelirleri Iç̧indeki Payı (\%) Kaynak: Eurostat

1995 ve 1997 yıllarında Estonya Avrupa Birliği ülkeleri içinde en düşük paya sahiptir. 20 yıllık sürece bakıldığında Estonya'nın 2005'e kadar genel olarak son sıralarda yer aldığ 1 , 2005'ten itibaren ise yükselmeye başladığı görülmektedir. Çevresel Vergi Reformu'nun başlatıldığı ve AB üyeliğini takip eden 2005 yılında, çevre vergilerinin payının artmış olduğu görülmektedir. 2008 ve sonrasında, AB ülkeleri içinde çevre vergi gelirlerinin toplam vergi gelirlerinden en çok pay aldığ ilk 10 ülke içinde yer almıştır. Letonya 1995 'te AB28 ülkeleri arasında Estonya'dan sonra en düşük yüzdeye sahip ülke iken, 2014'te 5.sırada yer almıştır. 1996-2006 arasında genel olarak sıralamada yükselirken, 2007 ve 2008 yıllarında tekrar 16.sıraya kadar gerilemiştir. 2009'dan itibaren en yüksek yüzdeye sahip ilk 10 AB ülkesinden biri olmuştur. Dönem başında Litvanya 14.sırada yer alırken, 2014 yılına gelindiğinde 20.sırada yer almıştır. 1999-2004 y1lları arasında 5 ila 8.sıra arasında yer alan Litvanya en yüksek yüzdeye sahip ilk 10 ülkeden biri olmuştur. Bununla birlikte, 2005 sonrası ise son sıralara doğru kaymıştır.

\section{4 Çevre Vergi Gelirlerinin GSYİH İçindeki Payı}

Estonya'da dönem başında \%0,88 olan çevre vergi gelirleri/GSYİH oranı 2014'e gelindiğinde \%203,41'lik artışla \%2,67'ye ulaşmıştır (Tablo 4). Çevre vergi gelirlerinin GSYİH'den aldığı payın 20 yıllık seyrine bakıldığında, en büyük artışın 1996'da yaşandığı görülmektedir. 1995 'te \% 0,88 olan oran \%60,23'lük bir artışla \%1,41'e yükselmiştir. İkinci büyük artış, 2009'da yaşanmıştır. Bir önceki yıl \%2,32 olan oran \%26,72'lik bir artışla 
\%2,94'e yükselmiştir. 3.büyük artış ise 1998'de görülmüştür. 1997 y1lında \%1,52 olan oran 1998'e gelindiğinde \%25'lik artışla \%1,9'a yükselmiştir. En büyük düşüş 1999'da görülmüştür (-\%11,05). En büyük ikinci düşüş 2011 'de (-\%6,83), üçüncüsü ise 2013'te görülmüştür (-\%6,25). 2010-2013 döneminde azalış trendine giren çevre vergi gelirleri/GSYIH payı 2014'te yeniden yükselişe geçmiştir. AB-28 ile karşılaştırıldığında 2008'den itibaren Estonya'nın AB-28'in üzerinde seyrettiği görülmektedir.

\begin{tabular}{|l|c|c|c|c|}
\hline Y1 & AB 28 & Estonya & Letonya & Litvanya \\
\hline 1995 & $:$ & 0,88 & 0,99 & 1,87 \\
\hline 1996 & $:$ & 1,41 & 1,51 & 1,88 \\
\hline 1997 & $:$ & 1,52 & 1,98 & 2,14 \\
\hline 1998 & $:$ & 1,9 & 2,79 & 2,54 \\
\hline 1999 & $:$ & 1,69 & 2,28 & 2,94 \\
\hline 2000 & $:$ & 1,69 & 2,25 & 2,45 \\
\hline 2001 & $:$ & 2,11 & 2,05 & 2,56 \\
\hline 2002 & 2,56 & 1,99 & 2,14 & 2,81 \\
\hline 2003 & 2,58 & 1,89 & 2,28 & 2,77 \\
\hline 2004 & 2,56 & 2,1 & 2,46 & 2,7 \\
\hline 2005 & 2,51 & 2,27 & 2,53 & 2,29 \\
\hline 2006 & 2,43 & 2,19 & 2,24 & 1,8 \\
\hline 2007 & 2,36 & 2,19 & 1,93 & 1,75 \\
\hline 2008 & 2,29 & 2,32 & 1,85 & 1,63 \\
\hline 2009 & 2,36 & 2,94 & 2,31 & 2,02 \\
\hline 2010 & 2,37 & 2,93 & 2,44 & 1,83 \\
\hline 2011 & 2,4 & 2,73 & 2,47 & 1,69 \\
\hline 2012 & 2,44 & 2,72 & 2,45 & 1,64 \\
\hline 2013 & 2,45 & 2,55 & 2,45 & 1,64 \\
\hline 2014 & 2,46 & 2,67 & 2,67 & 1,7 \\
\hline
\end{tabular}

Tablo 4. 1995-2014 Çevre Vergi Gelirlerinin GSYIH İçindeki Payı (\%) Kaynak: Eurostat

Letonya'da dönem başında \%0,99 olan oran 2014'e gelindiğinde \%169,70'lik artışla \%2,67'ye ulaşmıştır. 20 yıllık dönemde en büyük artışlar 1996, 1997, 1998 yıllarında görülmüştür ( sırasıyla \%52,53, \%31,13,\%40,91). 1999 yılında \%18,28'lik bir düşüş yaşanmıştır. İkinci büyük düşüş -\%13,84 ile 2007'de, sonraki ise -\%11,46 ile 2006'da gözlenmiştir. 2002-2005 döneminde yeniden yükselişe geçen oran, 2006-2008 arası düşüşe geçmiştir. 2008 sonrası ise genel bir artış trendi yaşandığı görülmektedir. 2005'te AB-28'in üzerinde olan Letonya, 2006 2009 arasında ise AB-28 oranının altında kalmıştır. Özellikle 2007 ve 2008 yıllarında AB-28'in epey altında kalmıştır. 2010 ve sonrası ise AB-28'in üzerinde seyrettiği görülmektedir.

Litvanya'nın dönem başında \%1,87 olan çevre gelirleri/GSYİH oranı, 2014'te \%9,09'luk bir düşüşle \%1,7'ye gerilemiştir. 1996-1999 döneminde artış eğiliminde olan GSYİH payı, en büyük artışı \%23,93'lük bir artışla 2009'da yaşamıştır. 2010'dan itibaren azalış eğilime giren oran, 2014'te \%3,66'lık bir artış kaydetmiştir. AB-28 ile kıyaslandığında, 2005'ten itibaren AB-28'in oldukça altında seyrettiği görülmektedir.

3 Baltık ülkesi karşılaştırıldığında, 2005 yılına kadar Litvanya'nın en yüksek orana sahip olduğu (1998 yılı hariç), 2006'dan itibaren ise son sırada yer aldığı görülmektedir. Estonya ise 2006 yılına kadar 2001 yılı dışında en sonda yer alırken, 2006'da Letonya'dan sonra ikinci sırada yer almış ve 2007 itibarıyla ise 3 ülke arasında lider konuma geçmiştir. 2007 ve sonrasında Letonya ikinci sırada yer almış, 2014’te Estonya ile birlikte birinci sırayı paylaşmıştır. Dönem başında Litvanya çevre vergilerinin GSYİH'den aldığı payda lider durumdayken, dönem sonunda ise GSYİH'den en az pay alan ülke haline gelmiştir. 2014 yılı AB ülkelerinin oranları incelendiğinde, Estonya ve Letonya'nın 11.sırada yer alırken, Litvanya'nın AB28 içinde en düşük orana sahip ülke olduğu görülmektedir. Dönem başında Letonya $(\% 0,99)$ ve Estonya $(0,88)$ AB28 ülkeleri içinde son 2 ülkedir. Litvanya ise 22.sira ile son siralarda yer almaktadir.

\section{Sonuc}

1990'lardan itibaren çevre koruma ve çevre vergilemesi konusunda Baltık ülkelerinde yasal düzenlemelerin yoğunlaştığ́ görülmektedir. İncelenen dönemde (1995-2014) toplam çevre vergi gelirlerinde en büyük oransal artışların genel olarak 1996, 1997 ve 1998 yıllarında gerçekleştiği görülmektedir. Her 3 ülke de AB'ye üye olmalarıyla beraber özellikle enerji ürünleri üzerindeki vergi oranlarını uyumlaştırmak için 2004'ten itibaren özel tüketim vergi oranlarını çeşitli düzenlemelerle arttırmışlardır. 1 Ocak 2016'ya ilişkin AB ülkeleri enerji ürünleri ve elektriğe ilişkin özel tüketim vergisi oranlarına (European Commission (DG TAXUD), 2016) bakıldığında her 3 ülkenin de $\mathrm{AB}$ minimum değerlerinde veya üzerinde yer aldığı görülmektedir. Bununla birlikte 3 Baltık ülkesi değerlendirildiğinde genel olarak Estonya'daki oranların daha yüksek olduğu, en düşük oranların ise genel olarak Letonya'ya ait olduğu görülmektedir. Genellikle Letonya AB sıralamasında sonlarda yer almaktadır. 
Vergi bileşiminde Baltık ülkelerinde de AB'deki gibi enerji vergileri en büyük payı almaktadır. 2014 itibarıyla, Litvanya $(\% 93,78)$, toplam çevre vergi gelirleri içinde enerji vergilerinin en yüksek pay aldığı $A B$ ülkesidir. $A B$ ülkeleri arasında Estonya $(\% 2,12)$ ve Litvanya $(\% 3,52)$ ulaşım vergilerinde en düşük paya sahip ülkelerdir. Estonya ve Litvanya'da otomobiller üzerinden yıllık taşıt vergisi alınmamaktadır. Estonya'nın kirletme/kaynak vergileri payı $(\% 10,9)$ AB oranıyla karşılaştırıldığında dikkat çekicidir. Letonya'da ise birçok AB ülkesindeki çeşitli kirletme ve kaynak vergilerini bünyesinde toplayan kapsayıcı bir doğal kaynaklar vergisi uygulanmaktadır (Hogg, 2016:391). 2014 yılı verilerine göre toplam vergi gelirleri içinde çevre vergilerinin payı bakımından Letonya $(\% 9,16)$ AB ülkeleri içinde 5.sırada, Estonya $(\% 8,22)$ ilk 10 içinde yer alırken Litvanya ise $(\% 6,06)$ AB-28'in biraz altında kalmıştır. 20 yıllık süreç değerlendirildiğinde, AB ülkeleri arasında Estonya'nın 2005'e kadar genel olarak son sıralarda yer aldığı, Çevresel Vergi Reformu'nu başlattığı 2005 'ten itibaren ise yükselmeye başladığ 1 görülmektedir. Letonya 1995'te AB ülkeleri arasında Estonya'dan sonra en düşük yüzdeye sahipken, 2014 yılında 5.sıraya çıkmıştır. Litvanya ise özellikle 2005 sonrası son sıralarda yer almıştır. GSYİH'den aldığ 1 paya göre Litvanya, AB ülkeleri içinde en düşük orana sahiptir.

\section{Kaynakça}

- Dudzińska, 2013, “The Baltic States' Success Story in Combating the Economic Crisis: Consequences for Regional Cooperation within the EU and with Russia", Polish Institute of International Affairs (PISM) Policy Paper No. 6 (54), March.

- Ekins, 1999, "European environmental taxes and charges: recent experience, issues and trends", Ecological Economics 31, p.39-62.

- Estonian Environment Agency, 2014, “Estonian Environmental Review 2013”, Tallinn

- European Commission (DG TAXUD), 2016, "Excise Duty Tables Part II -Energy products and Electricity, January,http://ec.europa.eu/taxation_customs/resources/documents/taxation/excise_duties/energy_products/r ates/excise_duties-part_ii_energy_products_en.pdf

- European Commission (DG ECFIN-DG TAXUD), 2009, "Monitoring revenue trends and tax reforms in EU Member States Joint EC-EPC 2008 Report”, Luxembourg

- European Commission (DG ECFIN-DG TAXUD), 2010, "Monitoring tax revenues and tax reforms in EU Member States 2010- Tax policy after the crisis"

- European Commission (DG ECFIN-DG TAXUD), 2011, "Tax reforms in EU Member States 2011,-Tax policy challenges for economic growth and fiscal sustainability", October, Brussels,

- European Commission (DG ECFIN-DG TAXUD), 2012, “Tax reforms in EU Member States 2012 - Tax policy challenges for economic growth and fiscal sustainability”, October. Brussels

- European Commission (DG ECFIN-DG TAXUD), 2013, “Tax reforms in EU Member States 2013 - Tax policy challenges for economic growth and fiscal sustainability".

- European Commission (DG ECFIN-DG TAXUD), 2014, “Tax reforms in EU Member States 2014 - Tax policy challenges for economic growth and fiscal sustainability", Brussels

- European Commission (DG TAXUD), Eurostat, 2003, "Structures of the taxation systems in the European Union, Data 1995-2001", Luxembourg.

- European Commission (DG TAXUD), Eurostat, 2004, "Structures of the taxation systems in the European Union, Data 1995-2002", Luxembourg.

- European Commission (DG TAXUD), Eurostat, 2005, "Structures of the taxation systems in the European Union, Data 1995-2003", Luxembourg.

- European Commission (DG TAXUD), Eurostat, 2007, “Taxation trends in the European Union-Data for the EU Member States and Norway", Luxembourg.

- European Commission (DG TAXUD), Eurostat, 2008, "Taxation trends in the European Union-Data for the EU Member States and Norway”, Luxembourg.

- European Commission (DG TAXUD), Eurostat, 2009, "Taxation trends in the European Union-Data for the EU Member States and Norway", Luxembourg.

- European Commission (DG TAXUD), Eurostat, 2010, "Taxation trends in the European Union-Data for the EU Member States, Iceland and Norway", Luxembourg.

- European Commission (DG TAXUD), Eurostat, 2013, "Taxation trends in the European Union-Data for the EU Member States, Iceland and Norway", Luxembourg

- European Commission (DG TAXUD), Eurostat, 2014, "Taxation trends in the European Union-Data for the EU Member States, Iceland and Norway 2014”, Luxembourg. 
- European Commission (DG TAXUD), Eurostat, 2015, "Taxation Trends in the European Union, 2015, Data for the EU Member States, Iceland and Norway"

- European Commission, 2016, Taxation Reforms Database, (http://ec.europa.eu/economy_finance/indicators/economic_reforms/taxation_reforms_database/)

- European Parliament, 1998a, "Environmental Policy in Estonia", Directorate-General For Research, Division of The Environment, Energy, Research and Stoa, Briefing No. 5, March.

- European Parliament, 1998b, "Environmental Policy in Latvia", Directorate-General For Research Division For The Environment, Energy And Research, Stoa, Briefing No.4, May.

- Eurostat, 2016, Environmental Tax Revenues, http://appsso.eurostat.ec.europa.eu/nui/show.do, Last update: 08-03-2016

- Hogg vd., 2016, Study on Assessing The Environmental Fiscal Reform Potential For The EU28 Final Report, Luxembourg: Publications Office of the European Union.

- Deutsche Gesellschaft für Internationale Zusammenarbeit (GIZ) GmbH, 2014, "Environmental Fiscal Reform Case Studies", June, https://www.giz.de/fachexpertise/downloads/giz2014-en-environmental-fiscalreform-case-studies.pdf.

- Kraav ve Lüpsik 2007a, Estonian Ecological Tax Reform, presentation at the COMETR workshop 22 May 2007, Prague, Czech Republic, http://www.ieep.cz/editor/assets/projekty/com/estonia.pdf

- Kraav ve Lüpsik 2007b, "Ecological Tax Reform in Estonia and Innovation Perspectives in the Energy Sector", paper presented at the 8th Global Conference on Environmental Taxation, 18-20 October 2007, Munich, Germany, http://www.worldecotax.org/downloads/Presentations/Silja_Lupsik_Eva_Kraav.pdf

- Kurtinaitytė-Venediktovienè vd., 2014, "Environmental Taxes in Northern Europe. The Recent Evolution and Current Status in the Baltic Countries", Socialinių mokslų studijos / Societal Studies, Vol. 6 Issue 2, p331-348.

- OECD, 2016, Database on instruments used for environmental policy, http://www2.oecd.org/ecoinst/queries/

- Poltimäe, 2014, The distributional and behavioural effects of Estonian environmental taxes, Dissertation is accepted for the defence of the degree of Doctor of Philosophy (in Economics) on 16 April 2014 by the Council of the Faculty of Economics and Business Administration, University of Tartu.

- Speck ve Jilkova, 2009, "Design of Environmental Tax Reforms in Europe”, Carbon-Energy Taxation, Andersen vd. (ed.), pp.24-52, Oxford, GB: OUP

- $\quad$ Speck vd., 2006, “The Use Of Economic Instruments in Nordic and Baltic Environmental Policy 20012005", TemaNord 2006:525, Nordic Council of Ministers, Copenhagen

- S Streimikiené, D., 2015, "Impact of Environmental Taxes on Sustainable Energy Developmnet in Baltic States, Czech Republic and Slovakia”, Ekonomie a Management Economics and Management, Vol.18, 4, p.4-23.

- Mező ve Bagi, 2012, Crisis management in the Baltic States, MPRA Paper No. 40366, http://mpra.ub.unimuenchen.de/40366/, p.426-439.

- United Nations, 1999, "Environmental Performance Reviews: Lithuania”, Economic Commission For Europe Committee On Environmental Policy, Environmental Performance Reviews Series No. 4, New York and Geneva 


\title{
İşletmelerde Kriz Yönetimi Çalışmaları ve İşletmelerin Kriz Öncesi, Kriz Anı ve Kriz Sonrası Yaptıkları Uygulamalara Yönelik Alan Araştırması
}

\section{Crisis Management of Organizations and the Field Research for the Applications Made Before, Meanwhile and After the Crisis}

\author{
Ph.D. Candidate Özgül Uyan (İstanbul Gelişim University, Turkey)
}

\begin{abstract}
Nowadays, the companies proceed to their business in more competitive and uncertain conditions due to the globalization. These conditions might be chances time to time or might be threats time to time and can cause to increase of possibility of crisis for the companies come face to face. Surviving in these circumstances depends on protecting from risks and taking advantages of the chances. To achieve that, the effective crisis management system has to be established. In this article, the importance and the procedures made by the business organizations before, meanwhile and after the crisis are aimed to find out. In this sense, the common and theoretical perspective are defined for the crisis and the management of the crisis, and, the search and data of 30 business organizations in Istanbul World Trade Center are presented. In the research, survey method was used to collect the data. Then the data were analyzed using SPSS statistical software and subjected to the frequency, ratio, correlation and alpha reliability tests. As a result of the study, it is observed that these companies usually implement the crisis management after the crisis started and the crisis management applications were not institutionalized in the organizations.
\end{abstract}

\section{Giriş}

Günümüz dünyasında her alanda görülen hızlı değişim ve artan belirsizlik, işletmeleri beklenmedik tehlike ve firsatlarla yüz yüze bırakabilmektedir. Diğer taraftan, globalleşmenin etkisiyle ülkeler arasında artan ekonomik entegrasyon ve yoğunlaşan rekabet, işletmelerin krizle karşılaşma risklerini oldukça artırmaktadır. Tehditleri bertaraf edebilmek veya olası firsatları değerlendirebilmek, işletmeler açısından, bu değişim ve belirsizlik durumlarına hazırlıklarıyla paralellik göstermektedir. Aksi halde, ticari, ekonomik, siyasi, sosyal, doğal kısacası her türlü çevre unsurunun dinamizmine ayak uyduramayan organizasyonlar için krizler kaçınılmaz olmaktadır.

Günümüzde kriz kavramı, adeta gündelik yaşamın parçası haline gelmiş ve tüm disiplinlerin önemsediği bir konu olmuştur. Genellikle ilk olarak finansal ve ekonomik nedenler akla gelse de, siyasi istikrarsıllıklar, sosyal olaylar, doğal afetler, kazalar, üretim ve yönetim sorunları, yolsuzluklar, kaynakların israfı, iç-dış borç yükü, riskli ülke sayılma ve hatta kurumsal gaflar dahi krize yol açabilmektedir. Bu sebeple kriz kavramı çok çeşitli şekillerde tanımlanmıştır (Erdoğan, 2010). Kriz kavramı, ister işletmeler için isterse insanlar için olsun, arzu edilmeyen koşulların cerayan ettiği, rutin faaliyetlerin yapılmasını engelleyen, kendine has koşulları olan ve her zaman karşılaşılmayan olağanüstü durumları ifade etmektedir (Titiz, 2003). Yapısı gereği krizler bir organizasyonun yaşam evresindeki tehlikeli anlar olup dönüm noktalarıdır, bununla beraber organizasyonu bazı yönlerden krizden önce olduğundan daha güçlü hale getirme potansiyeli ile de önemli firsatlardır. Örneğin Çin kültüründe krizler, özünde sosyal ve ekonomik hayatın negatif güçleri olarak değil, bilakis pozitif sonuçlara da yol açabilecek olan firsatlar olarak algılanmaktadır. Hatta Mandarin Çincesinde kriz kelimesi "tehlikeli firsat" olarak çevirebileceğimiz sembollerle ifade edilmektedir (Ulmer, vd, 2011).

Krizler istisna olmaktan çok uzak olgular olup aslında sadece gelişmekte olan ekonomilerde değil aynı zamanda gelişmiş sanayi ekonomilerinde de görülebilecek olan, her zaman bizimle olmuş ve olmayı sürdürecek olan normlardır. Yani krizler, geçmişte zannedildiği üzere, ABD gibi ekonomik güçleri değil de sadece az gelişmiş ve sorunlu ülkeleri sarsan durumlar değildir (Roubini ve Mihm, 2012). Çağlar boyunca dünyanın her yerinde pek çok kriz yaşanmış olup, küreselleşme olgusuyla birlikte özellikle 1980 ve sonrasında tüm dünya ülkelerini olduğu gibi Türkiye'yi de saran çok sayıda kriz görülmüştür. Türkiye son yirmi yılda, hem yurt içindeki problemlerden kaynaklanan, 1994 Nisan krizi, 1999 krizi, 2000 Kasım krizi ve 2001 Şubat krizi; hem de global olarak ortaya çıkan, 1991 Körfez krizi, 1997 Asya krizi, 1998 Rusya krizi, 2008 küresel ekonomik kriz (Soysal, vd, 2009), 2011 Avrupa Birliği borç krizi gibi önemli krizler atlatmıştır. Sözkonusu krizler, ülke ekonomisinde daralmaya yol açarak tüm piyasaları derinden etkilemiş bazı kesimlere de firsatlar sunmuştur.

İşletmeler yaşam süreleri boyunca az veya çok sayıda kriz ile karşı karşıya kalmaktadırlar (Murat ve Mısırlı, 2005) ve şüphesiz ki yaşanan bu krizler bütün işletmeleri negatif veya pozitif yönlü olarak etkilemektedir. Dolayısıyla bugünün iş dünyasındaki baş döndürücü gelişmelerle başa çıkabilmek ancak etkin ve kararlı bir kriz yönetimi modeli ile mümkün olacaktır. Buna rağmen araştırmalar göstermektedir ki, yöneticiler kriz yönetimi çalışmalarının gerekli olduğuna inandıkları halde işletmelerin çoğunun hala planlı ve sürekli bir kriz yönetimi çalışması bulunmamaktadır. Oysa ki organizasyonel yapı, model ve işleyişlerinde kriz yönetimi uygulamalarını 
kuran ve kurumsallaştıran örgütlerin krizleri aşabilmeleri kolaylaşacaktır. Böylece, işletmeler belirsizliklere karşı hazırlanabilecek, kriz durumunun olumsuzluklarını önleyebilecektir. Hatta kriz, işletmenin yaşamını riske sokan bir gerilim olmaktan çıkıp rekabet gücünü artıran bir firsata dönüşebilecektir (Soysal, vd, 2009). Gerek sosyal gerekse siyasi hayatta kriz konusuna iki türlü yaklaşanlara rastlanmaktadır; krizi yok sayanlar yahut krizi kabul eden fakat tedavi yerine sadece pansuman tedbirler öne sürenler. Oysa ki krizleri aşabilmek için bireysel, kurumsal ve toplumsal refleks yani her seviyede destek lazımdır (Bozgeyik, 2004). Aksi halde, rasyonel yanıtların verilemediği krizlerin hem kurum hem de ülke ekonomisi açısından yol açabileceği zararların boyutu büyük olabilecektir. Dolayısıyla günümüz işletmeleri için krize stratejik yaklaşmak kaçınılmaz bir hal almıştır.

$\mathrm{Bu}$ çalışmanın amacı, işletmelerin kriz yönetimine verdikleri önemi ve kriz öncesinde, kriz anında ve kriz sonrasında yaptıkları uygulamaları ortaya koymaktır. Bu bağlamda çalışmada ilk olarak kriz kavramı ele alınmıştır, ardından kriz yönetimine ilişkin teorik bilgiler sunulmuştur, daha sonra ise İstanbul Dünya Ticaret Merkezi’nde faaliyet gösteren 30 işletme üzerinde anket yöntemi ile gerçekleştirilen bir araştırmaya yer verilerek elde edilen araştırma bulguları yorumlanmıştır.

\section{Krizin Tanımı, Özellikleri, Kaynakları, Türleri, Așamaları ve Etkileri}

\subsection{Krizin Tanımı}

Kriz kelimesine ilk olarak askeri ve tıbbi alanda rastlanmakta olup 17'inci ve 18'inci yüzyıllarda sosyal bilimler alanında da kriz kavramının yaygınlaşmaya başladığı görülmektedir. 1929 büyük buhranıyla birlikte ise kriz kavramının ekonomi alanındaki kullanımının arttığı bilinmekte olup kavram günümüzde işletme yönetimi alanında da yoğun olarak anılmaktadır. Günümüzde kriz; psikoloji, davranış bilimleri hatta tıp gibi beşeri bilimlerin ve siyaset bilimi, ekonomi, işletme ekonomisi gibi sosyal bilimlerin kullandığı ortak bir kavramdır. Ne var ki literatürde, birçok disiplinin ortak konusu olan kriz kavramı hakkında bir tanım birliği bulunmamaktadır. Bu durumun, krizin belirsizlik niteliği içeren bir kavram olmasından kaynaklandığı söylenebilir.

Etimolojik olarak bakıldığında kriz kelimesinin Yunanca "karar", "ayrılmak" manasına gelen "krisis" kelimesinden geldiği görülmektedir (Khodarahmi, 2009). İngilizcede "crisis" olarak kullanılan kriz sözcüğü, Oxford Sözlüğ̈̈'nde, “yoğun zorluk veya tehlike anı” olarak tanımlanmaktadır (Oxford Dictionaries, 2016). Kriz kelimesi Türkçeye ise Fransızca "crise" kelimesinden uyarlanmıştır. Türk Dil Kurumu tarafından yayınlanan Güncel Türkçe Sözlük’te kriz kelimesi “bir ülkede veya ülkeler arasında, toplumun veya bir kuruluşun yaşamında görülen güç dönem, bunalım, buhran” olarak ifade edilmektedir (Güncel Türkçe Sözlük, 2016).

Kriz kavramı, enteresan bir şekilde, Çincede, "fırsat" ve "tehdit" anlamına gelen ve Wei-ji olarak söylenen iki sembolle anlatılmaktadır. Buradan da anlaşılacağı üzere kriz, yapısında pozitif ve negatif özellikler içermektedir. İlgili kişi ve kurumların kriz yönetimi konusundaki başarılarına bağlı olarak bu özelliklerden birisi öne geçecektir (Pira ve Sohodol, 2010). Antik yunan tarihçisi ve bir komutan olan Thukydides ve modern tıbbın babası olarak anılan Hippokrates de (Bonnard, 2013) kriz konusunu benzer bir bakışla ele alarak, krizi yaşam ile ölüm ve zafer ile yenilgi arasındaki kritik kararın alındığı hayati bir dönüm noktası şeklinde yorumlamışlardır (Örnek, 2007). Krizin Çincede fursat ve tehdit olarak belirtilen olumlu ve olumsuz iki yönü, bu tarihsel tanımda yaşam ve ölüm, zafer ve yenilgi ikilemleriyle karşımıza çıkmaktadır.

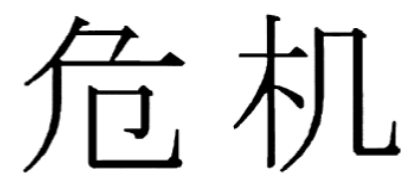

Şekil 1. Krizin Çince Sembolü Kaynak: Ulmer, vd, 2011.

Kriz kavramı, pek çok disiplin tarafından ele alınmaktadır. Örneğin, tıp bilimi krizi, kalp krizi gibi insanın yaşam merkezlerinden birinde yaşamı güçleştirecek veya tehdit edecek bir olayın ortaya çıkması hali; psikoloji bilimi krizi, bireyin sorunlarını çözme becerisini kaybetme hali; davranış bilimleri krizi, davranış bozukluğu veya toplumsal normlardan aşırı sapma hali; siyaset bilimi krizi, karar birimlerinin sorunları çözümleyemez duruma gelmesi hali; ekonomi bilimi krizi, ekonomik faaliyetlerin hızla ve uzun süreli olarak daralması hali olarak tanımlamaktadır (Birdal, 2011). Bütün bu farklı disiplinlerce yapılan tanımların kapsadığı ortak noktaya göre kriz, yaşamı zorlaştıracak hatta tehdit edecek nitelikteki hadiselerin ortaya çıkması ve dengeli yaşamı sağlayan sistemin, önüne çıkan bu sorunları alışılagelmiş yöntemlerle çözümleyemez hale gelmesidir.

İşletmeler açısından kriz; işletmenin faaliyetlerini engelleyici, bozucu ve hatta yıkıcı olaylar dizisidir (Gençtürk, 2002). Bir işletme için kriz, çalışanlarına, itibarına ve mali durumuna ani ve ağır zarar verme ihtimali olan herhangi bir olay olabilir (Luecke, 2008). Daha geniş bir anlatımla kriz, örgütün amaçlarını, temel değerlerini ve tüm kaynaklarını adeta tehdit altına almak suretiyle örgütün yaşamının devamını tehlikeye sokan, beraberinde getirdiği zaman baskısı ve belirsizlik sebebiyle örgüt üyelerinde stres ve paniğe yol açan, uygun tedbirlerin zamanında alınması halinde etkileri minimize edilebilecek veya ortadan kaldırılabilecek (Ataman, 2001) hatta firsata dönüştürülebilecek olan sıradışı olaylar dizisidir. 


\subsection{Krizin Özellikleri}

Günlük konuşmalarda gerek bireyler gerekse kurumlar tarafından kriz kelimesi oldukça gelişigüzel bir biçimde kullanılmaktadır. Oysa ki kriz, gündelik hayatta karşılaşılan rutin problemlerden çok daha farklıdır. Organizasyonlar için ele alınacak olursa, krizler örgütlerin tarihindeki benzersiz anlardır (Ulmer, vd, 2011). Ayrıca, kriz kavramı ilişkili görüldüğü stres, gerilim, endişe, felaket, panik gibi bazı terimler ile de karıştırılmaktadır. Bu sebeple genel olarak kriz tanımları krizin üç boyutunu vurgulayarak formüle edilmektedir. Bunlar; krizin örgütün yüksek öncelikli değerlerini tehdit etmesi, kısıtlı bir tepki süresi sunması, organizasyon için beklenmedik yani sürpriz bir durum olmasıdır (Hermann, 2008). Dolayısıyla krize ait özellikleri kısaca; "tehdit”, “zamansızlık" ve "sürpriz" şeklinde sıralamak mümkündür (Ulmer, vd, 2011). Krizler olağan gerilimlerden ayrılabilecek özellikler taşır. Mesela, krizler örgütün amaçlarını, kaynaklarını ve yaşamını dahi tehlikeye sokar; örgütteki standart karar alma, önleme ve uyum sistemini işlemez k1lar; kriz durumunda yönetim merkezileşir ve denetim artar; kriz ortamında oluşan stres altında ve sınırlı zamanda gelişigüzel kararlar verilir; krizler genellikle önceden sezilemeyen ani değişikliklerdir; kriz acil müdahale gerektiren ciddi bir hastalık gibidir; örgütte korku, gerilim, panik, endişe, belirsizlik, güven kaybı, motivasyonda düşme ve çatışmaya yol açar; krizler işgören, müşteri, devlet gibi örgüt ile ilgili 3’üncü şahısları fazlasıyla etkiler; krizin net bir çözümü bulunmadığından tekrarlayabilir; kriz örgüt için yaşamsal bir dönüm noktasıdır; tüm bunlara rağmen kriz mutlak bir felaket olmayıp firsata da dönüştürülebilir (Akıncı, 2010; Baltaş, 2002; Pira ve Sohodol, 2010).

\subsection{Kriz Kaynakları}

İşletmelerde krizin kaynakları çeşitlilik arz etme olup krize yol açan faktörleri genel olarak "İşletme dışı çevre faktörleri” ve "İşletme içi çevre faktörleri” olmak üzere iki grupta incelemek mümkündür (Milburn, vd, 1983).

İşletmelerde görülen krizin başlıca nedeni, işletmenin dış çevresi denen, yaşadığı ortamın değişmesi ve işletmenin bu değişime ayak uyduramamasıdır. İşletmelerin dış çevresi, işletmenin kontrolü dışındaki makro faktörlerdir (Doğan, 2010). Dış çevre; ekonomik, siyasi, yasal, sosyal, doğal, teknolojik ve uluslararası çevre gibi işletme faaliyetlerini dolaylı etkileyen unsurlarından oluşan "uzak dış çevre" ile müşteriler, rakipler ve rekabet koşulları, girdi piyasası, sektörün özellikleri gibi işletme faaliyetlerini doğrudan etkileyen unsurlardan oluşan “yakın dış çevre"den meydana gelmektedir (Birdal, 2011).

Araştırmalar, dış çevrenin durağan bir yapıda olmayıp devamlı değişmesinden ziyade, örgütün söz konusu değişime adapte olacak olanaklara sahip olmamasının yani iç çevre yetersizliklerinin krize yol açtığını ortaya koymaktadır (Asunakutlu, vd, 2003). İşletmenin iç çevresi, işletmenin kontrol sahasında kalan mikro faktörlerdir. İç çevre; örgütsel yapı, yöneticinin ve çalışanların niteliği, teknik donanım (Öztürk ve Türkmen, 2005), finansman imkanları, üretim ve satış potansiyeli gibi unsurlardan oluşmaktadır. Örgütün makro (dış) çevresindeki faktörler her ne kadar kontrol edilemese de dikkatlice yapılan çevre analizleri sayesinde bu faktörlerde oluşabilecek değişiklikler önceden isabetle tespit edilebilir (Dinçer, 1992). Mikro (örgütsel/iç) çevre faktörlerinde güçlü olan işletmeler, dış çevredeki bu değişime hızla adapte olarak krizi atlatabilirler.

\subsection{Kriz Türleri}

Krizler yukarıda bahsedilen örgüt içi ve örgüt dışı çevre faktörleri çerçevesinde farklı biçimlerde kategorize edilmektedir. Literatürde geniş ölçüde kabul gören çalışmalardan biri olan Mitroff'un sınıflandırması, yedi temel kriz nedenini ve bunlar çerçevesinde gelişen onlarca kriz türünü ortaya koymaktadır. Buna göre kriz sebepleri ve türleri: Ekonomik (grev, huzursuzluk, iş kıtlığı, hisse değerlerinde düşüşler, piyasalarda çöküşler, kazançlarda azalma), Bilgi ile İlgili (gizli bilgi ve tescil kaybı, yanlış bilgi, müşteri ve tedarikçilerle ilgili bilgilerin kaybı), Fiziksel Kayıplar (malzeme/teçhizat kayıp ve arızaları, patlama, kötü ürün tasarımı, düşük kalite kontrol), İnsan Kaynakları ile İlgili (önemli yöneticinin veya personelin kaybı, devamsızlıklarda artış, kazalarda artış, işyerinde şiddet, yolsuzluk), İtibarla İlgili (iftira, söylentiler, işletme itibarına verilen zararlar), Psikopatolojik Olaylar (ürün tahribi, adam kaçırma, rehin alma, terör) ve Doğal Afetler (deprem, yangın, sel, kasırga, toprak kayması) şeklinde kategorilere ayrılmaktadır (Mitroff ve Anagnos, 2000). Yöneticilerin krizi yönetmek için öncelikle krizin türünü bilmeleri gerekir, zira kriz türüne göre uygulanacak yöntemler farklılık arz etmektedir.

\subsection{Kriz Süreci ve Așamaları}

Kriz aniden ortaya çıkarak işletmenin varlığını tehdit eden bir gelişme olarak algılanmaktadır. Ne var ki işletmeler, yaşamlarını tehdit eden kriz ortamına bir anda girmemektedirler. Bu olumsuz gelişme bir süreç içinde ve artan performans kaybı sonucu oluşmaktadır. Nitekim, bu süreç adeta kanser gibi ölümcül bir hastalığın gelişme sürecine benzetilmektedir. Nasıl ki insanlar düzenli sağlık kontrolleri ile hastalığı erken teşhisle tedavi ettirebilirlerse, işletmeler de kriz sinyallerini önceden alarak krizi en az zararla atlatabilirler (Birdal, 2011). Bu durum firtınaya yakalanan denizcilerin firtınayı yok edemeseler bile kendilerini ve gemilerini firtınaya karşı hazırlayıp koruyabilmelerine de benzetilmektedir (Keown-McMullan, 1997). Kısacası, bütün krizler, beklenmedik bir anda ve önlenemez şekilde ortaya çıkmaz, aksine evvelinden defalarca ikaz eder. Kriz sürecini oluşturan aşamalardan her birinin kendine özgü birtakım belirtileri bulunmaktadır. Bu belirtileri zamanında saptayabilen işletmelerin krizlerle kısa sürede başa çıkabilme şansları yükselmektedir. Kriz Sürecini her biri alt aşamalardan oluşan "kriz öncesi dönem (körlük aşaması, eylemsizlik aşaması ve yanlış eylem aşaması), "kriz dönemi (kriz aşamas1)", "kriz sonrası dönem (sona erme aşaması)" olarak üç boyutta ele almak mümkündür. 
Örgütün dış çevresindeki değişimleri önceden sezerek tedbir alamadığı, örgütsel yetersizlikler, performans düşüklüğü gibi krize işaret eden bazı ipuçlarının geliştiği aşama krizin "körlük aşaması"dır (Kaya, 2009). Satışlarda azalma, stoklarda artı̧ vb şeklinde kendini gösteren bu performans kaybını yöneticilerin geçici görerek gözardı etmesi ise krizin "eylemsizlik aşaması" olarak adlandırılır (Avgan, 2010). Zaman içinde performans düşüşü işletmenin yaşamını tehdit eden bir boyuta ulaşır ve yöneticiler bu sorunun çözümü için, işten çıkarma, harcamaları kısma gibi panik halinde yüzeysel önlemler alırlar ki bu krizin "yanlış eylem aşaması" olarak bilinir (Birdal, 2011). Dolayısıyla asıl sorunun teşhisine ve çözümüne gidilmediğinden işletme "kriz aşaması" adı verilen safhaya gelir ve örgüt iklimi bozulur, işletme yöneticileri günü kurtarmaya çalışırlar, yeni planlar yapılmaz (Tağraf ve Arslan, 2003). Daha sonra ise, örgütün içine düştüğü krize cevap verebilmek için son şansı olan (Avgan, 2010) "Sona Erme Aşaması"na gelinir. Bu aşama bazı örgütler için iyileşmenin başlangıcı, bazıları içinse tamamen bitiş anlamına gelmektedir (Kash ve Darling, 1998). Eğer yöneticiler krizin safhalarında doğru çözüm ve stratejileri uygulayabilirlerse işletme krizi atlatabilir hatta avantaja çevirebilir. Ancak krize zamanında ve uygun yanıtlar verilmezse işletme içindeki kaos ve işletmenin çevresiyle yaşadığı çatışma çözümlenemez bir hal alır ve zaman içinde işletmenin çöküşü kaçınılmaz olur (Kaya, 2009).

\subsection{Krizlerin İşletmeler Üzerindeki Olumlu ve Olumsuz Etkileri}

Krizler, zamanı ve sebepleri belirli olmayan karmaşık durumlar olup işletmeler ve çıar gruplarını derinden etkilemektedir. Bu etkiler çoğunlukla işletmeleri zarara uğratan olumsuz durumlar olarak bilinse de krizlerin kimi zaman işletmelere yarar sağladığı da görülmektedir (Roux-Dufort ve Metais, 1999).

Yaşanan krizler örgütlerde, yetkilerin merkezde toplanmasi; acele, riskli ve kalitesiz kararların alınması; örgüt içi iletişimin ve departmanlar arası koordinasyonun bozulması; örgüt ikliminin bozulması, yönetici ve çalışanlarda psikolojik ve fizyolojik çözüntü; müşteri memnuniyetinin azalması; işletmenin itibar ve imajının zedelenmesi; işten ayrılmalar; üretimde aksamalar; pazar kaybı ve satışlarda düşüş; borçların ödenememesi ve alacakların tahsil edilememesi; yatırımların durdurulması ve nihayetinde işletmenin kapanmasına varan olumsuz sonuçlara yol açabilmektedir (Akıncı, 2010; Avgan, 2010; Okumuş, 2003; Özdevecioğlu, 2002).

Diğer yandan krizler ve firsatlar daima kol kola dolaşmaktadır. Krizlere hazırlıklı olmak krizi önlemese de usta manevralarla örgüt için olumlu sonuçlar verebilmektedir (Kadıbeşegil, 2001). Krizler başarıyla yönetildiğinde, işletmenin güçlü ve zayıf taraflarını görerek fiziki, mali, beşeri, kültürel, stratejik ve teknolojik anlamda kendini yenilemesine imkan sağlar; yeni ürünler üretme ve yeni pazarlara açılma olanağı verir, çalışanların yeni yetenek ve özgün fikirlerinin ortaya çıkmasını sağlar; eğitim etkinliklerinin ve ekip çalışmasının artmasını sağlar; en önemlisi de krizler öğrenme ve krizden ders çıkarma firsatı sunarak, hataların tekrarlanmamasını ve olası krizlere karşı tedbirli olmayı sağlar (Akıncı, 2010; Avgan, 2010; Aydemir ve Demirci, 2005; Okumuş, 2003)

\section{Kriz Yönetiminin Tanımı, Özellikleri ve Aşamaları}

\subsection{Kriz Yönetiminin Tanımı}

Günümüzün yöneticileri, örgütün ne zaman ve hangi türdeki krizlerle baş başa kalabileceğini evvelinden sezmek ve söz konusu krizleri zarar görmeden nasıl aşabileceklerini bilmek mecburiyetindedirler. Kriz dönemlerinde krize karşı etkin önlemler almak, mevcut tehlike ve tehditlerden en az zararla çıkmak ve kriz ortamındaki gelişmeleri firsata çevirmek ise ancak etkin bir "kriz yönetimi" ile mümkün olabilecektir.

Kriz yönetimi örgütün, insan sağlı̆̆ına veya güvenliğine yönelik tehdit, işletmenin maddi-mali varlığında veya kamusal imajında azalma gibi istenmeyen ve beklenmeyen durumlarla hızlı ve etkili bir şekilde mücadele etme kabiliyetini ifade eder (Pheng, vd, 1999). Kriz yönetimi, muhtemel bir krize karşı savunma ve önleme mekanizmalarının yerleştirilmesi ile oluşmuş bir krizin yok edilmesini ve krizin işletmede yol açabileceği negatif etkileri en aza indirgemeye yönelik bir dizi faaliyetleri kapsayan bir süreçtir (Sucu, 2000). Başka bir ifadeyle ise, kriz işletmedeki faaliyetlerin akışında meydana gelen sıradışı gelişmeler, kriz yönetimi ise bu sıradışı durumlara karşı gösterilen davranış biçimleridir (Gültekin ve Aba, 2011).

\subsection{Kriz Yönetiminin Özellikleri}

Kriz yönetimi, birden fazla evreden oluşan, kriz dönemi dışındaki normal zamanları da kapsayan, klasik yöneticilik anlayışından farklı bir bakış açısını gerektiren, kendine özgü birtakım özellikler gösteren, sürekli ve karmaşık bir süreçtir (Mitroff ve Pearson, 1993). Genel olarak kriz yönetimi, örgütün varlığını tehdit eden olaylarla ilgilidir; birçok safhadan oluşan komplike bir süreçtir; örgütün krizlere karşı her daim hazır olmasını sağlar; stratejik yönetim ve risk yönetimi ile benzerlik gösterir; ortaya çıan krizin türüne ve işletmenin özelliklerine göre farklı uygulama planlarını içerir; krizlerin yol açacağı zararı sınırlar; örgüte bir takım ek maliyetler yükler (Özden, 2009).

\subsection{Kriz Yönetimi Süreci ve Aşamaları}

Krizler aslında şekillendirilebilir, dinamik, kontrol edilebilir ve uygun stratejilerle yönetilebilir süreçlerdir. Kriz yönetimi sürecine, proaktif, reaktif ve interaktif olmak üzere 3 temel stratejiyle yaklaşılmaktadır. Proaktif kriz yönetimi modeli krizlerin henüz oluşmadan evvel öngörü ve hazırlıkla engellenebileceğini gösterir; reaktif kriz yönetimi modeli krizler ortaya çıktıktan sonra yapılacak faaliyetlere odaklanır; interaktif kriz yönetimi modeli ise 
öğrenme, kriz yokken ya da bir kriz deneyiminden sonra planların ve hazırlıkların devamlı gözden geçirilmesini içeren, krizin tüm safhalarını entegre eden bir modeldir (Seeger, vd, 2003; Pauchant ve Mitroff, 1992). Krizin türüne bakılmaksızın, işletmelerde uygulanacak etkili bir kriz yönetimi tüm krizlerin geçirdiği beş farklı aşamanın yönetimini kapsamaktadır. Buna göre, kriz yönetimi süreci her biri alt aşamalardan oluşan, "kriz öncesi işletme yönetimi (kriz sinyallerinin alınması aşaması, krize hazırlık ve önleme aşaması)", "kriz anı işletme yönetimi (krizin denetim altına alınması aşaması)", "kriz sonrası işletme yönetimi (iyileşme ve normal duruma dönüş aşaması, öğrenme ve değerlendirme aşaması)" olmak üzere üç boyutta incelenebilmektedir.

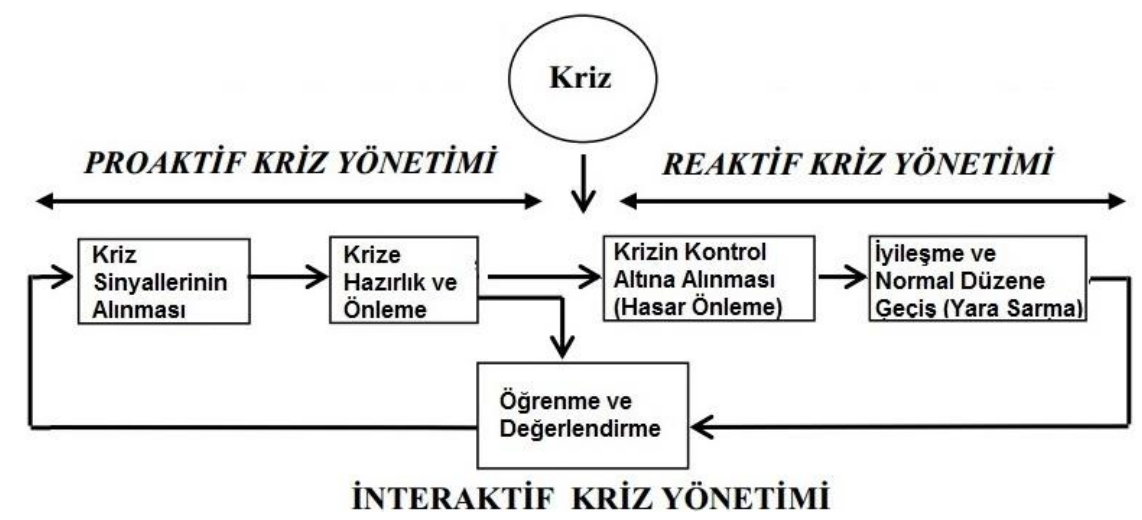

Şekil 2. Kriz Yönetimi Süreci Kaynak: Tă̆raf ve Arslan,2003.

Kriz Öncesi İşletme Yönetimi: "kriz sinyallerinin alınması” aşamasında, firmada krize ilişkin sinyalleri yakalayacak sistemler kurulmalıdır. Ardından "krize hazırlık ve önleme" safhasına geçilir ve sinyalizasyon sistemleri sayesinde sezilen belirtilere göre olası krizi önleme ve korumaya yönelik tedbirler üst yönetime sunulur (Birdal, 2011). Kriz öncesinde yapılabilecek kriz yönetim çalışmalarından bazıları şunlardır; kriz yönetim planının hazırlanması, kriz yönetim ekibinin belirlenmesi, erken uyarı sistemlerinin kurulması, kriz senaryolarının hazırlanması, sürekli iç ve dış çevre analizinin yapılması, bilginin etkin kullanılması, kriz öncesi eğitim ve motivasyon verilmesi, krize hazır bir örgüt yapısının oluşturulması (Akıncı, 2010; Tüz, 2004).

Kriz Anı İşletme Yönetimi: "krizin denetim altına alınması" safhasında, tepe yönetim krizi çözmek için sunulan önlemlerden uygun olanları seçerek ilgili birimlere bu önlemlerin yerine getirilmesi için talimat verir ve faaliyetlerin dosdoğru yürütülmesini izler(Birdal, 2011). Kriz anında yapılabilecek başlıca kriz yönetim çalışmaları şunlardır; krizin boyutlarının belirlenmesi, karar alma yöntemlerinden yararlanılması, kriz dönemi finansal yönetim politikasının geliştirilmesi, kriz dönemi personel politikasının geliştirilmesi, kriz döneminde yürütmenin sağlanması, etkileşimli halkla ilişkiler ve iletişim politikasının oluşturulması (Akıncı, 2010; Tüz, 2004).

Kriz Sonrası İşletme Yönetimi: “iyileşme ve normal duruma dönüş” aşamasında, kriz döneminin olağanüstü koşullarına göre oluşturulmuş olan örgüt yapısı normal çalışma düzenine döndürülür. Kriz yönetiminin son safhası olan "öğrenme ve değerlendirme" aşamasında ise yaşanan krizde alınan karar ve önlemler incelenerek gelecekte oluşabilecek krizlere hazırlık yapılır (Birdal, 2011). Kriz sonrasında yapılabilecek başlıca kriz yönetim çalışmaları şunlardır; kriz sonrası durum analizinin yapılması, yeniden yapılanma çalışmaları ve kriz sonrası rehabilitasyon çalışmaları (Akıncı, 2010; Tüz, 2004).

\section{4 İşletmelerin Kriz Öncesi, Kriz Anı ve Kriz Sonrası Yaptıkları Uygulamalara Yönelik Alan Araştırması}

\subsection{Araştırmanın Amacı ve Önemi}

Günümüzde yaşanan hızlı değişim ve küreselleşmenin etkisiyle ortaya çıkan acımasız rekabet, işletmelerin krizle karşılaşma risklerini artırmaktadır. Buradan hareketle bu araştırmada, işletmelerin kriz yönetimine verdikleri önem ile kriz öncesinde, kriz anında ve kriz sonrasında yaptıkları uygulamaların tespiti amaçlanmıştır. Araştırmada, İstanbul Yeşilköy'de bulunan İstanbul Dünya Ticaret Merkezi'nde (IDTM) faaliyet göstermekte olan işletmeler incelenmiştir. Araştırma, kriz yönetiminin kurumsallaştırılmasına dair işletmelerin ne türlü ve hangi düzeyde çalışmalar sarf etmekte olduklarının görülmesi açısından mühimdir. İDTM İş bloklarında uluslararası çalışan pek çok kurum da yer aldığından özellikle küresel krizlerden etkilenme olasılıkları yüksek olan bu firmaların kriz yönetimine bakışlarının ortaya konması da yararlı olacaktır.

\subsection{Araștırmanın Yöntemi}

Hipotezler;

Araştırmada İDTM iş bloklarında faaliyette bulunan işletmelerin kriz öncesinde, kriz anında ve kriz sonrasında yaptıkları kriz yönetimi çalışmaları incelenmiştir. Araştırmanın amacı doğrultusunda geliştirilen aşağıdaki hipotezler "kabul" veya "red" şeklinde test edilecek olan karşıt (alternatif) hipotezlerden ibarettir.

H1: İşletmeler kriz öncesinde kriz yönetimi çalışması yapmaktadırlar. 
H2: İşletmeler kriz anında kriz yönetimi çalışması yapmaktadırlar.

H3: İşletmeler kriz sonrasında kriz yönetimi çalışması yapmaktadırlar.

H4: Sürekli iç ve dış çevre analizi yapma ile krizin boyutlarının belirlenmesi (krizin tanımlanması) arasında ilişki vardır.

Kapsam;

Araştırma kapsamına alınan IDTM İş Bloklarında faaliyet gösteren işletmelerden, uluslararası faaliyet gösteren 75 işletme araşııımanın ana kütlesini (evren) oluşturmaktadır. Araştırmanın evrenini meydana getiren bu 75 işletme arasından ise kasti örnekleme yöntemini kullanarak, araştırmacının anketi amacı doğrultusunda cevaplayabileceğini tahmin ettiği, 30 işletmelik örneklem grubu oluşturulmuştur. Bu işletmelerin sahipleri ya da orta veya üst düzey yöneticileri üzerinde anket çalışması yapılmış olup örneklemin tamamı anketi doldurmuştur.

Sinırlıliklar;

Çalışmada elde edilen bulgular, anket tekniği sonucu elde edilen bulgularla sınırlıdır. Ayrıca anketteki soruların cevaplayan yöneticiler tarafindan doğru anlaşılıp doğru yanıtlandığı farzedilmiştir. Araştırma, IDTM İş Blokları sınırları içerisinde faaliyet gösteren işletmeler ile sınırlandırılmıştır. Araşıırmanın bir diğer kısıtı, anketi dolduracak kişilerin sadece işletmelerin sahipleri veya orta/üst kademe yöneticilerinden oluşmasıdır. Bunun nedeni ise, kriz yönetimi uygulamalarının genellikle bu kadrolar tarafından icra edilmesidir.

Veri Toplama Yöntemi ve Aracı;

Araştırmada anket yöntemi uygulanmıştır. Kullanılan anket sorularının hazırlanmasında daha önce bu konuda çalışmış olan araştırmacıların kaynaklarından yararlanılmıştır. Verilerin toplanması; anket formlarının bizzat araştırmacı tarafindan örneklem olarak belirlenen şirketlere elden teslim edilmesi ve 1 hafta içerisinde geri toplanması yöntemiyle gerçekleştirilmiştir. Veri toplama aracı üç bölümden ve toplam 26 sorudan oluşmaktadır. Birinci bölümde, "işletme hakkında genel bilgileri"i tespit etmek amacıyla hazırlanan 4 adet soru; ikinci bölümde, işletmelerde daha evvel yaşanan "kriz durumu"na ilişkin bilgileri edinebilmek için hazırlanan 2 tane soru; üçüncü bölümde, "kriz yönetimi çalışmaları"nı (kriz öncesinde, kriz anında ve kriz sonrasında işletme yönetimi) tespite yönelik 20 tane soru bulunmaktadır. İşletmelerde Kriz Yönetimine ilişkin düzenlenen anketin sorularında beşli likert tipi ölçek kullanılmış olup cevaplandıranlardan "kesinlikle uygulanmamaktadır", "uygulanmamaktadır", "bazen uygulanmaktadır", "uygulanmaktadır", "kesinlikle uygulanmaktadır" seçeneklerinden işletmeleri için uygun olanı seçmeleri talep edilmiştir. Araştırmada 5'li likert ölçüm düzeyinde sorulan sorular, denek sayısının azlığından dolayı anlamlı sonuçlar elde edilebilmesi açısından SPSS 16 Programı kullanılarak 3'lü likert ölçüm düzeyine indirilmiştir (uygulanmamaktadır, bazen uygulanmaktadır, uygulanmaktadır). Yöneticilerin ankete verdikleri cevapların tutarlılı̆ıını ölçmek maksadıyla yapılan güvenilirlik analizi kapsamında, "kriz yönetimi çalışmaları"na ilişkin tüm sorular için Cronbach Alpha $(\alpha)$ değeri 0,93 olarak hesaplanmıştır. Elde edilen bu $\alpha$ değeri, anketin toplam güvenilirliğini göstermekte olup literatürde beklenen $0.7^{\prime}$ den büyük olduğundan bilimsel bir araştırma için oldukça kabul edilebilir bir değerdir.

\begin{tabular}{|l|l|}
\hline Reliability Statistics \\
\hline Cronbach's Alpha & N of Items \\
\hline, 930 & 20 \\
\hline
\end{tabular}

Tablo 1. Cronbach's Alpha Güvenilirlik Testi

Verilerin Analizi ve Yorumu;

Verilerin analizi, SPSS 16 istatistiksel paket programı kullanılarak yapılmıştır. Bulguların yorumunda frekans ve yüzdelerin yanı sıra korelasyon analizinden faydalanılmıştır.

\subsection{Araştırmanın Bulguları ve Yorumları}

İşletme Hakkında Genel Bilgiler;

Araştırmaya katılan kişilerin yönetim kademesi ile ilgili bulgular incelendiğinde; \%56,7'sinin işletme sahibi, $\% 23,3$ 'ünün üst düzey yönetici, $\% 20$ 'sinin ise orta düzey yönetici olduğu görülmektedir. İşletmelerin faaliyet gösterdiği sektör ile ilgili bulgulara göre; \%43,3'ü hizmet, \%40’1 ticaret, \%16,7'si ise sanayi sektöründe faaliyet göstermektedir. İşletmenin faaliyet süresi ile ilgili sonuçlara göre; \%63,3’ü 10 yıldan az, \%26,7'si 10-19 yıl arası, $\% 10$ 'u ise 20 yıldan daha fazla süredir faaliyet göstermektedir. İşletmelerin personel sayısı ile ilgili bulgulara bakıldığında ise $\% 53,3$ 'ünde 20 ve daha fazla sayıda, \%43,3'ünde 10-19 arası, \%3,3'ünde ise 10'dan az sayıda personel çalıştığı anlaşılmaktadır.

\section{Kriz Durumu;}

İşletmede son 15 yıl içinde bir kriz dönemi yaşanıp yaşanmadığı incelendiğinde, işletmelerin tamamında kriz deneyiminin yaşanmış olduğu tespit edilmiştir. Bununla birlikte krizin işletmeyi nasıl etkilediği sorusuna verilen yanıtlar ise işletmelerin \%63,3'ünün krizden olumsuz etkilendiğini, \%33,3'ünün krizden etkilenmediğini, \%3,3’ünün ise krizden olumlu etkilendiğini ortaya koymaktadır. 
Kriz Öncesi İşletme Yönetimi;

Aşağıdaki tabloda araştırma kapsamındaki işletmelerin kriz öncesinde yaptıkları kriz yönetimi çalışmalarına ilişkin elde edilen bulgular gösterilmiştir. Tabloya göre firmaların \%76,7'si olası bir kriz durumu için kriz yönetim planı hazırlamamaktadır, \%66,7'si olası bir kriz durumu için kriz yönetim ekibi oluşturmamaktadır, \%76,7'si olası krize karşı erken uyarı sistemlerinden yararlanmamaktadır, \%73,3'ü sürekli iç-dış çevre analizi yapmamaktadır, \%43,3'ü bilgi yönetimi çalışmaları yapmaktadır, \%70'i krize hazırlık şeklinde özel eğitimler vermemektedir, $\% 56,7$ 'si krize hazır esnek örgüt yapısı oluşturmamaktadır. Bulgular topluca değerlendirildiğinde, firmaların 7 adet kriz öncesi çalışmadan sadece 1'ini (bilgi yönetimi) daha çok uyguladıkları görülmektedir. Buna göre araştırmaya dahil olan firmalarda kriz öncesinde kriz yönetimi çalışmalarının yapılmadığı ifade edilebilir. Böylece "İşletmeler kriz öncesinde kriz yönetimi çalışması yapmaktadırlar” şeklinde ifade edilen H1 hipotezi red edilerek, Ho hipotezi kabul edilecektir.

\begin{tabular}{|c|c|c|c|c|c|c|c|c|}
\hline \multirow{2}{*}{ Kriz Öncesi İşletme Yönetimi } & \multicolumn{2}{|c|}{ Uygulanmamaktadır } & \multicolumn{2}{|c|}{ Bazen Uygulanmaktadır } & \multicolumn{2}{|c|}{ Uygulanmaktadır } & \multicolumn{2}{|c|}{ TOPLAM } \\
\hline & Fre & $\%$ & Fre & & Fre & & & $\%$ \\
\hline $\begin{array}{l}\text { Olası bir kriz durumu için Kriz Yönetim Planının } \\
\text { hazırlanmas1 }\end{array}$ & 23 & 76,7 & 3 & 10 & 4 & 13,3 & 30 & 100 \\
\hline $\begin{array}{l}\text { Kriz olduğunda hemen göreve başlayacak özel bir Kriz } \\
\text { Yönetim Ekibinin oluşturulması }\end{array}$ & 20 & 66,7 & 7 & 23,3 & 3 & 10 & 30 & 100 \\
\hline $\begin{array}{l}\text { İşletmenizde krize karşı Erken Uyarı Sistemlerinden } \\
\text { yararlanılmas1 }\end{array}$ & 23 & 76,7 & 3 & 10 & 4 & 13,3 & 30 & 100 \\
\hline $\begin{array}{l}\text { İşletmenizde sürekli İç ve Dış Çevre Analizlerinin } \\
\text { yapılması }\end{array}$ & 22 & 73,3 & 4 & 13,3 & 4 & 13,3 & 30 & 100 \\
\hline İşletmenizde Bilgi Yönetimi çalışmalarının yapılması & 7 & 23,3 & 10 & 33,3 & 13 & 43,3 & 30 & 100 \\
\hline $\begin{array}{l}\text { İşletmenizde Krize Hazrllk şeklinde özel Eğitimlerin } \\
\text { verilmesi }\end{array}$ & 21 & 70 & 8 & 26,7 & 1 & 3,3 & 30 & 100 \\
\hline $\begin{array}{l}\text { İşletmenizde krize hazır Esnek bir Örgüt Yapısının } \\
\text { oluşturulması }\end{array}$ & 17 & 56,7 & 7 & 23,3 & 6 & 20 & 30 & 100 \\
\hline
\end{tabular}

Tablo 2. Kriz Öncesinde Yapılan Kriz Yönetimi Çalışmaları

Kriz Anı İşletme Yönetimi;

Aşağıdaki tabloda araştırma kapsamındaki işletmelerin kriz anında gerçekleştirdikleri kriz yönetimi çalışmalarına ilişkin bulgular verilmiştir. Tabloya göre firmaların \%63,3’ü kriz anında krizin boyutlarını belirlememektedir, \%66,7'si kriz anında karar alma yöntemlerinden yararlanmamaktadır, \%50'si kriz anında merkezi bir yapılanmaya gitmektedir, \%76,7'si olası kriz anında kriz odası ve acil bilgi merkezi kurmamaktadır, \%46,7'si kriz döneminde halkla ilişkiler çalışmaları yapmamaktadır, \%66,7'si krizden çıkış için personelini işten çıkarmaktadır, \%63,3'ü kriz anında personelin motivasyonunu yüksek tutmaya çabalamamaktadır, \%70'i krizden çıkış için harcamaları kısmaktadır, \%70'i krizden çıkış için varlıkları azaltmaktadır, \%43.3'ü krizden çıkış için bazen ürün ve pazar değiştirmektedir. Bulgular topluca ele alındığında, firmaların totalde 10 adet kriz anındaki yönetim çalışmasından 5'ini daha fazla kullanmış oldukları söylenebilir. Bunlar; merkezi bir yapılanmaya gidilmesi, personelin işten çıkarılması, harcamaların kısılması, varlıkların azaltılması, ürün ve pazar değiştirilmesi çalışmalarıdır. Buna göre ankete dahil edilen firmalarda kriz anı kriz yönetim çalışmalarının yapıldığı söylenebilir. Böylece “İşletmeler kriz anında kriz yönetimi çalışması yapmaktadırlar” biçiminde ifade edilen H2 hipotezi kabul edilecektir.

\begin{tabular}{|c|c|c|c|c|c|c|c|c|}
\hline \multirow[t]{2}{*}{ Kriz Anı İşletme Yönetimi } & \multicolumn{2}{|c|}{ Uygulanmamaktadır } & \multicolumn{2}{|c|}{ Bazen Uygulanmaktadır } & \multicolumn{2}{|c|}{ Uygulanmaktadır } & \multicolumn{2}{|c|}{ TOPLAM } \\
\hline & Fre & $\%$ & Fre & & Fre & & Fre & $\%$ \\
\hline $\begin{array}{l}\text { Kriz anında Krizin Boyutlarının Belirlenmesi (Krizin } \\
\text { Tanımlanmas1) }\end{array}$ & 19 & 63,3 & 10 & 33,3 & 1 & 3,3 & 30 & 100 \\
\hline Kriz anında, Karar Alma Yöntemlerinden yararlanılması & 20 & 66,7 & 9 & 30 & 1 & 3,3 & 30 & 100 \\
\hline $\begin{array}{l}\text { Kriz anında yönetimde Merkezi bir Yapılanmaya gidilmesi } \\
\text { (Yetkilerin üst yönetimde yoğunlaştırılması) }\end{array}$ & 3 & 10 & 12 & 40 & 15 & 50 & 30 & 100 \\
\hline Kriz anında Kriz Odası ve Acil Bilgi Merkezi kurulması & 23 & 76,7 & 6 & 20 & 1 & 3,3 & 30 & 100 \\
\hline Kriz döneminde Halkla İliş kiler çalışmalarının yapılması & 14 & 46,7 & 10 & 33,3 & 6 & 20 & 30 & 100 \\
\hline Krizden çıkış için personelinizin İşten Çıkarılması & 3 & 10 & 7 & 23,3 & 20 & 66,7 & 30 & 100 \\
\hline $\begin{array}{l}\text { Kriz anında Pers onelinizin Moralini Yüksek Düzeyde } \\
\text { Tutma yönünde çaba gösterilmesi (Motivasyon) }\end{array}$ & 19 & 63,3 & 6 & 20 & 5 & 16,7 & 30 & 100 \\
\hline Krizden çıkış için Harcamaların Kısılması & 0 & 0 & 9 & 30 & 21 & 70 & 30 & 100 \\
\hline Krizden çıkış için işletmenizdeki Varlıkların Azaltılması & 0 & 0 & 9 & 30 & 21 & 70 & 30 & 100 \\
\hline Krizden çıkış için Ürün ve Pazarın Değiştirilmesi & 7 & 23,3 & 13 & 43,3 & 10 & 33,3 & 30 & 100 \\
\hline
\end{tabular}

Tablo 3. Kriz Anında Yapılan Kriz Yönetimi Çalışmaları

Kriz Sonrası İşletme Yönetimi;

Aşağıdaki tabloda araştırma kapsamındaki işletmelerin kriz sonrası kriz yönetim çalışmaları ile ilgili bulguları sunulmuştur. Tabloya göre işletmelerin \%46,7'si kriz sonrası bazen durum analizi yapmaktadır, \%43,3'ü kriz sonrası yeniden yapılanmaya gitmemektedir ve \%60’1 kriz sonrası rehabilitasyon çalışmaları yapmamaktadır. 
Bulgular topluca incelendiğinde işletmelerin toplam 3 adet kriz sonrası yönetim çalışmasından yalnızca 1 'ini (durum analizinin yapılması) daha fazla uyguladıkları görülmektedir. Neticede araştırma kapsamındaki firmalarda kriz sonrası kriz yönetim çalışmalarının yapılmadığı söylenebilir. Böylelikle "İşletmeler kriz sonrasında kriz yönetimi çalışması yapmaktadırlar” şeklinde ifade edilen H3 hipotezi red edilerek, Ho hipotezi kabul edilecektir.

\begin{tabular}{|c|c|c|c|c|c|c|c|c|}
\hline \multirow[t]{2}{*}{ Kriz Sonrası İşletme Yönetimi } & \multicolumn{2}{|c|}{ Uygulanmamaktadır } & \multicolumn{2}{|c|}{ Bazen Uygulanmaktadır } & \multicolumn{2}{|c|}{ Uygulanmaktadır } & \multicolumn{2}{|c|}{ TOPLAM } \\
\hline & Fre & $\%$ & Fre & $\%$ & Fre & $\%$ & Fre & $\%$ \\
\hline Kriz sonrası iş letmenizin Durum Analizinin yapılması & 8 & 26,7 & 14 & 46,7 & 8 & 26,7 & 30 & 100 \\
\hline Kriz sonrası işletmenizde Yeniden Yapılanmaya gidilmesi & 13 & 43,3 & 11 & 36,7 & 6 & 20 & 30 & 100 \\
\hline Kriz sonrası Rehabilitasyon Çalışmalarının yapılması & 18 & 60 & 7 & 23,3 & 5 & 16,7 & 30 & 100 \\
\hline
\end{tabular}

Tablo 4. Kriz Sonrasında Yapılan Kriz Yönetimi Çalışmaları

Son olarak ise, sürekli iç ve dış çevre analizi yapma ile krizin boyutlarının belirlenmesi olarak belirtilen 2 değişken arasındaki ilişkiyi yön ve derece olarak saptamak maksadıyla yapılan korelasyon analizi kapsamında 0.01 anlamlılık seviyesinde korelasyon katsayısı 0.693 olarak hesaplanmıştır. Elde edilen korelasyon katsayısının pozitif olması ve 0,50-0,69 arasında bir değer olması literatürdeki genel kabule göre değişkenler arasında doğru yönlü ve orta düzeyde bir ilişkinin bulunduğu şeklinde yorumlanabilir. Neticede "sürekli iç ve diş çevre analizi yapma ile krizin boyutlarının belirlenmesi (krizin tanımlanması) arasında ilişki vardır” biçiminde ifade edilen H4 hipotezi kabul edilmiş olacaktır.

\begin{tabular}{|c|c|c|c|}
\hline \multicolumn{4}{|l|}{ Correlations } \\
\hline & & $\begin{array}{c}\text { İşletmenizde sürekli İç ve } \\
\text { Dış Çevre Analizlerinin } \\
\text { yapılması }\end{array}$ & $\begin{array}{l}\text { Kriz anında Krizin } \\
\text { Boyutlarının } \\
\text { Belirlenmesi (Krizin } \\
\text { Tanımlanması) }\end{array}$ \\
\hline \multirow{3}{*}{$\begin{array}{l}\text { İşletmenizde sürekli İç ve Dış } \\
\text { Çevre Analizlerinin yapılması }\end{array}$} & Pearson Correlation & 1 &, $693 * *$ \\
\hline & Sig. (2-tailed) & &, 000 \\
\hline & $\mathrm{N}$ & 30 & 30 \\
\hline \multirow{3}{*}{$\begin{array}{l}\text { Kriz anında Krizin Boyutlarının } \\
\text { Belirlenmesi (Krizin Tanımlanması) }\end{array}$} & Pearson Correlation &, $693 * *$ & 1 \\
\hline & Sig. (2-tailed) & ,000 & \\
\hline & $\mathrm{N}$ & 30 & 30 \\
\hline
\end{tabular}

Tablo 5. Korelasyon Analizi

\section{Sonuç ve Değerlendirme}

Küreselleşme olgusu ile birlikte, giderek ağırlaşan rekabet şartları, artan belirsizlik ve risk ortamı ve her alanda yaşanan hızlı değişim, işletmeleri sık sık krizlerle karşılaştırabilmektedir. Zamanında doğru hamlelerle yönetilemeyen krizler örgütlerin, ciddi hasara uğramalarına, faaliyetlerini durdurmalarına hatta yaşamlarının son bulmasına yol açabilmektedir. Ülkeler açısından sürdürebilir bir sosyal ve ekonomik kalkınmanın sağlanması ise olumsuz koşullarda ayakta kalabilen ve rekabet gücüne sahip işletmelerle mümkündür. Türkiye'deki işletmeler de gerek ülke içi gerek bölgesel gerekse küresel pek çok krizden etkilenmişlerdir. Dolayısıyla kalkınmamıza katkı sağlayacağı düşüncesiyle bu çalışmada ülkemiz işletmelerinin kriz yönetimi çalışmaları ele alınmıştır.

Bu çalışma kapsamında krizler ve kriz yönetimi konusu açıklanarak İstanbul Dünya Ticaret Merkezi’nde faaliyet gösteren otuz işletmenin kriz yönetimi çalışmaları incelenmiştir. Araştırma bulguları değerlendirildiğinde, söz konusu işletmelerin tümünün son on beş yıl içerisinde bir kriz dönemi yaşadıkları belirlenmiştir. Bu durum işletmelerin krizin etkileri ve alınması gereken önlemlere dair kısmen de olsa bilgi sahibi oldukları şeklinde yorumlanabilir. Araştırmaya katılan işletmelerden sadece birinin krizden olumlu etkilenmiş olduğunu belirtmesi ilgi çekicidir. Araştırma esnasında bu şirketin, atıl kapasite ve stok değerlendirme metodlarını içeren alternatif finans uygulamalarının da yardımıyla krizi lehine çevirmiş olduğu öğrenilmiştir. Ayrıca, araştırmaya katılan on işletme krizden etkilenmediğini, on dokuz işletme ise olumsuz etkilendiğini belirtmiştir. Bir diğer önemli bulgu ise, sürekli iç ve dış çevre analizi yapma ile krizin boyutlarının belirlenmesi arasında ilişki bulunmuş olmasıdır. Buna göre, çevresini devamlı izleyen ve buna göre yapılanan işletmeler olası krizleri ve boyutlarını belirleyerek krize karşı doğru strateji ve taktikler geliştirebileceklerdir. Araştırmaya dahil olan firmaların, toplam yedi adet kriz öncesi çalışmadan sadece birini (bilgi yönetimi) uyguladıkları saptanmıştır. Bununla birlikte firmaların, kriz anında yapılması gereken toplam on adet çalışmadan beşini (merkezi yapılanmaya gidilmesi, personelin işten çıkarılması, harcamaların kısılması, varlıkların azaltılması, ürün ve pazar değiştirilmesi) uyguladıkları tespit edilmiştir. Buna göre firmaların kriz anında kriz yönetimi çalışması gerçekleştirdikleri söylenebilir. Ayrıca araştırmadaki fïmaların toplam üç adet kriz sonrası çalışmadan sadece birini (durum analizi) uyguladıkları belirlenmiştir. Sonuç olarak incelenen firmalarda kriz öncesinde bir hazırlık yapılmadığı, kriz yönetimi çalışmalarının kriz anında daha fazla 
yoğunlaştı̆̆ı, yaşanan krizin ardından ise gelecek için tedbir alınmadığı söylenebilir. Öte yandan işletmelerde kriz yönetiminin kurumsallaştırılmamış olduğu, bilimsel temellere dayalı, bilinçli ve profesyonel bir kriz yönetim faaliyetinin uygulanmadığı ifade edilebilir. Ayrıca çalışmada ele alınan firmaların kriz yönetim politikalarının "proaktif" ve "interaktif" olmaktan çok "reaktif" olduğu söylenebilir.

İşletmelerin kriz ve yönetimi konusu üzerinde hassasiyetle durmaları gerekliliği ortadadır. Krize hazırlık kapsamında yürütülecek çalışmalar olası kriz durumlarında hayati önem taşımasının yanında, kriz olmayan zamanlarda da işletmelere büyük faydalar sağlayacaktır. Krizleri hasarsız atlatabilmek hatta bir firsata dönüştürebilmek için işletmelerin kriz yönetimi çalışmalarını; organizasyonun tüm formal yapısına aktarmaları, tüm işleyiş mekanizmalarına yerleştirmeleri, en nihayetinde bu çalışmaları uygulayacak olan beşeri unsurları tarafından benimsenmesini sağlamaları, kısacası kurumsallaştırmış olmaları önem taşımaktadır.

\section{Kaynakça}

- Akınc1, 2010. "Konaklama İşletmelerinde Kriz Yönetimi: Alanya Bölgesindeki Konaklama İşletmelerinde Kriz Sürecinde Karşılaşılan Sorunların Tespit ve Çözümüne Yönelik Bir Araştırma”, Yayınlanmamış Doktora Tezi, Süleyman Demirel Üniversitesi, S.B.E., Isparta, 2010.

- Asunakutlu, vd, 2003. "Kriz Yönetimi Üzerine Bir Araştırma”, Dokuz Eylül Üniversitesi S.B.E. Dergisi, 5(1), ss.141-163.

- Ataman, 2001. İşletme Yönetimi: Temel Kavramlar ve Yeni Yaklaşımlar. Türkmen Kitabevi, İstanbul.

- Avgan, 2010. "Kriz Yönetimi ve Türkiye'de Krizlerin Tarihsel Gelişimi: Bursa'daki İşletmelerde Kriz Yönetimi Üzerine Bir Araştırma", Yayınlanmamış Yüksek Lisans Tezi, Uludağ Üniversitesi, S.B.E., Bursa.

- Aydemir ve Demirci, 2005. "Son Dönemlerde Yaşanan Krizlerin İşletmeler Üzerindeki Olumlu Etkilerinin Analizi”, C.Ü. Sosyal Bilimler Dergisi, 29(1), ss.65-81.

- Baltaş, 2002. Krizde Firsatları Görmek: Yöneticiler İçin Krizde Yönetim El Kitabı. Remzi Kitabevi, İstanbul.

- Birdal, 2011. İşletmelerde Kriz Yönetimi. Ders Notları, İstanbul.

- Bonnard, 2013. Antik Yunan Uygarlığı 3: Euripidis’ten İskenderiye'ye. Çev.Kurtgözü, Evrensel Basım Yayın, 2.Basım, İstanbul.

- Bozgeyik, 2004. Krizleri Fırsata Dönüştürmek. Hayat Yayınları, İstanbul.

- Dinçer, 1992. Stratejik Yönetim ve İşletme Politikası. Timaş Yayınları, Istanbul.

- Doğan, 2010. “Örgütsel Öğrenme ve Kriz Yönetimi Arasındaki İlişkilerin İncelenmesi”, Yayınlanmamış Yüksek Lisans Tezi, Kadir Has Üniversitesi, S.B.E., İstanbul.

- Erdoğan, 2010. “Global Mali Krizin KOBİ’lerin Finansal Yapıları Üzerine Etkileri: İzmir İli Tekstil Sektöründe Bir Araştırma”, Yayınlanmamış Yüksek Lisans Tezi, Süleyman Demirel Üniversitesi, S.B.E., Isparta.

- Gençtürk, 2002. "Finansal Kriz Döneminde Şirketlerin Hisse Yapılarının Performanslarına Etkisi ve İMKB'de Bir Uygulama", Yayınlanmamış Doktora Tezi, Süleyman Demirel Üniversitesi, S.B.E., Isparta.

- Gültekin ve Aba, 2011. "Küçük ve Orta Ölçekli İşletmelerde Kriz Yönetimi: Şanlıurfa Örneği ", Girişimcilik ve Kalkinma Dergisi, 6(2), ss.205-226.

- Güncel Türkçe Sözlük, 2016. Türk Dil Kurumu, http://www.tdk.gov.tr/index.php?option=com_gts\&arama=gts\&guid=TDK.GTS.574c0751926d46.81735112

- Hermann, 2008. Some Consequences of Crisis Which Limit the Viability of Organizations", Crisis Management - Volume II. Ed.Boin, SAGE Publications, Thousand Oaks, California, pp.210-224.

- Kadıbeşegil, 2001. Kriz Geliyorum Der. MediaCat Kitapları, İstanbul.

- Kash ve Darling, 1998. "Crisis Management: Prevention, Diagnosis and Intervention”, Leadership and Organization Development Journal, 19(4), pp.179-186.

- Karakaya, 2004. "Stratejik Yönetim Sisteminin Kriz Yönetimine Katkisi Üzerine Bir Araştirma”, Teknoloji, 7,(2), ss.225-233.

- Kaya, 2009. “Kriz Yönetimi ve Ekonomik Krizlerin İşletmeler Üzerindeki Etkileri”, Yayınlanmamıs Yüksek Lisans Tezi, İstanbul Teknik Üniversitesi, F.B.E., İstanbul.

- Keown-McMullan, 1997. “Crisis: When Does A Molehill Become A Mountain?”, Disaster Prevention and Management, 6(1), pp.4-10.

- Khodarahmi, 2009. "Crisis Management”, Disaster Prevention and Management, 18(5), pp.523-528.

- Luecke, 2008. Kriz Yönetimi. Çev.Sarıaya, Türkiye iş Bankası Kültür Yayınları, İstanbul. 
- Milburn, vd, 1983. “Organizational Crisis, Part I: Defination and Conceptualization”, Human Relations, 36(12), pp.1148-1149.

- Mitroff ve Pearson, 1993. Crisis Management: A Diagnostic Guide for Improving Your Organization's Crisis-Preparedness. Jossey-Bass Business and Management Series, San Francisco, California.

- Mitroff ve Anagnos, 2000. Managing Crises Before They Happen: What Every Executive and Manager Needs to Know about Crisis Management, Amacom, Broadway, New York.

- Murat ve Misırl1, 2005. "Küçük ve Orta Ölçekli İşletmelerde Kriz Yönetimi: Çaycuma Örneği”, ZKÜ Sosyal Bilimler Dergisi, 1(1), ss.1-19.

- Okumuş, 2003. "İşletmelerde Kriz Yönetimi ve Krizlerin İşletmeler Üzerine Olası Etkileri”, Atatürk Üniversitesi İktisadi ve İdari Bilimler Dergisi, 17(1-2), ss.203-212.

- Oxford Dictionaries, 2016.Oxford University Press, http://www.oxforddictionaries.com/definition/english/crisis

- Ö̈nek, 2007. "Kriz Yönetimi Stratejileri ve Türkiye Bilişim Sektörü Örneği”,, Yönetim Bilimleri Dergisi, 5(1), ss.114-129.

- Özden, 2009. İşletme ve Örgütlerde Toplam Kriz Yönetimi. Beta Basım Yayım, İstanbul.

- Özdevecioğlu, 2002. "Krizin İşletmelerin Yönetsel ve Örgütsel Yapısı Üzerindeki Olumsuz Etkileri ve Kayseri Sanayi İşletmelerinde Yapılan Bir Araştırma”, Erciyes Üniversitesi İ.I.B.F. Dergisi, Sayı.19, ss.93114.

- Öztürk ve Türkmen, 2005. "Turizm İşletmelerinin Krizlerden Etkilenme Düzeylerine İlişkin Bir Araştırma”, Ballkesir Üniversitesi S.B.E. Dergisi, 8(14), ss.167-198.

- Pauchant ve Mitroff, 1992. Transforming the Crisis-Prone Organization: Preventing Individual, Organizational and Environmental Tragedies, Jossey-Bass Business and Management Series, San Francisco, California.

- Pheng, vd, 1999. "Crisis Management: a Survey of Property Development Firms”, Property Management, 17(3), pp. 231-251.

- Pira ve Sohodol, 2010. Kriz Yönetimi: Halkla İlişkiler Açısından Bir Değerlendirme. İletişim Yayınları, 3.Basım, İstanbul.

- Roubini ve Mihm, 2012. Kriz Ekonomisi: Dünya Ekonomisinin Çöküşü ve Geleceği. Çev.Tezcan, Pegasus Yayınları, İstanbul.

- $\quad$ Roux-Dufort ve Metais, 1999. "Building Core Competencies in Crisis Management Through Organizational Learning: The Case of the French Nuclear Power Producer", Technological Forecasting and Social Change, 60(2), pp.113-127.

- Seeger, vd, 2003. Communication and Organizational Crisis. Praeger Publishers, Westport, Connecticut.

- Soysal, vd, 2009. “KOBİ’lerde Kriz Yönetimi: Kahramanmaraş’ta Tekstil Sektöründeki KOBİ'lerde Bir Uygulama”, Selçuk Üniversitesi S.B.E. Dergisi, Sayı.21, ss.431-446.

- Sucu, 2000. Kriz Yönetimi. Yaşar Sucu Yönetim Serisi: 5, Elit Yayıncılık, Ankara.

- Tağraf ve Arslan, 2003. "Kriz Oluşum Süreci ve Kriz Yönetiminde Proaktif Yaklaşım”, Cumhuriyet Üniversitesi İ.I.B.F. Dergisi, 4(1), ss.149-160.

- $\quad$ Titiz, 2003. "Kriz Dönemi Yönetsel Kararların Kriz Sonrası İşletme Stratejileri Üzerine Etkileri", Süleyman Demirel Üniversitesi I.I. B.F. Dergisi, 8(2), ss.111-123.

- Tüz, 2004. Kriz Yönetimi: İşletmelerde Uygulama için Temel Adımlar. Alfa Yayınları, 3.Basım, İstanbul.

- Ulmer, vd, 2011. Effective Crisis Communication: Moving From Crisis to Opportunity (2nd Ed), SAGE Publications, Thousand Oaks, California. 


\title{
Yönetimde Yaratıcı Yenilik Bileşenlerinin Aydınlatılması Innovative Management Variables Enlightened
}

\author{
Prof. Dr. Erdoğan Taşkın (Beykent Universty, Turkey)
}

\begin{abstract}
Managers should understand the variables of innovation or the key points of creative innovation to ensure that businesses can decide fast and move correctly. Therefore, the purpose of this research is to analyze the key connections of innovation relations and creative innovation on management. This research will analyze five key issues: The processes of understanding the customers and users of the business. The ability of management to run the business and achieve business objectives. The employees' belief of creative innovation. The creative climate of the business. The support process of the business. As a result, five innovation variables of businesses will be analyzed and enlightened.
\end{abstract}

\section{Giris}

Günümüz uluslararası ticaret dünyası hızla değișen bir iktisadi, siyasi, beşeri, hukuki ve teknoloji ortamı içinde üst düzeyde keskin küresel rakiplerin, vefasız müşterilerin olduğu bulanık, çalkantılı ve karmaşık bir çevre içinde faaliyet gösterir. İşletmelerin yaratıcı yenilik yeteneğinin gerisinde bu denli değişken bir dış çevrede ayrıcalıklı rekabet üstünlüğünü sürdürmek kadar hayatta kalması da önemlidir. İşletme içindeki yaratıcı yenilik yeni bilgiyi geliştirme ve hızla değer yaratan uygulamaya dönüştürme kapasitesine bağlı olacaktır (Çavuşgil vd. 2003).

Latince "innovatus" kelimesinden çıkan "innovation” sözcüğü iki kelime ile yaratıcı yenilik veya tek kelime ile "yenileşim" olarak Türkçe' ye çevrilmiştir. Bu çalışmada kavram "yaratıcı yenilik" olarak iki kelime ile ifade edilecektir. Yaratıcı yenilik farklı, değişik ve yeni düşünceler geliştirmektir. Yeni değer yaratılmasıdır. Ticari bakış açısı ile yapılan yenilik çalışmalarının birleştirilmesidir (Kılıç, 2013; Arslan, 2014).

Yaratıcı yenilik, yeni veya belirgin ölçüde geliştirilmiş ürün ve süreçlerin, yeni pazarlama veya işletme yöntemlerinin yapılmasıdır. Yeni veya geliştirilmiş bir ürün piyasaya sunulduğu zaman yenilik yapılmış olur. Yeni süreçler, pazarlama yöntemleri veya işletme yöntemleri, işletme faaliyetleri içinde gerçekten kullanıldığı zaman yenilik yapılmış olur (www.uis.unesco.org/15.10.2015).

Bugünün profesyonel olarak yönetilen işletmeleri değişim dalgalarına karşı koymak veya bunları yönlendirmek için değil, işletmeyi piyasada en uygun duruma getirme ve denetleme amaciyla doğmuştur. Yöneticinin hedefi değişimi en aza indirmek, başarılı sonuç almayı en uygun şekle getirmek ve bütün yapılanları kontrol etmektir. Bununla birlikte klasik bilimsel yönetim öğretisi, yöneticileri yaratıcı yenilik konularından uzaklaştırmaktadır (Berkun, 2010).

Oysa yaratıcı yenilik her yöneticinin gerçek sorumluğudur. Sorumluluk firsatların sürekli araştırılması ile başlar. Yaratıcı yenilik şimdi küçük veya büyük her işletmenin önemli bir faaliyetidir. Bu faaliyet içinde tepe yönetime büyük sorumluluk düşmektedir. İşletmelerin pazarlama ve yenilik olmak üzere sadece en önemli iki işlevi vardır (Drucker, 1998; Prabhu, 2014).

Yapılan araştırmalarda büyük, çok uluslu ve uluslararası işletmelerin yönetim kurulu başkanları faaliyet amaçlarına erişmelerini, hayatta kalmalarını, satışlarını yükseltmelerini ve küresel başarılarının nedenlerini sorumlulukla yaratıcı yeniliğe odaklanmalarına bağlamaktadır (Christensen ve Raynor, 2003; Berger vd., 2009).

Mali kaynakları sınırlı, nitelikli çalışanları sayılı ve zamanı kısıtlı olan küçük ve orta boyutlu işletmeler de sürekli yaratıcı yenilik yapma stratejisine inanmaktadır. Yaratıcı yenilik mevcut şekillerinden bütünüyle farklı bir nitelik taşıyan ürün, hizmet, düşünce veya herhangi bir iş için yapılabilir. Stratejide önemli olan yaratıcı yeniliğin farklı kesimlere yayılması ve değer yaratacak biçimde uygulanmasıdır (Robertson, 1967; Gollin, 2010).

Değer yaratan, kapasite kullanan ve kaynak sağlayan bir süreç olan yaratıcı yenilik, işletmelerin kitlesel ve önemli piyasa bölümlerine ulaşması için zahmetli öte yandan ödüllendirici bir stratejidir. Örneğin enerji, inşaat, tarım ve sağlık alanında çalışan işletmelerde yapılan bir araştırmada yeni teknolojileri uygulamada öncü ve girişimciliği büyüme stratejilerinin temel bir parçası yaptıkları tespit edilmiştir. Bu işletmeler, daha esnek olmakta, müşteri taleplerine daha hızlı cevap vermekte ve piyasadaki değişime daha uyumlu olmaktadır (Thomas, Miller ve Murphy, 2015; Keegan ve Green, 2015).

İşletmelerin büyümelerinin ardında yatan gerçek ise ürün ve hizmetlerinde yaratıcı yenilik yaparak yarattıkları farklılık ile elde ettikleri ayrıcalıklı konumdur. Ürünlerde yaratıcı yenilik yapılması ile birlikte marka ve ürün hattının genişletilmesi mümkündür. Yenilik yapılan ürünlerin yenilik yapılmayan ürünlere göre satın alma oranı özellikle güçlü markalar ile genişletilen ürün hatlarında daha fazla olmaktadır (Sinapuelas, Wang, Bohlmann, 2015; Keegan ve Green, 2015).

İşletmelerin güçlü markalarının piyasada daima yaşamasının ardında basit bir kalıp vardır. Bu kalıp pazarlama bilgisi ve hayal gücü ile birleşen yaratıcı yeniliktir (Moralığlu, 2014). 
Hayal gücünün yanı sıra, işletmenin deneyim birikimi, dış çevresi, iç kaynakları ve mevcut kültür bileşenleri yaratıcı yenilik içine eklenebilir (Seelig, 2012).

Yatırıma dönüşen hayal gücü ve yaratıcı yenilik, yeni geleceği biçimlendirecektir. Coşku ve tutku ile uygulanan yaratıcı yenilik bütün dünyada geleceği etkileyecektir. Öncelikle küresel ticaret, teknoloji, iletişim ve bütün toplumlar yaratıcı yenilikten etkilenecektir. Bu eksende işletme yönetimlerini uygulamada etkileyen yaratıcı yenilik bileşenleri daha iyi aydınlatılmalıdır (Canton, 2007; Hollensen, 2008).

\section{Uygulamada Yaratıcı Yenilik}

Yaratıcı yenilik yapılmamasının sebebi mevcut kaynakların veya yaratıcı yeteneklerin kıt olması değil uygulama yönteminin olmamasıdır (Christensen, 2011; Wulfen, 2014; Gans, 2016).

Amaçlarına erişemeyen işletmelerde yaratıcı yenilik doğru uygulanmadığı için takımlar ve bölümler arasında karşılaştırma yapılamaz. Diğer yönden bir yaratıcı yenilik, başarısız olsa veya o ürünün imalatı uygulamada yapılmasa bile, işletmeyi değiştirmeye, çalışanlara esin kaynağı olmayı ve ustalık kazandırmayı sürdürür (Taşkın 2001; Hamel, 2012).

İktisadi ortam işletmelere yenilikçi fırsatlar sunarken aynı anda uygulamada farklı ve yaratıcı seçeneklerin bulunmas1 gerekir (Christensen ve Raynor, 2003; Keelley ve Littman, 2005; Keeley vd., 2013).

Geçmiş yıllarda yapılan sayısız araştırmalarda görüldüğü gibi uygulamada yaratıcı yenilik, hem faaliyet gösterilen ülkenin yaratıcı yenilik sistemine ve hem de yöneticinin farklı, çeşitli faaliyetleri yapmasını ve etkin katılımını gerektiren oldukça karmaşık bir iştir (Kırca ve Rubera, 2011; Trott, 2012; Kelly ve Kelly, 2013; Verganti, 2016).

Araştırma geliştirme faaliyetleri ile patentlere yatırım yapan hem nihai tüketicilere hem de işletmelerden işletmelere ticaret (B2) yapan işletmelerin başarısının bir başka değişle değer yaratmasının temelinde pazarlama, tasarım ve işletme alanında yaratıcı yenilik yapması vardır. Özellikle başarılı yeni düşünceler ile yeniliklerin yapılması her zaman başarılı bir pazarlama yönetimi tarafindan sağlanabilir (Rave, 2011; Ergin vd., 2015; Sinanoğlu, 2015).

Bunun için yenilik yönetimi ile uğraşanların yaratıcıllğın uygulanmasını zorlayan zihinsel engelleri aşarak gözlerinin önünde duran gerçeklere bakmalıdır. Son yıllarda artan müşteri talepleri ve yükselen küresel rekabet, işletmelerin piyasaya sundukları ürün ve hizmetlerde daha çok yenilik yapmasında neden olmuştur. Yenilik, işletmelerin hayatta kalması için zorunlu ihtiyaç olmuştur. Uluslararası pazarlamada yeni işler geliştiren ve yeni ürünler yapan işletmelerin yaratıcıllk açısından mükemmel işletmeler olduğu bulunmuştur. Önemli bir araştırmada sıradan işletmelere göre en üst düzeyde yaratıcı olan küresel işletmelerin satışlarını ikiye katlamış ve kârlılıklarını yükseltmiş olduğu anlaşılmıştır (Lindgren, 2012; Çavuşgil vd., 2012; McCaffrey ve Pearson, 2015).

Görüşleri toplamak için her müşteri temas noktasında, müşteri iç görü, ihtiyaç, istek ve kalite beklentileri düzgün tespit edilmelidir. Kalite, müşterilerin geri gelmesi ürünlerin geri gelmemesidir. Kalite yaratıcı yeniliğin daha hızlı yayılmasını sağlar. Geçmiş yıllarda işletme içinde yaratıcılık ve yenilik yapmak genellikle araştırma geliştirme veya üretim geliştirme bölümlerinin işi olarak düşünülüyordu. Son yıllarda ise müşterilerden, piyasadan ve işletmenin içinden çıkan düşüncelerin yaratıcılık ve yenilik için kullanılması işletme kültürü olmuştur (Doyle ve Bridgewater, 1998; Dibb, vd., 2012; Lindgren, 2012; Grant 2016).

Yapılan araştırmalarda işletmelerin pazarlama yeteneği ile yaptıkları yenilikler arasında belirgin ilişkiler olduğu tespit edilmiştir. Ürün, fiyatlandırma, tutundurma, dağıtım kanalları ile pazarlama karmasında yapılan bütün yenilikler, işletmelerin piyasadaki rekabet gücünü olumlu yönde etkilemektedir. Bu etkileme nedeniyle işletmeler, piyasadaki en güçlü rakiplerinin müşterilerini hangi yönden ve ne şekilde tatmin edeceğini tespit etmeli ve bunları değer yaratan uygulamalarına dönüştürmelidir (Hamel ve Prahalad, 1996; Taşkın, 2014; Rostami, 2015).

Önceki araş̧ırmalara göre işletmelerde yaratıcı yenilik bileşenlerinin uygulanmasının kolay olmadığı anlaşılmıştır. Özellikle son yıllarda yapılan araştırmalarda, ürün geliştirme ve yaratıcı yenilik yapılan ürün ve hizmetleri piyasaya sunarken, müşterinin artık gürülttüye dönüşen sesini dinlemenin pazarlamada yatırım geri dönüş oranının düş̧mesine, piyasaya sunulan yeni ürünlerdeki başarısızlık sayısının yükselmesine ve işletmelerin yanlış yönlere doğru gitmesine neden olduğu tartışılmaktadır. $\mathrm{Bu}$ tartışmalar nedeni ile pazarlama bölümleri yaratıcı yenilik bileşenlerine tekrar odaklanmaktadır. Yöneticilerin öncelikle yaratıcı yenilik alanın özgün kavramlarını bütünleştirmeleri gerekir. Bu özgün yön doğrultusunda etkileşimli yaratıcı yeni yerlere gidilmeli, farklı düşünceler üretebilmeli ve sorunların çözümü konusunda eşsiz iç görüler kazanmalıdır (Ofek ve Toubia 2010; Johansson, 2013; Watson, 2011).

Yöneticiler işletmede yeni fikirlerin geliştirilmesi konusunda duyarlı olmalıdır. Bugünlerde bütün işletmeler canlı, değişken ve karmaşık küresel rakipler ile karşılaşmaktadır. Bu karşılaşma işletmelerden hızla yaratıcı yenilik yapmasını talep etmektedir. Yaratıcı yenilik, işletme içindeki bilgi yönetiminin bir sonucudur. $\mathrm{Bu}$ nedenle yöneticiler, işletmenin içindeki yeniliklerin keşfedilmesi ve ortaya çıkartılarak kullanılması kapasitesini cesaretlendirmelidir. İşletmenin başarısı, yöneticilerin yaratıcı yenilik kapasitesini sürdürmesine bağlıdır. İşletme 
içinde yöneticiler ve bütün çalışanlar yeni bilgi üretmek için birlikte çalışmalıdır (Camisón ve Boronat-Navarro, 2011).

İşletme rekabet nedeniyle bir yandan yaratıcı yenilik taleplerini karşılamaya çalışırken diğer yandan çalışanların yapılan yenilikleri uygulamaya dönüştürmesi ve piyasaya sürmesi sırasında farklı engeller ile karşılaşmaktadır. Örneğin değer zinciri içinde tedarikçi ile nihai tüketici arasında kalan aracı işletmeler bu engeller ile doğrudan karşılaşmaktadır (Autio ve Thomas, 2014; Malerba ve Adams, 2014; Hintze, 2015).

Yöneticiler tarafından aydınlatılan mükemmel yeniliğin uygulamada beş temel bileşeni vardır (Lindgren, 2012).

1. Müşteri ve kullanıcıları anlamak: Yeni kavramları ortaya çıkartmak ve müşterileri yeniliğe dahil etmektir.

2. Yürütme iş yapma yeteneği: Düşünceleri değerli yeniliklere dönüştürecek iyi tanımlanan ve kullanılan süreçlere sahip olmaktır.

3. Kişisel inanç: Yenilik sürecini kuvveden fiile çıkartan taşıyıcı bir inanç sistemi yaratmaktır.

4. Yaratıcı iklim: Açık bilgi paylaşımı yapmak ve yaratıcı iklimi beslemektir.

5. Destek süreçleri: Çalışanları yaratıcılığı destekleme ve yeni düşünceleri getirmeye inandırmaktır.

\section{Araştırma Yöntemi ve Verilerin Çözümlenmesi}

Araştırma işletme yönetimlerinde mükemmel yeniliğin beş temel bileşenini ölçmek üzere tasarlanmıştır. Araştırmada ilk beş soru bu bileşenlere ayrılmış, ikinci beş soru araştırmaya katılanların demografik özellikleri, son dört soruda ise katılımcı yöneticilerin çalıştıkları şirketler aydınlatılmıştır. Yönetimde yaratıcı yenilik incelemesi bir araştırma şirketinin veri ambarlarından yararlanılarak web üzerinden yapılmış ve 148324 adet araştırma evrenine elektronik posta gönderilerek başlamıştır. Araştırma linkini 101886 kişi açmış, 161 kişi tıklamış, soruları 7 Ekim 2015 ve 7 Ocak 2016 tarihleri arasındaki üç aylık sistemin açık kalma süresi içinde 147 kişi yanıtlamıştır. Mükemmel yeniliğin bileşenlerini araştıran sorular tablolar yapılarak özetlenmiş, gösterilmiş ve kısaca yorumlanan çözümlemeler ile tanımlanmıştır (Ustabaş ve Hekim 2016; Bingör, 2016).

\begin{tabular}{|l|c|c|}
\hline & Siklık & $\%$ \\
\hline Evet & 97 & 66 \\
\hline Hayir & 50 & 34 \\
\hline Toplam & 147 & 100 \\
\hline
\end{tabular}

Tablo 1. İ̧sletmeniz bütün yenilik aşamaları sürecine müşteri görüşlerini alıyor mu?

Tablo 1 üzerinde gösterildiği gibi bu araştırmaya yanıt veren 147 katılımcının \%66 gibi önemli bir oranı, çalıştıkları işletmelerin bütün yenilik aşamaları sürecine müşteri görüşlerini aldığını belirtmiştir.

\begin{tabular}{|l|c|c|}
\hline & S1kl1k & $\%$ \\
\hline Evet & 119 & 81 \\
\hline Hayır & 28 & 19 \\
\hline Toplam & 147 & 100 \\
\hline
\end{tabular}

Tablo 2. Iş̧letme, çalışanların yaptıkları işlerden gelen düşünceleri, ürün geliştirme teklifleri ve piyasaya ilişkin gözlemleri, yeni ürünlere ve önerilere dönüşı̈rülmesine yardım ediyor mu?

Tablo 2 üzerinde gösterildiği gibi bu araştırmaya yanıt veren 147 katılımcının \%81 gibi çok yüksek bir oranı, işletmelerin, çalışanların yaptıkları işlerden gelen düşünceleri, ürün geliştirme teklifleri ve piyasaya ilişkin gözlemleri, yeni ürünlere ve önerilere dönüştürülmesine yardım ettiğini açıklamıştır.

\begin{tabular}{|l|c|c|}
\hline & S1kl1k & $\%$ \\
\hline Evet & 72 & 49 \\
\hline Hayır & 75 & 51 \\
\hline Toplam & 147 & 100 \\
\hline
\end{tabular}

Tablo 3. Iş̧letmenizin düzenli olarak farklı düşünceleri araştırdığından ve bunlar arasından en nitelikli olanları seçmek ve bunları desteklemek için finans kaynă̆ aradığından emin misiniz?

Tablo 3 üzerinde gösterildiği gibi bu araştırmaya yanıt veren 147 katılımcı, çalıştıkları işletmelerin düzenli olarak farklı düşünceleri araştırdığından ve bunlar arasından en nitelikli olanları seçmek ve bunları desteklemek için finans kaynağı aradığından emin değildir.

\begin{tabular}{|l|c|c|}
\hline & S1klik & $\%$ \\
\hline Evet & 91 & 62 \\
\hline Hayır & 56 & 38 \\
\hline Toplam & 147 & 100 \\
\hline
\end{tabular}

Tablo 4. İşletmenizin piyasadaki yaratıcılığını konuştuğunuz uygun bir iş ortamı var mı? 
Tablo 4 üzerinde gösterildiği gibi bu araştırmaya yanıt veren 147 katılımcının \%62 gibi önemli bir oranı, çalıştıkları işletmelerin piyasadaki yaratıcılığını konuştuğu uygun bir iş ortamı olduğunu vurgulamıştır.

\begin{tabular}{|l|c|c|}
\hline & Siklık & $\%$ \\
\hline Evet & 85 & 58 \\
\hline Hayır & 62 & 42 \\
\hline Toplam & 147 & 100 \\
\hline
\end{tabular}

Tablo 5. İ̧sletmenizdeki bütün çalışanlar, yaratıcılı̆̆ işlerinin bir parçası olarak dikkate alıyor ve bu çalışanların yöneticileri onlardan gelen fikirleri açık yüreklilikle kabul ediyor mu?

Tablo 5 üzerinde gösterildiği gibi bu araştırmaya cevap veren 147 katılımcının \% 58'lik oranı, işletmelerinde bütün çalışanların yaratıcılığı işlerinin bir parçası olarak dikkate aldıklarını ve bu çalışanların ilk yöneticilerinin astlarından gelen düşünceleri tereddütsüz kabul ettiğini vurgulamıştır.

\begin{tabular}{|l|c|c|}
\hline & Siklık & $\%$ \\
\hline Erkek & 118 & 80 \\
\hline Kadın & 29 & 20 \\
\hline Toplam & 147 & 100 \\
\hline
\end{tabular}

Tablo 6. Katılımclların Cinsiyeti

Tablo 6 üzerinde gösterildiği gibi bu araştırmaya yanıt veren 147 katılımcının \%81 gibi çok yüksek bir oranı erkektir. Sadece 29 kadın bu araştırmayı cevaplamıştır.

\begin{tabular}{|l|c|c|}
\hline & Siklik & $\%$ \\
\hline $18-25$ yaş & 16 & 11 \\
\hline $26-33$ yaș & 32 & 22 \\
\hline $34-41$ yaș & 42 & 29 \\
\hline 42-49 yaș & 23 & 15 \\
\hline 50 yaș ve üzeri & 34 & 23 \\
\hline Toplam & 147 & 100 \\
\hline
\end{tabular}

Tablo 7. Araştırmaya Katılanların Yaşı

Tablo 7 üzerinde gösterildiği gibi bu araştırmaya yanıt veren 147 katılımcının \%29'luk oranı 34-41 Aralığında, $\% 23$ 'ü 50 yaş ve üzerinde, \%22'si 26-33 yaş arasındadır.

\begin{tabular}{|l|c|c|}
\hline & S1klık & $\%$ \\
\hline İlköğretim & 2 & 1 \\
\hline Ortaöğretim (Lise) & 15 & 10 \\
\hline Yüksekokul (Ön Lisans) & 15 & 10 \\
\hline Fakülte (Lisans) & 85 & 58 \\
\hline Lisansüstü & 30 & 21 \\
\hline Toplam & 147 & 100 \\
\hline
\end{tabular}

Tablo 8. Eğitim Durumu

Tablo 8' e göre katılımcıların \%58 gibi önemli bir oranı dört yıllık fakültelerin lisans bölümlerinden, \%21 gibi bir oranı da üniversitelerin lisansüstü mezunudur.

\begin{tabular}{|l|c|c|}
\hline & S1klık & $\%$ \\
\hline Üst düzey yönetici & 47 & 32 \\
\hline Orta düzey yönetici & 61 & 42 \\
\hline İlk düzey yönetici & 31 & 21 \\
\hline Diğer & 8 & 5 \\
\hline Toplam & 147 & 100 \\
\hline
\end{tabular}

Tablo 9. Çalışma Düzeyi

Tablo 9'a göre araştırmaya daha çok \%42 orta ve üst düzey \%32 yönetici düzeyinde çalışan kişiler cevap vermiştir.

\begin{tabular}{|l|c|c|}
\hline & S1kl1k & $\%$ \\
\hline $0-5$ y1l & 67 & 46 \\
\hline $6-10$ y1l & 24 & 16 \\
\hline $11-15$ y1l & 27 & 18 \\
\hline 16 y1l ve üstü & 29 & 20 \\
\hline Toplam & 147 & 100 \\
\hline
\end{tabular}

Tablo 10. İsletmede Çalışma Süresi 
Tablo 10 üzerinde gösterildiği gibi çalışanların \%46'sı yaklaşık olarak yarısı en fazla 5 yıldır aynı iş yerinde çalışmaktadır.

\begin{tabular}{|l|c|c|}
\hline & S1klık & $\%$ \\
\hline $0-4$ kişi & 61 & 41 \\
\hline 5-9 kişi & 25 & 17 \\
\hline 10-15 kiși & 17 & 12 \\
\hline 16-50 kişi & 28 & 19 \\
\hline 50 ve üstü kişi & 16 & 11 \\
\hline Toplam & 147 & 100 \\
\hline
\end{tabular}

Tablo 11. Băğlı Çalışan Kişi Sayısı

Tablo 11 üzerinde gösterildiği gibi çalışanların \%41'i en fazla 4 kişiye yöneticilik yapmaktadır. 28 Katılımcı ise 16 ila 50 kişiyi yönettiklerini belirtmiştir.

\begin{tabular}{|l|c|c|}
\hline & Siklık & $\%$ \\
\hline Beyaz Eşya & 3 & 2 \\
\hline Bilişim & 8 & 5 \\
\hline Denetim ve Danışmanlık & 4 & 3 \\
\hline Eğitim & 5 & 3 \\
\hline Elektronik & 5 & 3 \\
\hline Finans & 3 & 2 \\
\hline Gayrimenkul & 2 & 1 \\
\hline Gida & 9 & 7 \\
\hline İnsan Kaynakları ve İletişim & 6 & 4 \\
\hline Kamu Yönetimi & 3 & 2 \\
\hline Lojistik ve Tașımacılık & 12 & 8 \\
\hline Mimarlık ve İnşaat & 7 & 5 \\
\hline Mobilya & 17 & 12 \\
\hline Otomotiv & 5 & 3 \\
\hline Pazarlama ve Satıș & 9 & 6 \\
\hline Sağlık & 7 & 5 \\
\hline Sigorta ve Güvenlik & 4 & 3 \\
\hline Tekstil & 4 & 3 \\
\hline Ticaret & 4 & 3 \\
\hline Turizm & 7 & 5 \\
\hline Üretim & 15 & 10 \\
\hline Diğer & 8 & 5 \\
\hline Toplam & 147 & 100 \\
\hline
\end{tabular}

Tablo 12. Işsletme Faaliyet Alanı

Tablo 12 araştırmaya cevap veren 147 katılımıının çalıştığı işletmenin faaliyet alanı en yüksek oranda mobilya ve üretim olarak işaretlenmiştir. Tablo araştırmanın mobilya dışında farklı kesimler tarafından yaklaşık aynı oranda cevaplandırılmış olduğunu göstermektedir.

\begin{tabular}{|l|c|c|}
\hline & Siklık & $\%$ \\
\hline Ulusal & 38 & 26 \\
\hline Uluslararas1 & 62 & 42 \\
\hline Yerel & 35 & 24 \\
\hline Bölgesel & 12 & 8 \\
\hline Toplam & 147 & 100 \\
\hline
\end{tabular}

Tablo 13. İşletmenin Faaliyet Yeri

Tablo 13 üzerinde 147 katılımcının çalıştı̆̆ işletmenin faaliyet yerine bakıldığında \%42 gibi oranda uluslararası işletme olduğu anlaşılmaktadır.

\begin{tabular}{|l|c|c|}
\hline & S1klık & $\%$ \\
\hline Yabanci sermaye & 15 & 10 \\
\hline Yerli sermaye & 132 & 90 \\
\hline Toplam & 147 & 100 \\
\hline
\end{tabular}

Tablo 14. İşletmenin Sermaye Yapısı

Tablo 14 ise 147 katılımcının çalıştığı işletmenin \%90 gibi çok yüksek bir oranının nerede ise hepsinin yabancı sermayeli işletme olduğunu açıklamaktadır. 


\begin{tabular}{|c|c|c|c|c|c|c|}
\hline \multirow[t]{2}{*}{ Değişkenler } & \multirow[t]{2}{*}{$\begin{array}{c}\text { Alt } \\
\text { değişkenler }\end{array}$} & \multirow[t]{2}{*}{$\begin{array}{c}\text { Tanımlayıcı } \\
\text { istatistik }\end{array}$} & \multicolumn{2}{|c|}{$\begin{array}{c}\text { İşletmeniz bütün yenilik } \\
\text { aşamaları sürecine } \\
\text { müşteri görüşlerini alıyor } \\
\text { mu? }\end{array}$} & \multirow[t]{2}{*}{ Toplam } & \multirow[t]{2}{*}{ Ki-Kare } \\
\hline & & & Evet & Hayır & & \\
\hline \multirow{8}{*}{$\begin{array}{l}\text { İşletmenin } \\
\text { faaliyet yeri }\end{array}$} & \multirow{2}{*}{ Yerel } & $f$ & 25 & 10 & 35 & \multirow{8}{*}{$\begin{array}{c}\mathrm{x}^{2}=6,214 \\
\mathrm{df}=3 \\
\mathrm{p}=, 102\end{array}$} \\
\hline & & $\%$ & 71,4 & 28,6 & 100,0 & \\
\hline & \multirow{2}{*}{ Bölgesel } & $\mathrm{f}$ & 7 & 5 & 12 & \\
\hline & & $\%$ & 58,3 & 41,7 & 100,0 & \\
\hline & \multirow{2}{*}{ Ulusal } & $\mathrm{f}$ & 19 & 19 & 38 & \\
\hline & & $\%$ & 50,0 & 50,0 & 100,0 & \\
\hline & \multirow{2}{*}{ Uluslararası } & $\mathrm{f}$ & 45 & 17 & 62 & \\
\hline & & $\%$ & 72,6 & 27,4 & 100,0 & \\
\hline \multirow{4}{*}{$\begin{array}{l}\text { İşletmenin } \\
\text { sermaye } \\
\text { yapısı }\end{array}$} & \multirow{2}{*}{ Yerli sermaye } & $\mathrm{f}$ & 85 & 47 & 132 & \multirow{4}{*}{$\begin{array}{c}x^{2}=, 475 \\
d f=1 \\
p=, 491\end{array}$} \\
\hline & & $\%$ & 64,4 & 35,6 & 100,0 & \\
\hline & \multirow{2}{*}{$\begin{array}{l}\text { Yabanc1 } \\
\text { sermaye }\end{array}$} & $\mathrm{f}$ & 11 & 4 & 15 & \\
\hline & & $\%$ & 73,3 & 26,7 & 100,0 & \\
\hline \multirow{6}{*}{$\begin{array}{l}\text { İşletmenin } \\
\text { çalışan sayısı }\end{array}$} & \multirow{2}{*}{ 0-10 kişi } & $\mathrm{f}$ & 61 & 32 & 93 & \multirow{6}{*}{$\begin{array}{c}x^{2}=, 164 \\
d f=2 \\
p=, 921\end{array}$} \\
\hline & & $\%$ & 65,6 & 34,4 & 100,0 & \\
\hline & \multirow{2}{*}{ 11-20 kişi } & $\mathrm{f}$ & 11 & 5 & 16 & \\
\hline & & $\%$ & 68,8 & 31,3 & 100,0 & \\
\hline & \multirow{2}{*}{$\begin{array}{l}21 \text { kişi veya } \\
\text { üzeri }\end{array}$} & $\mathrm{f}$ & 24 & 14 & 38 & \\
\hline & & $\%$ & 63,2 & 36,8 & 100,0 & \\
\hline
\end{tabular}

Tablo 15. “İşletmeniz bütün yenilik aşamaları sürecine müşteri görüşlerini allyor mu?” Sorusuna Verilen Yanıtların İşletmenin Faaliyet Yeri, Sermaye Yapısı ve Çalışan Kişi Sayısına Göre Karşılaştırılması

Tablo 15 incelendiğinde, yaratıcı yenilik yapan işletmelerin müşterilerini ve kullanıcılarını anlama durumlarının işletmenin faaliyet yerine $(\mathrm{x} 2=6,214 ; \mathrm{df}=3 ; \mathrm{p}=, 102)$, sermaye yapısına $(\mathrm{x} 2=, 475 ; \mathrm{df}=1 ; \mathrm{p}=, 491)$ ve çalışan sayısına $(\mathrm{x} 2=, 164 ; \mathrm{df}=2 ; \mathrm{p}=, 921$ göre istatistiksel olarak anlamlı düzeyde farklılaşmadığı görülmektedir.

\begin{tabular}{|c|c|c|c|c|c|c|}
\hline \multirow[t]{2}{*}{ Değişkenler } & \multirow[t]{2}{*}{$\begin{array}{l}\text { Alt } \\
\text { değişkenler }\end{array}$} & \multirow[t]{2}{*}{$\begin{array}{l}\text { Tanımlayıc1 } \\
\text { istatistik }\end{array}$} & \multicolumn{2}{|c|}{$\begin{array}{l}\text { İşletme, çalışanların yaptıkları } \\
\text { işlerden gelen düşünceleri, ürün } \\
\text { geliştirme teklifleri ve piyasaya } \\
\text { ilişkin gözlemleri, yeni ürünlere } \\
\text { ve önerilere dönüş̧ürülmesine } \\
\text { yardım ediyor mu? }\end{array}$} & \multirow[t]{2}{*}{ Toplam } & \multirow[t]{2}{*}{ Ki-Kare } \\
\hline & & & Evet & Hayır & & \\
\hline \multirow{8}{*}{$\begin{array}{l}\text { İşletmenin } \\
\text { faaliyet yeri }\end{array}$} & \multirow{2}{*}{ Yerel } & $\mathrm{f}$ & 28 & 7 & 35 & \multirow{8}{*}{$\begin{array}{c}\mathrm{x}^{2}=1,961 \\
\mathrm{df}=3 \\
\mathrm{p}=, 581\end{array}$} \\
\hline & & $\%$ & 80,0 & 20,0 & 100,0 & \\
\hline & \multirow{2}{*}{ Bölgesel } & $\mathrm{f}$ & 8 & 4 & 12 & \\
\hline & & $\%$ & 66,7 & 33,3 & 100,0 & \\
\hline & \multirow{2}{*}{ Ulusal } & $\mathrm{f}$ & 31 & 7 & 38 & \\
\hline & & $\%$ & 81,6 & 18,4 & 100,0 & \\
\hline & \multirow{2}{*}{ Uluslararas1 } & $\mathrm{f}$ & 52 & 10 & 62 & \\
\hline & & $\%$ & 83,9 & 16,1 & 100,0 & \\
\hline \multirow{4}{*}{$\begin{array}{l}\text { İşletmenin } \\
\text { sermaye } \\
\text { yapısı }\end{array}$} & \multirow{2}{*}{ Yerli sermaye } & $\mathrm{f}$ & 105 & 27 & 132 & \multirow{4}{*}{$\begin{array}{c}\mathrm{x}^{2}=1,661 \\
\mathrm{df}=1 \\
\mathrm{p}=, 198\end{array}$} \\
\hline & & $\%$ & 79,5 & 20,5 & 100,0 & \\
\hline & \multirow{2}{*}{$\begin{array}{l}\text { Yabanc1 } \\
\text { sermaye }\end{array}$} & $\mathrm{f}$ & 14 & 1 & 15 & \\
\hline & & $\%$ & 93,3 & 6,7 & 100,0 & \\
\hline \multirow{6}{*}{$\begin{array}{l}\text { İşletmenin } \\
\text { çalışan sayısı }\end{array}$} & \multirow{2}{*}{ 0-10 kişi } & $\mathrm{f}$ & 72 & 21 & 93 & \multirow{6}{*}{$\begin{array}{c}\mathrm{x}^{2}=4,527 \\
\mathrm{df}=2 \\
\mathrm{p}=, 104\end{array}$} \\
\hline & & $\%$ & 77,4 & 22,6 & 100,0 & \\
\hline & \multirow{2}{*}{ 11-20 kişi } & $\mathrm{f}$ & 16 & 0 & 16 & \\
\hline & & $\%$ & 100,0 & 0,0 & 100,0 & \\
\hline & \multirow{2}{*}{$\begin{array}{l}21 \text { kişi veya } \\
\text { üzeri }\end{array}$} & $\mathrm{f}$ & 31 & 7 & 38 & \\
\hline & & $\%$ & 81,6 & 18,4 & 100,0 & \\
\hline
\end{tabular}

Tablo 16. "Işsletme, çalışanların yaptıklart işlerden gelen düşünceleri, ürün geliştirme teklifleri ve piyasaya ilişkin gözlemleri, yeni ürünlere ve önerilere dönüşürülmesine yardım ediyor mu? ” Sorusuna Verilen Yanıtların Işsletmenin Faaliyet Yeri, Sermaye Yapısı ve Çalışan Kişi Sayısına Göre Karşılaştırılması

Tablo 16 İncelendiğinde, yaratıcı yenilik yapan işletmelerin yürütme iş yapma yeteneklerinin işletmenin faaliyet yerine $(x 2=1,961 ; d f=3 ; p=, 581)$, sermaye yapısına $(x 2=1,661 ; d f=1 ; p=, 198)$ ve çalışan sayısına $(x 2=4,527 ; d f=2$; $\mathrm{p}=, 104$ göre istatistiksel olarak anlamlı düzeyde farklılaşmadığı görülmektedir. 


\begin{tabular}{|c|c|c|c|c|c|c|}
\hline \multirow[t]{2}{*}{ Değişkenler } & \multirow[t]{2}{*}{$\begin{array}{l}\text { Alt } \\
\text { değişkenler }\end{array}$} & \multirow[t]{2}{*}{$\begin{array}{l}\text { Tanımlayıc1 } \\
\text { istatistik }\end{array}$} & \multicolumn{2}{|c|}{$\begin{array}{l}\text { İşletmenizin düzenli olarak farklı } \\
\text { düşünceleri araştırdığından ve } \\
\text { bunlar arasından en nitelikli } \\
\text { olanları seçmek ve bunları } \\
\text { desteklemek için finans kaynağı } \\
\text { aradığından emin misiniz? }\end{array}$} & \multirow[t]{2}{*}{ Toplam } & \multirow[t]{2}{*}{ Ki-Kare } \\
\hline & & & Evet & Hayır & & \\
\hline \multirow{8}{*}{$\begin{array}{l}\text { İşletmenin } \\
\text { faaliyet yeri }\end{array}$} & \multirow{2}{*}{ Yerel } & $\mathrm{f}$ & 13 & 22 & 35 & \multirow{8}{*}{$\begin{array}{c}x^{2}=6,698 \\
d f=3 \\
p=, 082\end{array}$} \\
\hline & & $\%$ & 37,1 & 62,9 & 100,0 & \\
\hline & \multirow{2}{*}{ Bölgesel } & $\mathrm{f}$ & 5 & 7 & 12 & \\
\hline & & $\%$ & 41,7 & 58,3 & 100,0 & \\
\hline & \multirow{2}{*}{ Ulusal } & $\mathrm{f}$ & 16 & 22 & 38 & \\
\hline & & $\%$ & 42,1 & 57,9 & 100,0 & \\
\hline & \multirow{2}{*}{ Uluslararas1 } & $\mathrm{f}$ & 38 & 24 & 62 & \\
\hline & & $\%$ & 61,3 & 38,7 & 100,0 & \\
\hline \multirow{4}{*}{$\begin{array}{l}\text { İşletmenin } \\
\text { sermaye yapıs1 }\end{array}$} & \multirow{2}{*}{ Yerli sermaye } & $\mathrm{f}$ & 63 & 69 & 132 & \multirow{4}{*}{$\begin{array}{c}\mathrm{x}^{2}=, 812 \\
\mathrm{df}=1 \\
\mathrm{p}=, 368\end{array}$} \\
\hline & & $\%$ & 47,7 & 52,3 & 100,0 & \\
\hline & \multirow{2}{*}{$\begin{array}{l}\text { Yabanc1 } \\
\text { sermaye }\end{array}$} & $\mathrm{f}$ & 9 & 6 & 15 & \\
\hline & & $\%$ & 60,0 & 40,0 & 100,0 & \\
\hline \multirow{6}{*}{$\begin{array}{l}\text { İşletmenin } \\
\text { çalışan sayısı }\end{array}$} & \multirow{2}{*}{ 0-10 kişi } & $\mathrm{f}$ & 42 & 51 & 93 & \multirow{6}{*}{$\begin{array}{c}\mathrm{x}^{2}=1,758 \\
\mathrm{df}=2 \\
\mathrm{p}=, 415\end{array}$} \\
\hline & & $\%$ & 45,2 & 54,8 & 100,0 & \\
\hline & \multirow{2}{*}{ 11-20 kişi } & $\mathrm{f}$ & 8 & 8 & 16 & \\
\hline & & $\%$ & 50,0 & 50,0 & 100,0 & \\
\hline & \multirow{2}{*}{$\begin{array}{l}21 \text { kişi veya } \\
\text { üzeri }\end{array}$} & $\mathrm{f}$ & 22 & 16 & 38 & \\
\hline & & $\%$ & 57,9 & 42,1 & 100,0 & \\
\hline
\end{tabular}

Tablo 17. "İşletmenizin düzenli olarak farklı düsünceleri araştırdığından ve bunlar arasından en nitelikli olanları seçmek ve bunları desteklemek için finans kaynağı aradı̆̆ından emin misiniz?" Sorusuna Verilen Yanıtların İsletmenin Faaliyet Yeri, Sermaye Yapısı ve Çalışan Kişi Sayısına Göre Karşılaştırılması

Tablo 17 İncelendiğinde, yaratıcı yenilik yapan işletmelerde kişisel inançların işletmenin faaliyet yerine $(\mathrm{x} 2=6,698 ; \mathrm{df}=3 ; \mathrm{p}=, 082)$, sermaye yapısına $(\mathrm{x} 2=, 812 ; \mathrm{df}=1 ; \mathrm{p}=, 368)$ ve çalışan sayısına $(\mathrm{x} 2=1,758 ; \mathrm{df}=2 ; \mathrm{p}=, 415$ göre istatistiksel olarak anlamlı düzeyde farklılaşmadığı görülmektedir.

\begin{tabular}{|c|c|c|c|c|c|c|}
\hline \multirow[t]{2}{*}{ Değişkenler } & \multirow[t]{2}{*}{$\begin{array}{l}\text { Alt } \\
\text { değişkenler }\end{array}$} & \multirow[t]{2}{*}{$\begin{array}{l}\text { Tanımlayıcı } \\
\text { istatistik }\end{array}$} & \multicolumn{2}{|c|}{$\begin{array}{l}\text { İşletmenizin piyasadaki } \\
\text { yaratıcılığını konuştuğunuz uygun } \\
\text { bir iş ortamı var mı? }\end{array}$} & \multirow[t]{2}{*}{ Toplam } & \multirow[t]{2}{*}{ Ki-Kare } \\
\hline & & & Evet & Hayır & & \\
\hline \multirow{8}{*}{$\begin{array}{l}\text { İşletmenin } \\
\text { faaliyet yeri }\end{array}$} & \multirow{2}{*}{ Yerel } & $\mathrm{f}$ & 23 & 12 & 35 & \multirow{8}{*}{$\begin{array}{c}\mathrm{x}^{2}=2,116 \\
\mathrm{df}=3 \\
\mathrm{p}=, 549\end{array}$} \\
\hline & & $\%$ & 65,7 & 34,3 & 100,0 & \\
\hline & \multirow{2}{*}{ Bölgesel } & $\mathrm{f}$ & 6 & 6 & 12 & \\
\hline & & $\%$ & 50,0 & 50,0 & 100,0 & \\
\hline & \multirow{2}{*}{ Ulusal } & $\mathrm{f}$ & 21 & 17 & 38 & \\
\hline & & $\%$ & 55,3 & 44,7 & 100,0 & \\
\hline & \multirow{2}{*}{ Uluslararası } & $\mathrm{f}$ & 41 & 21 & 62 & \\
\hline & & $\%$ & 66,1 & 33,9 & 100,0 & \\
\hline \multirow{4}{*}{$\begin{array}{l}\text { İşletmenin } \\
\text { sermaye yap1s1 }\end{array}$} & \multirow{2}{*}{$\begin{array}{l}\text { Yerli } \\
\text { sermaye }\end{array}$} & $\mathrm{f}$ & 82 & 50 & 132 & \multirow{4}{*}{$\begin{array}{c}x^{2}=, 026 \\
d f=1 \\
p=, 873\end{array}$} \\
\hline & & $\%$ & 62,1 & 37,9 & 100,0 & \\
\hline & \multirow{2}{*}{$\begin{array}{l}\text { Yabanc1 } \\
\text { sermaye }\end{array}$} & $\mathrm{f}$ & 9 & 6 & 15 & \\
\hline & & $\%$ & 60,0 & 40,0 & 100,0 & \\
\hline \multirow{6}{*}{$\begin{array}{l}\text { İşletmenin çalışan } \\
\text { sayısı }\end{array}$} & \multirow{2}{*}{ 0-10 kişi } & $\mathrm{f}$ & 55 & 38 & 93 & \multirow{6}{*}{$\begin{array}{c}\mathrm{x}^{2}=1,490 \\
\mathrm{df}=2 \\
\mathrm{p}=, 475\end{array}$} \\
\hline & & $\%$ & 59,1 & 40,9 & 100,0 & \\
\hline & \multirow{2}{*}{ 11-20 kişi } & $\mathrm{f}$ & 12 & 4 & 16 & \\
\hline & & $\%$ & 75,0 & 25,0 & 100,0 & \\
\hline & \multirow{2}{*}{$\begin{array}{l}21 \text { kişi veya } \\
\text { üzeri }\end{array}$} & $\mathrm{f}$ & 24 & 14 & 38 & \\
\hline & & $\%$ & 63,2 & 36,8 & 100,0 & \\
\hline
\end{tabular}

Tablo 18. "İ̧̧letmenizin piyasadaki yaratıcılı̆̆ını konuştuğunuz uygun bir iş ortamı var mı?” Sorusuna Verilen Yanıtların İşletmenin Faaliyet Yeri, Sermaye Yapısı ve Çalışan Kişi Sayısına Göre Karşılaştırılması

Tablo 18 İncelendiğinde, yaratıcı yenilik yapan işletmelerde yaratıcı iklimin işletmenin faaliyet yerine $(\mathrm{x} 2=2,116 ; \mathrm{df}=3 ; \mathrm{p}=, 549)$, sermaye yapısına $(\mathrm{x} 2=, 026 ; \mathrm{df}=1 ; \mathrm{p}=, 873)$ ve çalışan sayısına $(\mathrm{x} 2=1,490 ; \mathrm{df}=2 ; \mathrm{p}=, 475$ göre istatistiksel olarak anlamlı düzeyde farklılaşmadığı görülmektedir. 


\begin{tabular}{|c|c|c|c|c|c|c|}
\hline \multirow[t]{2}{*}{ Değişkenler } & \multirow[t]{2}{*}{$\begin{array}{l}\text { Alt } \\
\text { değişkenler }\end{array}$} & \multirow[t]{2}{*}{$\begin{array}{l}\text { Tanımlayıcı } \\
\text { istatistik }\end{array}$} & \multicolumn{2}{|c|}{$\begin{array}{l}\text { İşletmenizdeki bütün çalışanlar, } \\
\text { yaratıcıllığ işlerinin bir parçası } \\
\text { olarak dikkate alıyor ve bu } \\
\text { çalışanların yöneticileri onlardan } \\
\text { gelen fikirleri açık yüreklilikle } \\
\text { kabul ediyor mu? }\end{array}$} & \multirow[t]{2}{*}{ Toplam } & \multirow[t]{2}{*}{ Ki-Kare } \\
\hline & & & Evet & Hayır & & \\
\hline \multirow{8}{*}{$\begin{array}{l}\text { İşletmenin } \\
\text { faaliyet yeri }\end{array}$} & \multirow{2}{*}{ Yerel } & $\mathrm{f}$ & 24 & 11 & 35 & \multirow{8}{*}{$\begin{array}{c}\mathrm{x}^{2}=13,310 \\
\mathrm{df}=3 \\
\mathrm{p}=, 004\end{array}$} \\
\hline & & $\%$ & 68,6 & 31,4 & 100,0 & \\
\hline & \multirow{2}{*}{ Bölgesel } & $\mathrm{f}$ & 3 & 9 & 12 & \\
\hline & & $\%$ & 25,0 & 75,0 & 100,0 & \\
\hline & \multirow{2}{*}{ Ulusal } & $\mathrm{f}$ & 16 & 22 & 38 & \\
\hline & & $\%$ & 42,1 & 57,9 & 100,0 & \\
\hline & \multirow{2}{*}{ Uluslararası } & $\mathrm{f}$ & 42 & 20 & 62 & \\
\hline & & $\%$ & 67,7 & 32,3 & 100,0 & \\
\hline \multirow{4}{*}{$\begin{array}{l}\text { İşletmenin } \\
\text { sermaye yapısı }\end{array}$} & \multirow{2}{*}{$\begin{array}{l}\text { Yerli } \\
\text { sermaye }\end{array}$} & $\mathrm{f}$ & 76 & 56 & 132 & \multirow{4}{*}{$\begin{array}{c}\mathrm{x}^{2}=, 032 \\
\mathrm{df}=1 \\
\mathrm{p}=, 857\end{array}$} \\
\hline & & $\%$ & 57,6 & 42,4 & 100,0 & \\
\hline & \multirow{2}{*}{$\begin{array}{l}\text { Yabanc1 } \\
\text { sermaye }\end{array}$} & $\mathrm{f}$ & 9 & 6 & 15 & \\
\hline & & $\%$ & 60,0 & 40,0 & 100,0 & \\
\hline \multirow{6}{*}{$\begin{array}{l}\text { İşletmenin } \\
\text { çalışan sayısı }\end{array}$} & \multirow{2}{*}{ 0-10 kişi } & $\mathrm{f}$ & 51 & 42 & 93 & \multirow{6}{*}{$\begin{array}{c}\mathrm{x}^{2}=1,345 \\
\mathrm{df}=2 \\
\mathrm{p}=, 511\end{array}$} \\
\hline & & $\%$ & 54,8 & 45,2 & 100,0 & \\
\hline & \multirow{2}{*}{ 11-20 kişi } & $\mathrm{f}$ & 9 & 7 & 16 & \\
\hline & & $\%$ & 56,3 & 43,8 & 100,0 & \\
\hline & \multirow{2}{*}{$\begin{array}{l}21 \text { kişi veya } \\
\text { üzeri }\end{array}$} & $\mathrm{f}$ & 25 & 13 & 38 & \\
\hline & & $\%$ & 65,8 & 34,2 & 100,0 & \\
\hline
\end{tabular}

Tablo 19. "Işsletmenizdeki bütün çalışanlar, yaratıcılı̆̆ işlerinin bir parçası olarak dikkate alıyor ve bu çalışanların yöneticileri onlardan gelen fikirleri açık yüreklilikle kabul ediyor mu? " Sorusuna Verilen Yanıtların İşletmenin Faaliyet Yeri, Sermaye Yapısı ve Çalışan Kişi Sayısına Göre Karşılaştırılması

Tablo 19 İncelendiğinde, yaratıcı yenilik yapan işletmelerde destek süreçlerinin işletmenin sermaye yapısına $(\mathrm{x} 2=, 032 ; \mathrm{df}=1 ; \mathrm{p}=, 857)$ ve çalışan sayısına $(\mathrm{x} 2=1,345 ; \mathrm{df}=2 ; \mathrm{p}=, 511$ göre istatistiksel olarak anlamlı düzeyde farklılaşmadığ 1 , işletmenin faaliyet yerine $(x 2=13,310 ; \mathrm{df}=3 ; \mathrm{p}=, 004)$ göre ise istatistiksel olarak anlamlı düzeyde farklılaştığı görülmektedir. Yerel veya uluslararası faaliyet gösteren işletmelerde destek süreçlerine daha fazla önem gösterilmektedir. Bölgesel faaliyet gösteren işletmeler ise destek süreçlerine en az önem gösterenlerdir.

\section{Başlıca Bulgular ve Yorumlar}

İşletmelerin önemli bir oranda bütün yenilik aşamaları sürecine müşteri görüşlerini alması verilen cevaplar içinde aydınlatılmıştır. İşletmelerin çalışanların yaptıkları işlerden gelen düşünceleri, ürün geliştirme teklifleri ve piyasaya ilişkin gözlemleri, yeni ürünlere ve önerilere dönüştürmesine yardım ettiği ispatlanmıştır. Yanıt veren katılımcılar, çalıştıkları işletmelerin düzenli olarak farklı düşünceleri araştırma ve bunlar arasından en nitelikli olanları seçme ve bunları destekleme için finans kaynağı arama konusunda kararsız kalmıştır. Oysa yaratıcı yenilik için mali kaynakların bulunması ve bu konuya tahsis edilmesi gerekir. Bu araştırmaya katılan işletmelerde önemli bir oranda piyasadaki yaratıcılığın konuşulduğu uygun bir iş ortamı olduğu açıklanmıştır. Diğer işletmelerin de özellikle kitle iletişim araçlarında, kamuoyunda ve fisıltı gazetesinde yaratıcı yenilik yaptıklarından söz edilmesinin gerekli olduğu doğrulanmıştır. İşletmelerde çalışanların önemli bir oranının yaratıcılığı işlerinin bir parçası olarak dikkate aldıkları ve bu çalışanların ilk yöneticilerinin astlarından gelen farklı görüşleri çekinmeden benimsediği kanıtlanmıştır. Araştırmaya cevap veren ve büyük çoğunluğu yönetici olan katılımcıların farklı işletmelerde çalışması sonuçların güvenirliliğini yükseltmektedir. Araştırmaya cevap veren 147 katılımcı, beyaz eşya, bilişim, denetim, danışmanlık, eğitim, elektronik, finans, gayrimenkul, gıda, insan kaynakları, iletişim, kamu yönetimi, lojistik, taşımacılık, mimarlık, inşaat, mobilya, otomotiv, pazarlama, satış, sağlık, sigorta, güvenlik, tekstil, ticaret, turizm, üretim gibi alanlarda 22 farklı işletmede çalışmaktadır. Araştırmaya cevap veren katılımcıların büyük bir çoğunluğunun uluslararası ve yabancı sermayeli işletmelerde çalışması araştırmanın sonuçlarına ilişkin ulusal ve yerli şirketler için bir genelleme yapılmasına engel olmaktadır. Ancak aydınlatılan sonuçlara göre ulusal ve yerel işletmeler ile sermayesi yerli olan işletme yönetimlerinin yaratıcı yenilik bileşenlerini güçlendirmesi gerektiği söylenebilir. Ulusal ve yerel işletmeler, faaliyet amaçlarına erişmeleri, satışlarını yükseltmeleri ve küresel rekabet ortamında hayatta kalmaları için yaratıcı yeniliğe odaklanmalıdır. Engelleri geçme ve önce hayatta kalma için rekabette ayrıcalıklı olma, sonra satışları yükseltme, sürekli büyüme ve amaçlara ulaşmak için doğru liderlik, yönetimin inancı, çalışanların katkısı, kaliteli üretim ve hedef piyasaya odaklanma gerekir. Yerel veya uluslararası faaliyet gösteren işletmelerde destek süreçlerine daha fazla önem gösterilmektedir. Bölgesel faaliyet gösteren işletmelerdeki bütün çalışanların da destek süreçlerine daha fazla önem göstermeleri gerekir. 
$\mathrm{Bu}$ araştırmadan çıkartılacak başka bir ders, yönetimde yaratıcı yenilik oluşturmak önemli işletme faaliyetlerinden biridir. Bunu başarı ile gerçekleştirmek ise bütünüyle farklı bir konudur (Keegan ve Green, 2015).

Son ders ise her işletme kendi kaderini kendisi yazacaktır. Yaratıcı yenilik oluşturmak için yöneticilere büyük görevler düşmektedir. İşletmelerin geleceği gelecekte olacaklar değildir. Gelecek şimdi yapılanlar ile şekillenir (Hamel ve Prahalad, 1996).

Gelecekte yaratıcı yeniliğin ve özellikle teknolojinin gücü bugün değişik öngörüleri, büyük ve ateşli tartışmaları beraberinde getirmektedir (George, 2012; Watson, 2012).

\section{Sonuç}

$\mathrm{Bu}$ araştırmada yaratıcı yenilik bileşenlerinin incelenmesine bir bilişim şirketi verileri ile katkıda bulunmuştur. Bilişim işletmesinin veri ambarındaki 101886 yönetici olarak gözüken kişiye anket soruları iki kez belirli zaman aralığı verilerek gönderilmiş ve 147 kişinin anketi cevaplandırması sağlanmıştır. Alınan cevaplar 19 Tablo üzerinde gösterilmiştir. Bu araştırmaya katılanlar, çalıştıkları işletmelerin müsşteri ve kullanıcılarını önemli ölçüde anladığı, yönetimin işleri yürütme veya iş yapma yeteneği konusunda kararsız kaldığı, çalışanların kişisel olarak yaratıcı yeniliğe bir ölçüde inandığı, işletmelerde yaratıcı iklim ve işletmedeki destek süreçlerinin geliştirilmesi gerektiğini göstermiştir. Yönetim yaratıcı yenilik için öncelikle müşsterileri, tüketicileri ve kullanıcıların ihtiyaçlarını doğru anlamalıdır. Çalışanların düşüncelerini değerli yeniliklere dönüştürecek iyi tanımlanan ve kullanılan işletme süreçlerine sahip olması, yenilik sürecini uygulayacak bir inanç sistemi yaratması, iş ortamının yaratıcı iklime sahip olması, çalışanları yaratıcılığı destekleme ve yeni düşünceleri getirmeye inandırması 147 yönetici ile yapılan bu araştırma sonuçlarıyla ile kanıtlanmıştır. Araştırma konusuna uygun olan yönetimde yaratıcı yenilik bileşenleri aydınlatılmıştır.

Günümüz iş âleminde irili ufaklı, özellikle ulusal ve yerel çapta faaliyet gösteren işletmelerin açık olarak tanımlanmış amaçlarına ulaşması, beklenmedik gelişmelerle mücadele etmesi, değişime karşı koyması, piyasada anlamlı büyümesi, üretimini yükseltmesi, kârlılığını artırması, tüketici isteklerini karşılaması, müşteri tatmini sağlaması, etkin çalışması, değer yaratması, ürün geliştirmesi, iş süreçlerinin ihtiyaçlarına odaklanması, farklı sorunları çözmesi, sonuç üretmesi, uluslararası ölçekteki rakiplerinden üstün gelmesi, satış verimliliğini düzeltmesi, yatırım geri dönüşü sağlaması, yeni ürünleri tutundurması ve yaşaması buna bağlıdır. Bu durum ürün yeniliği, pazarlama yeniliği, süreç yeniliği ve işletme yeniliğini geliştirmek için son derece önemlidir.

Yaratıcı yenilik en çetrefilli meseleleri hesaba katar, bunları tanımlar ve sistemli olarak zarif çözümlere dönüştürür. Yaratıcı yenilik işletmenin falcılık, kâhinlik, büyücülük, üfürükçülük veya sihirbazlık gibi esrarengiz bir iş yapması değildir. Yaratıcı yenilik işletmenin can damarlarında dolaşan kan akışı gibi hayati derecede önemlidir. Yaratıcı yenilik günümüz işletmesinin tılsımlı bir ihtiyacıdır. Bütün yöneticilerin başlıca sorumluluğu bu ihtiyacı karşılamak için tutkuyla yaratıcı yeniliğe odaklanmaktır.

\section{Kaynakça}

- Adam Gant, "How to Built a Culture of Originality", Harvard Business Review, Vol.94, No.3 (March) 2016, pp.86-94.

- Ahmet H. Kirca ve Gaia Rubera, "The Role Of National Innovation Systems In The Firm InnovativenessPerformance Relationship", the 53rd Annual Meeting of the Academy of International Business, Nagoya, Japan, 2011.

- Brychan Thomas, Christopher Miller ve Lyndon Murphy, Innovation and Small Business: Volume 2, bookboon.com/22.11.2015.

- César Camisón ve Montserrat Boronat-Navarro, "Product Innovation as a Result of Knowledge Development Processes in Organisations", Knowledge Management for Process, Organizational and Marketing Innovation: Tools and Methods, Information Science Reference, New York, 2011, pp.134147.

- Charles E. Gaudet II, "Innovation vs. Marketing: Balancing The Two Key Elements Of Business Success", www.forbes.com/30.9.2015.

- Clayton M. Christensen ve Michael E. Raynor, The Innovator's Solution-Creating and Sustaining

Successful Growth, Harvard Business Review Press, Boston, Massachusetts, 2003.

- Clayton M. Christensen, The Innovator's Dilemma, Harper Business, New York, 2011.

- Didem Moralığlu, Ben Marka Olsam, Epsilon Yayınları, İstanbul, 2014.

- Elie Ofek ve Olivier Toubia, Marketing and Innovation Management-An Integrated Perspective, Now Publishers Inc. Hanover, 2010.

- Erdoğan Taşkın, İşletme Yönetiminde Eğitim ve Geliştirme, Üçüncü Basım, Papatya Yayıncılık, İstanbul, 2001. 
- $\quad$ Erdoğan Taşkın, Müşteri İlişkileri Eğitimi, Dördüncü Basım, Papatya Yayıncılık, İstanbul, 2014.

- Erkko Autio and Llewellyn D.W. Thomas, "Innovation Ecosystems Implication for Innovation Management?” The Oxford Handbook of Innovation Management, Ed. Mark Dodgson, David M. Gann and Nelson Phillips, Oxford University Press, 2014, s.204-228.

- Feridun Bingör ile yapılan araştırma görüşmesi ve şirket yazışması, Kendisine sağladığı veri ambarı için teşekkür ederim, İstanbul, 22.1.2016.

- Franco Malerba ve Pamela Adams, "Sectoral Systems of Innovation”, The Oxford Handbook of Innovation Management, Ed. Mark Dodgson, David M. Gann and Nelson Phillips, Oxford University Press, 2014, s.183-203.

- Frans Johansson, Yaratıcılı ve Inovasyon-Medici Etkisi Yaratmak, Çev. Dinç Tayanç, MediaCat Kitapları, İstanbul, 2013.

- Gary Hamel ve C.K. Prahalad, Competing for the Future, Harvard Business School Press, Boston, Massachusetts, 1996.

- Gary Hamel, What Matters Now-How to Win in a World of Relentless Change, Ferocious Competition, and Unstoppable Innovation, Jossey-Bass A Wiley Imprint, 2012.

- George Friedman, The Next Decade-Empire and Republic in a Changing World, Anchor Books, New York, 2012.

- Gijs Van Wulfen, The Innovation Expedition-A Visual Toolkit to Start Innovation, Bis Publishers, Amsterdam, 2014.

- Gülin Ustabaş ve Hakan Hekim araştırmanın tablolarını yapmıştır. Teşekkür ederim, İstanbul, 15.2.2016.

- Ian Clark S. Sinapuelas, Hui-Ming Deanna Wang, Jonathan D. Bohlmann, “The Interplay of Innovation, Brand, and Marketing Mix Variables in Line Extensions", Journal of the Academy Marketing Science, Vol.43, 2015, pp.558-573.

- Jaideep Prabhu, “Marketing and Innovation”, The Oxford Handbook of Innovation Management, Ed. Mark Dodgson, David M. Gann and Nelson Phillips, Oxford University Press, 2014, s.53-68.

- James Canton, The Top Trends That Will Reshabe The World in the Next 20 Years-The Extreme Future, A Plume Book, New York, 2007.

- Joshua Gans, “The Other Disruption-When Innovations Threaten the Organizational Model”, Harvard Business Review, Vol.94, No.3 (March) 2016, pp.78-84.

- Lale Ergin, Serdar Turan ve Merlin Özkan, “Inovasyonla Değer Yaratmak”, Harvard Business Review Türkiye, (Temmuz-Ağustos) 2015, s.42-51.

- $\quad$ Larry Keeley, Ryan Pikkel, Brian Quinn, Helen Walters, Ten Types of Innovation-The Discipline of Building Breakthroughs, John Wiley and Sons., New Jersey, 2013.

- Mats Lindgren, 21st Century Management-Leadership and Innovation in the Thought Economy, Palgrave Macmillan, London, 2012.

- $\quad$ Meryem Arslan, Inovasyon-Düşünmenin Zirvesi, Final Kültür Sanat Yayınları, İstanbul, 2014.

- Michael A. Gollin, Driving Innovation-Intellectual Property Strategies for a Dynamic World, Cambridge University Press, New York, 2010.

- Najibeh Abbasi Rostami, “Examining the Relationship between Marketing Capability and Innovation”, International Journal of Management, Accounting and Economics, Vol. 2, No. 1, January, 2015, pp.6472.

- Paul Trott, Innovation Management, Fifth Edition, Pearson Financial Times Prentice Hall, Harlow, 2012.

- Peter Doyle ve Susan Bridgewater, Innovation in Marketing, Chartered Institute of Marketing Professional Development, Butterworth-Heinemann, Oxford, 1998.

- Peter F. Drucker, “The Discipline of Innovation”, Harvard Business Review, Vol.76, No.6 (NovemberDecember) 1998, pp.149-157.

- Reşat Sinanoğlu, Verim Hedefli Yönetim, Türkmen Kitapevi, İstanbul, 2015.

- Richard Watson, Future Files-A Brief History of the Next 50 Years, Nicholas Brealey Publishing, London, 2012.

- $\quad$ Richard Watson, Future Mins-How to Digital Age is Changing Our Minds-Why This matters and What We Can Do About It, Nicholas Brealey Publishing, London, 2011.

- Roberto Verganti, “Eleştirinin Inovatif Gücü-Çı̆̆ır Açan Buluşların Yolu Fikirlerden Değil, Muhakemeden Geçer”, Harvard Business Review Türkiye, Y11 5, Sayı 1-2 (Ocak-Şubat) 2016, s.103-109. 
- Roland Berger, vd., Innovating at the Top-How Global CEOs Drive Innovation for Growth and Profit, Palgrave Macmillan, Hampshire, 2009.

- $\quad$ S.Tamer Çavusgil, Calantone, R. J. ve Zhao, Y., “Tacit Knowledge Transfer and Firm Innovation Capability.”, Journal of Business and Marketing, Vol.18, No.1, 2003, pp.6-21.

- S.Tamer Çavuşgil, Gary Knight ve John R. Riesenberger, International Business-The New Realities, Second Edition, Prentice Hall, Boston, 2012.

- Saïda Habhab-Rave, "Knowledge Management in SMEs: A Mixture of Innovation, Marketing and ICT: Analysis of Two Case Studies”, Knowledge Management for Process, Organizational and Marketing Innovation-Tools and Methods, Editors: Emma O'Brien, Seamus Clifford and Mark Southern, Hershey, 2011, pp.183-186.

- Sally Dibb, Lyndon Simkin, William M. Pride and O.C. Ferrell, Marketing: Concepts and Strategies, 6th Edition, Cengage Learning EMEA, Hampshire, United Kingdom, 2012.

- Scott Berkun, The Myths of Innovation, O’Reily, Printed in Canada, 2010.

- Serkan Kılıç, Inovasyon ve Inovasyon Yönetimi, Seçkin Yayıncılık, Ankara, 2013.

- Stephanie Hintze, Value Chain Marketing A Marketing Strategy to Overcome Immediate Customer Innovation Resistance, Springer International Publishing, Switzerland, 2015.

- Svend Hollensen, Essentials of Global Marketing, Pearson Education Limited, Edinburgh Gate, 2008.

- Thomas S. Robertson, “The Process of Innovation and the Diffusion of Innovation”, Journal of Marketing, Vol.31 No.1 (January) 1967, pp.14-19. http://doi.org/10.2307/1249295/05.01.2016.

- Tina Lynn Seelig, inGenius-A Crash Course on Creativity, Harper Collins Publishers, New York, 2012.

- Tom Keelley ve Jonathan Littman, The Ten Faces of Innovation, Currency Doubleday, New York, 2005.

- Tom Kelley ve David Kelley, Creative Confidence-Unleasing the Creative Potential Within us All, Crown Business, New York, 2013.

- Tony McCaffrey ve Jim Pearson, “Inovasyonu En Beklenmedik Yerde Bulmak”, Harvard Business Review Türkiye, Y1l 4, Sayı 12 (Aralık) 2015, s.94-101.

- Warren J. Keegan ve Mark C. Green, Global Marketing, Seventh Edition, Pearson, 2015. 


\title{
İnşaat Endüstrisinde İnovasyon ve Ekonomi Üzerindeki Etkisi Innovation in the Construction Industry and its Economical Effects
}

\author{
Asst. Prof. Dr. Fatih Kürşat Fırat (Aksaray University, Turkey) \\ Ph.D. Candidate Hümeyra Tosun (Aksaray University, Turkey)
}

\begin{abstract}
Construction sector in Turkey is one of the sectors that directly contribute to the national economy. The large volume projects done in the international arena shows that there is a major breakthrough in the Turkish construction sector. Turkish construction companies, which undertake an enormous amount of work in about ninety countries, have the second largest work capacity after China in the world. This shows clearly how much active the Turkey's foreign expansion strategy of the construction industry. When we look at the industry in general, it seems to be disastrous in innovation management compared to contracting services. In this respect, the various innovation studies must be made and the sector must be evaluated with all its parameters based on these innovation studies. The aim of this study is to examine the importance of innovation in the construction industry and to investigate economical effects. Within the context of the study, the importance of the construction sector in Turkey is firstly examined. Later, the importance of innovation activities in the construction sector is emphasized based on the available data. Consequently, the steps taken by the governments and employers are discussed on the subject of innovation studies in order to increase Turkey's competitiveness in the international market.
\end{abstract}

\section{Giriş}

Dünyada insan sayısı gittikçe artmakta ve teknolojiler geliştikçe yaşam standardı değişmekte, farklılıklar ortaya çıkmaktadır. Ülkeler çeşitli nedenlerden dolayı farklı kalkınma seviyelerine ulaşmaktadır. Bazı ülkeler gelişmişlik seviyesinin en üstündeyken bazı ülkeler gelişmelerini henüz tamamlayamamıştır. Bu gelişme farklılıklarının nedenleri arasında; doğal kaynakların dağılımı, nüfus artış hızı, yatırımlar, enerji kaynaklarına olan uzaklık, sanayileşme, bilim ve teknoloji rekabet üstünlüğü gibi faktörler sayılabilmektedir. Bu faktörlerin her ülkede farklı olması ülkelerin farklı standartları yakalamasına neden olmaktadır. Bazıları yoksulluk sınırında yaşarken bazıları da yüksek yaşam kalitesine sahip olabilmektedir. Geçmişten günümüze kadar dünyadaki bu farklılıkları anlayabilmek için gerek ulusal gerekse uluslararası pek çok çaba sarfedilmiş birçok teori geliştirilmiştir.

Yeni dönemin ekonomisi, küresel para piyasalarının, ileri teknoloji gerçekleştiren kuruluşların, imalat merkezlerinin birbirine entegre olduğu yapıya dönüşmüştür. Böyle bir küresel düzende genetik-psikoloji-nöroloji üçgeninde birey ve kitlelerin pozitif veya negatif bir şekilde manipüle edilmesi mümkündür. Bu gelişmeler, teknoloji ve bilgi çağında davranışsal ekonominin öneminin artacağı anlamına gelmektedir (Fırat, Kurtoğlu, 2014). Geçmişten günümüze kadar, bilim ve teknoloji konusunda rekabet üstünlüğü sağlamış ülkeler gelişmiş ülke statüsünde yer almış, gelişmekte olan ekonomilerin ise daha çok emek yoğun mal ve hizmet üretiminde bir üstünlükte sınırlı kaldıkları görülmüştür. Buna ilaveten düşük gelirin hâkim olduğu ekonomilerde emek yoğun mal ve hizmet üretimi belli bir aşamaya kadar avantaj sağlarken, bir süre sonra dezavantaja dönüşmüştür. Düşük gelirli ekonomilerin kalkınmalarının ilk dönemlerinde bol ve ucuz iş gücüne sahip olduklarından dolayı yükselişleri daha hızlı olmuştur. Ancak bu avantaj belli bir süre geçtikten sonra ortadan kalkmış ve bunun sonucu olarak rekabet edemeyen ekonomiler oluşmuştur. Dolayısıyla, teknolojinin geliştirilmemesi ve verimliliğin artırılmaması halinde, büyüme oranlarının bir üst seviyedeki gelir kategorisine uzun yıllar ulaşması mümkün olamamaktadır (Karagöl ve Karahan, 2014). Ekonomik kalkınma ve sürdürülebilir kalkınmanın ve istihdam yaratılmasında inşaat endüstrisinin çok önemli bir yeri vardır. İnşaat sektörü, bir ülkenin ekonomik büyümesinde motor görevi yapmaktadır. Bu bakımdan bir ülkedeki inşaat endüstrisi ne kadar gelişmişse ekonomik büyümeye katkısı o kadar fazla olacaktır. Bir ülkedeki konjonktürel dalgalanmalardan ve ekonomik krizlerden öncü sektörlerin başında gelen inşaat endüstrisi ve inşaat malzemeleri sektörü öncelikli olarak etkilenmektedir. İnşaat endüstrisi ve sektörün faaliyetleri ülkedeki makro ekonomik politikalardan doğrudan etkilenmektedir (F1rat, Akbaş, 2014). İnşaat sektöründe ülke içerisindeki üretim dolayısı ile tüketim çeşitliliğin fazla olması sebebiyle ülke sanayi açısından birçok yatırım olanaklarına sahiptir. Bu yapısı ile de inşaat malzemeleri sanayisini direkt olarak etkilemektedir. Binalar, yollar, köprüler, tüneller, metrolar, barajlar, güneş ve rüzgâr enerji santralleri gibi gerek kamunun gerekse özel sektörün her türlü faaliyetleri ekonomik kalkınma için gerekli yatırımlardır.

İnşaat endüstrisinde üretim faktörlerinden hammadde çok kullanılmaktadır. Her sektörde olduğu gibi inşaat sektöründe de üretim maliyetlerini minimum seviyeye indirmek, hammadde kullanımını azaltmak ve enerji israfindan kaçınmak sözkonusudur. İşletmeler karlarını maksimum yapmaya çalışırken bir yandan da üretim girdi ve işçilik maliyetlerini minimum yapmak için çalışmaktadırlar. İnşaat endüstrisinde en çok kullanılan malzemelerin başında beton, asfalt, ahşap, alüminyum, demir gibi malzemeler gelmektedir. Gelişmekte olan ülkelerin çoğunda bu malzemelerin dışarıdan ithal edilmesine gerek kalmamaktadır. Özellikle inşaat alanına 
yapılan yatırımlar ülkeler için önemli miktarlarda ekonomik ve hammadde kaynağı sağlamaktadır. Dünyanın sanayi çağından bilgi çağına doğru değiştiği dönemde insanlarda değişerek farklı yenilikler peşinde koşmuşlardır. $\mathrm{Bu}$ yenilik anlayışının hammaddeleri doğru ve yerinde kullanımıyla ilgili farklı çalışma anlayışlarının ortaya atılmasında önemi büyüktür.

Ülkeler küresel ekonomik ortamda Ar-Ge ve inovasyon faaliyetlerini arttırarak, inovasyon konusunda uzun dönemli çalışmalar yapmışlar, ekonomik büyüme ve kalkınma için inovasyon süreçlerine odaklanmışlardır (Işık ve Kılınç, 2012). Son zamanlarda her alanda olduğu gibi inşaat endüstrisinde de inovasyona talep artmıştır. Örnek olarak şu anda dünyada sudan sonra en çok tüketilen beton, daha çok kısa bir süre 30 yıl önceye kadar şantiyede elle karılarak el arabaları ile taşınıp imalat yapılırken, şu anda neredeyse bütün inşaatlarda, fabrikalarda ileri teknoloji ile üretilip şantiye sahasına özel taşıyıcılarla taşınarak beton pompaları ile kalıplara dökülmektedir (Şekil $1)$.
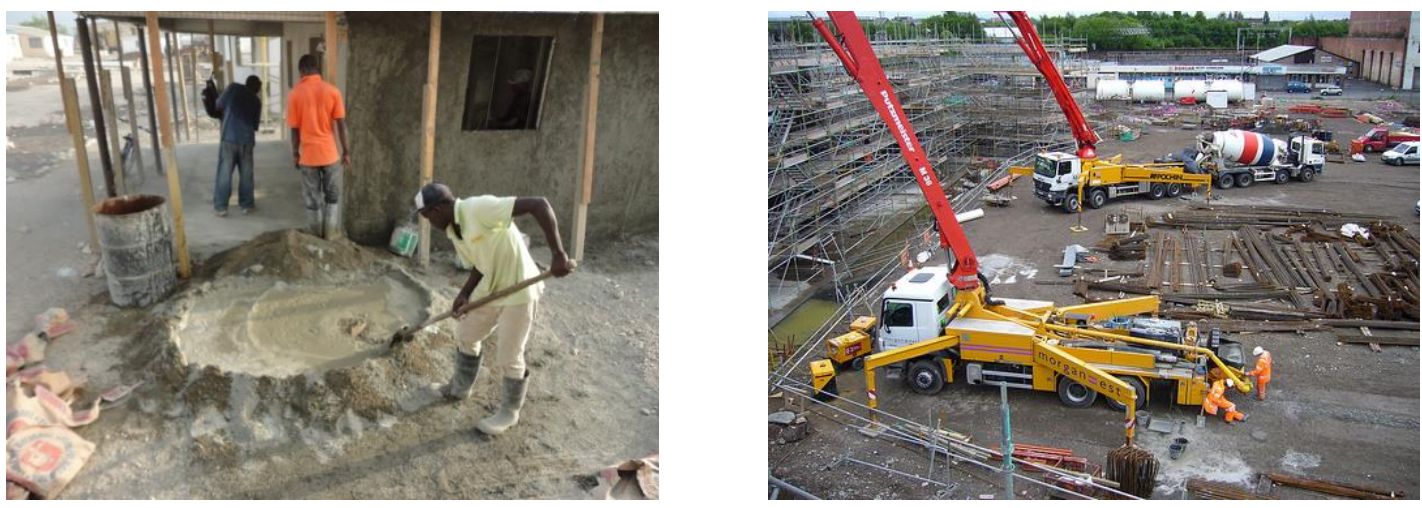

\section{Şekil 1. Eski ve Yeni Beton Döküm Şekli}

Son yıllarda ülkelerin kalkınması için salt ekonomik olarak büyüme yeterli görülmemiştir. Büyüyen ülkeler büyümesini toplumun diğer alanlarına yansıtıp kalkınma sürecine dahil etmek zorundadır. İnsan odaklı kalkınma ülkelerin mevcut durumlarını görmeleri ve kalkınmayı tetikleyecek adımlar atması gerekliliğini ortaya koyduğu için önemlidir. İnsan odaklı kalkınma kavramıyla birlikte Ar-Ge ve inovasyonun önemi bir kat daha artmış ekonomik kalkınmanın ölçülmesinde çeşitli endeksler geliştirilmiştir (Fırat, Aydın, 2015). Gelişmekte olan ülkelerin daha yüksek kalkınma aşamalarına ulaşabilmelerinin inovasyona bağlı olduğu günümüzde tartışma götürmez bir gerçektir. Firmaların kârlarını ve pazar paylarını artırmaları ve rekabet avantajı elde etmeleri konusunda inovasyon vazgeçilmez bir unsur olarak düşünülmektedir. Küreselleşen dünyayla birlikte teknoloji de hızla değişmektedir. Teknolojik gelişmeler inovasyonla iç içe geçmiş durumdadır. Ülkelerin bilim ve teknik alanındaki inovasyonları Ar-Ge çalışmalarıyla sağlanmaktadır. Bu yüzden Ar-Ge ve inovasyon faaliyetleri ülkelerin ekonomik büyüme ve kalkınma politikaları ile desteklenmektedir. İnovasyon sayesinde ülkelerin ekonomik, siyasi ve sosyal yapısı değiştirmekte ve küreselleşen dünyada rekabet artmaktadır. Bu nedenle bütün ülkeler bilim ve teknoloji politikalarını bir bütün olarak ele almakta ve bu ileri teknolojiye sahip olmak için Ar-Ge ve inovasyon faaliyetlerine ağırlık vermektedirler.

Günümüzde ülkeler ve işletmeler, inovasyon ve Ar-Ge faaliyetlerine önem vermekte bu konudaki hassasiyetlerini yaptıkları Ar-Ge ve inovasyon eğitimlerinde belirtmektedirler. Özellikle özel sektördeki yenilikçi işletmeler dikkat çekmektedir. İnşaat sektöründe de büyük firmalar, Ar-Ge ve inovasyona pazarlamadan daha fazla kaynak ayırmaktadır. Ar-Ge faaliyetlerinin sanayileşmiş ve gelişmiş ülkelerde yoğunlaşması endüstrileşmenin ArGe ile bağlantısını göstermektedir (Akbey, 2014). Ar-Ge ve inovasyon, hem teknolojik yenilik üretme çalışmaları hem de ekonomik süreç üzerindeki etkileri ile ilgili çalışmalar yeni olmamakla birlikte bu çalışma inşaat endüstrisinde yapılan Ar-Ge ve inovasyonun ekonomi üzerindeki etkisini vurgulamak amacıyla yapılmıştır.

\section{Ar-Ge ve İnovasyon}

İnovasyon, OECD’ye göre "bir fikri pazarlanabilir bir ürün ya da hizmete, yeni ya da geliştirilmiş bir imalat yahut dağıtım yöntemine, ya da yeni bir toplumsal hizmete dönüştürmektir”.

"Yenilik" kavramı aynı anlama geldiği için yerine kullanılsa da aslında birebir aynı değildir çünkü inovasyon kavramı bir yeni bir fikri ortaya atmak değil o fikri uygulayarak ülke ekonomilerine, kültür ve sosyal alanına dönüştürülüp farklı yenilikler oluşturmaya denmektedir (Uzkurt, 2010). Ülkelerin kalkınmaları açısından önemli olan inovasyon, günümüzde önemini artırarak ilgi odağı olmuştur. Çünkü ülkelerin kalkınmışlık düzeylerini arttırmanın yolu Ar-Ge faaliyetlerinin artması ve sektörler arasında bilgilerin yayılması ile yeni fikirler veya önceki fikirleri geliştirerek, farklı özellikler katılarak fikirler oluşturulup uygulamaya konularak ülkelerin kalkınmalarına katkıda bulunmaktadır (Işık ve Kılınç, 2012). 
Eski inovasyon sistemleri 1990'lı yılların başlarına kadar Ar-Ge, üretim ve pazarlama arasındaki ilişkiye bağlı olarak çalışmaktadır. Eski inovasyon sistemleri Ar-Ge, üretim ve pazarlama bölümleri arasındaki etkileşim sonucu ortaya çıkmıştır. 1990’lı yıllardan sonra küreselleşmenin de etkisiyle büyüyen pazarın ve artan teknolojik gelişmelerin etkisiyle birlikte bilimsel gelişmeler ve iletişim ağındaki yenilikler yakından takip edilmiş, pazarlama, Ar-Ge ve üretim arasında güçlü bir bağ geliştirilmiş modern inovasyon sistemleri kurulmuştur. 2000'li yıllarla birlikte, küresel çevre sorunlarının artması, bilim ve teknolojinin hızla değişmesi ve bilişim teknolojisindeki ilerlemeler sistemli ve yenilenen Ar-Ge ve inovasyon sistemlerinin doğmasına yol açmıştır. Günümüzde işletmeler ya da ülkeler inovasyonlarını bilgi ve teknolojiyle birleştirerek ulusal inovasyon ağlarını uluslararası ağlara açarak, etkileşim ve işbirliğine bağlı değişik inovasyon sistemleri geliştirmişlerdir. Girişimciler inovasyonla verimliliklerini arttırabilmekte, piyasa talebine cevap vermekte ve teknolojiyi gelişmiş ülkelerden gelişmekte olan ülkelere hızla yaymaktadır. Gelişmiş ülkelerin çoğu teknolojileri sayesinde bu bağlamda önemli kazanımlar elde etmiştir. Schacht (2000),'’n yaptığı bir çalışmada Amerika Birleşik Devletlerinin büyümesinde teknolojik gelişmenin etkisinin fazla olduğu açıklanmıştır (Uzkurt, 2010). Özel sektörde firmalar küreselleşme sonucu rekabetin artmasıyla küresel pazardan pay alabilmek için, Ar-Ge ve eğitim konularında bütün imkanlarını kullanarak inovasyonlarını artırma stratejileri geliştirmişler ve bilişim ve iletişim teknolojilerini yeni inovasyon yapmak için kullanmışlardır. Son yıllarda ülkeler de kamu politikalarıyla da inovasyon teşvik edilmiş, devlet politikalarıyla Ar-Ge ve inovasyon uygulamaları arttırılmış ve desteklenmiştir. Örneğin Çin, Japonya, Finlandiya, Almanya, Güney Kore, Singapur ve Amerika Birleşik Devletleri gibi gelişmiş ekonomilerde inovasyon sayıları artmış, yaratıcı uygulamalar küresel piyasalarda yerini almıştır. İnovasyon hem ülke ekonomisinin gelişmesinde hem de kişilerin milli gelirlerini artırmalarında en önemli faktör haline gelmiştir (Duran ve Saraçoğlu, 2009). İnovasyon, hem günümüz ulusal ekonomileri ve ülke kalkınmaları hem de işletmeler ayakta kalması için vazgeçilmez bir dinamizm kaynağı haline gelmiştir. İnovasyon; bölgesel ve ekonomik büyüme ve kalkınmanın, toplumlar için insani kalkınma düzeyinin, hem firmalar hem de ulusal ekonomilerin rekabet etme gücünün temeli haline gelmiştir. İnovasyonun ülkeler, bireyler ve işletmeler için olumlu sonuçlar yaratmaktadır (Uzkurt, 2010). Literatürde yaygın olarak rastlanan inşaat inovasyon modelleri; E.Sarah Slaughter'in 1998'de yaptığı çalışmada açıklanmaktadır. Araştırmacı; imalat aktiviteleri ve inşaatın doğası gereği oluşan farklılıkları mevcut inovasyon modellerindeki değişiklikle açıklamaktadır. İnşaat inovasyonlarını aşağıdaki 5 ana başlıkta toplamıştır (Fiş, 2010):

-Aşamalı İnovasyon

-Radikal İnovasyon

•Modüler/Ürün İnovasyonu

-Süreç/Mimari İnovasyon

-Sistem İnovasyonu'dur.

Bu modellerden; aşamalı inovasyon mevcut bilgi ve deneyime dayanan küçük değişikliklerdir. Buna karşıt olarak radikal inovasyonlar ise; sektörün karakterini ve doğasını değiştiren teknoloji ve bilime dayanan büyük değişimlerdir. Modüler ve Mimari İnovasyon bileşen ve sistemlerdeki değişiklikleri esas alır. Modüler inovasyon; bileşen içeriğinde önemli değişiği gerektirir ancak sistem ve diğer bileşenlerde etkisi olmaz. Mimari inovasyon ise her bir bileşende küçük ama nihai olarak sistemde büyük değişimleri gerektirir. Son olarak sistem inovasyonu; çoklu inovasyonların birbiri arasında entegrasyonudur. Tüm bileşen ve sistemlerdeki değişimleri kapsar (Fiş, 2010)

\section{Dünya'da ve Türkiye'de İnovasyonun Önemi}

Küreselleşen dünya ekonomisinde yeni firsatlar beraberinde sorunları da getirmiş, uluslararası rekabet edebilirlikte inovasyon ve Ar-Ge de önemlerini iyice arttırmışlardır. OECD (Ekonomik işbirliği ve Kalkınma Örgütü) araştırmalarına göre; gelişmiş ekonomilerin son otuz yıllarda gelişip daha da büyümesinin ve bu kategori içinde yer almasının ana aktörü Ar-Ge ve inovasyondur. Tablo-1'de, 2014-2015 yılları itibariyle AB'ye üye ve aday ülkelerden bazıları ile Türkiye'nin Küresel Rekabet Endeksi ölçümüyle ilgili olarak inovasyon sıralaması gösterilmiştir. 2014-2015 yılları itibariyle inovasyonda önde olan ülkeler; Finlandiya, Almanya, Hollanda, İsveç, Birleşik Krallık ve Danimarka iken, Türkiye'nin inovasyonda 56. sırada yer almıştır. Ülkemizin son y1llarda yeniden yapılandırma politikalarıyla olumlu ekonomik gelişmelerin yaşanmasına rağmen insani kalkınma düzeyinin gelişmiş ülkeler seviyesine çıkarılmasında, küresel rekabet gücünün artırılmasında, gelir seviyesinin ve yaşam standartlarının yükseltilmesinde, eğitim, istidam, Ar-Ge ve inovasyon konularında da aynı başarıyı yakalayamadığını göstermektedir. Böylece kalkınma sürecinde önemli rol üstlenen inovasyon konusunda, ülkemiz henüz istenilen düzeye gelememiştir. Bu bakımdan ülkemizin rekabet edebilirliğini arttırması için Ar-Ge, yenilikler yapması, ileri teknolojilerle ürünler üretmesi ve birçok sektörlerde farklılıklar yaparak gelişme göstermeli ki ülke hem refahını hem kalkınmasını hem de rekabet edebilirliğini arttırabilir. 


\begin{tabular}{|l|c|c|l|c|c|}
\hline Ülke & Sıra & ED & Ülke & Sıra & ED \\
\hline Almanya & 6 & 5,47 & İtalya & 35 & 3,73 \\
\hline Avusturya & 18 & 4,82 & Kıbrıs & 36 & 3,72 \\
\hline Belçika & 13 & 4,89 & Letonya & 70 & 3,27 \\
\hline Birleşik Krallık & 12 & 4,96 & Litvanya & 44 & 3,62 \\
\hline Bulgaristan & 105 & 2,94 & Lüksemburg & 16 & 4,85 \\
\hline Çek Cumhuriyeti & 39 & 3,67 & Malta & 45 & 3,60 \\
\hline Danimarka & 11 & 5,06 & Polonya & 72 & 3,26 \\
\hline Estonya & 30 & 3,95 & Portekiz & 28 & 4,08 \\
\hline Finlandiya & 1 & 5,78 & Romanya & 66 & 3,28 \\
\hline Fransa & 19 & 4,74 & Sirbistan & 108 & 2,89 \\
\hline Hollanda & 8 & 5,25 & Slovakya & 78 & 3,18 \\
\hline Hırvatistan & 93 & 3,10 & Slovenya & 42 & 3,64 \\
\hline İrlanda & 20 & 4,68 & Yunanistan & 79 & 3,18 \\
\hline İspanya & 37 & 3,69 & Makedonya & 68 & 3,28 \\
\hline İsveç & 7 & 5,37 & Türkiye & 56 & 3,42 \\
\hline
\end{tabular}

Tablo 1: 2014-2015 Yıllarl Arasında İnovasyon Konusunda AB Ülkeleri ve Aday Ülkeleri ile Türkiye Üzerindeki Küresel Rekabet Endeksi Ölçümü Kaynak: WEF, The Global Competitiveness Report 2014-2015,. Endeks Değeri http://www3.weforum.org/docs/WEF_GlobalCompetitivenessReport_2014-15.pdf, Erişim tarihi: 03.02.2016.

Gelişmiş ülkeler sanayiye ve temel bilimlere verdikleri destekler ve yatırımlar ile rekabetçi güçlerini ve yenilikçi yapılarını dengeli bir biçimde artırmaktadır. Ülkemizin rekabetçi bir ekonomi ve yenilikçi bir endüstriye sahip olabilmesi için yapılan yatırımlar içinde en çok inşaat gibi ekonominin lokomotifi olarak nitelendirilen temel endüstrilere önem vermesi, gerekmektedir. Bu duruma ekonomiyi destekleyecek nitelikte politikalar geliştirilerek katkı sağlanmalıdır. Hükümetlerin, inşaat endüstrisinin ülke ekonomisine katkısını gözönüne alarak Ar-Ge ve inovasyonu destekleyen ekonomik politikalar oluşturmak için gerekli yasal değişiklikleri ve teşvikleri de kendi politikalarına eklemeleri gerekmektedir.

Şekil 2'de Türkiye'de Ar-Ge harcamalarının GSYİH'ye oranı yıllar itibarıyla gösterilmiştir. Ar-Ge harcamalarının GSYİH'ye oranı 2008 yılında 0.73 iken 2014 yılında 1.01seviyesine yükselmesi Ar-Ge'ye verilen önemin gittikçe arttığını göstermektedir. Her ne kadar Türkiye'de yenilik ve teknoloji son yıllarda daha da gelişmiş ve büyümüş ve büyümeye devam etmekte olsa bile Türkiye yaşanan krizlerin etkisiyle de Ar-Ge, yenilik ve teknolojide geri kalmış bu sebeple de çoğu ürünü ihraç yerine ithal ederek gelişmekte olan ülke kategorisi içinde yer almıştır. Son yıllarda bu alanlarda yapılan gelişmeler ve ayrılan bütçelerinde artması ve insanların, firmaların ve ülkemizin inovasyon alanında kendini geliştirip bu alana yoğunlaşmasıyla daha hılı yol kat edilecektir.

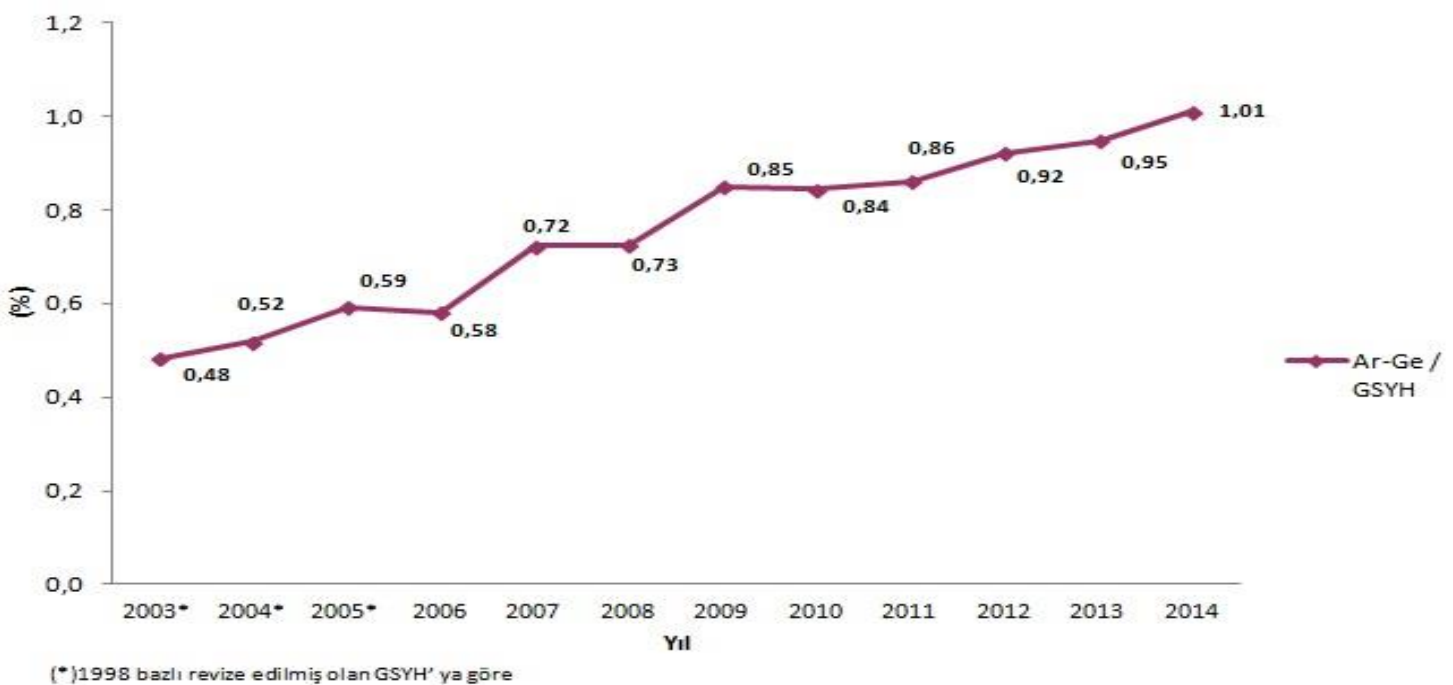

Şekil 2 Ar-Ge Harcamasinin GSYH içindeki payl. Kaynak: TÜIK (Türkiye İstatistik Kurumu) 


\begin{tabular}{|l|c|c|c|}
\hline Ülkeler & $\begin{array}{c}\text { Mevcut GSYH'nin } \\
\text { yüzdesi }\end{array}$ & $\begin{array}{c}\text { Ulusal Hedef } \\
\text { GSYH'nin yüzdesi }\end{array}$ & $\begin{array}{c}\text { Ulusal Hedef } \\
\text { yll }\end{array}$ \\
\hline Kore & 4.36 & - & - \\
\hline İsrail & 4.2 & - & - \\
\hline Finlandiya & 3.55 & 4 & 2020 \\
\hline İsveç & 3.41 & 4 & 2020 \\
\hline Japonya & 3.35 & 4 & 2020 \\
\hline Almanya & 2.98 & 3 & - \\
\hline ABD & 2.79 & 3 & 2020 \\
\hline Fransa & 2.29 & 3 & 2020 \\
\hline Çin & 1.99 & 2.5 & - \\
\hline Rusya & 1.12 & 1.77 & 2015 \\
\hline Türkiye & 1.01 & 3 & 2023 \\
\hline Yunanistan & 0.69 & 1.5 & 2020 \\
\hline
\end{tabular}

Tablo 2 Ar-Ge Harcamasının GSYH İçindeki Payı Cinsinden Bazı Ülkelere Göre Mevcut Olan Değerler ve Ulusal Ar-Ge Harcama Hedeflerinin Karşılaştırılmasl. Kaynak: Bilim, Teknoloji ve Sanayide Türkiye'nin Duruтu Raporu, Türkiye İsveren Sendikaları Konfederasyonu Yayını, 2015.

Özellikle 2000'li yıllarda giderek artan inovasyon faaliyetleri Türkiye'nin ekonomik kalkınması üzerinde olumlu etkiler yaratmakla birlikte diğer ülkelerle kıyaslandığında durum pek içaçıcı görünmemektedir. Tablo 2'de görüldüğü gibi Türkiye, 2023 yılına kadar Ar-Ge harcamasının GSYH'deki payının \%3 olması hedeflemiştir. Bununla beraber bu oran için hedef tespit eden birçok ülke içerisinde, şu andaki durumu ile hedefi arasında açıklığın en fazla olduğu ülkedir. Bir başka ifade ile Türkiye, 2023 hedefine ulaşmak için Ar-Ge ve inovasyon konusunun üzerine daha fazla eğilmeli diğer ülkelerden daha çok çalışmalar yapması gerekmektedir. Buna karşılık, Kore ve İsrail uzun vadeli bir hedef olmamasına rağmen sırasıyla \%4,36 ve \%4,20 ile \%3'ün üzerine çıkmışlardır. "Türkiye'de bilimsel yayın sayısı ve patent tescil sayısı bakımından 2014 yılı için 3.644 bilimsel yayın ve 2015 y1lı için 382 patent tescil sayısı ile öne çıkan alan makine-imalat alanı olmuştur. 2015 yılı itibariyle fonlamasının tamamı ya da bir kısmı kamu tarafından gerçekleştirilen Ar-Ge ve yenilik projelerinin sayısı bakımından 1.676 proje, 2015 yılında destek kararı verilen, yürürlükte olan ya da tamamlanmış olan projelere kamu tarafindan aktarılan fon bakımından 154 milyon TL, 2014 yılı bilimsel yayın sayısı bakımından 12.655 bilimsel yayın, 2015 yılı patent tescil sayısı bakımından 267 patent tescil sayısı, 2015 yılında uluslararası işbirliğinde yapılan Ar-Ge ve yenilik projeleri toplam bütçesi bakımından 27 milyon TL ile öne çıkmaktadır. 2015 yılında ulusal işbirliğinde yapılan Ar-Ge ve yenilik projeleri içinse 102 milyon TL ile uzay alanı öne çıkmaktadır". Türkiye'nin ekonomik ve toplumsal gelişimi için inşaat sektörü alanında Ar-Ge ve inovasyon faaliyetlerinin hızlanması, ülkemizin şimdiki ve gelecekteki rekabet gücünün artması ve ulusal güvenlik sorunun çözülmesi önem arz etmektedir. Yenilikçi ürünlerin üretilmesi ve geliştirilmesi kaynakların etkin ve verimli kullanılmasına yol açarak, ekonomik kalkınmayı sağlayacaktır. Bu yüzden inşaat endüstrisinin ekonomik ve toplumsal yararları dikkate alarak, çevreye zarar vermeyen, toplumun yaşam kalitesini yükselten küresel rekabet düzeyinde Ar-Ge ve inovasyon yapması gerekmektedir (Türkiye Bilimsel ve Teknolojik Araştırma Kurumu, 2016).

\section{Dünyada ve Türkiye'de İnşaat Endüstrisi'nde İnovasyon ve Ekonomik Etkileri}

Dünyanın birçok ülkesi küresel krizden olumsuz etkilenmiş, daralmaya giren inşaat sektörü, gelişmekte olan ülke ekonomilerde büyümeyi sürdürebilmiştir. Son yıllarda dünyada ve ülkemizde inşaat sektörü müşteri beklentilerinin ve taleplerine bağlı olarak hızla değişmiştir. Bu gelişmeler inşaat sektöründe yeni teknolojilerin doğmasına yol açmıştır. Böylelikle inşaat endüstrisinde hem müşteri taleplerini karşılayacak hem de maliyeti düşük teknolojiler yakalanmaya çalışılmıştır. Günümüzde inşaat endüstrisinde uluslararasılaşma ve farklılaşma en önemli hedefler arasında sayılmıştır. İnşaat endüstrisinin gelişiminde kentleşmenin çevreye verdiği zarar da önemli rol oynamıştır. Karbondioksit salınımının, enerji tüketiminin ve atıkların çevreye verdiği zararların boyutunun artması sonucu inşaat endüstrisinde çevre dostu yeni teknolojilere ihtiyaç duyulmuştur. Maliyet odaklı bir sektör olan inşaat sektörü Ar-ge ve inovasyon açısından pek başarılı olamamaktadır. Özellikle son dönemlerde çevresel sürdürebilirlik, enerji verimliliği, azalan kaynaklar, çevre kirliliği gibi küresel sorunların etkisiyle inşaat sektöründe teknolojik inovasyona gereksinim giderek artacaktır (Candemir vd., 2012). Yeni teknolojiler ve bu teknolojilere yapılacak olan yatırımlar inşaat sektöründe maliyetlerin düşmesine ve bunun yanında farklılaşan müşteri taleplerine karşılık vermesine, sürdürebilir kentleşme ve çevrenin korunması, imkanı tanıyacaktır. Bu bağlamda bakıldığında inşaat sektörünün bir dönüşüm eşiğinde olduğunu ve rekabet edebilirliğin teknolojik gelişmelerde yattığı öngörülmektedir.

Dünyada 2013 y1lı için inşaat sektöründe büyüme Şekil 3’te verilmiştir. Ülke ekonomilerinin en önemli yapitaş1 olan inşaat sektörü, 7,5 trilyon dolarla dünya üretiminin \%13,4'ünü oluşturmaktadır; 2020 yllında ise $\% 70$ büyüme ile 12,7 trilyon dolara ulaşacağı dünyadaki üretimin \%14,6'sını oluşturacağı tahmin edilmektedir (Candemir vd, 2012). İnşaat sektörü OECD ülkelerinde GSH'nın \%6,47'sini ifade etmektedir. Avrupa'da ise bu oran \%10 
civarındadır. Avrupa Birliğine üye olan 15 ülkede inşaat sektörünün istihdam oranı \%7 iken, sanayi istihdamı içindeki payı \%28'dir (Candemir vd, 2012). 2020 yılına kadar inşaat sektörünün çok hızlı bir büyüme kaydedeceği ve bunun sonucunda ekonomilerin ve pazarların önemli rol oynayacakları bilinmektedir. Bu kadar büyüme eğiliminde olan bir sektörde inovasyon yatırımlarının sonucunda elde edilecek ekonomik gelirler önemli oranda olacak ve ülkelerin milli gelirlerinin artmasına sebep olacaktır. Şekil 4'te Türkiye'de GSYH reel büyüme ve inşaat sektörü reel büyüme ilişkisi verilmiştir. Bu ilişkide Türkiye'de inşaat sektöründe meydana gelecek reel büyüme ile GSYH arasında doğru orantı olduğu açıkça ortaya konmaktadır. Bir diğer bağlamda inşaat endüstrisindeki inovasyon kazanımları GSYH'yi doğrudan olumlu yönde ciddi oranda etkileyecektir.

\section{Inșaat Sektöründe Büyüme (\%, 2013)}

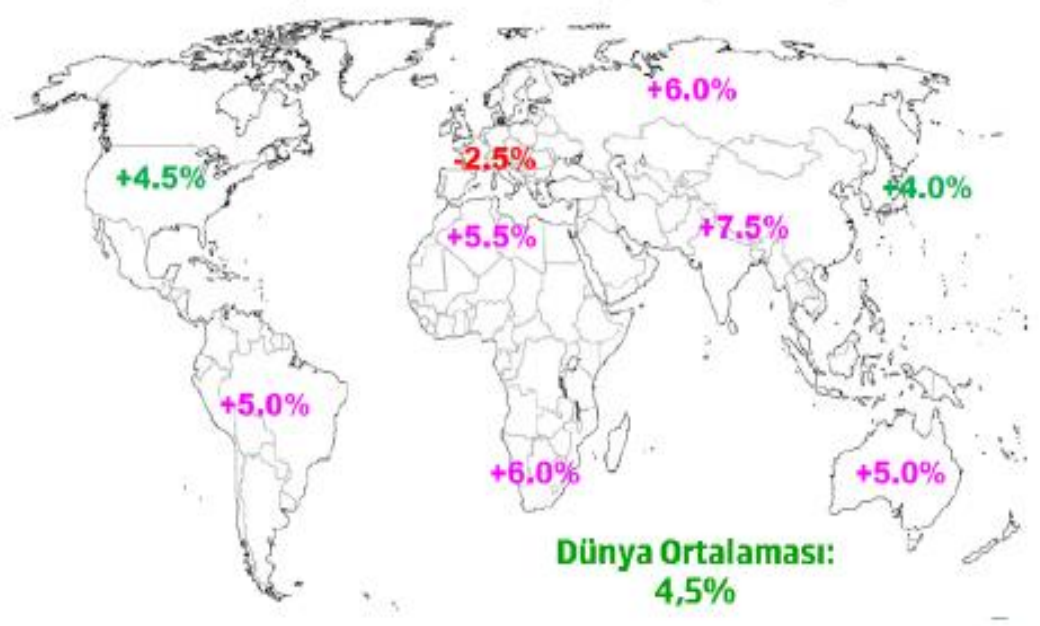

Şekil 3 Dünyada İşaat Sektöründe Büyüme, Kaynak: Inşaat Sektörü, Türkiye İş Bankası Yayınları

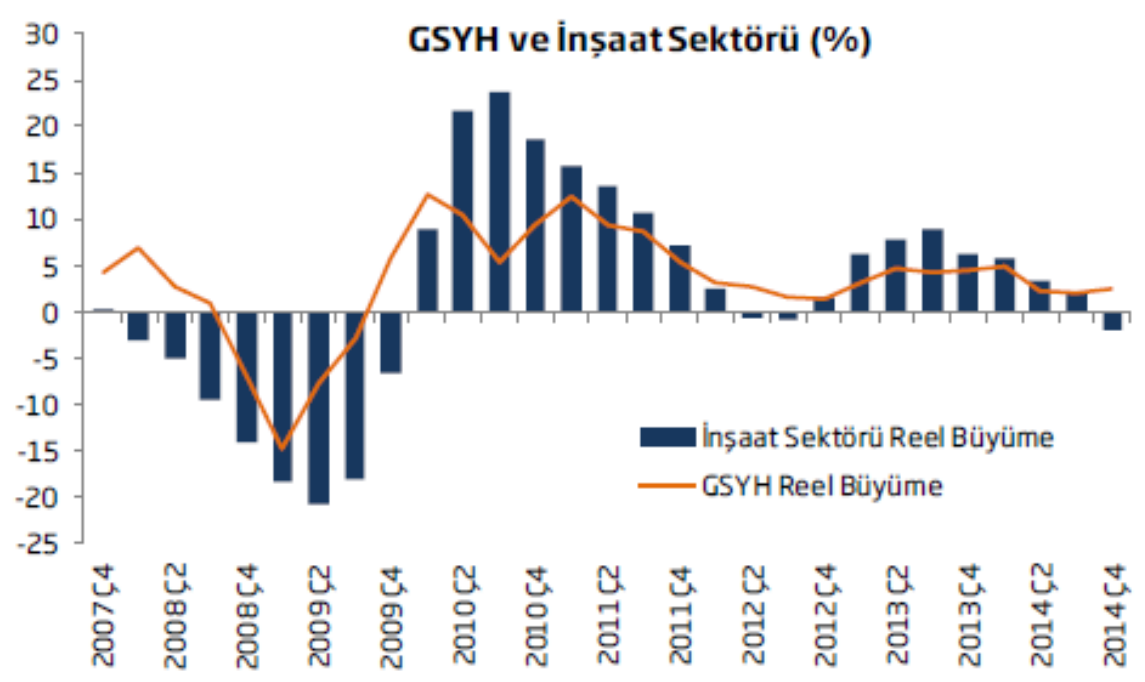

Şekil 4 Türkiye'de GSYH Reel Büyüme ve Inşaat Sektörü Reel Büyüme İlişkisi. Kaynak: Inşaat Sektörü, Türkiye Iş Bankası Yayınları

Türkiye'de yıllardan beri inşaat endüstrisinin sorunlarına çözüm yolları aranmıştır. İnşaat sektöründe denetim eksikliği ve çalışanların hukuki ihtiyaçlarının karşılanamaması en önemli sorunlar arasında yer almıştır. Modern bir sektör inovasyonunun yapılamaması sektör çalışanlarının motivasyonunu düşürmüş, yeni projeler ortaya çıkarılamamıştır. Ar-Ge çalışmalarının yetersizliği, ekonomide katma değer yaratılamamasına neden olmuş, verimlilik düşmüştür. Beşeri sermayeye verilen önemin arttırılamaması, sektör çalışanlarının eğitimi konusundaki yetersizlikler, üniversite sanayi işbirliğinin olmaması inşaat sektörünü olumsuz etkilemiştir. İnşaat sektöründe istihdam da önemli bir sorundur. Üniversite mezunlarının sektörde kendi uzmanlık alanlarında çalıştırılmaması sektörün profilini değiştirmiştir. İnşaat sektöründe Ar-Ge çalışmalarının yeterli seviyede olmaması ve kayıt dış1 ekonomisinin engellenememesi sonucu rekabet ortamı devlet politikalarıyla yaratılamamıştır. Oto finansman firsatlarının kaçırılması, "işçi ve işyeri emniyeti ve sağlığı”nın çok düşük olması, konut yapımında çağdaş 
tekniklerin kullanılamaması sektörün eksiklikleri arasındadır. Bu sorunlara ülke ekonomisinin ard arda krizleri ve Marmara Depremini yaşaması bu sorunların uzun süre çözülememesine neden olmuştur (Arığlu, 2006).

\begin{tabular}{|l|c|c|c|}
\hline Y1llar & $\begin{array}{c}\text { Toplam İstihtam } \\
\text { (Bin Kişi) }\end{array}$ & $\begin{array}{c}\text { İnşaat Sektörü } \\
\text { İstihtam1 (Bin Kişi) }\end{array}$ & $\begin{array}{c}\text { Yüzde } \\
\%\end{array}$ \\
\hline 2005 & 19.633 & 1.097 & 5,6 \\
\hline 2006 & 19.933 & 1.192 & 6,0 \\
\hline 2007 & 20.209 & 1.231 & 6,1 \\
\hline 2008 & 20.604 & 1.238 & 6,0 \\
\hline 2009 & 20.615 & 1.305 & 6,3 \\
\hline 2010 & 21.858 & 1.434 & 6,6 \\
\hline 2011 & 23.266 & 1.680 & 7,2 \\
\hline 2012 & 23.937 & 1.717 & 7,2 \\
\hline 2013 & 24.601 & 1.768 & 7,2 \\
\hline 2014 & 25.837 & 1.912 & 7,4 \\
\hline 2015 & 26.583 & 1.914 & 7,2 \\
\hline 2016 (Ocak) & 26.300 & 1.764 & 6.7 \\
\hline
\end{tabular}

Tablo 3. Inşaat Sektörünün Yıllara Göre Çalışanlar Iç̧indeki Oranları. Kaynak: TÜIK

\begin{tabular}{|c|c|c|c|c|c|}
\hline \multirow[t]{2}{*}{ Yil } & \multicolumn{4}{|c|}{ Çeyrek } & Y1llık ortalama \\
\hline & I & II & III & IV & . \\
\hline 2005 & 98.4 & 98.7 & 101.0 & 101.9 & 100.0 \\
\hline 2006 & 105.6 & 118.9 & 119.7 & 119.7 & 116.0 \\
\hline 2007 & 124.5 & 125.8 & 125.9 & 126.6 & 125.7 \\
\hline 2008 & 138.8 & 153.8 & 142.2 & 136.6 & 142.8 \\
\hline 2009 & 135.4 & 136.6 & 137.4 & 137.5 & 136.7 \\
\hline 2010 & 142.3 & 142.8 & 145.5 & 147.8 & 144.6 \\
\hline 2011 & 154.3 & 161.0 & 166.7 & 168.2 & 162.5 \\
\hline 2012 & 170.3 & 171.3 & 171.4 & 172.1 & 171.3 \\
\hline 2013 & 175.3 & 178.2 & 182.3 & 184.5 & 180.1 \\
\hline 2014 & 195.1 & 198.5 & 201.7 & 201.9 & 199.3 \\
\hline 2015 & 206.7 & 211.1 & 213.5 & 212.8 & 211.0 \\
\hline 2016 & 219.9 & & & & \\
\hline
\end{tabular}

Tablo 4. Bina İnşaatı Maliyet Endeksi ve Değişim oranları (2005=100), Kaynak: TÜIK

Türkiye'de çalışan nüfusun ortalama \%6'sı inşaat sektöründe istihdam edilmektedir. İnşaat sektörünün çalışanlar içindeki payı Tablo 3'de gösterilmiştir. Dünya çapında büyük bir kapasiteye sahip olan bu sektör, hem ulusal hem de uluslararası alanda yoğun bir istihdam yaratmaktadır. İnşaat sektörüne bağlı olarak iki yüzün üstünde alt sektör çalışmaktadır. İnşaat sektörü büyük potansiyele sahip bir istihdam kaynağı yaratmaktadır. Ayrıca, inşaat sektörü içinde yer alan inşaat malzemeleri de sanayinin yüzde 10'unu oluşturmaktadır. Türkiye'de inşaat sektörü yerli sermayeye dayanmakta olup, birçok meslek grubunu içeren 23 bin parçanın üretim ve istihdam sürecini etkilemektedir. İnşaat sektörünün yurtiçindeki büyüme performansı çeşitli faktörlere bağlı olarak değişmektedir. Projelerin dağılım performansı, özel sektör firmalarının yatırım konusundaki girişimleri, konut sektöründeki hareketliliğin artarak devam etmesi, siyasi ve ekonomik istikrarın devamı, uluslararası ekonomik ilişkilerde yaşanacak gelişmelerin ekonomi ve yabanc1 yatırımlar üzerinde yaratacağı etkiler gibi birçok faktör bunlardan bazılarıdır. Özellikle son yıllarda yapı malzemelerinde ve müteahhitlik hizmetlerinde yaşanan olumlu gelişmeler ile birlikte ihracatının artması sektörün ulusal ve uluslararası ekonomide önemini bir kez daha göstermiş, uluslararasında rekabet edebilir projelere önem verilmesi gerekliliğini göstermiştir (Fiş, 2010). Ancak inşaat endüstrisinin Türkiye'de milli gelir artış hızıyla ilgili olarak "toplam faktör verimliliğgi"ne katkısı çok düşüktür (\%11-14). Bazı ülkelerde inşaat sektörünün milli gelir artışına katkısı \%35-70 gibi yüksek değerlerdedir. Bu parametreler inovasyon çalışmalarının maliyetleri azaltma açısından ekonomide amaçlanan şekilde olmadığının bir göstergesidir (Arığlu, 2006). Ayrıca, Türkiye'de bina maliyetleri son yıllarda iki kat artmıştır (Tablo 4). Bunun sebepleri arasında yaşanılan büyük depremlerden sonra binaların göreceli olarak daha sağlam yapılması, Türk halkının yıllar içerisinde kendi kültürel değerlerindeki farklılıklardan oluşan lükse yönelme ve ekonomik gelirlerin artması gösterilebilir. 


\section{Sonuç}

Ülkeler yeni bir dünya düzeni içerisinde küreselleşme ve teknolojik değişmelere ayak uydurmak için akıl almaz bir yarışın içine girmişlerdir. Küreselleşme sonucu herşey hızla değişirken, ülkeler de ekonomik olarak stratejilerini değiştirmek zorunda kalmışlardır. Ülkeler ve firmalar varlıklarını devam ettirmek ve hedeflerine ulaşabilmek için uzun vadeli planlar yapmaktadırlar. Sürdürülebilir bir ekonomik kalkınma için gerekli inovasyon sistemleri Ar-Ge ile birlikte uygulanabilmelidir. Ülkelerin rekabet üstünlüğü elde edebilmeleri için uzun soluklu bir Ar-Ge stratejine ve süreklilik gösteren bir inovasyona sahip olması gerekmektedir. Ülkeler ve işletmeler rekabetçi ortamdan kazançlı çıkmak için hem araştırmacı hem de yenilikçi olmak zorundadırlar.

Türkiye'de bilgi, Ar-Ge ve teknoloji gibi ülkeyi kalkındıracak faktörlerin, inovasyona dayalı kalkınma ve büyüme politikalarıyla birlikte hareket edebilen bir mekanizma oluşturması gerekmektedir. Türkiye'nin sürdürülebilir ekonomik büyümeyi yakalaması, ekonomik, toplumsal ve politik sorunlarını çözüme kavuşturarak yaşam kalitesini yükseltebilmesi için inovasyon performansını iyileştirmesi çok önemlidir. İnovasyona dayalı kalkınma ve büyümeyi hedefleyen bir ülkede, tüm kesimlerde Ar-Ge ve inovasyonun önemi farkındalığın oluşturulması, kültür ve talebinin yaratılması hayati bir öneme sahiptir. Hükümetin ve ilgili tüm kesimlerin bu politikayı içselleştirerek ulusal ve bölgesel inovasyon sistemlerine işlerlik kazandırarak doğru stratejilerin belirlenip uygulanması gerekmektedir. İnovasyona dayalı kalkınma ve büyümeyi hedefleyen Türkiye'nin ulusal inovasyon sisteminin tüm aktörlerinin bulunduğu bir sistem oluşturulması, geliştirilmesi ve iyileştirilmesi önemlidir.

Türkiye geçmişte yaşadığı krizlerden büyük ölçüde etkilenmiş ve durgunluklardan uzun süre kurtulamamıştır. 1980 sonrası enflasyonun kronikleşmesi, artan iç borçlanma, kamusal giderlerin artması, yatırımların azalması, tüm sektörlerdeki politikalarda üretim ve istihdamın yaratılamaması ülke ekonomisini zarara uğratmıştır. Beşeri sermaye yatırımlarında ülkenin yetersiz kalması, eğitim ve Ar-Ge çalışmalarında gerçekçi programların olmaması, üretim ve sanayi arasındaki köprünün kurulamaması ihracatın yetersiz olması, rekabet kurallarının ArGe yoğunluklu çalışmalarla sağlanamaması, çevre ve kentleşme sorunlarının çözülememesi, konut sektöründe yanlış politikaların uygulanması, ülkemizin gündemini uzun süre meşgul etmiştir. Son yıllarda ekonomik alanda yeniden yapılandırma programlarıyla önemli adımlar atılmasına rağmen farklı sektörlerin de desteklenmesi gerekmektedir. İnşaat sektöründe az da olsa yapılan inovasyon çalışmalarının maliyetlere önemli oranda katkısı görülmemektedir. Yarattığı katma değer ve istihdam ile Türkiye'nin ekonomisinin lokomotifi olan inşaat endüstrisinin de acil bir inovasyon sisteminin oluşturulmasına ve geliştirilmesine ihtiyaç duyulmaktadır. İnşaat endüstrisinde katma değerin artırılması için yeni nanoteknolojiler geliştirilmelidir. Nanoteknolojinin geliştirilmesi için devlete, özel sektöre, üniversitelere ve araştırma geliştirme alanlarına büyük görevler düşmektedir. Sürdürülebilir bir gelecek için inşaat endüstrisinde doğal kaynakları etkin bir şekilde kullanan, küresel 1sınma ve iklim değişikliklerine duyarlı, enerji verimliliğine, sağlık, denetim ve güvenliğe önem veren bir inovasyon yapılmalıdır.

\section{Kaynakça}

- Akbey, F., 2014. "Ar-Ge, İnovasyon ve Kalkınma İlişkisine Yönelik Bir Literatür Taraması: Kuramsal” Özet, Maliye Dergisi, Sayı 166, Ocak-Haziran 2014.

- Arığlu, E., 2006. “Türkiye’de Ar-ge ve İnşaat Sektöründeki Yeri”, Yapı Merkezi Holding A.Ş.

- Candemir, B., vd, 2012. “Sürdürülebilirlik, Yeşil Binalar ve Nanoteknoloji Stratejiler”, Imsad ve Tüsiad, T2012 /10-533. 21-30, 90-98.

- Duran, C., Saraçoğlu M., 2009. "Yeniliğin Yaratıcılıkla Olan İlişkisi ve Yeniliği Geliştirme Süreci”, Celal Bayar Üniversitesi I.İ.B.F. Yönetim ve Ekonomi Dergisi, Cilt 16, Sayı 1, 57-71.

- Fiş, G., 2010. “İnşaaat Sektöründe İnovasyon”, İstanbul Teknik Üniversitesi, YüksekLisans Tezi , s.15-16, 35 .

- $\quad$ Fırat F.K., Akbaş F. “İnşaat Endüstrisinde Geri Dönüşüm Çalışmalarının Geliştirilmesi ve Ekonomi Üzerine Etkileri” Ulusararası Avrasya Ekonomileri Kongresi, 2015 http://www.avekon.org/papers/1415.pdf, s. 637,638 .

- Firat, E., Aydın A. “İnsani Kalkınma Endeksine Göre Türkiye’nin Eğitim Endeks Göstergelerinin OECD Ülkeleri ile Karşılaştırılması”, ,Selçuk Üniversitesi İktisadi ve İdari Bilimler Fakültesi Sosyal ve Ekonomik Araştırmalar Dergisi (The Journal of Socialand Economic Research) ISSN: 1303 - 8370 / Nisan 2015 / Y1l: 15 / Say1: 29, s. 83.

- Fırat E., Kurtoğlu, R. "Finans Dünyasının Krizler Karşısındaki Belirsizliği Davranışsal Ekonomí” Aksaray Üniversitesi İktisadi ve İdari Bilimler Fakültesi Dergisi . 7(1) . 87. (C) 2014 Aksaray Üniversitesi İktisadi ve İdari Bilimler Fakültesi http://iibfdergi.aksaray.edu.tr

- Işık, N., Kılınç, E.C., 2011. "Bölgesel Kalkınmada Ar-Ge ve İnovasyonun Önemi: Karşılaştırmalı Bir Analiz”, Eskişehir Osmangazi Üniversitesi, İBF Dergisi, Say1: 6(2). 
- İnşaat Sektörü, Türkiye İş Bankası Yayınları

- Karagöl, E., Tanas, Karahan, H., 2014. "Yeni ekonomi: Ar-Ge ve İnovasyon”, SETA, Say1:82, İstanbul, s. 1012.

- Rekabet Kurumu, Küresel Rekabet Edebilirlik Endeksi 2015 - 2016 Raporu

- Uzkurt, C., 2010. “İnovasyon Yönetimi: İnovasyon Nedir, Nasıl Yapılır ve Nasıl Pazarlanır”, Eskişehir Osmangazi Üniversitesi İ.I.B.F. İşletme Bölümü, Ankara Sanayi Odası Yayın Organı, Ankara, 37-51.-

- The Global Competitiveness Report 2015-2016

- TÜIK, 2015, Ar-Ge Faaliyetleri Araştırması, 2015.

- Türkiye İșveren Sendikaları Konfederasyon Bilim, Teknoloji ve Sanayide Türkiye'nin Durumu Raporu, Türkiye İşveren Sendikaları Konfederasyonu Yayını, 2015

- Türkiye İş Bankası : İnşaat Sektörü, Türkiye İş Bankası Yayınları https://ekonomi.isbank.com.tr, 25.05.2016

- Türkiye Bilimsel ve Teknolojik Araştırma Kurumu, "Ulusal Bilim, Teknoloji ve Yenilik Stratejisi 20112016” Ankara, Ocak 2016.

- Ulusal İnovasyon Girişimi 2006-2013 Dönemi Değerlendirme Raporu, (2014), 21.05.2016.

- https://biruni.tuik.gov.tr, Erişim Tarihi: 21.05. 2016

- http://www.tuik.gov.tr, Erişim Tarihi: 20.05.2016.

- http://tubitak.gov.tr , Erişim Tarihi: 21.05. 2016.

- https://ekonomi.isbank.com.tr/UserFiles/pdf/insaatsektoru.pdf, Erişim tarihi: 25.05.2016

- (http://tubitak.gov.tr/sites/default/files/gelismelere_iliskin_degerlendirmeler_1.pdf, Erişim Tarihi: 21 Mayıs 


\title{
Türkiye'nin Kalkınma Planlarında Turizm Politikası Tourism Policy in Turkey's Development Plans
}

\author{
Asst. Prof. Dr. Yaşar Akça (Bartın University, Turkey)
}

\begin{abstract}
Five-year development plans prepared by the Ministry of Development, formerly known as State Planning Organization (SPO), are the main policy documents indicating the growth Turkey will realize in economic, social and cultural fields in the long-term. Since 1963, ten development plans were prepared covering the period till 2018. Development plans provide unity in objectives not only for public but also for the society in general. The main objective of all the mentioned development plans is to make Turkish people happy and prosperous. Tourism is one of the elements to be considered in the development of a country. A country's tourism policy is first prepared in the development plans. While preparing the tourism policy, precautions towards all kinds of tourism activities are referred. The existing state of the tourism and the state it should be are given. Depending on increase in income, both domestic and international tourism activities are increasing. Tourism activities are continuously diversifying. The purpose of this study is to reveal the tourism policies in the development plans, to determine the existing state of the tourism sector and the targets for future. Also, another purpose is to emphasize the problems the sector faces as well as possible problems that could arise in the future. Suggestions are given towards these problems. In order for the tourism sector to contribute to the country's economy, it is important to diversify and develop it.
\end{abstract}

\section{Giriş}

Turizm denildiğinde dinlenmek, eğlenmek, görmek ve tanımak gibi amaçlarla yapılan geziler (Oktayer, Susam ve Çak, 2007:13), insanların geçici konaklamalarından doğan olaylar bütünü (Maviş ve Akoğlan, 1997:4) anlaşılmaktadır. Bu faaliyetleri gerçekleştiren kişi turisttir.

Eski uygarlıklara ait tarihi kalıntılar, coğrafi bitki örtüsü, doğal güzellikler, yerel halkın yaşayış biçimleri, örf ve adetleri, barınma ortamları insanların ilgisini cezbetmektedir. Diğer taraftan turizmin din dil, rrk ve ülke gözetmeden evrensel bir faaliyet olması dünya barışına katkı sağlamaktadır. Yine turizm sektörü, ülke kalkınmasına üretim, ticaret, döviz ve istihdam yönlerinden doğrudan ve dolaylı katkılarda bulunmaktadır. Örneğin konaklama bedeli, gezi yeri ücretleri, eğlence, restoran, ulaşım araçlarına yapılan ödemeler, hediyelik eşya harcamaları doğrudan gelir kalemlerinden başlıcalarıdır. Turizm faaliyetleri insan emeğini yoğun şekilde kullandığından işsizlikle mücadeleye yardım eder. Türkiye ekonomisinde en fazla yabancı sermaye girişi turizm sektöründe gerçekleşmektedir (Oktayer vd., 2007:167).

Bugün Türkiye'de turizm faaliyetleri hızla artmaktadır. Çünkü Türkiye, topraklarında barındırdığı tarihi miras, kültür, sanat, doğal güzellikler, gastronomi, dünya standartlarının üzerinde konaklama tesisleri ve misafirperver insanlarından kaynaklanan üstün bir turizm potansiyeline sahiptir.

\section{Turizm Çeşitleri}

Turizm faaliyetlerinin yılın oniki ayına yayılması isteğine yönelik olarak gün geçtikçe yeni turizm çeşitleri ortaya çıkmaktadır. Turizmin çeşitlenmesiyle doğru orantılı elde edilen gelir miktarı artmaktadır. Ayrıca kişilerin değişik ilgi alanlarını ve farklı boş zamanlarını dikkate alan turizm faaliyetleri sayesinde turist sayısında artış gerçekleşmektedir.

Başlıca turizm çeşitleri şunlardır (Oktayer vd., 2007:129-144):

1. Deniz ve yat turizmi: Temiz deniz ve uzun kıyılar gerekir. Deniz havası ve deniz suyu sağlığa iyi gelmekte, vücudu güçlendirirken hastalıklara karşı direnci artırmaktadır. Yat sahiplerine yönelik turistik hizmetler ile turistlere yönelik yat gezileri önemli turizm faaliyetleridir.

2. İnanç turizmi: İnsanların dini inanç çekim merkezlerine yaptıkları seyahatlerdir.

3. Sağlık ve termal turizmi: Termal suların tedavi amaçlı kullanımına yöneliktir.

4. Kongre turizmi: Ulusal ve uluslararası nitelikte gerçekleştirilen kongrelerden oluşur.

5. Eko turizm: Doğa sever turistlere yönelik olarak dağlık ve ormanlık bölgelerdeki turizmdir.

6. Yayla turizmi: Yüksek rakımlı yerlerdeki yaylaların turizme yönelik değerlendirilmesidir.

7. Mağara turizmi: Mağara niteliğinde ortaya çıkan jeolojik yapıların ziyaret edilmesidir.

8. Av turizmi: Yabani av hayvanlarının eğlence amaçlı avlanmasıdır.

9. Botanik turizmi: Bitki çeşitliliğinin gözlenmesine dayalıdır.

10. Dağ turizmi: Dağcılığı sevenlere yöneliktir.

11. Akarsu turizmi: Akarsularda rafting ve kano faaliyetlerinin gerçekleştirilmesidir. 
12. Kış turizmi: Kayak merkezlerindeki faaliyetlerdir.

\section{Türkiye'nin Planlı Dönem Öncesi Turizm Politikası}

Türkiye'nin planlı dönem öncesinde (1923-1963) karayolları, limanlar ve konaklama tesisleri yetersiz, turizmle ilgili çalışmalar son derece kısıtlıdır. 1929 dünya ekonomik buhranı, 1939'da başlayan ve altı yıl süren ikinci dünya savaşı turizm faaliyetlerini olumsuz yönde etkilemiştir. Turizmin kamu yönetimi içinde örgütlenmesi 1934 y1lında İktisat Bakanlığına bağlı Turizm Bürosu'nun kurulmasıyla başlar. Türkiye'de 1950'li yıllarda başlayan imar faaliyetleri, altyapı ve üst yapı yatırımları ile tarihi eserlerin restorasyonu ileriki yıllarda ortaya çıkacak olan turizm sektörüne katkı sağlamıştır (Oktayer vd., 2007:43). Bu dönemdeki önemli gelişmelerden birini 1953 y1lında yürürlüğe giren Turizm Endüstrisi Teşvik Kanunu oluşturmaktadır. Diğeri ise 1957 yılında Turizm Bakanlığı'nın kurulmasıdır. Turizm esas gelişimini planlı dönemde sağlamıştır.

\section{Türkiye'nin Planlı Dönemde Turizm Politikası}

Türkiye'de 1961 'de kabul edilen yeni anayasa ile birlikte kalkınma planları yapılmaya başlanmıştır. Ülkenin ekonomik hedeflerini ortaya koyan kalkınma planları, özel kesim için yol göstericidir. Kamu kesimi için emredici nitelikte bağlayıcıdır. Kalkınma planları sayesinde ülke kaynaklarının mevcut durumu tespit edilerek verimli kullanımı sağlanır.

Politika kavramı karar vermeye yol gösteren genel rehberdir (Yağc1, 2007:194). Kalkınma planları içinde yer alan turizm politikaları turizmin gelişimine yönelik faaliyetleri tespit eder. Turizm politikaları sayesinde turizm sektörüne yönelik kamuya ve özel kesime düşen görevler tespit edilir (Şahin, 1990:111). Böylece turizmden sağlanan kazançlar maksimuma çıkarılırken maliyetlerde minimuma indirilir (Olalı, 1990:30).

1963 yılından itibaren başlayan ve 2018 yılını kapsayan süreç içinde ortaya konulan on tane kalkınma planının hepsinde turizm sektörüne yer verilmiştir. Bütün kalkınma planlarında ülkenin sanayileşerek kalkınacağı, turizm faaliyetlerinin buna hız kazandıracağına işaret edilmiştir (Oktayer vd., 2007:44).

\subsection{Birinci Beş Yıllık Kalkınma Planı (1963 - 1967)}

Turizmin hızla gelişmesini sağlamak için gerekli temel harcamalar ve reklâm yapılacaktır. Yapılacak yatırımlarda geceleme tesislerine önem verilecektir (DPT, 1963:425). Turizme ayrılan kaynakların sınırlı olması sebebiyle yurdun turizme elverişli bölgelerinden özellikle turist çekme kabiliyeti yüksek ve kısa zamanda netice alınabilecek bölgelerde çalışmalar yoğunlaştırılacaktır. Dış turizmin geliştirilmesine paralel iç turizmin de geliştirilmesi teşvik edilecektir (DPT, 1963:428). Türkiye'nin bütün turizm işlerini gerekli yetki ve imkânlarla yürütmek üzere bir teşkilât en kısa zamanda kurulacaktır (DPT, 1963:427). Turistlere yönelik gümrük ve kambiyo işlemleri basitleştirilecek, tanıtıma yönelik danışma büroları açılacaktır (DPT, 1963:428). Bu plân döneminde turizm gelirlerinin turizm giderlerinden daha yüksek olması sağlanacaktır (DPT, 1963:510).

Turizmle ilgili projelerden en önemlileri şöylece sıralanabilir (DPT, 1963:427):

a) Turizmi geliştirecek oteller, tatil köyleri ve kamplar kurulacaktır,

b) Doğal ve tarihi kaynaklara önem verilecek, turizme elverişli millî parklar oluşturulacaktır,

c) Balkanlar, Yunanistan, İtalya ve İsrail ile Türkiye arasında her çeşit ulaştırma imkânları artırılacaktır.

d) Turizm personeli eğitimine öncelik verilecektir.

e) Turistik tesislerin kurulduğu yerlerde turistlerin ihtiyaçlarını karşılayacak yiyecek, içecek ve hatıra eşyasının mahallî gayretlerle üretimi ve satışı desteklenip düzenlenecektir.

\section{2 İkinci Beş Yıllık Kalkınma Planı (1968 - 1972)}

Turizmin İkinci Beş Yıllık Plan döneminde önemli bir gelir kaynağı olması beklenmektedir (DPT, 1968:93). Turizmin emek yoğun bir sektör olması istihdam seviyesini yükseltecektir (DPT, 1968:602). Bu durumu destekleyecek olan turizm eğitimi yeterli duruma getirilememiş (DPT, 1968:594) ve birinci plan döneminde turizm alanında hedef alınan gelişmeler sağlanamamıştır (DPT, 1968:31). Çeşitli kamu ve özel sektör kuruluşları arasında turizm alanındaki koordinasyon henüz sağlanamamıştır (DPT, 1968:594). Turizm gelirleri, yabancı turist sayısı ve ortalama tüketimin artırılması amaçlanmıştır. Turizm sektöründe yapılması öngörülen yatırımlar öncelikle konaklama tesislerine ve konaklama kapasitesinin artırılmasına ayrılacaktır. İkinci Plan döneminde turizm politikasının temel ilkesi yasal ve finansal kolaylıklarla kitle turizminin geliştirilmesidir. Konaklama kapasitesi, kitle turizmine yönelecek tesisler şeklinde ve turistik potansiyeli yüksek belirli bölgelerde kurulacaktır. Büyük kapasiteli tatil siteleri yatırımları özellikle desteklenecektir (DPT, 1968:299).

İkinci Beş Yıllık Kalkınma Planında izlenecek turizm politikasının temelleri şunlardır (DPT, 1968:593):

a) Diş turizm gelirleri ve iç turizm hareketleri geliştirilecektir.

b) Turistik tanıtıma önem verilecektir.

c) Turizm sektöründeki yatırım politikasında altyapı tesisleri ve örnek tesisler kamu sektörünce ele alınacak, diğer turistik tesis yatırımları özel sektörce yapılacaktır. 
d) Turizm yatırımları turistik potansiyeli yüksek bölgeler içindeki belli yörelerde (Marmara, Ege ve Antalya bölgelerinde) yoğunlaştırılacak, kitle turizmine uygun konaklama ve ulaşım imkânları sağlanacaktır.

e) Turizm faaliyetlerinin gelişebilmesi için çevre sağlığı ve gıda kontrollerine önem verilecektir.

f) Uluslararası alanda ve özellikle Akdeniz ülkeleri ile ortak turizm tanıtımı konusunda çeşitli işbirliği imkânları aranacaktır.

g) İkinci Beş Yıllık Kalkınma Planı döneminde doğal, tarihî ve arkeolojik değerlerin, anıt ve eserlerin korunması, değerlendirilmesi, onarımı çalışmalarında turistik konaklama tesislerinin yoğunlaştırılacağı yerlere öncelik tanınacaktır.

\section{3 Üçüncü Beș Yıllık Kalkınma Planı (1973 - 1977)}

1970'lerde başlayan petrol bunalımına bağlı ekonomik durgunluk turizm hareketlerini sekteye uğratmıştır. Planda yer alan hedeflere ulaşılamamıştır. Önceki dönemlerde turist sayısı, turizm gelirleri ve konaklama tesisleri kapasitesindeki gelişmeler plan hedeflerinin altında kalmıştır (DPT, 1972:614).

Üçüncü Plan döneminde konaklama tesisleri yatırımlarının öncelik bölgelerinde (Akdeniz, Göreme, Uludağ, Güney Ege ve kısmen Marmara) yoğunlaştırılmasına devam edilecek ve kurulacak tesislerin kapasite ve nitelikleri itibariyle kitle turizminin gereklerine uygun olmalarına dikkat edilecektir (DPT, 1972:618). Söz konusu bölgelerin alt yapı yatırımları içinde hava alanı yapımı, karayollarının iyileştirilmesi, su, elektrik ve kanalizasyon tesislerinin yapımı, yat yanaşma yerleri inşaatı gerçekleştirilecektir. Milli park yatırımları ile tarihi eserlerin onarımına devam edilecektir (DPT, 1972:619).

Turizm yatırım ve işletmeciliğinde özel sektör esas alınacaktır. Kamunun yatırımı ve işletmeciliği öncü ve örnek tesislere eşlik amacına yönelecektir (DPT, 1972:619). Turizm sektöründe yatırımların diğer bölgelere kaydırılması turist akımına paralel olarak geliştirilecektir (DPT, 1972:898). Geçmiş dönemlerde turizm hizmetleri için otelcilik okullarında yetiştirilen personel nicelik ve nitelik bakımından yetersiz kalmıştır. Ayrıca yetiştirilen elemanların tamamının da ihtisas alanlarında çalışmaları sağlanamamıştır. Dolayısıyla personel yetiştirilmesi ve istihdamının sağlanması için Otelcilik ve Turizm Meslek Liseleri açılacaktır (DPT, 1972:713). Turizm potansiyelini geliştirmek için yer altı ve yer üstü tarihi değerler titizlikle korunacaktır (DPT, 1972:1003). Sektörün kredi imkanları artırılacak ve yabancı sermaye yatırım işletmeciliğine yer verilecektir.

\subsection{Dördüncü Beș Yıllık Kalkınma Planı (1979 - 1983)}

Turizm alanında kamunun elindeki turistik tesislerin dış turizme açılması yolları aranacaktır (DPT, 1979:243). Kamu kuruluşlarına ait kamplar ve dinlenme tesislerinden daha geniş kitlelerin yararlanması gerçekleştirilecektir (DPT, 1979:243). Gençliğin ulusal ve uluslararası turizm etkinliklerine daha geniş ölçüde katılabilmesini sağlayacak düzenlemeler getirilecektir (DPT, 1979:287). Kitle turizmine yönelik büyük turistik konaklama tesislerinin yapımına öncelik verilerek konaklama kapasitesinin artırılmasına çalışılacaktır. Bu kapsamda en az 500 yataklı olması koşuluyla yabancı yatırımlar özendirilecektir (DPT, 1979:243). Yatak kapasitesindeki yetersizlik ve turizm tesislerindeki fiyatların yüksekliği iç talebi yurt dışında tatil geçirmeye özendirmektedir (DPT, 1979:430). Kırsal ve kentsel dinlenme bölgelerinin saptanması, tarihi çevrenin ve önemli savaş alanlarının, korunması suretiyle iç ve dış turizme yönelik değerlendirilmesi çalışmalarına hız verilecektir (DPT, 1979:297). Ev turizmi özendirilecektir (DPT, 1979:660). Bu plan döneminde turizm eğitimi politikası yeniden gözden geçirilerek ülke gereksinimini karşılayacak biçimde turizm eğitimi yaygınlaştırılıp hızlandırılacaktır (DPT, 1979:432).

\subsection{Beşinci Beş Yıllık Kalkınma Planı (1985 - 1989)}

Devlet özellikle konferans, termal, yat ve kış turizmleri için turizm alt yapısını geliştirmeye ağırlık verecektir (DPT, 1984:198). Üst yapının geliştirilmesi, yatak kapasitelerinin artırılması ve özellikle işletmecilik eğitimi konuları Devletçe desteklenecek ve yabancı sermaye teşvik edilecektir (DPT, 1984:42).

Söz konusu kalkınma planı döneminde izlenecek turizm politikaları şunlardır (DPT, 1984:120):

1) Türkiye'nin tabii, tarihi, arkeolojik ve kültürel varlığı, kış, av ve su sporları, festival, sağlık ve gençlik turizmi potansiyeli, ekolojik dengeyi koruma, çevreyi temiz tutma ve güzelleştirme ilkeleri doğrultusunda değerlendirilecektir.

2) Türkiye, OECD ve OPEC ülkelerinin yanısıra Balkanlar ve Üçüncü Dünya Ülkeleri ile turistik ilişkilerini geliştirecektir.

3) Kitle turizmine önem verilirken bireysel turizm de ihmal edilmeyecektir. Çalışanların en uygun şartlarda tatil yapmaları ve dinlenmeleri sağlanacaktır.

4) Doğal ve kültürel çevre değerlerini kapsayan turizm kaynakları envanteri çıkarılacaktır.

5) Turizm Bankası'nın doğrudan yatırım yapması yerine kredi kullandırması tercih edilecektir.

\subsection{Altıncı Beş Yıllık Kalkınma Planı (1990 - 1994)}

Turizm sektörüne ayrılan kamu kaynakları öncelikle eğitim ve teknik altyapının geliştirilmesine tahsis edilecektir (DPT, 1989:352). Turizm alt ve üst yapısının nitelik ile niceliğinin yükseltilmesine ağırlık verilecektir. Mevcut tesislerde doluluk oranlarını artırıcı ve faaliyet mevsimini yılın tamamına uzatıcı önlemler alınacaktır 
(DPT, 1989:3). İnsanlığın mirası durumundaki doğal güzelliklerin ve kültürel değerlerin korunması ve turizme açılması teşvik edilecektir (DPT, 1989:39).

Bu kalkınma planı döneminde izlenecek turizm politikaları şunlardır (DPT, 1989:281-282):

1) Turizmin çeşitlendirilmesi amacıyla kış, av ve su sporları ile festival, sağlık, gençlik, kongre, termal, golf turizmini daha cazip hale getirecek teşvik politikaları geliştirilecektir.

2) Turizm sektörüne hizmet verenlerin sayıca yeterli düzeye getirilmesi, bilgi ve becerilerinin artırılması sağlanacaktır. Eğitilmiş personel açığının kapatılması amacıyla otelcilik ve turizm meslek liselerine ağırlık verilecektir.

3) Yerli seyahat acentalarının tur operatörlüğü teşvik edilecektir.

4) Turistik tesis işletmeciliği geliştirilecek, küçük kapasiteli tesisler ve aile pansiyon işletmeciliği teşvik edilecektir.

5) Toplumun en uygun şartlarda tatil yapması sağlanacaktır.

\subsection{Yedinci Beş Yıllık Kalkınma Planı (1996 - 2000)}

Bu plan döneminde konaklama yatırımları yavaşlatılmış, altyapı ve yenileme yatırımları özendirilmiştir. Tanıtım ve pazarlama çalışmalarının teşvik edilmesine öncelik verilmiştir. Turistik tesis inşaatlarının kaynak sorunu nedeniyle uzun sürmesi sektörü olumsuz yönde etkilemektedir. Ayrıca turizmi çeşitlendirememekten kaynaklanan sorunlar da devam etmektedir (DPT, 1995:162).

Yedinci beş yıllık kalkınma planı döneminde izlenecek turizm politikaları şunlardır (DPT, 1989:162):

1) Rekabet gücü yüksek ve verimli bir turizm ekonomisinin geliştirilmesi doğal ve kültürel değerlerin zenginleştirilerek sürekliliğinin sağlanması sektörün temel amaçlarıdır.

2) Turizmin mevsimlik ve coğrafi dağılımını iyileştirmek, dış pazarda değişen tüketici tercihleri de dikkate alınarak golf, kış, dağ, yayla, termal, sağlık, yat, karavan, kurvaziyer, kongre ve eğlence turizmini geliştirme faaliyetlerine devam edilecektir.

3) Talep yapısındaki yeni eğilimlere bağlı olarak sektörde küçük ölçekli işletmelerin gelişmesine öncelik verilecektir.

4) Sektörde hizmet kalitesinin yükseltilmesi için sertifikasyon sistemine geçilmesi sağlanacaktır.

5) Turist rehberliği mesleğine mensup olanların mesleki etkinliklerini artırmak amacıyla Rehberler Birliği Yasası çıkarılacaktır (DPT, 1995:164).

\subsection{Sekizinci Beş Yıllık Kalkınma Planı (2001 - 2005)}

Turizme yönelik tanıtım ve pazarlama konusunda bir reform ihtiyacı mevcuttur (DPT, 2000:166). Turizmin, potansiyeli olan ancak bugüne kadar yeterince ele alınmamış bölgelere yayılmasına yönelik tedbirler alınacaktır (DPT, 2000:167).

Bu plan döneminde izlenecek turizm politikasının ilkeleri şunlardır (DPT, 2000:167-168):

1) Dünya turizm gelirlerinden alınan payın artırılması temel hedeftir.

2) Turizm teşviklerinde ağırlık pazarlama alanına, hava ulaştırmasına ve toplam kalite iyileştirmesine verilecektir.

3) Sektörde küçük ölçekli işletmelerin KOBİ statüsünde değerlendirilmeleri sağlanacaktır.

4) İşgücü niteliğinin iyileştirilmesine ve turizm işletmelerinde uluslararası standartlara öncelik verilecektir.

5) Fiziksel çevre, sit alanları ve tarihi mekânlar korunacaktır. Ekoturizmi geliştirmek amacıyla Milli Parklar ve benzeri alanlar yaygınlaştırılacaktır (DPT, 2000:140).

\subsection{Dokuzuncu Kalkınma Planı (2007 - 2013)}

Ülkedeki refah ve gelişmişlik dengesizliklerini azaltıcı doğrultuda turizm potansiyelinin değerlendirilmesi gereği devam etmektedir. Turizmin mevsimlik ve coğrafi dağılımını iyileştirmek için turizm potansiyeli olan ancak bugüne kadar yeterince ele alınmamış yörelerde turizm geliştirilerek ekonomik ve sosyal kalkınma sağlanacaktır (DPT, 2006:81).

Plan döneminde, kültürel etkinliklerin yaygınlaştırılması, ortak tarihi geçmişimiz olan ülkeler başta olmak üzere dünya ülkeleri ile ilişkilerimizin geliştirilmesi, yurt içi ve yurt dışında bulunan kültür varlıklarımızın tespiti, araştırılması, bakım-onarım ve restorasyonu yönündeki faaliyetlere devam edilecektir (DPT, 2006:45). Türkiye'nin fiyat, hizmet kalitesi ve jeotermal kaynaklar açısından rekabet üstünlüğü göz önüne alınarak, sağlık hizmetleri turizmi desteklenecektir (DPT, 2006:82). Turizm teşviklerinde pazarlama alanına, hava ulaştırmasına ve mevcut ürünlerde toplam kalite iyileştirilmesine öncelik verilecektir (DPT, 2006:82). Ayrıca, sektörle ilgili tüm yatırımların doğal, tarihsel ve sosyal çevreyi kollayıcı, koruyucu ve geliştirici bir yaklaşım içinde olmasına azami özen gösterilecektir. 


\subsection{Onuncu Kalkınma Planı (2014 - 2018)}

Turizmde nitelikli işgücü, tesis ve hizmet kalitesiyle uluslararası bir marka haline gelinmesi, daha üst gelir grubuna hitap edilmesi temel amaçtır (Kalkınma Bakanlığı, 2013:114). Planlı dönemlerin başından bugüne kadar turizm sektöründe önemli ilerlemeler sağlanmıştır.

Mesleki belgelendirme sistemiyle ilgili başlatılan çalışmaların sektörün tüm çalışanlarını kapsayacak şekilde yaygınlaştırılması ihtiyacı bulunmaktadır (Kalkınma Bakanlığı, 2013:113). Sürekli olarak yabancı turist sayısı ve turizm geliri artmasına rağmen turist başına elde edilen gelir seviyesinin düşüklüğü devam etmektedir (Kalkınma Bakanlığı, 2013:22). Örneğin uzun dönemde artması beklenen sağlık harcamalarına istinaden sağlık turizminin geliştirilmesi firsatı vardır (Kalkınma Bakanlığı, 2013:11). Dünyadaki eğilimler doğrultusunda turizm talebinin konfor ve macera motifleri ağırlıklı hale gelmesi beklenmektedir (Kalkınma Bakanlığı, 2013:114).

\section{Sonuç ve Öneriler}

Türkiye için turizm, dış pazarlarda rekabet gücü en yüksek sektörlerden biridir. Örneğin turistik alışverişe yönelik halı, deri, konfeksiyon, mücevherat ve el sanatları ürünlerine fazlasıyla sahiptir (Özel İhtisas Komisyon Raporu, 2007:14). Bu sektörde hizmet vermeye istekli genç, dinç, dinamik ve iyi eğitim almış insan kaynaklarına sahiptir.

İncelenen beşer yıllık kalkınma planlarında turizm sektörüne yönelik işaret edilen politikalar şu başlıklar altında özetlenebilir:

1) Çok isabetli bir tespitle, turizmin hızla gelişme yollarından birinin reklâm harcamaları (DPT, 1963:425) ve tanıtım (DPT, 1963:428) olduğuna ilk kalkınma planında itibaren diğer kalkınma planlarında (DPT, 1968:593) işaret edilmiştir. Bu kalem halen turizm faaliyetlerinde önemini korumaktadır.

2) Turizmin çeşitlendirilmesine yönelik olarak devlet özellikle konferans, termal, yat, av, su sporları kış ve gençlik turizmi gibi faaliyetleri geliştirmeyi teşvik etmektedir (DPT, 1984:198).

3) Turist sayısı, geceleme süresi ve ortalama harcama miktarını artırmak suretiyle turizm gelirlerini yükseltme (DPT, 1963:510; DPT, 1968:299) çabaları her zaman için doğru bir yaklaşımdır.

4) Kitle turizmi dikkate alınarak öncelikle gelişme potansiyeli olan bölgelerde konaklama tesisi yatırımlarının teşvik edilmesi (DPT, 1963:428; DPT, 1968:299), her zaman için kıt kaynakların rasyonel kullanımında doğru politikalardır.

5) Alt yapı tesislerinin yapımı kamu kesimince, üst yapı tesisleri özel kesim tarafindan yapılması (DPT, 1972:204) liberal ekonomi uygulamalarından biridir.

6) Tarihi eserlerin restore edilerek korunması, turistik özelliğe sahip orman alanları, deniz, göl ve nehir kıyılarının kamu yararına kullanımı (DPT, 1979:243) ideal uygulamalardır. İkinci beş yıllık kalkınma planında çevre sağlığı ve gıda kontrollerinin önemine işaret edilmesi (DPT, 1968:593), doğru evrensel değerde tespitlerdir.

7) Dış turizmin geliştirilmesine paralel, kamu çalışanlarına tatil imkânları sunularak iç turizmin de canlandırılması (DPT, 1979:243; DPT, 1984:120), doğru hedef kitlenin seçildiğinin bir göstergesidir.

8) Kalkınma planlarında işaret edilen Akdeniz ülkeleri, OECD, OPEC ülkeleri, Balkanlar, Yunanistan, İtalya ve İsrail ile Türkiye arasında ulaştırma imkânlarının artırılması suretiyle turizmin canlandırılması (DPT, 1963:427; DPT, 1968:593; DPT, 1984:120) yönünde alınan tavsiye karar, bugün de geçerliliğini korumaktadır. Dolayısıyla kalkınma planında turizm politikasını tespit eden komisyon üyelerinin konunun önemine vakıf olduklarını göstermektedir.

9) İlk kalkınma planından itibaren her kalkınma planında turizm personeli eğitimine işaret edilmesi (DPT, 1963:427; DPT, 1972:713; DPT, 1979:432; DPT, 1989:281) dikkate değer başka bir politikadır. Bugün Türk üniversitelerinde gerek önlisans ve gerekse lisans seviyesinde turizm eğitiminin üst seviyelerde olması bir tesadüf sonucu değildir.

10) Dördüncü beş yıllık kalkınma planında ev pansiyonculuğunun özendirilmesine işaret edilmiştir (DPT, 1979:660). Ev pansiyonu işletmeciliği bugün bile kırsal kalkınmayı gerçekleştirmekte kullanılabilecek bir araç olma vasfinı sürdürmektedir.

İncelenen kalkınma planlarında işaret edilen hususlar dikkate alınarak turizm sektörünü geliştirmeye yönelik öneriler şu başlıklar altında toplanmıştır:

1) Turizm faaliyetleri, doğal ve kültürel değerler ülke çapında çeşitlendirilerek yılın oniki ayına yayılmalıdır.

2) Turistlerin talep ve beklentilerine cevap verilmeli, hizmet kalitesi artırılmalı, çevre temizliğine önem verilmelidir.

3) Turizm yatırımlarına yönelik teşvikler devam etmelidir.

4) Turizm faaliyetlerinde maliyetleri düşürmek için Katma Değer Vergisi ve Özel Tüketim Vergisi oranları azaltılmalıdır.

5) Turizmde tanıtım ve pazarlama kanalları çeşitlendirilmelidir. 
6) Avrupalı ve Rus turiste bağımlılığı azaltmak üzere başta Arap ülkeler ile Çin ve Japonya gibi yeni ülkeler hedef pazar seçilmelidir. Böylece ipek yolu turizmi başlatılabilir (İlkin ve Dinçer, 1991:105)

7) Turizmin gelişmesini sağlayan başlıca faaliyetler olarak fuarlar, kongreler, festivaller ve spor ön plana çıkmaktadır (Sezgin, 2001:73-74). Yazılı ve görsel basın ile birlikte sosyal medya yoluyla kamuoyuna bu tür organizasyonların ülke çapında tanıtımı ve duyurusu yapılmalıdır.

8) Köy ve ormana dayalı eko turizm faaliyetlerine yönelik olarak ev pansiyonculuğu özendirilip yaygınlaştırılmalıdır.

9) Bir girişimcilik türünü oluşturan seyahat acenteliği ve tur operatörlügüü ülke çapında teşvik edilmelidir. Bu tür eğitimler öncelikle halk eğitim merkezleri bünyesinde yaygınlaştırılmalıdır.

10) Turizm sektörünün siyasi ve toplumsal olaylara, doğal afetlere, savaş ve terör olaylarına, salgın hastalıklara ve ekonomik krizlere karşı oldukça hassas olduğu hiçbir zaman unutulmamalıdır.

Sonuç olarak Türkiye sahip olduğu turizm potansiyelini harekete geçirebildiği ölçüde uluslararası turizmde söz sahibi olacaktır.

\section{Kaynakça}

İlkin, A. ve Dinçer, Z. (1991). Turizm Türk Ekonomisindeki Yeri ve Önemi, TOBB Yayın No: 217, Ankara.

- Maviş, F. ve Akoğlan, M. (1997). Genel Turizm Bilgisi, Anadolu Üniversitesi Yayın No: 938, Eskişehir.

- $\quad$ Oktayer, N., Susam, N. ve Çak, M. (2007), Türkiye'de Turizm Ekonomisi, İTO Yayın No: 2007-69, İstanbul.

- Olalı, H. (1990). Turizm Politikası ve Planlaması, İ.Ü.İşletme Fakültesi Yayın No:228, İstanbul.

- Sezgin, O.M. (2001). Genel Turizm ve Turizm Mevzuatı, 2.Baskı, Detay Yayıncılık, Ankara.

- Şahin, A. (1990). İktisadi Kalkınmadaki Önemi Bakımından Türkiye’de Turizm Sektöründeki Gelişmelerin Değerlendirilmesi, TOBB Yayın No:149, Ankara.

- Turizm Özel İhtisas Komisyon Raporu (2007), T. C. Başbakanlık Devlet Planlama Teşkilatı Yayın No: 2727, Ankara.

- T.C. Başbakanlık Devlet Planlama Teşkilatı Müsteşarlığı (1963). Birinci Beş Yıllık Kalkınma Planı (19631967), Ankara. http://ekutup.dpt.gov.tr/plan1.pdf (erişim tarihi 30.04.2016)

- T.C. Başbakanlık Devlet Planlama Teşkilatı Müsteşarlığı (1968). İkinci Beş Yıllık Kalkınma Planı (19681972), Ankara. http://ekutup.dpt.gov.tr/plan2.pdf (erişim tarihi 30.04.2016)

- T.C. Başbakanlık Devlet Planlama Teşkilatı Müsteşarlığı (1972). Üçüncü Beş Yıllık Kalkınma Planı (1973 1977), Ankara. http://ekutup.dpt.gov.tr/plan3.pdf (erişim tarihi 01.05.2016)

- T.C. Başbakanlık Devlet Planlama Teşkilatı Müsteşarlığı (1979). Dördüncü Beş Yıllık Kalkınma Planı (1979-1983), Yayın No: 1664, Ankara. http://ekutup.dpt.gov.tr/plan4.pdf (erişim tarihi 01.05.2016)

- T.C. Başbakanlık Devlet Planlama Teşkilatı Müsteşarlığı (1984). Beşinci Beş Yıllık Kalkınma Planı (19851989), Yayın No: 1974, Ankara. http://ekutup.dpt.gov.tr/plan/plan5.pdf (erişim tarihi 01.05.2016)

- T.C. Başbakanlık Devlet Planlama Teşkilatı Müsteşarlığı (1989). Altıncı Beş Yıllık Kalkınma Planı (19901994), Yayın No: 2174, Ankara. http://ekutup.dpt.gov.tr/plan/plan6.pdf (erişim tarihi 01.05.2016)

- T.C. Başbakanlık Devlet Planlama Teşkilatı Müsteşarlığı (1995). Yedinci Beş Yıllık Kalkınma Planı (19962000), Ankara. http://ekutup.dpt.gov.tr/plan/vii/plan7.pdf (erişim tarihi 01.05.2016)

- T.C. Başbakanlık Devlet Planlama Teşkilatı Müsteşarlığı (2000). Sekizinci Beş Yıllık Kalkınma Planı (2001-2005), Ankara. http://ekutup.dpt.gov.tr/plan/viii/plan8str.pdf (erişim tarihi 01.05.2016)

- T.C. Başbakanlık Devlet Planlama Teşkilatı Müsteşarlığı (2006). Dokuzuncu Kalkınma Planı (2007-2013), Ankara. http://ekutup.dpt.gov.tr/plan9.pdf (erişim tarihi 01.05.2016)

- T.C. Kalkınma Bakanlığı (2013). Onuncu Kalkınma Planı (2014-2018), Ankara. http://ekutup.dpt.gov.tr/plan10.pdf (erişim tarihi 01.05.2016)

- Yağcı, Ö. (2007). Turizm Ekonomisi, 2.Baskı, Detay Yayıncılık, Ankara 


\title{
Zincir ve Grup Otel İşletmelerinin Kurumsal Sosyal Sorumluluk Faaliyetlerini Duyurmada Web Sitelerinin Etkinliği Üzerine Bir Araştırma: Türkiye Örneği
}

\author{
A Research on Effectiveness of Web Sites in Announcing \\ Corporate Social Responsibility Activities of Chain and Group \\ Hotels: The Case of Turkey
}

\author{
Ph.D. Candidate Erhan Boğan (Sakarya University, Turkey) \\ Asst. Prof. Dr. Şevki Ulama (Sakarya University, Turkey) \\ Prof. Dr. Mehmet Sarışık (Sakarya University, Turkey)
}

\begin{abstract}
The term 'Corporate social responsibility', which is regarded as one of the most important way of developing good relationships between hotels and their stakeholders, provides competitive advantage to companies in long term. Hotel managers possessing a strategical awareness announce these activities they organize for public interest both in their web-sites and via different communication tools. Studies on this subject were scanned and it has been realized it has not been sufficiently examined how efficiently hotels in Turkey use web-sites which are a quite effective tool for announcing corporate social responsibility activities. The main purpose of this study aiming at filling this gap in literature is to analyze corporate social responsibility reports included in web-sites of chain and group hotels in Turkey. Scope of corporate social responsibility and sustainability reports in web-sites of hotel was discussed in terms of stakeholders (employees, society, customers and environment) and examined via content analysis. In addition, communication techniques that hotels use so as to announce these activities were researched. As a result of examination, any statement related to corporate social responsibility could not be found in web-sites of almost half of hotels. It was determined the number of hotels allocating a separate section for corporate social responsibility in their corporate social responsibility, sustainability or annual reports is quite low. From a general perspective, it was found out chain and group hotels in Turkey could not effectively use web-sites for announcing corporate social responsibility activities. Results were obtained through the analysis of findings and suggestions for hotel managers were developed accordingly.
\end{abstract}

\section{Giriș}

Günümüzde işletmelerin toplum içerisindeki yerinin akademisyenler, müşteriler, toplum, medya ve sivil toplum kuruluşları tarafından sorgulanması sonucunda ortaya çıkan kurumsal sosyal sorumluluk kavramı (Carroll, 1996, s. 30; Horrigan, 2010, s. 4; De Grosbois, 2012, s. 898; Hooghiemstra, 2000, s. 55) son 30 yıldır gerek yönetim, gerekse pazarlama çalışmalarına konu olmaktadır. Ayrıca bu kavramın işletme ve toplum var oldukça güncelliğini devam ettireceği düşünülmektedir. Kâr amacı taşıyan işletmelerin faaliyetlerini büyük ölçüde şekillendiren tüketicilerin çevresel bilinç düzeylerinin yükselmesi (Mihalic, 2000, s. 65; Rodriguez ve Cruz, 2007, s. 825) ve bunun yanında sivil toplum kuruluşları, devlet ve toplumun işletmeler üzerinde kurmuş olduğu baskılar sonucunda (Bohdanowicz ve Zientara, 2008, s. 271; Frankental, 2001, s.21) işletmeler vizyon ve misyon, politika ve yıllık raporlarında sürdürülebilirlik, sosyal sorumluluk, çevre gibi kavramlara yer vermek zorunda kalmıştır (Kang vd., 2010, s. 72). Ancak yapılan çalışmalar, işletme paydaşlarının işletmelerden sadece sorumlu davranışlar gösterilmesini beklemediği aynı zamanda, işletmelerin yapmış oldukları kurumsal sosyal sorumluluk faaliyetlerinin kapsamı ve uygulamaların verimliliği hakkında bilgi sahibi olmak istedikleri sonucunu ortaya koymaktadır. İşletme paydaşları elde ettikleri bu bilgileri çeşitli kararlarda kullanmaktadır. Örneğin bu bilgiler yatırımcıların yatırım kararlarında, devletin teşvik uygulamalarında ve tüketicilerin ürün satın alma tercihlerinde etkili olabilmektedir (De Grosbois, 2012, s. 898).

İşletmelerin toplum üzerinde oluşturduğu etkinin sorumluluğunu üstlenmesi (McGehee ve diğ., 2009, s. 418) olarak değerlendirilen kurumsal sosyal sorumluluk kavramının, sosyal, çevresel ve ekonomik olumlu ve olumsuz etkilerinin sıkça tartışıldı̆̆ı turizm endüstrisinde yeri ve önemi büyüktür. Kurumsal sosyal sorumluluk faaliyetlerinin turizm işletmesi performansını olumlu (Kang ve diğ., 2010; Inoue ve Lee, 2011; Wang, 2014), çalışan tutum ve davranışlarını olumlu (Park ve Levy, 2014; Çalışkan ve Ünüsan, 2011; Farooq ve diğ., 2014), müşteriler tarafından algılanan hizmet kalitesi, marka imajı, daha fazla ödeme talebinde olma ve konaklama kararı verme üzerinde olumlu (Kucukusta ve diğ., 2013) etkilediği belirlenmiştir. Yapılan bu çalışmalar ışı̆̆ında, özellikle konaklama işletmeleri gibi talep esnekliği ve işgücü devir oranının yüksek olduğu bir sektörde kurumsal sosyal sorumluluk faaliyetlerinin uzun dönemde işletmelere rekabet avantajı sağlayacağı düşünülmektedir.

Kurumsal sosyal sorumluluk faaliyetlerinin, otel işletmeleri için stratejik öneminin giderek arttığı günümüzde, ülkemizde faaliyet gösteren otel işletmelerinin bu realiteye karşı tutumlarının neler olduğu konusunda yapılan 
akademik çalışmalar oldukça kısıtlıdır. Perrini ve arkadaşlarına (2006) göre, zincir işletmeler kurumsal sosyal sorumluluk faaliyetlerinin uygulanması noktasında küçük ve orta büyüklükteki işletmelere öncülük etmektedir. Bunun yanında McGehee ve arkadaşlarına (2009) göre, büyük ölçekli ve lüks otel işletmeleri diğer işletmelere oranla daha fazla kurumsal sosyal sorumluluk faaliyetlerinde bulunma eğilimindedirler. Belirtilen bu nedenler doğrultusunda, Türkiye'deki zincir otel işletmeleri tarafindan yürütülen kurumsal sosyal sorumluluk faaliyetlerinin duyurumunda web sitelerinin rolünün ne olduğunun ortaya çıkarılması araştırmanın temel amacıdır.

$\mathrm{Bu}$ doğrultuda, aşağıda kurumsal sosyal sorumluluk kavramı ve konaklama işletmelerinde kurumsal sosyal sorumluluk faaliyetleri başlıklı literatür taraması sonucunda elde edilen bilgilere yer verilecektir. Daha sonra, çalışmanın metodolojisine, son olarak da araştırma sonunda elde edilen bulgulara ve tartışma kısmına yer verilecektir.

\section{Kurumsal Sosyal Sorumluluk}

Birer ekonomik kuruluş olarak yola çıkan işletmelerin toplum içerisinde rolü 2000'li yıllardan itibaren büyük bir değişime uğramıştır. Daha önceleri işletmelerin ekonomik kazanç elde etmesi ya da vergilerini zamanında ödemesi gibi temel sorumluluklar işletmeleri sorumlu işletme haline getirirken, günümüzde işletmeler sosyal, çevresel ve ekonomik boyutu olan birer kuruluş olarak toplumda faaliyet göstermektedir (Yamak, 2007, s. 9; Frankental, 2001; s. 19). Günümüzde işletmeler her alanda doğrudan ya da dolaylı birçok olumlu ya da olumsuz etkiye sahiptirler. Olumsuz etkilerin belirgin hale gelmesiyle medya, sivil toplum kuruluşları işletmeler üzerinde baskı kurmaktadır. Bu baskılar karşısında hareket geçmemek, sessiz kalmak ya da bu realiteyi yalanlamak, sürdürülebilirlik üzerine dünya çapında zirvelerin düzenlendiği günümüzde ayrı bir suç ortaklığı niteliği taşımaktadır (Frankental, 2001, s. 21). Carroll (1999, s. 270) tarafından "kurumsal sosyal sorumluluğun babası" nitelendirilen Bowen (1953, s. 6) göre kurumsal sosyal sorumluluk (KSS), "işletmelerin hem kendi amaçlarına hem de toplumsal değerler ve beklentilere uygun politikalar belirleme ve uygulama, karar verme ve faaliyetleri yerine getirmeyle toplumun yaşamını iyileştirmeye ilişkin yükümlülüklerinin bütünüdür”. Kurumsal sosyal sorumluluk, işletmelerin varlıklarını sadece kar açısından değil topluma sağlamış hizmetler açısından sorgulaması olarak tanımlanmaktadır. Bu yüzden kurumsal sosyal sorumluluk işletmenin bir yandan çalışanlar, tedarikçiler, müşterileri gibi paydaşlarının çıkarlarını gözetmesi, diğer yandan hayırseverlik ve çevresel sürdürülebilirliği destekleyici faaliyetlerini kapsayan geniş bir realitedir (Bohdanowicz ve Zientara, 2008, s. 271). Yapılan bu tanımlamada kurumsal sosyal sorumluluk kavramı çevresel sürdürülebilirlik, paydaşların çıkarlarını dengeleme ve hayırseverlik faaliyetleri olarak göze çarpmaktadır. Jones ve arkadaşlarına (2006, s. 330) göre başlangıçta KSS faaliyetleri işletmelerin sosyal sorunların çözümüne katkı sağlamak amacıyla gerçekleştirdiği hayırseverlik faaliyeti olarak değerlendirilirken, bu kavram günümüz iş dünyasında işletmelerin rekabet avantajı elde etmek, müşterileri elinde tutma amacına hizmet eden bir kavram haline dönüşmüştür.

KSS kavramının modern anlamda gelişimine en önemli katkılardan birini sağlayan Carroll (1979, s. 500) işletmelerin sosyal sorumluluklarını bir piramid şeklinde dört başlık altında toplamıştır. Bunlar; ekonomik, yasal, ahlaki ve gönüllü sorumluluklardır. Ekonomik sorumluluk, işletmenin hissedarlarına karşı olan kar elde etme sorumluluğudur. Yasal sorumluluk, işletmenin ekonomik faaliyetlerini yerine getirirken kanuni düzenlemelere uyma sorumluluğudur. Ahlaki sorumluluk ise, işletmenin toplumun değer yargılarına uymayan faaliyetlerde bulunmama sorumluluğudur. Son olarak gönüllü sorumluluk ise, işletmelerin tamamen gönüllülük esasına dayalı hayırseverlik faaliyetlerini kapsamaktadır.

Her ne kadar KSS işletmelerin ekonomik çıkarlarının ötesinde tüm paydaşlarını olumlu yönde etkileyecek kurumsal davranışlar (Türker, 2009, s. 189) olarak tanımlansa da, işletmelerin birer ahlaki acenta olamayacağına (Wartrick ve Cochran, 1985, s. 760) dair düşünceler de mevcuttur. Bu düşüncenin öncülerinden olan Friedman (1970)'a göre, işletmelerin temel sorumluluğu kar maksimizasyonudur. Dernek ve vakıf gibi sivil toplum kuruluşlarına ya da yardım kuruluşlarına maddi destek sağlamak işletmenin sorumluluğu değildir. Elde edilen kar yöneticinin sorumluluğunda olmayıp, yöneticinin kar üzerinden tasarruf yapma yetkisi yoktur (Hitt ve diğ., 2009 , S. 50).

İşletmelerin kurumsal sosyal sorumluluk performansının nasıl ölçüleceğine ya da kavramın kapsamına dair literatürde genel kabul görmüş yaklaşım söz konusu değildir. Bazı araştırmacılar (Çalışkan ve Ünüsan, 2011; Lee ve diğ., 2012; Wang, 2014) işletmelerin KSS ölçülmesinde Carroll (1979) tarafından oluşturulan dört boyutu ele alırken; bazıları (Turker, 2009; Farooq ve diğ., 2014; Park ve Levy, 2014), Freeman tarafından geliştirilen paydaş teorisine bağlı olarak işletmelerin spesifik olarak (müşteriler, çalışanlar, çevre vb.) paydaşlarına karşı sosyal sorumluluklarını ele almakta; bazıları ise (Martinez ve diğ., 2013; Cowper-Smith ve De Grosbois, 2011), sürdürülebilir kalkınmanın temel boyutlarını oluşturan ekonomik, sosyal ve çevresel faktörleri ele almaktadır.

\subsection{Konaklama İşletmelerinde Kurumsal Sosyal Sorumluluk}

1980'li yıllardan itibaren kitle turizminin esir aldığı önemli turistik destinasyonlarda bir alanda yoğunlaşmanın görülmesi ve doğal çevre ve toplumun turistik ürünün bir parçası olması (Henderson, 2007, s. 229) turizmin sosyal, çevresel ve kültürel alanda meydana getirdiği olumsuz etkinin daha da belirginleşmesine neden olmuştur. Turizmin doğal çevre üzerindeki olumsuz etkisini Ozturk ve arkadaşları (2015, s. 234) şu şekilde özetlemektedir; doğal 
kaynak tüketiminde yaşanan artış, sürdürülemez arazı kullanımı ve arazilerin bozulması, turizm işletmeleri ve turistik faaliyetler sonucunda eko-sistemde değişimin yaşanması, var olan altyapı üzerinde yoğunluk yaşanması, hava, su, gürültü ve çevre kirliliğinin artması. Turizmin sosyo-kültürel alanda meydana getirdiği olumsuz etkiler ise yine Ozturk ve arkadaşları $(2015$, s. 234) şu şekilde özetlenmektedir; anadilde yaşanan erozyon, yerel kimlik ve değerler üzerinde asimilasyon ve değişimlerin yaşanması, kültürün metalaştırılması, kültürel otantikliğin kaybı, geleneksel hayat tarzı ve misafirperverliğin yok olması, sosyal bağların ve aile yapılarının zayıflaması, turistler ve yerel halk arasında yaşanan kültürel çatışmalar. Turizmin tüm bu olumsuz sonuçları nedeniyle sosyal, çevresel ve ekonomik boyutlardan oluşan kurumsal sosyal sorumluluk faaliyetlerinin turizm işletmelerince uygulanması ve diğer işletmelerin de teşvik edilmesi gerekmektedir (De Grosbois, 2012, s. 898). Ancak Sheldon ve Park (2011, s. 1) ve Holcomb ve arkadaşlarına (2007) göre turizmin sosyo-kültürel çevre meydana getirdiği etki her ne kadar belirgin olsa da, turizm endüstrisinde kurumsal sosyal sorumluluk faaliyetleri denilince akla çevre koruma uygulamaları gelmektedir (Bkz. Erdogan ve Baris, 2007; Ayuso, 2006; Bohdanowicz, 2006; Carlsen ve diğ., 2001; Kasim, 2007; Chung ve Parker, 2010). Turizmin olumsuz etkilerini minimize etme amaciyla birçok konaklama işletmesi son 20-25 yıldır, KSS faaliyetlerini stratejilerle buluşturmaktadır (Kucukusta ve diğ., 2013, s. 20). Birçok ulusal ve uluslararası alanda faaliyet gösteren zincir otel işletmeleri (bkz Hilton Hotels Corporation, Marriot International, Wyndham Hotels, Accor Hotel, InterContinental Group, Bera Hotels) kurumsal sosyal sorumluluk adına yaptıkları faaliyetlerini gerek web siteleri aracılığıyla gerekse yıllık olarak yayınladıkları kurumsal sosyal sorumluluk raporu, sürdürülebilirlik raporlarında duyurumunu yapmaktadırlar (De Grosbois, 2012, s. 898). Bunun yanında birçok otel işletmesi, KSS faaliyetlerini önemli bir pazarlama ve stratejik bir yönetim aracı olarak görmektedir. Örneğin, Wyndham Hotels and Resorts kendi bünyesinde faaliyet gösteren restoran işletmelerinde, çevre dostu içecek menüsü geliştirme yönünde adımlar atmıştır. Bu kapsamda, "Bir içecek al, Bir ağaç dik" kampanyası restoranlarında uygulamaya konulmuştur (Kucukusta ve diğ., 2013, s. 19). Çelik ve Can (2014) Türkiye'de faaliyet gösteren zincir otel işletmelerinin kurumsal sosyal sorumluluk projelerine yönelik bir içerik analizi yapmıştır. Ancak, otel işletmelerinde kurumsal sosyal sorumluluk duyurumu konusu Holcomb ve arkadaşları (2007), De Grosbois (2012) gibi çalışmalarla ele alınsa da, Türkiye'de faaliyet gösteren zincir otel işletmelerinin bu karşı tutumunun ele alınmadığı belirlenmiştir. Bu çalışma, alanda yer alan bu boşluğu doldurmaya çalışmaktadır.

\section{Metodoloji}

\subsection{Veri Toplama ve Analiz}

Bu çalışmanın ana kütlesi Türkiye'de faaliyet gösteren zincir ve grup otellerdir. Bu otellerin listesi 2013 Turizm \& Yatırım Dergisi'nden elde edilmiştir. Buna göre, Türkiye'de 147 zincir otel işletmesi yer almaktadır. Bu çalışmada, bu otellerin oda sayısı kıstas olarak alınmış, 1000'in üzerinde odaya sahip zincir otellerin resmi internet sitelerinde, kurumsal sosyal sorumlulukla ilişkili bilgiler araştırılmıştır. Dergide yer alan listeye göre 1000'in üzerinde odaya sahip otellerin sayısı 64'tür. Bu araştırma kapsamında, otellerin kurumsal web siteleri, yıllık raporları, sürdürülebilirlik raporu ve web sitesinde mevcut diğer materyaller içerik analizine tabi tutulmuştur. Söz konusu bu veriler, 2016 yılının ocak ve şubat aylarında elde edilmiştir.

Toplanan veriler, birçok araştırmacı tarafından da başvurulduğu gibi (Jones ve diğ., 2006; Holcomb ve diğg., 2007; De Grosbois, 2012; Kennedy Nyahunzvi, 2013) içerik analizine tabi tutulmuştur. Bu çalışmada, otel işletmelerinin web sitelerinde kurumsal sosyal sorumluluk iletişiminde kullandıkları metodlar, De Grosbois (2012) tarafından da değerlendirildiği gibi, dört başlık altında ele alınmıştır. Bunlar; (i) ayrı bir KSS raporu veya çevre raporu ya da yıllık raporda KSS için ayrılan bir bölüm; (ii) web sitesinde tamamen KSS ya da sürdürülebilirlik için ayrılan bir bölüm; (iii) web sitesinde işletmeyi tanıtan bölümde KSS ya da çevre ile ilgili ifadeler (hakkımızda, ödüller, misyon, politikalarımız, değerler); son olarak (iv) web sitesinde KSS ilgili herhangi bir bilginin olmaması durumudur. Bunun yanında, işletmelerin sosyal sorumlulukları hedeflenen alana ve kitleye (paydaşlara) göre ele alınmıştır. Bunlar; çevre, toplum, müşteriler ve çalışanlardır. İşletmelerin çevre ve paydaşlara karşı sosyal sorumluluk temaları literatür taraması sonucunda oluşturulmuştur. Bu temaların listesi Tablo 1'de yer almaktadır. Buna göre işletmelerin web sitelerinden elde edilen verilerde bu temalara yer verilip verilmediği araştırılmıştır.

Veriler sadece bir araştırmacı tarafından toplanıp kodlanmıştır. Kodlamaların güvenilirliğini test etmek için ikinci bir araştırmacıya rastgele üç otel işletmesinin web sitesi linki ve kurumsal sosyal sorumluluk raporu verilmiş ve kodlanması istenmiştir. Daha sonra verilen cevaplarla kappa analizine uygulanmış, güvenilirliğin \%85 yani yüksek olduğu belirlenmiştir.

\section{Bulgular}

\subsection{Kurumsal Sosyal Sorumluluk İletişiminde Kullanılan Metotlar}

Araştırmanın örneklemini oluşturan 64 otel işletmesinin web sitesi incelenmiştir. Buna göre bazı otellerin web sitelerinin dili İngilizcedir. Araştırmada web sitesinin dili Türkçe ya da İngilizce olan oteller incelenmiştir. Otellerin KSS iletişiminde kullandıkları metotlar incelediğinde, 64 otelden 30'unun KSS, sürdürülebilirlik ya da çevre ile ilgili herhangi bir bilgiye yer vermedikleri saptanmıştır. 20 işletmenin web sitesinde KSS, 
sürdürülebilirlik ya da çevre ile ilgili bir bölümün olduğu belirlenmiştir. Web sitesinde ayrı bir KSS, sürdürülebilirlik ve çevre raporu ya da yıllık raporlarında KSS, sürdürülebilirlik ya da çevre için ayrılan bir bölüme sahip otel işletmelerinin sayısı yalnızca 8'dir. Son olarak web sitesinde oteli tanıtan bölümde (hakkımızda, misyon, politikalarımız, değerler, vb. gibi) KSS, sürdürülebilirlik ya da çevre ile ilgili ifadelerin olduğu otel sayısı 10'dur. Bazı işletmeler hem ayrı bir KSS ya da sürdürülebilirlik raporuna hem de web sitesinde KSS ve sürdürülebilirlik ile ilgili ayrı bir bölüme sahiptir. Dolayısıyla bu oteller hem birinci hem de ikinci kısma dâhil edilmiştir.

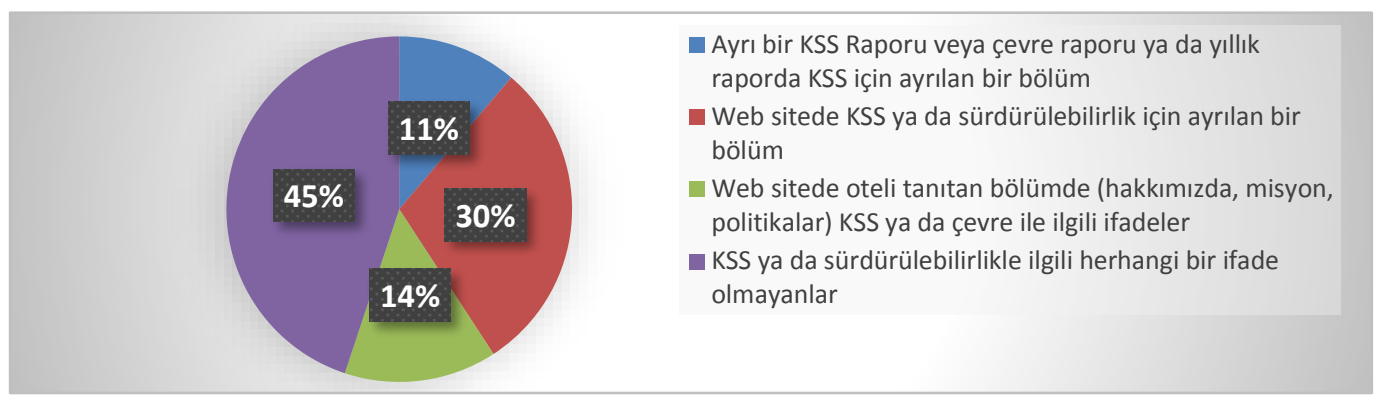

Tablo 1. Kurumsal Sosyal Sorumluluk Iletişiminde Kullanılan Metotlar

\subsection{Kurumsal Sosyal Sorumluluğun Kapsamı}

$\mathrm{Bu}$ bölümde, otel işletmelerinin kurumsal sosyal sorumluluk faaliyetlerinin kapsamı ele alınacaktır. $\mathrm{Bu}$ kapsamda dört farklı paydaş grubuna yönelik sosyal sorumluluk faaliyetlerine, söz konusu işletmelerin yer verip vermeme durumları ortaya konulacaktır. Bu paydaşlar çalışanlar, toplum, müşteriler ve çevredir. Bu ifadeler literatür taraması sonucunda oluşturulmuştur. Araştırma sürecinde, web sitede KSS ya da sürdürülebilirlikle ilgili herhangi bir ifade olmayan otellerin dışında tüm oteller ele alınmıştır. Dolayısıyla 29 otel işletmesinin web sitesi ve raporları tek tek incelenmiştir. Elde edilen bulgular Tablo 2'te yer almaktadır.

\begin{tabular}{|c|c|c|}
\hline Çalıșanlara Karşı Sosyal Sorumluluk & Var (Yüzde) & Yok (Yüzde) \\
\hline *Güvenli ve sağlıklı bir çalışma ortamı sunmak & $18(\% 62)$ & $11(\% 38)$ \\
\hline *Çalıșanlara adil ve saygılı davranmak & $13(\% 45)$ & $16(\% 55)$ \\
\hline * İyi bir iş-yaşam dengesi sunmak & $10(\% 34)$ & $19(\% 66)$ \\
\hline *Yetenek ve kariyer gelişimlerine yardımcı olmak & $18(\% 62)$ & $11(\% 38)$ \\
\hline *Adil ve makul bir maaş sunmak & $4(\% 14)$ & $25(\% 86)$ \\
\hline *Çalışanlar arasında ayrım yapmamak & $14(\% 48)$ & $15(\% 52)$ \\
\hline \multicolumn{3}{|l|}{ Müșterilere Karșı Sosyal Sorumluluk } \\
\hline *Müșteri memnuniyetini sağlamak & $19(\% 66)$ & $10(\% 34)$ \\
\hline *Yüksek kalitede ürün ve hizmet sunmak & $18(\% 62)$ & $11(\% 38)$ \\
\hline *Müşteri şikâyetlerine duyarlı olmak & $13(\% 45)$ & $16(\% 55)$ \\
\hline *Müșteri haklarına saygılı olmak & $11(\% 38)$ & $18(\% 62)$ \\
\hline \multicolumn{3}{|l|}{ Çevreye Karșı Sosyal Sorumluluk } \\
\hline *Alternatifler arasında çevreye daha az zarar veren ürünler satın almak & $13(\% 45)$ & $16(\% 55)$ \\
\hline *Müșterileri çevre duyarlılı̆̆ına teșvik etmek & $16(\% 55)$ & $13(\% 45)$ \\
\hline *Çevresel girişimleri desteklemek & $14(\% 48)$ & $15(\% 52)$ \\
\hline * Enerji tasarrufu sağlamak & $19(\% 66)$ & $10(\% 34)$ \\
\hline *Atık azaltımı ve geri dönüşümü desteklemek & $20(\% 69)$ & $9(\% 31)$ \\
\hline *Su tasarrufu sağlamak & $18(\% 62)$ & $11(\% 38)$ \\
\hline *Hava kirliliğini azaltıcı önlemler almak & $12(\% 41)$ & $17(\% 59)$ \\
\hline *Gürültü kirliliğini azaltmak & $4(\% 14)$ & $25(\% 86)$ \\
\hline *Ekosistem bitki çeşitliliğini korumak & $12(\% 41)$ & $17(\% 59)$ \\
\hline *Çevresel farkındalığı artırmak & $14(\% 48)$ & $15(\% 52)$ \\
\hline *Kimyasal maddelerin kullanımını azaltmak & $12(\% 41)$ & $17(\% 59)$ \\
\hline \multicolumn{3}{|l|}{ Topluma Karşı Sosyal Sorumluluk } \\
\hline *Toplumun yaşam kalitesini artırmak & $11(\% 38)$ & $18(\% 62)$ \\
\hline *Yerel kültür, gelenek ve mirasın korunmasına katkı sağlamak & $13(\% 45)$ & $16(\% 55)$ \\
\hline *Yerel yardım kuruluşlarını finansal olarak desteklemek & $9(\% 31)$ & $20(\% 69)$ \\
\hline *Toplumsal sorunlara ve toplumsal değerlere karşı duyarlı davranmak & $12(\% 41)$ & $17(\% 59)$ \\
\hline *Yerel topluma istihdam olanağı sunmak & $9(\% 31)$ & $20(\% 69)$ \\
\hline *Tedarikte yöresel ürün ve hizmetlerin satın alınmasına öncelik vermek & $11(\% 38)$ & $18(\% 62)$ \\
\hline $\begin{array}{l}\text { *Toplumun ihtiyaçları doğrultusunda park, hastane, okul vb. yapımına } \\
\text { maddi destek sağlamak }\end{array}$ & $14(\% 48)$ & $15(\% 52)$ \\
\hline
\end{tabular}

Tablo 2. Kurumsal Sosyal Sorumluluğun Kapsamı 
Otel işletmeleri belirlenen paydaşlara (çalışan, çevre, toplum ve müşteriler) karşı sosyal sorumluluklarını genel olarak değerlendirildiğinde yayınladıkları sürdürülebilirlik, kurumsal sosyal sorumluluk ve yıllık raporlarında yer vermektedir. Ancak şunu belirtmekte fayda var ki, işletmelerin raporlarında yer verdikleri söz konusu paydaşlara karşı sosyal sorumluluk girişimlerinin kapsamı otelden otele değişkenlik göstermektedir. Oluşturulan temalara bazı işletmeler raporlarında her bir sorumluluğu kapsamlı bir şekilde ele alırken, bazı işletmeler bu sorumlulukları sadece web sitelerindeki ilgili bölümlerde kısaca ifade etmişlerdir. İşletmelerin çalışanlara karşı sosyal sorumluluk kapsamında en fazla "çalışanların yetenek ve kariyerleri geliştirmek", "çalışanlara güvenli ve sağlıklı bir çalışma ortamı sunma" sorumluluklarına yer verdikleri belirlenmiştir. Ancak işletmelerin çalışanları yönelik "adil ve makul bir maaş sunmak" ve "iyi bir iş-yaşam dengesi sunmak" gibi önemli sorumluluklara yeterince yer vermedikleri belirlenmiştir. Müşterilere karşı sosyal sorumluluk kapsamında ise işletmelerin en fazla "müşteri memnuniyetini sağlamak" ve "müşterilere yüksek kalitede ürün ve hizmet sunmak" sorumluluklarına; en az "müşteri haklarına saygılı olmak" sorumluluğuna yer verdikleri belirlenmiştir. Çevreye karşı sosyal sorumluluk kapsamın işletmelerin raporların en fazla yer verdikleri sorumluluklar atık azaltımı ve geri dönüşümü desteklemek, enerji ve su tasarrufu sağlamak iken; en az yer verdikleri sorumluluklar ise, gürültü kirliliğini azaltmak, ekosistem bitki çeşitliliğini korumak, kimyasal maddelerin kullanımını azaltmak ve hava kirliliğini azaltıcı önlemler almaktır. Son olarak topluma karşı sosyal sorumluluklar kapsamında işletmelerin oldukça pasif olduklarını söylemek mümkündür. Yerel yardım kuruluşlarını finansal olarak desteklemek ve yerel topluma istihdam olanağı sunma gibi sorumluluklar işletmelerin raporlarında göz ardı ettikleri önemli sorumluluk alanlarıdır.

\section{Sonuç ve Değerlendirme}

Türkiye'de faaliyet gösteren zincir ve grup otel işletmelerinin kurumsal sosyal sorumluluk faaliyetlerini duyurmada web sitelerini kullanma etkinliklerini araştırmayı hedeflediğimiz bu çalışmada elde ettiğimiz bulgular oldukça çarpıcı sonuçlar ortaya koymuştur. Öncelikle, 2013 yılı itibariyle 1000 üzerinde yatak kapasitesine sahip Türkiye'nin en büyük zincir ve grup otel işletmelerinin, kurumsal sosyal sorumluluk faaliyetlerini duyurma noktasında oldukça etkisiz oldukları belirlenmiştir. İncelediğimiz otel işletmelerinin hemen hemen yarısının kurumsal sosyal sorumluluk adına web sitelerinde herhangi bir bilgiye yer vermemelerinin üç muhtemel sebebi olabilir. Birincisi otel işletmelerinin kurumsal sosyal sorumluluk adına herhangi bir girişim yürütmedikleri ihtimalidir. İkincisi ise, işletmeler KSS girişimlerinde bulunsalar dahi bu faaliyetleri duyurmanın kendilerine stratejik bir rekabet üstünlüğü sağlayacakları noktasında yeterli bir bilinç düzeyine sahip olmamalarıdır. Son olarak üçüncüsü ise, işletmelerin bu girişimleri duyurmada web sitelerinden ziyade farklı araçlar kullandıklarıdır.

Kurumsal sosyal sorumluluk girişimlerini yıllık raporlarında, sürdürülebilirlik raporlarında ya da KSS raporunda yer veren ya da web sitelerinde bu girişimler için ayrı bir bölüm oluşturan otel işletmelerinin KSS girişimlerinin kapsamı çalışanlar, müşteriler, çevre ve toplum gibi paydaşlar açısından incelendiğinde, işletmelerin topluma karşı sosyal sorumluluklarında oldukça etkisiz oldukları sonucu elde edilmiştir. Bu durum KSS kavramının otel işletmelerince yeterince anlaşılamamasının bir yansıması olabilir. Çünkü yukarı da belirtildiği gibi, otel işletmelerinde KSS faaliyetleri denildiğinde akla genellikle çevre koruma uygulamaları gelmektedir (Sheldon ve Park, 2011; Holcomb ve diğ., 2007). Bu durumun ayrı bir muhtemel sebebi Boğan (2015) tarafından da belirtildiği gibi, "sağ elin verdiğini sol elin görmemesi gerektiği”" şeklinde bilinen dini değerlere uygun kurumsal hayırseverlik faaliyetlerinin yapılması gerekliliği inancıdır.

$\mathrm{Bu}$ çalışma uygulamacılar için de önemli tavsiyeler ortaya koymaktadır. Öncelikli olarak, kurumsal sosyal sorumluluk farkındalık düzeyi yüksek olan turizm pazarlarından pay almakta olan Türkiye destinasyonunda faaliyet gösteren otel işletmeleri, KSS girişimlerinde bulunmalıdır. Bunun yanında yürütülen bu girişimlerden işletme paydaşlarının (müşteriler, toplum, çalışanlar) haberdar edilmesi gerekmektedir. Bunun da en kolay, ucuz ve efektif yöntemi de işletmelerin kurumsal web sitelerinde bu girişimlere yer vermektir. Bu durum, potansiyel turistlerin otel işletmesinde konaklama kararı almasında etkin rol oynayabilir ya da otelde konaklama kararı almasa da dahi müşteri zihninde olumlu bir imaj oluşturabilir. Otel işletmeleri ayrıca bu faaliyetlerle rakiplerinden kendilerini farklılaştırarak, rekabet üstünlüğü elde edebilirler.

Çalışmanın sonuçları daha sonra yapılabilecek çalışmalar için araştırmacılara bir takım öneriler de sunmaktadır. Öncelikle otel işletmeleri yöneticileri ile görüşüp, kurumsal sosyal sorumluluk realitesine karşı farkındalık düzeylerinin araştırılması gerekmektedir. Bunun yanı sıra kurumsal sosyal sorumluluk girişimlerinde bulunup, bu faaliyetleri duyurma noktasında isteksiz olan işletme yöneticilerinden bu durumun nedenleri ortaya koymaları oldukça faydalı bir araştırma olacaktır. Bu çalışma ayrıca bir takım sınırlılıklara da sahiptir. İlk olarak, çalışmanın sonuçlarını Türkiye'de faaliyet gösteren zincir ve grup otel işletmelerine genelleştirmek doğru değildir. İkincisi ise, araştırmanın yöntemi gereği sadece işletmelerin web siteleri ele alınmış, elde edilen bulgularla zincir ve grup otel işletmelerinin kurumsal sosyal sorumluluk girişimlerinde bulunmadıklarını ortaya koymak da doğru değildir. Dolayısıyla çalışmanın en büyük kısıtlılığ 1 veri çeşitlendirilmesinin yapılmamasıdır. 


\section{Kaynakça}

- Ayuso, 2006. "Adoption of Voluntary Environmental Tools for Sustainable Tourism: Analyzing the Experience of Spanish Hotels", Corporate Social Responsibility and Environmental Management, 13(4), p. 207-220.

- Boğan, 2015. “Çalışanlar Tarafindan Algılanan Kurumsal Sorumluluk Faaliyetlerinin Örgüte Güven Üzerindeki Etkisi: Alanya’daki Dört ve Beş Yıldızlı Otel İşletmelerinde Bir Uygulama”, Akdeniz Üniversitesi Sosyal Bilimler Enstitüsü, Yüksek Lisans Tezi.

- Bohdanowicz, 2006. "Environmental awareness and initiatives in the Swedish and Polish hotel industriessurvey results”, International Journal of Hospitality Management, 25(4), p. 662-682.

- Bohdanowicz, Zientara, 2008. "Corporate Social Responsibility in Hospitality: Issues and Implications. A Case Study of Scandic”, Scandinavian Journal and Hospitality and Tourism, 8(4), s. 271-293.

- Bowen, 1953. "Social Responsibilities of the Businessman”, New York: Harper and Row.

- Çalışkan, Ünüsan, 2011. "Hotel Employee Perceptions of Corporate Social Responsibility and Its Effects on Job Satisfaction and Intention to Stay”, Anatolia: Turizm Arastirmalari Dergisi, 22(2), p. 154-166.

- Carlsen, Getz, Ali-Knight, 2001. "The Environmental Attitudes and Practices of Family Businesses in the Rural Tourism and Hospitality Sectors”, Journal of Sustainable Tourism, 9(4), p. 281-297.

- Carroll 1979. “A Three-Dimensional Conceptual Model of Corporate Performance”, Academy of Management Review, 4(4), p. 497-505.

- Carroll, 1996. “Business and Society: Ethics and Stakeholder Management”, South-Western College Publishing, 3rd Edition, Cincinnati, Ohio.

- Carroll, 1999. "Corporate Social Responsibility Evolution of a Definitional Construct”, Business and Society, 38(3), p. 268-295.

- Chung, Parker, 2010. "Managing Social and Environmental Action and Accountability in the Hospitality Industry: A Singapore Perspective", In Accounting Forum, 34(1), p. 46-53.

- Cowper-Smith, de Grosbois, 2011. "The Adoption of Corporate Social Responsibility Practices in the Airline Industry", Journal of Sustainable Tourism, 19(1), p. 59-77.

- Çelik, Can, 2014. “Türkiye'de Faaliyet Gösteren Zincir Otel İşletmelerinde Kurumsal Sosyal Sorumluluk Projeleri Üzerine Bir İçerik Analizi”, 14. Ulusal Turizm Kongresi. Ankara Gazi Üniversitesi.

- De Grosbois, 2012. “Corporate Social Responsibility Reporting by The Global Hotel Industry: Commitment, Initiatives and Performance”, International Journal of Hospitality Management, 31(3), p. 896-905.

- Erdogan, Baris, 2007. "Environmental Protection Programs and Conservation Practices of Hotels in Ankara, Turkey”, Tourism Management, 28(2), p. 604-614.

- $\quad$ Farooq, Farooq, Jasimuddin, 2014. "Employees Response to Corporate Social Responsibility: Exploring the Role of Employees’ Collectivist Orientation”, European Management Journal, 32(6), p. 916-927.

- Frankental, 2001. “Corporate Social Responsibility- A PR Invention?”, Corporate Communications: An International Journal, 6(1), p. 18-23.

- Henderson, 2007. "Corporate Social Responsibility and Tourism: Hotel Companies in Phuket, Thailand, after the Indian Ocean Tsunami”, International Journal of Hospitality Management, 26(1), p. 228-239.

- Hitt, Black, Porter, 2009. "Management”, Pearson International Edition, $2^{\text {nd }}$ Edition, New Jersey.

- Horrigan, 2010. "Corporate Social Responsibility in the 21st Century”, Edward Elgar Publishing Limited, UK.

- Inoue, Lee, 2011. "Effects of Different Dimensions of Corporate Social Responsibility on Corporate Financial Performance in Tourism-Related Industries”, Tourism Management, 32(4), p. 790-804.

- $\quad$ Kang, Lee, Huh, 2010. "Impacts of Positive and Negative Corporate Social Responsibility Activities on Company Performance in the Hospitality Industry", International Journal of Hospitality Management, 29(1), p. 72-82.

- Kasim, 2007. "Towards A Wider Adoption of Environmental Responsibility in the Hotel Sector”, International Journal of Hospitality and Tourism Administration, 8(2), p. 25-49.

- Kennedy Nyahunzvi, 2013. "CSR Reporting among Zimbabwe's Hotel Groups: A Content Analysis”. International Journal of Contemporary Hospitality Management, 25(4), p. 595-613.

- Kucukusta, Mak, Chan, 2013. "Corporate Social Responsibility Practices in Four and Five-Star Hotels: Perspectives from Hong Kong Visitors”, International Journal of Hospitality Management, 34, p. 19-30. 
- Lee, Lee, Li, 2012. "The Impact of CSR on Relationship Quality and Relationship Outcomes: A Perspective of Service Employees”, International Journal of Hospitality Management, 31(3), p. 745-756.

- Martínez, Pérez, Rodríguez del Bosque, 2013. "Measuring Corporate Social Responsibility in Tourism: Development and Validation of an Efficient Measurement Scale in the Hospitality Industry", Journal of Travel and Tourism Marketing, 30(4), p. 365-385.

- McGehee, Wattanakamolchai, Perdue, Calvert, 2009. "Corporate Social Responsibility within The US Lodging Industry: An Exploratory Study”, Journal of Hospitality and Tourism Research, 33(3), p. 417-437.

- Mihalic, 2000. "Environmental Management of a Tourist Destinastion: A Factor of Tourism Competitiveness", Tourism Management, 21(1), p. 65-78.

- Ozturk, Ozer, Çaliskan, 2015. “The Relationship between Local Residents' Perceptions of Tourism and Their Happiness: A Case of Kusadasi, Turkey”, Tourism Review, 70(3), p. 232-242.

- Park, Levy, 2014. "Corporate Social Responsibility: Perspectives of Hotel Frontline Employees”, International Journal of Contemporary Hospitality Management, 26(3), p. 332-348.

- Perrini, Pogutz, Tencati, 2006. “Corporate Social Responsibility in Italy: State of The Art”. Journal of Business Strategies, 23(1), p. 65.

- Rodríguez, Cruz, 2007. "Relation between Social-Environmental Responsibility and Performance in Hotel Firms”, International Journal of Hospitality Management, 26(4), p. 824-839.

- Turker, 2009. "How Corporate Social Responsibility Influences Organizational Commitment", Journal of Business Ethics, 89(2), p. 189-204.

- Wang, 2014. "Do Ethical and Sustainable Practices Matter? Effects of Corporate Citizenship on Business Performance in the Hospitality Industry", International Journal of Contemporary Hospitality Management, 26(6), p. 930-947.

- Wartick, Cochran, 1985. "The Evolution of the Corporate Social Performance Model”, Academy of Management Review, 10(4), p. 758-769.

- Yamak, 2007, “Kurumsal Sosyal Sorumluluk Kavramının Gelişimi”, Beta Yayınları, İstanbul. 


\title{
Otel Oda Fiyatlarının Hedonik Model İle Analizi: Erzurum Örneği
}

\section{The Analysis of Hotel Room Rates Using Hedonic Model: The Case of Erzurum}

\author{
Asst. Prof. Dr. Cem Işı1k (Atatürk University, Turkey) \\ Asst. Prof. Dr. Nilgün Bilici (Atatürk University, Turkey)
}

\begin{abstract}
In this study, it is aimed to analyze the relationship between the hotel room rates and its features by using hedonic price approach. In this context, the data of 26 factors of 20 hotels in Erzurum have been tested by setting log-log regression model on EViews 8 program. It has been determined that these 15 factors in 26 are significant and it has been also found that 13 factors of them (chain hotel, room size, bathroom, breakfast, LCD TV, a bar, Wi-Fi, shuttle, conference room, restaurant, night club, fitness center and fax/copier) increase the hotel room rate and two of them (location and skiing facilities) reduce the room rates.
\end{abstract}

\section{Giris}

Hizmet; belirli bir fiyat karşılığında insanların ihtiyaçlarını karşılamak için satışa sunulan, mülkiyet gerektirmeyen fayda veya soyut faaliyetlerin bütünüdür. Hizmetlerin üretilmesi noktasında insan unsurunun öne çıkması hizmetleri farklılaşmaktadır (Lovelock, 1996; Üner ve Karatepe, 1996). Hizmetlerin emek-yoğun olması ve değişkenlik arz etmesi ise hizmetlere heterojen bir özellik kazandırmaktadır (Zengin ve Erdal, 2000). Bu özellik sunulan hizmetin standardına ve kalitesine bağlı olarak değişmektedir (Zeithaml vd. 1985). Ayrıca hizmetlerin farklılaşma derecesi alıcıların farklı kişilerden oluşması, hizmet deneyimlerinin farklılık içermesi ve satıcıların hizmet performansının çeşitlilik göstermesine bağlanmaktadır (Zeithaml ve Bitner, 1996).

Turizm sektöründe mal ve hizmetler bir bütün içerisinde arz edilirken satıcılar bu bütün içerisinde birbirine bağımlıdır (Işık, 2015). Bu açıdan bir yerde oluşabilecek olumsuz bir deneyimin tüm bölgeyi etkileyeceğinden hareketle tüm işletmelerin birbirleri ile yakın ilişki içerisinde olması önem taşımaktadır (Kozak, vd., 2010). Ayrıca işletmelerin yaşanan hızlı gelişmelere kayıtsız kalmadan tüketici ihtiyaçlarına hızlı ve doğru cevap vermeleri gerekmektedir (Işık, 2012). Bu durum ise hizmetleri farklılaştırırken pazar payını ve hizmet kalitesini artırmaktadır (Sökmen, 1999).

Bir mal veya hizmetin fiyatı, arz ve talep edilen miktarlara bağlı olarak belirlenmektedir. Satıcı en düşük maliyet ile en yüksek kâr elde etmeyi amaçlarken, bir takım maliyet yöntemlerini de kullanarak mal ve hizmetlerin fiyatlarını belirlemektedir. Diğer taraftan alıcının fayda fonksiyonunda ise fiyat, gelir ve tüketici zevk ve tercihleri yer almaktadır. Alıcı faydasını en yükseğe çıkarmak için çeşitli tercihlerde bulunmakta ve en yüksek tatmine ulaşmaktadır. Teorisyenlerin bu tatmin ve mutluluk derecesini ölçmek için kullandığı yöntemlerden biri hedonik fiyat modelidir (Yayar, 2011; Işık, 2015). Hedonik model, fayda teorisi temelli olup heterojen bir mal varsayımı altında fiyat analizlerinin yapıldığı bir yaklaşımdır. Hedonik modelde bir mal veya hizmetin piyasa fiyatı o malın çeşitli özelliklerinin bir fonksiyonudur. Böylece marjinal bir değer yaratan malın özellikleri fiyat farklılaştırmasının da temelini oluşturmaktadır (Cingöz, 2010).

\section{Literatür}

Hedonik fiyat yaklaşımına ilişkin teorik çalışmalar, bir mal veya hizmetin özellikleri ve onun fiyatları arasındaki ilişkinin araştırılmasına yöneliktir. Hedonik fiyat yaklaşımına ait teorik yaklaşım Rosen (1974) çalışmasına dayanmaktadır. Rosen (1974)'e göre hedonik model, heterojen bir malın (örneğin turistik ürün) karakteristik özelliklerinin belirlenmesi ve bu özelliklerin malın talebine etkisinin ölçülmesini kapsamaktadır. Turizmde hedonik fiyat çalışmalarına ilişkin literatür özeti Tablo 1'de çalışmayı yapan araştırmacı, yaptığı yer, kullandığ yöntem ve araştırma sonuçlara göre tasnif edilmiştir. 


\begin{tabular}{|c|c|c|c|c|c|}
\hline Yazar & Y1l & Yer & Yöntem & Sonuç & Değişkenler \\
\hline Espinet vd. & 2003 & $\begin{array}{l}4 \text { y1ldız } \\
\text { oteller / } \\
\text { Genel }\end{array}$ & $\begin{array}{l}\text { Hedonik } \\
\text { Model }\end{array}$ & $\begin{array}{l}\text { Konum (şehir merkezi veya } \\
\text { plaj) otel oda değerini } \\
\text { artırmaktadır. }\end{array}$ & $\begin{array}{l}\text { Yüzme havuzu, gece } \\
\text { eğlenceleri, bar, bahçe / } \\
\text { balkon, şezlong, oda servisi, } \\
\text { diskotek, çocuk yüzme } \\
\text { havuzu, kı1 aktiviteleri, } \\
\text { tenis kortu, TV salonu. }\end{array}$ \\
\hline $\begin{array}{l}\text { Monty ve } \\
\text { Skidmore }\end{array}$ & 2003 & Wisconsin & $\begin{array}{l}\text { Hedonik } \\
\text { Model }\end{array}$ & $\begin{array}{l}\text { Jakuzi, özel banyo, oda } \\
\text { genişliği, konum (merkeze } \\
\text { uzaklık), ay ve gün oda } \\
\text { fiyatlarını artırmakta, } \\
\text { şömine, manzara ve oda } \\
\text { servisi fiyat üzerinde } \\
\text { herhangi bir anlamlı etkide } \\
\text { bulunmamaktadır. }\end{array}$ & $\begin{array}{l}\text { Merkeze uzaklık, trafik, } \\
\text { sezon, hafta sonu, oda } \\
\text { büyüklüğü, jakuzi, özel } \\
\text { banyo, oda sayısi, şömine. }\end{array}$ \\
\hline $\begin{array}{l}\text { Rigall-I- } \\
\text { Torrent ve } \\
\text { Fluvia } \\
\end{array}$ & 2007 & $\begin{array}{l}\text { Katalonya/ } \\
\text { İspanya }\end{array}$ & $\begin{array}{l}\text { Hedonik } \\
\text { Model }\end{array}$ & $\begin{array}{l}\text { Konum otel oda değerini } \\
\text { artırmaktadır. }\end{array}$ & Konum \\
\hline Hamilton & 2007 & Almanya & $\begin{array}{l}\text { Hedonik } \\
\text { Model }\end{array}$ & $\begin{array}{l}\text { Kıyıda bulunan } \\
\text { dalgakıranların uzunluğu } \\
\text { ortalama konaklama fiyatını } \\
\text { düşürürken, kıyının açıklığı } \\
\text { ortalama konaklama fiyatını } \\
\text { artırmaktadır. }\end{array}$ & $\begin{array}{l}\text { Otel sinıfi, otel pansiyon tipi, } \\
\text { plaj özellikleri. }\end{array}$ \\
\hline Falk & 2008 & Avusturya & $\begin{array}{l}\text { Hedonik } \\
\text { Model }\end{array}$ & $\begin{array}{l}84 \text { kayak otelinin mekanik } \\
\text { tesislerin yüksek hızlı olması } \\
\text { fiyatları yükseltmektedir. }\end{array}$ & $\begin{array}{l}\text { Kayak pisti uzunluğu, } \\
\text { mekanik tesislerin taşıma } \\
\text { kapasitesi, telesiyej ve } \\
\text { gondolun hızı, sezon } \\
\text { uzunluğu, diğer kış } \\
\text { destinasyonlarına yakınlık, } \\
\text { bilet kullanım esnekliği. }\end{array}$ \\
\hline $\begin{array}{l}\text { Chen ve } \\
\text { Rothschild }\end{array}$ & 2010 & Taipei & $\begin{array}{l}\text { Hedonik } \\
\text { Model }\end{array}$ & $\begin{array}{l}146 \text { örnek üzerinden zincir, } \\
\text { oda büyüklüğü, LCD TV, } \\
\text { bar, internet, shuttle, } \\
\text { konferans salonu ve fitness } \\
\text { otel oda değerini artırırken } \\
\text { konum (merkeze uzak } \\
\text { olması) fiyatı düşürmektedir. }\end{array}$ & $\begin{array}{l}\text { Şehir merkezine uzaklık, led } \\
\text { TV, konferans salonu, } \\
\text { internet, fitness merkezi, oda } \\
\text { büyüklüğü, yıldız sayısı, } \\
\text { otelin zincir olup olmadığı, } \\
\text { banyo, kahvaltı, bar, shuttle, } \\
\text { yüzme havuzu. }\end{array}$ \\
\hline Kesbiç vd. & 2011 & Muğla & $\begin{array}{l}\text { Hedonik } \\
\text { Model }\end{array}$ & $\begin{array}{l}147 \text { dört yıldızlı otelin paket } \\
\text { tur fiyatları ile otel } \\
\text { özellikleri araştırılmış fiyat } \\
\text { üzerinde en çok etkiye sahip } \\
\text { faktörlerin yarım pansiyon, } \\
\text { güzellik salonu, oda - } \\
\text { kahvaltı ve self-servis } \\
\text { hizmeti olduğu } \\
\text { belirlenmiştir. }\end{array}$ & $\begin{array}{l}\text { Otel pansiyon tipi, güzellik } \\
\text { salonu, self servis. }\end{array}$ \\
\hline $\begin{array}{l}\text { Rigall-I- } \\
\text { Torrent vd. }\end{array}$ & 2011 & $\begin{array}{l}\text { Katalonya/ } \\
\text { İspanya }\end{array}$ & $\begin{array}{l}\text { Hedonik } \\
\text { Model }\end{array}$ & $\begin{array}{l}\text { Konum (plaja uzaklık) otel } \\
\text { oda değerini artırmaktadır. }\end{array}$ & $\begin{array}{l}\text { Plaj özellikleri, mavi bayrak, } \\
\text { mevsim, bahçe / balkon, oda } \\
\text { servisi, oda sayısı, yüzme } \\
\text { havuzu, spor faaliyetleri, } \\
\text { otopark, çocuk oyun odası, } \\
\text { yıldız tipi, güvenlik. }\end{array}$ \\
\hline $\begin{array}{l}\text { Rigall-I- } \\
\text { Torrent ve } \\
\text { Fluvia }\end{array}$ & 2011 & $\begin{array}{l}\text { Katalonya/ } \\
\text { İspanya }\end{array}$ & $\begin{array}{l}\text { Hedonik } \\
\text { Model } \\
\text { (OLS) }\end{array}$ & $\begin{array}{l}\text { Otel yöneticilerinin fiyat } \\
\text { kararında turizm ürünü ve } \\
\text { destinasyon faktörlerinin } \\
\text { etkili olduğu tespit edilmiştir. }\end{array}$ & $\begin{array}{l}\text { Yıldız tipi, plaja yakınlık, } \\
\text { oda servisi, bahçe / balkon, } \\
\text { otopark, yüzme havuzu, spor } \\
\text { faaliyetleri, mevsim, kültür, } \\
\text { liman, restoran, oda } \\
\text { genişliği, güvenlik, sahildeki } \\
\text { koy sayısı. }\end{array}$ \\
\hline Santos & 2016 & $\begin{array}{l}\text { Hostel/ } \\
\text { Dünya }\end{array}$ & $\begin{array}{l}\text { Hedonik } \\
\text { Model }\end{array}$ & $\begin{array}{l}\text { Otel oda fiyatlarına etki eden } \\
\text { en önemli karakteristik } \\
\text { özelliklerin başında temizlik, } \\
\text { konum ve tesis yer } \\
\text { almaktadır. }\end{array}$ & $\begin{array}{l}\text { Atmosfer, temizlik, imkânlar, } \\
\text { konum, personel, güvenlik. }\end{array}$ \\
\hline
\end{tabular}

Şekil 1. Turizmde Hedonik Fiyatlama Literatür Özeti 
Literatürdeki çalışmalar turistik ürün özellikleri ve ürün fiyatları arasındaki ilişkinin hedonik fiyat modeli ile analizini kapsamaktadır. Ülkemiz öznelinde ise turistik ürünün konu edinildiği hedonik model çalışması Kesbiç vd., (2011) dışında ele alınmamıştır. Bizi bu çalışmaya yapmaya özendiren nedenlerin başında literatürde Erzurum örneği üzerinden turizme ilişkin hedonik fiyatlama modelinin kullanıldığı bir çalışmanın olmayışıdır. Bu çalışma ile Erzurum ilinde otel oda fiyatlarının karakteristik özelliklerinin bu mal veya hizmetin fiyat oluşumuna etkisinin belirlenmesi noktasında literatürün geliştirilmesi hedeflenmektedir. Bu sayede turistik ürün özellikleri ve hizmet kalitesinin artmasına katkıda bulunulması beklenmektedir. Bu çalışmanın devamında ise metodoloji ile sonuç ve öneriler kısmı yer alacaktır.

\section{Model ve Veri Seti}

Hedonik fiyat modelinde Rosen (1974: 35) her bir malı özelliklerine göre gruplandırmış ve Zi sabiti ile göstermiştir. Rosen (1974) hedonik modelinde tam rekabet piyasası koşulları altında kısa ve uzun dönem piyasa dengesi için heterojen bir mal analizi yapmıştır.

$$
\mathrm{z}=\left(\mathrm{z}_{1}, \mathrm{z}_{2}, \ldots \ldots \mathrm{z}_{\mathrm{n}}\right)
$$

Satıcılar özellikleri farklı mal veya hizmetleri piyasaya arz ederken, alıcılar farklı seçenekler arasından tercih yapmaktadir.

$$
\mathbf{p}\{\mathrm{z}\}=\mathbf{p}\left(\mathrm{z}_{1}, \mathrm{z}_{2}, \ldots \ldots \mathrm{z}_{\mathrm{n}}\right)
$$

Eşitlik 2, bir mal veya hizmetin farklı özelliklerine bağlı olarak alım ve satım grubunu göstermektedir. Bu eşitlik aynı zamanda talep fonksiyonunu (fiyat ve özellik ilişkisi açısından) ifade etmektedir.

$$
\mathbf{p}_{\mathrm{zi}}=\partial \mathbf{p} / \partial \mathbf{z}_{\mathrm{i}}
$$

Bir malın özelliğinin talep üzerindeki etkisini gösteren Eşitlik 3 ise eşitlik 2'nin kısmi türevinin alınmış biçimidir.

Not: $\mathrm{z}=$ malın özellikleri; $\mathrm{p}=$ malın fiyatını ifade etmektedir.

Bu 3 eşitlik ile Rosen (1974) makalesinde ileri sürülen hedonik modelde fiyat oluşumuna ilişkin geçerli tercihleri ve ürün özelliklerinin fiyat üzerindeki etkilerini anlamak kolaylaşmaktadır.

\subsection{Hedonik model}

Heterojen bir mal veya hizmet, o mal veya hizmetin tüm özelliklerinin toplamıdır (Rosen, 1974). Hedonik modelde heterojen bir mal veya hizmetin bir fiyatı olduğu gibi her bir özellik de fiyat farklılaşmasında rol oynamaktadır. Tüketicinin fayda fonksiyonu $U=f\left(q_{a}, q_{b}\right)$ ise bu mal veya hizmetin özelliklerinden oluşmaktadır. $\mathrm{Bu}$ analiz kapsamında otel oda fiyatı, o odanın özellikleri toplamına eşittir.

\subsection{Veri seti}

Erzurum kent merkezinde bulunan 08.12.2015 ile 07.01.2016 tarihleri arasında çeşitli yıldızlara sahip 20 otel işletmesine ait 26 faktöre ilişkin veriler "booking.com” web sitesinden elde edilmiş, belirlenen değişkenler ise literatürden faydalanarak oluşturulmuştur. Derlenen verileri tam logaritmik regresyon modeli kurularak EViews 8 programında analiz edilmiştir. Analizlerde bağımlı değişkeni otel oda fiyatı, bağımsız değişkenleri ise aşağıdaki faktörler oluşturmaktadır.

\section{Ampirik Sonuçlar}

Analizlerde tam logaritmik (log-log) regresyon modeli kullanılarak katsayılar belirlenmiştir. Analiz sonuçları Tablo 2'de sunulmuştur. 
Otel Oda Özellikleri Ac̣ısından

\begin{tabular}{|l|c|c|c|c|c|c|}
\hline $\begin{array}{l}\text { En düşük fiyat 2181 TL } \\
\text { En yüksek fiyat 10291 TL }\end{array}$ & Ortalama & Std. S. & Çarpılık & Basılklk & Jarque-Bera & $\begin{array}{l}\text { Anlamllık } \\
\text { Düzeyi (P) }\end{array}$ \\
\hline Fiyat & 5432 & 3162,394 & 0.4677 & 0.210 & 1.186 & 0.025 \\
\hline Log (Fiyat) & 8.416 & 0.648 & -0.198 & 0.643 & 1.581 & 0.053 \\
\hline
\end{tabular}

\begin{tabular}{|c|c|c|c|c|c|c|}
\hline & \multicolumn{2}{|c|}{ Hafta $(N=40)$} & \multicolumn{2}{|c|}{ Hafta İci $(\mathbf{N}=\mathbf{2 0})$} & \multicolumn{2}{|c|}{ Hafta Sonu $(\mathrm{N}=\mathbf{2 0})$} \\
\hline Değişkenler & $\begin{array}{c}\text { Katsayi } / \\
\text { Anlamlilik } \\
\text { Düzeyi (P) }\end{array}$ & t-istatistiği & $\begin{array}{c}\text { Katsay1/ } \\
\text { Anlamlilik } \\
\text { Düzeyi (P) }\end{array}$ & t-istatistiği & $\begin{array}{l}\text { Katsayı / } \\
\text { Anlamlilik } \\
\text { Düzeyi (P) }\end{array}$ & t-istatistiği \\
\hline Ylldız sayıs1 (Uluslararası bir otel ise $=1$ ) & $-0.296(0.156)$ & -0.167 & $-0.457(0.215)$ & -0.186 & $-0.127(0.170)$ & -0.109 \\
\hline Zincir $($ Zincir otel ise $=1)$ & $0.071(0.023)$ & $1.234^{* *}$ & $0.075(0.041)$ & $1.112^{*}$ & $0.046(0.044)$ & $1.108^{* *}$ \\
\hline Oda büyülklüğü (Oda m²) & $0.033(0.008)$ & \multirow{2}{*}{$\begin{array}{l}3.451^{*} \\
-0.4687^{*}\end{array}$} & $0.043(0.047)$ & $3.261^{* *}$ & $0.055(0.006)$ & $3.856 *$ \\
\hline Konum (Merkeze uzak ise $=1$ ) & $-0.402(0.000)$ & & $-0.316(0.000)$ & $-0.4212 *$ & $-0.438(0.000)$ & $-0.4021 *$ \\
\hline Banyo (Oda içerisinde banyo varsa $=1$ ) & $0.054(0.002)$ & $2.864^{*}$ & $0.055(0.004)$ & $1.587^{*}$ & $0.055(0.003)$ & $2.145^{*}$ \\
\hline Türk hamamı (Türk hamamı varsa $=1$ ) & $0.035(0.064)$ & 1.653 & $0.034(0.065)$ & 1.456 & $0.034(0.068)$ & 1.532 \\
\hline Kahvaltı (Kahvalt dâhil ise $=1$ ) & $0.045(0.004)$ & $2.962^{*}$ & $0.041(0.005)$ & $2.346^{*}$ & $0.058(0.005)$ & $2.894^{*}$ \\
\hline LCD TV (LCD TV varsa = 1) & $0.024(0.005)$ & $3.453^{*}$ & $0.031(0.009)$ & $2.457^{*}$ & $0.015(0.003)$ & $2.147 *$ \\
\hline Iş oteli (Iş oteli ise $=1$ ) & $-0.005(0.071)$ & 0.214 & $-0.006(0.072)$ & 0.045 & $0.004(0.074)$ & -0.012 \\
\hline $\mathrm{Bar}(\mathrm{Bar}$ varsa $=1)$ & $0.032(0.007)$ & $2.415^{*}$ & $0.033(0.008)$ & $2.319^{*}$ & $0.032(0.009)$ & $2.169 *$ \\
\hline Wi-Fi (Internet varsa = 1) & $0.023(0.028)$ & $2.416^{* *}$ & $0.027(0.009)$ & $2.348 *$ & $0.018(0.017)$ & $2.021 * *$ \\
\hline Shuttle (Shuttle varsa $=1$ ) & $0.007(0.024)$ & $1.648^{* * *}$ & $0.009(0.048)$ & $1.465^{* *}$ & $0.005(0.042)$ & $1.118 * *$ \\
\hline Konferans (Konferans salonu varsa = 1) & $0.063(0.021)$ & $3.154^{* *}$ & $0.072(0.044)$ & $2.345^{* *}$ & $0.051(0.029)$ & $2.954^{* *}$ \\
\hline Yüzme havuzu (Yüzme havuzu varsa $=1$ ) & $0.038(0.083)$ & 0.521 & $0.036(0.086)$ & 0.498 & $0.031(0.092)$ & 0.423 \\
\hline Fitness (Fitness varsa $=1$ ) & $0.025(0.013)$ & $2.812^{* *}$ & $0.027(0.017)$ & $2.689^{* *}$ & $0.022(0.011)$ & $1.571^{* *}$ \\
\hline Kayak (Kayak imkânları yolksa $=1$ ) & $-0.548(0.000)$ & $-5.511 *$ & $-0.537(0.000)$ & $-4.457 *$ & $-0.597(0.000)$ & $-4.980 *$ \\
\hline Otopark (Otopark varsa $=1$ ) & $0.022(0.059)$ & 1.413 & $0.029(0.064)$ & 1.321 & $0.026(0.069)$ & 1.214 \\
\hline Oyun odas1 (Oyun odas1 varsa $=1$ ) & $0.020(0.060)$ & 1.417 & $0.023(0.066)$ & 1.354 & $0.028(0.067)$ & 1.221 \\
\hline Gece kulübü (Gece kulübü varsa = 1) & $0.027(0.037)$ & $1.325^{* *}$ & $0.024(0.068)$ & 1.207 & $0.029(0.008)$ & $2.865^{*}$ \\
\hline Restoran (Restoran varsa $=1$ ) & $0.030(0.038)$ & $1.295^{* *}$ & $0.038(0.063)$ & 1.231 & $0.032(0.009)$ & $2.2751 *$ \\
\hline Mini bar (Odada mini bar varsa $=1$ ) & $0.028(0.110)$ & 1.428 & $0.027(0.127)$ & 1.352 & $0.029(0.136)$ & 1.215 \\
\hline $\begin{array}{l}\text { Tesis bünyesindeki mağazalar (Tesis } \\
\text { bünyesindeki mağazalar varsa }=1 \text { ) }\end{array}$ & $0.023(0.105)$ & 1.345 & $0.021(0.129)$ & 1.212 & $0.026(0.186)$ & 1.274 \\
\hline Faks/fotolkopi (Faks/fotokopi varsa $=1$ ) & $0.010(0.028)$ & $2.461^{* *}$ & $0.011(0.009)$ & $2.545^{*}$ & $0.009(0.047)$ & $2.545^{* *}$ \\
\hline $\begin{array}{l}\text { Engelli konuklar için olanaklar (Engelli } \\
\text { konulklar için olanaklar varsa }=1 \text { ) }\end{array}$ & $0.101(0.107)$ & 1.547 & $0.096(0.127)$ & 1.486 & $0.105(0.178)$ & 1.875 \\
\hline $\begin{array}{l}\text { Döviz alım/satım (Döviz alım/satımı } \\
\text { yapılıyorsa = 1) }\end{array}$ & $0.026(0.109)$ & 1.566 & $0.025(0.128)$ & 1.494 & $0.027(0.132)$ & 1.128 \\
\hline Emanet kasası (Emanet kasası varsa $=1)$ & $0.024(0.112)$ & 1.590 & $0.024(0.126)$ & 1.552 & $0.025(0.125)$ & 1.621 \\
\hline $\begin{array}{l}\text { Sabit } \\
\text { F-değeri }\end{array}$ & $\begin{array}{r}5.127(0.021) \\
9.451 \\
\end{array}$ & $30.958 * *$ & $\begin{array}{r}5.130(0.025) \\
8.145\end{array}$ & $36.421 * *$ & $\begin{array}{r}5.126(0.024) \\
7.511 \\
\end{array}$ & $28.744 * *$ \\
\hline $\mathrm{R}^{2}$ & 0.899 & Bağın & 11 değişken orta & nasi & & 7.66487 \\
\hline Düzeltilmiş $\mathrm{R}^{2}$ & 0.868 & Değiş & en standard sap & & & 0.65321 \\
\hline Regresyonun standard hatas1 & 0.4942845 & AIC & Akaike Bilgi Kri & & & 0.702154 \\
\hline $\begin{array}{l}\text { Kalıntı (artık) kareler toplamı } \\
\text { Olabilirlik işlevi }\end{array}$ & $\begin{array}{l}7.48754 \\
-12.0213\end{array}$ & $\begin{array}{l}\mathrm{SC}(\mathrm{S} \\
\mathrm{HQ}(\mathrm{H}\end{array}$ & $\begin{array}{l}\text { hwarz Kriteri) } \\
\text { annan-Quinn } \mathrm{K}\end{array}$ & eri) & & $\begin{array}{l}0.742659 \\
0.731652\end{array}$ \\
\hline F-istatistiği & $8.1425 * *$ & DW & Durbin-Watson I & & & 1.81245 \\
\hline Anlamlilık Düzeyi (P) (F-istatistiği) & 0.000000 & & & & & \\
\hline
\end{tabular}

Not: *: \%1 ve **: \%5 anlamlılık düzeyini göstermektedir. Çarpıklık ve basıklık katsayısı normal dağılımı test etmenin bir yöntemidir. Analizlerden elde edilen bu değerler (-1 ile +1) arasında kaldığından dağılımın normal olduğu belirlenmiştir. Bu çalışmada Jarque-Bera normallik testi, White değişen varyans testi, Breusch-Godfrey ardışık bağımlılık testi için analizlerde kullanılmıştır.

\section{Tablo 2: Otel Oda Fiyatlarına İlişkin Log-Log Model Regresyon Tahminleri}

Regresyonun tamamının anlamlılık sınamasını gösteren $\mathrm{F}$ testi sonucuna göre $(\mathrm{F}=8.1425, \mathrm{p}<0,05) \mathrm{H}_{0}$ hipotezi reddedilmektedir. Böylece Tablo 2'de yer alan 26 değişkenden 15'inin (zincir otel, oda büyüklüğü, otelin konumu, banyo, kahvaltı, LCD TV, bar, Wi-Fi, shuttle, konferans salonu, fitness, kayak imkânı, restoran, gece kulübü, faks/fotokopi) otel oda fiyatları üzerinde anlamlı bir etkiye sahip olduğu belirlenmiştir.

Tüm hafta dikkate alınacak olursa 15 faktörün otel oda fiyatını artırma sırası șu șekildedir;

- Otelin zincir otel olması durumunda otel oda fiyat1 yüzde 7.1,

- Konferans salonu olması durumunda otel oda fiyatı yüzde 6.3 ,

- Otel odasinda banyo olması durumunda oda fiyatı yüzde 5.4,

- Oda fiyatına kahvaltı dâhil olması durumunda otel oda fiyatı yüzde 4.5,

- Oda büyüklügü bir birim artacak olursa otel oda fiyatı yüzde 3.3,

- Bar olması durumunda otel oda fiyatı yüzde 3.2,

- Restoran olmasi durumunda otel oda fiyat1 yüzde 3,

- Gece kulübü olması durumunda otel oda fiyatı yüzde 2.7,

- Fitness olması durumunda otel oda fiyatı yüzde 2.5,

- $\quad$ Odada LCD TV olmasi durumunda otel oda fiyatı yüzde 2.4,

- Wi-Fi olması durumunda otel oda fiyatı yüzde 2.3,

- Fotokopi/faks olması durumunda otel oda fiyatı yüzde 1,

- Shuttle olmasi durumunda otel oda fiyatı yüzde 0.7 artmaktadır.

Tüm hafta dikkate alınacak olursa 2 faktörün otel oda fiyatlarını düşürme sırası ise şu şekildedir; 
- Otelin kayak imkânları yok ise otel oda fiyatı yüzde 54.8,

- Otelin konumu merkeze uzak olması durumunda otel oda fiyatı 40.2 düşmektedir.

Hafta içi dikkate alınacak olursa 13 faktörün otel oda fiyatını artırma sırası șu șekildedir;

- Otelin zincir otel olması durumunda otel oda fiyatı yüzde 7.5,

- Konferans salonu olmasi durumunda otel oda fiyatı yüzde 7.2,

- Otel odasinda banyo olması durumunda oda fiyatı yüzde 5.5,

- Oda büyüklüğü bir birim artacak olursa otel oda fiyatı yüzde 4.3,

- Oda fiyatına kahvaltı dâhil olması durumunda otel oda fiyatı yüzde 4.1,

- Bar olmasi durumunda otel oda fiyatı yüzde 3.3,

- Odada LCD TV olmasi durumunda otel oda fiyat1 yüzde 3.1,

- Fitness olması durumunda otel oda fiyatı yüzde 2.7,

- Wi-Fi olması durumunda otel oda fiyatı yüzde 2.7,

- Fotokopi/faks olması durumunda otel oda fiyatı yüzde 1.1,

- Shuttle olmasi durumunda otel oda fiyatı yüzde 0.9 artmaktadır.

Hafta içi dikkate alınacak olursa 2 faktörün otel oda fiyatlarını düşürme sırası ise şu şekildedir;

- Otelin kayak imkânları yok ise otel oda fiyatı yüzde 53.7,

- Otelin konumu merkeze uzak olması durumunda otel oda fiyatı 31.6 düşmektedir.

Hafta sonu dikkate alınacak olursa 15 faktörün otel oda fiyatını artırma sırası şu şekildedir;

- Oda fiyatına kahvaltı dâhil olması durumunda otel oda fiyatı yüzde 5.8,

- Oda büyüklüğü bir birim artacak olursa otel oda fiyatı yüzde 5.5,

- Otel odasinda banyo olması durumunda oda fiyatı yüzde 5.5,

- Konferans salonu olmasi durumunda otel oda fiyatı yüzde 5.1,

- Otelin zincir otel olması durumunda otel oda fiyatı yüzde 4.6,

- Bar olmasi durumunda otel oda fiyatı yüzde 3.2,

- Restoran olmasi durumunda otel oda fiyatı yüzde 3.2,

- Gece kulübü olması durumunda otel oda fiyatı yüzde 2.9,

- Fitness olmasi durumunda otel oda fiyat1 yüzde 2.2,

- Wi-Fi olması durumunda otel oda fiyatı yüzde 1.8,

- Odada LCD TV olmasi durumunda otel oda fiyati yüzde 1.5,

- Fotokopi/faks olması durumunda otel oda fiyat1 yüzde 0.9 ,

- Shuttle olmasi durumunda otel oda fiyatı yüzde 0.5 artmaktadir.

Hafta sonu dikkate alınacak olursa 2 faktörün otel oda fiyatlarını düşürme sırası ise şu şekildedir;

- Otelin kayak imkânları yok ise otel oda fiyatı yüzde 59,7,

- Otelin konumu merkeze uzak olması durumunda otel oda fiyatı 43.8 düşmektedir.

\begin{tabular}{|c|c|c|c|}
\hline \multicolumn{4}{|c|}{ Breusch-Godfrey Ardışık Bağımlılık LM Sınaması } \\
\hline F-istatistiği & 0.069854 & Anlamlılık Düzeyi (P) & 0.5321 \\
\hline \multirow{3}{*}{$\mathrm{NR}^{2}$} & \multirow{2}{*}{0.325167} & Anlamlılık Düzeyi (P) & \multirow{2}{*}{0.8054} \\
\hline & & Ki-Kare (4) & \\
\hline & \multicolumn{2}{|c|}{ Değişken Varyans Sınaması: White } & \\
\hline F-istatistiği & 1.612452 & $\begin{array}{l}\text { Anlamlılık Düzeyi (P) } \\
\mathrm{F}(26)\end{array}$ & 0.25642 \\
\hline \multirow{2}{*}{$\mathrm{NR}^{2}$} & \multirow{2}{*}{11.43421} & Anlamlılık Düzeyi (P) & \multirow{2}{*}{0.25641} \\
\hline & & $\mathrm{Ki}$-Kare $(26)$ & \\
\hline \multirow{2}{*}{$\begin{array}{l}\text { Ölçeklenmiş } \\
\text { Açıklanan Kareler } \\
\text { Toplamı }\end{array}$} & \multirow{2}{*}{11.86184} & Anlamlılık Düzeyi (P) & \multirow{2}{*}{0.31677} \\
\hline & & Ki-Kare (26) & \\
\hline
\end{tabular}

Tablo 3: Breusch- Godfrey LM ve Değişken Varyans Test: White Sonuçları

Analizlerden elde edilen düzeltilmiş $\mathrm{R}^{2}$ değeri 0.87 ve anlamlılık düzeyi F.ist. $=0.000000$ 'dır. Ayrıca modelde katsayıların normal dağılıp dağılmadığını ve otokorelasyon probleminin oluşup oluşmadığı çeşitli testler ile sınanmıştır. Otokorelasyon probleminin oluşup oluşmadığını belirlemek için öncelikle modeldeki orijinal serinin 
otokorealasyon fonksiyonu ile karşılaştırılması Breusch-Godfrey LM sınaması ile yapılan hipotez şu şekilde kurulmuştur.

$H_{0}:$ 4. dereceden otokorelasyon bulunmaktadir.

$H_{1}$ : 4. dereceden otokorelasyon bulunmamaktadır.

Otokorelasyon sınaması yapıldıktan sonra hata teriminin koşullu varyansının değişkenlik gösterip göstermediği sonucu oluşabilecek problem Değişken Varyans Test: White ile araştırılmıştır. Test edilen modelde ortaya çıkabilecek problem otel oda değerinin özellikleri ile ilişkilendirildiğinden, otel oda değeri özelliklerine bağlı olarak farklılık gösterebilmektedir. Breusch- Godfrey LM ve Değişken Varyans Test: White sonuçları Tablo 3 'te sunulmuştur.

Tablo 3'e göre Breusch - Godfrey testi otokorelasyon bulunmadığını ve White testi ise modelde değişen varyans olmadığını ( $\mathrm{p}>0,05)$ göstermektedir. Breusch-Godfrey LM test sonucuna göre 0.8054 olarak belirlenen F-istatistik değeri 0.05 değerinden büyük olduğundan otokorelasyon probleminin oluşmadığı belirlenmiştir. Ayrıca Değişken Varyans Test: White sonucuna göre 0.25641 prob. F ve 0.31677 Anlamlılık Düzeyi (P) Ki-Kare değerlerinin 0.05 değerinden büyük olması da değişken varyans probleminin olmadığı göstermektedir. Böylece varyansın sabit olduğunu söyleyen boş hipotez reddedilmiştir.

\section{Sonuç ve Öneriler}

Hedonik fiyat modelinde heterojen bir mal veya hizmetin özelliklerinin bu mal veya hizmetin fiyat oluşumuna etkisi araştırılmaktadır. Bu çalışmada otel oda fiyatının odanın çeşitli özelliklerine bağlı olarak belirlendiği Erzurum ilinde faaliyet gösteren otel işletmeleri örneği üzerinden incelenmiştir. Elde edilen sonuçlara göre, hafta boyunca otel oda fiyatlarının belirlenmesinde kullanılan 26 değişkenden 15'inin önemli bir etkiye sahip olduğu tespit edilmiştir. Ayrıca bu 15 değişkenden 13'ünün otel oda değerini artırıcı ve 2'sinin ise otel oda değerini azaltıcı etki yarattı̆̆ belirlenmiştir.

Erzurum ilinde otel oda fiyatlarını tüm hafta en çok kayak (54.8) sonra otelin konumu (40.2) ve otelin zincir otel olmas1 (7.1) etkilemektedir.

Erzurum ilinde otel oda fiyatlarını hafta içi en çok kayak (53.7) sonra otelin konumu (31.6) ve otelin zincir otel olması (7.5) etkilemektedir.

Erzurum ilinde otel oda fiyatlarını hafta sonu en çok kayak (59.7) sonra otelin konumu (43.8) ve otel oda fiyatına kahvaltı dâhil olması (5.8) etkilemektedir.

Analizlerden elde edilen genel sonuçlar şu şekilde sıralanabilir;

- Kayak otellerinde oda fiyatı şehir otellerine göre daha yüksektir.

- Odanın değeri zincir oteli, oda büyüklüğü, kahvaltı, LCD TV, bar, Wi-Fi, shuttle, konferans salonu, faks/fotokopi, restoran, gece kulübü ve fitness gibi özelliklere bağlı olarak değişmektedir.

- Otelin konumu (merkeze yakın-uzak olması) otel oda fiyatını değiştirmektedir.

Analizlerden elde edilen sonuçların öngörüsü şu şekilde sıralanabilir;

Turizm sektöründe, oda değeri konumuna göre değişkenlik gösterebileceği gibi, özellik grubuna göre de farklılık göstermektedir. Bu açıdan çalışmadan elde edilen bulgular, Chen ve Rothschild (2010) ve Santos (2016)'un çalışma sonuçları ile genel olarak örtüşmektedir.

Alternatiflerin artması tüketicileri mevcut tercihlerinden uzaklaştırıp farklı alternatiflere yöneltebilir (Rusbult, 1980). Zira ziyaretçiler alternatif destinasyonlar arasında Erzurum otellerini tercih etme nedeni Erzurum otellerinin diğerlerinden ne kadar farklılaştığına bağlıdır.

Analizlerden elde edilen sonuçlara göre geliştirilen öneriler şu şekilde sıralanabilir;

- Uzun dönem dengesi için potansiyel talebi harekete geçirecek ve dolayısıyla sektörde dalgalanmayı azaltacak plan ve projelerin geliştirilmesi önem taşımaktadır. Bu kapsamda farklı gelir grupları için zevk ve tercihleri artıracak yeni turizm projelerine finansman olanakları sağlanması,

- Dağ otellerinden şehir merkezine, şehir otellerinden kayak merkezine ulaşım imkânlarının artırılması (shuttle hizmeti, kayak malzemeleri vb),

- Erzurum ilindeki mevcut otellerin marka değerinin ve güvenilirliğinin artırılması için zincir otel çalışmalarının yapılması,

- Odalardaki TV'lerin LCD TV ile değiştirilmesi,

Son olarak tarım, hayvancılık ve sağlık sektörleri dışında turizm ile de kalkınmaya çalışan Erzurum ilinin ekonomik şartları ülkemiz geneli ile benzerlik göstermektedir. Bu açıdan turizme yönelik analizlerin önemle ele alınması kritik öneme sahiptir. 


\section{Kaynakça}

- Chen, Ching-Fu. - R. Rothschild, 2010. “An Application of Hedonic Pricing Analysis to The Case of Hotel Rooms in Taipei”, Tourism Economics, 16(3), ss.685-694.

- Cingöz, A. R. A. A., 2010. “İstanbul’da Kapalı Site Konut Fiyatlarının Analizi”, Sosyal Bilimler Dergisi, (2), ss.129-139.

- $\quad$ Espinet, J. M. - M. Saez - G. Coenders - M. Fluvia, 2003. "Effect on Prices of The Attributes of Holiday Hotels: A Hedonic Prices Approach”, Tourism Economics, 9(2), ss.165-177.

- $\quad$ Falk, Martin, 2008. "Hedonic Price Model for Ski Lift Tickets”, Tourism Management, 29, ss.1172-1184.

- Hamilton, J. M., 2007. “Coastal Landscape and The Hedonic Price of Accommodation” Ecologicale Economics, 62, ss. 594-602.

- Işık, C., 2015. "Erzurum İlinde Konut Fiyatlarının Çevresel, Yapısal ve Sosyal Farklılaşması: Hedonik Fiyatlama Örneği”, Erzincan Üniversitesi Sosyal Bilimler Enstitüsü Dergisi (ERZSOSDER) VIII-II, ss. 2332.

- Işı, C., 2015. “Turizmde Otel Oda Fiyatı, Kişi Başı GSYİH ve Havaalanlarındaki İç Hat Yolcularının Otel Oda talebine Etkisi: Ardl Sınır Testi Yaklaşımı”, Kafkas Üniversitesi Sosyal Bilimler Enstitüsü Dergisi 16, ss. 163-174.

- Işı1, C., 2012. “The USA’s Internatıonal Travel Demand and Economıc Growth In Turkey: A Causalıty Analysis: (1990 - 2008)", Tourımos: An Internatıonal Multıdisciplinary Journal Of Tourlsm, 7(1), ss. 235252.

- Kesbiç, C. Y. - Bahar O.- Baldemir E. - İnci M., 2011. "Muğla Deniz Turizminde Hizmet Niteliğinin Piyasa Fiyatı Üzerindeki Etkileri: Hedonik Fiyatlandırma Modeli”, Finans Politik ve Ekonomik Yorumlar, 48(555), ss.65-82.

- Kozak, N. -Kozak M. A. -Kozak M., 2012. Genel Turizm İlkeler ve Kavramlar, Ankara: Detay Yayınevi.

- $\quad$ Lovelock, C. H., 1996. Service Marketing, 3. Bask1, Englewood Cliffs, N.J.: Prentice Hall Int.

- Monty, B. - Skidmore M. (2003. "Hedonic Pricing and Willingness to Pay for Bed and Breakfast Amenities in Southeast Wisconsin" Journal of Travel Research, 42, ss. 195-199.

- Rigall-I-Torrent, R. - Fluvia M. - Ballester R.- Albert S. - Eduard A. - Espinet J. M. (2011), "The Effects of Beach Characteristics and Location with Respect to Hotel Prices”, Tourism Management, 32(5), ss.11501158.

- $\quad$ Rigall-I-Torrent, R. - Fluvia M., 2007. "Public Goods in Tourism Municipalities: Formal Analysis, Empirical Evidence and Implications for Sustainable Development”, Tourism Economics, 13(3), ss.361-378.

- $\quad$ Rigall-I-Torrent, R. - Fluvia M., 2011. "Managing Tourism Products and Destinations Embedding Public Good Components: A Hedonic Approach”, Tourism Management, 32(2) ss.244-255

- Rosen S., 1974. "Hedonic Prices and Implicit Markets: Product Differentiation in Pure Competition”, Journal of Political Economy, 82(1), ss.34-55.

- Rusbult, C. E., 1980. "Commitment and Satisfaction: A Test of the Investment Model”, Journal of Experimental Social Psychology, 16(2) ss.172 - 186.

- Santos, G. Oliveria E., 2016. "Worldwide Hedonic Prices of Subjective Characteristics of Hostels", Tourism Management, 52, ss.451-454

- $\quad$ Sökmen, A., 1999. "Konaklama İşletmelerinde İş Özellikleri Modeli Yardımıyla Hizmet Kalitesinin Artırılmasına Yönelik Kavramsal Bir İnceleme”, Anatolia: Turizm Araştırmaları Dergisi, 10(2), ss.45-51.

- $\quad$ Üner, M. M. - Karatepe O. M., 1996. "Hizmet Pazarlaması Sorunlarına Franchising Çözümleri”. Hacettepe Üniversitesi İIBF Dergisi, 14(2), 185-208.

- Yayar, R., 2011. "Dizüstü Bilgisayar Piyasasında Hedonic Talep Parametrelerinin Tahminlenmesi”, KMÜ Sosyal ve Ekonomik Araştırmalar Dergisi, 13(21), ss.21-27.

- Zeithaml, V. A. - Bitner M. J., 1996. Services Marketing, Berkshire: Mc Graw - Hill International Editions.

- Zeithaml, V. A. - A. Parasuraman - Berry L. L. (1990), Delivering Service Quality: Balancing Customers Perceptions and Expectations, New York: The Free Press.

- Zengin, E. - Erdal A., 2000. "Hizmet Sektöründe Toplam Kalite Yönetimi”, Journal of Qafqaz University, $3(1)$, ss.43-56. 


\title{
Turizm Lisans Öğrencilerinin Girişimcilik Eğilimleri Üzerine Bir Araştırma: Sakarya Üniversitesi Örneği
}

\author{
A Research on Enterprising Tendencies of Undergraduate \\ Tourism Students: The Case of Sakarya University
}

\author{
Asst. Prof. Dr. Sevki Ulama (Sakarya University, Turkey)
}

\begin{abstract}
Tourism sector is an area that offers very attractive opportunities for young entrepreneurs. It is possible to set up tourism businesses with comparatively low capital and by benefiting from various supports. Young entrepreneurs who have innovative ideas and creative products may provide financial support from their families, benefit from Turkish Organization of Small and Medium Enterprises Development (KOSGEB) supports; use credit in appropriate conditions, or collaborate with the owners of capital who want to invest in the tourism sector. When the tourism literature is examined, the subject of young entrepreneurs in tourism has not been observed wide enough. In this context, the main purpose of this study is to specify enterprising tendencies and personality traits of undergraduate tourism students. It is thought to be important for offering expedient recommendations to young entrepreneurs. In the scope of the study, a survey is conducted to identify entrepreneurial characteristics, enterprising tendencies and personality traits of tourism students who would be graduated in the near future. Data were obtained from questionnaire responses and analyzed by and quantitative techniques. It is identified that there are correlations between (i) calculated risk taking and openness, (ii) need for achievement and conscientiousness and extraversion, (iii) locus of control and conscientiousness and extraversion and openness, and (iv) creative tendency and openness. Alongside some significant differences are stated for enterprising tendencies according to demographic variables. The results were reached by interpreting the findings and some suggestions were developed for graduate candidates based on the results.
\end{abstract}

\section{Giriş}

Turizm sektörü genç girişimciler için oldukça cazip firsatlar sunan bir alandır. Görece düşük sermaye ile ve çeşitli desteklerden yararlanarak turizm işletmeleri kurabilmek mümkündür. Küçük ölçekli turizm işletmeleri sektörde önemli roller üstlenebilmektedir. Örneğin bir seyahat acentesi kurmak, internet üzerinden aracıllk hizmetleri sunan web siteleri oluşturmak, küçük bir yiyecek-içecek işletmesini hayata geçirmek genç girişimciler açısından gerçekleştirilebilecek projeler arasında sayılabilir. Yenilikçi ve yaratıcı ürün fikirlerine sahip genç girişimciler ailelerinden finansal yardım sağlayabilirler, KOSGEB desteklerinden yararlanabilirler, uygun koşullarda kredi kullanabilirler veya turizm sektörüne yatırım yapmak isteyen sermaye sahipleri ile işbirliği yapabilirler.

Turizm yazını incelendiğinde, genç insanların turizm alanında girişimciliğini konu alan fazla sayıda çalışmaya rastlanmamıştır. $\mathrm{Bu}$ bağlamda çalışmanın temel amacı lisans düzeyinde turizm eğitimi alan öğrencilerin girişimcilik eğilimlerini ve kişilik özelliklerini belirlemek, girişimcilik eğilimi ve kişilik özellikleri boyutlarını saptamak ve bu boyutlar arasında ilişki olup olmadığını ortaya koymaktır. Girişimcilik eğilimi boyutlarının çeşitli demografik değişkenler itibarıyla farklılık gösterip göstermediğinin belirlenmesi de araştırmanın bir diğer amacıdır. Çalışma genç girişimcilere yararlı olabilecek öneriler sunacağı için önemli görülmektedir. Çalışmada öncelikle kavramsal çerçeve kapsamında ilgili yazın taranmış, araştırma bulgularının analizi ile sonuç ve öneriler sunulmuştur.

\section{Kavramsal Çerçeve}

Araştırma açısından önemli olan girişimcilik, girişimcilik eğilimi, girişimcilik ve kişilik özellikleri ile girişimcilik ve turizm ilişkisi hakkındaki bilgiler ilgili yazın incelenerek derlenmiştir.

\subsection{Girişimcilik}

Temel üretim faktörlerinden birisi olarak kabul edilen girişimcilik (Çokgezen, 2012:17), işletme bilimi bağlamında, herhangi büyüklükteki bir işletmenin kurulması veya kurulan işletmenin geliştirilmesi olarak tanımlanabilir (Erdoğan, 2012:27). Geniş anlamıyla girişimcilik ise; parasal ve kişisel tatmin ödülü karşıllı̆ğnda finansal, psikolojik ve sosyal riskleri üstlenerek, gerekli zaman ve çabayı harcayıp farklı değerde mal ve hizmet yaratma süreci olarak ifade edilebilir (Yurtseven, 2007:60). Ülke ekonomileri için yenilik, yeni işletmelerin kurulması ve istihdam yaratma açısından önemli olan girişimcilik (Apak vd, 2010:105) bilgi toplumuna geçiş ile birlikte, birey ve bireysel yeteneğe dayalı hale gelerek hızlı bir gelişme süreci içerisine girmiştir (İlter, 2010:9). Girişimcilik makroekonomik düzeyde iktisadi dinamizm ve iş yaratımının temellerinden biridir. Yeni işletmelerin ortaya çıkışı, ürün piyasasındaki rekabet düzeyini artırarak, etkili kaynak kullanım için harekete geçirici bir etkiye 
sahiptir. Girişimcilik teknoloji veya işletme yönetimi alanındaki yeniliklerin oluşturulması, yayılması ve uygulanması sürecini hızlandırır. Bu yenilenme süreci sürdürülebilir ekonomik büyümenin temelini oluşturur (OECD, 2007:29). Dolayısıyla girişimcilik ulusal ve bireysel düzeyde ekonomik refahın artırılması açısından önem taşımaktadır (Carsrud ve Brännback, 2007:6).

Girişimciliğin çağdaş toplumdaki önemi, ardı arkası kesilmeyen yenilikleri gerçekleştirmek şeklinde ortaya çıkmaktadır. Bu açıdan girişimin gücü; yenilik yapma ve yaptı̆̆ 1 yenilikleri iş dünyasında ticari ürünlere dönüştürebilme kapasitesine dayanır. Girişimci sürekli yenilik yapan kişi anlamında kullanılabilir (Tutar, 2003:161). Girişimci; yeni ürünler, süreçler veya pazarlar bulmak ve kullanmak suretiyle, iktisadi faaliyet yaratarak ve geliştirerek değer oluşturmaya çabalayan kişi olarak tanımlanabilir (OECD, 2010:15). Girişimci ile ilgili olarak yapılan tanımlamalarda yenilik yaratma (inovasyon) çabası ve bunun doğal sonucu olarak riske katlanma sorumluluğu öne çıkan unsurlardır. Girişimci kişiliğin; firsatları yakalama, kişisel fayda (kâr) arzusu, yönetim becerisi, değer yaratma, strateji oluşturma gibi etkenlerin varlığıyla şekillendiği ifade edilebilir (Kinay, 2007:23).

\subsection{Girişimcilik Eğilimi}

Girişimcilik eğilimi kişilerin girişimci olmasını etkileyen etmenlerle yakından ilgilidir. Bu eğilim, doğuştan kazanılmış olsa da belirlenmesi, geliştirilmesi ve yönlendirilmesi gereklidir. Girişimcilik eğiliminin oluşmasında (i) ekonomik, sosyal ve siyasal yapı, (ii) bölgesel ve çevresel koşullar, (iii) kişilik özellikleri, (iv) eğitim düzeyi gibi çeşitli faktörler etkili olabilmektedir (Güreşçi, 2014:27). Girişimcilik eğilimi kişinin yeni bir girişimde bulunma yönündeki yatkınlığını ifade eder Çocukluktan itibaren, yetişkinlik döneminin sonuna kadar bireyin gelişmesini etkileyen etmenlerin tümü girişimcilikte de etkilidir. Girişimcilik üzerinde etkili olan ve bireylerin girişimci olma kararlarını belirleyen; aile desteği, finansal imkanlar, devlet teşvikleri ve yetişme tarzı gibi psikolojik, sosyal ve ekonomik etkenlerin yanısıra eğitimin, özellikle de üniversitelerde verilen eğitimin gençlerin girişimciliğe bakış açılarını etkilemede önemli olduğu söylenebilir (Özdemir, 2105:44). Girişimcilik eğilimine yönelik çekim gücü oluşturan bir faktör olarak eğitimin, üniversitede öğrenim gören genç nüfusun girişimci ruhlarının teşvik edilmesi ve girişimciliğe yönelmeleri üzerinde olumlu etkileri olduğu kabul edilmektedir (Börü, 2006:28). Girişimcilik eğilimine yönelik yapılan araştırmalarda genellikle risk alma boyutuna odaklanılmaktadır. Ancak ilgili yazında bu boyuta ek olarak başarma güdüsü, yaratıcılık, kontrol odağı ve özerklik boyutları da önemli görülmektedir.

Risk alma; makul bir başarısızlık maliyeti oluşma ihtimali olan firsatlara önemli seviyede kaynak aktarılmasını ifade etmektedir (Akçakanat vd, 2014:139). Girişimci kişiler diğer insanlara nazaran daha fazla risk almaya eğilimlidirler. Genellikle girişimci için risk almak bir ön şart olarak kabul edilmektedir. Girişimci, göze aldığ riskleri firsata çevirebilmeli ve bu risklerden yarar sağlayabilmelidir (Korkmaz, 2012:2013).

Başarma güdüsü; girișimcilikte başarılı olmanın temel etkenlerinden birisi olarak kabul edilmektedir. Başarma güdüsü yüksek olan bireyler düşük olanlara nazaran; engelleri aşma, kaynakları verimli kullanma, rekabet edebilme, niteliklerini geliştirme gibi girişimcilik için gerekli olan özelliklere daha fazla sahiptirler (Collins vd, 2004:102). Ekonomik kalkınma, ilerleme ve işletmelerin büyümesi için kritik öneme sahip olan başarma güdüsü, girişimciliğin en önemli belirleyicilerinden birisidir (Bozkurt ve Erdurur, 2013:60).

Kontrol odağ1; girişimcilerin temel psikolojik özelliklerinden birisidir ve bireyin yaşamı süresince olaylar üzerinde sahip olduğu kontrol duygusunu göstermektedir. Bireyin kontrol odağını içsel ve dışsal olarak ikiye ayırmak mümkündür. İçsel kontrol odağı, bireyin kendi yaşamı üzerinde kontrol sahibi olduğunu ifade etmektedir (İlter, 2010:35). İçsel kontrol odağı olan insanlar davranışlarının sonuçlarının, kader ya da şans yerine kendi eylemlerinden kaynaklandığına inanırlarken; dışsal kontrol odağı olan insanlar olayların kontrolünün kendilerinin dışında olduğuna inanırlar (Çırakoğlu ve Tezer, 2010:31).

Yaratıcılık; girişimci bireylerin sorunları çözmede yaratıcı fikirler üretmesini, yaşamı diğer insanlardan farklı bir açıdan görmesini ifade eder. Yaratıcılıkla birlikte yenilikçilik ve başarma güdüsü girişimcilerin yeni ürün ve süreç geliştirmelerinde önemli rol oynar. Yaratıcllı yeteneğine sahip kişiler; yeni ve özgün fikirler geliştirme, güçlü sezgilere sahip olma, isabetli tahminler yapabilme, değişime odaklanma ve çok yönlü olma gibi özelliklere sahiptir (Keleş, 2013:32).

Özerklik, bireyin bir fikri veya bir vizyonu ortaya koymada ve onu başarmada bağımsız hareket etmesi anlamını taşımaktadır. Genel olarak özerklik, firsatları kovalamada kendi kendini yönlendirme imkân ve arzusu anlamına gelmektedir. Özerklik; girişimciliğin temel boyutlarından biridir. Çünkü yeni fikirlerin ortaya çıkabilmesi ve uygulamaya geçirilebilmesi için bireylerin özerk olabilmesi önemlidir (Kozak ve Yılmaz, 2010:90).

\subsection{Girişimcilik ve Kişilik Özellikleri}

Girişimci kişilerin gelişme ortamını açıklamada genellikle kişilik özellikleri ve çevresel faktörler olmak üzere iki alana vurgu yapılmaktadır. Gerçekte girişimciliğin gelişmesi çevresel faktörlerin sunduğu firsatlarla birlikte kişisel özelliklerin uygun olmasıyla mümkündür (Ross ve Lashley, 2009:3). Kişilik özellikleri girişimcilik eğilimlerini açıklamada önemli bir role sahiptir. Dünyada girişimci kişiliğine değinen pek çok araştırma mevcuttur (Chell, 2009:35). Eser ve Yıldız (2015:103) tarafından Türkiye'de girişimcilik araştırmalarının odağını belirlemek 
amacıyla yürütülen çalışmada "girişimci kişiliği” üzerine yapılan çalışmaların sayıca büyük üstünlüğe sahip olduğu vurgulanmaktadır.

Kişilik ölçümlerinin tarihsel gelişimine bakıldığında, ilk kişilik ölçümlerinin daha çok geniş kapsamlı (broadbandwith), birçok özelliği bir arada ölçen bütünsel yaklaşımlara sahip olduğu görülür. İlerleyen y1llarda kişilik alanındaki araştırma verilerinin birikmesi ile çok sayıda dar kapsamlı fakat belirli kişilik boyutlarını derinlemesine (high fidelity) ölçen kişilik ölçeklerinin ortaya çıktığı görülmektedir. Kişilik belirten sıfatlara dayalı olarak geliştirilen Beş Faktör Kişilik Modeline ilişkin çalışmalar yaklaşık 70 yıllık bir geçmişe sahiptir ve son yıllarda farklı dil grupları üzerine yapılan çalışmalarla da desteklenmiştir. Çeşitli araştırmacılar İngiliz dilinde Beş Faktör Modeli üzerine pek çok çalışma yapmışlar ve bu modeli destekleyici veriler sunmuşlardır. Beş Faktör Modelinin geçerliği dünyadaki diğer başka dillerde de araştırılmıştır. Kişilik tanımlayıcı terimlerle ilgili çalışmalar Flemenkçe, Almanca, İtalyanca, İspanyolca, Slovakça, İbranice, Macarca, Çince, Filipince, Lehçe ve Rusça'da yapılmıştır ve büyük ölçüde modeli destekleyici veriler sunmuşlardır. Beş Faktör Modelinin genellenebilirliğine ilişkin verilerin, yalnızca İngiliz diliyle sınırlı olmadığına dikkat çeken araştırmalar mevcuttur. Sözel ve sözel olmayan kişilik envanterleri ile farklı dillerin konuşulduğu ülkelerde yürütülen çalışmalarda Beş Faktör Modelini destekleyen bulgular elde edilmiştir. Bu araştırmalarda Beş Faktör Modeliyle kişilik ölçümünün, dile dayalı ölçümler kullanmaktan ve dilin yapısındaki kelime anlamlarının benzerliğinden kaynaklanmadığı belirtilmektedirler (Somer, vd, 2002:22).

Çok yaygın olarak kullanılan "Beş Faktör Modeli" kişilik özelliklerini açıklamada oldukça yararlı bir modeldir. Modelde yer alan beş faktör "yeniliğe açıklık, sorumluluk, dışadönüklük, uyumluluk ve duygusal denge"dir. Bu faktörler girişimcilikle doğrudan bağlantılıdır. Bir girişimci açık olmalı, sorumluluğunu bilmeli, dışa dönük hareket edebilmeli, takımıyla uyumlu olmalı ve onlarla duygusal bir denge kurabilmelidir (Ören ve Biçkes, 2011:69).

Dışadönüklük; enerjik, konuşkan, sıcakkanl, heyecanlı ve coşkulu ve sosyal olma gibi özelliklerden oluşmaktadır. Dışadönüklük düzeyi yüksek kişiler diğer insanlarla kolay ilişki kurabilen, sosyal, işbirliğine yatkın, sempatik bireyler olarak değerlendirilmektedir. Dışadönüklük düzeyi düşük olan, bir başka deyişle, içedönük olan bireyler ise içine kapanık, sosyalleşmeyi sevmeyen, insanlara karşı mesafeli, sessiz ve utangaç bireyler olarak ifade edilmektedir (Doğan, 2013:57).

Uyumluluk; temel olarak diğer tarafin isteklerini ve beklentilerini anlamak ve anlayışla karşılayabilmektir (Tozkoparan, 2013:199). Uyumluluk düzeyi yüksek olan kişiler, güvenilir, açık sözlü, yumuşak başlı ve alçak gönüllü olarak tanımlanmaktadır. Bu kişiler işbirliğine yatkın, nazik ve esnektir. Rekabetten çok uzlaşmaya önem verirler ve kişiler arası çatı̧̧malara girmekten kaçınırlar. Buna karşın, uyumluluk faktörü düşük olan kişiler kavgacı, düşmanca tutuma sahip ve başkalarına karşı kayıtsızdırlar (Ötken ve Cenkci, 2013:43).

Sorumluluk; bireylerin dürtülerini nasıl kontrol ettiğini ifade eder. Sorumlu bireyler genellikle hedef odaklı, güvenilir ve zeki olarak kabul edilirler. Sorumluluk duygusu yüksek bireyler; daha disiplinli, çalışkan, planlı ve tepkilerinde mantıklı olmaya eğilimlidirler. Sorumluluk duygusu düşük olanlara göre görevin gereklerine daha bağlı, zor görevleri üstlenmeye ve inisiyatif kullanmaya daha istekli, kurallara uyma konusunda daha tutarlıdırlar. Sorumluluğu yüksek olan bireylerin işkolik ve mükemmeliyetçi olabilmeleri olumsuz yönler olarak ifade edilebilir. Sorumluluk özelliği taşıyan bir bireyin sebatkarlığı ve özdisiplini görevi başarmasını ve tamamlamasını mümkün k1lar (Bitlisli vd, 2013:462).

Duygusal denge insanların duygu durumunu ifade eder. Duygusal açıdan dengeli bireyler güven verici, sakin, vb. kişilik özellikleri gösterirler (Erkuş ve Tabak, 2009:217). Bu kişiler kolay üzülmezler, istikrarlıdırlar ve kalıcı olumsuz duygulardan uzak dururlar. Duygusal dengesizlik (nevrotizm) ise, olumsuz duygular yaşama eğilimini ifade etmektedir. Duygusal açıdan dengesiz (nevrotik) kişiler her şeyden önce endişe, öfke ya da depresyon gibi duygulardan birini yaşamaktadırlar (Deniz ve Erciş, 2008:304).

Yeniliğe (gelişime) açıklık; entellektüel etkinliklere katılma, yeni duygu ve düşüncelere açık olma eğilimini temsil etmektedir. Yeniliğe açıklık, bir bakıma, entellektüel ilgi, estetik duyarlık, hayal gücü, esneklik ve geleneksel olmayan tutumlarla ilişkilidir (Çivitci ve Arıcıoğlu, 2012:82) ve kişilik yapısı içinde bilişsel yönü en fazla olan özelliktir. Yeniliğe açı olan kişiler, hayal gücü yüksek, özgün, yaratıc1, meraklı, kendi düşünce ve duygularına yönelen; düşük seviyedekiler ise geleneksel, tutucu, ilgisiz olarak nitelendirilmektedirler (Basım vd, 2009:23).

\subsection{Girişimcilik ve Turizm Sektörü}

Turizmin gelişimi genel olarak ekonomide büyümeye ve yerel düzeyde girişimciliğin artışına yol açmaktadır. $\mathrm{Bu}$ nedenle, gelişmiş ve gelişmekte olan ülkelerde turizm sektöründe girişimciliğin finansal araçlarla ve politikalarla desteklenmesi yaygınlaşmaktadır. Özellikle küçük ölçekli yerel girişimlerin desteklenmesine yönelik politikalara önem verilmektedir (Ateljevic ve Page, 2009:1). Turizm hizmetlerinin büyük bir kısmı dünyanın hemen her yerinde çok sayıda ve küçük ölçekli birimlerde turistlere sunulmaktadır. Bunun sonucu olarak da kendi işinde çalışanların toplam işgücü içindeki oranı önemli bir düzeye ulaşmaktadır (Yıldız, 2011:62).

İşsizlik oranının yüksek olduğu Türkiye'de, turizm gibi emek-yoğun yapıya sahip olan ve düşük yatırım tutarlarıyla yüksek sayıda istihdam sağlanabilen bir sektörde girişimciliğin desteklenmesi önem kazanmaktadır. 
Ülkemizde KOSGEB aracıllı̆ıyla turizm sektöründe girișimcilere yönelik çeşitli teşvikler verilmektedir (Kültür ve Turizm Bakanlı̆̆ı, 2012). Turizm sektörü büyük ölçekli yatırımların yoğun olduğu bir alandır. Bu yönüyle yabancı sermaye yatırımları için de oldukça caziptir. Yabancı sermaye ve yatırımlar ülkemiz için önemlidir, ancak yerel kaynaklardan en iyi biçimde yararlanabilmek ve turizm gelişiminin sürdürülebilirliğini sağlamak için iç dinamiklerin harekete geçirilmesi gereklidir. Bu bağlamda küçük ve yerel girişimlerin desteklenmesinin yararlı olduğu söylenebilir. Özellikle genç girişimcilere yönelik destekler küçük ölçekli işletmelerin kurulabilmesine olanak sağlayabilecektir. Turizm lisans eğitimi almış ve girişimcilik eğilimi olan kişiler küçük finansal desteklerle seyahat acentesi, yiyecek-içecek tesisi, bilişim teknolojisine dayalı turizm hizmetleri sunan işletmeler, vb. kurabilirler.

Türkiye'de özellikle üniversite öğrencileri üzerinde girişimcilik konusunda bir hayli çalışma bulunmaktadır. Üniversite öğrencileri üzerinde yapılan araştırmaların, genç girişimci adaylarına yol göstermeyi ve girişimcilik destekleme politikaları için veri sağlamayı amaçladığını söylemek mümkündür. Bu kapsamda turizm sektöründe girişimcilik konusunu ele alan akademik çalışmalar girişimciliği destekleme politikaları açısından yararlı olabilir. Ancak turizm sektöründe girişimcilik konusundaki araştırmalar pek fazla değildir (Li, 2008:1021). Ülkemizde bu konuda yapılan çalışmaların sayıca yetersiz olduğu söylenebilir. Ancak yapılan çalışmalarda önemli sonuçlara ulaşılmıştır.

Solmaz vd. (2014) turizm lisans ve önlisans öğrencilerinin girişimci kişilik özelliklerini karşılaştırmışlar ve iki grup arasında anlamlı farklılıklar belirlemişlerdir. Bozkurt ve Erdurur (2013) tarafindan turizm lisans eğitim alan öğrenciler üzerinde yürütülen çalışmada girişimci kişilik özellikleri ile girişimcilik eğilimi arasında pozitif yönde anlamlı bir ilişki olduğu saptanmıştır. Polat (2011) ise turizm işletmelerinde girişimcilik motivasyonu ile işletme yenilikçiliği arasında anlamlı ilişkiler olduğunu ortaya koymuştur. Kozak ve Yılmaz (2010) çalışmasında otel yöneticilerinin yenilik yapma ve stratejik yenilenme konuların iç girişimcilik kapsamında önemli buldukları belirlenmiştir. Yılmazdoğan ve Kaşlı (2011) turizm konusundaki katılımcı algılamalarının girişimcilik niyeti üzerinde etkili olduğunu tespit etmişlerdir. Yumuk (2013) turizm lisans ve önlisans öğrencileri üzerinde yaptığı araştırmada girişimcilik eğitiminin girişimcilik eğilimine kısmen etkisi olduğunu saptamıştır.

\section{Araştırma Bulguları ve Değerlendirme}

Çalışma kapsamında turizm lisans öğrencilerinin; girişimcilik eğilimlerinin boyutları nelerdir?, kişilik özellikleri ile girişimcilik eğilimleri arasında ilişki bulunmakta mıdır? ve girişimcilik eğilimleri demografik değişkenlere göre farklılık göstermekte midir? sorularına yanıt bulunması amaçlanmıştır. Bu amaç doğrultusunda lisans düzeyinde turizm eğitimi alan öğrencilerin girişimcilik eğilimlerini ve kişilik özelliklerini belirlemek üzere bir anket uygulanmıştır.

Girişimcilik eğilimini ölçmeye yönelik olarak Caird ve Johnson tarafından geliştirilen (Caird, 1991), daha sonra Caird (2013) tarafından güncellenen 54 değişkenden oluşan girişimcilik eğilimi ölçeğinden; kişilik özelliklerini ölçmek için ise yaygın olarak kullanılan ve farklı dillerde uygulanma olanağına sahip olan 44 değişkenden oluşan Beş Faktör Modelinden (John ve Srivastava, 1999:131) yararlanılmıştır. Öğrencilere ilişkin demografik bilgileri ve girişimcilik niyetlerini ölçmeye yönelik değişkenler araştırmacı tarafından belirlenmiştir.

Anket 2016 Mart ve Nisan aylarında Sakarya Üniversitesi İşletme Fakültesi Turizm İşletmeciliği bölümünde öğrenim gören öğrencilere uygulanmıştır. Toplam 1029 olan evreni temsil edebilmesi bakımından basit tesadüfi örnekleme yöntemi kullanılarak 421 anket toplanmıştır. Öğrencilerin ankete verdikleri cevaplardan elde edilen veriler nicel tekniklerle analiz edilmiştir.

Öncelikle verilerin parametrik testlere uygun olup olmadığını belirlemek için normallik testi ve değişkenlerin ölçümünün doğruluğunu belirmek için güvenirlik analizi yapılmıştır. Girişimcilik eğilimi ve kişilik özellikleri boyutlarını belirlemek için açıklayıcı faktör analizi, girişimcilik eğiliminin demografik değiş̧enlere göre farklılığını belirlemek için bağımsız gruplar t-tesi ve tek yönlü Anova, girişimcilik eğilimi ile kişilik özellikleri arasında ilişkileri belirlemek için korelasyon analizi yapılmıştır. Elde edilen bulgular yorumlanarak sonuçlara ulaşılmış ve sonuçlara dayalı olarak öneriler geliştirilmiştir. Araştırmadan elde edilecek sonuçların potansiyel girişimci adayı olan öğrencilere, girişimcilik konusunda karar alıcılara ve bu alanda akademik çalışma yapan araştırmacılara yarar sağlaması bakımından çalışmanın önemli olduğu söylenebilir.

Demografik bilgilerin sunulduğu Tablo 1 incelendiğinde katılımcıların; cinsiyetinin ve öğretim türlerinin yaklaşık olarak birbirine eşit olduğu, büyük çoğunluğunun 21-24 yaş aralığında bulunduğu, önemli kısmının 2 ve 3. sınıflarda eğitim gördüğü, büyük çoğunluğunun Marmara bölgesinde ikamet ettiği, aile gelirlerinin çoğunlukla orta düzeyde olduğu, önemli bir kısmının genel liselerden geldiği, çok düşük (\%5) bir kısmının ise turizm eğitimi verilen liselerden geldiği, turizm lisans eğitimi almaktan duyulan memnuniyetin yarıdan fazla olduğu, turizm sektöründe staj yapma/çalışma durumunun yarıdan biraz fazla olduğu, staj yapanların/çalışanların çoğunlukla yiyecek-içecek ve önbüro bölümlerinde çalıştıkları, önemli bir kısmının gelecekte kendi işini kurma düşüncesine sahip olduğu ve bu işlerin de çoğunlukla turizm veya ilgili sektörlerde olduğu, kendi işin kurma düşüncesinde olmayanların veya buna henüz karar vermeyenlerin genellikle özel veya kamu sektöründe prestijli bir işte çalışmak istedikleri görülmektedir. 


\begin{tabular}{|c|c|c|}
\hline Cinsiyet & Sayı & Yüzde \\
\hline Kadın & 198 & 47 \\
\hline Erkek & 223 & 53 \\
\hline Toplam & 421 & 100 \\
\hline \multicolumn{3}{|l|}{ Yaş } \\
\hline 20 ve alt 1 & 95 & 23 \\
\hline $21-24$ & 300 & 71 \\
\hline 25 ve üstü & 26 & 6 \\
\hline Toplam & 421 & 100 \\
\hline \multicolumn{3}{|l|}{ Sinıf } \\
\hline 1. sinif & 49 & 12 \\
\hline 2. sinif & 152 & 36 \\
\hline 3. sinif & 161 & 38 \\
\hline 4. sinif & 59 & 14 \\
\hline Toplam & 421 & 100 \\
\hline \multicolumn{3}{|l|}{ Ö̆gretim türü̈ } \\
\hline 1. öğretim & 229 & 54 \\
\hline 2. öğretim & 192 & 46 \\
\hline Toplam & 421 & 100 \\
\hline \multicolumn{3}{|l|}{ İkamet (Bölge) } \\
\hline Marmara & 329 & 78 \\
\hline Karadeniz & 22 & 5 \\
\hline Ege & 12 & 3 \\
\hline Akdeniz & 8 & 2 \\
\hline İç Anadolu & 17 & 4 \\
\hline Doğu Anadolu & 3 & 1 \\
\hline Türkiye diş1 & 28 & 7 \\
\hline Toplam & 419 & 100 \\
\hline \multicolumn{3}{|l|}{ Aile Gelir Düzeyi } \\
\hline Düşük & 30 & 7 \\
\hline Orta & 343 & 82 \\
\hline Yüksek & 48 & 11 \\
\hline Toplam & 421 & 100 \\
\hline \multicolumn{3}{|l|}{ Lise } \\
\hline Genel lise & 277 & 66 \\
\hline Turizm eğitimi verilen lise & 22 & 5 \\
\hline Diğer lise & 121 & 29 \\
\hline Toplam & 420 & 100 \\
\hline
\end{tabular}

\begin{tabular}{|c|c|c|}
\hline Turizm lisans eğitimi almaktan memnuniyet & Sayı & Yüzde \\
\hline Evet & 244 & 58 \\
\hline Hayır & 36 & 9 \\
\hline Kismen & 141 & 33 \\
\hline Toplam & 421 & 100 \\
\hline \multicolumn{3}{|l|}{ Staj Yapma/Çalışma Durumu } \\
\hline Staj yapmayan & 188 & 45 \\
\hline Staj yapan & 233 & 55 \\
\hline Toplam & 421 & 100 \\
\hline \multicolumn{3}{|l|}{ Staj yapma/Çalışma süresi } \\
\hline 3 ay ve daha az & 121 & 52 \\
\hline 4-9 ay & 61 & 26 \\
\hline 10 ay ve fazla & 51 & 22 \\
\hline Toplam & 233 & 100 \\
\hline \multicolumn{3}{|l|}{ Staj Yapılan/Çalışılan Bölüm } \\
\hline Önbüro & 47 & 20 \\
\hline Yiyecek-içecek servisi & 96 & 41 \\
\hline Diğer & 90 & 39 \\
\hline Toplam & 233 & 100 \\
\hline \multicolumn{3}{|l|}{ Gelecekte kendi işini kurma düşüncesi } \\
\hline Var & 266 & 63 \\
\hline Yok & 47 & 11 \\
\hline Kararsiz & 108 & 26 \\
\hline Toplam & 421 & 100 \\
\hline \multicolumn{3}{|l|}{$\begin{array}{l}\text { Gelecekte kurulması düşünülen işin turizm } \\
\text { sektörü̈yle ilgisi }\end{array}$} \\
\hline Turizm sektöründe & 62 & 23 \\
\hline Turizm sektörüyle ilgili & 141 & 53 \\
\hline Turizm sektörüyle ilgili değil & 44 & 17 \\
\hline Diğer & 19 & 7 \\
\hline Toplam & 266 & 100 \\
\hline \multicolumn{3}{|l|}{ Gelecekte çalışılması düşünülen sektör } \\
\hline Özel sektörde prestijli bir işte & 57 & 37 \\
\hline Kamu sektöründe prestijli bir işte & 36 & 23 \\
\hline Özel sektörde herhangi bir işte & 9 & 6 \\
\hline Kamu sektöründe herhangi bir işte & 11 & 7 \\
\hline Diğer & 8 & 5 \\
\hline Karar vermeyen & 34 & 22 \\
\hline Toplam & 155 & 100 \\
\hline
\end{tabular}

Tablo 1. Katılımcılar Illişkin Demografik Bilgiler

Girişimcilik eğilimi ve kişilik özellikleri değişkenlerine faktör analizi uygulamadan önce güvenirlik düzeyleri belirlenmiştir. Güvenilirlik analizi için Cronbach Alfa katsayısı kullanılmıştır ve bu katsayı girişimcilik eğilimi ölçeği için 0,81; kişilik özellikleri ölçeği için ise 0,76 olarak hesaplanmıştır. Ölçeklerin güvenilir olduğuna karar verilmiştir.

Girişimcilik eğiliminin belirlenmesine yönelik ifadelere katılımcıların verdikleri yanıtları özetlemek ve girişimcilik eğilimi boyutlarını belirlemek amacıyla açıklayıcı faktör analizi yapılmıştır. Tablo 2'de verilen girişimcilik eğilimi faktör analizinde değişkenlerden iki tanesi faktör yapısını bozduğu için çıkarılmıştır.

Faktörlerin aritmetik ortalamasını değerlendirmede katılım düzeyi için 1,00-1,79: çok düşük; 1,80-2,59: düşük; 2,60-3,39: orta; 3,40-4,19: yüksek; 4,20-5,00: çok yüksek kriterlerine göre yorum yapılıştır. Tablo 2’ye göre girişimcilik eğilimi ilgili yazına uygun olarak risk alma düzeyi (risk alma-almama), başarı güdüsü (yüksek-düşük başarı güdüsü), kontrol odağı (içsel-dışsal kontrol odağı), yaratıcılık düzeyi (yüksek-düşük yaratıcılık) ve özerklik düzeyi (özerk olma-olmama) olmak üzere beş gruba uygun olarak 10 boyut halinde belirlenmiştir.

Girişimcilik eğilimi faktör analizine göre risk almama faktörüne katılım orta düzeydeyken, risk alma faktörüne katılım yüksek düzeydedir. Yüksek başarı güdüsü faktörüne katılım yüksek, düşük başarı güdüsü faktörüne katılım ise orta düzeydedir. İç kontrol odağı faktörüne katılım yüksek, dış kontrol odağı faktörüne katılım orta düzeydedir. Düşük yaratıcılık faktörüne katılım orta, yüksek yaratıcılık faktörüne katılım yüksek düzeydedir. Özerk olma ve olmama faktörlerinin her ikisine de katılım yüksek düzeydedir.

$\mathrm{Bu}$ sonuçlara göre genellikle girişimcilik eğilimini olumlu etkileyen faktörlere katılımın yüksek ve olumsuz etkileyen faktörlere katılımın orta düzeyde olduğu söylenebilir. Lisans düzeyinde turizm eğitimi alan ve geleceğin potansiyel girişimcileri olan genç insanların girişimcilik eğilimini etkileyen boyutlara yüksek düzeyde katılım göstermeleri önemli bir sonuç olarak ifade edilebilir. 


\begin{tabular}{|c|c|}
\hline Faktörler & $\begin{array}{l}\text { Faktör } \\
\text { Yükleri }\end{array}$ \\
\hline F1-Risk almama $\quad$ (Özdeğer: 3,56 - Açıklanan varyans: $11,58 \%$ - Faktör ortalamast: 3,18 - Cronbach Alfa: 0,690$)$ & \\
\hline Bir yarışmaya girmek yerine piyango bileti satın almayı yeğlerim. & ,633 \\
\hline Bir karar vermeden önce ne kadar zaman alırsa alsın konu hakkındaki tüm verileri elde etmek isterim. & ,594 \\
\hline Diğer insanlardan yardım istemek benim için zordur. &, 549 \\
\hline Başarısızlık ihtimali olan bir işi yapmamayı tercih ederim. & ,478 \\
\hline İnsanların alışık olduğu şey (iş, görev, faaliyet, vs.) genellikle alışılmadık olandan daha iyidir. & ,447 \\
\hline Ücret düzeyi ortalama olan garantili bir işi, çalışmaya devam etmesi performansa bağlı olan yüksek ücretli bir işe tercih ederim. & 413 \\
\hline F2-Risk alma $\quad($ Özdeğer: $3,47-$ Açıklanan varyans: $9,42 \%$ - Faktör ortalamast: 4,10 - Cronbach Alfa: 0,701$)$ & \\
\hline Başarı şansı yarı yarıya olan bir şeyin (iş, görev, faaliyet, vs.) üstesinden gelmek istiyorsam risk alırım. & 660 \\
\hline Harcadığım zaman ve paranın karşılığını alma garantisi olmasa bile ilginç projelere başlamak isterim. & 630 \\
\hline Bana zevk verdiğini bildiğim ișleri yapmak yerine daha iyi bir ișe öncülük etme firsatından yararlanmayı tercih ederim. & ,528 \\
\hline Önemli bir karar vermeden önce, uzun süre düşünmek yerine, kararımın avantaj ve dezavantajlarını karşılaştırırım. & 490 \\
\hline Bir işte çalışmaya başlamadan önce zorluk derecesini test etmek isterim. & ,486 \\
\hline Para kazanmak için iyi bir fikrim olduğunda, gerçekleştirmek için zamanımı harcarım ve borç alırım. & ,454 \\
\hline F3-Yüksek başarı güdüsü $\quad$ (Özdeğer: 2,89 - Açıklanan varyans: $7,36 \%$ - Faktör ortalamast: 3,69 - Cronbach Alfa: 0, 697) & \\
\hline Bir riskle karşılaştığımda, başarısızlığın olumsuz etkileri yerine başarının sonuçları hakkında düşünürüm. & 622 \\
\hline Kolayca yaptığım işlerden sıkılırım ve yeteneklerimi zorlayan işleri severim. & 610 \\
\hline Eğer insanlar bir toplantıya zamanında gelmezlerse çok rahatsız olurum. & ,599 \\
\hline Belirli bir tarihte tamamlanması gereken bir işi yetiştirebilmek için erken kalkarım, yemek yemeyi geciktiririm veya yemem. & ,523 \\
\hline Bir işten ayrılmak benim için çok zor verilebilecek bir karardır. & ,499 \\
\hline Bir işi iyi yapmak insanları memnun etmeye çalışmaktan daha önemlidir. & 439 \\
\hline F4-Düsü̈k bașarı güdüsü $\quad$ (Özdeğer: 2,51 - Açılanan varyans: $6,65 \%$ - Faktör ortalamast: 2,96 - Cronbach Alfa: 0,723$)$ & \\
\hline Bir görevle ilgili olarak sorunlar yaşarsam onu bırakırım, unuturum ve başka bir göreve yönelirim. & 667 \\
\hline İşteki bir görevde tek başıma sorumluluk üstlenmek yerine takımın bir parçası olmayı tercih ederim. & 633 \\
\hline Eğer iyi bir ücreti ve emekli olana kadar çalışma güvencesi varsa sıradan ve basit bir işte çalışmak benim için sorun olmaz. &, 537 \\
\hline Gelecekten çok şimdiki zamanı ve geçmişi düşünürüm. & 529 \\
\hline İşinde iyi olan sevmediğim biriyle beraber çalışmak yerine, işinde iyi olmayan sevdiğim biriyle beraber çalışmayı tercih ederim. & 414 \\
\hline Tatillerde işleri unutuyorum ve rahatliyorum. & 400 \\
\hline F5-İç kontrol odă̆ı $\quad($ Özdeğer: $2,13-$ Açıklanan varyans: $5,94 \%$ - Faktör ortalaması: 3,84 - Cronbach Alfa: 0,709$)$ & \\
\hline Benim düşünceme göre, elde etmek istediğim şeylere ulaşmak çabalarımın bir ödülüdür. & 641 \\
\hline Başarılı olmak sıkı çalışmanın sonucudur, başarıda şansın payı çok düşüktür. & 600 \\
\hline Yaşamdan istediklerimi elde ederim çünkü onları gerçekleştirmek için çok çalışırım. &, 593 \\
\hline İnsanlar genellikle hak ettiklerini elde ederler. &, 532 \\
\hline Neredeyse her zaman yaptı̆̆ım planları başarırım. & 488 \\
\hline Yetenekli insanların başarılı olamama nedeni genellikle ortaya çıkan riskleri göze alamamalarıdır. & ,415 \\
\hline F6-Dış kontrol odağı $\quad$ (Özdeğer: 2,04 - Açıklanan varyans: $4,78 \%$ - Faktör ortalaması: 3,29 - Cronbach Alfa: 0,693) & \\
\hline İnsan herhangi bir şeyde doğal olarak iyidir ya da değildir, çaba göstermek durumu değiştirmez. & ,744 \\
\hline İnsanların yaşadıkları kötü durumların nedeni genellikle şanssızlıktır. & 613 \\
\hline Hayatta başıma gelen şeylerin bir nedeni olduğunu kabul etmeye çalışırım. & ,566 \\
\hline Doğru zamanda doğru yerde olmadıkça bir insanın başarılı olması çok zordur. & 550 \\
\hline İnsanların başarısızlığının nedeni nadiren onların kötü kararlarının bir sonucudur. & 486 \\
\hline Hayatta başıma gelenlerin kader tarafından belirlendiğine inanırım. & ,402 \\
\hline F7: Düşük yaratıcılık $\quad$ (Özdeğer: 1,85 - Açıklanan varyans: 4,42\% - Faktör ortalamast: 3,01 - Cronbach Alfa: 0, 694) & \\
\hline Yaşamımın düzenli olmasını isterim, böylece her şey yolunda gider ve planlarım gerçekleşir. & 629 \\
\hline İşleri yapmak için yeni yöntemler denemek yerine alışılmış yolları tercih ederim. & 605 \\
\hline Benim için değişime uyum sağlamak, alış1lagelen durumu sürdürmekten daha zordur. & 600 \\
\hline Çok nadiren hayal kurarım. & ,516 \\
\hline Yeni fikirlere, araç-gereçlere ve teknolojilere karşı temkinliyimdir. & ,445 \\
\hline F8: Yüksek yaratıcılık (Özdeğer: 1,67 - Açılanan varyans: $4,10 \%$ - Faktör ortalaması: 3,87 - Cronbach Alfa: 0, 726) & \\
\hline Diğer insanlar benim daima değişiklikler yapan ve yenilikleri deneyen birisi olduğumu düşünürler. & 693 \\
\hline Bazen insanlar fikirlerimi olağandışı bulurlar. & ,571 \\
\hline Bazen yeni fikirler ve çözümler bulana kadar konu hakkındaki bilgilere aşırı biçimde odaklanırım. & ,548 \\
\hline Bazen yoğun baskı altında olduğumu hissetmeme yol açan çok sayıda fikirlerim oluyor. & 493 \\
\hline Farklı düşünce tarzlarına sahip insanlarla zaman geçirmekten hoşlanırım. & 430 \\
\hline F9: Özerk olma $\quad$ (Özdeğer: 1,62 - Açılklanan varyans: 4,00\% - Faktör ortalaması: 3,52 - Cronbach Alfa: 0,714$)$ & \\
\hline İşte sıklıkla projeler üstlenirim ve bu projeleri diğer insanların ne düşündüğüne aldırmadan kendi bildiğim şekilde yürütürüm. & ,681 \\
\hline Eğer üstlerim veya çalışma arkadaşlarım benim yaptığım iyi bir işi kendilerine mal ederlerse çok rahatsız olurum. & ,551 \\
\hline Genellikle yaptığım işlerde başkalarının yardımına ve işlerin benim tarafimdan yapıldığının anlaşılmasına ihtiyaç duymam. & 424 \\
\hline 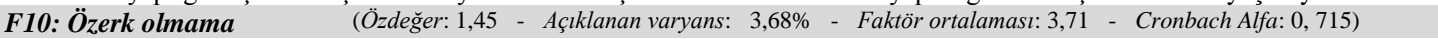 & \\
\hline İşte ne yapmam gerektiği konusunda tam anlamıyla emin olmak için bana yol gösterilmesine çok sevinirim. & ,498 \\
\hline Genellikle benden bekleneni yaparım ve talimatları dikkatle uygularım. & 379 \\
\hline Alışılmadık ve sıradışı olmaktan pek hoşlanmam. &, 366 \\
\hline
\end{tabular}

NOT: Varimaks rotasyonlu temel bileşenler analizi; Kaiser-Meyer-Olkin Örneklem Yeterliliği: 0,782; Bartlett küresellik testi: $p<0,05$; Ki-kare: 4769,680; df: 343; Açıklanan Toplam Varyans 61,93\% Yanit kategorileri: 1: Kesinlikle katılmıyorum - 2: Kat1lmiyorum - 3: Ne kat1liyorum ne katılmiyorum - 4: Kat1liyorum - 5: Kesinlikle katıliyorum

\section{Tablo 2. Girişimcilik Eğilimi Faktör Analizi Sonuçları}

Kişilik özelliklerinin belirlenmesine yönelik "kendinizi nasıl tanımlarsınız" sorusuna cevap oluşturan ifadelere katılımcıların verdikleri yanıtları özetlemek ve kişilik özellikleri boyutlarını belirlemek amacıyla yapılan açıklayıcı faktör analizi sonuçları Tablo 3'de sunulmuştur. Değişkenlerden üç tanesi faktör yapısını bozduğu için çıkarılmıştır. Tablo 3'e göre kişilik özellikleri ilgili yazına uygun olarak yeniliğe açıklık, duygusal denge, 
dışadönüklük düzeyi (dışadönük-içedönük), sorumluluk düzeyi (yüksek-düşük sorumluluk) ve uyum durumu (uyumlu-uyumsuz) olmak üzere beş gruba uygun olarak sekiz boyut halinde belirlenmiştir.

Kişilik özellikleri faktör analizine göre yeniliğe açık olma, dengeli duygusal yapı ve dışadönüklük faktörlerine katılım yüksek düzeydedir. Yüksek sorumluluk faktörüne katılım çok yüksek düzeydeyken düşük sorumluluk faktörüne katılım orta düzeydedir. Uyumluluk faktörüne katılım çok yüksek düzeydeyken, uyumsuzluk faktörüne katılım orta düzeydedir. İçedönüklük faktörüne katılım ise orta düzeydedir. Bu sonuçlara göre katılımcıların genellikle olumlu kişilik özelliklerine sahip olduklarına katıldıkları, ancak bazı olumsuz kişilik özelliklerine de orta düzeyde katılım gösterdikleri söylenebilir.

\begin{tabular}{|c|c|c|c|}
\hline \multirow{2}{*}{$\begin{array}{l}\text { Faktörler (1. Sütun) } \\
\text { F1-Yeniliğe açık olma } \\
\text { (Özdeğer: } 4,03 \text { - Açıklanan varyans: } 10,15 \% \text { - } \\
\text { Faktör ortalamast: } 3,98 \quad \text { - Cronbach Alfa: } 0,757)\end{array}$} & $\begin{array}{l}\text { Faktör } \\
\text { Yükleri }\end{array}$ & Faktörler (2. Sütun) & $\begin{array}{l}\text { Faktör } \\
\text { Yükleri }\end{array}$ \\
\hline & & $\begin{array}{l}\text { F4-Yükssek sorumluluk } \\
\text { (Özdeğer: } 3,01 \quad-\text { Açlklanan varyans: } 7,83 \%- \\
\text { Faktör ortalamast: } 4,20 \quad \text { - Cronbach Alfa: } 0,738)\end{array}$ & \\
\hline Yaratıcı & ,674 & İşgören (çalışan) olarak güvenilir & ,711 \\
\hline Yeni fikirler bulan, özgün & 657 & Bir işi bitirmede sonuna kadar sebat eden & ,709 \\
\hline Hayal gücü yüksek & ,651 & İşini titiz yapan &, 589 \\
\hline Pek çok şey hakkında meraklı &, 573 & İşleri etkili şekilde yapan & ,562 \\
\hline Düşünmeyi, fikirlerle meşgul olmayı seven &, 557 & Planlar yapan ve kararlılıkla uygulayan & ,476 \\
\hline Zeki, derin düşünen & ,454 & F5-Düsük sorumluluk & \\
\hline $\begin{array}{l}\text { Sanat, müzik veya edebiyatta konusunda bilgili } \\
\text { Sanatsal ve estetik denevimlere shin }\end{array}$ & ,440 & (Özdeğer: 2,50 - Açıllanan varyans: $7,35 \%$ - & \\
\hline & ,416 & Faktör ortalamasl: 3,32 - Cronbach Alfa: 0,715) & \\
\hline $\begin{array}{l}\text { (Özdeğer: } 3,79-\text { Aç̧klanan varyans: } 9,63 \%- \\
\text { Faktör ortalamast: } 4,07 \text { - Cronbach Alfa: } 0,726)\end{array}$ & & $\begin{array}{l}\text { Tertipsiz, düzensiz olmaya meyilli }(\mathrm{T}) \\
\text { Biraz dikkatsiz }(\mathrm{T}) \\
\text { Tembelliğe meyilli }(\mathrm{T})\end{array}$ & $\begin{array}{l}, 789 \\
, 677 \\
, 635\end{array}$ \\
\hline Kolayca sinirlenen $(\mathrm{T})$ & ,776 & Kolayca aklı karışan, şaşıran (T) & 420 \\
\hline Kolayca gerilen $(\mathrm{T})$ & ,760 & F6-Uyumluluk & \\
\hline Duygusal olarak kolay sarsılmaz, üzülmez & ,705 & (Özdeğer: 2,05 - Açılanan varyans: $6,75 \%$ - & \\
\hline Rahat, stresle başa çıkabilen & 659 & Faktör ortalamasl: 4,29 - Cronbach Alfa: 0,737) & \\
\hline Stresli durumlarda soğukkanlılığını koruyan & ,656 & Genellikle güvenilir &, 710 \\
\hline Bunalımlı (T) & ,476 & Diğer insanlara yardım eden, bencil olmayan & ,684 \\
\hline Karamsar $(\mathrm{T})$ & ,447 & Diğer insanlarla ortak çalışmayı seven &, 584 \\
\hline \multirow{2}{*}{\multicolumn{2}{|c|}{$\begin{array}{l}\text { F3-Dışadönüklük } \\
\text { (Özdeğer: } 3,36 \text { - Açılklanan varyans: } 8,64 \% \text { - } \\
\text { Faktör ortalamast: } 3,92 \text { - Cronbach Alfa: } 0,746)\end{array}$}} & Neredeyse herkese karşı düşünceli ve nazik & ,433 \\
\hline & & $\begin{array}{l}\text { F7-Uyumsuzluk } \\
\text { (Özdeğer: } 1,67 \text { - Açılanan varyans: } 5,69 \% \text { - }\end{array}$ & \\
\hline \multirow{9}{*}{$\begin{array}{l}\text { Heyecan uyandıran, coşku yaratan } \\
\text { Konuşkan } \\
\text { Çok enerjik } \\
\text { Kimi zaman utangaç }(\mathrm{T}) \\
\text { İddialı, kendine güvenen } \\
\text { Sempatik ve sosyal }\end{array}$} & ,668 & Faktör ortalamasl: $3,24 \quad$ - Cronbach Alfa: 0,711$)$ & \\
\hline & 622 & Diğer insanlarda kusur aramaya meyilli (T) &, 757 \\
\hline &, 549 & Başkalarıyla bozuşmaya hazır $(\mathrm{T})$ &, 702 \\
\hline & 495 & Soğuk, kendi halinde (T) & 676 \\
\hline &, 487 & Bazen diğer insanlara karşı kaba davranan $(\mathrm{T})$ & 620 \\
\hline & ,458 & $\begin{array}{l}\text { F8-İcedönüklük } \\
\text { (Özdeğer: } 1,36 \text { - Açılanan varyans: } 4,65 \%- \\
\text { Faktör ortalamast: } 3,37 \text { - Cronbach Alfa: } 0,715 \text { ) }\end{array}$ & \\
\hline & & Sakin, sessiz olmaya meyilli (T) & ,771 \\
\hline & & Çekingen $(\mathrm{T})$ &, 721 \\
\hline & & Sanatsal ilgileri az olan $(\mathrm{T})$ &, 720 \\
\hline \multicolumn{4}{|l|}{ NOT: } \\
\hline
\end{tabular}

\section{Tablo 3. Kişilik Özellikleri Faktör Analizi Sonuçları}

Girişimcilik eğilimi ile kişilik özellikleri arasında bir ilişki olup olmadığını belirlemek için yapılan ve Tablo 4'de sunulan korelasyon analizi sonuçlarına göre risk alma ile yeniliğe açık olma; yüksek başarı güdüsü ile sorumluluk ve dışadönüklük; iç kontrol odağı ile sorumluluk, dışadönüklük ve yeniliğe açık olma; yüksek yaratıcılık ile yeniliğe açık olma arasında ilişki bulunmaktadır.

\begin{tabular}{|c|c|c|c|c|c|}
\hline & Ort. & S.S. & Yeniliğe açık olma & Dişadönüklük & Sorumluluk \\
\hline Risk alma & 4,10 & 0,81 &, 569 & ,252 & 199 \\
\hline Yüksek başarı güdüsü & 3,69 & 0,76 & ,291 &, 513 & ,605 \\
\hline İç kontrol odağı & 3,84 & 0,92 & $\begin{array}{l}, 610 \\
(* *)\end{array}$ & $\begin{array}{l}634 \\
(* *)\end{array}$ & $\begin{array}{l}652 \\
(* *)\end{array}$ \\
\hline Yüksek yaratıcılık & 3,87 & 1,03 & $\begin{array}{l}766 \\
(* *)\end{array}$ & ,217 & ,124 \\
\hline
\end{tabular}

Tablo 4. Girişimcilik Eğilimi ve Kişilik Özellikleri Korelasyon Analizi Sonuçları 
Tablo 4'de görüldüğü gibi girişimcilik eğilimi faktörleri ile en fazla ilişkili olan kişilik özelliği yeniliğe açık olmadır. En yüksek korelasyon ise yeniliğe açık olma (kişilik özelliği) ile yüksek yaratıcılık (girişimcilik eğilimi) arasındadır. Olumlu kişilik özellikleri ile girişimcilik eğilimi arasındaki ilişkiler doğal karşılanabilir ve başka araştırmalarda da elde edilen bir sonuçtur.

Girişimcilik eğiliminin demografik değişkenlere göre farklılık gösterip göstermediğini belirlemek üzere bağımsız gruplar t-testi ve tek yönlü Anova yapılmıştır. Yalnızca anlamlı farklılık belirlenen sonuçlar tablo haline getirilmiştir. Tablo 5'e göre cinsiyet itibarıyla farklılık gösteren girişimcilik eğilimi boyutları risk almama, düşük başarı güdüsü ve düşük yaratıcılıktır. Bu boyutlar açısından kadınlar erkeklere nazaran risk almamaya eğilimli, başarı güdüsü ve yaratıcılık açısından düşük ortalamalara sahiptir.

\begin{tabular}{|c|c|c|c|c|c|c|}
\hline \multicolumn{2}{|c|}{$\begin{array}{ll}\text { Gir. Eğilimi } & \text { Cinsiyet }\end{array}$} & \multirow{2}{*}{$\begin{array}{c}\text { Sayı } \\
198 \\
\end{array}$} & \multirow{2}{*}{$\begin{array}{c}\text { Ortalama } \\
3,09 \\
\end{array}$} & \multirow{2}{*}{$\begin{array}{c}\text { St. Sapma } \\
, 818\end{array}$} & \multirow{3}{*}{$\begin{array}{r}\text { t değeri } \\
-2,353\end{array}$} & \multirow{3}{*}{$\begin{array}{c}\text { Anlamlılık } \\
, 001\end{array}$} \\
\hline \multirow{2}{*}{ Risk almama } & Kadın & & & & & \\
\hline & Erkek & 223 & 3,26 &, 842 & & \\
\hline \multirow{2}{*}{$\begin{array}{l}\text { Düşük başarı } \\
\text { güdüsü̈ }\end{array}$} & Kadın & 198 & 2,87 & ,929 & \multirow{2}{*}{$-1,603$} & \multirow{2}{*}{,009 } \\
\hline & Erkek & 223 & 3,04 & , 107 & & \\
\hline \multirow{2}{*}{$\begin{array}{l}\text { Düşük } \\
\text { yaratıcılık }\end{array}$} & Kadın & 198 & 2,93 & ,887 & \multirow{2}{*}{0,364} & \multirow{2}{*}{,018 } \\
\hline & Erkek & 223 & 3,07 & ,908 & & \\
\hline
\end{tabular}

Tablo 5. Girişimcilik Ĕ̈iliminde Cinsiyete Göre Farklılıklar

Tablo 6'ya göre staj yapma durumu itibarıyla farklılık gösteren girişimcilik eğilimi boyutları yüksek başarı güdüsü ve iç kontrol odağıdır. Bu boyutlar açısından turizm sektöründe staj/çalışma deneyimi olanlar staj/çalışma deneyimi olmayanlara nazaran daha yüksek ortalamalara sahiptirler.

\begin{tabular}{|c|c|c|c|c|c|c|}
\hline \multicolumn{2}{|c|}{ Gir. Eğilimi $\quad$ Staj Yapma } & Sayı & Ortalama & St. Sapma & t değeri & Anlamlılık \\
\hline \multirow{2}{*}{$\begin{array}{l}\text { Yüksek başarı } \\
\text { güddüsü }\end{array}$} & Staj yapmayan & 188 & 3,63 &, 884 & \multirow{2}{*}{$-2,092$} & \multirow{2}{*}{0,03} \\
\hline & Staj yapan & 233 & 3,74 & ,935 & & \\
\hline \multirow{2}{*}{$\begin{array}{l}\text { İc kontrol } \\
\text { odağl }\end{array}$} & Staj yapmayan & 188 & 3,77 & ,853 & \multirow{2}{*}{1,690} & \multirow{2}{*}{0,01} \\
\hline & Staj yapan & 233 & 3,90 & ,782 & & \\
\hline
\end{tabular}

Tablo 6. Girişimcilik Eğiliminde Staj Yapma Durumuna Göre Farklılıklar

Tablo 7'ye göre öğrencilerin okudukları sınıf itibarıyla farklılık gösteren girişimcilik eğilimi boyutları yüksek başarı güdüsü, yüksek yaratıcılık ve özerk olmadır. Farklılığın nedenini belirlemek üzere yapılan post hoc testi sonuçlarına göre sınıf yükseldikçe (öğrencinin aldığı eğitim arttıkça) bu boyutlara katılım düzeyi artmaktadır.

\begin{tabular}{|c|c|c|c|c|c|c|}
\hline Gir. Eğilimi & Sinıf & Sayı & Ort. & St. Sapma & F değeri & Anlamlılık \\
\hline \multirow{4}{*}{$\begin{array}{l}\text { Yüksek başart } \\
\text { güdüsüi }\end{array}$} & 1. sinif & 49 & 3,46 &, 880 & \multirow{4}{*}{3,962} & \multirow{4}{*}{,004 } \\
\hline & 2. sinif & 152 & 3,71 &, 814 & & \\
\hline & 3. sinif & 161 & 3,75 & 807 & & \\
\hline & 4. sinif & 59 & 3,81 & 1,047 & & \\
\hline \multirow{4}{*}{$\begin{array}{l}\text { Yüksek } \\
\text { yaratıcılık }\end{array}$} & 1. sinif & 49 & 3,58 & ,977 & \multirow{4}{*}{5,446} & \multirow{4}{*}{,000 } \\
\hline & 2. $\sin 1 f$ & 152 & 3,89 & ,862 & & \\
\hline & 3. sinif & 161 & 3,93 & ,990 & & \\
\hline & 4. sinif & 59 & 4,06 & ,904 & & \\
\hline \multirow{4}{*}{$\ddot{O}_{z e r k}$ olma } & 1. sinif & 49 & 3,51 & 1,024 & \multirow{4}{*}{3,486} & \multirow{4}{*}{,008 } \\
\hline & 2. sinif & 152 & 3,57 & ,7860 & & \\
\hline & 3. sinif & 161 & 3,82 & ,955 & & \\
\hline & 4. $\sin 1 f$ & 59 & 3,91 & ,892 & & \\
\hline
\end{tabular}

Tablo 7. Girişimcilik Ĕ̈iliminde Sınıfa Göre Farklılıklar

Tablo 8'e göre katılımcıların gelecekte iş kurma düşüncesi itibarıyla farklılık gösteren girişimcilik eğilimi boyutu risk almadır. Farklılığın nedenini belirlemek üzere yapılan post hoc testi sonuçlarına göre gelecekte iş kurma düşüncesinde olanlar diğerlerine nazaran risk alma boyutuna daha fazla katılım göstermektedirler.

\begin{tabular}{|l|l|c|c|c|c|c|}
\hline \multirow{3}{*}{ Gir. Ĕ̆ilimi } & İş Kurma Düşüncesi & Sayı & Ort. & St. Sapma & F değeri & Anlamlılık \\
\hline \multirow{3}{*}{ Risk alma } & Var & 266 & 3,77 &, 944 & & \\
\cline { 2 - 5 } & Yok & 47 & 3,29 &, 876 & \multirow{2}{*}{, 000} & \\
\cline { 2 - 5 } & Kararsız & 108 & 3,16 & 1,024 & & \\
\hline
\end{tabular}

Tablo 8. Girişimcilik Eğiliminde Iş̧ Kurma Düşüncesine Göre Farklılıklar

Yaş, öğretim türü, ikamet edilen bölge, ailenin gelir düzeyi, mezun olunan lise, turizm lisans eğitim almaktan duyulan memnuniyet düzeyi, staj yapılan bölüm gibi demografik değişkenlere göre girişimcilik eğilimi itibarıyla farklılık bulunamamıştır. 


\section{Sonuç ve Öneriler}

Sakarya üniversitesi turizm lisans öğrencileri üzerinde yapılan araştırmada girişimcilik eğilimi ve kişilik özellikleri boyutları belirlenmiştir. Belirlenen boyutlar ilgili yazında sözü edilen boyutlarla uygunluk göstermektedir. Katılımcıların girişimcilik eğilimlerinin genellikle yüksek olduğu ve genellikle olumlu kişilik özelliklerine sahip oldukları belirlenmiştir. Risk alma, yüksek başarı güdüsü, iç kontrol odağı, yüksek yaratıcılık girişimcilik eğilimi boyutları ile yeniliğe açık olma, dışadönüklük, sorumluluk kişilik özelliği boyutları arasında çeşitli ilişkiler tespit edilmiştir. Cinsiyet, staj yapma durumu, öğrenim görülen sınıf ve iş kurma düşüncesi değişkenlerine göre bazı girişimcilik eğilimi boyutlarında farklılıklar saptanmıştır.

Kadınların erkeklere nazaran risk almaya eğilimli olmadıkları, başarı güdüsü ve yaratıcılık açısından düşük düzeyde oldukları ortaya çıkmıştır. Bunun nedeni olarak geleneksel toplumsal yapının kadını temkinli olmaya yönelttiği gösterilebilir. Turizm sektöründe belirli bir süre staj veya çalışma yoluyla deneyim yaşayan öğrencilerin, bu deneyimi yaşamayanlara nazaran yüksek başarı güdüsü ve iç kontrol odağına sahip oldukları gözlenmiştir. Sektör deneyiminin, öğrencilerde okulda öğrendiklerini uygulama şansına sahip olarak, başarma inancını ve kendine güven duymayı pekiştirdiği söylenebilir. Öğrencilerin öğrenim süresi arttıkça başarı güdüleri ile yaratıcılık ve özerklik düzeyleri de artmaktadır. Bu durum eğitimin girişimcilik eğilimini olumlu yönde etkilediğine işaret etmektedir. Gelecekte iş kurma düşüncesinde olanlar olmayanlara göre risk almaya daha fazla eğilim göstermektedirler. Risk almanın girişimcilik eğilimi açısından önemli bir boyut olması ve iş kurma düşüncesinde olanların risk almaya daha fazla katılım göstermeleri kişilerin iç tutarlılığına işaret etmektedir.

Elde edilen sonuçlara dayalı olarak geliştirilen öneriler aşağıda sıralanmaktadır;

- Turizm sektöründe genç girişimcilere yönelik devlet destekleri artırılmalıdır,

- Kadın girişimciliği desteklenmeli, turizm sektöründe kadın girişimcilere pozitif ayrımcılık yapılmalıdır,

- Girişimcilik eğiliminin kişilik özellikleri ile ilişkisi dikkate alınarak turizm lisans eğitimi alan öğrencilerin olumlu kişilik özelliklerine katkı sağlayacak sosyal, kültürel ve sportif etkinlikler düzenlenmelidir,

- Turizm lisans derslerinde kapsama uygun olarak girişimcilikle ilgili konular ve örnek olaylar işlenmeli, ayrıca bir ders olarak girişimcilik dersi konulmalıdır,

- Henüz turizm sektörü deneyimi olmayan öğrencilerde girişimcilik hevesi uyandırabilmek için turizm sektöründen başarılı girişimciler ve yöneticiler konferans vermek üzere turizm lisans eğitimi veren kurumlara davet edilmelidir.

$\mathrm{Bu}$ araştırma sınırlı bir örneklem ve kısıtlı bir zamanda gerçekleştirildiği için sonuçların genelleştirilebilmesi açısından yeterli değildir. Bu çalışmaya benzer çalışmaların farklı örneklemlerde yapılması önerisi karşılaştırmalar yapma ve sonuçları genelleştirme bakımından yararlı olabilir. Turizm sektöründe girişimcilik konusunda daha fazla çalışma yapılması ve araştırmacılar tarafından konunun çeşitli boyutlarının ele alınması da bir diğer öneri olarak sunulabilir.

\section{Kaynakça}

- $\quad$ Akçakanat, T.; Mücevher, M.H. ve Çarıkçı, İ.H, 2014. "Sözel, Sayısal ve Eşit Ağırlık Bölümlerinde Okuyan Üniversite Öğrencilerinin Girişimcilik Eğilimlerinin Bazı Demografik Değişkenler Açısından İncelenmesi: SDÜ Örneği”, Afyon Kocatepe Üniversitesi İ.̇.B.F. Dergisi, 16(2), s.137-153.

- Apak, S.; Taşçıyan, K.H. ve Aksoy, M., 2010. Girişimcilik ve Sermaye Tedarik Yöntemleri, Papatya, İstanbul.

- Ateljevic, J. ve Li, L., 2009. “Tourism Entrepreneurship-Concepts and Issues” içinde Ateljevic ve Page (Ed.) Tourism and Entrepreneurship-International Perspectives, s.9-32, Butterworth-Heinemann, Oxford.

- Ateljevic, J. ve Page, S.J., 2009. "Introduction" içinde Ateljevic ve Page (Ed.) Tourism and EntrepreneurshipInternational Perspectives, s.1-6, Butterworth-Heinemann, Oxford.

- Basım, H.N; Çetin, F. ve Tabak, A., 2009. "Beş Faktör Kişilik Özelliklerinin Kişilerarası Çatışma Çözme Yaklaşımlarıyla İlişkisi”, Türk Psikoloji Dergisi, 24(63), s.20-34.

- Bitlisli, F. vd., 2013. "Beş Faktör Kişilik Özellikleri İle Akademik Güdülenme İlişkisi: Süleyman Demirel Üniversitesi Isparta Meslek Yüksekokulu Öğrencilerine Yönelik Bir Araştırma”, Süleyman Demirel Üniversitesi İ.I.B.F. Dergisi, 18(3), s. 459-480.

- Bozkurt, Ö. ve Erdurur, K., 2013. Girişimci Kişilik Özelliklerinin Girişimcilik Eğilimindeki Etkisi, Girişimcilik ve Kalkınma Dergisi, 8(2), s.57-78.

- Börü, D., 2006. Girişimcilik Eğilimi: Marmara Üniversitesi İşletme Bölümü Öğrencileri Üzerine Bir Araştırma, Marmara Üniversitesi SBE, İstanbul.

- Caird, S., 2013. "General Measure of Enterprising Tendency Test”, http://oro.open.ac.uk/5393/2/Get2test_guide.pdf 
- Caird, S.,1991. "Testing Enterprising Tendency in Occupational Groups", British Journal of Management, 2(4), s.177-186.

- Carsrud, A.L. ve Brännback, M.E., 2007. Entrepreneurship, Greenwood, London.

- Chell, E., 2009. "Introduction and Overview to theEntrepreneur and Entrepreneurial Process" içinde Ateljevic ve Page (Ed.) Tourism and Entrepreneurship-International Perspectives, s.33-51, Butterworth-Heinemann, Oxford.

- Collins, C.J.; Hanges, P.J. ve Locke, E.A., 2004. The Relationship of Achievement Motivation to Entrepreneurial Behavior: A Meta-Analysis, Human Performance, 17(1), s. 95-117.

- Çırakoğlu, O.C. ve Tezer, E., 2010. "Kontrol Odağ1 ve Eleştirel Düşünmenin Üniversite Öğrencilerinin İlişki Doyumsuzluklarına Verdikleri Tepkiler Üzerindeki Yordayıı Rolü”, Türk Psikoloji Yazıları, 13(26), s.29-41

- Çivitci, N. ve Arıcıoğlu, A., 2012. "Beş Faktör Kuramına Dayalı Kişilik Özellikleri, Mehmet Akif Ersoy Üniversitesi Eğitim Fakültesi Dergisi”, 12(23), s.78-96.

- Çokgezen, M., 2012. Türkiye’de Devlet, Girişimcilik ve Yerel Kalkınma, İstanbul Ticaret Odası, İstanbul.

- Deniz, A. ve Erciş, A., 2008. "Kişilik Özellikleri İle Algılanan Risk Arasındaki İlişkilerin İncelenmesi Üzerine Bir Araştırma”, Atatürk Üniversitesi İktisadi ve İdari Bilimler Dergisi, 22(2), s.301-330.

- Doğan, T., 2013. “Beş Faktör Kişilik Özellikleri ve Öznel İyi Oluş”, Doğuş Üniversitesi Dergisi, 14(1), s.5664

- Dönmez, P.D., 2013. “Girişimcilik Motivasyonu Ve İşletme Yenilikçiliği Arasındaki İlişkinin Araştırılmasına Yönelik Turizm İşletmelerinde Bir Araştırma”, Girişimcilik ve Kalkınma Dergisi, 6(2), s.227-253.

- $\quad$ Erdoğan, B.Z., 2012. Girişimcilik ve Kobiler. Ekin. Bursa.

- $\quad$ Erkuş, A. ve Tabak, A., 2009. "Beş Faktör Kişilik Özelliklerinin Çalışanların Çatışma Yönetim Tarzlarına Etkisi: Savunma Sanayiinde Bir Araştırma”, Atatürk Üniversitesi İktisadi ve İdari Bilimler Dergisi, 23(2), s. 213-242.

- $\quad$ Eser, G. ve Yıldız, M.L., 2015. "Türkiye’de Girişimcilik Araştırmalarının Odağı Nedir?-Yazın Üzerine Bir İnceleme”, Marmara Üniversitesi Öneri Dergisi, 11(43), s. 91-117.

- Güreşçi, E., 2014. “Girişimcilik Eğilimi Üzerine Bir Araştırma: İspir Hamza Polat Myo Örneği”, Girişimcilik ve Kalkınma Dergisi, 9(1), s.23-38

- $\quad$ İlter, B., 2010. Girişimcilik Sürecinde Kadın Girişimcilerin Karşılaştıkları Sorunların Analizi: Kagider Örneği, Adalet, Ankara.

- John, O.P. ve Srivastava, S., 1999. "The Big Five Trait Taxonomy: History, Measurement and Theorotical Perspectives" içinde Pervin, L.A. ve John, O.P. (Ed.), Handbook of Personality: Theory and Research, 2nd Ed., s.102-138, Guildford: New York.

- Keleş, H.N., 2013. “Girişimcilik Eğiliminin Kuşak Farkına Göre İncelenmesi”, Selçuk Üniversitesi İ.I.B.F. Sosyal ve Ekonomik Araştırmalar Dergisi, 13(26), s. 23-43.

- Kinay, H.F., 2007. Girişimcilik, Kalkınma ve Rekabet İlişkisi: Kütahya'da Kobilerin Girişimcilik Profili, TOBB, Ankara.

- Korkmaz, O., 2012. "Üniversite Öğrencilerinin Girişimcilik Eğilimlerini Belirlemeye Yönelik Bir Araştırma: Bülent Ecevit Üniversitesi Örneği”, Afyon Kocatepe Üniversitesi İ.I.B.F. Dergisi, 14(2) , s.209-226.

- Kozak, M.A. ve Yılmaz, E.G., 2010. “Otel Yöneticilerinin İç Girişimcilik Algılamaları: Frigya Bölgesi Örneği”, Anatolia: Turizm Araştırmaları Dergisi, 21(1), s.85-97.

- Kültür ve Turizm Bakanlığı, 2012. "Türkiye'de Turizm Sektörüne Sağlanan Teşvik ve Destekler”, http://yigm.kulturturizm.gov.tr/Eklenti/4788,turkiyede-turizm-sektorune-saglanan-tesvik-ve-destekler.pdf?0

- $\quad$ Li, L., 2008. “A Review of Entrepreneurship Research Published in the Hospitality and Tourism Management Journals”, Tourism Management 29(5), s.1013-1022.

- OECD, 2007. Girişimcilik ve Yerel Ekonomik Kalkınma, Çev. Mecit vd, TOBB, İstanbul.

- OECD, 2011. Entrepreneurship at a Glance 2010, http://dx.doi.org/10.1787/9789264097711-en.

- Ören, K. ve Biçkes, M., 2011. "Kişilik Özelliklerinin Girişimcilik Potansiyeli Üzerindeki Etkileri: Nevşehir'deki Yüksek Öğrenim Öğrencileri Üzerinde Yapılan Bir Araştırma”, Süleyman Demirel Üniversitesi I.I. B.F. Dergisi, 16(3), s.67-86.

- Ötken, A.B. ve Cenkci, T., 2013. "Beş Faktör Kişilik Modeli Ve Örgütsel Muhalefet Arasındaki İlişki Üzerine Bir Araştırma”, Marmara Üniversitesi Sosyal Bilimler Enstitüsü Dergisi, 10(39), s.41-51 
- Ö̈zdemir, L., 2015. "Kırgızistan-Türkiye Manas Üniversitesi Öğrencilerinin Girişimcilik Eğilimlerinin SosyoDemografik Özellikler Açısından Değerlendirilmesi”, Süleyman Demirel Üniversitesi İ.I.B.F. Dergisi, 20(1), s.41-65.

- $\quad$ Ross, D.L. ve Lashley, C., 2009. Entrepreneurship and Small Business Management in the Hospitality Industry, Butterworth-Heinemanni Oxford.

- Solmaz, A. vd, 2014. "Üniversite Öğrencilerinin Girişimci Kişilik Özelliklerinin Belirlenmesi: Turizm Lisans ve Önlisans Öğrencileri Üzerine Bir Alan Araştırması", KMÜ Sosual ve Ekonomik Araştırmalar Dergisi, 16(26), s.41-55.

- $\quad$ Somer, O; Korkmaz, M. ve Tatar, A., 2002. “Beş Faktör Kişilik Envanteri’nin Geliştirilmesi-I: Ölçek ve Alt Ölçeklerin Oluşturulması”, Türk Psikoloji Dergisi, 17(49), s.21-33.

- Tozkoparan, G., 2013. "Beş Faktör Kişilik Özelliklerinin Çatışma Yönetim Tarzlarına Etkisi: Yöneticiler Üzerinde Bir Araştırma”, Ekonomik ve Sosyal Araştırmalar Dergisi, 9(2), s.189-231

- Tutar, H., 2003. Girişimcilik ve Küçük İşletme Yönetimi, Seçkin, Ankara.

- Yıldız, Z., 2011. “Turizm Sektörünün Gelişimi ve İstihdam Üzerindeki Etkisi”, Süleyman Demirel Üniversitesi Vizyoner Dergisi, 3(5), s.54-71.

- Yılmazdoğan, O.C. ve Kaşlı, M., 2011. “Turizm Algısı Ve Girişimcilik Niyeti İlişkisi: Eskişehir'de Bir Araştırma”, 12. Ulusal Turizm Kongresi, 30 Kasım-4 Aralık 2011, Akçakoca-Düzce, s.591-600.

- Yumuk, G., 2013, “Turizm Bölümü Öğrencilerinin Girişimcilik Eğitimlerinin Girişimcilik Eğilimlerine Etkisi”, Trakya Üniversitesi İktisadi ve İdari Bilimler Fakültesi E-Dergi, 2(2), s. 96-120.

- Yurtseven, R., 2007. Girişimcilik: Küçük Bir İşletme Kurmak ve Yönetmek, Detay, Ankara. 


\title{
Petrol Gelirlerine Bağımlılığın Yüksek Olduğu Geçiş Ekonomilerinde Petrol Fiyatları, İhracat, İstihdam ve Ekonomik Büyüme İlişkileri
}

\section{The Relationships among Oil Prices, Export, Employment and Economic Growth in Transition Economies with Being High Dependency on Oil Revenue}

\author{
Prof. Dr. Murat Nişancı (Erzincan University, Turkey) \\ Asst. Prof. Dr. Ziya Çağlar Yurttançıkmaz (Atatürk University, Turkey) \\ Ph.D. Candidate Aslı Cansın Doker (Erzincan University, Turkey) \\ Prof. Dr. Ömer Selçuk Emsen (Atatürk University, Turkey)
}

\begin{abstract}
The argument of natural resources' curse explains that natural resource wealth of the country, leading to a kind of inertia in the economy causes "spendthrift" position. Accordingly, in the first place, the discovery of natural resources and its price rise have positive repercussions on country's income and welfare. In the long run, obtained this easy enrichment may well lead to remain barren of other sectors and also affect negatively on diversification of national income and export in natural resource-rich countries. In this study, along with the collapse of the former eastern bloc, the functioning of the argument of natural resources' curse in the natural resources-rich four transition economies, as the subject of descriptive study was conducted. In the literature of natural resources' curse, with creating crowding-out effect, natural resources income might well brake to the development of other sectors. In addition, this situation is defined such that with increasing weight of defense industry among other sectors in aggregate income and employment, also not transferred to the social and physical infrastructure investment, particularly in education. In this study, it is examined whether there is oil prices sensitivity on the export, employment, public expenditure and national income in natural resource-rich transition economies. From the analysis results, it can be said that there is significant movements between oil prices and chosen variables and considering those findings, strong/powerful of natural resources' curse is on process for chosen transition economies.
\end{abstract}

\section{Giriş}

Eski Doğu Bloğu olarak adlandırılan merkezi planlı ekonomilerde 1989’da Berlin Duvarının yıkılması ve 1991 Sovyetler referandumu sonrasında merkezi planlamacılıktan piyasa ekonomisine yönelim söz konusu olmuştur. Piyasa ekonomisine yönelen bu ekonomiler, başlangıç koşulları itibarıyla sahip oldukları sosyal-ekonomik-siyasal koşullar açısından eski sistemin doğası gereği mutlak eşitlikçi bir yapıda olmadıkları gibi bulundukları coğrafyanın bahşettiği doğal zenginlikler bakımından da benzeri özelliklere sahip değillerdi. Diğer bir ifadeyle sosyalist sistemin teoride vaat ettiği mutlak eşitlik, ne bireysel gelir açısından, ne de bölgesel eşitlik açısından pratikte sağlanamamıştı. Özellikle kurumsal ve güçlü sosyo-ekonomik yapılara sahip Batı Avrupa'ya yakın olan sosyalist ülkelerde, geçiş ile birlikte kurumsal yapıların tesis imkânı daha kolay ve hızlı gerçekleşirken, görece Avrupa'ya uzak ekonomilerde kurumsal yapıların tesis edilmesi daha güç ve sancılı olmuştur. Bu duruma aynı zamanda sosyalizm altında kalınan sürenin de etkili olduğu; yani bu süre ile kurumsal yapıları tesis edebilme hızı arasında bir tür negatif korelasyonun varlığından söz edilebilir. Diğer taraftan kurumsal yapı tesis edemeyen geçiş ekonomilerinde bunun gerekçesi olarak doğal kaynak zenginliğine sahip olmanın getirmiş olduğu ataletin de etken olduğu ileri sürülebilir. Buna bir de petrolden elde edilen kamu gelirleri ve ihracat yapmanın verdiği güven unsuru da eklendiğinde, bu ülkelerde diğer sektörlerin gelişiminin ortaya çıkmaması kuvvetle muhtemeldir.

Petrol gelirlerinin ülke milli hasılası ve istihdamında önemli yer tuttuğu ülkelerde, petrol fiyatlarındaki yükselişler, bu türden ekonomilerde refahta önemli sıçramalara ve kamunun gelirlerindeki artışa bağlı olarak da kamu gücünde artışa yol açar. Literatürde bu durumun her zaman olumlu sonuç meydana getirmeyeceği, yani “doğal kaynakların laneti iddiası”na yol açacağı ileri sürülür. Tersi durumda, yani petrol fiyatlarının düşüş göstermesinin, petrol gelirlerine bağımlılığı yüksek ekonomilerde, refahta olumsuzlukları beslemesi beklenmektedir. Ortaya çıkan bu durum, yani doğal kaynak fiyatlarına duyarlı bir yapının varlığı ise uzun dönemde ekonomik büyümeyi teşvik edici değil, adeta büyümenin önünde bir tür engel teşkil ettiği ileri sürülmektedir (Fan vd., 2012: 705). Dolayısıyla petrol fiyatlarının yükseliş dönemlerinde elde edilen refah etkilerinin sürdürülebilirliğinin koşulu, elde edilen petrol gelirlerinin fiziki ve sosyal altyapıya kaydırılabillirliğine bağlılığıdır. Böylece petrol fiyatlarının yükseldiği dönemlerde sağlanan avantajların petrol fiyatlarının düştüğü dönemde ikame etkisi yaratarak ekonomide sürdürülebilir etkiler yaratması beklenir. 
$\mathrm{Bu}$ çalışmada çağdaş-batılı anlamda kurumsal yapılar tesis edemeyen ve aynı zamanda doğal kaynak zenginliğine sahip geçiş ekonomilerinde, doğal kaynakların laneti iddiasına düşülüp düşülmediği ele alınacaktır. Dolayısıyla çalışmada bu ülkelerin gelirinin, istihdamının ve ihracatının petrol fiyatlarına duyarlılığı inceleme konusu yapılmıştır. Böylece yapılacak analizler ile geçiş ekonomilerinde gelir, istihdam ve ihracat değişkenlerinin petrol fiyatlarına duyarlılığı yüksek ise, petrol zenginliğinin atalete yol açarak gelişmeyi frenlediği söylenebilir. Aksi yönde bulgular elde edilmesi halinde ise, ele alınan ülke veya ülkelerin petrol gelirlerini sosyal ve fiziki altyapı yatırımlarına kanalize ederek sürdürülebilir bir ekonomik yapı tesis ettikleri ileri sürülebilir.

\section{Doğal Kaynakların Laneti}

Yeni bir doğal kaynağın keşfi ya da doğal kaynak fiyatlarındaki artışların gelir etkileri yaratarak ekonomide talep yönlü dinamikleri harekete geçirmesi beklenir. Bu durum kısa dönemde ekonomik büyüme üzerine olumlu etkileri yaratır. Ancak, talep şoklarının ekonomide fiyat mekanizmasında yaratacağı baskılar ve istikrarsızlıkların ise uzun dönemde ekonomik büyüme üzerinde olumsuz yansımalar meydana getireceği sav1 da bulunmaktadır. Olumsuzluklar üzerine dayalı literatüre karşılık, belirli koşulların yerine getirilmesi halinde, doğal kaynak sahipliğinin olumlu yansımaları da söz konusu olabilmektedir ki, buna başta doğal kaynak zengini Norveç olmak üzere, genelde Batılı ülkeler örnek verilmektedir.

Bilindiği gibi doğal kaynak keşfi de dahil, bir ekonomide ani bir sıçramaya yol açan olağandışı gelişmelerin olması "büyük itiş" olarak adlandırılmaktadır. Rosenstein-Rodan (1943, 1961) ile Murphy vd. (1989) tarafindan ele alınan büyük itiş kavramı, pazar hacmini genişletmek için fakir ekonomilerin genişlemeci talep politikalarına gereksinim duyduklarına ve böylece girişimcilerin sanayileşmenin sabit maliyetlerini düşürüp kârlarını yükselteceklerine temas etmişlerdir. Büyük itiş mantığında talebi teşvik eden unsurlar arasında genişlemeci kamu harcamaları programı, dış yardımlar, minerallerin keşfi veya doğal kaynakların dünya fiyatlarındaki artışları sayılmaktadır. Doğal kaynak keşfi ya da fiyatlarındaki artışlar toplam talep üzerinde artırıcı etkiler yaratmakta; bunun da doğal kaynak ihracatındaki artıştan kaynaklanan etkilere bağlı olacağı kabul edilir. Doğal kaynak keşfi ya da fiyatlarındaki artışların yarattığı etkilerin başında doğal kaynağa dayalı kalkınma formu olarak tanımlanmaktadır (Sachs ve Warner, 1999). Diğer taraftan doğal kaynakların bol ve ağırlıklı olduğu ekonomilerde modern Schumpeterci büyüme formuyla da değerlendirmelerde bulunmak mümkündür. Burada kaynak sahiplerinin elde ettikleri gelirde artışın ve böylece imalat sanayi mallarına kanalize ettikleri harcamaların uyarıcı etkiler yaptığına işaret edilmektedir. Schumpeterci bakış açısıyla imalat sanayinin ekonominin yenilikçi sektörü olması nedeniyle, ortaya çıkan gelir-harcama etkilerinin imalat sanayi malları için pazarın büyüklüğüne ilaveten, kaynak bolluğu yaratması ve kaynak bolluğunun da yenilikçi faaliyetleri teşvik ettiği ileri sürülür (Peretto, 2012: 142).

Diğer taraftan doğal kaynak zenginliği ve onun fiyatlarındaki istikrarsızlıkların ekonomide belirsizlikler yarattığı ve büyüme üzerine olumsuz yansımalara yol açtığına dair iddialar Hirschman (1958)'a kadar uzanmaktadır. Doğal kaynak sahipliği ve fiyat artışlarından doğan gelir artışlarının yatırımlardan ziyade tüketime kanalize olması, gelir artışlarını sürekli kılmayan en önemli unsurların başında geldiği de ileri sürülmektedir (Sachs ve Warner, 1999). Örneğin Nijerya'da 1990'ların sonundaki kişi başına düşen milli gelir, bağımsızlığını elde ettiği 1960'lar seviyesinin bile altındadır. Benzer şekilde 1965-1998 arası dönemde İran ve Venezuela'da yıllık ortalama fert başına GSMH büyüme hızı \%1, Libya'da \%2, Irak ve Kuveyt’te \%3, 1970-1995 arası için Katar'da \%6'dır. 19651998 dönemi için OPEC ülkelerinde fert başına GSMH \%1.3 azalırken, düşük ve orta gelirli diğer ülkelerde bu oran \%2.3 artış şeklinde gerçekleşmiştir. 65 petrol ihracatçısı ülkede genel anlamda beklenenin altında büyüme performansı gözlenmiştir. Ancak, bu grupta yer alan ülkelerden yalnızca Botsvana, Endonezya, Malezya ve Tayvan'da sermaye birikim hızı \%25'i ve fert başına GSMH artış hızı \%4'ü aşabilmiştir. Dolayısıyla doğal kaynak bolluğundan bodur ekonomik kalkınmaya geçiş/yayılma kanallarının bulunduğu ileri sürülmektedir. Bu kanallar da dört temel başlık altında ele alınmaktadır (Gylfason, 2001): (i) Hollanda Hastalığı, (ii) Rant Kollama, (iii) Aşırı Güven ve (iv) Eğitimin İhmali.

\section{Kaynakların Laneti Üzerine Literatür Araştırması}

Kaynakların laneti iddiasının çıkışı kalkınma iktisadı orijinli olarak 1950’lere dayanmaktadır. Kalkınma iktisadında az gelişmişliği açıklayan teoriler arasında yer alan yapısalcı yaklaşım, lanet olgusunu, "rant kollama" (rent-seeking) davranışları veya "Hollanda Hastalığı" (Dutch Disease) argümanı ile örtüştürerek, az gelişmişliğin temel dayanakları olduğunu ileri sürmektedir (Brunnschweiler ve Bulte, 2008). Özellikle doğal kaynak zenginliğinin keşfi ile birlikte, bu alanda ortaya çıkan ihracat gelirlerindeki artışın hem iç talepte meydana getirdiği değişmeler hem de kaynakların bu sektöre kayması ile birlikte ortaya çıkan dönüşümlerin yansıması olduğu ileri sürülmektedir. Bu çerçevede 1960'larda Hollanda özelinde gözlenen bu olgunun, 1970'lerde İngiltere'de yaşanması ile birlikte ortaya çıkan gelişmeler dikkatleri çekmeye başlamıştır. Hollanda Hastalığının akademik çevrelerde tartışılmaya başlaması ile birlikte ilk teorik çalışma Codren ve Neary (1982) tarafından ortaya konulurken, ilk ampirik çalışma ise Bruno ve Sachs (1982) tarafından İngiltere üzerine yapılmış ve daha sonrasında çok sayıda çalışmanın ortaya çıktığı gözlenmiştir (Ismail, 2010). 
İktisat literatüründe oldukça tartışmalı bir konu olarak kabul edilen kaynakların laneti iddiası, bir kısım iktisatçı (Sachs ve Warner, 1995, 1997; Sala-i-Martin ve Subramanian, 2003; Papyrakis ve Gerlagh, 2004) tarafindan da kabul edilir. Bir kısım iktisatçı (Alexeev ve Conrad, 2009; Cavalcanti vd., 2011) ise bu savın geçerli olmadığına (Clay ve Weckenman, 2014) ve hatta literatürün aksine, büyümeyi destekleyici bulgular verdiğine (Fan vd., 2012) dair araştırmalar sunmaktadır. Buna karşılık İran ekonomisi özelinde yapılan araştırmada, ekonomik yapının petrol fiyatlarına ve dolayısıyla petrol gelirlerine duyarlı bir yapının varlığı ortaya konulmuştur (Esfahani vd., 2013).

Özetle ampirik çalışmalarda kaynakların lanetinin varlığını ortaya koyan çalışmalar olduğu gibi, bunun ancak belirli koşullarda gerçekleşebildiğini ileri süren çalışmalar bulunmaktadır. Çok nadir de olsa bir kısım çalışmalarda doğal kaynakların lanet teşkil etmediği, bilakis ekonomik büyümeyi teşvik ettiği ileri sürülmektedir. Bu duruma da belirli bir kalkınmışlık düzeyinde ya da kalkınmada eşik değerleri aşmış ülke ekonomilerinde veya Çin özelindeki gibi otoriter yapılarda doğal kaynakların ne atalete yol açtığı, ne de sıkıştırma etkileri yarattığ belirlemesi yapılarak, ekonomik büyüme üzerinde olumsuzluktan ziyade, olumlu etkiler yarattığı tespit edilmiştir.

\section{Ampirik Sonuçlar}

Bu çalışmada, petrol fiyatlarının makroekonomik değişkenler üzerine etkilerinin, özellikle petrole bağımlılığı yüksek ekonomilerde daha üst düzeyde olacağı ve bu durumunda, geçiş ekonomilerinde geçerliliğinin araştırılması hedeflenmektedir. Bu çerçevede geçiş ekonomilerinin doğal kaynak sahipliği açısından yapıları dikkate alındığında, geçiş ekonomileri “zengin, orta ve fakir" ülkeler şeklinde tasnif edilmişlerdir (Fischer ve Sahay, 2004).

\begin{tabular}{|l|l|l|l|}
\hline Zengin & Orta & \multicolumn{2}{|c|}{ Fakir } \\
\hline Azerbaycan & Polonya & Arnavutluk & Macaristan \\
Kazakistan & Romanya & Beyaz Rusya & Makedonya \\
Rusya & Gürcistan & Bulgaristan & Moğolistan \\
Federasyonu & Ukrayna & Çek Cumhuriyeti & Moldovya \\
Türkmenistan & Özbekistan & Ermenistan & Slovakya \\
& Çin & Estonya & Slovenya \\
& Vietnam & Hirvatistan & Tacikistan \\
& & Kirgizistan & \\
& & Litvanya & \\
\hline
\end{tabular}

Tablo 1. Geçiş Ekonomilerinin Doğal Kaynak Düzeyleri

Dolayısıyla çalışmada doğal kaynakların laneti argümanın test edilmesi amacıyla, doğal kaynak zengini 4 geçiş ekonomisi (Azerbaycan, Kazakistan, Rusya Federasyonu ve Türkmenistan) ele alınmıştır. Veri seti 1991-2014 dönemi olup, yıllık bazlı veriler kullanılmıştır (Worldbank,2015). Veri seti Dünya Bankası veri tabanından ve Brent petrol spot fiyatlarından derlenmiştir (EIA, 2016).

Çalışmada doğal kaynak zengini 4 geçiş ekonomisinde ihracatın, işsizliğin, kamu harcamalarının ve ulusal gelirin petrol fiyatlarına duyarlılı̆̆ inceleme konusu yapılmıştır. Bu çerçevede petrol fiyatlarının ihracat, işsizlik, kamu harcamaları ve ulusal gelir üzerindeki etkilerinin araştırılmasında aşağıdaki temel eşitliklerden yararlanılmıştır:

$$
\begin{aligned}
& G S Y I H=f(O I L) \\
& G O V=f(O I L) \\
& E X P=f(O I L) \\
& U N E M P=f(O I L)
\end{aligned}
$$

Çalışmaya konu olan ve modelin bağımlı değişkenlerini oluşturan GSYİH, GOV, EXP ve UNEMP sırasıyla ulusal geliri, kamu harcamalarını, ihracatı ve işsizliği ifade etmektedir. Bu 4 eşitlikte bağımsız değişken olarak da OIL değişkeni, yani Brent petrol spot FOB fiyatları alınmıştır.

Çalışma daha çok görsel açıdan inceleme konusu yapılması planlanan GSYİH-OIL, GOV-OIL, EXP-OIL ve UNEMP-OIL ilişkileri dört petrol zengini ekonomi açısından ele alınmıştır. GSYİH rakamlarının petrol fiyatlarındaki değişikliklere duyarlı olması halinde, doğal kaynak zengini ülkelerde mal çeşitlemesine gidilememesi ve dolayısıyla kaynakların laneti iddiasının kuvvetli bir şekilde işlediği söylenebilir. GSYİH'ya benzer şekilde kamu gelirlerinin ve buna bağlı olarak kamu harcamalarının da, petrol fiyatlarına duyarlılığının yüksek olması beklenmektedir. Bu duruma özellikle petrolün kamu eliyle çıkartılıp piyasaya arz edildiği ve dolayısıyla kamu geliri olarak addedildiği ekonomilerde, kamu harcamalarının petrol fiyatlarına duyarlılığı yüksek olması beklenmektedir. Mal çeşitlemesine gidememenin bir diğer yansıması da ihracatta en önemli payı petrol ve gaz ile madenlerin almasıdır. Dolayısıyla bir veya birkaç maldan müteşekkil bir ekonomide dış satım için sunulacak mallar da bunlardan oluşur. Diğer taraftan mal çeşitlemesine gidilememesi ve böylece temel konumunda bulunan petrol ve ürünleri sektöründe sağlanan gelir artışları da, istihdam yapısının bu sektörde sağlanan genişlemelere duyarlı hale gelmesidir. Bu tespitin de doğal kaynakların laneti iddiasının bir sonucu olarak ortaya çıktığını düşündürebilir. 
Aşağıdaki tabloda petrol ve doğal gaz zengini dört geçiş ekonomisinde inceleme konusu yapılan değişkenlere ait özet istatistikler verilmiştir.

\begin{tabular}{|c|c|c|c|c|c|}
\hline & OIL & EXP & GOV & GSYİH & UNEMP \\
\hline Ortalama & 48.57333 & $5.91 \mathrm{E}+11$ & $2.26 \mathrm{E}+11$ & $1.17 \mathrm{E}+10$ & 7.170833 \\
\hline Medyan & 28.75500 & $2.38 \mathrm{E}+11$ & $8.85 \mathrm{E}+10$ & $4.97 \mathrm{E}+09$ & 6.650000 \\
\hline Maksimum & 111.6300 & $3.73 \mathrm{E}+12$ & $1.08 \mathrm{E}+12$ & $5.69 \mathrm{E}+10$ & 12.50000 \\
\hline Minimum & 12.76000 & $4.89 \mathrm{E}+10$ & $1.22 \mathrm{E}+10$ & $1.17 \mathrm{E}+09$ & 3.300000 \\
\hline Std. Sap. & 34.96400 & $9.42 \mathrm{E}+11$ & $2.88 \mathrm{E}+11$ & $1.61 \mathrm{E}+10$ & 1.527350 \\
\hline Skewness & 0.685761 & 2.300384 & 1.706022 & 1.903189 & 0.410482 \\
\hline Kurtosis & 1.903751 & 7.126350 & 4.724618 & 5.271478 & 4.705000 \\
\hline Jarque-Bera & 12.33133 & 114.5815 & 43.84906 & 58.94437 & 10.74302 \\
\hline Probability & 0.002100 & 0.000000 & 0.000000 & 0.000000 & 0.004647 \\
\hline Sum & 4663.040 & $4.26 \mathrm{E}+13$ & $1.62 \mathrm{E}+13$ & $8.45 \mathrm{E}+11$ & 516.3000 \\
\hline Sum Sq. Dev. & 116135.7 & $6.30 \mathrm{E}+25$ & $5.88 \mathrm{E}+24$ & $1.85 \mathrm{E}+22$ & 165.6288 \\
\hline Gözlem & 96 & 72 & 72 & 72 & 72 \\
\hline
\end{tabular}

Tablo 2. Değişkenlere İlişkin Özet İstatistikler

Petrol fiyatları en yüksek 111.63 dolar ile 2012 yılında, en düşük 12.76 dolar ile 1998 y1lında değer alarak, bu iki uç rakam arasında bir dağılım göstermiştir. İhracat rakamı açısından da 3.73E+12 ile Rusya'da, 4.89E+10 ile Türkmenistan'da gerçekleştiği ve bu dağılımın paralel bir şekilde hem GOV hem de GSYİH değerleri açısından ortaya çıktığı görülmektedir. Dolayısıyla ele alınan bu dört ekonomiden en güçlüsünün Rusya Federasyonu ve en zayıfının da Türkmenistan olduğu görülürken, Kazakistan'ın Rusya Federasyonu'ndan sonra ikinci büyüklüğe, Azerbaycan'ın ise Türkmenistan'dan daha büyük bir ekonomiye sahip olduğu söylenebilir.

İstatistiksel analizlerde örneklem üzerinde, gözlemlenen değerlerin dağılımının yanı sıra hesaplanan istatistikler de önemlidir. Bu istatistikler, serinin standart sapması ve normallik istatistiğidir. Serilere ait standart sapmalar, gözlemlenen değerlerin hangi miktarda ortalamadan uzaklaştığını göstermektedir. Normal dağılım ise, serinin standart sapmasının küçük hale gelmesini sağlamaktadır. Serilere ait tanımlayıcı istatistiklerden olan normal dağılım kriterine Jarque-Bera istatistiğine göre bakıldığında, serilerin normal dağılmadığına dair $\mathrm{H}_{0}$ hipotezi reddedilememektedir. Bu durum da, serilerin standart sapmalarının yüksek olduğunu göstermektedir.

Aşağıdaki Tablo 3'de de doğal kaynak zengini dört ülkede petrol fiyatları ile GSYİH, kamu harcamaları, ihracat ve işsizlik arasındaki ilişkileri yansıtır panel veri korelasyon katsayıları verilmiştir.

\begin{tabular}{|l|c|c|c|c|c|}
\hline & OIL & EXP & GOV & GSYİH & UNEMP \\
\hline OIL & $\mathbf{1 . 0 0}$ & & & & \\
\hline EXP & 0.41 & $\mathbf{1 . 0 0}$ & & & \\
\hline GOV & 0.36 & 0.98 & $\mathbf{1 . 0 0}$ & & \\
\hline GSYİH & 0.38 & 0.99 & 0.99 & $\mathbf{1 . 0 0}$ & \\
\hline UNEMP & -0.48 & -0.39 & -0.32 & -0.35 & $\mathbf{1 . 0 0}$ \\
\hline
\end{tabular}

Tablo 3. Değişkenler Arasındaki Korelasyon Katsayıları

Korelasyon katsayıları, “-1 ila +1” arasında bir değer almaktadır. Panel veri korelasyon hesaplamalarına göre doğal kaynak zengini dört ülkede, petrol fiyatlarına ihracatın, kamu harcamalarının ve GSYİH’nın pozitif ilişkili olduğu; buna karşılık işsizlik oranlarının ise negatif ilişkili olduğu gözlenmektedir. Katsayı değerleri işaret açısından petrol zenginliği ile ele alınan değişkenler arasında kaynakların laneti iddiasını destekler bulgu vermiştir. İstatistiki açıdan ise orta düzeyde ilişkilerin varlığı yakalanmıştır.

Diğer taraftan yukarıdaki genel eğilimi gösterir bilgilerin yanı sıra Azerbaycan, Kazakistan, Rusya Federasyonu ve Türkmenistan özelinde GSYİH değerleri ile petrol fiyatları arasındaki ilişkiler aşağıdaki şekilde gösterilmiştir. Grafiklerde petrol fiyatları ve GSYİH salınımları birlikte ele alınırken, bu salınımların kuvvetliliği de korelasyon katsayısı (r2) ile ortaya konulmaya çalışılmıştır. 


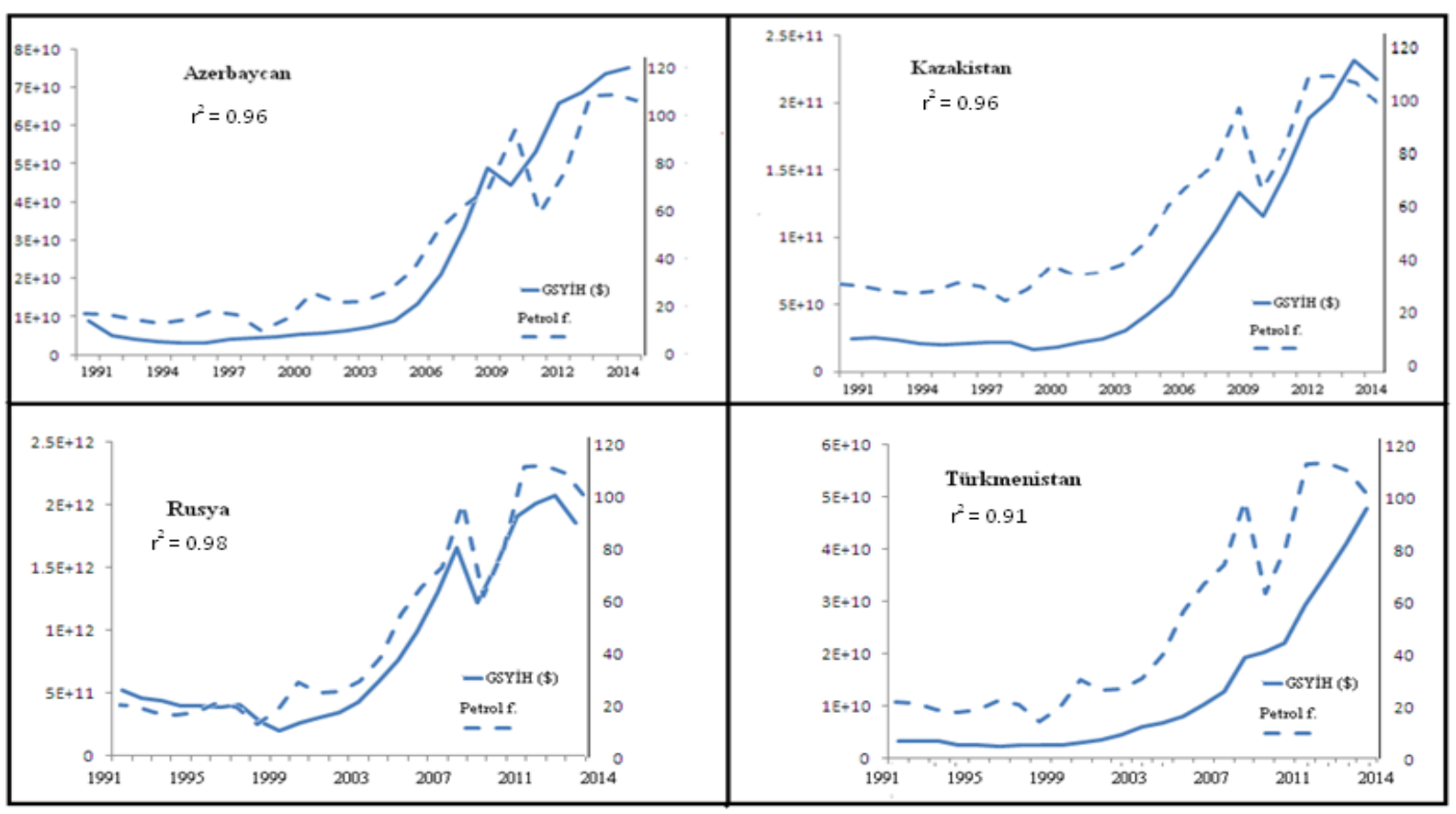

Şekil 1. Petrol Fiyatları ve GSYIH İlişkileri

Şekil 1'den de görüleceği üzere bu dört ülkenin GSYİH değerlerinin petrol fiyatlarındaki değişikliklere duyarlı olması, bu ülkelerde mal çeşitlemesine gidilememesinin ve buna bağlı olarak kaynakların laneti iddiasının kuvvetli bir şekilde işlediğine işaret etmektedir. Yukarıdaki grafiklere göre petrol fiyatları ile GSYİH salınımları arasında en güçlü ilişkilerin sırasıyla Rusya Federasyonu ( $(2=0.981)$, Kazakistan $(\mathrm{r} 2=0.965)$, Azerbaycan $(\mathrm{r} 2=0.960)$ ve Türkmenistan $(\mathrm{r} 2=0.912)$ 'da ortaya çıktığı görülmektedir. Diğer taraftan 2008 'de ABD'de başlayan ve yayılma etkilerinin 2009 'da hissedildiği küresel kriz ortamından etkilenme derecelerinin seçilen 4 geçiş ekonomisinde oldukça zayıf ve hatta hissedilmeyecek ölçüde olduğu dikkat çekmektedir. Bu yönüyle ekonominin dışsal şoklardan etkilenme derecesinin, gereken mal çeşitliliğinin olmamasının bir yansımasını yaşadığı; doğal kaynak zengini geçiş ekonomilerinde ortaya çıkan dışsal şokların daha çok petrol fiyatları kökenli olduğu ileri sürülebilir.

Petrol fiyatlarına duyarlılığın yüksek olması beklenen bir diğer ekonomik aktivite de kamu harcamalarıdır. Şekil 2'de kamu harcamaları ile petrol fiyatları arasındaki ilişsiler dört ülke ekonomisi için verilmiştir.

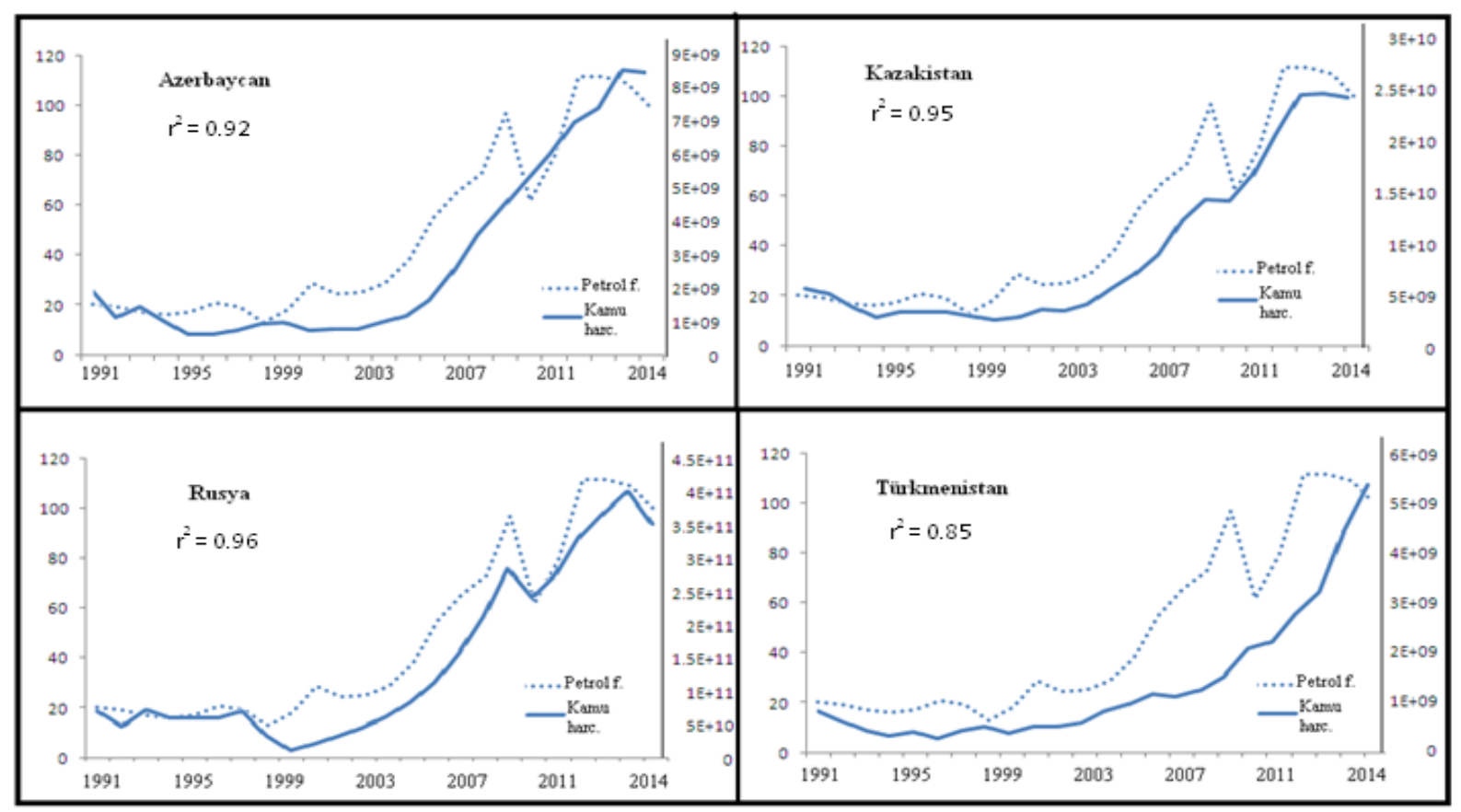

Şekil 2. Petrol Fiyatları ve Kamu Harcamaları İlişkileri 
GSYİH'dan daha güçlü bir ilişkinin varlığı, petrol fiyatları ile kamu gelirlerinin ve buna bağlı olarak kamu harcamalarında ortaya çıktığı gözlemlenmektedir. Zira bu duruma yol açan unsur, özellikle petrolün kamu eliyle çıkartılıp piyasaya arz edilmesi ve bunun aynı zamanda kamu geliri olarak addedilmesi, yani doğal kaynak gelirlerinin aynı zamanda kamu gelirlerinin de önemli bir kısmını oluşturmasıdır. Ekonomide, üretim alanlarında mal çeşitlemesinin olmamasının bir sonucu olarak vergilendirilecek kaynak yoksunluğu ortaya çıkmakta; dolayısıyla kamunun da var olan kaynakları vergilendirme noktasında atalete düşmesi kaçınılmaz olmaktadır. Böylece yegane kamu geliri olarak yalnızca petrol ve türevlerinin geliri kalmaktadır. Şüphesiz bu da petrol fiyatlarına oldukça duyarlı bir kamu ekonomisinin doğmasına yol açmaktadır. Bu durum aynı zamanda korelasyon katsayılarında da kendini göstermiştir. Yukarıdaki şekle göre petrol fiyatları ile kamu harcamaları arasında en güçlü ilişkilerin de sırasıyla Rusya Federasyonu $\left(r^{2}=0.968\right)$, Kazakistan $\left(r^{2}=0.955\right)$, Azerbaycan $\left(r^{2}=0.929\right)$ ve Türkmenistan $\left(\mathrm{r}^{2}=0.854\right)$ 'da ortaya çıktığı görülmektedir.

Mal çeşitlemesinin olmadığ 1 ekonomilerde dış alım daha yüksek ve buna karşılık dış satım, yani ihracatta da petrolün oldukça ağırlıklı olması kaçınılmazdır. Şekil 3'te petrol fiyatları ile toplam ihracat değeri arasındaki ilişkiler gösterilmiştir.

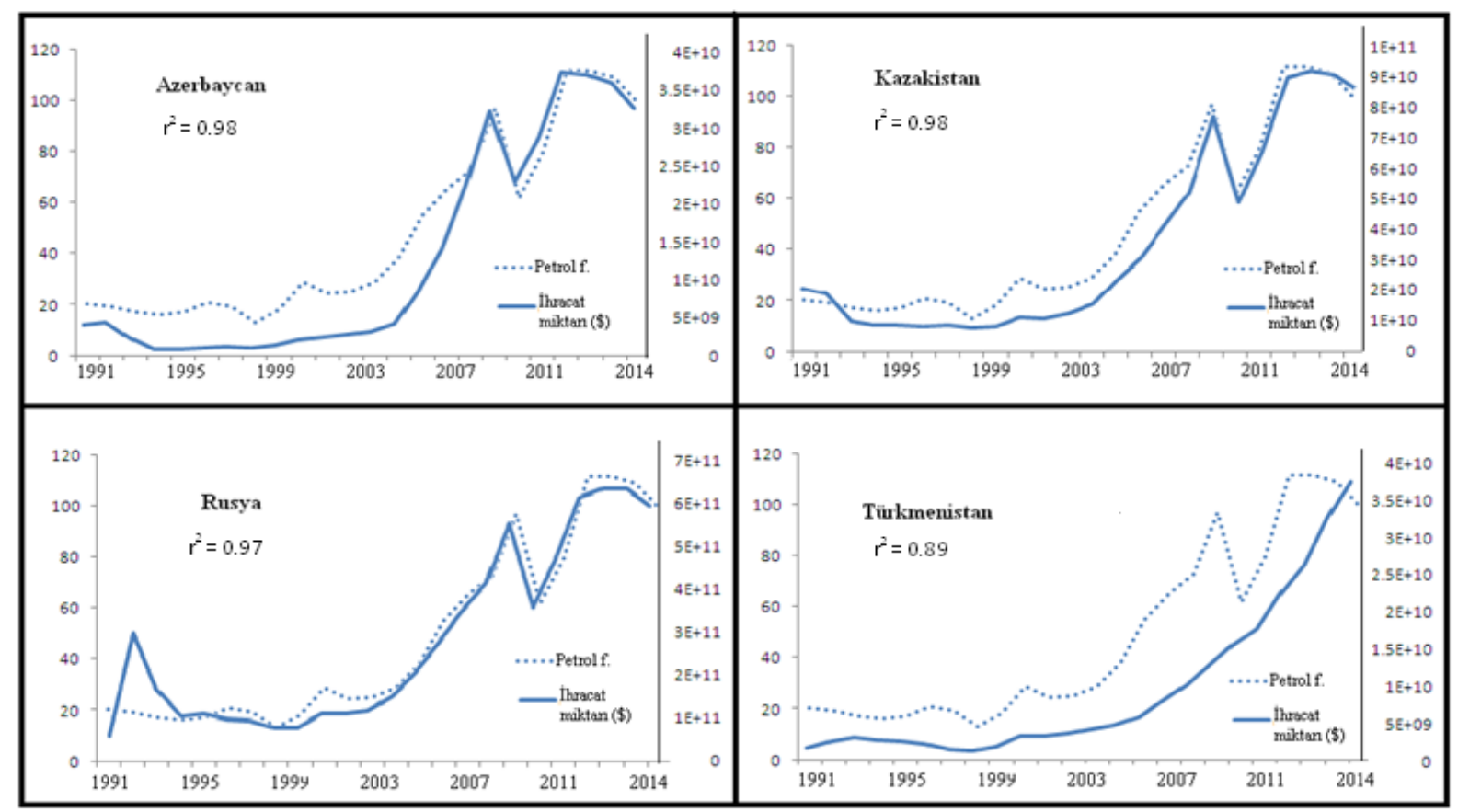

Şekil 3. Petrol Fiyatlarl ve İhracat Gelirleri İlişkileri

Mal çeşitlemesine gidememenin bir diğer yansıması, ihracatta en önemli yekûnu petrol ve gaz ile madenlerinin almasıdır. Dolayısıyla bir veya birkaç maldan müteşekkil bu türden ekonomilerde, dış satım için sunulacak mallar da ancak petrol ve gaz benzeri ürünlerden oluşmaktadır. Yukarıdaki şekle göre petrol fiyatları ile ihracat arasında en güçlü ilişkilerin de sırasıyla Kazakistan (r2=0.988), Azerbaycan (r2=0.980), Rusya Federasyonu (r2=0.972) ve Türkmenistan (r2=0.898)'da ortaya çıktığ1 görülmektedir. Türkmenistan'da görece daha düşük korelasyon katsayısının varlığı ise sahip olduğu doğal kaynakları dünya piyasalarına arz etmede yaşadığı sorundan kaynaklandığ 1 ileri sürülebilir.

Ekonomide petrol ve gazın oldukça ağırlıklı olmasının yansımaları arasında şüphesiz istihdam yapısının bu sektörde yoğunlaşmasıdır. Ayrıca petrol fiyatlarının uyarıcı etkileri ile ortaya çıkan bir tür çarpan mekanizmalarının işleyişine paralel olarak diğer sektörlerde, özellikle de hizmetler sektöründe canlanmaların ortaya çıkması kuvvetle muhtemeldir. Diğer bir ifadeyle petrol fiyatlarındaki artışlar başta petrole dayalı sektörler ile hizmetler sektöründe yaratacağı canlanma etkileri ile istihdamı artırma; yani işsizliği azaltıcı rol oynaması beklenmektedir. Şekil 4’te petrol fiyatları ile işsizlik oranları arasındaki ilişkiler resmedilmiştir. 


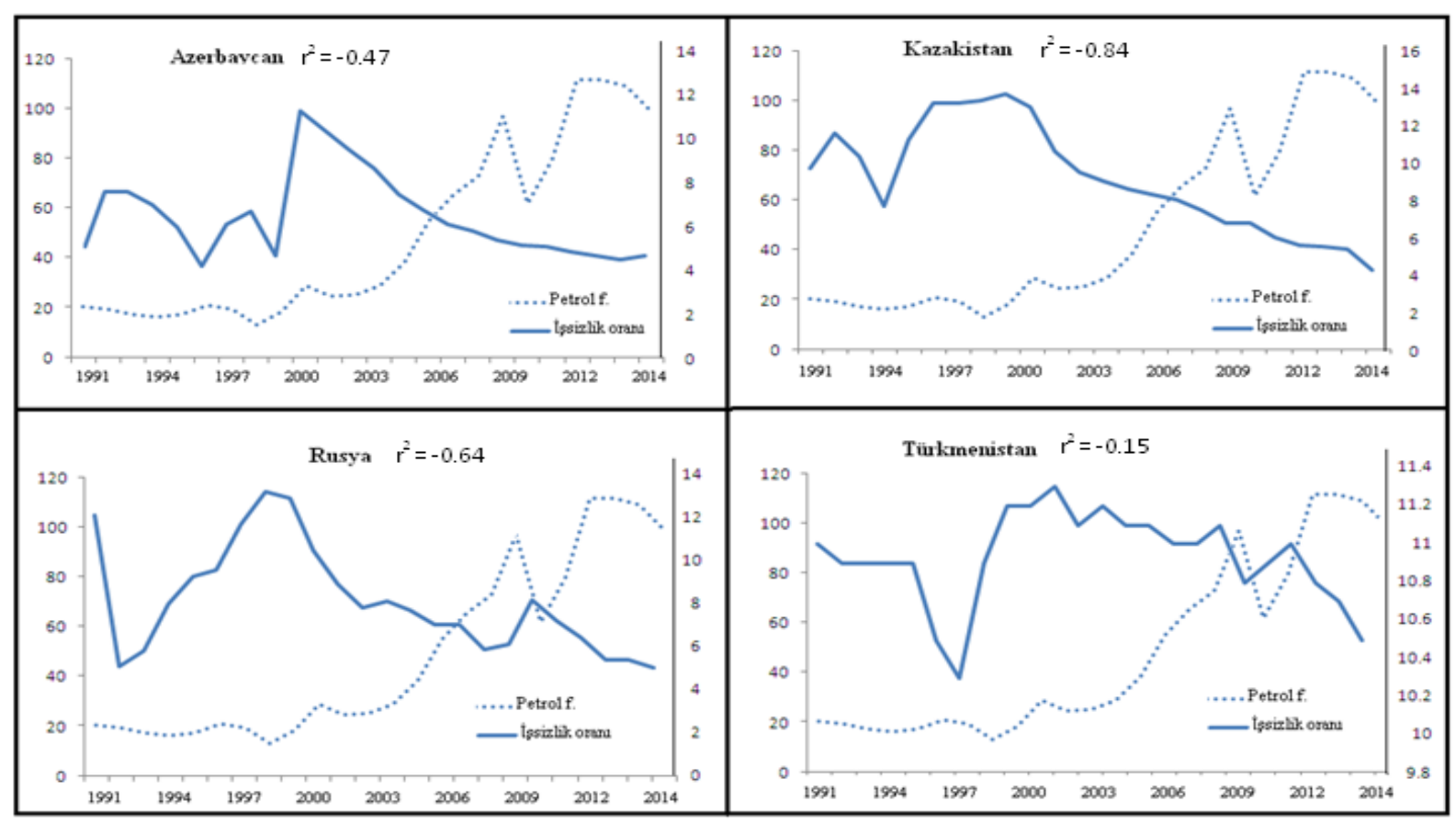

Şekil 4. Petrol Fiyatları ve İssizlik Oranı İlişkileri

Şekil 7'de üretimde mal çeşitlemesine gidilememesinin böylece temel konumunda bulunan petrol ve ürünleri sektöründe sağlanan gelir artışları da istihdam yapısının bu sektörde sağlanan genişlemelere duyarlı hale getirmiştir. Şekilde yer alan grafiklerde görüldüğü gibi bu durumun yansıması, petrol fiyatları ile işsizlik oranları arasında ters yönlü ilişkilerin varlığıdır. Yukarıdaki şekle göre petrol fiyatları ile işsizlik oranları arasında en güçlü ilişkilerin de sırasıyla Kazakistan ( $\mathrm{r} 2=-0.849)$, Rusya Federasyonu ( $\mathrm{r} 2=-0.649)$, Azerbaycan $(\mathrm{r} 2=-0.477)$ ve Türkmenistan ( $\mathrm{r} 2=-0.152)$ 'da ortaya çıktığı görülmektedir. Petrol fiyatlarına oldukça yüksek bağımlı ekonomilerde istihdamın da petrol fiyatlarından görece daha fazla etkilendiği gözlenirken; yine Türkmenistan'da bu etkilenme derecesinin oldukça zayıf çıkmasında sahip olduğu kaynakları dünya piyasasına arz edememesi ve dolayısıyla görece düşük petrol geliri etkilerine maruz kaldığından bahsedilebilir.

\section{Sonuç}

Başta petrol olmak üzere doğal kaynak zenginliğinin diğer sektörlere ağırlık verilmesinin önünde bir engel teşkil ettiğine dair bakış açısı ekonomi literatüründe doğal kaynakların laneti argümanı olarak adlandırılmaktadır. $\mathrm{Bu}$ argümanın işleyip işlemediğinin göstergeleri olarak petrol fiyatları ve bunun yansıması olan petrol gelirlerine (i) GSYİH'nın, (ii) Kamu harcamalarının, (iii) İhracatın ve (iv) işsizlik oranlarının duyarlı olup olmamasıyla tespit etmek mümkündür. Doğal kaynaklar argümanın özellikle doğal kaynak zengini geçiş ekonomilerinde işleyip işlemediğine buradaki değişkenlerin ilişkileri üzerinden bakıldığında, dört geçiş ekonomisinin de yoğunluklu olarak petrol fiyatlarına duyarlı birer ekonomi oldukları gözlemlenmiştir. Bu dört ekonomide petrol fiyatlarının GSYIH, kamu harcamaları, ihracat ve işsizlik oranlarına etkileri en güçlüden en güçsüze doğru şu şekilde siralanabilir:

- GSYİH açısından; Rusya Federasyonu > Kazakistan > Azerbaycan > Türkmenistan

- Kamu harcamaları açısından; Rusya Federasyonu $>$ Kazakistan $>$ Azerbaycan $>$ Türkmenistan

- İhracat açısından; Kazakistan > Azerbaycan $>$ Rusya Federasyonu > Türkmenistan

- İşsizlik oranları açısından; Kazakistan > Rusya Federasyonu > Azerbaycan > Türkmenistan

Genel bir değerlendirme yapıldığında, ele alınan dört değişken açısından petrol fiyatlarına görece daha az duyarlı ekonomi Türkmenistan olmuştur. Diğer taraftan GSYIH ve kamu harcamaları açısından en fazla etkilenen ülke Rusya Federasyonu; ihracat ve işsizlik oranları açısından da Kazakistan'dır. Bu ekonomilerin petrol gelirlerini sağlıklı bir şekilde diğer ekonomik faaliyetleri uyarıcı ya da besleyici olarak kullanılamamasının olumsuz yansımalarını yaşadıkları açıktır. Şüphesiz bu durum ekonomide çeşitleme yaratamamanın ve devlet eliyle zengin yaratmanın bir aracı konumundan öteye geçmediği söylenebilir. Diğer bir ifadeyle doğal kaynak zenginliği adeta bir nimet olmasına karşlık, ekonomide bir "el freni işlevi" gördüğü dikkate çekmektedir. Politika çıkarımı açısından ise bu ülkelerin petrol gelirlerini öncelikle; (i) ölçek ekonomileri yaratacak ve pozitif dişsallıklar doğuracak alanlara kanalize etmeleri, (ii) eğitim ve sağlı alanına yönlendirmeleri, (iv) rekabet gücünü yükseltmeleri ve (iv) avantajlı sektörlerde yatırımların teşvikine aktarmaları uzun vadede ekonomik gelişmişliği 
besleyeceği ileri sürülebilir. Bu çalışmadaki bulgular dikkate alındığında, ekonometrik analize izin vermeyen petrol fiyatlarının varlığı yerine, petrol ihracat gelirleri alınarak ekonometrik analizler yapılması ve petrol ithalatına bağımlı ülkelerin de kontrol değişken olarak modelle dahil edilmesiyle daha sağlıklı politika çıkarımına gidilmesi mümkün olabilir.

\section{Kaynakça}

- Brunnschweilera and Bulteb, 2008. The Resource Curse Revisited and Revised: A Tale of Paradoxes and Red Herrings, Journal of Environmental Economics and Management, 55, pp. 248-264.

- Clay and Weckenman, 2014. "Resource Curses: Evidence from the United States 1880-2012", Carnegie Mellon University and NBER, (Erişim, Kasım 2015; https://www.aeaweb.org/aea/2015conference/program/retrieve.php?pdfid=593).

- Esfahani, Mohaddes and Pesaran, 2013. "Oil Exports and the Iranian Economy”, The Quarterly Review of Economics and Finance, 53: 221-237.

- Fan, Fang and Park, 2012. "Resource Abundance and Economic Growth in China", China Economic Review, 23, pp. 704-719.

- Fischer, and Sahay, 2004. Transition Economies: The Role of Institutions and Initial Conditions, IMF mimeo. Washington D.C.

- Gylfason, 2001.” Natural Resources, Education, and Economic Development”, European Economic Review, 45: 847-859.

- Ismail, 2010. "The Structural Manifestation of The Dutch Disease: The Case of Oil Exporting Countries", IMF Working Papers, pp. 1-36.

- Papyrakisa, and Gerlagh, 2007. "Resource Abundance and Economic Growth in the United States", European Economic Review, 51: 1011-1039.

- Peretto, 2012. "Resource Abundance, Growth and Welfare: A Schumpeterian Perspective", Journal of Development Economics, 97(1): 142-155.

- Sachs, and Warner, 1999. "The Big Push, Natural Resource Booms and Growth”, Journal of Development Economics, 59: 43-76.

- Sachs and Warner, 1997. "Natural Resource Abundance and Economic Growth", Revised version, Unpublished manuscript, Harvard Institute for International Development, Cambridge, MA. (Erişim: Ocak 2016; http://www.cid.harvard.edu/ciddata/warner_files/natresf5.pdf).

- United States, US Energy Information Administration Statistics, (Erişim: Ocak 2016; http://www.eia.gov/dnav/pet/pet_pri_spt_s1_m.htm)

- Worldbank, 2015. World Development Indicators; (Erişim: Ocak 2016; http://databank.worldbank.org/data/reports.aspx?source=world-developmentindicators) 


\title{
Orta Asya Ülkelerinde CO2 Emisyonu, İktisadi ve Finansal Gelişme ve Fosil Yakıt Enerji Tüketimi İlişkisi \\ The Relationship Between CO2 Emissions, Economic and Financial Development and Fossil Fuel Energy Consumption in Central Asia
}

\author{
Asst. Prof. Dr. Mahmut Erdoğan (Kyrgyzstan-Turkey Manas University, Kyrgyzstan) \\ Asst. Prof. Dr. Junus Ganiev (Kyrgyzstan-Turkey Manas University, Kyrgyzstan)
}

\begin{abstract}
Although environmental deterioration is a main result of the process of economic growth, global warming and climate change has been threating the quality of human life. Though Central Asian countries (Azerbaijan, Kazakhstan, Kyrgyzstan, Georgia, Tajikistan, Turkmenistan, Uzbekistan and Armenia) signed to Kyoto protocol to decrease $\mathrm{CO} 2$ emission levels, these countries still have environmental pollution concerns. This paper examines relationships between $\mathrm{CO} 2$ emissions, economic and financial development and fossil fuel energy consumption for a panel of Central Asian countries over the period 1992-2013. The findings of this study show that an inverted U shape environmental Kuznets curve for Central Asia. Moreover, energy consumption and urbanization are found to have positive effects on $\mathrm{CO} 2$ emissions. However, analysis suggests that financial development and trade openness are essential factors for the reduction of $\mathrm{CO} 2$ emissions.
\end{abstract}

\section{Giriș}

Ekonomik kalkınma ve refah artışı amacına ulaşabilmek için ülke ekonomisinin belirli bir hızda büyümesi gerekmektedir. Fakat hızlı ekonomik büyüme ve sanayileşme süreci çevre kirliliği, iklim değişikliği, küresel 1sınma gibi sonuçlara yol açarak insan hayatının kalitesini tehdit edebilmektedir. Özellikle ekonomik gelişme sürecinde fosil yakıt enerji tüketiminin ve $\mathrm{CO}_{2}$ emisyonunun artması ciddi çevresel sorunlar arasında yer almaktadır.

Çevre kirliliği insanlarda fiziki sakatlığa ve psikolojik sorunlara neden olabilmektedir. Hava kirliliği; akciğer, göz, burun, ağız ve boğaz gibi organları etkileyerek insanlarda solunum sorunlarına ve astım hastalığına, kansere ve erken ölümlere yol açmaktadır (Rafia, vd, 2003). Ayrıca su kirliliği insanların kirli su tüketimi sonucu çeşitli enfeksiyonlara neden olmaktadır. Sonuçta hayat standartını olumsuz etkileyerek insanların refahının temel göstergesi olarak kabul edilen ekonomik kalkınmayı da negatif etkilemektedir.

Ayrıca, kirlenme insan sağlığını olumsuz etkileyerek işgücü verimliliğini azaltır ve diğer taraftan asit yağmuru, tarım koşullarının kötüleşmesi gibi iklim koşulları tarımsal üretimi olumsuz etkiler. Tüm bunların sonucunda toplam çıktı azalır (McConnell, 1997).

Bunun gibi nedenlerle ekonomik kalkınma ile çevre ilişkisi son yıllarda akademik çevrelerde çok araştırılan konulardan biri haline gelmiştir. 1990’lı yıllarda özellikle çevre kirliliğinin (yada temizliğinin) gelir esnekliği tartışmaların temel konusunu oluşturmuştur. Panayotou (1993) şekil üzerinden gösterdiği gibi -ki buna Çevresel Kuznets Eğrisi (Environmental Kuznets Curve: EKC) denmektedir- sanayileşme ve ekonomik gelişmenin ilk aşamalarında kişi başına milli gelir artışı çevre kirliliğini artırırken, belirli bir gelir seviyesinden sonra da gelir artışı çevre kirlenmesini azaltmaktadır (grafik 1). Bunun nedeni, ülkelerin ilk sanayileşme döneminde çevre kirlenmesine fazla önem vermemesi ve insanların zenginleştikten sonra çevre koşullarının sağlıklı ve temiz olmasına daha duyarlı olmaya başlamasıdır. Tüketicilerin çevreye duyarlı olması ve çevre dostu malları talep etmesi çevreye daha az zararlı üretim teknolojilerinin geliştirilmesine yol açar. Ayrıca, çevrenin korunması konusunda hükümetin daha katı politikalar uygulamaya başlaması da ekonominin daha az kirletici sektörlere ve teknolojilere kaymasına katkı sağlamaktadır (Panayoto, 1993).

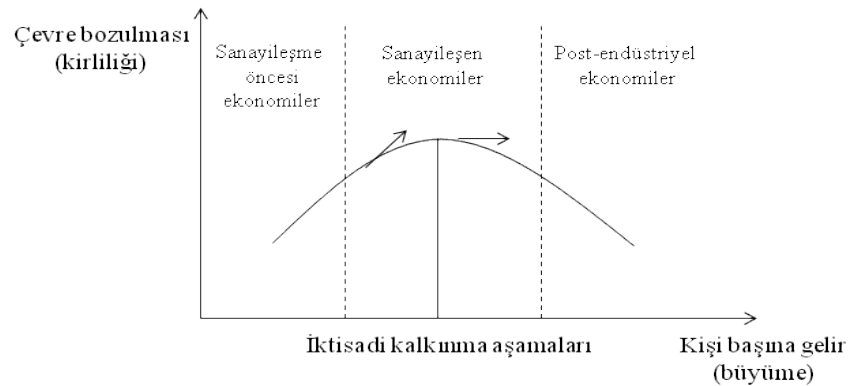

Grafik 1. Çevresel Kuznets Ĕ̆grisi: İktisadi Gelişme-Çevre İlişkisi Kaynak: Panayotou (1993) 
Çoğu empirik çalışmalar (örneğin, Lopez (1994), Selden ve Song (1995), Hitam ve Borhan (2012) vs.) ters-U (inverted-U) ilişkisi olarak nitelendirilebilen EKC hipotezini desteklerken, McConnell (1997) çevre kirliliği ile gelir arasındaki ters-U ilişkisinin kaçınılmaz olmadığını ortaya koymuştur. Bu konudaki tartışmalar daha çok gelir artışıyla beraber çevre kirlenmesinin azalmaya başlayacağı konusuyla ilgilidir.

Kiesel (2006) tüm kirletici maddelere uygulanabilecek tek bir EKC olmadığını savunmaktadır. Bunun daha çok yerli hava kirleticilerine ve kısmi sorunlara uygun olabileceği söylenebilir. Kurumsal konuların eksikliği durumunda gelir artışının çevre kirliliğini azaltmasını beklemek zordur. Diğer bir ifadeyle, çevrenin daha iyi korunmasında çevre kirliliğine karşı etkin devlet politikasının ve ülke sakinlerinin duyarlılığının önemli rol oynadığı bir gerçektir. Örneğin, Dasgupta, vd. (2004) Güney Kore'de yatırımcıların, ulusal çevre yasalarına ve düzenlemelerine uymayan şirketlerin listesinin yayınlanmasına olan tepkisini araştırarak sözkonusu listeye giren şirketlerin piyasa değerinde ciddi düşüşlerin yaşandığını ortaya koymuşlardır.

Goldemberg (1998) ise sanayileşmiş ülkelerin geçmiş dönemindeki adımlarını atlayarak, yani gelişme sürecinin başlangıç dönemlerinde modern ve etkin teknolojileri kullanarak çevre kirlenmesini önlemenin mümkün olacağını savunmuştur. Panayotou (1997) da bir ülkedeki politika ve kurumların kalitesinin düşük gelir düzeyinde çevre bozulmasının azalmasına ve yüksek gelir düzeyinde de olumlu gelişmelerin hılanmasına önemli katkı sağlayacağını ortaya koymuştur. Bu görüşler özellikle yeni sanayileşmekte olan ülkeler için çok önemlidir.

Fakat bu çalışmanın konusu olan ülkeler, yani Azerbaycan, Kazakistan, Kırgızistan, Gürcistan, Tacikistan, Türkmenistan, Özbekistan ve Ermenistan gibi Orta Asya ülkeleri de $\mathrm{CO}_{2}$ emisyon seviyelerini düşürmek için Kyoto Protokolü'ne imzalamalarına rağmen, kişi başına gelir düzeyi ve ekonomik kalkınma düzeyi düşük olduğu için çevre kirliliği sorununa fazla önem vermemektedir. Bunun sonucunda bir anlamda şu andaki sanayileşmiş ülkeler için geçmişte geçerli olan "önce kirlet, daha sonra kirlenmeyi kontrol et” ilkesine uymuş olmaktadırlar. Bunun yerine, geçmişteki hataları örnek alarak ilk baştan daha akılcı davranmaları iyi olacaktır.

Bundan dolayı bu çalışmada Orta Asya ülkelerinde çevre ve hava kirlenmesinin önemli bir göstergesi olan $\mathrm{CO}_{2}$ emisyonu ile ekonomik ve finansal gelişme arasındaki ilişkilerin empirik olarak araştırılması ve sürdürülebilir kalkınmanın önemli bir boyutu olan çevrenin korunması ile ilgili politika önerilerinde bulunulması amaçlanmıştır.

\section{Literatür Taraması}

Ekonomik kalkınma ile küresel ısınmada önemli rolü olan $\mathrm{CO}_{2}$ emisyonu arasındaki ilişki literatürde genişçe araştırılmış bir konudur. Meadows, vd. (1992) söylediği gibi, ekonomik büyüme uzun dönemde çevre için bir tehdit olmaktan ziyade, çevre kalitesinin korunmasında bir gereklilik gibi gözükmektedir. Uygun politik müdahalelerle ekonomik büyümenin çevre kirlenmesine olan etkisini önemli ölçüde azaltmak, hatta tersine çevirmek de mümkündür (Antle ve Heidenberk, 1995; Selden ve Song, 1994; Shafik, 1994).

Ekonomik kalkınmanın çevre kalitesine olan net etkileri konusundaki empirik bulgular sözkonusu etkinin çeşitli kirleticilerin özelliklerine bağlı olduğunu göstermektedir (Shafik ve Bandyopadhyay, 1992; Diwan ve Shafik, 1992). Sülfür dioksit, karbon monoksid ve nitrojen oksitleri gibi hava kirleticilerin ekonomik kalkınmayla ters-U şeklindeki bir ilişki içinde olduğu gözlemlenirken, Holtz-Eakin ve Selden (1995) CO2 emisyonunun EKC şablonuna uymadığını ortaya koymuşlardır. Shafik ve Bandyopadhyay (1992) ise CO2 emisyonunun kişi başına GSYİH ile birlikte monoton bir şekilde arttı̆̆ını göstermişlerdir. Bununla beraber, pek çok empirik çalışmalar (örneğin, Lopez (1994), Selden ve Song (1995), Hitam ve Borhan (2012) vs.) ters-U (inverted-U) ilişkisi olarak nitelendirilebilen EKC hipotezini destekler nitelikteki sonuçlara ulaşmışlardır.

Doğrudan yabancı yatırımların çevre kirlenmesine olan etkisi konusunda da birbiriyle çelişkili empirik çalışmalar mevcuttur. Bazı çalışmalar (List ve Co, 2000; Soysa ve Neumayer, 2004; Liang, 2006; Tamazian, vd, 2009) doğrudan yabancı yatırımlardaki artışın çevre kirlenmesini azaltacağı sonucuna ulaşmışken, bazıları da (Cole ve Elliot, 2005; Feridun, 2006; Hitam ve Borhan, 2012) tam tersine doğrudan yabancı yatırımların çevre kirlenmesini arttırdığını söylemektedir. Hitam ve Borhan (2012) Malezya'da $\mathrm{CO}_{2}$ emisyonunun doğrudan yabancı yatırımlara olan esneklik katsayısının yaklaşık ikiye eşit olduğunu ortaya koymuş ve doğrudan yabancı yatırımlar ve çevreyi koruma ile ilgili kanunların iyileştirilmesi gerektiğini savunmuşlardır.

Tamazian, vd. (2009) ülkedeki finansal gelişmenin; genelde tüm yatırımların ve özelde çevre projelerine olan yatırımların maliyetini düşürmek, teknolojik yenilikleri özendirmek gibi yollarla çevre performansını iyileştireceğini öne sürmüş, bununla beraber bu ilişkinin kanalları konusunda empirik delillerin çok sınırlı olduğunu kabul etmişlerdir. Sözkonusu çalışmada BRIC ülkelerine ait panel veri kullanılarak ekonomik ve finansal değişkenlerin $\mathrm{CO}_{2}$ emisyonuna olan etkisi araştırılmıştır. Araştırma sonucunda GSYİH büyüme oranı, sanayinin payı ve Ar-Ge harcamaları gibi ekonomik gelişme göstergelerinin kişi başına $\mathrm{CO}_{2}$ emisyonuna istatistiki olarak anlamlı etkilerinin olduğunu, GSYİH büyüme oranı ile sanayi payındaki artışların $\mathrm{CO}_{2}$ emisyonunu arttırdığını, Ar-Ge harcamalarındaki artışın ise $\mathrm{CO}_{2}$ emisyonunu azalttığını ortaya koymuşlardır. Ayrıca, BRIC ülkelerinde finansal liberalizasyon ve sermaye hesabı konvertibilitesi gibi finansal gelişme göstergelerinin de $\mathrm{CO}_{2}$ emisyonunu azalttığı sonucuna ulaşmışlardır. 
Ticari açıklık ile çevre kirlenmesi arasındaki ilişki konusunda ise hem ticari açıklığın çevre yanlısı olduğunu (Shafik ve Bandyopadhyay, 1992; Birdsall ve Wheeler, 1993; Ferrantino, 1997) hem de ticari açıklığın çevreye zarar verdiğini gösteren empirik çalışmalar (Suri ve Chapman, 1998; Lopez, 1994) bulunmaktadır. Yani bu konuda henüz bir fikir birliği sağlanmış değildir.

\section{Veri ve Yöntem}

$\mathrm{Bu}$ çalışmada $\mathrm{CO}_{2}$ emisyonu, fosil yakıt enerji tüketimi, ekonomik ve finansal gelişme ile ticari açıklık ilişkisi 1992-2013 döneminde Azerbaycan, Kazakistan, Kırgızistan, Gürcistan, Tacikistan, Türkmenistan, Özbekistan ve Ermenistan'a ait yıllık veriler kullanılarak incelenmiştir. Değişkenlere ait veriler Dünya Bankası'nın World Development Indicators (WB, 2016) veritabanından derlenmiştir.

Çalışmada kullanılan statik model 1 numaralı denklemde gösterilmiştir.

$l C O_{2 i t}=\beta_{0}+\beta_{1} \operatorname{lgdppc}_{i t}+\beta_{2} \operatorname{lgdppc}_{i t}{ }^{2}+\beta_{3}$ energy $_{i t}+\beta_{4}$ pop $_{i t}+\beta_{5}$ urban $_{i t}+\beta_{6}$ tropen $_{i t}+\beta_{7}$ fopen $_{i t}+\tau_{i}+\gamma_{t}+\varepsilon_{i t}$

Burada,

$\mathrm{CO}_{2 i t}$ i ülkesinin t zamanında fosil yakıt kullanımı ve çimento üretimi sonucu ortaya çıkan kişi başına düşen $\mathrm{CO}_{2}$ emisyonunun logaritmik değerini, $g d p p c_{i t}$ i ülkesinin t zamanındaki 2005 yılı fiyatlarıyla Amerikan doları olarak kişi başına düşen milli gelirin logaritmik değerini, energy $y_{i t}$ i ülkesinin t zamanındaki enerji kullanımını, $p o p_{i t} \mathrm{i}$ ülkesinin $\mathrm{t}$ zamanındaki yılortası nüfusunun kilometrekareye bölünmesiyle elde edilen nüfus yoğunluğunu, urban $_{i t}$ şehirleşme oranını, tropen $i t$ i ülkesinin t zamanındaki ihracat ve ithalat toplamının gayri safi milli hasılaya oranıyla hesaplanan ticari açıklık oranını göstermektedir. Buna ek olarak, fopen $n_{i t} \mathrm{i}$ ülkesinin $\mathrm{t}$ zamanındaki sermaye açıklığı derecesini gösteren endekstir. 1 ve 2 nolu denklemlerde $\tau_{i}$ gözlenemeyen bireysel etkileri, $\gamma_{t}$ gözlenemeyen zamana özgü etkileri ve $\varepsilon_{i t}$ ise hata terimi bileşenlerini ifade etmektedir. Kişi başına gelir ve çevre kirliliği arasındaki ilişkinin Çevresel Kuznets Eğrisi ile incelenmesi durumunda, $\beta_{1}>0$ ve $\beta_{2}<0$ olması halinde karbon emisyonu ve gelir arasında ters-U biçiminde bir ilişkinin bulunduğu ileri sürülmüştür (Stern, 2004). Gelirin hangi eşik değerinden sonra azalmaya başlayacağı önem taşımaktadır ve Grafik 1 'de yer alan azalma noktası $\frac{-\beta_{1}}{2 \beta_{2}}$ ile hesaplanmaktadır. Çalışmada kullanılan değişkenlere ait tanımlayıcı istatistikler Tablo 1'de sunulmuştur.

\begin{tabular}{lccccc}
\hline & Gözlem & Ortalama & Stn. Sapma & Min & Max \\
\hline lco2 & 176 & 0.914 & 1.117 & -1.238 & 2.766 \\
lgdppc & 176 & 6.902 & 0.816 & 5.326 & 8.599 \\
lenergy & 176 & 7.094 & 0.823 & 5.640 & 8.520 \\
pop & 176 & 0.546 & 0.372 & 0.055 & 1.212 \\
urban & 176 & 0.465 & 0.116 & 0.264 & 0.669 \\
tropen & 176 & 0.864 & 0.268 & 0.250 & 1.800 \\
fopen & 176 & -0.192 & 1.461 & -1.890 & 2.390 \\
\hline
\end{tabular}

Tablo 1. Değişkenlere Ait Tanımlayıcı İstatistikler

Tablo 1 her bir değişkene ait en küçük ve en büyük veri değerlerini, ortalama ve standart sapma değerlerini göstermektedir. Tablo 1 bazı ilginç durumları ortaya koymaktadır. Kişi başına gelir ve enerji tüketiminin en küçük değerleri 5,326 ve 5,640 iken en büyük değerleri ise sirasiyla 8,599 ve 8,520 olup birbirlerine yakın değerlerde dağıldığı gözlenmektedir. Nüfus yoğunluğunun en küçük değeri 0,055 iken en büyük değeri ise 1,212 'dir. Şehirleşme değişkeninin en küçük değeri 0,264 iken en büyük değeri ise 0,669'dur. Ticari açıklık değişkeninin en küçük değeri 0.25 iken en büyük değeri ise 1,80 'dir. Finansal açıklık değişkeninin en küçük değeri $-1,890$ olup en büyük değeri ise 2,390'dır. Çalışmada kullanılan değişkenlere ait korelasyon değerleri ise Tablo 2'de sunulmuştur.

\begin{tabular}{lrrrrrr}
\hline & lco2 & lgdppc & lenergy & ypop & urban & tropen \\
\hline lgdppc & 0.676 & & & & & \\
lenergy & 0.981 & 0.661 & & & & \\
ypop & -0.390 & -0.078 & -0.393 & & & \\
urban & 0.360 & 0.700 & 0.353 & 0.406 & & \\
tropen & 0.206 & 0.159 & 0.134 & -0.218 & -0.021 & \\
fopen & -0.475 & -0.052 & -0.521 & 0.377 & 0.286 & -0.007 \\
\hline
\end{tabular}

Tablo 2. Değişkenlere Ait Korelasyon 
Tablo 2'de $\mathrm{CO}_{2}$ değişkeni ile kişi başına enerji kullanımı arasında güçlü pozitif korelasyon değerleri raporlanırken, nüfus yoğunluğu ile $\mathrm{CO}_{2}$ emisyonu ve enerji tüketimi arasında negatif korelasyon olduğu gözlenmektedir. Benzer şekilde, finansal açıklık ile emisyon arasında ve ticari açıklık ile nüfus yoğunluğu arasında negatif korelasyon görülmektedir.

\section{Ampirik Bulgular}

Çalışmanın statik panel veri analizine ait bulgular Tablo 3'te sunulmuştur.

\begin{tabular}{|c|c|c|c|c|}
\hline $\mathrm{lco}_{2}$ & Sabit etkiler & Rassal etkiler & Dirençli & Prais-Winsten \\
\hline \multirow[t]{2}{*}{$\operatorname{lgdppc}$} & $1.204 * * *$ & 0.420 & $1.204 * * *$ & $1.814 * * *$ \\
\hline & $(0.308)$ & $(0.381)$ & $(0.389)$ & $(0.572)$ \\
\hline \multirow[t]{2}{*}{$\operatorname{lgdppc} c^{2}$} & $-0.069 * * *$ & -0.026 & $-0.069 * *$ & $-0.122 * * *$ \\
\hline & $(0.021)$ & $(0.027)$ & $(0.026)$ & $(0.041)$ \\
\hline \multirow[t]{2}{*}{ lenergy } & $0.853 * * *$ & $1.328 * * *$ & $0.853 * * *$ & $1.198 * * *$ \\
\hline & $(0.053)$ & $(0.037)$ & $(0.137)$ & $(0.049)$ \\
\hline \multirow[t]{2}{*}{ pop } & $-1.647 * * *$ & 0.017 & $-1.647 * * *$ & $-0.365 * * *$ \\
\hline & $(0.271)$ & $(0.062)$ & $(0.248)$ & $(0.102)$ \\
\hline \multirow[t]{2}{*}{ urban } & $1.911^{*}$ & -0.348 & 1.911 & 0.156 \\
\hline & (1.039) & $(0.275)$ & (1.957) & $(0.357)$ \\
\hline \multirow[t]{2}{*}{ tropen } & 0.024 & $0.289 * * *$ & 0.023 & 0.0198 \\
\hline & $(0.048)$ & $(0.058)$ & $(0.079)$ & $(0.086)$ \\
\hline \multirow[t]{2}{*}{ fopen } & $-0.036^{*}$ & $0.033 * *$ & -0.036 & -0.00407 \\
\hline & $(0.018)$ & $(0.015)$ & $(0.034)$ & $(0.020)$ \\
\hline \multirow[t]{2}{*}{ Sabit } & $-10.15^{* * *}$ & $-10.26^{* * *}$ & $-10.151 * * *$ & $-14.14 * * *$ \\
\hline & $(1.274)$ & $(1.254)$ & $(1.823)$ & $(1.850)$ \\
\hline $\mathrm{R}^{2}$ & 0.806 & 0.705 & 0.806 & 0.886 \\
\hline $\mathrm{F}(7,161)$ & $95.39(0,000)$ & & $67.43(0,000)$ & \\
\hline Wald chi2(7) & & $5527.20(0,000)$ & & $2507.76(0,000)$ \\
\hline Hausman & $78.21(0,000)$ & & & \\
\hline Gözlem sayısı & 176 & 176 & 176 & 176 \\
\hline Ülke sayısı & 8 & 8 & 8 & 8 \\
\hline Bhargava vd. & & & & \\
\hline Durbin-Watson & 1.095 & & & \\
\hline Baltagi-Wu LBI & 1.229 & & & \\
\hline Değiştirilmiş & & & & \\
\hline Wald & $1308.96(0,000)$ & & & \\
\hline Breusch-Pagan & & & & \\
\hline LM & $53.950(0.002)$ & & & \\
\hline Dönüm noktası & $\$ 6154$ & $\$ 3219$ & $\$ 6152$ & $\$ 1693$ \\
\hline
\end{tabular}

Tablo 3. Statik Panel Veri Analizi Sonuçları

Parantez içerisindeki değerler standart hataları göstermektedir. ***, **, * sırasıly $\% 1, \% 5$ ve $\% 10$ önem düzeylerinde anlamlı olduklarını ifade etmektedir. Tablo 3 'ün birinci sütununda sabit etkiler modeli yer almaktadır. Tesadüfi etkiler modelinin geçerliliğini test eden Hausman test istatistiği 78,21 ve istatistiksel olarak anlamlı bulunmuştur. Modelde sabit etkiler tahmincisi rassal etkiler tahmincisine göre daha tutarlı sonuçlar vermektedir. Sabit etkiler modelinde kişi başına $\mathrm{CO}_{2}$ emisyonu ve kişi başına gelir arasında pozitif ve istatistiksel olarak anlamlı ilişki bulunurken, kişi başına emisyon ve kişi başına gelirin karesi değişkeni arasında negatif ve istatistiksel anlamlı ilişki belirlenmiştir. Elde edilen bu bulgu, kişi başına emisyon ve kişi başına gelir arasında ters-U şeklindeki ilişkiyi kanıtlamaktadır ve Orta Asya ülkelerinde kişi başına gelir artarken çevre kirliliğinin azalmaya başlayacağı bir eşik noktasını ima etmektedir. Sabit etkiler modeline göre kişi başına emisyonun azalma trendine gireceği dönüm noktası \$6154 olarak tespit edilmiştir. lenergy değişkeni pozitif ve istatistiksel olarak \%1 düzeyinde anlamlı bulunmuştur. Enerji tüketimindeki \%1 artış, kişi başına $\mathrm{CO}_{2}$ emisyonunu \%0,85 artıracaktır. Bu sonuç; enerji 
üretimi, taşıma, tarımsal üretim ve fosil yakıt tüketimi ile Orta Asya ülkelerinde emisyon yoğunluğunun arttığını göstermektedir. pop değişkeni ise beklentilerle uygun şekilde negatif ve istatistiksel olarak oldukça güçlü anlamlı bulunmuştur. Bu sonuç, Orta Asya ülkelerinde popülasyon yoğunluğu arttıkça, toplumların daha az $\mathrm{CO}_{2}$ emisyonu salınımı yapacaklarını ifade etmektedir. Popülasyon yoğunluğunun artması, bu ülkelerde çevresel kanunların daha sıkı biçimde uygulanması ve daha fazla sayıda insanın birbirine yakın şekilde yaşamaları sonucunda araç kullanımının azalmasından dolayı emisyon yoğunluğunu azaltıcı etkide bulunacaktır.

urban değişkeni pozitif ve istatistiksel olarak \%1 seviyesinde anlamlıdır. Bu durum şehirlerin kırsal alanlardan daha fazla $\mathrm{CO}_{2}$ emisyonu salınımı gerçekleştirdiklerini ifade etmekte ve Cole ve Neumayer (2004) ile Sharma (2011) nın bulgularını desteklemektedir. Bir ülkede şehirleşme oranı arttıkça, şehirlerde sanayi ve insanlar tarafından daha fazla kirletilerek büyümektedirler. Bu durumun sebepleri, şehirleşmeyle daha fazla yol ağının yapılması, trafik yoğunluğunun fazla olması ve taleplerin karşılanması için daha fazla üretim faaliyetlerinin gerçekleştirilmesi olabilir.

Ticari açıklık değişkeninin katsayısı beklentilerle uygun şekilde pozitif bulunmuştur ancak istatistiksel olarak anlamlı bulunamamıştır. Taskin ve Zaim (2000) dış ticaretin serbestleşmesinin ilk dönemlerinin çevresel kirlenme artışına izin verdiğini ancak ülkelerin ticari açıklıkta belli bir eşik düzeyi geçtikten sonra çevresel kirlenmeyi azaltma çabalarının arttığını ileri sürmüşlerdir. Finopen değişkeni negatif ve istatistiksel olarak \%10 seviyesinde anlamlı bulunmuştur. Finansal açıklıktaki her \%1'lik artış, kişi başına $\mathrm{CO}_{2}$ emisyonunu \%0,036 azaltacaktır. Orta Asya ülkelerindeki finansal açıklık düzeyinin artışı ile birlikte bu ülkelerin yabancı yatıımlar açısından daha cazip hale gelmesi, yüksek teknoloji enerji yatırımlarına liderlik edecek potansiyel Ar-Ge yatırımlarını teşvik edecek ve bunun sonucunda emisyonların azalacağı şeklinde yorumlanabilir. Finansal açıklıkla ilgili sağlanan bu bulgu Tamazian vd. (2009) görüşlerini desteklemektedir.

Bhargava, Franzini ve Narendranathan (1982), AR(1) modeli kullanarak önerdikleri Durbin-Watson test istatistiğinde $H_{0}: \rho=0$ (otokorelasyon yoktur) ve alternatif hipotez $H_{a}:|\rho|<1$ şeklinde hipotez kurmuşlardır. Baltagi-Wu'nun (1999) yerel en iyi değişmez testinde de hipotezler benzerdir ve otokorelasyonun varlığını sınamaktadır. Sabit etkiler modelinde Bhargava vd. ve Baltagi-Wu LBI testi için değerler 2'den küçük bulunduğundan dolayı sabit etkiler modeli için otokorelasyonun ciddi olduğu yorumu yapılabilir. Birimlere göre heteroskedasitenin, Değiştirilmiş Wald testi için hipotez $H_{0}: \sigma_{i}^{2}=\sigma^{2}$ (varyanslar, birimlere göre homoskedastiktir) şeklinde kurulmaktadır. Sabit etkiler modeli için heteroskedasite testine göre $H_{0}$ hipotezi reddedilmekte, varyans birimlere göre değişmekte ve dolayısıyla birimlere göre heteroskedasitenin olduğu belirlenmiştir. Breusch-Pagan LM testi sonucuna göre birimler arası korelasyonsuzluğu ifade eden $H_{0}$ hipotezi reddedilmekte ve ülkeler arasında korelasyon olduğu sonucunu göstermektedir.

Sabit etkiler modelinde heteroskedasite, otokorelasyon ve birimler arası eşzamanlı korelasyon bulunması sebebiyle hata teriminin varyans kovaryans matrisi birim matrise eşit değildir ve bu sorunlardan en az birinin varlı̆ğında, dirençli standart hatalar elde edilebilir veya uygun yöntemlerle tahminler yapılır. Tablo 3 'ün üçüncü sütununda sabit etkiler modelinde, heteroskedasiteye karşı dirençli standart hatalara sahip model raporlanmıştır. Üçüncü modelde elde edilen parametre tahminlerinin sabit etkiler tahmincileri ile aynı olmakla birlikte standart hataların farklı olduğu görülmektedir. Dirençli standart hatalar ile hesaplanan $t$ istatistiklerine göre, sabit etkiler modelindekine benzer biçimde kişi başına gelir pozitif ve istatistiksel anlamlı iken kişi başına gelirin karesi değişkeni negatif ve istatistiksel anlamlı bulunmuştur. Bu model de Orta Asya ülkelerinde EKC'nin ters-U biçiminin varlığını göstermekte ve $\$ 6152$ eşik düzeyinden sonra gelir artmaya devam ederken çevre kirliliğinin azalacağını göstermektedir. Sabit etkiler modelinden farklı olarak, dirençli standart hatalara sahip modelde urban ve fopen değişkenleri istatistiksel anlamlı bulunmamıştır.

Bunun ötesinde Beck ve Katz (1995) birimler arası korelasyonu düzeltmek için "panel düzeltilmiş standart hataları" (PCSE) önermiştir. Birimler arası korelasyonu düzeltmek için büyük t asimptotik temelli standart hatalar üreten yöntemin küçük panellerde de kullanımının uygun olduğunu öne süren Beck ve Katz (1995) PCSE yöntem bulguları Tablo 3'ün dördüncü sütununda sunulmuştur. Prais-Winsten regresyon sonuçları da Orta Asya ülkelerinde ters-U biçimindeki EKC'nin varlığını kanıtlamaktadır. Elde edilen bu bulgu \$1693 kişi başına gelir eşik düzeyinden sonra gelir artmaya devam ederken çevre kirliliğinin yavaş yavaş azalacağını göstermektedir. Prais-Winsten regresyon ile elde edilen parametre tahminleri nüfus yoğunluğu dışında sabit etkiler modeli ile elde edilen katsayılardan daha yüksek bulunmuştur. Modelin belirlilik katsayısı $\% 88$ ve Wald istatistiği (sd 7, 2507.76(0,000)) anlamlidır.

\section{Sonuç}

Tüm ülkelerin ekonomik büyüme ve çevresel düzenlemelere karşı farklı yaklaşımları olmakla birlikte, birçok çalışma birbirleriyle çelişen çok farklı sonuçlar bulmuşlardır. Bazı çalışmalar $\mathrm{CO}_{2}$ emisyonları için EKC'nin varlı̆̆ı üzerine hemfikir olurken, diğer çalışmalar ise $\mathrm{CO}_{2}$ emisyonları için EKC'nin gerçekten varlığı ya da ekonometrinin yapay bir oluşumu olup olmadığını araştırmışlardır. Bu çalışma da Orta Asya ülkeleri için $\mathrm{CO}_{2}$ emisyonları, ekonomik kalkınma, enerji kullanımı, nüfus yoğunluğu, şehirleşme, ticari açıklık ve finansal açıklık arasındaki ilişkiyi 1992-2013 dönemi için panel veri analizi ile yeniden test etmiştir. 
Bu çalışmanın ampirik analiz sonuçları, sabit etkiler modeli, dirençli standart hatalar ve Prais-Winsten regresyon modelinde ters-U biçimindeki EKC'nin varlığına işaret etmektedir. Prais-Winsten regresyon sonuçları, çevre kirliliğinin ekonomik büyümeyle birlikte diğer iki model sonuçlarına göre daha hızlı artacağını göstermektedir. Bununla birlikte, kirliliğin azalmaya geçmesi için düşünülen eşik düzeyi sabit etkiler modelinden oldukça düşük düzeyde gerçekleşmektedir.

$\mathrm{Bu}$ çalışmanın ampirik analizleri, genel olarak finansal gelişmenin yüksek düzeyde Ar-Ge içeren yabancı yatırımları cazip kılma yoluyla çevreye verilen zararın azaltılabileceğine işaret etmektedir. Ayrıca, enerji tüketiminin emisyonları artıracağına dair güçlü kanıtlar elde edilmiştir. Orta Asya ülkeleri, enerjiye bağımlı ülkeler olup ekonomik büyümelerini artırabilmek için daha fala enerji talep eder karakterdedirler. Orta Asya ülkelerindeki politika yapıcıların insanları kendi araçlarını kullanmaktan ziyade toplu taşım araçlarını kullanmaya teşvik etmeleri emisyonların azalmasına etki edecektir. Benzer şekilde, metropolitan alanlarda yerleşim alanlarının çok uzaklarına yeni işyerlerinin inşa edilmesi sonucu insanlar yürüme/bisiklet ile ulaşımı bırakıp özel araç kullanımı artacağından dolayı şehir planlamalarını gözden geçirmeleri emisyonların azaltılması açısından faydalı olacaktır.

\section{Kaynakça}

- Antle J.M. ve Heidebrink G., 1995. "Environment and development: theory and international evidence". Economic Development and Cultural Changes 43, p. 603-625.

- Birdsall N. ve Wheeler D., 1993. "Trade policy and industrial pollution in Latin America: Where are the pollution havens?" Journal of Environment and Development 2, p. 137-149.

- Chinn M. D. ve Hiro I., 2006. "What Matters for Financial Development? Capital Controls, Institutions, and Interactions”. Journal of Development Economics 81(1), p. 163-192.

- Cole M.A. ve Elliot R.J.R., 2005. "FDI and the capital intensity of "dirty" sectors: a missing piece of the pollution haven puzzle". Review of Development Economics 9(4), p. 530-548.

- Cole, M.A., ve Neumayer, E. 2004. Examining the impact of demographic factors on air pollution. Population and Environment, 26(1), 5-21.

- Beck N. ve Katz J.N. 1995 "What to Do (and Not to Do) with Time Series Cross Section Data", American Political Science Review, 89, 634-647.

- Dasgupta S., Hong J.H., Laplante B., Mamingi N., 2004. "Disclosure of environmental violations and stock market in the Republic of Korea". Ecological Economics 58(4), p. 759-777.

- Diwan I. ve Shafik N., 1992. "Investment, technology and the global environment: towards international agreement in a world of disparities". In: Low, P. (Ed.), International Trade and the Environment. World Bank, Washington, DC.

- $\quad$ Feridun M., 2006. "Impact of trade liberalization on the environment in developing countries: the case of Nigeria”, MPRA Paper no. 731.

- Ferrantino M.J., 1997. "International trade, environmental quality and public policy”. The World Economy 20, p. 43-72.

- Goldemberg J., 1998. "Viewpoint: leapfrog energy technologies”. Energy Policy 26(10), p. 729-741.

- Hitam M.B. ve Borhan H.B., 2012. "FDI, Growth and the Environment: Impact on Quality of Life in Malaysia". Procedia - Social and Behavioral Sciences 50, p. 333-342.

- Holtz-Eakin D. ve Selden T.M., 1995. "Stoking the fires? CO2 emissions and economic growth". Journal of Public Economics 57, p. 85-101.

- Kiesel K., 2006. "International Economics and the Environmental Kuznets Curve”. EEP 101/ECON 125. Retrieved 2012, from http://are.berkeley.edu/ kiesel/section\%2011.pdf.

- $\quad$ Liang G., 2006. "International business and industry life cycle: theory, empirical evidence and policy implications". Paper accepted for presentation at the Annual Conference on Corporate Strategy, Berlin, 1920 May.

- List J.A. ve Co C.Y., 2000. "The effect of environmental regulation on foreign direct investment”. Journal of Environmental Economics and Management 40, p. 1-40.

- Lopez R., 1994. "The Environment as a Factor of Production: The Effects of Economic Growth and Trade Liberalization”. Journal of Environmental Economics and Management 27, p.163-84.

- McConnell K.E., 1997. "Income and the Demand for Environmental Quality. Environment and Development Economics”, 2(4), p. 383-400.

- Meadows D.H., Meadows D.L., Randers J., Behrens W., 1992. The Limits to Growth. Universe Books, New York. 
- Panayotou T., 1993. "Empirical tests and policy analysis of environmental degradation at different stages of economic development”. World Employment Programme Research, Working Paper, 238.

- Panayotou T., 1997. "Demystifying the environmental Kuznets curve: turning a black box into a policy tool". Environment and Development Economics 2, p. 465-484.

- Rafia A., Mohd N.H., Noor A.I., 2003. "Review of air pollution and health impacts in Malaysia". Environmental Research 92(2), p. 71-77.

- $\quad$ Selden T.M. ve Song, D., 1994. "Environmental quality and development: is there a Kuznets curve for air pollution emission?” Journal of Environmental Economics and Management 27, p. 147-162.

- $\quad$ Shafik N. ve Bandyopadhyay S., 1992. "Economic Growth and Environmental Quality: Time-Series and Cross-Country Evidence". Background Paper for World Development Report 1992. World Bank, Washington, DC.

- Shafik, N.T., 1994. "Economic development and environmental quality: an econometric analysis". Oxford Economic Papers 46, p. 757-773.

- Sharma S., 2011.Determinants of carbon dioxide emissions: empirical evidence from 69 countries. Applied Energy 88, 376-382.

- Soysa I. ve Neumayer E., 2004. "False Prophet, or genuine Savior? Assessing the effects of economic openness on sustainable development, 1980-1999”. International Trade 0409001, EconWPA, 13 October.

- Stern D., 2004. "The Rise and Fall of the Environmental Kuznets Curve”, World Development, 32(8), p. 14191439.

- $\quad$ Suri V. ve Chapman D., 1998. "Economic growth, trade and the environment: Implications for the environmental Kuznets curve". Ecological Economics 25, p. 195-208.

- Tamazian A., Chousa J.P, Vadlamannati K.C., 2009. "Does higher economic and financial development lead to environmental degradation: Evidence from BRIC countries”. Energy Policy 37, p. 246-253.

- $\quad$ Taskin F. ve O. Zaim, 2000. "Searching for a Kuznets Curve in Environmental Efficiency, Using Kernel Estimation”, Economics Letters 68, 217-223. 


\title{
Girdi-Çıktı Analizi Yaklaşımıyla Kırgızistan Ekonomisinde Ekonomik Büyümenin Kaynaklarının Belirlenmesi The Determination of the Sources of Economic Growth in Kyrgyzstan by the using of Input-Output Analysis
}

\author{
Assoc. Prof. Dr. Tuncer Özdil (Celal Bayar University, Turkey) \\ Asst. Prof. Dr. Aynura Turdalieva (Kyrgyzstan-Turkey Manas University, Kyrgyzstan)
}

\begin{abstract}
The input - output analysis reflects the production-consumption relationship between the economic production sector in a country's economy and widely applied as an analytical technique of economic analysis in both developed and developing countries. At the same time, this technique is the macroeconomic analysis tool for identifying sectoral economic relations in the industry by production and consumption dimensions. For this study, input-output tables for Kyrgyzstan for the period of 2005-2013 were used. Tables consist of the same content and number of sectors and the sources of economic growth for the given period was calculated by Syrquin Decomposition model. Syrquin Model is a demand-side approach, which decomposes economic growth into four main sources: domestic demand expansion, export expansion, import substitution and technological change. Also, the study investigates the source of production increase occurred in any economic production sectors. Within this framework, the results will be obtained for aggregated main 8 sectors and whole the economy. Admittedly, the results will give insight into the effectiveness of macroeconomic policies implemented in Kyrgyzstan. This aspect of the research results is expected to contribute to the creation of a more rational economic policy.
\end{abstract}

\section{Giriş}

Bir ekonomide sektörel üretim artışlarının kaynaklarının belirlenmesi hem geçmiște uygulanan iktisadi politikaların etkinliğinin değerlendirilmesi hem de gelecekte uygulanacak makroekonomik politikaların daha rasyonel şekillendirilmesi bakımından büyük önem taşımaktadır. Bunun yanısıra bu analiz; ekonomide yapısal dönüşüme neden olan endüstrilerin belirlenmesine yolaçarak kaynakların daha rasyonel kullanımına da imkan vermekte bu yolla ekonomik sorunların çözümüne de katkı sağlamaktadır.

Çalışmamızda, Girdi-Çıktı Analizi yaklaşımıyla Kırgızistan ekonomisindeki ekonomik büyümenin kaynakları araştırılmaktadır. Sözkonusu araştırma; sektör sayısı ve kapsam bakımından birbirinin aynı, yayınlanmış son tablolar olan 2005-2013 yılı girdi-çıktı tabloları yardımıyla Syrquin yapısal ayrıştırma modeli kullanılarak yapılmıştır. Talep yönlü bir yaklaşım olan Syrquin Yapısal Ayrıştırma Modeli, ekonomik büyümeyi dört ana kaynağa ayrıştırmaktadır. Bunlar; yurt içi nihai talep, ihracat, ithal ikamesi ve girdi katsayılarındaki değişmeyle tanımlanan teknolojik gelişmedir. Burada herhangi bir ekonomik üretim sektöründe meydana gelen üretim artışının ne kadarının hangi kaynaktan kaynaklandığı araştırılmaktadır.

Makroekonomik anlamda elde edilen verilerin daha kolay yorumlanarak daha çarpıcı sonuçların elde edilebilmesi bakımından ayrıştırma işlemi sekiz ana sektör üzerinden yapılmıştır. Bu nedenle Kırgızistan ekonomisine ait olan girdi-çıktı sonuç tabloları sekiz ana sektör üzerinden toplulaştırılarak dönem içinde bu sektörlerdeki üretim artışlarının kaynakları belirlenmiştir. Araştırmayla ulaşılan sonuçların Kırgızistan'da uygulanan makro-ekonomik politikaların etkinliği hakkında fikir vereceği ve bu yönüyle daha rasyonel ekonomik politikaların oluşturulmasına katkı sağlayacağı düşünülmektedir.

\section{Genel Olarak Kırgizistan Ekonomisi}

1991 yılında bağımsızlığını kazanarak eski Sovyetler Birliği’nden ayrılan Kırgızistan Cumhuriyeti, günümüze kadar geçen yaklaşık 25 yıllık süreçte bağımsızlığını koruyarak kendi ayakları üzerinde durabilecek şekilde sağlam bir ekonomik yapı oluşturma çabası içinde olmuştur. Bu süreçte, ayrılan Türk cumhuriyetleri arasındaki ekonomik ve doğal kaynakların dağılımı bakımından ortaya çıkan ekonomik bağımlılığın yanısıra Dünya ekonomisinde yaşanan küresel krizler ve Kırgızistan'ın kendi iç politik ve toplumsal çalkantıları bu çabaları ve ekonomik gelişmeyi doğrudan olumsuz yönde etkileyen temel unsurlar olmuştur. Kırgızistan'da 2005 ve 2010 yıllarında yaşanan yönetim değişikliğiyle sonuçlanan siyasal olaylar, ekonomik politikaların uygulanmasındaki deneyimsizlikler ve ülkenin kendi finansal kaynaklarının yetersizliğinin yanısıra Dünya ekonomisinde yaşanan 2008 ve 2012 ekonomik küresel krizlerin etkileri Kırgızistan ekonomisinin gelişmesini olumsuz yönde etkilemiştir. 


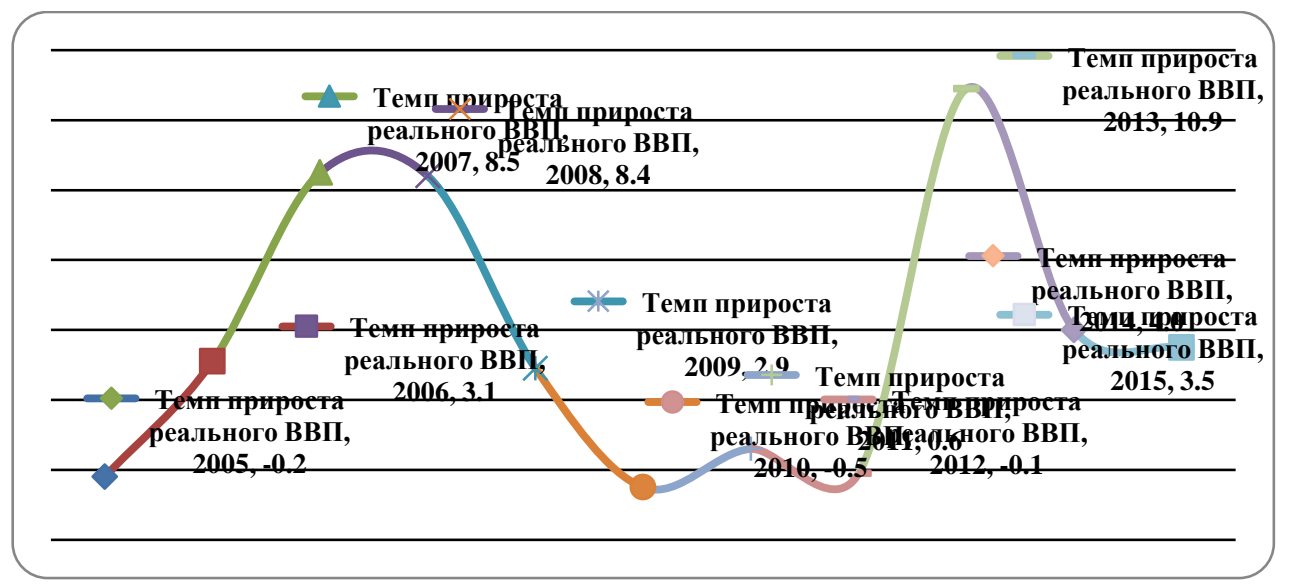

Grafik 1. 2005-2013 Dönemi Kırgızistan Ekonomik Büyüme (GSYIH) Hhızı (\%Pay). Kaynak: Kırgızistan Milli Istatistik Komitesi, www.stat.kg

Son 10 yıllık dönemde Kırgızistan ekonomisinin büyüme hızı incelendiğinde, yukarıda da kısaca açıklanan nedenlerle oldukça istikrarsız bir yapının ortaya çıktı̆̆ı görülmektedir. Dönem içerisinde2007 ve 2008 yıllarında $\% 8,5$ ve $\% 8,4$ büyüme oranlarına ulaşılırken 2013 yılında en yüksek $\% 10,9$ 'luk büyüme oranına ulaşılmaktadır. 2010 ve 2012 yllarında ise daha çok içeride yaşanan toplumsal huzursuzluklar nedeniyle $\% 0,5$ ve $\% 0,1$ 'lik negatif büyüme oranları yani küçülmeler ortaya çıkmıştır. Bu süreç genel olarak içsel ve dışsal nedenlerden dolayı ekonomik istikrarın sağlanamadığı kırılgan bir ekonomik yapıyı ortaya koymaktadır (Grafik 1).

Milli gelirin (GSYIH) sektörel dağılımına bakıldığında, 2005-13 döneminde milli gelirdeki payı en yüksek sektör hizmet sektörü olmaktadır. 2005 'te milli gelirde hizmet sektörünün payı $\% 41 \mathrm{iken}, 2013$ 'te ise bu pay \% 50 'ye çıkmaktadır. İkinci sıradaki sektör tarım sektörüdür. 2005'te tarımın payı \% 28,4 iken 2013 'te bu pay azalarak \% 14'e gerilemiştir. Üçüncü sırada ise sanayi sektörü yeralmaktadır. 2005 yılında sanayi sektörünün payı $\% 17$ iken, 2013’te tarımda olduğu gibi azalarak \%15,3'e gerilemiştir .(www.stat.kg)

Aynı dönemde Kırgızistan ihracatının sektörel dağılımı incelendiğinde, 2012 yılında ihracat payı en yüksek sektör $\% 38,5$ oranıyla Ana metal-metal eşyalar sektörüdür. Bunu $\% 14,4$ payla madencilik izlemektedir. Ardından $\% 13,4$ ve \%13,1'lik paylarla gıda ve tekstil ürünleri gelmektedir. İthalatın sektörel dağılımı incelendiğinde ise, 2012 yılında ithalat payı en yükssek sektör \% 24,3'lük payla makine, teçhizat ve ulaşım araçları sektörüdür. İkinci sırada \% 22,2 oranıyla madencilik yeralmaktadır. Üçüncü sırada ise, \%17 oranıyla gıda bulunmaktadır. Bu sonuçlara göre, tüm geçiş ekonomilerinde olduğu gibi, Kırgızistan da demir-çelik, altın gibi madenlerle gıda ve tekstil gibi ürünleri hammadde olarak ihraç edip karşıllğında makine, ulaşım araçları gibi katma değeri yüksek ürünleri ithal eden ülke konumunda yer almaktadır.

Tüm makroekonomik verilerin genel değerlendirilmesiyle Kırgızistan ekonomisinin üretim imkanları hem fiziksel olarak hem de teknik yönden zayıf, katma değeri yüksek ürünler üretemeyen daha çok hammadde ihracına dayalı, iç ve dış talebin şekillendirdiği kırılgan ekonomik yapıya sahip bir ekonomi olduğunu söyleyebiliriz. Dönem içinde milli gelirdeki, hizmet sektörü payının belirgin olarak artması buna paralel hem tarım hem de sanayi sektörlerinin paylarının azalması böyle bir sonucu desteklemektedir. Böyle olunca tüm ülkeler için olduğu gibi Kırgızistan için de, daha etkin ekonomik politikaların oluşturulması ve makroekonomik planlama mutlaka olması gereken temel öncelikler arasında yeralmaktadır.

Son 25 yıllık dönemde Merkezden planlı ekonomiden serbest piyasa ekonomisine geçişin sıkıntılarını yaşayan Kırgızistan'da piyasa ekonomisinin temel kurumlarını oluşturmaya yönelik serbest piyasa ekonomisine dayalı makro-ekonomik politikalar uygulanmaktadır. Son dönemlerde bu temel felsefeden vazgeçilmemekle birlikte daha çok ekonomik istikrar ve sosyal devlet ilkelerinin ağılıkta olduğu ekonomik politika anlayışına kayış sözkonusudur. Bu kapsamda 2013-17 dönemini kapsayan “Kırgızistan Cumhuriyeti’nin Sürekli Kalkınma Stratejisi” başlıklı stratejik ekonomik kalkınma planında sürekli büyüme stratejisini benimsemiş, çevreye duyarlı, doğal kaynakları koruyan, altyapıyı geliştirerek ekonomik kaynakların rasyonel dağılımına önem veren, gelir dağılımındaki dengesizlikleri gidermeye yönelik sosyal devlet ilkesini ön plana çıkaran ekonomik plan ve politikaların uygulanmasına çalışılmaktadır. Bu kapsamda Kırgızistan ekonomisinde, ekonomik büyümenin kaynaklarının belirlenerek daha etkin makroekonomik politikaların hazırlanması çok daha önemli hale gelmektedir.

\section{Girdi-Çıktı Analizi Yaklaşımıyla Ekonomik Büyümenin Kaynakları}

Bir ekonomide sektörel üretim artışlarının kaynaklarının belirlenmesinde girdi-çıktı modelleri çerçevesinde farklı teknikler kullanılmaktadır. Girdi-çıktı modelleri çerçevesinde büyümenin kaynaklarının belirlenmesinde en sık kullanılan yöntemlerin başında ayrıştırma (decomposition) çözümlemesi gelmektedir. Ayrıştırma tekniğinin 
değişik şekilleri olmakla birlikte, sektörel üretim düzeylerindeki değişmeler genellikle dört unsurun etkisine ayrıştırılır: (1) yurtiçi nihai talepteki değişmelerin etkisi, (2) ihracat talebindeki değişmenin etkisi, (3) ithal ikamesinin etkisi ve (4) teknolojik değişmenin etkisi. İthal ikamesinin ölçülmesindeki farklılıklara bağlı olarak, değişik ayrıştırma modelleri elde edilebilmektedir (Aydoğuş, 2010, s.144).

$\mathrm{Bu}$ tür ayrıştırma çalışmalarında M.Syrquin tarafından geliştirilen ayrıştırma modeli kullanılmaktadır. Söz konusu modelin iki versiyonu bulunmaktadır. Birincisi, sapmalar versiyonu, ikincisi de toplam paylar versiyonu olmaktadır. Bu çalışmada toplam paylar yöntemi kullanılmaktadır. Bu yöntemin hareket noktası açık ekonomi için temel Leontief Girdi-çıktı modelinin denge üretim denklemleridir. i sektörü için denge üretim denklemi,

$$
X_{i}=d_{i}\left(V_{i}+Y_{i}\right)+E_{i}
$$

(1) numaralı denklemde, $X_{i}$ - i sektörünün yurtiçi üretimi, $d_{i}$ - i sektörünün aragirdi talebi, $V_{i}$ - yurtiçi nihai talep ve $E_{i}$ - ihracat talebini göstermektedir. $d_{i}$ katsayısı ithal ikame etkisini ölçmek için geliştirilmiştir,

$$
d_{i}=\left(X_{i}-E_{i}\right) /\left(V_{i}+Y_{i}\right)
$$

(2) numaralı denklemde paydadaki terim i malına olan toplam yurtiçi talebi, paydaki terim ise yurtiçi üretime olan yurtiçi talebi göstermektedir. $d_{i}$ katsayısının paydasındaki terim net arzı;

$$
\left(\mathrm{V}_{\mathrm{i}}+\mathrm{Y}_{\mathrm{i}}=\mathrm{X}_{\mathrm{i}}+\mathrm{M}_{\mathrm{i}}-\mathrm{E}_{\mathrm{i}}\right)
$$

göstermektedir. Dolayısıyla, i malı ithalatındaki bir artış, paydanın büyümesine ve böylece $\mathrm{d}_{\mathrm{i}}$ katsayısının küçülmesine yol açacaktır. Buna bağlı olarak, pozitif ithal ikamesi olduğunda katsayı büyüyecektir ya da tersi. $d_{i}$ katsayıları bu anlamda yurtiçi arz katsayıları olarak yorumlanabilir (Aydoğuş, 2010, s.145). Bu sistem matris notasyonu ile yeniden yazılır ve yurtiçi üretim vektörü $\left(\mathrm{X}_{\mathrm{i}}\right)$ için çözülürse, denge çözüm denklemi,

$$
X=(I-D A)^{-1}(D Y+E)
$$

(3) numaralı denklemde D anaköşegen üzerindeki elemanları $d_{i}$ katsayılarından oluşan bir köşegen matristir.

(3) denkleminden $\mathrm{R}=(\mathrm{I}-\mathrm{DA})^{-1}$ kısaltması yapılır ve denklemin birinci farkı alınırsa,

$$
\begin{gathered}
\Delta X=R(t) D(t) \Delta Y+R(t) \Delta E+ \\
R(t) \Delta D[Y(t+1)+V(t+1)]+R(t) D(t) \Delta A X(t)
\end{gathered}
$$

(4) numaralı denklemde gösterildiği gibi, fark denklemi elde edilir, burada $\Delta$ simgesi ilgili değişkende $\mathrm{t}$ dönemi ile $(\mathrm{t}+1)$ dönemi arasında ortaya çıkan değişmeyi göstermektedir(Aydoğuş, 2010, s.146). Temel ayrıştırma denkleminin sol yanındaki terim, ele alınan dönemde sektörel üretimde ortaya çıkan değişmeleri; sağ yanındaki $R(t) D(t) \Delta Y$ - sektörel üretimlerdeki değişmelerin yurtiçi nihai taleplerde ilgili dönemde ortaya çıkan değişmelerden, $R(t) \Delta E$ - ihracat değişmelerinden, $R(t) \Delta D[Y(t+1)+V(t+1)]$ - ithal ikamesinden, $R(t) D(t) \Delta A X(t)$ girdi katsayılarındaki değişmelerden kaynaklanan kısımlarını, değerlerini vermektedir. Denklemin her iki yanındaki terimler $\Delta \mathrm{X}_{\mathrm{i}}$ 'e bölündüğünde, üretim değişmelerinin kaynakları göreli olarak elde edilmiş olacaktır (Aydoğuş, 2010, s. 146).

Burada elde edilen (4) no’lu temel ayrıştırma denklemi bazı özelliklere sahiptir. Bunlar; ekonominin iki ayrı dönemdeki denge durumları karşılaştırıldığı için analiz karşılaştırmalı-durağan niteliktedir. Sektörel üretimlerdeki değişmeler tamamen talep unsurlarındaki değişmelere bağlandığından arz yönü dikkate alınmamaktadır. Büyümenin yani kaynakların üretimdeki değişmelere katkıları, tüm terimler başlangıç yılı üretim değerlerine bölünmek suretiyle oransal (toplamdaki pay) olarak bulunabilmektedir. İthal ikamesinin katkısı, yurtiçi talep katsayılarındaki değişme ile ifade edilmektedir. Son olarak, tüm durağan girdi-çıktı analizlerinde olduğu gibi, burada da teknolojik değişme çok dar bir biçimde girdi katsayılarındaki değişim olarak tanımlanmaktadır. Bu nedenle bulguların ihtiyatlı yorumlanması yerinde olacaktır (Çalışkan, Aydoğuş, 2011, s. 501.).

\section{Kırgızistan Ekonomisi’nde Sektörel Büyümenin Kaynakları}

Kırgızistan ekonomisinde sektörel büyümenin kaynaklarının araştırılmasında Kırgızistan İstatistik Komitesi tarafından hazırlanan girdi-çıktı sonuç tabloları kullanılmıştır. Analizde 2005 ve en son yayınlanan tablo olan 2013 yıllarına ait girdi-çıktı sonuç tabloları kullanılmıştır. Her iki tablo da 34 ekonomik üretim sektöründen oluşmakta, kapsam ve içerik bakımından kesinlikle hesaplama sonuçlarını etkilemeyen çok küçük bir ayrıntı dışında aynı özelliklere sahiptirler. Söz konusu farklılık tarım sektöründeki alt sektörlerin 2005 ve 2013 yılı tablolarında farklı yerlerde gösterilmesinden kaynaklanmaktadır. 2005 yılı tablosunda balıkçılık sektörü ayrı bir alt sektör, kömür madenciliği ise petrol ve doğal gaz çıkarımı alt sektörü içinde gösterilirken, 2013 yılı tablosunda Balıkçılık alt sektörü Tarım ve Ormancılık sektörü içine katılmış, kömür çıkarımı ise petrol ve doğal gaz alt sektöründen ayrılmıştır (Tablo 1). Toplulaştırma işleminde tüm bu alt sektörler tarım ve madencilik ana sektörlerinde toplandığından bu değişiklik hesaplama sonuçlarını etkilememektedir. Daha çarpıcı güvenilir sonuçların elde edilebilmesi için söz konusu tablolar sekiz ana sektör üzerinden toplulaştırılmıştır. Toplulaştırma işleminde kullanılan çevrim anahtarı Tablo 1'de gösterilmektedir. 


\begin{tabular}{|c|c|c|c|c|c|c|}
\hline $\begin{array}{l}\text { Sira } \\
\text { No }\end{array}$ & $\begin{array}{l}2005 \text { Y1lı Ekonomik } \\
\text { Üretim Sektörleri }\end{array}$ & $\begin{array}{l}\text { Sira } \\
\text { No }\end{array}$ & $\begin{array}{l}\text { Sira } \\
\text { No }\end{array}$ & $\begin{array}{l}2013 \text { Y1lı Ekonomik Üretim } \\
\text { Sektörleri }\end{array}$ & $\begin{array}{l}\text { Sira } \\
\text { No }\end{array}$ & $\begin{array}{l}\text { Toplulaştırma } \\
\text { sonrası Ekonomik } \\
\text { Üretim Sektörleri }\end{array}$ \\
\hline 01 & Tarım-avcılık-orm. & \multirow{2}{*}{01} & 1 & Tarım-orm. balıkçılık & 01 & Tarım \\
\hline 02 & Balıkçılık & & 2 & Kömür-linyit madencilik. & \multirow{4}{*}{02} & \multirow{4}{*}{ Madencilik } \\
\hline 03 & Kömür-petrol-doğal g. & \multirow{3}{*}{02} & 3 & Petrol-doğal gaz & & \\
\hline 04 & Metal cev. Madenciliği & & 4 & Metal cev. Madenciliği & & \\
\hline 05 & Diğer madencilik & & 5 & Diğer madencilik & & \\
\hline 06 & Gida & \multirow{2}{*}{03} & 6 & Gida & \multirow{2}{*}{03} & \multirow{2}{*}{$\begin{array}{l}\text { Tüketim malı } \\
\text { üreten sanayiler }\end{array}$} \\
\hline 07 & Tekstil & & 7 & Tekstil & & \\
\hline 08 & Ağaç(mob. hariç) ürünleri & \multirow{5}{*}{04} & 8 & Ağaç(mob.hariç) ürünleri & \multirow{5}{*}{04} & \multirow{5}{*}{$\begin{array}{l}\text { Ara malı üreten } \\
\text { sanayiler }\end{array}$} \\
\hline 09 & Basım ve yayıncılık & & 9 & Basım yayıncılık & & \\
\hline 10 & Kok köm.-petrol ür. & & 10 & Kok köm.-petrol ür. & & \\
\hline 11 & Plastik ve kauçuk ür. & & 11 & Plastik ve kauçuk ür. & & \\
\hline 12 & Ana metal üretimi & & 12 & Ana metal üretimi & & \\
\hline 13 & Metal ürünleri imalat1 & \multirow{3}{*}{05} & 13 & Metal ürünleri imalat1 & \multirow{3}{*}{05} & \multirow{3}{*}{$\begin{array}{l}\text { Yatırım malı } \\
\text { üreten sanayiler }\end{array}$} \\
\hline 14 & Bilgisayar, elektronik & & 14 & Bilgisayar, elektronik & & \\
\hline 15 & Diğ. Mak.-ekipman & & 15 & Diğ. Mak.-ekipman & & \\
\hline 16 & Elektrik üretimi & \multirow{4}{*}{06} & 16 & Elektrik üretimi & \multirow{4}{*}{06} & \multirow{4}{*}{ Enerji } \\
\hline 17 & Gaz üretim-dağıt. & & 17 & Gaz üretim-dağıt. & & \\
\hline 18 & Buhar- iklimlendirme & & 18 & Buhar- iklimlendirme & & \\
\hline 19 & Su temini ve arıtma & & 19 & Su temini ve aritma & & \\
\hline 20 & İnşaat & 07 & 20 & İnşaat & 07 & İnşaat \\
\hline 21 & Toptan ticaret & \multirow{14}{*}{08} & 21 & Toptan ticaret & \multirow{14}{*}{08} & \multirow{14}{*}{ Hizmetler } \\
\hline 22 & Perakende ticaret, & & 22 & Perakende ticaret, & & \\
\hline 23 & Mot. Taş.bakım-on. & & 23 & Mot. Taş.bakım-on. & & \\
\hline 24 & Otel ve restoranlar & & 24 & Otel ve restoranlar & & \\
\hline 25 & Taşıma depolama & & 25 & Taşıma depolama & & \\
\hline 26 & Bilgi ve iletişim & & 26 & Bilgi ve iletişim & & \\
\hline 27 & Finansal aracıl1k-Sig. & & 27 & Finansal aracılık-Sig. & & \\
\hline 28 & Gayrimenkul-idari faaliyeti & & 28 & Gayrimenkul-idari faaliyeti & & \\
\hline 29 & Kamu yön.-savunma & & 29 & Kamu yön.-savunma & & \\
\hline 30 & Eğitim & & 30 & Eğitim & & \\
\hline 31 & Sağlık & & 31 & Sağlık & & \\
\hline 32 & Sanat, eğlence & & 32 & Sanat, eğlence & & \\
\hline 33 & Toplumsal kurum. faaliyeti & & 33 & Toplumsal kurum. faaliyeti & & \\
\hline 34 & Diğer hizmet faaliyeti & & 34 & Diğer hizmet faaliyeti & & \\
\hline
\end{tabular}

Tablo 1: Sektörel Toplulaştırma Anahtarı Kaynak: K.C. Istatistik Komitesi 2005 ve 2013 Yılı Girdi-Çıktı Sonuç Tabloları Kullanılarak Toplulaştırılmıştır.

Sekiz sektöre göre toplulaştırılan tablolar yardımıyla 2005-2013 dönemi için Kırgızistan ekonomisinde gerçekleşen ekonomik büyümenin kaynakları belirlenmeye çalışılmıştır. Burada karşılaştırma temel dönemi olarak 2005 y1lı seçilmiş 2013 yılı değerleri 2005 yılı değerleriyle karşılaştırılmıştır. Bu amaçla (4) no'lu denklemde belirtilen 2005 y1lı için teknik katsayılar matrisi, ithal ikamesinin etkisini ölçmeye yönelik $\mathrm{d}_{\mathrm{i}}$ köşegen matrisleri oluşturulmuş, bu matrisler dönem içinde gerçekleşen yurtiçi nihai talep, ihracat, toplam yurtiçi talep ve üretim fark vektörleriyle işleme alınarak dönem içinde gerçekleşen sektörel üretim artışlarının ne kadarının hangi unsurdan (nihai talep, ihracat, ithal ikamesi ve teknik katsayılardaki değişim unsurlarından) kaynaklandığı sektörel üretim artışlarının yüzdesi olarak hesaplanmıştır. Hesaplamalar sonucu elde edilen üretim farklarıyla girdi-çıktı sonuç tablolarından elde edilen farklar tamamen birbirine eşit çıkmıştır (Ek-1). Bu da bize seçilen baz dönemden ve yuvarlamalardan kaynaklanabilecek hesaplama hatalarının olmadığını göstermektedir. Elde edilen sonuçlar Tablo 2'de verilmektedir. 


\begin{tabular}{|l|c|c|c|c|c|c|}
\hline $\begin{array}{l}\text { Ekonomik } \\
\text { Üretim Sektörleri }\end{array}$ & $\begin{array}{c}\text { Üretim artış } \\
\text { hızı }\end{array}$ & Yurtiçi talep payı & $\begin{array}{c}\text { İhracat } \\
\text { artış payı }\end{array}$ & $\begin{array}{c}\text { İthal ikamesi } \\
\text { pay1 }\end{array}$ & $\begin{array}{c}\text { Teknolojik } \\
\text { değişme payı }\end{array}$ & Toplam \\
\hline Toplam & 252,81 & 84,41 & 32,74 & $-26,15$ & 9,01 & 100 \\
\hline Tarım & 170,89 & 99,62 & 42,96 & $-94,87$ & 52,29 & 100 \\
\hline Madencilik & 493,42 & 41,40 & 40,78 & 58,18 & 40,36 & 100 \\
\hline Genellikle Tük.Malı Ür. S. & 152,78 & 134,89 & 36,23 & $-87,47$ & 16,35 & 100 \\
\hline Genellikle. Aramalı Ür.S. & 200,71 & 73,19 & 55,72 & $-13,72$ & $-15,19$ & 100 \\
\hline Genellikle Yat.Malı Ür. S. & 308,92 & 22,74 & 54,20 & 6,41 & 16,66 & 100 \\
\hline Enerji & 97,33 & 233,98 & 53,66 & $-54,45$ & $-133,19$ & 100 \\
\hline İnşaat & 593,49 & 83,74 & 12,05 & 5,76 & $-1,55$ & 100 \\
\hline Hizmetler & 299,70 & 87,31 & 23,66 & $-6,61$ & $-4,36$ & 100 \\
\hline
\end{tabular}

Tablo 2. Sektörel Üretim Artışlarının Kaynakları (\%Pay, 2005-2013). Kaynak: K. C. İstatistik Komitesi 2005 ve 2013 Yılı Girdi-Çıktı Sonuç Tabloları Kullanılarak Hesaplanmıştır.

Dönem içerisinde Kırgızistan ekonomisi için genel ve sektörel büyüme oranlarına baktığımızda, 2013 yılında 2005 yılına göre Kırgızistan ekonomisi 2,52 kat büyümüştür. Bu büyüme değerlerini alt sektörler bazında incelediğimizde en çok büyümenin 5,93 kat ile inşaat sektöründe olduğunu bunu 4,93 katla madencilik sektörünün izlediğini görmekteyiz. Dönem içinde en az büyüme 0,97 katla enerji sektöründe oluşmuştur. Ekonomideki bu büyüme hızının kaynaklarına baktığımızda genel olarak, \%84,41 oranla yurtiçi talep artışının birinci sırada yer aldığını görüyoruz. Yani ekonomik büyümenin en önemli kaynağı dönem içinde gerçekleşen nihai talep artışı olmaktadır. Bu sonuç üretim imkanlarının kısıtlı olduğu daha çok talep yönlü bir ekonominin bulunduğu Kırgızistan için beklentilerle uyumlu çıkmıştır. Bunu \%32,74 ile ihracat artışları izlemektedir. İthal ikamesinin ise negatif etkisi söz konusudur. Yani dönem içinde ithalata bağımlılı̆̆ın daha da arttığı yurtiçi arz katsayılarına göre yapılan değerlendirmede yurtiçi girdi kullanımının yerini ithal girdiye bıraktığı sonucu ortaya çıkmaktadır. Teknik katsayılardaki değişimin payı ise \% $\%, 01$ ile düşük payda kalmakla birlikte dönem içinde teknolojik ilerleme yönlü girdi kullanım oranlarının azaldığı sonucu ortaya çıkmaktadır.

Alt sektör bazında incelemeler yapıldığında ise, tüm sektörlerde yurtiçi talep artışının ve ihracatın pozitif olumlu etkiye sahip olduğunu görmekteyiz. Özellikle enerji ve tüketim malı üreten sanayilerde talep artışı kaynaklı bir ekonomik büyümenin oluştuğunu söyleyebiliriz. Ara ve yatırım malı üreten sanayilerle enerjide ise ihracatın göreli olarak daha etkili olduğunu görmekteyiz. İthal ikamesi ise, madencilik, yatırım malı üreten sanayiler ve inşaat dışındaki tüm sektörlerde negatif etkiye sahiptir. Yani bunlar dışındaki tüm sektörlerde üretimde ithal girdi kullanımının arttığını söyleyebiliriz. Teknolojik gelişme paylı büyümenin en çok \%52,59 oranıyla tarımda gerçekleştiğini görüyoruz. Bunun dışında düşük paylarla olmakla birlikte tüketim ve yatırım malı üreten sanayilerde pozitif etkinin olduğunu yani bu sektörlerde katsayıların verimliliği arttıracak şekilde değiştiğini söyleyebiliriz. Bunlar dışındaki tüm alt sektörlerde teknik katsayılarda gerileme yönlü bir değişimin olduğunu görmekteyiz (Tablo 2).

\section{Sonuç}

Dönem içinde ekonomik büyümenin ana kaynağı yurtiçi talep genişlemesi olmuştur. Bunu ikinci sırada ihracat talebi izlemiştir. Teknolojik değişmenin katkısı ise ekonomi genelinde çok düşük kalmakla birlikte sektörel bazda çoğu sektörde negatif yönlü olmuştur. Sadece Tarım, Tüketim ve Yatırım malı üreten sanayilerde pozitif etki söz konusuyken, diğer tüm sektörlerde daha fazla girdi kullanımıyla teknolojik gerileme yönlü bir etkileşim ortaya çıkmıştır.

Genel olarak negatif ithal ikame etkisi elde edilmiştir. Yani bu durum; dönem içinde madencilik yatırım malı üreten sanayiler ve inşaat dışındaki tüm sektörlerde sektörel ara girdi ithalatının artarak dışa bağımlılığın arttığ anlamına gelmektedir. Tüketim malları sanayinde en büyük katkıyı yurtiçi piyasalardaki talep artışları sağlamıştır. İhracat talebindeki artışların ekonomik büyümeye etkisinin göreli olarak en fazla olduğu sektörler ara ve yatırım malı üreten imalat sektörleriyle enerji olmuştur.

Tüm geçiş ekonomilerinde olduğu gibi merkezden planlı ekonomiden serbest piyasa ekonomisine geçişin sıkıntılarını yaşayan Kırgızistan ekonomisi içinde dış piyasalara entegrasyon, genelde düşük katma değerli hammadde ihracına dayalı dış ticaret yapısı, tüketim ve aramalı ithalatına dayalı ekonomik yapının varlığı, katma değeri yüksek ürünlerin üretilemiyor olması, teknolojik gelişmeleri yeterince takip edememe, dışa bağımlılık gibi temel sorunlar burada elde edilen araştırma sonuçlarıyla bir kez daha desteklenmiştir (Özdil, Turdaliyeva, 2015). Bu yönüyle iç talep artışına dayalı ekonomik büyümenin yerini ihracata dayalı bir yapıya bırakması dışa açılmanın önemli olduğunu vurgulamakla birlikte dışa bağımlılık sorununun da göz ardı edilmemesi gerektiğini düşünüyoruz. 


\begin{tabular}{|l|c|c|c|c|c|c|}
\hline $\begin{array}{l}\text { Ekonomik Üretim } \\
\text { Sektörleri }\end{array}$ & $\begin{array}{c}\text { Sektörel } \\
\text { Üretim Fark1 } \\
(2005-13)\end{array}$ & $\begin{array}{c}\text { Yurtiçi talep } \\
\text { pay1 } \\
(1)\end{array}$ & $\begin{array}{c}\text { İhracat artış } \\
\text { payı } \\
(2)\end{array}$ & $\begin{array}{c}\text { İthal ikamesi } \\
\text { Payı } \\
(3)\end{array}$ & $\begin{array}{c}\text { Teknolojik } \\
\text { değişme pay1 } \\
(4)\end{array}$ & $\begin{array}{c}\text { Toplam } \\
(1+2+3+4)\end{array}$ \\
\hline Toplam & 514405,2 & 434211,014 & 168395,5 & 134540,777 & 46339,49838 & 514405,2 \\
\hline Tarım & $108.313,40$ & $107.899,89$ & $46.531,48$ & $102.758,71$ & $56.640,73$ & $108.313,40$ \\
\hline Madencilik & $4.840,90$ & $2.004,19$ & $1.974,00$ & $2.816,57$ & $-1.953,85$ & $4.840,90$ \\
\hline $\begin{array}{l}\text { Genellikle } \\
\text { Tük.Malı Ür. S. }\end{array}$ & $24.675,60$ & $33.284,87$ & $8.941,08$ & $-21.584,71$ & $4.034,36$ & $24.675,60$ \\
\hline $\begin{array}{l}\text { Genellikle. Aramalı } \\
\text { Ür.S. }\end{array}$ & $15.446,60$ & $11.305,13$ & $8.607,10$ & $-2.119,59$ & $-2.346,03$ & $15.446,60$ \\
\hline $\begin{array}{l}\text { Genellikle Yat.Mal1 } \\
\text { Ür. S. }\end{array}$ & $71.001,20$ & $16.142,34$ & $38.482,09$ & $4.548,59$ & $11.828,18$ & $71.001,20$ \\
\hline Enerji & $8.533,00$ & $19.965,17$ & $4.578,86$ & $-4.646,03$ & $11.365,00$ & $8.533,00$ \\
\hline İnşaat & $63.253,60$ & $52.969,78$ & $7.623,60$ & $3.641,56$ & $-981,34$ & $63.253,60$ \\
\hline Hizmetler & $218.340,90$ & $190.639,65$ & $51.657,24$ & $-14.438,46$ & $-9.517,53$ & $218.340,90$ \\
\hline
\end{tabular}

Ek-1: 2005-13 Dönemi Sektörel Üretim Artışlarının Kaynaklara Göre Mutlak Dă̆llımı (Temel Fiyatlarla Milyon Som.)

\section{Kaynakça}

- Aydoğuş, O., (2010), Girdi-Çıktı Modellerine Giriş, Efil Yayınevi, Ankara.

- Bocutoğlu, E. (1985). Girdi - Çıktı Analizine Giriş, Karadeniz Üniversitesi İktisadi ve İdari Bilimler Fakültesi Ders Notları, Yayın No:23, Trabzon

- Korum, U., (1963). Input Output Analizi, Sevinç Matbaası, Ankara.

- Öney, E., (1983), İktisadi Planlama, 3. Baskı, A.Ü.S.B.F. Yayın No:526, Ankara.

- Çalışkan E.T., Aydoğuş O. (2011). 'Türkiye Ekonomisinde Endüstriyel Büyümenin Kaynakları: Girdi-Çıktı Modeli ile Ampirik Bir Analiz (1985-2002)'. Ege Akademik Bakış. Cilt 11, Sayı 4, ss. 499-510.

- Özdil T., Turdaliyeva A., (2015). 'Kazakistan Ekonomisinde Ekonomik Büyümenin Kaynakları:Girdi-Çıktı Analizi Yaklaşımıyla Bir İnceleme'. Uluslararası Avrasya Ekonomileri Konferansı 2015 Bildiri Kitabı. ss. 841-845.

- Национальный Статистический Комитет Кыргызской Республики. Таблицы «Затраты-Выпуск» Кыргызской Республики за 2005 год.

- Национальный Статистический Комитет Кыргызской Республики. Таблицы «Затраты-Выпуск» Кыргызской Республики за 2013 год. www.stat.kg 


\title{
Devlet Harcamaları ve Gelirleri Arasındaki İlişkinin Test Edilmesi: Kyrgyzistan Örneği
}

\section{Testing the Relationship Between Government Spending and Revenue: Case of Kyrgyzstan}

\author{
Prof. Dr. Hakan Çetintaş (Kyrgyzstan-Turkey Manas University, Kyrgyzstan) \\ Dr. Damira Baigonushova (Kyrgyzstan-Turkey Manas University, Kyrgyzstan)
}

\begin{abstract}
Sound fiscal policy is very important to promote price stability and sustainable growth in real economy. Thus, understanding the relationship between government spending and revenue is also essential to evaluate how to address fiscal imbalances. So, the focus of this research is to investigate the relationship between government revenue and spending in Kyrgyzstan. For this purpose we have used an Autoregressive Distributed Lag (ARDL), also Variance Decomposition approach and found that this two data are cointegrated. Findings support "the taxspend hypothesis" for fiscal discipline in Kyrgyzstan over the period of 1995-2014. In other words, according to the results, increase in real government revenue results in even higher public expenditure.
\end{abstract}

\section{Giriş}

Giderek artan bütçe açıkları toplam talep, yurtiçi tasarruflar, yatırımlar gibi önemli makroekonomik büyüklükleri negatif etkilediğinden gelişmiş ya da gelişmemiş tüm ülkelerde büyük ekonomik sorun yaratabilir. Bilindiği gibi bütçe açıklarının azaltılmasının iki yolu vardır: kamu gelirlerinin artırılması ve/veya kamu harcamalarının azaltılması. Bu yollardan hangisinin izlenmesi gerektiği konusunda ise iki değişken arasındaki nedensellik yol gösterici olabilir. Bu nedenle bütçe açığı sorunu yaşayan ekonomilerde gelir ve harcama ilişkisine yönelik çok sayıda çalışma mevcuttur.

Sovyet Birliği'nin dağılımı ile bağımsızlığa kavuşan Kırgızistan’da da bütçe açığı sorunu giderek artmıştır. Diğer bağımsızlı̆̆ını kazanan ülkeler gibi Kırgızistan da bağımsızlık sonrası hemen piyasa ekonomisine geçiş süreci başlatmıştır. Geçiş süreci bir çok düzenlemeler gerektirmiş ve bu düzenlemelerde önemli masrafları beraberinde getirmiştir. Diğer taraftan GSYİH'daki hızlı düşüşler bütçe gelirlerinin azalmasına neden olmuştur. Buna bağlı olarak devletin harcamaları gelirlerine göre daha hızlı artış göstermiştir ve sürekli artan bütçe açıkları meydana gelmiştir. Bağımsızlıktan günümüze, 25 yıl geçmiş olmasına rağmen yolsuzluk, kayıt dışı ekonomi, üretim yetersizliği gibi birçok nedenden dolayı bütçe açıkları hala önemli ve giderek artan bir sorun olmaya devam etmektedir.

Kamu gelirleri ve harcamaları arasındaki nedensellik ilişkisine yönelik farklı hipotezler ortaya atılmıştır. Bunlar, "kamu gelirlerindeki artışlar kamu harcamalarını arttıracaktır" diyen vergi-harcama hipotezi (tax-spend hypothesis); "kamu harcamalarının arttırılması kamu gelirlerini arttırır" diyen harcama-vergi hipotezi (spend-tax hypothesis), "kamu harcamalarıyla gelirlerine ilişkin kararlar birbirine bağımlıdır" hipotezini savunan mali senkronizasyon (fiscal synchronization) ve "kamu harcamaları ve gelirlerinin birbirinden bağımsı" olduğunu ileri süren kurumsal farklılık (institutional seperation) hipotezidir.

Vergi-harcama hipotezi, Friedman (1978)'ın çalışmasına dayanmaktadır. Çalışmada vergilerin arttırılmasına yönelik bir politikanın kamu harcamalarını arttıracağı ve dolayısıyla tekrar bütçe açıklarına yol açacağı, bu sebeple denk bütçe yerine daha az kamu harcaması yapmak için vergilerin kontrol altına alınmasının önemli olduğu ileri sürülmektedir. Aynı hipotez, yani vergilerin harcamaları etkilediğini, fakat etki mekanizmasının biraz farklı olduğu Buchanan ve Wagner tarafindan açıklanmıştır. Araştırmacılar vergi gelirlerinin dolaylı ve dolaysız vergilerden oluştuğunu ve kamu harcamalarının büyüklüğünün de bu vergi türlerine bağlı olarak değiştiğini belirtmiş̧lerdir. Dolaylı vergilere dayalı bir ekonomide halk "mali aldanmaya" kapılarak kamu harcamalarının artmasına neden olmaktadır (Akçoraoğlu, 1999:53).

Harcama-vergi hipotezi kamu maliyesi literatüründeki "Sıçrama Tezi" ile açıklanmaktadır. Tezde kamu harcamaları ile vergi gelirleri arasındaki ilişkinin ekonominin o anda bulunduğu konjonktüre bağlı olduğu ifade edilmektedir. Diğer bir ifadeyle, savaş veya krizin olmadığı normal dönemlerde vergilendirme de istikrarlı olup, kamu harcamaları gelirlerin hacmine bağlıdır. Ancak, doğal afetler, savaş, kriz gibi olağanüstü durumlarda kamusal mal ve hizmet talebi hızla arttığından kamu harcamaları da hızla artmaktadır. Bu durumda kamu harcamalarının finansmanı için vergiler yükseltilecektir (Henrekson, 1993: 54). Bu hipotez Barro (1979)'nun "Ricardocu denklik" teoreminde de destek bulmaktadır.

Temeli, Musgrave (1966) ile Meltzer ve Richard (1981)'in çalışmalarına dayandırılan mali senkronizasyon hipotezi ise, kamu harcamaları ve gelirlerinin optimal düzeyine ilişkin kararların, kamusal hizmetlerin sağladığı marjinal fayda ile bu tür hizmetlerin yol açtığı marjinal maliyetin karşılaştırılması sonucu, eş zamanlı olarak 
verildiği için birbirinden etkilendiğini ileri sürmektedir (Dökmen, 2012:123; Akçoraoğlu, 1999:53; Kartakılıdıs, 1997:387).

Kurumsal farklılık hipotezi ise Baghestani ve McNown (1994)'un ABD ekonomisi üzerinde yapmış oldukları çalışmalara dayandırılmaktadır. Çalışmada iki bileşen arasında bir nedenselliğin olmaması optimal harcama hacmi ve optimal vergilendirme oranına ilişkin kararların birbirinden bağımsız farklı kurumlar tarafından alınması ile açıklanmaktadır.

\section{Kamu Gelir - Harcama İlişkilerini Araştıran Ampirik Çalışmalar}

Bütçe açığının azaltılmasında uygun politika seçimi amacıyla kamu harcamaları ve kamu gelirleri bileşenleri arasındaki ilişkileri araştıran yukarıda adı geçen hipotezler, gelişmiş ve gelişmekte olan birçok ülkede, farklı dönemler ve farklı ekonometrik teknikler kullanılarak tahmin edilmeye çalışılmıştır. Literatürdeki bu çalı̧̧malardan bazıları Tablo 1'de özetlenmektedir.

Tablo dikkatle incelendiğinde aynı ülke/ekonomi üzerine yapılmış çalışmalar arasında dahi bazen birbiriyle çelişen, farklı sonuçların bulunduğu açıkça görülecektir. Bu çelişki araştırmaya alınmış zaman dilimleri ya da serilerin frekansındaki farklılıklardan kaynaklanabileceği gibi, kullanılan yöntem ve verilerden de kaynaklanmış olabilir. Örneğin Türkiye ve ABD üzerinde yapılmış çalışmalar 4, Malezya, Yunanistan ve Pakistan 3, Kanada, Fransa, Peru ve Almanya'da 2 farklı hipotezi doğrulayan çalışmalar bulunmaktadır. Sadece Çin, Suudi Arabistan $(\mathrm{KG} \leftrightarrow \mathrm{KH})$, Quatar, Morityus ve Japonya $(\mathrm{KG} \rightarrow \mathrm{KH})$ üzerindeki çalışmalarda bir çelişki görülmemektedir.

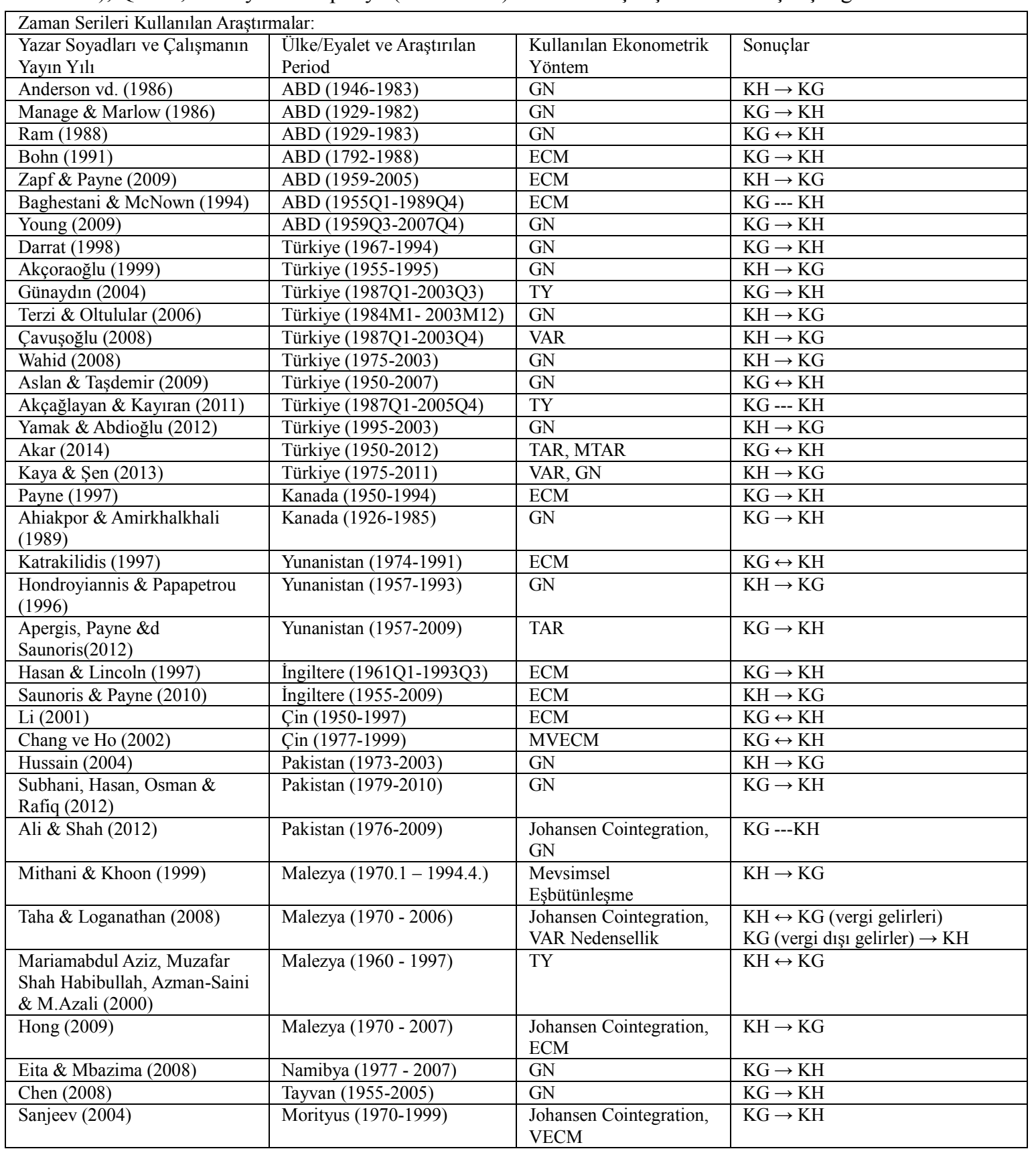




\begin{tabular}{|c|c|c|c|}
\hline Elyasi \& Rahimi (2012) & İ́ran (1963-2007) & GN & $\mathrm{KH} \leftrightarrow \mathrm{KG}$ \\
\hline Hye \& Jalil (2010) & Romania (1998:1-2008:3) & ARDL & $\mathrm{KH} \leftrightarrow \mathrm{KG}$ \\
\hline $\begin{array}{l}\text { Sikdar \& Mukhopadhyay } \\
\text { (2011) }\end{array}$ & İndia (1971-2008) & GN & $\mathrm{KH} \leftrightarrow \mathrm{KG}$ \\
\hline Aregbeyen \& İbrahim (2012) & Nigeria (1970-2008) & ARDL & $\mathrm{KG} \rightarrow \mathrm{KH}$ \\
\hline Park (1998) & Kore (1964-1992) & GN & $\mathrm{KG} \rightarrow \mathrm{KH}$ \\
\hline Al-Khulaifi (2012) & Quatar (1980-2011) & GN & $\mathrm{KG} \rightarrow \mathrm{KH}$ \\
\hline Ravinthirakumaran (2011) & Sri Lanka (1977-2009) & EG & $\mathrm{KG} \leftrightarrow \mathrm{KH}$ \\
\hline Al-Qudair (2005) & Suudi Arabistan (1964-2001) & ECM & $\mathrm{KG} \leftrightarrow \mathrm{KH}$ \\
\hline $\begin{array}{l}\text { Abual-Foul \& Baghestani } \\
\text { (2004) }\end{array}$ & $\begin{array}{l}\text { Misır (1977-1998) } \\
\text { Ürdün (1975-2001) }\end{array}$ & GN & $\begin{array}{l}\text { Misır KG } \rightarrow \mathrm{KH} \\
\text { Ürdün } \mathrm{KG \leftrightarrow KH}\end{array}$ \\
\hline $\begin{array}{l}\text { Gounder, Narayan \& Prasad } \\
\text { (2007) }\end{array}$ & Fiji (1968-2003) & GN & $\mathrm{KG} \leftrightarrow \mathrm{KH}$ \\
\hline Fasano \& Wang (2002) & $\begin{array}{l}\text { Körfez İşbirliği Konseyi } \\
\text { (KİK) (1975-2000) }\end{array}$ & $\begin{array}{l}\text { Johansen Cointegration, } \\
\text { ECM }\end{array}$ & $\begin{array}{l}\text { Bahreyn, BAE, Oman } \mathrm{KG} \rightarrow \mathrm{KH} \text {; } \\
\text { Quatar, Suudi Arabistan ve Kuveyt } \\
\mathrm{KG} \leftrightarrow \mathrm{KH}\end{array}$ \\
\hline Konukçu \& Tosun (2008) & $\begin{array}{l}\text { Rusya (1999:1-2006: 10) } \\
\text { Beyaz Rusya (1999:1- } \\
\text { 2002:12) } \\
\text { Kirgizistan }(1999: 1-2006: 12) \\
\text { Kazakistan }(1999: 1-2007: 4)\end{array}$ & GN & $\begin{array}{l}\text { Rusya, Beyaz Rusya KG } \rightarrow \mathrm{KH} \\
\text { Kırgizistan, Kazakistan } \mathrm{KG} \leftrightarrow \mathrm{KH}\end{array}$ \\
\hline \multicolumn{4}{|c|}{ Panel Veri Analizi Yöntemleri Kullanılan Araştırmalar } \\
\hline Yazarlar & Örneklem ve Zaman Dilimi & Yöntem & Sonuçlar \\
\hline Owoye (1995) & G7 Ülkeleri (1961-1990) & $\begin{array}{l}\text { Hata Düzeltme Modeline } \\
\text { Dayalı Granger } \\
\text { Nedensellik }\end{array}$ & $\begin{array}{l}\mathrm{KG} \rightarrow \mathrm{KH}: \mathrm{ABD}, \\
\text { Almanya, İngiltere, } \\
\text { Fransa, Kanada } \\
\mathrm{KG} \rightarrow \mathrm{KH}: \text { Japonya ve İtalya }\end{array}$ \\
\hline Payne (1998) & $\begin{array}{l}\text { ABD'deki } 48 \text { Federe Devlet } \\
(1942-1992)\end{array}$ & $\begin{array}{l}\text { Hata Düzeltme Modeline } \\
\text { Dayalı Granger } \\
\text { Nedensellik }\end{array}$ & $\begin{array}{l}\mathrm{KG} \rightarrow \mathrm{KH}: 24 \text { Eyalet } \\
\mathrm{KH} \rightarrow \mathrm{KG}: 8 \text { Eyalet } \\
\mathrm{KG} \leftrightarrow \mathrm{KH}: 11 \text { Eyalet }\end{array}$ \\
\hline Cheng (1999) & $\begin{array}{l}8 \text { Latin Amerika Ülkesi } \\
\text { Şili (1954-1994), Kolombiya } \\
\text { (1950-1993), Dominik } \\
\text { Cumhuriyeti (1955-1991), } \\
\text { Panama (1949-1993), } \\
\text { Brezilya (1962-1991), } \\
\text { Honduras (1950-1995), } \\
\text { Paraguay (1958-1993), Peru } \\
(1953-1994)\end{array}$ & $\begin{array}{l}\text { Hsiao-Granger- } \\
\text { Nedensellik }\end{array}$ & $\begin{array}{l}\text { KG } \leftrightarrow \text { KH: Şili, } \\
\text { Panama, Brezilya, Peru } \\
\text { KG } \rightarrow \text { KH: } \\
\text { Kolombiya, Dominik } \\
\text { Cumhuriyeti, } \\
\text { Honduras, Paraguay }\end{array}$ \\
\hline Fasano \& Wang (2002) & $\begin{array}{l}6 \text { Körfez İşbirliği Konseyi } \\
\text { Üyesi Ülke }\end{array}$ & $\begin{array}{l}\text { Hata Düzeltme Modeline } \\
\text { Dayalı Granger } \\
\text { Nedensellik }\end{array}$ & $\mathrm{KG} \rightarrow \mathrm{KH}$ \\
\hline Chang, Liu \& Caudill (2002) & $\begin{array}{l}\text { 10 Sanayileşmiş Ülke (1951- } \\
\text { 1996) }\end{array}$ & $\begin{array}{l}\text { Hata Düzeltme } \\
\text { Modeline Dayalı } \\
\text { Granger Nedensellik }\end{array}$ & $\begin{array}{l}\text { KG } \rightarrow \text { KH: Japonya, Güney Kore, } \\
\text { Tayvan, İngiltere ve ABD } \\
\text { KH } \rightarrow \text { KG: Güney Afrika, } \\
\text { Avustralya KG } \leftrightarrow \text { KH: Kanada }\end{array}$ \\
\hline Narayan (2005) & $\begin{array}{l}\text { Hindistan, Pakistan, Sri } \\
\text { Lanka, Tayland, Filipinler, } \\
\text { Singapur, Malezya, Nepal, } \\
\text { Endonezya }\end{array}$ & Granger-Nedensellik & $\begin{array}{l}\mathrm{KG} \rightarrow \mathrm{KH}: \text { Nepal, Singapur } \\
\mathrm{KG} \leftrightarrow \mathrm{KH}: \text { Endonezya, Sri Lanka } \\
\mathrm{KG} \text {--- KH: Hindistan, Malezya, } \\
\text { Pakistan, Filipinler, Tayland }\end{array}$ \\
\hline Narayan \& Narayan (2006) & 12 Gelişmekte Olan Ülke & TY & $\begin{array}{l}\text { KG } \rightarrow \text { KH: Morityus, El Salvador, } \\
\text { Haiti, Şili ve Venezüella } \\
\text { KG } \leftrightarrow \text { KH: Haiti } \\
\text { KG --- KH: Peru, } \\
\text { Güney Afrika, Guatemala, Uruguay } \\
\text { ve Ekvador }\end{array}$ \\
\hline Chang \& Chiang (2009) & $\begin{array}{l}15 \text { OECD Üyesi Ülke (1992- } \\
2006)\end{array}$ & Granger-Nedensellik & $\mathrm{KG} \leftrightarrow \mathrm{KH}$ \\
\hline Dökmen (2012) & $\begin{array}{l}34 \text { OECD üyesi ülkesi (1994- } \\
\text { 2007) }\end{array}$ & $\begin{array}{l}\text { Pedroni Panel Eş } \\
\text { Bütünleşme ve GMM } \\
\text { Nedensellik }\end{array}$ & $\mathrm{KG} \rightarrow \mathrm{KH}$ \\
\hline Afonso \& Rault (2009) & $\begin{array}{l}25 \text { Avrupa Birliği Üyesi Ülke } \\
(1960-2006)\end{array}$ & $\begin{array}{l}\text { Bootstrap ile Düzeltilmiş } \\
\text { Nedensellik Testi }\end{array}$ & $\begin{array}{l}\mathrm{KH} \rightarrow \mathrm{KG}: \text { İtalya, Fransa, İspanya, } \\
\text { Yunanistan Portekiz KG } \rightarrow \mathrm{KH}: \\
\text { Almanya, Belçika, Avusturya, } \\
\text { Finlandiya, İngiltere }\end{array}$ \\
\hline Vamvoukas (2011) & $\begin{array}{l}12 \text { EMU Üyesi Ülkeler } \\
(1970-2006)\end{array}$ & GTSLS ve GMM & $\mathrm{KG} \leftrightarrow \mathrm{KH}$ \\
\hline \multicolumn{4}{|c|}{ 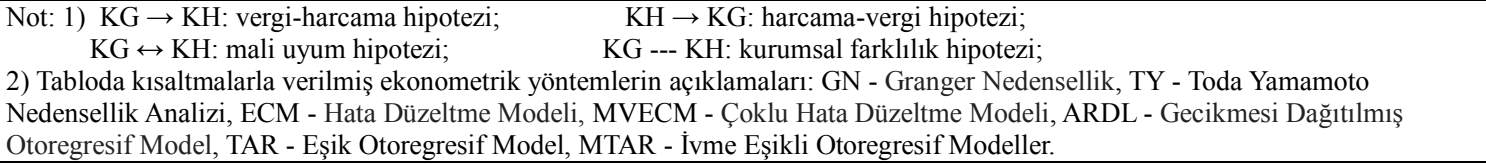 } \\
\hline
\end{tabular}

Tablo 1: Kamu Harcamaları ve Gelirleri İlişkisini Incelemeye Yönelik Ampirik Çalışmalar Kaynak: Tablo Dökmen (2012:124-126)'den Alınmış ve Genişletilmiştir. 
Kırgızistan'da kamu harcamaları ve kamu gelirlerine arasındaki ilişkiye yönelik yalnızca Konukçu ve Tosun (2008)'un çalışması mevcuttur. Konukçu ve Tosun (2008) 1999-2006 dönemine ilişkin aylık veriler kullanılarak toplam bütçe gelirleri ile harcamaları arasındaki ilişkiyi Granger nedensellik yöntemiyle incelenmiş ve iki bileşen arasında iki yönlü nedenselliğin olduğu sonucuna ulaşmıştır.

\section{Kırgızistan Devlet Bütçesinde Gelirler, Harcamalar ve Açıklar}

2005'den itibaren Kırgız Cumhuriyeti'nin bütçe politikasının başlıca amacı vergi ve vergi dışı ödemelerin zamanında ve eksiksiz olarak toplanmasını ve ilk olarak temel bütçe kalemlerinin finanse edilmesini sağlamak olmuştur (КР Статистика комитети, 2011: 35-37). Temel bütçe kalemleri: ücretler, sosyal fonlara kesintiler, ilaç ve gıda giderleri, düşük gelirli ailelere ödenekler, doğumdaki bir defalık ödenek, askerlere ve çok çocuk sahibi olan annelere emeklilik maaşı, özürlü ödenekleri, emeklilere elektrik kullanımı için tazminatlar v.s. içermektedir. Bütçe harcamalarının sektörlere göre dağılımı da bütçe politikasının amacına uygun olarak (finansal olmayan varlıkların alımı hariç) sırasıyla en çok eğitime, sosyal korumaya, sağlık sistemine, savunma ve güvenliğe, sonra da genel kamu hizmetlerine ayrılmaktadır (Şekil 1).

Bütçe harcamalarına genel olarak bakıldığında 1993-2005 dönemleri arası her yıl ortalama olarak 1-2 milyar somluk artış gösterse, 2006-2010 arası yaklaşık 10 milyar somluk artışlar göstermiştir. En yüksek artış 2010'a göre 22milyar 763 milyon som ile 2011'de gözlemlenmiştir. Bu da ülkedeki 2005 İhtilali sonrası yeni hükümetin sosyal kurumlara önemli destek vermesinden kaynaklanmıştır. 2013'de de devlet harcamaları ilk kez azaltılmıştır (20971,6 mln. som). Bu azalma da ekonomik aktivite ve ile ilgili diğer hizmetler kaleminden kaynaklanmaktadır.

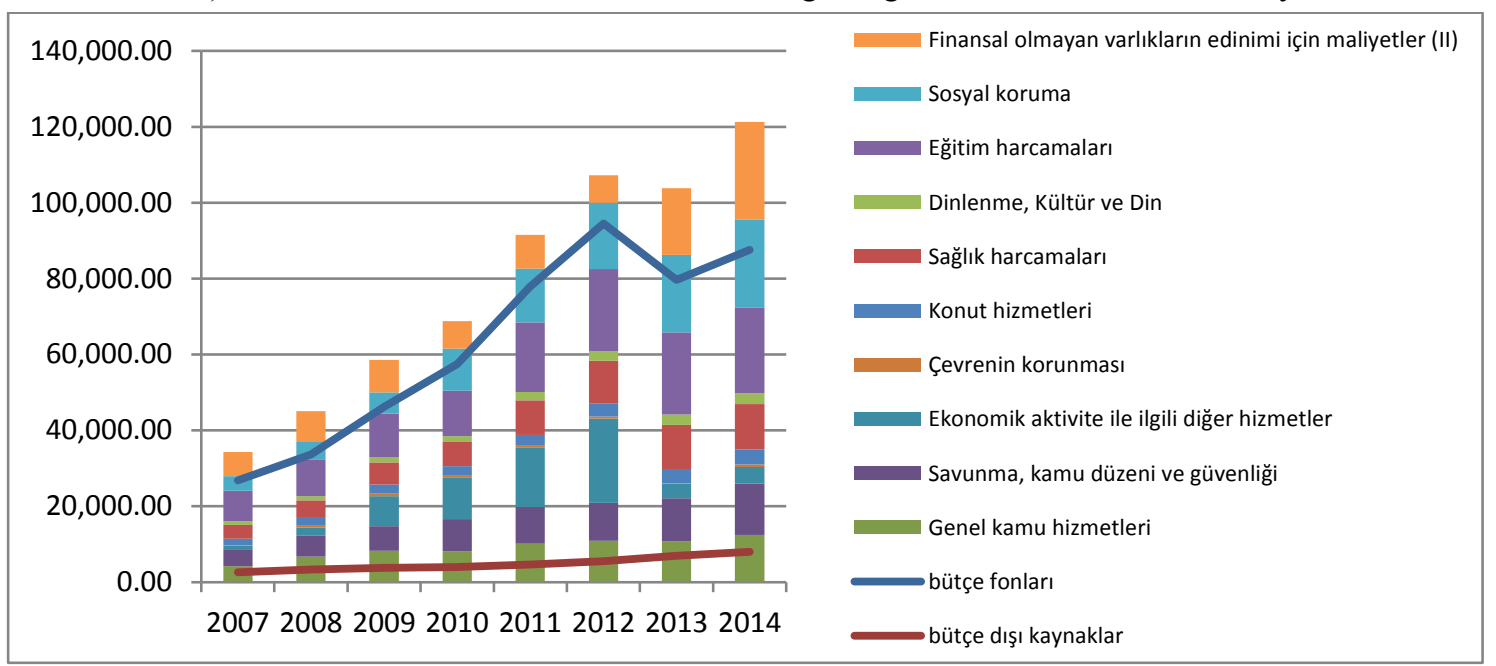

Şekil 1. Devlet Bütçesi - Harcamalar 2007-2014 Arası (Mln. Som) Kaynak: Şekil, Kırgız Cumhuriyeti İstatistik Komitesi'nin Verilerinden Yararlanılarak Oluşturulmuştur, www.stat.kg.

Not: Kırgızistan'da 2007'ye kadar farklı hesap düzeni kullanıldı̆̆ından dolayı şekle eklenememiştir.

Bütçe gelir kaynaklarına bakılacak olursa, vergi gelirlerinin önemli paya sahip olduğunu ve yıllar itibariyle istikrarlı artan bir trende sahip olduğunu söylemek mümkündür. Vergi dışı gelirler başta her ne kadar düşük gözükse de hızlı artış göstermektedir. Bunun tersine finansal olmayan varlık satışından elde edilen gelirlerde önemli azalma gözlenmektedir. Resmi transferler kaleminde de 2009 sonrası iyileşmeler fark edilmektedir (Şekil 2).

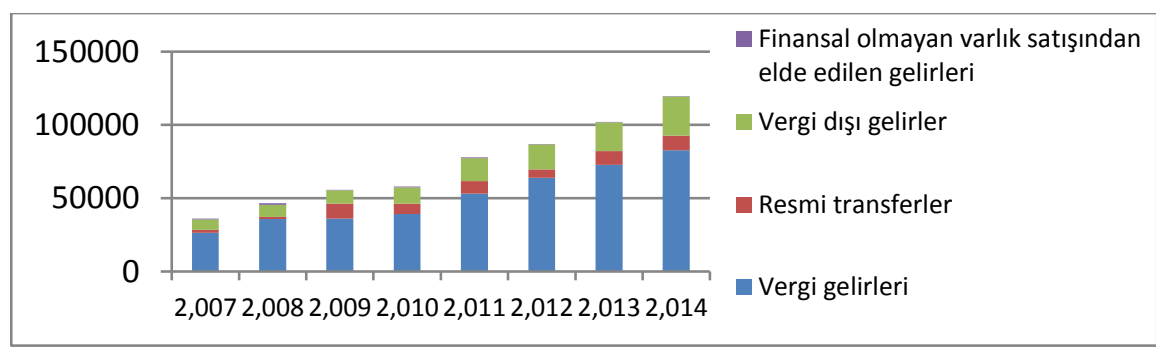

Şekil 2. Devlet Bütçesi - Gelirler 2007-2014 Arası (Mln. Som) Kaynak: Şekil, Kırgız Cumhuriyeti İstatistik Komitesi'nin Verilerinden Yararlanilarak Oluşturulmuştur, www.stat.kg.

Yukarıda ifade edilen rakamların hepsi nominal rakamlardır. Bilindiği gibi reel göstergelerde düşüşler olsa bile enflasyon nedeniyle nominal değerler daima artış gösterebilmektedir. Dolayısıyla bir ekonominin reel durumunu analiz etmede nominal değerlerin yanında reel rakamlardaki artışlar da büyük önem taşımaktadır. 
Kamu gelirleri, harcamaları, bütçe açıkları ve GSYİH verilerinin 1995 bazyılı olarak hesaplanmış GSYİH Deflatörü (quandl.com, 2016) ile reelleştirilmiş hallerine bakılacak olursa (Şekil 3) 2000 yılına kadar hem bütçe gelirleri hem de giderlerinde çok az artış ve düşüşlerle de olsa istikrarsızlık söz konusu olmuştur. 2001 sonrası ancak ikisinde de hızlı artışlar olduğu söylenebilir. Bütçe harcamalarında 2005 devrimi sonrası bazı harcamaların yapılmaması nedeniyle bir önceki yıla göre $10 \mathrm{mln}$. somluk bir azalma, 2013'te (nedenini yukarıda belirttiğimiz gibi) reel olarak $667 \mathrm{mln}$. somluk azalma söz konusu olmuştur. Bütçe gelirlerinde de 2010'da reel olarak $461 \mathrm{mln}$. somluk bir azalma gerçekleşmiştir. Bu azalmanın da 2008 Dünya Ekonomik Krizinin dolaylı etkisi olarak nitelendirmek mümkündür. Diğer bir ifade ile krizin etkisi ile ülkeye gelen resmi transferlerde azalma olmuştur, hem de vergilerde artış sağlanamamıştır.

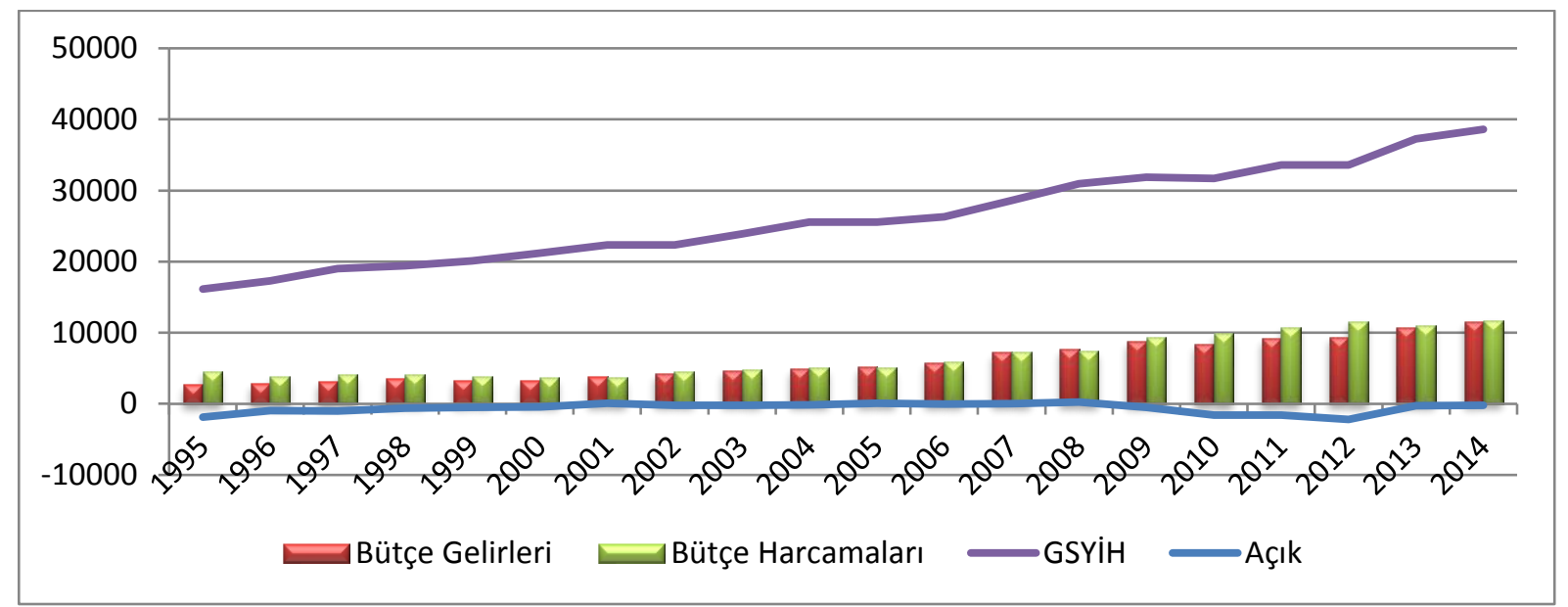

Şekil 3. Devlet Bütçesi Reel Harcama ve Gelirleri, 1995-2014 arası (mln. som) Kaynak: Şekil, Kırgız Cumhuriyeti İstatistik Komitesi’nin (www.stat.kg) ve Dünya Bankasinın (quandl.com, 2016) Verilerinden Yararlanilarak Oluşturulmuştur.

Genel olarak toplam gelirlerde önemli artışlar olmasına ve geçiş sürecinin gerektirdiği sistematik düzen değişikliklerin tamamlanmasına rağmen günümüze kadar Kırgızistan bütçe harcamalarını azaltamamaktadır. Bütçe gelirlerinin az olmasının en büyük nedeni ülkedeki üretim yetersizliği iken, mevcut olan üretimin büyük bir kısmının da kayıt dışı olması ikinci önemli nedenidir. Diğer taraftan da aynı faktörler bütçe harcamalarının azaltılamamasına da neden olmaktadır. Yani, özel sektörden destek olmayınca devlet, nüfusun artması ve mevcut kamu varlıklarının da eskimesi sonucu özellikle sosyal harcamaları artırmak zorunda kalmaktadır. Sonuç olarak devlet bütçe açıkları sürekli bir artış göstermektedir.

Bağımsızlık sonrası ilk en büyük açık 1995 'te kaydedilmiştir. Aynı yıl ülkede anayasa değişikliklerine ilişkin olarak yapılan reformlar, cumhurbaşkanlığı seçimi (constpalata.kg, 2014), ve Paris konferansı sonrası ülkeye donor ülkelerden sağlanmış olan büyük borçlar bu açığın en önemli nedenleri olarak sıralanabilir(eulaw.edu.ru, 2014).

Ülke bugüne kadar bütçe açıklarının kapatılmasında dış kaynaklardan sağlanan finansmana önem vermektedir. Hatta Şekil 4’te görüldüğü gibi bazı yıllarda iç piyasaya borçlar dahi dış borçlarla karşılanmıştır. Çünkü iç borçlanmanın maliyeti hem daha yüksek, hem de iç piyasanın daralmasına neden olabilmektedir. Yüksek orana ulaşmış bütçe açıklarının bulunduğu bir ekonomide, onların kapatılması için ülke ya vergileri ya da borçlanmayı artırmak zorunda kalacaktır (Akar, 2014:142).

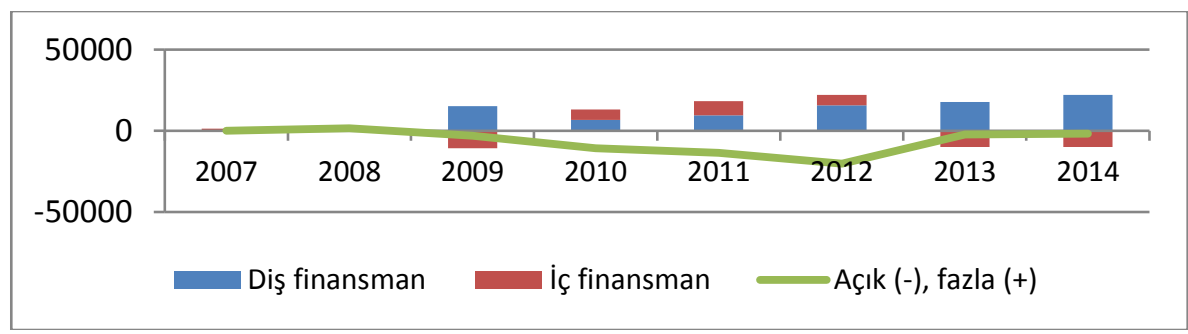

Şekil 4. Devlet Bütçe Açıkları ve Finansman Kaynakları, 2007-2014 (mln. som) Kaynak: Şekil, Kırgız Cumhuriyeti İstatistik Komitesi'nin Verilerinden Yararlanılarak Oluşturulmuştur, www.stat.kg. 


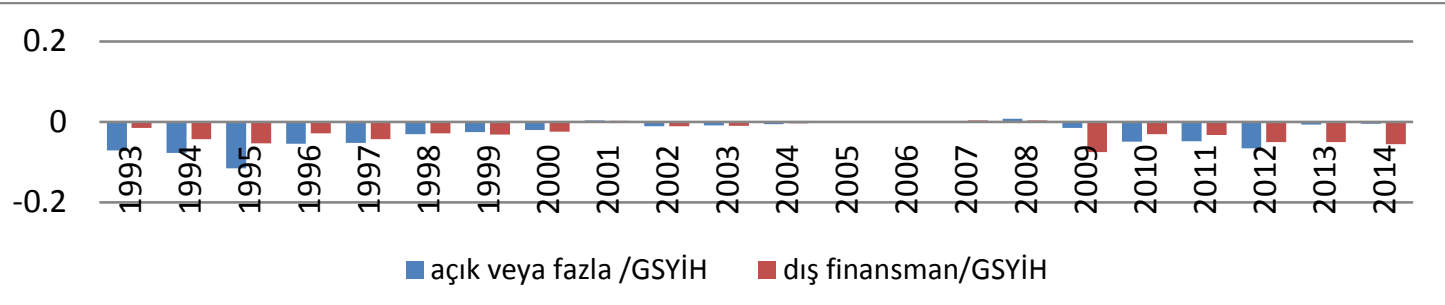

\section{Şekil 5. Bütçe Açıkları/Fazlalarının ve Dış Finansmanın GSYIH'daki Oranları. Kaynak: Şekil, Kırrgız Cumhuriyeti Istatistik Komitesi'nin Verilerinden Yararlanilarak Oluşturulmuştur, www.stat.kg.}

Kırgızistan'da toplam bütçe açıklarının GSYİH'daki payına bakıldığında durumun özellikle 2013 ve 2014'te iyileştiğini söylemek mümkündür. Ancak yukarıdaki şekilden de görüleceği gibi bütçe açıklarında dış finansmanın rolü son yıllarda hızla artmaktadır ve dış finansmanın GSYİH'ya oranı olarak baktığımızda durumun tersine gittiğini söylemek mümkündür. Devlet dış borçlanmada faiz oranlarının düşük olmasına da önem vermektedir. Bununla birlikte, dış borçlar ülkeye dövizle sağlanmakta ve geri ödenmesi de dövizle olduğundan, döviz kurlarındaki hızlı artışlar dış finansmanın maliyetlerini beklenenin üzerine çıkarmaktadır. Ülkenin toplam dış borcu sürekli artmakta ve her sene alınan kamu borçlarının üretimden daha çok tüketime harcanması, gelecek nesiller için önemli bir sorun oluşturacak gibi görünmektedir.

\section{Veri ve Ekonometrik Yöntem (Metodoloji)}

\subsection{Veri}

Çalışma 1995-2014 dönemini kapsamaktadır ve yıllık veriler kullanılmıştır. Kamu gelirleri (KG) ve kamu harcamalarına (KH) ait veriler Kırgızistan Milli İstatistik Komitesinden; GSYİH (Y) Kırgızistan Merkez Bankasından, GSYIH deflatörü dünya bankasının veri setinden (quandl.com, 2016) temin edilmiştir. Tüm serileriler GSYIH deflatörüne bölünerek reel hale dönüştürülmüş ve logaritmaları alınmıştır.

\subsection{Birim Kök Testleri}

İlk olarak serilerin durağanlığı araştırılmış ve bu amaçla değiş̧kenler birim kök testine tabi tutulmuştur. Burada, serilerdeki otokorelasyon sorununu dikkate alan Genişletilmiş Dickey-Fuller (ADF) ve değişen varyans sorununu dikkate alan Phillips-Perron (PP) birim kök testlerinden yararlanılmıştır. Test sonuçları aşağıdaki gibidir (Tablo 2).

\begin{tabular}{|c|c|c|c|c|c|c|}
\hline & \multicolumn{3}{|c|}{$\mathrm{ADF}$} & \multicolumn{3}{|c|}{ PP } \\
\hline Değişkenler & $\begin{array}{l}\text { Seviye/ } \\
\text { Sabitli }\end{array}$ & $\begin{array}{l}\text { Seviye/ } \\
\text { Sabit ve } \\
\text { Trendli }\end{array}$ & $\begin{array}{c}\text { Birinci } \\
\text { Farklar/ } \\
\text { Sabitli }\end{array}$ & $\begin{array}{c}\text { Seviye/ } \\
\text { Sabitli }\end{array}$ & $\begin{array}{l}\text { Seviye/ } \\
\text { Sabit ve } \\
\text { Trendli }\end{array}$ & $\begin{array}{c}\text { Birinci Farklar/ } \\
\text { Sabitli }\end{array}$ \\
\hline $\ln Y$ & $-0,29(2)$ & $-4,66^{* * *}(1)$ & $-3,99 * * *(2)$ & $-1,62(18)$ & $-6,93 * * *$ & $-9,92 * * *$ \\
\hline $\operatorname{lnKG}$ & $-1,12(0)$ & $-2,36(0)$ & $-4,40 * * *(0)$ & $0,34(3)$ & $-2,40$ & $-2,41 * * *$ \\
\hline $\operatorname{lnKH}$ & $0,57(0)$ & $-3,05(0)$ & $-4,48 * * *(0)$ & 0,55 (1) & $-3,04$ & $-4,46 * * *$ \\
\hline $\begin{array}{lr}\bullet & \mathrm{AL} \\
\bullet & * \\
\text { olasilik değe } \\
\bullet \quad \\
\text { belirlenmesi }\end{array}$ & $\begin{array}{l}\text { stinde sab } \\
0, * *-\% \\
\text { Eviews } 9 \\
\text { z içi değ } \\
\text { Akaike Bil }\end{array}$ & $\begin{array}{l}\text { nodel kullanil } \\
* * * \text {. } 1 \text { sev } \\
\text { nometrik pake } \\
\mathrm{r} \text { optimal ge } \\
\text { riteri seçilmiș }\end{array}$ & $\begin{array}{l}\text { Ir. Rakkamlar } \\
\text { inde durağan } \\
\text { gramı tarafin } \\
\text { ne uzunlukla } \\
\text { naksimum } 2\end{array}$ & $\begin{array}{l}\text { düzeltilm } \\
\text { dğunu göst } \\
\text { otomatik o } \\
\text { vermekted } \\
\text { kme alınm. }\end{array}$ & $\begin{array}{l}\text { atistik de } \\
\text { tedir. Ma } \\
\text { verilmekte } \\
\text { timum g }\end{array}$ & $\begin{array}{l}\text { idir. } \\
\text { hon tek kuyruklu } \\
\text { ne uzunluğunun }\end{array}$ \\
\hline
\end{tabular}

Tablo 2. Serilerin Birim Kök Testi Sonuçları

Tablodan da görüleceği gibi iki test sonucunda da KG ve KH serilerinin düzey itibariyle birim kök içerdiğini söyleyen $\mathrm{H}_{0}$ hipotezi $\% 5$ önem düzeyinde reddedilememektedir. Aynı testler durağan olmayan serilerin birinci farkları için yapıldığında, $\mathrm{H}_{0}$ hipotezi \%1 önem düzeyinde reddedilmekte, hem ADF hem de PP testine göre serilerin farklarının durağan olduğu sonucuna varılmaktadır. Y serisi de seviyede durağan olup, trend içerdiğini söylemek mümkündür.

Yapısal kırılmaların varlığı durumunda, durağanlığa yalnızca geleneksel test sonuçlarına göre karar vermek yanıltıcı olabilir. İkinci olarak Zivot ve Andrews (1992)'un tek kııılmalı birim kök testi (bundan sonra kısaltılmış ZA olarak geçecek) yardımı ile ayrıca serilerin durağanlık düzeyleri araştıılmış ve geleneksel testler ile bulunan test sonuçları kontrol edilmiştir. ZA testinde aşağıdaki gibi 3 farklı model kullanmaktadır.

$$
\text { A Modeli: } \Delta d_{t}=\mu_{0}{ }^{A}+\mu_{1}{ }^{A} d_{t-1}+\mu_{2}{ }^{A} t+\mu_{3}{ }^{A} D U_{t}+\sum_{j=1}^{k} \varphi_{j}{ }^{A} \Delta d_{t-j}+\varepsilon_{t}(1)
$$




$$
\begin{aligned}
& \text { B Modeli: } \Delta d_{t}=\mu_{0}{ }^{B}+\mu_{1}{ }^{B} d_{t-1}+\mu_{2}{ }^{B} t+\mu_{3}{ }^{B} D T_{t}+\sum_{j=1}^{k} \varphi_{j}{ }^{B} \Delta d_{t-j}+\varepsilon_{t}(2) \\
& \text { CModeli: } \Delta d_{t}=\mu_{0}{ }^{C}+\mu_{1}{ }^{C} d_{t-1}+\mu_{2}{ }^{C} t+\mu_{3}{ }^{C} D U_{t}+\mu_{4}{ }^{C} D T_{t}+\sum_{j=1}^{k} \varphi_{j}{ }^{C} \Delta d_{t-j}+\varepsilon_{t}(3)
\end{aligned}
$$

A Modeli - trend durağan olduğunu, B Modeli - trend fonksiyonun eğiminde değişim olduğunu, C Modeli bu iki değişimin aynı anda gerçekleştiğini varsayar.

Tablo 3 yapısal kırılmalı ZA birim kök test sonuçlarını göstermektedir. Kırılma yılları modellere göre değişim göstermektedir. Y serisi için A modeli 2010, B modeli 1998, C modeli de 2008 yılında ve KG serisi için A modeli 2007, B modeli 2001, C modeli de 2007 yılında; KH serisi için A modeli 2007, B modeli 2001, C'de 1999 y1lında yapısal kırılmanın olduğunu göstermektedir. 2007 Asya Krizinin ve 2010'da ülkedeki siyasi devrimin Y serisinde kırılmalara, 2007'deki İnşaat ve İletişim sektörlerindeki hızlı artış ve 2001'deki Kumtör Altın madeninden kaynaklanan krizin ise KG ve KH serilerinde kırılmalara ya da geçici şoklara neden olduğu söylenebilir. Her üç seri için, her üç modelde de test istatistiğinin mutlak değeri kritik değerden daha küçük olduğu için birim kök yokluk hipotezi \%5 önem düzeyinde reddedilememektedir. Diğer bir ifadeyle ZA birim kök test sonuçları

\begin{tabular}{|c|c|c|c|c|c|c|}
\hline & \multicolumn{2}{|c|}{ A Modeli } & \multicolumn{2}{|c|}{ B Modeli } & \multicolumn{2}{|c|}{ C Modeli } \\
\hline \multicolumn{7}{|l|}{$\ln Y$} \\
\hline Test istatistiğ $i$ & \multicolumn{2}{|c|}{-4.338} & \multicolumn{2}{|c|}{-4.160} & \multicolumn{2}{|c|}{-4.251} \\
\hline Kırılma noktası & \multicolumn{2}{|c|}{2010} & \multicolumn{2}{|c|}{1998} & \multicolumn{2}{|c|}{2008} \\
\hline \multicolumn{7}{|l|}{$\ln K G$} \\
\hline Test istatistiği & \multicolumn{2}{|c|}{-3.867} & \multicolumn{2}{|c|}{-3.047} & \multicolumn{2}{|c|}{-3.587} \\
\hline Kirllma noktast & \multicolumn{2}{|c|}{2007} & \multicolumn{2}{|c|}{2001} & \multicolumn{2}{|c|}{2007} \\
\hline \multicolumn{7}{|l|}{$\operatorname{lnKH}$} \\
\hline Test istatistiği & \multicolumn{2}{|c|}{-4.122} & \multicolumn{2}{|c|}{-3.311} & \multicolumn{2}{|c|}{-3.498} \\
\hline Kırllma noktasl & \multicolumn{2}{|c|}{2007} & \multicolumn{2}{|c|}{2001} & \multicolumn{2}{|c|}{1999} \\
\hline \multirow[t]{2}{*}{ Zivot and Andrews (1992)'den alınan kritik değerler } & $\% 1$ & $\% 5$ & $\% 1$ & $\% 5$ & $\% 1$ & $\% 5$ \\
\hline & $-5,34$ & $-4,80$ & $-4,93$ & $-4,42$ & $-5,57$ & $-5,08$ \\
\hline
\end{tabular}
kırılmalar dikkate alındığında serilerin farkının durağan olduğunu göstermektedir.

Tablo 3. ZA Test Sonuçları

\subsection{Koentegrasyon Analizi}

Birim kök testlerini takiben Pesaran vd. (2001) tarafından geliştirilen ARDL yöntemi kullanılarak seriler arasındaki uzun dönemli bir ilişkinin olup olmadığı araştırılmıştır. Bu yöntem, iki önemli avantajı nedeniyle tercih edilmiştir. Birincisi, bu yöntem ile değişkenlerin entegre düzeyi dikkate alınmaksızın eşbütünleme ilişkisini araştırmak mümkündür. Yöntemin ikinci önemli avantajı, gözlem sayısı sınırlı olan çalışmalar için de kolaylıkla uygulanabilmesidir (Narayan, 2005). Bu amaçla aşağıdaki modeller tahmin edilmiştir.

$$
\begin{aligned}
& \Delta \ln K H=\alpha_{0}+\alpha_{1} t+\sum_{i=1}^{k} \alpha_{2 i} \Delta \ln K H_{t-i}+\sum_{i=0}^{l} \alpha_{3 i} \Delta \ln K G_{t-i}+\sum_{i=0}^{m} \alpha_{4 i} \Delta \ln Y_{t-i}+ \\
& +\alpha_{5} \ln K H_{t-1}+\alpha_{6} \ln K G_{t-1}+\alpha_{7} \ln Y_{t-1}+\varepsilon_{1}(4) \\
& \Delta \ln K G=\alpha_{0}+a_{1} t+\sum_{i=1}^{k} \alpha_{2 i} \Delta \ln K G_{t-i}+\sum_{i=0}^{l} \alpha_{3 i} \Delta \ln K H_{t-i}+\sum_{i=0}^{m} \alpha_{4 i} \Delta \ln Y_{t-i}+ \\
& +\alpha_{5} \ln K G_{t-1}+\alpha_{6} \ln K H_{t-1}+\alpha_{7} \ln Y_{t-1}+\varepsilon_{1}(5) \\
& \Delta \ln Y=\alpha_{0}+a_{1} t+\sum_{i=1}^{k} \alpha_{2 i} \Delta \ln Y_{t-i}+\sum_{i=0}^{l} \alpha_{3 i} \Delta \ln K G_{t-i}+\sum_{i=0}^{m} \alpha_{4 i} \Delta \ln K H_{t-i}+ \\
& +\alpha_{5} \ln K G_{t-1}+\alpha_{6} \ln K H_{t-1}+\alpha_{7} \ln Y_{t-1}+\varepsilon_{1}(6)
\end{aligned}
$$

Üstteki denklemlerde seriler arasında bir eşbütünleşme ilişkisinin olup olmadığına, yani koentegrasyon olup olmadiğına ( $\boldsymbol{H}_{\mathrm{O}}: a_{5}=a_{6}=a_{7}=\mathrm{O}$ ) hipotezi test edilerek karar verilir. Tahmin edilen $\mathrm{F}$ istatistik değeri Pesaran vd. (2001) ve/veya Narayan (2005)'ın kritik değerleri ile karşılaştırılır. Tahmin edilen F değeri, Tablo alt kritik değerinden küçükse seriler arasında bir eşbütünleşme ilişkisinin bulunmadığına, üst kritik değerin üzerinde ise seriler arasında bir eşbütünleme ilişkisinin bulunduğuna karar verilir. F değeri alt ve üst kritik değerlerin arasında ise bu konuda bir karar verilemeyeceğinden dolayı yorum yapılamamakta, ilişkinin başka yöntemlerle araştırılması önerilmektedir.

Son aşamada tüm modeller için ARDL yöntemine dayalı uzun dönem ve hata düzeltme modeli tahmin edilmiştir. Yukarıda tahmin edilen koentegrasyon test sonuçları, değişkenler arasında uzun dönemli bir ilişkinin olabileceğini gösterdiğinden 6 modelin her biri için (7) nolu 


$$
\ln Y=a_{0}+\sum_{i=1}^{k} a_{1 i} \ln Y_{t-i}+\sum_{i=0}^{l} a_{2 i} \ln X_{t-i}+\varepsilon_{t}
$$

ve (8) nolu hata düzeltme modelleri tahmin edilmiştir.

$$
\Delta \ln Y=a_{0}+\alpha_{1} E C T_{t-1}+\sum_{i=1}^{m} a_{2 i} \Delta \ln Y_{t-i}+\sum_{i=0}^{n} a_{3 i} \Delta \ln X_{t-i}+\varepsilon_{t}
$$

Tablo 5 ve Tablo 6 sirasıyla uzun dönem ve hata düzeltme modeline modele ilişkin tahmin sonuçlarını göstermektedir ve bu modellerin tamamı \%5 önem düzeyinde tanımlayıcı testlerin hepsinden geçmiştir. ECT değişkeni (7) nolu uzun dönem denkleminden elde edilen hata terimleri serisinin bir dönem gecikmeli değerini göstermektedir. Katsayısının negatif ve anlamlı olması gerekir, ayrıca kısa dönemdeki dengesizliğin ne kadarının uzun dönemde düzeltileceğini gösterir.

Tablo 4 (4), (5) ve (6) nolu modeller ile tahmin edilen koentegrasyon test sonuçlarını göstermektedir. Tablodan görüleceği gibi lnY bağımlı değişken olarak alındığında tahmin edilen F istatistiğinin değeri 2.27'dir ve bu değer hem Narayan (2005) hem de Pesaran (2001) vd.'dan alınan alt kritik değerlerin altında olduğu için koentegrasyonun olmadığına karar verilmektedir. LnKH veya LnKG bağımlı değişken olarak alındığında tahmin edilen F-istatistiğinin değeri üst kritik değeri aşmakta ve değişkenler arsında bir eşbütünleme ilişkisinin bulunduğunu göstermektedir. Tablo 4.1'de sunulmuş CUSUM testleri sonuçları da tahmin etiğimiz modellerin

\begin{tabular}{|c|c|c|c|c|c|c|}
\hline Fonksiyon & $\begin{array}{l}\text { Uygun } \\
\text { gecikme }\end{array}$ & $\begin{array}{c}\text { Hesaplanan } \\
\text { F - } \\
\text { istatistiği } \\
\end{array}$ & \multicolumn{4}{|c|}{ Tanımlayıcı istatistikler } \\
\hline $\begin{array}{c}\text { Model } 1: \operatorname{lnKH} /(\operatorname{lnKG}, \\
\ln Y)^{\mathrm{a}}\end{array}$ & 2.1.3. & 24.91 & \multicolumn{4}{|c|}{$\begin{array}{c}R^{2}=0.96 ; \text { Düzeltilmiş } R^{2}=0.92 \mathrm{DW}=2.26 \mathrm{~F} \text {-ist }=21.84 \\
(0.00) \chi^{2}{ }_{N O R}=1.85(0.39) \chi^{2} L M=1.42(0.49) \\
\chi^{2}{ }_{S E R}=7.52(0.58)\end{array}$} \\
\hline 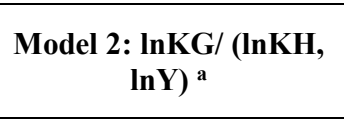 & 1.2.3. & 25.79 & \multicolumn{4}{|c|}{$\begin{array}{c}R 2=0.97 ; \text { Düzeltilmiş } R 2=0.92 \mathrm{DW}=2.03 \mathrm{~F} \text {-ist }= \\
23.75(0.00) \chi^{2}{ }_{N O R}=1.485(0.47) \chi^{2} L M=1.42(0.49) \\
\chi^{2} \operatorname{SER}=12.00(0.21)\end{array}$} \\
\hline $\begin{array}{c}\text { Model 3: } \ln Y /(\ln K G, \\
\operatorname{lnKH})^{\mathrm{a}}\end{array}$ & 1.2.3. & 2.27 & \multicolumn{4}{|c|}{$\begin{array}{c}R^{2}=0.95 ; \text { Düzeltilmiş } R^{2}=0.84 \mathrm{DW}=1.86 \mathrm{~F} \text {-ist }=8.50 \\
\text { (0.01) } \chi^{2} \text { NOR }=1.12(0.57) \chi^{2} \mathrm{LM}=4.02(0.13) \\
\chi^{2} \operatorname{SER}=8.99(0.62)\end{array}$} \\
\hline \multicolumn{7}{|c|}{ Kritik Değerler } \\
\hline & \multicolumn{2}{|r|}{$\% 10$} & & & \multicolumn{2}{|c|}{$\% 1$} \\
\hline & $\mathbf{I}(\mathbf{0})$ & $\mathbf{I}(\mathbf{1})$ & $\mathbf{I}(\mathbf{0})$ & I(1) & $\mathbf{I}(\mathbf{0})$ & $\mathbf{I}(\mathbf{1})$ \\
\hline Pesaran vd.(2001) & 4.19 & 5.06 & 4.87 & 5.85 & 6.34 & 7.52 \\
\hline Narayan(2005) & 3.437 & 4.470 & 4.267 & 5.473 & 6.183 & 7.873 \\
\hline
\end{tabular}
artıklarının yapısal kırılma içermediklerini göstermektedir.

F-istatistiğinin karşılaştırılmasındaki kritik değerler Pesaran vd. (2001) ve Narayan (2005) (Case V)'den alınmıştır. $\chi^{2} N O R$ - Jarque-Bera normallik test istatistiğini; $\chi^{2}$ SER - Breusch-Godfrey (BG) 'in birinci dereceden otokorelasyon test istatistiğini; $\chi^{2} L M$ - modelin artıklarının II mertebeden otokorelasyon test istatistiğini vermektedir. Parantez içindeki değerler test istatistiklerine ait olasılık değerleridir.

Tablo 4. Sınır Testi Sonuçlart

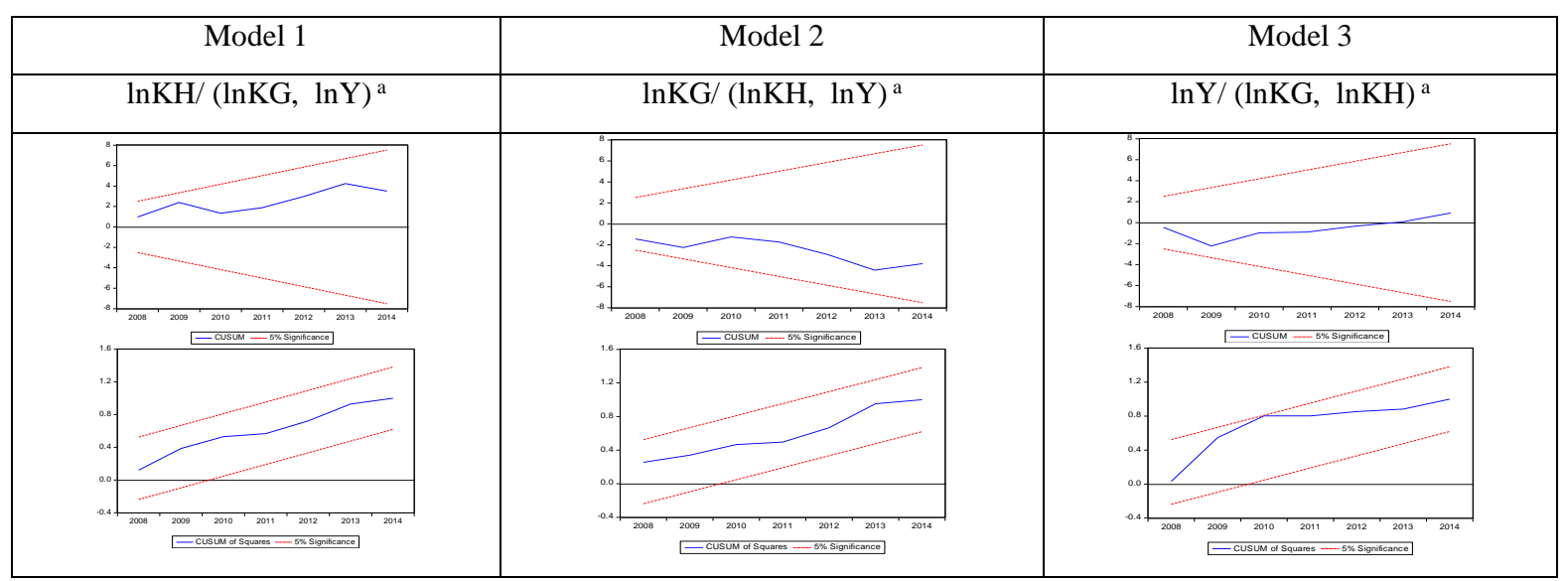

Tablo 4.1. Sınır Testi Modellerinin CUSUM Testleri Sonuçları 
Tablo 5 tahmin edilen (7) nolu modellerin uzun dönem katsayılarını göstermektedir. Model 1 de reel kamu gelirlerindeki \%1'lik artışın analiz edilen dönemde diğer şeyler sabitken reel kamu harcamalarında \%2.48'lik bir artışa, model 2 de kamu harcamalarındaki \%1'lik artışın ise aynı şekilde kamu gelirlerinde \%0.38'lik artışa neden olduğu görülmektedir. Bu bulgular temelinde kamu gelirlerinin kamu harcamaları üzerindeki etkisinin daha belirgin/güçlü olduğu, kamu harcamalarının kamu gelirleri üzerindeki etkisinin nispeten daha zayıf olduğu söylenebilir.

\begin{tabular}{|lccc|cccc|}
\hline \multicolumn{3}{|c|}{ Model 1 } & \multicolumn{4}{c|}{ Model 2 } \\
\hline \multicolumn{3}{|c|}{$\ln \mathrm{KH} /(\ln \mathrm{KG}, \ln \mathrm{Y})^{\mathrm{a}}$} & \multicolumn{4}{c|}{$\ln \mathrm{KG} /(\operatorname{lnKH}, \ln \mathrm{Y})^{\mathrm{a}}$} \\
\hline \multicolumn{2}{|c|}{$\ln \mathrm{KH}=-33.58+2.48 \ln \mathrm{KG}+2.33 \ln \mathrm{Y}$} & \multicolumn{3}{|c|}{$\ln \mathrm{KG}=13.68+0.38$} & $\ln \mathrm{KH}-0.93$ & $\ln \mathrm{Y}$ \\
$\mathrm{t}-$-değerleri: & -2.04 & 7.63 & 1.39 & $\mathrm{t}$-değerleri: & 2.12 & 7.43 & -1.40 \\
olasıllk: & $(0.08)$ & $(0.00)$ & $(0.20)$ & olasılık: & $(0.07)$ & $(0.00)$ & $(0.20)$ \\
\hline
\end{tabular}

Tablo 5. Modellerin Uzun Dönem Katsayılarının Tahminleri

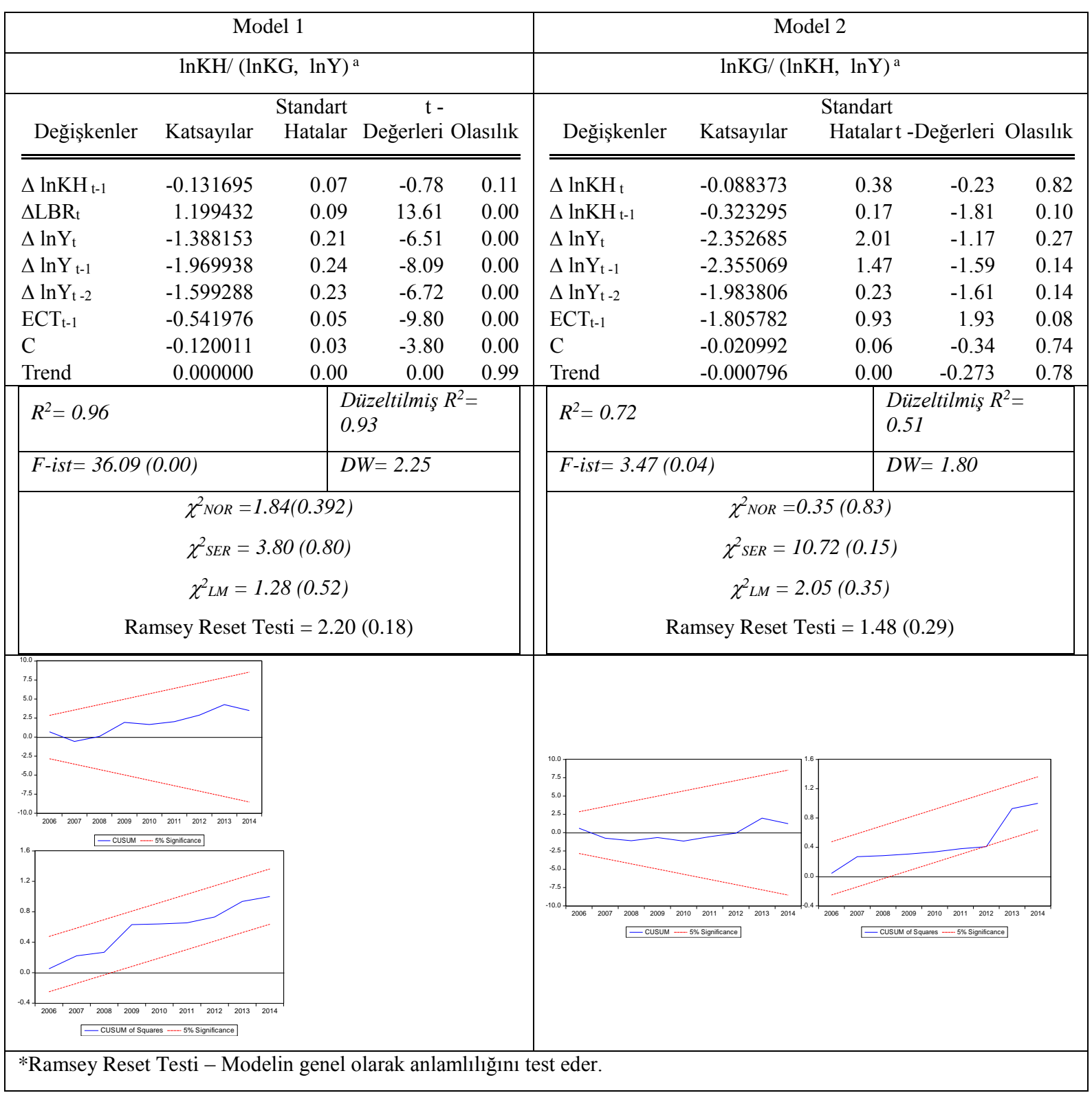

\section{Tablo 6. Klsa Dönem ARDL Modellerinin Tahminleri}

ARDL yaklaşımına dayalı olarak tahmin edilen (8) nolu hata düzeltme modellerinin tahmin sonuçları Tablo 6'da özetlenmiştir. Tahmin edilen her iki modelde de hata düzeltme teriminin katsayısı (ECT) beklenildiği gibi negatiftir. KH'nin bağımlı değişken olarak alındığı model de ECT \%1, KG'nin bağımlı değişken olarak alındığı model de ise \%10 önem düzeyinde istatistiki olarak anlamlıdır. Kamu harcamalarının bağımlı değişken olarak 
alındığı modelde ECT -0.54 olarak tahmin edilmiştir ve kamu harcamalarındaki herhangi bir dengeden sapmanın gelecek iki dönemde düzeltilebileceğini göstermektedir. Kamu gelirlerinin bağımlı değişken olarak alındığı fonksiyonda ise ECT -1.80 olarak tahmin edilmiştir. Narayan ve Smyth (2006a) ECT değerinin birden büyük olmasının, sistemin dalgalanarak dengeye ulaştığından kaynaklandığını ve bu dalgalanma uzun dönemde giderek azalarak dengeye dönüşünü sağlayacağıyla açıklamıştır.

(8) nolu hata düzeltme modeli aynı zamanda değişkenler arasındaki nedenselliği de göstermektedir. Tahmin edilen hata düzeltme modelindeki ECT katsayısının istatistik bakımdan anlamlılığı uzun dönem nedenselliği göstermektedir Tablo 6 görüleceği gibi model 1 de ECT katsayısı \%5, model 2'de ise \%10 önem düzeyinde istatistik bakımdan anlamlıdır. Daha açık bir ifadeyle uzun dönemde kamu gelirlerinin kamu harcamalarının granger nedeni olmadığı sıfır hipotezi \%1 önem düzeyinde reddedilirken, kamu harcamalarının kamu gelirlerinin granger nedeni olmadığı sıfır hipotezi $\% 5$ önem düzeyinde reddedilemezken, \%10 önem düzeyinde reddedilmektedir. Nedensellik tahmin sonuçları, uzun dönemde kamu harcamaları ve kamu gelirleri arasında kamu harcamalarından kamu gelirlerine zayıf, kamu gelirlerinden kamu harcamalarına ise güçlü bir nedenselliğin bulunduğunu göstermektedir.

\subsection{Varyans Ayrıştırma Analizi}

Varyans ayrıştırma analizi, analize seçilmiş değişkenlerin varyansında ortaya çıkan değişmenin kaynağının kendi ve diğer değişkenlerin gecikmeleri arasındaki dağılımını gösterir. Yani söz konusu analizden bir makroekonomik değişkenin daha çok hangi değişkenlerden etkilendiği ve nedenselliğin derecesi hakkında bilgi almak mümkündür.

\begin{tabular}{|c|c|c|c|c|}
\hline \multicolumn{5}{|c|}{$\Delta \operatorname{lnKG}$ K'nın Varyans Ayrıştırması: } \\
\hline Dönem & St. hata & $\Delta \ln K G$ & $\Delta \operatorname{lnKH}$ & $\Delta \ln Y$ \\
\hline 1 & 0.101756 & 100.0000 & 0.000000 & 0.000000 \\
\hline 2 & 0.103283 & 99.81185 & 0.072536 & 0.115612 \\
\hline 3 & 0.104531 & 97.49565 & 1.357226 & 1.147122 \\
\hline 4 & 0.109299 & 97.39184 & 1.547864 & 1.060297 \\
\hline 5 & 0.111072 & 94.32096 & 2.906465 & 2.772580 \\
\hline \multicolumn{5}{|c|}{$\Delta K H ' n i n$ Varyans Ayrıștırması: } \\
\hline Dönem & St. hata & $\Delta \ln K G$ & $\Delta \operatorname{lnKH}$ & $\Delta \ln Y$ \\
\hline 1 & 0.124405 & 80.69704 & 19.30296 & 0.000000 \\
\hline 2 & 0.134009 & 79.79052 & 17.57843 & 2.631049 \\
\hline 3 & 0.135132 & 78.46992 & 18.94223 & 2.587846 \\
\hline 4 & 0.137828 & 77.28926 & 18.43131 & 4.279427 \\
\hline 5 & 0.138226 & 77.04574 & 18.61664 & 4.337618 \\
\hline \multicolumn{5}{|c|}{$\Delta Y^{\prime}$ 'nin Varyans Ayrıştırması: } \\
\hline Dönem & St. hata & $\Delta \ln K G$ & $\Delta \operatorname{lnKH}$ & $\Delta \ln Y$ \\
\hline 1 & 0.024862 & 7.938076 & 62.61513 & 29.44680 \\
\hline 2 & 0.029479 & 10.42090 & 57.60615 & 31.97295 \\
\hline 3 & 0.036509 & 36.49173 & 38.94425 & 24.56403 \\
\hline 4 & 0.045699 & 58.51867 & 25.74525 & 15.73608 \\
\hline 5 & 0.046758 & 58.60846 & 25.08785 & 16.30369 \\
\hline
\end{tabular}

Tablo 7. Serilerin Varyans Ayruştırma Analizleri

Tablo 7'deki serilerin varyans ayrıştırma analizlerine baktığımızda kamu gelirlerinin oldukça dişsal olduğunu, yani en çok kendi gecikmelerindeki değişmelerden etkilenip, diğer değişkenlerden birinci dönem hiç etkilenmediğini, ancak uzun dönemde çok az (\%1 ile \%3 kadar) etkilendiğini söyleyebiliriz. Kamu harcamaları da \%80'lere kadar kamu gelirlerinden etkilenirken, GSYIH'daki değişmeden çok az (2-3. dönemler yaklaşık \%2 ise 4-5. dönemde \%4) etkilenmektedir. GSYİH’nın varyans ayrıştırma sonuçları da ülkede reel sektördeki değişmelerin kısa dönemde \%30 kadarı kendi gecikmelerinden kaynaklanırken 4 dönem sonra bu oranın \%15'e düştüğünü göstermektedir. Diğer yandan da kısa dönemde daha çok kamu harcamalarından (\%62) etkilenirken, uzun dönemde daha çok kamu gelirlerindeki değişmelere bağımlıdır. Genel olarak baktığımızda varyans ayrıştırma analiz sonuçları da ARDL sonuçlarını destekler niteliktedir, yani kamu gelirlerindeki değişmelerin kamu harcamaları üzerindeki etkisinin çok daha yüksek olduğu görülmektedir.

\section{Sonuç}

Bu çalışmada Kırgızistan'da bütçe gelirleriyle harcamaları arasındaki ilişkiler ve nedensellik ARDL yöntemi ve varyans ayrıştırma yöntemleri kullanılarak araştırılmıştır. 1995-2014 dönemine ait yıllık verilerin kullanıldığı çalışmadan elde edilen bulgular kamu harcamaları ile gelirleri arasında hem uzun, hem de kısa dönemde iki taraflı bir ilişkinin olduğunu, ancak, kamu harcamalarının kamu gelirleri üzerindeki etkisinin her iki dönemde de nispeten zayıf olduğunu göstermektedir. Varyans ayrıştırma analizinde de benzer sonuçlara ulaşılmıştır. Nedensellik test 
sonuçları uzun dönemde kamu gelirlerinden harcamalarına doğru işleyen güçlü tek yönlü bir nedenselliğin bulunduğunu göstermektedir. Bu güçlü tek yönlü nedensellik bulgusu analiz edilen dönemde Kırgızistan'da vergi harcama hipotezi geçerlidir şeklinde yorumlanabilir. Bu durumda bütçe gelirlerini artırma yoluyla bütçe açıklarının azaltılması mümkün olmayacağı söylenebilir. Dolayısıyla bütçe açıklarının azaltılabilmesinde kamu gelirlerinin kontrol altına alınmasına önem verilmesinin gerektiği söylenebilir.

\section{Kaynakça}

- Abdul Aziz, Mariam and Shah Habibullah, Muzafar (2000), "Testing For Causality between Taxation and Government Spending: An Application of Toda-Yamamoto Approach.” Pertanika Journal of Social Science \& Humanities, 8(1): 45-50.

- Abual-Foul, B. ve H. Baghestani (2004), "The Causal Relation between Government Revenue and Spending: Evidence from Egypt and Jordan”, Journal of Economics and Finance, 28 (2), 260-269.

- Ahiakpor, J. C. W. ve S. Amirkhalkhali (1989), "On the Difficulty of Eliminating Deficits with Higher Taxes: Some Canadian Evidence”, Southern Economic Journal 56, 24-31.

- $\quad$ Akar, S. (2014), "Türkiye'de Bütçe Gelir ve Harcamalarının Ampirik Analizi", Bankacılık Düzenleme ve Denetleme Kurumu, Bankacılık ve Finansal Piyasalar Dergisi, Haziran 2014:141-159.

- Akçağlayan, Anıl ve M. Kayıran (2010), “Türkiye de Kamu Harcamaları ve Gelirleri: Nedensellik İlişkisi Üzerine Bir Araştırma”, Osmangazi Üniversitesi İIBF Dergisi, Ekim 2010, 129-130.

- Akçoraoglu, A. (1999), "Kamu Harcamaları, Kamu Gelirleri ve Keynesci Politikalar: Bir Nedensellik Analizi”, Gazi Üniversitesi IIBBF Dergisi, 2, 51-65.

- Alfonso, A. ve C. Rault (2009), "Spend and Tax: A Panel Data Investigation for The EU”, Economics Bulletin, 29(4), 2542-2548.

- Ali, R. and Shah, M. (2012), "The Causal Relationship between Government Spending and Revenue in Pakistan”, Interdisciplinary Journal of Contemporary Research in Business, Vol: 3, No: 12, pp. 323-329.

- Al-Khulaifi, A. (2012), "The Relationship between Government Revenue and Spending in Qatar: A Cointegration and Causality Investigation", International Journal of Economics and Finance, Vol. 4, No: 9 , pp. 142-148.

- Al-Qudair, K.H.A. (2005), "The Relationship between Government Spending and Revenues in the Kingdom of Saudi Arabia: Testing for Cointegration and Causality”, JKAU: Econ. \& Adm., Vol: 19, No: 1, pp. 1-43.

- Anderson, W., Wallace, M.S. and Warner, J.T., (1986), “Government Spending and Taxation: What Causes What?” Southern Economic Journal, Vol: 52, No: 3, pp. 630-639.

- Apergis, N., J. E. Payne ve J. W. Saunoris (2012),"Tax-spend Nexus in Greece: Are There Asymmetries?", Journal of Economic Studies, 39 (3), 327 - 336.

- Aregbeyen, O. and Ibrahim, M.T. (2012). "Testing the Revenue and Spending Nexus in Nigeria: An Application of the Bound Test Approach”, European Journal of Social Sciences, Vol: 27, No: 3, pp. 374 380.

- Aslan, M. ve M. Tasdemir (2009), "Is Fiscal Synchronization Hypothesis Relevant for Turkey? Evidence from Cointegration and Causality Tests with Endogenous Structural Breaks", Journal of Money, Investment and Banking, 12, 14-25.

- Baghestani, H. and Mcnown, R. (1994) “Do Revenue or Spending Respond to Budgetary Disequilibria?", Southern Economic Journal, Vol: 6, No: 2, pp. 311-322.

- Barro, R. J. (1979), “On The Determination of The Public Debt”, Journal of Political Economy, 81, 940971.

- Bohn, H. (1991), “Budget Balance Through Revenue or Spending Adjustments?”, Journal of Monetary Economics, 27, 333-359.

- Buchanan, J. M. ve R. W. Wagner (1977), "Democracy in Deficit: The Political Legacy of Lord Keynes”, New York: Academic Press.

- Çavuşoğlu, A.T. (2008), "Türkiye’de Kamu Gelirleri ile Kamu Harcamaları Arasındaki İlişki Üzerine Ekonometrik Bir Analiz”, Dumlupınar Üniversitesi Sosyal Bilimler Dergisi, 20, 143-160.

- Chang T., W. R. Liu ve S. B. Caudill (2002), “Tax and Spend, Spend and Tax, or Fiscal Synchronization: New Evidence for Ten Countries”, Applied Economics, 34, 1553-1561.

- Chang, T. ve G. Chiang (2009), "Revisiting the Government Revenue-Expenditure Nexus: Evidence from 15 OECD Countries Based On the Panel Data Approach”, Czech Journal of Economics and Finance, 59(2), 165-172. 
- Chen, S. (2008), "Untangling The Web of Causalities Among Four Disaggregate Government Expenditures, Government Revenue and Output in Taiwan”, Journal of Chinese Economic and Business Studies, 6 (1), 99107.

- Cheng, B. S. (1999), “Causality Between Taxes and Expenditures: Evidence from Latin American Countries", Journal of Economics and Finance 23 (2), 184-92.

- Darrat, A. F. (1998), "Tax and Spend, or Spend and Tax? An Inquiry into the Turkish Budgetary Process", Southern Economic Journal, Vol: 64, No: 4, pp. 940-956.

- Dökmen, G..(2012), “Kamu Harcamaları ve Kamu Gelirleri Arasındaki İlişski: Panel Nedensellik Analizi”, Dokuz Eylül Üniversitesi İktisadi ve İdari Bilimler Fakültesi Dergisi,Cilt:27, Sayı:2, , ss.115-143

- $\quad$ Eita, J. H and Mbazima, D. (2008) “The Causal Relationship between Government Revenue and Spending in Namibia”, Munich Personal Repec Archive (MPRA) Paper, No: 9154.

- $\quad$ Elyasi, Y. and Rahimi, M. (2012), "The Causality between Government Revenue and Government Spending in Iran”, International Journal of Economic Sciences and Applied Research, 5(1), pp. 129-145.

- Fasano U. ve Q. Wang (2002), "Testing the Relationship Between Government Spending and Revenue: Evidence from GCC Countries", IMF, Working Paper, No. 21.

- Friedman, M. (1978), “The Limitations of Tax Limitation”, Policy Review, Summer, 7, 14.

- Gounder, N. ve P. K. Narayan (2005), “An Empirical Investigation of the Relationship Between Government Revenue and Expenditure: The Case of the Fiji Islands", In submission at International Review of Applied Economics, 24.

• Günaydın, İ. (2004), "Vergi-Harcama Tartışması: Türkiye Örneği”, Doğuş Üniversitesi Dergisi, 5(2), 163 181.

- Hasan, M. ve I. Lincoln (1997), "Tax Then Spend or Spend Then Tax? Experience in the UK 1961 - 1993", Applied Economics Letters, 4, 237-239.

- Henrekson, M. (1993), "The Peacock-Wiseman Hypothesis", The Growth of The Public Sector, Theories and International Evidence, Ed. In N. Gemmell, 53-71. Aldershot: Edward Elgar.

- Hondroyiannis, G., ve E. Papapetrou (1996), “An Examination of The Causal Relationship Between Government Spending and Revenue: Acointegration Analysis”, Public Choice, 89 (3-4), 363-374.

- Hong, T, J. (2009) "Tax-and-Spend or Spend-and-Tax? Empirical Evidence from Malaysia”, Asian Academy of Management Journal of Accounting and Finance, Vol: 5, No: 1, pp. 107-115.

- Hussain, M. H. (2004), "On the Causal Relationship Between Government Expenditure and Tax Revenue in Pakistan”, The Lahore Journal of Economics, 9(2), 105-118.

- Hye, Q. M. A. and Jalil, M. A. (2010), "Revenue and Spending Nexus: A Case Study of Romania", Romanian Journal of Fiscal Policy, Vol: 1, Issue: 1, pp. 22-28.

- $\quad$ Katrakilidis, C. P. (1997), "Spending and Revenues in Greece: New Evidence from Error Correction Modelling”, Applied Economics Letters, 4 (6), 387-391.

- Kaya \& H. Şen (2013), "How to Achieve and Sustain Fiscal Discipline in Turkey: Rising Taxes, Reducing Government Spending or A Combination of Both?”, Romanian Journal of Fiscal Policy, Vol: 4, Issue: 1(6), pp. 1-26.

- $\quad$ Konukcu, Ö. D. and Tosun, A. N. (2008) “Government Revenue-Spending Nexus: Evidence from Several Transitional Economies”, Economic Annals, Issue: 178/179, pp. 145-156.

- $\quad$ Li, X. (2001), "Government Revenue, Government Expenditure, and Temporal Causality: Evidence from China", Applied Economics, 23, 485- 497.

- Manage, N. ve M. L. Marlow (1986), “The Causal Relation Between Federal Expenditures and Receipts”, Southern Economic Journal, 52, 617-29.

- Meltzer, A. H., and Richard, S. F. (1981), “A Rational Theory of the Size of the Government”, Journal of Political Economy, Vol: 89, pp. 914-927.

- Mithani, D. M. and Khoon, S. G. (1999), "Causality between Government Spending and Revenue in Malaysia, A Seasonal Cointegration Test”, ASEAN Economic Bulletin, Vol: 16, No: 1, pp. 69-79.

- Musgrave, R. (1966), Principles of budget determination. In Public Finance: Selected Readings eds. H. Cameron and W. Henderson. New York: Random House.

- Narayan, P. K. (2005), “The Government Revenue and Government Expenditure Nexus: Empirical Evidence from Nine Asian Countries", Journal of Asian Economics, 15, 1203-1216. 
- $\quad$ Narayan, P. K. ve S. Narayan (2006), "Government Revenue and Government Expenditure Nexus: Evidence from Developing Countries", Applied Economics, 38, 285-291.

- Narayan, P.K., Smyth, R. (2006a), "What Determines Migration Flows From Low-Income To High-Income Countries? An Empirical Investigation Of FijiUS Migration 1972-2001”, Contemporary Economic Policy. Vol. 24, No.2, pp. 332-342.

- Owoye, O. (1995), “The Causal Relationship between Taxes and Spendings in the G7 Countries: Cointegration and Error-Correction Models”, Applied Economics Letters, Vol: 2, pp. 19-22.

- Park, W. K. (1998), "Granger Causality Between Government Revenues and Expenditures in Korea”, Journal of Economic Development, 23 (1), 145-55.

- Payne, J. E. (1997), “The Tax-spend Debate: Time Series Evidence from State Budgets”, Public Choice, 95 (3-4), 307-320.

- $\quad$ Ram, R (1988), “Additional Evidence on Causality Between Government Revenues and Government Expenditure", Southern Economic Journal, 617-628.

- Ravinthirakumaran, K. (2011), "The Relationship between Government Revenue and Spending in Sri Lanka", Proceedings of Second International Research Conference on Business and Information. Faculty of Commerce and Management Studies, University of Kelaniya, Sri Lanka.

- Taha R. ve Loganathan N. (2008), "Causality between Tax Revenue and Government Spending in Malaysia”, International Journal of Business and Finance Research, 2(2), 63-73.

- Sanjeev, K. (2004), "The Causality Between Tax And Spend Of The Public Sector In Mauritius: A VECM Approach", International Journal of Applied Econometrics and Quantitative Studies Vol.1-3(2004) ss. 115130.

- $\quad$ Saunoris J. W. ve J. E. Payne (2010), “Tax More or Spend Less? Asymmetries in the UK RevenueExpenditure Nexus", Journal of Policy Modeling, 32, 478-87.

- $\quad$ Sikdar, S. and Mukhopadhyay, C. K. (2011), "Central Government Revenue and Spending Relationship in the Economy of India: An Econometric Study", The IUP Journal of Public Finance, Vol: IX, No: 3, pp. 4157.

- $\quad$ Subhani, M. I., Hasan, S. A., Osman, A., and Rafiq, T., 2012. An Investigation of Granger Causality between Tax Revenues and Government Spendings. European Journal of Scientifics Research, 68(3), pp. 340-344.

- Terzi, H. ve S. Oltulular (2006), "Harcama-Vergi Geliri Hipotezi: Türkiye Örnegi”, Atatürk Üniversitesi IIBF Dergisi, 20(2), 1-18.

- Tüğen, K. (1997), Bütçe Açıkları ve Açı̆̆ın Finansmanında Iç̧ Borçlanmanın Rolü (1980 Sonrası Türkiye Deneyimi), İzmir: Bilim Ofset.

- Vamvoukas, G. A. (2011), "Panel Data Modelling and the Tax - Spend Controversy in the Euro Zone", Applied Economics, Vol: 1, pp. 1-24.

- Vamvoukas, G.A. (2011), "The Tax-Spend Debate with An Application to The EU", Economic Issues, 16(1), 65-88, March.

- Wahid, N.M. (2008), “An Empirical Investigation on the Nexus Between Tax Revenue and Government Spending: The Case of Turkey", International Research Journal of Finance and Economics, 16, 46-51.

- Yamak, R. ve Z. Abdioğlu (2012), “Ampirik Bağlamda Toplam ve Alt Kalemler Bazında Kamu Harcamaları ve Kamu Gelirleri Arasındaki İlişki: Türkiye Örneği”, Hacettepe Üniversitesi İIBF Dergisi, 30 (1), 173-193.

- Young, A. (2009), "Tax-Spend or Fiscal Illusion?" Cato Journal 29, 3.

- Zapf, M. ve J. E. Payne (2009), “Asymmetric Modeling of the Revenue- Expenditure Nexus: Evidence from Aggregate State and Local Government in the US", Applied Economics Letters, 16, 871-876.

- $\quad$ http://constpalata.kg/ru/about/istoriya, 05.06.2014, 14:21

- http://eulaw.edu.ru/documents/legislation/eea/pca_kyrgyz.htm, 05.06.2014, 14:21

- Krrgız Cumhuriyeti İstatistik Komitesi, www.stat.kg.

- https://www.quandl.com/data/WORLDBANK/KGZ_NYGDPMKTPXN-Kyrgyz-Republic-GDP-deflatorLCU, 


\title{
Orta Asya Türk Cumhuriyetlerinin Ekonomik Performanslarının Analitik Hiyerarşi Süreci ve VIKOR Metodu ile Karşılaştırılması \\ Comparison of the Economic Performance Turkish Republics in Central Asia with Analytic Hierarchy Process and Vise Kriterijumska Optimizacija I Kompromisno Resenje Methods
}

\author{
Dr. Engin Karakış (Cumhuriyet University, Turkey) \\ Prof. Dr. Ziya Gökalp Göktolga (Cumhuriyet University, Turkey)
}

\begin{abstract}
The aim of this study is to compare the economic performance of Turkish Republics in Central Asia with Multi Criteria Decision Making (MCDM) methods. Turkish Republics have been experiencing a transition from a centrally planned economy towards a market economy since their independence. In this study important macroeconomic and social indicators are used to determine economic performance. Economic performance evaluation of the countries an important issue for economic management, investors, creditors and stock investors. Vise Kriterijumska Optimizacija I Kompromisno Resenje (VIKOR) is an improved method for optimization in multicriteria case. VIKOR method is a method based on a compromise solution. VIKOR method returns a sorted index based on the measurement closeness to ideal solution. In this study Analytic Hierarchy Process (AHP) method is used in determining the criteria weight. VIKOR is used to measure economic performance of Turkish Republics. Economic Performance of Turkish Republics in Central Asia (Azerbaijan, Turkmenistan, Kazakhstan, Kyrgyzstan, and Uzbekistan) are compared with VIKOR method. Study provides comparisons of the economic performance Turkish Republics in Central Asia. İnvestigated with VIKOR method countries best and worst economic performance years are detected during mentioned period and results are analyzed.
\end{abstract}

\section{Giriș}

Orta Asya Türk Cumhuriyetleri 1990'ların başlarında bağımsızlıklarını kazanıncaya kadar Sovyet ekonomisi içerisindeki planlama ve işbölümü gereği tedarikçi ya da hammadde üreticisi konumunda kalmışlardır. Bağımsızlıklarını kazanmalarından sonra Türk Cumhuriyetleri kendi ekonomik faaliyetlerini yönetme imkânına kavuşmuşlardır. Orta Asya Türk Cumhuriyetleri bağımsızlıklarını kazandıktan sonra serbest piyasa ekonomisi içerisinde dünya ekonomisi ile ilişkiler kurarak ekonomik ve sosyal gelişmelerini sağlamaya çalışmışlardır. Türk Cumhuriyetlerinin ekonomik gelişmeleri yanında sosyo-kültürel gelişmeleri uluslararası alanda dünya ile bütünleşme sağlamaları için önemlidir. Bu çalışmada uzun yıllar kapalı bir planlı ekonomi içerisinde yer alan Türk Cumhuriyetlerinin sosyal ve kültürel gelişimleri ile ekonomik gelişimleri ve bunların etkileşimleri birlikte değerlendirilmek istenmiştir.

Çalışmada Orta Asya Türk Cumhuriyetlerinin ekonomik gelişimleri ve sosyal gelişimleri elde edilebilen önemli ekonomik ve sosyal gelişim göstergelerinden faydalanılarak ortaya konmaya çalışılmıştır. Ülkelerin ekonomik ve sosyal göstergelerine göre çok çeşitli yöntemler kullanılarak karşılaştırılmakta ve bu karşılaştırmalar ile ülke performansları arasında bir sınıflandırma ve sıralama yapılabilmektedir. Bu çalışmalarda elde edilen sonuçlar ülkelerin belirli dönemleri kapsayan ekonomik ve sosyal gelişim performansları olarak kabul edilmektedir. Ülkelerin ekonomik ve sosyal gelişim performansları, sahip oldukları kaynaklarını ne derece etkin kullandıklarını ifade etmektedir. Çok Kriterli Karar Verme (ÇKKV) yöntemleri pek çok alanda çeşitli karar problemlerinin çözümlenmesinde kullanıldığı gibi ülkelerin ve organizasyonların karşılaştırılmasında da kullanılmaktadır. ÇKKV yöntemleri çeşitli kriter ve amaçlara göre işletmelerin, sosyal organizasyonların ve ülkelerin sıralanması, sınıflandırılmasında ve seçilmesinde kullanılmaktadır(Ishizaka ve Nemery, 2013).ÇKKV yöntemler, Çok Amaçlı Karar Verme(ÇAKV) ve Çok Nitelikli Karar Verme(ÇNKV) yöntemleri olarak ikiye ayrılmaktadır. ÇAKV çok sayıda ve çelişen amaçlar arasından en uygununu belirlerken, ÇNKV yöntemleri ise çok sayıda ve birbiriyle çelişen kriterlere göre alternatifler arasından en uygununu seçmek ve sınıflandırmak için kullanılır (Zhou vd. 2006).

Günümüzde pek çok karar analizinde, ülkeler ve işletmeler arasında ekonomik karşılaştırmalar yapılmasında birden çok alternatif ve birden çok kriter sözkonusu olduğu için ÇNKV verme yöntemleri uygun yöntemler olarak görülmektedir. Ülkelerin performanslarının değerlendirilmesi sırasında çok sayıda ve önem ağırlıkları farklı ekonomik ve sosyal kriter kullanılmaktadır. Ülkelerin ekonomik ve sosyal gelişimlerinin sıralanması ve kıyaslanması çok sayıda kriteri birlikte değerlendiren matematiksel yöntemler ile yapılabilir. ÇNKV yöntemleri alternatifler arasında seçim, sıralama, sınıflandırma ve değerlendirme yapmak için geliştirilmiş yöntemleridir. Analitik Hiyerarşi Prosesi (AHP), Analitik Network Prosesi (ANP), Multiple Attribute Utility Theory (MAUT), The Preference Ranking Organization Methods for Enrichment Evaluation (PROMETHEE), Technique for Order Preference by Similarity to İdeal Solution (TOPSIS), Vise Kriterijumska Optimizacija I Kompromisno Resenje (VIKOR), Data Envolepment Analysis (DEA), Elimanation and Choice Translating Reality (ELECTRE), 
kullanılan karar yöntemlerinden bazılarıdır. Bu çalışmada Orta Asya Türk Cumhuriyetlerinin ekonomik ve sosyal gelişimlerinin diğer bir ifade ile ekonomik ve sosyal performanslarının çok kriterli karar verme yöntemlerinden AHP ve VIKOR bütünleşik karar yöntemleri ile incelenmektedir. Bütünleşik olarak kullanılan AHP ve VIKOR yöntemleri ile ülkelerin ekonomik ve sosyal verileri matematiksel olarak ifade edilerek, ülkeler performanslarına göre siralanmaktadir.

Çalışmada öncelikle AHP ve VIKOR yöntemleri açıklanmış, daha sonra ekonomik ve sosyal performans karşılaştırmasında kullanılan kriterlerle ilgili bilgi verilerek ülkelerin 2014 yılı için performans analizi yapılmıştır. Çalışmada kullanılan kriterlerin önem ağırlıkları AHP yöntemi ile belirlenmiş ve daha sonra bu kriterlere göre ülkelerin performans analizi VIKOR yöntemi ile yapılmıştır.

\section{AHP}

Analitik Hiyerarşi Prosesi(AHP) Thomas L. Saaty tarafından ÇKKV problemlerinin çözümü için 1980 yılında geliştirilen bir yöntemdir. AHP karar analizinde kriter ve alternatifler arasında insani düşüncesine uygun bir şekilde ikili karşılaştırmalara dayalı olarak karar analizi gerçekleştirmektedir. Burada öneli olan ikili karşılaştırmalarda mantıksal hatalara düşülmemiş olması diğer bir ifade ile karşılaştırmalarda tutarlı davranmak gerekmektedir. Çok sayıdaki kriter ve alternatif basitçe ve insan düşüncesine uygun olarak ikili karşılaştırmalar şeklinde daha az sayıda ele alınarak daha anlaşılır hale getirilmektedir. "AHP, karmaşık ve iyi yapılandırılmamış bir durumun bileşenlerini ve değişkenlerini hiyerarşik bir düzende ifade ederek, her bir alternatifin karşılaştırmalı önem düzeylerine ilişkin kişisel yargılara kantitatif değerler atama ve elde edilen yargıların sonucuna göre değişkenlerin öncelik düzeylerini ortaya koyarak sentez yapma yöntemi olarak tanımlanabilir”(Alp ve Gündoğdu, 2012:10). AHP karar analizine sübjektif ve objektif yargıların katılması dışında bireysel ya da grup kararı alabilmeyi sağlayan bir yöntemdir.

AHP karar problemlerini hiyerarşik bir yapıda ele almaktadır. AHP karar vericiye karmaşık bir karar problemine ait amaç, hedefler(kriterler), alt hedefler ve alternatifler arasındaki ilişkiyi hiyerarşik yapıda modelleyerek veri, tecrübe ve sezgilerin doğru ve mantıklı bir şekilde uygulanmasına imkan vermektedir(Özdemir ve Saaty, 2006: 349-359). AHP' de karar probleme etki eden kriter ağırlıklarını bulmak için aşağıdaki aşamalar izlenir;

1. Aşama: Her bir kriter diğer bir kriter ile karşılaştırılarak ikili karşılaştırma matrisi oluşturulur. Kriterlerin İkili karşılaştırmasında Thomas L. Saaty tarafından önerilen ve Tablo 1'de gösterilen ikili karşılaştırma ölçeği kullanılır. Ölçek ile bir alternatif ya da kriterin diğerine göre önem seviyesi ikili karşılaştırmalar yapılarak belirlenir.

2. Aşama: Karşılaştırmaların tutarlılı̆̆ını sağlamak amacıyla tutarlılık oranı hesaplanır. Eğer ikili karşılaştırmalarda mantıksal hatalar ve tutarsızlık var ise karşılaştırmalar tekrar gözden geçirilir. Çünkü tutarsızlık olması durumunda AHP yöntemi doğru sonuçlar vermeyecektir.

3. Aşama: Karşılaştırmaların tutarlı olup olmadığını bulmak için öncelikle ikili karşılaştırma matrisi normalize edilir. Her bir sütun toplamına göre normalize edilmiş karar matrisinde her satırın aritmetik ortalaması alınarak öncelikler vektörü elde edilir. Öncelikler vektörü ve başlangıçtaki karşılaştırma matrisi çarpılarak Tüm öncelikler matrisi oluşturulur. Buradan hesaplanacak en büyük özdeğer ile karşılaştırmaların tutarlılığg incelenir.

\begin{tabular}{|l|c|l|}
\hline \multicolumn{1}{|c|}{ İkili Karşılaştırma Tercihleri } & $\begin{array}{c}\text { Önem } \\
\text { Derecesi }\end{array}$ & \multicolumn{1}{c|}{ Açıklama } \\
\hline Eşit derecede önemli & 1 & İki faktör önemi eşittir. \\
\hline Az önemli (Az üstün olma hali) & 3 & Bir faktör diğerinden biraz daha önemlidir. \\
\hline $\begin{array}{l}\text { Oldukça önemli (Oldukça üstün olma } \\
\text { hali) }\end{array}$ & 5 & $\begin{array}{l}\text { Bir faktör diğerinden kuvvetle daha } \\
\text { önemlidir. }\end{array}$ \\
\hline Çok önemli (Çok üstün olma hali) & 7 & $\begin{array}{l}\text { Bir faktör diğerinden yüksek derecede } \\
\text { önemlidir. }\end{array}$ \\
\hline $\begin{array}{l}\text { Son derece önemli (Kesin üstün olma } \\
\text { hali) }\end{array}$ & 9 & $\begin{array}{l}\text { Bir faktör diğerinden çok yüksek derecede } \\
\text { önemlidir. }\end{array}$ \\
\hline Ara değer & $2,4,6,8$ & $\begin{array}{l}\text { İki faktör arasında tercihte küçük önem fark1 } \\
\text { bulunur }\end{array}$ \\
\hline
\end{tabular}

Tablo 1. Ikkili Karşılaştırmalar Ölçeği. Kaynak: Saaty L. Thomas (2008) "Decision Making with the Analytic Hierarchy Process” Int. J. Services Sciences, Vol. 1, No. 1, s. 86.

\subsection{AHP'de Tutarlılık (Uyum Oranı)}

Tutarlılık verilerin yargıların mantıksal tutarlılık içinde olması veya çelişmemesi olarak ifade edilebilir. AHP'de karar vericinin karşılaştırma yaparken tutarlı olup olmadığını tespit etmek için Tutarlılık Oranı hesaplanır. Bulunan tutarlılık oranı 0,10 'un altında ise karşılaştırma matrisinin tutarlı olduğu kabul edilir. Tutarlılık ya da uyum oranının 0,10’un üstünde olması halinde karar vericilerin ikili karşılaştırmalarını tekrar gözden geçirmeleri gerekmektedir. Tutarlılık oranının hesaplanması aşağıdaki aşamalarla yapılır (Timor 2010:307). 
Karar matrisinin normalize edilmesiyle elde edilen normalize edilmiş karar matrisinde her bir satırının aritmetik ortalaması bulunarak hesaplanan Öncelikler Vektörü başlangıç matrisi olan karşılaştırma matrisi ile çarpılarak Tüm Öncelikler Matrisi elde edilir. Sonra bir sütun vektörü olan Tüm Öncelikler Matrisinin her elemanı Öncelikler vektörü elemanlarına bölünerek, elde edilen yeni matris elemanlarının aritmetik ortalaması alınmaktadır. Hesaplanan son sütun vektörünün aritmetik ortalaması ise en büyük özdeğer olan $\chi$ max değerini vermektedir. Bir karşılaştırma matrisinin tutarlı olabilmesi için en büyük özdeğerinin ( $\chi$ max) matris boyutuna (n) eşit olması gerekmektedir.

Tutarlılık oranının hesaplanmasında kullanılan $\chi$ max değeri her zaman n'ye eşit veya n'den büyüktür. Tutarlılık indeksi CI aşağıdaki formül ile hesaplanmaktadır. Tutarlılık İndeksinin hesaplamasında kullanılan formüldeki $\mathrm{n}$ karşılaştırılan kriter sayısını gösterir.

$$
\mathrm{CI}=(\chi \max -n) /(n-1)
$$

Tutarlılık indeksi CI'nın hesaplanmasından sonra indeks, rastgele indeks değeri(RI) ile karşılaştırılır. Tutarlılık Oranının(CR) hesaplanması için aşağıdaki formül kullanılır. Hesaplanan CR değerinin $\mathrm{CR}<0,10$ bulunması halinde karşılaştırma matrisi tutarlı kabul edilir.

$\mathrm{CR}=\mathrm{CI} / \mathrm{RI}$

\begin{tabular}{|l|c|c|c|c|c|c|c|c|c|c|c|c|c|c|c|}
\hline $\mathbf{N}$ & $\mathbf{1}$ & $\mathbf{2}$ & $\mathbf{3}$ & $\mathbf{4}$ & $\mathbf{5}$ & $\mathbf{6}$ & $\mathbf{7}$ & $\mathbf{8}$ & $\mathbf{9}$ & $\mathbf{1 0}$ & $\mathbf{1 1}$ & $\mathbf{1 2}$ & $\mathbf{1 3}$ & $\mathbf{1 4}$ & $\mathbf{1 5}$ \\
\hline $\mathbf{R I}$ & 0 & 0 & 0.5 & 0.90 & 1.12 & 1.24 & 1.32 & 1.41 & 1.45 & 1.49 & 1.51 & 1.48 & 1.56 & 1.57 & 1.59 \\
\hline
\end{tabular}

Tablo 2. RI Değerleri Tablosu. Kaynak: Alonso Antonio Jose, Lamata Teresa(2006) “Consistency In The Analytıc Hierarchy Process: A New Approach” International Journal Of Uncertainty, Fuzziness And KnowledgeBased Systems Vol.: 14, No: 4, s.449.

\section{VIKOR}

Opricovic tarafından geliştirilen VIKOR yönteminde diğer ÇNKV yöntemlerinde olduğu gibi alternatiflerin karara etki eden kriterlere göre değerlendirmesi yapılmaktadır. VIKOR yöntemi çelişkili ve ortak birimle ölçülemeyen çok sayıdaki kriter içeren çok kriterli karar problemlerinin çözümü için geliştirilmiş bir yöntemdir. Seçeneklerin her bir kritere göre değerlendirildiğinde uzlaşık sıralama her bir alternatifin ideal çözüme yakınlıkları karşılaştırılarak bulunur. Uzlaşık sıralama için uzlaşık çözüm $L_{p}$ metrik formundan başlamıştır. $\mathrm{j}$ tane alternatif $a_{1}, a_{2}, \ldots a_{n}$ ile ve $a_{j}$ seçeneğinin i. kriter ölçümü $f_{i j}$ olarak gösterilir (Opricovic ve Tzeng, 2004).

$$
L_{p j}=\left\{\sum_{i=1}^{n}\left[w_{i}\left(f_{i}^{*}-f_{i j}\right) /\left(f_{i}^{*}-f_{i}^{-}\right)\right]^{p}\right\}^{1 / p}, 1 \leq \mathrm{p} \leq \infty ; \mathrm{j}=1,2,3, \ldots \mathrm{j}
$$

Yöntem karara etki eden çelişkili kriterler içinde uzlaşmacı bir çözüm öneren bir ya da daha fazla seçenek üzerinde odaklanır(Opricovic ve Tzeng, 2007). Uzlaşmacı çözüm $F^{c}$ ideal çözüm $F^{*}$ 'a en yakın uygun bir çözümdür. Uzlaşma karşılıklı kurulan bir anlaşma, konsensüs anlamına gelmektedir. Şekil 1'de uzlaşmacı çözüm gösterilmektedir(Opricovic ve Tzeng, 2004). Şekilde Uzlaşı çözüm, $\Delta f_{1}=f_{1}^{*}-f_{1}^{c}$ ve $\Delta f_{2}=f_{2}^{*}-f_{2}^{c}$ ile gösterilen uzlaşma ve anlaşmayı ifade eder.

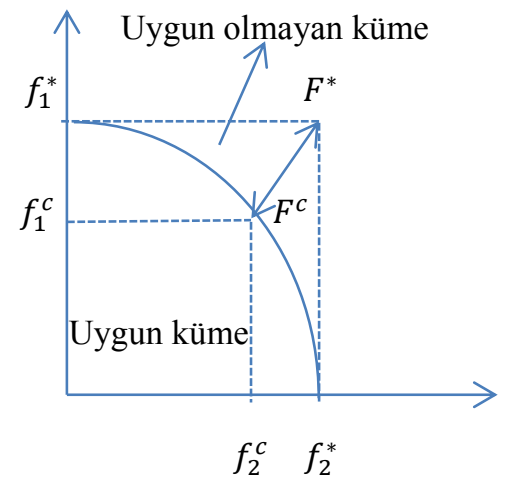

Şekil 1. İdeal ve Uzlaşık çözümleri. Kaynak: Oprlcovıc and Tzeng, 2004. "The Compromise solution by MCDM methods: A comparative analysis of VIKOR and TOPSIS”, European Journal of Operational Research, 178, s.447.

VIKOR yönteminde öncelikle karar problemi ve probleme etki eden karar kriteleri belirlenmektedir. Belirlenen karar kriterlerinin niteliğine göre maliyet ve fayda kriterleri farklı değerlendirilmektedir. Örneğin maliyet kriteri olduğunda en düşük tercih edilirken fayda kriteri olduğunda en yüksek değer tercih edilmektedir. Daha sonra karara etki ettiği düşünülen karar kriterlerinin nisbi önemi, diğer bir ifade ile önem ağırlığı belirlenmelidir. Kriterlerin önem ağırlıkları alternatiflerin değerlendirilmesinde kriterin ne derece etkili olduğunu belirleyen bir ölçüdür. Kriterlerin önem ağırlıkları oransal olarak ifade edilmekte ve bütün kriterlerin önem ağırlıkları toplamı 
1'e eşit olmaktadır. VIKOR yönteminde, birden çok kriter birlikte değerlendirilip ideal çözüme en yakın olan uygulanabilir çözümler üretilir ve alternatifler arasından en iyi olanın seçilmesi veya bu alternatiflerin performanslarına göre sıralanması için kullanılır (Özden, 2012).

Karar analizinde etkili olan kriterin belirlenen önem ağırlığına göre alternatifler değerlendirilmektedir. Farklı etkileri olan kriterlere göre en uygun çözümü belirleme amacı ile çok kriterli optimizasyon yöntemi olan VIKOR yöntemi diğer çok kriterli karar yöntemleri ile karşılaştırıldığında doğrusal normalizasyon kullanır(Opricovic ve Tzeng, 2004). VIKOR yöntemi diğer yöntemlere göre farklı oranlarda uzlaşmacı bir çözüm önermesi ile de farklılık göstermektedir(Tzeng vd, 2005).VIKOR yönteminin uygulama aşamaları aşağıda gibidir;

1. Aşama: Karar matrisinin oluşturulması.

Yöntemin uygulanması için öncelikle karar matrisi oluşturulur. Karar matrisinin satırları alternatifleri, sütunları ise kriterleri göstermektedir. Karar matrisi karar verici tarafından oluşturulan ve karar problemine ait alternatif ve kriterleri gösteren ve kriterlerin alternatiflere göre aldığı sayısal değerleri gösteren matris olup aşağıdaki şekilde gösterilebilir:

$$
X_{i j}=\left[\begin{array}{cccc}
x_{11} & x_{12} & \cdot & x_{1 n} \\
x_{21} & x_{22} & \cdot & x_{2 n} \\
\cdot & \cdot & \cdot & \cdot \\
\cdot & \cdot & \cdot & \cdot \\
x_{m 1} & x_{m 2} & \cdot & x_{m n}
\end{array}\right]
$$

$X_{i j}$ matrisinde satırlar $(\mathrm{i}=1,2,3, \ldots \mathrm{m})$ alternatifleri, sütunlar ise $(\mathrm{j}=1,2,3, \ldots . \mathrm{n})$ kriterleri göstermektedir.

2. Aşama: En iyi ve en kötü kriter değerlerinin belirlenmesi.

Karar matrisinin oluşturulmasından sonra her bir kriter için en iyi $f_{j}^{*}$ ve en kötü $f_{j}^{-}$değerleri belirlenir. En iyi ve en kötü kriter değerleri kriterlerin maliyet ve fayda kriteri olmasına göre belirlenir. Eğer bir kriter fayda kriteri ise en iyi $f_{j}^{*}$ ve en kötü $f_{j}^{-}$değerleri,

$$
\begin{aligned}
& f_{j}^{*}=\max x_{i j} \\
& f_{j}^{-}=\min x_{i j}
\end{aligned}
$$

eşitliğinden hesaplanır. Eğer kriter maliyet kriteri ise en iyi $f_{j}^{*}$ ve en kötü $f_{j}^{-}$değerleri,

$$
\begin{aligned}
f_{j}^{*} & =\min x_{i j} \\
f_{j}^{-} & =\max x_{i j}
\end{aligned}
$$

eşitliği ile bulunur.

3. Aşama: Normalize edilmiş matris oluşturulması.

Karar matrisinin değerlerini karşılaştırılabilir hale getirmek için karar matrisi değerleri normalize edilir. Normalizasyon işlemi için çeşitli yöntemler uygulanabilmektedir. Normalizasyon işlemi ile karar matrisi değerleri birimlerinden arındırılmış olup aşağıdaki formül yardımı ile normalize edilir:

$$
r_{i j}=\frac{f_{j}^{*}-x_{i j}}{f_{j}^{*}-f_{j}^{-}}
$$

Hesaplanan normalize karar matrisi R aşağıdaki gibi ifade edilir.

$$
R_{i j}=\left[\begin{array}{cccc}
r_{11} & r_{12} & \cdot & r_{1 n} \\
r_{21} & r_{22} & \cdot & r_{2 n} \\
\cdot & \cdot & \cdot & \cdot \\
\cdot & \cdot & \cdot & \cdot \\
r_{m 1} & r_{m 2} & \cdot & r_{m n}
\end{array}\right]
$$

4. Aşama: Ağırlıklandırılmış normalize karar matrisinin oluşturulması.

Normalize karar matrisinin sütunlardaki değerlerinin her bir kriterin önem ağırlığı ile çarpılması ile ağırlıklandırılmış normalize karar matrisi elde edilir. $w_{i j}$ kriter ağırlıklarını ifade etmek üzere normalize karar matrisi elemanları $v_{i j}$

$$
v_{i j}=r_{i j} \cdot w_{i j}
$$

formülü ile hesaplanır. Ağırlıklandırılmış normalize karar matrisi $V$, 
şeklinde gösterilir.

$$
V_{i j}=\left[\begin{array}{cccc}
w_{1} r_{11} & w_{2} r_{12} & \cdot & w_{n} r_{1 n} \\
w_{1} r_{21} & w_{2} r_{22} & \cdot & w_{n} r_{2 n} \\
\cdot & \cdot & \cdot & \cdot \\
\cdot & \cdot & \cdot & \cdot \\
w_{1} r_{m 1} & w_{2} r_{m 2} & \cdot & w_{n} r_{m n}
\end{array}\right]=\left[\begin{array}{cccc}
v_{11} & v_{12} & \cdot & v_{1 n} \\
v_{21} & v_{22} & \cdot & v_{2 n} \\
\cdot & \cdot & \cdot & \cdot \\
\cdot & \cdot & \cdot & \cdot \\
v_{m 1} & v_{m 2} & \cdot & v_{m n}
\end{array}\right]
$$

5. Aşama: $S_{i}$ ve $R_{i}$ değerlerinin hesaplanmas

$S_{i}$ ve $R_{i}$ değerleri i. alternatif için ortalama ve en kötü grup değerlerini göstermektedir.

$$
\begin{aligned}
& S_{i}=\sum_{j=1}^{n} w_{i j} \cdot \frac{f_{j}^{*}-x_{i j}}{f_{j}^{*}-f_{j}^{-}} \\
& R_{j}=\max \left(w_{j} \frac{f_{j}^{*}-x_{i j}}{f_{j}^{*}-f_{j}^{-}}\right)
\end{aligned}
$$

6. Aşama: $Q_{i}$ değerlerinin hesaplanması.

$Q_{i}$ değerlerinin hesaplanması için gerekli olan $S^{*}, S^{-}, R^{*}$ ve $R^{-}$değerleri sırasıyla aşağıdaki eşitliklerle bulunur.

$$
\begin{aligned}
S^{*} & =\min S_{i}, & & S^{-}=\max S_{i} \\
R^{*} & =\min R_{i}, & & R^{*}=\max R_{i}
\end{aligned}
$$

$Q_{i}$ değerleri aşağıdaki formül ile hesaplanır. Formülde kullanılan ' $a$ ' değeri kriterlerin çoğunluk ağırlığını ifade ederken (1-a) değeri karşı görüşün minimum pişmanlığını ifade eder. Uzlaşma çeşitli düzeylerde; çoğunluk oyu $(\mathrm{a}>0,5)$ ile konsensus $(\mathrm{a}=0,5)$ ile ve veto $(\mathrm{a}<0,5)$ ile sağlanmaktadır (Özden vd. 2012).

$$
Q_{i}=\frac{a \cdot\left(S_{i}-S^{*}\right)}{S^{-}-S^{*}}+\frac{(1-a) \cdot\left(R_{i}-R^{*}\right)}{R^{-}-R^{*}}
$$

7. Aşama: Alternatiflerin sıralanarak uzlaştırıcı en iyi çözümün bulunması ve şartların denetlenmesi.

$S_{i}, R_{i}$ ve $Q_{i}$ değerlerinin küçükten büyüğe doğru sıralanması ile üç sıralama elde edilir. Siralamaların doğruluğunu denetlemek için minimum $Q_{i}$ değerinin aşağıdaki iki şartı sağlayıp sağlamadığı incelenir.

Şart 1. Kabul edilebilir avantaj: $Q_{i}$ değerlerinin küçükten büyüğe doğru sıralanması ile ilk sıradaki alternatif ve ikinci sıradaki alternatif $A_{1}$ ve $A_{2}$ ile gösterildiğinde Kabul edilebilir avantaj,

$$
\mathrm{Q}\left(A_{2}\right)-\mathrm{Q}\left(A_{1}\right) \geq \mathrm{DQ}
$$

şartına bağlıdır. DQ değeri alternatif sayısı ile bulunmaktadır. Alternatifleri $n$ ile göstermek üzere,

eşitliği ile hesaplanmaktadır.

$$
\mathrm{DQ}=\frac{1}{n-1}
$$

Şart 2. Kabul edilebilir istikrar şartı: $Q_{i}$ değerlerinin küçükten büyüğe doğru sıralamasından sonra $\mathrm{S}$ ve $\mathrm{R}$ değerlerinin de sıralanması ile oluşan üç ayrı sıralama aynı olmalıdır. Böyle bir durumda uzlaşılan çözüm aynı zamanda istikrarlıdır. Uzlaşık çözümün grup faydasını maksimum ölçüde sağlayacağı ve pişmanlığı ise minimum düzeyde tutacă̆ kabul edilir (Göktürk vd. 2012).

Eğer bu iki şart birlikte sağlanmaz ise uzlaşı çözüm şu şekilde oluşturulur; Eğer 1. Şart sağlanamaz ise $\mathrm{Q}\left(A^{n}\right)$ $\mathrm{Q}\left(A^{1}\right) \leq \mathrm{DQ}$ ve olursa $A^{n}$ ve $A^{1}$ aynı uzlaştırıcı çözüm olur. Eğer 2. şart sağlanamaz ise $A^{1}$ 'in nispi bir avantajı olsa da karar vermede tutarsızlık vardır. Bundan dolayı $A^{1}$ ve $A^{2}$ uzlaştırıcı çözümleri aynıdır. Q değeri en kü̧̈ük olan en iyi alternatifin seçimi yapılır (Yıldız ve Deveci, 2013).

\section{Orta Asya Türk Cumhuriyetlerinin Ekonomik Performanslarının Karşılaştırılması}

Çalışmada Orta Asya Türk Cumhuriyetlerinden Azerbaycan, Kazakistan, Kırgızistan, Türkmenistan, Özbekistan ve Tacikistan'ın 2014 yılındaki ekonomik performansları ÇNKV yöntemlerinden AHP VE VIKOR yöntemlerinin bütünleşik olarak kullanıldığı bir yöntemle incelenerek sıralanmıştır. Ülkelerin ekonomik performansları ekonomik ve sosyal kriterlere göre değerlendirilmiştir. Çalışmada ülke performanslarının belirlenmesinde büyüme hızı, kişi başına gayri safi yurtiçi hasılaları, işsizlik oranları, enflasyon oranı, doğrudan yabancı sermaye yatırımları olmak üzere 5 ekonomik gösterge ve doğumda beklenen yaşam süresi, lojistik performans indeksi, beş yaş altı ölüm oranı, cep telefonu kullanımı, internet kullanımı olmak üzere 5 sosyal gösterge kullanılmış̧ır. Çalışmada ülke performanslarına etki eden ekonomik ve sosyal toplam 10 adet gösterge kriter kullanılmıştır. Kullanılan kriterler Çalışmada kullanılan kriterlere ilişkin veriler Dünya Bankasının internet sitesinden temin edilmiştir. Belirlenen ekonomik ve sosyal kriterler ve ülkelerin performanslarına etkileri Tablo 1.'de gösterilmişsir. 


\begin{tabular}{ll}
\hline Kriterler & Performansa Olan Etki \\
\hline Büyüme Hızı & Pozitif Etki \\
Kişi Başına Gayri Safi Yurt İçi Hasıla & Pozitif Etki \\
Enflasyon Oranı & Negatif Etki \\
Beş Yaş Altı Ölüm Oranı & Negatif Etki \\
Doğrudan Yabacı Sermaye Yatırımları & Pozitif Etki \\
Lojistik Performans İndeksi & Pozitif Etki \\
Cep Telefonu Kullanım Oranı & Pozitif Etki \\
İşsizlik Oranı & Negatif Etki \\
İnternet Kullanım Oranı & Pozitif Etki \\
Doğumda Yaşam Beklentisi & Pozitif Etki \\
\hline
\end{tabular}

Tablo 3. Kriter Olarak Kullanılan Ekonomik ve Sosyal Göstergeler

Orta Asya Türk Cumhuriyetlerinin Tablo’3 te verilen kriterlere ilişkin 2014 yılı verileri Dünya Bankasının internet sitesinden elde edilmiştir. Elde edilen veriler Tablo 4'te verilmiştir. Karar matrisini oluşturulan veri matrisinde kriterin niteliğine göre en iyi ve en kötü çözüm noktalarının tespitinden sonra normalize edilmiştir. Daha sonra Tablo 4'te gösterilen kriterlerin önem ağırlıkları AHP yöntemi kullanılarak bulunmuş ve normalize matris ile kriter ağırlıkları çarpılarak ağırlıklandırılmış normalize karar matrisi bulunmuştur. $Q_{i}$ değerlerinin hesaplanması için gerekli olan $S^{*}, S^{-}, R^{*}$ ve $R^{-}$değerlerinin bulunmasından sonra $Q_{i}$ değerleri bulunmuştur. $S_{i}$, $R_{i}$ ve $Q_{i}$ değerlerinin küçükten büyüğe doğru sıralanması ve sıralamaların doğruluğunun denetlenmesi yapılmıştır. Çalışmada AHP ve VIKOR yöntemleri ile yapılan işlem aşamalarının çözümleri verilememiş, çalışmanın sonuçlarına yer verilmiştir.

\begin{tabular}{|c|c|c|c|c|c|c|c|c|c|c|}
\hline & 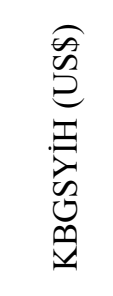 & 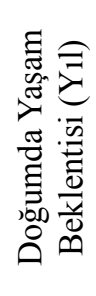 & 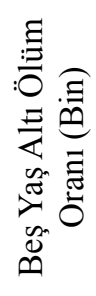 & 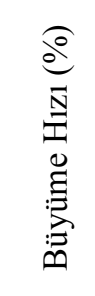 & 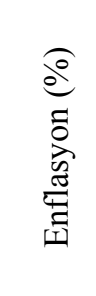 & 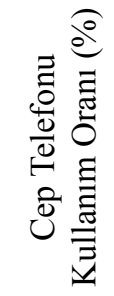 & 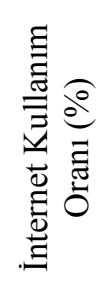 & 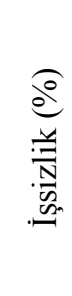 & 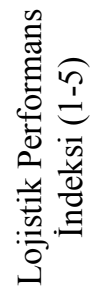 & 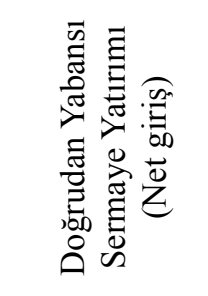 \\
\hline ÖZB & 2.090 & 68 & 40 & 8,1 & 12,62 & 73,791 & 43,55 & 10,6 & 2,39 & 751.433 .911 \\
\hline AZE & 7.590 & 71 & 33 & 2 & 0,19 & 110,90 & 61 & 5,2 & 2,45 & 4.430 .466 .000 \\
\hline KAZ & 11.670 & 72 & 15 & 4,3 & 3,37 & 168,62 & 54,89 & 4,1 & 2,7 & 7.597 .703 .264 \\
\hline KIR & 1.250 & 70 & 23 & 3,60 & 7,92 & 134,46 & 28,3 & 8,1 & 2,21 & 210.512 .100 \\
\hline TÜR & 8.020 & 66 & 53 & 10,29 & 5,95 & 135,78 & 12,2 & 10,5 & 2,3 & 3.163 .500 .000 \\
\hline TAC & 1.080 & 70 & 46 & 6,69 & 5,46 & 95,12 & 17,49 & 10,9 & 2,53 & 260.785 .960 \\
\hline
\end{tabular}

Tablo 4. Belirlenen Kriterlere Göre Ülkelerin 2014 Yllı Verileri.

Çalışmada ülkelerin performanslarını incelemede kullanılan temel ekonomik ve sosyal göstergelerin kriter ağırlıkları uzmanlar ve akademisyenlerin görüşleri doğrultusunda AHP yöntemi ile belirlenmiştir. AHP yöntemi kullanılarak kriterlerin önem ağırlıkları (w) aşağıdaki tablodaki gibi bulunmuştur. İkili karşılaştırmaların tutarlılık oranı (CR) 0,067 olarak hesaplanmış ve karşılaştırmalar tutarlı bulunmuştur.

\begin{tabular}{|c|c|c|c|c|c|c|c|c|c|c|}
\hline & 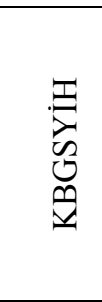 & 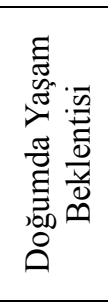 & 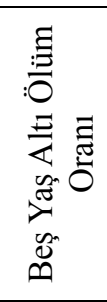 & 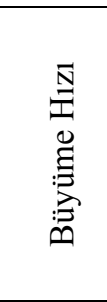 & 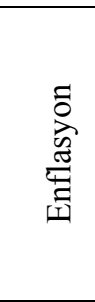 & 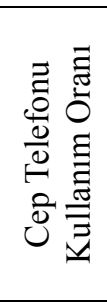 & 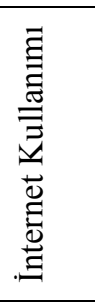 & 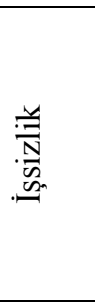 & 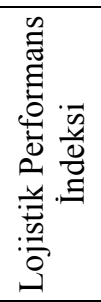 & 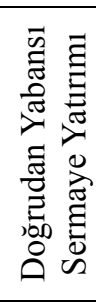 \\
\hline $\mathbf{w}$ & 0,160 & 0,135 & 0,135 & 0,140 & 0,098 & 0,044 & 0,060 & 0,119 & 0,059 & 0,050 \\
\hline
\end{tabular}

Tablo 5. Kriterlerin Önem A ğırlıkları

Kriterlerin önem ağırlıklarının AHP ile değerlendirilmesi sonucunda kişi başına gelir \% 16 önem seviyesi ile en önemli kriter olarak ifade edilirken bu kriteri \%14 ile büyüme oranı, \% 13,5 ile doğumda yaşam beklentisi ve beş yaş altı ölüm oranı, \%11,9 ile işsizlik kriteri, \%9,8 ile enflasyon izlemiştir. Bu kriterleri internet kullanımı, lojistik performans oranı, doğrudan yabancı sermaye yatırımı ve cep telefonu kullanımı kriterleri izlemiştir. Bu 
kriterlerden lojistik performans kriteri sevkiyat, ulaşım alt yapısı, gümrükleme gibi lojistik altyapı ile ilgili bir değerlendirme kriteridir. Kriter 1-5 arasında değerlendirilir. Kriter dünya bankası tarafindan şirketler ve lojistik şirketleri ile pek çok ülke için yapılan anketler ile oluşturulan bir indekstir.

\subsection{Bulgular}

AHP ve VIKOR yöntemlerinin entegre edilerek oluşturulan karar analizinde Orta Asya Türk Cumhuriyetlerinin seçilmiş ekonomik ve sosyal kriterlere göre 2014 yılı için Tablo 6'da yer alan $S_{i}, R_{i}$ ve $Q_{i}$ değerlerine farklı uzlaşma sevileri için hesaplamalar yapılarak ulaşılmıştır.

\begin{tabular}{lccccccc}
\hline & $\boldsymbol{S}_{\boldsymbol{i}}$ & $\boldsymbol{R}_{\boldsymbol{i}}$ & $\begin{array}{c}\boldsymbol{Q}_{\boldsymbol{i}} \\
\mathbf{a = 0 , 0 0}\end{array}$ & $\begin{array}{c}\boldsymbol{Q}_{\boldsymbol{i}} \\
\mathbf{a = 0 , 2 5}\end{array}$ & $\begin{array}{c}\boldsymbol{Q}_{\boldsymbol{i}} \\
\mathbf{a = 0 , 5 0}\end{array}$ & $\begin{array}{c}\boldsymbol{Q}_{\boldsymbol{i}} \\
\mathbf{a = 0 , 7 5}\end{array}$ & $\begin{array}{c}\boldsymbol{Q}_{\boldsymbol{i}} \\
\mathbf{a = 1 , 0 0}\end{array}$ \\
\hline ÖZB & 0,7217 & 0,1446 & 0,7399 & 8,1752 & 69,373 & 305,64 & 117,72 \\
AZE & 0,3859 & 0,1400 & 0,6619 & 7,1753 & 60,779 & 267,72 & 103,11 \\
KAZ & 0,1336 & 0,1012 & 0 & $-1,308$ & $-12,13$ & $-54,03$ & $-20,86$ \\
KIR & 0,6396 & 0,1573 & 0,9562 & 10,947 & 93,199 & 410,77 & 158,24 \\
TÜR & 0,6358 & 0,1350 & 0,5767 & 6,0830 & 51,391 & 226,29 & 87,154 \\
TAC & 0,6942 & 0,1598 & 1 & 11,508 & 98,021 & 432,05 & 166,44 \\
& & & & 5 & & & \\
& $S^{*}$ & 0,1336 & & & & & \\
& $S^{-}$ & 0,7217 & & & & & \\
& $R^{*}$ & 0,1012 & & & & & \\
& $R^{-}$ & 0,1598 & & & & & \\
\hline
\end{tabular}

Tablo 6. Hesaplanan $S_{i}, R_{i}$ ve $Q_{i}$ Değerleri.

$S_{i}, R_{i}$ ve $Q_{i}$ değerlerinin küçükten büyüğe doğru sıralanması ile ülkelerin kriterlere göre performans sıralaması yapılmıştır. Çeşitli $Q_{i}$ değerlerine göre yapılan 2014 yılı Performans sıralaması Tablo 7'de gösterilmiştir. Tabloda görülen sıralamada ülke performansları sıralamasının farklı uzlaşık çözümler için değişmediği görülmüştür. Belirlenen kriterlere göre ülkelerin performans sıralamasında Kazakistan ilk sırada yer almış bu ülkeyi sırasıyla Türkmenistan ve Azerbaycan izlemiştir. Özbekistan, Kırgızistan'ın ardından Tacikistan sıralamada yer almıştır.

\begin{tabular}{|lllll|}
\hline ÖZB & 4 & 4 & 4 & 4 \\
\hline AZE & 3 & 3 & 3 & 3 \\
\hline KAZ & 1 & 1 & 1 & 1 \\
\hline KIR & 5 & 5 & 5 & 5 \\
\hline TÜR & 2 & 2 & 2 & 2 \\
\hline TAC & 6 & 6 & 6 & 6 \\
\hline
\end{tabular}

Tablo 7. Farklı Q Parametrelerine Göre 2014 Yllı Ülke Performansı Siralaması.

\section{Sonuç}

Karar analizlerinde kullanılan ÇNKV yöntemlerinin ülke performanslarının değerlendirilmesinde birçok araştırmacı, kurum ve kuruluş tarafından kullanıldığı görülmektedir. Çok amaçlı karar verme ve çok nitelikli karar verme yöntemleri alternatiflerin seçim, sıralama, sınıflama ve değerlendirilmesi amacıyla kullanılmaktadır. $\mathrm{Bu}$ çalışmada ÇNKV yöntemlerinden AHP ve VIKOR yöntemleri entegre edilerek kullanılmıştır.

Çalışmada Orta Asya Türk Cumhuriyetlerinin ekonomik performansları ve ekonomik performansın etkilerini gösteren eğitim ve sağlık göstergelerinden bazıları kriter olarak incelenmiştir. VIKOR yöntemi kriterlere göre İdeale en yakın uzlaşık çözümü veren bir yöntemdir. Çalışmada uzman ve akademisyenlerin görüşleri doğrultusunda AHP yöntemi ile önem ağırlıklarının belirlendiği on kritere göre ülkelerin performansları VIKOR yöntemi ile sıralanmıştır. Kriter olarak alınan ekonomik ve sosyal göstergelere göre ülkelerin performanslarına bakıldığında Kazakistan, Türkmenistan ve Azerbaycan'ın sırasıyla öne çıkan ülkeler olduğu görülmektedir. Özbekistan, Kırgızistan ve Tacikistan'ın belirlenen kriterlere göre bu ülkeleri takip ettiği görülmektedir.

Çalışmada kriter sayısının ve kriterlerin önem ağılıklarının değişmesi sonuçları etkileyecek ve değiştirecektir. Günümüzde ekonomik gelişmişlik ekonomik veriler yanında sosyo-ekonomik kriterlerle incelenmektedir. Ülkelerin performans analizini incelemek üzere yapılacak çalışmalarda ekonomik gelişmenin sonuçları olarak ifade edilebilecek sosyal ve kültürel gelişmişliği yansıtan çok sayıda sosyal ve ekonomik veri çalışmalarda kullanılarak çok boyutlu ve daha bütüncül performans analizi yapılabilir ve yeni çalışmalar geliştirilebilir. 


\section{Kaynakça}

- Alonso and Lamata, 2006. "Consistency In The Analytic Hierarchy Process: A New Approach" International Journal Of Uncertainty, Fuzziness And Knowledge-Based Systems Vol.: 14, No: 4, p.449.

- Alp ve Gündoğdu, 2012, "Kuruluş Yeri Seçiminde Analitik Hiyerarşi Prosesi Ve Bulanık Analitik Hiyerarşi Prosesi Uygulaması" Dokuz Eylül Üniversitesi Sosyal Bilimler Enstitüsü Dergisi, Cilt:14, Sayı:1, s.7-25.

- Ertuğrul ve Özçil, 2014. "Çok Kriterli Karar Vermede TOPSIS ve VIKOR Yöntemleriyle Klima Seçimi”, Çankırı Karatekin Üniversitesi, İktisadi ve İdari Bilimler Fakültesi Dergisi, 4(1), 267-282.

- Göktürk, Eryılmaz, Yörür ve Yuluğkural, 2011. "Bir İşletmenin Tedarikçi Değerlendirme Ve Seçim Probleminin Çözümünde AAS ve VIKOR Yöntemlerinin Kullanılması” DPÜ Fen Bilimleri Enstitüsü Dergisi, Say1 25. s.61-74.

- Ishizaka and Nemery 2013. Multi-Criteria Decision Analysis, Methods and Software. John Wiley\&Sons, Ltd., London.

- Opricovic and Tzeng, 2004. "The Compromise solition by MCDM methods: A comparative analysis of VIKOR and TOPSIS", European Journal of Operational Research, 178, p.445-455.

- Opricovic and Tzeng, 2007. "Extented VIKOR method in comparison with outranking methods", European Journal of Operational Research, 178, p.514-529.

- Özdemir ve Saaty, 2006. "The Unknown in Decision Making”, The European Journal of Operations Research, 174, p.349-359.

- Özden, Başar ve Kalkan, 2012. "IMKB'de İşlem Gören Çimento Sektöründeki Şirketlerin Finansal Performanslarının VIKOR Yöntemi ile Sıralanması” İstanbul Üniversitesi, İktisat Fakültesi, Ekonometri ve İstatistik Sayı:17, s.23-44

- Özden, 2012. “AB’ye Üye Ülkelerin Ve Türkiye’nin Ekonomik Performanslarına Göre Vıkor Yöntemi İle Siralanması”, İstanbul Ticaret Üniversitesi Sosyal Bilimler Dergisi Yı1: 11 Sayı: 21, s.455-468.

- Saaty, 2008. "Decision Making with the Analytic Hierarchy Process" Int. J. Services Sciences, Vol. 1, No. 1, p. 86.

- Timor, 2010. Yöneylem Araştırması. Türkmen Kitabevi, İstanbul.

- Tzeng and Huang, 2011. Multiple Attribute Decision Making Methods and Applications. CRC Press, Taylor \& Francis Group, Newyork.

- Tzeng vd, 2005. "Multi-criteria analysis of alternative-fuel buses for public transportation", Energy Policy 33, 1373-1383

- World Bank, 2016. http// databank.worldbank.org/data/views/reports/tableview.aspx

- Yıldırım ve Önder, 2014. Operasyonel, Yönetsel ve Stratejik Problemlerin Çözümünde Çok Kriterli Karar Verme Yöntemleri. Dora Basım-Yayın Dağıtım, İstanbul.

- Yıldız ve Deveci, 2013. "Bulanık VIKOR Yöntemine Dayalı Personel Seçim Süreci” Ege Akademik Bakış, Cilt:13, Say1:4, s. 427-436.

- Zhou, Ang, Poh, 2006. "Decision analysis İn Energy And Environmental Modeling: An Update" Energy 31, 2604-2622. 


\title{
Enerji Fiyatlarının Dünya Gıda Fiyatları Üzerine Etkisi: Bir Sınır Testi Yaklaşımı
}

\section{The Impact of Energy Prices on World Food Prices: A Bounds Testing Approach}

\author{
Assoc. Prof. Dr. Neşe Algan (Çukurova University, Turkey) \\ Asst. Prof. Dr. Erhan İșcan (Çukurova University, Turkey) \\ Ph.D. Candidate Duygu Serin (Çukurova University, Turkey)
}

\begin{abstract}
Economic developments of the countries are highly interrelated with food prices due to food security. World food prices have dramatically changed in recent years. The rise of food prices have warned all governments because of socio-economic implications and stimulated extensive academic discussions. Increase of food prices is not surprising while energy prices increased during the same periods. Therefore, the energy prices can be seen as one of the determinant of food prices. Energy prices influence food price movements in many ways. Firstly, increasing energy prices result in a rise in input costs. Second, the increase in energy prices will increase the transport costs thus; changes of the energy prices directly affect production cost of food and consequently food prices. Therefore, detailed analysis is essential for understanding the nature of food prices. The aim of this study is to investigate the impact of energy prices on world food prices. Therefore, we investigate the long-run equilibrium relationship between world energy prices and world food prices using the ARDL approach to cointegration and error correction models. We establish the model by using the quarterly data of 2009Q1-2015Q4 period provided by IMF-IFS database. The empirical results imply that there is a long-term significant statistical relationship between world energy prices and world food prices. This study provides evidences to policy makers for sensible decision, and literature for further researches. These results suggest that policy makers should get under control the energy prices to stabilize the food prices to ensure the food security.
\end{abstract}

\section{Giris}

Son yıllarda enerji fiyatları ile dünya gıda fiyatlarının hızla artan bir eğilim içerisinde olduğu görülmektedir. $\mathrm{Bu}$ iki fiyat düzeyi arasında ki paralellik ise medyada ve akademik literatürde yer almasının yanı sıra hükümetler ile uluslararası kuruluşların da dikkatini çekmektedir (Abott, vd, 2009). Bu nedenle enerji fiyatlarının gıda fiyatları üzerine etkisi farklı bakış açıları ile ele alınmaya başlanmıştır. Enerji fiyatlarında görülen değişimler farklı alanlarda etkisini göstermektedir. Bu değişimlerin en önemli yansıması gıda fiyatlarında görülmektedir. Şöyle ki, enerji fiyatlarındaki dalgalanma genel olarak enflasyon ile birlikte hareket etmekte ve özellikle gıda enflasyonu olarak ortaya çıkmaktadır. Bu yüzden, enerji fiyatlarındaki değişim dolaylı olarak gıda enflasyonu aracıllığılla temel ihtiyaçlarımız üzerinde etkili olmaktadır (Chen, vd, 2010). Şekil l'de enerji ve gıda fiyatlarının beraber hareketi gösterilmektedir.

Gıda fiyatlarında artışın en önemli nedenlerinden biri enerji fiyatlarında gerçekleşen artışlardır. Bu nedenle de son yıllarda birçok çalışma gıda fiyatlarındaki artışın arkasında yer alan faktörün enerji kullanımı ve fiyatları ilişkisine odaklanmaktadır. Örneğin, fosil yakıt alternatifi olan biyoyakıta olan talepteki artışın gıda fiyatlarındaki dalgalanmandan kaynaklandığı saptanmıştır (Headey ve Fan, 2008; Mitchell, 2008; Rosegrant, vd, 2008). Aynı zamanda birçok çalışma ham petrolün yanısıra metal fiyatlarındaki artışında gıda fiyatlarında yükselmeye neden olacağını vurgulamaktadır (Radetzki, 2006; Headey ve Fan, 2008; Du, vd, 2010).

Enerji fiyatları gıda fiyatları hareketlerini birçok yönden etkilemektedir. Birincisi, tarımın geleneksel olarak enerji yoğun olması nedeni ile enerji fiyatlarının, tarımsal emtia fiyatları ile doğrudan bağlantı oluşturmasıdır. Şöyle ki, enerji fiyatları arttı̆̆ zaman, üretim için söz konusu olan taşımacılık ve üretim için gerekli olan girdi maliyetleri artacak ve sonucunda gıda fiyatları paralel olarak artış gösterecektir (Hanson, vd, 1993). Benzer şekilde ekinlerin gübrelenmesi adımlarından başlamak üzere nihai ürünlerin taşınmasına kadar enerji yoğun olarak kullanılmaktadır ve bu nedenle enerji fiyatlarındaki artış gıda fiyatlarını büyük oranda arttırmaktadır. Diğer taraftan, tarımsal üretim ve tüketici tüketimlerinde görülen şokların yanı sıra, yüksek enerji fiyatları tahıllar için biyoyakıt hammadde olarak kullanıldığından daha fazla talep artı̧ı yaratarak, gıda fiyatlarının yükselmesine neden olmaktadır. Bununla birlikte, yüksek ve değişken gıda fiyatlarının etkisi zengin ülkelerden daha çok fakir ülkeler üzerinde yoğunlaşmaktadır. Diğer bir söylemle, gıda fiyat değişimleri en önemli besin maddesi mısır ve pirinç gibi tarımsal üretime dayalı gelişmekte olan ekonomilerde daha büyük bir olumsuz etkiye sahiptir (Gilbert ve Morgan, 2010).

Enerji ekonomik büyümenin önemli etkenlerinden biri olarak kabul edilmektedir. Bu nedenle enerji fiyatlarında herhangi bir artış hem sektörel büyümeyi hem de artan taşımacılık ve üretim maliyetleri açısından kamu harcanabilir gelirini, sanayi üretimini ve aynı zamanda ekonominin genel olarak kalkınmasını ve büyümesini 
etkilemektedir. Özellikle enerji fiyatlarının hareketleri gıda fiyatları üzerinde etkili olduğu için de ekonominin kalkınmasını ve büyümesini etkilemektedir (Maurya ve Thenmozhi, 2013). Çalışma yukarıda söz edilen nedenlerden dolayı özgün bir yaklaşımla 2009Q1-2015Q4 dönemine ait üçer aylık verileri kullanarak enerji fiyatlarının dünya gıda fiyatları üzerine olan etkisinin araştırmak üzere hazırlanmıştır. Bu açıdan literatüre katkı sağlayacağı değerlendirilmiştir. Böylece enerji fiyatları ile dünya gıda fiyatları arasında uzun dönemli bir denge ilişkisinin varlığını ARDL Sınır Testi yaklaşımı ile test ederken değişkenler arasında kısa dönem dinamiklerinin tespit edilmesi amaçlanmıştır. Çalışmanın ikinci bölümünde enerji fiyatları ve dünya gıda fiyatları arasındaki ilişkinin incelendiği literatüre yer verilmiştir. Üçüncü bölümünde ise kullanılan yöntem ve veriler hakkında bilgi verildikten sonra dördüncü bölümde elde edilen uygulama sonuçlarına gösterilmiştir.

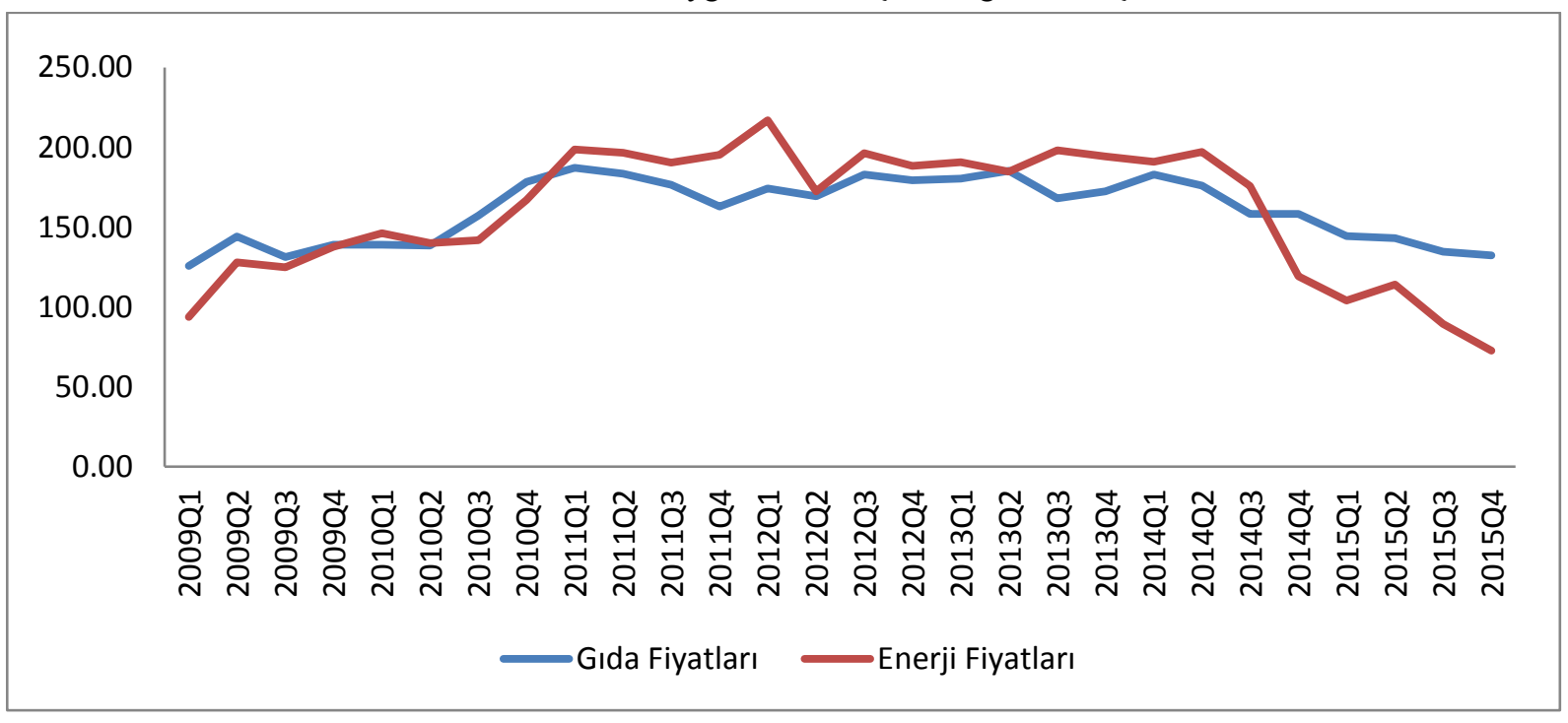

Şekil 1. Enerji ve Glda Fiyat Endeksleri $(2005=100)$

\section{Literatür}

Emtia fiyatlarının hızlı artış göstermesi hem gelişmiş hem de gelişmekte olan ülkeler açısından endişe teşkil etmektedir. Çünkü enerji ve özellikle gıda fiyatlarının önemli makroekonomik değişkenler üzerine güçlü bir etkisi vardır. Bunun nedeni zorunlu mallara ekonomik doğası gereği nispeten esnek olmayan talebin söz konusu olmasıdır. Özellikle 1970'lerde enerji fiyatları artış trendi göstermesinden sonra, bu fiyatları konu alan çalışmalar küresel anlamda ekonomik durgunluğa neden olmasından dolayı çoğu araştırmacının ilgisini çekmeye başlamıştır (Alom, vd, 2013). Yerel veya küresel ekonomi üzerinde enerji fiyatlarının etkisini gösteren çok sayıda çalışma olmasına rağmen, enerji fiyatlarının dünya gıda fiyatları üzerine etkisini inceleyen çok fazla çalışma bulunmamaktadır. Çalışmaların bulguları farklı olup, iki kategoriye ayrılmaktadır: talep yönlü ve arz yönlü faktörler. Talep yönlü faktörler gıda fiyatlarını yükselten temel güç olarak düşünülmektedir. Nüfusun artış göstermesi, hızlı ekonomik büyüme, tüketimin artması tarımsal ürünlere olan talebin artmasına neden olmakta ve böylelikle gıda fiyatlarını arttırmaktadır. Arz yönlü faktörler daha yüksek tarımsal fiyatlara neden olmaktadır. Bunların nedenleri arasında tarımsal üretimde yavaş büyüme, ham petrol fiyatlarında görülen artış ve kuraklık belirgin arz yönlü açıklamalardır (Abdlaziz, vd, 2002).

Mevcut literatür çoğunlukla ham petrol fiyatları ile gıda fiyatları arasındaki nedensellik ilişkisine odaklanmaktadır. Baffes (2007) petrol fiyatlarının gıda dahil olmak üzere uluslararası ticarete konu olan birincil emtia fiyatları üzerine etkisini incelemiştir. Çalışma sonucunda petrol fiyatlarının emtia fiyatları üzerinde büyük bir etkiye sahip olduğu ve gıda emtia piyasalarının petrol fiyat şoklarına diğer emtia piyasalarından daha hassas olduğu tespit edilmiştir. Alghalith (2010), Trinidad ve Tobago gibi petrol ihraç eden ülkelerin, ham petrol fiyatlarının gıda fiyatlarını büyük ölçüde etkilediğini vurgulamıştır. Du vd. (2010), Bayesci ekonometrik yaklaşımı kullanarak ham petrol, mısır ve buğday piyasaları arasında oynaklık etkileşimini kanıtlamıştır. Benzer şekilde, Esmaeili ve Shokoohi (2011) temel bileşen analizini kullanarak, ham petrol fiyat endeksinin gida fiyat endeksi üzerine etkisini ortaya koymuştur. Chen vd. (2010) çalışmasında mısır, soya fasulyesi, buğday gibi küresel tahıl fiyatlarının ham petrol fiyatlarında gerçekleşen değişmelerden önemli ölçüde etkilendiğini vurgulamıştır. Abdel ve Arshad (2008) ham petrol fiyatlarının bitkisel yağ fiyatları üzerinde pozitif etkisi olduğunu tespit etmiştir. Baffes ve Dennis (2013) petrol fiyatları değişikliklerinin gıda fiyat endeksi üzerine güçlü bir etkisi olduğunu ortaya koymuştur. Ibrahim (2015) petrol fiyatlarındaki artış ile gıda fiyatları arasında uzun dönemli ilişkinin var olduğunu araştırmıştır. Baffes ve Haniotis (2010) çalışmasında enerji ve enerji dışı emtia fiyatları arasındaki güçlü ilişkinin özellikle gıda ve piyasalardaki gelişmeler üzerinde hâkim etkisi olduğunu bulmuştur. Gilbert (2010) girdi maliyeti olarak petrol fiyatı etkisinin tarımsal gıda talebinin büyüklüğüne bağlı olduğunu vurgulamıştır. Eğer talep düşükse, maliyet artışı fiyatları daha olumsuz yönde etkilemektedir. 
Literatürde yer alan diğer değişkenlerle petrol fiyatlarının etkilerini ele alan farklı çalışmalar da bulunmaktadır. Gıda fiyatları üzerinde enerji fiyatları etkisini araştırırken, döviz kuru hareketleri göz ardı edilemeyecek kadar büyük bir öneme sahiptir. Harri vd. (2009) petrol fiyatları, mısır ve döviz kuru arasında uzun dönem denge ilişkisinin olduğunu tespit etmiştir. Kwon ve Koo (2009) enerji fiyatı nedeni ile döviz kuru dalgalanmalarının gıda piyasası enflasyon oranı üzerine etkisini Amerika'da 1998-2008 yılları arası için açıklamıştır. Baek ve Koo (2010) döviz kuru ve tarımsal emtia fiyatlarının Amerika'da gıda fiyatlarının kısa ve uzun vade hareketlerinin belirlenmesinde temel bir rolü olduğunu ispatlayarak literatürde yer alan önceki çalışmaları desteklemiştir. Nazlıŏglu ve Soytaş (2011) 24 tarımsal emtia fiyatları, petrol fiyatları ve önemli para birimleri karşısında reel efektif döviz kuru arasında ilişkiyi araştırmıştır. Çalışmada Panel eşbütünleşme ve Granger nedensellik yöntemleri kullanılarak, doların değerinde ve petrol fiyatında görülen herhangi bir değişimin tarımsal emtia fiyatları üzerinde etkisi olduğu sonucuna ulaşılmıştır. Serra vd. (2011) mısır, petrol ve benzin fiyatları arasında görülen fiyat geçişlerini araştırmıştır. 1990-2008 döneminin ele alındığı ABD analizinde uzun vadede bu fiyatların birbirini etkilediği tespit edilmiştir.

Gıda fiyatları artışına neden olan birçok faktör vardır. Bununla birlikte, dünya gıda fiyatlarını etkileyen en önemli faktörlerden biri tarımsal emtia ürünlerin üretim ve tüketiminde görülen küresel değişimler ve enerji fiyatları ve gıda fiyatları ile ilişki olarak doların değer kaybetmesidir. Nazlığlu ve Soytaş (2012) panel analizi kullanarak petrol fiyatları ile dünya tarımsal emtia fiyatları arasındaki ilişkiyi analiz etmiştir. Çalışma sonucunda, dünya petrol fiyatları ve tarımsal emtia fiyatları arasında güçlü kanıtlar tespit edilmiştir. Aynı zamanda, doların değer kaybetmesinin gıda fiyatları üzerinde olumlu etkisi olduğu ifade edilmiştir. Teera Kiatmanaroch (2014a) ham petrol fiyatlarının palmiye ve soya yağı fiyatları üzerine etkisini Asya ülkeleri için araştırmıştır. Çalışma sonucunda, petrol fiyatları ile palmiye ve soya yağı fiyatları arasında küçükte olsa bir ilişkinin var olduğu tespit edilmiştir. Bir başka çalışmasında Teera Kiatmanaroch (2014b), dolar döviz kuru ile palmiye ve soya yağı fiyatları arasındaki ilişkiyi genelleştirilmiş otoregresif koşullu değişen varyans (ARCH) (1-1) modelini kullanarak incelemiş̧tir. Analiz sonucunda, döviz kuru, palmiye yağı ve ham petrol fiyatlarının uzun dönemde oynaklığı tespit edilmiştir.

Literatürde petrol fiyatları ile gıda fiyatları arasında pozitif ilişki olduğunu destekleyen kapsamlı literatür olmasına rağmen, bazı çalışmalar ham petrol fiyatlarının gıda fiyatları üzerine etkisinin olumsuz olduğu yönündedir. Nazlığlu ve Soytaş (2010) tarımsal emtia fiyatları üzerindeki petrol fiyatlarının etkisini döviz kurlarını dikkate alarak Türkiye için araştırmıştır. Toda ve Yamamoto yöntemi kullanılarak tarımsal emtia (buğday, mısır, pamuk, soya fasulyesi ve ayçiçeği) fiyatları, petrol fiyatları ve döviz kurları arasında ilişkiyi incelenmiştir. Analizde Türkiye'de tarımsal emtia fiyatlarının döviz kuru ve petrol fiyatları değişimlerinden etkilenmediği sonucu elde edilmiştir. Yu vd. (2006) dünya ham petrol fiyatları ve bitkisel yağ fiyatları arasındaki ilişkiyi eşbütünleşme analizi ile araştırmıştır. Çalışma sonucunda dünya petrol fiyatlarının bitkisel yă̆ fiyatları üzerinde herhangi bir etkisinin olmadığ sonucuna ulaşılmıştır. Kaltalığlu ve Soytaş (2009) bu sonuçlara paralel olarak dünya petrol fiyatlarının, dünya gıda fiyatları ve tarımsal ham madde fiyatları üzerine önemli bir etkiye sahip olmadığını tespit etmiştir. Zhang ve Reed (2008) çalışmasında Ocak 2000-Ekim 2007 dönemi için Çin 'de petrol fiyatlarının mısır ve soya fasulyesi fiyatları üzerine etkisini incelemiştir. Bulgular sonucunda dünya petrol fiyatlarının seçilen tarımsal emtia fiyatlarındaki dalgalanmalar üzerinde herhangi bir etkisinin olmadığı tespit edilmiştir.

\section{Model ve Veri Seti}

$\mathrm{Bu}$ bölümde enerji fiyatları ile dünya gıda fiyatları arasında kısa ve uzun dönemli ilişkinin olup olmadığ eşbütünleşme analizi ile araştırılmaktadır. Analizde, Pesaran, Shin ve Smith (2001) tarafından geliştirilmiş olan ARDL sınır testi yaklaşımı 2009Q1-2015Q4 dönemi üç aylık verileri kullanılmıştır. Uygulamada değişkenlere ait zaman serileri IMF-IFS ( IMF-International Financial Statistic) çevrimiçi veri sisteminden elde edilmişstir. Modelde kullanılan değişkenler ve tanımları aşağıdaki gibidir. Değişkenlerin isimlerinin önünde yer alan " $L$ " ise, değişkenlerin logaritmik dönüşümlerinin yapılmış olduğunu ifade etmektedir.

LEF: Enerji fiyatları göstergesi (2005 Ort=100)

LGF: Gıda fiyatları göstergesi (2005 Ort=100)

Çalışmada kullanılan değişkenlere ait veri setlerinin logaritmik dönüşümleri yapılmış. İlk olarak seriler mevsimsel etkilerden arındırılmış daha sonra bireysel olarak durağanlıkları incelenmiştir. Daha sonra enerji fiyatları ile dünya gıda fiyatları arasında uzun dönem ilişkinin varlığının araştırılması için ARDL yöntemi kullanılmıştır. Bu yöntem, Pesaran ve Shin (1995) tarafindan ortaya konulmuş olup, daha sonra Pesaran vd. (2001) tarafından geliştirilmiştir. ARDL sınır testi yöntemi kullanılan değişkenler arasında uzun dönem ilişkinin ortaya konulmasında güçlü sonuçlar vermekte ve uzun dönem ilişkinin yanı sıra kısa dönem ilişkinin de incelenmesine imkân vermektedir.

\section{Uygulama Sonuçları}

Ele alınan serilerin durağanlık analizi Dickey ve Fuller (1981) tarafından geliştirilen ADF birim kök testi ile incelenmiştir. Tablo 1'de ADF birim kök testi sonuçları verilmektedir. Sıfir hipotez serinin stokastik trend taşıdığını 
yani birim kök içerdiğini, alternatif hipotez ise serinin deterministik trend taşıdığını aynı zamanda birim kök içermediği şeklinde kurulmaktadır. ADF test sonuçlarına göre, değişkenlerin düzeyde durağan olmayıp birim kök içerdiğini, daha sonra birinci farkları alındığında durağan hale geldiği ifade edilmektedir.

\begin{tabular}{|l|l|l|l|l|l|}
\hline Değişken & \multicolumn{1}{|c|}{$\begin{array}{c}\text { Düzey Test } \\
\text { İstatistiği }\end{array}$} & $\begin{array}{c}\text { Mac Kinnon Kritik } \\
\text { Değer (\%5) } \\
\text { (Düzey) }\end{array}$ & $\begin{array}{c}\text { 1. Farklar Test } \\
\text { İstatistiği }\end{array}$ & $\begin{array}{c}\text { Mac Kinnon Kritik } \\
\text { Değer (\%5) } \\
\text { (1.Fark) }\end{array}$ & Sonuç \\
\hline LEF & $-1.834132(0)$ & $-2.976263^{*}$ & $-5.654844(0)$ & $-2.981038^{*}$ & $\mathrm{I}(1)$ \\
\hline LGF & $-4.474831(0)$ & $-2.981038^{*}$ & $-0.587926(0)$ & -2.976263 & $\mathrm{I}(1)$ \\
\hline
\end{tabular}

Tablo 1. ADF Birim Kök Testi Sonuçları (*, Regresyon sabit terim ve trend içermiyor. Parantez içerisindeki rakamlar uygun gecikme uzunluğunu göstermektedir.)

ARDL modelinin ilk adımı uygun gecikme uzunluğunun belirlenmesidir. Çalışmada ARDL sınır testi, değişkenlerin en uygun gecikme uzunluğu kriteri minimum AIC değeri dikkate alınarak 4 olarak elde edilmiştir. ARDL sınır testi için, eşbütünleşme ilişkisinin sınanması amacıyla F istatistiği hesaplanmıştır. Eğer, F istatistiği kritik üst sınırdan büyükse seriler arasında eşbütünleşme ilişkisinin varlığına, alt kritik değerin altında kalıyorsa eşbütünleşme ilişkisinin yokluğuna karar verilir. Ĕger, F istatistiği alt ve üst kritik değerin arasında kalıyorsa böyle bir durumda kesin bir karara varılamamaktadır. Tablo 2'de kullanılan değişkenler arasında eşbütünleşme ilişsisi olmadığını ifade eden sıfır hipotezini sınamak amacıyla hesaplanan F istatistiği değeri ve Pesaran, Shin ve Smith (2001)'den alınan kritik değerler yer almaktadır. \%5 anlamlılık düzeyinde hesaplanan F istatistiği değeri (5.5258), üst kritik sınır (4.16) değerinden büyüktür. Bu nedenle enerji fiyatları ile dünya gıda fiyatları arasında uzun dönem ilişkinin varlığına işaret etmektedir.

\begin{tabular}{|l|l|l|l|}
\hline \multirow{2}{*}{$\mathrm{k}$} & \multirow{2}{*}{ F-ist } & \multicolumn{2}{|l|}{ Kritik Değerler (\%5) } \\
\cline { 3 - 4 } & & Alt Sınır & Üst Sinır \\
\hline 1 & 5.5258 & 3.62 & 4.16 \\
\hline
\end{tabular}

Tablo 2. Sınır Testi Sonuçları ( $k$, denklemdeki bă̆ımsız değişken sayısıdır. Gecikme uzunluğunun belirlenmesinde AIC kullanılmıştır. Kritik değer sınırları Pesaran vd (2001, s.300) TabloC1(iii) 'ten alınmıştır.)

Değişkenler arasında uzun dönemli ilişki saptandıktan sonra, uygun ARDL modelleri ile uzun ve kısa dönem katsayılar elde edilmiştir. Kısıtlanmamış hata düzeltme modeli tahminine dayanan sınır testi, enerji fiyatlarının dünya gıda fiyatları üzerine uzun dönemli etkisinin araştırıldığı ARDL modeli aşağıdaki gibi kurulmuştur (Denklem 1).

$$
L G F_{t}=\sum_{i=1}^{k} \beta_{1} L G F_{t-1}+\sum_{i=0}^{l} L E F_{t-i}+u_{t}
$$

Enerji fiyatlarının dünya gıda fiyatları üzerine uzun dönemli ilişkinin varlığı tespit edildikten sonra, uzun dönem parametrelerin tahminine geçilmiştir. Uzun dönem ilişkisinin araştırılacağı model ARDL $(4,4)$ modelidir. Tablo 3'de bu modele ilişkin uzun dönem katsayısı verilmiştir.

\begin{tabular}{|llcc|}
\hline Değişken & Katsayı & Standart Hata & t-istatistiği \\
\hline LEF & 0.4395 & 0.053400 & $8.232192(0.000)$ \\
\hline
\end{tabular}

Tablo 3. ARDL $(4,4)$ Modeli için Hesaplanan Uzun Dönem Katsayıları (Bă̆ımlı değişken LGF'dir. Parantez içindeki değer, istatistiğe ilişkin olasılık değerini göstermektedir.)

Tablo 3'de ifade edildiği gibi enerji fiyatları ile dünya gıda fiyatları arasında pozitif bir ilişki söz konusudur. Enerji fiyatları katsayısı 0.4395 olarak tespit edilmiştir. Uzun dönem katsayısı, istatistiki olarak anlamlı ve işaret literatüre paralel olarak pozitiftir. Bu sonuçlar, ele alınan zaman aralığında enerji fiyatlarının dünya gıda fiyatlarını etkilediğini kanıtlamaktadır. Şöyle ki, enerji fiyatlarının \%1 oranında arttırılması, dünya gıda fiyatlarında yaklaşık 0.43 oranında artışa neden olduğu şeklindedir.

\begin{tabular}{|l|l|}
\hline \multicolumn{2}{|l|}{ Tanısal Test Sonuçları } \\
\hline$R^{2}$ & 0.907 \\
\hline Düzeltilmiş- $R^{2}$ & 0.848 \\
\hline Breusch-Godfrey LM & $8.5832(0.0049)$ \\
\hline ARCH LM & $3.0849(0.0936)$ \\
\hline Jarque-Bera Normallik Testi & $0.5485(0.7601)$ \\
\hline Breusch-Pagan Değişen Varyans Testi & $0.6241(0.7590)$ \\
\hline Ramset Reset & $0.0216(0.8852)$ \\
\hline
\end{tabular}

Tablo 4. ARDL Sinır Testine Ait Tanısal Test Sonuçları 
Enerji fiyatları ile dünya gıda fiyatları arasında uzun dönemli ilişkinin varlığı tespit edildikten sonra tanısal testlere yer verilmiştir. Tablo 4 tanısal test sonuçlarını göstermektedir. Test sonuçlarına göre, modelde otokorelasyon (Breusch-Godfrey LM Testi), değişen varyans (ARCH LM) sorunu olmadığını, hata terimlerinin normal dağılım (Jarque-Bera Normallik Testi) sergilediğini ve model kurma hatasının (Ramsey Reset Testi) olmadığı tespit edilmiştir. Ele alınan ARDL modelinin istikrarlılığını incelemek yani değişkenlere ilişkin yapısal kırılmanın olup olmadığını ortaya koymak amacıyla, geri dönüşümlü hata terimlerinin karelerini kullanan ve bu yöntemle değişkenlere yönelik yapısal kırılmayı inceleyen CUSUM ve CUSUM ${ }^{2}$ grafikleri araştırılmıştır (Brown, vd, 1975). Şekil 2'de CUSUM ve CUSUM ${ }^{2}$ istatistikleri \%5 anlamlılık düzeyinde kritik sınırlar içerisinde yani iki çizgi arasında yer aldığını, ARDL modelindeki katsayıların kararlı olduğu, herhangi bir kırılmanın olmadı ̆̆ görülmektedir. ARDL modeli uzun dönem katsayılarının istikrarlı olduğu ve herhangi bir yapay değişken kullanılmadan modelin hesaplanabileceği tespit edilmiştir.

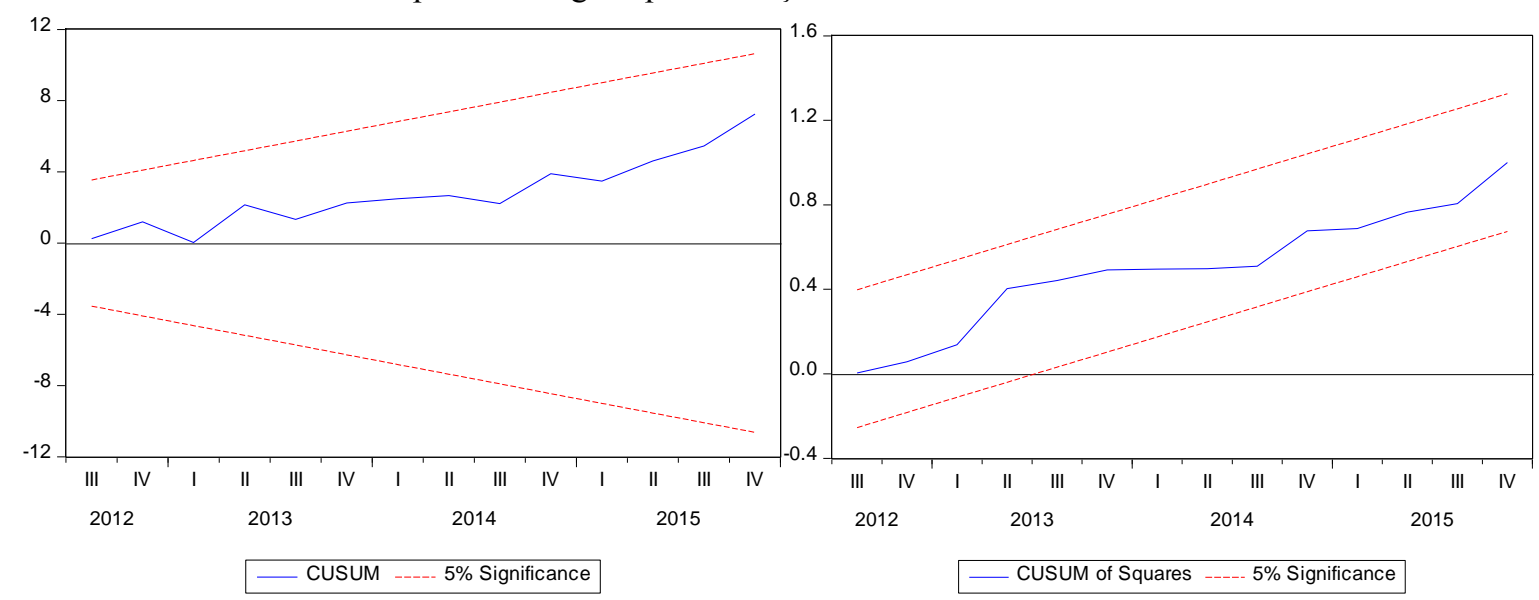

Şekil 2.CUSUM ve CUSUM² Grafikleri

Enerji fiyatları ile dünya gıda fiyatları arasında kısa dönem ilişki, ARDL yaklaşımına dayalı hata düzeltme modeli ile incelenmiştir. Hata düzeltme modeli aşağıdaki gibi oluşturulmuştur (Denklem 2).

$\Delta L G F_{t}=\beta_{0} E C_{t-1}+\sum_{i=1}^{k} \beta_{1} \Delta L G F_{t-1}+\sum_{i=0}^{l} \Delta L E F_{t-i}+u_{t}$

Denklemde yer alan $\Delta$, değişkenlerin birinci farklarını ifade etmektedir. $E C_{t-1}$ terimi, hata düzeltme katsayısı olup, kısa dönemde oluşabilecek sapmaların uzun dönemde ne kadarının düzeltilebileceğini ifade etmektedir. Bu katsayının negatif ve istatistiki açıdan anlamlı olması gerekmektedir. Tablo 5 'te ARDL $(4,4)$ modeli hata düzeltme sonuçları yer almaktadır.

\begin{tabular}{|l|l|l|l|}
\hline Değişken & Katsay1 & Standart Hata & t-istatistiği \\
\hline$\Delta \mathrm{LGF}(-1)$ & 0.5508 & 0.2060 & $2.6731(0.018)^{*}$ \\
\hline$\Delta \mathrm{LGF}(-2)$ & 0.1591 & 0.2068 & $0.7691(0.454)$ \\
\hline$\Delta \mathrm{LGF}(-3)$ & 0.5884 & 0.2039 & $2.5913(0.021)^{*}$ \\
\hline$\Delta \mathrm{LEF}$ & 0.3891 & 0.0994 & $3.9138(0.001)^{*}$ \\
\hline$\Delta \mathrm{LEF}(-1)$ & -0.3679 & 0.1359 & $-2.7054(0.017)^{*}$ \\
\hline$\Delta \mathrm{LEF}(-2)$ & -0.5708 & 0.1098 & $-0.5195(0.611)$ \\
\hline$\Delta \mathrm{LEF}(-3)$ & -0.4197 & 0.1147 & $-3.6568(0.002)^{*}$ \\
\hline$E C_{t-1}$ & -0.9796 & 0.2250 & $-4.3526(0.000)^{*}$ \\
\hline
\end{tabular}

Tablo 5. ARDL $(4,4)$ Hata Düzeltme Modelinin Sonuçları Not: Bă̆ımlı değişken $\Delta L G F^{\prime}$ dir. Parantez içerisindeki değerler, istatistiklere ilişkin olasılık değerlerini göstermektedir. *, \%5 anlamlılık düzeyinde istatistiksel olarak anlamlılı̆̆ göstermektedir.

Hata düzeltme modeli sonuçlarına göre, hata düzeltme katsayısı beklenildiği gibi negatif işaretli ve istatistiki açıdan anlamlıdır. Bu durum hata düzeltme mekanizmasının çalıştığını ifade etmekte ve uzun dönemli ilişki olduğu bir kez daha kanıtlanmaktadır. Bu katsayının tahmin değeri (-0.97) kısa dönem şokların ardından uzun dönem dengesinde ortaya çıkabilecek sapmaların bir dönem sonra yaklaşık \%97'sinin giderilebileceğini ifade etmektedir. Aynı zamanda kısa dönemde de enerji fiyatlarının dünya gıda fiyatları üzerine etkisi anlamlı ve pozitif olup, katsayısı da 0.38'dir. Bu katsayı, enerji fiyatlarında meydana gelecek \% 1'lik artışın dünya gıda fiyatlarında yaklaşık $\% 3.8$ oranında arttıracağı şeklinde yorumlanır.

\section{Sonuç}

2000'li yılların sonuna doğru görülen gıda emtia fiyatlarının sürekli artması sonucu birçok olumsuzluğa neden olması araştırmacıları, politika yapıcıları ve yatırımları bu artışların nedenlerini araştırmaya yönlendirmektedir. 
Literatürde gıda fiyatlarının artmasına neden olabilecek birçok neden ifade edilmektedir. Bu nedenlerin en başında enerji fiyatlarında görülen artışların olmasının yanı sıra iklim değişikliği nedeniyle hasatların azalması, küresel gıda stoklarının düşük seviyesi, gelecek piyasalarda görülen spekülatif faaliyetler, ülkelerin ihracat yasakları, tarımsal gelişmeler için daha az yatırım yapılması ve doların değer kaybetmesi gösterilebilir. Bununla birlikte, bu çalışma enerji fiyatlarının dünya gıda fiyatları üzerine etkisine odaklanmıştır. Çalışmada, enerji fiyatları ve dünya gıda fiyatları arasındaki uzun dönemli ilişkinin araştırılması için ARDL sınır testi yaklaşımı kullanılmıştır. Hem uzun dönem analizinden hem de hata düzeltme modelinden çıkarılan sonuçlara göre, enerji fiyatları ile dünya gıda fiyatları arasında uzun dönemli bir ilişkinin var olduğu tespit edilmiştir. Sonuçlar literatürde yer alan çalışmalarla uyum göstermektedir. Sonuç olarak, enerji fiyatları, yakıt ve gübre fiyatları yoluyla doğrudan, biyoyakıt etkisiyle dolaylı olarak gıda fiyatlarını olumsuz yönde etkilemektedir.

Enerji fiyatları ile gıda fiyatlarının paralel olarak hareket etmesi nedeni ile bu piyasalarda oluşacak fiyatların tahmin edilmesi politika uygulamaları için önem arz etmektedir. Ekonomi politikalarının başarısı küresel anlamda bu fiyatları etkileyen dinamikleri anlamaya bağlıdır. Bu dinamikleri anlamak için biyoyakıt, farklı gıda maddelerinin bireysel fiyatlarının ve farklı tarımsal endeksler (buğday, mısır, soya vb) arasında görülen fiyat etkileşimleri üzerine daha fazla çalışma yapılması gerekmektedir. Oluşturulacak olan enerji ve gıda politikalarının temelinde ki bu çalışmalardan elde edilecek sonuçlar ekonomik büyüme ve kalkınmayı destekleyecektir. Bu politikaların temelinin güçlü olması gerekmekte, çünkü enerji fiyatları ve gıda fiyatlarındaki artış özellikle gelişmekte olan ülkelerde farklı sosyal problemlere neden olabilmektedir. Örneğin, Runge ve Senauer (2007) enerji fiyatlarında görülen artışın biyoyakıt kanalı aracılığı ile gelişmekte olan ülkeleri aç bırakabileceği görüşündedir. Yaptıkları çalışmada, özellikle temel gıda fiyatları üzerinde etkileri açısından biyoyakıtların dünyanın geri kalanı üzerinde daha yıkıcı etkiye sahip olduğunu tespit etmiştir. Eğer enerji fiyatları yüksek seyrine devam ederse, biyoyakıt patlaması fakir ülkelerde gıda eksikliğine neden olarak petrol ithalatını etkiyebilmektedir. Enerji fiyatlarının gıda fiyatları üzerine etkisi son zamanlarda giderek önem kazandığı için, hükümetler yoksul sayısının artmasına neden olan biyoyakıt endüstrilerine yapılan sübvansiyon politikalarını tekrar gözden geçirmese gerekmektedir. $\mathrm{Bu}$ nedenle, politika formülasyonu yapılırken düzenleyicilerin sağlam bir politika ortaya koyabilmeleri için enerji piyasaları ile gıda piyasası arasındaki etkileşimi göz önüne alması gerekmektedir.

\section{Teșekkür}

Bu çalışma Çukurova Üniversitesi Bilimsel Araştırma Projeleri Koordinasyon Birimince Desteklenmiştir.

\section{Kaynakça}

- Abbott, P. C. ,Hurt, C. and Tyner, W. E. (2008), "What's driving food prices?", Oak Brook, IL: Farm Foundation, pp.1-80.

- Abdel, H.A. and Arshad, F.M. (2008), "The impact of petroleum prices on vegetable oils prices: evidence from cointegration tests", Paper presented at International Borneo Business Conference on Global changes, Malaysia, December.

- Abdlaziz, R. A., Rahim, K. A., \& Adamu, P. (2016). "Oil and Food Prices Co-integration Nexus for Indonesia: A Nonlinear ARDL Analysis", International Journal of Energy Economics and Policy, 6(1), 82-87.

- Alghalith, M. (2010) "The interaction between food prices and oil prices", Energy Economics, Vol. 32, No. 6, pp.1520-1522

- $\quad$ Alom, F., Ward, B.D., Hu, B. (2013), "Macroeconomic effects of world oil and food price shocks in Asia and Pacific economies: Application of SVAR models", OPEC Energy Review, 37(3), 327-372.

- $\quad$ Baek, J., Koo, W.W. (2010), "Analyzing factors affecting U.S. food price inflation", Canadian Journal of Agricultural Economics, 58(3), 303-320.

- $\quad$ Baffes, J., Dennis, A. (2013), "Long-Term Drivers of Food Prices", May. p35.

- Baffes, J., Haniotis, T. (2010), Placing the 2006/08 Commodity Price Boom into Perspective. World Bank Discussion Papers, 5371(July). p1-40.

- $\quad$ Baffes, J. (2007), "Oil spills on other commodities", Resources Policy, Vol. 32, pp.126-134.

- Brown, R. L., Durbin, J., \& Evans, J. M. (1975). "Techniques for testing the constancy of regression relationships over time", Journal of the Royal Statistical Society. Series B (Methodological), 149-192.

- Chen, S-T., Kuo, H-I. and Chen, C-C. (2010) 'Modeling the relationship between the oil price and global food prices’, Applied Energy, Vol. 87, No. 8, pp.2517-2525.

- Dickey, D. A., \& Fuller, W. A. (1981). "Likelihood ratio statistics for autoregressive time series with a unit root. Econometrica: Journal of the Econometric Society", 1057-1072.

- $\quad$ Du, X., Yu, C.L. and Hayes, D.J. (2011) "Speculation and volatility spillover in the crude oil and agricultural commodity markets: a Bayesian analysis", Energy Economics, Vol. 33, No. 3, pp.497-503.

- Esmaeili, A. and Shokoohi, Z. (2011) "Assessing the effect of oil price on world food prices: application of principal component analysis", Energy Policy, Vol. 39, No. 2, pp.1022-1025.

- Gilbert, C. (2010). "How to understand high food prices. Journal of Agricultural Economics", 61(2), 398-425. doi: 10.1111/j.1477-9552.2010.00248.x 
- $\quad$ Gilbert, C.L., \& Morgan, C.W. (2010), "Food price volatility". Philosophical Transactions of the Royal Society of London. Series B, Biological Sciences, 365(1554), 3023-3034.

- Hanson, K., Robinson, S. and Schluter, G. (1993) "Sectoral effects of a world oil price shock: economy wide linkages to the agricultural sector", Journal of Agricultural and Resource Economics, Vol. 18, No. 1, pp.96116.

- Harri, A., Nalley, L., Hudson, D. (2009), "The relationship between oil, exchange rates, and commodity prices", Journal of Agricultural and Applied Economics, 2, 501-510

- Headey, D. and Fan, S. (2008) "Anatomy of a crisis: the causes and consequences of surging food prices", Agricultural Economics, Vol. 39, No. s1, pp.375-391.

- Ibrahim, M.H. (2015), "Oil and food prices in Malaysia: A nonlinear ARDL analysis". Agricultural and Food Economics, 3(1). Available from: http://www.doi.org/10.1186/s40100-014-0020-3.

- $\quad$ Kaltalioglu, M. and Soytas, U. (2009) "Price transmission between world food, agricultural raw material, and oil prices", GBATA International Conference Proceedings, pp.596-603, Prague.

- $\quad$ Kiatmanaroch, T., \& Sriboonchitta, S. (2014)."Dependence Structure between Crude Oil, Soybeans, and Palm Oil in ASEAN Region: Energy and Food Security Context", In Modeling Dependence in Econometrics (pp. 329-341). Springer International Publishing.

- Kwon, D., Koo, W.W. (2009), "Price transmission channels of energy and exchange rate on food sector : A disaggregated approach based on stage of process". Selected Paper Prepared for Presentation at the Agricultural \& Applied Economics Association 2009 AAEA \& ACCI Joint Annual Meeting, Milwaukee, Wisconsin, July 26-29, 2009.

- Maurya, S., \& Thenmozhi, M. (2013). "Contagion Effect Among Crude Oil and Food Prices in India". Available at SSRN 2371018.

- Mitchell, D. (2008), "A Note on Rising Food Prices", The World Bank, Policy Research Working Paper Series: 4682.

- Nazlioglu, S., \& Soytas, U. (2010). World oil prices and agricultural commodity prices:evidence from an emerging market. Energy Economics, 488-496.

- Nazlioglu, S., \& Soytas, U. (2011), "Oil price, agricultural commodity prices and the dollar: A panel cointegration and causality analysis" Energy Economics, doi:10.1016/j.eneco.2011.09.008

- Nazlioglu, S., Soytas, U. (2012), "Oil price, agricultural commodity prices, and the dollar: A panel cointegration and causality analysis" Energy Economics, 34(4), 1098-1104.

- Pesaran, M. H., \& Smith, R. (1995), "Estimating long-run relationships from dynamic heterogeneous panels" Journal of econometrics, 68(1), 79-113.

- Pesaran, M. H., Shin, Y., \& Smith, R. J. (2001). "Bounds testing approaches to the analysis of level relationships", Journal of applied econometrics, 16(3), 289-326.

- $\quad$ Radetzki, M. (2006) "The anatomy of three commodity booms", Resources Policy, Vol. 31, No. 1, pp.56-64.

- Rosegrant, M.W., Zhu, T., Msangi, S. and Sulser, T. (2008) "Global scenarios for biofuels: impacts and implications", Review of Agricultural Economics, Vol. 30, No. 3, pp.495-505.

- $\quad$ Runge CF, Senauer B. (2007), "How biofuels could starve the poor". Foreign Aff; 86(3):41-53.

- Serra, T., D. Zilberman, J. M. Gil and B.K. Goodwin (2011) "Nonlinearities in the U.S. corn-ethanol-oilgasoline price system", Agricultural Economics 42 35-45.

- $\quad$ Teera Kiatmanaroch, S.S. (2014), "Relationship between exchange rates, palm oil prices, and crude oil prices: A vine copula based GARCH approach". Advances in Intelligent Systems and Computing, 251, 399-413.

- Yu, T.E., Bessler, D.A. and Fuller, S. (2006) "Cointegration and causality analysis of world vegetable oil and crude oil prices", The American Agricultural Economics Association Annual Meeting, Long Beach, California, 23-26 July.

- Zhang, Q. and Reed, M. (2008) "Examining the impact of the world crude oil prices on China's agricultural commodity prices: the case of corn, soybean and pork", The Southern Agricultural Economics Association Annual Meetings, Dallas, TX, 2-5 February. 


\title{
Küresel Ekonomiye Entegrasyon Süreçlerinde Türkiye İçin Küreselleşme Derecesinin Büyümeye Etkisinin Ölçülmesi, 1961-2013
}

\section{Measuring the Effect of Globalization Level to Economic Growth for Turkey in the Duration of Integration to the Global Economy, 1961-2013}

\author{
Asst. Prof. Dr. Hakan Acaroğlu (Eskişehir Osmangazi University, Turkey) \\ Assoc. Prof. Dr. Zeki Kartal (Eskisehir Osmangazi University, Turkey)
}

\begin{abstract}
The economic problems due to foreign trade and foreign direct investments are recently solved in the frame of global economy. This study surveys the effects of globalization to the economic growth in Turkey in the period 1961-2013 by the channels of the trade openness (OPENNESS) and foreign direct investments (FDIs) by using annual time series data. The data are obtained from Penn World Tables and World Development Indicators (2014 for Turkey). It is found with setting up the econometric model that, the trade openness is positively affecting the investment level and economic growth in the long term. On the other hand, the results of the applied economy policies are affecting the trade openness and economic growth significantly and positively. Those findings tell that Turkey is a successful actor of globalization process. In addition to this, what the economic policies that Turkey needs to do for a sustainable economic growth are emphasized in the study.
\end{abstract}

\section{Giriș}

Türkiye ekonomisi son 35 yll içerisinde dünya ekonomisi ile birlikte ticari bir entegrasyonu tecrübe etmektedir. Ticarette dışa açıklık üzerinden açıklanan ve küreselleşme süreci olarak da ifade edilen, dünyada ve Türkiye'de son 40 yılda ivme kazanmış liberal gelişme stratejisi (yabancı sermaye ve ihracatın çeşitlendirilmesi diversifikasyon-) çerçevesinde küresel entegrasyon ile ekonomik büyüme arasındaki ilişkinin incelenmesi bu çalışmanın amacıdır. Yine bu bağlamda, küresel ekonomiye entegrasyonunun Türkiye için risk mi veya şans mı? Sorusu da bir ölçüde açıklığa kavuşmuş olacaktır. Dışa açıklık ile ekonomik büyüme arasındaki ilişki, ekonomistler arasında hep bir tartışma konusu olarak önemini sürdürmektedir. Çünkü dünya üzerindeki ülkelerin gelişmişlik düzeylerinde ciddi ekonomik farklılıklar söz konusudur. Teorik çerçeve ve ampirik gözlemlere göre gelişmiş bir ülke küreselleşme sürecindeki ticari etkileşimden payını daha yüksek derecede almakta ve büyümesi kendisini ekonomik gelişme açısından daha olumlu yönde etkilemekteyken, az gelişmiş bir ülkede bu sürecin tam tersi yaşanmaktadır. Grossman ve Helpman (1991) biri gelişmiş diğeri az gelişmiş iki ülke arasındaki ticari ilişkilerden uzun dönemde az gelişmiş ülkenin büyümesini arttırdığını gösterirken, Young (1991) ve Stokey (1991) belirtilen sürecin az gelişmiş ülkenin uzun dönemli büyümesini azaltabileceğini göstermiştir. Gelişmiş bir ülke ile az gelişmiş bir ülke arasındaki ticaretin sonucunda gelişmiş ülkedeki uzun dönemli büyümenin olumsuz etkilenebileceği de Spilimbergo (2000) tarafından gösterilmiştir. Ancak aşağıda belirtildiği gibi bu bakış açısının dışında kalan ülke örnekleri de söz konusudur. Türkiye gibi gelişmekte olan ülkeler açısından ise bu ilişkinin durumu belirsizdir ve ilişsi dönemler itibariyle ekonomideki ticari politikalardan etkilenmektedir. İlgili ekonomi politikalarının niteliksel ve niceliksel yönlerini öncelikle betimsel yaklaşımlar sonrasında da analitik çözümlemelerle ifade etmek bu çalışmada cevaplanmak istenen soruların üzerine oturduğu bir kalıp niteliğindedir.

Ticari dışa açıklık ile uzun dönemli büyüme arasındaki ilişkinin nasıl olduğunun ülkeler arasındaki gelişmişlik farklılıklarından dolayı ampirik olarak değişen cevapları bulunmaktadır. Bu ilişkinin pozitif olduğunu ortaya koyan kesit-ülke (cross-section) analiz yöntemiyle yapılmış çalışmalar; Barro (1991), Dollar (1992), Dollar ve Kraay (2001, 2003), Edwards (1998), Frankel ve Romer (1999), Sachs ve Warner (1995) olarak gösterilebilir. Diğer taraftan bu ilişkinin negatif olduğunu ortaya koyan çalışmalar; Clemens ve Williamson (2001), Irwin (2002) ve O’Rourke (2000) olarak gösterilebilir. Ancak bulgulardaki bu farklılığı sadece ülkelerin gelişmişlik düzeylerindeki farklılıklarla açıklamak eksik kalmaktadır. Zayıf teorik bulgular, düşük kalitedeki veriler, uygun olmayan ekonometrik teknikler bu farklılığı yaratan diğer faktörler olabilmektedir (Musila ve Yiheyis, 2015; Baldwin, 2003; Rodrigez ve Rodrik, 2001; Samman, 2005; Srinivasan ve Bhagwati, 2001).

Srinivasan ve Bhagwati (2001)'e göre dışa açıklıkla uzun dönem büyüme arasındaki ilişkiler ülkeler arası karşılaştırma yerine tek bir ülke analizinde daha derinlemesine ortaya konulabilecektir. Musila ve Yiheyis (2015), Kenya için bu ilişkiyi araştırmışlardır. Kenya'nın az gelişmiş bir ülke olduğu düşünüldüğünde buldukları ampirik sonuç; teorideki beklenen şekliyle ilişkinin negatif oluşudur. Bu ilişkinin Türkiye gibi "yükselen ekonomiler" olarak adlandırılan bir ülkede ne sonuç vereceği bu sebeple merak konusudur ve çalışmanın önemli motivasyon kaynaklarından bir tanesidir. 
Bu çalışma, küreselleşmenin büyümeye etkisini, ülkedeki ihracat ve ithalatın toplamının ülkenin gayri safi milli hasılasına olan oranı [(X+M)/ GDP] olarak tanımlanan ticarette dışa açıklığın Türkiye'deki ekonomik büyüme hızını nasıl etkilediğini yıllık düzeyde zaman serisi verileri kullanarak tahmin etmektedir. Musila ve Yiheyis (2015), konuyla ilgili önceki çalışmalardan farklı olarak Kenya'daki ticaretteki dışa açıklık ile büyüme arasındaki doğrudan bir ilişki kurmak şeklinde değil de bu ilişkiyi bir üretim fonksiyonu ve yatırım mekanizması üzerinden tahmin etmektedir. Diğer çalışmalardan oldukça farklı ve ilginç olması sebebiyle bu çalışma Musila ve Yihehis'de kullanılan ekonomik modeli izlemektedir. Çalışmanın ithal ikameci politikaların terk edilmesiyle, özellikle, 1980'den sonra uygulanan dişa açılma ile ekonomik aktivitelerin canlanmasıyla kaydedilen ekonomik büyümeye ilişkin pozitif sonuçları ortaya koymasından dolayı önemli ticari politika önerileri içerdiği düşünülmektedir. Ayrıca çalışmada, 1980'den günümüze ampirik olarak ortaya konulan bu ilişkiler 1961'den 1980'e kadar olan dönemlerde de betimsel olarak tartışılmaktadır.

Çalışmanın geriye kalan bölümleri takip eden şekliyle organize edilmiştir. Sonraki bölüm küresel ekonomi kavramını tarihsel boyutuyla açıklamaktadır. Takip eden bölümde Türkiye'nin 1960 sonrası küresel ekonomiye entegrasyonunu ele almaktadır. Bir diğer bölümde Türkiye'nin küresel ekonomiye entegrasyonun sanayileşme stratejileri bağlamında değerlendirilmektedir. Sonrasında Türkiye'deki küreselleşme derecesinin niteliğini ve büyümeye etkisi teorik olarak ortaya koymaktadır. Ardından teorik modele uygun olarak seçilmiş regresyon modelleri ve veriler eşliğinde ekonometrik metodun tahminleri yapılmaktadır. Son bölümde ise çalışmanın özeti ve sonucu yer almaktadir.

\section{Küreselleşme Derecesinin Niteliği ve Büyümeye Etkisi}

\subsection{Teorik Çerçeve}

Yeni büyüme teorisi ticarette dışa açıklık ile büyüme arasında yatırımlar ve teknoloji faktörlerinin varlığını ortaya koymaktadır. Yatırım faktörü perspektifinden bakıldığında, ticarette dışa açıklığın yatırım olgusunu ön plana çıkartmasının sebepleri; ticarete konu olan sektörün sermaye yoğun nitelikte olması, yatırım malları üretimi bir dereceye kadar ithal ara mallarını kullanması ve uluslararası piyasalardaki rekabetin sermayenin fiyatını düşürüyor olması (bknz. Baldwin ve Seghezza, 1996a) olarak gösterilebilir. Ticarette dışa açıklık teknolojiyi de takip eden sebeplerden ötürü ilerletecektir. Bu sebepler; teknolojinin yayılma etkisi, araştırma-geliştirme ve kalkınmada kullanılan ekonomilerin etkisi ve girişimcilerin elde ettikleri yüksek karlar (bknz. Grossman ve Helpman, 1991; Rivera-Batiz ve Romer, 1991a,b; Romer, 1990; Krugman, 1990) olarak suralanabilir.

$\mathrm{Bu}$ çalışma ticarette dışa açıklık ile reel fert başına GSYİH'daki büyüme ilişkisini yeni büyüme teorisi perspektifinden ele alarak analiz etmektedir. Yukarıda da belirtildiği şekliyle, reel fert başına GSYİH'daki büyüme ile dışa açıklık arasında üretim faktörlerinin de kullanılmasıyla oluşturulacak bir üretim fonksiyonu ile teorik modelin ilk basamağı kurulmaktadır. Çalışmada kullanılan bu teorik modelin ilk basamağı olan üretim fonksiyonunu takip eden şekliyle formülüze etmek mümkündür:

$$
\text { GSYIHFB }=f(k, h, x(\text { Ticarette Dışa Açılık (TDA), } \theta))
$$

Denklem 1'de GSYİHFB; reel fert başına GSYİH düzeyini, k; fert başına fiziksel sermaye düzeyini ve $h$ ise; fert başına beşeri sermaye düzeyini, TDA; ticarette dışa açıklık düzeyini ve $\theta$ 'da; teknoloji düzeyini etkileyebilecek tüm diğer etkileri içermektedir.

Teorik modelin ikinci basamağında yatırım kalemi ile ticarette dışa açıklık ve büyüme arasındaki ilişki formüle edilmektedir. Bu ilişkinin formülüzasyonu takip eden şekliyledir:

$$
\mathrm{Y}_{\mathrm{o}}=\mathrm{F}(\mathrm{rGSYIH} \text {, TDA, w) }
$$

Burada, Yo; yatırım oranını (yatırım/GSYIH), rGSYİH ; reel GSYİH hızını ve w ise; yatırım oranını içeren tüm diğer faktörleri ifade etmektedir.

\subsection{Regresyon Modelleri, Veriler ve Metod}

Çalışmanın bu kısmında ekonometrik modeller teorik çerçevede yer almış Denklem 1 ve 2'de belirtilen esaslara göre, tahmin edilmektedir. Bu tahminler yapılırken ekonometrik modellerin anlamlılıklarını arttıracağı düşünülen önemli bir takım iktisadi kontrol değişkenleri de kullanılmaktadır. Kullanılan kontrol değişkenleri takip eden alt başlıkta ifade edilmektedir.

\subsection{Ekonometrik Modeller}

Bu çalışmada kullanılan uzun dönem ekonomik büyüme modeli kontrol değişkeni olarak yıllık enflasyon düzeyini (yıllık bazda hesaplanan tüketici fiyat endeksi) içermektedir. Tahmin edilecek regresyon modeli takip eden şekliyle ifade edilebilir:

$$
\begin{aligned}
\left(\mathrm{rGSYIHFB}_{\mathrm{h}}\right)_{\mathrm{t}} & =\alpha_{0}+\alpha_{1}\left(\mathrm{SSTOK}_{\mathrm{h}}\right)_{\mathrm{t}-\mathrm{i}}+\alpha_{2}\left(\mathrm{BSTOK}_{\mathrm{h}}\right)_{\mathrm{t}-\mathrm{i}}+\alpha_{3}\left(\mathrm{ENF}_{\mathrm{ti}}+\alpha_{4}\left(\mathrm{TDA}_{\mathrm{h}}\right)_{\mathrm{ti}}+\alpha_{5}\left(\mathrm{SSTOK}_{\mathrm{h}}{ }^{*} \mathrm{DA}_{\mathrm{h}}\right)_{\mathrm{ti}}\right. \\
& +\alpha_{6}\left(\mathrm{rGSYIHFB}_{\mathrm{h}}\right)_{\mathrm{t}-\mathrm{i}+1}+\alpha_{7} \mathrm{D} 80+\mu_{\mathrm{t}}
\end{aligned}
$$

Burada rGSYİHFB ; reel fert başına GSYİH büyüme hızını, SSTOK ; fert başına sabit sermaye stoğu büyüme hızını, BSTOK ; fert başına beşeri sermaye stoğu büyüme hızını, ENF; tüketici fiyatları endeksiyle hesaplanan yıllık enflasyon oranını, TDA $\mathrm{h}_{\mathrm{h}}$; ticarette dışa açıklıktaki büyüme hızını, $\left(\mathrm{SSTOK}_{\mathrm{h}}{ }^{*} \mathrm{TDA}_{\mathrm{h}}\right)$; fert başına sabit 
sermaye stoğu büyüme hızı ile ticarette dışa açıklık büyüme hızının çarpımı ya da bahsi geçen iki değişken arasındaki etkileşimi, D80; ticaretteki serbestleşme ya da ticarette dışa açıklığa karşılık gelen kukla değişkeni (eğer y1l $>1980$ ise; $\mathrm{D} 80=1$, diğer durumlarda $\mathrm{D} 80=0)$, $\mu$; hata terimini ve $\alpha_{\mathrm{i}}$ ler de tahmin edilecek katsayıları belirtmektedir.

Regresyon Denklemi 3'ün ekonometrik tahmininden önce beklenen tahmin sonuçlarına göre $\mathrm{SSTOK}_{\mathrm{h}}$ ve BSTOK $_{h}$ değişkenlerinin pozitif olması öngörülürken, ENF değişkeninin negatif olması öngörülmektedir. TDA değişkeninin işaretinin nitelik ve niceliksel anlamda ne olacağı gelişmekte olan ülkeler arasında gösterilen Türkiye için merak konusudur. Diğer taraftan $\left(\mathrm{SSTOK}_{\mathrm{h}}{ }^{*} \mathrm{TDA}_{\mathrm{h}}\right)$ teriminin katsayısı şayet pozitif anlamlı bulunursa bu durumda büyümenin fert başına sermaye büyümesindeki marjinal etkisi ekonominin uluslararası ticarete açılması durumunda daha da artacağı yolunda ip uçları verecektir.

Reel fert başına GSYİH büyüme hızına ek olarak, yatırımlar için teorik çerçevede bahsi geçen ampirik model, doğrudan yabancı sermaye yatırımları (DYSY) ve enflasyonu kontrol değişkenleri olarak kapsamaktadır. Böylece, yatırımlar için geçerli olan ampirik model takip eden şekliyle ifade edilmektedir:

$$
\left(\mathrm{Y}_{\mathrm{o}}\right)_{\mathrm{i}}=\beta_{10}+\sum_{i=0}^{k} \beta_{2 i}\left(\mathrm{rGSYIHHFB}_{\mathrm{h}}\right)_{-\mathrm{i}}+\sum_{i=0}^{l} \beta_{3 i}\left(D Y S Y_{o}\right)_{-\mathrm{i}}+\sum_{i=0}^{k} \beta_{4 i}(E N F)_{-\mathrm{i}}+\sum_{i=0}^{n} \beta_{5 i}(T D A)_{-\mathrm{i}} * \mathrm{D} 80+\varepsilon_{\mathrm{i}}
$$

Burada rGSYİHFB ${ }_{\mathrm{h}}$; reel fert başına GSYİH büyüme hızını, DYSY ; GSYİH'daki DYSY oranını, $\beta_{\mathrm{ji}}$; tahmin edilecek katsayıları ve $\varepsilon_{\mathrm{i}}$; hata terimini temsil etmektedir. Diğer değişkenler daha önce tanımlanmış halleriyle Denklem 4'te yer almaktadır.

Regresyonun ekonometrik tahmininden önce rGSYIHFB $_{h}$ ve DYSY değişkenlerinin katsayılarının pozitif olması beklenmektedir. Bununla birlikte eğer ENF değişkeninin katsayısı negatif ve istatistiksel olarak anlamlı olursa bu durumda Türkiye'de uygulanan makroekonomik politikaların yatırımları olumsuz etkilediği sonucuna varılabilir. Enflasyon hedeflemesi politikasında olan hükümet "bu politikasının olumlu sonuçlarını ticarette dışa açıklık perspektifinden elde edebiliyor mu?" sorusu burada cevap bekleyen önemli sorular arasında kendini göstermektedir. Diğer taraftan, (TDA*D80) değişkeninin katsayısının ne olacağı ticarette dışa açıklık ile ticarette serbestleşme politikaları arasındaki etkileşmenin Türkiye'deki yatırımları nasıl etkilemekte olduğunun yanıtını verecek önemli bir diğer soru konumundadır.

\subsection{Veriler ve Bazı Ekonometrik Hususlar}

Gerek büyüme denklemini, gerekse yatırım denklemini tahmin etmek için 1961-2013 dönemine ait yıllık veriler kullanılmaktadır. Burada bahsi geçen dönem verilerinin tedarik edilebilmeleri kısıtı altında belirlenmiştir. Ancak belirtilen dönemin Türkiye'nin ithal ikameci ve ticarette dışa açılma politikalarını kapsadığı için, hedeflenen amaca uygun analizler yapabilme imkânını sağlamaktadır. Kukla değişken olarak kullanılan D80; 1980 yılından sonra ithal ikameci ticaret politikalarının terk edilerek yerini ticarette dışa açılma politikalarına bıraktığı zaman periyodunu temsil etmektedir. Modelleri temsil etmede kullanılan verilerden beşeri sermaye verisi $\left(B_{S T O K}\right)$ Penn Dünya Tablo'larından (Penn World Tables), diğer değişkenlere ait veriler ise Dünya Bankası Kalkınma Belirleyicileri'nden (World Development Indicators, 2014 for Turkey) elde edilmişlerdir.

Veriler elde edildikten sonra veri analizindeki ilk aşama modelin uygun tahmin prosedürünü yerine getirebilmek için değişkenlerinin durağanlık derecesine bakmak olmuştur. Augmented Dickey-Fuller (ADF) ve Phillips-Perron (PP) birim kök testleri tüm değişkenler için uygulanmış, durağan olmayan değişkenlerin durağanlık sağlanana kadar farkları alınmıştır. Elde edilen durağan veri setiyle Johensen Co-integration testleri sayesinde ekonomik büyüme ile dış ticarette dışa açıklık arasındaki ilişki uzun dönemde bir kez de nedensellik testleriyle sınanmış olmaktadır. Yapılan tahminlerin amacı ampirik tahminlerin sağlamlığını nedensellik açısından da ortaya koymaktır.

\section{Ampirik Bulgular}

Çalışmanın bu kısmında Denklem 3 ve 4'ün en küçük kareler (EKK) yöntemiyle tahminlerini ortaya koyarak bu tahminleri tartışacağız. Model 1 ile gösterilen bulgular sadece kontrol değişkenlerinin kullanıldığı regresyonu tanımlamaktadır. Model 2 ile gösterilen bulgular Model 1'e ilave olarak ticaret politikası etkisindeki dışa açılık büyümesini içermektedir. Model 3 ile gösterilen bulgular hem ticaret politikası etkisindeki dışa açıklık hem de kontrol amacıyla kullanılan (Fiziksel sermaye büyümesi * ticarette dışa açıklık büyümesi) değişkenini içermektedir. Model 4 ve 5 ticaret politikası etkisindeki dışa açıklık değişkeni yerine toplam ticarette dışa açıklık büyümesinin kullanılmasıyla elde edilen buğuları içermektedir.

\subsection{Büyüme Denkleminin Tahmini}

Tablo 1 büyüme denkleminin çeşitli varyasyonlarının tahmin edilmiş sonuçlarını sunmaktadır. Modellerin açıklama gücü \%42.9'dan \%65.6'ya kadar değişen değerler almaktadır. Göreceli olarak düşük açıklama yüzdesinde modelde sadece kontrol değişkenleri yer almakta iken ticarette dişa açıklık büyümesini belirleyen değişkenlerin modele dâhil edilmesiyle modelin açıklama yüzdesinde anlamlı derecede artışlar gözlemlenmektedir.

Model 3 ile tahmin edilen katsayılara göre; reel fert başına GSYİH büyümesi ile ticaret politikası etkisindeki dışa açıklık büyümesi arasında pozitif ve istatistiksel olarak anlamlı bir ilişki görünmektedir. Bunun ötesinde, 
fiziksel sermaye büyümesi ile ticarette dışa açıklık büyümesi arasındaki etkileşimi yansıtan değişkenin katsayısı 0.005 değeri ile istatistiksel olarak pozitif ve anlamlıdır. Bunun iktisadi yorumu; fiziksel sermayenin uzun dönemli büyümesi artan ticarette dışa açıklık ile yükseliyor olmasıdır.

Tablo 1'de gösterilen Model 1, 2 ve 3'den anlaşılan bulgulara göre ticaret politikası etkisindeki dışa açıklık büyümesi ile reel fert başına GSYİH büyümesi arasında istatistiksel olarak güçlü ve pozitif bir ilişki söz konusudur. D80 kukla değişkeni ile ifade edilen ve 1980 yılından sonra Türkiye'nin ticarette dişa açık politikalar izlemesinin bu büyüme ilişkisinde oynamış olduğu pozitif etki de analizlere yansımaktadır. Son yıllarda uygulanan enflasyon hedeflemesine yönelik politikalara rağmen enflasyon değişim hızının reel fert başına GSYİH büyümesini olumsuz olarak etkilediği sonucu da görülmektedir.

Diğer taraftan, toplam ticarette dışa açıklık büyümesi değişkeninin regresyon denklemine dâhil olmasıyla katsayıların negatife dönüştüğü görülmektedir. Model 4'de istatistiksel anlamlılık sağlanamaz iken Model 5'de istatistiksel anlamlılık sağlanmaktadır. Model 5'deki bu istatistiksel anlamlılık (fiziksel sermaye büyümesi ile ticarette dışa açıklık büyümesi değişkenleri arasındaki etkileşimden kaynaklandığı düşünülmektedir. Model 4 ve 5'in iktisadi yorumu; pratikteki ticaretteki dışa açıklığın Türkiye'nin uzun dönem büyümesine katkı yapmıyor olduğu şeklindedir. Bu bulgularla birlikte, bir taraftan fert başına fiziksel sermaye büyümesinin reel fert başına GSYİH büyümesini pozitif ve istatistiksel olarak anlamlı etkilediği ortaya konulmakta iken, diğer taraftan da fert başına fiziksel beşeri sermaye büyümesinin reel fert başına GSYIH büyümesini negatif ve istatistiksel olarak anlamlı etkilediği de ortaya konulmaktadır. Enflasyon değişim hızının ise reel fert başına GSYİH büyümesini 5 modelde de negatif ve istatistiksel olarak anlamlı etkilediği ortaya konulmaktadır.

Tüm bu analizlerden ortaya çıkan temel bulgu, Türkiye'nin büyüme analizinde ticaret politikası etkisindeki dışa açıklık büyümesinin reel fert başına GSYİH büyümesini gerek tek başına gerekse fiziksel sermaye büyümesi ile etkileşimli bir şekilde arttırdığı şeklindedir.

\subsection{Yatırım Denklemi İçin Ampirik Tahminler}

Bir önceki bölümde Tablo 1 ile gösterilen bulgular bu bölümde yatırım denkleminin tahminiyle farklı bir açıdan ele alınmaktadır. Farklılığın ortaya çıktığı değişkenler "ticaret politikası etkisindeki dışa açıklık büyümesi” ile "toplam ticarette dışa açıklık büyümesi” ve bu değişkenlerin gecikmeli durumlarına ilişkin değerleridir.

Tablo 1'de büyüme denklemlerinin tahmini esnasında ticaret politikası etkisindeki dışa açıklık büyümesi istatistiksel olarak anlamlı ve pozitif iken, yatırım denklemlerinin tahminine ait bulguların sunulduğu Tablo 2'de istatistiksel olarak anlamsız hale dönüşmektedir. Benzer şekilde, Tablo 1'de sunulduğu üzere toplam ticarette dişa açıklık büyümesi istatistiksel olarak anlamlı ve negatif iken bu değişken Tablo 2'de yatırım denklemleri tahmini esnasında istatistiksel anlamlılığını yitirmektedir. Bu iki farklı kanaldan elde edilen bulgular birbirlerini destekler nitelikte Türkiye'de meydana gelen büyümenin yatırımlar üzerinden kaynaklanmadığının göstergeleridir. Tablo 2'de bulguları sunulan ekonomik model yatırım oranlarındaki değişimin en az \% 72 'lik kısmını açıklamaktadır. Bu modelde Durbin-Watson (DW) istatistiği 0.97 ve 1.07 arasında yer almakta ve herhangi bir otokoralasyon probleminin mevcut olmadığını belirtmektedir. Tablo 2'deki tüm modeller ayrıca Durbin'in alternatif testleriyle de sınanmış ve her model için H0: serisel korelasyon yoktur hipotezi \%1 anlamlılık düzeyiyle kabul edilmektedir. 


\begin{tabular}{|c|c|c|c|c|c|}
\hline Açıklayıcı değişkenler & Bağımlı değişken & reel fert başına GSY & üyümesi & & \\
\hline & Model 1 & Model 2 & Model 3 & Model 4 & Model 5 \\
\hline Sabit & $8.674^{* * *}(2.22)$ & $20.662^{* * *}(3.53)$ & $15.795^{* * *}(3.12)$ & $9.583^{* * *}(2.32)$ & $6.861^{* * *}(2.00)$ \\
\hline $\begin{array}{l}\text { Fert başına fiziksel } \\
\text { sermaye büyümesi }\end{array}$ & $0.891^{* * *}(4.86)$ & $0.899^{* * *}(5.21)$ & $0.480^{* * *}(2.75)$ & $0.872^{* * *}(4.68)$ & $0.355^{* *}(1.91)$ \\
\hline $\begin{array}{l}\text { Fert başına beşeri } \\
\text { sermaye büyümesi }\end{array}$ & $-10.709^{* * *}(-3.42)$ & $-21.340^{* * *}(-4.27)$ & $-14.418^{* * *}(-3.20)$ & $-11.191^{* * *}(-3.48)$ & $-5.274^{* *}(-1.82)$ \\
\hline $\begin{array}{l}\text { Enflasyon değişim } \\
\text { hızı }\end{array}$ & $-0.133^{* * *}(-5.58)$ & $-0.133^{* * *}(-5.95)$ & $-0.081^{* * *}(-3.63)$ & $-0.131^{* * *}(-5.42)$ & $-0.067^{* * *}(-2.20)$ \\
\hline $\begin{array}{l}\text { Ticaret politikası } \\
\text { etkisindeki dışa } \\
\text { açıklık büyümesi }\end{array}$ & -- & $0.260^{* * *}(2.63)$ & $0.229^{* * *}(2.73)$ & -- & -- \\
\hline $\begin{array}{l}\text { Toplam ticarette dışa } \\
\text { açıklık büyümesi }\end{array}$ & -- & -- & -- & $-0.020(-0.70)$ & $-0.048^{* *}(-2.00)$ \\
\hline $\begin{array}{l}\text { Fiziksel sermaye } \\
\text { büyümesi*ticarette } \\
\text { dışa açıklık büyümesi }\end{array}$ & -- & -- & $0.005^{* * *}(4.38)$ & -- & $0.005^{* * *}(4.83)$ \\
\hline D80 & $4.253^{* *}(1.97)$ & $3.144^{*}(1.52)$ & $0.950(0.52)$ & $4.756^{* * *}(2.08)$ & $4.253^{* *}(1.97)$ \\
\hline $\begin{array}{l}\text { Reel Fert başına } \\
\text { GSYİH büyümesi (-1) }\end{array}$ & $-0.335^{* * *}(-2.71)$ & $-0.418^{* * *}(-3.47)$ & $-0.314^{* * *}(-3.01)$ & $-0.336^{* * *}(-2.70)$ & $2.733^{* *}(1.43)$ \\
\hline $\mathrm{R}^{2}$ & 0.429 & 0.505 & 0.656 & 0.436 & 0.631 \\
\hline Düzeltilmiş $\mathrm{R}^{2}$ & 0.367 & 0.439 & 0.601 & 0.360 & 0.573 \\
\hline $\begin{array}{l}\text { Regresyonların } \\
\text { ortalama standart } \\
\text { hatalarının kara kökü }\end{array}$ & 3.095 & 2.913 & 2.457 & 3.112 & 2.544 \\
\hline F-istatistiği & $6.92^{* * *}$ & $7.66^{* * *}$ & $11.97^{* * *}$ & $5.79^{* * *}$ & $10.76^{* * *}$ \\
\hline
\end{tabular}

Tablo 1. Büyüme Denklemlerinin En Küçük Kareler (EKK) Yöntemiyle Tahminleri ${ }^{a, B}$.

Tahmin edilen katsayılar Tablo 2'de de görülebileceği gibi ticaret politikası etkisindeki dışa açıklık büyümesi ve yatırım oranları arasında istatistiksel olarak anlamlı olmayan ancak pozitif bir ilişkiyi belirtmektedir. Toplam ticaretteki dışa açıklık büyümesi söz konusu olduğunda da istatistiksel anlamlılık değişmemektedir. Değişkenlerin gecikmeli durumları söz konusu olduğunda ise, Model 4'ün dışında ticarette dışa açıklık ölçümlerinin yatırım aktivitelerini ters yönlü olarak etkilediği görülmektedir. Ayrıca, ticarette dışa açıklık ve ticaret politikası reformu niteliğindeki D80 kukla değişkeninin etkileşimiyle (çarpımı) oluşan değişkenin katsayısı pozitif ve istatistiksel olarak anlamlı olması, yatırımlar üzerindeki ticarette dışa açıklık politikasının dış ticaret politikası reformları (1980'den sonra dişa açılma) ile desteklendiğini göstermektedir.

Yatırım denklemlerinin tahminlerindeki bir diğer önemli bulgu da "reel GSYİH büyümesi” katsayısının istatistiksel olarak anlamlı ve pozitif bulunmasıdır. Bununla birlikte, DYSY oranları katsayılarının istatistiksel olarak pozitif ve anlamlı bulunmaları Türkiye'deki ulusal yatırımlarda doğrudan yabancı sermaye yatırımlarının yadsınamayacak bir etkilerinin varlığını ortaya koymaktadır. Diğer taraftan "enflasyon oranındaki değişim" değişkeninin katsayılarının istatistiksel olarak anlamlı ve pozitif bulunması Türkiye'de ulusal yatırımların enflasyon politikasından olumlu etkilendiğinin bir göstergesidir. Bu bulgu izlenen enflasyon hedeflemesi politikasının yatırımlar açısından işlerliğinin kanıtıdır. Ancak burada toplum tarafından ödenen işsizlik (özellikle genç nüfusta) alternatif maliyetinin varlığını belirtmekte de fayda vardır.

\section{Sonuc}

Bu çalışma küreselleşmenin Türkiye'deki ekonomik büyümeye olan etkisini TDA ve DYSY üzerinden 19612013 periyodunda ve yıllık düzeyde zaman serisi verileri kullanarak ölçmektedir. Öncelikle, küresel ekonomiye 
entegrasyon süreçlerinde ticari dışa açılık ve uygulanan ekonomi politikalarının derecelerinin niteliği belirlenmektedir. Sonrasında da kurulan ekonomik modelde, ticari dışa açıklığın kısa ve uzun dönemler itibariyle yatırım düzeylerini ve ekonomik büyümeyi pozitif olarak etkilediğini ortaya konulmaktadır.

TDA ile ekonomik büyüme arasındaki ilişki birçok çalışmada ele alınmış bulunmakta ancak bu çalışmada bahsi geçen ilişki gelişmekte olan Türkiye açısından küreselleşme ekseninde incelenmektedir. Kurulan ekonomik modelde küreselleşmenin bir belirleyicisi olması nedeniyle DYSY'ye de yer verilmektedir. Ayrıca, ülkenin makroekonomik değişkenlerinden yatırım oranları da ekonomik model kurgusuna dâhil edilmektedir.

Yapılan analizlerde iki çeşit TDA ölçütü kullanılmaktadır. Bunlardan ilki; ticaret politikası etkisindeki dışa açıklık büyümesi ve ikincisi de; toplam ticarette dışa açıklık büyümesidir. Her iki etki de büyüme modeli ve yatırım denklemi tahmin modelinde yer almaktadır. Çalışmada ortaya çıkan en somut bulgu; ticaret politikası etkisindeki dışa açıklık büyümesinin, Türkiye'nin büyümesini istatistiksel olarak anlamlı ve pozitif etkilediği sonucudur. Ticaret politikası etkisindeki dışa açıklık büyümesi, yatırım denklemleri üzerinde istatistiksel anlamlılığını yitirmekte ancak pozitif etkisi devam etmektedir. Bu bulgunun iktisat politikası bağlamındaki açılımının; 1961'den günümüze kadar olan süreçte Türkiye'nin dünyada meydana gelen küreselleşme olgusuna entegrasyonunun gerçekleşmiş olduğu şeklindedir. Bunun sonucu olarak da küresel ekonominin ürettiği pastadan alınan payın göreceli olarak arttığı anlaşılmaktadır.

Diğer taraftan, toplam TDA büyümesi, Türkiye'nin büyümesini istatistiksel olarak anlamlı ancak negatif olarak etkilemektedir. Yatırım denklemleri üzerinden analizlere bakıldığında istatistiksel anlamlılık durumunu yitirmekte ve etkinin şiddeti de azalmaktadır. Bu bulgunun iktisat politikası açısından açılımı; 1961'den günümüze kadar olan süreçte gerçekleştirilen toplam ticaret hadlerinin Türkiye'yi fert başına GSYİH anlamında büyütmediği ve yatırım politikalarının bu büyümede etkisiz kaldığ şeklinde yorumlanabilir.

Büyüme denklemlerinin bir kontrol değişkeni olan fert başına beşeri sermaye büyümesi, büyümeyi istatistiksel olarak anlamlı fakat negatif olarak etkilemektedir. Bu çarpıcı bulgunun iktisat politikası perspektifinden açılımı; gelişmekte olan bir ülke konumundaki Türkiye'de hayati bir öneme sahip beşeri sermaye yatırımlarının yeterince ya da etkin bir şekilde yapılamadığını, bunun sonucunda da fert başına GSYİH'nın bundan olumsuz olarak etkilendiğinin düşünülmesidir. Diğer bir kontrol değişkeni olan enflasyon değişim hızı, büyüme denklemlerini istatistiksel olarak anlamlı ve negatif olarak etkilerken, yatırım denklemlerinde bu durum istatistiksel anlamlılığını korumakla birlikte pozitife dönüşmektedir. Buradan çıkan iktisadi yorum; enflasyon gibi önemli bir ekonomik göstergenin ancak yatırımlar yoluyla bir problem olmaktan çıkacağı şeklindedir. Türkiye 2000'li yılların başından itibaren enflasyon hedeflemesini seçerek bu problemi belli bir seviyede çözmüş bulunmaktadır.

Ancak bunun karşılığında alternatif maliyet olan işsizliğe de boyun eğmek zorunda kalındığını belirtmek gerekmektedir. Kısmi olmayan iktisadi çözümün ise enflasyon ile birlikte işsizliğin eş zamanlı azaltılabilmesi olarak özetlenebilir. Son olarak doğrudan yabancı sermaye yatırımları değişkeni, ulusal yatırımları istatistiksel olarak anlamlı ve pozitif etkilemekte olduğu görülmektedir. Buradan yola çıkarak da ekonomik anlamda DYSY'nın fert başına GSYİH'yı yatırımlar yoluyla arttırdığı sonucuna ulaşılmaktadır. 


\begin{tabular}{|c|c|c|c|c|c|}
\hline \multirow[t]{2}{*}{ Açıklayıcı değişkenler } & \multicolumn{5}{|c|}{ Bağmlı değişken = Yatırım oranı (Örneğin; yatırım / reel GSYİH) } \\
\hline & Model 1 & Model 2 & Model 3 & Model 4 & Model 5 \\
\hline Sabit & $8.564^{* * *}(7.68)$ & $8.330^{* * *}(7.50)$ & $7.407^{* * *}(4.28)$ & $8.487^{* * *}(7.35)$ & $8.831^{* * *}(7.59)$ \\
\hline Reel GSYİH büyümesi & $0.583^{* * *}(6.28)$ & $0.525^{* * *}(5.39)$ & $0.521^{* * *}(5.31)$ & $0.581^{* * *}(6.10)$ & $0.535^{* * *}(5.40)$ \\
\hline $\begin{array}{l}\text { Reel GSYİH büyümesi (- } \\
\text { 1) }\end{array}$ & $-0.260^{* * *}(2.99)$ & $0.228^{* * *}(2.61)$ & $\begin{array}{l}0.21618^{* * *} \\
2.42)\end{array}$ & $0.278^{* * *}(2.96)$ & $0.242^{* * *}(2.67)$ \\
\hline DYSY oranı (-1) & $1.650^{* * *}(2.31)$ & $1.116^{*}(1.45)$ & $1.110^{*} \quad(1.44)$ & $1.612^{* * *}(2.20)$ & $1.191^{*}(1.53)$ \\
\hline DYSY oranı (-2) & $1.395^{* *}(1.88)$ & $0.969 \quad(1.26)$ & $0.951 \quad(1.22)$ & $1.452^{* *}(1.90)$ & $1.078(1.34)$ \\
\hline $\begin{array}{l}\text { Enflasyon oranındaki } \\
\text { değişim }\end{array}$ & $0.129^{* * *}(9.98)$ & $0.111^{* * *}(7.03)$ & $0.115^{* * *}(6.90)$ & $0.139^{* * *}(9.60)$ & $0.113^{* * *}(6.61)$ \\
\hline $\begin{array}{l}\text { Ticaret politikası } \\
\text { etkisindeki dışa açıklık } \\
\text { büyümesi }\end{array}$ & -- & $0.066 \quad(0.77)$ & $0.167 \quad(1.02)$ & -- & -- \\
\hline $\begin{array}{l}\text { Ticaret politikası } \\
\text { etkisindeki dışa açıklık } \\
\text { büyümesi (-1) }\end{array}$ & -- & $-0.009 \quad(-0.10)$ & $-0.008 \quad(-0.09)$ & -- & -- \\
\hline $\begin{array}{l}\text { Toplam ticarette dışa } \\
\text { açıklık büyümesi }\end{array}$ & -- & -- & -- & $0.001 \quad(0.01)$ & $-0.001 \quad(-0.05)$ \\
\hline $\begin{array}{l}\text { Toplam ticarette dışa } \\
\text { açıklık büyümesi (-1) }\end{array}$ & -- & -- & -- & $0.010 \quad(0.48)$ & $0.004 \quad(0.19)$ \\
\hline $\begin{array}{l}\text { Ticarette dışa açıklık * } \\
\text { D80 }\end{array}$ & -- & -- & $-0.071 \quad(-0.71)$ & -- & $0.048^{*}(1.48)$ \\
\hline $\mathrm{R}^{2}$ & 0.719 & 0.738 & 0.742 & 0.720 & 0.734 \\
\hline Düzeltilmiş $\mathrm{R}^{2}$ & 0.687 & 0.696 & 0.692 & 0.674 & 0.683 \\
\hline $\begin{array}{l}\text { Regresyonların ortalama } \\
\text { standart hatalarının kara } \\
\text { kökü }\end{array}$ & 2.349 & 2.317 & 2.330 & 2.407 & 2.365 \\
\hline DW-istatistiği & & & & & \\
\hline F-istatistiği & $22.97^{* * *}$ & $17.34^{* * *}$ & $15.06^{* * *}$ & $15.80^{* * *}$ & $14.47^{* * *}$ \\
\hline
\end{tabular}

a Parantez içindeki değerler t oranlarıdır. Yıldız işaretleriyle gösterilen ***, ** ve * sembolleri sırasıyla, \%1, \%5 ve \%10 anlamlılık düzeylerini göstermektedir.

b Burada kullanılan "ticarette dışa açıklık" değişkeni ticaret politikası etkisindeki dışa açıklık ile toplam ticarette dışa açıklık arasında hangisinin daha öncelikle kullanıldığına göre yer değiştirmektedir. Örneğin, eğer ticaret politikası etkisindeki dışa açıklık modelde kullanıldığında ticarette dışa açıklık ticaret politikası ektisindeki dışa açıklığı temsil etmektedir.

\section{Tablo 2. Yatırım Denklemlerinin EKK Yöntemiyle Tahminleri ${ }^{a, B}$.}

Tüm bu sonuçların dışında önümüzdeki süreçte Türkiye ekonomisinin önünde duran en önemli sorun, iktisatçıların ve ekonomiyi yönetenlerin de teslim ettiği gibi “orta gelir tuzağından” kurtularak "üst gelir gurubunda" yer alabilmektir. Bunun da yolu, genelde öngörüldüğü üzere, ar-ge faaliyetlerini artırmak ile teknoloji üretimini geliştirmekten ve küresel pazara katma değeri yüksek ürün sunmaktan geçmektedir. Bunlarla bağlantılı olarak da toplumsal dinamikleri harekete geçirmek; toplumu merkezine alan sivil bir anayasa yapmak; değişim, dönüşüm ve gelişmenin önünü tıkayan idari sistemi dönüştürmek gibi pratikler küreselleşmeyi Türkiye için şans haline getirebilir. İşte Türkiye küresel ekonominin kendisine getirdiği bu şansları idrak edebildiği ve ona doğru şekilde entegre olabildiği ölçüde, önemli ve dikkate alınan bir ülke haline gelebilir. Aksi halde içine kapalı, önemsiz bir çevre ülke olarak varlığını sürdüreceği düşünülmektedir.

\section{Kaynakça}

- Baldwin, R. E., ve Seghezza, E., 1996a. “Trade-induced investment-led growth”, NBER working paper no. 5582, Cambridge, MA: NBER.

- Baldwin, R. E., 2003. “Openness and growth: What's the empirical relationship?” NBER working paper no. 9578, Cambridge, MA: NBER.

- Barro, R., "Economic growth in a cross section of countries", Quarterly Journal of Economics, 1991, 106, s. 407-443. 
- Clemens, M. A., ve Williamson, J. G., 2001. “A tariff-growth paradox?: Protection's impact the world around 1875-1997”, NBER working paper no. 8459, Cambridge, MA: NBER.

- Dollar, D., 1992.“Outward-oriented developing economies do grow more rapidly: Evidence from 95 LDCs, 1976-1985”, Economic Development and Cultural Change, 40, s.523-554.

- Dollar, D., ve Kraay, A., 2001. "Trade, growth and poverty”, Mimeo, World Bank. Washington, DC: World Bank.

- $\quad$ Dollar, D., ve Kraay, A., 2003. “Institutions, trade, and growth”, Journal of Monetary Economics, 50, s.133162.

- Edwards, S., 1998. “Openness, trade liberalization, and growth in developing countries”, Journal of Economic Literature, XXXI, s.1358-1393.

- Frankel, J. A., ve Romer, D., 1999. “Does trade cause growth?”, American Economic Review, 80, s.379399.

- Grossman, G. M., ve Helpman, E., 1991. Innovation and growth in the global economy, Cambridge, MA: MIT Press.

- Irwin, D. A., 2002. "Did import substitution promote growth in the late nineteenth century", NBER working paper no.8751. Cambridge, MA: NBER.

- $\quad$ Krugman, P., 1990. Rethinking international trade, Cambridge, Massachusetts: MIT Press.

- Musila J. W. ve Yiheyis Z., 2015. "The impact of trade openness on growth: The caseof Kenya", Journal of Policy Modeling, 37, s. 342-354.

- O'Rourke, K. H., 2000. “Tariffs and growth in the late 19th century”, Economic Journal, 110, s.456-483.

- $\quad$ Rivera-Batiz, L., ve Romer, P., 1991a. "Economic integration and endogenous growth”, Quarterly Journal of Economics, 106, s.531-555.

- Rivera-Batiz, L., ve Romer, P., 1991b. "International trade with endogenous technological change", European Economic Review, 35, s.715-721.

- Rodriquez, F., ve Rodrik, D., 2001. Trade policy and economic growth: A skeptic's guide to the grossnational evidence. In B. Bernanke, ve K. S. Rogoff (Eds.)", NBER macroeconomic annual 2000. Cambridge, MA: MIT Press.

- Sachs, J., ve Warner, A., 1995. "Economic reform and the process of global integration”. Brookings Paper on Economic Activity, 1, s.1-117.

- Samman, E., 2005. “Openness and growth: An empirical investigation”, Human development report occasional paper, 2005/22.

- Spilimbergo, A., 2000. "Growth and trade: The north can lose", Journal of Economic Growth, 5, s.131-146.

- Srinivasan, T. N., ve Bhagwati, J., 2001. "Outward-orientation and development: Are revisionists right. In D. Lal, ve R.H. Snape (Eds.)”, Trade, development and political economy: Essays in Honour of Anne O. Krueger. NY: Palgrave.

- Stokey, N. L., 1991. "The volume and composition of trade between rich and poor countries", Review of Economic Studies, 58, s.63-80.

- Young, A., 1991. "Learning by doing and the dynamic effects of international trade", Quarterly Journal of Economics, 106, s.369-405. 


\title{
Doğrudan Yabancı Yatırımların Ekonomik Büyüme Üzerindeki Etkisi: Türkiye Örneği \\ The Effect of Foreign Direct Investment on Economic Growth: Turkey Case
}

\author{
Ph.D. Candidate Yılmaz Köprücü (Eskişehir Osmangazi University, Turkey)
}

\begin{abstract}
From the second half of the 20th century, foreign direct investment (fdi) has gone to the devoloping countries and has affected economic growth. The so-called effect has taken attention of some researchers and they have provided a consideriable amount of papers for growth literature. Hence, theories about fdi were improved by scientists. In this paper, the long run relationship between fdi and growth in Turkey for the years 1980-2011will be examined. The method used for investigating the relationship is Johansen coentegration. The variables are the growth rate of GDP per person (y), foreign direct investment (fdi), human capital (hc), openness (open) and investment (i). We use natural logarithm of GDP per person and investment variables. The data acquired from World Bank web site and Penn World Tables web site. According to analytical findings, we monitored that the variables' first differences are stationary and there is a long run relationship between fdi and economic growth.
\end{abstract}

\section{Giriş}

Geçmişten günümüzde ve özellikle 1980 sonrasında büyümenin belirleyicileri arasında doğrudan yabancı yatırımların (DYY) payı hiç de azımsanmayacak boyuttadır.

Doğrudan yabancı yatırımlar Türkiye'de genellikle "doğrudan yabancı sermaye yatırımı" olarak isimlendirilmiştir. Ancak yatırım kavramı doğası gereği sermaye unsurunu da barındırdığından dolayı bu çalışmada "doğrudan yabancı yatırım kavramı" kullanılacaktır (Açıkalın, vd, 2006:271).

Yabancı yatırım iki biçimde yapılabilir: "Yeşil alan" (green-field) veya "boz alan" (brown-field) yatırımları. Birincisinde yeni bir tesis kurulur- yabancı bir yatırımcının yeni bir tesis inşa etmesi gibi. İkincisinde, mevcut yerli firmaların varlıklarının satın alınması yoluyla şirketler birleşir veya devralınır. Yatıımcının yerleşik olmadığı bir ülkede gayrimenkul satın alması da DYY olarak sınıflandırılır (Chang, 2005:142).

Teknoloji transferi şeklinde olan yabancı yatırımlar ev sahibi ülkenin büyümesi üzerinde önemli bir etken olurken, 2000 yıllarının sonlarına doğru dünyadaki para bolluğu sonucu yüksek faize yönelen sermaye, gittiği ülkenin kırılganlığını artırabilme potansiyeline sahip olmuştur.

Bu çalışmada, öncelikle DYY'nın ekonomik büyümeye ne tür etkilerde bulunabileceği araştırılmıştır. Daha sonra, bu konuda önceden ortaya konulan uygulamalı çalışmalar ve elde edilen sonuçlar incelenmiştir. Son olarak ekonomik büyüme ile DYY, dışa açıklık, beşeri sermaye, yatırım arasında uzun dönemli bir ilişkisi olup olmadığını bulabilmek için koentegrasyon analizi yapılmıştır. 1980-2011 dönemindeki Türkiye'ye ait veriler dikkate alınarak söz konusu değişkenler arasındaki ilişki test edilmiş ve sonuçlar üzerine politika önerileri geliştirilmiştir.

\section{Literatür Taraması}

Literatürde doğrudan yabancı yatırımların büyüme üzerinde etkisi olup olmadığı ve bu ilişkinin tespiti aşamasında eşbütünleşme yaklaşımını kullanan araştırmacılar azımsanmayacak düzeydedir. Bunlardan birisi, Dar vd. (2016) çalışmalarında yabancı yatırımların büyüme üzerinde etkisi olduğu ve aralarında uzun dönemli bir ilişkinin varlığı varlığını Johansen eşbütünleşme yaklaşımıyla ortaya koymuşlardır. Büyüme yazınında büyük bir etki yapan içsel büyüme teorileri çerçevesinde yaklaşan araştırmacılar doğrudan yabancı yatırım, beşeri sermaye ve dışa açıklık arasında da uzun dönemli bir ilişki bulmuşlardır. Bu bulgular ışığında araştırma geliştirme faaliyetleri Pakistan'ın teknolojik kapasitesini artıracağı sonucuna ulaşmışlardır.

Borensztein vd. (1998) çalışmalarında 69 gelişmekte olan ülke ile panel veri yöntemini takip ederek SUR modelleri kurmuşlardır. Ev sahibi ülkeye gelen DYY, teknoloji transferleri ve taşma etkilerini araştırma konusu olarak ele almışlardır. Analitik bulgularına göre, DYY ve hc değişkenlerinin büyüme üzerinde güçlü bir tamamlayıcı etkisinin olduğu sonucuna varmışlardır. Li ve Liu (2005) araştırmalarında DYY ve büyüme arasındaki ilişkiyi 1970-1999 yıllarını kapsayan zaman dilimi için gerçekleştirmiş̧lerdir. Yöntem olarak 3SLS kullanılmış olup, söz konusu makalede DYY ve ekonomik büyümenin birbirlerini tamamlayan bir özelliğe sahip olduklarını vurgulamışlardır. Ayrıca elde ettikleri bulgular neticesinde gelişmekte olan ülkelerde DYY'nın ekonomik büyümeyi artırdığı sonucuna ulaşmışlardır.

1980 ve 1990'lar boyunca farklı araştırmacılar; Paul Romer (1986), Robert Lucas (1988) benzer bulgulara ulaşmışlardır. Nelson ve Phelps (1966) beşeri sermaye ve ileri teknoloji kullanımının büyüme için önem arzettiğini belirtmişlerdir. Ayrıca beşeri sermaye ile teknolojik gelişme arasında ilişki olduğunu vurgulamışlardır. Hsiao ve 
Shen (2003) 1976-1997 yıllarını kapsayan 23 gelişmekte olan ülkeyi analize dahil ederek panel verilerle çalışmışlardır. DYY ve büyüme arasında ilişsiyi tespit etmişler ve özellikle Çin'in 1970'lerin sonuna doğru açılmasıyla diğer gelişmekte olan ülkelere kıyasla daha fazla DYY alıcısı konumunda olmuştur. Mohan (2007)'nin Asya ülkeleri olan Malezya, Singapur, Tayland, Endonezya ve Filipinleri kapsayan çalışmalarının tahmin sonuçlarına göre DYY ve ekonomik büyüme arasında pozitif bir ilişki bulunmuştur.

Rodriguez ve Rodrik (2000)'de ampirik sonuçlarına göre ticaret sınırlamaları ile ekonomik büyüme arasında negatif ilişkiye ulaşmışlardır. Söz konusu makale de dışa açıklık ve uzun dönem büyüme arasındaki ilişkinin varlı̆ı̆ına vurgu yapılmıştır. Bengoa ve Sanchez-Robles (2003) 1970-1999 yıllarını kapsayan dönemde 18 Latin Amerika ülkelerinin verileri ile panel veri yöntemini kullanmışlardır. Panel veri analizi çerçevesinde, Hausman test sonucuna göre fixed effect tahmincisi seçilmiştir. Bu sonuçlara göre ekonomik serbestliğin sermaye akışkanlığı üzerinde güçlü etkisi gözlenmiş̧tir ve DYY ile ekonomik büyüme arasında pozitif bir korelasyon olduğu sonucuna ulaşılmıştır.

Chakraborty ve Basu (2002) DYY ve büyüme arasında koentegrasyon yöntemi kullanarak uzun dönemli ilişkinin var olup olmadığını araştırmıştır. Kısa dönem modeli kurularak hata düzeltme mekanizmasının çalıştığı görülmüş ve değişkenler arasında uzun dönemli bir ilişkinin varlığı tespit edilmiştir.

Ekinci (2011), 1980-2010 yıllarını kapsayan dönemde Türkiye'ye gelen DYY ve büyüme arasında uzun dönemli ilişkiyi araştırmıştır. Bunun için sistem yaklaşımı olan Johansen yaklaşımı kullanılmıştır. Buna göre iz testine göre bir tane eşbütünleşme vektörünün olduğuna işaret etmiş̧ir. Bu nedenle, DYY ve büyümenin uzun dönemde birlikte hareket ettikleri sonucuna ulaşılmışıtır.

Ağayev (2010) panel eşbütünleşme ve panel nedensellik yöntemlerini kullanarak 25 geçiş ekonomisini incelemiştir. Pedroni eşbütünleşme yaklaşımı kullanılmış olup, uzun dönemde DYY ve ekonomik büyümenin birlikte hareket ettikleri ve ortak bir yönelime sahip oldukları tespit edilmiş̧ir.

\section{Veri Seti, Uygulama ve Bulgular}

Bu çalışmada Türkiye'ye ait 1980-2011 arasını kapsayan yıllık veriler kullanılmıştır. Söz konusu veriler World ve Penn World Table veri tabanlarından elde edilmiştir. Kullanılan değişkenler ve kısaltmaları şu şekildedir: kişi başına düşen gelirin büyüme oranı (logy), doğrudan yabancı yatıım (dfi), beşeri sermaye (hc), dış açıklık (open), yatırım (logi).

Zaman serileri ile model kurulurken ve özellikle eşbütünleşme yaklaşımı için değişkenlerin durağan olmaları gerekmektedir. Serilerin durağan olup olmadıklarını belirlemek için bazı testler yapılmışıtır.

\section{ADF Durağanlık Testi}

Değişkenlerin durağan olup olmadıklarını test etmek için ADF Durağanlık testini değişkenlere uygulanmıştır. Elde edilen ADF test sonuçları; logy, dfi, open ve logi değişkenlerinin kendilerinin değil birinci farklarının durağan olduğu sonucunu vermektedir. Yani söz konusu seriler I(1)'dir. Ancak he serisinin durağan olmadığı tespit edilmiştir.

\begin{tabular}{|c|c|c|c|c|}
\hline \multirow[b]{2}{*}{ DEĞİŞKENLER } & \multicolumn{2}{|c|}{ TEST İSTATISTTIĞİ } & \multicolumn{2}{|c|}{$\begin{array}{c}\text { KRITTiK DEĞER } \\
\text { \% } 95 \text { GÜVENILIRLIK }\end{array}$} \\
\hline & KENDİSI & 1. FARKI & KENDİSI & 1.FARKI \\
\hline $\log y$ & -1.688 & -4.758 & -3.365 & -3.378 \\
\hline dfi & -2.688 & -3.348 & -3.365 & -3.378 \\
\hline open & -2.810 & -7.665 & -3.262 & -3.378 \\
\hline hc & -1.715 & -2.186 & -3.365 & -2.764 \\
\hline $\operatorname{logi}$ & -2.626 & -6.830 & -3.262 & -3.378 \\
\hline
\end{tabular}

Tablo 1: ADF Testi

Not: Tabloda verilen kritik değerler stata 12 paket program'den alınmıştır.

ADF testine göre değişkenlerin trend durağan değil ancak fark durağan özellik taşıdıkları Tablo 1'den gözlenmektedir.

ADF testinin güçsüz olduğu varsayımı altında DF-GLS testi de yapılmıştır. Ve test istatistikleri Tablo 2'de verilmiştir.

DF-GLS testi

Dickey-Fuller testinin güçsüz olması nedeniyle DF-GLS testi de uygulanmıştır. Bu test ile amaçlanan daha etkin tahminler elde edebilmektir. Bu test DF testinin dönüşümüne dayanmaktadır (Becketti, 2016: 384).

Değişkenlerin durağan olup olmadıklarını test etmek için DF-GLS durağanlık testi ile sınanmıştır. Ve değişkenlerin fark durağan değişken özelliği taşıdıkları gözlenmiştir. 


\begin{tabular}{|c|c|c|c|c|}
\hline \multirow[b]{2}{*}{ DEĞİŞKENLER } & \multicolumn{2}{|c|}{ TEST İSTATİSTİĞİ } & \multicolumn{2}{|c|}{$\begin{array}{c}\text { KRİTİK DEĞER } \\
\% 95 \text { GÜVENİLİRLIK } \\
\end{array}$} \\
\hline & $\underline{\text { KENDISII }}$ & 1. FARKI & KENDİSI & 1.FARKI \\
\hline $\log y$ & -2.526 & -5.890 & -4.80 & -4.80 \\
\hline dfi & -5.797 & -5.546 & -4.80 & -4.80 \\
\hline open & -5.303 & -7.908 & -4.80 & -4.80 \\
\hline hc & -2.942 & -3.364 & -4.80 & -2.764 \\
\hline $\operatorname{logi}$ & -4.252 & -7.013 & -4.80 & -4.80 \\
\hline
\end{tabular}

Tablo 2: DF-GLS Testi

Not: Tabloda verilen kritik değerler stata 12 paket program'den alınmıştır.

DF-GLS test istatistiklerine göre tüm seriler fark durağan süreç özelliği taşımaktadırlar. ADF test istatistikleri sonuçlarına göre durağan olmayan beşeri sermaye değişkeni, birinci farkı alındıktan sonar durağan hale gelmiştir.

\begin{tabular}{|c|c|c|c|c|}
\hline \multirow[t]{2}{*}{ DEĞİŞKENLER } & \multicolumn{2}{|c|}{ MIN. TEST İSTATİSTİĞI } & \multicolumn{2}{|c|}{$\begin{array}{c}\text { KRİTİK DEĞER } \\
\% \text { 95 GÜVENİLİRLIK }\end{array}$} \\
\hline & $\underline{\text { KENDİSI }}$ & 1. FARKI & $\underline{\text { KENDİSI }}$ & $\underline{1 . F A R K I}$ \\
\hline $\log y$ & -2.526 & -5.890 & -4.80 & -4.80 \\
\hline dfi & -5.797 & -5.546 & -4.80 & -4.80 \\
\hline open & -5.303 & -7.908 & -4.80 & -4.80 \\
\hline hc & -4.659 & -3.664 & -4.80 & -4.80 \\
\hline $\operatorname{logi}$ & -4.252 & -7.013 & -4.80 & -4.80 \\
\hline
\end{tabular}

Tablo 3: Zivot-Andrews Testi

Not: Tabloda verilen kritik değerler stata 12 paket program'den alınmıştır.

Minimum test istatistiklerini dikkate alan Zivot-Andrews test sonuçlarına göre beşeri sermaye dişında tün değişkenler fark durağan süreç özelliği taşımaktadırlar. Diğer bir ifadeyle, I(1) sürecini takip etmektedirler.

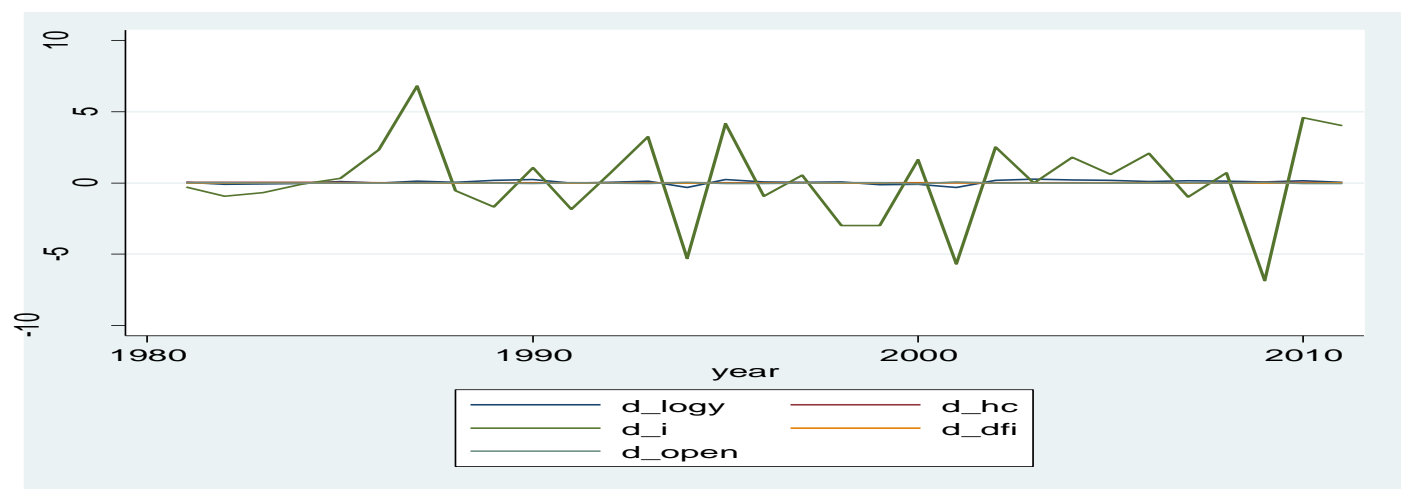

Grafik 1: Değişkenlerin Farklarının Grafiğ i

Grafik 1'den de anlaşılacağı üzere, değişkenlerin birinci farkları alındığında durağan hale geldikleri gözlenmektedir. Daha sonra Johansen eşbütünleşme yaklaşımı uygulanarak uzun dönemli bir ilişkinin var olup olmadı̆̆ araştırılmıştır.

Johansen Eșbütünleșme ve Analitik Bulgular

Tek denklemli yaklaşımların aksine Johansen yaklaşımı modeli bir sistem içinde test etmemizi sağlamaktadır. Johansen eşbütünleşme test istatistikleri, katsayılar ve analitik bulgular Tablo 4'de düzenlenmiştir.

\begin{tabular}{lll}
\hline Maximum rank & Trace statistic & $5 \%$ critical value \\
\hline 0 & 87.8088 & 68.52 \\
\hline 1 & $34.9213^{*}$ & $47.21^{*}$ \\
\hline
\end{tabular}

Tablo 4: Johansen Eşbütünleşme

Johansen eşbütünleşme test sonuçlarına göre, “koentegrasyon yok”a işaret eden boş hipotez reddedilmiştir. Bu durumda ekonomik büyüme ile doğrudan yabancı yatırımlar, beşeri sermaye, yatırımlar ve dışa açıklık arasında uzun dönemli bir ilişkinin varlığından söz edilebilir. Dar vd. (2016) Johansen eşbütünleşme yaklaşımını kullanmışlar ve uzun dönemli bir ilişkinin varlığı sonucuna ulaşmışlardır. Ayrıca Chakraborty ve Basu (2002) kısa dönem modelini kurmuşlar ve hata düzeltme mekanizmasının çalıştırdığını tespit etmişlerdir. Bu nedenle DYY ile büyüme arasında uzun dönemli bir ilişkinin varolduğu sonucuna varmışlardır. 


\begin{tabular}{llll}
\hline Değişkenler & Tahmin değerleri & t-istatistiği & P değeri \\
\hline fdi & $\begin{array}{l}0.0000201 \\
(0.0001)\end{array}$ & 2.49 & 0.019 \\
\hline open & $\begin{array}{l}-1.5508 \\
(1.7205)\end{array}$ & -0.90 & 0.375 \\
\hline hc & $\begin{array}{l}2.0309 \\
(0.2648)\end{array}$ & 7.67 & 0.000 \\
\hline logi & $\begin{array}{l}0.4066 \\
(0.2236)\end{array}$ & 1.81 & 0.080 \\
\hline cons & $\begin{array}{l}-4.3770 \\
(0.8452)\end{array}$ & -5.18 & 0.000 \\
\hline
\end{tabular}

Tablo 5: Analitik Bulgular

Model'de anlamsız olan tek değişken dışa açıklık değişkenidir. Rodriguez ve Rodrik (2000)'de ise dişa açıklık ve büyüme arasında uzun dönemli pozitif bir ilişkinin olduğuna vurgu yapılmıştır. Diğer değişkenler istatistiki olarak anlamlıdır. Türkiye bağlamında doğrudan yabancı yatırımlar ekonomik büyüme üzerinde pozitif etkiye sahiptirler. Diğger bir ifadeyle, Türkiye'ye gelen doğrudan yabancı yatırımlar büyümeyi artırmaktadır.

Yatırım değişkeni de hem istatistiki olarak anlamlı hem de iktisadi beklentilerimizle uyumlu bir işarete sahiptir. Beşeri sermaye de ülke geliri üzerinde olumlu bir etki yaratmaktadır.

\section{Sonuç}

Bu çalışmada, günümüz dünya ekonomisinin bir gerçeği olan küreselleşmenin beraberinde getirdiği sermaye olgusu incelenmiştir. Bu sermayeden pay alma yarışına giren ülkelerin arasında Türkiye'de yerini alma çabası içindedir.

Bu bulgular çerçevesinde, 1980-2011 döneminde, Türkiye’ye gelen DYY'nin milli geliri artırıcı bir girdi olduğu söylenebilir. Bu yüzden ülke kırılganlığını artıran sıcak para hareketlerine şüpheyle yaklaşılmalı ve teknoloji transferi ile yeşil alan yatırımları şeklinde yapılan yatırımlar teşvik edilmelidir. Diğer bir ifadeyle, üretim düzeyini artıracak yatırımlar konusunda adımlar atılmalıdır.

Bunların yanında, beşeri sermayenin üretim artışı üzerinde etkisi her zaman göz önünde bulundurulmalıdır. Beşeri sermayenin kalitesinin artırılması için politika yapıcılarının daha gayret ve özen göstermeleri gerekmektedir.

\section{Kaynakça}

- $\quad$ AÇIKALIN, Sezgin, Ekrem Gül, Ercan Yaşar, 2006. "Ücretler ve Büyüme ile Doğrudan Yabancı Yatırımlar Arasındaki İlişkinin Ekonometrik Analizi”, Dumlupınar Üniversitesi Sosyal Bilimler Dergisi, Sayı: 6, ss.271- 282.

- Ağayev, S. (2010). "Doğrudan yabancı sermaye yatırımları ve ekonomik büyüme ilişkisi: Geçiş ekonomileri örneğinde panel eşbütünleşme ve panel nedensellik analizleri”. Gazi Üniversitesi IIBBF Dergisi, 12(1), 159184.

- $\quad$ Becketti, S. 2013. Introduction to Time Series Using Stata. $1^{\text {st }}$ edn, Stata Press, Texas

- $\quad$ Bengoa, M., Sanchez-Robles, B. 2003. "Foreign direct investment, economic freedom and growth: New evidence from Latin America". European Journal of Political Economy, 19(3), 529-545.

- Borensztein E., 1998. “Gregorio J. De and Lee J-W. How does foreign investmentaffect economic growth?”, Journal of International Economics 45 115-135.

- Chakraborty, C., Basu, P. (2002). "Foreign direct investment and growth in India: A cointegration approch". Applied Economics, 34(9), 1061-1073.

- CHANG, Ha-Joon, 2005. Kalkınma Yeniden, İmge Yayıncılık.

- Dar, A. A., Muhammad T., and Mehmood B. 2016. "Is there a relationship between foreign direct investment, human capital, trade openness and economic growth of Pakistani economy?”, Sci. Int. (Lahore), 28(1), 715-719.

- Ekinci, A. (2011). "Doğrudan yabancı yatırımların ekonomik büyüme ve istihdama etkisi: Türkiye uygulaması (1980-2010)”. Eskişehir Osmangazi Üniversitesi IIBBF Dergisi, 6(2), 71-96.

- Hsiao, C., Shen, Y. 2003. "Foreign direct investment and economic growth: The importance of institutions and urbanization". Economic Development and Cultural Change. 51(4), 883-896. 
- $\quad$ Li, X., Liu, X., 2005. "Foreign direct investment and economic growth: An increasingly endogenous relationship", World Development, 33(3), 393-407.

- Lucas, Robert E. 1988. “On the Mechanics of Economic Development”, Journal of Monetary Economics, 22, 3-42.

- Mohan R. 2007. "A panel data analysis of FDI, trade openness and liberalization on economic growth of the ASEAN-5”, The Emprical Economics Letters, 6(1), 35-44.

- Nelson, R., Phelps, E., 1966. "Investment in humans, technological diffusion and economic growth", American Economic Review, 56(1/2), 69-75

- $\quad$ Rodriguez, F., Rodrik, D. 2000. "Trade policy and economic growth: A skeptic's guide to the cross-national evidence". National Bureau of Economic Research. 15, 261-338.

- $\quad$ Romer, Paul M. 1986. "Increasing Returns and Long-run Growth”, Journal of Political Economy, 94, $1002-$ 37.

- Penn World Tables,2016. http://www.rug.nl/research/ggdc/data/pwt/pwt-7.1

- World Bank, 2016. Data, http://data.worldbank.org/ 


\title{
Ekonomik Büyüme ve Finansal Gelişme İlişkisi: Türkiye Örneği The Relationship between Financial Development and Economic Growth: The Case of Turkey
}

\author{
Ph.D. Candidate Müge Manga (Çukurova University, Turkey) \\ Ph.D. Candidate Mehmet Akif Destek (Gaziantep University, Turkey) \\ Prof. Dr. Muammer Tekeoğlu (Çukurova University, Turkey) \\ Prof. Dr. Erkut Düzakın (Çukurova University, Turkey)
}

\begin{abstract}
The relationship between financial development and economic growth and the direction of causality between them have been received a lot of attention recently by many scholars. It is also important to analyze this relationship and the direction of causality due to implications of policies. In this study the relationship between financial development, trade liberalization and economic growth for Turkey are examined using three different models. Model 1, 2 and 3 investigate the effect of domestic loans to the private sector and trade liberalization on GDP, the impact of the domestic credit provided by banks to the private sector and trade liberalization on GDP and the effect of M2 money supply and M2 trade liberalization on GDP, respectively. Data extracted from World Development Indicators. Autoregressive-Distributed Lag Bound Test (ARDL) is used as a co-integration test to determine the long run relationship between variables. In addition, Toda and Yamamoto (1995) is utilized to test the direction of causality between financial development and economic growth according to the three financial indicators such as domestic loans to the private sector, the domestic credit provided by banks to the private sector and M2 money supply. According to the results there is a unidirectional relationship from economic growth to domestic loans to the private sector and the domestic credit provided by banks to the private sector. Additionally, the results indicate that a bidirectional relationship exist between M2 money supply and economic growth.
\end{abstract}

\section{Giriş}

Finans piyasalarının ekonomi üzerindeki etkilerinin belirginleşmesiyle finansal gelişim ve ekonomik büyüme ilişkisinin sıklıkla incelenmeye başlandığı görülmektedir. Ekonomik büyüme için yeterli düzeyde tasarrufların birikmiş olmasının yanı sıra bu tasarrufların yatırımlar aracılığıyla ekonomiye kazandırılması da büyük önem arz etmektedir. Biriken fonların yatırımlara dönüştürülmesinde aracılık yapan en aktif alanın finans sektörü olması, gelişmiş bir finans piyasasının ekonomik büyüme için ne kadar önemli olduğunu göstermektedir. Finansal sistemin büyüklük ve yapı itibariyle uğradığı değişikliği ifade eden finansal gelişmenin göstergesi olarak farklı değişkenler kullanılmaktadır. Miktar ölçütleri, yapısal ölçütler, finansal fiyatlar, ürün çeşitliliği gibi farklı kategorilerde finansal gelişme göstergeleri bulunmaktadır (Ağır, 2010). Finansal gelişmişliğin ekonomi politikalarının geliştirilmesi ve düzenlenmesinde kullanılan önemli bir kavram olması sebebiyle göstergelerinde de çeşitliliğe neden olduğu söylenilebilir.

Literatürde finansal gelişmişlik ve ekonomik büyüme arasındaki ilişkinin önemi vurgulanmakta ve bankacılık sektörünün ekonomik büyümeye olan etkisi incelenmektedir. Schumpeter (1912), iyi izleyen bir finansal sistemin ve kurumların varlığının büyümeye önemli katkı sağladığına vurgu yapmıştır. Ona göre, iyi izleyen bir bankacılık sektörü yenilikçi ürün ve teknoloji üreten girişimcileri destekleyerek katma değeri yüksek yatırımlarla ekonomik büyümenin ivme kazanmasını sağlayacaktır (Levine, 1997).

Ekonomik büyüme ve finansal gelişme arasındaki ilişkinin incelendiği çalışmalarda genel olarak bu iki kavram arasındaki nedensellik boyutunun incelendiği görülmektedir. Ekonomik büyüme ve finansal gelişmişlik arasındaki nedenselliğin yönüne yönelik değerlendirmeler dört başlık halinde incelenebilir. "Arz Öncüllü (İtici) Hipotez" olarak adlandırılan görüş, finansal gelişmişliğin ekonomik büyümeyi arttırıcı yönde etkilendiğini, finansal gelişmenin ekonomik büyüme için itici bir güç olduğunu savunurken; "Talep Takipli (Sürükleyici) Hipotez" şeklinde adlandırılan görüş, finansal gelişmenin ekonomik büyümeyi takip ettiğini, ekonomik büyümenin finansal gelişimin bir sonucu değil nedeni olduğu görüşünü savunmaktadır. Arz Öncüllü Hipoteze göre gelişmiş, istikrarlı ve güvenilir finansal sistemlere sahip olan ülkelerde tasarrufların ekonomiye kazandırılmasında finansal sistem ekonomik büyüme için son derece önemlidir. Talep Takipli Hipoteze göre ise, finansal sistemin gelişimi ve sürekliliği için gerekli olan talep artışı ancak ekonomik büyüme ile gerçekleşecektir. Yani ekonomik büyüme ile finansal gelişmişlik arasındaki nedenselliğin yönü ekonomik büyümeden finansal gelişmeye doğrudur. Finansal gelişmişlik ve ekonomik büyüme arasındaki nedensellik ilişkisini ifade eden “Karşıllklı Etkileşim” görüşüne göre ise, finansal gelişmişlik ve ekonomik büyüme arasında karşılıklı etkileşim söz konusudur. Lewis (1955)‘e göre, finansal piyasaların ekonomik büyümenin sonucu olarak geliştiği ve sonrasında finansal piyasaların reel ekonominin büyümesinde teşvik edici bir fonksiyon üstlendiği iki yönlü bir ilişkiyi önermektedir. "Etki Yok" görüşüne göre ise, finansal gelişmişlik ile ekonomik büyüme arasında herhangi bir etkileşim söz konusu değildir. 
Lucas (1988), ve Stern (1989)'nin, çalışmaları finansal gelişmişlik ile ekonomik büyüme arasında ilişki yoktur görüşünü desteklemiştir (Güneş, 2013).

Ekonomik büyüme ve finansal gelişme arasındaki ilişkinin incelendiği çalışmalarda genellikle ticari liberalizasyonun da modellere dahil edildiği görülmektedir. Ticari liberalizasyonun finansal sistem ve ekonomik büyüme üzerindeki etkilerine yönelik çeşitli görüşler mevcut olmakla birlikte genel kabul gören görüş, ülkelerin ticari ve sermaye akışı bakımından dışa açılma süreçlerinin finansal sistemde rekabeti arttıracağı ve mevcut yüksek faiz kazançlarını önleyeceği dolayısıyla finansal sistemin gelişimine katkı sağlayacağı yönündedir.

Bu çalışmada öncelikle finansal gelişim, ticari liberalizasyon ve ekonomik büyüme arasındaki ilişkiye yönelik olarak yapılan çalışmalara yer verilmiş daha sonra bu üç değişken arasındaki ilişki ampirik analizlerle belirlenmeye çalışılmıştır. Ampirik analizlerde ilk olarak değişkenler arasındaki uzun dönemli ilişkinin varlığı sınanmış daha sonra değişkenler arasındaki nedenselliğin yönünün belirlenmesi amaçlanmıştır. Türkiye'deki 1960-2013 dönemi için uygulanan ARDL sınır testi yaklaşımı ve Toda-Yamamoto nedensellik testleri sonuçlarına göre, seçilen finansal gelişmişlik göstergelerinin ekonomik büyüme ve ticari serbestleşme ile eşbütünleşme ilişkisi içinde olduğu görülmüştür. Ayrıca yapılan analiz sonucunda, Türkiye'de ekonomik büyümeden finansal gelişmişliğe doğru nedenselliğin mevcut olduğu ve talep takipli hipotezin geçerli olduğu sonucuna ulaşılmıştır.

Çalışma beş bölümden oluşmaktadır. Birinci bölüm olan giriş kısmında, finansal gelişme ve ekonomik büyüme teorisi ile genel bilgilere yer verilmiştir. İkinci bölümde ilgili literatür özetlenmiş ve üçüncü bölümde araştırma yöntemi ile verilere ilişkin açıklamalar yapılmıştır. Dördüncü bölümde analiz bulguları yorumlanmış ve sonuç bölümünde ise kısmında yapılan analiz sonuçlarına yer verilerek çeşitli değerlendirmelerde bulunulmuştur.

\section{Literatür Taraması}

Finansal gelişmenin büyüme üzerindeki etkisi 1980'li yılların ikinci yarısına kadar Neo-Klasik büyüme modellerinin hakim olması dolayısıyla göz ardı edilmiştir. Neo- Klasik büyüme model ülkeler arasındaki gelişmişlik düzeylerinin farklarını tam olarak açıklayamadığından geliştirilen yeni büyüme modelleri ile finansal gelişme ile ekonomik büyüme arasındaki ilişki öne çıkmaya başlamıştır. Yeni büyüme modelleri, Solow'un (1956) modelindeki büyümenin nasıl meydana geldiğinin ifade edilmesindeki eksikliğin Romer (1986a), ve Lucas'ın (1988) çalışmalarında bu eksikliklerin giderilmesiyle ortaya çıkan modellerdir. Yeni büyüme modellerinde teknolojinin içsel olduğu ifade edilmiş ve artan getirinin kaynağına ilişkin çeşitli önerilerde bulunulmuştur. Bu öneriler, Romer (1986a;1990b) tarafından Ar-Ge çalışmalarının, Barro (1990) tarafından kamu harcamalarının; Rebelo (1991) tarafından kümülatif sermayenin; Pagano (1993), tarafından finansal piyasaların ve Lucas (1988), tarafından beşeri sermayenin önerilmesi şeklinde ifade edilebilir (Ağır, 2010). Pogano (1993), çalışmasında, ekonomik büyüme ile finansal gelişmişlik arasındaki ilişkiyi yatay kesit analiz yöntemiyle ölçen birçok çalışma olduğu ve genel olarak finansal gelişmişliğin ekonomik büyümeyi pozitif yönde etkilediğini ancak bunun bazı istisnaları olduğunu, eğer finansal sistem düzgün işleyen bir piyasa türü ise bu durumda büyümeye katkı sağlayacağı ifade edilmektedir. Finansal gelişmişlik ve ekonomik büyüme arasındaki ilişkiyi açıklayan çalışmalardan Gurley ve Shaw (1995-1967), finans sektörü ile ekonomik büyüme arasındaki ilişkiyi nedensellik yönünü tam olarak ifade etmeden ele almışlardır.

Finansal gelişim, ticari liberalizasyon ve ekonomik büyüme arasındaki ilişkiyi inceleyen birçok çalışma mevcuttur. Levine (1997), seçilmiş ülkeler üzerine uyguladığı yatay kesit analizi ile ekonomik büyüme ile finansal gelişmişlik arasındaki ilişkiyi incelemiş ve telekomünikasyon, bilişim, finansal olmayan sektör politikalarındaki gelişmelerin de finans sektörünün verimliliği için oldukça önemli olduğunu, teknolojik gelimlerin finans sektöründeki maliyeti düşürdüğünü böylece finansal gelişmenin teknoloji alanındaki gelişmeler ile ekonomik büyümeyi desteklediğini savunmuştur. Bir başka çalışmada Thangavelu ve James (2004), Avustralya'daki finans piyasalarında ayrıma giderek piyasa temelli finans piyasası ile bankacılık odaklı piyasaların gelişimi ile ekonomik büyüme arasındaki ilişkiyi Granger nedensellik testi ve VAR modeli ile test etmişlerdir. Yapılan çalışmada ekonomik büyümeden finansal gelişmişliğe doğru herhangi bir nedensellik ilişkisinin olmadığını, finansal piyasalardaki gelişmişliğin ekonomik büyümenin nedeni olduğu şeklinde sonuçlara ulaşıldığını ifade etmişlerdir. Arestis vd, (2001), ABD, Almanya, Japonya, İngiltere ve Fransa'daki 1972-1998 yılları arası için üçer aylık veriler kullanarak finansal gelişme ve büyüme ilişkisini hata düzeltme modeli ve eşbütünleşme yöntemlerinden faydalanarak analiz etmiş ve finansal piyasalardaki gelişmelerin ekonomik büyümeyi pozitif yönde etkilediği sonucuna ulaşmışlardır.

Türkiye'deki finansal gelişmişlik ve ekonomik büyüme arasındaki ilişkinin analizi için yapılan çalışmalarda ise, Kandır vd, (2007), 1988-2004 dönemi için üçer aylık veriler kullanılarak Türkiye'de finansal gelişme ve ekonomik büyüme arasındaki ilişkiyi Johansen eşbütünleşme ve hata düzeltme modeline bağlı nedensellik yöntemlerinden faydalanarak analiz etmişlerdir. Yapılan çalışmada finansal gelişmişliğin ekonomik büyümeyi desteklemediğini fakat ekonomik büyümenin finansal gelişmeyi etkilediği sonucuna ulaşmışlardır. Altıntaş ve Ayrıçay (2010), Türkiye'deki 1987-2007 dönemi için üçer aylık verileri kullanarak finansal gelişmişlik ve ekonomik büyüme arasındaki ilişkiyi ARDL yöntemi ile test ettikleri çalışmalarında, reel büyüme, finansal gelişme, dışa açıklık ve reel faiz oranı arasında uzun dönemli eşbütünleşme ilişkisi olduğunu tahmin etmişlerdir. Ayrıca bu çalışmada, reel 
faiz oranlarındaki artışın tasarruf ve reel gelirde artış sağlaması dolayısıyla çalışmada elde edilen sonuçların yeni kurumların finansal sisteme girişini engelleyen düzenlemelerin ortadan kaldırılmasının finansal gelişmişlik için önemli olduğunu ifade eden Mckinnon- Shaw hipotezi ile tutarlı olduğu sonucuna ulaşılmıştır. Güneş (2013), çalışmasında 1988-2009 yılları için Türkiye'deki finansal gelişme ve ekonomik büyüme arasındaki ilişkiyi 6 aylık verileri kullanarak Vector Error Correction Model (VECM) test etmiştir. Yapılan çalışmada, finansal gelişmenin iktisadi büyümeye neden olduğu sonucuna ulaşılmamıştır. Mercan ve Peker (2013), Türkiye'deki 1992-2010 dönemler aylık verileri kullanılarak finansal gelişmenin ekonomik büyüme üzerindeki etkisini nedensellik testleri ve ARDL yöntemlerinden faydalanarak test ettikleri çalışmalarında uzun dönemde değişkenler arasında eşbütünleşme ilişkisi olduğu ve finansal gelişmenin ekonomik büyüme üzerinde etkili olduğunu sonucuna ulaşılmıştır. Aydın vd, (2014) iktisadi büyüme ile finansal gelişme arasındaki nedensellik ilişkisinin varlığını Türkiye için 1988-2012 dönemi çerçevesinde yıllık veriler ile Toda-Yamamoto testi ile inceledikleri çalışmalarında nedensellik ilişkisinin yönünün finansal gelişmeden büyümeye doğru olduğunu tespit etmişlerdir. Ayrıca yine bu çalışmada ve Türkiye'nin özelinde nedensellik ilişkisinin finansal gelişmeden büyümeye doğru olduğunu bu nedenle arz öncüllü yaklaşımın desteklendiği ifade edilmiştir. Kar ve Pentecost (2000) Türkiye için finansal gelişmişlik ve ekonomik büyüme arasındaki ilişkiyi 1963-1995 yıllarını esas alarak Granger nedensellik ve VECM kullandıkları çalışmada 5 farklı gösterge kullanmışlardır. Buna göre kullanılan değişkenlere göre sonuçlar farklılık gösterebilmektedir. Finansal gelişmişlik ölçütü olarak kullanıldığında nedensellik finansal gelişmişlikten ekonomik büyümeye doğru şekillenmektedir. Bunun yanında banka mevduatı, özel kredi ve yerli kredi ölçüt olarak kullanıldığında büyümenin finansal gelişmeyi tetiklediği sonucuna ulaşmışlardır.

\section{Model ve Veri}

Finansal gelişmişlik ve ekonomik büyüme literatürü incelendiğinde finansal gelişmişlik göstergesi olarak genellikle dört farklı göstergenin kullanıldığı görülmektedir. Bu göstergeler sırasıyla; özel sektöre sağlanan yurtiçi kredilerin milli gelire oranı, özel sektöre bankalar tarafından sağlanan yurtiçi kredilerin milli gelire oran1, M2 para arzının milli gelire oranı ve M3 para arzının milli gelire oranı şeklindedir. Finansal göstergelerin tamamının aynı modelde kullanılması yapılacak analizlerde çoklu doğrusal bağlantı sorununa yol açabilmekte ve hatalı sonuçlara yol açabilmektedir (Menyah vd. 2014). Bu sebepten dolayı çalışmada üç farklı model kurularak her finansal gösterge farklı bir modelde kullanılmıştır. Çalışmada kullanılan modeller;

$$
\begin{aligned}
& \ln K B G_{t}=a_{0}+a_{1} \ln Y K_{t}+a_{2} \ln T A_{t}+\varepsilon_{t} \\
& \ln K B G_{t}=\beta_{0}+\beta_{1} \ln B K_{t}+\beta_{2} T A_{t}+\delta_{t} \\
& \ln K B G_{t}=\gamma_{0}+\gamma_{1} \ln P A_{t}+\gamma_{2} \ln T A_{t}+\mu_{t}
\end{aligned}
$$

denklemlerde bulunan değişkenlerden;

KBG: 2005 sabit fiyatlarıyla kişi başına düşen GSYH'yı (dolar),

YK: Özel kesime sağlanan yurtiçi kredilerin milli gelire oranını,

BK: Bankalar tarafından özel kesime sağlanan yurtiçi kredilerin milli gelire oranını,

PA: M2 para arzının milli gelire oranını,

TA: Ticari dışa açıklık oranını (ihracat ve ithalat toplamının milli gelirdeki payı) ifade etmektedir.

Literatürde kullanılan bir diğer değişken olan M3 para arzı değişkeni, veri seti eksikliği nedeniyle modellere dahil edilememiştir. Çalışmada gözlem aralığı olarak 1960-2013 yılları kullanılmıştır. Tüm veriler, Dünya Bankası veritabanından (World Development Indicators 2015) elde edilmiştir. Serilerin tamamı logaritmik forma dönüştürülmüştür. 1 no'lu modelde, özel kesime sağlanan yurtiçi kredilerin ve ticari liberalizasyonun milli gelire etkisi; 2 no'lu modelde, bankalar tarafından özel kesime sağlanan yurtiçi kredilerin ve ticari liberalizasyonun milli gelire etkisi; 3 no'lu modelde M2 para arzının ve ticari liberalizasyonun milli gelire etkisi araştırılmaya çalışılmıştır

\section{Ekonometrik Yöntem ve Bulgular}

Çalışmada üç farklı model doğrultusunda Türkiye'de finansal gelişmenin ve ticari liberalizasyonun milli gelir üzerindeki etkileri eşbütünleşme ve nedensellik testleri incelenmiştir. Değişkenler arasındaki eşbütünleşme ilişkisinin araştırılması amacıyla Pesaran vd. (2001) tarafından geliştirilen ARDL (Autoregressive Distributed Lag) yaklaşımı kullanılmıştır. Değişkenler arasındaki nedensellik ilişkisinin araştırılması amacıyla Toda ve Yamamoto (1995) tarafından geliştirilen Toda Yamamoto prosedüründen faydalanılmıştır.

\subsection{Eşbütünleşme Testi}

Pesaran vd. (2001) tarafından geliştirilen ARDL yaklaşımı, farklı düzeylerden durağan olan seriler arasında eşbütünleşme ilişkisi aranmasına izin vermesi nedeniyle sıklıkla faydalanılan bir testtir. Ayrıca ARDL yaklaşımının bir diğer temel avantajı da değişkenlerin uzun ve kısa dönemli katsayılarını belirleyebilmesidir (Nazlıoglu ve Bayrakdaroglu, 2009). Çalışmada kullanılan modellerin ARDL versiyonları sırasıyla;

$$
\begin{aligned}
& d K B G_{t}=\beta_{0}+\sum_{i=1}^{n} \beta_{0, i} d K B G_{t-i}+\sum_{i=1}^{n} \beta_{1, i} d Y K_{t-i}+\sum_{i=1}^{n} \beta_{2, i} d T A_{t-i}+\delta_{0} K B G_{t-1}+\delta_{1} Y K_{t-1}+ \\
& \delta_{2} T A_{t-1}+\mu_{t}
\end{aligned}
$$




$$
\begin{aligned}
& d K B G_{t}=\sigma_{0}+\sum_{i=1}^{n} \sigma_{0, i} d K B G_{t-i}+\sum_{i=1}^{n} \sigma_{1, i} d B K_{t-i}+\sum_{i=1}^{n} \sigma_{2, i} d T A_{t-i}+\delta_{0} K B G_{t-1}+\delta_{1} B K_{t-1}+ \\
& \delta_{2} T A_{t-1}+\mu_{t} \\
& d K B G_{t}=\vartheta_{0}+\sum_{i=1}^{n} \vartheta_{0, i} d K B G_{t-i}+\sum_{i=1}^{n} \vartheta_{1, i} d P A_{t-i}+\sum_{i=1}^{n} \vartheta_{2, i} d T A_{t-i}+\delta_{0} K B G_{t-1}+\delta_{1} P A_{t-1}+ \\
& \delta_{2} T A_{t-1}+\mu_{t}
\end{aligned}
$$

verilen modellerde değişkenler arasında uzun dönemli eşbütünleşme ilişkisinin olmadığ yönündeki boş hipotez $\left(H_{0}: \delta_{0}=\delta_{1}=\delta_{2}=\delta_{3}=\delta_{4}=0\right)$ alternatif hipoteze $\left(H_{0}: \delta_{0} \neq \delta_{1} \neq \delta_{2} \neq \delta_{3} \neq \delta_{4} \neq 0\right)$ karş1 test edilmektedir. ARDL yaklaşımını uygulayabilmek amacıyla öncelikle çalışmada kullanılan her model için uygun ARDL modelinin belirlenmesi ve F-istatistiklerinin belirlenmesi gerekmektedir.

\begin{tabular}{llll}
\hline \hline Model & ARDL Modeli & $F$-istatistiğ & ECT(-1) \\
\hline Model 1: $K B G_{t}=f\left(Y K_{t}, T A_{t}\right)$ & $(1,1,1)$ & 3.976 & $-0.328^{* * *}[-3.819]$ \\
Model 2: $K B G_{t}=f\left(B K_{t}, T A_{t}\right)$ & $(1,0,1)$ & 4.359 & $-0.374^{* * *}[-3.868]$ \\
Model 3: $K B G_{t}=f\left(P A_{t}, T A_{t}\right)$ & $(1,1,0)$ & 3.892 & $-0.165^{* * *[-3.437]}$ \\
\hline \hline
\end{tabular}

Tablo 1: ARDL Modelleri ve F-istatistikleri

Not: Kritik değerler Pesaran vd. (2001) Tablo CI(iii)'dan alınmıştır. Kritik değerler \%10 için I(0):3.17, I(1):4.14; \%5 için $I(0): 3.79, I(1): 4.85$; \%1 için I(0):5.15, I(1):6.36. Köşeli parantez içindeki değerler t-istatistiğini göstermektedir. *,**,*** strasıyla \%10, \%5 ve \%1 düzeyinde anlamlılı̆̆ göstermektedir.

Tablo 1'de üç farklı model için uygun ARDL modeli seçimleri ve F-istatistik değerleri görülmektedir. Model 2 için hesaplanan F-istatistiğinin \%10 düzeyindeki üst sınır kritik değerden (4.14) yüksek olması nedeniyle değişkenler arasında eşbütünleşme ilişkisinin olmadığını ifade eden boş hipotez reddedilmiştir. Model 1 ve Model 3 için hesaplanan F-istatistiklerinin ise \% 10 düzeyindeki alt sınırın (3.79) ve üst sınırın (4.85) arasında kaldıkları görülmektedir. Bahmani-Oskooee ve Brooks (1999), hesaplanan F istatistiğinin ara bölgede olması durumunda uzun dönemli ilişkinin varlığının, hata terimi düzeltme katsayısının istatistiki olarak anlamlı olması ile geçerli olduğunu belirtmişlerdir. Bu nedenle Tablo 1'de tüm modeller için hesaplanan hata terimi düzeltme katsayıları ECT(-1) verilmiştir. Model 1 ve Model 3 için hesaplanan hata terimi düzeltme katsayılarının istatistiki olarak

\begin{tabular}{|c|c|c|c|}
\hline & Model 1 & Model 2 & Model 3 \\
\hline \multicolumn{4}{|l|}{ Uzun Dönem Katsayılar } \\
\hline Sabit & $6.616^{* * *}$ & $7.421 * * *$ & $5.647 * * *$ \\
\hline $\operatorname{lnYK}$ & 0.217 & - & - \\
\hline $\operatorname{lnBK}$ & - & $0.134 * * *$ & - \\
\hline $\operatorname{lnPA}$ & - & - & $0.704 * * *$ \\
\hline $\operatorname{lnTA}$ & $0.418 * * *$ & $0.433 * * *$ & $0.189 *$ \\
\hline \multicolumn{4}{|l|}{ Kısa Dönem Katsayılar } \\
\hline Sabit & 0.006 & $0.010^{*}$ & 0.090 \\
\hline DlnYK & $0.114 * * *$ & - & - \\
\hline DlnBK & - & $0.106^{* * *}$ & - \\
\hline DlnPA & - & - & -0.055 \\
\hline DlnTA & $-0.041^{*}$ & $-0.047 *$ & -0.016 \\
\hline ECT(-1) & $-0.328 * * *$ & $-0.374 * * *$ & $-0.165^{* * *}$ \\
\hline \multicolumn{4}{|l|}{ Teşhis Testleri } \\
\hline ARS & 0.632 & 0.474 & 0.422 \\
\hline JB & $3.563[0.168]$ & $2.857[0.239]$ & $1.327[0.514]$ \\
\hline Breusch-Godfrey $\chi^{2}$ & $0.741[0.690]$ & $0.344[0.841]$ & $1.225[0.541]$ \\
\hline $\mathrm{ARCH} \chi^{2}$ & $0.686[0.407]$ & $0.725[0.394]$ & $0.018[0.893]$ \\
\hline Ramsey & $2.110[0.153]$ & $0.844[0.363]$ & $0.048[0.827]$ \\
\hline CUSUM & İstikrarlı & İstikrarlı & İstikrarlı \\
\hline CUSUMQ & İstikrarlı & İstikrarlı & İstikrarlı \\
\hline
\end{tabular}
anlamlı olmasından dolayı tüm modellerde değişkenler arasında eşbütünleşme ilişkisinin olduğuna karar verilmiştir. $\mathrm{Bu}$ aşamadan sonra ARDL modeli doğrultusunda değişkenlerin uzun ve kısa dönemli katsayılarının belirlenmesi ve modellerin gerekli varsayımları sağladığının tespiti için teşhis testlerinin yapılması gerekmektedir

Tablo 2: Uzun ve Klsa Dönem Katsayılar

Not: $* * *, * * *$ sırasıyla $\% 10, \% 5$ ve $\% 1$ düzeyinde anlamlılığı göstermektedir. Köşeli parantez içindeki değerler prob. değerleridir. Model 1'de finansal gösterge olarak, özel kesime kullandırılan yurtiçi krediler; Model 2'de finansal gösterge olarak, özel kesime bankalar tarafından sağlanan yurtiçi krediler; Model 3'de finansal gösterge olarak, M2 para arzı kullanılmıştır. ARS, Uyarlanmış $R^{2}$ 'yi ifade etmektedir. 
Teşhis testleri sonuçları Tablo 2'de görülmektedir. CUSUM ve CUSUMQ testlerine göre parametrelerin istikrarlı olduğu sonucuna ulaşılmıştır. Otokorelasyon sorununun geçerliliğinin incelendiği Breusch-Godfrey testine göre modelde otokorelasyon sorununun olmadığı görülmüş; ARCH testine göre hata terimlerinin sabit varyanslı olduğu sonucuna ulaşılmış ve son olarak Ramsey-Reset testine göre fonksiyonel formun doğru seçildiği görülmüştür.

Uzun ve kısa dönemli katsayılar da Tablo 2'de görülmektedir. Uzun dönemli katsayılar incelendiğinde, Model 1'de incelenen özel kesime sağlanan yurtiçi kredi değişkeni katsayısının istatistiki olarak anlamsız olduğu görülmektedir. Ticari liberalizasyonun ekonomik büyüme üzerindeki etkisinin ise pozitif olduğu sonucuna ulaşılmıştır. Model 2'de bir diğer finansal gösterge olarak kullanılan özel kesime bankalar tarafindan sağlanan yurtiçi kredi değişkeninin de ticari liberalizasyon değişkeninin de pozitif işaretli ve istatistiki olarak anlamlı olduğu görülmektedir. Model 3 dahilinde incelenen M2 para arzı değişkeninin de ekonomik büyümeyi olumlu yönde etkilediği ve diğer finansal göstergelere göre ekonomi üzerinde daha fazla pozitif etki oluşturduğu görülmektedir.

Kısa dönemli sonuçlar incelendiğinde ise özel kesime sağlanan yurtiçi kredi değişkeni ve özel kesime bankalarca sağlanan yurtiçi kredi değişkeninin ekonomik büyümeyi pozitif yönde etkilediği sonucuna ulaşılmış, buna karşın uzun dönem sonuçların aksine M3 para arzı değişkeni kısa dönem de ekonomik büyüme üzerinde etkisiz olduğu görülmektedir. Hata terimi düzeltme katsayılarının tüm modellerde negatif işaretli ve istatistiki olarak anlamlı olması da hata düzeltme mekanizmasının çalıştığını, kısa dönemde ortaya çıkacak şokların uzun dönemde giderildiğini göstermektedir.

\subsection{Nedensellik Testi}

Değişkenler arasındaki nedensellik ilişkisinin tespit edilmesi amacıyla ARDL yaklaşımında olduğu gibi serilerin farklı düzeylerden durağan olması durumunda dahi nedensellik ilişkisinin aranmasına izin veren Toda ve Yamamoto (1995) testinden faydalanılmıştır. Toda ve Yamamoto testi uzun dönem nedensellik ilişkisi şeklinde de yorumlanabilmektedir. Toda ve Yamamoto (1995) prosedürü VAR analizine bağlı olarak VAR modelindeki parametrelere kısıt uygulanması ve k optimum gecikme uzunluğu ile $\mathrm{d}_{\max }$ maksimum bütünleşme derecelerinin göz önünde bulundurulması sonucu düzenlenmiş Wald-istatistiği ile hesaplanan bir nedensellik testidir. Düzenlenmiş Wald-istatistiği $\operatorname{VAR}\left(\mathrm{k}+\mathrm{d}_{\max }\right)$ modeli üzerinden hesaplanmaktadır.

Bu bilgilerden hareketle finansal gelişim ve ekonomik büyüme arasındaki nedensellik ilişkisi Model 1 için $\mathrm{k}=1$ optimum gecikme uzunluğu ve $\mathrm{d}_{\max }=1$ bütünleşme derecesi sonucunda VAR(2) modeli üzerinden, Model 2 ve Model 3 için $\mathrm{k}=2$ optimum gecikme uzunluğu ve $\mathrm{d}_{\max }=1$ bütünleşme seviyesi sonucunda VAR(3) modeli üzerinden incelenmiştir.

\begin{tabular}{clll}
\hline \hline & Boş Hipotez & Wald-istatistiği & Nedensellik \\
\hline Model 1 & & & \\
& $\mathrm{KBG} \nRightarrow \mathrm{YK}$ & $8.526^{* *}$ & Var \\
& $\mathrm{YK} \nRightarrow \mathrm{KBG}$ & 0.611 & Yok \\
Model 2 & & & \\
& $\mathrm{KBG} \nRightarrow \mathrm{BK}$ & $10.840^{* * *}$ & Var \\
& $\mathrm{BK} \nRightarrow \mathrm{KBG}$ & 0.711 & Yok \\
Model 3 & & & \\
& $\mathrm{KBG} \nRightarrow \mathrm{PA}$ & $14.273^{* * *}$ & Var \\
& $\mathrm{PA} \nRightarrow \mathrm{KBG}$ & $6.540^{*}$ & Var \\
\hline \hline
\end{tabular}

Tablo 3: Uzun Dönem Nedensellik Testi Sonuçlarl (Finansal Gelişim ve Ekonomik Büyüme)

Not: *,** ve *** \%10,\%5 ve \%1 düzeyinde anlamlılı̆̆ ifade etmektedir.

Toda ve Yamamoto nedensellik testi sonuçları Tablo 3'de görülmektedir. Elde edilen sonuçlara göre ekonomik büyümeden üç farklı finansal göstergeye doğru nedensellik ilişkisinin olduğu görülmüştür. Finansal gelişmenin büyümeye etkisi incelendiğinde ise sadece M2 para arzından ekonomik büyümeye doğru bir nedensellik ilişkisi var olduğu sonucuna ulaşılmıştır.

Finansal gelişim ve ticari açıklık arasındaki nedensellik ilişkisi Model 1 ve Model 3 için k=2 optimum gecikme uzunluğu ve $\mathrm{d}_{\max }=1$ bütünleşme derecesi sonucunda $\operatorname{VAR(3)~modeli~üzerinden,~Model~} 2$ için $\mathrm{k}=1$ optimum gecikme uzunluğu ve $\mathrm{d}_{\max }=1$ bütünleşme seviyesi sonucunda VAR(2) modeli üzerinden incelenmiştir. 


\begin{tabular}{|c|c|c|c|}
\hline & Boş Hipotez & Wald-istatistiği & Nedensellik \\
\hline \multicolumn{4}{|l|}{ Model 1} \\
\hline & $\mathrm{TA} \nRightarrow \mathrm{YK}$ & 0.817 & Yok \\
\hline & $\mathrm{YK} \nRightarrow \mathrm{TA}$ & 1.890 & Yok \\
\hline \multicolumn{4}{|l|}{ Model 2} \\
\hline & $\mathrm{TA} \nRightarrow \mathrm{BK}$ & 1.795 & Yok \\
\hline & $\mathrm{BK} \nRightarrow \mathrm{TA}$ & 0.401 & Yok \\
\hline \multicolumn{4}{|l|}{ Model 3} \\
\hline & $\mathrm{TA} \nRightarrow \mathrm{PA}$ & $4.776^{*}$ & Var \\
\hline & $\mathrm{PA} \nRightarrow \mathrm{TA}$ & 3.822 & Yok \\
\hline
\end{tabular}

Tablo 4: Uzun Dönem Nedensellik Testi Sonuçları (Finansal Gelişim ve Ticari Açıklık)

Not: *,** ve ***\%10, \%5 ve \%1 düzeyinde anlamlılı̆g ifade etmektedir.

Finansal gelişim ve ticari açıklık arasındaki uzun dönemli nedensellik ilişsisi Tablo 4'de görülmektedir. Elde edilen sonuçlara göre uzun dönemde finansal gelişim göstergelerinin hiçbiri ticari liberalizasyonun nedeni değildir. Ticari liberalizasyondan finansal gelişime doğru nedensellik ilişkisi incelendiğinde ise daha önce elde edilen sonuçlara benzer şekilde sadece M2 para arzından ticari açıklığa doğru bir nedensellik ilişkisinin olduğu görülmektedir.

\section{Sonuç ve Değerlendirme}

Bu çalışmada farklı finansal gelişmişlik göstergelerinden faydalanarak Türkiye'de finansal gelişim ile ekonomik büyüme arasındaki ilişkinin incelenmesi amaçlanmıştır. Bu amaçla 1960-2013 dönemi ARDL sınır testi yaklaşımı ve Toda-Yamamoto nedensellik testleri ile incelenmiştir. Ayrıca ticari serbestleşmenin söz konusu değişkenler ile incelenmesi amacıyla, oluşturulan tüm modellere ticari serbestleşme oranı da dahil edilmiştir.

Değişkenler arasındaki uzun dönemli ilişkinin incelendiği ARDL sınırlar testi yaklaşımı sonuçlarına göre tüm finansal gelişmişlik göstergelerinin ekonomik büyüme ve ticari serbestleşme ile eşbütünleşik olduğu görülmüştür. Uzun dönemli katsayılar incelendiğinde ise özel kesime bankalar tarafından sağlanan yurtiçi kredilerin ve M2 para arzının ekonomik büyümeyi pozitif yönde etkilediği, buna karşın özel kesime sağlanan toplam yurtiçi kredilerin ekonomik büyüme üzerindeki etkisinin istatistiki olarak anlamsız olduğu sonucuna ulaşılmıştır. Ayrıca ticari serbestleşmenin ekonomik aktiviteler üzerindeki pozitif etkisi tüm modeller için desteklenmiştir. Nedensellik testi sonuçları incelendiğinde, M2 para arzı ile ekonomik büyüme arasında çift yönlü nedenselliğin olduğu görülmüştür. Ayrıca, ekonomik büyümeden özel kesime sağlanan toplam kredilere ve özel kesime bankalar tarafından sağlanan yurtiçi kredilere doğru tek yönlü nedensellik ilişkisinin varlığı desteklenmiştir.

Elde edilen bulgular doğrultusunda Türkiye'de ekonomik büyümeden finansal gelişmişliğe doğru nedenselliğe işaret eden talep takipli hipotezin geçerli olduğu görülmektedir. Türkiye'de finansal sisteme süreklilik ve derinlik kazandıracak talep artışının ve gerekli tasarrufların ekonomik gelişim ile sağlandığ fakat finansal sistemin henüz ekonomik büyümeyi olumlu yönde etkileyebilecek kadar gelişmediği sonucuna ulaşılmıştır.

\section{Kaynakça}

- Ağır, H. 2010. Türkiye’de Finansal Liberalizasyon ve Finansal Gelişme İlişkisinin Ekonometrik Analizi, BDDK Aroks Doküman Merkezi, Ankara.

- Altıntaş, H. \& Ayrıçay, Y. 2010. “Türkiye'de Finansal Gelişme ve Ekonomik Büyüme İlişkisinin Sınır Testi Yaklaşımıyla Analizi: 1987-2007”. Anadolu Üniversitesi Sosyal Bilimler Dergisi, 10(2), s. 71-98.

- Arestis, P. \& Demetriades, P. 1997. "Financial Development and Economic Growth: Assessing the Evidence." The Economic Journal,1 07(442), p. 783-799.

- Aydın, M. K., Ak, M. Z., \& Altıntaş, N. 2014. "Finansal Gelişmenin Büyümye Etkisi: Türkiye Özelinde Nedensellik Analizi”. Maliye Dergisi, 167, s. 149-162

- Bahmani-Oskooee, M. \& Brooks, T. J. 1999 "Bilateral J-Curve between US and Her Trading Partners" Weltwirtschaftliches Archiv ,135, p. 156-65.

- Barro, R., 1990. “Government spending in a simple model of endogenous growth”. Journal of Political Economy, 98 (1), p. 103-117

- Gurley, J. G. \& Shaw, E. S. 1955 "Financial Aspects Of Economic Development", American Economic Review, c. 45(4), p. 515-538. 
- Gurley, J. G. \& Shaw, E. S. 1967. "Financial Structure And Economic Development", Economic Development and Cultural Change, 15(3), p. 257-268.

- Güneş, S. 2013. "Finansal gelişmişlik ve büyüme arasındaki nedensellik testi: Türkiye örneği”, Doğuş Üniversitesi Dergisi, 14(1), s. 73-85.

- Kandır, S. Y., İskenderoğlu, A. G., \& Önal, Y.B. 2007. "Finansal Gelişme ve Ekonomik Büyüme Arasındaki İlişkinin Araştırılması”. Çukurova Üniversitesi Sosyal Bilimler Enstitüsü Dergisi, 16(2), s. 311-326

- Kar, M. \& Pentecost E. 2000. "The Direction of Causality Between Financial Development and Economic Growth in Turkey: Further Evidence", Loughborough University, Department of Economics, Economic Research Paper No: 00/27, December

- Levine, R. 1997. "Financial Development and Economic Growth: Views and Agenda", Journal of Economic Literature, 35, p. 688-726.

- $\quad$ Lewis, A.1955. The Theory of Economic Growth, London, Allen and Unwin

- Lucas, R.E. 1988.”On The Mechanics Of Economic Development”, Journal of Monetary Economics, 22 (1), p. 3-42

- Menyah, K., Nazlioglu, S., \& Wolde-Rufael, Y. 2014. "Financial Development, Trade Openness and Economic Growth İn African Countries: New İnsights From A Panel Causality Approach”. Economic Modelling, 37, p. 386-394.

- Mercan, M., \& Peker, O. 2013. "Finansal Gelişmenin Ekonomik Büyümeye Etkisi: Ekonometrik Bir Analiz". Eskişehir Osmangazi Üniversitesi İktisadi ve İdari Bilimler Dergisi, 8(1), s. 93-120

- Nazlioglu, S., \& Bayrakdaroglu, A. 2009. "Financial Development and Economic Growth: Cointegration and Causality Analysis for Turkey". Banking and Finance Letters, 1(2), s. 59-66

- Pagano, M. 1993 "Financial Markets and Growth, An Overview”, European Economic Review, 37, p. 613622.

- Pesaran, M. H., Shin, Y. \& ,Smith, R. J. 2001. "Bounds Testing Approaches To The Analysis Of Level Relationships", Journal of Applied Econometrics, 16, p. 289-326.

- Rebelo, S. 1991." Long-Run Policy Analysis And Long-Run Growth”, Journal of Political Economy, 99, p. 500-521.

- $\quad$ Romer, P. M. 1986a. "Increasing returns and long-run growth". The journal of political economy, 94(5), p. 1002-1037.

- $\quad$ Romer, P. M., 1990b. "Endogenous Technological Change”, The Journal Of Political Economy, 98(5), Part 2, "The Problem Of Development: A Conference Of The Institute For Free Enterprise System”, Oct., p. 71-102

- Schumpeter J. 1912. The Theory of Economic Development. Harvard University Press Cambridge, MA

- Solow, R. M. 1956. "A Contribution to the Theory of Economic Growth". The Quarterly Journal of Economics, p. 65-94.

- $\quad$ Stem, N. 1989 "The Economics of Development: A Survey" The Economic Journal, 100, p. 597-685

- Thangavelu, S.M., Ang, J., \& Jiunn, B. 2004.’Financial development and economic growth in Australia: An empirical analysis". Empirical Economics, 29(2), p. 247-280

- Toda, H.Y \& Yamamoto, T., 1995."Statistical Inference In Vector Autoregression With Possibly Integrated Processes”. Journal of Econometric, 66, p. 225-250

- Worldbank, 2016, World Development Indicators, http://databank.worldbank.org/data/home.aspx

Bilgi notu: Bu çalışma Çukurova Üniversitesi Rektörlüğü Bilimsel Araştırma Projeleri Birimi tarafindan desteklenmiştir. 


\title{
Kalkınmakta Olan Ülkelerin Dış Borç, Büyüme Sorunları ve Türkiye Örneği
}

\section{The Developing Countries External Debt and Growth Issues and Example of Turkey}

\author{
Assoc. Prof. Dr. Oğuz Bal (Kocaeli University, Turkey)
}

\begin{abstract}
Today; country economies are dealt with from a global perspective. International capital, and technological developing, had accelerated the flow of factors also. This case demonstrates the international economic interdependence. In industrialized countries after the Second World War, while exports of industrial products increased by busy; In 1970's years, the oil crisis shocks had been lived. In the 1980s, in the world debt problems emerged. In the 1990s, world economy, has become multi-polar world with together globalization, and in order to the crisis by IMF and World Bank were began effective interventions, in the 2000s there has been a global crisis together with debt crises. The economic problem is a basic reason of the main of all crises. These crises are occurring frequently in emerging markets such as Turkey. For Turkey the real economy to financial fragility adversely affects and therefore the Current Account Balance / GNP status is important. This problem cited above, were discussed in five parts in the article. In the first part; In the case of Turkey was discussed; in general, the increase causes in imports were discussed. In the second chapter; increase in exports and imports coverage rate was examined. In the third chapter, the growth phenomena of dependent to import was discussed. In the fourth chapter; borrowing requirements, growth and debt relations were discussed. In the fifth chapter, conclusions and recommendations took place. The method used; the deductive method. CBT, Treasury data, World Bank data, Turkey Statistical Institute data were used.
\end{abstract}

\section{Giriş}

Günümüzde ülke ekonomileri küresel bir bakış açısıyla ele alınmaktadır. Uluslararası sermaye ve teknolojik gelişmişlik, aynı zamanda faktör akımlarını da hızlandırmıştır. Bir ülkenin GSMH'sı diğer ülkeleri etkilemektedir. $\mathrm{Bu}$ durum uluslararası ekonomik bağımlılığı ortaya koyar. Herhangi bir ülkenin üretim faktörlerindeki kitlıklar, diğer ülkelerin pazarı olmak için bir yeterli bir nedendir. Günümüz ekonomilerinde sadece bir alanda uzmanlaşma modası geçmiş bir teoridir. Ülkelerin belirli bir kaynağa sahip olması, o ülkenin kalkınmasına ve gelişmesine yardım etmez.

İkinci Dünya savaşından sonra sanayileşmiş ülkeler, sanayi ürünlerinin ihracatını artırmakla meşgulken;1970'li yıllarda petrol şokları dolayısıyla krizler yaşanmıştı. 1980 'li yıllarda ise dünyada borçlanma sorunları ortaya çıkmıştı, 1990'larda dünya küreselleşme ile birlikte çok kutuplu hale gelmiş ve meydana gelen krizlerde IMF ve DB etkin müdahalelerde bulunmaya başlamışı, 2000'li yıllar borçlanma krizleriyle birlikte global kriz ortamı yaşanmıştır. 2008 yılında başlayan finansal krizin reel ekonomiye yansıması sonuçları yıkıcı olmuştur. Günümüzde bile krizin etkileri hâlâ tam toparlanmış değildir.

Ekonomik problem tüm krizlerin temelinde yatan bir olgudur. Ülkeler yaşam savaşını bu problemi aşarak sürdürmek zorundadır. Bu da krizlerle beraber yaşamın devam edeceği anlamına gelir. Bu krizler Türkiye gibi yükselen pazarlarda sıklıkla yaşanmaktadır. Türkiye için finansal kırılganlık reel ekonomiyi olumsuz etkilemekte ve bu nedenle Cari İşlemler Bilançosu/GSMH'nın durumu önem kazanmaktadır. Türkiye'nin cari açık sorunu kronik olarak devam etmektedir. Cari açığın yüzde 70'i enerji kaynaklıdır. Bu yapısal, kronikleşmiş bir sorun üretim politikalarının, ithalata bağımlılı̆ıını ortaya koyuyor. Bir taraftan ithalat artarken, diğer taraftan da büyüme pozitif olarak artmaktadır. Tartışmaya neden olan bu olgu; ihraç edilebilecek mallar için sektörlerce girdi olan ithal malları kullanarak üretim gerçekleşiyor ve ihracat yapılıyor, büyüme de bu yolla gerçekleşiyor. Bu ise ithalata bağlı büyüme olgusunu ortaya çıkarıyor. Örneğin bir araştırmaya göre Türkiye'nin enerjide 2009 yllı itibariye ithalata bağımlılık oranları şöyle: Katı yakıtlarda; $\% 41,2$, petrolde; $\% 92,3$, doğalgazda; $\% 98$ ve genel olarak; $\% 71,4$. olarak hesaplamıştır.

\section{2 İthalat Kavramı, Kapsamı, Önemi ve Türkiye Örneği}

\section{1 İthalat (Import)}

Yabancı bir ülkeden mal ve hizmet alınmasıdır. Her gerçek kişi ve tüzel kişi ithalat işlemlerini yürütebilir. Ülkelerin, ekonomik yapısını değerlendirmede ithalat rakamları önemli yer tutmaktadır. Buna göre; eğer bir ülke sürekli ithalat yapıyorsa veya ithalat pazar payı ihracattan yüksekse, ülkenin sanayisi gelişmemiş, iş gücü ve sermayesi az, kısaca gelişmemiş bir ülke olarak kabul edilir. İthal ürünlerin ülkeye girmesi, yerli üreticiyi çökerterek ülkenin mali yavaşlamasına neden olur (George; 1980). Genelde İthalat; Daha ziyade ham madde ve ara malları sermaye (yatırım) malları ve tüketim malları makine ve ulaştırma araçlarını kapsar. Bunu madeni 
yakıtlar ve yağlar takip etmektedir. Zengin yer altı ve yer üstü kaynaklarına sahip olmayan ancak kalkınma yolunda aşama kaydetmiş Türkiye gibi ülkeler, ihtiyacı olan petrol ve doğal gazın tamamına yakınını ithal etmektedir. Gelişmekte olan ülkelerde ithalata harcanması gereken fonların kaynağı; ya vergilerden, ya ihracat tan kazanılan dövizlerden, ya da borçlardan sağlanmaktadır (Bağcı; 2001). Bu sayılanların üçü de ülke ekonomisinin en önemli sorunlarındandır. Türkiye ekonomisi açısından yatırım için donanım malları ithalatındaki artış ve ithalata konu olan mal bileşimi, büyümenin habercisi olarak değerlendirilmektedir.

$\begin{array}{ccccccc}\text { YILLAR } & \begin{array}{c}\text { İHRACAT } \\ \text { (MilYAR \$) }\end{array} & \begin{array}{c}\text { İTHLAT } \\ \text { (MILYAR \$) }\end{array} & \begin{array}{c}\text { İH/iT } \\ \text { (ÜRETIM CARİ) }\end{array} & \begin{array}{c}\text { GSYİH BORÇ } \\ \text { (MLYR TL) }\end{array} & \begin{array}{c}\text { DIŞ } \\ \text { BORÇ/GSMH }\end{array} \\ 1989 & 11.625 & 15.792 & 0,74 & 106.123 & 43.911 & 30.8 \\ 1990 & 12.959 & 22.302 & 0,58 & 149.195 & 52.381 & 26.1 \\ 1991 & 13.593 & 21.047 & 0,65 & 149.156 & 53.623 & 26.7 \\ 1992 & 14.715 & 22.871 & 0,64 & 156.656 & 58.595 & 27.8 \\ 1993 & 15.345 & 29.428 & 0,52 & 177.332 & 70.512 & 29.6 \\ 1994 & 18.106 & 23.270 & 0,78 & 131.639 & 68.705 & 38.8 \\ 1995 & 21.637 & 35.709 & 0,61 & 168.080 & 75.948 & 33.6 \\ 1996 & 23.224 & 43.427 & 0,53 & 181.077 & 79.299 & 32.6 \\ 1997 & 26.261 & 48.459 & 0,54 & 188.735 & 84.356 & 33.2 \\ 1998 & 26.974 & 45.921 & 0,59 & 270.947 & 96.351 & 35.6 \\ 1999 & 26.578 & 40.671 & 0,65 & 247.544 & 103.123 & 41.7 \\ 2000 & 27.775 & 54.501 & 0,51 & 265.384 & 118.602 & 44.7 \\ 2001 & 31.187 & 41.399 & 0,76 & 196.736 & 113.592 & 57.7 \\ 2002 & 36.059 & 51.554 & 0,70 & 230.494 & 129.597 & 56.2 \\ 2003 & 47.253 & 69.340 & 0,68 & 304.901 & 144.092 & 47.3 \\ 2004 & 63.167 & 97.540 & 0,65 & 390.387 & 161.010 & 41.2 \\ 2005 & 73.476 & 116.774 & 0,63 & 481.497 & 170.500 & 35.4 \\ 2006 & 85.537 & 139.576 & 0,61 & 526.429 & 208.361 & 39.6 \\ 2007 & 107.272 & 170.063 & 0,63 & 648.754 & 250.412 & 38.6 \\ 2008 & 132.027 & 201.964 & 0,65 & 742.094 & 281.098 & 37.9 \\ 2009 & 102.143 & 140.928 & 0,72 & 616.703 & 269.091 & 43.6 \\ 2010 & 113.883 & 181.544 & 0,61 & 731.608 & 291.920 & 39.9 \\ 2011 & 134.907 & 240.545 & 0,56 & 773.980 & 304.428 & 39.3 \\ 2012 & 152.470 & 236.581 & 0,64 & 786.283 & 339.018 & 43.1 \\ 2013 & 151.803 & 251.661 & 0,60 & 823.044 & 389.054 & 47.3 \\ 2014 & 157.610 & 242.177 . & 0,65 & 799.370 & 402.482 & 50.4 \\ 2015 & 143.862 & 207.207 & 0,69 & 719.967 & 405.985 & 54.7\end{array}$

Tablo 1. 1989-2015 Ihracat, Ithalat, Ih/İt; GSYIH, Dış Borç, Dış Borç/GSYIH Kaynak: TCMB. TÜIK

Tablo 1 deki veriler 1şı̆̆ında Türkiye ekonomisinde ithalat rakamlarında sürekli olarak artış gözlenmektedir. İthalatın yapısına bakıldığında Türkiye'nin daha ziyade hammadde ve ara malı ithal ettiğini görülmektedir. Hammadde ve ara malı ithalatını sırasıyla sermaye/sanayi malları ve tüketim malları ithalatı izlemektedir. Linder'e göre sanayi mallarının ithalini belirleyen unsur ise talep ağırlıklı olmaktadır (Linder;1961). İthal edilen mallarda tür ve kalite önemli olup, ülkenin kişi başına düşen gelirinin artmasıyla bağlantılıdır. Bu durum; ekonomide gelişme aşamasında olduğunu göstermektedir. Gerçekten de ülke ekonomisinin "Gelişmekte Olan Ekonomiler" kategorisinde olduğu söylenebilir.

\section{2 İthalata Müdahale}

İthalatın artması karşısında hükümetler, bu artışın meydana getireceği kayıpları önleyici politikaları uygulamaktadır. Bu müdahale politikası; zaman, konu, cins, tür, miktar, ölçü gibi standartlara sahiptir. İthalata müdahale araçları geleneksel olarak gümrük tarifeleridir ki bunlar; malların ülke sınırlarından geçişi sırasında alınan vergilerdir. Tarife dışı araçlardan miktar kısıtlamaları devletin ithalatı doğrudan doğruya belirli bir miktar ile sınırlandırma politikasıdır. İthalat kotaları ve yasaklamalar bu kapsamdadır. Tarife benzeri faktörler ise; Yerli katkı oranları, ithal ikamesi endüstrilere sübvansiyonlar gibi yerli üretim karlılığını arttırıp, ithalatı pahalılaştıran yöntemleri içerir (Balassa; 1980; Kazgan;1988). Görünmez engeller ise; temel olarak hükümetlerin halk sağlı̆̆1 ve çevre korunması nedenlerine bağlı olarak çıkardığı müdahale yöntemi olarak bilinirler. Doğrudan dış ticaret amaçlı olmasa da etkisinin diş ticaret üzerinde görüldüğü müdahalelere denmektedir. Dış ticaret politikası ithalatı kısıtlama eğiliminde olabileceği gibi ihracatın ya da genel olarak döviz kazanan işlemlerin özendirilmesi şeklinde de olabilmektedir.

Geleneksel tarifelerden diğer tarife dışı korumacılık türlerine geçildikten sonra dış ticarette saydamlık azaldı ve belirsizlik artış göstermekte bu da dünya ticaret akımlarını olumsuz yönde etkilemiştir. Mamul madde artışı yönünden İthalat artışının eğiliminin, düşük maliyetler dolayısıyla yerli sektör üzerinde yıkıcı etkisini önlemek 
amaçlanmaktadır. Örneğin gümrük vergileri ve tarifeler gibi. Günümüzde uygulanan Liberal politikalar açısından koruyucu politikalar artık kabul edilemez bir durumdadır. Her ne kadar koruyucu önlemler dış ticaret açığının giderilmesinde yararlı olsa da ticaret hacmini daraltmak bakımından sakıncalara da neden olmaktadır.

\subsection{Ithalat ve Para Politikası}

Liberal ekonominin bir gereği olan esnek kur rejimlerinde ithalat, döviz kuruna da bağlıdır. Döviz piyasasında TL nin pahalılaşması ithalatı artıracaktır. Serbest kur rejiminin bir aracı olan faiz oranındaki artış, ülkeye yabancı para girişini artırır, TL değerlenir. Bu sonuç da ithalatı artıracak ve ihracatı azaltıcı sonuçlar doğuracaktır.

Dışa açık ülkelerin bilançolarındaki cari işlemde yer alan mal ve hizmet akımlarının iç ve dış fiyat durumu, döviz kurları, GSMH gibi durumlarla etkilenen bölümdür. Kısa vadeli fonların girişleri genelde faiz oranları farklarından yararlanmak için dolaşır (Akdiş, 2004). Cari işlemlerdeki açık; cari açı̆̆ı ifade eder. Ekonomide tüketim ve yatırım için harcamaları için talep arttıkça hem ithalata hem de ithal mallarına talep artar. Bu, diş açıklara neden olur. Enflâsyon artışı olurken Merkez Bankası kur artışına karşı önleme müdahalelerine başlamasıyla TL nin aşırı değerlenmesi sonucu ortaya çıkar. İhracat 1 azaltır ve ithalat özendirilir. İthalat artışı dış ödemeler açıklarını artırmaktadır. Aşırı değerlenen kur fiyatları dış borçları da büyütecektir.

\section{İthal mallarının üretimi> İhraç mallarının üretimi $\Rightarrow$ GSYİH da düşer}

İthalat rakamları Türkiye'de devamlı artış gösterirken, ihracattaki artış hızı ise ithalattan daha yavaş ilerlediği görülüyor. Bu durum ihracatın ithalatı karşılama oranında gerilemeye yol açıyor. Verilere göre ihracatın ithalatı karşılama oranı, Türkiye sadece yüzde 60’ını karşılıyor.

\begin{tabular}{|c|c|c|}
\hline YILLAR & İTHALAT(\$) & YÜZDE DEĞișīiM \\
\hline 2015 & 207.207 .000 .000 & $-14,44$ \\
\hline 2014 & 242.177 .000 .000 & $-3,77$ \\
\hline 2013 & 251.661 .000 .000 & 6,37 \\
\hline 2012 & 236.581 .000 .000 & $-1,77$ \\
\hline 2011 & 240.833 .236 .364 & 29,80 \\
\hline 2010 & 185.544 .331 .852 & 31,66 \\
\hline 2009 & 140.928 .421 .211 & $-30,22$ \\
\hline 2008 & 201.963 .574 .109 & 18,76 \\
\hline 2007 & 170.062 .714 .501 & 21,84 \\
\hline 2006 & 139.576 .174 .148 & 19,53 \\
\hline 2005 & 116.774 .150 .907 & 19,72 \\
\hline 2004 & 97.539 .765 .968 & 40,67 \\
\hline
\end{tabular}

\begin{tabular}{|c|c|c|}
\hline 2003 & 69.339 .692 .058 & 34,50 \\
\hline 2002 & 51.553 .797 .328 & 24,53 \\
\hline 2001 & 41.399 .082 .953 & $-24,04$ \\
\hline 2000 & 54.502 .820 .503 & 34,01 \\
\hline 1999 & 40.671 .272 .031 & $-11,43$ \\
\hline 1998 & 45.921 .391 .902 & $-5,43$ \\
\hline 1997 & 48.558 .720 .673 & 11,31 \\
\hline 1996 & 43.626 .642 .496 & 22,17 \\
\hline 1995 & 35.709 .010 .773 & 53,46 \\
\hline 1994 & 23.270 .019 .027 & $-20,93$ \\
\hline 1993 & 29.428 .369 .530 & 28,67 \\
\hline 1992 & 22.871 .055 .114 & - \\
\hline
\end{tabular}

Tablo 2. Ithalattaki Yıllık Değişim Oranı.

\begin{tabular}{|c|c|c|}
\hline YILLAR & İHRACAT (\$) & YÜZDE DEĞișiM \\
\hline 2015 & 143.862 .000 .000 & $-8,72$ \\
\hline 2014 & 157.610 .000 .000 & 3,83 \\
\hline 2013 & 151.803 .000 .000 & $-0,44$ \\
\hline 2012 & 152.470 .000 .000 & 12,98 \\
\hline 2011 & 134.954 .361 .571 & 18,50 \\
\hline 2010 & 113.883 .219 .184 & 11,49 \\
\hline 2009 & 102.142 .612 .603 & $-22,64$ \\
\hline 2008 & 132.027 .195 .626 & 23,08 \\
\hline 2007 & 107.271 .749 .904 & 25,41 \\
\hline 2006 & 85.534 .675 .518 & 16,41 \\
\hline 2005 & 73.476 .408 .143 & 16,32 \\
\hline 2004 & 63.167 .152 .820 & 33,68 \\
\hline
\end{tabular}

\begin{tabular}{|c|c|c|}
\hline 2003 & 47.252 .836 .302 & 31,04 \\
\hline 2002 & 36.059 .089 .029 & 15,08 \\
\hline 2001 & 31.334 .216 .356 & 12,81 \\
\hline 2000 & 27.774 .906 .045 & 4,47 \\
\hline 1999 & 26.587 .224 .962 & $-1,43$ \\
\hline 1998 & 26.973 .951 .738 & 2,71 \\
\hline 1997 & 26.261 .071 .548 & 13,08 \\
\hline 1996 & 23.224 .464 .973 & 7,34 \\
\hline 1995 & 21.637 .040 .881 & 19,50 \\
\hline 1994 & 18.105 .872 .075 & 17,99 \\
\hline 1993 & 15.345 .066 .893 & 4,28 \\
\hline 1992 & 14.714 .628 .825 & \\
\hline
\end{tabular}

Tablo 3. İhracattaki Yıllık Yüzde Değişimler

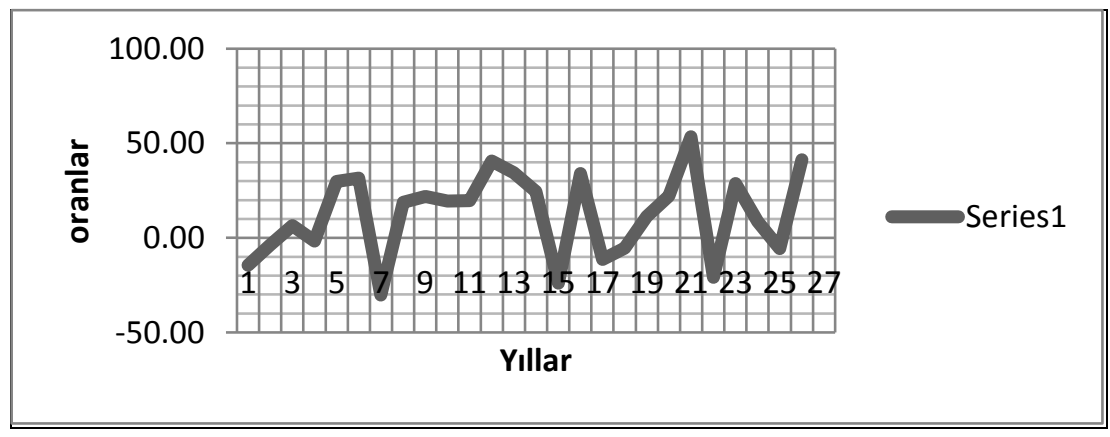

Şekil 1. İthalatta Yıllık\% Değişim 
Tablo 1 ve 2 den anlaşıldığı gibi ithalattaki artış ile büyümenin (GSMH'nın, artmış olması) artma eğiliminde olduğunu görülmektedir. İthalattaki artış, ülkenin dış açık verme nedenlerinden biri olduğu halde, büyüme rakamlarının sürekli artış göstermensin nedenlerinin ekonomiyi değerlendirme açısından önemli bir husustur. Ülkede GSMH artışının, ithalattan sağlanan hammadde girişlerinin üretimde kullanarak sağlanan gelirler dolayısıyla gerçekleşmesi, GSYİH'daki büyümenin ithalata bağımlı bir büyüme olduğunu ortaya çıkarmaktadır.

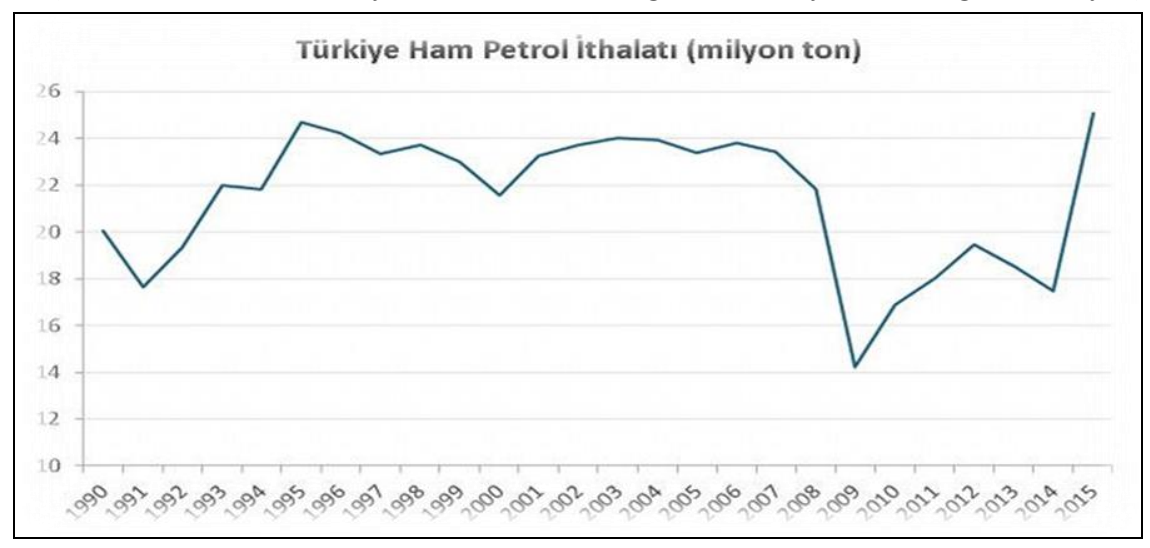

Şekil 2. Türkiye'nin Petrol İthalatı Kaynak: TÜIK

\section{3 İhracat Kavramı, Kapsamı, Önemi ve Türkiye Örneği}

\section{1 İhracattaki (Export) Gelişmeler}

Teorik olarak bakıldığında geçmişte yaşanmış, bu gün de hâlâ etkileri devam eden hammadde ağırlıklı ihracatı konu edinen kolonyonal Merkantilizm'i hatırlatmaktadır. Dış ekonomik ilişkilerde uygulanan sınırlayıcı politikalar merkantilist sistemi akla getirebilir (Chang; 2003:17). Özellikle yeniden bunalıma düşme korkusu bunu teşvik etmektedir. Buna göre; dış ticarette ödeme yükümlülüklerini serbest bir diş ticaret anlayışıyla değil, takas ve kliring sistemleriyle karşılama yoluna gidildi. Amacı ise diş ticaret ilişkilerini geliştirmek ve üretimi artırmaktır.

Merkantilistler, hammadde ithalatının ülke avantajına olduğunu ancak işlenmiş ürün dışında ihracat yapılmaması gerektiği üzerinde durmaktayken, Adam Smith ve David Ricardo'nun temsil ettiği "Klâsik Liberal” teoriyi oluşturmuşlardır. 1776-1936 döneminde geçerli olan Klâsik Makro Teori toplam arzı ön plânda ihracatı, arkasında ithalat politikaları izlerken 18.yy'ın son çeyreğinde Osmanlı ne fizyokrat ne de merkantilist idi. Fiskalist politikalar izlemekteydi (McGowan,1981; Toprak, 2005, 222). Keynesyen Makro İktisat Teorisi ise toplam talebe dayanır ve öne plânda ithalat arkasından ihracat politikaları önerilir.

Konjonktür dünya ticaretinin ve elbette tarımsal ürün ticaretinin de serbestleşmesi yönünde önemli gelişmelerin yaşandığı dönemler olmuştur. Bu süreçte dünya ticaretinin serbestleşmesi için çabalayan ve bu süreci garantileyen bazı kurumsal yapılanmalar söz konusudur. Ulusların, ekonomik, siyasi ve kültürel olarak birbirine bağımlılığın artmasıdır. Özellikle oligopolistik güce sahip uluslararası şirketler tarafından yürütülen, yatırım ve ticaretteki büyüme, üretimde yeni teknolojilerin kullanımı ile günümüz ekonomilerinde sermaye hareketleri, ticaretteki istisnaları tanımaz bir şekilde bütünleşmiştir. Bu hareketlenme ve liberalleşme ihracat 1 öne çıkarıp ithalatı ikinci adım olarak sunmaktadır.

Genelde bir ülke dışa ne kadar açılıyorsa, dünya olaylarından etkilenme derecesi de o ölçüde fazladır; çünkü dış ticaret GSMH'nın öylesine yüksek bir oranıdır ve ülke büyümesinde ihracat artışının payı o kadar büyüktür. Dış ticarette koruma ne kadar azsa, dünya piyasasındaki değişmelerin iç piyasaya intikali o kadar daha kolaydır (Kazgan, 2005).

\section{2 İhracat ve Büyüme İlișkisi}

\section{İhraç mallarının üretimi>İthal mallarının üretimi $\Rightarrow$ GSYIH da artar.}

İhracattaki artış oranı GSYİH'daki artış oranından fazla olursa buna ticareti artırıcı büyüme denir. İthalattaki artış oranı GSYİH'daki artıştan fazla ise böyle büyümeye de ticarete karşıt büyüme denir. İhracat az artıyor. İthalat daha hızlı büyüyorsa, Türkiye gibi gelişmekte olan ekonomiler, yüksek katma değerli ürün ihracatına geçme sorununu çözmek durumundadır. Aksi durumda cari açıktaki büyüme önüne geçilemeyecektir. Cari açığın finansmanı için daha fazla sıcak paraya ve daha yüksek faize ihtiyaç duyulur.

Piyasa ekonomisinin geçerli olduğu ekonomiler açık ekonomilerdir. Hangi malların ne miktarda üretileceğine üreticilerce ve karlılık nispetinde karar verilmektedir. İthalatın yapısı sanayileşmiş ülkelerle sanayileşmemiş ülkeler arasında ayrı kategorilerde gerçekleşir Linder'e göre ithal edilen sanayi mallarının türü ve kalitesi kişi başına düşen milli gelire bağlıdır (Linder,1961).

1980'lerde Türkiye'de ihracat önemli bir yer tutmaktadır. Bu tarihten sonra uygulanan ithal - ikamesi politikalarının, ihracat aleyhine yol açtığı çarpıklık dolayısıyla ihracattaki gerilemenin önlenmesi sağlanmaya 
çalışılmıştır. 1980-88 yılları arasında iç talep kısılıp ihracat ta ki artış ile ülkeye döviz girişini artırma politikası uygulandı.1990 lı ilk yıllarda geliştirilen politika ise ülkeye ihracat yoluyla döviz girişini sağlamak amaçlandı. İhraç ürünlerinin kompozisyonunda sanayi ürünleri sadece \%36'lık bir paya sahipken, tarım ürünleri ihracatı \%57 düzeyindeydi. Türkiye'nin gelişimi ve dönüşümünün bir yansıması olarak; 2000 yılında sanayi ürünleri toplam ihracatın \%83'ünü, tarımsal ürün ihracat $1 \% 15,2$ 'sini, 2010 yılında ise sanayi ürünleri toplam ihracat in \%82,3'ünü, tarımsal ürün ihracat 1 ise 13,2'sini oluşturmuştur (Doğu Marmara Kalkınma Ajansı;2011). 2012 yılında ihracat in sektörel dağılımında en önemli paya sanayi sektörünün sahip olduğu görülmüştür. İhracat içerisinde sanayinin payı yüzde 75,31, tarım sektörünün payı yüzde 12,61 olmuştur (www.setav.org, 2013).

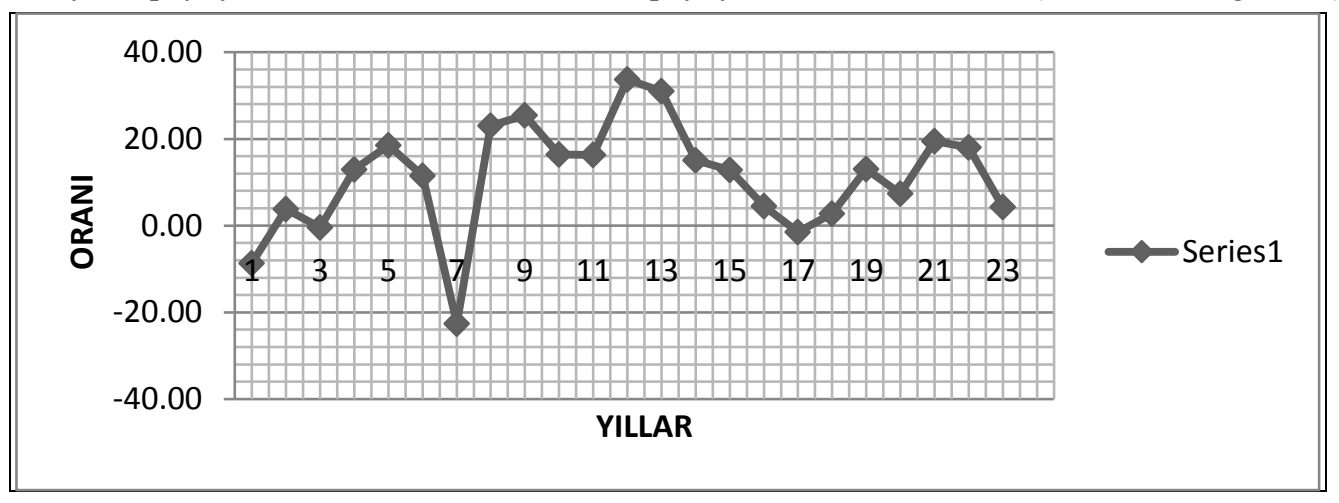

Şekil 3. Ihracatta Yıllık\% Değişim

\section{Dışa Açılmanın Bedeli ve Dış Borçlanma Sorunu}

Kapitalist dünya ekonomisinin dünya çapında toplam borç miktarı (kredi değerli kâğıtları bazında); 2010 yılı itibariyle 95 trilyon dolara çıkmıştı. Bu miktar 1990'da 18; 2000'de 35 ve 2005 'te de 59 trilyon dolardı. Dünya borç miktarı 1990'dan 2000'e yaklaşık 2; 2005'e yaklaşık 3,3 ve 2010'a da yaklaşık 5,3 misli artıyor. 2005 teki borç miktarı 2008 dünya GSH sına eşit. 2010'da dünya borç miktarı aynı yılda dünya GSH'sından (satın alma paritesine göre) 20,46 trilyon dolar daha fazla; yani dünya GSH's1 dünya borcunun yüzde 78,5'ine eşit. Dünya kamu borçlarının 2009'daki toplam miktarı aynı yılın dünya GSH'nın \% 56,8'ine; 2010'da da yüzde 59,3'üne eşit düşüyor. Mutlak değer olarak dış borç rakamlarına bakıldığında 2001 sonunda dış borç stoku ise 70 milyar \$. 2002'de kamunun dış borcu \% 23 kamu dış borç stoku da yine \% 10 gibi yüksek bir oranda artarak USD 95 milyar \$.a ulaşmıştır. 2004'e dış borç stokunun USD 95 milyar \$.dan, USD 92 mia. a gerilediğini, 16 mia dolarlık cari işlemler açığı vermişti. 2001-2004 döneminde kamu dış borç stoku dolar bazında \% 31 oranında artmıştır. Ayrıca aynı dönemde özel sektörün dış borç stoku da \% 36’lık bir artışla USD 45 mia. dan USD 62 mia. a yükselmiştir. Bütün ülkelerin toplam (özel ve kamu) dış borç tutarı 31 Aralık 2009 itibariyle tahmini olarak 61,95 trilyon dolardı; bu miktar 31 Aralık 2010'da 60,28 trilyon dolara düşüyor. Dünya GSH sına eşit bu miktar, genel anlamda dünya koşullarının üstünde gerçekleştiğini gösterir (www.ibrahimokcuoglu.blogspot.com, 2011).

Türkiye'de kamu borcu/GSYİH oranı yüzde 41,6 olduğu bu oran, batacağı yönünde tartışmaya konu olan Yunanistan'da yüzde 142, İtalya'da yüzde 119, Portekiz'de yüzde 83, İrlanda'da yüzde 96, İspanya'da yüzde 60, Euro Bölgesi'nde ortalama yüzde 85 olduğu, 2011 yılında ise adı geçen bu ülkelerin tümünün bu borç oranlarının yüzde, yüzü geçeceği öngörülmektedir. Diğer yandan bu oranın 2010 yılında ABD'de yüzde 91,6 ve Japonya'da yüzde 220 olduğu görülmektedir (akademikperspektif.com,2012).

Brüt dış borç stoku mutlak olarak artıyor ama geliri daha fazla arttığı için gelir içindeki borç payı göreli olarak azalıyor. Harcamaların kısıtlanmasına yönelik politikalar, ithalata dayalı büyüme politikasını izleyen ekonomilerde ekonomik gelişmeyi olumsuz etkilemektedir. Yani borçlanma ile elde edilen mali olanaklar iktisadi gelişmeyi canlandırmanın yanında, GSMH'yı hızla artırması, meydana gelecek açıkları massedebilme yeteneğinin de olmasını gerektirir. Tersi bir durumda, krize davetiye çıkaran bir konumda olabilir.

\section{Türkiye Açısından Dış Borç Meselesi}

Teorik olarak bu sorunun kaynağı Türkiye açısından yüz elli yıllık arka plâna sahiptir. Batının askeri, siyasi ve iktisadi gücüyle karşılaşan kapitalizme açılmaya başlayan 19.yy.lın yarısından itibaren başlamıştır. Dış borçlanma ve dolaysız yatırımlar aracılığıyla yabancı sermaye ülkeye girmeye başlamıştı (Pamuk; 2005). Borç kalemlerinin artması demek dış finansman ihtiyacının ortaya çıkması anlamına gelmektedir. Bir ülkede yatırım yeterli tasarruflarla sağlanmalıdır. Eğer plânlanan yatırımlar için yurt içindeki tasarruflar yetersizse, dış finansman kaynaklarına başvurulur. Dışa açık, gelişmekte olan ekonomilerde kaynak ihtiyacı, döviz yetersizliğinin, ödemeler dengesi açıklarının ve bir dizi krizlerin ana nedenlerindendir. Dış borçlanmalarda en önemli ölçüt; Dış borç/GSMH oranı olarak görülmektedir. Yukarıda geçen Tablo 1 de bu oran \%55 e dayanmaktadır. Karşılaştırmak için grafik 5 ve 6 ya bakınız. 


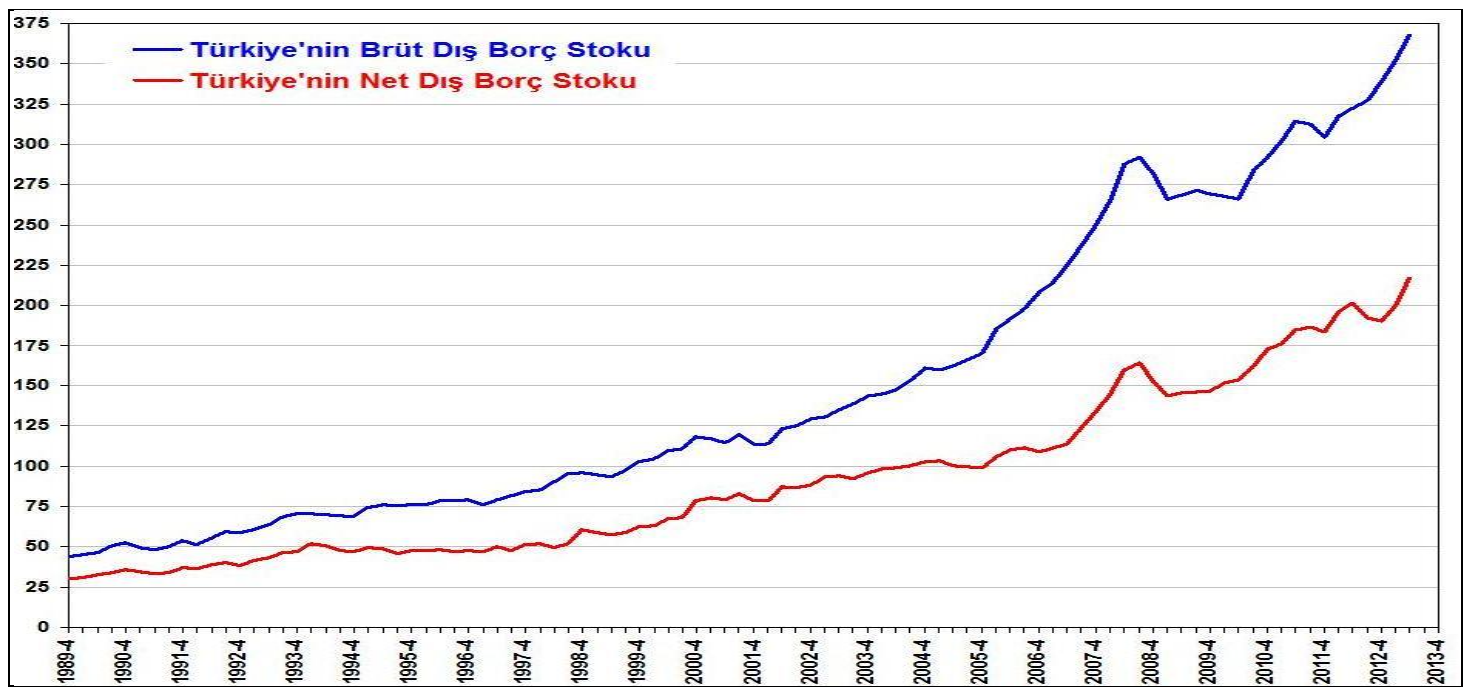

Şekil 4. Türkiye'nin Dlş Borç Grafiği Kaynak: HMVDS ve TCMB EVDS; AK'nin çizimleri.

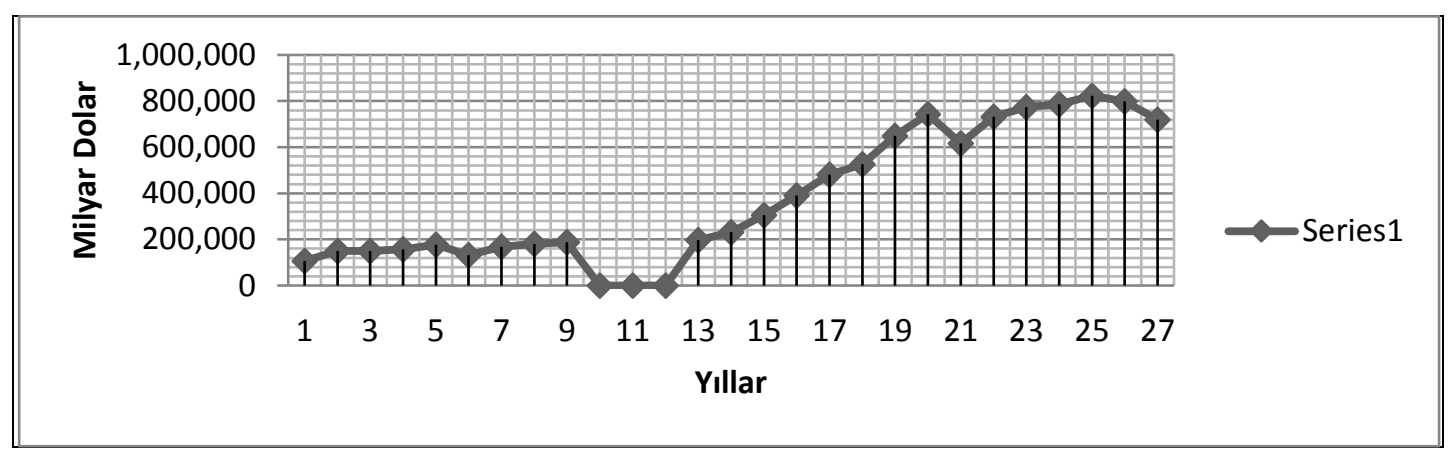

Şekil 5. Yıllara Göre GSYİH Grafiği

\subsection{Veriler Işığında İthalat, İhracat, Dış Borç, Büyüme Durağanlık Saptamasının Ampirik Yöntemi}

\subsubsection{Literatür}

M. Şimşek ve C. Kadılar tarafından yapılan çalışmalarında ifade edildiği gibi F testlerinden elde edilen sonuçlar; ihracat talebi ile fiyat endeksi ve gelir değişkenlerinin eşbütünleşik olduklarını, yani bu değişkenler arasında uzun dönemli bir ilişsinin bulunduğunu göstermektedir. Gelir artışııın ithalatı da artırması nedeniyle elde edilen esneklik katsayısı ekonomik büyümenin, ticaret dengesi üzerinde negatif bir etkiye sahip olacağı anlamına gelmektedir (Doğuş Üniversitesi Dergisi; 2005).

E. Baday Yıldız ve M. Berber' in çalışmalarında ise Türkiye ekonomisine ait üçer aylık veriler kullanarak toplam ithalat, yatırım malı ithalatı ve aramalı ithalatı ile ekonomik büyüme arasındaki nedensellik ilişkileri incelenmiştir. Türkiye ekonomisinde ithalata dayalı ihracat ve ithalata dayalı büyüme düşüncesini desteklemektedir ( Atatürk Ü. İ̈BF Dergisi; 2011).

D. Uysal, v.d. çalışmalarında "Dış borçlanmanın üretken yatııımları finanse etmek amacıyla kullanılması halinde ulusal çıktı düzeyi üzerindeki olumlu etkisi” olduğunu Granger Nedensellik Testi ile ispatlamış (Atatürk Üniversitesi İktisadi ve İdari Bilimler Dergisi;2009).

İ. Çöğürcü - O. Çoban, 2011 de yaptıkları çalışmada" alınan dış borçlar, üretken ve geri dönüşümü olan alanlara yatırılırsa ekonomik büyümeyi artırmaktadır. Fakat alınan dış borçlar borç ödemek ve cari harcamaları karşılamak amacıyla veya verimsiz alanlarda kullanılırsa ülke ekonomisine negatif etki sağlamaktadır." yargısına ulaşmıştır ( KMÜ Sosyal ve Ekonomik Araştırmalar Dergisi;2011).

Zaman serisi; bir zaman dilimi üzerinde bir ya da birden fazla değişkenin değişimlerinin gruplanması anlamınadır. Değişkenlerin değerler ardışık bir şekilde gözlendiği sayısal büyüklüklerdir. Çeşitli nedenler, zamanla ilişkili değişkenlerin yön ve şiddet değerlerinde değişikliklere neden olur. Bu değişmelerin neden ve sonuçları çözümlenmedikçe olumlu sonuçlara ulaşılamaz. Zaman serilerini çözümlemeye geçmeden önce, seriler eğer gerekliyse, söz konusu etkilerden arındırılmalıdır. Zaman serileri çözümlemesindeki temel süreçlerden birisi durağanlıktır. Zaman serilerinin durağan olması ile kastedilen şey; zaman içinde varyans ve ortalamanın sabit olması ve gecikmeli iki zaman periyodundaki değişkenlerin ko-varyansının değişkenler arasındaki gecikmeye bağlı olup zamana bağlı olmamasıdır (Gujarati, 1995). Bir başka deyişle eğer bir seri durağansa; Ortalaması, 
Varyansı, Kovaryansı zaman içerisinde değişmemektedir. Burada geçen terimlerin ne anlama geldiği aşağıda belirtildiği gibidir:

a) Varyans; En yaygın olan dağılım ölçülerinden varyans, bir rassal değișken, bir olasılık dağılımı veya örneklem için istatistiksel yayılımın, mümkün bütün değerlerin beklenen değer veya ortalamadan uzaklıklarının karelerinin ortalaması şeklinde bulunan bir ölçüdür. Varyans için ölçülme birimi orijinal değişkenin biriminin karesidir. Varyansın karekökü standart sapma olarak adlandırılır; bunun ölçme birimi orijinal değişkenle aynı birimde olur ve bu nedenle daha kolayca yorumlanabilir.

b) Ko-varyans ise; iki rastgele değişkenin ne kadar beraber değişimlerini gösteren bir olgudur. Eğer kovaryans pozitifse $X$ ve $Y$ arasında pozitif lineer ilişki vardır. Sıfırsa bağımsızdırlar. Negatifse $X$ ve Y birbirlerinden ters yönde hareket ediyor demektir.

c) Korelâsyon katsayılarının yorumu ve ölçütleri aşağıdaki tabloda görülür

\begin{tabular}{|l|l|l|l|l|l|l|}
\hline KUVVETLI & ORTA & ZAYIF & ZAYIF & ORTA & KUVVETLI \\
\hline$-1 \leq \mathrm{R}<-0,9$ & $-0,9 \leq \mathrm{R} \leq-0,5$ & $0,5<\mathrm{R} \leq 0$ & $0<\mathrm{R} \leq 0,5$ & $0,5<\mathrm{R} \leq 0,9$ & $0,9<\mathrm{R} \leq 1$ \\
\hline
\end{tabular}

Tablo 4. Korelâsyon Katsayılarının Yorumu

\begin{tabular}{|c|c|c|c|c|}
\hline & DBORC & GSYIH & IHRÂCÂT & ITHÂLÂT \\
\hline DBORC & 1.000000 & 0.986852 & 0.989133 & 0.278033 \\
\hline GSYIH & 0.986852 & 1.000000 & 0.989719 & 0.233552 \\
\hline IHRÂCÂT & 0.989133 & 0.989719 & 1.000000 & 0.223100 \\
\hline ITHÂLÂT & 0.278033 & 0.233552 & 0.223100 & 1.000000 \\
\hline
\end{tabular}

Tablo 5. Veriler Işı̆̆̆ında Korelâsyon Katsayıları

\begin{tabular}{|c|c|c|r|r|}
\hline & DBORC & GSYIH & IHRÂCÂT & ITHÂLÂT \\
\hline DBORC & 8294.162 & 20680.08 & 4018.586 & 712643.5 \\
\hline GSYIH & 20680.08 & 52945.32 & 10159.16 & 1512476. \\
\hline IHRÂCÂT & 4018.586 & 10159.16 & 1990.053 & 280105.4 \\
\hline ITHÂLÂT & 712643.5 & 1512476. & 280105.4 & $7.92 \mathrm{E}+08$ \\
\hline
\end{tabular}

Tablo 6. Veriler Işı̆̆ııda Kovaryans Katsayıları

Zaman serisine yapılacak doğrusal trend ilavesi ile yani trendsizleştirme sonucunda eğer zaman serisi durağan hale geliyorsa bu zaman serisinin deterministik bir trende sahip olduğunu, ancak eğer doğrusal bir trend ilavesi eğer zaman serisini durağan hale getirmiyorsa, bu durumda fark alınarak zaman serisi durağan hale getirileceğinden stokastik bir trend geçerlidir (Franses, 1998).

Trend (Genel Eğilim); zaman serilerinin uzun sürede gösterdiği kararlı düşme ve yükselme durumudur. Bu durumda zaman serilerinin kullanılacağı öngörümleme ve regresyon denklemlerinde sahte regresyon benzeri durumlar ortaya çıkar, oluşturulacak regresyonun sonuçları gerçekçi olmaz. Bu durumda standart $t$ istatistikleri ve $R^{2}$ değerleri olduğundan daha yüksek çıkar. Ayrıca durağan olmayan serilerde oluşan geçici bir şok kalıcı etkiye neden olur. Bu da durağanlığı engeller. Deterministik trend, oldukça uzun bir dönemde ortaya çıkan ve yükseliş ve alçalış zikzakları arasında belli bir yöndeki uzun dönemdeki eğilimi ifade etmektedir.

Durağanlık Tespiti

Zaman serilerinden her biri fark alındıktan sonra durağan hale geliyorsa ve bu serilerin doğrusal bileşimleri de durağansa, söz konusu serilerin koentegre (eşbütünleşik) oldukları söylenir. Bir serinin durağan olup olmadığını anlamak için; yapılması gerekenleri şu şekilde sıralayabiliriz (1) Serinin korelogramını incelenerek, (II) birim kök testleri uygulayarak. Durağanlık tespiti için korelogramdan şu şekilde yararlanılır: Oto korelâsyon fonksiyonuna (ACF), ACF eğer çok yüksek bir değerden başlayıp çok yavaş küçülüyorsa, bu serinin durağan olmadığının bir göstergesidir. Durağan olmayan seriler birim kök (unit root) içerirler. Seri tesadüfî yürüyüş süreci izliyorsa o seri durağan değildir. Durağan olan serilerde şok geçici etki yaratır; durağan olmayan serilerde ise kalıcı etki yaratır. Zaman serilerinin durağan olmaması durumunda, stokastik ya da deterministik trend içermektedirler.

\subsubsection{Durağan Olmama (Non-Stationary) Halinin Tespiti:}

Serinin değerleri belirli bir değer etrafinda dağılmaz ve sabit ortalamaya sahip değildir.

Varyans zamana bağlıdır ve sonsuza yaklaşan bir örneklem periyodu gibi sonsuza gider.

Gözlemler arasındaki ilişki, gözlemlerin birbirlerine uzaklığı arttıkça azalmaz.

Durağanlığın Birim Kök İle Sınanması ve Dickey-Fuller Birim kök testi

$Y_{t}=\rho Y_{t-1}+u_{t}$

$H_{0}: \geq 1$ (Seri durağan değildir) 
$H_{1}: \rho<1$ (Seri durağandır)

$\boldsymbol{\rho}=1 \Rightarrow Y_{t}$ nin bir birim kökü vardır, rassal yürüyüş serisidir, durağan değildir.

Hipotezi test etmek için kullanılan istatistik, istatistiği olarak bilinir. Eğer hesap edilen mutlak değeri, eşik $\boldsymbol{\tau}$ mutlak değerinden büyük çıkarsa, seri durağandır.

Yukarıdaki verilere göre önce ihracat rakamlarının durağan olup olmadığg belirlemeye yönelik yapılan birim kök analizinin sonuçları aşağıdaki gibidir:

\begin{tabular}{|c|c|c|c|}
\hline \multicolumn{4}{|l|}{ İthalat verileri için } \\
\hline $\begin{array}{l}\text { T istatistik değeri } \\
\text { Mutlak değer }\end{array}$ & \multicolumn{3}{|l|}{$\begin{array}{l}\text { t kritik değerleri } \\
\text { mutlak değer }\end{array}$} \\
\hline \multirow{2}{*}{$\begin{array}{l}4.788374 \\
(\mathrm{Lag}: 2)\end{array}$} & $\% 1$ & $\% 5$ & $\% 10$ \\
\hline & 3.752946 & 2.998064 & 2.638752 \\
\hline \multicolumn{4}{|l|}{ İhracat verileri için } \\
\hline $\begin{array}{l}\text { T istatistik değeri } \\
\text { Mutlak değer }\end{array}$ & \multicolumn{3}{|l|}{$\begin{array}{l}\text { t kritik değerleri } \\
\text { mutlak değer }\end{array}$} \\
\hline \multirow{2}{*}{$\begin{array}{l}1.234299 \\
(\mathrm{Lag}: 2)\end{array}$} & $\% 1$ & $\% 5$ & $\% 10$ \\
\hline & 3.752946 & 2.998064 & 2.638752 \\
\hline \multicolumn{4}{|l|}{ GSYIH verileri için } \\
\hline $\begin{array}{l}\text { T istatistik değeri } \\
\text { Mutlak değer }\end{array}$ & \multicolumn{3}{|l|}{$\begin{array}{l}\text { t kritik değerleri } \\
\text { mutlak değer }\end{array}$} \\
\hline \multirow{2}{*}{$\begin{array}{l}0.417270 \\
(\mathrm{Lag}: 2)\end{array}$} & $\% 1$ & $\% 5$ & $\% 10$ \\
\hline & 3.752946 & 2.998064 & 2.638752 \\
\hline \multicolumn{4}{|c|}{ DBORC verileri için } \\
\hline $\begin{array}{l}\text { T istatistik değeri } \\
\text { Mutlak değer }\end{array}$ & \multicolumn{3}{|l|}{$\begin{array}{l}\text { t kritik değerleri } \\
\text { mutlak değer }\end{array}$} \\
\hline \multirow{2}{*}{$\begin{array}{l}2.242490 \\
(\mathrm{Lag}: 2)\end{array}$} & $\% 1$ & $\% 5$ & $\% 10$ \\
\hline & 3.752946 & 2.998064 & 2.638752 \\
\hline
\end{tabular}

Tablo 7. İthalat Serisi Dură̆an; İhracat, GSYIH, Dış Borç Zaman Serileri Dură̆an Değildir.

\section{Sonuç}

Tablo 4, 5 ve 6'dan anlaşılacağı gibi bütün değişkenler pozitif yönlü olup birbirleri ile ilişkilidir. Değişkenler arası ilişkilerin şiddetinin tespiti de korelâsyon tablosundan anlaşılmaktadır.

İktisadi açıdan etkin ve tutarlı tahminler için gerekli bir koşul olan durağanlık, bir denge durumunu ifade etmektedir. Durağanlık tesbiti için de birim kök analizi yapıldı. Belirlenen zaman aralığındaki verilere göre aşağıdaki bulgular elde edilmiştir. Buna göre; GSYİH verilerinin birinci dereceden diferansiyeli alınarak, durağan olduğu görülmüş, ihracat ve ithalat verilerinin de aynı yöntemle durağan ve sürekli artış eğiliminde olduğu saptanmıştır. Dış Borç verileri de aynı yöntemle sınanarak alındı \%5 ve \%10 anlamlılık düzeyinde durağan olduğu ve aynı sonuca ulaşıldığı belirlenmiştir.

Gelişmekte olana ülkelerin en önemli sorunu dış açıktır. Türkiye örneğinde bu sorun; ithalattan kaynaklanmaktadır.

Türkiye sanayiinin ana girdisi petrol ve doğal gazdır. Bu temel girdi, büyük ölçüde ithalat yoluyla sağlanmaktadır. İthalat ise dış açığa neden olmaktadır. Dış açık problemini çözmek için yerli alternatif enerji kaynaklarına yönelmelidir.

Verilere göre Türkiye GSYİH'ındaki büyümenin ithalata bağımlı bir büyüme sağladığı anlaşılmaktadır. Bu ayrıca dış açıkların finansmanında riskli kronik sorunlar oluşturmaktadır.

\section{Kaynakça}

- $\quad$ Atatürk Ü. İIBF Dergisi, 2011)10. Ekonometri ve İstatistik Sempozyumu, Cilt:25;2011

- AKDİş, Muhammet (2004), “'Kısa Vadeli Sermaye Hareketlerinin Yol Açtığı Finansal Krizler ve Bu Krizleri Önlemede Kullanılabilecek Araçlar: Tobin Vergisi”, Bankacılık ve Finans Dergisi, Y1l:6, Say1:36,ss:36-48.

- $\quad$ Atatürk Üniversitesi İktisadi ve İdari Bilimler Dergisi, Cilt: 23, Say1: 4, 2009

- BAĞCI, H. , Kamu Borçları Yönetimi ve Türkiye İçin Bir Değerlendirme. Ankara. SPK Yay. Yayın no: 135. s;118

- BALASSA Béla, The Process of Industrial Development and Alternative Development Strategies, World Bank Staff Papcr No: 438. 1980. 
- CHANG, Ha. J (2003). Kicking Away the Ladder: Development Strategy in Historical Perspective, Wimbledon Publishing Company Ltd.2003,s:17

- C ÇÖ̆ÜRCÜ İ. - O. Çoban / KMÜ Sosyal ve Ekonomik Araştırmalar Dergisi, 13 (21): 133-149, 2011

- Doğuş Üniversitesi Dergisi, 6 (1) 2005, 144-152

- $\quad$ FRANSES, Philip Hans, Time Series Models for Business and Economic Forecasting, Cambridge University Press, UK, 1998, ss.80-90.

- $\quad$ GEORGE, Henry; Protection or Free Trade, (1886), New York, Robent Schalkenbach Foundation, 1980, s. 47.

- GUJARATİ, Damodar N., Basic Econometrics, Third Edit, MC-Graw-Hill, İnc., USA,1995. s.712-713.

- $\quad$ http://akademikperspektif.com.Küresel Ekonomik Krizin Avrupa Birliğine Etkileri, 2012

- http://tcmb. gov.tr/cbt.html

- http://www.ibrahimokcuoglu.blogspot.com, 2011

- $\quad$ KAZGAN, Gülten; Ekonomide Dışa Açık Büyüme, Altın Kitaplar Yay.İst.1988.s:344-352

- $\quad$ KAZGAN, Gülten; Türkiye Ekonomisinde Krizler (1929-2001) ,Bilgi Ünv. Yay.İst.;2005;s:149

- Karamanoğlu Mehmetbey Üniversitesi(KMÜ) Sosyal ve Ekonomik Araştırmalar Dergisi;2011

- $\quad$ LINDER, S. B.; An Essay on Trade and Transformation (StockhoLm: ALmqvist and Wiksell InternationaL. 1961

- McGOWAN,B. Economic Life in Ottoman Europe, Taxation, Trade and Struggle for Land 1600-1800, Cambridge Unv.Press., 1981, s.18 ve 28.

- PAMUK, Şevket, Osmanlı Ekonomisinde Dışa Bağımlılık ve Büyüme 1829-1913”Tarih Vakfı Yay. 3. Bask1,İst.2005,s.7-9

- $\quad$ Siyaset, Ekonomi ve Toplum Araştırmaları Vakfi, www.setav.org,2013, No: 14

- $\quad$ TOPRAK, Zafer. İktisat Tarihi, Zirveden Çöküşe Osmanlı Tarihi, C. II, Haz. Sina Akşin, Doğa Ofset. İst.2005,s: 222

- T.C. Doğu Marmara Kalkınma Ajansı,www.marka.org.tr 


\title{
Kalkınmada Ar\&Ge ve İnovasyonun Önemi; Türkiye Örneği The Importance of R\&D and Innovation in Development; The Case of Turkey
}

\author{
Asst. Prof. Dr. Emine Firat (Aksaray University, Turkey) \\ Prof. Dr. Zeynep Karaçor (Selçuk University, Turkey) \\ Prof. Dr. Serdar Altınok (Gazi University, Turkey)
}

\begin{abstract}
There are many different ways for the development of a country. Some countries are enriched with intensive industries and some with natural resources. Countries should have creative forces and ideas to develop besides the natural resources and hardware. With the globalized world order, countries will be able to develop depending on $\mathrm{R} \& \mathrm{D}$ and innovation. In recent years, the necessity of research and development and innovation has been emphasized and accordingly, the importance of conceptions of learning, research, creativity and innovation has increased for realization of the development. Today with accelerated globalization, both companies and countries have been forced to adopt policies based on technological innovation and provided information and competitive advantage to adapt to change. As a result of policies of the country, the increase in innovation performance has contributed to the development. Information, technology and learning processes have been effective in improving their innovation performance. In this study, Turkey's regional R \& D and innovation activities are evaluated and the importance of innovation and research and development activities for development are highlighted. Consequently, R \& D and innovation projects contribute to the improvement and development of Turkey, thereby enabling effective and efficient use of sources. The results demonstrate that there is an increase in R \& D and innovation activities, but not sufficiently in recent years in Turkey and in this regard there should be more steps for public and private sectors.
\end{abstract}

\section{Giris}

Kalkınmada Ar-Ge ve inovasyonun önemi her geçen gün hız kazanmakta olup, bu durumun farkında olan ülkeler Ar-Ge ve inovasyona daha fazla ağırlık vermektedir. Küreselleşmeyle birlikte ülkeler ayakta kalabilmek ve piyasada rekabet edebilmek için bilim ve teknoloji alanına yönelmektedirler. Bu yüzden son yıllarda "Ar-Ge" ve "İnovasyon" kavramları sık sık kullanılmaya başlanmıştır.

Ar-Ge, yeni ürün ve üretim süreçlerinin geliştirilmesiyle birlikte işletmenin ihtiyacı olan; pazarlama, finansman ve iş gücünün temin edildiği yaratıcı çalışmaların bütünü olarak ifade edilmektedir. İnovasyon ise, bilginin ekonomik ve toplumsal faydasından oluşmaktadır. İnovasyon iktisadi, sosyal ve teknolojik süreçlerin birbirleriyle etkileşim içinde olduğu sistemler bütünüdür. $\mathrm{Bu}$ nedenle Ar-Ge ve inovasyon, ülkeler ve bölgeler için sürdürülebilir kalkınmanın sağlanmasında, toplumsal refahın artııılmasında ve yaşam kalitesinin yükseltilerek bölgeler arasındaki farklılıkların en aza indirilmesinde önemli bir kavram olarak görülmektedir. Kalkınma, kişi başına gelir ve üretimin artmasıyla birlikte az gelişmiş bir toplumda; sosyal, kültürel ve iktisadi yapıda bir değişimin meydana gelmesidir. Bir ülkenin veya bölgenin gelişebilmesi, refah seviyesinin yükseltilebilmesi için inovasyona, bilime, araştırma-geliştirme faaliyetlerine hız verilmesi gerekmektedir. Ülkelerin gelişmişlik düzeylerinin belirleyicilerinden biri Ar-Ge diğeri ise inovasyondur. Bu noktada Ar-Ge ve inovasyon harcamaları, inovasyon, eğitim, altyapı, sağlık gibi toplumsal kurumların gelişmesinde ülkelerin kalkınmasında önem taşımaktadır.

1980'li yıllardan sonra ekonomide etkili olan öğeler bilgi birikimi, öğrenme ve teknoloji olmuştur. Kalkınma için inovasyonun, öğrenmenin ve bilgi birikiminin önemi anlaşılmıştır. Türkiye ve bölgelerinde inovasyonun sağlanması için ulusal ve bölgesel sistemlerin ve yeni teknolojilerin geliştirilmesine çalışılmaktadır. İnovasyon ile üniversiteler ve araştırma-geliştirme merkezleri bilginin çeşitli kuruluşlar arasında yayılımını sağlayarak, beşeri, fiziksel ve finansal sermaye etkinliğini artırarak, kalkınmanın gelişimine katkıda bulunulmaktadır. Bu açıdan kalkınmada inovasyonun ve Ar-Ge'nin tüm dünyada olduğu gibi Türkiye'de önemi giderek artmaktadır.

\section{Ar-Ge, İnovasyon ve Kalkınma}

Ar-Ge, bilimsel ve teknik bilginin yeni uygulamalarda kullanımı olarak ifade edilmektedir. Ar-Ge günümüzde her türlü iktisadi çalışma alanlarına konu olmakla birlikte üretim ve üretim tekniği ile ilgilidir. Ar-Ge, amacı ve niteliği yönünden etkinlikte, ekonomide, verimlilikte artış yaparak daha iyiye ve faydalıya ulaşmayı sağlayan bir araçtır (Mucuk, 1998). Ar-Ge harcamaları, yeni bilgilerin üretilmesi aşamasında ölçeğe göre artan getiri sağlamaktadır. Ölçeğe göre artan getiri sağlamasının nedeni ise, bilginin yalnızca nihai bir öğe değil aynı zamanda yeni bilgilerin üretilmesi noktasında temel girdi özelliğine sahip olması ve tüketilemez özelliğinden dolayı her aşamada yeniden kullanılmasıdır (Eşiyok, 2004). İnovasyon ise, yeni ürün, hizmet ve yöntemlerini günümüzün 
rekabet toplumunda bilgiye dayalı olarak geliştirilerek bunun da ticari gelir elde etme amaçlı olarak desteklenmesidir (Dulupçu ve Sungur, 2007). İnovasyon kavramı ilk olarak Joseph Schumpeter (1934)'e göre kalkınmanın itici gücü şeklinde ifade edilmiştir. Schumpeter, 1934'te İngilizce'ye çevrilen "The Theory of Economic Development" adlı eserinde inovasyonu; yeni pazarların kurulması, hammaddelerin ve yarı mamullerin karşılanması için yeni kaynakların ortaya çıkarılması ile sanayinin yeni organizasyona kavuşması olarak ifade etmiştir (Elçi ve Diğ., 2008). 1900'lü yılların başlangıcından itibaren inovasyon kavramı gelişmiş ülkelerin gündem konusu olmuştur (Arbak ve Bulut, 2012). İnovasyon, hızlı teknolojik gelişim ve küreselleşme süreçlerinin etkisiyle 1990'lı yıllardan itibaren iş dünyası ve devlet yönetimine hakim olan temel küresel fikir ve faaliyet süreçlerinden en önemlisi olmuştur. İnovasyon, başkalarının yaptıklarını izlemek yerine yeni bir düşünceyi zamanında rakiplerinden daha farklı ve hızlı bir şekilde geliştirerek onu uygulamaya geçirmektir (Tosunoğlu, 2003). Ülkelerin ve işletmelerin amacı günümüzde hizmet ve ürün çeşitliliğinden faydalanarak yenilikler ortaya çıkarmak ve rakiplerine karşı önde olmak için faaliyette bulunmaktır. Böylece üreticiler en küçük katma değer ile olumlu kazanımlar elde etmiş olacaktır. Bu katma değeri yaratan kavramlar günümüzde Ar-Ge ve İnovasyondur (Erkek, 2011). İnovasyon, yeni ürünlere ve fikirlere yönelik olarak mevcut potansiyel üzerinde ilerlemeler sağlamaktadır. Ar-Ge ve teknoloji faaliyetleriyle inovasyon bütünleşerek girişimcilere sektörel yönden yeni olanak ve firsatlar dahilinde bir ülkenin veya bölgenin gelişmesine katkı sağlamaktadır (Recepoğlu ve Doğan, 2014). ArGe çalışmalarında, ülkelerin veya bölgelerin bilgi ve iletişim teknolojilerine yapılan yatırımlar ile ekonomik potansiyelleri göz önüne alındığında kişi başına düşen Ar-Ge harcamaları, Ar-Ge iş gücü, patent-marka tescil ve sayıları ile bilimsel yayın sayıları belirleyici olmaktadır.

"Kalkınma, herkesin temel hak ve temel sağlık, adalet, güvenlik, istihdam ve eğitim hizmetlerine ve bilgi kaynaklarına kolayca ulaşabildiği, piyasa koşullarının adil bir şekilde işlediği, katılımcı, cinsiyet dengeli, demokratik ve kültürel dönüşümlere açık, saydam/hesap verebilir yönetim yapılarına sahip, toplumsal anlamıyla tüm dezavantajlı grup ve tabakaların ortadan kalktığı, sorun çözme yeteneği gelişmiş, doğal kaynakları koruyan ve geliştiren, insanların geleceğe güvenle baktığı toplum ya da topluluklar yaratma eylemidir." (Açıkalın, Saltık, 2007). Kalkınma, üretimin ve kişi başına gelirin artırılmasıyla beraber azgelişmiş bir toplumda iktisadi ve sosyokültürel yapının da yenileştirilerek değiştirilmesidir (Han, Kaya, 2012). Kalkınma, bir ülkenin ekonomisinde belirli dönemler aralığında ortaya çıkan gelişme ve büyüme, üretilen ürünlerin kalitesinde, toplumun yaşam standartlarında ya da üretim mekanizmasında gelişmelerin yaşandığı ekonomik ortamı ifade etmektedir. Bir ülkede oluşan niceliksel ve niteliksel yönde gerçekleşen tüm pozitif yönlü ilerlemelerin bir arada yer almasıdır. Ülkelerin Gayri Safi Milli Hasılası (GSMH)'nın büyüklüğü niceliksel durum olurken; demografik yapı, gelir dağılımı, sosyal refah ise, niteliksel durum içerisinde değerlendirilir (Sevinç, 2011). Kalkınma, Ar-Ge ve inovasyon, toplumların her zaman üzerinde yoğunlaştığı ve tartıştığı konulardandır. Kalkınmada meydana gelen her büyük sıçramada, var olan inovasyonlardaki ilerlemelerle yeni inovasyonlar ortaya çıkmakta inovasyonlar kalkınmanın önemli bir tetikleyicisi konumuna gelmektedir (Işık ve Kılınç, 2012).

\section{Kalkınma ve İnovasyon Arasındaki İlișkiye Yönelik Bölgesel Yaklaşımlar}

Kalkınma ve inovasyon arasındaki ilişkiye yönelik yaklaşımlar, mezo ve makro düzeyde ele alınmıştır. Mezo düzeyde ele alınan yaklaşımlar; yeni sanayi odakları, öğrenen bölgeler, inovatif çevreler, bölgesel inovasyon sistemi, endojen bölgesel kalkınma, bölgesel rekabet edilebilirlik iken makro düzeyde; Schumpeterci kalkınma yaklaşımı, tekno-ekonomik paradigma, yeni Schumpeterci yaklaşım, yeni gelişim teorisi ve ulusal inovasyon sistemidir (Işık ve Kılınç, 2012). Mezo düzeyde yaklaşımlar, bölgesel, ulusal ve sektörel inovasyon sistemleri ile birlikte açıklanarak birbirlerinin tamamlayıcısı niteliğindedir (Tutar ve Diğ., 2013). 1970'li yıllarda enerji fiyatlarında meydana gelen bunalımlar sonucunda Batılı ülkeler başta olmak üzere geleneksel sanayi bölgelerinde yapısal problemler yaşanmıştır. Kırsal az gelişmiş bölgeler hızlı bir sanayileşme sürecine girerek yeni sanayi odakları ortaya çıkmıştır. Yeni sanayi odakları yüksek teknolojiye dayalı sektörlerle birlikte geleneksel emek yoğun sektörlerde de gelişme göstererek dünya piyasalarına girme şansını yakalamıştır. Kitle üretim yerine işletmelerin esnekliği ön plana çıkmıştır. Yeni sanayi odaklarıyla birlikte bölgesel bazlı üretimin ileri teknolojili piyasalarda rekabet edebilmesiyle yaratıcılık-buluşçuluk kapasitesiyle bu kalkınma merkezleri diğerlerinden ayrılır (Özgür, 2010). Bilgi altyapısı, kurumsal altyapı, üretim altyapısı, müşteri ve talep yapısı bölgelerin öğrenme kapasiteleri üzerinde belirleyici olmaktadır. Başarılı bir bölgesel öğrenmenin gerçekleşebilmesi için bu öğelerin karşılıklı etkileşim göstererek öğrenmeyi kalkınmanın anahtarı sayarak işletmelere destek olmalıdırlar (Albeni ve Karaöz, 2003). İnovatif çevre, kaynakların optimum kullanımına katkı sağlayan, çevresel etkenleri azaltmayı ya da önlemeyi hedefleyen çevreci inovatif ürünler, teknikler, süreçler ve hizmetler olarak ifade edilmektedir (Vatan ve Zengin, 2014). Rennings ve Ramner (2010)'a göre, inovatif çevrenin tanımları incelendiğinde üç özelliğin ön plana çıktığını belirtmişlerdir. Bunlardan ilki inovatif çevrenin dünya ve pazar için yeni olmayıp yalnızca o işletme için yeni olmasıdır. İnovatif çevre bu noktada yeni bir enerji, tasarruf teknolojisinin kabul gördüğü artımsal inovasyon olarak da ifade edilmektedir. İkincisi, inovatif çevrenin yeni süreç ve ürünlerin geliştirilmesi gibi öncelikli bir hedefi olması önem taşımamaktadır. Üçüncüsü ise, ortaya çıkan inovasyonların alternatifleri ile karşılaştırıldığında çevre yönünden yararlı olmasıdır (Yiğit, 2014 aktaran Rennings ve Rammer 2010). Endojen bölgesel kalkınma, yerel kaynaklara, yerel kaynakların endojen dinamiklerine ve bölgesel özelliklere önem veren 
kalkınma stratejisidir (Muehlinghaus ve Dĭ̆., 2001 aktaran Çetin, 2005). Endojen yani içsel büyüme ve gelişme teorileri uzun süreli, kalıcı büyüme ve gelişmenin arkasındaki unsurun teknolojik değişim ve know-how olduğu söylemine dayanmaktadır (Ar-Ge ve İnovasyon Strateji Belgesi, 2014). Endojen bölgesel kalkınmada önemli olan konu yerel aktörler ve diğer dinamiklerin organize edilmesiyle bölgenin gelişmesi, kalkınabilmesi için gerekli spesifik kaynaklarla orijinal çözümler üretilmelidir. Bunun için cazibe merkezleri oluşturularak yeni modeller geliştirilmelidir (Aktakas, 2006). Rekabet gücü, bir ülkenin daha yüksek yaşam koşullarına ve reel gelir seviyesine ulaşabilmesi iken; bölgesel rekabet gücü ise, bir bölge veya şehrin ulusal özellikle de ihraç pazar payında diğer bölge ve şehirlerle yaptığı rekabetteki başarısıyla beraber yüksek ve sürdürülebilir gelir düzeyi sağlayabilme yeteneğidir (Kumral, ve Diğ., 2011). Bu açıdan az gelişmiş bölgelerin uzun vadede büyümelerinin ve gelirinin artırılması için beşeri ve fiziki sermayeye yatırım yapılmalı, bölgeler arası gelişmişlik farkları en aza indirgenerek bölgelerin tümüne rekabet gücü kazandırılmalıdır. Bu bağlamda, Ar-Ge ve inovasyona sağlanan desteklerin artırılmasına, eğitim, sağlık, teknoloji, bilgi, enerji, ulaşım gibi temel altyapıların iyileştirilmesine, bölgenin ihtiyaçları doğrultusunda işgücü piyasasının sağlanmasına, başta KOBİ'ler olmak üzere yatırım destekleri ile firmaların geliştirilmesine ve yeni iş olanaklarının sağlanmasına çalışılmalıdır (Bayındırlık ve İskan Bakanlığı, 2009). İşletmelerin rekabet gücünü artırmak, inovasyona dayalı işletmelerle beraber vasıflı işgücünü yetiştirmek ve bölgeler arasındaki gelişmişlik farklarını makul seviyeye indirmek üzere faaliyet gösteren yöntem ve politikalar Bölgesel İnovasyon Sistemi (BİS) olarak ifade edilir (Işık ve Kılınç, 2011). BİS, inovasyon becerisinin birbirini destekleyen öğrenme süreçleriyle bütünleşerek arz ve taleple desteklenmesi sonucunda gelişir. İnovasyon becerisi, bölgesel kalkınma çabaları ile birlikte teknolojik farklılaşmadan faydalanma, kurumsal ilerleme, bölgesel rekabet üstünlükleri yaratma ve bölgesel beraberliği artırma kapsamında yürütülerek BİS ile desteklenmelidir (Durgut, 2007). BİS, Ulusal İnovasyon Sistemleri (UİS) gibi başarılı olması ve aktif bir şekilde belirlenip uygulamaya konulabilmesi için özel sektör, kamu sektörü ve üniversiteler olmak üzere üç birime ihtiyaç duymaktadır. Bu üç birim üçlü sarmal modeli ile adlandırılmakta olup modelde yer alan üniversiteler, bölgedeki firmaların ihtiyaçları doğrultusunda insan gücünü yetiştirir, bölgedeki farklı kaynaklardan faydalanarak araştırmanın sonucunu ticari boyuta taşır ve bölgedeki işletmelerle işbirliğine girerek Ar-Ge çalışmalarını yürütürler. Bölge işletmeleri ise, işbirliğine, etki alanının genişletilmesine, yeni bilginin üretilmesine ve inovasyon için kullanılmasına yönelik öneminden bahsetmektedir. Kamu sektörü de, yeni işletmelerin inovasyona yönelik olarak kurulmasını teşvik edici ortamın oluşturulmasına zemin hazırlayarak özel sektörle üniversitelerin birlikte etkileşim içerisinde çalışmasını sağlamaktadır. Böylece, inovasyonu destekleme, teknoloji geliştirme ve araştırma faaliyetleri bölgedeki işletmelerin gereksinimleri doğrultusunda tasarlanıp uygulamaya konulmaktadır. Araştırma merkezleri ve üniversitelerin işbirliğiyle bölgesel ve yerel düzeyde de kamu satın alımlarıyla işletmelerin inovasyon faaliyetleri desteklenmiş olur (Elçi ve Diğ., 2008).

\section{Türkiye'de Ar-Ge ve İnovasyon}

Türkiye'de inovasyona yönelik politikaların, bilim ve teknoloji politikaları kapsamında ilk kez ele alınması ve ana hedefinin benimsenmesi Yedinci Beş Yıllık Kalkınma Planı ile gerçekleşmiştir. Planda belirtilen inovasyona yönelik politika ve amaçlar "Türk Bilim Teknoloji Politikası (1993-2003)" ile "Bilim ve Teknolojide Atılım Projesi (1995)" olmak üzere iki kısımda ele alınarak şekillendirilmiştir. 1997 yılında inovasyonu merkez alan bilim ve teknoloji politika belgesini, Bilim ve Teknoloji Yüksek Kurulu (BTYK) onaylamıştır. 1960'lı yıllarda planlı dönemlere geçilmesiyle kurumsal yapılanma, 1963 yılında Türkiye Bilimsel ve Teknik Araştırma Kurumunun (TÜBITAK) kurulmasıyla Türk inovasyon politikası şekillenmeye başlamıştır (Elçi, 2006).

Ar-Ge çalışmalarına 2000'li yıllardaki kalkınma döneminde ağırlık verilmiştir. Bu yıllardan sonra stratejik politikalara yönelmekle birlikte, üniversiteler ve özel sektör bu konuda özendirilmiş, çeşitli farkındalık ve teşvik mekanizmaları devreye girmiştir. Özellikle TÜBITTAK kaynaklı olmak üzere çok çeşitli finansal destek programlarıyla Ar-Ge ve inovasyonda hız kazanan Türkiye'de aynı zamanda nitelikli insan gücünün sağlanması amacıyla TÜBİTAK Bilim İnsanı Destekleme Dairesi Başkanlığı (BİDEB) tarafından çalışmalar başlatılmıştır. Alanında eğitim almış nitelikli personelin toplam istihdamdaki payı bilim ve teknolojide gelişimin temelini oluşturmuş, ülkenin Ar-Ge ve inovasyon gücünü yansıtan önemli göstergeleri haline gelmiştir. Türkiye 2002 yılından sonra, bilim ve teknoloji politikalarını inşa etmek için TÜBİTAK'ın desteğiyle Vizyon 2023 Projesi'ni uygulamaya koymuştur. Türkiye bu dönemden sonra ulaştığ 1 istikrar ve uyguladığı başarılı reformlar sonucunda birçok makroekonomik yapıda iyileştirmeler sağlamıştır (Karagöl ve Karahan, 2014). Makroekonomik yapıda iyileştirmelerin sağlanabilmesi için Türkiye'nin Vizyon 2023 doğrultusunda, kişi başına milli geliri 25 bin \$, milli geliri 2 trilyon dolar, ihracat hacmini 500 milyar \$, işsizliği \%5 seviyesine çekme, Ar-Ge'nin GSYH içerindeki payını \%3'ler seviyesine çıkarmaya yönelik hedefleri yer almaktadır.

Ar-Ge konusunda Türkiye birçok dünya ülkesini geriden takip etmektedir. Ama son y1llarda teşvikler, vergi indirimleri, 9. Kalkınma Planı doğrultusunda gerçekleştirilen faaliyetler sonucunda küreselleşmeyi yakalamaya ve rekabet edilebilirliğini muhafaza etmeye çalışmaktadır. Buna bağlı olarak üniversite ve sanayi işbirlikleri geliştirilmektedir (Erkek, 2011).

\begin{tabular}{|c|c|}
\hline Y1llar & Oran(\%) \\
\hline 2008 & 0.73 \\
\hline
\end{tabular}




\begin{tabular}{|l|l|}
\hline 2009 & 0.85 \\
\hline 2010 & 0.84 \\
\hline 2011 & 0.86 \\
\hline 2012 & 0.92 \\
\hline 2013 & 0.95 \\
\hline 2014 & 1.01 \\
\hline
\end{tabular}

Tablo 1: Gayri Safi Yurtiçi Ar-Ge Harcamasl/GSYH Kaynak: TÜIK (Türkiye Istatistik Kurumu), 2014.

Türkiye'de Ar-Ge harcamalarının GSYİH'ye oranı yıllar itibarıyla gösterilmiştir. Tablo 1'e göre Ar-Ge harcamalarının GSYİH'ye oranı 2008 yılında 0.73 iken 2014 yılında Ar-Ge harcamalarının GSYİH'ye oranının 1.01 seviyesine yükselmesi Ar-Ge'ye verilen önemin gittikçe arttığını göstermektedir. Tablo'dan da görüldüğü gibi son 10 yılda ekonomi ve sanayi politikalarında AR-GE ve inovasyonun ağırlığı belirgin bir şekilde artmıştır. Son yıllarda gittikçe artış gösteren AR-GE ve inovasyon faaliyetleri Türkiye'nin ekonomik kalkınma üzerinde de olumlu etkileri de göstermektedir. Hem insanların bilgi dağarcığında var olan, hem de teknolojik altyapıda mevcut olan Ar-Ge çalışmaları, ekonomik gelişme için her zaman büyük bir öneme sahip olmuştur. İleri teknoloji endüstrilerindeki büyüme ve gelişmelerde görüldüğü gibi ekonomik faaliyetler daha çok Ar-Ge'ye dayalı olmaya başlamıştır. AR-GE, eğitim-öğretim ve inovasyon ve bilgiye yapılan yatırımların ekonomik büyüme ve kalkınmanın anahtar niteliğinde olduğunu göstermektedir.

\begin{tabular}{|l|c|c|c|}
\hline & $\begin{array}{c}\text { Yenilik Ciro } \\
\text { (Toplam Ciroya Oran1) }\end{array}$ & Sanayi & Hizmetler \\
\hline 2004 & 27 & 28 & 25 \\
\hline 2006 & 37 & 53 & 18 \\
\hline 2008 & 40 & 40 & 39 \\
\hline 2010 & 28 & 34 & 21 \\
\hline
\end{tabular}

Tablo 2: Yenilik Ciro’nun Sektörel Dağılımı (Toplam Ciro'ya Oranı) Kaynak: www.tuik.gov.tr, Erişim Tarihi: 20 Mayls 2016.

Ülkemizde sanayi-tarım-ihracat bağlantısının, olması gereken düzeyde kurulmamış olduğu ve yüksek katma değerli malların ihracat içinde oldukça düşük kaldığı görülmektedir. Tarım sektörü geri plana atılıp sanayi ve hizmet sektörü üzerine yoğunlaşarak bu sektörlerde ürünler ve yenilikler yapılmaktadır. Türkiye'nin kalkınmasını engelleyen dezavantajlardan biriside tarım sektörünün de inovasyonun gerçekleştirilememesidir. Coğrafi koşullar olarak tarım sektöründe gelişmeye çok uygun fakat olan ülkemizde bu alanlarda verimli şekilde inovasyon sistemleri kullanılamamaktadır.

\section{Türkiye ve Bölgelerinin Ar-Ge ve İnovasyon Verileri}

Türkiye'nin Ar-Ge harcamaları, insan gücü, bilgi yoğun sektörlerdeki istihdamı, yüksek teknolojili ürünlerin ihracatı, fikri mülkiyet hakları, patent-marka tescil ve sayıları gibi göstergeleri inovasyon, teknoloji ve bilim alanındaki en önemli bileşenlerini oluşturmaktadır.

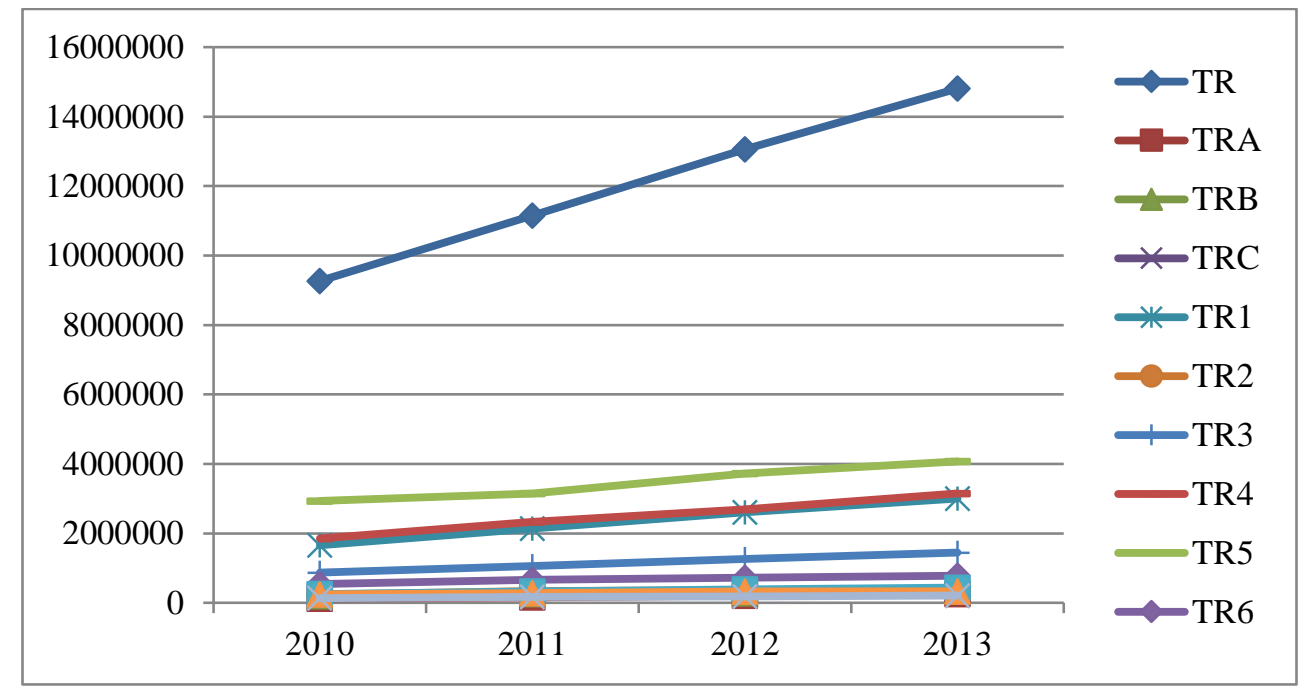

Grafik 1: Gayri Safi Yurtiçi Ar-Ge Harcamaları (1000 TL) Kaynak: TUIK, www.tuik.gov.tr, Erişim Tarihi: 20 Mayls 2016. 
Tüik'den, Düzey-1 Bölgeleri: TRA (Kuzeydoğu Anadolu), TRB (Ortadoğu Anadolu), TRC (Güneydoğu Anadolu), TR1 (İstanbul), TR2 (Bat1 Marmara), TR3 (Ege), TR4 (Doğu Marmara ), TR5 (Bat1 Anadolu), TR6 (Akdeniz), TR7 (Orta Anadolu), TR8 (Batı Karadeniz), TR9 (Doğu Karadeniz), olarak oluşturulmuştur (www.tuik.gov.tr, Erişim Tarihi: 20 Mayıs 2016).

Grafik-1'de, Türkiye ve bölgelerinin Gayri Safi Yurtiçi Ar-Ge harcamaları gösterilmiştir. Türkiye'nin Gayri Safi Yurtiçi Ar-Ge harcamaları 2010 yılında 9 milyon bantlarında iken; 2013 yılında 14 milyonun üzerinde seyretmiş olup her yıl düzenli bir şekilde artış göstermiştir. Grafikte TR9 (Doğu Karadeniz), TR8 (Batı Karadeniz) ve TRA (Kuzeydoğu Anadolu)'da Arge harcamaları en düşük seviyede iken; Arge harcamalarının en yüksek olduğu bölgeler TR5 (Batı Anadolu), TR4 (Doğu Marmara) ve TR1 (İstanbul)'dir.

2013 yılında Ar-Ge çalışmalarına yönelik yapılan araştırma sonuçlarına göre, Gayri Safi Ar-Ge harcamalarının kamu sektörü içerisindeki payı \%10,4, yükseköğretim kurumları içerisindeki payı \%42,1 ve özel sektördeki payı da \%47,5 olarak gerçekleşmiştir. Bu yıl içerisinde, özel sektör Ar-Ge harcamalarının \%48,9'u, \%26,6’sı kamu sektörü, \%20,4’ü yükseköğretim, \%3,3’ü yurtiçi diğer kaynaklar, \%0,8'inin de yurtdışı kaynaklar tarafından finansmanı sağlanmıştır (www.tubitak.gov.tr, erişim tarihi: 19.10.2015).

Türkiye ve bölgelerinin Ar-Ge çalışmalarında istenilen performansa ulaşabilmesi için özel sektör Ar-Ge yatırımlarına hız kazandırması gerekmektedir.

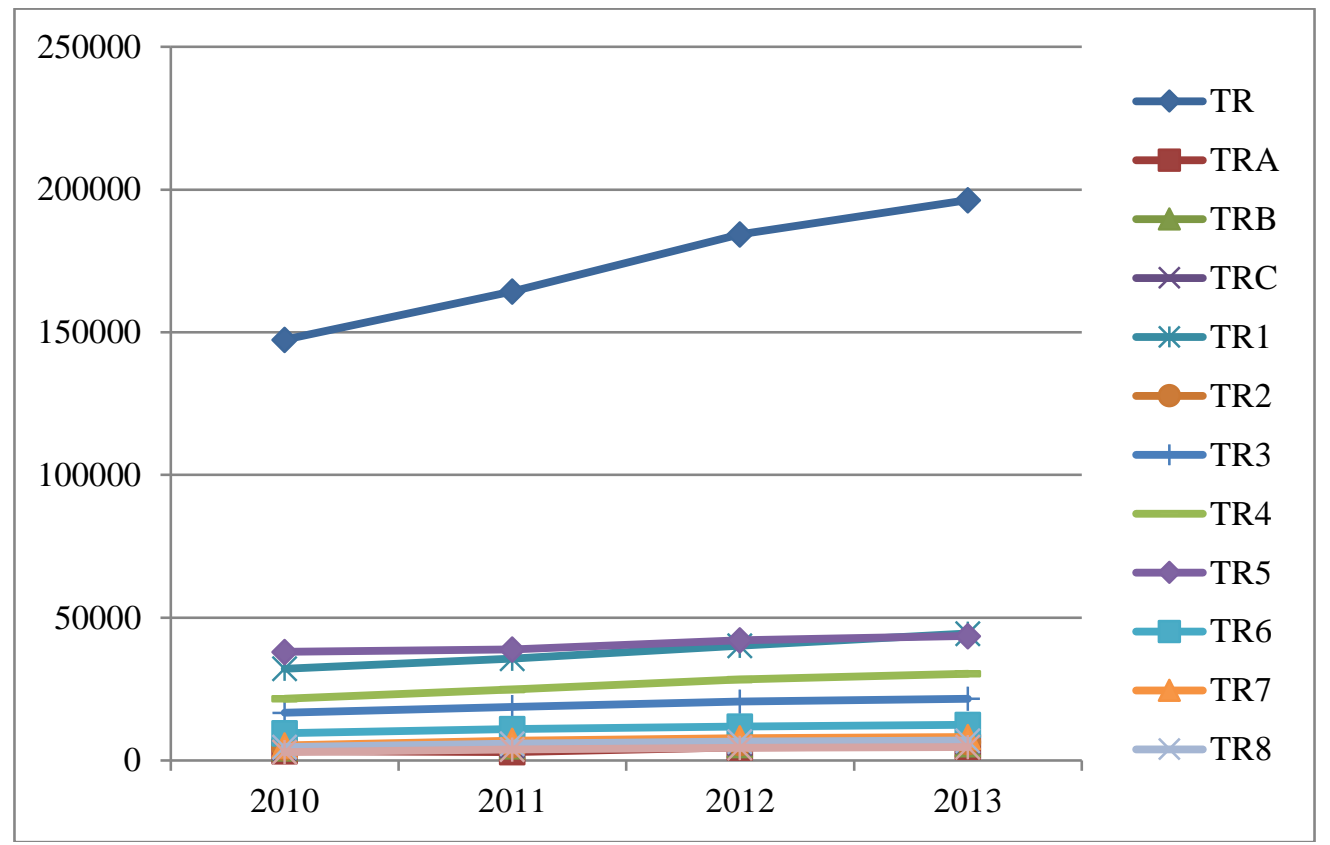

Grafik 2: Ar-Ge'de Yer Alan Kişi Sayısı Kaynak: TUIK, www.tuik.gov.tr, Erişim Tarihi: 20 Mayıs 2016.

Grafik-2'de, Türkiye ve bölgelerinin Gayri Safi Yurtiçi Ar-Ge harcaması içerisinde insan gücünün etkisi gösterilmiştir. Türkiye'nin Ar-Ge'de yer alan kişi sayısının 2010 yılındaki bant aralığı 147 bin kişi iken; 2013 yılında 196 bin kişiye yükselmiş olup her yıl düzenli bir şekilde artış göstermiştir. Türkiye'nin Düzey-1 bölgelerinin Ar-Ge'de yer alan kişi sayısı da 0-50 bin bant aralığında seyrederek düzenli bir şekilde artış göstermektedir.

Bir ülkede bilime verilen önem ve desteğin en önemli göstergelerinden biri de Ar-Ge sektöründe çalışan insan gücünün genel istihdam içerisinde aldığı paydır. İnsan gücü Ar-Ge çalışmalarının yapı taşını oluşturmaktadır. Rekabet üstünlüğünün ele geçirilmesi, Ar-Ge çalışmalarının başarılı bir şekilde yürütülmesi ve etkin sonuçlara ulaşılması için bir ülke, firma ya da bölgenin nicelik ve nitelik açısından daha fazla Ar-Ge'de insan gücü çalıştırması gerekmektedir (Ünal ve Seçilmiş, 2013). 


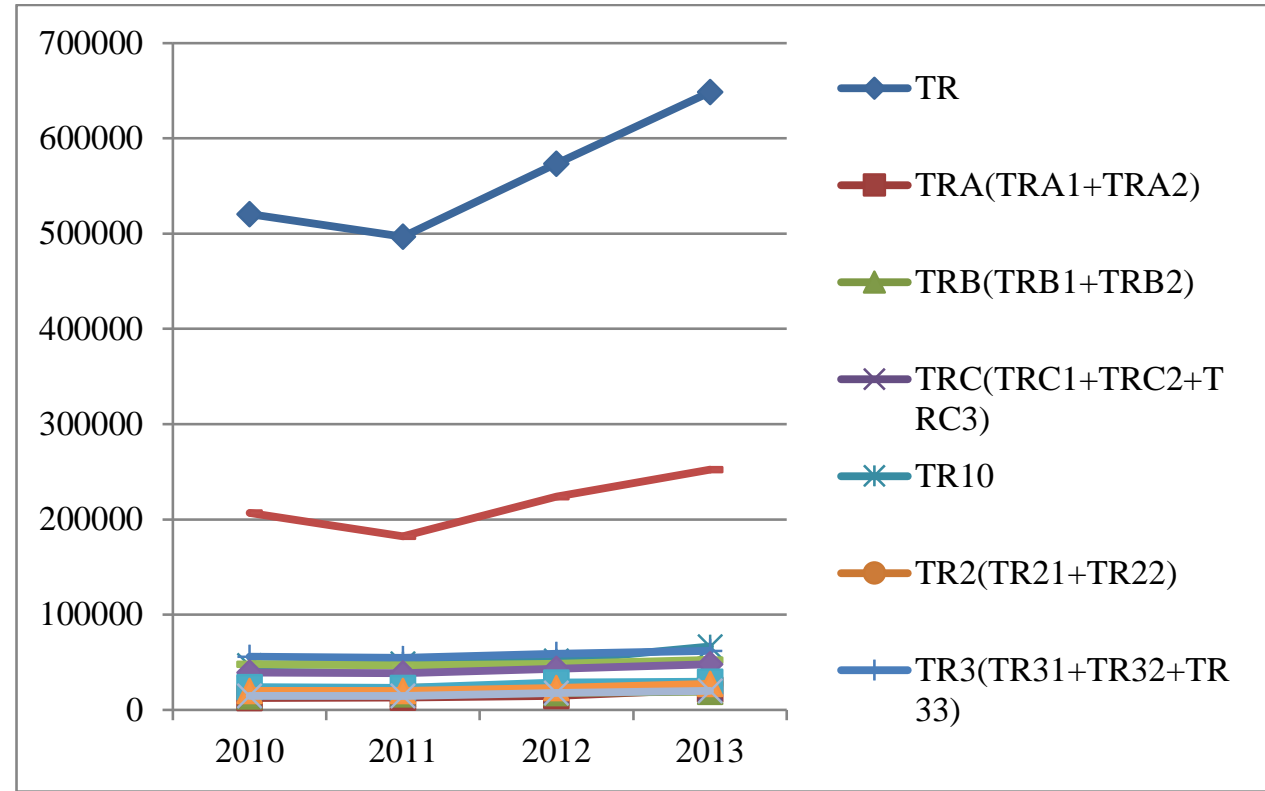

Grafik 3: Türkiye ve Düzey-2 Bölgelerinin Yüksekögretimde Mezun Sayısı Kaynak: TUIK, www.tuik.gov.tr, Erişim Tarihi: 20 Mayıs 2016.

Grafik-3’te, 2010-2013 yılları aralığında Türkiye ve Düzey-2 bölgelerinin yükseköğretimden mezun sayısı gösterilmiştir. Türkiye'nin yükseköğretimden mezun sayısı 2011 yılından itibaren sürekli artış göstermiş̧tir. Bölgeler içerisinde yükseköğretimden mezun sayısı en fazla olan bölge TR4 (Doğu Marmara) bölgesi olup diğer Düzey-2 bölgeleri 0-100 bin bantları aralığında yükseköğretimden mezun vermiştir. Kalkınmanın ve inovasyonun sağlanabilmesi için bölgelerimizde üniversitelerin kurulmasına hız kazandırılarak nitelikli insan gücünün ihtiyaç duyduğu eğitime, araştırma-geliştirme çalışmalarına, bilime önem verilmelidir.

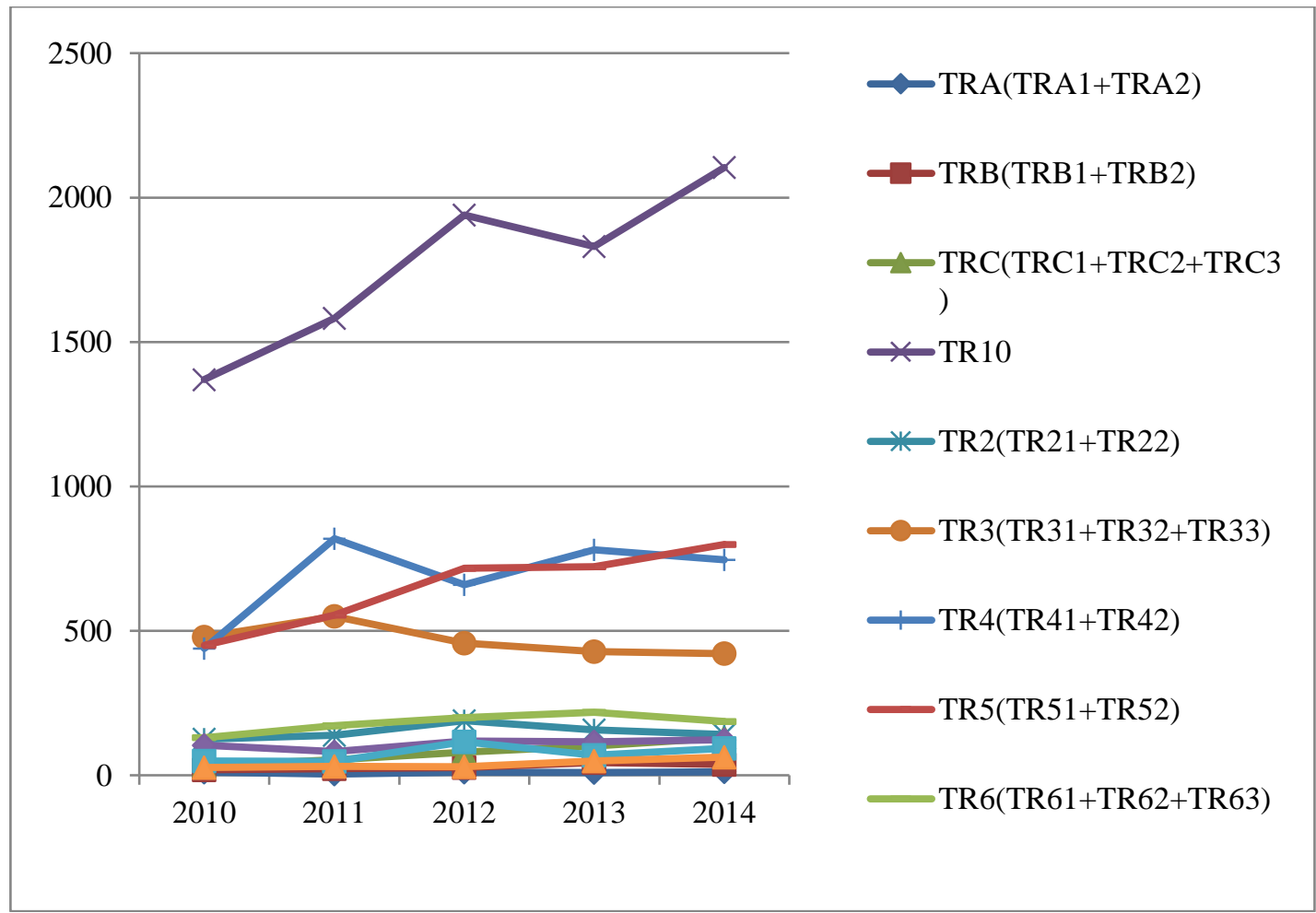

Grafik 4: Düzey-2 Bölgelerinin Patent Başvuru Sayısı Kaynak: TPE, www.tpe.gov.tr, Erişim Tarihi: 29.01.2016.

Düzey-2 bölgelerindeki illerin patent tescil ve sayısı bölge düzeylerinde ayrı ayrı toplanarak oluşturulmuştur (TPE, www.tpe.gov.tr, erişim tarihi: 29.01.2016). Patent, yeniliğe, buluşa ve sanayiye uygulanabilirliktir (TPE, 2014: 5). Ülkenin ve bölgenin inovasyon potansiyelini yansitan patent sayısı, ülkede ve bölgede ne kadar yeni buluş yapıldığının göstergesidir. Ar-Ge'nin başarısı bu noktada bir ülke ve bölgede patent sayısının çok olması ile ilgilidir (Seçilmiş ve Ünal, 2013: 18). Grafik-4’te, patent başvuru sayısı Düzey-2 bölgeleri kapsamında 2010-2014 
yılları arasında değerlendirilmiştir. Patent başvuru sayısının en fazla olduğu bölge TR10 (İstanbul) bölgesi olup bunu TR51(Ankara), TR41 (Bursa, Eskişehir, Bilecik) ve TR31 (İzmir) takip etmiştir. TR10 (İstanbul) bölgesindeki patent başvuru sayısı diğer bölgelerdeki patent başvuru sayısından fazla olup aradaki fark açılmaktadır.

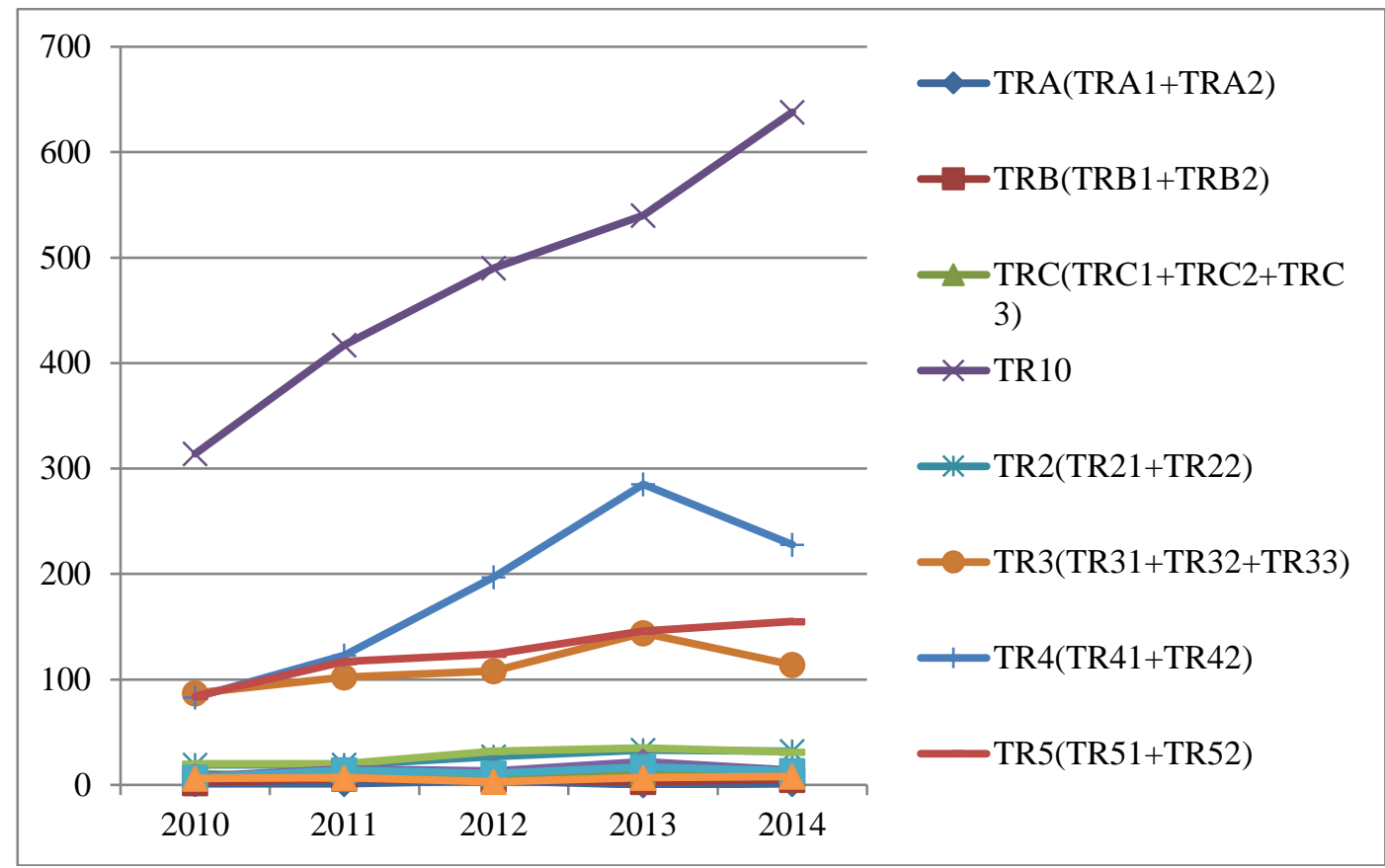

Grafik 5: Düzey-2 Bölgelerinin Patent Tescil Sayısı Kaynak: TPE, www.tpe.gov.tr, Erişim Tarihi: 29.01.2016.

Grafik-5'te, Düzey-2 bölgelerinin 2010-2014 yılları aralığında patent tescil sayısı gösterilmiştir. Patent tescil sayısının en fazla olduğu bölge TR10 (İstanbul)'dur. Patent tescil sayısını daha sonra TR41 (Bursa, Eskişehir, Bilecik), TR42 (Kocaeli, Sakarya, Düzce, Bolu, Yalova), TR51 (Ankara) ve TR52 (Konya, Karaman) takip etmiştir.

\section{Sonuc}

Kalkınma, teknoloji ve üretimde meydana gelen gelişmelerle beraber ortaya çıan toplumsal ve iktisadi gelişmeleri kapsamaktadır. Kalkınma, gelir dağılımındaki iyileşmeyle birlikte dağılımda adaleti de içermektedir (Arslan, 2013). Gelir dağılımının daha adil ve eşit dağılması, Türkiye'de ele alınması gereken konulardandır. Bunun için yatırımların, üretimin ve istihdamın artırılmasına çalışılmalıdır.

Türkiye'de inovasyon verileri içerisinde Gayrisafi Ar-Ge harcamaları ve Ar-Ge'nin insan gücünde önde olan bölgeler TR5 (Batı Anadolu), TR4 (Doğu Marmara) ve TR1 (İstanbul)'dir. Bu bölgeler diğer bölgelere göre kalkınmanın sağlanması aşamasında diğer bölgelere göre daha iyi performans göstermiş̧ir. Bu bölgeler teknolojide, bilimde diğer bölgelere göre daha iyi konumdadır. Ar-Ge harcamaları kalkınmanın sağlanması hususunda önem taşımaktadır.

Türkiye'nin bölgeleri içerisinde patent başvuru ve tescil sayılarında da TR1 (İstanbul), TR4 (Doğu Marmara) ve TR5 (Batı Anadolu) diğer bölgelere göre daha iyi konumdadır. Patent başvuru ve tescil sayısının en az olduğu bölgeler ise, TRA (Kuzeydoğu Anadolu), TRB (Ortadoğu Anadolu), TR9 (Doğu Karadeniz)'dur. Bu bölgelerde inovasyon faaliyetleri bölgelerarası gelişmişlik farklarının olması nedeniyle istenilen düzeyde gerçekleşememiştir. $\mathrm{Bu}$ yüzden inovatif çalışmaları hızlandırmak ve bölgeler arası gelişmişlik farklarını azaltmak için kalkınma planları hazırlanmalıdır. Türkiye'nin inovasyon verilerinden olan insan gücü, altyapı, bilimsel yayınlar, patent ve markalar aynı zamanda Türkiye'nin kalkınma verilerini de oluşturmaktadır. Türkiye'de bölgeler arasındaki dengesizlikler ciddi boyutta olup bu inovasyon verilerinde iyileştirmeler yaparak bölgeler arasındaki dengesizlikler giderilmeye çalışılmalıdır. Bu nedenle inovasyon, Ar-Ge, insan kaynakları, yüksek teknolojili ürünlerin ihracatı gibi inovasyon bileşenlerini geliştirmeye yönelik çalışmalara hız kazandırılmalıdır.

İnsan kaynakları, inovasyonun ve kalkınmanın sağlanmasında bir diğer bileşen olarak görülmektedir. Eğitim, vasıflı insan gücünün sağlanması açısından önem taşımaktadır. Bilgi ve teknolojinin hakim olduğu bir çağda üniversiteden mezun olan öğrencilerin sayısı artırılmalıdır. Nitelikli araştırmacı ve eğitimcilerin yetişmesi için üniversitelerin kaliteli eğitim ve araştırma çalışmalarını yürütmesi gerekmektedir.

Sonuç olarak Türkiye'yi ele aldığımızda, her bölgede araştırma-geliştirme çalışmalarının, inovasyonun, kalkınmanın farklı olduğu görülmektedir. Bölgeler arasında insan kaynaklarının, teknolojinin ve bilginin istenilen 
düzeyde geliştirilemediği, kaynakların etkin dağılmadığı görülmektedir. Bölgeler arasında gelişmişlik farklarının olması inovasyonun, kalkınmanın, araştırma geliştirme çalışmalarının yavaşlamasına neden olmaktadır. Ulusal ve bölgesel inovasyon sistemlerinin oluşturulması için, kalkınmanın, büyümenin, yaşam standartlarının, refah seviyesinin yükseltilmesi gerekmektedir. Ülkelerin ve bölgelerin refahını ve yaşam standardını artırmanın yolları Ar-Ge ve inovasyondan geçmektedir. Böylece kalkınmanın sağlandığı ülkelerde ve bölgelerde Ar-Ge ve inovasyon faaliyetleri daha çok etkili olacak ve gelişme sağlanacaktır.

\section{Kaynakça}

- Açıkalın, O. Saltık, A. (2007). “Kalkınmada Yeni Kavram ve Stratejiler”. Sosyoloji Araştırmaları Dergisi, 2007/1, 5-27.

- $\quad$ Albeni, M. ve Karaöz, M. 2003. "Bölgesel Kalkınmada Öğrenme, Bilgi Birikimi ve Yenilik: Türkiye İçin Bir Perspektif”, Süleyman Demirel Üniversitesi İktisadi İdari Bilimler Fakültesi, Cilt: 8, Sayl: 2, s. 157-170, 163-164.

- Aktakas, B. G. 2006. Bölgesel/Yerel Kalkınma, Bölgesel Gelişme İçin Bir Model, Çukurova Üniversitesi, Yüksek Lisans Tezi, Adana, s.39.

- $\quad$ Arbak, H. ve Bulut, Ç. 2012. "Yenilik- Yenilişim-İnovasyon Dünyasına Bir Yolculuk, İnovasyon, Direnç ve İletişim: Kavramsal Bir Tartışma”, Yaşar Üniversitesi, Sosyal Bilimler Enstitüsü, İzmir.

- http://www.egiad.org.tr/wp-content/uploads/arastirma-raporlari/inovasyonraporu.pdf, erişim tarihi: 26.01.2016.

- $\quad$ Arslan, G. E. 2013. “Ekonomik Büyüme, Kalkınma ve Gelir Dağılımı”, Hitit Üniversitesi Sosyal Bilimler Enstitüsü Dergisi, Yıl: 6, Sayı: 2, ss. 47.

- Bayındırlık ve İskan Bakanlığı, 2009. Bölgesel Eşitsizlik, Yerel Kalkınma ve Rekabet Edebilir Kentler Komisyonu Raporu, Ankara, s.69.

- http://www.kentges.gov.tr/_dosyalar/sura_raporlari/kitap8.pdf, erişim tarihi: 26.01.2016.

- Çetin, M. 2005. "Endojen Bölgesel Kalkınmaya Farklı Bir Bakış", Erciyes Üniversitesi, İ.I.B.F. Dergisi, Say1: 24, s.1-3.

- Durgut, M. 2007. “Üniversite-Sanayi İşbirliğinin Bölgesel İnovasyon Sistemi Çerçevesi”. Erciyes Üniversitesi Kayseri Bilgi ve Araştırma Merkezi Sempozyumu. s.10.

- Dulupçu, M. A. ve Sungur, O. 2007. Yenilik, İşbirliği ve Girişimcilik, Batı Karadeniz Bölgesi (Antalya, Burdur, Isparta, IBBS TR61), KOBİ'lerin Tutumlarının Değerlendirilmesi. s. 8

- http://www.bagev.com/Static/Documents/UserUpload/yenilik_isbirligi_ve_girisimcilik.pdf, erişim tarihi: 10.06.2015.

- Elçi, Ş. 2006. İnovasyon: Kalkınmanın ve Rekabetin Anahtarı, Genişletilmiş Yeni Baskı, Ankara: Feryal Matbaacilik. s.87-88.

- $\quad$ Elçi, Ş., Karataylı, İ. ve Karaata, S. 2008. Bölgesel İnovasyon Merkezleri: Türkiye İçin Bir Model Önerisi. s. $25,39,40$.

- http://utikad.org.tr/db/files/TUSIAD\%20Bolgesel\%20Inovasyon\%20Merkezleri.pdf, erişim tarihi: 26.01.2016.

- Elçi, Ş. 2012. İnovasyon: Nedir, Ne Değildir? OSTİM Organize Sanayi Bölgesi

- http://www.ostim.org.tr/tr/informationcenterdetail/inavasyon-nedir-ne-degildir/85, erişim tarihi: 18.05.2014.

- $\quad$ Erkek, D. 2011. AR-GE, İnovasyon ve Türkiye Neredeyiz? s.30.

- http://geka.org.tr/yukleme/dosya/16f80581dc639ad5f68c7f3b891eccd0.pdf, erişim tarihi: 18.05.2014.

- $\quad$ Eşiyok, B. A. 2004. Türkiye'nin Kalkınma Sürecinde Teknoloji, Yenilik ve Bilişim Sektörü, Türkiye Kalkınma Bankası, Genel Araştırmalar, Ankara. S.24.

- Han, E. ve Kaya, A. A. 2012. Kalkınma Ekonomisi Teori ve Politika, Ankara: Nobel Yayınları, (7. Baskı). s.2.

- Işı1k, N. ve Kılınç, E. C. 2011. "Bölgesel Kalkınma'da Ar-Ge ve İnovasyonun Önemi: Karşılaştırmalı Bir Analiz”, Eskişehir Osmangazi Üniversitesi IIBFF Dergisi, Ekim 2011, Cilt:6, Sayı:2, s. 9-29.

- Işık, N. ve Kılınç, E. C. 2012."İnovasyon Güdümlü Kalkınma: Avrupa Birliği Ülkeleri ve Türkiye Üzerine Bir İnceleme”, Girişimcilik ve Inovasyon Yönetimi Dergisi, Cilt:1, Sayı: 1, s. 36,42.

- Karagöl, E. T. ve Karahan, H. 2014. Yeni Ekonomi Ar-ge ve İnovasyon, SETA Rapor, Say1: 82, s. 22-29.

- Kumral, N., Akgüngör, S. ve Güçlü, M. 2011. "Rekabet Gücü, Yaşam Kalitesi ve Yaratıc1lık: Türkiye Düzey 2 Bölgeleri”, 6. Bölgesel Kalkınma ve Yönetişim Sempozyumu Bildiri Kitabı, Ankara: TEPAV, s.33. 
- Mucuk, İ.1998. Modern İşletmecilik, İstanbul: Türkmen Kitabevi, (9. Baskı).s. 362.

- Mevlana Kalkınma Ajansı 2014. Ar-Ge ve İnovasyon Strateji Belgesi 2014, Konya-Karaman 2014-2023, Konya.s.13.

- Özgür, E. M. 2010.Bölgesel Kalkınma, Ankara Üniversitesi, Dil ve Tarih-Coğrafya Fakültesi, Coğrafya Bölümü Ders Notlar1, s.24-25.

- http://www.geography.humanity.ankara.edu.tr/ders_notu/COG323.pdf, erişim tarihi: 09.06.2014.

- Seçilmiş, N. ve Ünal, T. 2013. “Ar-Ge Göstergeleri Açısından Türkiye ve Gelişmiş Ülkelerle Kıyaslanması, İşletme ve İktisat Çalışmaları Dergisi, Cilt: 1, Sayı: 1, s. 17-18.

- Sevinç, H. 2011. "Bölgesel Kalkınma Sorunsalı: Türkiye'de Uygulanan Bölgesel Kalkınma Politikaları”, Girişimcilik ve Kalkınma Dergisi (6: 2). s.40.

- $\quad$ Recepoğlu, M. ve Doğan, K. C. 2014. "Bölgesel Kalkınmada Girişimciliğin ve Teknolojinin Yeri: TR 83 Bölge Analizi”, Gümüşhane Üniversitesi, Sosyal Bilimler Elektronik Dergisi, Sayı:10. s. 63.

- Tosunoğlu, B. T. 2003. Girişimcilik ve Türkiye’nin Ekonomik Gelişme Sürecinde Girişimciliğin Yeri, Doktora Tezi, Anadolu Üniversitesi Sosyal Bilimler Enstitüsü, Eskişehir. s.15-16.

- $\quad$ Tutar, F., Fırat, E., Erkan, Ç. ve Tutar, E. 2013. "Yerel Ekonomilerin Yeni Aktörü, Bölgesel İnovasyon Stratejileri: RIS Mersin Uygulaması”, Internatıonal Conference on Eurosian Economies.

- Vatan, A. ve Zengin, B. 2014. “Çevresel İnovasyon ve Konaklama İşletmelerindeki Uygulamalar Üzerine Bir Araştırma: İstanbul Örneği”, Akademik Sosyal Araştırmalar Dergisi, Yıl:2, Sayı: 8, ss. 511-517-530.

- Y Yiğit, S. 2014. "İnovasyonun Çevreci Yüzü ve Türkiye”, Celal Bayar Üniversitesi İIBF, Yönetim ve Ekonomi, Cilt: 21, Say1: 1, ss. 251-254.

- http://www.avekon.org/papers/726.pdf, erişim tarihi: 26.01.2016.s.628.

- $\quad$ https://www.tubitak.gov.tr, erişim tarihi: 19.10.2015.

- https://biruni.tuik.gov.tr/bolgeselistatistik/degiskenlerUzerindenSorgula.do, erişim tarihi: 29.01.2016.

- $\quad$ http://www.tpe.gov.tr/TurkPatentEnstitusu/statistics/, erişim tarihi: 29.01.2016.

- $\quad$ http://www.tuik.gov.tr/PreTablo.do?alt_id=1097, Erişim Tarihi: 20 Mayıs 2016. 


\title{
Yükselen Piyasalarda Ar-Ge ve İnovasyonun Kalkınma Üzerindeki Etkisi
}

\section{Influence of R\&D and Innovation on Development in Emerging Markets}

\author{
Esra Soyu (Aksaray University, Turkey) \\ Prof. Dr. Serdar Altınok (Gazi University, Turkey) \\ Asst. Prof. Dr. Emine Frrat (Aksaray University, Turkey)
}

\begin{abstract}
The concept of development has been interpreted in different ways from past to present. This concept was discussed previously on economic, social and cultural aspects; but now it has transformed into concepts like human capital, education, health, innovation, technological development and poverty. A country needs producing for development, and it is necessary to increase efficiency for obtaining profits from this production. At this point the inclination to $\mathrm{R} \& \mathrm{D}$ and innovation is increasing. Today, it is experiencing the transition of a new era. This process can be distinguished by technological change resulted from knowledge creation, innovation and R\&D. In addition to the production factors, knowledge and technology have become indispensable where the importance is increasing. R\&D and innovation are seen as factors which are increasing economic growth, prosperity and quality of life and which provide competitiveness and productivity growth between countries. In this study, R\&D and innovation activities are evaluated and their importance are highlighted in the issue of development for emerging markets. The increasing R\&D and innovation projects provided that resources are using more effectively and efficiently by contributing to the development of emerging markets. The purpose of this study is to determine the impact of R\&D and innovation on development by considering sample emerging markets economies and to make the attention of the scientific community focus on these issues.
\end{abstract}

\section{Giriș}

Gelişmiş ya da gelişmekte olan ülkelerin kalkınmalarında çeşitli farklılıklar görülmektedir. Kalkınmışlık farklılıklarının nedeni; doğal kaynakların yetersiz olması, hızlı nüfus artışı, yatırımların yetersiz oluşu, enerji kaynaklarına olan uzaklık, sanayileşmeyi tamamlayamama gibi faktörlerdir. Bu faktörlerin var olması insanların farklı standartlarda yaşamasına neden olmaktadır. Bazıları yoksulluk sınırında yaşarken bazıları da yüksek yaşam kalitesine sahiptir. Dünyada bu farklılıkları azaltabilmek için gerek ulusal gerekse uluslararası pek çok kuruluş çalışmakta ve projeler geliştirmektedir. Amaç; farklılığın getirdiği olumsuzlukları azaltabilmektir.

Ekonomide bir büyüme sağlayabilmek ülkeler açısından oldukça önemlidir. Küresel olguyla birlikte dünyada büyüme ile yenilik sayısı arasında bir ilişkiden söz edilmektedir. Ülkeler ekonomik anlamda rekabet edebilmek ve güçlerini devam ettirebilmek için hem Ar-Ge'ye hem de yenilik faaliyetlerine gereken önemin verilmesiyle mümkün olabildiği görülmektedir. Teknolojik anlamda ileri düzeyde olan ülkeler gelişmiş ülkeler olarak görülmektedir. Ayrıca teknoloji alanında yapılan gelişmeler ne kadar büyükse ekonomik büyüme de o derece artış göstermektedir (Uzun Kocamış ve Güngör, 2014). Gelişmekte olan ülkeler sürekli olarak refah seviyelerini artırma arayışı içinde olmuşlardır. Ancak bu arayışlarda uygulanan farklılıklar gelişme seviyelerinde kendini göstermiştir. Küreselleşmeyle birlikte inovasyon ve Ar-Ge toplumların gelişmişlik seviyelerini belirleyici kavramlar haline gelmiştir.

Küreselleşmeyle birlikte üreticiler pazar bulabilmek ve piyasada rekabet edebilmek için Ar-Ge ve inovasyona zorlanmaktadır. Bunun için ise son dönemlerde "Ar-Ge" ve "İnovasyon" terimleri sıkça kullanılmakta ve kalkınma aşamasında bunlara yapılan vurgu giderek artmaktadır.

Kalkınma kavramı ekonomik, sosyal ve kültürel yönleri ele alan geniş bir yelpazeye sahiptir (Fırat ve Aydın, 2015). "Kalkınma, herkesin temel hak, sağlık, adalet, güvenlik, istihdam ve eğitim hizmetlerine ve bilgi kaynaklarına kolayca ulaşabildiği, piyasa koşullarının adil bir şekilde işlediği, katılımcı, cinsiyet dengeli, demokratik ve kültürel dönüşümlere açık, saydam/hesap verebilir yönetim yapılarına sahip, toplumsal anlamıyla tüm dezavantajlı grup ve tabakaların ortadan kalktığı, sorun çözme yeteneği gelişmiş, doğal kaynakları koruyan ve geliştiren, insanların geleceğe güvenle baktığı toplum ya da topluluklar yaratma eylemidir" (Açıkalın ve Saltık, 2007). Aynı zamanda kalkınma kavramı, toplumların gelişim sürecine göre farklı içerikler kazanmıştır. Bu içerikte birbirine yakın anlamlar taşıyan sanayileşme, modernleşme, ilerleme, büyüme ve yapısal değişme gibi kavramlarla içiçe geçmiş, onların yerine kullanılmıştır (Yumuş, 2009).

Son zamanlarda hem firmalar hem de hükümetler inovasyon ve Ar-Ge faaliyetlerine daha çok ağırlık vermektedir. Ayrıca büyük firmalar Ar-Ge ye diğer departmanlardan daha fazla kaynak ayırma eğiliminde olmaktadırlar. Diğer yandan Ar-Ge faaliyetleri daha çok sanayileşmiş ülkelerde yoğun olarak görülmektedir 
(Akbey, 2014). Bu ülkelerin ekonomik yapılarında meydana gelen köklü değişimlerin ana kaynağını iletişim ve enformasyon teknolojileri oluşturmaktadır. Bu alandaki değişim hızla tüm dünyaya yayılmaktadır. Hem ekonomik hem de politik alanda meydana gelen değişimler piyasada rollerin değişmesine aynı zamanda sosyal ve kültürel bazda tüm dünya değerlerinin birbirine yaklaşmasına neden olmaktadır. Son zamanlarda yaşanan gelişmeler neticesinde teknoloji ve sermayenin hızla yer değiştirmesi yükselen ekonomiler olarak nitelendirdiğimiz devletlere çeşitli firsatlar sunmaktadır (Çivi ve Çavuşgil, 2001). İnovasyon ve Ar-Ge harcamalarının göstergeleri yükselen ekonomilerin gelişmesinde ve kalkınmasında önem taşımaktadır

Günümüzde Ar-Ge ve inovasyon çokça kullanılarak kalkınma sürecinin önemi giderek artmıştır. Gerek dünyada gerekse Türkiye'de Ar-Ge ve inovasyon konularında verilen kamusal teşvikler sayesinde oldukça önemli mesafeler alınmıştır. Ekonomik kalkınmanın sağlanabilmesi için teknolojik yenilik ve Ar-Ge faaliyetlerinin önemi oldukça büyüktür ve ülke ekonomisi için olumlu sonuçlar doğurmaktadır (Akbey, 2014). Yapılan akademik çalışmalar açısından bakıldığında Ar-Ge ve teknolojik yenilik üretme çalışmaları hem de ekonomik süreç üzerindeki etkileri ile ilgili çalışmalar yeni değildir. Bu çalışmada da Ar-Ge ve inovasyon destekli çalışmaların kalkınma üzerindeki etkisini vurgulamak amacıyla yapılmıştır.

\section{Türkiye'de Ar-Ge ve İnovasyon}

Ar-Ge (Araştırma-Geliştirme), bilgi birikimini kullanarak var olan tecrübesinin gelişmesini sağlayan birtakım çalışmalardır. Aynı zamanda Ar-Ge, "yeni ürünler veya yeni üretim süreçlerinin geliştirilmesi” olarak tanımlamakta mümkündür. Bu nedenle üretim aşamasının bir parçası olarak düşünülmektedir. Ayrıca işletmenin insan kaynakları, pazarlama, finansman gibi pekçok alanında ihtiyaç duyduğu bir yaklaşımdır. OECD' ye göre ise Ar-Ge, "Bilgi dağarcığını artırmak amacıyla sistematik olarak sürdürülen yaratıcı çalışma ve bu bilginin yeni uygulamalar yaratmak için kullanılması” olarak tanımlanmaktadır (Müsiad, 2012).

Ar-Ge faaliyetleri farklı türdeki bilgileri kapsamakta ve elde edilen bilgilerin gelişmesini sağlamaktadır. Ayrıca işletmelerde yeni ürünlerin keşfedilmesiyle birlikte yeni üretim süreçlerinin meydana gelmesi sonucu yaratıcı bir çalışma ortaya konmaktadır. Ar-Ge çalışmaları, bilim ve teknolojinin gelişmesini sağlayarak yeni bilgileri elde etmek, piyasadaki firsatları yakalayıp değerlendirmek, elde edilen bilgiler dahilinde ürün üretmek veya mevcut bilgilerle var olan ürün ve araçları geliştirmek için kullanılmaktadır. Ar-Ge faaliyetleri neticesinde elde edilmiş olan yeni ürünün ve üretim yönteminin geliştirilmesiyle birlikte yeni bir pazarın ortaya çıkması amaçlanmaktadır. Üretilen bu bilgileri kullanan işletmelerin rekabet gücü artmaktadır. Bunun sonucu olarak ise bir işletmede üretilen her türlü bilgi başka işletmelere de yayılarak ülkelerin gelişmesine önemli bir etki sağlamaktadır (Işık ve Kılınç, 2011).

Son zamanlarda bilim ve teknoloji alanında rekabet üstünlüğünü yakalamış ülkeler genellikle gelişmiş ülke statüsünde yer alırken, daha çok emek yoğun mal ve hizmet üreten ülkeler ise gelişmekte olan ülkeler statüsünde yer almaktadır. Düşük gelirin hakim olduğu ekonomilerde emek yoğun mal ve hizmet üreten ülkeler belli bir seviyeye kadar avantaj sağlarken bir süre sonra olumsuz etkisi görülmeye başlamaktadır. Düşük gelirli ekonomiler, kalkınmalarının ilk aşamalarında bol, aynı zamanda ucuz iş gücüne sahip oldukları için yükselme daha hızlı olmaktadır. Ancak bu yükselişin getirdiği avantaj belli bir süre devam ettikten sonra ortadan kalkmakta ve bunun sonucu olarak rekabet edemeyen ülkeler oluşmaktadır. Dolayısıyla, bilim ve teknoloji alanında herhangi bir gelişme yakalanamaması ve verimliliğin arttırılamaması halinde büyüme oranlarının bir üst seviyedeki gelir kategorisine uzun yıllar ulaşmasının mümkün olmayacağı anlaşılmaktadır. Bunun sonucunda ise ülkelerin bu aşamada yakalandıkları kısır döngüye ‘Orta Gelir Tuzağı' adı verilmektedir (Karagöl ve Karahan, 2014). Orta Gelir Tuzağı kavramı özellikle gelişmekte olan ülkeler için kullanılmaktadır. Kişi başına gelir bakımından orta gelir düzeyine sahip olan ülkelerin, bu seviyeyi aşamamasıyla birlikte bir üst seviye olan yüksek gelir grubuna geçememesi şeklide açıklanabilmektedir. İktisat teorisinde büyümenin ilk aşamalarında ülkeler geleneksel tarım ağırlıklı üretimden hafif tüketim malları üretimine geçerler. Bu aşamada tarım kesiminde meydana gelen işgücü fazlalığı sanayi alanlarına kaymakta ve yüksek kar nedeniyle nispeten büyüme oranları gözlemlenmektedir. Ülkeler, orta gelir grubuna yaklaştıkça, yüksek kârlar düşme eğilimine girer, teknoloji eskir ve büyüme hızlarında yavaşlama görülür. Bu durumda artık büyümenin kaynaklarının yerini üretim değil, üretkenlik alır ve Ar-Ge, beşeri sermaye gibi faktörler öne çıkmaya başlar (Alçın ve Güner,2015).

Son dönemlerde Türkiye'de “Orta Gelir Tuzağı” kavramından sıkça söz edilmektedir. Buna bağlı olarak Türkiye 2000'li yılların başında alt orta gelirli ekonomi sınıfında yer alırken günümüzle kıyaslandığı zaman aynı avantajlara sahip olmadığı açıkça ortadadır. Türkiye'nin 2000'li yıllar öncesine dönme riskinin uzak olmasına rağmen, gelecek dönemlerde hedeflenen büyüme rakamlarına Ar-Ge ve inovasyon ile ulaşabilecektir. Ar-Ge ve inovasyon yüksek verimliliği de beraberinde getirmektedir. Verimlilik ise Ar-Ge performansına bağlılık göstermektedir. Türkiye'nin belirlenen 2023 hedeflerine ulaşabilmesi için orta gelir tuzağı riskinden korunması gerekmektedir. Buna bağlı olarak Ar-Ge ve inovasyona gerekli önemi vermesi ve gelişmesi için gerekli müdahalelerde bulunması gerekmektedir. Ayrıca devlet politikaları ile gerekli yönlendirmelerin yapılması önem arz etmektedir (Karagöl ve Karahan, 2014). 
Türkiye'de inovasyonla ilgili politikalar ilk 1963 yılında Türkiye Bilimsel Araştırma Kurumu'nun (Tübitak) kurulmasıyla birlikte görülmektedir. Tübitak'ın kurulmasıyla birlikte Ar-Ge faaliyetlerinin arttırılması ve teknolojinin geliştirilmesi amaçlanmıştır. Önemli bir diğer gelişme ise 1983 yılında 'Bilim ve Teknoloji Yüksek Kurulu'nun (BTYK) kurulmasıdır. Bu kurumun amaçları arasında ulusal inovasyon sistemini kurmak, diğer mekanizmalarla sistemli bir şekilde çalışmak, bilimsel ve teknolojik Ar-Ge aktivitelerini geliştirmek, ekonomik ve sosyal fayda sağlamak sayılabilir (Tutar vd, 2013). "İnovasyon" terimi başarının bir anahtarı olarak dünya piyasasında herkesin dikkatini çekmektedir. Yenilik kavramı buluş, keşif, yaratıcılık, yenilikçilik, inovasyon gibi kelimelerde eş anlamlı olarak kullanılmaktadır. Ancak son zamanlarda bunlar arasından en çok kullanılan kavram “inovasyon"dur. İnovasyon, müşteri taleplerini karşılamak amacıyla yeni yetenekler sayesinde yeni bilgilerle işletmelere yeni fırsatlar yaratmaktır. Bir buluşun yenilik kapsamında değerlendirilebilmesi için ticari olarak ondan yararlanılması gerekmektedir. Yani bir buluşun piyasaya ilk defa sunulmuş bir ürün gibi tanıtması ya da üretimde yeni bir aşamada kullanılması zorunlu görülmektedir. Benzer şekilde yaratıcılık süreci yenilik sürecidir. Günümüzde firmaların başarısından söz edebilmek için yeni ürünlere ve teknolojiye sahip olmaları ve bunu koruyabilmeleri önem arz etmektedir (Kaygısız,2015).

Yeni bir düşünceye sahip olmakla birlikte, yeni bir işlem, yeni bir süreç, yeni bir organizasyon şekli, yeni bir tasarım veya yeni bir üretim şekli her ne olursa olsun alışılmış kalıpları, algıları ve iş yapma modellerini ürün veya hizmetleri değiştirmek, "inovasyon" olarak görülmektedir (Çebi, 2015).

Yenilik temelinde iki taraflı bir olgu veya bir eşleşme faaliyetidir. Yenilik bir taraftan iktisadi bir mantıkla düşünüldüğü zaman farklı bir ürün veya oluşabilecek bir talebin iyi anlaşılmasını gerektirirken diğer yandan yeni ve özgün bilimsel ve teknolojik bilgiler de gerektirmektedir. Deneysel geliştirme ve tasarım, deneme üretimi ve pazarlama, teknik imkanlarla piyasanın buluşturulma süreciyle ilgilidir (Freeman ve Soete, 1997).

Tübitak, tarafından yayımlanan Ulusal Bilim ve Teknoloji Politikaları 2003-2023 Strateji Belgesi'nde öncelikli faaliyetler olarak belirlenen stratejik teknolojiler;

- bilgi ve iletişim teknolojileri,

- biyoteknoloji,

- gen teknolojileri,

- nanoteknoloji,

- mekatronik,

- üretim, süreç teknolojileri,

- malzeme teknolojileri,

- $\quad$ enerji ve çevre teknolojileri,

- tasarım teknolojileri olmak üzere farklı başlıklar altında belirlenmiştir.

Türkiye'nin 2023 yılı hedeflerine ulaşabilmesi için öncelikle rekabet gücünü arttırıcı çalışmaları yapması gerekmektedir. Kaynakların kıt olmasından dolayı harcamalar konusunda dikkatli davranılmalı ve önceliklerin neler olduğuna karar verilmesi gerekmektedir. Sektörler bazında dağılım yapılırken pekçok destek programının gözden geçirilmesi ve tekrar planlamalarının yapılması gerekmektedir. Bununla birlikte Türkiye'de uygulanmakta olan çoğu programların Ar-Ge ve inovasyon sürecinin aşamaları olan "altyapı oluşturma ve geliştirme, temel araştırma, uygulamalı araştırma, deneysel geliştirme, patent alma ve ticarileştirme" basamaklarından hangisine ait olduğunun belirlenmesine yönelik detaylı bir çalışmanın gerekliliği ortaya çıkmaktadır (Şeflek, 2015).

\begin{tabular}{|l|c|c|c|c|c|c|}
\hline Y1llar & Ticari & Kamu & Yükseköğretim & $\begin{array}{c}\text { Toplam Ar-Ge } \\
\text { Harcamalar1 }\end{array}$ & $\begin{array}{c}\text { Personel } \\
\text { Harcamas1 }\end{array}$ & $\begin{array}{c}\text { Diğer } \\
\text { Harcamalar }\end{array}$ \\
\hline 2008 & 3.048 .503 .098 & 823.650 .071 & 3.020 .895 .031 & 6.893 .048 .199 & 3.245 .282 .852 & 3.647 .765 .348 \\
\hline 2009 & 3.235 .272 .345 & 1.016 .522 .342 & 3.835 .657 .913 & 8.087 .452 .600 & 4.004 .846 .364 & 4.082 .606 .236 \\
\hline 2010 & 3.942 .908 .434 & 1.060 .683 .036 & 4.263 .998 .147 & 9.267 .589 .617 & 4.756 .600 .202 & 4.510 .989 .415 \\
\hline 2011 & 4.817 .272 .485 & 1.263 .503 .530 & 5.073 .373 .782 & 11.154 .149 .79 & 5.726 .332 .115 & 5.427 .817 .683 \\
\hline 2012 & 5.891 .214 .749 & 1.436 .923 .417 & 5.734 .125 .228 & 13.062 .263 .39 & 6.892 .626 .906 & 6.169 .636 .489 \\
\hline 2013 & 7.031 .518 .974 & 1.543 .493 .558 & 6.232 .309 .394 & 14.807 .321 .92 & 7.996 .726 .569 & 6.810 .595 .351 \\
\hline 2014 & 8.760 .019 .770 & 1.705 .399 .800 & 7.132 .697 .872 & 17.598 .117 .44 & 9.219 .848 .997 & 8.378 .268 .443 \\
\hline
\end{tabular}

Tablo 1: Sektöre ve Harcama Grubuna Göre Ar-Ge Harcaması Kaynak: TÜIKK (Türkiye İstatistik Kurumu)

Tablo 1' de yer alan Türkiye'de sektöre ve harcama grubuna göre Ar-Ge harcaması daha önceki yıllarla karşılaştırıldığı zaman bir büyüme ve gelişme söz konusudur. 2008-2014 yılları arasının değerlendirildiği TUİK verilerine göre en yüksek harcamanın 2014 yılında olduğu görülmektedir. Ar-Ge ye verilen önemi Ar-Ge harcama rakamlarına bakarak görmek mümkündür. Türkiye'de özel sektör ve kamu sektörünün Ar-Ge harcamaları karşılaştırıldığında özel sektörün yapmış olduğu harcama kamu harcamasına göre çok ciddi boyuttadır. Ar-Ge personeline yapılan harcamalar ise Türkiye'nin yıllar itibariyle bu konuya verdiği önemi göstermektedir. Türkiye, 2023 yılında şirketlerin Ar-Ge harcamalarının GSYİH içindeki payının \%2 olmasını hedeflemektedir. Ar-Ge harcamaları, bir ülkenin hem rekabet gücünü arttırmakta hem de ekonomik gelişmişliğin bir göstergesi olarak 
kabul edilmektedir. Aynı zamanda Ar-Ge harcamaları sonucu yenilik yaratılmakta olup ekonomik gelişmeyi desteklemektedir (Uzun, Kocamış ve Güngör, 2014).

\begin{tabular}{|c|c|}
\hline Y1llar & Oran(\%) \\
\hline 2008 & 0.73 \\
\hline 2009 & 0.85 \\
\hline 2010 & 0.84 \\
\hline 2011 & 0.86 \\
\hline 2012 & 0.92 \\
\hline 2013 & 0.95 \\
\hline 2014 & 1.01 \\
\hline
\end{tabular}

Tablo 2: Gayri Safi Yurtiçi Ar-Ge Harcaması/GSYH Kaynak: TÜIK (Türkiye İstatistik Kurumu)

Tablo 2'de, Türkiye'de Ar-Ge harcamalarının GSYIH'ye oranı yıllar itibarıyla gösterilmiştir. Ar-Ge harcamalarının GSYIH'ye oranı 2014 yılında en yüksek seviyesine ulaşmıştır. Teknolojik gelişmelerin sunduğu olanaklar ile teknoloji alanında küreselleşmeye uyum sağlanabilir. Ar-Ge harcaması, patent sayısı gibi veriler teknolojik faaliyetlerin gelişmiş ülkede yoğunlaştı̆̆ anlamına gelmektedir. İşletmeler Ar-Ge faaliyetleri sonucu yeni ürünler geliştirerek kaliteyi arttırmak ve maliyeti azaltmak yoluyla hem ekonomik gelişmeyi sağlamakta hem de toplumsal faydayı oluşturmaktadır. Türkiye ile gelişmiş ülkeler arasındaki teknoloji açığı kapatabilmek için ArGe harcamaları büyük önem taşımaktadır (Uzun, Kocamış ve Güngör, 2014).

\section{Yükselen Piyasalarda Ar-Ge ve İnovasyonun Rolü}

Yükselen piyasa kavramı güncel bir terim olmasına bakımından farklı tanımlamalarla karşı karşıya kalmaktadır. Yükselen piyasalar, kısa dönemde işletmenin ihtiyaçlarının karşılanması için uygun pazarlar olmasının yanında, ekonomide yaşanan rekabet ve değişime uyum sağlama konusunda önemli bir kavramdır. Yükselen ekonomiler ve gelişmekte olan ülkeler ekonomik açıdan birbirlerine benzer görünseler de rekabet, gelişmişlik farkı ve ülke vatandaşlarının refah seviyesi gibi faktörler açısıdan birbirlerinden ayrıldıkları görülmektedir (Çivi ve Çavuşgil, 2001).

Yükselen pazarlar BRIC (Brezilya, Rusya, Hindistan, Çin) ve "Sonraki Onbir" ülkeleri olarak kategoriye ayrılmaktadır. BRIC ülkeleri Brezilya, Rusya, Hindistan ve Çin ülkelerinden oluşmaktadır. BRIC ülkeleri hızla gelişen ve ekonomik açıdan en yüksek potansiyele sahip ülkelerdir. Bunlar arasında ise en yüksek büyüme Çin'e aittir.

"Sonraki onbir" sınıflandırması ise Türkiye'nin de içinde bulunduğu Bangladeş, Mısır, Endonezya, İran, Güney Kore, Meksika, Nijerya Pakistan, Filipinler ve Vietnam'dır. Bu sınıflandırma içerisinde bulunan ülkelerin özellikleri birbirinden farklı görünmektedir. Ülkelerin bir kısmı gelişmekte olan ülkeler arasında yer alırken, bir kısmı da yeni sanayileşen ülkeler arasında yer almaktadır. Yeni sanayileşen ülkeler daha fazla endüstriyel kapasiteye sahip oldukları için sanayi ürünleri ihracatına başlamışlardır. Dolayısıyla daha yüksek yaşam kalitesine ve hayat standartlarına sahiptirler (Zengin, 2014).

Ülke ekonomilerinde meydana gelen yapısal değişiklikler sonucunda hem üretim hem de bilgi kullanımı her geçen gün artmaktadır. Günümüzde bilim ve teknoloji alanında büyük fark yaratan ve rekabette en önde olan ülkeler, Gayri Safi Yurt İçi harcamalarında en büyük payı Ar-Ge ve inovasyona ayırmaktadırlar. Hükümetin yapmış olduğu yatırımları, kamu kuruluşlarının çalışmaları olmasına karşın Ar-Ge ve inovasyonda en büyük yatırımlar özel teşebbüslere aittir. Bu yatırımlar sivil halkın ihtiyaçlarına göre yönlendirilmektedir. Hükümetlerin özel teşebbüsleri Ar-Ge ve inovasyon konusunda cesaretlendirme çabası politikalara yansımakta ve uzun dönemli tedbirler ve kararlar almaya itmektedir. Bununla beraber özel teşvikler oluşturulmakta, Ar-Ge ve inovasyon alanında yapılacak yatırımlar için ise kolaylıklar sağlanmaktadır.

Yükselen ekonomi olma yolunda ilerleyen ülkeler Ar-Ge ve inovasyon alanında başarılı olan ülkelerdir. Bunlar, küresel piyasada fark yaratabilmiş ve rekabette öne çıkmış ülkelerdir: ABD, Kanada, Japonya, Almanya, Kore vb. Türkiye ise bu yarışta geride kalan ülkeler arasında yer almaktadır (GEKA, 2011).

Gelişmekte olan ülkeler ve yükselen piyasalar karşılaştırıldığı zaman farklılık açıkça görülmektedir (Moskin, 1988).

\section{Gelişmekte Olan Ülkeler (1990 Öncesi)}

- Dış ticaret ve yatırım alanında yüksek riskle karşılaşılması

- Ekonomik ve teknolojik yapıdaki geriye doğru yönelimin yüksek olması

- Tüketicilerin satın alma güçlerinin düşük olması

- Yatırım alanlarının sinırlı olması

\section{Yükselen Ekonomiler (1990 Sonrası)}

- Riskin yönetilmesi konusunda sorun yaşanmaması

- Gelişmiş ülkelere göre gelir artış hızının daha yüksek seviyelerde olması 
- Teknoloji üretimi konusunda rekabetçi yapının olması

- Tüketicilerin satın alma güçlerinde hızlı bir şekilde artış yaşanması

- Keşfedilmeyen pazarlar için işletmecilere büyük firsatlar sunmaları

- Düşük maliyetli ve yüksek kaliteli kaynakların bulunması

IMF Küresel ekonomik görünümü 2015 raporuna göre (Tablo 3), gelişmekte olan ekonomiler incelendiğinde, 2014 yılında \%4,4 oranında bir büyüme gerçekleşmiştir. 2016 yılında ise \%4,7 oranında bir büyüme beklenmektedir.

Bu tabloda büyüme oranıyla diğer ülkelerden ayrılan ülke Çin'dir. Aslında Çin'in büyüme hedefi daha yüksek olmakla birlikte istenilen hedefe ulaşamamıştır. Çünkü piyasalarda var olan durgunluğun etkisi hissedilmektedir.

\begin{tabular}{|l|c|c|c|}
\hline & $\mathbf{2 0 1 4}(\mathbf{\%})$ & $\mathbf{2 0 1 5}(\mathbf{\%})$ & $\mathbf{2 0 1 6}(\mathbf{\%})$ \\
\hline Dünya Ortalaması & 3,3 & 3,5 & 3,7 \\
\hline Gelişmiş Ülkeler Ortalaması & 1,8 & 2,4 & 2,4 \\
\hline ABD & 2,4 & 3,6 & 3,3 \\
\hline Euro bölgesi Ortalaması & 0,8 & 1,2 & 1,4 \\
\hline Japonya & 0,1 & 0,6 & 0,8 \\
\hline İngiltere & 2,7 & 2,6 & 2,4 \\
\hline Kanada & 2,4 & 2,3 & 2,1 \\
\hline Gelişmekte Olan Ülkeler Ortalaması & 4,4 & 4,3 & 4,7 \\
\hline Rusya & 0,6 & $-3,0$ & $-1,0$ \\
\hline Asya & 6,5 & 6,4 & 6,2 \\
\hline Çin & 7,4 & 6,8 & 6,3 \\
\hline Hindistan & 5,8 & 6,3 & 6,5 \\
\hline Latin Amerika ve Karayipler & 1,2 & 1,3 & 2,3 \\
\hline Brezilya & 0,1 & 0,3 & 1,5 \\
\hline Meksika & 2,1 & 3,3 & 3,5 \\
\hline Orta Doğu, Kuzey Afrika, Afganistan, Pakistan & 2,8 & 3,3 & 3,9 \\
\hline Sahra altı Afrika & 4,8 & 4,9 & 5,2 \\
\hline Nijerya & 6,1 & 4,8 & 5,2 \\
\hline Güney Afrika & 1,4 & 2,1 & 2,5 \\
\hline
\end{tabular}

Tablo 3: IMF (Uluslararası Para Fonu) 2014 Gayrisafi Yurtiçi Hasıla Rakamlarl ve 2015 - 2015 GSYH Büyüme Öngörüleri Kaynak: IMF Dünya Ekonomik Görünümü Raporu, 2015

Yükselen piyasaların önemli derecede büyüme oranlarına sahip olmaları dikkat çekicidir. Son zamanlara bakıldığı zaman yükselen piyasalar ticaret konusunda önemli atılımlar gerçekleştirmiştir. Dünya Ticaret Örgütü tarafından belirlenen dünya mal ticaretinde ihracatçılar listesinde ilk sıralara yerleşen ülkeler genellikle yükselen pazarlar olmaktadır. Tablo 4'te belirtildiği gibi ilk 10 ihracatçı listesinde Çin, Güney Kore ve Rusya dikkat çekmektedir. Aynı zamanda BRIC ülkeleri olarak değerlendirildiği zaman da Çin dünya ihracatında lider konumda olduğu görülmektedir (Ekonomi Dış Ticaret Raporu, 2015). 


\begin{tabular}{|l|l|c|c|c|c|c|}
\hline \multirow{2}{*}{ Sıra } & \multirow{2}{*}{ Ülke } & \multicolumn{2}{|c|}{ İhracat (Milyar Dolar) } & $\begin{array}{c}2013 / 2014 \\
\text { Değişim } \%\end{array}$ & \multirow{2}{*}{2014 Pay \% } & 2013 siras1 \\
\cline { 3 - 6 } & & 2014 & 2013 & 6 & 12,4 & 1 \\
\hline 1 & Çin & 2.343 & 2.209 & 3 & 8,6 & 2 \\
\hline 3 & ABD & 1.623 & 1.580 & 4 & 8,0 & 3 \\
\hline 4 & Jlmanya & 1.511 & 1.453 & -4 & 3,6 & 4 \\
\hline 5 & Hollanda & 672 & 672 & 0 & 3,6 & 5 \\
\hline 6 & Fransa & 583 & 580 & 0,5 & 3,1 & 6 \\
\hline 7 & Güney Kore & 573 & 560 & 2 & 3,0 & 7 \\
\hline 8 & İtalya & 529 & 518 & 2 & 2,8 & 11 \\
\hline 9 & Hong Kong & 524 & 536 & -2 & 2,8 & 9 \\
\hline 10 & İngiltere & 507 & 542 & -6 & 2,7 & 8 \\
\hline 11 & Rusya & 497 & 523 & -5 & 2,6 & 10 \\
\hline 12 & Kanada & 474 & 458 & 3 & 2,5 & 13 \\
\hline 13 & Belçika & 469 & 469 & 0 & 2,5 & 12 \\
\hline 14 & Singapur & 410 & 410 & 0 & 2,2 & 14 \\
\hline 15 & Meksika & 398 & 380 & 5 & 2,1 & 15 \\
\hline 16 & BAE & 359 & 379 & -5 & 1,9 & 16 \\
\hline 17 & S. Arabistan & 354 & 376 & -6 & 1,9 & 17 \\
\hline 18 & İspanya & 323 & 317 & 2 & 1,7 & 18 \\
\hline 19 & Hindistan & 317 & 313 & 1 & 1,7 & 19 \\
\hline 20 & Tayvan & 314 & 305 & 3 & 1,7 & 20 \\
\hline
\end{tabular}

Tablo 4: Dünya İhracatında Ülkeler Kaynak: Türkiye İhracatçılar Meclisi, Ekonomi Dış Ticaret Raporu, 2015.

\begin{tabular}{|l|c|c|c|c|c|}
\hline & \multicolumn{2}{|c|}{ GCI 2015-2016 } & \multicolumn{3}{c|}{ GCI 2014-2015 } \\
\hline Ülkeler & Sıra & Değer & Sıra & Değer & Değişim \\
\hline İsviçre & 1 & 5,76 & 1 & 5,70 & - \\
\hline Singapur & 2 & 5,68 & 2 & 5,65 & - \\
\hline ABD & 3 & 5,61 & 3 & 5,54 & - \\
\hline Almanya & 4 & 5,53 & 5 & 5,49 & 1 \\
\hline Hollanda & 5 & 5,50 & 8 & 5,45 & 3 \\
\hline Japonya & 6 & 5,47 & 6 & 5,47 & - \\
\hline Hong Kong & 7 & 5,46 & 7 & 5,46 & - \\
\hline Finlandiya & 8 & 5,45 & 4 & 5,50 & -4 \\
\hline İsveç & 9 & 5,43 & 10 & 5.41 & 1 \\
\hline İngiltere & 10 & 5,43 & 9 & 5,41 & -1 \\
\hline Katar & 14 & 5,30 & 16 & 5,24 & 2 \\
\hline Fransa & 22 & 5,13 & 23 & 5,08 & 1 \\
\hline Avustralya & 23 & 5,15 & 21 & 5,16 & -2 \\
\hline Suudi Arabistan & 25 & 5,07 & 24 & 5,33 & -1 \\
\hline Güney Kore & 26 & 4,99 & 26 & 4,96 & - \\
\hline Çin & 28 & 4,89 & 28 & 5,25 & - \\
\hline İspanya & 33 & 4,59 & 35 & 4,55 & 2 \\
\hline Şili & 35 & 4,58 & 33 & 4,60 & -2 \\
\hline Portekiz & 38 & 4,52 & 36 & 4,54 & -2 \\
\hline İtalya & 43 & 4,46 & 49 & 4,42 & 6 \\
\hline Rusya & 45 & 4,44 & 53 & 4,37 & 8 \\
\hline Güney Afrika & 49 & 4,39 & 56 & 4,35 & 7 \\
\hline Türkiye & $\mathbf{5 1}$ & $\mathbf{4 , 3 7}$ & $\mathbf{4 5}$ & $\mathbf{4 , 4 6}$ & $\mathbf{- 6}$ \\
\hline Bulgaristan & 54 & 4,32 & 54 & 4,37 & - \\
\hline Hindistan & 55 & 4,31 & 71 & 4,21 & 16 \\
\hline Meksika & 57 & 4,29 & 61 & 4,27 & 4 \\
\hline İran & 74 & 4,09 & 83 & 4,03 & 9 \\
\hline Brezilya & 75 & 4,08 & 57 & 4,34 & -18 \\
\hline Yunanistan & 81 & 4,02 & 81 & 4,04 & - \\
\hline Cezayir & 87 & 3,97 & 79 & 4,08 & -8 \\
\hline & & & & & -1 \\
\hline
\end{tabular}

Tablo 5: Bazı Ülkelerin Küresel Rekabet Edebilirlik Endeksi (GCI) Stralamasi Kaynak: World Economic Forum, Global Competitiveness Report 2014-2015, 2015-2016 
Dünya Ekonomik Forumu (World Economic Forum WEF) tarafından yapılan "Küresel Rekabet Edebilirlik Endeksi 2015-2016 Raporu"nda rekabet gücü sıralamasına bakıldığı zaman İsviçre başı çekmektedir ve bunu takip eden ülkeler ise Singapur ve ABD' dir. İlk 10 sirayı devam ettiren ülkeler ise Almanya, Hollanda, Japonya, Hong Kong, Finlandiya, İsveç ve İngiltere yer almaktadır. Ar-ge ve inovasyonu destekleyen ülkeler ise bu rapora göre en yüksek düzeyde yer alan ülkelerdir.

Türkiye açısından bakıldığı zaman 2012-2013 Küresel Rekabet Edebilirlik Endeksi’ne göre performans olarak önemli gelişmeler sağlanarak 16 basamak yükselmesine karşın, 2013-2014 raporunda 148 ülke arasında 44. sirada, 2014-2015 raporunda 144 ülke arasında 45. sırada yer aldığı görülmektedir. 2015-2016 yılı raporunda Türkiye'nin rekabet edebilirlik puanının düşme göstermesi ise makroekonomik ortamın bozulmasından kaynaklı olduğu tespit edilmiştir.

Ülkelerin kalkınmışlık aşamasını belirten noktalardan bir tanesi de GSYİH'da meydana gelen artış olmaktadır. 2015-2016 y1lı raporunda Türkiye 2014 satın alma gücü paritesine göre hesaplanan 806.1 milyar dolar GSYİH's1 ile dünya toplamında \%1.40’lık bir paya sahip olmuştur. Ülkelerin kalkınma aşamalarına göre gruplandırılarak incelendiğinde 2015-2016 raporunda Türkiye, "Verimlilikten, İnovasyon Odağına Geçiş Ülkeleri” arasındaki konumunu korumaktadır (Üstündağ, Demir, 2014).

Dünya Ekonomik Forumu'nun her yıl kapsamlı şekilde ele aldığı rekabetçilik endeksinde Türkiye'nin notunun rakiplerine göre geride kaldığı saptanmıştır. Hem rekabetçilikteki sırası hem de inovasyon endeksi sırası yaklaşık olarak aynı seviyededir. Günümüzde firmalar rekabetçiliği yakalayabilmek amacıyla "düşük maliyet politikası" veya "inovasyon" stratejileri uygulamaktadır. Fakat "düşük maliyet" uygulamaya çalışan firmaların kar oranları düşük olmaktadır. Bu nedenle firmalar güçlü bir silah olarak inovasyonu görmekte ve bunu sürekli kullanıp muhafaza etmeye çalışmaktadırlar. Yani rekabetçilik ile inovasyon arasında direkt bir ilişki olduğunu söylemek mümkündür. Nitekim ülkelerin rekabet gücünü belirleyen asıl faktör inovasyondur. Bunu rakiplerine göre daha erken keşfeden firmalar yarışta en ön safhada yer almaktadır. Ayrıca OECD, bir ülkede refah artışını sağlamanın ve istihdamı arttırma yolunun inovasyondan geçtiğini söylemektedir. Aynı zamanda Avrupa Birliği'de inovasyonu Avrupa için ortak bir sorun olarak görmekte ve acil çalışmalar yapılması gerektiğini söylemektedir (Müsiad, 2012).

\section{Sonuc}

Dünya'da yaşanan rekabet gün geçtikçe hızla artmaktadır. Bunun için ülkeler farklı yollar arayışına girmiştir. Özellikle neoliberalizmin şiddetli yaşandığı küreselleşen dünyada rekabet hızla artmış, özel sektör ve girişimcilik ön plana çıkmıştır. Bazıları başkalarının ürettiklerini kullanarak ayakta kalmaya çalışsa da sürdürülebilir bir kalkınma için rekabet edebilmek şart olmuştur. Bunun için farklı ve özgün çalışmalara ihtiyaç duyulmaktadır. Küresel ortamda gelişmiş ülkelerden yapılan transferler geçici çözüm olmakla birlikte ülkenin hantallaşmasına yol açmakta aynı zamanda ithalatı arttırarak ödemeler dengesi sorunlarına yol açmaktadır. Bunlar ekonomik olarak ülke için ağır bir yük anlamına gelmektedir. Artık ülkeler ithal mal kullanmak yerine kendi ürettiklerini pazarlamak ve ülkeye ekonomik olarak artı bir değer sunmak istemektedirler. İhracat yapan ülkeler açısından düşünüldüğü zaman bilim ve teknoloji alanında yenilikler yapılmalı ve üretilen ürünlerden daha fazla getiri sağlanabilmelidir. Bunu küresel ortamda gerçekleştirecek olan firmalardır. Firmalar uluslararası alanda rekabet edebilmek için ArGe ve inovasyonu geliştirmeli ve özgün üretimler sonucunda küresel pazarda söz sahibi olabilmelidir.

Çalışmada küresel rekabet edebilirlik endekslerine bakıldığında, Almanya, Japonya, Güney Kore, Çin gibi ülkelerin küresel rekabet edebilirlik seviyelerinin oldukça iyi durumda olduğu sonucunda ulaşılmıştır. Aynı zamanda "dünya ihracatında ülkeler" listesine bakıldığ 1 zaman yine bu ülkelerin ilk siralarda yer aldığ gözlenmektedir. Yükselen piyasalar olarak adlandırdığımız bazı ülkeler, gerek rekabet endeksi gerekse ihracat listesinde aynı paralellikte ilerlemektedir. Yükselen piyasalar arasında Ar-Ge ve inovasyon konusunda gerekli desteğin verilmesi sonucu son zamanlarda çıkış yakalayan ülkeler mevcuttur. Türkiye'nin ise küresel rekabet edebilirlik endeksinde 51. sırada yer alırken ihracat listesinde sonlarda yer alması Türkiye'nin rekabet etmek için gerekli potansiyelinin henüz yeterli seviyeye ulaşmadığg sonucuna varılmıştır.

Türkiye'de Ar-Ge harcamasının GSYİH'daki payı \%1 düzeyindedir. Durum böyle iken Türkiye'nin Ar-Ge konusunda ciddi adımlar atması gerekmektedir. Bu veri şunu göstermektedir ki; Türkiye'de Ar-Ge ve inovasyon konusunda yapılan yatırımlar yetersiz kalmaktadır. Yükselen pazarların gelişimi dikkate alınarak, iyi aşama kaydetmiş ülkeler örnek alınmalı, birbirleriyle Ar-Ge ve inovasyon alışverişleri arttırılmalıdır. Yükselen pazarlar arasındaki ilişkiler iyileştirilmeli büyük firmalardan destek alınmalıdır. Pazarlar sürekli olarak takip ve kontrol edilmeli yeni ürün ve hizmetler Yükselen pazarlarda yerini bulmalıdır. Dev firmalar büyük Ar-Ge ve inovasyon sistemlerini geliştirmeli devletleri tarafından gerekli teşvikler sağlanmalıdır. Bunun için üniversite ve sanayi bir araya getirilmeli, üniversite öğretim üyelerinin ve sanayicilerin etkin ve verimli bir şekilde çalışması desteklenmelidir. Yeni yatırım alanlarının açılması ve yetenekli bireylerin bu alanda istihdam edilmesi için eğitime verilen önemin arttırılması gerekmektedir. Ar-Ge ve inovasyon konusunda uzun vadeli hedefler saptanmalı ve bu hedeflere ulaşmak için sürdürülebilir politikalar uygulanmalıdır. Yükselen pazarlar Ar-Ge ve inovasyonla küresel rekabette fark yaratabilecekler ve yüksek refah seviyesini yakalayabileceklerdir. 


\section{Kaynakça}

- Açıkalın, O. ve Saltık, A. 2007. "Kalkınmada Yeni Kavram ve Stratejiler”. Sosyoloji Araşttrmaları Dergisi, 2007/1, 5-27.

- Akbey, F. 2014. “Ar-Ge, İnovasyon ve Kalkınma İlişkisine Yönelik Bir Literatür Taraması: Kuramsal Özet”, Maliye Dergisi, Sayı: 166, Ocak-Haziran 2014.

- Alçın, S., Güner, B., 2015. “Orta Gelir Tuzağı: Türkiye Üzerine Bir Değerlendirme”, Marmara Üniversitesi İ.I.B. Dergisi Yıl: 2015, Cilt XXXVII, Sayı I, S. 27-45 Doi No: 10.14780/iibd.66467, ss.27-45.

- Çebi, A. 2013. "Ezber Bozan İnovasyon İklimi”, Türkiye'de Ar-Ge ve İnovasyon Yönetimi, Mimar ve Mühendisler Grubu, Sayı: 74, ss:30.

- Çivi, E. ve Çavuşgil, E. T. 2001. "Yeni Dünya Düzeninde Güç Kazanan Ülkeler: Yükselen Ekonomiler", Celal Bayar Üniversitesi İ̈BF, Yönetim ve Ekonomi Dergisi, Cilt: 7, Sayı:1, ss.113-128.

- Fırat, E. ve Aydın, A., 2015. İnsani Kalkınma Endeksine Göre Türkiye'nin Eğitim Endeks Göstergelerinin OECD Ülkeleri İle Karşılaştırılması”, Selçuk Üniversitesi İktisadi ve İdari Bilimler Fakültesi Sosyal ve Ekonomik Araştırmalar Dergisi (The Journal of Socialand Economic Research) ISSN: 1303 - 8370/ Sayı: 29.

- Freeman, C. ve Soete, L. 1997. Yenilik İktisadı, Çeviren: Ergun Türkcan, Türkiye Bilimsel ve Teknik Araştırma Kurumu, 2003, Tübitak Yayınları, Ankara.

- Geka, 2011. Ar-Ge, İnovasyon ve Türkiye-Neredeyiz?

- http://geka.gov.tr/Dosyalar/o_19v5e6jpd10591tg915tg1ltt1kav8.pdf (Erişim Tarihi: 23.05.2016).

- Işık, N. ve Kılınç, E.C. 2011. "Bölgesel Kalkınmada Ar-Ge ve İnovasyonun Önemi: Karşılaştırmalı Bir Analiz”, Eskişehir Osmangazi Üniversitesi, İ̈BF Dergisi, Sayı: 6(2).

- Imf, Küresel Ekonomik Görünüm Raporu, 2015.

- Karagöl, E. Tanas ve Karahan, H. 2014. "Yeni Ekonomi: Ar-Ge ve İnovasyon”,Sayı:82, s. 10-12, Seta, İstanbul.

- Kaygısız, B. 2015. “İnovasyon”, Bilim, Sanayi ve Teknoloji Bakanlı̆g, Sayı: 324, ss:9-13.

- Moskin, R. 1988. “The Third World Asks for a Fair Deal”, World Press Review, ss. 33-34.

- Müsiad, 2012. Küresel Rekabet İçin AR-Ge ve İnovasyon, Stratejik Dönüşüm Önerisi,Araştırma Raporları: 76, Pelikan Basım, İstanbul, s. 56.

- Şeflek, T. 2015. "Türkiye'deki Ar-Ge ve İnovasyon Ekosisteminde Uygulanmakta Olan Politikalar ile Ekosistem İçerisinde Yer Alan Kurumsal Yapılanmalar Üzerine Yeni Bir Yol Haritasının Hazırlanması", Bilim, Sanayi ve Teknoloji Bakanlığl, Sayı:324, ss: 20-23.

- Tüik (Türkiye İstatistik Kurumu), Ar-Ge Faaliyetleri Araştırması, 2015.

- T.C. Bilim, Sanayi ve Teknoloji Bakanlığı, 2015. İnovasyon, Kalkınmada Anahtar Verimlilik, yıl:27, Sayı: 324, Ankara.

- Tim (Türkiye İhracatçılar Meclisi), 2015. Ekonomi ve Dış Ticaret Raporu.

- Tutar, F., Firat, E., Erkan, Ç., Tutar, E., 2013. "Yerel Ekonomilerin Yeni Aktörü, Bölgesel İnovasyon Stratejileri: RIS Mersin Uygulaması”, International Conference On Eurasian Economies, ss.627-634.

- Uzun Kocamış, T. ve Güngör, A. 2014. "Türkiye'de Ar-Ge Harcamaları ve Teknoloji Sektöründe Ar-Ge Giderlerinin Kârlılık Üzerine Etkisi: Borsa İstanbul Uygulaması”, Maliye Dergisi,Sayı:166, Ocak-Haziran 2014.

- Üstündağ Demir, S. 2016. Küresel Rekabet Edebilirlik Endeksi 2015 - 2016 Raporu, Rekabet Kurumu, Ekonomik Analiz ve Araştırma Dairesi Başkanlığı.

- World Economic Forum, The Global Competitiveness Report 2015-2016,

- Yumuş, A. 2009. "Kalkınma Planları Çerçevesinde Toplumsal Cinsiyet Eşitliği Anlayışııın Ekonomik, Toplumsal ve Siyasal Boyutları” T.C. Başbakanlık Kadının Statüsü Genel Müdürlüğ̈̈, ss. 9-11.

- Zengin, A.Y. 2014. Yükselen Pazarlarda Yenilikçiliğin İhracat Performansı Üzerine Etkisi, Gazi Üniversitesi Sosyal Bilimler Enstitüsü, İşletme Anabilim Dalı, Doktora Tezi, Ankara. 


\title{
Kalkınmada Ar\&Ge ve İnovasyonun Önemi; Güney Kore Örneği The Importance of $R$ \&D and Innovation in Development; The Case of South Korea
}

\author{
Prof. Dr. Bedriye Tunçsiper (Balıkesir University, Turkey) \\ Asst. Prof. Dr. Emine Frrat (Aksaray University, Turkey)
}

\begin{abstract}
The concept of development has been interpreted by different economic opinions within historical process. This has prevented the description of development concept in a single theoretical perspective or as a definitive statement. Development, also being of a broad concept incorporating economic, social and cultural aspects here of, was evaluated very purely economic phenomenon until the 1970s. The development concept has been tried to measure with the national income per capita by many economists. After the 1970s, the level of development began to be considered with concept such as human capital, innovation, education, health and standard of living, overtly, equality and so on in addition to economic criteria and the concept is being assessed by human development level. There are many different ways for the development of a country. Recently, the urgency of research and development and innovation has been put forward and it appears that significance of the notions of learning, research, ingenuity and innovation has gone up for substantiation of the progress. In this study, South Korea's R \& $\mathrm{D}$ and innovation doings are judged and the value of innovation and research and development activities for evolution are underlined. Hereby, R \& D and innovation projections conduced to the advancement and refinement of South Korea, sorendering efficacious and satisfactory use of sources possible.
\end{abstract}

\section{Giriş}

Kavram olarak çok eski olmasına rağmen, İkinci Dünya Savaşı'nın bitiminden günümüze kadar geçen sürede öne çıkan kalkınma kavramı küreselleşme ve yeni oluşan olguların etkisiyle ekonomik ve sosyal açıdan sürekli olarak farklı konularla bütünleşmiştir. Kalkınma kavramı toplumların ilerleme aşamasına paralel olacak şekilde farklı dönemlerde farklı anlamlar kazandığı gibi benzer dönemlerde farklı anlamlarla da kullanılmıştır. Hatta bu kavram kendine yakın anlamları olan büyüme, gelişme, ilerleme, sanayileşme, modernleşme, teknolojiye ayak uydurma gibi kavramlarla içiçe geçmiş ve birlikte kullanılmıştır. Kalkınma, en az iki nesil boyunca devam eden toplam gelir ve kişi başına düşen gelir olarak ifade edilirken diğer bir perspektifle bakıldığında; eğitim seviyesindeki artışlar, teknolojiyi yakalayabilme, teknik bilgi ve bununla birlikte insan kaynaklarındaki artışlar da kalkınmanın kapsamında değerlendirilmektedir (Fırat, Aydın, 2015).

İkinci Dünya Savaşı öncesinde de kalkınma yerine daha çok "büyüme ve ilerleme” kavramlarını kullanmıştır. Kalkınmayı gerek Adam Smith "maddi ilerleme", gerekse John Stuart Mill "ekonomik ilerleme" kavramlarıyla anlatmaya çalışmışlardır (Mıhçı, 1996: 65).İkinci Dünya Savaşı’nın bitiminden günümüze kadar geçen sürede öne çıkan kalkınma kavramı küreselleşme ve yeni oluşan olguların etkisiyle ekonomik ve sosyal açıdan sürekli olarak farklılaşmıştır. Bölgesel kalkınma kavramı toplumların ilerleme aşamasına paralel olarak farklı dönemlerde farklı anlamlar kazanacağı üzere benzer dönemlerde farklı anlamlarla da kullanılmıştır. Hatta bu kavram kendine yakın anlamları olan büyüme, gelişme, ilerleme, sanayileşme, modernleşme, teknolojiye ayak uydurma gibi kavramlarla iç içe geçerek kullanılmıştır.

Kalkınma ile ülkeler son yirmi senelik zaman diliminde yenilikçi stratejiler bularak inovasyon ve Ar-Ge'ye önem vermişler, yeni araştırmalar içerisine girmişlerdir. Son yıllarda Ar-Ge ve inovasyon üretim sürecinde en önemli faktörler olarak yer almıştır. Zamanımızda sermaye ve emek gibi klasikleşmiş üretim unsurlarından farklı olarak bilginin üretim sürecine girmesi, bilgiye önemin arttığını ve transformasyon sürecine etkisini göstermiştir Bir ülkenin gelişmişliğinin ölçüsü, bilim ve teknolojiye verilen önemle yakından alakalıdır. Ayrıca, AraştırmaGeliştirme (Ar-Ge) harcamaları için Gayri Safi Yurtiçi Hasıla (GSYH)'dan ayrılan pay büyük önem taşımaktadır. Ayrılan payın \%2'nin üzerinde çıkması durumunda bu pay ülkelerin gelişmişliği noktasında önemli bir oran olarak kabul görmektedir (Işsk ve Kılınç: 2011: 9). İnovasyon ve Ar-Ge ülkelerin gelişmişlik seviyelerinin belirleyicilerini oluşturmaktadır. İnovasyon ve Ar-Ge harcamalarının göstergeleri bu açıdan ülkelerin gelişmesinde ve kalkınmasında önem taşımaktadır. İnovatif çalışmaların önemini önce kavrayıp bu kapsamda yeni yöntemler geliştiren ülkeler, günümüz toplumlarında gelişmiş ülke statüsünü yakalamışlardır. Gelişmekte olan ülkeler refah seviyelerini devamlı artırma arayışı içinde olmuşlardır. Ancak bu arayışlarda uygulanan farklılıklar gelişme seviyelerinde kendini göstermiştir. Birbirleriyle yaklaşık olarak aynı dönemlerde kalkınma atağını başlatmasına rağmen Güney Kore ve Türkiye, günümüz perspektifinden değerlendirildiğinde, kalkınma noktasında Güney Kore Türkiye'nin üzerinde ileride bir performans göstermiştir. Güney Kore, inovasyonun önemini kavrayan ülkelerin önde gelen ülkelerindendir. Çalışmanın kapsamında Güney Kore'nin ekonomik durumu, inovasyonun Güney Kore'nin kalkınmasındaki rolü ve inovasyonun gelişim aşamaları Güney Kore çerçevesinde ele alınmıştır. 


\section{Kalkınma Ar-Ge ve İnovasyon}

Günümüzde kalkınma, herkesin istihdam edildiği, bilgiye, güvenliğe, temel hak, adalet ve eğitim hizmetlerine kolayca ulaşılabildiği, piyasa mekanizmasının adaletli biçimde yürütüldüğü, cinsiyet ayrımcılığı olmadan, katılımcı, demokratikleşmeye ve kültürel gelişimlere açık, saydam/hesap verebilir yönetim sistemi olan, topluma bakış açısı olarak bütün dezavantajlı grup ve tabakaların yok edildiği, sorunları çözme yeteneği güçlü, doğal kaynaklarına sahip çıkan ve bu kaynakların gelişmesini sağlayan, insanların geleceğe güvenle bakabildiği toplum veyahut topluluklar oluşturma çabasıdır (Işık ve Kılınç, 2011: 12). Kalkınma ekonomik faaliyetlerin yanında sosyal, kültürel, politik etmenlerle de birebir bağlantılıdır. Diğer bir ifade ile kalkınma ekonomik ve sosyal faaliyetlerin oluşturduğu bir bütündür.

Toplumların her zaman üzerinde tartıştığı konuların başında Ar-Ge, inovasyon ve kalkınma gelmektedir. Kalkınmada gerçekleşen her önemli aşamada mevcuttaki inovasyonlarda yaşanan ilerlemeler yeni inovasyonları ortaya çıkarmakta ve yeni inovasyonlar kalkınmayı tetiklemektedir (Işık ve Kılınç, 2012:36).Ar-Ge, firmalarda yeni üretim süreçlerinin ve ürünlerin ortaya çıkması için uğraşılan yaratıcı ve sistematik çalışmalardır. Böylece Ar-Ge sayesinde teknoloji ve bilim gelişip, var olan bilgiler ışığında yeni malzemeler ve ürünler üretilmektedir. $\mathrm{Bu}$ yeniliklere çağımızın en önemli sektörlerinden olan yazılımda eklenerek Ar-Ge hizmet, sistem ve süreçleri geliştirilmiştir. Ar-Ge artış gösteren bilimsel bilgiye yönelik düzenlemelerden ya da süreç ve ürün inovasyonuna yönelik çabalardan oluşmaktadır (Zerenler vd., 2007: 656-657). 20. yüzyılın başlangıcında ismi yeterince yankı bulmayan Ar-Ge, 20. yüzyılın ikinci yarısından itibaren sanayileşmiş ülkelerin vazgeçilmez kriteri kabul edilmiştir. Araştırma kavramının temeli bilim kadar eskiye dayanmaktadır. II. Dünya Savaşı'na kadar araştırma ve sonrasında olması gereken geliştirme arasındaki güçlü bir ilişki kurulamamıştır. 21. Yüzyılın başlarında temel bilimler ile uygulamalı bilimler birbirlerinden ayrılmıştır (Korkmaz, 2010:3325).İnovasyona yoğunlaşılan zamanda Ar-Ge yeni düşünceler yaratarak önemli çıktılar sağlamıştır. Bu süreçte Ar-Ge ile birden çok yeni fikir kaynağı ve transformasyonu gerçekleştirilmiştir. Girişimcilik açısından ele alındığında Ar-Ge sonucu ortaya çıkan yenilikçi yaklaşımlar ve bu yeniliklerin ticarileştirilmesi sonucunda inovasyon ortaya çıkmaktadır (Müsiad, 2012). İnovasyon, ülkeler ve işletmelerin uzun dönemli varlığı, performansı, büyüme ve başarısı için ön koşullarındandır. $\mathrm{Bu}$ nedenle, işletmeler ve endüstriler yenilikleri, bir tercihten çok stratejik bir zorunluluk olarak görmektedir (Aydemir ve Karakoyun, 2011). Yeni üretim tekniklerinin ve teknolojilerin tercih edilmesi 1970'li y1llardan itibaren yayılmış, hızlı bilgi, farklı hizmet ve malların ortaya çıkmasıyla rekabet küresel boyuta taşınmıştır. Küresel rekabet ile yeni bölgeselleşme modelleri oluşturulmuş, bölgeler birtakım avantajlar elde etmeye başlamışlardır. Literatürde öğrenen bölgeler, sanayi bölgeleri, kolektif etkinlik, bölgesel kümeleşme gibi farklı isimlendirmeler yapılmaya başlanmıştır. Fransa'da Bilimsel Kent, ABD’de Silikon Vadisi, Routu 128, Orange Şehri, Almanya'da Baden Wüttenberg Bölgesi, Avustralya'da Salzburg, İtalya'da E. Romagna Dünya'da başarılı olan bölgelere örnek olarak gösterilebilir (Müftüoğlu, 2006 aktaran Işık ve Kılınç, 2011: 25). Eski liberalist ülkelerde 1980’lere kadar bölgesel kalkınma stratejileri önemli ölçüde bölgeler arasındaki dengesizliğin giderilmesini hedefleyen işletmeyi teşvik ve standartlaşmaya dayanırken; küçük üretime yönelik bölgesel ekonomilerin iç dinamiklerini artırıcı uygulamaları yeni-liberal politikalarla önem kazanmıştır. Bunların sonucunda bireyler-özel-kamu sektörü arasında dayanışma, koordinasyon ve bilgi yayılımı artış göstermiş, özellikle inovasyon çalışmaları bölgelerin gelişiminde önemli yer tutmaya başlamıştır (Işık ve Kılınç, 2011: 24). Bu bağlamda, bölgeler arasındaki dengesizlikleri en aza indirmek amacıyla ilk olarak 1933'te ABD'de faaliyet gösteren Kalkınma Ajansı kurulmuştur. Problemlerin ortaya çıkarılması ve neticeye ulaştırılmasının kalkınma ajansları sayesinde yerinden çözüleceği görüşünden yola çıkılarak kalkınma ajanslarının sayısı ABD’den sonra arttırılarak pek çok ülkede yerinden yönetim anlayışı bir politika aracı niteliği kazanmıştır. Bu çerçevede; Brezilya, Japonya, İrlanda, Avusturya, Fransa, Belçika 1950 yılında, İtalya, Hollanda, Almanya, İngiltere'de 1960-1970'li yıllarda, Danimarka, Finlandiya, İspanya, Yunanistan'da 1980-1990'lı yıllarda, Ukrayna, İsveç, Estonya, Çek Cumhuriyeti, Bulgaristan, Litvanya, Portekiz, Slovakya, Macaristan, Polonya'da 1990 yılından sonra kurulmuştur. Bu ülkelerin ardından2006 yılında ülkemizde de Kalkınma Ajansları'na yönelik kanunun çıkarılması sonucunda ilk olarak 6 Temmuz 2006' da İzmir (TR31) ve Çukurova (TR 62)'da Kalkınma Ajansları kurularak çalışmalara başlamışlardır. Daha sonra Kalkınma Ajansı 8 Düzey 2 bölgesinde faaliyete geçmiştir. Son olarak 14 Temmuz 2009 tarihinde geriye kalan 16 Düzey 2 bölgesinde daha Kalkınma Ajansı kurulmasına yönelik karar yayınlanarak yürürlüğe girmiştir (Işık vd. 2010: 17).

\section{Kalkınma ve İnovasyon Arasındaki İlişskiye Yönelik Yaklaşımlar}

Ulusal boyuttaki inovasyon sistemleri, makro anlamdaki inovasyon sistemleri ile açıklanmaktadır (Tutar ve Diğ., 2013: 628). İktisadi kalkınma, Schumpeter'e göre yeni mal ve hizmetlerin, yeni üretim süreç ve tekniklerinin ya da üretimle ile yeni araçların yaratılması şeklinde ifade edilir (Kaynak, 2003: 18). Kalkınma teorisi modeli Schumpeter'e göre, girişimcinin tarafından yenilikleri uygulama, satın alma gücünü oluşturabilme ve inovasyon yapma olmak üzere üç temel aşamada açıklamıştır. Kalkınma Schumpeter'in ifadesiyle kalkınmanın inovasyona bağlı kalıp sıklıkla duraksayacağını savunarak Neoklasik görüşü benimsememiştir (Aydoğuş, 2009: 9-10). Teknoekonomik paradigma; ülkeler, teknoloji ve işletmeler söz konusu olduğu durumda "Schumpeterci ekonomik gelişme kuramı" Kondratiev'in "uzun dalgalar" teorisi ile birleşerek merkezlerine teknolojik inovasyonu koymaktadır (Eşiyok, 2004: 20). Yeni tekno-ekonomik paradigma, ekonomik sistem ile bu sistemin krize girmesini 
II. Dünya Savaşı sonrasında araştıran bir teorik modelin bir parçasıdır. Bu yaklaşım ekonomik yapının oluşması ve ekonomik krizlerin yaşanması sürecinde teknolojiye ağırlık vererek krizden kurtulmayı ve yeniden yapılanmayı amaçlamaktadır (Yılmaz, 2008: 17). Yeni gelişim teorisi literatürde, 1960'lardan itibaren bilgi toplumunun gelişmesiyle yoğunluk kazanmış, ürün devreleri, ölçek ekonomileri, teknoloji açı̆̆ı, nitelikli insan gücü gibi kavramlara dayanan yeni gelişim teorisiyle 1980'li yıllarda bilgiye dayalı içsel modellerle şekillenmiştir. Bu teori, yaparak öğrenme, araştırma-geliştirme ve teknolojik ilerleme faaliyetlerini esas almaktadır (Bayraktutan, 2003: 184). Ulusal İnovasyon Sistemi günümüzde ileri teknolojili ürünler üretmek, ekonomik büyümeyi sağlamak ve uluslararası alanda rekabet üstünlüğün̈̈ kazanmak için teknolojik inovasyonda uzmanlaşmanın önemi artmaktadır. UİS bu bağlamda ülkelerin inovasyon üretebilme becerilerini geliştirmeyi amaçlayarak son dönemlerde yaygınlık kazanmaktadır. UİS'in bu kadar hızla yayılması, çağımızdaki bilgiye dayalı gelişme ve teknolojik ekonomik rekabetin sonucudur (Saatcioğlu, 2005: 180). UİS'in asıl öğelerini; araştırma kurumları, üniversiteler, devlet ile firmalar arasında köprü görevi gören kuruluşlar, tüm sektörleri kapsayan işletmeler, teknoparklar, teknoloji transfer merkezleri, ortak araştırma merkezleri, eğitim merkezleri, patent ofisleri gibi diğer kamu ve özel sektör kuruluşları oluşturmaktadır (Elçi, 2006: 46). UİS, bu öğeler arasındaki karşılıklı etkileşimle oluşmuş olup teknoloji ve bilgi yaratılır, yayılır ve kullanılır. UİS yaklaşımı bir ülkenin teknolojilerinin ve yeniliklerinin yayılmasını belirleyerek işgücü verimlilik kapasitesini dolaylı yönden etkileyen öğe olarak ortaya çıkmaktadır. Türkiye'nin UİS'inin gelişmesi için uluslararası standartların dikkate alınması gerekmektedir. Türkiye'nin ekonomik yapısı gereği birtakım sorunların üstesinden gelinmesi gerekmektedir. Bu sorunlar Türkiye'nin teknoloji ve inovasyon stratejileriyle ilgilidir. Ekonomik büyüme ve kalkınmanın sağlaması, istihdamın yaratılması için teknoloji ve inovasyon stratejilerini destekleyecek yönde politikalar koyulmalıdır (İnovita, 2009: 2).

\begin{tabular}{|c|c|c|c|c|c|c|}
\hline \multirow[b]{2}{*}{ Ülke } & \multicolumn{2}{|c|}{ İnovasyon Gelişmişliği } & \multicolumn{2}{|c|}{ İş Gelişmişliği } & \multicolumn{2}{|c|}{ İnovasyon } \\
\hline & Sira & ED & Sira & ED & Sira & ED \\
\hline Almanya & 4 & 5,56 & 3 & 5,65 & 6 & 5,47 \\
\hline Avusturya & 14 & 5,11 & 7 & 5,41 & 18 & 4,82 \\
\hline Belçika & 12 & 5,51 & 10 & 5,34 & 13 & 4,89 \\
\hline Birleșik Krallık & 8 & 5,21 & 6 & 5,45 & 12 & 4,96 \\
\hline Bulgaristan & 106 & 3,27 & 105 & 3,61 & 105 & 2,94 \\
\hline Çek Cumhuriyeti & 36 & 4,07 & 35 & 4,46 & 39 & 3,67 \\
\hline Danimarka & 9 & 5,19 & 11 & 5,33 & 11 & 5,06 \\
\hline Estonya & 34 & 4,14 & 48 & 4,32 & 30 & 3,95 \\
\hline Finlandiya & 3 & 3,57 & 9 & 5,36 & 1 & 5,78 \\
\hline Fransa & 19 & 4,86 & 22 & 4,98 & 19 & 4,74 \\
\hline Hollanda & 6 & 5,41 & 5 & 5,57 & 8 & 5,25 \\
\hline Hurvatistan & 87 & 3,47 & 83 & 3,83 & 93 & 3,10 \\
\hline İrlanda & 20 & 4,85 & 20 & 5,02 & 20 & 4,68 \\
\hline İspanya & 39 & 4,06 & 38 & 4,42 & 37 & 3,69 \\
\hline İsvec & 7 & 5,38 & 8 & 5,38 & 7 & 5,37 \\
\hline İtalya & 29 & 4,26 & 25 & 4,79 & 35 & 3,73 \\
\hline Kıbris & 38 & 4,06 & 40 & 4,41 & 36 & 3,72 \\
\hline Letonya & 61 & 3,68 & 61 & 4,09 & 70 & 3,27 \\
\hline Litvanya & 44 & 3,97 & 49 & 4,31 & 44 & 3,62 \\
\hline Lüksemburg & 18 & 4,93 & 21 & 5,00 & 16 & 4,85 \\
\hline Malta & 41 & 4,03 & 36 & 4,45 & 45 & 3,60 \\
\hline Polonya & 63 & 3,66 & 63 & 4,06 & 72 & 3,26 \\
\hline Portekiz & 31 & 4,19 & 51 & 4,29 & 28 & 4,08 \\
\hline Romanya & 78 & 3,53 & 90 & 3,77 & 66 & 3,28 \\
\hline Surbistan & 121 & 3,05 & 132 & 3,21 & 108 & 2,89 \\
\hline Slovakya & 73 & 3,59 & 65 & 4,00 & 78 & 3,18 \\
\hline Slovenya & 50 & 3,88 & 59 & 4,11 & 42 & 3,64 \\
\hline Yunanistan & 74 & 3,55 & 74 & 3,91 & 79 & 3,18 \\
\hline Makedonya & 76 & 3,53 & 89 & 3,78 & 68 & 3,28 \\
\hline Türkiye & 51 & 3,86 & 50 & 4,31 & 56 & 3,42 \\
\hline
\end{tabular}

Tablo 1. Inovasyon Gelişmişliğinin AB Ülkeleri ve Aday Ülkeleri ile Türkiye Üzerindeki Küresel Rekabet Endeks Ölçümü (2014-2015) Kaynak: WEF, The Global Competitiveness Report 2014-2015, s.20. ED: Endeks Değeri, www3.weforum.org/docs/WEF_GlobalCompetitivenessReport_2014-15.pdf, erişim tarihi: 03.02.2016.

Dünya Ekonomik Forumu (WEF)'nun hazırlamış olduğu 2009-2010 Küresel Rekabet Endeksi Raporu'na göre Türkiye inovasyon performansında dünyada 69. sırada iken; aynı performans bakımından değerlendirdiğimizde; Amerika Birleşik Devletleri, Çin, Singapur, Japonya, Kore, Almanya gibi ülkelerin inovasyon performansında üst sıralarda yer aldığı görülmektedir (Işık ve Kılınç,2011: 10). AB'ye üye ve aday ülkelerin 2014-2015 yılları arasında Türkiye'nin Küresel Rekabet Endeksi ölçümü kapsamında inovasyon gelişmişlik sıralaması Tablo 1'de 
açıklanmıştır. 2014-2015 yılları arasında inovasyon gelişmişlik sıralamasında ön sıralarda yer alan ülkeler; Finlandiya, Danimarka, Birleşik Krallık, İsveç, Hollanda, Almanya iken; iş gelişmişliği sıralamasında ilk sırada olan ülkeler; Almanya, Hollanda, Birleşik Krallık, Avusturya ve İ́sveç’tir. Türkiye'nin, inovasyon performansını değerlendirdiğimizde ise, Türkiye inovasyonda 56. sıradadır. Ülkemizin kalkınması için, rekabetçi yapıların güçlendirilmesinde, hayat kalitesinin artırılmasında, iş imkânlarının geliştirilmesinde önemli bir görevi olan inovasyonun henüz istenilen şekilde yapılamadığını göstermektedir.

\section{Güney Kore Ekonomisi}

Başkenti Seul olan Güney Kore'nin GSYH'sı 1,4 trilyon dolar olup, nüfusu 51 milyondur. Güney Kore Çin ve Japonya'nın ardından Uzak Doğu'nun en büyük ekonomik gücüne sahip olan ülkesidir (Tedsiad, 2014). Birleşmiş Milletler Kalkınma Programı (UNDP) tarafından 1990'dan buyana her yıl düzenlenen ülkelerin kalkınmışlı seviyesini sağlık, eğitim ve hayat standartlarıyla ölçerek kalkınmanın insani yönünü ele alan İnsani Gelişme Endeksi (İGE) (Fırat ve Aydın, 2015: 63) değerlendirildiğinde, ülkeler arasında Güney Kore 15. sırada yer almış, ekonomik gelişmedeki başarısını kalkınmada da göstermiştir. 1970'li yıllarda Türkiye'nin epey gerisinde olan Güney Kore, 1980'li yıllarda Türkiye'yi yakalamıştır. Dünya ekonomistleri tarafindan Güney Kore, geçmiş dönemde çoğu bakımdan benzerlikler göstermesi sebebiyle Türkiye ile karşılaştırılmıştır. Güney Kore 2000'li yıllardan beri gerçekleştirdiği büyük atılımlar ile gelişmekte olan ülke konumundan gelişmiş ülke konumuna gelmiştir. Jeopolik konumu ve doğal zenginlikler bakımından Türkiye kadar avantajlı olmamasına rağmen Güney Kore'nin başarısını ekonomistler eğitime, Ar-Ge'ye ve inovasyana yapılan yatırımlara bağlamaktadır. 25 Haziran 1950 yilında, Kuzey Kore'nin Güney Kore'ye savaş açmasıyla Soğuk Savaş 1953 senesine kadar devam etmiş, böylece yarımada iki ülkeye bölünmüştür (Tetsiad, 2014). Devlet Başkanı 1948'de Syngman Rhee olup, serbest pazar ekonomisini uygulayarak ithalatın ikamesine ve devletin kurumsallaşmasına yönelik politikalar izlemiştir. 1960 yılında Rhee hükümeti ve sonrasında Park Chung Hee'nin döneminde alınan yardımlar, özel sektördeki firmalara kullandırarak ihracat teşvik edilmiş ve ağır sanayiye önem verilmiştir (Atay, 2012). Güney Kore, kalkınma hamlesini beş yıllık kalkınma planıyla başlatmış daha sonraki beşer yıllık dönemlerde hazırladıkları planlarla kalkınmasını hızlandırmıştır.1960 yılında ilk Ekonomik Planlama Kurulu oluşturulmuş, bu yıldan itibaren planlı bir şekilde kalkınma süreci başlatılmıştır. Planlarda uygulama aşamalarını yakından takip etmeye, ülkenin ekonomi yapıcılarını plandan sorumlu tutmaya ve devletin üst düzey yardımlarını kontrol etmeye büyük önem vermiş̧lerdir. Birinci Beş Yıllık Kalkınma Planı (1962-1966), Ekonomik Planlama Kurulunun bu konuda tecrübeli olamamaları ve planın aceleye getirilmesi sebebiyle başarılı olmamıştır. Böyle olmasına rağmen ülke $\% 7,1$ büyümüştür. Bu durum planın başarısızlığını geride bırakıp, toplumun devletine ve ülkesine olan güvenini arttırmıştır (Ekodialog). 1960 yılında Kore'de ihracata yönelik sanayileşmeyi gerçekleştirecek işletmeler, kurumsallaşma çabalarını yeni yöntemlerle sağlamaya çalışmışlardır. Ayrıca emek faktörü de eğitime ve motivasyona önem vererek kalkınma için gerekli şartları sağlamıştır. Devletin 1960'lı yıllarda kalkınma politikası, tarım sektörüne önem veren, dolaylı teknoloji transferi yapan, güvenilir bir pazarın sağlandığı, fiyat dalgalanmalarının olmadığı, yetişmiş işgücünün varolduğu, istikrarlı bir makroekonomik ortamda oluşturulmuştur. Devletin piyasaya müdahale ederek finans kontrolünü sağlaması, dolaysız kredilerdeki ve ihracat destek teşviklerindeki uygulamaları politikaların başarısını artırmışıı. Bunların dışında devlet politikacılarının özellikli kişilerden seçilmesi, işinin ehli üst düzey yöneticilerin başa gelmesi, ekonomik politikaların devamlı takip ve kontrolü yeniden yapılandırılmanın başarısını arttırmıştır (Tüsiad 1996 aktaran Oğuztürk, 2011: 50). Bu yıllarda ulaşım, elektrik, iletişim gibi temel altyapının ihracatının teşvikine, rafineri, gübre, çimento gibi ithalatın ikamesine dönük temel endüstrilere ve iş gücüne dayalı hafif sanayinin (peruk, kontraplak, ayakkabı, tekstil gibi) gelişimine yönelik çalışmalara yoğunlaşılmıştır (Chung vd. ve Ungson vd. 1997 aktaran Atay, 2012: 241-242).

İkinci Beş Yıllık Kalkınma Planı'nda (1967-1971) sanayi altyapısının modernleştirilmesi ve ülke ekonomisinin kendine yetmesi hedeflenmiştir. Bu dönemde vergi gelirleri \%200, ihracat \%417, GSMH \%80 oranında artış göstermiştir. Üçüncü Beş Yıllık Kalkınma Planı (1972-1976)'nda gelir dağlımı konusu üzerinde durulmuştur. Bölgeler arasındaki farkın giderilmesine yönelik faaliyetlerin geliştirilmesine, özel sektörün ekonomik yapıda daha çok ön plana çıkarılmasına ve kırsal alanlardaki yatırımlara ağırlık verilmesine yönelik çalışmalar yapılmıştır. Büyüme \%10,2 olarak gerçekleşmiştir. Dördüncü Beş Yıllık Kalkınma Planı (1977-1981) dünya petrol krizi sebebiyle başarıya ulaşamamıştır. Planlanan büyüme \%9,2 olarak saptanırken \%4,3’te kalmış, enflasyon 1980 'de \%25,6'ya yükselerek ekonomi \%8 oranında daralmıştır. Beşinci Beş Yıllık Kalkınma Planı (1982-1986) ülkenin makro olarak büyümesini ve özellikle ihracatı arttırmasını amaçlamışıı. Makro bileşenlerde iyileşme sağlanırken \%7,5 olarak planlanan büyüme hedefi \%8,7 olarak gerçekleşmiştir. Altıncı Beş Yıllık Kalkınma Planı (1987-1991) prodüktiviteyi ve küreselleşen piyasalarda rekabet üstünlüğü sağlamayı ön planda tutmuştur. Daha sonraki yıllarda finansal piyasaların özelleştirilmesi ve devletin rolünün azaltılması Güney Kore'nin liberalleşme politikalarını oluşturmuştur (Ekodiyalog). 1961'den 1992'ye kadar askeri yönetimlerle planlı bir ekonomik kalkınma hamlesi başlatan Güney Kore'de 1992'deKim Yong Sam demokratik bir seçimle devletin başına geçmiş̧ir. Bu yıllarla birlikte demokratikleşme sürecinde ciddi gelişmeler yaşanmış ve ekonomik kalkınma son aşamasına ulaşmıştır. $\mathrm{Bu}$ süreç içerisinde bilginin hızla yayılması ve teknolojik inovasyonun hızlanması, eğitim ve ulaştırma sistemlerinin güçlenmesi, küresel dünya ile entegrasyonu sağlamıştır. Bu entegrasyon ile uluslararası yatırımcılar 
ülkeye daha hızlı getirilmiş, motivasyona ve çok çalışmaya dayalı eğitim ve teknoloji odaklı stratejiler izlenmiştir (Atay,2012).

\section{Güney Kore'nin Ar- Ge ve İnovasyon Politikası}

1980’lerden günümüze olağanüstü ekonomik gelişimiyle Güney Kore, teknoloji ve bilim alanındaki üstün kabiliyeti, aktif ve sürekli araştırma gelişme faaliyetleri ile diğer gelişmekte olan ülkelere örnek teşkil edecek şekilde hızla büyümektedir. Güney Kore, ekonomik kalkınmadaki hamlesi, Ar-Ge ve inovasyon alanlarındaki başarısıyla dikkat çeken bir ülke olmuştur. Hükümet 1980'lerden itibaren ağırlığını ciddi ölçüde sanayi stratejisinden, teknoloji stratejisine yönlendirmiştir. Bu farklılık Ar-Ge harcamalarında, özellikle özel sektörde büyük bir atılım yaratmıştır.

1980’li yıllarda Güney Kore’nin yaşadığı transformasyonla Ar-Ge’nin önemli bir bölümünü özel sektörün yapması sonucunda ürün geliştirme satış ve pazarlaması kolaylaşmış, uluslararası pazarlarda özel sektörün rekabetçi bir yapıya kavuşması sağlanmıştır (Arslanhan ve Kurtsal, 2010). 1971 yılında, özel sektörün toplam ArGe harcamalarının payı \%32 iken; 2008 yılında \%80’e yükselmiştir (Oğuztürk, 2011). Güney Kore ekonomisine devletin inovasyon politikasının hükümetlere bağlı kalmadan uygulanması ve sürekliliğinin, eğitime yatırımın devamlı artmasının, Ar-Ge yatırımlarının ekonomi politikası haline gelmesinin, sanayinin ve özel sektörün ArGe’ye yüksek yatırımının, eğitim seviyesi yüksek iş gücü ve dünya ile rekabet halindeki global şirketlerin, teknolojik ve endüstriyel yeniliklere hızlı adapte olabilme kabiliyetinin önemli katkıları olmuştur (Kim, 2000).

\begin{tabular}{|l|l|l|}
\hline Rank & Country & Patent Applications \\
\hline 1 & China & 652,777 \\
\hline 2 & United States & 542,815 \\
\hline 3 & Japan & 342,796 \\
\hline 4 & South Korea & 188,915 \\
\hline 5 & European Patent Office & 148,56 \\
\hline 6 & Germany & 61,34 \\
\hline 7 & Russia & 44,211 \\
\hline 8 & India & 43,955 \\
\hline 9 & Canada & 35,242 \\
\hline 10 & Brazil & 30,116 \\
\hline
\end{tabular}

Tablo2: Patent Başvuru Siralamasında İlk 10 Ülke Kaynak: Kistep R\&D and Beyond, 2014

Güney Kore'de, Ar- Ge ve teknolojiye olan yatırımın ilk belirtisi olarak patent sayılarındaki artış görülmüştür. Patent sayısı 1960'l yıllarda 219 iken 2007'de 564 kat artarak 123.705 'i bulmuştur. Alınan patentlerin endüstri kollarına göre dağılımları incelendiğinde öncelikle telekomünikasyon ve elektronik alanlarda alınan patent sayısı yıllar itibariyle yükseliş göstermektedir (Atay, 2012). Güney Kore 2014 yılı itibariyle Çin, ABD ve Japonya'nın ardından 188.915 patent sayısıyla 4. sıraya yükselmiştir (Tablo2). Güney Kore, ürün ve hizmet üretimi, geliştirmesi ve ticaretinde, sağlam bir Ar-Ge yapısının oluşturulmasını amaç edinmiş, bu amaçları farklı stratejilerle desteklemiş ve Ar-Ge ile bütünleşmiş bir inovasyon sistemini yaratmıştır.

Güney Kore'nin patent sayısını artırmasında geçtiği süreçlerde bazı stratejiler ön plana çıkmıştır. Bunlardan en önemlisi eğitime verilen önem olmuştur. Özellikle Ar-Ge eğitimini geliştirmeye yönelik çalışmalara ağırlık verilmiş, Ar-Ge sisteminin gelişimini sağlamak için büyük gayret gösterilmiştir. Güney Kore önce imitasyon sürecini (1960-1970), 1980'lerde transformasyon süreci ve 1990'lı y1llardan sonrada inovasyon sürecini başarılı bir şekilde tamamlamıştır. Özel sektör kendi Ar-Ge sistemini kurmuş, büyük firmaların Ar-Ge sistemini faaliyete geçirmeleri devlet tarafından desteklenmiş, teknoloji içeren küçük işletmeler ve Ar-Ge merkezleri ile KOBI'lerin yoğunluğu artırılarak Ar-Ge çalışmaları desteklenmiş, Ar-Ge harcamalarında özel sektörün çıkarları gözetilmiş, araştırmanın dişında ürün geliştirmeye ve uygulamaya pay ayrılarak doğrudan katma değer ve maddi değer sağlanmış, patent ve lisans haklarına yönelik çalışmalar hızlandırılmış böylece patent sahiplerinin motivasyonu arttırılmış, özel sektörlere yapılan yatırımlar desteklenmiştir. Son yıllarda Güney Kore'de Ar-Ge harcamalarının Gayri Safi Milli Hasıla'dan ayrılan payın artması, kaynak aktarmada devamlılığın sağlanması ve Ar-Ge harcamalarının karlı yatııımlara dönüşmesi, Ar-Ge'de bazı sektörlerin ön plana çıkması bu politikaların başarısının devamlılığını sağlamıştır. Güney Kore'de bilim, teknoloji ve otomotiv gibi sektörle de inovasyon patlaması yaşanmış, yeni ürünler dünyaya ihraç edilerek ülkenin gelişmesine büyük katkı sağlamıştır. Ülke ekonomisinde tekstil ve tarım gibi emek yoğun üretimler yerine hafif sanayiye ikinci olarak ağır sanayiye ve en son da ileri teknolojili sanayilere önem verilmiştir (Arslanhan ve Kurtsal, 2010). 


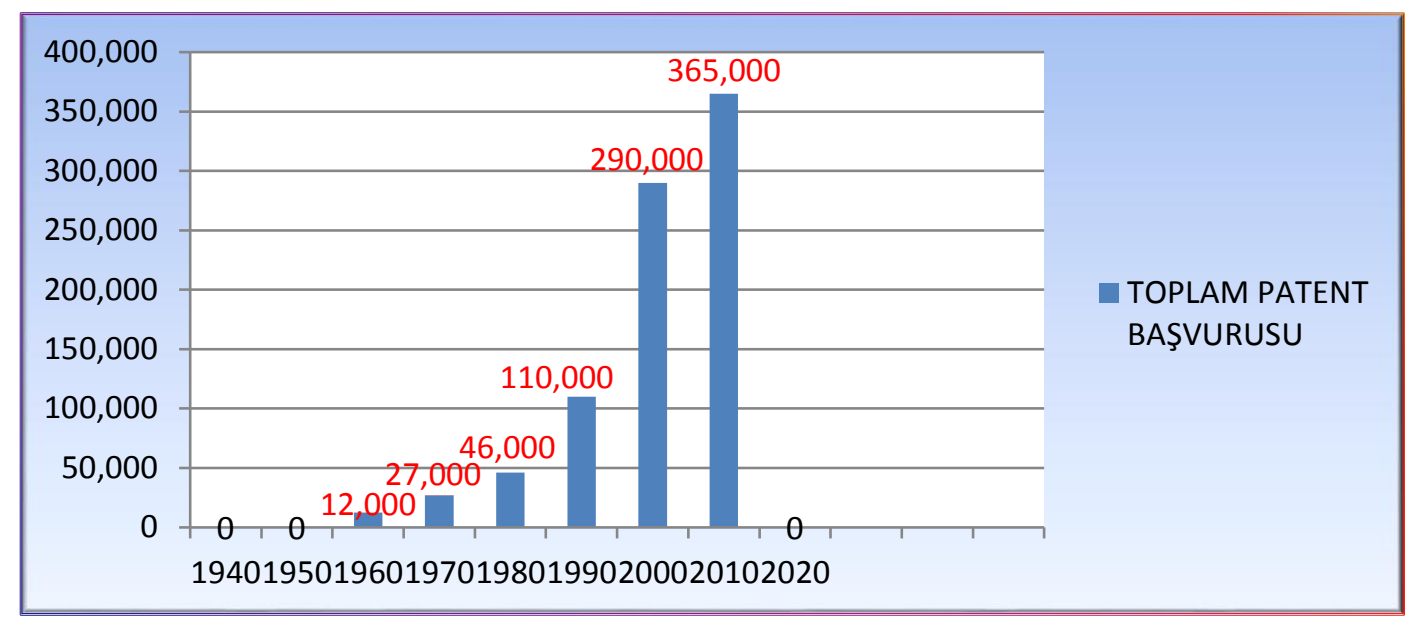

Grafik 1: Toplam Patent Başvurusu Kaynak: Kistep R\&D and Beyond, 2014

Grafik 1'de, 1940-2020 yılları arasında Güney Kore'nin toplam patent başvuru sayısı gösterilmiştir. Güney Kore'de 1940-1950 yılları arasında patent başvurusu gerçekleşmemiştir.1960 yılında ise patent başvuru sayısı 12000 iken 2010 yılında 365000 bin olmuş ve 10 yıllık zaman dilimleri içerisinde düzenli bir şekilde artış göstermiştir.

\begin{tabular}{|l|l|l|}
\hline Rank & Country & Patent Applications \\
\hline 1 & South Korea & 10,584 \\
\hline 2 & Japan & 7,160 \\
\hline 3 & China & 4,980 \\
\hline 4 & Germany & 2,596 \\
\hline 5 & Switzerland & 2,575 \\
\hline 6 & France & 2,090 \\
\hline 7 & United States & 1,988 \\
\hline 8 & Sweden & 1,722 \\
\hline 9 & Denmark & 1,667 \\
\hline 10 & Luxembourg & 1,414 \\
\hline
\end{tabular}

Tablo 3: Patent Başvurusunun Milli Gelire Oranı Sıralamasında İlk 10 Ülke Kaynak: Kistep R\&D and Beyond 2014

1980-1985 yılları aralığında Güney Kore'de, Ar-Ge harcamalarının GSYH içerisindeki payı iki katına yükselmiştir. Özel sektörün 1980'lerden sonra Ar-Ge çalışmalarını hızlandırması, toplam harcamaların artışında da kendisini göstererek ürün geliştirme ve geliştirilen ürünlerin pazarlanmasını sağlamış, uluslararası pazarlara girmeyi ve aynı zamanda ekonomik büyümeyi gündeme taşımıştır (Arslanhan ve Kurtsal, 2010). Tablo 3'e göre, patent başvurusunun milli gelire oranı sıralamasında ilk sırayı Güney Kore almaktadır. Güney Kore'nin patent başvurusunun milli gelir içerisindeki oranı 10.584 olup ilk on ülke içerisinde ilk sırada yer almaktadır. Güney Kore'den sonra 7.160 ile Japonya ve 4.980 ile Çin takip etmektedir. Güney Kore ilk on ülke içerisinde ilk sırada yer alırken Lüksemburg ise, 1.414 ile 10. sırada yer alarak patent başvurularının milli gelir içerisindeki payı en düşüktür.

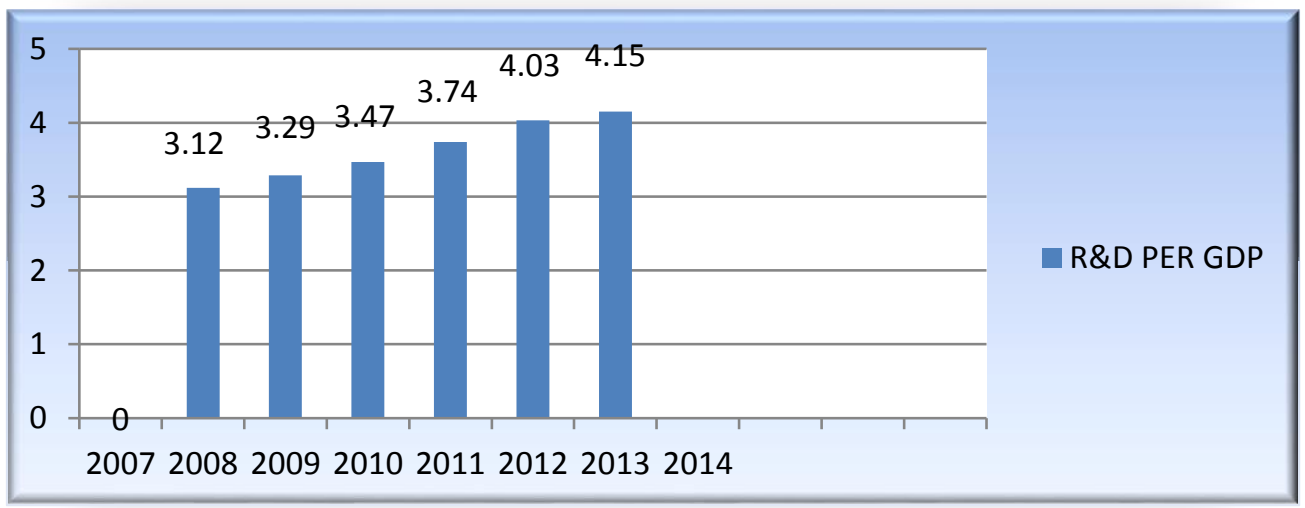

Grafik 2: Ar-Ge Harcamalarının Milli Gelire Oranı Kaynak:2013 Survey of Research and Development in Kore 
Grafik 2’de, 2007-2014 yılları arasında Güney Kore'nin Ar-Ge harcamalarının milli gelire oranı gösterilmiştir. Ar-Ge harcamalarının milli gelire oranı 2008 yılında 3.12 iken 2009'da 3.29'a, 2010'da 3.47, 2011'de 3.74, 2012 'de 4.03 ve 2013 'te artarak 4.15'e kadar yükselmiştir. Güney Kore 2007 yılında Ar-Ge harcamalarına milli gelirden pay ayırmazken 2008 yılında 3,12 ve 2013 yılında 4,15 pay ayırarak 2008-2013 yıllara arasında düzenli bir şekilde Ar-Ge'nin milli gelir içerindeki payı artış göstermiştir.

Güney Kore'de Chaebol denilen özel firmalar, ekonominin gidişatını belirledikleri için; Güney Kore ekonomisi için ciddi bir paya sahip olmuşlardır. 1990 yılında, 5 büyük Chaebol öncelikle Kore'nin patent sayısının birçoğuna sahip olmuşlardır. Ar-Ge'nin ekonomi üzerindeki pozitif etkisini anlayan büyük firmalar Ar-Ge ve inovasyon konusunda özel stratejiler geliştirmişler, ilerlemeye yönelik politikalar içerisine girmişlerdir. 4 büyük Chaebol 2000'de,Hyundai, LG, Samsung ve SK toplam 4,731 milyar Kore Wonu harcamasını Ar-Ge'ye yönelik yaparak 2001 'de de bu eğilimini sürdürmüştür. Özel işletmeler 2000'de,\%20 Ar-Ge genişleme eğilimi gösterirken; kamu güdümlü üniversite, enstitü ve laboratuvarlar yalnızca \%9 genişleme eğilimine girmişlerdir. Güney Kore Dünya'da toplam patent sayısı bakımından 5. sırada olup toplam patentlerin $\% 5$ ' ine sahip olan ülkedir. Chaebollerin patent alma konusunda büyük bir rolü olup, Samsung Chaebolü bir numaradır (Oğuztürk, 2011).

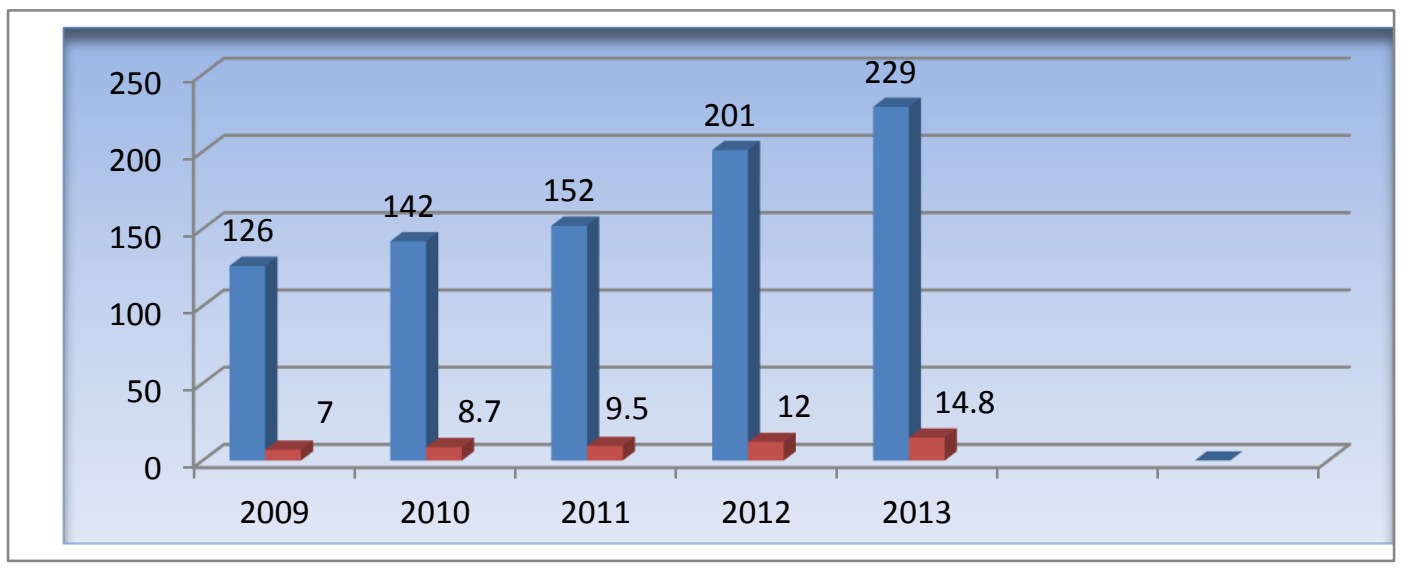

Grafik 3: Samsung Electronics Ar-Ge Yatırım Rakamlarl (Milyar Us) Kaynak: Samsung Electronics Sustainability Report, 2014.

Grafik 3'te Güney Kore'nin 2009-2013 yılları arasında Samsung Electronics'ın Ar-Ge yatırım rakamları gösterilmiştir. Yıllar itibariyle Ar-Ge yatırımları düzenli bir şekilde artış göstermiştir.

2009 yılında Samsung Electronics’ın üniversite-sanayi işbirliğine ayırdığı fon 26,3 milyon ABD\$ iken 2012 yılında bu yıllar aralığında artış göstererek 90 milyon ABD\$ olmuştur. Böylece Güney Kore sanayinin güçlendirilmesine, araştırma faaliyetlerinin geliştirilmesine ve fonların artırılmasına yönelik çalışmalara hız kazandırarak gelişme sağlamaktadır (Samsung Electronics,2014).

\section{Sonuç}

Günümüzde toplumları diğer toplumlardan ayıran en önemli güç faktörü eskiden olduğu gibi teknolojidir. Tarihi süreç göz önünde bulundurulduğunda toplumlar strateji olarak da mücadele etmektedir. Yeni teknolojiler ve inovasyonlar, toplumları güçlü yapmakla kalmayıp aynı zamanda ülkeleri refaha kavuşturmaktadır. Azgelişmiş ve gelişmiş ülkeler arasında giderek artan bir fark söz konusudur. Bu fark makro dengesizliklerin ve mali göstergelerin yanısıra teknolojik farktan da kaynaklanmaktadır (Müsiad, 2012: 26). Bu nedenle, neoliberalizmin yol açtığg küresel rekabet içerisinde yer almanın koşulu teknolojik Ar-Ge ve inovasyondan geçmektedir. Gelişmiş ülkeler, kendi Ar-Ge ve inovasyon sistemlerini geliştirerek ekonomik ve toplumsal farklılıklarını yaratmışlardır. İleri seviyede Ar-Ge ve inovasyon faaliyetinde bulunan güçlü sanayi ülkeleri, rakiplerine karşı fark atmışlardır. Ülkeler Ar-Ge harcamalarının GSYİH içindeki paylarını artırmakla birlikte Ar-Ge ve inovasyon ile rekabet güçlerini de artırmaya çalışmışlardır.

ABD, Türkiye ekonomisinin yarısı kadar Ar-Ge harcaması yapmakta ve Güney Kore Türkiye'nin 7 katı Ar-Ge yatırımı yapmaktadır (Müsiad, 2012: 26). Gelişmiş ülkeler rekabet güçlerini korumak ve lider ülke konumuna geçmek için Ar-Ge ve inovasyona büyük önem vermişlerdir. Gelişmekte olan ülkelerin rekabet ortamında yer alamamalarının bir nedeni de geliştirme konusunun iyi anlaşılamamasıdır. Ekonomik olarak kalkınmanın yolu teknolojik gelişmeden geçmektedir. Gelişmekte olan ülkelerin birçoğu bunun önemini kavrayamamıştır

İkinci Dünya Savaşı sonrasında yaşanan küreselleşmeyle Güney Kore kişi başına düşen gelir yönünden Türkiye'nin gerisinde kalmış olmasına rağmen küreselleşmenin hızlanmasıyla kalkınma hamlesini Ar-Ge ve inovasyonla gerçekleştirmiştir. Son yıllarda Güney Kore'de milli gelirden Ar-Ge'ye ayrılan pay giderek artmış, fiziki alt yapının tamamlanması için gerekli düzenlemeler yapılmış, küçük ama emin adımlarla küresel rekabet içerisine girilmiştir. $\mathrm{Bu}$ başarısını ülkede yaşayan tüm bireylerin motivasyonuna ve milli çıkarlarına 
sahiplenmesine borçludur. Ayrıca özel sektörün girişimciliğine ve devletin Ar-Ge ve inovasyon politikalarına da bağlı olarak ekonomik büyüme ve kalkınma sağlanmıştır. Güney Kore'nin kalkınma hikâyesinin arkasında yatan unsurların Ar-Ge ve inovasyon olduğu unutulmamalıdır. Bu hikâyenin en önemli kahramanları hiç kuşkusuz eğitimli ve yetenekli halkı olmuştur. Güney Kore'de büyük finale giden yol eğitimden geçmiştir. Eğitime önem verilerek üniversite ile sanayi işbirliği çerçevesinde stratejik kararlar alınmıştır. Devletin de eğitimi destekleyen politikaları bu uzun ve sancılı süreçte büyük önem taşımıştır. Güney Kore'de ülkenin yetersiz olduğu alanlar öngörülmüş bu alanlara yatırımlar yapılmıştır. Gerek devlet gerekse özel sektör tarafından girişimci ve dinamik bir şekilde Güney Kore'de odak sektörlere yatırımlar yapılarak, sistemli Ar-Ge ve inovasyon uygulamalarına geçilmiştir. Güney Kore'nin gelişmiş ülkelerle yarışı farklı aşamalardan geçmiş, bu tecrübelerden iyi dersler çıkararak kendi inovasyon sistemlerini geliştirmiştir. Güney Kore dünyanın gidişatını öngörerek teknoloji konusundaki atılımlarını zamanında yapmıştır.

Türkiye'nin 1980 sonrası yaşamış olduğu krizlerden sonra uyguladığı yeniden yapılandırma programı değerlendirildiğinde ekonomik büyüme ve istikrar gibi konularda başarılar sağlandığ 1 ancak Ar-Ge ve inovasyon konusunda yeterli seviyede olmadığ 1 görülmüştür. Türkiye'nin küresel ortamda emek yoğun stratejileri kullanarak rekabet etmesi zor görünmektedir. Gerek doğal kaynaklar gerekse coğrafik konum olarak Güney Kore'den çok daha iyi firsatlara sahip olan ülkemizin rekabet avantajı sağlayan konulara odaklanması gerekmektedir. Türkiye'nin rekabetçi yapısıyla dünyada önemli bir eşikte bulunmasına rağmen, küresel rekabette yerini genişletebilmesi için, hem özel sektör hem de devlet olarak Ar-Ge ve inovasyona odaklanması gerekmektedir. Türk girişimcilerinin ihracat yaptıkları ülkelerde rekabet yapabilmeleri için ürünlerini, hizmetlerini ve ihracat stratejilerini yenilemesi gerekmektedir.

Türkiye'nin “Orta Gelir Tuzağı”na yakalanmaması için yenilikleri bulması ve uygulaması şarttır. G. Kore'nin kalkınma hamlesini gerçekleştirdiği yıllardaki stratejileri Türkiye’nin şartlarına uygun hale getirilerek, dönüşüm süreci hızlandırılmalıdır (Arslanhan ve Kurtsal, 2010). Güney Kore halkının ülkesine sahip çıktığı gibi Türk halkı ve Türk özel sektörünün de ülkesine sahip çıkıp, zenginliklerinin ve manevi değerlerinin kıymeti bilinmelidir. Üniversite ve sanayi arasında yapılan sözleşmeler arttırılmalı, ortak çalışmalar desteklenmeli, üniversitelerde akademisyenleri teşvik programları hazırlanmalı, Güney Kore'de olduğu gibi devlet araştırma-geliştirme çalışmalarına ve inovasyon uygulamalarına aktiflik kazandırmalıdır. Toplumun inanç ve geleneklerine sahip çıkılarak, birlik ve beraberlik içerisinde ileriye dönük hedefler gerçekleştirilmelidir. Unutulmamalıdır ki “inanmak başarmaktır".

\section{Kaynakça}

- $\quad$ Aydemir C. ve Karakoyun İ. 2011. Yeni Bölgesel Kalkınma Yaklaşımı ve Kalkınma Ajansları Karacadağ Kalkınma Ajansı Örneği, Ekin Yayınları, Bursa.

- $\quad$ Aydoğuş, O., Türkcan, B., Çalışkan, E. T. ve Kopurlu, B. S. 2009. "Kriz Teorileri: Kondratieff Schumpeter Wallerstein", Ege Üniversity Working Papers In Economics.

- $\quad$ http://iibf.ege.edu.tr/economics/papers/wp09-01.pdf, erişim tarihi: 26.01.2016.

- Arslanhan, S. ve Kurtsal Y. 2010. “Güney Kore İnovasyondaki Başarısını Nelere Borçlu? Türkiye İçin Çıkarımlar”, Tepav Politika Notları.

- Atay, E. ve Karsan, G. 2012. "Kore Ekonomik Gelişiminin Sosya Kültürel Dinamikleri: Yeni Devletçi Yaklaşımı", G. Avrasya İncelemeleri Dergisi, I.1, 29-73.

- Bayraktutan Y. 2004.Global Ekonomide Büyüme Trendleri Bölgeselleşme ve Küreselleşme, Nobel Yayınları, Ankara.

- $\quad$ Chung, K. H., Lee, H. C. ve Jung, K. H. (1997). "Korean Management: Global Strategy and Cultural Transformation", Newyork: Walter de Gruyter, Berlin, Newyork.

- Elçi, Ş. 2006.İnovasyon: Kalkınmanın ve Rekabetin Anahtarı, Genişletilmiş Yeni Baskı, Feryal Matbaacılık, Ankara. s.87-88.

- $\quad$ Eşiyok, B. A. 2004. Türkiye'nin Kalkınma Sürecinde Teknoloji, Yenilik ve Bilişim Sektörü. Türkiye Kalkınma Bankası, Genel Araştırmalar, Ankara. S. 24.

- $\quad$ Fırat, E. ve Aydın, A. 2015. “İnsani Kalkınma Endeksine Göre Türkiye’nin Eğitim Endeks Göstergelerinin OECD Ülkeleri ile Karşılaştırılması”, Selçuk Üniversitesi İktisadi ve İdari Bilimler FakültesiSosyal ve Ekonomik Araştırmalar Dergisi (The Journal of Socialand Economic Research), ISSN: 1303-8370/Nisan 2015, Y1l: 15, Say1: 29.

- Işı, N., Baysal D. ve Ceylan O. 2010.“Bölgesel Kalkınma Farklılıklarının Giderilmesinde Bir Politika Aracı Olarak Kalkınma Ajansları”,Niğde Üniversitesi İktisadi ve İdari Bilimler Fakültesi Dergisi, 3(2).

- Işık N. ve Kılınç E. C. 2011. "Bölgesel Kalkınma’da Ar-Ge ve İnovasyonun Önemi: Karşılaştırmalı Bir Analiz”, Eskişehir Osmangazi Üniversitesi İ̈BF Dergisi, S. 6(2). 
- Işı1k, N. ve Kılınç, E. C. 2012. “İnovasyon-Güdümlü Kalkınma: Avrupa Birliği Ülkeleri ve Türkiye Üzerine Bir İnceleme”, Girişimcilik ve İnovasyon Yönetimi Dergisi, Cilt 1, Sayı 1, 31-68.

- İ́novita, 2009. “Dünya Bankası Türkiye Ulusal İnovasyon Sistemi Raporundan Özet Notlar”, Güncelleme: 15 Nisan 2012.

- https://inovita.org/uploads/1391513725_1335514903Dunya_Bankasi_TR_UIS_Raporu_Nisan_2012.pdf, erişim tarihi: 26.01.2016.

- Kaynak, M. 2003. "Kalkınma İktisadının Kilometre Taşları ve Teknoloji, Yeni Dünya Düzeni ve Kalkınma Kongresi”, Ankara: Gazi Üniversitesi.

- Korkmaz, S. 2010. “Türkiye'de Ar-Ge Yatırımları Ve Ekonomik Büyüme Arasındaki İlişkinin Var Modeli İle Analizi”, Journal of Yaşar University 2010 20(5).

- $\quad$ Kistep R\&D and Beyond, 2014.

- Mıhçı, H. 1996. “Kalkınma: Bir Terim Neyi Anlatır?”, Ekonomik Yaklaşım, S.23, Ankara.

- Müftüoğlu T. 2006. Küresel Rekabetin Cazibe Merkezi: Yerel/Bölgesel Dinamikler, Derleyen: Aylan Arı, Bölgesel Kalkınma Politikalar ve Yeni Dinamikler, Derin Yayınları, İstanbul, ss. 117-175.

- Müsiad,2012. “Küresel Rekabet için Ar-Ge ve İnovasyon, Stratejik Çözüm Önerisi”,Araştırma Raporlart:76.

- $\quad$ Oğuztürk, B.S. 2011. “Güney Kore’nin Kalkınmasında İnovasyonun Rolü”, Süleyman Demirel Üniversitesi Suleyman Demirel University Vizyoner Dergisi, C. 3, S.5. s.48-53.

- $\quad$ Özer, A. 2015. "Kalkınmada Üniversite - Sanayi İşbirliği, Ar\&Ge ve İnovasyonun Önemi; Güney Kore Örneği”, 3. Uluslararası Avrasya Kongresi, 2015.

- Saatcioğlu, C. 2005. "Ulusal Yenilik Sistemi Çerçevesinde Uygulanan Bilim ve Teknoloji Politikaları: İsrail, AB ve Türkiye Örneği”, İstanbul Üniversitesi, Sosyal Bilimler Dergisi,2005/1.

- http://www.acarindex.com/dosyalar/makale/acarindex-1423869721.pdf, erişim tarihi: 26.01.2016.

- Survey of Research and Development in Kore, 2013.

- Samsung Electronics Sustainability Report, 2014.

- $\quad$ Tetsiad, Güney Kore Ülke Raporu, 2014.

- Tutar, F., Firat, E., Erkan, Ç. ve Tutar, E. 2013. "Yerel Ekonomilerin Yeni Aktörü, Bölgesel İnovasyon Stratejileri: RIS Mersin Uygulaması", Internatıonal Conference on Eurosıan Economies.

- $\quad$ Tüsiad, Görüş Dergisi, 1996.

- Ungson, G. R., Steers, R. M. ve Park, S. H. 1997. "Korean Enterprise: The Quest for Globalization", Harvard Business School Press, Boston, Massachusetts.

- Y1lmaz, L. 2008. Avrupa Birliği’nin Sosyo-Ekonomik Geleceği: Lizbon Stratejisi ve Küreselleşme, Avrupa Birliği Uzmanlık Tezi, Ankara.

- Zerenler, M., Türker, N. ve Şahin, E. 2007. “Küresel Teknoloji, Araştırma - Geliştirme (Ar-Ge) ve Yenilik İlişkisi”,Selçuk Üniversitesi Sosyal Bilimler Enstitüsü Dergisi, (17).

- WEF, The Global Competitiveness Report 2014-2015, s.20. ED: Endeks Değeri http://www3.weforum.org/docs/WEF_GlobalCompetitivenessReport_2014-15.pdf, erişim tarihi: 03.02.2016.

- $\quad$ www.ekodialog.com. Güney Kore Ekonomik Kalkınma Modeli erişim tarihi:26.05.2016. 


\title{
Rekabet Kavramına Yeni Bir Alternatif Yaklaşım: Sistemik Rekabet
}

\section{A New Alternative Approach to The Concept of Competitive: Systemic Competitiveness}

\author{
Asst. Prof. Dr. Nurgün Topallı (Bozok University, Turkey) \\ Assoc. Prof. Dr. Birol Mercan (Necmettin Erbakan University, Turkey)
}

\begin{abstract}
The concept of "Systemic competitiveness" takes its fundamental from subject of economic development and industrialization. This term generally describes factors which enables individual companies becoming competitive. Traditional economic development approach analyzes the concept of competition in micro and macro level. However, in the systemic competitiveness approach, stable micro and macro framework is not enough to ensure competition although it's necessary. Therefore, the concept of competition should be examined in four levels which are "micro", "macro", "meso", "meta" for a healthy development. Another aspect that differentiates the approach of systemic competition from the concept of traditional competition is systemic competition benefits from different disciplines such as innovation economics, business economics, management, economics and industrial sociology in the analyses. The purpose of this study is to summarize the conceptual framework for the concept of systemic competitiveness in a systematic way and observe the sample of countries.
\end{abstract}

\section{Giriş}

Rekabet kavramı iktisat literatüründe önemini koruyan ve tartışılan bir konudur. Ülkelerin rekabetçi firmalara sahip olması ve ekonominin rekabetçi bir yapıya dönüşmesi ekonomik kalkınma için önemli bir faktör olarak görülmektedir. Son yıllarda rekabet kavramının daha çok bilgi ve teknoloji temelli dinamik rekabetçi üstünlüklere dayandığı dikkatleri çekmektedir. Firmaların sanayi kümelerini, sanayi bölgelerini, iş anlaşmalarını, arzcılarla uzun dönemli sözleşmeleri, teknolojik iletişim ağlarını benimsemeleri onları daha rekabetçi hale getirmektedir. Rekabetçi olabilen ülkeler örgütlenmede, etkin öğrenmede, karar oluşturma süreçlerinde ve iş oluşturma aşamalarında diğer ülkelere göre daha başarı göstermektedir.

Klasik iktisada göre bireylerin ve toplumun refahının artmasında rekabet önemli bir yer almaktadır. Neo-klasik iktisatta ise rekabet piyasa yapısı çerçevesinde ele alınmış ve rekabeti belirleyen en önemli unsur firma sayısı olarak kabul edilmiştir. Piyasada tek bir firma olduğunda tekel oluşmakta ve rekabetten söz edilememektedir. Tam rekabet durumu ancak piyasada çok sayıda firmanın olduğu ancak tek bir firmanın piyasa üzerinde etkisi olmadığ durumda gerçekleşmektedir (Kırankabeş, 2006). Klasik iktisatçılara göre tam rekabet piyasasında arz edilen ve talep edilen miktarı birbirine eşitleyen fiyat denge fiyatı veya piyasa fiyatıdır. Bu denge kararlı bir dengedir. Piyasa fiyatının denge fiyatının altında ya da üstünde oluşması durumunda alıcılar ve satıcılar arasındaki rekabet fiyatın tekrar denge fiyatına ulaşmasını sağlamaktadır (Dinler, 2013). Piyasada dengeyi sağlayan unsur alıcılar ve satıcılar arasındaki rekabettir. Diğer taraftan firmalar arasındaki rekabet ürün geliştirme, ürün farklılaştırma ve yenilik gibi konuları da içermektedir (Tokatlığlu, 1999). Son yıllarda Klasik iktisadın varsayımlarına ve kullandığ yöntemlere yönelik yapılan eleştiriler yeni iktisadi akımların ortaya çıkmasına neden olmuştur. Bu yaklaşımlardan biri kurumsal iktisattır. Acemoğlu ve Robinson (2014) tarafından gelişmiş ve az gelişmiş ülkeler arasındaki farklılığın en önemli nedeni olarak ülkelerdeki siyasal ve ekonomik kurumlar gibi faktörler üzerinde durulmaktadır (Acemoğlı ve Robinson, 2014). Kurumsal iktisatta rekabet kavramı kurumlar ve organizasyonlar arasındaki etkileşimin rekabete dayandırılmasıyla ele alınmaktadır. Kurumsal etkileşim ve değişim ise organizasyonların sürekli bir biçimde bilgi ve yeteneğe yatırım yapmalarından ve bireyler ile organizasyonların firsatlara yönelik algı ve seçimlerinden kaynaklanmaktadır (Dumludağ, 22).

"Sistemik rekabet" kavramı en genel olarak özel firmaların rekabetçi hale gelmesinde etkili faktörleri açıklamakta kullanılan bir kavram olarak karşımıza çıkmaktadır. 1990'lı yıllarda Esser vd. (1995) tarafından sistemik rekabet kavramı neden bazı ülkelerin sanayileşme çabalarının başarılı ve bazılarının başarısız olduğunu açıklamakta kullanılmıştır. Bu yaklaşımın temel argümanlarından biri; ekonomik performans farklılıklarının sadece başarılı sanayileşme politikaları ya da teknoloji transferi gibi izole edilmiş "anahtar faktörler" ilişkisine bağlanamayacağı yönündedir. Sanayileşme politikaları ya da teknoloji transferi gibi faktörlerin iyi çalışmasının nedeni bu faktörlerin diğer faktörler tarafından desteklenmesidir. Bu nedenle ülkelerin, bölgelerin ve firmaların ekonomik performanslardaki farklılıkları anlayabilmek için sistemin bazı bileşenlerine değil sistemin tümüne bakmak gerekmektedir (Meyer-Stamer, 2005). Bu çalışmanın amacı sistemik rekabet yaklaşımının kavramsal çerçevesini sistematik bir şekilde ortaya koymaktadır. Çalışma dört bölümden oluşmaktadır. İkinci bölümde yaklaşımla ilgili temel kavramlar açıklanmıştır. Üçüncü bölümde sistemik rekabet yaklaşımı çerçevesinde ele alınan ülke örneklerine yer verilmiştir. Sonuç kısmında genel bir değerlendirme yapılmıştır. 


\section{Rekabet Gücü Kavramsal Tanımı}

Stiglitz (1965) tarafından rekabet kavramı en genel olarak "iki ya da daha fazla kişinin yarıșmacı faaliyeti" olarak tanımlanmaktadır. Klasik iktisatçılar tarafından rekabet kavramı dinamik bir yapıyı ifade ederken, NeoKlasik iktisatçılar rekabet kavramı ile tam rekabet modelleri içinde statik dengeyi analiz etmişlerdir. Jevon's tarafından rekabet kavramının önemi ise "eğer ekonomik ajanlar ve işçiler arasında rekabet yoksa, iktisat biliminin yapabileceği çok az şey vardır, hatta hiç bir şey yoktur", şeklinde ifade edilmiştir. Becher, piyasadaki çok sayıdaki üretici arasındaki rekabetin fiyatları düşürdüğünü, monopollerin ise fiyatları artırdığını ifade etmektedir. A. Smith'a göre ise rekabet ekonomik bir aktivite olup, ekonomik stratejilerin belirlenmesinde özgürlük olarak belirtilmektedir. Ayrıca Smith "serbest ve global rekabeti firmaların kendini korumak için başvurduğu bir araç" olarak görmektedir (Tokatlığlu, 1999). Seyidoğlu (2002)'de rekabet kavramı “Bir piyasada satıcıların, birbirleri aleyhine daha fazla müşteri çekerek mal ve hizmet satışlarını, dolayısıyla kârlarını artırmak için, aralarında giriştikleri yarış" olarak belirtilmektedir (Seyidoğlu, 2002).

Rekabet gücü kavramı hem mikro hem de makro düzeyde üzerinde yoğunlukla tartışılan bir konu olmakla birlikte tanımlanması konusunda net bir uzlaşıya varılamamıştır. Bu kavram en genel olarak "bir iktisadi birimin (birey, firma, endüstri, ülke, bölge), veri başlangıç koşullarına göre, belirlenen amaçlara ulaşma süreci ve sonucunda hedef göstergeler açısından rakiplerine göre üstünlüğe sahip olması" ş̧eklinde ifade edilebilmektedir. Dünya ekonomik forumu tarafından ise rekabet gücü "bir ülkenin verimlilik düzeyini belirleyen politikalar ve kurumlar seti” olarak tanımlanmaktadır (Çakmak ve Sarıdoğan, 2014). Tablo 1'de Porter'e göre rekabet gücünün tanımı özetlenmiştir.

\begin{tabular}{ll}
\hline Faktör Donatımı +Verimlilik & $\rightarrow$ Refah \\
\hline$\uparrow$ & \\
Rekabet Gücü & \\
\hline
\end{tabular}

Tablo 1. Rekabet Gücünün Tanımı Kaynak: Çakmak ve Sarıdoğan, E. (2014). “Türkiye Ekonomisinde Sürdürülebilir Ulusal ve Bölgesel Kalkınma İçin Bir Öneri: Küresel Rekabet Gücü Destek Sistemi, ss.519.

Yukarıdaki tabloda özetlendiği gibi rekabet gücü kavramı verimlilik kavramı ile yakından ilişkili olup verimlilik göstergesi önemli bir rekabet gücü göstergesi olarak değerlendirilmektedir.

Geleneksel iktisat yaklaşımına göre firmalar çevreye uyumun sonucu olarak rekabetçi hale gelmektedir. Bu çerçevede analizler mikro ve makro düzey kapsamında gerçekleştirilmektedir (Meyer-Stamer, 2014). Tablo 2'de geleneksel yaklaşıma göre rekabetçilikte mikro ve makro düzeydeki etkili unsurlar verilmiştir.

Makro Ekonomi

-Ekonomik koşulların çerçevesi,

-Yasalar ve kurumlar aracılığıyla doğru teşvikler yaratmak, (servet haklar gibi)

-Genel politika (döviz kuru, para politikası, açık ekonomi politikası vs)

$\downarrow$

Mikro Ekonomi

-İşleyen piyasalarda girişimcilik aracılığıyla büyüme

Tablo 2. Geleneksel Yaklaşımda Ekonomik Çevre Kaynak: Meyer-Stamer, J.,(2014) . Systemic Competitiveness: Understanding The Factors That Make or Brake Dynamic Development, ss. 3.

Makroekonomi düzeyinde yasalar, kurumlar, genel politikalar kullanılarak ekonomik alan için gerekli koşullar yaratılmaktadır. Uygun ekonomik çevrenin yaratılması mikro düzeyde girişimcilik faaliyetlerini oluşturarak büyümeye neden olmaktadır.

Firma düzeyinde rekabetçilik, firmanın piyasadaki pozisyonunu sürdürme yeteneği olarak tanımlanmaktadır. Bu yetenek ise belirli hedefleri gerçekleştirmeye bağlı olmaktadır. İlk olarak firma ürününü yeterli kalitede, zamanda ve rekabetçi fiyatlarla gerçekleştirmesi gerekmektedir. Ayrıca firmaların ürün farklılaşmasına giderek çeşitlenmiş talebi karşılaması ve talep davranışlarındaki değişmelere hızlı bir şekilde tepki vermesi gerekmektedir (Altenburg vd., 1998). Endüstri düzeyinde rekabet gücü ise, aynı ya da birbiri ile ilişkili mal ve hizmet üreten firmaların rakiplerine göre eşit ya da daha düşük maliyetli üretim gerçekleştirme ve satma yeteneği olarak tanımlanmaktadır. Diğer bir ifadeyle endüstri düzeyinde rekabet gücünde firmalar rakiplerine göre eşit ya da daha yüksek verimlilikte üretim gerçekleştirmekte ve bu üretimi sürdürebilmektedir (Kırankabeş, 2006). Bir endüstrinin (sanayinin) rekabet durumu yeni yatırımcılar, tedarikçiler, müşteriler, ikameler, endüstrideki rakipler-rekabetin yoğunluğu olmak üzere beş temel güce bağlı olmaktadır (Pearce ve Robinson, 2015 çev. Barca, 2015). Ulusal rekabet gücünü belirleyen faktörler arasında arz ve talep koşulları, firmaların yapısı, firmaların rekabet stratejileri, bağlantılı ve destekleyici sektörler, hükümetin rolü, şansa bağlı diğer faktörler yer almaktadır (Çakmak ve Sarıdoğan, 2014). Ulusal rekabetçilikte bir ulusun serbest ve açı piyasa koşullarında uluslararası piyasaların talebini karşılayacak mal ve hizmetleri üretirken aynı zamanda uzun dönemde insanlarının reel gelirlerini sürdürmesi ve yükseltmesi önem kazanmaktadır (Altenburg vd., 1998). Uluslararası düzeyde rekabet kavramı ilk olarak A. Smith tarafindan ortaya 
atılan Mutlak Üstünler Teorisinde ve daha sonra David Ricorda tarafindan ileri sürülen Karşılaştırmalı Üstünlükler Teorisinde ele alınmıştır. Mutlak Üstünlükleri Teorisine göre bir ülke diğer ülkeye göre hangi malları daha düşük maliyetle üretiyorsa o malların üretiminde üstünlüğe sahip olmaktadır. Bu malların üretiminde uzmanlaşmalı ve bu malları ihraç etmeli, yüksek maliyetle ürettiği diğer malları ise ithal etmelidir. Karşılaştırmalı üstünlük teorisinde ise önemli olan mutlak üstünlük değil üretimde sahip olunan üstünlük derecesidir. Bu nedenle ülke diğer ülkeye göre hangi malların üretiminde daha yüksek oranda üstünlüğe sahipse o malların üretiminde uzmanlaşıp ihraç etmelidir (Seyidoğlu, 2013). Porter'a göre uluslararası rekabet gücünün en önemli belirleyicisi firmaların sahip olduğu rekabet gücüdür. Firmalar verimli, düşük maliyetli ve yüksek kalitede üretim yaparak rekabet güçlerini artırabilmektedirler. Diğer bir ifadeyle firmanın rekabet gücü yüksek kalite ve düşük maliyette üretim yeteneği ile özdeşleşmektedir (Kırankabeş, 2006). Ülkelerin küresel düzeyde rekabet gücü ve ekonomik gelişme arasındaki ilişki dört aşamada gerçekleşmektedir. İlk aşamada temel üretim faktörleri diğer bir ifadeyle faktör koşulları (doğal kaynaklar, coğrafi dağılım, vasıfsız işgücü) önem göstermektedir. 1980 öncesi Kanada, Avustralya, G. Kore ülke örnekleri verilebilir. İkinci aşamada 1960'larda Japonya ve 1980'li y1llarda G. Kore'de olduğu gibi sermaye mallarına yatırım ve teknoloji transferi gelmektedir. Üçüncü aşamada rekabet avantaj1 inovasyona dayanmakta olup ulusal avantajın dört temel bileşeni yeni teknoloji yaratımında etkileşim içinde işlemektedir. Son aşamada ise rekabetçi avantajlar ve zenginlik gerilemeye başlamaktadır. Bu duruma en güzel ülke örnekleri ise II. Dünya Savaşı sonrası İngiltere, 1980'lerden itibaren ABD, İsviçre, İsveç ve Almanya'dır (Çakmak ve Sarıdoğan, 2014).

\subsection{Sistemik Rekabet Gücü Kavramı}

Sistemik teriminin kökeni Fransızca “systemique” kelimesinden gelmektedir. Kavram Türk Dil Kurumu'nda "sayısal ve ekonomik konulara belli sistemler çerçevesinde bakan" şeklinde tanımlanmaktadır (TDK, 2015). Sistemik rekabet yaklaşımında "sistem (system)" kavramı; aktörler, kurumlar, organizasyonlar ve politika örnekleri anlamındadır. Ekonomik sistemde bu faktörler karmaşık geri besleme mekanizmaları ile birbiri ile ilişkilidirler ve birlikte uyumlu bir mevcudiyet yaratmaktadır (Meyer-Stamer 2005). Sistemik rekabet yaklaşımında sistemik kavramının kullanılması ile birkaç noktaya vurgu yapılmak istenmektedir. İlk olarak bir firma; arzcıları destekleyen bir çevre, üretime yönelik hizmetler ve yerel rekabetçilerin rekabet baskısı olmadan sadece kendi çabalarıyla rekabetçi hale gelemeyecektir. Diğer bir ifadeyle mikro-düzeydeki rekabet sadece firmaya bağlı olmamakta firma ve diğer aktörler arasındaki etkileşime dayanmaktadır. Etkileşim aracılığıyla öğrenme firmaların yenilik sürecinin temel faktörüdür. Ayrıca firmalar ve destekleyici kurumlar arasındaki geri beslemeler dinamik rekabetçi avantajı kurmak için önemlidir. İkinci olarak firmaların davranışlarını şekillendiren teşvikleri belirlemede, ulusal sistemin normlarında, kurallarında ve kurumlarında yerleşmiş olan rekabetçiliği sürdüren bir çevrenin olması etkili olmaktadır. Üçüncü olarak devlet, sanayinin gelişmesinde ve yeniden yapılandırılmasında önemli bir rol oynamaktadır. Yeni yönetim biçimleri, devlet ve sosyal aktörler arasındaki yatay iletişim ağlarındaki etkileşime dayanmaktadır. Burada önemli bir faktör olarak karşımıza tekrar etkileşim ve geri besleme ağları çıkmaktadır. Özetlersek sistemik rekabet başarılı sanayi (endüstri) gelişmesinin hem politik hem de ekonomik belirleyicilerini incelemektedir. $\mathrm{Bu}$ yaklaşıma göre devletler (eyaletler) ve sosyal aktörler bilinçli bir şekilde başarılı sanayi gelişiminin koşullarını yaratmaktadır. Özellikle en yenilikçi endüstriler pozitif dışsallıklar üzerine kurulmaktadır. Bu pozitif dışsallıklar arasında ara mal ve makine dünya sınıfı arzcıların varlığı, tüketici talebi, özelleşmiş iş hizmetleri ve iş çevresini destekleyici diğer faktörler yer almaktadır. Sanayi örgütlerinin karmaşıklığ arttıkça sistemik rekabet yaklaşımının önemi artmaktadır (Altenburg vd., 1998).

\subsection{Sistemik Rekabet ve Diğer Disiplinler ile Olan İlişsileri}

Sistemik rekabet yaklaşımı yenilik iktisadı, kurumsal iktisat, yönetim bilimi, politika bilimi ekonomi sosyolojisi, sanayi sosyolojisi, ekonomi coğrafyası gibi diğer disiplinlerden faydalanmaktadır. Tablo 3'de sistemik rekabet yaklaşımının etkilendiği disiplinler özetlenmiştir

\begin{tabular}{|l|l|}
\hline Ekonomi & Sosyal Bilimler \\
\hline $\begin{array}{l}\text { Yenilik İktisadı : *Kümülatif ve birbirini etkileyen bir süreç } \\
\text { şeklinde yenilik; *Tamamlanmış yenilik yerine örtük bilgi; } \\
\text { *Patika bağımlılığı; *Ulusal ve bölgesel yenilik sistemleri }\end{array}$ & $\begin{array}{l}\text { Politika Bilimi: *Yeni devlet yaklaşımları *Politika Ağı } \\
\text { (Networks) }\end{array}$ \\
\hline Post- Yapısalcılar: *Piyasa ekonomisinde devletin rolü & $\begin{array}{l}\text { Ekonomi Sosyolojisi: *Ekonomik işlemlerdeki güç ilişkisi; } \\
\text { güven ve ilişkisel sözleşme *Endüstriyel Bölgeler }\end{array}$ \\
\hline Kurumsal İktisat: *Mülkiyet Hakları; *İşlem Maliyetleri; & $\begin{array}{l}\text { Sanayi Sosyolojisi: *Yeni Üretim Yaklaşımları, *Sistemik } \\
\text { Rasyonalizasyon, }\end{array}$ \\
\hline Yönetim Bilimi: *Rekabetçi üstünlüklerin yaratılması & $\begin{array}{l}\text { Ekonomi Coğrafyası *Bir araya toplanma- yığın ilişkisi } \\
\text { *Uzaysal bakış açısı }\end{array}$ \\
\hline
\end{tabular}

Tablo 3. Sistemik Rekabetin Kavramsal Zemini Kaynak: Meyer-Stamer, J. (2005). Systemic Competitiveness Revisited Conclusions for Technical Assistance in Private Sector Development, Mesopartner Working Paper, ss. 7 
Sistemik rekabet yaklaşımı yenilik iktisadının üzerinde durduğu patika bağımlılığı ve örtük bilgi kavramları üzerinde durmaktadır. Örtük bilgi formel bir eğitim olmadan özel ve çalışma ortamında öğrenme ile elde edilen bilgi türüdür. İnsanlar bu bilgiyi ortamlarına bağlı olarak ve yaşayarak öğrenmektedir. Bu nedenle kişilerin yetişme ve çalışma ortamının kişilere farklı bilgi birikimi kazandırmasından dolayı ortaya çıkmaktadır. Sonuç olarak örtük bilgi homojen değil heterojendir ve kişiye özel niteliktedir (Oğuztürk, 2003). Sistemik rekabet yaklaşımına göre patika bağımlılı̆̆ ve örtük bilgi nedeniyle, neo-klasik görüş rekabet ile ilgili yeterli açıklamayı sağlayamamaktadır. Neoklasik görüşe göre tercihler, transferler ve teknolojiler arasında tam bir serbestlik varsayılmaktadır. Ancak teknolojik bilgi her zaman tamamen kopyalanamamaktadır. Bundaki en önemli neden örtük bilginin varlığıdır. Bu bilgi kolayca transfer edilememekte ve büyük kısmı kişiye ve firmaya özel olmaktadır (Alternburg, 1998). Patika bağımlılığı görüşünde ise, günümüzdeki teknolojik durumun, gelişmelerin, yaşadığımız koşulların geçmişle ilişkili olduğu ve tarihin izlerini taşıyarak şekillendiği ileri sürülmektedir. Bu bağlamda patika bağımlılığı günlük koşullar yerine daha önceden yaşanan koşullara göre oluşan ekonomik çıktılara olan bağımlılık olarak tanımlanmaktadır. Patika bağımlılı̆̆ı pozitif geri bildirim mekanizmalarının sonucu ortaya çıkmakta ve bu süreçte tarihin devam eden bir etkisi bulunmaktadır. Karar alma sürecine geçmiş etkilerin, mevcut fiziki yapının ve rastlantıların etkisi olmaktadır. Kendi kendini organize edebilme yeteneği, çoklu denge gibi kavramlar patika bağımlılığının önemini yenilik iktisadı açısından artırmaktadır (Hamamcı, 2010). Bu kavramlar sistemik rekabet yaklaşımı açısından rekabetçiliğin kazanılmasında etkili unsurlar olarak görülmektedir. Yeni kurumsal iktisat yaklaşımında kurumların etkinliğini ve kurumsal değişimi etkileyen faktörler mülkiyet haklarının güvence altına alınması, işlem maliyetlerinin düşük olması ve yaptırım gücünün yüksek olmasıdır (Dumludağ, 2014:18). Mülkiye hakları ve işlem maliyetleri yeni kurumsal iktisat içeresinde önemli bir yer tutmaktadır. Coase(1960) "Sosyal Maliyet Sorunu" ve Demsetz (1967) "Mülkiyet Hakları Teorisine Doğru” çalışmaları ile mülkiyet hakları ile ilgili literatüre önemli katkı sağlamışlardır. Coase (1937), "Firmanın Doğası" ise işlem maliyetlerinin yer aldığı çalışmadır. Mülkiyet hakları; bireylerin sosyal hayatta yapabileceklerini, sorumluluklarını ve özgürlüklerinin sınırlarını tanımlar. Mülkiyet hakları teorisine göre, mülkiyet ve servet arasında doğrusal bir ilişki mevcuttur. Mülkiyet hakları olmadan ne ticaret ne de firmalar arasındaki rekabet gerçekleşmeyecektir. Mülkiyet hakları iyi belirlenmiş bir ekonomide ise bireyler arasındaki çatışmalar azaltılarak rekabetin artması sağlanabilmektedir. Ekonomik gelişmenin alt yapısını rekabet oluşturmaktadır (Aktan, 2016). Bir ülkede yaşanan siyasal istikrarsızlıklar ise mülkiyet haklarının tehlikeye girmesinde büyük ölçüde etkili olmaktadır (Acemoğlu ve Robinson, 2014: 36). İşlem maliyetleri, mülkiyetin elde edilmesi, korunması ve transfer edilmesi ilgili maliyetlerdir. Toplumsal düzeni ve sözleşmeleri yerine getirilmesini sağlamanın maliyeti ile işlem maliyetleri ve devlet ilişkisi vurgulanmaktadır. Devlet işlem maliyetlerini düşürecek bir takım önlemleri aldığ gibi bazı durumlarda kendisi işlem maliyetlerini artırıcı etkide bulanabilir. İktisadi kalkınmada toplumsal işlemlerin yürütülmesinde kuralların konulması ve bu kurallara uyulup uyulmadığının denetlenmesi önem kazanmaktadir(Aktan, 2016)

\subsection{Sistemik Rekabette Ekonomik Düzey Sınıflaması}

Sistemik rekabet yaklaşımında temel vurgulanmak istenen düşüncelerden biri, başarılı kalkınma için güçlü makro-ekonomik koşulların ve işleyen piyasaların gerekli olduğu ancak yeterli olmadı̆̆ıdır. Dinamik kalkınma, en başta hükümet-güdümlü girişimlerden ziyade girişimci dinamizmine dayanması gerekmektedir. Bununla birlikte tarım, sanayi ve hizmetlerdeki başarılı özel kesim gelişimi sadece dinamik girişimcilerin ya da kolektif organizasyonların bireysel çabalarından da kaynaklanmamaktadır. Bu kalkınma, aynı zamanda toplumun kolektif faaliyetlerinden ve gelişen hükümetten ya da hem kolektif faaliyetler hem de devletin etkileşimi sayesinde bu faktörlerin çevreyi şekillendirme yeteneğinden kaynaklanmaktadır. Toplum, hem piyasa mekanizmasının çalışmasını sağlamak hem de özel-iş (business) gücünün çabalarının dağılımını desteklemek ve ilerletmek şeklinde ekonomik çevreyi şekillendirmektedir. Bir ülkedeki iş alemi -özel kesim (business)nin diğer ülkelere göre neden daha iyi işlediğini anlamak için mikro elemanlara (firmalar, tüketici, piyasalar) ve makro faktörlere (faiz ve döviz kuru, bütçe ve ticaret politikası vb) bakmak önemli ama yeterli değildir. Sistemin bütününü anlamak için mikro ve makro-ekonomiden ayrı olarak diğer iki bütüne başvurma ihtiyacı da vardır. Bu düzeyler "Meso-düzey" ve "Metadüzey" düzeyler olarak adlandırılmaktadır. Meso-düzey en genel olarak firmaların rekabeti için önemli olan ancak piyasa tarafından kendiliğinden yaratılmayan faktörlerin incelendiği düzeydir. Meso-düzey olarak adlandırılan bu analitik seviye, makro-seviyenin makroekonomik çevre koşul türleri ve mikro-seviyenin firmalar ve piyasaları arasına uygun düşmektedir. $\mathrm{Bu}$ düzey, özel politikaların ve özel kesimi destekleyen araçların, özel kesimin desteklenmesinde özel ve kamu kurumlarını içeren alanları kapsamaktadır. Meso-düzey şu gibi soruların açıklanmasında etkili olmaktadır: İlk olarak belirli bir toplumdaki aktörler neden özel kesim- (business) için elverişli- uygun çevreyi yaratmada başarılı ya da başarısız olmaktadır? Hükümet ve hükümet dişı aktörler nasıl birbirlerini etkilemektedir ve tamamen etkilemekteler mi? Genel olarak toplum tarafindan ekonominin nereden yönetildiği konusunda ortak bir görüş ve vizyon var mı? Toplumdaki kilit aktörlerin temel yönelimleri, piyasa mekanizmasının yönelimleri, dış ticaret (açık ekonomi ya da kapalı ekonomi) yönelimlerinin göreli önemi paylaşılıyor mu? Bu seviyedeki analizler meta- düzey olarak adlandırılmakta ve makro-ekonomik faktörlerin kapsamından daha öteye geçmektedir (Meyer-Stamer, 2005). Makro düzey ve meso düzey arasındaki temel fark makro-seviye politikaları geneldir tüm ekonomik konulara aynı yolla başvurur. Meso-seviye politikalar özeldir, bu 
politikalar özel sektörleri (sanayinin branşları, geniş anlamda sanayi, ya da özel bir sektörü örneğin balıkçılık sektörü) ya da özel amaçları (yenilik gibi) hedefleri içerir (Meyer-Stamer 2005).

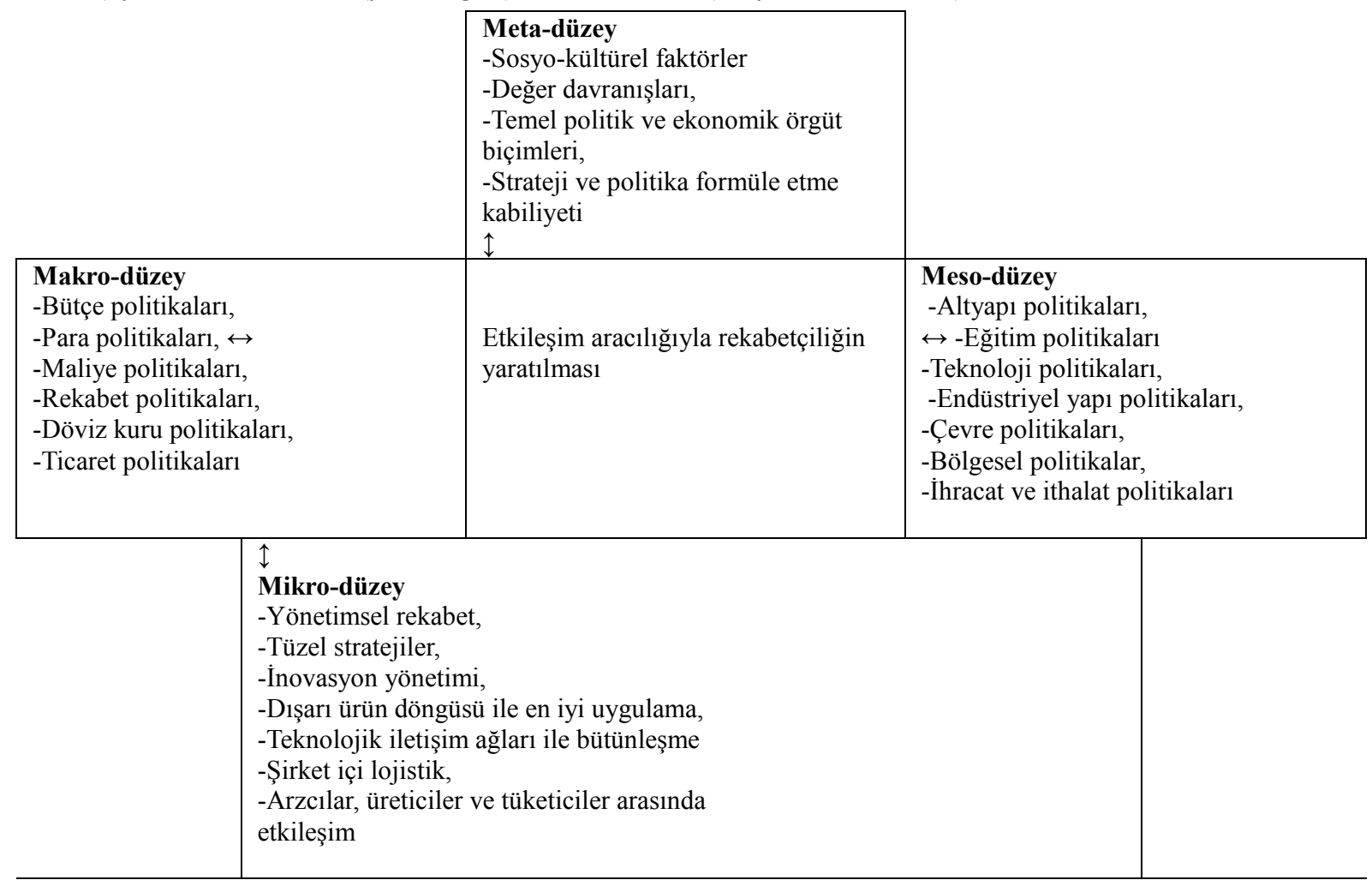

Tablo 4. Sistemik Rekabette Önemli Faktörler Kaynak: Esser vd. (1995) Systemic Competitiveness New Governance Patterns for Industrial Development. London, 28

Bu faktörler hem dış kaynaklı hem de içsel olarak ikiye ayrılabilir. Meta-düzeyde dış kaynaklı faktörlerden biri diğer ülkelerin rekabetçi yapıları ve dünya genelinde kalkınma yaklaşımlarındaki değişim yer almaktadır. Mesodüzeyde ise sistemik rekabetin sağlanmasında kalkınma işbirlikleri önemli bir dış faktör olarak görülmektedir. İç kaynaklı faktörler arasında ise kalkınma yanlı değer yaratma anlayışı, öğrenme ve işbirliğini destekleyen kültürün varlığı gibi faktörler yer almaktadır.

\begin{tabular}{|c|c|c|}
\hline & Dıştan Kaynaklı & İçten Kaynaklı \\
\hline Meta & $\begin{array}{l}\text { *Başarılı komşu ülkelerden } \\
\text { kaynaklanan performans baskısı } \\
\text { *Kalkınma paradigmalarındaki } \\
\text { değişim }\end{array}$ & $\begin{array}{l}\text { *Rekabet ve dünya piyasalarına dönük } \\
\text { yönlendirmeye, alternatif olmaması } \\
\text { *Kalkınma yanlı değer sistemi } \\
\text { *Öğrenme ve işbirliği yanlı kültür } \\
\text { *Girişimci başarısı sayesinde sosyal prestij }\end{array}$ \\
\hline Makro & $\begin{array}{l}\text { *Yapısal uyum yönünde baskı } \\
\text { *Uluslararası sermaye piyasalarıyla } \\
\text { bütünleşmeden meydana gelen } \\
\text { performans baskısı }\end{array}$ & $\begin{array}{l}\text { *Uzun dönemli sorumluluk ve hesaplanabilirlik } \\
\text { (hesap sorumluluğu) } \\
\text { *Hiperenflasyon ve stagnasyon /deneyimlerde } \\
\text { (experience) düşüş }\end{array}$ \\
\hline Meso & *Kalkınma İşbirlikleri & $\begin{array}{l}\text { *Özel firmaların başarısına dayanan, tabanlı, } \\
\text { destekçi kurumların performanslarının dönüşümü } \\
\text { *R@D kurumları: Akademik ve uygulama } \\
\text { yönlendirmeleri- döngüleri arasında uygunluk } \\
\text { *Yaratıcı politika oluşturmak için sorumluluğun ve } \\
\text { serbestliğin adem-i merkeziyetçiliği } \\
\text { *Ortak işbirliğinde, birliklerde katılımcı yapılar ve } \\
\text { performans baskısı }\end{array}$ \\
\hline Mikro & $\begin{array}{l}\text { *Küresel ürün-mal zincirleri } \\
\text { *Uluslararas1 standartlar } \\
\text { (ISO 9000, 14000, QS 9000) }\end{array}$ & $\begin{array}{l}\text { *Rekabet baskısı } \\
\text { *Tüketiciler tarafindan baskı ve destek } \\
\text { *Iyi, göze çarpan, performansların maddi teşviki }\end{array}$ \\
\hline
\end{tabular}

Tablo 5. Sistemik Rekabetin Yükselmesini Uyarlayan Teşvik Edici Yapılar Kaynak: Jörg Meyer-Stamer (2005), "Systemic Competitiveness Revisited Conclusions for Technical Assistance in Private Sector Development", Mesopartner Working Paper, ss. 4 
Meso-düzeyde hükümet kaynaklı kurumlar arasında Kalkınma Bankaları, Kamu Eğitim ve Çalışma(training) Kurumları, KOBİ Destek Ajansları yer alırken, hükümet dışı kurumlar arasında odalar ve işbirlikleri ve vakıflar yer almaktadır. Meta-düzeyde önemli bir faktör diğer ülke piyasalarındaki rekabet düzeyi iken, ulusal düzeyde uygulanan kalkınma modelleri ve yenilik sistemleri öncelikli olmaktadır. Bölgesel düzeyde ise bölgesel aktörlerin strateji belirleme ve uygulama kapasiteleri önem göstermektedir. Yerel düzeyde ise yerel aktörlerin iş birlik, güven, yenilik kapasiteleri dikkatleri çekmektedir. Genel olarak özetlenirse Altenburgvd., (1998) çalışmasında başarılı bir sanayi gelişmesi için temel öneriler belirtilmiştir: Meta-düzeyde: İlk olarak, toplumun büyük bir kısmı tarafından paylaşılan gelişmeye-yönelik kültürel değerler, ikinci olarak sanayi gelişimi ve dünya piyasalarına rekabetçi olarak bütünleşme gerekliliği üzerinde temel uzlaşı, üçüncü olarak sosyal aktörlerin vizyon ve strateji birlikte formüle etme ve politikaları uygulama becerilerini göstermek. Makro-düzeyde: İstikrarlı ve tahmin edilebilir makroekonomik yapı. Örneğin yerel sanayiyi teşvik edecek gerçekçi bir döviz kuru politikası ve genel dış ticaret politikasının uygulanması. Meso-düzeyde: Sanayi ve sanayi çevresini ( teknoloji enstitüleri, eğitim merkezleri, ihracat finansmanları vb.) şekillendirmek ve rekabet avantajı yaratmak için spesifik politikalar ve spesifik kurumlar. Ayrıca firmaların çevrelerini güçlendirmeye yönelik yerel ve bölgesel sanayi rekabeti girişimleri. Mesodüzeyde faaliyet gösteren kurumların bir çoğu hükümet-dışı varlıklardır. Örneğin kar gütmeyen varlıklar ya da firma işbirlikleri (business associations). Mikro-düzeyde: Güçlü dışsallıklarla firmaları ve iletişim ağlarını sürekli geliştirmek. Geçmişte başarılı sanayileşme güçlü devletler ve güçlü piyasalar arasındaki etkileşime dayandırılmıştır. Bu nedenle gelişmekte olan ülkeler zayıf devlet ve zayıf piyasalardan zarar görmüştür. Ancak dinamik sanayi gelişme hem hükümet hem de sosyal aktörlerin kasıtlı bilinçli faaliyetlerini gerektirmektedir. Bu bilinçli faaliyetler firmaların rekabet avantajı yaratma çabalarında firmaları teşvik etmek ve desteklemek şeklinde kendini göstermektedir. Diğer bir ifadeyle firmaların rekabetçi hale gelmesi sadece görünmez el sonucunda oluşmamaktadır. Günümüzdeki sanayi gelişimindeki yönetim anlayışına bakıldığında sosyal aktörlerin stratejilerin ve politikaların belirlenmesinde devlet ile etkileşim içinde olduğu görülmektedir (Altenburg, vd., 1998).

\section{3 Ülke Örnekleri}

Bu bölümde Latin Amerika ve Doğu Asya ülke deneyimlerine ve diğer ülke örneklerine yer verilmiştir. Sistemik rekabet kavramı neden bazı ülkelerin başarılı bir gelişme gösterirken bir grup ülkenin bunu sağlayamamasını açıklamaya çalışmaktadır. Latin Amerika ve Doğu Asya ülkelerinde ekonomik durum dört farklı düzeyde ele alınmıştır. Tablo 6'da Latin Amerika'da uygulanan politikalar ve sonuçları ile Doğu Asya ülkelerinde uygulanan politikalar ve sonuçları özetlenmiştir.

\begin{tabular}{|c|c|c|}
\hline & Latin Amerika & Doğu Asya \\
\hline Meta-düzey & $\begin{array}{l}\text { *İthal ikameci sanayileşme (bebek endüstri koruması } \\
\text { şeklinde olmamakla birlikte dünya piyasalarından ayrılma } \\
\text { şeklinde), } \\
\text { *Kırsal oligarşinin güçlülüğünden dolayı sanayileşmenin } \\
\text { önceliği, hakkında ortak bir görüş birliği yoktur; } \\
\text { *Genel olarak açık kalkınma oryantasyonlarının olmaması: } \\
\text { öğrenme, uyum ve formüle stratejilerinde düşük kapasite }\end{array}$ & $\begin{array}{l}\text { *ìhracata yönelik sanayileşme } \\
\text { stratejisi, açık kalkınma sorumluluğu- } \\
\text { bağlılı̆g, } \\
\text { *Kırsal oligarşinin gücünü aşındıran } \\
\text { erken toprak reformları, } \\
\text { * Öğrenme, uyum ve formülasyon } \\
\text { stratejilerine yönelik yüksek kapasite }\end{array}$ \\
\hline Makro-düzey & $\begin{array}{l}\text { *İthal ikameci sanayileşme politikasının doğasındaki zayıflık } \\
\text { nedeniyle istikrarsız makro ekonomik politika(hammaddelere } \\
\text { bağlllık, ihracat fiyatlarındaki dalgalanmalarla birlikte } \\
\text { tarımsal ürün ihracatı) } \\
\text { *Kronik ödemeler dengesi krizleri } \\
\text { *Yüksek enflasyon }\end{array}$ & $\begin{array}{l}\text { *Göreli istikrarlı makroekonomik } \\
\text { politika; } \\
\text { *Yüksek tasarruf oranları nedeniyle } \\
\text { gelişme sürecinin güçlü bir şekilde } \\
\text { finanse edilmesi, } \\
\text { *1990'ların ortalarından beri } \\
\text { spekülatif balonlara gösterilen } \\
\text { tolerans nedeniyle artan istikrarsız }\end{array}$ \\
\hline Meso-düzey & $\begin{array}{l}\text { *Üretim kapasitesini oluşturan geçici başarılı sanayileşme } \\
\text { politikası, ancak az sayıda rekabetçi sanayiler içermekte; } \\
\text { *Düşük rekabet baskısı nedeniyle meso-kurumların } \\
\text { hizmetlerine talebin düşük olması (özellikle teknolojinin } \\
\text { gelişmesinde ve yayılmasında) }\end{array}$ & $\begin{array}{l}\text { *Başarı sanayileşme politikası, } \\
\text { *Bir birini izleyen yeni sanayilerin } \\
\text { oluşturulması; } \\
\text { *Yüksek etkin eğitim, } \\
\text { geliştirme(training) ve teknoloji } \\
\text { politikaları ve yüksek performanslı } \\
\text { meso- kurumların yükselmesine } \\
\text { öncülük eden ihracat teşvikleri }\end{array}$ \\
\hline Micro-düzey & $\begin{array}{l}\text { *Kapalı bir piyasada daha az inivasyona ihtiyacı olan ve bu } \\
\text { piyasaya uygun olan firmaların düşük rekabetçiliği, } \\
\text { *İstikrarsı makroekonomik çevrenin kısa dönemli } \\
\text { oryantasyon yaratması, böylece strateji formülasyonunda } \\
\text { daha az çaba }\end{array}$ & $\begin{array}{l}\text { *İstikrarlı makro ekonomik politika } \\
\text { ve yurtiçi piyasalarda rekabet eden } \\
\text { firmaların ithalat korumalarına } \\
\text { rağmen ve ihracat amacıyla devlet } \\
\text { tarafından satın alınmasına rağmen } \\
\text { yükselmesini hedefleyen } \\
\text { mesopolitikalar, }\end{array}$ \\
\hline
\end{tabular}

Tablo 6. Latin Amerika ve Doğu Asya Deneyimi Kaynak: Meyer-Stamer. J. (2005). Systemic Competitiveness Revisited Conclusions for Technical Assistance in Private Sector Development, Mesopartner Working Paper, s.6 
Tablo 6'da görüldüğü gibi Latin Amerika ülkelerinde meta düzeyde ithal ikameci sanayileşme politikasının tercih edilmesi, kırsal oligarşinin varlığı nedeniyle sanayileşmenin gerekliliği hakkında ortak bir görüş birliğinin oluşmaması, stratejilerin öğrenilmesi, uyumu ve uygulanmasında düşük kapasitenin olması gibi sorunlar görülmektedir. Doğu Asya ülkelerinde ise Latin Amerika ülkelerinin aksine ihracata dayalı sanayileşme modelinin uygulanması, kırsal oligarşinin erken dönemlerde kırılması ve toprak reformlarının gerçekleştirilmesi, öğrenme, uyum ve formülasyon stratejilerine yönelik yüksek kapasitenin oluşması gibi gelişimler dikkatleri çekmektedir. Meso-düzeyde ise Latin Amerika ülkelerinde rekabetçi sanayilerin az oluşana karşın Doğu Asya ülkelerinde başarılı sanayileşme politikaları ve yeni sanayilerin kurulması dikkatleri çekmektedir. Ayrıca Doğu Asya ülkelerinde yüksek etkin eğitim, geliştirme(training) ve teknoloji politikalarının ve yüksek performanslı mesokurumların yükselmesine öncülük eden ihracat teşviklerinin ekonomik gelişmede etkili olduğu söylenebilir.

Kuzey Amerika ve Latin Amerika ülkelerinin gelişmişlik farklarının incelendiği Acemoğlu ve Robinson (2014) çalışmasına göre Kuzey Amerika ülkelerinin Latin Amerika ülkelerinden daha gelişmiş olmasının gerisinde ise Kuzey Amerika'da yatırım yapmayı ve ekonomik çalışmayı teşvik eden ekonomik ve siyasal kurumların varlığı yatmaktadır. Örneğin Meksika'nın tarihsel sürecinde yerli halkın sömürülmesine ve tekelci toplumun oluşmasına izin veren kurumlar nüfusun büyük bir bölümünde ekonomik teşvikleri ve girişimleri kısıtlamıştır. Bu durum ise Meksika'nın sanayi devrimini gerçekleştirmesi yerine daha yoksullaşmasına neden olmuştur (Acemoğlu ve Robinson, 2014). Beş gelişmekte olan ülkede dinamik sanayi gelişimini teşvik eden ve engelleyen faktörleri analiz etmek için sistemik rekabet yaklaşımı kullanılmıştır. Tüm ülke örneklerinde meso-düzey üzerine yani sanayi politikalarının ve kurumların güçlü yönleri ve zayıf yönleri üzerine odaklanılmıştır (Altenburg vd., 1998).

\section{Sonuç:}

Dünya genelinde ülkelerin kalkınmalarını gerçekleştirmek her geçen gün daha rekabetçi hale gelmeleri gerekmektedir. Rekabetçi firmalar, rekabetçi piyasalar ve rekabetçi ülkelerin oluşmasında alternatif bir yaklaşım sistemik rekabetin oluşturulmasıdır. Sistemik rekabet yaklaşımı en genel olarak firmaların rekabetçi hale gelmesinde etkili faktörleri açıklamakta kullanılan bir kavram olarak karşımıza çıkmaktadır. Ancak geleneksel rekabet yaklaşımından farklı olarak rekabetçiliğin sağlanmasında sistemin bütününü anlamanın gerekli üzerinde durulmaktadır. Bu ise bilinen mikro ve makro- düzeyin ötesinde meso ve meta düzeylerinin anlaşılmasına ve bu düzeydeki aktörlerin birbiri ile geri beslemeye dayalı etkileşimine bağlı olmaktadır. Günümüzde firmaların ya da piyasaların tek başlarına rekabetçi hale gelmeleri gittikçe zorlaşmaktadır. Bu nedenle gerekli ekonomik ve siyasi kurumların oluşturulması gerekmektedir. Özellikle firmaları destekleyici ekonomik teşviklerin ekonomik kurumlar tarafından gerçekleştirilmesi, tüm ekonomik aktörler tarafından geri beslemeye dayalı bir rekabet kültürünün oluşturulması önem kazanmaktadır.

\section{Kaynakça}

- Acemoğlu, D., Robinson, J.A., 2014. Ulusların Düşüşü Güç, Zenginlik ve Yoksulluğun Kökenleri, Doğan Kitap, 7. Bask1, İstanbul, p.16-17.

- Altenburg, T., W. Hillebrand, J.Meyer-Stamer, 1998, "Building Systemic Competitiveness Concept and Case Stuides from Mexico, Brazil, Paraguay, Korea and Thailand", German Development Institute Reports and Working Paper, p.1-75.

- Çakmak, N. S., Sarıdoğan, E.,2014. "Türkiye Ekonomisinde Sürdürülebilir Ulusal ve Bölgesel Kalkınma İçin Bir Öneri: Küresel Rekabet Gücü Destek Sistemi, ss.517-543. (editörler Aysan, A. F., Dumludağ, D. (2014). Kalkınmada Yeni Yaklaşımlar), İmge Kitabevi, p. 518-519.

- $\quad$ Dinler, Z. ,2013. İktisada Giriş, Ekin Kitabevi, 19. Basım, Bursa, p.77-78.

- Dumludağ, D. (2014). “Kurumlar, Kurumsal Değişim ve Ekonomik Kalkınma”, (editörler Aysan, A. F., Dumludağ, D. (2014). Kalkınmada Yeni Yaklaşımlar), İmge Kitabevi,p.22.

- $\quad$ Esser, Klaus, Hillebrand, Wolfgang, Messner, Dirk, Meyer- Stamer, Jörg., 1995. Systemic Competitiveness New Governance Patterns for Industrial Development. London, 1-172(http://www.meyerstamer.de/1996/sysco-book.pdf, 2015)

- Hamamcı, D. P., 2010. Patika Bağımlılığı: Patent ve Patika Bağımlılı̆̆ı, İstanbul Teknik Üniversitesi Fen Bilimler Enstitüsü, Yüksek Lisans Tezi,

- Kırankabeş, M. C., 2006. “Küresel Rekabet Gücü Boyutunda AB Ülkeleri ile Türkiye’nin Karşılaştırmalı Analizi”, Dumlupınar Üniversitesi Sosyal Bilimler Dergisi, 16, p.232.

- Meyer-Stamer, J.,2005. "Systemic Competitiveness Revisited Conclusions for Technical Assistance in Private Sector Development", Mesopartner Working Paper, p.5.

- Meyer-Stamer, J.,2014. "Systemic Competitiveness:Understanding the factors that make or brake dynamic development”, 1-20. http://led.co.za/sites/led.co.za/files/139.pdf, 2014 
- Oğuztürk, B.S., 2003. "Yenilik Kavramı ve Teorik Temelleri”, Süleyman Demirel Üniversitesi, İktisadi İdari Bilimler Fakültesi, 8(2), p.253-273.

- $\quad$ Pearce, J. A., Robinson, R.B.,2015, Strategic Management Formulation, Implementation, and Control (M. Barca Çev. (2015) Stratejik Yönetim Geliştirme, Uygulama ve Kontrol), Nobel Kitabevi, 12.Ankara, 1-851.

- Seyidoğlu, H., 2002. Ekonomik Terimler Ansiklopedik Sözlük. Geliştirilmiş 3. Baskı, İstanbul.

- Seyidoğlu, H.,2013. Uluslararası İktisat Teori Politika ve Uygulama, Güzem Yayınları, Genişletilmiș 18. Bask1, İstanbul, p.1-908.

- $\operatorname{TDK}(2015)$

http://www.tdk.gov.tr/index.php?option=com_gts\&arama=gts\&guid=TDK.GTS.561b8f4f83da83.78200111, 2015

- Tokatlığlu, İ.,1999. “İktisadi Analizde Rekabet Kavramının Gelişimi”, Ekonomik Yaklaşım, 10(33), p.5-10.

- Mülkiyet Hakları ve İşlem Maliyetleri”, http://www.canaktan.org/ekonomi/kurumsal-iktisat/yenikurumonculer.htm\#_ftn10, 2016 


\title{
Ekonomik Büyümede Girişimcilik Eğitiminin Önemi The Importance of Entrepreneurship Education on Economic Growth
}

\author{
Prof. Dr. Harun Bal (Çukurova University, Turkey) \\ Asst. Prof. Dr. Erhan İşcan (Çukurova University, Turkey) \\ Birgül Katar (Çukurova University, Turkey)
}

\begin{abstract}
Entrepreneurship is one of the prominent individual properties in transition from industrial society to artificial intelligence society. It is extremely important to raise entrepreneurs who can easily adapt to changing circumstances, in a society's economic growth and development. An entrepreneurship has different qualities in terms of manners and attributes such as leadership, ability to see the opportunities, to pursue the innovations, to take risk, independence, diligence, creative thinking, fast problem solving. It is thought to be the economic growth depended on physical capital increase as well as labor and capital. Education is the most crucial component of human capital. In recent years, the most striking result of endogenous growth model of Romer who contributed the improvement of human capital theory is relatively the economies that have higher sum of human capital rate will have higher economic growth rate. The main aim of this study is to determine the impact of the entrepreneurship education on economic growth and development. For this aim a questionnaire is prepared to analyze the potential impact of the entrepreneurship education on economic growth and development. Results of analyze shown that the entrepreneurship education is necessary and important for entrepreneurship. Therefore, entrepreneurship education and training is sufficient for economic growth. The policy makers should spend more resources on the education that increases the human and social capital.
\end{abstract}

\section{Giriş}

İnsanlık tarihinin başlangıcından itibaren gelişme ve ilerleme için yenilikçiliğin uzantısı olarak girişimcilik faktörü her ne kadar yakın zamanda tanımlansa da tüm dönemler boyunca çok önemli bir yere sahip olmuştur. Tarihin ilk yıllarından günümüze değin insanların ekonominin tanımında da olduğu üzere sınırsız ihtiyaçlarını karşılamak üzere olan faaliyetleri girişim olarak tanımlanabilmektedir. İnsan ihtiyaçlarındaki çeşitliliğin artmasıyla birlikte, yapılmakta olan işlerin de çeşitliliğinde artış meydana gelmiştir. Bu çeşitlenmeyle birlikte rekabet şartlarının gerekliliği de ortaya çıkmaya başlamıştır. Böylece rekabet şartlarının gelişmesiyle birlikte, girişimciliğin gelişme süreci de hızlanmaya başlamıştır (Kuvan, 2008).

Globalleşmenin tüm ülkeleri kapsadığı günümüz dünyasında şirketlerin rekabette üstünlük sağlayabilmeleri girişimcilik potansiyellerini gerçekleştirebilmelerine bağlıdır. Girişimci, insanoğlunun yeni ihtiyaçlarını fark eden, aynı mal veya hizmeti yeni ve daha verimli bir yöntemle üretmeyi başaran, yada yeni bir organizasyon şekliyle verimliliği arttıran veya özel olarak icatları inovasyona çeviren ekonomik ajan olarak tanımlanabilmektedir. Başarma arzusu yüksek olan girişimci sürekli yeni fikirler ortaya çıkarır ve daha iyisini üretmekten de zevk almaktadir.

Yaygın olarak yapılan tartışmalardan biride girişimciliğin doğuştan gelen bir yetenek olup olmadığıyla ilgilidir. $\mathrm{Bu}$ yönde yaygın kanaat ise girişimciliğin doğuştan gelen bir yetenek olmaktan öte eğitimle kazanılan bir özellik olduğu yönündedir. Bu nedenle girişimcilik eğilimini arttırmak için ilgili eğitimlerin yaygınlaştırarak ekonomik ajanların girişimcilik özelliklerinin artmasına katkıda bulunabiliriz. Eğitim, girişimcilik yeteneğinin oluşmasına veya girişimcilik yeteneğinin daha da artmasını sağlamaktadır. Girişimcilik eğitimleri her seviyedeki girişimcinin yeteneğine katkıda bulunmaktadır.

Ülkelerin gelişmişlik ve kalkınmışlık düzeyleri öncelikli olarak milli gelir ya da kişi başına düşen milli gelir ile ölçülmektedir. Aynı zamanda gelişmişlik ve kalkınmışlık düzeyi sağlıklı ve uzun ömürlü bir yaşam, eğitilmiş insan gücü oranını bir yönde ifade eden beşeri sermaye ile de anlatılmaya başlanmıştır. Eğitim, beşeri sermayenin en önemli bileşenlerindendir. Dolayısıyla, eğitimin artması hem girişimcilik yeteneklerinin artması anlamına hem de beşeri sermayenin artması anlamına gelecektir. Özellikle literatürde beşeri sermayenin büyüme ve kalkınma üzerindeki etkisi çokça vurgulanmaktadır. Eğitim alanındaki gelişmelerin özellikle teknolojide olmak üzere yenilikçiliği ve bağlı olarak da verimliliği arttırarak üretim artışına neden olduğunu ve dolayısıyla ekonomik büyümeyi etkilediği literatürün ortak noktası olmaktadır.

Özellikle girişimciliği destekleyecek en önemli iki etken ise bireylerin girişimci olabilmesi için motivasyon ve firsatları başarılı bir girişime çevirmek için doğru yetenekler olmaktadır. Bu doğrultudaki verilecek olan eğitim bir yandan var olan girişimcilik potansiyelinin ortaya çıkarmaya ve yeteneklerin güçlenmesine sağlayacaktır. Bu çalışmada, öncelikle girişimcilik kavramına ve girişimciliğin ekonomik büyüme üzerindeki etkisine yer verilecektir. Eğitimin girişimcilik üzerindeki etkisinin tartışılmasından sonra Çukurova Üniversitesi İktisadi ve 
İdari Bilimler Fakültesi İktisat Bölümü 1. ve 3. sınıf öğrencilerine uygulanan anket sonuçları değerlendirilmiştir. Son olarak ise genel değerlendirme yapılarak politika önerisinde bulunulmuştur.

\section{Girişimcilik Kavramı}

Girişimcilik kavramını için ait tek bir tanım yapabilmemizin imkanı bulunmamaktadır. İlk defa Cantillon'un yazılarında görülen girişimci belirsizlik altında iş yapan kişi olarak tanımlandığını görmekteyiz. Marshal ise onu yeni yolların öncüsü olarak nitelemiştir. Tabii ki birçok iktisat düşünürü girişimci üzerine olan fikirlerinin ortaya koyarken Schumpeter ise yenilikçi girişimciye dikkatleri çekmiştir.

Ekonomik gelişmenin temel dinamiği olarak gösterilen girişimcilik, bir iş girişimi başlatmak için gerekli kaynakları organize etme ve bu iş ile ilgili risk ve kazançları öngörme sürecidir (Daft, 2005). Bugünkü modern, yenilikçi anlayışına göre hareket eden ekonomik ajanlar düşündüğümüzde girişimcilik kavramı, esneklik, kar odaklılık, yenilikçilik, yaratıcılık ve değişim odaklı olma gibi kavramlarla açıklanabilmektedir. Bu kavramları düşündüğümüzde ise ekonominin neden temel dinamiği olduğunu görebilmekteyiz. Eğer gelişme üretim artışı yani milli gelirin artışı demek ise yenilikçilik ve girişimcilik ise yeni mal ve hizmet üretimi yada verimliliğin artışı olduğundan ekonominin büyümesinin temel dinamiği olduğu anlamına gelecektir.

Girişimciliği işletmeleri ve ürünlerini daha iyi durum için değiştiren bir süreç olarak açıklayan Schumpeter, girişimciliğin yaratıcı yıkım özelliğini belirterek mevcut ekonomik düzenin yıkılarak yeni bir oluşumda bulunulmasını yıkıcı girişimcilik olarak ifade etmiştir(Coulter 2001).

Schumpeter'e göre girişimciliğin özünde yenilik kavramı vardır. Girişimciliği iş dünyasında karar alma düzeyinde ortaya çıkan bir düşünce biçimi olarak gören Schumpeter bu düşüncenin önemli özelliğini yenilikleri takip etme ve bu yenilikleri toplum ihtiyaçları için piyasaya sürme olarak belirtmiştir(Eyüboğlu, 2007).

Klaus Rainer Kirchoff girişimciliği, sosyal kalkınmada önemli olarak gösterilen yeni refah yaratımı ve refahın dağılımı olgularını gerçekleştirmeye çalışan bir araç olarak göstermektedir(Gürol, 2006).

Özellikle girişimciliğin tüm kaynaklarındaki tanımlarına baktığımızda atıf yapılan en önemli tanımın Hisrich'in tanımı olduğunu görmekteyiz. Ona göre girişimcilik; psikolojik, ekonomik ve sosyal riskleri göze alıp zaman ve çaba harcayarak farklı bir değer yaratma sürecidir. Kişiler bu süreç sonunda kişisel isteklerini tatmin ederler ve doyuma ulaşırlar. Bu yönde yeni bir bilginin yaratılması süreci girişimcilik olarak tanımlanacaktır (Hisrich ve Peters 2001).

Hardy ise girişimciliği, piyasalarda ortaya çıkan fırsatları değerlendirmede, insanların içinde oldukları sosyal, kültürel, politik ve ekonomik çevrelerin etkisiyle çalışır hale gelen faaliyetler bütünü olarak tanımlamaktadır.(Hardy, 1998).

Girişimcilik birçok faktörün bir araya gelmesiyle ortaya çıkabilecektir. Yüksek girişimcilik eğilimine sahip olan bireylerin aynı zamanda girişimcilik faaliyetinin desteklendiği bir çevrede girişimciliğin ortaya çıkmasında önemli bir etkendir. Aile başta olmak üzere toplumun, motivasyonun, beşeri sermayenin, ağ sermayesinin, psikolojik özelliklerin, demografinin, sektörel yapının kişiyle olan bileşimin girişimciyi ortaya çıkaracağını söyleyebiliriz. Özellikle gençlerin ve kadınların girişimci olabilmelerinin en önemli faktörü bu çerçevede eğitim olabilmektedir. $\mathrm{Bu}$ nedenle girişimcilik için önemli olanın sadece sermaye olduğu algısının doğru olmayacağıdır. Sermayeden daha önemli olan ise fikri sermayeye sahip olmaktır.

\section{Ekonomik Büyümede Girişimciliğin Önemi}

Ekonomi biliminin en önemli konusu olan ekonomik büyümeyi Adam Smith ilk defa eğitim ile ilişkilendirdiğini görmekteyiz. Smith'e göre alınan eğitimin sonucunda elde edilen birikim doğal olarak sermaye birikimi olacaktır ve bu birikimden toplum da faydalanacaktır (Türkmen, 2002).

Lucas'a göre, beşeri sermaye birikimi büyümenin kaynağı olmaktadır ve büyümenin sürdürülebilir olmasını sağlayacaktır. Beşeri sermaye ise kuşkusuz ki sürekli olarak eğitim ile arttırılabilecektir. Aynı yönde Romer (1986, 1990)'de yeni mal ve hizmet üretimini sağlayan yeniliklerin kaynağının beşeri sermaye olduğunu ifade etmiştir.

$\mathrm{Bu}$ yönde çeşitli büyüme teorilerine ve literatürüne baktığımızda teknoloji, icatlar, patentler, yeni fikirler, yenilikler veya yeni organizasyon şekilleri ekonomik büyümenin sağlamaktadır. Beşeri sermaye birikimini ise emeğin verimliliğini yükselterek, girişimlerin yenilikçiliğini arttırarak taşma etkisi yaratacaktır.

Gelişen ekonomiler için önem taşıyan yenilikçilik ve bağlı olarak girişimcilik, özellikle kullanılmayan kaynakları kullanmanın, mal ve hizmet üreterek milli geliri arttırmanın ve yenilik yaparak daha fazla kar elde etmenin yolu olarak görülmektedir. Girişimcilik ve yenilikçilik gerek ülkenin büyümesi ve kalkınmasında gerekse de bölgenin büyümesi ve kalkınmasında önemli bir rol oynayacaktır. Bu özelliklerinin yanı sıra girişimcilik yaratacağı iş alanları ile istihdamın arttırılmasına katkıda bulunacaktır.

Girişimcilerin topluma yaptığı katkı ise bu yönde yadsınamaz çünkü toplumsal refah düzeyi ve yaşam kalitesini arttıran girişimci kullanılmayan potansiyelleri kullanarak mal ve hizmet üretimini arttırırken yenilikçi karakteri ile de bilim ve teknolojinin gelişmesine öncülük ederler. Artan girişimciliğe bağlı olarak artan girişim sayısı da 
istihdam oranının artmasına katkıda bulunacaktır. Ekonomik büyümeyi arttıran girişimciler daha fazla girişimcinin de ortaya çıkmasını sağlayacaklardır.

Girişimci, sınırsız ihtiyaçları gidermede kullanmak üzere kaynakların düşük verimliliğe sahip alanlardan yüksek alanlara aktarılmasını sağlamaktadır. Girişimci üretim için kullanılacak olan kıt kaynakların en yüksek faydayı sağlayacak şekilde üretilmesini düşünen kişidir. Yeni üretim yöntemini, organizasyonu, mal veya hizmeti, endüstriyi, teknolojiyi ya da bunların hepsinin bir araya gelmesini sağlayan girişimci firsatları fark ederek yeni piyasalarda, yeni mal veya hizmetler ile risk alan kişilerdir. Kısaca ekonomik büyüme ve gelişme için girişimci önemli bir faktör olmaktadır.

\section{Eğitimin Girişimcilik Üzerindeki Etkisi}

Beşeri sermayenin eğitim, geçmiş tecrübeler ve özellikli bilgiden oluştuğunu ve bunun girişimciliğin başarısı için en önemli faktör olarak vurgulayabiliriz. Buradan yola çıkarak genel eğitim ile girişimcilik arasında ilişkinin önemini vurgulayabiliriz. Aynı zamanda girişimcilik çerçevesinde beşeri sermaye ve beşeri sermayenin arttırılması için verilen eğitim resmi eğitimden daha farklı bir anlama gelmektedir. Özellikle girişimciliği ortaya çıkarmak için olsa da olan girişimciliği desteklemek için de eğitim tasarımlanmalıdır. Günümüz girişimcilerinin bilinen klasik girişimci kimliği ve görüntüsünün üzerine çıkma zorunluluğu vardır. Bilişimci girişimci diye adlandırılan bu yeni girişimci tipi örgütlerin ulusal ve uluslararası rekabette en önemli itici gücü olacaktır. Bilgi teknolojilerinin genel anlamda iş dünyası, özelde ise girişimcilik biçimlerine yaptığı dönüştürücü etki göz önüne alındığında; bilgi tabanlı iş dünyasında bilgi yönetiminin ilkelerinin rasyonel şekilde uygulanabilmesi, bilişimci girişimcilerin yetişmesine olanak sağlayacaktır (Ögüt, 2007).

Kişilik gibi bireysel özellikleri etkileyen, daha girişimci olunmasını sağlayan veya girişimcilerin başarısını arttıran eğitim özellikle önem taşımaktadır. Eğitim kişinin kendi yönetebileceği bir gelişim alanını da ifade etmektedir. Bilgi olmadan girişimcilik bir strateji ile buluşturulamaz. Pek çok girişimci yönetim, finans, planlama ve pazarlama alanlarında eğitime ihtiyaç duyar. Bireysel ve kurumsal girişimcilerin yetiştirilmesi için işletmeye ilişkin donanımlarının artırılması kaçınılmaz bir gereksinimdir. Girişimcilik eğitimi, girişimciliğin de bir kariyer olarak düşünülmesine ve küçük işletmelerin sağlıklı gelişimine olumlu katkı sağlayacaktır (Henderson ve Robertson, 1999). Girişimcilik eğitimindeki amaç kişide var olan ama gizli kalmış girişimci niteliklerini ortaya çıkarmaktır. Aynı zamanda girişimcilere verilen eğitim, onların yanlış işler yapmalarını önleyerek, sermaye, emek, doğal kaynaklar gibi üretim kaynaklarının boşa harcanmasını engellemektedir. Girişimcilik eğitimi; girişimciliğin ve girişimcinin desteklenmesi ve teşvik edilmesi ve böylece girişimciliğin gelişiminde önemli bir faktör konumundadır. Bunun farkında olan tüm dünyadaki üniversitelerde bu eğitimin verilmesi ile ilgili gelişmeler yaşanmaktadır. Eğitim sisteminin tüm düzeylerinde hızlı bir şekilde ilerleyerek yerini alan girişimcilik eğitim programlarının yanı sıra günümüzde girişimcilik alanında verilen kurslar, akademisyenler ve girişimcilik programlarının sayılarında da görülen artış bu durumun bir göstergesi olmaktadır(Hytti ve O’Gorman, 2004). Günümüzde işsizlik sorununa çözüm üretmek, ekonominin genel dengesini sürdürülebilir kılmak, bütçe açıklarını azaltmak gibi hususların girişimciliğin gelişimi ile mümkün olacağı düşüncesi girişimcilik eğitimini en stratejik konulardan biri haline getirmiştir (Yelkikalan ve ark. , 2010).

Girişimcilik eğitiminin birey ve işletme bazındaki olumlu etkilerinin yanı sıra ülke bazındaki yani makro etkileri de çok önemlidir. Ülkelerin istihdam ve yenilikçilik başta olmak üzere ekonomik kalkınmalarında önemli bir rolü olan girişimciliğin geliştirilmesi Avrupa Birliği’nin öncelikli politikaları arasında yer almaktadır. AB üyelik sürecindeki ülkeler için girişimcilik politikaları oldukça önemlidir. Çünkü $A B$ aday konumundaki ve $A B$ üyesi olan ülkelerin girişimcilik politikalarını ve bu yöndeki performanslarını izlemektedir. AB'nin girişı̇mciliğin geliştirilmesi doğrultusunda oluşturulan hareket planları arasında girişimcilik eğitimleri düzenlenmesini öncelikli hedeflerine almışlardır. Girişimcilik eğitimleri ile bireylerin girişimciliğin oldukça cazip bir seçenek olduğu konusunda bilgilendirilmeleri, girişimci adaylarının ve girişimcilerin bu yönde motive edilmeleri ve bu yöndeki hedeflerin başarılı birer girişimcilik faaliyetine dönüştürülebilmesi için bireylere gerekli bilgi ve becerilerin kazandırılması hedeflenmektedir (TİSK, 2004).

Bu bilincin öğrencilere yerleştirilmesi ve girişimcilik konusunda detaylı bilgi verilmesi, onların girişimcilik için gerekli olan sermayeye nasıl ulaşacakları konusunda yol gösterici olacaktır. Kişiler aldıkları eğitimler sonucu iyi bir girişimci olma konusunda bilgi ve becerilerini arttıracaktır.

\section{Yöntem ve Sonuçlar}

Bu çalışmanın amacı, iktisat öğrencilerinin girişimcilik dersi almadan önce ve girişimcilik dersi aldıktan sonraki aşamada, bu eğitimin girişimcilik eğilimi üzerine etkisini belirlemektir. Araştırmada kullanılacak verilerin toplanması için anket yöntemi kullanılmıştır. Ankete katılan öğrencilerin girişimcilik eğiliminin belirlenmesi amacıyla 40 soruya cevap vermeleri istenmiştir. Çalışma Çukurova Üniversitesi İktisadi ve İdari Bilimler Fakültesi 1. ve 3. Sınıf öğrencileri üzerinde gerçekleştirilmiştir. Ankete birinci sınıf ve üçüncü sınıf öğrencilerinden toplam 200 öğrenci katılmıştır. Ankette 5'li ölçek kullanılmış ve elde edilen veriler için analiz edilmiştir. Anketteki sorulardan örnek olarak temel değerlendirme yapmak amacı ile 7 tanesi girişimcilik eğitiminin girişimcilik 
eğilimine olan etkisini göstermek üzere çalışmada yorumlanmak için seçilmiştir. Seçilen sorular ve elde edilen bulgular Tablo 1'de ve Tablo 2'de gösterilmiştir.

\begin{tabular}{|l|l|}
\hline 1 & Girişimci sermayesi olan kişidir. \\
\hline 2 & Ben girişimciyim. \\
\hline 3 & $\begin{array}{l}\text { Girişimci olup kurduğum işler birçok kez başarısız olsa bile başarılı olana kadar denemeye devam } \\
\text { edebilirim. }\end{array}$ \\
\hline 4 & Beni girişimci olmaktan sermayem alıkoyuyor. \\
\hline 5 & Girişimcilik için kaynak sağlayan risk sermayesi şirketlerinin olduğunu biliyorum. \\
\hline
\end{tabular}

Tablo 1. Seçilen Sorular

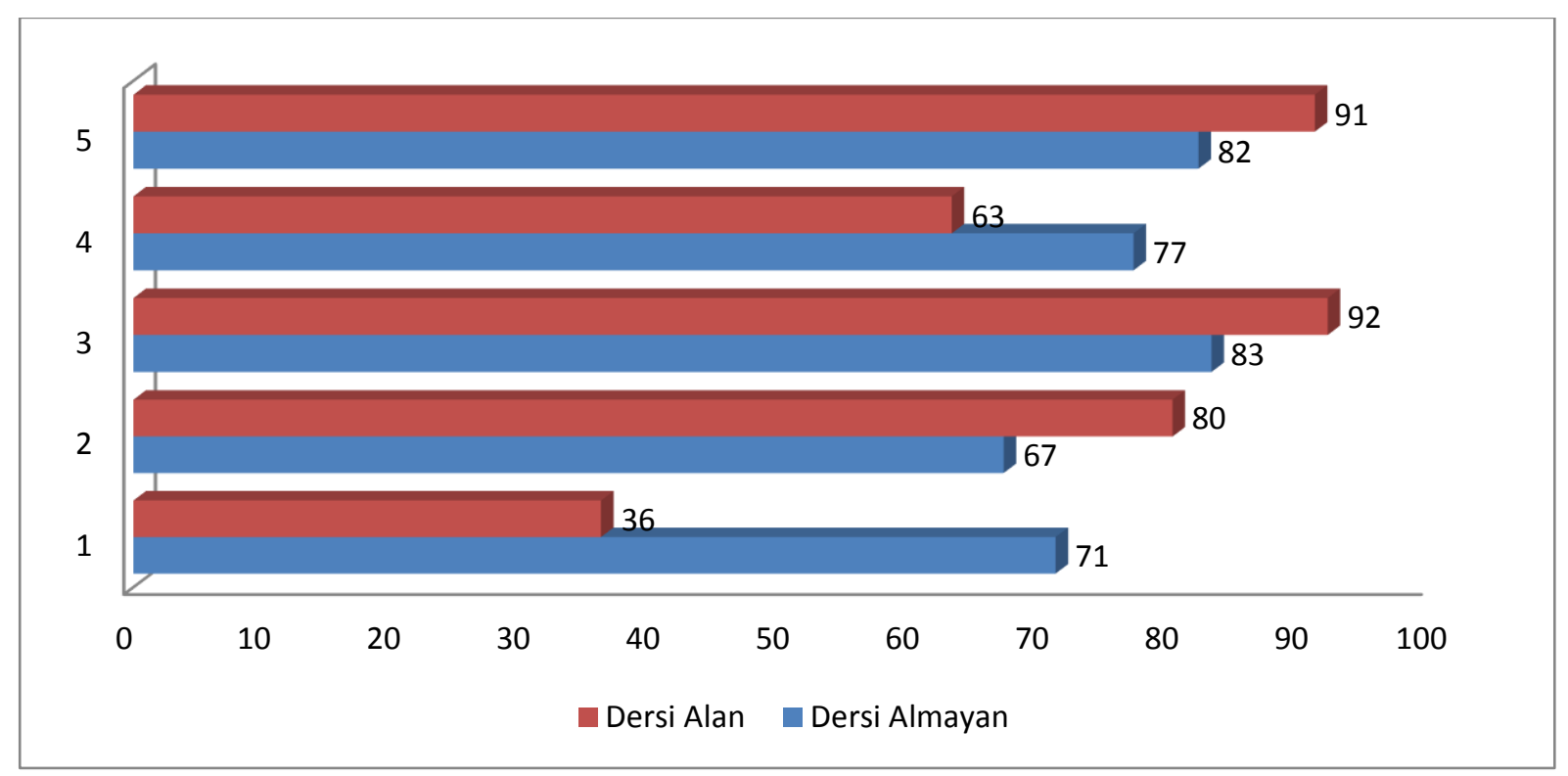

Tablo 2. Önermeye Katılmayanlar Dışındaki Oran

İlk soruyu değerlendirdiğimizde özellikle dersi alan ve almayan öğrenciler arasında belirgin bir farklılık ortaya çıkmaktadır. 1. sınıf öğrenciler girişimciyi sadece sermayesi olan kişi olarak tanımlamaktayken dersi alan öğrencilerin girişimciliği aldıkları eğitim ile beraber doğru bir şekilde tanımladığını görmekteyiz. Girişimcilik eğitiminin beklenen öncelikli amaçlarından birisi tanımlamaları doğru yapmak ve buna bağlı olarak öğrencinin kendini gördüğü yeri daha net ortaya koyabilmesini sağlamaktır.

İkinci soruda dersi alan öğrenciler kendisini daha girişimci olarak tanımlamaktadırlar. Burada dikkati çeken bir önemli bir nokta bulunmaktadır. Dersi alan öğrencilerin belirgin bir şekilde kendini daha iyi bir girişimci olarak tanımlamasına rağmen dersi almasa bile öğrencilerin \%67 si kendisini girişimci olarak tanımlamaktadır. Burada karşımıza çıkan genç girişimcilerin yeteneklerinin arttığı sonucudur. Öğrenciler kendilerini girişimci olarak tanımlarken ders ile birlikte kendilerini daha iyi bir girişimci olarak tanımladıklarını söyleyebiliriz.

Üçüncü soruda öğrencilerin başarısızlığa karşı direncinin yükseldiğini görmekteyiz. Bunun doğrudan girişimcilik eğitimi ile ilgili olduğunu söyleyebiliriz. Çünkü öğrenci girişimcilik yeteneğinin farkına varmıştır ve başarısızlıkta bir veya birkaç defanın etkili olmadığını düşünmektedir.

Dördüncü soru ise dersi alan öğrencileri girişimci olmaktan sermayenin alıkoyması ile ilgilidir. İkinci soruda elde ettiğimiz sonuca paralel olarak öğrencilerin yeteneklerinin artmasıyla birlikte daha çok girişim fikri olmasına rağmen yeterli sermayelerinin olmaması onların girişimci olmalarında bir engel olmadıklarını düşünmektedirler. Gerçekten de verilen eğitimde sadece sermaye bulmanın girişimcilik olmadığı anlatılmaktadır. Burada yine yeteneklerin girişimcilik eğitimi ile arttırıldığını görmekteyiz.

Son soru ise girişimcinin finansman kaynaklarının farkındalığı ile ilgilidir. Eğitim programının içerisinde yer alan finansman kaynakları eğitimi öğrencilerin farklı bir finansman kaynağını öğrenebilmelerini sağlamıştır. Bu önemli bir gelişme olarak görülmektedir. Çünkü en bilinen risk sermayesi şirketlerinin yanı sira daha özellikli finansman yöntemlerini öğrenmiş bulunmaktadırlar. Tecrübe ya da çevreden kolaylıkla öğrenilemeyecek olan bu ve benzeri konuların girişimcilik eğitimi ile verildiğini gözlemlemekteyiz.

Genel olarak değerlendirdiğimizde iki farklı sonucun olabileceğini gözlemlemekteyiz. Birincisi, üniversite öğrencilerinin genç girişimci olarak değerlendirilerek eğitimlerini buna göre tasarımlanması gerekliliğidir. İkincisi ise genç girişimcilere yönelik olarak tasarımlanan bir eğitim programı ise girişimcilik eğitimini arttırmıştır. 


\section{Genel Değerlendirme}

Küreselleşme ile birlikte yaşanan köklü değişim ile birlikte yaşanan hızlı teknolojik ilerleme işsizliği özellikle gelişmekte olan ülkeler için önemli bir problem haline gelmiştir. İşsizliği azaltmak için girişimci kişi sayısını arttırmak, girişimci sayısını arttırmak için de girişimci yetiştirme konusunda çaba harcamak gerekmektedir. Girişimcilik ekonomik büyümeyi teşvik etmede önemli bir role sahiptir. Girişimciliği destekleyen ülkeler hem bu günlerine hem de geleceklerine yatırım yapmış olmaktadırlar. Girişimciliğin yoğun olduğu ülkelerin yapısı incelendiğinde, bu ülkelerin ekonomik büyüme ve kalkınmışlık konusunda da daha önde oldukları görülmektedir.

Girişimcilik faaliyetleri, sadece girişimciliğin teşvik edilmesi değildir. Girişimcilik niteliklerine sahip kişileri ortaya çıkarmak için eğitim kurumlarında girişimcilik eğitimleri verilerek mevcut potansiyel girişimcileri belirlemek ve onları sahaya çıkarmanın yollarını bulabilmektir. Bir ülkenin girişımci niteliklerine sahip birey sayısı ne kadar fazla ise o ülke ekonomik büyüme ve kalkınma konusunda daha başarılı olacaktır. Bu amaca ulaşabilmesi için girişimciliğin önündeki tüm engellerin kaldırılıp girişimciliğe destek verilmesi gerekmektedir. Ekonomik yaşamda risk almadan başarıya ulaşılması imkânsızdır. Başarı eğilimli olan girişimciler; güçlüklere karşı koyan, işini en iyi şekilde yapan, yeteneklerini kullanan ve bağımsız olan ekonomik ajanlardır. Girişimci bu yeteneklerini kullanarak alacağı başarı ödülünün yani karın peşindedir. Başarının ödülü olan karı en yüksek seviyede tutmak için kendini geliştirmek ve belli bir bilgi yüküyle donatmak zorundadır. Bu bilgiye ulaşmak için sürekli eğitim alması gereken girişimci için eğitim kurumlarında verilecek olan eğitimin önemi artmıştır. Girişimcilik eğitimini veren belki de tek ama en önemli kurum olan üniversiteler sürekli olarak gelişen ve değişen, küresel değişmeleri topluma yansıtan kurumlardır. Buradan yola çıkarak üniversitelerde verilen girişimcilik eğitiminin, öğrencilerin, girişimcilik için gereken kişilik özelliklerinin ortaya çıkmasına temel oluşturmaktadır. Eğitim sürecinde girişimci ekonomik ajanların artmasını sağlamak için öğrencinin hür düşünce ile yeteneklerinin ortaya çıkmasını sağlayacak sistemin benimsenmesi gerekmektedir.

Girişimcilik eğitiminin öğrencilerin girişimci olma veya olmama konusundaki kararlarını etkilediğini ortaya çıkarmak için bir anket çalışması yapılmıştır. Çalışmamızın anket sonuçlarından elde edilen bilgiler doğrultusunda, İİBF İktisat bölümü 3. sınıfında girişimcilik dersi alan öğrencilerin, girişimcilik konusunda, bu dersi almayan öğrencilerden daha istekli oldukları görülmüştür. Girişimcilik dersi almayan öğrenciler, kendi işini kurmak düşüncesine pek sıcak bakmamaktadır çünkü girişimcinin özelliklerini ve tanımını aslında bilmemektedir. Yeni fikirler üretmek, tepkileri göze alarak yeni girişimlerde bulunmak ve risk almak konusunda girişimcilik dersi alan öğrencilere nazaran daha uzak bir görüntü sergilemektedirler. Bu dersi almayan 1. sınıf öğrenciler, düşük riskli işler istemekte yani belirli bir hayat standardına razı olmaktadırlar.

Girişimcilik eğitimini almış öğrencilerle, girişimcilik eğitimini almamış öğrenciler arasında, öğrencilerin sorulara verdikleri cevapların karşılaştırmalarında, bu dersi almış 3. sınıf öğrencilerinin, eğitim sonrasında daha fazla girişimcilik eğilimine sahip oldukları söylenebilmektedir.

Günümüzde girişimcilik, üniversiteden yeni mezun olmuş tüm ekonomik ajanlar için önemli bir kariyer firsatıdır ve aldıkları girişimcilik eğitimi, kişilerin içinde var olan girişimci ruhunun dışarıya çıkartacaktır. Bu girişimeilik ruhunun başarılı bir girişimcilik faaliyetine dönüşmesi için, girişimcilik eğitimi veren kurum ve kuruluşlara çok görev düşmektedir. Bu kuruluşların görevini yerine getirebilmeleri için de devlet tarafindan daha çok desteklenmeleri gerekmektedir. Girişimciliği destekleyen politikalar sayesinde ekonomik gelişme uyarılacak ve bu da istikrarlı bir ekonomik büyümeye yol açacaktır.

\section{Teşekkür}

Bu çalışma Çukurova Üniversitesi Bilimsel Araştırma Projeleri Koordinasyon Birimince Desteklenmiştir.

\section{Kaynakça}

- Ağca, V.(2007), “'Avrupa Birliğinin Girişimcilik Politikası ve Türkiye’ye Yansımaları”, Türkiye'de İşletmecilikte Yeni Perspektifler, editörler Kurt, M. Ve Bayraktaroğlu, S. , Gazi Kitabevi, Ankara, s. 169194.

- Arıkan, S.( 2002), Girişimcilik Temel Kavramlar ve Bazı Güncel Konular, Siyasal Kitabevi, Ankara.

- Arslan, K. (2002),'Üniversiteli Gençlerde Mesleki Tercihler ve Girişimcilik Eğilimleri”, Doğuş Üniversitesi Dergisi, 2002/6, s.1-11.

- Balaban, Özlem ve Yasemin Özdemir(2008). 'Girişimcilik Eğitiminin Girişimcilik Eğilimi Üzerindeki Etkisi: Sakarya Üniversitesi İIBF Örneği’, Girişimcilik ve Kalkınma Dergisi, 3(2), s.133-147.

- Bayraktaroğlu, S.(2005), Girişimcilik Ders Notları, Sakarya Kitabevi, Sakarya.

- Bird, B.J. (1989), Entrepreneurial Behavior, Illinois: Foresman and Company.

- Bozkurt, Ö.(2007), 'Girişimcilik Eğiliminde Kişilik Özelliklerinin Önemi”, Girişimcilik ve Kalkınma Dergisi, 1(2), s.93-111. 
- Cansız, E.(2007). Üniversite Öğrencilerinin Belirlenmesi: Süleyman Demirel Üniversitesi Öğrencileri Üzerine Bir Çalışma. Yayımlanmamış yüksek lisans tezi, Süleyman Demirel Üniversitesi Sosyal Bilimler Enstitüsü, Isparta.

- Coulter, M. (2001), Entrepreneurship in Action, Small Business 2000(New Jersey: Prentice- Hall).

- Daft, Richard L.(2005). The Leadership Experience, Third Edition, Canada, Thomson South-Western College Publishing.

- Denison, E.(1962). The Sources of Economic Growth in the United States and Alternatives Before US, Supplemantary paper NO.13, New York: Committe for Economic Development.

- $\quad$ Eyüboğlu, D.(2007), Girişimcilik Eğitimi, MPM yayınları, No:697, Ankara.

- $\quad$ Gürak, H.(2009), Ekonomik Büyüme, 1-319.

- Gürol, Y. ve Atsan N.(2006), ' Entrepreneurial Characteristic amongst University Students: Some Insights for Entrepreneurship Education and Training in Turkey", Education+Training, 48(1), s.25-38.

- Hardy K.(1998), “What Do Entrepreneurs Contribute?”, Ivy Business Journal, Vol 64, Issue 2.

- Henderson R. , Robertson M.(1999), Who wants to be an entrepreneur? Young adult attitudes to entrepreneurship as a career, Education and Training; 41:236

- Hisrich. Robert D. ve Peters M.(2001), Entrepreneurship, 5th Edition, McGraw-Hill Higher.

- Işı1k, N. , Göktaş, D. , Kılınç, E. (2011), “'Iktisadi Büyümede Girişimciliğin Rolü’, Girişimcilik ve Kalkınma Dergisi,6(1).

- İpçioğlu, İ. Ve Taşer, A.(2009), “'̇şsletme Bölümlerinde Verilen Eğitimin Girişimci Adayı Öğrenciler Üzerindeki Etkileri”, Süleyman Demirel Üniversitesi Sosyal Bilimler Enstitüsü Dergisi, 2(10), s. 13-25.

- Kılıç, R. , Keklik, B. , Çalış, N.(2012), 'Üniversite Öğrencilerinin Girişimcilik Eğilimleri Üzerine Bir Araştırma: Bandırma İIBF İşletme Bölümü Örneği”, Süleyman Demirel Üniversitesi İiBF Dergisi, 17(2), s. 423-435.

- Kutanis, Özen R. , Hancı, A.(2004), “'Kadın Girişimcilerin Kişisel Özgürlük Algılamaları”, Osmangazi Üniversitesi, İIBF, 3.Ulusal Bilgi, Ekonomi ve Yönetim Kongresi, s. 457-464.

- Kuvan, H.(2008), Örgün ve yaygın eğitimin girişimciler üzerindeki etkileri, Yayımlanmamış yüksek lisans tezi. Malatya: İnönü Üniversitesi Sosyal Bilimler Enstitüsü.

- $\quad$ Lambing, A.P. ve Kuehl, C. (1997), Entrepreneurship, USA: Prentice-Hall.

- Öğüt, A.(2007), Bilgi Çağında Yönetim. 3. Baskı Konya: Çizgi Kitabevi.

- Özdemir, A.A.(2014), Kültür, Benlik Saygısı ve Girişimcilik Eğilimi: Amerikan ve Türk Üniversite Öğrencilerinde Karşılaştırmalı Bir Çalışma. İstanbul Üniversitesi Işsletme Fakültesi Dergisi, 43(2), 351-367.

- $\quad$ Romer P.M.(1990), Endogenous technological change, Journal of Political Economy, 98(5), 71-102.

- Sarı, R., Soytaş, U. (2006), Income and Education in Turkey: A Multıvariate Analysis, Education Economics, Vol. 14, No. 2.

- $\quad$ Serin, N.(1979), Eğitim Ekonomisi, Ankara Üniversitesi Eğitim Fakültesi Yayınları, 1979.

- Sezer, C.(2013), Girişimcilik Kariyerine Yönetim Nedenleri ve Girişimcilik Dersinin Etkisi Üzerine Bir İçerik Analizi: KTMÜ Örneği. Manas Sosyal Araştırmalar Dergisi, 2(4), 63-86.

- Shultz, T. W.(1961), Investment in Human Capital, The American Economic Review, Vol. 51, No.1, March, 117.

- $\quad$ TİSK, Türkiye İşveren Sendikaları Konfederasyonu(2004), Avrupa Birliği'nde Girişimciliğin Geliştirilmesi Türkiye 'ye Yol Gösteren İlke, Politika ve Uygulamalar, Yayın No:245.

- Tutar, H. ve Küçük, O.(2003), Girişimcilik ve Küçük İşletme Yönetimi, Seçkin Yayıncılık, Ankara.

- Türkmen, F.(2002), Eğitimin Ekonomik ve Sosyal Faydaları ve Türkiye'de Eğitim Ekonomik Büyüme İlişkisinin Araştırılması, DPT-Uzmanlık Tezleri, Yayın No:DPT:2655, Sosyal Sektörler ve Koordinasyon Genel Müdürlüğ̈̈, Eylül, 1-114.

- TÜSİAD(2002), Türkiye'de Girişimcilik, Lebib Yalkın Yayınları, İstanbul.

- Ulaş, D.(2006), 'Franchising Sisteminin Girişimcilik Açısından Değerlendirilmesi”, G.Ü.I.I.B.F. Dergisi, 8/3: 133-151.

- Üzülmez, H. (2008), Girişimcilik ve Konya'da Girişimciliğin Geleceği”, Girişimcilik ve Kalkınma Dergisi,3(1): 21-23.

- Yelkikalan, N. , Akatay, A., Yıldırım, M.H., Karadeniz, Y. , Köse, C. , Koncagül, Ö. ve Özer, E.(2010), ‘'Dünya ve Türkiye Üniversitelerinde Girişimcilik Eğitimi: Karşılaştırmalı Bir Analiz”, KMÜ Sosyal ve Ekonomik Araştırmalar Dergisi, 12(19), s. 51-59. 


\title{
Avrasya'nın Rekabet Gücü Türkiye Eurasian Competitive Capacity Turkey
}

\author{
Asst. Prof. Dr. Hakkı Çiftçi (Çukurova University, Turkey) \\ Aliye Erşahinoğlu (Çukurova University, Turkey)
}

\begin{abstract}
New ventures and creation of market awareness and industrial competition make competition as a prior concept. From this, evaluation of Eurasian competition capacity from the viewpoint of Turkey gains importance as an issue. Within the scope of EU 2020; 3 thematic priorities, 5 main targets, 7 initiatives were determined as a basis. This study that aims developing innovative management and achieving sustainable and more balanced growth with powerful innovative competition capacity, will take basic policies, which will create the competition capacity leans from Turkey to Eurasia, as a basis. This study also includes the analyses of sectoral competition capacity from Turkey to Eurasia as well as legal regulations, energy, trade, employment and geographical dimensions. As the method of this study, data regarding the indications of competition capacity over the last decade will be evaluated, deficiencies will be determined, source distribution will be directed, technological development functions will be achieved, efficient and function competition will be coordinated with the economic growth and a series of measurements will be taken and competition policies will be established in this regard. This study will also analyze the competition policies of Turkey and Eurasia and their objectives, efficiency and measurement of competition, general overview of Eurasian economies, global competition in Eurasian countries, index sequencing and scores in accordance with developed innovation in terms of Azerbaijan, Kazakhstan, Kyrgyzstan, Tajikistan and Turkey. Through the evaluation of rankings of Eurasian economies within Global Competition Index as well as the scores and Global Competition Report, the study will be concluded.
\end{abstract}

\section{Giriș}

İktisadi büyüme süreçleri hakkında Smith, Malthus, Ricardo Marx gibi klasik iktisatçılar, iktisadi gerçekliğin bütününü açıklamaya yönelik kapsamlı kuramlar anlamında temellendirmeleri, ekonomilerin büyüme problemini, serbest bir rekabet ortamını inceleyerek atmışlardır (Tezel 1995). Bir ülkenin iktisadi büyümesinin kökenleri üretime katkı koyan faktörler açısından incelendiğinde işgücündeki ve fiziksel sermayedeki artış kuvvetli etkenler olarak ortaya çıkmakta ama izah edilemeyen önemli bakiye teknoloji, bu bakiyeyi ise yarına bir değer bırakacak ve rekabetin ana öğesini ve öznesini oluşturacak bireye yatırım beşeri sermaye birikimi, yani eğitim ve deneyim büyük ölçüde açıklamaktadır (Çiftçi, 2004). Bunun yanı sıra; yeni ekonominin de temellendirmelerini de oluşturan; Bilgi İletişim Teknolojisinde(BİT) yaşanan gelişmeler globalleşmenin yayılmasının en önemli sebeplerinden biridir (Dunning 1992.1996.1998).

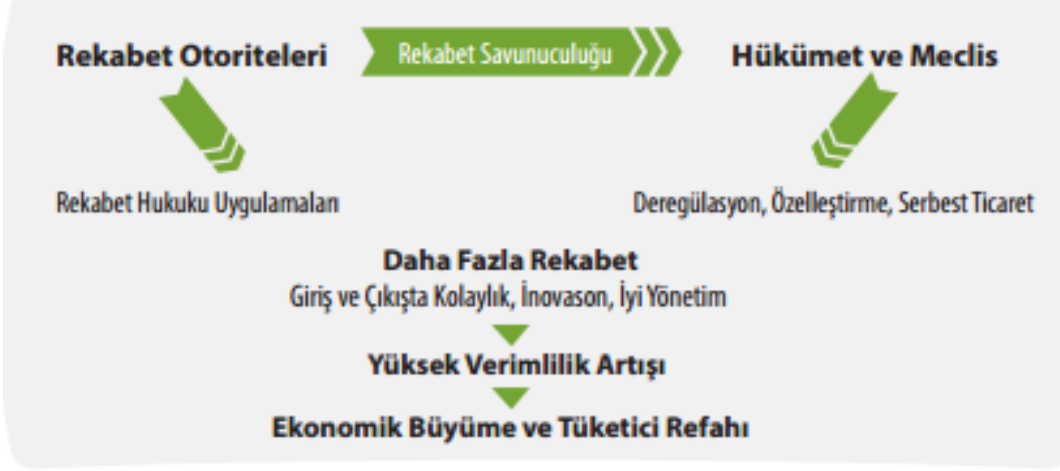

Şekil: 1. Rekabet ve Büyüme Kaynak: OECD, Factsheet on Competition and Growth, 2013

Şekil 1'de de görüldüğü üzere, belirli pazarların seçilmesi, iktisadi faaliyetler bakımından rekabetin asgari ölçüde sınırlandırılması, politik, ekonomik, sosyal, teknolojik, kültürel, çevresel ve bölgesel gereklilikler ya da devletin kalkınmaya yönelik uzun dönemli amaçları açısından gerek duyulması makul olarak değerlendirilebilir (Arnold,2011).

Günümüzde, rekabet gücü açısından hız; esneklik ve pratiklik dikkate alındığında bilgi ve iletişim teknolojilerindeki yeniliklerin ve bu teknolojilerin yaratacağı etkilerin tamamının anlaşıldığını ve tanımlandığını söylemek oldukça güçtür(OECD,2014). Yeni ekonomik gelişmelerle beraber; bilgi ve iletişim teknolojileri aynı zamanda, teknolojinin evrensel boyutlarda baş döndürücü bir hızla yayılmasının verdiği ivmeyle büyüme performansını "yeni ekonomi" kavramıyla açıklamaya çalışan referans çerçevesini ve rekabet gücünün de temellerini oluşturmaktadır (Karacasulu 2000). 
On yedinci yüzyılın ortaları ile onsekizinci yüzyılın başlarında birinci sanayi devrimi dediğimiz evreden başlayan bir sürecin Avrupa'daki diğer ülkeleri ve ABD'yi sanayileşmeye yöneltmiş hem toplam, hem kişi başına sanayi üretimlerini artırarak, dünya üretimindeki paylarını çoğaltmışlardır(Yozgatlı, M.Koray(2001). Sanayileşme'nin temelinin atılmasıyla beraber; onsekizinci yüzyılın ortalarında kişi başına sanayileşme oranı Avrupa'da ve diğer ülkelerde yaklaşık olarak birbirine benzerdi (İpekgil 2000).

Rekabet gücünün değişkenleri içerisinde özellikle ihracatı özendirici tedbir ve teşviklerle ekonominin dış ticarete ve yabancı yatırıma açılması, piyasalara düzenleyici politikaların yerleşmesi, hukuka uygun rekabet ortamının oluşturulması, bilgi teknolojisi altyapısının gelişmesi, rekabet piyasasının etkin bir biçimde uygulanması, iletişim ile hava taşımacılığının geliştirilmesi gibi etkenlerdir (DPT ÖİK, 2000, DPT ÖİK, 1988), (Arnold,2011). Teknoloji yeteneğinin yükseltilmesi, AR-GE'nin ve inovasyon kültürünün sanayiye yaygınlaştırılması ve bu amaçla kamunun uluslararası ölçekte kaynak ayırarak teşvik etmesi de rekabet gücünü artırıcı politikalar arasındadır. Dünya piyasa fiyatlarıyla serbest ithalat, ihracata dayalı endüstrileri teşvik edici mali piyasalar, pazarlama ve teknolojiye dayalı enformasyon sistemi, stratejik koordinasyon kalkınma stratejilerinin önemli aşamaları olmalıdır (Islatince 1998, s. 355). Rekabet gücü açısından vergi oranlarının yeniden düzenlenmesi; sivil toplum kuruluşlarının, meslek örgütlerinin ve sanayi kuruluşlarının yeniden yapılanması, özgün stratejiler ile özgün ürünler tasarlanması, küresel liderlerle, iş sahipleri ve yöneticilerin ufuklarının genişletilmesi rekabet gücünü artıran etkenlerdir. Bu çalışmada; rekabet gücü temel kavramları ve teorisi açısından bakış ile bir başlangıç yapılmış; rekabet gücünü belirleyen faktörlere yer verilerek hem tanımsal, hem teorik Avrasya Ekonomileri’nin rekabet ve rekabet gücü üzerinde durulmuştur. 2014-2015 Küresel Rekabet Raporuna göre Avrasya ülkelerinden; Azerbaycan, Kazakistan, Kırgızistan ve Tacikistan ekonomilerinin Türkiye ile ilişkileri gözden geçirilerek değerlendirilmiştir.

\section{Tanımsal ve Teorik Açıdan Rekabet Gücü}

Rekabet kavramı Adam Smith’e göre işletmelerin müşteri memnuniyeti için bir yarışma olarak tanımlarken; tüketiciler en kaliteli ürünleri, en iyi fiyatlarla ulaşacaklardır böylelikle başarısız ve yetersiz olan işletmeler piyasalardan devre dışı kalacaklardır. Erdal Türkkan'ın yaptığı tanıma göre ise; 'politik, ekonomik ve teknolojik alanda yapılan bir yarışma oyunu' olarak tanımlamaktadır. Rekabet gücü kavramı, ölçütlerine göre özel ve genel boyut olarak farklı biçimlerde tanımlanmaktadır. Rekabet gücü kavramı Scoot ve Lodge’nin 1985 yılında yaptıkları tanıma göre; ülkelerin kaynaklarından elde ettikleri gelirler artarken, uluslararası ticarete yönlendirebileceği ürün ve hizmetlerin üretilip bu üretilen kaynakların dağıtılmasıdır. Hastasapoulos, Krugman ve Summers'ın yaptığı tanıma göre; yaşam standartlarında belirgin artışlar sağlanırken, ülkenin dış ticaret bilançosunun gelir ve giderleri arasındaki farkı en aza indirebilme özelliğidir (Çivi 2001).

Teorik açıdan ise klasik iktisadi ekonomide ve doğal olaylarda bir düzen olduğunu içsel otomatik dengeleyiciler dediğimiz denge unsurları ile gözlem ve ahlâk hissi ile görünmeyen el olarak adlandırdığı serbest piyasa sisteminde fiyat mekanizmaları ile tespit edilebileceğini ifade eden Adam Smith (1766)'da; Mutlak Üstünlük Teorisi ile rekabet gücünün temel belirleyicileri olarak Mutlak Maliyet Avantajlarına işaret etmiş ve rekabet gücünün temel kaynağını ise; faktör verimliliği, doğal ve kazanılmış üstünlükler ile açıklamıştır. Adam Smith'in "Ulusların Zenginliği" isimli eseriyle tanışması ile iktisata karşı bir ilgisiyle borsayı bırakıp ekonomi ve siyasetle uğraşmaya başlayan Ricardo (1817)'da ise rekabet gücünün temel belirleyicileri Karşılaştırmalı Üstünlük Teorisidir. Uluslararası ticaret teorisini geliştirici çalışmalar ile bilinen Faktör donatımını yeğane rekabet gücü unsuru olarak ifade eden Eli Heckscher ve Bertil Ohlin (1933)'de ise rekabet gücünün temel belirleyicileri; Faktör Donatımı Teorisi rekabet gücünün belirleyicisi olarak Ürün Dönemleri Teorisi teorisini ortaya atmışlar. Ülkelerin dişa açılmayı yararlı hale getirmeye çalıştığı bir dönemde ise Porter (1990'da yaptığı çalışmada; Porterdan etkilenen Rugman ve D’Cruz (1993) ise işi bir adım daha ileri götürerek; Çifte Elmas Modeli ile rekabet gücünü belirlemeye dönük faaliyetlerini incelemişlerdir. Kaynağına ise Rekabetçi Üstünlük Teorisi (Elmas Modeli) ile temel rekabet gücü belirleyicisi olarak teorisinde ele almaktadır (Gökmenoğlu S.M, Akal M., Altunişik R.(2012).

$\mathrm{Bu}$ teori, kavram ve tematik öğeler doğrultusunda, rekabet edilebilirlik; hem faktör donanımını esas alan faktör odaklılık, hem rantabilite, karlılık ve etkinliği ifade eden verimlilik, hem de değişimin rekabet gücünü artıracağını ve her yeniliğin bir avantaj sağlayacağını ifade eden inovasyon odaklı rekabet edilebilirlik odaklarını vermektedir. 


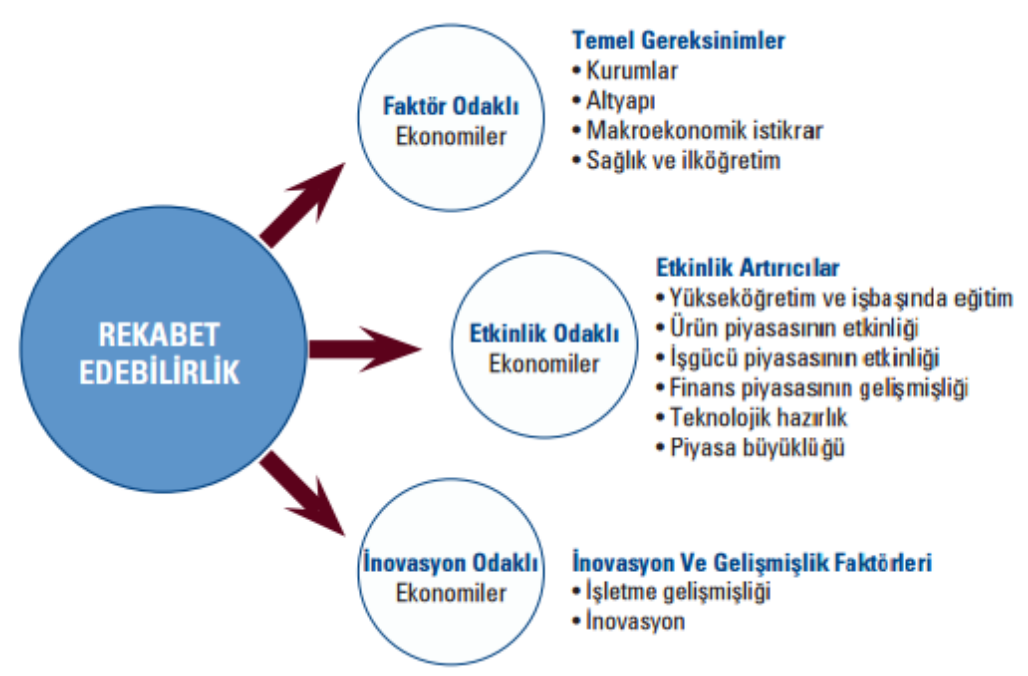

Şekil 2. Rekabet Edebilirlik Kaynak: Kuzey Kıbrıs Rekabet Edilebilirlik Raporu 2014-2015

Yukarıda çeşitli teorilerle kronolojik olarak verilip ve tanımı yapılan tematik öğeler çerçevesinde verimlilik, karlılık, teknolojik gelişme gibi tanımlardan ve görüşlerden hareketle ulusal rekabet gücünün temel özellikleri şu şekildedir; farklılık, odaklanma, yenilik, karlılık, verimlilik, teknolojik gelişme, fiyat farklılaşması, maliyet liderliği gibi özgün ürün, küresel liderden oluşmaktadır (KTTO 2014-2015). Birinci sınıf standartlar da gelişme gösterip yaşam standartlarını artırabilmek temel olmalıdır. Rekabetçi üstünlük teorisini ileri süren Porter' a göre, rekabet gücünün oluşmasında verimlilik kavramından yola çıkılması gerektiğini, ülkelerin rekabet gücünün ancak verimlilikle sağlanabileceğini vurgulamaktadır. Uluslararası pazarda lider devletlerin büyük pazara sahip olmasının en büyük nedeni makroekonomik politikalar olduğu ve bu politikaların ulusal rekabet gücünü sürekli olarak arttırdığı görülmüştür. Kaynakların rekabet gücü üzerinde önemli etken olduğunu savunmuşlardır. Mikro rekabet gücü daha çok içsel kaynaklarla incelenmiş ve bu kaynaklar üzerinde çalışmalar örgütsel, çevresel ve yapısal değişkenlerin belirlediği de savunulmuştur (Çivi 2001).

\subsection{Rekabet Stratejisi ve Rekabet Gücünü Etkileyen Faktörler}

Stratejik rekabet gücü faktörleri, ekonomik yapı farklılıkları ve rekabet gücü kazanılması rekabet gücünün elde edilmesi için gerekli olan etkenlerdir. Rekabet kabiliyetinin oluşabilmesi için erişilebilir hedeflere maliyet liderliği, ürün farklılığı, odaklanma, hız, esneklik ve pratiklik açısından hem kaliteyi artırmak, hem de uzun dönemli ve küresel odaklı ürünler elde etmektir.

\begin{tabular}{|c|c|}
\hline $\begin{array}{l}\text { Stratejik Rokabet Güc0 } \\
\text { Faktoorleri } \\
\text { - Sirket Bir lesmeler inin Art ması } \\
\text { - Yoksek Duzeyde Borçanma } \\
\text { - Oron f ar klılasmasının Art ması } \\
\text { - Insana Yapılan Yat ır ımlar ın } \\
\text { Azlığı } \\
\text {-Zayıf Işlet me Kalt oro }\end{array}$ & 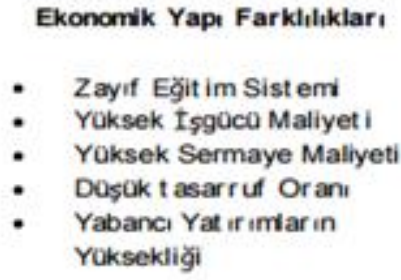 \\
\hline
\end{tabular}

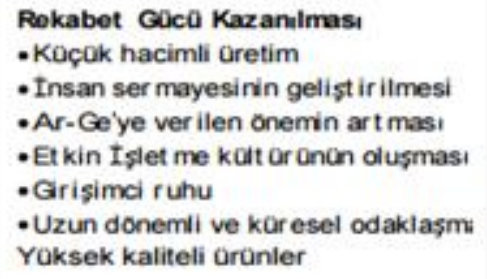

Şekil:3. Rekabet Gücünün Elde Edilmesi Kaynak: Çivi Emin(2001), Rekabet Gücü: Literatür Araştırmasl; Yönetim Ve Ekonomi Yı l:2001 Cilt:8 Sayı: 2 Celal Bayar Üniversitesi, Manisa

Rekabet kabiliyeti ise; ürün kalitesinin artmasını teşvik edici ulusal kalite altyapısı ölçüm, standardizasyon, test, belgelendirme, akreditasyon aktivitelerinin güvenilirliği ve uluslararası geçerliliği, kendi bölgelerine özgü kalite altyapı kurumları oluşturulması ile mümkündür (İpekgil, 2000). 


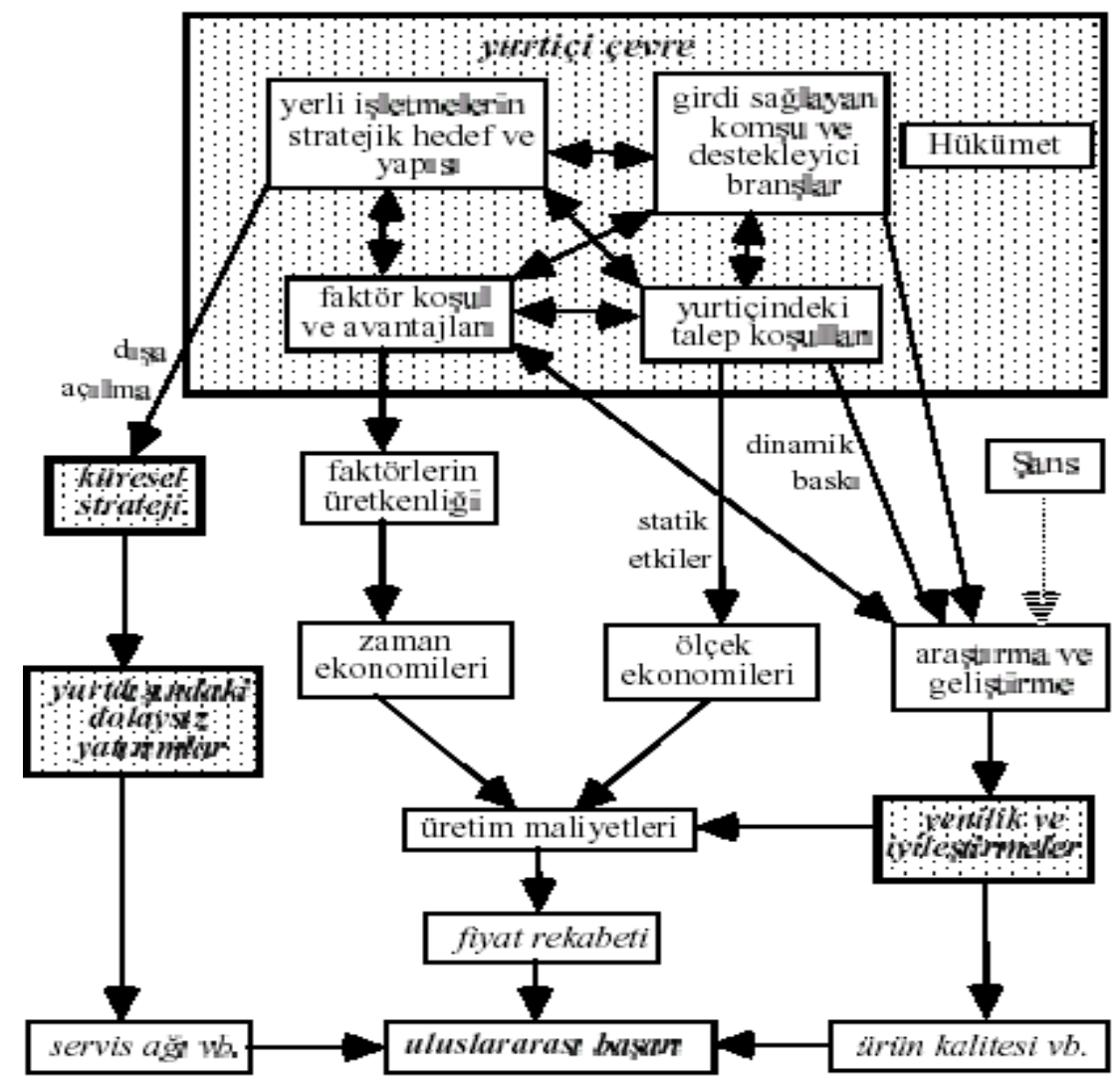

Şekil: 4.Porter'a Göre Uluslararası Rekabet Gücünün Kaynakları Kaynak: Kibritçioğlu Aykut(2002) 'Porter'in Rekabetçi Avantajlar Yaklaşımı' AÜ SBF İktisat Ankara

Rekabet gücü (RG) stratejilerinin maliyet düşürücü olanları, ürün farklılaştırma stratejileridir. Bu stratejilerde de toplam maliyet liderliği, farklılaştırma ve odaklanma, diğer rakipleri devre dışı bırakma konusunda önemli unsurlardandır (Porter 2002). Yine rekabet edebilirlik özelliği kazandırmada hızlılık, yenilik, farklılık ve verimlilikte önemlidir (Çetintaş 2001, s. 9). Rekabet gücünün arttırılması; üretim faktörlerinin iyileştirilmesi, rekabet kabiliyetinin kazanılması ile mümkündür (İSO 2001).

Rekabet yaratıcı güç olarak; globallik ya da dar çevrecilik, çekicilik ya da saldırganlık, varlıklar (assets) ya da süreçler, bireysel risk ya da toplumsal uyum olarak 4 kuvvet tanımlanmıştır (Gür 1997). Bir ekonominin performansını ölçmede kullanılan en temel göstergelerden biri verimliliktir. Verimlilik, makro düzeyde üretim hacmi ile üretimde kullanılan faktörler arasındaki oranı ifade eder. Bu bağlamda, ithalatın serbestleştirilmesi ve ihracatın artışı, gayrisafi yurtiçi hasılanın ve kişi başına düşen milli gelirin artması ulusal ekonominin verimliliğinin artması ile mümkündür. Birim emek, sermaye ve doğal kaynak ile üretilen mal ve hizmetlerin değeri olarak tanımlanan ulusal ekonominin verimliliği ise mikro ölçekte birbirleriyle karşılıklı olarak ilişkili olan, firmaların bireysel rekabet stratejilerinin ve işlemlerinin düzeyi, ulusal iş ortamının girişimlerinin artmasıyla belirlenir (Foroutan1991, s.7). Verimlilikte ilk akla gelen belirleyici ana unsur kaynakların karı maksimize edici, maliyetleri minimize edici şekilde etkin dağılmasıdır (İSO 2001). 


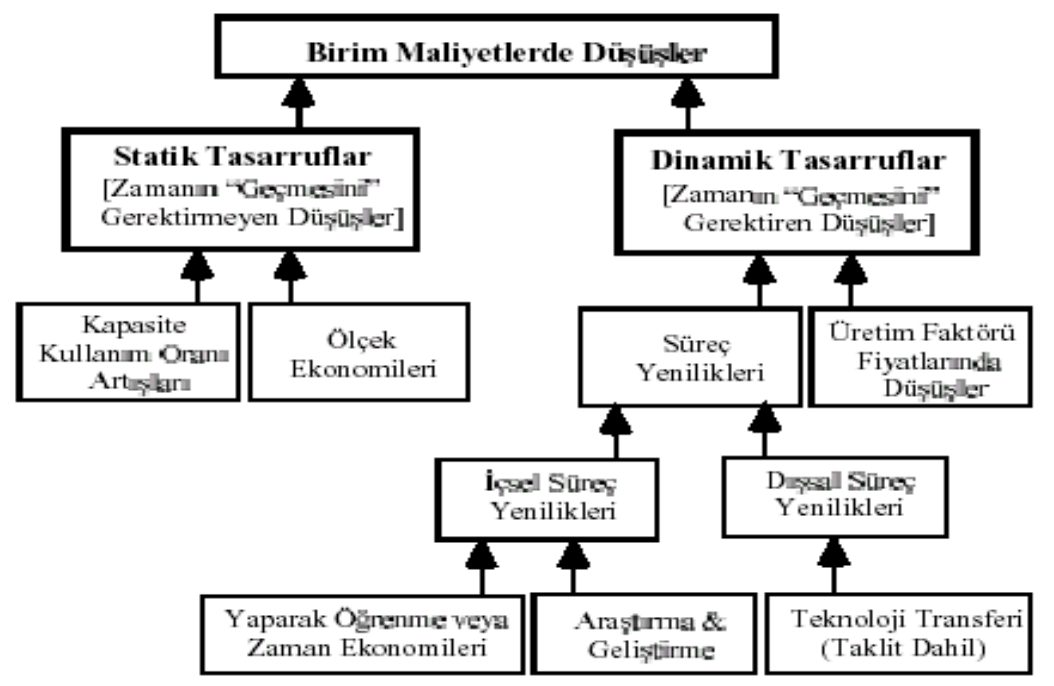

Şekil 5. Mikroekonomik Açıdan Maliyet Tasarruf Kaynak: Kibritçioğlu(2001).

Altyapı kalitesinin uluslararası yatırımları tek başına etkilediği bilinmektedir. İnternetten yoğun ve ucuz kullanım sağlanabilmektedir (Odyakmaz 2000). Sanayinin gelişmiş ekonomik yapısına rağmen üretim potansiyelini tamamen kullanamamaktadır. Esnek üretim yaklaşım teknolojilerinin ön plana geçme sebebi; bir yandan üretim maliyetinin düşürülmesi, diğer yandan da kalitenin arttırılması sonucu, maliyeti düşük verimliliği yüksek üretim tarzıdır (TİSK 2001).

\section{Küresel Rekabet Gücü Endeksleri ve Avrasya Ekonomileri}

Dünya Ekonomi Forumu (WEF) merkezi İsviçre'nin Cenevre kentinde yer alan uluslararası bir kuruluştur. 1979'dan beri yapılan bu forum dünyanın en önemli siyasetçilerini ve iş adamlarını bir araya getiren, uluslararası sorunlarını tartışıldığı önemli bir forumdur. Ülkeler gayrı safi yurt içi hasılalarına göre 1. aşama, 2. aşama ve 3. aşama ülkeleri olarak tanımlanmaktadır. Bu 3 aşamaya dahil olmayan başka bir grup ülkeler ise geçiş ülkeleri olarak ortaya tanımlanmaktadır. GSYH'sı 2000 \$'ın altındaki ülkeler 1. Aşama grubuna dahildir. Avrasya ekonomilerinden Kırgızistan ve Tacikistan bu grubun içerisindedir. Azerbaycan ve Kazakistan gibi GSYH'sı 20003000 \$ aralığında yer alan ülkeler, 2. Aşamaya geçiş ülkeleri olarak gösterilmektedir (Taşar, Çevik, 2010).

\begin{tabular}{|l|l|l|l|l|l|l|}
\hline AVRASYA ÜLKELERİ & \multicolumn{2}{|l|}{ TEMEL UNSURLAR } & \multicolumn{2}{l|}{$\begin{array}{l}\text { GELIŞTIRILMIŞ ETKINLİĞE } \\
\text { DAYALI UNSURLAR }\end{array}$} & \multicolumn{2}{l|}{ YENİLİÇİ UNSURLAR } \\
\hline AZERBAYCAN & 43 & 4.9 & 69 & 4.0 & 66 & 3.6 \\
\hline KAZAKİSTAN & 46 & 4.9 & 45 & 4.4 & 78 & 3.5 \\
\hline KIRGIZISTAN & 106 & 4.0 & 99 & 3.6 & 122 & 3.0 \\
\hline TACIKİSTAN & 94 & 4.2 & 111 & 3.5 & 81 & 3.5 \\
\hline TÜRKIYY & 57 & 4.7 & 48 & 4.3 & 56 & 3.7 \\
\hline
\end{tabular}

Tablo 1.Avrasya Ekonomilerinin 2014-2015 Küresel Rekabet Endeksi İçerisindeki Sıralama ve Skorları Kaynak: The Global Competitiveness Report 2014-2015'den derlenmiştir.

Her bir ülkenin rekabet ve verimlilik açısından 3 ana gruba ayırmıştır. Bunlar; temel unsurlar, etkinliğe dayalı unsurlar ve yenilikçi unsurlar olarak ayrılmaktadır.

\subsection{Azerbaycan}

Azerbaycan Kafkaslarda, büyük Kafkas ile küçük Kafkaslar arasında yer almaktadır. Azerbaycan'ın konum olarak en önemli özelliği ticaret yolları üzerinde stratejik öneme sahip olmasıdır. Azerbaycan kişi başına düşen gayri safi yurt içi hasılası 7,900 dolardır. Azerbaycan yıllık ihracat rakamı 15.9 milyar dolar dır. İthalat ise 9.0 milyar dolardır. Başlıca ihraç ürünlerimiz; mobilya, demir/çelikten aksamı, kıymetli metaller, muhtelif inşaat malzemeleridir. Başlıca ithal ürünlerimiz; işlenmemiş alüminyum, etilen polimerleri (ilk şekillerde), petrol yağları, asiklik hidrokarbonlar, hayvan derileri, petrol gazları ve diğer gazlı hidrokarbonlar, işlenmemiş kurşun, pamuk ipliğidir. 


\begin{tabular}{|l|c|c|c|c|}
\hline YILLAR & İHRACAT & ITHALAT & HACİM & DENGE \\
\hline 2011 & 2.063 & 1.388 & 3.453 & 677 \\
\hline 2012 & 2.584 & 1.638 & 4.222 & 946 \\
\hline 2013 & 2.960 & 1.726 & 4.686 & 1.233 \\
\hline 2014 & 2.876 & 2.229 & 5.105 & 646 \\
\hline 2015 & 1.900 & 1.626 & 3.526 & 272 \\
\hline
\end{tabular}

Tablo 2. Yıllar Itibariyle Türkiye-Azerbaycan Dış Ticareti (Milyon Dolar) Kaynak: TUIK(2016), Ekonomi Bakanlı̆ $\mathrm{l}$

Türkiye ve Azerbaycan arasında 2011-2013 yılları arasında ihracatta bir artış gözlemlenirken, 2014-2015 yılları arasında bir düşüş söz konusudur. İthalatta ise; 2011-2014 yılları arasında artış olurken 2015 yılına gelindiğinde azalış söz konusudur (Ekonomi Bakanlığı,2015). Küresel rekabet raporu analizine göre; Azerbaycan 2013-2014 küresel rekabet indeksine göre; 148 ülke arasından 4.5 skorla 39. sırada yer alırken, 2014-2015 indeksine göre 144 ülke arasından 4.5 skorla 38. sırada yer almaktadır. Azerbaycan kendi bölgesinden yüksek puanlara sahip komşu ülke ekonomilere göre daha iyidir. Düşük enflasyon ve olumlu kamu maliyesi ile güçlü makroekonomik ortamdan yararlanır. Ancak, bu yılki petrol ve doğal gaz fiyatlarındaki son düşüş, kamu bütçesi üzerinde önemli bir etkiye sahip olabilir. Azerbaycan iki ana zorlukla karşı karşıyadır. İlk olarak yolsuzluk, iş yapmayı engelleyen en önemli faktör olarak devam etmektedir. İkinci olaraksa, ekonomik pazar ve üretim halen yeterli seviyede değildir. Bu ekonomisini güçlendirmek ve üretim çeşitliliğini artırmasını en engelleyen faktörlerdir. Azerbaycan gibi ülkeler bu tip sorunlarla mücadele edip dış yatırımcıları için cazibe merkezi haline gelmelidir (WEF(2016)Global Competitiveness Report,2015).

\subsection{Kazakistan}

Kazak ekonomisinin üretim gelirinin tamamına yakını petrol ve doğal gazdır. Bu ekonomide coğrafi koşullar; üretimin şeklini ve boyutunu önemli ölçüde etkilemektedir. Kırsal alanların üretime elverişli olamaması doğal olarak da üretimin ona göre şekil almasını sağlamaktadır. Bu sebeple üretim iç talebi karşılamakta yetersiz kalmaktadır. Üreticilerinin çoğunluğu ise fiyat ve kalite bakımından yabancı mallarla rekabet edebilir düzeyde değildir. Kazakistan topraklarının büyük ve geniş olması sınır kontrolünün sağlamayı güçleştirmekte ve kaçak mal giriş çıkışını engelleyememesine yol açmaktadır. Kazakistan kişi başına düsen gayri safi milli hasıla 12.843 dolardır. Kazakistan'ın yıllık ihracatı 46.3 milyar dolar, ithalatı ise, 33,6 milyar dolardır. Kazakistan ile başlıca ihracat yaptığımız ürünler; Mücevherci eşyası ve aksamı, plastik ürünleri, inşaat malzemeleri, halı ve yer kaplamalarıdır. Başlıca ithalat ürünlerimiz; ham petrol, doğalgaz, rafine edilmiş bakır ve bakır alaşımları (ham), işlenmemiş çinko ve alüminyum, buğday ve mahlut, işlenmemiş kurşundur.

\begin{tabular}{|l|c|c|c|c|}
\hline YILLAR & İHRACAT & İTHALAT & HACIM & DENGE \\
\hline 2011 & 947,8 & 3.020 & 3.968 & -2.072 \\
\hline 2012 & 1.068 & 3.371 & 4.439 & -2.302 \\
\hline 2013 & 1.039 & 3.106 & 4.145 & -2.067 \\
\hline 2014 & 977 & 2,453 & 3.431 & -1.475 \\
\hline 2015 & 750,2 & 1.390 & 2.140 & $-639,5$ \\
\hline
\end{tabular}

Tablo 3.Yıllar İtibariyle Türkiye-Kazakistan Dış Ticareti (Milyon Dolar) Kaynak: TUIK, Ekonomi Bakanlı̆̆g

Türkiye ile Kazakistan arasında 2011-2012 yılları arasında ihracat rakamlarında artış gözlemlenirken, 20122015 yılları arasında azalış söz konusudur. İthalatta ise, 2011-2012 yılları arasında bir artış gerçekleşirken, 20122015 yılları arasında azalış söz konusudur. Küresel rekabet analizine göre; ülkedeki yolsuzluklar ve finansal erişilebilirlikteki sıkıntılar en önemli problem olarak gözlenmektedir (Global Competitiveness Report,2015).

\subsection{Kırgizistan}

Kırgızistan'ın kişi başına düşen gayri safi milli hasıla 1,280 dolardır. Yıllık ihracatı ise, 1,67 milyar dolar, ithalatı ise, 3,8 milyar dolardır. Başlıca ihraç ürünlerimiz; mücevherci eşyası ve aksamı, tekstil ürünleri, dokunmuş halılar, kişisel temizlik ürünleri, kakao içermeyen şeker mamulleri, elektrikli su 1sıtıcıları, elektrotermik cihazlar, ortam 1sıtıcıları, saç ve el kurutucuları, ütüler. Başlıca ithal ürünlerimiz; kuru baklagiller, pamuk, bakır hurdaları, konserve sebzeler, aluminyum hurdaları, altın, taze ve kurutulmuş meyveler, işlenmemiş kurşun ve alüminyum.

\begin{tabular}{|l|c|c|c|c|}
\hline YILLAR & İHRACAT & İTHALAT & HACIM & DENGE \\
\hline 2011 & 180.241 & 52.123 & 232.364 & 128.118 \\
\hline 2012 & 257.470 & 45.226 & 302.697 & 212.244 \\
\hline 2013 & 388.336 & 36.964 & 425.300 & 351.372 \\
\hline 2014 & 421.980 & 65.648 & 487.628 & 356.332 \\
\hline 2015 & 294.818 & 77.857 & 371.676 & 217.9 \\
\hline
\end{tabular}

Tablo 4. Yıllar Itibariyle Türkiye-Kırgızistan (Milyon Dolar) Dış Ticareti Kaynak: TUIK, Ekonomi Bakanlığl

Türkiye ile Kırgızistan arasında 2011-2014 yılları arasında ihracat rakamlarında bir artış gözlemlenirken, 2015 yılına gelindiğinde ise azalma durumu vardır. Kırgızistan 2013-2014 küresel rekabet raporuna göre; 148 ülke 
arasından 3.6 skorla 121. sırada yer alırken, 2014-2015 raporunda 144 ülke arasından 3.7 skorla 108. sirada yer almaktadır. Kırgızistan 1. aşama ülkesi olarak nitelendirilirken, ülkedeki politik istikrarsızlıklar ve yolsuzluklar en önemli sorunlar arasında yer almaktadır (Global Competitiveness Report,2015).

\subsection{Tacikistan}

Tacikistan Dünya ekonomisinin yaklaşık \% 0,03’ünü oluşturur. GSMH'sı 8,5 milyon dolar, kişi başına düşen gayri safi milli hasıla 1,045 dolardır. Y1llı ihracat rakamı ise, 526 milyon dolarken, ithalat rakamı, 3.2 milyar dolardır. Başlıca ticaret ortakları; Rusya, Kazakistan, Çin, İsviçre, Türkiye’dir. Başlıca ihraç ürünlerimiz; kişisel temizlik ürünleri, halı, plastik ürünleri, mücevherci eşyası ve aksamı, kümes hayvanı ürünleri, alüminyum çubuk ve profiller, temizlik maddeleri, elektrikli küçük ev aletleridir. Başlıca ithal ürünlerimiz; işlenmemiş alüminyum, pamuk ve pamuk ipliği, hayvan post ve derileridir.

\begin{tabular}{|l|c|c|c|c|}
\hline YILLAR & IHRACAT & ITHALAT & HACIM & DENGE \\
\hline 2011 & 172.575 & 324.283 & 496.858 & -151.707 \\
\hline 2012 & 234.947 & 345.178 & 580.125 & -110.231 \\
\hline 2013 & 283.620 & 371.358 & 654.978 & -87.738 \\
\hline 2014 & 277.505 & 160.947 & 438.452 & 116.558 \\
\hline 2015 & 162.192 & 203.760 & 366.688 & -40.831 \\
\hline
\end{tabular}

Tablo 5. Yıllar Itibariyle Türkiye-Tacikistan Dış Ticareti (Milyon Dolar) Kaynak: TUIK, Ekonomi Bakanlı̆̆l

Türkiye- Tacikistan arasında2011-2014 yılları arasında artış gözlemlenirken, 2015 yılında azalışa geçmiştir. İthalatında ise, 2011-2014 yılları arasında bir artış varken, 2015 yılında ise azalış söz konusudur. Tacikistan 20142015 küresel rekabet raporuna göre 148 ülke arasından 3.9 skorla 91.sırada yer almaktadır. Avrasya ekonomileri arasında Kırgızistan İle birlikte küresel rekabet raporunda yer alan; temel unsurlar, geliştirilmiş etkinliğe dayalı unsurlar ve yenilikçi unsurlar arasında en alt sıralamalarda yer almaktadırlar. Tacikistan'da yaşanan yolsuzluklar, vergi oranlarının yüksekliği ve vergi düzenlemelerindeki sıkıntılar ülkedeki en büyük problemler olarak görülmektedir (Global Competitiveness Report,2015).

\section{Sonuç ve Öneriler}

$\mathrm{Bu}$ çalışmanın temel amacı, rekabetin ve rekabet gücünün tanımlanması, rekabet gücünü etkileyen faktörlerin belirlenmesi ve Avrasya ekonomilerinden seçilen ülkelerin 2014-2015 Küresel Rekabet Raporu Endeksleri incelenerek, 148 ülke içerisindeki durumlarına bakılmıştır. Rekabet ve rekabet gücü kavramları üzerinde belli bir tanım birliğine varılamamıştır. Yeni ekonomideki bilgi iletişim ve teknoloji alanındaki yeni gelişmeler doğrultusunda rekabetin de iyi yönetişim ilkelerine uygun ilerlemesi büyük önem arz etmektedir. Günümüzün küreselleşen dünyasında ekonomilerin dışa açık bir piyasa yürütmeleri ve dışa açık bu küresel ekonomilerin piyasaların rekabet ortamında ayakta kalabilmeleri için pazar paylarını genişletmeleri gerekir.

1990'lardan itibaren Avrasya ülkeleri siyasi ve ekonomik yapılarında pek çok değişikliğe gitmiştir. SSCB'nin katı siyasi ve ekonomik baskısından kurtulan Avrasya Ülkeleri geç de olsa yeni dünya düzenine ayak uydurma yolunda yeni bir adım atmıştır. Bu pazarda çok yeni olan bu ülkeler günümüzde ticarette azımsanamayacak kadar büyük öneme sahiptirler. Bu yeni düzendeki yapısal değişikliklere ayak uydurabilmek ve bu değişikliklerin yol açtığı sorunlarla baş edebilmek için Avrasya ülkeleri politik olarak yeni yöntemlere yönelmişlerdir. Küreselleşme yüksek bir ulusal rekabet gücüne ulaşmada verimliliğin arttırılmasına yönelik yeni bir sistemi gerekli kılarken daha iyi bir ulusal performans için makro ekonomik olarak bazı adımların atılmasını zorunlu kılmıştır.

Bu çalışmada Avrasya da incelemeye konu edinilen Azerbaycan, Kazakistan, Kırgızistan, Tacikistan'ın Türkiye ile ilişkilerinin genel görünümünün incelendiği ekonomilerde ise hazırlıksız bir süreç damga vurmuştur. Süreç ve süreçle ilgili uyum neticesinde dışa açılmayı yararlı hale getirme çabalarının daha çok 2010'lu yıllardan sonra ortaya çıtı̆̆ inceleme döneminde (2011-2015) tespit edilmiştir. Bununla beraber Avrasya Ekonomilerinde rekabet gücü göstergelerinin, ulusal rekabet gücünü yansıtma kabiliyeti daha zayıftır. 2014-2015 Küresel Rekabet Raporuna göre Avrasya ülkelerinden; Azerbaycan, Kazakistan, Kırgızistan, Tacikistan ekonomilerinin Türkiye ile ilintisi incelenmiştir. Avrasya ülkelerinin dış ticaret ilişkilerine bakılmış ve Azerbaycan, Kazakistan, Kırgızistan, Tacikistan ekonomilerinin ile ihracat rakamları incelendiğinde hepsinde 2015 yılına gelindiğinde bir düşüş gözlemlenmiştir. İthalat rakamlarında ise Azerbaycan ve Kazakistan da 2015 yılına gelindiğinde bir azalma durumu olurken, Tacikistan ve Kırgızistan da bir artış durumu söz konusudur. 2014-2015 Küresel Rekabet Raporuna göre temel unsurlar, geliştirilmiş etkinliğe dayalı unsurlar, yenilikçi unsurlar olmak üzere 3 durum üzerinde Avrasya Ülkelerinin dünya ülkelerinin arasındaki sıralama ve skorlarına bakıldığında Azerbaycan bu 3 durum arasında ilk sıralamayı alırken, Tacikistan ve Kırgızistan son sıralarda yer aldığı görülmektedir. Avrasya ekonomileri için rekabet gücünün uluslararası sıralamalar açısından pek iç açıcı olmadığı gözlemlenmiştir. Bu rapora göre, Avrasya ülkelerinin en önemli problemlerinin yolsuzluk olduğu ve bu olgunun Avrasya Ülkeleri açısından ileriye dönük olumlu bir beklenti oluşturamayacağı Türkiye ile işbirliğinde ise rekabet gücü faktörleri açısından rekabet gücünün artabileceği söz konusu olabilir. 
Öncelikle ülkeleri verimlilik artışı sağlayıp daha etkin bir duruma getirmek için kaynakların verimsiz alanlardan daha verimli alanlara yönlendirilmelidir. Yeni piyasa koşullarının rekabetçi olmasına özen gösterilmeli, yeni bin yılda önemi daha da artacak olan bilgi iletişim teknolojileri özümsenmelidir. Bir yandan sınai üretimin verimliliği ve rekabet gücünü artıran teknolojik gelişme ve yenilikler izlenirken, öte yandan gelir dağılımını düzeltici politikalar uygulanmalı ve verimlilik artışından geniş toplum birimleri yararlanmalıdır. Ulusal kalite altyapısı geliştirilmeli, ISO 9000 dışındaki sertifikasyon hizmetleri özendirilmelidir. Ulusal tasarım politikasıyla ülkenin uzun dönemli ekonomik ve endüstriyel gelişme stratejileri belirlenmeli ve yeni markalar geliştirilmelidir. Sanayi sektörüne yatırım heyecanını yeniden kazandıran kararlar alınmalıdır. Vergi, sosyal sigorta yüklerinin hafifletilmesi, girdilerde indirim yapılması, diğer ülkeler karşısında firsat eşitliği ve rekabet gücü yakalamaya yönelik ekonomik ve sosyal standartlar yükseltilmelidir. Ekonomiyi ve sanayiyi döviz kurunda istikrar iç talebi canlandıracak tedbirler, işletmelere finansal destek, yerli malların teşviki, tasarrufun Euro'ya transferi, ekonomik kararlarda reel sektör ile koordinasyon gibi alt yapı çalışmalarının tamamlanması önerilen politikalardır.

\section{Kaynakça}

- Arıkan Necati, 2000. “Türk Ekonomisi ve Sanayi: Nasıl Canlanır?” ISO Ekim, Sayı 427, İstanbul

- Arnold, J.M., G. Nicoletti and S. Scarpetta, 2011. "Does Anti-Competitive Regulation Matter for Productivity? Evidence from European Firms”, IZA Discussion Paper, No. 5511.

- Boratav Korkut, 1993. “Türkiye’de Sanayileşmenin Yeni Boyutları ve KİT’ler” Tarih Vakfi Yurt Yayınları, İstanbul

- Borrus Micheal, François Bar, 1997. "Why Competition is Necessary" US Information Technology Office (USITO), Beijing, China September 24-25

- Çetintaş Hakan, 2001. "Global Bir Ekonomide Yabancı Yatırımlar ve Rekabet” Dış Ticaret Dergisi, Temmuz Ankara

- Çiftçi, Hakkı, 2004. "İktisadi Gelişmede Uluslararası Rekabet ve Ulusal Kurumlar Dinamiği", Seçkin Yayıncılık, Ankara, ISBN: 9789753477161

- Çivi Emin, 2001. ' Rekabet Gücü: Literatür Araştırması; Yönetim Ve Ekonomi”' Yı1:2001 Cilt:8 Say :2 Celal Bayar Üniversitesi, Manisa

- DPT, 2000. "Sanayi Politikaları” ÖİK Raporu, Rekabet Gücünün Arttırılması, Alt Komisyonu Raporu, DPT Yayını: No: 2529, Ankara

- DPT, 2000. "Sanayi Politikaları” ÖİK Raporu, Rekabet Gücünün Arttırılması, Alt Komisyonu Raporu, Sanayinin Gelişme Perspektifi Alt Komisyonu Raporu

- DPT, 1988. “Türk Sanayinin AT Sanayii Karşısında Rekabet İmkanları” ÖIK Raporu, DPT Yayını No: 2141, Ankara

- Dunning, J.H., 1992. "The Competitive Advantage of Countries and TheActivities of Transnational Corporations", Transnational Corporations, No:1, s. 135-168.

- Duning, J.H. ,1996. "The Geographical Sources of the Competitiveness of Firms: Some Results of a New Survey", Transnational Corporations, No:5(3), s.1-29.

- Duning, J.H. ve S.M. Lundan, 1998. "The Geographical Sources ofCompetitiveness of Multinational Enterprises: An Econometric Analysis”,International Business Review, No:7, s.115-133.

- Foroutan Faezeh 1991, "Foreign Trade and its relation to Competition and Productivity in Turkish Industry" World Bank, February, WPS, 604

- Gökmenoğlu S.M, Akal M., Altunişik R.(2012); " Ulusal Rekabet Gücünü Belirleyen Faktörler Üzerine Değerlendirmeler"; Rekabet Dergisi; Cilt/Volume:13 Say1/Number: 4 Ekim/October 2012, ISSN 1302-552X).

- Gür Muzaffer, 1997. ‘Avrupa Sanayiinin Rekabet Gücü’, Dış Ticaret Dergisi, Sayı 6, Ankara

- Henriksen Sturla, 1992. "Sanayide Devlet Yardımları ve Teşvikler” ISO Yayını, Yenilik Basımevi

- ISO, 2001. 'Rekabet Gücü Raporu Özet', İstanbul Sanayi Odası Yayını, İstanbul IMD, www.imd.ch

- İstanbulİpekgil(2000), Dogan Özlem 'Kalite Uygulamalarının İşletmelerin Rekabet Gücü Üzerine Etkisi” Dokuz Eylül Üniversitesi Sosyal Bilimler Enstitüsü Dergisi Cilt 2 Say1 1 Ocak Şubat Mart 2000

- Iİslatince Hasan, 1998. “Güney Kore'de Uygulanan Sanayileşme Stratejisinin Analizi” A.Ü. İBF. Dergisi Cilt, XIV Sayı 1-2 1998

- Karacasulu Nilüfer, 2000. 'Türkiye’de Bilimsel ve Teknolojik Göstergeler’ Dış Ticaret

Dergisi, Sayı:15, Ekim, Ankara

- Kibritçioğlu Aykut, 2001. 'Porter'ın Rekabetçi Avantajlar Yaklaşımı’ AÜ SBF İktisat Ankara

- Küçük, 2002. “Türk Sanayi ve Ekonomisinin 2002 Yılı Beklentileri” ISO Yayın No: 430, Ocak İstanbul 
- Porter Micheal E., 2002. "Rekabet Stratejisi” Sistem Yayıncılık, Çev. Gülen Ulubilgen, Yayın No: 206, İstanbul

- Odyakmaz Necmi, 2000. 'Bilgi Teknolojileri, Küreselleşme ve Kalkınma', Dış Ticaret Dergisi, Sayı:18, Temmuz, Ankara

- OECD, 2014. "Economic Policy Reforms, "Going For Growth Interim Report”, Chaper 2, Reducing

- Regulatory barriers to competition

- Rekabet Raporu, 2013. “Rekabet Politikası Perspektifi nden Kamu Müdahaleleri”, Rekabet Kurumu.

- Rodrik Dani, 2000. "Yeni Küresel Ekonomi ve Gelişmekte olan Ülkeler” Sabah Kitapları 107, İstanbul

- Taşar, Çevik, 2010. "'Rekabet Politikası Ekseninde Avrasya Ekonomileri” 2010, Uluslararası Avrasya Ekonomileri Konferansı

- Tezel Yahya Sezai, 1995. "Sanayileşme, Büyüme ve Piyasa toplumu” TUSİAD Görüş Dergisi, Sayı: 21 Temmuz - Ağustos İstanbul

- TİSK, 2001. “Türk Sanayiinde Sektörel Sorunlar ve Çözüm Önerileri’ Isşveren dergisi Temmuz, Sayı 10, Ankara

- TUSİAD, 2001. “Rekabet Stratejileri ve En İyi Uygulamalar” Bölüm 1 s. 44.

- Yeldan Erinç, Köse H. Ahmet (1998) "Dışa Açılım Sürecinin Dinamikleri” Toplam Bilim Dergisi, 1998,İstanbul

- Yozgatlı M.Koray(2001), 'Uzakdoğu Ülkelerinin Kalkınma Stratejileri’ Dış Ticaret Müsteşarlı̆̆l, Ekonomik Araştırmalar ve Değerlendirme Genel Müdürlüğü, Ankara

- $\quad$ http://www.rekabet.gov.tr/File/?path=ROOT $\% 2 \mathrm{fl} \% 2 \mathrm{fDocuments} \% 2 \mathrm{fG} \% \mathrm{C} 3 \% \mathrm{BCncel} \% 2 \mathrm{fraporlar} \% 2 \mathrm{fraporp}$ erspektif.pdf

- http://www.ktto.net/wp-content/uploads/2015/02/KTTO2014-2015.pdf

- http://www3.weforum.org/docs/WEF_GlobalCompetitivenessReport_2014-15.pdf

- $\quad$ http://www.rekabet.gov.tr/File/?path=ROOT\%2F1\%2FDocuments\%2FRekabet\%2BDergisi\%2Fdergi70.pdf

- KKTO(2014-2015); http://www.ktto.net/wp-content/uploads/2015/02/KTTO2014-2015.pdf

- $\quad$ http://www.ekonomi.gov.tr/portal/faces/home;jsessionid=t1b2H22XoH2jnH3117T3EJ7VhwA9AB3cVr3ilNz if0IfhYAgET0q!764232839?_afrLoop=2751019033202754\&_afrWindowMode=0\&_afrWindowId=null 


\title{
Kurumsal Sürdürülebilirlik Yaklaşımı - Bir Örnek Corporate Sustainability Approach - An Example
}

\author{
Ph.D. Candidate Binnur Gürül (Istanbul Gelisim University, Turkey)
}

\begin{abstract}
Today there are various corporate sustainability indexes which are indicators of company performance. However, establishing exactly corporate sustainability indicators for all companies is quite difficult. Because corporate sustainability includes not only internal factors but also external factors (for example environmental factors) that affect company performance. In this study; firstly, sustainability, corporate sustainability and dimensions of corporate sustainability concepts will be explained, then corporate sustainability performance of an international company (X Company) will be evaluated. Data were acquired from the company's annual reports. Indexes, which used in previous studies on this topic, were based; thus corporate sustainability indicators have been established. In the study, the company's corporate sustainability performance will be analyzed with TOPSIS (Technique for Order of Preference by Similarity to Ideal Solution) Method that is a multi-criteria decision making (MCDM) method. In this study, the objective has been reached and accurate results were obtained because of mathematical methods for the assessment of corporate sustainability performance. Corporate sustainability performance with more indicators can be analyzed in the future studies. Also; other methods (for example; AHP, ELECTRE Method or Fuzzy Set Theory), which are instead of Entropy and TOPSIS methods, will be used in the future studies.
\end{abstract}

\section{Giriş}

21. yüzyılda nüfusun ve buna paralel olarak talebin artması, diğer taraftan dünyadaki çevresel ve fiziki şartların kötüleşmesi (küresel ısınma, çevre kirliliği, su kaynaklarının kirletilmesi, enerji fiyatlarının artması vb.) ve doğal kaynakların azalması; tüm dünyanın ana gündem maddelerini oluşturmaktadır. Bu sorunlar, firmaların ve bunlara bağlı olarak sektörlerin geleceğinin planlanmasını önemli kılmaktadır. Bu nedenle; firmaların gelecekte var olabilmeleri için ve gelecekte yaşanılabilir bir dünya olması açısından kurumsal sürdürülebilirlik ve sürdürülebilir üretim üzerine yapılan çalışmalar son yıllarda hız kazanmıştır.

Günümüzde firmalar sadece yenilikçi ürün ve hizmetler üretmekle kalmayıp, aynı zamanda çevreye duyarlı üretim ve/veya hizmet süreçleri geliştirmeleri gerekir. Bir diğer deyişle, firmaların sosyal ve çevresel sorumluluklarının da olması ve tüm üretim ve/veya hizmet süreçlerine ve karar alma mekanizmalarına bunları dâhil etmesi gerekir; kısacası firmaların kurumsal sürdürülebilirlik konusuna bir bütünsel sistem anlayışılla yaklaşmaları gerekir.

Bu noktadan hareketle oluşturulan bu çalışmada; kurumsal sürdürülebilirlik konusunda yaşanan değişimin işletmeler açısından incelenmesi ve irdelenmesi amaçlanmıştır. Bu amaçla; bu çalışmada Türkiye' de deri sektöründe faaliyet gösteren uluslararası bir firmanın (X Şirketi'nin) sayısal verilerinden yararlanılarak, 4 yıla (2012, 2013, 2014 ve 2015) ilişkin X Şirketi' nin kurumsal sürdürülebilirlik performans1 araştırılacaktır. Bu çalışmada gerçekleştirilecek olan deneysel araştırma; ÇKKV (Çok Kriterli Karar Verme) yöntemlerinden biri olan TOPSIS yöntemi ile ortaya konulacaktır. Türkiye' deki deri sektörüne yönelik olarak, sürdürülebilirlik konusunda daha öncesinde böyle bir çalışma yapılmadığından bu çalışma önem arz etmektedir.

Kurumsal sürdürülebilirliği konu alan bu çalışmada birinci bölümde öncelikle sürdürülebilirlik, kurumsal sürdürülebilirlik kavramları açıklanacak ve daha sonra da kurumsal sürdürülebilirlik boyutları ve göstergeleri hakkında bilgi verilecektir. İkinci bölümde ise; çalışma kapsamında kullanılacak yöntem detaylı bir şekilde açıklanacaktır. Üçüncü bölümde; çalışmaya konu alınan X Şirketi’nin sayısal verileri kullanılarak kurumsal sürdürülebilirlik performansına dair hesaplamalar / bulgular ortaya konulacaktır. Çalışmanın son bölümü olan sonuç kısmında ise X Şirketi'nin kurumsal sürdürülebilirlik performansı yorumlanacak ve gelecek çalışmalara önerilerde bulunulacaktır.

\subsection{Sürdürülebilirlik Kavramı}

Günümüzde şirketlerin performanslarının göstergesi olan rakamsal değerler; artık tek başına şirketin gelecekteki değerini göstermemektedir. Son zamanlarda önemli olan, şirket performansının ve göstergelerinin sürdürülebilirliğidir. Sürdürülebilirlik; şirketin sadece kendi içsel etkenleri ile ilgili değil, dışsal faktörleri de içine alan ve bunların değerlendirilmesini kapsayan önemli bir göstergedir. Sürdürülebilirlik göstergeleri ekonomik, çevresel ve sosyal düzeyde incelenmektedir (Sarıkaya ve Erdoğan, 2010).

Sürdürülebilirlik ayrıca, işletmenin ekonomik, sosyal ve çevresel gelişmelerden kaynaklanan riskleri görüp doğru bir şekilde değerlendirilmesiyle de yakından ilgilidir. Bunun yanı sıra, sürdürülebilirlik şirket değerine yansıyarak, hissedarların ve/veya paydaşların değerlerinin maksimum kılınmasına olanak sağlamaktadır. Kısacası şirketin sürdürülebilirliği, uzun vadede hissedarlar için değer yaratmayı amaçlamaktadır (Greenberg ve Quillian, 2012). 
Sürdürülebilirlik kavramı, ilk olarak 1987 yılında Dünya Çevre ve Kalkınma Komisyonu (DÇKK) tarafından hazırlanan Brundtland raporunda ayrıntılı olarak tanımlanmıştır. Bu raporda sürdürebilirlik; gelecek nesillerin ihtiyaçlarını karşılayabilecek bir üretim düzeyinden uzaklaşmadan, bugünün ihtiyaçlarını karşılama yeteneği olarak tanımlanmıştır. DÇKK' nın tanımından birkaç yıl sonra Dünya Koruma Birliği, sürdürülebilirlik kavramını yaşam kalitesi ile birleştirmiştir. Sürdürülebilirlik konusunda bir yandan akademisyenler bir yandan da uygulayıcılar tarafından farklı tanımlar yapılmaktadır. Sürdürülebilirlik kavramının, çok geniş bir anlamının olduğu ve tüm toplum birimlerini etkilediği kabul edilmektedir. Sürdürülebilirlik konusunda yapılan tanımların ortak olarak birleştiği nokta, kavramın üç boyutunun olmasıdır. Sürdürülebilirlik kavramının 'ekonomik, çevresel ve sosyal' boyutların bir bütünü olarak ele alınması gerekmektedir (Altuntaş ve Türker, 2012).

Ekonomik beklentilerin ve/veya ihtiyaçların, çevresel ve sosyal duyarlılık ile ele alınmasına "sürdürülebilirlik" denmektedir. Diğer bir ifadeyle sürdürülebilirlik; şirketlerin ekonomik faaliyetlerine, tüm üretim ve iş yapma süreçlerine (karar alma mekanizmaları dâhil) sosyal ve çevresel sorumluluklarını da katmalarıdır. Bu nedenle sürdürülebilirlik konusuna bir anlamda toplumun yapılandırılması şeklinde de bakabiliriz. Sonuç olarak; sürdürülebilirlikle beraber ekonomik, sosyal ve çevresel hedefler arasında makul bir denge oluşturulur. Tüm bunların yanı sıra sürdürülebilirlik; ekonomik büyümeyi, paydaş değerini, kurumsal itibarı, müşteri ilişkilerini, ürün ve hizmet kalitesini de içermektedir (Torum ve Yılmaz, 2009).

\subsection{Kurumsal Sürdürülebilirlik ve Boyutları}

Geçtiğimiz on y1l içerisinde daha fazla bilinçlenen ve içinde bulunduğu toplum için daha iyisini talep etmeye başlayan tüketiciler nedeniyle, sürdürülebilirlik kavramı firmalar düzeyinde de ciddiyetle ele alınması gereken bir kavram haline gelmiştir (Engin ve Akgöz, 2013). Dolayısıyla günümüzde sürdürülebilir kalkınma boyutundan, kurumsal sürdürülebilirlik boyutuna geçilmiştir. Kurumsal sürdürülebilirlik; firmaların / şirketlerin sadece ekonomik değil, çevresel ve sosyal konulardaki iş süreçlerini de içine almaktadır. Diğer bir ifadeyle kurumsal sürdürülebilirlik; ekonomik, çevresel ve sosyal gelişmelerden kaynaklanan firsatları değerlendirip yöneterek ve riskleri bertaraf ederek, uzun vadede değer yaratan bir yaklaşımdır. Bu nedenle kurumsal sürdürülebilirliğin; çevresel, sosyal ve ekonomik konuların bütünsel bir bakış açısıyla birbirinden ödün vermeden dengeli bir şekilde yönetilmesi gerekir (Bekmezci, 2014). Buradan da anlaşıldığı gibi; kurumsal sürdürülebilirliğin çevresel, sosyal (toplumsal) ve ekonomik olmak üzere üç boyutu vardır. Bu boyutlar; aşağıdaki şekilde gösterildiği gibi dişli çarklar şeklindedirler ve dolayısıyla da birbirleriyle etkileşim halindedirler.

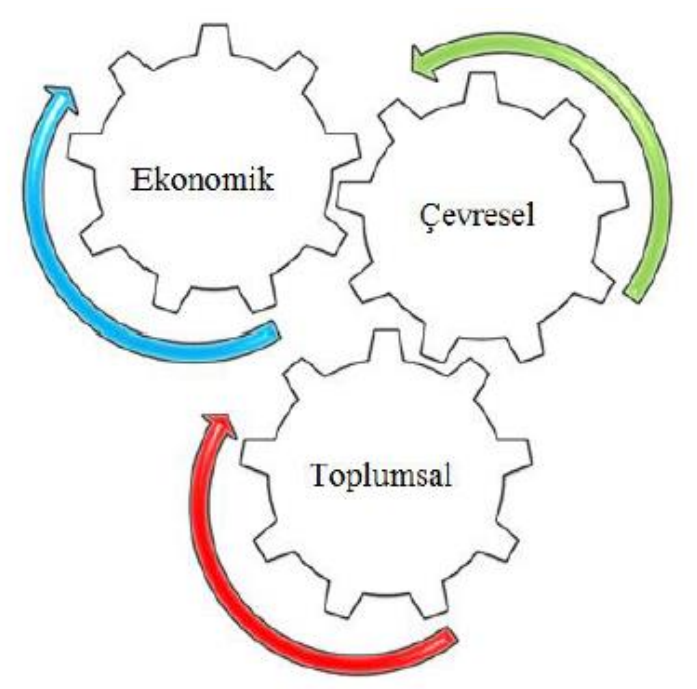

Şekil 1. Kurumsal Sürdürülebilirlik Boyutlart

Yazarlar sürdürülebilirliğin ekonomik boyutunu, gelecek kuşaklara yüksek bir yaşam kalitesi bırakabilmek için gerekli mal, hizmet ve parasal adaletin sağlanması ve bunun yanında sosyal ve ekolojik olarak dengeli bir ekonomik sistemin yaratılması olarak tanımlamışlardır. Sonuç olarak ekonomik olarak sürdürülebilir bir firma, yeterli nakit akışını sağlayabilen ve ortaklarına ortalamanın üzerinde bir likiditeyi garanti edebilen bir işletmedir. Çevresel sürdürülebilirlik geniş anlamda bir işletmenin üretim ve faaliyetlerinin, günümüz ve gelecek kuşakların hakkı olan doğal sermayeyi tüketmemesi olarak tanımlanmaktadır. Bu yüzden üretimden kaynaklanan kirlilik ve emisyonun sınırlandırılması ve denetlenmesi, fiziksel kaynakların etkili bir şekilde yönetilmesi ve doğal ekosistemlerin sağlı̆̆ının korunması gerekir. Dar anlamda ise çevresel sürdürülebilirlik, işletmelerin çevre ve küresel ısınma üzerindeki etkilerini azaltması; faaliyetlerinin neden olduğu doğal kaynakların tüketimini, kirliliği ve emisyonu etkin bir şekilde yönetmesidir. Son olarak sosyal sürdürülebilirlik kısaca; çalışanların beşeri sermayesini arttırmak ve paydaşlarının sosyal sermayesini geliştiren faaliyetlerle, bulunduğu ortama değer katmaktadır (Tuna, 2014). 
Firmaların toplumsal sorumluluklarından en önemlisi, çevresel olumsuzlukları en aza indirmektir; bu yüzden firmalar çevreyi koruma duyarlılıklarını önemle ele almalı, üretim fonksiyonlarını çevre koruma konuları ile birlikte değerlendirmelidirler. $\mathrm{Bu}$ nedenle sürdürülebilir üretim anlayışıyla, çevre dostu üretim süreçlerini/teknolojilerini kullanma konusunda bilinçlenmiş firmaların sayısı giderek artacaktır (Sequeira, 2010).

\subsection{Kurumsal Sürdürülebilirlik Göstergeleri}

İşletmelerin kurumsal sürdürülebilirlik performanslarını, bazı indikatörlere/göstergelere dayandırarak ölçüp değerlendirebiliriz. Öncelikle kurumsal sürdürülebilirlik performansını üç boyutu altında değerlendirebiliriz. Sürdürülebilirlik göstergelerine; doğal kaynak tüketimi, enerji, su ve malzeme kullanımı, çalışanların gelişmesi ve ürün yaşam döngüsü önemli alanlar/konular olarak dâhil edilir. Bütün bu ayrı ayrı konular / boyutlar ve bu boyutlara ilişkin göstergeler arasındaki ilişkiler ve ölçümler, sürdürülebilirlik performansı ile ilişkilidir (Tseng, Divinagracia ve Divinagracia, 2009).

Kurumsal sürdürülebilirlik göstergelerinden bazılarını üç boyut (ekonomik, çevresel ve sosyal) altında şu şekilde sıralayabiliriz (Alp, Öztel ve Köse, 2015):

\begin{tabular}{|c|c|c|}
\hline Ekonomik Göstergeler & Çevresel Göstergeler & Sosyal Göstergeler \\
\hline Gelir & $\begin{array}{l}\text { Enerji Tüketimi/Kullanımı (Elektrik, } \\
\text { Doğal Gaz vs. Tüketimi) }\end{array}$ & $\begin{array}{l}\text { Çalışanların Refahı ve İş } \\
\text { Memnuniyeti }\end{array}$ \\
\hline Faaliyet Kârı & Su Tüketimi & İş Kazası \\
\hline Yıllık Kâr & Karbondioksit Salınımı & Kadın Çalışan Yüzdesi \\
\hline Satınalma Maliyetleri & Sera Gazı Emisyonu & Müşteri Şikâyeti \\
\hline $\begin{array}{l}\text { Ürünlerin Yurtiçi } \\
\text { Pazarlarda Tüketilme }\end{array}$ & $\begin{array}{l}\text { Oluşturulan Zararlı Atık Madde } \\
\text { Miktarı }\end{array}$ & $\begin{array}{l}\text { Ulusal Halk/Toplum İçin İstihdam } \\
\text { Olanakları }\end{array}$ \\
\hline İhracat Oranı & Katı Atık Miktarı & $\begin{array}{l}\text { Çalışan Ortalama Hizmet Süresi } \\
\text { (Kıdem Ortalaması) }\end{array}$ \\
\hline Sermaye Artırımı & Atık Su Miktarı & Çalışan Yaş Ortalaması \\
\hline $\begin{array}{l}\text { Kullanilan Sermayenin } \\
\text { Getirisi }\end{array}$ & Girdilerde Zararlı Madde Kullanımı & Çalışan Sayısı \\
\hline Personel Giderleri & Yok Edilen Atık Miktarı & Eğitim Olanağı Bulan Çalışan Oranı \\
\hline \multirow[t]{11}{*}{ AR-GE Harcamaları } & Atık Geri Kazanım Miktarı & $\begin{array}{l}\text { İşle İlgili Yaralanma ve Hastalık } \\
\text { Sonucunda Kayıp İş Günü }\end{array}$ \\
\hline & $\begin{array}{l}\text { Yenilenebilir Kaynaklardan Enerji } \\
\text { Kullanımı }\end{array}$ & $\begin{array}{l}\text { Yeşil Çevre ve Yeşil Üretim } \\
\text { Konusunda Çalışanların Eğitimi }\end{array}$ \\
\hline & Yerel/Yurtiçi Tedarikçi Yüzdesi & AR-GE Çalışan Sayısı \\
\hline & $\begin{array}{l}\text { \% } 100 \text { Geri Dönüşümlü Ambalaj } \\
\text { Kullanımı }\end{array}$ & $\begin{array}{l}\text { Üst Düzey Yönetici Pozisyonunda } \\
\text { Kadın Çalışan Oranı }\end{array}$ \\
\hline & $\begin{array}{l}\text { Geri Dönüşüm Sağlanmış Ürünlerin } \\
\text { Yüzdesi }\end{array}$ & Çalışan Devir Oranı \\
\hline & $\begin{array}{l}\text { Çevre Sağlığına ve Güvenliğine } \\
\text { Uymak İçin Ödenen Miktar/Maliyet }\end{array}$ & Engelli Çalışan Sayısı / Oranı \\
\hline & & Toplam İş Gücünde Stajyer Oranı \\
\hline & & Çalışan Başına Eğitim Günü \\
\hline & & $\begin{array}{l}\text { Çalışan Başına Eğitim Programı } \\
\text { Harcaması }\end{array}$ \\
\hline & & $\begin{array}{l}\text { Çalışanların Karıştığı Ölümcül } \\
\text { Kazalar }\end{array}$ \\
\hline & & $\begin{array}{l}\text { Kalite, Sosyal ve Çevre Sağlığı - } \\
\text { Güvenliği Performansında } \\
\text { Çalışanların İyileştirme Önerilerinin }\end{array}$ \\
\hline
\end{tabular}

Tablo 1. Kurumsal Sürdürülebilirlik Göstergeleri

\section{Metodoloji}

Yöntem olarak; Entropi ve TOPSIS kullanılacaktır. Bu yüzden çalışmaya öncelikle karar matrisinin oluşturulmasıyla başlanılacaktır. Karar matrisi aşağıda gösterilmektedir: 


$$
A_{i j}=\left[\begin{array}{cccc}
x_{11} & x_{12} & \ldots & x_{1 n} \\
x_{21} & x_{22} & \ldots & x_{2 n} \\
\cdot & & & \cdot \\
\cdot & & & \cdot \\
\cdot & & & \cdot \\
x_{m 1} & x_{m 2} & \ldots & x_{m n}
\end{array}\right]
$$

Burada her bir satır, bir alternatifi ve her bir sütun ise, bir değerlendirme kriterini göstermektedir. Örneğin; matrisin $x_{12}$ elemanı; 1. alternatifin 2. kritere göre başarı değerini göstermektedir.

$$
\begin{aligned}
i=1, \ldots \ldots ., m & \rightarrow \text { Alternatifler } \\
j=1, \ldots \ldots, n & \rightarrow \text { Kriterler }
\end{aligned}
$$

X Şirketi için aşağıda yapılan çalışmada karar matrisi; alternatif olarak satırlara yılları ve kurumsal sürdürülebilirlik göstergeleri de kriter olarak sütunlara yazarak oluşturulmaktadır. Çalışmada öncelikle kurumsal sürdürülebilirlik göstergelerinin birbirlerine göreceli olarak önemlerini belirlemek için, Entropi yöntemiyle ağırlık değerleri hesaplanacaktır. Entropi yönteminden sonra da, TOPSIS yöntemi (İdeal Noktalarda Çok Boyutlu Ağırlıklandırma Yöntemi) uygulanacaktır.

\subsection{Entropi Yöntemiyle Kriterlerin Göreceli Ă̆ırlıklarının Hesaplanması}

Entropi Yöntemi; Wang ve Lee tarafından 2009 yılında bir ağırlık hesaplama yöntemi olarak geliştirilmiştir. Bu yöntem 3 adımdan oluşmaktadır. Yöntemin adımlarını aşağıda detaylı şekilde görebilirsiniz (Çınar, 2004):

1. Adım: Karar matrisinin normalizasyonu

Karar matrisinin normalizasyonu aşağıdaki formülden yararlanılarak elde edilir:

$$
r_{i j}=\frac{x_{i j}}{\sum_{i=1}^{m} x_{i j}}
$$

2. Adım: Her bir kriter için entropi değerinin hesaplanması

Kriterler için entropi değerleri aşağıdaki formülden hesaplanır:

$$
\begin{gathered}
e_{j}=-k \sum_{i=1}^{m} r_{i j} \ln \left(r_{i j}\right) \\
\text { Burada } k=(\operatorname{Ln}(m))^{-1}
\end{gathered}
$$

3. Adım: Her bir kriterin entropi ağırlık değerinin hesaplanması

Kriterlerin entropi ağırlıkları aşağıdaki formülden yararlanılarak elde edilir:

$$
W_{j}=\frac{1-e_{j}}{\sum_{j=1}^{n}\left(1-e_{j}\right)}
$$

\subsection{TOPSIS Yöntemi}

TOPSIS (Technique for Order Preference by Similarity to Ideal Solution) yöntemi; 1981 yılında Hwang ve Yoon tarafindan ELECTRE yöntemine alternatif olarak geliştirilmiş Çok Kriterli Karar Verme (ÇKKV) yöntemlerinden birisidir. Yöntem Hwang ve Yoon (1981) referans alınarak Chen ve Hwang (1992) tarafından geliştirilmiştir. Bundan sonra, bu yöntem farklı alanlardaki birçok konuda çok kriterli karar verme problemlerini çözmek için adapte edilerek yaygın kullanım alanına sahip olmuştur.

$\mathrm{Bu}$ yöntemde yapılan işlem; pozitif ideal çözüm ve negatif ideal çözüm oluşturmaktır. Yani, yöntemin temel esası; ideal çözüme göre alternatiflerin sıralanması esasına dayanır. Yöntemde; ideal çözüme görece yakın olan 
alternatiften başlamak üzere bir sıralama yapılır. Bu yöntemin altında yatan temel düşünce, pozitif - ideal çözüme en yakın alternatiflerin seçilmesi ve böylece çözümün fayda kriterlerini maksimize ederken maliyet kriterlerini de minimize etmesidir. Kısacası TOPSIS yöntemi, pozitif ideal çözümden en kısa mesafe ve negatif ideal çözümden en uzak mesafe alternatiflerinin seçilmesine dayanmaktadır. Pozitif ideal çözüm; ulaşılabilir bütün en iyi kriterlerin bileşimidir. Negatif ideal çözüm ise ulaşılabilir en kötü ölçüt değerlerinden oluşur. TOPSIS yöntemi 6 adımdan oluşmaktadır. Yöntemin adımları aşağıda detaylı şekilde anlatılmıştır (Yıldırım ve Önder, 2014):

1.Adım: Karar Matrisinin (A Matrisi) Oluşturulması

Karar matrisinin satırlarında karar noktaları, sütunlarında ise karar vermede kullanılacak değerlendirme faktörleri yer alır. Karar matrisi aşağıdaki gibi gösterilir:

$$
A_{i j}=\left[\begin{array}{cccc}
x_{11} & x_{12} & \ldots & x_{1 n} \\
x_{21} & x_{22} & \ldots & x_{2 n} \\
\cdot & & & \cdot \\
\cdot & & & \cdot \\
\cdot & & & \cdot \\
x_{m 1} & x_{m 2} & \ldots & x_{m n}
\end{array}\right]
$$

$A_{i j}$ matrisinde m karar noktası sayısını, $\mathrm{n}$ ise değerlendirme kriteri sayısını göstermektedir.

2. Adım: Standart Karar Matrisinin (R) Oluşturulması (Karar Matrisinin Normalize Edilmesi)

Standart Karar Matrisi (R); A matrisinin yani karar matrisinin elemanlarından yararlanarak ve aşağıdaki formül kullanılarak hesaplanır.

$$
r_{i j}=\frac{x_{i j}}{\sqrt{\sum_{k=1}^{m} x_{k j}^{2}}}
$$

Normalize edilmiş R matrisi aşağıdaki gibi gösterilir:

$$
R_{i j}=\left[\begin{array}{cccc}
r_{11} & r_{12} & \ldots & r_{1 n} \\
r_{21} & r_{22} & \ldots & r_{2 n} \\
\cdot & & & \cdot \\
\cdot & & & \cdot \\
\cdot & & & \cdot \\
r_{m 1} & r_{m 2} & \ldots & r_{m n}
\end{array}\right]
$$

3. Adım: Ağırlıklı Standart Karar Matrisinin (V) Oluşturulması

Öncelikle değerlendirme kriterlerine ilişkin ağırlık değerleri ( $w_{j}$ ) Entropi yöntemiyle belirlenir. Daha sonra $\mathrm{R}$ matrisinin her bir sütunundaki elemanlar ilgili $w_{j}$ değeri ile çarpılarak V matrisi oluşturulur. V matrisi aşağıdaki gibi elde edilir:

$$
\begin{aligned}
& \sum_{j=1}^{n} w_{j}=1 \\
& V_{i j}=\left[\begin{array}{cccc}
w_{1} r_{11} & w_{2} r_{12} & \ldots & w_{n} r_{1 n} \\
w_{1} r_{21} & w_{2} r_{22} & \ldots & w_{n} r_{2 n} \\
\cdot & & & \cdot \\
\cdot & & & \cdot \\
\cdot & & & \cdot \\
w_{1} r_{m 1} & w_{2} r_{m 2} & \ldots & w_{n} r_{m n}
\end{array}\right]=\left[\begin{array}{cccc}
v_{11} & v_{12} & \ldots & v_{1 n} \\
v_{21} & v_{22} & \ldots & v_{2 n} \\
\cdot & & & \cdot \\
\cdot & & & \cdot \\
\cdot & & & \cdot \\
v_{m 1} & v_{m 2} & \ldots & v_{m n}
\end{array}\right]
\end{aligned}
$$


4. Adım: Pozitif İdeal $\left(V^{+}\right)$ve Negatif İdeal $\left(V^{-}\right)$Çözümlerin Belirlenmesi

TOPSIS yöntemi, her bir değerlendirme kriterinin monoton artan veya azalan bir eğilime sahip olduğunu varsaymaktadır.

Pozitif ideal çözüm setinin oluşturulabilmesi için, V matrisindeki ağılıklandırılmış değerlendirme kriterlerinin yani sütun değerlerinin en büyükleri (ilgili değerlendirme kriteri minimizasyon yönlü ise en küçüğü) seçilir. Pozitif ideal çözüm setinin bulunması aşağıdaki formüllerde gösterilmiştir:

$$
V^{+}=\left\{\left(\max _{i} v_{i j} \mid j \in J\right),\left(\min _{i} v_{i j} \mid j \in J^{\prime}\right)\right\}
$$

Negatif ideal çözüm seti ise, V matrisindeki ağırlıklandırılmış değerlendirme kriterlerinin yani sütun değerlerinin en küçükleri (ilgili değerlendirme kriteri maksimizasyon yönlü ise en büyüğü) seçilerek oluşturulur. Negatif ideal çözüm setinin bulunması aşağıdaki formülde gösterilmiştir:

$$
V^{-}=\left\{\left(\min _{i} v_{i j} \mid j \in J\right),\left(\max _{i} v_{i j} \mid j \in J^{\prime}\right)\right\}
$$

Her iki formülde de J fayda (maksimizasyon), J' ise kayıp (minimizasyon) değerini göstermektedir. Gerek pozitif ideal gerekse negatif ideal çözüm seti, değerlendirme kriteri sayısı yani n elemandan oluşmaktadır.

5. Adım: Ayırım Ölçülerinin Hesaplanması (Karar Noktaları Arasındaki Mesafe Ölçülerinin Hesaplanması)

TOPSIS yönteminde her bir karar noktasına (yani alternatife) ilişkin değerlendirme kriterinin, pozitif ideal ve negatif ideal çözüm setinden sapmalarının (uzaklıklarının) bulunabilmesi için Euclidian Uzaklık Yaklaşımından yararlanılmaktadır. Buradan elde edilen karar noktalarına ilişkin sapma değerleri ise Pozitif İdeal Ayırım $\left(S_{i}^{+}\right)$ve Negatif İdeal Ayırım $\left(S_{i}^{-}\right)$ölçüsü olarak adlandırılmaktadır. Kısacası; ideal noktaların/çözümlerin tanımlanmasının ardından 5. adımda maksimum ve minimum ideal noktalara olan uzaklık/sapma değerleri aşağıdaki formüller yardımıyla hesaplanmaktadır:

$$
\begin{aligned}
& S_{i}^{+}=\sqrt{\sum_{j=1}^{n}\left(v_{i j}-v_{j}^{+}\right)^{2}} \\
& S_{i}^{-}=\sqrt{\sum_{j=1}^{n}\left(v_{i j}-v_{j}^{-}\right)^{2}}
\end{aligned}
$$

Burada hesaplanacak $S_{i}^{+}$ve $S_{i}^{-}$sayısı, karar noktası (alternatif) sayısı yani m sayısı kadar olacaktır.

6.Adım: Alternatiflerin İdeal Çözüme Göreceli Yakınlığın Hesaplanması

Her bir karar noktasının yani alternatifin ideal çözüme göreceli yakınlı̆̆ının $\left(C_{i}^{*}\right)$ hesaplanmasında pozitif ideal ve negatif ideal ayırım ölçülerinden yararlanılır. İdeal çözüme göreceli yakınlık değerinin hesaplanması aşağıdaki formülde gösterilmiştir:

$$
C_{i}^{*}=\frac{S_{i}^{-}}{S_{i}^{-}+S_{i}^{+}}
$$

Bu formülde kullanılan ölçüt; negatif ideal ayırım ölçüsünün, toplam ayırım ölçüsü içindeki payıdır. Burada $C_{i}^{*}$ değeri $0 \leq C_{i}^{*} \leq 1$ aralı̆̆ında değer alır ve $C_{i}^{*}=1$ ilgili karar noktasının yani alternatifin pozitif ideal çözüme, $C_{i}^{*}=0$ ilgili karar noktasının (alternatifin) negatif ideal çözüme yakınlığını gösterir. Son olarak ise; elde edilen değerler, büyüklük sırasına göre dizilerek karar noktalarının (alternatiflerin) önem sıraları belirlenmektedir.

\section{3 Örnek Çalışmanın Bulguları}

\subsection{Entropi Yöntemiyle Kurumsal Sürdürülebilirlik Göstergelerinin Ağırlık Değerlerinin Hesaplanması}

Çalışmada kurumsal sürdürülebilirlik göstergelerinden kullanılacak olanlar aşağıdaki tabloda birimleri ile verilmiştir. Ancak; yukarıda Tablo 2.'de bahsedilen ekonomik, çevresel ve sosyal boyuta ait olan göstergelerden bazıları karışık bir şekilde bu çalışmada ele alınmıştır. Kurumsal sürdürülebilirlik performansı için bu göstergelerin alınma sebebi; öncelikle bunların en temel göstergeler olması ve şirketin / firmanın sanayi sektöründe yer 
almasından dolayı daha çok üretime yönelik göstergeler alınmıştır. Ayrıca bu göstergelerle ilgili sayısal verilere ulaşılması nedeniyle de çalışmaya konu olmuştur. Hesaplamalar Excel'de yapılmıştır.

\begin{tabular}{|l|l|l|}
\hline KS1 & Elektrik Tüketimi & $\mathrm{kWh}$ \\
\hline KS2 & Su Tüketimi & $\mathrm{m} 3$ \\
\hline KS3 & Ulusal Pazar İçin İstihdam & Ortalama Kişi Sayıs1 \\
\hline KS4 & Kayıp İş Günü & Gün \\
\hline KS5 & İş Kazası Sayıs1 & Adet \\
\hline KS6 & Kalite, Çevre vs. Öneri Sayıs1 & Adet \\
\hline KS7 & İhracat Oranı & $\%$ \\
\hline KS8 & Yurtiçi Satış Oranı & $\%$ \\
\hline KS9 & Müşteri Şikayeti & Adet \\
\hline
\end{tabular}

Tablo 2. X Şirketi İ̧̧in Kullanılacak Göstergeler

Çalışmaya öncelikle karar matrisini yazarak başlarız (X Şirketi’ nin faaliyet raporlarından yararlanarak). Kurumsal sürdürülebilirlik göstergeleri için karar matrisi aşağıda gösterilmektedir:

\begin{tabular}{|l|l|l|l|l|l|l|l|l|l|}
\cline { 2 - 10 } \multicolumn{1}{c|}{} & KS1 & KS2 & KS3 & KS4 & KS5 & KS6 & KS7 & KS8 & KS9 \\
\hline $\mathbf{2 0 1 2}$ & $11.946,05$ & $8.196,52$ & 1905 & 12 & 2 & 1 & 50 & 50 & 39.557 \\
\hline $\mathbf{2 0 1 3}$ & $15.456,72$ & $14.711,57$ & 1883 & 22 & 3 & 2 & 56 & 44 & 35.300 \\
\hline $\mathbf{2 0 1 4}$ & $19.298,20$ & $14.921,88$ & 1884 & 45 & 0 & 1 & 55 & 45 & 32.211 \\
\hline $\mathbf{2 0 1 5}$ & $17.446,50$ & $13.272,61$ & 1753 & 9 & 1 & 2 & 48 & 52 & 30.326 \\
\hline
\end{tabular}

Tablo 3. X Şirketi İçin Karar Matrisi

Yukarıdaki matriste satırlar yılları ve sütunlar ise kurumsal sürdürülebilirlik göstergelerini belirtmektedir.

1. Adım: Normalize edilmiş karar matrisi aşağıda verilmiştir:

\begin{tabular}{|l|l|l|l|l|l|l|l|l|l|}
\cline { 2 - 10 } \multicolumn{1}{c|}{} & KS1 & KS2 & KS3 & KS4 & KS5 & KS6 & KS7 & KS8 & KS9 \\
\hline $\mathbf{2 0 1 2}$ & 0,1862 & 0,1604 & 0,2566 & 0,1364 & 0,3333 & 0,1667 & 0,2392 & 0,2618 & 0,2879 \\
\hline $\mathbf{2 0 1 3}$ & 0,2410 & 0,2879 & 0,2536 & 0,2500 & 0,5000 & 0,3333 & 0,2679 & 0,2304 & 0,2569 \\
\hline $\mathbf{2 0 1 4}$ & 0,3008 & 0,2920 & 0,2537 & 0,5114 & 0,0000 & 0,1667 & 0,2632 & 0,2356 & 0,2344 \\
\hline $\mathbf{2 0 1 5}$ & 0,2720 & 0,2597 & 0,2361 & 0,1023 & 0,1667 & 0,3333 & 0,2297 & 0,2723 & 0,2207 \\
\hline
\end{tabular}

\section{Tablo 4. Entropi Yöntemi İle Normalize Edilmiş Karar Matrisi}

2. Adım: Her bir kurumsal sürdürülebilirlik göstergesi için entropi değerleri aşağıda verilmiştir:

\begin{tabular}{|l|l|l|l|l|l|l|l|l|l|}
\cline { 2 - 10 } \multicolumn{1}{c|}{} & KS1 & KS2 & KS3 & KS4 & KS5 & KS6 & KS7 & KS8 & KS9 \\
\hline $\boldsymbol{e}_{j}$ & 0,9893 & 0,9822 & 0,9996 & 0,8616 & 0,7296 & 0,9591 & 0,9985 & 0,9982 & 0,9963 \\
\hline
\end{tabular}

Tablo 5. Göstergelerin (Değerlendirme Kriterlerinin) Entropi Değerleri

3. Adım: Entropi yöntemiyle hesaplanan kurumsal sürdürülebilirlik göstergelerinin ağırlık değerleri aşağıda verilmiştir:

\begin{tabular}{|l|l|l|l|l|l|l|l|l|l|}
\cline { 2 - 9 } \multicolumn{1}{c|}{} & KS1 & KS2 & KS3 & KS4 & KS5 & KS6 & KS7 & KS8 & KS9 \\
\hline$W_{j}$ & 0,0221 & 0,0367 & 0,0008 & 0,2851 & 0,5569 & 0,0841 & 0,0031 & 0,0036 & 0,0076 \\
\hline
\end{tabular}

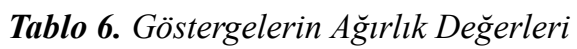

Ağırlık değerlerine baktığımızda, kurumsal sürdürülebilirlik performansına en fazla etkisi olan göstergenin "iş kazası" (\%55,69) olduğunu; buna karşılık olarak da kurumsal sürdürülebilirlik performansına en az etkisi olan göstergenin "ulusal pazar için istihdam" $(\% 0,08)$ olduğunu görüyoruz.

\subsection{TOPSIS Yöntemi İle Kurumsal Sürdürülebilirlik Göstergelerinin Değerlendirilmesi}

1. Adım: Buradaki karar matrisi; yukarıda entropi yönteminde yazdığımız karar matrisine eşdeğerdir/eşittir.

2. Adım: Normalize edilmiş Karar Matrisi (Standart Karar (R) matrisi), aşağıda verilmiştir: 


\begin{tabular}{|l|l|l|l|l|l|l|l|l|l|}
\cline { 2 - 9 } \multicolumn{1}{c|}{} & KS1 & KS2 & KS3 & KS4 & KS5 & KS6 & KS7 & KS8 & KS9 \\
\hline $\mathbf{2 0 1 2}$ & 0,3672 & 0,3138 & 0,5129 & 0,2295 & 0,5345 & 0,3162 & 0,4775 & 0,5223 & 0,5729 \\
\hline $\mathbf{2 0 1 3}$ & 0,4751 & 0,5632 & 0,5069 & 0,4207 & 0,8018 & 0,6325 & 0,5348 & 0,4596 & 0,5112 \\
\hline $\mathbf{2 0 1 4}$ & 0,5932 & 0,5712 & 0,5072 & 0,8606 & 0,0000 & 0,3162 & 0,5252 & 0,4701 & 0,4665 \\
\hline $\mathbf{2 0 1 5}$ & 0,5363 & 0,5081 & 0,4719 & 0,1721 & 0,2673 & 0,6325 & 0,4584 & 0,5432 & 0,4392 \\
\hline
\end{tabular}

Tablo 7. TOPSIS Yöntemi İle Normalize Edilmiş Karar Matrisi

3. Adım: Ağırlıklı Standart Karar Matrisi (V matrisi) aşağıda verilmiştir:

\begin{tabular}{|l|l|l|l|l|l|l|l|l|l|}
\cline { 2 - 10 } \multicolumn{1}{c|}{} & KS1 & KS2 & KS3 & KS4 & KS5 & KS6 & KS7 & KS8 & KS9 \\
\hline $\mathbf{2 0 1 2}$ & 0,0081 & 0,0115 & 0,00041 & 0,0654 & 0,2977 & 0,0266 & 0,0015 & 0,0019 & 0,0044 \\
\hline $\mathbf{2 0 1 3}$ & 0,0105 & 0,0207 & 0,00040 & 0,1199 & 0,4465 & 0,0532 & 0,0016 & 0,0017 & 0,0039 \\
\hline $\mathbf{2 0 1 4}$ & 0,0131 & 0,0209 & 0,00040 & 0,2453 & 0,0000 & 0,0266 & 0,0016 & 0,0017 & 0,0035 \\
\hline $\mathbf{2 0 1 5}$ & 0,0119 & 0,0186 & 0,00037 & 0,0491 & 0,1488 & 0,0532 & 0,0014 & 0,0020 & 0,0033 \\
\hline
\end{tabular}

Tablo 8. Ăgırlıklı Standart Karar Matrisi

4. Adım: Pozitif İdeal ve Negatif İdeal Çözüm Setleri aşağıda verilmiştir:

\begin{tabular}{|l|l|l|l|l|l|l|l|l|l|}
\hline Pozitif İdeal Çözüm Seti $\left(V^{+}\right)$ & 0,0081 & 0,0115 & 0,00041 & 0,0491 & 0,0000 & 0,0532 & 0,0016 & 0,0020 & 0,0033 \\
\hline Negatif İdeal Çözüm Seti $\left(V^{-}\right)$ & 0,0131 & 0,0209 & 0,00037 & 0,2453 & 0,4465 & 0,0266 & 0,0014 & 0,0017 & 0,0044 \\
\hline
\end{tabular}

Tablo 9. Pozitif İdeal ve Negatif İdeal Çözüm Setleri

5. Adım: Her bir karar noktası yani yıl için hesaplanan pozitif ideal ayırım ölçüleri aşağıda verilmiştir:

$$
\begin{aligned}
& S_{1}^{+}=0,2993 \\
& S_{2}^{+}=0,4522 \\
& S_{3}^{+}=0,1983 \\
& S_{4}^{+}=0,1491
\end{aligned}
$$

Her bir karar noktası yani yıl için hesaplanan negatif ideal ayırım ölçüleri ise şu şekildedir:

$$
\begin{aligned}
& S_{1}^{-}=0,2337 \\
& S_{2}^{-}=0,1282 \\
& S_{3}^{-}=0,4465 \\
& S_{4}^{-}=0,3576
\end{aligned}
$$

6. Adım: Dört karar noktası için (yani 2012, 2013, 2014, 2015 yılları için) ideal çözüme göreceli yakınlık değerleri aşağıda hesaplanmıştır:

$$
\begin{aligned}
& C_{1}^{*}=\frac{0,2337}{0,2337+0,2993}=0,4385 \\
& C_{2}^{*}=\frac{0,1282}{0,1282+0,4522}=0,2209 \\
& C_{3}^{*}=\frac{0,4465}{0,4465+0,1983}=0,6924 \\
& C_{4}^{*}=\frac{0,3576}{0,3576+0,1491}=0,7058
\end{aligned}
$$

Sonra bu değerler büyüklük sırasına sokulduğunda karar noktalarının yani yılların önem sırası aşağıda verilmiştir: 


\begin{tabular}{|l|c|c|}
\hline Yillar & C Değeri & Siralama \\
\hline 2015 & 0,7058 & 1 \\
\hline 2014 & 0,6924 & 2 \\
\hline 2012 & 0,4385 & 3 \\
\hline 2013 & 0,2209 & 4 \\
\hline
\end{tabular}

Tablo 10. C Değerleri (İdeal Çözüme Göreceli Yakınlık Değerleri)

Yukarıdaki tablodan görüldüğü üzere; $X$ Şirketi’ nin kurumsal sürdürülebilirlik performansının en iyi olduğu yıl 2015 iken, sürdürülebilirlik performansının en kötü olduğu yıl ise 2013’ dür.

Son olarak; X Şirketi' nin kurumsal sürdürülebilirlik performansının eğilimini görmek için aşağıdaki şekil oluşturulmuştur:

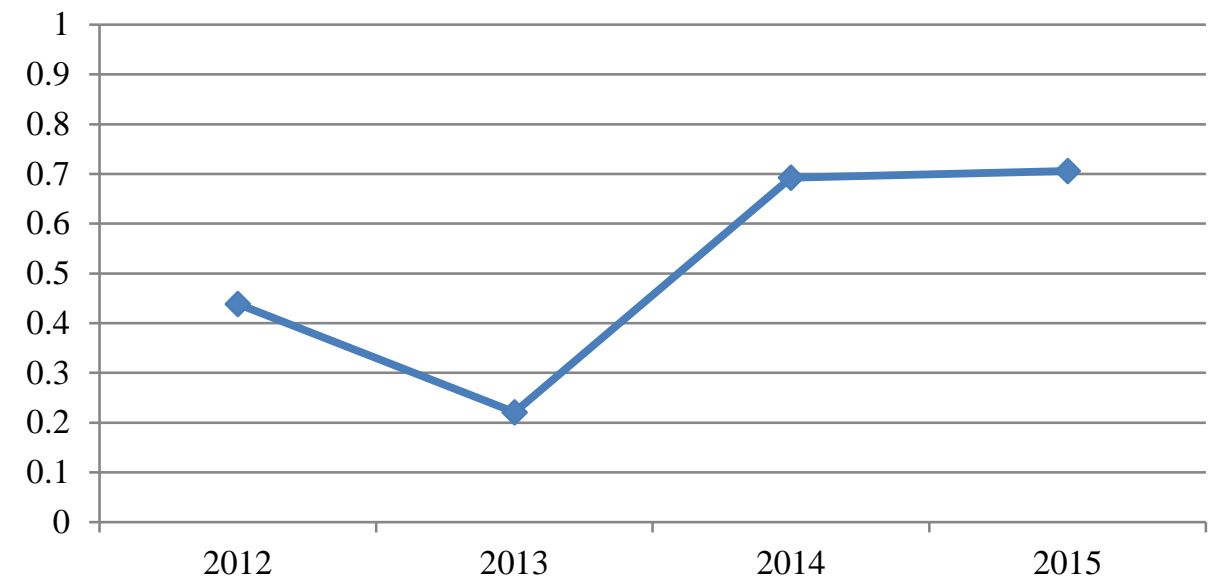

Şekil 2. Yıllara Göre X Şirketi’nin Kurumsal Sürdürülebilirlik Performansı

\section{Sonuç ve Öneri}

$\mathrm{Bu}$ çalışmada kurumsal sürdürülebilirlik performansının değerlendirilmesi amaçlanmıştır. $\mathrm{Bu}$ doğrultuda öncelikle uygun sürdürülebilirlik göstergeleri seçilmiştir. Daha sonra entropi yöntemi ile göstergelerin önem seviyesi belirlenmiş ve son olarak da TOPSIS yöntemi ile X Şirketi' nin kurumsal sürdürülebilirlik performansı incelenmişsir.

Yapılan analiz sonucunda X Şirketi' nin kurumsal sürdürülebilirlik performansının genel olarak yükselme trendinde (eğiliminde) olduğu görülmüştür. Ancak; 2013 sürdürülebilirlik performansının, bir önceki yıla göre düşüş göstermesinin nedeni, öncelikle Avrupa' daki ekonomik krizin derinleşmesidir. Diğer önemli ve en büyük neden ise; 2010, 2011 ve 2012 yıllarında X Şirketi'nin yurt içindeki başarısı nedeniyle, şirketin 2013 yılında yatırım yaparak üretim hacmini arttırmasıdır. Üretim hacminin arttırılmasından dolayı şirketin özellikle elektrik, su tüketimi bir önceki yıla oranla çok yükselmiş̧ir. Artan üretime bağlı olarak doğal kaynak tüketiminin (su ve enerji tüketimi) artması, kurumsal sürdürülebilirlik performansının 2013 yılındaki azalışın nedeni olabilir.

Bu çalışmada kurumsal sürdürülebilirlik performansının değerlendirilmesinde kullanılan yöntemler, yoruma ve sübjektif kriterlere yer vermeyen matematiksel yöntemler olduğu için objektif ve kesin sonuçlara ulaşılmıştır.

Gelecek çalışmalarda daha fazla sayıda gösterge ile kurumsal sürdürülebilirlik performansı analiz edilebilir ve performans boyutlar bazında yani ekonomik, sosyal ve çevresel sürdürülebilirlik şeklinde de yapılabilir. Ayrıca; ileriki çalışmalarda Entropi ve TOPSIS yöntemleri yerine başka yöntemler (örneğin; AHP ve ELECTRE yöntemi veya Bulanık Küme Teorisi) kullanılabilir.

\section{Kaynakça}

- Alp, İ., Öztel, A., \& Köse, M.S., 2015. "Entropi Tabanlı MAUT Yöntemi İle Kurumsal Sürdürülebilirlik Performansı Ölçümü: Bir Vaka Çalışması”, Ekonomik ve Sosyal Araştırmalar Dergisi, 11, 65-81.

- Altuntaş, C., \& Türker, D., 2012. "Sürdürülebilir Tedarik Zincirleri: Sürdürülebilirlik Raporlarının İçerik Analizi”, Dokuz Eylül Üniversitesi Sosyal Bilimler Enstitüsü Dergisi, 14(3), 39-64.

- Bekmezci, M., 2014. "Strategies For Corporate Sustainability", Journal of Management, Marketing and Logistics - JMML, 1(3), 218-240.

- Çınar, Y., 2004. Çok Nitelikli Karar Verme Ve Bankaların Mali Performanslarının Değerlendirilmesi Örneği (Yayınlanmamış Yüksek Lisans Tezi). Ankara Üniversitesi Sosyal Bilimler Enstitüsü, Ankara. 
- $\quad$ Engin, E., \& Akgöz, B.E., 2013. "Sürdürülebilir Kalkınma Ve Kurumsal Sürdürülebilirlik Çerçevesinde Kurumsal Sosyal Sorumluluk Kavramının Değerlendirilmesi”, Selçuk Iletişim, 8(1), 85-94.

- Greenberg, A., \& Quillian, L., 2012. "Managing Sustainable Production: A Framework for Integrating Sustainability In The Manufacturing Sector”, Environmental Quality Management, 21(4), 25-40.

- Sarıkaya, M., Erdoğan, M., \& Kara, F.Z., 2010. "İnternet Ekonomisi ve Kurumsal Sürdürülebilirlik”, Eskişehir Osmangazi Üniversitesi IIBBF Dergisi, 5(2), 31-50.

- $\quad$ Sequeira, R., 2010. Sustainable Production Strategies For Environmentally Sensitive Industries (Unpublished PhD thesis). University of Cincinnati, Cincinnati, USA.

- $\quad$ Torum, O., \& Yılmaz, A., 2009. “Havacılıkta Sürdürülebilirlik Yönetimi: Türkiye’deki Hava Limanları İçin Sürdürülebilirlik Uygulamaları Araştırması”, Havacılık ve Uzay Teknolojileri Dergisi, 4(2), 47-58.

- $\quad$ Tseng, M.L., Divinagracia, L., \& Divinagracia, R., 2009. "Evaluating Firm's Sustainable Production Indicators In Uncertainty”, Computers \& Industrial Engineering, 57, 1393-1403.

- Tuna, Ö., 2014. Kurumsal Sürdürülebilirlik Yaklaşım Ve Uygulamaları: KOBİ'lere Yönelik Bir Araştırma (Yayınlanmamış Doktora Tezi). Afyon Kocatepe Üniversitesi, Afyon, Türkiye.

- Yıldırım, B.F., \& Önder, E. 2014. Çok Kriterli Karar Verme Yöntemleri. Dora Yayıncılık, İstanbul. 


\title{
Структура Экономики Раннесредневековых Кыргызов Economic Structure of Early Medieval Kyrgyz
}

\author{
Assoc. Prof. Dr. Muratbek Kozhobekov (Kyrgyzstan-Turkey Manas University, Kyrgyzstan)
}

\begin{abstract}
The level of the command economy is primarily determined by how it is adapted to the environment and then using only spectacular food-producing economy to nasushnoy needs of the population. The close relationship between the natural and geographical conditions and economic activities shows the ethno-political determenirovannost nomadic society. Despite the huge reservoir of the study and the availability of general works on the history of the Kyrgyz period under consideration, remain controversial questions of economic structure, species composition of herds, the existence of ancillary hozyayaystva, the value and location of the household and the level of development of commodity-money relations. The use of empirical research base and the historical and cultural interpretation of material evidence allow rekonstruktrirovat structure of the economy and the Kyrgyz life.
\end{abstract}

Уровень развития номадной экономики определяется прежде всего, насколько она адаптирована к окружающей среде и потом только эффектным использованием производящего хозяйства к насушной нужде населения. Тесная связь между природно-географическими условиями и хозяйственной деятельностью показывает этнополитическую детерменированность кочевого общества. Несмотря на огромный пласт изучения и наличие обобщающих работ по истории кыргызов рассматриваемого периода, остаются спорными вопросы структуры экономики, видовой состав стада, существовании подсобного хозяяйства, значение и место домашнего хозяйства и уровня развития товарно-денежных отношений. Использования эмпирической исследовательской базы и историко-культурной интерпретации материальных свидетельств дают возможность реконструктрировать структуру экономики и жизнедеятельности кыргызов.

По мнению некоторых ученых на территории Кыргызского каганата сформировались три основных хозяйстенных уклада: земледельческий (с ведущей ролью орошаемого земледелья), скотоводческий и охотничий, которые соответствуют трем географическим зонам Южной Сибири (равнинная, горная и лесная). Эти хозяственно-культурные уклады образовали замкнутый цикл воспроизводства и обепечивало население страны всеми необходимыми продуктами, при этом нивелируя поль внешней экспанции. Физическая приближенность ландшафтов, вмещающих хозяйственные уклады, создала предпосылкидля раннеого разделения труда и развития обменных процессов.

В изучении истории древних кыргызов связь между человеком хозяйствующим и природой, их предпосылки и формы осуществления особо не затрагивался. Социоестественный подход как раз предусматривает универсальный процесс движения и взаимосвязь социума с естественой средой. Данный метод прост для понимания, но крайне труден с точки зрения практической реализации нацеленных целей и задач. Для осуществления такого подхода имеется достаточный объем информации в виде письменной, археологической, палеоботанической, климатологической, географической. Однако, проблема заключается в том, что эти данные крайне разрознены и слабо введены в исследовательский оборот.

Рельеф Южной Сибири являет собой сочетание равнин и гор. Причем на любом широтном срезе представлены как равнины, так и горные участки. Таким образом, каждый из регионов Кыргызского каганата обеспечивал сосуществования трех зон, весьма отличных по свои природным условиям, на основе которых в исторический период получили полноформатное развитие три хозяйственно-культурных комплекса. Граница государства енисейских кыргызов включала обширные пространства Южной Сибири и сопредельные территории. По свдениям китайских источников “Хягас (кыргызы - М. К.) было сильное государство, по пространству равнялось тукюеским (тюркским - М. К.) владениям”. Всточные пределы государсва доходило до Прибайкалья, там где жили курыканы, на юге западе до Алтая, т.е. до страны карлуков, а северная часть проходила в районе Красноярска, где кыргызы граничили с народом бома (Бичурин, 1950: 354). По мнению Л. Н. Гумилева восточная граница кыргызов было две: основная, первая, проходила по подножию Восточных Саян, а вторая - по водоразделу Оки (приток Ангары) и Ангары. В промежутке между двумя границами жили три племени - дубо, милигэ и эчжи (Гумилев, 1967: 264). Исходя из этих соображений можно предположить, что у Кыргызского государства было две границы, первая основная, внутри которого сконцентриовалась политическая власть и была налажена экономическая связь между регионами. Вторая граница - являлась по существу вассальной, где обитали подчиненые племена и этнические общности. Отношения между кыргызами и “вассальными” племенами были договорными и урегулировались они разными уровнями политического, экономического и военного сотрудничества. Естественно среди этих факторов существенную роль в налаживании взаимосвязи между “центром" и “периферией” играла экономическая районирования страны. Метрополия кыргызов находилась до 
середины IX в. в Минусинской котловине. На территории современной Тувы, до Танну_Ола, селились телеские племена, чики и азы, известные из древнетюркских рунических надписей. В разные периоды исторического развития они находились под властью различных государств. Для кыргызов территория чиков и азов в первую очередь служила буферной зоной от захватнической политики южных соседей; во вторых, необходимые товары номадного производства.

Известно, что карлуки, чики и азы постоянно выступали в качестве политических союзников кыргызов и, скорее всего, были связаны с ними тесными отношениями.

В числе ближайших соседей кыргызов на Енисее источники называют три тукюеских (т. е. тюркских. М. К.) аймака - дубо, милигэ и эчжи (Бичурин, 1950: 354). Дубо - одно из крупных телеских (гаогюйских) племен - описываются следующим образом: “Земли поколения Дубо к северу прилежали к Малому морю (считается, что оз. Косогол. - М. К..), на западе смежны с Хагасом (кыргызами. - М. К.), на юге с Хойху (уйгурами. - М. К.)... жили в шалашах из травы; ни скотоводства, ни землепашества, не имели. У них много сараны: собирали ее коренья и приготовляли из нее кашу. Ловили рыбу, птиц, зверей и употребляли в пищу. Одевались в соболье и оленье платье, а бедные делали одежду из птичьих перьев...

Покойников полагали в гробы и ставили в горах или привязывали на деревях" (Бичурин, 1950: 354). Данное описание соответствует хозяйственно_культурным особенностям общества с присваивающей экономикой, характерной для лесных (или горно_таежных) районов. Несколько диссонансом при этом звучит сообщение о том, что у дубо “при свадьбах богатые давали лошадей, а бедные приносили оленьи кожи и саранные коренья " (Бичурин, 1950: 348). Не менее интересно суммарное описание дубо, милигэ и эчжи, содержащееся в том же источнике: “Живут в избах, берестою покрытых. У них много хороших лошадей. В обыкновении кататься по льду на деревянных лошадях. К ногам подвязывают деревянные лыжи, а под мышками упираются на клюки. При каждом упоре подаются шагов на сто вперед чрезвычайно быстро. По ночам занимаются воровством и грабежом. Хягасы ловят их и употребляют в работу " (Бичурин, 1950: 354).

Данные письменных памятников достаточно полно иллюстрируют хозяйственно-культурный тип (или типы) лесных племен (охотников, собирателей, рыболовов), причем, вероятно, на разных стадиях развития. Первым это отметил С. В. Киселев, выделяя в горно_таежной области, расположенной к востоку от территории расселения енисейских кыргызов, три района: I - наиболее восточный, к западу от р. Селенги - “его население не знало ни лошадей, ни овец.

Домашним скотом были олени. Ими, по_видимому, питались, на них ездили, шкуры их употребляли на одежду. Охота на соболей была одним из важных промыслов. Жили в деревянных низких юртах»; II северо_западнее Косогола в восточно_саянской тайге - здесь “обитало население, отличавшееся иным охотничье_рыболоведческим бытом. Оно питалось рыбой, зверем и птицей, а также дикорастущей сараной, приготовляя из ее кореньев кашу. Лишь у немногих имелись олени и лошади, жилищем служили шалаши" (этот вариант соответствует приведенному выше описанию дубо и эчжи); III - наиболее высокий, в Западном Прибайкалье и Канском районе, где "как и на Енисее, занимались скотоводством, а местами и пашенным земледелием. Жилища здесь были более совершенные - деревянные срубы, крытые берестой” (Киселев, 1951a: 31). К последнему типу, по классификации С. В. Киселева, относились и крайние восточные соседи енисейских кыргызов - курыканы (кит. гулигань), которые описываются в письменных источниках как самый северный из всех телеских народов, занимающийся преимущественно коневодством (Бичурин, 1950: 348-349).

Как показывает опыт мирового хозяйствования, каждый из таких компленксов может быть вполне самодостаточным. Однако, особенность становления Кыргызского каганата предопрелелил тесную физическую приближенность их друг к другу.

Идеологическое осознание нерасторжимости хозяйственного комплекса на уровне правящей элиты наблюдается очень рано. Комплекс кыргызской руники на Енисее (памятник с р Тэле, памятник с р. Кемчик Жыргак, памятник с д. Ачур, памятник с Бегре, памятник с Суджи), объединяют в себе картину мира как племен скотоводческих, так и принадлежащих культурному ареалу охотичье-собирательских.

Современные исседователи склонны подчеркивать длительное сосуществование культуры поливного земледелия с суходольными культурами (просо, ячмень, темное просо, конопляное семя и др.). Однако, многочисленные остатки ирригационных сооружений в Минусинской котловине говорит об общей тенденции расширение росевово пшенициы и постепенное вытеснение менее эффективных культур. Так, по сведениям “Тан шу” кыргызы предстают главным образом как народ земледельческий: “Сеют просо, ячмень, пшеницу. Мелют муку ручными мельницами; хлеб сеют в третье, а убирают в девятой луне. Вино квасят из каши", сообщает китайский источник.

В качестве основного земледеьческого орудия, судя по археологическим находкам, использвался плуг с железным наконечником, сошником или лемехом. Урожай ибирали серпами; обмолотом производился при помощи специальных мельниц с жерновами. По мнению С. В. Киселева такая примитивная мельница может дать до 50 кг муки за 12 часов работы, что и говорит о значительном увеличении значения 
земледелия (Киселев, 1951: 320-321). К этому следует добавить находки в погребениях, сельскохозяйственых орудий и обломков жерновов на поселениях, наличие развитого керамического производства и металлургии. Население кыргызов в начале становления Кыргызского каганат составляло около 400 тысыч человек и они могли выставить 80 тысяч войска. Судя по Карабалгасунской надписи численность кыргызов к началу IX века достигло до двух миллионов человек. Тем не менее не вдаваясь в достоверность данного памятника, следует заметить, что это свидетельствует о высокой степени самоорганизации кыргызского общества и разумеется, это могло произойти лишь на основе производства значительного прибавочного продукта. Интенсификация кыргызского хозяйства проходила по двум следующим направлениям: во-первых, широкое применение металлических орудий труда; во-вторых, устройство ирригационных систем, что потребовала кооперации общества. Для сооружения ирригационных систем кыргызы использовали пленных из горно-таежных племен, как дубо, милигэ и эчжи.

В результате значительно увеличилась площадь обрабатываемой земли, возросло количество население, которое могло прокормиться с нее, усилилась общая централизация жизни.

Земледелие у кыргызов носило пашенного направления, которое невозможно без домашнего скотоводства. По данным “Тан шу” в кыргызском хозяйстве “были верблюды и коровы, но более коров и овец” или “верблюдицы, быки, бараны, особенно много быков”. Крупный рогатый скот несомненно использовался кыргызами как тягловая сила в земледельческом производстве. "Богатые землепашцы, отмечает тот же китайский источник, - водят их несколько тысяч голов” (Бичурин, 1950: 351-353.

Некоторая часть кыргызов занимались отгонным скотоводством. Это подверждается составом скота лошади, овцы, верблюды, т.е. требующим именно такой формы содержания животных; видами пищи или по сведениям китайских источников “они питались мясом и кобыльим молоком”; типом жилища “кыргызы жили в палатках, обтянутой войлоками”; обычаями или “они при браках калым платили лошадьми и овцами” (Бичурин, 1950: 353).

По сведениям восточных авторов жители таежных районов занимались охотой и платили дань кыргызам “соболями и белкою”.

Представляется, что сложившийся в Кыргызском каганате хозяйственно-культурный комплес ограничивал экспанцию во внешний мир: цикл воспроизводсвта имел замкнутый и самодостаточный характер и терриотория Минусинского края располагала всем необходимым для его поддержания. Главными условиями самодостаточности были: комплексный характер хозяйства, что сопуствовала ему комплекса территориальной агрессивности; а также Саянские горы служили естественной границей сдерживания агрессии извне и в свою очередь со стороны кыргызов за Саяны.

Объективно существовавшие исторические факторы служили в канонизации культа предков, в особенности почитания авторитета старших, правителей и наставников. Вся эта социальная политика была направлена для поднятия политической и экономической мощи страны.

\section{Литература}

- Бичурин Н. Я. (Иакинф). Собрание сведений о народах, обитавших в Средней Азии в древние времена. Ч. 1. М.; Л., 1950.

- Гумилев Л. Н. Древние тюрки. М.; Л., 1967. С. 264.

- Киселев С. В. Краткий очерк древней истории хакасов. Абакан, $1951 \mathrm{a}$.

- Киселев С. В. Древняя история Южной Сибири. М., 1951. 


\title{
Экономический Рост И Перспективы Развития Аграрной Экономики Кыргызстана В Условиях Экономической Интеграции
}

\section{Economic Growth and Development Prospects of Agricultural Economics in Kyrgyzstan in Condition of Economic Integration}

\author{
Prof. Dr. Jusup Pirimbaev (Kyrgyzstan-Turkey Manas University, Kyrgyzstan) \\ Prof. Dr. Dzhumabek Dzhailov (Ministry of Agriculture, Kyrgyzstan) \\ Umet Momunov (Osh Technological University, Kyrgyzstan)
}

\begin{abstract}
The evaluation of the current state of development of agrarian sector of the national economy and its competitiveness. Conceptual foundations of growth and development of the agricultural sector in the context of deepening integration. The recommendations for the strategic development of the sector in the framework of the Eurasian Economic Union. Particular attention is paid to the problems of reformatting the agricultural production structure, improve the regional and zonal specialization of agricultural production and the balanced development of agriculture. The directions of development of cooperation, integration links in a format forming a single food market. The mechanisms to improve the management system of competitive development of the agrarian economy of Kyrgyzstan.
\end{abstract}

В условиях суверенитета кардинальные реформы были проведены в сельском хозяйстве постсоветских стран. Несмотря на определенные различия в ее направлениях и темпах во всех государствах стран СНГ была проведена земельная реформа, приватизация на этой основе сельскохозяйственных предприятий, разрушение прежних тесных интеграционных связей в отраслях АПК не только внутри отдельных стран, но и полный разрыв интеграционных связей в сфере АПК между странами СНГ и Евразийского Экономического Союза(ЕАЭС). В результате этого произошла дезинтеграции единого экономического пространства, что несомненно, сказалось на падение в странах ЕАЭС объёмов производства сельскохозяйственной продукции и рост импортозавимости внутренних продовольственных рынков (табл.1).

В структуре национальных ВВП доля сельского хозяйства снизилась в России до 4,0 \%, Казахстана до $5,0 \%$ Беларусь-до 7,5 \% и Кыргызстана -до 15,4 \%. Это вкупе с низкими темпами роста сельскохозяйственного производства привело к росту импортозависимости внутренних продовольственных рынков. Доля импортного продовольствия из третьих стран составляет в общем объёме потребления продовольствия в России-36,0\%, в Казахстане-30,0\%,в Кыргызстане-29,1\%. Сравнительно низкий уровень импортного продовольствия отмечается в Беларусь-15,0\%.Следует также отметить то обстоятельство, что кроме Беларусь, в остальных трех странах ЕАЭС (России, Казахстан, Кыргызстан) снижается уровень самообеспеченности продовольствием, особенно, мясо-молочной продукцией, фруктами. В целом рост зависимости от импортного продовольствия свидетельствует о низком уровне конкурентоспособности и эффективности аграрного сектора этих стран, что обусловлено существенными страновыми различиями в структуре аграрного производства, формах хозяйствования, эффективности государственного регулирования и поддержки развития отрасли.

На фоне этого выделяется Кыргызстан, в котором несмотря на высокую доля сельского хозяйства продолжает усугубляться проблема импортозависимости потребления продовольствия. По основным социально-значимым продуктам питания - мясу, зерну, сахару и растительному маслу уровень потребления давно перешел критическую черту, что сказывается на снижении объемов производства этих видов продукции в стране. В сравнительном рейтинге потребления продуктов питания со странами Евразийского Экономического Союза (ЕАЭС) республика также уступает Российской Федерации, Казахстану и Республике Беларусь. Так, по сравнению с Казахстаном, Беларусью и Россией мяса потребляется соответственно на 32; 37 и 49 кг, молока -на 14; 78 и 49 кг, яйц- 69; 105 и 131 шт., сахара -на 1846 и 12 кг. меньше ( Калиев Г.А, 2013).

Сравнительные данные свидетельствуют о том, что в Кыргызстане, в экономике которого среди стран ЕАЭС сельское хозяйство занимает самую высокую долю (более $15,0 \%$ ), отмечается самые низкие темпы ее развития. Об этом также косвенно может свидетельствовать то, что за период доля сельского хозяйство в ВВП страны уменьшилась почти в двое. На фоне незначительного уменьшения доли отрасли в структуре национальных экономик других стран ЕАЭС, что является следствием пропорционального роста удельного веса других отраслей экономики, подобное резкое уменьшение доли сельского хозяйств во многом обусловлено нарастающими тенденциями неустойчивого ее развития( табл.2). 


\begin{tabular}{|c|c|c|c|c|c|c|c|c|}
\hline \multirow{2}{*}{ Показатели } & \multicolumn{2}{|c|}{ Россия } & \multicolumn{2}{|c|}{ Казахстан } & \multicolumn{2}{|c|}{ Беларусь } & \multicolumn{2}{|c|}{ Кыргызстан } \\
\hline & 2005 & 2014 & 2005 & 2014 & 2005 & 2014 & 2005 & 2014 \\
\hline $\begin{array}{l}\text { Доля отрасли в структуре } \\
\text { ВВП, в \% }\end{array}$ & 5,0 & 4,0 & 6,6 & 5,0 & 9,8 & 7,5 & 31,3 & 15,4 \\
\hline $\begin{array}{l}\text { Доля субсидий в стоим. ВВП } \\
\text { c/x-a, в \% }\end{array}$ & - & 33,8 & - & 4,1 & - & 18,8 & - & 0,3 \\
\hline $\begin{array}{l}\text { Размеры субсидий в расчете на } \\
1 \text { га пашни, долл. США }\end{array}$ & - & 60,0 & - & 18,0 & - & 255,0 & - & 7,0 \\
\hline $\begin{array}{l}\text { Структура продукции по } \\
\text { категориям хозяйств, в\% } \\
\text {-с/х.предприятия }\end{array}$ & & & & & & & & \\
\hline -х-ва населения & 44,6 & 49,5 & 24,8 & 23,1 & 63,3 & 76,2 & 3,0 & 1,7 \\
\hline -крестьянские( фермерские) & 49,3 & 40,5 & 53,5 & 45,6 & 35,7 & 22,2 & 38,0 & 38,4 \\
\hline х-ва & 6,1 & 10,0 & 21,7 & 31,0 & 1,0 & 1,7 & 59,0 & 59,9 \\
\hline $\begin{array}{l}\text { Доля импорта в общем } \\
\text { потреблении продовольствия }\end{array}$ & - & 36,0 & - & 30,0 & 17,0 & 15,0 & 27,5 & 29,1 \\
\hline
\end{tabular}

Таблица 1. Основные экономические показатели развития сельского хозяйства стран ЕАЭС Источник: Данные государственных органов статистики стран ЕАЭС

Как наглядно видно из табл.2 за анализируемый период 2006-2014гг. в сельском хозяйстве страны сложились минимальные индексы роста годовых объёмов сельскохозяйственной продукции, что намного ниже соответствующих темпов естественного прироста населения страны. Средневзвешенный индекс роста объёмов производства продукции сельского хозяйства в целом за указанный период составил всего $1,0 \%$. При этом из анализируемого периода в 9 лет в двух их них зафиксировано снижение индексов роста и двух- нулевой рост., т.е., из 9 лет только в 5 годах отмечается небольшой рост индексов.

Единичные и совершенно низкие индексы роста производства сельскохозяйственной продукции в стране обусловлено, прежде всего, недостаточным финансированием аграрного сектора. Как видно из данной таблицы, за указанный период в отрасли сложились самые минимальные по сравнению с другими отраслями национальной экономики размеры инвестиций в основной капитал и в финансировании реального сектора экономики. Причем доля сельского хозяйства в инвестициях в основной капитал уменьшилась с 2,6 \% в 2006 г. до 1,0 \%в 2014г., а в финансировании реального сектора экономики - резко уменьшилась и находится на крайне минимальном уровне $(0, \%)$.

\begin{tabular}{|c|c|c|c|c|c|c|c|}
\hline Показатели & 2006 & 2009 & 2010 & 2011 & 2012 & 2013 & 2014 \\
\hline $\begin{array}{c}\text { Индекс физического объёма продукции } \\
\text { сельского хозяйства, в \% }\end{array}$ & 101,7 & 100,7 & 97,4 & 102,0 & 101,2 & 102,7 & 99,4 \\
\hline $\begin{array}{c}\text { Доля сельского хозяйства в финансировании, } \\
\text { \%. }\end{array}$ & 0,75 & 0,21 & 0,12 & 0,4 & 0,14 & 0,17 \\
\hline $\begin{array}{c}\text { Доля сельского хозяйства в прибыли, в \% } \\
\text { Доля сельского хозяйства в кредитах, в \% }\end{array}$ & 0,54 & 0,37 & 0,45 & 0,21 & 0,73 & 1,06 & 1,24 \\
\hline $\begin{array}{c}\text { Доля сельского хозяйства в инвестициях в } \\
\text { основной капитал, в \% }\end{array}$ & 2,6 & 2,0 & 1,9 & 1,6 & 1,3 & 1,1 \\
\hline Кредиторская задолженность, млн. сом & 628 & 558 & 513 & 417 & 732 & 589 & 939 \\
\hline Дебиторская задолженность, млн.сом. & 340 & 341 & 384 & 227 & 439 & 329 & 426 \\
\hline
\end{tabular}

Таблица 2. Экономические индикаторы развития сельского хозяйства Кыргызской Республики Источник: НСК КP

Совершенно недостаточные темпы роста инвестиций в отрасль и отсутствия финансирования самым пагубным образом отражаются на крайне удручающем состоянии материально-технической базы аграрного сектора, ограниченности применения и использования инновационных приемов и методов агро - и зоотехники, что сказывается на низких уровнях урожайности сельскохозяйственных культур и продуктивности скота, на низких качествах производимой сельскохозяйственной и продовольственной продукции.

Тем не менее, в качестве положительного тренда следует отметить, что с 2011по 2013 гг. а наблюдается некоторый перелом в более сравнительно существенном изменении индексов роста продукции отрасли, за 
исключением последнего 2014 года. Это выражается в том, что индексы ежегодного роста продукции отрасли преодолели 2,0 \% барьер. В качестве фактора, способствующему такому росту, следует отметить, рост относительных и абсолютных размеров кредитных вливаний в отрасль. Если доля отрасли в кредитных ресурсах в национальную экономику в среднем за 2006-2010гг составила 7,0 \%, то за период 2011-2014 гг более чем удвоилась и достигла уровня 17,0 \% в 2014г. Такой рост кредитных ресурсов в сельское хозяйство страны во многом обусловлен практикой выделения правительством страны льготных кредитов сельским товаропроизводителям в рамках государственной программы «Доступные кредиты фермерам», реализуемой в республике с 2011г..

Однако, надо также отметить, что рост индексов физического объёма продукции сельского хозяйства крайне несоразмерен отмеченному более существенному росту кредитных ресурсов в сельское хозяйство страны. И это, на наш взгляд, во многом обусловлено усугубляющейся мелкокрестьянской структуры аграрного производства. Как видно из табл. 1 в республике сложилась крайне неэффективная структура хозяйствования, когда мелкокрестьянский сектор хозяйствования, представленной хозяйствами населения и крестьянскими (фермерскими) хозяйствами производит подавляющую часть $(98,3 \%)$ продукции отрасли. Практически мелкокрестьянская структура аграрного производства ограничивает возможности эффективного использования растущих кредитных ресурсов, что и подтверждается достигнутыми невысокими темпами и уровнями роста сельскохозяйственного производства. На евразийском пространстве именно, на наш взгляд, мелкокрестьянская структура агарного производства будет создавать дополнительные трудности эффективной трансформации агропродовольственного рынка и сбалансированного решения проблем продовольственной безопасности.

Низкий удельный вес отрасли в полученных прибылях ( 1,24 \%в 2014г.), а также растущее расхождение между кредиторскими и дебиторскими задолженностями сельского хозяйства( коэффициент превышения кредиторской задолженности над дебиторской в 2006г.составлял1,84, а в 2014г.-2,24) свидетельствуют о слабости финансов-экономического потенциала отрасли.

Низкая доходность отечественных сельхотоваропроизводителей в результате отсутствия действенного механизма стимулирования наращивания объёмов ее производства, слабость ее финансов-эконмического потенциала также являются одной из важных причин неустойчивого и неэффективного развития сельскохозяйственного производства в республике. В виду этого не подкрепленная необходимыми объёмами государственной поддержки приоритетность сельского хозяйства в структуре национальной экономики страны носит декларативный характер, что подтверждается самыми низкими объёмами государственной поддержки отрасли на евразийском экономическом пространстве (табл.1). Объём предоставляемых субсидий на сельское хозяйство (это в основном предоставление субвенций по льготным кредитным ресурсам в сельское хозяйство в размере1000,0 млр.сом) незначителен и в общей стоимости продукции сельского хозяйства страны составляет 0,3 \%, а в расчете на 1 га пашни равняется 7 долл. США, что намного ниже соответствующих показателей господдержки сельского хозяйства в Российской Федерации, Казахстане и, особенно, в Беларусь.

Для Кыргызстана, в экономике которого аграрному сектору принадлежит ключевая роль, ухудшение ситуации в обеспечение населения продовольствием свидетельствует о том, что проблема обеспечения продовольственной безопасности не стала одной из центральных и приоритетных проблем в системе национальной безопасности страны. Вступление Кыргызской Республики в ЕАЭС создает благоприятные предпосылки для возрождения традиционных отраслей и в целом обеспечения экономического роста в отрасли. Эффективная трансформация сельского хозяйства Кыргызстана в ЕАЭС настоятельно требует корректировки аграрной политики государства в направлении:

-импортозамещения и совершенствование региональной специализации сельскохозяйственного производства с учетом конъюнктуры евразийского агропродовольственного рынка и рынка стран дальнего зарубежья;

-проведение мероприятий по развитию сельскохозяйственной кооперации - между субъектами хозяйствования в сельском хозяйстве, между смежными отраслями АПК и включение эффективных хозяйствующих субъектов в кооперирование экономических связей на евразийском пространстве;

-межгосударственная кооперация в развитие агропромышленного комплекса, привлечение частных и корпоративных инвестиций из стран ЕАЭС требует внесения необходимых изменений в действующее законодательство, в частности земельного, снятие содержащихся в них ограничений для бизнеса;

-повышение инвестиционной привлекательности агробизнеса с целью приоритетного развития агроперерабатываюшей сферы АПК по более глубокой переработке мясо-молочной продукции, овощей и фруктов, стимулирование создания в этих целях совместных агрохолдингов и других предприятий;

-усиление мер и механизмов государственной поддержки агросектора, направленных на стимулирование развития приоритетных отраслей сельского хозяйства. 
Одной из центральных проблем в системе интеграционных связей является обеспечение коллективной продовольственной безопасности, развитие импортозамещения и взаимовыгодного обмена продовольствием, чем и обусловлен возросший интерес к исследованию данной проблемы. По мнению А.И.Алтухова (Алтухов А.И,, 2014) и А.Б. Молдашева (Молдашев.А.Б.,2014) для решения этих вопросов в условиях резкого обострения конкурентной борьбы на мировом агропродовольственном рынке эффективно в рамках ЕАЭС активнее использовать возможности евразийского экономического пространства.

В условиях развития евразийской интеграции проблема обеспечения национальной продовольственной безопасности приобретает также наднациональный характер, должна усиливаться значение мер по обеспечению коллективной продовольственной безопасности . По опыту стран Европейского Союза также в рамках ЕАЭС должна установится двухуровневая система обеспечения продовольственной безопасности . В рамках национального ее уровня каждый участник интеграционного формирования должен исходя из имеющихся условий определить приоритетные направления развития национального агропродовольственного сектора, выделить и всесторонне поддерживать развитие конкурентоспособных отраслей АПК. В рамках же наднационального уровня совместными усилиями стран ЕАЭС должны определятся возможности коллективного решения проблем обеспечения продовольствием на основе взаимовыгодной торговли и обмена продовольствием, создания единого продовольственного баланса и резервов.

С учетом развития интеграционных процессов на евразийском экономическом пространстве продовольственная безопасность Кыргызской Республики должна обеспечиваться как преимущественно за счет собственного производства ,так и частично за счет преимуществ евразийской интеграции. что требует корректировки специализации сельскохозяйственного производства страны. В свою очередь это скажется на пересмотре и корректировке специализации отечественного сельского хозяйства.

Совершенствование специализации отрасли необходимо рассматривать прежде всего под углом зрения формирования на евразийском рынке ядра будущего национального агропромышленного комплекса, конкурентоспособного на региональных и глобальных рынках. Речь идет об определении наиболее перспективных отраслей растениеводства и животноводства, обладающих наибольшими конкурентными преимуществами. Такими для Кыргызстана является мясо-молочное скотоводство, овцеводство, базирующейся на более полном использовании благоприятных естественных условий (пастбища и т.д.), овощеводство, плодоводство, картофелеводство.

Так, Ошская и Джалал-Абадская области имеют благоприятные условия для наращивания производства на евразийский рынок конкурентоспособной продукции, экологически чистых продуктов питания, отличающихся к тому же своей уникальностью, целебными свойствами ( хлопка-сырца, табака, овощей и фруктов, сухофрукты) .

Учитывая специфику курортного региона и ожидаемое увеличение отдыхающих в условиях единого экономического пространства сельская экономика курортной зоны Иссык-Кульской области должна специализироваться на производстве скоропортящейся молочной продукции, ягод, фруктов, картофеля, яиц и др. Необходимо и дальше развивать мясомолочную отрасль с глубокой переработкой и выпуском транспортабельных мясомолочных изделий, плодоовощные комплексы с приоритетным производством их на тепличных условиях.

Экономика высокогорной Нарынской области основана преимущественно на производстве животноводческой продукции. Учитывая многолетнюю хозяйственную направленность области на производство животноводческой продукции, богатый опыт ведения животноводства, необходимо особое внимание уделять развитию животноводства, его племенной и кормовой базы. В частности, учитывая растущий спрос на экологическую животноводческую продукцию (мяса) следует принять меры по возрождению интенсивного овцеводства, необходимо закладывать основы формирования экспортного потенциала мяса молодой баранины и ягнятины.

Перспективными направлениями развития приграничной Баткенской области по-прежнему остается специализация в земледелии: производство хлопка-сырца, табака, овощей, масличных культур, а также выращивание высококачественных сортов абрикосов, персиков, вишни, винограда, колированной черешни и других Данный регион Кыргызстана имеет уникальную возможность стать центром по производству, переработки и поставки на региональные рынки стран ЕАЭС пользующейся растущим спросом плодов и фруктов.

Таласская область в дальнейшем должна концентрировать на дальнейшем расширении производства зернобобовых ( фасоли), которая экспортируется в страны дальнего зарубежья. Условия индустриального развитой Чуйской области позволяют и дальше наращивать производство сахарной свеклы для внутреннего потребления и на экспорт, организовать производство семян сахарной свеклы и люцерны на экспорт в страны дальнего и ближнего зарубежья, а также значительно увеличить производство и переработку молока и мяса и поставки их на экспорт в страны ЕАЭС. 
Таким образом совершенствование региональной специализации сельскохозяйственного производства с учетом вступления страны в ЕАЭС , а также складывающейся благоприятной рыночной конъюнктурой позволит более эффективно использовать конкурентные преимущества Кыргызстана в производстве и экспорте конкурентоспособной продукции (мяса ,молока, овощей и фруктов, картофеля и др.) на евразийский рынок. Получат преимущественное развитие отрасли по производству и переработке животноводческой продукции, овощей и фруктов, технических культур, особенно, сахарной свеклы. В то же время, формирование единого аграрного рынка создают Кыргызстану благоприятные условия для решения проблем с недостаточным производством определенных видов продовольствия, в частности, пшеницы, растительного масла.

Сохранение различных форм и уровней господдержки национальных товаропроизводителей не будет способствовать интеграции аграрных экономик и поэтому требует в рамках ЕАЭС выработки согласованной аграрной политики в этом направлении. Мы считаем, что в рамках ЕАЭС, также необходимо как в странах ЕС проводить господдержку развития отрасли на национальном и наднациональном уровнях . На национальном уровне господдержка должна быть направлена на решение проблем импортозамещения на внутреннем рынке, а наднациональном уровне- на решение вопросов развития сбалансированного и конкурентоспособного развития евразийского агропродовольственного рынка.

В этой связи в ближайшее время необходимо решить вопрос об увеличение объёмов господдержки отрасли в Кыргызстане и доведения ее объёмов до среднего уровня стран ЕАЭС. Для решения этой проблемы можно также использовать средства ,выделяемые нашей республике в рамках российскокыргызского фонда развития . В нынешних условиях только таким образом кардинально решится вопрос о существенном стимулировании отечественных сельхозтоваропроизводителей в увеличении производства и поставки пользующейся повышенным спросом на евразийский рынок агропродовольственной продукции (мясо-молочной продукции, фруктов, овощей и т.д.). В целом существенные изменения региональной специализации, объёмов государственной поддержки отрасли обеспечат экономический рост в сельском хозяйстве и положительно скажется на ее конкурентоспособном развитии на евразийском экономическом пространстве.

\section{Литература}

- Статистические сборники «Кыргызстан в цифрах», «Сельское хозяйство Кыргызской Республики: 2008-2012»,www.stat.kg

- Статистический сборник «Сельское хозяйство, охота и охотничье хозяйство, лесоводство в России» www.gks.ru

- Статистический сборник «Сельское, лесное и рыбное хозяйство Казахстана», stat.gov.kz

- Статистический сборник «Сельское хозяйство Беларусь», www.belstat.gov.by

- Калиев Г.А.( 2013) Актуальные проблемы развития АПК Казахстана .-Алматы.-с.23.

- Алтухов А.И.( 2014). Развитие АПК России в условиях формирования ЕАЭС и членства в ВТО //Проблемы агропромышленного комплекса в условиях развития интеграционных процессов: мат. межд. научно-практ. конф.-Алматы.-с.44-50.

- Молдашев А.Б.(2014) .Аграрно-экономическая наука и ее роль в научном обеспечении АПК Казахстана //Проблемы агропромышленного комплекса в условиях развития интеграционных процессов: мат. межд. научно-практ. конф.-Алматы.-с.20-29. 


\title{
Необходимость Диверсификации Промышленности Азербайджана
}

\section{The Necessity of Diversification of Industry of Azerbaijan}

\author{
Assoc. Prof. Dr. Lala Hamidova (Azerbaijan State Economic University, Azerbaijan)
}

\begin{abstract}
The article reveals the benefits of diversification of industry, measures for overcoming of "curse of natural resources" in relation to the conditions of Azerbaijan and moving from the resource development industry in the country are studied there. This issue has three aims. Firstly, it is disclosure of necessity of diversification of industry, secondly - justification of the benefits of diversification, the third aim - the development of scientifically based recommendations for opportunities of diversification of the economy of the country. Two ways are used for fight against "curse of natural resources": backup of oil revenues in the State Oil Fund of the Azerbaijan Republic and the creation of the necessary political and economic institutions. The results of the research show that diversification is necessary in the countries depending on export of hydrocarbon resources. Diversification of economy of Azerbaijan should be directed to increase in human capital, development of infrastructure, support of financial institutions and stimulation of development of private business.
\end{abstract}

\section{1 Введение}

В статье раскрыты преимущества осуществления диверсификации промышленности, исследованы меры по преодолению «проклятия природных ресурсов» применительно к условиям Азербайджана и отходу от сырьевого развития страны. Настоящее исследование преследует три цели. Во-первых, это раскрытие необходимости диверсификации промышленности, во-вторых - обоснование преимуществ диверсификации, третья цель - выдвижение научно-обоснованных выводов и рекомендаций по возможностям диверсификации промышленности Азербайджана. Для борьбы с «проклятием природных ресурсов» используются два пути: резервирование нефтяных доходов в Государственном Нефтяном фонде Азербайджанской Республики и создание необходимых политических и экономических институтов.

Результаты исследования показывают, что диверсификация необходима в странах, зависящих от экспорта углеводородных ресурсов. Диверсификация экономики Азербайджана должна быть направлена на повышение человеческого капитала, развитие инфраструктуры, поддержку финансовых институтов и стимулирование развития частного предпринимательства.

\section{2 Преимущества диверсификации}

Диверсификация промышленности, предполагающая снижение сырьевой зависимости, отход от нефтяного сектора, развитие отраслей с высокой долей добавленной стоимостью, создание высокотехнологичных производств на основе модернизации, является ключевым приоритетом развития экономики Азербайджана. По мнению большинства ученых, осуществление политики диверсификации промышленности нужно в первую очередь странам, имеющим богатые природные, а особенно - топливноэнергетические ресурсы. Это особенно необходимо в случае преобладания в валовом внутреннем продукте страны сырьевых ресурсов при слабом развитии сельского хозяйства, туристической сферы, сферы услуг, низком уровне развития производства товаров общественного потребления (Гуриев, vd, 2010).

Следует отметить, что экономика стран, основанная на экспорте минеральных ресурсов, особенно нефти, имеет ряд отличий от экономики стран-экспортеров других сырьевых товаров. К ним относятся слабые производственные связи с другими секторами, высокая степень концентрации природной ренты, получаемой в основном в форме налоговых поступлений, сравнительно небольшое количество напрямую создаваемых добывающей отраслью рабочих мест.

Рассмотрим преимущества и необходимость диверсификации промышленности. К преимуществам диверсифицированного промышленного сектора относятся следующее:

- на диверсифицированную промышленность не оказывают сильного влияния различные колебания в развитии других отраслей, а также возможные резкие изменения цен на внешнем рынке. Это объясняется тем, что при диверсифицированной промышленности в случае даже спада в той или иной отрасли, данный спад способен возместиться ростом в иной отрасли, тем самым обеспечивается в целом устойчивое развитие экономики;

- диверсифицированное производство создает большие возможности и способствует формированию более эффективного рынка рабочей силы. Это происходит за счет оттока рабочей силы из одной отрасли в другую, что свойственно процессу диверсификации; 
- благодаря диверсифицированной промышленности страна проявляет меньшую зависимость от факторов внешней среды, становится менее зависимой от импортной продукции. Это связано с тем, что в связи с появляющимися в результате диверсификации более устойчивыми межотраслевыми связями происходит формирование и развитие внутреннего спроса на продукцию (Баумунг, 2012).

Основное же преимущество диверсификации промышленности - независимость от одной отрасли. Если возникнут проблемы в отрасли или на том или ином рынке, то в итоге такое не приведет к спаду экономики в целом.

\section{3 Необходимость диверсификации}

Необходимость диверсификации экономики можно свести следующему:

1. Ее перспективность в долгосрочном плане. Главная особенность диверсификации промышленности состоит в том, что несмотря на то, что ряд крупномасштабных реформ происходит в настоящее время, но результат, отдача от реформ происходит не сразу, а достаточно далеком будущем. То есть, можно с уверенностью утверждать, что диверсификация направлена на перспективу. Однако несмотря на временной разрыв между проведением диверсификации и ее результативностью этого процесса, отдача от диверсификации будет охватывать долгий период времени. Прямые государственные инвестиции в различные сектора и отрасли экономики, в том числе в сферу обслуживания, в туризм, промышленность, приводит к стимулированию предпринимательской деятельности, активизации этого процесса. В результате появляются и укрепляются межотраслевые связи, создаются условия для увеличения экспортного потенциала, выхода на международные рынки. Все перечисленное может привести в будущем к повышению социального благосостояния населения, увеличению спроса и предложения. Рост продажи товаров на внутреннем рынке в стране поднимет общие макроэкономические показатели государства.

2. В странах с богатыми природными ресурсами скорость добычи природных ископаемых ниже, чем показатели прироста населения. Таким образом, в таких странах постепенно снижается уровень дохода на душу населения, падает уровень жизни. Также отметим, что специфика нефтедобывающей промышленности заключается в том, что она не способствует увеличению занятости, открытию большого количества рабочих мест. А это, в свою очередь, способствует появлению угрозы нарушения социальной стабильности в обществе, что в итоге может привести к экономическому и социальному кризису (Ларионов, 2014).

3. Мировые цены на международном рынке ставят в зависимость стран-экспортеров с богатыми сырьевыми ресурсами. Здесь вступает в силу фактор волатильности (колебания цен). Это связано с тем, что высокие цены на сырье порождают временный экономический подъем, при падении же цен наблюдается резкий спад в экономике. Азербайджан, являясь экспортером природных ресурсов, очень сильно зависим от колебаний цен на нефть на мировом рынке. Ценовая политика резко изменяется, несмотря на то, что очень часто происходят договоры о ценах между странами-экспортерами нефти. Примером может послужит ситуация, в которой оказался Азербайджан в 2015 году: в результате обвального падения цен на мировом рынке цена на нефть Azeri Light упала более чем в 3 раза. Застраховаться от этих рисков можно, имея развитую финансовую систему.

4. Не стоит забывать, что обладание богатыми природными ресурсами является для любой страны плюсом, важным конкурентным преимуществом перед другими странами, несмотря на концепцию «проклятия ресурсов». Не стоит отказываться от такого важного конкурентного преимущества, необходимо правильно использовать его путем диверсификации экономики.

\section{4 Борьба с «проклятием ресурсов»}

В экономической литературе известны два стержневых способа борьбы с «проклятием природных ресурсов». Во-первых, это накопление поступающих нефтяных доходов в форме валютного резерва, или другими словами, в форме фонда национального благосостояния. Во-вторых, создание благоприятных условий для осуществления институциональной политики (Немченко, 2008).

Первый метод борьбы с «проклятием ресурсов» благополучно реализуется в Азербайджане благодаря осуществляемой начиная с 1994 года Государственной нефтяной стратегии. В целях выработки механизма рационального использования доходов, полученных от добычи нефти и газа в 1999 году был образован Государственный Нефтяной Фонд Азербайджанской Республики. В Государственном Нефтяном Фонде Азербайджанской Республики накапливаются денежные средства от продажи нефти и газа, которые выделяется в дальнейшем для решения жизненно важных экономических и социальных проблем страны.

Что касается второго инструмента борьбы с «проклятием ресурсов» - создания институтов, наиболее прогрессивной институциональной системы (здесь имеется ввиду современная система общественного контроля, достижение прозрачной деятельности органов государственной власти), развитие экономической инфраструктуры, связанной с защитой прав собственности, 
совершенствованием бюджетно-налоговой политики, созданием условий для развития рыночных отношений, свободы предпринимательства, то он пока находится на стадии формирования. В целях диверсификации и конкурентоспособности экономики в стране была утверждена и успешно реализуется Государственная программа по развитию промышленности на 2015-2020 годы, разработана Концепция «Азербайджан 2020: взгляд в будущее».

Отрасли промышленности, избранные государством в целях проведения диверсификационной политики, должны иметь или по крайней мере обеспечить привлекательную структуру. Это означает, что соответствующая, «привлекательная» структура должна обеспечить конкурентные преимущества. Пока данное условие не выполнится, диверсификация не сможет привести к достижению высокой прибыли.

Отметим, что одновременное осуществление как политики диверсификации промышленности, с одной стороны, и ослабления сырьевой зависимости страны, с другой, сложная задача. Нефтяной сектор в странах с богатыми сырьевыми ресурсами очень слабо связан с другими экспортными отраслями с точки зрения используемой технологии и навыков. Но в целом мировой опыт подтверждает, что несмотря на сложности, ресурсозависимые страны способны диверсифицировать экономику, инвестируя, прежде всего, в человеческий капитал (здоровье и образование) и инфраструктуру, поддерживая финансовые институты, контролируя правильное распределение доходов от нефти в другие отрасли и обеспечивая прозрачность стабилизационных фондов. Эти меры помогают поднять уровень жизни населения и поддержать развитие частного предпринимательского сектора.

\section{5 Направления диверсификации}

Таким образом, диверсификация необходима именно в тех странах, зависящих от экспорта и продажи сырьевых, в особенности, топливно-энергетических, ресурсов. В общем, диверсификация экономики Азербайджана должна быть направлена на повышение человеческого капитала и развития высокой производительности отраслей промышленности и услуг, которые требуют высококвалифицированного труда и должна включать следующее:

- прямые инвестиции в образование, включая в науку и технику, в техническое и профессиональнотехническое образование;

• развитие определенных секторов и несырьевых отраслей промышленности;

- инвестиции в инфраструктуру и укрепление институтов, чтобы уменьшить затраты на ведение бизнеса (включая через зоны свободной торговли);

- поддержку предпринимательства и инноваций через улучшенный доступ к информации, коммуникационные технологии, увеличение расходов на научные исследования (Aslanli, vd, 2013).

\section{Литература}

- Kanan Aslanli, Zohrab Ismayil, Rovshan Aghayev, Azer Mehtiyev. 2013. Assessment of Economic and Export Diversification - Azerbaijan. Free Economy, Baku.

- Э.В.Баумунг, 2012. «Исторические аспекты диверсификации производства». Современные научные исследования и инновации. 2, с. 87

- С.Гуриев, А.Плеханов, К.Сонин, 2010. «Экономический механизм сырьевой модели развития». Вопросы экономики, 3, с. 23

- А.О.Ларионов. 2014. «Диверсификация как приоритетное направление развития промышленности региона». Проблемы развития территории, 3 (71), с.25

- Г.Немченко, 2008. «Диверсификация производства: цели и направления деятельности». Г.Немченко, С.Донецкая, К.Дьяконов. Проблемы теории и практики управления. 1. с. 107 - 111. 


\title{
Влияние финансово-кредитной политики на социально- экономическое положение Кыргызской Республики The Impact of the Financial and Credit Policy for the Socio-
Economic Situation of the Kyrgyz Republic
}

Prof. Dr. Merim Koichueva (Kyrgyz-Russian Slavic University, Kyrgyzstan)

\begin{abstract}
Finances are a necessary tool for the economy and an integral part of the methods of state regulation. Financial and credit system of the state is a reflection of the forms and methods for the specific use of finance in the economy, and it cannot be better than the society that serves, so major improvements in it can only be as a result of the overall progress in the economy, political system and administrative structure of the society. Being a part of social and economic policy and derived from the development of the economy financial and credit policy should actively influence economy. A key component of successful development of the economy is stable functioning of financial system. The society should be confident that the state system properly fulfills its function to ensure the stability and security in the country. The article examines the impact of the financial and credit policy of the state on its socio-economic situation of the Kyrgyz Republic.
\end{abstract}

Основной, первостепенной частью рыночных отношений - являются финансы, и, они же - есть основной инструмент реализации государственной политики. То есть ни одна социально-экономическая и политическая, программы не осуществимы при отсутствии финансов. Финансово-кредитная политика, будучи производной от развития экономики должна активно влиять на экономику страны, являясь составной частью социально-экономической политики государства.

Финансово-кредитная система государства - это методы формирования и использования финансов и денежных средств в экономике. И эта система напрямую зависит от развития того общества, которое она обслуживает, поэтому улучшения в ней возможны только тогда, когда само государственное устройство в виде экономики, политики, социального сектора, будет прогрессивно развиваться. Ключевой составляющей развития экономики является стабильно функционирующая финансово-кредитная система. Общество должно быть уверенно, что государство должным образом выполняет свои функции для обеспечения стабильности и безопасности в стране. При этом важно понимать, что те или иные проблемы в отдельных секторах экономики, не могут привести к нарушению всей финансово-кредитной системы.

Налогово-бюджетная политика Кыргызской Республики сосредоточена на реализации совершенствования налогового законодательства; выравнивании налоговой нагрузки; обеспечении полноты сбора налогов; совершенствовании и автоматизации налогового администрирования. Также, в свете вхождения государства в Евразийский экономический союз проводится работа по освоению новых инструментов администрирования, которые должны обеспечить эффективность данной интеграции.

В 2015 году наблюдалось замедление реального роста ВВП Кыргызской Республики на 0,5 процентных пункта, что было обусловлено спадом производства, а именно снижением объемов производства на золоторудном месторождении «Кумтор». Прирост ВВП на 4,5 процента (в 2014 году 5,0 процента) произошел за счет предоставленных услуг, строительства и сельского хозяйства.

Естественно замедление темпов роста в экономике приводит в увеличению дефицита бюджета в государстве. Главным источником пополнения доходной части бюджета являются налоговые поступления и таможенные сборы. Дефицит бюджета Кыргызской Республики в 2015 году увеличился и составил 1,5 процента к ВВП (в 2014 году с дефицитом в 0,5 процента к ВВП). Доходы государственного бюджета от операционной деятельности составили 30,2 процента к ВВП, и выросли на 7,3 процента (в 2014 году доходы увеличились на 17,3 процента). Занимающие основную долю в структуре доходов налоговые поступления, выросли на 2,4 процента. 62,2 процента было обеспечены за счет поступлений от Государственной налоговой службы Кыргызской Республики и 37,8 процента - Государственной таможенной службы Кыргызской Республики.

Наибольший удельный вес пришелся в основном на НДС и акцизный налог, на товары, ввозимые на территорию Кыргызской Республики от государств - членов ЕАЭС (функция администрирования данных налогов со вступлением Кыргызской Республики в ЕАЭС передана налоговым органам), а также за счет поступлений денежных средств от золоторудных месторождений «Джеруй» и «Тереккан, Перевальное» и золотосурьмяного месторождения «Терек».

Как видим, при формировании бюджета основную роль продолжают играть косвенные налоги. Это можно объяснить относительной малоэффективностью реального сектора и низкой доходностью населения. 
С начала обретения независимости Кыргызстана, его бюджет формировался и учитывался согласно параметрам, которые были определены и рекомендованы зарубежными экспертами, что соответствует современным требованиям к уровню экономического развития государства. Формирование бюджета конечно же должно быть максимально сосредоточено на внутренних ресурсах и обеспечивать снижение его дефицита. И здесь важно соблюсти баланс в обеспечении увеличения доходов в соответствии с социально-экономическими приоритетами государства. Так, например, попытки расширения налоговой базы, без обеспечения динамического развития реального сектора, не дадут положительных результатов.

В целом налоговое бремя в республике не превышает порога, достаточного для эффективного развития экономики. Более того, налоговая политика Кыргызстана считается наиболее либеральной и «щадящей» по сравнению с налоговыми политиками в других странах постсоветского пространства. Однако, не смотря на вышесказанное, «теневой сектор» продолжает занимать существенную долю - объемы теневой экономики в Кыргызстане, по разным данным, достигают от 40 до 60 процентов. Государственная налоговая служба Кыргызской Республики намерена сократить долю теневой экономики посредством внедрения системы контроля по учету денежных средств через «фискализацию» контрольно-кассовых машин с функцией онлайн передачи данных в налоговую. «Фискализация» представляет собой применение специального кассового аппарата, с которого будет оперативно передаваться информация о производимом расчете, через телекоммуникационные связи в Центр обработки данных ГНС, в функции которого будут входить хранение, обработка и передача данных. Этот инструмент даст возможность эффективно контролировать правильность, полноту расчетов, уплату налогов и администрировать налоги. Ожидается, что этот новый нового механизм принесет ощутимые выгоды не только государству, но и добросовестным налогоплательщикам. Увеличатся налоговые сборы за счет легализации денежного оборота, будут созданы прозрачная фискальная система и конкурентная среда для налогоплательщиков, а также сократятся различные формы контроля (рейдовые и хронометражные проверки) в отношении добросовестных субъектов. Кроме того, новый механизм призван обеспечивать защиту прав потребителей.

Вместе с тем налоговая политика Кыргызской Республики в ближайшей перспективе должна быть направлена на: устранение диспропорций в налогообложении; развитие малого и среднего предпринимательства; легализации теневой экономики; преодоление фискального дисбаланса (дефицита бюджета).

Что касается государственного долга, т.е. суммы задолженности государства внешним и внутренним кредиторам, по данным Министерства финансов Кыргызской Республики, на конец 2015 года государственный внешний долг составил 3,6 млрд долларов США или 64,5 процента к ВВП (в 2014 году 3,4 млрд долларов США или 50,5 процента к ВВП), внутренний долг - 15,5 млрд сомов или 3,7 процента к ВВП (в 2014 году - 12,4 млрд сомов или 3,1 процента к ВВП). Расходы на обслуживание государственного долга 3,4 процента к ВВП, из них процентные выплаты составили 1,0 процента к ВВП (в 2014 году расходы на обслуживание государственного долга составили 3,4 процента к ВВП).

Основными целями управления государственным долгом Кыргызской Республики являются: обеспечение потребностей Правительства Кыргызской Республики в финансировании посредством заимствования с возможно наименьшими затратами и разумным уровнем риска; - развитие рынка государственных ценных бумаг Кыргызской Республики; поддержание устойчивости государственного долга.

В части внешнего долга принято, что новые внешние заимствования будут привлекаться только на наиболее приоритетные программы и проекты, которые будут содействовать экономическому росту и сокращению бедности. Привлечение новых государственных внешних заимствований будет осуществляться при соблюдении минимального уровня льготности займов (грант-элемент) в 35 процентов. В целях диверсификации портфеля внешнего долга и сокращения потенциальных рисков, связанных с концентрацией долга, Правительство Кыргызской Республики в процессе привлечения внешних заимствований будет руководствоваться количественным ограничением образования задолженности перед одним кредитором не более чем 50 процентов общей суммы внешнего долга. Принимая во внимание текущие размеры внешнего долга, во избежание потенциально высоких издержек и рисков Правительство Кыргызской Республики заявило, что воздержится от привлечения заимствований посредством выпуска и размещения на внешних финансовых рынках облигаций в иностранной валюте.

В части управления внутренним долгом государства, привлечение государственных внутренних, заимствований осуществляется только посредством выпуска государственных ценных бумаг. Размещаются государственных ценных бумаг только через рыночные механизмы ценообразования - через аукционы. И далее Правительство продолжит мероприятия по увеличению общего срока обращения государственных ценных бумаг путем: наращивания удельного веса государственных казначейских облигаций в общей структуре ежегодных эмиссий государственных ценных бумаг; предложения казначейских облигаций со сроками обращения свыше 2 лет. 
Развитие рынка государственных ценных бумаг Кыргызской Республики должно служить не только для целей финансирования, но и оказывать влияние на развитие финансового сектора, в целях более эффективного распределения доступных ресурсов для развития бизнеса. Для достижения этих целей управление государственным внутренним долгом должно осуществляться с соблюдением принципов прозрачности, простоты и ликвидности.

Основными инструментами регулирования внешней торговли государства являются таможенные тарифы. Государственной таможенной службой при Правительстве Кыргызской Республики за 2015 год обеспечен сбор налогов и платежей в размере 97,2 процентов от плана. Невыполнение планового показателя наблюдается по НДС на товары, ввозимые на территорию Кыргызской Республики до присоединения к ЕАЭС, акцизному налогу на товары, ввозимые на территорию Кыргызской Республики из третьих стран, и, по ввозным таможенным пошлинам из государств-членов ЕАЭС. Не достижение запланированных доходов от поступления ввозных таможенных пошлин из государств-членов ЕАЭС связано со снижением объема импорта товаров государств-членов ЕАЭС из третьих стран. Так, по данным Евразийской экономической комиссии, объем импорта товаров государств - членов Евразийского экономического союза из третьих стран за 2015 год составил 205,4 млрд. долларов США. По сравнению с 2014 годом объем импорта уменьшился на 35,3\% или на 112,1 млрд. долларов США. Кроме того, по данным Национального статистического комитета, за 2015 год объем импорта, составив 4 069,5 млн. долларов, снизился к предыдущему году на $29 \%$.

Надо отметить, что Кыргызская Республика стала полноправным государством-членом ЕАЭС с 12 августа 2015 г. С этой даты вступил в силу Договор о присоединении Кыргызской Республики к Договору о Евразийском экономическом союзе от 29 мая 2014 г. Отменен таможенный контроль товаров и транспортных средств, перемещаемых через кыргызско-казахстанский участок государственной границы, а также в аэропортах при воздушном сообщении между Кыргызстаном и другими странами Евразийского экономического союза. Полный объем мероприятий по выполнению условий присоединения Кыргызской Республики к ЕАЭС в таможенной сфере должен быть выполнен до 12 августа 2017 г. На данный момент уже в полном объеме проведена модернизация информационно-программных средств, обеспечивающих обязательное предварительное информирование о товарах, ввозимых автомобильным транспортом на таможенную территорию Евразийского экономического союза.

Количественным ориентиром денежно-кредитной политики является удержание уровня инфляции в пределах 5-7 процентов в среднесрочном периоде, определенных Национальной стратегией устойчивого развития Кыргызской Республики на 2013-2017 годы. Целью деятельности Национального банка Кыргызской Республики, который определяет денежно-кредитную политику является «достижение и поддержание стабильности цен посредством проведения денежно-кредитной политики». в 2015 году, меры денежно-кредитной политики НБКР были ориетнированы на ограничение монетарной составляющей инфляции и давления на обменный курс. Основными же факторами динамики индекса потребительских цен были плановое повышение тарифов на электрическую и тепловую энергию (в соответствии со Среднесрочной тарифной политикой Правительства Кыргызской Республики на 2014-2017 годы) и, удорожание непродовольственных импортируемых товаров. Также на это повлияло изменение курса доллара США и повышение таможенных пошлин в связи с вхождением республики в ЕАЭС. Национальный банк Кыргызстана проводит валютную политику в режиме плавающего обменного курса и, для смягчения колебаний обменного курса использует валютные интервенции.

Еще одной важной составляющей социально-экономической политики Кыргызской Республики является ценовая политика. С момента обретения независимости Кыргызской Республики политика либерализации цен открыла возможности установления новый ценовых отношений, основывающихся на рыночных механизмах - на спросе и предложении. Помимо спроса и предложения, цены стали также отражать количество денег в обращении и структурные сдвиги в экономике. Внутренний рынок в Кыргызстане полностью либерализован, регулирование цен которого со стороны государства носят косвенный характер, посредством воздействия на изменение спроса или предложения товаров. Контроль за ценами сохраняется на товары, услуги или работы: субъектов естественных или разрешенных монополий; подлежащих «разбронированию» из государственного резерва и направляемых на бюджетные нужды; подлежащих закладке в Фонд госматрезервов и т.П. Перед государством стоит задача научного обоснования перечня услуг, оказываемых государственными органами исполнительной власти и их структурными подразделениями на платной основе.

Для Кыргызстана характерна устойчивая тенденция общего снижения объемов капитальных вложений, в следствие чего республика испытывает и еще достаточное время будет испытывать дефицит собственных инвестиций и заинтересована в привлечении иностранных инвестиций. Основными источниками финансовых вливаний и инвестиций в нефинансовые активы являются собственные средства предприятий, которых катастрофически не хватает. Роль государства «локомотива» инвестиционной деятельности ничтожно мала. У частного сектора недостаточно возможностей, а главное, нет стимулов для долгосрочного инвестирования. Институциональные рыночные механизмы инвестирования в реальный 
сектор, например, такие как - гарантии, система страхования инвестиционных рисков, негосударственных пенсионных фондов слабо развиты. Обеспечение действительного инновационного скачка потребует создания соответствующих условий для этого. А на это нужно время. Но формирование этих условий на возникновение и осуществление инновационных решений будет влиять на ходу, т.е. отдача будет проявляться в процессе создания предпосылок. Она будет тем больше, чем больше возрастут эти условия. Но в масштабе страны эффект будет тогда значителен, когда инновационный подход охватит большинство отраслей и предприятий. Для накопления инвестиционных ресурсов важно добиться прибыльной работы действующих предприятий в реальном секторе экономики. Но, внутренних ресурсов для сбережения, накопления и инвестирования в реальный сектор имеется в весьма скромных размерах. Еще, ведь, из этой суммы надо произвести налоговые и прочие обязательные отчисления и платить по долгам. Органической составной частью этой политики должно быть привлечение внимания зарубежных инвесторов и предпринимателей к малому и среднему предпринимательству в Кыргызстане. И сегодня важнейшая задача - это совместными силами проанализировать деятельность предприятий, определить причины недостатков и выработать конкретные меры для обеспечения эффективной деятельности всех совместных и иностранных предприятий малого и среднего бизнеса. Эти действия должны включать как благоприятные налоговый режим и другие условия для работы, так и строгий подход при оценке экономической состоятельности отечественных и иностранных предпринимателей, намеревающихся «открыть дело» и получить разрешительную лицензию. Важно защитить предпринимателей и от чиновничьего, бюрократического произвола, когда нечистоплотными элементами допускаются поборы. Нужно очистить дорогу малому и среднему предпринимательству от коррупционеров.

Результаты финансово-кредитной политики и ее влияние на социально-экономическое положение государства, напрямую зависят от выработки концепции проведения политики, которая должна предусматривать и учитывать состояние и стадии экономического развития государства, и, естественно учитывать закономерности общественного развития. Финансово-кредитная политика считается составной частью экономической политики государства, но, зачастую она сводится только к бюджетно-налоговой политике. При этом финансово-кредитная политика должна согласовываться и взаимоувязываться с другими политиками государства, а именно с денежно-кредитной, ценовой, валютной, инвестиционной, и, политикой в области страхования.

\section{Литература}

- Годовой отчет Национального банка Кыргызской Республики за 2015г. - http://www.nbkr.kg

- Материалы семинара по макроэкономическому анализу и политике «Макроэкономические счета, анализ и прогнозирование. - Институт МВФ.

- Мэрим Койчуева. Предпосылки к инновационному развитию экономики Кыргызстана. - ж. Общество и экономика, №1, 2011г. - М.: «Наука».

- Отчет об исполнении Государственного бюджета Кыргызской Республики за 2015 год. http://www.minfin.kg

- Стратегия управления государственным долгом Кыргызской Республики на 2015-2017 годы. http://www.minfin.kg

- Экономика Кыргызской Республики: Под ред. академика Т. Койчуева. - Б.: КТУМ, 2003 


\title{
Качество Медицинских Услуг В Кыргызстане The Quality of Medical Services in Kyrgyzstan
}

\author{
Assoc. Prof. Dr. Damira Japarova (Kyrgyzstan-Turkey Manas University, Kyrgyzstan) \\ Dr. Damira Baigonushova (Kyrgyzstan-Turkey Manas University, Kyrgyzstan)
}

\begin{abstract}
Human health determines the measure of socioeconomic development of the country. Inspiration of health workers' work's quality does not go beyond the salary. Doctors noted a lack of motivation to improve the quality of medical services. The reason for the low quality of treatment is the lack of modern technology and the deficiency of specialists. A significant part of the funds should be directed to financing of outpatient level instead of expensive hospital care. It is necessary to implement financing on disease prevention. The quality of polyclinics should be evaluated by considering the number of prescribed or treated patients, where the patient gives his vote using his personalized account.
\end{abstract}

\section{1 Введение}

Здоровье отдельного члена общества определяет состояние здоровья нации в целом. Здоровая нация является залогом развития экономики и культуры страны. Следовательно развитие здравохранения, её доступность и качество должны стать первоочередной задачей государства (Rosmedstrah, 2016). Согласно определению всемирной организации здравоохранения, “Здоровье - это состояние, характеризующее не только отсутствие болезней и физических дефектов, но и полное физическое, умственное и социальное благополучие" (Narya, 2016).

Это повышает ответственность в сохранении собственного здоровья граждан. В развитых странах государство является организатором современной системы здравохранения. Главным показателем развития здравохранения является не толко воостановление здоровья, но и профилактическая работа для снижения рисков заболевания.

\section{2 Анализ качества оказания стационарной помощи}

Анализ качества оказания стационарной помощи в Кыргызстане выявил в I квартале 2014г. 1375 дефектных случаев. Из них дефекты лечения составляют 44,2\%, количество необоснованных госпитализаций - 23,4\%, за что были удержаны финансовые санкции на общую сумму 1150,1 тыс. сомов. Попытаемся выяснить причину такой картины с помощью анализа анкетных данных проведенных в 2014 году.

В ходе анкетирования 61,8\% врачей, доктора отметили отсутствие мотивации, т. е. материального стимула в работе к повышению качества труда. 93\% врачей не устраивает их заработная плата. Другая причина низкого качества лечения состоит в отсутствии современной технологии лечения. Во многих стационарах, особенно в регионах, в виду ограниченности ресурсов, невозможно провести даже развернутый общий анализ крови, или сделать рентген. В ходе анкетирования мы были свидетелями того, что врачи больниц и поликлиник особенно в регионах, вместо лечения больных были заняты ремонтом помещений лечебного учреждения за свой счет и на свои средства. Они ждали комиссию по аккредитации лечебного учреждения (Чуйская область Город Токмак).

Третья причина, по мнению врачей, состоит в отсутствии самостоятельности лечения. Клинические протоколы устарели - 2008 года. Врачи считают, что они ограничивают лечение. В целях экономии средств, по нормативу заложены относительно дешевые лекарства. Лечение амоксицилином, мукалтином, к чему организм привыкает с детства, эффекта не дает. Отказ от клинического протокола грозит штрафом. Таким образом, ограничения ведут к некачественному лечению, и болезнь приобретает хроническую форму. Проверенные на практике лекарства врачи назначать не могут, в итоге происходит хронизация болезни и увеличение инвалидности, особенно среди детей, о чем говорили врачи в ходе прямой беседы с ними.

По результатам опроса 89,9\% врачей хотят получить больше самостоятельности в работе. Сроки пребывания пациентов в больницах ограничены. Для тех больных, которых должны госпитализировать, например, с диагнозом: двусторонняя пневмония, рекомендуется лечение в поликлинике, без наблюдения врача, что нужного эффекта не дает. Врачи говорят об увеличении хронических больных. Много ограничений со стороны ФОМСа. Врачи - эксперты ФОМСа не клиницисты, но проверяют, возмущаются врачи.

Доказательная медицина не соответствует возможностям пациентов, так как по ней прописываются дорогие витамины, что не по карману нашим пациентам. Согласно опросу 83,7 \% больных стационара, имеют доходы ниже 10 тысяч сомов в месяц. 
Главная причина низких показателей лечения - недостаток врачей - специалистов в Бишкеке, не говоря о регионах. Обеспеченность детскими врачами составляет от 30 до 60\%. Не хватает врачей-педиатров, неонатологов, реаниматологов. Отсюда и высокие показатели детской смертности, считают врачи.

Не хватает молодых специалистов. Низкая заработная плата, отсутствие жилья и других поддерживающих программ, способствуют тому, что молодые врачи выезжают за пределы страны, или переходят в частные медицинские центры.

В регионах молодых специалистов практически нет. Из 518 опрошенных врачей, значительную часть 51,1 \% представляют люди пожилого возраста. Депозит молодого врача составляет 3 тысячи сом. И заработная плата работников без стажа - 5 тысяч сом по тарифу, в итоге молодые врачи получают 8 тысяч сом. Имеет место утечка кадров в частные медицинские центры. Например, областная больница в регионе в течение 3 лет работает без лор врача! (г. Талас). Оплата труда врачей осуществляется из единого фонда заработной платы работников здравоохранения. Согласно законодательству, выплачивается основная гарантированная и дополнительная заработная плата и в соответствии с «Условиями оплаты труда работников организаций здравоохранения Кыргызской Республики», утвержденными постановлением Правительства Кыргызской Республики № 411 от 6 июня 2006 года (ФОМС КР, 2015) соблюдается следующая пропорция: 85\% фонда заработной платы предназначены для выплаты заработной платы медицинским работникам. Оставшиеся $15 \%$ расходуются для административных работников и АХЧ.

Основная и мотивирующая части заработной платы, вместе состовляют фонд оплаты труда. Поэтому они взаимозависимы.

С повышением заработной платы медицинских работников в Кыргызстане, их доходы увеличились. Однако желание получать дополнительные доходы от пациентов не исчезло. Как показывает практика, оплата медицинской помощи, производимая неформально, в руки медицинским работникам, получила широкое распространение в здравоохранении Кыргызстана. Это не только роняет имидж врачей, также создаёт материальные проблемы пациентов. Низкая заработная плата врачей сосдаёт условия неофициальной платы в медицине КР. Как было отмечено выше, из числа опрошенных врачей 93\% не устраивает их низкая заработная плата.

Основная часть сельского населения не имеет страховки, значит, нет поступлений средств на их лечение, отказать им в лечении невозможно, так как эти люди с запущенной формой заболеваний. Очевидно, это и является причиной необоснованных госпитализаций.

Помимо указанных причин низкого качества лечения, врачи указывают на большую загруженность. Например, $40 \%$ пациентов в Токмакской территориальной больнице представители из Чуйского района. За них страховые деньги не поступают. Стационар имеет непредусмотренные расходы, за иногородных деньги не получает. В данном случае, принцип страхования - деньги идут за пациентом не срабатывает. В результате миграции аналогичная ситуация сложилась и в городских поликлиниках и больницах города Бишкек. В связи с этим идентификация и введение электронных счетов позволило бы использовать страховые средства по месту обращения пациентов за медицинской помощью и по месту лечения. Частые проверки фискальных органов - счетной палаты, ФОМСа мешают основной работе, считают врачи.

Кроме того причинами роста госпитализаций в стационарных учреждениях республики отмечаются следующие факторы:

Методы оплаты медицинских услуг стационарных учреждений за пролеченный случай стимулируют организации здравоохранения увеличивать госпитализацию;

Рост числа льготных категорий населения, получающих медицинские услуги по Программе государственных гарантий на бесплатной основе, приводят к несбалансированности государственных обязательств и финансовых ресурсов.

Рассмотрим расходы на содержание стационаров по статьям затрат. Расходы финансовых средств на душу населения по регионам республики неравномерны. Относительное преобладание финансирование здравоохранения в Бишкеке определяется многими причинами. При этом следует учесть, что в Бишкеке расположены лечебные центры третичного уровня, где получают лечение с многих регионов, так как там отсутствуют узкие специалисты. Кроме того административные центры, министерство и ведомства тоже расположены в столичном центре, что связано с расходом финансовых ресурсов.

\section{3 Анализ качества первичной медико-санитарной помощи}

В республике фунционируют 64 ЦСМ, 28 ЦОВП, где работают 691 ГСВ. Количество посещений врачей составляет 19 миллионов. Базовая программа обязательного медицинского страхования влючает первичную медико-санитарную помощ, профилактику и услуги скорой помощи. Качества медицинских услуг на первичном уровне, дефекты лечения составили 46,4\%. Для выяснения причин рассмотрим структуру и динамику расходов программы государственных гарантий по поставщикам медицинских услуг. 


\begin{tabular}{|l|c|c|c|c|c|}
\hline Показатели & 2009 & 2011 & 2013 & 2015 & $2015(\%)$ \\
\hline Стационарная помощь & 2837,0 & 4298,3 & 6116,9 & 6682,4 & 58,7 \\
\hline Амбулаторная помощь & 1838,1 & 2866,1 & 3541,4 & 3020,8 & $6 \%$ \\
\hline
\end{tabular}

Таблица 1 Динамика и структура расходов программы государственных гарантий по поставщикам медищинских услуг за 2009-2013 годы.(млн.руб.) Источник:составлена по данным ФОМС КР 2009-2015 $20 \partial b l$

Из таблицы мы видим, что до 58,7\% средств Программы государственных гарантий направляется на оказание стационарной помощи, которая увеличилась в 2015 году по сравнению с 2009 годом почти в 2,2 раза. И за последние 5 лет продолжается тенденция преимущественного финансирования стационарного лечения по сравнению с оказанием первичной санитарно- профилактической помощи населению. В поликлиниках подушевое финансирование составляет 502 сома на приписанного человека, тогда как в стационары за пролеченный случай предусмотрена выплата 7300сомов. Отсюда, кажется, что изначально настрой на то, чтобы пациенты получили осложнение и были направлены на стационарное лечение.

По учреждениям первичной медико-санитарной помощи нормативы финансирования по регионам с 2010 года единые. Нормативные показатели подушевого финансирования представляют собой усредненный показатель финансирования в расчете на одного приписанного человека с учетом поправок. Количество пациентов, вынужденных обращаться в стационар, растет. Итак, стационарное лечение по затратам намного превышает финансовые расходы амбулаторий и поликлиник. Поэтому существующее распределение финасовых средств считается крайне без результативным.

При этом наблюдается большая нагрузка. Например лор врач в поликлинике в районном центре должен принять в месяц 420-460 человек, что нереально. Одна машина скорой помощи на поликлинику. Очень узкий перечень больных можно лечить в стационарах. Хронизация идет огромная, дети болеют каждые 23 месяца. У многих детей возраста 6-7 лет гайморит, говорят врачи.

В Республике Беларусь, например, 70\% больных получают полноценное лечение в поликлиниках и нет необходимости их дальнейшего лечения в стационарах. Поэтому там люди живут дольше, чем в других странах СНГ и очень низкий уровень смертей новорожденных детей. Методы оплаты стационарных услуг за «пролеченный случай» приводят к искусственному увеличению количества госпитализаций и необоснованному назначению диагностических и лечебных процедур.

В этой связи значительную часть средств Единого плательщика необходимо направлять на финансирование поликлинического уровня по сравнению с дорогостоящим стационарным лечением.

Необходимо осуществить финансирование на профилактику болезней.

\section{4 Использование финансовых ресурсов}

Как было отмечено выше, важным моментом в реформировании системы финансирования сектора здравоохранения стал переход на формирование и исполнение бюджета на бесстатейной основе в программном формате. 


\begin{tabular}{|c|c|c|c|c|c|c|}
\hline Наименование & 2009 & 2011 & 2013 & 2014 & 2015 & $\begin{array}{c}2015 \text { г. в \% к } \\
2009 \text { г. }\end{array}$ \\
\hline \multicolumn{7}{|l|}{ Республик. Бюджет: } \\
\hline Стационары - базовая ставка & 1340 & 1550 & 4400 & 4627 & 4848 & 328,3 \\
\hline ЦСМ-подушевой норматив & 57,4 & 74 & 176 & 170,38 & 170 & 306,6 \\
\hline $\begin{array}{l}\text { Стоматология -подушевой } \\
\text { орматив }\end{array}$ & 12,5 & 18 & 18 & 40 & 40 & 320,0 \\
\hline $\begin{array}{l}\text { Скорая помощь - норматив на } 1 \\
\text { бригаду }\end{array}$ & 175000 & 240000 & 550000 & 550000 & 550000 & 314,3 \\
\hline \multicolumn{7}{|l|}{ Средства ОМС } \\
\hline Стационары & 700 & 1200 & 1950 & 1950 & 1950 & 278,5 \\
\hline ЦСМ/ГСВ & 65 & 80 & 100 & 1010 & 1010 & 153,8 \\
\hline ДП ОМС - подушевой норм. & 30 & 30 & 45 & 45 & 50 & 150,0 \\
\hline \multicolumn{7}{|l|}{ Местный бюджет г. Бишкек } \\
\hline Стационары -базовая ставка & 1340 & 1340 & 1110 & 3387 & 2855 & 213,0 \\
\hline ЦСМ - подуш. Норм. & - & 97 & 94 & 220 & 222,8 & - \\
\hline ГСВ - подуш. Норм. & - & 97 & 93 & 220 & 222,8 & - \\
\hline Стоматология & - & 16 & 14 & 36 & 32,9 & - \\
\hline Скорая помощь, на 1 бригаду & - & 166038 & 176540 & 372252 & 377000 & - \\
\hline
\end{tabular}

Таблица 2. Базовые нормативы для формирования бюджета Программы государственных гарантий по видам оказываемых медицинских услуг в разрезе источников финансирования, сом. Источеик: составлена по данным ФОМС КР 2009-2015 годы.

Как видно из таблицы, нормативы по ПГГ в 2015 году по сравнению с 2009 годом увеличились по всем источникам финансирования. Особенно высокими темпами выросли нормативы за счет республиканского бюджета, более чем в 3 раза, из них на оказание стационарной помощи в 3,3 раза. Средства бюджета г.Бишкек также направлены на увеличение нормативов финансирования стационаров, ЦСМ, ГСВ, стоматологии и скорой медицинской помощи. Вместе с ежегодным увеличением нормативов финансирования за пролеченный случай, наблюдается и рост госпитализаций по всем регионам республики.

По средствам республиканского бюджета установлены единые нормативы финансирования по всей стране. В 2015 годах для ГСВ подушевой норматив на одного застрахованного гражданина в год был утвержден в размере 176,67 сомов, за пролеченный случай в стационаре - 4849сом.

Меньшими темпами росли также нормативы, финансируемые из ФОМСа, но опять-таки большая часть из них направлена на стационарную помощь. Нормативы финансирования по средствам ОМС в 2015 в стационарах составили 1950сомов, а ГСВ 110 сомов.

Из анализа расходов на оказание стационарной помощи по статьям затрат, при общем увеличении расходов в 2,4 раза наблюдается значительный рост по заработной плате медицинского персонала в 2,7 раза, достигнув $69,3 \%$ от общих расходов в 2016 году.

Меньшими темпами росли расходы на медикаменты и питание, соответственно, в 1,7 и в 1,9 раза. Льготные расходы на лекарства составляют $2 \%$ государственных расходов на здравоохранение.

Вывод: Стационары перегружены, амбулаторно-поликлинические лечебные учреждения испльзуются неэффективно и полностью отсутствуют лечебные центры по реабилитации больных, а также профилактики болезней.

Ограниченные ресурсы в здравоохранении используются неэффективно. По данным Министерства здрвоохранения, для льготных категорий населения расходуются 94\% государственных средств направленных на медицину. 


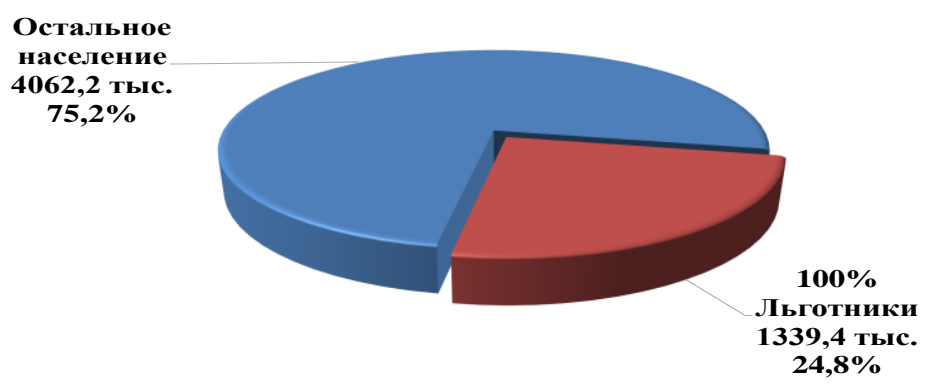

Диаграмма 1. Доля льготников, имеющих право на бесплатное получение медико-санитарной помощи по ПГГ за 2013 год, (тыс.чел.,\%) (Составлена по данным ФОМС КР 2009-2015 годы)

И для поциентов без льгот остаются всего 6\% выделенных государством средств. На лекарство каждого пациента тратится 11 сомов, на еду -28 сомов, выделенных государством денег. Результат такого распределения средств - некачественное лечение. В итоге программа государственных гарантий не финансируется в достаточном обьеме и носит деклоративный характер. Больные сами оплачивают лечение.

Ясно, для развития здравоохранения необходим экономический рост. Однако это в будущем, а заболевших людей надо лечить сегодня. Чтобы решить эту проблему, необходимо сократить количество льготников и перевести их на платное лечение.

Диаграмма 2. Категории граждан, имеющих право на получение медико-санитарной помощи по Программе государственных гарантий бесплатно и на льготных условиях на 2013 год

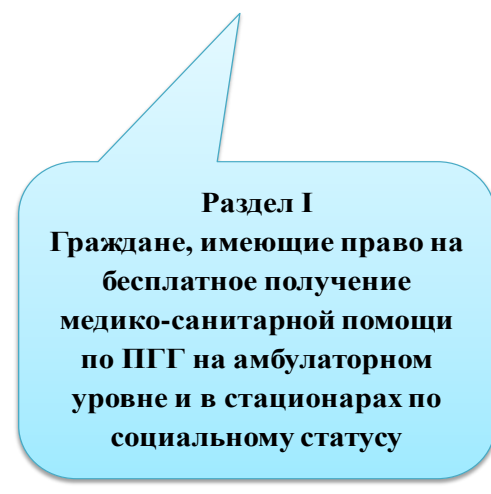

28 категорий (1133,3 тыс.)

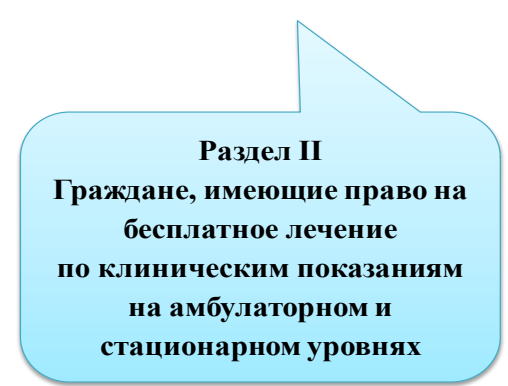

17

категорий (206,1 тыс.)

Наблюдается увеличение госпитализации по всем регионам. Это показатель неэффективной работы на первичном уровне, т. е. недолеченные в поликлиниках больные становятся пациентами стационаров. В 2016-м году стационарное лечение получили 400 тысяч граждан страны. Увеличение госпитализированных больных наблюдается по всему кыргызстану. В стационаре в 2015-м году лечились 7,1 на 100 человек, в 2014-м 6,9 (24.kg, 2016).

В здравоохранении КР финансовые средства расходуются без эффекта. Медицинские учреждения имеют низкий уровень технологии. Большая часть средств расходуются в стационарах. Недооценивается роль первичной медицинской помощи в поликлиниках.

Динамика роста госпитализаций характеризует тот факт, что лечение в стационарах не сокращается, а напротив, увеличивается, что противоречит целям реформы в здравоохранении. Это показывает, что ограниченные ресурсы в здравоохранении используются неэффективно. 


\section{5 Выводы}

В ходе анкетирования $61,8 \%$ врачей отметили отсутствие мотивации, т. е. $93 \%$ врачей не устраивает их заработная плата.

Другая причина низкого качества лечения состоит в отсутствии современной технологии лечения.

Третья причина, по мнению врачей, состоит в отсутствии самостоятельности лечения. Клинические протоколы устарели - 2008 года. Врачи считают, что они ограничивают лечение. В целях экономии средств, по нормативу заложены относительно дешевые лекарства.

Значительную часть средств Единого плательщика необходимо направлять на финансирование поликлинического уровня по сравнению с дорогостоящим стационарным лечением.

В структуре средств ФОМС следует предусмотреть фиксированную долю средств на развитие материально-технической базы поликлиник с целью своевременного диагностирования болезней и качественного лечения на уровне поликлиник.

Качество работы поликлиники необходимо оценивать по количеству приписанных больных по выбору самого больного, где больной голосует своими средствами, которые имеются на его персонифицированном счете.

\section{Литература}

- www.foms.kg.

- $\quad$ Narya (2016). «Здоровье как общественное благо». http://www.narya.ru/20.shtml

- Rosmedstrah (2016). «Определение медицинской услуги». http://www.rosmedstrah.ru/articles.php?show $=1 \& \mathrm{id}=479 \&$ offset $=40 \&$ theme $=9$.

- ФОМС КР (2015) «Условиями оплаты труда работников организаций здравоохранения Кыргызской Республики», утвержденными постановлением Правительства Кыргызской Республики № 411 от 6 июня 2006 года.

- $\quad$ 24.kg (2016). «Здоровье населения и деятельность организаций здравоохранения Кыргызской Республики в 2011 году».

http://24.kg/zdorove/16751_v_kr_s_nachala_goda_gospitalizirovali_bolee_400_tyisyach patsientov/ 


\title{
Перспективы Туристического Бизнеса В Кыргызстане Tourism Perspectives in Kyrgyz Republic
}

\author{
Prof. Dr. Anara Kamalova (Kyrgyz National University, Kyrgyzstan)
}

\begin{abstract}
The level of services is increasing in modern economic development of Kyrgyz Republic, and tourism plays an important role in this process. Tourism in Kyrgyz Republic is one of the prioritized spheres of economy that can create opportunities for further integration of Kyrgyz economy into the Eurasian Economic Union.

This paper includes theoretical issues of tourism development in Kyrgyz Republic and simultaneously gives an analysis of its development. Article allots a special section for tourism development along the path of Silk Road in Central Asian countries. Moreover, current problems of tourism are emphasized and recommendations on further development of tourism are given.
\end{abstract}

За 25 лет независимости Кыргызской республики мы определились в приоритетах, как в общественном развитии, так и в экономике и культуре. И во всех вариантах развития экономики, туризм рассматривался нами как одно из главных приоритетных направлений.

Хотелось бы отметить, что Кыргызстан с 2002 года является членом Всемирной туристской организации. Членство в этой авторитетной международной организации благоприятно сказывается на развитии туризма в целом. Перспективу развития этой отрасли для республики доказывает провозглашение 2001 года «Годом туризма».

Кыргызстан издревле входил в зону развитой центральноазиатской цивилизации и служил основным резервом и перевалом на трассах международных торговых караванных путей. Благодаря Великому Шелковому пути, происходило взаимообогащение культур стран Востока и Запада.

На протяжении многих сотен лет наши предки бережно относились к окружающей среде, и перед нашим поколением стоит очень важная задача - в свою очередь сохранить для своих потомков всю природную красоту нашей родины.

На территории Кыргызстана компактно расположены 88 горных хребтов общей протяженностью 7657 км. Около 6500 ледников общей площадью более 800 кв. км. Среди них привлекательные для многих туристов и альпинистов мира, пик Ленина и семитысячники пики Хан-Тенгри и Победы.

Наши естественные природные объекты (горы, ущелья, озера, пещеры и др.) сохранившие свой первозданный вид, дают нам реальную возможность развивать самые различные виды туризма:

1. развлекательно-оздоровительный вид туризма, ориентированный на пассивный отдых, лечение;

2. экскурсионно-познавательный туризм, связанный в основном с историко-культурными объектами.

Но наибольшие перспективы, в сфере активного отдыха конечно же, имеет приключенческий туризм, который включает горный альпинизм и спелеотуризм (пещеры), водный (сплав по горным рекам) горнолыжный, конный, велосипедный и др. Именно эти виды туризма привлекают самое большое число участников, поскольку для этого есть природные условия. Но наличие одних природных условий явно недостаточно. По мнению международных экспертов по туризму, Кыргызстан - драгоценный камень, который трудно выставить на рынок потребителей без отработки, т.е. нужно поднять туристский сервис на международный уровень.

В бывшем Союзе ССР Кыргызстан славился как край курортных и туристических достопримечательностей, включая самый широкий спектр предлагаемых услуг: отдых в спортивнооздоровительных лагерях, санаториях, пансионатах, в горнолыжных курортах, походы по горнотуристическим маршрутам, охота.

По Кыргызстану проходили такие известные всесоюзные туристические маршруты как: маршрут по Киргизии и Казахстану (Фрунзе - озеро Иссык-Куль - Алма-Ата); маршрут «из Средней Азии в Казахстан» (Ташкент - Чимкент - Джамбул - Фрунзе - Алма-Ата); а также действовали многочисленные местные туристические маршруты.

Жемчужина Кыргызстана - озеро Иссык-Куль - было излюбленным местом отдыха граждан Союза и котировалось наравне с Крымом и Черноморским побережьем Кавказа. Распад СССР повлек за собой развал экономической системы и экономических связей между республиками.

Таким образом, все вышесказанное доказывает, что в настоящее время Кыргызстан располагает уникальными природными и историко-культурными ресурсами, представляющими интерес для развития туризма как самостоятельной и перспективной отрасли экономики. 
Природное богатство Кыргызской республики позволяет создавать заповедники и национальные природные парки, что дает еще большую возможность для привлечения иностранных туристов в нашу страну. В таблице 1 приведены данные о развитии заповедников и природных парков в республике за 20102014 годы.

\begin{tabular}{|l|l|l|l|l|l|l|}
\hline & 2010 & 2011 & 2012 & 2013 & 2014 & $\begin{array}{l}2014 \text { в \% к } \\
2010\end{array}$ \\
\hline Число природных нац. парков & 9 & 9 & 9 & 9 & 10 & 111,1 \\
Их площадь, тыс. га & 304,4 & 304,4, & 304,4, & 304,4, & 363,6 & 119,4 \\
Число заповедников & 10 & 10 & 10 & 10 & 9 & 90 \\
Их площадь, тыс. га & 503,8 & 503,9 & 591,1 & 610,4 & 551,4 & 109,4 \\
Число охотничьих хозяйств, ед. & 35 & 41 & 47 & 49 & 50 & 142,9 \\
Их площадь,тыс.га. & - & $12 ;$ & 12,7 & 12,8 & 12,8 & - \\
\hline
\end{tabular}

Таблица 1. Развитие заповедников и природных наџиональных парков Кыргызской Республики. Источник: Туризм в Кыргызстане 2010-2014 г2. Стат.сборник-Бишкек 2015.

Как видно из таблицы, несмотря на кризисное состояние развития экономики республики, на охрану природы и естественной красоты края уделяется большое внимание. Число заповедников в 2014 году, по сравнению с 2010 годом, возросло на 9,4\%, их площадь на 42,9\%; за этот же период число национальных парков увеличилось на $11,1 \%$, их площадь в $19,4 \%$, число охотничьих хозяйств на $42,9 \%$, тем самым появляются возможности дальнейшего развития туризма в республике.

В настоящее время туристическая инфраструктура представлена различными объектами туризма и отдыха. Рассмотрим динамику развития санаторий и учреждений отдыха по стране за 2010 - 2014 годы.

В республике на 1 января 2015 года действуют следующие развлекательные для туристов объекты: на 20 профессиональных театров, 65 музеев, 42 кинотеатра, 6 концертных организаций и т.д. За анализируемый период объекты туризма и отдыха в республике увеличились на 36,9\%, а в 2014 году насчитывалось около 9524 объекта, среди которых 45,2\% рестораны, 34,6\% туристические, тогда как удельный вес таких важных объектов туризма, как предприятия туризма и отдыха $(8,9 \%)$, санаторно-курортные учреждения (всего лишь $0,9 \%$, мизерные проценты. Кроме того, эти объекты в основном морально и физически изношены, характеризуются низким уровнем комфортабельности проживания и предоставляемых услуг, отсутствием квалифицированного персонала и т.д.

\begin{tabular}{|l|l|l|l|l|}
\hline & \multirow{2}{*}{2010} & \multicolumn{2}{|c|}{2014} & 2014 в \% к \\
\cline { 3 - 4 } & & Количество & удельный вес, \% & 2010 \\
\hline Гостиницы & 611 & 966 & 10,1 & 158,1 \\
Предприятия туризма и учреждения отдыха & 642 & 843 & 8,9 & 131,3 \\
Рестораны & 2909 & 4306 & 45,2 & 148,0 \\
Туристические агентства & 2697 & 3300 & 34,6 & 122,5 \\
Санаторно-курортные учреждения & 86 & 90 & 0,9 & 104,7 \\
Природные парки и заповедники & 10 & 19 & 0,2 & 190,0 \\
ВСЕГО & $\mathbf{6 9 5 5}$ & $\mathbf{9 5 2 4}$ & $\mathbf{1 0 0}$ & $\mathbf{1 3 6 , 9}$ \\
\hline
\end{tabular}

Таблица 2. Развитие объектов туризма и отдыха в Кыргызской республике на начало года (единии) Источник: Туризм в Кыргызстане 2010-2014 г2. Стат.сборник-Бишкек 2015.

В 2014 г. экспорт туристических услуг, по оценочным данным составил 408,1 млн, долларов США и по сравнению с 2010г. увеличился в 2,8 раза, При этом, на долю доходов от приема иностранных граждан в 2014 г. в общем объеме экспорта услуг пришлось более $45 \%$.

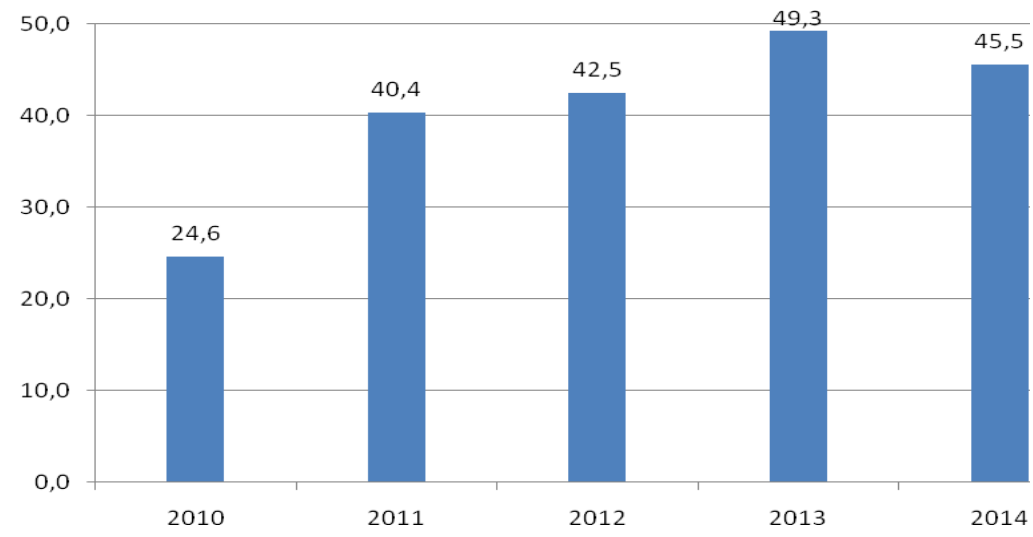


Pис. 1. Экспорт туристических услуг в Кыргызской республике за период 2010-2014 г2. (в процентах к общему объему экспорта услуг). Источник: Туризм в Кыргызстане 2010-2014 г2. Стат.сборник-Бишкек 2015.

По статистическим данным Кыргызской республики, в 2014 году страну посетило 151 тыс. туристов из дальнего зарубежья, принося ей доход 3 млн. долларов, при прогнозе на этот год 30,0 тыс. туристов (доход 13,2 млн. долларов). Фактически за счет нестабильной политической ситуации в Джети-огузском районе Иссык-кульской области, приграничном с Таджикистаном районах и по ряду других причин, страна потеряла 10,2 млн. долларов, т.е. нашу республику посетило в 10 раз меньше туристов из дальнего зарубежья, чем предполагалось.

Если анализировать число туристов, приехавших в Кыргызскую республику из стран дальнего зарубежья, то они занимают небольшую долю: туристы из Турции - 1,2\%, Китай - 1\%, Германии и США $1 \%$.

Как мы уже отметили, в Кыргызстане туризм признан приоритетным направлением в экономике, поэтому для усовершенствования и улучшения работы, а также дальнейшего развития туризма, Правительством КР было создано Государственное агентство КР по туризму и спорту. В 1998 году была разработана концепция развития туризма в Кыргызстане на период до 2010 года, а в 1999 году утверждена государственная программа развития туризма до 2010 года, 2010 до 2020 г. Эти документы определяют основные направления развития туризма в Кыргызстане, что в перспективе даст возможность развития всей индустрии.

Несмотря на такой рост туристических объектов, принятие вышеперечисленных государственных документов, доля туризма в ВВП остается незначительной.

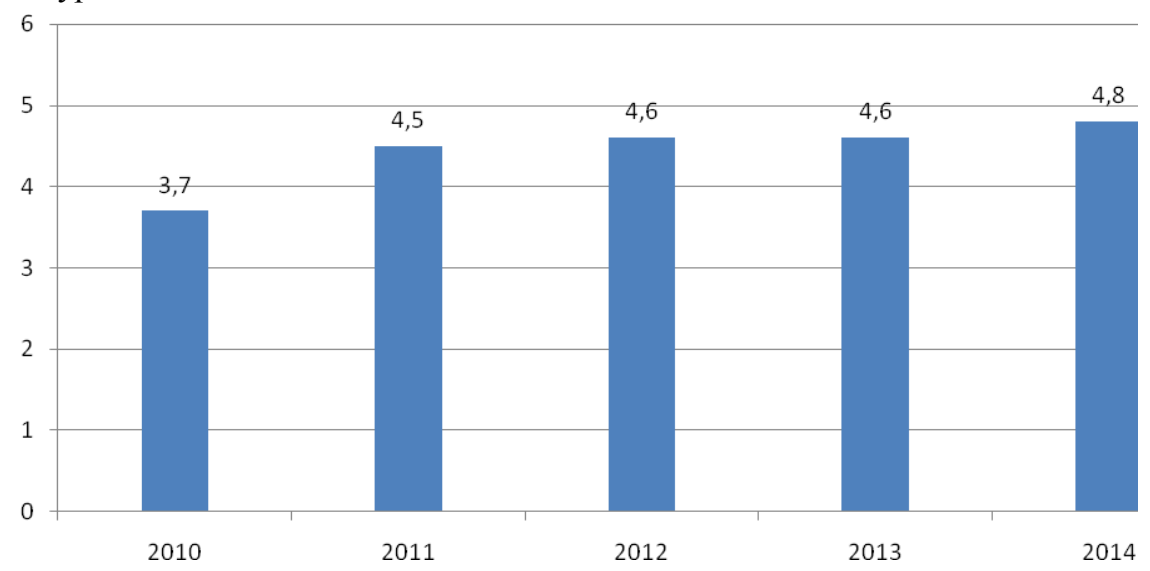

Pис.2. Валовая добавленная стоимость в сфере туристической деятельности (в \% к ВВП) Источник: Туризм в Кыргызстане 2010-2014 г2. Стат.сборник-Бишкек 2015.

Как видно из рисунка в 2014 году, доля сферы туризма в ВВП достигла всего лишь 4,8\%, тогда как в некоторых зарубежных странах этот показатель достигает около 50\%. Какие же основные причины сдерживающие развитие туристического бизнеса в стране? Этот вопрос волнует всех заинтересованных сторон: и бизнесменов, работающих в этой стране, и правительство страны, и ученых, занимающихся этой проблемой, и самое главное, потребителей туристических услуг - отдыхающих. В данной статье мы хотим остановиться на самых распространенных проблемах в сфере туризма и попытаться искать пути их решения. На наш взгляд, самыми актуальными проблемами на сегодняшний день являются следующие:

- недостаточное развитие инфраструктуры туризма;

- активное освоение туризма, в основном в иссык-кульском регионе;

- слабый акцент логистики туризма по республике;

-нет сглаженного развития государственно-частного партнерства в сфере туризма;

- существование случаев сокрытия доходов туристических фирм от государства;

- недостаточное внимание маршрутам отдыха «Великий Шелковый Путь»

- не на должном уровне туристический маркетинг,

- слабое развитие внутреннего туризма.

Для определения перспективы развития туризма в Кыргызстане, необходимо хорошо изучить этот рынок, его можно разделить на три части: рынок стран СНГ, дальнего зарубежья и внутреннего рынка:

1. В странах СНГ сложился устойчивый рынок, ориентированный на Кыргызстан, в частности иссыккульский регион. Основной туристический поток приходится на республик СНГ - Россия, Казахстан и 
Узбекистан. На наш взгляд необходимо расширить рынок сбыта туристической продукции и в другие республики СНГ. Наиболее выгодным считаем рынок Туркменистана и Прибалтийские государства. В связи с последними событиями в России, у нас открываются возможности привлечения туристов из этой страны.

2. Большой интерес к республике придают туристы из дальнего зарубежья. Кыргызстан для них является, не так известен. На мировом туристическом рынке вообще пользуется высокой известностью место назначения "Центральная Азия", включающая страны СНГ (Казахстан, Узбекистан, Таджикистан и Туркменистан), соседствующие с Кыргызстаном.

Страны мира стараются привлекать туристов на свои территории с целью увеличения получаемой от туристов иностранной валюты. Привлечением туристов в свою страну занимаются не только развивающиеся страны, нуждающиеся в иностранной валюте, но и передовые государства, как США, Англия и др. Поэтому во многих странах существуют Министерство туризма и Департамент туризма для грандиозного проведения политики привлечения туристов. Тремя наибольшими рынками (странами и регионами), отправляющими туристов, являются Северная Америка, Европа и Азия (особенно, Восточная Азия), в последнее время активно включается Китай. Места назначения развертывают сильное соревнование за привлечение туристов с этих рынков в свои страны. Это называется: "соревнование между местами назначения" на международном туристическом рынке.

Странам СНГ с низкой известностью, как место назначения, в том числе и Кыргызстан, невыгодно стремиться индивидуально привлекать туристов в свои государства, с точки зрения, и экономического эффекта, и затрат. Пяти странам Центральной Азии необходимо объединиться в одно место назначения под названием "Центральная Азия" с более высокой известностью для выступления на мировом туристическом рынке. То есть, благоразумно принять меры по увеличению своей доли путем объединения в одно место назначения и увеличения прибыли, чем бороться за малые прибыли.

Туристов из дальнего зарубежья интересует туризм по центрально-азиатской части Шелкового пути, т.к. оазисные города, исторические памятники, остатки традиций, фольклоры, оставленные Шелковым путем, представляют собой наибольшую привлекательность и сильную сторону туризма по Центральной Азии. Более того, к 2020 году, согласно прогнозам Всемирной туристической организации, наиболее популярным направлением среди туристов станет Великий Шелковый Путь.

Ниже приводятся города и посещаемые туристами местности, часто включенные в туристические маршруты на тему Центральной Азии и Шелкового пути в нисходящем порядке известности: Самарканд, Бухара, Хива, Пенджикент, Ош, Узген, Туркистан. Большинство из них находится на территории Узбекистана. Освоение и развитие туристического потенциала Великого Шелкового пути поможет создать универсальный турпродукт, включающий в себя наиболее перспективные и оперативные виды туризма, пользующиеся спросом. Для Кыргызстана выгодны следующие комплексные транзитные туры по маршруту Великого Шелкового пути: Кашгар - Нарын - Иссык-Куль - Бишкек - Джамбул; либо Кашгар Ош - Узген - Джалал-Абад - Самарканд - Бухара - Хива. На наш взгляд, первоочередной задачей является решение на государственном уровне вопроса открытия единой туристической визы для посещения этих мест.

Для успешного продвижения туризма в Центральной Азии (на примере Кыргызстана) необходимо сделать также следующее:

а. Улучшить впечатление Центральной Азии как место назначения.

Пяти странам СНГ, в том числе и Кыргызстану, необходимо, прежде всего, улучшить известность как центрально-азиатские места назначения на международном туристическом рынке, путем совместного накопления средств, людских ресурсов и ноу-хау пяти стран, для чего нужна реализация следующих работ:

- установление организации сотрудничества в поощрении туризма в пяти странах региона;

- отыскание туристических ресурсов, объектов и учреждений (с достопримечательностями, отвечающими требованиям на международном туристическом рынке);

- разработка и установление разнообразных туристических маршрутов и предложений, покрывающих эти государства, составление рекламных материалов;

- организация рекламной деятельности, ограниченная рынками с высокой возможностью отправления туристов.

б. Проводить разработку туризма в сотрудничестве с Китаем, изучая опыт других государств. Для китайских туристов необходимо разработать программы отдыха с посещением торговых точек, продающих кыргызские золотые и серебряные изделия.

Для улучшения работы по продвижению туристической продукции Кыргызстана на рынок, необходимо провести также следующие мероприятия: 
1. организация рекламы турпродукта Кыргызстана через средства массовой информации, в том числе открытие информационного центра в Бишкеке и областных центрах для обслуживания иностранных туристов и контингента иностранцев, проживающих в Бишкеке и странах СНГ (как агентство и мини выставочные центры);

2. установление контактов с ведущими международными туроператорами с целью размещения коммерческих предложений в западных каталогах;

3. организация совместно с НАК «Кыргызстан аба жолдору» презентационных туров для туристских журналов, туроператоров, турагентов, авиалиний, телевидения и радио под названием «Добро пожаловать в Кыргызстан - центр Великого Шелкового пути»;

4. активное участие в ташкентской турбирже «Великий Шелковый путь», в Лондонской турбирже отдельным стендом «Кыргызстан - сердце Центральной Азии»;

5. подписание договора о сотрудничестве в организации сквозных туров по Великому Шелковому пути и совместной продаже их на внешних рынках с ПК «Узбектуризм» и Минтурспортом Казахстана;

6. открытие туристских офисов за рубежом на взаимовыгодных условиях с иностранными туристскими компаниями;

7. подготовка к изданию пакета информационных материалов по Кыргызстану.

3. Огромная роль в развитии туристического бизнеса играет, прежде всего успешное развитие внутреннего туризма. Как нам известно, внутренний туризм за последние годы не развивается и никто не уделяет должного внимания. Например, житель севера республики не едет отдыхать на юг и наоборот, естественно кроме иссык-кульской области, куда летом едут со всех регионов. Достопримечательности других регионов многие жители даже не знают. Следует отметить, что в регионах Кыргызстана много исторических, этнических, культурно-развлекательных достопримечательностей, которые еще не раскрыты полностью для туристов.

Также в последние годы кыргызстанцы часто предпочитают отдыхать за границей, нежели у нас. И вот для того, чтобы удержать хотя бы своих внутренних туристов, необходимо применять современные маркетинговые методы продвижения туристического продукта, рекламировать достопримечательности наших земель внутри страны. С учетом природно-климатических условий, особенности местной достопримечательности, необходимо развивать туризм в регионах. Основные перспективные виды туризма в областях на наш взгляд следующие:

- в Нарыне и Таласе можно развивать эко и этно-туризм;

- а Иссык-Куле - летний и зимний спортивный туризм, медицинский туризм;

- Джалалабаде - медицинский и этно-туризм;

- в Оше, Баткене необходимо развивать религиозно-паломнический и исторический туризмы, зимние виды туризма.

В целом, можно сказать, что в республике есть перспективы развития туризма и на наш взгляд, можно эффективно и своевременно решить современные проблемы в этой отрасли.

\section{Литература}

- Бейшембаева Ж.Т., Абдукадырова А.К. (2000). «Туризм Кыргызстана». Б.

- Дудашвили С.Д. (2004). «Туристские ресурсы Кыргызстана». Бишкек.

- Дурович А.П. (2001) «Реклама в туризме». Минск.

- Жыргалбеков Т. (1998). «Туризм Кыргызстана: современность и перспективы». Бишкек.

- Камалова А. (2008) «Маркетинг». Бишкек.

- Максудинов А. Камалова А. (2016) «Маркетинг услуг». Бишкек.

- Чудновский А.Д., Жукова М.А., Сенин В.С. (2005). «Управление индустрией туризма». М.

- З Закон КР «О туризме» от 25 марта 1999 г.

- Национальный статистический сборник «Туризм Кыргызстана».

- Стратегия развития страны до 2020 года.

- Концепция развития туристической отрасли в КР до 2020 г. года. 


\title{
Обязательное медицинское страхование в Кыргызстане: проблемы и пути совершенствования
Compulsory Health Insurance in Kyrgyzstan: Problems and Development

\author{
Assoc. Prof. Dr. Damira Japarova (Kyrgyzstan-Turkey Manas University, Kyrgyzstan)
}

\begin{abstract}
In Kyrgyzstan, the "compulsory health insurance" is not a true model of insurance. Mandatory contributions to compulsory health insurance (CHI) are a kind of state tax and state-funding of the health system. Employers are not motivated to support health insurance, as the payers don't know how his payments are used. Therefore, the main contributors of $\mathrm{CHI}$ in Kyrgyzstan are public sector workers. Some people working in private sector, with higher incomes, is almost not covered by health insurance. Foreign citizens living in Kyrgyzstan are not able to insure their health. Therefore, it is necessary to reform the current fiscal and insurance system of financing healthcare to the system of financing based on the insurance principle.
\end{abstract}

Ключевые слова: медицинское страхование, структура бюджета фонда обязательного медицинского страхования, персонификация средств обязательного медицинского страхования, гибкая система страхования.

Государство располагает одним из важных инструментов финансирования государственных услуг. Это Фонд обязательного медицинского страхования, за счет которого населению предоставляется возможность пользоваться гарантированным со стороны государства пакетом медицинских услуг. Основу фонда составляют обязательные отчисления, которые осуществляют работодатели из фонда заработной платы.

Нужна ли система страхования? Для того чтобы это понять, рассмотрим причину ее появления. Как правило, человек не планирует свои расходы на медицинское обслуживание, поскольку не знает, когда он заболеет и заболеет ли вообще. Несомненно, он принимает во внимание этот риск и связанные с ним расходы. Поскольку он не всегда в состоянии нести большие расходы на поддержание своего здоровья или устранение какой-либо болезни, то вынужден прибегать к помощи различных фондов медицинского страхования. Будучи здоровым, человек отчисляет определенную сумму в специальный фонд, управляемый страховым институтом или компанией, и таким образом обретает средства на лечение.

Система обязательного медицинского страхования (ОМС), обеспечивая как финансирование, так и управление качеством медицинских услуг, распространена во многих странах мира и СНГ и является уникальной возможностью осуществления независимой экспертизы качества медицинской помощи и источником дополнительных внебюджетных средств для национального здравоохранения. С его помощью государство обеспечивает социальную защиту интересов населения страны, касающихся охраны здоровья. При необходимости человеку предоставляется возможность воспользоваться гарантированной помощью из средств, накопленных страховщиком. В каждой стране существует своя система госфинансирования медицинских услуг. Из всего их многообразия можно выделить две системы: обязательного медицинского страхования (еще ее называют социальное медицинское страхование) и бюджетного финансирования.

Система обязательного медицинского страхования основана на страховых взносах, уплачиваемых самими работающими или их работодателями. Они принимают на себя обязательства перед государством осуществлять взносы в виде фиксированного процента к фонду оплаты труда. Преобладают страны, в которых согласно системе ОМС выплаты производят и работодатели, и работники почти в равных долях. В России это обязательство закреплено исключительно за работодателем.

Для неработающего населения существуют два способа страхования: 1) работающий страхуется вместе с неработающими членами семьи, а сумма выплат, которую осуществляют работающий или работодатель, является страховым взносом как для работающего, так и для членов его семьи; 2) источником страховых взносов для неработающих становится государственный бюджет или внебюджетный фонд.

Граждан, имеющих медицинскую страховку, в Кыргызстане насчитывается 4 млн. 105 тыс., или 75\% населения страны (zdorovie.akipress.org/news:22370)

Принятая в Кыргызской Республике система ОМС не есть истинная модель страхования, она служит для перераспределения средств (в виде налогов и страховых взносов), собираемых налоговыми органами и поступающих затем в Социальный фонд, из которого они направляются в Фонд обязательного медицинского страхования.

Можно усмотреть в обязательном взносе на медицинское страхование некий вариант государственного налога и формы финансирования предоставления медицинской помощи. А один из недостатков данной 
системы ОМС, причем существенных, видится в необеспеченности экономически оправданной формой и механизмом введения застрахованного лица, как потребителя этой помощи, в систему отношений страхования.

Анализ экономического аспекта системы обязательного медицинского страхования показывает на отсутствие понятий «страховой случай» и «страховой риск». И критерием для финансирования служат количественные параметры, к которым отнесены стоимость каждой услуги, амбулаторное посещение и койко-дни.

1. Установлено, что застрахованный пациент не вовлечен в систему субъектных отношений ОМС. Не упорядочен пакет медицинских услуг, предоставляемых по системе страхования, поэтому сложно определить границу между страховыми и нестраховыми, бесплатными и гарантированными со стороны государства услугами. Анкетный опрос позволил установить, что $63 \%$ опрошенных ничего не знают о существовании медицинских услуг, предоставляемых бесплатно в рамках госпрограммы гарантий, более того, 28,6\% (почти каждый третий) неофициально оплачивают свое лечение, вступая во внесистемные отношения с медработниками. Среди таких пациентов 27,4\% постоянно неофициально оплачивают свое лечение, 43\% делают это иногда в виде платы за лекарства ( Rezultati anketirovania vracheey I psientov,2014g.).

Самое главное - сложившаяся практика не вызывает у пациента уверенности в том, что он как потребитель медицинских услуг будет находиться на первом месте в приоритетах взаимоотношений.

Фонд обязательного медицинского страхования работодатели пополняют ежемесячно в виде отчислений от разного рода выплат. В Кыргызстане они составляют $2 \%$, в странах ближнего зарубежья и СНГ их размер значительно выше (табл. 1).

\begin{tabular}{|c|c|c|}
\hline \multirow{2}{*}{ Страна } & \multicolumn{2}{|c|}{ Отчисления в Фонд обязательного медицинского } \\
\cline { 2 - 3 } & от работодателя & от физического лица \\
\hline Кыргызстан & 2 & - \\
\hline Россия & 5,1 & - \\
\hline Грузия & 3 & - \\
\hline Молдова & 3,5 & 3,5 \\
\hline Германия & 7,45 & 7,45 \\
\hline
\end{tabular}

Таблица 1. Действующие тарифы ОМС в странах СНГ и зарубежья и КР Источник: V Kirgizstane predldgauyt povisit otchislenia na obiazatelnoe medisinskoe strahovanie za schet dohodov rabotnika s 2 do 3\%

Если взять Германию, то, согласно Книге социальных законов, средний налогоплательщик отчисляет на медицинскую страховку14,3\% от своей заработной платы, почти половину этой суммы выплачивает работодатель. Это средние значения, сумма может колебаться в пределах 12-15\%. Предполагается, что вследствие старения населения и роста расходов на здравоохранение, размер взноса к 2030 г. достигнет $25 \%$, Взнос застрахованного в этой стране напрямую зависит от размера его дохода. А вот услуги ему предоставляются в строго определенном объеме, а не от того, какую сумму он внес в кассу медицинского учреждения. Более того, в категорию застрахованных попадают и другие члены семьи, доход которых не выходит за пределы установленной суммы. Из этого можно заключить, что система государственного медицинского страхования в Германии предоставляет равные права пациентам на пользование медицинскими услугами, поскольку не имеют значения ни возраст, ни состояние здоровья, ни финансовая ситуация пациента (akipress.org/zdorovie/news:17203/).

Рассмотрим еще один принцип, присущий германской системе медицинского страхования. Это управляемость государственными больничными кассами, предусматривающая самоуправление. Таким образом, вся цепочка: кассовые работники, сотрудники больниц, врачи и сами пациенты - то есть любой застрахованный гражданин может быть избран в органы самоуправления больничных касс. И если сравнивать немецкую систему с американской, швейцарской, голландской, ориентированных на платежеспособность граждан, то, благодаря этим принципам и более широкому спектру гарантированных услуг, она от них выгодно отличается. (Gosudarstvennoe medisinskoe strahovanie v Germanii).

Финансирование здравоохранения Кыргызской Республики осуществляется из разных источников. Их удельный вес в общих расходах приведен в табл. 2. 


\begin{tabular}{|l|c|c|c|c|c|c|c|}
\hline $\begin{array}{l}\text { Источник } \\
\text { финансиро- } \\
\text { вания }\end{array}$ & 2009 & 2010 & 2011 & 2012 & 2013 & $\begin{array}{c}2013 \text { г. по } \\
\text { отношению к } \\
2009 \text { г., } \\
\text { млн. сом. }\end{array}$ & $\begin{array}{c}2013 \text { г. в \% } \\
\text { к 2009 г. }\end{array}$ \\
\hline Бюджет & 78,5 & 79,0 & 80,2 & 81,9 & 80,5 & - & $+2,0$ \\
\hline ФОМС & 15,0 & 14,5 & 14,1 & 12,5 & 13,2 & - & $-1,8$ \\
\hline Частные & 6,5 & 6,5 & 5,7 & 5,6 & 6,3 & - & $-0,2$ \\
\hline Всего & 100,0 & 100,0 & 100,0 & 100,0 & 100,0 & - & - \\
\hline
\end{tabular}

Таблица 2. Удельный вес источников финансирования в Кыргызстане в общих расходах здравоохранения

(\%) Источник: Tablisa sostavlena po dannim Ministerstva zdravoohranenia v KR za 2009-2013 gg

В 2013 г. отмечается низкий процент страховых поступлений в Фонд обязательного медицинского страхования. По официальным данным этот показатель составил только 13,2\% доходной части Единого плательщика. Низкий удельный вес поступающих взносов объясняется невысокой платежеспособностью основных плательщиков, каковыми являются представители бюджетной сферы, что свидетельствует об ограниченности реальных источников страховых поступлений в системе ОМС.

Таким образом, выделим причины, объясняющие низкую обеспеченность населения услугами здравоохранения, предоставляемыми на средства ОМС:

- низкая доля государства в структуре расходов на здравоохранение;

- снижение величины налоговой базы вследствие увеличения доли незанятого населения и сокращения доходов, декларируемых официальным сектором экономики;

- $\quad$ рост числа нетрудоспособных

\begin{tabular}{|c|c|c|c|c|c|c|}
\hline & 2009 & 2010 & 2011 & 2012 & 2013 & $\begin{array}{c}2013 \text { г в } \\
\text { \% } 2009 \text { г. }\end{array}$ \\
\hline $\begin{array}{c}\text { Собственные } \\
\text { средства ОМС из }\end{array}$ & 765,4 & 774,4 & 1062,2 & 1209,9 & 1390,0 & 181,6 \\
\hline $\begin{array}{c}\text { Средства ОМС из } \\
\text { республиканского }\end{array}$ & 259,4 & 25,4 & 259,4 & 259,4 & 259.4 & 100,0 \\
\hline $\begin{array}{c}\text { Спе. средства и } \\
\text { сооплата }\end{array}$ & 261,4 & 278,5 & 356,1 & 434,1 & 548,6 & 209,9 \\
\hline $\begin{array}{c}\text { Всего } \\
\text { Удельный вес, \% }\end{array}$ & $\mathbf{1 2 8 6 , 2}$ & $\mathbf{1 3 1 2 , 3}$ & $\mathbf{1 6 7 7 , 7}$ & $\mathbf{1 9 0 3 , 4}$ & $\mathbf{2 1 9 8 , 0}$ & $\mathbf{1 7 0 , 9}$ \\
\hline $\begin{array}{c}\text { Собственные } \\
\text { средства ОМС из } \\
\text { Социального фонда }\end{array}$ & 59,5 & 59,0 & 63,3 & 63,6 & 63,2 & $+3,7$ \\
\hline $\begin{array}{c}\text { Средства ОМС из } \\
\text { республиканкого } \\
\text { бюджета }\end{array}$ & 20,2 & 19,8 & 1,5 & 13,6 & 11,8 & $-8,4$ \\
\hline $\begin{array}{c}\text { Спец. средства и } \\
\text { соплата }\end{array}$ & 20,3 & 21,2 & 21,2 & 22,8 & 25,0 & $+4,7$ \\
\hline Всего & $\mathbf{1 0 0 , 0}$ & $\mathbf{1 0 0 , 0}$ & $\mathbf{1 0 0 , 0}$ & $\mathbf{1 0 0 , 0}$ & $\mathbf{1 0 0 , 0}$ & - \\
\hline
\end{tabular}

Таблиц 3. Динамика и структура бюджета ФОМС Кыргызстана за 2009-2013 годы, млн. сом. Источник: Tablisa sostavlena po dannim Ministerstva zdravoohranenia v KR za 2009-2013 gg.

В период 2009-2013 гг. отмечались медленные темпы роста средств Фонда обязательного медицинского страхования по сравнению с государственными расходами на здравоохранение. Если их доля в 2009 г. составляла 15\%, то в 2013 г. зафиксировано всего лишь 13,2\%. Причина видится в том, что с 1997 г., то есть со времени учреждения ОМС, размер страховых взносов не пересматривался, его норма по-прежнему составляет 2\% фонда заработной платы работодателя. Сумма средств, поступивших в ФОМС в 2016 г., насчитывает 1 млрд. 819 млн. сом. [Ро dannim Ministerstva zdravoohranenia v KR za за 2014-2015 гг].

Обратимся к структуре показателей бюджета Фонда обязательного медицинского страхования. В его доходную часть увеличились поступления из фонда оплаты труда на 3,7\%, от сооплаты граждан и спецсредств организаций - на 4,7\%. Уменьшились отчисления из республиканского бюджета за пенсионеров и детей (до 16 лет) на 8,4\%, несмотря на то, что численность этих лиц, получающих 
социальные пособия, отнюдь не уменьшилась. Причина в том, что в течение длительного времени подобный контингент не анализировался и оставались неизменными финансовые потоки.

Надо отметить, что правительство предоставило 28 категориям граждан (1133,3 тыс. чел.) право на получение бесплатной медицинской и санитарной помощи по ПГТ в зависимости от социального статуса, a 17 категорий граждан (206,1 тыс. чел.) могут бесплатно пользоваться помощью медицинских работников в зависимости от того или иного основного заболевания уже по клиническим показаниям.

\begin{tabular}{|c|c|c|c|c|c|}
\hline \multirow{2}{*}{ № ח/П } & \multirow{2}{*}{$\begin{array}{l}\text { Категория } \\
\text { населения }\end{array}$} & \multicolumn{2}{|c|}{$\begin{array}{c}\text { Застрахованные граждане } \\
\text { на 01.09.2014г. }\end{array}$} & \multicolumn{2}{|c|}{$\begin{array}{c}\text { Застрахованные граждане } \\
\text { на } 01.09 .2015 \text { г. }\end{array}$} \\
\hline & & тыс.чел. & $\%$ & тыс.чел. & $\%$ \\
\hline & Работающие & 812,6 & 20,0 & 787,2 & 19,2 \\
\hline & Пенсионеры & 528,7 & 13,0 & 522,7 & 13,0 \\
\hline & $\begin{array}{l}\text { Дети в возрасте до } \\
16 \text { лет }\end{array}$ & 1837,2 & 45,3 & 1872,1 & 45,6 \\
\hline & $\begin{array}{l}\text { Дети от 16-18 лет } \\
\text { (школьники) }\end{array}$ & 206,2 & 5,1 & 201,7 & 4,9 \\
\hline & Фермеры & 568 & 14,0 & 583,5 & 14,2 \\
\hline & $\begin{array}{l}\text { Лица, получающие } \\
\text { социальные } \\
\text { пособия }\end{array}$ & 87,1 & 2,1 & 87,2 & 2,1 \\
\hline & $\begin{array}{l}\text { Лица, } \\
\text { самостоятельно } \\
\text { приобретшие } \\
\text { полис ОМС }\end{array}$ & 13,6 & 0,3 & 38,5 & 0,9 \\
\hline & $\begin{array}{l}\text { Беженцы, } \\
\text { которых } \\
\text { поступают взносы } \\
\text { из УВКБ ООН }\end{array}$ & 0,2 & 0,005 & 0,2 & 0,04 \\
\hline & Военнослужащие & 2,9 & 0,1 & 2,5 & 0,06 \\
\hline & Всего: & 4056,5 & 100,0 & 4105,2 & 100,0 \\
\hline
\end{tabular}

Таблица 4. Динамика и структура застрахованных граждан по республике за 2014-2015 г2. Источник: Tablisa sostavlena po dannim Ministerstva zdravoohranenia v KR za 2014-2015gg.

По данным табл. 4, наблюдаются большие изменения по структуре застрахованных лиц. Например, сократился удельный вес работающих - с 20,0 до 19,2\%, а ведь именно от них работодатели производят основную часть страховых отчислений. Поскольку у работодателя отсутствуют мотивы для поддержания медицинского страхования, ведь неизвестно, на что тратятся эти средства, то он и стремится не увеличить, а наоборот, сократить эти выплаты.

Среди участников страхования преобладают потребители этих средств. Работающие и оплачивающие ОМС составляют 19,2\%.Основную часть пользующихся средствами ОМС составляет категория детей до 16 лет (45,6\%), затем следуют фермеры (14,2\%) и пенсионеры (13,0\%). Практически не охвачены системой страхования работники коммерческих структур, доходы которых наиболее высокие.

Незначительную долю составляют сборы от фермеров и предпринимателей, несмотря на их ключевые позиции в реформе здравоохранения

ФОМС, накапливая бюджетные и страховые средства, распределяет их в системе единого плательщика, способствуя выравниванию качества медицинских услуг и финансирования по регионам.

Привлечь коммерческие структуры в систему ОМС можно только путем их личной заинтересованности в этом. Необходима также персонификация учета средств ОМС. Идентифицируя счета, мы тем самым способствуем увеличению численности застрахованных.

Есть еще нерешенные проблемы. Одна из них - это незастрахованные иностранные граждане, долго проживающие в Кыргызстане. Они не имеют такой возможности. Хотя наша республика, в условиях дефицита денежных средств, нуждается в дополнительном источнике поступления средств на нужды медицины. Другая - жители сельской местности, которые не имеют основного места работы. И это около $70 \%$ проживающих в сельской местности. Значит, не отчисляя в ФОМС денежные средства, они не имеют возможности поправить свое здоровье за счет средств страховки, хотя нуждаются в этом в большей степени, чем городское население. И эту проблему, касающуюся охраны здоровья безработных граждан страны, надо решать. 
Из-за отсутствия финансовых средств страна лишена возможности внедрять в систему здравоохранения передовые технологии. Медицинское оборудование уже много лет не обновляется, отживает свой моральный и физический срок, ветшают административные и больничные здания, требуя капитального ремонта.

Усугубляет положение и существенный рост цен на товары и услуги. В этой связи невозможно обеспечить расходы медицинских учреждений на предоставление качественных медицинских услуг ни за счет средств бюджета, ни за счет средств ОМС.

Есть предложение со стороны ФОМС об увеличении размера страхового взноса за счет доходов работника с 2 до $3 \%$.

Население республики незаинтересованно в уплате страхового взноса по той причине, что система не является накопительной. Действительно, лишаясь работы, человек лишается и права на средства страховки. Поэтому предлагаем рассмотреть возможность перехода на накопительную систему страхования здоровья.

В настоящее время в отрасли здравоохранения действует бюджетно-страховая система финансирования, в основе которой лежит страховой принцип. Нам следует перейти на более гибкую систему, дифференцированную, в которой учитываются и сфера деятельности, и возраст, и иные критерии. Эта система должна быть прозрачной, то есть иметь доступ застрахованного человека к счетам.

\section{Выводы}

- Трансформировать бюджетно-страховую систему финансирования в систему, основанную на реальном страховом принципе.

- Увеличить удельный вес средств из республиканского бюджета, предназначенных на выплаты пенсионерам и детям (до 16 лет).

- Обеспечить персонификацию учета средств ОМС.

- В качестве потенциального источника финансирования здравоохранения предусмотреть страхование иностранных граждан.

- Осуществить поиск источников финансирования лечения безработных.

- Рассмотреть возможность перехода на накопительную систему страхования здоровья.

- Перейти на более гибкую, дифференцированную систему, в которой учитываются и сфера деятельности, и возраст, и иные критерии. Обеспечить ее прозрачность, то есть доступ застрахованного человека к счетам.

\section{Литература}

- Budjet FOMS na 2016 g. sostavlaet okolo 2 mlrd. som. млрд. сом. http://zdorovie.akipress.org/news:22546

- Gosudarstvennoe medisinskoe strahovanie v Germanii. Istoricheskie korni prinsipi. http://www.medicusamicus.com/index.php?action=7x994-9egx1)

- Rezultati anketirovania vracheey I psientov bolnis I poliklinik v gorode Bishkek i 7 regionov Kirgizstana (2014)g.

- Tablisa sostavlena po dannim Ministerstva zdravoohranenia v KR za 2009-2013 gg.

- Tablisa sostavlena po dannim Ministerstva zdravoohranenia v KR za за 2014-2015 гг.

- V Kirgizstane medisinskuy strahovku imeuyt 75\% naselenia. http://zdorovie.akipress.org/news:22370

- V Kirgizstane predldgauyt povisit otchislenia na obiazatelnoe medisinskoe strahovanie za schet dohodov rabotnika s 2 do 3\% http://www.akipress.org/zdorovie/news:17203/ 


\section{Author Index}

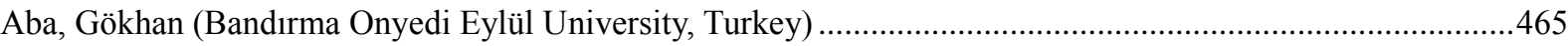

Abdieva, Raziiakhan (Kyrgyzstan-Turkey Manas University, Kyrgyzstan) …………..............................652, 677

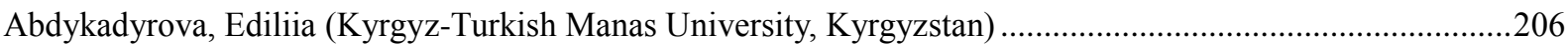

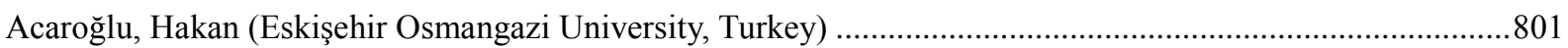

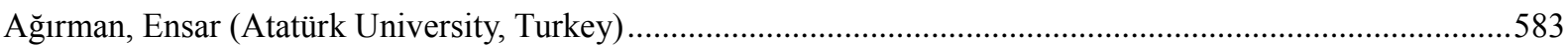

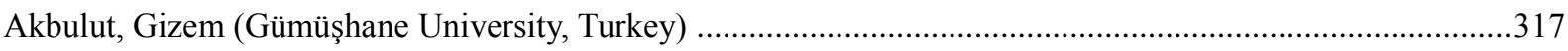

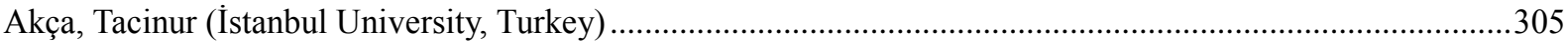

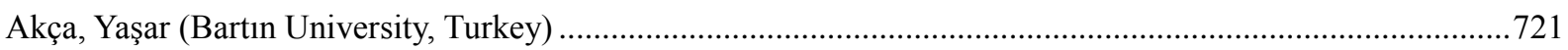

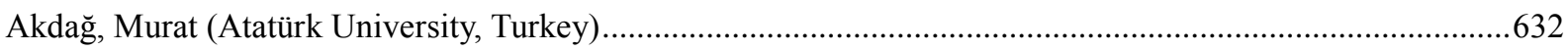

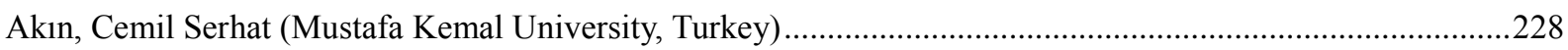

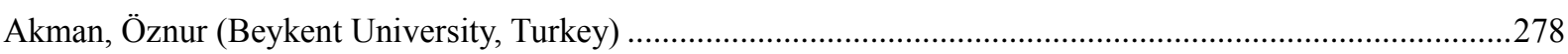

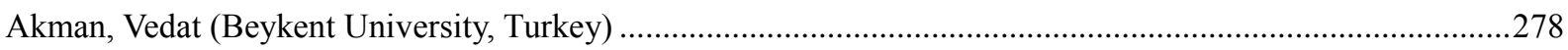

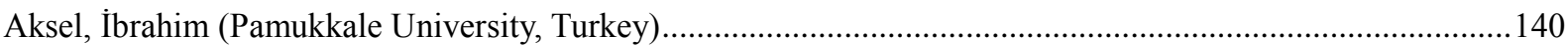

Algan, Neşe (Çukurova University, Turkey) .............................................................228, 404, 605, 624, 794

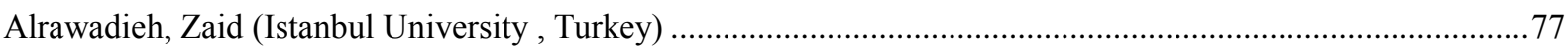

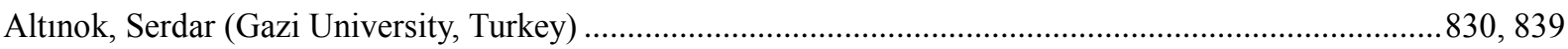

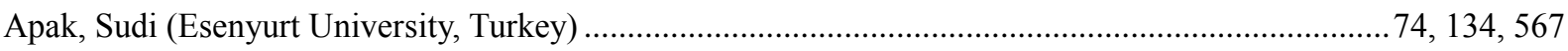

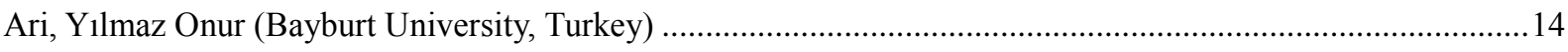

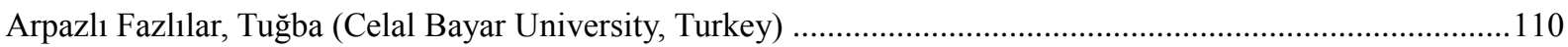

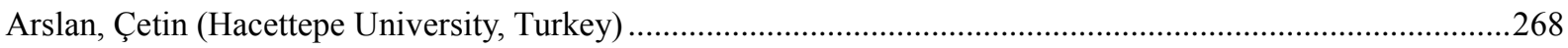

Aseinov, Dastan (Kyrgyzstan-Turkey Manas University, Kyrgyzstan) .............................................................549

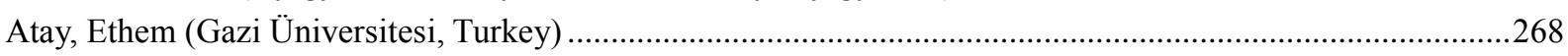

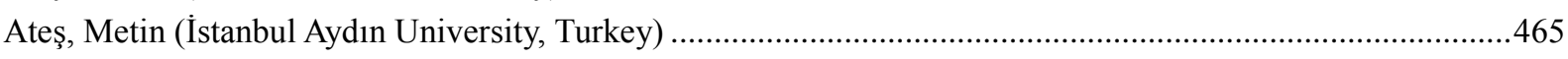

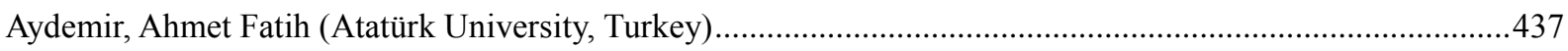

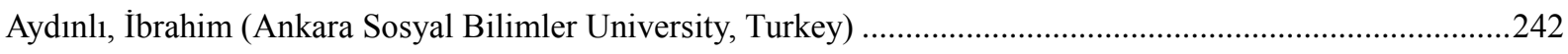

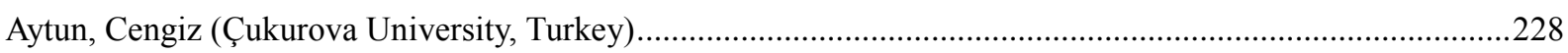

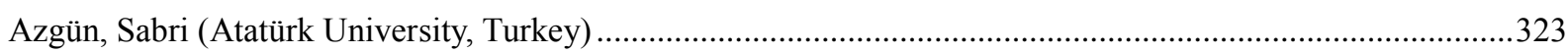

Babacan, Sümeyra (Muğla Sıtkı Koçman University, Turkey) ……………………………..........................181

Baigonushova, Damira (Kyrgyzstan-Turkey Manas University, Kyrgyzstan) ………................................773, 904

Bal, Harun (Çukurova University, Turkey) ............................................................311, 404, 605, 624, 864

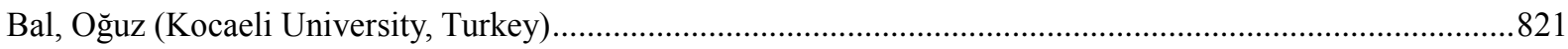

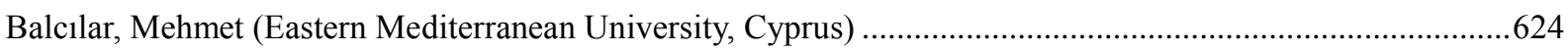

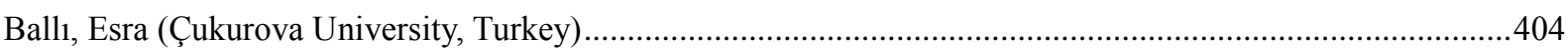

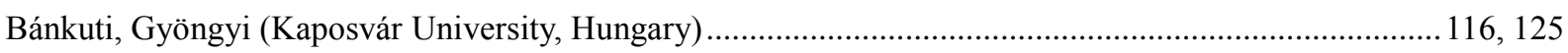

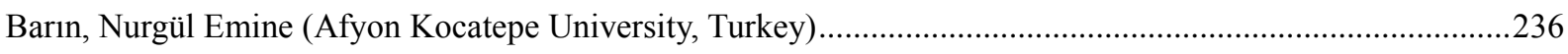

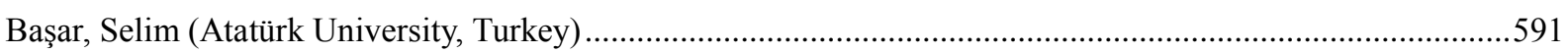

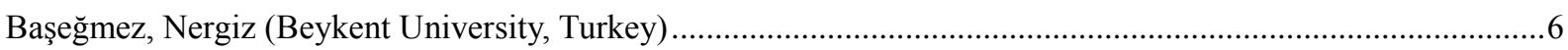

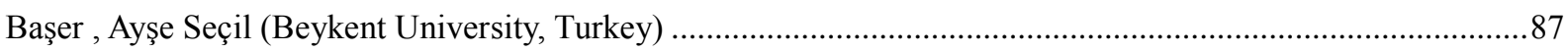

Başol, Serkan (Pamukkale University, Turkey) ……………......................................................................170

Bayrak, Metin (Kyrgyzstan-Turkey Manas University, Turkey)...........................................................533, 549

Bayrak Kök, Sabahat (Pamukkale University, Turkey)............................................................140, 160, 181

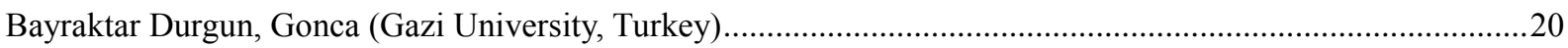

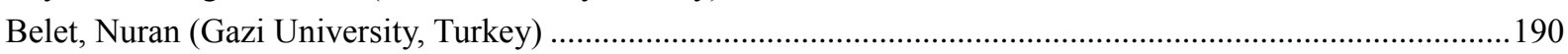

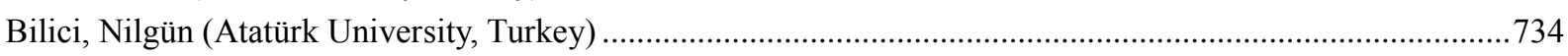

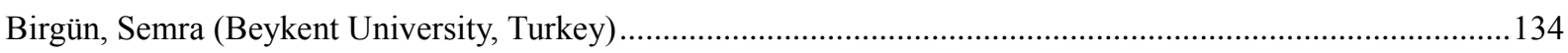

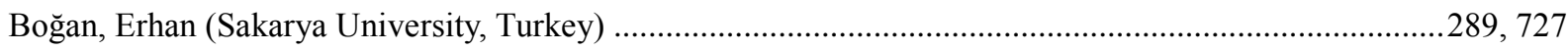

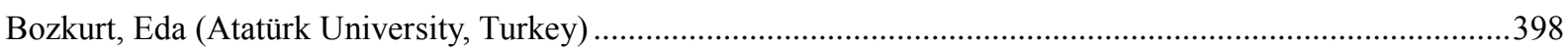

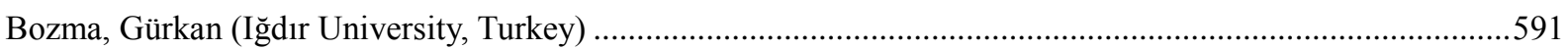


Buzdağlı, Özge (Atatürk University, Turkey) 632,641

Çağlayan Akay, Ebru (Marmara University, Turkey) ......................................................................................652

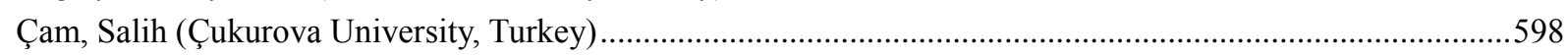

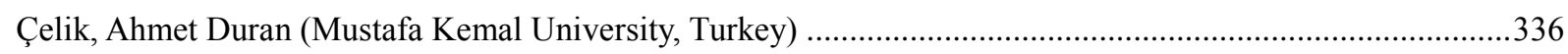

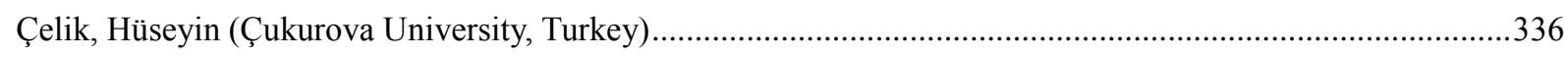

Çelik, İsmail Erkan (Beykent University, Turkey) .....................................................................278, 558

Çelik, Sabahat Binnur (Beykent University, Turkey) ...............................................................................256

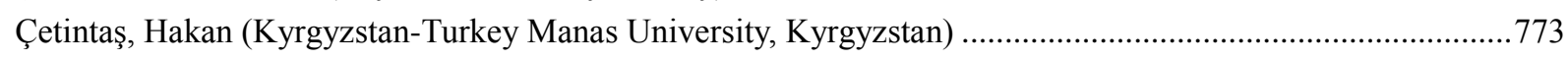

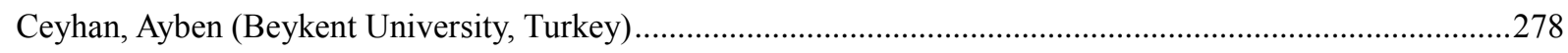

Çiftçi, Hakkı (Çukurova University, Turkey) .................................................................................311, 870

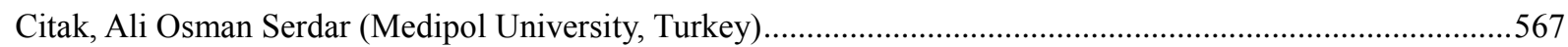

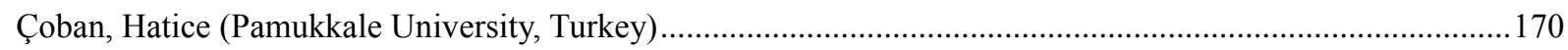

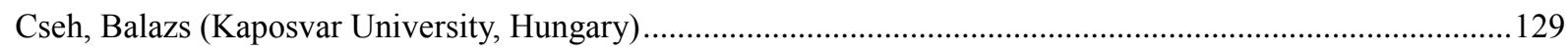

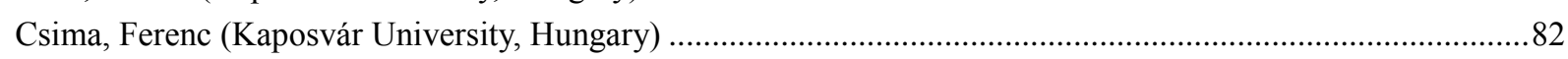

Cumakunova, Tolkun (Kyrgyzstan-Turkey Manas University, Kyrgyzstan) .................................................677

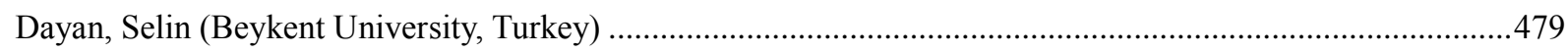

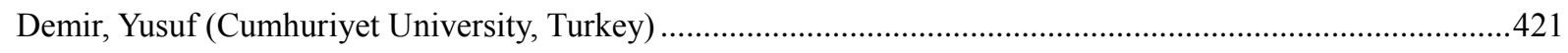

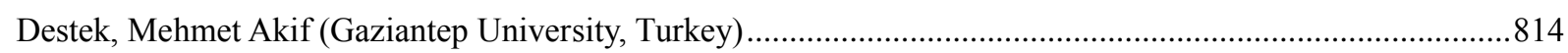

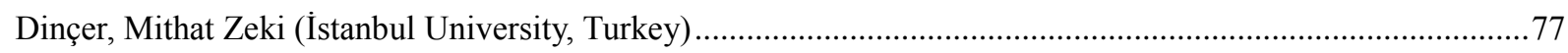

Doker, Aslı Cansın (Erzincan University, Turkey) ...........................................................................412, 752

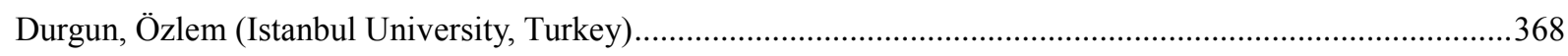

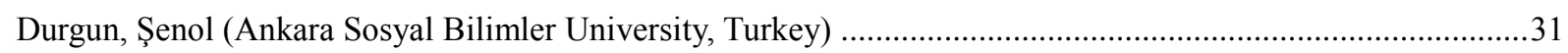

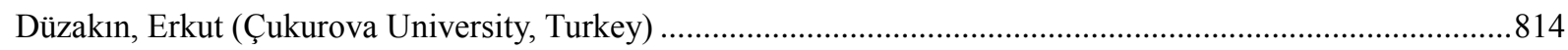

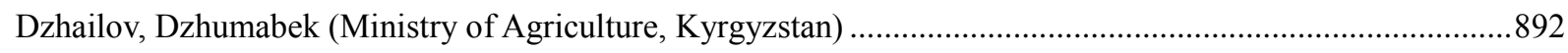

Emir, Zeynep (Beykent University, Turkey) .............................................................................................273

Emsen, Ömer Selçuk (Atatürk University, Turkey) ............................................... 412, 437, 632, 641, 752

Erdoğan, Mahmut (Kyrgyzstan-Turkey Manas University, Kyrgyzstan) ...................................................760

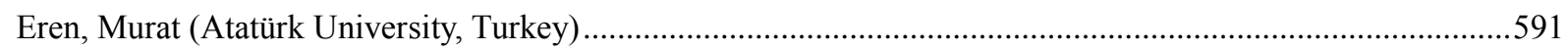

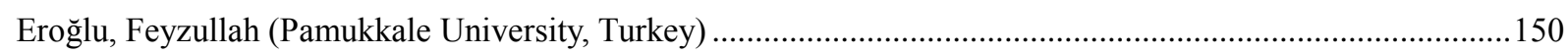

Eroğlu, Şeyma Gün (Muğla Sitkı Koçman University, Turkey) ...................................................................150

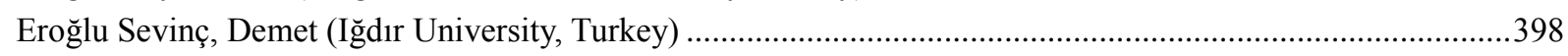

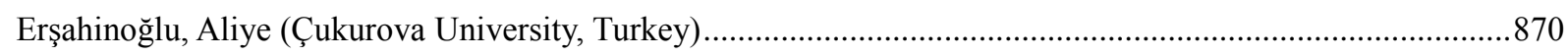

Ersin, Özgür Ömer (Beykent University, Turkey) ..........................................................................................44

Everest, Bengü (Çanakkale Onsekiz Mart University, Turkey) ...................................................................519

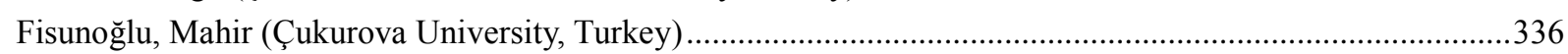

Firat, Emine (Aksaray University, Turkey) ....................................................................... 830, 839, 847

Fırat, Fatih Kürşat (Aksaray University, Turkey) ..................................................................503, 712

Ganiev, Junus (Kyrgyzstan-Turkey Manas University, Kyrgyzstan) ...........................................................760

Gencer, Ayşen Hiç (Istanbul Aydın University, Turkey) ............................................................................220

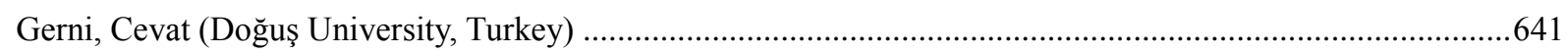

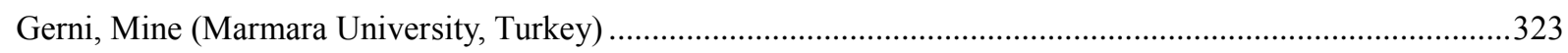

Gökçek Karaca, Nuray (Anadolu University, Turkey) ...............................................................375, 388

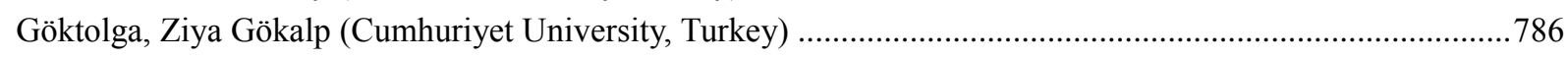

Görkem, Hilal (Çanakkale Onsekiz Mart University, Turkey) ......................................................................681

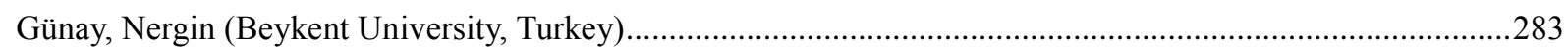

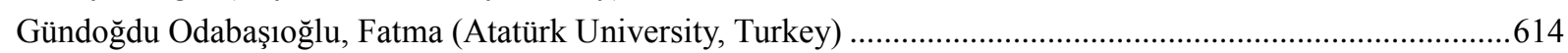

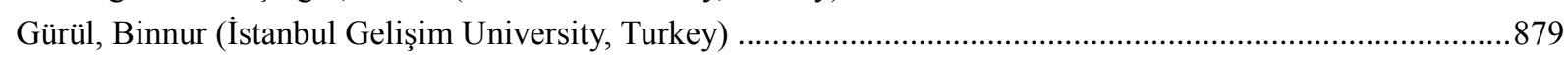

Hacıŏlu Deniz, Müjgan (İstanbul University, Turkey) ............................................................................471

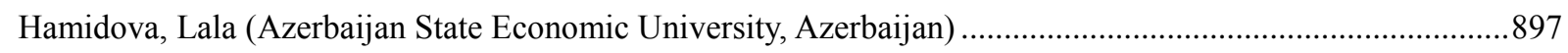


Hasdemir, Mehmet (Ministry of Food, Agriculture and Livestock, Turkey)

496,510

Hasdemir, Mine (Agricultural Economy and Policy Development Institute, Turkey) ..........................................496

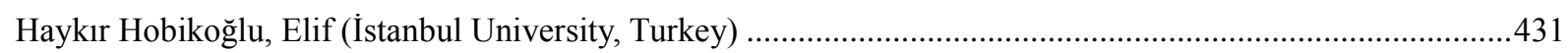

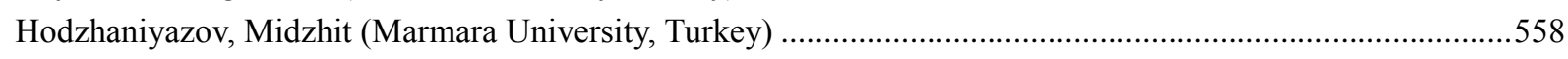

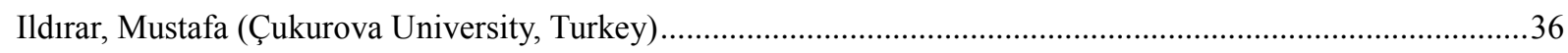

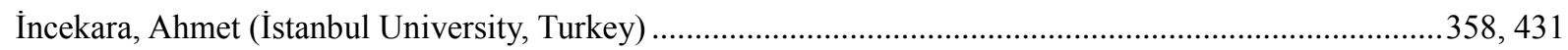

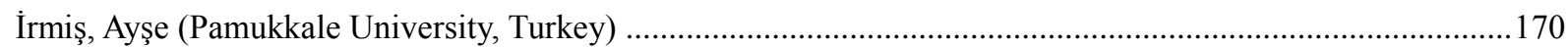

İşcan, Erhan (Çukurova University, Turkey)..........................................................................36, 311, 794, 864

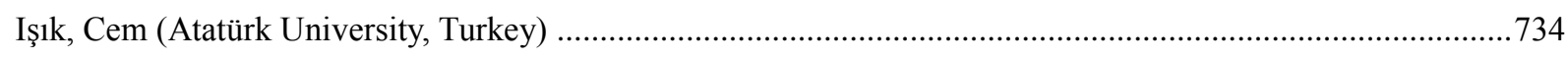

İstanbullu Dinçer, Fatma Füsun (İstanbul University, Turkey) …………………………....................................77

Japarova, Damira (Kyrgyzstan-Turkey Manas University, Kyrgyzstan).....................................................904, 915

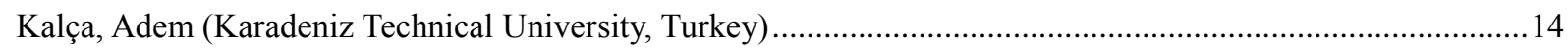

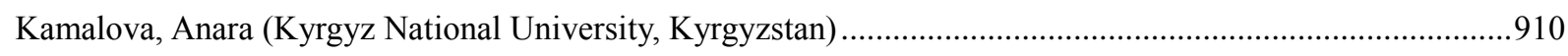

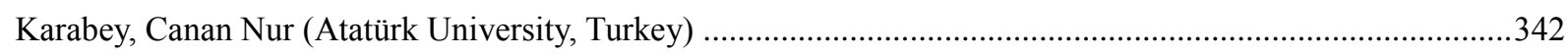

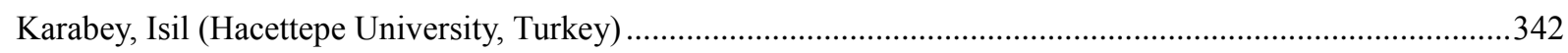

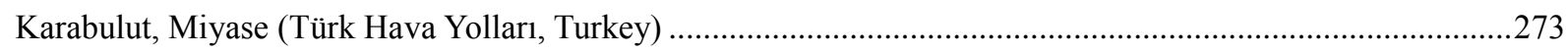

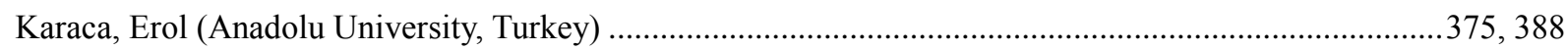

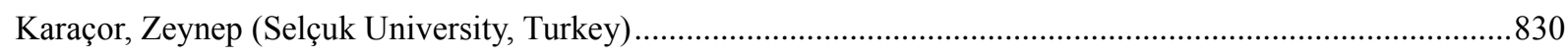

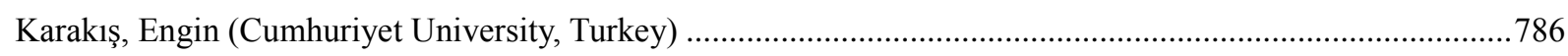

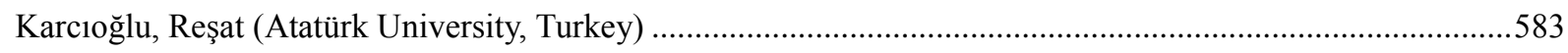

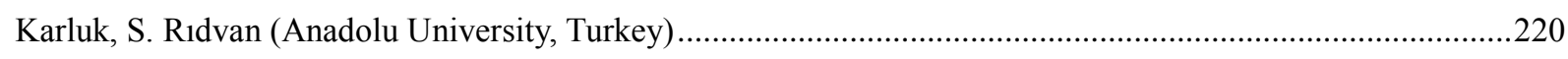

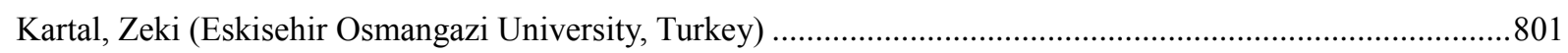

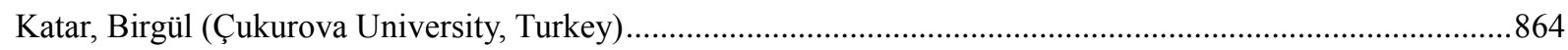

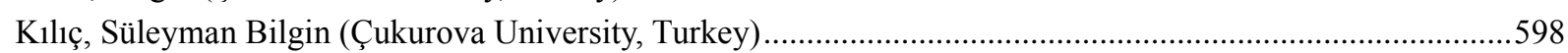

Koichueva, Merim (Kyrgyz-Russian Slavic University, Kyrgyzstan) …………………………………..........900

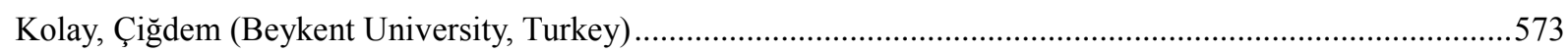

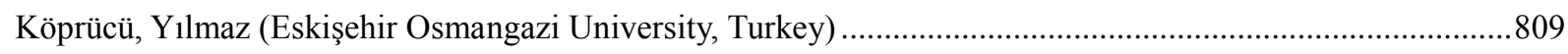

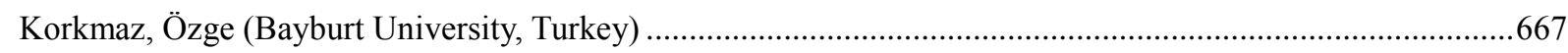

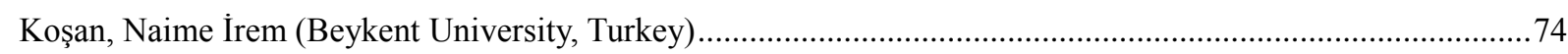

Kozhobekov, Muratbek (Kyrgyzstan-Turkey Manas University, Kyrgyzstan) ……………................................ 889

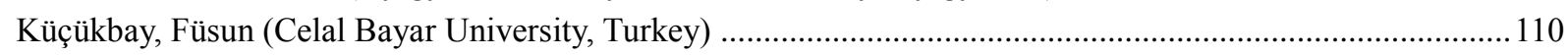

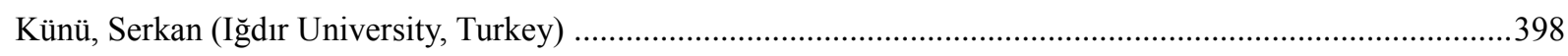

Kuşçu, Ayşe Dudu (Konya Necmettin Erbakan University, Turkey) ……………………………………..........330

Manga, Müge (Çukurova University, Turkey) ………………............................................... 404, 624, 814

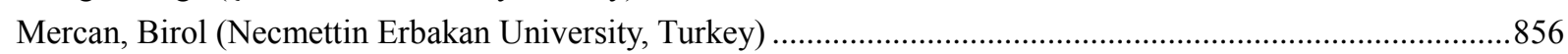

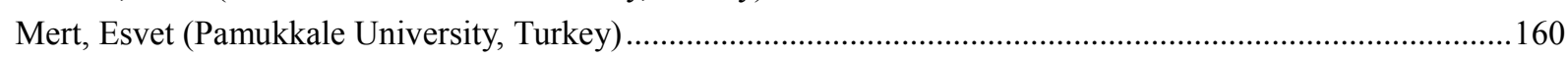

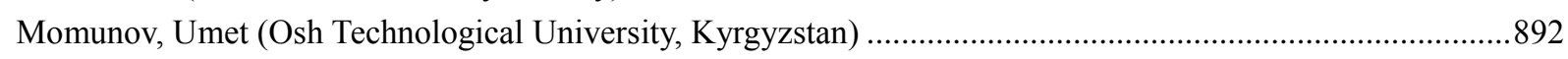

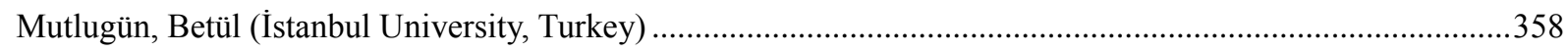

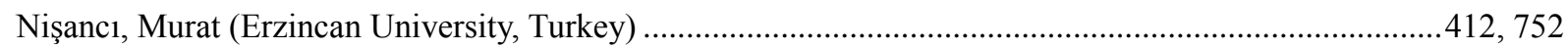

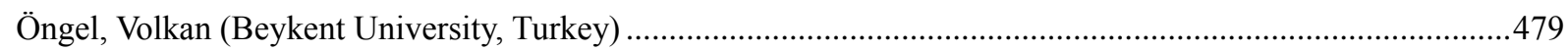

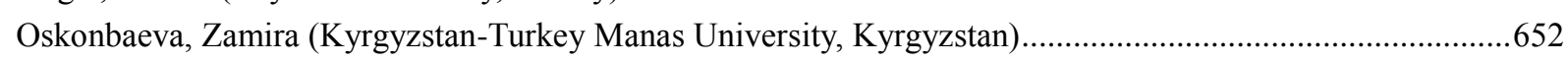

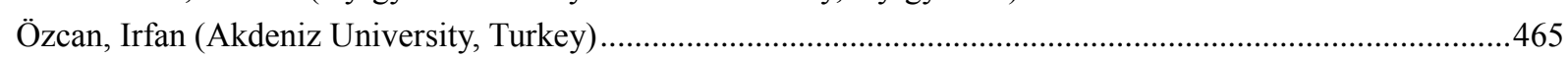

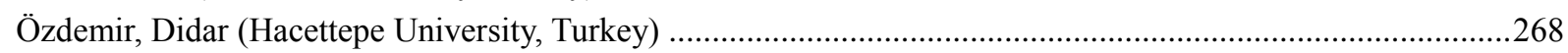

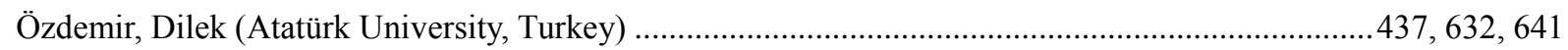

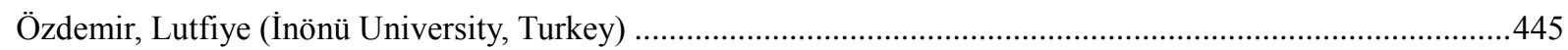

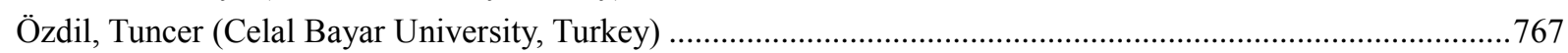

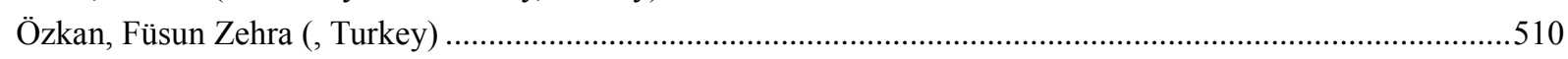

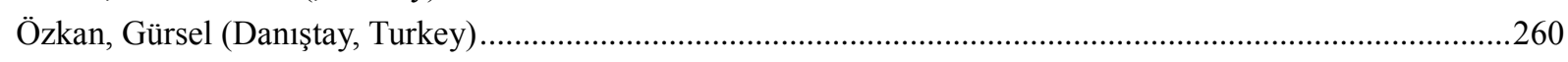

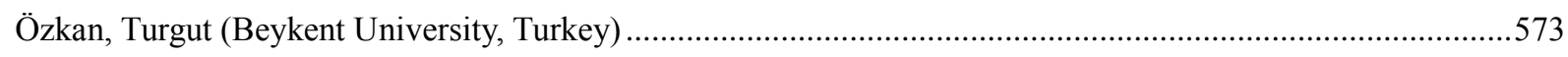




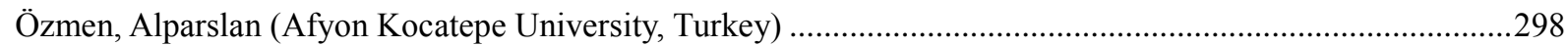

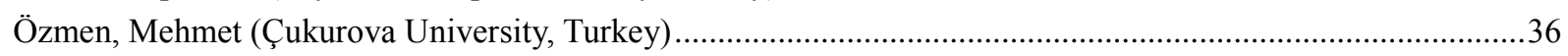

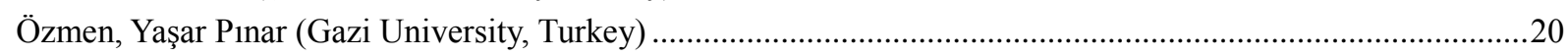

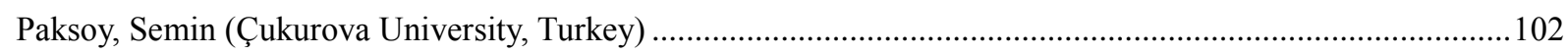

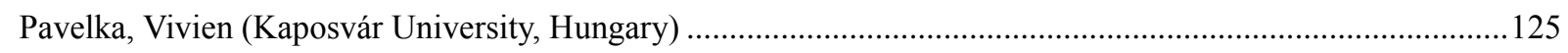

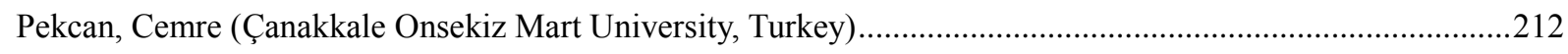

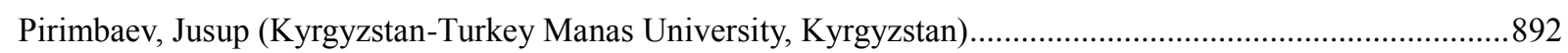

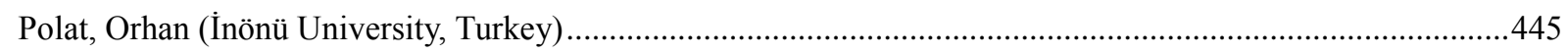

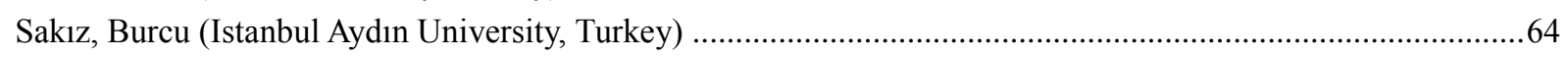

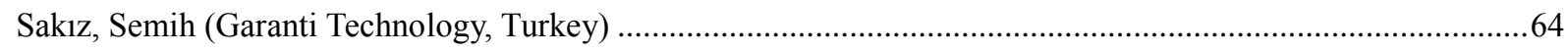

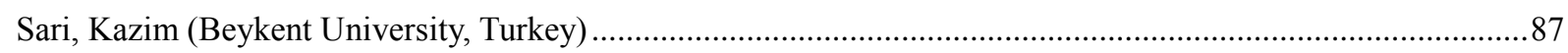

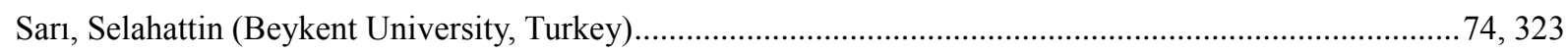

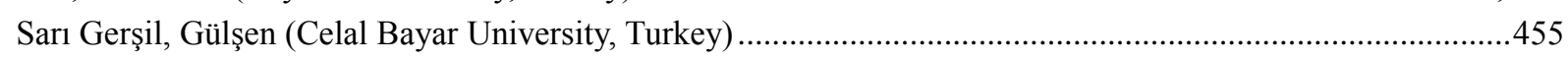

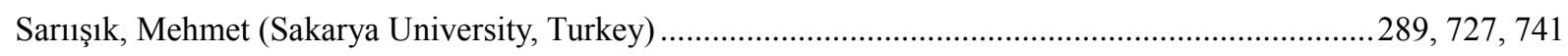

Sarkaya, Mehtap (Pamukkale University, Turkey) ………………………................................150, 181

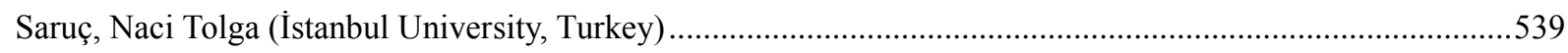

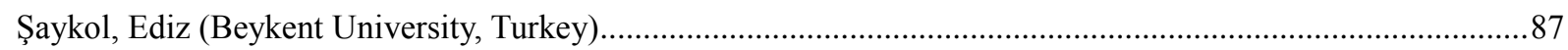

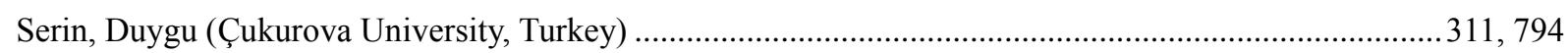

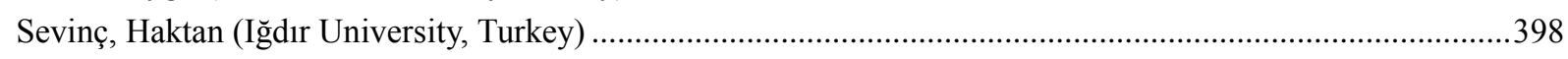

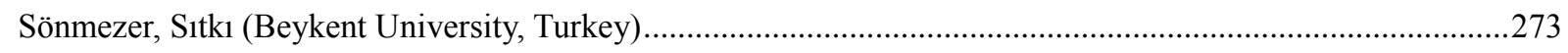

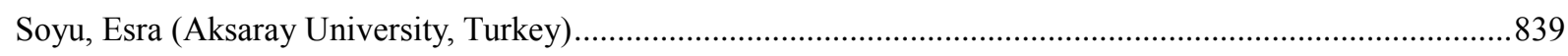

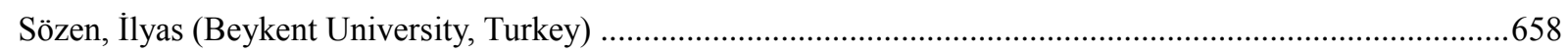

Sultakeev, Kadyrbek (Kyrgyzstan-Turkey Manas University, Kyrgyzstan).............................................533, 549

Sümer, Kutluk Kağan (İstanbul University, Turkey) ..........................................................................56, 93, 471

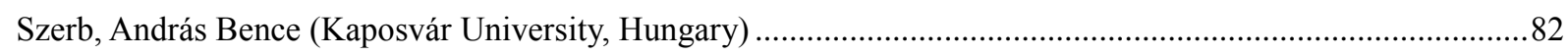

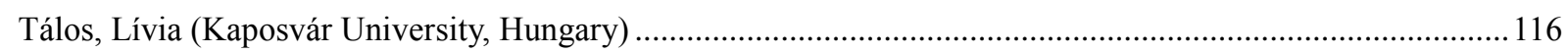

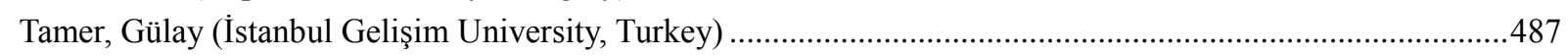

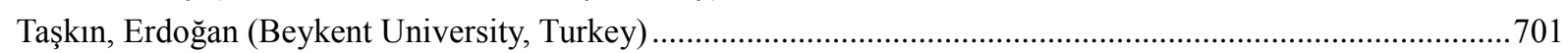

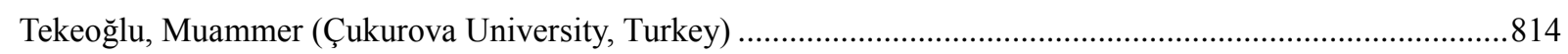

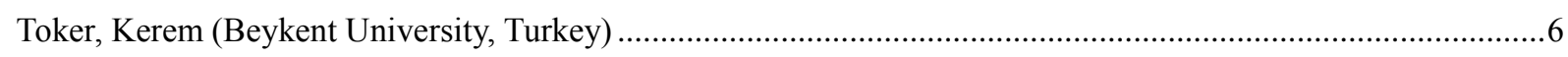

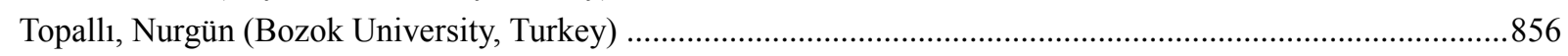

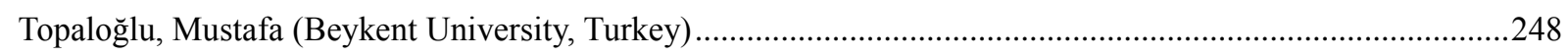

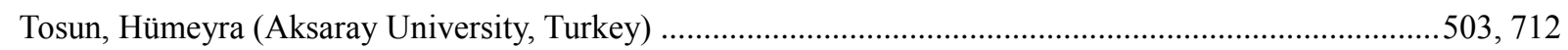

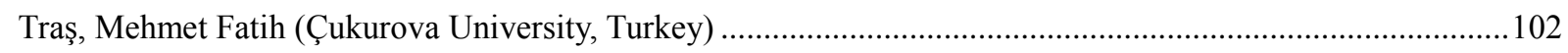

Tufaner, Mustafa Batuhan (Beykent University, Turkey) ................................................................................658

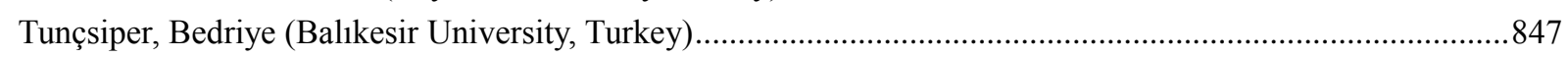

Turdalieva, Aynura (Kyrgyzstan-Turkey Manas University, Kyrgyzstan) …………………………............... 767

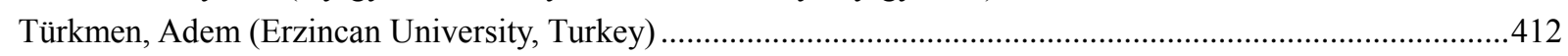

Uçgunoğlu, Meltem (Gaziosmanpaşa University, Turkey) .................................................................................421

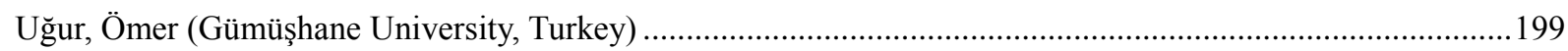

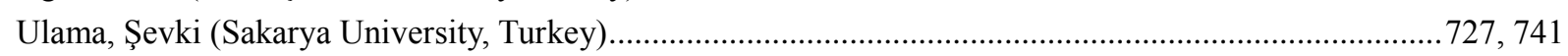

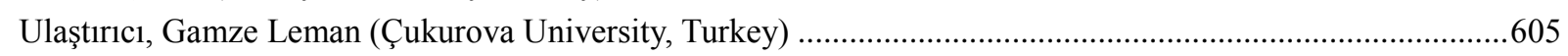

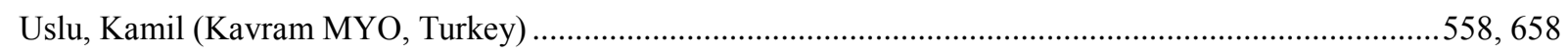

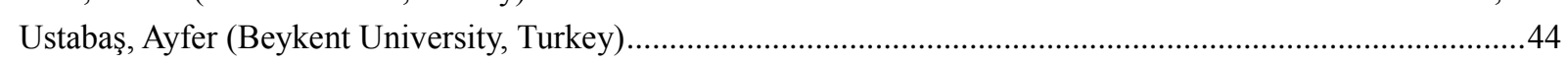

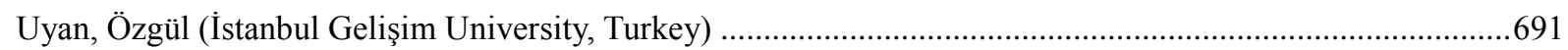

Varga, Jozsef (Kaposvar University, Hungary) …………………………………………..........116, 125, 129

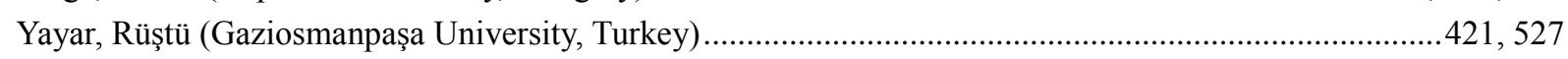

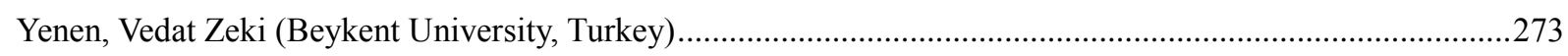

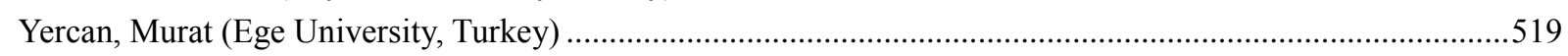




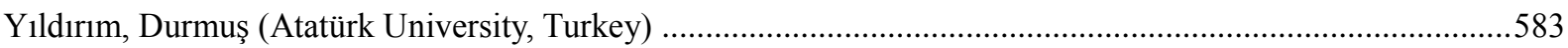

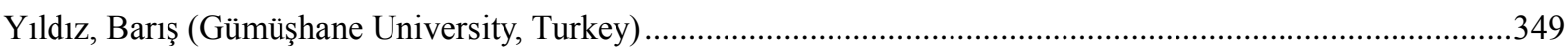

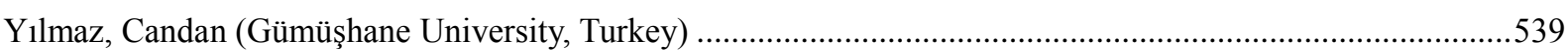

Yılmaz, Durmuş (Central Bank of Turkey, Turkey) …….............................................................................

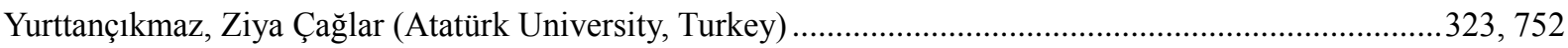

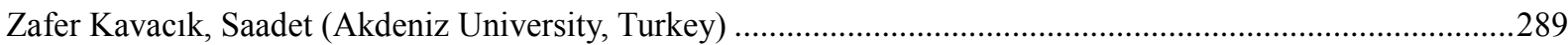


